(n)

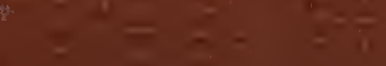




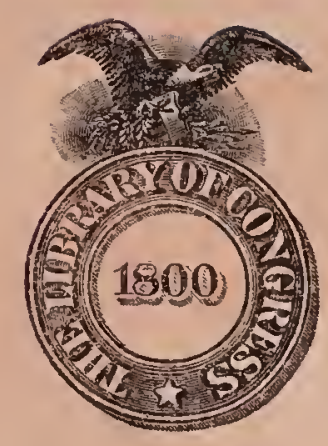



'To the throng of eager question ing brothers and sisters in the art of bee culture, in our own and other countries, this work is especially dedirater. 'Tisf A ITTmons. 


\section{THE}

$A B C$ and $\mathrm{XYZ}$ $\mathrm{OF}$

A Cyclopedia of Everything Pertaining to the Care of the Honeybee: Bees, Hives, Honey, Implements, Honey Plants, etc. Facts Gleaned from the Experience of Thousands of Beekeepers, and Afterward Verified by the Authors.

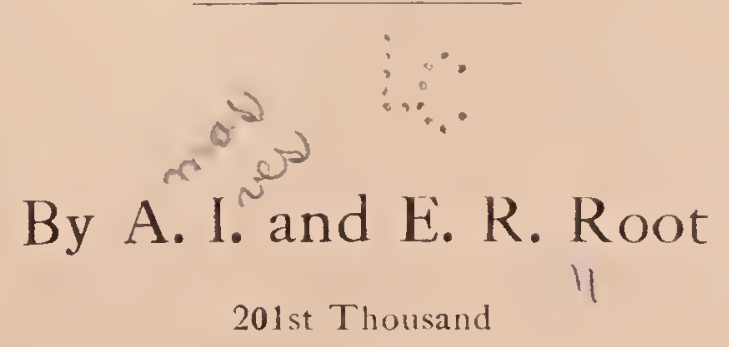

MEDINA, OHIO

THE A, I. ROOT COMPANY

1923 


$$
\begin{gathered}
S F_{523} \\
R 4 \\
1923
\end{gathered}
$$

$\therefore \therefore$

\section{MAY - 7'23}

(C) ClA705314

$$
\text { no } 1
$$




\section{Preface}

In preparing this work I have been much indebted to the books of Langstroth, Moses Quinby, Prof. A. J. Cook, and some others, as well as to all of the bee journals; but, more than to all these, have I been indebted to the thousands of friends scattered far and wide who have so kindly furnished the fullest particulars in regard to all the new improvements as they have come up in our beloved branch of rural industry. Those who questioned me so much a few years ago are now repaying by giving me such long kind letters in answer to any inquiry I may happen to nake that I often feel ashamed to think what meager answers $I$ have been obliged to give them under similar circumstances. A great part of this $\mathrm{A} \mathrm{B} \mathrm{C} \mathrm{book} \mathrm{is} \mathrm{really} \mathrm{the} \mathrm{work} \mathrm{of} \mathrm{the} \mathrm{people;} \mathrm{and} \mathrm{the} \mathrm{task} \mathrm{that} \mathrm{devolves} \mathrm{on}$ me is to collect, condense, verify, and utilize what has been scattered thru thousands of letters for years past. My own apiary has been greatly devoted to testing carefully each new device, invention, or process as it came up. The task has been a very pleasant one, and if the perusal of the following pages affords you as much pleasure I shall feel amply repaid.

November, 1877.

A. I. Root.

\section{Preface to the 1923 Edition}

Little did A. I. Root, when he wrote the preface to the 1877 edition, realize that his work of 200 pages, written expressly for beginners, would develop during the following 45 years into the $A B C$ and $X Y Z$ of Bee Culture, a work which meets the needs of both beginners and professional beekeepers. Since 1877 great changes have taken place in the bee world. Then beekeeping was hardly. recognized as a business, but today it has grown to enormous proportions, as is shown in the FOREwORD following. Thousands of colonies are now handled by individuals and syndicates, and honey is shipped by the carload to various parts of the world-an achievement which would not have been believed possible when the first edition of this book was published. Not only has this industry taken a great stride in a commereial way, but thousands of people are keeping a few hives of bees on their farns and back lots. They have discovered that bee eulture is not only a pleasurable pastime, but an important source of income since both honey and more and better fruit are securer. See BEEs AND Fruit in the body of this work.

After the third edition, failing health, the cares of a rapidly growing business in the mannfacture of beekeepers' supplies and the publication of Gleanings in Bee Culture made it impossible for the author, A. I. Root, to keep pace with all the developments of beekeeping and make the necessary revisions. In assistant editor was required; and this position was naturally taken by Mr. Root's elder son, the present author and reviser, who had been his father's chief helper in the apiary and who had for many years been in constant touch with his experimental work with bees. At the same time he assuined the duties of revising the $A B C$ of Bee Culture, he also became assistant editor of Gleanings in Bee Culture and later editor-a position he has held for 35 years. While the earlier editions of the $A B C$ of Bee Culture described correctly the methods of beekeeping in northeru Ohio and in other portions of the North where the climate and honey flora are similar, it soon became evident to the junior editor, as the result of an extensive corlespondence, that conditions in other parts of the United States, where climate and soil are radically different, required a modified trentment. 
In 1890, after some nine editions of this work had been published, it became apparent that it was very desirable that the new editor and author shonld make extensive trips among the beekeeper's of the different States. The first trip was made in 1890. Other trips followed in rapid succession continuing up to the present time, reports on which have appeared in Gleanings in Bee Culture. The data gathered during the first few trips showed conclusively the importance of adapting the teachings to the locality; and numerous changes and additions were incorporated giving the experience of the most successful beekeepers in every State in the Union. But in all cases the old matter originally written by $\mathrm{A}$. I. Root has been retained so far as possible. So extensive have been the additions that the original work of 200 pages has expanded into the present volume of nearly 1,000 pages. Thus three-fourths of the 1923 edition, outside of the scientific matter, has been written by the junior author.

It must not be supposed that all of the changes made and all of the new material added are the work of the junior author alone. He has consulted many of the leading beekeeper's of the country, frequently submitting to them his manuscripts for criticism. Among the foremost of these authorities in earlier days were Dr. C. C. Miller, G. M. Doolittle, A. C. Miller, and last, but not least, A. I. Root himself; in later years he has consulted Dr. E. F. Phillips, in charge of Bee Culture at Washington, and his former assistant, Geo. S. Denuth.

Mr. Demuth is now editor-in-chief of Gleanings in Bee Culture, and chief of the Bureau of Information of The A. I. Root Company. For many years he was engaged in the production of comb honey at Peru, Indiana. His methods have been so successful that the sum of money he has made with 200 colonies of bees in one month has frequently exceeded the salary he received during the other eleven months. For nine years Mr. Demuth was assistant to Dr. Phillips in the Department of Bee Culture at Washington, D. C. In this position he had exceptional facilities for engaging in research work with bees. In the preparation of the 1923 edition of the $A B C$ and X Y $Z$ of Bee Culture he has made many valuable suggestions. Sereral of the articles, as AFTER-SwABMing, Artificial Swarming, Bulluing Up Colonies, Comb Honey, and Swarming, were entirely rewritten by him. On these five subjerts lie is acknowledged to be one of the best living authorities.

Dr. Phillips, the author of Beekeeping, has likewise offered important suggestions: and furnished valuable information in regard to bee diseases, which has been incorporated under various topics. Assisted by Mr. Demuth he has developed the science of wintering bees, and explained most of the reactions that then take place in the colony. (See TEMPERATURE.) A knowledge of bee behavior in general, or what may be described in more popular language as the domestic economy of the beehive, and many problems in bee culture, formerly obscure, have also been worked out by Phillips and Demuth.

In later years $\mathrm{H}$. H. Root, the younger son of A. I. Root, came on the scene of action. He inherited all of the enthusiasm of his father for genuine research, and as a result has invented and improved many new and useful appliances, which greatly facilitate the work of seculing a crop of honey. The articles on Extractors and Extracting show much of his handiwork. He also wrote a large part of the article on WAx, and helped in revising various other articles.

It was impossible for the author, who for 35 years was editor of Gleanings in Bee Culture, in revising the $\perp B C$ and $X Y Z$ of Bee Culture to specialize in zoology and botany. Both of these sciences are so intimately connected with bee culture that the author finally employed Mr. John H. Lovell of Waldoboro, Maine, an entomologist, botanist and beekeeper, to write all the articles relating to them. Mr. Lovell has one of the largest private collections in the Inited States of the solitary and social bees, and of insects valuable as agents in the pollination of flowers. For many years he has specialized in botany and entomology, and has contributed numerous articles to the scientific journals giving the results of original investigations of the biology of flowers, the senses of the honeybee and the classification of bees. He has also for nearly a score of years been an enthusiastic beekeeper and student of bee economy. Such a combination in one man, who 
has deroted his entire lifetime to these subjects, could scarcely be found elsewhere. In this connection it should also be stated that lie is the author of a popular work entitled The Flower and the Bee: Plant Life and Pollination, and of The Honey Plants of North America, at the present time in manuscript, but which will be published during the current year. Among the articles contributed to the present edition by Mr. Lovell are PoLLination of Flowers, Pollination of Fruit Bloom, Honey Plants, Bumblebees, Solitary Bees, Locality, Propolis, and witl a few partial exceptions all the descriptions and photographs of honey plants.

It seemed very desirable that the article discussing the laws relating to bees and beekeeper's' rights should be written by one who was both a lawyer and a beekeeper; and, therefore, Leslie Burr, formerly a practicing attorney and now a judge, who has kept bees in several States in the Union, was selected to write Laws ReLating to BeEs.

The article on the Anatomy of the Honeybee was written by R. E. Snodgrass, formerly of the Bureau of Entomology, Washington, D. C.

Dr. James A. Nelson, likewise formerly of the Bureau of Entomology, and the author of a valuable work on the Embryology of the Honeybee, wrote Develop MENT OF BEES.

Mrs. J. H. Comstock, an entomologist of national reputation and a backlot beekeeper, wrote BEEKEEPING FOR WOMEN.

The topies, Honer and Honey Analysis, have been handled by A. Hugh Bryan, formerly chemist in the United States Department of Agriculture, and now an expert on sugars for the American Refining "Company. Helpful suggestions and additions have been made by E. Wynne Boyden, a grandson of A. I. Root, who has specialized in the chemistry of honey. Possibly no one in the United States has given more careful and thorongh investigation to the general subject of honey as a food than Mr. Boyden. The articles on Honey Vinegar and Honey aS A FOOD were written by him. Many of the honey recipes and the article on Vitamines In HoNEY were written by Mrs. A. L. Boyden, a daughter of $\mathrm{A}$. I. Root. It will be noticed that the $A B C$ and $\mathrm{X} Y Z$ of Bee Culture still remains very much a family affair.

The discriminating reader may discover in the treatment of the various articles apparent repetitions of what has been said elsewhere under other heads. Where this occurs, it is for a purpose. The restatement of a certain proposition from a different angle necessarily clears up a subject that might otherwise be misunderstood. For example, it will be found that the treatment of WINDBREAKS under APIARIES and under WINTERING OUTDOors, while similar, is enough different to require a special restatement under each heading. Again, in so complex a subject as the management of bees the reiteration of the same facts in a different form, as well as from a different angle, helps to make plain to the beginner a matter that he should not and must not misunderstand, if he would succeed. How to open a hive of bees is considered under the heads of $A B C$ of BeEkeEprng, Anger of Bees, Manipulation of Colonies, Robbing and Stings. Under the general head of Swarming there will be found the subhead, The Cause of Swarming, and likewise the subhead, Prevention of Swarming. There is some material under both heads that is similar. Knowing the cause, one would naturally apply the remedy; but in explaining the remedy it is important that many details in connection with the cause be stated.

The author has traveled over all the United States and given hundreds of lectures on beekeeping; and he finds that many important subjects are misunderstood for the simple reason that they have not been amplified enough. It requires line upon line, and more or less repetition in a different form and from a different viewpoint. For this reason it has seemed best to repeat some propositions from different anoles, especially when they are important. The author, therefore, makes no apology for the repetitions that occur, notwithstanding which he is convinced that many of his readers will make some mistakes.

A special feature of the 1923 edition is a very complete indox of general subjects which will be found in the back of the volume. 'This is by far the most complete index that the $A B C$ and $X Y Z$ of Bee Culture has ever had. It was thought in a work of reference like this, altho it is arranged in alphabetical order, making it easy for the reader to find any general subjert, that an index of all subjects could not be too complete. The 


\section{PREFACE}

author therefore believes that this volume will be much more helpful than any previous edition, especially as it contains so many new subjects.

As did A. I. Root in his modest preface of 1877, so the present author feels that he is indebted in a very large way to the thousands and thousands, over all this land, who have not only shown him their methods and appliances, but have by letter and otherwise helped to furnish the material that is given in these pages.

Feb. 1, 1923.

ERNEST R. ROOT. 


\title{
Introduction to the First Edition
}

\author{
BY A. I. ROOT.
}

About the year 1865, during the month of August, a swarm of bees passed overhead where we were at work, and my fellow-workman, in answer to some of my inquiries respecting their habits, asked what I would give for them. I, not dreaming he could by any means call them down, offered him a dollar, and he started after them. To my astonishment, he, in a short time, returned with them, hived in a rough box he had hastily picked up, and, at that moment, I commenced learning my A B C in bee culture. Before night I had questioned not only the bees but every one I knew, who could tell me anything about these strange new acquaintances of mine. Our books and papers were overhauled that evening; but the little that I found only puzzled me the more, and kindled anew the desire to explore and follow out this new hobby of mine: for, hear reader, I have been all my life much given to hobbies and new projects.

Farmers who had kept bees assured me that they once paid, when the country was new, but of late years they were no profit, and everybody was abandoning the business. I had some headstrong views in the matter, and in a few days I visited Cleveland, ostensibly on other business, but I had really little interest in anything until I could visit the book stores and look over the books on bees. I found but two, and I very quickly chose Langstroth. May God reward and forever bless Mr. Langstroth for the kind and nleasant way in which he unfolds to his readers the trutlis and wonders of creation to be found inside the beehive.

What a gold mine that book seemed to me as I looked it over on my journey home! Never was romance so enticing-no, not even Robinson Crusoe; and, best of all, right at my own home I could live out and verify all the wonderful things told therein. Late as it was, I yet made an observatory hive and raised queens from worker eggs before winter, and wound up by purchasing a queen of Mr. Langstroth for \$20.00. I should, in fact, have wound up the whole business, queen and all, most effectually, had it not been for some timely advice toward Christmas, from a plain practical farmer near by. With lis assistance, and by the purchase of some more bees, I brought all safely thru the winter. Thru Mr. Langstroth I learned of Mr. Wagner, who shortly afterward was induced to recommence the publication of the American Bee Journal, and thru this I gave accounts monthly of my blunders and occasional successes.

In 1867, news came across the ocean from Germany, of the honey-extractor; and by the aid of a simple homemare machine I took 1,000 lbs. of honey from 20 stocks, and increased them to 35 . This made quite a sensation, and numbers embarked in the new business; but when I lost all but 11 of the 35 the next winter, many said: "There! I told you how it would turn out."

I said nothing, but went to work quietly and increased the 11 to 48 during the one season, not using the extractor at all. The 48 were wintered entirely without loss, and I think it was mainly because I took care and pains with each individual colony. From the $48 \mathrm{I}$ secured $6,162 \mathrm{lbs}$. of extracted honey, and sold almost the entire crop for 25 cents per $1 \mathrm{lb}$. This capped the climax, and inquiries in regard to the new industry began to come in from all sides. Beginners were eager to know what lives to adopt, and where to get honey-extractors. As the hives in use seemed very poorly adapted to the use of the extractor, and as the machines offered for sale were heavy and poorly adapted to the purpose, besides being "patented," there really seemed to be no other way before me than to manufacture these implements. Unless $\mathrm{I}$ did this $\mathrm{I}$ shoul he rompelled to undertake a correspondence that would occupy a great part of my time without affording any compensation of any account. The fullest directions I knew how to give for making plain simple hives, etc., were from time to time published in the American Bee Journal; but the demand for further particulars was such that a circular was printed, and, shortly 


\section{INTRODUCTION}

after, a second edition; then another, and another. These were intended to answer the greater part of the queries; and from the cheering words received in regard to them it seemed that the idea was a liappy one.

Until 1873 all these cireulars were sent out gratuituously: but at that time it was deemed best to issue a quarterly at 25 cents per year, for the purpose of answering these inquiries. The very first number was received with such favor that it was immediately changed to a monthly at 75 cents. The name of it was Gleanings in Bee Culture, and it was gradually enlarged, mutil, in 1876 , the price was changed to $\$ 1.00$. During all this time it lias served the purpose excellently of answering questions as they came up, both old and new: and even if some new subscriber slonld ask in regard to something that had been discussed at length but a slort time before, it is an easy matter to refer him to it or send him the number containing the subject in question.

When Gleanings was about commeneing its fifth year, inquirers began to dislike being referred to something that was published lialf a dozen years before. Besides, the decisions that were then arrived at perhaps needed to be considerably modified to meet present wants. Now you can see whence the necessity for this A B C book, its office, and the place we propose to have it fill.

December, 1878.

A. I. Root. 



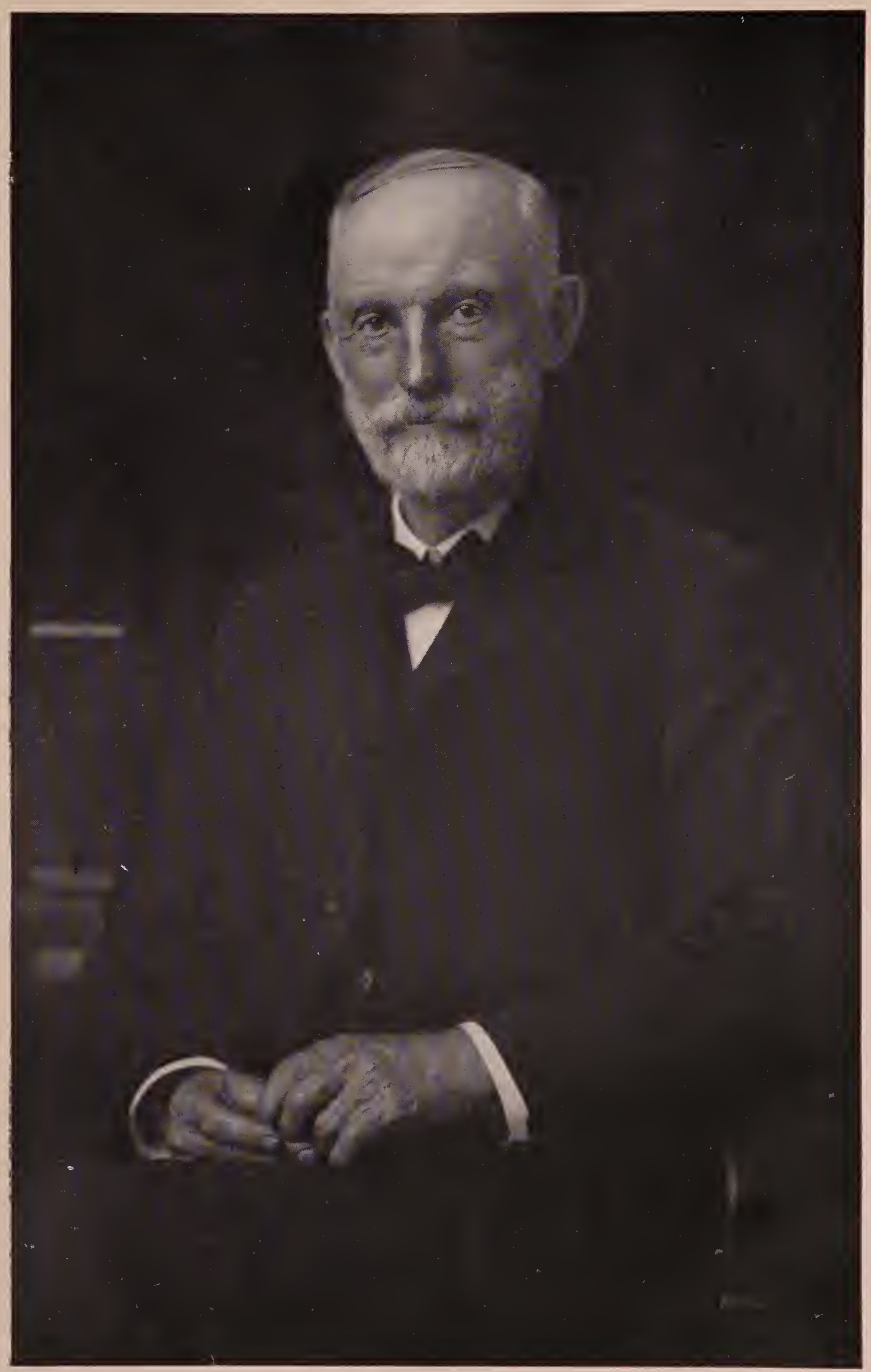

A. I. ROOT 


\section{Foreword}

It is hardly necessary to remind the reader that this is an encyclopedia on bees. It should not therefore be read consecutively, but taken up subject by. subject in the order indicated later. A preliminary statement should first be made in order that the beginner, at least, may be able to form at the very outset some idca of the scope and character of the industry which he is to study.

Bees have been kept from time almost immemorial. References to bees and "honey in the honeycomb" appear all thru ancient history. Honey, aside from the sugar in fruit, was the only swcet then known, and hence was always highly prized. Bees were kept in caves, earthen jars, old logs, straw baskets or skeps. When man contrived the art of making boards out of trees he constructed rude boxes which werc called gums or hives. The skeps were made of braided straw, and these are still used to a considerable extent in Europe among the peasant classes who cannot afford modern equipments, and who lack, even more, the mental capacity to put into effect modern methods. See "Skeps."

The keeping of bees in the old days was but little more than an avocation or sideline in connection with some other business or profession. While the great majority of the beekeepers of today are probably amateurs or backlotters, those who keep a few bees for pleasure and profit, there are now thousands upon thousands who make beekeeping a vocation or business. Their colonies are numbered by the hundreds and even thousands, and their annual production of honey is measured by the ton and carload. While there were a few, both in Europe and America, who had as many as two or three hundred colonies, and produced honey by the ton, beekeeping as a specialty and as an exclusive business was scarcely known until after the advent of the movableframe hive of Langstroth and the honey-extractor of Hruschka. (See "Hives", and "Extractors.") These inventions revolutionized the industry to such an cxtent that it is now possible for the beekeeper to produce tons where he could produce only pounds before.

In addition to the specialist class of beekeepers there are many hundreds of thousands who lieep a few colonies in the back yard in cities and towns. There is also another large class, the farmer beekeepers, who keep a few colonies on the farm, not only for the purpose of pollinating their fruit trees, the clovers, and buckwheat, but to supply the family table with honey, the purest and best sweet in the world.

The time was when Moses Quinby, in the 50 's, and that was before the invention of the movable-frame hive by Langstroth, sent a canalboat-load of honey to the city of New York. 'This was more than the metropolis had ever' seen beforc-so much loney, indecd, that it "broke down the market," and the honey went begging for a customer. In these latter days that same market is able to dispose of hundreds and hundreds of carloads of hourey that have been shipped in from all over the United States, but mainly from the irrigated regions of the West.

A conservative estimate of the total number of persons who keep bees, either as a vocation or as an avocation, is 1,000,000 beekeepers in the United States alone.

On a very conservative estimate, based on United States statisties and on the records of sales of the largest bee-supply factories in the United States, 
there is at least $\$ 75,000,000$ worth of honey produced annually in the United States, and also about $\$ 3,000,000$ worth of beeswax. The business of keeping bees has grown to be so enormous that there are several large bee-supply manufacturers who send out carloads of hives and honey-boxes all over the United States and to foreign countries.

During the great World War, and especially during the years 1917 to 1919 . the production of honey was enormously increased. This was due to the fact that sugar was very scarce and high-priced much of the time, and rationed out to families in lots not exceeding two pounds. During this period also sugar was almost unobtainable in Europe.

It is a well-known fact that honey or sugar is a necessary element in food in the human dietary. When sugar was obtainable in only very small lots, the only substitute of any sweetening value and of good flavor was honey. The call was sent over the land to produce more food, and that, of course, included honey. Honey began to go to Europe by the shipload, and the price rose from 6,7 , and 8 cents in carlots for extracted, to 20, 22, and even 27 cents in New York; and when it arrived in Europe, the price was from $\$ 1.00$ to $\$ 2.00$ a pound in small bottles.

Not only the business of honey production was very greatly stimulated in the United States, but the price of bees rose from $\$ 5.00, \$ 6.00$, and $\$ 7.00$ per colony up to $\$ 15.00$ and $\$ 25.00$. The bee-supply factories were rushed almost day and night to keep up with orders. In the meantime the housewife was obliged in place of sugar to use honey, which she could buy in any quantity if she had the price-50 cents per pound in pound bottles.

After the war was over, prices naturally began to sag, so that they were soon down almost to a pre-war basis. But comb honey continued to be sold at its former price, retailing all the way from 40 to 50 cents a pound. The result of the late war was to introduce honey as a food into families where it had never been eaten before. It was also forced into the arts and trades, so that the future of the honey business is greater than ever. Of course it can not run at the high pace it did during the war.

Modern appliances and modern methods have now made it possible for specialists, backlotters, and farmers to handle bees with few or no stings; to take the honey away without destroying the hives, combs, or bees-indeed. they all alike find both pleasure and profit in the study and in the handling of these wonderful little inscets, that, in the language of the day, "work for nothing and board themselves." "While this is not literally true, of course, the little creatures will toil day in and day out and allow their owner to take the product of their toil before their very eys, and rob them day after day, without so much as offering a single sting, that is, provided, of course, their owner knows how. It is the province of this work to show "how" all these things can be done and are being done by many thousands scattered all over the United States.

The modern movable frame, as already mentioned, has made it possible for the owner of bees to go clear thru his hives, remove the combs, and inspect every portion of the hives and the bees. After learning their condition he can put the combs back, close the hive up, and, if he follows directions, he will probably receive no stings.

The bee-smuker (see "Smoke and Smokers") will quiet bees, and when necessary, and that is not often, drive them down thru the combs in utter confusion. In fact, smoke so diverts their attention from the thought of defense and offense that they become passive and tractable. While the smoker may be used as a means of control, it also in the hands of an ignorant or careless person may be used as all instrument of tortule. If instructions are followed there will be no 
need of causing any pain to the bees, much less of killing any by its use. See "Stings" and "Smole and Smokers."

The use of the bee-smoker and bee-veil to protect the face, and sometimes gloves for the hands of the more timid, has made it also possible for the owner to play with bees as he might with kittens; to rob them of their honey whenever he sees fit; to invade their homes; to take away their queen; to take everything they have, if he is so minded, without a protest and without a sting.

In this connection it would be unfair to imply that the modern beekeeper never receives any stings. He certainly does; but when he knows the modern methods that are taught in this work or any other standard book on bees, the bugaboo of stings fades away.

As a matter of fact the beekeeper receives comparatively few stings, and what he does get leave no after-effect in swelling, because his system soon becomes immune to the poison, and, beyond the sharp prick of pain which lasts for a full minute, there is no local.fever nor swelling.

Honey is being used as a food as it never was befole. (See "Honey," " Honey as a Food," "Extracted Honey,' and "Comb Honey.") Honey is now found in the best hotels and restaurants, on dining-cars of the great trunk line railroads, and in all leading groceries. It is now being put up attractively in comb and liquid form. Traveling men are out buying and selling it as a regular commodity. Sometimes they will contract for ten or even twenty carloads at a time. It is then repacked, put up in small paokages, and sold to the consuming trade, either direct or at the large wholesale or retail groceries. See "Bottling Honey.',

Some of the darker and stronger-flavored honeys are being used by the large baking concerns in making their cakes and cookies. Honey is an invert sugar, and as such it keeps the cakes, cookies, and jumbles soft and moist for months at a time. The cakes that contain the most honey are lsnown as "honey jumbles," some of which have kept for a period of twelve years, and were found to be still as good, almost, as the day they were made. See "Honey as a Food."

As a food, honey merits a rather unique position. In the first place, it is the only concentrated sweet found as such in Nature. Perhaps this very fact would lead one to expect that which dietitians tell us to be true: that honey does not burden the digestion like ordinary sugar. Altho honey is chiefiy invert sugar, it differs from the commercial product in several important respects. Among these might be mentioned the occurrence in honey of a variety of mineral elements, all of which are essential in proper nutrition. The amounts in which these elements are present are not negligible, as some have assumed. On the contrary, they are of considerable importance, especially when it is considered that no other commercial invert contains any available minerals worth mentioning.

It has also been determined that comb honey, at least, and probably extracted honey, contain vitamines so necessary to life. It is not known at this writing just how much extracted honey may contain; but Prof. Phillip B. Hawk, of the Jefferson Medical College, Philadelphia, the great food specialist and a contributor to scientific and popular journals on foods, shows that comb honey, at least, contains "distinct amounts of fat or soluble A" vitamines, and that a small amount may be present in extracted honey. For further particulars on vitamines in honey see "Vitamines in Honey," in the body of the work.

The question might be raised at this point whether there are not too many beekeepers already. The fact is, more nectar goes to waste than is gathered. It has been estimated that 75 per cent of it is lost simply because there are no bees in the vicinity to gather it. Dr. Phillips, Apicultural Expert of the De- 
partment of Agriculturc, in his book, 1915, "Beekeeping," ventures an estimate that ten times the present honey crop could be produced.

At least it would be conservative to say for the present time (1922) that the resources of this country could furnish $\$ 300,000,000$ worth of honey. If that much were produced next year the market would certainly be glutted. But cxperience shows that the increase in the number of beekeepers keeps at about an even pace with the increase in the number of honey consumers, so that by the time the bees produce $\$ 300,000,000$ worth of honey there will be a market for every pound.

The farmers of this country are just beginning to discover the value of sweet clover as a for"age plant for cattle and logs (see "Sweet Clover"). In many localities it is nearly if not quite the equal of alfalfa. This clover will grow on poor land, and restore poor soil as almost nothing else will do. The farm papers all over the country are already proclaiming the virtues of sweet alover. 'The experiment stations extol it everywhere. So far from being a "noxious weed," it is onc of the most valuable legumes ever known. Now, sweet clover is a honey plant-one of the best in this country.

Owing to the fact that many of the former clover soils are not growing (lover as they formerly did, the experiment stations of the country, as well as the general agricultural press, are advocating the use of lime in one and two ton lots to the acre. Where this has been applied there has been an enormous inclease in the production of all the clovers. Alsike clover, on account of the practice of liming the soil, is being introduced into localities where it has never been known before. So thoroly is the gospel of lime being disseminated over the country that the business of honey production, which had been largely dependent on the clover, is being enormously stimulated. See "Clover."

The work being done by the Bureau of Entomology, Washington, D. C., to stimulate apiculture in the United States, is beginning to have its effect. This, coupled with the work done by the various state experiment stations, and the extension men of the farm bureaus, is spreading not only the gospel of lime but also the gospel of honey production and the pollination of certain legumes and fruits.

We made the statement that something over $\$ 75,000,000$ worth of honey is: produced annually in the United States alone. If that were all the bees do in this country it would be a fine record. From an economic standpoint they do far more than this. There is no other agency in the world that does such perfect work in pollination - that is, bringing the pollen of one blossom to that of another-as the honeybees. There are countless thousands of them at a time of the year when comparatively few other insects are present. They therefore make it possible to produce more and better fruit. See "Fruit Blossoms," also "Pollination."

This in brief is a general survey of the industry. It will now be proper to refer the reader to the series of subjects which he should take up. Each will be found in its appropriate alphabetical order; and when these have been read, the readel can then take up the other subjects as he chooses. But it is suggested that, if he can possibly secure a colony of bees, he should do so in order that he may study them intelligently and apply the teachings of this book as he goes along. The following course of reading is recommended:

A B C of Beekeeping; Beginning with Bees; Anger of Bees ; Manipulation of Colonies: Apiary: Smoke and Smokers; Stings ; Hives: Transferring; Robbing; Feeding; Backlot Beekeeping; Swarming; Extracting: Comb Honev : Spring Management: Uniting; Wintering. The other subjects may be taken up in any order that may seem best.

E. R. ROOT. 


\section{A}

A B C OF BEEKEEPING. - In this preliminary article it will be assumed that the reader knows nothing about bees or beekeeping except that "they sting, and are ready to sting anywhere at any time any one who approaches within a hundred yards of their hive." By reading this article and the one on Strugas it will be seen that nothing could be further from the tr'uth.

$\Lambda$ the rery outset it is important that a general bird's-eye view be taken of the whole industry; and to do this it will be necessary to make a brief summary of the contents of this work. The reader, having a comprehensive view of the business, the ways and means and wherefores, will then be able to take up specifically a course of reading as suggester at the close of the Foreword.

There are two different kinds of beessolitary bees (see Solitary Bees) and social bees, those that live in colonies or communities. There are many species of both kinds; but for the purpose of this work we shall concern ourselves with the social bees and mainly the species known as Apis mellifica, or "honey-makers." same organs in the only true female, known as the "queen." See Polilen.

A colony of bees may contain anywhere from 25,000 to 75,000 individuals, and in rare cases as high as 100,000 , all the daughters of one queen bee. But the average good colony for producing honey will run anywhere from 50,000 to 75,000 workers. During the winter this number will be reduced less than half; for Nature apparently goes on the assumption that it is wise not to produce a lot of unnecessary consumers for winter.

The duties of the worker bees are quite varied. Primarily their business is to gather nectar or sucrose, and by some chemical process, which no one seems to understand fully, change it into invert sugar or loney. Since they gather nectar and make it over into honey, it is scientifically accurate to say that bees "make honey."

Bees also gather pollen from the flowers, and store it in combs the same as they store honey. The pollen and honey are used for making a milky-white nitrogenous food to feed the larvæ of baby bees. This food is very much like thin condensed milk. As the larvæ develop, this same food
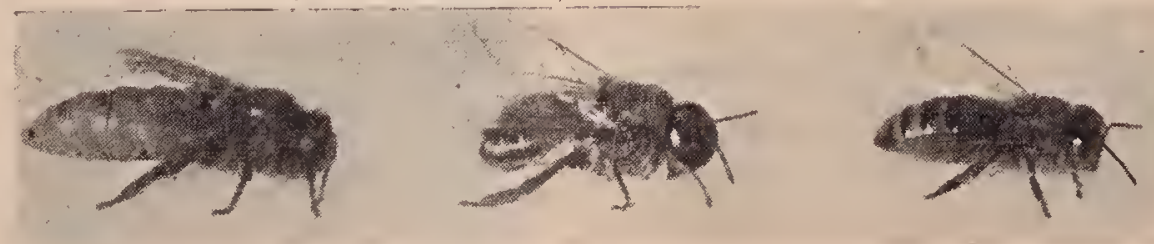

Queen, drone and worker bee in order from left to right.

There are three classes of individuals in each colony-namely, the queen bee or true female, the drones, and the workers, or neuter bees as some call them, but more correctly undeveloped females. Each worker bee is functionally the same as the queen bee except that lier tongue, mouth parts, pollen-gathering bristles on the legs, and the sting are more fully developed than the or. "pap" is made richer and stronger. See Development of Bees.

Bees also gather a kind of glue for making up what is called bee glue, or propolis. This is used to seal up all eracks that might let cold air into the hive. The word "propolis" is derived from two Greek wordspro, meaning in front, and polis, a city. In ancient times, especially with some strains 
of Apis mellifica, the bees used this substance in front of the hive to contract the entrance in order to keep out other insects and rodents, hence the name, in front of the city, or propolis.

Worker bees naturally fall into two divisions-young bees for taking care of young brood, building comb, protecting the entrance against robbers, and in other ways performing the inside work of the hive. The older bees, or "fielders," are those that gather the nectar, pollen, and bee glue. When there are few or no young bees the older ones can and do assume the duties of nurse bees. See Brood.

The fully developed, or true female, is what is called the "queen." As already stated, she functionally is much the same as the workers with this difference: Her mouth parts, pollen-gathering apparatus, as well as her sting, are atrophied or aborted, while her ovaries are highly developed. She is capable of laying as many as 5,000 eggs in a day, but usually 3,000 is the limit. During the height of the season she will not average, probably, over 1,000 eggs a day. At the close of the active season her: egg-laying diminishes greatly, sometimes stoppingaltogether. This sems to be a wise provision in nature to prevent the rearing of a lot of useless consumers that would simply use up all the stores before winter comes on. Along in the fall, if there should be a fall flow, egg-laying will start again. and a lot of young bees will be reared to make up a colony that will go into winter quarters. The bees that gather the crop during an active honey season very seldom. if ever, live to go into winter quarters. The fruit of their toil goes to their successors.

Only one queen bee, under normal conditions, is allowed in the hive at a time. The worker bees, apparently, are willing to tolerate one or more queens; but evidently the queens themselves are jealous of each other, and, when they meet, a mortal combat follows, during which one of them receives a fatal sting. The reigning queen bee, then, is often the survival of the fittest. Sometimes mother and daughter will get along very nicely together and perhaps even winter together, but usually along toward fall the mother disappears. Whether the daughter helps to make away with her, whether she dies of old age, or whether the bees take a hand in the matter, is not known.

The average queen bee will remain the mother of a colony for from two to three years. She may live to be as old as five or six years, but these cases are very rare.

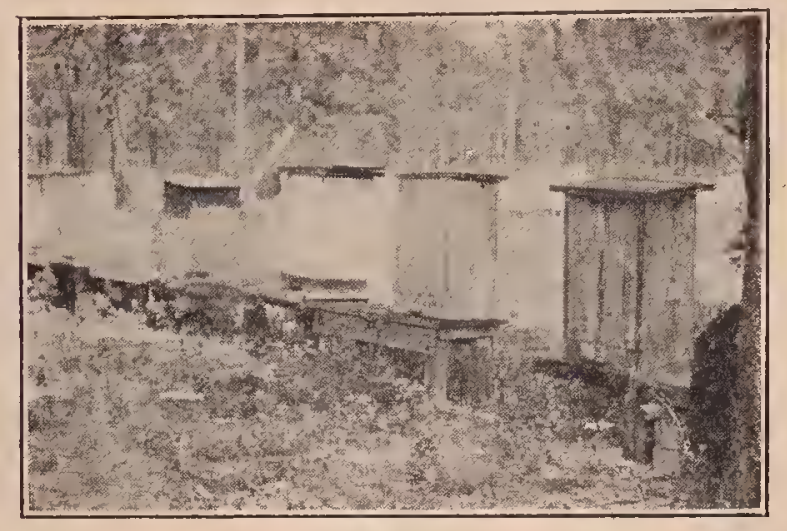

A typical box-hive apiary such as is to be seen all orer the Southland.

Usually a queen over two year's old is not worth much, and most of our best beekeepers believe that a queen over a year should be replaced by a younger one. See AGE OF BEES.

The other individuals in the hive are male bees or drones. Their mouth parts and pollen-gathering apparatus are all ver'y much aborted, and they have no sting. They are completely at the mercy of their sisters, and their only function is to mate the queen bee. This act takes place in the air, for apparently Nature has designed to prevent in-breeding. After the main honey

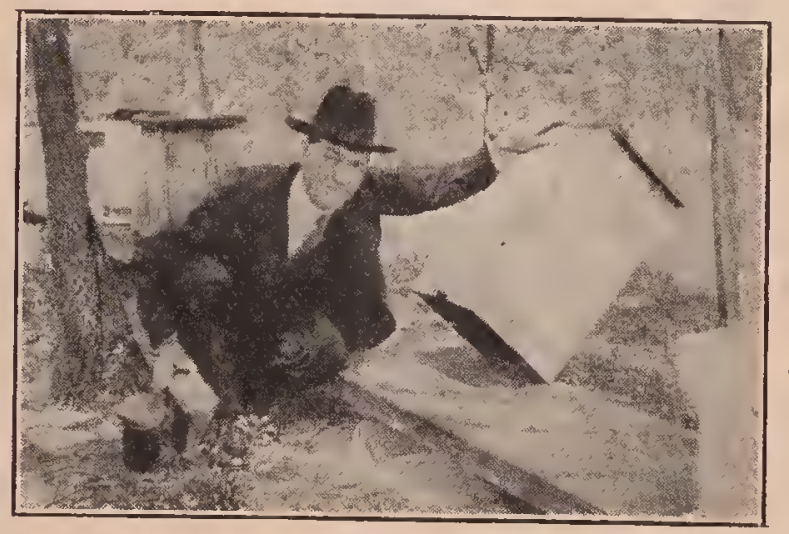

Tipping up the hives in a box-hire apiary, one after another, and looking "up under" to learn their condition. This is all the "inspection" with box hives.

flow is over, the drones are rudely pushed out at the entrance by their sisters, where they soon starve to death. See Drones.

The average young queen, when she sallies forth in the air on her wedding trip, may or may not find her consort from the 
same hive, but the probabilities are she will find one from some other hive. As soon as the act of copulation has taken place the two whirl around in the air until they drop, when the queen tears herself loose, carrying with her the drone organs, after which the drone dies. Soon after she enters her hive the drone organs are removed by the worker bees, but the spermatic fluid is retained in the spermatheca, where a supply sufficient to last the rest of her life is held. The queen is from that time on able to lay fertilized eggs that will produce worker bees, and infertile eggs that produce only drones. See Bees and Dzierzon THEORY.

The same egg that produces a worker bee, strangely enough, will also produce a queen bee. The question of whether an egg shall be developed into a queen or an ordinary worker depends entirely on conditions. If. the bees desire to rajse a queen, or several of them, they will build one or more large cells, and feed the baby grubs a special food. (See Queens and Queen-Rearing.) In 16 days a perfect queen will emerge: while in the case of a worker, fed on a coarse food in small cells, 21 days elapse. Such, in brief, is a statement concerning the inmates of the hive and their duties.

Before proceeding any further it will be proper to say something about the house or hive. In doing this the old box hive of our forefathers will be shown, working up to the modern hive which has made it possible to handle bees with such infinite pleasure and profit.

THE OLD WAY OF KEEPING BEES.

The old primitive box hive of our grandfathers, consisting of a rude box (hence the name), was 12 or 15 inches square, and from two to three feet deep. Thru the center were secured two cross-cleats at right angles to each other, to help support the combs. (See Box Hives.) This box hive standing on a board or slab usually had a notch at the bottom in front, to provide an entrance and exit for the bees. The bees, when building their combs in such a hive, fastened them to the sides and ends over and around the cross-cleats before mentioned. The combs, when so built, would, of course, permit of no examination nor handling, as do the modern hives; and when it was desired to take the honey, the bees of the heaviest hives in the fall were brimstoned, while those of the lightest were allowed to live over until the next season, to provide for swarms to replace those brim-

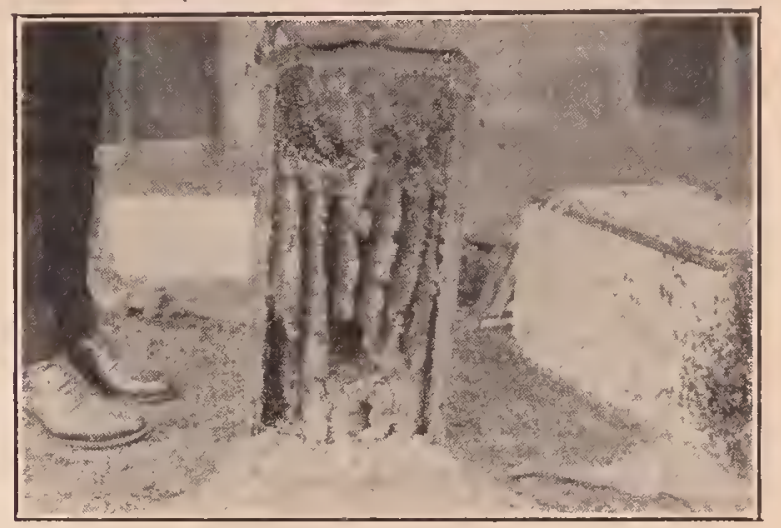

The "inards" of a box hive after the bees have been drummed out. Notice how immovable the combs are.

stoned. The honey taken from box hives was mixed with beebread and brood, and was of inferior quality. The combs were cut out of the hive and dumped into buckets to be used as necessity requirer.

The modern hive has long since elimin-

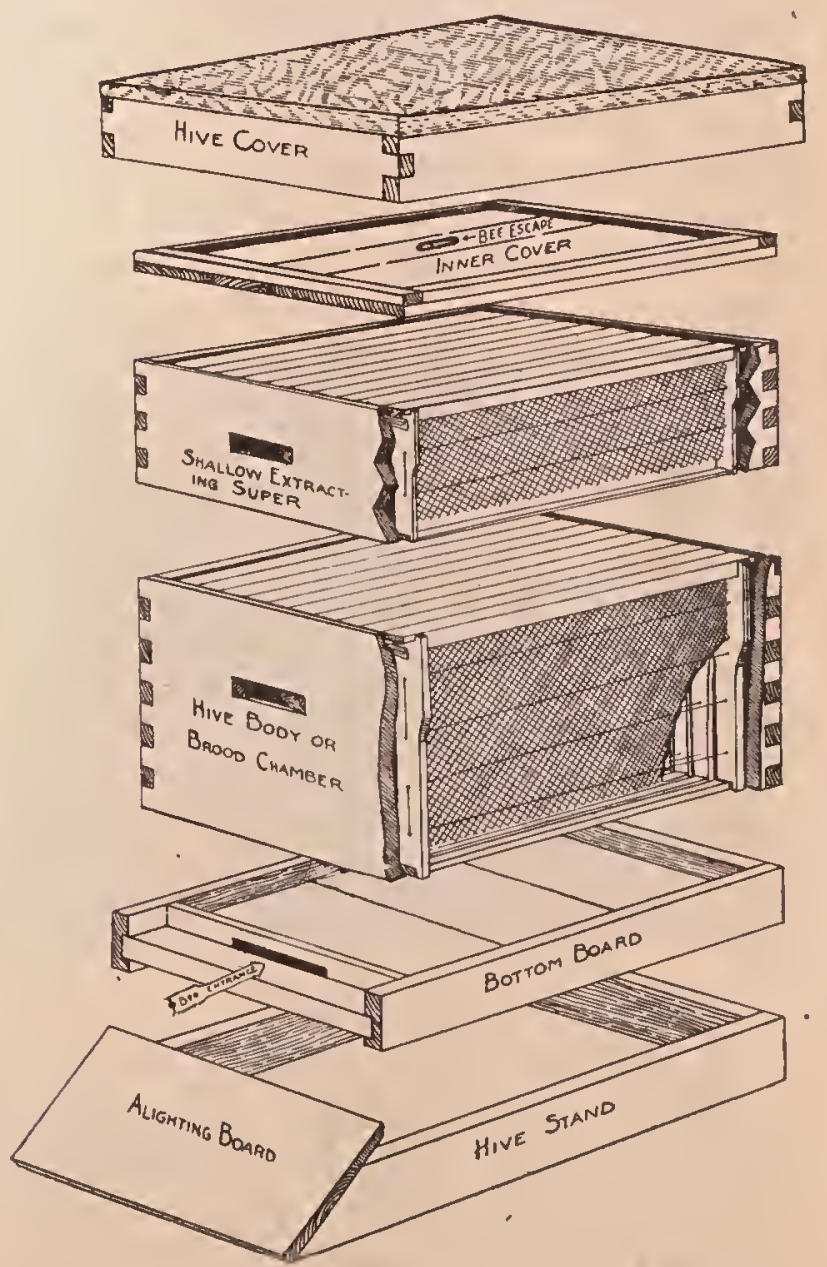

Modern Hive with Hoffman frames for production of extracted honey. Between super and hive body should be a queon-excluder. (Deop extracting super identical with hive body may be substituted for shallow extracting guper.) 
ated these crude and cruel methorls, and in their stead there is accessibility to every part; and, so far from destroying the little servants, one can take their honey without a sting if directions are followed. Every comb is now built in movable frames that permit of easy examination. (See Frames.) One can open the hive and remove the frames, playing with the bees by the hour if he knows how. There is no more alluring pastime for the business or professional man or the housewife than the keeping' of bees. They all say it's just fun, and it's "fun" that makes money. See BAckLOT Beekeeping.

THE MODERN HIVE FOR THE PRODUCTION OF COMB AND EXTRACTED HONEY.

The modern hive, or exterior housing, in its simplest form consists of a floor or bottom-board; a hive body (box without cover or bottom) to hold the frames or racks to contain the combs; supers (shallow box rims) to hold section-holders for the sections or extracting frames for extracted honey; a thin wooden lid, or "super cover," and over the whole a "telescope cover," as shown, to shield the hive from the weather. In addition there is an entrance-contracting cleat that can be removed so that a wide or narrow entrance may be used, depending on the season. In the best-regulated apiaries, hive-stands are used for holding the hives. These protect the bottom and hive proper from unnecessary exposure to the ground and rot, and at the same time provide an easy grade or alighting-board for the convenience of heavily laden bees as they come in from the field.

Eacl of the hive parts here enumerated is separable. One part can be piled on top of another in such a way as to accommodate the largest colonies and the largest yields of honey that may be secured.

\section{BROOD-FRAMES.}

Movable frames to hold the combs are called "brood-frames." The tops of these have projections resting upon rabbets cut in the upper ends of the hive. (See acrompanying. illustrations.) The end bars of the frames have, near the top, projecting ends just wide enough so that the combs will be spaced the correct distance apart.
Such self-spacing frames for holding the combs are called "Hoffman brood-frames," and any one of them can be removed and replaced. A set of frames of the same pattern, but shallower, is sometimes used. Any hive containing a set of frames in which there is brood (unhatched bees) is called a brood-chamber. A hive containing a set of

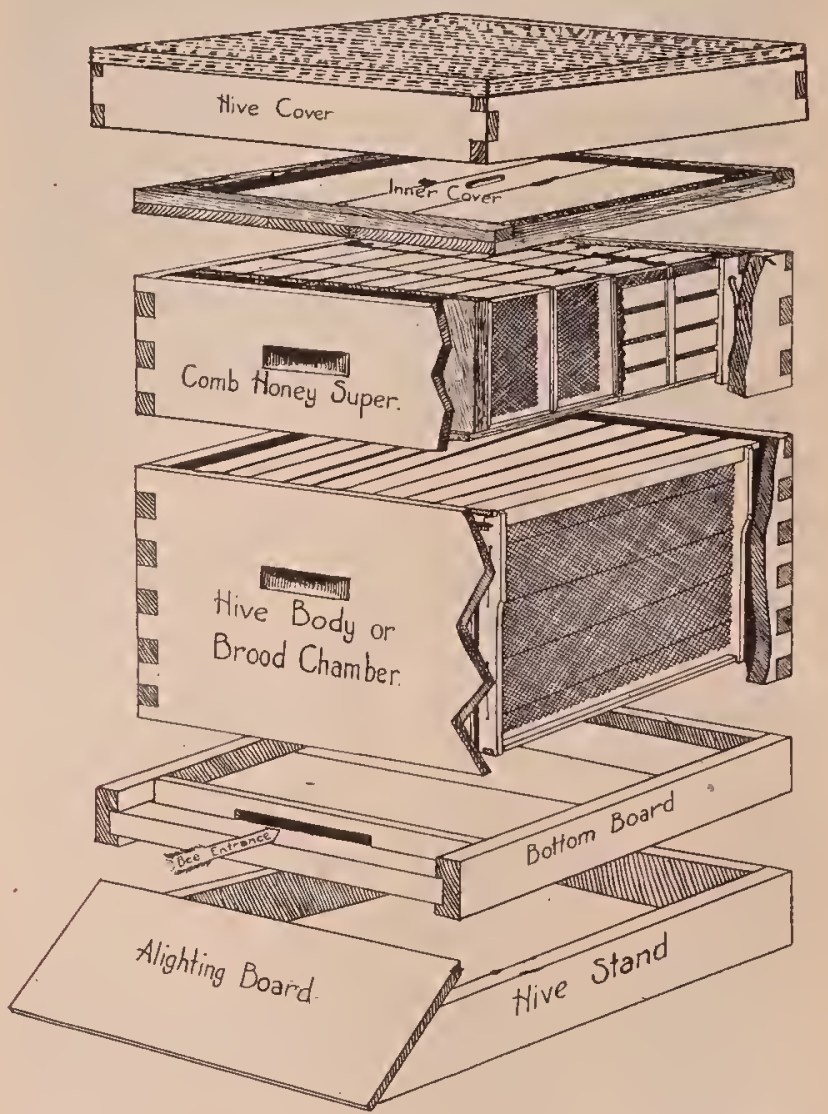

Modern Hive with Hoffman frames for the produc. tion of coub honey. (Any style of comb-honey super may be used.

frames used for the storage of surplus honey is called a "super." Brood-chamber's are generally deep, but the supers may be either deep or shallow. The honey may be removed by cutting the combs from the frames in the supers and storing them in tin cans, or it may be "extracted" from the frames of combs by means of a honeyextractor. The honey so taken is called extracted honey. See Extracting.

Every comb has a series of honey cells on each side, which, when filled with honey, are capped over with a thin film of wax. This capping is sliced off with a sharp-bladed knife made for the purpose, called an "uncapping-knife." The combs, with the cappings removed, are then placed in the baskets, or wire pockets, of a centrifugal honey-extractor. These baskets, fastened in multiples of two or more in a reel, are 
geared to run at a relatively high rate of speed inside of a metal can. The honey is thrown out by centrifugal force from the side of the comb next to the can. The ma-

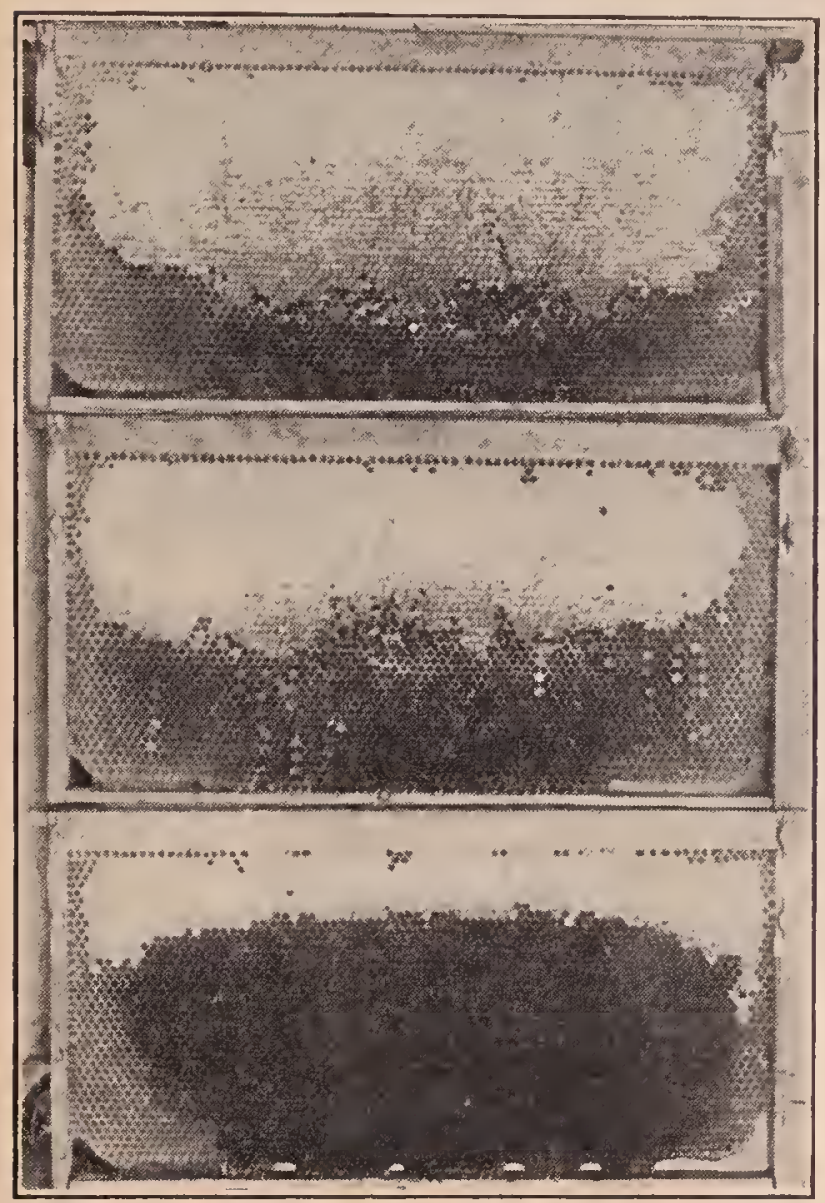

Combs one-fourth, one-half. and three-fourths capped. The uppermost is fit for extracting after sharing off the caprings as shown by the part in white.

chine is stopped; the combs are reversed, when the reel is started revolving, throwing the honey out from the other side also. When emptied the combs are put back into the hive and refilled with honey, after which they are again extracted as before. This process may be repeated one or more times during the season, or as long as the honey flow lasts.

Extracted honey can be produced for less money than that in the comb, because the empty combs can be used over and orer again, year after year. As the bees consume at least 5 to 10 pounds of honey to make a pound of wax, the extracted honey. or honey separated from the comb, saves making comb each time. As a matter of fact, before the Great War the market price for extracted was bit a little more than half that of romb honey.
SECIIONS AND SEPARATORS AS USFN IN CONBHONEY PRODUCTION.

The production of loney in the comb requires a different set of fixtures. Comb honey is produced in little square boxes technically called "sections." These are usually either $4 \times 5 \times 13 / 8$ inches wide, or $41 / 4$ square by $17 / 8$ wide. These sections. four in number, are placed in a sort of frame called a "section-holder." Between each two rows of sections, when placed on the hive, is a wooden separator consisting of a thin piece of veneer wood a little narrower than the section is deep. Sometimes a series of thin slats, fastened together by cross-cleats, are used in place of separators. Technically these are called fences. The function of the separator or fence is to separate the rows of sections from each other. Without them the bees would build the comb in these sections too fat or too lean. So far as possible it is highly important, from the marketing point of view, to have each comb in each section approximately the same weight-sometling between 12 and 14 ounces. While the sections, including the wood, will hold an even pound when filled entirely full, it is rery seldom that the producer of comb honey can get his bees to make his sections run uniformly one pound in weight. The aver-

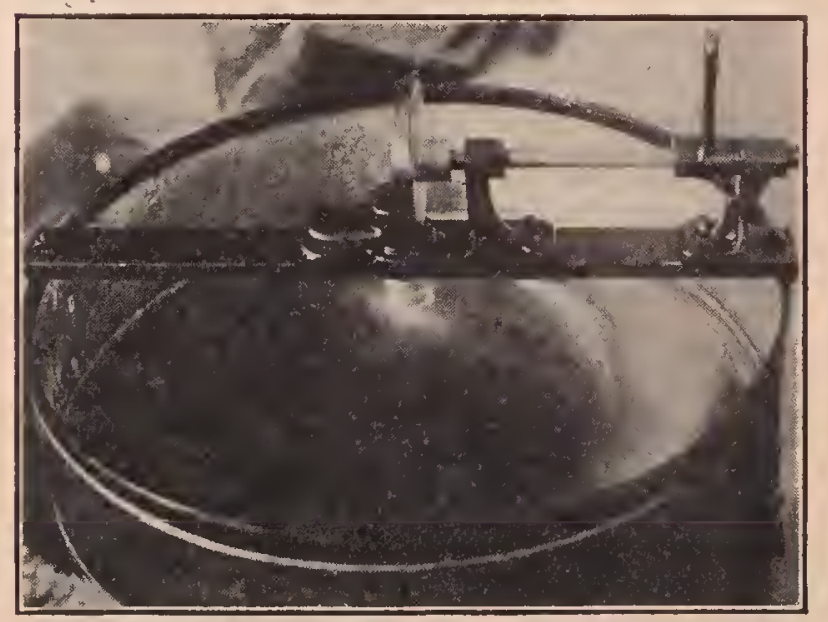

The honey is thrown out of the comb by centrifugal force

age market permits and expects that combhoney sections will run slightly less than one pound. See Comb Honey.

\section{COMB FOUNDATION.}

In order to start the bees building their combs centrally in the section or brood- 


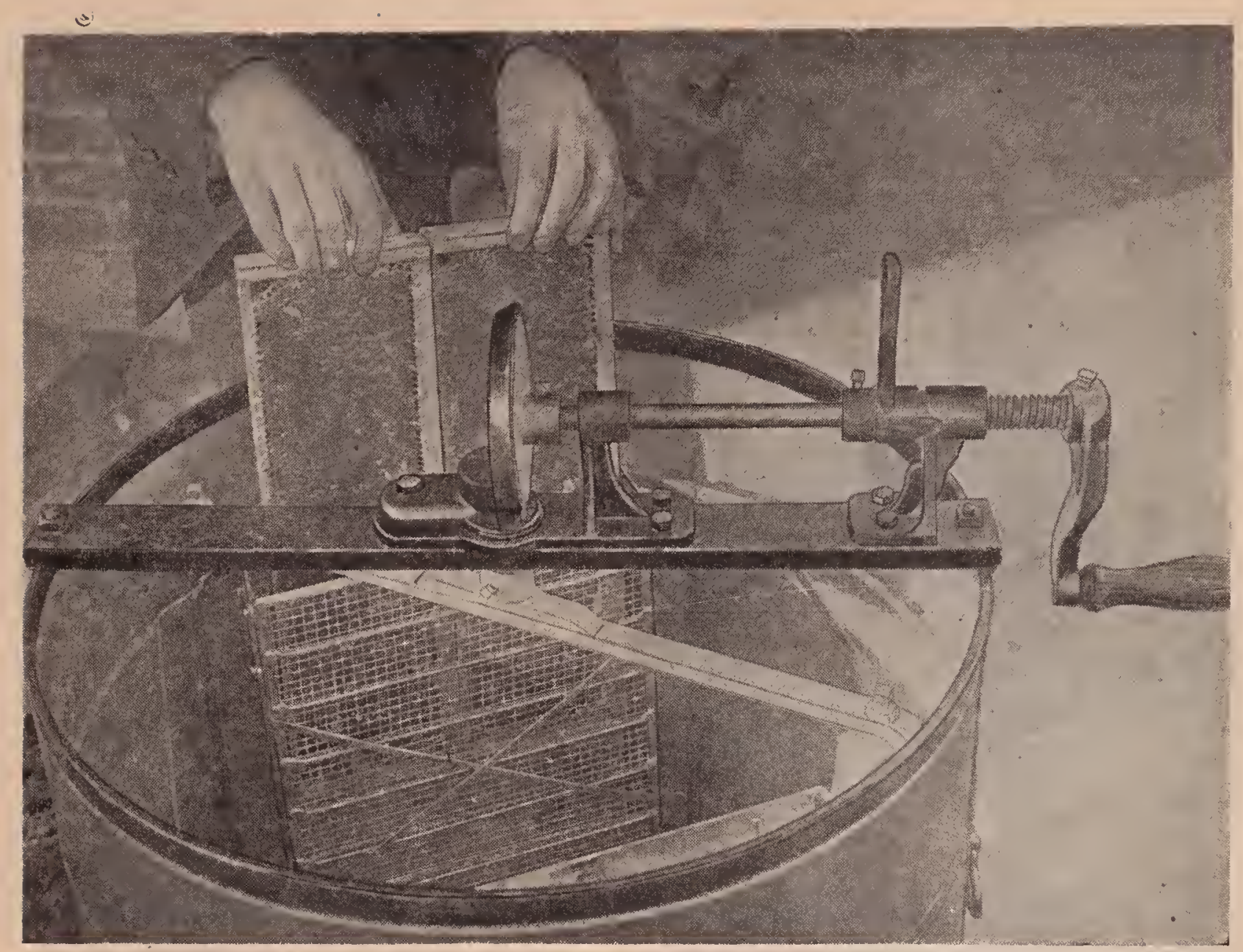

The: uncapper rombs heing lowered into a honey-extractor.

frames, a product known as "comb foundation" (quite generally abbreviated "fdn.") is used. This consists of a thin sheet or sheets of pure beeswax embossed or favosed, so that the surface shall be an exact duplicate of the midrib or center of the honeycomb with the cells sliced off. In other words, comb foundation is a duplicate of the foundation of the natural comb, and hence the name. The artificial product has more wax in the initial cells than the natural product. This surplus is used by the bees in building out their combs.

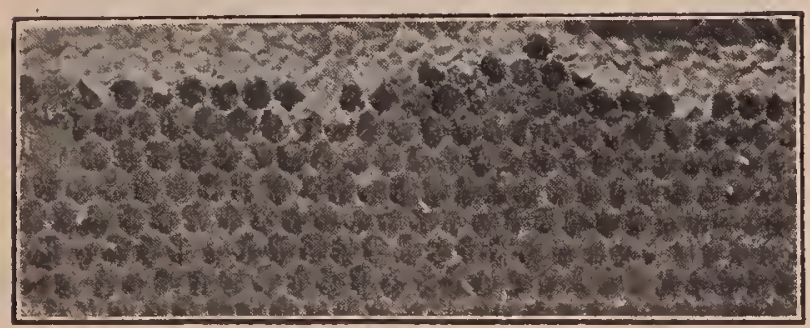

The empty comb after extracting may be put back and refilled by the bees.

In moder'n apiculture foundation is almost an indispensable article. It is used either in narrow strips called "foundation starters," or in full sheets. The latter are preferable, because the bees will build more nearly perfect combs-combs that are flat as a board and a duplicate of the article

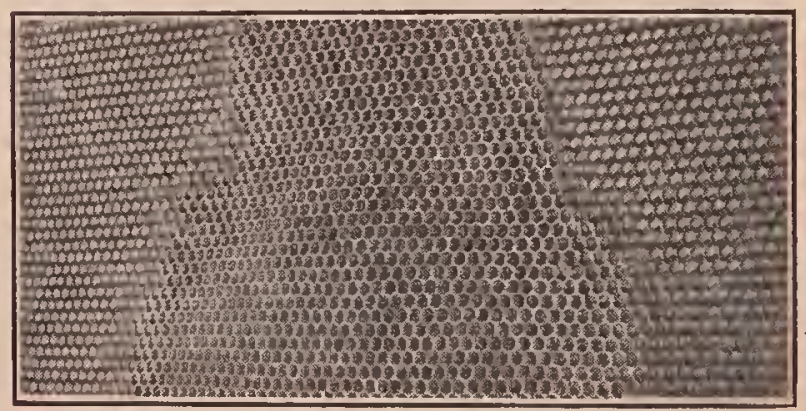

Comb foundation, which the bees have started to draw ont in the center.

built wholly by the bees. Without comb foundation the bees will show a tendency to build their own product in all kinds of fantastic shapes, crosswise of the section honey-boxes or the brood-frames. Practically all the combs in modern apiculture today are built on comb foundation. This is filled with honey by the bees, and cap- 
ped over, and in all respects is equal and even superior to that made by the bees without the use of starters. See Comb Foundation.

\section{TOOLS FOR HANDLING BEES.}

The tools required by a beekeeper for opening his hives and doing other necessary "rork in the production of honey are not, elaborate. The total outlay need not exceed $\$ 5.00$. First and foremost, there must be a bee-smolier - a device consisting of a stove and bellows for blowing smoke from some slow-burning fuel on the bees. Without smoke, many manipulations would be very difficult; and the novice, at least, would be inclined to give up the business after his first experience in trying to handle a colony of bees, especially if weather conditions were unfavorable. But with smoke, and an instrument for applying it, one can, if he knows how, perform all possible manipulations with bees when weather conditions are right. In fact, a large number of beekeepers, except during a time when the weather is bad, do not use a veil, gloves, nor any suecial protection except the smoker, as an intelligent use of the latter will often put the bees on their good behavior, to such an extent that the use of

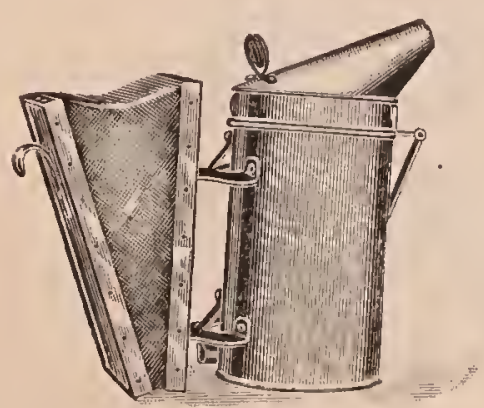

Bee-smoker.

other protectors is rendered useless. Perhaps a majority of honey-producers work with a veil on the hat, but not drawn down except when an angry bee seems disposed to show fight.

The other tool, if it may be so regarded. is designed for face protection. This may be in the form of a wire-cloth cylinder witl suitable cape to protect the neck and shoulder's, or it may be made of some sort of netting, preferably black, so as to obscure the vision as little as possible. The higherpriced veils of silk Brussels netting offer practically no obstruction to the eyes, and at the same time give the wearer a sense of security that he cannot otherwise have.

Some beekeeper's wishing to get thru witl as large an amount of work as possible, and knowing that rapid manipulation

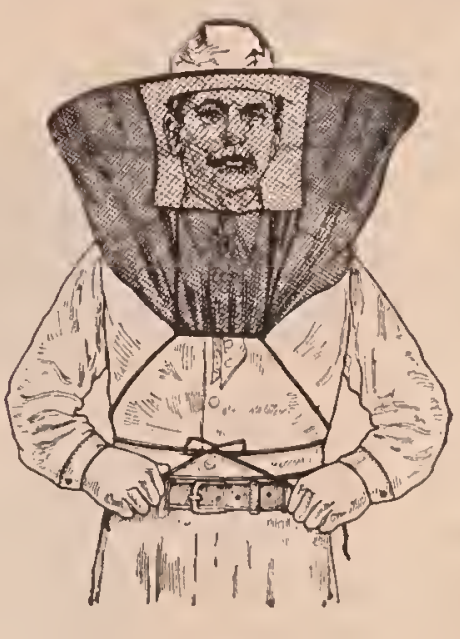

Bee-reil.

has a tendency, in spite of smoke, to make bees sting, wear both bee-reil and gloves; and a few of the careless bunglers go so far as to wear cowhide boots in addition, tucking the trousers into the boots. Good bee-

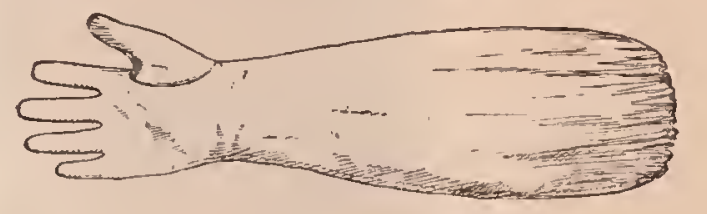

Bee-gloves with fingers.

lieepers do not approve of such bungling, slam-bang methods, that only irritate the bees. One will accomplish as much or more in a day, provided he works cautiously and deliberately, using headwork to save making a multiplicity of quick moves. A few slow movements carefully planned will alccomplish much with bees.

Almost the only other tool required is a strong screwdriver, a knife witl a good stiff blade, or, better still, a specially construeted hive-tool made of spring steel with a

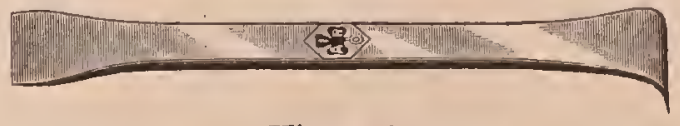

Hive-tool.

broad, blade for the purpose of a pry or scraper. A tool of some sort is indispensable for separating the frames and the parts of a hive, because the bees make use of what is known as bee glue, cementing the frames together. In warin or hot weather this bee glue does not cause as much trouble 
in handling the hives as during cold weather, when it is stiff and hard. Ordinarily bees should not be handled at such times.

One more tool is sometimes used, and that is a swarming-box or a swarm-basket. A wire basket is mounted on the end of a long pole so that a majority of the bees can be reached and captured from the ground. If the wings of the queens are clipped, as explained under QueENs and Swarming, no such appliance is needed except in instances when a second swarm comes off with a virgin queen.

MANIPULATING A COLONY OF BEES.

Having considered the inmates of a hive, the hive itself, and the sereral parts and the tools for manipulating the same, it is now in order to take up the manipulation of the hive, or the handling of a colony of bees.

The average beginner at this point may feel that he has a job on his hands. $\mathrm{He}$
After having lighted his smoker (see SMokers), he should put on his veil and gloves and approach his hive. He should be sure that the smoker delivers a good smoke. The best fuel is old rags or greasy waste, which can be had for the asking at almost any machine shop. The smoke of this is not pungent, but is a bluish white and quite opaque. This can be easily ignited with a mateh. Work the bellows until a good volume of smoke is secured. Care should be taken not to work the smoker bellows too hard, as otherwise the inel will burst into flame.

With the smoker just right, blow a light puff of smoke into the entrance. Too much smoke will start the bees on a stam-pede, especially if they are blacks or hybrids. While bees will not sting in this condition, it renders subsequent manipulation exceedingly difficult.

The next movement is to take the serewdriver or hive-tool and pry the cover up

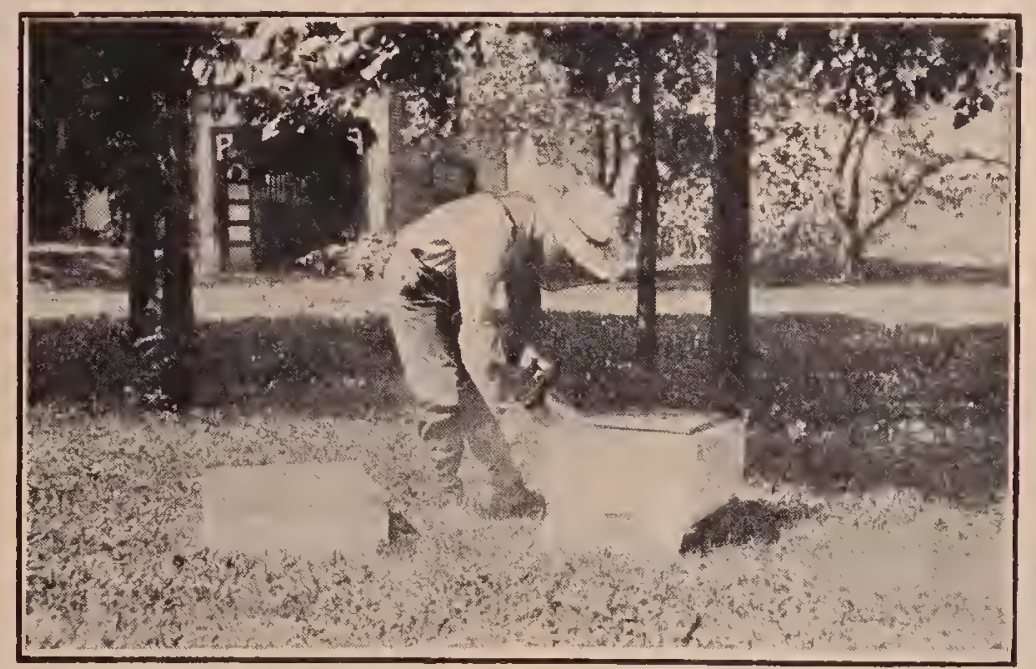

Smoking thru a narrow gap under inner cover.

may get stung, when his face will be disfigured so that he will not be presentable to company. While it is not denied that he may get stung, the one who tries for the first time to handle bees should protect his hands with gloves and his face with a veil, not because they are essential, but because it will take away that feeling of fear that might cause him to make a false move and thus incite the bees to sting.

If he will follow the directions that are now given, he should not receive a single sting even in his clothing. First of all, it is important that the beginner select a warm day, between ten and tliree o'clock. about a sixteenth of an inch-not wider, because the bees would escape. Thru the gap so made between the cover and the hive itself two puffs of smoke should be blown. Next, the cover should be gently lifted, the movement being followed with perhaps two or three light puffs of smoke. It is just as important not to use too much smoke as not enough.

One may now proceed to lift out individual frames. If they are stuck together on account of the bee glue, a little smoke may be required to follow each operation in separating the frames; but usually the smoker can be set down alongside the hive, 


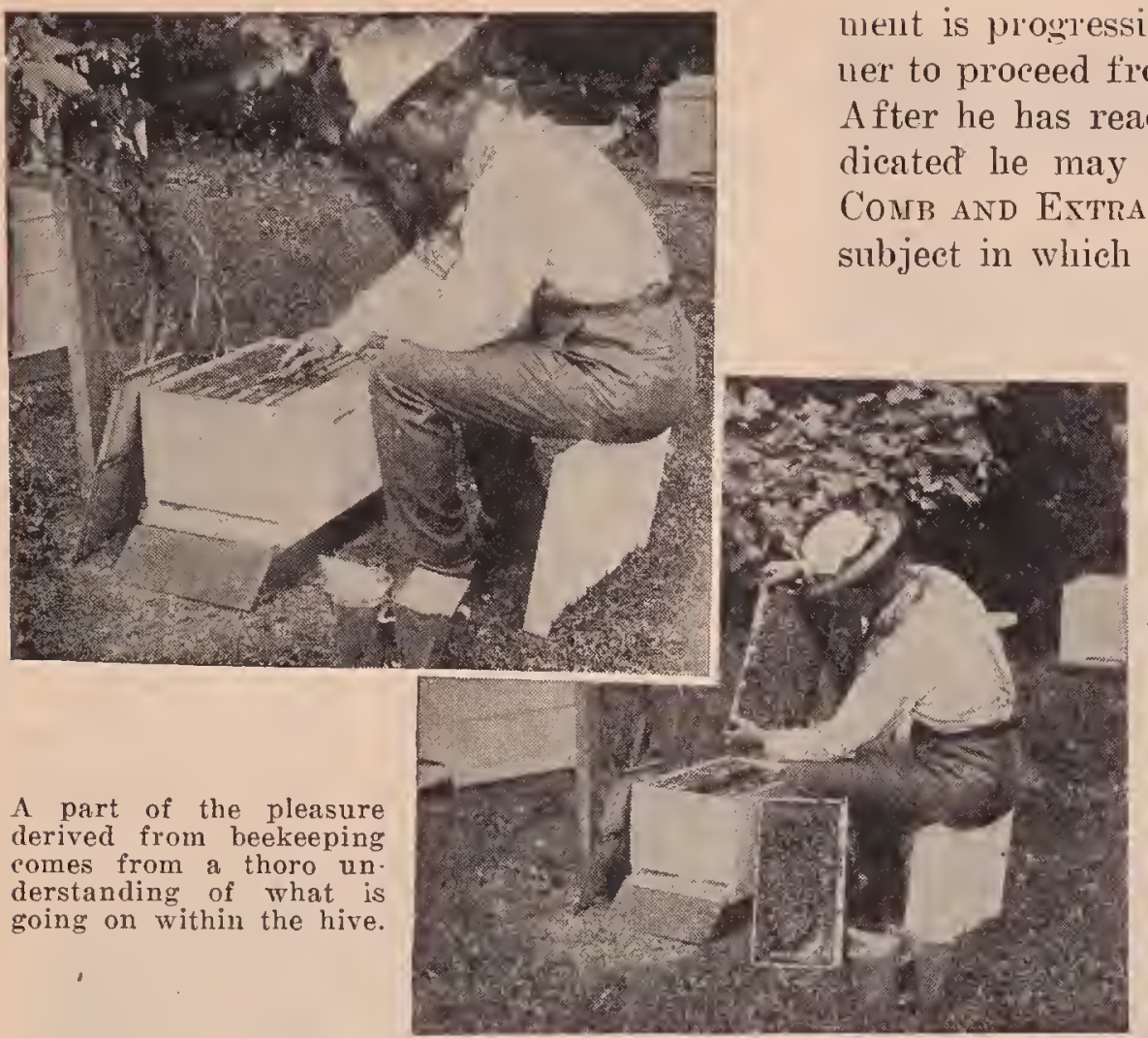

ment is progressire, and enables the beginner to proceed from one subject to another. After he has read the subjects already indicated lie may take up QUEEN-REARING, Comb and ExTracted Honey, or any other subject in which he may be interested.

A B N O R M A L ITIES OF BEES.--See Hermaphrontte BeEs: a lso "D rones with Heads of Different Colors," under Drones.

\section{A B S C O N D I N G} SWARMS.-No p a r t of animated creation exhibits a greater love of home than do the honeybees. No matter how luumble or uninviting the surroundings they seem very much attached to their

and frame after frame be lifted out witlout receiving a single sting.

Care should be taken not to pinch any bees. The fingers should always be placed at some point where there are no bees. If they are very numerous, they should be gently brushed over to one side by pushing the fingers down between them, being careful not to pinch them in doing it.

$\Delta$ fter one has opened a hive a few times he will be able to discard the gloves, and later he can dispense with the veil at times, becanse he will find that an intelligent use of the smoker will do more to eliminate stings than any other one thing. After one has acquired a sense of freedom and knows the bees will not sting. he can work over them for hours at a time, getting more real joy out of his pets than from anvthing else on the place. See MaxipuIATTON OF COLONIES.

Before the reader proceeds further he should read very carefully the following subjects, found in their alphabetical order, viz., Beginning with Bees. ManipulaTION of Colonies, Brood and Brood-Rearing, Anger of Befs, Stings, Smoke ant, Syokers, Aptary, Backlot Befkeeping, Farmer Beereeping, Hives, 'T'ransfermang, Robitag, Uniting, and Wintering. This order is suggested because the arrange- home; and, as they parade in front of their doorway after a hard day's work, they plainly indicate that they have a keen idea of the rights of ownership and exhibit a willingness to give their lives freely, if need be, in defense of their hard-earned stores. It is difficult to understand how they can ever be willing to abandon it altogether, and with such a sudden impulse and common consent. No matter if they have never seen or lieard of such a thing as a hollow tree, and have for innumerable bee generations been domesticated in hives made by human hands, none the less they have that instinctive longing that prompts them to seek the forest or rocks in mountainous country as soon as ther get loose from the chains of civilizer man.

It is very unusual for a swarm to wo to the roods without clustering: the bees usually hang from i.j minutes to an ho'u, and many times several hours; in fact, we lare known them to hang over night, anrl sometimes stay and build comb; but nsually it is better to take care of them inside of 15 or 20 minutes to make sure of them. Long before swarming tima hives should all be in readiness, and they should also be located near where the new colony is to stand. If one is going to have 


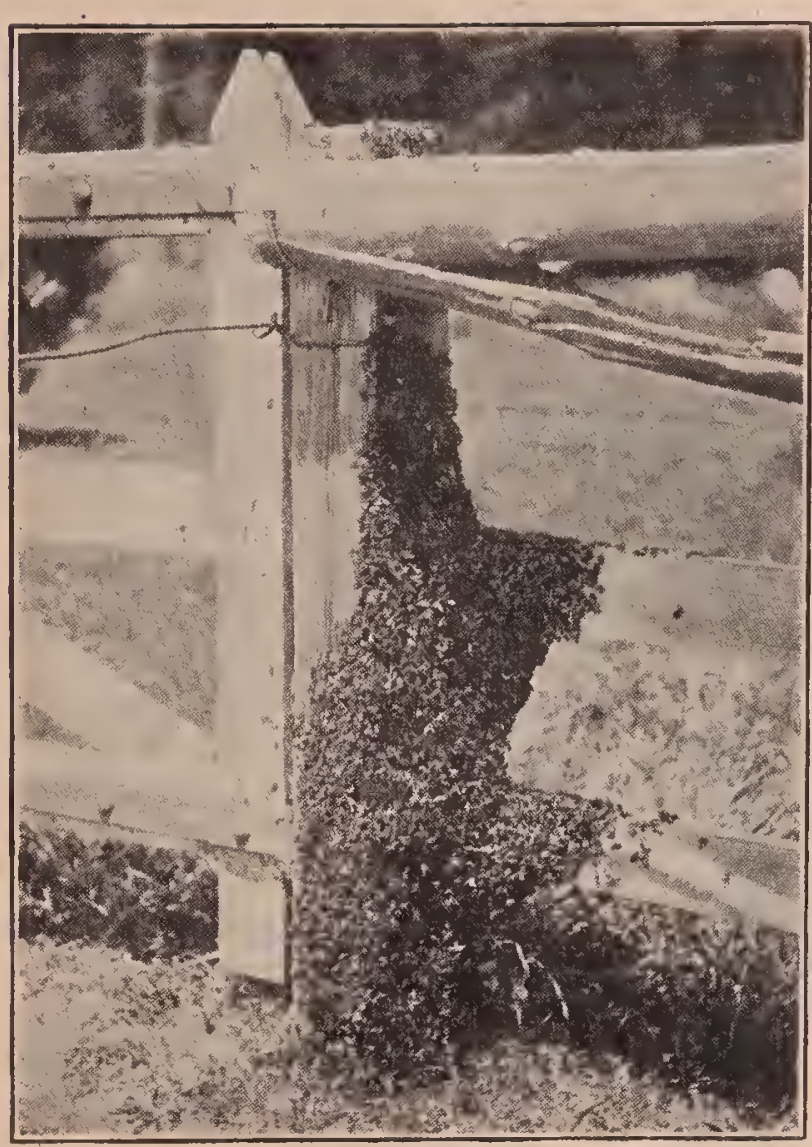

As a rule, a swarm will cluster on a limb of a tree or a bush. In a few cases, they will clustel $n \mathrm{n}$ the ground and in the grass. In rare cases. they will alight on a fence, as here shown.

a model apiary, he should not think of waiting until the bees swarm before he lays it out, but take time by the forelock, and with careful deliberation decide where every hive shall be before it is stocked with bees. if he would keep ahead and prevent his hees from taking "French leave."

But they sometimes leave, even after they have been carefully hived in modern hives on frames of foundation. If the swarming mania gets under way in a beeyard, a swarm is more apt to come out the second time, even when hived in a new location in a different hive, than where there is only a very little swarming. It was once thought that giving a frame of unsealed brood to these second-time absconders would hold them. While this, no doubt, acts as a restrainer, yet when a swarm leaves its new quarters it should be recaptured. hived back into the hive, and then carried down cellar, where it should be kept several days until it gets over its mania. The bees may then be set out on their permanent summer stands.

How is one to aroid losing the occasion- al swarm that goes off without clustering at all? or the quite frequent cases of coming out unobserved, or when no one is at home? There is a very certain and safe remedy for all cases of first swarming, in having the wings of the queen clipped, or using an Alley trap so she cannot fly. (See QueEns, subhead "How to Clip the Queen's Wings.") Wing-clipping is in very general use, and answers excellently for all first swarms; but, alas! the after-swarms are the very ones that are most apt to abscond, and the wings of their queens cannot be clipped, nor should such queens be restrained by an Alley trap, because they-have not yet taken their wedding flight. What shall be done? In the first place, second or after-swarms should not be allowed. If the parent hive, after it has cast its first swarm, is treated as recommended under the head of AFTER-SWARMing, there will be no further swarming from that colony for that season. The Heddon method, given at the close of AFTER-SWARMING, is recommended for the prevention of after-swarms.

Clipping the wings of the queen (or putting on drone-traps - see Drones) will prevent losing first swarms by ahsconding;

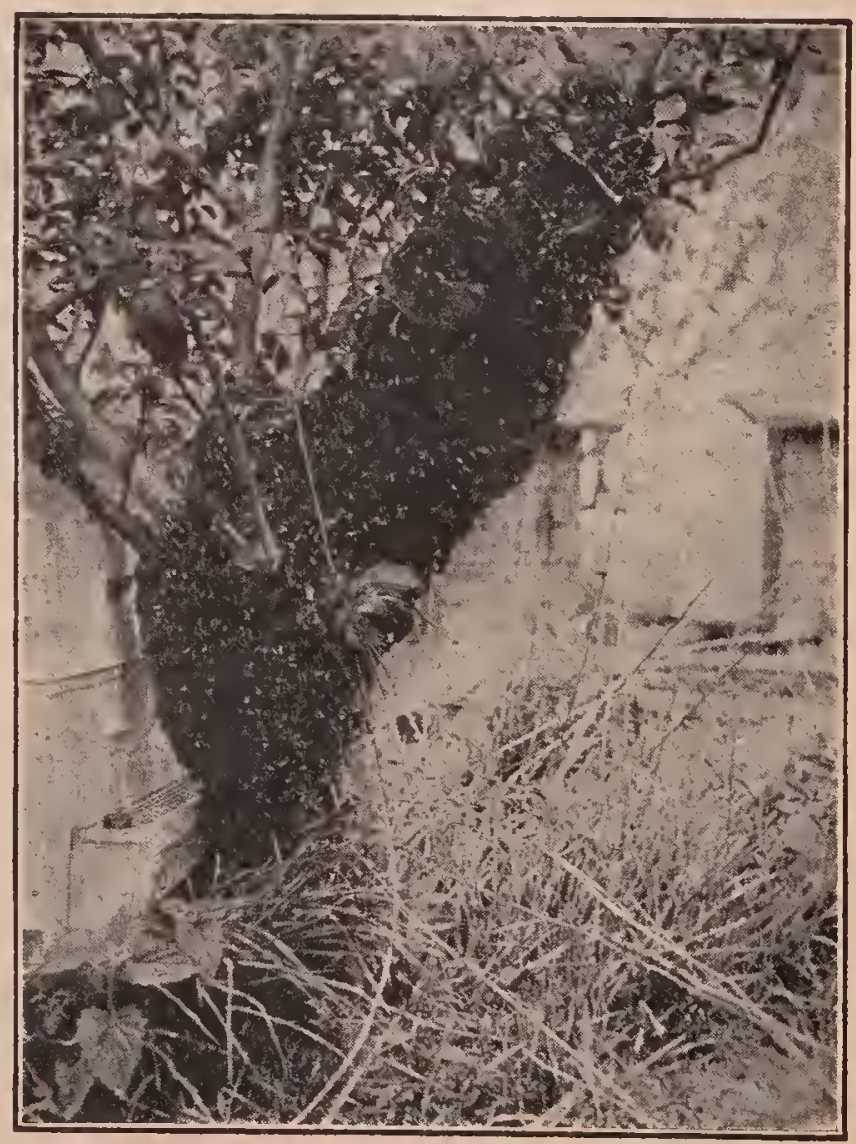

A swarm that came back because the queen was , held in an Alley trap. 
but it does not always prevent losing the queen. She groes out with the bees as usual, and, after hopping about in front of the hive, sometimes gets ready to go back at about the same time that the bees do, after having discovered she is not in the crowd. Even if she goes some little, distance from the hive, the loud hum they make as they return will guide lier home many times; but unless the apiarist is at hand to look after affairs, many queens will be lost, and the bees will rear a lot of young queens and go into after-swarming in good earnest:

A friend, who knows but little of bee culture, once told us our bees were

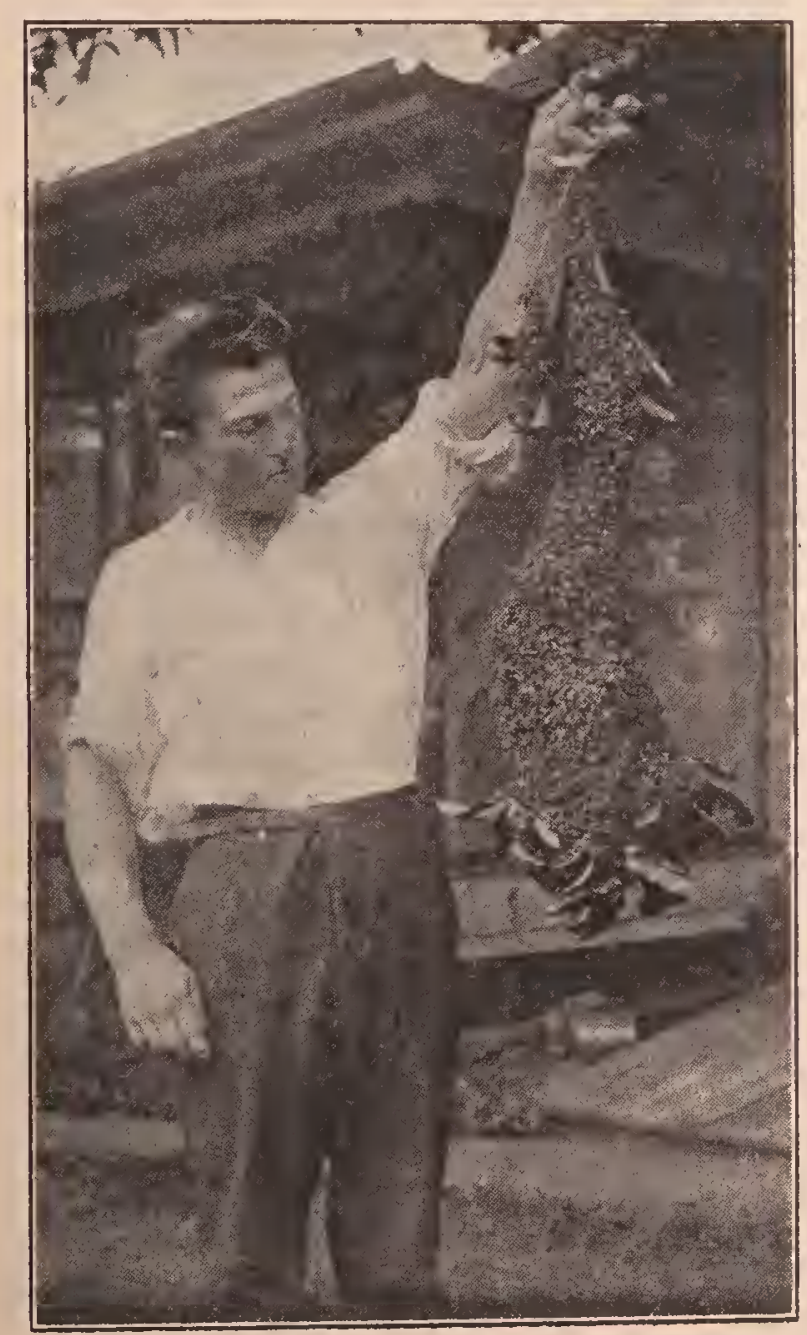

A swarm that clusters on a small limb can be easily captured by cutting the limb just above the bees with a sharp pocketknife. Care should be taken not to jar the cluster in cutting. A sharp knife is much better than a saw for this purpose.

swarming, and if we did not ring the bells, they would certainly go to the woods. As we quietly picked up the queen in passing the hive, we told him if they started to go away we would call them back. Sure enough they did start for the woods, and laad gone so far that we really began to be frightened. ourselves, when, away in the distance, we saw them suddenly wheel about, and then return to the hive at our very feet. While he gave us the credit of having some supernatural power over bees, we felt extremely glad we had taken precautions to clip all our queens' wings but a few days before. After this we felt a little proud of our control over these wayward insects, until a fine swarm of Italians started off under similar circumstances, and, despite our very complacent, positive remarks, to the effect that they would soon come home, they went off and stayed "off." In a humble and wiser frame of mind, we investigated, and found they had joined with a very small third swarm of black bees that had just come from one of the neighbor's hives. We tried to "explain," but it required a five-dollar bill to make matters so clear that we could carry back our rousing swarm of yellow bees, and sort out the black unfertile queen, that they might be made to accept their own.

\section{ABSCONDING FOR WANT OF FOOD.}

Aside from normal swarming perhaps bees oftener desert their hives because they are short of stores than from any other cause; and many times, in the spring, they seemed to desert because they were nearly out. This generally happens about the first spring day that is sufficiently warm and sunny. They issue from the hive, and alight in a tree very much like a normal swarm during the swarming season. The remedy, or, rather, preventive, is so plain that it need not be diseussed. After they have swarmed out, and are put back into the hive, give a heary comb of sealed stores: if that cannot be obtained, feed them a little at a time, until they have wenty, and be sure that they have brood in the coubs. If necessary. give them a comb of unsealed larræ from some other hive. and then feed them until they have a great abundance of food. One should be ashamed of having bees abscond for want of food.

\section{ABSCONDING NUCLEUS.}

A very small nucleus-if it contains no mole than 200 bees-is liable to swarm out. Queen-breeders, in attempting to mate queens in baby nuclei containing only one 
or two section boxes, had considerable trouble in keeping the bees in the hive, especially when the young queen went out to mate. Accordingly it was found necessary to make the baby hives much larger, with frames $5 \% / 8 \times 8$ inches, and two nuclei to a hive. See QueEN-REARING.

With these there will be much less trouble from swarming, provided that they lave some brood and honey and are not too strong, and provided also the queen is taken out as soon as she is laying.

\section{ABSCONDING FOR MORE SATISFACTORY} QUARTERS.

There is still another kind of absconding that seems to be for no other reason than that the bees are displeased with their hive, or its surroundings, and, at times, it seems rather difficult to assign any good reason for their having suddenly deserted. We have known a colony to swarm and desert their hive because it was too cold and open, and we have known them to desert because the combs were soiled and filthy from dysentery in the spring. We have known them to swarm because their entrance was too large, and, if we are not mistaken, because it was too small.

We have also known them to swarm because they were so "pestered" with a neigliboring ant hill-see $\Lambda$ NTs - that they evidently thonght patience ceased to be a virtue.

ABSCONIING IN THE SPRING.

They often swarm in the spring where no other cause can be assigned thian that they are weak and discouraged, and in such cases they usually try to make their way into other colonies. While it may not always be possible to assign a reason for such behavior with medium or fair colonies, one may rest assured that good, strong colonies, with ample supplies of sealed stores. seldom, if ever, go into any such foolishness.

It seems to oceur just at a time when their owner can ill afford to lose a single bee, and worse still, only when his stocks are, generally, rather weak; so that he dislikes to lose any of them. In this case they do not, as a general thing, seem to care particularly for going to the woods, but rather take a fancy to prshing their way into some of the adjoining hives, and, at times, a whole apiary will seem so crazy with the idea as to become utterly demoralized.

A neighbor, who made a hobby of small hives-less than half the usual size-one fine April day had as many as 40 colonies leave their hives and cluster together in all sorts of promiscuous combinations. To say that their owner was perplexed, wonld be stating the matter very mildly.

Similar cases, tho perhaps not so barl, have been reported from time to time, ever since novices commenced to learn the science of bee culture; and altho cases of swarming in the spring were known once in a great while before the recent improvements, they are nothing like the mania that has seemed to possess entire apiariessmall ones-since the time of artificial swarning and honey-extractors.

\section{ACTIVITIES OF BEES.-See BeE BE-} IIAVIOR.

\section{ADULTERATION OF HONEY.-The} adulteration of this product dates back many years, but the methods of detecting the same are of comparatively recent date. Accum, in his "Treatise on Adulterations of Food and Culinary Provisions" (one of the earliest works devoted to food adulteration), published in London in 1820, does not cover the subject of honey. Hassall in his "Adulteration Detected," published about 185.5, mentions honey. His examinations were made with the microscope, and he was able from the pollen to tell the kinds of flowers visited by the bees. $\mathrm{He}$ also noted crystals of sucrose intermingled with those of dextrose when a honey was evaporated to a crystallization point. In his later editions be gives methods for detection of sucrose and also commercial glucose. The tro works cited above were written in England. Hoskins in his book, "What to Eat," possibly the first book on food adulteration written by an American, and pulylished in Boston about 1861, states that "Factitions and adulterated honey is rer"y common in our markets. The substances used are generally ordinary sugar, made into a syrup with water, and flavored with different articles. This preparation is usually mixed with genuine honey, and so extensive is this practice that very little 'Strained Honey' can be found which is 
pure. The only really injurious adulteration as regards health which I have found in such honey is alum." He noted "glucose and starch sugar among the adulterants of honey," but never verified their presence. Later work has brought forth the same statement as above, viz., "If one wants pure honey, he should purehase it in the comb." This statement was possibly true up to the passage of the National Purefood Law, which went into effect January 1, 1907. Yet just previous to this time extracted honey was not as much adulterated as formerly, due in part to the many state food laws, and also, in greater part, to the fact that chemical methods had advanced to a point where adulterations with glucose, sugar syrup, ete., were easily recognized. Since 1910 all adulterations of honey have practically ceased. One can now be sure that ally honey he buys is pure.

Part 6, Bulletin 13, of the Division of Chemistry, U. S. Department of Agrieulture (a report of investigations made under direction of Dr. H. W. Tiley about 1890), contains some 75 pages devoted to honey. In this are given numerous analyses of honey. The adulterants noted were glucose, cane sugar, and invert sugar. The number of samples containing glucose was very large. See Glucose, Canf Sugar, Invert SUGAR for descriptions of the substances; also Analysis of Honey for methods of their detection.

Examining the first 4.000 Notices of Judgment given pursuant to Section 4 of the Food and Drug Act, published from the office of the Secretary, United States Department of Agriculture, which represents the whole published information on prosecutions under this act up to October 21, 1915, one finds 12 notices referring to honey.

In one. No. 1,123, the product was labeled as containing 8 ounces of honey, but examination showed that the containers were short some 4.86 per cent. In another, No. 352. the label stated the rontents as "one pint," but examination showed much less to be present. Both cases resulted in faror of the Government.

In one, No. 269, the product was labeled "Compound Pure: Comb and Strained
Honev and Corn Svrup." Analysis revealed that the product was largely composed of corn syrup (commercial glucose) with some comb honey and strained lioney. The case was lost by the Gorernment in that it was held that "it was impossible to say what portion of the label as printed would signify greater percentage of the product." In opposition to this, some state laws require that the substances composing a compound should be stated on the label in tlie order in which they predominate in the finished product.

In the other cases, the adulteration was with invert sugar (see INvert Sugar). Nos. 18, 19, 20, and 21 refer to shipments in barrels where the only mark was a capital $\mathrm{H}$ enclosed in a square, but this product had been consigned as a pure strained honey. Examination showed it to contain invert sugar and some glucose. The case was not fought in court, the clamant failing to answer a decree of seizure, and condemnation was rendered by the court.

In the other cases, Nos. 3401, 2, 3, 4, and 6 , evidence was introduced on each side, with the result that the jury returned a verdict in favor of the United States. This being an important cáse, it is well to give it with some detail. The trial came off in Philadelphia on November 20-25, 1913. The product was placed on the market in 36and 60-pound cans labeled "Excelsior" Choice Pure Strained Honey."

The manufacturer claimed that the mixture in the cans consisted of Cuban and buckwheat honey, and that he boiled and strained this. It was koshered for the purpose of selling to the Jewish trade. On direct testimony the manufacturer stated that the skimming was the koshering, but on being recalled to the stand he stated that the boiling and the straining-in fact, the whole process, was the koshering. The jurge in his cliarge to the jury says on this point: "He boils this article that is here in question (the eans of honey), and whether it was for the purpose of koshering it or not is not very clear in his statement, because honey is cleaned.by straining it, and it is heated to a certain point; but lie says he boils and skims the top off and then strains it, and then he calls it koshered honey." The chemist for the 
manufacturer gave an analysis similar to the Government chemists', but not as full as theirs. The Government chemists showed that no Cuban nor any buckwheat honey ever contained less than .07 per cent ash. (The chemist for the manufacturer also claimed this.) The sample in question contained only .028 per cent ash, hence there could be only 40 parts of these honeys in every 100 parts of the mixture, and the other 60 was commereial invert sugar which had no ash. They also showed that the honey in question responded to all the color tests indicative of commercial invert sugar (the manufacturer's chemists claimed that these color tests were produced by the boiling of the pure honey, a point not held by the government chemists). The government chemists also showed that the sample under question contained 0.08 per cent tartaric acid, an acid not hitherto found in pure honey, and the acid that is used in making commercial invert sugar (see $I_{N-}$ VERT SUgar). It was also shown that Cuban honey at $4 \frac{1}{2}$ cts. a pound and buckwheat honey at $71 / 2 \mathrm{cts}$. a pound used in the mixture in the proportion of 80 parts Cuban to 20 parts buckwheat would cost $\$ 5.10$ a hundred pounds, while with sugar at $6 \frac{1}{2} \mathrm{cts}$. a pound 100 parts of invert sugar would cost $\$ 4.55$ a hundred pounds. Hence a possible motive for the use of invert sugar.

In the course of his charge to the jurv the judge says :

"Every man, woman, and child in the United States when hungry needs food, and when sick needs drugs, but the individual citizen is unable to see to it that the food purchased or the drugs lie must purchase are pure, and the Government has taken on itself the work of performing that for the whole people. So that this is a contest for pure food; for the protection of the individual citizen who has not the facilities or the information to protect himself, and it is a very beneficial and commendatory act. because we all know that impure foods are manufactured and sold, and it is against the raanufacturer and vendor of these impure foods and the manufacturer and vendor of these impure drugs that this act is aimed, and it has no terrors for the man who manufactures or sells a pure article and brands it what it is. Notwithstanding the attempt to throw a very great deal of doubt and uncertainty over the work of the experts in this case, chemistry has been brought to such a high point of efficiency that it can be told with certainty, or, at any rate, with that degree of certainty which should authorize us to act, what is contained in almost any substance you put into the possession of the expert chemist. He can tell whether or not honey is pure, or whether it has some substance mixed in it, and it may be that he cannot tell it with the same degree of certainty that you can work a geometrical demonstration, but he call say, with a degree of certainty that should authorize us to act, in the examination of questions which come before courts as to whether foods or drugs of a specific kind are pure or adulterated or misbranded. . . . . Now you will notice, gentlemen of the jury, that an article is adulterated if any substance has been substituted wholly or in part for the article. It is not the dictionary definition of adulteration. You must take the statutory definition. It makes no difference what the article is: if any substance bas been substituted wholly or in part it is an adulteration. There is no question as to whether it is deleterious or injurious to lealth; it may or may not be; the substitution may be as beneficial as or more beneficial than the original article. What the law aims at is to guarantee to the consumer that when he desires to purchase a certain article, and goes to a manufacturer or vendor for that article, and states what he wants, he shall know that he gets what he pays for.

The evidence upon whieh you will have to rely to ascertain whether it was pure or adulterated, and, if adulterated, misbranded. is the evidence adduced upon the stand by the experts for the Governmont, and by the experts and the defendant for the defendant."

The jury retired and retuimed a readict in favor of the United States Government. Oll May 13, 1915, final judginent of condemnation and forfeiture was entered, the court finding the product adulterated and misbranded, and it was ordered that the product should be sold by the United States Marshal, and the owners should pay all costs of the proceodings.

The winning of this case by the Govern- 
ment has stopped much of the adulteration of honey with commercial invert sugar. Furthermore, since the passage and genoral enforcement of federal and state purefood laws, honey adulteration, instead of being common, is becoming exceedingly rare.

AFTER-SWARMING.-All swarnis that come out after the first swarm, or are led out by a virgin queen or a plurality of them are generally termed after-swarms; and all swarms after the first are accompanied by such queens. There may be from one all the way up to a half-dozen swarms, depending on the yield of honey, amount of brood or larvæ, and the weather; but whatever the number, they are all led off by queens reared from one lot of queen-cells, and the number of bees accompanying them is, of necessity, less each time. The last ones frequently contain no more than a pint of bees, and, if lived in the old way, would be of little use under almost any circumstances; yet when supplied with combs already built and filled with honey, such as every enlightened apiarist should always keep in store, they may develop into the very best of colonies, for they have young and vigorous queens.

It has been said that when a colony has decided to send out no more swarms, all the young queens in the hive are sent out, or, it may be, allowed to go out with the last one. Whether this is true or not is uncertain; but during the swarming season, some novice writes about the wonderful fact of his having found three or four, or it may be half a dozen queens in one swarm. On one occasion, a friend, who weighed something over 200, ascended to the top of an apple tree during a hot July day to hive a small third swarm. He soon came down, in breathless haste, to inform us that the swarm was all queens; and, in proof of it, he brought two or three in his closed-up hands.

Years ago after-swarming was considered a sort of necessary evil that had to be tolerated because it could not be obviated: but in no well-regulated apiary should it be allowed. Many consider it good practice to permit one swarm-the first one. After that all others are rastrained. Cutting ont all the queen-cells but one may have the effect of preventing a second swarm; but the practice is objectionable-chiefly because one cannot be sure that he destroys all but one. If there are two eells not the same age the occupant of one of them. when she emerges, is likely to bring out an after-swarm; indeed, as long as there are young queens to hatch, there are likely to be after-swarms up to the number of three or four.

But many practical honey-producers consider cell-cutting for the prevention of these little swarms as waste of tine, altloo they may and do cut out cells to prevent prime or first-swarins. There are some who deem it advisable to prevent swarming. The plan usually adopted to prevent afterswarms is about as follows:

The wings of all laying queens in the apiary should be clipped, or entrance guards should be placed over the entrances of all colonies having laying queens. As soon as the first swarm comes forth, and while the bees are in the air, the queen, if clipped, is found in front of the entrance of the old hive. She is caged, and the old hive is lifted off the old stand, and an empty one containing frames of foundation or empty combs is put in its place. A perforated zinc honey-board is then put on top, and finally the supers, taken from the old hive. The queen in her cage is placed in front of the entrance, and the old hive is next carried to an entirely new location. In the meantime the swarm returns to find the queen at the old stand; and when the bees are well started to rumning into the entrance she is released, and allowed to go in with them. Most of the old or flying bees that happen to be left in the old colony, now on the new location, will go back to the old stand to strengthen further the swarm. This will so depopulate the parent colony that there will hardly be bees enough left to cause any after-swarming, and the surplus of young queens will have to fight it out among themselves-the "survival of the fittest" being of course, the only one left. She will be mated in the regular way. and the few bees with her will not, of course, follow her. In a short time comparatively the old parent colony will be strong enough for winter.

\section{HEDDON'S METHOD.}

The first swarm is allowed to come forth; 


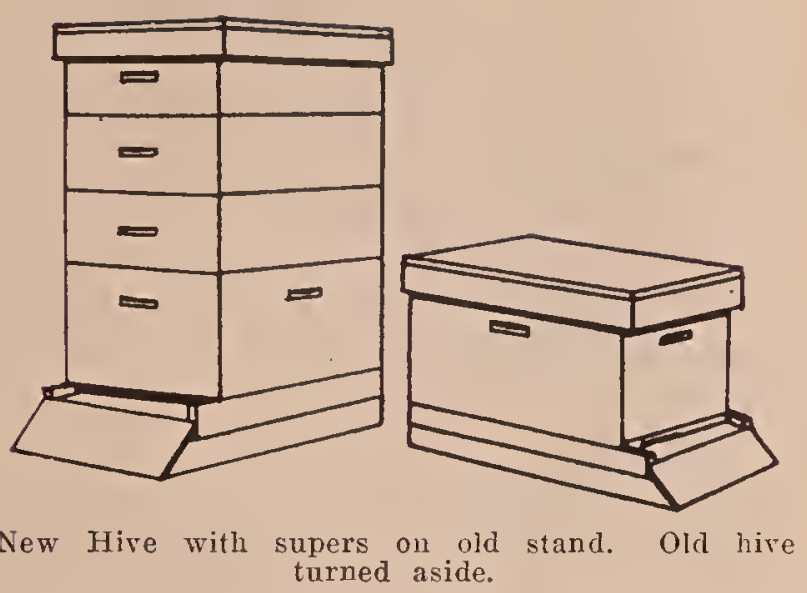

and while it is in the air the parent colony is removed from its stand and placed a few inches to one side, witl its entrance pointing at right angles to its former position. For instance, if the old hive faced the east, it will now look toward the north. Another hive is placed on the old stand, filled with frames of wired foundation. The swarm is put in the hive on the old stand, and at the end of two days the parent hive is turned around so that its entrance points in the same direction as the hive that now has the swarm. Just as soon as young queens of the parent colony are about to emerge, it is carried to a new location during the middle of the day or when the bees are flying thickest. This should be done car'efully without disturbing the colony, so the bees in leaving the hive will not mark the new

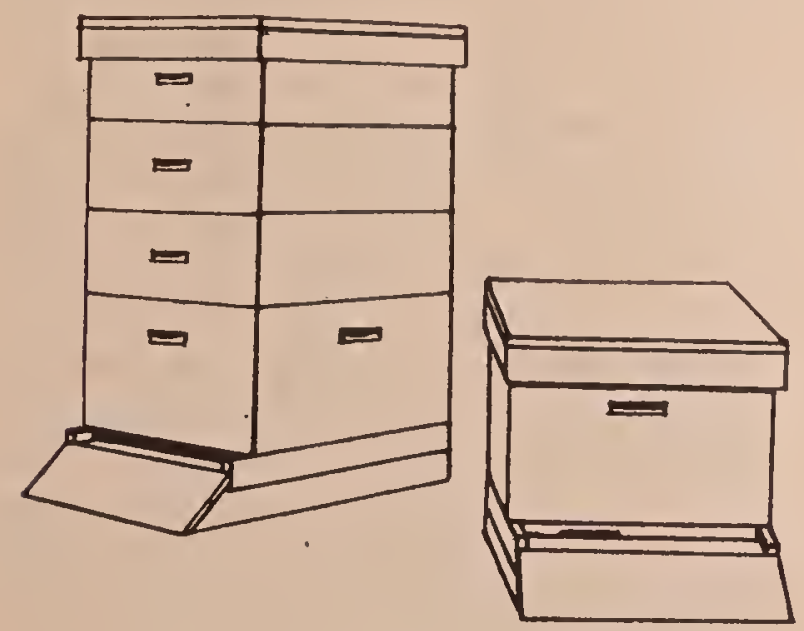

Old hive turned back toward new one after swarm has entered.

location. Usually this should be done on the seventh or eighth day after the prime swarm issued. The result is, these flying bees will go back to the hive having the swarm. This, like the other method described, so depletes the parent hive that any attempt at after-swarming is effectnally forestalled.

The only reason for turning the entrance of the old hive to one side at first is to prevent any of the bees entering it while the swarm is being hived in the new one and until the bees of the new swarm become accustomed to the new order of things. In making artificial swarms it is

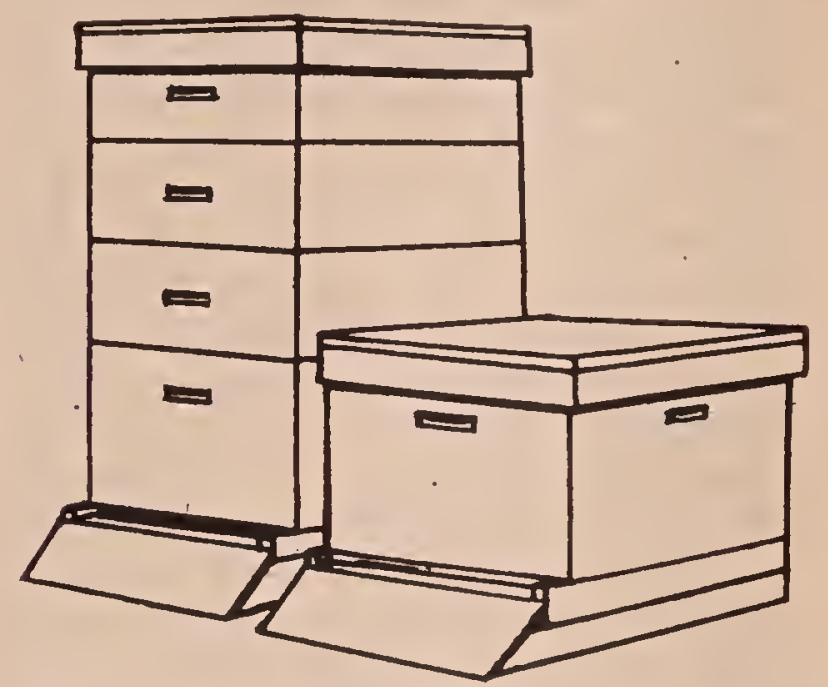

Old hive set close to new to le mored away on seventh day.

not necessary to turn the entrance of the old live away, for in this case theje is less danger of the bees of the swarm entering the old hive.

AGE OF BEES,- - It may be rather difficult to decide how long a worker bee would live if kept from wearing itself out by the active labors of the field; six months certainly, and perhaps a year; but the average life during the summer time is not over three months, and perhaps during the height of the clover bloom not over six or eight weeks. The matter is easily determined by introducing Italian queens to hives of black bees at different periods of the year. - If done in May or June there will be all Italians in the fall; and if a record is kept when the last black bees emerge, and the time when no black bees are to be found in the colony, a pretty accurate idea of the age of the blacks may be secured. The Italians will perlaps hold out under the same circumstances a lialf longer. If the Italian queen be introducerl in September in the nortliern States. hark bees will be found in the live until the montly of May following-they may disappear a little earlier, or may be found 
a little later; depending largely upon the time they commence to rear brood. The bees will live considerably longer if no brood is reared, as has been several times demonstrated in the case of strong queenless colonies. It has been said that black bees will lire longer in the spring than Italians-probably because the latter are more inclined to push out into the fields when the weather is too cool for them to do so with safety; they seldom do this, however, unless a large amount of brood is on hand, and they are suffering for pollen or water.

During the summer montlis, the life of the worker bee is cnt short by the wearingout of its wings, and, at the close of a warm day, liundreds of these heavily laden, ragged-winged veterans will be found making their way into the hives slowly and painfully, as compared with the nimble and perfect-winged young bees. If the ground around the apiary be examined at nightfall, numbers of these old bees may be seen hopping about, evidently recognizing their own inability to be of any further use to the community. The anthor has repeatedly picked them up and placed them in the entrance, but they usually seem bent only on crawling and hopping off out of the way where they can die without hindering the teeming rising generation. During the lieight of a honey flow workers probably do not live more than six weeks.

\section{AGE OF DRONES.}

It is somewhat difficult to decide upon the age of drones, because the poor fellow: are so often hustled out of the way for the simple reason that they are no longer wanted (see Drones); but it may be assumed to be something less than the age of a worker. If kept constantly in a queenless hive. they might live for three or four months. Occasionally some live over winter, from September to April.

\section{AGE OF THE QUTEEN.}

As the queen seldom if erer leares the hive except at mating and at swarming time one would naturally expect her to live to a good, old age, and this she does, despite her ardnous egg-laying duties. Some queens die, seemingly of old age, the second season, but generally they live thru the sec- ond or third, and they have been known to lay very well even during the fourth year. They are seldom profitable after the second or third year, and the Italians will sometimes have a young queen "helping" mother before the beekeeper recognizes the old queen as a failing one. Some good beekeepers think it profitable to requeen yearly.

ALFALFA. (Medicago sativa L.).-Alfalfa belongs to the pulse family, or Leguminosae, which includes more than 5,000 species. Many of the species are very abundant, and valuable for fodder or edible seeds or dyes, as white and yellow sweet clover, the true clovers, sainfoin, and the vetches, peas, beans, and lentils, and indigo. The cassias and acacias are also placed in this family by Gray. Alfalfa is a perennial, herbaceous plant with trifoliate leaves; violet-purple, irregular flowers in short racemes; and spirally twisted pods, each containing several kidney-shaped seeds. A most important character of alfalfa is the taproot, which may extend downward to a depth of 15 feet, enabling the plant to obtain food materials and water inaccessible to other field crops. The genus Medicago contains more than 100 species and varieties, natives of the Caucasus and western Siberia, the Mediterranean region and northern Africa. One species ( $M$. arborea) is a shrub growing in the vicinity of the Mediterranean Sea 10 feet tall and producing a hard dark wood resembling ebony. The foliage furnishes excellent forage for cattle and sheep. In California it is cultivated as an ornamental shrub for its bright yellow flowers.

\section{HISTORY,}

The common alfalfa is probably of Asiatic origin, as it has been found growing wild in Afghanistan, Persia, and the region south of the Caucasus. In China it has been "under cultivation from a-very early date. The plant was brought into Greece at the time of the Persian war, 470 B. C., from Media whence the scientific name Medicago. In Italy it has been cultivated from about the first century, and is well described by Virgil and Pliny. During the Middle Ages it received the vernacular name of lucerne from the Valley of 
Luzerne in Piedmont, northern Italy. It was long popularly known under this name in Europe outside of Spain, and in eastern North America.

This species was also very early introduced in northern Africa, where it was called alfalfa, a word of Arabic origin signifying" "the best fodder." During the Moorish invasion it was carried into Spain, and later was brought by the Spaniards to Mexico and South America; and finally, in 1854, was carried from Chile to California. It is first heard of in England about 1650. Under the name of lucerne the early colo-

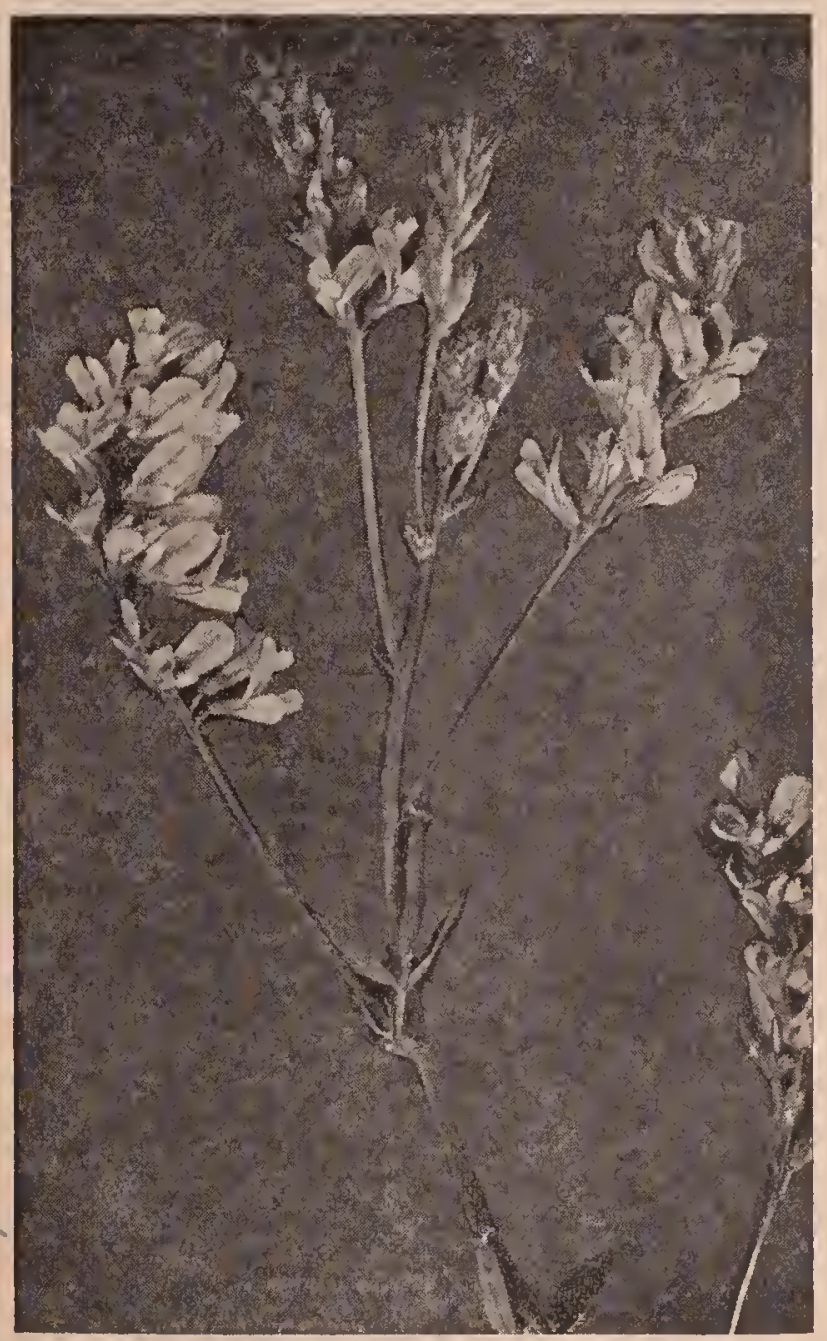

Alfalfa blossom

nists introduced it into eastern North America, where it still grows spontaneously in fields and waste places; but the first attempts to cultivate it proved unsuccessful. Other common names are Spanish trefoil, Burgundy, Brazilian, and Chilian elover. It is also known as purple medie from the color of the flowers and the Latin word medica (Media); and snail elover from its twisted pods.
Other and more hardy strains have been discovered in Siberia and northern Europe, and brought to this country by Hansen and other agrieultural explorers. They found alfalfa growing under cultivation and also growing wild in the extreme northem parts of Siberia. From these high latitudes we get a type of plant called the Hardy or Northern Alfalfa, as distinguisher from the Southern or Non-liardy Alfalfa.

The culture of the plant has become established in erery State in the Union and every province in Canada. Its claim to the attention of beekeepers lies in its extreme importance as a honey plant in the West. To discuss alfalfa from the standpoint of the beekeeper, this article will first consider the nature of alfalfa honey; second, alfalfa as bee pasturage; and, finally, conditions and methods of its culturè.

\section{ALFALFA HONEY.}

Most alfalfa honey has a pleasant slightly minty taste. The best alfalfa honey, thick, rich, and delicious, has proved a farorite with the public where the honey can be eaten before granulation commences. Altho difficult to handle on that account, dealers hesitate to discard so well-flavored an article. It runs 12 to 13 pounds to the gallon while other honeys seldom exceed 12 pounds, its thickness making it difficult to extract.

A marked characteristic of alfalfa honey is its tendency to granulate, especially that from certain localities. In examining a given lot of alfalfa honey it is impossible to say when granulation will be likely to set in. If kept in a warm room some alfalfa honey will continue liquid for an entire season; but, on the other hand, it may be solid in a very few weeks. When granulated it is fine and ereamy; lence it is often retailed in the solid form in eartons. See Granulated Honey.

As with other honeys, low temperatures, and especially variable tentperature, have the same effect in hastening granulation. and higher and uniforn temperatures in retarding. In tests conducted by the $\mathrm{Bu}$ reau of Chemistry, Washington, D. C., alfalfa samples shown to be purer than the others (that is, freel from other honeys) granulated solid. The statement has been made that pure alfalfa honey will scarcely 
granulate at all, and that when it solidifies early it is mixed with honey from wild flowers. 'In view, however, of the uniform granulation of samples of known purity tested by the government, this statement is apparently not generally true. Moreover, tests made by the Bureau with other honeys show that impure samples, those with a high percentage of dextrose and undetermined matter, do not candy readily. A hard white lard-like solid seems to be the ultimate state of even the best of alfalfa honey.

The color of alfalfa honey varies from so-called "water-white" to light amber, according to the humidity, the season, and the character of the soil. In localities of little rainfall or where the soil is sandy the color is white. In alluvial soils where the water is close to the surface the loney is amber and even darker after extracting. To the percentage of water in the honey itself is largely due directly the shade of color, as shown in the government tests alluded to above. Parts of California and Arizona produce a darker alfalfa honey. Alfalfa honey from Inyo County, Calif., east of the Sierra Nevadas, and from country around Reno, Nev., both very dry regions, is water-white. Imperial County, Calif., and Yunıa County, Ariz., yield a darker honey. Usually honey from the second and third crops of alfalfa is lighter. in color than that from the first crop, the reason, of course, being the greater amount of water present in the plants at the opening of the season.

The content of nitrogen, protein, dextrine, and undetermined matter in alfalfa honey is low. Conversely, the sucrose content is higher than in most other honeys. See HoNEYs.

\section{BEE PASTURAGE.}

The striking and beautiful appearance displayed by the great fields of alfalfa in the West, when in bloom, can hardly be realized by one who has not seen them. The lilac-purple flowers present a nuass of color which is measured, not by the arre but by the square mile. Such a landscape of purple coloring can be found nowhere else in the world. One may ride for miles and miles thru fields of alfalfa stretehing away on either side as far as the eye can reach. While alfalfa is grown in every State in the Union, less than 6 per cent of the acreage in 1910 was east of the Missouri River. New England reported only 1,255 acres, but in New York there were 35,343 acres. Near East Syracuse during the past dozen years the bloom is reported to have yielded from 10 to 30 pounds of surplus every other year. Unless the weather is very dry and hot little nectar is gathered; and it is, therefore, from the second bloom in July and August that most of the surplus is secured. The fields are usually mowed in this State before alfalfa begins to bloom. In Ohio there were 29,000 acres, and Tndiana and Illinois contained about 18,000 acres each. At Peru, Tnd., honeybees were observed gathering nectar from the bloom, and it was estimated that there were about ten bees to the square rod. But, in general, alfalfa rarely secretes nectar east of the Mississippi River; it is a good honey plant only in arid or semiarid regions under irrigation.

Pennsylvaniz, New. Jersey, Delaware, Maryland, Virginia, and West Virginia reported 35,000 acres; Kentucky, which has a large area of limestone soils, contained 20,000 acres, and Tennessee 5,000 acres. In North Carolina, South Carolina, Georgia, and Florida, where the soils are largely acid, the total acreage was only 1,467 acres. In the Black Prairie of Alabama and Mississippi there were 16,000 acres, in Louisiana 12,000, and in Arkansas 16,000 acres. There is a lieavy rainfull in these States, exceeding 50 inches, and no honey is secured from the bloom. There were 29,000 acres of alfalfa in Iowa; but: according to Pammel, it is of no importance in that State as a honey plant. Many beekeepers in Missouri, which has 39,000 acres of alfalfa, report the bloom as nectarless.

In the semiarid tier of States west of the Missouri River the acreage of alfalf: shows an enormous increase; but, as it is largely grown by dry farming methods. the yield of honey is very variable. In South Dakota there were 66,000 acres. In the valleys of the Black Hills, as in Belle Fourche Valley, a crop of alfalfa honey ranging from 100 to 200 pounds per colony is obtained nearly every year. There are at least 100,000 acres of irrigable land in 


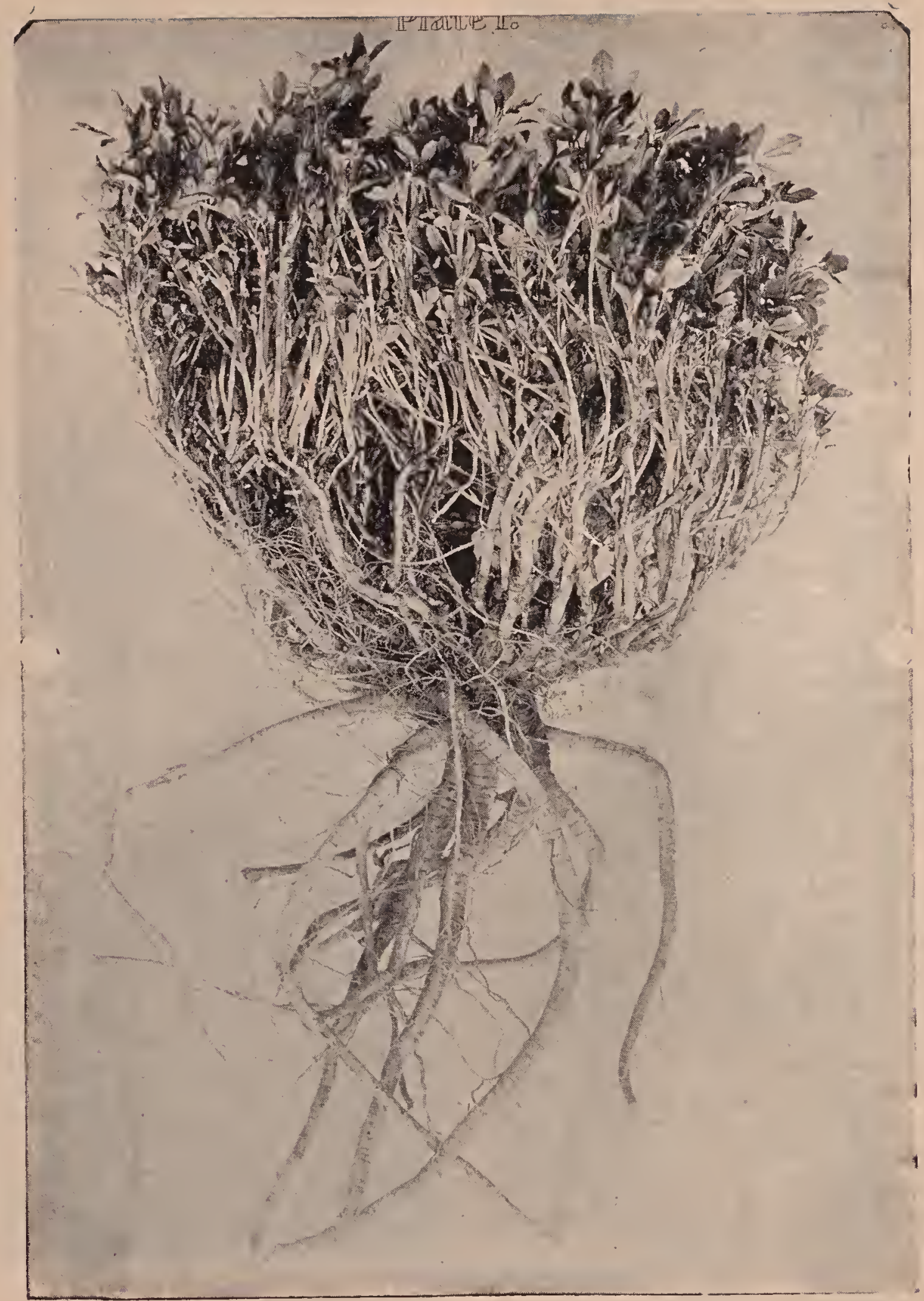

THE CELEBRATED ALFALFA PLANT AND ROOT.

The plant represented in this plate grew in rich, loose soil, with a heary clay subsoil and an abundant supply of water, the water level ranging from 4 to 8 feet from the surface at different seasong of the year. The diameter at the top was 18 inches, and the number of stems 360 . The plate shows how these crowns gather soil around them, for the length of the underground stems is seen to be several inches, and this rep. resents the accumulation of nearly this much material about it.

This is one of the largest plants that I have yet found. The specimen, as photographed, was dug April 30, 1896.-Dr, Headden, in Bulletin No. 35 "Alfalfa."

this region. Beekeeping is in a very undevelopegd state, and thousands of pounds of nectar remain ungathered every year.
In south-central Nebraska, central Kansas. and western Oklahoma there were 1,850,000 acres of alfalfa, the densest area in 
the United States. Kransas with an acreage of nearly a million acres is in advance of every other State. In the valley of the Platte River, Nebraska, where imigation is possible, beekeeping is almost wholly dependent on alfalfa. But where it is grown without irrigation the yield varies greatly in different years. The surplus comes chiefly. from the second crop of bloom which opens in July. Sufficient rain in May will cause a vigorous growth of the plant and ensure a bountiful supply of nectar; but during a rery rainy season little nectar is gathered. The first crop blooms in June and the third in August. Around Sutherland on the Platte River there is a large acreage of irrigated alfalfa and sweet clover, and a good opening for several apiaries. On the Republican River in the southern portion of the State alfalfa is the most important source of honey, but a crop is not secured every year.

In Kansas alfalfa is nectarless or nearly so in the eastern rain belt. In the country around Topeka hees work on the bloom oceasionally. in old resident says that one of his neighbors has fields of alfalfa 18 vears old, but that he has never seen a bee on the bloom, nor a pound of alfalfa honey produced in easter'n Kansas, altho lie lias lived there 35 years. The alfalfa belt in the central portion of the State occupies six tiers of counties and is about 160 miles in width. Alfalfa is most dependable in the valleys of the rivers and smaller streams, where immense crops of forage are harvested from three or four cuttings. If the long taproots can reach water at a depth of not more than 10 feet. the bloom will yield nectar during the entire season. On lighl ground alfalfa yields only after showers. In Jewell County during droughts it is reported to fail entirely. In the valley of the Arkansas River the surplus is gathered from alfalfa, sweet clover, and heartsease. Good crops are obtained except in very dry or very wet seasons. In Oklahoma alfalfa is a dependable honey plant under the same conditions as have been described in Kansas. It yields nectar most freely near the rivers and in soils where underground water can be reached by the roots. Both in Kansas and Oklahoma the future of beekeeping will depend largely on the increase of the acreage of sweet clover.

In Texas, which reporteil 55,000 acres of alfalfa, it is of value as a honey plant only in the irrigated areas of the TransPecos region. In the vicinity of El Paso there has not been a failure in the crop of lioney for 10 years, but at Barstow, Ward Co., on the Pecos River, it is not always dependable.

In each of the remaining 11 States there is an immense acreage of alfalfathe total amounting to $2,445,000$ acres. In general, the crop is always reliable, failure being due more often to bad management on the part of beekeepers than to nonsecretion of nectar by the bloom. The 225,000 acres of irrigated alfalfa in Montana are found chiefly along the Yellowstone River and its southern tributaries, especially in Yellowstone County. The land away from the rivers is a barren waste. The larger part of the 170,000 acres of alfalfa in Wyoming are in Big Horn County in the northern part of the State and in the southeast corner around Laramie. Immense crops of alfalfa lioney are produced; but many colonies are lost in winter, as they are given no additional protection fiom the cold.

In the eastern section of Colorado, occupied by the Great Plains, beekeeping is restricted to the valleys of the South Platte and Arkansas rivers, where there are 1,300,000 acres of irrigable land. In Larimie, Boulder, and Jefferson counties an immense surplus of alfalfa honey is produced nearly every year. There are relatively few bees in the Rocky Mountains in the center of the State. Excellent crops of honey are also obtained on the Western Slope, which is less densely stocked with bees than the Great Plains. In this section beekeeping is wholly dependent on alfalfa, as sweet clover grows only along the ditches. Colorado reported 509,000 acres of alfalfa. In New Mexico in the valleys of the Rio Grande. San .Juan. and Pecos rivers, there were 103,000 acres of alfalfa.

Eight-tenths of the irrigated land in Idaho lies in the valley of the Snake River where there are 310,000 acres of alfalfa. The largest surplus of honev is producer in the Boise Valley and in the vicinity of 
Twin Falls and Idaho Falls. It is an objection to beekeeping in this section that the pasturage in the spring is insufficient for building up strong colonies. Many commercial beekeepers move their bees to California for the flow from orange bloom, and later bring them back to Idaho in time to secure a crop from alfalfa. In Utah there are 284,000 acres of irrigated alfalfa in the Uinta Basin south of the Uinta Mountains, in Emery County, and in the central mountainous strip of land, where irrigation is extensively practiced. Serious losses of bees have been sustained liere in winter, but the crop of loney is seldom an entire failure. Western Nevada pro-

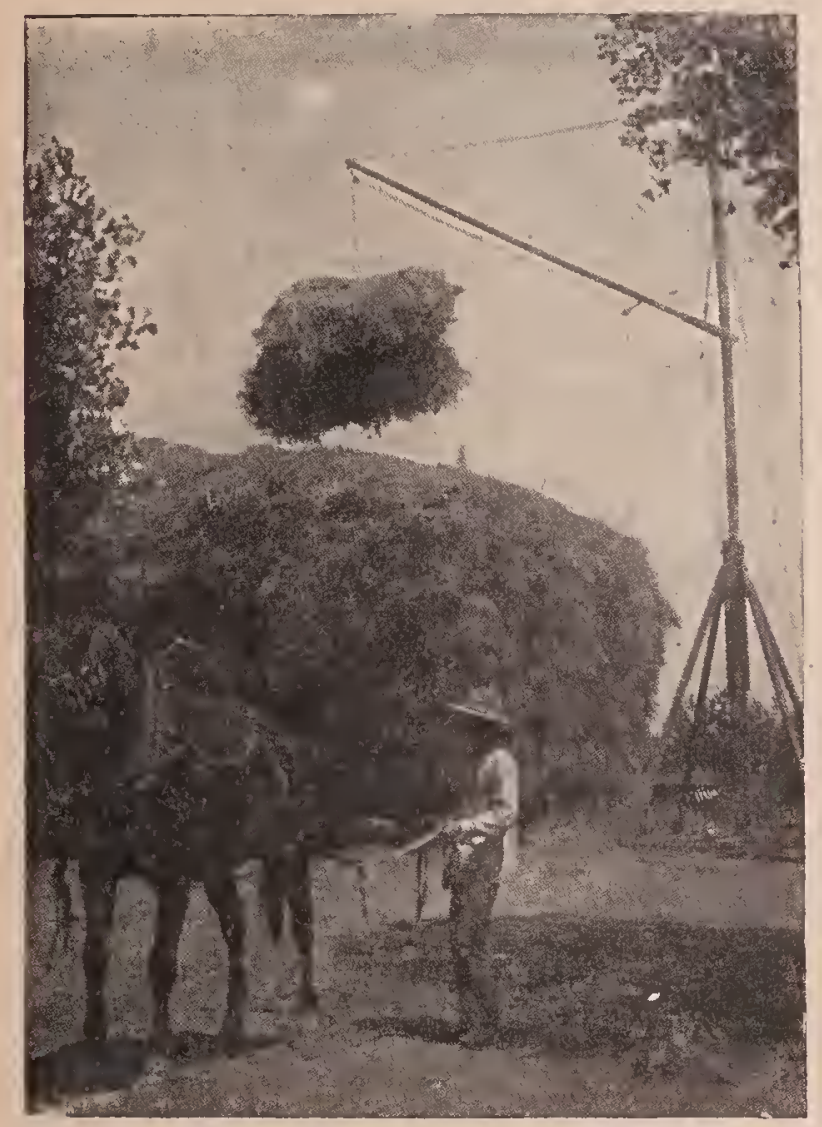

Method of stacking alfalfa hay.

duces a white alfalfa honey which is regarded as the type of the hest alfalfa honey produced in the United States. In Arizona the larger part of the irrigated alfalfa is in Maricopa County.

In Washington alfalfa is grown chiefly in the irrigated areas of the Yakima Valley. The larger part of the crop comes from the second bloom in July. Commercial beekeeping in Oregon is most successfully pursued in Umatilla County on the Colnnubia River and in Malleur County along the Malheur and Owyhee rivers. In California the largest area of alfalfa is grown in the Great Central Valley and in Imprerial Valley in the southern part of the State. According to Richter it yields no nectar along the coast. In the San Joaquin Valley the second and third crops of alfalfa are the source of most of the honey, while the first and last crops yield little nectar. The honey is usually more or less amber-colored, but in Inyo County it is white, similar to that of Nevada. In dry seasons, when the sages wither on the Coast Range, alfalfa, of which there are 484,000 acres, becomes the chief dependence of the California beekeeper.

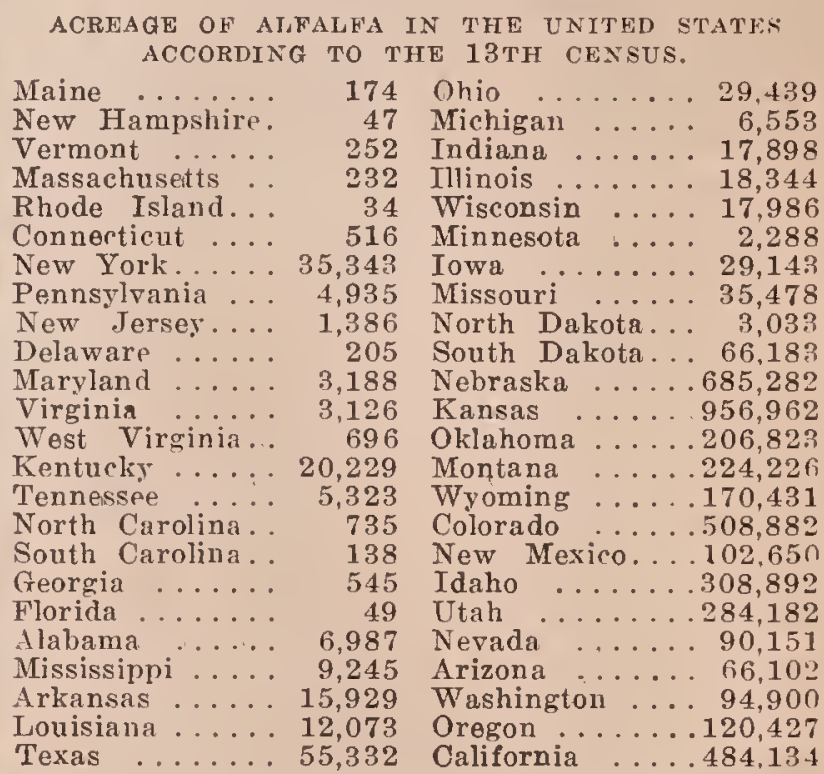

The largest surplus of honey is obtained from alfalfa in arid or seniarid regions where irrigation is practiced. Conditions which favor a large crop of seed, will also produce a large yield of honey. But irrigation alone does not ensure a bountiful flow of nectar, for in both Nebraska and Kansas there are great fields of irrigater? alfalfa which are the source of very little honey. There must be proper soil and climatic conditions as well as irrigation. The largest surplus of alfalfa honey is obtained during very warm seasons. With ample moisture in the soil, a succession of hot days with little wind will cause an astonishing flow of nectar. Fields which are allowed to go to seed will yield nectar abundantly for weeks. In a given acreage there is no plant, unless it is basswood, tupelo, or logwood, that will support so many colonies of hees. In several localities in Colorado within a radius of five miles 


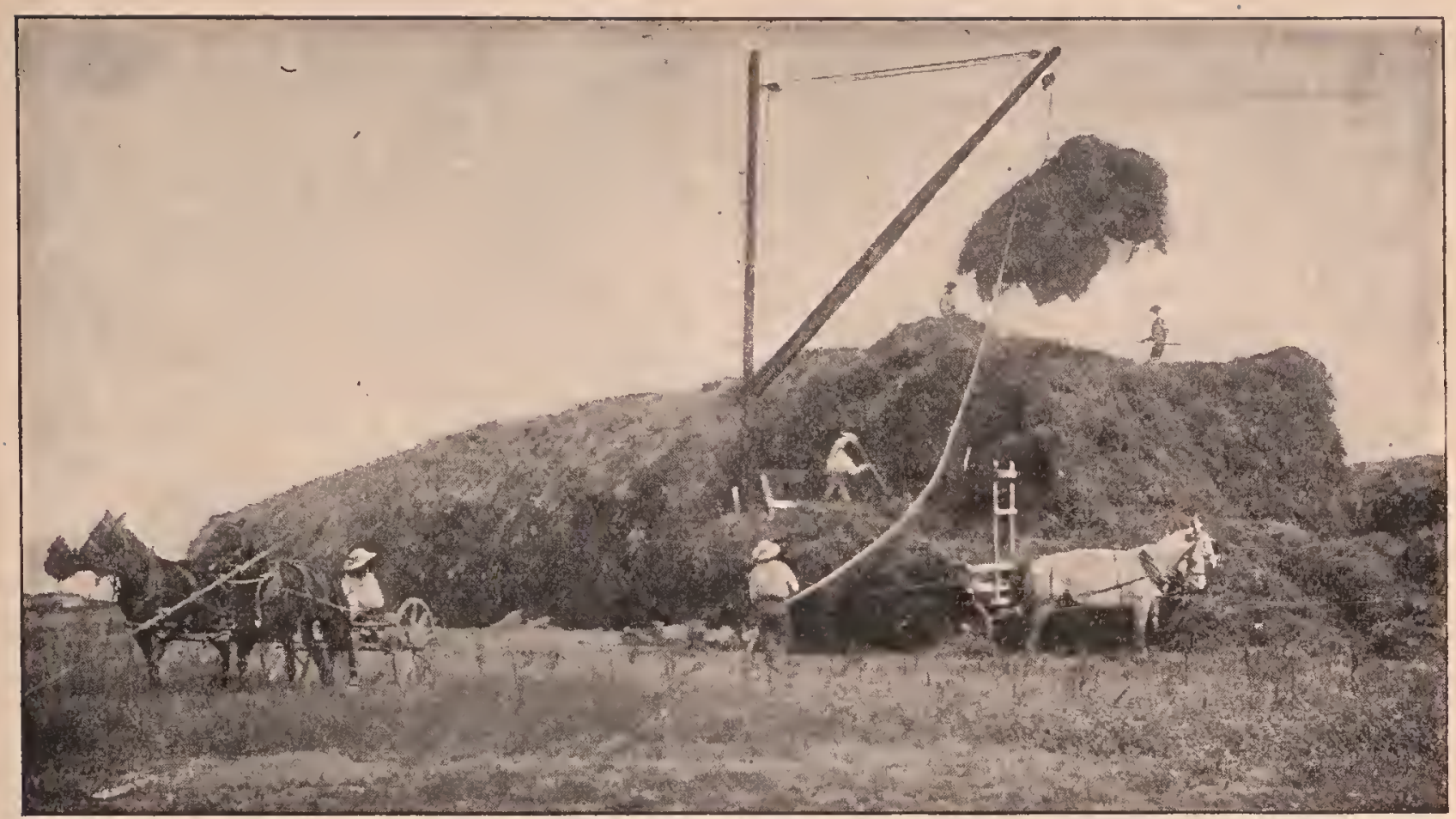

An alfalfa haystack on a 5,000-acre farm assumes enormous proportions.

there are from 2,000 to $\tau, 000$ colonies of bees -a larger number, probably, than can be found elsewhere in an equal area in the world. So many beekeepers, indeed, have rushed to the great alfalfa-growing regions that the apiaries are often located less than a mile apart; and it is not profitable for a yard to contain more than 100 or 150 colonies. Other localities will support from 200 to 300 colonies in a single apiary. In Colorado most of the honey is obtained from the first and second crops. Honey from the third crop is stored not once in 10 years, owing to cold nights. But occasionally there is warmer weather during the last of August, and much additional honey is then brought in by the bees.

Land above 7,000 feet is reported to be unsuitable for beekeeping. The high altitude affects the temperature, which in turn checks the flow of nectar. The nights are often cold and frosty, and in the higher valleys the days are never as warm as in the lower lands. In the Upper Arkansas Valley, around Salida, Colo., in the mountains there are large fields of alfalfa, but the apiaries are small. In the San Lais Valley at an altitude of 7,000 to 8,000 feet alfalfa grows well, but bee culture receives little attention. A moderate increase in elevation is, however, reported in both
Kansas and Colorado to stimulate the flow of nectar. I heekeeper at Grand Junetion, Colo., states that three apiaries in 1919 in that locality were barely self-supporting, while three others 40 miles away. 1,800 feet higher, had filled the supers and produced a good crop. In eastern Kansas, according to A. V. Small, alfalfa yields well above 1,000 feet, but below 850 feet nectar- secretion ceases. Since alfalfa secretes nectar most freely in the Imperial Valley below the level of the sea, the flow of nectar is evidently not necessarily dependent on elevation.

The lower part of the Arkansas Valley in Colorado has in recent years berome less suitable fur bee culture. The lessened honey production is due to the more general cultivation of other crops, to the increase of insect pests, and to the exhaustion of the soil preventing alfalfa from making the luxuriant growth of former times. Other causes injurious to the honey flow from alfalfa are freezing weather in late spring, too much water. the alfalfa butterfly, and a multitude of thrips (more than 40 of these little insects are sometimes found in a single flower). A fow years ago many alfalfa ranges were largely used for grazing, and made valuable apiary sites; but they have disappeared as general farming and fruit-grow- 
ing have developer. Where alfalfa is cut for hay the beekeeper can secure only a part, and often only a small part, of the nectar. There has been much diversity of opinion as to the best time for cutting alfalfa; but the weneral practice is to cut in early bloom, or when the new basal sloots which produce the succeeding crop are just starting, while a few advocate waiting until the plants are in full bloom. Where alfalfa is ent at the beginning of bloom it is of but little value to the beekeeper; and it is, therefore, desirable to locate in sections where seed is raiser. Such fields yield nectar in great abundance for several weeks.

\section{THE CULTIVATION OF ALFALFA.}

When the conditions for its growth are favorable, alfalfa is a sturdy plant, and, unlike its near relative, sweet clover (which est growth in the hottest weather. 'To the entire range of elevation in this country, it seems to be equally adapted. One ean find a southern rariety flourishing in the Imperial Valley, 100 feet below sea level, and in the San Luis Valley, 7,500 feet above. In Colorado, the Grimm, the Baltic, and the Hardy Turkestan grow in altitudes higher than 8,000 feet. While alfalfa has been most extensively planted in the West. particnlarly in the regions opened to cultivation by ilrigation projects, its culture has been found highly profitable of late years in the older soils of the East, in places where its habits are understood. It does almost equally well in the hilly and gravelly land of New England, and the clay and loam of the corn belt.

Most pronounced advantages of its cultiration have been observed in alkaline soils in the West. Here the long taproot, pierc-

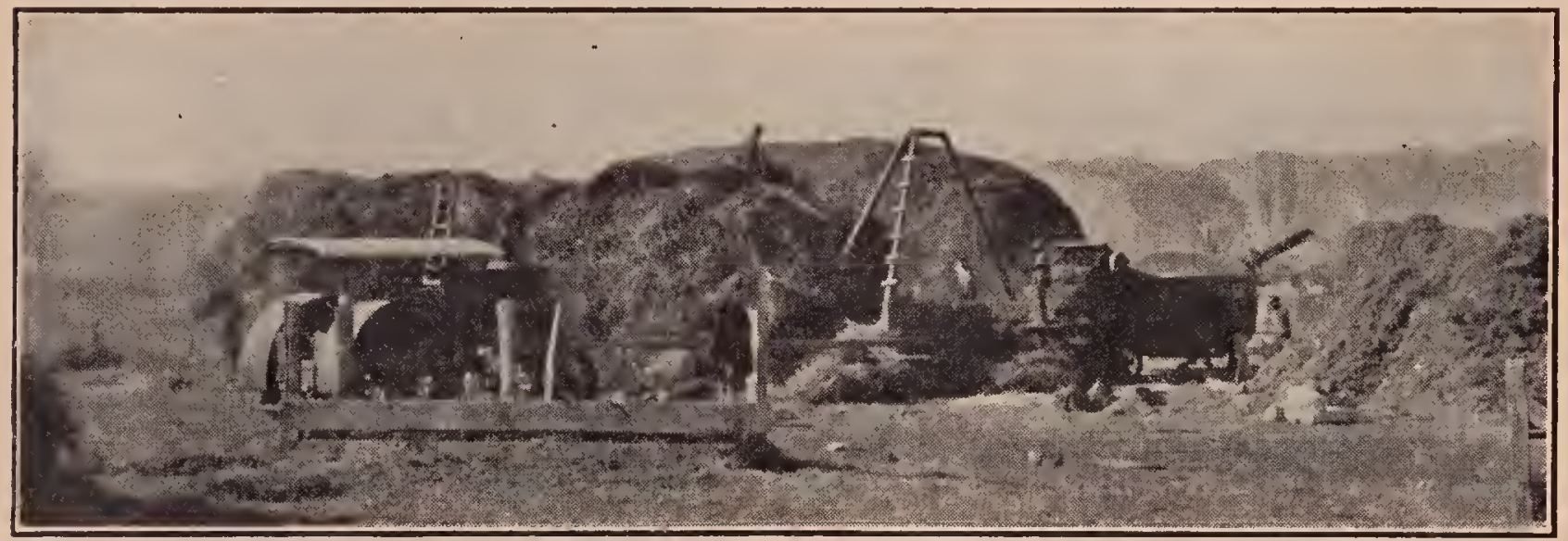

ALFALFA GROWING IN NEVADA.

In and near Reno it has been found that bees increase the seed crop threefold.

is a biennial) it is a perennial. Some fields have been reported half a century old. While it draws on the fertility of the soil it keeps the ground well supplied with nitrogen for the use of later crops. Its ability to survive dry periods, which would kill other plants except sweet clover, adapts it to arid and semiarid regions. Nothing is superior to it as a forage crop. Not only is the food value high, but crop after crop can be taken off in a single season.

While alfalfa is better adapted to all parts of the United States, than was generally imagined, the varieties thrive best where there is plenty of lot sunshine and deep, rich soils, and they make their rich- ing layers of subsoil to a depth of 10 to 20 feet, leaves millions of openings for air and moisture and brings up stores of plant food to enrich the soil; the roots themselves when they decay furnish a heavy store of nitrogen. Naturally rich in potash, lime, and phosphate, the soils lack the nitrogen and organic matter, both of which are liberally supplied by the growth of alfalfa. The same is also true of sweet clover. See SweEt Clover.

WELL-DRAINEI, WHLI-TIMEED, FERTILE SOIL.

On the other hand, wide as the range of alfalfa seems to be, there are some distinct conditions which must be met before its cultivation can be successful. It demands 
well-drained land, a sweet fertile soil, the right kind of bacteria in the soil, and freedom from weeds. To get a successful stand, a firm, fine seed bed is necessary. After this it demands little attention. In general any soil that grows corn or red clover. successfully will grow alfalfa.

Wet and soggy land, land where the ground water stands within three or four feet of the surface, or where water stands half a day at a time, are not suitable. In springy, seepy soil in the northern parts of the country, the alternate freezing and thawing heaves out the plant and completely destroys the stand. In this respect a sandy loam is a little better than a clay loain. Properly drained soil is again necessary on account of the great depth to which the taproot plunges. The roots must get nitrogen from the air, but they cannot do this if surrounded by water. The plant cannot take nitrogen in any other way than thru the roots; in fact, alfalfa needs more thoro drainage than any other crop. Not only must the soil be well drained, but a second and equally important essential is that it be free from acidity and even have an alkaline reaction. Alfalfa does not do well on an acid soil. In the East especially, where very few soils are not acid, it is necessary to sweeten very heavily with lime. Alfalfa requires more lime than any other forage crop. It demands not only a neutral soil but one with an excess of lime for its own use.

Before sowing alfalfa one should be sure of the state of the soil in this respect. One good way is to wrap a moist piece of earth in blue litmus paper; if the paper shows a tendency to redden, the soil is doubtless badly in need of line. This may be applied in two ways: either the ground unburned limestone (carbonate of lime), two to four tons to the acre; or burned lime, one or two tons. (See Clover.) Since the lime stays where it is put, thoroly harrow it in. Often it is well to apply the lime the year before putting in alfalfa, say with corn.

Alfalfa will thrive only in soils which are rich in lime. An acid soil is destructive to the bacteria. Humus cannot be former from decaying organic matter without lime. It prevents the loss of the nitrogen in the soil thru the leaching of rains; in fact, car- bonate of line seems to be the foundation of fertility itself.

Except in the wonderfully rich land of the West, one's treatment of the soil can not stop here. While alfalfa has been much praised as a restorer of fertility, it is nevertheless true that it makes heavy drafts upon the phosphate and potash in the soil. As with lime, when these are not present they must be supplied. Unlike sweet clover, it requires a fertile soil to start with. On worn-out fields, phosphorus should be supplied; 400 to 600 pounds of steamed bone ineal to the acre or natural rock phosphate mixed with manure has been recommended. Plenty of well-rotted stable manure should be given, or, lacking that, cow peas, crimson clover, and soy beans can be planted for green manure. When potash may be lacking in the sail, wood ashes or commercial potash may be applied. Summing up, it is more important, as the late J. E. Wing pointed out in his book on alfalfa, to fill the soil with plant food than to get the seed bed right.

\section{SOIL INOCULATION.}

A third essential for successful alfalfa cultivation is that the right kind of bacteria be present in the soil. Only in comparatively recent years has this been understood. Minute vegetable organisms inhabit the small pale nodules which can be seen with the naked eye about the roots of the plant; their function is to gather nitrogen from the air and convert it into a form in which it can be assimilated by the plant. If the soil is wet or acid, they will not thrive. Where they are not present in the soil already, they have to be put there. This process, known as inoculation, is universally demanded where alfalfa and sweet clover have not been grown before.

One of the two or three, satisfactory methods of inoculation is the soil-transfer. Soil should be gathered from a field in which alfalfa has been grown before $01^{\circ}$ from about the roots of sweet clover (the sweet clover and alfalfa bacteria are identical), then pulverized and screened thoroly, mixed with the alfalfa seed, and sown 300 to 400 pounds to the acre. Since the sun's rays are fatal to these germs, the mixing should be done in the shade and the sowing in the erening or on a clonty day. 
If the earth is broadcasted it should be harrowed in immediately. A smaller quantity of earth is required by wetting the seed with water in which enough glue has been dissolved to make the water sticky; the seed should be mixed with fine earth from another field.

The Department of Agriculture, Washington, D. C., sends out pure cultures of the bacteria in tubes, making inoculation convenient where soil is not readily obtained. Simply follow directions.

In the humid regions of the country, weeds are very troublesome, in many localities being the worst enemy of alfalfa. If the soil is fertile, has been well limed, and has been placed in proper condition before the alfalfa is sown, little need be feared from weeds. After alfalfa once gets a start it can kill out most of the weeds naturally. A clean field can usually be secured by preceding alfalfa with some clean cultivation crop. By seeding in the late summer the alfalfa plants by spring will have the start of the weeds. If weeds threaten to injure an old stand, their stalks can sometimes be burned out in the spring before the alfalfa starts.

Dodder is one of a few weeds to be feared. Especial care should be taken to get seed free from dodder. The stems come up with the alfalfa, twine around it, and finally wither away. From that time until the death of both plants the dodder lives parasitically on the juices of the alfalfa. Therefore if dodder makes its appearance in a field of alfalfa and becomes well established, the alfalfa should be rooted out by using the field for some other crop for several years. Wild barley often ruins the first crop in irrigated regions of the West. Quack or couch grass, Kentucky blue grass, and foxtail grass are weeds dangerous in, other regions.

\section{PUTTING IN THE SEED.}

A great many facts have been collected on seeding alfalfa, not all of which apply to a particular locality by any means, nor even agree with one another in some cases. The time of sowing varies widely between one part of the country and another. Midsummer sowing is probably most popular in the North and East. If the seed is put in between June and the first of September, the young plants are usually strong enough to resist winterkilling. Some advise spring sowing - the last of May and early June, but this is not best where weeds are likely to disturb the young plants. In the hot irrigated portions seed may be sown any time between April and August. Fall seeding is most common-September, October. or November.

Early maturing crops do well to precede alfalfa. The clean culture of potatoes and garden truck rids the land of weeds, aerates the soil, and makes an introductory appliration of nitrogen unnecessary. Corn in the North and cotton in the South are both suitable. A crop of crimson clover cut for hay builds up the soil and gives plenty of time to get the land ready for alfalfa.

Too much care can hardly be given to the selection of seed. Not only thru carelessness in this respect do weeds get their foothold, but failure often comes from adulterated seed or seed of poor quality. The average quality of alfalfa seed in the market is low. A considerable quantity of dead seed has been sold and it is sometimes adulterated with trefoil. In every case before buying, samples should be tested for germination, either by a home testing-plate or sending to the seed laboratory of the Department of Agriculture, Washington. D. C., which does this testing free of charge. A home test should show a germination of at least 95 per cent. If the germination is low, a larger quantity should be sown than if the germination is high.

Seed grown in the northern States may be planted with success in the southern, but the reverse is not true. It is always well to get seed grown in the same latitude in which it is to be sown. While ordinary alfalfa is very satisfactory, certain kinds have local advantages. Superior resistance to the cold, as well as greater tonnage to the acre, is claimed for the Grimm alfalfir and the commercial sand lucerne. The Baltic has also been found a superior strain.

It is necessary to plow deeply for alfalfa. The roots need all the moisture they can get, and the ground should be thoroly stirred up, so that air can penetrate to the nodules. The seed bed should be fine on top, but thoroly settled; for this reason it is well to let the land rest for six weeks after plowing and then to give it a light 
disking. If plowing is done on hot days, it should be followed immediately with a harrow to break up clods before they harden. Then the soil should be pulverized with a drag, disk, and smoothing harrow. For spring sowing it is not so necessary to have a perfect seed bed; the plants have a long start by winter.

Seeding alfalfa in irrigated regions requires an entirely different procedure. Inoculation is unnecessary; so is fertilizer. It is well to level the land, plow deeply. follow with the disk and harrow immediately, and let stand a month. It is advisable to irrigate before and after seeding. and to irrigate again if the young plants seem to be suffering for lack of water. They should be watered after each outting. Upon the irrigation of alfalfa Mr. Kezer of the Colorado Experiment Station writes as follows:

Different soils, different climates, and different sources of water supply would all be causes of different methods. In some sections it is necessary to irrigate two or three times for each cutting; in other sections, one irrigation to the cutting is sufficient, in which case the best practice is to irrigate a week or tell days prior to the cutting or the expected tine of cutting, and then cut as soon as the ground is settled enough to bear the weight of the haying machinery. This water puts the soil in good condition for the succeeding crop and causes it to start forward more quickly and more vigorously: Irrigation practice varies quite widely and must vary' quite widely because of the diversity of conditions. A complete statement covering the most of the known conditions would require several pages. Suffice it to say, that in some regions best results are obtained by a flooding method, in others by a furrow method, and in some regions the basin methods give the best results. Climatic and soil conditions chiefly govern.

The amount of seed to the acre likewise varies with the locality. For honey production in the West 10 pounds gives a good stand; in the Atlantic and southern States, 24 to 28 pounds; between the Appalachian Mountains and the Mississippi, slightly less than this. Wing estimates 15 to 20 pounds under ordinary circumstances and with ordinary soils. One plant to the square foot is enough nnder the best of conditions, but they must stand more thickly as a rule. Since more come up than can exist. only the strongest plants survive.

Alfalfa may be sown either broadeast or with a wheelbarrow seeder or a drill. Broadeasting requires more seed than drilling, and must be followed by a harrow or some other implement to cover the seed almost an incl deep. In arid lands it is covered about an inch and a half. In drilling it is advisable to sow across field in one direction and then at right angles. No further treatment need be given the rest of the year except for the appearance of dorder. Wagons and stock should be carefully kept off the field.

After seeding in the late summer, the stand will usually be eight or ten inches high by fall. With the spring sowing a clipping may need to be given in the late summer, but no hay can be taken off until the next season. Should the plants show a lack of vitality or trace of disease, cutting them will often prove salutary, and in the East a top dressing of nitrate of soda is effective. In a great portion of the West this would not be beneficial. If weeds are troublesome, the field may be disked with the disks set upright. This hinders the growth of weed and grass and lets air and water into the soil.

Alfalfa is seldom successful with a nurse crop except in irrigated land, for the reason that the nurse crop often chokes out the young plants just as weeds do. Barley grown for hay, and hay only, can be made a success with spring. sowing of alfalfa, and gives a larger return to the acre, but to let it grow until it is ready to harvest as erain seriously injures the forage stand. In irrigated sections with good water rights, alfalfa is usually successful with a nurse crop, altho more vigorous growth can usually be obtained without it. Mixtures of alfalfa with certain of the grasses are successful, the grasses being seemingly more rigorous than when alone, and the alfalfa almost as goor.

ALFALFA AS HAY.

Alfalfa is one of the most palatable and highly nutritious of all forage crops, either green or as hay. One estimate gives alfalfa hay slightly more than double the food value of timothy. No other forage crop is so rich in digestible protein. Wheat bran which runs $\$ 25$ to $\$ 30$ a ton is about as rich, tho more easily fed. While protein is hard to get and expensive, it is the one 
AVERAGE PERCENTAGE COMPOSITION OF ALFALFA AND OTHER FORAGE CROPS.

\begin{tabular}{|c|c|c|c|c|c|c|c|}
\hline Kind of forage & $\begin{array}{c}\text { Number } \\
\text { of } \\
\text { analyses. }\end{array}$ & Water & Ash & Protein & $\begin{array}{l}\text { Crude } \\
\text { fiber }\end{array}$ & $\begin{array}{c}\text { Nitrogen } \\
\text { free } \\
\text { extract }\end{array}$ & $\begin{array}{l}\text { Ether } \\
\text { extract } \\
\text { (fat) }\end{array}$ \\
\hline Fresh alfalfa........ & 23 & $71.8 \%$ & $2.7 \%$ & $4.8 \%$ & $7.4 \%$ & $12.3 \%$ & $1.0 \%$ \\
\hline Fresh clover......... & 43 & 70.8 & 2.1 & 4.4 & 8.1 & 13.5 & 1.1 \\
\hline Alfalfa hay... & 21 & 8.4 & 7.4 & 14.3 & 25.0 & 43.7 & 2.2 \\
\hline Clover hay.... & 38 & 15.3 & 6.2 & 12.3 & 24.8 & $:: 8.1$ & 3.3 \\
\hline Timothy hay. & 68 & 13.2 & 4.4 & 5.9 & 29.0 & 45.0 & 2.5 \\
\hline Cowpea hay......... & 8 & 10.7 & 7.5 & 16.6 & 20.1 & 42.2 & 2.2 \\
\hline
\end{tabular}

thing absolutely necessary for the production of stock or milk. While dairymen are bankrupting themselves buying bran and cottonseed meal to get this necessary protein, they could feed just as much and make enormous saving by growing alfalfa on their own farms. Alfalfa has three times as much protein as corm, but in fat and carbohydrates is decidedly inferior.

The market price of alfalfa hay is governed simply by supply and demand. The number of euttings which may be made in one season has been as high as eight and even nine in the Southwest. In favorable years in the North three are possible, but two are most common in the eastern part of the country. Thirty or forty days of hot weather are usually all that are necessary to mature a crop. A good yield amounts to two tons to the acre.

\section{CUTTING BEFORE IT BLOOMS.}

Shall the farmer cut the alfalfa before it cones to bloom, or while it is in bloom, or wait until the blossoms are all gone? 'This is a matter of decided concern to the beekeeper, since his crop of honey depends upon it. If the stand is mown before bloom, the bees get no nectar at all, and the beekeeper may find his colonies starving in the midst of miles of alfalfa.

The old rule with alfalfa-growers was to cut hay when the stand was about onetenth in blossom. Arizona growers claimed that the alfalfa is richer for milk production at that time than at any other, but for horses and mules it is more nourishing if cut in full bloom. The Utal Experiment Station after a series of investigations reached this conclusion: "To insure a large yield of dry matter and the largest amount of albuminoids, lucerne should be cut not earlier than the period of medium bloom, and not much later than the first full flower. . . . It is a more serious matter to cut too early than to eut too late." On the same point the national bulletin says: "The general rule is to cut alfalfa just as it is coming into bloom. Feeding experiments show that the feeding' value is highest when alfalfa is eut in early bloom."

Of late years a new rule has taken the place of the old. Authorities now advise alfalfa-growers to mow when the shoots of the new growth at the base of the plant are just showing. In Ohio this comes about June 1. When the shoots appear it is time to cut immediately. If this is done too soon the second growth is retarded; if too late a great many of the leaves are lost, and in them lies much of the food value. Danger of winterkilling is also increased. The net result, so far as the beekeeper is concerned, is often more farorable under the new plan.

Another fact to his advantage is the habit of men, whatever the rule, of being just a little late. In some places the practice is to cut while the fields are well into bloom. The growers fear that if cut too early it will canse bloat in cattle, and is likely to powder in euring. The state of growth at which to mow the alfalfa also varies between one crop and another; the third eutting is often made when the plants are in full flower.

Immediately. after eutting, fields look brown and bare for the first few hours, but the plants soon rally, and are flourishing. again in a surprisingly short time. The field should not be disturbed until the time for the second cutting.

Making hay with alfalfa in the West is a struggle to get it stacked before the leaves dry so much that they drop off. In the East is a similar struggle to get it cured between showers. On the ranches the farmers harvest a green hay which is practically impossible to get in humid regrions. It is 
esteemed highly as horse feed, altho for cows a brown hay is quite as good. Stacks of this green hay keep their color indefinitely. To the Easterner it is surprising to cut into a stack and find the interior as green as the field itself.

Curing in windrows is better than in the swatl. The hay is raked the same day it is cut, and as soon as cured is cocked and stacked, or baled directly from the cocks. The tedder is of little value since it shatters the leaves too much. Most of the protein is contained in the leaves, which are somewhat licher than bran. Where showers are frequent, the alfalfa should be raked into windrows soon after being cut, in order to iroid damage by rains. Special alfalfa rakes are on the market. Of the ordinary machinery the side-delivery rake is very useful. If the hay is put into the bain too green, it may ignite.

\section{ALFALFA AS PASTURE ANDD SOILING; SEED PRODUCTION.}

Alfalfa pastures, while not uncommon, must be grazed sparingly if a good stand of the plants is to be maintained. Fields should never be used for this purpose the first season or two. Horses and sheep graze more closely than cattle do, and are therefore more destructive to the stand. Hogs on alfalfa pasturage should be ringed. In the autumn stock should be taken off in order to give the plants a start for winter. The tendency of cattle and sheep to bloat when turned on an alfalfa field can be overcome, it has been suggested, by feeding before turning them in, and then keeping them on the pasture all the time, altho there are few places east of the Rocky Mountains where either sheep or cattle can be pastured on alfalfa with safety, except when the plants are in a dormant state. In the West are great alfalfa ranches for lorses, cattle, and even ostriches.

Alfalfa land will support three times as many animals by soiling as by pasturing. Let the crop mature and then carry it to them. A better way even is to combine both pasturing and soiling-feed the animals with alfalfa, then give them access to the pasture. Alfalfa makes silage if properly handled, but the silage is inferior to "orn, kafir, feterita, milo, or sorghum.

In the arid regions of the country where seed can be grown, there are great opportunities for profit. Seed now brings $\$ 10$ to $\$ 12$ a bushel, but the culture would be worth while with seed at half that price. The crop which matures in the driest season is always the one saved. A thin stand is necessary; for best results the plants are set in long rows about 20 inches apart and cultivated just as corn. East of the Mississippi very little seed has been produced.

\section{POLLINATION.}

The form of the flower is papilionaceous. or butterfly-shaped, bearing a general resemblance to the flower of the garden pea. The manner of pollination is of great interest both to beekeeper's and seed-growers. The flowers are known as explosive flowers. The anthers and stignna are held in the keel under elastic tension, which resides in the staminal column formed by the union of the filaments of 9 of the 10 stamens. When a bee presses down the wings and keel, says Burkill, it pulls two triggers and fires off the flower, that is, the two processes which restrain the staminal column in the carina separate, and permit the stamens and pistil to fly forcibly upward, bringing the pollen in contact with the under side of the bee's body. A slight elicking sound may sometimes be heard when the stigma strikes against the standard, and a little cloud of pollen is visible. The stigma stands a little in advance of the anthers, and strikes the pollen-brush of the bee first; if the latter is covered with pollen from another flower, previously visited, cross-pollination is effected. Both of these organs then move upward against the erect petal called the standard, where they are out of the way, and do not again come in contact with insects. A single normal visit is sufficient to effect pollination, and all subsequent visits are useless. After the flowers have been exploded, or "tripped," they still continue. however, to secrete nectar and receive insect visits. This is clearly an imperfection, since the attraction of visitors is no longer an advantage.

In different seasons and different localities there is a wide difference in the quantity of seed produced by alfalfa. In the Milk River Valley of Montana a yield of from 10 to 12 bushels pel acre lias been ohtained in farorable years, while in others 
it was almost a complete failure. Contradictory assertions have been repeatedly made by various observers that the flowers are self-fertile or self-sterile in the $a b$ sence of insects. For the purpose of settling this question definitely, numerous experiments were conducted by Piper and his assistants, the results of which were published by the Bureau of Plant Industry in 1914.

More than 24 species of wild bees, besides many butterflies, flies, and beetles. have been observed on the flower's; but many of these are useless as pollinators. In localities where alfalfa is nectarless it is almost entirely ignored by honeybees, but where it serretes nectar freely they are attracted in great numbers. T'sually they obtain the nectar thru a loole in the sirle of the flower without tripping it. Out of 500 visits observed by Westgate a flower was tripped in only one instance. In California. according to McKee, few flowers are tripperl by honeybees; but in Fingland, Burkill saw then tripping the flowers in great numbers. Even if an individual honeybee tripped a flower only oceasionally, the aggregate exploder in a day orer a large area of alfalfa would be laroe. In Colorarlo. western Kansas, and Nevada, where bee culture has been greatly developed in recent years, it is claimed that the alfalfa seed crop in fields near apiaries is much hearier and of better quality than that of fields a few miles away. lin the former fields the amount of seed was at least 50 per cent greater than in those which were remote from colonies of bees. In one instance in Nevada it is claimed that the presence of bees increased the crop of seed by over 300 per cent. Bumblebees are nore important than honeybees, and trip the flowers frequently - in Washington and Montona about 30 per cent of the flowers visited. But the leaf-cutting bees (Megachile) are the most efficient pollinators. $M$. latimanus trips 9 out of erery 10 flower's risited, and three of these bees were observed to trip flowers at the rate of 552 per hour. Butterflies are common visitors, especially in Californin, where the alfalfa butterfly (E:trymus eurytheme) is abundant: but they obtain the nectar thru the orifice in the side of the flower without depressing the carina. In South America small birds called honey- suckers visit the flower for nectar. Pollination by the wind does not oecur.

Untripped flowers seldom produce seed, but in the absence of insects a large percentage may explode automatically. At Chinook, Montana, 33 out of 57 marked flowers on one plant became self-tripped. and set 21 pods: and on a second plant 36 flowers out of 64 tripped automatically: and produced 16 pods. In the first case 63 per cent of the self-pollinated flower's produced porls, and in the second 44 per cent. In rare instances flowers develop pods without trippin... Variability in selftripping is strongly influeneed by climatic factors, as temperature, lumidity, and bright sunshine. A single alfalfa plant was screened from inserts for 10 days $0^{\circ}$ longer until it was in full bloom. "Tlke screen was then removed for 15 minutes on a very warm clear day. The flowers quickly began exploding with a snapping sound. at times three or four being heard simultaneously. It was estimated that more than one-half of the flowers were self-tripped before the sereen was replaced. In the West, automatic self-tripping probably results in the production of as many pods as insect pollination. This observation is inportant since it explains the production of a large crop of seed in the absence of insects.

A series of experiments was conducted to test the comparative effects of self-pollination and cross-pollination of alfalfa flowers. Nine thousand and seventy-four flowers were artificially tripped, and consequently self-pollinated, and set $2,78+$ pods. The different plants on which the flowers were thus self-pollinated ranier greatly in the production of porls, 68 per cent of the flower's in one instance setting. pods, while other's yielded none. Pollinition from a different flower on the same plant is of little advantage over self-pollination. Five hundred and thirteen selfpollinated flower's set 165 pods, or 32 per cent; while 437 flowers pollinated from another flower on the same plant set 134 pods, or 30 per cent. When 446 flowers were each cross-pollinated with pollen from another plant 206 pods were produced, or 46 per cent. The avernge.number of seerks ner pod of the self-pollinated flowers was 1.4; of the flowers pollinated from another 
flower on the same plant, 2.02: and of the cross-pollinated flowers 2.38. Cross-pollination is, therefore, more potent than self-pollination, and consequently pollination by insects is an advantage.

It is now well established that the production of seed is greatly influenced by climate; and practical experience lias shown that it can be raised in paying quantities only in those States which possess a lot, dry season. Too much moisture is injurious, and consequently the eastern portion of the country with its larger rainfall is not well adapted for this purpose; while in the irrigated sections one irrigation is usually omitted. It is of interest to beekeepers to know that most of the seed is raised in Arizona, California, Utah, Colorado, Kansas, and Idaho. The best results are obtained with a thin stand of alfalfa, or where it is cultivated in rows. The domestic supply is far below the demand, and millions of pounds are annually imported.

\section{AUTHORITIES.}

While certain general principles can be laid down regarding alfalfa for all parts of the United States, it has not been possible in this article to go into those local details with which the well-informed grower should be familiar. Any one interested in the plant should first find out what his state experiment station has published on alfalfa-growing in his locality. The literature is thoro and comprehensive.

The best work on the subject is J. E. Wing's "Alfalfa in America" (1912): A somewliat more extensive work is F. D. Coburn's "The Book of Alfalfa" (1906). The Department of Agriculture, Washington, publishes Farmers' Bulletin No. 339, entitler "Alfalfa," by J. M. Westgate. Of the various publications by state experiment stations, those by the Colorado, Illinois, Utah, and Kentucky stations are especially valuable. All of the works citerl were rised in the preparation of this article. Grateful acknowledgment is made to $\mathrm{Mr}$. Alvin Kezer, Chief Agronomist at the Colorado State Experiment Station, for reading the manuscript and making suggestions.

ALFILERILLA (Erodium cicutarium (L.) L'Her).-Alfilerilla is derived from the Spanish word for pin, also linown as alfilaria, pin-clover, musk clover, storksbill, heron's bill, and pin-grass. The fruit resembles a heron's bill, whence the name of the genus Erodium, the Greek for heron. Naturalized from Europe, and widely distributed; one of the leading honey and pollen yielders of California and Arizona. It is regarded as an excellent forage plant by stockmen, quite equal in feeding value to alfalfa, and probably more palatable, because much less woody in character. An analysis by the chemist of the Arizona $\mathrm{Ex}$ periment Station shows it is quite equal to any clover for feeding. It is being rapidly spread by sheep and cattle in the extreme Southwest, for it is easily disseminaterl, and requires no particular cultivation. In this respect it resembles sweet elorel'; but animals do not have to be educated to eating it; on the contrary they are fond of it from the start. As a honey and pollen plant it ranks very high, both as regards quantity and quality.

ALGARROBA.--See Mesquite.

ALSIKE CLOVER.-See Clover.

ALUMINUM COMBS. - See MeTAL CoMBs.

AMATEUR BEEKEEPING. - $\mathrm{S}$ e e Backlot Beekeeping; also A B C of BeeKEEPING.

ANALYSIS OF HONEY.-See HONEY and Honey ANalisis.

ANATOMY OF THE BEE.-The three parts of the body of the bees are well separated by constrictions. The head carries the eyes, antennæ, and mouth parts; the thorax, the wings and legs; and the abdomen, the wax-glands and sting.

The head is flattened and triangular, being widest crosswise thru the upper corners, which are capped by the large compound eyes. It carries the antennae, or feelers, on the middle of the face (Fig. 2, $A, A n t$ ) : the large compound eyes (E) laterally; three small simple eyes or ocelli $(O)$, at the top of the face, and the mouth parts ( $M d$, $M x$, and $L b$ ) ventrally. Eaclı antenna consists of a long basal joint and of a series of small ones hanging downward from the end of the first. The antennæ are very sensitive to touch, and contain the organs of smell. At the lower edge of the face is a loose flap 


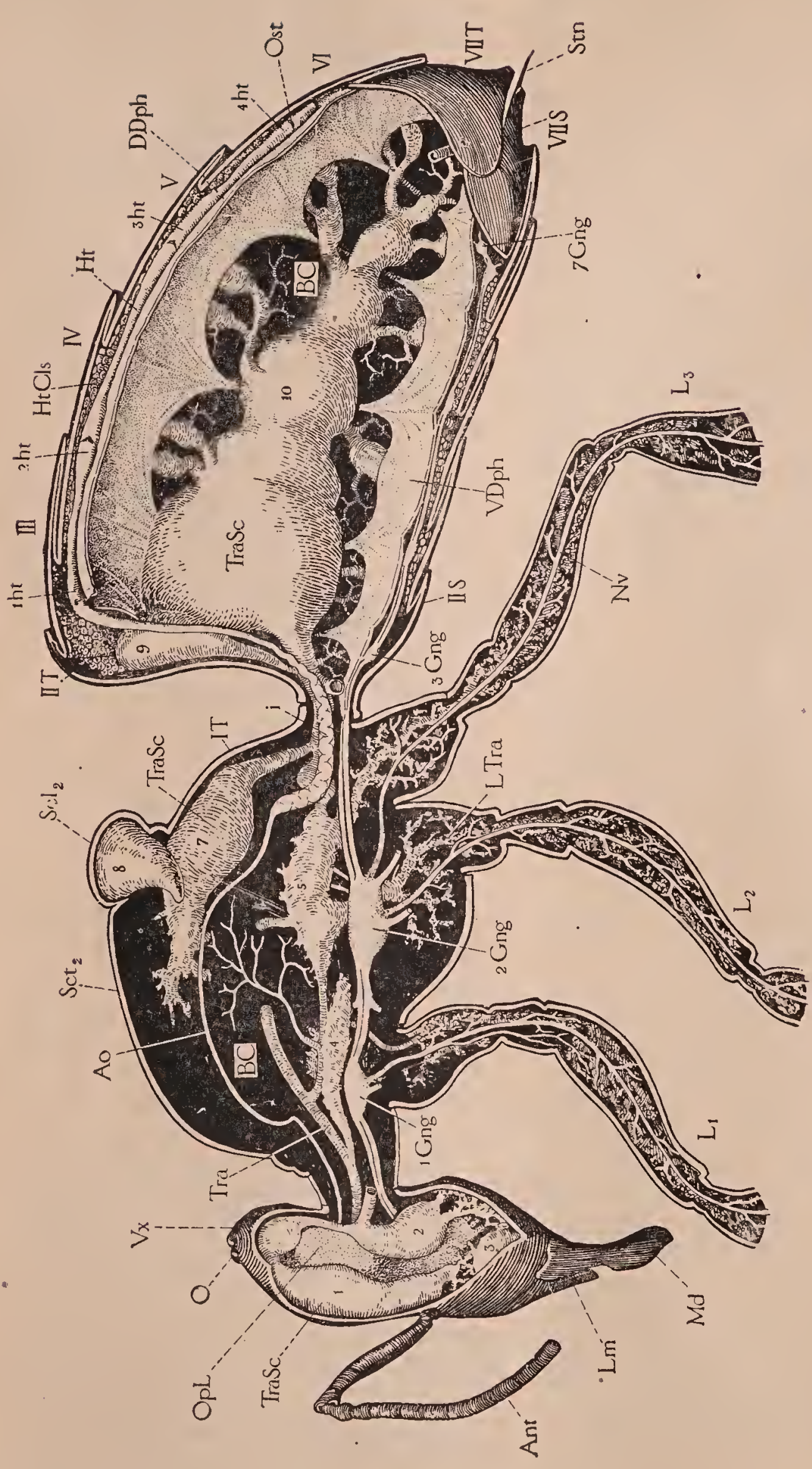

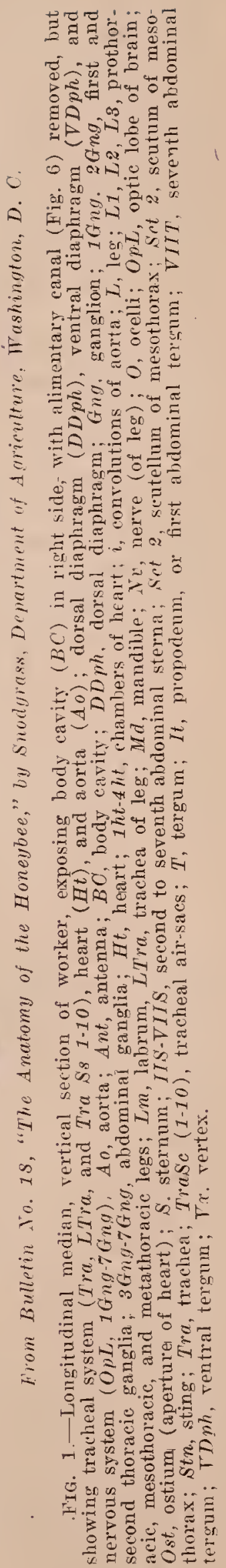


(Fig. 2, $\wedge, L m$ ) forming an upper lip aalled the labrum. On its under surface is a suall soft lobe called the epipharynx on which are lorated the organs of taste. At the sides of the labrum are the two lieavy jaws, or mandibles ( $M d$ ), which worli sidewise. They are spoon-shaped at their ends in the worker, but sharp-pointed and tootherl in the queen and drone. Those of the queen are largest, those of the drone smallest. Behind the labrum and the mandibles is a bunch of long appendages, usually folded back beneatl the head, which together constitute the proboscis (Fig. 2, A, Prb.) These organs correspond with the second pair of jaws, or maxillae, and the lower lip, or labium, of other insects. In Fig. 2 they are cut off a short distance from the head and flattened out in Fig. 3, D. The middle series of pieces $(S m t-L b l)$ constitutes the labium, the two lateral series $(C d-M x)$ the maxilla. The labium consists of a loasal submentum ( $S m t)$, and a mentum (Mt). which supports distally the slender, flexille, tongne-like glossa $\left(G l_{s}\right)$, the two delicate paraglossae $(P g l)$, and the two lateral, jointed labial palpi $(L b, P l p)$. Each maxilla is composer of a basal stalk, the cardo $(C d)$; a main plate, the stipes $(S t)$, and a wide terminal blade $(M x)$ called the galea. At the base of the galea is a rudimentary maxillary palpus ( $M x$ $P(p)$, representing a part which in most insects consists of several slender joints.

As before stated, the part of the maxillæ and the labium together constitute the proboscis, which, as shown in Fig. 2, is suspended from a deep cavity (ProFs) on the lower part of the lack of the head haring a membranous floor. The nasal stalks $(C d)$ of the maxillix are hinged to knobs on the sides of this carity, while the labium is attached to the maxillary stalks by means of a flexible band called the lorum (Fig. 3. D, $L r)$.

When the bee wishes to suck up any liquid, especially a tlick liquid like honey or syrup, provided in considerable quantity, the terminal lobes of the labium and maxillæ are pressed close together so as to make a tube between them. The labium is then moved back and forth between the maxillæ with a pump-like motion produced by muscles within the liead.. This brings the liquid up to the mouth, which is situ- ated above the base of the proboscis, between the mandibles and beneath the labrum. The food is then taken into the mouth by a sucking action of the pliarynx, produced by its muscles.

A more delicate apparatus is probably necessary, however, for sucking up minnte drops of nectar from the bottom of a flower. Sucl a strueture is provided within the glossa. This organ (Fig. 3, D, Gls), ordinarily called the "tongue," is terminated by a delicate, sensitive, spoonlike lobe known as the labella (Fig. $3, \mathrm{~A}, \mathrm{~B}$, and $\mathrm{D}$, $267)$, and has a groove $(k)$ running along its entire length on the ventral side. Within the glossa this groove expands into a double-barrel tube (Fig. 3, E. Lum.) A flexible chitinous rod $(r)$ lies along the clorsal wall of this channel, which is itself provided with a still finer groove (l) along its rentral surface. Thus the very smallest quantity of nectar may find a channel suited to its bulk thru which it may run up to the base of the glossa by eapillary attraction. But since the glossal channels are rentral the nectar must be transferred to the dorsal side of the labium by means of the palaglosse, the two soft lobes (Fig. 3), $\mathrm{D}$ and $\mathrm{F}, \mathrm{Pgl}$ ) whose bases are on the upper sirle of the mentum, but whose distal ends underlap the base of the glossa, and thus afford conduits for the nectar around the latter to the upper side of the labium. The glossa is highly extensible and retractile by means of muscles attached to the base of the rod, and its movements when a hee is feeding are very conspicuous, and interesting to watch.

The thorax of an insect carries the wings and the legs. The two wings of the bees on each side are united to each other by a series of minute hooks so that they work together, and the four wings are thus practically converted into two. Fach wing is hingerl at its base to the back, and pivoted from below upon a small knob of the side wall of the thorax. The up-and-down motion of the wings is produced, not by numscles attached to their bases, but by two sets of enormous muscles, one vertical and the other horizontal, attached to the walls of the thorax, whose rontractions elevate and depress the back plates of the thorax. Since the fulcrum of each wing is ontside of its attachment to the back, the depres- 

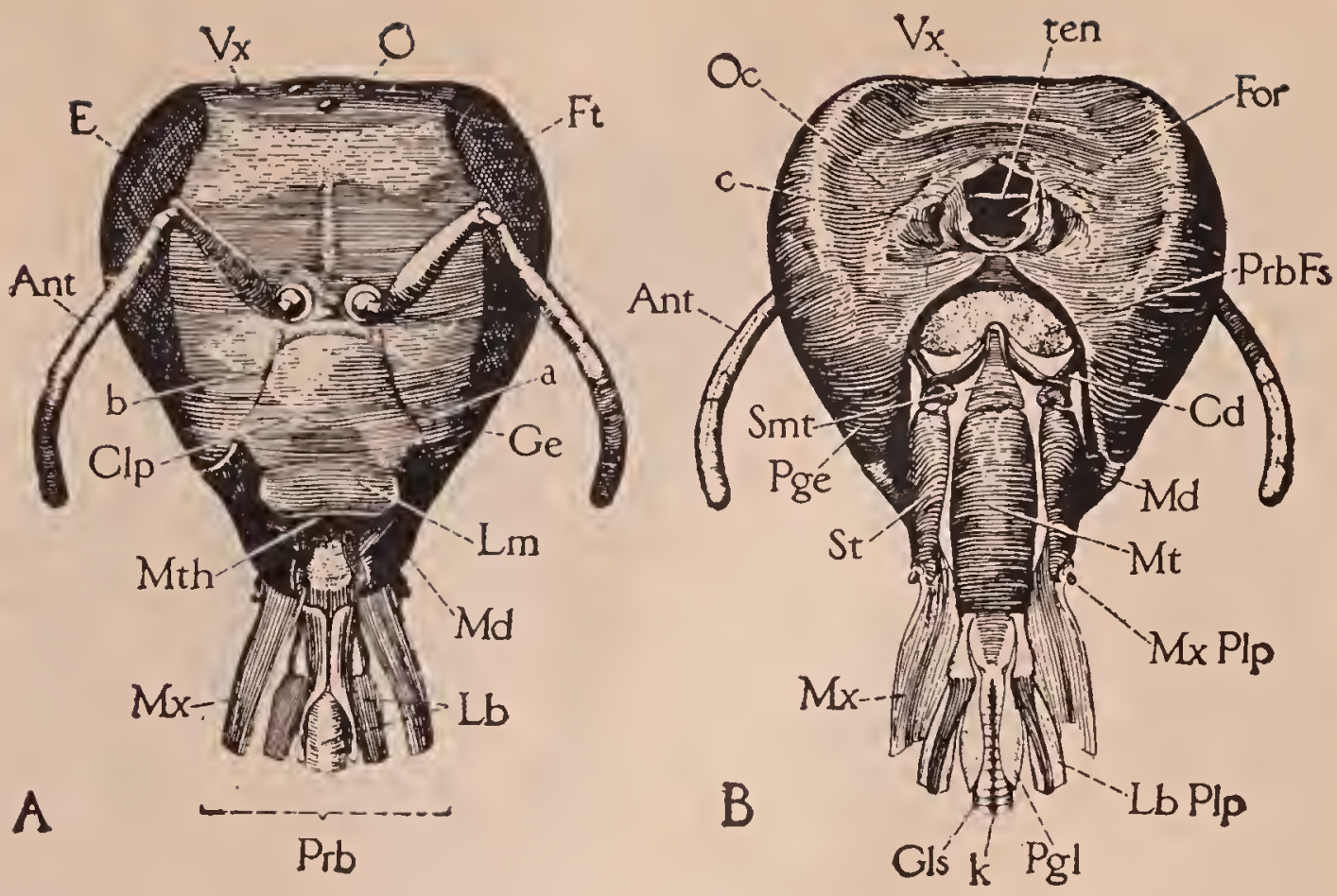

From Bulletin No. 18, "The Anatomy of the Honeybee," by Snodgrass, Dept, of Ag., Tushington, D. C.

FIG. 2.- Head of worker with parts of proboscis cut off a short distance from their bases. $A$, anterior'; $B$, posterior; $a$, clypeal suture: Ant antenna; b pit in clypeal suture marking anterior end of internal bar of head; $c$, pit on occipital surfuce of head, narking posterior end of internal bar; $C d$, cardo; $C l p$, clypeus : $E$. compound eye ; For, foramen magnum ; Ft, front ; Ge, gena: Gls, glossa, or "tongue;" $k$, ventral groove of glossa; Lb, labium; LbPlp, labial palpus; Lm, labrum; IId, mandible; $\boldsymbol{M t}$, mentum; $\boldsymbol{M}$ th, mouth; $\boldsymbol{M} x$, terminal blade of maxilla: MxPlp, maxillary palpus; $O$. ocelli; $O c$, acciput; Pge, postgena; $P g l$, paraglossa: Prb, base of proboscis; PrbFs, fossa of proboscis; Smt, submentum; St, stipes; ten, small bar of tentorium arching over foramen magnum; $V x$, vertex.

sion of the latter elevates the wing, and an elevation of the back lowers the wing. But the bee flies by a propeller-like action, or figure- 8 motion of the wings. This is produced by two other sets of mucl smaller muscles acting directly upon the wing bases, one before and the other behind the fulcrum of each. The combined result of all these muscles is that the down stroke of the wing is accompanied by a forward movement and a deflection of the anterior adge, while the up stroke reverses this.

The legs of the bee are too familiar to need any extensive description here. Their special characters, such as the antennæcleaners on the first and pollen-baskets and brushes on the last, are illustrated in Fig. 4. The tarsi are each provided with a pair of terminal claus $(E, C l a)$, by means of which the bee clings to rongh objects. while between the claws is a sticky pad. the empodium ( $E m p)$, which is brought into play when the bee alights on or walks over any smooth surface like glass.

The hind part of the thorax of bees, wasps, and their allies is composed of a segment, which, in other insects, is a part of the abdomen. It is known as the propodeum. The middle division of the body of a bee, wasp, or ant, therefore, is not exactly the equivalent of the thorax of a grasshopper, fly, or butterfly.

The abdomen of the bee has no appendages corresponding with those of the head or thorax; but it bears two important organs, viz., the wax glands and the sting. The wax glands are simply specially developed cells of the skin on the ventral surfaces of the last four visible abdominal segments of the worker. There are only six segments visible in the apparent abdomen: but remembering that the propodeum of the thorax is really the first, the wax glands occur, therefore, on segments four to seven inclusive (Fig. 1, IV-VII). The wax secreted by the glands is discharged thru minute pores in the ventral plate of each segment, and accumulates in the form of a little scale in the pocket above the underlapping ventral plate of the segment next in front.

The sting is such a complicated organ that it is very difficult to describe it clearly in a few words. Fundamentally it consists 
of three slender, rlosely appressed pieces forming the sharp piereing organ that projects from the tip of the abdomen (Fig. 1, $S t n)$, and of two soft fingerlike lobes, sometines also visible, all of which arise from three pairs of plates belonging to the eighth and ninth segments of the ablomen. but which are coneealed within the seventh segment.

Fig. 5 shows, somewhat diagrammatically, all the parts of the left side. The acute stinging shaft swells basally into a large bulb $(S h B)$ which is connected by a basal arm on each side with two lateral plates
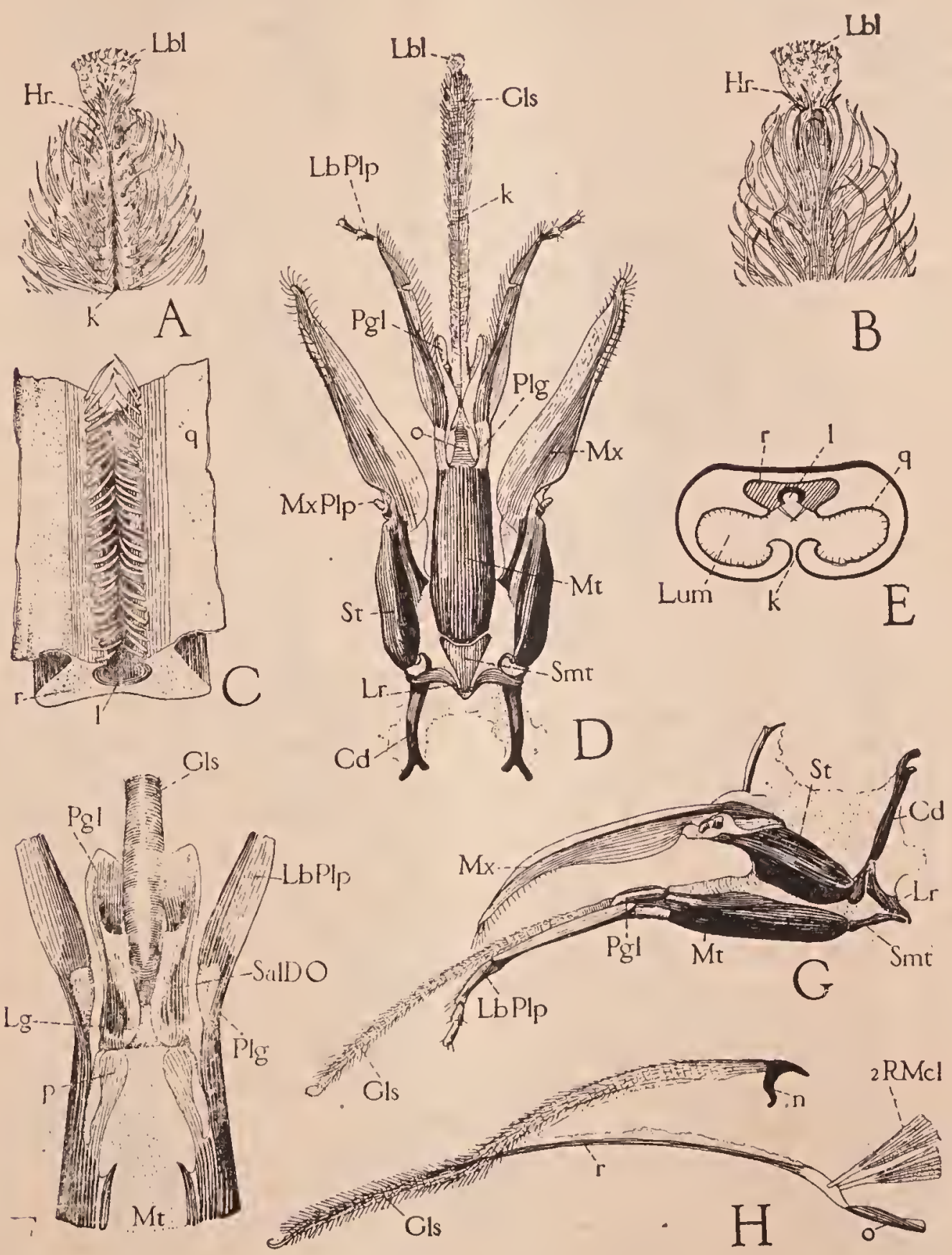

Fom Bulletin Xio. 18, "The Anatomy of the Honeybee," by swodgras, Lept. of Ay., Washington, D. C.

FIG. 3.-Details of mouth parts of worker. A, tip of glossa, ventral; $B$, tip of glossa, dorsal; $C$, piece of glossal rod $(r)$ showing rentral groove $(l)$ with parts of wall $(q)$ of glossal channel attached; $D$, parts of proboscis (naxilla and labium) flattened out in ventral view: $E$. coss-section of glossa, showing its channel (Lum) open below along the groove $(k)$, the internal rod $(r)$ in roof of channel, and its groove (l); $F$. distal end of mentum ( $M t$ ), dorsal, showing opening of salivary duct (SalDO) on base of ligula; $G$, lateral view of left half of proboscis; $H$, glossa ( $G l s$ ) with its rod $(r)$ partly torn 8 way, showing retractor muscles $(2 R M C l)$ attrched to its base; $C d$, cardo; $H r$, long stiff hairs near tip of glossa; $k$, ventral groove of glossa; l, ventral groove of glossal rod; $L b l$, labella; $L b P l p$, labial palpus; $L g$, ligula; $L r$, lorum; $L u m$, channel in glossa; $M t$, mentum; $M x$, terminal blade of maxilla; $M x P l p$. maxillary palpus; $n$, basal process of glossal rod; o, ventral plate of ligula, carrying base of glossal rnd; $p$, dorsal plates of mentum; Pgl, paraglosen: Plg. palpiger: $q$, inner wall of glnssal channel; $r$, rnd of glossa; $2 K M r l$, retractor nuuscle of glossal rod: Salno, opening of sulivary duct; Smit, submentum; St, Stipes, 
(Ol, and Tri). The fingerlike lobes, called the palpi of the sting (StnPlp) are carried also by the lower of these two plates $(O b)$ while the upper (Tri) carries the third and laresest plate $(Q d)$ which partially overlaps the lower $(O b)$.

A close examination of the sting proper shows that both the bulb and the tapering sliaft are formed of three pieces. One is dorsal ( $S h B$ and $S h S$ ) while the other two (Let) are ventral (of course only one of the latter shows in side view). Furthermore, the basal arm on each side is formed of two pieces, one of which $(S h A)$ is continuous with the dorsal piece of the sting. while the other (Lct) is continuous witl the ventral rod of the same side. Since these rentral rods are partially enclosed within a hollow on the under side of the dorsal piece, the latter is called the sheath of the sting. It consists of the terminal shaft of the sheath (ShS), the bulb (ShB). and of a basal arm $(S h A)$ on each side. The ventral pieces $(L c t)$ are slender sharppointer rods having barber extrenities, and are known as the lancets. The shaft of the slieatl is grooved along the enthre lengtl of its rentral surface, the groove enlarging into a spacious eavity in the bulb. The lancets lie close together against the rentral edges of the sheath, but slide freely upon minute tracks on the latter. The three parts, therefore, inclose between them a cavity which is tubular in the shaft, but enlarged into a wirle chamber in the bulb. The great poison-sac (Fig. 8, PsnSc) of the acid glands of the sting opens into the base of the bulb along with the smaller tubular alkaline gland $(B G 7)$. By morements of the triangular plates (Fig. 5. Tri) the lancets slide back and forth against the sheath while the poison exudes in tiny drops from an opening between them near the tips. The poison-sac has no museles in its walls, and, hence, cannot force the poison thru the sting. The poison, in fact, is driven out of the latter by a foree pump inside of the bulb. This consists of. two pouchlike lobes situated on the upper edges of the lancets, having their carities open posteriorly. When the lancets move forward the walls of these pouches collapse; but when the motion is reverserl they flare apart and drive the poison rontained in the bulb back thrn the shaft and ont at the end.

The poison is an acid liquid formed by the glands (Fig. 8, $A G l, A G l$, and $B G l$ ). Two of these $(A G l$ and $A G l)$ are simply small enlargements at the ends of two lone roiled tubes $(A G l D)$, which latter unite into a shor't single tube that opens into the anterior end of the great poison-sae (Psn $S c)$. The secretion of these glands is acid. The thind gland $(B C l)$ is a short, somewhat twisted tube opening into the bulb of the sting along with the poison-sac. Its secretion is alkaline. Carlet has shown that it is only the nixture of these two secretions that has the full strength in stinging properties.

The alimentary canal (Fig.6) consists of a tube extending thru the entire body, and eoiled somewhat in the abdomen. The first part above the mouth in the head is widened to form the plarynx (Phy). Then follows the long slender nesophagus $(E)$. running clear thro the thorax and into the front of the abrlo'nen, where it enlarges into a thin-waller hag, callerl, in general, the crop, but which is known as the honeystomach ( $H S$ ) in the bee. Back of the honey-stomach is a short narrow proventriculus (Prent), which is followed by the large U-shaped stomach, or ventriculus ( Tent). Then comes the slender small intestine (SInt) with a circle of Malpighian tubules $(M a l)$ arising from its anterior end. Finally, forming the terminal part of the alimentary canal, is the large intestine. or rectum (Rect), consisting of an enormous sac, varying in size according to its contents, but often occupying a large part of the abdominal carity. Six opaque longitudinal bands on its anterior end are known as the rectal gland ( $R G l)$.

The honey-stomach is of special interest in the worker because the nectar gathererl from the flowers is held in it, instead of being swallowed on down into the stomach, and is regurgitated into the cells of the courb, or given up first to another bee in the hive. 'The upper' end of the proventriculus sticks up into the lower end of the loney-stomach as a small cone with an X-shaped opening in its summit. This opening is called the stomach mouth. Its four lips are very active, and take whatever food the rentriculus requires from 
the honey-stomach, for it must all go into the latter first, while at the same time it affords the bees a means of retaining nertar or honey in the honey-stomach.

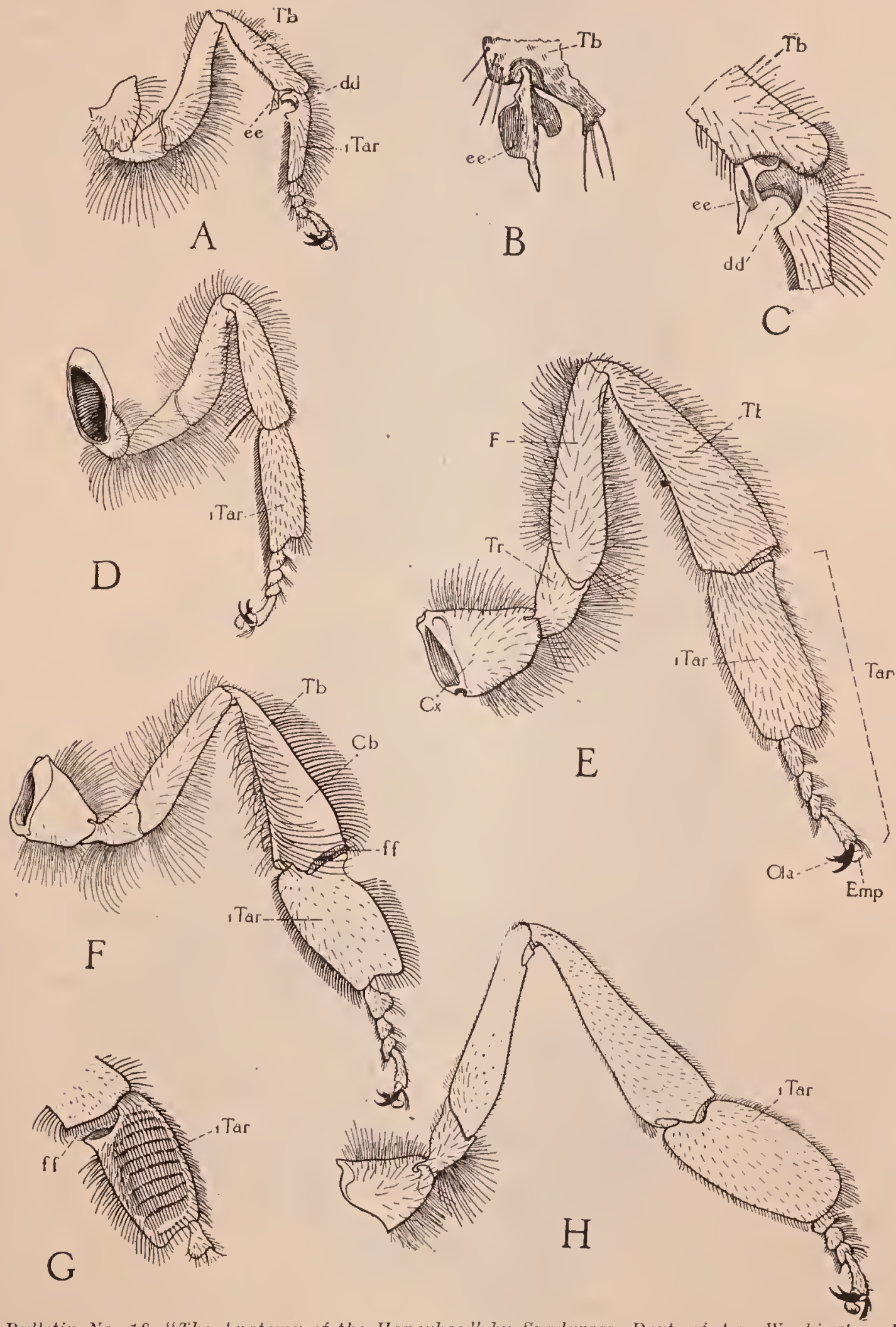

From Bulletin No. 18, "The Anatomy of the Honeybee," by Srodyrass, Dept. of Ay., Washington, D. O.

FIG. 4.-Details of legs. A. front leg of worker, showing position of antenna-cleaner (dd and ee); $B$, end of tibia of front leg showing spine (ee) of antenna-cleaner; $C$, antenna-cleaner, more enlarged $; D$ middle leg of worker; $E$, hind leg of queen; $F$, hind leg of worker, showing pollen-basket (CU) on outel surface of tibia; $G$, inner riew of basal joint of hind tarsus of worker, showing the brusli of pollen-gathering hairs; $H$. hind legs of drone; $C b$. corbidulum, or pollen-basket; Ola. claws; Cr, coxa; dr. notch of antenna cleaner on basal joint of first tarsus; $\rho \rho$, spine of antenna-cleaner on distal end of tibia; Emp. empodium. sticky pad betwren the claws for walking on smootl surfaces; $F$. fenmr; ff, "Wax shears;" Tar, 1:lrsus; $1 T a r$, first joint of tarsus; Tl, tibia.

The matural food of bees consists ol" pollen, nectar, and honey. The first contains the mitrogen of their diet, and the ot?er two the hydrowen, carbon, and oxy-

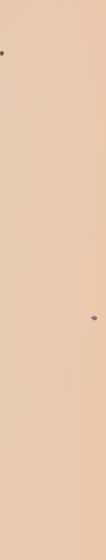


gen. Observations made by the writer indicate that the pollen is not digested until it gets into the intestine, for masses of freshlooking grains nearly always appear in the rear part of the ventriculus, which is otherwise filled with a brownish slime. On the other hand, the nectar and honey are very probably digested in the ventriculus, and in large part absorbed from it.

The salivary glands, located in the back part of the head (Fig. 6, 2Gl) and in the front part of the thorax $(3 G l)$ open upon the upper part of the labium (Fig. 3, F, SalDo). The saliva can thus affect the liquid food before the latter enters the moutl, or it can be allowed to run down the pro-
(LDysh and $f D_{p} / \mathrm{h}$ ), stretching aross the dorsal and ventral walls of the abdomen, but leaving wide openings along their sides between the points of attachment. The heart consists of four consecutire chambers Tht-4ht, which are merely swellings of the tube, each having a vertical slit or ostium (Ost) opening into each side. The blood is the colorless liquid that fills the spaces about the viscera of the body cavity. The dorsal diaphragm and the heart pulsate forward. The blood in the cavity above the former enters the ostia of the heart, and is pumped forward thru the aorta and out into the cavity of the liead. From liere it percolates back thru the thorax and enter's

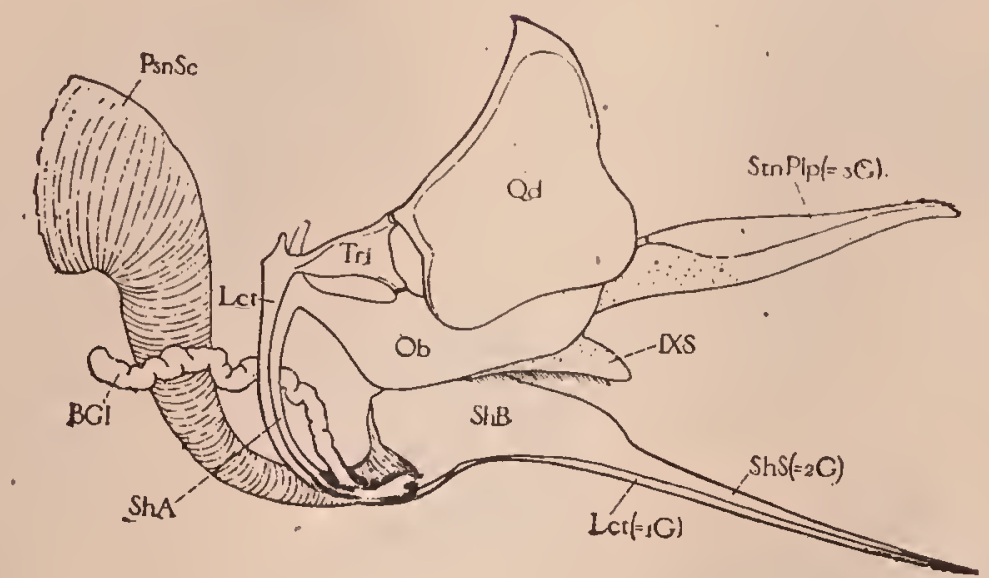

From Bulletin No. 18, "The Anatomy of the Honeybee," by Snodyruss, Dept. of Ag., Washington, D. C.

FIa. 5.-Left side of sting and its accessory plates, with alkaline gland ( $B G 7$ ) and base of poison-sac (PsnSc) attached. $B G l$, alkaline-poison gland; Let, lancet; $O b$. oblong plate; Pansc, base of poison-sac holding secretion from acid-gland (see Fig. 8); Qd, quadrate plate; IXS. median part of ninth abdominal sternum; ShA, arm of sheath; ShB, bulb of sheath; ShS, shaft of sheath; StnPlp. palpus of sting; Tri, triangular plate.

boscis upon hard sugar in order to dissolve it, for the latter is eaten with the proboscis, not with the mandibles.

The large glands( Fig. 6, 1Gl) situated in the front part of the head are supposed, by some students of the bee, to form the white pasty brood food and the royal jelly. Others think that these substances come from the stomach. More investigation of the subject must be made, however, before the question can be decided; but the contents of the stomachs of the workers have no resemblance to the brood food.

The circulatory system is very simple, consisting of a delicate, tubular, pulsating heart (Fig. 1, Ht), in the upper part of the abdomen, of a single long blood vessel, the aorta $(A o)$, extending forward from the heart thru the thorax into the head, and of two pulsating membranes, the diaphragm: the space beneath the ventral diapliragm $(V D p h)$ of the abdomen. This membrane pulsates backward, and the blood is driven posteriorly and upward, thru the lateral openings, around the abdominal viscera, and again into the dorsal or pericardial eavity of the abdomen, where it begins its circulation anew. In insects the principal function of the blood is to distribute the food which dissolves into it from the alimentary canal.

The respiratory system is very highly developed in the bee, consisting (Fig. 1) of large air-saes (TraSe, 1-10) in the head, thorax, and abdomen, and of tubes called tracheæ given off from them, (Tra, LTra). Fig. 1 shows principally the parts in only the right side of the body. In the abdomen a largen sac (10) lies on each side connected with the exterior by short tubes opening 


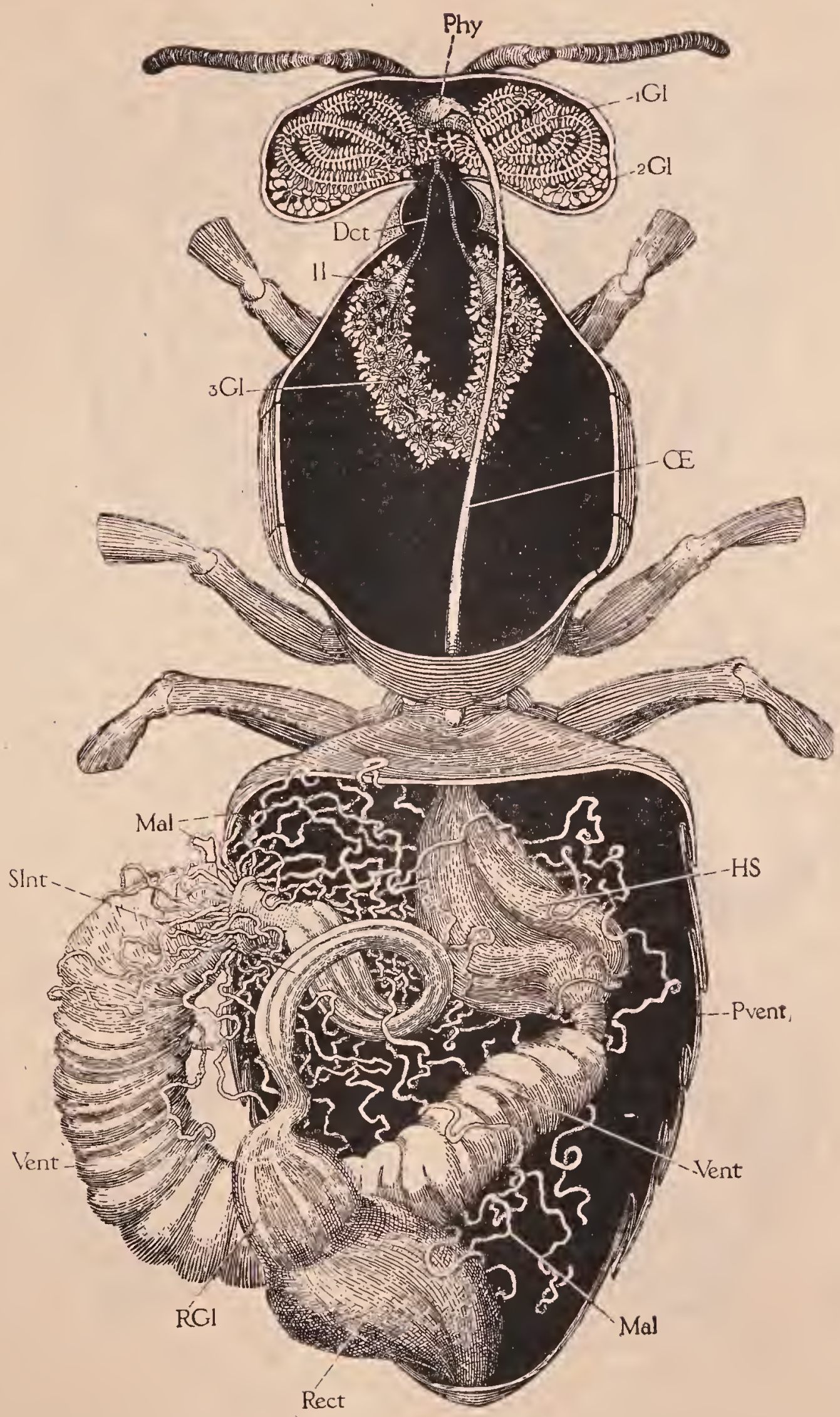

From Bulletin No. 18, "The Anatomy of the Honeybee," by Snodarass, Dept. of Ag., Washington, D. C.

Fia. 6.-Alimentary canal and salivary glands of worker, dorsal. Dct, salivary duct; 1Gl, pharyngeal glands of head (supracerebral glands); $2 G l$, salivary glands of head (postcerebral glands); $30 l$, salivary glands of the thorax; E, cosophagus; Ply, pharynx; Pvent, proventriculus; Rect, rectum; Rgl, rectal glands; SInt, small intestine; Vent, ventriculus. 


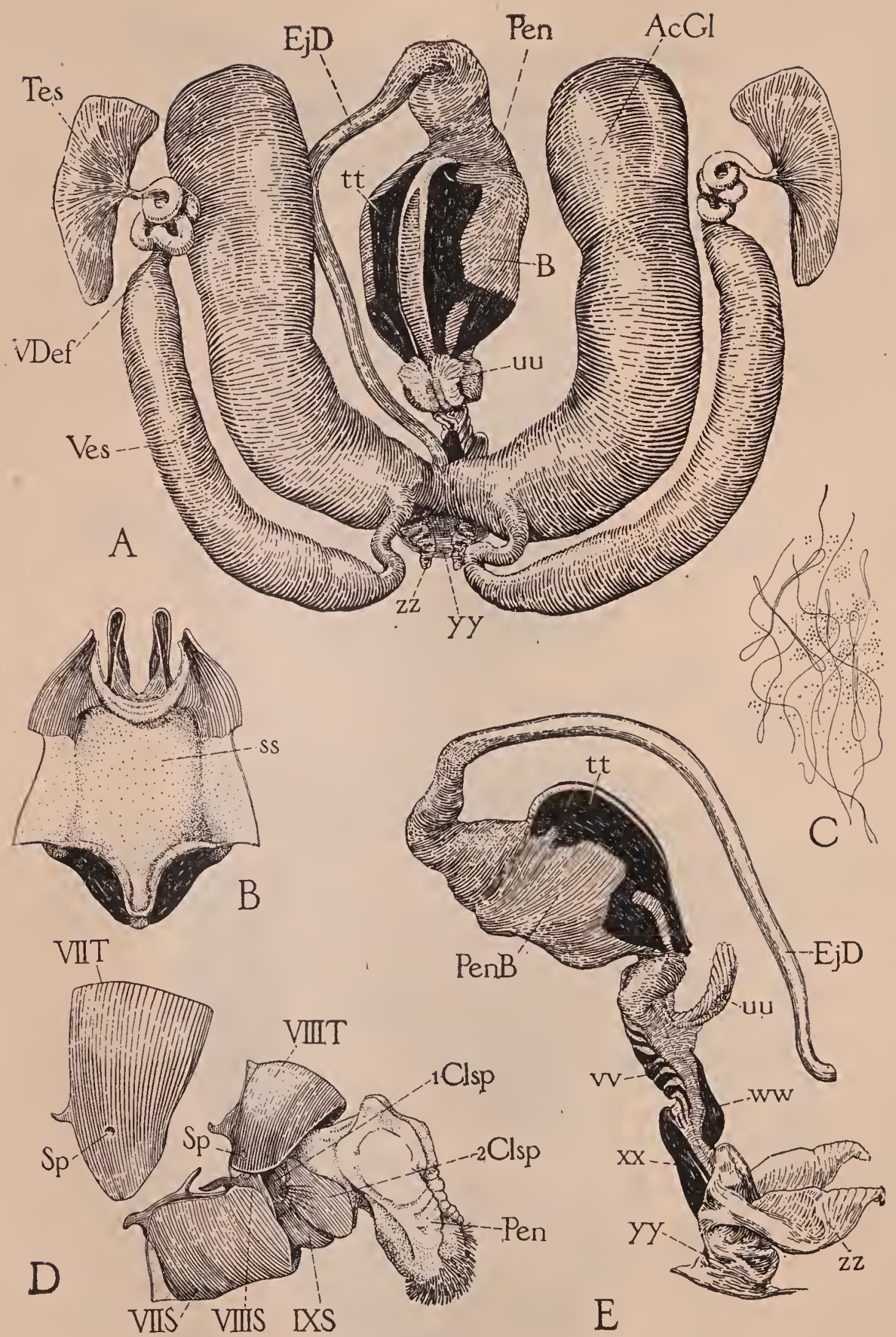

From Bulletin No. 18, "The A uatomy of the Honeythee," by Snodgrass, Dept. of Ag., Washington, D. C.

FIG. 7.-A, reproductire organs of drone, dorsal; $B$, inner view of dorsal wall of penis; $C$, group : $f$ spermatozoa: I), terminal segments of drone, lateral, showing penis ( $I^{\prime} e n$ ) partly protruded; $I^{\prime}$, lateral view of penis and ejaculatory duct $(E j D)$; $d c G l$, accessory mucous gland; $B$, bulb of penis; $1 C l s p$, 2(lsj, clasping organs of ninth abdominal sternum; Pen, penis; PenB, bulb of penis: FIIS-IXS, seventh to ninth abdominal sterna: ss, gelatinous mass of juner wall of bulb of penis: VIIT-VIIIT, seventl and tighth abdominal terga; $t$, dorsal plates of bulb of penis; Tes, testis; uu, fimbriated lobe at base of bull, of penis; $v v$, ladder-like plates of penis; VDef, vas deferens; Ves, seminal resicle; wu, dorsal and ventral plates in wall of penis; !'!y, terminal rhamler of penis thru which the rest is everted; $z z$, copulatory pouches of penis. 
on the sides of the finst seven segments. Three other prirs of such openings occiul in the thorax; but the last of these, being in the propodeum, really belong's to the abdomen. Thus there are in all ten pairs of breathing apertures, and they are called the spiracles. None oceur on the head. The tracheal tubes given off from the air-sacs branch minutely to all parts of the body and penetrate into most of the tissues. Hence oxygen is carried directly to the cells that use it, and the blood of insects is thus relieved of the work of distributing itone of its principal functions in vertebrate animals. The respiratory movements are produced by muscles of the abdomen.

The life processes of the cells of the body result in the formation of products excreted by the cells into the surrounding blood. These products are poisonous to the system unless immediately changed into simpler substances. This change is effected partly by the inhaled oxygen combining with the waste products, resulting in the formation of compounds of nitrogen which dissolve in the blood, and of carbonic acid gas which diffuses into the traclieal tubes and is exhaler. The nitrogen compounds are supposed to be remored by the Malpighian tubules (Fig. 6, Mal), which are regarted as the kidneys of insects.

The nervous system consists of a scries of small masses of nerve tissne called gamglia, lying along the median rentral line of the body eavity (Fig. 1, 1 ( mng-r (Gng), the two of the thorax being much largel than those of the abdomen. Each two are connected by a pair of cords called commissures. Nerves aie given off from these ganglia to the various organs and parts of the body, and to the legs and wings. In the head therè are two ganglionic masses. One is called the brain $(O p L \lambda$, and is situated above the osophagus, where it gives off nerves to the eyes, the antennæ, the front, and the labrum. The other, called the suboesophageal ganglion, lies in the lower part of the head, and innervates the mouth parts, while it is connected by commissures with both brain and the ffirst thoracic ganglion.

The reproductive system consists of those organs that produce the spermatozoa in the male and the eggrs in the female and their accessory parts.
The spermatozon are formed in the testes of the male (Fig. 7, 1 , Tes), a prair of small borlies in the front part of the abdonen, said to be developed at their highest in the pupal stage. Each is connected by a coiled tube, the vas deferens ( I Def), with a long sac, the seminal vesicle ( $T^{\top} e s$ ) in which the spermatozoa are stored during the adult stage of the drone's life. The two resicles open into the bases of two enormous mucous glands $(A C G l)$ which come together in a narrow muscular tube, the ejaculatory duct $(E j D)$. 'This opens into the anterior end of the penis (Pen). This is a complicated organ, shown at E, Fig. 7. It is ordinarily contained within the cavity of the abdomen; but during copulation it is entirely everted, and its basal pouches $(z z)$ lock into colresponding pouches of the oviduct of the queen.

The eggs are formed by the ovaries of the female (Fig. 8, Or), each of which consists of a thick mass of tubules called the ovarioles (ov), within which the egas grow from simple cells at their upper ends into the mature ergs found at their lower ends. The ovarioles of each ovary open into an oviduct $(O r D)$, which two unite into a wide median tube called the vagina ( $\mathrm{T} \mathrm{ag}$ ) that swells posteriorly into a larese. pouch known as the bursa copulatrix $(B C p x)$, opening to the exterior in the eighth segment beneath the base of the sting.

During copulation the drone ejects the spermatozoa into the npper end of the ragina of the queen. The spermatozor consist of minute vibratory threads (Fig. 7, C.) which, probably, by their own motion, make their way np thru a small tube opening into the dorsal wall of the ragina, and so reach a globular sar (Fig. 8. $S \mathrm{Pm}$ ) called the spermatheca. Here they are held during the rest of the lifetime of the queen, to be extruded in small bundles. of about a hundred each, according to Breslaw, upon the eggs passing out of the ragina. Thus are the female eggs fertilized, the drone egg's developing withont the addition of the male element.

ANGER OF BEES. - The author does not like the term "anger," when applier to bees, and it almost makes him angry when he hears people speak of bees being 
"mad," as if they are always in a towering rage, and delight to inflict severe pain on everything and everybody coming near them. Bees are, on the contrary, the pleasantest, mast sociable, genial, and goodnatured little beings that are met in all

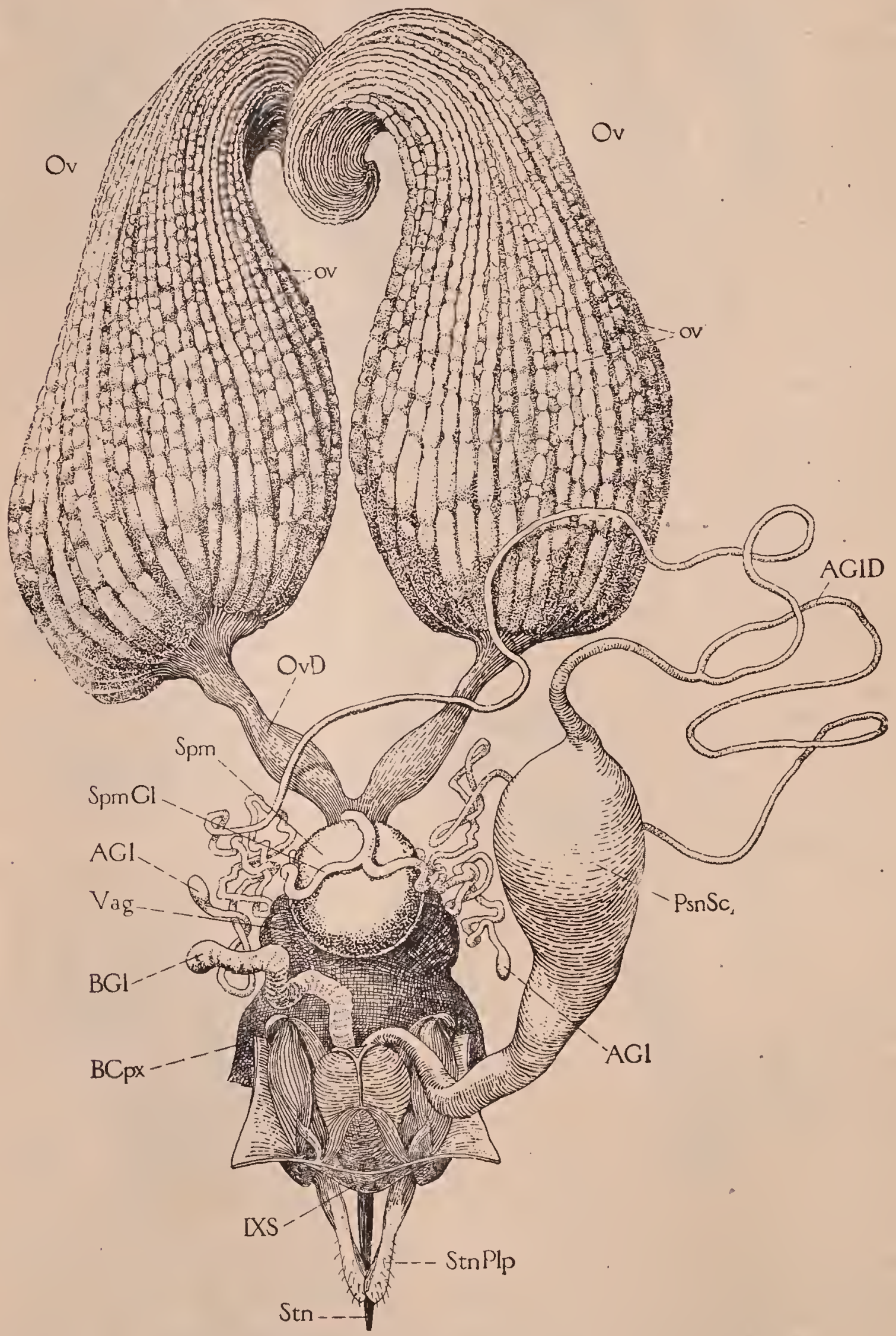

From Bulletin No. 18, "The dnatomy of the Honeybee," by Snodgrass, Dept. of Ag., Washington, D.C.

FiG. 8.- Reproductice organs of queen, dorsal, togethel with sting, its unseles, glands, and poison-sac, $A G l$, acid-glands of sting; $A G l D$, durt of acid-glands; $B C p x$, bursa copulatrix; $B G L$, alkaline gland of sting; Ov, ovaries; ov, ovarioles; $O r D$. oviduct; Psnsc, poison-sac; $I X S^{4}$, median part of ninth abdominal sternum; $S p m$, sac of spermatheca; SpmGl, spermathecal gland; Stn, sting; StnPlp, palpus of sting; Vag, vagina. 
animated creation, when they are understood. Their beautiful comb can be torn all to bits right before their very eyes, without their showing a particle of resentment; and with all the patience in the world they will at once set to work to repair it and that, too, without remonstrance. If they are pinched they will sting; and a human being who has energy enotigh to take care of himself would do as much had lie the weapon.

How to open hives in such a way as to avoid stings, see ManipUlation of COLONies, and Stings.

In order that the reader may better understand that which follows, it may be well to set forth two or three fundamental conditions under which bees become cross or nervous and umpleasant to handle. First, a slackening or a shutting-off of the supply of food obtained either from the fields in a natural way, or from exposed sweets, always has a tendency to make bees ill-natured. If the honey flow is unusually strong, and then slackens up very rapidly. the bees in the whole yard become cross. This is particularly noticeable at the closing of basswood or after the drying up of certain honeydews deposited on the leares of trees. Then the bees are robbing, and combs or syrup are carelessly exposed. and these combs or syrup are suddenly put under cover, so that not another drop can be secured, bees will nsually sting furrously, when, if their supply were allowed to stand and gradually diminish, they will be much better natured.

If some one carelessly exposes sweets in ruantities during a dearth of loney when bees are disposed to rob, this will have a tendency to stir up the whole apiary. The roal of the excitement may be heasd some distance from the apiary. Thousands and thousands of bees will be found flying around everywhere to discover where this new supply is located; but, as a general thing, bees are not cross when trving to find the source of the sweet. The real trouble begins about the time the supply gives out.

During the middle hours of the day when the air is warm and balmy and the bees are going into the fields, they are ganerally very gentle. But if a sudden rainstorm comes up, shutting off the supply of nec- tar, they will usually be quite ross, and this bad temper will last until the normal supply begins to come in again.

Bees are apt to be cross on cool or chilly days. When all are at home, and the hives are opened unceremoniously, they may resent the intrusion. It is then that beginners discover, much to their sorrow, that bees should not be handled during cool or chilly weather, right after a rain, nor at night.

By keeping these facts carefully in mind, when the following incidents are related, one will more readily discover why bees are cross :

A few years ago a very intelligent man procured some Italians, an extractor, etc., and commenced bee culture. $\mathrm{He}$ soon learned to handle them, and succeeded finely; when it came time to extract, the whole business went on so easily that he was surprised at what had been said about experienced hands bein $\%$ needed to do the work. He had been in the habit of doing his work as directed, toward the middle of the day, while the great mass of bees were in the fields; but in the midst of a heary rield of clover honey, when the hives were full to orerflowing, they were one day stopped by a heavy thundershower. This, of course, drove the bees home, and at the same tirre washed the honey out of the blossoms so completely that they had nothing to do but remain in the hives until more was secreted. Not so with their energetic and enthusiastic owner. As. soon as the rain had ceased, the hives were again opened, and an attempt made to take out the frames, as but a few hours before; but the bees that wore all gentleness then, seemed now possessed of the very spirit of mischief; and when all the operators had been severely stung, they concluded that prudence was the better part of valol. and stopped operations for the day. While loads of honey were coming in all the while, and every bee rejoicing, none was disposed to he cross: but after the shower. the bees weie standing around idle: and when a hive was opened. each was ready to take a grab from its neighbor, and the result mas a free fight in a rery short time.

There is nothing in the world that will induce bees to sting with such wicked reck: lessness as to have them get to quarreling 
orel combs or honey left exposed when they have nothing to do. When the supply is exhausted their frenzy reaches its lieight. From a little carelessness in this respect, and nothing else, whole apiaries have been so demoralized that people were stung when passing along the street several rods distant. During the middle of the day, when bees were busily engaged on the flowers during a good yield, we have frequently left filled combs standing on the top of a hive from noon until evening without a bee touching them; but to do this after a hard rain, or at a time when little or no honey is to be gathered in the fields, might result in the ruin of sereral colonies, and the bees being voted a nuisance by the whole neighborlhood.

Almost every season the author gets more or less letters complaining that bees have suddenly become so cross as to be almost unmanageable, and those letters come along in July, after the clover and linden have begun to slacken. As already pointed out, at the beginning of this article, it is the slackening or stoppage of the flow that makes the bees irritable.

Bees are not so very unlike mankind after all, and all one has to do is to avoid opening a live for a few days, until the bees get used to the sudden disappointments of having avenues thru which they were getting wealth so rapidly, eut off. $\Lambda$ fter a week or 10 days they will be almost as gentle as in times when they gathered half a gallon of honey daily, if care is taken not to let hives be open too lone nor to leave any bits of honey or comb about.

It is not easy to explain why bees sting so remorselessly and vindictively after having had a taste of stolen sweets, ret nearly all the instances where there is trouble with stinging have been from this rery cause. Bees from colonies that have a habit of robbing will buzz about one's ear's and eyes for hours, seeming to delight in making one nerrous and fidgety if they suceed in so doing, and they not only threaten, but oftentimes inflict, the most painful stings, and then buzz about in an infuriated way, as if frantic because unable to sting one a dozen times more after their stings are lost. The eolonies that furnish this class of. bees are generally hybrid, or perhaps black bees haring just a trace of Italian blood.
These bees seem to have a perfect passion for following one about and buzzing before the nose from one side to the other (until one gets cross-eyer in trying to follow their elratic oscillations), in a way that is most decidedly provoling. One such colony annoyed us so much while extracting that we killed the queen, altho she was very prolific, and substituted a pure Italian. It is seldom an Italian follows one about in the manner mentioned, yet an occasional colony may contain bees that do it: at least we have found such, where the workers were all three-banded. That it is possible to have an apiary without any such disagreeable bees, we have several times demonstrated; but oftentimes it will be necessary to discard some of the rery best honey-gatherers, to be entirely rid of them. On occasions like this it is advisable to use robber-traps. See Robbers.

With a little practice the apiarist will tell as soon as he comes very near the apiary whether any angr'y bees are about, by the high keynote they utter when on the wing. It is well known that with the feerling of meal (see Pollex) there may be perfect tranquillity, altho bees from every hive in the apiary are working on a square yard of meal. Now, should honey be substituter for the meal, there would be a perfect uproar, for a taste of loney found in the open air during a dearth of pasturage. or at a time when the bees have learned to get it by stealing instearl of honest industry. seems to have the effect of setting every bee crazy. In some experiments to determine how and why this result came about, we had considerable experience with angry bees. After they had been robbing and had become tranquil, we tried them with dry sugar; the quarrelsome bees fought about it for a short time, but soon resumed their regular business of hanging abont the well-filled hives, trying to creep into every crack and crevice, and making themselves generally disagreeable all around. If a hive was to be opened, they were into it almost before the cover was raised, and then resulted a pitched battle between them and the inmates; the operator was sure to be stung by one or both parties, and, pretty soon, some of the good people indoors would be asking what in the world made the bees so awfully cross, 
saying that they even cane indoors and tried to sting. Now, why conld they not work peaceably on the sugar as they do on the meal, or the clover blossomis in June? We dampened the sugar with a sprinkler, and the bees that were at work on it soon started for home witls a load; then began the higl keynote of robbing, faint at first, then louder and louder, until we began to be almost friglitener at the mischief that might ensue. When the dampness was all licked up they soon subsided into their usual condition. The effect of feeding honey in the open air is verv much worse than that of feeding any kind of syrup.

HOW THE SOURCE FRONI WHICII BEES ARE GATHERING AFFECTS THEIR TEXPER.

It has been found that bees are crosser when working on some blossoms than on others. For example, they seem to be more inclined to sting when working on buckwheat than on clover. This is probably due to the fact that the latter yields nectar all day, while the former will in most localities yield an hour or two in the morning and again toward night. The stoppage of the flow seems to affect the bees adversely.

In the same way they are cross when working on honeydew from hickory and oaks. This yields heavily in the morning, and lets $u p$ and stops during the middle hours of the day. The morning dews soften the saccharine matter secreted on the leaves of these trees, and when it dries up again the nectar supply is cut off and the bees are cross. During 1909, when there was so much honeydew from oaks and hickories from all orer the country. bees that year were reported to be exceptionally cross.

To make bees good-natured, a honey plant must be a continuous yielder all day. So long as it keeps up its supply, there is quiet.

HOW THE PRESENCE OR ABSENCE OF SIIRUBBERY OR TREES AFFECTS TIE TEMPER OF THE BEES IN THE YARD.

It has been shown time and time again that the same bees that are docile as kittens in the home yard, with plenty of shrubbery to shut off the view of individual colonies. will often be as closs as hornets when placed in an out-apiary on a level piece of ground where their hive is in riew of every other hive, without any obstructing slırubbery or trees. The reason of. it is plain. If there are any cross bees in the air, and they see a moving: object like a beekeeper, for example, going thru the yard, they will immediately come buzzing about him with the peculiar angry scream that a mad bee always has. Those same bees when located in a yard where there is plenty of shrubbery, and where they cannot see moving objects as readily, will forget all about the source of their irritability, and either $\boldsymbol{g}$ o to the fields or into their own hives.

Several times we have been tempted to kill all the queens in a certain yard because their bees were so very cross, only to discover later on that when we moved them to the home yard, where there were grapevines shutting off the view of their colony or hive, that there was nothing the inatter with the "bees but only with their previous environment. For that reason alone, some of the crossest bees we have ever known have become very tractable when placed in a small orchard or piece of woods. The crossest bees will also become very docile when put into a house-apiary. When the owner is inside he cannot be seen, of course, and he can work inside of the building without hindrance.

Colonies that are located in dense shade thruout the day, are usually ill-natured, while those out in the sun are roorlnatured.

How to make bees good-natured by feerling, see Feeding Outdoons; also see Robbing, Stings, and Manipulation of ColoNIES.

ANTS-Altho we have given the matter considerable attention, we cannot find that ants are guilty of anything in the North that should warrant the apiarist in waging any great warfare against them. Some years ago a visitor frightened us by saying that the ants about our apiary would steal every drop of honey as fast as the bees could gather it. Accordingly we prepared ourselves with a teakettle of boil'ng water, and not only killed the ants but sone grapevines growing near. Afterward there came a spring when the bees, all but about eleven colonies, dwindled away and 
died. and the hives filled with honey, seattered about the apiary. unprotected, seemed to be as fair a chance for the ants, that had not "dwindled" a particle, as they could well ask for. We watched to see how fast they rould carry away the honey, but, to our astonishment, they seemed to care more for the hives that contained bees than for those containing only honey. We soon determined that it was the warmth from the clnster that especially attracted them; and, as the hives were directly on the ground, the ants soon mored into sereral that contained a small cluster only, and for a while both used one common entrance. As the bees increased, they began to show a decided aversion to having two families in the same lonse, altho the ants were evidently inclined to be peaceable enough until the bees tried to "push" matters, when they turned about and showed themselves fully able to bold possession. The bees seemed to be studying over the matter for awhile, and finally we found them one day taking the ants, one by one, and carrying them high up in the air, and letting them drop at such a distance. from their lome that they rould surely never be able to walk back again. The bees, as fast as they became strong colonies, drove the ants out; and our experience erer since has been, that a good colony of bees in the North is nover in any danger of being troubled in the least by ants. One weak colony, after battling a while with a strong nest of the auts, swarmed out; but they might have done this any way, so we do not lay much blaure to the ants.

Put ants do prove to be rery. "annoying in those aplaries where there is any attempt to keep the grass down with a lawnower. The little hillocks that they make all over the yard disfigure it to some extent, as well as forming more or less obstrutetion to the scythe and lawnower. While, as we have already said, ants lo little if any danage to lives in the North, yet as it is so easy to eradicate them it may be well to consider methods for their extermination.

TIOW TO DERTROY ANTS' NESTS.

With \& crombar or a sbort stick and a mallet make a hole an inch or so in diameter, and about a foot deep, down thr'u the center of the nest. Around this hole make two or three other similar ones, or more if the nest is a large one. Go to the drugstore: and get about a dime's worth of bisulphide of carbon. Be careful with the stuff, for it is rely explosive, and the fumes of it should not be allowed to collect in the room where there is a gasoline flame or any stove or lamp burning. From this bottle pon' about a tablespoonful of the liquid in each hole; then immediately stop each up with a plug of earth, for it is desired to have the fumes of bisulphide penetrate all the gallevies of the nest, thus destroying ants. larvæ and egg's. In a day or so it will be found that everything formerly animate in and about the nest is dead.

But if the nests are not very large, one can sepure ahmost as good results by using coal oil or gasoline in place of the bisulphide. But in using these, about twice or three times the quantity should be poured in each hole. We have tried both gasoline and kerosene, and have found eacb effective in destroying the nest. Of the two. the kerosene seems to be preferable. In using bisulphide of carbon. gasoline, or kerosene, be careful about spilling or pouring any of it on the top of the nest, as that will kill the grass, learing a brown spot right where it should be green. The bisulphide is more apt to kill the crrass than the gasoline or kerosene, as it is much more powerful.

The best time to destroy ants nests is in the spring, before the ants lave harl an opportunity to make much of a hillock: then there will be less liability of killing the grass: or, rather, a better opportunity: for the grass to recover from its "dose" during the early spring rains.

ANTS IN THE SOUTH.

These insects are much more troublesome in the southem States, and all warm climates, in fact, than in the North. Sometimes they are so large and powerful that they even set abont to destroy the colony. When the nest has been discovered, proceed to destroy it by the use of lerosene or gasoline. If these do not prove to be powerful enoug!, use bisulphide of carbon, maling three or four boles to the square foot of nest; but in the case of bisulphide, one must be eareful to have each hole stopped up tight with plugs of earth, otherwise the 
gas will escape, and the effect of the liquid will be largely lost.

But there is a species of ants in warm climates that have nests in trees that are inaccessible. Other ants are so small, and

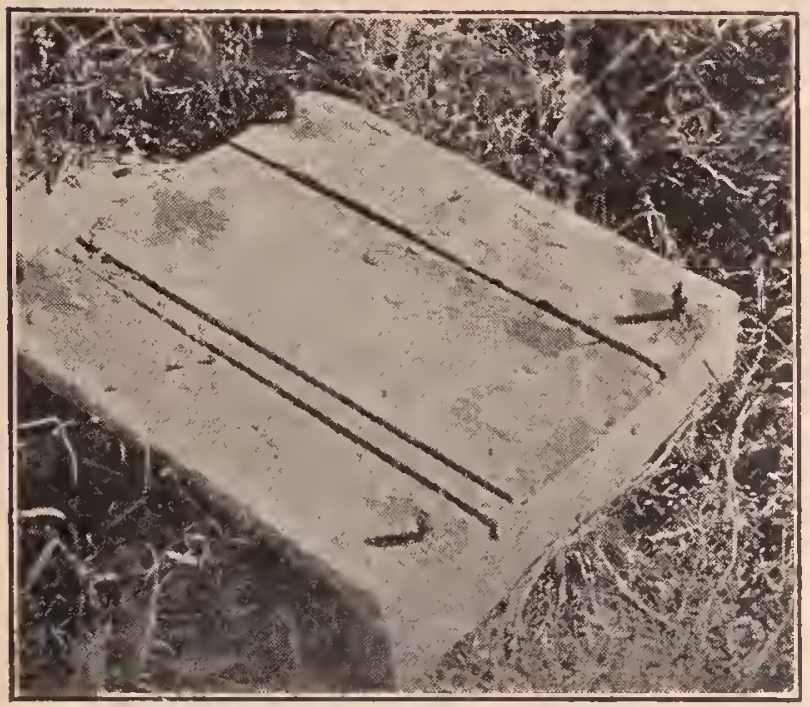

Fig. 1.-The Calkins ant.proof hive-stand. It differs from no other hive-stand except that near each of its four corners it has 20.penny spikes driven in about halt their length, and gauged to fit snugly to the inside rim of the reversible bottom-board on each side. Around the projecting portion of the spikes is wound felting which is afterward soaked in axle grease. On top of these four nails is carefully adjusted a colony of bees as shown in Fig. 2. Fol obvious reasons the alighting board connects with the hive-stand and not with bottom-board of hive.

come such long distances, that it is almost impossible to find their nest. In such cases it has been recommended to place within their reach some syrup or honey mixed with arsenic, Paris green, London purple, or strychnine. It is unnecessary to say that all vassels containing such poisonous mixtures should be placed in a box covered with sereen just fine enough to keep out the bees, and coarse enough to admit the ants. They will work on these poisonous mixtures, and carry them home to their young, with the result that both mature insects as well as larvæ will be destroved, no matter where the nest may be.

The box containing the poisonous sweet should be put in the trail of the auts. It is usually necessary to get the ants started on something that they like that is not poisonous-a piece of fat chicken meat, for instance, then add the poison when they are well started.

When it does not seem practicable to destroy the pests they may be kept away from the hive temporarily by pouring a little narrow trail of kerosene clear around the hive or hives: or, better, by the plan here shown.

Mr. Poppleton of Florida has graphically described in Gleanings the carnivorous ants.

With onc exception these ants are the worst enemies bees have here in Florida, and only constant vigilance from Septernber to December inclusive will prevent the loss of many colonies every season. These ants are usually found in our hummoek lands, and only occasionally in elean pine woods; ate red in color; of a very large size; frequently measuring nearly or quite lialf an inch in length; are strictly nocturnal in their habits, being seldom seen in daytime except when disturbed or waging battle witl a colony of bees; are usually found in decayed wood, thru which they eat out galleries for use as living-apartments. A favorite place is in a saw-palmetto root in the ground. Nearly every cabbage-palnetto tree contains a colony of them among the "boots" near its top, and for this reason a thick palmetto grove is one of the worst places where an apiary can be located. They are also found in piles of old boards, and on the ground under boards or logs. They also like to enter our

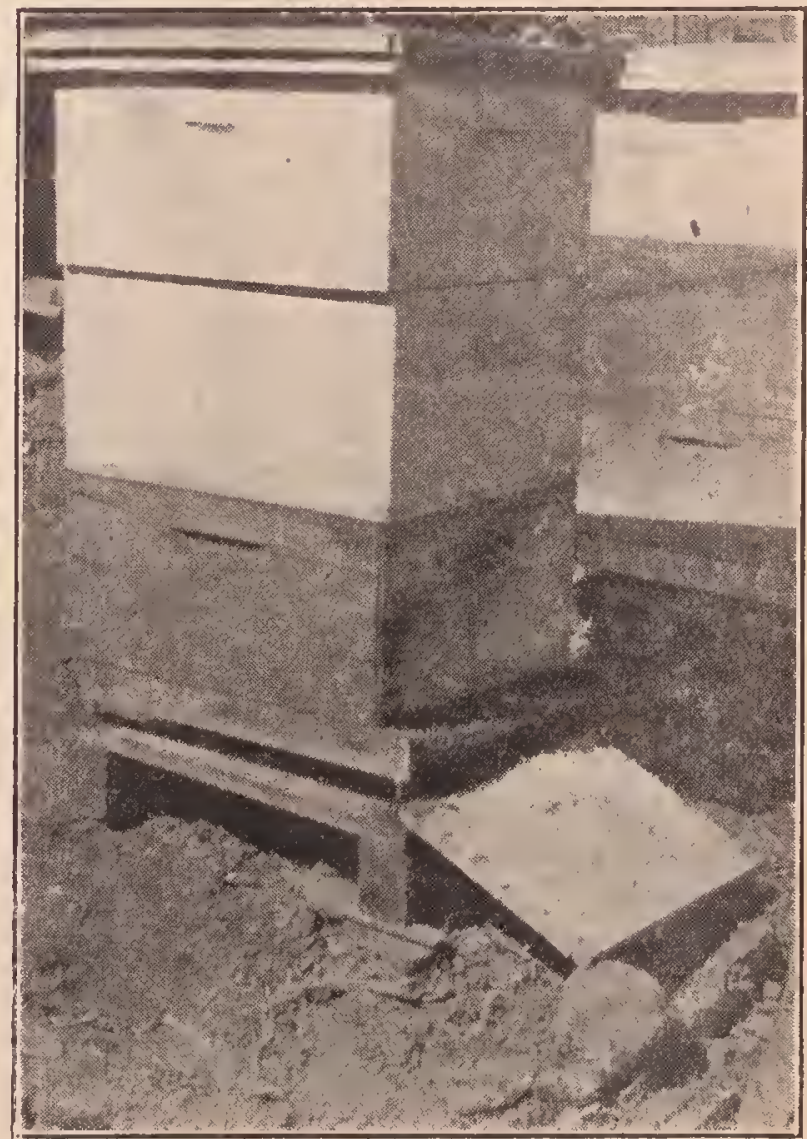

Fig. 2.- 1 rolony of bees restins on fuur zo-penny nails driven half-way down into the hive-stand. As explained in Fig. 1, these nails are surrounded with felting which is dipped in axle grease. which does not evaporate so readily as creosote, altho the latter. would be satisfactory. The colonies thins protected wre free from any furthe visitation of their old friends the enemy. Ints are real pests in California, 
homses and locite in trunks, boxes, Arawers, and in ahmost any place where they can find a few inches of space to ocempy. They are frequently found in the tops of our hires, if there is sufficient space above the bees under the covel.

At sundown they start on their nightly quest of food; and if near an apiary a few of them will usually be seen running on some of the hives. As long as only two or three can be seen on any one hive, no special attention need be given them; but if a dozen or more are secn, it means that they have probably selected that hive for their own use, and it neerls close watching. They will continue their regular attentions to that one hive, gradually increasing in numbers unintil they decide they are strong enough, when mearly the entire colour of ants will boldly attack the bees by biting off their wings and legs, and roppling them so they are of no more use. Bees fight back courage ously, the battle continuing for hours, and sometimes a day or two, according to the relative strength of the two belligerents. The inside of the hive and the ground near by will be strewn with dear ants and dead and crippled bees: but it alwars ends with the destruction of all the bees, and the moving into and occupation of the hive by the ant colony. When ants have once chosen a certain colony of bees to work on, the bee master has to destroy the ants, or they will in time destroy tlie bees. If a part only of the ants are destroyel, they will simply bide their time until they lave built up strong enough, and then do the work. I know of few or no living creatures more persistent in evil works than are these hec-killing ants. They also, in certain localities, do great damage to queen-rearing muclei.

During the fall months I make it a practice almost every evening after dark in my home apiarr, and as oftell as possible in the ont-apiaries, to see by the light of a lantern the front of every hive; and any one on which I see three or four or more ants run ning over has a mark placed on it. If the number of ants on any one of these marked hives increases each night. I give that hive special attention until the ants get numerous enough to begin to worry the bees. When this occurs, bees commence to whine, as I call it-that is, utter a fine, sharp note with their wings. As the ants gets bolder the ery of the bees becomes louder and more frequent-so much so that I have frequently heard it 50 feet away. The ants usually worry the bees coutimually for several nights, when suddenly the whole colony of ants starts in on a battle royal, which continues for hours or even a dav or two, until every hee is disabled or driven out. A great many of the ants will also be killed; hut how the bees do this is a mystery to me.

When the battle has once been joiner, the beekeeper has a difficult task to save the hers: but this condition is preventable. When the ants become plentiful enough at the live to bogin worrying the bees, there is usually a trail of going and returning ants. from their nest to the lịve, and this can usually be located and traced to their nest, which, when found, should be left undisturbed until the following day, when all the ants will be at home. If the nest camnot be found the first time trying, I search again until it is found. As soon as the mest is found, or search for it is given up for that night, I sprinkle some insect powder on their trail near the hive; also wherever on or around the hive I can do so to worry the ants and not injure the bees. This will usually keep the ants from doing any more harm that night.

The next day when all the ants are at home, I take a kettle of boiling water, tear open the nest, and, if possible, kill every ant and egg. If a few of them are left they are likely to gather together, increase in time to their former strength, and again attack that same colony of bees. Whenever the nest is found in a box or picee of wood that can be easily moved with all the ants, the easiest and best plan is to cary them into the chicken-yard, break open the nest, and the hens will glarly do the rest of the business. They are very fond of hoth ants and eggs: and they not only find them good to eat, but give their owner lots of fun watching the old rooster especially, kick and scold erery time an ant bites one of his feet. J have had many a hearty laugh watching this performanee.

The ants are a great pest here in Floricl. They destroy in the aggregate a great many colonies every fall. I know of one alviary which was entirely lost, largely, I jurlge from what I hear, br these ants. At the best they are a great nuisance because they compel the beekeeper to remain at hom watching them at a season of the year when nothing is doing in the apiary, and the apiarist could, but for them, he away on a holiday, or have some outside business.
Stuart, Fla.
O. O. Poppleton.

Ants are a serious pest to bees in many tropical countries, notably in South America, where they are omnipresent and almost omnipotent. A species similar to that described by Mr. Poppleton in Florida exists all orer tropical America, narticularly in the southern continent. He has so graphically described it, there is no necessity to enlarge on it further. The roorst feature of these ants is their readiness to travel, so that, when one does destroy their nests, there is no assurance that the apiary is safe from their attacks. Another bad feature is their habit of traveling by night: in fact, nearly all their depredations are made in the dark.

To cipcumvent them it is necessary to 
destroy all their nests within a radius of 100 yards of the apiary by the application of bisulphide of carbon to their nests. But this precantion alone will not suffice, and it will be necessary to adopt further measures. Luckily it is not diffeult to do this. as tropical beekeepers are obliged to keep their hives under a shed, for excellent reasons.

In erecting a sherl, therefore, we can take measures to prerent effectually the ants having aceess to the hives at all. All

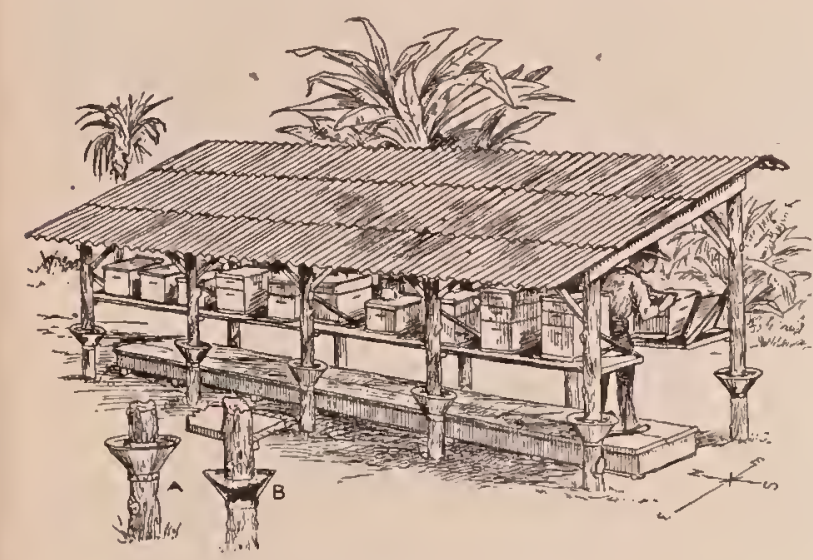

Morrison's ant-pioof beehive shed.

we have to do is to add cups to all the posts used to support the structure. The illustration preceding shows very clearly how this is accomplished with but little expense or trouble. The cups are filled with coal tar, creosote, or crude petroleum, all of which the ants positively dislike for two reasons-they stick to their feet and the smell is repulsive. No ant will attempt to cross such a mess as this, hence the bees are secure. The warn climate keeps the tar. ete, always soft; and if some rain falls into the emps it does no harm, as the water also tastes of the tar.

In working ivith the bees care should be talien to see notling is left which will form a "briclge" whereby the ants will manage to reach the beelives while the apiarist is absent. One of the worst things that can happen is to allow the ants to get a taste of the bees; for once they do they are sure to linger around waiting for an opportunity to get into the hive.

APIARIST.-An apiarist is one who manages one or mole yards of bees for profit.

APIARY. - A place where a number of "olonies of bees is kept is ealler an apiary or bee-rand.

\section{LOCATION.}

There is searcely a spot on the surface of the earth where mankind finds sustenance that will not, to some extent, support bees, altho they may do much better in some localities than in others. A few years ago it was thonght that only localities especially favored would give big honey crops; but since the introduction of modern races, and the new methods of management, we are each year astonished to hear of big yields here and there, and from almost every quarter of the globe. It will certainly pay to try a colony or two of bees, no inatter where one may be locater.

Beekeeping is practiced eren in the heart of some of our large eities. In the suburban distriets bees can be kept on a small plot of ground in the back yard. In the heart of business sections bees are rery often liept on the roofs of buildings, sometimes on the rery top of skyscrapers. In such cases, on account of the intense sunlight and lack of natural shade in the form of bushes, shade-boards should be provided as described further on in this article. Such an apiary should be established like those on the ground in all essential points.

It is not always possible to select just the location for an apiary that one might like, and it is therefore necessary to take what he can get; but where conditions permit it is adrisable to select the rear of a village lot; or, if located on a farm, back of the liouse in an orehard. Aroid locating the bees next to a line fence on the other side of which is a cultivater field. A team of horses while rorking the soil may get stung.

The ground for the apiar slould be rolled and snoothed down so that a lawn mower can be run ovel every portion of it. as the grass should be kept down around the hives. Moreover, a smooth plot of ground renders the use of a wheelbarrow or handear for handling loads much more pleasant and convenient. An ideal spot would be an orchard of young trees 75 or 100 feet from the road or highway. Usually the rear end of the village lot just back of the house will answer very nicely. If the apiary must be located close to the lighway. then a high board fenre should he flarerl between the bees and the street. 


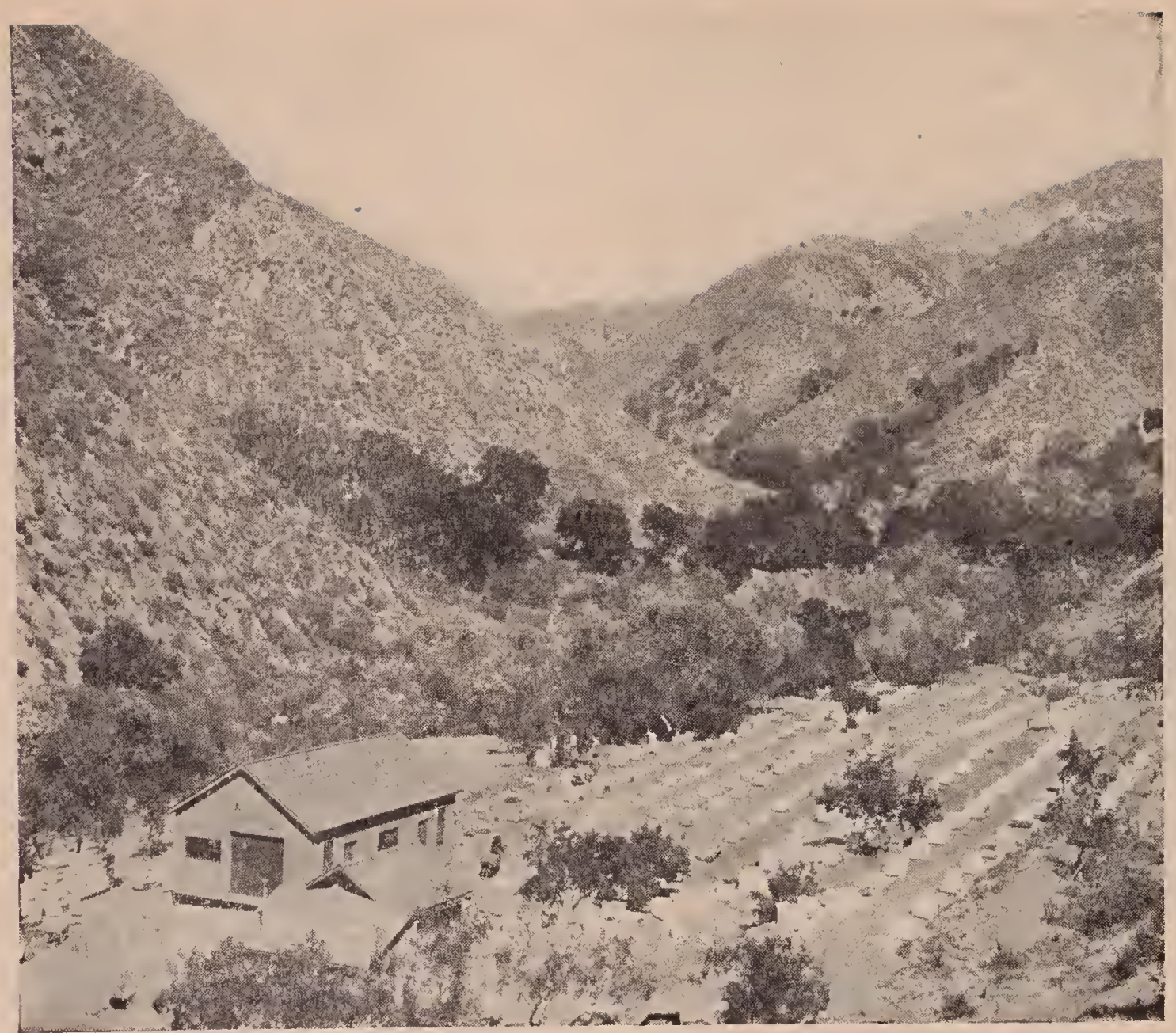

APIARY OF M. H. MENDDLESON.

This apiary occupies a very unique position down in the botton of the canyon, where it is well pro tected. The ground has been leveled off and terraced, and the rows of hives are straight and parallel. This is one of the most picturesque spots for an ausiry in lle world. From it some of the best sage honey of California is obtained, and no wonder: for the mountain sage is always in sight and in reach of the bees. T'he patches of white, black, and buttom sage on the mountain sides can be plainly seen.

When the author visited this yard in 1901, he considered it one of the best-located yalds in all California-well protected and the bee pasturage at close range. But for the fact that there is only about one good yield of honey in five years, this would be a veritable bee paradise indeed.

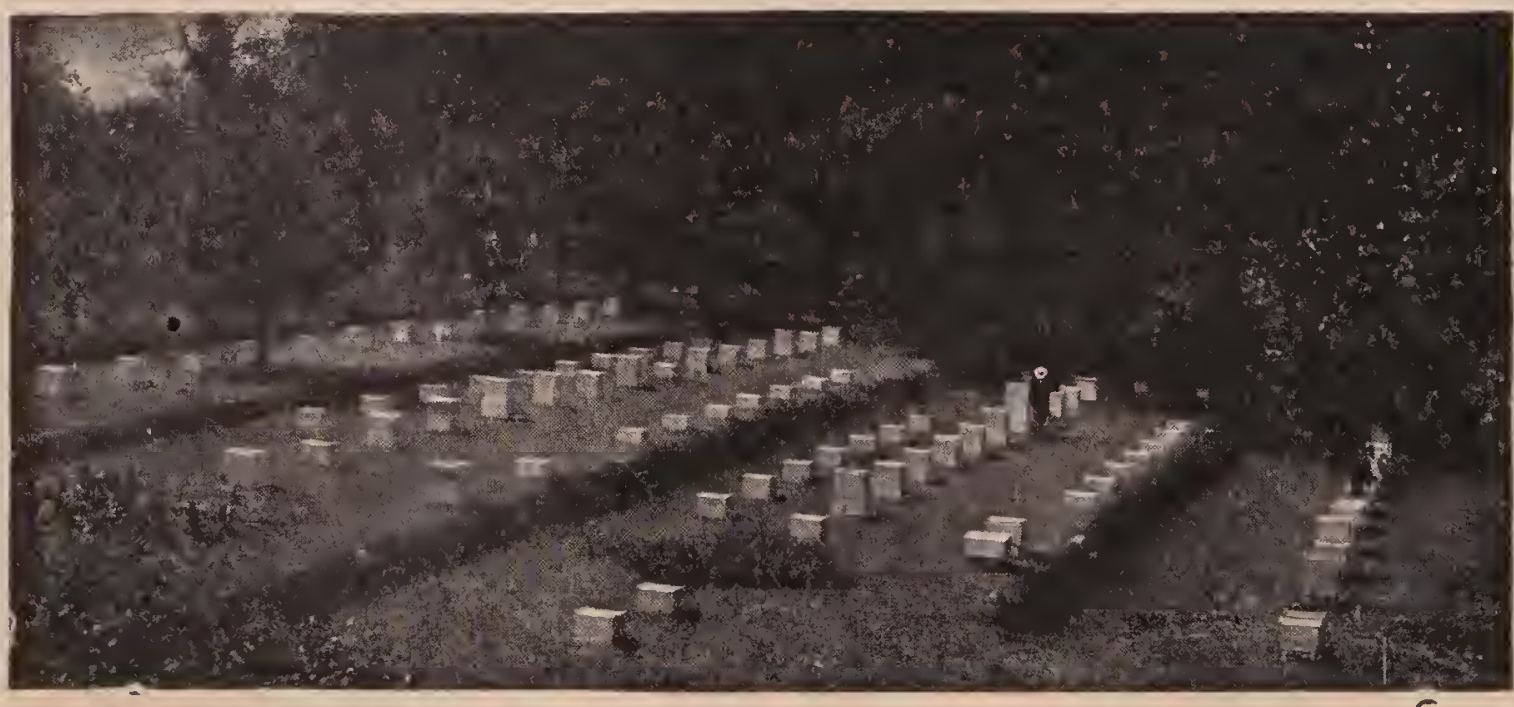

THE PUBLISHERS' APIARY AT JENKINTOWN, PA.

This was an exhibition apiary in the suburbs of Philadelphia, used to demonstrate the various processes and methods of handling bees. Here are also shown to the visitors the various races, their characteristics, and markings.

This yard at the time was a model one in every respect, and was so pronounced. The ground was nicely terraced and here and there were flower gardens so arranged as to give a pleasing effect.

In June, 1905, and again in 1906, a general field day of beekeepers was held at this apiary. Experts were present to describe and illustrate their various methods of handling bees, to the crowds that assembled from all over the country. At the field meet of 1906 there were somewhat over 1,000 beekeeper's present. making by far the largest gathering of beekeepers the country has ever seen. The location was only leased, and has since been sold and is now used for other purposes. 


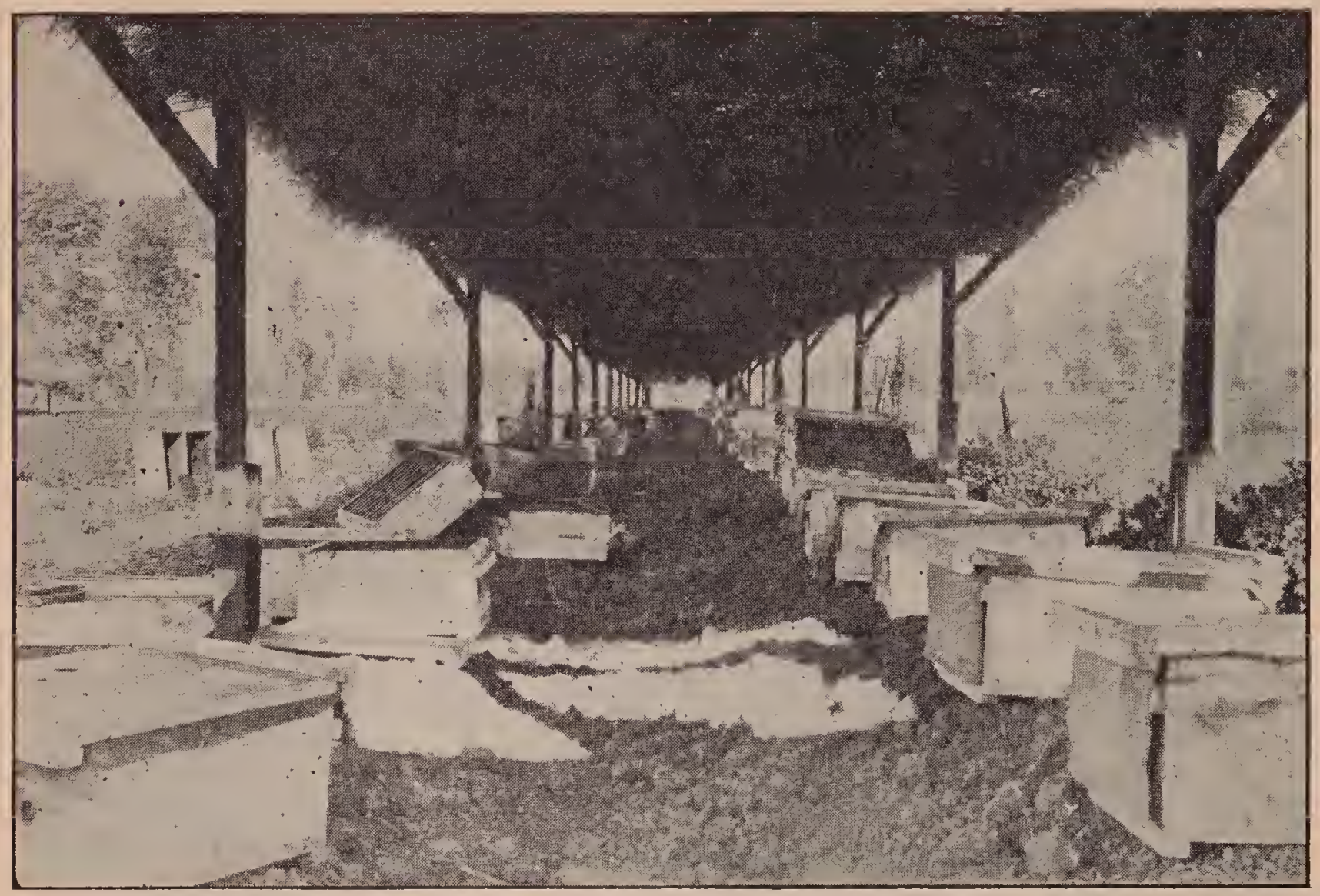

CLTATER APIART AT CLLEXICO, C'LLTFORNIL.

This method of shading an apiary in New Mexico, Arizona, and the Imperial Valley, southern California, where the temperatule during the hottest weather often goes alove 100 degrees, is almost universal. The roof consists of dried arnss or leaves laid on top, and secured by wires laid orer the whole.

be allowed to go directly from their hires on a line that would encounter vehicles or pedestrians; otherwise their owner may have a lawsuit on his liands for alleged damages from bee-sting's. See BeEs as a NUISATCE.
THE IMIPORTANCE OF SHRUBBERT OR SMALL TREES IN THE BEE-YARD.

Under the head of ANGer of BeEs, at the close of the article attention is called to the ralue of small shrubbery or trees to shut off the views of individual colonies from each

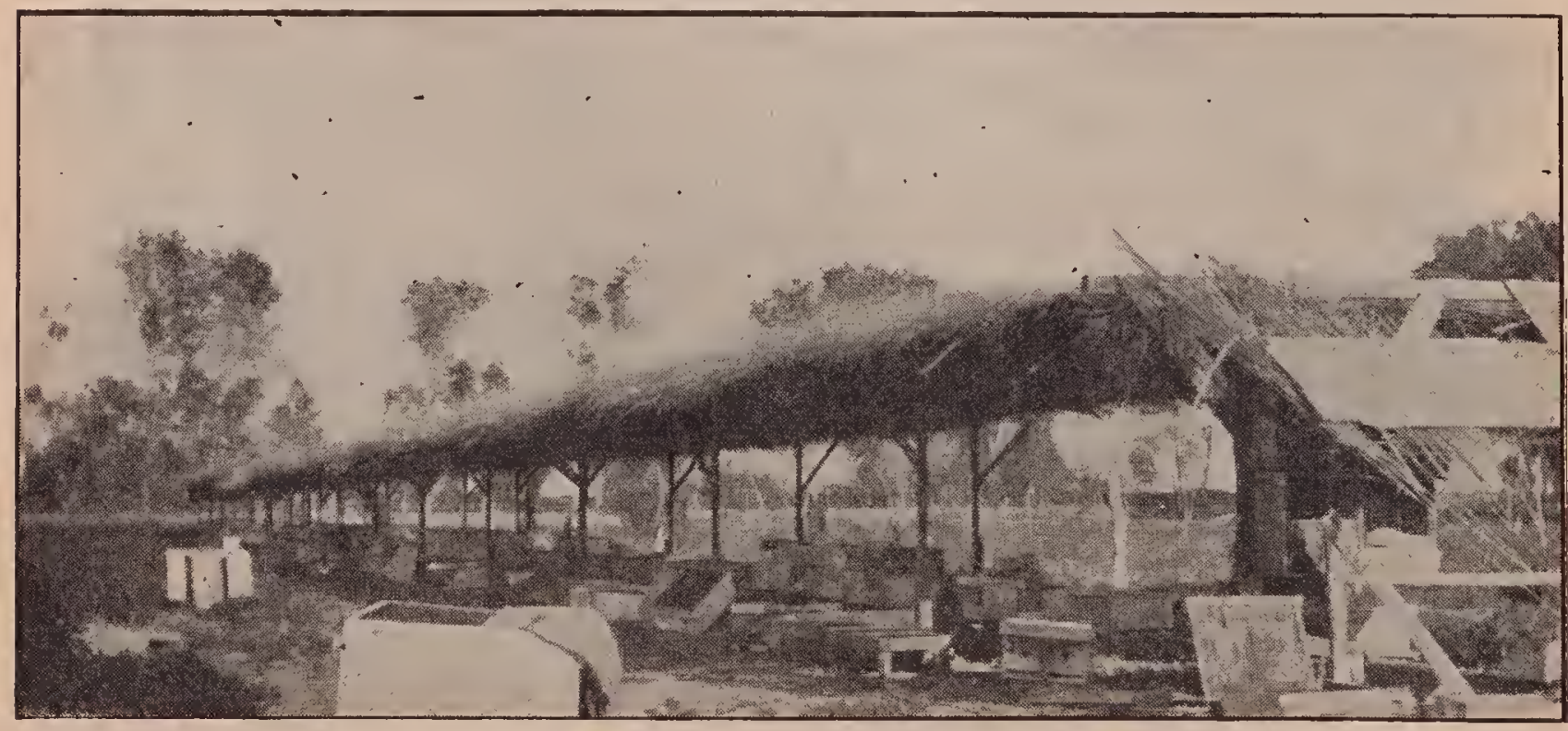

SIDE AND END VIET OF THE SAME APIARY.

The climate in this ralley is very hot in summer, the same as it is in Arizona. Shade is very necessnry. 


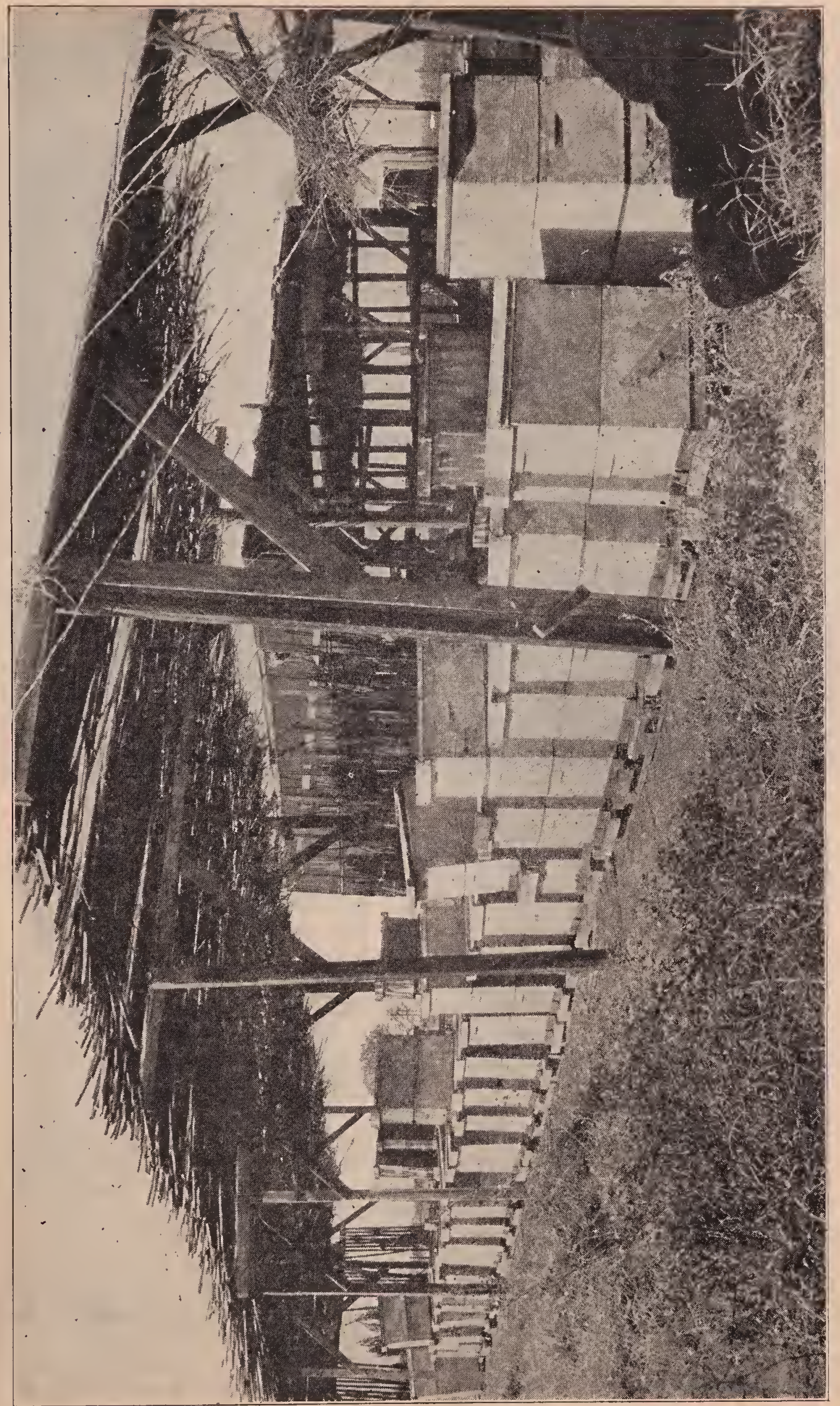

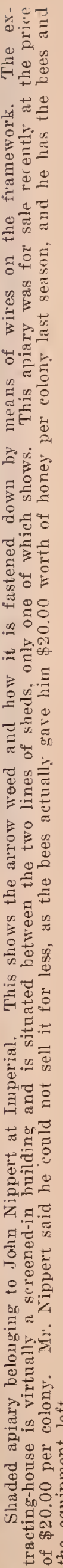




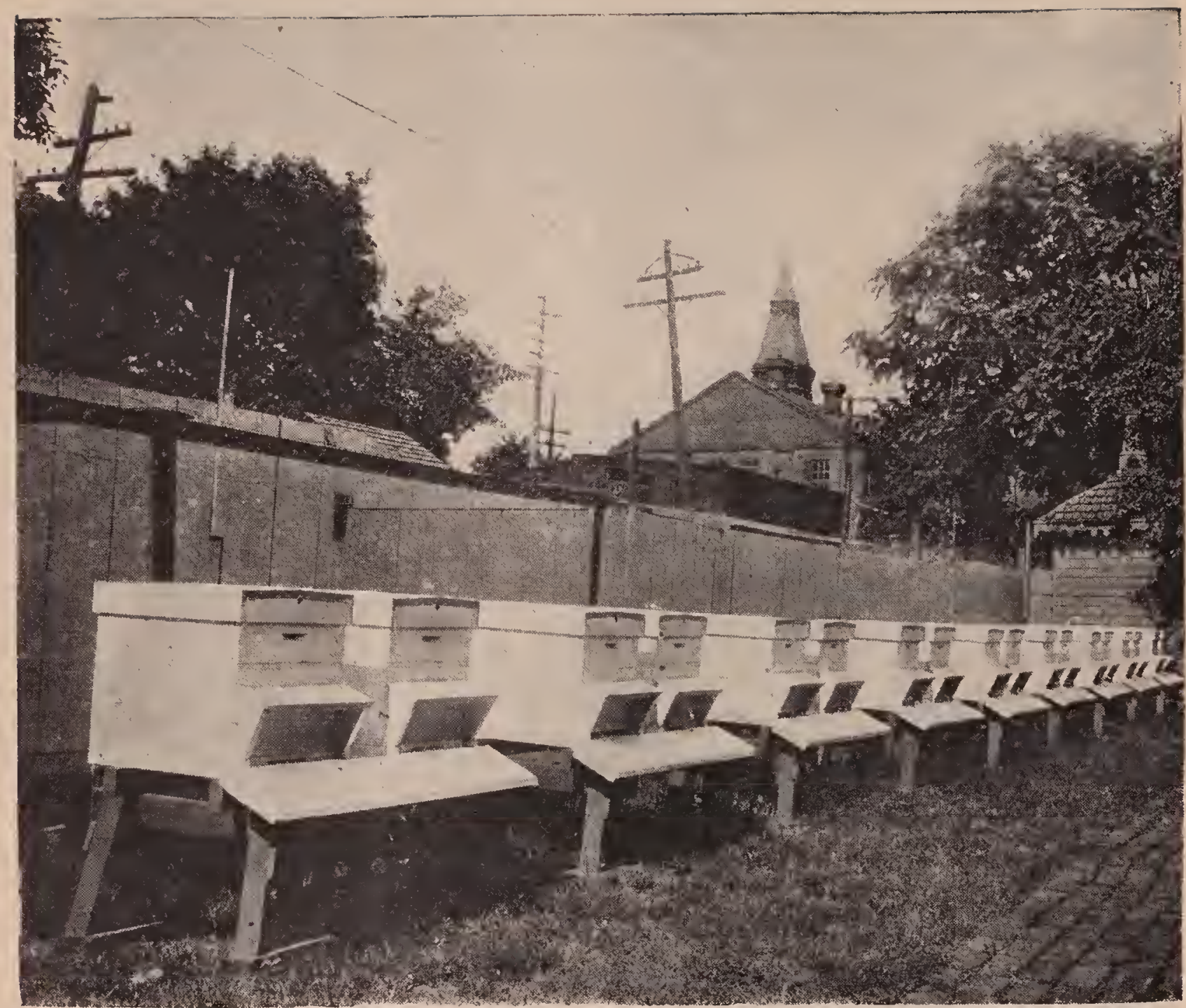

API.IL OE CH.S. Y. H.IKE, YORK, I'L

This is a backlot apiary that is well screened from prevailing winds, as most yards of tlis kind are. It therefore follows "that such yards winter better than the large apiaries out in tle open. Mr. Hake has his colonies elevated on hive-stands for convenience in handling. The objection is that during bad, chilly weather some bees drop short of the entrance. If they were on or near the ground, the bees could crawl in and be saved. The arrangement used by Robert Peschko, shown at the close of this article, is much better.

other. The matter is so important that it is mentioned again in order that the reader may wisely locate his bees.

The same hees that are gentle at the home yard where they are well sereener or located, sometimes beconse very rross when placed out in the open field withont shrubbery or trees. I little shade on lot days is of great value in protecting the hive from the direct rays of the sun. Aside from the value of the shade, if the shrubbery is tall enough it adds a great deal to the comfort of the apiarist himself. In an open yard it usually becomes necessary to wear a reil to prevent the bees from stinging the face without warning. In a yard that has surubbery, one ean often work all day without a reil, and sometines with but very little smolie. It is not always possible to locate a yard in the midst of shrubhery or anull trees: and one. therefore, has to take what lie can find, which rery often is an open sinace in one corner of a lot.

Shrubbery consisting of sulall bushes or trees luas an additional value in that it enables the bees to locate theil entrances a little more easily. When the hives are placed together without any space between, there is more or less drifting-that is to say, the bees make mistakes and go into the wrong hives. (See Driftisa.) The unfortumate part of it is that the strong colonies will draw from the weaker, because the young bees, in their initial flight, are quite inclined to join the hive where there are the most bees flying. At the an- 
within a year or two. $\Lambda$ graperine trellis. way 8 feet lighl and 10 or 12 feet long. running from east to west, well covered with a vine, can be made to protect from

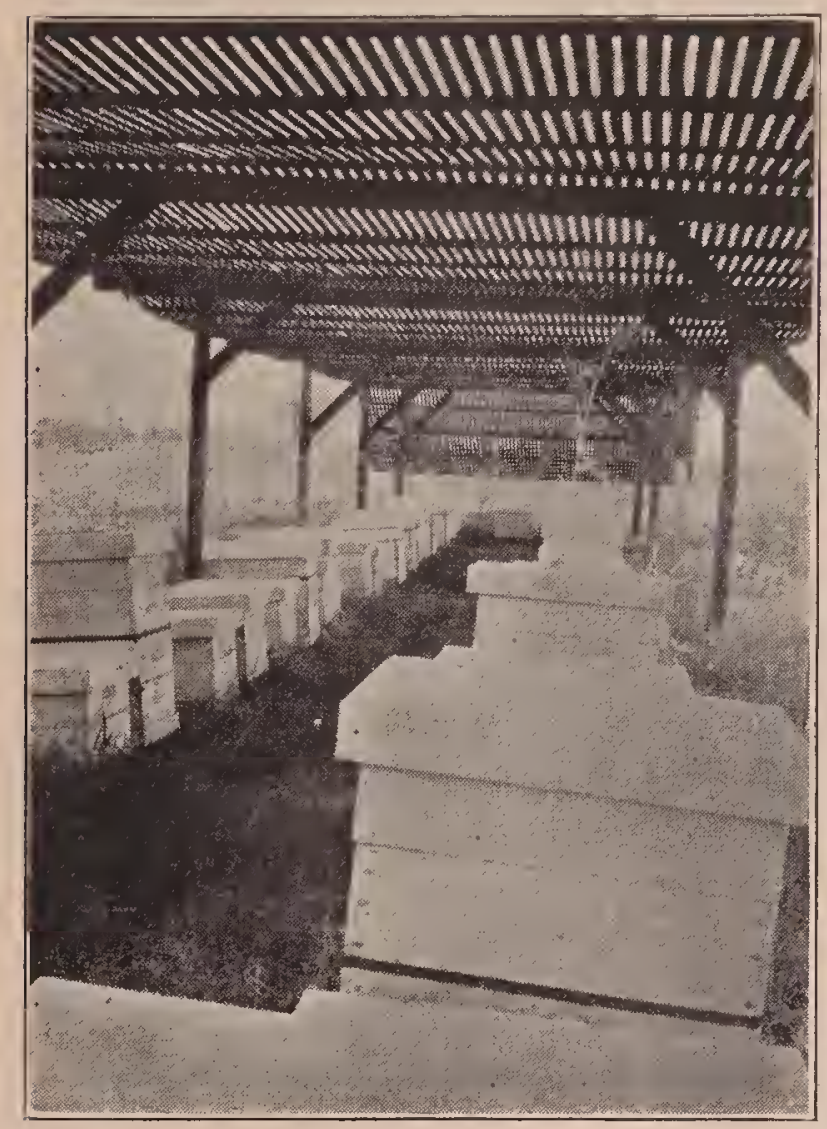

Shaded apiary belonging to F. J. Severin at Imperial, Calif. The slats are placed mpon a framework and spaced about $3 / 8$ juch apart. This arrangement breaks up the rays of sunlight, giving just the right amount of shade and at the same time allowing enough light so the beekeener can see eggs in the comlys. These sheds can easily be taken down and moved to a new location, while the sheds having grass or weeds for the top cannot be mored readily.

five to ten hives. On this trellis, graperines or any other quick-growing rine may be rearer to provide sharle during the heat of the day. The fourth and last plan is to nse an overhead trellis, making nse of straw, dried grass, or brusl for covering such as is used in Arizona and Cuba. These trellises are about seven feet high. and lun from east to west. so that the sun, nearly orerhear as it is in Arizona and southern California, never strikes the hives from morning till night. These trellised shades, if there are no trees, are indispensable in hot, dry climates. They thoroly protect the bees, prevent combs from melting down, and render the rork of the apriarist pleasant.

Some beekeepers prefer to use shadeboards. These may be made of large cov- er's cleated at the ends, and romposed of two or three hoards of the cheapest lumber that can be had, or they may be made of common shingles in the manner shown in the illustrations. Some will, perhaps, prefer them nailed up as Mr. Marchant nses them. Others would prefer to put them together as Mr. Robertson makes them. In some cases it may be advisable to lean them up against the lives rather than to place them on top. When used on top they should be large enough to project a foot over the front and rear, and an equal distance on the south side where the live faces east or west. They are then' held securely in place by a stone weighing 15 or 20 pounds.

But whenever one manipulates these lives he is required to lift a heary stone and remove an awkward shade-board before he can do any work with the bees.

When hives are placed in long rows close together, as under a shed or on a roof, it is rery essential that they differ from each other in appearance so that the bees may distinguish their own hive from all the rest. The differentiation may be accomplished in various ways: first, by painting the lives different colors: second, by uning a different entrance or alighting-board;

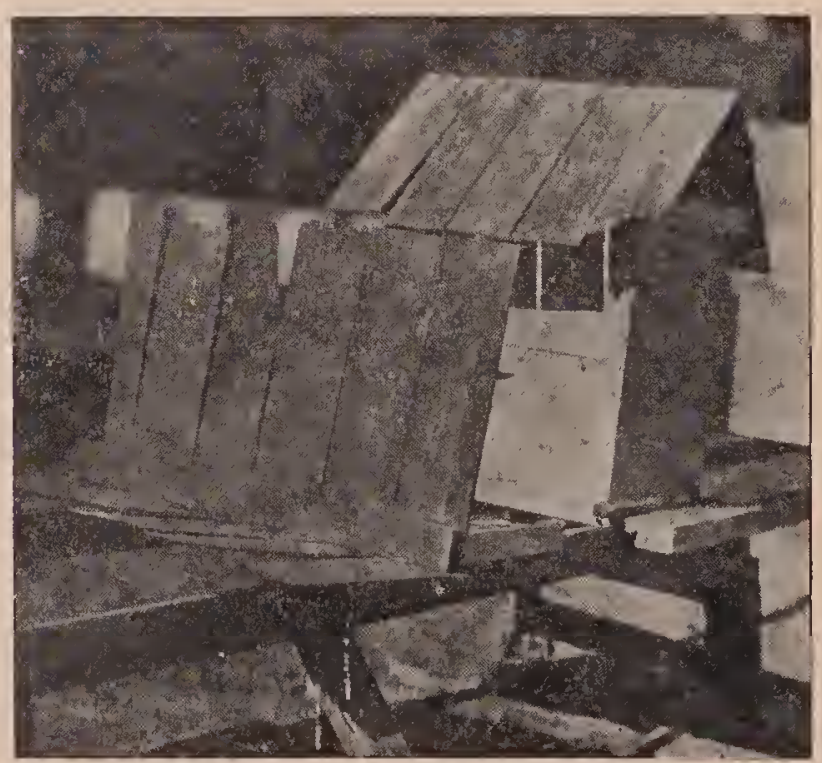

Marchant's shade-board. This provides better ventilation than the ordinary flat shade-board.

third, by placing a stone or other distinguishing object near the entrance. The intea is to place some distinetive mark by which each hive may be quickly recognized by its tenants. The best way to make such 


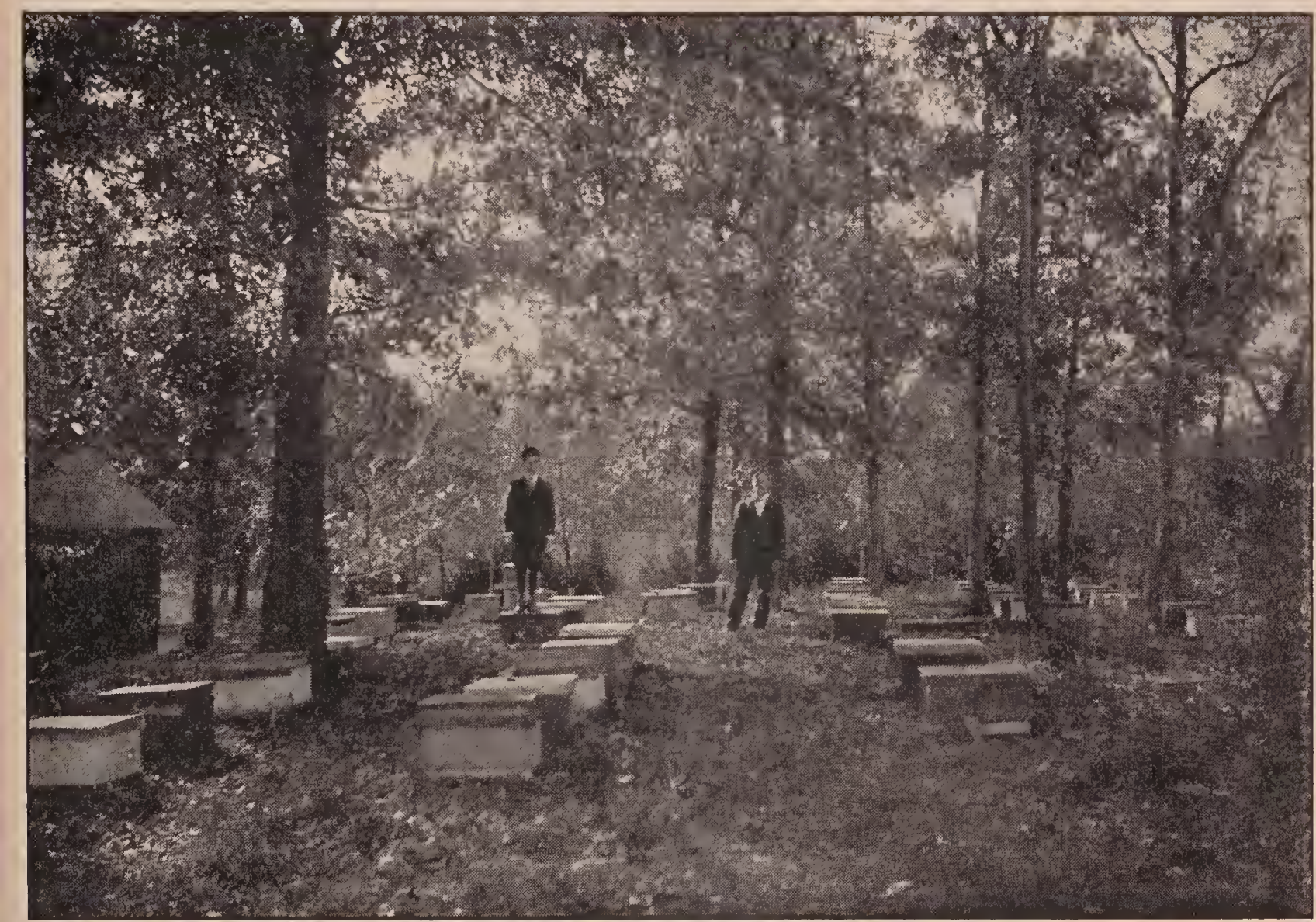

PART OF THE OLD APLARY OF E. A. DUAX, CHIPPEW. FALLS, IVIS.

This yard is sheltered on the west and north by al cedar hedge; but the shade is a little too dense. Too mmch shade does as $111 \mathrm{uch}$ harm as too little.

mark is at the entrance so that all the bees can see it, both on leaving and returning. See ARRANGEMIENT OF HIVES.

\section{WINDBRFAKS.}

'The most perfect windbreak is an in(-losure of woods on three sides, with an opening to the soutl. 'Tlhis, however, is not available to all. In apiary so situated that there is a elump of woods on one side and buildings on the other two sides, leaving only a southern aspect, is well sheltered from the prevailing winds. But, as already stated, if there are woods or building's around the east side of the beoyard, enough to shade the hives until about noon, the bees will not build up as fast in the spring as those that can get the morning sun up to $10 \mathrm{ol}^{\circ} 11$ o'clock. In the absence of any natural or accidental protection whatever, it is highly important that some sort of windbreak be provided. If it is desirable to put up something permanent, and something that will not rot out or require repairs, the apriary should ba outskirted with rows of hardy-growing evergreens, sucl as are, seen in the illustration of the jublishers' apiary shown further on. These, for the first few year's, would afford but a scanty protection; but in 10 vears' time they answer their purpose admirably. In 1879 we enclosed our apiary with everoreens. They have proved

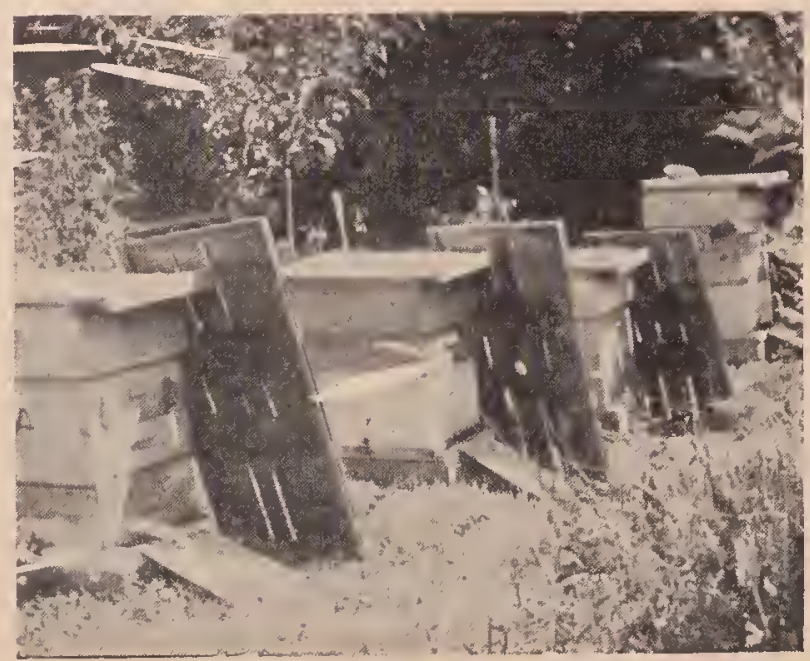

liobertson method of shiding the hives and the entrances in lite moruling. 


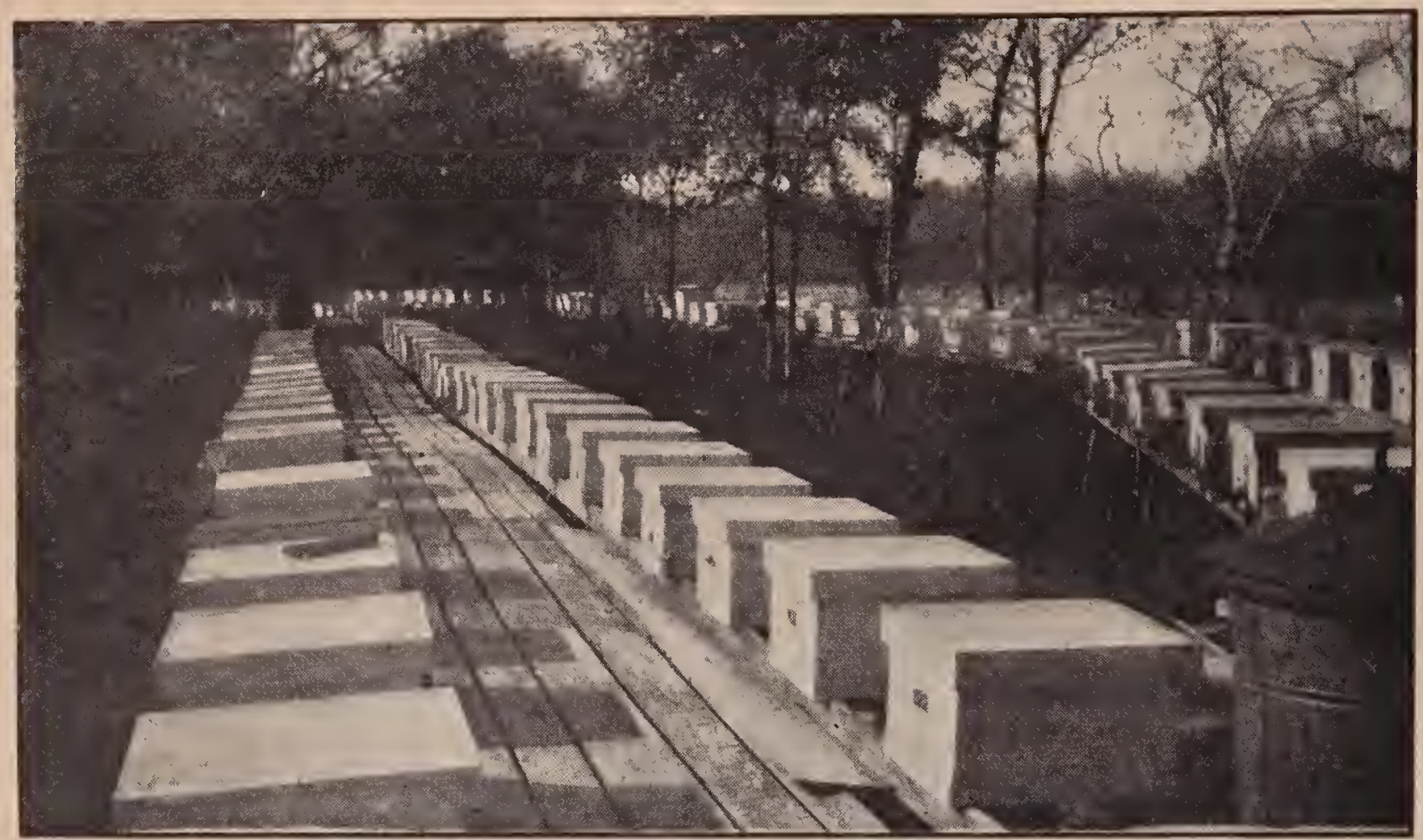

APIARY OF THE A. I. ROOT CO., ON THE AP.ALACHICOLA RIVER, FLORID I, IN 1914.

This shows a general view of 300 colonies placed on raised platforms or scaffolding five or six feet high, or above lrigh-water mark. While these platforms are somewhat expensive, they are very convenient in affording easy access to all colonies. There is no uneven ground, no shrubbery nor weeds to interfere with the flight of bees, and a wheelbarrow has good wheeling to every hive. It would have been better if the hives had been arranged in groups of twos, threes, and fours, as explained under the engraving and apiary of L. F. Howden.

to be very hardy and thrifty, and are now large trees.

A good windbreak is now regarded, for winter protection, as about as important (and some think more important) for outdoor-wintered bees, as packing and doublewalled hives. Of course, it is better still to have hives packed as well as protected from the prevailing winds. Experience has shown that colonies, even tho well packed. but placed where there are sharp wind exposures on an elevation, will often die before spring, or become so weakened as to be practically worthless, when colonies of the same strength in single-walled hives screened against the wind will winter comraratively well.

In a location on a prairie, especially if it is permanent thruout the vear", "are should be taken to see that the apiary is protecterl on the north and west. Sometimes an apriary can be placed at the bottom of a hill lying at the nortls; but it would be far better if shrubbery were Haced at the brow of the lill to prevent the wind from diving down and striking the colonies with full force.
The best windbreak we have found consists of trees or shrubbery of some sort. A solid fence is not so effective, because

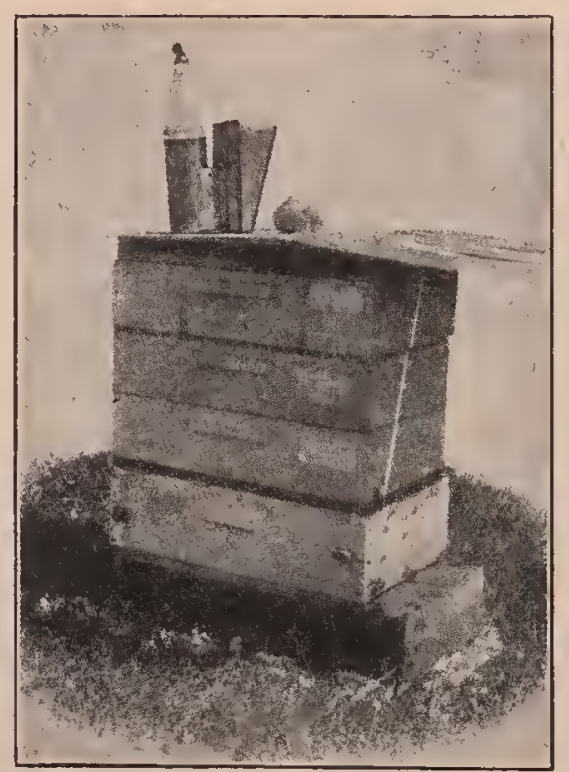

Shading tops and fronts of hires during the hottest part of the day.

the wind will strike it squarely and glance upward, when the on-rushing blast will cause it to roll and dive downward.

At one of our outyards we had a high board fence on the north, and it was dis- 


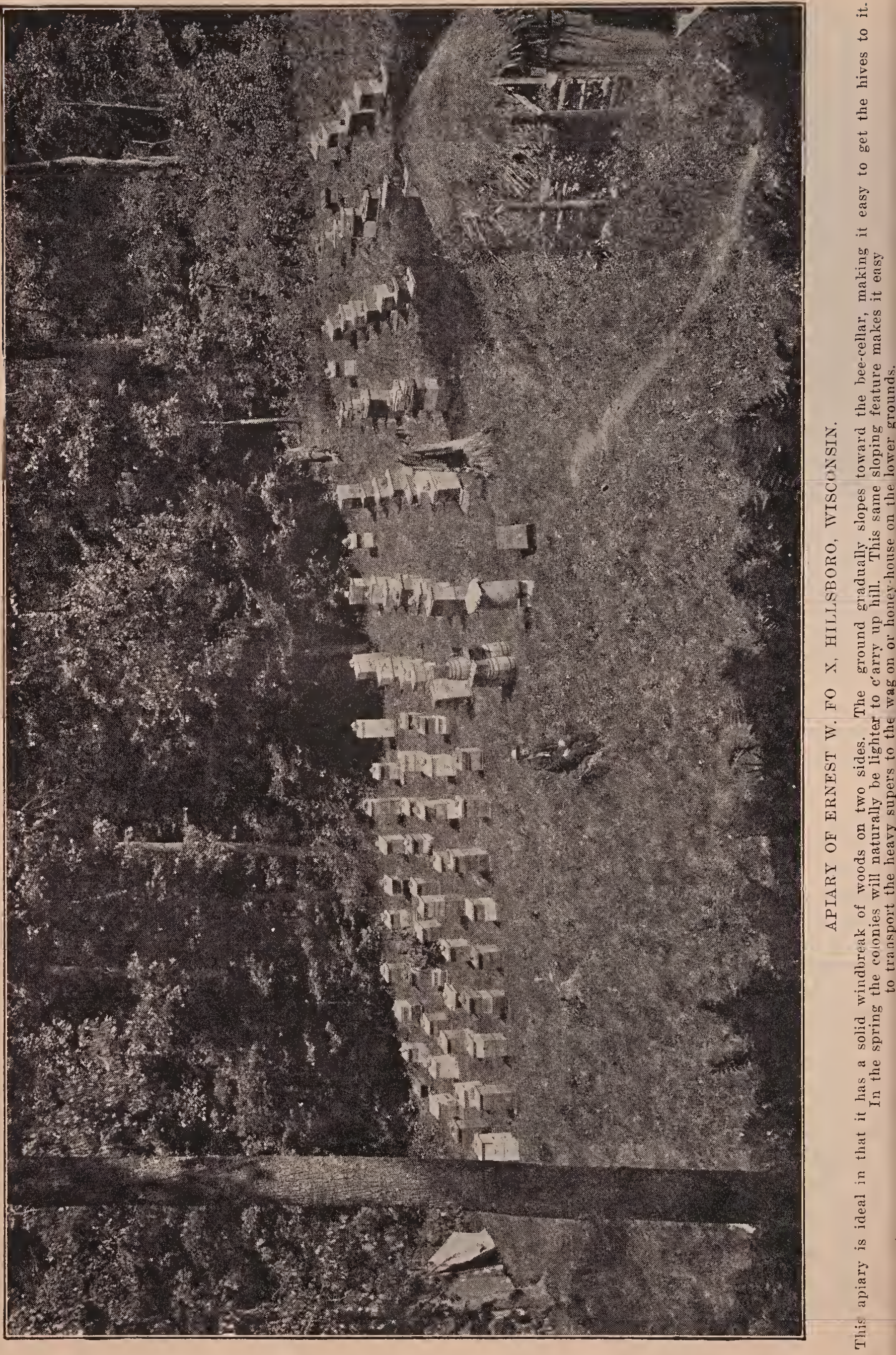




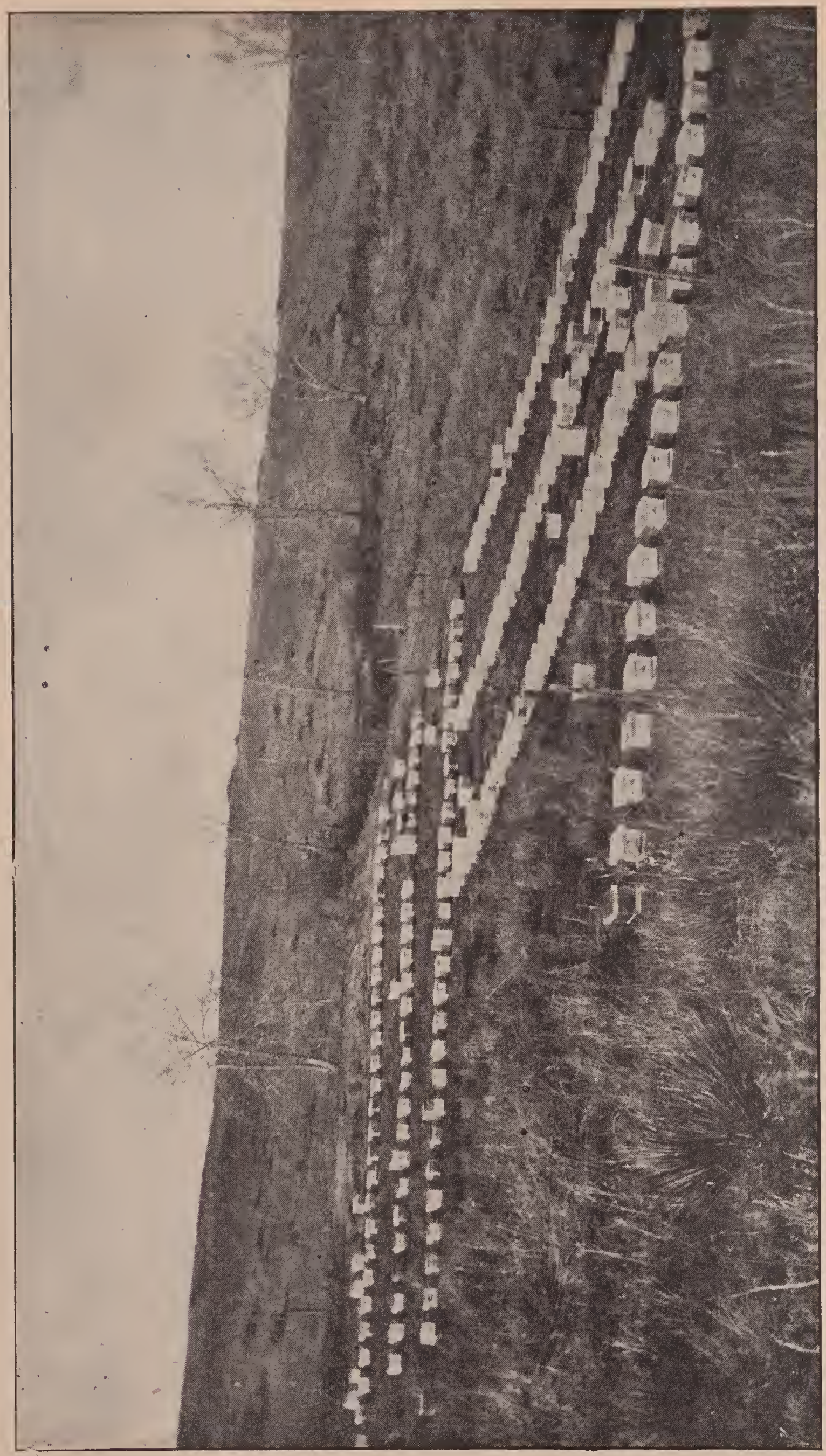


ground to the hive is very important on cool days when the bees can not fly readily. They will alight on the ground, and, if they can, crawl into the hive. During a heary honey flow bees will come in heavily laden.

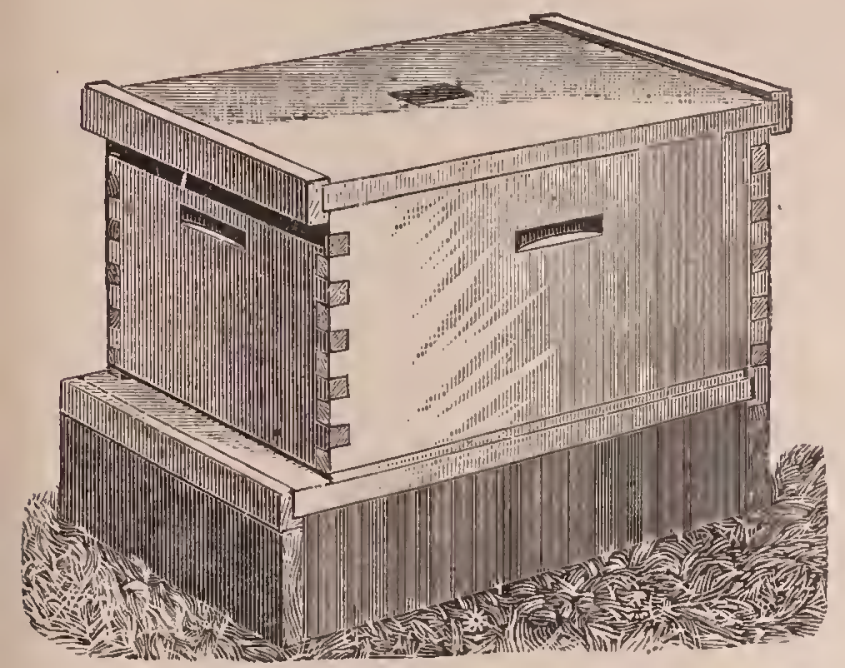

Heddon hive-stand.

and land just in front of the hive. In either case it is important to have hivestands so constructed that the bees can crawl into the hive, as shown in the next illustration.

A modified form with slanting front, while slightly more expensive, is much better. A wood-shop or planing-mill can

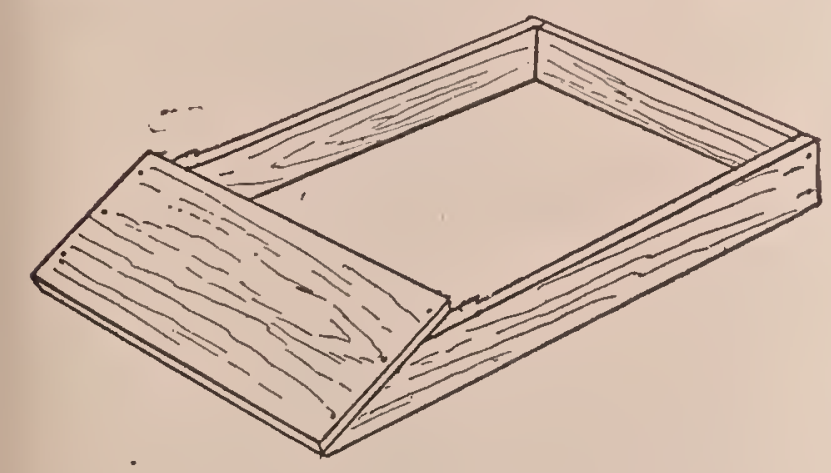

Hive-stand with slanting front.

("ut a board thru the middle on a bias as easily as it can square in two. There will then be two boards, right and left, for the sides. The illustration shows how it is made.

The tendency now among the largest producers is to use a double hive-standthat is, a stand after the pattern of the Heddon, but long enough and wide enough also to take on two hives crosswise, and vet leave a space of six or eight inches between. The illustration shows a design that is very cheap and effective. The front and rear boards are made of one-inch lum- ber, preferably unplaned, from three to four inches wide. These two pieces are tied together by a couple of $2 \times 4$ 's or scantling, crosswise as shown. It is advisable to have these last-named pieces back five or six inches from the ends of the side boards. When constructed in this way, the hive can be placed more nearly over the point of greatest strength, and at the same time allow room for the toes of the operator to project under the hive while working over it.

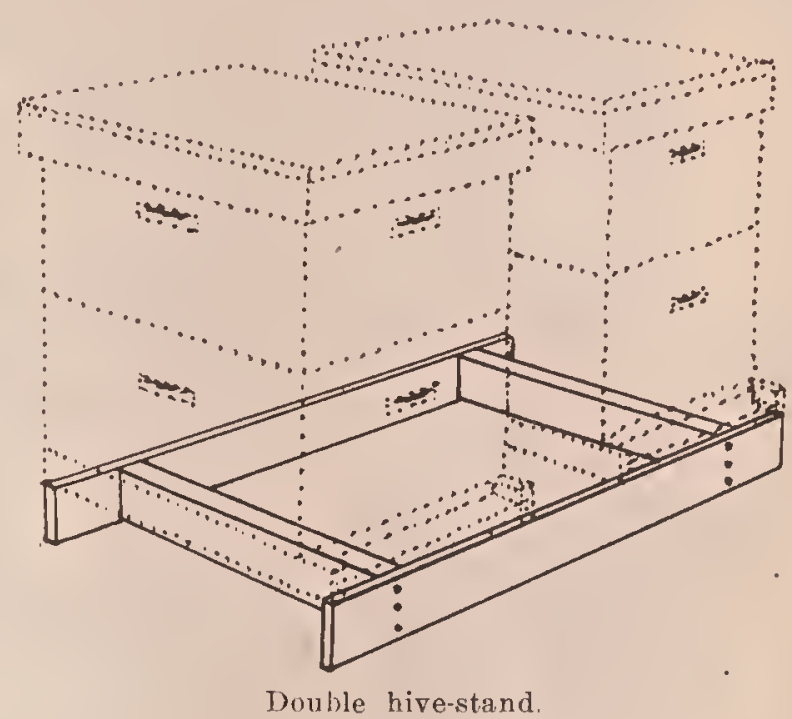

This form of hive-stand has much to recommend it. It is almost as cheap as the single hive-stand, and yet will accommodate two hives. Colonies worked in pairs on it do very nicely. In the fall, if one of them should be a little weak it is possible to mite them by putting the stronger colony in the center of the hivestand to ratch all the flying bees and then remove the other hive. It is also possible to put a one or two frame nucleus on one end of the hive-stand, leaving the colony on the other end. This nucleus can be used during the season for rearing queens. and at the close it can be easily united with the full colony on the other end, which should be moved to the center of the hive-stand. See Uniting.

This double hive-stand lends itself to the plan of wintering when two colonies are put in a winter case; or it will work very nicely when four colonies are put in a single case, provided there are two double hive-stands placed back to back. See Wintering OUTDOORS: subhead QUADRUPLE CASES. 


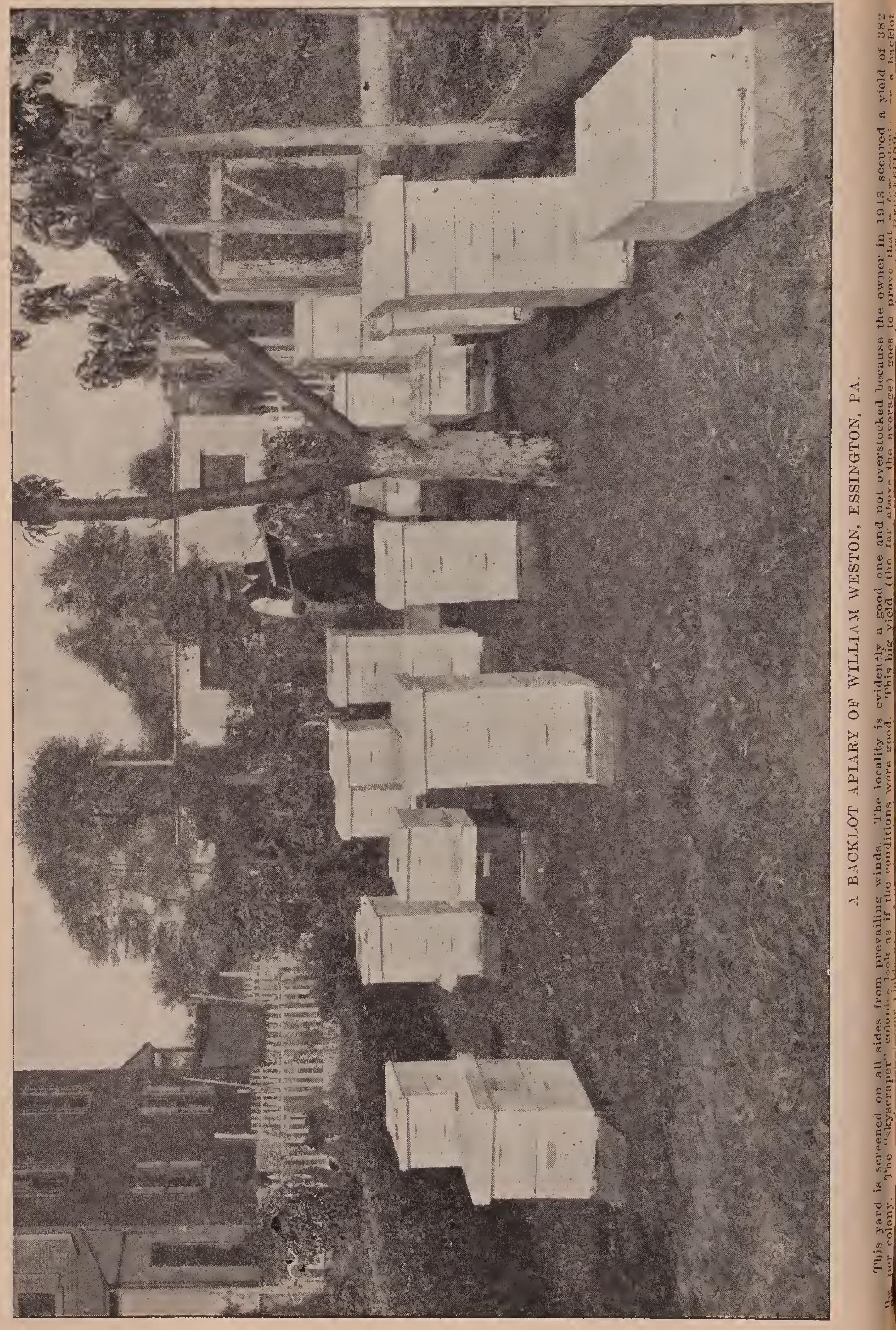




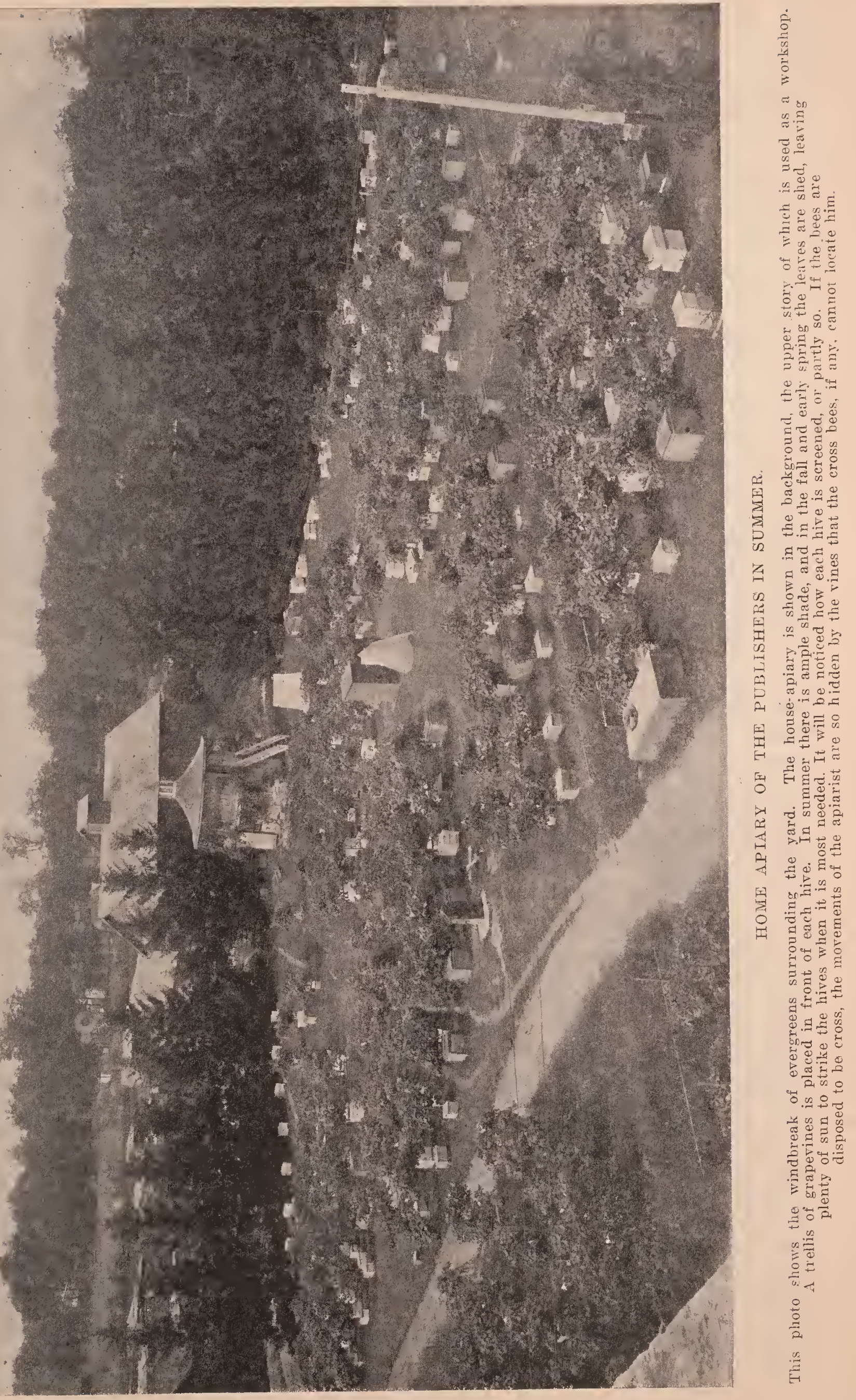




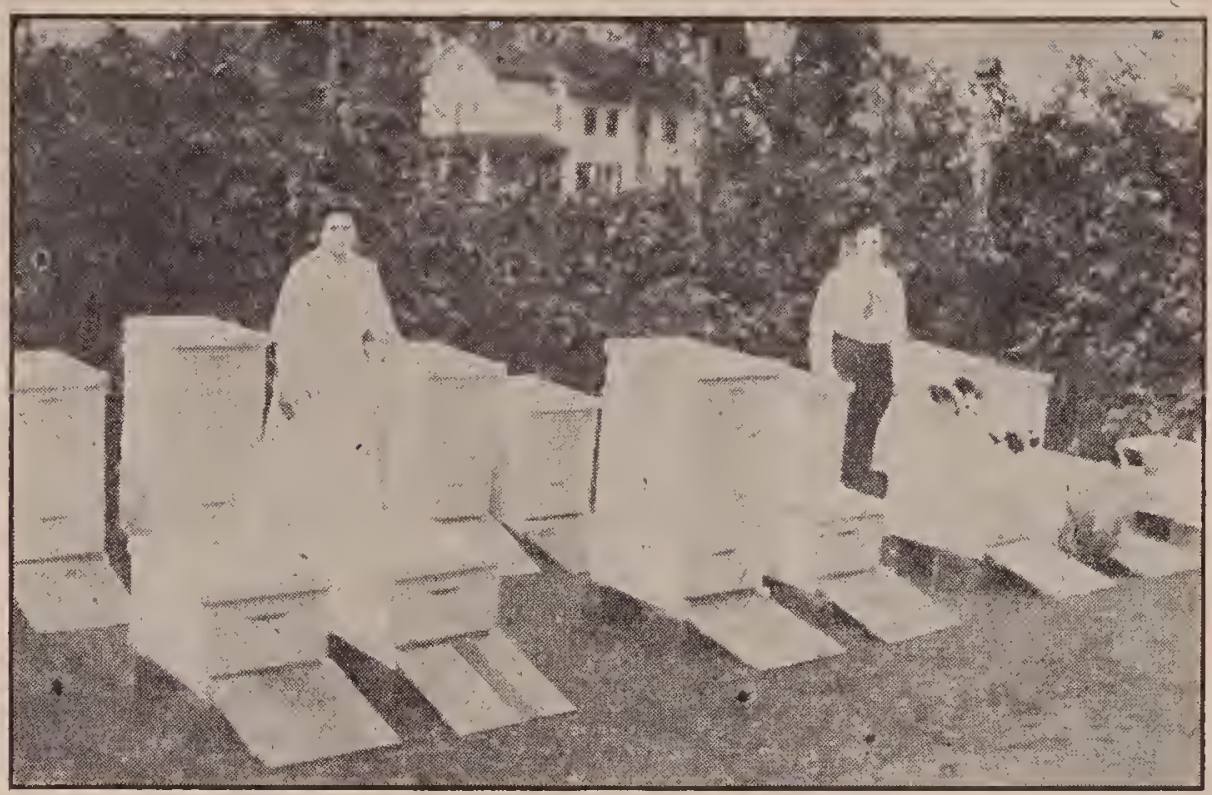

BACKLOT APIARY OF ROBERT PESCHKO. DANBURY, CT.

This rard, like other backlot apiaries where there is a small number of colonies, has given a large yeld per colony. One can judge by the height of the hives. As explained in the text, a small apiary will give larger yields in proportion than a large yard, provided, of course, there are no other bees in the immediate locality. While Mr. Peschko puts his hives up ou stands, he realizes the importance of having easy runways from the ground up to the entrance. In cool or chilly weather this saves the lives of a good many bees.

\section{HIVE-STANDS OR PLATFORMS FOR SWAMPY COUNTRY.}

Where land is swampy, or liable to be overflowed as it is in many places in the South, elevated trellises or platforms should be constructed. It is customary to have these long enough to take on 30 or 40 colonies. Illustrations of this form of elevated platforms are shown in the A. I. Root Company's Apalachicola River apiary.

\section{ARRANGEMENT OF HIVES.}

Having decided upon the location, kind of shade, windbreaks, and hive-stands, how shall we arrange the hives in the apiary? This question can best be answered by studying the plans adopted by some of the prominent apiarists. The lay of the land and exposure to high winds will, of course, have to be taken into consideration.

The usual plan is to arrange the hives in long straight rows, each hive so many feet distant from its neighbor, and on an exact line drawn by a string. While such an arrangement is pretty, it has one serious objection. When hives all face in the same direction, and in straight rows, each hive by itself, the bees are apt to become mixed up at the entrances, especially if the hives are only two or three feet apart.
When the young bees are out at their playflights, they are liable to join the group where the bees are flying the thickest. The result is, their own colony is depleted while the one that makes the biggest demonstration for the time being is getting more bees than it can easily take care of. This causes some colonies to be too strong, and swarm too early, while the others are too weak, and do nothing all summer. See Drifting.

It very often happens, also, that when bees are taken out of the cellar and put into regular rows they will drift in the same way; and this drifting makes trouble.

This whole drifting difficulty can be corrected by giving each hive or group of hives an individuality of its orvn. It is desirable to put hives in groups of two, three, or five; two here, three there, five there, and so on. They may be regular groups of two or groups of three, but in either case there should be a bush or tree at or near each group to enable the bees to distinguish one group from another.

The following plans have been suggested where great economy of space is desired; but instead of following any one of the plans, it is desirable to adopt a combination so that the groups will be irregular in size and number of hives, especially if 
there is no distinguishing shrubbery or trees.

Many beekeepers alrange their lives on the plan shown here, which, as will bx seen, will work nicely in connection witl louble hive-stands.

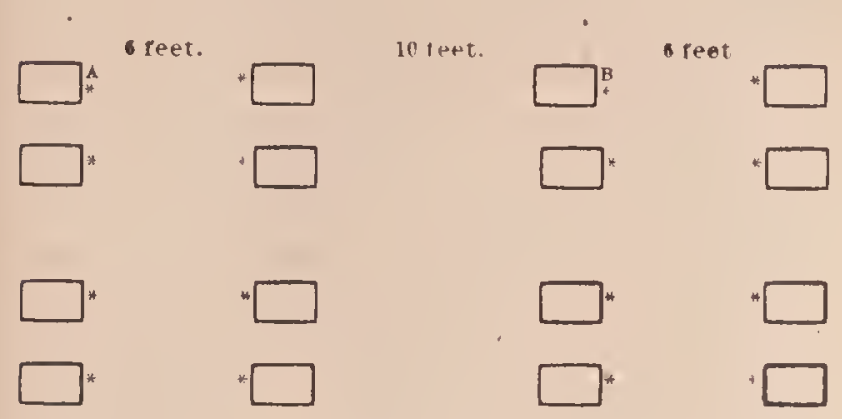

A part of an apiary arranged on the straight-row plan.

'The stars indicate the entrances. There are two lanes, or alleyways; one six feet wide for the bees, and one ten feet wide for the apiarist and his horse and wagon. It will noticed that the hives are arranged in pairs, in such a way that they face each other witl entrances six feet apart. In the next alley their backs are toward each oth(', with plenty of room for a roadway.

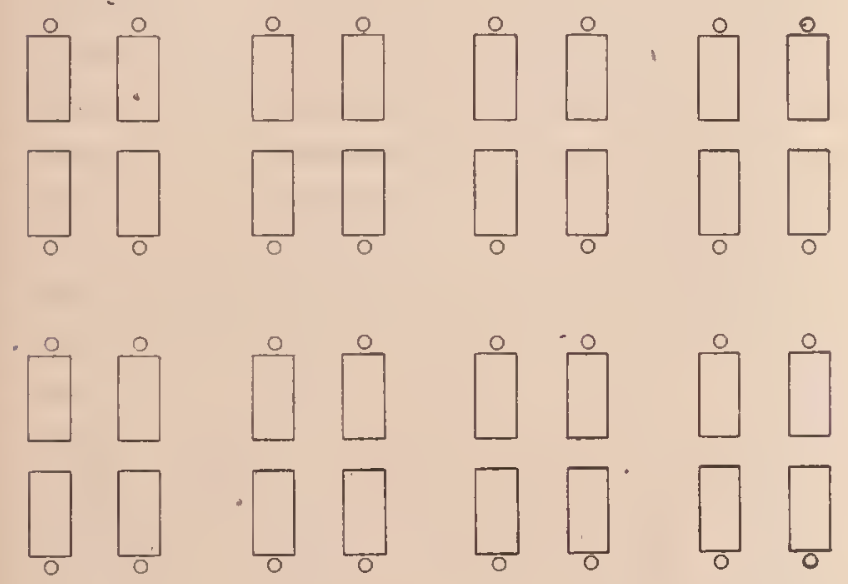

Dr. C. C. Miller's scheme for placing hives.

If the bees are to be wintered in quadruple winter cases, as described under Wintering OutDoors at the close of this work, the hives should be arranged in groups of four. During. the summer time the hives are placed from 10 to 15 inches apart; but during the winter they are placed inside of the winter cases close together, back to back and side to side, without any intervening space. They are then packed as described under the head of WiNTERING OUTDOORS.

In some localities, especially where the bees are moved very much,. it has been found advantageous to place the hives in groups of four by placing the entrances at the four corner's, as the accompanying diagram will explain, and there is then a little less trouble from drifting than where the
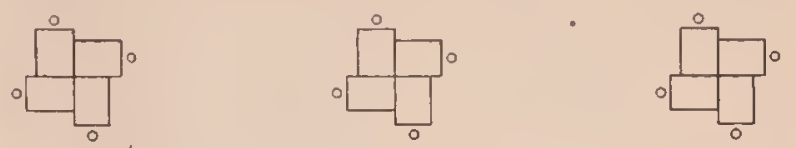

WINTER ARRANGEMENT.
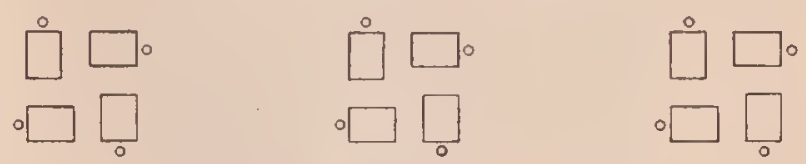

SUMMER ARRANGEMENT

The hives for summer are placed 12 inches apart, and each rinup 8 feet apart. For winter, the hives are shored close together as shown. The objection to the plan is that the operator is sure to encounter the flight of liees. If there is no windhreak from the north, one colony will have its entrance facing north.

hives are placed in pairs with entrances side by side. When the bees drift, especially in spring, one colony in the pair may be very strong and the other weak. One will be inclined to swarm and the other die during fruit bloom.

\section{S. E. MILLER'S PLAN OF AN APIARY.}

This plan is arranged with a view of still greater economy of space, not losing sight of the scheme of a highway for bees and an alleyway for the apiarist. Instead of being in pairs they are arranged in groups of five each. Little circles in front of the hives indicate the entrances. The groups can be from 10 to 20 feet apart; but if put exactly 16 feet apart, and the hives in the group 18 inches apart, an

ALLEY FOR APIARIST,
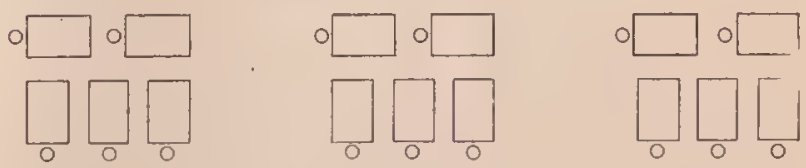

HIGHWAY FOR BEES.
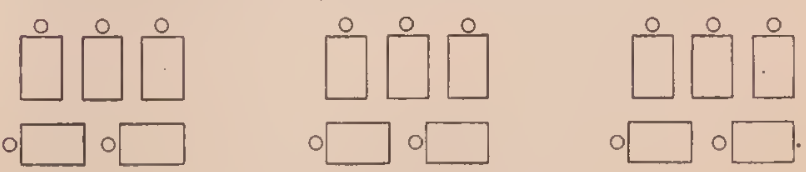

ALLEY FOR APIARIST.
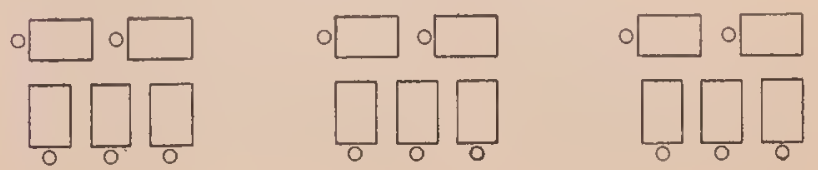

HIGHWAT FOR BEES. 
apiary of 80 colonies ean be accommodated on a plot 75 feet square, or in the back vard of an ordinary town lot. One adrantage of this gromping plan is, that the apiarist can sit on one hive while he is working on another; and his tools, such. as sinoker, honey-knives, bee-brushes, ete., are right at hand for the whole five hives. Where there is only one hive on a stand, the tools have to be carried to each hive.

The objection to the S. E. Miller arrangement is that one row of hives may have to face prevailing winds, or north or west exposure. In the northern climates this should be avoided. ' It is best, therefore, to put hives in pairs and threes, and facing either the south or east.

One can crowd more colonies on a given area on the S. E. Miller plan (and yet leave room to run wagons or carts among the hives) than with any other. It is specially well adapted to a location in a grove: but as trees vary in size and the foliage is sometimes lopsided or scant on some of the trees, hence it is neither practicable nor advisable to put five hives at each tree. It is our practice to place beside the smallest trees only one hive; beside those a trifle larger, two hives: those still larger. three hives; and, when they are of fair size, five, as in the Miller plan. $\Lambda \mathrm{r}$ ranging the hives thus gives each group of one, two, three, or fire, as the case may be, an individuality of its own, thus affording the bees a better chance to distinguish their own group. In every case the precaution must be observed of placing the hives on the north side of the tree. Where there are two or three in a group, the beekeeper can have the entrances facing toward the south; or, if there are only two in a group, he can have one hive with its entrance facing toward the south, and the other hive toward the east. In any case he should avoid having hives face the north and west. This is rery important from the standpoint of wintering.

REEPING DOWX TIE GRASS AT ENTRANCES OF THF HIVES.

If the bees are lorated in a town or city in some back lot it is desirable to lave the grass kept down with a lawnmower for appearance sake if notling more; but, in large commercial yards, especially outyards (sec Out-aplaries), it is hamlly practicable to do this. If the grass or weeds get rery long or in the way, enough to impede travel thru the yard, they should be cut with a scythe. During the time when honey is coming in freely it is very important to have the grass kept down for a foot or two around the entrances of the lives, as otherwise bees coming in heavily laden with honey will get tangled more or less while getting to their entrances. At the same time, these obstructions wear out their wings. No good beekeeper can afford to allow his entrances to become clogged, and so he should cut away the grass around the entrances with a pair of grass-shears or a sharp sickle; but he should not attempt to do this without first blowing a little smoke into the entrance. Many, however, as a matter of economy of time, prefer to use a rough board of the cheapest lumber, as long as the hive is wide, and from 12 to 18 inches wide. If this reaches from the ground to the entrance it will leave an easy runway for the bees to get into the hive, and at the same time lieep away the grass and weeds from the immerliate front of the hive. Salt is sometimes used for killing off all kinds of vegetation around the entrances. It must be liberally applied in front of every live at the beginning of the season.

Sheep are very good for keeping down the grass in the whole beeyard. Unlike cattle or horses they. will not knock over a hive; and should they be stung arome the face or nose they will pusli their heads into a bush where they will be perfectly safe. Their heavy coat of wool protects their bodies.

\section{THE HOUSE-APIARY}

This is a term that is used to designate a building to enclose a whole apiary. The hives are usually arranged on shelves next to the outside walls and haring direct communication with the ontside.

As a rule, an outdoor apiary is cheaper and more satisfactory than one in a building. For the house-apiary, the capital to put up the building must be furnished in addition to that necessary to get the hives. But there are conditions under which the building may be and is used to alvantage -in fact, affords the only method of keep- 
ing bees. There land is raluable, suel as in or near the city, or in localities occasionally visited by thieves or mischievous boys, where bees, honey and everything, so far as possible, must be kept under lock and key, a house-apiary is a necessity. A small building, also, to accommorate 35 or 40 colonies, even when these conditions do not exist, may often be used very advantageously in connection with the regular apiary outroors. Wrhen robbers are bad, or when the day is rainy, the work can continue right on inside the building because the apiarist can leave the outdoor bees and resume operations inside, free from robbers in the one case, or protected from inclement weather in the other.

Until very recently louse-apiaries have not been regarded with very much favor among practical beekeepers, principally on account of faulty construction, and because bee-escapes, when house-apiaries began to come into use in certain quarter's, were not known; but since the advent of these laborsaving devices, the troubles arising from bees leaving the hives and crawling over the floor to die, or to be trampled on if not already dead, at the first visit of the apiarist, are eliminated. These and other inconveniences have been almost wholly removed; and perliaps the only reason why the house-apiary is not more generally used is the expense of first cost.

\section{HOW TO CONSTRUCT A HOUSE-APIARY.}

The building may be oblong, square, octagonal, or round. The round or octagonal form would, perhaps, save steps during the operation of extracting; but it is too expensive to construct. It is advisable to put up a plain oblong building. Where the winters are cold it should by all means be double-walled. Walls should not be less than four inches thick and six would be much better. Sawdust or some sort of packing-material should be poured in between the two walls. Unless it is very warmly packed there will be bad wintering.

As to doors and windows, in the case of a small building 20 by 30 feet, there should be only one window, and that opposite the door, so as to allow a draft to pass directly thr't, because the building at best becomes very sultry in hot summer weather. An ordinary tight-fitting door should be used, hinged in the usual way. To the outside of the door frame there should be a selfclosing wire-cloth sereen door. At two of the upper corners of the doors and windows for the escape of bees clustering on the wire eloth, attach Porter honey-house bee-escapes.

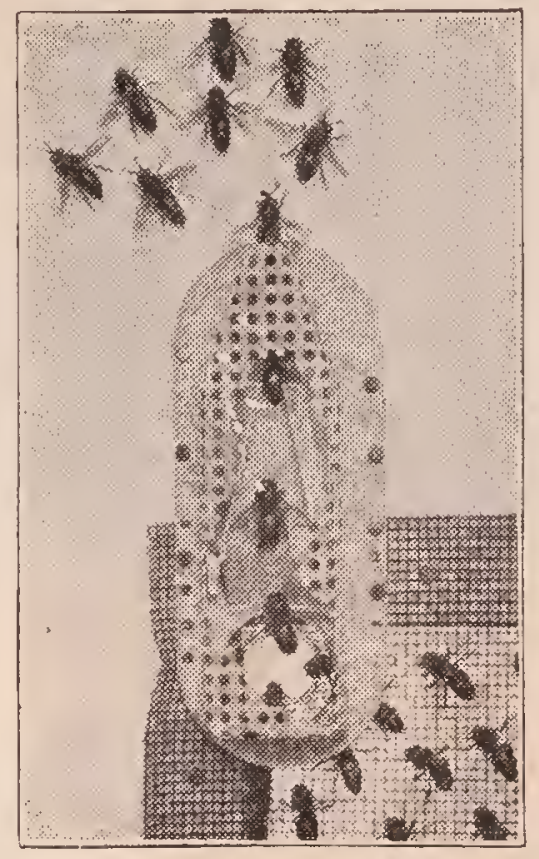

Porter honey-house bee-escape.

At several points, close on a line with the floor, should be one-inch holes, on the outside of which should be more Porter honeyhouse bee-escapes. The purpose of the opening in these escapes is to let the bees that liappen to be inside after handling crawl out toward the light; and, once outside, they will enter their own hives, with the possible exception of a few young ones, and they will be accepted at any of the entrances.

A few years ago it was the practice to make compartments as a part of the building to hold the frames, but this was found to be very objectionable; and those who manage house-apiaries now prefer to use ordinary outdoor hives instead, primarily because the bees can be more easily confined to the hives; and, secondly, because the indoor and outdoor hives are one and the same, and interchangeable.

The hive entrances should be so arranged that they communicate with openings thru the side of the building. Ordinary eqver's should be used to confine the bees strictly 


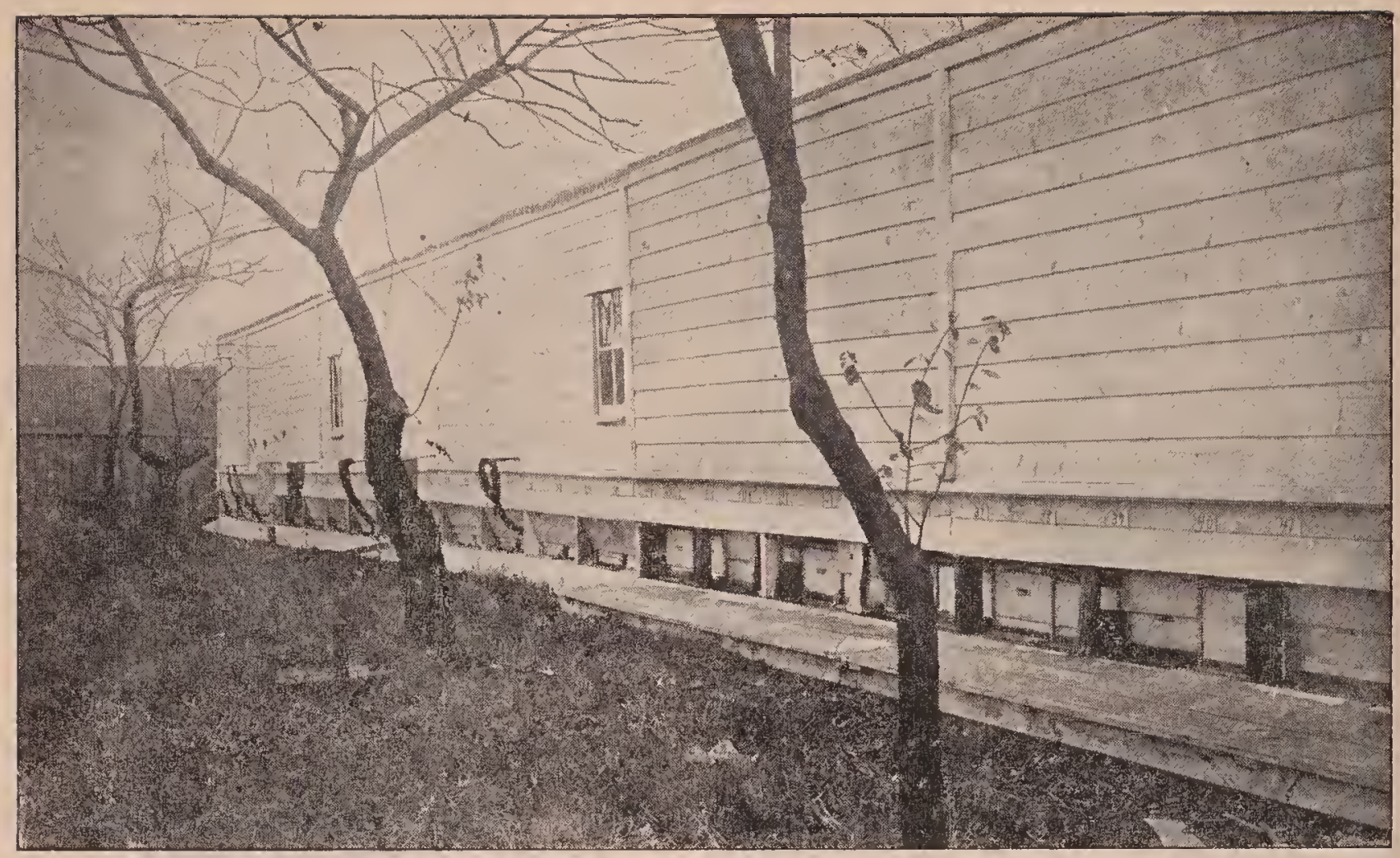

W. C. Sorter's house-apiars. The rags of different colors are used to enable the bees to mark their own entrances more easily.

within the hives. In lieu of a cover a thin $3 / 8$ board, or inside super cover, may answer just as well; but, so far as possible, the house-apiary should be so constructed that everything outdoors may be moved inside, and vice versa, whenever requirements make it necessary.

When the building of a house-apiary is double-walled, it is necessary to provide some sort of bridgework or housing to cover the runway between the entrances of the hives inside and the openings outside. In the author's original building a two-inch round tube was used, because it was easier to insert a tube than to make a narrow rectangular box or housing. But a round hole, as large as this, is not as desirable as a covered runway thru the building to the regular entrance of the hive.

On account of convenience in handling frames, many prefer to have the hive sides against the building. In that case there will have to be a slot in the side of the bottomboard instead of the end. Others prefer, on account of economy of space, to place the front end of the hive against the building. When this is done it involves no change in the structure of the bottomboard; but it makes the handling of the frames a little awkward, as will readily be discovered when one tries the plan.

To economize the space of the building still further, there may be another tier of hives about four feet above the floor; and these should be supported by shelving that reaches entirely around the room. The same arrangement with regard to entrances may be employed as described for the bottom tier.

PUTTING CROSS COLONIES IN HOUSE-APIARIES.

The crossest bees are but little inclined to sting inside of a building. When they fly from the combs that one is handling, they find themselves inclosed; and this so disconcerts them that they immediately fly to the screen windows and escape. James Heddon said, "If you have a cross colony, put it in the house-apiary and see how tame it will become."

\section{HOUSE-APIARIES FOR IVINTERING.}

As the building is double-walled, and is (or ought to be) packed, colonies will require less protection than outdoows. Indeed, about all that is necessary to put them into winter quarters is to put on an extra comb-honey super, tuck in a chaff cushion, replace the cover, when the bees 


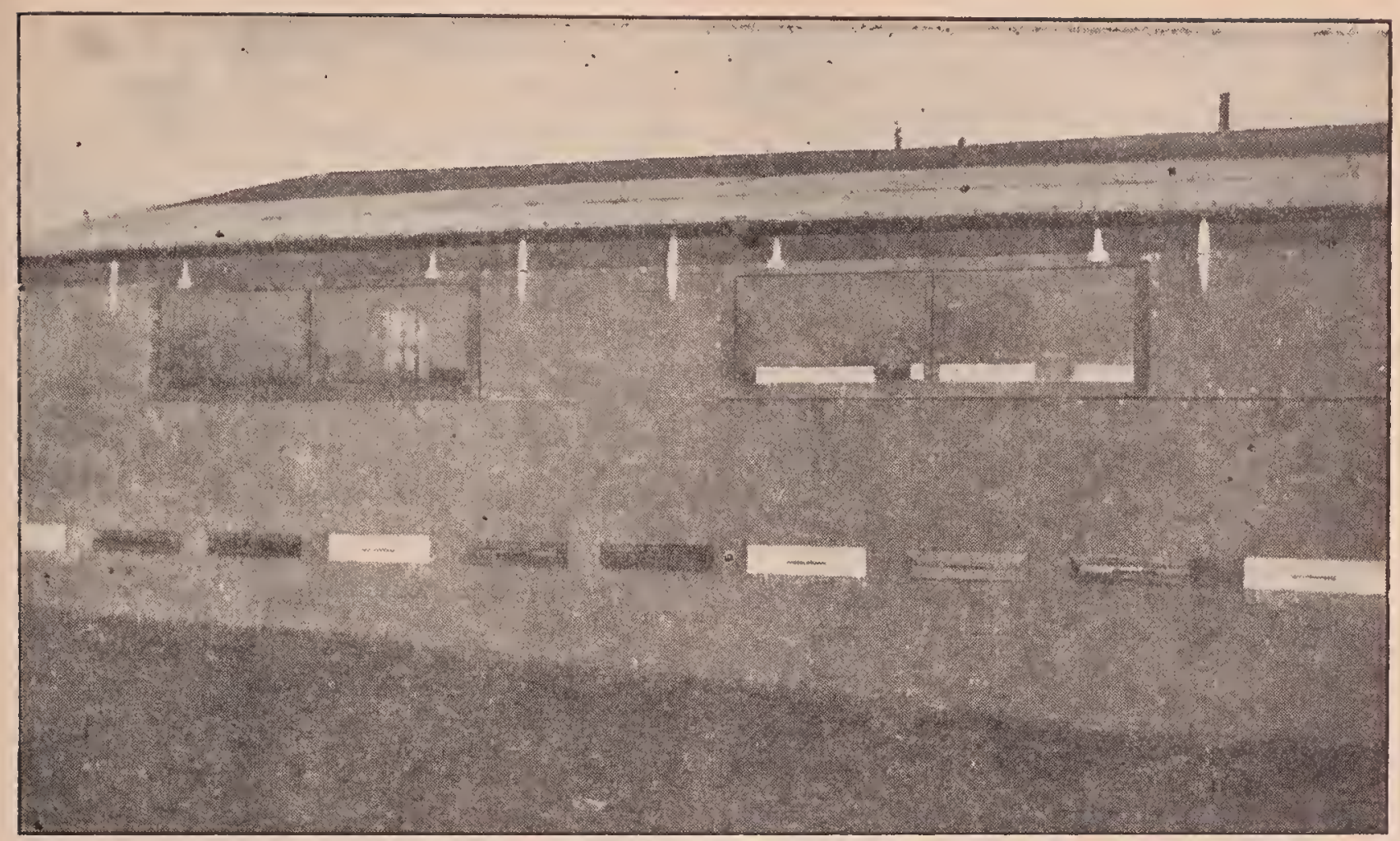

Addition built on the south side of E. C. Barber's shop, 20 feet long and 5 feet wide. It is covered with two-ply paper, granite finish. Cost for material and labor, $\$ 22.50$. Ten colonies are wintered inside this building, temperature 45 to $50 \mathrm{Fahr}$. In hot weather the side can be opened to give plenty of ventilation. There is also a door in each end.

will be preparea. In very severe cold weather, a small fire, or heat from a large lamp in the room, may, perhaps, be used to advantage; but artificial heat in wintering should be used sparingly and with care, for oftentimes it does more harm than good. See Artificial Heat.

E. C. Barber of Framingham, Mass., whose house-apiary is shown, thus summarizes the advantages of keeping bees inside of a building:

I prefer the house-apiary instead of the outside yard for several reasons. First, you can work at your bees and not be among those flying in the air, especially if the windows in the house are closed. What few bees fly away from any hive you are working on inside of the house, instead of trying to frighten or sting you, will fly to the window to get out. Second, you do not have to carry the hives in and out of the cellar in the spring and fall, or move them to their winter quarters. Third, your bees are always protected from the snow, rain, and winds. Fourth, they are at leisure for a flight in the winter any time when it is warm enough, such as the past few days have been, when the thermometer was around 70. Fifth, in this house-apiary I can see a big difference in spring brood-rearing; also protection during cold nights, when bees are working in sections during the summer.
APIARY, OUT,--See OUT-APIARIES.

APIS DORSATA.-See RACES OF BeES.

ARTIFICIAL FERTILIZATION-After the reader has read the subjects of Drones, Queens, and Quefen-Rearing, he will fully understand that the mating of the drone and the queen in a state of nature takes place on the wing in the air, and never occurs inside the hive. Nature has seemed to design, for the purpose of avoiding inbreeding, that the queen shall find her mate in the open air, where, according to the law of chance, she will in all probability meet some drone not directly related to her, and also one that is vigorous, because it is only the strongest flyers that overtake the queen. Attempts have been made at various times to bring about fertilization within the hive or within some small tent connected with the hive entrance. But alp such attempts have resulted in failure, because the drones and the queens, as soon as they find they are confined in a small enclosure, will bump against the sides of the mosquito netting or wire cloth, vainly trying to escape.

A good many years ago J. S. Davitt 
of Aragon, Ga., put up a tent of mosquito netting, 30 feet tall and 30 feet in diameter. Hives of bees containing select drones were placed around the bottom edge of the tent, each hive having two entrances -one opening into the inclosure and the other into the outer air. The latter was covered with perforated zine in order to compel the queen and drones, when seeking flight, to pass out of the other entrance into the enclosure. This inside entrance was liept closed for about a week; then on some farorable day, from 11 A. II. to 1:30 P. M., it was opened and the drones and queens were allowed to go into the tent. Mr. Davitt reported that a very pretty school of drones would be found flying at the top, and that he was successful in mating many queens. It will be noticed that worker bees, accustomed as they are to the outside entrance, which is always open, do not go into the inside of the tent during the mating lours, so that the drones and the queens are largely by themselves.

Unfortunately, this general plan has been tried by only oure or two others, but without success. So far no one else has had the nerve to try it.

MATING IN A GREENHOUSE.

Still another plan is to have queens mater in some of those mammoth cucumber greenlouses found in rarious parts of the country. An experiment of this kind was conducted on a very large scale in one of the largest greenlouses in the United States at Ashtabula, Ohio, in 1918 and 1919. Inasmuch as bees would fly out and pollinate the cucumber blossoms, it was thought that queens and drones could be induced to mate in the same environment. After repeated attempts to effect artificial fertilization, without success, the attempt was finally given up. While the bees became accustomed to the glass and visited cucumber blossoms, it seemed impossible to keep the queens and drones from bumping against the glass. Mating under normal conditions permits of unlimited flight. When drones and queens sally forth in their mating excursions they appear to desire to fly around considerably before they find their mates. The limitations of the greenhouses, even the largest of them, make this impossible.

\section{MATING ARTIFICIALLY.}

One enthusiastic beekeeper reported having tried taking a drone of mating age and pressing him until the drone organs were distended. The spermatozoa were then injected into the body of a queen of mating age. He stated that, altho the wings of the queen had been clipped when she was one day old, she began to lay and the eggs developed into worker brood. The experiment is worth trying, and the author suggests that some of the A B C scholars try it out and report results.

\section{MATING ON DESERTS OR SMLALL ISLANDS.}

Some beekeepers in the West are located near large tracts of desert country, with nothing but sagebrush and the jack-rabbit. Such a place would be ideal for the mating of queens. Of course, the bees would have to be fed. There would be no other bees, and it would be possible to secure perfect mating from a hive or hives containing a large number of select drones.

There are occasional islands so situated that there would be no bees on them, and where one could locate a mating yard containing' a hive 'of good drones. If the island is of any size, and there is a honey flow of any sort, there are likely to be wild bees there. The island for special queen-mating purposes should be small, and at least 10 miles from any other yard or from the mainland. Near the irrigated regions of the West there are many desert areas where perfect mating to select drones could be arranged for. Since islands exactly suited for the purpose are rather rare, it would seem that the desert would be more feasible for mating than the islands.

\section{FICLUDING UNDESIRABLE DRONES FOR MATING.}

So far, for most beekeepers the only feasible plan for mating with select drones is to put perforated zine over the entrances of all colonies not haring choice drones, leaving only select drones to have the freedom of the air. If there are $n 0$ other bees in the locality except from hives haring sereened entrances, the chances will be largely in faror of having the queens miated to the drones of the colonies se- 
lected. See Queens, Queen-rearing, and Drones.

ARTIFICIAL HEAT.-As strong colonies early in the season are the ones that get the lioney and furnish the early swarms as well, and are in fact the real sonrce of profit to the beekeeper, it is not to be wondered at that much time and money have been spent in devising ways and means whereby all might be brought up to the desired strength in time for the first yield of honey. As market gardeners and others hasten early regetables by artificial heat. or by taking: advantage of the sun's rays by greenlouses, it would seem that something of the kind might be done with bees: in fact, the author, by the aid of the heat of a stove, has succeeded in rearing roung bees every montli in the rear in a greenhonse, even while the weather outside was at zero or lower; but the scheme resulted in failure, so far as profit was concerned. The bees, it is true, learned to fly under the glass and come back to their hires: but for erery bee that was raised in confinement, two or three were sure to die, from one cause or another.

Experinents have been rondurted on a large scale at Ashtabula, Ohio, where there is about 40 acres under glass. The owner of one of the large greenhouses trier out the experiment of seeing what he could do in raising bees in a spring or summer temperature under control. He noted that they pollinated his eucimber blossoms: and if he could raise bees under glass he could recuperate his loss by raising a fiesh supply of bees during the months when he was raising arumbers. The experiment of raising bees was a failure. but the pollinating of the blossoms was a perfect success. See Pollen.

At another time experiments were made with artificial heat while the bees were allowed to fly ont at pleasmre: and, nltho it seemed at first to have the desired effect, so far as liastening brood-rearing was concerned, the result was, in the end, just about as before; more bees were reared, but the unseasonable activity killed off twice as many as were reared, and the stocks that were let alone in the good old way came out ahead.

Attempts have been made in the way. of using small electric heating coils in the top of individual colonies under packing for the purpose of holding an even temperature in the hive irrespective of outside weather conditions. The colonies inmediately went to brood-rearing; but, as might be expected, breeding always foreed the bees out of the hive for water and pollen. All attempts to heat individual colonies by means of electricity, like all similar attempts, have ended in failure.

For the benefit of those who may be inclined to experiment, the author would state that he corered almost his entire apiary one spring with manure on the plan of a hotbed, and had the mortification of seeing nearly all the bees die of spring dwindling. Another time he kept the houseapiary warmed up to a summer temperature with a large oil lamp, for sereral weeks, just to have them beat those out of doors. The investment resulted in losing nearly, all the house-apiary with spring dwindling, while those outside stayed in their lives, as honest bees should, until settled warm weather, and then did finely, just because he was "too busy to take care of them" (?) as he used to express it.

WINTERING BEES IN A WARM ROOM.

But a number lave wintered single colonies of bees in the living-room of a house where the temperature was kept between 65 and 72 , night and day. In the cases mentioned, the colonies were placed on a shelf next to a window, with the entrance communicating with the outside. All old and superannuated bees can thus escape at any time: and when the weather is suitable the bees can fly. A colony of bees was placed in one of the offices of the A. I. Root Co. and was there for at least three years. Some year's it seemed to winter very nicely; but taking one year with another, these indoor colonies did not seem to get ahead like those outdoor's. The warmer' atmosphere in which the hive is placed has a tendeney to start brood-rearine. This forces the bces out on unfarorable days, with the result that they never return. The slight amount of brood liatched does not compensate for the number lost in this way; and the result is, the colony gradually goes down. By the time spring comes on, the queen is not ready for the active 
duties of the hive, for the simple reason that she has been laying more or less all winter; and, probably, if she were a human being, she would say she was "all petered out."

Packing the hives with chaff, sawdust, or any other warm, dry, porous material, so as to economize the natural heat of the cluster, seems to answer the purpose much better, and such treatment seems to have none of the objectionable features of working with artificial heat. The packing needs to be as close to the bees as possible; and to this end all the combs should be removed except such as are needer to hold their stores. Bees thus prepared seem to escape the ill effects of frosty nights in the early part of the season, and exactly what was hoped for by the use of artificial heat is accomplished for brood-rearing.

By turning to the general subject of "Temperature," it will be seen that artificial heat or a sudden rise in temperature has a tendency to start brood-rearing in a colony. Ordinarily it requires something like 95 degrees Fahrenheit in the cluster for the rearing of brood. When this point is reached, no matter what the outside temperature may be, brood-rearing will be started; but when the temperature outside is below freezing, so that the bees can not fly, artificial heat does much more harm than good, because brood-rearing in midwinter usually spells disaster for the colony before spring. During open winters, lowever, especially if the colonies are well packed, and toward spring, breeding does no harm. If a colony is of normal strength it will raise brood as soon as it can safely. To stimulate brood-rearing by means of artificial heat is always a mistake. By reading the whole article on Temperature elsewhere in this work one will understand why this is so.

For a further consideration of this subject see Temperature.

ARTIFICIAL PASTURAGE. - Altho there was formerly quite a trade in seeds and plants to be cultivated for merely their honey alone, little encouragement can be given to those who expect to realize money by such investments. There is certainly a much greater need of taking care of the honey that is almost constantly wasting just for lack of bees to gather it.* A field of buckwheat will perhaps occasionally yield enough honey to pay the expense of sowing, as it comes in at a time when the bees in many places would get little else; and if it does not pay in honey, it certainly will in grain.

Alfalfa, sweet clover, and alsike clover at the present time afford the best examples of artificial pasturage of anything known. But neither sweet clover nor alfalfa will grow everywhere, at least, until the soil has been put in the right condition with proper inoculation.

Sweet clover furnishes an artificial as well a as wild pasturage, and is now being grown as a regular farm crop. In many portions of the West where the land is too dry to grow alfalfa, sweet clover will thrive. In many parts of Kentucky, Kansas, Nebraska, South Dakota, Oklahoma, Indiana, Illinois, Michigan, and Missouri, sweet clover is coming to be a very profitable crop. It often does well on land that will not grow anything else, especially on rocky hillsides. See Sweet Clover.

Alsike clover also furnishés artificial pasturage in the eastern States. It often takes the place of ordinary red clover that fails to do well. Alsike can stand wet feet, but red clover will not. This discovery has caused many farmers to grow it either with timothy or exclusively, and the result is that wherever it is extensively grown the keeping of bees is profitable.

In general, it may be said: Plant and sow all that will be sure to pay aside from the honey crop, and then, if the latter is secured, you will be so much ahead; but beware of investing much in seeds that are for plants producing nothing of value except honey. Alsike, white Dutch elover, buckwheat, rape, alfalfa, and the like, it will do to invest in; but catnip, mignonette. Rocky Mountain bee-plant, ete., should be handled rather sparingly.

The question, "How many acres of a good honey-bearing plant would be needed to keep 100 colonies busy?" has often been asked. If 1.0 acres of buckwheat would an. swer in full bloom, perhaps there would be needed 10 other similar fields sown with rape, mustard, catnip, etc., blossoming at as many different periods, to keep them

\footnotetext{
* See Foretrorp.
} 
going the entire warm season. Alfalfa, sainfoin, sweet clover, buckwheat, rape, alsike clover, crimson and red clover, cowpeas of the South, and some others, are the only cultivated plants that unquestionably have given paying crops of honey. See Honer Plants.

ARTIFICIAL SWARMING.-Artificial swarming is the act of creating conditions within the hive comparable to that of a recently hived natural swarm. It is a great convenience for those who may be away from the apiary at swarming time. Business and professional men, by a little attention to their bees once a week during the swarming season, can by this means anticipate swarming, thus forcing the swarm at the convenience of the beekeeper instead of permitting the colonies to swarm when they get ready, usually at the most inconvenient time. Extensive honey producers who operate several apiaries can control swarming by visiting each apiary about once a week and making artificial swarms when colonies are found that are preparing to swarm. Before the reader takes up this subject he should read carefully the article on Swarming in order that he may understand the conditions that bring about swarming in a natural way. $\mathrm{He}$ will then be in better position to understand the principles involved in $a r$ tificial swarming.

Usually it is not considered to be a good plan to make artificial swarms from colonies that are not making preparations to swarm naturally, for colonies which are willing to work well thruout the season without swarming should not be disturbed by swarming them artificially. As a rule, the bees do not swarm naturally until the first of the queen-cells built preparatory to swarming are capped, or about ready to be capped. By examining the broodcombs of each colony once a week to see if queen-cells have been started, it is possible to detect which colonies may be expected to swarm within the next seven or eight days and these may be swarmed artificially.

Italian bees sometimes swarm before the queen-cells are eapped, and in extreme cases they may swarm almost immediately after starting queen-cells, but this does not often happen. For this reason it is well if much swarming is expected, as in producing comb honey, to clip the queen's wings, even when artificial swarming is practiced, to prevent the loss of swarms that may issue before the next weekly visit to the apiary. Bees do not often postpone swarming for long after the first queencells are capped, unless they are prevented from swarming by adverse weather.

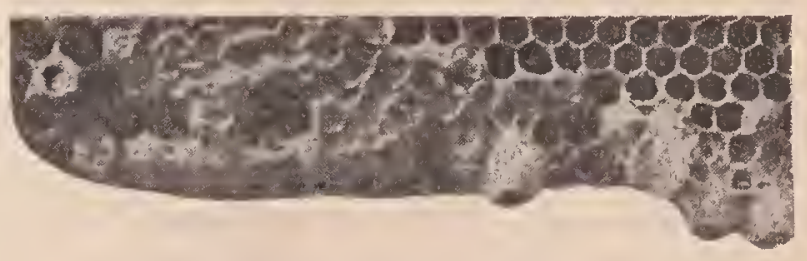

Initial swarming cells shown at the right. It is these that give the apiarist warning of the colony's intention to swarm.

When making these examinations, if queen-cells are found which contain only eggs or very small larvæ, these cells may be destroyed and the colony left another week. Sometimes they will give up swarming when this is done, but often they build more queen-cells immediately and will be ready for treatment at the time of the next visit a week later. When destroying queen-cells in this way it is necessary to shake most of the bees from the combs to be sure that none of them are overlooked; for, if one is left, a swarm may issue before the next visit.

When queen-cells are found that con. tain large larvæ there is no use destroying these, expecting the colony to give up swarming, for destroying such queen-cells usually does not prevent swarming: When well-advanced queen-cells are found the colony may be treated at once if there is a honey flow at the time. If the bees prepare to swarm before the beginning of the main honey flow, they can usually be induced to give it up by destroying the queen-cells and giving a second story of empty combs, especially if some of the combs of brood are raised up into the second story.

The operation in artificial swarming, in brief, is as follows: The old hive is moved to one side of its stand and an empty one, just like it, is put in its place. In this hive are placed frames having foundation starters or full sheets of foundation, preferably the latter. If neither of. 
these are available, frames of empty combs may be used, especially if for extracted honey, but a full set of empty combs is not best for comb honey. Most of the bees, including the queen, are then shaken or brushed from the combs in front of the entrance of the new hive so arranged that they will rum into the hive readily; $o r$, if preferred they may be shaken on top of the frames in the new hive. Some prefer to find the queen and set the comb on which she was found into the new hive first being sure that it contains no queencells; some find the queen and run her in at the entrance of the new hive; while other's shake and brush all the bees witlout looking for the quieen. Whatever the method employed, the queen must be in the new hive when the operation is complete.

If comb lroner is being prodnced, usually two conbs with adhering bees shorlit be left in the old hive in order that there will be enough hees to take care of the brood. The number of bees necessary to leave for this purpose depends upon the weather. more being needer if the nights are cool. The combs containing the finest queen-cells should not be shaken if increase is to be male from the parent colony, since shaking the combs injures the immature queens in their cells. The queen-cells on all the other combs which have been sliaken should be lestroyed to prevent any crippled queens emerging; for such a queen, if she emerges first. mimht destroy the perfect younw queens in their cells on the unshaken rombs.

The supers from the parent hive are next put on the new hive, and the hive of the parent colony is placed by the side of the new one, with its entrance facing in the same direction but having its entrance contracted. The bees should now continue work in the supers and rush the incoming nectar above, especially if foundation is used in the new brood-chamber, for until this is drawn o'lt into comb there is no place to store it belorv.

The hive containing the parent colony is left beside the new one a week. Then at a time when the bees are working well in the fields, and preferably while many young bees are taking their playfight (see Plapflights of Young Bees), the old hive should be moved to a new location for increase. The old hive should be landled carefully while being carried away to prevent disturbing the bees, so that when the field bees that are in the live go out after another load they will not note the cliange in location of the hive. The live should be earried far cno'irll away that the returning bees will not find it, and should not be located too close to other hives where bees from an arljarent hive might enter it by mistake. Then this is done most of the young bees whicl have become field worker's during the week will now, as they return from the fields. enter the new live on the old stand, and at the same time the parent hive is so repleted of its bees that after-swarming is prevented. See AFrer-Swarming, HeDdon IETHOD.

If extracted honey is being produced, all the bees may be brushed or shaken from their combs when an artificial swarm is made, and the old brood-chamber with its rombs of brood can then be placed on top of the supers as tho it were an additional super, first destroying all the queen-cells and placing a queen-excluder between the lower brood-chamber and the sipers. When the combs of brood are shaken and brushed clean, it is not necessary to find the queen to be sure that she is in the new brood-chamber.

In this way the parent colony is above the supers, and the swarm is below the supers, both being in the same hive. They are, in fact, a single colony with the young and emerging bees in the upper hive-body and the queen and the new brood-chamber now being established in the lower hiveborly. As the brood emerges the combs in the upper hive-body will be filled with honey and the former brood-chamber now becomes a super. It may be adrisable again to destroy all queen-cells in the old brood-chamber 10 days later, tho this is not always necessary, especially if sereral simers are between the lower broorlchamber and this one on top. If increase is desired the queen-cells should not be destroyed, and the old brood-chamber with its emerging brood should be taken avay a week after the artificial swarm was made and used for increase.

The question may be asked here why 
this method is not renommended when producing comb honey. To place the old brood-chamber above the comb-honey supers would result in the cappings of the comb honey being discolored; and, unless the honey flow is quite rapid, too much of the honey would be stored in these brood-combs as the brood emerges, causing the bees to neglect the comb-honey supcrs. Some have reported success by placing the old brood-chamber with its emerging brood on top of the comb-honey supers but with a ventilated bee-escape board between. By doing this the brood is kept warm by the heat passing thru the wire cloth in the escape board and the young bees passing thru the bee-escape are added to the colony below.

Tarious devices have been used to cause the young bees of the parent colony to unite with the swarm; such as cone escapes or tin tubes over the entrance of the parent hive which lead the bees to the entrance of the new live, so that when the young bees $s$ out for their first flight they do not find their way back into their own hive but enter the new one. In this way the emerging bces of the parent hive can finally all be added to the swarm; but the simpler plan of moring the parent hive to a new location is most commonly used.

Instead of moving the old hive away when making an artificial swarm, the bees may be shaken back into their own hive, and the combs of brood placed into another hive which is now to house the parent colony.

If only frames containing foundation are used in the new brood-chamber, the bees may swarm out and desert their hire the next day or even two or three days after the artificial swarm was made. To prevent this, it is sometimes best to remove only a part of the brood at first. leaving from one comb up to half of the combs of brood, being sure that no queencells are left. Frames of full shects of foundation are then put in to take the place of the removed brood." Two or three days later, when the foundation is well drawn out, the remaining combs of brood should be removed. Even when but one comb of brood is left to discourage swarming out, it should be remored within about three days; for, if the bees are well along in their preparations for swarming at the time of making the artificial swarm, they may inmediately start queen-cells on this comb of brood, and sometimes swarm even when most of the brood has been taken away.

Combs of honey are sometimes used on which to hive artificial swarns. If this honey is unsealed, the bees usually carry it above promptly; but, if combs of sealed honey are used, the bees are not inclined to move it up promptly, and they may work with less vigor when much sealed honey is in the brood-chamber.

Under the head of InCREASE, the question of various methods for inereasing the number of the colonies by dividing or otherwise is taken up. The reader should understand that "artificial swarming" is one thing, and "increase by dividing" is entirely another. The former is used to prevent natural swarming, or, rather, to put it at a time to suit the convenience of the beekeeper and yet get a crop of honey. Thic latter does not contemplate the idea of securing honey, but rather an increase in the number of colonies.

ASTER.-(Aster, the Greek word for star.) Asters are also called starworts, and in England Christmas daisies from their late period of blooming. This is a genus of the Compositae, the largest and most inıportant plant family, to which also belong the goldenrods, sunflowers, thistles, and daisies. There are about 142 species of asters in North Anserica, and about half that number in northeastern America. The species are very difficult to distinguish, as there are numerous rarieties and hyorids. Asa Gray declares in one of his letters that the asters threatened to reduce him to blank despair. The so-called flower of an aster is in reality a compact cluster, or composite, of many small sessile flower's subtended by scale-like bracts, termed a head or capitulum. The marginal or rayflowers have strap-shaped corollas, and are blue, purple, or white, but never ycllow. The central or dise flowers are tubular, and range in color from dark to golden yellow, changing in some species in the later stages of the flower to erimson purple, brown purple, or purple. The genus is repre- 
sented by a larger number of species in North America than in any other continent.

Aster honey is gathered chiefly from the very common species $A$. multiflorus, $A$. vimineus, A. lateriflorus, $A$. Tradescanti, and $A$. paniculatus, all of which produce dense clusters of small white or pale bluewhite-rayed heads, except $A$. multiflorus, which has the rays white or purplish. Over large areas in Kentucky, Indiana, and other States the bloom is so abundant that the fields look as if covered with snow. The plants are often rery bushy, growing

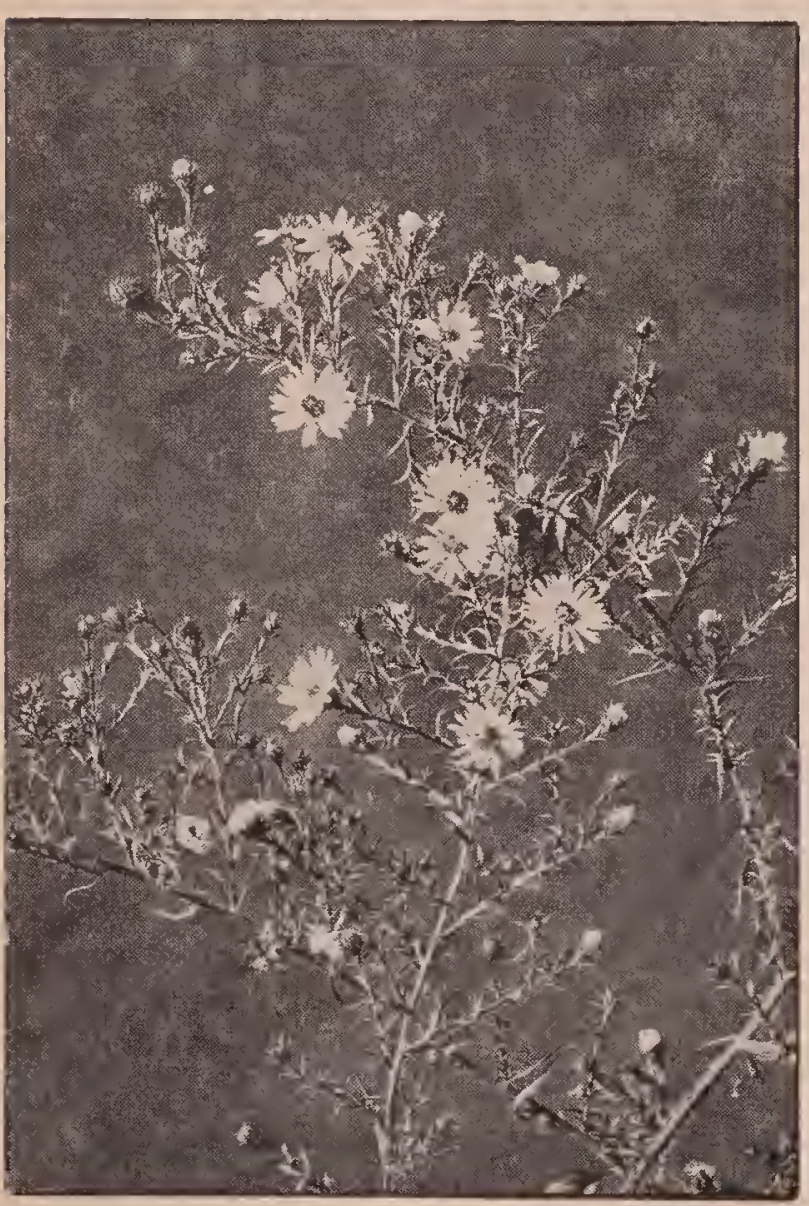

Aster

from six inches to three feet tall. When the weather is favorable colonies will pack their combs with aster honey, or if combs have already been filled from an earlier source a surplus is often stored. One season at Underwood, Ind., there were hundreds of acres of white aster in bloom, and 100 pounds of comb honey per hive is reported to have been obtained. At Langnau, $\mathrm{Ky}$., the scales showed a gain of 25 pounds in four days from Oct. 2 to 5 . Forty-eight colonies harvested 3,000 pounds, of which one-half was surplus.
There were ninety-five acres of white aster rithin reach of the bees. During 12 days of hot weather in September, 1914, J. L. Byer reports that 250 colonies 100 miles north of Toronto, Can., simply jammed the brood-nests solid with aster honey.

Pure aster honey is white-as white, according to boekeepers familiar with it, as white-clover loney; but it is seldom obtained pure. Usually it is colored amber $m$ yellow by honey from goldenrod or other late-blooming autumnal flowers. The asters, however, remain in bloom longer than the goldenrods. When newly gathered the honey has a rank odor, but this disappears when it has ripened. It has a pleasant aromatic taste, and is so thick that at times it is extracted with difficulty. It crystallizes quickly with a finer grain than goldenrod. It has been stated to be unsuitable for table use, but $\mathrm{O}$. H. Townsend writes that in Michigan he sells aster honey for the same price as red raspberry, and that it has a fine flavor and good body. Other beekeepers also describe the flavor as agreeable.

Many beekeepers have complainęd that their colonies suffered more or less loss when wintering on aster honey. So strong has been the opposition to it for this purpose that its removal and the replacing of the stores by feeding sugar syrup have been repeatedly advised. It is not improbable that aster honey gathered so late that it only partially ripens and remains unsealed is liable to deteriorate and become deleterious before spring; but any other honey or even sugar syrup under similar conditions would be objectionable. Its tendency to candy quickly and solidly, making it onl partially available to the bees, has also added to its poor reputation as a winter food. Mismanagement on the part of the apiarist seems likewise in some instances to have been laid to the fault of aster honey. But if this honey possessed properties that were actually injurious to bees, they would appear uniformly everywhere, but this is not the case. The experience of scores of beekeepers, continued thru many years, proves that aster honey well ripened and sealed is an excellent winter food for bees. And why should it not be? The asters are bland innocuous herbs, which are readily eaten by domestic animals, 


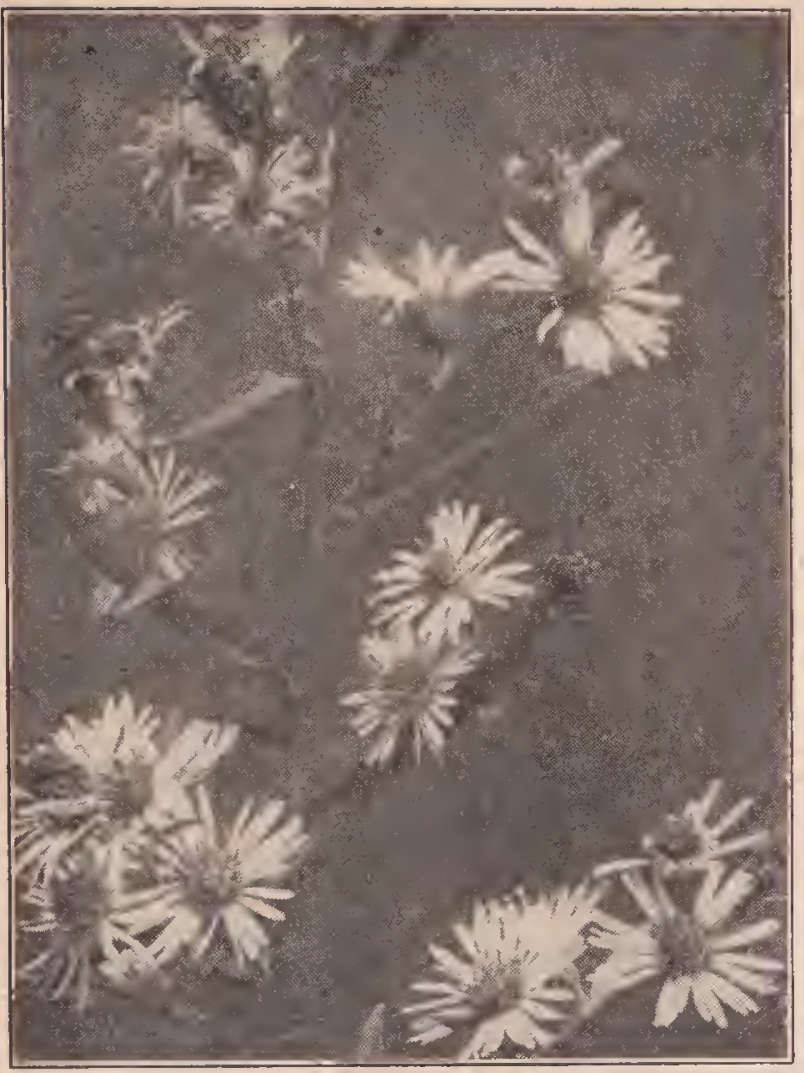

Aster paniculatus.

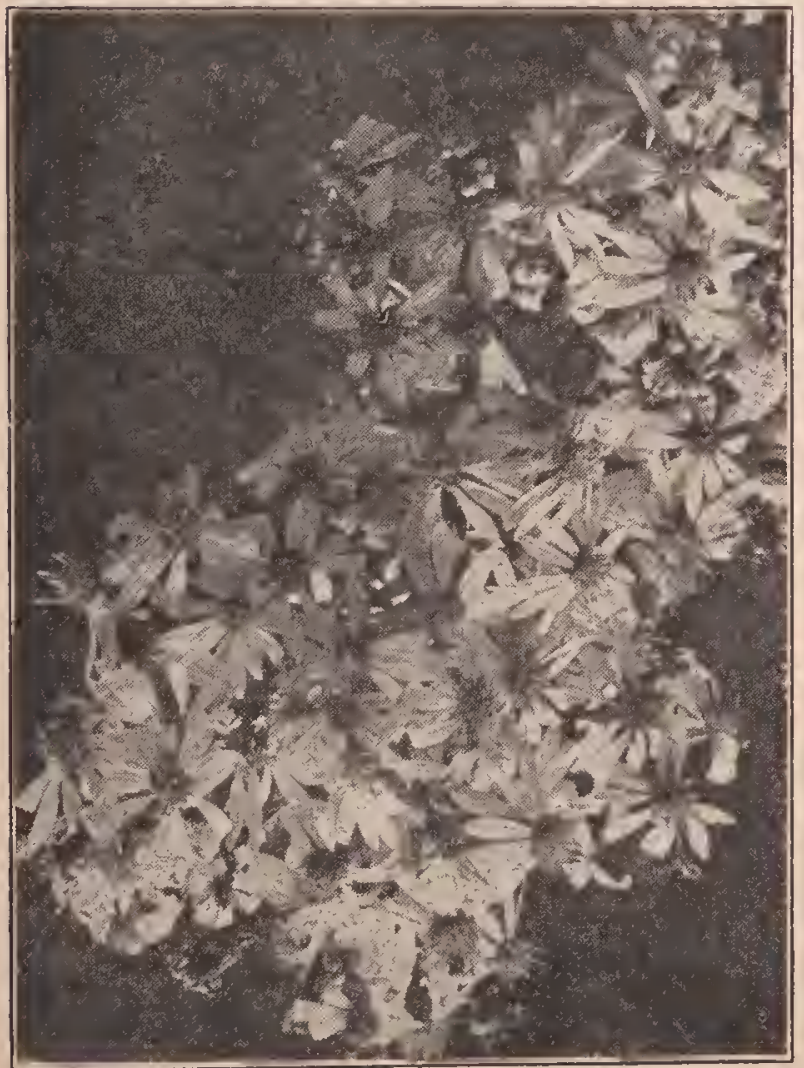

Aster Tradescanti.

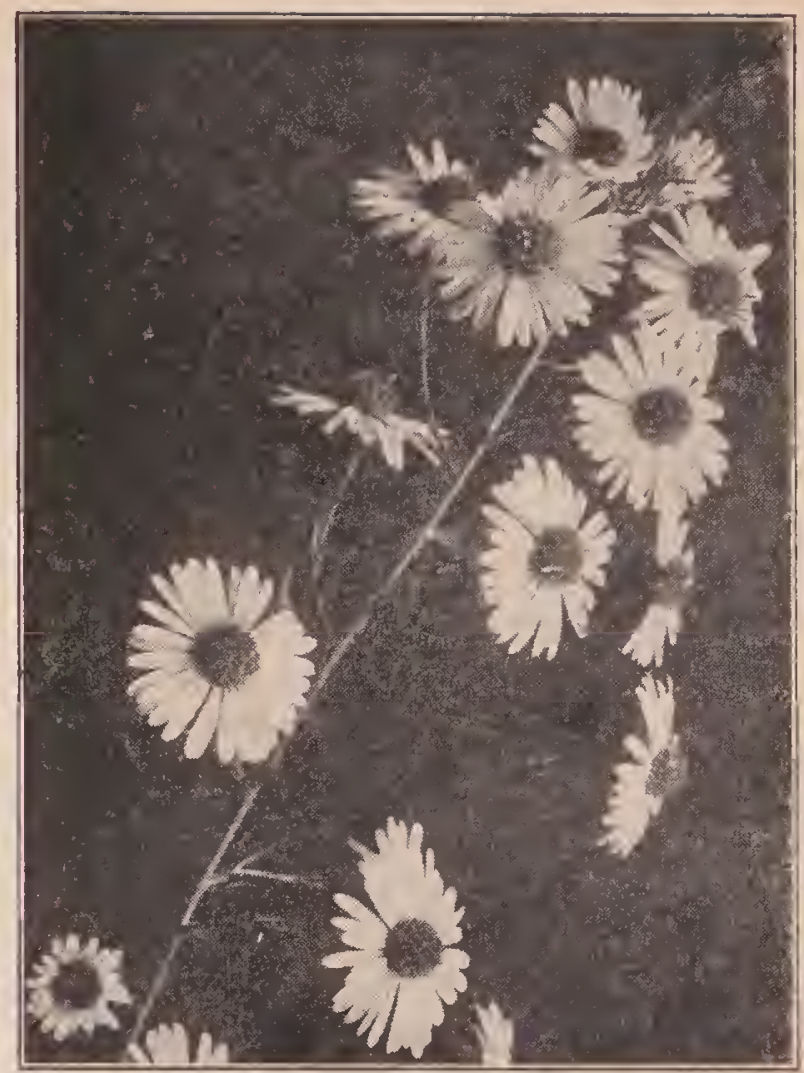

Aster multiflorus.

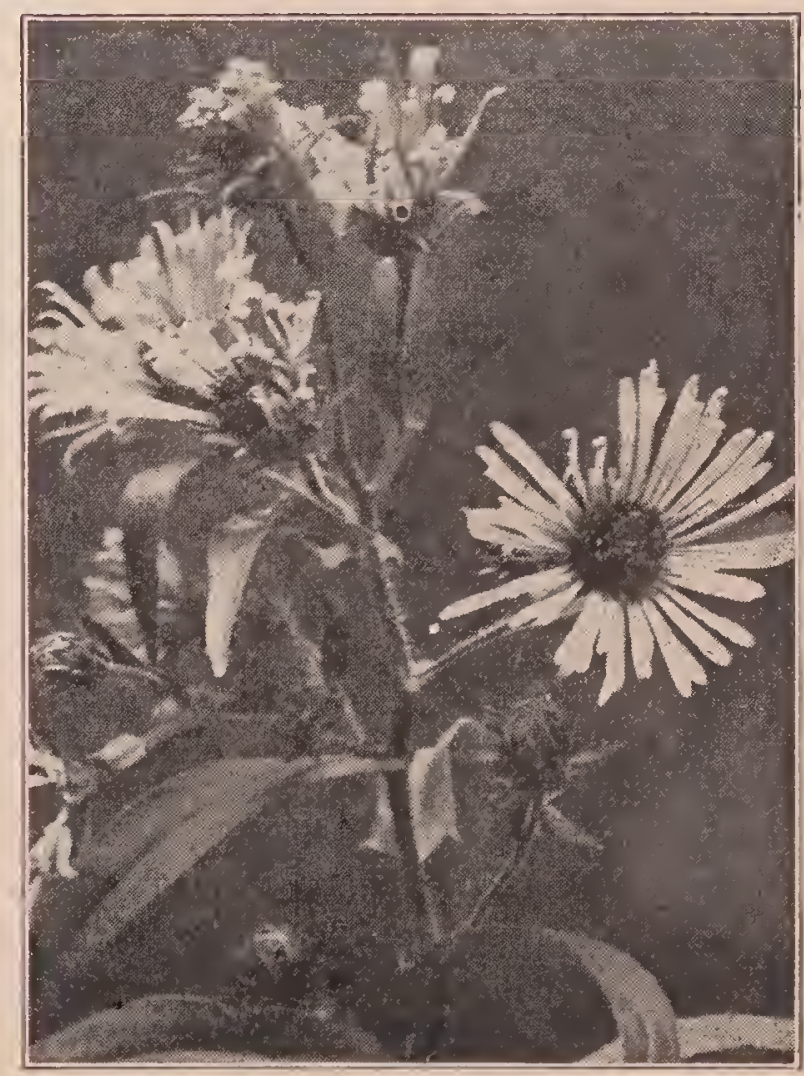

Aster puniceus. 
either dried as hay or green in the pastures. The 250 colonies of J. L. Byer, which packed their hives with aster honey, survived the winter in fine condition. In a symposium, published in Gleanings in Bee Culture, Aug. 15, 1915, many beekeepers testified that they had wintered bees successfully year after year on aster lioney with very little loss. It has been suggested that perhaps different species of aster yield different kinds of honey; but there is no ground for such a supposition. On the contrary, the nectar of the various species, as in the case of the goldenrods, is very similar.

In Georgia several species of aster (the most common are $A$. adnatus and $A$. squarrosus) grow all over the State, and in many places are the main reliance for winter stores. In a few localities a surplus is obtained. The honey is medium in quality, of fair color, but candies quickly in the comb if not sealed. The blooming time is from September to November.

Several widely distributed and abundant species of aster are well worthy of cultivation for their handsome flowers. A very common form is A. patens, or purple daisy which has bright blue-purple flowers. The New England aster (A. novae-angliae) has stout hairy stems, eight feet tall, with violet-purple rays, rarely white, or in one variety pink. Very common along the Atlantic Coast, especially in swampy marshes, is A. novi-belgii. The purple-stemmed aster, cocash, or meadow scabish (A. puniceus), which is common in swamps, is a tall hairy species with purple stems and flowers.
BACKLOT BEEKEEPING. - A very large number of those who keep bees are those who might properly be called backlotter's-those who live in cities and towns and who keep a few bees in connection with a few chickens or a little garden. The backlotter's comprise professional and business men, as well as women and children of their families. Included in this class might be also the farmer's' wives who have a few colonies to pollinate fruit trees, and who likewise desire recreation, amusement, and a little money on the side for the family. Bees will earn as much money as chickens and often do much better.

Backlot beekeeping does not differ greatly from the keeping of bees on a large scale except that there are no outyards, no expensive moving-truck and elaborate extracting-outfits, and no hired help. The backlotter, primarily, whether man, woman, or child, is one who desires to take up some form of amusement or recreation-something that will keep him outdoors and something that will take up his time while he is out of the store, office, or shop. If the backlotter happens to be an orerrvorked business or professional man, he will surely need some line of diversion-something that will rest his mind, by taking it off from his business or profession, and allowing it to rest and recuperate in new lines of thought. Why not beekeeping? See BEEKEEPING FOR WOMEN.

While there are those who take up the hobby of kodaking or taking pictures, of running a little garden, or keeping a few chickens, the number of those who are taking up bees in a small way is increasing very rapidly. The average back lot in the eity will not pernit of a very extensive garden-in fact, in most cases no garden at all. The chicken business is liable to cause trouble with the neighbors, especially if the chickens fly over the fence and scratch up Mrs. Neighbor's posy bed. While bees will not scratch up gardens they may soil Mrs. Neighbor's wash on the line; but a box or two of honey in advance will so sweeten her up that she will toler- 
ate any inconvenience of this kind, which fortunately occurs only about once a year. After bees have been confined for the winter, on their first flight they discharge their liquid feces on the white linen if it happens to be on the line at the time; but a rinsing of the clothes will make them as clean as before, and a pail or box of honey will do wonders in advance by sweetening up feelings that would otherwise be sour. The neighbor should be advised not to hang out her clothes just after the bees are set out of the cellar in the spring. Or better, the beekeeper should not put the bees out till after wash-day. and yet out of all these thousands of little apiaries it is only about once in four or five years that we hear of a single case of trouble, and only once in about 25 years that resort is had to the courts. See Laws Relativg to Bees and Bees as a NutSANCE.

The danger from stings may be averted by reading carefully the articles on APIaries, Robeing, Sttings, Bee-surokers, and Manipulation of Coloxies-particularly the last named. There is no good reason why any backlotter should stip up liis colonies to a furions stinging. If he will carefully inform himself by reading the arti-

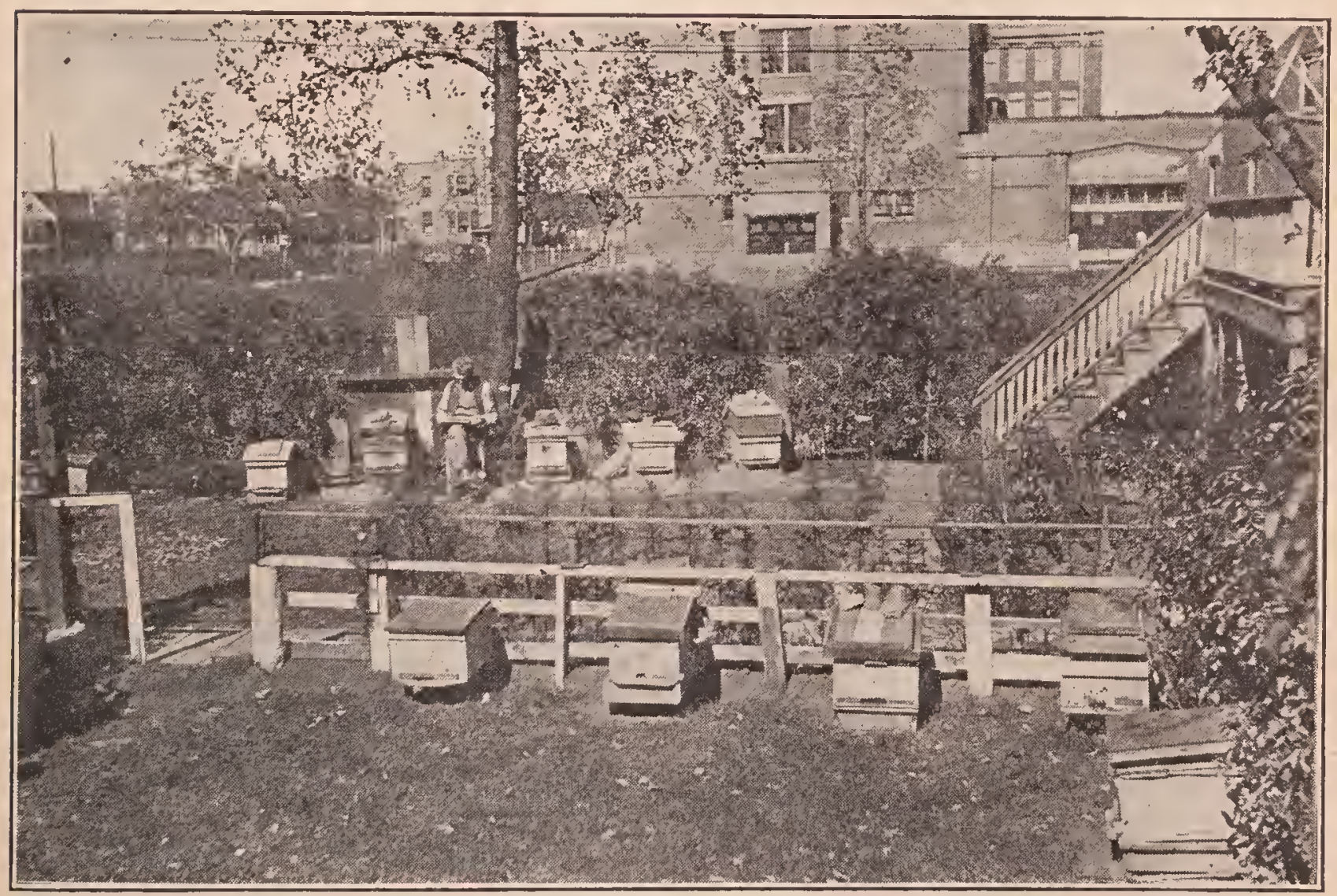

Thos. O'Donnel's apiary, which has proved a success, altho kept within the city limits of Chicago.

But the objection may be made that bees may sting the neighbor's children. While this may happen, such occurrences are not common. If one will follow the plain and simple directions with regard to handling bees, there will be no trouble. Indeed, there are backlot apiaries in all of our large cities (and even on the roofs of some large office buildings) - hundreds and hundreds of them; and when we consider the backlot apiaries in the smaller towns, their number can be measured by the thousands; cles mentioned, his next-door neighbors will never know he has any bees except as they may see the hives and the bees flying out to the fields. If lie will take the further precaution to give those neighbors a box of honey now and then, they will be willing to overlook any occasional annoyance resulting from a lack of experience and mismanagement.

Every backlotter should, if possible, visit some practical beekeeper. He can get more information of a practical sort in an hour 


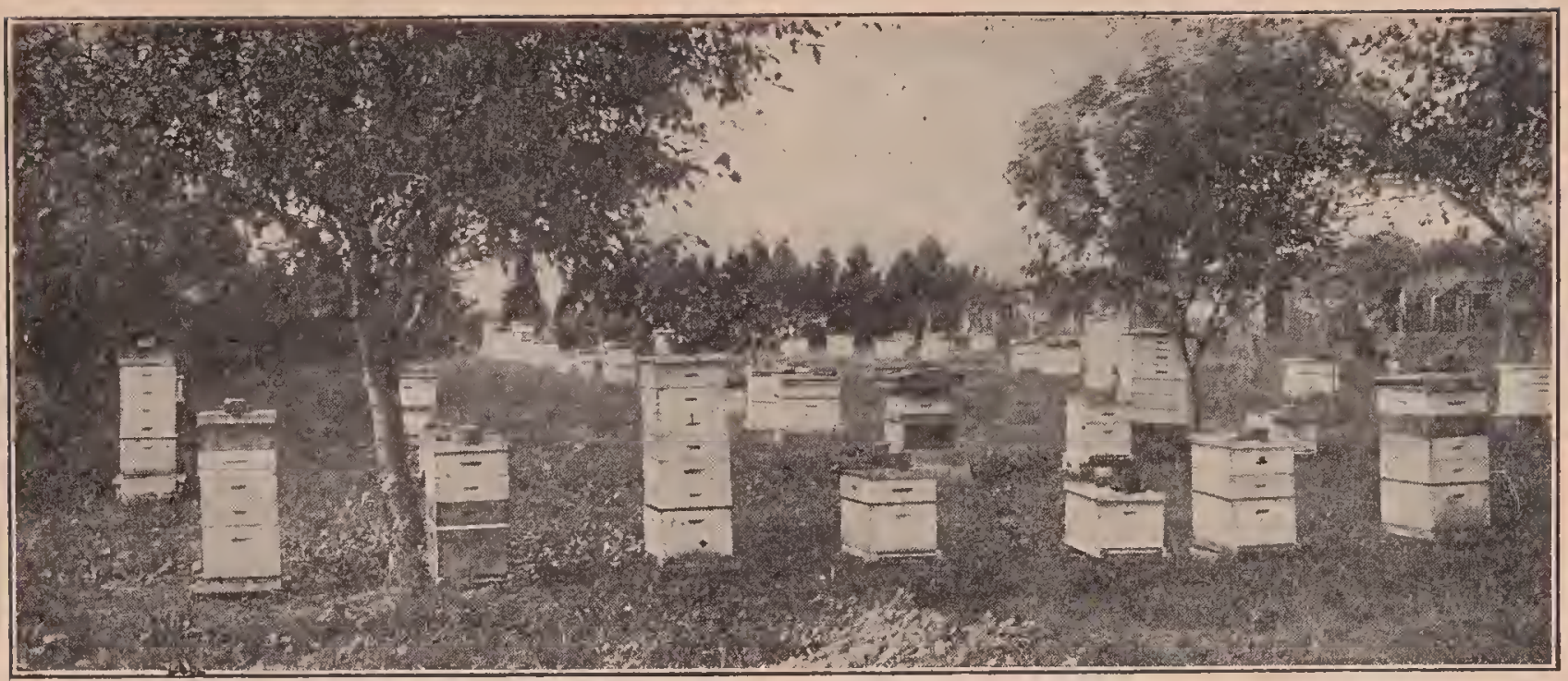

View of D. J. Blocher's apiary, Pearl City, Ill. The grass is kept mowed all summer with a lawn-mower.

by seeing some good beekeeper open up a hive than he can get from a book in several days. In fact, it would pay Mr. Backlotter well to take a trolley trip off into the country, hunt up some person who is keeping bees, and, if he approaches his man with the idea of purchasing a colony or two, he will be able to get all the information he desires; and in this connection it may be said that it is usually cheaper for one to make a start by buying a few colonies than to send away to some dealer, unless he buys them in pound-package form. See $\mathrm{BF}_{\mathrm{F}}$ GIN NING WITH BEES.
Besides the allurements of a restful hobby, of diversion from the cares of the office, shop, factory, and of the home for the wife, backlot beekeeping affords in addition a profit, provided, of course, that one follows directions, and provided further that there is something.in the locality on which bees can work. In most of our cities white clover thrives on lawns. No matter how dry the season, the constant sprinkling and mowing keep white clover in bloom for a much longer period than the average pasture lot. Besides white clover, sweet clover is being grown extensively along

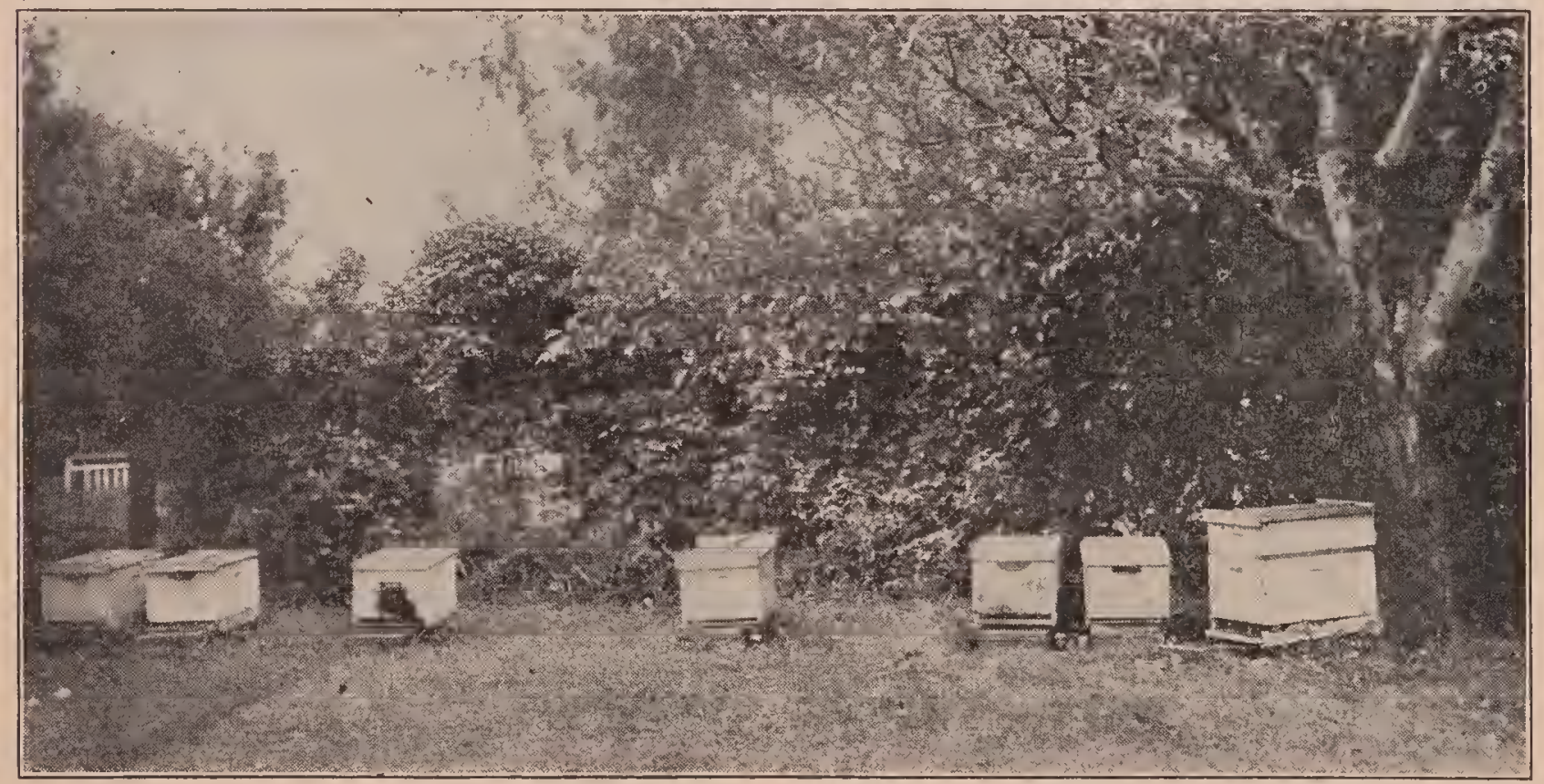

APIARY OF E. S. BRINTON, WEST OHESTER, PA.

The apiary is well protected in the back lot by apple trees and shrubbery. It appears to be an ideal place for wintering bees; but the colonies should, of course, be packed in winter cases in order to get the best results. 
railroad embankments, in waste fields, and lots unoscupied, that are being held until a suitable price can be secured.

Small-fruit trees and the clovers in the back yards of our cities afford some pasturage in the spring when they are in bloom. The ever present dandelions, that are an irrepressible nuisance on almost all lawns in the North, also afford pollen and honey. See DANDELION.

The conditions for keeping a few bees in a city or town are usually very favorable. As stated under the head of APIARY and under the head of Overstocking, a few colonies of bees-five, ten, or twenty-five, will give much larger yields per colony than a larger number-say fifty or a hundred. Of course, if there are any considerable number of persons in the city who adopt the beekeeping hobby, the yield per colony will be less in proportion; but as a general rule these backlot yards will not be closer than one or two miles, and the yield should be fairly good even then.

By referring to Profitis in Bees one can get some idea of the returns; but it can be safely stated that our backlot beekeeper will do even better than there stated, for the reason he will have the field all his own.

We have known some backlotters to secure two or three hundred pounds of honey per colony. (See some of the legends under the cuts in APIARY.) As the market is right at hand much of the honey can be sold at retail without sharing the profits with middlemen. Backlot beekeeping, therefore, offers exceptional opportunities for making a little money on the side as well as seculing an unlimited amount of pleasure and a new field for thought in the realm of nature.

It is safe to say that any man or woman who takes up the pleasurable pastime of beekeeping will be bigger and broader, and will live longer. The great troible with the American people today, especially with the residents of our cities, is the awful rush after the "almighty dollar," and in this scramble to get ahead the mind and body wear out. If more of our city folks would have side lines of diversion and ride hobbies, particularly the hobby of keeping beesthey would live longer, live happier, and in the end make a little money.
BAIT SECTIONS.-See CoMb Honey, to Produce.

BALLING OF QUEENS.-See QUEENS, QUEEN-REARING, and INTRODUCING.

\section{BANAT BEES.-See RACES OF BeEs.}

BARRELS.-The regular size used for the storage and shipping of extracted honey is about 31 or 32 gallons. Barrels of 45 to 50 gallons capacity are a little too heary. and being very unwieldy are liable to be broken or jammed by freight-handlers in shipping. As to the kind of barrel, secondhand barrels may be used, provided they are not charred on the inside. Before taking barrels of any kind it is very necessary to determine what the character of the lining is on the inside. Molasses or syrup barrels may be used, if they be thoroly cleansed, but barrels that have a sour or musty smell should not be considered; for, even if cleaned, they may taint and ruin the honey.

After the barrel has been cleansed it should be put in a dry place, so that it will dry thoroly inside and out. One should never use barrels, the wood of which has become soaked with 'water; for honey has the quality of absorbing moisture from the wood; that is to say, a wet barrel filled with honey will actually become dry. The staves shrink, and then, of course, the honey leaks out. If one does a large business in shipping honey in barrels, he should buy new ones. The staves should be made of sound kiln-dried lumber; and iron hoops, not wooden ones, should be used. The barrels should be kept in a dry place, and then, before using, they should be well coopered and tested, as will be explained.

\section{KEGS.}

Wooden packages holding from 100 to 150 pounds are sometimes used in some parts of the South. They are usually constructed of cypress, and, when well made, make a very good package. The general directions that apply to barrels apply also to kegs.

BARRELS FAEQUENT CAUSE OF COMPLAINT.

It may be said that no slovenly, careless, or slipshod beekeeper should use barrels. He will be too careless to see that they are tight. He will put his honey into them, 
ship them, and in all probability the barrels will begin to leak en route; and he will receive a complaint from the consignes that "the honey arrived in bad condition," "half of it gone." There have been more ill feeling and hard words because of inexcusable carelessness or lack of proper knowledge concerning this matter of shipping honey in barrels than, perhaps, any other thing connected with the marketing of extracted honey. If the directions are carefully followed, and good barrels are selected, there will be little or no trouble outside of the arid regions.

Another frequent cause of complaint arises from the fact that the barrels are filled too full. Honey, during the process of granulating, will expand. If it is put into the barrel long before it is candied, the barrel should not be filled quite full. Just before shipping put in a little more and then ship. TVe have received several consignments of looney that had candied in barrels. The barrels had been filled full; the honey candied, and burst the barrels.

HOW TO TEST BARRELS FOR LEAKS.

Barrels that are intended for the storage of honey should not be kept in a cellar but in a dry place. Before filling, the hoops should be driven down tight all around. To test for. leakage, A. C. Miller suggests the following plan:

With a tire pump fitted orer a specially prepared bung, force in air until there is quite a pressure in the barrel. Now listen for air leaks. If there are any, there will be a hissing in one or more places. Holding the palm of one hand over the bung thru which the air was forced, dip the free hand into some water, and push it along to where the air seems to be hissing out. This will prove whether there is a leak at that point. If there is one, there will be a sputtering or bubbling. Wherever the air is found leaking thru, drive the hoops down until the opening's are closed. Then, again, force air into the barrel and try for leaks as before.

Do not, under any circumstances, test a barrel for leakage with water, as it soaks up the wood, and the latter would swell up and close the leak. After the honey is put into the barrel it would absorb the water, and the barrel would leak just at the time it could be least afforded-when it would be halfway on its jomney.

\section{THE NEED OF PARAFFINING OR WAXING BARRELS.}

The author is well aware that some of the best honey-producers say it is not necessary to wax or paraffin barrels inside; but our experience shows that it is very important, not so much for the purpose of closing up any possible leals as to prevent the honey from soaking into the wood of the barrel or the wood itself from giving a taint to the honey. The average person has little idea of the amount of honey that can be soaked up inside of an unwaxed barrel, and be charged up to the shipper. After having tested the barrels for leaks by the air-pressure plan recommended, and making them tight, wax or paraffin the insicle of the barrels; don't depend on the waxing to close up the leaks-the barrel should be tight before.

Paraffin, being a good cleal cheaper than beeswax, and melting at a lower temperature, is, therefore, to be recommended. Melt up about 10 or 12 pounds, and when hot pour it thru a large funnel into one bunghole of the barrel. Quickly drive in the bung, roll it around, twirl it on each end; then give it another spin so as to cover perfectly all around the cline. This operation will warm the air inside to such an. extent that the liquid will be forced into every crevice. As soon as the inside is covered, loosen the bung with a hammer; and if the work is well done the bung will be thrown into the air with a loud report. Pour out the remaining liquid, warm it up again, and treat the other barrels in a like manner'.

The operation as a whole takes but very little time; and if one has taken pains to prove the barrel tight by the air-pressure plan, the coating of paraffin on the inside will make it doubly serure. Serond-hand barrels especially should be paraffined; and even new barrels should be so treated to prevent a great loss of honey that would necessarily soak into the wood. Steel bar-. rels are not recommended.

\section{SLIPPING HOOPS.}

It is very important that the barrels be made tight before honey is put. into them. 
If they once begin to leali en roule, driving the hoops down will not do much good, for the simple reason that the lealing loney makes a sort of lubricant, causine the hoops to slide 1 im immediately after receiving a blow from a hammer.

The publishers of this work liave had some very unsatisfactory experience with shipping loney in barrels; and on arriving at Medina the loney was leaking orer the sides of the barrels. This honey came with a carload of bees, and the man in charge who saw the leaks attempted to drive the hoops downward; but the more he drove, he said, the more they slipped back again. If it were possible to exert pressure enough on all sides of the hoops at once, and then drive nails above the hoops, something might be done to stop the leaks.

The barrels in the first place should be bone-dry before they are paraffined: and just before the waxing the hoops should be driven down as far as they will go. If there is any danger of the barrels leaking, tacks should be driven above the hoops to prevent their slipping. But it is penny wise and pound foolish to use any barrel that is not perfect. 'The difference between the cost of a good barrel and a poor one is only a few cents; while a barrel of lioney costs many times the price of the barrel.

BARRELS OR SQUARE CANS.

In California, Colorado, and other hot or dry States, barrels and keg's should never be used. The ordinary 60-pound tin cans, described under ExTRACTED Honey, are the only suitable shipping packages. Indeed, they are the only package that nine-tenths of the beekeeper's of this land can use safely. While they cost considerably more per pound, yet the honey is nearly always reported as going thru in good order. Even if one has a. hole punched in it, only 60 pounds of honey is lost; while in the case of a leak or break in a barrel, sometimes from five to eight times that amount is wasted. Thru the entire West-and that is where the great - bulk of the extracted honey in the United States is produced-the square tin can is used exclusively. These are packed two in a rase, and for safe shipment there should be a wooden partition between the cans. Beekeepers are strongly urged to use these cans is preference to birrols. While the tin package costs a little more per pound, it also brings in a little more on the market; for the buyer can take as large or small a quantity as he neerls. Where the purchaser hesitates to buy a whole barrel of honey for his own local trade, he will readily take one or more cans of 60 pounds each.

\section{REMOYING GRANULATED HONEX FROM} BARRELS.

Good thick honey will nsually become solid at the approach of frosty weather, and perhaps the readiest means of getting it out of the barrel in such cases is to remove one of the heads and take it out with a scoop. When it is quite liard, one may at first think it is difficult to force a seoop down into it; but if he presses steadily and keeps moving the scoop slightly, he will soon get down its whole depth. If the barrel is kept for some time near the stove, or in a very warm room, the honey will become liquid enough to be drawn out thru a large-sized honey-gate.

A more wholesale way of removing candied loney is to set the barrel or keg in a tub or woolen tank of water, the latter heing lept hot by a small steam pipe. In 24 or 36 hour's the honey will be melterl. and can then be drawn out in the usnal way.

BASSWOOD.-Of the twelve describer species three are indigenous to the United States. The most common species is Tilia americana L., a tall tree go'owing in forests from New Brunswick to Nebraska and Texas, and especially abundant in the Alleghanies. T. Michauxii Nutt. (T. pubescens is a synonym) extends from Connecticut to Florida and Texas; and $T$. heterophylla Vent. from Pennsylvania to southern Illinois and Alabama, but is most common in linestone regions. The three species nuay be separated by the following leaf characters: $T$. ameriruma has the leaves smooth on botl sides: in T. Michauxii the leaves are smootl above, but pubescent beneath: and in T'. heterophylla smootl above and silvery white below. The European linden ( $T$. europaea L.) is widely cultivated in this country as an ornamental tree. Other vernacular names are linden, lime tree, beetree, whitewood, and whistlewood. 


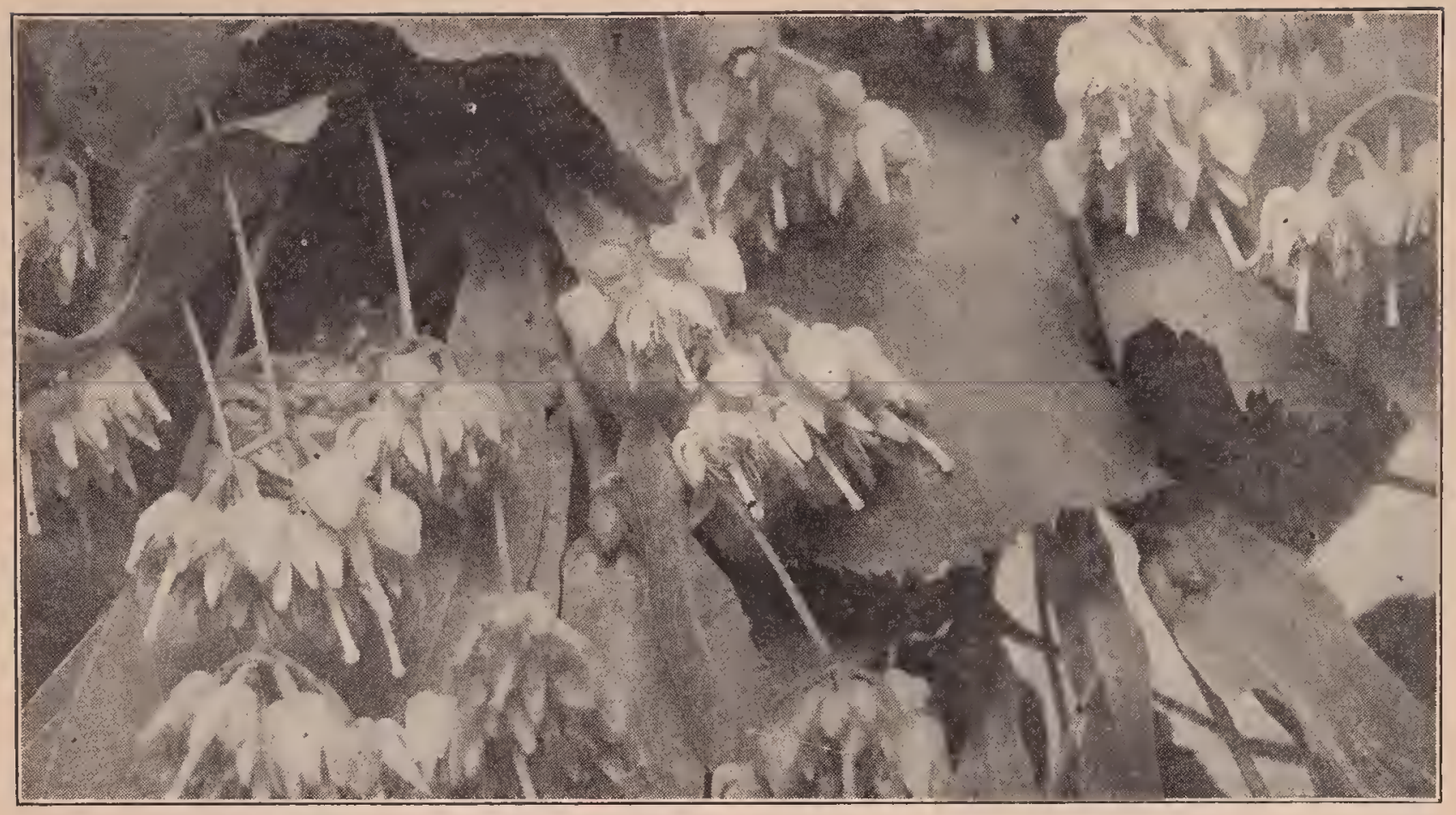

Basswood in full bloom.

It is a variable source of honey, but it is seldom that it fails entirely to yield nectar. In eastern New York, late in the spring, a drop in temperature sufficient to freeze ice has been known to kill all the flower buds in low ground, and greatly injure those on the hills. Even when the trees are laden with flowers if the weather is cold, cloudy, and windy, no surplus will be obtained. Hot clear weather and a humid atmosphere are the conditions most favorable for the active secretion of nectar. Small drops may then be seen sparkling in the bloom, and a bee may at times obtain a load from a single blossom. During a favorable season, when the atmosphere and temperature were both propitious, nine tons of basswood honey have been obtained as surplus at Delanson, N. Y. The best yield of honey at Medina, Ohio, ever secured from a single hive was from basswood bloom, the quantity being 43 pounds in three days. The best ever: recorded from clover was 14 pounds in one day. At Orchard, Iowa, a yield of 600 pounds of basswood honey from a single colony in 30 days was once seeured, an average of 20 pounds per day. A colony at Borodino, N. Y., stored 302 pounds in ten days, and an average of about 55 pounds per colony has been obtained for 30 years. The length of the honey flow from basswood may vary from five to twenty-five days; while the date of blooming is influenced by locality, altitude, and temperature. From 10 to 15 days may intervene between the opening of the flowers in a cold season and a hot one. In localities where basswood grows both in the ralleys and on high hills the bees will have a much longer time to gather the nectar, since the trees in the lowlands will bloom earlier than those at a greater height.

Basswood honey is white and has a strong aromatic or mint-like flavor, and it is easy to tell when the blossoms are out by the odor about the hives. The taste of the honey also indicates to the beekeeper the very day the bees begin to work on the flowers. The honey, if extracted before it is sealed over, has so strong and distinctive a flavor as to be disagreeable to some persons. The smell and taste have been likened to that of turpentine or camphor-very disagreeable when just gathered; but when sealed over and fully ripened in the hive almost every one considers it delicious. A pure basswood extracted honey, on account of its strong flavor, should be blended with some honey of milder flavor, as for example, that of mountain sage.

The illustration shows the appearance of basswood flowers and leaves. The clusters of from five to flfteen flowers are drooping, 
thus protecting the nertar from the rain. The stem of the cluster is adnate to an oblong membranous bract. The nectar is secreted and held in the fleshy sepals; and it is often so abundant that it appears like dewdrops in the sunlight. The blossoms are small, light yellow, and exhale a honeylike fragrance. The stamens are numerous, and the anthers contain a small amount of pollen, but honeybeesseldom gather it when the nectar is abundant; if, however, the nectar supply is scanty, then both honeybees and bumblebees may be seen with little balls of pollen on their thighs. In England basswood seldom sets seed. The inner bark is tough and fibrous, and is largely used by agriculturists and florists for binding purposes.

The basswoods have been so cut off during the last few years for packing-boxes and furniture factories that basswood honey has almost disappeared from the market.

\section{CULTIVATION.}

If a beekeeper is content to wait, say 10 or 15 years for the realization of his hopes, or if he has an interest in providing for the beekeepers of a future generation, it will pay him to plant basswood. A tree that was set out about 10 years ago on a street in Medina, Ohio, now furnishes a profusion of blossoms almost every year; and, judging from the way the bees work on them it would seem that they furnish considerable nectar. A hundred such trees in the vicinity of an apiary would be, without doubt, of great value. In the spring of $1872 \mathrm{~A}$. I. Root set out 4,000 trees north of Medina, and in 1877 many were bearing fair loads of blossoms. While seedlings may be obtained by planting the seeds, by far the better and cheaper way is to get small trees from the forest. They can be bought for a very low price. These can be obtained in almost any quantity in the eastern States from any piece of woodland from which all stock has been $\theta x$ cluded. Cattle feed upon the young basswoods with great avidity, and pasturing the woodlands will eventually cut short the growth of basswoods as well as many other valuable trees from our forests. Trees all the way from one to ten feet tall have been planted here at Medina, but the largest ones, as a general rule, have done the best.

The growth of basswood is strongly influenced by climatic conditions. Among the hills of New York the leaves assume mammoth proportions. The author measured one that was 14 inches long from a small tree. While this leaf was among the largest, yet the leaves were, on the average, about twice the size of those in the locality of Medina. In Illinois the basswoods seem to be less thrifty than in Ohio.

The European basswood, which is fully as good a honey-producer as the American species, is famous as an avenue tree. The famous street in Berlin, Unter-der-Linden, is shaded by this species. It is known in England as "the lime tree," and is there a great favorite for street planting. The famous "Lime-tree Wall" of Cambridge is well known. It is also an excellent tree for street planting in the northern part of the United States. It is to be regretted that basswood is not more abundant, since where it grows it is one of the mainstays of the honey-producer, and is also a most valuable wood for manufacturing purposes. It will hardly do for outside exposure to the weather, but is admirably adapted for packing-boxes and for furniture, forming the bottom and sides of drawers, the backs of bureaus and dressing-cases. It is also employed extensively in the manufacture of paper.

As large quantities of the timber are used in making section honey-boxes, the question has been raised, "Why do the manufacturers of supplies use the tree that produces so much honey and of such fine quality?" Is it a case of "killing the goose that lays the golden egg?" The answer is, that the amount used by the makers of sections is only a drop in the bucket compared with that used in the other arts. Even if all the bee-supply manufacturers should discontinue the use of basswood, the difference in the amount of honey produced from that valuable tree would never be noticed. For the making of section honeyboxes there is no timber available that has the same degree of toughness to stand the fold at the $V$ edge in the ordinary onepiece section. The four-piece section has now practically dropped out of the market on account of the expense and time taken in preparing it for the hive. 
$\Lambda$ fter all, there is one redeeming feature; the basswood is a very rapid grower. If basswood will replace itself in 10 or eren 20 years, so that it is again large enough for lumber, there is yet hope that it will continue to bless the beekeeper. Over against this is the stubborn fact that the basswoods are disappearing rapidly over the whole country. During late years, when there has been such a great advance in pine lumber, basswood has been used very largely for house-building, with the consequence that millions of feet liave been consumed.

Basswood, and perhaps most other forest trees, require shade, especially when young. Much to the author's surprise young trees that were set directly under large whiteoak trees did better than any of the rest. The trees should be planted not closer than 12 feet apart.

BEE BEHAVIOR.-Behavior is a term used to describe the activities of animal life whether induced by external or internal causes. Under this head will be described some of the various life activities of the bees, particularly those which have more or less to do with the practices of bee culture.

\section{THE LARVAL BEE.}

On the hatching of the egg the tiny larva wriggles and twitches much as does a caterpillar when poked with a straw. Almost at once it is supplied with food by a "nurse" bee. This part of the life of a larva has not received sufficient study to warrant any definite statement as to the frequency of the feeding, the amount supplied, its possible varying quality, etc. It must suffice now to say that the periods of feeding seem to be irregular and the amount of food received by different larvæ varies largely.

When the larva lias completed its feeding period and lias stretched out to its full length in the cell, the bees proceed to seal the cell. 'There are some exceptions to this when the larvæ are left unsealed, tho usually the cell walls are slightly extended and the opening contracted. Beekeepers speak of this as "bareheaded brood," and it often causes the novice much concern. (See Broon ant Broon-rearing.) The condition hals been ascribed to excessive heat; but as it occurs at other times than during the hot weather, and as some colonies seldom or never have brood in such condition while others almost always do, it is reasonable to look upon it as a congenital trait. In some cases uncovered brood is due to the work of the wax worm; but such brood looks very different and is always in the. path of the worm's work.

After a brief rest the bee larva begins spinning its cocoon. Slowly the liead turns from side to side and back and forth, gradually reaching the middle of the cell; and slowly doubling on itself, the larva extends its work to the base and lies at full length reversed in the cell. Before its labors cease, however, it resumes the former position of its head toward the outer end.

In the case of the queen larva, the spinning begins and proceeds in the same way, but when she is reversed in the cell she reaches as far up as she can, but that is not to the base; and, as she cannot climb, there is no silken web on that part of the cell.

When spinning has ceased, the larva turns on its back and lies still. The changes which follow take place so slowly that only after considerable intervals are the results noticeable. When the metamorphosis is rirtually complete (see Development of BEEs), there is seen in place of the larva a bluish-white bee lying motionless on its back.

The only appendages seemingly missing are the wings. Careful examination will reveal each pair folded up in a little case (pellicle), which lies against the side of the thorax between the first and the second pairs of legs.

The first sign of coloring is seen on the ends of the antennæ, then on the eyes and feet, and gradually it extends over the whole body. As the time approaches for the bee to emerge from the cell slight tremors are to be seen in the feet and legs, or an antenna mores. About the beginning of the last day the encased wings begin to quiver and move. Slowly they turn until they lie under the bee and at once they unfold. As soon as this occurs, the bee turns over and begins to cut its way out.

THE YOUNG BEE.

$\Lambda$ most as soon as out, it berins to move over the surface of the combs; and when it 
comes to a cell of lioney it enters and eats. Just when it begins to eat pollen is undetermined. After eating, the young bee conlmences to comb itself and this procedure continues more or less steadily for a day or more. At this tender age the insect's vision seems to be very imperfect. Also, it is unable to fly; and, if tossed into the air, it makes no attempt to use its wings. This function appears only at a later age. Drones, queens, and workers all spend the early hours of their life in much the same way, except that queens seem to be able to fly sooner than workers. Probably, queens most precocious in this way have been held in the cells longer than normally and have matured in there.

'The color of the young' bee deepens with age. When they first emerge they are much lighter in color than a day or two later. This difference is more noticeable with queens than with workers or drones.

\section{HOME LABOR OF BEES.}

The first duty of the worker is the feeding of the larvæ, and then a little at a time it extends to pollen-packing, propolizing, comb-cleaning and repairing, honey-ripening, and comb-building.

\section{THE FIRST POLLEN OF THE SEASON.}

When a bee comes in from the field with a load of pollen, she is often surrounded by other bees, all trying to get a bite of the coveted food. This is especially noticeable in the spring when fresh pollen first appears. It is amusing to watch a pollenladen bee sidestep, whirl, shake, and go thrn all sorts of actions.

\section{THE UNLOADING OF THE POLLEN.}

On their return to the hive with their loads of pollen the bees differ widely in their behavior. A part walk slowly over the combs, while a part, presumably the younger bees, appear greatly excited, shaking their bodies and moving their wings. $\Lambda$ cell may be selected with little hesitation or many may be examined before one is found satisfactory to the bee. The pollen may be stored in an empty cell, or in one already partly filled with pollen, either of the same kind or of different kinds: but drone comb is seldom used, altho this oerasionally happens.
The way in which the bee unloads the masses of pollen has been fully described by Casteel. Grasping one edge of the cell with its fore legs, it arches its abdomen so that its apex rests on the opposite side of the cell. The hind legs hang down freely in the cell with the pollen masses about level with its edge. The planta (metatarsus) of the middle leg' on each side is then raised and thrust downward between the pollen mass and the tibia so that the mass is shoved ontward and falls into the cell. The middle legs are now rested on the edge of the cell. Casteel was unable to determine definitely whether the spurs were of any aid in dislodging the pollen, as asserted by Cheshire, or not.

The bee usually departs without any further attention to the pollen masses, and another worker shortly afterward attends to the packing. Entering the cell headfirst, the bee breaks up the pellets of pollen, mashes them down on the bottom of the cell, and adds sugar and perhaps other seeretions which change the chemical constitution of the pollen. See Pollen.

PROPOLIS. HOW GATHERED AND USED.

Propolis is brought in on the pollen-basliets. When it is gathered fresh from the buds, it looks like a glistening bead in the pollen-baskets; but when it is gathered from old frames, hives, ete., the pellets are more irregular. Propolis is always packed while the bee is standing, while pollen which is packed and carried in the same baskets is adjuster while the bee is flying. This difference in the way of using the same limbs for different materials is very interesting.

Propolis is taken from the legs of the field bees and stuck into all sorts of places and is movel and reworked as suits the vagaries of the bees. Much of the propolis is sprear with the tongue. Whether or not the bee varnishes the inside of brood-cells witl propolis is unknown. Certainly they spend much time polishing the inside of such cells, going over and over the surface with their tongues; and when they have finished, the cell walls shine as if varnished. This is not done to new combs used for lıoney only; but let sucl be once used for broor, then it gets its polishing before being used for anything else. 
Comb-repairing and building seems to be a haphazard job, and the work of one bee is often at once undone by another. Propolis is used in the construction of new comb, sometimes as much as one-half to three-quarters of an ounce being added to a pound of wax. It adds to the strength of the comb and makes its fastening to the wood more secure.

\section{HOW BEES DEPOSIT THEIR LOAD OF NECTAR.}

The honey-laden bee on returning from the field is not in a hurry to get rid of her load, and it is not at all unusual for her to keep it for half an hour or more before depositing it. She may walk aimlessly about or settle quietly down somewhere and seemingly forget the world, or she may, after an extended journey over the combs, select a cell for her load. She enters the cell with her back down and feet up. If the cell has no honey in it, she goes in until her mandibles touch the upper and rearmost angle. The mouth and mandibles are opened and a drop of nectar appears, welling up until it touches the cell wall. Slowly the bee turns her head from side to side, spreading the nectar against the upper part of the cell. All this time the mandibles are kept in motion; and as the nectar cover's their gland openings, it is possible that the secretion of those glands is being added to the nectar.

When the bee is adding her load to honey already in a cell, the proceeding is the same, except that the mouth parts are submerged in the honey already there. The mandibles are kept in motion as before. The tongue in neither case takes any part in the proceeding, but is kept folded behind the head.

THE RESTING PERIODS OF BEES.

When rid of her load, the worker may at once return to the field, but usually she loiters about the hive for a while-from a few minutes to half a day. So commonly do such bees crawl into a cell and go to sleep for a half-hour or so that it is reasonable to assume that such is the customary proceeding. By sleeping is meant as nearly a complete suspension of movement as possible. The customary pulsation of the abdomen nearly, if not quite, ceases, or is suspended for minutes at a time, and the occasional pulsation is very slow.

When the nap is over, the bee backs out, combs off her head just as if "scratching for a thought," and starts off in more or less of a hurry.

Presumably, all the bees of a colony do some of this sleepting, and drones and queen are no exception; but in the case of the latter two, the sleeping is not usually done in cells.

When bees are getting stolen sweets, a very different condition arises; a feverish excitement is noticeable in the returning workers, and it is not long before the whole colony is in a more or less disturbed state. Sleeping then is not in evidence. Why a load or several loads of honey should cause so marked a difference from several loads of nectar is unknown, and until we know more about the bee it is idle to speculate.

\section{HOW BEES RIPEN HONEY.}

The process by which the bees evaporate and gradually convert the thin nectar into thick honey is called ripening.

Honey-ripening is a slow but interesting process. After a day's work is about over, almost the whole colony spreads out over all available surface, and nearly every bee has her sac full of honey. All the bees hang vertically with head up, and all seem to prefer not to be crowded too closely by the other bees. Then each bee opens her mandibles and mouth and forces up a drop of nectar. This drop fills the mouth and extends up over the upper lip and fills the space between the mandibles, covering the openings of the glands connected therewith. The tongue. meantime is kept folded behind the head. Next, the bee begins a chewing motion with the lower "jaw" and this causes the drop to pulsate. The mandibles are held still. They are not moved as in depositing nectar.

For about ten minutes this operation is continued; then the drop is swallowed, and after a few moments' pause another drop appears, and the process is renewed. This is continued by the colony until about 11 P. M., or sometimes later, and then work stops and all hands go to sleep.

While the work is in process, the heary hum so pleasant to the ears of beekeepers 
is continuous; but after the work ceases, the hive becomes almost silent. This varies with the amount of loney gathered during the day. Sometimes the humming lasts almost all night, and sometimes it ceases early in the evening.

COMB-BUILDING AND ITS RELATION TO THE RIPENING OF HONEY.

Comb-building is rapid when most of the bees are ripening nectar. If the flow is good and many bees have to retain their loads for a while, as, with a recently hived swarm. wax secretion is rapid. Or if the flow is heavy and nearly all have to work at the ripening process, wax secretion is forced. The bees cannot help producing it then. "Its production seems to be closely comnected with the conversion of nectar into honey. If this view is correct, it affords an explanation of the failure to ob-. tain satisfactory results in feeding back ripe honey to have sections completed. Honey extracted "raw" or "green" (that is before it is sufficiently ripened) and fed to comb-building colonies gives much better results.

\section{VARIATION IN COMB-BUILDING.}

No satisfactory explanation has been found to account for the construction of the two sizes of cells. Several theories have been advanced, but so far are only interesting.

Great variations in comb work is found between bees of different strains or of different colonies closely related. Some colonies build comb of wonderful smoothness and uniformity, and others never produce good combs. One will rarely use a braceor a burr-comb, that is combs built irregularly on sides of hives or combs, while another stieks them everywhere. By selection the beekeeper can weed out the stock with undesirable traits and perpetuate the others.

The difference in capping is well recognized, and selection is as effective in this case as in the former. The difference between colonies in building out to frame or section sides and down to bottom-bars or of rounding off the edges has often been remarked. It may be stated in a general way that the bees which build clear to the wood usually leave the outer cells unsealed, while those bees which round off the edges of the combs seal all cells. (This was first defined by Allen Latham.) Of course, there are all gradations, but fundamentally the law holds good.

THE ARRANGEMENT OF BROOD, POLLEN, AND HONEY.

The arrangement of brood, pollen, and honey, the first in the center, then the others in order about it, is interesting, and with rare exceptions is always the arrangement. As the brood increases in the spring, we may say the pollen is forced outward and the honey forced beyond that. In the closing of the season the process is reversed, and under what we may be permitted to call natural conditions, as in a tree, box, or undisturbed frame hive, the brood is slowly worked downward and forward, so that at the end of the season the cluster is down by the entrance with the stores at each side of, and behind it. This is not always the location of the cluster in our frame hives; but if man has not meddled after midsummer, it will generally be found to be so.

\section{THE QUEEN.}

This individual is unquestionably the most interesting member of the bee community, and more talked of and written about than any other, and perhaps more misunderstood. From earliest infancy she is subject to more vagaries than any of the other bees.

The presence or absence of the functional odor may have something to do with the introduction of alien queens, or it may be wholly their behavior.

After handling a laying queen, bees from any hive will run over one's hand, apparently eagerly seeking the queen, and the behavior of all workers is the same whether they are from the queen's hive or from another.

There is much difference in the temperament of queens. Some are very timid, and will run on the slightest disturbance, and, if handled or anointed with any foreign substance, seem to becomie really frantic. Such queens are very apt to be balled or killed by the bees. Other queens will passively submit to all sorts of treatment, and, 
as soon as let alone, will quietly resume their duties.

Virgin queens are almost always nervous or timid; and if put into a strange colony. large or small, very often, or perhaps it would be more accurate to say generally. run out and fly away, by no means always returuing.

Before mating; a queen hunts up her own food from the combs; but after she begins to lay she turns to the workers for virtually all lier food. Once in a great while she will dip her tongue into a cell of honey, but not often. As she passes about her duties, she from time to time crosses anteunze with workers. Finally one is found with a supply of foor; the worker's moutl opens and the queen inserts leer tongue and begins to eat. 'The worker's tongue is kept folded behind the head. It is quite common to see several other workers extend their tongues and try to get a taste of the food, and sometimes one will succeed in putting her tongue in witl the queen's. It is not at all unusual to see two workers getting food thus from another worker, and the drones obtain their food in the same way.

Egg production is influenced by several factors. Queens differ in fecundity, and egrg development is dependent on food. The food supply comes chiefly from the younger bees; and, if they are not numerous, the queen cannot produce eg's's in abundance. If honey and pollen are searce or temperature is low, food is not prepared freely.

If the queen is young and vigorous and the colony small, she may deposit several eggs in each cell. If comb surface is insufficient and bees abundant, she will use cells of any shape, deep, shallow, or crooker. and will put in each one an egg which will produce a worker. If no drone cells are available, a normal queen may at times put into worker cells eggs which will produce drones.

So many are the ragaries of a queen that only by observation and experience call most of them be learner, and the seasoned veteran not infrequently runs across some new peculiarity.

A normal laying queen proceeds over the comb depositing drone eg.rs in drone cells and worker egos in worker cells. appirent- ly being able to lay either drone or worker eggs at will. After an egg is put in a cell a worker is pretty sure to pop in and inspect it, and it has been supposed that possibly they did something to it. Inspection of thousands of bees occupied in examining egg's has failed to find a single one that touches an egg in any way. Bees often take their nap in cells containing eggs $\mathrm{Ol}^{\circ}$ larvæ.

During a heavy flow of nectar, the bees often deposit it in cells containing eggs. sometimes filling the cells half full. Such nectar is removed within a few hours, and the egres hatch as usual.

\section{DRONES.}

Drones have many interesting habits, and are well worth closer study than they have yet received. They are much slower to mature after emergence from cells than the workers. They are very fond of warmth. and may often in cool weather be found massed shoulder to shoulder in outlying sealed brood.

It seems to take a lot of preparation on the drone's part before he can take wing. Drones pay no attention to a virgin queen anonw them in the hive, no matter what her age.

\section{SWARMING.}

Swarming apparently starts with a bee here and there. Such a bee surdenly begins to run a few steps one way, thien a few another, then spins around and finally appears to work itself into a veritable frenzy. Other bees take it up and soon a rush is mate, and is quite as apt to be from as towart the entrance. As soon, lowerer, as part of the flood begins to emerge from the entrance the tide turns that way and the majority of the bees begin poming from the hive by thousands until the air is filler with a great cloud of humming bees. I'sually they cluster on the branch of a tree not far from their hive, waiting to make certain that the queen is with then before learing for their new home, which generally has been chosen by the scouts sent out several days before the swarm issues. See Swarming.

For the behavior of bees during winter. see Temperature, sub-liear "T'emperature of the Cluster in Winter." 
BEEBREAD. - A term in common use, applied to pollen when stored in the combs. In olden times (and in parts of the South yet) bees were killed with sulpluur to get the honey, more or less pollen being usually found mixed with the honey; it has something of a "bready" taste, and hence, probably, came its name. Since the advent of the extractor and section boxes, it is very rare to find pollen in the honey designed for table use. See Polizen.

\section{BEE-DRESS.—See VEILS.}

\section{BEE-ESCAPES.-See COMB Honey,} also Extriating.

BEE-HUNTINC. - In some loralities wild bees are located in hollow trees, crevices in rocks, between the walls of buikings and under cornices of buildings. The art of bee-luunting, however, is usually confined to the locating and capturing of hees in bee-trees.

The reader is given the warning so often, against leaving sweets of any lind about the apiary, and about being careful not to let the bees get to robbing each other. that it may seem strange for us to tell how best to encourage and develop this very robbing propensity.

The only season in which one can trap bees is when they will rob briskly at home: for while honey is to be found in the flower's in plenty, they will hardly deign to notice bait of even honey in the comls. Before starting out, it will be policy to learn if there are any bees liept in the vicinity, for one might otlerwise waste much time in following lines that lead into the hives of his neiglibors. The lunter should be at least a mile from any one who has a colony of bees when lie commences operations, and it is safer to be two miles. This does not mean that there are no bee-trees near large apiaries, for a number will often be found within half a mile of one's own: but those who are just learning would, rery likely, be mucl perplexed and both. ered by lining bees that proved to be his neiglibor's.

\section{LINING THE BEES.}

Perhaps the readiest means of doing this is to catclu the bees that will be fomd on the flowers, especially in the early part 4 of the day. They should be induced to take a sip of the honey brought for that purpose, and they will, true to their instinctive love of gain, speed homeward with their load, soon to return for another. To find the tree, it is necessary to watch and see where they go.

The bee-lunter can get along with very simple implements; but, if time is valuable, it may pay to go out fully equipped. For instance, a small glass tumbler will answer to catcli bees; and after one lias been caught, the glass can be set orer a piece of honeycomb. It should now be covered with a handkerchief to stop the bee's buzzing against the glass, wlien it will soon discover the honey and load up. As soon as it is really at work on the loney, the glass should be raised and the bee-huntel should creep away where he may get a good view of the proceedings. $\Lambda \mathrm{s}$ soon as it takes wing it will circle about the honey, as a young bee does in front of the live, that it may lnow where to return: for a whole "chunk" of honey, during the diy autumn days, is apparently quite a little gold mine in its estimation. There may. perliaps, be a thousand or more hungry mouths to feed, away in the forest in its leafy home.

If one is quick enough to keep track of the bee's eccentric circles and osrillations, he will see that these circles hecome larger and larger, and that each time the bee comes around it sways to one side; that is. instead of making the honey the center of its circles, it makes it almost on one erge, so that the last few times the bee comes around it simply comes back after it has started home, and throws a loop, as it were, about the honey to make sure of it for the last time. Now one an be pretty sure which way its home lies almost the very first circuit it makes, for it has its lome in mind all the time, and hears more and more toward it.

If the bee-hunter can keep lits eye on the bee until it finally takes the "loee line" for home, he does pretty well, but a beginner can seldom do this. $\Lambda$ fter the bee is out of sight, the observer has only to wait until it comes back, which it will surely do, if honey is scarce. Of course, if its lome is near by it will get back soon; and to determine low far it is by the length of 
time the bee is gone, brings in another very important point. The honey that bees get from flowers is very thin; in fact, it is nearer sweetened water than honey, and if one wishes a bee to load up and fly at about a natural "gait," he should give it honey diluted with water to about this consistency. Unless he does, it will not only take a great deal more time in loading. up, but the thick honey is so much heavier. the bees will very likely stagger under the load, and make a very crooked bee line of its homeward path. Besides it will take much more time to unload. Sometimes, after circling about quite a time, the bee will stop to take breath before going home, which is apt to mislead the hunter unless he is experienced; all this is avoided by filling the honeycomb with honey and water, instead of with honey alone.

It takes quite a little time to get a bee caught and started at work, and it is best to have several bees started at the same time. To do this expeditiously, a beehunting box made as in the following eut should be used.

\section{BOX FOR BEE-HUNTING.}

A suitable box for bee-hunting may easily be made from an ordinary cigar box. But it should be well aired as bees do not like the odor of tobacco. In the lid should be eut a small hole, perhaps an inch square.

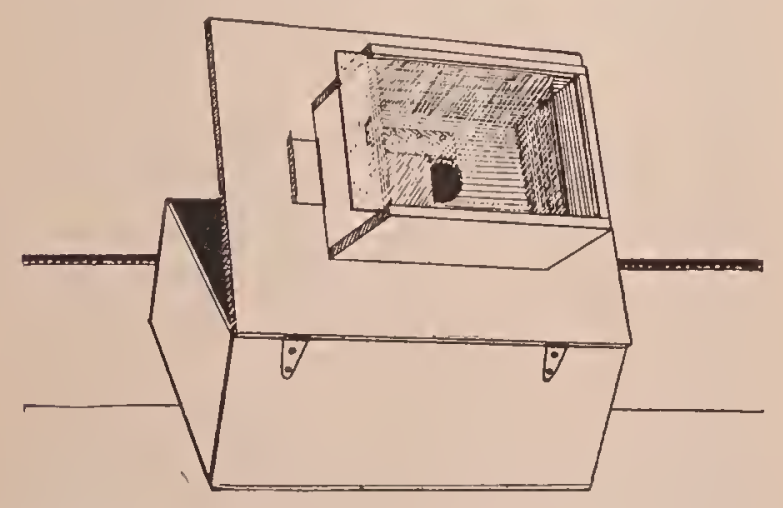

Improved hunting-box used by Mell Pritchard, Medina, Ohio. The construction of the box is plainly shown in this illustration.

Over this a tin slide should be arranged so that the hole may be opened and closed as desired. On the cover of the cigar box, and covering this hole, should be attached a small box with a sliding glass top and no bottom. In the bottom of the cigar box a small feeder should be placed.
HOW TO USE THE HUNTING-BOX.

The hunter should take with the box about a pint of diluted honey in a bottle. If he fills the bottle half full of thick honey, and then fills it up with warm water, it will be about right. In the fall he will be more likely to find bees on the flowers in the early part of the day. When he gets on the ground, near some forest, where he suspects the presence of wild bees, he should pour a little honey into the feeder. and, with open box, cautiously approach a bee feeding ripon some flower.

As soon as the box is near enough, the bee should be caught in the box and the lid quickly closed. In a short time, the bee will have sipped a load of honey and, seeing the light thru the small hole above, will soon emerge into the upper box and buzz against the glass. The lower tin slide may then be closed and the box placed on some elevated point, such as the top of a stump in an open space in the field and the glass slide withdrawn. The hunter should stoop down now, and be ready to keep his eye on the bee as it flies, whichever way it may turn. If he keeps his head low, he will be more likely to have the sky as a background. If he fails in following the first bee, he must try another; and as soon as he gets a sure line on one as it bears finally for home, he should be sure to mark it by some object that he can remember. If he is curious to know long it is gone, he can, with some white paint and a pencilbrush, mark it on the back or he may dust the entire bee with flour. This is quite a help where one has two or more lines working from the same bait. Bees vary in their flight. But it has been found that on an average they will fly a mile in five minutes, and spend about two minutes in the live or tree. Of course, they will spend more time in a tree when they have to crawl a long distance to get to the broodnest, hence we may deduce the rule: Subtract two from the number of minutes absent, and divide by ten. The quotient is the number of miles from the stand to the tree. This applies to partially woorled country. Perhaps in a clearing they conld make better time. On a very windy day it takes them longer to make trips. When a bee comes back, it can be recognized by 
the peculiar inquiring hum, like robbers in front of a hive where they have once had a taste of spoils. If the tree is near by, each one will bring others along in its wake, and soon the box will be humming with a throng so eager that a further filling of the feeder from the bottle will be needed. As soon as the hunter is pretty well satisfied in which direction they are located, he can close the box and move along on the line, nearer the woods. After the box is again opened, the bees will soon be as busy as ever. To aid in deciding just where they are, he can move off to one side and start a cross-line. Of course the tree will be found just where these lines meet. It is a waste of time to look for the bee-tree, or to make cross-lines, until one gets beyond the tree. When the bees fly back on the line he may rest assured that he is beyond the tree. He should then move his last two stands closer together (lining the bees carefully), so that they are only 10 or 15 rods apart. As there will be bees flying from two directions into the tree he will probably discover where they are immediately. When one gets where he thinks they should be, he. should examine the trees carefully, especially all the knot-holes, or any place that might allow bees to enter and find a cavity. If he places himself so that the bees will be between him and the sun, he can see them plainly, even if they are among the highest branches. He should make a careful and minute examination of every tree, little and big, body and limbs, even if it does make his neck ache. If he does not find them by carefully looking the trees over, he should go back and get his hunting-box, bring it up to the spot, and give them feed until he gets a quart or more at work. He can then see pretty clearly where they enter. If he does not find them the first day, he can readily start them again almost any time, for they are very quick to start, when they have once been at work, even tho it is several days afterward. Bees are sometimes started by burning what is called a "smudge." Some old bits of comb containing beebread as well as honey may be burned on a small tin plate sitting over a little fire. The bees will be attracted by the odor of the burning honey and comb, and, if near, will sometimes come in great numbers.

A telescope is very convenient in finding where the bees go in, especially if the tree is very tall; even the toy telescopes sold for a dollar or two are sometimes quite a lielp. The most serviceable, however, are the achromatic opera glasses that cost five or ten times this amount. With these, one can use both eyes, and the field is so broad that no time is lost in getting the glass instantly on the spot. He can, in fact, see bees with them in the tops of the tallest trees almost as clearly as he can see them going into hives placed on the ground.

After one has found the tree, probably he will be in a hurry to get the bees that he knows are there, and the honey that may be there. One should not put his expectations too high, for he may not get a single pound of honey. Of two trees that the author took a few years ago, one contained just about as much honey as he had fed the bees, and the other contained not one visible cell full. The former were fair hybrids, and the latter well-marked Italians. If the tree is not a valuable one, and stands where timber is cheap and plentiful, perhaps the easiest way is to cut it down. This may result in a smashed heap of ruins, with combs, honey, and bees all mixed up with dirt and rubbish, or it may fall so as to strike on the limbs or small trees, and thus ease its fall in such a way as to do little injury to the tree or contents. The chances are rather in favor of the former, and on many accounts it is advisable to climb the tree and let the bees down with a rope. If the hollow is in the body of the tree, or so situated that it cannot be cut off above and below the bees, the combs may be taken out and let down in a pail or basket; for the brood-combs, and such as contain but little honey, the basket will be rather preferable.

\section{CLIMBERS FOR BEE-IIUNTERS.}

For climbing trees 12 to 18 inches in diameter, a pair of climbers should be used, such as can be obtained at any teleplone office.

If the tree is large, the climber should provide himself with a withe or whip of some tough green bough, and bend this so it will go around the trunk, while an 
end is held in each hand. As he climbs upward, this is hitched up the tree. If he keeps a sure and firm hold on this whip, and strikes his climbers into the trunk firmly, he can go up most trees with reasonable safety. Some light cord, a clothesline, for instance, should be tied around his waist, so he can draw up such tools as he may need. Those needed are a sharp ax, a hatehet, saw, and an anger to bore in to see just how far the hollow extends. If the bees are to be sared, the limb or tree should be cut off above the hollow, and allowed to fall. A stont rope can then be tied about the $\log$ hive, passed over some limb above, the end brought down and wrapped about a tree until the live is ent off ready to lower. After it is down, it should stand an hour or two, or until sundown, when all the bees will have found and entered the hive; then, the entrance having been covered with wire cloth, the hive may be taken home.

There are some trees, indeed, so large that it would be impossible to climb them in the manner given. A very ingenious plan, however, has been put into execution by Green Derrington of Poplar Bluff, Mo. Here is given his deseription, together witl an engraving made from a photograph which he sent.

I send you a photograph of a very large tree, which I climbed by means of spikes and staples. To prevent the possibility of falling I put a belt under my arms. To this I attached two chains. At the end of each chain is a suap. My method of climbing is as follows: After ascending the ladder as far as I call go, I drive into the side of the tree a large bridge spike, far enough into the wood to hold my weight. A little further up I drive another spike. In between the spikes I drive the first staple, and to this I attach the first chain by means of the snap, and ascend by the nails as far as the ehain will allow me; I then drive another staple, and attach the other chain, and next loosen the lower snap. After driving in more spikes, I again ascend as high as the chain will allow me, and attach the other chain to another staple. In this manner I "an make my ascent with perfect security.

IIOW TO GET BFFS OUT OF BEE-TREES OR FROM BETWEFN TIIE SIDINGS OF A HOUSE WITHOUT MUTILATING FITHER THE TREE OR THE IIOTSE.

It sometimes happens that a colony of

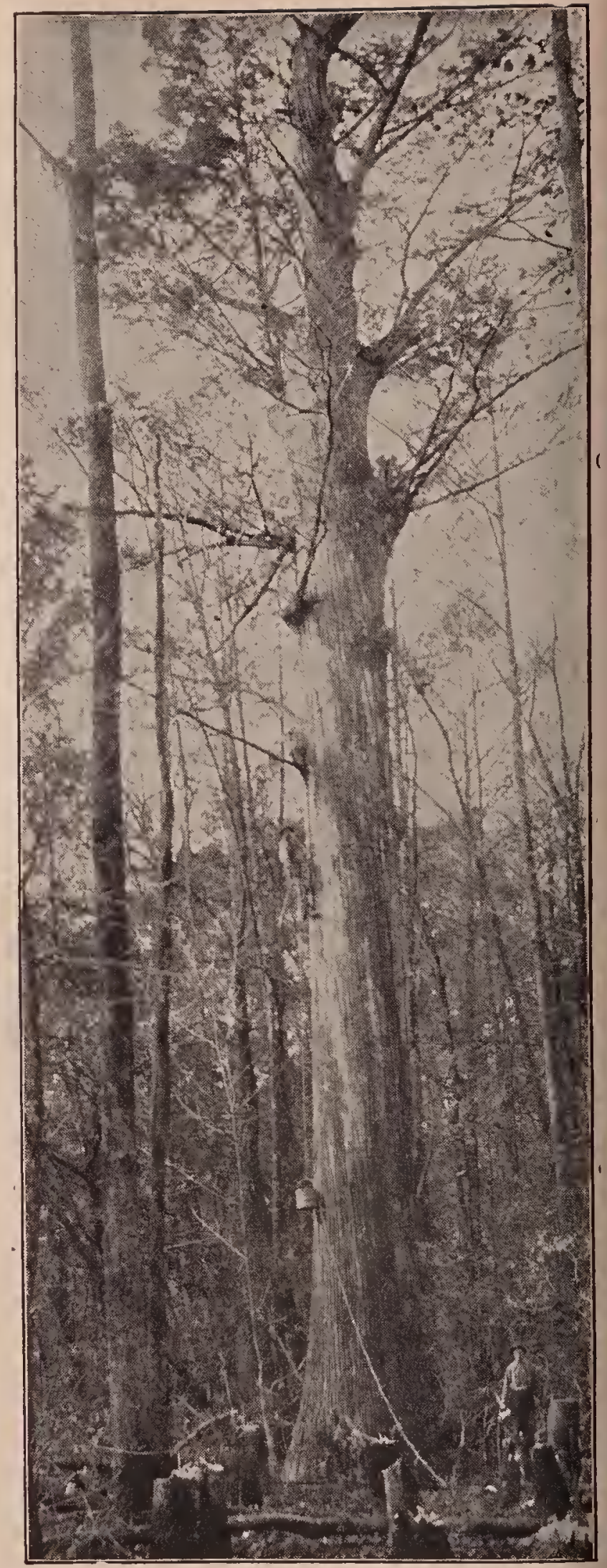

1 bee-tree 11 feet in diameter climbed by Green Derrington.

bees will take their aborle in some fine shade tree in a park, which the anthorities will not allow to be cut: ol they will domicile in the woods of some farmer, who. while he will allow the bee-hunter to get the bees, 
will not let him eut the tree; or, as it often happens, a colony will make its home between the plaster and the clapboarding of a house. How, then, ean such bees and their honey be secured without doing any damage to the tree or the building that gives them a home and protection? The matter is made very easy by the use of the modern bee-escape. For particulars regarding this device, see Comb HoneY and ExtraCted HonEy.

Having the bees located in the bee-tree, the hunter prepares a small colony of bees or a nucleus with a queen, putting it into a light hive or box, which can be carried to the scene of operations. He takes along with him a hammer, a saw, some nails, and lumber, with which he can make a temporary platform. On arriving on the spot he lights his smoker and then prepares to set up his platform directly opposite to or in front of the flight-hole of the bee-tree, or the knot-hole of the dwelling. The platform he constructs out of the lumber he has brought. Before doing so it will be necessary for him to blow smoke into the flight-hole, in order to prevent bees from interfering with the building of the temporary hive-stand. He next puts a Porter bee-escape over the flight-hole of the tree or building, in such a way that the bees can come out but not go back in. Last of all he places his hive with the bees which he has brought, with its entrance as near as possible to the bee-escape (now placed over the old entrance).

His work is now complete, and he leaves the bees to work out their own salvation.

The bees from the tree, as fast as they come out, are, of course, unable to return. These, one by one, find their way into the hive on the temporary platform. At the end of four or five weeks the queen in the tree or dwelling will have very few bees left, and there will also be but little brood for that matter, thru lack of bees to take care of it, for her subjects are nearly all in the hive on the outside.

At this time Mr. Bee-hunter appears on the scene. He loads his smoker with fuel (brimstone), removes the bee-escape and brimstones the old colony, or what is left, which by this time is probably not more than a handful of bees with the queen.

Again he leaves the scene of operation; but the bee-escape is not replaced. What happens now? The bees in the hive, including those that were captured, rob all the honey out of the old nest in the tree or louse in the course of three or four days: arrying it into the live on the extemporized platform.

The bee-hunter now takes away the hive, removes the temporary hive-stand and carries the bees home. If they be taken a mile or a mile and a half, they will stay where placed. If the distance is less, the colony should be moved to a temporary location two miles or more away and left a week before being taken homè.

In the meantime, no damage has been done either to tree or building, as the case may be. All that will be left in the tree will be some old dry combs which, in the form of wax, probably would not amount to fifty cents, if the time of rendering be taken into account.

This method of taking bees could not very well be practiced where the bees are located in inaccessible positions, as in high trees; but it will be found very useful where a colony is located in some building or shade tree in a park.

The author is indebted for the general prineiples of this plan to Ralph Fisher of Great Meadows, N. J., who has practiced this plan with great suceess.

DOES BEE-HUNTING PAY?

From the point of view of securing bees at a low cost, it is safe to say that it never pays. Bees can always be purchased in the open market cheaper than to get them from trees; but from the standpoint of a royal half-holiday of fun, where one can not only get the outdon air and good scenery but some real thrills, it is a great success. It should be understood that bee-hunting is hazardous-not because of stings, but because of the danger of climbing large trees.

Where the woods have one or more colonies of black or hybrid bees, and one desires to raise queens or keep his own stock pure for honey production, it will pay to hunt out and capture the bees in these old trees, if for no otlier pupose than to get rid of the drones.

If there is any brood disease in the locality, the bee-trees will be almost sure to 
have it. As long as these are present within half a mile of an apiary of bees it would be impossible to keep them clean. In such a case the owner of the bees can well afford to liunt out every bee-tree in range. Mevely trapping the bees out of the trees wonld not be sufficient. He would have to get permission to eut down the trees and burn up the logs or limbs containing the cavity.

\section{PEE-TREES MENACE TO QUEEN-BREEDERS.}

It should be explained further that if one is trying to Italianize his apiary the presence of black bees in the woods will seriously interfere with pure mating. When bees build their combs naturally in trees they build an excessive amount of drone comb. The blacks will, therefore, raise drones out of all proportion to the number raised in hives of Italians where only combs from foundation are used. It is not any exaggeration to say that one colony of blacks on natural combs will raise as many drones as 40 or 50 colonies of Italians whose combs are built from all-worker foundation. It would, therefore, pay and pay well to get all the bee-trees of blacks or hybrids, even if there were no foul brood or no financial gain in the honey or bees so secured.

\section{BEEKEEPING AS A SPECIALTY.-} See Beginning with bees, Profits in Bees, and Specialty in Bees.

\section{BEEKEEPING FOR WOMEN.}

[ Tt is presumed, of course, that no ordinary man would be entirely competent to write on a subject of this kind. In looking about for some woman to Io this, the author could think of no one more able than Mrs. Anna B. Comstock, author of a charming work for beginners on "How to Keep Bees." Mrs. Comstock is the wife of Prof. J. Henry Comstock, of Cornell University, and both of them are entomologists. We engaged her to write the following article.

Two questions invariably pop up at us when this matter of feminine beekeeping is discussed: One is, "Why shouldn't a woman keep bees?" and the other is, "Why should a woman keep bees?" Like most other questions these may be answerer! nore or less rationally witl proper consider'ation.

Taking the "why shouldn't" question first, we are bound to confess that nowadays there is no effective reason why a woman slould not do almost any thing that she takes into her enterprising little liead to do. But quite aside from the consideration of woman's prowess, there are one or two reasons that might deter some of the faint-hearted fair from undertaking beekeeping. There is no use trying to gloss over the fact that there is a great deal of hard work and heavy lifting in the care of a profitable apiary. The hard work is really no objection, as most women of whatever class are doing it anyway. But lifting heavy hives is certainly not particularly good exereise for any woman, altho I must confess that I have never lifted half so strenuously when caring for the bees as I used to on the farm when we moved the cook-stove into the summer kitchen, accomplishing this feat by our feminine selves, rather than to bring to the surface any of the latent profanity which seems to be engendered in the masculine bosom when taking part in this seasonal pastime.

There are at least two ways of obviating this feminine disability in beekeeping. One, practiced successfully by several women, is thru the use of a light wheelbarrow, which almost solves the problem if the bees are wintered out of doors and do not have to be carried up and down cellar stairs; the other method is to get some nian to do the lifting and carrying." It may be the husband, the father, the brother, the son, or the hired man; but as this work can be done at a time which can be planned for, it is not so difficult for the men of the establishment to give the help needed. I am sure my husband would say that I am quite enthusiastically in favor of the man solution of this problem; but his opinion does not count for much, because he loves the bees so enthusiastically I have to beg for a chance to work with them at all, altho he virtuously points out the hives to people as "Mrs. Comstock's bees."

Another "shouldn't" reason might be that women are afraid of bee-stings. This falls flat, from the fact that women are not a bit more nerrous than men in this respect. This year when I was struggling to hive a swarm from a inost difficult position, an interested man stood off at a safe distance in a most pained state of mind. He was a

*Some frail women remore all hopey, one comb at a time. 
couteous gentleman, and he felt that it was outrageous for me to liave to do the work alone, but he did not dare to come to my aid, and I think he considered my temerity in dealing with the swarm as almost scandalous.

Thus having disposed of all the reasons I can think of why women shouldn't keep. bees, I turn gladly to the more interesting. reasons why she should look upon the apiary as one of hel legitimate fields of labor. There ale so many reasons for this that I could not enumerate them even if a conplete number of a bee journal were given me for the purpose. So I shall speak of just a ferv of the most important reasons. I should put first of all, and as embracing all other reasons, that beekeeping may be made an interesting arocation which can be carried on coincidentally with other employments; it is an interesting study in natural history; it cultirates calmness of spirit, self-control, and patience; it is a "heap" of fun: incidentally it may supply the home table with a real luxury; and it may add a very considerable amount to any woman's spending-money. It can also be carried on as a regular business, to support a family.

But it is as an arocation that I am especially interested in the apiary. Any woman who keeps house needs an avocation to take the mind and attention completely off her lousehold eares at times. There is something about the daily routine of houselieeping that wears mind and body full of ruts. even in the case of thiose who love to do housework better than anything else. Talk about the servant question! It is not the serrant question, but the housework question. If some means could be devised by which housework could be performed with inspiration, zeal, and enthusiasm, the servant problem would solve itself; but this ideal way of doing housework can be carried on only when the spirit is freed from the sense of eternal drudgery. I am not a wizard to bring about this change; but I know one step toward it, and that is the establishment of some permanent interest for woman that will pull her out of the ruts and give her body and mind a complete change and rest. Fmbroidery, lace-making, wearing, painting, and several other like occupations, may serve this purpose in a measme; and, perhaps, if carried on in the right way, may achieve more in this line than they do at present. But these are all indoor occupations: and what a woman needs is something to take her outdooi's where she can have fresh air. Excess of perspiration induced by the cook-stove is weakening; but honest sweat called forth in the open air by the application of generous sunshine is a source of health and strengtlr.

Beekeeping is one of the best of these life-saring, nerve-healing avocations; it lakes the mind from household cares as completely as would a trip to Europe, for one cannot work with bees and think of anything else. Some of the attributes which make beekeeping an interesting avocation I will mention: First of all, bees are such wonderful creatures, and so far beyond our comprehension, that they have for us always the fascination of an unsolved problem. I never pass our hives without mentally asking, "Well, you dear little rascals, what will you do next?" Bees are of particular interest to every woman for several reasons; if she likes good housekeening, then the bee is a model: if she likes a woman of business, again is the bee a shining light; if she is interested in the care of the young, then is the bee-nurse an example of perfection; if she believes in the political rights of women, she will find the highest feminine political wisdom in the constitution of the bee commune. In fact, it is only as a wife that the bee is a little too casual to pose as ideal, altho as a widor she is certainly remartkable and perhaps even notorious.

Another phase which makes beekeeping a pleasing arocation for women is that much of the work is interesting and attractive. I never sit down to the "job" of folding sections and putting in starters without experieneing joy at the prettiness of the work. And if there is any higher artistic lappiness than cones from cleaning up a section holding a pound of well-capped amber honey and putting the same in a dainty carton for market, then I have never experienced it: and the making of pictures has been one of my regular arorations. By the way, woman las never used her artistic talent rightly in this matter of cartons. Fach woman beekeeper ought to make her 
own colored design for the carton, thus serming something so individual and attractive as to ratch at once the eye of the ('nstomer'.

As a means of cultivating calmness, patience, and self-control the bee is a wellrecognized factor. Bees can be, and often are, profoundly exasperating; and yet how worse than futile it is to evince that exasperation by word or movement! No creature reacts more quickly against irritation than the bee. She cannot be kicked nol spanked; and if we smoke her too much, we ourselves are the losers. There is only one way to manage exasperation with beesthat is, to control it; and this makes the apiary a means of grace.

The money-making side of beekeeping is a very inmportant plase in arousing and continuing the woman's interest in her work. I think woman is by birth and training a natural gambler, and the uncertainty of the nectar supply and of the honey market adds to rather than detracts from her interest in her apiary. I know of several women who have made comfortable incomes and supported their families by beekeeping; but, as yet, I think such instances are few. Howerer, I believe there are a large number of women who have adder a goorly sum yearly to their amount of spending money, and have fornd the work a joy instead of drudgery. Personally, I have had very little experience with the commercial side of beekeeping. Once when our madideningly successful apiary grew to 40 hives when we did not want more than a dozen at most, and the neighborhood was surfeited with our bounty, we were "just naturally" obliged to sell honey. The enjoyed greatly getting the product ready for market, and were somehow surprised that so much fun could be turned into ready cash. As a matter of fact, both my husband and myself have absorbing vocations anil arocations in plenty, so that our sole reason for keeping bees is because we love the little creatures, and find them so interesting that we would not feel that home was really home without them; the sight of our busy little co-workers adds daily to our psychic income. Tre are so very busy that we have but very little time to spend with them, and have finally formulated our ideal for onr own beekeeping, and that is to keep bees for honey and for "fun." W'e shall have plenty of lioney for our own table, and just enongh to bestow on neighbors so they will not get tired of it; and fun enough to season life with an out-ofdoor interest and the feeling that no summer day is likely to pass without a surprise. See TEILs.

BEE LEGISLATION.-See Latrs R.LATING TO BEES.

BEE MOTH.-See MIOTII Mindur.

BEE PARALYSIS.- See DISHASES OF BEEs.

BEE-SPACE.-This term is applied to spaces left by the bees both between combs they. bnild and between the parts of the hive and the combs. It varies all the way from 3-16 to 3-8; but 5-16 is considered the correct average. But in hive-construction it has been found that a space of $1 / 4$.incl will be more free from the building of bits of comb and the depositing of propolis than a little wider spacing. Any less space than $3-16$ will be plugged up with propolis and wax. See Frames.

Father Langstroth, in the great invention which he gave to the world-the first practical movable frame-made the discovery that bees recognize and protect passageways which are now called bee-spaces. Taking advantage of this fact he made a frame (for holding comb) so that there would be a bee-space all around between it and the hive, and a bee-space between it and any other frame. All who preceded him had failer to grasp the fact that bees would leave such spaces unfilled with wax or propolis. Before Langstrotli's time it was necessary to pull out frames stuck fast to the hives with propolis, or tear or cut loose the combs with a thin-bladed knife, before they could be remored for the purpose of inspection.

By bringing out his bee-spaced frame the "father of modern apiculture" solved, with one great master stroke, a problem that had been puzzling the minds of beelieeper's for centuries.

In later years, manufacturers of hives have been compelled to recognize this great principle, that there are certain parts inside of the hive that must be bee-spaced from every other part or else they will be 
stuck or irlued together in a way that will make them practically inseparable. For example, the bottoms of supers containing the sections must be $5 / 16$ inch above the tops of the brood-frames in the lower part of the hive. It has come to be a general practice to put the bee-space in the bottom-board, leaving the bottoms of the frames in the brood-nest nearly flush with the botton of the hive. This makes it necessary to have the sides and ends of the hive project above the general level of the frames about $5 / 16$ inch. In the same way the supers have a bee-space on top but not on the bottom. If a super be removed, and a hive-cover be put in its place, there will still be a space between the cover and the brood-frames.

There are a few who believe that the bee-space should always be under the frames or sections. This will necessarily require that the top of the hive or super be even with the tops of the frames or sections, and that the covers have cleats on the outside edges a bee-space thick. Such a combination is objectionable, because these cleats could not be made tight enough to keep out cold, and because there are many beekeepers who like to use a flat board cover that may be used either side up. It is very much more satisfactory to have the bottom-board cleated in the manner stated than the cover. Even if the cleats are not tight, warm air would not escape at this point. Practically all the beekeeping world is united in favor of having a bee-space on top of the frames and sections rather that under, and probably 99 per cent of all the hives in use are so built. Any beginner or other person who will attempt to devise a hive with a beespace on the bottom will be making a great nistake. His stuff will not match other equipment; and if the time comes when he will have to sell he would have to dispose of it at a considerable reduction in price, for the reason that the bees would have to be transferred into other hives that would fit appliances commonly in use.

It is customary to make a space between the bottoms of the frames and the hottom-board much greater than the space on top. Modern hives usually provide from $7 / 8$ to 1 inch of space under the frames to allow for plenty of ventilation during hot weather. Such a space should have an entrance $7 / 8$ incl deep. This is none too large during the hottest part of the year. See Entrances to Hives.

During the winter, whether in the cellar or outdoors, the extra space allows for an accumulation of dead bees under the frames. If the bee-space under the frames is only $5 / 16$ it might soon clog up with dead bees, thus preventing ventilation, finally ending in the destruction of the colony.

BEES.-See Races of BeEs; also ITALIAN BEES.

BEES AND SCHOOL TEACHING.Beekeeping fits in well with school teaching, for the bees usually need but little attention during the winter term of school. In the North even when the school is continued until the first of June or a little later, the management of the bees can usually be such that the attention necessary for them can be given an Saturdays when school is not in session. See BuILding UP COLONIES.

At the close of the school year, beekeeping furnishes for the tired teacher pleasant outdoor recreation, often better fitting him for the next year's work than do other forms of vacation which yield no profit but consume much of his winter earnings. On the other hand, at the close of the beekeeping season, teaching affords the beekeeper an opportunity for thought and study in the many fields into which beekeeping naturally leads the thoughtful beekeeper.

BEES AND FRUIT-GROWING.-Under Fruit Blossoms and also under PoLLEN it has been shown that beekeeping is very intimately related to fruit-growing. The production of much of the fruit from many trees and shrubs is dependent on the pollen being carried by bees to the bloom from different individuals or varieties of the same species, and in most cases the quantity is increased and the quality of the fruit is improved by such cross-pollination. The two industries can, therefore, be united with great advantage. Fruit-growers have learned to appreciate the valuable work performed by bees. As they became convinced that the services of these little friends were indispensable, 
from California and Wrisconsin to New lork and Florida, they not only began buying colonies of bees, but gradually increased their number until now it is not uncommon for a fruit-grower to own a large apiary. So far from adding to the expenses of fruit culture, the surplus of honey obtained has proved that beelieeping, in this connection, may become a very profitable side line. One man, or force of men, can care for the bees a part of the time, and for the fruit trees the other part, and thus be able to furmish two of the finest sweets in the world--the sugar. in fruit and the sugar in the nectar of the flowers.

Within the last few years the citrusgrowers of California and the southern States, particularly Florida and the Isle of Pines, have in many instances increased the quantity of fruit produced by their groves by the introduction of the domestic bee. While the number of colonies required has been estimated as low as one per acre, to pollinate the blooin thoroly four or five are desirable.

In warm climates where the bees can fly during the entire period the bloom is open, a less number of bees will be required than in the North where the work of pollination may lave to be accomplished in a single day, or even two or three hours. During the time the trees are in full bloom, there are often many days that are cloudy and clilly when the bees can not get out. Unless there is one warm day, or at least a few hours of bright sunshine, there may be a shortage of fruit because the bees are unable to get out and do their work. Should there be only two or three hours of good weather wlien the bees can fly, obviously there will be need of more bees than if there were a whole week of warm air and sunshine. In a cherry orchard not many miles from where this is written, it happened one spring that there were only two or three hours during the entire time when the bees could fly. The result was apparent the following summer. Only those trees that were within 50 feet of a hive had full frnitage, while those located further away had few or no cherries. The case was so marked that the owner of the orchard sent word to have the anthor come and see what the bees had done. He then remarked that if he had had ten times as many bees in the orchard, a live under every tree, he could have secured full fruitage. As it was he had only one colony to the acre. With four or five days of good weather this would have been enough.

BEES AND POULTRY. - Under the head of BeEs AND FrUIT-Growing it is shown how beekeeping and fruit-growing go well together. If there is any industry, aside from that of growing fruit, that combines nicely with the keeping of bees, it is poultry. When the bees require the most attention, the poultry needs the least. When chickens demand the most time, the bees are taking their long winter sleep, and, of course, require no attention, or very little. In the more northern States, at least, the bees are put into winter quarters along in the fall, and require almost no attention until the following spring, along in April or May. During this time the clickens require considerable care. If one would have early broilers in the spring, he must start his incubator going early. He must feed his chickens so that they will lay during the winter, and not only that, but give him fertile eggs so that he can start his incubator. Incubator work and the brooding of chickens take place in the spring. The bees at that time require a little attention in the way of feeding and going over to see whether any of them need uniting; but, beyond that, they will not rennire very much care until about the middle of May or the first of June in the northern States. In the South honey would come in much earlier and of course chickens would be able to take care of themselves that much earlier. Just about the time the bees begin to require considerable attention, the hens will begin to lessen their laying, and the weather will be such that they will not require such careful feeding; for usually they can get a good deal of their green food directly from the ground. At that time the beekeeper will be either giving lis colonies more room or extracting. If the chickens require a good deal of his time then, he can simply put extra supers on his hives, piling them one on top of the other, until he has the hives stacked nip three or four stories high. If he practices swarm prevention by the methods 


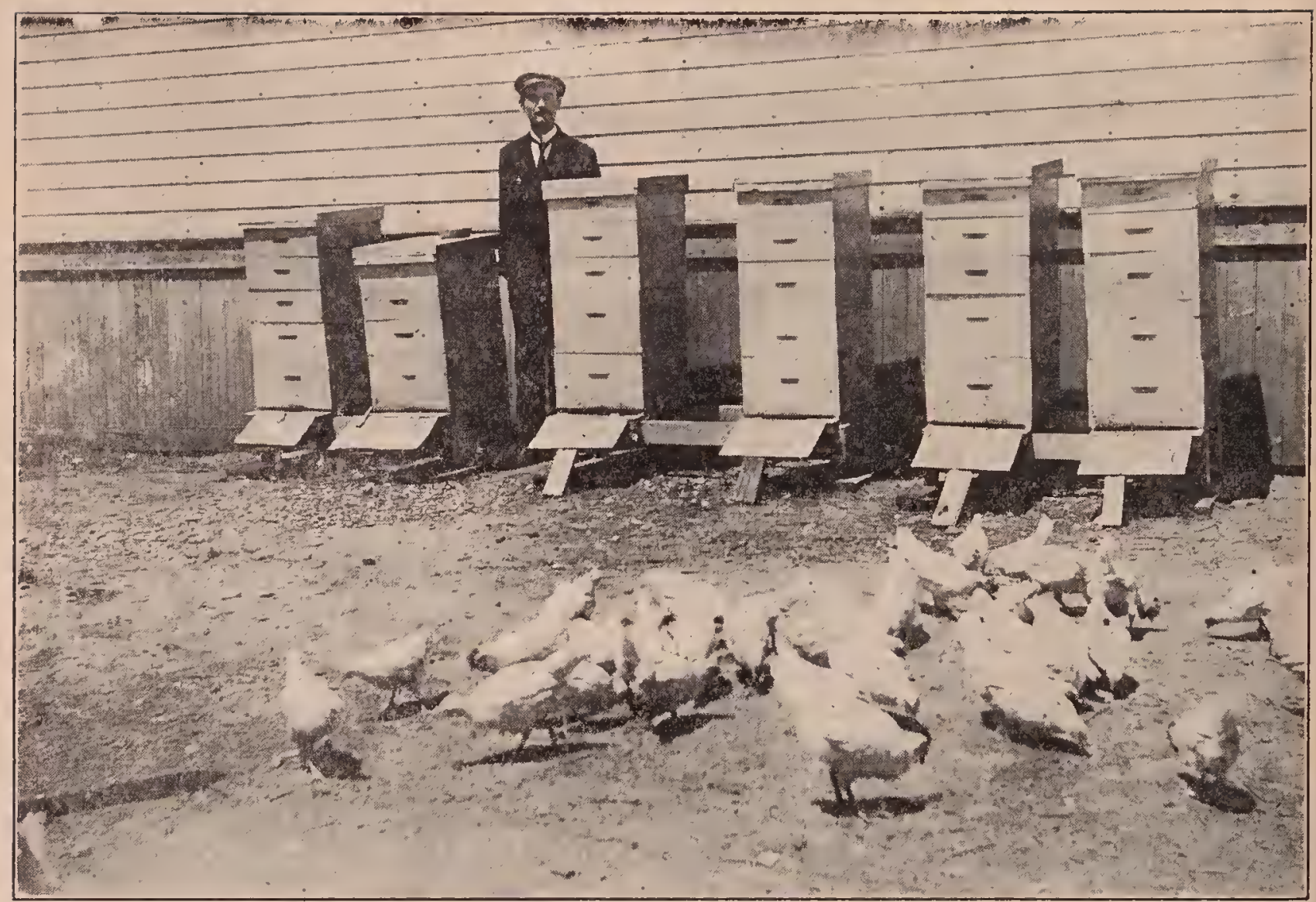

Bees and chickens in the same back lot, Detroit, Mich.

given muler the head of SwAPAFrg and Artificial Swabang he will not have much trouble with swarms. Taking it all in all, he can postpone the greater part of his bee-work until his chickens do not require very much attention: and then he can take off his honey, scrape his sections, or extract if necessary.

The great majority of those who keep bees in the United States work them in connection with some profession or some other industry, like fruit-growing or poultry-keeping. Some localities do not make it feasible for beekeeping to be the sole means of livelihood. While it is true there are a great many specialists, especially in the West, they are in localities that are particularly farorable for the keeping of bees in a large way. One can scarcely make a living from one or two hundred colonies; but that number in connection with poultry-keeping or the growing of fruit helps to make up the general income of the family. For a further consideration of the question of whether bees can be made the sole means of livelihoorl, see Profits in Bees, Backlot Befkefping. Specialty in Bees, and the Foreword.
BEES AND TRUCK GARDENING.Beekeeping can be managed in connection witl truck gardening', but they do not make nearly as good a combination as bees and poultry. The difficulty in combining bees with gardening is that the latter requires its greatest attention when the bees also need a large amount of care. There are times and cireumstances, however, when beekeeping, fruit-growing, and poultrykeeping miglit all three be worked together"; but in most cases, probably the man who attempted this would be a "Jack of all trades and master of none."

BEES AND FARMING.-See FARMERBEEKEEPER.

BEES AS A NUISANCE.-It would seem almost out of place to discuss this question in a work intended for study by those who believe (and rightly, too) that bees are not a nuisance; but, as will be shown, there are rery good reasons why the matter should be calmly discussed in order to aroid trouble that may arise in the future. ('ertain difficulties have arisen between the keepers of bees and theil. neiglibor's. Perhaps the bees, after a long 
winter confinement, or after several 'days' confinement at any time, have taken a flight and soiled the washing luung on a line in a neighbor's yard. Possibly, some of his children have been stung, or there hare been times when he has been greatly annoved while in the peaceable possession of his own property by bees coming on his premises and smelling around, as they sometimes do during the fruit-canning season when the aroma of sugar and juicy fruits escapes thru the doors and windows of the kitchen. Possibly, the offended neighbor keeps chickens, and members of his feathered tribe have trespassed on the grounds of the beekeeper. 'The result of claimed and a lawsuit follows, with the result that a feeling of resentuent is stirred up against the beekeeper.

Or again, the beekeeper may liave an apiary in his front yard, bordering on the common highway. A nucleus is robbed out, the bees become cross and sting passers-by. Perhaps a span of horses is attackerl; il runaway follows; damages are clained, and another lawsuit is becun.

In the foregoing, possible instances liave been supposed. It is proper to state that they are only types of what has oceurred and may oceur again, so it behooves the beekeeper to be careful.

In the first case mentioned (the agrorier-

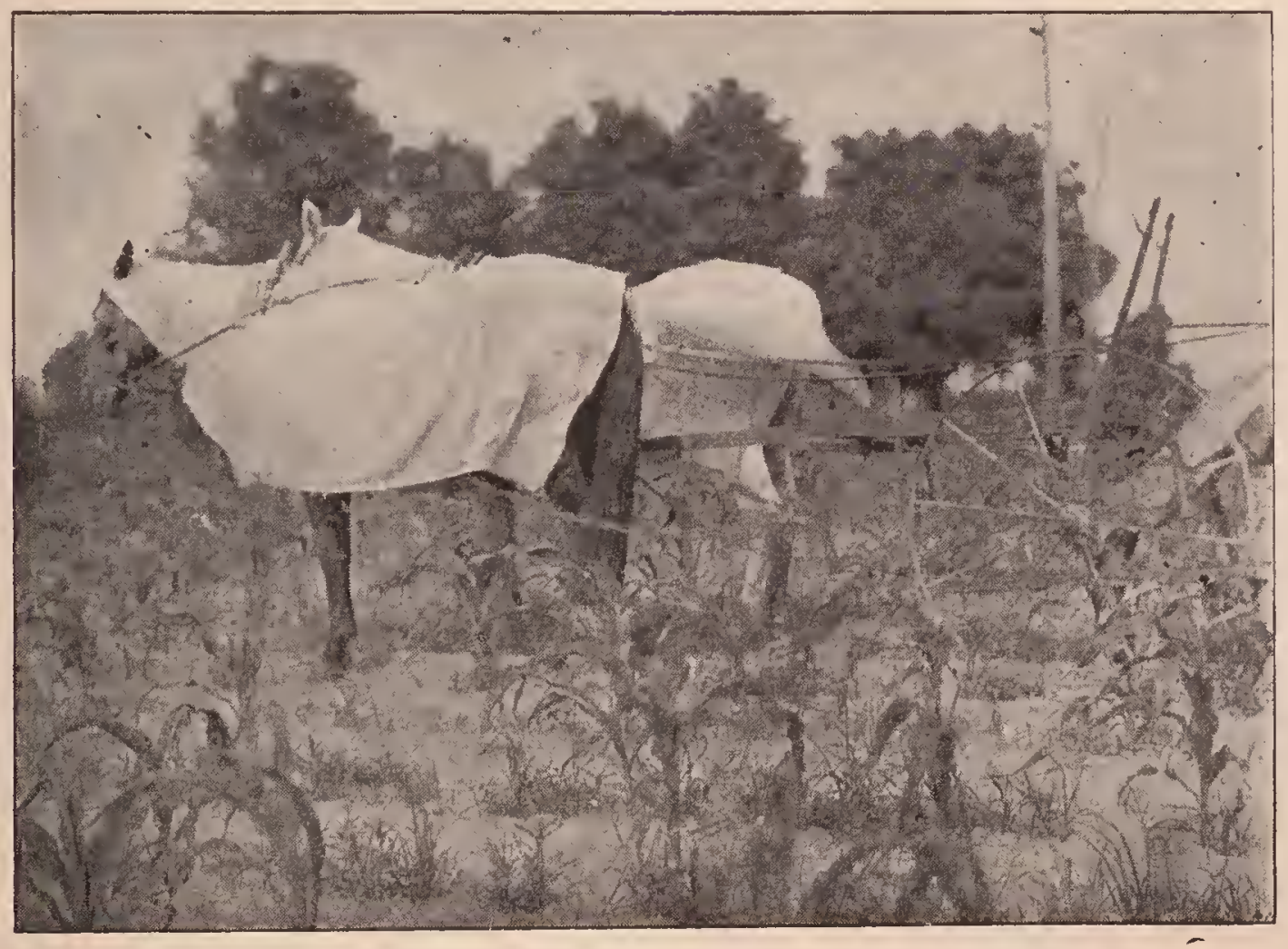

Scheme for plotecting horses while cultivating a ficl next to a bee-ynd.

all this is that bad feelings arise. Contplaint is made to the village officer's; an ordinance is proposed declaring bees within the limits of the corporation to be a nuisance, and requiring the keeper to remove them at once or suffer the penalty of fine or imprisonment, or both. See LAws Relating to Bees.

In some instances, live stock has been stung; a cow or a calf or a horse may get near the entrances of the lives, which, possibly, are within a foot of a dividing line between the two properties. Perhaps the stock is stung nearly to death. Damage is. ed neighbor's washing soiled by the stains from bees affected with dysentery), it is well for the beekeeper to send orer sereral nice sections of lioney, or to offer to pay for the damage done to the washing. Notl1ing makes a woman. more angry than to have her nice clean white linen, after she has scrubbed, rinsed, and luung it out to dry, daubed with nasty, ill-smelling brown stains. But if the beekeeper shows a disposition to make the matter good and takes pains to offer an apology before the woman makes complaint, trouble will in most cases be arerted. And right here it 
should be said, if the bees are in the cellar. they should not be set out on a wash-day; or if they are outdoors, and the sun comes out bright so they begin to fly strongly from the hives, one should send word to the neighbors and ask them not to hang out their washing, if it is a wash-day, for a few hours. It might be well also to send along a few boxes of honey, and keep the folks across the way "sweetened up." Ninetynine neighbors out of a hundred, with such treatment, will put up with a great deal of inconvenience, and say; "Oh! that is all right. It won't take long to rinse out the clothes again." great caution needs to be exercised. The extracting-room slould be screened off, and no honey left exposed to the bees. Whenever possible, he should take off all surplus by the use of bee-escapes rather than by shaking. See RobBing and Extracting.

Under the head of ANGER OF BEEs, in the latter part of the article, and under the head of APIARIES, emphasis is put upon the importance of placing the hives so that they shall be sereened by shrubbery or small trees from other hives and objects in the yard. Nothing is more conducive to insuring good temper on the part of bees than to place the individual lives so that

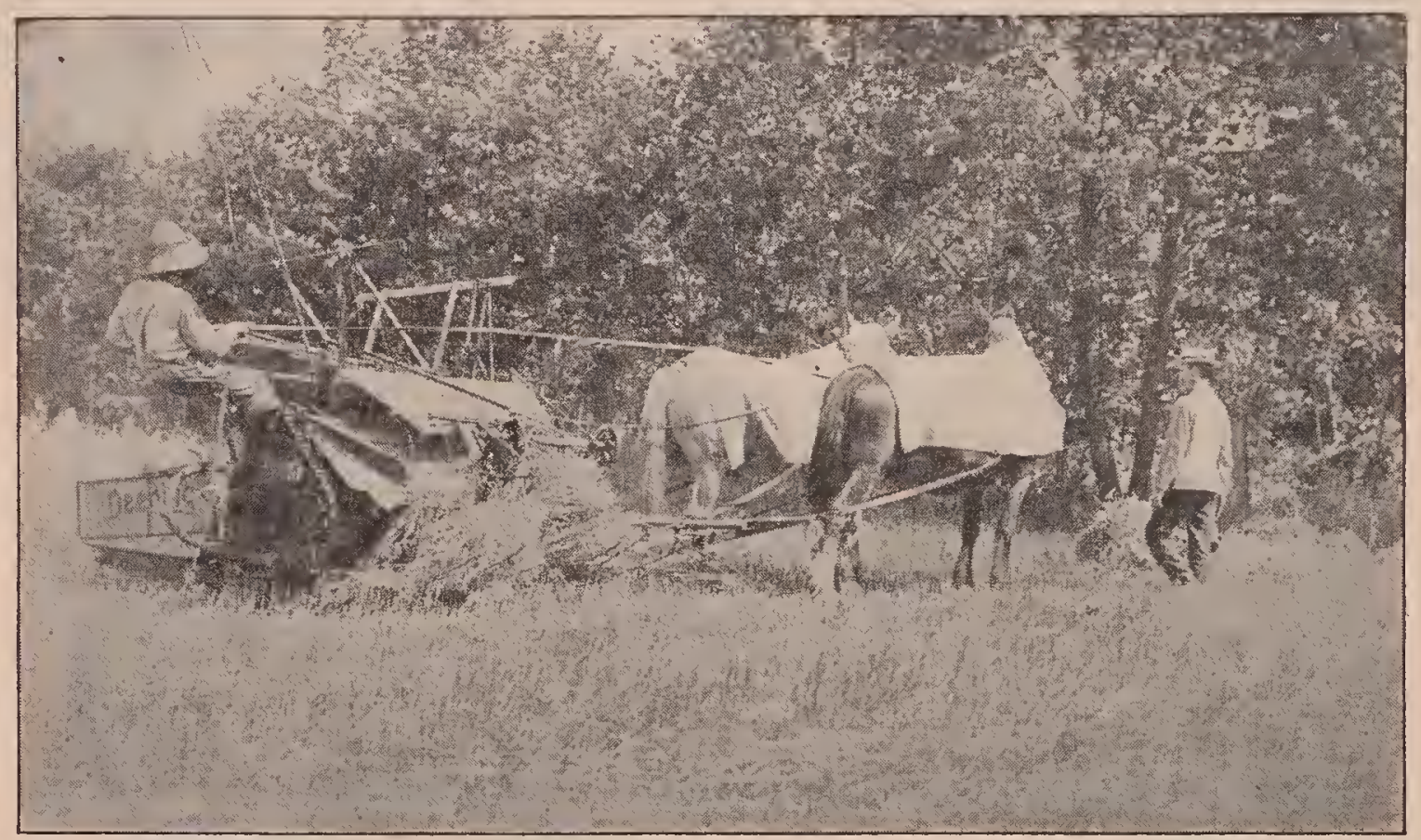

When the team was in the flight of the bees the smoker was ljeld in readiness should the hor'ses be stung.

It will now be in order to consider the more serious cases--those in which horses or cattle have been stung. If the beekeeper has been foolish enough to place hives near the highway or near his neighbor's line fence where he has loose stock, such beekeeper may have to pay pretty dearly for it before he gets thru. The remedy is prevention. He should always put his bees in the back yard, and not too close to a neighbor's line fence. He should be careful, also, to prevent robbing. He should see that there are no weak nuclei with entrances too large. As soon as the honey flow stops, he should contract the entrances of all the weaker colonies. If extracting is done after the honey flow, the inmates from their own doorsteps can not see moring objects in the immediate vicinity. When the space where the apiary is located is open, without shrubbery or trees to screen the lives, the bees are much crosser than when placed belind obstructing objects. The average backlot beekeeper will have much better bees to handle, and no trouble with neighbors, if he puts his hives among the bushes. If he has a high board fence, or a hedge of evergreens to shut off the little apiary from passing teams, pedestrians, or children that play in the next yard, the conditions will be much better. See BAckiot BeEKEEPING. 
WHAT TO DO WHEN THE BEES ATTACK NEIGHBOR'S HORSES.

But it sometimes happens that something must be done at once to avert an attack upon teams of horses working in fields adjoining a bee-yard. Te have one outyard located near a field where our neighbor's horses have been attacked by the bees on several occasions. We supplied our neiglbor with clover seed for this field; and when he came to cut the crop the horses would occasionally be stung while drawing the mower. In one case there came very near being a serious mixup, as the team nearly ran away with the mowing machine.

Two years later corn was planted in this same field. When the horses were cultivating up and down the rows they were attacked again by the bees, for they were going in great droves across this field to a patch of clover beyond. Notwithstanding we had a high board fence to raise the flight of the bees above the team when near our yard, there was more or less trouble. On one occasion the driver was stung pretty severely, and the lorses became unmanageable. Fortunately, the driver got them under control witlout any serious consequences.

Now, our neighbor is a kindly man; and when he telephoned what had happened we saw that something would have to be done. We told him to go to the harness-shop and secure some large horse-blanliets that would cover the necks and backs of the horses, and we would pay the bill. TVe then directed him to secure some large squares of mosquito netting and fold this around the horses' heads. In the meantime we supplied him with veils for himself and man.

When the next day came for cultivating, the blankets were put on and we went down to watch developments. We found that the blankets helped very materially, as they protected the horses from the onslaught of bees around their backs and necks where they could not brush or switch them off. Our neighbor did not think it was necessary to put the mosquito netting over their heads, as he said his horses did not mind bees on the face, as they could be brushed. off on the forelegs. With these large blankets the horses went up and down the rows with very little trouble.
We found upon investigation that the bees were not disposed to be cross, but in going to and from the fields in search of honey they were interrupted in their flight. The switching of the tails of the horses angered them, witl the result as stated.

In cases of this kind it is an advantage to have an experienced beeman, and also an experienced horseman, if the two can be combined in one person. We litpluened to bave just such a man in our employ, and sent him along around with the mower and reaper with a lighted smoker. If he found the bees were flying around the horses' heads, he used a little smoke and drove them away. It was not necessary for him to follow the machine clear around the field, but only along that side next to the flight of the bees.

But suppose the neighbor is unreasonable and ugly, and he brings suit for damages; or suppose that the bees are located in a city or village.

Do not move the bees if reasonable precaution has been used, but write at once to the author.

Suppose attorneys liave been retained. Any number of decisions have been lianded down to prove that bees are not a nuisance per se; that, when they are properly kept, and due precautions are used, they cannot be driven out of the corporation. There are several precedents from various courts. even from the Supreme Court of Arkansas. to show that bees have the right to be kept within a corporation like any live stock, so that any ordinance not in conformity with these decisions can be declared unconstitutional. Several ordinances declaring bees to be a nuisance have been repealed. See Laws Rejating to Bees.

Bees have been accused of spreading fire blight on fruit trees on the mistaken notion that in visiting the affected blossoms they carry the blight to healtlyy blossoms on other trees. There is now very definite proof that the bees are not guilty. See Fire Blight-Do Bees Carry It?

\section{BEES, DO THEY ATTACK FRUIT?} -Occasionally complaints have been made that bees will attack fruit; and to a casual observer, at least, they apparently do bite thru the skin and extract the juices until the specimen is shriveled up to a mere 
semblance of its former shape and size. However, careful investigation has slown repeatedly that bees never injure sound fruit, no matter how soft the skin nor how juicy and pulpy the contents within the skin.

'Lhe anthor has attended varions horticultural and pomological conventions, both state and national. Among the progressive fruit-growers and horticulturists there is a general acknowled ment that bees do not attack sound fruit; that the little harm they do to damaged fruit is compensated for a lundred times over by the indispensable service they perform in pollinating fruit blossoms early in the season when no other insects or means of pollination exist. The best fruit-grower's are now keeping a few colonies of bees in each of their orchards. Often they invite beekeepers to locate yards of bees either in the orchards or as near as it is practicable to put them.

Some year's ago, Prof. N. W. MeLain, then in the employ of the Department of Agriculture, Waslington, D. C., conducted an elaborate series of experiments in which he placed sound fruit, consisting of grapes, peaches, apricots, and the like, in hives containing bees that were broaglit to the

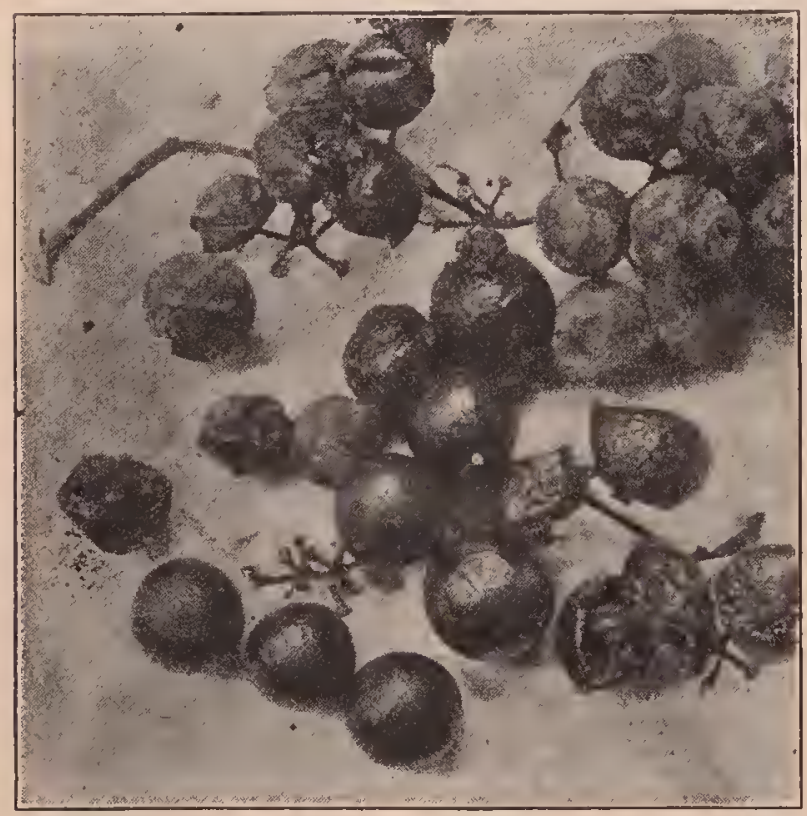

Grapes punctured by birds and despoiled by bees.

verge of starvation. This fruit was left in the lives day after day, but it was never once molested. Then he tried breaking some of the fruit, and in every case all such specimens were attarker by the bees and the juices sucked out until nothing but

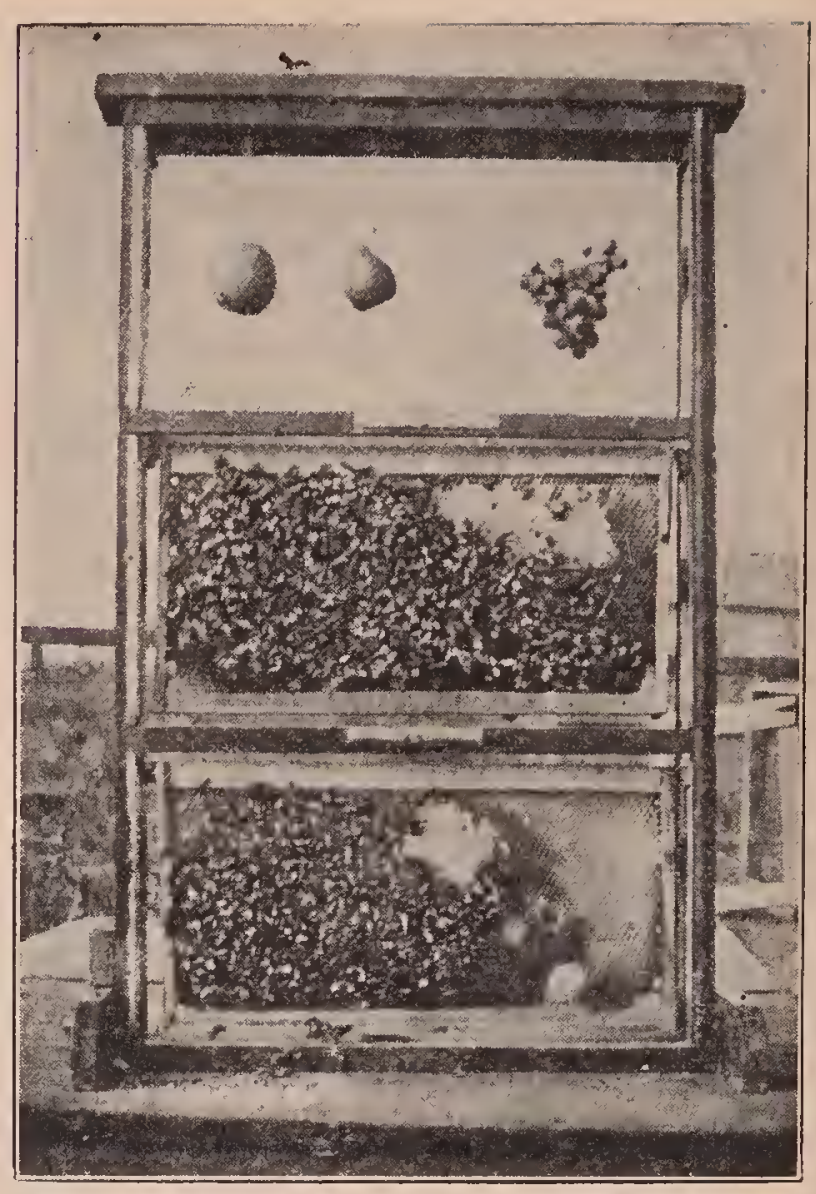

One of the exhibits of bees at the Grange Fair, in Wilmington, Del, held in September, 1908. A card in the hive read, "Bees do not injure sound fruit."

a dried skin and the stones or seeds were left.

Jears later, Prof. H. A. Surface, then econonic zoologist at Harrisburg, Pa., tried a similar experiment, but in no case did the bees attack sound fruit, altho they partook freely of that which he had broken.

At the Wilmington State Fair, lield in September, 1908, in Delaware, Joel Gilfillan of Newark, Del., liad on exlibition a three-story observation hive containing two combs of bees. In the third story were humg a peach, a pear, and a buncl of grapes. This hive was kept on exhibition during the entire fair where the general public could see it. As is shown, this fruit was never once visited by the hees. The general verdict of those who saw it, fruitmen and farmers alike, was that bees did not injure this fruit.

The publishers of this look lave larr, during the past 40 years, between three and four hundred rolonies located in a vineyard at their liome apiary. Notwitlstanding hundreds and hundreds of pounds 


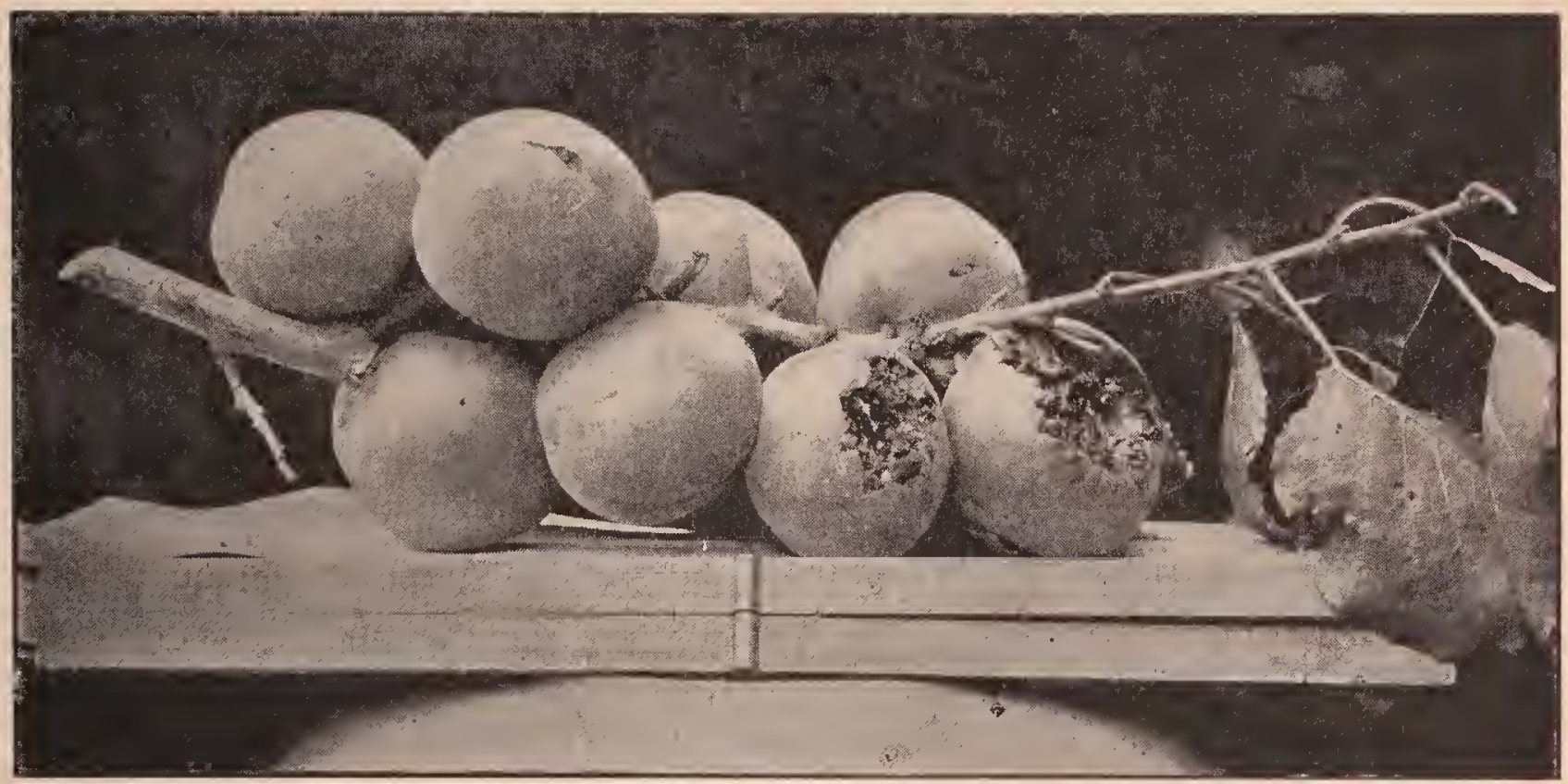

Apricots damaged by birds; fruits thus injured are sucked dry by bees, which store the juice as honey.

of grapes are raisel erery year, the buuches lianging within three or four feet of the entrance of the hives, the sound liuit is nerel injured; but, during a dearth of honey, a broken or otherwise bruised bunch of grapes will often be visited by a few bees.

But a casual observer might easily get the impression that bees not only suck damaged fruit dry, but actually puncture and eat the sound fruit. Some years ago a neighbor sent word that he would like to have us come to his vineyard and lie would give us indisputable proof that our bees were actually puncturing his grapes and sucking out the juice. We looked at the luscious bunclies as they were lianging down, and, sure enough, there were small needle-like holes in almost every grape that the bees rele working on. It looked like a clear cașe of "caught in the act" evidence against them. For the time being we were unable to offer a satisfactory explanation. We brought the matter to the attention of an old farmer who had been a beekeeper. for many years. Finally one norning he sent word to us that lie had found the culprit, and that if we would come down to his place early some morning he would point him out. This we dirl. He showed us a little biled, quick of fliglit, and almost never to be seen around the vines when any human being was present. This bird, about the size of a sparrow, sriped, and called the Cape May warbler (Dendroica tigrima), has a long sharp needle-like beak. It would alight on a bunch, and about as fast as one could count them, would puneture grape after grape. After his birdship has done his mischief he leaves, and then come the innocent bees during the later hours of the day and finish the work of destruction by sucking the juices and the prulp of the grape nutil it becomes a withered skin orer a few seeds. Thus the grapes were punctured by the birds during the early hours of the day; but the bees, coming on later, received all the blame for the mischief.

The Cape Mar warbler is not the only bild ruilty of puncturing grapes. There ale many other species of small birds tlat learn this habit, and among them may be named the erer present sparrow and the beautiful Baltimore oriole, the sweet singer that is sometimes called the swinging bird, from its habit of building its nest on some overhanging limb.

Some seasons the bird visitors are much more numerous than others. Several year's may pass before any complaint is made, and then the beekeeper will have angry people in the vicinity of his bees calling him up on the telephone, saying the bees are eating up their grapes. The thing to do is to call on each complainant, and prove that the birds are the ones that do the mischief in the first place, and that it 
is only by careful watching at intervals that they can be seen at their work.

In order to determine their presence the observer should go away from the grapevine about 50 or perhaps 100 feet. The early morning hours are the most farorable for catching the miscreant at work. The Cape May warbler is a shy little fellow, and he will not usually show himself if any one is near the vines. It is for tliat reason that the bird is seen on the grapes only at brief intervals; and the bees, working on the bunches all day, get the blame for all the damage.

CRACKED. AND PUNCTURED SKINS OF FRUIT.

Bees will not attack or bite thr'u the skin of sound fruit. From a physiological standpoint they are unable to do this, and they never do; but bees will suck the juices out of overripe grapes and other fruits, which, after a brief period of hot weather and frequent rains, develop so rapidly that their skins crack. Such fruit is already damaged, and would not keep very long. In the case of overripe grapes where the skins have cracked, bees will do damage. Such overripe fruit has a market value if sold at once. Before it is picked, the bees will visit the bunches and leave nothing but shriveled skins. In this particular case bees ruin the sale of fruit already damaged but having a market value if sold immediately.

Bees are often wrongly blamed on account of the work done by other insects equipped with cutting jaws, and by certain rarieties of birds. When the skin of any fruit is broken from any cause, the bees will suck out the juices, prorided no honey is coming from the blossoms.

Yellow-jackets are well equipped with cutting jaws. 'They are very fond of fruit. They will cut thru the skins, suck what juice they want, and, later on, the bees will visit the same punctures. The bees are, of course, more numerous, look like yellow-jackets, and are by the uninitiated given blame for all of the mischief-puneturing as well as sucking the skin dry.

Yellow-jackets 'are particularly numerous in the fall after a frost. They cut thru the skins of fruit unpicked; and the bees, because the frost has killed natural sources of nectar, will help themselves to fruit juice made available by the previous act of the yellow-jackets.

For further information regarding grape-puncturing birds, refer to bulletins by Dr. Merriam of the United States Department of Agriculture, Washington, D. C.

WHEN BEES MAY DAMAGE FRUIT.

But there are times when bees are a nuisance, and it is then that their owner should compromise; or, better still, seek means to avoid trouble in the first place. In the fruit-drying ranches of California, apricots and peaches are cut up into small pieces and laid upon trays exposed to the sun's rays. If there is a dearth of honey at this time, and a large number of bees in the locality, this fruit may be attacked. The bees may visit it in such large numbers that they suck out the juices, learing nothing but the shriveled form of the fruit. The property is, of course, damagerl, and its sale ruined. Before anything of this kind can happen, the beekeeper should move his whole yard to a point three or four miles distant from any fruit-dlyving operations. Failing to do so the fruitgrower, if the bees caused trouble, might enter suit for damages, and possibly recover the value of his crop.

Years ago we had trouble witl a cidermaker. He clained that our bees would lick up the cider from the press as fast as he could make it. We easily adjusted this difficulty by screening his building with mosquito netting.

In every case of this sort the owner of bees should avoid trouble. In the case of the fruit-drying ranches and the cider mills, the beekeeper had better err on the safe side by avoiding suit for damages, because no lawyers would be able to give much assistance where it was clearly proven that the bees were doing an actual damage.

BEES EXONERATED BY A JURY.

In 1900, trouble arose at Amity, N. Y., between two brothers named Utter. One was a beekeeper and the other a fruitgrower. The latter averred that the former's bees punctured his peaches, and, in consequence of the alleged damage, he claimed he was unable to raise any fruit. There had not been very good feeling be- 
tween the brother's for years. The fruitgrower brought suit against the beekeeper, and the case was tried on Dec. 17, 18, and 19, 1899, at Goshen. There was no lack of legal talent on either side. The case was a very hard-fought one from beginning to end. Among some thirty odd witnesses examined, the Government expert, Frank Benton, then of the United States Department of Agriculture, Washington, D. C., gave his testimony to the effect that bees never puncture sound fruit; that it is practically impossible for them to do so, owing to the fact that they have no cutting jaws like those found in the wasp and other insects of that character. He also showed that wasps and birds will, under some conditions, puncture fruit; that these minute holes they make will, during a dearth of honey, be visited by bees. Other expert testimony was offered, nearly all of which exonerated the bees. After all the evidence was in and the arguments were made, the jury returned a verdict for the defendant.

For further particulars regarding this, the reader is referred to the publishers of this work.

In case trouble arises, the owner of the bees will do well to read BEes as a NUISANCE, and also the other subject found in its alphabetical order, Laws Relating to BeEs.

\section{BEES, CROSS.-See ANGER OF BEES.}

\section{BEES, CROSSES OF.-See HyBRIDS.}

BEES, HANDLING.-See A $\mathrm{B} C$ OF Befkeeping, Manipulation of Colonies, and HoNey Exhibits.

BEES ON SHARES.-In some localities, notably in California, Colorado, and the great West, bees are often kept on shares. While this methor of doing business has often been condurted quite successfully and satisfactorily to both parties, yet many disputes have arisen, perhaps because there was a lack of contract; or, if there was one, there was nothing in it to cover the point in dispute.

The following form of contract was very carefully drawn by an attorney, and it is hoped it will meet every condition.

\section{ARTICLES OF AGREEMENT.}

This agreement, made and entered into at $\longrightarrow$, this day - of $-19-$, by and between - - of - …, party of the first part, and hereinafter called the owner, and of - - , party of the second part, and hereinafter called the employee,

Witnesseth: First, that said owner has agreed, and in consideration of the covenants and agreements herein contained and to be performed by said employee, thes hereby agree to provide a good location for keeping bees, at or near —, and furnish and put thereon, on or before the - day of $-19-$, not less than - colonies of healthy bees, and then and thereafter at such times as needed during the continuance of this contract, to provide and furnish, at his own cost and expense, all hives, tools, implements, machinery, and buildings necessary to enable said employee to carry on successfully the business of producing and securing honey and wax from said bees; and further to pay one-half of the cost and expense of all sections, cans, bottles, shipping cases, and packages that may be required to put the honey and wax into marketable shape; and in case it shell be necessary to feed said bees, to provide and furnish feeders and sugar for making the syrup; and said owner further agrees to give and deliver on the said premises, to said employee, as and for his compensation for labor done and provided by him in caring for said bees and securing honey and wax, the full one-half of all marketable honey and wax produced and secured from said bees.

Second: In consideration of the above covenants and agreements, the said employee, hereby agrees to enter the employ of said owner on said —_ day of 19-, and at once care for sair bees in a proper manner; do, perform, and provide all labor necessary to carry on successfully the business of producing and securing honey and wax ready for market; pay one-half the cost and expense of all sections, cans, bottles, shipping cases, and packages that may be required to put the honey and wax into marketable shape; feed the bees, when neeessary that they shall be fed, and deliver on the premises to the said owner the full onehalf of the marketable honey and wax produced and secured from said bees. and to accept the remaining half as and for his full compensation for labor done and provided by him in the care of said bees and the production and securing of honey and wax.

Provided, and it is mutually agreed and understood by and between the parties hereto, that said employee shall double up all of said hives at the close of the season or leave them reasonably strong and well supplied with stores and prepared for winter; and if any of said colonies of bees are lost thru the carelessness or negligence of said employee, said owner may recover from said employee as damages an amount not greater than one-half what it would cost to replace said bees and queens; all 
increase of swarms (artificial or natural) to belong to said owner. It is further mutually agreed and understood that in case no honey is secured, or the amount runs below ten (10) pounds per colony, said owner shall pay to said employee, as and for his compensation for all labor done and provided by him on and about said bees, an amount not exceeding-cents per hour for each and every hour of labor so performed, and provided by said employee on and about said bees, and in such case all honey to belong to said owner.

Signed in duplicate by sạid parties, the day and year first above written.

Signed in presence of

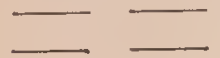

The foregoing complises the essential features of a contract; but local conditions may render it necessary to make some modifications.

The contract as drawn would be very favorable to the owner of bees, provided he could always have a competent man and a good season. If, for example, he liad 500 colonies, and secured an arerage of 100 pounds per hive, he might make something like 100 per cent oll his investment. But if the emplovee is incompetent, or not strictly honest, or if the season wele poor or a failure, the owner might actually lose money. The contract, as drawn, assumes that the average employee will not get as much out of the bees as the owner. Moreorer, if the employee is a little careless, foul brood might get started among all the bees. Eren if the season were good, the cost of treating the entire apiary, and the reduction in crop by reason of the ravages of disease, miglit likewise canse an entire failure. On the other hand, the employee, even if he liad done his best, might lose ont also, if the season were a failure. For that reason the last clause in the contract is inserted as a matter of fairness to him.

If no honey should be secured, he has performed his part of the contract in good faith, and, moreover, has improved the apiary-perliaps increased it-so that it will be in better condition the following year for a honey crop. For this betterment it is no more than right that the owner should pay his man a reasonable sum, whatever amount may be agreed on: or, if preferred, a certain number of colonies. One can readily see that, in case the honey season was an absolute failure, the employee would suffer a total loss except for a provision of this kind, and the owner would still have his bees, the increase, his implements, and everything necessary to carry on the business for another season.

By the above contract it is to the interest of both parties to keep down increase. The employee must know, if he is a practical beekeeper, that, the greater the increase, the less the honey; and he will, therefore, bend all his efforts and skill to keep the colonies in the best condition to obtain a crop of honey.

Keeping bees on shares is practiced quite extensively in Colorado and California. It very often happens that a beekeeper lately arrived from the East desires to try a locality to determine whether it will be suited to his liealth, and whether or not he can make the keeping of bees a success. He accordingly finds a beekeeper whose othel business leads hini to desire some one competent to manage his bees for him. But where one is well settled in a locality, and has the means whereby he can purchase the bees, he should do so.

The business of keeping bees on shares luas not always been an unqualified success; and where one can buy bees outright, paying for them out of his earnings, he would better do so. But the owner of the bees should, of course, be secured by a chattel mortgage until the last payment is made.

BEES, STINGLESS.--Their habitat extends from the boundary between the United States and Mexico down to Buenos Aires in Argentina, embracing an area of $8,000,000$ square miles. One comparatively unimportant species inlabits most of the Trest India islands. There are a few species in Asia and Africa.

By entomologists these bees are nsually classed under two great genera-Melipona and Trigona; but some naturalists are disposed to add another, Tetragona. There is an extraordinary variety of these bees, which is supposed to embrace at least 100 species, whereas there are not more than 8 speries of Apis. The variation in size is also great, for some are no larger than a mosquito, while others are considerably larger than the hive bee. A number of 
naturalists lave studied them with a view to the proper classification and arrangement by species.

There is an equal variation in the number of bees per colony, for some consist of only a few (100) individuals while others are supposed to contain not less than 100,000 bees. and Koster, in his 'Travels in Brazil, carefully mentions them. Spanish writers on Central America casually noticed them in the 16tl century; but no European seems to have been interested enough in them to make a comprehensive study of their life history and habits. The work was left for the twentietl-century naturalists. Geoffrey

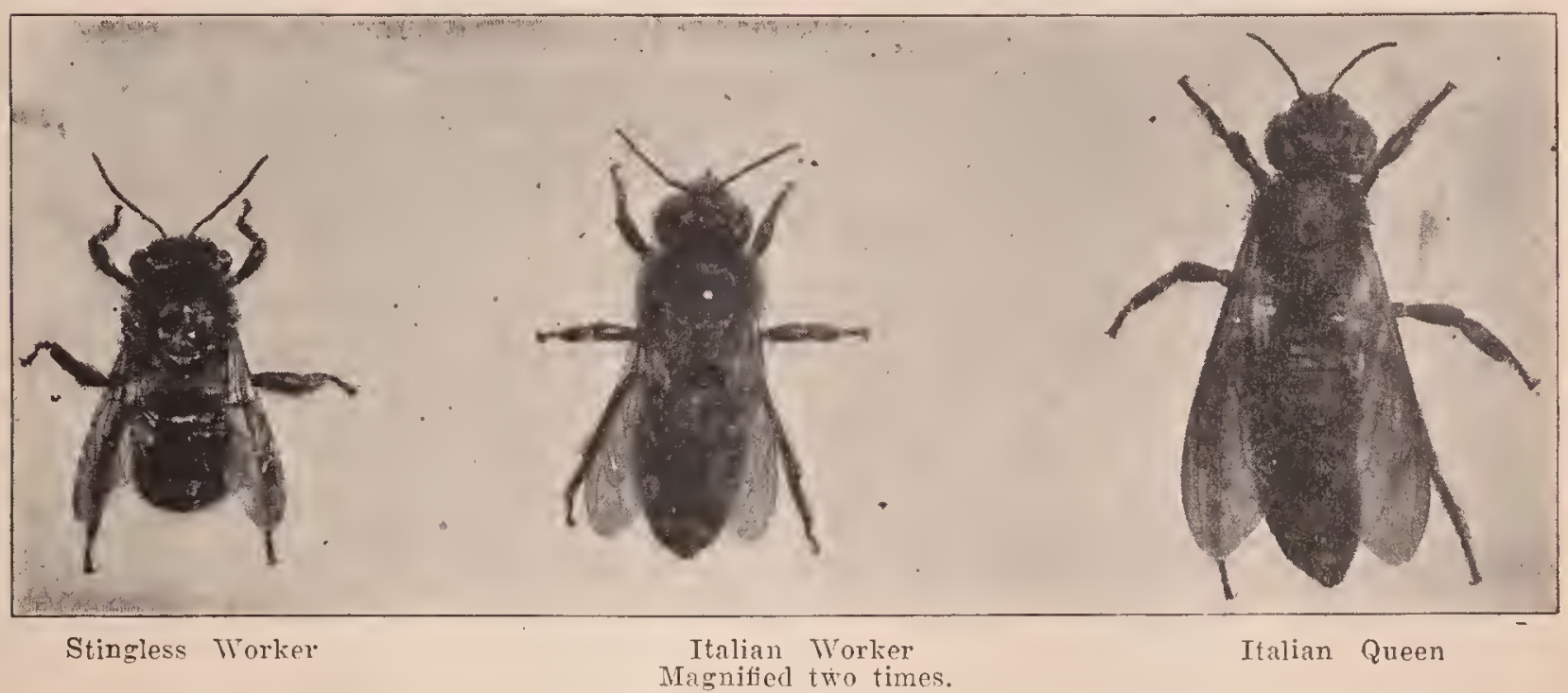

Some build only small nests, not much larger than an orange; others construct a home as large as an ordinary flour-barrel. Some build in a lole in the ground; others in the open air, as wasps and hornets do, while quite a number build their nests in the hollows of forest trees.

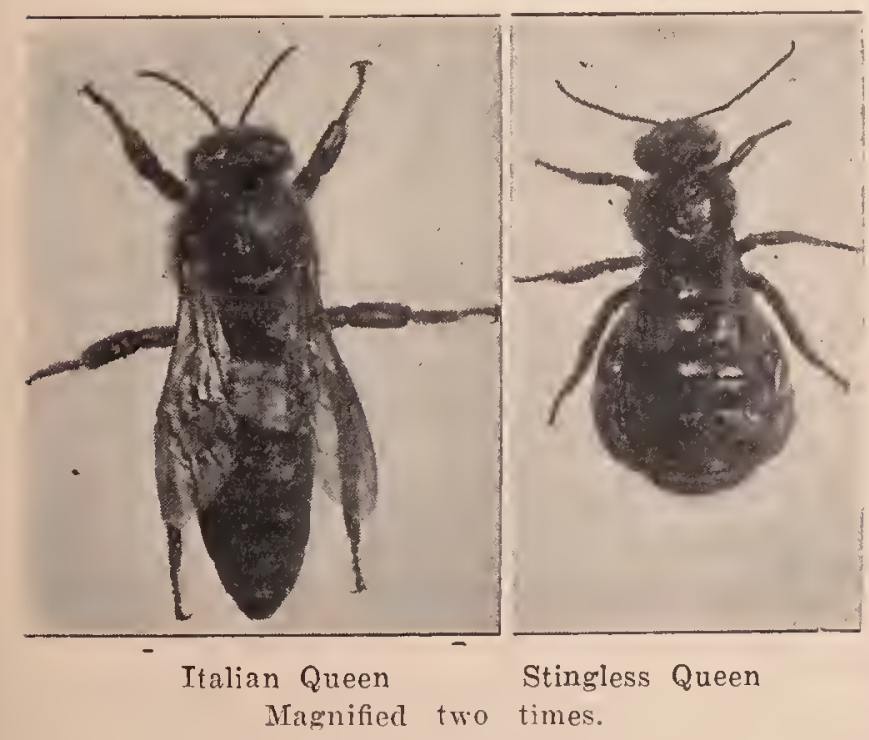

Early travelers in Sonth and Central America did not fail to notice the stingless. bees, and quite freqnently referred to them. Capt. Basil Hall, in the 18th century, noticed apiaries of them in Peru;
St. Hilaire, a naturalist-explorer, did something to awaken interest by his now classical observations on honey-gatlering wasps of Paraguay, of which he furnished a complete account in 1825 (Paris). Azara, a similar explorer, also called attention to them in his travel thru Paraguay. He describes a species twice as large as Apis mellifica.

Other explorers have mentioned them from time to time, but nothing of real value was elicited until lately. Their study has now been taken up in earnest. White men have been inclined to dismiss them as worthless for practical purposes; but the natives of South America are certainly not of that opinion. On the contrary, they regard them as superior to the "stinging" fly" of the white man. In Southern Mexico, Central America, and South America, they are quite frequently kept in a domesticated state by the native inhabitantsthat is to say, they have them in hollow logs which have been brought from the forests. These "hives" are generally hung" up by ropes around their dwellings to protect the bees from their chief enemy, the lizard. The logs are robbed at stater intervals, the keeper being well satisfied if he can secure a gallon of honey per hive 


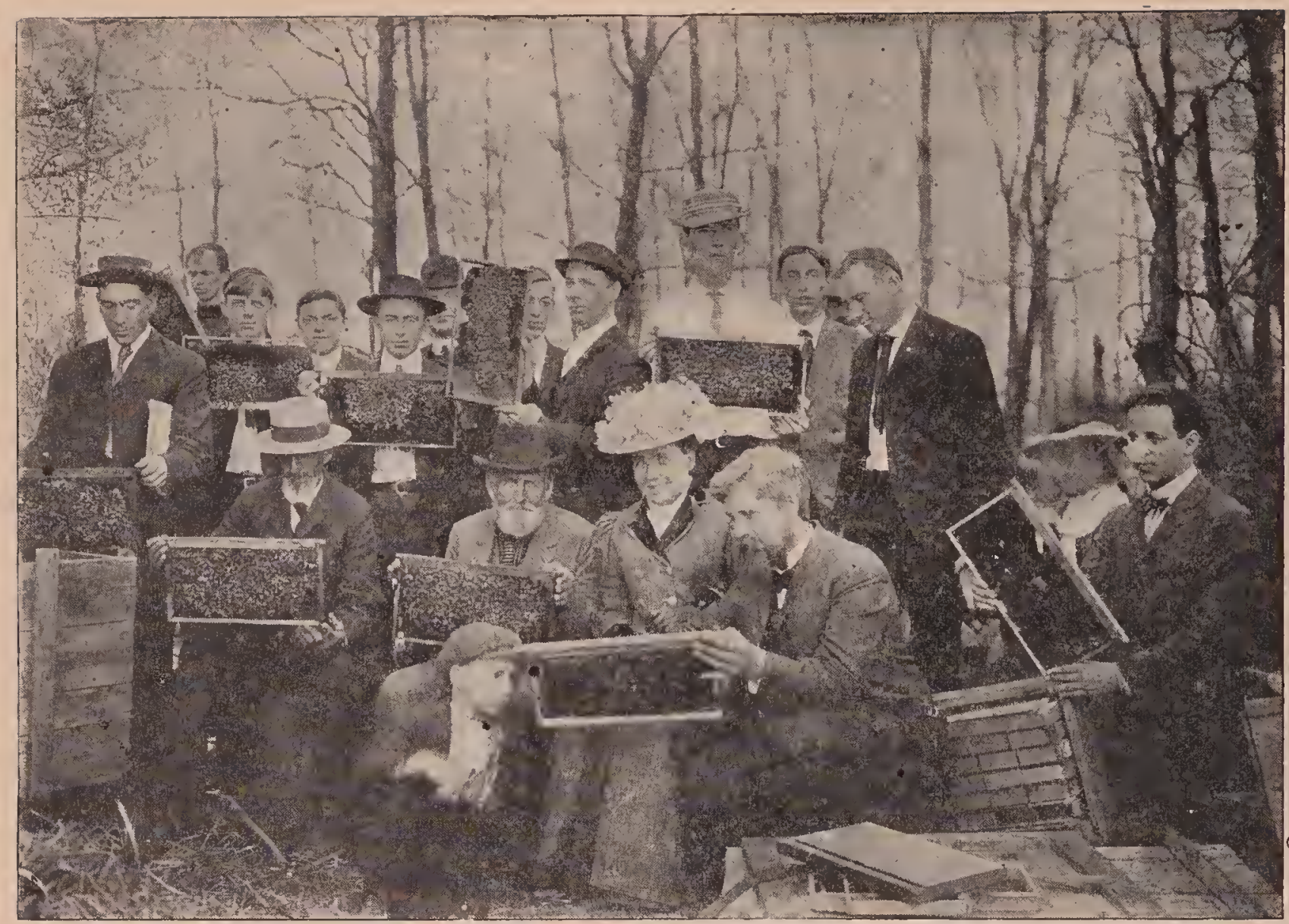

Prof. H. A. Surface, Zoologist, at Harrishur. Pa., with his beginner's' class in beekeping.

at the robbing, depending somewhat on the species used for domestication.

Apparently no effort has ever been made to intent a hive suitable to their wants. It is noticeable that the natives use only those species whose homes are made in lollow trees, no effort being made to utilize the many other species whose nests are made in holes in the ground or on tree branches.

The quality of the honey and wax varies very much, some of it being quite good and some quite the opposite. The wax is apt to be mixed with propolis to a great extent; but at least one species inhabiting the upper tributaries of the Orinoco, in Colombia, furnishes a desirable wax, which has been frequently sold in this country.

While the stingless bees cannot sting they bite and worry in a way to surpass bees possessed of a sting. At the Philadelphija field-day meeting at which a thousand beekeepers were present, in June, 1906, two colonies of a large species of stingless bee were exhibited. A hive of them was torn apart and opened for inspection. Did those stingless bees take such intrusion without any objections?
Not at all. They attacked their despoiler's in a way they will not soon forget. They would bite, grasp the hair and eyelashes, twist and pull, and even crawl into the ears and noses of their tormentors. So vicious was their onslaught that they drove one man, who had a hand in breaking up their lome, from the scene of action. While the pain of their bite is infinitesimal, yet the high-note hissing sound, getting into the hair, pulling at the eyes and eyelashes, and crawling into the nostrils and ears, almost make one crazy.

It is fair to state that stingless bees do not offer such attack unless provoked to fury; ordinarily they can be handled without any protection whatever.

BEGINNING WITH BEES.-The beginner should, first of all, read the A B C. OF BeEkEEPING, the initial article of this work. He should also when possible visit some well-known beekeeper. He will then find that he will be able to understand the articles and appliances in this work much more readily. If he can afford it, it would be well for him even to go some distance 


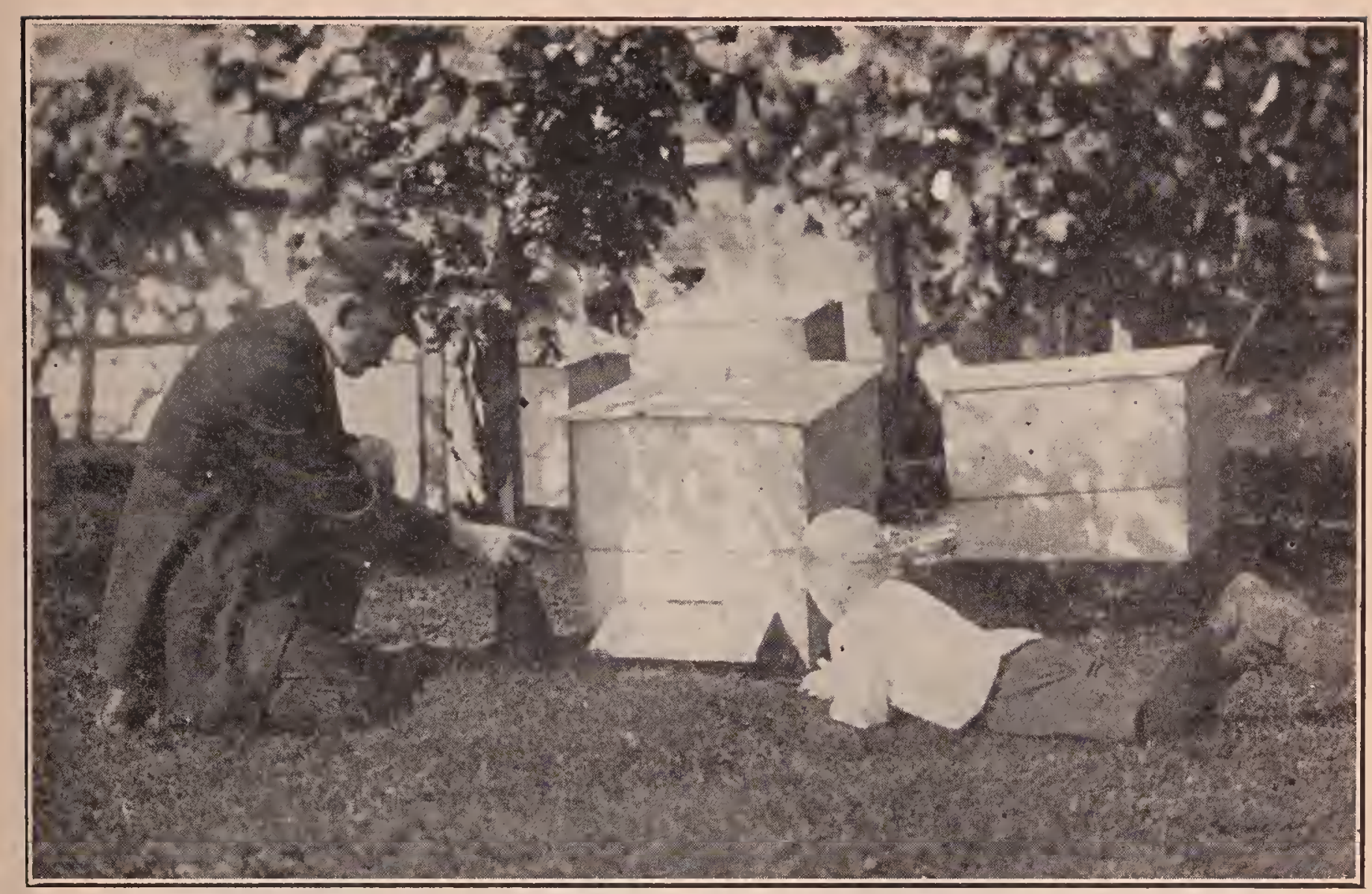

Dad and sonny watching their bees work for nothing and board themselves. Both are thinking of the honey they are going to take from those bees.

to see some progressive beekeeper, and spend a whole day where he will be able to pick up tricks of the trade, and a fund of information that might take him weeks or months to get out of textbooks. Such a beekeeper could very easily illustrate the proper manner of opening a hive and handling the frames - in short, make a practical demonstration of many of the manipulations here explained. If there is no beekeeper he can visit, he should send to his nearest dealer and get a two- or threeframe nucleus with a queen. Let him follow carefully the directions on the outside of the shipping-box; then, with the bees before him, read and study his $A \mathrm{~B} C$. Having seen the bees and learned bow to open a hive, what next?

The importance of a small beginning with as little expense as possible cannot be urged too strongly, for nothing is more discouraging after having plunged into the business extensively than to lose a large nortion of the bees, eitler thru bad wintering or from some other cause-all for the want of a little practical experience, or even a theoretical knowledge. Many a per- son has met with disaster from starting out with bees on altogether too large a scale. Sometimes one is offered a bargain of 50 or 100 colonies including hives, bees. implements, smoker's, etc., and the temptation becomes strong to buy. He had better not invest unless he has read the several articles indicated at the close of the FoneWORD at the beginning.

After investing $\$ 100.00$, one should put no more into the business until the bees bring in some returns. In other words, the bees should be made to pay their way. It is very easy to put good money into the renture and get no returns; because beekeeping, perhaps as much as any business, depends greatly upon weather conditions. For this reason it is not advisable for any beginner to rely on bees as a sole means of livelihood. True it is that there are many beekeeping specialists; but they are men who have gradually grown into the business, and, as a general rule, have an especially farorable location, keeping from 200 to 1,000 or more colonies.

The keeping of bees is generally more successfully carried on in connection with 


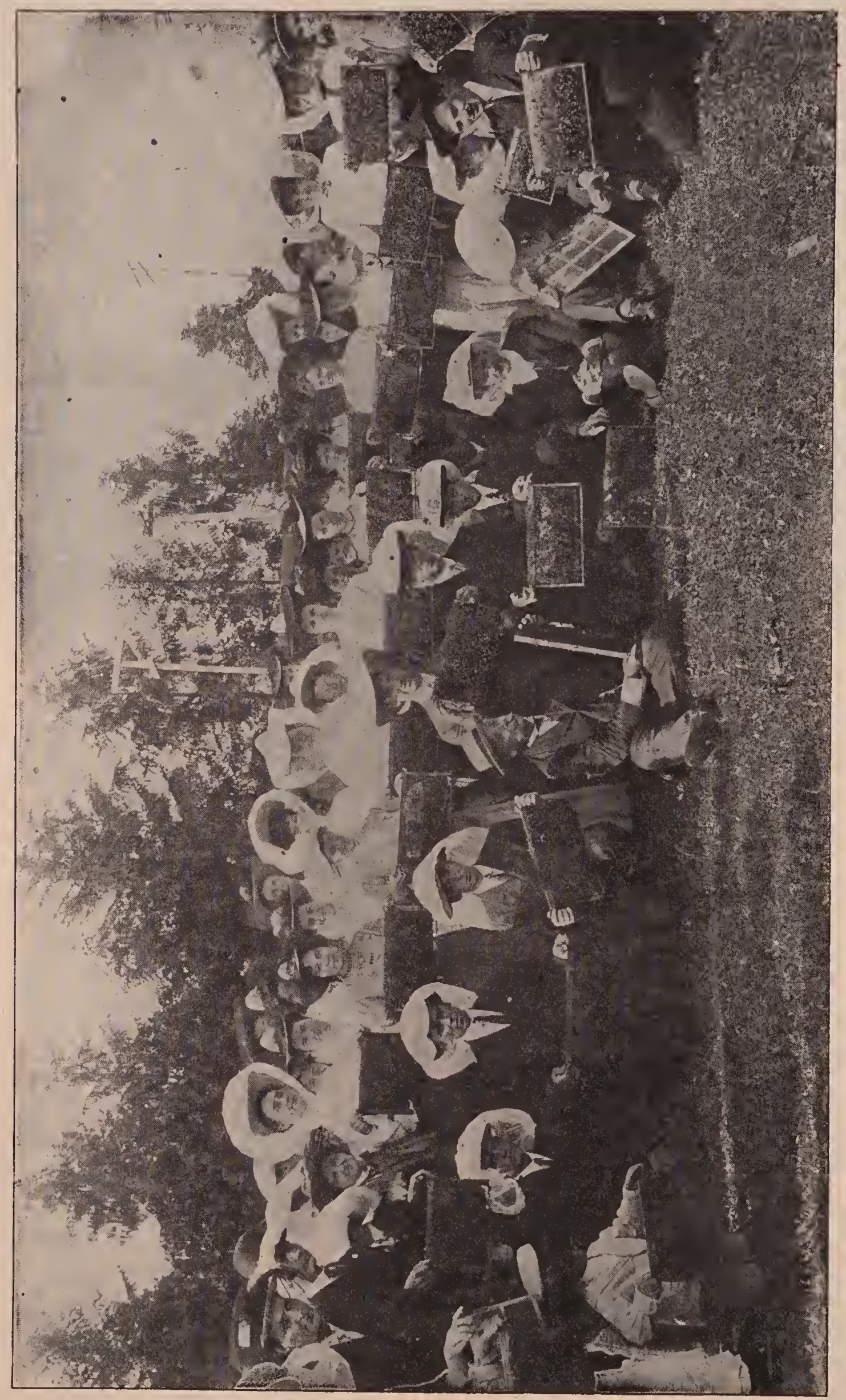

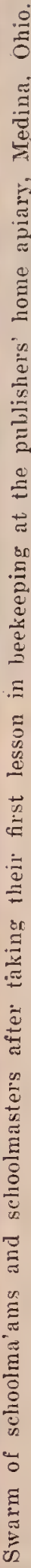


some other line of business. (See BeEs and Fruit-growing; also Bees and PoulTRY.) Many a professional man desires some sort of light recreation, and a few bees will afford him just the diversion he needs. Farmers, fruit-growers, or horticulturists may keep from 50 to 100 colonies without greatly interfering with any other work; and nearly erery one, as explained under Aprary, can keep a few colonies in his back yard. Ten or twenty colonies will be almost certain to yield a much larger revenue, per colony, than ten times that number. See BAcklot Beekeeping.

\section{HOW AND WHERE TO BUY BEES.}

In practically all of the northern States, and in all of the western States, bees are kept almost entirely in movable-frame speeted, and whether he can show a certificate to that effect, telling when the bees were examined. Even then it will be well, before closing the contract, to have it understood that the seller guarantees the bees to be free from disease of any kind, and to replace at his own cost any that, within ten days from purchase, show disease.

Swarms of bees during the swarming season can often be purchased of farmer beekeepers for from 50 cents to $\$ 1.00$ per pound. $\Lambda$ medium swarm will weigh about five pounds and a large one eight or nine pounds. These, if hived on frames of comb foundation, would not calry bee disease even from a yard or colony containing foul brood. (See Foul Brood.) Where bees can be purchased in this form locally,

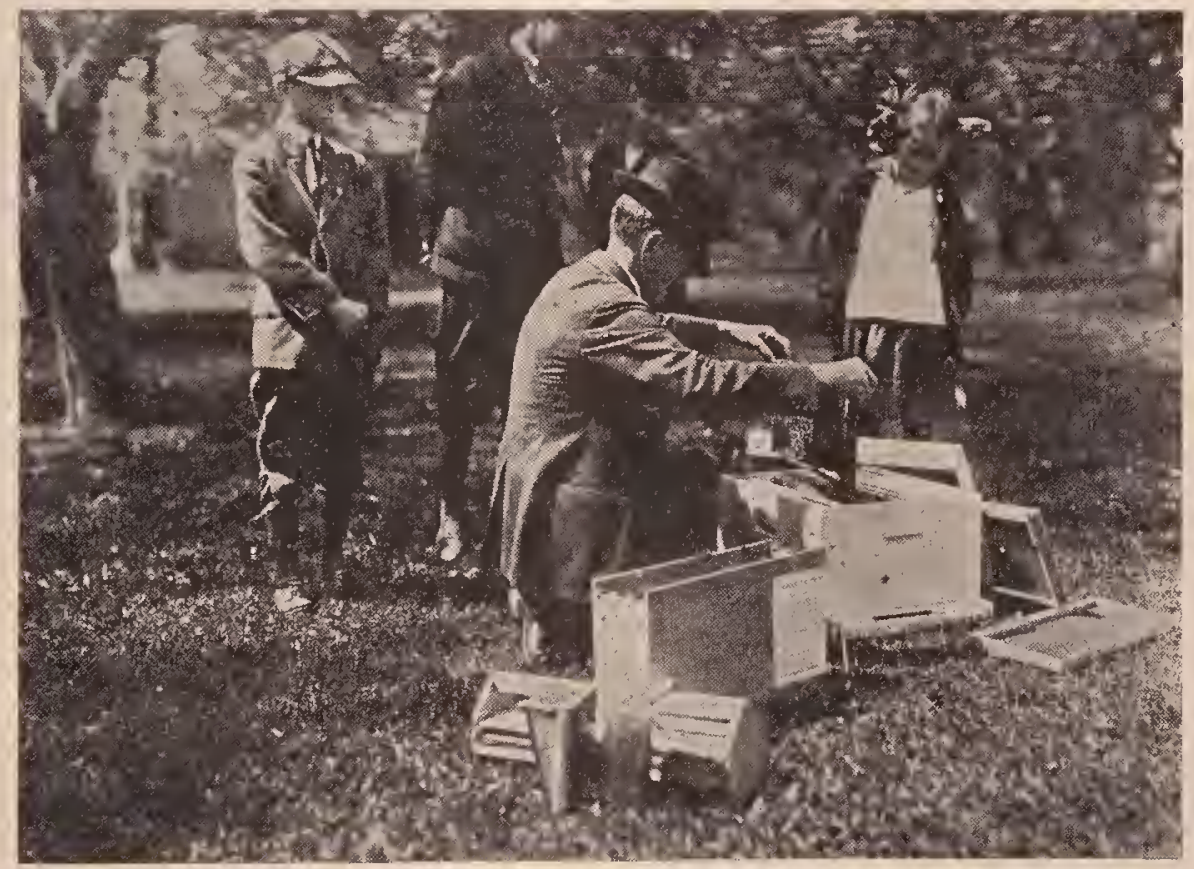

Father's new pets. The whole family is interested when the beginner's outfit (bees and all) arrives and is being set up.

lives of some sort. Were it not for the danger of contracting bee disease it would be advisable for the beginner to buy two colonies from some local beekeeper. If he can be assured that the latter has no disease, this is the thing to do. In some of the southern States black bees in box hives ('an be furnished at very reasonable rates. As' a l'ule, these bees are free from disease. In some States the owner of bees will not be able to sell then without a permit from the State inspector: It would be adrisable. therefore, before purchasing, to ask Mrr. Bcekeeper whether his bees have been in- at say, 50 cents per pound, they would be a good investment. Swarms at even a dollar or a dollar and a half a pound would pay if they can be purchased at a time when there will be a couple of weeks of honey flow ahead. They would then nearly pay for themselves the first season.

It would be well to hive them the same as package or combless bees obtained from the South. These will be mentioned ful'ther on.

As a rule, it will be much sal ele for the beyinner to buy of some reputable dealer who makes a business of furnishing first- 
class bees that are under State inspection. A list of the reputable dealer's f urnishi $n g$ good bees can be obtained by consulting leading bee journals.

Early in the season the average beg inner will do better to get a full col-

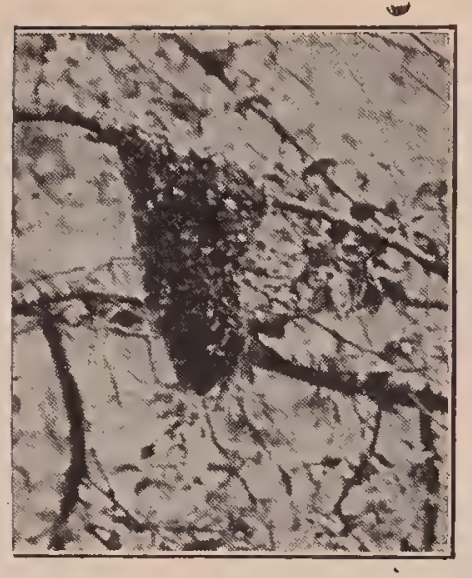

If you buy a swarm from some near-by beekeeper don't get a little one like this with only about a pint and a half of bees.

ony or a nucleus of two or three frames of brood and bees than he will to buy a package of combless bees, unless he secures them in the Root improved cage. By "nucleus"

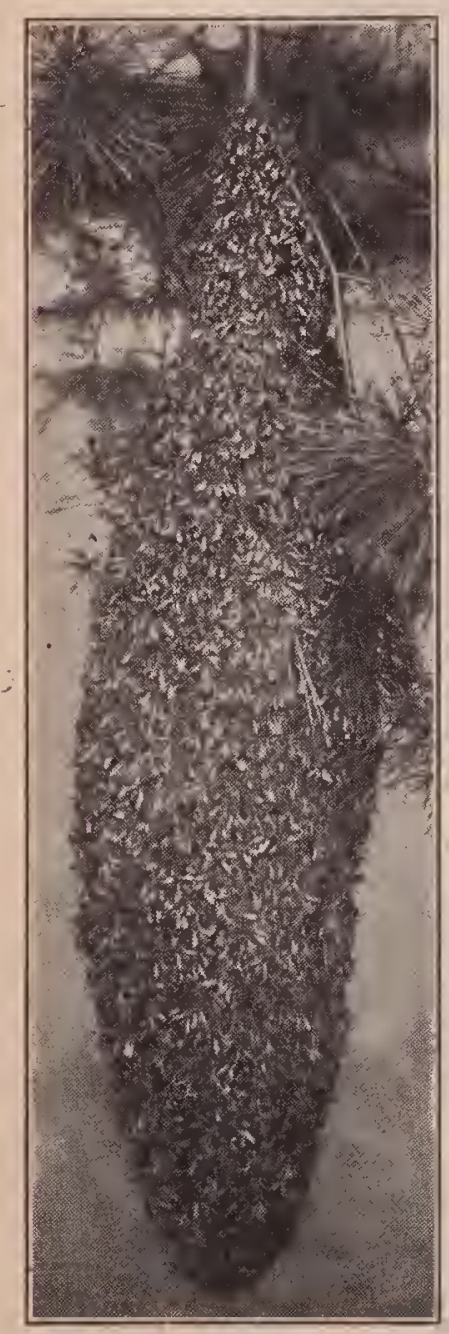

B u y ing a good-sized swarm fiom a near-by beekeeper is the best way to make a start. One is enough to begin with. is meant a small colony of one or two combs of bees and brood, including a $q$ u e e n. The usual package of combless bees sent out by the dealers consists of a wire cage containing one, two, or three pounds of bees and a queen, without combs. With either' form of shipment, one must have on hand hives ready to receive the bees. $\Lambda$ package of five hives can be bought in the flat from the nearest dealer, a $\mathrm{n} \mathrm{d}$ sometimes from the one wh o furnishes the bees. These should be put together a $\mathrm{n} d$ nailed, and the hives painted before the bees arrive. The hive or hives should then be placed in some permanent spot in the garden or in the back yard, but not near a neighbor's line fence. (See APIARY and BACKLOT BEEKEEPING for particular's on how and where to place the hives.) If nuclei are purchased they can be placed in hives without difficulty. A little smoke (see SMOKERS) should be blown over the tops of the frames before the wire screen is removed. If by an oversight a smoker was not included with the hives, ignite a roll of paper, or, better, some old rags. and then blow the smoke over the top of the wire screen. (See A B C of BEEKEEPING, subhead MANIPULATING A COLONY OF BeEs; aiso Manipulation of Colonies of

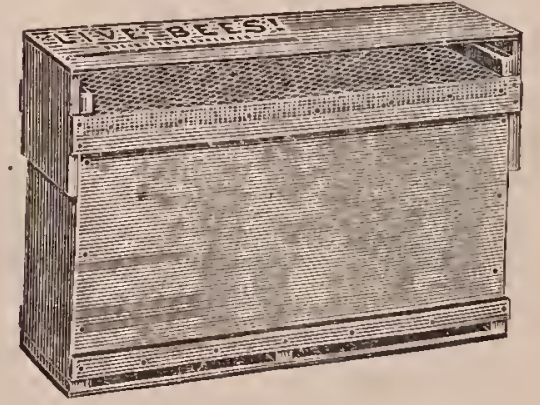

Three-frame nucleus shipping box.

BeEs further on.) After smoke has been applied, the frames may then be lifted out and set in the center of one of the hives. The entrance of the hive should be contracted to the smallest point possible.

Bees without combs can be bought for less money, and the three-pound package of bees will make a force which, if bought in the spring, would have a reasonable chance to produce a crop of honey the first season, while the three-frame nucleus would hardly be able to build up to more than a colony, and perhaps get a very little surplus. A five-frame nucleus would be about equivalent to three pounds of bees.

Bees without combs will not carry brood diseases. No matter who the dealer is, one could be reasouably sure of getting stock which, when hived on frames of foundation or clean combs, would carry no disease. In some States there are laws against the transmission of colonies or nuclei containing combs unless they carry a certificate that they have been inspected in the State whence they came. But pack- 
agre bees-that is, bees without combs-can be sent anywhere.

Right here it would be well to emphasize again that combless bees especially should never be ordered unless hives containing frames of foundation( better full sheets) are all ready to receive them. 'To a less extent this applies also in the case of nuclei.

Assuming that the hives are in readiness, one can order at least from one to three pounds of bees to the package. There should be a queen in each package, unless the bees are for the purpose of strengthening weak colonies. (See Uniming.) A single pound of bees, if ordered early in the spring, could build up to a full colony; but, if one desires to get the honey the

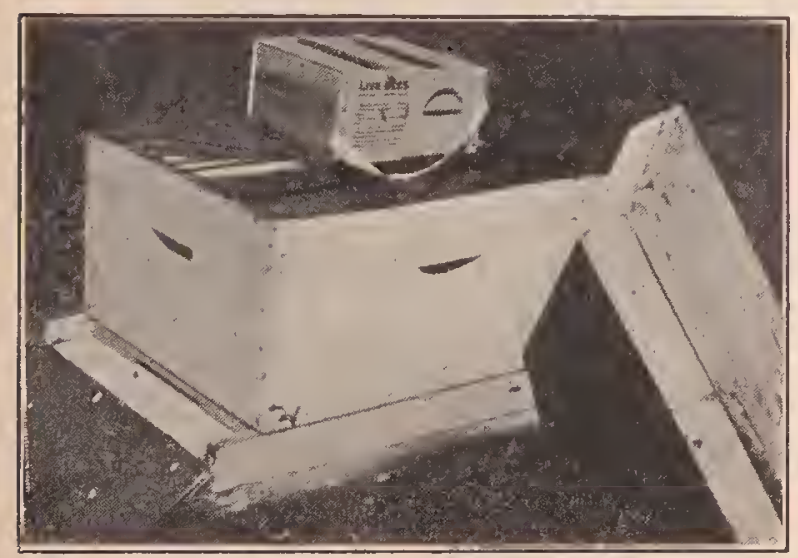

Buying bees by the pound is a good way to start, provided rou don't get too small a package. Cut the wire clotli from one side of the cage and lay this open side flat on the frames. Put on an empty super, then the cover, and let the bees work their way down into the hive.

first season, the bees should be ordered early, and there sliould be at least two pounds, or better, three.

Package bees are liable to cause the beginner trouble if hived on frames of foundation during the middle hours of the day. The strange surroundings and the newness of the live sometimes cause the bees to swarm out, so it is advisable to use perforated zinc or excluders over the entrances for the first two or three days or until the bees get quieted down. (See Drones.) In case they should swarm out the excluder holds the queen in the live, and, of course, if they swarm out the bees will come back to the queen. See Swarming.

A very much better plan, after putting the bees in the prepared hive, is to set the whole in a dark cellar, on the cellar floor,

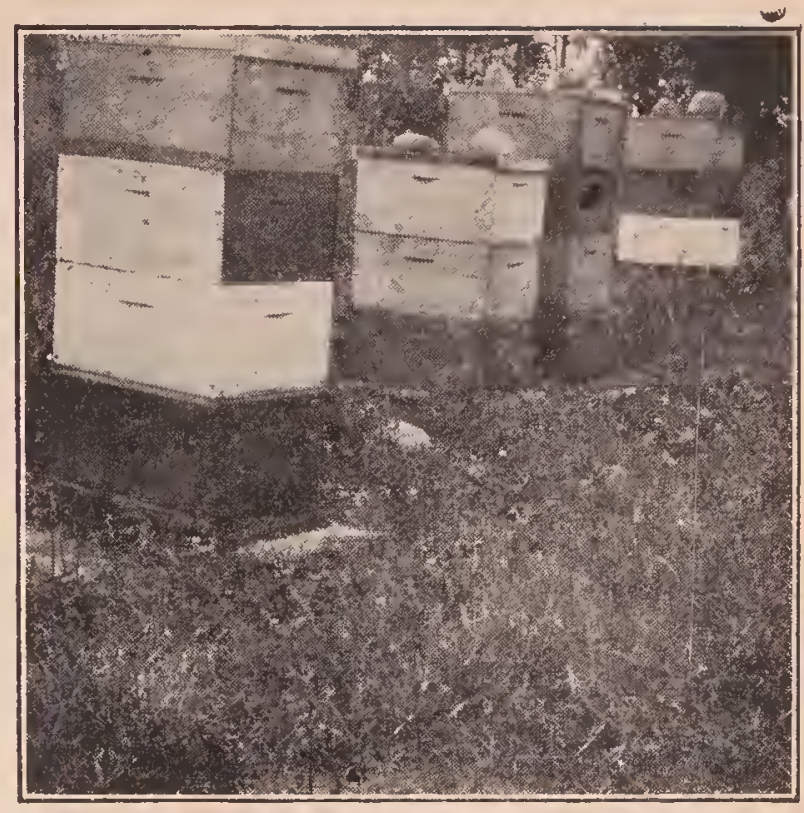

The picture shows a row of hives, the colonies of which came from two-pound packages received from the South, and which, according to David Running, held their own against bees that wintered in the cellar under the most favorable conditions.

where it is cool, and keep it there for several days. At the end of that time the hive can be set outdoors on its permanent stand. This should be done at night rather than in the day.

The bees when set outdoors have in the meantime become accustomed to their new

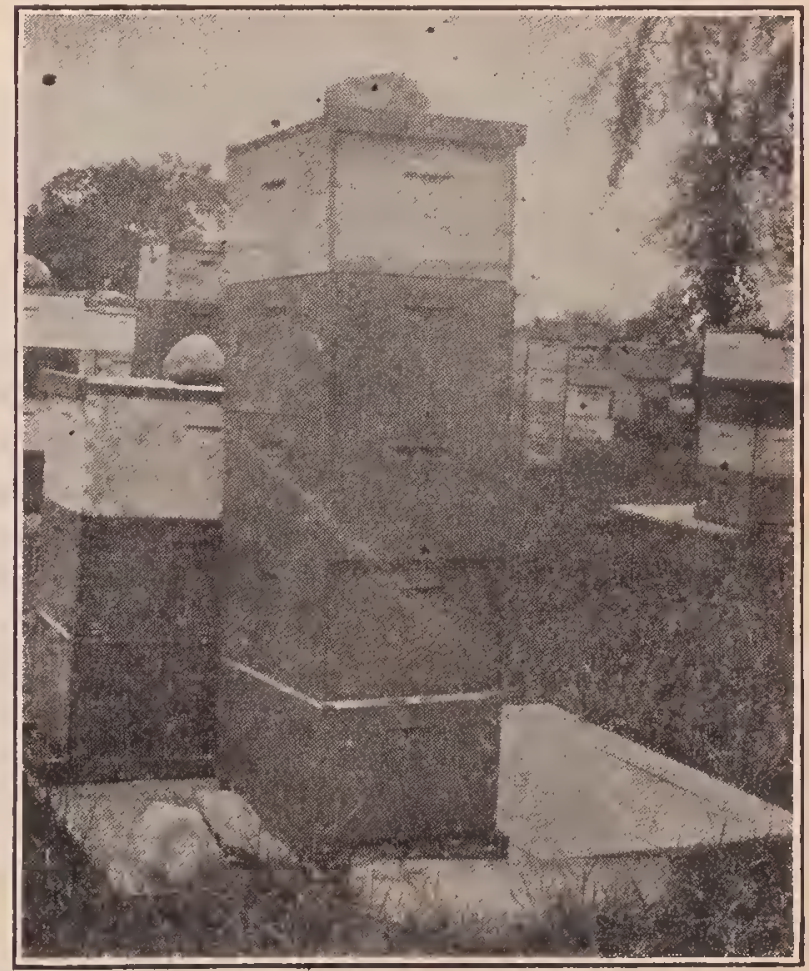

This colony occupying the five-story hive is one started from two pounds of bees received in the litter part of $\Lambda$ pril, 1918 , at David Rmmning's home yard. These two-pound packages received 1y express from the South will often go ahead of the colonics wintered in the North. 
lome. They will likewise be very much less liable to swarm out $01^{\circ}$ to be attacked by robber's from other hives in the vicinity. See Robring.

Something should be said on how package bees are loosed in the hive before setting them in the cellar, for it is not an easy trick for a beginner. Reniove all the frames of foundation from the prepared hive where the bees are to be released. If possible, in their place put three or four combs containing honey from some colony. A comb containing a little brood will help to add to the home feeling of the new bees. If the combs do not contain much honey, a sugar syrup made of 50 per cent hot water and 50 per cent of sugar, well stirred in, should be given. (See Feeding.) Open up the cage by removing the wire eloth or removing the ean containing the food. But before this is done a little smoke should be applied to the bees. If the queen is caged separate from the rest of the bees, lift her out and put her next to the frame of brood. Shake out some of the bees from the big eage, then lay it down in the side of the hive not oceupied by the combs, and put on the corer. The hive should then be put in the cellar as explained. The remaining bees will soon work over to the queen. If the queen. is not caged separate from her bees sliake her and all her bees out of the big cage on to the combs and then take the cage away, as the bees might go back into it again.

But we will suppose that the beginner has no extra combs nor frames of brood, much less any other bees in the vicinity. He can let the bees loose on the frames of foundation, the same as on the combs. The feeder containing the syrup should be placer in the live in the space not oceupied by the frames.

The cover should be placed on the live last of all, when the bees should be put in the dark cellar. When the combless bees are hived on frames of foundation it is all the more important that they be confined in a dark cellar for three or four days before they are allowed to fly, at the end of which time they will have deserted the eage and started to draw ont the foumdation. Towad nient they an then be set on their permanent summer stands. In either case the entrances should be con- tracted for at least three or four days after the bees are set out.

In case it is found that the bees are not leaving the cage and going on to the foundation, a little smoke should be used and the cage be opened still further, áfter which the bees should be jarred out into the space not occupied by the frames. When most of them are out, place the cage with a few remaining bees in front of the entrance and put on the cover.

A new form of combless cage has been invented by which the bees will draw out foundation en route, and the queen lay in it. Such a shipment can be treated in every respect as frames of brood and bees from nuclei and full colonies.

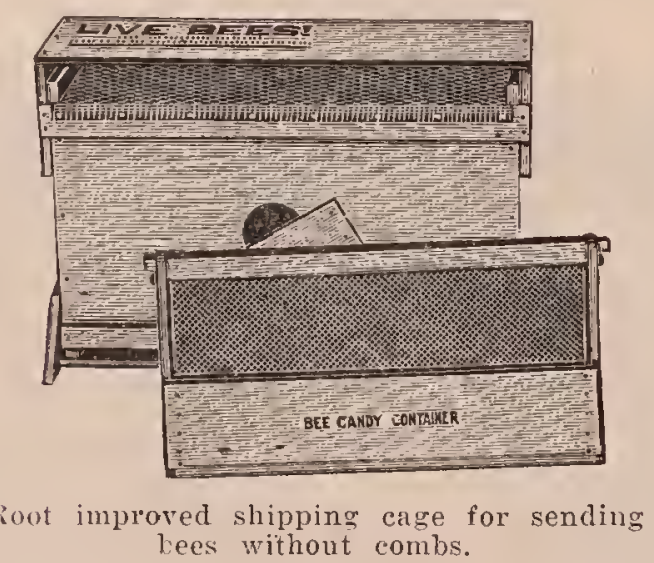

Too strong empliasis ean not be laid on the importance of keeping the cellar absolutely dark wliere bees are temporarily confined. A heary blanket or a quilt can be tacked temporarily against each window to shut out the light.

The job of living combless bees on frames of foundation is not easy for a beginner.' As a rule he is advised to get nuclei or combless bees in the Root improved cage, or to get a full colony. When the bees come on combs, especially combs containing a little brood, the problem of the beginner who has no knowledge of handling bees except what he has lead will be very much simplified.

Where one can afford it he is advised to buy full colonies, or two or three of them, as advised at the ontset: or, better.yet, get a complete beginner's outfit from his nearest dealer. 'T'his will consist of one or' more colonies, extra empty lives containing. franes of foundation, supers ready for the storage of honey, bee-reil, bee-glores, a book of instructions, and, last of all, a bee- 
smoker. The dealer will be glad to give full instructions on how to handle them, and the cliances are that Mr. Beginner will be able to get some honey the first season. Beginners' outfits cost all the way from $\$ 35.00$ to $\$ 50.00$. Where more than one colony is purchased the price might be $\$ 100.00$. One can make a very nice start witl one colony, a couple of extra hives, book of instruction, a veil, and a smoker.

After midsummer a beginner should buy nothing less than a full colony. If, however, he has had some experience he can buy two pounds of bees or a threeframe nucleus, and build them up to a fair colony by October 1 if he is not too far north.

If the beginner has colonies a little weak during the late summer, he would do well to buy a pound of bees from the dealer to strengthen all such. But before he lets some strange bees into another hive he should follow instructions under the head of Uniting. That is to say that the queen should be caged, and both the old bees and the new should be smoked before they are put together. See Introducing and UNITTNG.

In some cases beekeepers will be located remote from any express office. In that case the bees in package form can be se- cured thru the mails. As a rule, however, experience shows that shipments come thru more successfully by express.

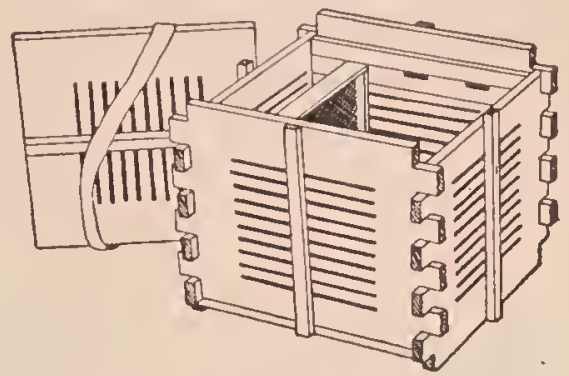

Parcel post mailing cage for bees without combs.

No beginner should attempt to make any start with bees without instruction books of some sort. Of course the reader of these lines will have all he can read before he takes up any other work. But he would do well to subscribe for some bee journal, as most of the journals now have beginner's' departments that are very helpful. By subseribing for a journal he will be free to submit his individual problems to the editor for solution. If the reply is not published he will get an answer by mail.

Before one does very much with bees he ought to take up the course of reading suggested in the FOREwOrD at the beginning of this work. The initial article inmediately following the FOREWORD-THE A B C of Beereeping-will give him the general bird's-eye view of the subject.

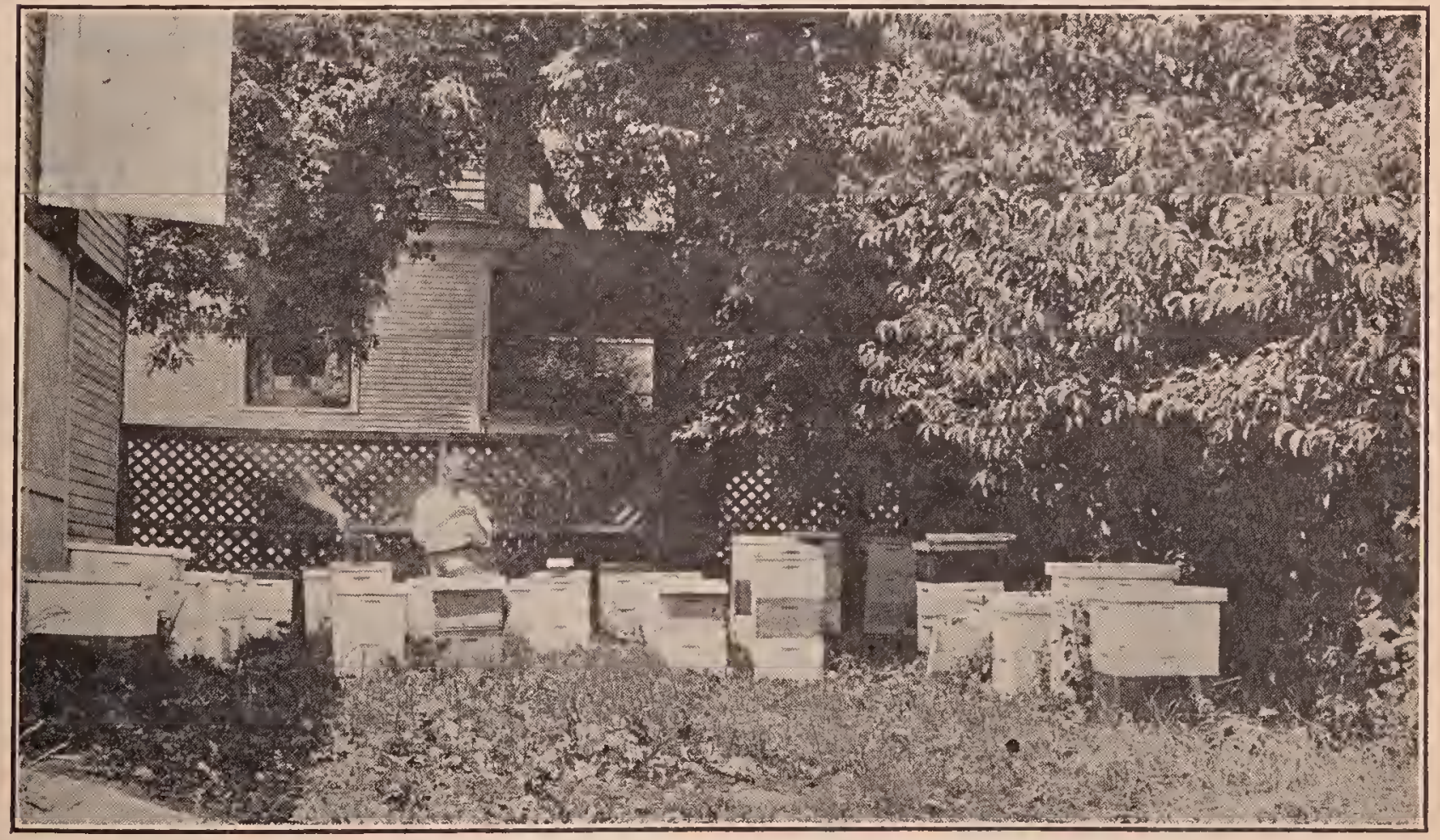

Wilson and Fracker's 20 colonies started from two-pound packages. 
If the beginner lives in town he would do well to keep on the right side of his neighbors at the very start. If he should be so successfnl as to secure some honey the first year, it would be good policy to give a bottle or a section of honey to the neighbors on each side and those in front across the street. Occasionally bees will sting the children who might get close to the line fence where they are flying. Occasionally bees will soil the neighbors' wash by dropping stains on the clothes on the hives do not cross common highways, practically no trouble will be encountered. See Backiot Beekeeping, Bees as a Nutsance, Manipulation of Colonies, and ROBBING.

\section{BELLFLOWER.-See CAMPANILLA.}

BLAOK BROOD.-See FOUL BroOD.

BLACK GUM.-See TUPELO. Also called black tupelo and water tupelo. A forest tree growing in swamps from southern New Jersey to Florida and Louisiana.

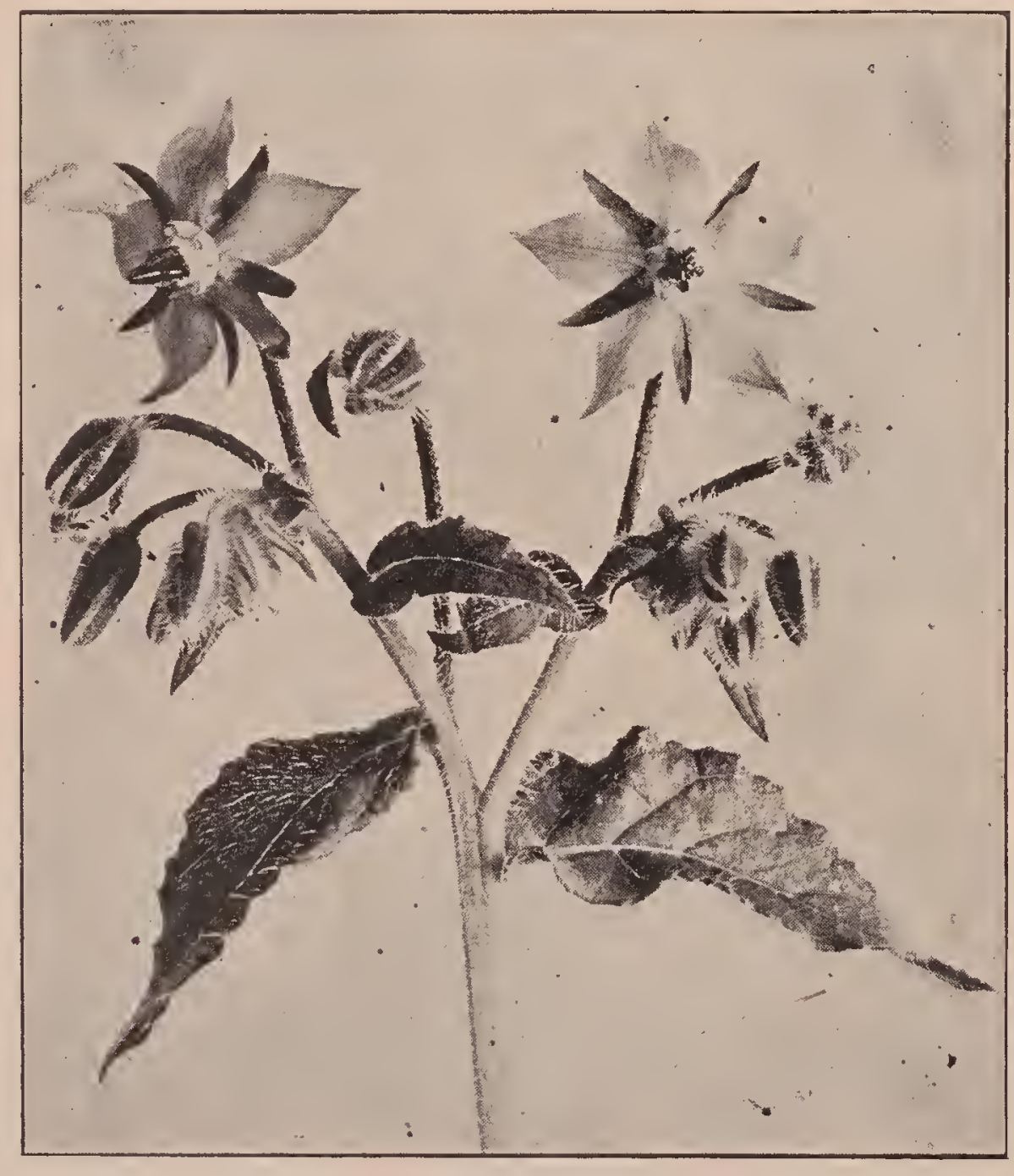

Common borage.

line; and occasionally, too, bees may be a little bothersome around the screen doors when the neighbor is busy making sweet pickles or preparing anything that gives off a sweet odor. A little honey given in advance will save hard feelings, and perhaps neighborhood trouble.

If one will read carefully the directions against letting bees get to robbing, and place his hives in the yard in such a way that the bees as they fly from their
BLIGHT.-See Fire Bligit.

BORAGE (Borago officinalis L.) - The common borage, introduced from Enrope, is cultivated as a honey plant and for ornament. The rotate or wheel-shaped flowers are sky-blue witl a black cone of anthers in the center. Under the dome formed by the anthers nectar is freely secreted by the pale vellow base of the ovary. The more or less inverted position of the flow- 
ers which face the earth protects them from rain. The anthers mature long before the stigmas. Each anther contains about 120,000 grains of pollen.

Honeybees constantly visit the flowers for both nectar and pollen. Two groups of flowers, one containing five and the other four flowers, were watched for 10 minutes. The first received 15 and the second 13 visits from honeybees. The value of the blue corollas in attracting bees was shown by the following experiment. When they were all removed from the flowers of the first group, the visits of the bees ceased entirely. To reach the nectar the bee hangs under the flower and inserts its tongue between the stamens. The anthers open slowly and the free pollen falls out into the conical chamber between them. On each anther there is a tooth-like projection. When a bee grasps with its claw the handle on the lower anther, it is pulled downward and the pollen is sprinkled over its body. As soon as released the anther springs back in place, and later more pollen collects in the conical chamber. The stigmas are at first concealed beneath the anthers; but after all the pollen has been removed they grow out and become receptive. The flowers are also visited by bumblebees and solitary bees.

The eagerness with which bees visit the borage blossoms shows that it possesses a fine flavor, and the honey is reported to be excellent. The plants can be easily grown from seed, and produce a profusion of flowers from midsummer until frost. In the extreme southern part of Australia, where there is abundant rain, borage has spread sparingly, and is of medium value as a honey plant. It will not, however, be found profitable to cultivate borage for loney alone. The leaves are sometimes used in salads and in medicine.

BOTTLING HONEY.- When honey is put into any other container than glass it is impossible to determine its character, its color; or its specific gravity, that is, how thick it is. When put in glass its color attracts the eye and teases the palate. When a bottle of it is turned upside down a linge air bubble in the form of a beautitiful transparent sphere will slowly rise. thus indicating that the contents are not only beautiful in color, but thick and waxy.

There are thousands upon thousands of people who do not eat honey. In order to interest them it is first necessary to tease their appetite by showing them an article that is intrinsically beautiful. For this reason honey in a retail way and for table
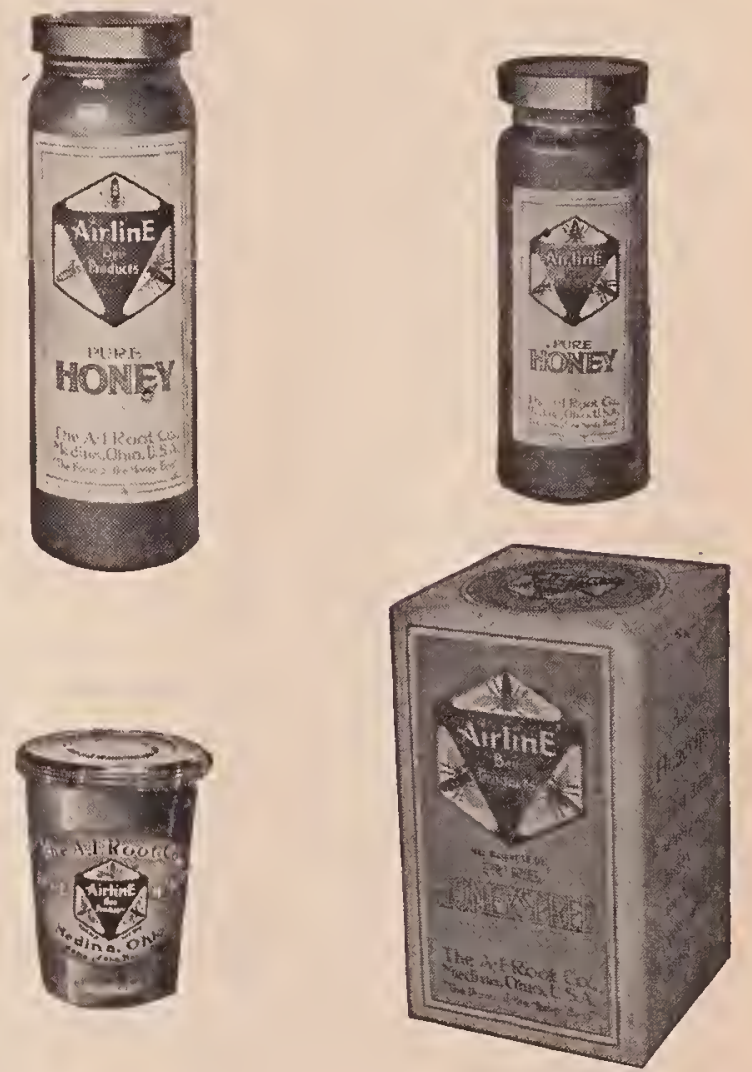

use is usually sold in glass just as jellies and jams and all other commodities of like nature are sold. After the consumer, or more exactly the housewife, who buys the food, discovers what honey is from the

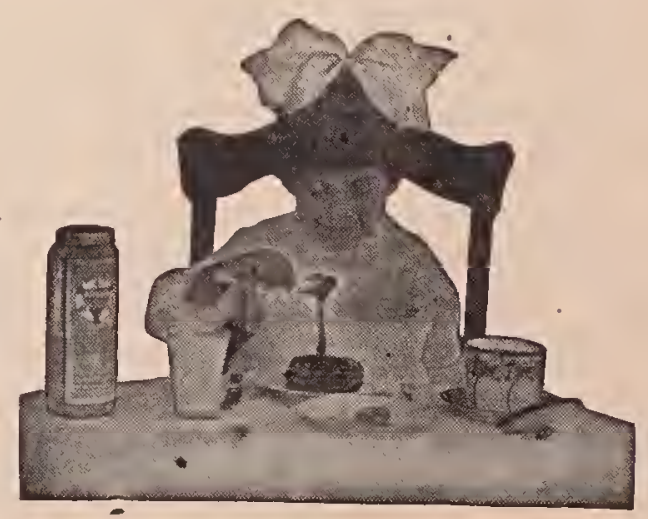

purchase of a small bottle sle will be interested in getting a larger bottle and finally $21 / 2,5$, and 10 pound pails or tin eans. The experience of the trade shows very clearly that she is going more and more to the large sizes. This is encomraging in that 
it will mean a much larger consumption of honey.

It is important to get hold of her first thru the avenue of the eye, which in turn tempts the appetite and results in the purchase of a sample. That sample leads to the purchase of other samples, until she will buy in bulk.

But, there is another class of customers, mainly working people, especially those in the cities, who cannot afford to buy a large quantity of anything. They will purchase a little of this and a little of that, and perhaps, a tumbler or bottle of honey. No inatter how well they like it, they will never be able to buy a larger quantity. The probabilities are they will never get to the stage of buying their foods in large quantities at a time. For this class of leople (and it probably represents a large proportion of the honey buyers) the glass package is exactly suiter.

During the last ten years and particularly the last three or four, the amount of honey sold in bottles has increased by leaps and bounds. As explained in the FOREWORD of this work at the outset, when sugar was relatively searce and highpriced during the Great War, the housewife bought honey, which she could secure in any quantity, if she was willing to pay the price. This very condition of affairs enormously stimulated the demand for honey, with the result that several large corporations went to bottling honey in a large way.

It will not be the purpose of this anticle to explain how loney is put into bottles at the big plants any more than is shown in some large illustrations near the close. The machinery and equipment necessary are very elaborate and expensive. The reader of this work desires some simple plan by which he can bottle his honey for his own local trade. With that in view it has been thought best to describe a simple apparatus which can be secured at a very sinall cost.

It should be understood at the outset that practically all extracted honey will granulate unless it has been raised to a temperature of about 160 degrees Fahr. Ordinary honey placed in bottles without. lieating would candy in a few months; and as the general public is not familiar with honey in the solid form it is best to put it up so it will keep liquid until used.

Under the head of Granulation of HoNey it is explained that nearly all honeys at the approach of changeable or cool weather will granulate unless heated. If the temperature is raised abore 160 degrees Fahr. there is danger of impairing the flavor. If not heated higher than 110 degrees granulation will set in, altho the process will be considerably delayed. Granulated lioney in clear glass would be unsalable, and therefore it is important to consider first all methods of heating the honey and putting it into bottles.

Steam from a boiler is, of course, the most convenient method for heating looney that can be employed: but as the arerage reader of this work probably cannot get it he must use something else. While the ordinary cooking-range or cook-stove, using either wood or coal, may be used for heating honey, a gas or gasoline store with three burners is far better-better, because the heat can be perfectly controlled. A wood or coal fire is apt to burn too strongly at one time or go down at another. If the honey be overheated it will be injured, both in color and flavor. It may be scorched, $\mathrm{Or}^{\circ}$ the flavor so impaired that it will sell at only a moderate price.

There are two methods for heating honey to put in glass or tin. One is, to draw it off from a large can while cold, into botthes or tumblers, and, before they are sealed, heating the honey while the bottles are standing up to their necks in hot water. The other plan, and the one generally used, is to heat in bulk and then draw off into bottles while hot, and seal. This method has the adrantage that warm or hot honey flows more freely, and, of course, can be handled more rapidly. On the other hand, heating honey in the retail glass packages has the advantage of being better adapted to a small business.

HFATING HONEY IN BOTTLES, OR BOTTLING FOR A LOCAL TOWN TRADE.

Provide a square or oblong galvanizediron pan as large as the top of the store. with perpendicular sides, and about six or seren inches deep. If a gasoline stove is used, the pan should be as long and as broad as the top'; and, if the thiee burners 
will be seen; and when the mercury rises to about 150 (not higher than 160), the honey is drawn off by means of a siphon into a filling tank that stands on a lower step of the stove. The siphon may be of glass or flexible tubing. The latter is to be preferred, because it is more convenient to handle. While the honey is hot the tubing should be immersed in the honey until it is filled. To do this, attach a string at both ends, and submerge it. Draw out one end and run it over into the filling tank, which is lower down. The hot honey will now immediately run out; and as the can is emptied, the water surrounding the can should be drawn off or else the can will float and tip over. From the filling tank the honey is drawn off while hot, or about as near 140 as possible, into honey

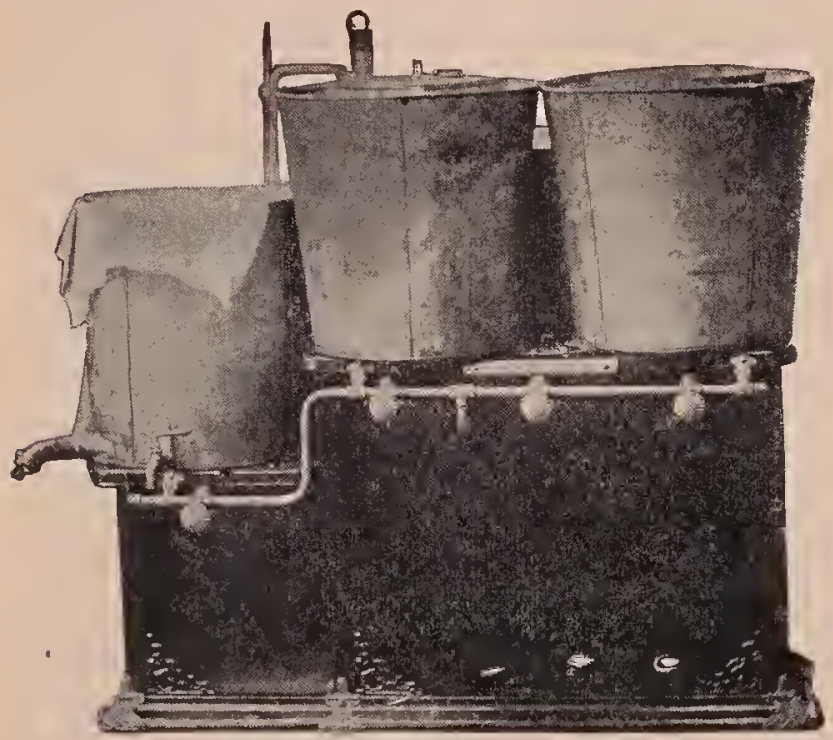

Mr. Fowls' melting-tanks, siphon, and gasoline stove.

tumblers, Mason jars, Muth jars, or any of the packages already described. When filled they should be sealed while hot; after which, as soon as they are sponged off with warm water, they may be labeled, when they are ready for market.

\section{HOW TO INSERT CORKS IN BOTTLES.}

Two or three methods are employed. One is, to use a rubber mallet, which can be purchased at any of the rubber stores. The ends of the mallet being soft, a cork that is barely entered can be driven into the bottle with a blow.

Another plan is to use a lever, as shown at $\mathrm{D}$, in cut. This lever should have" a projection on the under side so the cork can be foreed down into the bottle about a sixteenth of an inch. It is important, after corking, to pour a layer of paraffin or wax over the top of the cork. Some go so far as to dip the corks into hot paraffin, then

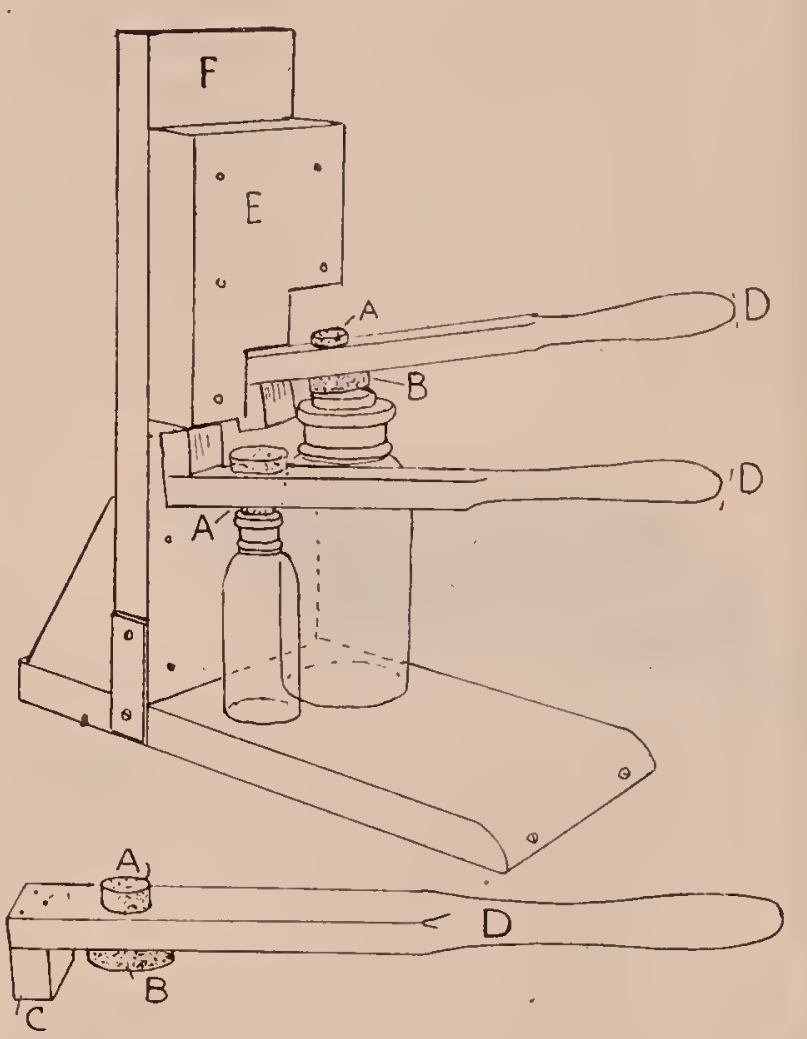

pour a hot layer on top after they are inserted in the bottles. Some go even further. After the corks have been paraffined they put on a neat tinfoil top. If the honey has been heated up to 160 , and sealed while hot, and the cork is made impervious, it will remain liquid for months. Samples of honey put up in Muth jars have been kept in a refrigerator six months, and yet would remain perfectly clear all the time. But the grocer's customers should not be advised to put honey in a cold place. The bottles should not be handled more than is necessary, but be kept in a warm place at as uniform temperature as possible.

Assuming that no directions are necessary for sealing packages using rubber rings, it is important that the sealing be made as tight as possible. In the case of Mason jars, the tops should be screwed down with a wrench, and screwed down tight.

In sealing jelly tumblers, cut circles of paper( preferably paraffined paper) larger than the size of the top of the tumbler. When the jar is filled, put the paper on top of the jar, and squeeze the top down with 
the palur of the hand, putting a large part of the weight of the body on it. If the top goes down too easily, use thicker paper or two thicknesses.

\section{BOTTLING ON A LARGER SCALE.}

The Fowls plan will take care of several towns of two or three thousand inhabitants each; but it is not well adapted to a general business, taking a whole state or a series of them. An ordinary stove or a gas stove is not well adapted to take care of a large business; hence it will be necessary to purchase a five- or ten-horse-power boiler and install it in a room or basement in the tin containers. Much of this honey will be granulated before the bottling season comes on.

There are two ways of melting honey in square cans. One is, to submerge them three-fourths their depth in a large tank of water heated by str:an until all the honey is melted. But this is objectionable, in that the melted portion has to remain with the portion still granulated until the whole bulk has been brought to a liquid condition. This impairs the flavor, for the longer honey is kept hot, the more its delicate aroma and color are sacrificed. The plan also necessitates the lifting of heavy

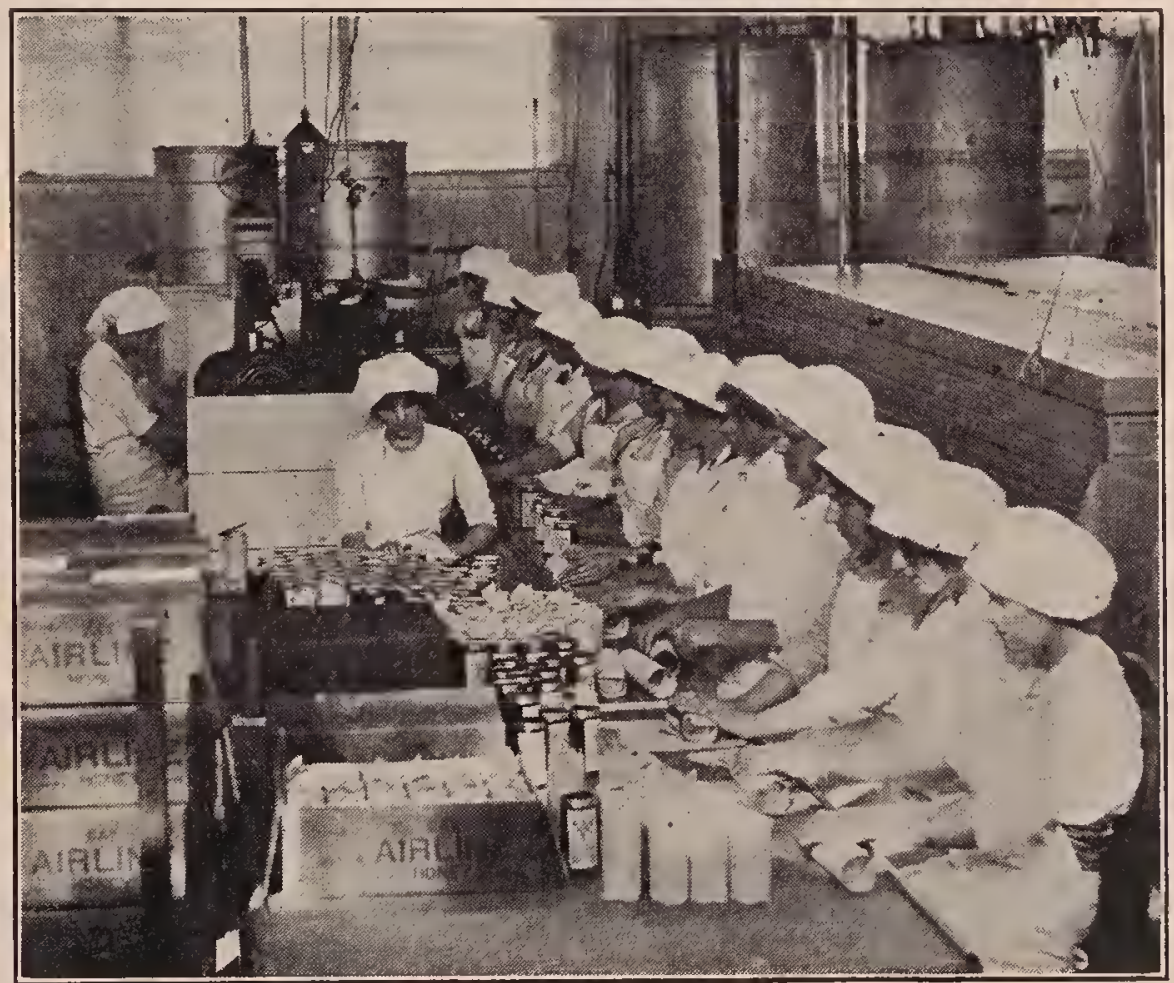

BOTTLTNG HONEY AT A IAARGE COMMERCIAI, PIANT.

The bottles as fast as they are filled are capped, labeled, sponged and and wrapped. The bottles are carried on a traveling' belt to eatch girl who has a detail of the work to do.

where the bottling is to be carried on. Steam is by all odds the best heating agent in a general bottling establishment. It is more convenient, cheaper, and there is not so much danger of overheating the honey.

The great bulk of the honey for bottling purposes will come in $60-1 b$. square cans. While some of it may be secured in kegs or barrels, producers and buyers generally prefer to sell and buy honey in large square cans, even at an extra price of half a cent; so we may as well figure that in a bottling business the honey will be received cans of honey out of their bath of lot water and emptying them into the filling tank.

A far better plan is to heat these cans with hot air, while inverted, in a steam oven. The caps are, of course, removed. and as fast as the honey melts it runs out and is caught in a receiving trough beneath. Thence it flows immediately into another container, or is pumped out with an ordinary honey-pump; such as is used in connection with power-driven honey-extractors. 
Illustrations showing a honey-heating oven will be found under GranULATEI Honer. See Figs. 1 and 2, Pouder's meth. od.

While Mr. Pouder uses a gas jet, it is preferable to use steam pipes, so placed as to be out of the way of the honey that runs out of the screw tops into the bottom of the oren or tank. Enongh stean radiation should be provided to bring the temperature of the air in the oren up to $180 \mathrm{or}$ 190 degrees. is important, as it is not practicable to have the oren placed on a level abore the filling tank. A honey-pump to deliver the honey to the tank is much more satisfactory than a tank and honey-melting oren placed at different elerations.

The receiving tank is made on the double-boiler principle-one tank inside of the other. The outer one should be at least two inches larger in dianneter, and the space of about one inch between the tanks shoull be filled with water heated by steam.

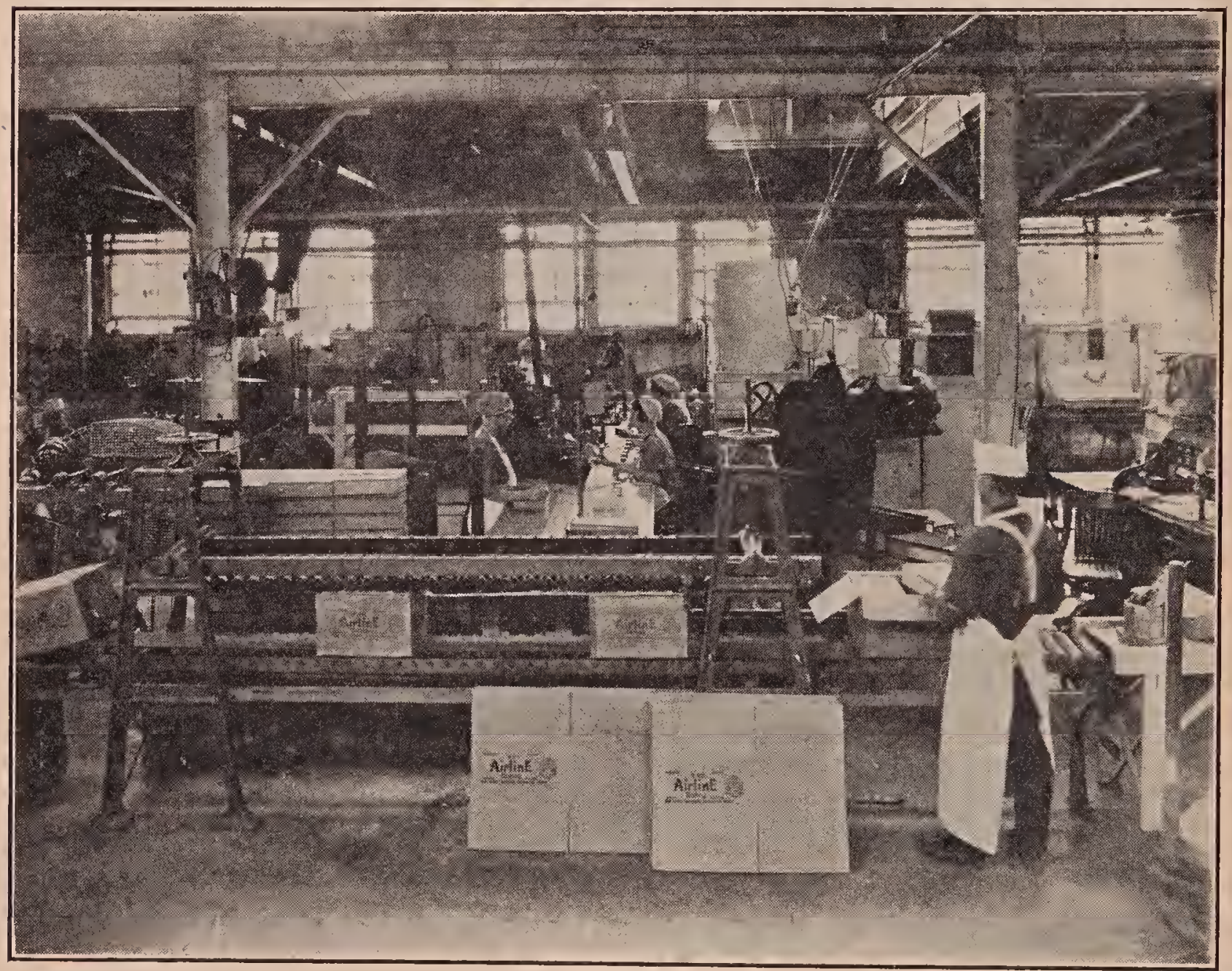

BOTTLING HONEY BY THE CARLOAD

With the hottling and labeling equipment shown with illustration, a dialy output of nearly a carload of homer, packed in glass container. can he maintained.

When steam is used as a heating agent for these honey-melting ovens, it is not necessary to use a metal box, but a large double-walled wooden box with lid, with packing material between the walls, and a galvanized tray or trough in the bottom to catch the honey. The melted honey should not be allowed to accumulate in the oren, but should be drawn or pumped out into a receiving or filling tank immediately. This
The innel tank to hold the honey should have a tube at the bottom, passing thru the hot water to the outer tank, to which is attached a honey-gate. This gate may be used for filling the bottles direct, or the tank may be used for making up the blend referred to further on, as practically all bottled honeys nowadays are made ip of two or three different flarors. When a blend is used it is custonnay to l'um the 
honey from the leceiving tank into a separate filling tank. From the filling tank there should be attached a three-quarter steam loose five or six feet long. On the ond of this loose is attached a specially made honey-gate, with a spout long enough to reach slown to the bottom of the bottles or glass jars. While packages can be filled fiom a honey-gate attached directly to the tank, it is much more convenient and better to use rubber hose with a gate on bles that make the homey look frotily on top, and, besides, hasten granulation. In filling, the snout should be put clear to the bottom of the jar; and as the jar fills, the gate slould be lifted slowly until the jar is full. This feature is important. The process is repeated with the next jar nutil all are filled. Another tray of jar's is placed within reach of the rubber hose, and the process is repeated. After the jars are filled they are sealed while hot,

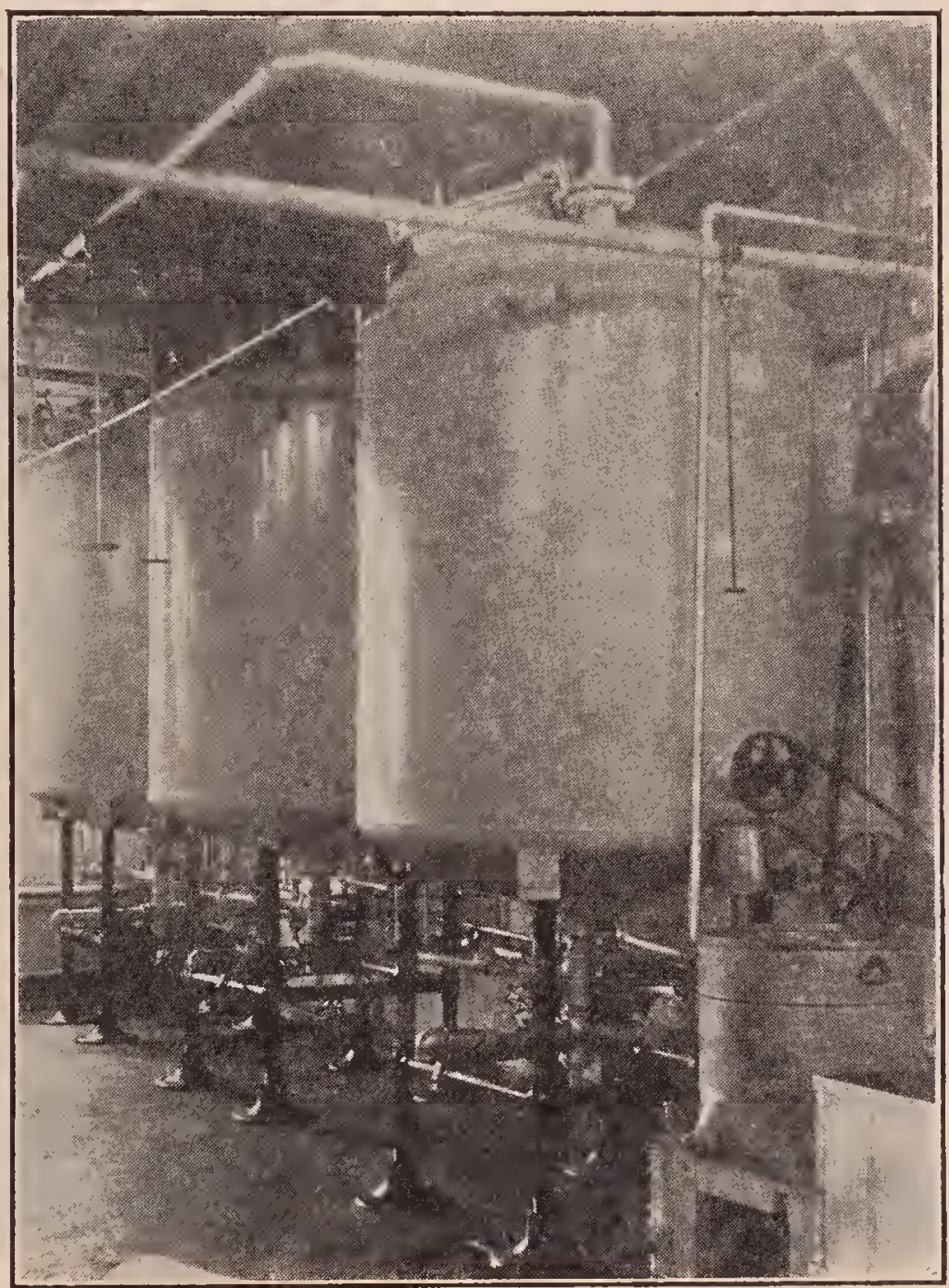

Bottling and packing of honey has kept pace with the advanced methods and improvement in equipment of the beekeeping industry in general. These jacketed steel tanks, glass enameled on the inside, in contrast with the old, unsanitary, open tanks, are convineing proof that honey packed by this method reaches the consumer in the most sanitary condition possible.

the end. The bottles should be placed in groups of one or two dozen in a tray; and ly means of the flexible lose and honeyfilling gate, each package is filled without liandling. Moreover, a long snout on the gate enables one to direct the stream of loney clear down to the bottom of the jar, thus aroiding the accumulation of air bub- then labeled and wapped, realy to be put in paper cartons.

\section{A BLEND OF SEVERAL KINISS OF HONEY HOR BOTTLING PURPOSES.}

The seasons for honey production are so uncertain at times that one finds himself unable to supply his trade with the honey 
he produces from his own yard. If, for example, his honey is almost exclusively from clover, with little or no basswood or fall flow, the trade will become educated to like that particular flavor, and will reject all other honeys of other flavors on the ground that they are impure. To provide against a contingeney of this kind it is advisable to use from the start for bottling purposes a honey that can always be furnished year after year. It is usually customary to make a blend of white clover,
25 per cent of sage, and 25 per cent of alfalfa. It may be assumed, for example, that he has a season of failure, and yet the bottling trade keeps up just the same. He usually buys a mixture of clover and basswood. His taste will become educated so he can determine the percentage of the one to the other. Then, by putting in a small amount of alfalfa, which he can always procure, he will be able to supply his trade with the proper blend.

If one lives in a locality where alfalfa

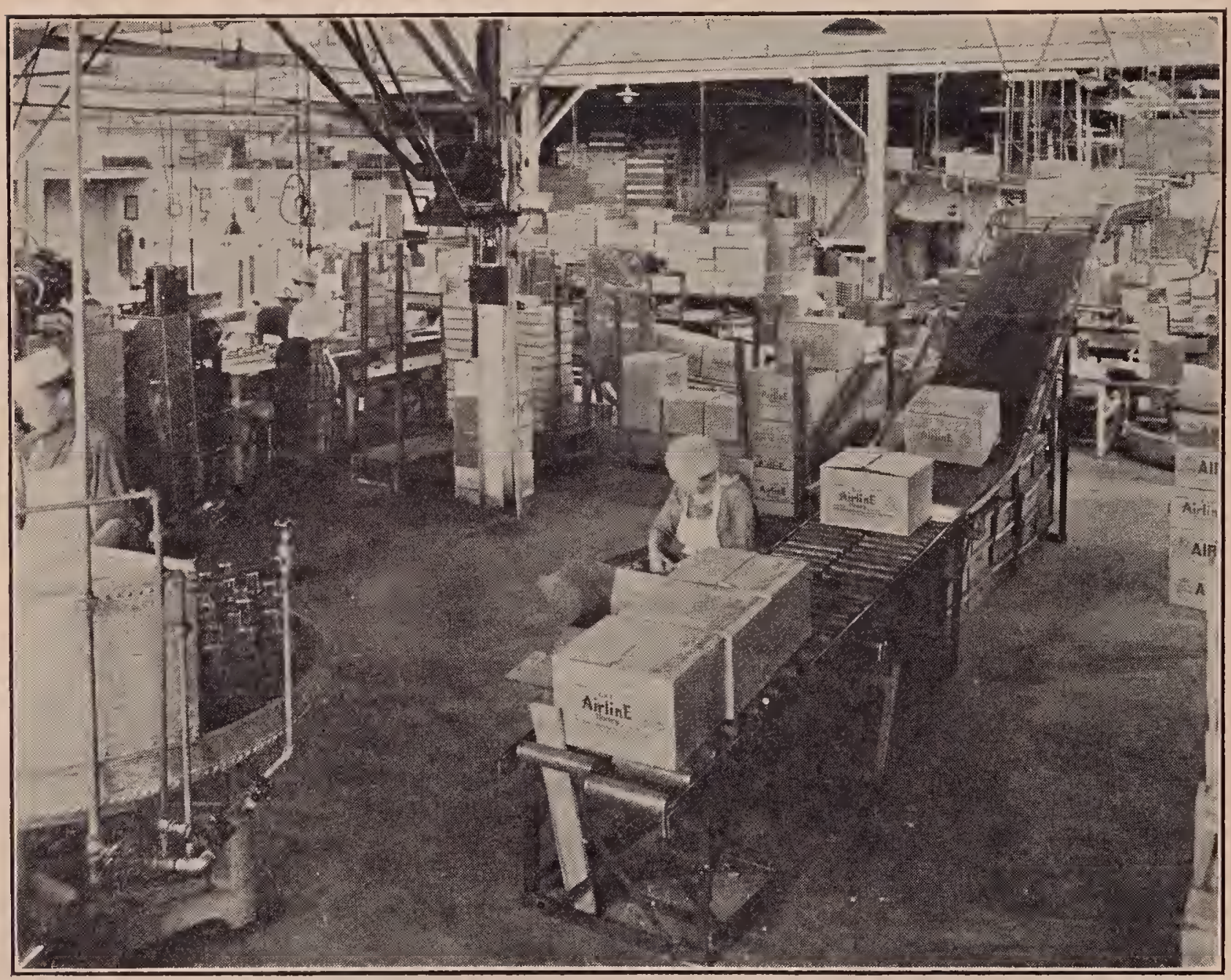

Glass containers are carried from the stockrooms direct to the bottle-washers by automatic conveyors. The latest-type bottle-washers deliver the glass to the filling machines, crystal clear and thoroly sterilized.

basswood, alfalfa, and mountain sage, and, if the trade is supplied witl this blend from the very start, it will become accustomed to it. Such a blend can be made up of honeys that one can purchase when local honey fails; whereas if one puts up only white clover at the beginning, he will find it difficult to purchase a strictly pure clover except at highest prices. Where one lives in a clover locality he will do well to make up a blend of 50 per cent of clover, is produced extensively, there will be 110 need of having a special blend, because the pure alfalfa can usually be obtained in sufficient quantity.

In mixing the different flavors of honey it will be necessary, after putting into the tank the requisite amount of each kind, to stir them slightly while heating. This is to prevent overheating a part of the honey, and to bring about a thoro blend. The stirring may be done with a paddle; but a 
better arrangement is a sort of extractolreel having blades that will thoroly mix the honey. The reel should revolve four or five times a minute. Faster than this will not be necessary. The little motor that is userl to operate the honey-pump can also l'un a countershaft geared back so that the inixing reel inside of the blending tank will not revolve faster than the time stated. age used for lioney designed for table purposes should be spotlessly clean.

REQUIREMIENTS OF THE LAW AS TO LABELS.

The national pure-food law, and in some cases state laws, requice that the label shall indicate the exact contents of a package; and therefore it would not be advisable to call a blend, such as has been deseribed, a pure clover. It will be perfectly proper to.

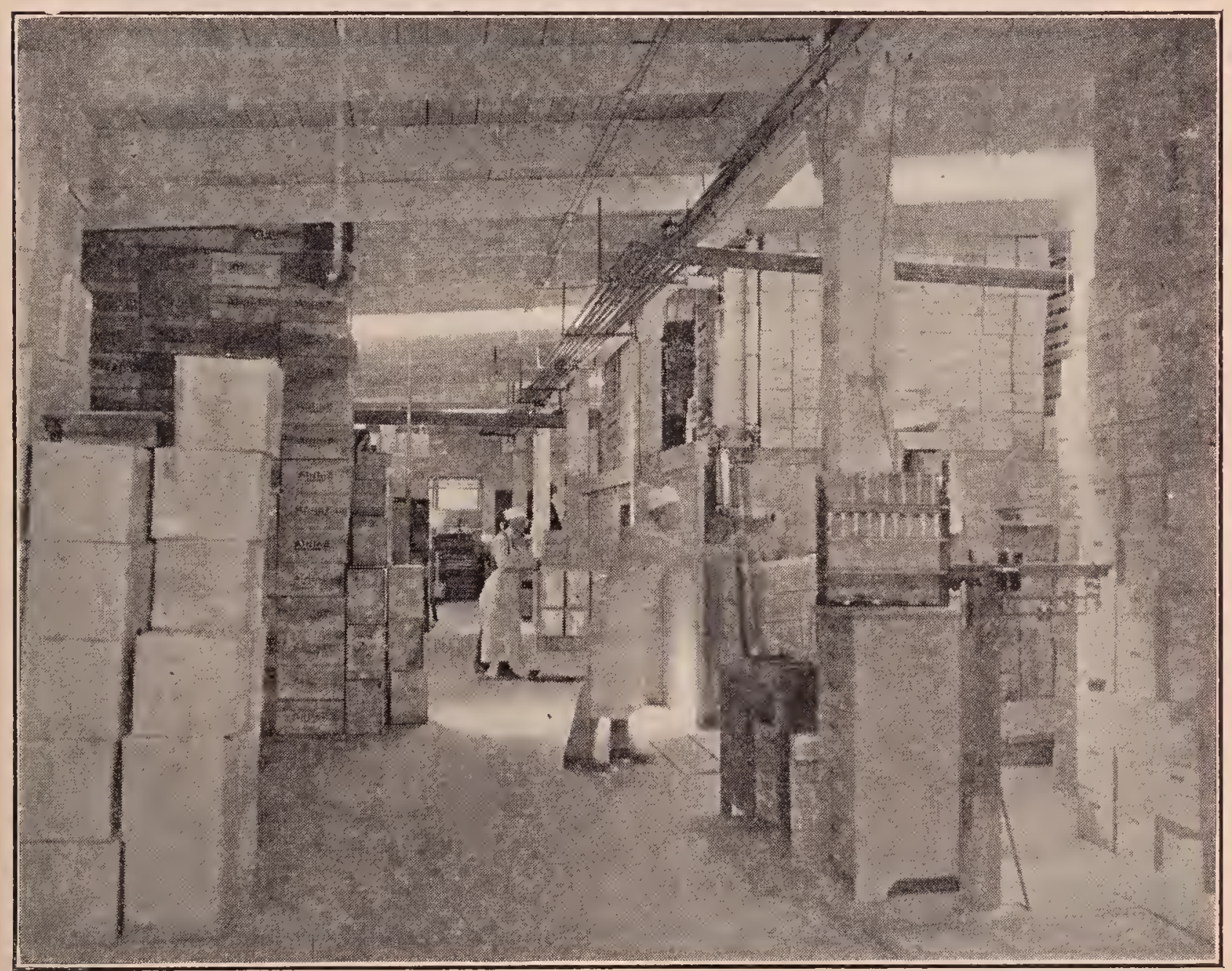

There is no time from the hive to the bottle when honey should not have most careful attention and be stored in clean, airy stockrooms where proper temperatures can be maintained. This stockroom shown is equipped with portable piling machines, live steam, hot water, and every sanitary device.

WASHING AND CLEANING BOTTLES.

Prepare several tubs of water-one of them with strong suds-and then have on hand a few ounces of shot-No. 6 is about right. If particles of glass or dirt cling to the inside of the bottles, pour in four or five ourues of shot and give the bottle a shaking. This will dislodge all particles, when the shot may be poured into another bottle, to be sinilarly treated. In rinsing use clear soft water. Hard water is liable to leave traces of sediment. Any glass pack- say "pure extracted honey bottled by Jolın Jones;" but John Jones must not say "pure extracted honey from the apiary of John Jones" unless such honey did actually come from his apiary.

Allusion has already been made to the fact that the federal laws, and in some instances state laws, require that the exact quantity by weight or measure of the contents for retail purposes shall show on the label. It should be stated, in this connection, that the Bureau of Chemistry has 
ruled that anything under 'one pound should be stated in ounces. Anything above a pound should be stated in terms of pounds and ounces. It is contraly to the ruling to make a label read "36 ommces, net weight," when it should read "two pounds and four ounces, net weight." The purpose of this is to prevent confusing the consumer by making a statement which may be at the same time misleading. If the lahel states, for example, that the package contains 60 ounces, the consumer has to make a mental calculation to determine how much honey or other food product he is getting. The purpose of the law is to give the consumer an opportunity to lnow just what he is getting, and the exact weight in terms that are the most easily understood.

\section{LABELANG BOTTLED MONEY.}

As a general rule, small circular labels should be used. The big ones tluat cover up the whole jar do not usually afford as pretty an effect as the small, neat, tasty labels that give the enstomer an opportunity to see the honey. It is the honey that sells; and if it is a fine quality, the grocer should be indneed to display it in such a way in his window that the light will sparkle thru it, and it will then readily sell itself.

\section{BOTTLING IONEY IN A COMHERCIAL WAY.}

There are sereral large bottling concerns in the country that have put up honey in glass in an extensive way. During the active season they will send out two or three carloads of bottler goods a week. These big concerns necessarily have to employ extensive apparatus-something which, at the same time, will be sanitary. First the bottles must be washed and sterilized; the honey must be heated in large tanks; glasslined, and it must then be conveyed to a bottle-filler which automatically fills the bottles just so full and no more. The bottles are then carried by a traveling belt to a capping-uachine, and then to a labeling machine, and finally to the box which receives the packages after they have been sponged off and wrapped. Some of the large illustrations here will give one an idea of how honey is put up in glass in a large way.
For putting 10 in tin cans see ExtractED Honey.

BOX HIVES.-It seems as if any description of box hives in a work to teach modern apiculture would be ont of place: but the facts are, there are thousands upon thousands of colonies kept in these old gums in the south Atlantic States where there are more bees and beekeeper's to the square mile than anywhere else in the United States.

These hives, as the name indicates, are merely boxes containing neitler broodframes nor movable fixtures. They usually consist of a l'ude, rough box about 12 or 15 inches square, and from 18 to 24 inclues high. Thru the center there are two crosssticks, the purpose of which is to help sustain the weight of the combs built in irregular sheets within the hive.

At the close of the season it was and is the custom for the owner of box hives to go around and "heft" his hives. Those that are heary are marked to be brimstoned; and those that are light are left to winter orer for the next season if they ran. The bees of the first named are destroyed with sulphur fumes, and then the beebread, honey, and ererything are cut out.

In the more modern box hives there are boxes with glass ends that can be drawn out from an npper part, leaving the lower intact. In this case the bees are not destroyer. In any case there is no opportunity to inspect combs, hunt queens, divide, nor perform any of the hundred and one operations peruliar to morern apicnlture.

A's stated at the outset, in some of the souther'n States, particularly the south Atlantic - Virginia, North Carolina, South Carolina, Alabama, and Georgia - box hives or log gums are used very largely. Inteed, there are very few modern hives or modern beekeeper's. The mountaineer's in some of those States are of the purest of pure Anglo-Saxon blood. Their ancestors came from England 300 years ago. $\Lambda$ s their isolation $u p$ in the mountain shuts them out completely from the outside world, many of the old customs and modes of speecly still cling to them. At all events, they appear to be keeping bees in box hives 


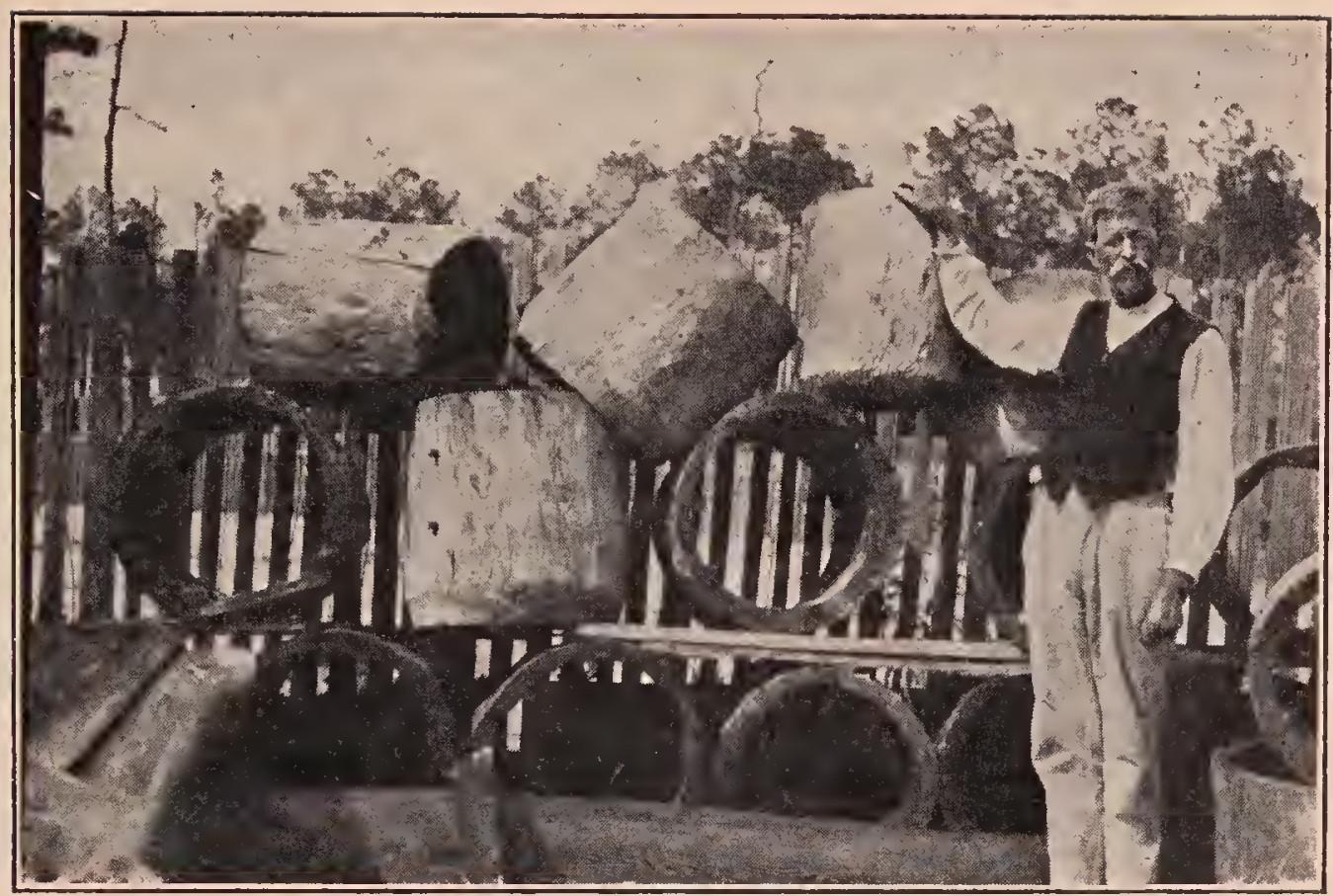

The passing of the log gum in the South.

or gums just as it was done in England 300 vears ago. They have no knowledge of modern methods. The moth miller, swarming, and poor wintering are the handieaps that prevent them from getting murh honey. The most of them, for example, know nothing of hiving the first swarms on the old stand, and placing the parent colony to one side $\mathrm{Ol}^{\circ}$ in an entirely new location in order to catch all the flying bees with the swarm. They leare the parent colony on the old stand, and, of course, it continues to swarm itself weak. In the meantime the moth miller and winter perform their destructive work. The result is that little or no increase is made, and the prime swarms are the only ones that yield any return. If foul brood ever gets a foothold here, the business, such as it is, will be wiped out.

No matter what the season is, even tho the crop has been only half harvested, the colony must be brimstoned and the honey taken off at some particular phase of the moon.

Possibly, here is a case showing that if ignorance is bliss 'tis folly to be wise; but the United States eridently thinking' otherwise, has recently been sending experts down into this country to teach modern methods; for statisties show that there are more bees and beekeepers in this Southland than in any other portion of the
Inited States. The country is exceedingly farorable for the keeping of bees, and the day should not be far distant when modern apiculture will supplant the old box-hire system, coupled as it is witl ignorance and superstition.

It is only fair to state, however, that the class of box-hive keepers here described does not represent all of this Southland: but there are enough of them to require the earnest"attention of the extension workers or county agents sent out by the Federal Gorermment.

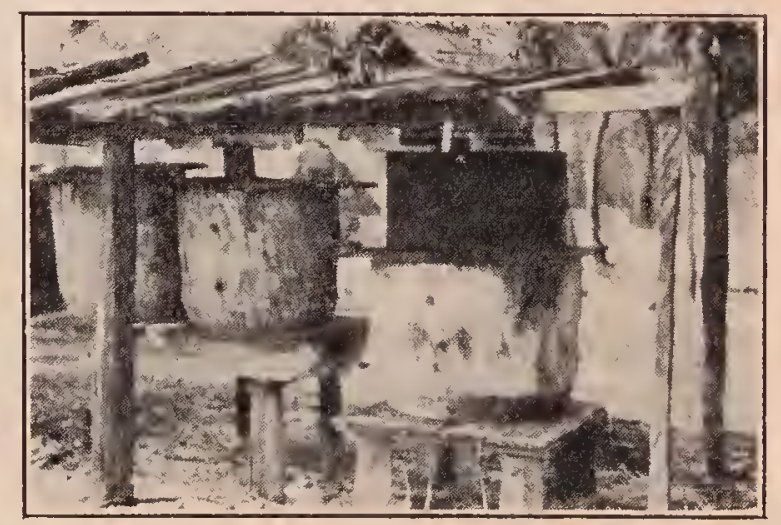

Log gums used for moducing comb honey, with the "supers" in position.

As a matter of fact, extension men lave done a splendid work in instructing the beekeepers of the southern States on how to keep bees by modern methods. Many hundreds in the South are now transferring to modern hires; and with the new 
hives they are now following the new methods of management. It is needless to say that the difference in the size of the crops of honey so secured over the old way is so marker that the bee-extension men work in edueating beekeepers of his State to the new ways of producing honey. Hundreds of beekeepers of his State are now transferring; and it is very evident that at no distant day the box hive, and with it

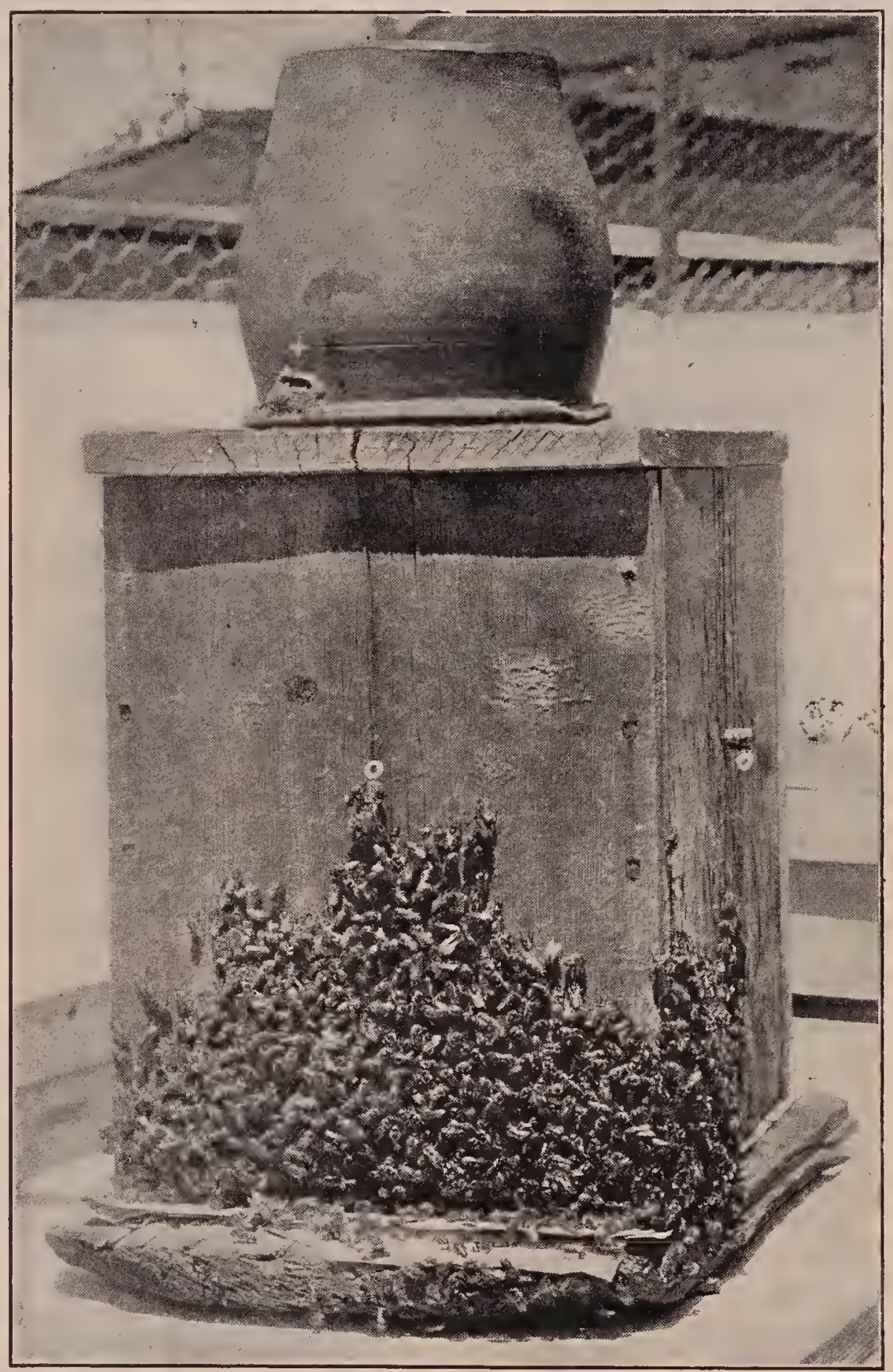

A TYPICAI BOX HIVE WITH AN EARTHEN CROCK FOR A COMB. HONEY SUPER.

These crocks would be cold, hut when once filled would keep the honey safe from leaking after taking off the gum.

are being called upon to demonstrate how to transfer as well as how to keep bees better. C. L. Sams, special bee-extension man of the Department of Agriculture, Raleigh, N. C., is doing a wonderful its companion the $\log$ gum, will almost be things of the past, just as it is in the North at the present time.

Some of these people live in almost absolute porerty when they might just as 
well get a fair living, if they could but know of the modern methors of handling even box lives.

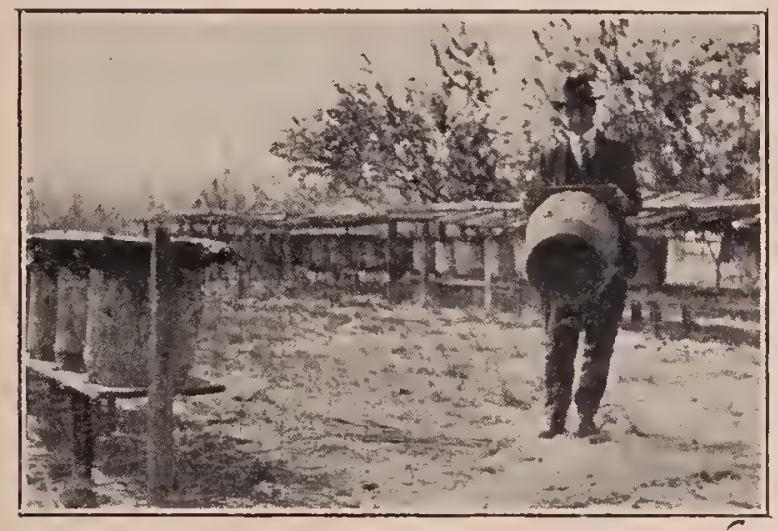

Log-gum apiary of J. S. Kelly near Wilmington, N. C. Mr. Sams holding an empty gum, and altho the bees were stinging him unmercifully, he stood his ground while the picture was being taken.

Moses Quinby, in the early '50's, liandled box hives so that he made honey; and if these people cannot afford movable-frame hives, they could, by the simple expedient of hiving a swarm back on the parent stand and remoring the parent colony, rastly increase their resources. Father Quinby did not brimstone his bees; and neither will these purest of pure Anglo-Saxons up in the mountains of the soutl Atlantic States be compelled to do so. Quinby's old book

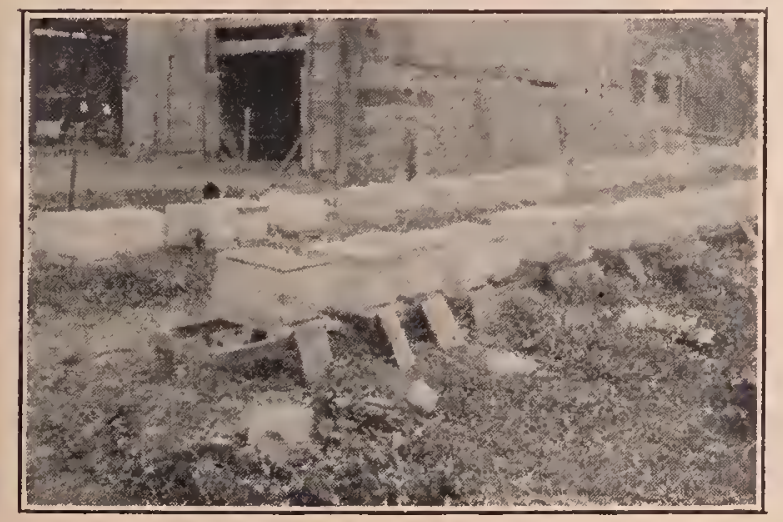

Modern hives into which bees in "gums" had been transferred by Mr. Sams and his helpers.

of 1853-a reprint of which has been made by the publishers of this volume-explains low bees can be kept on the box-hive system without the use of: brimstone. While the tricks of the trade taught in this old work of Quinby would enable the Highlanders to increase their yields per colony, the modern live with movable frames would enable them to do rastly better.

BRACE COMBS. - See THICK TOP FRAMIES runder FraMES.
BREEDING STOCK.-Every well-regnlated apiary ol series of apiaries should have one or more choice quecins from which to breed. Such queens should, of course, be the very best in the apiary, or, better still, the best out of a series of outyards including the home apiary. They should not only be prolific but be the mothers of workers that are energetic and good workers - that is, bees that will store more honey than any others. It is important, also, that they be of pure stock in order that they may the better transmit their qualities. While gentleness is desirable, it is sometimes necessary to sacrifice this desirable quality in order to get bees for business.

When using Italian stock one should not be misled by the fad of a bright golden or rellow color. If it comes about accidental$\mathrm{l}_{\mathrm{y}}$ without the sacrifice of business qualities, the beekeeper is that much ahead. As a rule, the darker strains of Jtalians will show more desirable points than the brightcolored ones.

Ability to stand a severe winter is a necessary quality. It usually follows that bees that will breed up early in the spring, and prove to be good workers, are also good winterer's. Bees that have difficulty in resisting the winter will be too weak, if they survive, to be good for anything in the season. It follows as a natural inference that a colony of bees that can pile up super after super of honey is also good for wintering.

It has been proven that some strains of bees will resist disease much better than others. While no stock is immune, there are some that do not readily contract disease, while other's will fall easy victims. If possible a breeding queen should be one whose bees have demonstrated their ability to ward off disease, and there are some that have shown great superiority in this respect.

In this connection, good breeding drones should not be forgotten. It is generally accepted that a male is more able to transmit his good or bad qualities than the female; and the same rule holds goor in bee culture. In selecting breeding queens one should select not only those that will produce good daughters but those that will beget good sons. It very often and gener- 
ally happens that, in order to prevent inbreeding, one niust go to some other breeder to get stock for crossing with his own.

The average beginner should buy his breeding stock, especially if he has only a few colonies; and even after lie becomes fairly expert, if he has only one apiary it will be advisable for lim to buy a breeding queen of two or three of the best breeders in the country. A good queen is worth from $\$ 5.00$ to $\$ 10.00$-usually the latter figure. Sometimes as mucl as $\$ 25.00$ is pair. When one buys a breeder he should always have her sent to him in a nucleus rather than thru the mails. Usually a breeding queen is not less than one year old, for it takes at least a vear, unless the season is exceerlingly farorable, to measure up her value. A rueen one or two year's old will not staud transmission thru the mails like an untested queen that has just begun to lay.

After one receives a breeder he should give her the utmost care, not expecting that slie will live mor'e than a year, especially if she is already two years old. He must lieep her in a suiall nucleus, for no breeding queen during the active season should be the mother of a powerful colony. She should be kept down, and given as little egg-laying to do as possible; and then in the winter, when the active season is over, lier colony should be gradually built up with combs of emerging brood. She should be given young brood in this way until she is the mother of a large colony, and then in addition she should be given every advantage by lousing her colony in a larg'e double-rralled hive in a protected location. Or. if one has a good cellar where he can control conditions, her colony should be placed indoors. See Wristering Outdoors and Wintering in Celiars.

The use of a good breeding queen may mean the difference between profit and loss in a year's business. It is folly to keep scrub cows on the farm when good cows on the same feed will furnish two or three times the milk. It is equally foolish to breed from anything lout the best queen stock obtainable. A good strain of bees will produce anywhere from two to three times as much loney as a poor one. See QUEFes AND QUEFin-REaring.

\section{BROOD AND BROOD-REARING.}

"Brood" is a term rommonly user to designate the young of the bees in the cells that have not emerged. It may be young bees just before they have come from the cells, the larre in various stages of growth, or even the eg's.

Tery often the beginner is confused berause he is not able to distinguish capper honey from eapped brood; nor does he know the difference between drone and worker brood. Sealed brood is of a light to dark-brown color, depending on the age and color of the comb itself. In ordinary worker broor, in cells five to the incl, the cappings are made up of wax and fibrous material, smooth and slightly convex if the brood is not diseased. Drone brood is the same in appearance except that the rappings are mole convex with four cells to the inch. The cappings over honey are white, bluish-white, or vellow, are more or less irregular, and somewlat flattened. The honey may be in either worker- or dronecells. By comparing the illustrations of brood shown on following pages, together with the cappings of comb honey under' Cons Honer, the beginner will easily make the distinction.

The average beginner may not be able to see eggs at first. One trouble is, he does not know where to look nor what to expert. When he peers down into the bottoms of the cells and sees tiny little objects standing on end at an angle lie hardly knows what they are. The cuts on, next page show the eggs in the bottoms of the cells, altho photography is not able to show the depth of the cell. The cut, page 142, shows brood in various stages of development.

HOW THE PRESENCE OR ABSENCE OF BROOD REIEALS THE REAL CONDITION OF THE COLONT.

It is the presence of egg's 'or young' larre that shows that the bees have a queen and are beginning to lear brood. This may show even during midwinter if the weather has been warm for a fer days; or it may occur, as it usually does, in early spring. Broot will be found in all stages of growth as the season progresses.

On the other hand, the alosence of msealed brood, and esperially the ahsence of 


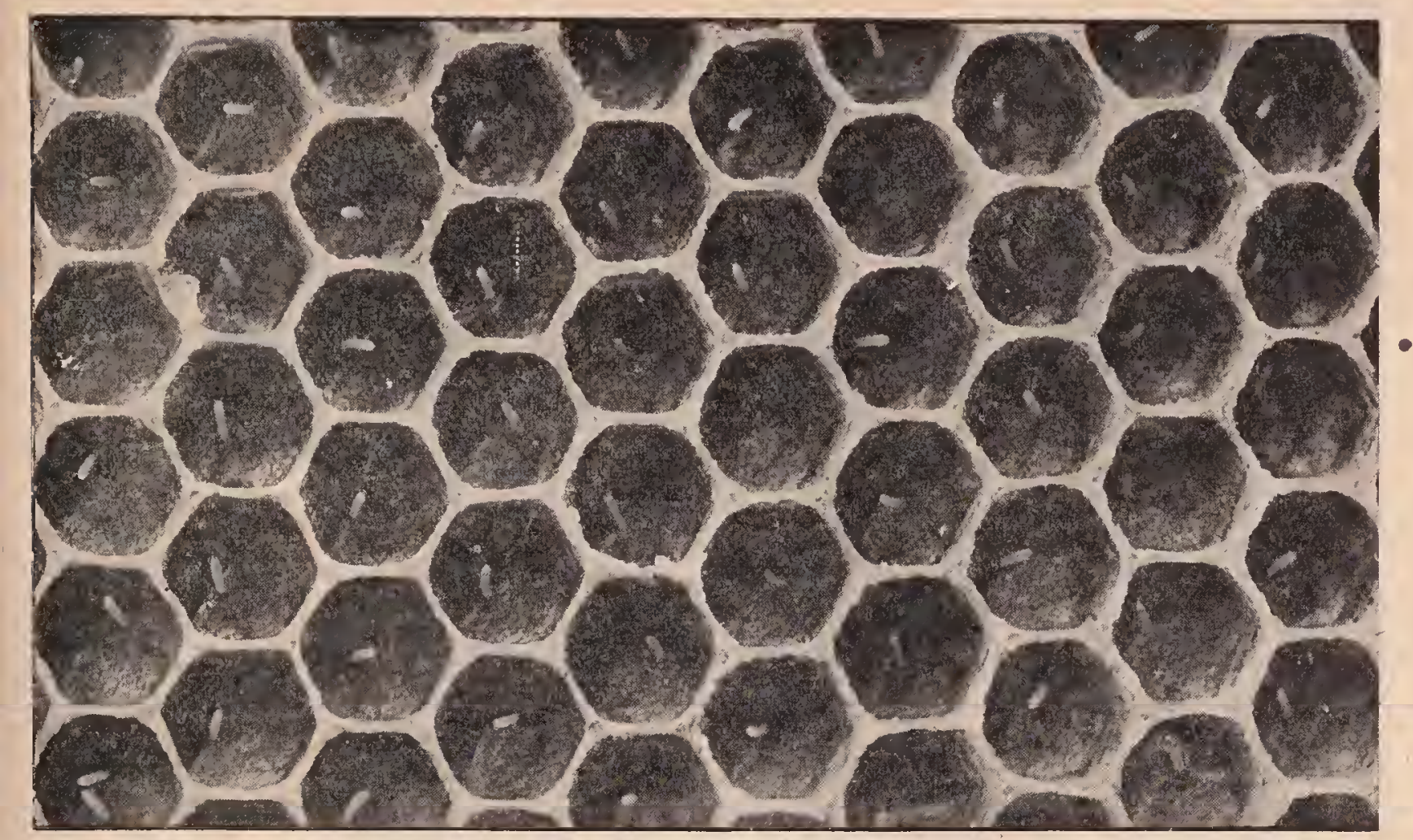

Close riew os egogs. Notice the cell in the lower left-hand corner contains two egogs, while that at the right-hand corner has a larva.

eggs, may be an indication that the colony is queenless. During spring and early summer there will be, or should be, brood in all stages, including egos. Such a condition indicates general prosperity, and the beekeeper can feel that his pets are doing well. But if there are no eggs nor young larra. and the queen cannot be found: and if: also, there are initial queen-cells during spring and the fore pant of summer, the strong probabilities are that the queen has recently died or that a swarm has issued. It may further be said that the absence of eggs and the presence of initial queen-cells during the active season are fairly good proof either that the queen is not in the hive, or that the one that is there is about to be replacer. It will be seen, then, that the presence or absence of brood in various stages of growtli, and especially young brood and eggs, gives one a prettr accurate irlea of the condition of the colony.

After the main houey flow, which usually: necur's in the northerr States firom July 1 to August 1, the activity of the queen in egg-laying will decrease and the amount of brood, even in a normal colony, will be very much less than at any time precering the loney flow. Sontetimes there will be almost no larræ nor eggs, and but very little sealed brood. The beginner will be inclined to think the queen is failing. when, as a matter of fact, sle and her colony are pursuing a normal course. Nature evidently works on the plan that there is no use in prorlucing a lot of worker bees and consumers when they can be of no possible help to the rolony: so she husbands her

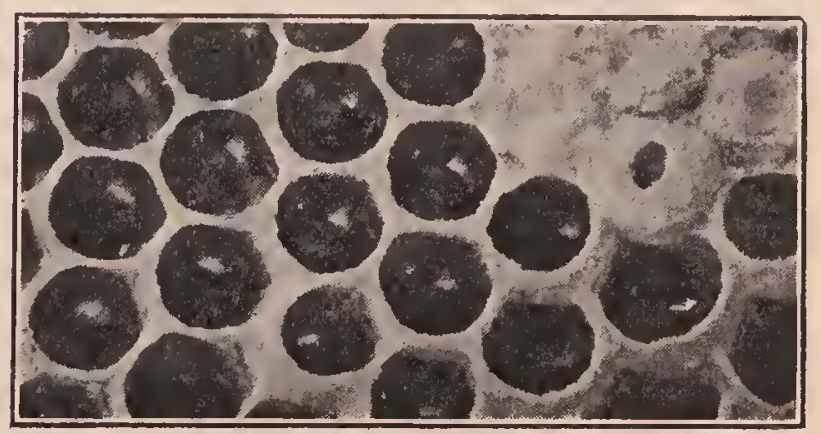

Insealed. partially sealed, and fully sealed honer, which may lie in either worker or drone rell. Capilliry attraction wrevents the unsealed honey from running out.

forces nutil another luney flow comes on toward fall. At that tine brood-rearing will start up again; and possibly the hives may have as much brood as at any time during spring or early summer. But if cool or frosty nights come on, the amount, prob- 


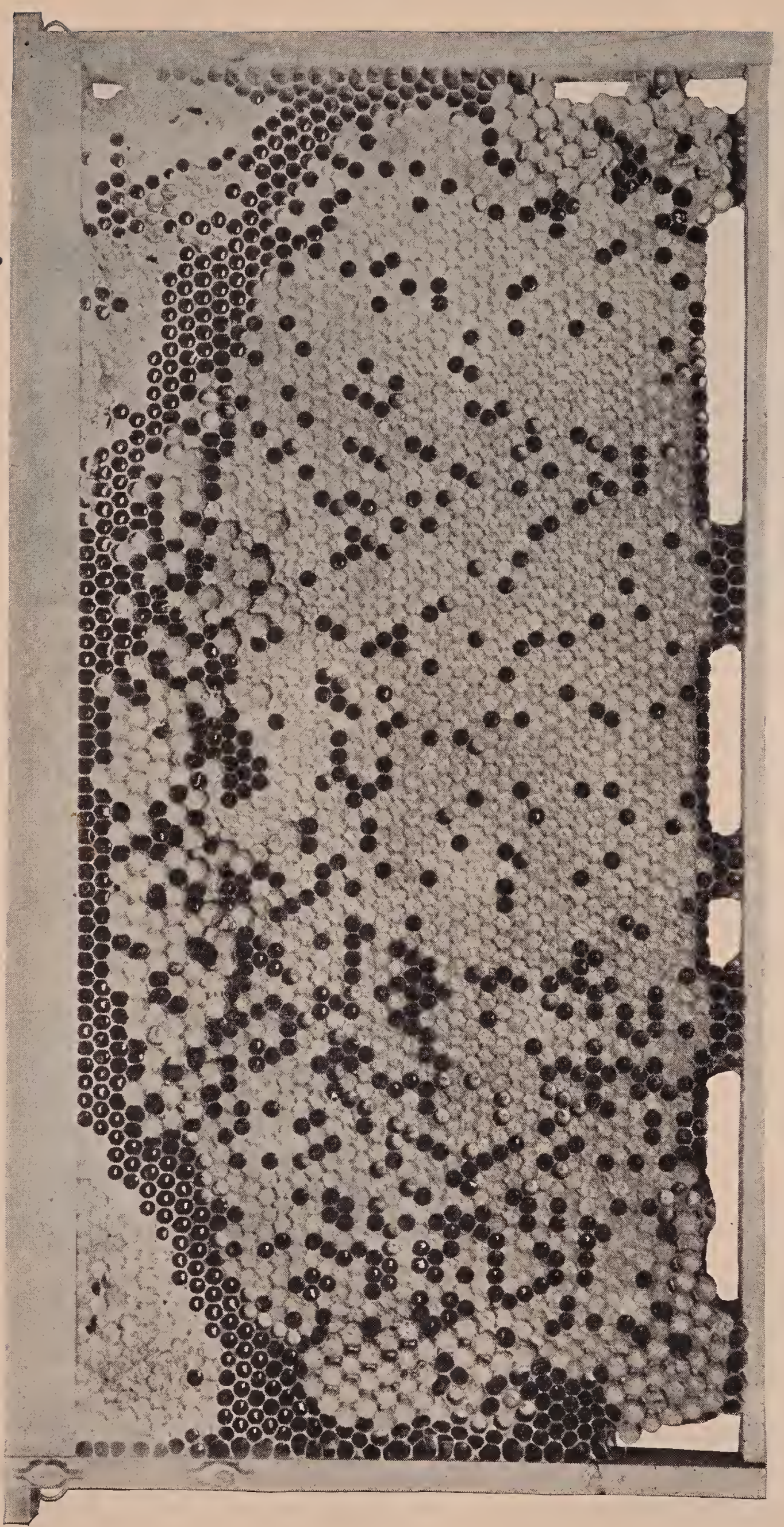

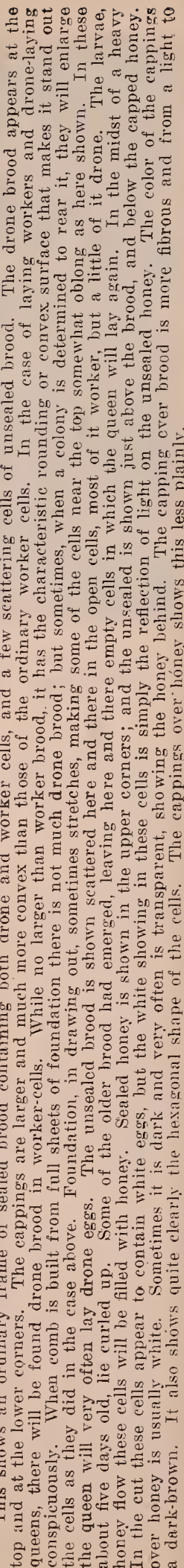


ably, will not go beyond one or two frames. If considerable brood is in the hive when a severe cool or cold spell comes on, it is apt to result in a lot of chilled brood.

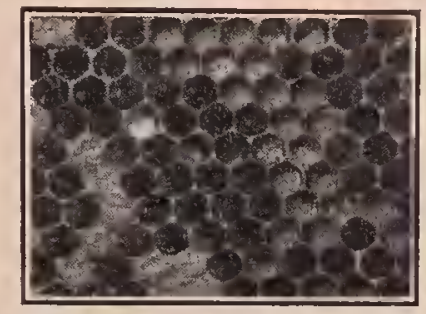

Capped brood in lower left corner, pollen above and at the right.

Sometimes during the flow, when late flowers are in bloom, the bees and queen apparently become excited and begin breeding heavily. A chilly, rainy spell may come on for four or five days, but not cold enough to kill the blossoms in the fields. During the interim the cluster contracts, especially at night. The young brood outside of the cluster chills and dies. In a day or two these larvæ will be found scattered around the entrance of the hive, and the beginner is inclined to come to the conclusion that something is wrong-that some bee disease like foul brood is in the hives.

The statement was made that egg-laying would begin to decrease after the main honey flow. This is true with all except young laying queens. A queen reared in June will probably continue laying all thru the summer, and the colony will contain brood in all stages. One reared in September will begin laying immediately, no matter what the conditions, and she will keep it up till cool or cold weather shuts it off.

In some localities it is an advantage to use young queens in order that there may be a large force of young bees for the honey flow that will follow the main one. The secondary flow, perhaps, will be from buckwheat, aster, goldenrod, or all of them. It is important to have a strong force of bees for it. Brood-rearing should, therefore, be continued from the first flow either by having young queens or by stimulative feeding, if honey is not coming in from natural sources. See FeEDING, subhead "Feening to Stimulate"; also BuILDING UP COLONIES.
"BY THEIR FRUITS YE SHALL KNOW THEM."

The amount of brood, the manner in which the eggs are laid-whether in scattering or inregular patches-also give one a fair idea, even tho he has not seen lier, of the kind of queen he has in the hive. If there is only a scant amount of brood, and egg's are scattering when other colonies are well supplied, the presumption is that the queen is poor, and that a better queen should be put in her place. After slee is found, the probabilities are that she will be small, not inuch larger than a worker.

If, on the other hand, brood is found in six or seven frames, in all stages of growth from eggs to the emerging bees, in a tenframe colony; the conclusion may be drawn that the queen is a good one, even tho she luas not been seen. "By their fruits ye sliall know them." When located, the queen will probably be discovered to be large, handsome, long or full-bodied. By waiting a moment, one may have the pleasure of seeing her lay an egg, for such a queen is usually on the job night and day.

As already stated, after the main honey flow egg-laying may almost entirely cease. One is more apt to find this condition at the close of the general harvest where the queen is one or two years old. A young queen reared in spring will usually continue to lay thruout the season. But usually any queen will begin laying when new lioney begins to come in or when the colony is given stimulative feeding. Broodrearing late in the fall, when the general weather is such that bees cannot fly, should not be attempted since it does more harm than good. There slould be no brood in the hives during winter in the North until about February or March, and then in only small patches and in outdoor colonies.

Too early brood-rearing during winter may or may not be a good omen. Much will depend on the climate and the winter. A mild winter or a mild climate will start breeding, especially if the bees can fly; but if a sharp cold snap follows, much of the brood will die, and the colony will suffer. In the South, brood-rearing on account of the mildness of the climate may or may not progress every month in the year. Breeding always requires a large amount of stores, and this explains why 
bees in the southern States ronsume more stores during winter than those in the Nortl.

\section{BIOOD-REARING IN THE SOUTH.}

Bees in the South will lave to gather from 200 to 250 pounds of lioney for colony maintenance before they can get a surplus. So mucl lioney is consumed in 'onstant brood-rearing and flying every day for 11 or 12 montlis that the beekeeper of the Southland should figure on at least two or three pounds of loney to maintain a colony to every pound he will get for surplus. In many instances the ratio would stand four to one. In the far souther'n States some of the best beekeepers admit that, during the winter, their bees have to raise two or three families of brood before they can get one to aather the honey. That means that the hive will have to be filled with brood two or three times, each generation dying off before the third or fourth generation can gather the main crop.

On the other hand, northern bees, during winter for five or six montls, are in a semi-dormant state, during which they raise but little brood, consume very few stores, and last, but not least, require no attention.

\section{BROOD-REARING DLRING MIDWINTER.}

Mention has loeen marle of the fact that brood may be found in the live during mirlwinter, particularly with bees outdoors. If the weather is milr, or if bees are located in a southern climate, brood may be found in the hive every month in the rear. Ordinarily, in the northern States no brood will be found much before February; but breeding may be starter either in the cellar or ontdoors by giving slabs of hard candy laid flat on top of the brood-nest with two $3 / 8$-inch cleats to hold it up from the top of the frames. (See Candy, marticularly Hard Candy.) Disturbance of the brood-nest in or out of the cellar will also often start breeding. The arerage beginner would do well not to hasten things before the bees themselves commence. If brood-rearing begins too early, there is danger of dysentery setting in. In order to maintain brood-rearing, the temperature of the colony must be up to about blood heat-94. This stimulates the activities of the colony, causing a large consumption of stores; but if the bees are not able to make winter flights, the retention of the feces may cause dysentery. When this starts in Jannary or February it will probably mean the loss of the colony before spring. (See 'D ysentery.) However. an experienced beekeeper in the northern States may start brood-rearing sometimes by giving slabs of candy, and the result will be that the colony will be stronger by spring than in the fall. But the arerage beginner should let the bees severely alone, provided he is sure they have plenty of stores and are well housed.

For a further discussion of brood and brood-rearing, see FeEdixg, subhead FeEDing to Stmurulate; Candy; Spreading Brood; Queens and Queen-rearing. For a discussion of brood diseases, elilled brood, and neglected brood, see Four BROOD.

\section{DRONE BROOD.}

This lias the general characteristics of worker brood, except that the cells are larger and the cappings more convex. While worker brood emerges in from 20 to 21 days from the laving of the egg. drone brood emerges in from 23 to 24 days. See large half-tone plate.

A drone-laying queen or a laving worker (see LAYING WORKER) may lay drone eggs in worker-cells. In that case the brood will be worker size, but the alppings will be more convex than ordinary worker.

Drone lrood will often rie from neglec.t. It will smell like foul brood, but lack the characteristics of either European or American foul broor. Beginner's sometimes suppose it to be a disease. But dead drone brood usually means nothing serious, especially if the worker brood in the hive is normally healthy.

AMOUNT OF HONEY REQUIRED FOR BROODREARING.

The author estimates the amount of honey nser by a colony of bees for its own maintenance at 200 to 250 pounds per year in the southern States. This is the amount the bees must have before any surplus can be secured. While this amount may seem excessive to some, it is not so high as simi- 
lar estimates made by other's. The data which are arailable on this subject are meager, but they all indicate that surprisingly large quantities of honey are used by the bees during the active season.

Beekeepers have no means of knowing exactly how much it costs in honey for the bees to rear a given amount of brood, and one can only guess as to the amount of honey used by adult bees when they are active as during a honey flow. Some work done by R. L. 'Taylor in the Michigan Experimental $\Lambda$ piary in 1896 yielded figures indicating that four pounds of honey are used to produce a frame of brood, Langstroth size. These figures were obtained by carefully conducted experiments. M. T. Pritchard reports that, in his queen-rearing operations, he feeds his cell-bnilding colonies, after the honey flow, one quart of sugar sylup made of two parts of water to one part of sugar, which is about the equivalent, in sugar content, of a pound of honey. This causes the bees to rear brood at the rate of fire frames of brood every 20 days, these five frames being remover from the brood-chamber every 20 days and placed above a queen-exchuder. Five combs every 20 days is at the rate of one comb every four days, to produce which he feeds the equivalent of four pounds of honey. If no nectar is coming in from the fields, these "olonies use a small amount of their reserve stores in addition to the quart of thin syrup per day. These figures agree closely with Taylor's figures of four, pounds of honey to produce a frame of brood.

In 1901 Adrian Getaz collected all of the lata which had been published up to that time in American beekeeping literature on the subject of "feeding back" extracted honey for the completion of unfinished sections. These figures indicate quite consistently that a colony of bees, when actively engaged in storing comb honer in sections, uses one and a half pounds of honey daily. In practically every recorded case brood-rearing was restricted, while the colonies were being fed, by reducing the brood-chamber to five combs. From this great mass of figures on feeding back Getaz concluded that 170 pounds of honey is the lowest amount consumed by a normal colony during the year.
Disregarding the brood reared previous to about $\Lambda$ pril 1 and assuming that a colony rears two frames of brood during the first period of 21 days, five frames of brood during the second period of 21 days, and 10 frames of brood during the third period of 21 days, we have a total of 17 frames of brood, which, aceording to the above figures, cost 68 pounds of honey. Some colonies will probably produce 20 combs of brood in this time costing 80 pounds of loner. This takes the colony up to about the first of June. Assuming an average of five frames of brood thru. July and August, we have 1.5 frames of brooding costing 60 pounds of honey. Assuming three frames of brood thru August and September, we lave nine frames of brood, ora total of 164 to 176 pounds for brood-rearing alone. 'To this must be added 15 to 20 pounds for winter and the amount of honey used by the adult bees when they are active during a honey flow. On this point we have but. little information: but, if the above figures are nearly correct, normal colonies of bees must consume nore than 200 pounds of honey annually, eren in the North.

The large amount of stores needed for brood-rearing during the spring, in some cases apparently as much as 80 pounds, enthasizes the neer of close attention as to stores during this time when the bees may not be able to gather much from the fields.

Under the head of BEe BeHavior and Devitopalent of Beis, the scientific sirle of the growth of the bee from the egg to the fully developed worker has been discussed: but, as there may be some who do not care to go into the science of this, something here is presented that will enable one to follow out for himself the egg up to the time that the bee emerges, and even after it begins to perform some of the duties of the hive.

\section{THE DETELOPJIFNT OF BROOD.*}

During warm weather, while bees are gathering honey, open the hive about noon. and put in the center a frame containing a sheet of foundation. Examine it every morning, noon, and evening, until eggs can be seen in the cells. By inserting it between two combs already containing

\footnotetext{
* See also Developirent of BeEs.
} 
brood, eggs will be found in the cells the next day.

If one has never seen an egg that is to produce a bee, he may have to look very sharply the first time, for they are white like polished ivory, and scarcely larger than the letter " $\mathrm{i}$ " in this print. (See DEVELOPMENT OF BEES.) They will be seen in the center of the cells attached to the comb by one end. The egg under the microscope much resembles the cut. It is covered, as will be noted, with a sort of lacelike penciling, or network it night properly be called. Immeriately on discovering eggs, the date should be marked.

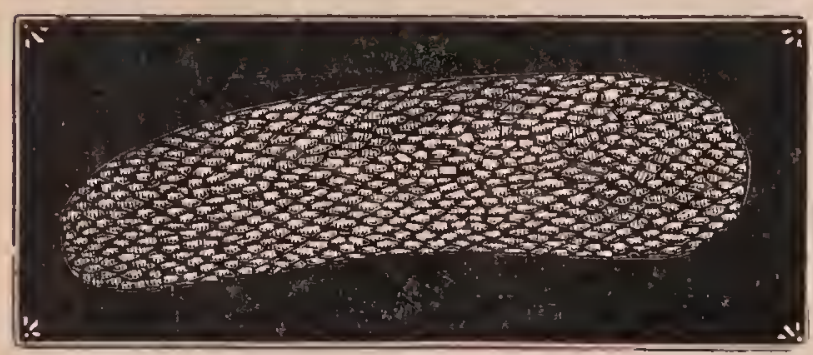

I queen's egr under the microscope.

If the weather is farorable, these eggs will hateh out in about three days or a little more, when, in place of the egg, if one looks sharply enough, he will see a tiny white worm or grub floating in a minute drop of milky fluid. If he watehes he will find bees incessantly poling their heads into these cells. Just before the inmate breaks its way out of the shell a milky food is placed on and about the egg. Experiments have proven this necessary to the development of the egg; for if eg's are removed from the hive and subjected to the proper temperature they will hatch if supplied with the milky food; otherwise not. These worms that hateh from the eggs are really young bees 'in their larval state, and we shall in the future call them larræ. They thrire and grow very rapidly on their bread-and-milk diet, as can be seen if they are looked at very often. They will more than double in size in a single half-rlay. This seems almost incredible; but there they are, right before our eyes. Probably it is owing to the highly concentrated nature of this bread-and-milk food that the workers are so constantly giving them that they grow so rapidly. If the comb is taken away from the bees for a little while, the larvæ will be seen opening their moutlis to be fer, like a nest of young birds.

\section{RATE OF GROWTH.}

Figures under the cut represent the age in days from the laying of an egg. First, the larva just having broken the egg-shell

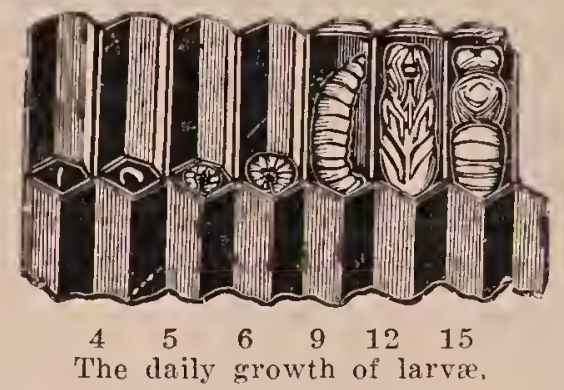

on the third day; next, a larva on the fourth day. During the fiftl and the sixth days they grow very rapidly, but it is diffecult to fix any precise mark in regard to size. On the ninth day, the larva having straightened itself out, worker bees cap it over. (See Developurfent of Bees.) The antlor has made some careful observations on this point, and it was just six days and seven hour's after the first ege hatehed that the bees completely capped it over. During the warmest weather, this may be reduced to less than six days. To determine when larrae begin to have legs and eyes, see Developanent of Bees. The wings develop toward the last of the growth.

After the larvæ are 6 days old, or between 9 and 10 days from the time the egg was laid, one will find the bees sealing up some of the largest. This sealing is done with a porous-like substance in which are found wax shreds, old silk, bee hair, and sometimes pollen: and while it shuts the roung bee up, it still allows it a chance to breathe thrn the pores of the capping. It is given its last food, and the nurse bees seem to say, "There! you have been fed enough. Spin your cocoon, and take care of vourself." See Developirext' of Bees.

After this the young bee is generally left covered up until it gnaws off the capping and comes out a perfect bee. This will be in about 21 days from the time the egg was laid, or it may be 20 if the weatler is very favorable; thorefore it is shut up 11 or 12 days.

There is an exception to this last state- 
ment, and it lias caused not a little trouble and solieitude to beginners. During very warm summer weather, the bees, for one reason or another, decide to let a part of their children go "bareheaded," and there-

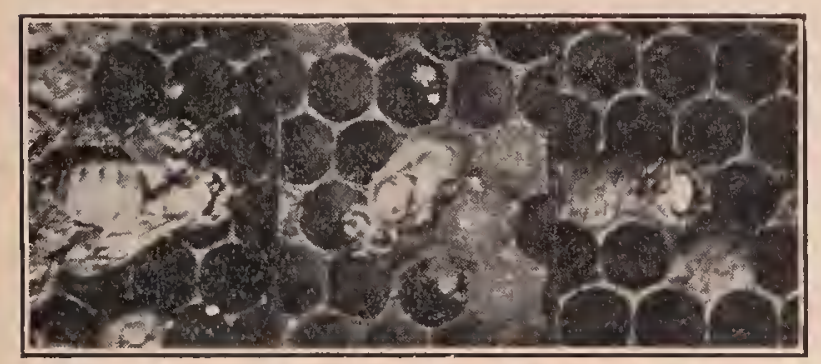

Bees gnawing thru the eappings and emerging from their cells.

fore, on opening a live, whole patches of immature bees will be found looking like silent corpses with their white heads in tier's just about on a level with the surface of the comb. 'This seems to be peculiar' to the offspring of some queens or strains. and is sometimes so pronounced that almost no brood are perfectly sealed at any season. At this stage of growth they are motionless, of course, and so the young beekeeper sends a postal card, saying the brood in his hive are all dead. Some have imagined that the extractor killed them, others that it was foul brood (see Four Brood). One can't help thinking of the family which moved from the eity into the country. When their beans began to come ilp, they thought the poor things had made a mistake by coming up wong end first; so they pulled them all up, and replanted them with the bean part in the ground. leaving the proper roots sprawling in the air:' One cin rest assured that the bees always know when it is safe to let the children's heads go uneovered.

It is very important, many times, to discover just when a queen was lost or a colony swarmed: hence one should learn these data thoroly; the development of a bee oceupies 3 days in the egg, 6 in the larval state, and 12 days sealed ip.

\section{YOUNG BEES AFIER TIIEY EMIERGE.}

The young bee, when it gnaws its way out of the cell, commences to rub its own nose, straighten out its feathers, and then push its way among the busy throng, doubtless rejoicing to hecome one of that vast commonwealth. Nobody says a word, nor, apparently, takes any notice of the youngster; but for all that, these young bees, as a whole, feel encouraged, and rejoice in their own way at a house full of young follis. If a colony is kept without young bees for a time, one will see a new energy infused into all hands just as soou as young bees begin to gnaw out.

If one should vary the experiment by putting a frame of Italian eggs into a colony of black bees, he will be better able to follow the newly emerged young bee as it matures. The first day it does little but crawl around; but about the next lay it will be found dipping greedily into the cells of unsealed honey. After about the first day it will begin to look after the wants of the monsealed larvix, and very soon assists in furnishing the milky food for them. While so doing, a large amount of pollen is used, and it is supposed that this larral food is pollen and honey, partially digested by these young nurses. Bees of this age or a little older supply royal jelly for the queen-cells, which is the same, probably, as the food given very small larvie. Just before they are sealed up. larvae to produce. worker bees and drones are fed on a coarser, less perfectly digested mixture of honey and pollen. Very possibly the only difference in this food is the addition of honey with its contained pollen, to the food previously given by other and perhaps younger nurses. Young bees have a white downy look until they are a full week old, and continue a peculiar young aspect until they are quite two weeks old. At about this latter age they are generally active comb-builders of the hive. When a week or ten days old they take their first flight out of doors: there is no prettier sight in the apiary than a host of young Italians taking a playflight in the open air. in front of their hive. Their anties and wambols remind one of a lot of young lambs at play. See PLAYFLights.

It is also very interesting to see these young bees bringing their first load of pollen from the fields. If there are plenty of other bees in the hive of the proper age, they will not usually take up this mork until about two weeks old. The first load of pollen is to a young bee just about what the first pair of pants is to a boy 
baby. Instead of going straight into the live with its loarl, as the reterans do, a rast amount of cireling round the entrauce must be done; and, even after the young bee has once alighted, it takes wing again, then returns and rushes all thrn the hive. jostling nurses, drones, and perhaps the queen too, seeming to say as plainly as could words, "Look! Hece au I. I gathered this, all myself. Is it not nice?"

One might imagine some old reteran, who had brought thousands of sueh loads. answering giufly, "Trell, suppose you did: what of it? You had better put it in a cell and start off after more, instead of making all this row and wasting time, when there are 'so many mouths to feed." Yet, apparently, no one scolds or finds fault, and the children are never forced to work, unless they wisli. If they are improvident, and starvation comes, they all suffer alike, and, it is probable, without any hard feeling or censure toward any one. They all work together, just as the right liand assists the left; and if one would understand the economy of the bechive. it were well to bear this point in mind.

Shortly following the impulse for pollen-collecting, comes that for honey-gathering: and the bee is probably in its prime as a worker when a month old. At this stage it can, like a man of forty, "turn its hand" to almost any domestic duty; but if the hive is well supplier with worker's of all ages, it now probably does most effective service in the fields. See BEe BerarIOR; also AgE of BeEs.

When a colony is formed of young bees entirely, they will sometimes go out into the fields for pollen when but five or six days old. Also when a colony is formed wholly of adult bees they can build comb. feed the larrae, construct queen-cells, and perform work generally that is usually rone by younger bees; ret it is probably better economy to have bees of all ages in the hive.

BROOD, SPREADING.-See SPRiAdINF BroOI.

BUCKBUSH (Symphoricarpos occidentalis).-Wolfberry. A branching shrub, three to five feet tall. common in Washington and Idaho. In Tdaho it is one of the most important honey plants yielding a surplus, on an average, of 25 pounds per colony. Near Fraser in the northern part of the State the lioney is secured by the thousand pounds. The extracted honey is water-white with a rery pleasant flaror and is slow to granulate, a bottle of it remaining liquid after three years. It blooms from June 15 to July 20 . The small white flowers are white tinged with pink, bell-shaped, hairy within, and are in small clusters in the axils of the leaves. They secrete nectar freely, and are rery attractive to wasps whence they have been called wasp-flowers. The fruit is a white berry, which is eaten by pheasants and cattle.

This bush is also abundant in western Iowa, where it yields well in dry weather. The honey is white and rery similar to that of white clover. In the Missouri River basin, especially on the loess bluffs, this is a very common species: but it ceases to be valuable east of $\mathrm{T}$ isconsin and south of Nebraska.

Coral-berry or Indian currant ( $S$. orbiculatus) extends southwari from Towa to Texas and is abundant along the Missouri River. The small berries are rerl resembling red cur'ants. It blooms for two or three weeks and secretes a large quantity of nectar.

Snowbery (S'. racemosus) is a northern species found from Alaska to Nova Scotia, and southward on the east coast to Pennsylvania and on the rest roast of California. In Iowa, in summer, a large amount of excellent honey is obtainer from it. It is frequently cultirated for ornament because of its large white berries.

BUCKWHEAT (Fagopyrum esculentum Moench.).-The English name is derivel from the German buchweizen (beechnut), so called from the close resemblance of the sharply three-angled seed to the beechnut. The generic name Fagopyrum is Greek for beechwheat. The common species belongs to the buckwheat family, or Polygonacex, which likewise includes such familiar weeds as the sorrels, docks, and smartweeds. Heartsease, an important honey plant in the West, also belongs here. There are about six species of buckwheat and they are all natives of Asia. Besides the com- 
mon buckwhert two other speries ane (andtivated for grain. 'Tartary buckwheat ( $F$. taturiatm) endures the cold better, but the seeds are smaller. It is grown in the nountainous.regions of Asia and to some extent in eastern ('anarla and Maine. Noteh-seeded buckwheat (F. emarainatum) is grown in the highlands of northeast India, where the grain is used for food.

\section{HISTORY.}

The common species grows wild on the banks of the Amur River in Manchuria and near Lake Baikal, and possibly also in ('hina and northern India. It was nnknown to the Greeks and Romans, and its cultivation is first mentioned in China about the tenth century. It was introduced into Europe thru Russia and was.

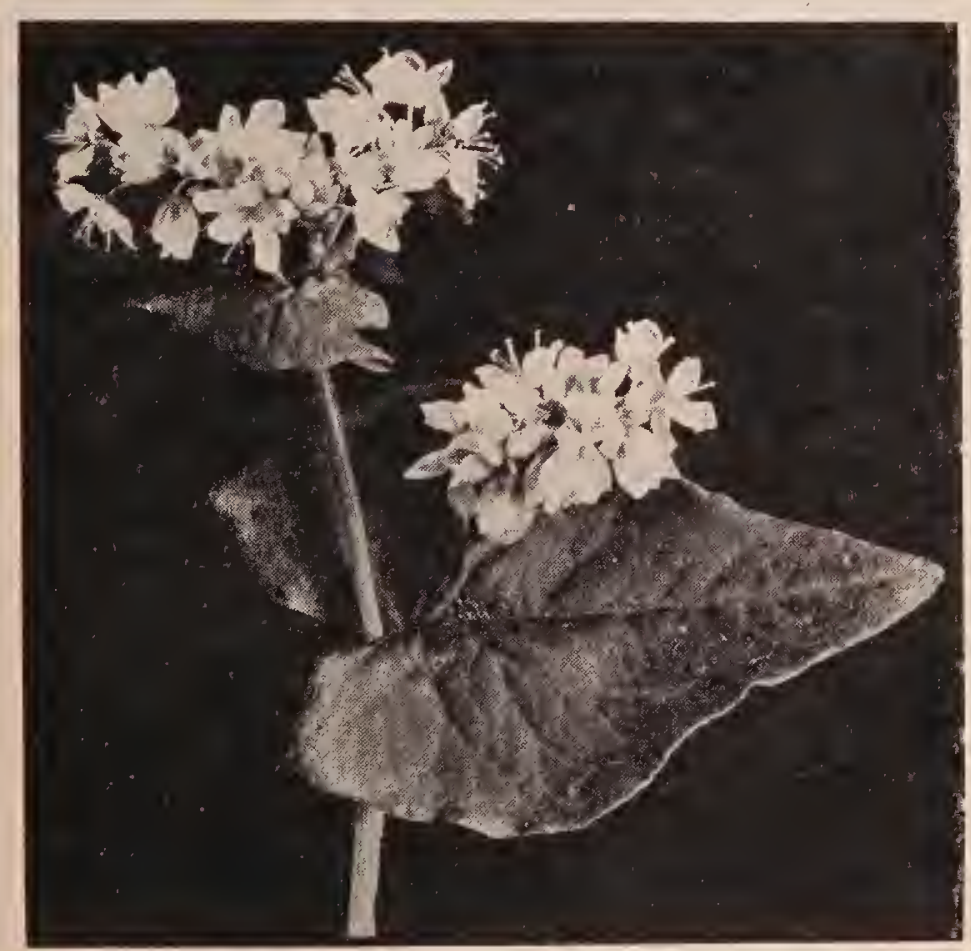

Buckwheat blossom.

grown in Germany in 1436. In the 16th century it was cultivated in both France and Italy. It was early brought to the American colonies where it was largely used as a substitute for wheat.

POLLINATION.

The plant is a nearly smootl annual, growing from one to four feet tall. The leaves are halbert-shaped. T'he small flowers are clustered and possess a strong fragrance: the petals are ranting but the sepals are white or rose-colored. 'T'he nec- far is secreted la eight round yollow whols interposed between the same number of stamens. This species is dinorplice, that is there are two forms of flower's, one with long stamens and short styles and the other with short stamens and long styles. This arrangement promotes cross-pollination. In the long stamened flower's most visitor's touch the anthers with the under side of the body and the stigmas with the head; and the converse takes place in the shortstamened flowers. Each plant bears flowers of one form only, but the seed from either form will produce both forms in about equal numbers.

When the flowers are legitimately pollinated, that is, when pollen is brought from flower's with short stamens to flower's with short styles, or from flower's witl long stamens to flowers with long styles, the seeds are more numerous and leavier than when the flower's are pollinated illegitimately. The pollen of the two different forms of flower's differs in size and is less active upon its own stigma than upon the stigma of a flower of the other form, or it may be entirely inactive (impotent) upon all flowers of the same form as the flower producing it. Thus the functions of the flowers are such that the artvantages of cross-pollination are secured, and yet every flower may produce seed. Whereas in plants which liave the stamens and pistils in different flowers only half the flower's can be fruitful. The flowers of buckwheat, according to Darwin, possess the power of self-fertilization, but when covered witl nets they are early in the season almost wholly self-sterile and produce hardly any seed. Flower's cross-pollinated artificially at the same time produce seeds in abundance. Later in the séason, during September, both forms of flower's became highly self-fertile. They did not, however, pioduce as many seeds as some neighboring uncovered plants which were visited by insects. Thus the erop of seed is largely dependent on insects, chiefly lioneybees. which are estimated to make nine-tenths of the visits. There are planted in the Lniter States annually 800,000 to $1,000.000$ acres 


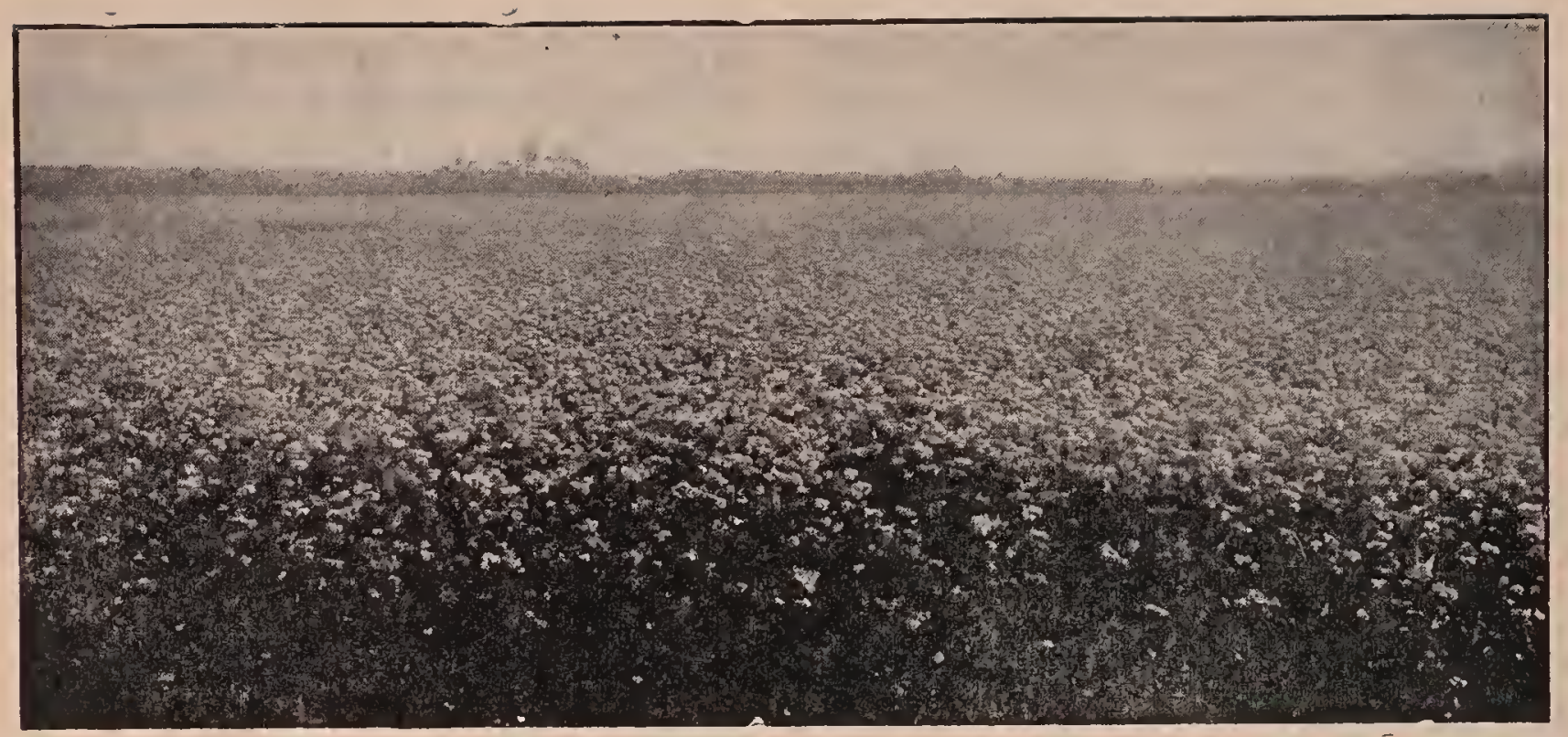

Japanese buckwheat 34 inches high in a little over three weeks from the time the seed was planted.

of buckwheat, and yet the value of the services of the honeybee in pollinating this great expanse of bloom is almost wholly unknown. The buckwheat-growers and beekeepers of New York are mutually dependent.

\section{BUCKWHEAT AS A HONEY PLANT.}

Buckwheat ean be cultivated thruout the Nortl Temperate Zone. It is extensively grown in Asia, especially in Japan, and is also widely cultivated in Europe. An immense quantity of buckwheat honey is gathered in Russia. In North America, while it is grown to some extent in Canada, it is chiefly valuable for grain in the United States. It is best adapted to New Tork, Pennsylvania, Ohio, Michigan, Wiscousin, and New England; and to the mountainous sections of Maryland, West Virginia, Kentucky, North Carolina, and Tennessee. About two-thirds of the crop is now raised in New York and Pennsylvania. In 1899 about $2,000,000$ farms reported an average acreage of four acres each.

In New Tork and Pennsylvania there are thousands of acres of buckwheat within a radius of a few miles. On one hilltop in Schoharie County, N. Y., the bees were reported a few years ago to have access within a radins of three miles to 5,000 acres of buckwheat, all of which was within range of the eye. So great is the acreage of it in New York that from 2,000 to 3,000 colonies can be kept in some counties, and immense quantities of buckwheat honey are stored annually. There are hundreds of farmers who keep a few colonies in order that they may get the honey as well as the grain. One may ride for an entire day thruont the buckwheat region of this State without losing sight of the buckwheat fields. So immense is the area of bloom that the atmosphere is heavily charged with its odor.

One beekeeper in the heart of the buckwheat country, who lived near Cayuga Lake, harvested one year with 1,000 colonies 78,000 pounds of honey; another year 50,000 pounds; for many years his erops, obtained chiefly from buckwheat, have been in carloads. E. W. Alexander of Delanson, N. Y., also produced immense quantities of this honey. His apiary consisted of 700 colonies, and from the top of the hill, where it was located, there were in sight 1,500 acres of buckwheat. Nowhere does buckwheat thrive better than on the hillsides of eastern New Iork, nor are the climate and the soil elsewhere more farorable to a luxuriant growth.

The flowers of buckwheat secrete nectar only in the morning; toward noon the flow lessens and ceases entirely during the afternoon, but begins again vigorously the next morning. The risits of the bees quickly decrease in number until they cease almost entirely, and they remain idle about the hives for the balance of the day. Thus in the afternoon, notwithstanding the great expanse of bloom and its strong fragrance, 


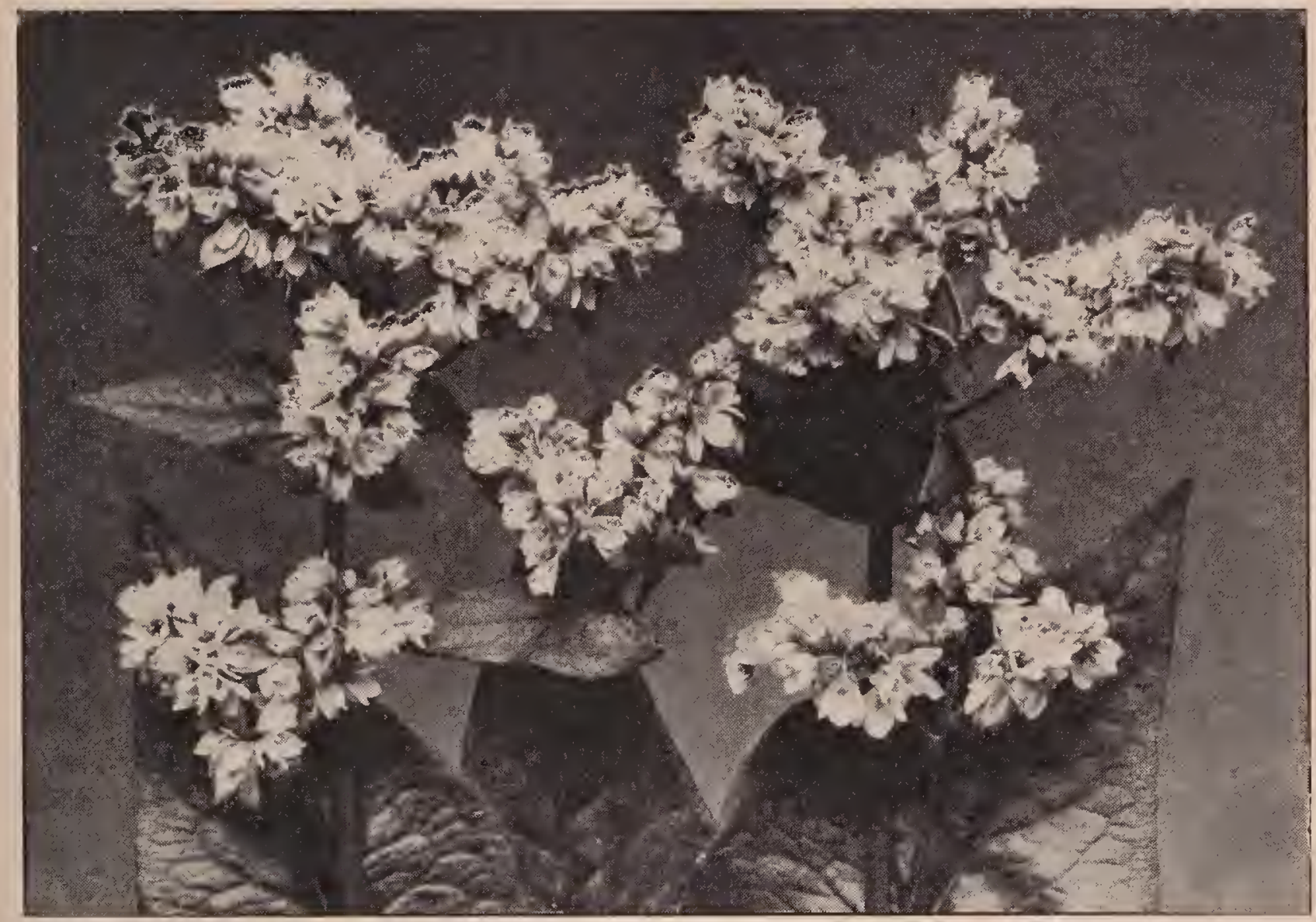

Honey for the bees, seed for harvest, fertilizer for the ground-buckwheat should be planted extensively

only a few bees can be found in the fields. Probably no beekeeper has ever had a more extended experience with buckwheat as a honey plant that E. W. Alexander. He observed that the secretion of nectar varied greatly with the temperature and the condition of the weather. He says:

"Several years ago I kept nearly 200 colonies in a location where there were barely 100 acres of buckwheat within reach of $\mathrm{my}$ bees, that is, within four niles or in a circle eight miles in diameter. Still with this small acreage it was no uncommon thing to harvest a surplus of 15 to 20 pounds of fine buckwlieat section honey per colony. As a result I became very anxious to lieep bees in a buckwheat location, where thousands of acres were raised annually, so I moved to Delanson, N. Y. But I soon found out to my sorrow that the amount of bloom had but little bearing on the amount of surplus I obtained, and that in this respect buckwlieat was no exception to other flowers. It does its best when we have quite cool nights followed by a clear sky and a bright hot 'sun with little or no wind; then from about 9 oclock in the morning until 2 in the after-
1 noon it secretes nectar very fast. We seldom find a bee on it much earlier or later in the day.

"A few years ago during our August harvest, when our bees had at least 1,500 acres of buckwheat bloom to work on, and were bringing in honey very fast, a heavy shower came down from the north about 2 P. M., which caused the mercury to drop 21 degrees in less than half an hour. Then this low temperature, with windy cloudy weather, lasted some 11 days, during which time the bees destroyed large quantities of brood, for there was no nectar in the flowers and they were ready to rob any hive that was opened.

"I never saw the buckwheat harrest stop so suddenly, with so little cause, as it did in August, 1906. From the morning of the 21st to the night of the 24th, the bees brought in the honey very fast. Our hive on scales averaged a gain of about 8 pounds a day, and we extracted a tankful of a little more than two tons each day for four consecutive days, and yet our men all agreed there was more honey in the apiary each night than there was in the morning. But on the night of the 24th we had a 


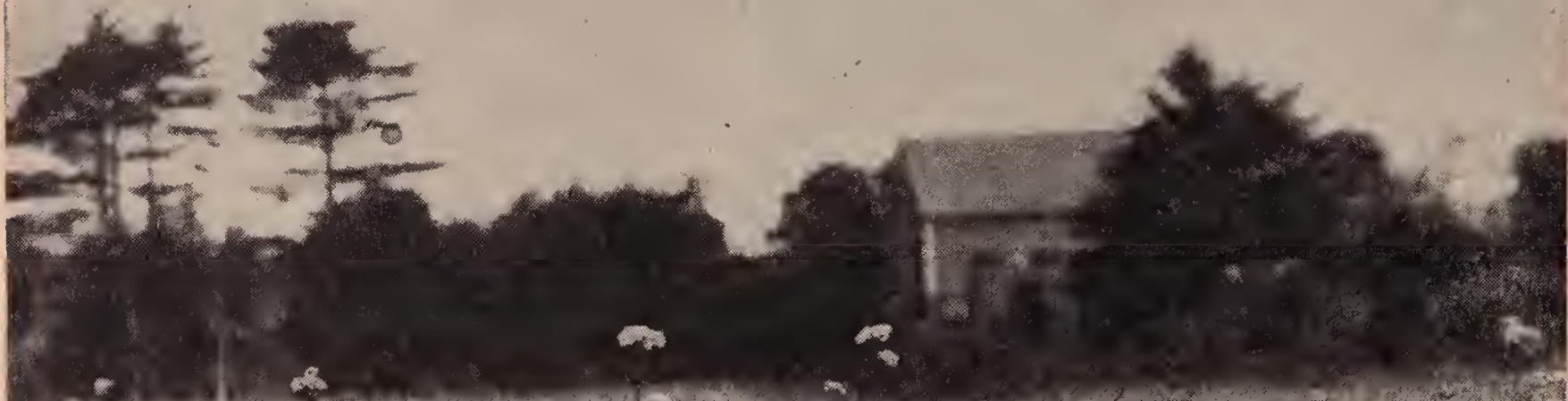

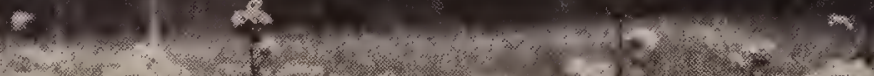

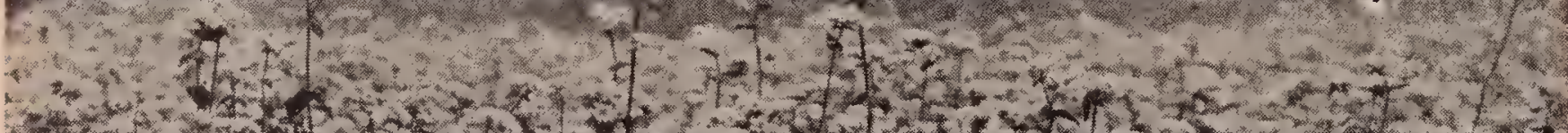

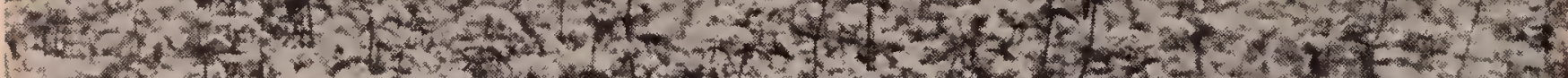

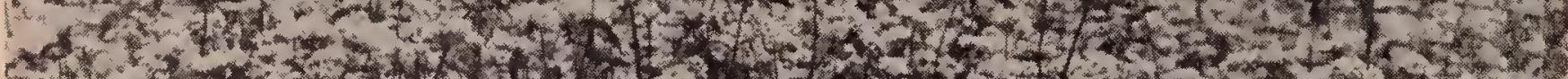

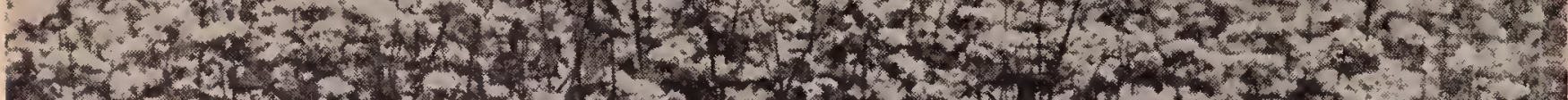

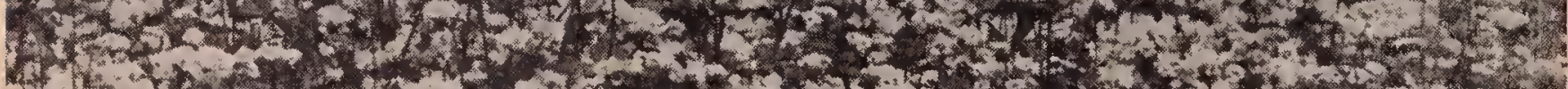

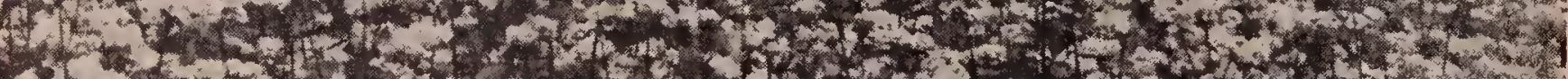

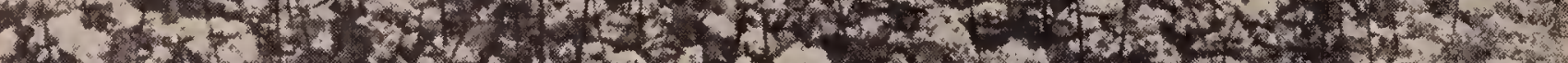

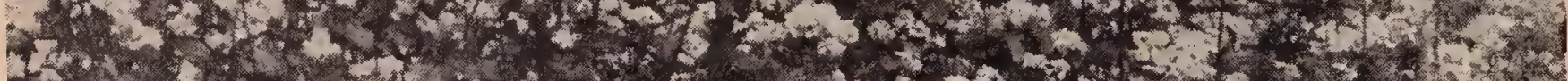

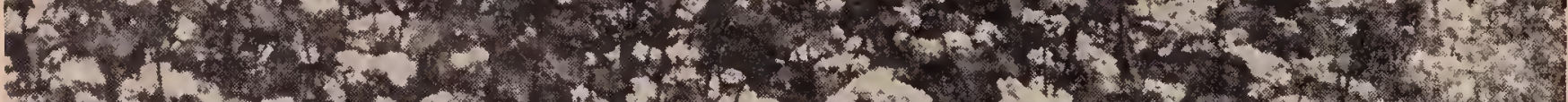

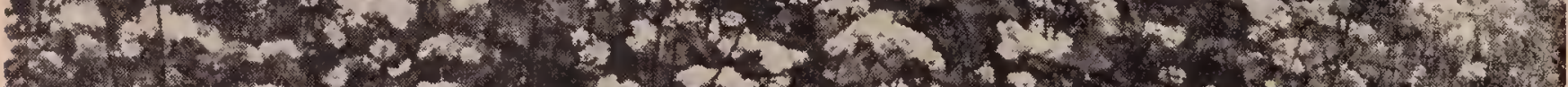

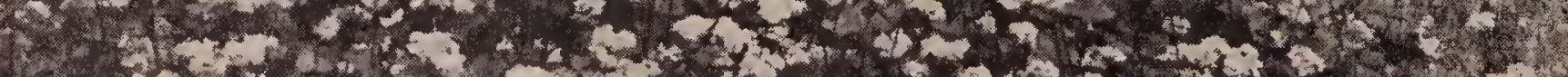

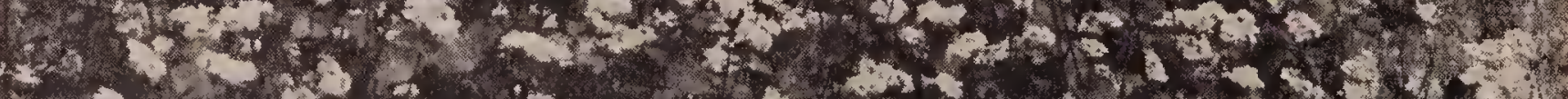

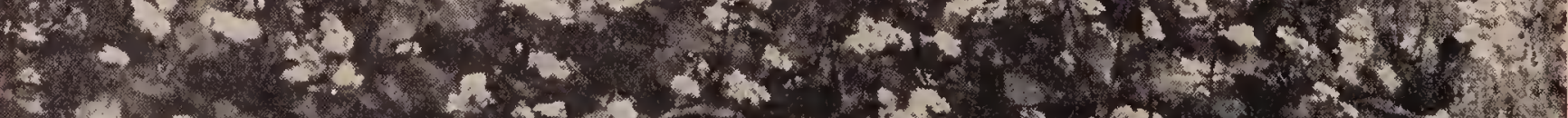

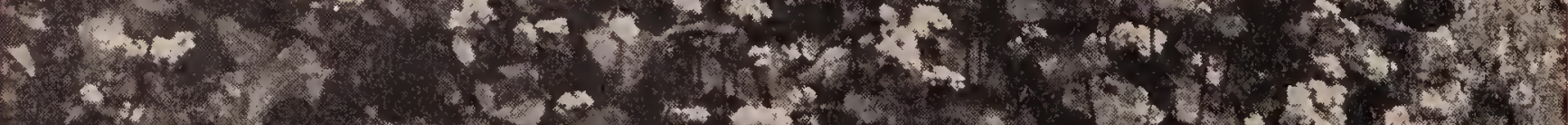

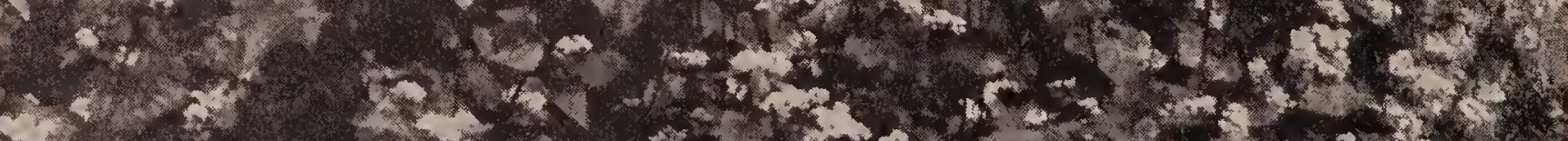

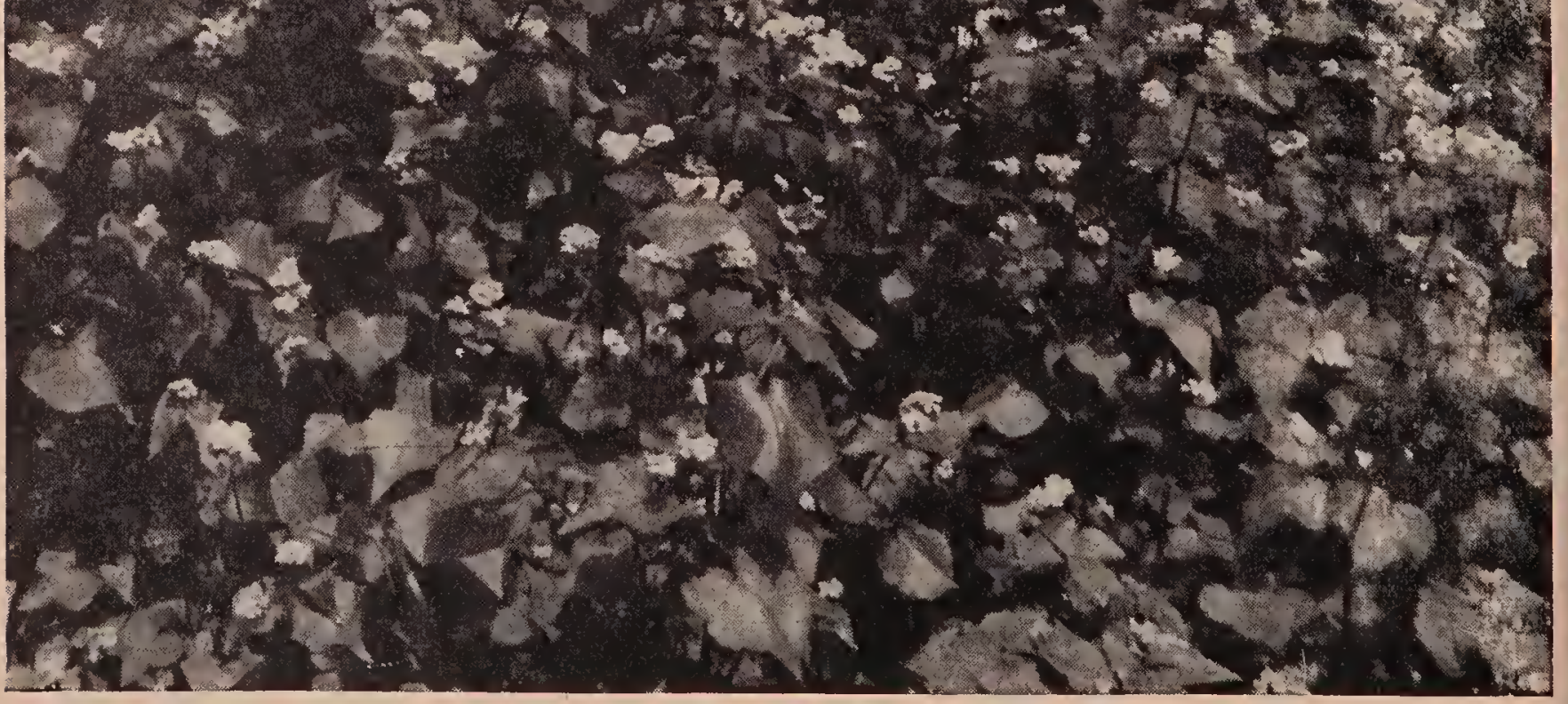




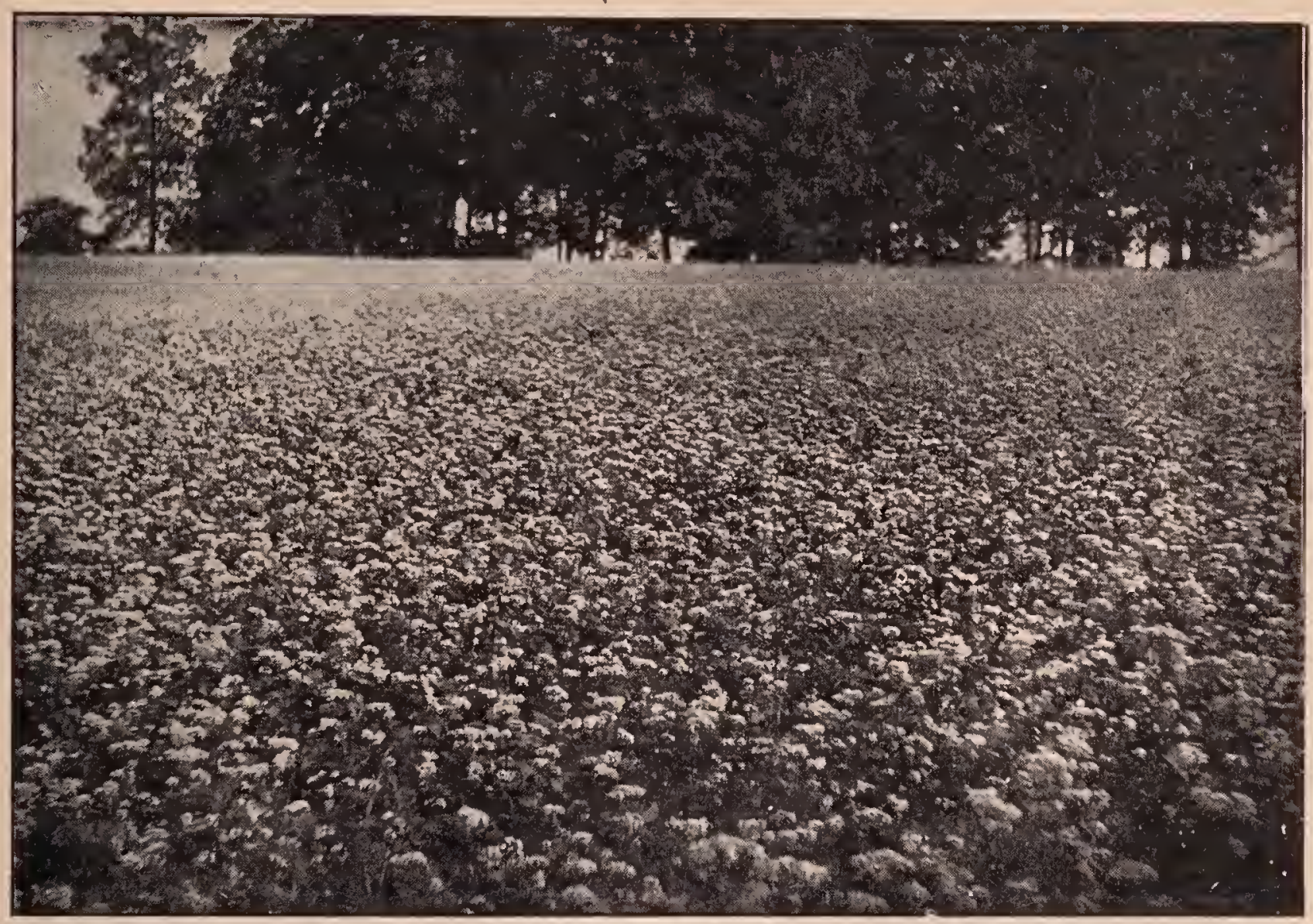

Buckwheat in full bloom in Butler Co., $\mathrm{Pa}$.

slight shower with a fall in temperature of 11 degrees. The bees were rery quiet the next morning until about noon; then when it warmed up a little thev were ready to rob anything they could get at, and there were thousands tring to get into our loner-louse around the screened windows-and we knew from past experience that the honey season of 1906 liad drawn to a close. 'Tlie hive on scales did not gain one-half pound any day after that shower and fall in temperature, altho there was considerable buckwlieat in bloom. At other times I have noticed that when the weatliel remains warm without any rain the flow of nectar would last until Sept. 5."

In New York buckwheat can be depended upon almost every year to yield a crop of lioney, but in the West it is more uncertain, some year's vielding no honey and in others a fair amount. In Ohio the vield of nectar from buckrveat is so irregular and scanty that there is seldom a season that much honey is obtained from it. Since in the East it is almost always very reliable, when even basswood and clover fail. as they do sometimes in every locality, the beekeeper is usually able to make lis expenses and a fair profit. In New York it is seldom that he is not able to make a fair, living from buckwheat alone.

Imong cultivated crops there are few which will afford a better artificial honerpasture than buckwheat. The beekeeper' who raises this cereal largely for honey showd plant at three different times in order to prolong as mucle as possible the flow of nectar. On an arerage it will occupy the land a little over 60 days. It will commence to rield nectar in 15 or 20 days flom the time it is planted, and take about 10 days to mature after the honey flow ceases. If the first crop is sown on the 20 th of June, the second crop on the 4 th of July, and the third about the 18th of this month, the beekeeper will be assured of a nood bee-pasturage from the middle of July, when basswood and clover are past, to the middle of September, when the fall wild flowers begin to bloom.

Buckwheat seed may sometimes be given away profitably to farmers in localities where this grain is not grown. By furmishing the seed free for one or two years farmers may perhaps be induced to grow 
this crop regularly in after years. It is not advisable to give the seed after the second year; during the third and the fourth years it should be furnished at halfprice. It should not be supplied free to any one living more than a quarter of a mile from the bees.

\section{BUCKWHEAT HONEY.}

Buckwheat honey is of a dark-purplish color, and looks much like the old New Orleans or sorglium molasses. The flavor to one who is a lover of clover and basswood honey and is unaccustomed to that of buckwheat is more or less sickisll: but those who have always eaten buckwheat honey, or at least many of them, prefer it even to that of clover or basswood.

A lady from the East once called at a store and looked over the honey. She was shown several samples of choice clover and basswood honey.

"I do not like this," she said. "It looks like manufactured sugar honey. Haven't you any buckwheat honey?"

"Yes, but we did not suppose that you would like that, because such honey rarely sells in our locality."

Some sections of buckwheat honey were placed before her and these suited her exactly.

"That is real bee honey," said she, with a look of satisfaction, and she carried home several sections.

Her father had been a beekeeper in a locality where buckwheat was abunḑant: and unless loney had the strong flavor and dark color of the honey with which she was familiar in her childhood days, it was not honey to her. There are thousands like her in the East who prefer buckwheat honey; and this trade is so large in New York and Albany that it brings almost as high a price as the fancy grarles of white. But in the wèstern markets, principally in Chicago, it is without pureliasers and sells as an offorade honey.

Notwithstanding the color of buckwheat honey itself is purplish, the comb honey is very attractive, since the cappings, especially if made by black bees, are almost pearly white.

Buckwheat honey occasionally contains 33 per cent of water, and is, therefore, too thin, according to the formula of the national pure food law passed June 30, 1906, which limits the amount of water in honey to 25 per cent. It is thus necessary to evaporate thin honey in order that it may conform to the law. This may be done by means of a honey evaporator, or by storing it for a while in a hot dry room. The quality of the honey is so greatly improved that it will fully compensate for the trouble involved.

\section{THE CULTURE OF BUCKWHEAT.}

Buckwheat is very sensitive to cold and is killed by the first heavy frost. It should not be sown too early in the spring since it is liable to be killed by the frost after it has sprouter, or the very lot weather of midsummer may blast the flowers so that they will produce no seed. No other cereal crop requires so short a season to mature, and under the most favorable conditions a crop may be obtained in from 8 to 10 weeks, but the average time is about 12 weeks. As it fills best in cool weather, the time of seeding for any locality "may be determined with a fair degree of accuracy by allowing a period of 12 weeks for growth before the first killing frost is expecterl. When seeded the last week in June or the first week in July in New York and Pennsylvania, or about a week earlier in Michigan and Wisconsin. it is most likely to escape injury from hot weather. Over 40 bushels per acre of grain have been harvested from a crop drilled in with 300 pounds of phosphate as late as August 4. Buckwheat grows so quickly that it can succeed another crop. as barley, rye, or oats, or it may be sorvn where corn or some other erop has been planted but failed to grow. Such fields should be immediately ploughed and harrowed. Buckwheat leaves the land extremely mellow, which is an advantage in the case of heary soils, but undesirable if the soil is light. With the exception of corn, the yield of which, it is claimed, is reduced, any crop may follow buckwheat with excellent results. It is subject to very little injury from insects or fungi.

\section{THE SEED-BED.}

There is probably no othęr crop that will yield better on infertile soil, such as old meadow and pasture lands, than will 
buckwheat. It is well suiter to light, welldrained soils such as sandy loams and to the silt-loam soils. It will not grow on land that is wet and heavy, or where the water stands and dries up gradually, leaving the soil in a hard condition. It is very frequently grown on land which for some reason was not planted early, or on land on which some other crop has failed to grow. Altho the poorest soil may be used a fertile soil will, of course, give a larger yield of both grain and straw. In general, the land should be prepared as for any other grain. The best results are obtained when the land is plowed early and is well prepared, but good results may be obtained by sowing immediately after plowing and harrowing. Buckwheat needs but little lime, growing well in an acid soil without lime where alfalfa and led clover would not be a success.

\section{FERTILIZER.}

Where the soil is poor it is profitable to use fertilizer, but where good wheat and corn crops can be produced it is unnecessary for the buckwheat crop. On the poorest hill land a small application of nitrogen and phosphorus is advisable, but generally nitrogen is not needed. The plant, however, responds very readily to applications of phosphates. Low-grade fertilizers containing phosphates and a small amount of potash can be used to advantage on the crop where the land is poor. The use of 100 to 150 , to even 300 pounds of bone phosphate per acre has been recommended. Potash will usually produce a favorable effect on a sandy soil, altho it may not be required on heavier soils.

\section{VARIETIES.}

Three varieties of buckwheat are commonly grown in the United States, the Japanese, Silver Hull, and Common Gray, the last two being best for honey. Japanese has a large dark-colored seed, while Silver Hull has a smaller seed, glossy or silvery in appearance. The plant of the Japanese variety has a larger stalk, and the flowers do not blast so readily from heat; but it is believed not to yield nectar as freely as the other two varieties.
RATE OF SELDING.

Buckwheat should generally be seeded at the rate of 3 to 4 pecks to the acre. If the soil is fertile and a drill is used and the seed is of good vitality, as little as two pecks may be sufficient. As many as five peeks are sometimes used. It is best to use a grain drill, but this is not essential as the seed can be broadeasted and harrowed in with satisfactory results. It should be sown from one-fifth of an inch to two inches deep, depending on the condition of the soil. It is better to sow while the land is dry, rather than immediately after rain. After sowing on such soil it should be immediately rolled to compact it, as the grain sprouts better and more quickly, sometimes making its appearanee in less than four days.

\section{HARVESTING.}

Buckwheat is usually harrested in September as soon as the first blossoms have matured their seed, and before there has been a frost. The old-fashioned cradle will do the work well, or the drop reaper will prove a very satisfactory machine for this purpose. Many farmers use the ordinary binder, which practice is advisable where it can be followed. The seed will mature in a few days if, after cutting, the crop is left in loose bundles where they are sropped from the cradle or reaper. Afterwards they may be tied near the top with the straw and set up on end singly to dry. As the straw remains partially green and is liable to heat, these shocks are seldom stacked or stored in the barn. It should be thrashed either with a flail or thrashing machine on a dry 'windy day, and should be at once winnowed as the damp chaff may injure the grain. The grain should be stored in bags and not in large quantities in bins.

THE YIELD PER ACRE.

The average yield per acre in the United States is fiom 14 to 18 bushels, but it may vary from five to forty bushels. In Pennsylvania three fields were sown on July 6, 11 and 19 respectively, with buckwheat, the seed being drilled in. The first yielded 16 bushels per acre with medium straw; the second 22 bushels with heavier 
straw than the first; the thind 2.) bushels witl straw like that of the first field. $\Lambda$ s a rule, early sowing gives large straw and a poor yield of grain, while late sowing gives the opposite. Twenty-fire bushels per acre is considered a satisfactory crops.

In Canada, Michigan, New York, and Pennsylvania the legal weight of a bushel of buckwheat is 48 pounds; in other States it is either more or less.

USES OF BUCKTHEAT.

Both in Europe and America the flour is widely used in making buckwheat cakes. In the Russian army buckwheat groats form a part of the soldiers' rations. Eaten too constantly it is said to produce a feverish condition. Poultry are very fond of the seeds, which are believed to stimulate. egg production. When ground it makes an excellent feed for dairy cows, and a mixture of ground buckwheat, corn, and oats is highly recommended.

Buckwheat is also often ploughed under for green manuring. It will pay for its cost as a fertilizer, and some buckwheatgrowers make a practice of enriching their soil in this way, waiting, if beekeepers, until blooming is over in order to obtain the honey. Two or even three crops may be plonghed in. one after the other, when it is desired to get the olound in a high state of cultiration. A crop of buckwheat will help greatly in eradieating weeds and subduing rough land.

Information in regard to the culture of buckwheat has been furnished by C. E. Leighty of the Department of Agriculture, Washington, D. C. Other articles on buckwheat culture will be found in "The Cereals in America," by Hunt, and "The Small Grains," by Carleton.

BUILDINGS.- - It is manifestly impossisible to recommend any standard design of buildings for beekeepers' use that would suit all requirements. Some beekeepers require a room that can be used for extracting only; others sereral rooms for workshop, storage room, and extracting. The same room may often be used for different purposes at different times of the vear, but, nevertheless, the purpose for which the building is to be used principally should be taken into consideration when it is planned.

The construction and materials for these buildings also vary greatly from the light framework covered with canvas to the most substantial concrete structure. Except the buildings erected at home apiaries, tempol'ary or demountable or take-downable buildings are the rule for the reason that out-apiaries often have to be moved about.

Sone use small buildings that can be easily loaded on a low wagon and hauled about from place to place. Still others use buildings made in sections, bolted together. so that the various sections may be taken apart and loaded on a wagon in the flat. E. D. Tormsend of Michigan has used such building for year's. Such a construction costs a little more than the usual type built solid from the ground up, but the convenience, prorided there is a likelihood of frequent moves, more than offsets the extra cost.

In order to make the rarious sections strong enongh to hold together after being unbolted, $2 \times 4$ material is used for the framework. There are six sections in all - not counting the floor-the two ends, the two sides, and the two lialves of the roof. Before nailing on the siding on the 2 by 4's Mr. 'Townsend tacks on a good grade of tar' paper which is proof against depredations of mice. This makes the building more beeproof as well, certainly an essential feature when extracting has to be done after the honer flow when bees are inclined to rol.

In locating a building the place most convenient to the apiary must be taken into consideration: but if the lay of the ground permits, a downhill grade to the building makes it much easier to wheel or cart stuff to the building. In many instances it is of advantage to have a twostory building, the second floor, where the extracting is clone, on a level with the apiary. The honey can then be piped into a tank in the lower story, the floor of which should be on a level, say, with the bed of a wagon on the ground at the lower end of the building.

When there is no sidehill and the "gravity plan" is, therefore, impractical a honey- 


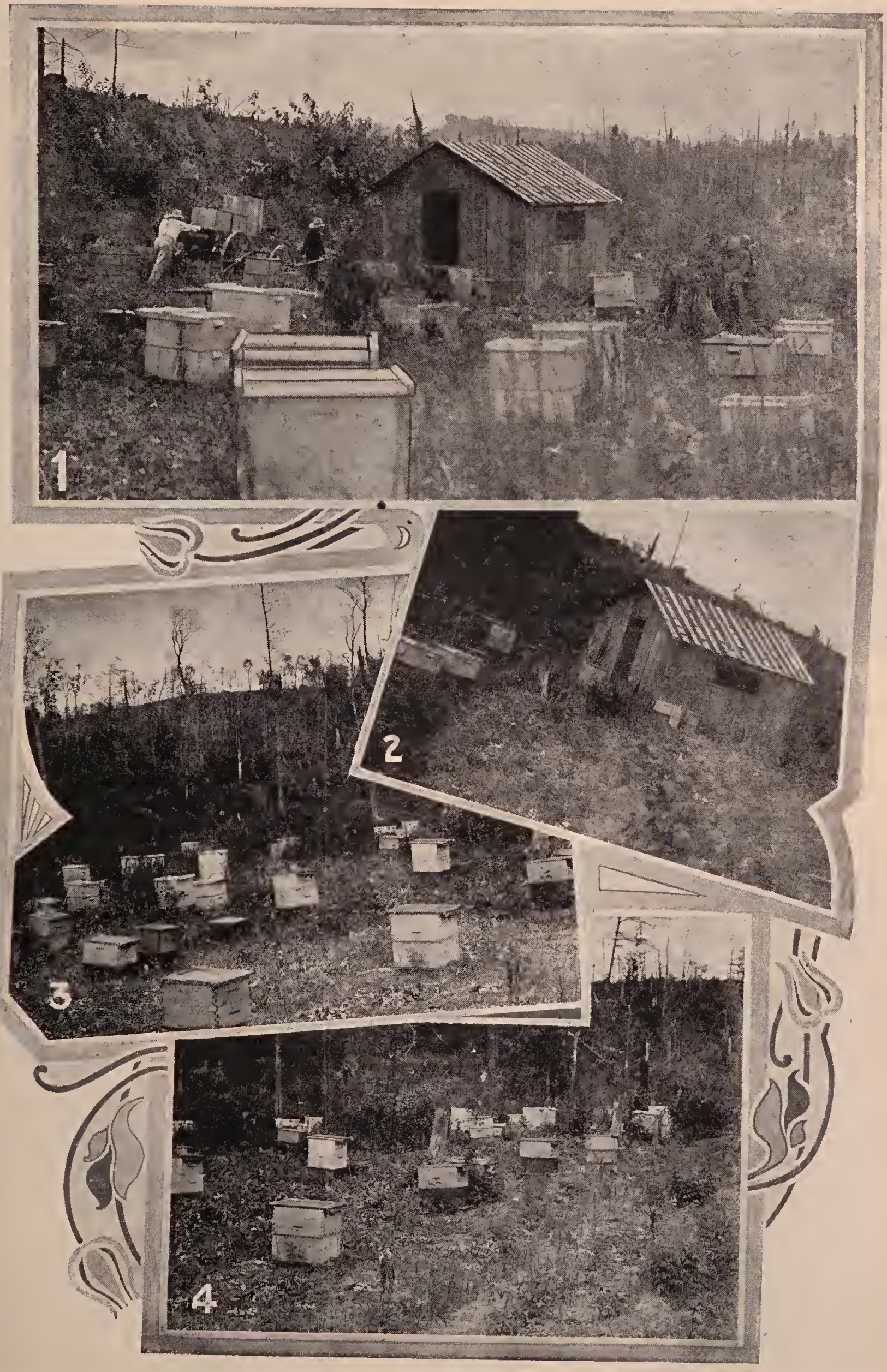

E. 1). Townsend's Spring Brook Apiary and sectional extracting-house. This building is made in six separate panels or sections, besides the floor, which bolt together at the comess, maling it perfectly rigid. 'If'desired, it may' be quickly' taken apart and moved on a wagon. 


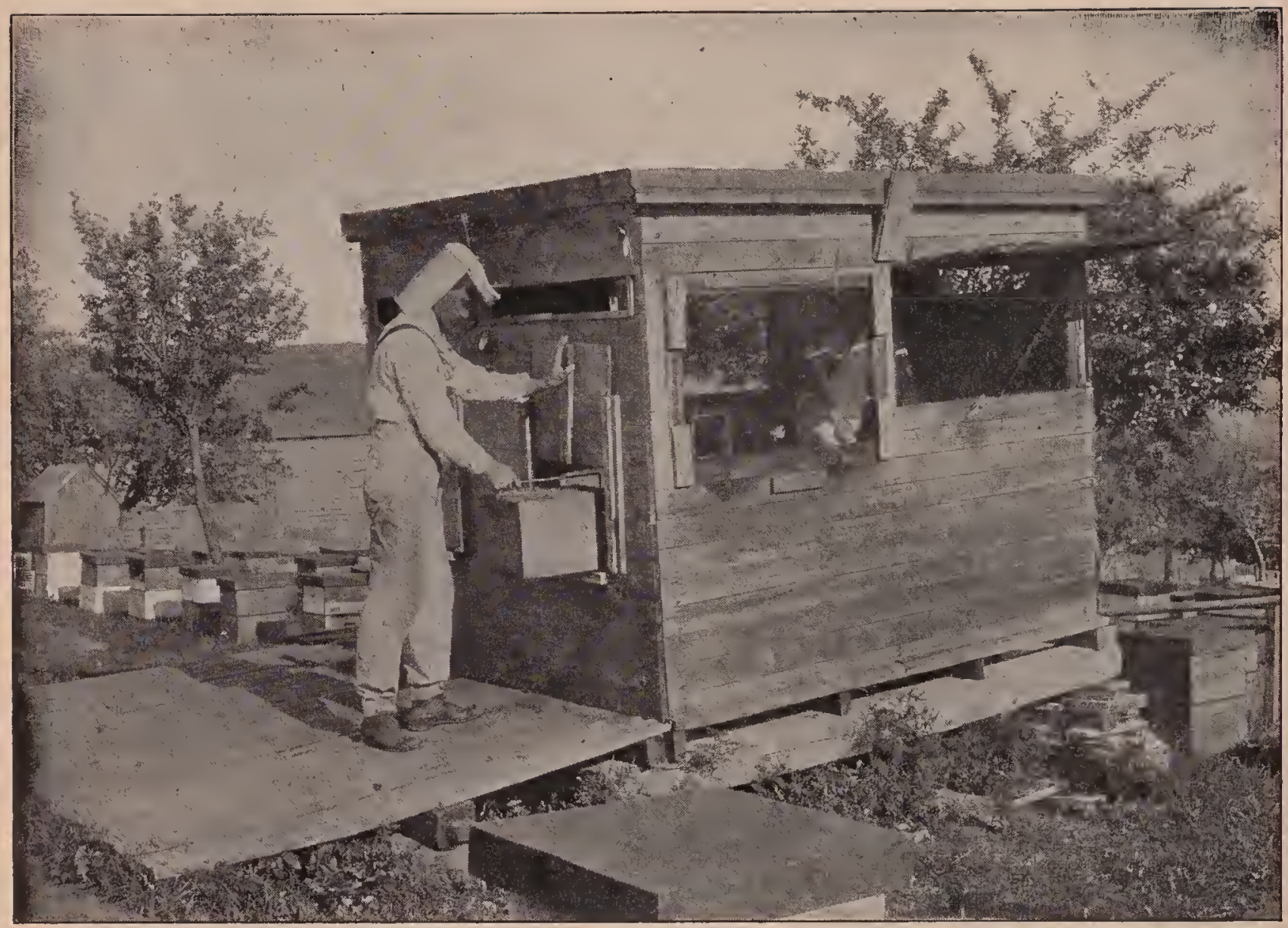

A small inexpensive extracting-room as formerly used by $\mathrm{E}$. W. Alexander of Delanson, N. Y. There are two openings in the end of the building that close with sliding doors. The full combs are put in thru one door, and the empty ones taken out the other one. $A$ pipe conveys tle honer from the extractor to a tank in another building down the hill.

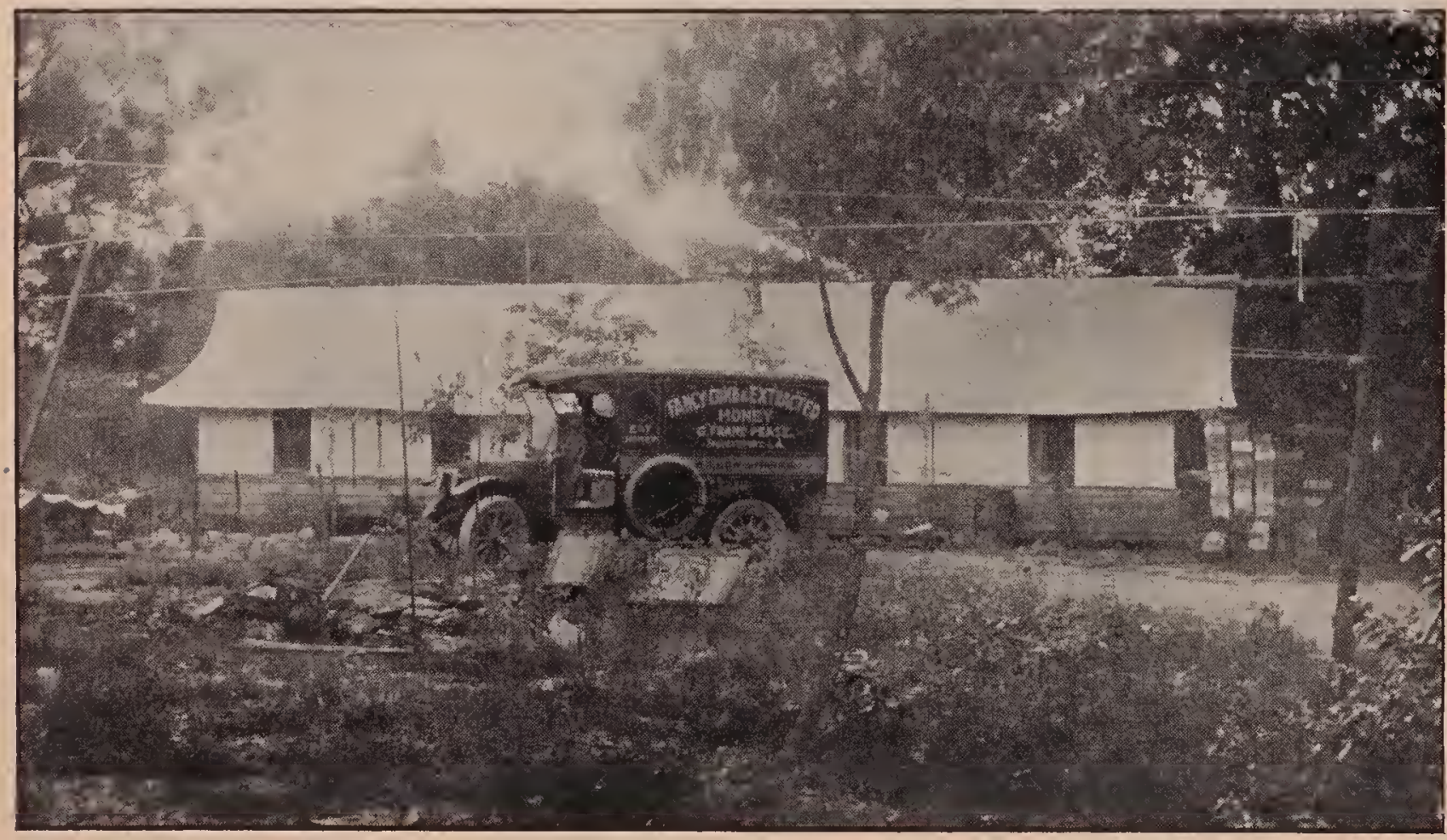

An inexpensive and quickly constructed building that answers every requirement. Walls and floor of wood, roof of canvas. A good canvas roof gives a letter light inside and is cooler than a solid roof. 
pump is a real necessity to elevate the honey so that heavy lifting and consequent loss of time are aroided. (See Extracting.) In hilly or mountainous countries, however, there is no difficulty in selecting a sidehill. If desired, as is the custom in many parts of California, large honey-tanks may be located out of doors on the lower side of the building, the honey running from the extracting-room direct to the tank.

The late E. W. Alexander of Delanson, N. Y., a beekeeper who had 750 colonies all in one apiary, used for many years a small

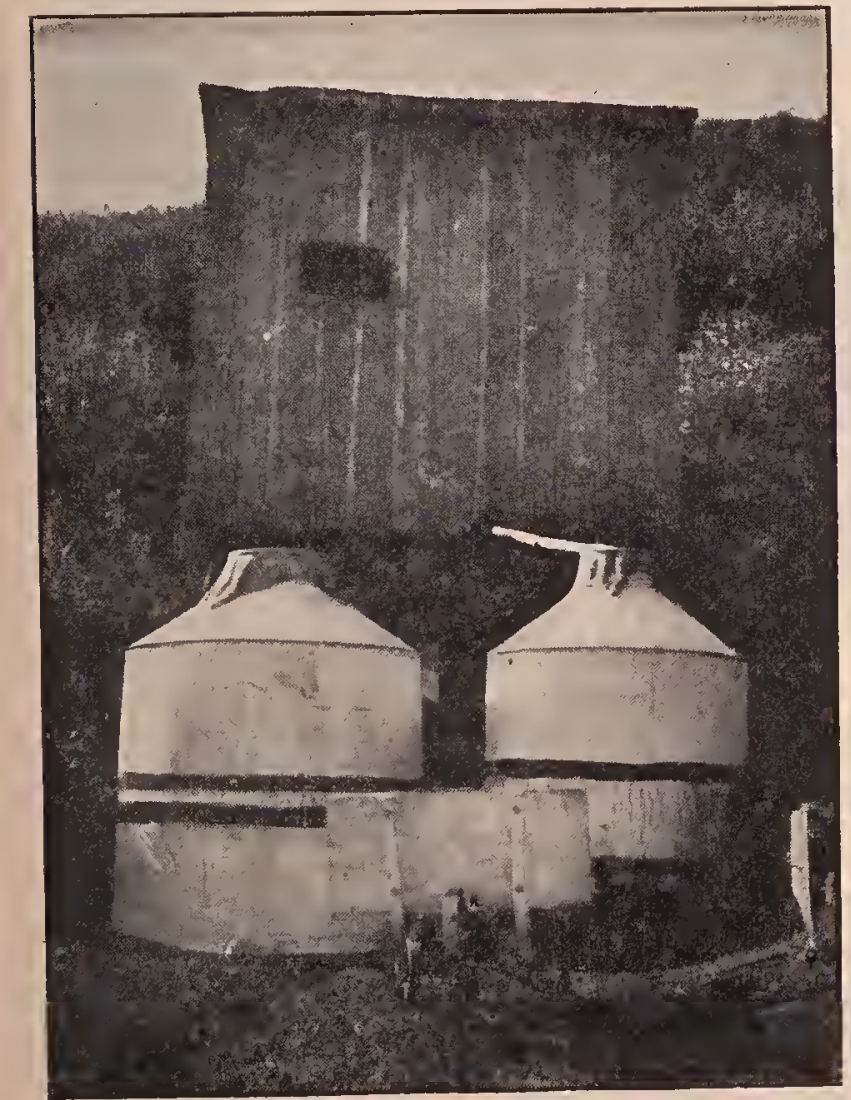

Typical sidehill California honey-house. The honey runs by gravity from the extractor thru pipes into the large tanks located below the building on the outside.

extracting-house just large enough to r'eceive an extractor, uncapping-box, and space to receive and pass out combs thru openings in the side of the building, ordinarily covered with sliding doors. A tin pipe conveyed the honey by gravity to a large tank in anotlee building on lower ground.

E. S. Miles of Dunlap, Iowa, has a very conveniently arranged building having two large rooms, the floor's of which are on different levels, the floor of the ell being $3 \frac{1}{2}$ feet below that of the main room. Needless to say, Mr. Miles has room for a workbench where he nails shipping cases, cases for comb honey, hives, and other stuff. Each room has an outer door with a platform just about the height of a wagon-bed. These two doors are on a side of the building opposite from the bees so that there is little danger in driving right up with a team of horses.

The sides of the building are of $2 \times 4$ studding, 24 inches apart, boarded with shiplap, then papered, and finally sided with regular 6 -inch house siding. The roof is made of $2 \times 4$ rafters, 24 inches apart, covered with sheathing and shingled. The material for the whole building cost about $\$ 300$. The main room is $16 \times 48$ feet; the addition, or ell, 12 by 18 feet. A building of this size is ample for all the work in connection with the handling of 300 colonies. By using a cheap shed for additional storage it would be large enough for 500 colonies.

\section{VENTILATION AND WINDOWS.}

A common fault of beekeepers' buildings is that the ceiling's are too low and there is inadequate ventilation so that the temperature on a hot day becomes almost unbearable. A ceiling three or four feet higher than it would actually have to be adds but very little to the general cost and at the same time permits a wide shelf, perhaps seven feet from the floor, running the entire length on either side of the building. Such shelves not only help to keep the room cooler, but furnish much additional space for temporary storage.

For light and ventilation a very good plan is to ent out long horizontal windows in each side and perhaps in one end also, having hinged wooden shutters which can be lowered to keep out the storm in bad weather. A tight-fitting frame covered with galvanized wire eloth makes the opening bee-tight. There should be one or two glass windows as well to permit of interior work in stormy weather when it wonld be best to have the shutter's elosed. All screened openings should be provided with several honey-house bee-escapes at the top to let out bees that are bound to get inside during extracting time. A sereened door is a positive disadvantage, for the bees keep hovering around the door, and when it is opened many of them get in. $\Lambda$ solid 


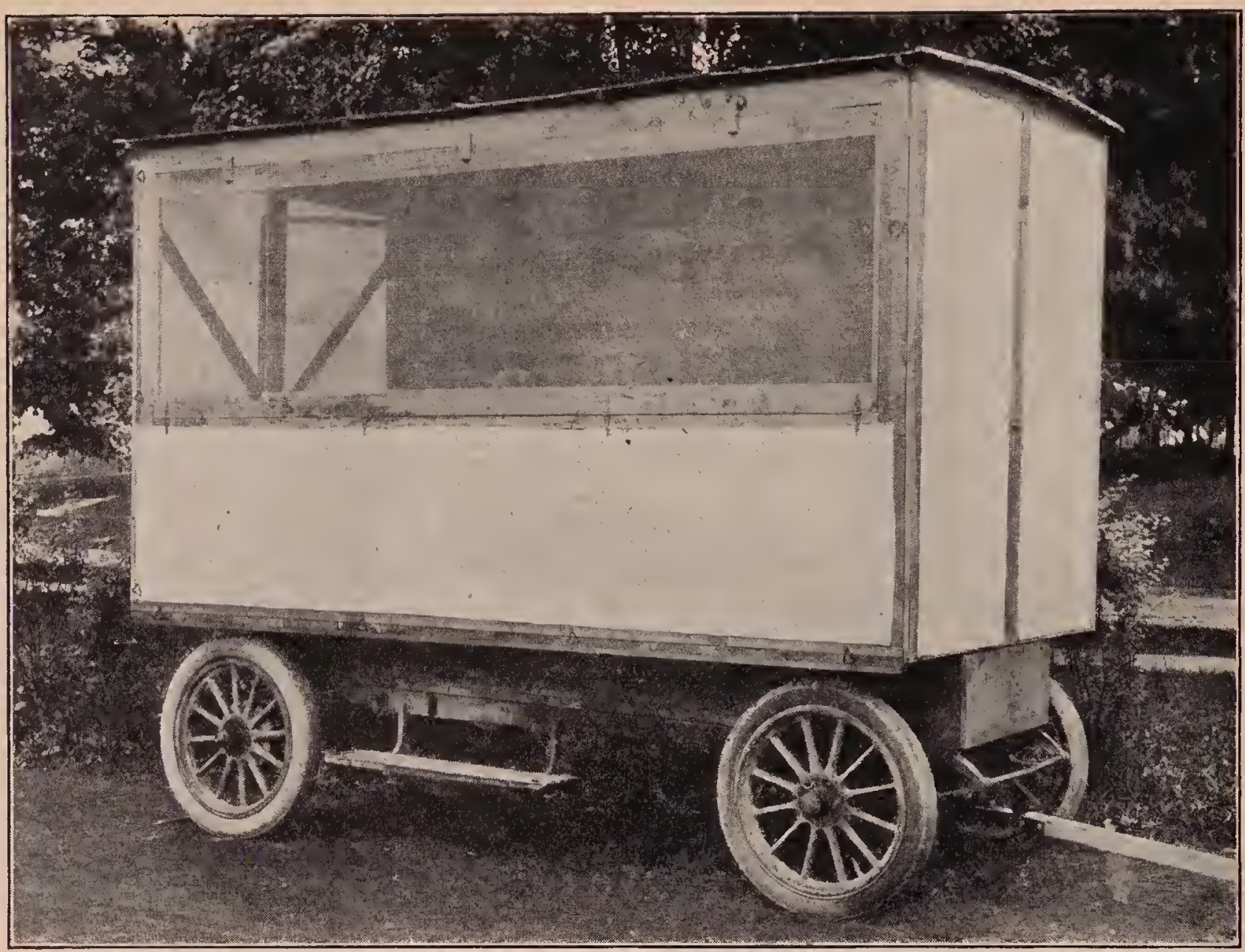

Canvas extracting-100m built over an old touring-car converted into a trailer. 'There are two floors made

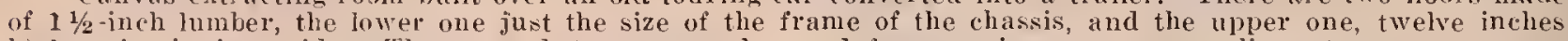
higher, is six feet wide. The space between may be used for carrying supers, supplies, ete.

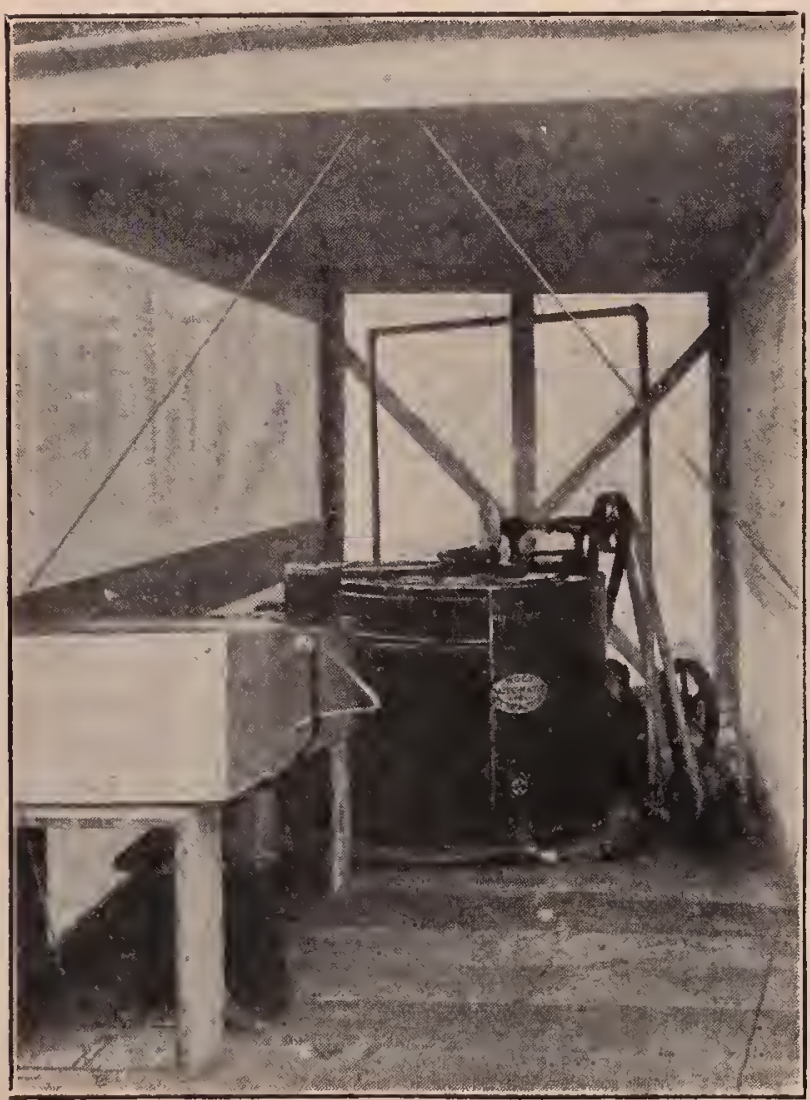

Interiol of the extracting-room on wheels. The capping-hox stands near the front on the left. The empty spice at the right is for the supers. door or one having glass in the upper part is to be preferred.

During a time when robbers are bar. allowing the bees to escape to the outsicle as fast as they get in the room is barl practice. A number of large beekeepers. instead of using bee-escapes, have the window sereens remorable or hingerl at the bottom. The bees collect on the screens during the day; and after the work is finished, or late in the afternoon, the screens are remored or swung out at the top so that all the bees escape at once to their hives. The building thus acts as a robber-trap until the bees are releaser when flying is nearly over for the day. By moining the excitement will be orer.

C. F. Hochstein of Cuba leaves an ovening three feet wide all around his building. This he cover's with leavy galvanized wire elothi. Ingeniously made bee-escapes, constructed of wedge-shaped blocks of wood between the wire cloth and the siding, are located along the upper edge. For a tropical climate this construction is all right, but in other localities smaller open- 
ings which can be entirely closed by means of hinged shutters are to be preferred. All honey-house bee-escapes which operate on the "cone" principle ought to be so constructed that the openings can be entirely closed in case the bees should get to robbing and should find the small exits.

A substantially constructed tent makes a light, cool, and easily moved structure. G. Frank Pease and A. E. Lusher have very comfortable four-room work tents. The floors and side walls are of wood, making a very substantial construction and yet inexpensive.

\section{EXTRACTING-HOUSES ON WHEELS.}

There are many ingenious portable extracting-rooms consisting of a canvas or sereen-covered framework on an extended

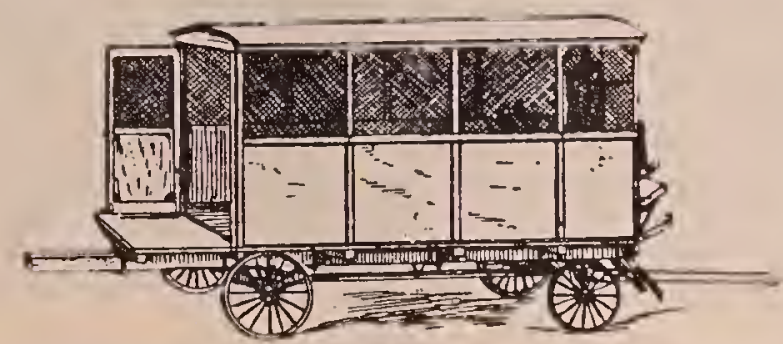

Jefferson's portable extracting-house. A 200-gallon lroney-tank is located under the floor between the axles.

wagon-bed. W. D. Jefferson of Safford, Ariz., uses a low wagon with small widetired wheels. The platform is wide enough to extend out even with the outer edges of the wheels and long enough to give sufficient room for extracting purposes. Under the platform is a shallow tank, hanging between the front and rear axles, which

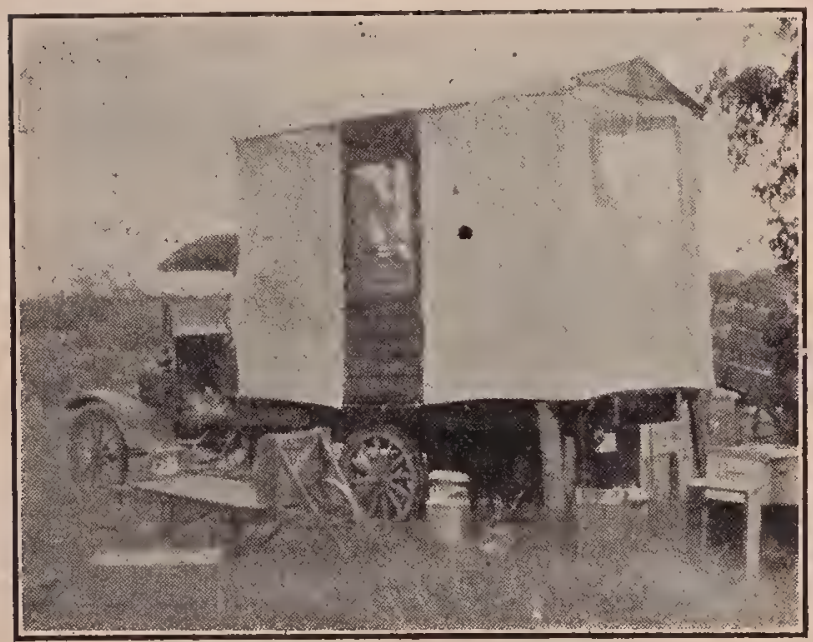

C. W. Johnson's one-ton Ford truck with screened extracting-house on the platform. Notice that the platform, while in use for extracting, is braced by two-by-fours. The wheelbarrow in the foreground carries the supers back and forth.

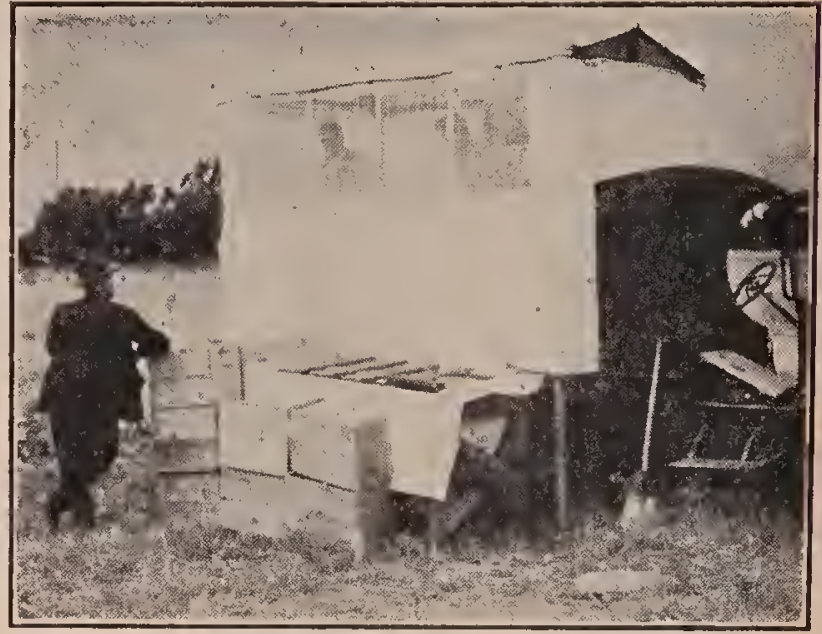

The other side of the one-ton Ford extracting-house, showing the mosquito-netting windows for ventilation and light. Chas. F. M. Stone is talking to the operators. With this extracting-house on wheels $\mathrm{Mr}$. Johnson takes his honey from his thousand colonies.

holds 200 gallons. The screen for the honey is in the floor over the tank where it can be changed easily as often as it becomes clogged. The honey, of course, runs from the extractor on to the screen and then into the tank.

This portable outfit is hauled from yard to yard, and the honey as fast as extracted is hauled home so that none of it is left at the outyard.

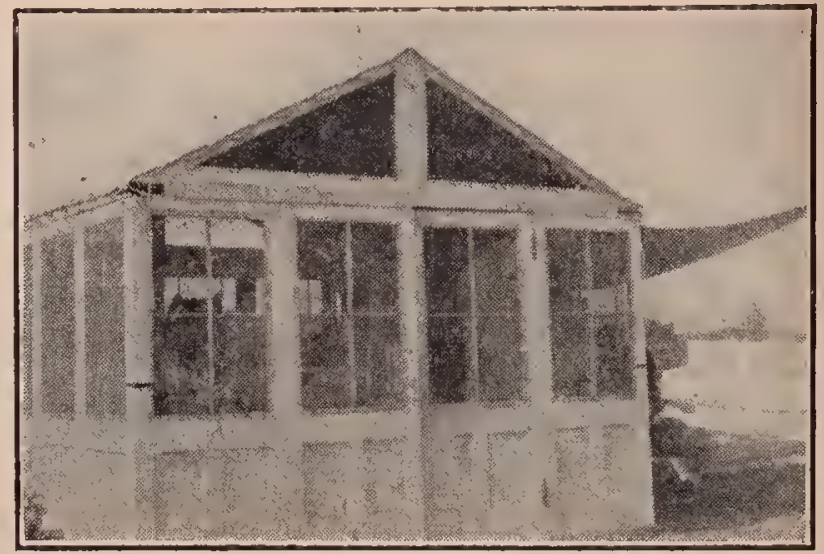

Portable extracting-house of $A$. F. Tice, Los Angeles, also shown in another cut. This structure is made up of door panels held together by clamps and bolts. The fact that Mr. Tice is a carpenter and builder explains why it is so neat and well designed. It is one of the best portable dismonntalole extracting-liouses in California.

THE AUTHOR'S PORTABLE FY'TRACTINGHOUSE.

For an extracting-house that may be easily moved from one apiary to another, the running gear of an old discarded outof-date touring car can often be nsed to very good advantage, with a superstructure similar to that of the Jefferson outfit. 


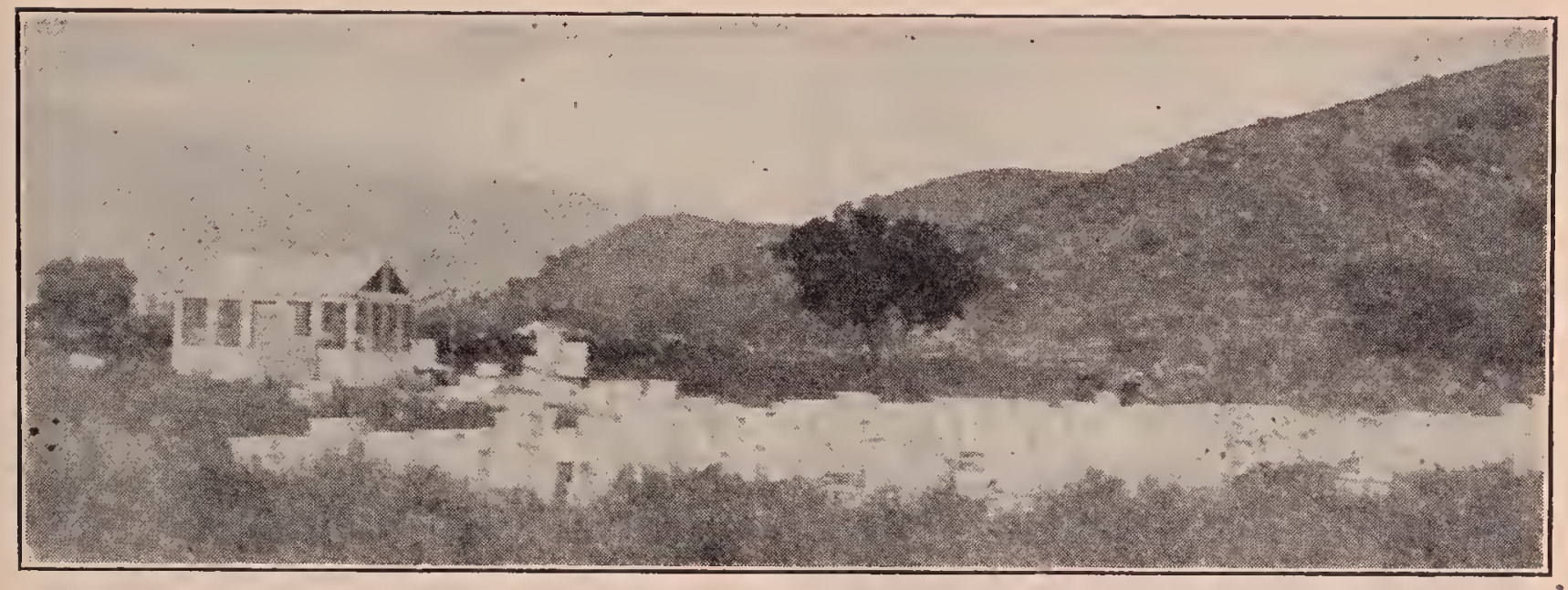

Apiary and extracting-house of $A$. F. Tice, up among the orange groves, showing apiary and building. The apiary was operated by his son, A. W. Tice.

These old automobiles can usually be bought for little more than scrap priceanywhere from $\$ 25$ to $\$ 50$. If there are not tires on the machine already, secondhand ones can be secured at a moderate price. The whole outfit will not have to make any considerable mileage-only short

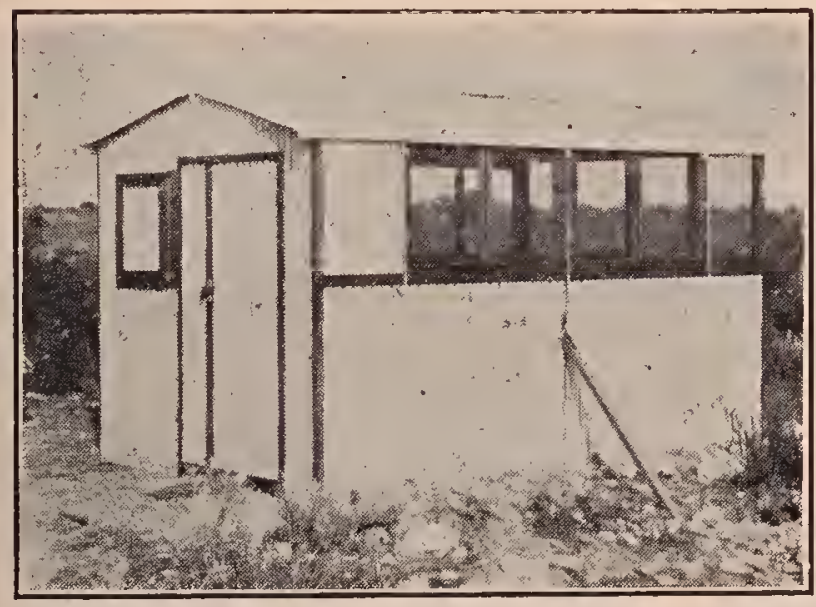

This dismountable extracting-house used by $H . A$. Stearns of Duarte differs from the others in that it is made of corrugated metal. It is very neat and well designed, and should last indefinitely. The roof is covered with canvas. er's, and other equipment for general extracting.

The room on top is made in six parts or panels held together by means of hooks or Van Deusen clamps. The two sides are screened so they can be opened up, while the rest of the panels are made of canvas. The power extracting engine and uncapping-box are arranged. with the greatest economy of floor space, so that the operator will have plenty of room for uncapping and extracting. The honey is pumped from the extractor into a receiving tank. From here it is drawn by gravity into square tin cans by a pipe passing thru the floor.

extracting plant and haul the combs into

Whether it is better to have a central it from the yard, returning them after they are empty, or whether it is better to have a portable outfit that can be used at each yard, and thus do away with a long haul for all the combs, will depend on conditions. As a general thing, the major-

distances to outyards. Cheap tires that have seen their best days will answer'a good purpose for an extracting-trailer. The illustrations, page $\mathbf{1 6 0}$, show an outfit the author has used with considerable satisfaction. The superstructure consists of two floors, one resting directly upon the channel frame of the machine, and the other on two by twelve joists to clear the wheels. The lower floor is to hold tools, contain-

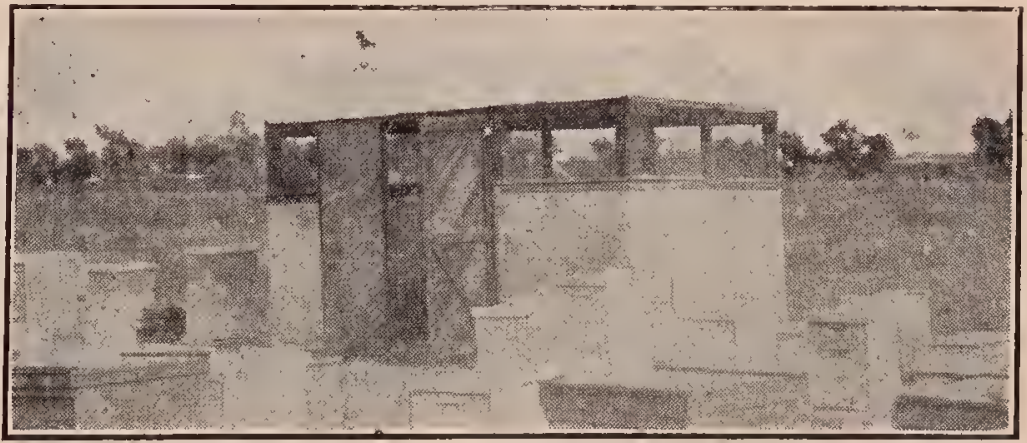

Dismountable extracting-house of Frank MeNay, Pasadena. This is made of four large panels or trames covered with cloth and mosquito netting. It is held together at the corners by means of large metal hinges. When it is desired to move, the bolts to the hinges are withdrawn, when the two sides of the hinges come apart, releasing the frames, when they are loaded one by one on to a truck. This building is very cheap and serviceable. 


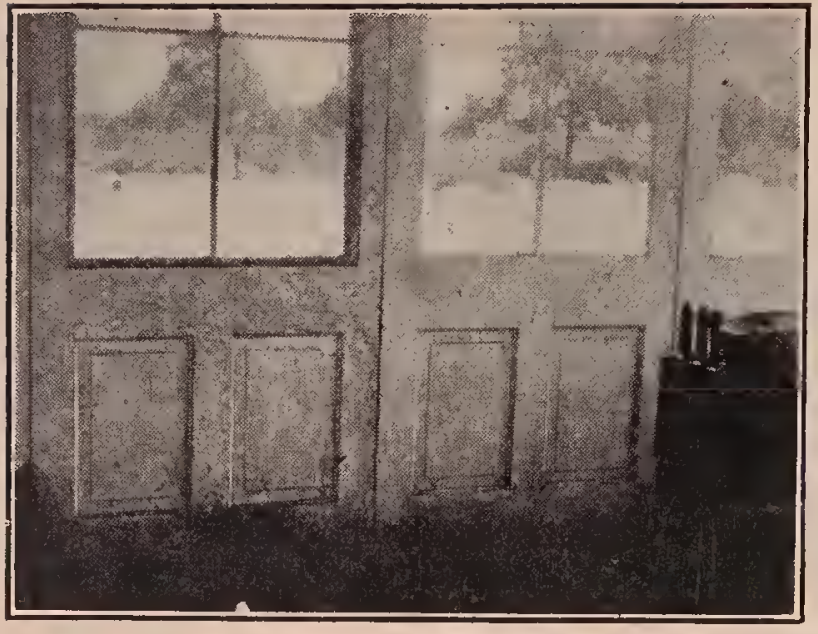

Tnterior" of Tice building. looking out into the apiarv. The end of the uncapping-can and the handles of threè uncapping-knives sticking up are shown at the right.

ity are in faror of the portable outfit. After the extracting season is over, the extracting equipment, together with the superstructure, can be removed. leaving a first-class trailer that can be hitched to an

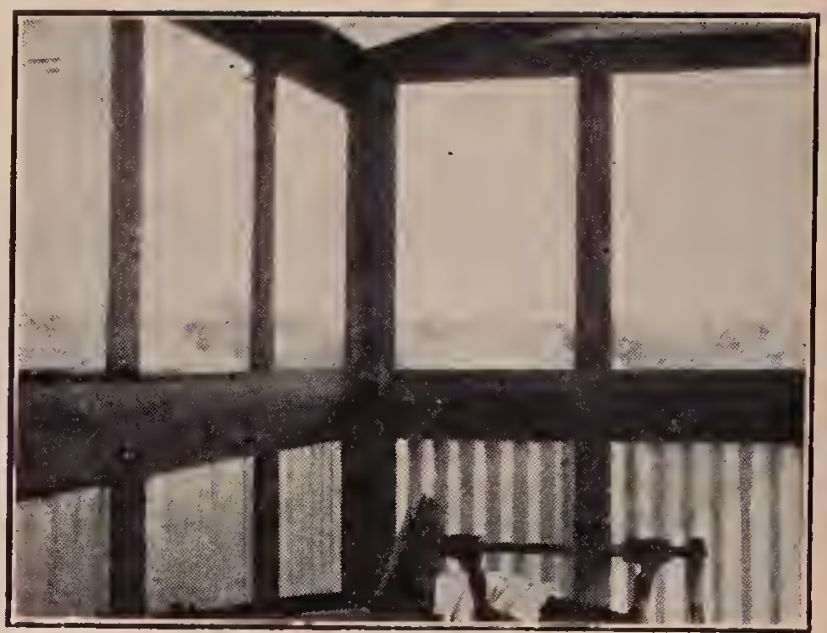

Interiol of building. It is he'd together by barn door hasps and wooden peos on the inside of the cornels. The windows are wooden frames with wire screen.

automobile or horse-dlawn wagon, and this trailer can be used for carrying any kind of loads, and will be specially serviceable in moving a whole apiary from one ard to another. If the roarls are not too

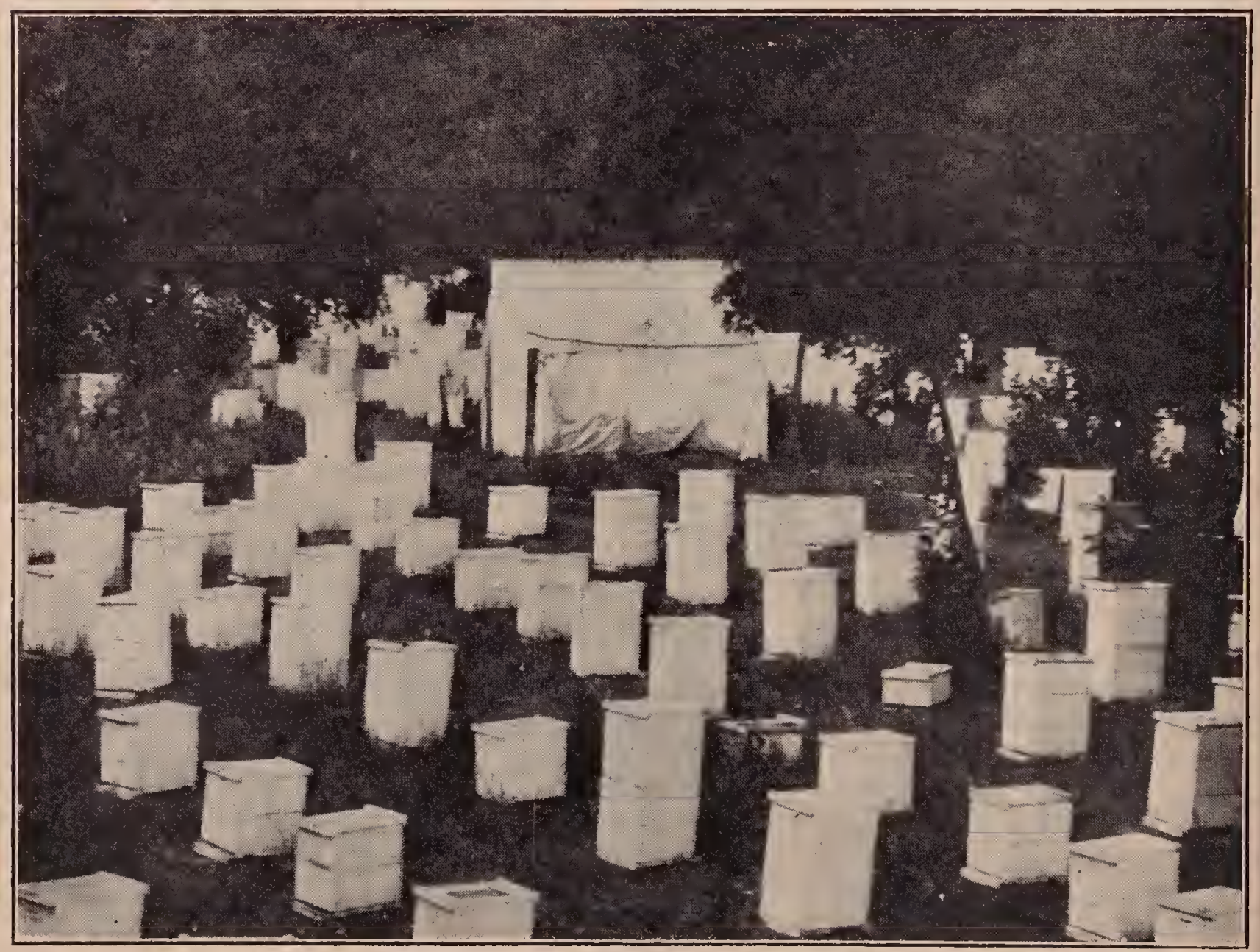

I small portion of a 400-colony apiary of A. F. Lusher of Califormia. The extracting-"house" consists of a lent with high side walls. The end of the tent opposite the door has a lange window covered with mosquito netting for light and. ventilation. 'There is no ctuduing the fact that it is the most poutalile of any of the structues liere shown; and the fact that it is nsed and preferred ly men who win and operate 1,800 colonies most successfully lroves that it must have merit. 


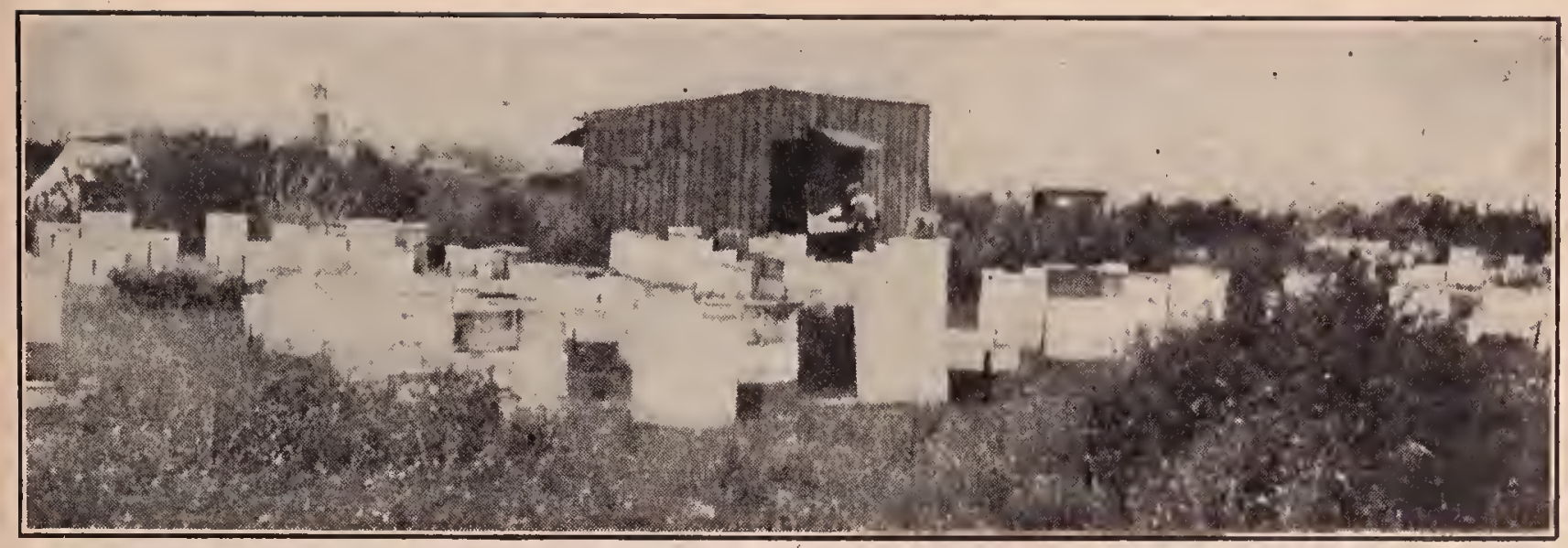

One of the apiaries of G. P. Iarinan, Pasadena, who owns and operates over one thousand colonies. He uses permanent extracting-houses at cach location, as he prefers to operate with an eight-frame powerextractor outfit, and have plenty of room for supers and equipment.

lilly, a Ford or other light machine will pull this trailer aro:mel very easily.

THE SUBSTANTYAL IBUILDING FOR THE HOME YARD OR CENTRAL EXTRACTING-PLANT.

As has been mentioned, the building: suitable for an out-apiary is usually inadequate for the home yard where there must be room for considerable storage, for making supplies, and for all the inside work, in fact, in connection with the business. For this reason expensive conveniences are usually out of place in a building in an outyard. At lome it pays to erect a larger and more substantial building, including such conveniences as are time and labor savers. David Running of Filion, Mich., has one of the best and most completely equipped concrete buildings in the country. Conerete, so far as the cost of naterial is concerner, especially where gravel is cheap, often rosts less than lumber. Mr. Rurning's building is $16 \times 40$ feet, with two different floors besides the basement used as a bee-cellar. To save the expense of so much cement, a large number of stones were userl, which cost nothing but the labor of picking them up. The walls, moreover, are only six inches thick. In most instances eight inches for solid conerete is thin enough. The lumber used for making the forms is not wasted, for it can all $g_{0}$ into the roof.

More and more beekeepers are using automobiles or auto trueks in their business. While it is not alwars possible nor desimable it is oftentimes conrenient, if the honey-house and workshop inchudes also the garage. Henry Hograve of Wanketa, Wis., has such a building, which he finds a distinct adrantage. Mr. Hograve has a driveway thru the center of his aprary, and he uses the auto for carrying full supers right into the garage. From there they are pushed thru an opening on to a platform in the extracting-room. It would doubtless facilitate loading and unloading and save considerable lifting, if the floor of the garage could be two or three feet lower than the roor of the adjoining room.

BUILDING UP COLONIES - - T'nde. the heads of Increase, Spring ManageIIENT, and UNITING, will be found lints on building up colonies in the spring and fall; but this article will confine itself to the question of building up colonies so that they will be ready for the honey flow.

The number of worker bees in a normal colony varies during the different seasons of the year from a few thousand up to 80,000 , or even in some cases probably as many as 100,000 . The number is usually lowest in established colonies in early spring at about the time the first young bees begin to emerge in any eonsiderable numbers. From this time on, if conditions are favorable for brood-rearing the amount of brood is increased rapidly until the greatest eapacity of the queen for egg-laying has been reaehed. This maximum egg-laying is maintained for a short time only after which the amount of brood is greatly reduced, and later in the season as the older bees die off, the number of worker's in the colony decreases to that which is nomal 


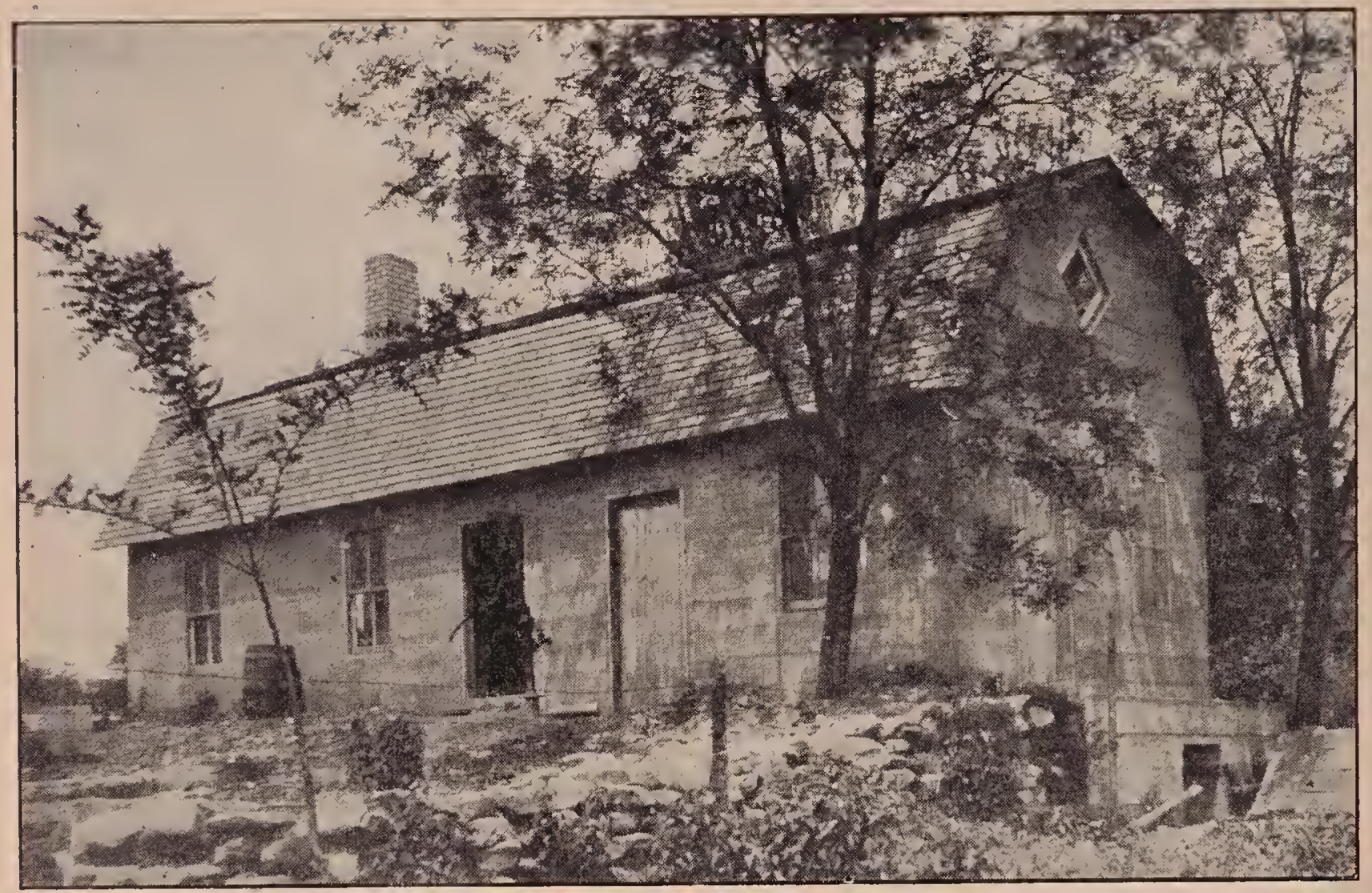

David Running's $16 \times 40$-foot concrete building. There are two different floors besides the cellar where the bees are wintered. The cellar has a capacity for nearly 350 colonies. Where gravel is cheap, concrete is cheaper than lumber in the long run.

for winter. Thus in early spring a colony is strong as to numbers if it contains as many as two and a half to three pounds of bees ( about 12,000 to 15,000 individuals), but it is not really strong two montlus later unless it contains 60,000 to 100,000 workers, the increase in numbers during the spring building-up period being usually more than fivefold in prosperous colonies.

It is fortunate for the beekeeper that the bees regulate their numbers in this way according to the needs of the season; for this makes it possible for them to store a surplus of honey during the honey flow and reduce the amount they consume at other times, provided the large population comes on at the right time for the honey flow. The most important thing in all beekeeping management is to have the largest number of worliers come on the stage of action at the right time to take full advantage of the honey flow.

After brood-rearing is begun in earnest in the spring it usually requires about two months for colonies of normal early spring strength to build up to full working strength, the gain during the first month usually being slow but becoming rapid during the second. In localities where the main honey flow usually begins about two months after the beginning of spring brood-rearing, this works unt well for the beekeeper, since it furnishes a large force of young workers just when they are most needed. For example, in the northern portion of the United States where the honey flow usually begins in June most of the workers that gather the crop must be reared during April and May, and, in order that these worker's shall be young and vigorous when the loney flow begins, most of them should be reared during May. Colonies which build up most rapidly just before the main honey flow usually store more surplus than those of equal numerical strength which buikd up more slowly, since more of their workers are young and, therefore, capable of a greater amount of work.

These workers are the "liarvest hands" of the hive; and, if the flowers and weather 'do their part, the crop of honey will usually be much or little according to whether the workers to gather it are many or few. A great horde of workers coming 
on the stage of action at just the right time is the goal toward which the beekeeper lias been working since last summer. So far as he is concerned, this great army of workers is that for which all the workers born at other times have existed. The bees reared previously liave been useful only in as much as they have contributed to the final production of these "harvest hands," and bees reared latel are useful only in as much as they are able to contribute to the maintenance of the colonies until next season, unless there is a later honey flow which they may help to gather.

The period of brood-rearing just preceding the honey flow, therefore, has a significance not found at any other season. Whether the main honey flow comes in March and April as among the orange groves of California and in the tupelo and orange regions of Florida, in June and July as in the clover region of the North, or during August as in the buckwheat region of New York and Pennsylvania, the size of the crop of honey that can be harvested depends largely upon the amount of brood reared during the six or eight weeks just preceding tle beginning of the main honey flow.

Since the tendency to rear brood is strongest in the spring, the beekeeper whose location furnishes the main honey flow inmediately after the period of natural spring brood-rearing, is fortunately located, for he then produces his workers for the honey flow at the time the bees are most willing to co-operate. If anything prevents the colony from reaching its peak in brood-rearing in the spring, such as weakness $01^{\circ}$ insufficient food, it mav climb to its maximum strength later in the season when normally the tendency to rear brood would be less intense; but, after the first spurt of extensive brood-rearing of the season, it is difficult to induce colonies again to rear as much brood during the same season.

When there is a succession of honey flows during the season having an interval of dearth between, the bees usually increase brood-rearing in response to each honey flow. They can also be induced to rear a large amount of brood after the natural period of lieavy brood-rearing in the spring by stimulative feeding (see FEEDING AND
Feeders, sub-head FEeding to stimulate IBROOD-REARING), but during the natural building-up period of spring they will rear brood extensively even in the absence of an early honey flow and without stimulative feeding, provided they have enough bees to take care of a large amount of brood, a good queen, plenty of honey and pollen stored within the hive, and water easily available. Brood-rearing at this time is apparently stimulated chiefly by the oncoming of spring, tho even in the spring more brood is usually reared if some early nectar and pollen can be brought in from the fields.

Building up for an early lioney flow, especially in the North, is therefore a relatively simple matter with colonies that have wintered well and have a good queen. Colonies that come thru the winter with three pounds of bees that have not been unduly aged by winter and that have a vigorous queen need only to have abundant food (honey, pollen, and water), ample room for the queen to lay eggs, and protection from cold winds and low temperatures of early spring, to cause them to build up to powerful colonies within two months. Weaker colonies build up slowly, sometimes requiring three or four months to reacl full summer strength.

To have most of the colonies strong in early spring involves not only good wintering (see WINTERING), but also conditions during the previous late summer and fall favorable to the rearing of sufficient young bees for winter. The first steps toward the building-up of colonies for an early honey flow should, therefore, be taken the preceding July or August by seeing that each colony lias a vigorous queen (preferably young) and also sufficient stores, if there is no fall flow, as well as sufficient brood-rearing room to insure the rearing of young bees for winter. The second step is that of good wintering to conserve the energy of the bees which form the winter colony: and the third or final step is that of providing conditions favorable to heavy brood-rearing in the spring when the instinct to rear a large amount of blood is the strongest. Weak colonies in the spring' are 'usually unprofitable and should be eliminated as far as possible.

Remembering that the bees are more 
than willing to do their ntmost in broodrearing in the spring, especially in the North, the beekeeper neerls only to see that the bees are not hindered in carrying out their own program in their own way. If ega-laving should be stopperl entirely-for a single day when the queen should be layins at full capacity, the number of workers that will be ready for the early honey flow is thereby reduced by the number of eggs the queen should have laid. In some cases the egos laid by a queen in a single day at this time result in a half pound of young bees three weeks later. It is, therefore, extremely important that nothing. slall be permitted to interfere witl broodrearing at this critical time.

During the first half of the building-rup period it is better if the bees rear brood only moderately. The cool weather of early spring (April in the North, February or March farther south) is adrantageous in tending to lold back extensive brood-rearing during the first montl of the buildingup period. Stimnlative feeding and the sprearling of broor to increase brood-rearing should not be practiced at this time. 'These, if donc at all, should be done later' during the montl just preceding the main honey flow. Usually the instinct to rear brood extensively is so strong in early spring that feeding to stimulate broodrearing is unnecessary if the colony is well supplied with stores.

When stimulative feeding is practiced it should not be begun intil three or four reeks previous to the beginning of the main honey flow and should be continued until the honey flow begins. Stimulative feeding and spreading brood are of greater ralue in locations which do not furnish a surplus honey flow immediately after the spring building-up period, in which case these measures may be necessary to increase brood-rearing after the colonies have passed their period of heavy broodrearing in the spring, especially if there is a dearth of nectar at the time the bees should be rearing the worker's for the honey flow.

Colonies that have been wintered outside should be left packed until a week or two before the honey flow, if this am be done without too much trouble. ('olonies that were wintered in the cellar should be well protected frou wind and the corers should be left sealed down during early spring unless it becomes necessary to open the hive. By looking in from below, they may be examined without removing the corer. In some locations beekeepers find that it pays to pack the bees after they are taken out of the cellar, tho in most cases this is not lone.

In order that the bees may rear the great army of workers for the honey flow there must be sufficient room in the combs for the greatest amount that the colony can produce, which in the Nortlı may be 60,000 to 70,000 cells in the best colonies. While this number of cells of brood might all be crowded into ten or eleven standard combs, it is usually spread over more.

For this reason the combs should be as nearly perfect as possible, for imperfect combs in the brood-frames not only reduce their capacity for brood-rearing, but they also stand in the way of the rapid expansion of the brood-nest in the spring. (See (oxrbs.) If a comb which is not suitable for brood-rearing is between the comb on which the queen is working and the other rombs beyond, this imperfect comb stands as a barrier to progress in brood-rearing. Drone counh in the lower corners of the brood-frames and comb that is too bally stretched to he used for worker brood in its upper portion greatly reduce the capacity ,for worker brood, and when two stories of such combs are used to supply sufficient room for brood-rearing, this imperfect romb near the top-bar stands as a barrier to the free expansion of the brood-nest thru the two stories.

Most colonies, that are nol'mal in $A$ pril but which fail to derelop their full strength before the looney flow in June, fail because of a lack of stores. One of the liardest thing's for beekeepers to learn is the surprisingly large amount of stores needed for the colony to rear the large force of workers required to gather the crop of honey. During the latter half of the building-up period the amount of brood is increased with astonishing rapidity, provided the bees have sufficient food to convert into young bees. When there is no opportunity to gather nectar from the fields at this time on account of cold or wet weather the stores of loney within the lives disappear rap- 
idly: but, if the reserve supply runs low, brood-rearing is reduced to a rlegree that is ruinous at the very time that the "harvest hands" are being reared.

In the clover region there is an old saying among beekeepers something like this: "If the bees do well on the early flowers and fruit bloom, there will be a good crop of honey in June." This old saying implies some mystic relation between the two, by which it is possible to predict what the honey crop will be by noting how well the enrly flowers yield. This relation is no longer a unsterious one; for the up-to-date beekeeper, by supplying the defieiency in stores when the early flowers fail, is still able to produce a crop of honey, as he thus furnishes the food which is necessary to produce the workers that gather the crop.

During the month of May in many of the northern States, and during April or earlier farther south, most of the brood which is destined to make the "harvest liands" are being reared. Whether the food used in rearing them is being brought in from the fields or is being supplied by the beekeeper thru feeder's or is stored in the hive, the amount must be sufficient if the colony is to attain full strength in time. One of the easiest ways to insure this is to give eaclı colony a second story of combs which are about two-thirds filled with honey. This second story becomes an automatic feeder, feeding the bees only as food is needed; and, in many localities at least, such a feeder, in addition to being automatic in its action after being filled the first time, is usually refilled each season without cost to the beekeeper, because of the better condition of colonies thus abundantly supplied with stores.

Such a large supply of honey apparently stimulates brood-rearing in the spring, and as the honey is consumed, the queen usually enters the second story, expanding the brood-nest into it, during the period of greatest brood-rearing when a single story may not furnish enough room for the brood. This second story partly filled with honey, therefore, not only acts as an automatic feeder, but it also supplies room for arditional broor-learing at the tine this is most needed. Some beelieepers use a shallow extracting-super for this purpose. which they all the food chamber. One shallow super is supplied for each rolony. 'This is tierer up amone the other supers duing the honey flow so that it is filled with good honey, and, at the close of the season when the reg'ular super's are taken off, this food chamber now filled with sealed honey is left on the live.

If a second story is not nsed to supply the bees with ample stores for spring brood-rearing, the next best way is to save over combs of sealed honey and give these to the colonies as needed during the spring. Each colony should have the equivalent of at least two full combs of honey on hand as a reserve supply at all times thruont the building-up period. If combs of honey have not been saved for this purpose it is necessary to feed the bees during the buildingup period, unless the colonies were unusually well supplied with stores the previous fall or early nectar is abundant. The syrup may be given in small amounts daily as in stimulative feeding, or ten to fifteen pounds may be given at one time if more convenient.

It is important that bees in early spring should have reserve combs of pollen. These are almost as important as combs of sealer stores. In some localities when there is no natural pollen in the hive the bees will rush out in the early spring, go to some barn searching for feeding-troughs in stables, and help themselves to the ground feed; for brood cannot be reared without something besides mere honey or syrup. (See PoLlex; read as to the necessity of pollen for brood-rearing.) Of couise, after bees can get natural pollen from the fields during warm weather they usually find an abundance for all their needs.

Sometimes the main honey flow does not follow immediately the period of heavy brood-rearing of spring and these "harvest hands" may become consmmers instead of producers; but these strong colonies can usually gather enough to live on, being better able to gain a living from minor sonces of nectar than weaker colonies, except during a complete dearth of nectar. But after the colonies have built up to great strength it is difficult to maintain their strength until a later honey flow on account of the reduction in the amount of brood.

In some locations, suchl ins in sone of the 
southern States and in a strictly buckwheat region, the main honey flow may come as much as two months after the bees have passed the peak of spring brood-rearing, assuming that the colonies were normal in strength and had sufficient food to have reached their maximum in brood-rearing in the spring. In such eases some beekeepers resort to such measures as stimulative feeding or spreading the brood, to induce more brood-rearing just previous to the main honey flow. Others move their bees to another location to gather a crop of honey from some earlier source while the colonies are strong, and then move them back again for the later honey flow. (See Migratory Beekeeping.) Some southern beekeepers sell package bees to utilize the excess of workers which would be too old to be of use when the honey flow comes on later; while still others divide the colonies before they reach their maximum in. spring broodrearing, performing the division at a time which will permit both colonies to build up to the greatest strength in time for the belated honey flow. The last-named plan has been used quite successfully in the buckwheat region.

When the main lioney flow comes at the same time that the bees are rearing the great horde of "harvest hands" in the spring, as too often happens in the case of weaker colonies and an early honey flow, of course a full crop of honey cannot be secured, for the field force is then small and the amount of brood to feed is large. The only hope in such cases is that the honey flow will last long enough later to gather some surplus before it closes, but the remedy is better wintering and earlier building up.

When there is a possibility of a honey flow still earlier, at the beginning of the heavy brood-rearing period of spring, as sometimes happens in the North when the maples yield profusely, or in the citrus region when the bloom comes unusually early and the bees are late in building up, broodrearing is greatly stimulated and but little honey is stored because of a lack of "harvest hands."

During the latter half of the building-up period, some beekeepers make a practice of equalizing the brood among the colonies in order to build them up alike in strength.
This should not be attempted until the strongest colonies liave at least six or seren frames of brood. At this time a frame of brood, most of which is nearly ready to emerge, may be taken from each of the strongest colonies and together with the adhering bees given to the colonies which are less strong, but not to the weakest ones. Care must be taken to be sure that the queen is not taken away with these frames of brood. The comb of brood in each case should be given adjacent to the other combs of brood in the weaker colony to keep the brood-nest as compact as possible, thus preventing any brood being chilled during cool nights. The bees on the empty comb taken from the weaker colony to make room for the frame of brood are shaken back into their hive, and the empty comb is given to the colony from which the brood was taken, placing it between the outer comb of brood and the comb which contains honey and pollen at the side of the brood-nest. The weakest colonies are left until after all of the medium colonies have been brought np to the same number of combs of brood as the strongest ones, after which these may be built up quickly by giving them several frames of emerging brood from the stronger colonies. When several combs of emerging brood with adhering bees are given at one time the combs from different colonies should be alternated to mix the bees so there will be no fighting. When equalizing the brood in this way, it frequently happens that the stores may also be equalized, taking frames of honey from colonies having more than they need and giving to those having less than they need.

If at the beginning of the honey flow more combs of brood are needed than can be drawn from the stronger colonies, they may be drawn from weak colonies, thus reducing these to one or two frame nuclei which are then left to build up to full colonies for winter.

If either of the brood diseases is present in the apiary, it is not safe to exchange the combs in this way.

It is sometimes advisable to unite two $\mathrm{Ol}^{\circ}$ more weak or medium colonies to make one stronger colony, but it is usually best not to do this early in the spring. It should be done at the beginning of the honey flow. See Uniting. Also read carefully the ar- 
ticles on Spring Management, Spring Diwindiing, and Feeding.

\section{BULK COMB HONEY. - See COMB HONEY.}

BUMBLEBEES.-The bumblebee family, or Bombidae, includes only two genera, Bombus, or the nest-building bumblebees, and Psithyrus, or the parasitic bumblebees. About 234 species and varieties of Bombus have been deseribed in the world and 57 of Psithyrus. Bumblebees are found thruout North and South America, extending northward to Discovery Harbor, in latitude $81^{\circ}$; and to an altitude of 13,600 feet at Cuzco, Peru. The arctic bunblebees, which are on the wing less than three months, are very industrious and gather pollen and nectar from flowers for the larger part of the 24 hours of the day. Bumblebees are also widely distributed in Europe, Asia, and North Africa, but the great Saharan deserts offer an effectual barrier to their southward extension. Australia and New Zealand have no native species, but three species were introduced into New Zealand from England in 1884.

\section{BUMBLEBEES AND FLOWER POLLINATION.}

As agents in the pollination of flowers bumblebees are second in importance only to honevbees. Many flower's-are adapted small flowers with a scanty supply of neetar, they resort to a great variety of blossoms, many of which yield valuable fruits. Altho seldom seen on the inflorescence of the pear, they seek the apple bloom in large numbers. They are likewise very helpful in pollinating many blueberries, cranberries, gooseberries, and currants. While leaf-cutting bees (Megachile) are the chief pollinators of alfalfa, many flowers are tripped by bumblebees. The flowers of the squash, cucumber, and pumpkin are also rery attractive to them. As in these plants the stamens and pistils are in separate blossoms, their productiveness is largely dependent upon bees.

But their numbers, wide distribution. and industry enable the bumblebees to perform a service of the greatest value in the pollination of red clover, one of the most important of fodder plants. As there were no native bumblebees in New Zealand red clover seed could not be profitably raised for market until after the introduction of European species. They now annually benefit these islands to the extent of thousands of dollars. In one province alone, in 1912, 6610 acres were sown with red clover, which, it is estimated, yielded. an average of $15 \dot{8}$ pounds to the acre. Fields which were almost barren in the absence of bumblebees produced a perfect mass of seed after. their adrent. At Canterbury 26 acles of red clover were the resort of thousands of bumblebees and yielded 400 to 500 pounds of seer to the acre. The Bureau of Plant Industry reports that from 757 heads of red clover, covered with tarlatan to exclude insects, an average of only one-tenth of
obtained; while from 311 heads visited by bumblebees there was an average of 30 seeds per head. Bumblebees visit as many as 30 to 35 flowers a minute. They are less abundant in the great central plain of the United States wholly to their visits and are called bumblebee flower's, as the larkspurs, aconites, columbines, red clover, jewelweed, turtlehead, Linaria, snapdragon, the closed and fringed gentians, besides a number of orchids. While they generally aroid very

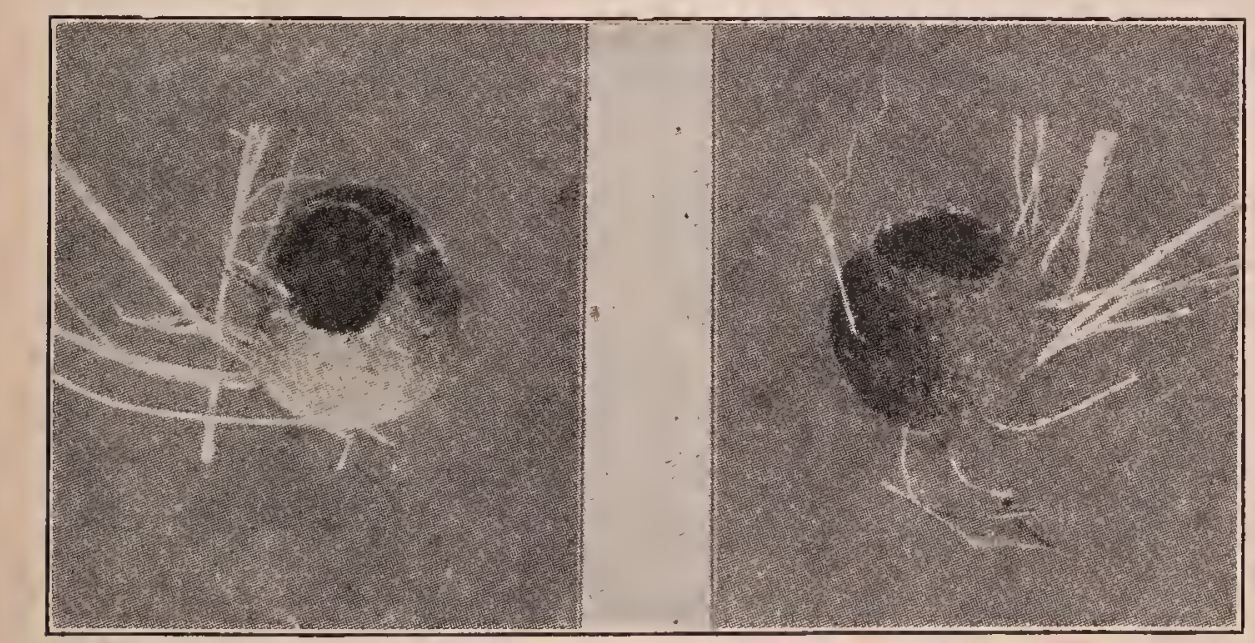

FIG. 1.-Two views of honey-pot of Bombus lapidarius. (After Sladen.) 
tham in the Atlantie and l'acifie highlands. LIFE HISTORY AND HABTS.

In mirlsummer or early autumn a bumblebee colony produces males and queens. The males, which are about the size of the workers, are pleasantly scented and make long flights over the meatows and the open lands in search of the less active females. Belore leaving the nest to which they seltom return, the virgin queens fill the honeysac with honey; and rery soon after inpregnation conceal themselves in moss or leaves, or burrow in the ground, where they remain till the following season. The perior of libernation is about nine months, species which begin sleeping in July awak-

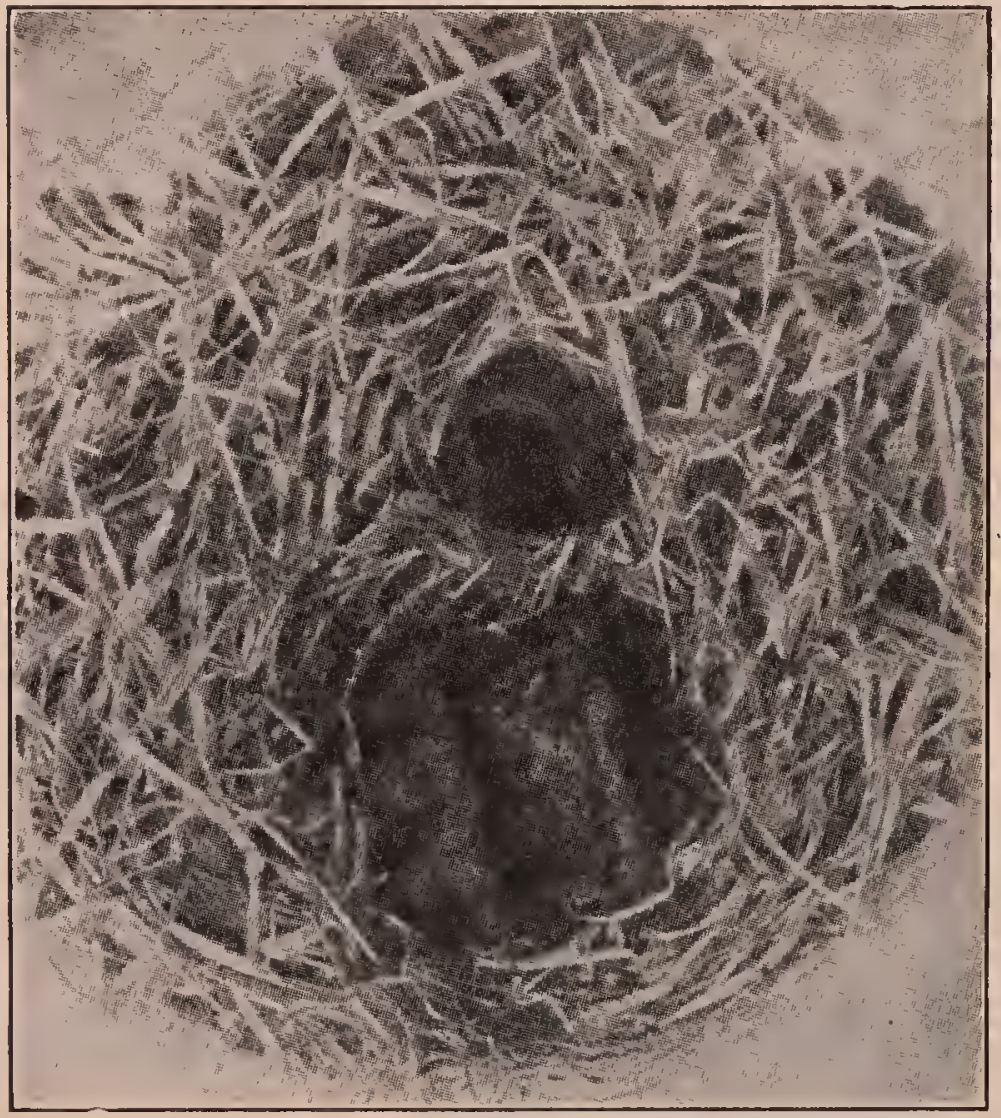

Fig. 2.-Nest of Bombus terrostris showing (-luster of cocoons with groove in the center in which the queen sits, and honey-pot. (. Ifter: Sladen.)

ening in March, while later species do not fly until May or June. The economy of Anerican bumblebees is little known, and this account is based largely on Sladen's observation of the English species.

Soon after the warmer weather of spring permits the queen to leare permanently her place of hibernation she begins to seareh for the nest of a mouse or mole in which to rear her colony. I mouse nest consists usually of a mass of soft died grass with a hollow in the enter. Many species of bumblebees prefer nests which are underground, while other's select those which are on the surface. Access to the subterranean nests is aained thru a tunnel usually not far from two feet in length and about an incle in diameter. Queens may often be seen examining the ground in fields in search of the openings to these trinnels. Before she departs for the field, the queen forms a memory picture of the location by describing above it a series of gradually widening circles.' In the center of the nest a small earity is formed abont an inch in diameter and a little less in lieight. with an entrance about the size of the queen's body.

On the center of the floor of this cavity she stores a small mass of pollen gathered from flowers and moistened witl honey. In a round cell of wax about the size of a pea, built on top of the pollen, from six to twelve eggs are laid, and the top of the cell is then sealed over. According to Sladen the wax is much softer than that of the honeybee, and exudes from between the segments on the upper. side of the abrlomen instead of being excreted in little pockets on the rentral side of the abdomen as in the honerbee. A honey-pot is built in the entrance to the eavity and filled witl loney, which the queen uses in the night time and in rainy weather. It is about the size and shape of a small marble, with open mouth, and, altho very thin and fragile, it remains intact for a month, which is as long as it is needed (Fig. 1). The supply of honey is frequently consumed and renewed and is, consequently, much thinner than that of the honeybee.* In large colonies additional honey-pots are built near the edge of the comb, and many of the cocoons are filled with honey, the number of which may amount to three or four hundred.

*'The queen's honey-pot in a nest of 13 . forrilus examined at Ottawa, Canada, in 1915. Was found to he completely closed, possibly a provision of nature, preventing ants, etc., from discoveling the honey when the queen is ahsent from the nest.-F. W. L. S. 
Except wh en she leares the nest to procure food the queen incubates the cell constantly to keep the e $g$ s s warm. They hateh in four days. The larve feed on the mass of pollen and also on a milky food of partially digested pollen ard honey prepared by the queen. This liqiid is injected into the wax cell thru a minute hole in the top. At first the larræ are provided with a common supply, but later each is fed separately. When the larve are five davs old they begin to grow rely rapidly, and the cell expands into a large globular bunch or bag, in which the position of each ran easily be discemed. On the elerenth day they reach their full size, and each larra spins abont itself a thin papery but very

tough cocoon. The cocoons stand upright and form a compact cluster with a smooth concave groove in the center, in which the queen sits to furnish the warmtl needed to matme the first brood of rorlier's (Fim. 2). On the 22d or $23 d$ day the perfect workers emerge from the cocoons by cutting a hole in the top either alone or with the aid of the queen. Thle

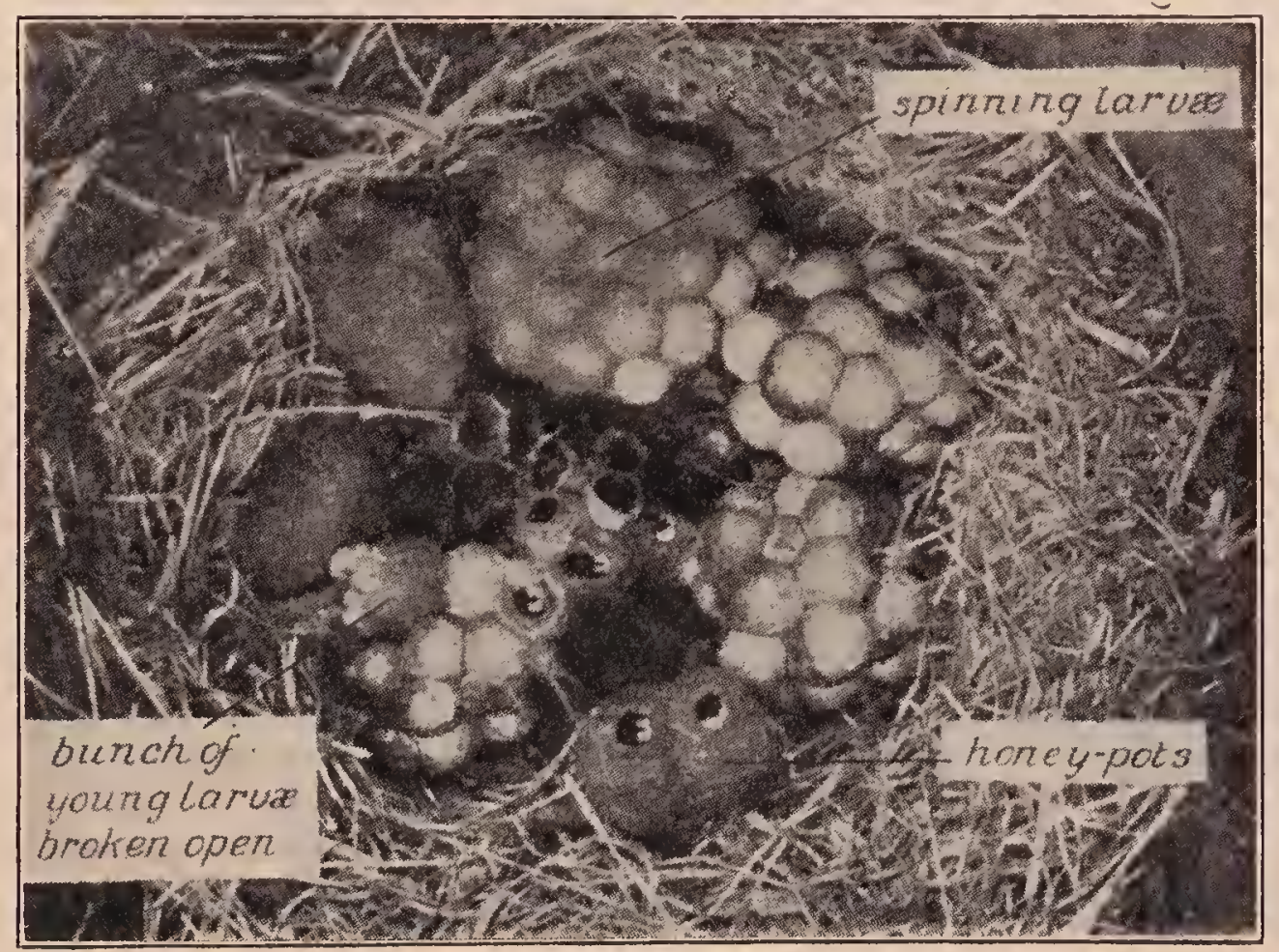

N1G. 1.-Nest of Bombus Lavidarins. (After Sladen.) newly hatcherl bees are a rlull way and move about veg:y feebly, but by the thind day they have acquived tolu gir l natural color a 11 a strength and are ready to repart for the field. The life of a workel bumblebee in midsummer is about $f \circ \quad 11$ r weelis.

As soon as the lalvale of the first broorl 


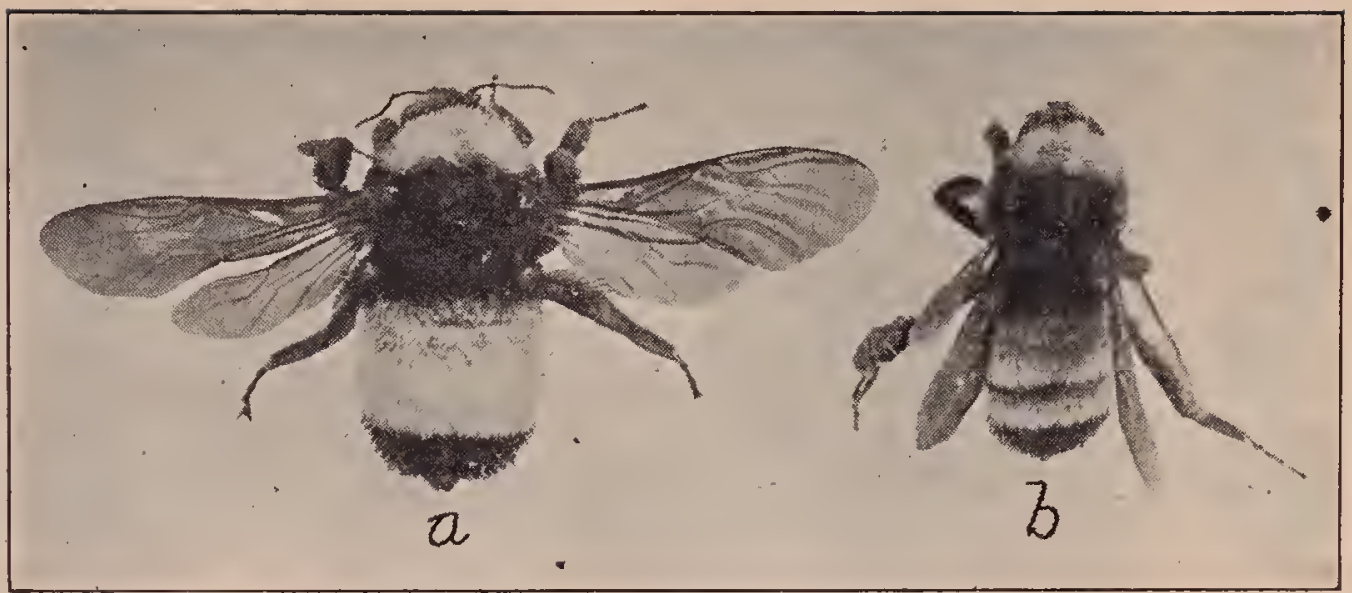

FIG. 5.-Bombus americanorum; $a$, чqueen; $b$, worker. (After Sladen.)

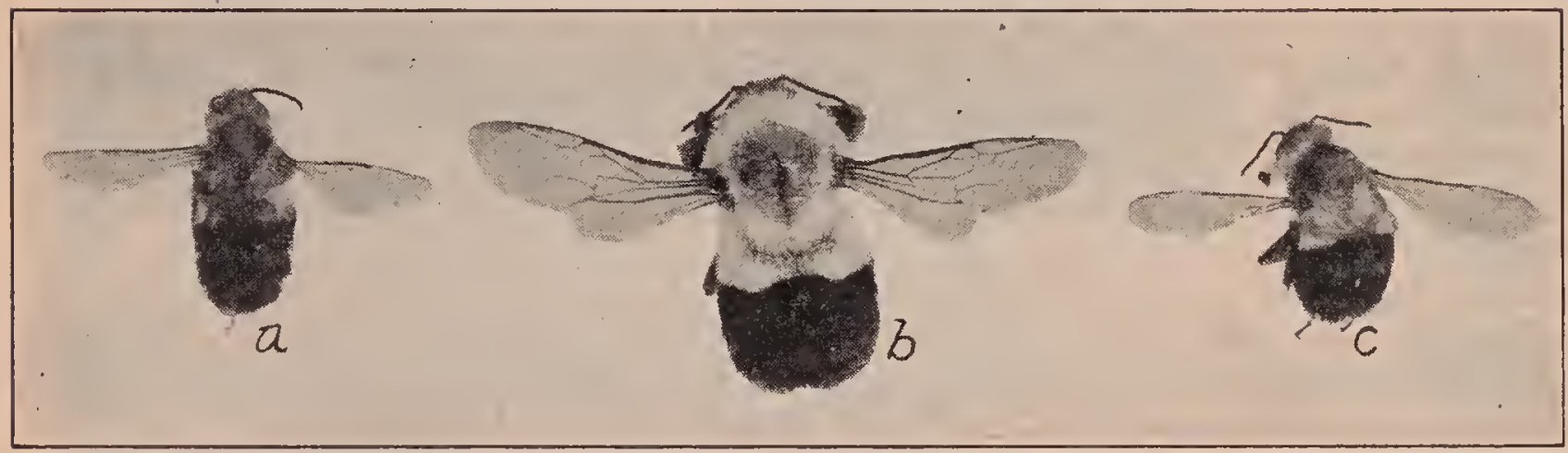

FIG. 6.-Bombus fervidus; $a$, male; $b$, queen; $c$, worker. (After Sladen.)

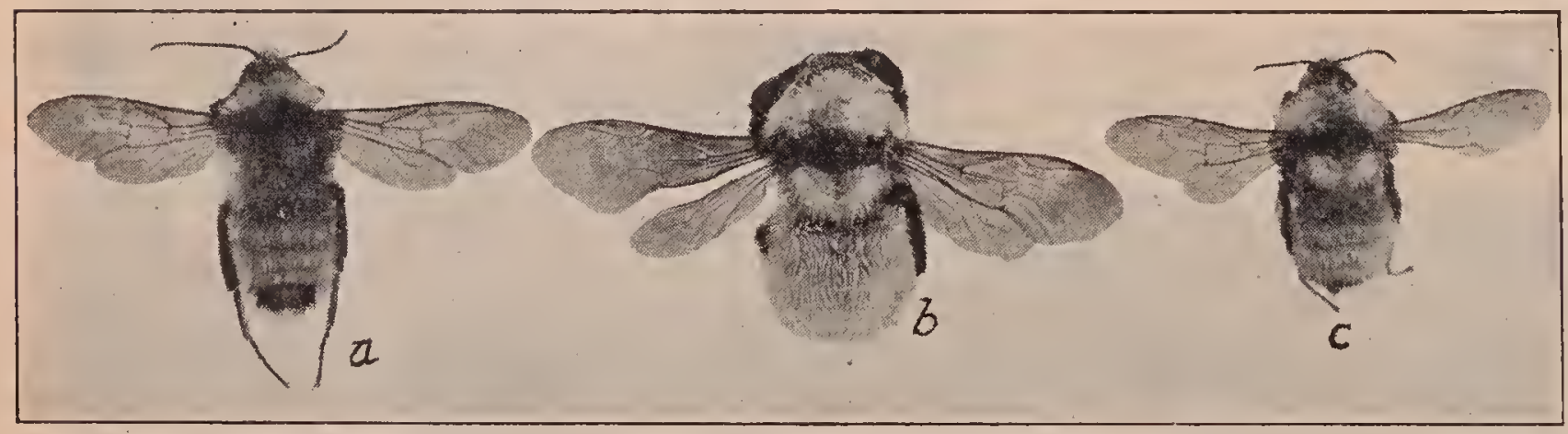

FIG. 7.-Bombus impatiens; $a$, male, $b$, queen; c, worker. (After Sladen,)

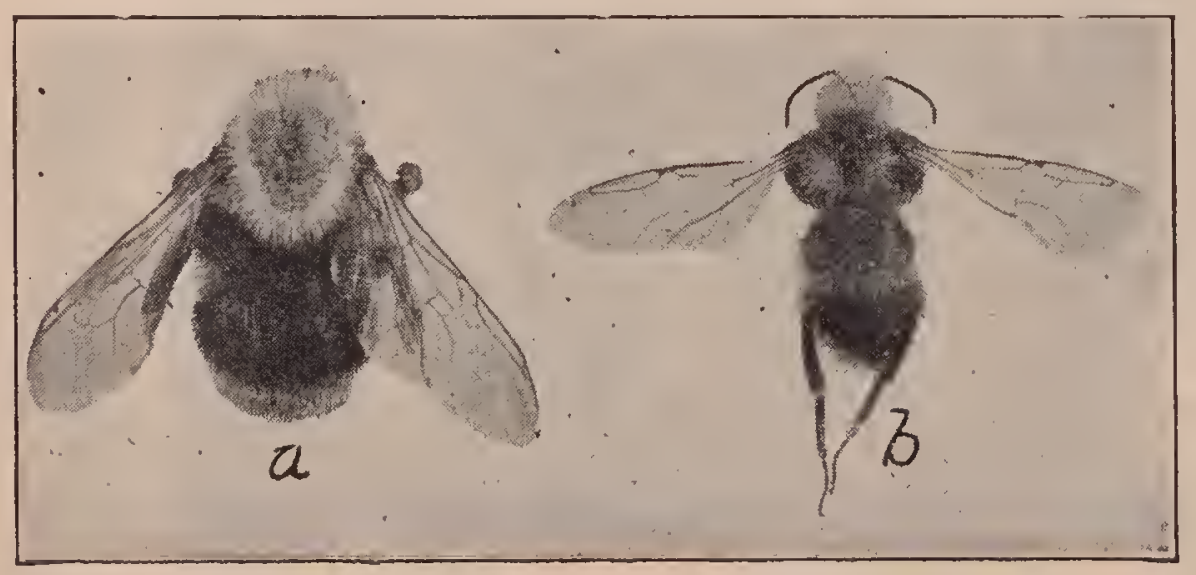

FIG. 8.-Psithyrus laboriosus; $a$, queen; $b$, male. (After Sladen.) 
spin their cocoons, the queen begins to build a row of cells along the onter edge of one side of this cluster parallel with the central groove, and later a second row on the other side of the cluster. She then lays a variable number of eggs, but usually from six to twelve in each cell. As soon as the workers become sufficiently numerous to provide supplies for the colony the queell no longer leaves the nest and may lay a new lot of eggs daily. The history of the eggs in the later cells is similar to those in the first cell except that the larvæ are fed largely or wholly by the workers and the cluster of cocoons is convex without a central groove. The structure of the cocoon clusters varies with different species. Those of the English Bombus terrestris are loose and irregular, while those of $B$. agrorum are compact and globnlar and are arranged symmetrically in a ring around the nest (Fig. 3). Underground species may protect the top of the comb by a roof of wax; but this in surface dwellers is reduced to a mere disc or is entirely wanting. On very hot days the nest is ventilated by one or more workers standing on the comb or in the entrance and rapidly fanning with their wings. Night brings no rest to the colony. Its activity even increases, for now the entire population are at home and busily engaged in caring for the brood and comb (Fig. 4).

Pollen is never put in cells containing honey, but is stored in empty cocoons or in tall columnar cells, which may be over an inch high and half an inch in diameter, near the center of the nest. A few species store it in little pockets on the side of the wax-covered bunches of larvæ, called by Sladen pocket-makers to distinguish them from the pollen-storers. The workers gather the pollen and load it in the pollenbaskets in the same manner as described for the honeybee.

The culninating erent in the history of a bumblebee colony is the production of males and queens, for it is upon this act that the life of the species depends. This is not undertaken until the old queen has laid from 200 to 400 worker eggs, according to the species, and the colony is in a high state of prosperity. Both sexes may occur in the same cluster of cocoons, or it may consist wholly of males or females.
In exceptional cases a colony produces exclusively males or queens. The males appear earlier and are about twice as numerous as the females. One hundred to five hundred males and queens may be raised, according to the strength of the colony. As in the case of the honeybee the bumblebee queens are probably fed on a different kind of food than the workers, altho no difference has yet been observed. The males live for about three weeks, and, like the queens, after once leaving the nest seldom return.

With the departure of the males and virgin queens from the nest. the purpose of the colony has been attained in providing for the continuance of the species another year, and the closing days of its existence are now fast approaching. The old queen begins to fail, her body becomes denuded of hair, and her productiveness decreases. There are not sufficient eggs to keep the colony busy, and laying workers appear, which, however, produce only males. Finally brood-rearing ceases, and the comb begins to mold. There is no longer an abundance of flowers, and the surplus of honey is consumed: then the older workers die one by one and the dozen or more remaining become idle. "One night, a little cooler than usual," says Sladen, "finding" her food supply exhansted, the queen grows torpid, as she has done many a time before in the early part of her career, but on this occasion, her life work finished, there is no awakening."

There are 47 species of bumblebees known in America north of Mexico, and 40 species in America south of Mexico, one species ( $B$. dahlbomii) being common on the Straits of Magellan. A large and common species east of the Rocky Mountains is Bombus americanorum, which has a tongue $14 \mathrm{~mm}$. long (Fig. 5). The colonies live in deserted mouse-nests both underground and on the surface. B. fervidus is another common species found in nearly every State in the Union and in Canada (Fig. 6). This species is a surface dweller, and its nests may be found in a variety of locations. Putnam found on July 27 a nest of paper and rags under the floor of a shed, which contained 70 bees, 150 cells with brood, and 200 larvæ in various stages of growth in the pollen masses, besides 50 
cells of honey. B. impatiens occu's thruout the eastem ['niter States (Fig. 7). It is a subterranean species. A nest taken by Franklin, Aug. 31, contained :3t0 bees. of which 4 were queens and 15 males. It was $2 \frac{1}{2}$ feet below the surface of the ground. There were 330 unbroken rells, the majority of which were queen-cells. Another very common species of bumblebee is Bombus vagans, which ranges from Maine to the eastern Rocky Mountains, and southward to Kentucky and Nortl Carolina. According to Franklin the honeypots of American species appear to be made not of wax but of pollen grains cemented with propolis.

\section{THE PARASITIC BCMBLEBEES.}

Many bumblebee colonies are destroyer by parasitic or false bumblebees belonging to the genus Psithyrus. They are also called inquiline $0 \mathrm{I}^{\circ}$ guest bumblebees. 'They closely resemble bumblebees in appearance and are both no doubt descended from common ancestors. About ten species are known in Americal north of Mexico, and three or four more in Mexico and Central America. It is a singular fact that not a single speries is celtainly known from South Lmerica. A common species widely distributer in the Cnited States is Ps. luboriosus (Fig. 8). The worker caste is entirely absent and only males and females are producerl. They do not build combs nol aither pollen and nectar for their roung, but live in the nests of the true bumblebees, at whose expense their brood is reared.

'They were long supposer to be commensals living with the bumblebees and doing little laa'm or possibly of some benefit; but much information in regard to the luabits of two English species has been gained thru the observations of Sladen." Like the bumblebees. they hibernate during the winter, but begin to fly a little later in the spring. $\Lambda$ P'sillygrus queen seeks to enter the nest of the host bumblebee soon after the first broor of workers las appeared. Little opposition is then offered by the doomed colony, which soon becomes accustomerl to her presence. So long is the

*One of these is I's. Mestalis. which dwells in the nest of $B$. terrestris. Ps. ashtoni, the representative of Ps. restalis in Eastern Canada, possihly assoriates in the same way with B.terricola.-I. W. L. S. workers are too few to provide ample food supplies, the intrduer with instinctive cunning waits until they have become numerous enough to care for herself and her brood. As soon as the nest has become populous a crisis is precipitated by the Psithyrus queen preparing to lay egg's. Aroused by this invasion of her rights, the bumblebee queen apparently attacks the usurper, altho she is doomed beforehand to defeat. Protected by a thick tough integinment and armed with a larger and more curved sting, the parasitic queen invariably kills the bumblebee queen. The Psithyrus queen is at first compeller to protect her eggs from the Bombus worker's, but they soon care for her brood as faithfully as for theil own. In Austria two species of Psithyrust are reporter to live amicably with their hosts, both producing males and females.

If the Psithyrus queen waits too long and then enters a colony of the lost bumbleblee which has a strong, company of worker's, she is at once furiously assailer by overpowering numbers: and, altho fighting valiantly, is finally slain. Before she is destroyed, howerer, a dozen or more of lier assailants are sometimes killed. If two P'sithyrus queens enter the same nest they seem nerer to fight with each other. but one soon goes away. The parasitic bumblebees visit a rariety of flowers, but they show a preference for Composites like the thoronghwort and goldenrod which are rich in nectar. Their visits are marle in a leisurely way very unlike those of the bumblebees.

The two genera, Bombus and P'sithyrus, have doubtless been deriver from a conlmon stock. I'sith!yrus shows evidence of degeneration in the loss of the pollenbaskets, the smaller eyes, and the untootherl manribles. In explanation of the origin of the parasitic laabit Sladen points out that the queens of sereral common species of Bombus often enter the nests of other species of this genus, fight a duel to the death with the queen, and if successful (which is unusual) lay their egres and assume the duties of the foundress of the colony. B. terrestris behaves in this way in the nest of the nearly-related species $\dot{B}$. luco-

\footnotetext{
†Represented in North America br Ps. laboriosus, Ps. insularis, and Ps. fermaldae. F. W. L. S.
} 
$r u m$, but with the difference that she usually sucreeds by means of her greater alertness and ferocity in killing the lucorum queen, and, lucorum being an early species, she frequently does not enter the lucorum nest until the first workers are beginning to emerge. If this practice were to become labitual, an inquiline bee similar to Psithrurus would be likely to result.

Bumblebee nests are destroyed by nice. and Darwin suggested that in the vicinity of towns their numbers were partly detelmined by the number of cats. The comb and brood are devoured by the larve of wax moths and of several species of flies. Ants destroy-neśts in the early stages. Among other insects found in the nests are flies belonging to the genus rolucella, which mimic bumblebees in their appearance and habits of flight so closely that they are often mistaken for them. Two of these flies were collected and sent to the writer as bumblebees by an entomologist of great experience. Like the bumblebees they risit flowers for pollen and nectar.

For further information on bumblebees see "Habits of Some Species of Humble Bees," F. W. Putnam: "The Bombida of the New World," H. .T. Franklin: and "The Hunble-bee," F. W. L. Sladen, Macmillan \& Co.

BURR COMBS.-See 'Thick Top Frames under the liead of Frames.

\section{CAGES FOR QUEENS.-See Intro-} DUCING.

CAMPANILLA.-There are two species of Convolvulaceae, or morning-glory faulily, which are of great importance to the beekeepers of Cuba as lioney plants: namely, Ipomoea sidaefolia Choisy, and I. triloba L. Popular English and Spanish names of $I$. sidaefolia are white bellflower, campanilla blanca, campanilla, Christmas pop, and agumaldo de paseuas. It is a perennial, the vines sometimes olotaining the size of from two to three inches in diameter, and is generally found growing among trees and shrubs or along fences and stone walks. The height of bloom is about Christmas, for which reason it is also called the "aguinaldo de pascuas," and at this season of the year it is a common sight to see almost every tree, shrub. 'and fence along' the road one solid 'mass of white aguinaldo bloom. The odd feature. about this plant is its irregular blooming. It will blooni only every other day, anil then, again, several days in succession. The days of blooming ate always universal.
One day every rine is in full bloom: the next day not a single vine is to be seen in bloom in miles of travel.

\section{PINK CAMPANILLA.}

The pink campanilla, I. tritoba, is also known as campanilla morada, aguinaldo rosado, and marrullero. It blooms during the montlis of October and November. It is found principally in western Cuba, in the region known as the "vuelta abaja," the great tobacco region; and it is the growing of tobacco that makes possible the great amount of this particular variety of the campanilla, for tobacco seed is, as a rule, always sown on virgin soil. Large tracts of land, on both mountain and coast. are cleared every year, just to grow one erop of tobacco plants. When the plants are big enough to be transplanted they are pinlled and shipped by railroad, ox-cart, or mule-train, to where the tobaceo is to be grown. These tobaceo-seed beds are, by the next year, and for years to come, corered by the vines of the rampanilla morada, which in western ruba, springs up wherever the land has been cultivated. 


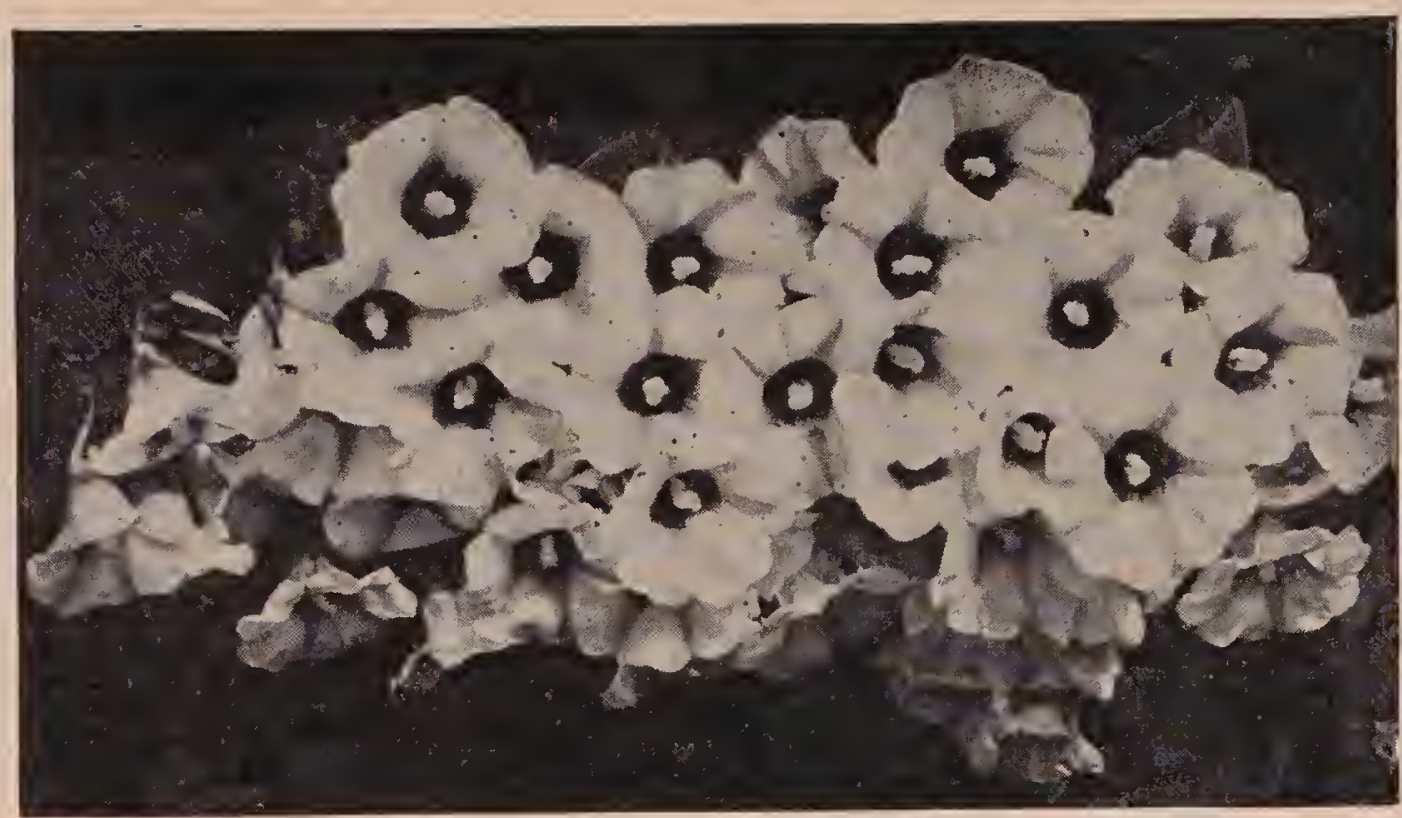

Campanilla

The honey from the campanilla, in color and flavor, is equal to alfalfa or sage. The comb built during the campanilla flow is pearly white, and when melted it produces wax as white as tallow.

\section{CAMPECHE.-See LOGWOOD.}

CANADA THISTLE (Cirsium arvense). -Altho this very troublesome weed, naturalized from Europe, is condemned by agriculturists and is outlawed everywhere, it is a source of a small quantity of honey in parts of Canada. Like most pernicious weeds it belongs to the family Compositae. The heads are small but very numerous, each head composed of about 100 rose-purple tubular florets. The nectar is secreted so freely that it rises in the corolla tubes to a point where it can be reached by nearly all insects. Honeybees gather both neetar and pollen. The honey is light colored, of very fine quality with a delightful flavor, and is fully equal to the best elover or basswood honey in the market.

Canada thistles will live in a great variety of conditions, but they luxuriate in rich bottom lands where they take almost complete possession of the soil. It is a commercial asset to the beekeeper chiefly in those localities where it has become a pest to farmers who would gladly exterminate it root and branch. Beekeepers should also do everything in their power to destroy it; but the Canada thistle is difficult to eradicate since it multiplies by underground. ereeping rootstocks, a small fragment of which, if left in the soil, will give rise to a new plant.

CANDIED HONEY.-See Granulated HONEY.

CANDY FOR BEES.-There is just one kind of candy that is used universally by beekeepers for queen-cages. Thile excellent for this purpose it slould not be used as winter food unless in pans, where, if it becomes soft, it will not run down and kill the bees.

It is none other than what is popularly called the "Good" candy, after I. R. Good of Nappanee, Ind., who introduced it into this country. It was, however, first made many years before by a German named Scholz. (See "Langstroth on the Honerbee," page 274, 1875 edition.) By Europeans it is, therefore, called the Scholz candy.

\section{HOW TO MAKE.}

It is made of a first quality of extracted honey or invert sugar and powdered sugar. If honey is used it should be of the best quality of table extracted honey from an apiary where there is no foul brood and, if possible, from a locality where there has never been any disease. The powdered sugar must have no starch in it. There are two kinds of frosting sugar-one with stareh and the other without. The latter should be used. While starch is not necessarily fatal to queen-cage candy, experi- 
ence shows that queens can be sent only short distances on a food containing it.

Haring secured the right ingredients, the honey (or invert sugar syrup) if granulated, should be heated to a temperature of 140 degrees F. to liquify, and allowed to cool to about 100 degrees. The pulverized sugar should then be stirred in, a little at a time, with a big strong spoon or stick, adding all that it is possible for the honey to absorb; and when the stick or spoon can not stir in any more, some powdered sugar should be spread on a molding board. The mixture should then be removed from the pan to the board and the dough kneaded the same as ordinary bread dough, adding sugar from time to time to prevent sticking. The candy should be worked and worked by some good strong arms and hands until all the sugar lias been incorporated that it is possible to get in, and yet not have it too stiff nor too soft and inoist. The proportion should be about two pounds of invert sugar or honey to five pounds of powdered sugar. The kneading should be kept up for at least lualf an hour. If too mucl sugar is worked in, the candy will become dry and hard; if not enough, it will be soft. sticky, and shiny. If the candy has been handled properly it should hold its shape or form and not become sticky or "run" out of the candy hole in a queen-cage at a temperature of 80 degrees. Summer temperature will seldom exceed this: and if the candy holds its shape at this temperature it will do so when it is colder. It may then be set away in a closed tin pan and nsed as a food to fill cages.

During very moist hot weather it may be necessary, just before filling the cages, to knead in a little more sugar.

During exceptionally hot summers it requires two pounds of invert sugar or honey to six of powdered sugar.

The holes for holding the candy in queen-cages should be lined with paraffin or beeswax, and the top covered with palaffin paper. The object of this is to prevent the moistule of the candy from eraporating and being absorbed into the wood. This absorption and evaporation would make the bee-feed dry and hard. It should be maintained not sticky but slightly moist and soft, to the journey's end.
Postal regulations in the Tnited States require on the part of every queen-breeder who sends queens by mail one of two things - a certificate of inspection from a duly authorized bee inspector certifying that no bee disease has been discovered in the yard in which the queens are reared, a copy of this to go on every package; or in the event that there is no bee-inspection law, and, of course, no inspector, the postal authorities require a statement, duly attested before a notary, that the honey of which the candy has been made has been boiled 20 minutes in a closed vessel.

But experience shows that boiled honey does not make good queen-cage candy. The character of the honey is so changed by boiling that queens are apt to die on it in the space of a short time. The real intent of the regulation, which is to prevent the dissemination of bee disease, can be better subserved by using invert sugar in place of honey. (See INver'T SugAR.) This is a syrup liaving about equal proportions of levulose and dextrose; and in this one respect it is very similar to honey; but, of course, it lacks sonie of the food elements of nature's product. However, because it has never been in contact with the bees, and therefore could contain no gelms of disease. and because clremically it is so nearly like lroney, it can be used in place of honey in making candy. As there is so much foul brood present over the country, it is always safer to give to bees a candy that contains no honey.

Invert sugar syrup can usually be obtained of.any large candy-maker. A very good article is sold under the name of nullomoline by the Nullomoline Co., New York. This is made without acids, from granulated sugar, and is preferable to the ordinary invert sugar syrup made with the use of acids.

For long-distance shipments, and for raluable queens, where proper precautions are taken in securing a honey that is free from disease, it is advisable to use a lightcolored extracted honey of best quality in making queen-cage candy. 'This honey should come from a locality where there has never been any foul brood, in order to be really safe. $\Lambda$ queen-cage candy using honey will hold its shape and consistency, or, more exactly, a soft mealy condition, 
slightly longer than a candy made of an invert sugar. It probably contains some food elements also that are essential to long shipments. For many years the only queen-cage candy known was made from. honey: but as the latter might convey bee disease to a new locality, an invert sugar candy is recommended for general shipments, using honey only for long distances and for raluable queens.

\section{HARD CANDY FOR WINTER AND SPRING} FEEDING; HOW TO MAKE IT.

Into a dish of hot water on the stove is slowly poured granulated sugar, which shonld be stirred constantly. The syrup should be rery thick and the sugar all dissolved before boiling commences. If this precaution is not observed, some of the undissolved sugar is likely to burn, injuring the flavor of the candy and almost surely causing trouble with the bees later. If one has a candy thermometer, he should watch the temperature, and not let it go above 275 to 280 degrees F. Tests should frequently be made by dropping a very litthe of the syrup into cold water (about 50 to 55 degrees $F$.). When the boiling has continued long enough the drop of candy. having been cooled in the water, should be hard and brittle when taken out; but when placed in the mouth it should soften slightly, and become tongh. Then this time has arrived, the syrup should inmediately be poured on to paraffined or waxed paper on a table. The table should be perfectly level, and around the outside of the paper should be placed wooden sticks $1 / 4$ inch livgh to confine the srrup and prevent it from running off. When the candy is nearly hard, it may be creased or ent with a heavy knife so that it can be broken up into right-sized squares when lard.

The color of the candy when cold should be about that of light basswood honey. If it is darkened rery much, it is scorched and unfit for the bees. 'T'o preyent the scorching, the fire torard the Tast should be reduced so that the syrup will boil but slowly.

When the candy is first made, it is hard and glassy, and perfectly tramsparent: but after it stands for a little time it lecomes somewliat watery and erystalline; but this is all the better so far as the bees are con- cerned, for they are enabled to take it more easily.

'The thin ealies of candy being only $1 / 4$ incli thick may be placed over the frames and under the regular corer, and in this way a colony may be saved that would otherwise be lost. The feeding of syrup. especially in the spring, is apt to cause great excitement and possibly robbing, and for this reason the candy is safer as it is taken slowly.

Caution.-Thoever makes the candy should clearly understand that if the mixture is scorched, even the slightest, it will make unfit food for spring or winter feeding. When the syrup is cooked nearly enough, there is great danger of burning. and it is then that the greatest care should be exereised.

CANE SUGAR.-This is the coumon name applied to the sugar-sucrose. Sucrose is made from the sugar cane and also from the sugar beet. When derived from the beet it should go under the name of beet sugar. Suerose is found in pure hones in amounts rarying from nothing up to 8 per cent. Only in a very few cases las pure honey been found which showed the higher figures. 'The standards for pure loney allow 8 per cent to be present. New honey generally contains more sucrose than old honey. There are present in honey before leating sone enzymes (morganized ferments) which have the power to invert the sucrose. Hence on aging, if heat has not been applied to kill this action, the per rent of sucrose decreases. Sucrose on hydrolysis or inversion forms equal parts of dextrose and levulose, these latter being the predominant sugars of honey. See Sugar: Invertr Sugar: also Honey, ANALYSIS OF.

CANS FOR HONEY.--See EXTRACTED HONEY.

CARNIOLANS.--See RACES OF Befs.

CARPENTER BEES. - See SOLITARY Befes.

CARPET GRASS (Lipria nodiflora). -Two other relnacular names are fogfintit and mat grass-a prostrate, creejing, herbaceous perennial, only a few inches high, which forms dense mats in 
damp soil and on river banks. It is of great ralue in preventing the erosion of sandy land and is in consequence lnown as a "sand-binder." In Florida it would be a boon for that purpose alone. Stock will eat it; and it holds up its head when everything else is burned np by the sun. 'The flowers are small, white, resembling' those of the sweet-scented garden verbema from China, which belongs to the same genus. Both species belong to the Verbenaceae, or verbena family. Common carpet grass is widely distributed in the warmer regions of North America, extending from Central America and the West Indies to Florida, Georgia, and Texas. It is rery abundant in Sutter County and in the Sacramento Valley, California, carpeting the slopes of the Sacramento River, where it produces a large amount of honey. It blooms from May until September. The honey is white, of the mildest flavor, and crystallizes with a very fine grain. In Texas carpet grass grows along rivers and small streams, but is of little importance as a honey plant.

O'THER SPECIES OF CARPET GRASS.

The carpet grasses, of which there are about 100 species, belong chiefly to the warmer regions of the old and New Worlds: but are most abundant in tropical and subtropical America. They vield much nectar in Central America and are also raluable honey plants in the West Indie: and the Bermudas. There are about nine species in the United States distributerl over an area extending from New Jersey

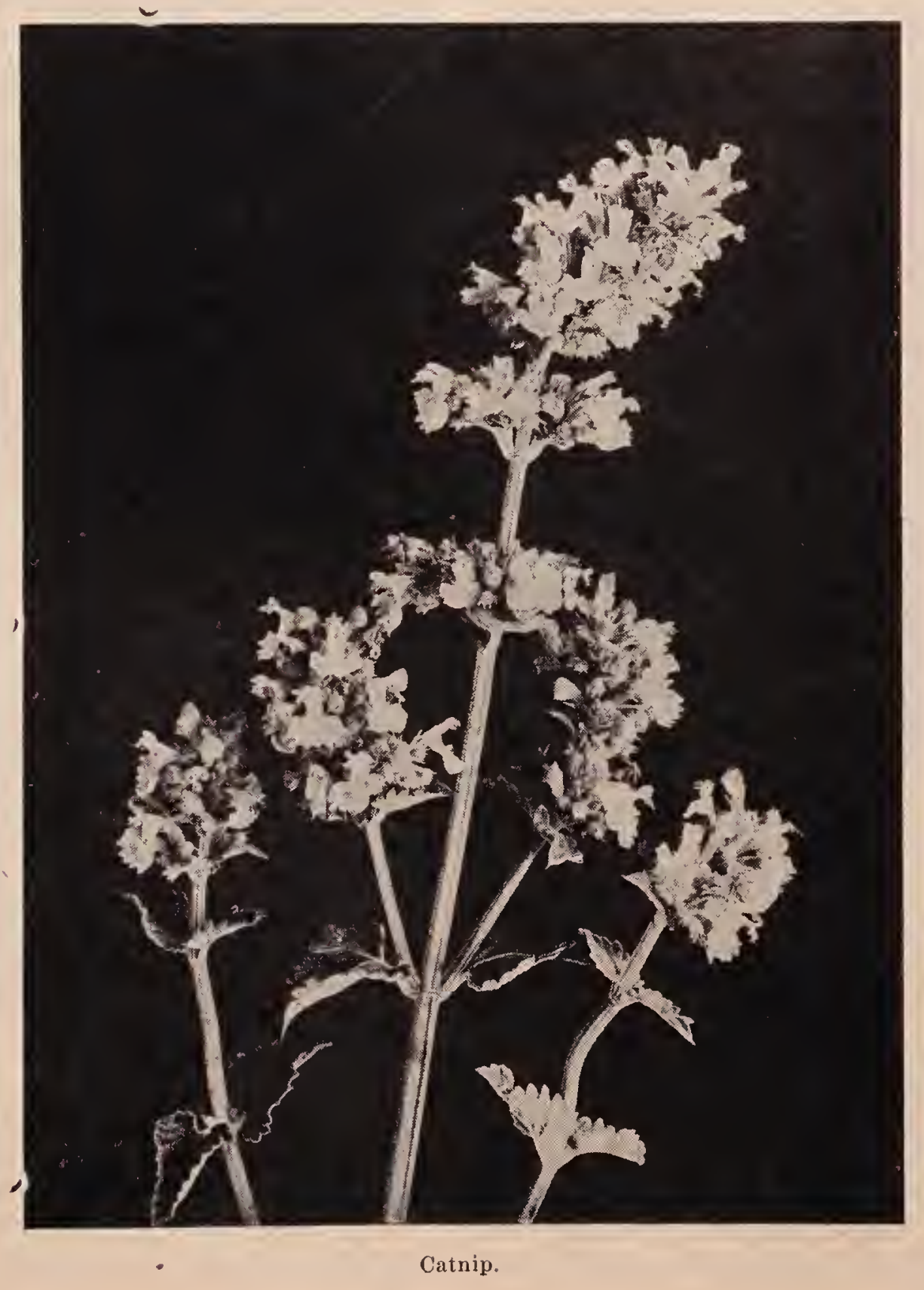


to Nebraska and Kansas, southward to Georgia and Texas, and rest to Arizona and California.

In 1900 Lippia repens Hort. was introduced from Italy into California, where it now covers thousands of acres. Because of its thickly matted growth it is widely used for covering lawns and tennis courts. Only one or two euttings are required during the summer. It thrives in the poorest soils, smothers weeds, requires but little water, and looks as well as any grass; but during two or three months it turns brown and ceases to grow, when its appearance is less pleasing. A new growth appears in early spring. The small flowers are visited by many honeybees and probably the honey does not differ from that of the common carpet grass.

Lippia lanceolata Michx. grows in New Jersey, Texas, Mexico, and California, and is also valued as a honey plant.

CATNIP (Nepeta Cataria L.).--Often called catmint. Flowers bilabiate, nearly white, spotted witl purple. Moses Quinby (see Quinby) once said that, if he were to grow any plant extensively for the honey it produces, that plant would be catnip; and very likely he was not far from right. But as there has never been any definite report from a sufficient field of it to test it alone, either as to quality or quantity of the honey, there is almost as much doubt in regard to it as there was at the time Quinby made the statement many years ago. Sereral have cultivated it in small patches, and have reported that in a state of cultivation it apparently yielded more honey than in its wild state, for bees were found on it almost constantly, during several months in the year, but rarely one gets a full load. It has been called the "bees' bar-room," as they are so constantly hanging around it. Tet no, one is prepared to say positively that it would pay to cultivate it for honey alone.

CATSCLAW (Acacia Greggii, Gray).Known also as paradise flower and devil's claws. The acacia trees are most abundant in Australia and Africa; but 16 species occur in the southern States, chiefly in Texas. Several species are valuable for both honey and pollen: A. Greggii Gray and 1. Berlandieri Benth, are two of the most important howey plants of Texas, and yield immense quantities of excellent honey that ranks with the best white honey of the North. Several species of acacia are cultivated in California, and vield much honey. While possibly it would not sell alongside of our clover's, yet in localities where it is produced it is praised very highly for table use, no honey being classed higher except that from huajilla. See Huajilla.

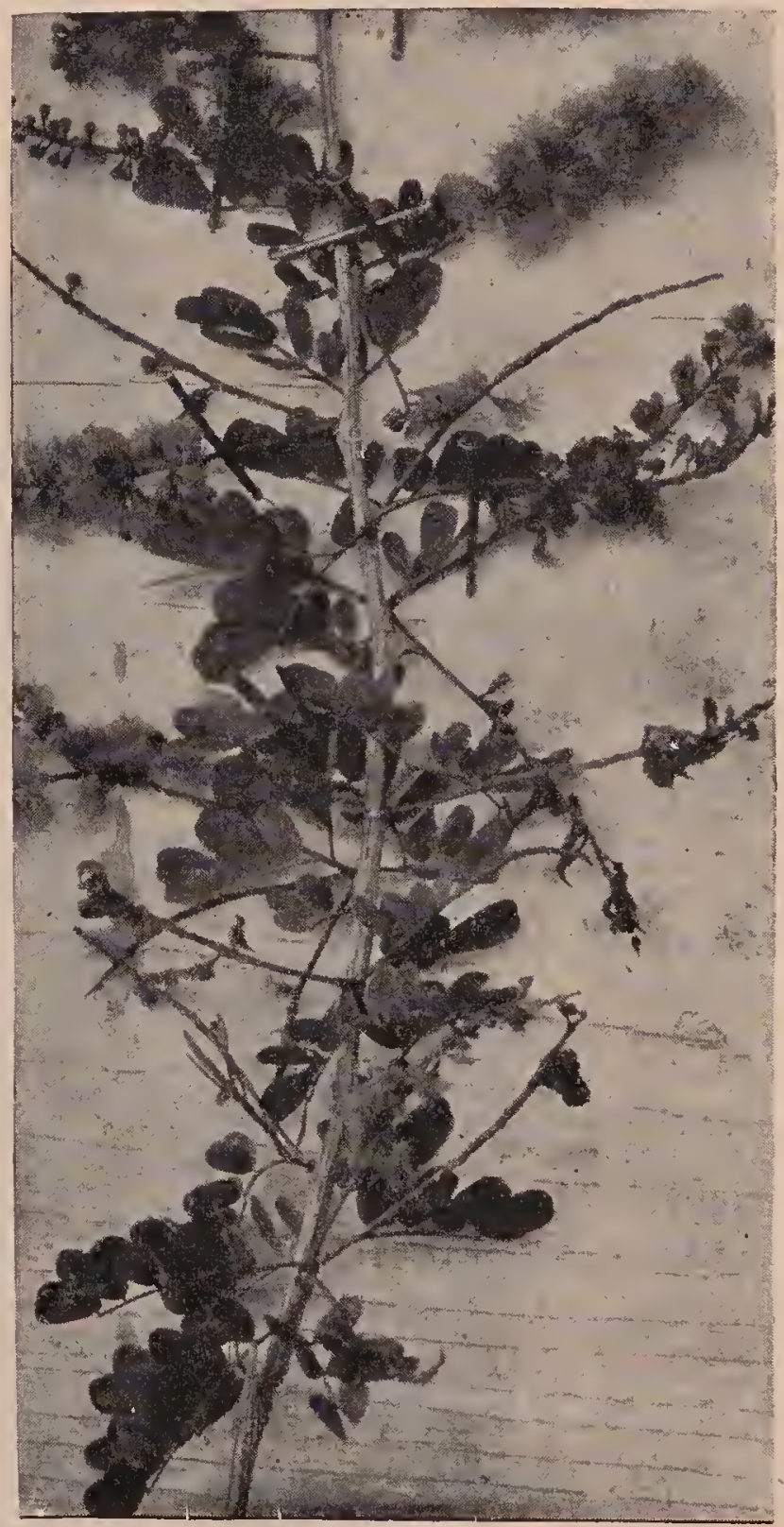

Catsclaw leaf, twig, and blossoms; life-size.

The catsclaw is a bushy tree with lowspreading branches, attaining a height of anywhere from 15 to 20 feet. It derives its name from the bushy and fuzzy blossoms suggestive of the furry coat of a cat, and the peculiar kind of claws or hooks, 
shaped rery much like the claw of a conmon house eat. If one tries to push thru the bushes or among the branches he will conclude that, unless he "backs up," he may "remain hooked." Perhaps he will anyhow.

The illustration on the preceding page shows a small twig, life size. The leaves are small and in clusters while the blossoms have a cottony or downy look. One of the seed pods, after the blossoms have been cast off, is shown at the upper left-hand corner of the plate.

The tree comes into bloom about the first of May, and yields honey for a considerable length of time before going out of bloom. In July there is a second crop.

Like the huajilla and mesquite it grows in the semi-desert regions of Texas and Arizona where it would be impossible to carry on farming without irrigation. There are vast areas in both States mentioned that will probably never be used for anything more useful to man than catsclaw, huajilla, and mesquite; so that the onward march of civilization will not displace these honey trees with more profitable farm crops. We may reasonably conclude that catsclaw will remain one of the permanent sources of honey supply.

We are not sure but it would pay to introduce these valuable honey-bearing trees in otler semiarid regions. It has been introduced into Southern Europe, whence large quantities of its flowers are exported to France and England. It is there known as mimosa.

CAUCASIANS.-See RaCes of Bees.

CELLAR WINTERING.-See WINTERING IN CELLARS.

CELLS, QUEENS. - See QueEns and QUEEN-REARING.

CHUNK HONEY.-See "Bulk Comb Honey," under head of Comb Honey.

\section{CLIPPING.-See QUEENS.}

CLOVER (Trifolium).-No group of plants yields more or better honey than the clovers. About 250 species belong to the genus Trifolium; but only a few of them, as white clover, alsike clover, red clover, and crimson clover, are of great importance to bee culture. Under the general term "elover" alfalfa, sweet clover, sainfoin clover, and pin clover are sometimes included; but they belong to different genera, and, in the case of pin clover to a different family. So broad a license in the use of the word "clover" is not admissible. Clover, alfalfa, sweet clover, and sainfoin all belong to the pulse family (Leguminosae), a very extensive family, which contains many other valuable honey plants.

Some 30 or 40 years ago a failure to obtain a crop of elover honey was almost unknown. In more recent year's intensive agriculture has tended to exclude white clover from cultivated fields and to confine it to the roadsides, hedgerows, and unploughed pastures. Its place was taken by red clover and alsike clover, but these

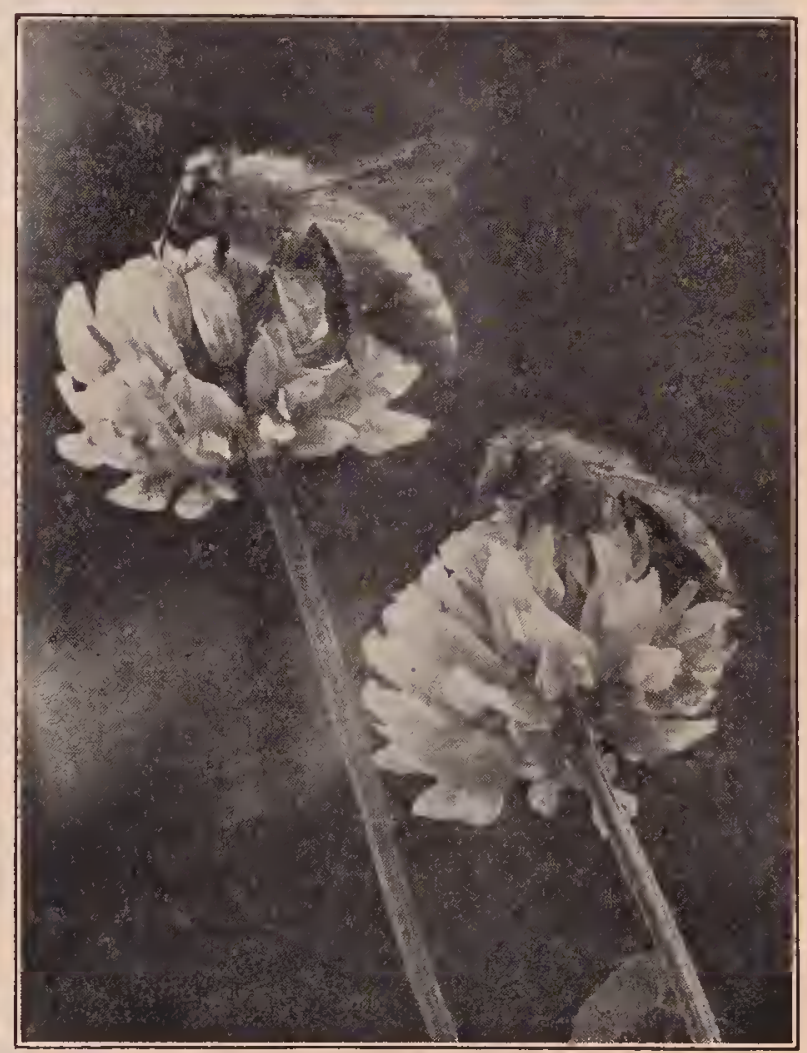

What is sweeter than honey?

species in turn have lately begun to disappear. Lands that formerly yielded clover in abundance, in some eases produce it only sparingly, or not at all, and are called by the farmers "clover-sick." The cause of this difficulty was soon discovered to be an insufficient amount of lime in the soil. The clovers will not grow on an acid soil. Alsike requires less lime than red clover, but the time finally comes when the land will not support alsike. When the land was new, or before it was tilled, it 


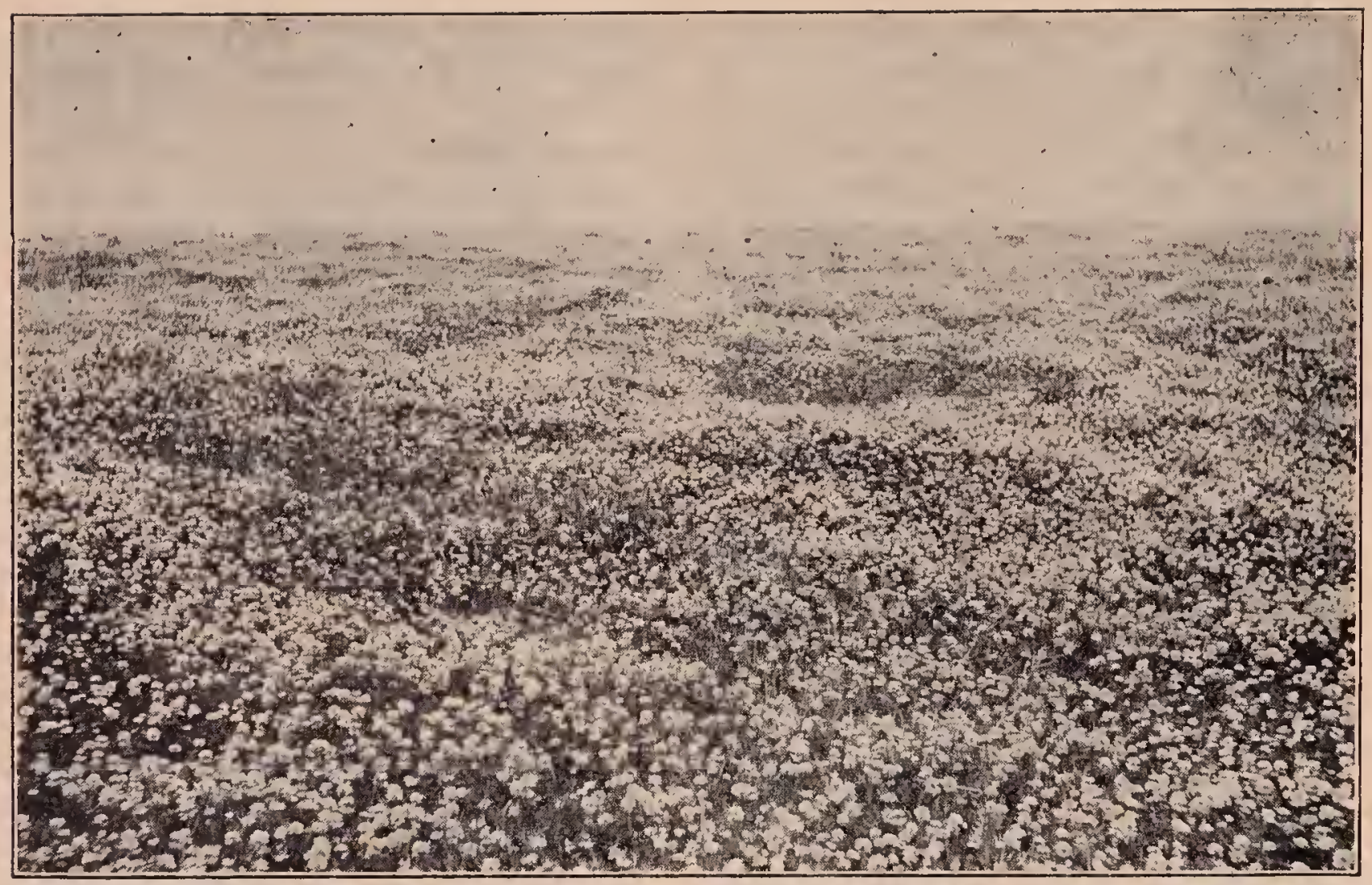

$\Lambda$ field of white rlover in Iowa.

contained a larger amount of lime; but constant cropping has largely exhausted the natural supply. Hence the soil is "clover-sick," or requires lime.

If sorrel is growing on the land, or blue litmus paper placed in damp soil turns red, it naty be assumed safely that there is a lack of lime. Beekeepers slould earefully inform themselves as to whether the clover fields in their locality are deficient in lime or not, and slould endeavor to induce the farmers to get in touch with the nearest experiment station and seek advice in regard to this matter. From 500 to 2,000 or 3,000 poinds of ground limerock may be required.

The attention of farmers should also be called to the part clover plays in increasing the nitrogen in the soil. On the roots of the clover's there are little nodules or tubereles, from the size of a pin hear to that of a pea, in which there live multiturles of bacteria. These bacteria are able to fix the free nitrogen of the air in nitrogenous compounds, which after the death of the bacteria the elover plants are able to obtain. The fixation of nitrogen is aided by lime and lumus in the soil, and is retarderl by an acid soil or one which is compart and not well aerater. 'lhe tubercles do not survive the winter, but are formed anew each season.

Since alsike clover requires less line than red elover, the gradual decrease of lime in the soil las in many localities led to its substitution for the latter. While this has been a great arlvantage to beekeepers temporarily, it will not prove a permanent one unless line is applied, since finally the soil will become so acid that alsike will not grow in it. White clover, likewise, is largely dependent on a soil rich in lime, and it las been disappearing not alone because of intensive agriculture, but also because of the increasing acidity of the land. Years ago there was no difficulty in getting annually a surplus of honey from white clover.

LIMING THE SOIL AND ITS EFFECT ON BEEKEEPING.

In parts of the northeastern United States where temperature conditions are favorable for the clovers, the soil is so deficient in lime that the rlover's do not do well. In some regions when the soil conld no longer support a slowth of elover. farms have been abandoned because of the poverty of the soil. Within recent years many of these abandoned farms lave been 
built up, and good crops are now being raised largely thru the nse of line and the growing of clover.

Extension men frou the agricultural colleges are now preaching the doctrine of liming the soil. County agents and farm bureans are not only telling farmers that it pays to lime the soil, but demonstrations are being made on farms here and there to show the great value of line. $\Lambda$ s a result of all this, great areas in eastern Olio and parts of New York and Pennsylrania, these regions alsike clover has already been introduced and when once it gets into a locality it stays, if conditions are at all suitable, springing up in meadows, along roadsides and in fence corner's.

Beekeepers in these regions will do well to find out where the most lime is being used by the farmers, as a guide in locating out-apraries, for where farmers are using a ton or more of "wround limestone to the acre, beekeping should flourish, if other conclitions are at all farorable.

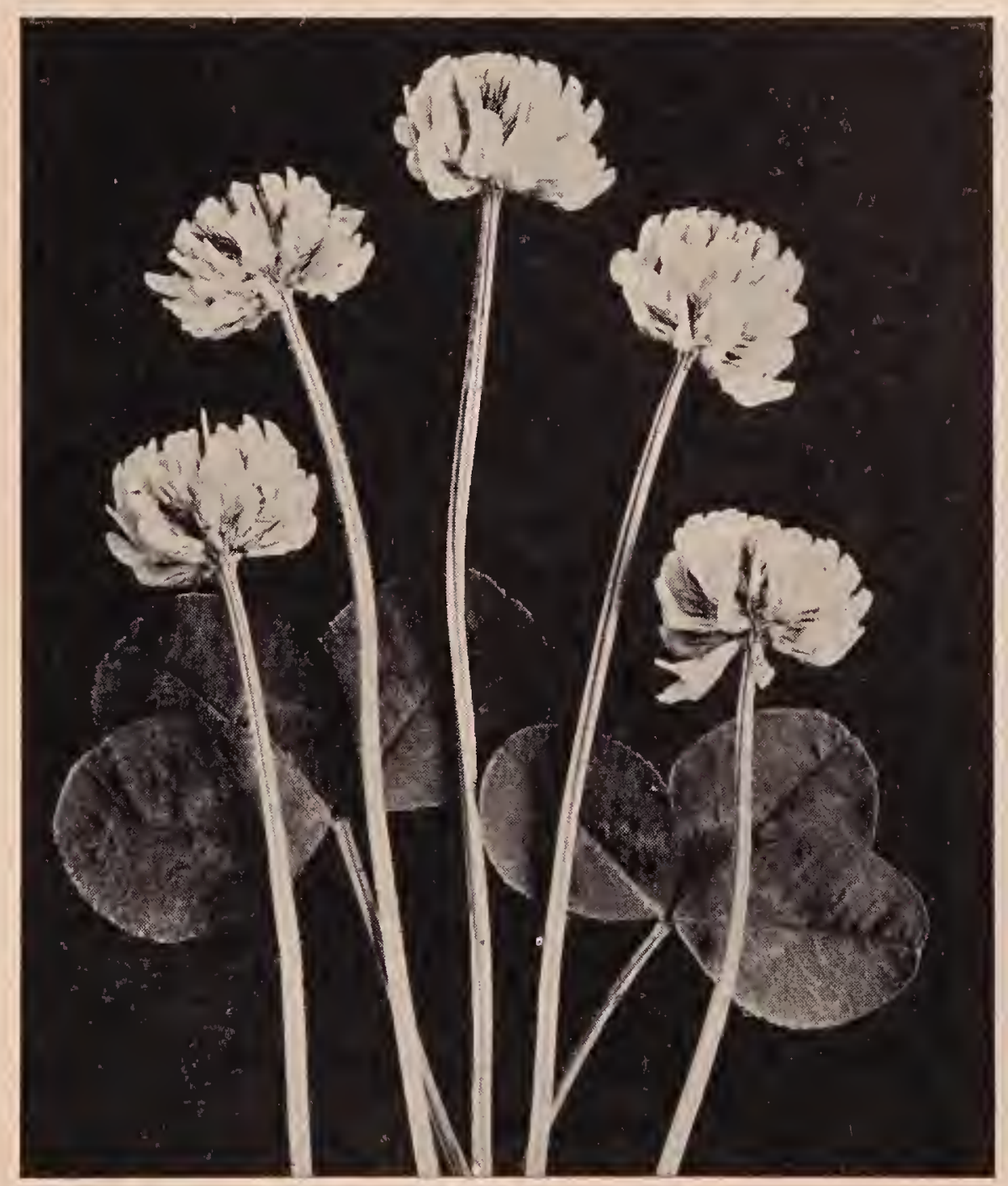

White clover blossom-first stige.

outside of the buckwheat region, which were formerly poor territory for beekeeping, are now becoming good beekeeping. territory on account of the return of the clovers. The practice of liming the soil spreads from farm to farm, as neighboring farmers become convinced that it pays, intil large areas of cood clover territory spread from these center's where liming was begun sereral years ago. In most of
WHITE CLOVER ('Trifolium repens L.).--In the central and eastern States no other honey plant is so universally known as white clorer, and white clover honey is the honey par excellence-the honey with which all other honeys are compared. It is a delicious white loney of the finest quality. While not so thick and heavy as goldenrod nor so pronouncer in flavor as burkilheat or basswoor, it yet possesses 
the qualities which satisfy the largest number of consumers and fill most perfectly the demand for a table honey of the highest grade. It is given the preference by most purchasers, and the highest praise which can be bestowed on any honey is to pronounce it equal to that of white elover. As a confectionery its appearance is most attractive, while for medicinal purposes it is unsurpassed.

In general in northeastern America where it is sufficiently abundant white clo- sisting of a succession of lot humid days, altho the strain of bees and the care they received were important factors. The flow began about June 1 and continued until the last of August, the bees then gradually changing to sweet clover and heartsease. During this long even flow there were up to Sept. 1 only two rainy days. At other times the rain eame during the night, the weather becoming clear again before the bees were ready to begin work in the morning. In central Kentucky, in 1906 ,

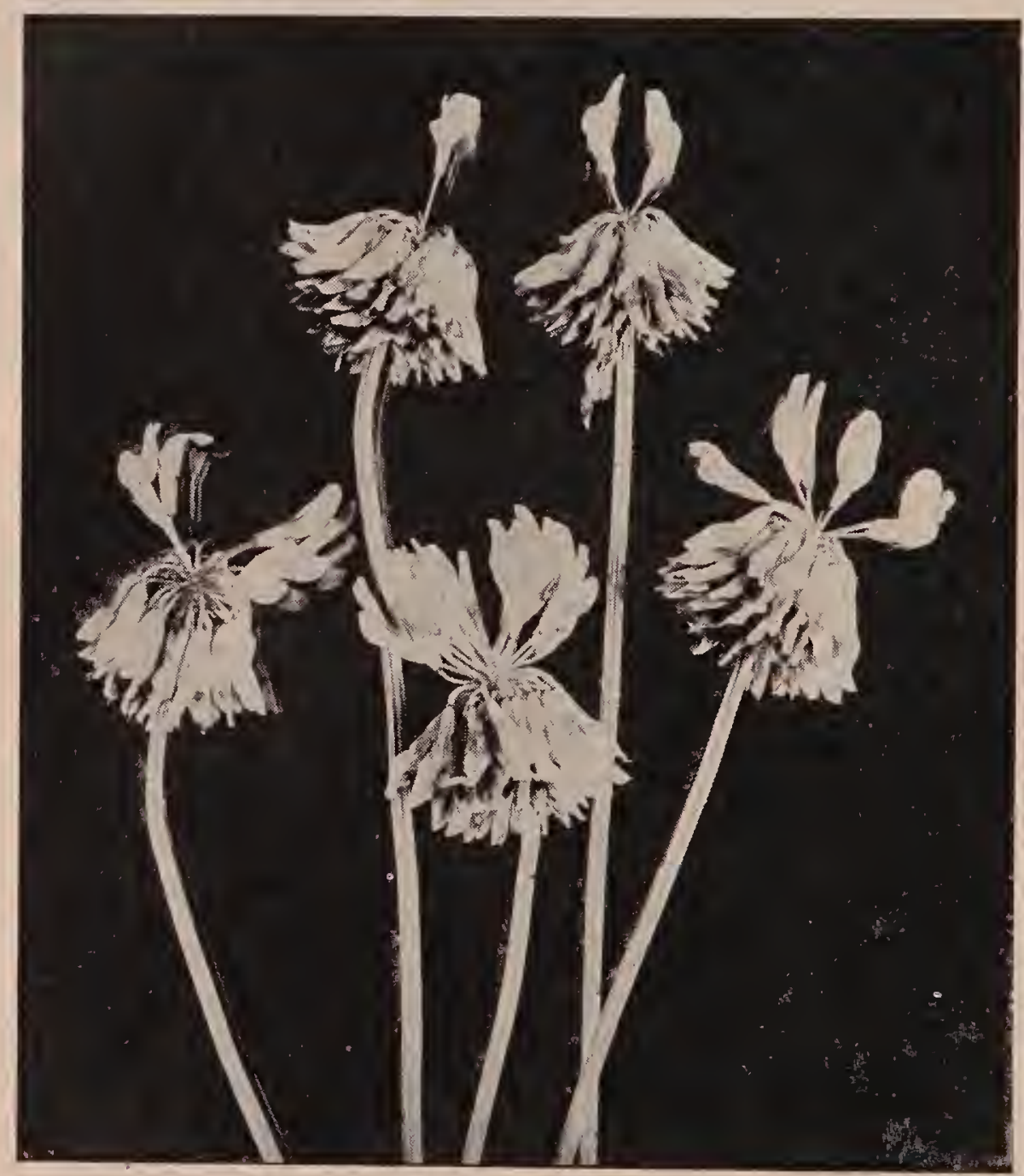

White clover blossom-second stage.

ver usually yields excellent honey harvests, which are not far from surpassing all records. In 1913, at Marengo, Ill., Dr. C. C. Miller obtained from 72 colonies, spring count, 19,186 sections of chiefly whiteclover honey, or an average of 266.47 sections per colony. The three best colonies yielded 390, 395, and 402 sections respectively. This phenomenal surplus was largely due to a most favorable season con-
115 colonies stored 12,000 pounds of whiteclover honey and increased to 240 colonies. From the same apiary in the following year the product was 30,000 pounds, while in 1908 drouth reduced the crop to 15,000 pounds.

The flowers of white clover are familiar to every one since the plant finds a congenial labitat in the vicinity of human dwellings. It carpets the lawns, fringes 
the paths and roads, and is common in the fields and pastures. There are in each head or flower-cluster from 57 to 89 small florets. At first all the florets stand erect, but as the marginal ones are pollinated they cease to secrete nectar and are bent backward and downiward against the stem. By preventing useless visits this change in position is beneficial to both flowers and insects. When they expand the flowers are white, but they often turn reddish after they are reflexed. The calyx is only three millimeters long so that not only honeybees, act as levers to depress it. The stamens and pistil are completely inclosed in the keel, and ordinarily are not visible. A bee can not collect pollen from white clover as it does from a rose, because there is none in sight, and it is not directly accessible. Bees never visit the flowers for the purpose of gathering only pollen, and one has never been observed trying to open the keel.

There are 10 anthers, each of which produces a small amount of pollen. The filaments unite to form a tube, at the bottom

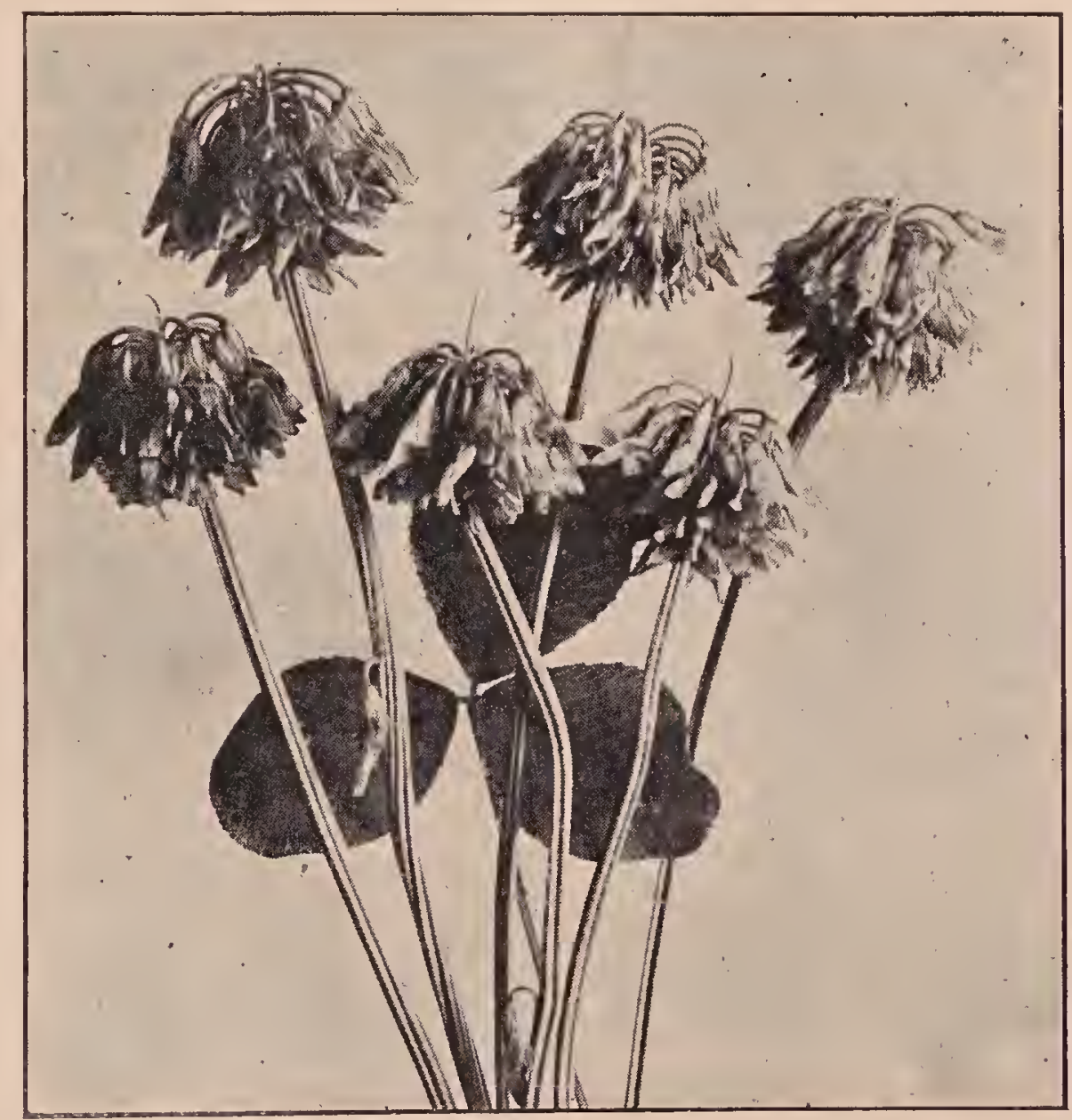

White clover blossom-third stage.

but many other insects are able to reach the nectar. Honeybees also often gather loads of yellow pollen, altho this is not abundant.

\section{THE POLLINATION OF WHITE CLOVER.}

There are five petals. The upper petal, called the standard, is much the largest. 'The two lower petals partly cohere to form a sac termed, from its form, a carina or keel. The two lateral petals, called the alæ, or wings, are attached to the keel, and of which the nectar is secreted. But the superior stamen is free, leaving two small openings at the base of the staminal tube thru which a bee may insert its tongue to obtain the nectar.

It is manifest at a glance that the individual flowers of a white elover head are far too small to hold a honeybee. The bee clings with its legs to several flower's, and only its head rests on the flower from which it is sucking nectar. When a bee pushes its head beneath the standard, the keel and 
wings are forced downward, the anthers and stigma emerge, and a little pollen is deposited on the under or inner side of the head, which may be covered with a layer of moist pollen. If a pointed pencil be thrust into a mature flower, when it is withdrawn a little mass of pollen will be found on the other side. As soon as the bee moves to another flower the elastic petals cause the anthers to return again within the keel. The collection of pollen is, therefore, an incidental lesult over which the bee has no control. While it is visiting white-clorer flowers, more or less pollen is necessarily rubbed on the under side of the head; but a part of it is again rubbed off on the stigmas of the flowers subsequently visited, effecting cross-pollination, for the stigma stands slightly in advance of the antlier's. A part of this pollen may also be transferred to the pollen-baskets, where it appears as little brown balls rarying from the size of a shot to an almost inappreciable quantity.

The pollen grains, when examined under a high magnifying power, appear oblong, cylindrical, rounded at each end, with three longitudinal slits or grooves on the sides, and the bands or spaces between the slits are finely roughened with many shallow pits or depressions. A knowledge of the form of the pollen is essential in order that it may be recognized with certainty either in the hive or in the honey. The little balls of pollen in the pollen-baskets appear brown instead of yellow (the color of the pollen in the anthers) because they are composed of a moist compact mass of grains which lıave been manipulated by the bees' legs.

According to Darwin, when insects were excluded from white clover by a fine net the clover was only one-tenth as productive as when they were freely admitted.

\section{THE SECRETION OF NECTAR.}

The factors controlling the secretion of nectar by the flowers of white clover are very imperfectly understood. In England. Canada, and the northeastern portion of the United States, it is usually a good loney plant, but in France and Switzerland one may travel for sereral kilometers and not see a bee on the flowers. At Ronen, France, during one day of white clover bloom a hive on seales actually lost 300 grams in weight. In various localities in the United States it is also reported to be almost a total failure at times. One beelieeper" says: "As an actual fact, the amount of clover honey is not measured by the quantity of the bloom: for I lave seem the fields white with an abundance of it. but only a fair crop. I remember one rear when there was a great scarcity of bloom, and yet there was a good crop of clover honey. I have also seen fields white witl clover, but no lioney." At Plainfield, N. J., altho the ground is often white with the bloom, a good flow is reported to be obtained only about once in 10 years. In general the secretion of nectar is not reliable in sections where the mean annual summer temperature exceeds 77 degrees F.; but occasionally, if the summer is cool and there have been sufficient rains in the spring to produce a luxuriant growth, a good crop is obtained south of this isothermal line. White clover is much more abundant on soils where the underlying rock is limestone than on soils derived by the disintegration of sandstones and shales. On soils rich in lime nectar is secreted much more freely than on neutral or acid soils. In southern Minnesota, southern Wisconsin, and southern Michigan where the summers are cool and the soils are of limestone origin, white clover seldom fails to vield a lare surplus: but in Illinois a full crop is obtained only about one year in three, and in central Kentucky and Tennessee only occasionally. In the southern States as in Alabama and Mississippi, it is of little importance, as it is neither abundant nor a good source of nectar. Scholl reports, however, that white clover yield's a surplus in northeastern Texas.

Climate and soil exert a very marked effect on the growth of white elover and consequently mpon the yield of nectar. In wet clay ground in regions where the winters are serere, the roots may be much broken and drawn out upon the surface, or the plants may be killed outright by repeated lifting, caused by the alternate thawing and freezing of the soil. The destructire work of the frost, however, is much lessened by the natural mulch af forded by the dead recetation found in waste places and in meadows which have 


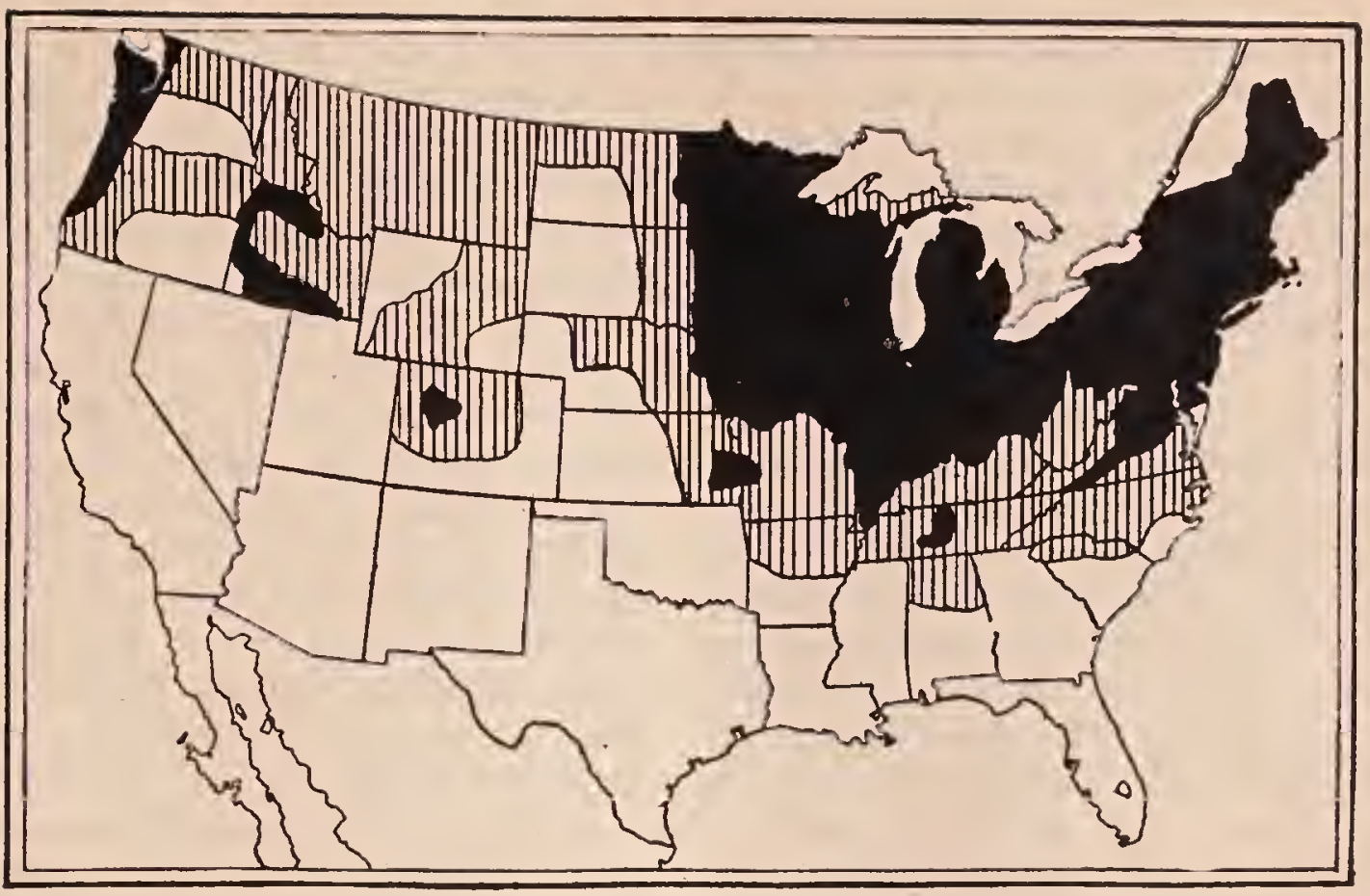

Outhine nap of the United States, showing loughly the area in which alsike clover is grown. The black area shows where alsike closer is more or less regularly used as a forage or seed crop; the hatched area, where jt is rarely grown or only in special places. (From Farmers' Bulletin 1151, United States Department of Igriculture.)

not been eropperl too closely. Snow also offers excellent protection; and, when it covers the ground for the most of the winter, clover suffers little or no damage. Winterkilling from freezing in well-drained sandy soils or in warmer climates is practically unknown.

In Kentucky, and the surrounding territory, where there are light soils, it seems to be well established that there will be a rery small honey flow if the preceding season has been very dry. If there is no rain after July, the drought destroys the old plants of feeble vitality, checks the growth of offshoots, prevents the germination of seedlings, and retards the formation of an extensive root system, with the result that there are few blossoms and little nectar the following season. This statement does not call for discussion since all herbaceous plants growing in porous sandy soil suffer, if there is a large decrease in the normal rainfall. Altho the injury wrought by the drought does not become apparent until the next season, it should not be attributed to winterkilling, but to the correct cause-the absence of sufficient moisture in the soil. But if there is a good stand of white clover in early spring a drought in May or June, if copious rains follow, will only retard the bloom and delay the har- rest. "I have seen elover parched by drought in June," says a beekeeper, "and not a blossom in sight. Then cane a succession of soaking rains, and, presto! bloom and a crop of honey." Similar results hare been described at London, Can. An exceptionally dry fall after Angust 1, was followed by a dry spring until the last of May, when a series of warm rains commenced which continued àlmost daily until about the 20 th of June. The effect was marvelous. July found the fields and roadsides a beautiful mass of white and alsike clover, and the honey crop was the best. that memory can recall, A rery cols spring may also cause failure, even if there is a normal rainfall. In 1907 in parts of New Tork the arerage temperature of April, May, and June was four degrees below the respective means for these months in other years, and there was no white elover honey.

Cold or rainy weatlier during the honey flow will both lessen the quantity of nectar and prevent the bees from working on the bloom; for the best results there must be a series of warm, humid days. Finally where white clover has been grown indefinitely in the same fields the soil conditions may become deleterious. Microscopic protozoa may multiply until they destroy a 
large part of the beneficial bacteria, or the soil may become acid and require a liberal application of lime. Such land is said to be "clover-sick," as explained at the beginning of the general article on CLOVER. Nearly all of northeastern Ohio and the major part of Pennsylvania show a deficiency of lime. This is also true of Massachusetts where very little white clover honey is produced. The remedy, of course, is to apply lime as previously explained.

In the same locality the surplus of honey stored from white clover varies greatly in different seasons and from day to day. At Clarinda, Page Co., Iowa, J. L. Strong carefully recorded from day to day for 29 years, from 1885 to 1914 , the weight of one hive and the weather conditions. White clover is the most important honey plant in this locality. An analysis of these statistics by L. A. Kenoyer (Bull. 169, Iowa Agr. Exp. Sta.) gave the following results: The largest amount of honey was brought into the hives on clear days. Of the entire gain in weight, 61 per cent was made on clear days; 13 per cent on partly cloudy days; 13 per cent on cloudy days; and 13 per cent on rainy days. On a part of the rainy days there was practically no increase. In June 56 per cent of the increase was obtained, and in July about 22 per cent. The July flow was largely determined by that of June. The largest amount of honey, or 46 per cent, was secured on days when the temperature was between 80 and 90 degrees F. Of the total yield of honey 17 per cent was stored on days when the temperature was less than 80 degrees, and 37 per cent when it was over 90 degrees. For the production of honey, days with a wide range of temperature are best. A good year is usually followed by a poor year. The average crop for 10 good years was 136 pounds. The average crop for the 10 years succeeding the best 10 years was 71 pounds. A heavy snowfall in winter was farorable to a large yield the following summer.

\section{BEE PASTURAGE.}

There are no statistics, as in the case of alfalfa, giving the acreage of white clover in the different States of the Union. Introduced from Europe it grows without cultivation over a large area in fields and pastures, in the vicinity of dwellings, and along the roads. In New England the coast lands, as the blueberry barrens of Maine and the sandy outwash plains of Massachusetts and Connecticut, are too acid for white clover; but it is abundant on the limestone soils of the eastern part of Aroostook County, Me.; in the Chanıplain Valley, Vt.; and in the Berkshire Valley, Mass. There is a large area of calcareous glacial till soil in the northern part of the State of New York in St. Lawrence County. A small area of this soil is also found along the northern edge of Franklin County, and in the southern portion of Jefferson County it again occurs. White clover is here very reliable, and nowhere else in this country does it provide better bee pasturage. From Buffalo there extends across the State nearly to the Hudson River a belt of land 20 to 50 miles in width, extending northward along Lake Erie and southward among the F'mger Lakes, covered with soils of glacial origin rich in lime. The clovers grow well thruout this strip, and the secretion of nectar is dependable. South of this belt is the buckwheat region with neutral or acid soils on which the clovers do not prosper. In the southeast corner of Pennsylvania, "the garden of the State," a productive limestone soil covers the larger part of York, Lancaster, Berks, and Chester counties. Dairy farming is one of the principal industries and there is much alsike clover. Deep within the Appalachian Mountains, which occupy the central portion of the State, walled in by ridges 1,000 feet high, are many fertile valleys with limestone floors where all the clovers flourish. In western Pennsylvania the soils are more nearly neutral or acid and require lime.

White clover as a honey plant is at its maximum in "the white clover belt," which includes western Ohio, Indiana, Illinois, Michigan, Minnesota, and Iowa. But it is not equally abundant in all parts of these States, nor are the limits of the belt strictly defined by their boundary lines. In the opinion of Phillips "the best clover territory in the United States is probably northwestern Ohio, northeastern Indiana, Micligan, Wisconsin, and Minnesota, all of which are covered with a heavy deposit of glacial 
drift, 10 to 1,000 feet deep. Of course there is an enormous variation depending on the presence of outwashed plains, bogs, mairshland, etc., but the moraines of the middle West constitute our best clover country." In northwestern Ohio, Toledo claims to be the g'reatest clover seed market in the world, and nearly every farmer. in this section is growing alsike clover for seed. Southern Ohio has an average annual summer temperature a little too high for the best results. In eastern Indiana the underlying rock is limestone, but in the southwestern portion the soils have a different origin and white clover is less common. In southern Michigan dairy farming is one of the principal industries, and is dependent on the great acreage of white clover and alsike elover which yield the surplus honey. In the Upper Peninsula alsike clover is very abundant. On the fertile limestone soils of southern Minnesota white clover supports a great number of colonies of bees, and only rarely is there a failure in the crop. Thruout Iowa white clover is reported to be the principal source of honey. In many localities no other plant yields a surplus. In the eastern part of the State it is hardly reliable more than two years in three, as it may winterkill or the season may be too wet or too dry. At Colo, the state center, there have been only four years in twentythree, in which it was nearly a total failure. In the western part of the State a fair average is an annual crop of 50 pounds per colony.

In no part of Illinois does white clover succeed so well as in the northeast corner, especially in Stephenson County. It yields less nectar in the southern half of the State than in the northern. Central Illinois is largely devoted to growing corn and oats. When white clover fails on the uplands along the Mississippi as the result of dry weather a fall crop is gathered from Spanish needles and other fall flower's on the bottomlands. Northern Missouri is also largely devoted to growing the cereals and, owing to dry weather, a crop from white clover is obtained only about once in four years. The yield from fall flowers along the rivers is, however, usually certain. The larger part of the soilforming rocks of the Ozark Plateau in southern Missouri is limestone; but as the soils are the oldest in the State and the land is generally hilly, much of the lime has been removed by leaching. White clover is only moderately valuable, but the bee pasturage could be greatly improved by extensively planting sweet clover.

Kentucky and Tennessee are too far south and the summer temperature is too high for white clover to be very important as a honey plant. The famous blue grass region of Kentucky, or Lexington Plain, is the section of the State best adapted to the g'rowth of the clovers. It is a welldrained limestone area broken by many rounded hills and knobs. At Richmond a normal crop from white clover comes about once in five years, viz., 1897, 1902, 1906, and 1910. White clover is not dependable in Tennessee. The climate perhaps shows as great fluctuations as that of any State in the Union. The limestone soils are favorable and when the weather is cool secretion is good. In the central valley around Nashville and in the eastern valley of the Tennessee River, which are limestone areas, white clover occasionally yields bountifully. At Springfield in Maury County, in 1913, 500 colonies in one apiary could not gather all the nectar available, but since then not more than a fourth of a crop has been obtained. Phillips roughly estimates that under good management tulip trees would year after year produce four times as much as white clover in this region. Unfortunately few. beekeepers are ready for the flow from tulip trees as they refuse to pack their bees in winter, and the climate owing to the frequent changes of temperature is harder on the colonies than that of Ohio.

In New Jersey, Delaware, and Maryland beekeeping is pursued chiefly as a sideline. White clover is valuable in northern New Jersey, but in Maryland it is not reliable. West of the Blue Ridge Mountains in Virginia is the Great Limestone Valley, which is 20 miles in width and extends from New York to Alabama. In the extreme southwestern section of Virginia and in eastern West Virginia there are a number of smaller limestone valleys in the mountains, where white clover is apparently a fair honey plant. 
Along the Ohio River in West Virginia it is fairly reliable, and in Gilmer County it is reported to make a luxuriant growtl.

Thruout the Coastal Plain from Virginia to Florida and Texas the pine barrens and swamps have largely acid soils, and the rlimate along the coast is subtropical. The leading hay crops in the cotton States are cowpeas and corn fodder, and comparatively few acres of alsike clover or l'er clover are harvested. In South Carolina, for example, only 375 acres of clover alone are grown. This is evidently a poor region for clovers of all kinds. In northeastern Texas, in northwestern Arkansas, and on the bottomlands of the rivers in the eastern part of this State, white clover is reported to yield well; but it is possible that these reports are based largely on the presence of bloom rather than upon the amount of honey secured. In general white clover in the Gulf States is probably an unimportant honey plant; and, except to a limited extent in northern Alabama, there is no alsike clover under cultivation in this region.

West of the Mississippi River (see ALfalfa, also The Honey Plants of North Axrerica) alfalfa is by far the most abumdant and valuable honey plant. The acreage of sweet clover is likewise rapidly increasing and promises a very valuable bee pasturage in the near future. Thruout the southern portion of this region it is too hot and too dry for the clorer's. In Wyoming, Colorado, New Mexico, Utah, Nevada, Arizona, and Texas the area of (lovers alone under cultivation is only 3,480 acres. In the eastern portions of North Dakota, Soutl Dakota, Nebraska, and Kansas white clover is common, and is frequently reported as a source of honey. In the river valleys of Montana both white and alsike clovers occur sparingly. White clover is abundant in northern Idaho, and in some localities, as Moscow, is reported to furnish the larger part of the surplus. Trest of the Cascade Range in Trashington white clover is on the increase in the sections from which the timber has been cut; 'but, according' to scullen, it probably secretes nectar less freely than in the Mississippi Valley. "White clover is also important in both Stevens and Pend Oreille counties in the nortlieast corner of the State. In Oregon, as in Washington, white clover is common west of the Cascades, but after July it dries up. Vine maple and willow-herb fumish most of the surplus. In northwestern Oregon there is a lar'e acreage of alsike clover. Thite clover is rapidly extending over the northern counties of California; and, as it is a dependable source of nectar here, this section will soon offer excellent locations for the production of honey.

\section{WHITE CLOYER, HOW PROPAGATED.}

There is no more important or interesting subject to the beekeepers of "the white clover belt" than the life history of white clover and its problems. The plant is propagated both by seeds and rumners which root at the nodes and finally become independent stocks. As in the case of the strawberry, a single plant may in a farorable season cover witl its runners a circle of ground two or three feet in diameter. If these new plants winter uninjured, they will bloom the following season in the same manner as strawber'ry runners. The older plants, as is again true of the strawberry, exhausted by multiplying both sexually and vegetatively, are easily killed by drought or cold. When the ground is densely covered with an old growth there will be little opportunity for runners to root or seed to germinate. Consequently there may come years when there are few new plants to bloom.

White clorer seeded in the spring will produce, if there is sufficient rain, a heary crop of bloom in July and a fair amount of seed. Much depends upon locality. Clover raised from seed is more valuable for nectar the second season than during the first.

ALSIKE CLOVER (Trifolium hybridum L.).-This species was called hybridum by Linnæus since le supposed it to be a lyybrid between white and red clover, but it is now believed to be a ristinct species, It was named alsilie clover from the parish of Alsike in Tpland, Swerlen, where it was first discorered and where it grows abundantly. It is now known as alsike or Swedish clover in Scotland, England, Denmark, Germany, France, and America. It was introduced into England in 1834 and later into this country. It is a very hardy 
perennial plant adapted to cultivation in a cold climate.

\section{POLLINATION.}

The branching leafy stems of alsike clover are from one to three feet long, erect or ascending, and rooting at the nodes like white clover. The small fra- arcessible to short-tongued insects. As the inclividual flowers are small only the head of the honeybee rests on the flower, from which it is sucking nectar, and comes in contact with the pollen. Few honey plants yield nectar in larger quantities.

In relation to the pollination of alsike $\mathrm{D}_{1}$. Ernest Kohn of Grover Mill, Oliio,

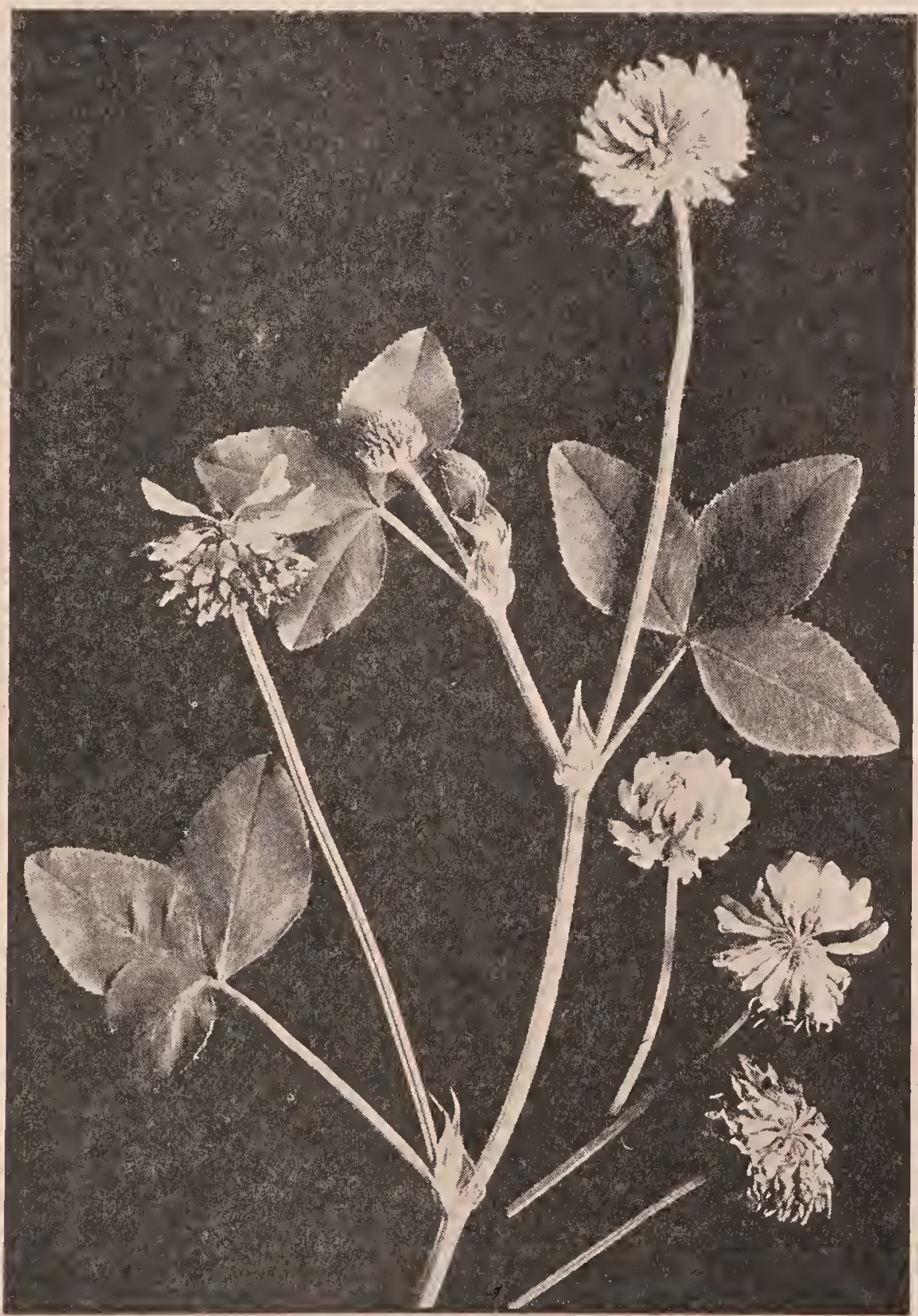

Alsike clover.

grant flowers are in lieads and at first point upward and are pink or reddish; but after pollination they bend downward and turn brown (see figure). The mechanism of the flower is the same as that of white clover. (See White Clover.) The nectar is secreted inside of the staninate tube, and is offers some remarkable testimony showing the ralue of bees:

In the spring of 1918 , while considering the location of an outyard, a farmer asked me to place some bees in his 40 -acre alsike field. He had a relative who told him of the increase in yield due to the proximity of bees. I placed 75 three-pound pack- 


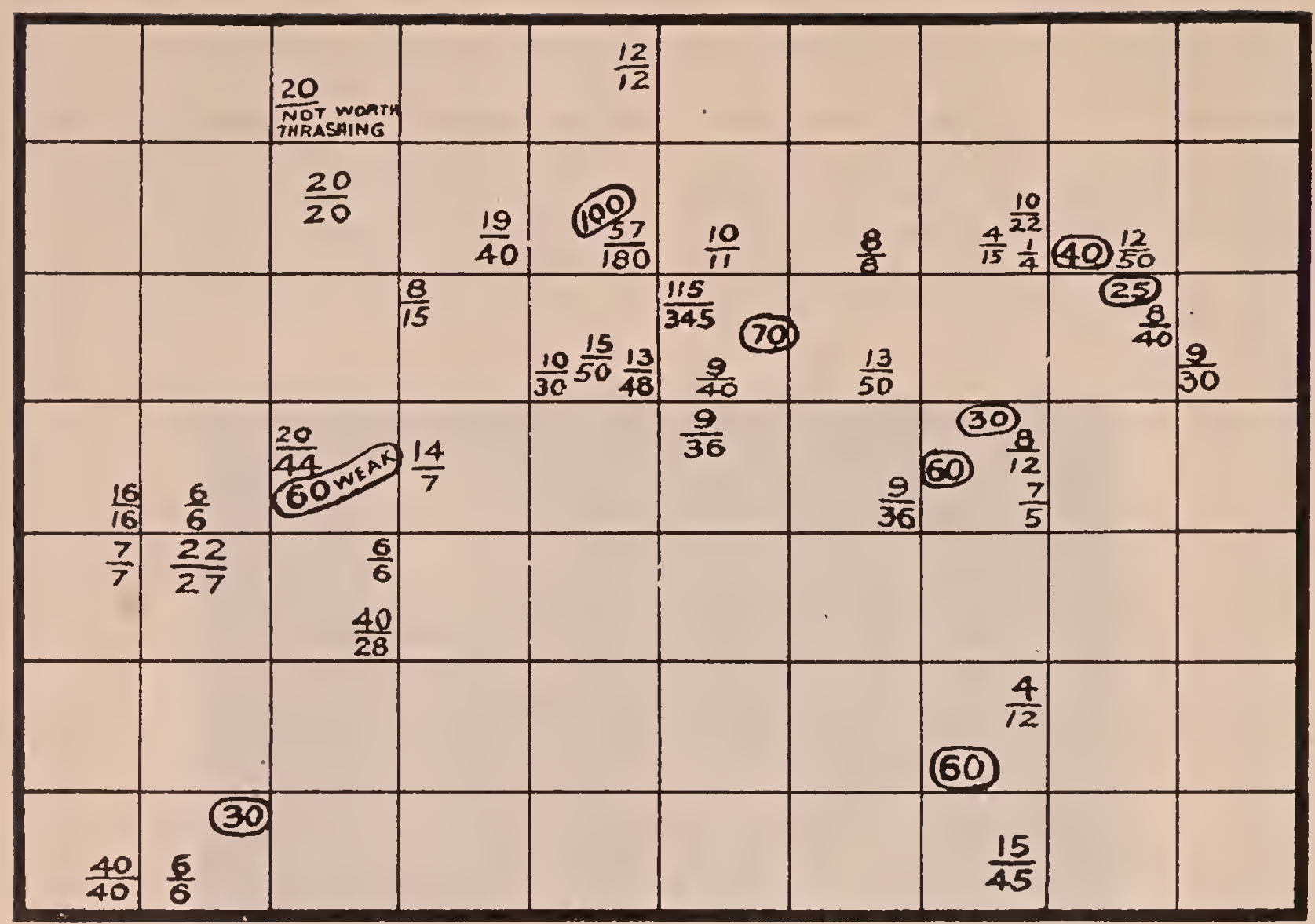

The circles show the location of the colonies. The numerators of the fractions represent the number of acres of alsike and the denominators the number of bushels threshed.

ages in his field. His yield was three bushels per acre. By inquiry I found that fields more than two miles from bees were not worth threshing that year. This farmer was well pleased, but insisted that there were not enough bees. As he had 40 acres for 1919, and several of his meighbors had sown alsike, I placed 100 old colonies on his farm.

I have made a complete survey of the township, and got all information possible from threshers and other sources, concerning about 80 square miles, giving the location of bees, with the number of colonies, and the location of alsike clover fields, with acreage and yield.

The accompanying map shows in circlès the location of bees, with the number of colonies. The numerator of the fractions represents the number of acres in alsike, and the denominator denotes the number of bushels threshed.

The yield was not heavy at any place, as drought shortened nectar flow at least three weeks. It will be noticed, however, that near a large number of colonies the yicld is three to four bushels per acre, while two miles or more from bees the yield is not more than one bushel per acre.

The lesson of this article is interesting to the farmer as well as the apiarist. The farmers near the bees received more cash per acre from the seed than they did from any other crop produced, and at the same time they were storing fertility in their soil.

Another lesson learned is that the major- ity of farmers are "from Missouri" - they must be shown. Notice the number of alsike fields near some of the bees, while mile after mile where there are no bees there is no alsike. I plead guilty to doing mission ary work near my beevards.

Grover Hill, O.

Ermest Kohn.

The experience of Dr. Kohn has been duplicated in many other localities where alsike is grown, particularly in Ontario, Canada. There the growers are asking beekeepers to put bees on their farms.

\section{ALSIKE CLOVER AS A HONEY PLANT.}

Alsike clover is far more hardy than red clover and will grow on damp or wet land on which the latter will not grow. It is adapted to moist clay soils and sandy. loam soils rich in humus, but it will not thrive in dry sandy or gravelly land. Lime is essential but less is required than by either white or red clover. In Ontario. Canada, it is regarded as the foremost honey plant, and in many localities it is the only source of honey in quantities. Hundreds of acres are glown in this province exclusively for seed; but there is probably no region in this country, in which it produces larger yields thin in that of the 
Great Lakes. From Michigan southward to Ohio there has been an immense increase in the acreage. Within 10 years it has been estimated that the area of alsike clover uncler cultivation has increased ten to twenty-fold. In perhaps one-half of the fields alsike is mixed witl timothy, in one-quarter with red clover, and in the remaining quarter alsike is grown by itself. In Michigan and some other States there would be no clorer honey if it were not for alsike, since white clover has disappeared to a great extent. In the eastern States the culture of alsike has also spread very rapidly; for instance, in Lancaster Connty, Pa., about 10 years ago the hay crop consister chiefly of alsilie mixed with timothy; torlay three-fourths of the hay is alsike, as it is alnost impossible to get a stand witl red clover. Beekeeping is areatly benefited by the change, as there are practically no other lioney plants of importance in this locality; and beekeeper's declare that if the farmers should stop sowing alsike they would be compeller to stop keeping bees. Here the seed dealers are all encouraging the sale of alsike seed to the exclusion of that of red clover. In Kentucky and Tennessee it is highly prized for liay and pasturage and its cultivation is steadily increasing. In Tennessee it is replacing red clover since there is a greater certainty of getting a goor stand. While it will grow with less lime in the soil than red clorer, it responds favorably to the addition of lime both in growtl and in the secretion of nectar. In Virginia alsike is growing, too, in favor with the farmers. There it endures well adverse conditions of weather, and is so much better adapted for grazing purposes that it shonld be a constituent part of all grazing mixtures. In the West alsilse is very successful in the irrigated valleys of the Rocky Mountains and in the regions of the Pacific Ocean.

It is generally conceded that alsike clover yields nectar more freely, and is a more reliable lioney plant than white clover. An acre of alsike has been estimated to be worth two or three of white clover, but this does not appear to hold true in all localities. The honey is so similar that it is doubtful if one can be distinguished from the other. It has been observer orer and over again that apiaries in the imme- diate vicinity of alsike clover will vield more honey per colony than those laving access to only white clover even in great abundance. A field of 20 acres of alsike will take care of 50 colonies of bees very well, provided it is supplemented by white clover in the vicinity. The period of bloom of alsike is also much longer than that of white clover, lasting when pastured nearly all summer. While alsike, as a r'ule, does not yield a heavy second crop, the late bloom is of great value. During the first year it seldom makes a lieary growth, not attaining its full luxuriance until the second and third year.

The fact that alsike rlover is replacing the red species in so many localities is of much importance to American beekeepers. Consider how many localities wonld be literally transformed if red clover were replaced by alsike. Beekeepers should take advantage of this steady movement in the riglit direction, and, in arddition to meaching the gospel of sowing alsike, should offer to pay a part of the cost of the seed. At Medina, Ohio, it has been the practice for some year's to furnisl seed to farmers at lialf price provided that the fields, where it was sown, were within half a mile of one of the beeyards; while it has been supplied free to those who would sow it only a few rods away. As a result of this policy the acreage within half a mile of the apiaries has been very greatly increased. The amount of clover honey obtained lias become noticeably larger', and less feeding' of sugar in the fall has been found necessary. After alsike has once been introduced it is self-sowing, and springs up where the other clovers fail to make a satisfactory growth. It is soon widely scattered thru the fields, improving the quality of the lhay and increasing the quantity of honey. Ifter a few years it will not be necessary to supply the seed free, for the farmers will have learnerl from experience that the crop is so valuable that they will be willing to buy the seed for themselves. Care should be taken to ascertain that the land on which the seed is to be sown is suitable for the growth of this clover. The honey flow will be much prolonged if the alsike is sown witl timotly or some otlier forage crop, since when sown alone it is often cht two 
weeks before other hay and before the larger part of the nectar, which it is possible to obtain, has been gathered.

\section{THE CULTURE OF ALSIKE CLOVER.}

A loamy soil containing sufficient lime, phosphates, and vegetable matter or humus is best adapted to growing alsike clover. The ground should be thoroly ploughed, turning under carefully all weeas and grass. "The application of manures for the clover in any considerable amount is unnecessary. If clovers are grown on manures they will feed on the nitrogen in the manure; they will not draw from the air for that element. Growing clover on manures, therefore, is not the best economy." Moreover, the grasses, sucly as tinothy and redtop, with which clover is usu. ally sown, will make a vigorous growth and crowd out the clover so that the hay will contain little of it. On eastern soils 400 to 600 pounds of a fertilizer, containing a moderate percentage of nitrogen and phosphoric acid but rich in potash, may be used. In the West less potash is needed. All the clovers require lime, but alsike will succeed with a less amount than the other cultivated species. The bacteria, which live on the roots and appropriate the nitrogen from the air, will die in an acid soil. 'The presence of sorrel indicates an acid condition; or, if a piece of blue litmus paper placed in damp soil turns red, lime is required. It may be applied in various: forms, such as air-slacked lime or grounrl limestone; but the latter is advised as it is equally efficient and cheaper in price. From 2,000 to 4,000 pounds to the acre may be used to advantage. After the lime has been distributed by hand or al manure spreader, the soil should be thoroly halrowed and leveled.

\section{SEEIING}

Asilie elover may he seeded with the cereals, or with various kinds of grasses and forder plants, or alone. As when fully grown it is liable to lodge and rot, it is adrisable to sow with grass, as redtop or orchard giass on wet land, and timotly ou drier land. When used with cereals, it may be sown either in the fall or early in the spring when the ground is soft and wet. Tt may be seeded with oats altho bar- ley is preferred, while with wheat it may prove an entire failure. If a heavy crop of grain is raised, the clover will suffer from want of water and a poor stand will be obtained. If the clover is the first consideration, the seeding of the nurse crop of grain must be very light. From three to four-fold as many pounds of clover cau be obtained when it is sown alone as with oats.

Alsike clover seed is about half the size of that of red clover, and it may be easily separated from the latter by means of a sieve with meshes of the proper size. It is desirable that the seed should be tested, as much inferior seed containing a great quantity of weed seed is placed on the market. When alsike is sown alone 12 to 16 pounds to the acre are recommended. If, however, it is sown with timothy or redtop, as advised above, from 2 to 5 pounds of alsike, 12 pounds of timothy, or 10 pounds $0^{\Omega}$ rerltop, may be used. These numbers are only approximate and will vary according to conditions. Red clover is sometimes seeded with alsike, as it increases the crop the first year or two and disappears later. It is resirable that the seed slould be lightly rovered with a smoothing harrow.

C'URING ALSIKE' FOR HAY.

In curing alsike for liay great care should be taken to prevent the leaves and smaller stems, which contain the larger portion of the proteins, from being lost: and to protect it as much as possible from (xposure to rain or dew, or to the sum. It should not be cut before it is in full bloom and the blossoms are beginning (r) turu hrown: lont, if permitted to stand too long, the stems will becone woorly. It is msually rured in the windrow, aroilling any unnecessary exposure to the sum, which canses the leaves to bleach and hecome brittle. If' raked into windrows, or buneherl, or platceel in the mow when wet with either dew or rain, it will be injured. It should never be stored in stacks ontrloors, if this cau be avoided. Is a forage plant it is equal or superior to red rlover or timothy, producing a large flow of rely rich milh.

\section{GATHERINE THE SEED.}

The seed is always saved from the first 'rop' of blossoms, and it should be allowed 
to stand about two weelis longer than when eut for hay. It sliould always be mowed either early in the morning, or late in the cvening, when it is wet with dew, otherwise the ripel pods with the best seed will fall off and be lost. Ifter mowing it is turned once or twice and housed as soon as dry. It is thrashed with a clover-hnller made expressly for clover seed, and then cleaned with a fanning mill with appropriate sieves. In small quantities it may be more satisfactorily thrashed with the flail. Timothy seed is very nearly the same size and for its removal a fanning mill haring a proper blast arrangenent is required. As the alsike weighs 60 pounds to the bushel and timothy 45 , these is no great difficulty in doing this effectually. On one estate in Swerden where 20 acres were set apart for raising the seed, the average annual production for five years was 133 pounds per acre, while the production one year was 200 pounds per acre.

\section{THE FUTIRE OF ALSILE CLOVER IN THE ['NITED STATES.}

Juring the last few years a new condition of thing's has arisen. More and more farmers who formerly grew red clover in a large way have found that their soil harl become clover-sick-that is, defieient in lime to such an extent that they were forced to try some other crop. In some cases they have grown timothy; but the demand for this kind of hay is growing less and less because the automobile and farmers' tractor's are rapidly taking the place of horses. Timothy is well adapted for feeding horses. In the meantime dietitians and the public in general are beginning to learn the value of milk as a food, and especially milk as a restorative to those who have a weak digestion. Some sanitariums are making a specialty of healing by the use of milk alone. In order to get plenty of milk, cows should be fed on a lecrume of some sort. Alsike, especially where the soil is deficient in lime, meets the situation. It costs only about half as much to seed a given acreage of ground with alsike as it does with red clover.

Immediately following the period of the Great War help was scarce and high-priced. While the farmer knew that lime would restore his clover-sick soil, his lime cost moner, and, moreover, it required extra help-help that he could not get-to put it on the land. As alsike readily grows on a soil deficient in lime the farmer put that into his ground, and, quite to his surprise, it made ricl and valuable hay for his rows; and, moreover, the farmer discovered that alsike hay would grow on land too wet or too dry for red clover. All of these factors have made a marvelous increase in the use of alsike rlover orer the clover regions of the United States. In some cases the red clover lias almost disappeared, and alsike has taken its place. In other instances the farmer's have bought lime and put it on the land at the rate of two tons per acre. When thus applied they can grow red clover. But these cases were comparatively rare.

There has been another powerful factor that has stimulated the use of alsike in place of red clover. The county agents, mentioned at the outset, lave been urging the use of alsike in place of red clover where the farmer could not or would not lime his soil. In some instances the county agent has been advocating a moderate amount of lime and sechling with alsike. The richer in lime, the better the growth of this raluable leg'ume.

The author believes, therefore, that alsike, as well as the new annual sweet clover, will, to a great extent, in the future take the place of red elover. Both are invaluable for dairy purposes; and as milk must be had in increasing quantities, especially during the lot weather, for babies, so alsike and sweet clover will take the place of timothy and red clover.

It is not necessary in a work of this kind to state that alsike is the greatest loney plant known to beekeepers east of the Mississippi River and north of the Ohio. Along with the demand for milk will come the demand for honey. In the Jangruage of the good Book, "Milk and honey shall he eat."

\section{IS ALAIKE POISONOUS TO WHITE-NOSED HORSES?}

Occasionally complaint is made that alsike produces a form of skin disease in white-nosed horses. In reply Dr. J. Aikenhead says: "I have been practicing the 
reterinary profession since 1874 - 18 year's in Ontario and since then in Maryland, and I have nerer seen a case of poisoning from alsike clover. I have been called to see many cases supposed to be the result of poisoning from alsike pasture fields, but have had dozens of the same lind of cases on pastmes that never had alsike clover on them. I have hạd many patients which, when green food was eut for them, would eat the alsike clover first, showing that they prefer'ed it to other kinds of grass. I find from my experience that alsike clorer makes the best kind of pasture for all kinds of stock, and ranks next to alfalfa for hay."

RED CLOVER (Trifolium pratense L.). - Red clover is pollinated chiefly by bumblebees, and is therefore called a bumblebee flower. This reciprocal relation will be marle clear by a brief history of the introduction of red clover into New Zealand. There were neither bumblebees nor honeybees in those islands at the time of their discorery; consequently, when the colonists attempted to grow this raluable forder plant it failed to produce seed. To remedy this diffieulty about 100 bumblebees, belonging to three different species, were imported from Furope, and subsequently the red clover heads became fertile. It seems to have been supposed that any bumblebee would answer for this purpose, as one of the species brought from Europe was Bombus terrestris, which has too short a tongue, and has formed the habit of biting holes in the corolla tubes and robbing the flowers of their nectar without rendering any service in return. After the holes liave once been made, other insects, which are themselves unable to puncture the corolla, use them to abstract the nectar. Thus, so far as the red clover is concerned, it would have been better if this bumblebee had never been brought to New Zealand. In the course of time this fact was leamed by experience: and as recently as 190.) the New \%ealand goverment wrote to an experiment station in Canada inquiring in regard to the bumblebee useful in pollinating red clover in that comntry. As has been pointed ont by Dr. Graenicher, two of the common and lardy bumblebees (Bombus americanorum and $B$. fervidus), which have tongies 14 millimeter's long, would be well adapted for this work. See Buxblebers.

In a farorable season, when there is an abundant rainfall, and the flowers of the red clover are fully developed, a bee can not reach the nectar unless it has a tongue 9 millimeters long. As the tongue of the Italian bee is only $61 / \frac{1}{4}$ millimeters in length, the nectar is then wholly inaceessible to it. This has been the canse of much regret among beekeeper's, for these flower's not only secrete nectar very freely but the nectaries are much less influenced by weather conditions than those of many other plants. Repeated attempts have been made to develop a permanent strain of red clover bees; but all such attempts have proved unsuceessful. It is no easy matter to lengthen the tongue of the hon-

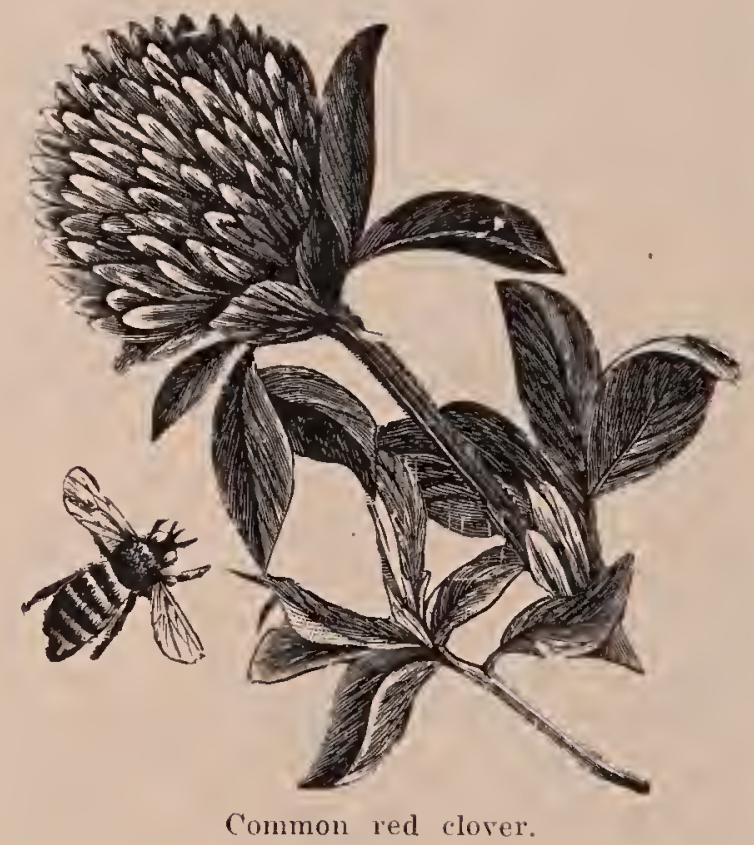

eybee $23 / 4$ millimeters. The production of a race of red clover with shorter corolla tubes has also received consideration.

But the second crop of red claser usually has shorter corolla tubes, and occasionally in rery dry seasons the tubes are so short that large vields of loney are obtained. The late G. M. Doolittle said that two or three times in 30 years at Borolino, N. Y., red clover hard been a very valuable somre of honer: and that one year he obtained fully 60 pounds to the colony on the arerage. IT. Z. Hutchinson stated that he remembered one year when his bees stored 500 pounds of pure red clover honer, as surplus, in the section loney-boxes. It was when the second crop 


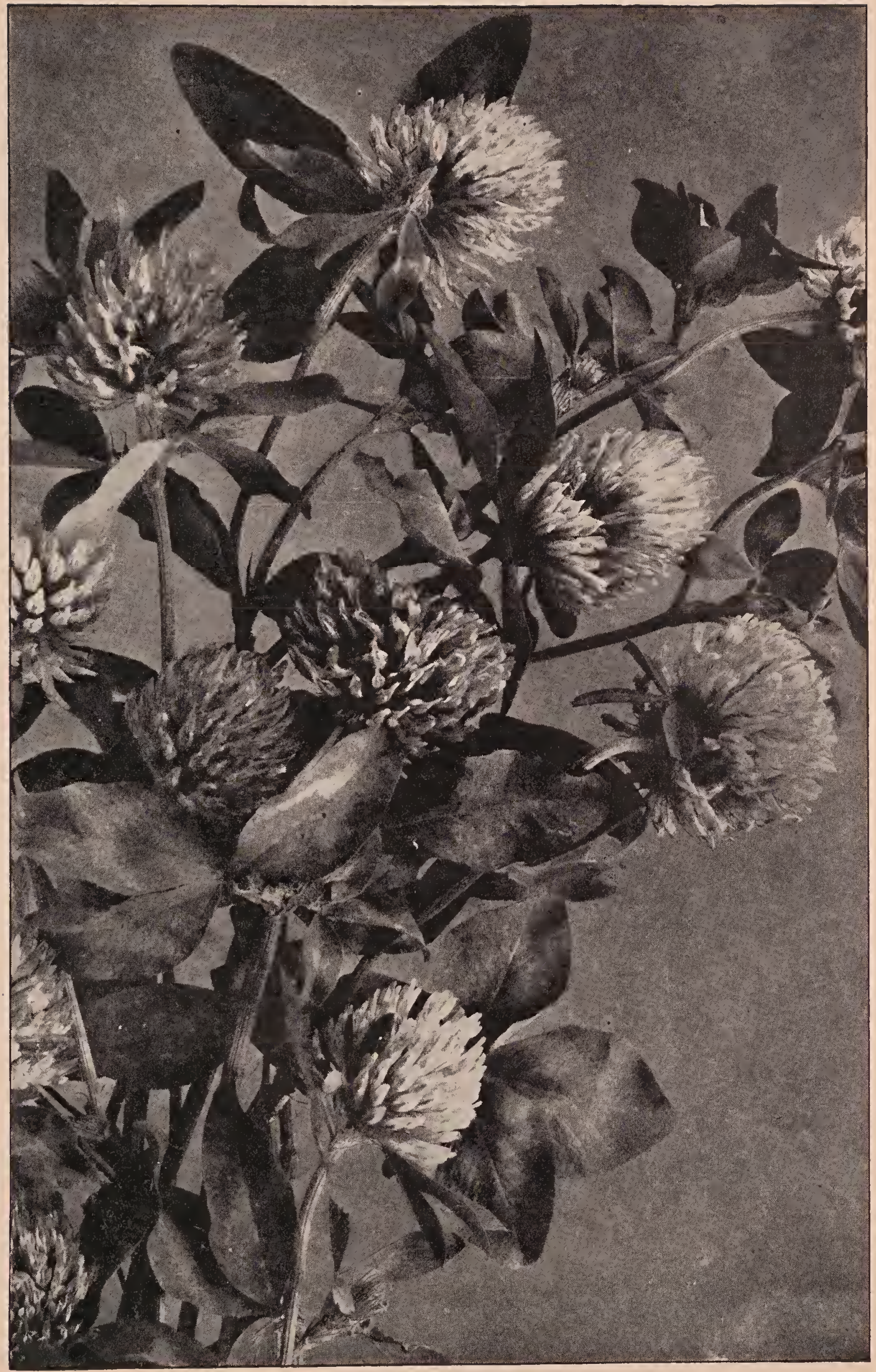


had been stunted by droutli. The blacks stored none of the honey, the liybrids storer a little, but the bulk of the 500 pounds was furnished by the pure Italians.

A remarkable illustration of the correlation existing between the weather and the length of the corolla tubes of the red clover was observed by the autbor in 1906. There was almost a drouth during the latter part of the 'season at the north beeyard, two miles north of Medina. Adjoining this yard were several fields of red clover, for the farmer's were furnished witl seed of red clover and alsike free of charge. Owing to the dry weather the corolla tubes of the red clorer heads were shorter than usual. and great numbers of bees were attracted by the nectar which was now within their reach. When one of the farmers began to cut lis red clover that season there came near being a bad stinging-fracas; for when the cuitter-knives of the mower went thru the field they stirred up the bees, with the result that they attacked the horses and the man on the mower. So greedily dic the hees work on that field that it looked as tho they were not going to let anybody cut off their honey supply. Other farmers in the ricinity also had considerable trouble in cutting their red clover because the heads were so covered with bees.

Singularly enough, at Medina, and the south beeyard, only two miles away, there was plenty of rain. When the author went orel' a big field of rank elover at the south yard, scarcely a bee could be found; while quite the reverse had been true the whole season on the fields at the north yard, where there liad been a drouth. The clover at the lome and south yard, by reason of the plentiful rains, had attained a rank growth. The corolla tubes were so long that the bees could not get any neetar from them, and consequently there were no bees on the heads. Thus two beekeepers living only two miles apart might have arrived at diametrically opposite conclusions as to the value of red clover as a honey plant.

PEAVINE OR MAMMOTH CLOVER (Trifolium pratense perenne).-As the English name indicates, this is the largest rariety of red clover. It blooms principally in the months of August and Septem- ber. It is an excellent forage plant to plow under for the purpose of reclaiming an exhausted soil. The flowers have the same structure as those of red clover, and probably vield nectar under similar conditions.

(RIMSON.CLOVER (Trifolium incarnutum).-Othei English names are Italian clover and calnation clover. It is also called annual clover, since if sown in the fall it will form a stand before cold weather, remain green thruout the winter, start again very early in the spring, and mature its seed before summer. It grows wild in southern Europe and in a few more northern localities; and is. widely cultivater for forage in Italy, Germany, France, and Great Britain. It was introduced into this country about 1822, and during the last 30 years has been extensively cultirated in the sandy soils of the middle and southern States. In the northern States it is usually killed by the severe winters.

In the southern States it is being introduced very extensively by the farm bureaus and by the extension men. But it ean not be wown successfully unless the land is limed. Then this is done it makes a very fine and valuable forage crop for cattle and horses, and an excellent bee pasturage. Tt is being introduced very largely especially in North Carolina and South Carolina.

\section{CRTISSON CLOVER AS A HONEY PLANT.}

The sessile flowers are in oblong terminal heads 1 to 2 inches long. $A$ field of erimson clover in full bloom possesses great beauty, and passers-by often stop to gather and admire the flowers. It is difficult for one who has never seen an acre of crimson clover to comprehend the beautiful display presented by the broad expanse of deep red flower's mingled with the vivid green of the leares. The structure of the flower is very similar to that of red clover. The corolla tube is 8 or more millimeters long: and, as in the case of red clover, is adapted to bumblebees, which are conmon visitors to tliis species. It is likewise much more productive when cross-pollinated than when self-pollinater. At Medina, Ohio, almost as many lioneybees have been observed on the flowers as have been seen on buck- 


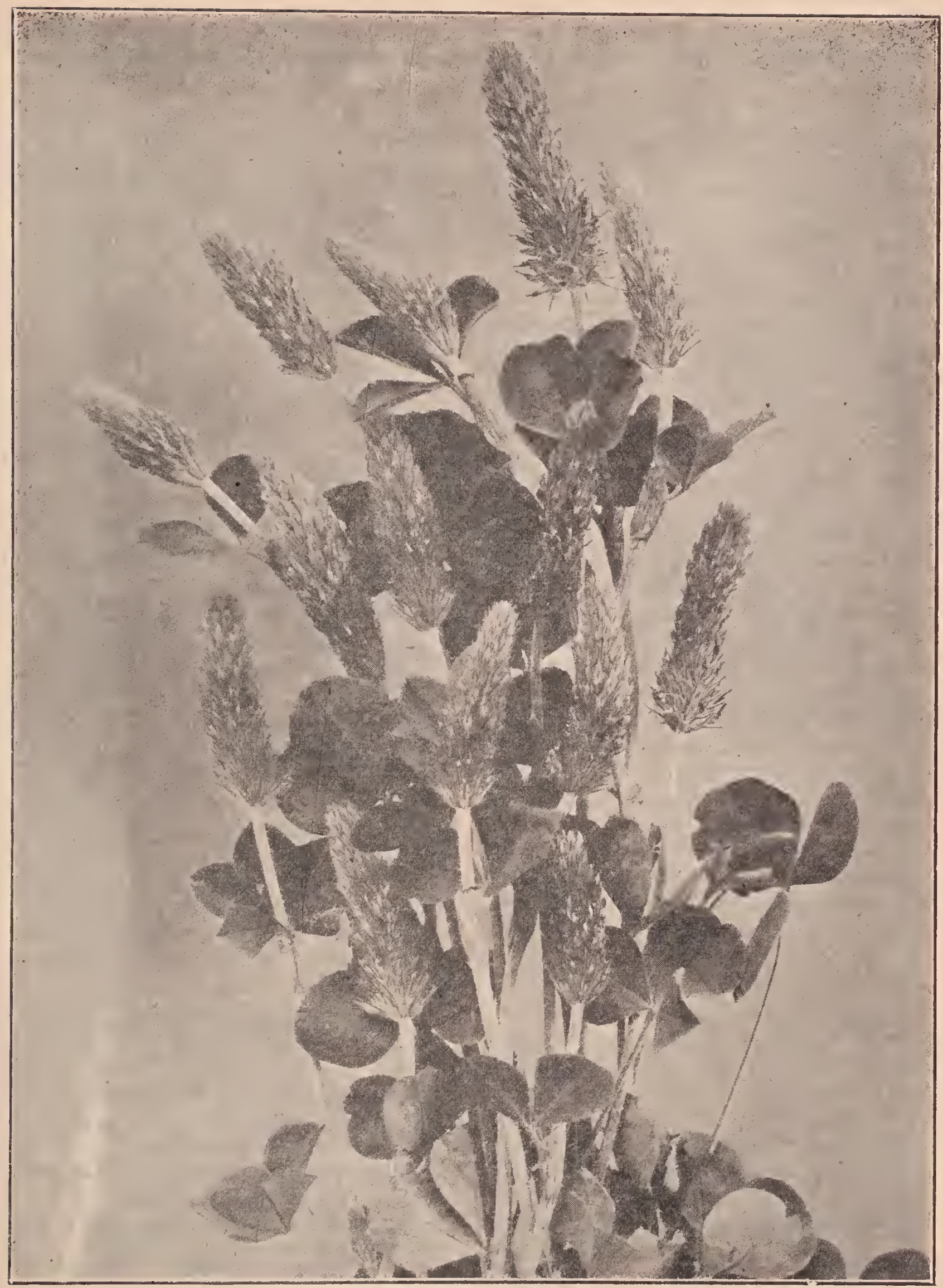

Crimson clover.

wheat: and so eagerly did they seek the nectar that as fields in full bloom were ploughed under they still continued to fly orer the land. In riew of the length of the corolla tube it would seem to be impos- sible for honeybees to obtain all of the neetar under normal conditions. It is a special adrantage that it blooms earlier than the other clovers, filling in the interval between the bloom of the orchards and that of white 
clorer. The quality of the honey appears to be rery similar to that of red elover.

\section{CULTURE OF CRIMSON CLOVER.}

Land should be selected for growing crimson clover that is well drained, has been previonsly cultivated and leveled, is fairly fertile, contains sufficient lime,' and has been inoculated with the proper bacteria. As the seedlings are tender and easily destroyed, it is a good plan to test the suitability of a locality by growing first a small experimental plat. At the time of seeding the soil should be well settled, fine, and in a moist condition. If crimson clover follows a crop, as potatoes, which has been well fertilized, the soil will probably be sufficiently fertile; but otherwise an application of barnyard manure or about 400 pounds of acid phosphate is desirable. If the soil is acid it should be lined as described for the other clovers. In sections where crimson clover has been grown previously, inoculation is usually not required, but in a new section it is generally necessary. The beneficial effects of inoculation were very clearly shown by experiments performed at the Alabama State Agricultural Experiment Station. When the plants were inoculated 4,057 pounds of crimson clover were obtained, but in the absence of inoculation only 761 pounds. In another test the inoculated plat yielded 6,100 pounds of cured hay per acre, while the uninoculater was a total failure.

\section{SEEDING.}

Crimson clover is usually seeded at the rate of 15 pounds to the acre, altho the quantity used may vary from 12 to 20 pounds according to conditions. It may be broadcasted by hand or drilled in; but should not be covered deeper than one inch in sandy soil and half an inclı in clay soil. Ten pounds of seed per acre, if every seed germinated, would produce 30 plants to the square foot; but in actual experience nuch of the seed fails to appear above ground. If seeded in early spring, blooming time comes during hot dry weather', which kills many of the young plants; sometimes, however, an excellent crop is obtained if there is an abundance of rain and the temperature continues moderate well into the summer. South of the Ohio River erimson elover may be sown from August to Oetober, but north of this boundary it must be sown during .July or August. It should be stated that in the northern part of the State of Ohio there hare been many failures. One of our standard writers on agriculture says that thousands of dollars have been wasted by farmers in trying to grow crimson clover; yet at Medina, Ohio, four or five acres each year have been seeded with no failure. Thie reason for this sucress is largely that the ground is thoroly underdrained and highly enricher with barnyard manure.

A fine stand of crimson clorer has been obtained by seeding the land inmediately after a crop of potatoes, which had been planted comparatively early, had been remored. Before sowing the clover the soil was worked with entaway and Acme harrows. Sown in August it wintered splendidly, in September fairly well, but laterseeded plants were ahmost a total failure. But it is seldom grown alone, usually being seeded with corn, wheat, rye or other grains, and with buckwheat, cowpeas, turnips, truck crops, or cotton. When seeded with wheat, r'ye, or winter oats, both the clorer and the grain may be eut at the same time the following spring; and a larger vield is thus obtained than if the clover were sown alone, and it is also prevented from lodging badly. A most luxuriant growth of wheat and clover has been obtained at Medina by April 25, the wheat acting as a mulch during the winter.

\section{SEEDING CRIMSON CLOVER WITH BUCKWHEAT.}

Crimson clover may be grown in land lightly seeded with buckwheat or cowpeas. these crops affording protection from the heat of the sun in uidsummer. The buckwheat and clover come up together, but the buckwheat being the stronger grows more rapidly, and the clover makes but little showing until the buckwlieat is harvester. Then the crimson clover during the cool moist weather of fall rapirlly covers the ground. Should frost kill the buckwheat, the clover will rise above it in a very brief period: while the dead buckwheat straw makes an excellent mulch. The finest crop of crimson clover ever obtained at Medina 
was sown in this way, and turned muler the following June for planting potatoes.

SEEDING CRLASON CLOVER WTTH CORN.

Some of the best crops of crimson clover at Medina have been secured by broadcasting the seed among early corn at about the time of the last enltivation. A rotary seed-sower was used, the operator sitting on horseback in order that the top of the corn might not interfere with the distribntion of the seed. The hor'se's ears should be corered with small bags to prerent the entrance of the flying seed. Probably half of the crimson clover raised in this country is sown among corn. Westgate says: "It is nsually possible to make such a seeding, obtain a good growth during the fall and early'spring, and mature a crop of hay in time for breaking up the land for another crop of corn. South of the latitude of central Delaware it is eren possible to mature a crop of clover seed in time for corn-planting. In this way it is possible to grow a crop of corn each rear, and at the same time steadily increase the fertility of the soil for a series of rears. Treated in this manner each succeeding crop of corn can ordinarily be materially increased. Instances are reported where the yield of corn has been gradually in"reased by this means from 10 bushels per acre at the start until as high as 70 bushels per acre were secmed."

PLOUGHIAG UNDER TO JAPROVE THE SOII.

It lıas been estimated by an experiment station that a good stand of erimson clover ploughed nnder while in bloom is equiralent to 10 tons per acre of the best stable manure. As it blooms so early, it may be plonghed under for most crops. It is also an excellent cover crop for orchards, and is a good green feed for poultry in winter. Were it not for the danger of winterkilling, it wonld probably be much more widely cultivated.

'IIF, QUALITY OF CRIASON CLOTER HONEY.

The quality of the honey from crimson clover is said to lank fairly well with that of any other clover. In fact, the honey from any of the clovers is good. There is so little crimson clover grown, comparatively, that a strictly crimson elover honey is unknown in the market. What little is pro- dueed is probably mixed with that of other clovers. In any case it would not impair the quality of the honey from any other somree.

On the culture of crimson clover" see "Crimson Clover: Growing the Crop," by J. M. Westgate, Farmer's' Bulletin 550.

COLOR OF HONEY.-SE HONEY AND ITS COLOR.

COMB FOUNDATION.-The invention of the morable frame by Langstroth; the loney-extractor by Hruschka; the bellows smoker by Quinby, and last, but not least, comb foundation by Mehring, made it possible to keep bees on a commercial scale never before attempted.

Comb foundation is just what its name signifies. It is the base, midrib, or foundation of honeycomb without the superstructure of the cells. If a piece of comb be taken and sliced down on both sides nearly to the bottom of the cells, there will be found the fonndation of the comb, with initial cell walls, and lience the name. The comb foundation of commerce is much the same thing except that it is artificial, made of pure beeswax, with walls enough heavier so that the bees can use the sulplus in drawing ont and extending the rells into completer comb.

Comb foundation is made by pass no a thin sheet of pure beeswax between a set of rolls or dies, the surfaces of which have been stamped or engrared in such a way as to give the imprint of the natural base of the honercoml) itself. The invention or discovery, rather, lay in the fact that the bees would ntilize this article mate by man, and change it into perfect comb inside of 24 or 48 hours when honey is coming in at a good rate.

THE HISTORY OF THE INVENTION OF COMB FOUNDATION.

To J. Mehring of Frankenthal, Gelmany, is accorded the credit of liaving inrented comb foundation in 1857: but his product was rery crude, having only the indentation of the bottoms of the cells with no cell walls. In 1861 Samuel Waener, the first editor of the American Bee Journal, improved the foundation of Mehring by adding shallow cell walls. This, besides giving the bees wax to build 
the cells, also strengthened the sheet itself'. Up to this time the article had been made between engraved flat metal plates; but Wagner was the first to conceive the idea of turning out the product between a pais of suitably engraved or stamped rolls 'operated on the principle of a mangle or a common laundry wringer. But, evidently, he never developed the principle.

\section{FOUNDATION-ROLLS.}

In 1866 the King brothers of New York, and in 1874 Frederic Weiss, made foundation-rolls; but, apparently, the product that they turned out from these rolls was very crucle. It was not until 1875 that $A$. I.

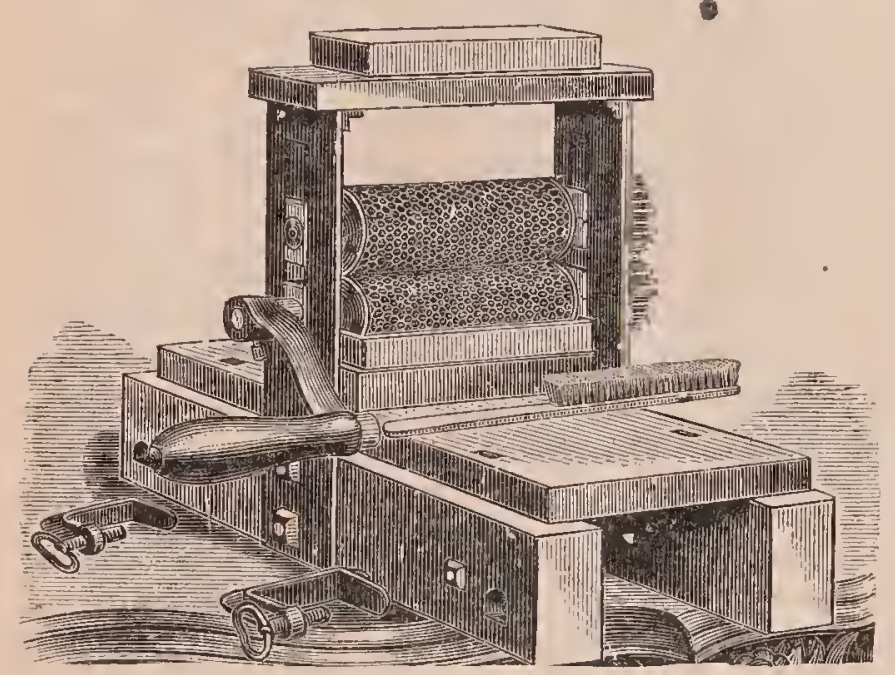

Griginal Washlurn toundation-mill.

Root, in collaboration witl a friend of lis, A. Washburn, a fine mechanic, brought out a machine on the mangle prineiple that turned ont sheets good enongli and rapidly enough to be of commereial importance. This old original Washburn machine was so nearly perfect that its product was the equal of that from any cut mill made on a similar pattern today.

About this time, also, or perhaps a little later, Frances Dunham and J. Vandevort of New Tork built rolls that turned out an excellent product. About the same time J. E. Van Deusen, also of New York, built a machine that made foundation having flat bases, and incorporated in it fine wires. While the flat bases were not natural, of course, yet the purpose was to get a thinner base and to use wire. The bees, it is true. would reconstruct the bases, but they apparently dir not take to flat-bottomed foundation as well as to the article baving natural bases, and it subsequently disap- peared from the market. In later years Charles Ohln of Wisconsin built a machine for engraving rolls with angle bases by the use of entting-knives or gravers.

Early in 1900 F. P. Weed, the man who developed what is known as the "Weerl process" foundation, worker out a plan for making rolls using metal type, east at a type-foundry, and of the same metal that is used in printers' type. This orig' inal machine developed some deferts that were not easy to overcome. Finally in 1918-1919 H. C. Blanchard and H. H. Root worked out the problem, so that it is now possible to make a comb foundation by using die-cast faces that are a perfect duplicate of the bottom of natural comb. The new foundation, including a methoul of refining, is sold under the trade name of Airco.

It was not possible, by using cuttin! knives, to engrave lolls so as to give the exact natural base; but it was possible to make a steel die perfect in all respects. and from this to cast hard-netal type that would give for the first time in the world's history a comb foundation having a base with the same angles and nearly as thin as in natural comb. The diawram accompanying will explain more exactly. The old engraved or cut fare on soft metal is shown in the heavy black line marked $B$. The new one is shown by the light line with the sharper anglesa difference of 20 degrees. Tntil 1919 no fcundation ever put on the market had a base that the bees did not have to modify, requiring, of course, the

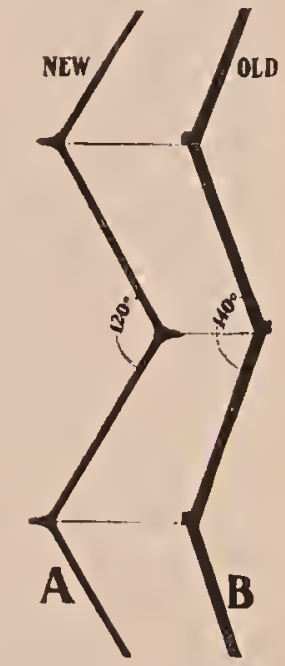

Drawing illustrat ing the difference between the Airco foundation $A$, and the old forntation. B. The lat ter has the thickor base, the flatter angle, and the unavoidable d istortion. outlay of a good deal of physical energy on the part of the bees, to say nothing of the time consumed in reconstructing the base.

As a matter of fact, the bees aftel a fashion worked over a flat-bottomed foundation of years ago, as was previously cxplained. The old foundation from the engraved rolls was not accurate, be- 
cause it was impossible to cut or engrave the die faces on a soft netal having a curved surface that would be as symmetrical and accurate as the bees make them and troublesome in the old cut mill. The distortion of the base on the old soft metal would rery quickly become greater; and so after a rery short time the foundation,

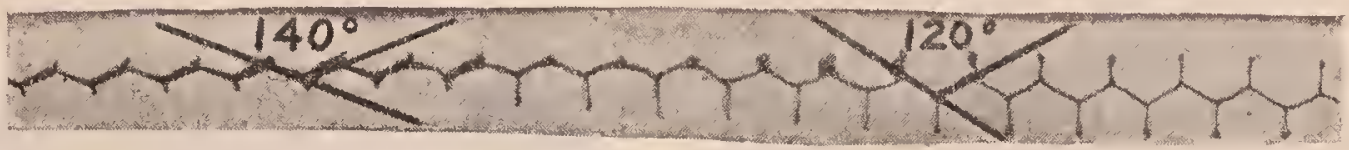

\begin{abstract}
A llaster cast, cruss section view of the old comb foundation showing the flat angle of $i 40^{\circ}$. At the right the bees have built this same foundation into comb, thinning the base and changing the closs section angle to $120^{\circ}$
\end{abstract}

at the same time hold their shape. A metal that is soft enough to ent or stamp will rear rapidly, and at the same time flatten out so that the angles will become still more at variance with those of nat- never perfect at the start, becomes less and less suited to the requirements of the bees.

Comparative tests in the hive show that the bees aprreciate having foundation that

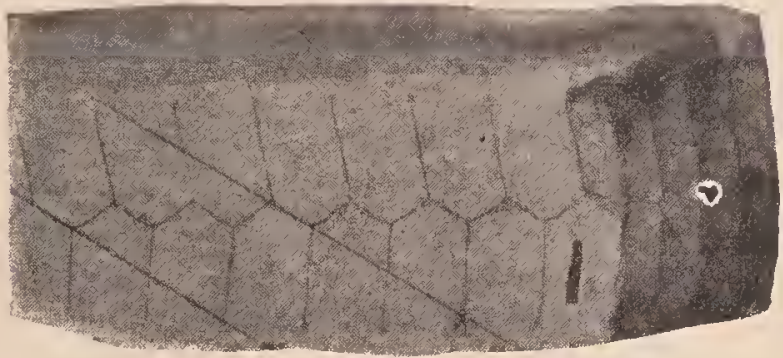

Plaster casts of (1) llatural comb, (2) Airco comb foundation, (3) Airco comb foundation with one end drawn nut by the bees into comb. Notice that the pencil lines drawn thru the various bises are all parallel, showing, therefore, that the angles are the same in. all three or the angle as the bees make it.

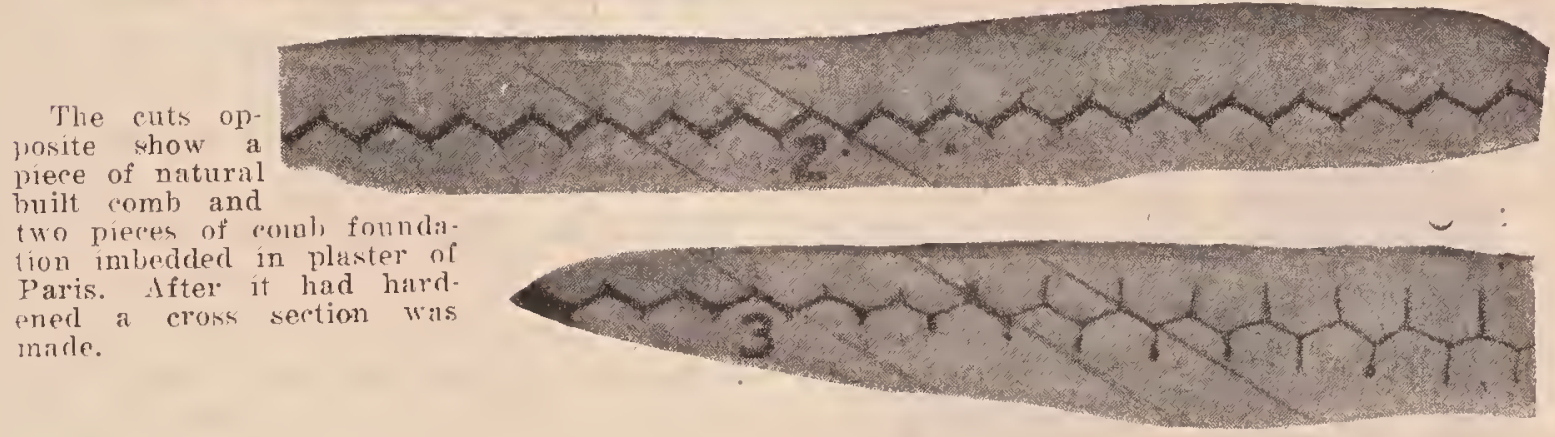

ural comb. By using a cast-type tace, made of a metal so hard that it could be neither cut nor stamped, it is possible to get away from the wear and rrushing so

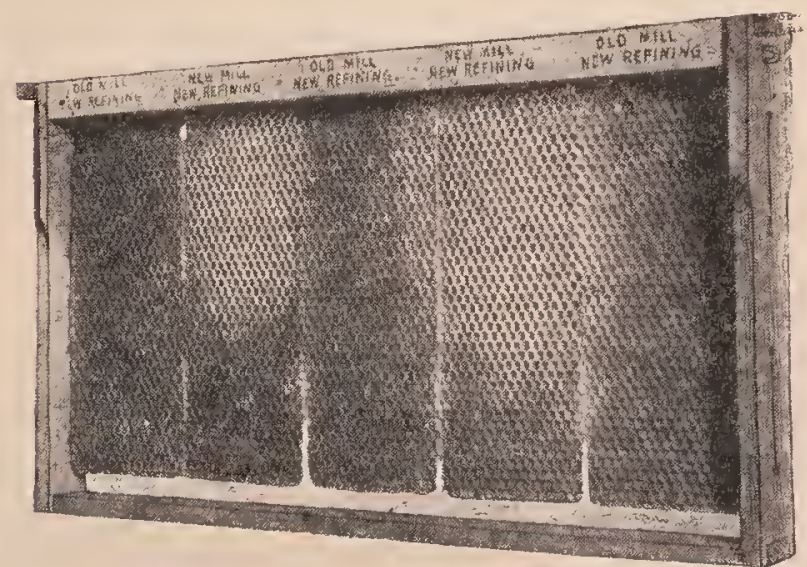

All this foundation was refined by the AIRCO process, but only two pieces, the two the bees accepted first, were milled on AIRCO mills This shows the bees' preference for the natural base." they do not have to modify. In making these tests, strips of foundation, old milling and new, were put sicle by side in the same frame in the center of a strong colony. It was apparent that the bees in most cases

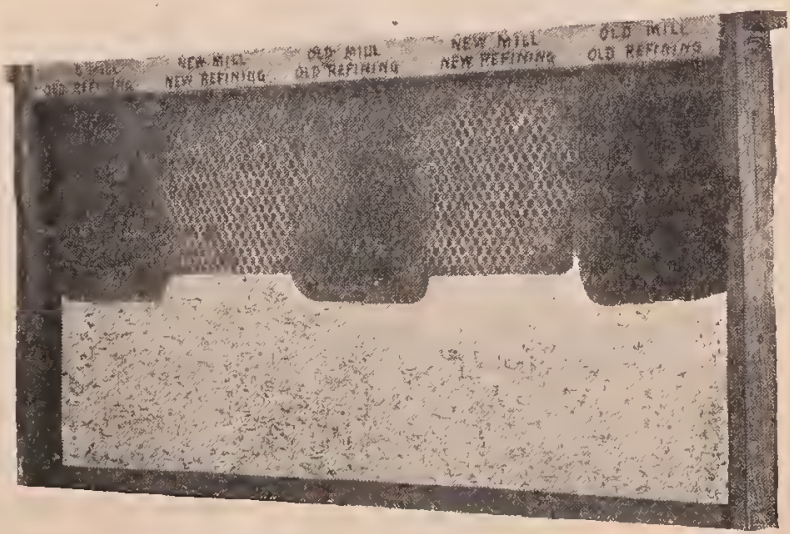

The AIRCO comb foundation (AIRCO milling. IRCO refining) compared with foundation milled and refined by the old process. The bees' prefer. ence, as might be expecter, is unmistakable. 
would draw out the new or natural-base foundation much more readily than a foundation which had flattened or distorted angles, as shown in the diagram at $B$.

\section{FLAT-PLATE FOUNDATION-MACHINES.}

About the time that the Root-Washburn comb-foundation rolls were being developed, the Given press nsing flat die-plates was brought out. Some few preferred the product from that machine becanse, as they said, the foundation could be made right on the wires of a frame, and because the bees could work the wax a little more readily. The reason for this was that no press at that time (in the early 80 's) had been made that could exert as great a pressure as that given by a pair of rolls; and the result was, there was a large waste of wax in the bases. The foundation made good combs, and the bees worked it read-

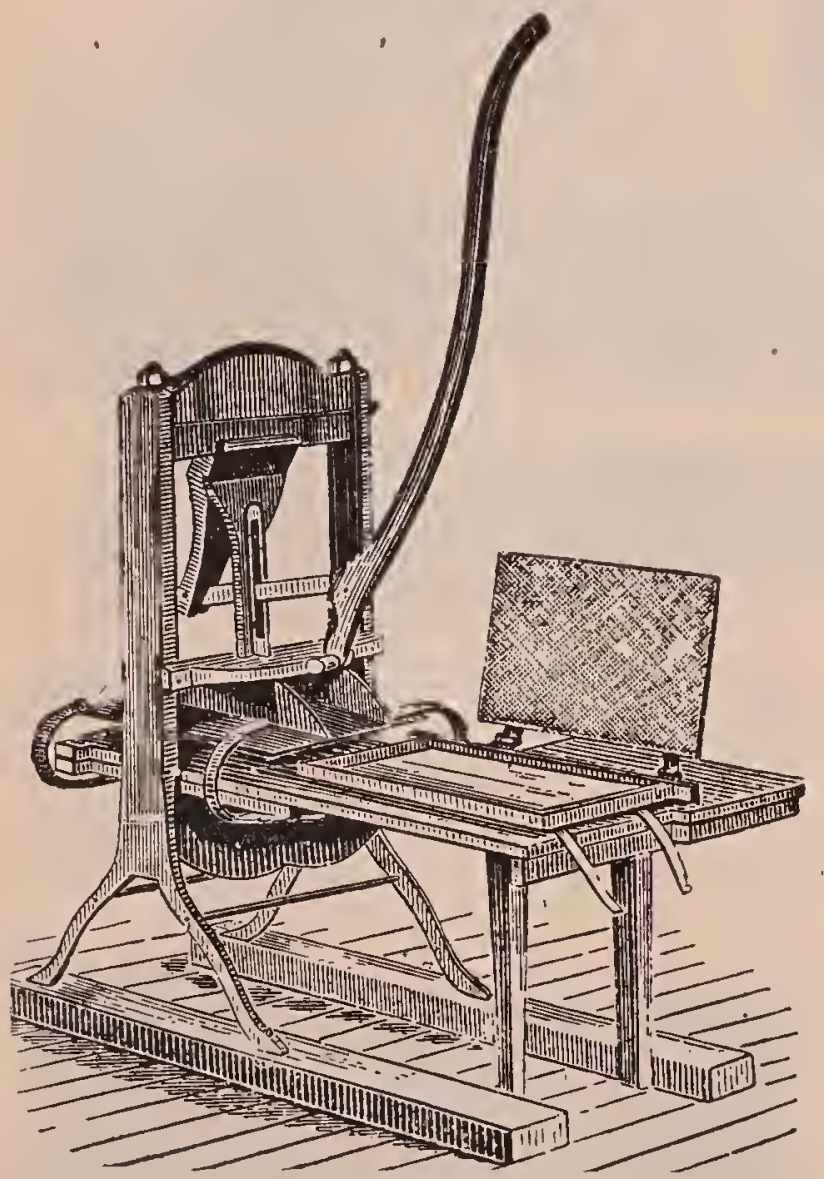

Given foundation-press.

ily; but the individual sheets were too exlensive as compares with the product turned out on rolls by the manufacturers, and so the Given press disappeared from the market.

In the early 80 's various flat-plate machines were brought out. Among the num- ber was one using flat dies made of plaster of Paris. By taking a perfect sleet of comb foundation it was possible to take off molds in plaster. But these molds would not stand pressure, and therefore it was necessary to pour melted wax over them

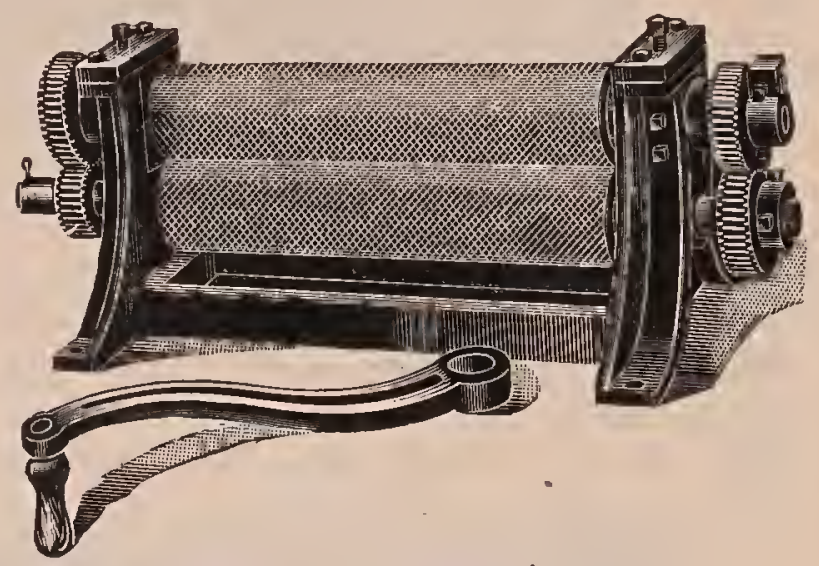

Standard comb foundation-rolls.

and close the dies. As soon as the wax cooled, the dies were opened and the sheet remored. But difficulty was experienced in getting this cast foundation (for that is just what it was) from the plaster molds. About this time, also, electrotype plates were taken off from a perfect sheet of forndation-a process that was comparatively simple, and one that any electrotype founder could readily carry thru. Various patterns of these copper-faced machines; including the Giren, appeared on the market; but the only one that survived at the time was the Rietsche press, made in Germany. A good many thousands of these were sold in Europe; but the objection to it was the waste of wax left in the cell bases. None of the Rietsche presses have been sold in the United States.

In 1921 The A. I. Root Company built a flat plate press for making a wood base foundation that at this writing. (July, 1921) promises to be a success. This will be referred to more specifically a little far'. ther on under WIRING Frames.

\section{WEED SHEETED FOUNDATION.}

Up till 1895, practically all the sheeted wax used in making comb foundation was made by dipping a thin board into melted wax and then into cold water. Two sheets of wax of the size of the dipping board were thus produced. The thirkness of the sheet was regulated by the number of dippings. For thin foundation a single dip 
was suffieient; for brood foundation, two or three dips were required. But the objection to this was that the wax sheet was thicker at the bottom than at the top. This was overeome somewhat by reversing the ends of the board when dipping.

Many efforts had been made to produce wax slieets in continuous rolls; but it was not till 1895 that E. B. Weed built a waxsheeting machine that would tum out wax sheets any length desired, and of an absolutely uniform thicliness. The quality and quantity of this product were such that every nuanufacturer of comb foundation in the world, with one or two exceptions, has abandoned the old sheeting methods and adopted the Weed process. Probably 95 per cent of all the comb foundation made in the United States turmed out by manufacturers is first sheeted on the TTeed machine and then put thru embossing rolls generally called "comb-foundation maclines."

\section{FOUNDATION MIADE DY LARGE FACTORIES,}

The art of making foundation is very complicated, and its manufacture has now gravitated into the hands of the large supply manufacturers who are able to turir out a product which for quality and thinness of base is far superior to that made by individual beekeepers. It is a trade in itself to make foundation having thin bases, because an average beekeeper does not possess the rerfuisite slill to malie foundation without wasting wax and ruining the deliate die faces of the comb-foundation rolls.

Great inprovements have been made in refining wax by which the use of all acids is eliminated. 'The result of the new treatment is to retain the natural aroma of virgin wax, and at the same time make it more dense and ductile for the bees.

\section{WHAT FOUNDATION HAS ACCOMPLISHED.}

Before the economic uses of comb fouldation as now employed in modern apiculture are discussed, it is proper to make a statenent of what can be arcomplished by the use of the invention. Its introduction has solved many difficult problems of the earlier days. Our forefathers had diffirulty, for example, in getting the bees to build combs straight and all worker cells.
Before this invention, drones were reared in enormous numbers because there was so much drone comb. In modern apiculture only a very few, and those the most select for breeding, are reared. By the use of allworker foundation there will be but very few drones in a hive. The rearing of so many useless consumer's not only involved a serious drain on the resources of the colony, but it took the labor of the nurse bees. The elimination of drones by the use of comb foundation materially inceases the worker force in a colony, and this has made it possible to increase the actual yicld of lioney per colony proportionally, See Brood and Brood-rearing and Drones.

Mention is made of the fact that our forefathers were unable to secure straight combs in their movable frames. The combs, besides lharing an excess of drone-eells, were more or less wavy, and it was not a little difficult to get the bees to build their produet on a straight line and parallel with and directly underneath the top-bar. of the frame. (See Frajies, also Comiss.) $V$-shaped comb-guides, or narrow strips of wood, the edges of which projected downward, were used as a coaxer to get the bees to build their combs parallel with the topbar. But every now and then they would build them crosswise, zigzagwise, and every other wise except the right way. The use of even a nar'ow strip of foundation compels the bees to stant the comb on a renter medial line beneath the top-bar of the frame; and when a full sheet is used, the comb built from it is not only true and straight, but it will be all worker, as before explained.

THE EVOLUTION OF THE SECTION HONEY BOX.

The old box live of our father's contained combs built inregularly in small boxes holding from five to ten pounds, the ends of these boxes being glassed. But such a package was too large for retail purposes. The time came when there was a demand for a small package, or one holding about a pound. Comb foundation made it possible for the beekeeper to compel his bees to build combs straight and even in little boxes holding approximately a pound. Without comb foundation, comb loney in sections would be impossible: and therefore the invention of foundation 
paved the way for the one-pound honey section box that sprang into use shortly after comb foundation was introduced on a commereial scale. See Cons Hontr.

\section{FOUNDATION AND ITS ECONOAIC USES.}

Comb foundation may be divided into two general elasses: That designed for the brood-chamber and that for the supers, or where the surplus honey is stored. Each of these general classes is subdivided still further, viz., "thin super." running 10 to 11 square feet to the pound; "extra thin," 12

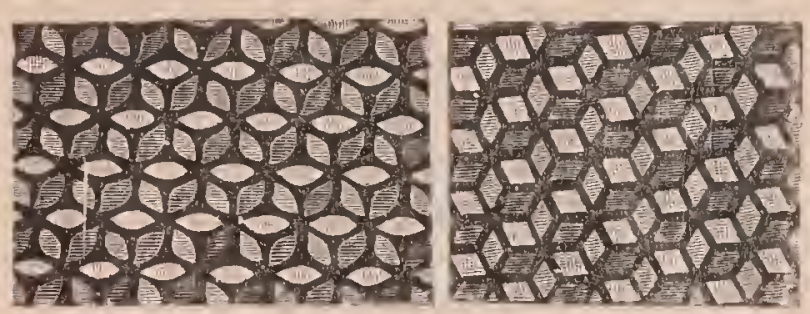

Heary and medium brood.

Light brood.

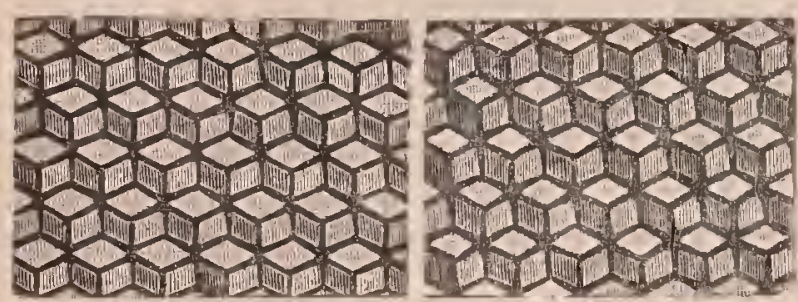

Thin super.

Fxtra thin swper.

to 13 for the supers or sections: "light brood," used only in the brood-nest, running 8 to 9 feet: "medium hrood," for the brood-nest, 7 to 8 feet. Thin super is generally used for sections, and light broot for the brood-frames.

The four illustrations used above represent the different grades. The medium has heen used for the brood-nest, because of its tendency to resist sag while the bees are drawing it out into comb: stronger. hecause there is more wax in the corners of the hexagons. It has been found that bees will utilize all the wax in the walls, and draw it out into cells. The more wax that can he given to them in the wall, the quicker ther will draw it out into romb. The objection to the medium hrond is the expense.

WHAT WEIGHT OF FOUNDATION TO USE.

The light brood is now generally used for the brood-nest where frames are wired. As will be seen by comparison of illustra- tions, there is less of wax in the wall and less strength to the sheet. On this account it is not recommended that light brood foundation be put into hrood-frames that are not wired, yet it is advisable that all brood-frames he wired. The thin siner has lighter walls still than the light brood: and the extra thin super lighter walls still and a thinner base. Both of these are for use in sectional honey boxes.

The ordinary thin super is generally preferred because the bees are less inclined to gnaw it down; and when they do begin work on it they draw it out more readily. The extra thin is preferred by some, when full sheets are used, because it is believed it makes less midiih.

It was formerly supposed that the liearier grades of foundation used in sections would cause the bees to build too heavy a midrib in the combs: that such heavy midrib would be very objectionable to the consumer, in that it would give rise again to the stories about manufactured comb honey. (See Comb Honex.) But late experience seems to indicate that the bees will generally thin down the heavier grades. and, what is more, will accept the foundation much more readily than the extra thin grades. But the real objection to heavy foundation is the expense.

Owing to the tendency of foundation in cause midrib in comb honey, some think that using a starter would remore the ohjectionable feature. They argue that nearly all the comb would have to be natural, and it would, therefore, be delicate and friable like the old comb honey on the farm. But it has heen shown that in a majority of cases, the natural-built comh will be composed of store or drone cells. the bees being able to build these larger. heavier cells more readily. Some recent tests seem to show that natural-built drone comb has as much or more wax to the cubic inch than worker comb built from full sheets of thin worker foundation. If the bees, on the other liand, would maks their naturai comb all worker, the resultant comb for delicacy and friableness would be all that could be desired. Dronecomb cappings do not have nearly the pleasing appearance of torker. If for no other reason, full sheets of worker foundation should be used. 
MEAXS FOR SLPJORTLNG FULL SHEETS IN BROOD-FRAMES.

With ordinary brood-frąmes at least, or shallow extracting-frames, it is quite important to use some sort of support for the foundation; and unless these supports are used, the was stretches in drawing out into comb. What is of still more importanee, the finished comb will have no stability in the frame. When colonies are latuled over rough roads to out-apiaries the frames get some severe jolts. The super combs also receive more or less rough handling at extracting time. They are often shaken to remove the bees, and in the extractor are subjected to severe centrifugal foree, which throws the honey out of the cells. On account of all this it is very important 10 have the comb when drawn from the foumdation held by neans of wires of a fine gauce, these wires being strung across the frames before the foundation is inserted.

\section{VALUE OF IVIRING BROOD-FRAMES.}

Some beekeepers secure the foundation to the top-bar without using any stays or wires to hold the sheet in place; but the great majority seem to prefer to have all their frames wired-that is to say, strands of No. 28 wire stretched rertically, horizomtally, or botn, arross the frame: these

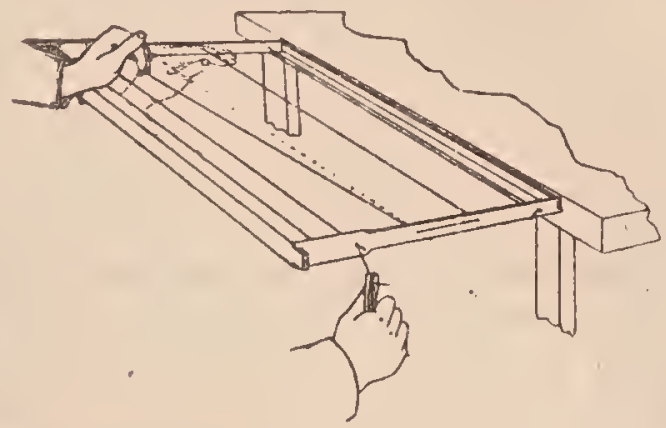

Method of drawing the wire preparatory to fastening.

are then imbedded into a sheet of foundation which fills the frame. The combs. when drawn from the foundation, will be better anchored to stand the rough nsage of the extractor, and to stand shipment when colonies are sent by express or freight or hauled over rough roads to outyards.

Most beekeepers say that the expense of the wiring is so slight in comparison with the great benefits secured that they could not think of dispensing with it; and, what is of considerable importance, during the process of drawing out the foundation the wires tend to rerluce materially the stretehing of the rax.

There has been almost endless discussion in the bee journals on how to prevent foundation, from stretehing or sagring in brood-frames while leing drawn out. When the bees build combs from it there is a slight cxpansion of the sheet horizontally and vertically. The greatest stretehing, however, occurs after the comb is fully drawn during hot weather and when the cells are filled with loney. 'This stretehing or elongation of the cells rertically causes that portion of the comb for two or three inches beneath the top-bar to be slightly distorter. Instead of being exactly hexa-

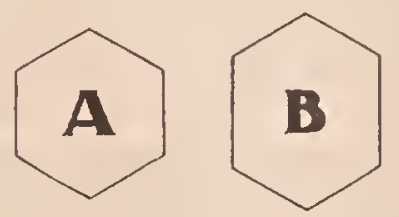

gonal the two rertical sides of the rells will be elongated, making the cell deeper than wide. The diagram will show what occurs. The stretched cells the queen will avoid for egg-laying. The result will be no brood nearer than two inches of the toprbar unless the foundation is properly braced. The space above where the distorted cells are, is filled with honey-in a few instances with drone brood. But this rarely occurs, for the reason that these cells are neitluer drone nor worker, and conseruently the queen aroids them, and the workers fill them with honey.

The result of this stretching or distortion of the cells is to reduce the brood capacity of the hive, either eight or ten frame Langstrotl, by about 20 per cent. As a single brood-chamber ten-frame Langistroth is not large enough to accommodate the average goor queen in the height of the breeding season, even if all the cells of the frames were occupier by the queen, it will be seen that this distortion or stretching makes its capacity just that much shorter still. Obviously it is impossible for the average beekeeper, owning hundreds and perhaps thousands of these hives, to enlarge their capacity witlout going to great expense. But, fortun- 
ately, it is possible for him to increase the capacity of his brood-frames for holding brood by approximately 20 per cent by so staying or supporting the foundation (and, later on, the comb) so that it can not sag. This is accomplished by the use of full sheets of worker foundation wired in such a manner that stretching, either vertically or horizontally, is made inpossible.

\section{HOW TO WIRE FRAILES.}

Alunost every beekeejer has his own particular method which he considers much better than the otler' fellow's. 'T'lue result is that hundreds of different schemes have been shown in the bee journals, some of which are good, some of which are good but too expensive, some of which are bad, and some of which are not only poor but expensive.

In the early 80 's, $A$. I. Root, in order to prevent stretching in all directions, used a series of rertical whires passing thru holes in the top and bottom bars, then two diagonal wires reaching from the two upper cornel's of the frame down to the middle of the bottom-bar. A metal bar reaching from this point to the top was then userl to support the center of the topbar, which was $1 / 4$ inch thick and $7 / 8$ wide. The completed frame is shown in the illus-

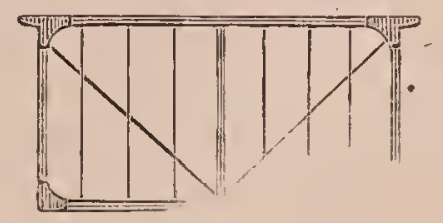

tration. This plan of wiring gave excellent results and solid frames of brood going clear to the top-bar. The objection to the method was the expense and the tendency of the bees to leave a ridge next to the metal support on the middle. Many user these frames without any wires whaterer. The top-bar would sag, and, worse than all, burr and brace combs would be built. See Frazres, subhead Thich-тor FRAMES.

Along in the 90 ' 5 the whole beekeeping' world, in order to aroid burr and brace combs (see Frajies), went over to a frame harmg a thick top-bar which, of course, could not salg. This made it impracticable to wire frames on the vertical plan. Horizontal wires were then used, passing thru holes pierced in the end-bar's, four holes

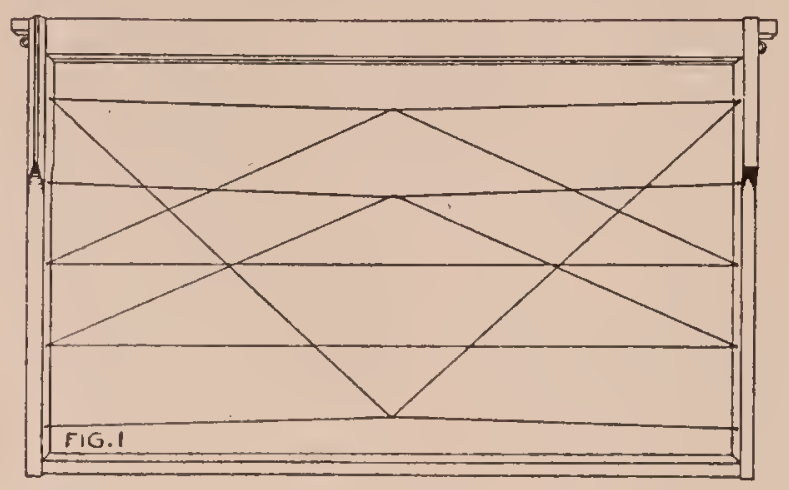

Fig. 1. This will prevent the sagging of the foumdation, lut is altogether too expensive and complicated. It would not permit of electrical imbedding.

to the end-bar: This method was generally nsed by most beekeeper's, and continued on until 1918 and '19, when it was discovered almost all at once that it did not prevent the elongation or distortion of the cells

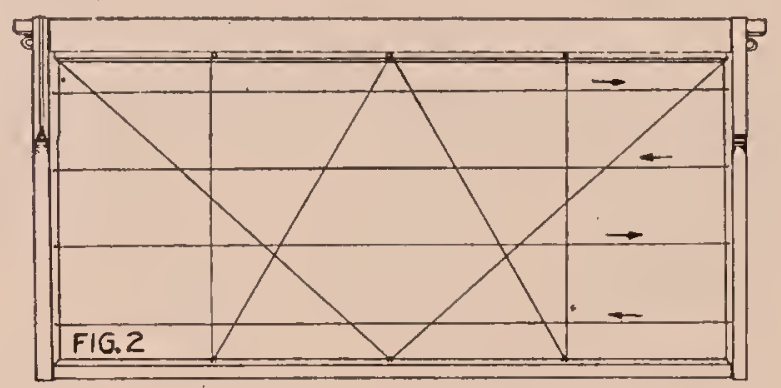

Fig 2.-This will prevent sagering, lut is too complicated, and will not admit of elertrical imbedding.

two or three inches below the top-bar. Attention was directed to the fact that some beekeepers in c'alifornial were using a combination of the four horizontal and diagonal wires in a manner that would pre-

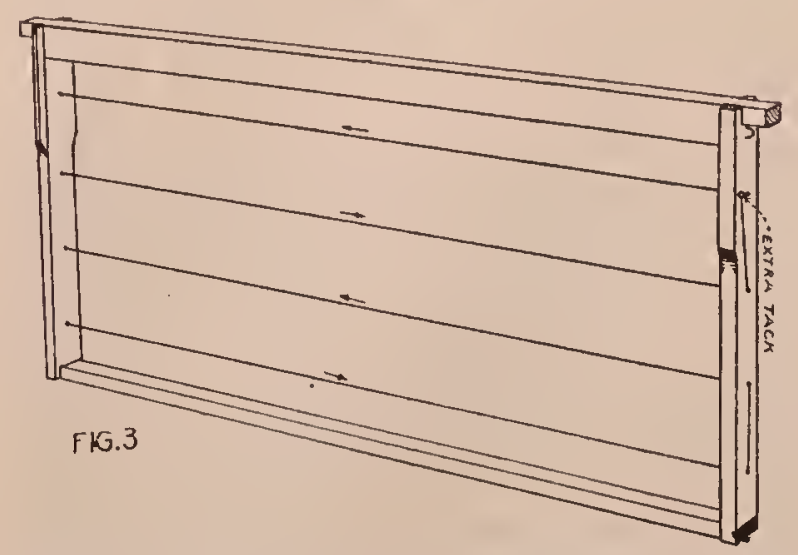

Fig. 3.-The old-style horizontal wiring that was used for a good many years. It made nice beantiful combs. but did not prevent the distortion of the cells within two inches of the top-bar. 
vent the stretching of the cells and allow the brood to extend clear up to the top-bar. This matter was presented thru the columins of Gleanings in Bee Culture in 1919 ,

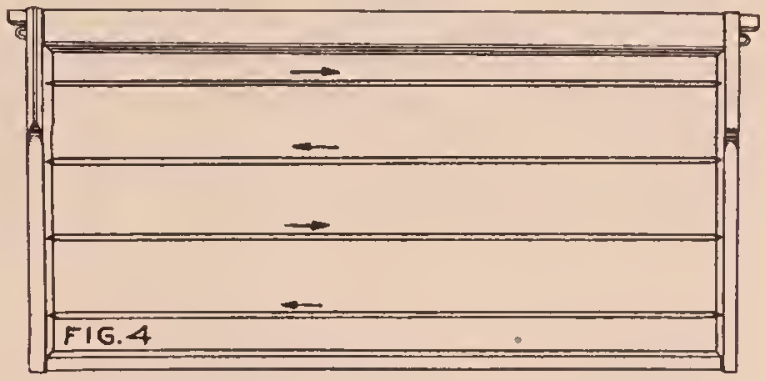

Fig. 1.-This is the same as No. $B$, except that donble wires are used. The slueet of foundation should be placed between the two sets of wires. Ijike No. 3 it will not prevent sagging near the top-bal.

with the result that the whole beekeeping world seemed to wake up to the fact that the breeding capacity of a Langstroth hive could be increased at a rery slight expense.

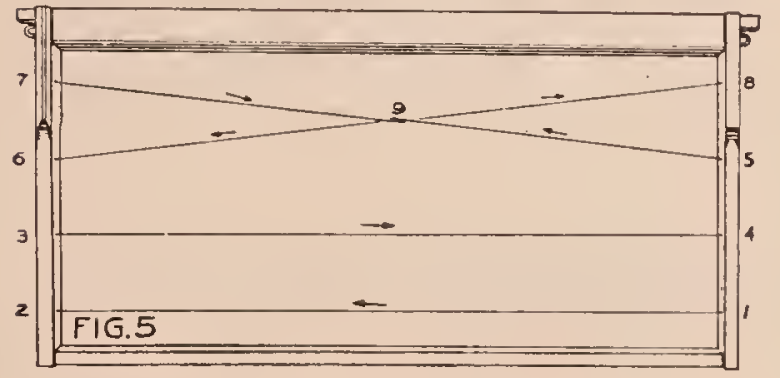

Fig. 5.-This is very good. It will prevent silnging of the foundation, but will not permit of electrical imbedding because the wiles intersert at 9.

Hundrerls of different schemes for wiring were then sent in. some of which were grood, but most of them either poor or ex-

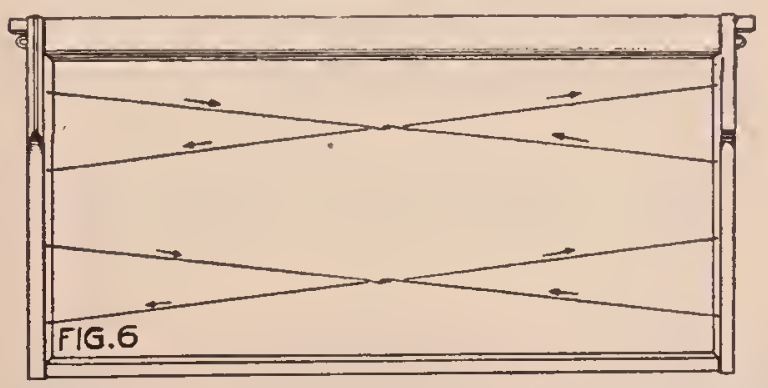

Fig. 6.-This is faulty, like No. 5, and is more difficult to accomplish.

pensive. For the benefit of those readers who have not seen this discussion it has been thought best to reproduce a number of the plans that were described, pointing out, by the legends beneath, the bad and good features of all of them.

In a general way it should be stated that the most practicable plan seems to be to use four horizontal wires, and then diagonal wires reaching from the two bottom holes and passing either up over the top

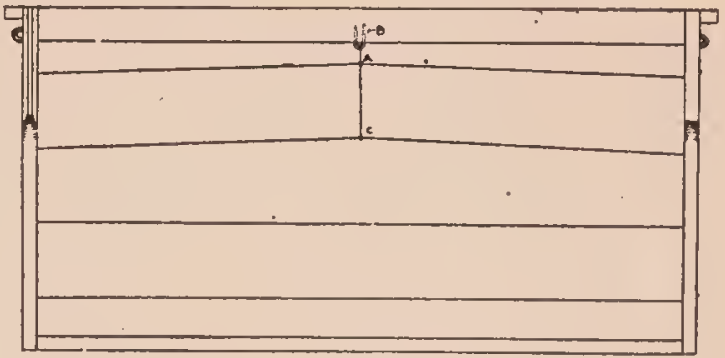

Wig. 7. -lhis will plevent sagging, lut is too complinaterl, and does not permit of electrical imLedding:

of the top wire, or, better still, running up to the top-bar, at which point it is held by a staple or nail. See Figs. $7,9,10,12,13$, 14 , and 15. It is rery important, as will be shown later, to have the sheet of foundation

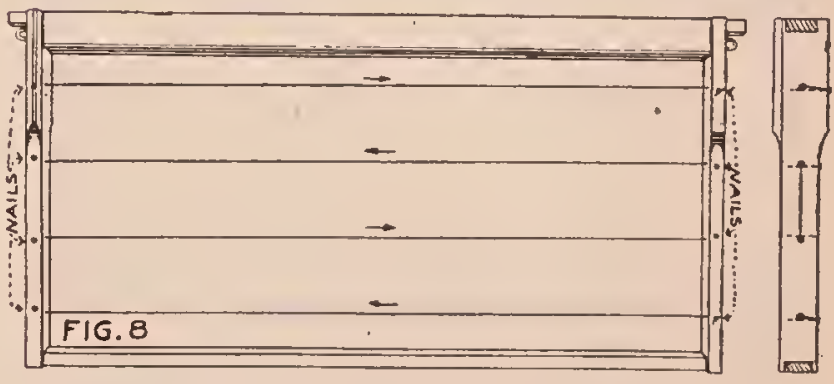

Fig. 8.-This plan is the same as $\mathrm{No} ; 3$ except that nails are driven in the encl-bars as indicated. This prevents the wires from cutting into the wood.

placed between the four horizontal wires on the one side and the tro diagonal wires on the other. Trhere both diagonal and

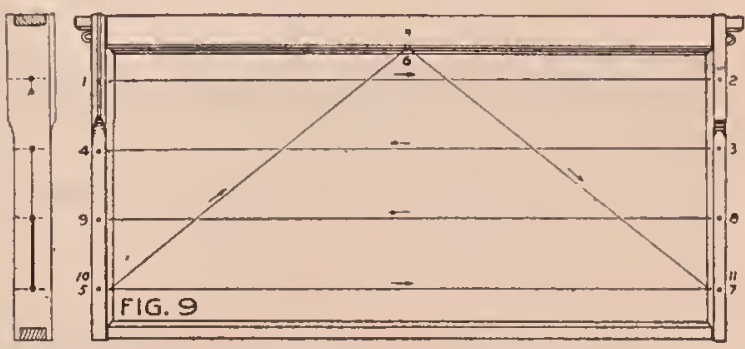

Fig. 9.-This is one of the best of any of the plans shown. The sheet of foundation should be placed between the diagonal and the four horizontal wires, when imbedding with electricity can be accomplished. It effectually prevents sagging of the foundation, but is not quite equal to the plans shown in Figs. 14 and 15.

horizontal wires are on one side of the sheet it is impossible to use electricity for imbedding, on account of the "short circuits" caused by the intersecting of the wires. These short circuits cause some of 
the wires to berone red-hot, while some of them will hardly be warm. By placing the sheet between the two sets of wires, the intersecting wires are insulated so that the

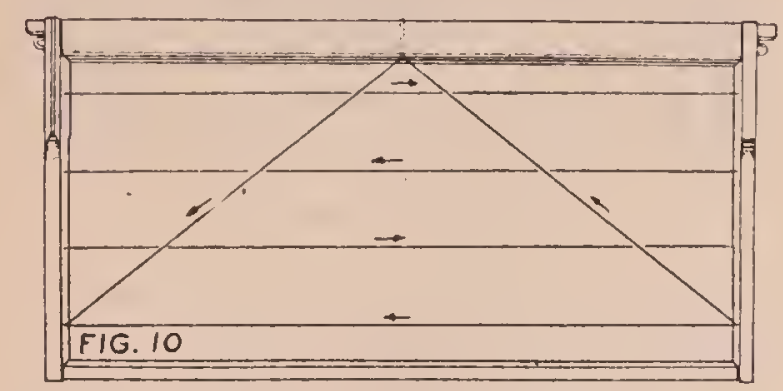

Fig. 10.-This is the same as Fig. 9. lut it reguires an extra hole thrn the top-bar. "It is, therefore, unnecessary.

electric current can be passed thru both the horizontal and diagonal wires all at the same time, all of them haring the

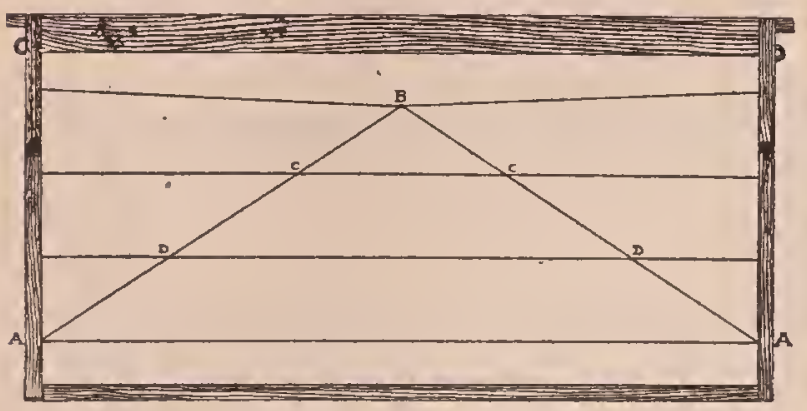

Fig. 11. - Jhis ulan bas been used very largely in California. It was there that the author saw that hrood in comlss wired this way would go rear in the top-bal. Beraluse of the rlifficulty of electris. ally imbedring on account of the wires interserting at the fops, Nos. 14 and 15 are recommended in. stead.

right imberdiny tempreature. 'The plan that the publishers finally adopted is the one shown in Figs. 15 and 16, the end-bar

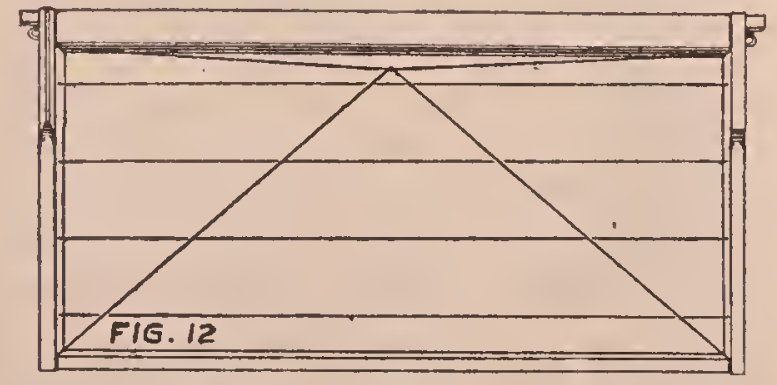

Fig. 12.-This is rely good, but not as simple as 1.iv. 9. and is defective in that it will not allow elfortrical wiring.

laving four holes pierced in the regular way. At the bottom of each end-bar is a shallow saw-cut, which, when the bottombar is nailed in place, makes an additional hole. The wire is first passed thru the two saw-cuts next to the bottom-bar at 1 and 2, Fig. 15. Then it is threaded back and forth thru the holes $3,4,5,6,7,8,9$, and 10 successively until the last hole is reached. The slack is taken out when the

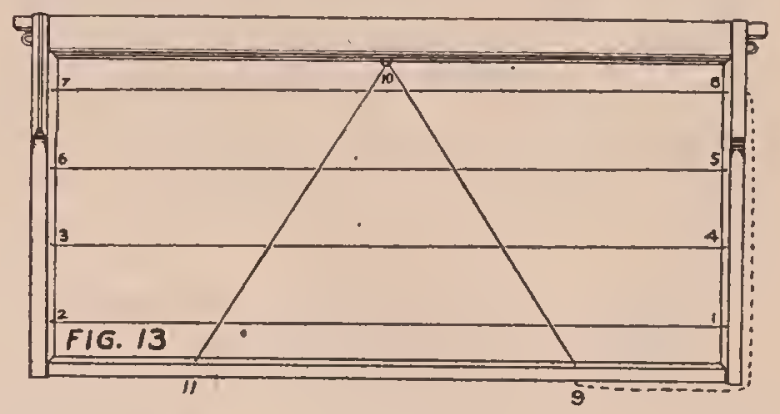

Fig. 13.-This plan is good, but it requires two extra holes in the lottom-bav.

wire is fastened at the last lonle. The wire passing thro the saw-cuts is made slick. as will be explained later.

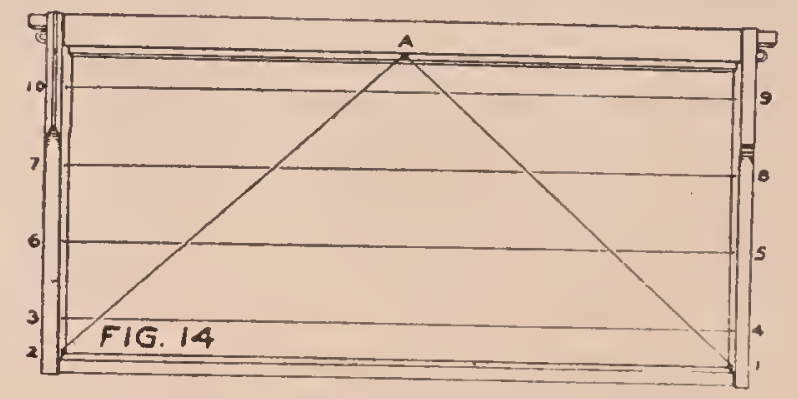

Fig. 14.- This and No. 15 are the plans that the atiogr recommends mole than iny of the othel plans here shown.

It is easier to do wiring with the frante upside down. resting it on a slanting board. The wires in place, a full sleet of foundation is now laid on them, after

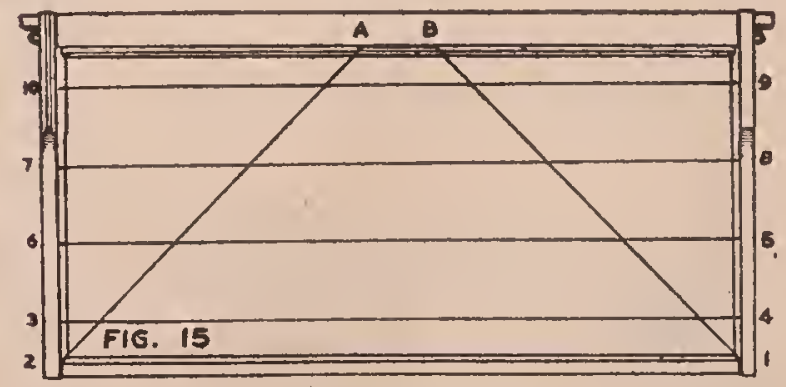

Fig. 15.-This is the sane as Fig. 14, except that it uses two tucks ol nails for the top support in stead of one. Both 14 and 15 permit of electrical inbedding provided the directions are followed.

which the slack wire next to the bottombar, which passes thru the two saw-ents in the end-bar's, is drawn down orer the sheet of foundation, and hooked over two nailheads, A and B, Fig. 15, driven in the top-bar. 
If the work has been done right the sheet of foundation will be under the two diagonal wires and over the four horizontal wires. After the wire las been hooked over the nail-heads the remaining slack is taken up and fastened by winding it around the other tack. This is driven home, after which the two nails in the topbar are driven down. The foundation is secmred to the top-bar by one of the werlaeshaped strips describer further on.

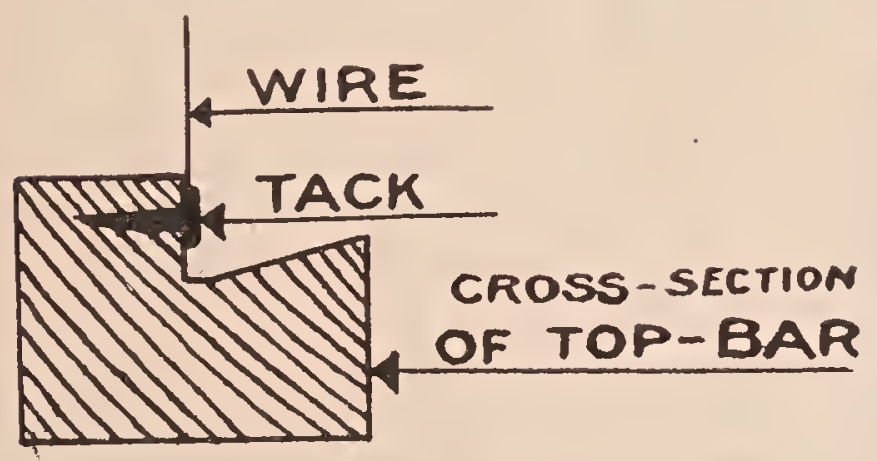

The two diagonals, while on one side of the sheet, and the four horizontals, can all be imbedded by electrieity at one operation in oue eireruit, as will be explained further oll.

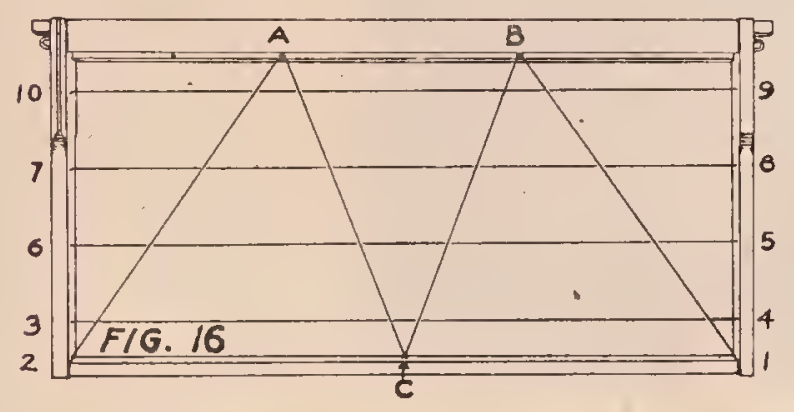

In Fig. 16 a staple is driven crosswise in the center of the bottom-bar. The wire is then passed thru slot No. 1 in the endbar, thru the before-mentioned staple, C, and then on thrm Nos. 3, 4, etc. The strand next to the bottom-bar is grasped on each side of the staple, and hooked over tacks A and B in the top-bar as shown opposite. This plan stiffens the comb next to the bottom-bar, and for extracting it will be better than either Figs. 14 or 15 . It takes, howevel, a little extra work and wire.

Where there is much work to be done in wiring and imbedding, a frame-loolder or form should be made. The general design of it is shown in the illustration below. It consists of two parts-a general framework to hold the frame at an angle of 4.5 degrees while the wires are being threaded thru the holes back and forth. This is hinged at the bottom to a board. The frame to be wired is laid on, when the four horizontal wires are tlireaded back and forth, including the wire next to the bottom-bar. The sheet of foundation is laid on the four horizontal wires, bottom-bar npward. The strand of wire close to the bottom-bar, which is now at the top, is drawn down and hooked over. one or two nails as the case may be, after which all the wires are drawn taut and fastened. This leaves the sheet of foundation between the four horizontal wires and the two diagonal wires running to the top-har. As soon as this is done the framework loolding the frame and the foundation is pushed down to a horizontal position. This act closes the electrie cireuit, when the wires are heated and imbedded. As soon as they sink into place, the framework is lifted up to the 45-deg'ree angle, when the eircuit is broken. The wired frame with its foundation may now be taken out.

A rely convenient tool is a little woorlen roller to bring pressure on the foundation and on the wires while hot. The three operations are shown successively in the halftone engraving below.

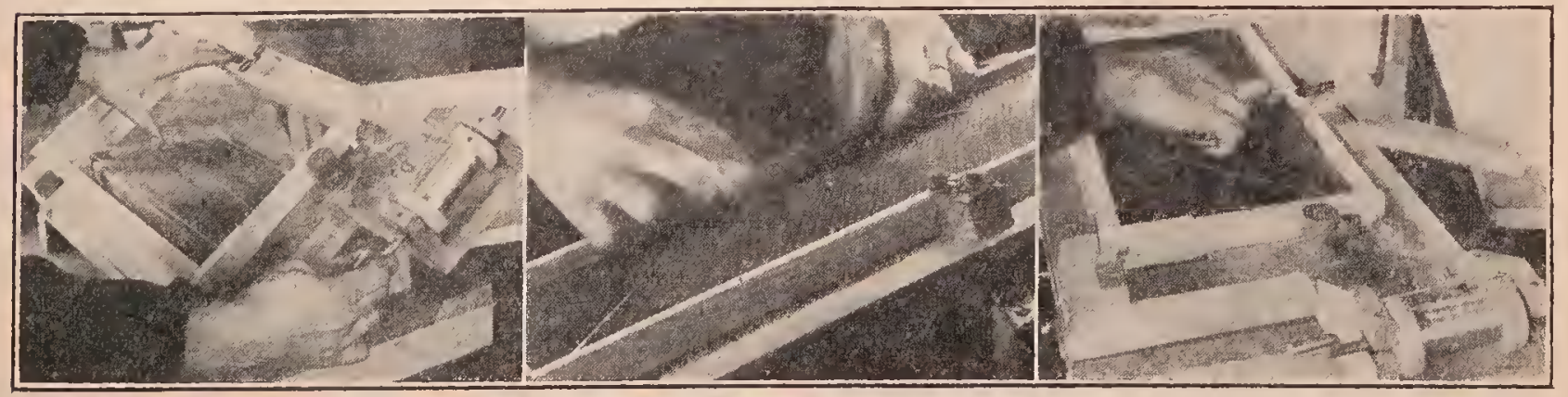

Frame for wiring and imbedding the wirex 
'VITE WOOD-SPLINT P'LAN.

Dr. C. C. Miller of Marengo, Ill., orercame the difficulty of cells next to the topbar stretching, by using wooden splints instead of wires. These he secured in the manner" described in his "Fifty Tears Among the Bees."

The splints should be about $1 / 16$ inch square and about $1 / 4$ inch shorter than the insicle depth of the frame. A bunch of them should be thrown into a square shallow tin pan that contains hot beeswax. They will froth up because of the moisture frying out of them. When frothing ceases, and the splints ale saturated with wax, they are rearly for use. The frame of foundation is lail on the board as before. With a pair of pliers a splint is lifted out of the wax (kept. just hot enough over a gasoline stov(s), and placed mpon the foundation so that the splint shall be perpendicular when the frame is hung in the hive. As fast as a splint is laid in place, an assistant immediately presses it lown into the foundation with the wettal eige of a board. About 11/2 has been built down, but the cells not very fully drawn out, they will do more or less at gnawing a passage. To make a suecess the frames should be given at a time when work goes on unintermptedly until fulldepth eclls reach the bottom-bar.

Under some conditions the bees will gnaw around the wooden stays, as shown by the illustration. This occurs more particularly when bees have not much to do: and when they rum across anything which is fibrous they will then show a disposition to remove it.

The suggestion has been made that in no case should the splints be allowed to project beyond the edge of the foundation: or, better still, the sheet should reach clear to the botton-bar.

But, there is no reason why the foundation should not expand between the vertical splints the same as it expands between the rertical wires. While Dr. Miller says that

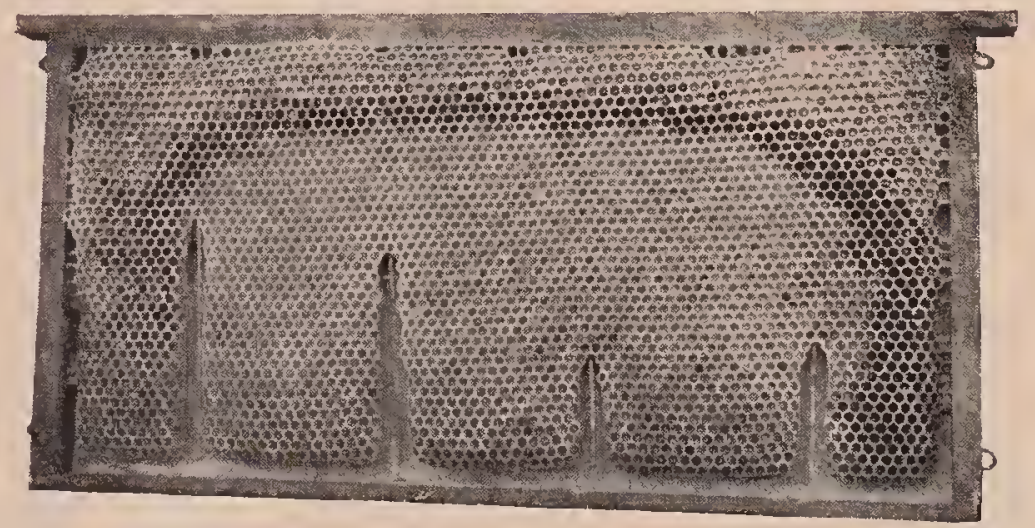

In some rases woolen splints are gnawed by bees.

inches from each end-bar is placed a splint, and between these two splints three other's at equal distance. Then these are built out they make beautiful combs, and the splints do not seem to be at all in the way.

A little experience will enable one to judge, when putting in the splints, how hot to keep the wax. If too hot there will be too light a coating of wax.

It must not be understood that the mere use of these splints will under any and all circunstances result in faultless combs built securely down to the bottom-bar. It seems to be the natural thing for bees to leave a free passage muler the comb, no matter. whether the thing that comes next below the combs be the floor board of the hive or the bottom-bar of the frames. So if a frame be given when little storing is going on, the bees will deliberately dig away the foundation at the bottom; and even if it lie has had no trouble of that sort, it is because he uses foundation heary enough so that he orercomes this stretching or expanding. As the rooden supports prevent the sagroing of the foundation or the comb only after it is drawn out, and do not secure the comb to the frame, it may be a question whether it is not safer and more satisfactory all around to use wires previously shown, especially if one is going to do rel'y much extracting or intends to ship or more bees to any extent. The splints only prevent the sagging of the foundation while being drawn out, but during moring or extracting do not hold the comb securely like wires threaded thru the end-bars, as shown on previous pages. 
PAPER AS A BAST: FOL FOUNDATION.

Other derices have been used, such as paper imbedded in the center of the foundation; but this is rery objectionable because the bees soon discorer that this is a foreign substance, and proceed to tear it out bit by bit, ntterly ruining the foundation. They do not aluays do this; but sooner or later they will; when they have nothing else to do they will begin to tear out the paper, thinking, perhaps, that the fiber is a part of the silken gallery of the moth worm.

COALBS JBUL'T FROAI FOUNDATION PRESSED ON THIN WOOD VENEER.

Tears ago A. I. Root tried comb foundation pressed ont of pure beeswax on each side of a sheet of thin basswoor veneer, but lis foundation, so made, was rery crude. and finally the plan was given up as it was believed that bees needed holes thru the combs in winter. The authors began experimenting "with wood reneer foundation again early in 1920. Such combs have been in nse ever since. So far as can be determined there is no appreciable snawing of the wood, and, the cells being perfect, the bees draw out the foundation imnediately into perfect combs.

With the wood reneer foundation the frames can be made with thin top-bars and thin bottom-bars, allowing at least three extra rows of cells. Moreover, the

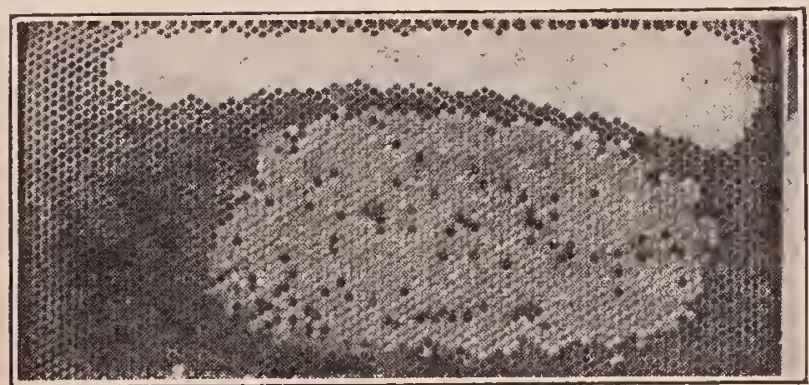

Comb built on wood veneer foundation, in thin top. bar frame. No sagging, no imperfect cells.

brood and honey being that much closer to the top-bars, the bees enter the super's more readily. This is especially important in case of comb-honey production.

The great advantage of an indestructible comb is the freedom from stretching of the cells and the increased amount of room thereby made possible for brood-rearing.
In comb-honey-production especially it is often difficult to get bees to enter the super's if there is room for the storing of honey in any great quantity under the top-bars of the brood-frames. Absolute freedom from stretehing adds nearly 25 per cent to the brood capacity of the live.

$A$ rood base foundation also makes a nuch stronger comb-one that will stand hard usage in an extractor and a greater speed, insuring dryer combs.

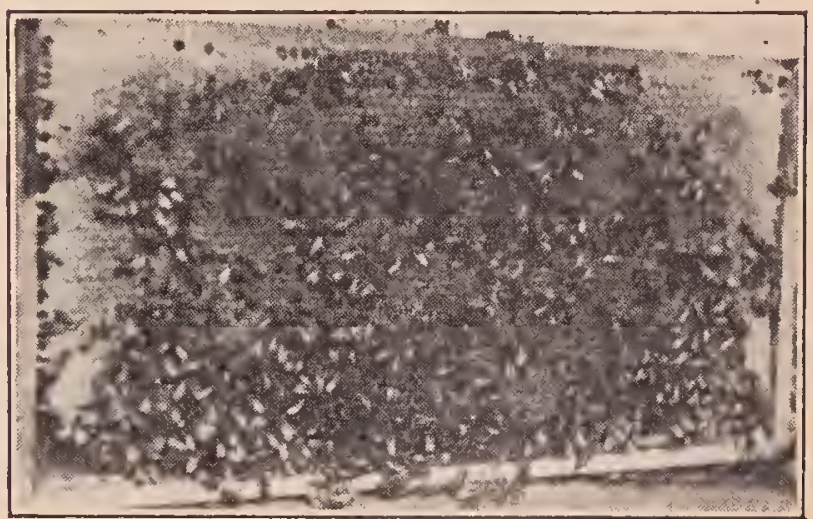

TTorker brood remled close to tols-bar in comb built from wood reneel folldation. This particular' comb is one of ten in use for more than eighteen months, the hive wintering out of doors.

These combs seen to be a success, but they lave not ret been tried on a large enough seale to permit a positive statement of their value.

INTESTRUCTIBLE COMIBS.

In spite of all the experimenting that has been done with various forms of wiring the frames, including rertieal wires, horizontal wires, dıagonal wires, wires incorporater in the foundation itself, ete., it is adinitted that while the most approved methods of wiring prevent comb brealiage for ordinary handling of the combs and eren to a great extent in the extractor, yet the rery best plans of wiring do not prevent all sagging of combs and consequent construction of storage-cells or eren drone-cells in the upper part of the frames. The comb does not have to sag rery much before the cells become unfit for worker brood.

The aluminum combs, introduced in California in 1919 and 1920, which are a modification of the old metal combs experimented with by Quinby, have been given extensive tests in all parts of the country. While it is too early ret to predict the final 
mutcome of the tests it is known that queens lay in aluminum combs only when there are no natural wax combs at their risposal. It is also known that in many localities queens cease laying sooner after the honey flow than they do when they lave wax combs. This is a serious objection, for if true it would result in older bees to go into winter quarters witl bees which probably would not winter as well as would younger bees. There is no question also but that there is much more danger of overheater and chilled brood in the aluminum combs, as aluminum itself is one of the best conductors of heat of any of the metals. In England, where a somewhat different form of almminum comb has been tried, the consensus of opinion is that the hives inust be well insulated and also shaded if aluminum combs are used.

Some advocates of aluminum combs see a future for them for extracting purposes only; but since modern methods of extracted-honey production contemplate more or less exchange of combs between extracting-super's and brood-chambers and since the queen is usually allowed the run
I MBELOING THF WIRE.

$V$ arious methods of imbedding the wire have been used; but one of the simplest is the spur wire-imbedder.

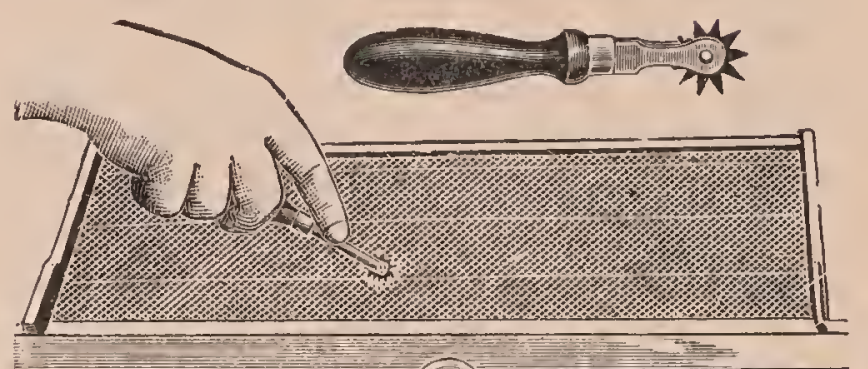

1.

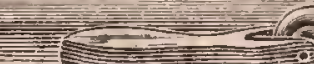

Spur wire imbedder.

$\Lambda$ sheet of foundation is laid on a board of such size that it will just go inside of the frame. A frame with wires stretched across it is laid on top. The wide-toothed spur imbedder, after being heated by being placed over the top of a common lamp, is drawn over the wires, the operator exerting a slight pressure as he does so, causing the wires to be imbedded in the foundation. The hot teeth, as they pass orer the wire,

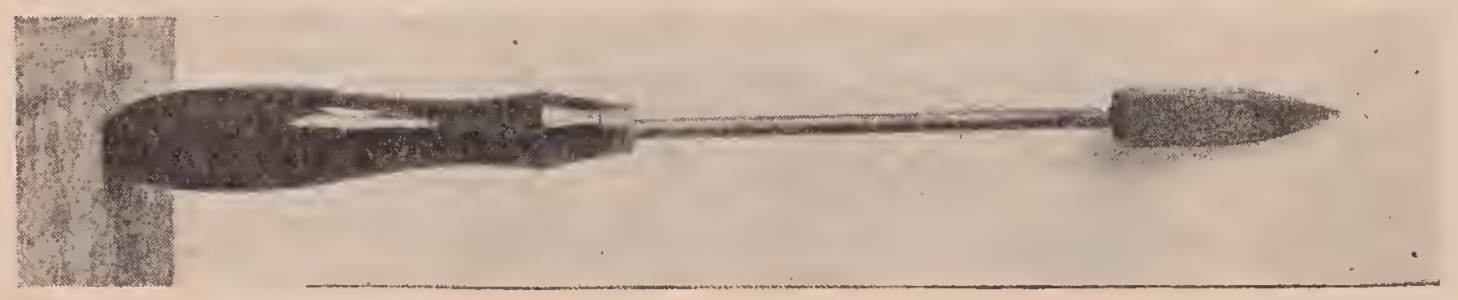

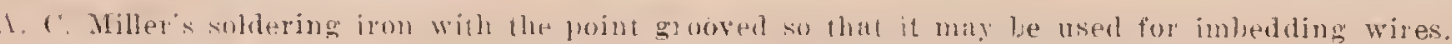

of the first and sometimes the second super of extracting-combs during the fore part of the season, it is evident that an extracting-comb must be a good brood-comb also.

The aluminum comb should not be conremned without a very thoro test; but so far as the experience of the authors is concerned and so far as they have collected reports from other beekeepers, this much can be said: Aluminum combs have not ret proved to be an unqualified success. They may serve in a limited capacity in one way or another, but the fact remains that, sinee many who have tried the'n liave abandoned them, any one desiring to test them should not invest too much eapital in then at the start. cause a little bridge of melted wax to form across a wire. The sheet is, therefore, tied at intervals between each of the teeth.

Another tool that has found favor with quite a number, including A. C. Miller of Providence, R. I., and Dr. Burton $\mathrm{N}$. Gates, apicultural instructor, Amherst. Mass., is a small soldering iron with a fine groove just wide enough to ride over a 28 gauge wire, such as is used for wiring the frames. This little tool, after heating orer a common lamp, is drawn slowly over the wires, one by one. As it passes over, it heats the wire, causing it to imbed itself in the foundation as it cools. The tool is heated again, and applied to the other wires in like manuer. 
IALBEDDING BX ELECTRICITY.

After all is said and done, the most satisfactory method of imbedding wires in comb foundation is by means of electricity : and if one has access to an electric-light cireuit, as so many beekeepers now have, the best way is to imbed all the wires at once by attaching the current to the tacks on the outside of one of the end-bars of the frames, around which the ends of the wires are wrapped, the current then flowing thru all the wires. Dry batteries may be used for this purpose, but it takes eight to a dozen batteries to heat all four wires quickly, and even then it is a rather hard strain on the batteries. For lieating one wire at a time it takes four cells. The trouble with dry batteries for imbedding is that they must be fresh to be efficient, and after a little of this kind of work they are no longer fresh.

Obviously with the straight electric-light current, if that were attempted, the wires would be heated red-liot in an instant, ol', what is more likely, a fuse somewhere on the circuit would be blown out. The current must first be run thru a "resistance" to reduce it, just as steam when run thru a steam engine is exhansted, and of much lower pressure thereafter. If one has an electric flatiron to put on the circuit, that furnishes about the right amount of resistance. In that event the two wires that go to the switch which turns the flatiron on and off, have just about the right amount of current to do the imbedding nicely. If there is no switch, the flatiron may be hooked in on one of the wires, the current going first thru the flatiron before it goes thru the wires in the frames.

With no electrically heated flatiron available, a resistance coil can be made in a few minutes' time. First, get abont 400 feet of No. 24 iron wire. The exact amount ean not be given, for the wire varies slightly in size; furthermore, different operators may prefer different currents to work with. The best plan is to get 400 feet of the wire and then not use quite all of it, if more heat is lesired. In order to have the wire in convenient form to handle, wind it on a long iron rod, or pipe, the outside diameter of which is about $1 / 2$ of an inch. Twist the wire around one end of the pipe tightly, so it will not slip; then have some one else turn the pipe slowly, while you wind it on erenly and tightly, with no space between the coils. When it is all wound on, let the

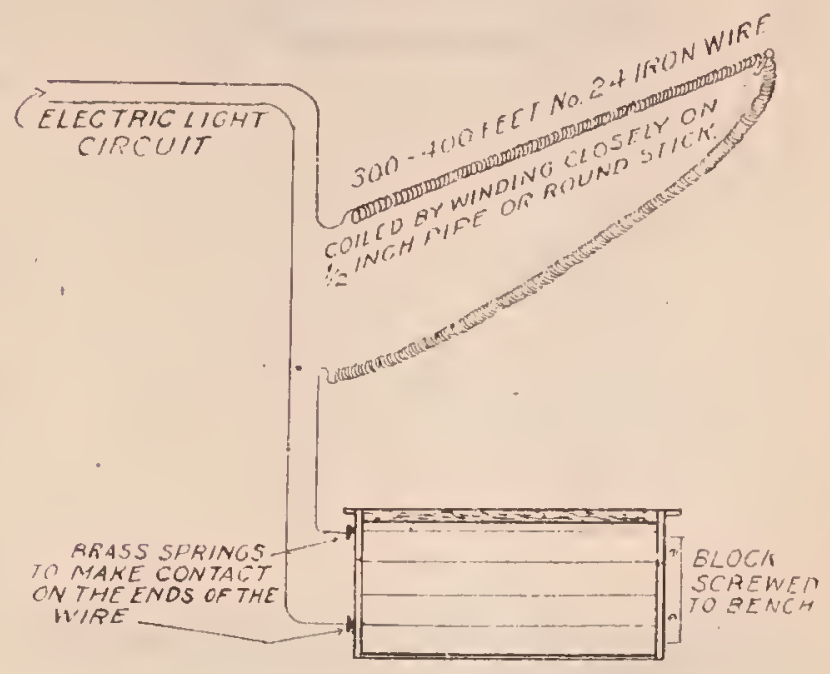

Electrical imbedding derice.

wire loosen up, cut the end that was first twisted on and slide the whole thing off the pipe. Hang the coils on nails in the wall or ceiling, being eareful that the different lengths of the wire do not touch each other. The electricity after passing thru all these coils of wire will be "tame" enough to be handled by any one. These directions are for the standard voltage, 110 , found almost universally. It makes no difference whether it is direct current or alternating-one works as well as the other.

\section{ANOTHER IIETHOD OF REDUCING ELECTRIC} LIGHT CURRENT.

Jay Smith has devised another and much simpler method for reducing any electric-light current sufficiently so that it may be used for imberding the wires in connection with the imbedding form described above. (See article in Gleanings in Bee Culture, December, 1917, page 938.) This simple device is merely a quart Mason fruit jar with two wires or strips of copper or brass extending down into soine watel. A pinch of salt should be added to allow the current to pass thru the water. The current from one wire of the circuit passes into the jar thru one electrode, thence thru the water to the other electrode, then to the imbedder. The other electric wire passes directly to the imberder. The 


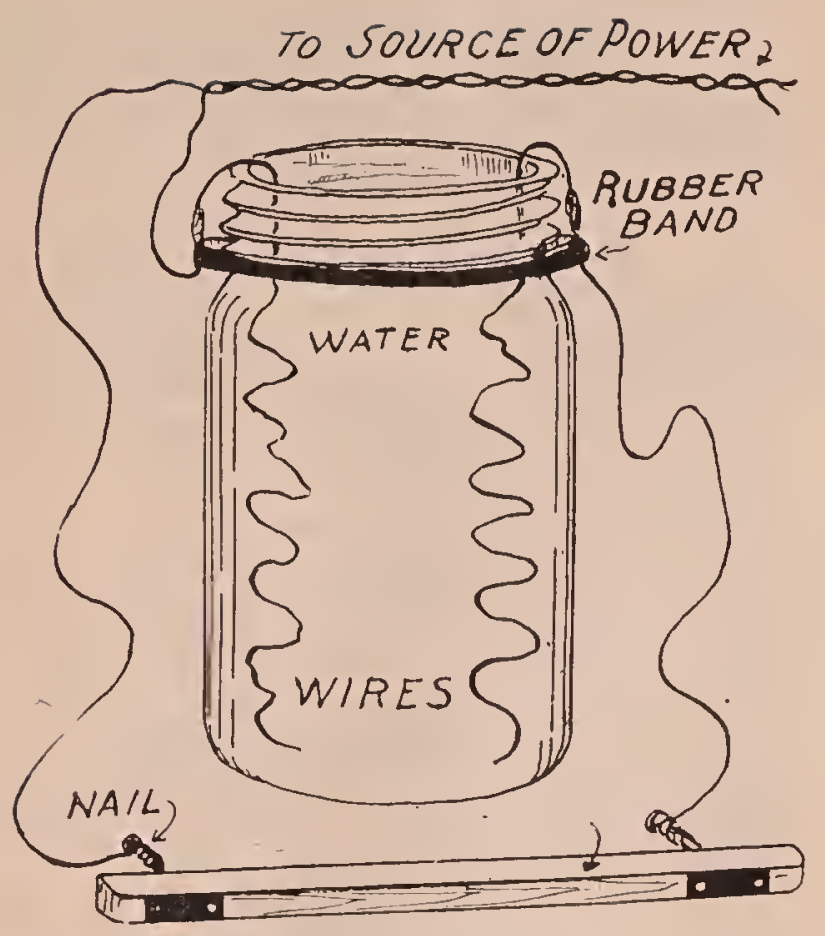

strength of the current used may be rhanged by merely changing the strength of the salt-water solution in the jar.

TSE OF SALALL ELECTIIC THANSFORMER.

The small transformers sold by supplydealer's for use in imbedding can be attacherl to any electric-light socket having' 110-11.5 rolt 60 -eycle alternating current, and it gives, without the use of batteries, just the right amount of current for imberding all four wires at once, or only one wire, at the will of the operator. It is used in connection with the imbedding form described elsewhere, and is a very satisfactory method of imberding.
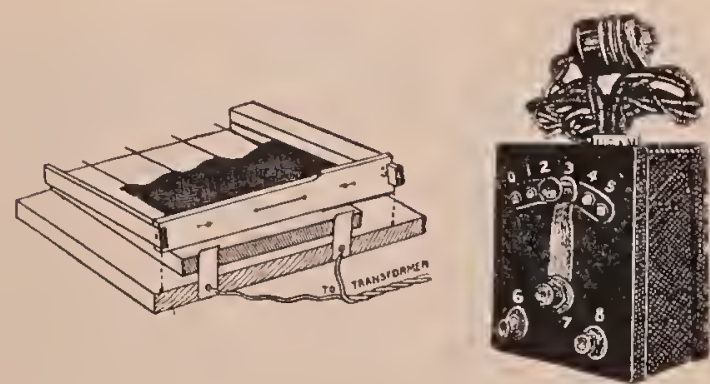

To do the imbedding, take a boand wider than the frame and near one end screw two pieces of sheet brass, which will stick up) about an inch. These are to be spaced the light distance apart, so that if the end-bar of the frame is pushed up against the piece of brass, one tack, around which the end of the wire is wrapped, will touch one brass spring and the other tack the other. For best results there should be a switeh for turning the eurrent on and off.

The sheet of foundation should be on top of the wives, instearl of the wires on top of the foundation. There diagonal wires are used the sheet of foundation should be put between the diagonal and the horizontal wires. This prevents the bees from making holes where the wires cross. As soon as the curcent is turned on witl the left hand, a light wooden roller, that will just tit inside the frame, should be rapidly rolled across the wax, pressing it down orer the lieated wires.

Imbedding all four wires by means of electricity, while not particularly easy for the first few frames, is far more rapid than any other method and capable of the very finest work. A good operator that has imbedded a few hundred wires can do the work so nicely that it is almost impossible to detect which side of the foundation the wire went in, the wire itself showing no more on one side than on the other.

IMBEDDING ONE WIRE AT A TIME WITH AUTOMOBTLE BATTFIY IMBEDDER.

'T'here has recently been placed on the market a very landy electric imbedding derice which uses the current of an ordinary automobile storage battery. From the accompanying illustration it will be seen that

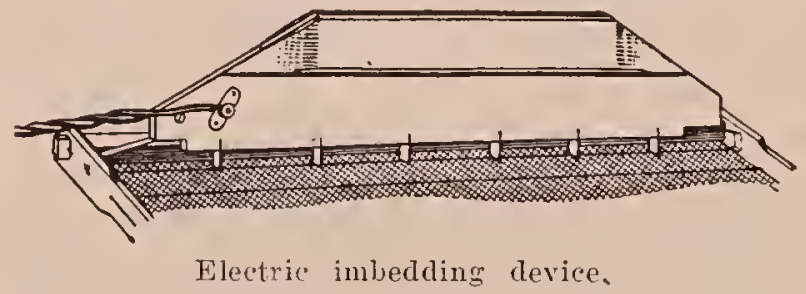

this tool imbeds one wire at a time. The current enters the wire at either end thru brass spring's attached to the ends of the tool. When in use the tool should be pressed firmly down upon the wire with a form blork beneath the foundation and wires, and held just long enough for the current to heat the wire until it las melted the wax and thoroly imbedder the wire into the wax. Then when the tool is remover the wax instantly cools, leaving the wire firmly joined into the wax. When using a 12-rolt battery less time is required than with a 6-volt battery.

This tool does rery rapid work and is 
just the thing for the beekeeper who has an antomobile with electric storage battery, but who has no other source of getting curlent. This tool may also be used to good adrantage from any electric light circuit when used in series with proper resistance, such as an electric flatiron described elsewliere, or witl a small transfor'mer',

FASTENTAR FOUNDATION TO THE TOP-BARS OF BROOD-FRAMES.

After the firames have been wired, but before the wires are imberded the foundation is fastened to the top-bars, either with the Van Deusen wax-tube or double grooveand-wedge plan shown next.

Some of the supply factories furnish these kinds of top-bar's because some beekeepers still prefer them. There is a double groore, one of which is in the center of the top-bar. In this groore is in-

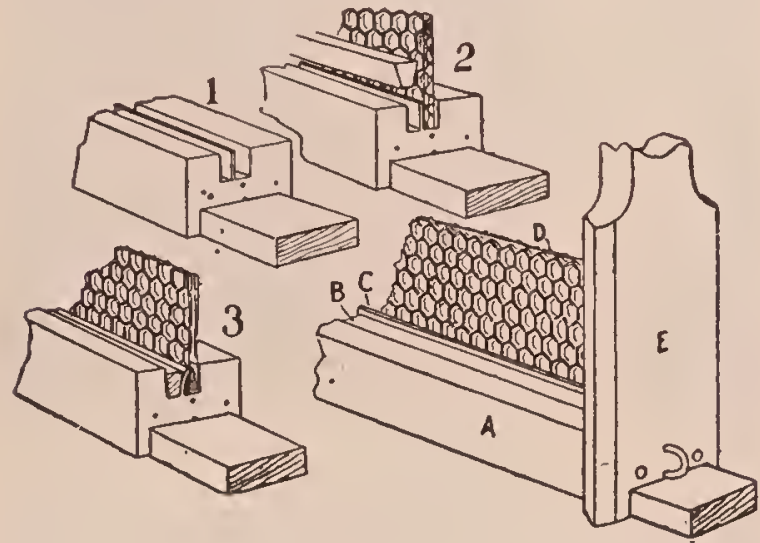

Wedge top-loar method of fastening foundation.

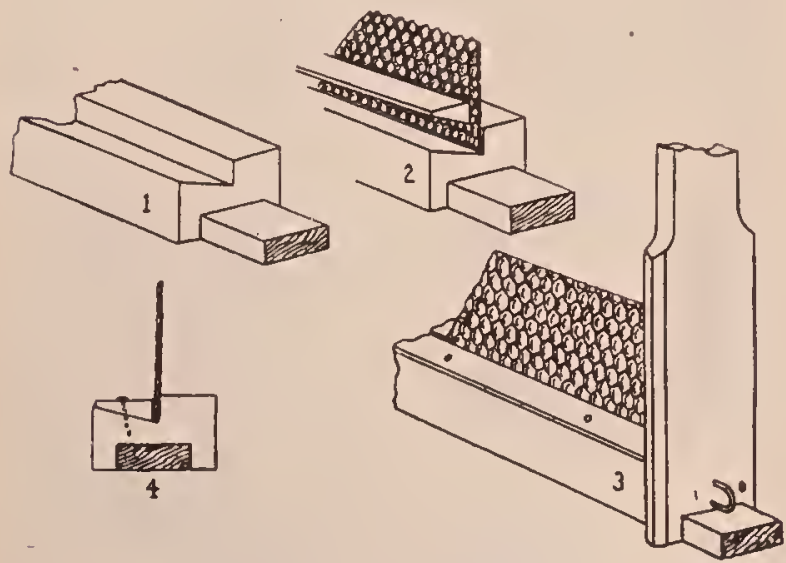

corner-cut top-bar method of fastening foundation.

serted the sheet of foundation, as at $D$. The wedge-shaped strip of wood B is then driven into the other groove as far as it will go, crowding the central partition firmly against the fomdation. It is rery important that it be driven below the sur- face of the wood, as otherwise it may work out, allowing the foundation to fall out. When the work is properly done it is thus held firmly in place without any special tools or finssing with melted wax.

Another top-bar known as the cornercut top-bar is used now in preference to the other plan. 'The loose triangular strip, when toe-nailed as shown in the illustration, grips the foundation firmly.

'There are a few who prefer the meltedwax plan of fastening foundation. Where the under side of the top-bar is plain without arooves or molded edge, this is perhaps the best. 'The best tool for depositing a hot stream of wax along the edge of the foun-

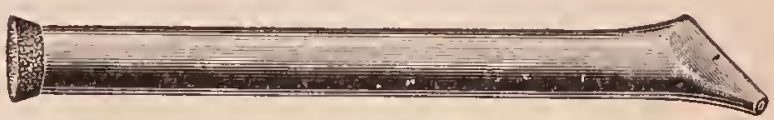

dation is undoubtedly the Van Deusen waxtube fastener. It is simply a tube tapering to a small hole at the apex. On one side is bored anotler small hole which may be opened $\mathrm{Ol}^{\circ}$ closed with the thumb. When the tube is stoor up in a cup of hot wax the air will escape from the upper hole, and the wax flow in at the other small hole at the bottom. The thumb is closed over the upper one, while the tool with the contained wax is raiserl to the top-bar. Then the thmmb is lifter from the upper hole and the point slowly drawn along the edge of the foundation in contact with the topbar, learing a fine stream of hot wax to cement it.

FASTENING FOUNDATION IN SECTIONS.

Foundation starters, or preferably fill sheets, are used also in comb-honey sections. There are two different ways for fastening the foundation to the sections, by pressure and by melted wax. The pressnre method is little used now, because it takes longer and the wax is not so fimly secured to the sections. Moreorer, it wastes foundation.

By far the best plan of securing foundation in sections is with melted wax, either by the nse of additional wax applied with the Van Deusen wax tube or by the hotplate method which melts a small quantity of the wax on the edge of the foundation. If full sheets of foundation are used instead of starters, the sheets if desired may 
he fastened not only at the top but twothirds the way down each side, provided the wax-tube method is used. It is not a good plan to fasten the full length on each side, as this would have a little more tendeney to cause the foundation to buckle. On the other hand, if a full sheet is fastened at the top only, the bees by elustering on one side sometimes swing the sheet away from the center of the section.

To do rapid work with the Van Deusen wax tube, a rack should be made to hold four sections at a time. On a board should be nailed four blocks a little less than half as thick as the section is wide and of a size that will just fit inside the section. The blocks slould be so spaced that four sections slipped over them will be close together. A section-holder should be erowded around the four sections, the foundation placed in position, and the operator will then be ready for the wax tube. If he desires to apply the melted wax to the sides of the foundation as well as the top, the wax should be started on the side of the section, allowed to run down to the corner, then across the bottom or what is really the top of the section, and then two-thirds the way up the other side. Of course, as the tube is moved along, the rack should be turned accordingly, so that the wax may run downhill, thus facilitating the work. As soon as one section is finished the tool is moved to the next, and so on.

\section{THE HOT-PLATE FASTENER.}

The hot-plate type of fastener, originally devised by Arthur C. Miller. melts a small amount of wax on the edge of the foundation so that it adheres instantly to the wood. This is used more than any other method, principally on account of the neatness and the strength of the work. Moreover, it is the most rapid of any plan. There are a number of these fasteners on the market, all of which do good work. Some of them fold, the sections as well as fasten the foundation. This is quite an advantage.

In most of these hot-plate fasteners the heat is furnished by a small alcohol or kerosene lamp placed directly under the plate to be heater. This plan is sometimes objectionable, owing to the difficulty of maintaining a constant temperature. In case of the kerosene lamp there is always more or less soot which sometimes gets on to the sections, spoiling their appearance. In the Rauchfuss fastener this difficulty js

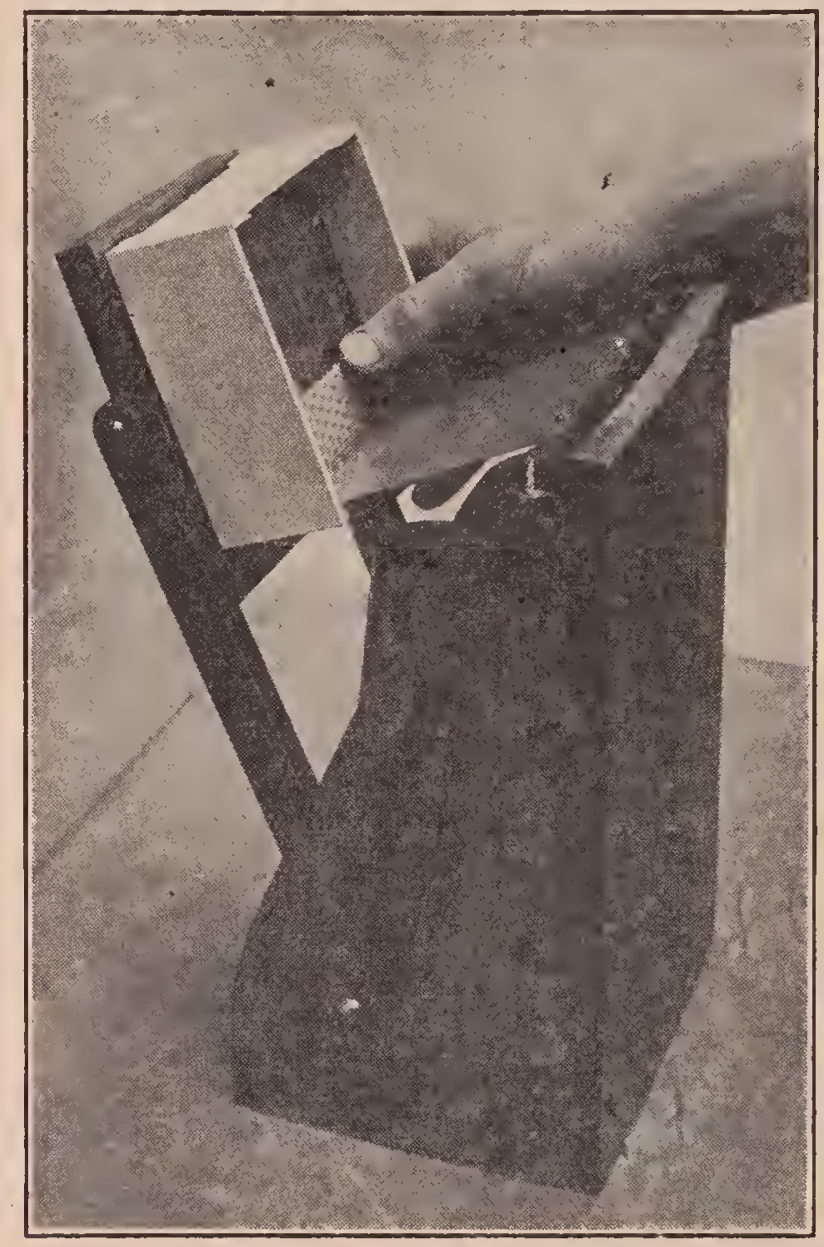

Byard fastener.

orereome by the use of an alcohol lamp, which is much cleaner, altho the heat is not quite as easily controlled.

The Root fastener is a small hand tool, which is hung over the lamp to be heated.
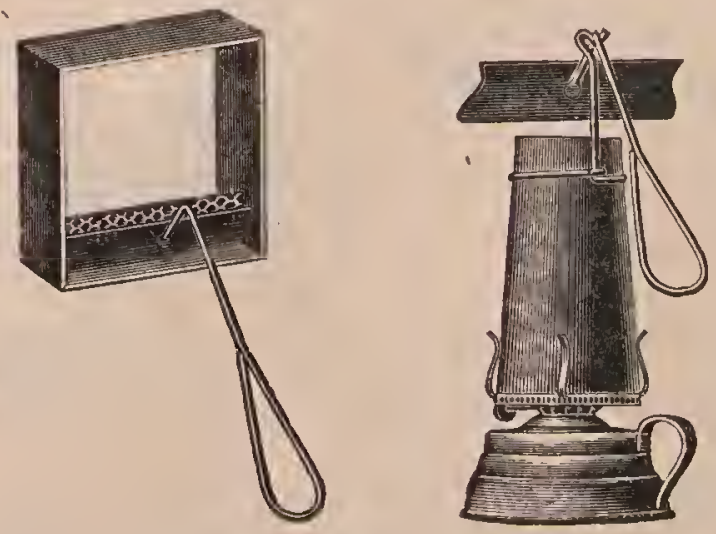

To use it, a rack should be made to hold four sections as described above, and the section-holder slipped over them. Then having put the foundation in place and, 


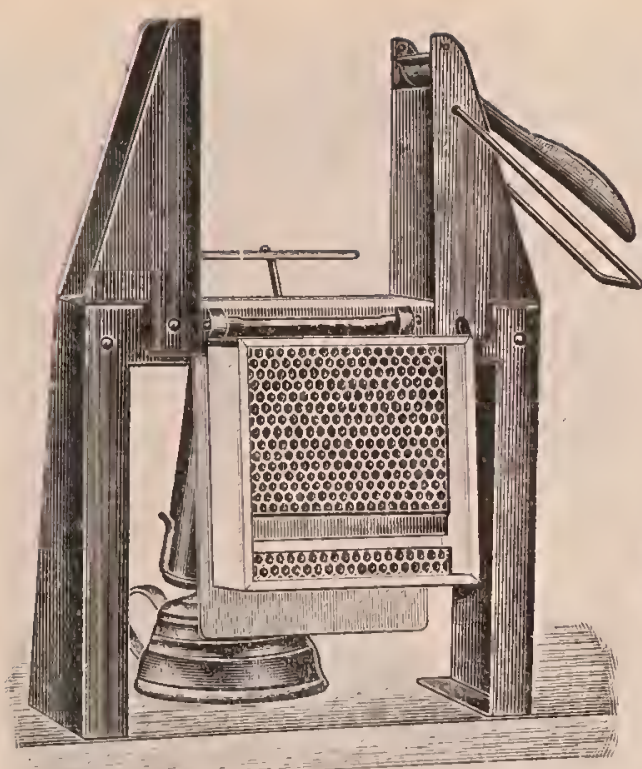

Woodman rombiued folder and foundition-fistener. This tool is construeted of metil and does fine work.

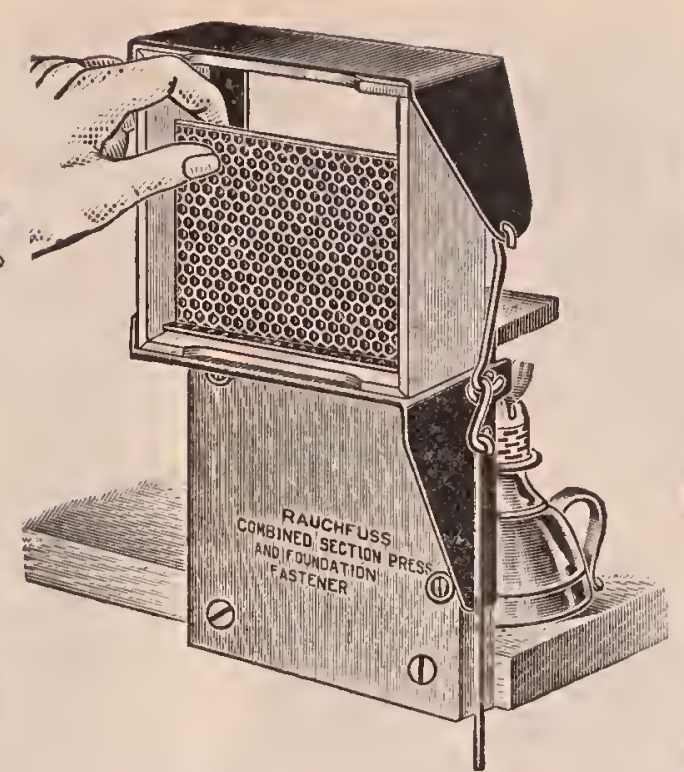

Rauchfuss rombined section folder and fastener. One of the simplest and best combined tools on the nurket.

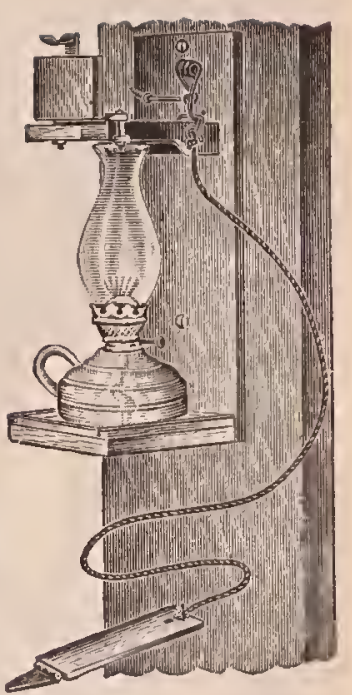

Lewis foundation-filstener. A simple and riapisl outfit.

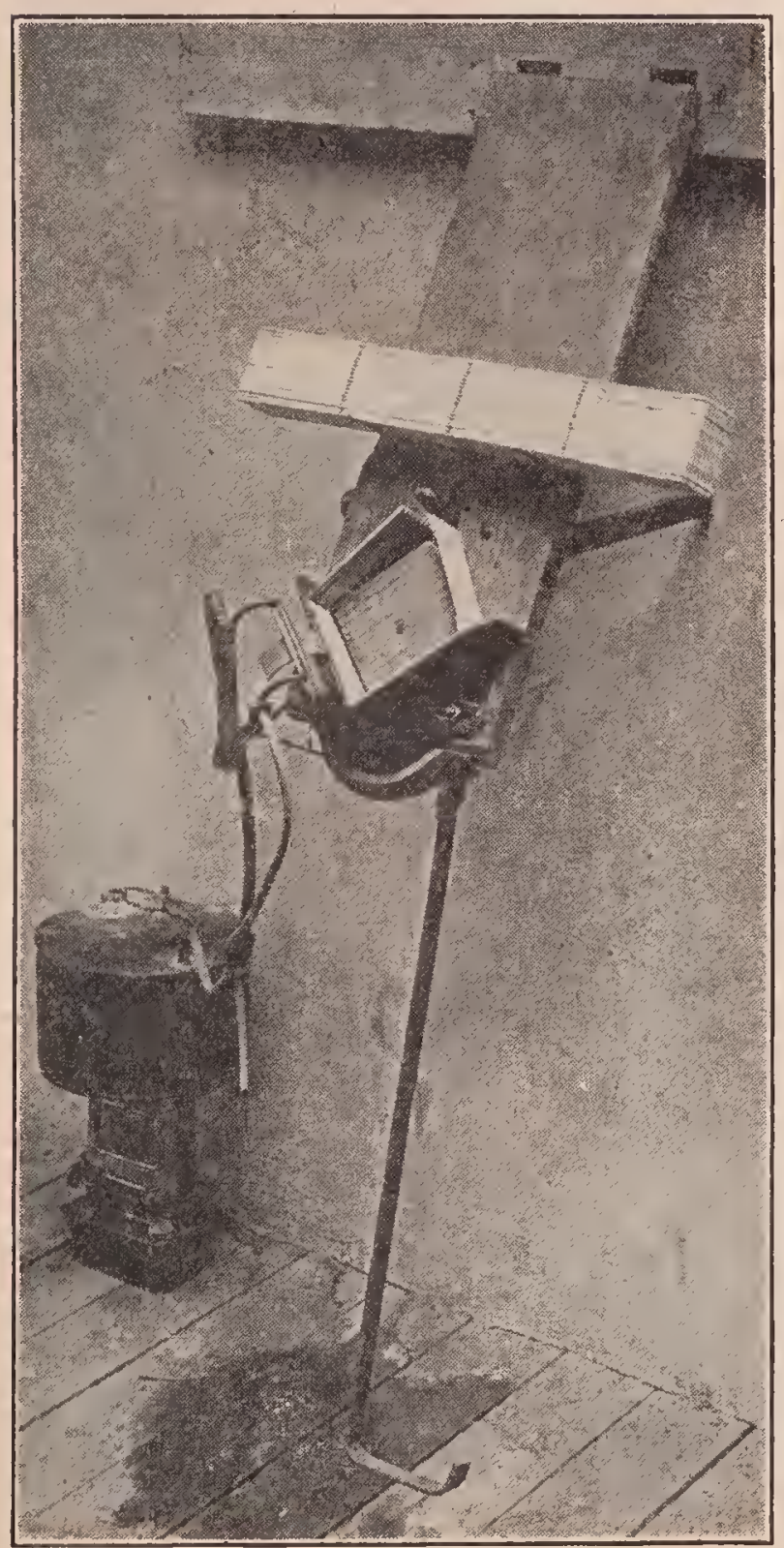

The Root section-folder and steam foundation fastener. Steam is generated in the small boiler, rises thril the tube and keeps the plate at a constant and uniform temperature. while pressing lightly on the upper elge with the fingers of the left hand, the operator should slide the hot blade under the edge of the wax as it rests against the wood. All surplus melted wax will be wiped off on to the wood so that the founration will be most firmly attacherl. The tool will remain hot long enough to fasten all four starters.

The Root steam foundation-fastener has a hot plate kept at a constant temperature by means of steam. There is no troublesome lamp to work over, no soot, and, of course, absolutely no danger of fire from wax dropping into the lamp. Moreover. the steam is also used for dampening the sections, for this deyice is a folder as well as a foundation-fastener, a most desirable feature. Sections dampened by steam are not easily broken and there is no dinger that the wood may swell so that the section when folded is dianond-shaped.

When the foot-trealle is pushed forwarl the notched ends of the section are firmly crowded together. The same movement brings the steam-lieated plate into position. The starter is dropped into place and held for an instant, until enough wax is melterl to hold it firmly. The same backwarl movement of the foot that releases the section causes the hot plate to move out of the way so that the finished section with its foundation is ready to be placed in the super. It is impossible to remove foundation so fastened without actnally tearing the sheet. 


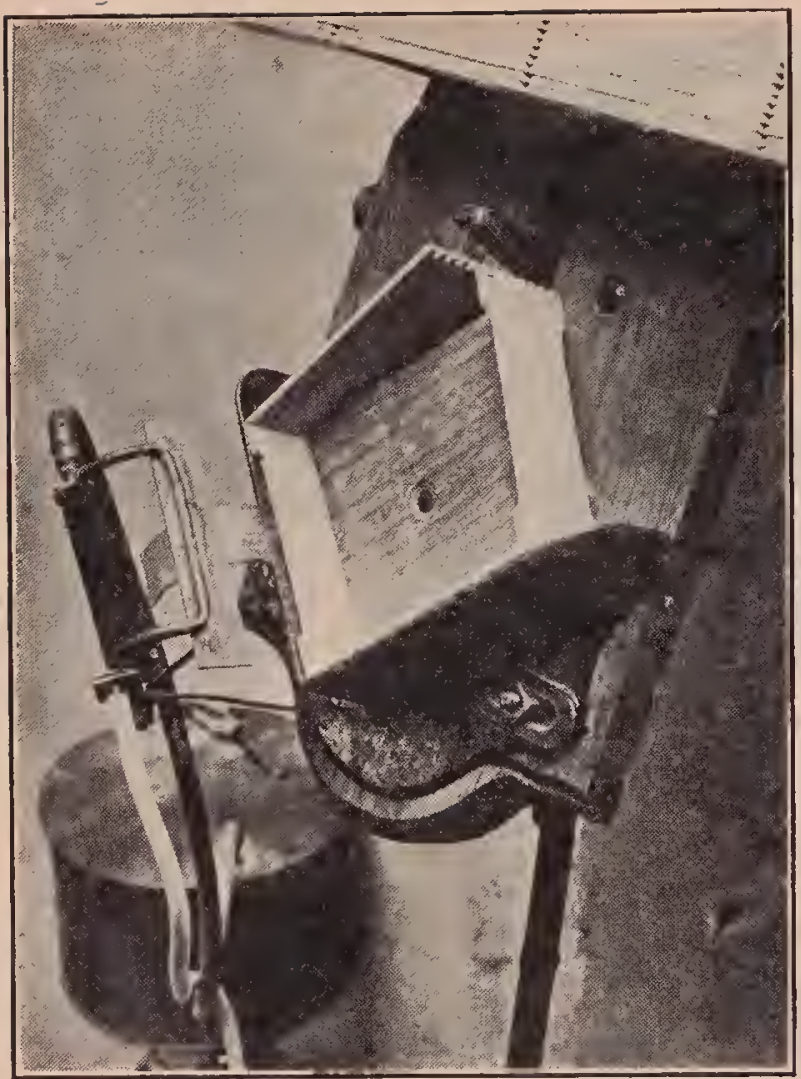

1

When the foot is in the back position the hot plate is out of the way-nothing to interfere with putting the section in position ready to fold.

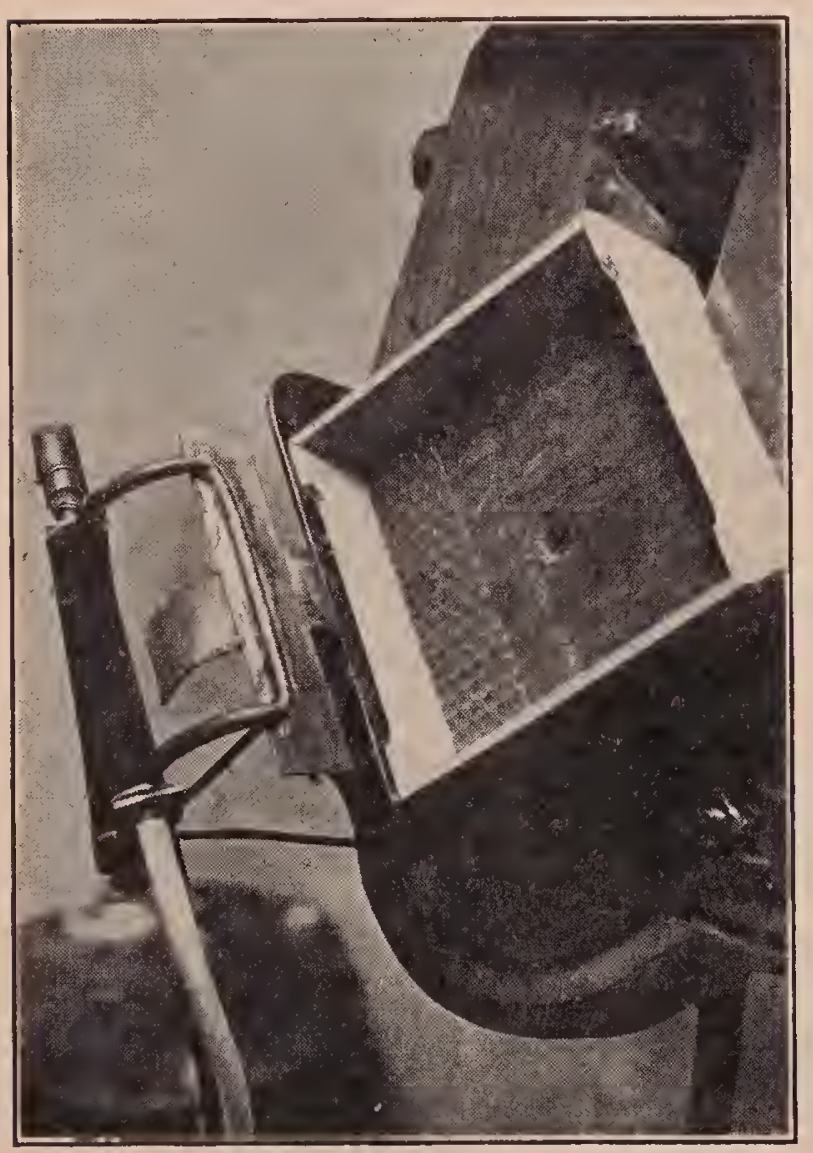

As the font swings forward, the colners of the section are forced together and at the same time the hot plate slides into position ready for the starter or full sheet of foundation to be applied.

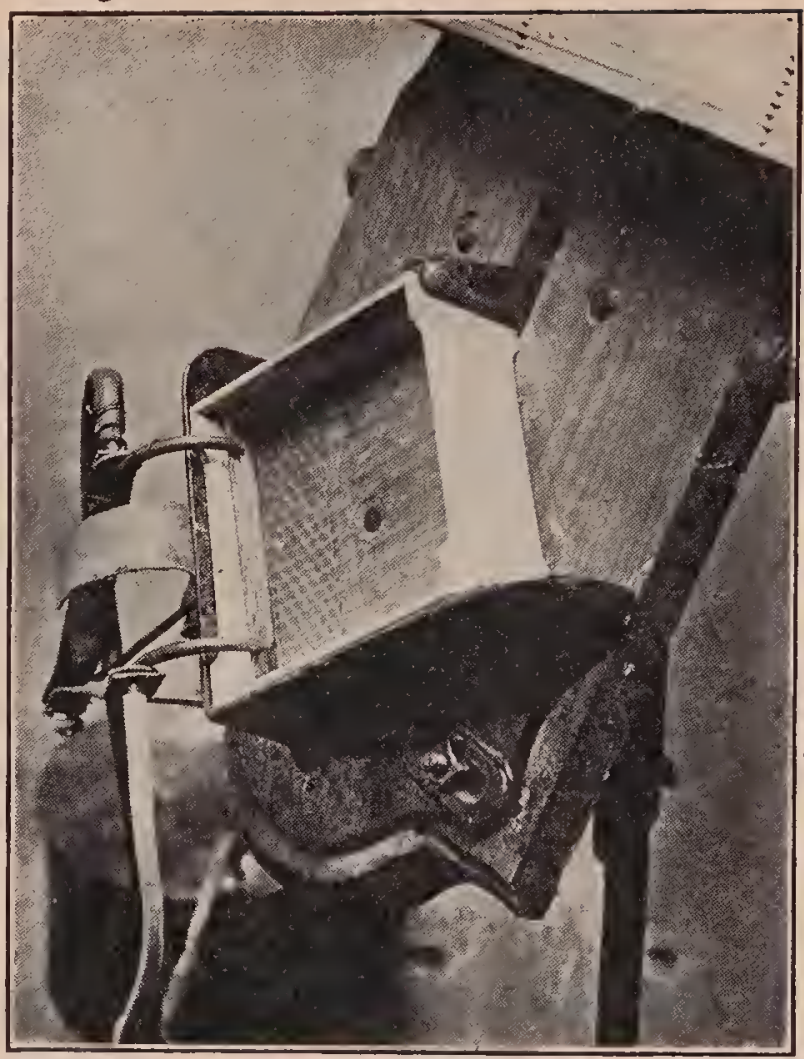

3

The movement of the foot backward slowly with. dratws the hot plate. The wax is all wiped off on to the section and the foundation is firmly "cemented" in place.

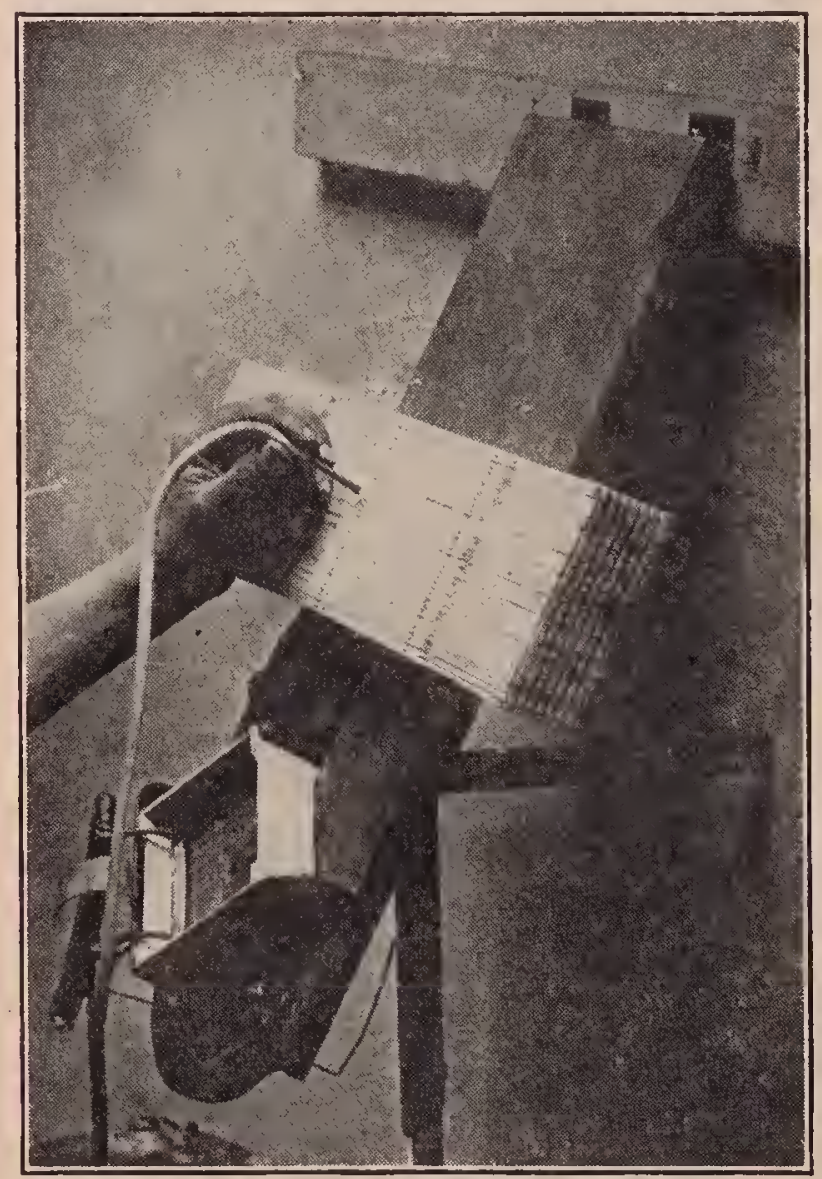

4

Fifty or seventy-five rections may be thoroly rampened in a few seconds' time by allowing the stean to blow thru the $V$ grooves. Steam-dampened stean to blow thru the $V$ grooves. Steam-dampened
rections almost never break, and the sections remain true and square. 


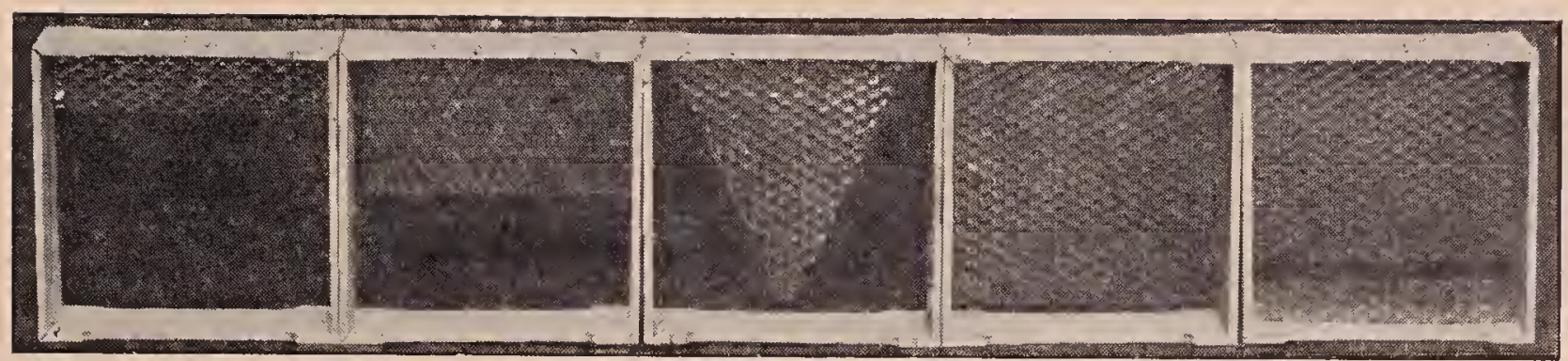

The different metlods of cutting foundation for the sections.

STARTERS VS. FULL SHEETS FOR SECTIONS.

In the illustrations under Comb Honey, slowing the supers, only narrow sheets of foundation (or starters) are shown in the sections. The expert comb-honey producer will never be content with a startel. He will buy his foundation of such size that he can cut it to suit his own individual notions. Some comb-honey producers cut it in sheets one-fourth of an incli narrower and half an inch shorter than the inside of the section. It is then fastened to the top, as shown previously, with any one of the several styles of foundation-fastener's. Others eut the sheets in the shape of a letter $V$; still other's use half a sheet.

But the great majority of producers prefer to use two pieces - a large one secured to the top, and a strip about $5 / 8$ inch wide fastened to the bottom. The larger sheet is so eut as to reacl within $1 / 8$ or $1 / 4$ inch of the bottom starter when in place to allow for stretching.

During the subsequent process of drawing out, the bees will make one complete comb, which is fastened to the top and bottom. Where only a starter or even one large slieet is put into a section, the finished comb in some instances may be fastened only at the top and part way down on each side; but when the bottom starter is used in connection witli a large sheet of foundation, there surely will be a fastening at the bottom as well as at the outer edges. The result is a comb fastened to all four sides, one that is neater in its general filling, and, in consequence, will conmmand a higher price; and last, but not least, a section that will stand shipping. A nice super of sections with combs not fastened at the bottom is liable to arrive at destination in bad condition-many of the combs broken out; and it is, therefore, always advisable to use a bottom starter.
$\Lambda$ few beekeepers adrise eutting the foundation so it will just neatly fill the section on all four sides. A section is then slipped over a block a little less than lialf

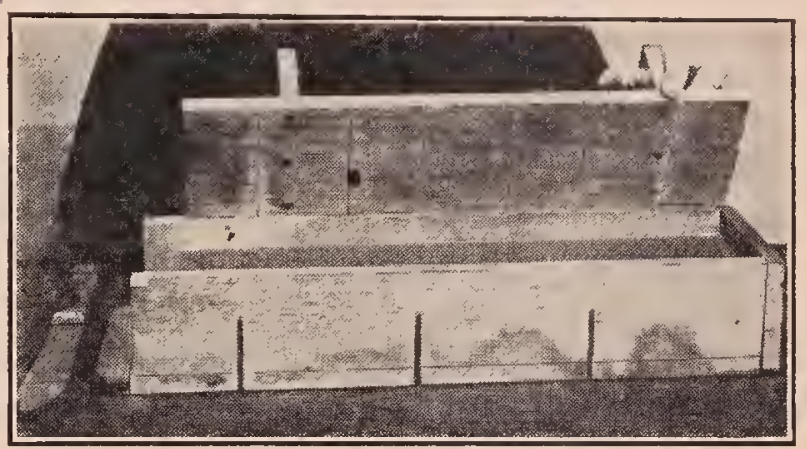

Fig. 1.

Long sheets of foundation laid in the box ready to cut. (The distance between the saw-cuts determines the size of the starter's.)

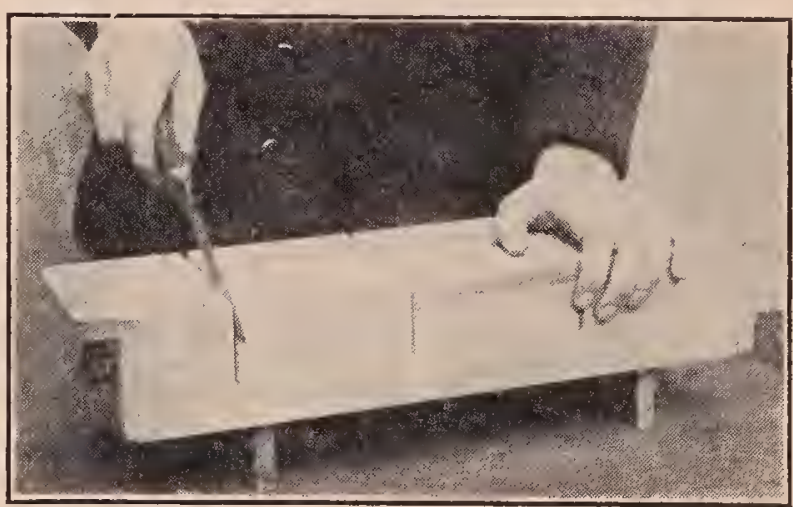

Fig. 2.

Box turned orer for ruttiug. Use sharp thin knife wet with soajusuds, and cut on drawing stroke only.

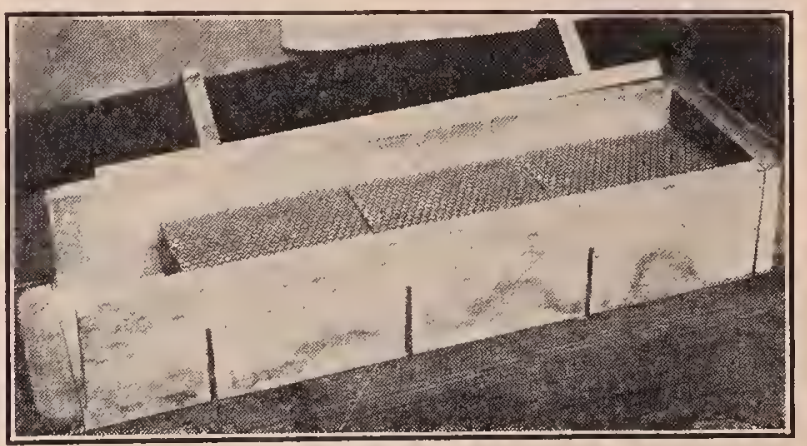

Fig. 3.

The box reversed to original position with foundition cut to size ready to take out. 
its thickness so that when one of these justright-sized sheets of foundation is laid on the block, the foundation will be perfectly entered in the section. With the Van Deusen wax tube shown on a previous page the sheet is then secured to all four sides by the stream of hot wax.

Probably the nicest plan-the one that furnishes the most perfect comb honey, is the scheme of having the section-blanks grooved about $1 / 8$ inch wide and half the deptl of the section on a medial line runliing from end to end of the blank, as shown. Squares of comb foundation cut slightly larger than the inside surface of the section are slipped into the groove before the section is folded. The foundation should not be ent so large that the sheet would buckle af the section is folded.

Neither melted wax nor hot plate-in fact, no heat of any kind-is needed to hold the sheet in place. The work of inserting the sheet is quickly and neatly done, and at the same time the foundation can expand slightly in the groove while being drawn out, "provided the sheet is not cut too large in the first place.

It should be mentioned that there is one difficulty - that of cutting the sheets of exactly the right size. If one has never used this method, he should cut two or three trial sheets and try them out first. When the sheet is cut right for the inside of the folded section there should be a slight amount of end and side play to allow for a slight expansion that necessarily takes place when the sheet is drawn out. When the right size has been determined on, a wooden f,or'm should be made as shown in Figs. 1, 2, 3, so as to eut the sheets exactly right.

Experience shows that when the sheet of foundation fills the section a much more perfect comb honey is produced than when there is a large sheet and a small one at the bottom, and certainly better than when a starter is used and fastened at the top only. If the right methods of production are employed, when these full sheets are used, the combs will be even, well filled out, without an open corner. 'Some strains of bees, if crowded for room, will sometimes run the filled cells of honey clear to the wood, without leaving any so- "alled "pop-holes," or, more exactly speaking, a line of unsealed cells next to the wood on the sides and bottom.

The best ar'angement for cutting the foundation is the miter-box. This device can be quickly made by almost any one, the construction being plain from the illusstrations. The box should be placed on a table with the saw-cuts down as in Fig. 1, and from five to twenty sheets of foundation laid in, care to be taken to see that the ends are even. Then the cleated board should be put on top of the slieets of foundation, and the box turned over so that it rests on the eleats, as shown in Fig. 2. For cutting, a keen-edger butcher-knife should be used. It need not be hot, if kept well lubricated with soapy water. The knife slould be held at an angle as shown, and moved rapidly but lightly back and fortl, entting only on the drawing stroke. If the saw-cuts are carefully spaced and the whole box put together in a square workmanlike manner, the sheets can be quickly and accurately eut.

COMB HONEY.- While all honey in the comb is what may be called "comb honey" yet the term as ordinarily used refers to small squares of comb, built into frames of wood technically called section honey-boxes, or "sections" for short; therefore all references to comb honey, whether in the mal'ket quotations or in the ordinary literature relating to bees, are understood to apply to the article built in sections.

More recently little chunks of sealed comb honey about an inch and a halt square are being put up in paraffin paper; and the whole slipped into a neat little carton. This is what is called the "individual comb-honey service," and may be found in some of our best restaurants, hotels, and dining-cars.

In the southern States there is another article called chunk or "bulk comb honey." The combs are built usually in shallow extracting-frames, and cut ont in varioussized chunks of a size that will fit tin buckets or glass jars. The spaces between the combs and around them are filled with a good quality of extracted honey. They are sealed or covered with the ordinary covel of the tin bucket. Bulk comb honey is prodnced very largely, particularly in tlee 
South, and where bull honey is sold, very little comb honey in sections is produced. Bulk comb honey lias the advantage that it does not require as much skill to produce it as the ordinary comb honey in sections; neither is it necessary that every piece of comb be as perfect as to capping, filling, $\mathrm{or}^{\circ}$ shape. In localities where there is any suspicion of manufactured comb honey, bulk comb honey is readily sold. Generally speaking, its sale is confined to the southel'n States-Texas and the Southwest, while in the North, and practically all the rest of the United States, comb honey is put up in sections.

The time may come, however, when collsumers everywhere will learn to appreciate bulk or chnnk comb honey, especially after they learn that it costs less to produce and at the same time retains nearly all the fine

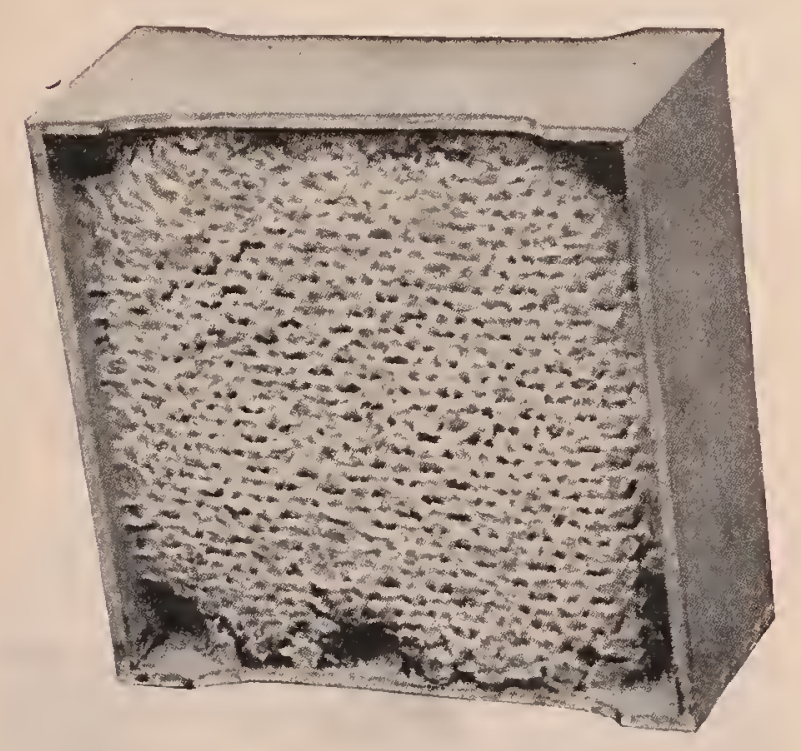

cating qualities of the article in sections. It may also come to pass that cut comb honey wrapped in paraftin paper, and further protected with a neat carton, will take the place of section comb honey. There is no doubt that such honey will ship better than comb honey built solid in sections.

The greatest objection to the use of bulk comb honey in the northern States is the danger of the liquid portion granulating. When this takes place the whole will have to be melted up in a wax-extractor, even tho the comb honey is not candied.

When the extractor was first invented, in 1865, it was supposed that nothing but honey out of the comb would be sold for the reason that it could be producer 8 more cheaply. But our best connoisseurs now know that even our very best extracted loney seldom has the fine delicate aroma of loney that is lield in the comb, just as nature gives it to ns. Comb honey holds the flavor and the delicate aroma of the individual flower's from which it was gathered much better than after it is removed from the comb. The flavors of honey, it is said, are made np of ethyl alcohols that are very volatile. It follows that, when the honey has been removed from its original container, on exposure to air, it loses some of its flavor, especially if it be heated to prevent granulation. (See Extractels Honey, Bottling Honey, and GrantLATED HoNEY.) If ever a majority of consumers prefer comb honey, it will be because to them it has more flavor, and because, probably, the erushing of the delicate cells in the mouth gives the eater a certain degree of satisfaction since he has something to "chew." Extracted honey on the other hand is swallowed, while comb honey is masticated, or "chewed," as food should be. Of course the little pellets of wax, after the honey has been eaten, are grenerally expelled. To some this very accumulation of wax in the mouth is an objeetion, and many will be found who prefer extracted honey, because they prefer to have something they can chew on bread and butter and bisenit, without having wax mixed with the food.

Comb loney has been determined by Professor Hawk, the great foor specialist, to contain vitamines. By referring to the article, Vitamines in Honfy, it will be seen that these are an inscrutable something that makes life and glowth possible, without whicls the areinge animal or man wonld die in a complaratively short space of time. While it has not yet been proved that extracted honey contains vitamines, it has been sl.own that comb honey does. For a fullel examination of the subject, see Vitamines in Honer, at the rlose of this book.

Infortunately of late years, many honeydealers have refused to handle comb honey because of the amount of breakage and leakage and the tendency to granulate after rold weather has set in. The result is that the demand for extracted has increased 
while the call for comb honey has become less and less. That is wrong. So long as it is admitted that comb honey has a little finer flavor than the same honey out of the comb, beekeepers should foster the demands of all classes of consumers. When it is remembered that comb honey, as a rule, retails at two or three times the price of extracted, it goes to show that there are thousands and thousands of consumers who prefer honey in that form, even if they have to pay double price.

In the early 80 's the statement was made that comb honey could be manufactured"combs marle out of paraffin, filled with glucose, and capped over with appropriate machinery." This canard went like wildfire over the country; and even to this day there are some who believe that honey in sections is manufactured, because it is unlike the honey they saw on the old farm. Except in a very small, way it is impossible to make honeycomb as perfect and delicate as the bees do. On a commercial basis it is an utter impossibility. Dies could be made that would press wax in a semi-melted condition in the shape of a honeycomb. So far, so good; but it would be impossible to make any dies that will free themselves from the comb after it is pressed into shape without tearing' the comb to pieces. Any mechanic or die-maker knows that the idea is utterly absurd. Even if it were possible to construct the combs, it would be impossible to fill them with glucose, and equally impossible to spread a film of wax orer the filled cells that wouhl come anywhere near imitating the appearance of comb produced by the bees. Any consumer who has a suspicion that combs in sections are manufactured, has only to look over a dozen or more sections at any grocery. He will find no two of them alike. If combs were built from dies, they would appear all alike, like the common rough-faced cement blocks which are made in one mold. But a comparison of any two boxes of comb honey will show that bees make each section different from all others. The attachments at the sides of the sections rary, as well as the surfaces of the cappings.

It is hardly necessary to tell the reader of this work that combs are not manufactured; but sometimes he will meet prospective eustomer's who will tell him in the most brazen way that the product he is trying to sell them is "manufactured."

\section{COMB HONEY, APPLIANCES FOR.}

- Years ago, most comb honey was produced in glass boxes. These were about five inches square, fifteen or sixteen inches long, glassed on both ends. They were not altogether an attractive package, and were never put upon the market without being more or less soiled with burr-combs and

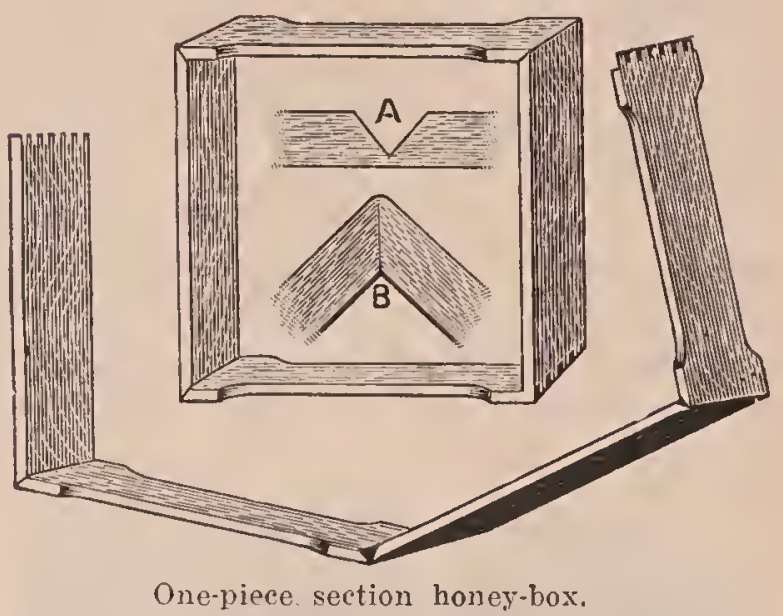

propolis. As they held from 10 to 1.5 pounds of honey each, they rontained a larger quantity than most families earerl to purchase at once. To obviate these and other diffeulties, what is popularly known as the "section honey-hox" was invented, holding little less than a pound.

It was what was wanted-a small package for comb honey. Thus was aceonl-

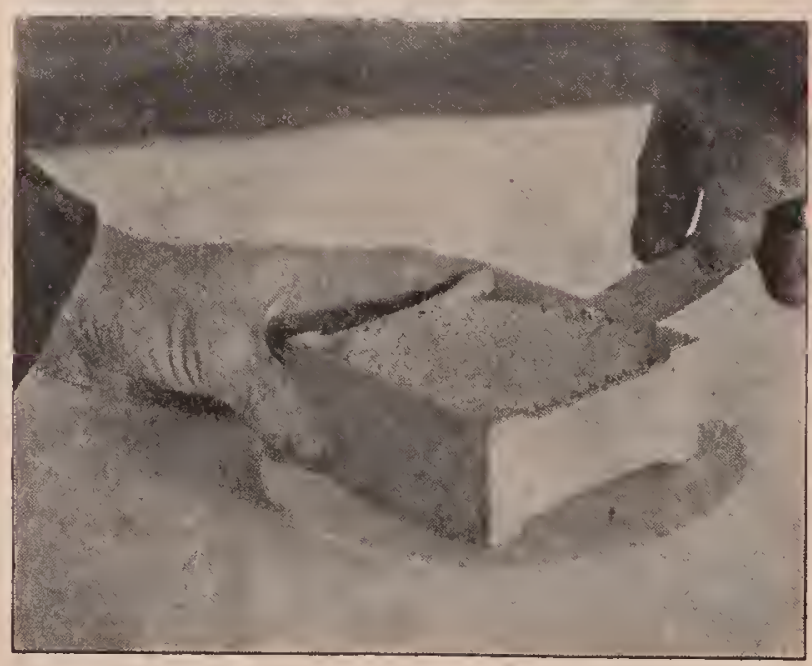

plisheid, not only the introdnction of a smaller package for comb honey, but one attractive and readily marketable. The retailer is able to supply his customer with a small quantity of comb honey without 
daubing, or fussing witl plates. The houservife, in turn, has only to lay the package upon a plate, pass a common table knife around the comb, to separate the honey from the section proper, and the honey is ready for the table, without drip.

WHAT SIZE OF SECTIONS TO USE.

A fer years ago there were a good many varieties and sizes and styles of sections on the market. For instance, there were the tro-pound prize sections, the half-pound sections, and three-quarter pound sections; but in later year's everything has been reduced down to practically three styles: viz., the $41 / 4 \times 41 / 4 \times 17 / 8$ beeway sections, the plain $4 \frac{1}{4} \times 4 \frac{1}{4} \times 1 \frac{1}{2} ;$ and the $4 \times 5 \times 13 / 8$ plain sections. All of these three hold a scant pound of honey, section included; but under the federal net-weight law (see LABELS) and some state laws it is not permissible to include the square of wood around it, and therefore the section must be sold in weights from 10 ounces for the lightest to 14 ounces for the heaviest.

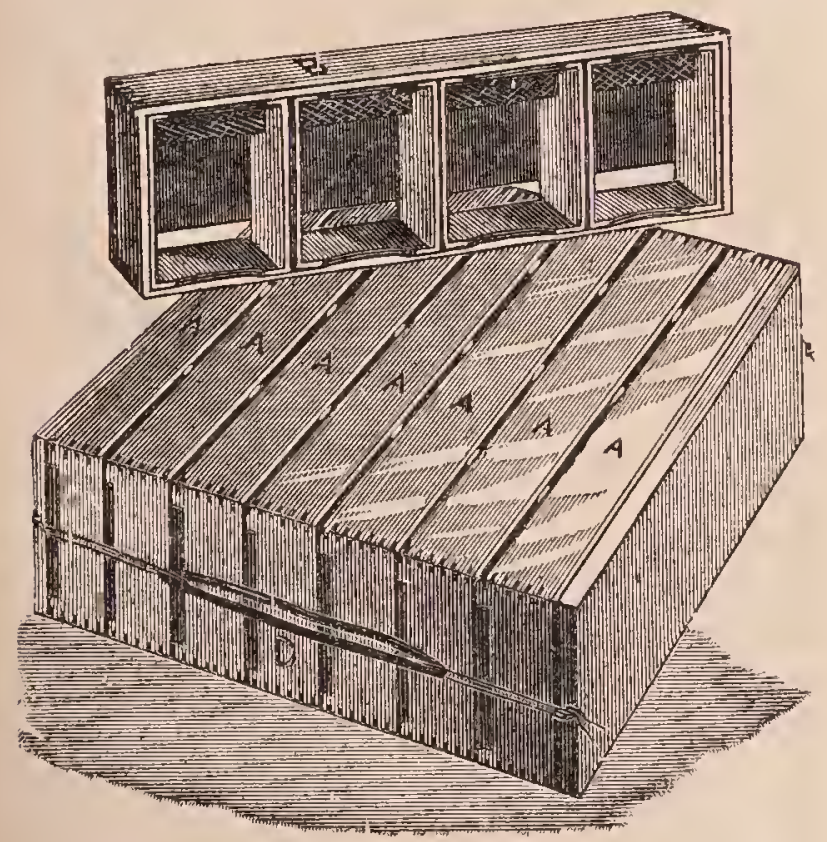

Doolittle's single-tier wide frames.

While it might be desirable to have something holding an even pound, yet no two sections will run exactly the same weight. See Grading Comb Honez.

\section{TALL VS. SQUARE SECTIONS.}

The standard section for a good many years has been and is $4 \frac{1}{4}$ inches square; but, notwithstanding, during all this time, a good many beekeepers, principally in New
York, have been using a section taller than broad. The late Capt. J. E. Hetherington, who had the reputation of being the most extensive apiarist in the world, used a section $37 / 8 \times 5$. Other beekeepers in New

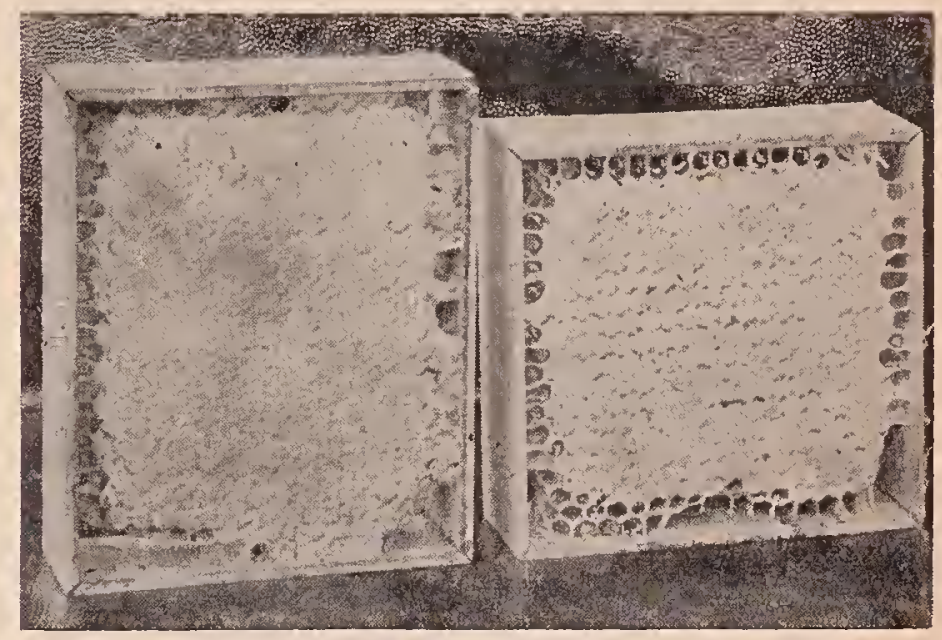

Comparative size of tall and square sections of the same weight.

York use them slightly larger or slightly smaller, but of the same proportion. See Hives.

Some of the reasons that have been urged in favor of the tall sections are as follows :

1. Weight for weight, and for the same thickness of comb, a tall section presents a bigger appearance than the arerage square one. In the $4 \times 5 \times 13 / 8$ tall plain section, for example, there is about the same actual weight as the $4 \frac{1}{4} \times 41 / 4 \times 1 \frac{1}{2}$ plain; and yet, as will be seen by the engravings, the former looks the larger. As a result the tall box brings in some of the markets from one to two cents more per pound, but in other markets it brings no more. If this were the only reason why the tall box is preferred, we would say nothing about it here; but there are other reasons for this preference.

2. By long association we have come to like the proportion of objects all about us that are taller than broad. Doors and windows of their present oblong shape are much more pleasing than if square. Nearly all packages of merchandise, such as drugs and groceries, are oblong in shape-that is, taller than broad. To cater further to this taste, brought about by long association with the common objects around us, the tall section was introduced, and outside of its relative appearance of bigness as com- 
pared with the square box, rery many consicler the tall one much more pleasing.

3. R. C. Aikin, one of the closest observer's in all beedom, laid it down as a rule that "in comb-building the downward progress exceeds the sidewise in the proportion of about three to two . . . . It, then, comb construction goes on in this way, a section as wide as deep will be finished down the center before it is at the oiter. erlces." A tall section, then, more nearly conforms to the natural instincts of the bees.

4. A greater number of tall sections holding approximately a pound can be accommodated on a given hive surface.

5. A tall section will stand shipping better, because the perpendicular edges of contact of the comb itself are greater than in a square box. This is not theory, but shipments of comb honey by the carload prove this.

GLASSED SECTIONS.

Glassed sections were simply sections of comb honey with squares of glass fitted in between the projecting sicles of the section. The glass was held either by glue, tin

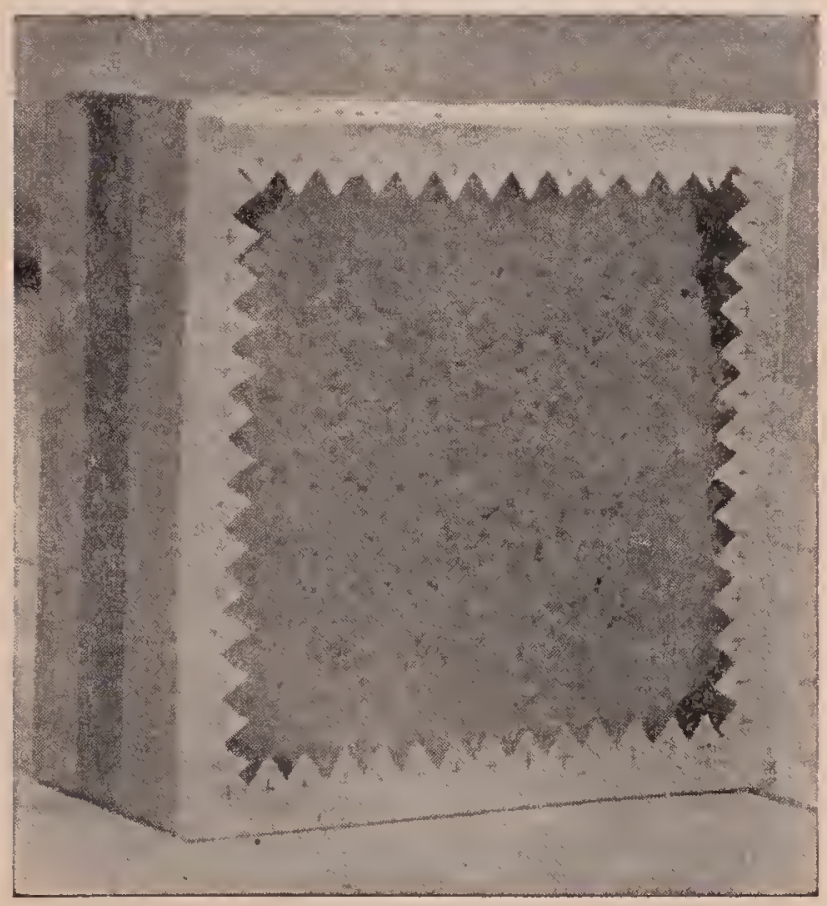

An English glassed section

points, or paper pasted over the top and bottom of the section, and lapping orel upon the glass a little way. When the section was sold to the retailer, the glass wis inchuled in the price of the honey. Of comse, the protucer could afford to sell glass at the price of the honey per pound; bnt under the federal net-weight law this is prohibiter. On account of the fact that the producer has to pay the cost of the glass, glassed comb honey has practically disappeared from the market.

\section{PASTEBOARD CARTONS FOR ONE-POUND SECTIONS OF COMB HONEY.}

While sections with glass panels have been practically eliminated from the niarliet, ('omb honey in paper cartons is becom-

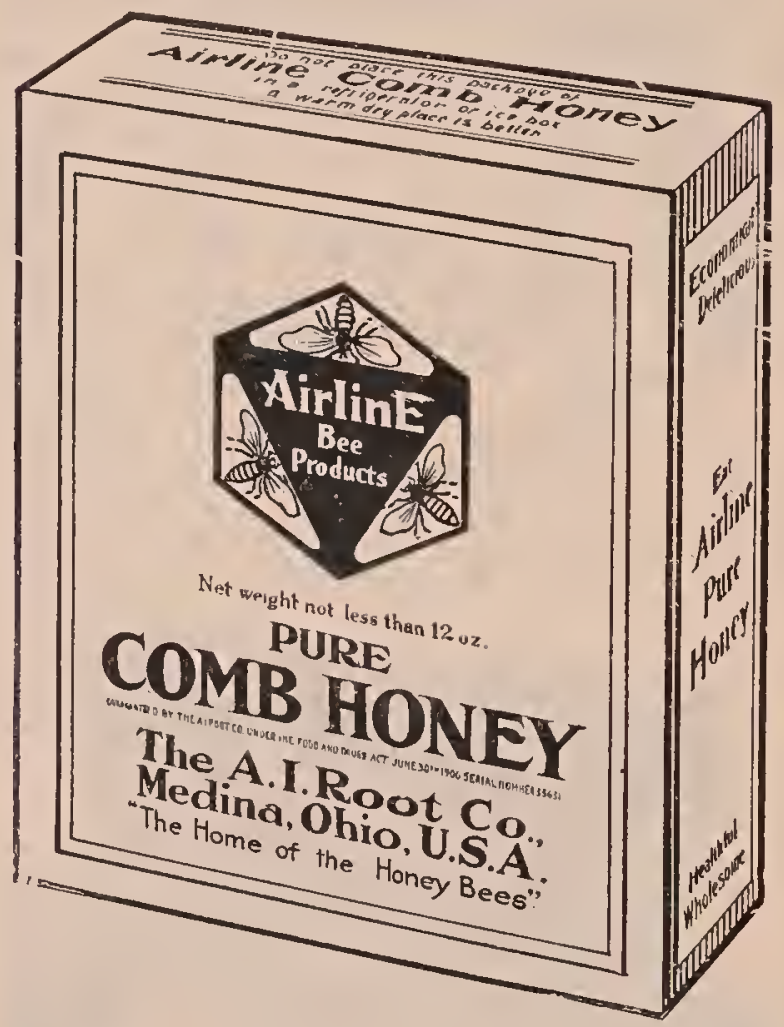

ing more and more popular. In some cities a definite ordinance requires that all food packages be sealed to keep out insects. and especially flies, that "ary the germs of disease. It is evident that legislation of this kind will go from eity to eity and from State to State. But suppose there is or will be no legislation, the housewife sometimes has trouble with a section of honey breaking and leaking over her groceries when delivererl. She will thereafter buy her comb honey put up in neat cartons" that specify the exact weight of the honey, not inclurling the section, as it is not allowable to sell the section by weight, section and all.

Several attractive designs of cartoner (ounl) honey are now on the market; and the fact that the demand for comb honey

* The paper cartons are comparatively cheap and can be given awa with the honey. The glass-panel scheme proterts the honey but it is too expensive to furnish with the honey. 
in this shape is growing, even where there is 110 legislation requiring sealed packages, shows that not many years hence comb honey will have to be put ip in that form. if for no other reason than to shut out the typhoid house fly.

Some beekeeper's sell their honey in folding cartons, the top) and bottom sliding into slits provider. But such cartons do not seal the packaye hermetically.

The publishers of this work lave for several years back put out a package sealed with glue under the name of "Airline," such name being drawn from the name of A. I. Root, the original author of this work. and presirlent of the company. $\Lambda$ illine means beeline: and the fact that the A. I. Root Co. is selling comb honey in these sealed packages -tens of thousands of dollars in value-shows that the demand for comb honey put up in attractive form. and sealed from the typhoid fly and other. insects, is on the increase.

For hints on marketing see Fxtrar"TEn Honer, Bottuing Honet, Pendung HonEY, and particularly Marketrang Honer, found in their alphabetical order:

DEVICES FOR HOLWING SECTIONS WHJLE BBFIXG FILLEI) ON THE HIVE.

Sections rammot rery well be placed on the hive to be filled by bees without some sort of arrangement to hold them. There are a score of different sorts of wide frames, racks, trars, boxes, clamps, all of which possess some special features. It would be impracticable to show all of them; but for the sake of illustrating some principles it may be well to mention some of those that have been used most largely.

What was known as the double-tier wirle frame was perhaps the first device for holding sections in the hive. This consisted of a frame of the same inside repth and length as the ordinary brood-frame, but of the same widtl as the section, eight sections to the frame. It was used very largely for a while. lout in the course of time it was discovered that it had several oljectionable features. First, a whole hivefinl of them grave the bees too mueh eaparity to start on : and, as a consequence, this discouraged them from beginning work. Second, they did not permit tiering up to advantage.
The Dorolittle surplus arrangement consisted of a series of single-tier wide frames having no projections to the top-bars, altho shallow wide frames have been marle with such projections. Both the double and single tier wide frames har the merit of protecting the surfaces of the sections from travel-stain and bee glue.

\section{T SUI'El?.}

The 'T super at one time was one of the most popular forms of section-riates, and a few prefer it to anything else. It is so named for the $T$ tins that support the sections. The tins are folded in the form

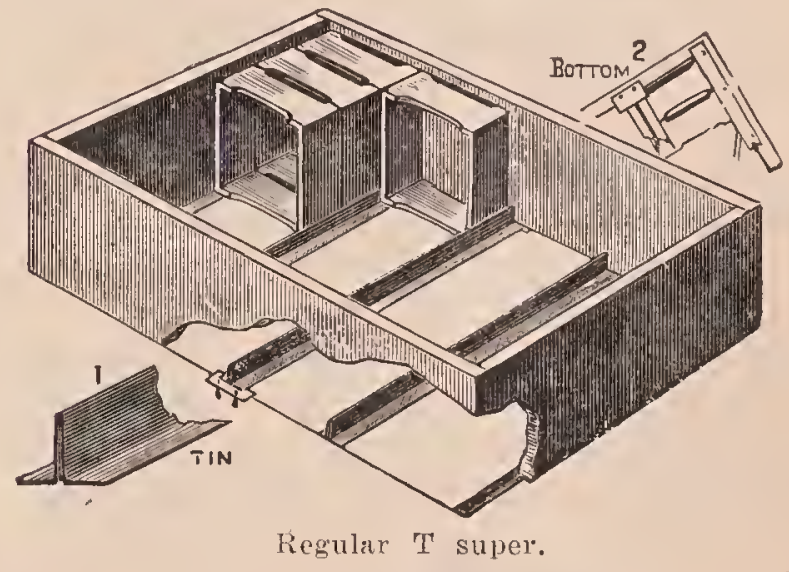

of a letter $T$ inverted, such construction making a rery stiff and rigid support. This appliance takes separator's very nicely, the separators resting on the ' $\mathrm{T}$ tins.

Some, like the late Dr. Miller, prefer to have the $T$ tins rest loosely on a little piece of strap iron, or bent staple, both for conrenience in filling the supers, and in emptying the same after the sections are filler. But there were other's who objected to

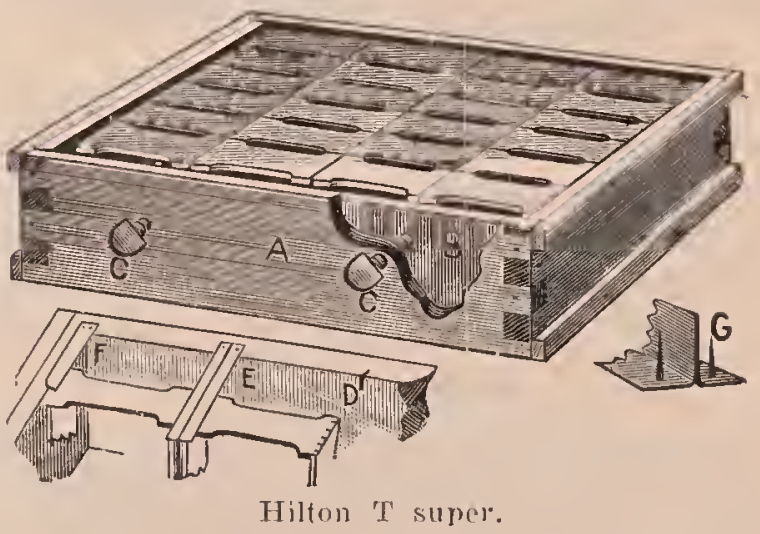

loose pieces, and preferred the super with stationary tins, the tins being nailed to the hottom inside edges of the super.

But the ' $\mathrm{T}$ super has its objections. If the sections are inclined to be a little out 
of square, or diamond-shaped, when folded, they will not be squared up in the $T$ super unless an extra set of $\mathrm{T}$ tins or strips of wood are used to fill up the gaps between the rows on top. And, again, it is not practicable to alternate the several rows of sections. Sometimes, in a poor honey flow, it is desirable to move the center row of sections to the outside, and the outside to the center.

SUPERS WITH SECTION-HOLDERS FOR BEEWAY SECTIONS.

The doretailed super with section-holders for beeway sections is the form of super that has been, perhaps, used more largely than any other. It is a sort of compromise between the old-style wide frames and the $\mathrm{T}$ super. It consists of a series of section-holders that are open at the top. Each holder is supported at the end by a strip of tin nailed on the inner erlge of the ends of the super.

Four sections in each section-holder are held snugly and squarely in position with no spaces between the rows of sections as in the case of the $\mathrm{T}$ super. When beeway

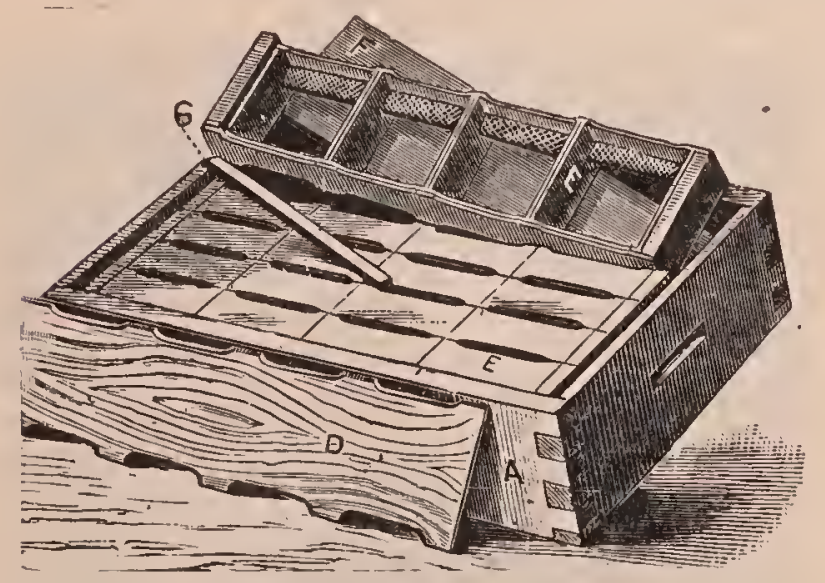

Super for beeway sections.

sections are used the bottom-bars of the sections are scored out to correspond with the beeways. Between the rows of sections is dropped a wooden separator, as shown at $\mathrm{D}$.

\section{SUPER SPRINGS.}

In the illustration of the Hilton super, it will be noted that thumbserews are used to crowd a follower up against the sections. In the other form of $\mathrm{T}$ super a super spring between the side of the super and the follower performs the same office. Indeed, this spring is nsed nowaday's in nearly all modern section-super's.
'There is no denying the fact that in any form of surplus arrangement the sections and separators should be squeezed together to reduce accumulations of propolis. The objection to thumbscrews or wedges is that if the sections in a super become swelled

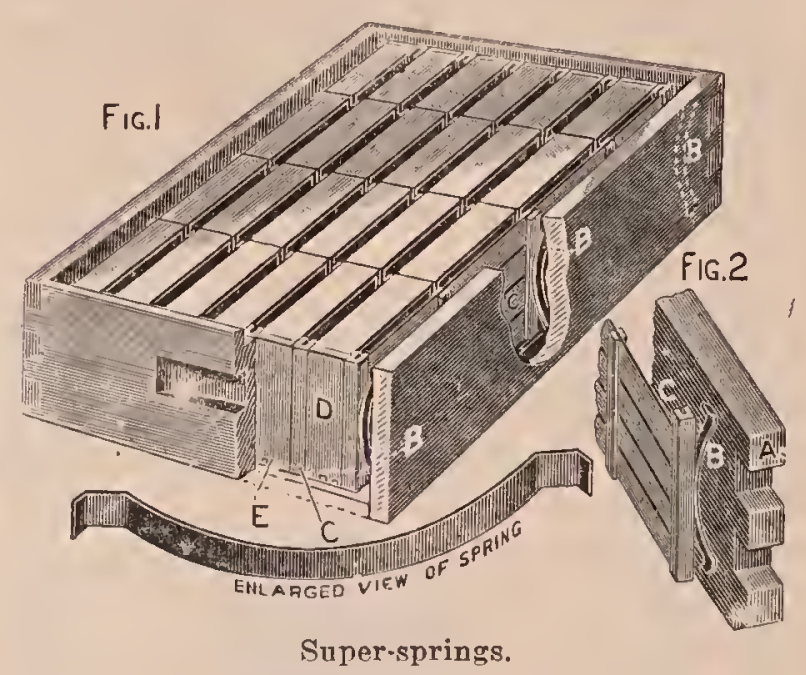

by dampness, the rigid screw or wedge becomes stuck and this sticking makes it hard to remove the sections. If the joints of the sections have been moistened to prevent breakage when the sections are folded, when the super is put on the hive there is a slight shrinkage. This shrinkage makes more trouble than swelling, for the contents of the super become so loose that the woolen wedges fall down, leaving the sections very loose in the super. Of course. the bees improve the opportunity to crowd a line of propolis in all the cracks.

To remedy all this trouble the steel super spring luas come. Its pressure is constant. It adapts itself to any swelling that may occur, and equally adapts itself to any shrinking, so as to press the parts together at all times enough to prevent the bees from crowding in propolis.

In the illustration it will be seen at $B, B$, $B$, that a spring is crowded vertically between the side of the super and post of the fence. When a follower is used, two springs (one at each end) are crowded vertically or diagonally between the side of the super and the follower. Some use only a single spring at the middle of the follower.

\section{SEPARATORS.}

In connection with appliances for holding sections in the hive, there is a derice known as the separator, or fence. These 
separators are put in alternation, one in a place between the several rows of sections. Each separator consists of a strip of wood or metal a little less in width than the leight of the sections, and in length equal to four sections standing side by side, or the separator may be a fence made

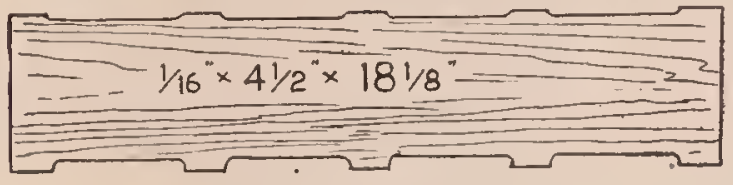

Separator.

of the same size, but consisting of horizontal strips. The purpose of the separator. or fence is to prevent the bees from building their comb from one section to another. Without them the sections or combs would be irregular in weight and unmarketable. Some will be too lean, while other.s will be so fat that their surfaces will be bruised by coming in contact witl other' sections when they are put in a shipping case for urarketing.

Since the net-weight law went into effect (see Labels; also Grading Comb Honey) unseparatored comb honey camnot be graded satisfactorily. The law has in effect made the use of separators imperative.

\section{THE FENCE -AND PLALN-SECTION SYSTEM.}

The sections and section-supers shown. heretofore have been of the beeway type. Broor-frames, when in the live, must be placed a bee-space apart; so also must the sections. Almost the first honey-boxes that were introduced had the bee-space cut out of the top and bottom of the sections

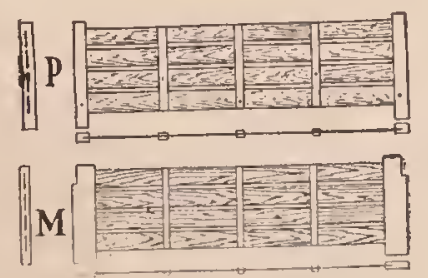

Fence.

thenselves, so that they could be placed directly. in contact with each other or the separator. This kind of sertion continued' almost up to 1897 , when there was intıoduced a section without beeways, luaving. plain straight edges all around. This lad been used for some 10 or 12 years previously by various beekeepers who found it to be in every way satisfactory. But plain sections (even width all around, witlout beeways) necessitate some scheme for holding them a bee-space apart while on the hive. Arcordingly, a separating fence was derised, having transverse cleats at regular intervals on both sides, binding the series of slats together-cleats so spaced as to come opposite the uprights in the sections. It will be seen that the fence system provides for a narrower section, and yet this same section holds as much honey

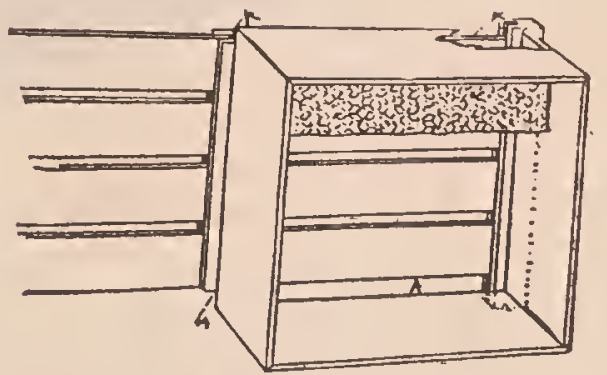

as one $3 / 8$ incl wider, because the extra width is taken up by the thickness of the cleats on the fences, als shown at $\mathrm{A} \Lambda \mathrm{A}$ in previous cut or what would be in the old section two beeways of 3-16 inch each. In the euts shown below there are specinens of beeway sections and no-beeway, the last being generally termed plain sections. 'T'le plain save a little wood, and consequently
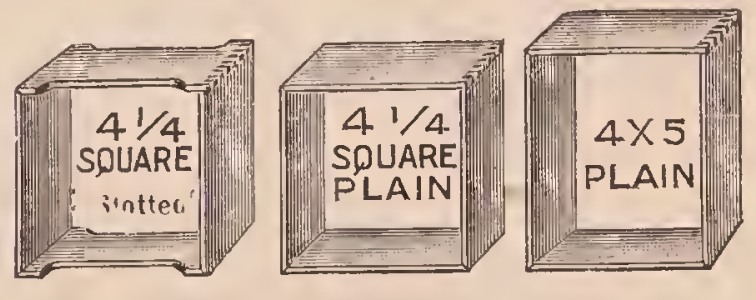

Beeway and plain sections.

take somewhat less room in shipping cases. The twelve and twenty-four pound shipping cases can be made somewhat smaller. because it is not necessary to have each comb bee-spaced apart in the marketing cases, the same as while on the hive. Moreover, the plain straight edges of plain sections offer special arlvantages in the inatter of seraping. There are no insets, often roughly cut (as in beeway sections), to work into and around with a scrapingknife. A single sweep of the linife on each of the four edges will remove the propolis, or, better still, if the blade of the linife is long enough, one can scrape 


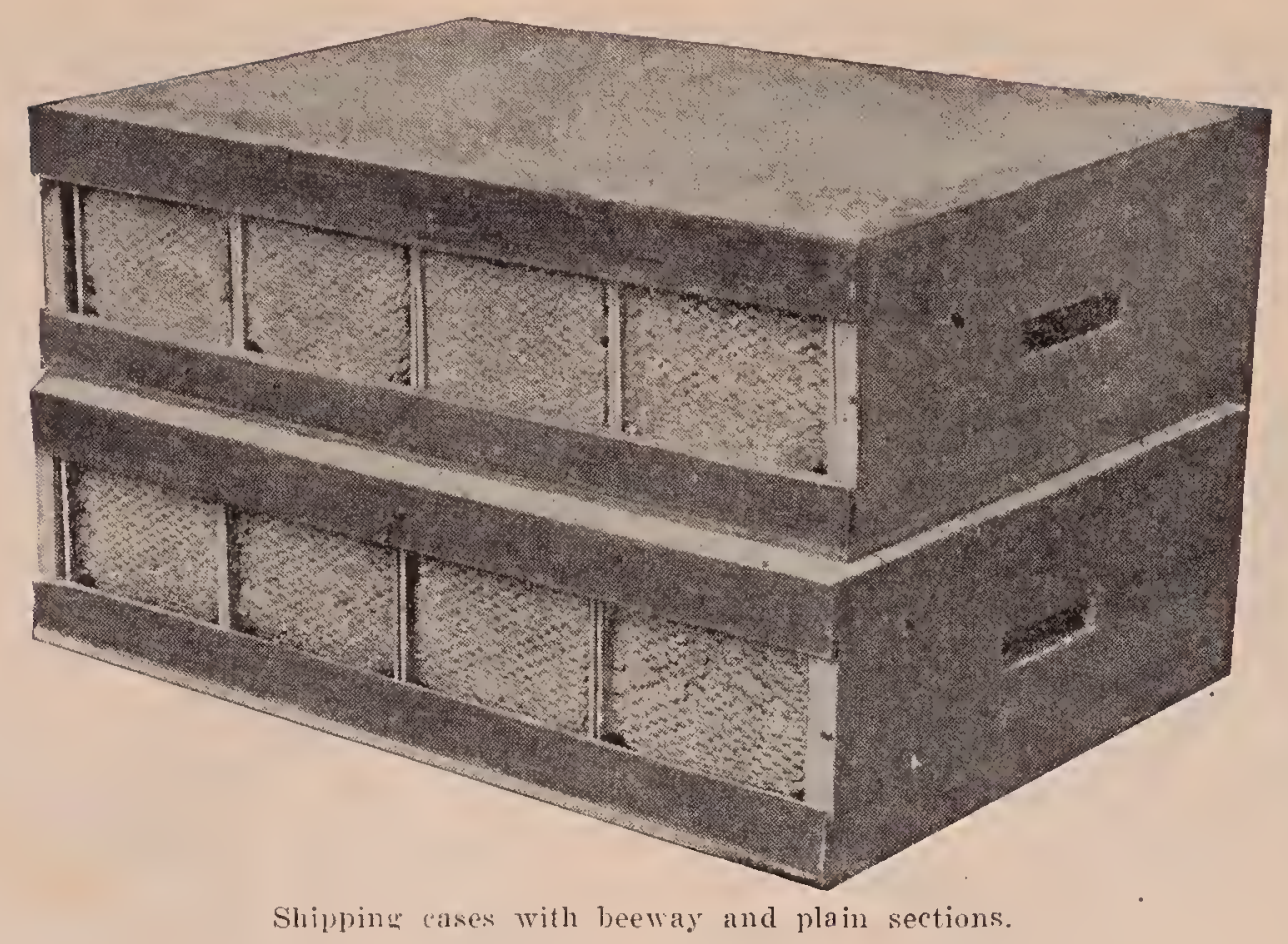

two edges at a time. Weight for weight, and of the same filling. a comb in a plain section looks fuller than one liaving beeways. The illustration on this page shows beeway sections in one slipping case. and plain sections in the other. (Plain sections in upper case.)

The fences are made up of a series of slats having a scant bee-space between each slat; and as the cross-cleats, or posts, are $1 / 2$ inch shorter than the length of the section, the beeway is very much wider. Instead of being a narrow opening thru the top as in the old section, the opening is clear across the top, and part way down and up each of the sides. This gives the bees freer communication, and, in consequence, has a tendency to reduce the size of the corner holes in each section.

Horizontal openings between each of the slats allow free communication from one section to another, not only crosswise but lengthwise of the super. On account of this a good many have already testified that they secured much better and nore perfect filling of combs in plain sections than in the old style with solid separators: that the bees enter plain sections sooner. and that in some malkets hetter prices are secured. There are other's who say they can see no difference.

Under the same conditions the plain sections will be filled no better than the beeway. If there is any lifference in the filling, it is because the one offers special advantages in the way of freer communication. In the ordinary old-style, with solid separators, each section, so to speak, is shut off in a little box by itself, and it has been proven that bees are disinclined to work in little compartments almost completely shint off from the rest. Open-corner sections. divided off by means of slatter separators, without cleats, should and would be filled just as well as plain sections dividerl off by fences. 'l'he conditions will be precisely the same, because the beeways, made part and parcel of these sections, exactly correspond to the beeways (cleats) on the fences. But one would lose many of the advantages of plain sections, if he were to adopt the open-corner boxes. They would not look, with even filling, as pretty as plain sections.

\section{SUPERS FOR PLAIN SECTIONA.}

In the main, supers for plain sections differ very little from the section-holder super already slown and described for the old-style sections. The section-liolders themselves are the same width as the sections. Petween each row of sections in a section-holder is placerl a fence, the endpost of the fence resting upon the strip of tin nailed on the bottom inside edge of the end of the super. An arlditional fence is inserted on the outside of each outside row of sections, because it was demonstrated by 
S. 'T'. Pettit that a perforater diviler, or what is exactly the same thing in principle, the fence, when placed between the ontsile rows and the super sides, will result. in

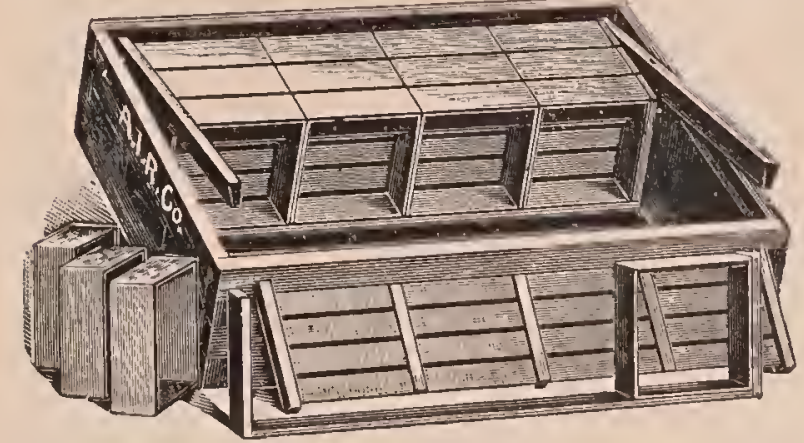

Snjer for $4 \frac{1}{1} \cdot \mathrm{x}+1 / 4$ plain sections.

lail in w those ontside rows of sections fillerl, in m:any instances, as well as those in the renter. The reason of this is, that it places a wall of bees on each side of the fence, between the comb honey and the super

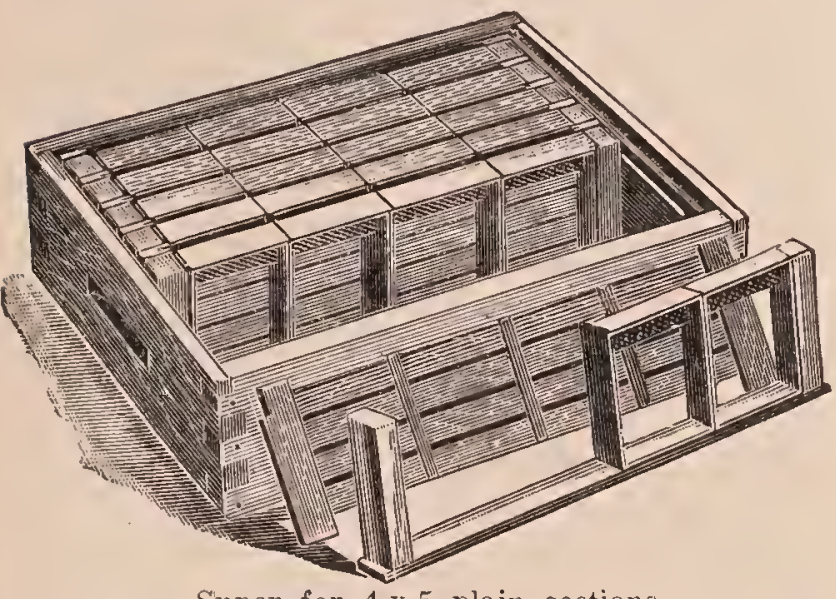

Super for $4 \times 5$ plain sections.

side: and these walls of bees, so to speak, help to conserve the heat so they can draw out the comb and complete the sections on the outside as well as in the center.

COMB HONEY, TO PRODUCE.-In order to secure comb honey the colonies must be very strong-that is to say, the hives must be fairly boiling over with bees - so strong, indeed, that some of the colonies will be inclined to swarm as soon as the honey flow starts. But of this, mention will be made later on.

There is not much use in trying to produce comb honey, if the colonies are only two-thirds or one-half strength. In order to bring all of these up to loney-gathering pitch the reader should turn to the general subject of Burding up Colonise found in its alphabetical order. Be sure that the directions that are given are carefully followed. Assmming that this has been or will be done, it is also important that there
Hould be the proper propiortion of hees ol Hying age-that is, fielders. $\Lambda$ colony, for example, might have enough bees, hut an insulficiency of bees old enough to go to the fields. Many a beginner fails right here. 'The hees should not be younger than 10 days or two weeks. It will, therefore, require that eggs that lave been laid to produce bees for the field should be laid from a montl to six weeks ahead of the expected harvest.

If it is not practicable to buile up the "olonies by uniting, or' if it is desirable to run for both comb loney and extracterl, the medium colonies may be left as they are, and rum for extracted honey, and those of proper strengtl rum for comb honey. The weak colonies-that is, those of two and three frame size - should be united to the medium-strength colonies; for even in the production of extracted. more honey, relatively, will be secured per 1000 bees from a strong colony than from a comparatively small or medium force.

The medium colonies an be built to proper comb-honer pitch without uniting. movided the weather conditions are such that the bulk of the eggs can be laid flom a month to six weeks aliead of the harrest. If that is not possible, it will be necessary, perlaps, to unite.

Colonies that are very strong in the spring will build up faster, relatively, than the weaker ones; and these can sometimes supply frames of emerging brood and bees to the stocks that are below par, as explained at the outset.

In order that the colonies may build up properly in early spring, they should be well housed-preferably in double-willed lives. If they are in wintel packing-cases. as described under Wintering Outmoors. leave the packing on until settled warm weather has arrived. Cool or frosty nights will quickly penetrate the walls of hives having only a single-board thickness. This necessarily cuts down the brood-rearing. and consequently reduces the amount of loney, either comb or extracter, that will be secured.

There should also be a liberal supply of stores in the hives the previons fall, not only to prevent starvation, lont to make boot-rearing possible. If the supply is scant, the antomt of biood and bees in the 
brood-nest will be correspondingly small, and then it may be necessary to resort to stimulative feeding. (See FeEding то Stimulate.) But experience has shown over and over again that the feeding should be done in the fall if possible. If it is done in the early spring it has a tendency to over-stimulate. It forces the bees out of the hive on cool days when they ought to be inside; and, therefore, it is lighly important that all colonies be liberally supplied with stores, either natural or artificial, in late fall.

$\Lambda$ this point the reader should read carefully the article Building up Colonies. Failure to have the colonies of the right strength at the beginning of the honey flow may mean a failure of the crop.

Faving gotten the colonies up to combhoney pitch, it will be found that some of them, as soon as the harrest opens, will be inclined to swarm. This may be shown by the building of initial queen-cells or clustering out in front of the entrance. Cells should be cut out every 8 days; and while this practice does not entirely stop swarming it goes a long way toward checking and prerenting it entirely in most of the colonies. There will be some other stocks that will make no effort to swarm at all. These should be carefully noted, and queens from them be used for breeding. 'The swarming nuisance can be very materially reduced by breeding from the queen whose colonies keep on storing honey without swarming. 'This was the practice of the late Dr. C. C. Miller, one of the best combhoney producers in the United States.

Just as the harvest opens or a little before, as may be shown by the combs being whitened and bulging near the top, the hive should be lifted up on four blocks as illustrated and described under the head of Swarming, Prevention of. It has been proven that the giving of a large amount of bottom rentilation in this way will check swarming to a very gréat extent. - This rentilation should be supplied a little before the harvest opens, to prevent queencells in colonies that are not inclined to swarm, and discourage the building of such cells in colonies that show a disposition to swarm.

Swarning may also be discouraged by the use of a super of shallow extracting- combs, and, after the bees are started in this, substituting a super of sections. Extracting-combs may also be put in the side of a comb-honey super, as explained further on, or partially built sections from the previous season, called bait sections, may be used. A couple of these placed in the center of each super on the lives will do much to discourage swarming and get the bees up into the super.

Where one is at home, or can be near his comb-honey-producing bees, the preventive measures already described are adrised: but, if for any reason the producer must be away from his bees thru the middle hour's of the day or if he operates outrards, it is advisable to. shake the swarm so that the work can be performed at the convenience of the apiarist. The shakeswarm plan has been used to a limited extent, altho it should be said that the majority of comb-honey producers, where they can do so, allow the first swarm to come off naturally, live it on the old stand, carrying the parent colony to ane other stand, or allowing it to stand beside the new hive, but with the entrance at right angles. The comb-honey super, if there was one on the old hive, is given to the swarm. As soon as most of the brood emerges, the parent colony is removed, when the flying bees join the swarm. This keeps down increase, and at the same time boosts the swarm so that it produces a large crop if the season hang's on long enough. For particulars regarding any or all of these methods, see Swarming, Prevextion of; also Artifictal Swarming.

In all the foregoing, it is assumed that the main harvest of nectar comes on at the time expected. Sometimes clover or other sources furnishing the main crop will be out in abundance, and yet not yield a drop of nectar. At other times there will not be much clover in sight, and the bees will gather a large amount of honey.

When the season is poor, it is better for the beginner at least to run for extracted, and that is why the author advocates the production of both comb and extracted honey at the same time. Either the Barber or the Townsend plan will commend itself at such times. If the season starts in well. and the colonies are strong, practically all comb honey can be produced if desirer. 
It may be necessary to use bat sections to staut the bees going abore. More about this will be said further on.

BROOD-CHAMBER SHOULD !: F FILLED WITH BROOD.

Another important requirement in combl)loney production is that the brood-chanber be well filled with brood at the beginning of the honey flow, thus making it necessary that the bees begin work in the supers at once to provide a place for the incoming nectar. While the same condition is lesirable in extracter-honey produetion, it is not so essential as in comb-honey production, since the giving of a super of empty extracting-combs constitutes a strong. invitation to the bees to "come up stairs" and expand their work into the supers eren tho there may still be some empty comb below. To a certain extent, the bees must be forced into comb-honey supers by a lack of room in the brood-chamber for the ineoming nertar. Too often in romb-honey production the honey flow begins before the brood-chamber is filled with brood, and if storing is begun in the brood-chamber and honey is sealed down elose to the brood, the bees usually enter the supers reluctantly, being apparently satisfied with the snug and thrifty condition of having sealed honey above and around the brood area as if prepared for winter. Under such conditions the bees sometimes act as if they had finished the season's work, even tho the honey flow is just beginning, ant they often waste much valuable time loafing even during a good honey flow. Such colonies are usually among the first to prepare to swarm.

On the other hand, colonies that have their brood-chambers well filled with brool when the honey flow begins, should enter and begin work in the supers promptly and should expand their work into additional supers, building combs in advance of their needs so that, eren tho they may be much stronger thau the colonies which began their storing within the brood-chamber, ther are much less inclined to swarm.

'This lighly desirable condition in all, or nearly all, of the colonies at just the light time is not easily attained, and too often only a small percentage of them liappen to be just right in this respect when the honey flow begins: for it means that just at the begiming of the honey flow the colonies nust have consumed practically all of the honey that had been stored within the brood-chamber for winter and spring, and at the same time must reach their maximum in brool-rearing. Colonies that happen to be in this condition just at the right time are usually the ones which work in the super's with the greatest energy and give the least trouble from swarming.

To find the proper size for a brood-chamber that would hold just enough honey to carry the colony up to the beginning of the honey flow (at which time the honey should be practically all used up and the combs of the brood-chamber almost completely filled with brood) has been the dream of comb-honey producers for years. But the great variation in the way the bees come thru the winter, the variation in the amount of honey stored previous to the main honey flow from minor sources, and the rariation in the time of the beginning of the honey flow have preveuter the attainment of this goal.

Many comb-honey producers who have an equipment of 8-frame hives use two stories previons to the honey flow, to provide sufficient room for extra stores anil brood-rearing, permitting the queen the free range of both stories. When the honey flow begins the hives are reduced to a single story by taking away most of the honey and leaving most of the brood. At the same time two comb-honey super's are usually given so that the total hive capacity is not reduced.

The combs that were remored (which may contain considerable honey and brood) are then given to other colonies, which need not be strong and which are not used for comb-honey production, where they are to be refilled with honey as the brood emerges, then put back upon the hires again after the comb-honey supers have been iemoved at the close of the season. The hive-bodies containing the combs that were removed may be piled six or seren high on top of weaker colonies. These "piles" soon become powerful colonies becanse of the large amount of emerging brood.

While this involves considerable labor it puts the colonies in excellent condition to begin work immediately in the comb-honey super's. It is open to the objection that 
two sets of combs must be sorted, and it is sometimes necessary in this sorting to leave some of the combs which lave a rim of sealed loney in the upper portion, these being combs from the upper hive-body. The plan is an excellent one, howerer, and may be used even with the 10-frame hive.

To bring about similar results with less labor some comb-honey producers who use the 10-frame hive have provided a shallow extracting super for each colony. Thess shallow extracting-supers contain the extric stores needed for safety during the spring, thus permitting the standard brood-chanber to be used almost entirely for broor. 'They are taken off at the besinning of the honey flow when the comb-honer supers are given. In this way, the objectionable barrier of honey at the top of the hive is removed: and the comb-lioney super's are placed down adjacent to the brood, which is a great advantage in stimulating the bees to expand their work into the supers and in reducing the tendency to swarn. This principle has been recommended by several extensive beekeepers even when extracted honey is being produced.

The shallow extracting-super's should be tiered up on weak colonies which are not being used for comb-honey production, for they should be refilled with honey as tho suall anount of brood which they usually contain emerges. After they have been filled with honey these food chambers are ready to be given back to the colonies after the crop of comb honey has been remored from the hives.

'The extra stores provided by either of these plans stimulate the bees to rear a large amount of brood during the spring. usually resulting in at least one standard brood-chamber being well filled with brood at the beginning of the honey flow and colonies, so strong that they begin work in the super's with a rush.

Thus by using a separate chamber for honey and a brood-chamber slightly sualler than the rapacity of good queens, the safety of the colonies, so far as stol'es are concermerl, is insured without laborious and expensive feeding which is too often not done when most needed; and, at the same time, the objectionable lim of loney at the top of the hive can be lifted off and the comb-lioney supers placed upon a brood-clamber almost full of hrool and practically fiee from honey.

Where honey sranulates readily the large surplus of stores may sometimes be objectionable, but where honey granulates readily comb-honey production is not advisable anyway. ('olonies so provisioned usually build up so strong in the spring tliat most of the extra loney may be user up and the combs in the food cliamber are refilled with honey from early sourres.

WHEX AND HOW TO PUT ON SLPFRS.

If the colony is in one story and the bees hegin to work well in the fiels. while the rombs are whitened near the top's, and the frames fairly well filled witl hroor and honey, super's slrould be put on.

The usual practice is to put the comblroney super on at the start; but Italians especially are sometimes slow about entering the sections unless the colony is quite strong.

Two correspondents sent to Gleanings in Bee Culture their method of using extracting-combs to bait the bees above. One uses a whole super of shallow extracting-combs. and the other uses both sections and extracting-combs in the same super. Both are given here. The first mentioned writes:

I have been, for several years, very much interested in trying aud comparing different. methods of handling bees for homeycomb. I have been in the business for eight years. and have had fair success. For the first five years I tried a different method each vear. Three years ago I tried an experiment that succeeded so well I have followed it up, and have in a measure overeome the two greatest diffeulties that I had to contend with-loafing and swarming. We use the eight-frame dovetailed lives with sectionholders for $4 \frac{1}{4} \times 4 \frac{1}{t}$ sections. Our bees would always begin to loaf or hang out on the front of the hives when we put on the sections, and most of them would do but little in the sections until they had lost several days, and then would swarm, thus losing several days of the first alfalfa bloom.

I had 60 colonies of Italians in my outapiary, and in trying my experiment I tricel to be fair. I took 30 supers of lalf-depth extracting-frames full of comb from the home apiary, and put them on 30 hives in the out-apiary at the same time that I put sections on the other 30 hives. In four or five days the extracting-combs were full of new honey, and the bees excited and busy at their work, while most of those having sections were loafing, and some hail swarmed. 


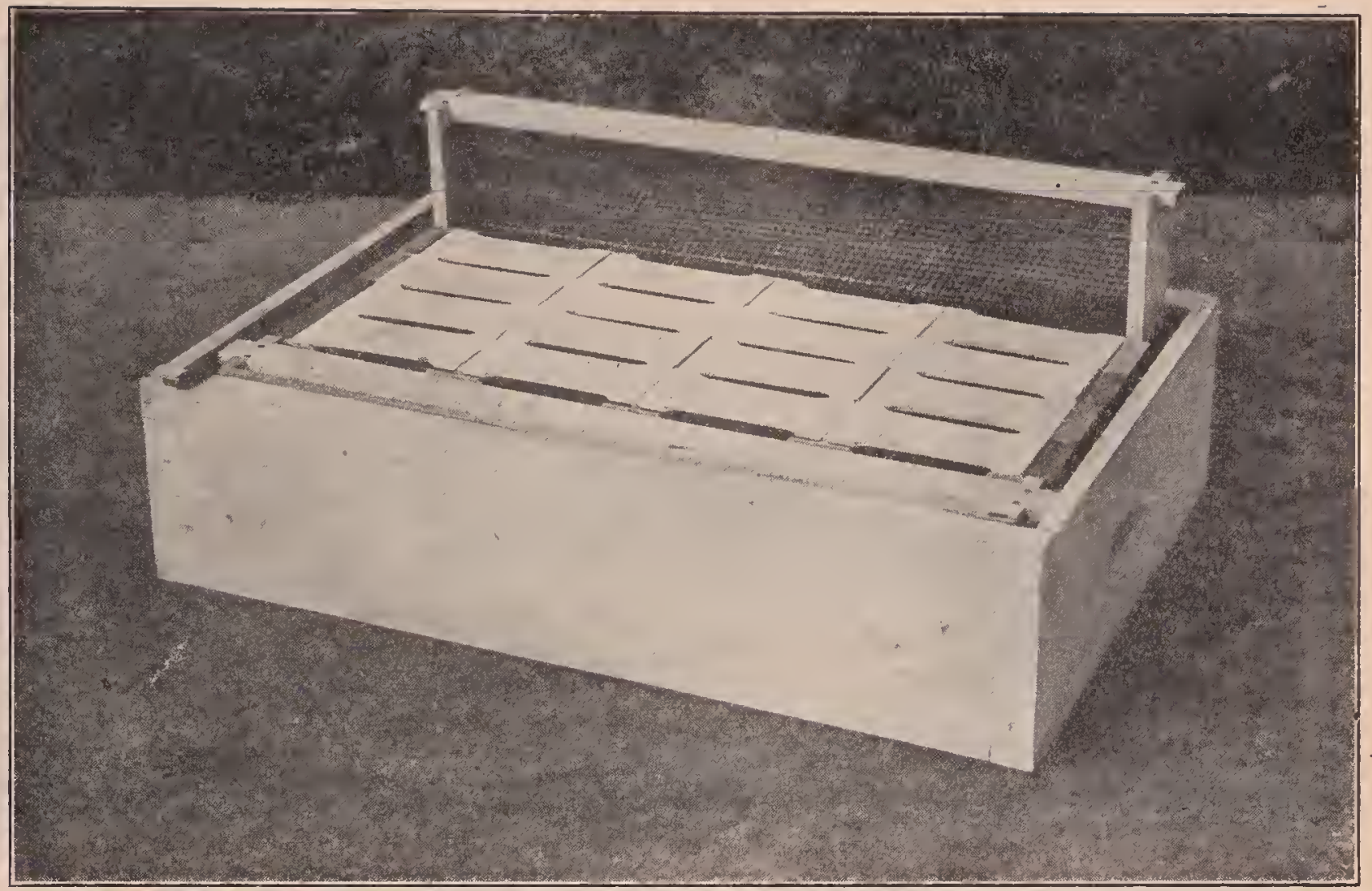

Super contrining two cxtracting-frames with wide end-bars, so that they take up the same amount of room as a section-holder:

I raised the comles by putting a super of sections betwe'n them and the hroorlnest. At the end of two weeks from putting on the combs those sections under the comlls were hetter filler than those on the lives that had no combs. As soon as the combs were sealed, I put them away to extract: having that amount of loney extra, and the bees started nicely in theil work. I harl only about a third as mally swarms from those hives as from the ones with sections and no combs.

I liked the flan so well that last rear I had enough of those little combs hinit to furnish a super of them to every colony that was to be run for section honey.

I tried the plan again this yeal, aud from 75 colonies at the out-apiary I had 8000 finc white marketable seetions, about .500 khs, of mufinished and imperfect sections, 1500 Jhs. of extracted homer, aml 60 lbs. of beeswax, durl two harrols of rinegar.
Mancos, Colo.
Mrs. A. J. Barber.

Other correspondents to Gleanings in Bee Culture have reported cood results from following the same methods. It is fraticularly applicable where both comb and extracted are called for.

E. D. Townsend of Northstar, Mich., the other correspondent, goes one step further than the Barber plan by producing comb and extracted lioney in the sume super.
Instead of putting on a rase of extractingrombs, and afterward substituting therefor one containing sections, he has a special super which contains both extractingcombs and sections.

The illustration shows a counb-honey super containing' $4 \mathrm{x} 5$ sections. 'This is equipperl precisely the same as any other super for sections except that it has extracting-combs with closed-end franses on each outside. When it is placerl on a hive the bees immediately occupy the drawn comb at the sides of the super and hegin their storing. The rombs already drawn out are very inviting plares in whicl the bees ran begin storing honer. Haring made a nice start in the two side extractingcombs they wolk toward the renter-that is to say, they hegin to draw out the full sheets of fomdation in $4 \times 5$ sections next to the combs, and store in them. Then work is once in full progress in the side sections of the super, the center ones will take care of themselves with the lesult that every section is finished about the same time, and of about equal fullness. When the super is completed, the two extracting-combs will be filled and capped as 


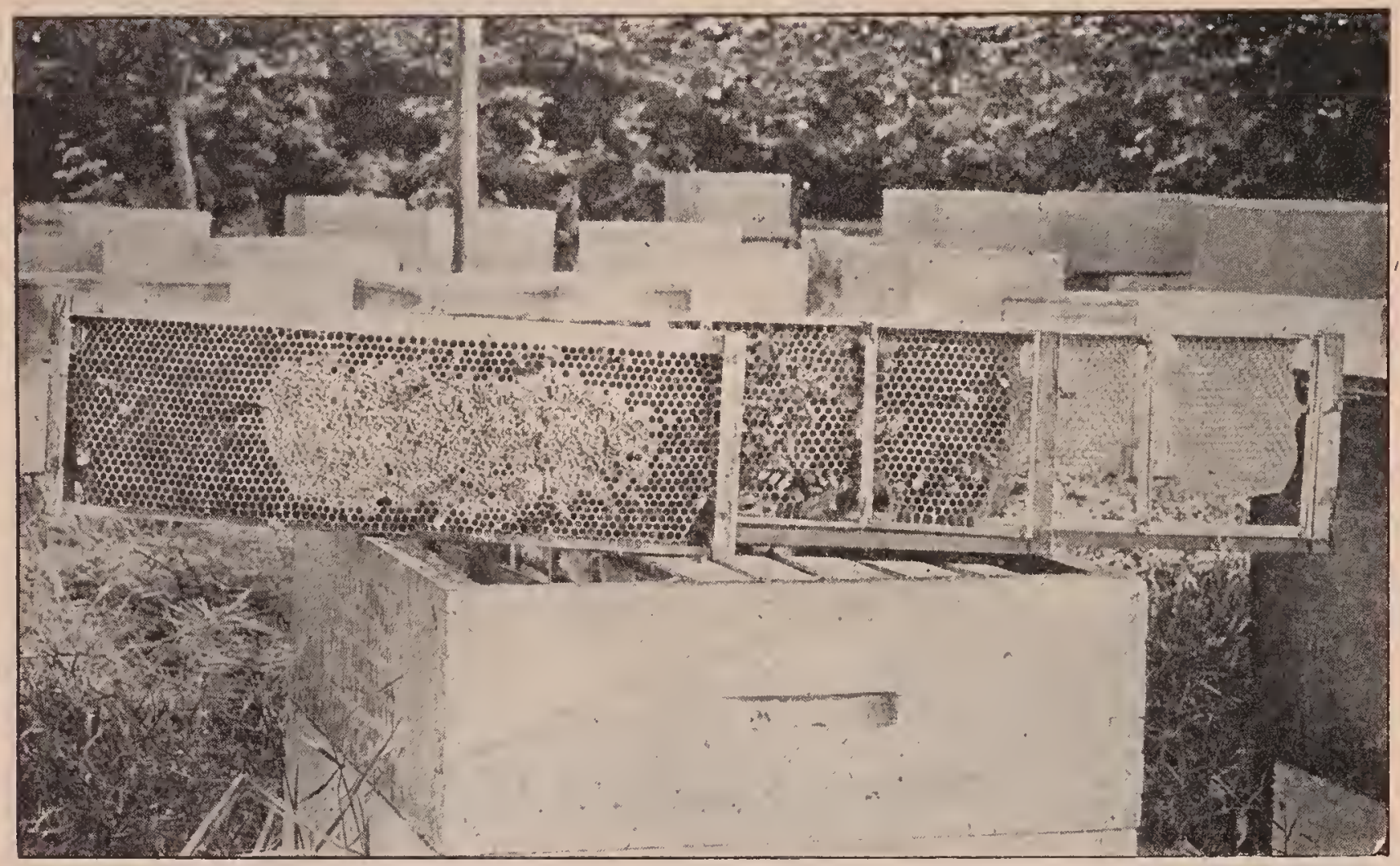

The work well started in the extracting-combs at the side of the comb-honey super. Note that the row of sections just back of the extracting-frame is well along and that the second row back is started.

well as the section honey-boxes. The former can be extracted and used again.

It will be seen that the extracting-combs serve the purpose of excellent baits. Mr. Townsend draws attention to the fact that, when such baits are placed at the sides instead of in the center, they cause an even filling of the entire super; whereas by the old plan of putting bait combs in the middle of the super the storing begins around the baits, gradually working from the center to the outside. This naturally brings about a better filling of the center sections. learing those toward the sides at a much later stage of comb-building and filling. The result of this is that the center sections will be filled in advance of the outside ones; and by the time these latter are filled, all the former will be travel-stained. and may induce swarming in the mean time.

Then Mr. 'Townsend first began this scheme of comb and extracted honey production from the same super he had in mind only baiting the bees up into the sections; but he incidentally discovered that, inasmuch as the bees would enter such supers without hesitation, he thereby almost entirely ,overcame swarming,
It is well known, that after bees are once started going above, there is less inclination on their part to swarm. $\Lambda_{1}$. Townsend finds that the two side extracting-combs that he puts in every comb-super

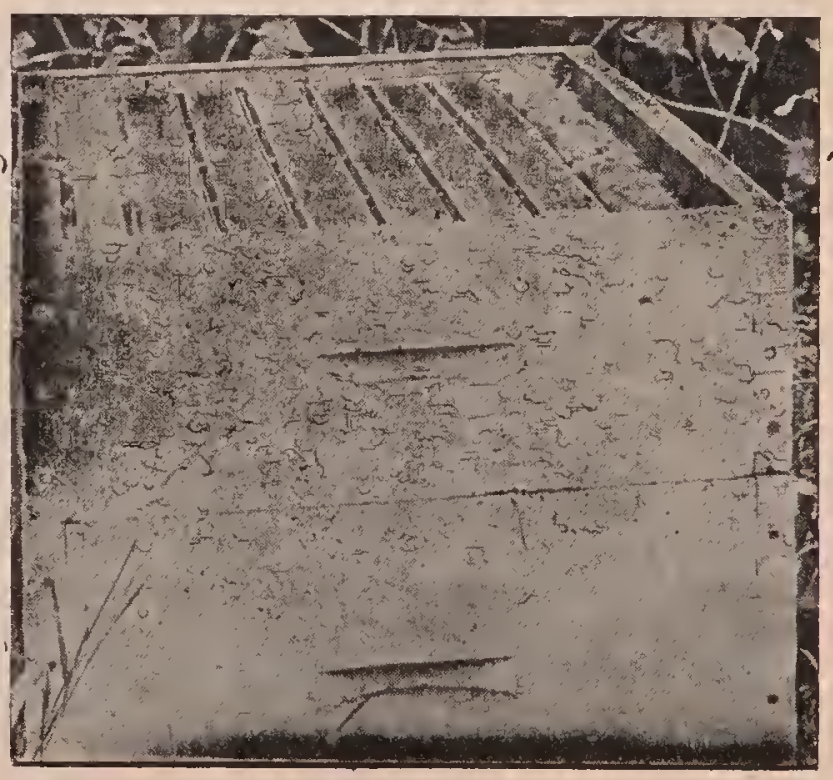

One of Jay Smith's hives, showing extractine-combs at the side of the super, a la Townsend.

start the bees into the super about as readily as they would if containing extractingcombs only. The whole effect of this procedure is such that swarming is reduced to a minimum-almost brought under control. 
For the local markets, the side extracting-combs can be cut out and sold for chunk honey at about the same price as that in the sections; so that there need be practically no loss; or when there is a call for liquid honey it can be extracted.

The deep super, already described, with its $4 \times 5$ sections and section-holder's, is well suited to carry out the Townsend plan.

Wven the shallower supers using $41 / 4 \times 41 / 4$ sections can be similarly arranged.

Jay Smith of Vincennes, Ind,, among many others who have been using the Townsend plan with good success, writes:

I have been using Mr. Townsend's plan of putting extracting-combs at the outside of the sections, and feel that in this $\mathrm{Mr}$. Townsend has given the bee frateruity a most valuable kink. In the engraving will. be seen a super just set on the hive. The bees immediatcly took possession to clean it up. They will at once go to work and store honey in the comb. The other picture shows the work as it progresses. The outside ex. tracting-frame is partly capped. The combhoney section next to it has honey in it, while the third has work just commenced. After the bees begin in the center ones. they will push the work there a little faster, with the result that the entire super is finished at once and can be set aside for market without sorting.

I am running 80 colonies on this plan this year, and I have never had a single case of loafing, and the bees work with. all the energy they possess. When I lead of some who let the hive-body get elogged witl honey, and the bees chuster out, and they "shake" energy into them, I thought the beekeeper was the one who needed shaking instead of the bees. With the above system I usually have about six pel cent of swarms. This was the worst year for swarms I crer had, and the per.cent of swarms was ten.

\section{BAIT SECTIONS.}

Some beekeeper's, howerer, while admitting the excellence of the plans given for those who want part of their crop in extracted honey, say that there is no need to use extracting-frames to start the bees at work in supers, since the same thing can be better accomplished by means of what are called "bait sections," thus securing the entire crop in sections.

A bait section is one which has been partly filled with honey, which honey is afterward emptied out by the bees, generally in the fall. It is thus a section containing drawn comb, but having no honey in it, is to all intents and purposes an extracting-comb on a small scale. Bait sections thus prepared are kept over winter, to be used at the beginning of the next lioney harvest.

If a single bait section is put in the middle of the first super that is given to a colony, some claim that the bees will begin work in it as promptly as they will begin work in an extracting-coml. Others use more than a single bait in a super, but there may be no great advantage in this. and the number of baits should be limited as much as possible, for when a section is thus filled the second time it is not so beautiful as one filled the first time. A bait section is not needed in any super after the first.

One serious objection to bait sections is their tendency to granulate early; and on account of this they should never be put into a shipping case with other sections of comb honey. They are never as nice, and should always be sold near home as soon as possible after they are taken off the hive.

Some producers have made the serious mistake of putting their bait sections when completed in with other sections and sending them in one case to the city market. Is these baits granulate rery quickly, the city dealer is quick to discover it, and he will, therefore, conclude that the whole are is just as bad.

\section{WHAT TO IO WILA THE BEES REFUSF TO} ENTER THE SECTIONS.

There have already been given some general suggestions that should enable the producer to get the bees up into the supers. One is, to give the bees a super of emptr extracting-combs; and then when they have once started in them, place a super of sections, between it and the hive. Another is, to use the extracting-combs as well as sections in the same super, $a$ la Townsend; and still another is, to use bait secctions. And still another is to run the colonies two-story during the breeding season, then remove the upper story, and put on a super of sections as explained elsewhere. When all of these devices fail. it may indicate that the weather is too cold. even tho there is plenty of bloom, or the colony not strong enough to go into the supers. If the weather is cool or chilly or the colony not strong enough, no amount 
of "haiting" will wet the bees above. "The weather conditions must be right, and honey must be coming in at a fairly good pace, eren if the colony is strong enough, before the bees will go above. But when they are once starter they will keep it 11 ; as long as anything is coming in.

If some colonies are storing in the supers, and others are not, it indicates that the weather conditions must be right; and the presumption is that the lagrards are not strong enough to go above. If they have plenty of bees, it is sometimes advisable to give a super from some other hive in which the bees liave already started building comb and storing honey. In other cases, either bait or empty conibs may be user on the sides. It is important that the bees in lot weather are not driven out of the supers by the direct rays of the sum. In some localities at least, shade must be provided, so that the bees will be protected during the middle hours of the day. See APTARY, and especially "Shadeboards."

If the bees of a strong colony liang out in front of the entrance, while the bees of other colonies are storing honey, perhaps enlarging the entrance or putting the hive up on four blocks, as slown and illustrater nnder Swarming, may serve the purpose of getting the bees inside at work in the supers.

It sometimes happens that the brood-nest is not filled with brood and honer. Until that takes place, there will not be much work done in the supers unless the colony is very strong or honey coming in rapidly.

\section{TIERING UP.}

After work is begun in the first super, if no other supers are given nntil the rombs are built out, it shonld be noterl that the space within the super that can be oc-

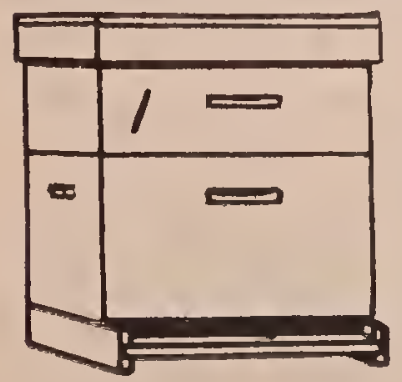

Fig. 1.-1 prompt beginning in the first super is important. eupied by bees is being reduced as the combs are drawn out, until finally there is only abont one-fourth of an inch left between the comb and the separator, so that most of the bees a re crowded out

and nunst so barck into the brood-chiamber. 'l'his is almost sure to cause the rolony to work less vigorously. The same thing happens if the bees are driven from the super because it is too lot or because the hive is not well rentilated. If the colony is strong enougl to draw out the foundation uniformly in all of the sections, and the loney flow is promising, a second super should be given, even tho but little loney is stored in the first one.

In ordel to induce additional coubbuilder's to go up into the supers, this second super may be placed below the first one. If conditions are farorable, the foundation in the second super will be drawn out within a few days and these shallow cells can be used for the evaporation of the incoming nectar. The bees apparently enjoy spreading out the raw nectar, a little in each cell, thus lastening its ripening by increasing the surface of the nectar exposed to the air. Before nucli lioney has been stored in the second super it may in turn be raised up and a third super given. This operation may be repeated as often as necessary to keep the bees busy drawing out foundation and to attract more and more of the younger bees from the broodchamber into the super's. In order to hasten the completion. of the first super that was given, it may be placed immediately above the super in which the bees are drawing ont foundation, while the other supers are arranged above it in the order that they were put on the hire, the one in which the least work is done being placed on top.

If it were possible to foretell the number of supers that each colony would finish during the honey flow, it would be well to induce the bees to draw out the foundation and begin comb-building in that many su-

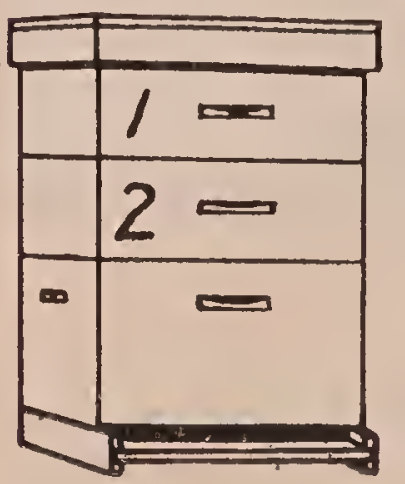

Fig. 2.-Second a $11 \mathrm{p}$ e r placed below the first. pers as early in the honey flow as possible, then give an extra one to be placed on top as soon as the foundation is completely drawn, the purpose of this extra super being to contain the orerflow of nectar during the process of rip- 
ening. 'This extra super', having served as an evaporating chamber this season, can then be taken off before the combs and sections berome soiled with propolis and be given as the first super next year.

\section{CAUTION.}

Colonies that are not strong. enough to send a large foree of romb-builders into the first supers should not have their super room expanded so rapidly. A good rule to follow is to place the new super under those in which work las been started, prorided the colony is strong enough, and the honey flow is good enough to cause the bees to draw out the foundation uniformly thruout the super. If they draw out only those in the middle of the super, the

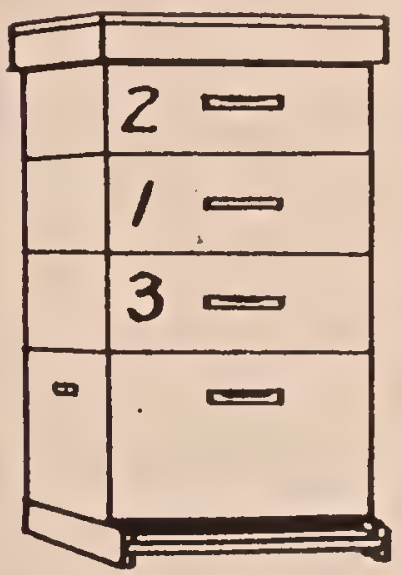

Fig. 3.-Third s u per placed below and first iust abore it. s e c o n d super should be placed on top at first, and llo super should be raised up and another put under it until the foundation has bee $\mathbf{n}$ completely drawn in all of the sertions. If the honey flow is slow $\mathrm{or}^{\circ}$ if the nectar is thicker when first gathered, the work of drawing out the foundation, romb-building, the ripening of nectar, and sealing the honey may all be done in a single super. In this case the newly added super should be placed on top.

The thing to keep in mind when adrling supers is to aroid, on the one liand, too many unfinished sections by giving additional room too fast; and to avoid, on the other hand, the lack of stimulation which comes, from newly added room for new work and an abundance of comb surfare for ripening nectar. The surplus apartment, whether made up of one super or half a dozen supers, should have some fresh foundation being drawn until near the rlose of the honey flow. Rapid expansion of super work should take place inling the early part of the honey flow, while during the latter part of the honey flow the super work should be concentrated.

During hot weather added ventilation may be given by pushing the first super forward on the brood-chamber about an inch. This will form an opening at the back of the hive just above the ends of the top-bars of the brood-frames. Such openings should not be made between the supers, since the bees may fail to finish the sections nearest openings.

The beekeeper who by skillful supering is able to entice most of the rapidly on-

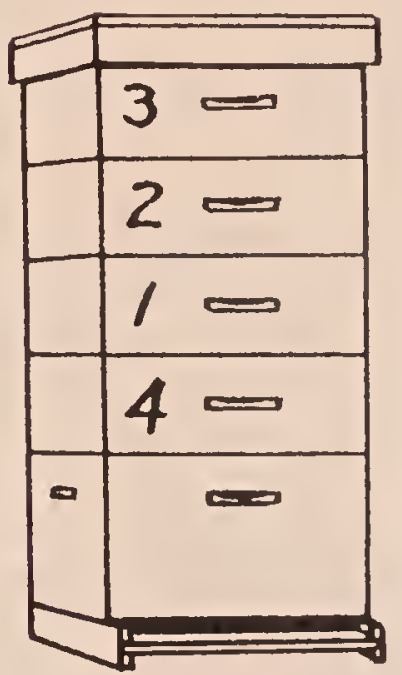

Fign. 4.-First super left in same position until finished. c 0 m in g' youngel bees into the super's early in their I i ves, and who keeps his colonies comfortable at all times, therebv increases his crop. With most of the younger bees in the supers and most of the older bees in the fields during the heat of the d a $y, t$ li e colonies work with the gieatest en e r g $\mathrm{y}$ and are much less inclined to swarm than when the supering is not properly managed.

\section{AS CLOSE OF HONET SEASON APPLOACHES.}

The first step in anticipation of the closing of the season is the giving of ardritional super room more sparingly. Ifter the beekeeper has been doing his utmost to induce the bees to orempy and begin work in more and more supers during the fore part of the honey flow, the tendeney is to go ahead giving additional room at the same pace too long. It a rertain stage in the honey flow the empliasis should dhange from the expansion of the surplus room to a concentration of the super' work to the smallest number of supers possible and still give the bees sufficient room.

It is sometimes a good thing if the beelieeper runs out of supers during the lattes: part of the honey flow, for it is surprisine how much can be done in the way of fulnishing erough room without giving arditional supers by shifting supers from one rolony to another, thus giving a little more room to colonies that are beginning to be erowded and redueing the super room in 
those having more than they need. In fact there comes a time during the latter part of the honey flow when it is better to have the colonies erowded a little for super room, but the difficulty is to know when this time has arrived. The bees will usually stand a degree of crowding at this time which earlier in the season would hare caused them to swarm or to loaf badly. Any new supers that are given at this time should usually be placed on top of those already on the hive.

The second step in preparation for the close of the season is that of reducing the number of supers on each hive to one or two as soon as possible, concentrating the unfinished sections in these supers. Sometimes the bees are slow about sealing the honey, when it may be necessary to tier up the super's, four, five, or even six ligh, before any of them are ready to be taken off. At other times they seal the honey more promptly, so it is not necessary to tier up more than three supers high. Usually the bees seal honey more'promptly toward the latter part of the honey flow.

As a rule it is not advisable to leave the supers on until all of the sections are finished; for the longer the honey is left on the hives, the more travel-stained it will become, and the more it will be soiled with propolis. This is especially true late in the honey flow. When most of the sections are finished the super should be taken off and the unfinished sections sorted out to give back to the bees for.completion. It is not safe to assume that a super is ready to be taken off by looking in at the top only. It is better to look in at the bottom also, for sometimes the sections of honey are sealed near the top and not sealed near the bottom.

Let us suppose that, as the close of the season approaches, a colony has five supers, four of which are nearly filled, and work has just been started in the fifth, there being enough unfinished sections seattered thru the four supers to fill one super. If these four silper's are now taken off, the unfinished sections sorted out and assembled in one super which is put back on the hive, the work of finishing these sections will be carried on more rapidly, especially if the super of nearly finished sections is placed next to the brood-chamber, with the one in which but little work has been done on top.

Of course these four supers would probably not all be ready to be taken off at once, but by going over all the supers every four or five days at this time, taking off and sorting those nearest completion, the supers can soon be reduced to a single nearly finished one for each colony, with an empty or nearly empty one to act as a safety valve if more room is needed. If there are not enough supers, in which but little work has been done, to go around, an empty super should be given, provided there is still enough nectar coming in so that the bees will draw out the foundation, for the nearly finished super is usually finished more promptly if the bees are permitted to build comb in another super at the same time.

If the beekeeper has guessed well, the lower one of these two supers should be nearly finished just before the honey flow entirely ceases and the upper one should have but little unsealed honey stored in it, ret the foundation should be well drawn out and some of the combs at least partly built. This super, if taken off promptly and the bees permitted to clean out the little honey it contains, is just right for the first super next year. It is not possible always to guess so well as this, and while some colonies may come out just right, others will store cousiderable honey in the top super, while still others will not complete the lower one, so a further but final sorting of sections becomes necessary.

During the time this last super is being finished it is well to watch closely for colonies that are good finishers, as usually sercral colonies will be found in an apiary of sixty to eighty which do much better work at finishing than the others. These should be marked to be used in the final work of finishing.

The third step toward closing the season is that of remoring all of the super's, doing this, if possible, before the honcy flow entirely ceases and before the bees begin to valnish the cappings of the honey and the section boxes with propolis. The sections in the nearly finished supers should again be sorted and the unfinished ones given back to those colonies which were marked as the best finishers. This time, in assem- 
bling these unfinished sections in the super's, those nearest completion should be placed in the middle, putting sections only partly filled in the outside rows. These sections for the outside rows may be taken from those supers which were on top acting as safety valves. As these supers are now arranged, the finishing is to be done in the middle of the super where it will be done more promptly, while the comb-building, if any, is done on the two outside rows.

\section{WHAT TO DO WITH UNFINISHED SECTIONS.}

The supers in which but little work has been done can now be piled up crisscross near the apiary and the bees invited to help themselves, provided there are enough such supers so that the bees will not crowd each other so much that they will tear down the comb. This, of course, should not be done if there is any foul brood among the colonies or if the apiary is too close to a neighboring residence.

The last supers which were given to the finishing colonies should not be left too long, but should be removed as soon as most of the sections are finished. Usually it does not pay to return the unfinished sections from this last lot of supers for completion. Some of these may be sold as culls, or cut out and sold as chunk honey. Many comb-honey producers extract the honey from these unfinished sections and save the combs for bait sections the next season.

The important thing in taking care of unfinished sections to be used again the next year is to take them off before the wood is soiled with propolis and the founlation gnawed at the edges and also rapnished orer with propolis.

If the honey flow fails suddenly, affording no opportunity to return unfinisherl sections to the bees for completion, they may be completed by feeding back extracted honey. (See Feedrag Back.) In this case, the unfinished sections may be sorted into different grades and the lightest ones extracted to secure the honey to feed back in finishing the heaviest ones.

Feeding back extracted honey to secure the completion of unfinished sections was formerly practiced to a considerable extent by comb-honey producers, but has been discontinued by most of them. Comb honey finisled by feeding back is usaally inferior in appearance, tends to granulate early in the winter, and much more honey must be fed than is finally stored in the sections, a large amount being consumed by the bees during the process. Successful feeding back depends so much mpon selecting colonies that are in just the right condition for this work and upon weather conditions at the time the feeding is done, that few will care to attempt it, preferring to sell the unfinished honey as culls and extracting that which cannot be sold in this way.

HOIV TO TAKE OHF COMB HONEY.

The most satisfactory arrangement for getting bees out of supers is the doubleend Porter bee-escape. This is mo:unted in a board, cleated at the ends and sides, in such a way as to provide a bee-space on

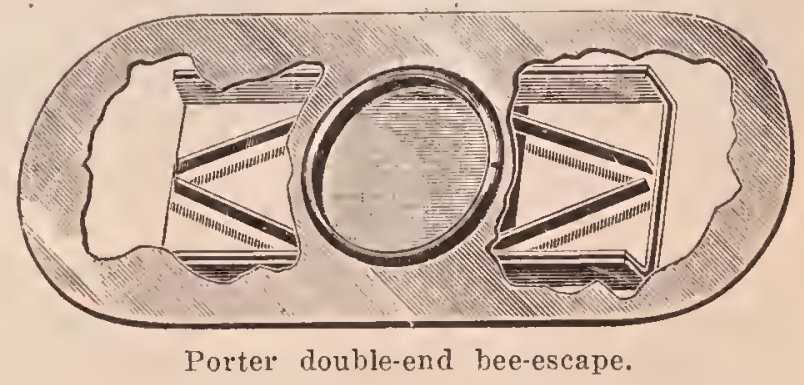

one side, so that it can be placed between the supers and the brood-nest beneatl. But care should be taken that it be placed right sicle up-that is, the side up as shown in the illustration. If the derice be put on in the morning, practically all the bees will be out of the super by the next morning.

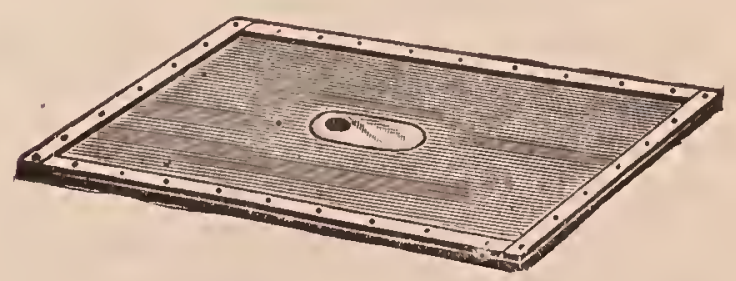

One method of putting on one of these escape-boards is as follows: Witl a hivetool, screw-driver: putty-knife. or pry, loosen the super so that propolis connections will be broken. With one hand tilt up the super at one end enough to make a gap, and with the other hand take the smoker and blow in two or three whiffs of smoke to drive the bees back. Lift the end of the super up a little further so. that it will stand at an angle of nearly 45 degrees. With the free hand set down the smoker 


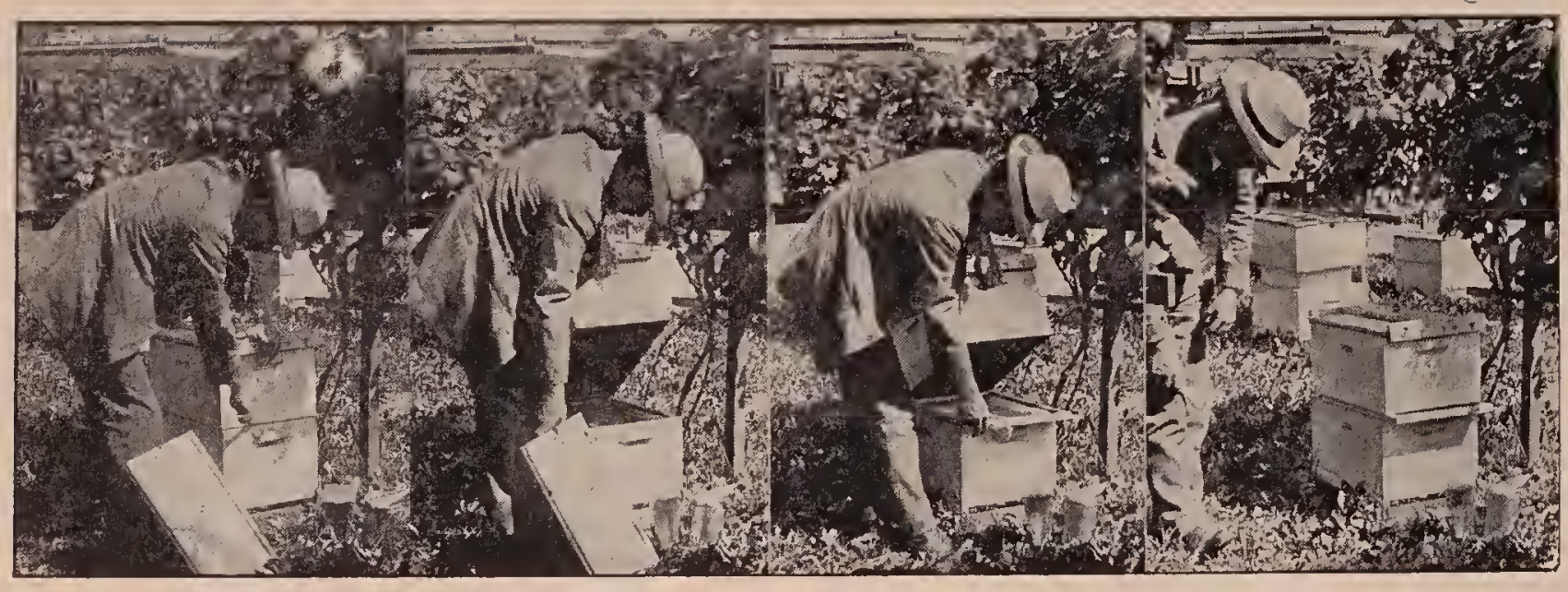

Method of inserting the escape-board.

and pick up the es ape-board, which slould be leaning conveniently against the leg: Slide this on tol' of the hive as far as it will go, bee-space side up. Let the super down gently on the escape-board, and, last of all. bring the escape-board and super into alignment with the hive. This method eliminates hard lifting, sares tine, prerents angering the bees, and aroids killing then. See illustrations above.

The best time to put on Porter escapes is always in the morning. The field bees in the supers will leave to go to the field during the day and, of course, can not get back. If 30 or 40 of the escapes are put on, the next morning about nine o'clock there will be 30 or 40 supers ready to come off, with but few bees in them. If there are three or four bees left, or a dozen, they will usually take wing as soon as the super is uncovered.

In taking off comb honey during a good honey flow, bee-escapes are not needer?. In f'act for out-apiaries it is inconvenient to use them, since an extra trip nust be made to put them in place, but at the close of the scason bee-escapes are almost a necessity.

When removing supers during the lioney flow without bee-escapes a good operator soon learns the trick of driving the bees out quickly and taking the super away before any can return. As the corer is lifted, the bees shonld be started down at once with smoke and kept on the go until they leave the super. They must not be permitted to stop on the way to fill themselves with honey, for when they once get their heads into the cells, they pay but little attention to smoke.
Quite a number of bees can be hrus!ne:l off the tol of the sections when the hive is first opened, bushing and smoking at the same time. While the bees are be:ng driven down, the super should be pried loose from the one below but not lifted until nnost of the bees are out, when one end of the super. is lifted quickly, and at the same time pulled backward slightly, so it will rest upon the super below at one end, while being brought alnost to a rertical position. when the bees that are on the botton of the super should be brushed off. All this should be done so quickly that the bees on the bottom of the super do not have time to get bark :mong the sections hefore they can be brusher off.

If robluels are not troublesome the super's still rontaining a few bees may be simply leaned against the live, standing on end, until the bees go out of them. If robbers begin to come, the supers can be piled up in the apiary, eight $\mathrm{or}^{\circ}$ ten in a pile, placing the first one on a hire cover or hottom. being careful to leave no opening: where hees can enter. The top of the prle may be kept closed with a hive cover or an inner cover which is pusher off as each super is added, then ruickly put back in place on the top of the pile. As these piles are uncovered from time to time in adding more supers many of the confined bees esrape. Finally while loading the supers to take them lome, most of the remaining bees will leave them.

Sometimes the sections of honey can be sorted in the apiary without robber's bothering, and the unfinished sections returned to the bees at once, but frequently this 


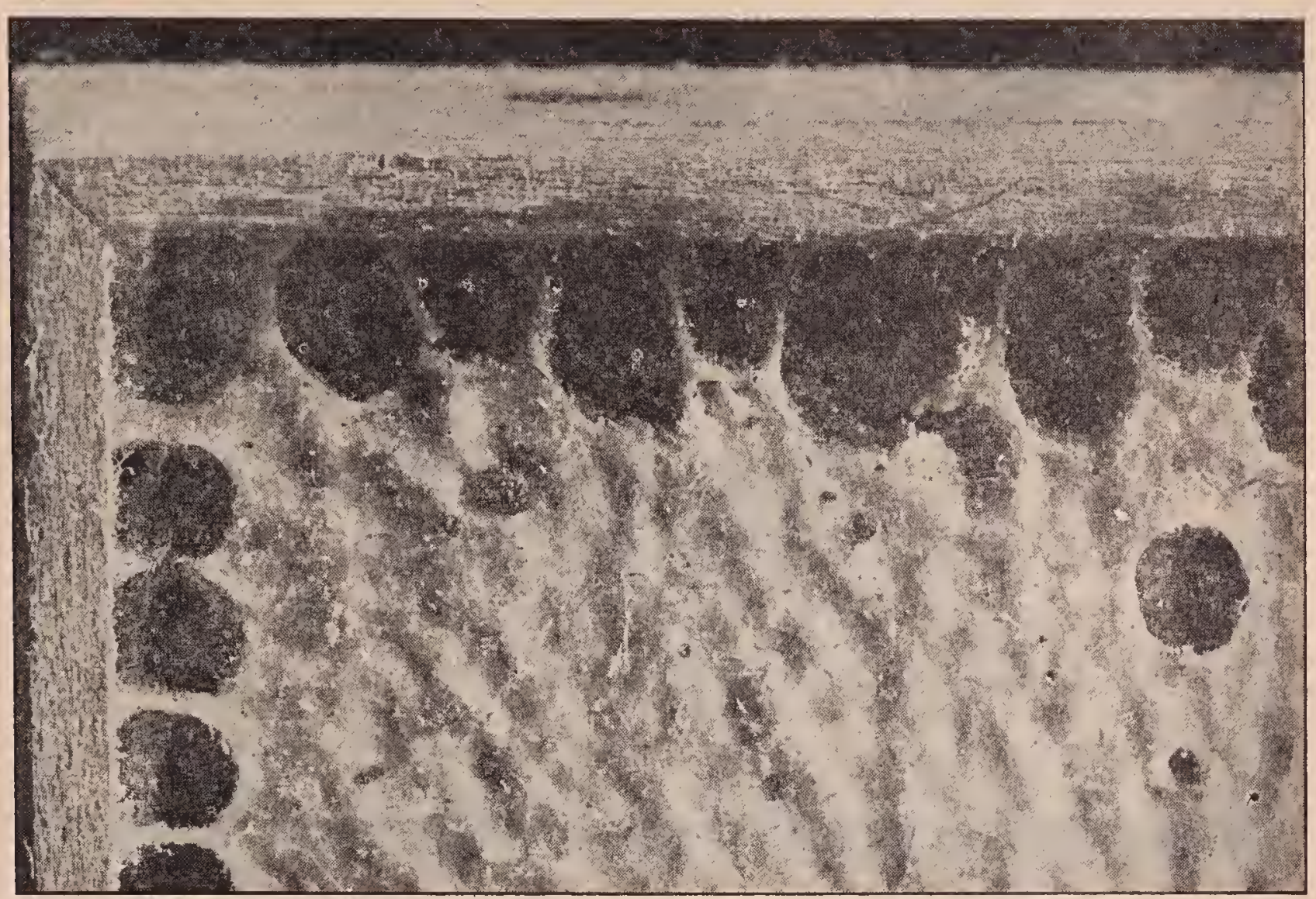

I comer of a section of honey enlarged to show the dust of wool and propolis seattered over the surfale of the alppincs. This troulde is canser by carelessness in cleaning the propolis from the wood.

cannot be done and it becomes necessary to haul the supers home to be sorted, ,unless there is a small portable honey-liouse at the apiary. When the super's are sortel at home, the unfinished sections can be taken to another apiary to be visited the next day, or given to any colonies that will finish them.

STORING COMB HONEY.

It was formerly advised that comb honey be stored in a well-ventilated room and the supers piled in such a manner that the air could circulate freely among the sections, the theory being that this arrangement would permit a further ripening of the honey after being removed from the hives. The plan is open to the serious objection that honey so exposed may absorb moisture if subjected to any great variation in temperature, for warm air which may contain considerable moisture coming in contact with cold honey, if chilled sufficiently, will give up some of its moisture, causing condensation on the surface of the honer. Honey that is well ripened is usually safer if the super's are piled in tight piles, the piles being closed at top and bottons. Its aroma will be better also.

$$
\text { SCRAPING SECTIONS. }
$$

In order to make sections present a clean and marketable appearance all the propolis should be scraped off. Some and perhaps most beekeepers prefer for this purpose a common case knife, and others a sharp jackknife. Sometimes the edge of a seraping-knife is ground square, and the scraping is done with a corner of the knife. But the general practice seems to faror the ordinary edge. Others prefer to use No. 2 sandpraper. A sheet of it is laid flat on the table; and the section, edges down, is rubbed back and forth on the rough surface. If the day is not too warm. nor the propolis soft, the sandpaper will do faster work than a knife. But the edges of the sections are a little roughened, and more or less fine dust at times gets on the surface of the romb. Sometimes a dealer on receiving such honey objects to this dust, thinling it to be the exerenent of the moth worm. (See cut.) The objection is also made that the sandpaper fills up with 
bee glue, and that is true. But sandpaper is cheap, and when one sheet is filled, another can be used, and so on.

When one has a large amount of comb honey the work can be done with sandpaper more expeditiously by fastening it on a revolving cylinder or on the flat surface of a revolving disk operated by foot power or a small motor. Where one has a gasoline engine for a large power-driven honey-extractor, he can use that as a motor power.

It was stated that rubbing the section on a flat sheet of sandpaper by hand leaves the edges rough, and dust on the surface of the comb. The illustration, which is enlarged to illustrate the details, shows how the fine dust lodges on the comb and how the edges of the sections are roughened, leaving hairs or fibers of wood clinging to the edges. The author's experience is, however, that a power-driven eylinder or disk on account of the high speed, does not scratch the sections nor leave the surfaces of the comb covered with dust.

BOOMHOWER KNIFE-SCRAPING TABLE.

Frank Boomhower of Gallupville, N. Y., has a section-scraping table like the one shown herewith. As will be seen, "two serapers can work at a time, the sides of the box or tray being eut away in such a

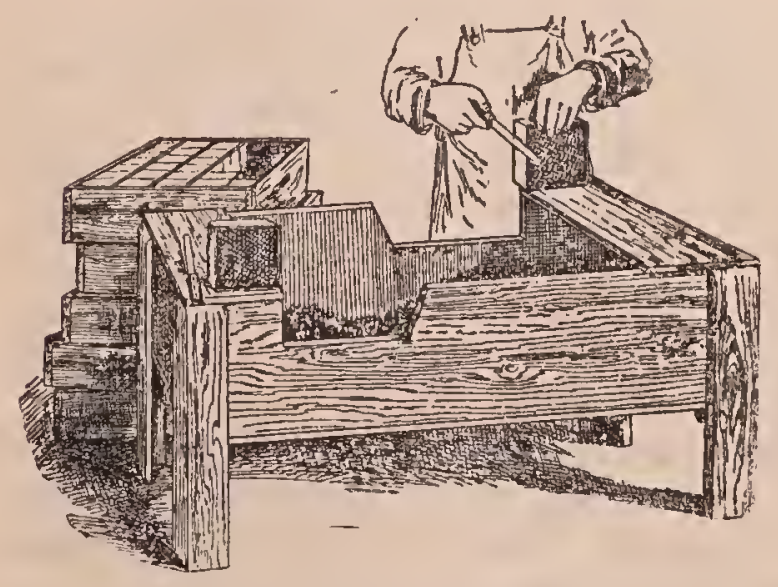

Knife-scraping table.

way as to allow a knife to scrape down clear past the edge of the section. Each section, as it is scraped, is put into the shipping ease.

Those with only a few sections will not be likely to have such a table, and some large producers might prefer not to use it. Any ordinary table may be used for the work, or a board on the lap will answer.
It is easier to do the work sitting. A block 2 inches thick, more or less, and 4 inches square, the size not being important, lies on the table, or on the board on the lap. When the section is placed upon this block, projecting orer one side, it allows free play for the knife. If the super is of such character that the sections may be taken out en masse, the work may be greatly shortened by cleaning all the tops at one operation, and the bottoms in the same way. No matter what the super, one may shorten the work in this way: Make a rim, or box without top or bottom, whose depth is an inch less than the height of the sections to be cleaned, and an inch or so wider and longer than the superful of sections. Have two boards as large as, or a little larger than, the rim mentioned. Lay a board on the table, set the rim on the board, and then fill the rim with sections. Put into one end a thin board as a follower and wedge it up. Do the same at one side. Now, with a cabinet-maker's scraper or some other tool scrape the propolis off the entire surface. Follow this np with No. 2 sandpaper. Now lay the other board on top of the sections. Turn the whole thing upside down. Take the top board off the sections. Loosen the wedges as much as necessary to, let the rim drop down on the board and then wedge tight again. Scrape and sandpaper as before. The sections may now be taken out and finished on the little blocks as before mentioned. It is a convenience to have a large table and a number of boards. Each board may be slid along on the table out of the way, or it may be piled up on anotler boardful of sections.

Both seraping and sandpapering will work better when it is so cool that the glue is brittle. Indeed, sandpaper will not work on soft glue.

\section{GRANULATED COME HONET; WEAT TO DO WITH IT.}

If dealers are not suspicious regarding comb honey nor have had their heads filled with stories of artificial comb honey, they ean probably sell granulated comb honey at very near the same price as that which is still in the liquid form; for granulated loney in the comb is fine for table use. Some explanation should be made, how- 


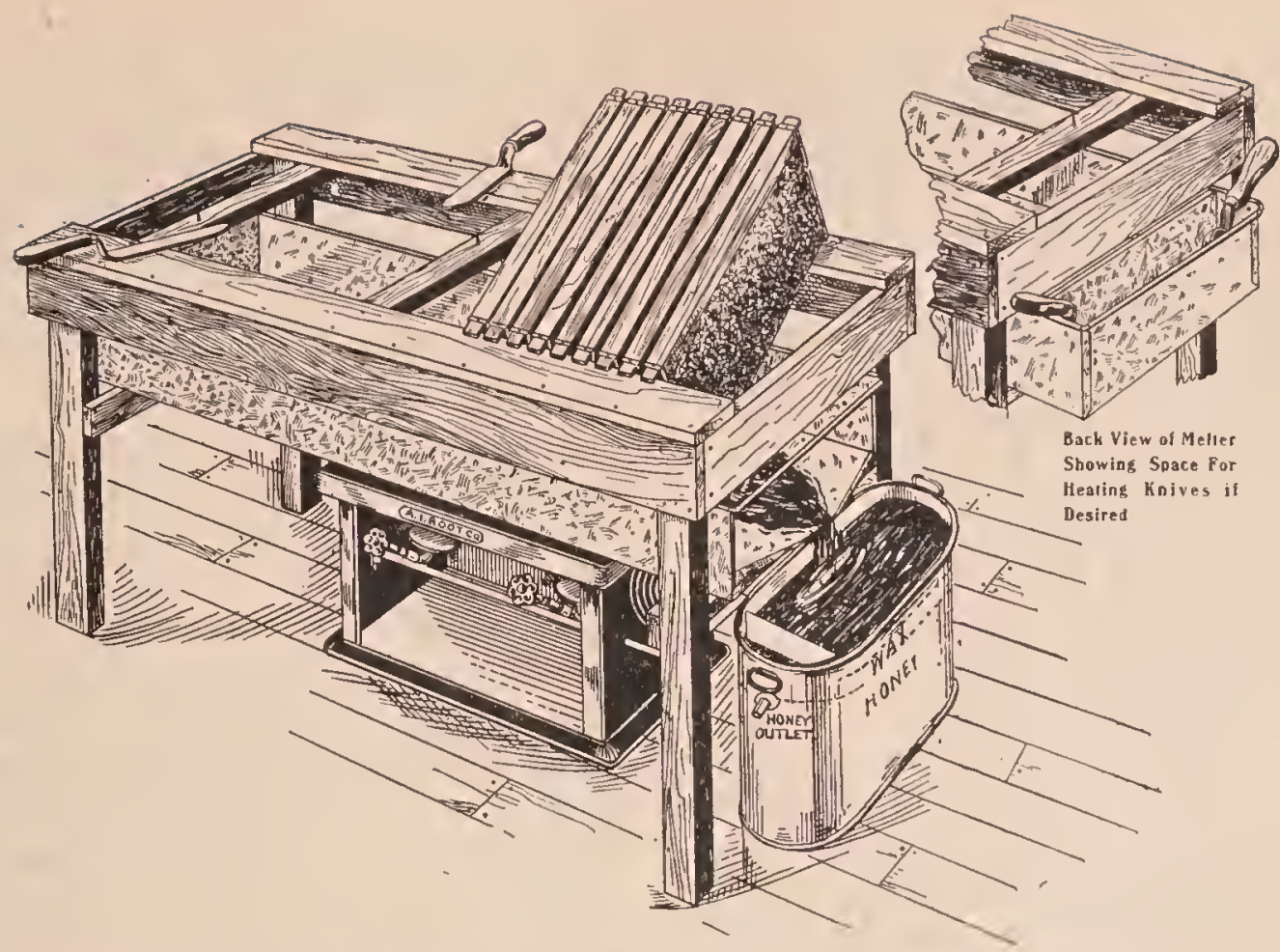

The Peterson capping melter and wax-separator here recominended for liquefying candied honer. Altho designed for melting cappings as explained under ExTRACTEI FiONEY, it may be used as a liquefier if a screen is put across the open end to prevent the solid portions from sliding out. Is soon as the honey is melted, it runs out, away from the heat.

ever, to the effect that the honey going "back to sugar" does not indicate at all that the bees were fed sugar syrup, and that nearly all kinds of pure honey will granulate in time. See Granulated HowEY.

The Jews, in their religious festirals. at certain seasons of the year, use considerable granulated comb honey. The honey and wax make up the right combination for their purpose, and very often granulated comb honey ean be sold to the Jews at fair prices.

If it is impossible to sell granulated comb honey at a reasonable figure, it may be melted up in a capping-melter, and the liquid honey and wax saved and sold separately. If there is any great amount of honey to melt up in this way a large capping-melter should be used, for it is important to have a good-sized heating surface so that the melted honey and wax may be separated as soon as possible. If a small melter is used and overloaded, much of the honey is likely to be confined in close contact with the heated surface for some time; and this, in connection with the wax, inparts to it a flavor that, while not disagreeable, distinguishes it from loney not so treater. On this account the outlet of the melter must not be allowed to dam up so as to confine the honey.

A framework, on which a wide board may be secured directly over the melter; should be made to fit the top of the melter:

Use a sharp butcher-linife or steam uncapping-knife to cut the comb out of the section, then strike the notched or dovetailed corner of the section, causing it to fly open allowing three sides of the section to lie flat on the board. Beginning at the right-hand end, move the edge of the knife with a scraping motion toward the left, holding the section in the left hand by the fourth side, which should be at right angles to the other three sides lying flat on the board. Then use the other edge of the knife: and, beginning at the top of the fourth side, cut down to the board, thins removing quickly all the wax adhering to the woor. Witl a little practice the looner may be eut out of the sections very rapidly - perhaps faster than the melter can hanale it; but in the interrals the heaps of seraper sections may be removed, and new cases of honey set in readiness on the bench.

The mixture of melted honey and wax. as it comes from the melter, should pass rirectly into a separator made on the prin- 
(iple of the Aikin separator. 'The large rut show's the whole melter', separator, ete. At the end of the day, or when the work is finished, the honey should be drawn off as close as possible to the wax, so that the smallest amount will be left to cool with it. The reason for this is that any honey is given a slightly waxy flavor if allowed to cool under wax. As soon as the honey is drawn off, and while it is still warm, it should be strained thr'm a cheese cloth, so that it will be ready for market.

\section{HOW 'TO KEEl COMB HONEY AND AT THF SAME TIME PREVEN'T I'T FROM GRANULATING.}

It is sometimes desirable to lieep comb honey for a better market, or loold it for a reserve supply the year round. To keep it with unimpaired flavol it must not be subjected to dampness. If water condenses on the surface of the comb, the loney is soon diluted, and then it sours. On this account the honey should never be put into a cellar or other damp room. It should be kept in a warm dry room: and that there may be a free circulation of air, without admitting bees or flies, the windows should be covered witl painted wire cloth. The publishers are accustomed to keep comb honey the year round, and rarely does it deteriorate in the least. The same plan will, in the main, apply to keeping extracted honey. During damp and rainy weather, the doors and windows of the honey-room or honey-liouse should be closed and opened again when the air is dry.

Comb honey should under no circunstances be stored where it is likely to freeze, as freezing contracts the wax so as to break the combs and let the honey run. It shonld be kept as nearly as possible between 80 and 90 degrees F., not be exposed to rapid changes in temperature at any time; and it slould never go below 70, if it is possible to avoid it. Variations of temperature lave a strong tendeney to make honey granulate; and notlıing ruins comb honey quicker than this.

Perhaps one in a small way might be able to keep a room hot by the use of a hard-coal stove, from which a regular heat will he given off; but this would be expensive, and make the honey cost too much,
In some instances one might store the honey in the cellar near the furnace. This would give a uniform lieat night and day. After the furnace goes out for the winter the honey should be moved to where it is dry.

THE TEMPERATURE TO ARREST GRANULATION AFTER IT BEGINS.

The publishers of this work made some experiments to see how hot they could keep the room and not have the combs melt down. They found that the temperature must not go higher than $103^{\circ} \mathrm{F}$. While this may seem excessively high, yet, if the honey begins to granulate the only way to arrest the process is to bring the temperature up to $103^{\circ}$, and maintain it there. But there is the difficulty. They accomplished it by putting steam coils in the l'oom with sufficient radiation so that the temperature could be held between $101^{\circ}$ and $103^{\circ}$. If it goes above the high point, an automatic regulator, something on the plan of an incubator-valve, allows the heat to escape. As the temperature drops, this valve closes.

They kept some $2000 \mathrm{lbs}$. of honey in this room for two months. Some of the honey had already begun to granulate, and it was their hope that they could not only arrest the granulation but bring the granulation back to a liquid condition. In this last they were disappointed, but they succeeded admirably in stopping the process that would have soon ruined this whole lot of honey.

They are not sure but a temperature of $100^{\circ} \mathrm{F}$. might do as well, and possibly such a degree would be safer for the arerage person to use, because, if the thermometer shows higher than $103^{\circ}$, there is great danger that the combs will be overlieater, sag. and set the honey to leaking. It should be stated that a temperature of $100^{\circ} \mathrm{F}$., while it will stop granulation will cause the lioney to become very thick and waxy. This is objectionable to some of the trate.

COMBS.-- Tnder HonEyconrs, further on, comb is discussed as a container to hold the honey gathered by the bees, its general structure, how the bees build it without artificial aid, and the so-called artificial comb, which does not exist, and never dir. Inder ('om forsuatrox is described par- 
ticularly low combs are built by the use of artificial aids; under MANIPULATION OF Colonies, how combs ol frames are liandled; and under this head will be discussed the economic and comparative value of good and poor combs when used in brood-frames.

In the olden days, before foundation was known, there was a much larger proportion of inferior and bad combs than there is today when, in a well-regulated apiary, they are built almost entirely from full slreets of foundation. (See Comb FounDATION.) By the use of foundation and self-spacing frames, it is possible to have erery comb in the live a good one-all of them uniform, with little or no drone comb, and as flat as a board, containing very few drone-cells.

The beekeeper who has moder'n hives well painted, and yet who has the average natural-built or poor combs, will lose a large part of the value of his investment. The rearing of drones means a big waste to the colony; and while it is possible, as will be explained further on, to make the bees build all-worker combs without any artificial aids, the problem is far easier to use full sheets of foundation well wired, or better vet use wood base foundation, as explained and illustrated in Cours FousDATION, subhead WIRING FRAMES.

There is not a better asset in the beeyard than a full quota of good combs. If the extracted-honey producer has only enough to fill the hives at the approach of the honey flow, he will lose a large amount of honey by not having an extra supply on hand. Inserting frames containing full sheets of foundation will help out some in an emergency. While the bees may draw them out, it absorbs a large force of bees that might otherwise be occupied in the field gathering honey. Nor is this all. The beekeeper who has a large stock of good straight combs on hand can control swarming to a great extent as well as secure a larger crop of honey. (See Swarming.) In the production of extracted honey there should be at least two extra supers of drawn combs in reserve. These should be kept carefully stored in empty supers or hire-bodies bee and moth tight, awaiting the harvest.

Some rears ago, when the anthor was op- erating outyards for extracted lioney, we managed without any swarming imtil we lan out of drawn combs. The only thing we could give the bees was full sheets of foundation in brood-frames. As soon as we supplied them witl these, swarming commenced. They acted as if they were disgusted because they had to stop and build combs, and then they proceeded to swarm. While we could have extracted the filled combs already on the lives and returned them, such combs were only partly sealed, and, of course, the honey was not thoroly ripened. As explained under ExTRACTED Honey, the quality of the honey is very greatly improved by leaving it on the hives until every cell is sealed. By leaving it on the lives two or three weelss longer in warm weather the honey will acquire a certain mellowness and richness that are delicious.

The novice will see, then, the importance of having a large stock of empty combs on hand. If one does not have the combs, how can he get them? They can be secured by giving the bees frames of foundation in the fall, when they are gathering an inferior honey. They may then be extracted and held in reserve until the following season, until the main crop of white table honey comes on. Of course, one can have the combs drawn out during the main honey flow; but that will probably mean some swarming and a decrease in the crop. The swarming nuisance can be materially reduced by alternating the frames containing brood with frames of full sheets of foundation. Bees will quickly draw out the combs, and the queen will entel them. This will usually check swarming: but it may mean increasing the force of bees that will come on at a time of year when they will be of little use to the colony but will simply be consumers.

THE ECONOMIC WASTE FRON THE USE OF POOR COMBS.

At the ontset mention was made of the economic difference between good and poor combs. The aceompanying illustm: tion will give an idea of what constitutes is good comb, a medium one, and a poor one. First of all, the combs strould be well wired to stand lapid handling, moving full colonies from one yald to another, and 


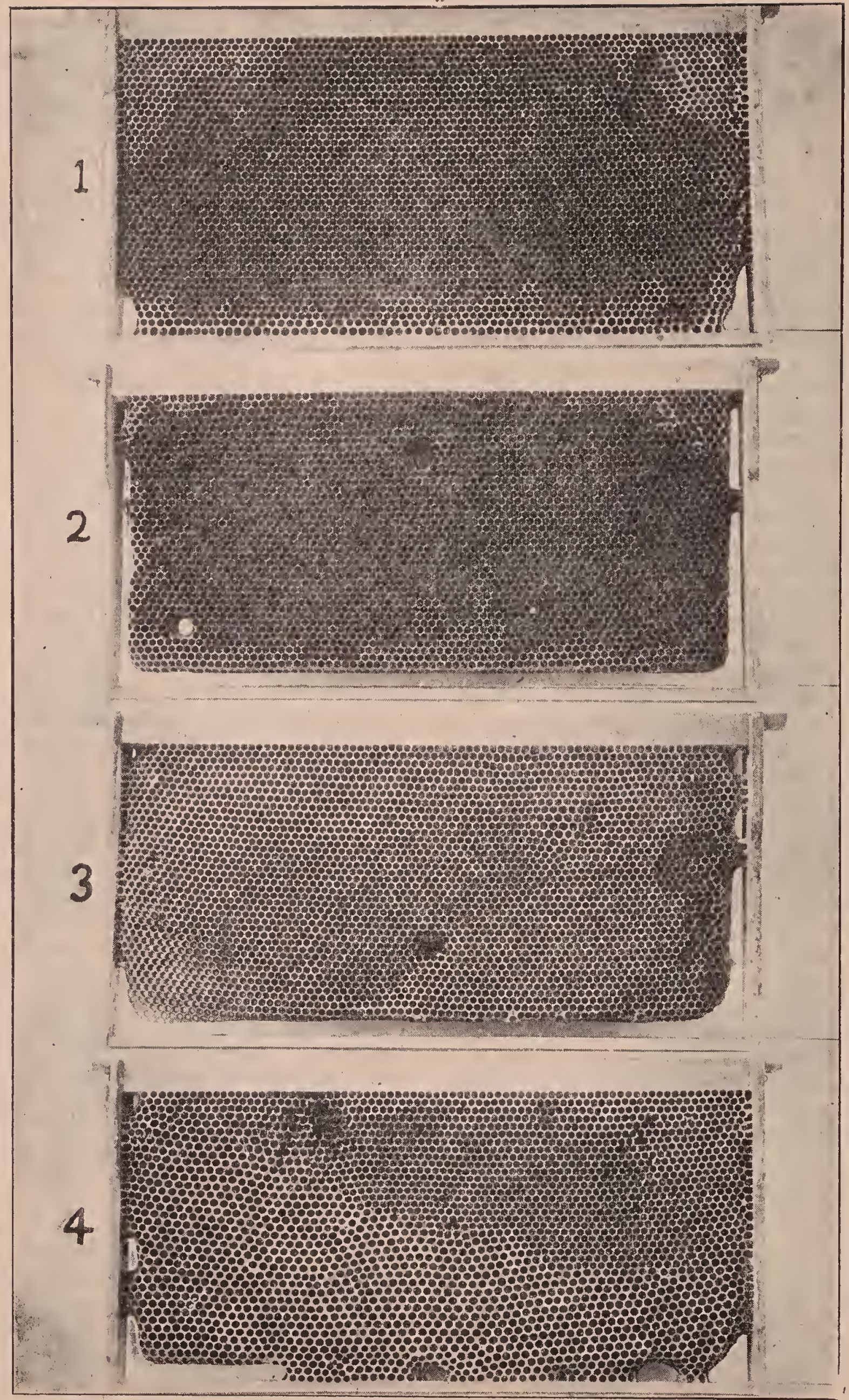

1, perfect; 2, grood; 3 , modium; 4, poor combs, 


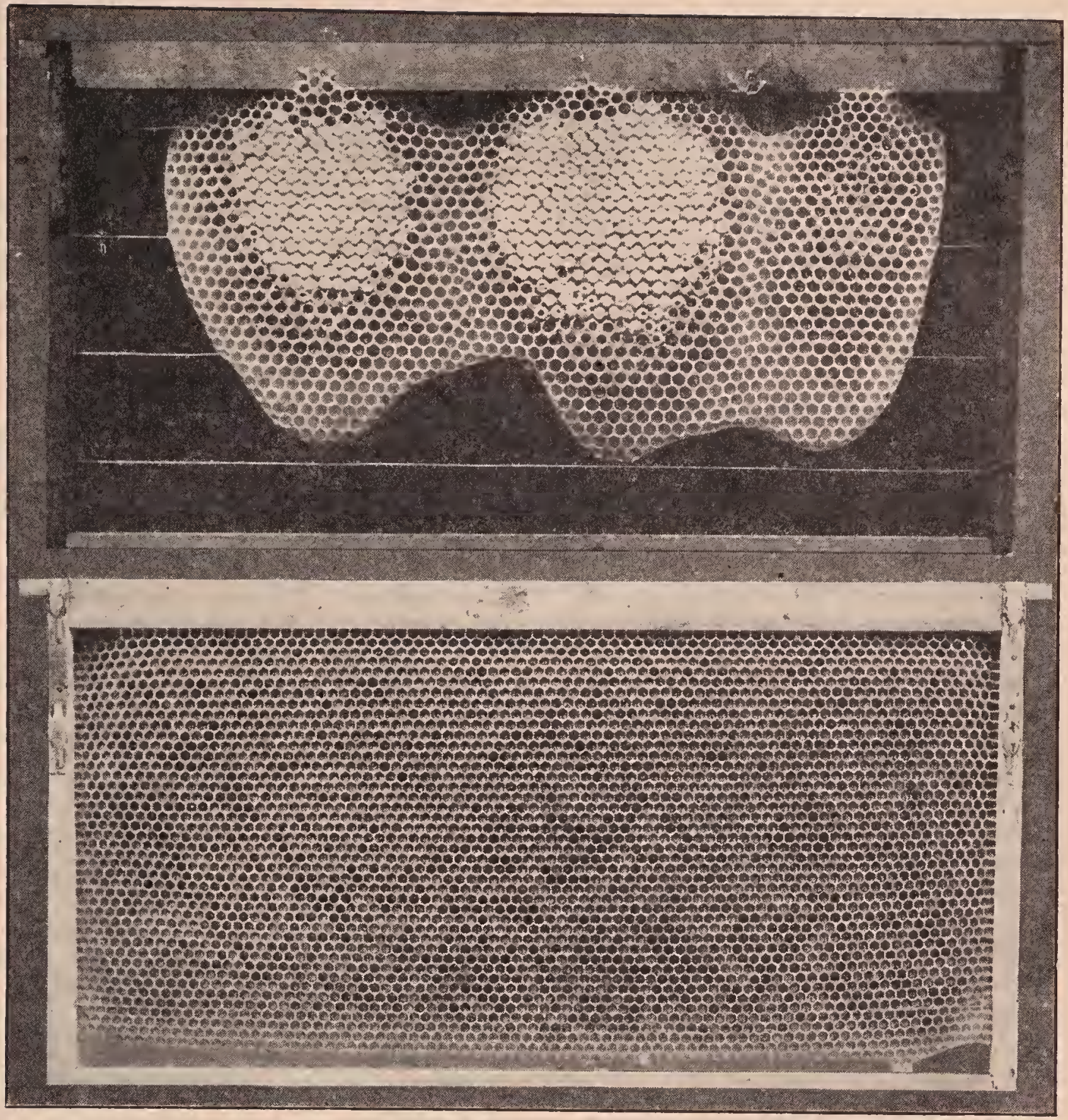

The upper frame, by mistake, contained no foundation, altho it was wired. Note the drone-cells. The lower frame contined a full sheet of foundation, and every cell is a worker-cell.

more or less rough usage in and out of the extractor. (See Comb Foundation and ExTRACTORS.) When the honey is thick the extractor must be revolved at full speed; and unless the combs are well wired or on a wood base they are liable to break out of the frames.

It is essential, also, that the comb be well fastened to the end-bars, and built clear down to the bottom-bar. No. 1 is an illustration of a fairly good comb. No. 2 is fair. No. 3 is a poor one, and both 2 and 3 are defective in that they are only rartially attached to the end-bars. In a year or two perhaps, especially during a good honey flow, the combs may be extended and attached to the end-bars. If the flow is an extra heavy one the bees may build them down in contact with the bottom-bars as shown in No. 1 . If the comb is attached only to the top-bar as in No. 2 there will be a bee-space next the end-bars and the bottom-bar's-just the nicest place for a queen to hide when one desires to locate her.

Attachments to the bottom-bar's can be made very quickly by turning a super upside down, and leaving it so for a week or two, or eren twenty days, during which the bees will probably build the comb 
upward and attach to the bottom-bar, which is now at the top. (See Reversing.) No. 4 , while fairly well fastened, is rery bad on account of the presence of so much drone comb. It may be used for the production of extracted honey; but the objection to it is that the queen, unless excluding zine is used, may go on it and fill it with drone eggs. Extracterl honey can be producert in it as well as in all-worker comb, but the average beekeeper will do well to ent out any comb like No. $t$ and melt it.

The ideally perfect comb is one that is attached to all four sides of the frame, and which lias no holes like No. 2. In a good honey flow these holes will be filled up, but probably with drone-cells; and the presence of these is as bad as the holes themselves.

There are about 132 square inches in the surface of a standard Langstroth comb, and this will make the average comb contain approximately 6500 worker-cells on the two surfaces provided the comb is perfect. If the combs are like No. 4, it will be seen there is a big loss in the breeding capacity for worker brood. One may, therefore, have a ten-frame hive and still have only fifty or sixty per cent capacity for worker brood. As it takes approximately a cell of honey to raise a cell of brood, it will be seen that a given area of drone brood will mean an equal area of honey that is actually lost.

\section{HOW TO MAKE BEES BUILD ALL-WORKER}

COMB WIIEN ONLY STARTERS ARE USED.

If one thinks he cannot afford the expense of full sheets of foundation, it is well to know how to make the bees eliminate all drone combs. E. D. Townsend of Northstar, Mich., tells in. Gleanings in Bee Culture how this may be accomplished.

The secret soems to be in having just the right number of workers and just the right amount of honey coming in, so that the bees will draw out the combs no faster than the queen can occupy them with brood. As long as this condition lasts we should expect the hees to build worker combs. From this we see that, in order to get good results in comb-building from a natural swarm, this colony should be of just the right size, and there should be a honey flow of three or four pounds a day.
Wo will suppose a barge swarm is hived during a period when honey is coming in freely. At this time there is too much honey coming in for the best results in comb-building in the brood-nest, if the whole force of workers is compelled to do all their work in the brood-nest. The remedy is to put most of the workers at work in the supers. Most begimners fail in doing this; but the principle is to make the surplus receptacles more inviting to the workers than the brood-nest, and the bees will immediately go up into the supers on being lived. Our comb-honey super with extracting-combs at the sides makes an ideal arrangement for this very thing.

It is plain to see that, if most of the honey being earried in is placed in the sections, where it should be, the queen will not be hurried to keep pace with the workers, consequently nearly all-worker comb will be built. The brood-nest should be filled with comb during the first 23 days after the swarm is hived, for the queen must keep up with the workers and lay in nearly every cell as fast as it is drawn out, or the bees will begin to store honey in the cells. When this condition arrives, the bees, on the supposition that the queen has reached her limit, and that the rest of the combs will be used for storing loney, begin to build the storage size or the drone-cells in the broodnest. This is likely to occur in about 23 days after the swarm is hived; for by this time the brood is beginning to hatch out in that part of the live where the laying began. From this time on the queen has nearIy all she can do to keep the cells filled with eggs where the young bees are hatching. This meaus that the comb-building part of the hive is neglected, and that the bees build store or drone comb to a great extent until the hive is filled.

There are artificial ways of handling bees so that they will build good worker combs. I refer to the plan of shaking the bees into an empty hive, in the same way that a swarm is hived. If a colony is divided into nuclei of, say, two or three combs each, and each nucleus given a young queen reared the same rear, such little colonies will build very nice worker combs; but the beginner will not be interested in this artificial way of making increase, for he should stick to the naturalswarming plan for his increase until such time as he has had experience and made a success of getting a crop of lioney. In fact, there are many things to be learned before a begimner should take up artificial ways of making increase.

CONTRACTION. - Along in the 80's contraction of the brood-nest during the summer seemed to be all the rage. It was aroued that most colonies, Italians especially, after they hat put a little honey in the brood-nest, would be disinelined to go 
above into the supers. To force them above, some beekeepers took out three or four of the brood-frames below and contracted the brood-nest and then placed snpers on top. This was very pretty in theory, and in practice it did force thing's. It forced the bees into the supers, but more often forced swarming.

Another set of contractionists argued in favor of hiving swarms in a contracted brood-chamber. They did not believe in contracting the brood-nest in an established colony; and, therefore, when they contracted at all they did so only during swarming time. 'This form of contraction is certainly better than the other"; but, as the years go by, less and less is heard about contraction and more and more about expansion-how to get stocks strong-big, rousing, powerful colonies.( See Hives, Coure Honey, to Produce; also Bulldinfi up Colonits.) An eight-frame brood-nest is usually small enough. Indeed, a tenframe may be none too big. See Hrves, Drmensmons of, elsewhere, for the further çonsideration of this subject.

For contraction during the winter see WINTERING OUtUOORS.

EXCESSIVE CONTRAC"ION AND IIOW IT MADE POOR SHASONS IN TIE 80'S.

In his early experiments Langstrotl found that the storage of too much honey in the brood-chamber previous to the beginning of work in the boxes coukl be areatly reduced by the use of a shallow hive, and in adopting the particular depth of the Langstroth hive he was greatly influenced by this fact. In effect the shallow hive cuts off the lioney at the top and permits placing the boxes down close to the brood, which is so important in inducing the bees to begin work in the boxes.

Langstrotl built his live to hold 10 frames and considered this to be the best size for the production of honey in the 6 to 10 pound boxes which were the "supers" of that time.

In using the Langstroth hive to produce loney in sections, beekeepers soon learned that better results could be secured from the weaker colonies by removing any combs not well filled with brood at the beginning of the honey flow and filling the racant space with wide frames, each holding eight sections, or with thick division-boards, which came to be known as "dummies." Later, the wide frames and side storing were abandoned and dummies became a part of the regular equipment for combhoney production.

REDUCTION IN THE SIZE OF THE BROODCHAMBER,

Since the majority of colonies usually have some combs not filled with brood at the beginning of the honey flow, many beekeepers in the 80 's reduced the size of the hive, cutting it down to eight frames, in order to make sure that most of the colonies would have their brood-chambers full of brood at the beginning of the honey flow. In this case, if any colonies should become crowded for room before the main honey flow, a comb of emerging brood conld be exchanged with an empty comb from some colony with less than eight frames of brood. In other words, these beekeepers reasoned that better results could be secured thru a series of years by using a brood-chamber which areraged a little too small instead of one averaging a little too large.

These problems were discussed freely in the bee jomrnals from 1885 to 1890 , at which time the eight-frame hive had practically become the standard hive in this country. It should be remembered that at this time comb honey was being produced by a great majority of beekeepers.

Later, however, it was found that the advantage of the eight-fiame hives was being lost, for after a few years they in turn were not well filled with brood at the beginning of the honey flow. Within a few years beekeepers were reporting the same difficulties with the eight-frame hive that they formerly had experiencer with the ten-frame hive. Instead of recognizing the cause of the smaller colonies being in the reduced capacity of the brood-chamber. with its attendant danger of a shortage ot honey at the most eritical periods, many beekeepers sought a remedy in a further reduction in the size of the brood-chamber. The dummies of the days of the 10 -frame hive were again brought into use, and the "contraction" of the broor-chamber was advocated by most comb-honey producers. 
FURTIER CONTRACTION OF THE EIGHTFRAME HIVE.

This time the brood-chamber was reduced from eight frames to five frames. This contraction was done by some at the beginning of the honey flow when the comb-honey supers were put on and by others only when hiving strarms; but since most of the strong colonies swarmed and the weak ones had to be contracted to induce them to work in the supers, most of the colonies were contracted to five frames at some time during the season, the contractionist advising that parent colonies be contracted to five frames and supplied with a super in order to utilize them as well as the swarm in honey production.

At this time many of the leaders in beekeeping in this country considered five frames to be sufficient capacity for the brood-chamber except during the period of heaviest brood-rearing just previous to the honey flow from elover when the broodchamber was temporarily expanded to eight frames. These things were taught in the beekeeping literature at the time; and at a beekeeper's' convention held in Chicago in 1893 when the question was asked as to the proper size for the brood-chamber for comb-honey production, it was found that the majority of those present favored a brood-chamber of five or six frames capacity.

POOR SEASONS FOLLOWED REDUCTION IN SIZE OF TROOD-CHAMBER.

It is not surprising that the beekeeping industry suffered a period of severe depression at about this time, for the small hives. and severe contraction of that period, together with the gradual elimination of basswood and fall flowers, made the existence of colonies of bees a precarious one indeed unless much feeding was practiced. The series of so-called poor seasons in the clover regions which followed the contraction fad almost wrecked the industry in this excellent honey-producing region, and looking back now it seems remarkable that beekeeping has even partially recovered from the terrible setback of that time.

In November, 1891, Hutchinson wrote in the editorial columns of the Beekeepers' Review as follows: "In 1888 the average yield in my apiary was 10 pounds per colony. In 1889 it was 20 pounds; in 1890 not one pound; in 1891, five pounds. * * * * The honey stored in my apiary the past four years would not have kept us in food more than one year. I am forced to believe that hundreds of beekeepers could make a similar report." After some remarks abont the changes in lis location, brought about by better agricultural methods, he continues: "What puzzles me is that we had good crops for ten year's, then poor crops for four years. It seems as tho the change ought to have been more gradual."

POOR SEASONS CAUSED BY LACK OF STRONG COLONIES.

That the management was more at fault than the seasons was well brought out in the same journal the next month by Taylor, who wrote as follows: "In my home apiary the past season, I had one swarm for about every 25 colonies, an average of abont five pounds of comb honey to the colony. But there was one colony that cast a swarm and gave a surplus of 75 pounds of comb honey over and above sufficjent winter stores for the two colonies. **** There was no accession of bees from other colonies nor any robbing. Wherein was the power of this colony? Was it from the fortuitous conjunction of conditions at the most favorable times so as to produce extraordinary exertion at the nick of time? Did it possess a secret knowledge of some rich acre of elover in a sunny nook? Or was it possessed of inbred characteristies which gave it powers to excel? If in the first or last, as seems most likely, we have in them a rich field for exploration. He who finds out how to time the conjunction of conditions and to perpetuate the most desirable characteristics will abolish poor seasons, not simply find a doubtful remedy therefor."

Early the next year the same writer revealed this desirable "conjunction of conditions, which has since played such an important part in "abolishing poor seasons," in the following significant statement: "In the leanest of the late lean years, every colony that cast a swarm as soon as the first opening of the white clover has given me more than an arerage amount of sur- 
plus comb honey, and by that I nean more than an average in good seasons. Now it has come to be a fond dream of mine that all reasonably good colonies having good queens can be brought to the swarning point by that time."

The poor seasons continued for many year's in the clover region when comb honey was produced. In 1901 in a personal interview with the writer, James Heddon, who at that time was a leader in American beekeeping, stated that his location had failed during the preceding 15 years, and that he had given up hope that the State of Michigan would ever prodnce another "rop of honey.

\section{GOOD SEASONS ARE RETURNING.}

Gradually, however, the tide turned in the direction of better crops, as beekeeper's learned to leave more honey in the hives and quit nursing along little colonies in little brood-chambers by furnishing them food on the "from hand to mouth" plan. Gradually the colonies of better beekeepers have grown larger and larger until now eren the 10-frame Langstroth hive has become too small in many cases to hold all the brood of a good colony at the beginning of the lioney flow, and those who are using a smaller hive now usually expect to have two stories better filled with brood at the beginning of the honey flow than was the single story of 25 to 30 years ago. The comb-honey producers of the present who are still nsing the eight-frame live do not find it necessary to take out empty combs from the brood-chamber and insert dummies to fill the vacant space. Instead of this they are making increase with the extra frames of brood left over when they reduce this hive from a two-story hive to a single story at the time the comb-honey supers are put on at the beginning of the loney flow.

These changes for the better liave come about so gradually that many beekeepers have failed to notice the changes in their management which are largely responsible for them, and some are inclined to believe that the seasons are growing better. Others say that we have developed better queens which can fill 12 to 15 frames with brood instear of 5 to 8 as during the days of extremely small brood-chamber's.
Bnt to be convineed that the greater amount of stores which the better beekeepers are now leaving with the bees is largely responsible for the better conditions of today, it is only necessary to visit a few of the many beekeeper's who still compel their colonies to live from hand to mouth, for some have not yet learned the lesson from the perior of depression from which our industry has not yet fully recovered.

\section{CORAL-BERRY.-See BuckBUSTr.}

CORN SYRUP.-See GutCOSE.

\section{CORN SUGAR.-See SUGAR.}

COTTON (rossypium).-The number of species of cotton have been placed from tive to fifty-four, but conservative aluthority admits of seren woll-definer species. The number of varieties with English names is very large, but the common names give no issistance; they even tend to lead the botanist astray as to the origin of the species, e. g., a cotton called Siamese conies from America. Only four or five species are of interest to the beekeeper. The Asiatic cottons (Gossypium herbaceum) are extensively cultivated in India and China, and have been known for more than $2000^{\circ}$ years. American upland cotton was long referred to this species by mistake. Tree cotton ( $G$. arboreum), a taller species with purple flowers, is a native of Africa, but was held sacred by the Hindus of India and cultivated about their temples. The botanical name of the Egyptian cottons is uncertain, but by many they are considered forms of $G$. harbadense.

Two species of cotton are cultivated in the United States. They are Sea Island cotton (G. barbadense) and American upland cotton (G. hirsutum). Sea Island cotton yields a very fine long staple ( $1 \frac{1 / 2}{2}$ to 2 inches in length), but it is grown only along the coast of South Carolina and inland in southern Georgia and northern Florida. Upland cotton (G. hirsutum) forms more than 99 per cent of the cotton crop of the United States. Two principal commercial types are grown in the United States-short staple upland cotton (fibers nonder $1 \frac{1}{8}$ inches in length), which has by far the largest acreage; and long staple upland cotton (fibers $11 / \mathrm{s}$ to $1 \frac{1 / 2}{2}$ inches long), which is largely 'onfined to the Ya- 
zoo Delta, Miss., a few counties in South Caroliua, and the Imperial Valley of southern California. Egyptian cotton, which has a very long staple ( $1 \frac{1 / 4}{4}$ to $13 / 4$ inches), is grown in the Salt River Valley, Ariz. Cotton was cultivated in Mexico and Peru at the time of their discovery by the Spaniards, and the American species probably originated in tropical America. The Asiatic cottons liave white seeds while the American cottons are black-seeded. There is a ralid species of cotton indigenous to the Sandwich Islands and another to the Society Islands.

Upland cotton (G. hirsutum) is a perennial, but is commonly treated as an annual. It requires at least six months free from frost. The plant grows from 3 to 10 feet tall and bears altemate, palmate leares with 3 to $j$ lobes. The large erect flowers are 3 inches across and on the first day are a creamy white or pale yellow, but soon after midday they begin to turn reddish and on the second day are a deep reddish purple. The flowers of Sea Island cotton are yellow with a reddish purple spot at the base of each of the 5 petals. The 5 sepals are united into a cup or calyx, and below the flower there is an involucre or whorl of 3 green leaf-like bracts. The involucre becomes dry and brittle and is often torn off with the boll by careless pickers.

LONG STAPLE AND SHORT STAPLE COTTON.

When ripe the boll, or seed ressel, splits into 3 to 5 lobes, locules, or locks, containing the seeds covered with long fibrous hail's or cotton, a provision for their dispersal by the wind. A lock seldom contains more than 9 seeds. Cotton fiber is known as lint, floss, or staple and varies greatly in length, the greatest difference between short staple and long staple rarieties being nearly an inch. When the fibers are under $1 \frac{1}{8}$ inches in length the cotton is short staple, and when more than this lengtl it is long staple. In Sea Island cotton the staple or lint may be 2 inches long. The lint varies greatly in strength, and in color from white to yellowish brown. As the fiber dries it becomes flattened and twisted into a spiral like a corkscrew, when it can be spun into a thread, even by the

fingers, since the spirals adhere to each other.

\section{THE COTTON BELT.}

Cotton ranks second in value among the crops of the United States, and in the cotton belt its value exceeds that of all other crops combined. In 1920 the acreage was $35,504,000$ acres and the average annual number of bales produced during five years (1914-1918) was 12,424,000. The northern limit of cotton-growing in this country follows closely the mean anmual temperature line of $7 \tau$ degrees, and very little cotton is grown where there are less than 200 days without frost. There must be an annual rainfall of 23 inches. The cotton belt comprises chiefly easter'n North Carolina, South Carolina, Georgia, northel'n Florida, Alabama, Mississippi, the western lowlands of Tennessee, Arkansas, Louisiana, Oklahoma, and eastern Texas; the densest areas are in the Piedmont Plateau and Upper Atlantic Coastal Plain of South Carolina and Georgia, the Black Prairie of Alabama and Mississippi, the Yazoo Delta in northwestern Mississippi, the Red River Valley in Arkansas, and, most important of all, the Black Prairie of Texas.

The thirteenth census gives the acreage under cultivation in the southern States as follows :

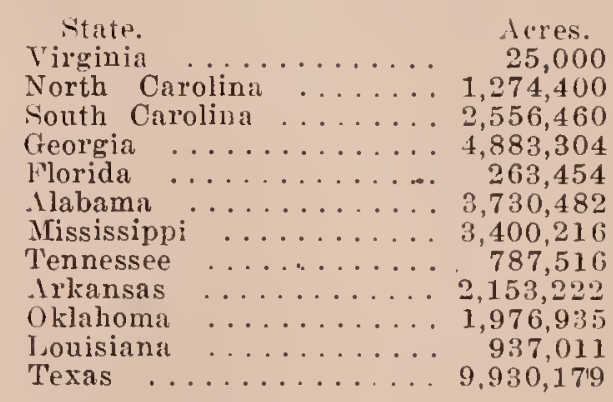

Bales. 1,480 665,130 $1,279,800$ $1,992,408$ 65,053

$1,129,500$ $1,127,156$ 264,562 776,879 $556,47 \div$ 268,909 $2,455,174$

American upland cotton (G. hirsutum) is almost exclusively planted over this rast area. More than 600 varieties have been named and described, which are divided into groups according to the size of the boll, the length of the staple, and earliness of fruiting. The big boll group is the most popular and widely grown since the cotton can be more easily and quickly picked.

\section{NECTARIES.}

The cotton plant has both floral and extra-floral nectaries. The floral nectary 
consists of a narrow band of papilliform cells at the base of the inner side of the calyx. The five petals overlap except at their base, where there are five small openings leading down to the nectar. These gaps are protected by long interlacing hairs, which exclude insects too small to be of use as pollinators, but present no obstruction to the slender tongues of longtongued bees and butterflies. Trelease saw the flowers risited by many bees, and Allard saw honeybees, bumblebees, and solitary bees (Melissodes) enter the corolla. After the flowers have changed in color from pale yellow to red, they cease to secrete nectar, and bees pay little attention to them.

There are two sets of extra-floral nectaries - the involucral nectaries and the leaf nectaries. Below the flower there are the three leaf-like bracts called the involucre. At the base of each of these bracts there is a nectary both on the inner and the outer side--six in all. The three inner involucral glands are situated between the calyx and the involucre, and are present in both the American and Asiatic species of cotton, but are sometimes absent in individual flowers. In form they are round, shield-shaped or heart-shaped. The three outer involucral glands are at the base of the bracts on the outside. They are entirely absent in the Asiatic cottons. Greatly magnified, "they strikingly resemble a shallow round dish with the bottom covered by a layer of large shot." According to Trelease the involucral nectaries secrete nectar abundantly, which in the daytime attracted bees, ants, and humming-birds, and at night two species of moths.

The statement has been made that honeybees gather the surplus of cotton honey wholly from the leaf nectaries, but this is incorrect. Many beekeepers report that a large quantity of honey is gathered from the bloom. At Waxahachie, Texas, so little honey is gathered on the uplands nntil cotton blooms that it is necessary to feed the colonies. Late in the fall, 1909, at Trenton, Texas, cotton bloomed profusely from the middle of October until mid-November and two supers of honey were secured. The bees were laden with pollen as well as nectar, and the queens laid as in the spring. Prominent beekeepers at Cor- dele, Ga., and Sulphur Springs, Ark., report that cotton blossoms yield a great amount of excellent honey.

The leaf nectaries are located on the under side of the main rib of the leaves, and vary in number from one to five. They are absent from individual leaves and entirely wanting in Gossypium tomentosum. They are small pits, oval, pear-shaped, or arrow-shaped with long tails running down toward the base of the leaves. In the Tropics they are soon overrun and blackened by a growth of mold. (Tyler, J. T. The Nectaries of Cotton. Bu. Pl. Ind. Bull. 131, Pt. 5, 1908.) The leaf-glands seen to be most active at the time the leaf reaches full maturity. When the conditions are favorable nectar will collect on these glands in such large drops that it can be readily tasted, and a bee can obtain its load in a very few visits. Honeybees then neglect the blossoms, and honey comes in very rapidly. The honey secured from the foliage of the cotton does not differ either in color or flavor from that gathered from the flowers. Samples submitted to the United States Bureau of Chemistry were reported to be normal pure honey.

COTTON AS A HONEY PLANT.

The surplus obtained depends largely upon locality, soil, season, and atmospheric conditions. There are many factors which influence the nectar flow and cause it to vary in different places and at different times. One of the most important factors is the soil. Cotton is grown on a great variety of soils as sandy loams and clay loams. Rich alluvial soils and black prairie soils are admirably adapted to its culture; but, by the use of fertilizers the poor pine lands of the Atlantic slope and in the vicinity of the Gulf can be made to produce a crop. Lime seems to be required, since the Black Prairie of Texas, the most important cotton area in the United States, is underlaid by Cretaceous limestone. Little neetar is secreted by cotton on light sandy soils, and even in the black-land area on the lighter soils the plant is unreliable. The growth of the plant may be as luxuriant as on the heavier soil, but no matter how promising its appearance no cotton honey is obtained. A beekeeper at Levita, Texas, states that on the river locations in the tim- 
ber region he never obtains any surplus from cotton, but that five miles southward on the black land of the prairie he secures a large amount of honey. On the lighter and drier soils of the uplands the color of the honey is reported to be lighter than on the bottom lands.

Thruout the larger part of the Atlantic and Gulf Coastal Plain cotton does not secrete sufficient nectar to afford a surplus. Opinions differ greatly as to its value as a honey plant and are often contradictory. A series of accurate observations in the different states by a flower biologist is greatly to be desired. In North Carolina the cotton belt, which occupies a portion of the Coastal Plain, is the poorest section of the State for beekeeping. Altho cotton covers over 2,000,000 acres of South Carolina there are no reports of a surplus from this source. At Cordele, Ga., from one to three supers of cotton honey may be stored, and in other portions of southern Georgia it is apparently of value; but in northern Georgia it is a minor honey plant. In Ben Hill County it was formerly an excellent source of honey, but since the advent of the boll weevil the cotton fields do not supply much nectar. In Alabama at Demopolis a beekeeper states that bees will not work on cotton if they can find anything else, even bitterweed. In Talladega County, northern Alabama, cotton does not yield a surplus but furnishes a part of the winter stores. A beekeeper at Greenville in the rich Yazoo bottoms along the Mississippi, a center of cotton production, is positive that the greater part of his surplus comes from cotton, but another beekeeper in the same town is just as positive that none of his surplus comes from this source. In western Tennessee a part of the surplus is reported to come from cotton. In Louisiana bees are said to be seldom seen on cotton, altho it is the staple crop. In the Arkansas River Valley in Arkansas there is an immense acreage of cotton, and 96 pounds per colony in an apiary of 12 colonies was obtained chiefly from this source. In $\mathrm{Pu}$ laski County at Sulphur Springs a great amount of cotton honey is secured. In 1918 the surplus was 40 pounds per colony, but in 1919 only 20 pounds. In Oklahoma cotton ranks next to coirn both in acreage and value. Temperature and rainfall permit of its cultivation in every part of the State except along the north border. $\Lambda$ dense area occurs near the center of the State, and another in the southwest counties. The humid conditions required to stimulate the secretion of nectar occur only occasionally, and it is consequently a very unreliable honey plant. It is, however, frequently reported as furnishing more or less surplus, the flow in Love County lasting from July 20 to September 30.

It is in Texas that cotton rises to the rank of a great honey plant, where it yields nearly one-fifth of the entire crop of honey produced in this State. Altho there are $10,000,000$ acres of cotton under cultivation. it is chiefly in the Black Prairie that cotton secretes nectar abundantly. Either to the east or west of this belt the honey flow shows a marked decrease. In Metagorda County on the coast cotton secretes nectar well only occasionally. At Bay City cotton is not dependable, but in some seasons good yields are secured from it. At New Braunfels and northward to Waxahachie cotton is the main dependence for honey. "In an average season," according to Scholl, "a good yield may be expected from cotton in the black land districts and the river valleys. Under favorable conditions it is not excelled by any other nectar yielder in the cotton-growing belt. On poor soil and on sandy land it does not secrete nectar plentifully and in some sections under certain weather conditions not at all." On the bottom lands of the Brazos River there are cotton plantations which are several thousand acres in extent. Cotton is the only source of nectar, and an average of about 75 pounds of bulk comb honey is secured annually; one season the surplus exceeded 100 pounds per colony. In 1919 one of the larger producers of the cotton belt, before the beginning of the fall flow, had taken off 20,000 pounds, and there still remained in the hives 10,000 pounds to be extracted. For the fall flow 5,000 pounds would not be an overestimate. Waco, McLennan County, is near the center of the cotton belt; and in this county and around Waxahachie more than 500,000 acres of cotton are cultivated. The apiaries are numerous and often average per colony 60 to 70 pounds of honey. In Hunt 
County, northern Texas, cotton is also the main dependence for a honey crop.

\section{HONEY FLOW.}

The honey flow may last from June until long after the first frosts, yielding in some localities as much surplus as all other sources combined. Even after the first frost, if there is pleasant weather, the bees may continue for two weeks longer to work upon the plants and make a large increase in the honey crop. Cotton yields best when the atmosphere is warm and damp. The yield is most abundant in the early morning, and decreases toward the middle of the day as the atmosphere becomes drier. In the afternoon, unless the season is very dry and hot, the yield begins to increase again. During cloudy days or when the atmosphere is damp, nectar is secreted abundantly thriout the entire day. The flow has also been observed to increase toward the close of the season.

\section{COTTON HONEY.}

Cotton honey is very light in color and mild in flavor when thoroly ripened, and it compares favorably with the very best grades of honey. When first gathered cotton honey has a flavor very characteristic of the sap of the cotton plant itself, but this disappears as the honey ripens. During a heavy flow there is a strong odor in the apiary like that produced by bruising cotton leaves. At Trenton, Texas, in 1909, during a very long drought a very fine and pure grade of cotton honey was obtained from cotton growing on rich bottom land. It was so thick that it was almost impossible to extract it, and entirely out of the question to strain it thru even a single thickness of cheese eloth. It was light in color, mild in flavor, and very heavy, and was considered superior to the famous huajilla honey. Ordinarily cotton honey granulates quickly, and in the granulated form is almost pure white and very fine-grained. THE HONEYBEE AND THE COTTON-GROWFR.

How far is beekeeping beneficial to the cotton-grower by more effectively pollinating the flowers and increasing the number of bolls? This is a question of far-reaching importance which deserves careful attention. The percentage of cotton flowers that develop into mature bolls is generally low, a great number proving sterile. The period during which pollination is possible is only a few hours in length. The flowers open soon after sunrise, and at midday commence to wither and close in the evening when the stigma is dry. On the second or third day they fall off from the plant. The long staple varieties of cotton are better adapted to cross-pollination than the short staple. In the former the pistils are longer than the stamens, the stigmas standing $15 \mathrm{~mm}$. (7/12 of an inch) in advance of the anthers, while in the flowers of the short staple varieties the pistils are of the same length as the stamens, and the anthers come readily in contact with the stigmas. According to R. .M. Meade the bolls of the long staple varieties have 23 to 45 per cent of aborted seeds, which it seems not unreasonable to attribute in part to imperfect pollination. He found by experiment that the bolls failed to set unless at least 25 grains of pollen were applied to the stigma. Even with this number only one or two seeds matured to each cell or lock, whereas the normal number should be 8 or 9 . In order that all the ovules or young seeds may mature there should be over 50 grains of pollen placed on the stigma. In 1913 Meade performed the following experiment at San Antonio, Texas, to determine whether complete pollination would increase the number of bolls produced. A long staple cotton (Durango), in the flower of which the stigma stood in advance of the anthers, and a short staple variety (Acala), in which the stigmas were on a level with the anthers, were selected. Two rows of each variety (or 4 in all) were planted. One row of each variety was carefully pollinated by hand, the other row of each variety was left untouched. The following results were noted: (1) The hand-pollinated rows were much more productive than the rows untouched. (2) The long staple cotton (Durango) received greater benefit (nearly 11 per cent increase) from artificial pollination than did the short staple cotton (Acala). Insects were not excluded from any of the flowers and the weather was clear during the experiment. Meade concludes that grower's of the long staple varieties might find beekeeping a distinct advantage to the cotton crop. The value of hon- 
eybees in this connection is recognized in some localities. Unfortunately Meade's death prevented further continuation of the experiments.

\section{THE INSECT VISITORS OF COTTON.}

Manifestly, as is easily proved by observation, cotton bloom yielding little or no nectar will receive fewer visits from bees than bloom in which nectar is abundant. But the pollen grains of cotton are very large and the supply is ample. If there were many colonies of bees in the vicinity, the pollen alone would probably attract sufficient visits to effect pollination. At Thompson's Mills, northern Georgia, Allard carefully observed the insect visitors of cotton. One hundred and twenty insects entered the flowers. Of this number 45 were long-tongued bees belonging to the genus Melissodes, 45 were honeybees, 6 were wasps (Elis plumipes), 16 were bumblebees, and 8 were small solitary bees. At the beginning of the experiments species of Melissodes ( $M$. bimaculata) were very common in the cotton fields, especially on heavy red clay soils. At first honeybees entered the flowers but later confined their visits solely to the outer involucral nectaries. They were especially common near domestic colonies or bee-trees. Many bees (1500) were observed to inspect the flowers without entering them, which would indicate that they contained little nectar. It would appear from these observations that there were not sufficient honeybees in the cotton fields to properly pollinate the flowers and that the presence of more colonies would have been beneficial. It is evident that in order to pollinate the vast area of cotton bloom numberless bees are necessary. Several colonies should be located on every acre. Certainly the experiment is well; worthy of trial.

\section{COTTON IN THE SOUTHWEST.}

There is evidence that cotton was grown in Arizona by the prehistoric eliff-dwellers before the discovery of America. The Indians and early settlers likewise attempted the cultivation on a small scale of short staple cotton. About 1900 a variety of a long staple was introduced from Egypt where in the valley of the Nile it had been grown successfully for many years. At the Government Experiment Station at Sacaton a new variety, known as the Pima, was developed from the Egyptian plant. No other cotton in the world has a greater length ( $15 / \mathrm{s}$ inches) or a greater degree of fineness. In 1911 about 400 acres of Pima cotton were planted in the Salt River Valley. This was the beginning of the growing of long staple cotton as a commercial crop in Arizona. The acreage gradually increased until 1917, when the supply of long staple cotton used in the manufacture of automobile tires became wholly inadequate, and the price increased to one dollar per pound. One of the large American tire companies in the spring of 1918 bought several thousand acres of land in the Salt River Valley and seeded them with the American variety of Egyptian cotton. The alfalfa growers ploughed up their fields and raised cotton instead. In 1920 about 110,000 acres of long staple cotton were growing in Maricopa County, and it was expected that the crop would be 100,000 bales. The average yield is one-half a bale per acre, but on fertile soil one bale per acre is not unusual.

The high price of cotton also greatly stimulated its production in southern California; Imperial Valley, Palo Verde Valley, and Kern County are recognized as cotton-growing centers. In Imperial Valley, Calif., and Lower California, it is estimated that in 1920 there were 120,000 acres of short staple and 33,000 acres of long staple cotton. The total acreage in California was about 200,000 acres. It -was demonstrated that long staple cotton can be grown satisfactorily in this State where there is a season of 250 frostless days and high temperatures occur while the crop is maturing. But the recent decline in the price of cotton has checked its cultivation thruout the Southwest, and many acres in the Palo Verde Valley were not harvested in the fall of 1920 .

Cotton does not yield as much nectar per acre as alfalfa, and, in localities where it has largely supplanted alfalfa, beekeepers are not securing as large a surplus as formerly. In the vicinity of Chandler, Ariz., 90 per cent of the alfalfa has been ploughed up and the land planted with cotton. In the Buckeye Valley alfalfa has been large- 


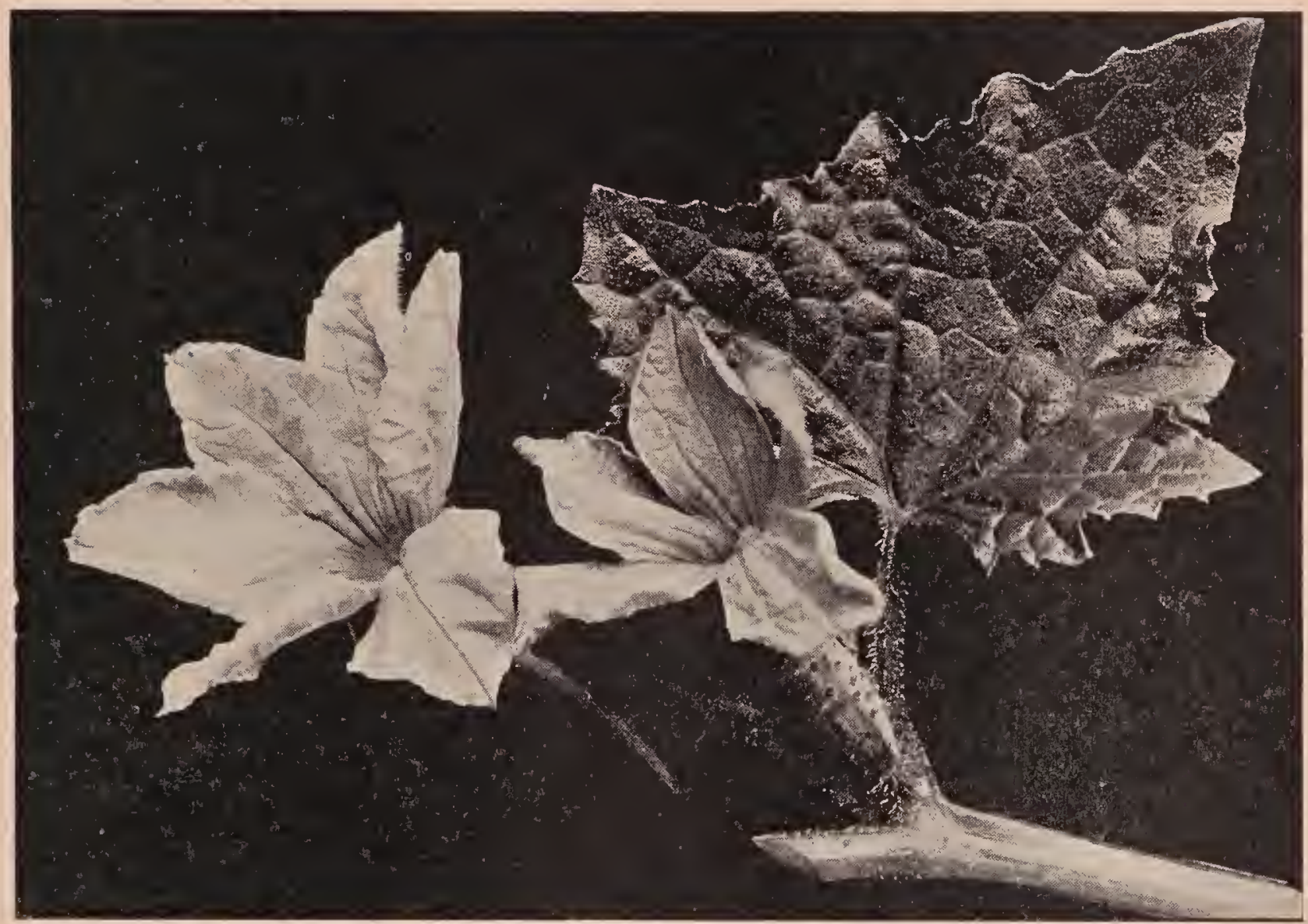

CUCUMBER.

Staminate flower on the left, pistillate flower on the right.

ly replaced by cotton, which here yields so little nectar that 2,000 colonies have been moved out of the valley. 'The larger acreage of cotton, and the longer blooming season will to some extent compensate for the decrease in the alfalfa acreage.

\section{ASIATIC COTTON.}

About two-fiftlis or 40 per cent of the world's cotton is grown outside of the United States, chiefly in Egypt, India, and China. India is the most ancient cottongrowing country, and five centuries before the Christian era the clothing of the people consisted chiefly of cotton garments. It produces about 18 per cent of the total cotton crop of the world. In Egypt, which ranks third in the production of commercial cotton, the crop can be raised only under irrigation. The land suitable for this purpose is restricted to the delta and a strip along the river about a mile wide. The Asiatic cottons, cultivated as a commercial erop, are varieties of $G$. herbaceum. China produces about 16 per cent of the world's cotton; and Russia, Peru, and Brazil also yield a small amount.
CRIMSON CLOVER.-See Clover.

CROSS BEES. - See ANGER OF Bees

CROSSES OF BEES.-See Hybrids.

CUCUMBER (Cucumis sativus L.).--In the vicinity of pickle factories large areas are devoted to growing cueumbers. Two factories at Marengo, Tll., are supplied by 600 acres which yield from 75,000 to 100,000 bushels of pickles annually. The fields vary in size from half an acre to three or four acres, and the ground is completely covered by the large heartshaped leaves. The total number of acres cultivated for eneumbers thruont the country must be very large. As many as 300,000 cucumbers have been produced on a single acre, but this is more than double the average crop.

In the absence of bees cucumber blossoms, whether in the field or hothouse, remain barren. The stamens and pistils are in different flowers on the same vine. the staminate flowers being more abundant on the main stems and the pistillate on the lateral branches. The former are sometimes incorrectly called "male" and the 
latter "female" blossoms. The nectar is secreted in the bottom of a cup formed by the fusion of the floral leaves at base. In the staminate flowers this cup is covered by

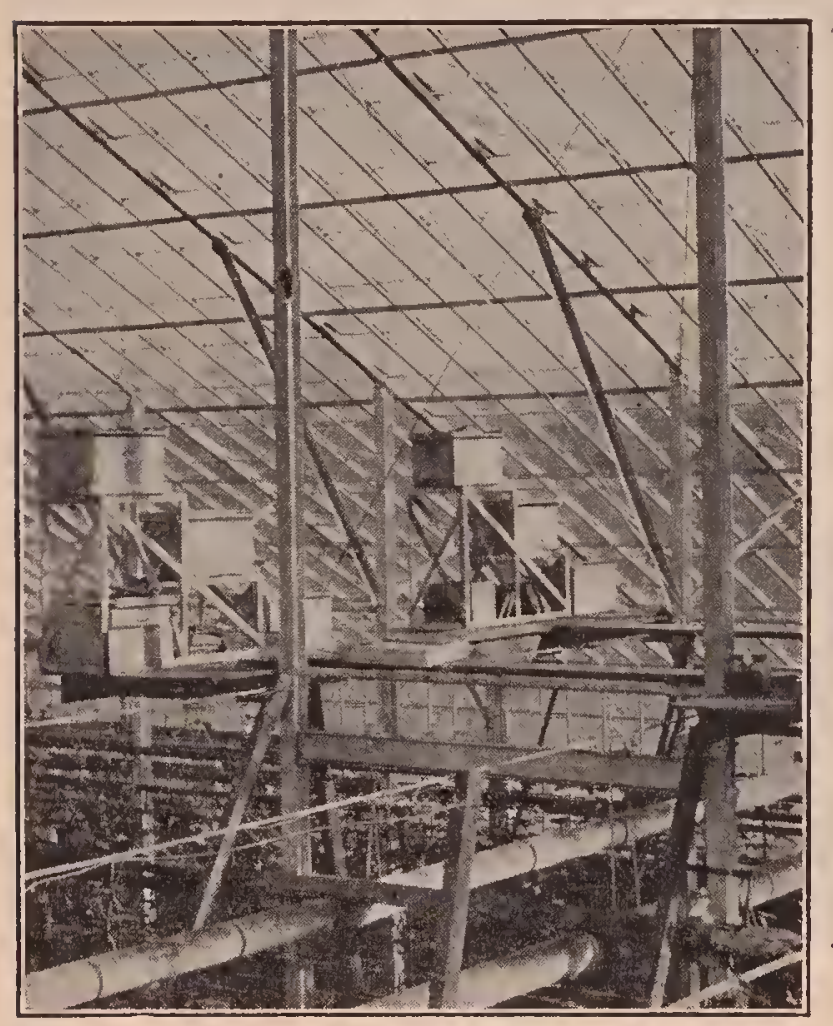

A part of the "apiary" located above the wires some twelve feet from the ground.

the fleshy expanded stamens, and access to the nectar is gained thru three narrow lateral passages between the anthers. When an insect inserts its tongue in one of these passages both sides of its head are dusted with pollen. In the pistillate flowers the pistil rises from the center of the cup. The staminate flowers are the larger and open first.

In order that the pistillate flower may be fruitful, pollen from the staminate flowers must be brought to the stigmas; and in the fields this work is chiefly performed by honeybees, other insects than bees being of little importance. A market gardener in Manitoba states that during three years he was unable, without colonies of the domestic bee, to obtain more than a dozen cucumbers, and in the case of these exceptions the flowers were pollinated by hand. He purchased a colony of bees, later increasing them to eleven colonies. That year cucumbers to the value of $\$ 55$ were sold. It may be regarded as an axiom in cucumber growing: No bees, no fruit.

Cucumbers raised under glass must either be pollinated by hand or by. hives of bees placed at each end of the hothouse. In Massachusetts, Ohio, and New Jersey cucumbers are grown very extensively in hothouses, and more than 2000 colonies of bees are required annually to pollinate the blossoms. A single grower is reported to have 40 acres under glass. Pollination was formerly effected by hand, but the bees have proved most efficient pollinators, and enormous crops of cucumbers are obtained. The cucumbers themselves are much more symmetrical in shape, bringing a better price. In the small greenhouses many bees are lost by bumping up against the glass. In the large ones there is very little trouble of this sort. See Fruit Blossoms, subhead "POLLINATION OF CUCURBITACEOUS FRUITS."

The honey obtained from cucumber blossoms is pale yellow or amber, and has at first a rather strong flavor, apparently suggestive of the fruit; but this probably largely disappears in time. In localities

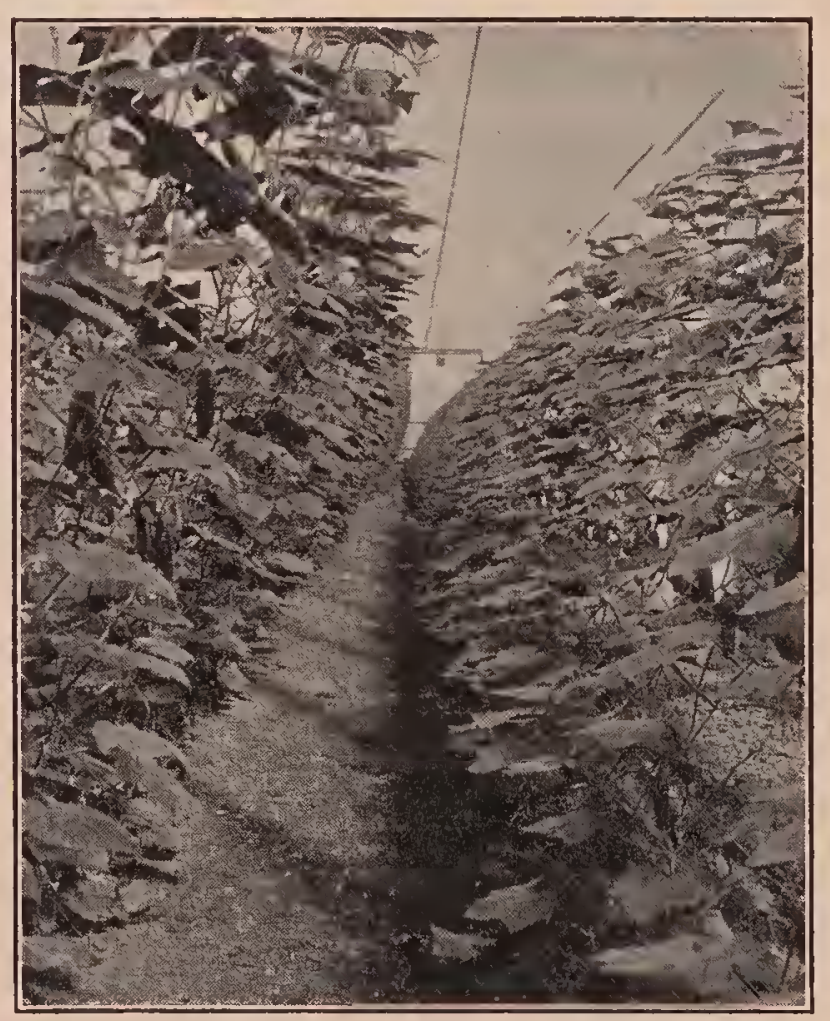

Looking down between two of the rows of cucumber vines growing seven to nine feet high.

where there are pickle factories beekeepers find the cucumber a valuable addition to the honey flora. Sufficient honey for wintering is often secured besides a small surplus.

The cucumber has been in cultivation in 
India for over 3000 years and was known to the Greeks and Romans. According to De Candolle it was one of the fruits of
Egypt regretted by the Israelites in the desert.

CYPRIAN BEES.-See ITALIANS.
DANDELION (Taraxicum officinale Weber.) - Other English names are lion's tooth, blowball, yellow gowan, and priest's crown. It is widely distributed over Europe, Asia, North America, the Aretic regions, and in many other parts of the civilized world. At Medina, as is shown in the photograph, and in many other localities the flowers are in some years so abundant that the fields and lawns are an almost unbroken sheet of golden yellow. The effect is most cheerful and pleasing, and in its season there is no other wild flower that can vie with the dandelion for ornamental

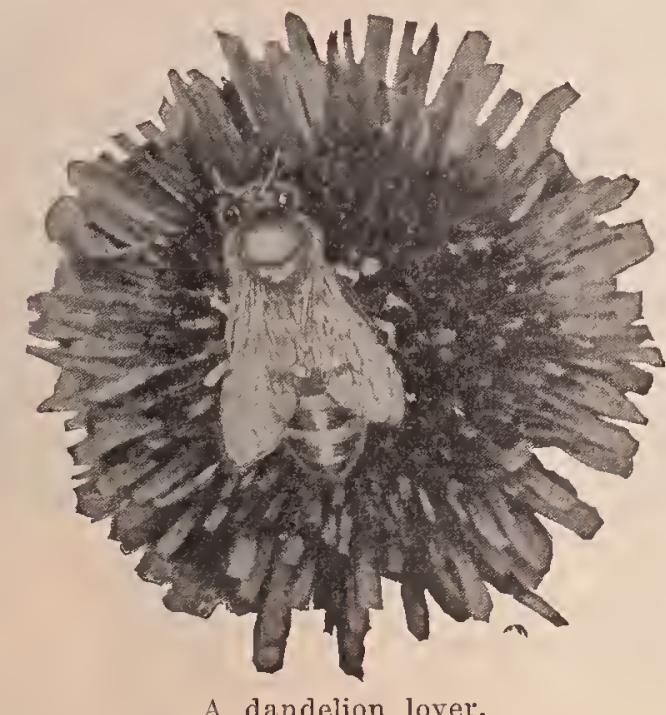

purposes on a large scale. Coming as it does in early spring, preceding fruit bloom, it is a most valuable plant for bees. Some seasons it furnishes not a little honey, and besides it affords a large amount of pollen at a time when bees require a rich, nitrogenous food for brood-rearing.

The dandelion belongs to the Compositae, and is related to the hawkweed and chicory. The head or capitulum consists of from 100 to 200 florets. The corolla of each floret is strap-shaped, but at base unites to form a short tube which holds the nec- tar. At night and in damp weather the head closes so that there is little visible except a protecting whorl of green bracts. The pollen and nectar are thus completely sheltered from dew and rain. In fair weather the hour of opening in the morning varies from 6 to 8 or 9 o'clock, and the time of closing from 2 until sunset, according to the montl and latitude. The flowers open much later in September than in midsummer, and in northern regions than in the United States. The dandelion often blooms a second time in the fall, but much less freely than in spring.

As the nectar and pollen are readily accessible a great variety of insects are attracted, and more than 100 different species of bees and flies have been observed seeking the flower food of this species. The supply of nectar some seasons is abundant. The pollen is plentiful and a special source of attraction. The grains are large, many-sided, and spinous, and so firmly do they hold together that bees can carry large packets of them.

In many widely separated localities a surplus of dandelion honey is not infrequently obtained, and oceasionally it is placed on the market. A beekeeper in central Illinois reports that about 10 pounds of dandelion honey per colony was one season stored in the supers. In Colorado it is common for the hives to be filled with dandelion honey, and a few beekeepers have offered the extracted honey for sale. Finished sections can also be produced. But most of the dandelion honey gathered is consumed in the hives before alfalfa begins to blossom. 'In many locations it is more highly prized than fruit bloom. In Vermont, hive after hive is filled witl dandelion honey; and, with the exception of the elovers, it ranks with the 


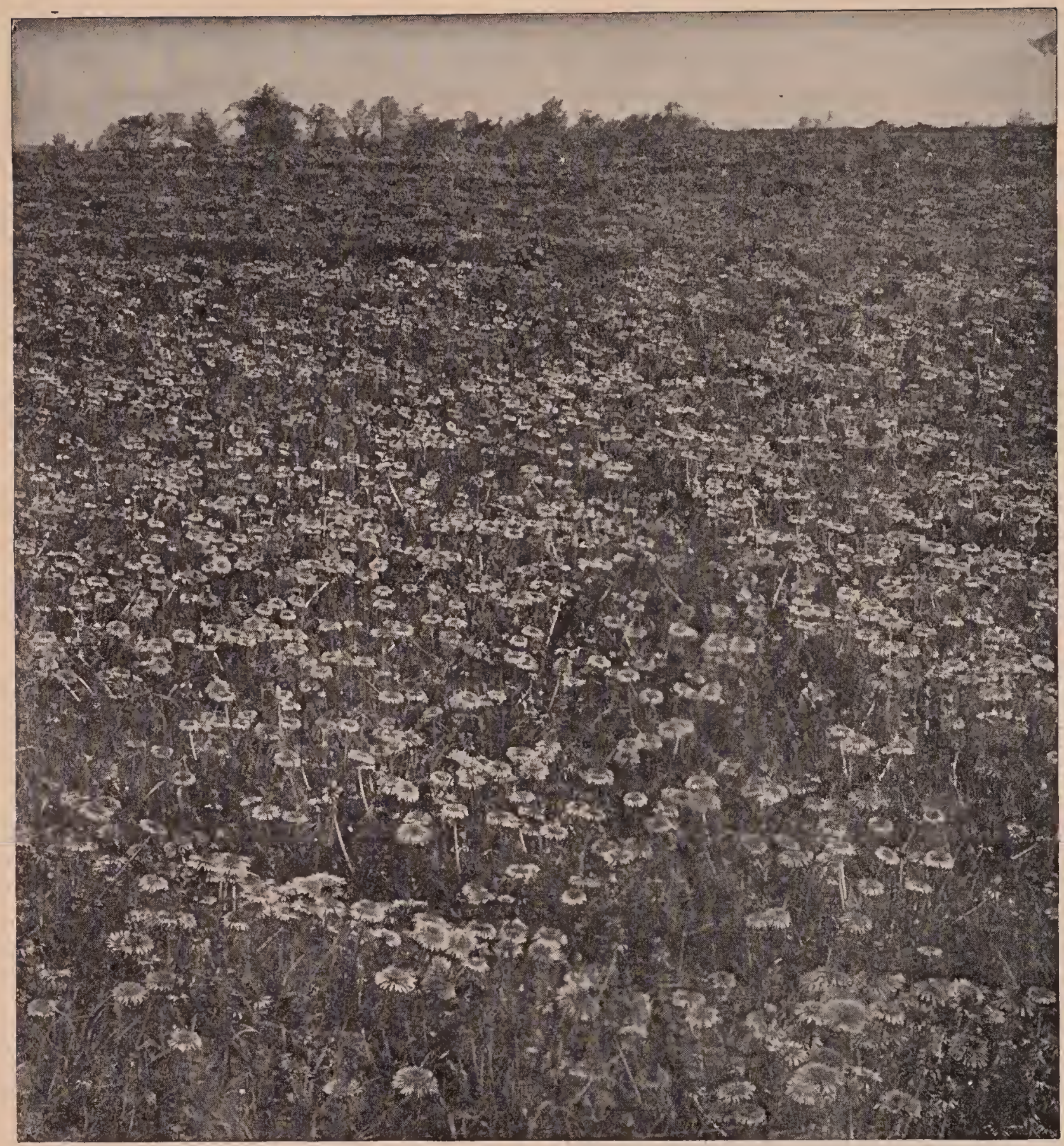

A part of a field of dandelion in full bloom at Medina. This, and other felds like it near Medina furnish considerable honey and pollen in early spring-just when they can do the most good. We do not find that the plant hurts the hay or pastures in the least.

best honey plants of this section. Altho it does not possess a fine flavor, it is used as a breakfast honey. On many farms in Ontario and Quebec dandelion produces more honey in early spring than any other plant. A strong colony will store in the super from 30 to 40 pounds. On May 29, 1916, the warmest day of the month, the temperature at noon being 75 degrees, there was, says Sladen, a gain of nine pounds and twelve ounces for the 24 hours, by a colony on scales at the Experiment Farm, Ottawa, mainly from dandelion. This plant is also said to yield a surplus at Fort William. It is apparently rapidly spreading, both in Canada and the United States, and becoming yearly of more importance to bee culture.

The dandelion is also a valuable honey plant in Europe, and is listed in the honey floras of Spain, Holland, Austria, Germany, and Norway. In Holland, in May the meadows are often literally covered with a golden carpet of dandelion bloom. In southern Germany it is abundant, and furnishes the first honey of the season. It has a deep-yellow color, and crystallizes, after extracting, in a week or two. Very 


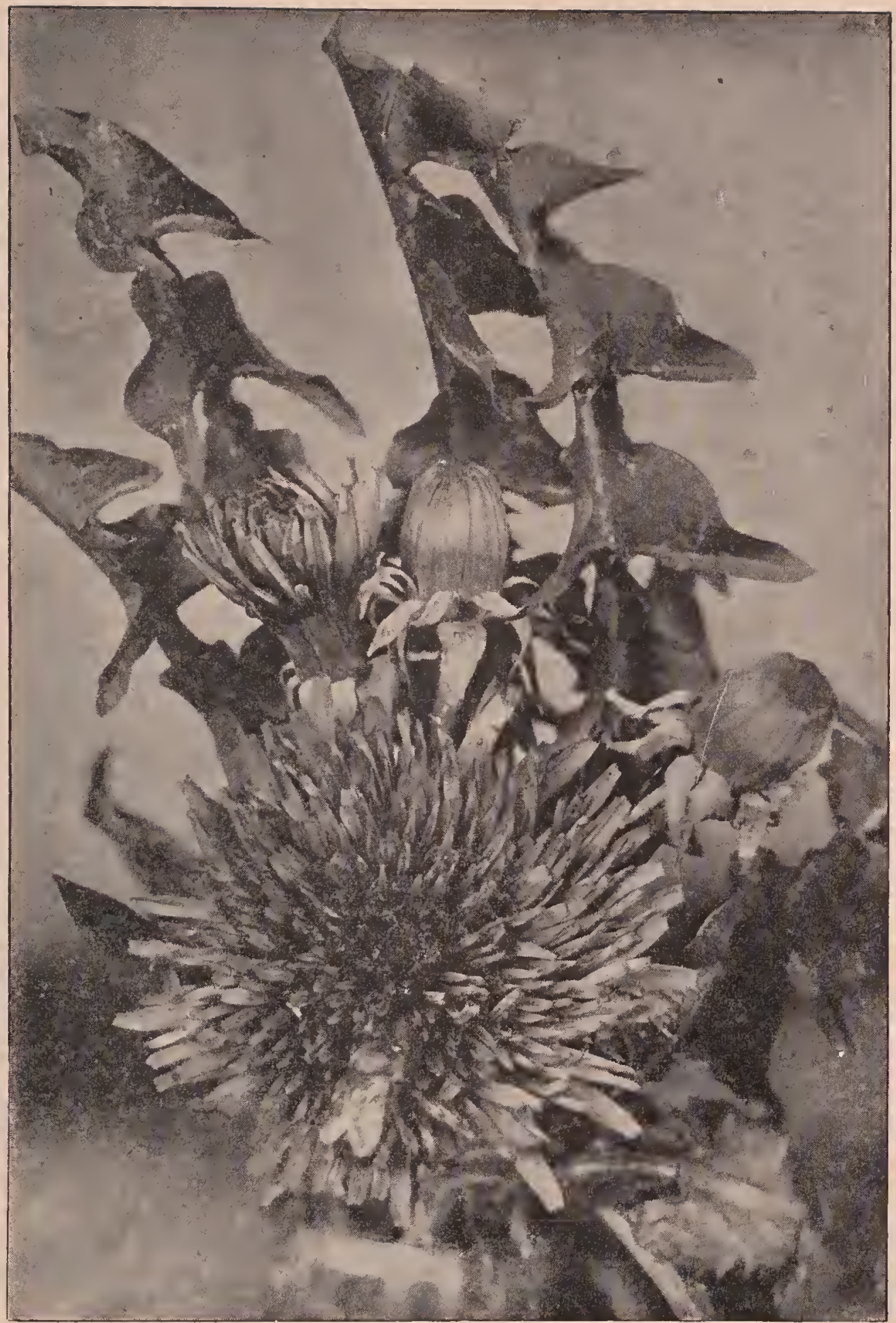

A large specimen of dandelion blossom, buds, and leaves-life size. The blossom here shown is larger than the average. The usual size is about two inches across.

little of it is left in the live at the beginning of winter, which is fortunate, since it is too hard to be easily eaten by the bees.

The flow from dandelion in May lasts for about two weeks, and is increased by a succession of warm days. The honey varies in color from bright yellow to a deep amber-a little darker than that of goldenrod. Comb built when bees are working on dandelion is a beautiful shade of light yellow, even the older comb becoming yel- lowish. When newly gathered the honey has the strong odor and flavor of the dandelion flower; but when fully ripened it has an agreeable taste, altho persons accustomed to a mild honey might consider it too strong. If the brood-chamber is crowded with it, it is likely to be carried up into the super, injuring the quality of the surplus. It is thick and viscous, and erystallizes with a coarse grain in a short time. It would seem as tho a variety of 
this species might be obtained which would yield nectar freely over a wide area.

There are several speeies of dandelion which, like the honeybee, possess the power of reproduction by parthenogenesis. The upper half of the unopened heads of $T$. vulgare, $T$. intermedium, $T$. obovatum, and of several other species, has been cut off with a razor, and all the anthers and stigmas removed before they, had ripened, so that fertilization was impossible, yet the plants developed perfect fruits.

The dandelion has both beauty and utility, and an attempt to exterminate it, even if this were possible, would be a grave mistake. "Of the attractiveness of the bloom there can be no doubt. Attentively considered it will be seen that it is a model of symmetry." It is of no injury in the hay fields, and as a pasture feed it increases the flow of milk and improves its quality. Tons of the leaves, both wild and cultivated, are boiled as "greens" and afford a most palatable and wholesome food-to be had for the gathering. Large quantities are also salted for winter use. The roots serve as a tolerable substitute for coffee, and are reputed to be of medicinal value in cases of disordered liver. The seeds are eaten by poultry, and even the flowers are occasionally utilized.

But more than one futile crusade has been organized against the dandelion based on the complaint that it is a pestiferous weed in lawns. However, a rich soil and a dense turf will do nuch to eradicate or exclude it; but happily nature has made its wholesale extermination difficult. Contrary to general belief, it ean be killed in most cases if it be cut off level with the ground. If this is not effective a drop of kerosene applied with a spring-top oil-can will do it. If the dandelion is not invulnerable, it is invincible. Says A. I. Root: "This plant has been called only a pest, but it is one of God's greatest and most precious gifts in making our northern Ohio elay soil 'a land flowing with milk and honey,' and both at the same time."

DAISY.-See AsTERS.

DEMAREE PLAN OF SWARM CONTROL.-See Swaraing.

DEXTRIN.-See HoNEY.
DEVELOPMENT OF BEES.-The literature on the development of the honeybee available to the beekeeper is scant. This is especially true as regards the development in the egg (embryology) and the metamorphosis. The origin of drones from unfertilized eggs has been much discussed in the journals devoted to beekeeping, but such discussion has, as a rule, contributed but little to our knowledge of the facts. This condition of affairs is somewhat surprising, considering the attention which has been given to the anatomy of the honeybee, and also to the development in the egg. The facts concerning this development are well known, having been decribed by the following investigators: Butschli (Germany) in 1870, Kowalevsky (Russia) in 1871, and

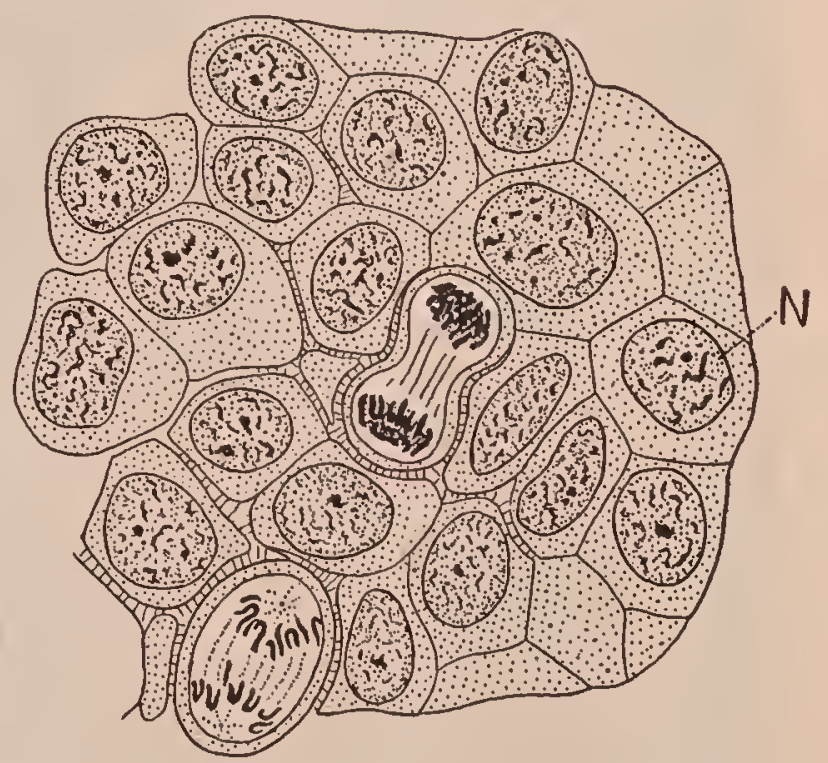

FIG. 1.-Group of tissue cells from the skin of a joung salamander (greatly magnified). $N$, nucleus. Two cells are shown in process of division, and are indicated by their lighter shade.

Grassi (Italy) in 1884. The metamorphosis was described in detail by Anglas (France) in 1900 .

Before taking up a description of the development of the bee, a few words should be said in regard to what the student of plant or animal life knows as a cell. This word has several meaning's, but is used here in a restricted and special sense. All plants and animals are, without exception, composed of one or more cells. The cell is the unit of structure, as the brick is the unit of structure of the chimney, or the soldier of the army. Cells are commonly microscopic in size, so that it requires many millions of them to make up even so smail an animal as a bee. A group of typical 


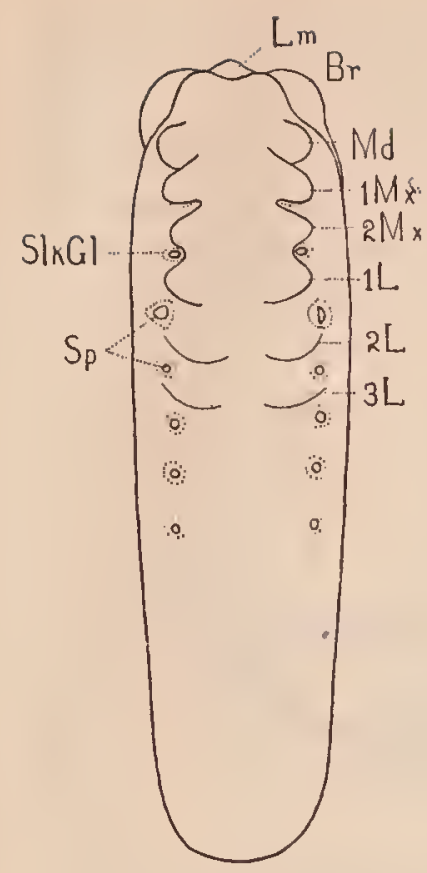

a

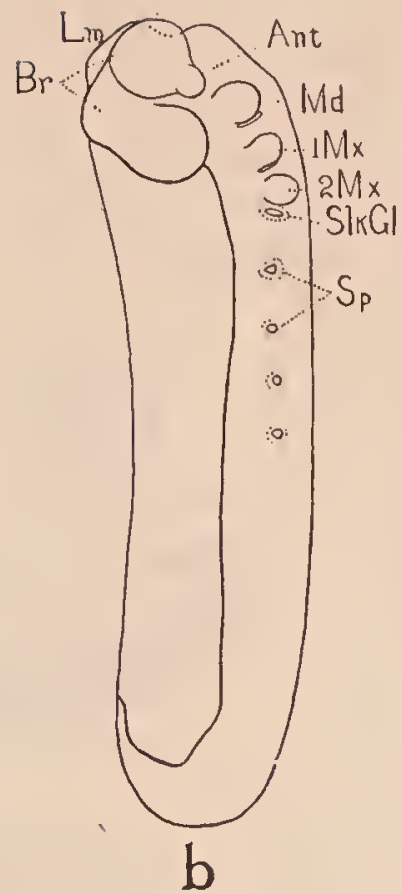

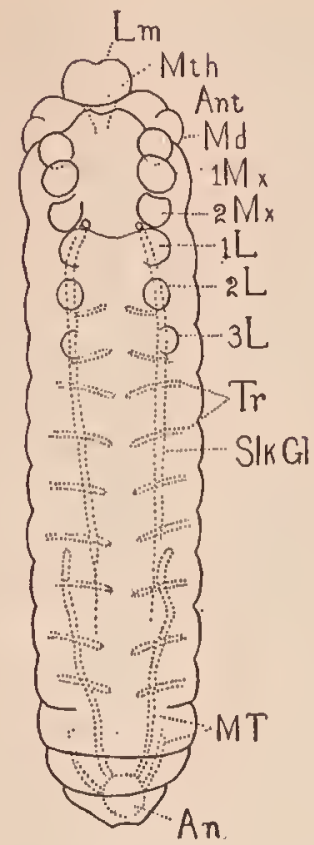

C

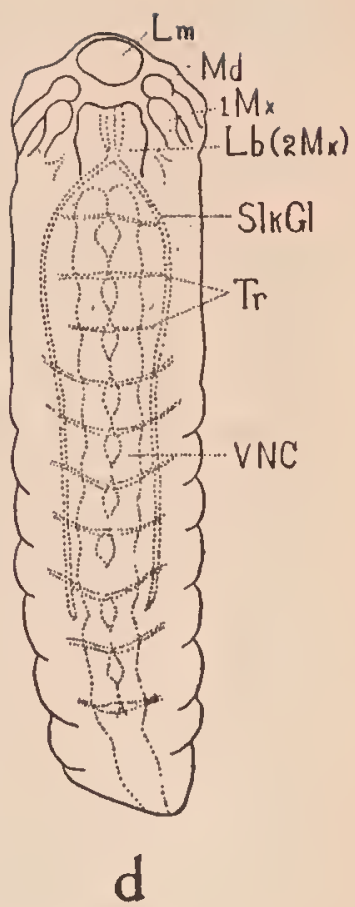

FIG. 2.-Three stages to the development of the egg (greatly magnified). The earliest stage at which the rudiments of the appendages are seen is represented by a and $b$; $a$, egg seen from the ventral (lower) side; $b$, from the right side; c, later stage, showing the development of the mouth parts, silk glands, etc. $d$, embryo just prior to hatching, the development within the egg being completed; An, anus; Ant, antenna; Br, brain; $1 \mathrm{~L}, 2 \mathrm{~L}, 3 \mathrm{~L}$, thoracic legs; Lb, labium (Iower lip) ; Lm, labrum (upper lip) ; Md, mandible; MT, malpighian tubules; $1 \mathrm{Mx}, 2 \mathrm{Mx}$, first and second maxillæ; SlkGl, silk gland; $\mathrm{Sp}$, rudiment of spiracle; Tr. trachea; VNC, ventral nerve cord.

tissue cells is shown in Fig. 1. A cell may be defined as "a mass of protoplasm (living material) containing a nucleus." Both nucleus and protoplasm are interdependent; neither is capable of continued existence without the other. The nucleus (N) is a body usually more or less rounded in form, containing within it a substance commonly believed to be the bearer of the hereditary qualities of the individual and of the race. Every cell is to a certain extent independent, carrying on its own vital functions, such as the assimilation of nourishment and the elimination of waste. In addition, in the higher organisms, it usually has a special function; for example, the special function of the liver cell is to secrete bile, that of the nerve cell to transmit nerve impulses. All the cells in an organism are, however, so co-ordinated that the sum total of their activities is a unified whole, that is, an individual, capable, under the proper conditions, of maintaining itself and contributing to the reproduction of its kind. One property of the protoplasm and nucleus of a typical cell is the power of multiplying by selfdivision. This division always produces daughter cells, each receiving a part of the parent cell. In Fig. 1 two cells are in process of division.

On beginning its development every egg is essentially a single cell. In addition to the protoplasm and nucleus of a typical cell, the egg contains also a certain amount of non-living material, yolk, which serves as a store of food for the developing embryo. Before it can begin development, the unfertilized egg or female cell must usually be first united with a much smaller and more condensed cell, the spermatozoon, or male cell. This cell supplies the male half of the inherited characters and also stimulates the egg into development. This phenomenon is fertilization. In certain cases eggs may develop without the stimulus of the spermatozoon, and they therefore inherit their characters only thru the mother; this is parthenogenesis.

The development of the egg or cell formed by the union of the male and female cells consists in its repeated division, by which many cells, united together, are formed; the shifting and rearrangement of these to form organs and tissues; the gradual appearance of differences between the cells forming the various tissues and organs, so that the cells become changed or 
modified in accordance with the function which they are to assume.

The egg of the honeybee is shaped somewhat like a banana and is about 6-100 of an inch long. One end is slightly larger than the other, the egg adhering to the bottom of the cell by the smaller end. The embryo is always formed on the longer or convex side of the egg, its lower or ventral surface directed outward, the head at the larger end. The egg is in appearance pearly white, and slightly translucent. It is covered externally by a very thin but tough membrane whose surface is covered by a delicate network of ridges. The egg of the bee contains a relatively large quantity of yolk, the protoplasm being comparatively small in amount. On this account cell division is restricted to the interior of the egg, the cells thus formed later rising to its surface to form a layer from which all the parts of the future larva are formed.

The first conspicuous evidence of the future embryo is the appearance, during the second half of the second day, of a bandlike thickening on the long side of the egg (Fig. 2). On this thickening, at the larger end of the egg the appendages begin

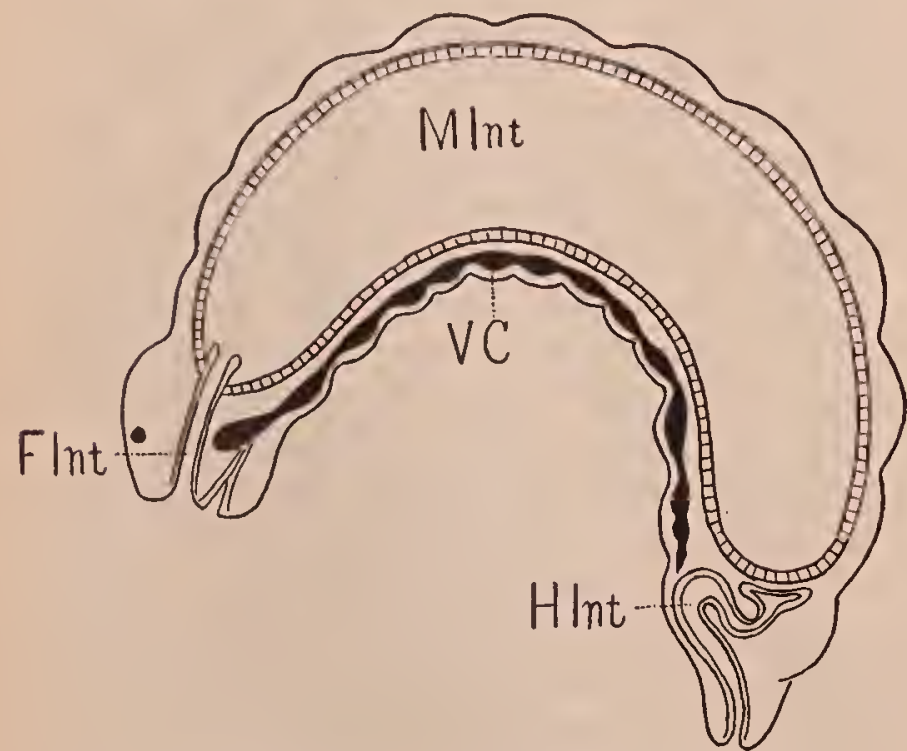

FIG. 3.-Diagram of a longitudinal section thru a larva. Flnt, fore intestine; HInt, hind intestine; MInt, mid intestine; VNC, ventral nerve cord.

to appear as rounded protuberances, the antennæ (Ant) and the mouth parts (mandibles and maxillæ, $\mathrm{Md}$. $1 \mathrm{Mx}, 2 \mathrm{Mx}$ ) being the first to appear. Behind them are the rudiments of the three pairs of legs ( $\mathrm{L} 1$, $\mathrm{L} 2, \mathrm{~L} 3$ ). At about the same time the rudiments of the stigmata and tracheal sys- tem appear as a single row of pits on each side $(S p)$. The rudiments of the silk or spinning glands (Slk G) also appear as pits just behind the second maxillæ. On the upper or dorsal side of the head are also seen two pairs of swellings $(\mathrm{Br})$ which constitute the rudiments of the brain. At

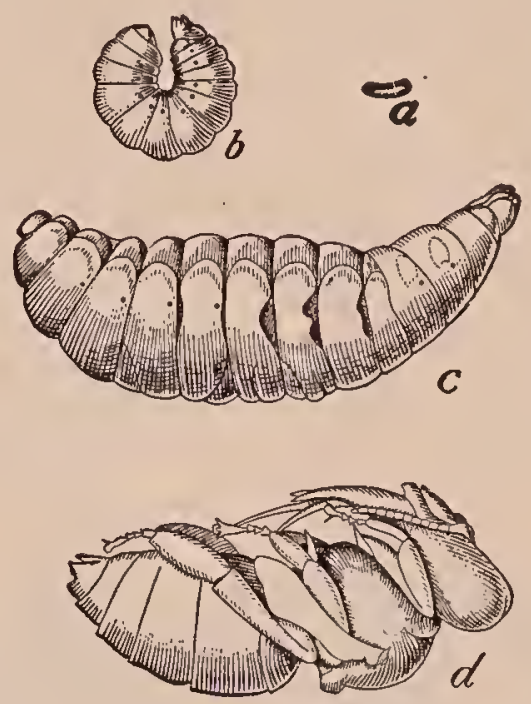

Fra. 4.-Four stages in the development of the honeybee: $a$, egg; b, young larva; $c$, old larva; $d$ pupa.

this stage, therefore, nearly all of the important organs of the larva are outlined. The changes leading to the completed larva are illustrated by Figs. $2 c$ and $2 d$. In Fig. 2e a number of important changes are seen to have taken place. The bandlike embryo has widened, growing toward the dorsal or concave side of the egg. The mouth (Mtl) and anus (An) appear as deep pits at the two opposite ends of the embryo. They join with cell masses on the interior to form the alimentary canal, the parts forming the fore and hind intestines, the cell masses the mid intestine (Fig. 3, Mlnt). The mouth parts have changed little, but the upper lip $(\mathrm{Lm})$ is now represented by a flap-like growtlı. The Malpighian tubules, MT, the excretory organs of the larva, have arisen as outgrowths of the hind intestine. The pits constituting the tracheal invaginations have enlarged to form sacs, and each of these in turn sends out three hollow outgrowths, one of which extends forward and one backward, to meet those of the neighboring segments, and one extends downward to join the corresponding branch in the same segment on the opposite side (Fig. 2, Tr). The pit-like rudiments of the silk-glands (Slk-Gl) have 
grown backward to form long tubes. The ring's ol segments of the body are now marked off by constrictions, as they are in the larva. In Fig. $2 d$ the development in the egg is practically completed. The important changes to be noted are: The disappearance of the rudiments of the antennæ and leg's, the joining together of the second maxillæ to form the lower lip; the completion of the tracheal loops ( $\mathrm{Tr}$ ), and the development of the nervous system. The embryo has by this time completely surrounded the egg, closing up the gap on the back as seen in Fig. 2b. The embryo next breaks the egg shell and becomes a larva, the development in the egg having lasted a trifle over three days.

It is interesting to note that cleavage and in general what may be called "the preparation of the materials," from which the parts of the embryo are formed, consume from 42 to 44 hours, or over half of the entire period of development. After this the embryo develops very rapidly, as shown by the three embryos represented in Fig. 2. The embryo represented by Fig. 2, $\alpha$ and $b$, is about 45 hours old; Fig $2 c$, about 56 hours old; while that shown by Fig. $2 d$ is completely developed.

The yolk, which forms the greater part of the egg, remains in the interior of the egg, the embryo being formed on the exterior and then gradually surrounding the yolk, the lateral edges of the embryo finally uniting in the dorsal mid-line. The yolk' meanwhile is being used up by the growth processes and undergoes considerable shrinkage. Toward the end of development it becomes enclosed in the mid-intestines and is finally digested there.

In respect to their later development insects are usually divided into two classes -those with a complete metamorphosis and those with an incomplete metamorphosis. The honeybee is an excellent illustration of the first class, while the grasshopper is an illustration of the second. When the young grasshopper hatches from the egg it is clearly recognizable as a grasshopper and would never be mistaken for another insect, since it resembles the adult in every important particular except that its wing's are only short pad-like structures. Moreover, its food and habits of life are those of the adult, and it faces the same difficulties and dangers. Its development into the adult is simple; it is little more than an increase in size. The honeybee, on hatching from the egg, is, however, quite a different creature from the adult, being without organs of locomotion ( $\operatorname{legs}$ ), touch (antennae), or sight (eyes). Moreover, its integument is thin and not hardened as in the adult. The larval stage in insects with complete metamorphosis is a short cut in development, by which the young insect is enabled to obtain food more advantageously and to grow more rapidly, and, in the case of the bee, is also protected from enemies. The bee larva is especially adapted by nature for rapidly digesting and assimilating food. As Fig. 3 shows, its mid-intestine or stomacl occupies the greater portion of the body of the larvæ. As one beekeeper expressed it, "a larva is all stomach." For" this reason and because of the rich and easily digested food supplied by the worker bees, and also because the young or larval bee is not required to use up any energy in escaping enemies or in obtaining food, all its energies being bent on eating and growing, it is enabled to complete its growth in a short space of time. This is accomplished in the case of the workel bee in a little less than five days. When the larva is first hatched it lies bent in the form of the letter $\mathrm{C}$ on the bottom of the cell. As it increases in size it becomes more tightly curled until, when about three days old or a trifle older, it is so large that it covers the bottom of the cell with its back against the wall of the cell and its two ends close together. It should be noted that a larva of this age is actually much larger than those commonly supposed by beekeepers to be three days old and is much too large to be used in queen-rearing. Notwithstanding its cramped position the larva does not alter its position in the cell, but remains curled on the bottom. Since the walls of the cell prevent further expansion in that direction the larva grows in the only other direction possible-that is, toward the mouth of the cell. When a larva is nearly full grown it fits the cell like a tight plug, and if it could be frozen or otherwise fixed in this position, when taken out it would present a veritable cast of the lower half of the cell, reproducing 
its rounded bottom and its six flat sides. In fact, during the fourth and fifth days, the larva fits the cell so snugly that its removal is scarcely possible without severe damage to either larva or cell. It is thus evident that, during the later stages of growth, the larva is greatly distorted. When removed from the cell, however, it presents the appearance shown in Fig. 4e, and it is scarcely conceivable that such a plump-looking creature could ever have occupied such narrow quarters. During the first three days of the larval stage of the worker bee, and during all of the larval stage of the queen, it is fed a highly nitrogenous food produced by the nurse bees. The origin of this food, whether it is a secretion from special glands of the nurse bees, or is regurgitated from their stomachs, is not at present known. After the first three days, however, the worker bees are fed honey and pollen. When the larva has attained its full size, which in the case of the worker bee occurs after about five days, it is sealed up in its cell by the worker bees, which place a thin cap of porous wax and pollen over the mouth of the cell. Next the entire interior of the cell is lined with a delicate but tough silken cocoon spun by the larva and secreted by special glands which become active at this time - the silk-glands (Fig. 2, $c$ and $d$, SlkGl). To accomplish this task the larva has to turn lengthwise of the cell at least twice. At the time of spinning the cocoon a connection between the mid and hind intestines (Fig. 3, MInt, HInt) becomes established, and the dark-colored residue of the food digested during the feeding period is evacuated on the bottom of the cell, usually in its angles. Soon after the spinning of the cocoon, which consumes about one day's time, the larva gradually becomes motionless, lying extended on its back, with its head toward the mouth of the cell. The larva now becomes a semipupa or pronymph. Its form is much like that of an old larva, but its color seems paler and less glistening. If touched a semipupa seems soft and pulpy, and if an attempt is made to remove it from the cell it will be found very delicate and easily ruptured. After about three days in this stage, or four days after capping, the semipupa moults its larval skin and becomes. a pupa, with the form and all the parts of an adult bee (Fig. 4d). These-legs, antennæ, etc. -have been developing rapidly during the semipupal stage, but were covered and therefore hidden from view by the larval skin. On the eleventh day after hatching, the eyes begin to turn from white to pink, which color later turns to reddish brown and finally, on the sixteenth day, to black; the thorax at the same time becomes a light yellowish brown. On the nineteenth day after hatching the development is complete, the young bee sheds its pupal skin and gnaws its way out of the cell. The duration of the larval and pupal stages in the development of queens and drones is different from those of the worker. See Bee Metamorphoses, in "Beekeepers' Dictionary," in the back part of this work.

It is evident that, during the period after the larva is sealed up in the cell, the developmental changes which it undergoes must be active and radical indeed in order to bring forth a creature as different from the larva as is the adult bee. The following is only a brief sketch of these complex processes. In general they involve a tearing down and rebuilding of many of the tissues of the bee as well as the coming into activity of portions of the larva which have been. dormant ever since it left the egg, or even before this time. To the former category belongs in particular the alimentary tract, which is literally torn down and cast away, being replaced by new cells. To the latter category belong the legs, wings, and eyes, which are developed from groups of cells whose activities have been held in abeyance during the larval period. These are formed from growth centers of the body wall which are formed before the larva hatches from the egg, but which are quiescent during the growth period of the larva. After the larva is sealed up these rudiments are roused into activity. The legs and wings are formed in pockets of the body wall, and, after the moult of the propupal skin, are pushed out by blood pressure from the interior, as the fingers of a glove may be pushed out by blowing into them. The muscles of the larva are partly torn down and replaced by new muscles, and partly persist as the muscles of the adult. The changes undergone by the nervous, system and the trachea are 
much less radical. All these changes consume energy, which is shown by the fact that there is considerable loss of weight during the pupal period. This energy is stored up in the larva largely in the form of fat contained in the fat-body which surrounds the mid-intestine.

DEXTRIN.-This may be regarded as an intermediate product between starch and the sugar dextrose. When starch is treated with dilute acid, or acted on by heat or by certain ferments, it becomes soluble in cold water and loses its gelatinous character. It is then dextrin. Dextrin is found in all starchy foods which have been considerably heated, viz., toast and the brown crust of bread. It is produced commercially for use as an adhesive. Postage stamps and gummed labels are nearly always coated, with dextrin. Dextrin is found to a large extent in commercial glucose or corn syrup and to a very small extent in normal honey. Honeydew honeys contain larger amounts. See also Sugar.

DEXTROSE.-This is the name of one of the five common food sugars. It is variously termed dextrose, starch sugar, corn sugar, grape sugar, or glucose. It occurs in honey, of which it constitutes a little less than one-half the solid part. It is also found in many fruits, notably grapes; hence the name, grape sugar. Commercially, it is to be found in invert sugar, of which it constitutes one-half, and in commercial glucose or corn syrup, where the proportion is somewhat smaller. It is interesting to note that practically all the starch we eat is converted into dextrose during digestion. See also InverT SugAR and SUgAR.

DIAGNOSING COLONIES.-The term "diagnosing," when used in bee culture, applies to a method or methods of determining the internal condition of a colony from surface indications, mainly at the entrance, and without opening the hive. In the height of the honey flow, expert beekeepers, when rushed with their work, can tell pretty accurately what colonies in the yard are or will be needing attention by a glance at the hive. The knowledge of how to do this enables the expert to administer treatment at once to colonies that would be likely to swarm and go to the woods during his absence, or which might otherwise begin to loaf for the simple reason that they would not have a single cell of storage space available. When bees are crowded for storage room they will even occupy cells that the queen would use for breeding; and the result is she is so cramped for space in which to lay eggs that she is "honey-bound." If the honey flow continues there will not be young brood to come on to supply bees to care for the late flow.

All this goes to show the necessity of giving the powerful colonies room when they need it. To go thru every hive, comb by comb, in the height of the season would be impossible; and so the expert beekeeper picks out by surface indications first those colonies that need attention at one or more of his yards, then, later on, takes care of those that are in no urgent need of care. But knowing how to pick out those that will swarm or waste valuable time in the height of the season, is a trick of the trade worth knowing. Even the beginner who has only a few colonies will find that, after a little practice, he can pick out his best ones by looking at the outside. If Mr. Beginner is a professional man, busy during the hours of the day with other work, he can, at his odd moments, when at home, tell which colonies should liave immediate attention. This saves his time, of which he may not have too much at his disposal.

\section{TO DETERMINE IVHETHER A COLONY NEEDS ROOM.}

Now then for the "know how." The most reliable indication of what a colony is doing or will do is the flight of the bees going in and out of the hive. If one colony, for example, has its bees pouring in at the entrance by the score, and coming out in the same way, and another one right by the side of it has only one-half or onefourth as many going in and out, it is very evident that the first mentioned is very strong and will shortly need room, even if it does not already. The last-mentioned colony may have a poor queen. It may have had poor food during the winter, or insufficient protection. As a natural consequence it will probably have only about one-half or one-fourth as many fly- 
ing bees. It will not need more room, and for the time being can be allowed to take care of itself. The other colony, with its busy rush of bees going in and out, should be opened up. If it has little spurs of wax built along the top edges of the comb, if it is full of brood, and if, further, storage space is being cramped, another super should be added. It is possible, if the weather is getting hot, that the entrance should be enlarged. See ENTrances.

At the same time that the entrances of the strong flyers are being observed it is advisable to get back of the hives of such flyers, and by hefting see whether the hive is getting heavy. With a little practice one can get a pretty fair idea of the amount of honey in the hive by lifting or attempting to lift the back end of the hive. If the bees are flying strong, and the hive seems light, it will, of course, have plenty of room for the storage of new honey. But if it feels heavy, or too heavy to lift, then, of course, room should be given at once.

In like manner the apiarist should go thru the whole apiary, walking down the rows, carefully inspecting the entrances. and hefting the hives. In five minutes' time he can go thru 100 colonies, laying a stick, block, or a small stone as a distinguishing mark on top of the strong fliers and heavy hives. All others he will ignore for the time being. $\mathrm{He}$ and his men will then proceed to examine the indicated colonies first. These may use up all extra supplies he has brought with him, if it is an outyard. Later on, when he has more time, he can take care of those that are not flying strong to determine whether the queen herself is inherently poor or whether the colony did not have a fair chance at the start on account of insufficient protection or poor food. If it is a nucleus or a late swarm in the fall, no matter how much protection it might have, it would have insufficient bees to protect it.

At this point the beginner, at least, should make a careful distinction between the playflights of young bees (see PLAYFLightS) and bees that are rushing to and from the fields. In the case of the former the bees will be seen flying nervously around the entrance, some going in and some flying aimlessly around in the air for several minutes near the front of the hive. When busy at work going to the fields they will fly from the entrance directly to some distant point, as soon as they rise above surrounding objects. In the same way they will come in from the field going directly into the entrance, or perhaps dropping on the alighting-board or ground near by if heavily laden.

Neither must the beginner be confused by a case of robbing and bees actually at work in the fields. When the colony is being robbed out, only one hive, or at most two or three, in the apiary will be involved. The sound of robbing is quite different from the sound of actual workers. In robbing, the bees stealthily dodge in at the entrance as if they expected to be grabbed by the defenders of the home. Real busy honest workers going to and from the fields show no such dodging or nervousness. For the behavior of robber bees, see Robitng.

\section{HOW TO DETECT INCLINATION TO SWARMI.}

A surface indication of natural swarming is a large bunch of bees-three or four quarts of them-clustered closely around the entrance of the hive during the middle hours of the day, with only a few bees flying to and from the field. This big' crowd of bees out in front means nothing if the weather is excessively hot and there -is no honey flow on at the time. If the entrance is small a powerful colony will cluster out in front during very hot weather, and it may do so during a honey flow toward night, but not isually during the day unless the hive is out in the open exposed to the boiling rays of the sun. In that case shade-boards should be appliedsee SHADE-BOARDS unde the head of APIARY; and the entrance should be enlarged-see ENTRANCES.

If the colony persists in clustering out in front during the time when other bees are actively going to the fields, and not many workers going in and out, it may indicate that the bees are preparing to swarm. An examination of the hive will probably show swarming cells more or less toward completion. Merely cutting out the cells may not prevent swarming. If the entrance has not been enlarged, treatment should be applied as recommended under 
Swarming, particularly under Swarming, Prevention of.

During very hot sultry weather in the height of the honey flow; half of the best colonies in the apiary may have a quart of bees clustered out in front at night. This indicates nothing abnormal; for when all the field bees are in the hive there is not room enough to accommodate them and yet allow for proper ventilation.

When everything is progressing normally, and the colony is doing just what it ought to do, there will be a contented roar at the entrance of each colony gathering loney. If a match be ignited and held near the entrance, it will be found by the direction of the flame, that the air is going in at one side and coming out at the other side of the entrance. The contented roar one hears in an apiary where the bees are evaporating nectar into honey can be observed distinctly as one goes down thru the yard. It is a kind of noise that is sweeter than music to the owner of the bees. They have toiled hard during the day, and are now working to evaporate the nectar that they have gathered. At the same time that they evaporate they are lipening and converting the nectar, or sucrose, into invert sugar, or honey. The mere fanning at the entrance only eliminates the surplus of water, and it is an indication that the colony during the day has done enough work to require night work. This contented roar that one hears in front of a strong colony occurs only during the height of the honey flow or during excessively hot weather, when there is no flow on. But the roar of honey evaporation, or nectar evaporation, rather, is much more pronounced than the buzz or noise from a hive on account of the heat. A colony can not stand a higher temperature, no matter what the weather is, than 95 degrees $\mathrm{F}$.

\section{THE PRESENCE AND KIND OF QUEEN.}

There is another indication of the internal condition of the colony, and that is, the way bees carry in pollen. It used to be said that they will not bring in pollen if a colony is queenless. This is true only in part. When it needs pollen it will bring it in whether there is a queen or not. But a colony that has a good queen, and plenty of room for breeding, will require much more pollen than one that has no queen or a poor one. When it is possible to see many busy flying bees going into the hive, and a great deal of pollen going in, it indicates that that hive probably has a good queen, and that breeding is progressing in a perfectly normal manner. Bnt when little or no pollen is coming in, and the bees are not flying much, it shows that the colony did not have a fair chance during winter or spring, or that it has a poor queen. On the other hand, the colony may have ever so good a queen; but if there is any large amount of foul brood, either American or European, there will be but little need of pollen.

DEAD BROOD AT THE ENTRANCE.

If one can tell the difference between a young baby queen and young workers dead at the entrance he will be able to tell whether supersedure is taking place within the hive. If the old mother fails the bees will proceed to raise a number of cells. The first virgin that emerges will be quite liable to puncture the cells of all of her rivals and sting them. These victims will be thrown out at the entrance, clearly indicating that some young miss is boss of the ranch.

An inspection of the entrances will likewise show, oftentimes, whether a colony is on the verge of starvation, whether its brood has been chilled or overheated, or whether there are moth worms in the hive When several full-grown larvæ or perfectly formed young bees, brown or yellow, are found dead in front of the entrance, it may indicate any one of the possibilities just mentioned. When the bees are on the verge of starvation they will not only stop brood-rearing but they will carry out their young larvæ. They apparently go on the principle that they should save able-bodied living bees rather than to lose all in the attempt to raise the babies.

In early spring some of the young brood near the outside edges will become chilled. This brood will be taken out of the cells and deposited in frant of the entrance. At other times, if the live-entrance should be closed for a short time on a very hot day so that the bees are on the verge of suffocation, not a little of the brood will be 
overheated. That which dies will be carried out in front.

When the moth worm is present (see BEE МоTH) some of the brood will be destroyed along the line of the galleries made by the worms. These will be deposited in front of the entrance the same as larvæ dead from any other cause.

The presence of dead young brood out in front of the hive is always an indication that something is wrong. When it is dead from overheating or chilling there is nothing that the apiarist can do, because the damage is already done; but when it is dead because of near starvation, colonies should have immediate attention. In the case of the wax moth, the galleries should be removed as soon as it is convenient to do so.

\section{WINTER DIAGNOSIS.}

During winter and early spring one can often get a very fair idea of what is taking place in the colony by entrance diagnosis. If the front of the hive and ground in front are spotted with yellow, yellowishbrown, or brown or black spots, and if, further, there is a large lot of bees out in front with abdomens looking greasy and black and much distended, it shows the presence of dysentery, and probably no attention need be given, because nothing can be done, since the colony will die away, in all probability. Before that eventuality takes place, the entrances should be closed to prevent robbing.

During late winter or early spring, in front of some of the best colonies may be found perhaps a hundred or more dead bees. If their bodies are shrunken, and if there are no yellow or brown spots, it may be assumed that the colony is in a prosperous condition, and that the dead bees in front are only the superannuated that would have died anyway. Beginners very often ask, when they see dead bees in front of a hive, what the matter is. The fact is, there is nothing wrong. If, on the other hand, there should be a quart or two of dead bees, their bodies ill-smelling, it would indicate that the colony is not wintering as well as it should; but usually when there is an abnormal number of deaths, it is because of dysentery induced by insufficient protection or poor food, or by the well-meaning owner who is tinkering with his colony during midwinter to see how they are coming on.

During late winter or early spring it is not advisable to open up the hives any more than is absolutely necessary. This "necessary" should be only when the colony needs feeding.

To determine which colonies are running short, it is advisable to lift up on the back of the hive.

\section{ADULT BEE DISEASES.}

The presence of bee paralysis or of the disappearing disease can be determined by the behavior of sick bees in the grass neal the entrance. Bees affected with paralysis have swollen bodies looking something like those: that are affected with dysentery. Occasionally they will void a yellowish transparent fluid, but not an opaque yellow, or a brown or black substance such as appears in the case of dysentery. (See DysENTERY.) Bees affected with the disappearing disease show no swollen abdomens. They will run at a furious pace in the grass, some of them crawling up on spears of grass and weeds, and finally dying. For particulars of how to treat, see Diseases OF BEES.

\section{FOUL BROOD BY THE ODOR.}

The presence of American foul brood in an advanced stage can sometimes be detected by the odor at the entrance of a hive affected. When one finds, as he goes thru the apiary, an odor resembling that of an old gluepot, having some suggestion of spoiled meat, he would do well to place his nose near the entrance of some of the colonies. The author has on one or two occasions discovered the presence of foul brood by the odor at the entrance, even when an examination of the combs for the time being has failed to reveal any dead larvæ in the cells. Such diagnosis for foul brood, however, is by no means reliable; but when the familiar odor is detected near a hive, all colonies near by should be examined.

Occasionally the old queen may be found in front of the hive dead. If it is during the spraying season it may be surmised that she was killed by one of the poisons used for spraying fruit trees, to kill the 
codling moth. The hive should be examined at once, and either a laying queen be given or a ripe cell.

\section{CHECKING UP SURFACE INDICATIONS.}

So far, surface indications shown at the entrance will indicate to an expert, and even to a beginner who has made a study of the matter, how to determine which colonies will need attention first, or what is the probable condition of any or all of the colonies. Except in the case of hunting for positive evidence of foul brood, either American or European (see Four Brood), it is not necessary to examine every square inch of comb or brood. A good beekeeper will diagnose his colonies first by the entrance. He will then, if necessary, get a much closer knowledge of what a colony is doing by looking at a single frame of brood in the center of the brood-nest. A quick glance at this frame will show whether the queen is a good or a poor one. If in a little doubt after examining the first frame, he may pick out another frame, after which he will apply treatment if any is needed. See BROOD AND BROOD-REARING.

In short, when a beeman goes thru his apiary he should use methods which will give him a knowledge of his colonies and of what they are doing-in as short time as possible. In this way he saves labor and will increase his profits.

The author has personally handled several outyards, largely by surface indications, or, as here defined, diagnosing from the outside. By placing a stick, stone, or other identifying object on top of the hives that needed attention at once, as determined by surface indications, he used to manipulate only those colonies, and leave the rest alone until they could work up to a pitch when they likewise began to show they were doing business.

DISEASES OF BEES.-A few years ago it was believed that bees were freer from disease than perhaps any other class of animated nature, for the reason that individual members of the colonies were so constantly giving way to the younger ones. But this has been shown to be, to some extent at least, a mistake. Apparently there are at least three or four distinct diseases with which the beekeeper has to con- tend; and it is well for the beginner to have an idea, at least, of what they are like. The time to cure a disease of a contagious character is to take it at the start, or, better still, take precautionary measures such as will prevent its making even a beginning:

\section{HOW TO AVOID DISEASE.}

Contagious diseases spread very rapidly among bees, just as they make rapid headway in crowded centers of the human family. Unfortunately, bees are disposed to rob from each other during a dearth of honey; and, if the germs of disease or infection reside in the honey, they may be scattered over the entire apiary in a few days. Any infected colony is naturally weakened and discouraged, and as a result the bees do not make the defense that they would under normal conditions. During a dearth of honey the healthy bees all over the yard are quite disposed to rob the weak or the sick ones, so that the infection is scattered right and left.

One of the best precautions against disease is good food, and keeping all colonies strong. A healthy human being is much more able to resist the germs of infection than one who is "all run down." A person, for instance, is not likely to come down with typhoid fever unless his system is greatly reduced.

TWO CLASSES OF DISEASES.

The diseases with which the beekeeper has to contend may be divided into two classes-those that affect the mature flying bees, and those that attack the brood. The latter are considered under FouL BRoon.

Among the diseases that attack the mature bees may be mentioned "spring" dwindling." This, perhaps, should hardly be considered a disease, but it is a malady with which one has to deal. Still another trouble is dysentery. This in some cases may be a germinal disease; and in most cases assumes the nature of ordinary diarrhea. See Drsentery.

\section{BEE PARALYSIS.}

This is a disease that is much more prevalent and virulent in warm than in cold climates. Almost every apiarist in the North has noticed at times one or two colo- 
nies in his apiary that show bees affected with it. Yet it seldom spreads or makes any great trouble; but, unfortunately, this is not true in some parts of the South and West. In the South it is known to affect whole apiaries, and seems to be contagious.

\section{SYMPTOMS.}

In the early stages an occasional bee will be found to be crawling from the entrance, with the abdomen greatly swollen, and in other respects the bee has a black, greasy appearance. While these sick bees may be scattered thru the hive, they will sooner or later work their way toward the entrance, evidently desiring to rid the colony of their miserable presence. The other bees also seem to regard them as no longer necessary to the future prosperity of the colony. In fact, they will tug and pull at them about as they would a dead bee until they succeed in getting them out in the grass, where the sick bees seem willing to go and die alone.

Another symptom is, that the bees often show a shaking or trembling motion. Along with this is an effort to scratch and tug at their abdomens with their legs as if there was an itching or irritation.

\section{TREATMENT AND CURE.}

In most cases, destroying the queen of the infected colony, and introducing another from a healthy stock, affects a cure. This would seem to indicate that paralysis is constitutional, coming from the queen; but in the South, where the disease is much more prevalent and destructive, destroying the queen seems to have but little effect. Spraying the combs with a solution of salt and water, or of carbolic acid and water, has been recommended; but these do little or no good. One writer recommends removing the diseased stock from its stand, and putting in its place a strong healthy one. The affected colony is then removed to the stand formerly occupied by the healthy bees. He reports that he tried this in many cases and found that an absolute cure followed in every instance. The rationale of the treatment seems to be that the bees of the ordinary colony having bee paralysis are too much discouraged to remove the sick: as a consequence, the source of infection-that is, the swollen, shiny bees-are allowed to crawl thru the hive at will. But when the colonies are transposed, the healthy vigorous bees of the sound stock carry the diseased bees entirely away from the hive. The sick and the dying removed, the colony recovers.

O. O. Poppleton of Florida had a large experience. One plan that he used is as follows:

He sprinkled sulphur over the affected bees and combs, but not until all the brood in the diseased colony had been removed, and put them into a strong healthy one. Mr. Poppleton said that sulphur kills all unsealed brood and eggs but no harm results from putting the brood among healthy bees, as he found the source of the malady is not in the combs or brood. $\mathrm{He}$ repeatedly put combs from colonies affected with paralysis into healthy ones and never (but once) did the disease develop in any such colony, and that was a year afterward.

At first, said Mr. Poppleton, the disease seems to get worse instead of better. The colony will dwindle, but in two weeks there will be a decided improvement, and finally it will be cured. In many cases, he thouglit, it might be necessary to repeat the application of the sulphur about 10 days after the first time. This makes sure that every bee has received a curative quantity of the sulphur, even if it were not in the hive at the first dose.*

While the foregoing plan worked well, yet, because it is attended with a rapid reduction of the strength of the colony so treated, and because the disease has a tendency to run in certain strains that are very susceptible to it, Mr. Poppleton thought that, in the long run, it might be better to use the following plan: Form as many nuclei from strong healthy stocks as there are sick colonies to be treated. As soon as the nuclei have young laying queens, give to each, as fast as they can take care of them, one or two frames of the oldest capped brood from each of the paralytic colonies, and thereafter till all the brood of such colonies is used up. Next destroy the diseased bees and queen with sulphur fumes, fumigating the hives at the same time.

*Always dust the sulphur on in the evening. 
BEE PARALYSIS IN AUSTRALIA; DEVELOPING A STRAIN OF BEES IMMUNE TO IT.

As already mentioned, bee paralysis seems to be more virulent in hot climates than in cold ones; and it also appears that some strains of bees are less immune to it than others. F. R. Beuhne of Tooberac, Australia, one of the most extensive beekeepers of that country, has had a very large experience with it. But Mr. Beuhne has it well under control by developing and propagating a strain of vigorous leathercolored Italians. The yellow strains he does not find to be very resistant to the disease. It appears that, by paying careful attention to breeding, the tendency to contract this disease may be almost entirely eliminated, and Mr. Beuhne has succeeded. On one occasion he had shipped into his locality 50 colonies, and almost immediately every one of them became badly affected. By killing off the queens and introducing bis own stock he eured the disease.

Repeated tests have shown that paralysis is never transmitted by the brood or combs, but that it is carried by the dead or sick bees. It is, therefore, important, in giving the combs to the nuclei, that there be no dead bees in the cells.

\section{ISLE OF WIGHT DISEASE.}

This is a condition that was first described from the Isle of Wight, south of Great Britain, in 1904. It continued from year to year until it came very near wiping out all the bees on the island. It was feared that it might get on the mainland of England, and in 1907 it did make a start there. At first but little attention was paid to it; but the beekeepers of the British Isles leamed that it is something very serious - much more so than European or American foul brood.

A careful, reading of the reports in the British Bee Journat, covering a period of ten years, indicates the symptoms of Isle of Wight disease are as follows:

A few bees will be crawling out of the hives the same as when attacked by bee paralysis, crawling up spears of grass; and if they can fly at all, it is but a few feet. In a few cases the abdomens are distended by fecal accumulations. In other and most cases there is no distention. Sometimes the smaller or the larger wings in some specimens seem to be out of joint. In bee paralysis the wings appear normal, but show a tremulous motion; but very little of this tremulous condition has been seen in the Isle of Wight disease. The bees sometimes lose the use of one or more pair of legs or drag their hind legs, tho the others may be more or less vigorous. The bees become listless, and cluster in bunches around the entrance of the hive. In bee paralysis there may be somewhat similar clustering; but the bees are more scattered. The affected bees of the Isle of Wight disease, from reports, are rarely black and shiny as in the other disease. In fact, in many cases they seem to be quite normal in their appearance, differing only in their behavior. As the disease advances, the crawling bees will drag their abdomens on the ground, seeming not to have the power to carry them as they ordinarily do, owing to their inability to take the cleansing flight. As it progresses further, every bee in the hive will be involved, and finally the cluster will be reduced to just a very few in the live centering around the queen. The queen seems to be the last one affected.

The intestines of some of the infected bees are said by some writers to contain a large amount of undigested pollen. When this disease is contracted, the bees seem to have an unusual fondness for nitrogenous food, even gorging themselves with pollen of all kinds without collecting any in their pollen-baskets. This is doubtless what causes the abdomens of some of the bees to be swollen. So distended at times are they that it appears to interfere with the proper action of the breathing spiracles.

Sometimes, more especially in early spring, the affected bees seem to lose control of the museles of the bowel and discharge a liquid looking very mnch like that of ordinary dysentery.

CAUSE AND CURE OF ISLE OF WIGHT DISEASE.

The Isle of Wight disease is the most serious of any adult-bee disease known to bee culture-possibly even more serious than either of the brood diseases, bad as they are. While its ravages at present writing seem to be confined entirely to 
Great Britain, there is, of course, danger that it may spread to other countries thru the importation of queens or bees from the British Isles.

For many years the cause of this disease was unknown. In 1912 and 1913 it was believed that it was due to a protozoan, Nosema apis; and this view was held until 1920, when Drs. Rennie and White, and Elsie J. Harvey of Great Britain (particularly the last named), discovered that the primary cause was not due to a protozoan or a bacterium, but to a parasite or a mite, Tarsonemus woodi. This parasite, according: to their paper, published in the Transactions of the Royal Society of Edinburgh, Vol. LII, Part 4, attacks the bees thru the breathing orifices. To quote exactly it "occupies a very restricted region in that part of the tracheal system which has its origin at the anterior thoracic spiracle. In a well-established case of infection it will be found that, extending inward from this spiracle on either side indifferently, parasites in all stages of development may be present in any part of this portion of the respiratory system, whilst the ill effects of their presence may be seen not only in the region of occupation but in the muscular tissue to which these extend. It is not an infrequent occurrence in advanced cases of the disease for these wider tracheae to be occupied by mites in closely packed formation. All stages of development occur; e. g., ova, larvae, nymphs, and adults may be found together. In the smaller branches, frequently these are occupied as far as their diameter will permit, when a single individual may be found practically blocking the tube, and sometimes a linear succession of individuals may be seen in such a position. *** The primary parasitic invasion takes place thru one or both of the first pair of spiracular orifices, and apparently thru these alone." The infection may be on one or both sides. Quoting again: " $A$ single mite may enter the bee, or several may enter together or at intervals. *** It is usually only during the latter stages of attack that the mite attains the smaller tracheae, the thoracic air-sac, and the vessels of the head."

In speaking of bees obtained from Italy and elsewhere, Dr. Rennie says: "In all, several hundreds of bees were obtained from this source. These, along with others obtained direct from Italy, were searched for the presence of Tarsonemus. The result of these examinations was that the bees were found entirely free from the parasite. The evidence is so far satisfactory that it may be accepted that Tarsonemus is not being introduced to this country in Italian bees. Smaller numbers of Dutch bees so imported have also yielded on examination a similar result. Bees in limited numbers have also been obtained from Switzerland and from North America, all of which were also free from this parasite." On the question of whether bees in England are more susceptible to this disease, Dr. Rennie says again:

"It has been suggested that British bees of the present time are of a deteriorated breed, and have lost resisting power, so that Tarsonemus, a relatively non-pathogenic parasite ordinarily, is able to breed excessively. My provisional answer is that other racial forms are relatively affected. For example, Egyptian, Dutch, Punic, and Italian bees can be readily infected, and in these Tarsonemus multiplies with disastrous results, as in British bees. But the question of the ability of a stock to survive a prolonged period of Tarsonemus infection is not a simple one. Amongst other factors it involves the question of relative fertility of particular queens, as well as that of individual tolerance of the parasite."

In a later paper published in the Report of the Aberdeenshire \& Kincardinshire Beekeepers' Association for 1920, pages 19-21, Dr. Rennie goes somewhat more into details as follows:

"The organism norv known to science by the name of Tarsonemus woodi, n. sp.- to give its full deseription-which is invariably present in bees suffering from Isle of Wight disease, is a soft-bodied, beanshaped, scantily haired, colorless, eight- legged creature, invisible to the naked eye. - It belongs to the .class, Acarina, and ranks amongst the tiniest of a group of animals whose popular title serves in our language as a common term to indicate excessive smallness. This particular mite, tho one of the minutest of its class, has a complex organization, and has much in this respect in common with the bees themselves. Beyond a knowledge of external detail, of 
little interest to the lay reader, we have not yet learned very much regarding its life and habits. The fully grown egg-laying female, the largest of the species, is about 1/130 of an inch in length. She lays eggs singly, at intervals, which almost immediately after deposition are larger than herself, and where a few of such females are present in the air tubes of a beé, these early become packed with rows of sausageshaped eggs. From the egg there emerges a six-legged young form or larva, which in turn becomes transformed into an eightlegged immature adult. The adult female alone of all the forms possesses a breathing system similar to that of the bee itself, but with a smaller number of spiracles. She is a tracheate mite, while her mate breathes thru the general surface of his body. The male Tarsonemus is the smallest of all the forms and is not' usually larger than 1/230 of an inch. It seems likely that the pairing of the mites takes place within the bee, and that subsequently the fertile females migrate to the outside and enter fresh hosts. These mites thus. do not appear normally to exist apart from the bee for any great length of time. They are true parasites, breeding and increasing in numbers within it, feeding upon its blood, which they do by piercing with needle-shaped mandibles the breathing tubes, and imbibing the surrounding blood. This repeated pricking maintains a continued irritation in the walls of the trachea, which results in their becoming thickened, blackened in color, and brittle in texture. The air supply is impeded and vitiated by the crowds of parasites, and it has been a matter of surprise to us to find that bees are able to work and live as long as they do whilst harboring these parasites. It is the disorganization of the colony, resulting from the prolonged infection of large numbers, which is the essential crisis in this disease, rather than the actual mortality amongst the bees, which may be a long-delayed event.

"In the course of the investigations at present in progress, thousands of individual bees have been examined during the last nine months. In every stock suffering from Isle of Wight disease, Tarsonemus woodi has been found in every sick member of these. These examinations covered bees taken from diseased stocks in all the year's from 1916-1921. One of the most important discoveries has been that for some time before the disease becomes apparent to the beekeeper thru the familiar crawling symptoms, there may be a quite high proportion of infected individuals in the stock; bees foraging and carrying pollen or nectar have frequently been found. in this condition, both in stocks showing' a proportion of "crawlers" and in stocks supposed to be healthy.

"Such discoveries admitted of at least two possible interpretations. It might be that Tarsonemus woodi was not causally connected with Isle of Wight disease, but was merely a common and comparatively harmless inmate of the bee, or one which became established in an otherwise smitten bee. It may be mentioned that appearances within infected bees are very much against such a view. On the other hand, there was the possibility that some time might elapse after infection was established in a stock, while the mite brood was slowly increasing in numbers, during which the infected bee was able to continue working. There would thus be a period of infection in which the presence of the disease was unsuspected by the beekeeper, because the bulk of the bees continued to work, a period of small undetected losses, whilst all the time the proportion of infeeted bees was mounting up within the stock. Results have shown that the degree and rate of infection within a stock depend in some measure, upon the continuance of fresh infections from the outside, as well as upon other factors which need not here be discussed in detail. The real test lies in the continued observation of such stocks, and in all of those which have been under our observation, with the exception of a very few cases not yet accounted for, the familiar symptoms of the disease eventually developed and the stock died out. More convincing evidence could not be obtained, and I regard the proof that Tarsonemus woodi is causally related to Isle of Wight disease as virtually complete."

A careful reading of the two papers seems to show that the real cause of the Isle of Wight has been discovered. It is encouraging to know that so far the authori- 
ties above mentioned have not found any Tarsonemus woodi in any of the bees from Italy or any other foreign country, including North America. So far, however, only a few specimens have been inspected from these other countries. Provisionally in America at least, it may be hoped that there is no disease of the kind here. The nearest to it that is found here is what is known as the disappearing disease. But this has one marked characteristic or symptom that is decidedly different from any found in the Tsle of Wight disease. Colonies infected with the latter seldom recover without treatment, and the disease continues on unabated unless there is an extra good queen, in which case she may supply new bees faster than the old bees die off. In the case of the disappearing disease of this country, so far as known, the malady or disease or whatever it is, never lasts more than 10 days, at the end of which time the trouble disappears-hence the naine, disappearing disease.

It appears that the parasite, Tarsonemus woodi, may be found in apparently perfectly normal or healthy bees. Bees earrying the mites will go to the fields and apparently function as well as bees that are healthy or without the mite; but, as the parasite begins to develop, the first symptom of their host or vietim will be its inability to fly, altho it may appear to be perfectly normal in all other respects. After a time it joins other affected bees out in front of the entrance of the hive, there to die. The disease, therefore, is insidious in that a beekeeper may have it and not know it until in the later stages he finds evidence showing disjointed wings and many bees crawling around in front of the entrance. It is rather remarkable, even where only one or two of the first pair of spiracles may be affected, that paralysis of one or both of the wing muscles takes place. Apparently the perfect functioning of the first pair of tracheae is necessary in order to insure a normal flight on the part of the bees.

That the closing of the spiracles from any cause has a direct influence on the wings is proved by the fact that the same effect is produced by using any other means of elosing these openings, such as warm paraffin. Experiments by Rennie lave shown that, when these orifices are closed with paraffin, flight is made impossible almost immediately, altho the bee seems to be perfectly normal in all other respects, and may continue so for several weeks at a time. The fact that it can not fly, however, soon results in the elogging of the intestinal passage. This was what gave rise to the belief that the disease or malady was due to a protozoan or bacterium in the intestines. Bees normally will not discharge their feces except in flight.

In this country beekeepers will often find in the apiary crawling bees unable to fly. Such bees are not infrequently found at the beginning of a honey flow or during a temporary attack of disappearing disease. While it is possible that the parasite may be in this country, the presumption is rather in favor of the supposition that some foreign substances-possibly some dirt or pollen grains-have closed the first pair of spiracles, thus bringing on paralysis of the wings. Until more definite proof is furnished, this can be only a surmise or a guess. Until then the beekeepers of the United States slould send all cases of bee paralysis, disappearing disease, and all bees around the entrance that are unable to fly, to the Bureau of Entomology, Washington, D. C.

In the mean time the lope has been entertained in this country that the Isle of Wight disease can not thrive here. The climatic conditions in this country are so different from those in Great Britain that a disease that might thrive in a damp or humid amosphere might find it difficult to get a foothold here. The papers given above would seem to indicate that the hope is not well founded, because the authorities state that other races of bees can be readily infected with the parasite,

\section{SUGGESTED CURE FOR ISLE OF WIGHT DISEASE.}

It has been found that Tarsonemus woodi affects mainly the old or field bees. Whether the mite or parasite lodges in the blossoms that have been infested by other bees is not yet shown; but, in the absence of any evidence to the contrary, it may be inferred that flying bees going to a neighboring hive by mistake might carry the parasite from colony to colony. One would naturally expect, as in the case of 
foul brood, that the hives near the one infected, with the entrances in the same direction, would soon have the parasite. It would also be inferred that the pests would be carried thru the agency of robbing. It might also be transmitted thru hives and appliances.

Nothing in the report by Rennie, White, and Harvey gives a treatment or cure for the Isle of Wight disease; but it has beea suggested in the British Bee Journal that traps might be used to catch the incoming bees of colonies badly infected, and then giving young vigorous queens so that the new young blood would take the place of the old. I.f all the bees carrying the parasite could be trapped out there would be a possible chance that their successors might be freed from the parasite.

In the Bee World (British) reports give hope that the destruction of all bees in colonies affected with Isle of Wight disease, and putting the brood and the queen in an incubator until most of the brood emerges, may effect a cure. As only the adults are affected, especially the flying bees, this looks reasonable and in entire harmony with the facts regarding the cause now believed to be proved. It is to be hoped that this cure will be absolute. If so, it will be no more difficult to apply than the cure for American foul brood, based on the same principle of the removal of the infected material.

\section{THE DISAPPEARING DISEASE.}

This is a malady very similar to the Isle of Wight disease. It has been found in numerous apiaries of the United States. At one time it was believed that this might be Isle of Wight disease; but at the present time the evidence would seem to indicate that it is something else. There are two distinguishing symptoms that would seem to put the disappearing disease in a class by itself. As already pointed out, it disappears in from ten days to two weeks. This is something that seldom if ever occur's in the Isle of Wight disease, the ravages of which continue on indefinitely until the colony succumbs. Another marked symptom from that found in the Isle of Wight disease is the fact that sick bees with disjointed wings in front of the entrance run like erickets, or as if in great distress. They keep up this mad rush until exhausted. From this time on the symptoms are similar to those observed in the Isle of Wight disease.

In 1915 (which was unusually wet) there was a scourge in this country, particularly around Portland, Ore. Many of the symptoms were the same as those described for the Isle of Wight disease and bee paralysis. In the disease reported from the Northwest, it was stated that the brood itself was sometimes involved. But if there was a large loss of bees it is apparent that the brood would be neglected, and therefore die of starvation.

A condition similar in many respects was noticed down in the Mississippi Valley, in parts of Texas, California, and in some of the West Indies in 1915, and in the '90's in Florida; but as soon as settled warm, dry weather came on it disappeared.

Again in 1917 there was an outbreak in the United States. The author examined a number of apiaries where these attacks occurred. In a few cases whole colonies were depleted of bees. In other cases the owners of the apiaries reported that if the decimation continued there would not be a bee left in any hive; but fortunately the disease, whatever it was, after reaching a certain height would suddenly disappear, and hence it is called the "disappearing" disease." The name seems to be appropriate because the bees disappear as the disease itself disappears or the colonies dwindle down. During the last few years this disease has in many places materially cut down the honey crop and in some cases has wiped out entire apiaries. In 1919, Herman Ahlers of Oregon reported a loss of 400 colonies from this cause. This, instead of being the disappearing disease, might have been the real Isle of Wight disease. The former, apparently, does not kill colonies outright.

While the author was in California in 1919 an outbreak of the disappearing disease was observed in certain parts of Ventura County during the spring of that year. He was asked to investigate and give his opinion. An investigation showed a typical case of the disappearing disease. In ten days' time all active symptoms of the malady had disappeared, and the colo- 
nies assumed their normal condition without any treatment whatever. But as the disease or malady developed right in the midst of a honey flow the crop was lost.

The cause of disappearing disease is not definitely known. In some cases at least Nosema apis has been found in the intestinal tract of dead specimens taken from affected colonies. The Nosema was at one time supposed to be the cause of Isle of Wight disease. It is probable, however, that disappearing disease has no relation to Isle of Wight disease, altho the outward symptoms are much the same.

\section{THE MAY DISEASE.}

In Europe, especially in Germany and France, there has been reported a disease not unlike the Isle of Wight trouble, except that it is never seen after early summer. In France it has been called mal de mai; in Great Britain, "May disease; in Germany, Maikrankheit. They all refer, of course, to the same condition; but apparently the symptoms of this disease are not the same as those of the Isle of Wight disease. It comes on in May and June, and then disappears. It is more in the nature of dysentery, and warm weather seems to abate it. It is probable that it is not the same condition as described for the destructive Isle of Wight disease.

\section{DISTANCES BEES FLY.-See FLIGHT OF BEES.}

DIVIDING.-Under the head of ARTIficial Swarming, Increase, Nucleus, and SWARMING, are shown various methods of dividing. But dividing, as it is ordinarily understood, has to do with the operation of increasing the number of colonies or stocks by taking part of the frames and adhering bees, with or without a queen, and putting them in another hive on another stand. Generally speaking, dividing is unscientific and wasteful, while artificial swarming or division on the plans described under NuCLEUS and INCREASE are scientific and profitable, because they are worked in such a way as to secure a honey crop as well as an increase in the number of bees or colonies. Dividing may be performed. so as to ruin all chances of a honey crop, and in addition leave the apiary with a lot of weak nuclei in a totally unfit condition to go into winter quarters, for it is an axiom in beekeeping that one good, strong colony will secure more honey than that same colony unintelligently split into halves and put on two different stands.

\section{DOMESTIC ECONOMY OF THE} HIVE.-See BeE BeHAvior, BROOD AND Brood-ReAring; also Development of BEES.

DRIFTING.-This is a word that has been coined by beekeepers to designate bees in the air that by mistake have gone into the wrong hive. Young bees in their playflights (referred to under "Playflights of Young Bees and under RoBBing), not having thoroly learned the location of their homes, will drift to a hive or hives where many bees are flying strongest, and go in just as if it were their regular home. Even the old bees, when all the hives are set out of the cellar, will very frequently drift into the wrong hive. The colonies that are making the biggest hubbub in front of the entrance will attract flying bees from their weaker neighbors.

Drifting also takes place when a large number of similar hives are placed in one row. When the conditions at each entrance are practically the same, the bees become more or less confused. Sometimes drifting under conditions like this results in robbing. If there is any disease in any hive, drifting will carry it to the neighboring hives. Under the head of APIARY is emphasized the importance of so placing the hives in a yard that each colony of bees can recognize its own entrance. The hives should face different points of the compass, except toward the north, and stand near some distinguishing object. Shrubs or bushes of different sizes, a tree, a stump here and a building there, all serve the purpose of giving each hive a location and an identity all its own.

When the hives are placed in pairs there it not much danger of the bees of the weaker colony drifting into the stronger one, for the bees seem to know the difference between right and left in going back home; but they do not readily distinguish their own individual entrance when the hives are painted the same color, and when each hive looks exactly like other hives in the row.

The arrangement of the hives in the 
publishers' Cuban apiary, as illustrated under ApIaries, is very bad, and decidedly conducive to drifting. The hives would not have been so placed except that the apiarist was very much cramped for room. It would have been far better if he had reversed the entrances and placed the hives, some zigzagwise and some square with the world.

Many of those using the quadruple winter packing cases, having two entrances on the side, report considerable drifting and great variation in the size of colonies in the spring. This can be corrected by nailing a board three or four inches wide between the two entrances.

Drifting when taking bees out of the cellar can be avoided somewhat if the directions are followed under WINTERING IN Cellars, subhead "Time of Day to Take Bees Out." Drifting can be avoided when locating bees at outyards by moving them toward night, and placing them on their stands when it is too late for them to fly, being careful to place the hives so that each colony will easily distinguish its own hive. Next morning they will mark their entrances.

WHY ARE NOT DRIFTING BEES STUNG LIKE ROBBERS.

The novice will, perhaps, ask the question why, when bees drift into the wrong hive, they are not instantly killed by the guards at the entrance, the same as happens in a case of robbing. When bees drift, as already explained, it is because a new condition has been created, or because the young bees when at play have not yet thoroly learned their location. When they go by mistake into the hive, they enter as tho it were their own hive. Robber bees (see RobBing) show by their nervous actions that they are afraid of being grabbed by the guards of the hive they propose invading. Their guilty actions, seeking by stealth or quick dodging to get into the hive, betray them at once. On the other hand, the drifting bees show no such behavior, and of course go directly into the hive as if they belonged there.

In the case of bees just out of the cellar, many, l'ushing out into the air, scarcely know whence they came, and the result is they will return to the entrance of the strongest flyers, or where the greatest dem- onstration is being made, and so go in without arousing suspicion.

When bees are out for a playflight there will be a big hubbub in front of the hive whence they came. Other young bees in the air, or in near-by hives, attracted by their anties in the air, are quite inclined to join in the fun, for fun it evidently is. When the frolic is over, nothing can be more natural than for the whole bunch of them to go into the hive whether they belong there or not. If the hives are properly located, there will be very little drifting as a result of playflights.

DRONES.-These are the male bees of the colony. They are large noisy fellows that do a great amount of buzzing, but never sting anybody, for the very good reason that they have no sting. The beekeeper who has learned to recognize them, both by sight and sound, never pays any attention to their noise, but visitors are many times frightened by their loud buzzing.

If the colonies are prosperous, one may find eggs in the drone comb of some of the best hives as early as March, but not, as a general thing, until April. The drone-cells ean be told from the worker at a glance by the size. (See Honercomb; also Brood AND BROOD-REARING, large eut.) Whenever eggs are seen in the large cells, it may be assumed they are drone eggs. It is not meant by this that the eggs that produce drones look any different from any other egg's that the queen lays, for in appearance they are precisely the same. They are the same in every respect, except that the eggs that produce the worker bees have been impregnated, while the others have not; but more of this anon. The egg, like those producing workers, remains brooded over by the bees until it is about three days old, and then by one of nature's wonderful transformations it is gone, and a tiny worm appears, a mere speck in the bottom of the cell. This worm is fed as before, until it is about a week old, and is then sealed over like a worker larva, except that the cap to the cell is raised considerably more; in fact, the cappings very much resemble a lot of bullets laid closely together on a board. (See BROOD AND BROOD-REARING.) The young drones will begin to cut the caps of these cells in about 24 or 25 
days; the caps come off in a round piece, very much like those from a queen-cell.

The body of a drone is hardly as long as that of a queen, but it is so much thicker thru than that of either queen or worker that no one will ever mistake him for either. His two compound eyes are much fuller, his head is much thicker, and his wings larger. He has no baskets on his legs in which to carry pollen, and his tongue is so unsuited to the gathering of honey from flower's that le might starve to death in the midst of a clover field in full bloom.

\section{THE MATING OF QUEEN AND DRONE.}

The young drones are ready to leave their hive after they are about two weeks old*, and they do this shortly after noon of a warm pleasant day. They come out with the young bees as they play, and first try their wings; but their motions are far from being graceful and easy, and they frequently tumble about so awkwardly that, as they strike against one's face, he might almost think them either drunk or crazy. It is not easy to decide how old a drone must be to fulfill the sole purpose of his existence, the fertilization of the queen, but it may be from 25 to 30 days.

Some facts seem to indicate that drones, as well as the queen, may fly long distances from the hive - perhaps two miles or more. There is now satisfactory evidence that the meeting between queens and drones takes place not very high up from the ground. Several observers have reported seeing this meeting not far from the hives, during the swarming season. The queens and drones sally forth during the middle of the day, or afternoon, and in from 15 minutes to an hour, or possibly two hours, the queen returns with a white appendage attached

*AGE OF SEXUAL MATURITY OF DRONES.

By a histological and anatomical study of the drone organs and their secretinns, as well as by other means, Bishop (Bishop, Geo. II., 1920, Fertilization in the Honeybee) found that the drone is not sexually mature at the time of emergence, but undergoes a further growth period of at least nine to twelve days. During this period many changes takes place in the drone organs, especially up to the sixth day, after which the changes are slight.

F. W. L. Sladen, Apiarist of the Canadian Department of Agriculture, conducted some experiments by carrying virgin queens and young drones to an island for mating. He reports that queens mated to drones under two weeks of age produce a large percentage of infertile eggs, thus confirming in a practical way the findings of Bishop. to the extremity of her body, that microscopic examination shows to be the generative organs of the drone. These facts have been observed by hundreds of beekeepers, and are well authenticated. In attempts to have queens fertilized in wirecloth houses the author, after letting the queens out, has seen the drones pursue them until both ranished from sight. Still another fact: If one takes a drone in his hand some warm afternoon just as the drone has sallied from the hive, and presses him in a certain way, he will burst open, something like the popping of a grain of corn, extruding the very same organ that is found attached to the queen, and dying instantly.

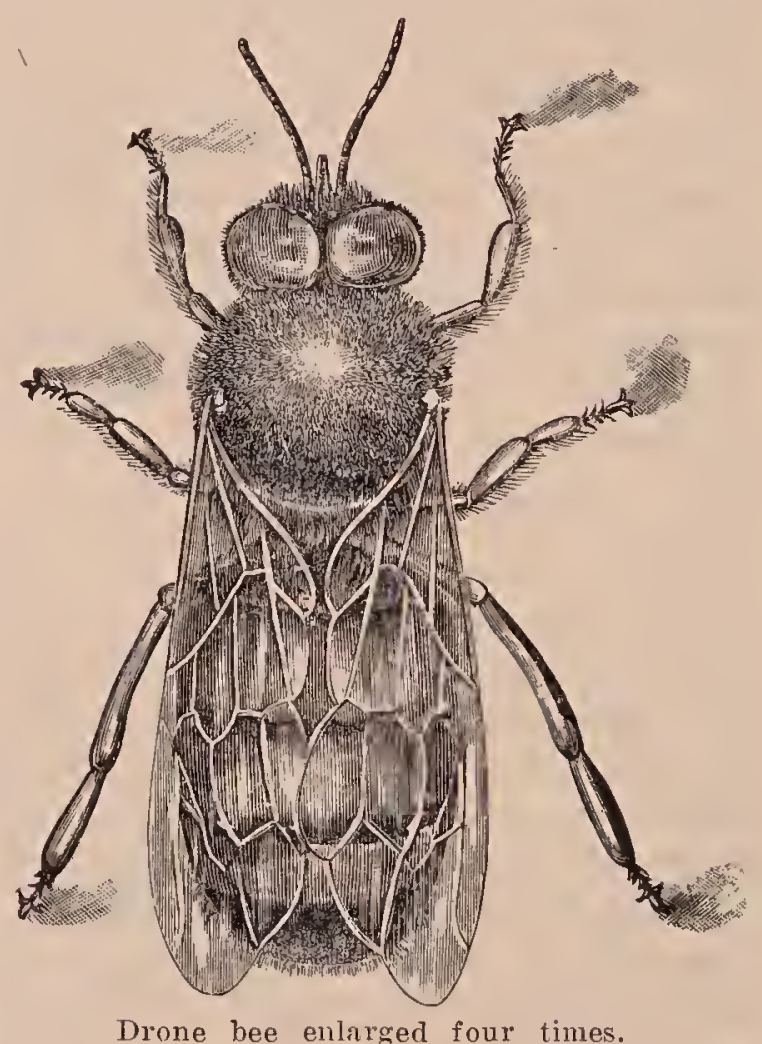

The manner in which the meeting of the drone and queen takes place has been witnessed a great many times; but two statements will suffice to describe the act.

I have this day witnessed the act of copulation between a queen and a drone. About $2: 30$ o'clock on the afternoon of Thursday, July 2 , I was standing near a fertilizing-box filling a feeder when my attention was attracted by an unusual commotion in the way of extra loud buzzing, as of drones on the wing. I looked and saw a queen rapidly flying toward the fertilizing-box, evidently her home. She was closely followed by two drones, one of which turned and flew off, but the other remained in pursuit. They were flying not six inches from the ground, and 
were not over eight feet from the fertilizing-box when the act took place. It was done so quickly that I marveled at it, and I wish here to record the facts as I witnessed them. I could not see that the queen was flying in any but the usual way when returning to her hive, but the drone was unusually swift of wing. They were both flying rapidly; and as they flew the drone made two circles about the queen as tho to head her off; and as these circles were made about the queen she rose slightly each time. Directly after making the second circle about the queen the drone flew at her like a worker with the intention of stinging in earnest. His abdomen was curved, and his wings rattled in about the same manner. Directly the drone was in contact with the queen there was a sudden lurch sidewise, and they went together some distance into the field until I lost sight of them. As they flew together they much resembled workers when they attempt jointly to bear off their dead. I remained by the fertilizing-box perhaps three. minutes, and saw the queen return and enter, bearing the marks of having met a drone. I still lingered by the box, and soon saw a worker bear out the telltale white speck. I later opened the box, and saw the queen bearing the usual thread from the male contact. A queen bee is very swift of wing; but I am convinced that a drone is ten times swifter; for to be able to encircle the queen in the manner this one did, such must be the fact.
Swarthmore, Pa.
E. L. Pratt.

\section{Mr. Pritchard thus describes it:}

I find that the meeting usually takes place not more than 15 feet from the ground.

During the warmest part of the day the drones congregate in sheltered locations in such large numbers as to make a loud humming noise. This attracts virgin queens out seeking their mates. In one instance in particular about 3 o'clock in the afternoon a loud humming was heard near our apiary. Investigation showed that it was made by an unusually large collection of drones in the air. Unfavorable weather had kept them in the hives for two days back, but now the sun was out bright, and both virgins and drones were coming out in astonishing numbers. When a virgin came from under the tree tops a number of drones (in some instances apparently 20 or more) would circle close about her, the bunch resembling a small but very active swarm. They would dash high and low for a few seconds when one of the drones would clasp her and they would fall together, the rest of the drones following them nearly to the ground. Four such swarms of drones were seen at one time after a queen.

On two occasions I have seen drones meet with the queen close to the entrance of the hive. In both of these instances they met facing each other, clinging by their fore legs, their bodies being perpendicular. Simultaneously a sharp sound like a miniature explosion was distinctly heard when they dropped to the ground.

The manner in which the queen frees herself from the drone is similar to that of a fly caught in a spider web, whirling around and around, while the drone clings to anything lie can grasp. In this way the male organs are torn from him and carried away by the queen.

Medina, $\mathrm{O}$.

M. T. Pritchard.

\section{DOES THE DRONE HAVE ONLY ONE PARENT?}

One of the most wonderful things about the drone, or male bee, is that it is hatched from an egg that is unimpregnated. So wonderful, indeed, is this that the mattel was for years disputed. By unimpregnated is meant that queens that have never met the male bee at all will lay eggs, and these eggs will hatch, but they always produce drones, and never workers. Those who have had the care of poultry are well aware that the hens will lay eggs right along, if no cock is kept in the yard at all; and a pullet will lay her full quota of eggs, even if she has never seen a male bird.

Nearly the same is true with regard to the queen bee. If she fails to meet a drone during the first 30 days of her life (if the bees do not kill her before), she usually begins to lay eggs; but she never lays as many, or with the same regularity, as a fertile queen. If no cock is kept, the egg's a hen lays, if she is allowed to sit, never produce any chicks. The eggs laid by a queen, under the same circumstances, do hatch, but always produce drones. There is one more fact connected with the common fowl: If a male bird is put in the yard with the hen for one day only, good fertile eggs will be laid for many days, possibly a whole laying. If a Black-Spanish cock should get among a flock of white hens for a single day, all the egg's laid for many days afterward will produce chicks with more or less black feathers on them. The point to be observed is that the eggs of even the common fowl are fertilized as they are laid by the hen, or possibly a few days before. With the fowls, one meeting with the male bird suffices for the fertilization of an egg daily, for a week or more; with the queen bee, for her whole life of three or even four years.

The her does not have the power of 
laying fertile or unfertile eggs at will; but a queen bee lays both fertilized and unfertilized eggs, alternating from one kind to the other in rapid succession. Skillful microscopists have carefully dissected eggs from worker-cells, and found the living spermatozoa. These living spermatozoa were precisely identical with those found in dissecting a mature drone. Again: Every egg a queen lays passes a little sac in her body containing a minute quantity of some fluid; the microscope shows that this fluid contains thousands of these spermatozoa.

Again, the egg that is taken from a drone-cell contains no trace of spermatozoa. - Therefore, like the unimpregnated egg of the common fowl, it should never hatcl. Strange to say, it does hatch and produce the drone. The first glimpse one gets of the little bit of animated nature is the tiny speck alive at the bottom of the cell. Does he grow out of nothing, without parentage, at least on the paternal side? If his mother, was an Italian, he is also an Italian; if a black queen, he is also a black. It is necessary to conclude, perhaps, that he is the son of his mother, and nothing more. The egg that has never been impregnated in the usual way, must, after all, have some living germ incorporated in its make-up, and this germ must come only from the mother.

The reader will see how clear it is that drones are in no way affected by the fertilization of the queen; or, in other words, that all daughters of a purely fertilized Italian queen produce drones absolutely pure whether they have been fertilized by a black drone or not.

\section{DRONES FROM WORKER BEES.}

Drones are also.hatched from eggs laid by worker bees. These drones are usually smaller in size than those from a queen, because they are generally reared in worker-cells, and the question as to whether they are capable of fertilizing queens, so as to be of soine value, like other drones, is one that has never been decided. Some facts have been brought to light that seem to offer good evidence on each side of the question; but, so far, there is nothing very definite.

COST OF REARING MANY DRONES.

Until the invention and general adoption of foundation, there was no easy way of repressing the production of drones in far greater numbers than could ever be desirable. (See Comb Foundation.) Since the introduction of that article, it is found to be quite an easy matter to make almost every cell in the hive. a worker-cell. On the other hand, one can have a hive entirely filled with drone comb, and a good queen could be induced to raise nearly, if not quite, a full quart of drones at a time. By this means one can have his drones raised from such stock as he chooses, and he can save the vast amount of honey that has so long been wasted by rearing an unnecessary number of drones.

As many as several pounds of drone larvæ have been found in a single hive in which no foundation has been used; and, to save the honey they would consume, it is customary to shave their heads off with a very sharp knife. This is certainly rather expensive business.

Since the life of every colony depends. on the mating of its queen, nature is very lavish in providing a great number of drones in order that the virgin may be successful in her bridal flight, even tho there are very few bees in the immediate vicinity. But where several colonies are kept in one apiary, and especially where they are run for honey production, the rearing of so many drones is an unnecessary expense, the cost of which is nicely shown in an article written by G. M. Doolittle, in which he says:

Taken in round numbers, a square foot of comb will give 8000 workers or about 5000 drones. It takes 24 days to perfect the drones while the workers will emerge in 21 days from the laying of the egg. And it will take about the same amount of food for the rearing of each, since both occupy the same space; and when all these 8000 workers have emerged from this foot of comb we have a fair-sized swarm of honey-gatherers added to the other forces of the hive, which will almost if not quite turn failure into a successful surplus.

This general subject is covered in Combs and in a more technical article called PARTHENOGENESiS elsewhere in this book, and also under head of QuEENs.

REARING DRONES OUT OF SEASON.

When the honey flow is drawing to a close, and the bees may be expected to be- 


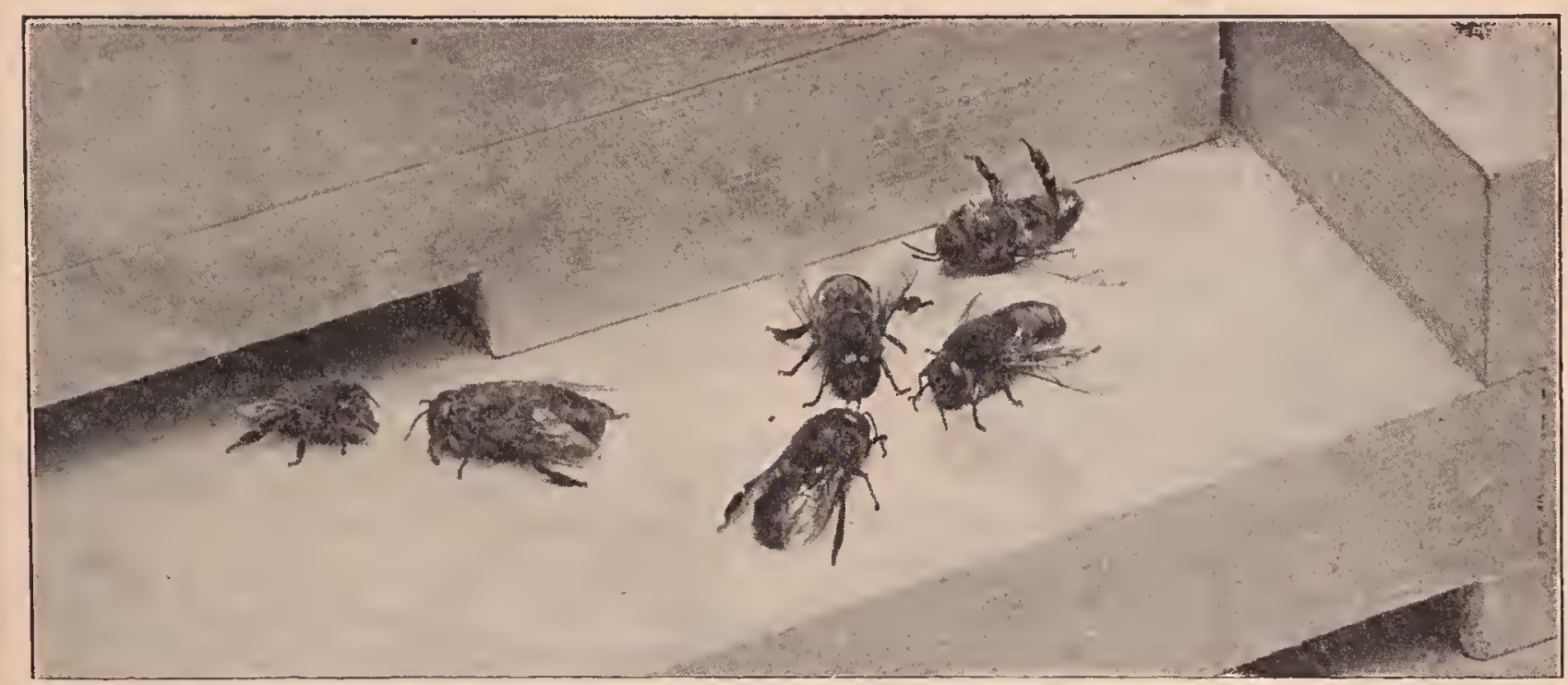

THE LAMENT OF THE DRONES.

Grace Allen, Nashville, Tein.

No more?

Not ever, ever more within the hive

No more to feel its friendly shelter 'round?

No more to share its pulsing peace, alive

With vibrant hum of motion and of sound?

And we so powerful-winged and light of heart!

Of all this life we love are we a part

No more?

\section{No more.}

Not ever, ever more within the hive.

An unimaginable end has come.

The things are turning dead that were alive And all the singing voices turning dumb

And Life herself, who one time bade us be,

Has turned away her eyes, which we shall see No more.

gin disposing of their drones, take frames containing drone brood from the colonies having the best queens to breed from, and place them in a strong colony. The colony should be made and kept queenless as long as it is desirable to have drones in the yard; or, if not made queenless, should be given one pint or more of syrup (two parts of water to one of sugar) every day as long as drones are needed. The feeding must be kept up, for bees are very easily discouraged; and if a stoppage occurs in the daily supplies they will not hesitate to pull the young drones out of their cells and sacrifice them without mercy.

\section{DRONES FROM DRONE-LAYERS.}

Queen-breeders find that one or more drone-layers of good stock, rearing fully developed drones, if supplied with plenty of worker brood, will furnish a fine lot of nice drones in and out of season; but drones from laying workers, or from queens that have never been fertilized, probably
And this the end?

No end but this for those uncounted days Of banqueting, or those mad hours of bliss

We went careening, careless thru the ways of miracle and light? No end but this?

No end but this. No proud sustaining thought

Of deed with rapture or with patience wroughtNo end but this.

More and more

The dripping night that stalks without the hive Draws round us dread and ghostly, grim and stark ;

Within, the deepest shadows are alive

With warmth and fragrance, and the very dark Dreams day to come. But tho the great sun burns A million dawns awake, the day returns

To us, no more-no more.

should be avoided. Drones from queens that have once laid worker eggs, and then failed, are as good as the drones from any queen.

\section{DESTRUCTION OF DRONES IN THE FALL.}

This does not necessarily occur in the fall, but may take place at any time in the summer. Drones have been killed off between apple bloom and white clover, only because supplies ceased, causing the bees to become discouraged and give up swarming for the time being. There is no way in which one can tell so well that the yield of honey has ceased as by the behavior of the bees toward their drones. When, in the midst of the honey season, a worker is seen buzzing along on the back of a drone that seems to be doing his best to get away from the hive, it may be concluded that the yield of honey is failing. So far as known, bees do not sting drones, but they sometimes pretend to do so. It is probable that it is only a feint to drive them away. The 
poor drone, at such times, after vainly trying to go back into the hive, will sometimes take wing and soar away off in the air, only to return after a time to be repulsed again, until, thru weakness perhaps, and want of food, he flutters hopelessly in the dust, and so submits to the fate that seems to be a part of the inexorable law of nature and of his being.

DRONES WITH HEADS OF DIFFERENT COLORS.

This is a queer feature in natural history. Almost every summer some one writes or sends specimens of drones with heads of different colors. The matter has been reported and commented on at different times in Gleanings in Bee Culture. Not only are drones witl white heads occasionally found, but also with heads of a cherry color; again, of a bright green, and at other times yellow. Why should this peculiarity show itself in the drones more than in the queens and workers? Again, why should heads be the subject of these bright rainbow colors? See Hermaphrodite BEES.

\section{RESTRAINING UNDESIRABLE DRONES.}

Drones undesirable for breeding purposes may be prevented from going out to meet the queens, by keeping them from going out of the hive, or by letting them go out into a cage thru which workers can pass and they cannot. This is done by taking advantage of the fact that a worker bee will pass readily thru slots in perforated metal (or between bars properly spaced) where a drone cannot.

THE PROPER SIZE FOR THE PERFORATIONS.

The oblong holes must be of such a size as to permit the easy passage of workers, but exclude not only drones but even

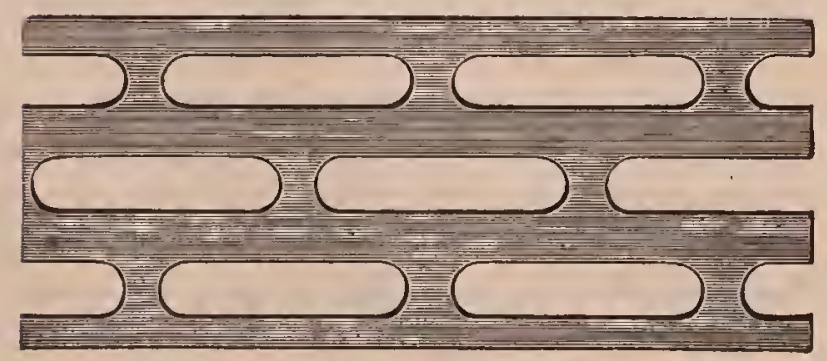

Perforated zinc.

queens (see Extracted Honey and Swarming). It is no great task to make the perforations drone-excluding; but to make them queen-excluding at the same time, and yet not hinder the easy passage of workers, requires a very nice adjustment in the width of the perforations. The first sheet of perforated zine was eut in England, and imported to this country. This had perforations 18-100 of an inch in width. While this answered a most excellent purpose, a few claimed that queens would occasionally get thru it. To obviate this, zine was made with the perforations a little narrower.

The width of this was 5-32 or 16-100 of an inch. While no queen succeeded in get-

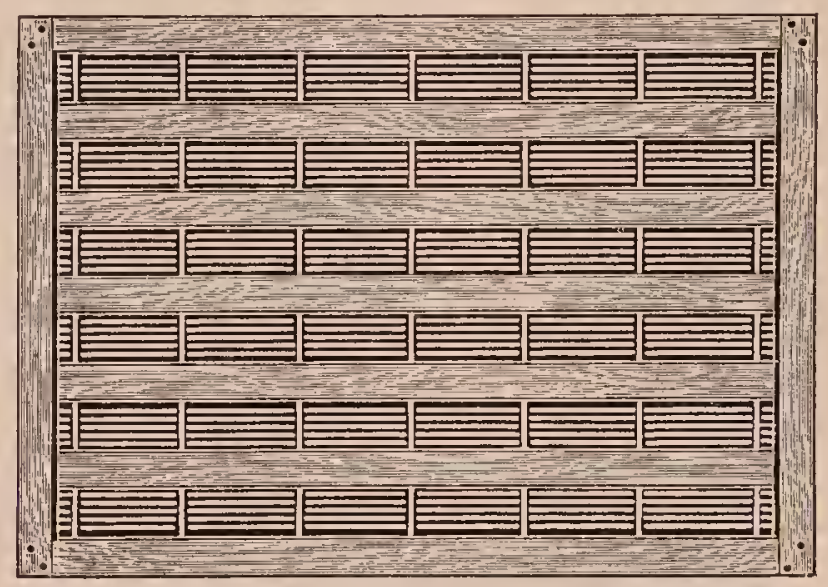

Wood and wire honey-board.

ting thru this, reports, as well as the author's experience, showed that this size was too narrow. It not only proved to be a great hindrance to the workers when their honey-sacs were empty, but, when gorged with honey, they were scarcely able, if at all, to pass thru. Later, perforated zine was made in this country on a different pattern, but with perforations exactly 1631000 of an inch in width, or a trifle smaller than the foreign. Years of experience have shown that this is right for perforated metal but too wide for wire bars.

In 1908 there was put on the market a new form of queen-excluder consisting of wire bars held at the required distances apart by means of soft-metal cross-ties at every two or three inches. These bars consist of No. 14 hard-drawn galvanized wire that has been straightened in a wirestraightener so that it is as true as a die. Contrary to what one might expect, the spaces between these bars are more exact than the width of the various perforations in sheet metal. In the process of making, the bars are laid in metal forms having 
grooves that are spaced exactly right, and then a soft metal in a molten state is made to flow in certain cross-grooves of the metal form. As the metal cools almost instantly, the wires are held at exactly the right intervals. The smootl rounding edges of the bars afford less obstruction to the bees passing and repassing, and practical tests show that this form of excluder is much superior to the old perforated metal. On account of the rounding smooth edges of the wires, they must be slightly closer or 162-1000 of an inch.

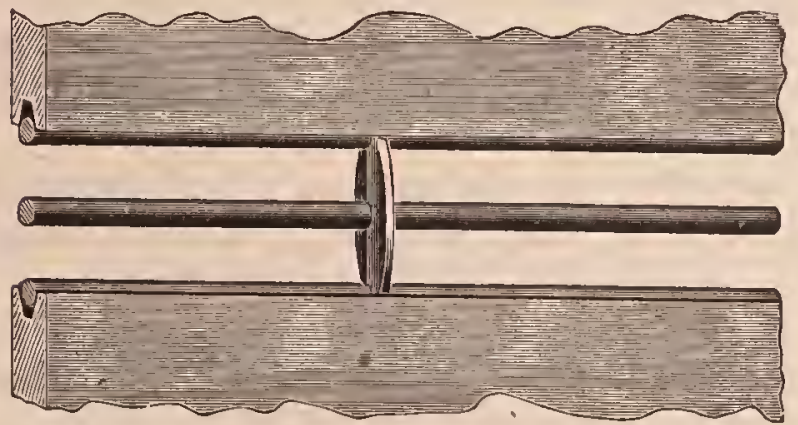

Full-sized wire-excluder.

In the manufacture of the perforated zinc, unless the dies are very sharp, there will be a slight rough burr edge on the under side of the sheet. It is impossible to remove this edge without reducing the width of the perforation. For this reason the wire excluder is superseding the other form of perforated zinc.

DRONE-EXCLUDING ENTRANCE-GUARDS.

If a strip of perforated zinc or wire excluder is placed over the entrance, the worker bees can go out, but the drones cannot.

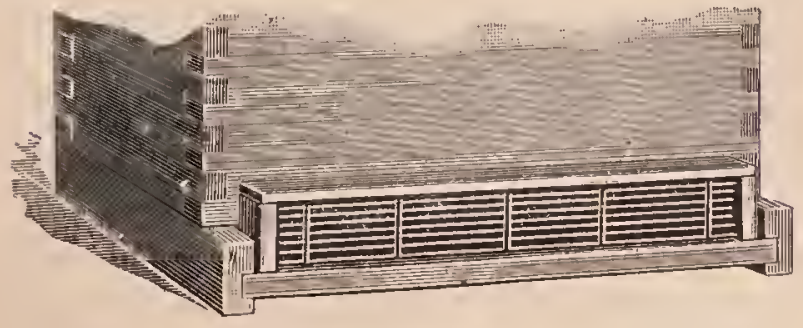

Wire entrance-guard.

When it is desirable to get the drones all out of a hive without permitting any to get back again, the guard is put over the entrance and all the bees are shaken in front of the hive. The workers will, of course, crawl back on the combs; but the drones will have to stay out, and the queen* too,

*This method is sometimes used to catch the queen in a colony of black bees. unless she is put in the hive. In the morning, when the drones are stiffened with cold, they may be fed to the chickens or otherwise destroyed.

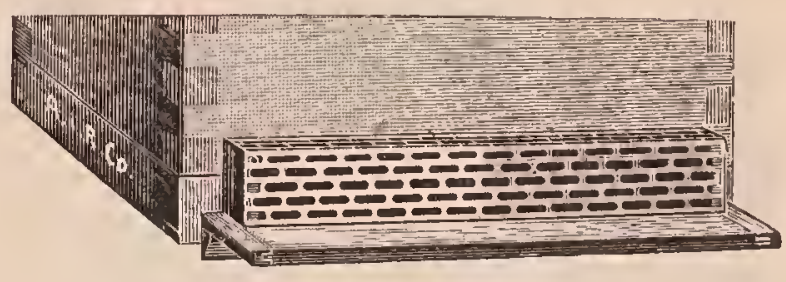

Zinc entrance-guard.

The drone-excluder just described is not automatic. Accordingly, Henry Alley of Wenham, Mass., devised the one, shown next.

This is similar to the one just described, only it has a wire-cloth cone in the top. The drones, after making a fruitless attempt to

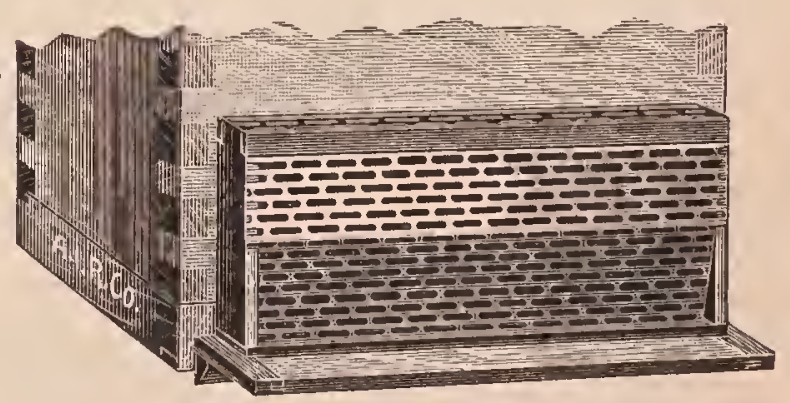

Perforated zinc Alley trap.

pass the metal, will enter the wire-cloth cone in the top, and escape; however, none will go back the way they came, but will huddle together outside and await their fate.

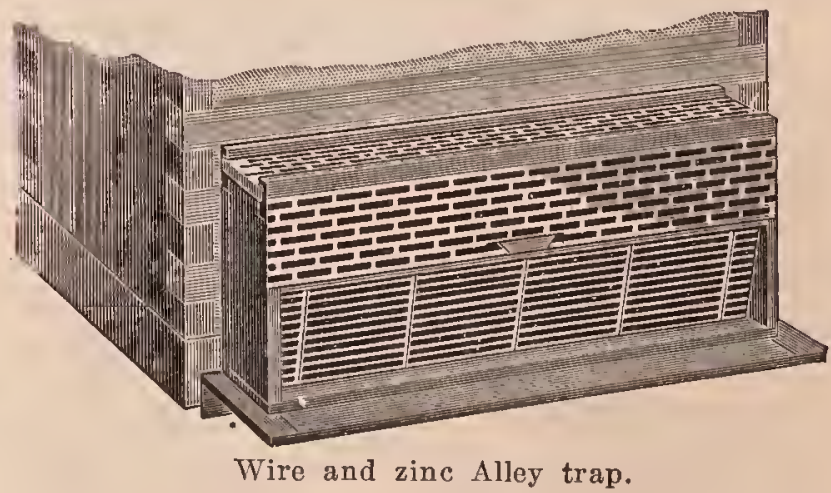

If it is desirable to get the drones into a box, so they may be carried to some other apiary, for instance, a cage is made with

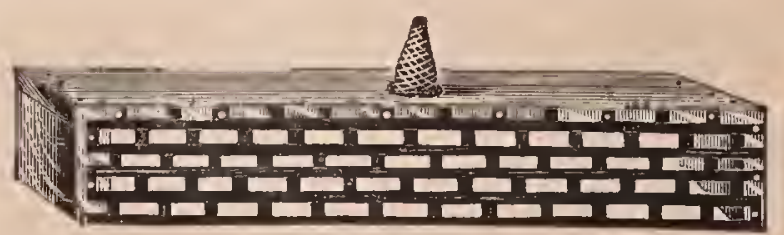

Alley's drone-excluder. 
an upper story, and a couple of these wire cones conduct the drones "upstairs." If any worker bees should go up too, they can

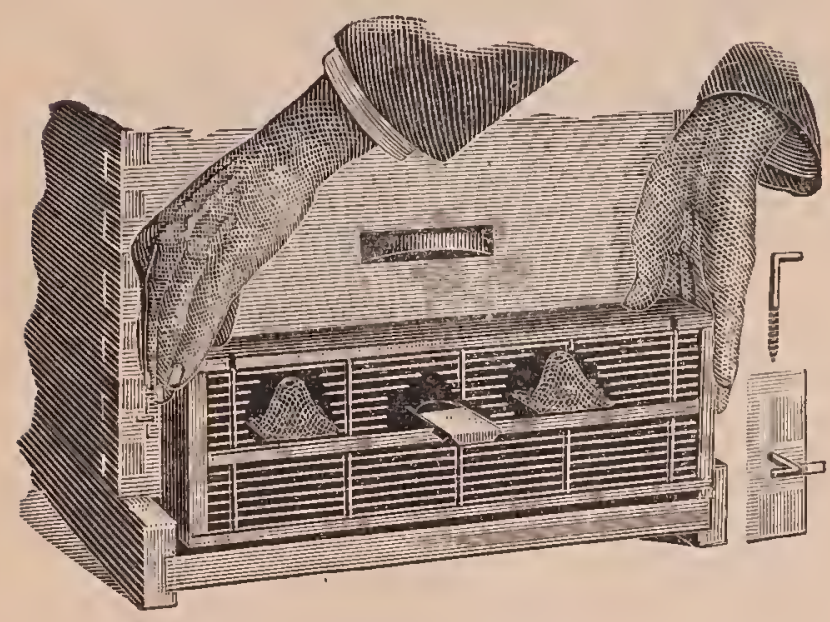

Manner of attaching wire Alley trap.

readily go up thru the perforated zine. This latter arrangement is shown in the cut above.

DYSENTERY.-This is really a form of diarrhea that afflicts bees. It is not a disease as would be the case in real dysentery, but a functional disorder due to too long retention of the feces, bad food or improper protection, or both. The term "dysentery" is here retained, not because it is accurate, but because it has been used so generally in bee literature.

\section{SYMPTOMS.}

The fecal discharge is thin and watery, ill-smelling, and from a light yellow to a dark brown. In advanced cases the color is almost black. The abdomens of the bees are swollen considerably, and sometimes are almost twice the size of those of normal bees. The bees have a dark greasy-looking appearance, and act listless. Individual bees will be seen crawling out of the entrance, and the front of the hive will be stained with yellow, brownish, or nearly black splotches. Ordinary dysentery, when destructive, is a malady that shows up only during winter or early in the spring.

At any time of the year, however, when the weather has been cold or rainy for several days, normal bees as soon as they can fly will void on the hives, walks, and ground yellowish-brown spots or dark spots or dark strings of excrement in a more solid form. Bees that have been confined in the cellar all winter and have win- tered well will, when set out, void their feces in a more or less liquid form over everything. (See BeEs AS a NuIsance.) Some of the hives at this time in the spring may have real dysentery; but probably the majority of them, if they wintered well, will be in a perfectly normal condition. The presence of these spots on the hives during summer is not a bad omen, because active bees, when shut in the lives after flying for several days, always throw out some discharge when they fly.

In an advanced form of dysentery-the kind that destroys bees or colonies-the outside of the hives will be badly smeared up with dark-brown (almost black) stains. These stains, when the trouble has progressed to a point where most of the bees are dead, will be smeared all over the combs and the inside of the hive; and when the colony reaches that stage no amount of good weather will help it. The queen, however, will be all right, and may be introduced into any colony. The bees remove the feces from the queen as fast as necessary, so that she never suffers as do her subjects from an impacted bowel tract that causes dysentery.

\section{CAUSE OF DYSENTERY.}

The real causes are bad food and longcontinued low temperature that prevents bees from flying. In order to keep up sufficient animal heat the bees have to overeat, surcharging their intestines. The longletained fecal matter results in purging or dysentery. Any food alone would hardly produce the disease, as one rarely, if ever, finds bees suffering from anything they will gather, in warm summer weather. Aster honey (see A.STER) or the sweet juices gathered from rotten fruit or cider are very productive of this complaint, and are almost sure to kill bees at the approach of cold weather. A woman once boiled up a mass of sweet apples and allowed the bees to extract the sweetness because, as she said, she could not afford to buy sugar for them. They all died of dysentery long before spring. Where dampness accumulates from the breath of the bees, and settles on the combs, diluting the honey, it may cause trouble. Sorghum syrup has brought on a very aggravated form, and burnt candy or sugar is almost sure death 
to bees during cold weather, altho such feed may be given with impunity in the middle of the suminer.

All candy or honey containing much gums or dextrins should also be avoided; for, except in a few rare instances in which another substance is involved, these gums or dextrins are the substances that cause dysentery. The dextrin content of the different honeys varies considerably, being greatly reduced during a rapid honey flow.

On account of the dextrin content, New Orleans molasses and common glucose should not be given to bees. As a matter of fact, they will not take either.

While it is very certain that no such symptoms of dysentery are found in warm weather, it is also certain that a strong colony in a hive with soft, warm, dry porous walls, will stand an amount of bad food that a weak one, or one exposed to drafts of cold air, will not. A powerful colony, if left with their hive uncovered during a rain storm, will soon dry themselves; and while they are doing this they remind one of a sturdy cart horse as he shakes the water off his hide and dries himself by his internal animal heat. While they have the health and numbers to repel moisture in this way, they are safe against almost anything. But to help them to keep this internal strength, they should have close and comfortable quarters, very much such as we would need for ourselves to enable us to pass a severe winter's night in health and comfort. (See WINTERING OUTDOORS.) The hives often used are so large and barn-like, in respect to the winter's brood-nest, that comfort is almost out of the question, for it does little if any good to pile straw, corn-fodder, etc., over the outside of the hives while the cluster within has no sort of protection at all. If they were in a hollow tree, the diameter of which was so small that they could fill it completely, they would be in a much better place, especially if the sides were lined with soft dry rotten wood.

THE AGENCY OF THE APHIDES IN PRODUCING DYSENTERY.

The poorest winter food is, without doubt, the honey gathered from the aphides (see Honeydew); or, at least, most complaints have been made of this honey. As bees seldom touch this, except during drouths or unfavorable seasons, it, no doubt, has been the cause of some of the mischief. If all the early honey is extracted from the brood-combs, and the bees left with nothing but this bad honey, gathered in the summer, the matter is much worse; and many cases have been reported of colonies dying where the extractor has been used, while those untouched had been free from the disease. The obvious remedy is to refrain from extracting too closely from the brood-apartment. Let the bees fill their brood-chamber with a good quality of honey, just before the yield ceases, extracting, toward the close of the harvest, only from the combs in the upper story, unless it is decided to feed them up for winter on sugar syrup or candy. There have been one or two favorable reports of wintering on the aphidian honey, from which it may be concluded that it is not always deleterious.

\section{PREVENTION OF DYSENTERY.}

There are two important factors in the prevention of dysentery-protection against extremes of cold during winter, and good food. Under the head of WiNtering Outdoors, Wintering in Cellars, Spring Dwindling, and Spring ManageMENT, full particulars are given on how. to house bees properly.

Good food may be in the form of good honey or sugar-syrup stores well ripened. Any of the good table honeys make suitable food; and there are many of the fall honeys that do very well. Aster honey, unless well ripened and sealed in the combs, sometimes brings on dysentery. Some winters it is worse than others (see A.sTERs). Honeydew usually should not be used. It is generally dangerous (see HONEYDEw).

\section{CURE FOR DYSENTERY OUTDOORS.}

If the affected colonies are outdoors, about the only real remedy is settled warm weather. Even one good warm day will often serve to alleviate the trouble, as it gives the bees a chance to void their excrement out in the open air, away from the bives and the combs. Otherwise the continned confinement during an extended cold spell sometimes compels the bees to retain their feces or excreta so long that they are 
finally forced to void it over the combs and over the hives. In such cases, where one has good clean combs of sealed honey he may take out the soiled combs and replace with the clean ones. At the same time the brood-nest should be contracted to a space the bees can fill. This work should never be done on a cool day-only when it is warm and balmy. But the practical beekeeper of today does not fuss with colonies affected with dysentery; for he knows that, as soon as warm weather comes, the trouble will disappear of itself, in all colonies not too far gone and too weak to recover.

Combs taken out of the bive in cold weather, and stained with dysentery, may be given to strong colonies in late spring or summer to clean up. Indeed, there is no danger in hiving swarms in hives where colonies have died with dysentery during the previous winter. They will quickly clean up and use the stores that are left.

DYSENTERY IN BEE-CELLARS.

After a long and cold winter, if the, temperature in the cellar goes much below 40 degrees Fahr., or if the stores are of poor quality, there is a liability of some colonies being affected with dysentery. The best remedy is prevention. The cellar should be dry, and the temperature should be between 45 and $50^{\circ} \mathrm{F}$. It should never go below $40^{\circ}$ for a longer period than three or four days. If the temperature of the cellar can not be kept up, a small stove with a connection to a chimney should be used to bring it up to the requisite point.

Some authorities think that dampness has nothing to do with causing dysentery in the cellar; but dampness in combination with a temperature below 40 degrees for several weeks is a very common cause of dysentery in cellar repositories.

But what should be done if the bees do get dysentery, Suppose the food is bad, and the cellar one where it is not practicable to use artificial heat, at an outyard for example. If there are days during midwinter when the bees can fly (and some localities do afford such weather for one day and possibly two), take the diseased colonies out on one such day and let them have a flight, then at night put them back in the cellar. A cleansing flight will do a world of good. Some authorities disagree here; but our own experience has shown conclusively, over and over again, that it does pay. If the bees are suffering from an over-accumulation of poisonous fecal matter, why will there not be almost instantaneous relief as soon as it can be voided? If the food is bad, give the bees better next year. Some recommend taking away all fall stores and feeding sugar syrup. For further consideration of this subject, see Wintering in Celuars.

\section{DZIERZON.*-The life of Dr. Dzierzon} was a simple, uneventful one, similar to that of many elergymen in Germany. He was born on Jan. 16, 1811, at Lowkowitz, near Kreuzburg, Upper Silesia. He attended the school of Lowkowitz till his tenth year, and was afterward transferred to the University of Breslau, where he attained such excellence in his studies that, after having finished his course, he had been first in every class in his college, and left the University in the autumn of 1830 with a certificate as having passed No. 1.

Erom early childhood young Dzierzon had a great partiality for bees. His father kept a few colonies in log hives, mostly placed in an upright position; these were at that time the kind in general use in Silesia. He always found the greatest pleasure in the contemplation of the indefatigable industry of bees, and while studying at the University he was in the habit of taking his walks near to an apiary, or where a colony of bees occupied a hollow tree, so that he might enjoy the sight of the industrious insects and listen to their joyful humming.

His fondness for bees made him clioose a calling in which it would be possible for him to follow the bent of his inclination.

Dzierzon was ordained on March 16, 1834, and having acted as chaplain in the Schalkowitz District of Oppeln till July, 1835, he received a clerical appointment at Karlsmarkt. This brought him a very small income; but, as in succeeding years it suited him entirely, it never occurred to him to seek a more richly endowed living. The garden of his parsonage was a tolerably large one, and his first care was to arrange a place for bees. He soon stocked it with some colonies from his father's 
apiary in the old-fashioned hives mentioned above. His bees did very well in them. He, however, was not content with these primitive hives, but proceeded to make various elianges in them, so that he might have a more perfect control over lis bees. These changes gradually led to the invention of movable combs, which enabled him to take out a full brood-comb, or honeycomb, and insert it in another hive. He introduced bars, to which the bees built the combs, and, as these were usually attached to the sides of the hives (there being no side bars), Dzierzon conceived the idea of opening the hive at the back so as to enable him to cut the attachments. At the commencement Dzierzon used single hives called "Lagers" and. "Standers," but afterward constructed hives to hold two, three, six, or eight colonies, in order to economize material and space. Owing to the advantages thus gained the number of his colonies increased in a few year's to 400 , and he was constantly making new hives and planting outapiaries in the neighboring villages. He had twelve of them, but his apiary at Karlsmarkt was chiefly used for observations and experiments, and, after his introduction of the Italian race, for breeding these bees and keeping them pure. This apiary was visited by numerous people desirous of increasing their knowledge in beekeeping, especially by schoolmaster's, many of whom came by desire and at the expense of the Government. He was at all times ready to communicate the results of his experience to his visitors; he also made known his views in the Frauendorf Journal, which enjoyed a large circulation at that time. $\dagger$ These articles were afterward col-

* Captain Baldenstein, when stationed in Italy, was the first to notice the exceeding industry of the Italian bee When he retired from the army he settled in Switzerland, and procured a colony from Italy in September, 1843. His observations im pelled Dzierzon to make an effort to procure the Ttalian bee; and by the aid of the Austrian Agrirultural Society he succeeded in obtaining, late in February, 1853, a colony from Mira, near Venice. Dzierzon bestowed much pains in maintaining the purity of his Italian bees, and thirty years after the first introduction he exhibited at Neustadt, near Vienna, a perfectly pure descendant from his orig. inal stock. lected and published in the form of a pamphlet entitled "Pfarrer 'Dzierzon's Improved Method of Beekeeping." This pamphlet was very incomplete, and Dr. Dzierzon was induced to publish his views in a more complete form, which work, after passing thru several editions, was published under the title of "Rational Beekeeping," the latest and most complete edition of which appeared in the year 1878. In 1880 this

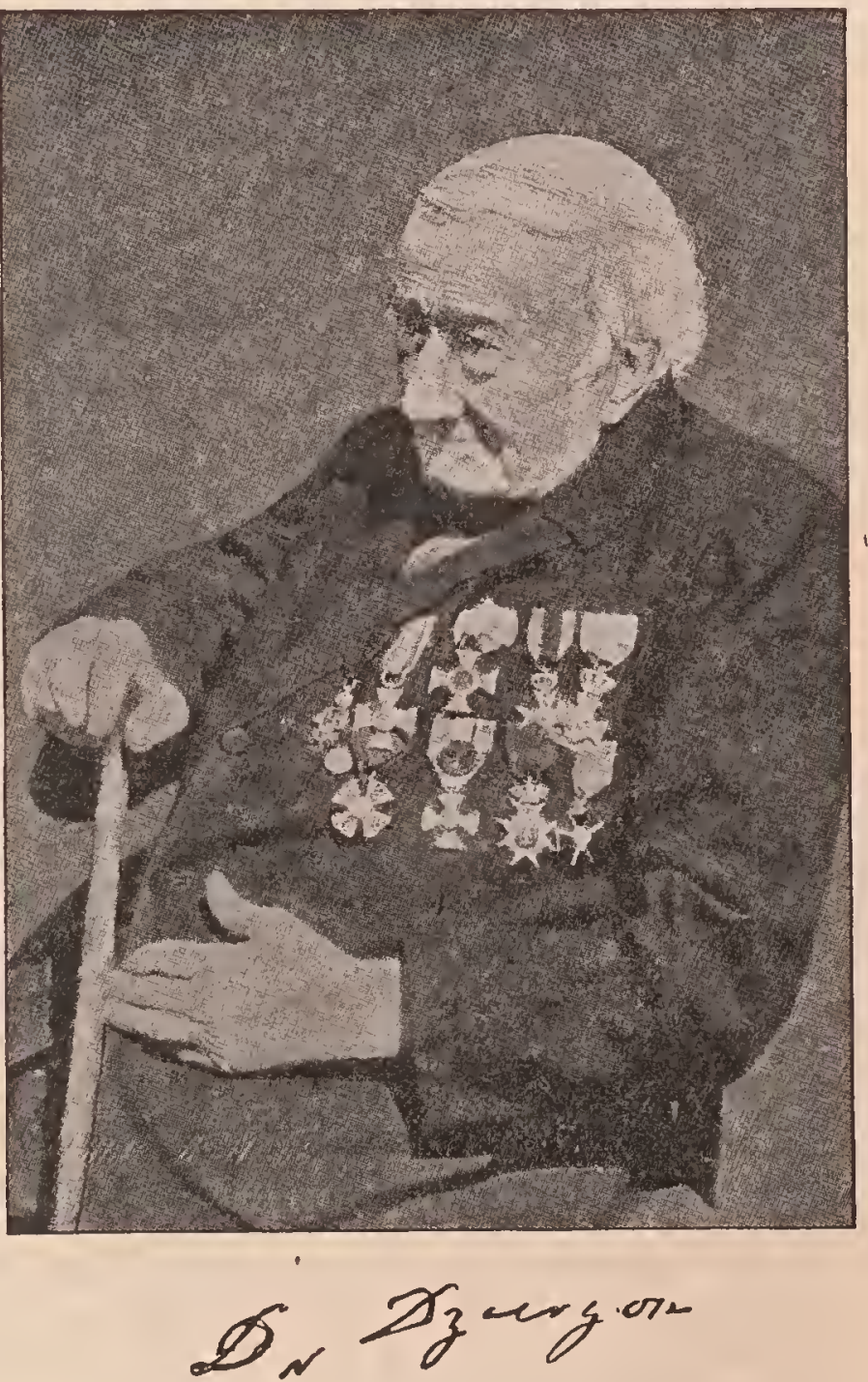

edition was translated into English by $\mathrm{H}$. Dieck and S. Studderd, and edited by C. N. Abbott, who then introduced it to British beekeepers. The last book he wrote, "Der Zwillingstock," was published in 1890. From 1854 to 1856 he published

+ Several of the governments of Europe took great interest in spreading among their people a knowedge of Dzierzon's system of beekeeping. Prussia furnished monthiy a number of persons from different parts of the kingdom with the means of acquiring a knowledge of this system; while the Bavarian government prescribed instruction in Dzierzon's theory and practice of bee culture as a part of the regular course of studies in its teachers' seminaries. 
"The Bee Master of Silesia," but the greater part of his observations and experiences appeared in the Bienenzeitung. In this publication appeared his views on parthenogensis, and for eight years, from 1845 to 1853 , he had to fight hard to defend his theory, which met with the most strenuous opposition, and it was not until he introduced Italian bees in 1853 that he was clearly able to demonstrate the correctness of his statements. Baron von Berlepsch at first vigorously opposed it, but was at length convinced of his mistake, acknowledged his error, and openly declared he would come into Dzierzon's camp "with bag and baggage." Dzierzon's theory, according to which drones originate from unfertilized eggs, and all impregnated eggs produce females, gradually found adherents and recognition among men of science; and its correctness was proved by the microscopical and physiological researches of Professors Dr. von Siebold and Leuckart.

In recent years M. Dickel made a violent attack on this theory, and stated that all eggs laid by the queen were fecundated and that the bees themselves determined the sex of the eggs by means of a secretion from special glands. Dickel and Dzierzon met at the annual congress of beekeepers in Salzburg in 1898, where they vigorously defended their theories in the presence of a large gathering of beekeepers. Dzierzon's arguments were so forceful that they constantly elicited applause. $\mathrm{He}$ has had his partisans and detractors; some, like M. Perez, have discussed the theory most courteously; a few others have done so with extreme rudeness, especially to a man of his age. It is gratifying to find that Dzierzon lived long enough to see his theory triumphantly vindicated before he passed away from among us.

From all parts of the continent, and from many of the reigning sovereigns, Dzierzon has received distinctions and honors. One of the first which he received was that signed by Archduke John in his capacity as president of the Agricultural Society of Graz. The honorary title of "Doctor" was conferred on him by the University of Munich. At the Beekeepers' Congress at Darmstadt, the then reigning Grand Duke of Hesse invested him with the order of Ludwig, and from the Emperor of Austria he received the Order of Francis Joseph. The Emperor of Russia conferred upon him the Order of St. Anne, and the King of Sweden the Order of Wasa. The photograph we reproduce from the Bienen-vater shows the venerable old man decorated with these orders. He has also been made an honorary member of a great many societies, and his name is known in every portion of the globe.

To Dr. Dzierzon we are indebted for the various artificial substitutes for pollen. With his eye ever open to discover any means that would be of assistance to his bees, he observed them bringing from a neighboring mill rye-meal, before they were able to secure a natural supply for the food of the larvæ; and ever since beekeepers have been in the habit of supplying the bees with artificial pollen when natural pollen is lacking in the spring.

Dr. Dzierzon, like many other beekeepers, has had sad experiences of the virulence of foul brood. In 1848 this plague broke out in his apiary, destroying several hundred stocks, and leaving only ten untouched.

So vigorous was his fight against the disease that three years later, in 1851, he was able with pride to point to the 400 colonies of healthy bees which he had worked up from the ten survivors of the disaster.

His apiary passed thru several troubles. At one time 70 hives were stolen, then 24 were lost in a flood, and 60 were destroyed by fire.

In consequence of various ecclesiastical troubles which occurred at Karlsmarkt, he decided to leave the place where he had lived 49 years. He removed to Lowkowitz, the place of his birth, in 1884, and took up his abode with his nephew, the youngest son of his brother, whose wife accompanied him to the last in his visits to conventions of beekeepers. At Lowkowitz he lived a happy, peaceful, contented life, his time being wholly taken up with his bees. He died on Oct. 26, 1906.

To beekeepers his loss is great, and his name will always stand out prominently in the history of beekeeping in the nineteenth century.

DZIERZON THEORY.-In 1845 the Rev. John Dzierzon enunciated what is now 
known as the "Dzierzon Theory," and thus in reality laid the foundation for much of our scientific and practical knowledge of bees. While he was not original in the discovery of parthenogenesis, he threw a great deal of light on the subject. (See Parthenogenesis, elsewhere, and sketch of his life just preceding.) That the reader may know just what the theory was, the several propositions as given by Dzierzon are as follows:

I. A colony of bees, in its normal condition, consists of three characteristically different kinds of individuals - the queen, the workers, and (at certain periods) the drones.

II. In the normal condition of a colony, the queen is the only perfect female present in the hive, and lays all the eggs found therein. These eggs are male and female. From the former proceed the drones; from the latter, if laid in narrow cells, proceed the workers, or undeveloped females; and from them also, if laid in wider acornshaped and vertically suspended so-called royal cells, lavishly supplied with a peculiar pabulum or jelly, proceed the queens.

III. The queen possesses the ability to lay male or female eggs at pleasure, as the particular cells she is at any time supplying may require.

IV. In order to become qualified to lay both male and female eggs, the queen must be fecundated by a drone or male bee.

$\mathrm{V}$. The fecundation of the queen is always effected outside of the hive, in the open air, and while on the wing. Consequently, in order to become fully fertile, that is, capable of laying both male and female eggs, the queen must leave her hive at least onne.

VI. In the act of copulation the genitals of the drone enter the vulva of the queen, are there retained, and the drone simultaneously perishes.

VII. The fecundation of the queen, once accomplished, is efficacious during her life, or so long as she remains healthy and vigorous; and, when once become fertile, she never afterward leaves her hive except when accompanying a swarm.

VIII. The ovaries of the queen are not impregnated in copulation; but a small vesicle or sac which is situated near the termination of the oviduct, and communicating therewith, becomes charged with the semen of the drone.

IX. All eggs germinated in the ovary of the queen develop as males, unless impregnated by the male sperm while passing the mouth of the seminal sac or spermatheca, when descending the oviduet. If they be thus impregnated in their downward passage (which impregnation the queen can effect or omit at pleasure), they develop as females.

$X$. If a queen remain unfecundated, she ordinarily does not lay eggs. Still, exceptional cases do sometimes occur; and the eggs then laid produce drones only.

XI. If, in consequence of superannuation, the contents of the spermatheca of a fecundated queen become exhausted; or, if from enervation or accident, she lose the power of using the muscles connected with that organ, so as to be unable to impregnate the passing egg, she will thenceforward lay drone eggs only, if she lay at all.

XII. As some unfecundated queens occasionally lay drone eggs, so also in queenless colonies, no longer having the requisite means of rearing a queen, common workers are sometimes found that lay eggs from which drones only proceed. These workers are likewise unfecundated, and the eggs are uniformly laid by some individual bee, regarded and treated more or less by her companions as their queen.

XIII. So long as a fertile queen is present in the hive, the bees do not tolerate a fertile worker. Nor do they tolerate one while cherishing the hope of being able to rear a queen. In rare instances, however, exceptional cases occur. Fertile workers are sometimes found in the hive immediately after the death or removal of the queen, and even in the presence of a young queen, so long as she has not herself become fertile.

When this was put out originally in the Bienenzeitung, it called forth most strenuous opposition. Even the Baron von Berlepsch opposed it; but later on, when Italian bees were introduced, and the theory could be demonstrated, Berlepsch became its most staunch supporter. Indeed, he published a series of articles defending it; but there has been more or less opposition to it ever since. In 1895 M. Dickel made a violent attack on the theory, stating that all egg's laid by the queens were fecundated, and that the bees themselves determined the sex of the eggs by means of a secretion from the glands. For a number of years the European journals were filled with discussion, some supporting Dickel and some Dzierzon. Finally, in 1898 the Dickel theory was shown to be untenable.

Those who desire to see the original arguments in support of the theory will be interested in reading the booklet entitled "The Dzierzon Theory," by the Baron von Berlepsch, published by The A. I. Root Co. In the mean time the reader is referred to PARTHENOGENESIS, where more information is given on the subject. Some recent work by Nachtsheim seems to make Dzierzon's position still stronger. 
RECENT EVIDENCE IN PROOF OF DZIERZON THEORY.

Any reliable evidence either for or against Dzierzon's theory, that the drones of the honeybee are produced from unfertilized eggs, is at the present time of more than usual interest to beekeepers. In one of the issues of the American Naturalist, T. H. Morgan describes some experiments made by Newell at Houston, Tex., in mating Italian and Carniolan bees.

When yellow virgin Italian queens were mated with grayish Carniolan drones, both the workers and queens which came from fertilized eggs were yellow, from which it was inferred that yellow is dominant over gray. The drones also were yellow like the Italian mother. Now this, too, might have been caused by the dominance of the maternal color (yellow); or, on the other hand, it might have been caused by the fact that in accordance with Dzierzon's theory these drones inherited from the mother only,that is, that the eggs that produced them were not fertilized by the drones. The experiment, therefore, as Morgan points out, is not decisive.

The reciprocal experiment was, however, decisive. When gray Carniolan queens were crossed with yellow Italian drones, the workers and queens were yellow as before, due to the dominant yellow of the father. But the drones were gray like the gray Carniolan mother and the pure stock of Carniolan drones. That is, they inherited from the mother alone. Otherwise, they would have been yellow. This proves that they came from unfertilized eggs. Prof. Morgan characterizes these crosses as furnishing the long-sought evidence demonstrating that the drones inherit only the characters of their mother in accordance with Dzierzon's theory.

According to Fabre's observations parthenogenesis also oceurs among the solitary bees in the genus Halictus. The males of this genus do not appear until fall. After mating with the females they fly about among the flowers for a week or so and then all perish, none surviving the winter. The fecundated females hibernate in their old nests, or in the crevices in stone walls, or other retreats. With the return of warm weather they reappear, dig new burrows, and provision their cells with little masses of pollen and honey, on each of which they lay an egg. From these eggs come only females, and at this season of the year there are no males of this genus in existence with which they can mate. This first generation of females soon build new groups of cells, the daughters of a single mother extending the old nest, and all using the old entrance-tunnel in common. The eggs of these unimpregnated females give birth to both males and females; thus in the second generation both sexes are produced by parthenogenesis. After mating the males die, and the females survive the winter and the eyele is repeated as before.

Fabre sums up as follows: "The Halicti have two generations a year; one in the spring, issuing from the mothers who have lived thru the winter after being. fecundated in the autumn; the other in the summer, the fruit of parthenogenesis; that is to say, of reproduction by the powers of the mother alone. Of the union of the two sexes feniales alone are born. Parthenogenesis gives birth at the same time to females and males." 


\section{$E$}

EGGS.-See Brood and Brood-REaring.

ELEMENTARY BEEKEEPING.-See A B C OF BEEKEEPING.

EMBRYOLOGY OF BEES.-See DEVELOPMENT OF BEES.

ENEMIES OF BEES.-Kingbirds and bee martins, and a few other insectivorous birds prey on bees. The author once saw a single kingbird capture six or eight bees in as many trips, on the wing. It would alight on the peak of the barn near the apiary, and then make a dive thru the air, grab one bee on the wing, return to its perch to dispose of its morsel, and then catch another.

There have been a number of conflicting reports as to whether kingbirds do or do not swallow their victims. Some have asserted that they do, and afterward expelled the ball of bees. At one experiment station a number of kingbirds were shot, and the conclusion, after examining their crops, was that they did not swallow bees. From observations that have been made since, it appears that the kingbird does not generally swallow worker bees. It grabs the bees, flies away, and after it alights on some perch with its victim in its beak, bites away until it absorbs the honey or juices, when it drops the carcass, and flies away for another, which it treats in the same way. Observers have reported seeing these carcasses of bees below the birds' favorite perches.

There are other birds that do swallow bees. Cases are on record where they throw up the dead carcasses of the bees after they have absorbed the honey.

The loss of a few bees which the birds might kill amounts to nothing in a yard run for honey; but in large queen-rearing yards, if the birds are allowed to go unmolested there is quite likely to be a loss of young queens. The birds select the largest and noisiest-flying bees, and these, of course, will be queens and drones. If such be the case, the owner of a queenrearing yard would do well to use his shotgun until everything in the way of beekilling birds is destroyed.

MICE.

Mice do harm only when they get into the hives, and this part of the subject will be sufficiently noticed under the head of Entrances. Mice sometimes make sad havoc among surplus combs, when stored away with small patches of honey in them. The combs will be completely riddled during the winter time, if they are left where mice can get at them. On this account the honey-house should be mouse-proof; and for fear that a stray one may by accident get in, it is well to keep a trap ready, baited with toasted cheese. If one does not have a tight room, he should make a tight box, large enough to hold all the surplus combs which have lioney in them. See ENTRANCES.

\section{PARASITES.}

There is a parasite known as the Braula coeca, or Italian bee louse, and it is seldom seen except on bees just imported from Italy. This does little or no damage; but there is a parasite that is very destructive to bees. See Diseases of BeEs, subhead ISLE OF WIGHT DISEASE.

SKUNKS.

Skunks are justly coming to be regarded as one of the most serious enemies of the beekeeper; and, owing to the legal protection given them in most States, together with their ability to multiply very rapidly, they are constantly beconing more numerous. Not only do they eat great numbers of bees, but by seratching at the front of the hives they keep the bees in an excited condition which is noticeable for several hours after the nightly raid of the skunk 


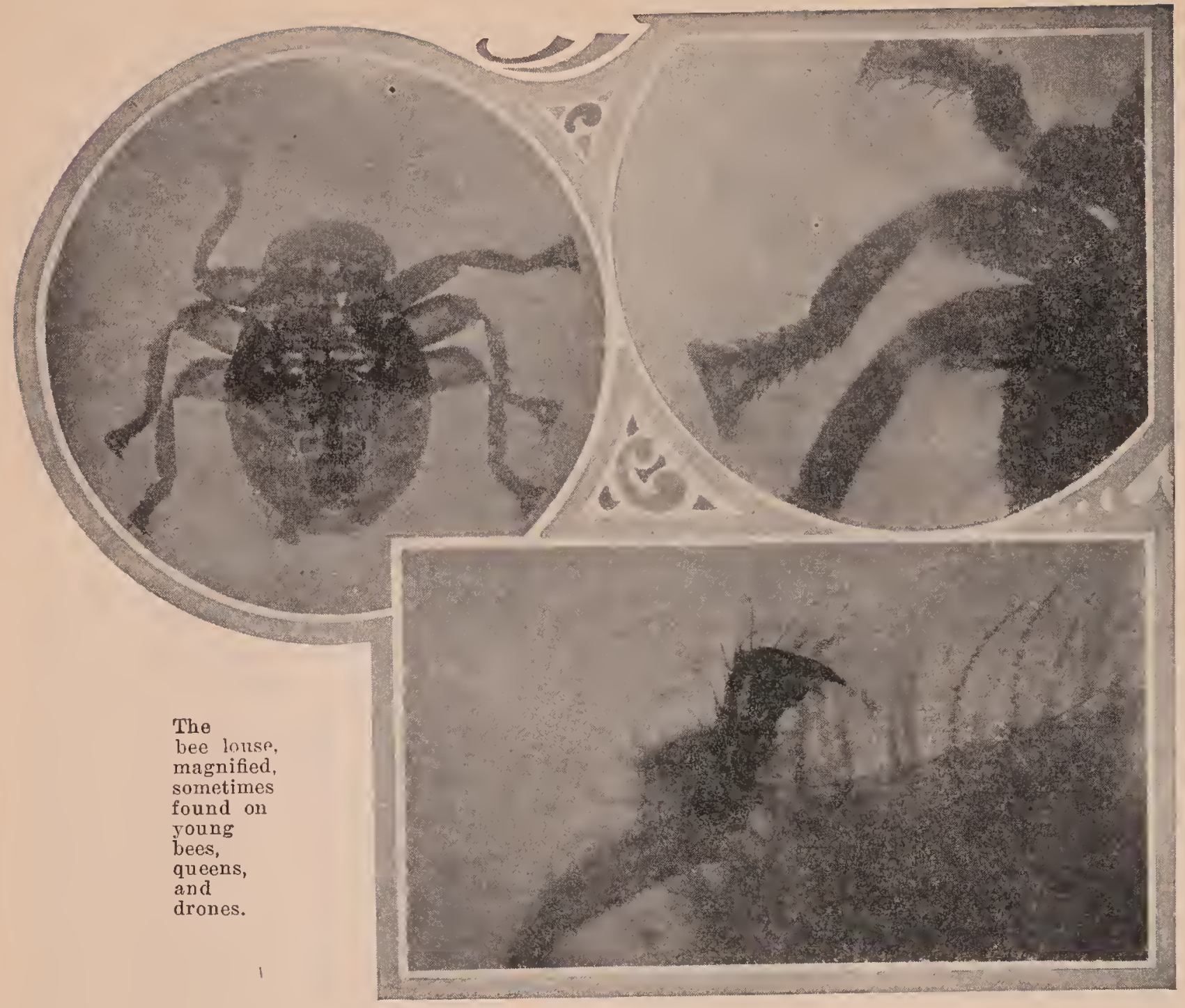

is finished. Young skunks that leave their nests and start foraging for themselves during midsummer and autumn seem to do the greater part of the damage, causing the colonies to dwindle rapidly at a time when they should be building up for winter.

Skunks may be poisoned by putting stryclnine or Rough on Rats inside of small chunks of beef, leaving the beef at night on the entrance of the hive at which the skunks are working, remembering to remove it early the next morning. This could not be done safely where valuable cats or dogs would be likely to get it. Some beekeeper's have reported good results by stirring the poison into eggs. Others are protecting their yards by fencing them in with four-foot poultry-netting, one foot of which is folded at a right angle so as to be flat on the ground on the outside of the fence, the outer edge being held close to the ground by being weighted or staked down. The skunks apparently do not know enough to start digging back of that part of the netting lying on the ground.

\section{ANTS.}

Certain ants in the more southern States, particularly in Florida and Texas, will attack a colony of bees and utterly ruin it. For further particulars see ANTs, subhead "Ants in the South."

\section{SPIDERS.}

Spiders as well as toads seem to have a rare appreciation of a heavily laden bee as it returns to the hive; one should therefore be careful that all spider webs be faithfully kept brushed away from the hives, and that they have no corners or crevices about them to harbor such insects. Be sure there is no place which the broom will not clear out at one sweep; for where one has a hundred hives he cannot well spend a great amount of time on each one.

Many of these so-called enemies probably 
take up the destruction of bees only as a chance habit, and it is not always to be looked for nor expected. Common fowls sometimes get a habit of eating their own eggs; but it is so unusual an occurrence that it can hardly be regarded as a matter of any very serious importance. It may be well at times to look out for the enemies that prey on bees; but, as a general thing, they are quite capable of fighting their own battles if they are given the proper care and suitable hives.

It was L. L. Langstroth, just before he died, who showed how spiders may be of value to the beekeeper. If, he said, they have access freely to the combs stored in stacked-up hives in the apiary, there never need be any fear that moth worm or moth miller would be able to do any damage, for the spiders will shortly destroy them.

\section{WASPS.}

Wasps and hornets sometimes capture and carry off honeybees; but, unless they should take part in the work in great numbers, there need be no solicitude in regard to them.

\section{MOSQUITO HAWKS.}

Mosquito hawks, sometimes called "devil's darning-needles," and "bee hawks," at certain seasons of the year, are very destructive to bees in some of the southern States, particularly in Florida. They give more trouble along the Florida rivers, especially along the marshy lands, where they breed very rapidly. In April and May they come in such countless numbers that the sky is black with them. As the habits of these insects are predatory, they will attack any insects, including mosquitoes and bees. When they are very numerous, the bees have learned the trick of staying in the hives, realizing that the mosquito hawks are their natural enemies. These insect hawks are so destructive at times that they weaken a whole apiary.

One year, when the publishers of this work had some 300 to 400 colonies on the Apalachicola River, their apiarist there estimated that the mosquito hawks did damage to the extent of a thousand dollars in four or five days. Arrangements had been made to move the bees north to escape this pest, but it was then too late.

\section{THIEVES.}

Thieves are sometimes troublesome at outyards. The best way to end their depredations is to put up a sign or two offering fifty or a hundred dollars reward for the arrest and conviotion of the g'uilty parties. The thief is immediately warned that a price is upon his head, and that he had better stop stealing. It is seldom that the reward money is ever called for, and further annoyance is stopped.

\section{THE WORST ENEMY.}

By all odds the most serious enemy to the bees and beekeeping is the careless or ignorant beekeeper himself who harbors disease in the hives, either because lie does not care or because he does not know any better. Such a man places in jeopardy the interests of every other beekeeper for miles around. While bees do not ordinarily fly over two miles (see FLIGHT OF BEES), and one is usually safe if he is that far from a foul-brood apiary, yet in the course of a year or two the colonies in the diseased yard will die, when bees a mile and a half away can easily rob out the honey from these dead colonies, and carry the infection to their own yards. These in turn become diseased, forming new centers of infection reaching out a inile or perhaps two miles farther. This; in fact, is the way bee disease proceeds from yard to yard by robbing. To prevent this spread arises the need of foul-brood laws and bee inspectors. See Laws Relating to Foul Brood; also INSPECTORS.

ENTRANCE DIAGNOSIS.-See DiaGNOSING ColONIES.

ENTRANCE GUARDS.-See DRONES..

ENTRANCES TO HIVES. - At the botton of the hive is the usual and by far the best location for the entrance. Having the entrance below makes it much easier for the bees to retain the warmth of the cluster. Moreover the bees when flying during chilly weather have less difficulty in entering the hive. They can also, while in the hive, easily remove bits of refuse comb, dirt, or dead bees from the bottom-board.

On account of the tendency of returning bees to clsill in cold weather, there should 
be a large alighting-board if the hive is raised off the ground; or if on the ground, there should be an easy slanting grade or

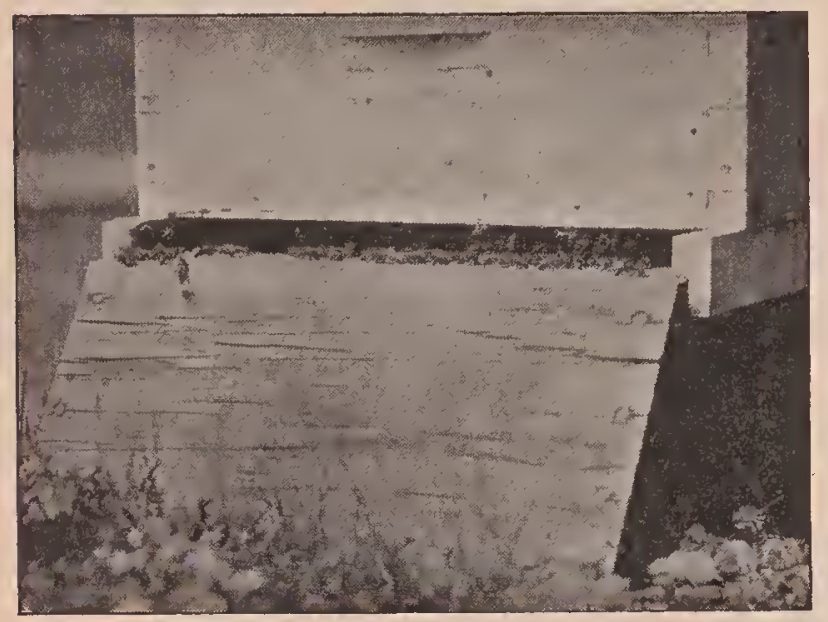

doorstep to the entrance. All grass and weeds should be kept down within at least a foot of the front of the hive. Bees that come in heavily laden are often knocked down by bumping into tall weeds or sprigs

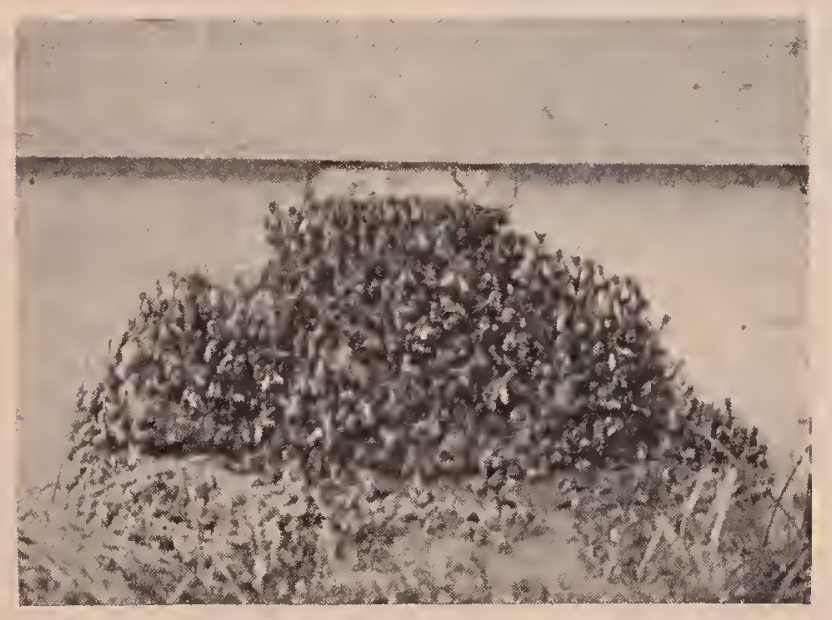

$\Lambda$ colony with an entrance too small, where the bees have formed the loafing habit.

of grass. While they ultimately take wing, making another attempt, and finally land in the hive, such obstructions, if hindering to the bees, cause a loss to their owner. See APIARY.

\section{KEEPING DOWN THE GRASS.}

It is impossible to estimate just how much the loss in honey is; but, if the actual figures could be secured, the producer would be surprised. When it is such an easy matter to cut away the weeds, or keep them away from the entrance with a little sprinkling of salt or with a wide board, it is "penny wise and pound foolish" to wear out the wings of our little servants trying to pass this obstruction, at the same time delaying them when every moment counts. Farmer beekeepers especially seem to have the idea that bees will work for nothing and board themselves, and in three cases out of five one will find the entrances of their hives, what few they may have, all tangled up with grass and weeds. On mornings when there is a heavy dew such obstruction is very considerable.

Very many use a scythe, lawnmower, or a common sickle, to cut down the grass. Others keep it down with a small handful

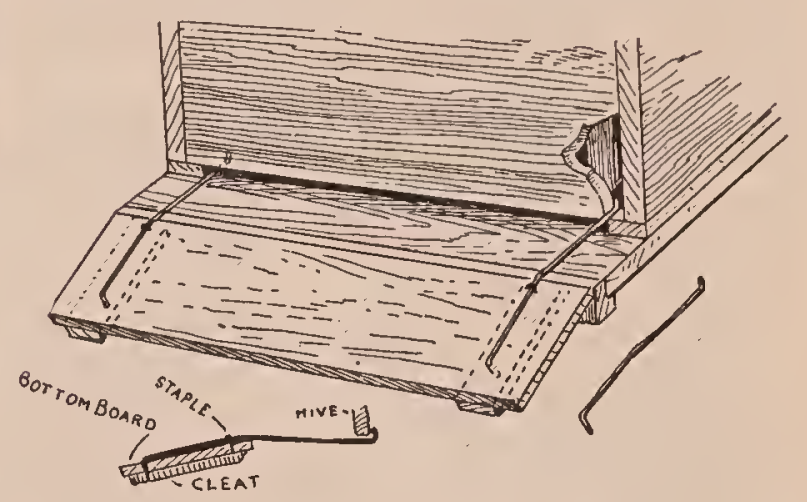

of salt scattered around the front of the hive. Still others prefer to use a piece of board about a foot or more wide, and as long as the hive is wide. Rough unplaned lumber of the cheapest kind is better than clear planed stuff, as the bees can cling to it more easily. The boards should be cleated and laid directly on the ground, abutting up close to the bottom-board if it rests on or is close to the ground. No grass or weeds can grow, of course, where these boards are laid; and general practice shows it is cheaper and better to use such boards than to be compelled to use salt or cut down the obstructions every few days in front of the hive.

One of the drawings contains a suggestion which can be very easily applied to the cleated boards just described. Bend some iron wires, about No. 8, with hook at each end. Drive one of the hooks into the board as here illustrated, and secure in position by means of a common blind-staple near the other edge. If the wires are cut right, this alighting-board can be easily hooked into the entrance and make a nice easy grade from the ground up to the hive. At any time these alighting-boards can be unhooked, the grass cut with a lawnmower, and the board replaced. 


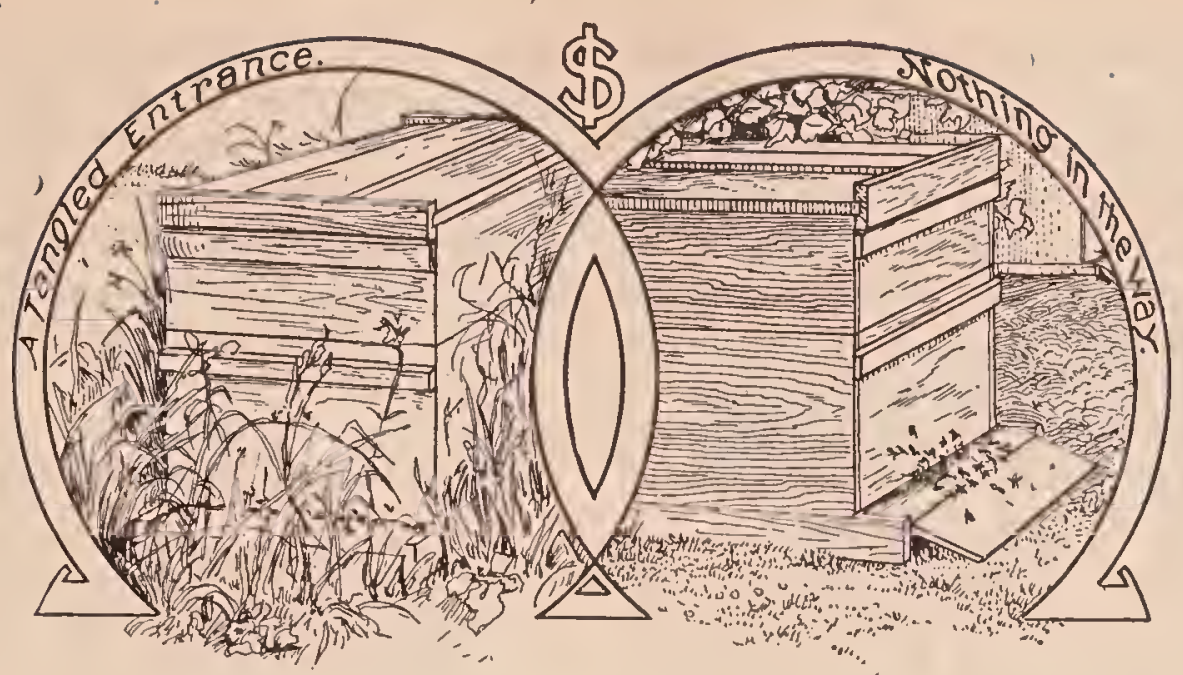

SIZE OF SUMIIER ENTRANCE.

The proper size of entrance depends on the location, season of the year, size of colony, amount of protection, and whether the bees are wintered indoors or out. During the height of the honey flow the aperture should be as large as the bottom-board or hive will permit--not less than $7 / 8$ inch deep by the width of the hive. If too small there will be insufficient ventilation, causing loafing and clustering on the front of the hive, often resulting in swarming. See SwARMing.

Nuclei or weak colonies must have no larger entrances than they can easily defend. They should be as small as possible after the regular honey flow, for then it is that robbers are liable to rush in pellmell and overpower the guards of the little colony, depriving it of the scanty store it may have. (See Robbing.) A two-frame nucleus should not have an opening larger than will admit two or three bees at a time during the robbing season. When the honey flow is on, it may be larger; but it should be contracted as soon as the flow eases up.

\section{SIZE OF WINTER ENTRANCE.}

When cool weather comes on the entrances of all colonies should be contracted, both strong and weak, and kept so during the entire winter if bees are left outdoors. Formerly the practice was to allow the full size; but experience has shown that this is a serious mistake. There is no more reason why the bees should have their doors wide open in midwinter, letting chilling drafts blow in, than that their owners should leave their doors open. A ten-frame Langstroth hive should have an entrance about $3 / 8$ inch deep by one to eight inches wide, the length of the entrance depending: on the climate and the size of the colony. During very severe weather it might be still smaller. With a contracted entrance it may be necessary for the apiarist to hook the dead bees out with a wire two or

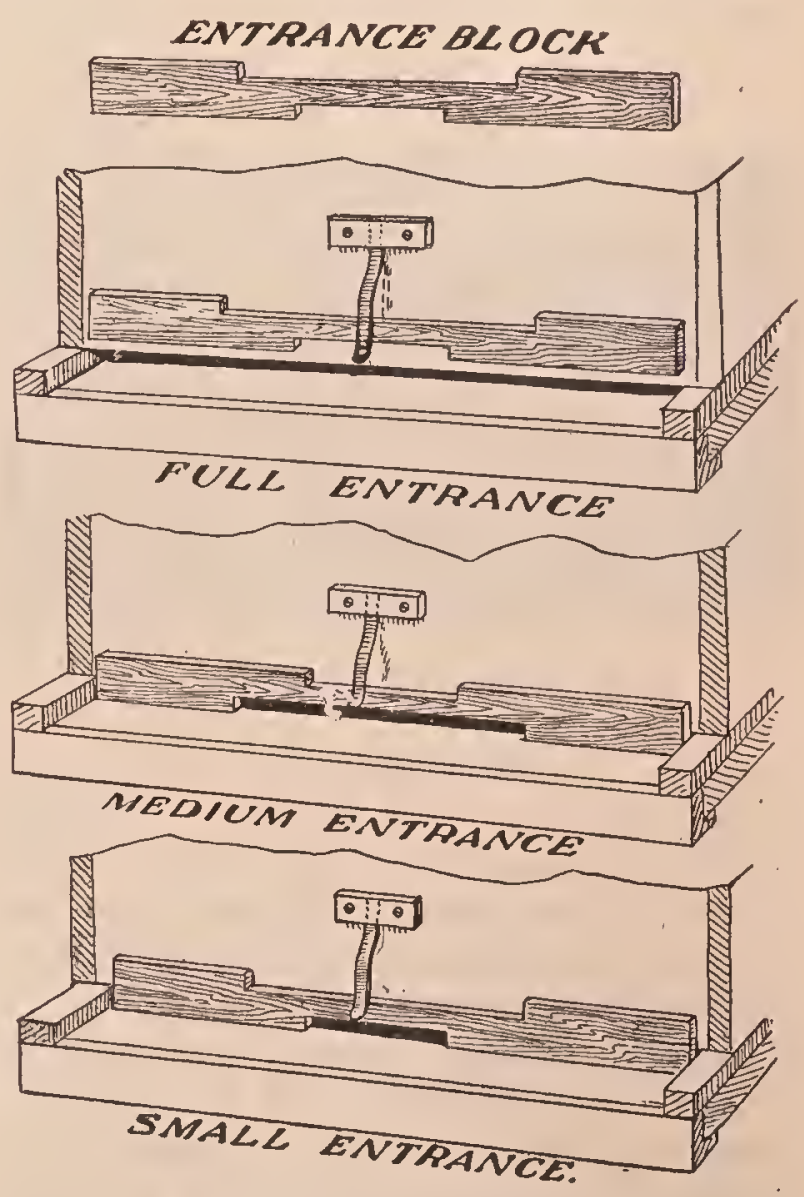

Contracted cleats for summer use.

three times during the winter, and possibly once in the spring; for in no case must the opening be clogged up.

Demuth and Phillips recommend the use of a small entrance in the form of a circular hole from $1 / 2$ to $3 / 8$ inch diameter 
where the bees are packed in quadruple winter cases, such as are clescribed under head of "Wintering" at the close of this work. A number of prominent apiarists all over the country have used very small entrances like this with excellent results during winter, but such small entrances are not practicable unless there is at least 6 inches of packing on the sides of the winter case, then 6 inches on top and 4 inches on the bottom. With that amount of packing the interior of the brood-nest is so warm that bees can easily pick up the dead and poke them out of the entrance. When hives are only single-walled and outdoors, so small an entrance would probably be too much of a good thing, as the dead bees would accumulate so fast that the entrance would clog up.

In California it is getting more and more the practice, even with large colonies, to contract the entrance down to $1 / 2$ inch wide, or a space where not more tlian two or three bees can pass at a time, but as the

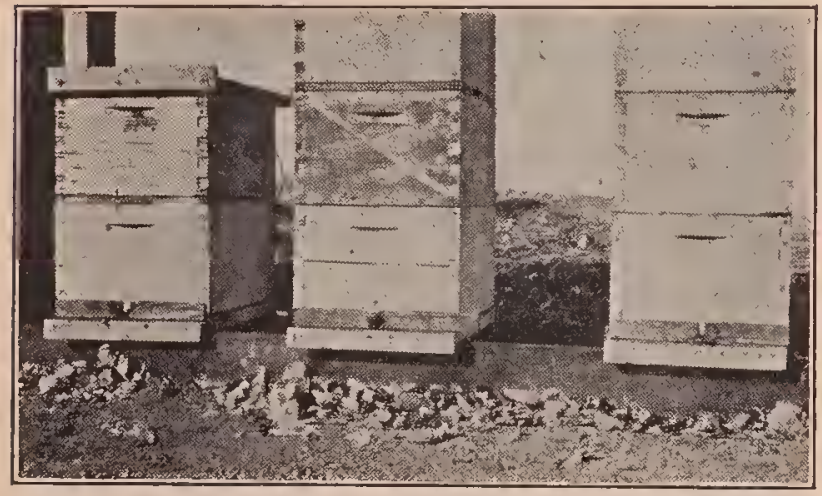

Hives owned by John Nippert, at Imperial. Calif.

bees can fly nearly every day during the winter, they can easily carry out any dead that may accumulate. The object of the close contraction of the entrance in California is to obviate robbing and to hold the heat in the hives.

The use of very closely contracted entrances during the winter, as advocated by California beekeepers, can be practiced to excellent advantage in other semi-tropical countries during that part of the year when the days are warm and the nights cold.

It is customary to have some sort of cleat to reduce a wide entrance to a small slot. This, when inserted slot side down, reduces the opening to the proper size for outdoor- wintered bees. In cleaning out the dead bees the entrance-stop should be removed entirely, making the entrance the full size. Any dead bees that may have accumulated should be raked out and the stop put back. If it is discovered that the colony is weak, the slot should be reduced to one inch or

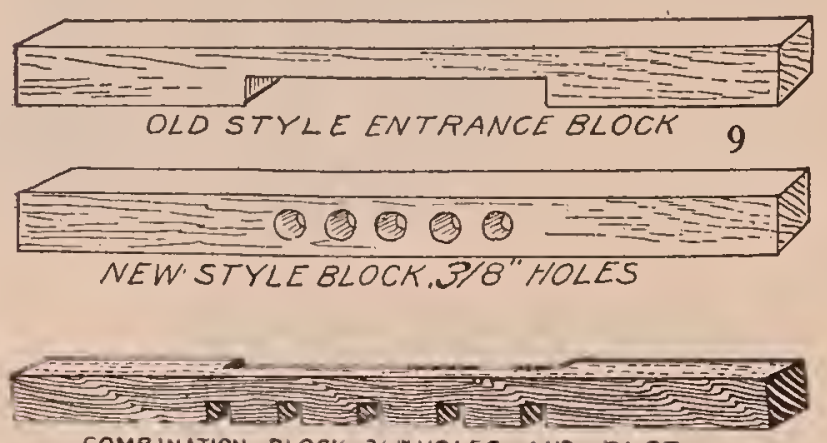

COMBINATION BLOCK $-3 / 8=$ HOLES AND SLOT

less in width. At the same time the frames should be contracted to the number that the bees can reasonably occupy or cover. If they are compelled to keep a large room warm, they may die from cold.

The illustrations show very simple cleats which can be made at any planing mill, or can be cut at home, using nothing but a common handsaw and a chisel. These cleats give various-sized entrances according to the way they are attached. When the cleats are removed entirely the full opening of the hive is provided.

If the block containing' $3 / 8$-inch holes is used, at least two of the holes may be closed during very cold weather.

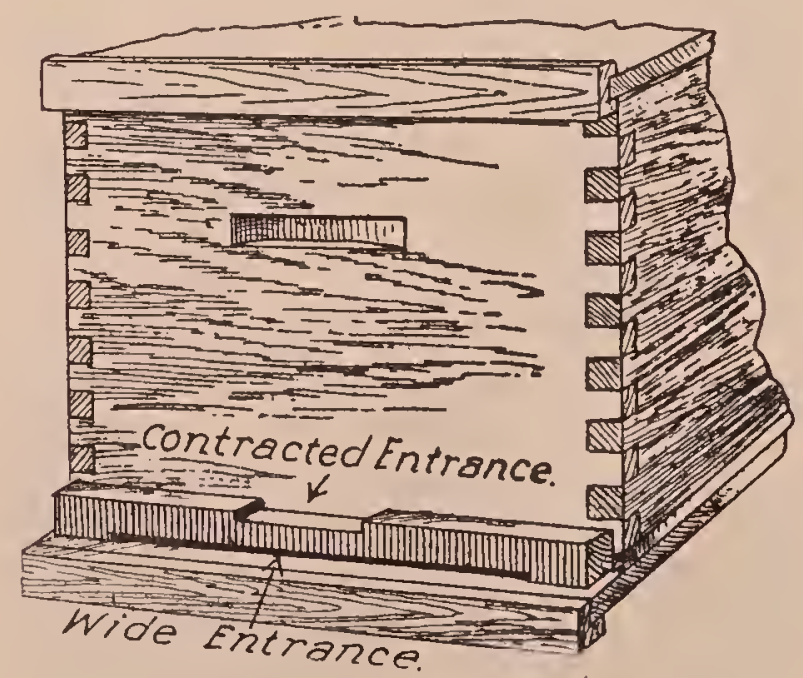

No matter whether the slotted entrance, or one consisting of a series of holes, is used, it is very important that there be no doorstep or ledge to catch snow and ice in packing-cases. 
Under the heading ENEMIES OF BEES reference was made to the depredations of mice during the winter. It often becomes necessary to screen the entrances of hives put in the cellar. W. D. Keyes of Wilkinsburg, Pa., uses a very simple device, consisting of two triangular blocks and a strip of coarse-mesh cloth, just coarse enough to let bees thru it and yet exclude the mice. It is very quickly applied; and, if there is

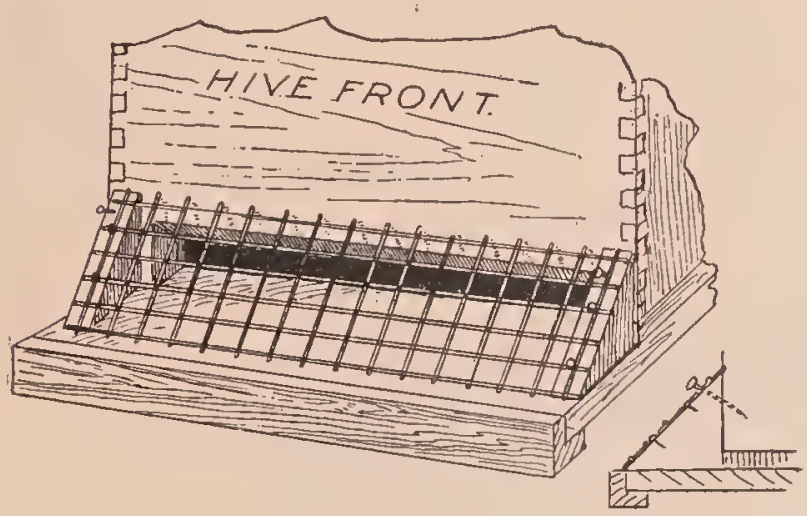

Coarse wire mesh that will let bees thru but ex clude mice.

one to each hive, it will make very little expense, especially considering that a mouse on even one frame of young brood may do enough mischief in a single colony to pay the expense of the excluder. They will seldom gnaw a $3 / 8$-inch slot in an entrance-contracting cleat. For colonies wintered outdoors such a contracted entrance is all that is necessary for excluding mice.

The accompanying illustrations show how the entrance is provided for in a modern dovetailed hive. The bottom is made up of

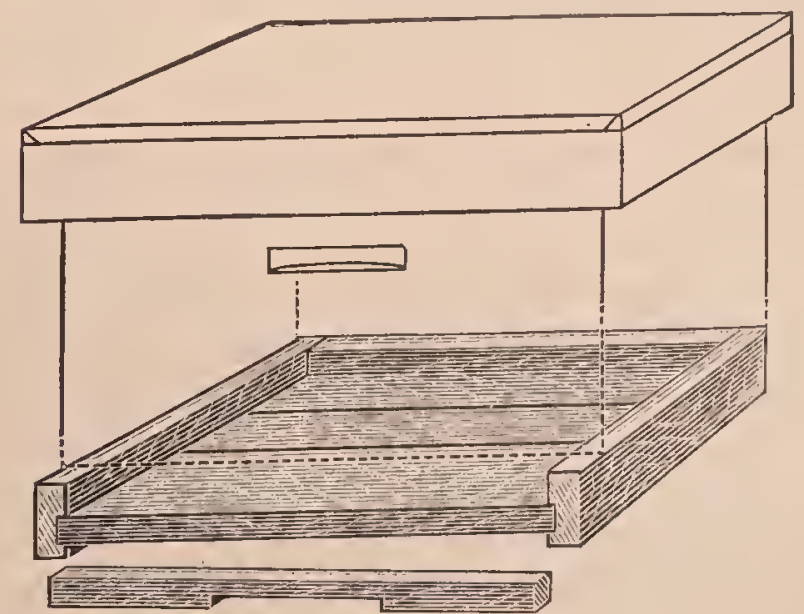

an outside rim of framework, into which are inserted the floor-boards $7 / 8$ inch thick. These slide into grooves so cut that on one side the bottom-board provides a $3 / 8$-inch space, and on the other side $7 / 8$. The usual practice is to use the deep side up, and an entrance-contracting cleat as shown.

While some prefer to use the shallow side of the bottom-board up the year round, it is better to use the deep side, and then

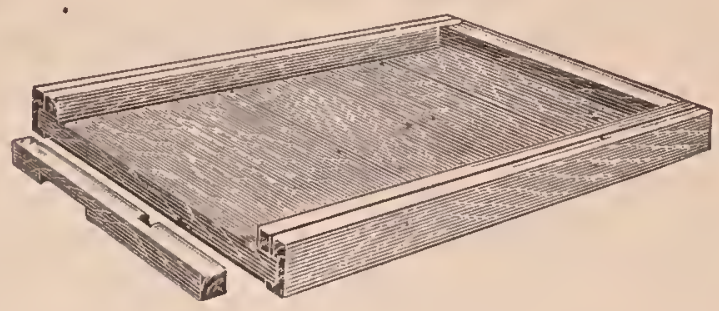

make the necessary contraction of entrance with the contracting cleat as shown. During the warm part of the year, when bees need an abundance of ventilation (spoken of under Cons Honey, to Produce, and Swarming, Prevention of), the wide or deep entrance is used withont the entrance cleat. As cooler weather comes on, or if the colony is not strong, the cleat is inserted in the entrance.

\section{A PLURALITY OF ENTRANCES.}

While it is true that a plurality of entrances may be a detriment in a broodchamber, this does not necessarily hold good during the honey season when the hive is tiered up two or three stories high. It then becomes difficult, and wasteful of bee energy that might be better employed, to ventilate the whole hive from one entrance, however large it is, for the bees have to maintain a current of air rushing in, and another going out at the same aperture. If queen-excluders are used the case is made worse. It alniost goes without saying, that, during the period in which the honey is evaporated while in the combs, there should be more than one entrance to the hive - at least two, and, during very hot weather, more, one to each story, with the cover or roof slightly raised at the back to furnish additional means for the bad air to escape at the top of the hive.

It is said by those who have tried this method of air control that it is a great preventive of swarming, and it looks reasonable. The brood-chamber is far less crowded, since the field workers arrive and depart from the upper entrance to a great extent, saving overcrowding of the broodchamber, which surely leads to swarming. On the other hand, there is danger of the 
honey-chambers being rendered too cool by so many entrances; but if this is the case, it is also too cool for honey-gathering, and the upper stories should be removed. If the colony is weak, upper entrances are unnecessary; and in that case, also, the honey-chambers should be removed, since such a colony can not gather a surplus in any event.

Some of our well-known writers on bee culture heartily recommend upper entrances-notably so Dr. C. C. Miller, C. P. Dadant, R. F. Holtermann, and, in early times, Adam Grimm, who, with the money he made with his bees, established a bank.

Dr. C. C. Miller, in Gleanings in Bee Culture for June 1, 1907, writes: "Prof. Cook says, p. 312 , that bees ventilate so effectively at the entrance that it is best to have only one opening to the hive, evidently meaning at all times; and W. K. Morrison, page 686 , asks if I subscribe to that doctrine. Emphatically, no. If running for extracted honey I would generally have one more opening than the number of stories in use-the regular entrance and an opening at the top of each story. Each year for years I have had one or more piles thus ventilated, and none has ever swarmed. Many years ago I learned from Adam Grimm to have an opening for rentilation at the top of the brood-chamber at the back end when running for comb honey. I gave it up because it interfered with the finishing of the sections near such openings. But I have gone back to it again, believing that sucl disadvantage is overbalanced by the gain in ventilation. You can't make me believe that it is not easier for the bees to have one hole for the air to go out and another for it to come in than to make the air go both ways in the same hole."* The practical beekeeper will soon discover for himself when and how to use a plurality of entrances, for much depends on the climate. Evidently it does not work so well with

* It is a very interesting experiment to light a match and hold it in front of the entrance while the evaporation of nectar is going on in the hive. On one side the flame will be sucked into the entrance and on the other side the flame will be blown away from it. So strong is the current that the match will be sucked in, in one case and blown out in the other. It shows that bees, like a series of little electric fans, are sucking fresh air in one side and forcing the air laden with moisture from evaporation on the other side. The direction of the air current can also be determined by the lise of a little smoke. comb-honey production as it does with extracted; yet even this may be satisfactorily arranged. It looks now as if plural entrances were a long step toward swarm prevention by causing the field workers to leave the brood and confine their energies to storing honey in the upper chambers. See Swarming.

\section{ENTRANCES FOR INDOOR WINTERING.}

Authorities differ as to the size of entrance that should be used for indoor wintering. Some argue that, the larger the openings, the better. A few go even so far as to urge that the bottom-boards be removed entirely, one hive piled upon two others, leaving an opening between the two lower hives of about one-third of the size of

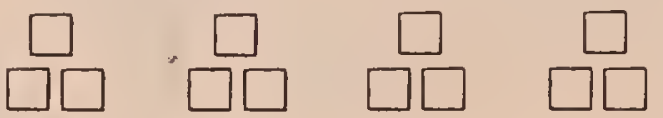

the entire bottom of the hive. Others advise a regular bottom-board, but an entrance two inches deep by the full width of the hive; while others recommend no larger entrance than the bees have during the summer.

The size of the entrances of the hives in a bee-cellar is dependent on two factors - the size and temperature of the cellar itself and the size of the colony. Large colonies should have larger entrances than weak ones. If the temperature inside of the cluster at any time drops below 57 degrees Fahr., the bees will generate heat artificially, expand the cluster, and possibly start brood-rearing. . The cluster should be kept at a temperature as near 60 degrees as possible. This will insure the greatest degree of quiescence or sleep. On the other hand, if the cellar is too warm, the temperature of the cluster will rise to a point of activity that will start brood-rearing. If it is too cold, or if the entrance is too large, the internal temperature of the cluster may fall below 57 degrees, with the result that muscular activity will be started, and in either case it means a too large consumption of stores, and possibly broodrearing. As it would be impracticable to take the temperature reading of every colony of bees in the cellar in order to determine the size of the entrances, it is possible to arrive at it by putting a thermometer thru the entrance, allowing it to rest on 
the floor board. The temperature at this point should be approximately between 48 and 52 degrees to insure 57 or more within the cluster. If it is below these points the entrance should be contracted. If the temperature on the floor board reaches 60 to 65 degrees the entrance should be enlarged.

From these considerations it will be seen that no definite size of entrance can be prescribed for all the colonies in the cellar, unless the colonies are of about equal strength.

Colonies could be divided, perhaps, into two or three different groups as to strength. The temperature reading on the floor board the qualities of which are being tested and compared. To a much smaller extent they have been planted in Arizona and the Gulf region of Texas. Few encalyptus trees will endure a temperature below 20 degrees, or above 120 degrees $\mathrm{F}$. They grow very rapidly and promise to become very valuable sources of timber and other commercial products, and are likewise very effective as avenue and landscape trees. A number of the species are popularly known as gum trees because a resinous gum flows from incisions in the bark; others are called iron-bark trees from their very hard bark, and still others from their fibrous bark are

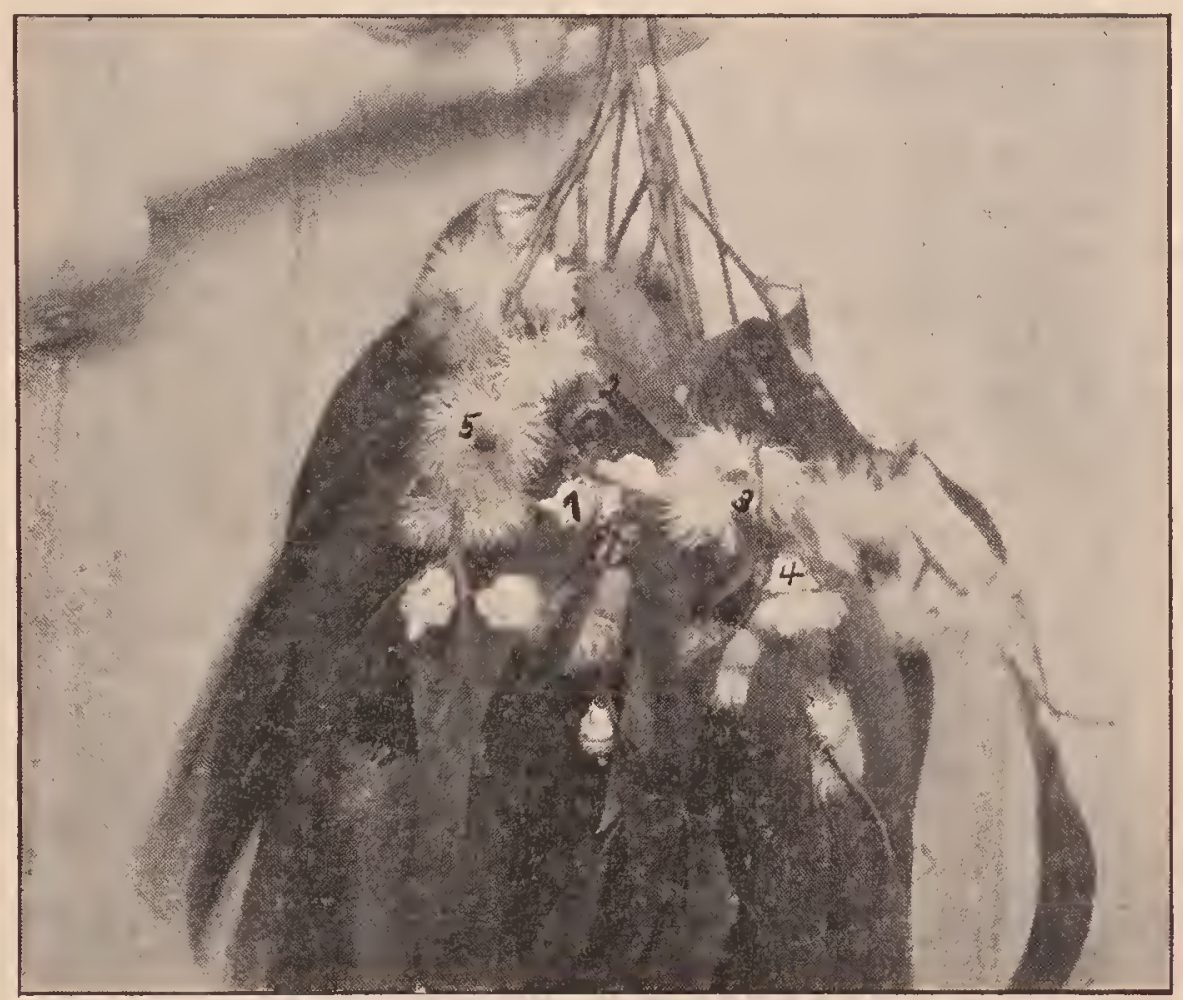

The eucalyplus is of vast importance in California for brood-rearing.

should be taken of about a dozen of each group. The entrances of these colonies should then be regulated to a point between 48 and 52 degrees. All other colonies of the same group should have entrances of the same opening.

EUCALYPTUS.-A large genus of evergreen trees growing chiefly in the coast region of Australia and New Guinea. About 150 species have been described, of which not far from 100 have been introduced into California. At the Forestry Station at Santa Monica there have been planted nearly 70 specios and varieties, termed stringy-bark trees. To this genus belongs the tallest tree in the world, $E$. amygdalina, which attains the height of 480 feet.

By far the most widely planted and probably the best adapted to the climatic conditions of California is the blue gum, or E. globulus, which is found in almost every town in the State from San Francisco to San Diego, and inland as far as the edge of the Imperial Desert region. It is apparently as vigorous in California as in its native Australia. It is claimed to be the fastest growing tree in the world. Seedlings will average a growtl of 50 feet 
in height in six years and 100 feet in ten years; and under favorable conditions a seedling may reach a height of 35 feet in eight months, and in three years a height of 70 feet. In Australia some trees grow 375 feet tall. The wood is very heavy, hard, and strong, and is valued at the same price as oak. It is used for innumerable purposes from telegraph poles, railroad ties, and shipbuilding to cabinet work and wagon wheels, as well as for fuel; while the leaves yield large quantities of medicinal oil. Windbreaks of two or three rows of blue gum afford excellent protection to orchards. The cost of setting out and cultivating a plantation for two years is about .\$25 per acre, while the returns at the end of ten years will usually not exceed $\$ 160$ per acre.

The bark of the blue gum is smooth and pale brown. The leaves are sword-shaped, 6 to 12 inches long, tough, leathery, and bluish green in young trees, but dark green in older trees. The flowers are solitary (in most other species they are in small clusters), in the axils of the leaves and appear from December to June. The flower bud expands by the top of the calyx dropping off, when there is a "veritable starburst" of some 100 creamy-white stamens. A flower consists of the cup-shaped lower portion of the calyx, which is well adapted to hold the very abundant supply of nectar, and a ring of stamens, with the pistil in the center-there are no petals. The seed cases are round, top-shaped, or in the blue gum angular, and a pound of seed will produce over 10,000 plants. E. globulus was introduced into California in 1856.

Other species of eucalyptus, which are promising commercially, are the sugar gum (E. corynocalyx), the red gum (E. rostra$t a)$, and the gray gum (E. tereticornis); but none of them are comparable to $E$. globulus in rapid growth, value of timber, and ability to flourish over a wide range of conditions in California. The sugar gum is much used in southern Califormia as a street tree and for windbreaks. It strongly resists drouth, but succumbs easily to frosts. The red gum has been largely planted in the Sacramento and San Joaquin Valleys, and also withstands well the intense heat of the Imperial Valley. The gray gum endures drouth and cold better than many species, and can, therefore, be planted over a wide range of the State. The timber of all three species is strong and valuable.

All of the species yield nectar, but most, of them are so rare outside of experimental grounds that their value as honey-producers remains to be determined. The blooming time of the various species varies so widely that there are, at least, from three to seven species in flower during every month of the year, and a species may even bloom twice in the same year. The blue gum (E. globulus) is the only species"which is yet sufficiently abundant to be of much importance to apiarists.

The honey is amber-colored and inferior in quality. It is valuable to beekeepers in California chiefly because it yields nectar the larger part of the winter. The quantity of honey gathered varies greatly in different years. Occasionally there is a fair surplus; but, as a rule, only sufficient honey is secured to stimulate brood-rearing and to support the colony, so that the reserve stores, left in the hive to prevent starvation in case the winter flow fails, are not consumed. A large number of beekeepers in this State move their bees many miles to the eucalyptus trees in order that they may build up during the winter and be strong enough to gather a crop of honey from orange bloom.

Several species are reputed to yield fine honeys with exquisite flavors. The sugar gum ( $E$. corynocalyx) secretes nectar copiously, and two or three bees may often be seen around a single blossom seeking a load of nectar. The flowers, which are in pretty white clusters about two inches broad, exhale a most agreeable odor suggestive of a ripe cantaloupe. The mahogany gum ( $E$. robusta), which thrives in swampy localities, is also very valuable. White iron bark (E. leucoxylon) with a vanilla-like fragrance, and the honey-scented gum ( $E$. melliodora) are reported to be wonderful yielders of nectar and to be very eagerly visited by bees. They all bloom during the earlier half of the year when their value in stimulating brood-rearing is almost beyond estimate.

But eucalyptus honey in America probably belongs chiefly to the future. The commercial importance of eucalyptus cul- 
ture, which has now passed the experimental stage, will lead to the planting of thousands of trees, which will offer a bee pasture of extraordinary richness. If the neictar production of these immense plantations equals expectation, the possibilities of bee culture in California can hardly be overestimated. It is, however, unfortunate that the blue gum, which financially is the most promising species, should yield a honey of inferior quality. For descriptions and illustrations of the more important species of eucalyptus and the methods of cultivation see Bulletins No. 196 and No. 225, Agriculture Experiment Station, Berkeley, Cal., and Cireular 59 of Forest Service, United States Departinent of Agriculture.

EXTRACTED HONEY.-Up to the year. 1865 all liquid honey obtainable was pressed and strained from the combshence the term "strained" honey. Such a product is generally full of sediment owing to particles of wax, pollen, propolis, and dirt. The more modern product of liquid honey is extracted from the combs by centrifugal force. A reel holding two or more combs and revolving inside of a cylinder or can, throws the liquid honey from the cells, leaving the empty combs intact for the bees to fill up again. (See ExTracrING.) The honey so obtained is called "extracted." It is free from impurities-moreover, it is not impaired in flavor by bits of pollen and propolis. Practically all the liquid honey on the market today is separated from the combs by the use of the extractor, and is, therefore, extracted honey. Occasionally there is a honey-for example, the far-famed heather honey of Scotland-that is so thick that it cannot be readily separated from the comb by centrifugal force, unless it is placed in a warm room for twenty-four hours before extracting.

There are as many varieties and flavors of honeys as there are of apples and other fruits. Extracted honey may be divided into two general classes, one suitable for table use and the other for manufacturing purposes. Among the first named are the light-colored honeys, such as the clover, basswood, alfalfa, sage, orange, tupelo, palmetto, and raspberry, all of which are of fine body and flavor, and of course suitable for use on the table. While it is not invariably true, yet generally the light-colored honeys are mild and delicious. The darker honeys are nearly always stronger in flavor and must be marketed in a locality where the consumers are accustomed to the flavor, or they must be sold for baking purposes. Hundreds, yes, thousands of carloads of dark honeys are used by the large baking concerns, for no artificial product* that has ever been produced quite takes the place of honey for keeping cakes soft and moist for months. Some cakes, like honey jumbles, contain a larger percentage of honey than others. Honey is also often used along with molasses and cheaper syrups in baking. See Honex AS A FOOD.

As is pointed out under COMB HoNEY there is some difference in flavor between comb honey and extracted, owing to the fact that the latter, especially if improperly handled, loses some of its aroma and because it usually has to be heated one or more times, as explained under BotTuING. Overheating, even for a very short time, impairs the flavor of honey. Moreover, some producers, in their eagerness to obtain all the honey possible, extract it from the combs before it is fully "ripened." Honey when it is first stored in the cells is thin and watery, and does not have the exquisite flavor that it has when evaporated and changed chemically by the bees and sealed over. Honey which has been allowed to stay in the hive some time after it is sealed acquires a body and a richness that honey only partially sealed does not have. Some producers, who use specially constructed evaporating tanks maintain that unripe honey may be evaporated by artificial means and made just as heavy in body as that evaporated by the bees. If an extensive equipment is used this is probably true, but the flavor is not as rich as tho the honey had been left on the hive, fully evaporated and capped over by the bees before being extracted. Most beekeeper's who have tried to ripen honey artificially have not succeeded, and the thin honey which they attempt to sell not only lacks in flavor and body, but in many instances

\footnotetext{
* Invert sugar, when it is cheaper than honey, is sometimes used as a substitute, but it lacks flavor. See INVERT SugAR.
} 
actually sours, irreparably damaging future sales and injuring the reputation of the producer. Unless honey is coming in so fast that there is not a reserve of combs to take care of it, it is penny wise and pound foolish to extract unripe honey. It is not possible to produce an extracted honey that will have all the delicate aroma that it possessed before being removed from the comb, and every extracted-honey producer, therefore, should err on the safe side by letting the bees do their part fully.

In $1870 \mathrm{~A}$. I. Root extracted over three do so, also leaving a thin watery part, which, if it does not sour, acquires in time a disagreeable brackish flavor. Unripe honey will often show the peculiar quality of pushing the bungs out of barrels, corks out of bottles, and it may actually burst cans, to the disgust of every one who has anything to do with it.

Now honey, even that which is fully capped over, often has a peculiar odor and taste. Sometimes, where there is a great amount of goldenrod a disagreeable smell is noticeable in the apiary while the gold-

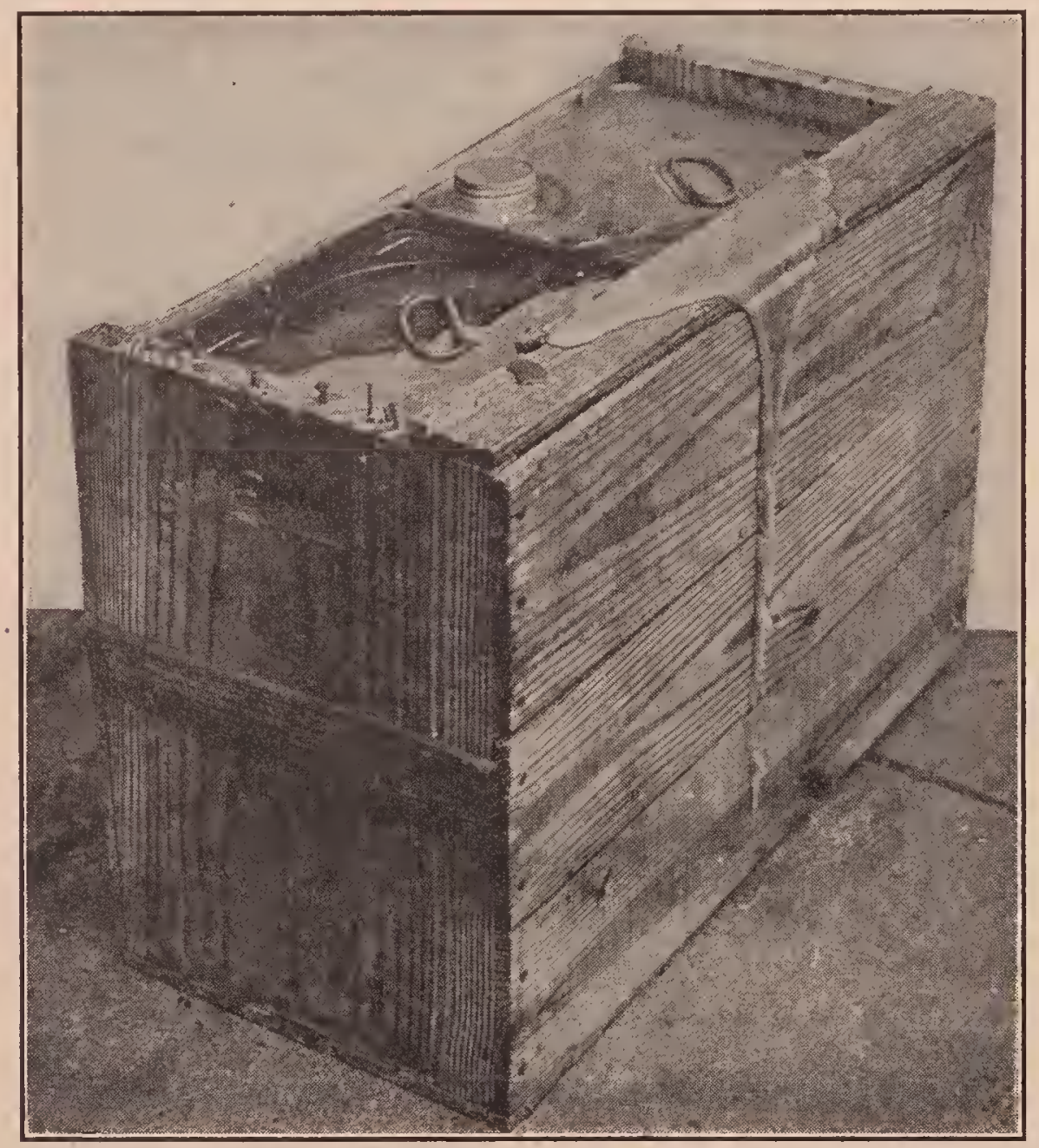

Unripe honey. Fermentation and consequent expansion caused the honey to leak out around the screw-caps.

tons of honey flom an apiary of less than fifty colonies. During the fore part of the season it had been allowed to become capped over; but during the basswood bloom, when the bees were fairly crazy in their eagerness to bring in the nectar, some of it was extracted that was little better than sweetened water. This granulated when the weather became cold, and nearly all of it had to be sold at a loss. Almost all honey will granulate; but an unripe honey will enrod honey is ripening. In a few weeks, however, all this passes away and the honey shows nothing of the former disagreeable odor or flavor. In certain localities where onion seeds are raised for market, the honey, when first gathered, has so strong a flavor of onions that it cannot be used. Later on, however, mucl of the disagreeable quality disappears.

Even basswood honey, when first gathered, is so strong, and has such a pro- 
nounced "twang" that it is often unpleasant. After standing, especially if left in the hives, it greatly improves.

One season the extracting could not be attended to when the honey was capped over, and so the filled supers were raised up and supers of empty combs placed under them next to the brood-chamber. This occupied little time, and the bees were not hindered in their work. This was continued until the latter part of the summer, before any honey was extracted. While honey that has stood in the hives is somewhat thicker and harder to extract, it has a richness of flavor that can be obtained in no other way. Of course, in localities where there are honey flows from two or more sources it is necessary to extract after each flow, if one desires to keep the flavors separate.

\section{HOW TO KEEP EXTRACTED HONEY.}

It is usually best to sell the crop at once when the market is good; but sometimes it is advisable to hold, awaiting a further higher price. It is impossible to recommend any invariable rule, for conditions are different in different seasons. It is pretty safe to assume, however, that honey brings a better price before the holidays than after.

Comb honey cannot be kept indefinitely, because there is danger that it may granulate (see Сомв Honer), but, if extracted honey is properly cared for, it may be kept for years without deteriorating. All comb honey should be kept in a room as near summer temperature as possible. The thermometer should not go below 70 degrees F., and no harm is done if it goes as high as ordinary summer temperature permits, even 90 degrees in the shade. Extracted honey keeps perfectly when stored in tin cans or in large tanks, even when the temperature is down to freezing or lower. At the low temperature it will granulate. For the purpose of shipping it is much better to have it in a granulated condition. Tanks holding more than 500 pounds are ordinarily made of galvanized iron. Some objection has been made to this metal because of the zinc contained in the spelter; but in the large-sized tanks no injury to the honey has ever been noticed. However, it would be a mistake to leave a very thin layer of honey for a long time in the bottom of a large galvanized tank, as the honey might take on enough of the zine to be poisonous. In California and other western. States where great quantities of extracted honey are produced, it is customary to store honey in large galvanized tanks, some of them practically good-sized cisterns above the ground. In hot climates the honey will remain liquid for some time and can be kept clear until cool weather comes on. If the honey has a tendency to granulate soon after extracting, it is not advisable to store it for any length of time in large tanks, but it should be drawn off into smaller cans of convenient size to handle after it granulates. In such cans it is not difficult to liquefy it, if desired. (See BotTling Honex and Granulated Honey.) It is an expensive matter to dig granulated honey out of a large tank. Some have attempted to supply heat by means of a steamjacketed tank, or by means of coils of steam pipes; but in most instances this, too, is expensive, and it is better to get honey into smaller cans as soon as possible.

In some localities barrels are extensively used for storing. They require careful watching, however, on account of the danger of leaking. The hoops need to be driven down occasionally to compensate for the slight shrinkage of the wood, of which there is danger, especially in a hot climate. The barrel should be thoroly waxed on the inside as described under BARRELS. The bung should be left out, and the honey stored in a dry room. When ready to ship, the bung should be driven in, a piece of tin tacked over it, and the hoops tightened.

\section{IS EXTRACTED HONEY ALWAYS PURE?}

Years ago adulterated extracted honey was marketed in considerable quantities; but in late years, owing to the enactment and enforcement of pure-food laws the adulterated product has been practically eliminated from the market. One may be nearly certain, therefore, that any liquid honey that he buys will be the pure product of bees. Some may be of poor quality, it is true; but that does not signify that it is adulterated. See Adulteration of 


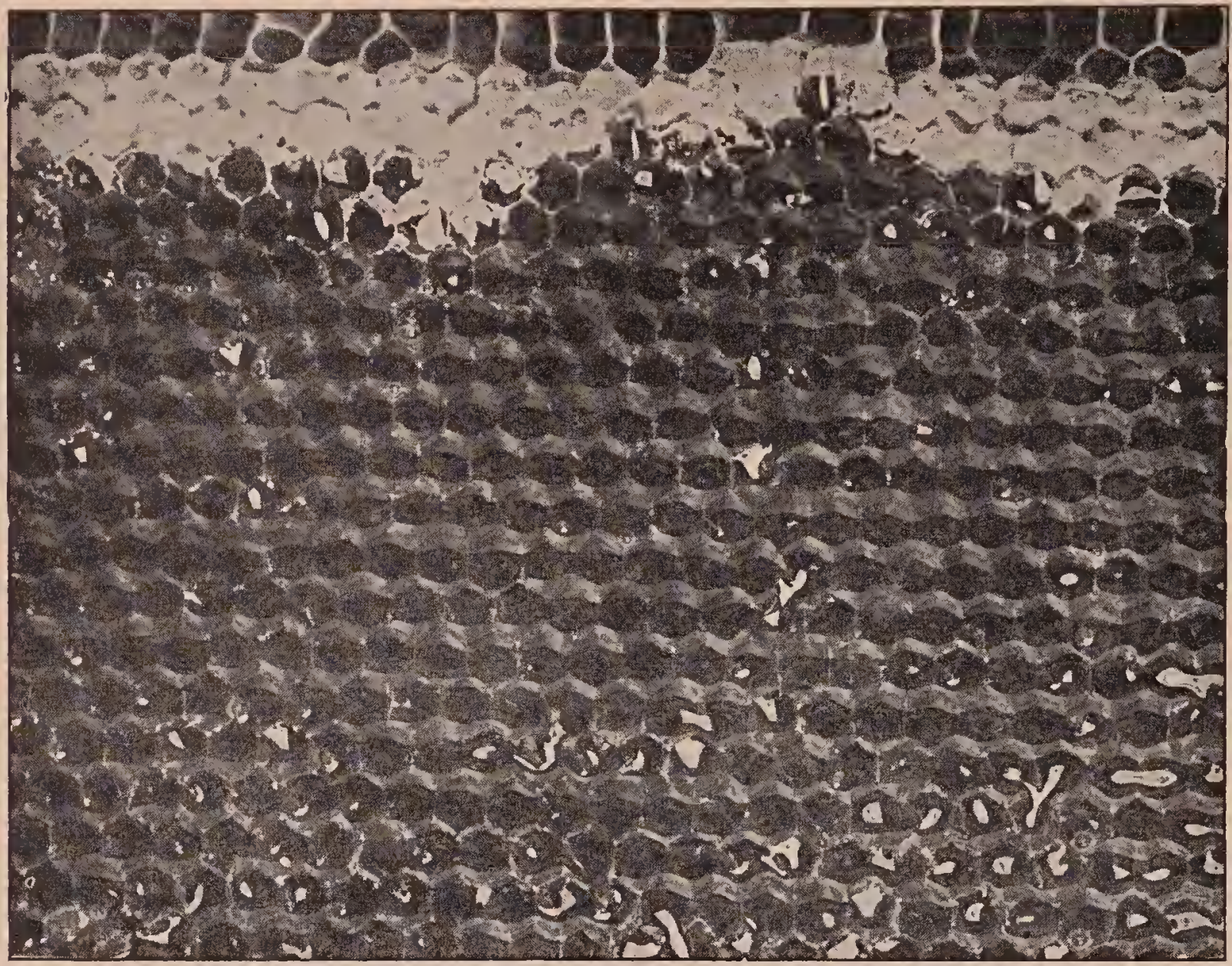

A comb of honey with cappings shaved off by a sharp knife.

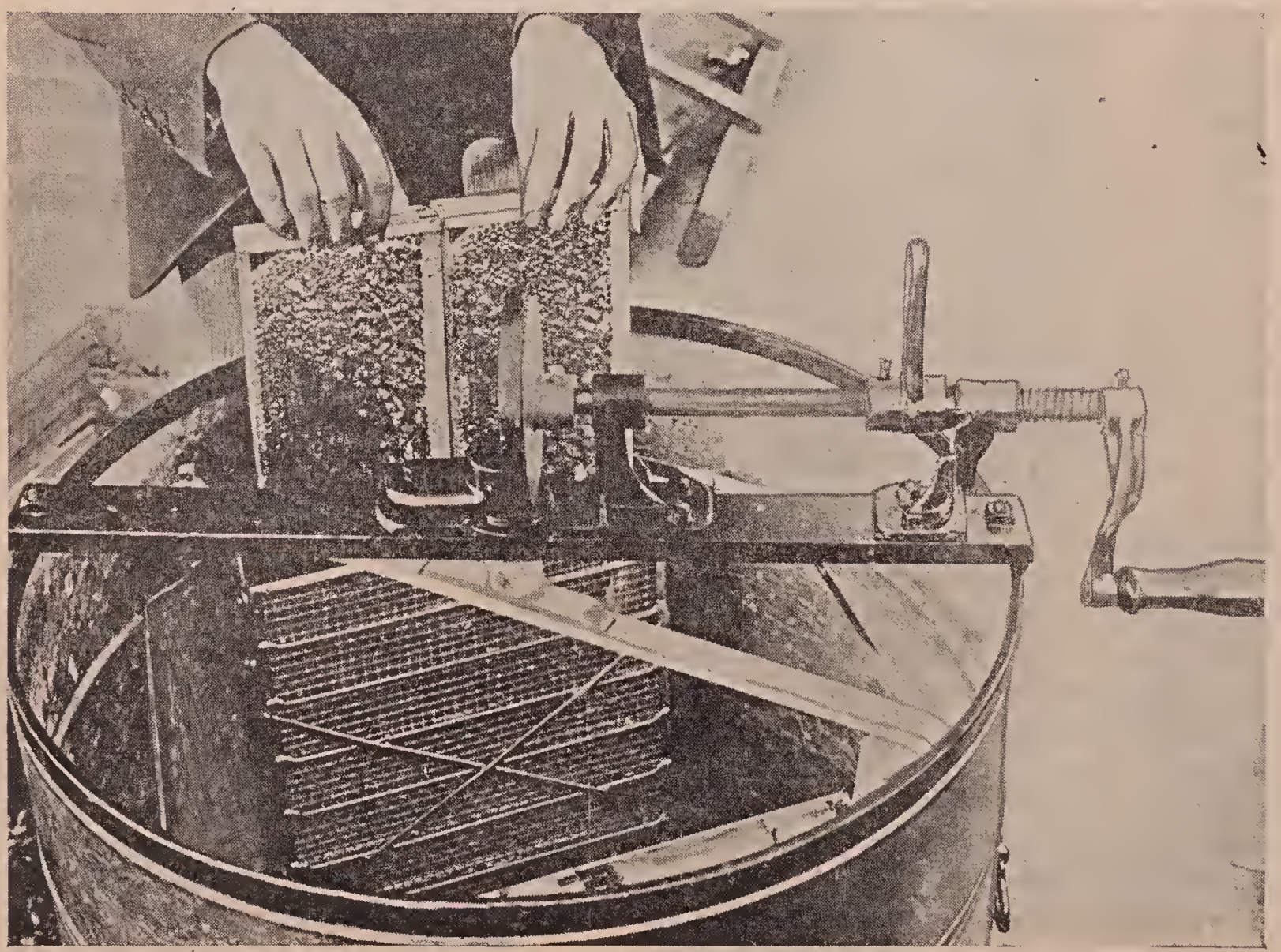

Uncapped combs being lowered into a honey-extractor. 


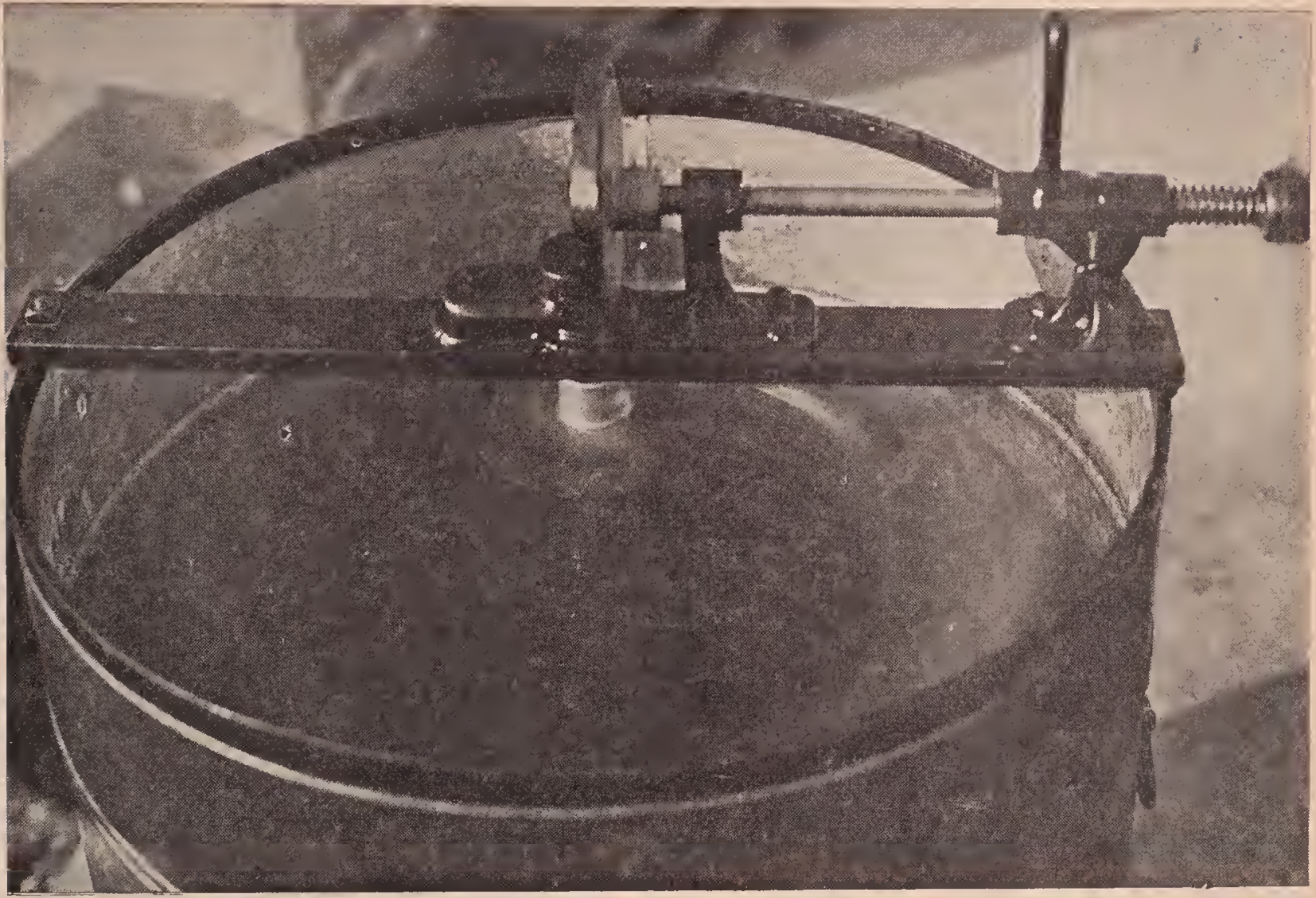

When the combs are whirled rapidly, the centrifugal force throws the honey out of the cells against the side of the can.

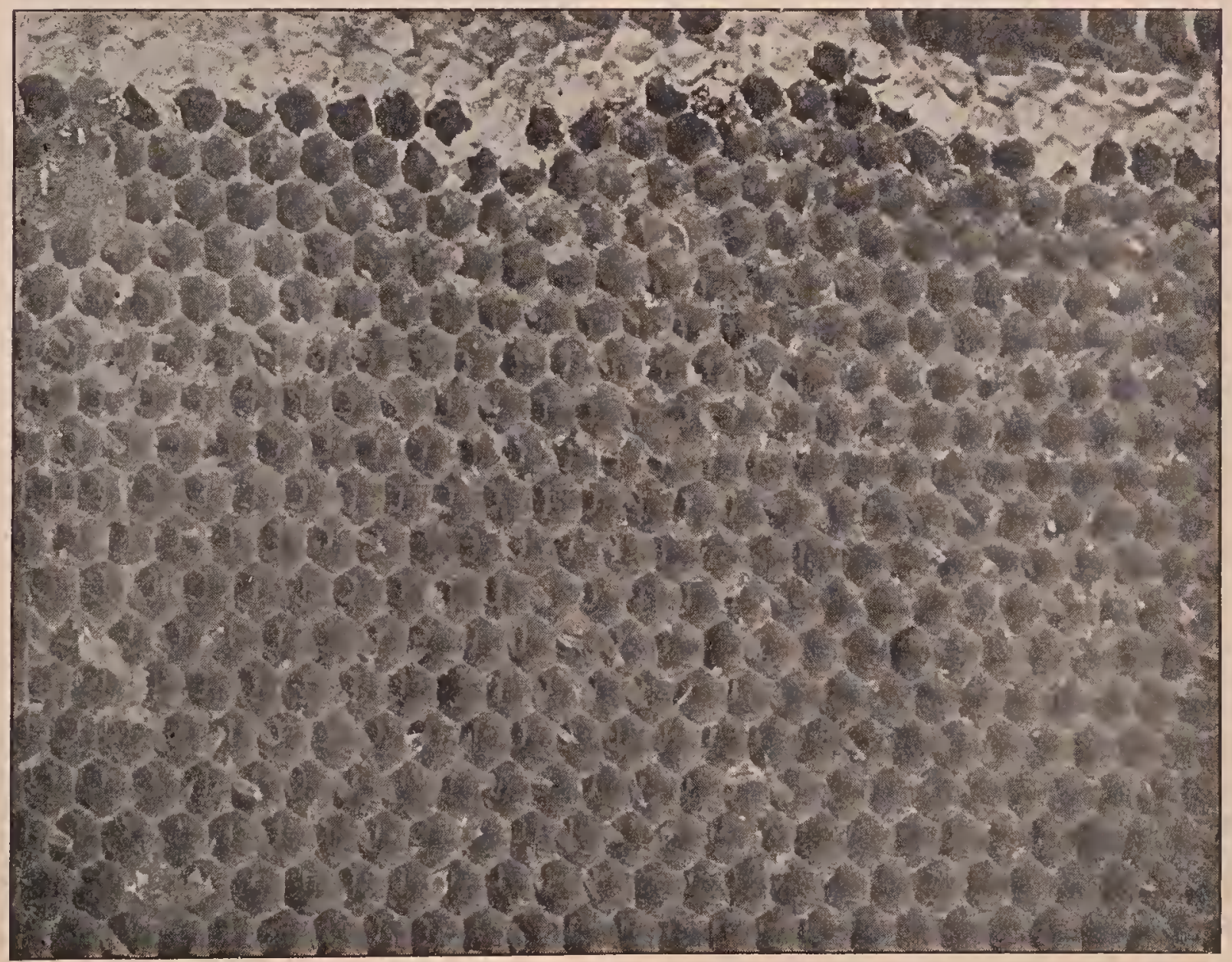

The comb after being taken from the extractor is as good as new and is ready to be filled again by the bees. 
Honey, also LABELS, for a further discussion of this question.

\section{PACKAGES FOR SHIPPING AND SELLING EXTRACTED HONEY.}

For the shipment of honey, tin containers are much more satisfactory than wooden. When tin is used there is never any loss by honey soaking into the package, while in case of barrels or kegs the loss is sometimes 2 or eren 5 per cent, and this is considerable. Such loss is greatly reduced by waxing; but that in turn includes much additional labor. In the West, the dryness of the climate causes wooden packages, such as barrels and kegs, to shrink to such an extent that they are entirely useless. If tin containers are tiglit in the first place they will remain tiglit, and no degree of dryness will affect them. While they are somewhat more expensive, yet this disadvantage is more than offset by the greater convenience and safety in handling.

Yet, whatever package is used, care should be taken to insure safe shipment. Every year in this country an enormous amount of honey is lost by the honey-shipper's carelessness in failing to provide proper shipping equipment when putting his erop aboard cars. Railroads are supposed to stand all loss in transit; and, therefore, in order to realize the necessary profit, excessive loss in transit compels them to raise the rates, and thus the shipper is ultimately obliged to pay from his own pocketbook for his failure to provide strong shipping-cases.

A round can as a container for honey or other liquid has long been condemned as a failure by the railroad companies. This is becanse of the fact that there is no way of keeping a round container upright and in its place on the car floor, and, once tipped over, it rolls about with every jolt of the car and gets battered or even knocked to pieces. As for the wooden jacket (a wooden veneer about $1 / \mathrm{s}$ inch thick) it is about as good as nothing. The accompanying illustration shows the battered and leaky condition in which jacketed cans sometimes arrire at their destination.

When such packages are used, not only is the honey itself liable to be lost in transit, but often the honey runs down upon other merchandise in the freight car, caus- ing considerable damage. It is on account of these repeated instances of loss and damage caused by leaking honey, that some shippers have recently been advocating steel drums, holding 15 gallons or possibly 30 gallons. These are especially advised for export shipments to foreign countries where the packages receive very rough treatment, as on shipboard. The only possible objection to shipping honey in this way is, that the drums are rather heavy. and can not be lifted without a hoist. Moreover should the honey granulate in them, it would require a long lieating process to reliquefy it. When steel drums are used, they must be either tin-lined or galranized.

By far the most popular package for

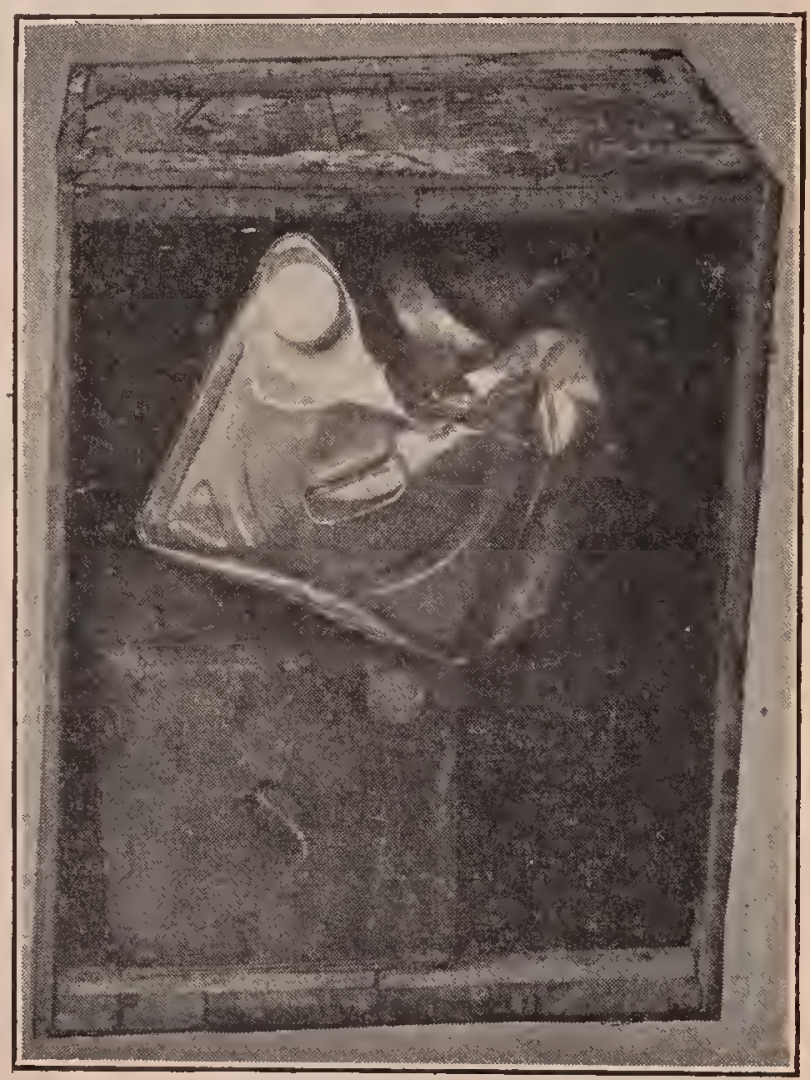

A honey can after being shipped loose in a box. Most of the honey had leaked out.

shipping exiracted lioney in bulk is the five-gallon sixty-pound square can. In later years it has come to be almost universal. There are usually two cans to the wooden case, as shown. Note the strong $7 / 8$ inch partition between the two cans. This is essential for safe shipment. Without this partition the case is too frail to stand such a weight of honey together with the rough handling it is sure to receive in shipment. 
A very convenient device to use when pouring honey from the five-gallon cans is the screw-cap honey-gate, as shown. This simple gate may be made by any one. Take

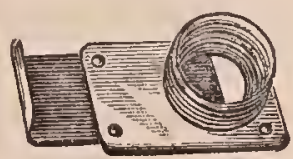

a piece of heavy tin, $2 \frac{1}{2} \times 3$, and make a square bend $1 / 4$ inch from each long edge. A heavy piece of sole leather, $2 \times 3$ inches, of a size to fit into this, should be riveted

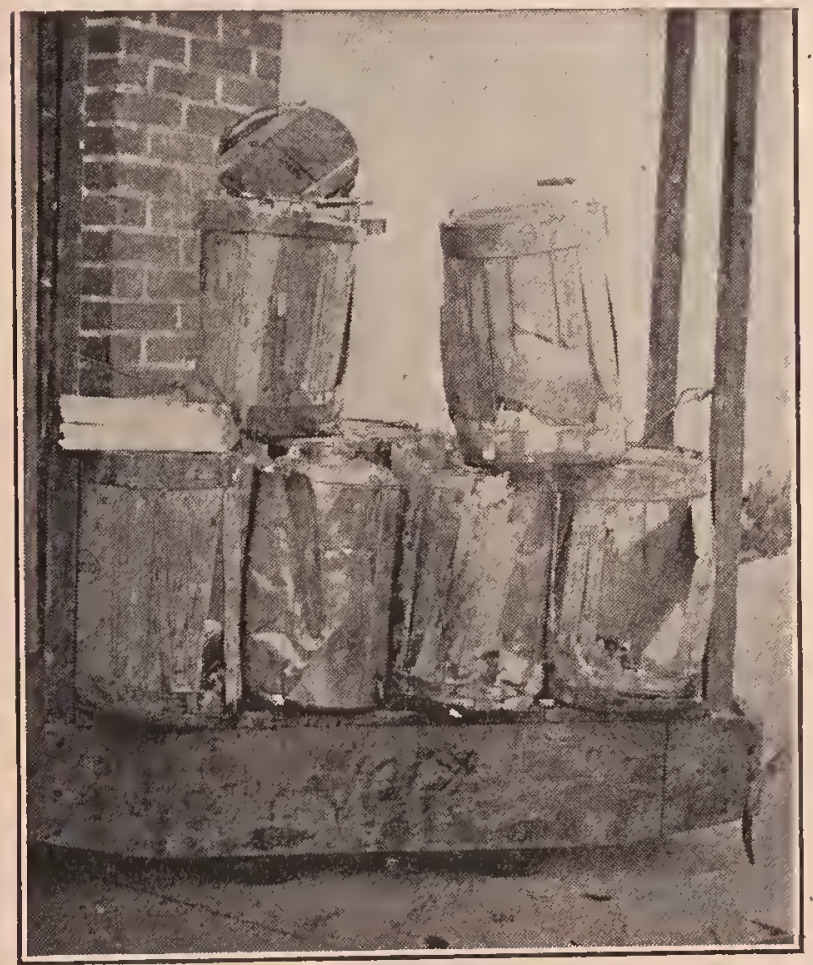

A truck-load of round wooden-jacketed cans just as they were received after shipment.

firmly at the four corners. Solder to it a serew-cap the right size to fit the cans used, and with a tinner's punch cut a hole thru the cap, tin, and leather. A tin slide, to be pushed in between the leather and the folded tin, completes the device, which, when screwed on the can, is ready for use.

To meet the demand for smaller tin packages the manufacturers of square cans have introduced smaller-sized cans holding one, one-half, and one-fourth gallon respectively. The gallon cans are usually sold in boxes of ten each.

\section{HOW TO TEST TIN CANS FOR LEAKS.}

Ordinarily by looking into the can while it is held toward the light, one may determine whether or not the can has leaks. Even a tiny hole will let in a bright ray of light which will be readily seen if the can is turned slightly toward one side or the other.

If solder becomes loosened at some point, however, this test might not locate the defect. Therefore some beekeepers prefer to serew the caps tiglitly on the cans and then immerse the cans in hot water. The inside air expanding will cause small bubbles to escape from all leaks. Another plan sometimes employed is to have a cap specially prepared for attaching the tube of an auto pump, and then foreing air into the can. If there is a leak, one will hear the sound of escaping air.

\section{HOW TO CLEAN SECOND-HIAND OANS.}

Opinions vary as to the advisability of. using second-hand cans. Frequently gasoline or kerosene cans may be bought for about half the price of new ones. Unless .one is very careful in cleaning, however,

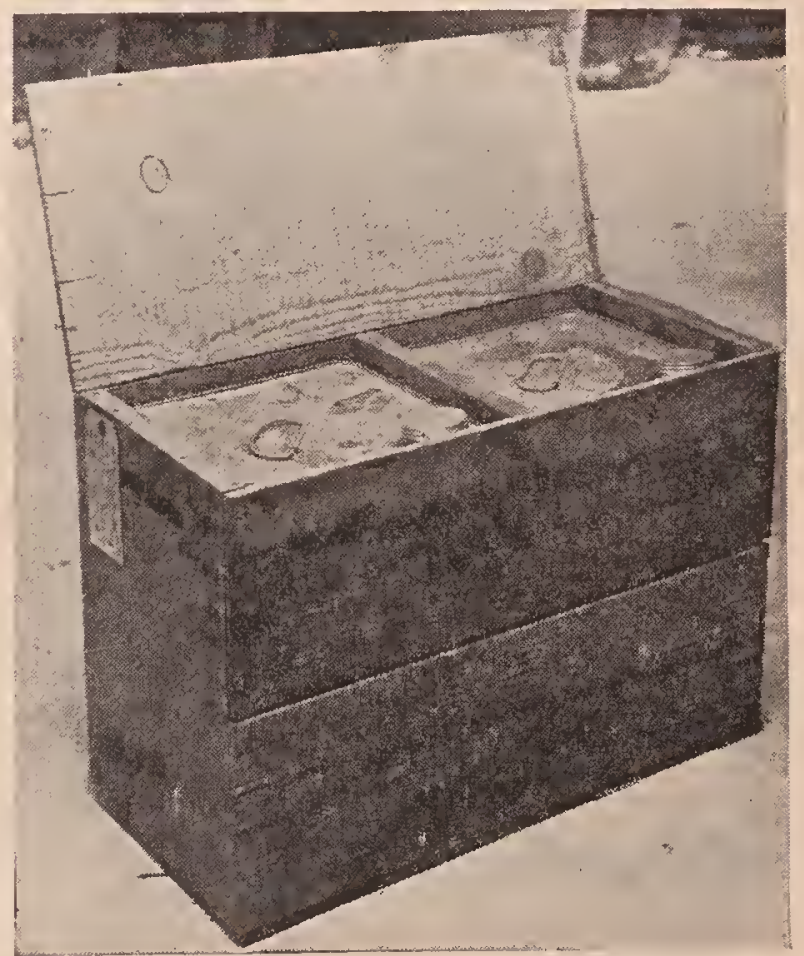

Standard two-can shipping case with strong par. tition in middle between the cans. Each 5-gal. can holds $60 \mathrm{lbs}$. of honey.

honey placed in them is likely to be ruined. The general consensus of opinion is that bright new cans are the cheapest for fine light honey. Honey that is dark or ill flavored may be shipped in secondhand cans if they are carefully inspected and rigidly cleaned. If a can has held oil of any kind, it may be cleaned by putting 

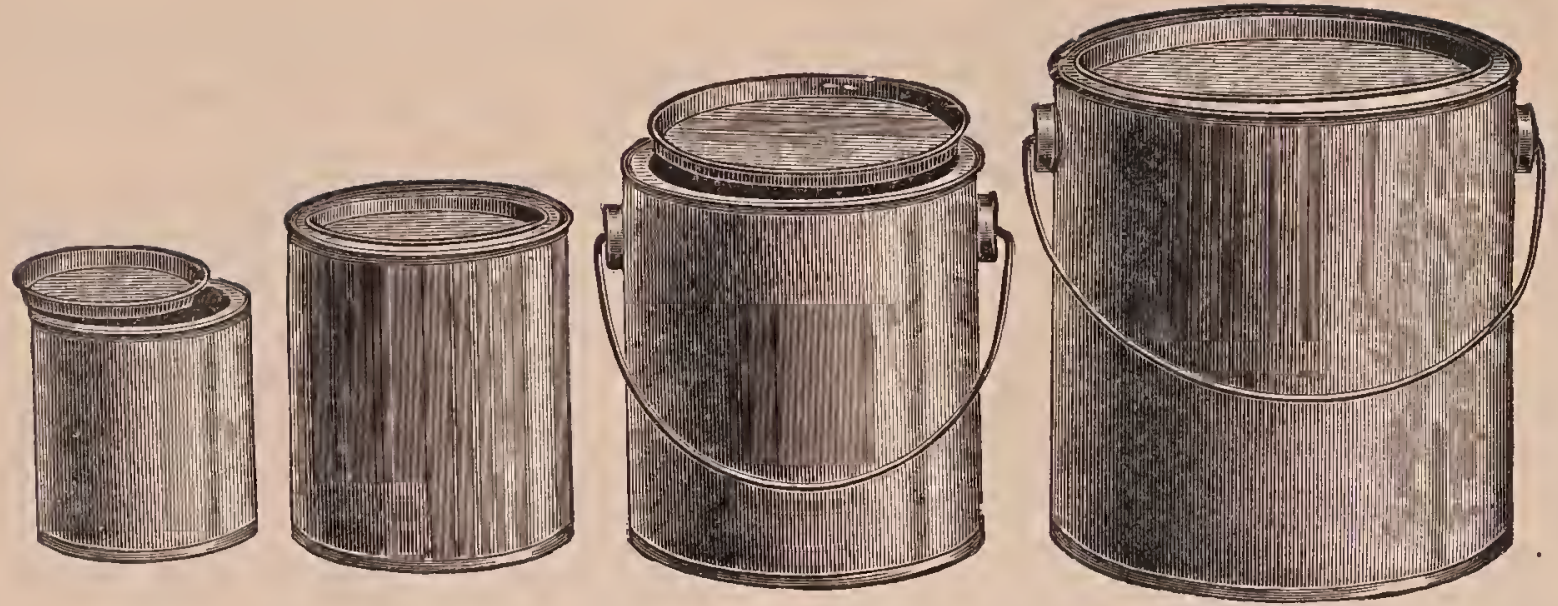

Friction-top cans and pails.

a handful of unslacked lime into it with three or four quarts of boiling water. After the lime is slacked, it should be shaken well and afterward rinsed out twice with cold water.

Rusty cans must never be used for loney. The rust not only discolors the honey, but it indicates weak spots in the tin, which. may cause leaks almost any time.

Some beekeepers insist that even new cans should be rinsed out with boiling water before the honey is put in them, to remove the dust or any other foreign matter. Others claim that it is so difficult to dry the cans after they are thus cleaned that it does not pay. If the cans are not carefully dried, the moisture left is almost sure to cause rusting. We have rarely found new cans that require rinsing.

\section{FRICTION-TOP PAILS.}

Among the smaller tin packages for holding a gallon or less the friction-top cans and pails are very popular. The opening at the top is very large, and this adds greatly to the convenience in filling. The caps, when they are properly pressed

into position, are tight and will not work loose.

GLASS PACKAGES FOR EXTRACTED HONEY.

The appearance of extracted honey is beautiful. For this reason the lighter grades should be retailed in glass instead

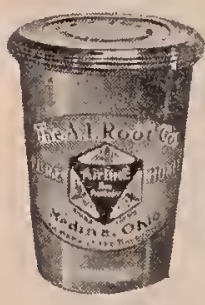

of tin. (See Bottuing Honey.) A tin package must depend upon its label for its attractiveness. Honey in clear white glass speaks for itself. The label does not need to be gaudy; in fact, it should serve only to call attention to the honey.

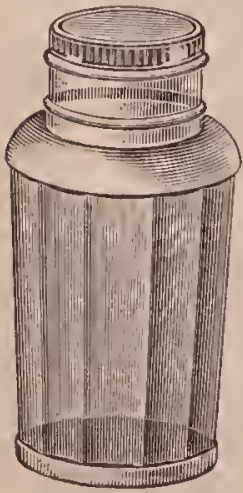

Taper-panel jar

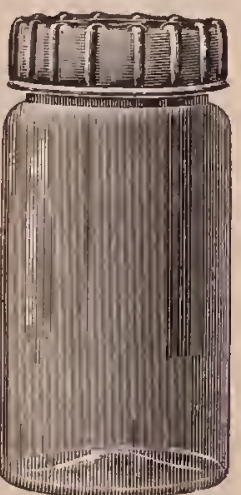

Federal jar

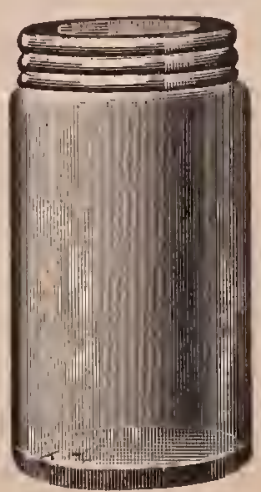

Round jar

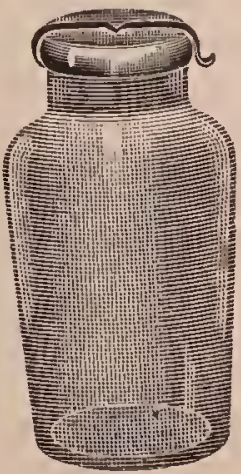

Tip-top jar

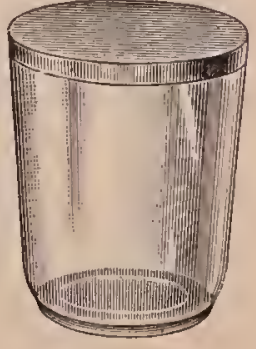

Tumbler 
There is a great variety of different types of jars from the smallest tumbler to the large two-quart Mason jars. Square bottles with large mouths using corks were very popular a few years ago and are still used quite largely. These are obtainable with a picture of a straw skep pressed in the glass on the front.

Mason fruit-jars and jelly tumblers are popular because they can be bought anywhere, and no one objects to buying them with honey, since they are always useful. Whenever possible select crystal-white glass rather than that of a greenish tint, for green does not show the honey to the best advantage.

Paper milk-bottles have been used for honey to some extent for local trade; but, while these are very satisfactory for granulated honey, they do not answer for long shipments of liquid honey that is not granulated. For this reason they are not very popular.

Extracted honey is one of the purest and best foods. It should not be classed with cheap syrups, and therefore it deserves the best and most attractive package.

EXTRACTING.-To produce extracted honey one must have a big force of bees, as in the case of comb honey. The productiveness of an apiary can not be measured by the number of colonies it contains, but by the number of bees in the individual colonies. To achieve the best results is to see that each colony is in good working order by the time the flow opens, and to do this it is necessary to examine each separately in order to ascertain its condition. Special attention must be given to each queen; and every one that is in any way defective should be replaced with another that is young and vigorous. It will never do to retain a queen whose prolifieness is doubtful, for the colony of such a queen-will yield very little surplus, or, in all probability, none at all. It is far better to replace such a queen, even if another has to be bought. The next important thing to be careful about is the strength of each colony. If the honey flow begins a month or six weeks ahead, and the weak colonies have young prolific queens, an effort may be made to build them up to full strength in time for it; but if the flow is near at liand, it is better to unite the weaklings.

In some localities, the main honey flow is preceded by a light flow from some other source, while in others there is a dearth until the opening of the harvest. Where the former is the case the bees will make good progress in brood-rearing, and the colonies consequently will build up nicely; but where there is but one flow, some colonies may be in the poorest kind of condition when it commences.

If the colonies were prepared properly in the fall, and left with sufficient stores, they may need no further attention until the honey flow; but if they lack stores or necessary room for the queen to lay, the matter should not be neglected; for in order to get a good crop it is imperative that at the beginning of the honey flow the hives be overflowing with bees. In the case of those colonies that need attention, the number of bees actually present at the opening of the flow will depend entirely upon the manipulations begun some six or eight weeks previously.

During these weeks the colonies should be kept always supplied with plenty of stores. At all times there should be at least from ten to twelve pounds of honey in the hive-more if possible; for during spring breeding great quantities of stores are needed, full colonies sometimes needing three or more pounds each week. It is necessary to have stores in excess of their actual needs, in order that brood-rearing may continue at the proper rate. Therefore close watch should be kept in order that the stores may not run low and thus curtail brood-rearing.

If some colonies are short of honey, it is generally possible to find others in the apiary which can easily spare a few combs; and if no disease is present in the apiary, these stores should be equalized; or lacking these stores it may be necessary to feed syrup or candy. See FeEding iN Spring and Building up Colonies.

However, the general opinion of the majority of large producers is that it is better to avoid spring feeding if possible. If in need of stores they should be fed; but the better way, as mentioned before, is to have strong colonies of young vigorous bees with an abundance of good stores in 
the fall to last until the main flow begins in the spring.

At this point the reader should read carefully the article on BuILDING UP CoLoNIES. If the colonies are strong enough at the right time the crop will not be a failure if there is any honey in the fields.

WHAT KIND OF HIVES TO USE FOR PRODUCING EXTRACTED HONEY.

For most localities the best results will be secured with ten-frame hives of Langstroth dimensions. There are, perhaps, some who would prefer the ten-frame Jumbo hive with an extracting-super of Langstroth depth; and there are a few who would consider a twelve or thirteen frame hive, Langstroth depth, most suitable. But the objection to these very large hives is that they are very heavy to handle; and where the individual units are smaller it is easier on the beekeeper.

Either the eight or ten frame Langstroth hive is standard. Either is light enough so that any one can pick it up, transfer it to a wheelbarrow or cart, on which it is then carried to the extracting-house. If the time ever comes when the beekeeper wishes to sell out he will get a better price for something that is standard than if he has some freak or odd equipment that the prospective purchaser is not used to and would not like.

Another thing in favor of the Langstroth dimensions is the fact that they are just right for the brood-nest or for the extractor. Where one uses hives of extra depth like the Jumbo he is compelled to have a super of shallower dimensions, as it is not practicable to extract from the large deep frame. By adopting the Langstroth depth thruout, one not only has a standard equipment, but his supers and frames are interchangeable, either for breeding purposes or for extracting. This one fact alone should decide the extractedhoney producer in favor of the Langstroth dimensions, even if there were no other considerations. Moreover, when brood-nest and super are one and the same the cost is less.

If one is well advanced in years, or a person happens to be a woman, an eightframe is a little easier to handle. But the ten-frame is much more of a standard, and the authors strongly advise adopting an equipment that is not only uniform but universal in this country.

There are some few extracted-honey producers who prefer the ten-frame Langstroth brood-nest and a shallow extractingsuper having frames $5 \%$ inches deep. This equipment is standard, and has the further merit that the supers are much lighter than the full-depth Langstroth brood-nest. Shallow frames are very easy to uncap, and require a little less wiring. On the other hand, it should be clearly understood that nearly two frames must be handled to take the crop in place of one. This makes extra manipulation in uncapping, in taking the frames out of the supers, and putting them in the extractor.

HOW FAR TO SPACE THE FRAMES FOR PRODUCING EXTRACTED HONEY.

Most of the Hoffman frames in use are made on a spacing of $13 / 8$ inches from center to center. But there are many beekeepers who space even these combs in their extracting-supers $13 / 4$ inches, or about eight combs to a ten-frame Langstroth super. Many prefer nine combs to the super or a spacing of almost 15/8. One would think that a self-spacing frame would have to be spaced in the hive so that the projections of the end-bars would come in contict. As a matter of fact, they can be spaced as far apart as the old-style unspaced frames, the bees bulging the combs in proportion to the spacing. The fat combs are a little easier to uncap because there will be no low spots. Furthermore, it is perfectly evident that one can uncap eight combs in less time than he can do the work on ten spaced the regulation distance.

It is for these reasons that the wide spacing, eight combs to the ten-frame Langstroth super, is almost universal among extracted-honey men. If it is desired to use these combs in the brood-chamber again, the uncapping-knife cuts them down to their normal depth. Large numbers of extracted-honey men believe that it is good practice, and that it pays, to cut off thick slices during uncapping. The combs are then as smooth and level as a board either for brood-rearing or for extracting in a year or so of such treat- 


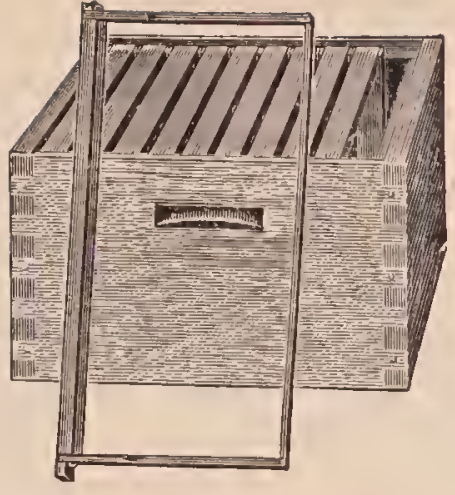

Fig. 1. Ten-frame Standard hivebody or brood-chamber.

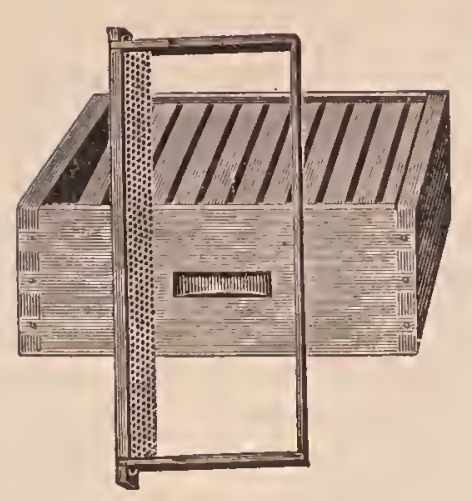

Fig. 2. Ten-frame shallow extract- Fig. 3. Jumbo deep hive-body or ing super.

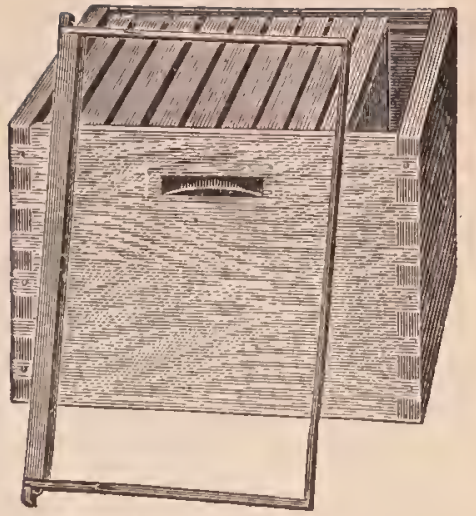

brood-chamber. ment. A hot knife especially will slide thru readily, and the surplus wax always brings a good price. Wide spacing, therefore, makes it possible to produce both extracted honey and wax.

At this point the beginner should be cautioned against spacing frames containing full sheets of foundation $15 / 8$ or $13 / 4$ inches from center to center. Unless they are spaced the regulation distance of $1 \frac{3}{8}$ while the foundation is being drawn out, intermediate pieces of comb will be built in between, making a bad mess of the whole. After the foundation is once drawn out the combs can be spaced wide as before mentioned.

PUTTING ON SUPERS AT OPENING OF-FLOW.

Many make the fatal mistake of waiting until the last minute before purchasing' their supplies. It is folly to go to the expense and trouble of establishing an apiary, and then, when the time arrives to reap the reward of the labor, to lose it all simply because the goods have not come. Long before the harvest opens, the supers should be put together and painted, the frames nailed up, supplied with full sheets of foundation, etc. If the deep frames of Langstroth dimensions are used, they should be well wired to prevent comb breakage in the extractor; but with the shallow frames the wires, while not so necessary, are essential.

It will be assumed that the colonies are in good condition for the honey flow, and the supplies all in readiness. The next thing is to put a super on each of the colonies not already supplied with a. second story, and even on those if they seem crowded for room. Yet the supers should not be put on before the bees are ready for them, as nothing is gained, and it is harder for the bees to keep up the necessary heat, especially in cold climates. On the other hand, the putting-on of supers must not be delayed too long, for thus time would be wasted, and the bees on account of the crowded condition would probably start preparations for swarming. This should be avoided, since much swarming is bound to cut down the honey crop.

Many beekeepers are so situated that they can not visit their yards just when the supers should be put on the hives. It does no harm to put them on a week or ten days ahead of time, altho, of course, it would be better not to give room too soon. Where the yard is located at home, one would not have to give room until just about as the honey flow starts. This may be determined by the way the bees are flying in at the entrance (see DiagnosING Colonies) and by the appearance of the combs. If on opening up the hive little spurs of new wax are being built along the upper edges of the combs, the supers should be put on. The beginner, however, should be cautioned that it is better to give the bees extra room early rather than too late. In the latter event the bees might be started to building swarm-cells. By giving supers a few days ahead of time he will be more apt to avoid having the bees make preparations for swarming.

If the season has been early, and the bees have been able to build up rapidly, it may be advisable to put on extra supers a couple of weeks ahead of time in order to give room. After the honey flow starts it may be necessary to put on one more super and place a queen-excluder between 
the upper and lower stories, putting the queen below. See Demaree Plan under the head of Swarming.

There are some who claim that it is not necessary to use queen-excluding honeyboards between brood-chambers and super's; but the author advises that, whether the brood-chamber is one story or two stories, it be separated from the supers above by a queen-excluder, for otherwise the queen is likely to go up into the extracting-combs, and, instead of nice white honeycomb, there will be a mixture of brood in all stages, pollen, drone, and possibly queen-cells. By special management the queen may be kept out of the supers after the flow begins, even tho no excluders are used; but ninety-nine out of one hundred who attempt this will fail. It is not necessary to state that honey extracted from combs containing unsealed brood is not as nice for table use. Furthermore, the queen, if allowed in the supers, will be in a most

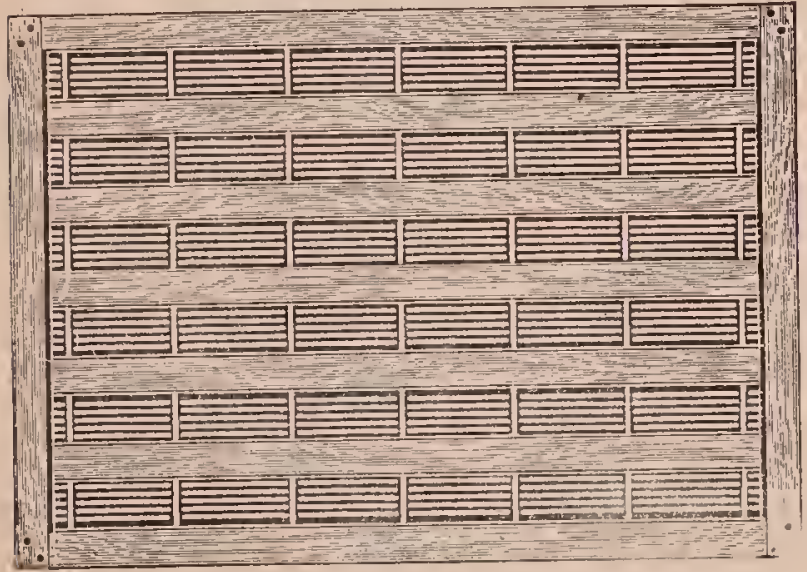

Fig. 4. Seven-wire and wood queen-excluding honey-board.

dangerous position, and every time the extracting-combs are handled will stand a chance of being killed. It is also a very difficult matter to find a queen if no excluder is used, for there would be so many more combs to look over. This would also be true in reference to the finding of queen-cells at swarming time.

One of the greatest objections to the non-use of the queen-excluders is that it is impossible to remove bees from a super by means of a bee-escape, if the super contains brood. It is plain to see, that, if there is any brood in the supers, the bees will not desert it and go down below. On one occasion, when in the height of extracting, a queen and her attendants were placidly located on a large comb of honey, apparently taking in the situation. The colony had had no queen-excluder over the brood-chamber and the queen was in the super when the escape was put on. It was next to impossible to tell to what hive she belonged, and the whole proceeding meant extra work and worry that would have paid for many excluders.

The objection that used to be made by some to the use of queen-excluders was that they obstructed the passage of the bees into the supers, but with the new wood-wire construction this is entirely obviated.

As soon as the first super is filled and the process of sealing has begun, remove it, put an empty one in its place, and over it put the nearly completed one. The colony will then be occupying a hive of three stories, in case full-depth supers are used, or approximately two stories, if the shallow supers are used. Put the empty super nearest the brood-nest, as the bees start to work in it more readily; and, as it is nearer, they have a shorter distance to travel. After the first extracting the empty combs can be put back again and it will be found that the filling and sealing are done much more rapidly the second time, as the combs are already drawn out and the bees do not have to waste any time in combbuilding.

Mention has been made of the advisability of spacing the combs further apart in the supers than in the brood-chambers, on account of the greater ease in uncapping the thick comb. Ordinarily, eight combs should be placed in a ten-comb super, the space between being regulated so that it is just the same. If this is not done, a part of the combs will be no thicker than ordinary brood-combs while others will be entirely too thick, or else the bees may possibly build natural combs in between the frames. Let no one get the idea that, in order to space frames further apart, non-spacing frames should be used, for the regular Hoffman frame is the best under all conditions. The point is that it is very important to have uniform equipment. It does not pay to have special frames for extracting, for in the fall and in the spring it is desirable to have such frames spaced the regulation distance 
apart. Moreover, it is frequently an advantage to use extracting combs in the brood-chamber. The self-spacing feature costs very little extra, does not, interfere

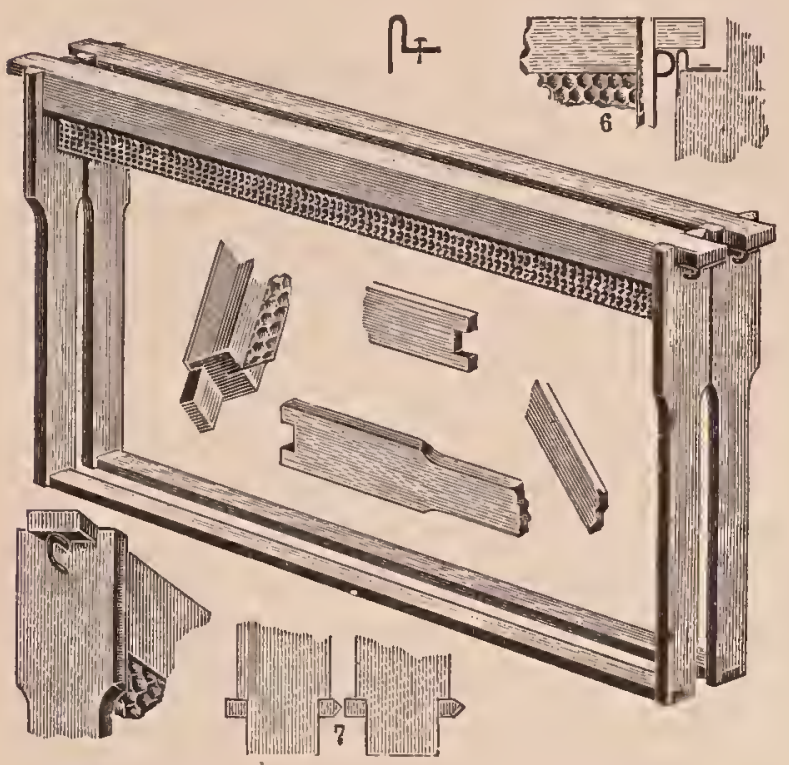

Fig. 5. Hoffman frames, regular.

in any way with spacing the combs farther apart during the extracting season, and makes possible standard uniform equipment. In localities where propolis is very plentiful, the metal-spaced Hoffman frame is desirable, altho it requires a little more care in uncapping the metal-spaced frame

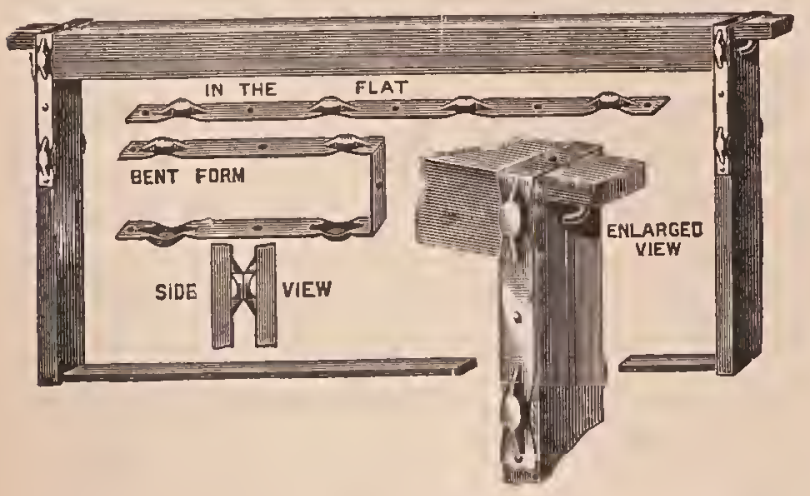

Fig. 6. Hoffman frames, metal-spaced pattern.

to avoid dulling the uncapping-knife. The regular Hoffman frame, then, should be usually used in the super, altho the metalspaced type is always better in the broodchamber where propolis is plentiful.

\section{THE CONTROL OF SWARMING.}

The extracted-honey producer does not have as much trouble preventing swarms as does the comb-honey man, since there is no objection to giving plenty of room as fast as the bees need it, and perhaps a little faster. In some localities bees swarm before and in others during the honey flow, and in a few localities they swarm after the flow is almost over; but in any case, swarming is a hindrance to the best results in honey. production. The bees should be working with concentrated energy in one hive. If divided into half a dozen diminutive swarms, they are generally of no use to themselves or to the beekeeper, so far as the production of honey is concerned.

When artificial swarms are made to anticipate the issuing of natural swarms in producing extracted honey, it is not necessary to set the parent hive at one side, as in comb-honey production (see COMB Honey, to Produce); but the parent colony and the swarm may both be left in the same hive, the swarm being in the new brood-chamber and the parent hive (having all queen-cells destroyed) being placed above the supers. A queen-excluder used over the lower brood-chamber prevents the queen from going back to the combs of brood now above the supers. This plan is a variation of the Demaree plan in which the chamber çontaining the brood is placed directly above the queen-excluder, the supers being placed on top. See Demaree Plan under Swarming.

Placing the brood above the supers in this way separates the old brood-chamber from the new one more completely, which probably reduces the chances of a swarm issuing if a young queen should emerge in the old brood-chamber. In fact, some beekeepers who use this method do not find it necessary again to destroy the queen-cells that may be built in the old brood-chamber after it is put above the supers provided there are at least two full-depth extracting supers between the new brood-chamber at the bottom of the hive and the old broodchamber now at the top of the hive. In addition to this, placing the supers directly above the new brood-chamber" usually results in the bees working in them better than when they are more remote.

When artificial swarms are made in tlis way the new brood-chamber may be filled either with empty combs or frames containing full sheets of foundation, together with one empty comb. This plan for swarmcontrol is used by many successful producers of extracted honey, being especially 
adapted to conditions usually prevalent in the clover region.

A condition similar to this can be brought about with but little labor in all colonies, whether they are preparing to swarm or not, by the following plan: If the bees are wintered in single stories, add a second story of empty combs, preferably dark combs in which brood has been reared previously, adding this second story early, before the colonies become crowded, permitting the queen to have a free range thru both stories. At the beginning of the honey flow add another extracting super as soon as needed. Under these conditions the queen usually abandons the lower broodchamber, working chiefly in the second story.

About a week after the beginning of the honey flow or after the queen has abandoned the lower brood-chamber longe enough so that the brood in this chamber has all been sealed, put the queen into the lower brood-chamber, confining her there by means of a queen-excluder; add another super of empty extracting combs, if needed; and, finally, put the brood-chamber, which was formerly the second story and which now contains most of the brood, on top of the supers.

The bees are now compelled to establish their brood-nest anew in the lower broodchamber, which at this time usually contains some sealed brood and much pollen. They are usually rather slow in preparing cells for the queen, and the new brood-nest is not expanded rapidly.

While one might think at first that confining the queen to a single story after she has had a free range of the hive would increase the tendency to swarm, it will be seen that colonies treated in this way are in a condition similar to colonies that are hived on a set of empty or nearly empty combs. Apparently the re-establishment of the brood-nest in these combs, which have been abandoned for brood-rearing, is just as effective as tho these combs had been brought from the shop or honey-house instead of being a part of the hive at the time of the manipulation. If the honey flow is short, colonies treated in this way usually go thru the season without attempting to swarm, but they may do so if the honey flow is of long duration.
David Running, Filion, Mich., gives a second story early, then later puts the queen below an excluder, as outlined above. About ten days later he shakes the bees of the lower brood-chamber, together with the queen, into a new brood-chamber filled with frames of foundation and one empty comb or a full set of empty combs, and puts the brood from which the bees have just been shaken on top of the supers, thus combining the two methods given above, to insure that no swarms shall issue during a prolonged honey flow.

\section{WHEN TO PEMOVE HONEY FROM HIVES.}

It will be assumed again that the colonies were in good condition for the flow, that swarming was kept well under control, and that the supering. was done judiciously so that now the attention may be turned to extracting. It is well to look over all the upper stories and mark those which contain sealed honey. Beekeepers, especially beginners, often like to rush matters and extract honey that is unsealed. This is one of the worst moves possible.

Honey should never be extracted until it is thick and well ripened. As soon as the bees consider it just right they begin capping it over. During hot weather, therefore, combs at least three-fourths capped would probably be completely sealed in a few hours if left on the hive, and may, therefore, be safely extracted. But if honey is extracted before the bees have ripened it, it will be thin and of unpleasant flavor, and, after being kept for a time, fermentation will doubtless result. If such honey is sold, it will in all probability cause the loss of reputation with the wholesale honey-dealers, as well as with the local trade.

It is not always necessary to wait until the end of the flow before extracting, as it is sometimes advantageous to extract, before the end of the flow, all ripe honeythat is, all honey that is sealed, as at that time there is no robbing to contend with since the bees are busy, and the combs extracted will be ready for putting on again and getting refilled. As long as the honey flow lasts, only that which is well sealed should be extracted, the partly sealed combs being left until after the flow, in order to get the honey in the cells ripened as 
much as possible. It may be mentioned here that some large extracted-honey producers prefer to leave all honey on the hives as long as possible, claiming that by so doing they get a much thicker and better grade. This is a very good plan for localities where there is no dark honey flow soon after the light flow. Where dark honey comes in soon after the light, or where there is a mixture of honey, it is better to extract the combs as soon as they are sealed in order to keep the different kinds of honey by themselves as far as possible. When the flow is over, and all the honey is removed, the combs should be carefully sorted, all the unripe honey extracted by itself and used for feeding, or sold for manufacturing. purposes. Such honey should never be used for the table.

If the honey is extracted after it is sealed there will not be so large an amount taken from the hives at one time as if it had been extracted while still warm and uncapped, so that in the extractor it will be thrown out of the cells cleaner. On the other hand, if it is allowed to remain on the hives until the end of the flow, then removed, stacked up in the honeyhouse and extracted at a later date, it will be colder, and will consequently take more time to extract.

Moreover, if the supers are stacked up on the hives until the end of the flow it requires more extracting-combs, and more supers to hold them, than if the combs are extracted about as soon as sealed. However, it is the opinion of some of the largest producers that it actually pays to extract the honey all at one time after the honey flow, since at that time work is not so pressing, and more time can be given.

The employment of this plan may result in a somewhat smaller crop the first year because of the necessity of the bees drawing out so much foundation; but it should be remembered that the same combs may be used year after year, probably for the remainder of one's lifetime.

\section{HOW TO FREE THE COMBS FROII BEES.}

Since the invention of the ventilated escape-board and double bee-escape, it is not advisable for any one, whether beginner or expert, to free the combs of bees by means of the smoke, shake, and brush method, which is too slow and troublesome, and during a dearth it is quite certain to start robbing. However, since the great majority of extracted-honey producers used this method in the past, and many still use it, it will be discussed briefly.

When brushing bees from extractingcombs a serviceable brush is necessary. A

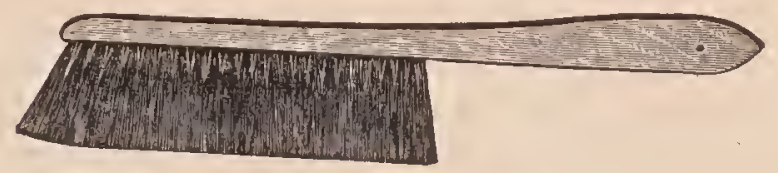

The bristle bee-brush.

makeshift is never economical. Either the bristle or the Coggshall brush answers every purpose, and, what is of prime importance, they may be washed when they become sticky with honey.

In case any disease is suspected the combs should never be brushed or sliaken, for if robbers gain access to the smallest drop of diseased honey, the disease would be certain to spread.

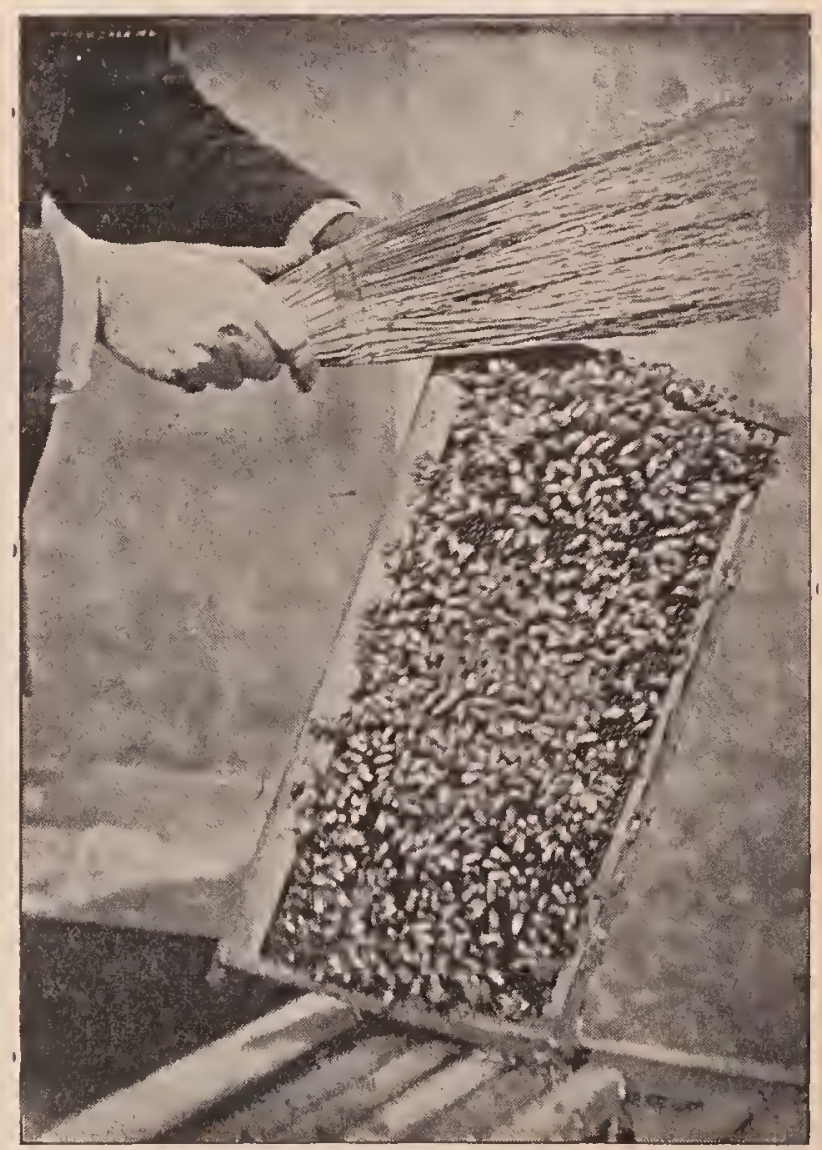

How to hold the Coggshall bee-brush.

There is no question but that it is easier to get the bees from shallow combs than from those of full depth. Smoke may be used in either case, altho better results fol- 
low from its use on the shallow combs, since there is more of a chance for the smoke to go down thru. Some follow the plan of giving a vigorous smoking, and raising the supers and blowing smoke thru between the combs to get out the last few bees. The combs then need but very little brushing to render them practically free.

If any comb should chance to have many bees on it, it is held by the top-bar or endbar as preferred, and given a sharp jarring shake so that the bees will be jarred off on the alighting-board in front of the hive. If they are shaken back into the super they collect on the other combs and have to be shaken again. After shaking, the few remaining bees are brushed off. When brushing, the combs are held in the left hand by the end of the top-bar, both sides being brushed without turning the frame. As fast as the combs are brushed they are placed in an empty super near by; and finally, when the combs are all out, the super just emptied should be taken to the next live to use in the same way. There is more or less objection to the use of smoke, one being that the bees are likely to uncap the honey to some extent, altho this is not so important in extracted-honey pro- duction as in comb-honey production. The greatest objection to the use of smoke is that it is quite slow, and uncertain in results, and, furthermore, the honey is sometimes tainted a little by the smoke, especially that which is sliced off with the cappings. On this account some prefer to use practically no smoke, depending almost entirely on brushes for getting the bees off, each comb being taken out by itself, both sides brushed quickly, and then set into the empty super waiting. A large feather is sometimes used; but feathers irritate the bees, and it is better in the long run to use a brush especially for the purpose. It is probable that a combination of both the smoke and the brushing is better than either one alone; but it must be remembered that all this work, if done during a time when no honey is coming in, must be carried on very rapidly, and the super and all the honey kept covered up every instant in order to be kept away from robber bees. When robbers once get to following the operator around the yard it becomes very troublesome indeed, and the best way is to work quickly and go from one place to another so rapidly that they do not get a chance to start.
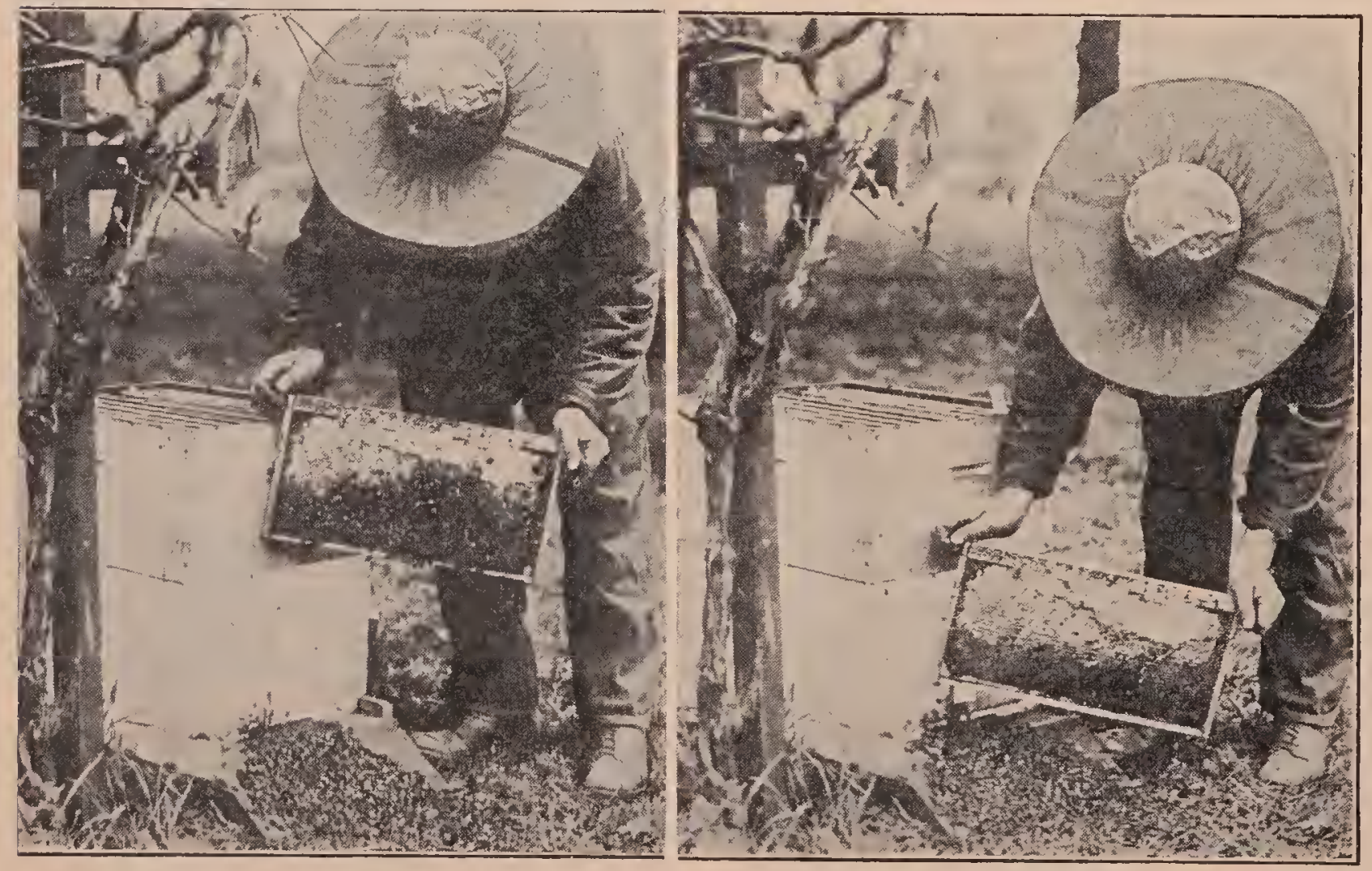

To shake bees from a comb. hold it as shown and give a sharp jerk. Most of the bees will be dislodged at the second or third jerk. It does not pay to try to shake off every bee. The few remaining
should be brushlied off. 
When so many combs are being shaken and brushed, the trouser legs should be tied around the ankles, or should be stuffed inside the stockings, since it is the nature of bees to crawl upward. The most con-

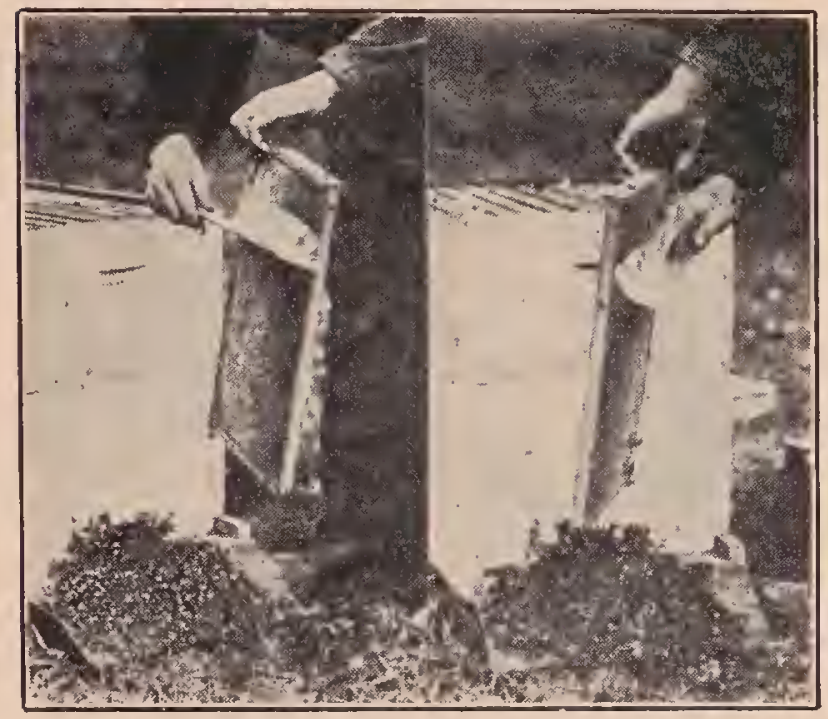

A goood way to brush bees from a comb. Both sides may be brushed without changing the position of the comb very much.

venient arrangement is a pair of bicycle pants-guards. Many beekeepers take the additional precaution of wearing fingerless gauntlet gloves in order to prevent the bees from crawling up the sleeves.

\section{THE USE OF BEE-ESCAPES.}

Of course by far the easiest and nicest way to free supers from bees is to use the Porter bee-escape, the use of which is explained under Comb Honey. The escapeboards, if placed under the supers in the

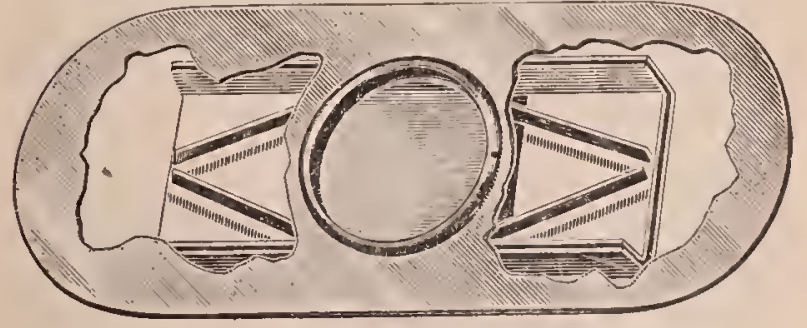

Porter double bee-escape.

afternoon, will almost entirely free the combs of bees the following day. Sometimes more time is required, but usually this is enough. The honey is then removed without knowledge of the bees; there is no danger of robbing, no stings, no loss of time, and no disturbance. There is not even any need of using a smoker. If the colony has two supers, and the upper one only is ready to come off, the escape should, of course, be put between the upper and lower super, so that the bees will not be prevented.from working in the super not yet finished.

In the production of comb honey the use of the bee-escape for r'emoving bees from the super is almost universal, and is rapidly becoming so in the case of extracted honey also. Formerly there were two objections to the escape. It was found that in the 24 or 48 hours required for the bees to pass down into the brood-chamber, the honey became cold, and therefore much harder to extract. The second objection was that the bees did not leave the extracting-combs quite as readily as they did the comb-honey sections on account of the fact, probably, that there are always some uncapped cells, and the bees are slow in leaving thru the escape on this account.

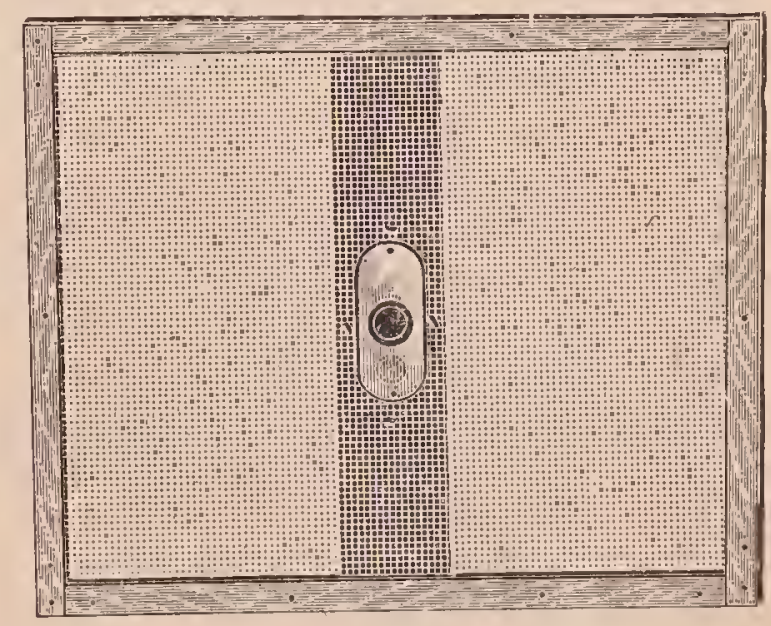

Hodgson rentilated bee-escape board.

The first objection has been largely orercome by the ventilated or screened escapeboard. As the name implies, the beeescape, instead of being placed in the center of a solid board, is put in the center of a screen, bound with a wooden frame. The warmth of the bees below rises and keeps the honey warm-almost as warm as tho the bees were on it, so that it extracts easily.

The second objection has been overcome by the use of the double bee-escape. If the combs are entirely capped over, the super may be taken off in the morning if the escapes are put on the day before.

The ventilated escape-board, which is the invention of Arthur Hodgson of Jarvis, Ontario, has brought the escape into gen- 
eral use among the producers of extracted lioney.

Another method for freeing supers of bees (the carbolized-cloth method) is used by a few beekeepers.

The beekeeper provides himself with five or six pieces of cotton cloth a little larger than the common super. These are soaked in a solution of one part of pure carbolic acid to nine parts of water. The surplus moisture is wrung out, and the damp cloth is laid directly on the super after the bees have been smoked somewhat. The hivecover, or other board, is then put on top to prevent the cloth from drying out too rapidly. When one hive is thus prepared the beekeeper goes to the next, and so on, until the cloths are all on. By that time the bees are practically out of the first super, and that cloth may be placed on another super, and so on.

This method works best on shallow extracting-supers, but is very effective on the deep supers.

If the crude carbolic acid is used, the odor is stronger, and there is a little more danger of tainting the honey. Unsealed honey, especially, takes on this odor easily. and for this reason the liquid used should not be too strong.

The advantage of the carbolized-cloth method over the others is that there is no danger of starting robbing, even if the honey flow is over, and the honey may be removed from the bees almost immediately while it still holds all the heat from the bees.

\section{TAKING THE COMBS TO THE EXTRACTOR.}

If combs are taken from the hives to the extractor at a time when no honey is coming in, care should be taken to keep them covered so that no bees may gain access. A little carelessness in this respect will make all kinds of trouble.

There are various methods in use for transporting the combs of honey from the hive to the extracting-room. In small apiaries the tin comb-buckets with a tightfitting cover holding half a dozen combs are very satisfactory.

Others use larger comb-carriers consisting of a full-sized super, with tin nailed on the bottom, a handle across the top, and a tight-fitting cover in two halves hinged together in the center.

Probably the majority of producers use a wheelbarrow witl a specially constructed

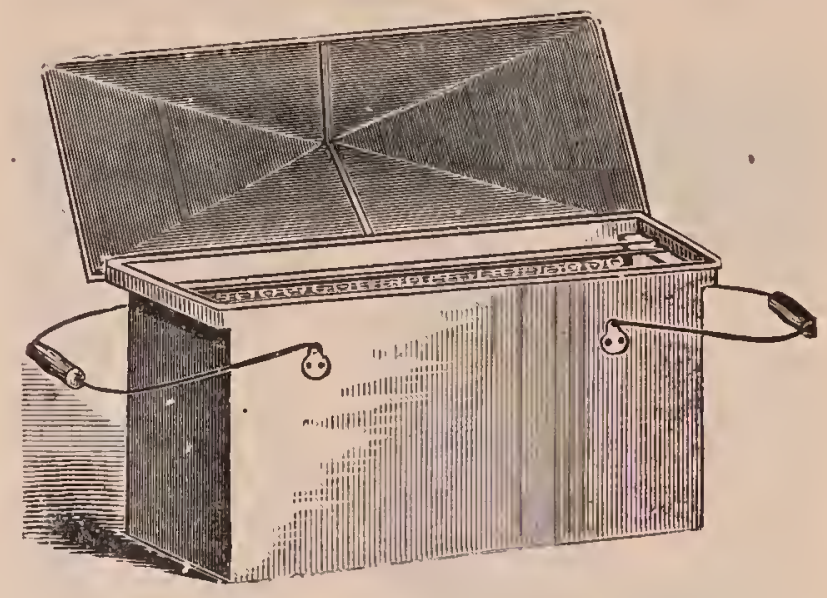

comb-bucket.

box or platform to liold sereral supers. Some apiaries are located where the ground is too rough for a wheelbarrow, but by a little work the rough places may be smoothed up enough to answer very well. Certain it is that it is easier to move several supers with a wheelbarrow than by any other plan.

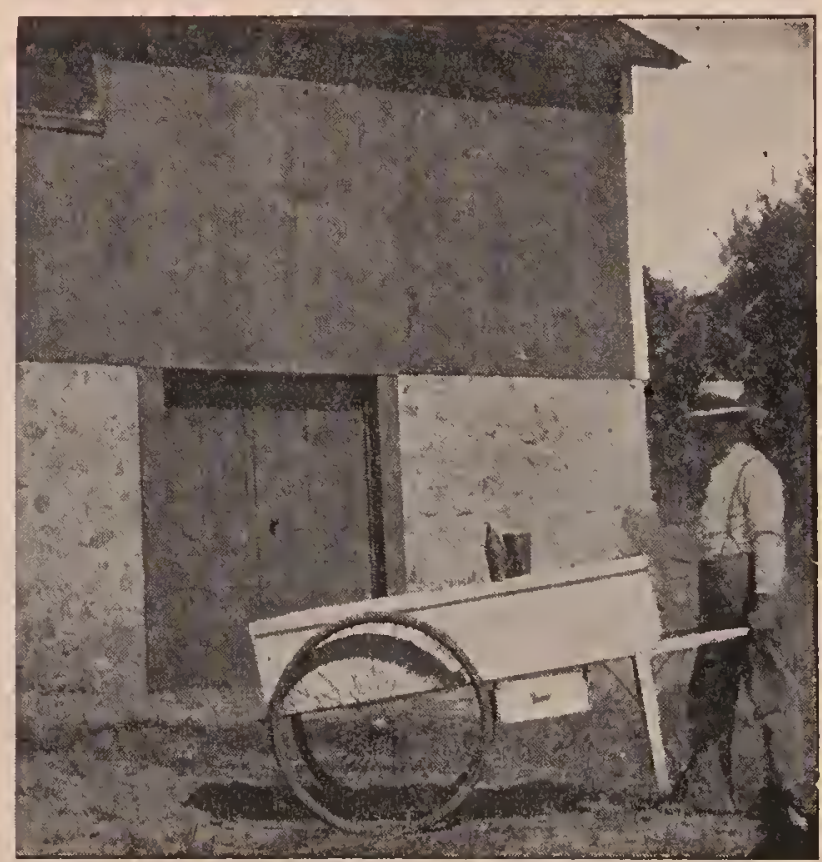

Mercer's cart.

Sometimes a cart having two large wheels can be handled easier on rough ground than a wheelbarrow. L. E. Mercer of California uses such a cart, equipped with pneumatic-tired wheels and a long box to receive the combs.

With either a wheelbarrow or a cart, it is adrisable to use a specially constructed box 
or platform, for by so doing almost double the ordinary load may be carried with but little additional exertion.

R. F. Holtermann of Canada lays a wooden track at eacl extracting-yard from the building down thru the hives.

A light four-wheeled truck is loaded up with eight or ten full supers and pushed along with little effort to the extractingroom where the supers are slipped thru an opening in the side of the building.

\section{EXTRACTING HOUSE.}

Any well-ventilated bee-tight building will answer for this purpose, altho it must be large enough to hold the necessary machinery, the supers of combs ready to ex-

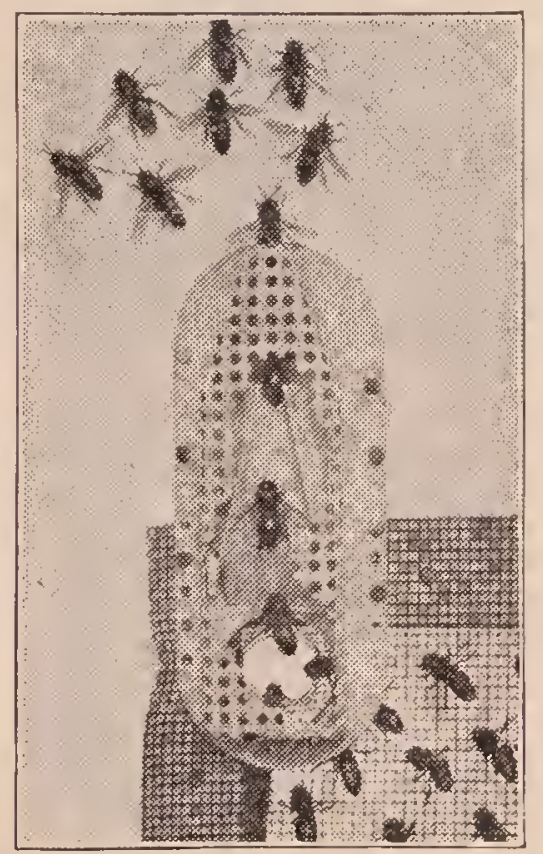

Escape in position on honey-house window.

iract, and in some instances the cans of honey that have been extracted, altho in most cases it is better to store the honey in some other place and not fill up the extracting-room in this way. The windows should be large, so as to admit plenty of light and air, and it would be better if they could be so arranged as to be removed entirely, wire-cloth sereens taking their place. On the outside of the upper corners of the windows, honey-house escapes, made on the same principle as the hive-escapes before mentioned, should be attached, so that any bees taken into the room on one of the combs will go at once to the windows and make their escape. The door, instead of being made of wire screens, should be solid wood, so that the bees will not be attracted to it and interfere with the operator going in and out. The bees attracted to the building, then, will ordinarily be flying around the open windows instead, leaving the door comparatively free from bees.

One who does not own a bee-tight building might do the extracting in any kind of open shed at night, but it is necessary to clean every thing up thoroly in the morning or else the bees will take possession and make considerable trouble the next day.

\section{EXTRACTING FOR A TWENTY OR THIRTY COLONY APIARY.}

For the beekeeper with 20 to 30 colonies a simple and practical outfit may be provided at small cost. A honey-house 8 by 12 would be quite large enough for extracting. For the work of extracting he will need a small two-frame extractor, and for convenience it should be made reversible so that the baskets may be swung àround to the other side to extract the other side of the combs. Two-frame automatic extractors are not recommended, as there is little if any advantage gained by their use, since the two baskets for the combs can be easily reversed by hand.

The extractor shonld be securely attached to a solid box firmly bolted to the floor, the box being of the right height for draw-

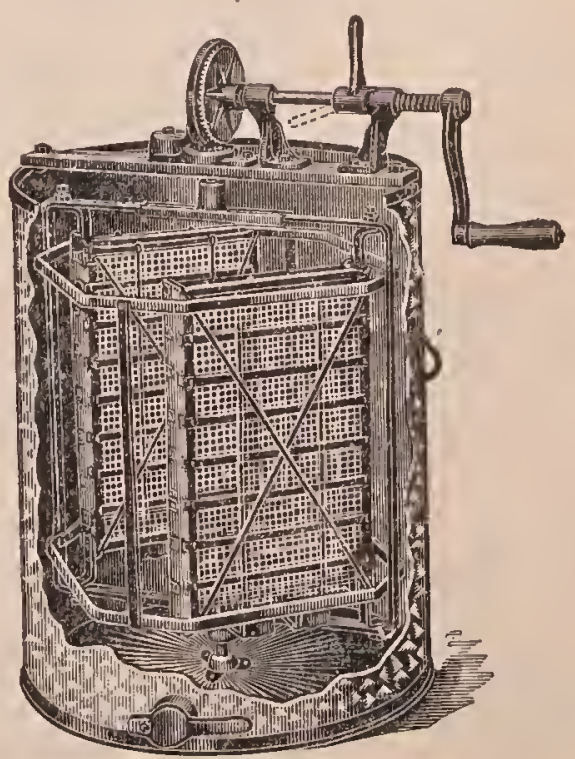

Two-frame reversible honey-extractor.

ing off the honey. The best location is near the wall, where there is less vibration when in operation, for continued vibration is apt to pull the can or box loose, especially if 
care is not taken to place combs of equal weight in the two sides of the extractor. For convenience in working, the extractor should be placed in one of the corners furthest from the door. Near this extractor, close to a window, where there will be plenty of light, should be placed the uncapping receptacle. It is handy to have it on the same side of the room as the extractor, so that the combs may be handy to the extractor as soon as uncapped. This uncapping-receptacle may be made of a barrel with botlı ends knocked out, and a coarse screen nailed over the bottom; across the top, about one-third of the distance from one side, a two-inch strip of lumber should be nailed. (Rather than nailing this strip to the barrel, some prefer to attach cleats to the under side of the strip, so that it may be movable.) At the middle of this strip a sharp-pointed nail projects upward, about an inch, to hold the frames while uncapping. The barrel itself should be supported in a tub into which the honey from the cappings falls, the barrel being sup-

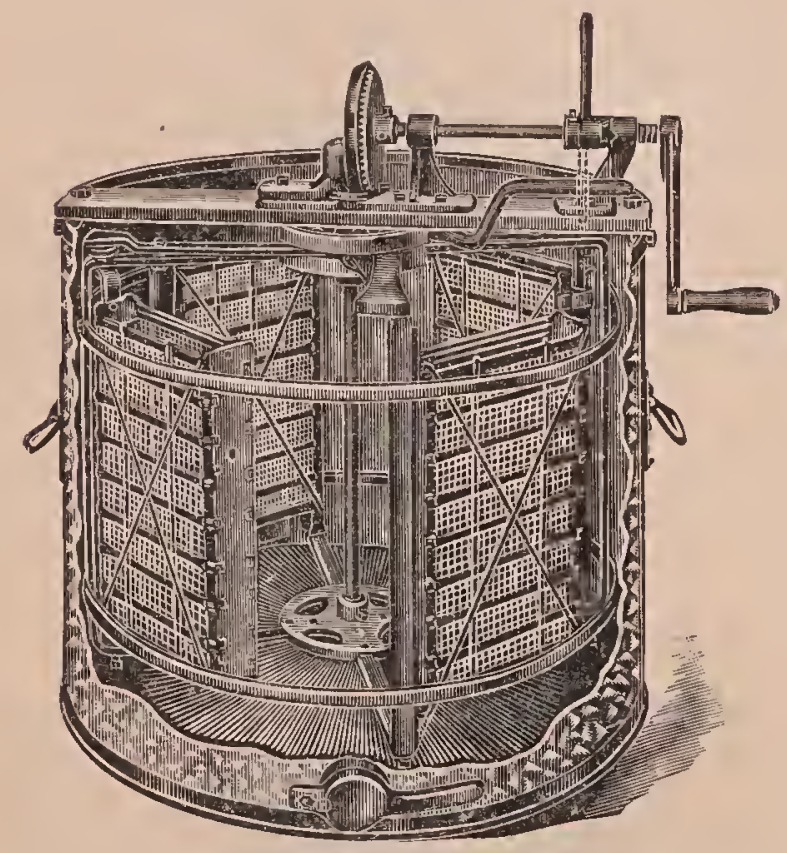

Root automatic four-fráme extractor.

ported by means of four hooks made of heavy wire. A simpler way of supporting the barrel is to nail, to the staves, at the right point, a couple of cleats just long enough to go across and rest on the edges of the tub. The cleats have the advantage that they furnish handles with which to lift the barrel.

A very much better uncapping-outfit is the Root machine that is supplied by prac- tically all dealers. It consists of a can 21 inches in diameter and 30 inches deep. Inside there is a removable perforated-metal basket that extends down to about half the

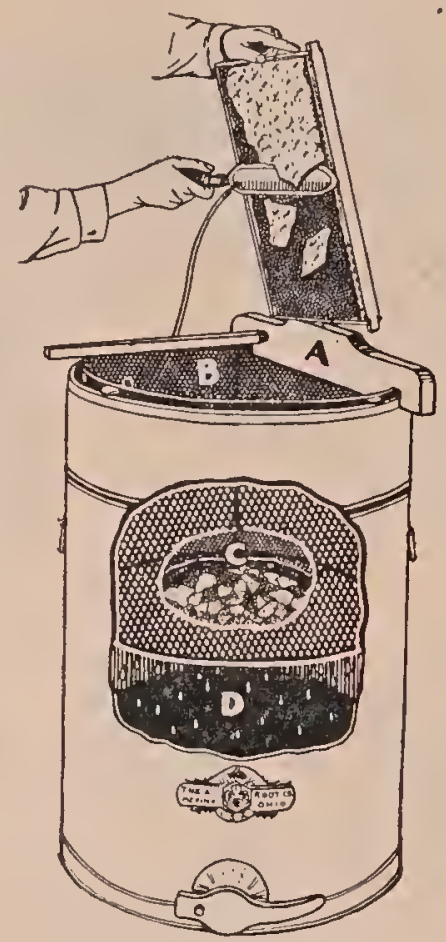

Root uncapping can.

depth of the can, leaving storage for 20 gallons of honey. It is an inch smaller in diameter than the outer can so that the flow of loney may ooze from the cappings as fast as they accumulate from the sides of the basket as well as from the bottom. This basket will hold a day's uncapping; and as soon as it is filled an extra basket can be used, so that the work can go on uninterruptedly. The filled baskets can be placed in an ordinary tub to drain still further. When the cappings have stopped draining they can be melted up or transferred to a common barrel to be melted later.

The straining-can may be placed wherever convenient, but should not be too far from the extractor, as this would involve extra labor when lifting pails of honey from the extractor-gate to the strainingcan. In this can or barrel is suspended a large wet cheese-cloth bag attached to a barrel hoop supported by the top of the can. Too much honey should not be drawn from this can. There should always be enough honey left to cover the strainer; for if the honey gets low the cappings and bits of wax that would otherwise float on the surface of the liquid will collect on the strainer and soon clog it. 


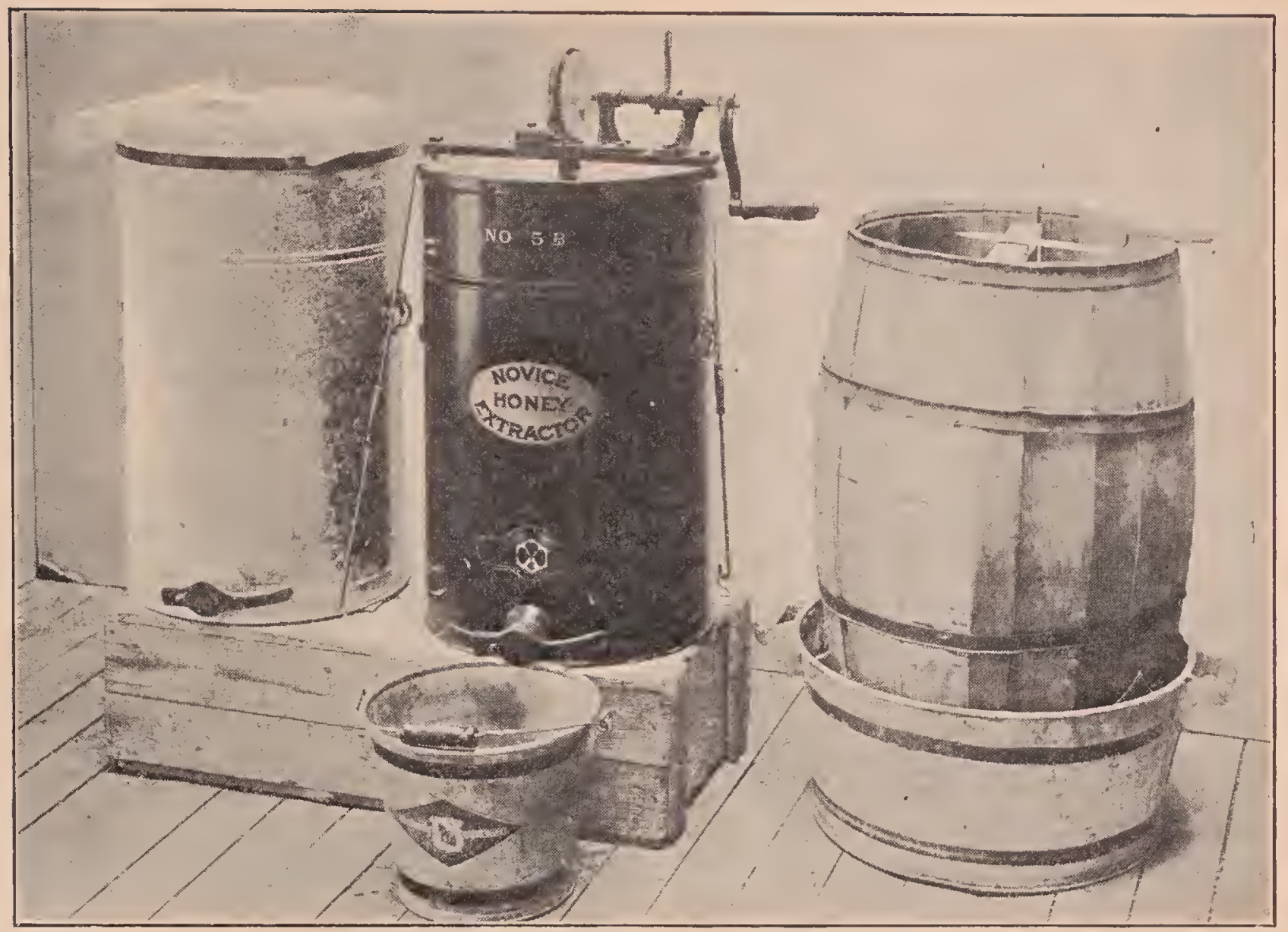

A practical extracting outfit for the beginner. The barrel with loth lieads knocked out and a coarse screen nailed to the bottom makes a very good uncapping-can when supported over a tub. A leaky barrel is all the better. Instead of a screen a large number of holes may be bored in the bottom and sides; then when one barrel is full it may be replaced by another. A large cheese cloth bag with a barrel-hoop nailed to the mouth, and supported in a can, makes an efficient strainer that fills all requirements. The honey is not supposed to be drawn off until the straining-can is full. Bits of cappings and other impurities will thus float to the surface instead of gathering in the cloth and filling it up. Of course a good tight barrel will answer just as well as a metal call, provided it has a faucet or gate at tlie bottom.

The knives used in slicing off the cappings must be especially made. Largesized butcher-knives may be used; but, ordinarily, these do not give good results. See use of Pingham knife, page 332.

The supers of combs to be extracterl should be placed within easy reach of the uncapping-receptacle. Then one at a time

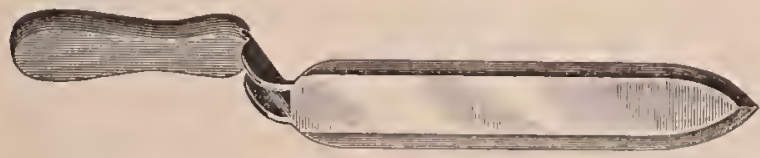

Root improved uncapping knife.

the combs are removed and held with the top-bar away from the manipulator, and the end-bar resting on the nailpoint of the cross-bar. Holding the upper end of the frame with the left hand, and tilting the upper end slightly to the right so that the cappings may fall freely, begin at the lower end of the comb and with an ordi- nary uncapping-knife (dipped in hot watel if desired) cut the cappings from the entire right side of the comb, performing the operation with a kind of sawing motion. If the comb contains any depres-

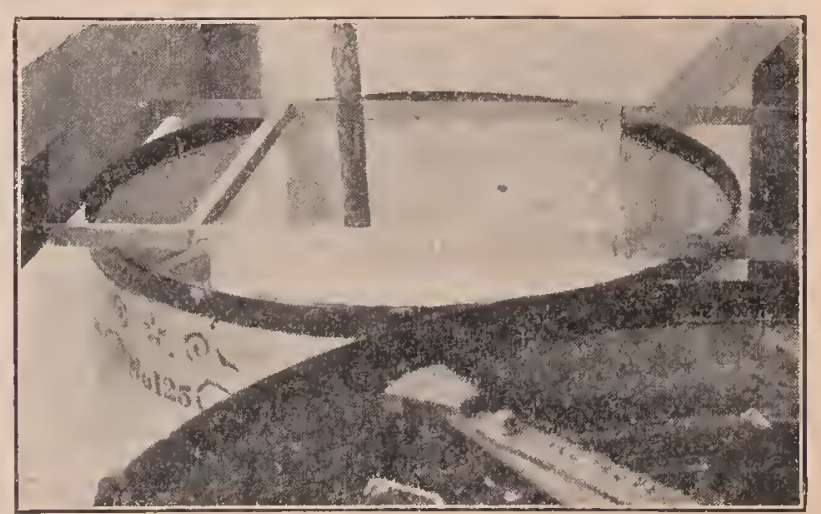

Gravity method of clarifying. A large cheesecloth bag is supported in the tank. No honey is drawn off into cans until the tank is full, and then no faster thnn it is poured in. All bits of cappings float to the surface of the bag, hence the cheese cloth does not clog up. A heavy wire hoop in the bottom of the bag orercomes any tendency of the cloth to float. The honey is drawn off into cans. 
s.ons the heel of the knife should be used. Then reverse the comb, still keeping the top-bar away from you, and slice a thin layer also from the other side, using the cross-piece to scrape off any capping's that may adhere to the knife.

The uncapped combs may next be placed one in each basket of the extractor, the top-bar being placed next to the hinge. It is quite important to use combs of about the same weight opposite each other in the extractor, for if not perfectly balanced the extractor will run unsteadily and become loosened from its support. In a two-frame extractor this is especially necessary. In the four-frame and larger sizes one need not be so particular. In case of old dark combs whose cell walls are strengthèned by many layers of cocoons, there will be but little danger of the combs breaking. When new combs are extracted-those in which brood has never been raised-greater care will be necessary to prevent the combs from breaking out of the frames. Such combs should be extracted until about half of the honey is out of the cells of the first side. The combs should next be reversed and the opposite side entirely extracted, and then the remainder of the honey taken from the first side.

The gate of the extractor should be kept closed until the honey comes almost up to the reel in the extractor; then, when the gate is opened the pail will fill quickly, and almost no time lost. Leaving the gate of the extractor open, so that the honey may run into the pail, as fast as it is extracted, is bad practice; for sooner or later one will let the pail run over on to the floor. After drawing the honey into the pail, from the faucet, it is then emptied into the straining tank, from which it is run into 60 -pound cans, or other receptacles in which it is to be stored.

As fast as the combs are extracted they may be again placed in the supers and stacked up in the honey-house. Along toward night these may be piled five or six on each hive, over a queen-excluder, leaving the bees to clean out the honey still adhering.

The best place for keeping honey is in a dry room of even temperature-about 70 to 100 degrees Fahrenheit.

Honey should be stored in tin cans, and never in large tanks and left to candy, as it would be exceedingly difficult to remove it for bottling.

\section{EXTRACTING APPARATUS AND METHODS OF LARGE PRODUCERS.}

The apparatus and methods of the large producers differ from those of the small producers to such an extent that. it seems well to enter into a detailed description of extracting on a larger scale. See ExTRACTORS.

POTER-DRIVEN HONEY-EXTRACTORS.

A few years ago a power-driven extractor was a curiosity, only one or two such outfits being in use. Large extractors driven by gasoline engines have now become very common. Where access can be had to electric current, electric motors are also used, and in some localities water motors. However, on account of the fact that extracting plants are usually in isolated places the gasoline engine is by far the most common source of power. The engines have been perfected to such a point that they are very reliable and efficient. Twenty years ago it took an expert to start a gasoline engine, and sometimes another one to keep it running. Refinements in design brought about by experience of designers of automobile engines have rendered the farm gasoline engine a really practicable and reliable source of power. There are a number of makes of very good engines that can be bought for a very low price; and since a 11/2-horse-power engine driving the largest extractor would not consume more than two or three quarts of gasoline a day, it can be seen that such machines are very economical.

While a $1 \frac{1}{2}$-horse-power engine is ample to drive an eight-frame extractor, there are times. especially if the honey is cold, that a $1 \frac{1}{2}$-horse-power engine is taxed to the limit. For this reason, and also because it is easier to keep a little larger engine running steadily without attention, it is sometimes advisable to use a two or eren a three horse-power.

The method of transmitting the power of the engine to the extractor is shown in the accompanying illustrations.

In view of the fact that it is not practicable to stop and start the gasoline engine 
every time the combs are put in and taken out of the extractor, a friction-drive is employed with means for engaging the power, so that the extractor can be stopped and started. In fact, any speed desired is obtained simply by the movement of a cam lever on the horizontal shafít of the extractor. The engine and the horizontal shaft of the extractor run all the time, the reel being started as the metal dise on the horizontal shaft is moved into contact with the paper pulley on the vertical shaft of the reel.

When the small handle is in a horizontal position no pressure is exerted on the horizontal shaft, and the metal disc does not tonch the paper-rimmed pulley on the reel. As this lever is moved upward into a vertical position the cam gradually exerts a lateral pressure on the spring, which forces the dise into engagement with the before-mentioned paper-rimmed pulley. The reel starts smoothly without any jerk. In case of new fragile combs, when it is necessary to start very slowly at first so that the bulk of the honey will be thrown out before the reel catches full speed, the cam lever may be moved very slowly into its vertical position, or the adjustable collar, against which the spring pushes, may be set to the left--that is, toward the metal disc-so that the spring does not push against it so hard. The lever may then be thrown into its vertical position instantly, and yet the reel will start slowly and pick up speed gradually, not reaching full speed until the bulk of the honey is thrown out.

Where the honey is very thick and the combs are new and not strengthened, therefore, by layers of cocoon always found in the cells of combs used for brood-rearing, it is often necessary to start the extractor slowly and let it run a few revolutions until perhaps two-thirds of the honey is thrown out of the first side of the comb: then reverse, and extract all of the honey from the other side of the comb, finally reversing back again to the first side and extracting the rest of the honey there. This plan does away with the danger of comb breakage. Under such conditions requiring great care it can be seen that if all the honey were extracted from the first side, which would necessitate running at full

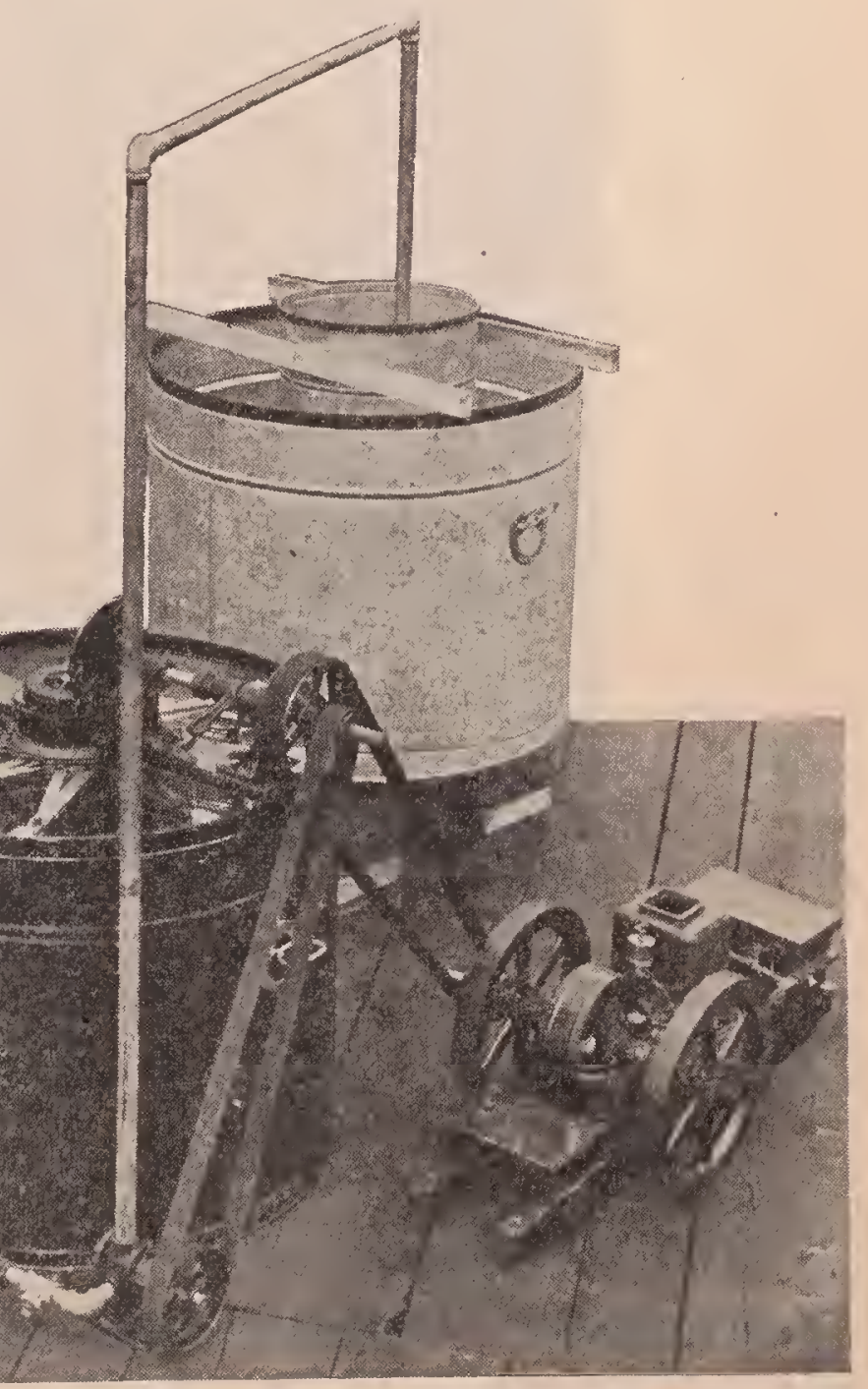

Ideal arrangement of extractor, pump, engine, tanks, ete. 
speed, the entire amount of honey on the other side would probably crack the comb. On the other hand, if the combs have been used for brood-rearing for a time before they are put into use for extracted honey, they are greatly strengthened by the fibrous cocoons. With such combs, and especially if the extracting is done in hot weather, when pact. For a central extracting plant the eight-frame Buckeye extractor. is the one to select, the latter sizes requiring power for turning, such as a gasoline engine, for they are too heavy to turn by hand except in an emergency. The large extractors have a great advantage over the small ones in that the combs can be

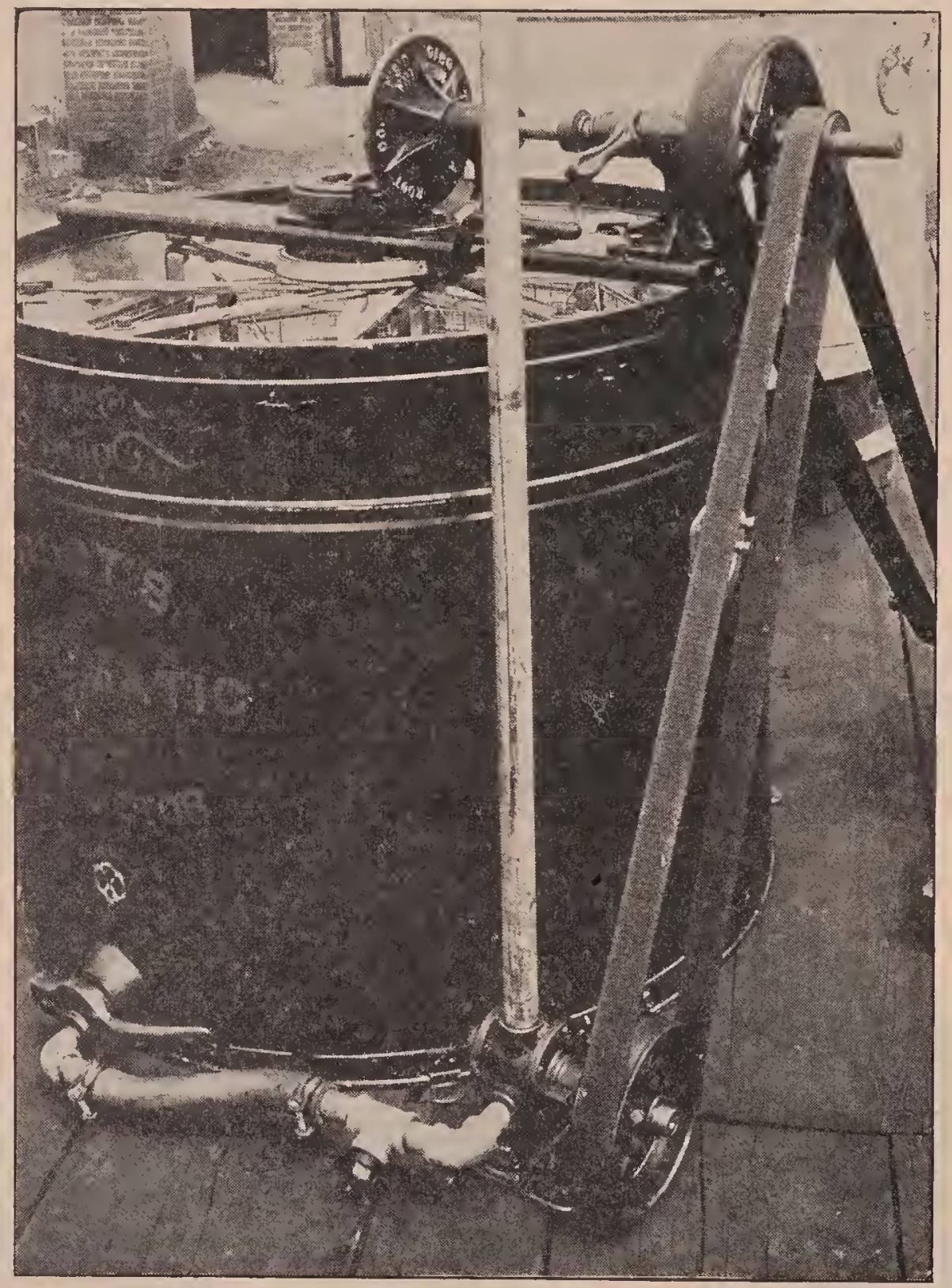

$A$ closer view of the pump, showing the construction, method of belting, arrangement of pipe and hose connections and manner of tapping into honey-gate.

the honey is not likely to be thick and waxy, it is not necessary to observe so much caution.

\section{CHOOSING AN EXTRACTOR FOR THE LARGER PRODUCER.}

For hauling from one outyard to another the four-frame reversible extractor is just the thing, for it is small and com- kept in motion so much longer. For instance, in the large size eight combs can be kept going until eight more have been uncapped; and, of course, this longer time than is practicable, say, with a fourframe machine, means that the combs are extracted just that much cleaner. Any honey left in the cells is wasted. 


\section{HONEY-PUMPS.}

Along with the adoption of power honey-extractors came the demand for pumps that would elevate the honey into tanks, for it is not always possible to build a honey-louse on a sidehill where the extractor can be located on one floor and the honey run by gravity into the tanks on a floor underneath. The earliest experiments with honey-pumps revealed the fact that very few water-pumps, even the rotary pumps, are suitable for pumping honey, for honey is very different in consistency from other liquids usually pumped. Howerer, pumps especially designed for honey are now obtainable, and they are perfectly satisfactory. Belted direct from the cross-shaft of the extractor they frame or other foreign material may be thrown from the pocket of the extractor into the extractor can and find its way to the pump. In case the pump were positively driven something would be sure to break. With a belt drive, the belt merely slips off. Then the pulley may be turned backward a few revolutions until the foreign material, whatever it is, is removed. Usually, if the pump is worked by hand, back and forth, the bit of wood may be broken up and work may proceed at once.

\section{THE LOCATION OF THE EQUIPMENT.}

When for any reason one does not wish to use a honey-pump, eut a hole in the floor underneath the gate of the extractor, making a pit into which a large pail may be

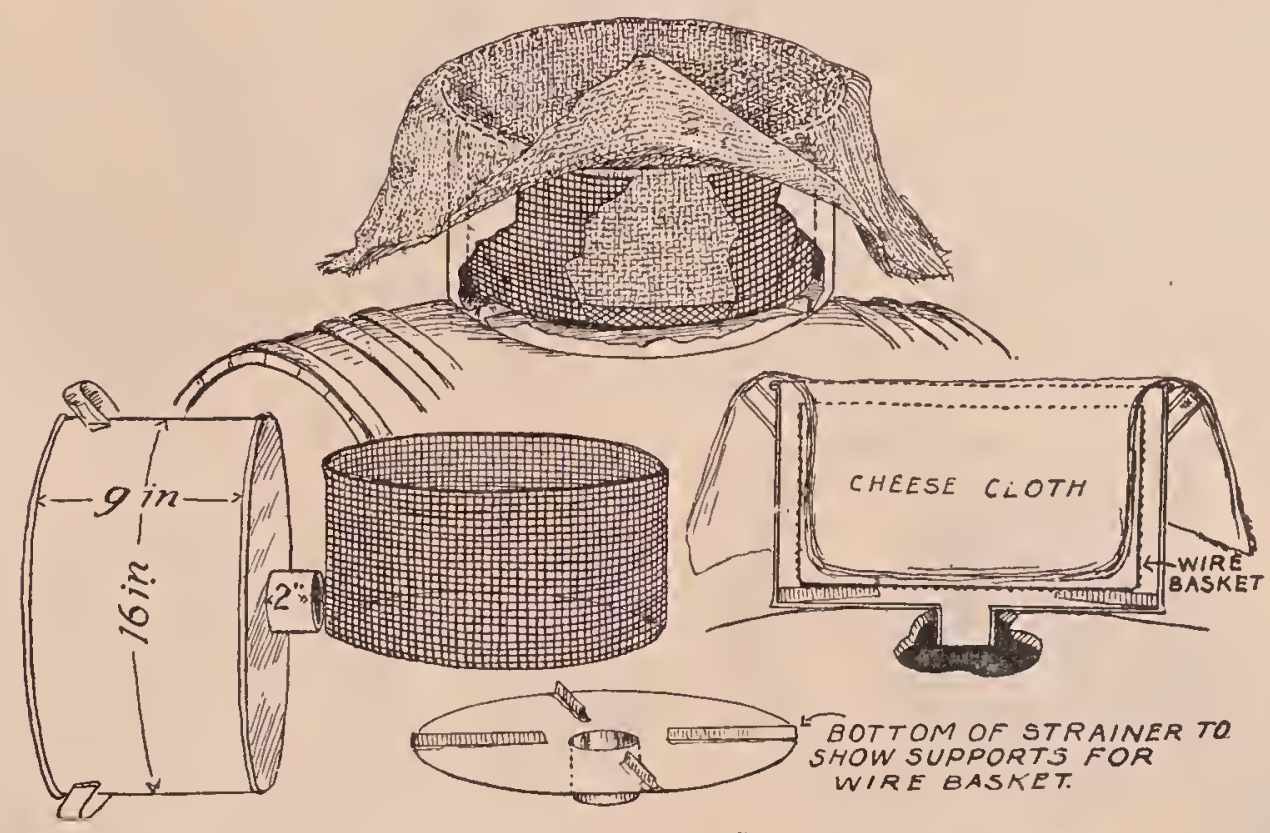

Pettit honey-strainer. (See page 337.)

run all the time that the engine is running. Consequently, the extractor can be kept empty, the honey being elevated to the tank as fast as extracted. It is not practicable, ordinarily, to elevate thick honey more than eight to ten feet.

The use of the honey-pump permits placing the extractor right on the floor where it may be firmly anchored, and where it is far more convenient than if elevated on a platform, even tho the platform be low.

Some have attempted to drive a honeypump by means of a chain. We do not regard this as advisable, for occasionally a bit of wood such as a broken corner of a set to catck the honey. This allows the extractor to stand on the solid floor. When the machine is set down on the floor it is much easier to get the combs in and out, and a great deal of time is saved. Of course, if there is a basement to the extracting-house or to some other building close by into which the honey can be run thru a pipe into a tank, so much the better.

As is pointed out under Burldings, for the larger producer there are great advantages in having the honey-house built on a sidehill where there are different floor levels. The simplest arrangement of all is to have the honey from the extractor run by 
gravity into the straining or settling tank, which must be, of course, in a lower room. Where this is impossible the honey-pump is a necessity for a complete equipment.

\section{UNCAPPING THE COMBS.}

In dry climates under certain conditions honey may. be ripe enough to extract when it is but half-capped over-that is, when only the upper half of the comb is capped; but under ordinary cireumstances it is nuch safer to wait until the combs are almost entirely sealed or capped, for the honey will be thicker and richer. See the discussion on this subject under ExTRACTED HONEY.

There are various sizes and shapes of knives used for eutting the cappings from the combs. Some begin at the top of the comb and eut down; while others, the majority, perhaps, begin at the bottom and cut upward. No definite rule can be laid down; for the way that might be the easiest for one operator might be the hardest for the next. Each producer should uncap with the kind of knife and stroke that seems the most natural. Some use a common butcher knife with a long blade. The very great majority of producers use a knife originally designed by T. F. Bingham.

The shank connecting the blade with the handle has a semi-cireular projection on each side, folded at a right angle, to afford a good grip for the thumb and forefinger. As the blade is on a different plane from the handle one can get a better hold and in a position to exert more leverage

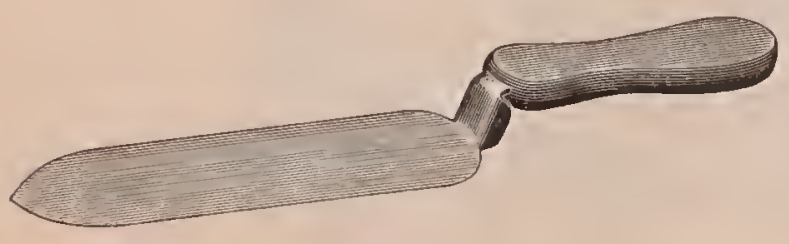

by grasping the shank itself with the thumb and forefinger, the rest of the fingers encircling the flat handle, as shown.

A right-handed operator, to uncap, should hold the frame with top-bar away from him and one end-bar resting on a nail-point sticking up about an inch from the center of a cleat nailed across the top of the receptacle to hold the cappings. The combs should be held by the left hand on the upper end-bar and top-bar. When the knife first starts cutting the cappings on the lower end of the comb, the frame should be held about vertical. As the knife is pushed upward toward the upper end-bar, the frame should be leaned to the right so

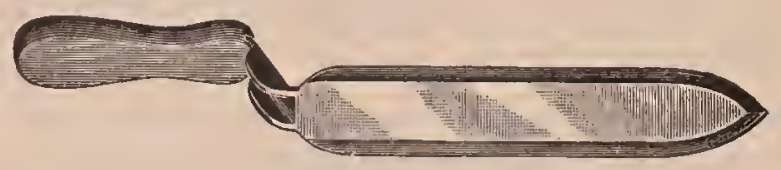

that the cappings as they are sliced from the comb may fall directly into the receptacle underneath as they drop from the knife. If the frame is held straight or leaning slightly to the left, a sheet of capping may slide back upon the comb and be held there by capillary attraction of the honey, and it requires extra time and fussing to scrape it off again.

After one side of the comb is uncapped, it may be swung around on the nail-point to expose the other side. Many prefer to turn the frame end for end rather than to swing it around in order to keep the topbar always to the outside, the idea being that, the end-bar being narrower, it is not so much in the way of the knife.

When uncapping one should not try to take off merely a very thin layer of capping, for it does no harm to uncap deep, since the wax and honey cut off are by no means wasted. A good rule is to uncap down to a level even with the side of the top-bar. Combs which have been used for brood-rearing are a little harder to uncap the first time, owing to the layers of cocoons; but when these have ance been shaved down even with the side of the topbar they are very easy to uncap on subsequent extractings. The cocoons toughen the comb so that it is not so easily crushed out of shape by the knife nor broken in the extractor.

The point of the knife should be started on the nearest lowest corner of the comb and pushed toward the top-bar until the cappings are cut from the end of the comb. Then the knife should be started toward the other end-bar by, a sawing motion. It is much easier to uncap bulged combs. Therefore, in a ten-frame super, for instance, it is not a good plan to put in the full ten combs. Eight combs equally spaced in an extracting, super contain the same 
amount of honey, or even more, and the comb, being bulged, ean be nutch more quiekly uncapped since there will be few depressions.

A cold knife must be kept very sharp, and there is need of constant scraping or washing to keep the wax from gumming up the sharp edge, thus interfering with the work. A dull cold knife or one that is badly gummed up and very dirty does not make a clean cut, but tends to crush the comb.

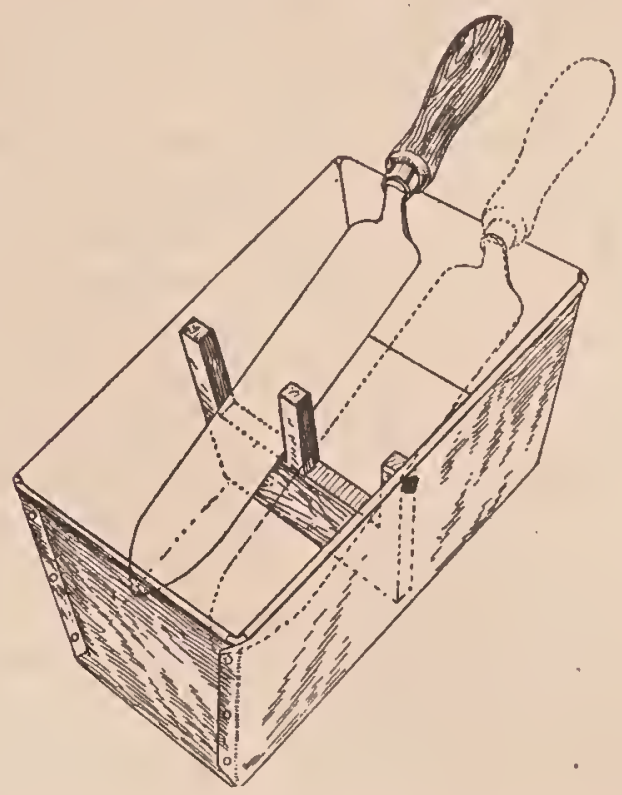

Because of the necessity for frequent cleaning and sharpening, an increasing number of producers prefer to work with a hot knife, and especially in case of thick honey there is no question but that a hot knife will do quicker and faster work with less strain on the wrist. When ordinary knives are used it is customary to have two of them, one to be left in hot water over a small stove, while the other is used to uncap both sides of a comb.

Where the honey is thick and cold sometimes a knife heated in hot water will be cooled off by the time it is half way thru the cappings of one side of the comb, so that it is little better than a cold knife. In fact, the wax has a tendency to gum up a warm blade even more rapidly than it does one that is entirely cold. The blade should be either hot or cold, therefore, and not lukewarm.

Because of the necessity of frequent changes in and out of the hot water a knife heated by steam, popularly called the steam uncapping-knife, has become very popular in the last few years.
A piece of non-rusting metal is soldered on top of the kmife-blade, and steam is introduced thru a tube near the shank of the knife, circulates over the blade, and blows

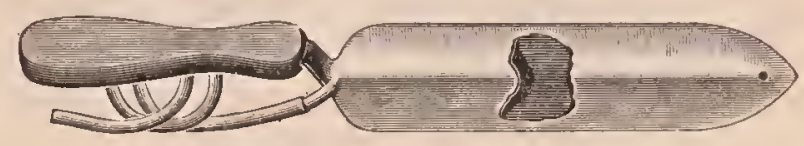

Steam-heated uncapping-knife.

out thru a small opening at the point. This knife keeps lot continuously, the wax melts off, and, consequently, there is no gumming up, nor delay necessitated by scraping and cleaning the edge of the blade. Tubing especially adapted for the purpose conveys the steam to the knife from a small boiler over a stove. Ordinary rubber tubing does not stand the action of the steam, while a specially constructed steam hose would be too stiff to be flexible.

A regular copper boiler or other can may be used for a boiler, if one takes the precaution of making a safety valve as shown in the next illustration. Any tinner can make such an arrangement with a

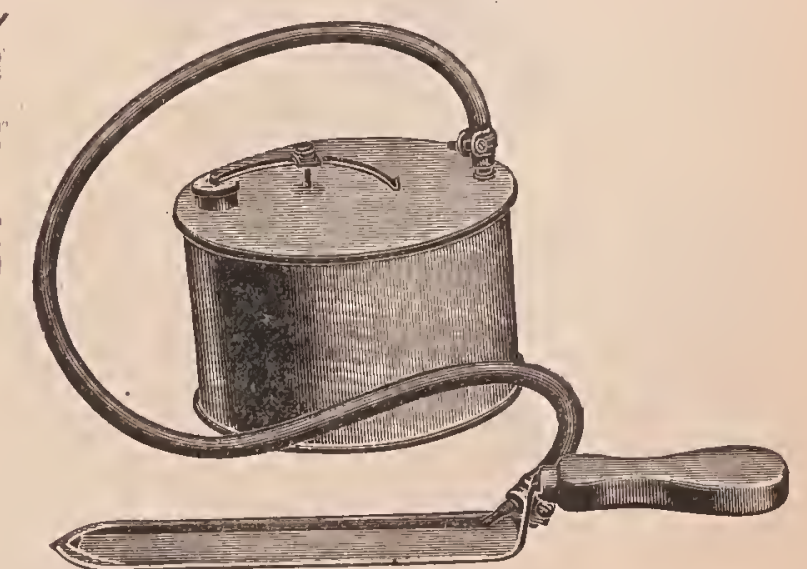

Steam honey-knife and boiler, showing construction of the safety valve, made of super spring at filter hole.

super spring and small tin cap, and it also furnishes a very convenient opening for filling the boiler.

\section{DISPOSING OF THE TVET CAPPINGS.}

When the cappings fall from the uncapping-knife they are saturated, of course, with honey. There are two different methods in use of separating the wax and the honey. The first embodies the principle of draining the cappings until practically all of the honey is separated; and the second, an entirely different principle, which contemplates melting the cappings as fast as 
they are sliced from the combs so that the melted wax and the honey by reason of their different weights separate at once, the wax floating on top of the honey. The devices which operate on the draining principle are usually called uncapping-boxes or cans, while those which melt the cappings are called capping-melters.

In any method of draining eappings it is very important to stir up the cappings frequently with a stick. This serves to break up the small particles of comb, which would otherwise hold the honey and prevent it from draining out freely. The efficiency of the draining method depends upon the thoroness with which the cappings are stirred and punched with a good heary stick.

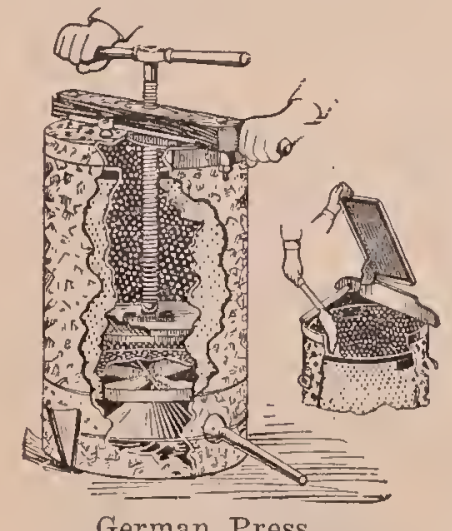

An uncapping-can which is provided with a plunger and schew, by means of which great pressure can be applied to the semi-dry cappings, is the German press.

A burlap sack is supposed to be hung in the can and held in place by the comb-rest, which has notches eut to fit the top of the can. When the bag is full the top is pinned together with nails, the comb-rest removed, and the cross-arm carrying the screw and plunger put in position. The plunger is run down slowly, the honey gradually being pressed out so the cappings are made nearly dry. The plunger and screw are removed; a circular cleated division-board put on top of the first bag of eappings; another empty sack put in, and the process repeated. At the end of the day the pressure may be applied to two or even three sacks of cappings and left on all night. In the morning the bags of practically dry cappings may be removed, and later on if desired the cans may be set over a stove, steam generated in the lower part, and the cappings melted into wax.

Several apiarists use for an uncappingbox a long square tank made of galvanized metal. It is six feet long, two feet high, and two feet wide.

The slatted framework at the bottom is made a little smaller than the can so that it may be easily removed for washing. There is only $1 \frac{1}{2}$ inches space under the cleats, so the gate at the end of the tank is left open all the time. In this way nearly all of the space inside the tank is arailable for the storage of cappings.

A tank of this size will hold all the cappings for one whole extracting of the average-sized yard. A short-handle fork is used for handling the cappings, and each

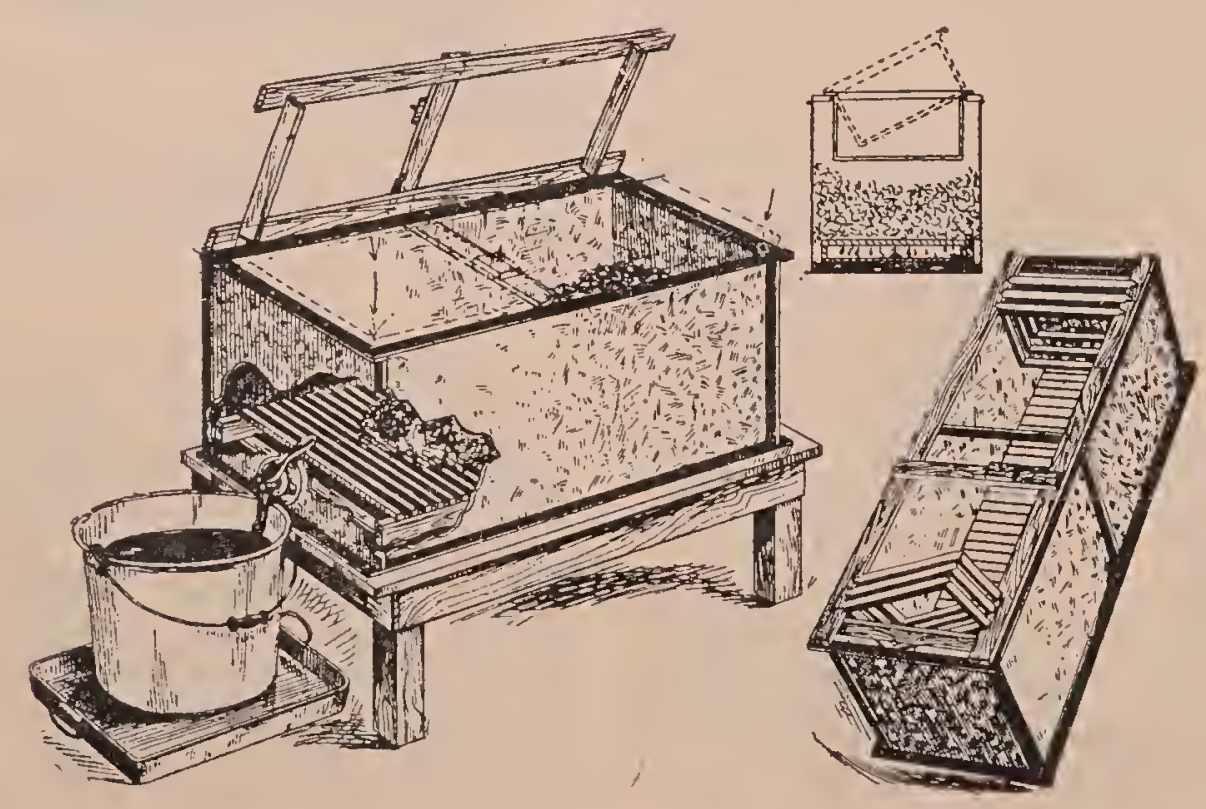

Townsend uncapping-box. 
day the accumulation from the day before is pitehed toward one end of the tank, and in this way the honey from the new cappings does not have to drain thru the dry ones again.

Still another plan, that has come into use recently, consists of a series of cleated trays. One tray is supported just high enough so that one end can rest on the top of a common wash-boiler to catch the honey. The cappings fall from the knife directly upon the tray, and are spread around occasionally. When the first tray holds all the cappings that can be put on without falling off, they are spread out somewhat and another tray put on top of it, and the process repeated. The weight of the two trays above presses the honey out of the cappings below. The longer the work continues, the greater the weight on the lower trays. Finally, the under trays may be removed, the dry cappings scraped off, and the trays used over again.

Each tray has a solid tin bottom, two sides and one end of which are turned up to prevent the honey from dripping off. The open end, which should be the lowest, is placed orer the wash-boiler. The cleats are evenly spaced and rigidly held by perforated metal nailed on top. When one tray is full and the next tray put on top, it should be so placed that the open end is perhaps a half-inch beyond the end of the tray beneath, so that the honey may drip directly into the boiler, and not on the end of the tray beneath.

The total outfit of trays is not very expensive, but this plan, of course, does not lend itself very well to a portable outfit.

\section{CAPPING-MELTERS.}

There is no plan of draining cappings which secures all of the honey. A small percentage is always left, for the process of draining cannot be kept up indefinitely, owing to the tendency of the honey to granulate. The cappings after several days, tho they may look hard and dry, really contain considerable honey, the exact amount depending upous the effreiency of the plan used. Of course, when these cappings are transferred to a solar wax-extractor the honey and wax are separated, but the honey is darkened and injured by the process.
To separate the honey and wax immediately so that everything can be cleaned up when the extracting is over, capping-melters have gradually come into use. It can not be denied that it is a great convenience to get rid of the cappings as fast as the work progresses, for it is hard work to handle eappings that are heavy with honey. When the day's work is finished, nothing is left but a layer of melted wax, which, after it has cooled over night, needs only scraping to be ready for market, the honey meanwhile being in shape to strain and empty into the main tank with the rest. Honey that has been taken from the capping-melter strains quickly because it is warm.

If the capping-melter is crowded too fast, or if one having a too limited capacity is used, it may clog up so that a quantity of the honey will be confined and thus subjected to the heat for a considerable length of time.' Under such circumstances it is likely to become darkened and scorched slightly in flavol. With a properly designed melter, however, or one that is large enough for the work on hand, there is scarcely any difference to be noted between the honey that has gone thru it and that which has been extracted from the combs in the regular way. It is true that if honey has been allowed to cool under the wax, it takes on a waxy flavor, which, while not disagreeable, is yet pronounced enough to enable one to distinguish it from the rest of the honey. On this account a separating can should be used to separate the honey from the hot wax as soon as possible.

There are some localities where honey in cappings candies very quickly-sometìnes in 24 or 48 hours, and under these conditions a capping-melter is almost a necessity. When one desires to melt up granulated honey or granulated comb honey, a capping-melter is the very best arrangement to use, because there is practically no danger of scorching the honey, and yet the work may be done quickly.

One of the simplest capping-melters is a hot-water jacketed can having a gate at the bottom for an outlet on the principle of a double boiler. The melter is not adapted for the largest apiaries as it is designed for a single-burner stove only. 
The Peterson eapping-nelter shown in the illustration, is a simple construction, the. long shallow pan having a double bottom, the space between being filled with hot water. The water compartment is extended beyond the edge of the table, as shown, so, if desired, knives may be placed in the water to heat.

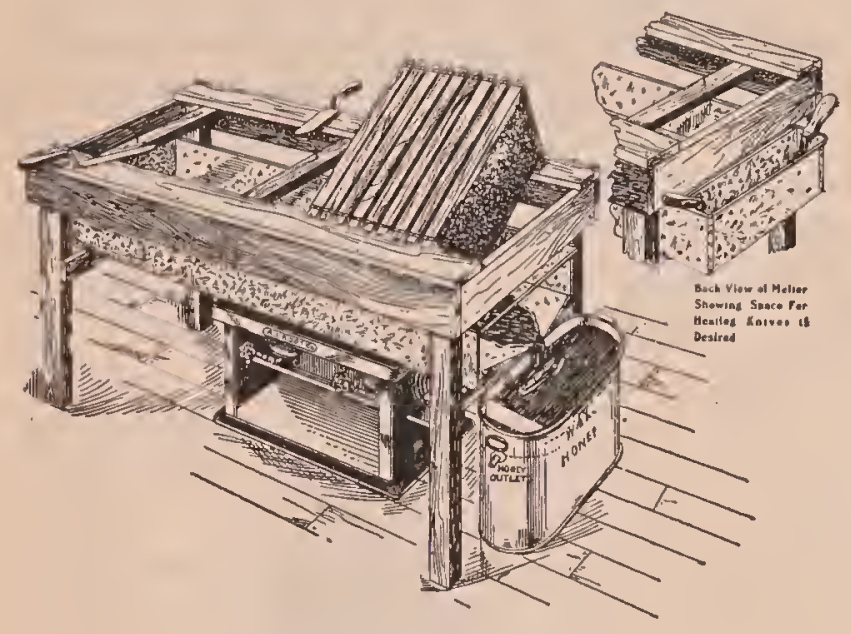

Peterson capping,melter.

This melter is large enough to be heated by a two-burner stove, hence it has a much greater capacity than the round-can design described above. Furthermore, there is space at the end of the table for the uncapped combs to rest upon before they are placed in the extractor. The open end of the long trough is about an inch lower than the other end so that the honey and melted wax run down into the separatingean beneath.

DISPOSING OF THE WAX AND HONEY THAT RUN FROM THE MELTER.

When capping-melters first came into use the stream of hot wax and honey was run directly into a pail or can, and as soon as it was full another was put in its place. This plan is objectionable in that it requires too many cans of hot wax standing around in the way. Furthermore, the honey underneath takes on a taste of tlie wax to some extent, if it is allowed to remain in contact with it until the wax cools. To overcome this difficulty a gate may be provided at the bottom of the can, so that the honey may be drawn off whenever the can becomes full. Care must be taken, of cou'se, to shut the gate before any wax begins to run out. In this way the wax remains in the can until the next day, when it is emptied out in the form of a solid cake.

A much better arrangement, however, is a separating-can made according to a principle first described by $R$. C. Aikin of Colorado. As shown in the illustration of the Peterson capping-melter an ordinary wash-boiler may be used with a tin partition soldered near one end, coming to within one-half inch of the bottom of the can. Some loney should be left in the boiler before the work is started. When the new wax and honey run in, the wax floats on top of the honey in the larger compartment of the boiler, the honey alone escaping into the small compartment, since the levels in the two compartments will be nearly the same. When the boiler is full the loney will escape continuously from an outlet in the end of the boiler, while the wax will remain in the large compartment.

In actual use this separating-can should be insulated by being placed inside a wooden box, having a cover fitted over the top with a funnel to receive the wax and honey. It would be all the better if some insulating material could be wrapped around the boiler before it is enclosed in the box.

E. L. Sechrist of California uses a specially made separątor, as shown herewith. He provides a wax outlet, but if the sepalator is large enough this is not necessary.

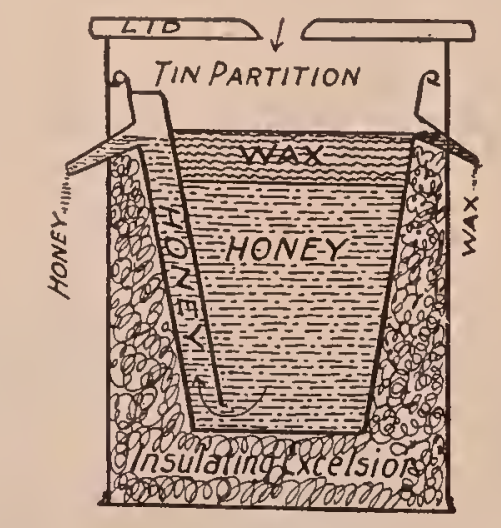

Sechrist's honey and wax separator.

A small stream of drizzling wax is a nuisance. If a can as large as a washboiler is used, it will hold all the wax for the average day's run even in an extensive vard, and, therefore, the wax part of the outfit requires no attention. When the work is over for the day, the cover of the box is 
renoved so that the. wax will have a chance to haxden, and the next morning it may be lifted out, the honey drained off, the under side of the cake scraped to get rid of the refuse, and the wax will be ready for market.

\section{STRAINING HONEY.}

A convenient arrangement for straining honey is to have a large piece of heavy wire screen attached to the top of the straining tank. This should be pressed down in the middle so that it is four or five inches lower than the top of the tank. The wet cheese cloth may be laid on this screen without the necessity of tying around the top of the tank. When one cloth is clogged so that the honey strains too slowly it may be drawn over to one side and left to drain while another cloth is placed in position without delay.

S. T. Pettit of Aylmer, Ont., Can., devised a very convenient can strainer having a large surface of cloth supported by a coarse wire-screen basket as shown, page 331.

The author has used such a strainer, but finds it more convenient to have, instead of the opening in the center of the bottom of the strainer, a gate soldered to one side near the bottom. If the strainer is used for filling cans the stream of honey may be

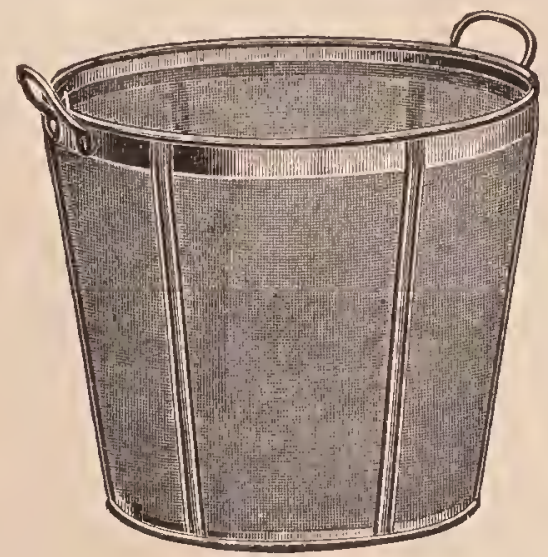

Alexander honey-strainer.

shut off by means of the gate when the can is full. Fresh cloths can be substituted for those that are clogged at any time.

To do away with eloth strainers E. W. Alexander used an ordinary ten-quart milk-pail, cutting out the sides and bottoms. These were united by upright tin braces, as shown in the illustrations.
The open spaces were filler in with a fine mesh of brass wire clotli securcly soldered in place. The honey is poured thru such a straining pail into the tank. It is necessary to have two or more pails so that one may be in use while the other is being cleaned.

\section{THE GRAVITY METHOD OF STRAINING AND} CLARIFYING HONEY.

Of late the gravity principle of straining has received much attention on the part of honey-producers on account of its simplicity and freedom from vexatious delays necessitated by changing f filled-up cloths and washing straining surfaces. Briefly, the plan consists in the use of a relatively tall tank sufficiently large for holding a day's extracting and containing nothing by way of equipment except a suitable gate at the bottom and a float to break the current of the honey when it is poured in at the top, thus preventing an active circulation of the new honey with the rest of the honey in the can. The plan is to draw no honey from the bottom until the tank is nearly full. If the honey is not allowed to circulate carrying particles of cappings and bits of comb down to the bottom, the honey when drawn off at the gate is found to be very clear. The last of the honey can not be drawn off in this way, for it will contain too much of the cappings. The last few inches, therefore, should be dipped out and strained or poured into the uncapping tank or box.

In extremely hot weather when the honey is comparatively thin, the gravity system alone leaves little to be desired; but, in cool weather, or whenever the honey is quite thick, it is found that, in order to be clarified sufficiently, the tank must stand for several days. This makes necessary a somewhat elaborate outfit of expensive cans in order that the work may not be hindered. For a small outfit one tank alone would be sufficient.

The only additional equipment necessary beyond a regular storage tank is an additional can without a bottom, a little higher than the regular tank preferably, and smaller in diameter, altho no exact ratio between the two diameters is necessary. Over the lower end of the smaller can cheese cloth is stretched and tied firmly. 


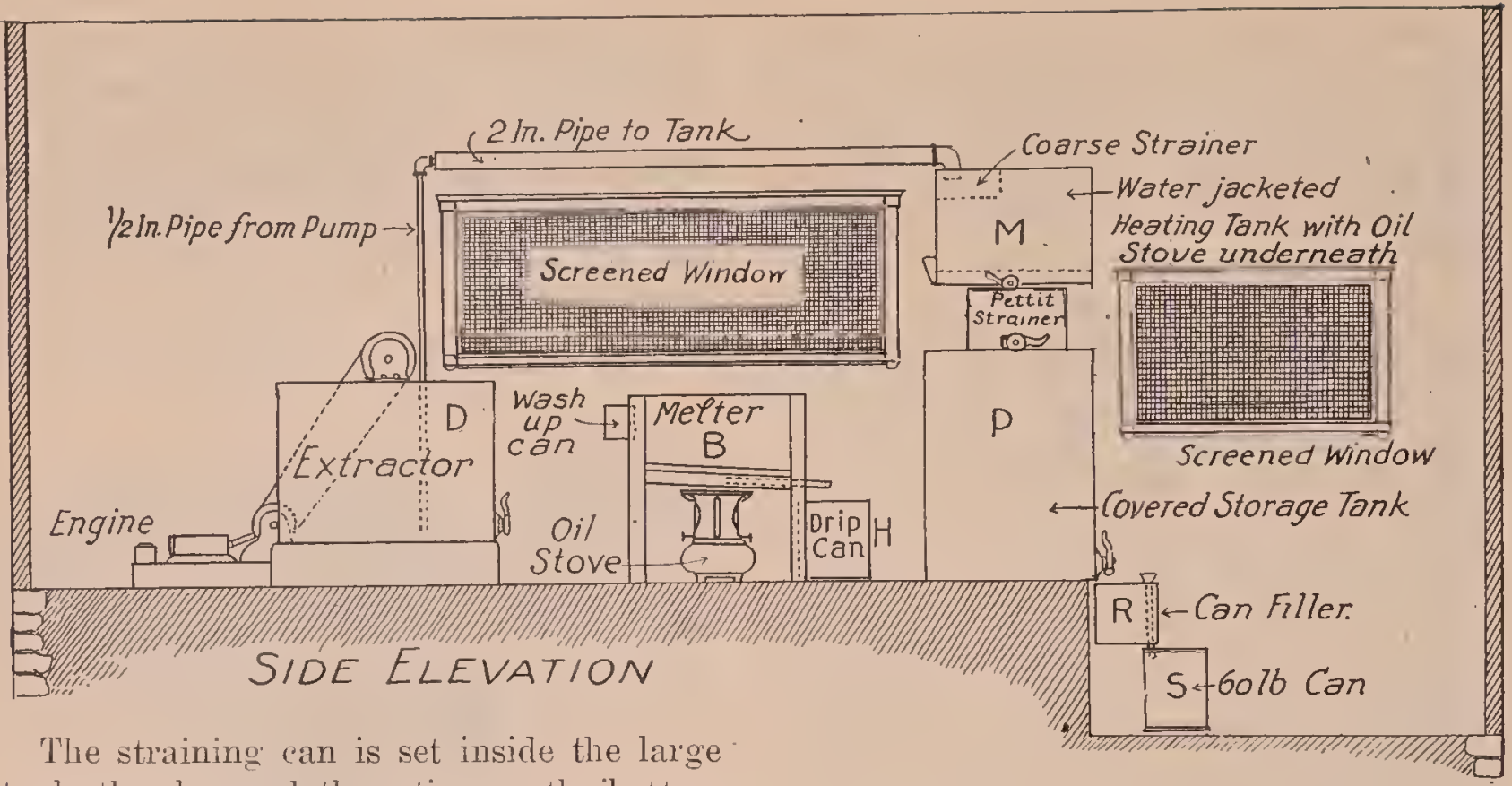
tank, the cheese cloth resting on the bottom of the latter. Two or three inches of clear honey should be poured in at the start to prevent the cheese cloth from becoming clogged. As the new honey is poured in, it gradually percolates thru the cheese cloth into the main tank outside, the level in the two cans always remaining the same, or practically the same. As the work progresses the inner can should be raised so that the cheese cloth will be several inches from the bottom of the tank. This should not be done, however, until the main tank is half full. It will be seen that all foreign. material that will float will be kept away from the cheese cloth. When the work is

over the inside tank may be raised so that all of the honey in it will strain out. However, as long as the cheese cloth does its work the process is continuous, for the honey may be drawn out of the main tank as soon as it becomes full. From this time on it should be drawn off only fast enough to keep it from running over. The greater the depth of honey about the cheese cloth strainer the less the probability of the cloth becoming clogged.

When the work is over and the main tank finally emptied the cheese cloth will strain the last of the honey inside the straining tank without clogging apprecia-

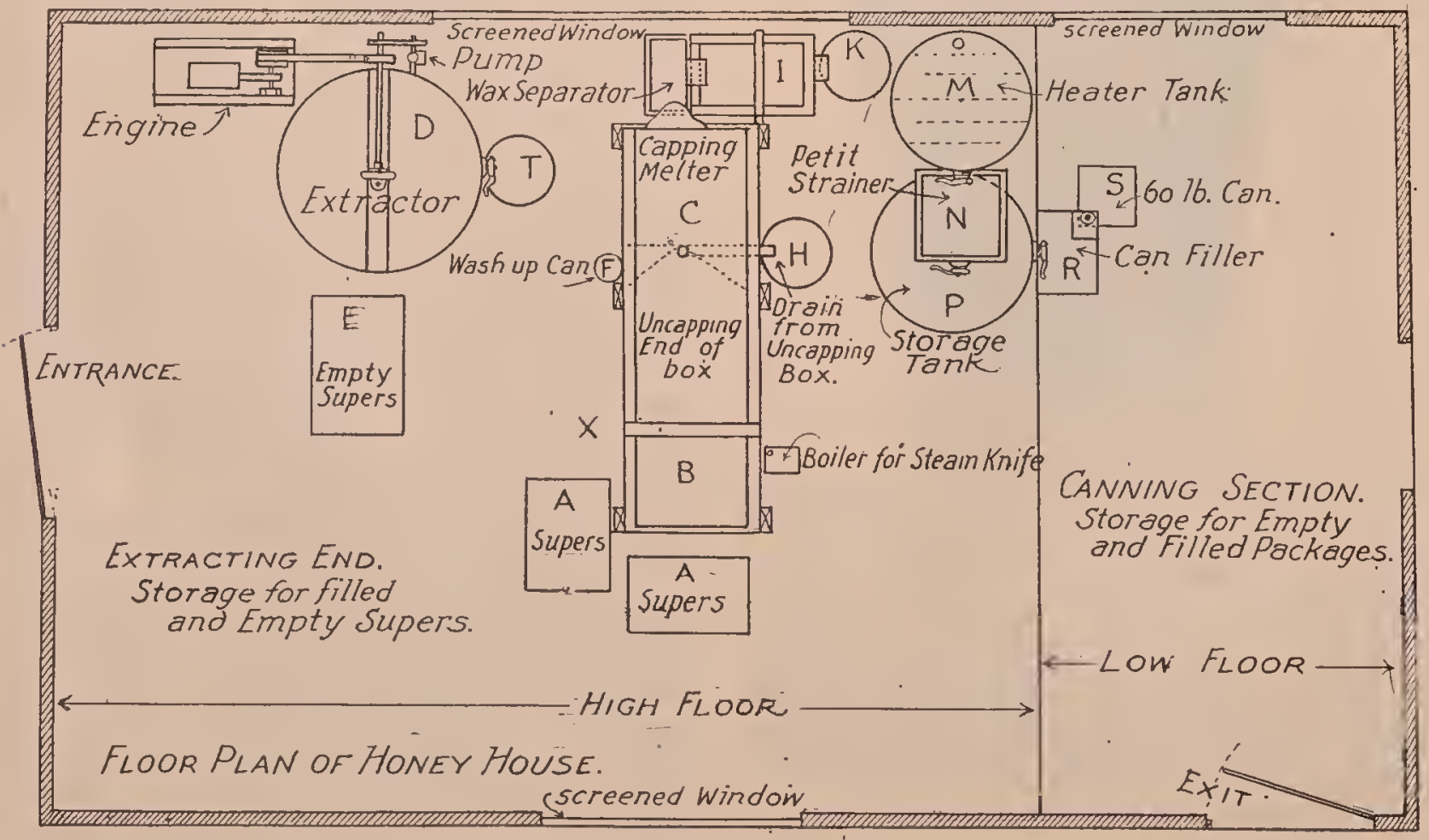




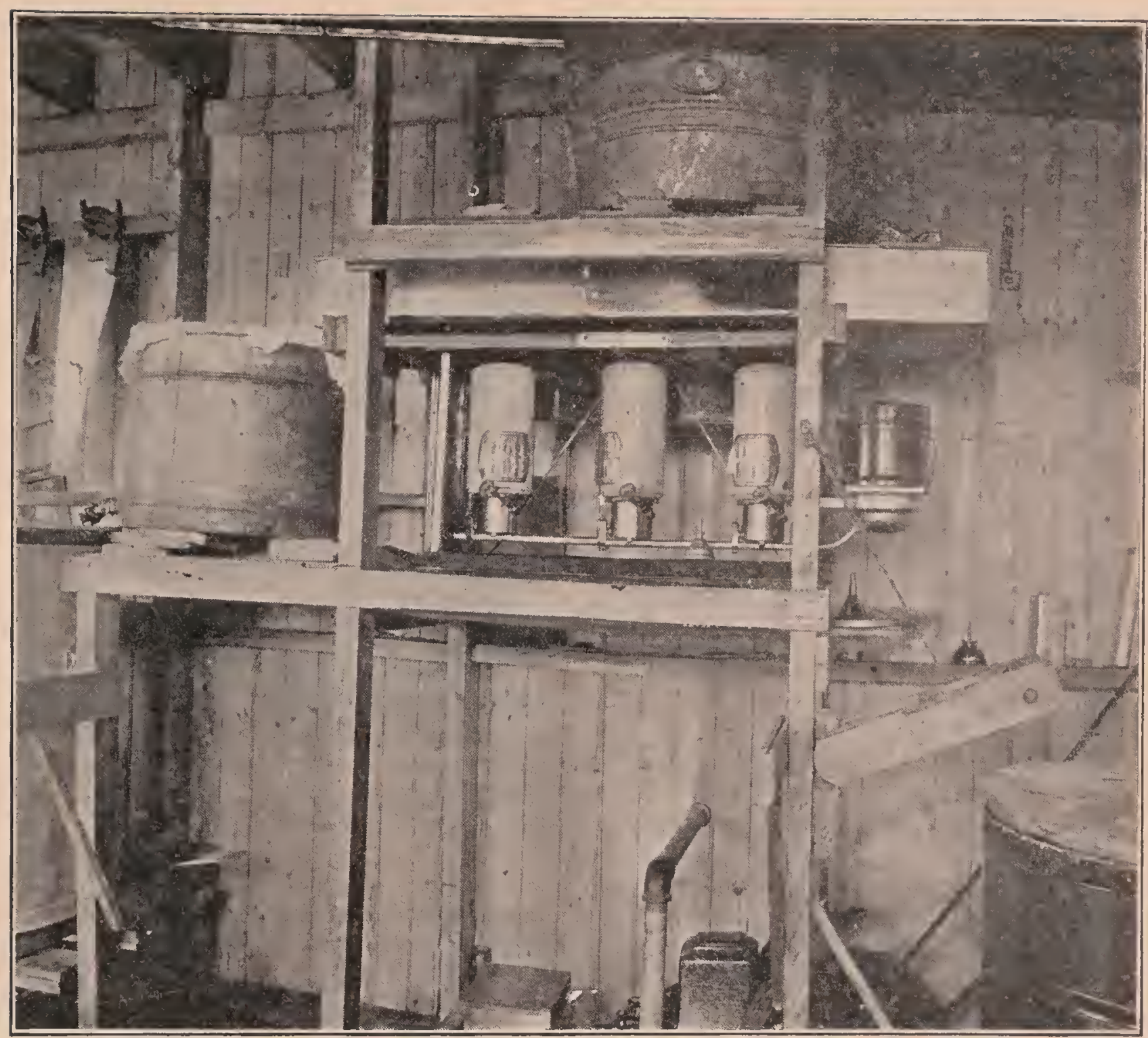

This picture should be studied in connection with the next cut. The honey is pumped from the extractor. into the washtub above; passes into a double-bottom water pan beneath, the water being kept hot by means of a Standard Oil kerosene stove just beneath the pan. The honey is heated as it passes orer this double bottom, strained as it runs thru the tank at the left, and finally runs into a large receiring tank below.

bly. One cloth will last much longer witlout clogoring than if all the honey were poured thru it in the regular way, for by this plan the refuse floats to the top and the strainer really has comparatively little to do.

Instead of a can with cheese cloth orer the bottom, as mentioned above, a still better plan is to have a framework across the top of the large honey tank as shown on page 327 , this square framework being just the right size for holding the top of a chcese cloth bag tacked firmly to it. This bag should be weighted down with a heavy wire hoop at the bottom to keep it from floating. The advantage of this over the can with the cheese clotli at the bottom is that there is so much additional straining surface.
HEATING THE HONEY TO FACILITATE STRATNING.

In some localities the honey when extracted, is so cold and thick that it is almost waxy, and straining or clarifying eren on the principle above described becomes something of a problem. Under such conditions it is necessary to do the extracting in very hot weather, or else in a room artificially heated. If the extracting is done late in the season when the weather has turned cool, it is sometimes necessary to keep the combs in the heated room 24 hours or longer before the honey is thin enough to extract and strain quickly.

By means of power extractors, even very thick honey may be extracted, but a power extractor does not help much on the straining problem. 
Several large producers have used àn extractor having a double wall, the space between filled with hot water or steam. As the honey runs down toward the outlet it is warmed to such an extent that it strains easily. If an engine of fairly good size is used (two to three horse-power), the hot water surrounding the cylinder may be piped to the extractor. In other words, the space between the two walls of the extractor serves as a water tank, and the waste heat of the engine is made use of for warming the honey.

Ordinarily, a simpler and better plan is to run the honey from the extractor thru a pipe, either by gravity or by means of a pump, which pipe in turn passes thru a larger pipe containing hot water heated either by the cylinder of the engine or by means of a stove.

E. L. Sechrist, formerly of Fair Oaks, Cal., pumped his honey into a special tank, which is water-jacketed, heated by a stove underneath. The honey is thus heated before it passes into the strainer.

Some beekeepers have tried running the honey as it comes from the extractor thru a trough having a stove underneath to warm the surface of the trough and thus raise the temperature of the honey. This plan is a little dangerous, for it is necessary to have considerable heat, since the honey runs thru the trough rapidly, and there is danger the honey along the edges may burn. A better way is to run the honey thru a pipe submerged in water heated by a stove.

Adams \& Myers, Ransomville, N. Y., use a three-burner kerosene stove under a Peterson capping-melter, as shown in the preceding cut. The honey is pumped from the extractor, and then run into a tub over the melter. It then flows into the melter and then after leating into the strainer at the left. This may be hot enough to make the honey lun freely so that it will pass readily thru a strainer before it goes into the square cans. These people are not only large beekeepers but fruit-growers. They do a big business in selling fruit as well as honey in pails and 60-pound square cans. They desire to have the honey heated hot enough, not only for straining but to prevent granulation. The plan shown works out very nicely, and is comparatively cheap to put in operation.

Some beekeepers prefer to have a small hot-water boiler for heating water in a jacket surrounding the extractor as it

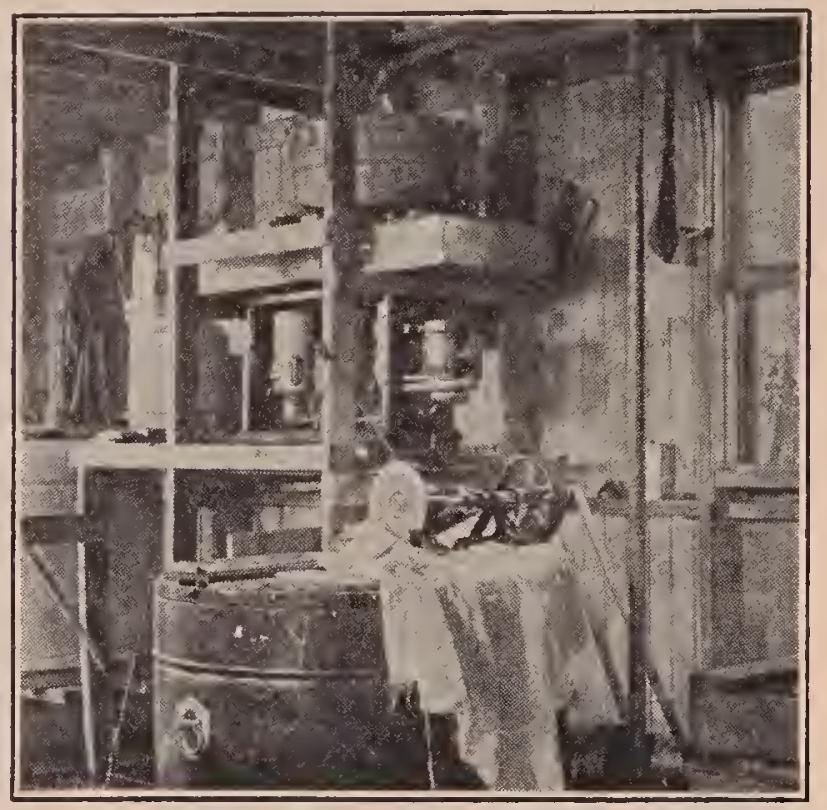

Another view of the honey-processing room of Adams \& Myers, showing the power plan and extractor.

comes thru the pump, heating the capping-melter, and finally delivering the honey hot, or at least warm, inside of the 60 -pound square cans or 10-pound tins or pails. But the hot-water boiler of the kind described would not, unless it were in the same room, heat the combs so that they could be extracted clean, if they were cold.

Kerosene hot-water heater's can be installed at low cost, of sufficient capacity to heat the water around a double-jacketed honey-extractor.

Adams \& Myers do their extracting after the season is past. The combs are stored in supers in their honey-house. This they heat with a stove until the temperature is around 80 or 90 degrees. This temperature is held until all the combs are warmed so that the honey will flow freely. The heat may continue two days before the warm air in the room will penetrate all the combs in the supers.

AUTOMATIC DEVICES FOR RINGING A BELL WHEN A CAN IS FULL.

In drawing honey into a 60 -pound can from a tank, it is a great convenience to 
volved, and the honey ran out thru a hole in the center of the bottom. The same force that threw the honey from the combs, however, held it to the sides of the can, and

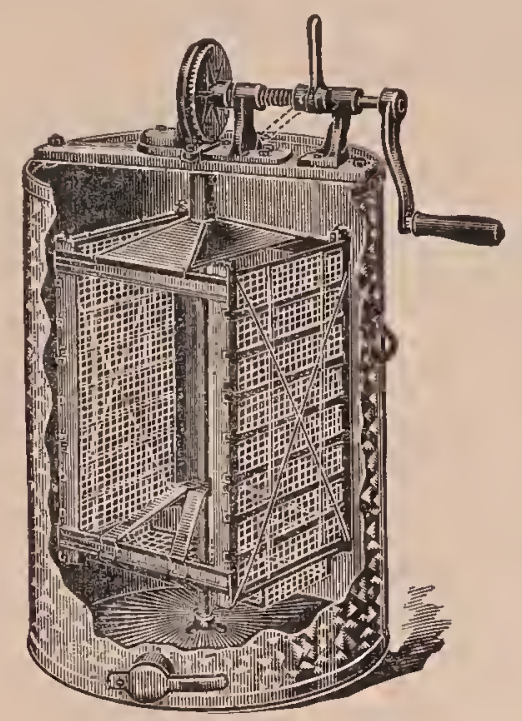

Novice non-revèrsing extractor.

none would run out until the machine was stopped. In 1869 A. I. Root constructed what he called the Novice honey-extractor. This was so great an improvement over all that had preceded that it found a ready sale at once. Only the inside framework for holding the combs revolved. The crank was geared so that one revolution made three revolutions of the combs.

\section{REVERSIBLF EXTRACTOR.}

When the honey from one side of the romb was extracted in the Novice machine the comb had to be lifted out and turned around in order to throw the honey out of

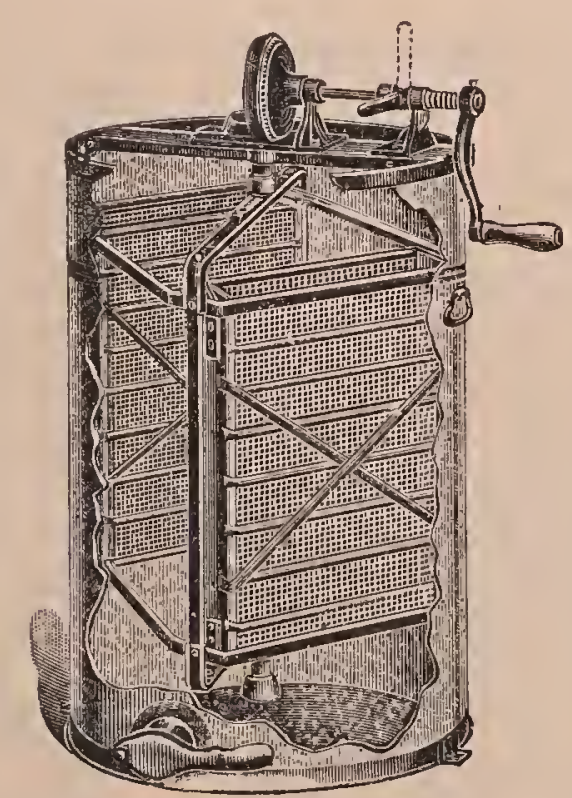

Two-frame Reversible Honey-extractor. the other side. About the time that A. I. Root was experimenting along this line Thomas William Cowan, editor of the British Bee Journal, constructed what was then known and is still called the Cowan reversible extractor. Several "baskets" holding the combs and liung on hinges like a door, could be swung from side to side, and either side of the comb could be next to the outside. The first side could be extracted, and then the pocket, or basket, swung around so that the honey could be thrown from the other side without taking out the comb and reversing it.

\section{THE ROOT IIULTIPLE REVERSING EXTRACTOR.}

In using the Cowan extractor when one desires to reverse, it is necessary to stop the machine, and with the hand eatch hold of the pockets and swing them around to the other position. The inultiple reversing extractor, as its name indicates, reverses the pockets simultaneously when the brake is applied. The lever acts as a brake until the extractor has been reduced in speed to a certain point when the hub of the reel is held stationary by the brake, and the reel, which continues to turn, accomplishes the reversing of the pockets by means of the reversing levers located on the top of the reel. This action is always positive and reliable. The strain of reversing is borne entirely by the brake, thus relieving the driving mechanism of all stress.

\section{CENTRAL PIVOT REVERSING EXTRACTOR.}

All reversible honey-extractors on the market.make use of one of two principles for changing the sides of the combs. The first one has been used for the last 20 years, and it has given very good satisfaction; but it has its limitations. The other one, perhaps, just as old, but newer in its application, is attracting a large amount of farorable comment. In the older type the baskets or pockets are hinged on the sides, after the principle of a common door. The reversing is accomplished by swinging the pockets on their hinges from one side clear over to the other. This principle necessitates the stopping of the machine, or nearly stopping it, before the reversing can be accomplished. Even at slow speed the centrifugal force tends to throw the bas- 
kets over to the reverse side with a bang unless care is used. With new or tender combs, or combs not wired, there is more or less breakage, especially when hired help does the work.

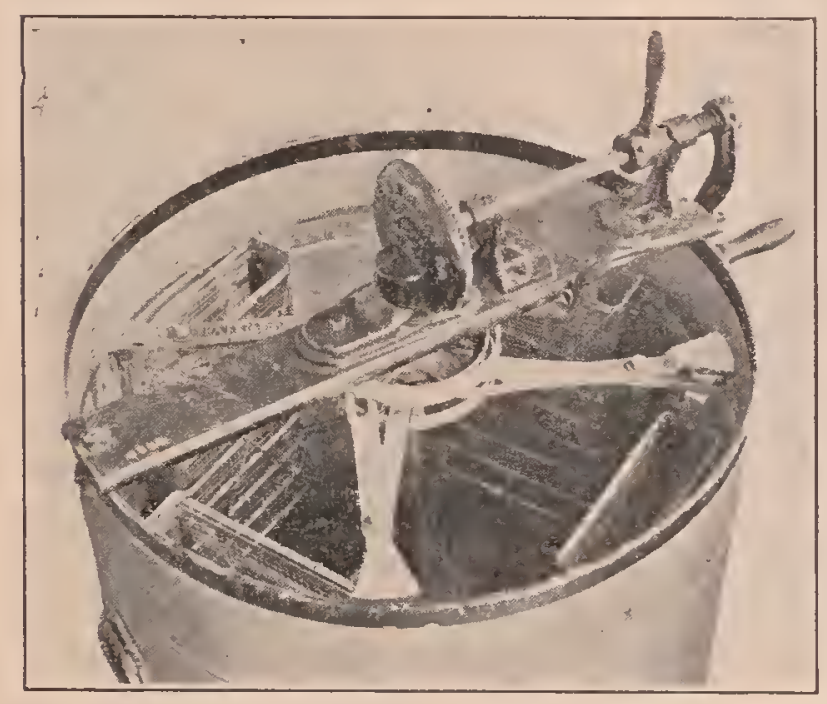

This shows the principle of reversing of the old automatic extractor. The pockets at the top and bottom are hinged on one side. The lever here shown connects each pocket with the reversing drum, which when temporarily slowed dow"11, and then stopped, canses the lever to shift from one position to the other. An internal sector gear is connected with each pocket on one end of the lever, and a slot and pinion on the other end. The other cut shows the pockets in the aet of reversing, when the pockets will be revolved clear around to the other position, subjecting the other side of the comb to the action of the centrifugal force.

In modern practice it is the almost universal custom to start throwing out most of the honey on one side at a comparatively slow speed to reduce the weight of the comb. It is then reversed, when the other side is extracted clean. The first side is then returned to its first position and extracted again. This makes two reversings, and each time the machine must be slowed down, or stopped and started up again, all of which consumes raluable time right in the midst of the honey season when time is precious and help that is not afraid of bees is often hard to find. In hand-driven machines it also wastes energy.

The other principle, altho it is as old as the first, but newer so far as the general use is concerned, is rapidly coming to the front. The baskets, instead of being hinged on the side and swinging like a door, are pivoted in the center. If the reader will imagine a shaft passing thru the center of the comb pockets or baskets and thru the center of the comb lengthwise, and if he can see in lis mind's eye this comb or bas- ket revolving on this shaft like a top, he will understand the principle. Of course it is impossible to have. a shaft go thru the comb; but it is possible to have the basket piroted at the top and bottom; or, more exactly, it is impossible to have the basket revolve on a shaft running thru its center, because there can be no shaft going thru the center of the pocket without interfering with the insertion of the combs. Machines are now built embodying this idea, so that the combs can be reversed on a central axis. This makes it possible to reverse at full speed without stopping or slowing down the machine. It not only sares loss of time when time is precious, saves power, saves honey, but it also saves comb breakage. Machines built on this minciple are slightly more expensive, but far more efficient, both in time and in the amount of loney secured from the combs.

One of the latest machines inrolving the principle of the central-pirot reversing is shown on next page. As will be seen by the illustrations, the baskets are pivoted at the bottom, and at the top they are held in position by a small gear wheel meshing inside of the ring that surmounts the top of each basket. This small gear wheel is journaled in a large rim or ring attached to the center shaft of the extractor. The pinion serves the purpose of reversing the

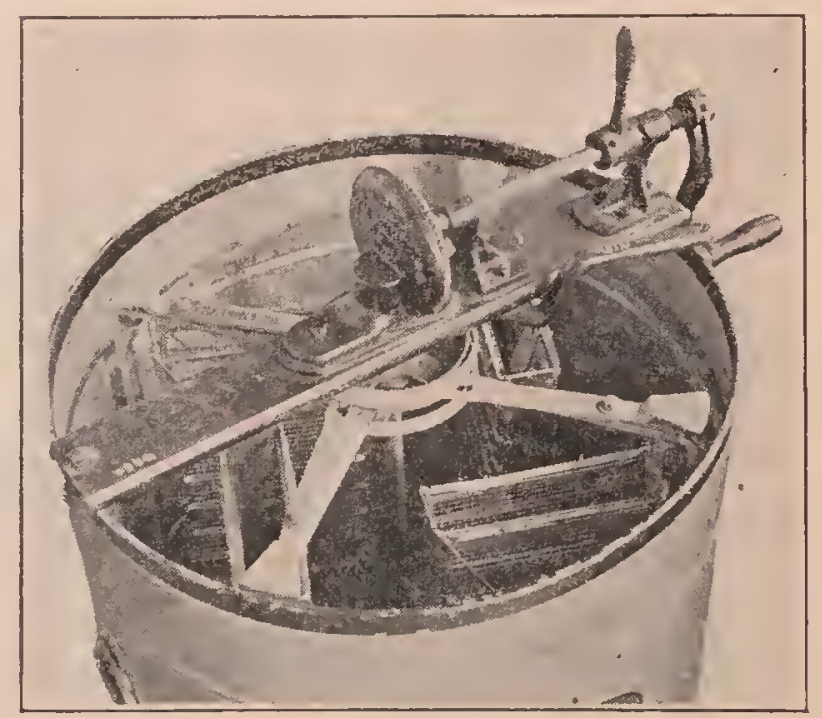

The pockets are in the act of rerersing in the manner explained. The usual plan is to start the extractor up and throw out most of the honey on one side of the comb at a relatively slow speed. A pressure on the brake lever retards and stops the reversing-drum while the reel itself is run slightly faster. The result is, the lerels here shown throw the pockets the other side to. When this side has been cleaned the brake lever is applied, the reel is stopped, and, while the pressure is being applied to the brake, the combs are reversed. 
pockets, and at the same time holds the top of them against the centrifugal force that is enormous. A pressure on the re-

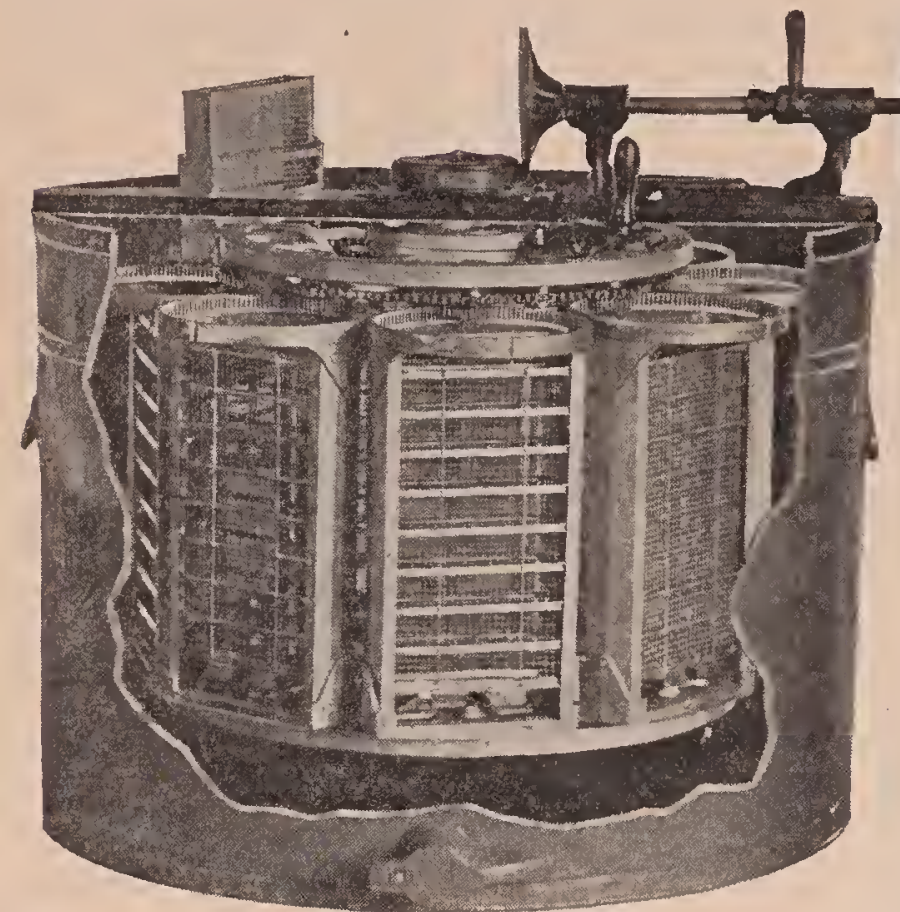

The Buckeye central-pivot reversing extractor is much more efficient in time and labor, and in the saving of the breakage of combs than the other machine during the period of reversing. The reversing can be accomplished at low speed, full speed, or constantly, without stopping or slowing down the reel. As will be seen, each pocket is surmounted at the top with a ring, inside of which are teeth that mesh with a small pinion, the purpose of which is twofold-to prevent the top of the pocket from flying out by centrifugal force, and to assist in reversing. The ring and pinion at the top of the basket make it possible to insert the combs and yet allow it to reverse on a central pivot or on the imaginary axis that passes thru the center of the comb and the pockets lengthwise. Exactly in line with this axis is a pinion at the bottom, mounted on a large ring or spider which is secured to a hollow shaft loosely journaled to the main shaft to which power is applied.

versing lever causes all the baskets to reverse simultaneously, even tho the reel of the extractor is running at full speed. The arrangement of the internal gear or pinion leaves the pockets clear, so that it is possible to insert the combs and to remove them as soon as they are extracted.

With this machine it is possible to reverse every comb four or five times at full speed; but it is better to take most of the honey from one side at a comparatively slow speed. This will remove three-fourtlis of the honey on that side. "The combs are then reversed at slow speed, when the machine can be speeded up to its capacity; but before it reaches full speed most of the honey is extracted from both sides of the comb. A second reversing cleans the first side. The combs lightened of their weight can be cleaned almost dry at a high speed. There is no slowing nor stopping two tines in order to reverse, as in the older styles of machines.

Where American foul brood is present in the locality the beekeeper may be compelled to melt up many of his old combs and rely largely on new ones built from foundation. It is these new first-year combs that are favoled in the new machine reversing on a central pivot.

The wire baskets for holding the combs in this machine are removable-a feature that will be appreciated by those who like to clean or sterilize the extractor after ex-

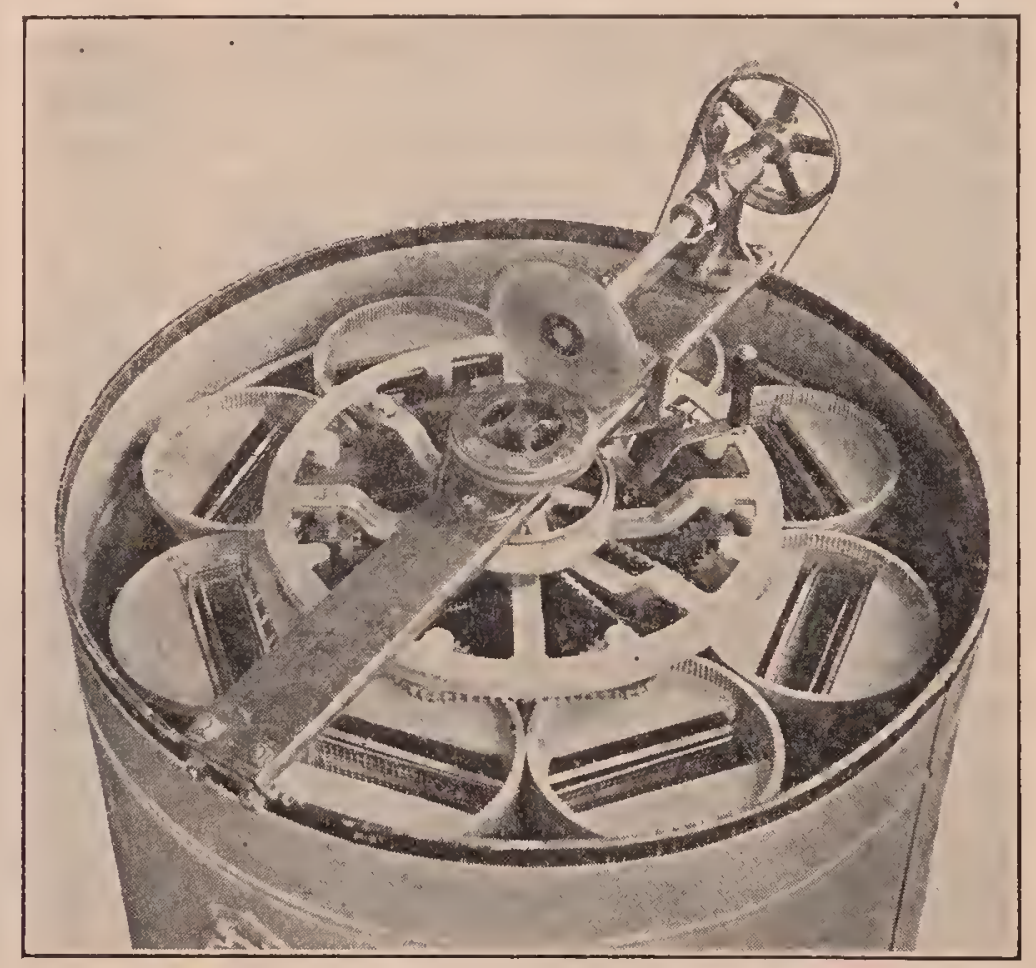

This is a top view looking down into the eight-frame Buckeye extractor, the pockets of which are reversed on a central pivot. It will be seen that it is perfectly easy to insert and remove the combs, and the tops of the pockets are firmly held in place, no inatter how severe a strain may be placed on them. The act of reversing is accomplished by means of sprocket wheels that are made integral with the pinions meshing with the internal gear or rims at the top of each pocket. Eacl of these sprockets is actuated by a chain driven from a sprocket mounted on a hollow shaft loosely journaled on the min shaft from which power is received. 
tracting combs liaving a look suspicious of foul brood.

The machine is built strong to stand the, heavy strains that come from high speed. The difficulty of supporting the tops of the pockets of the central-pivot extractor here shown from the enormous strain of centrifugal force and yet leave it possible to insert the combs, has been solved by the use of the internal gears which also accomplish the reversing.

The time is coming when beekeepers will wake up to the fact that they are not extracting their combs clean enough. To do this as it should be done, the combs should be thoroly wired, and the extractor should be built to stand a higher speed than has even been thought necessary. The machine here shown was constructed with this end in view.

It is a mistake to think that all the honey from very wet combs, because the extractor could not do a cleaner job, will be saved by permitting the bees to clean them up. The dryer the combs, the more honey and the

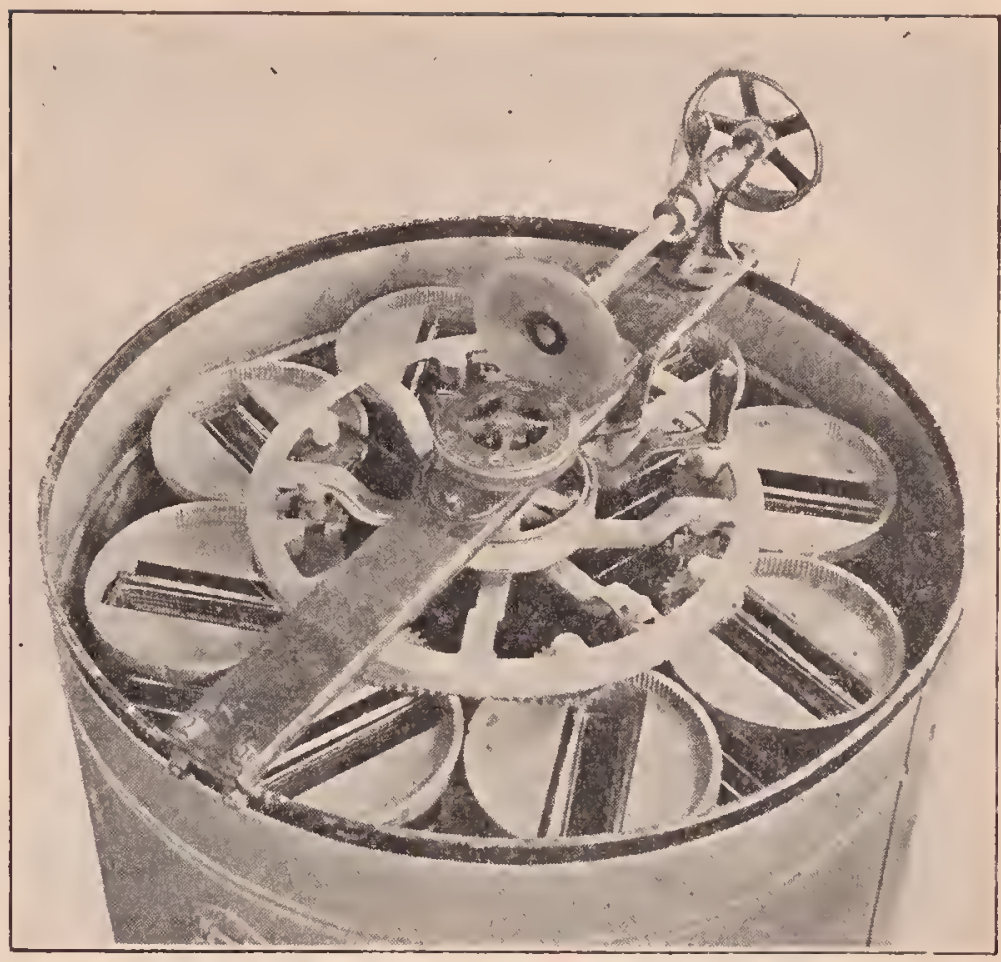

A pressure on the reversing-lever as shown by the upright handle slows down the reversing-dloum very slightly. This action causes every one of the sprockets and the comb pockets to revolve half way, even tho the reel may le running at full speed. In this picture the comb-pockets are seen in the act of reversing. In the space of a second all of the eiglit comlss will be reversed, even tho the extracting-reel is recolving at full speed. The usual plan of procedure is to extract most of the honey from one side of the comb at a relatively slow speed, reverse without stopping or slowing down the extractor, clean all the honey out from the second side (still at slow speed) when the reversinglever is pulled, thus causing the first side to come back to its first position while the honey is cleaned out at full speed. One more reversing at full speed cleans the second side. There is no loss of time in reversing, which can be done as often as desired, at full or slow speed. The reversal on a central axis is much easier on the combs, causes almost no breakage, and at the same time the work is done much more thoroly than in the older styles of extractors.

less the waste when the combs are cleaned by the bees. It is here that power extractors have an immense àdvantage over those driven by hand.

To determine exactly how much honey is left in the cells after extracting, the authors in 1921 made a number of tests with combs that for $2 \frac{1}{2}$ minutes had been in an eight-frame Buckeye extractor, speeded up to 350 revolutions per minute. Eight combs were carefully weighed before and after uncapping and extracting, then after these weights were secured the combs were cut out of the frames, melted up, and the loney, thus separated from the wax, was weighed and compared with the original amount of honey extracted from those eight combs. After several tests the amount of honey left in the cells was found to vary from 3 to $3 \frac{1}{2} \%$ of the original amount in the combs. These combs when taken from the extractor looked perfectly dry- that is, the exact angular shape of the base of each cell could be seen clearly. Where there is enough honey left in the cell so that the angles of the base all run together it is safe to assume that the percentage of honey left is very high, perhaps between 10 and $20 \%$. It is this large proportion of honey left because of inefficient extracting that causes gorging on the part of the bees.

Mention should be made of the fact that at a high speed of 350 revolutions per minute it is quite necessary to pull on the brake lever momentarily to slow down the reel slightly before each reversing, not because the extractor itself will not stand the strain, but because the combs at that high rate of speed are imbedded somewhat in the screen of the pocket and being reversed so suddenly are apt to be somewhat mutilated. The slowing down takes very little extra time, and it is a paying proposition 


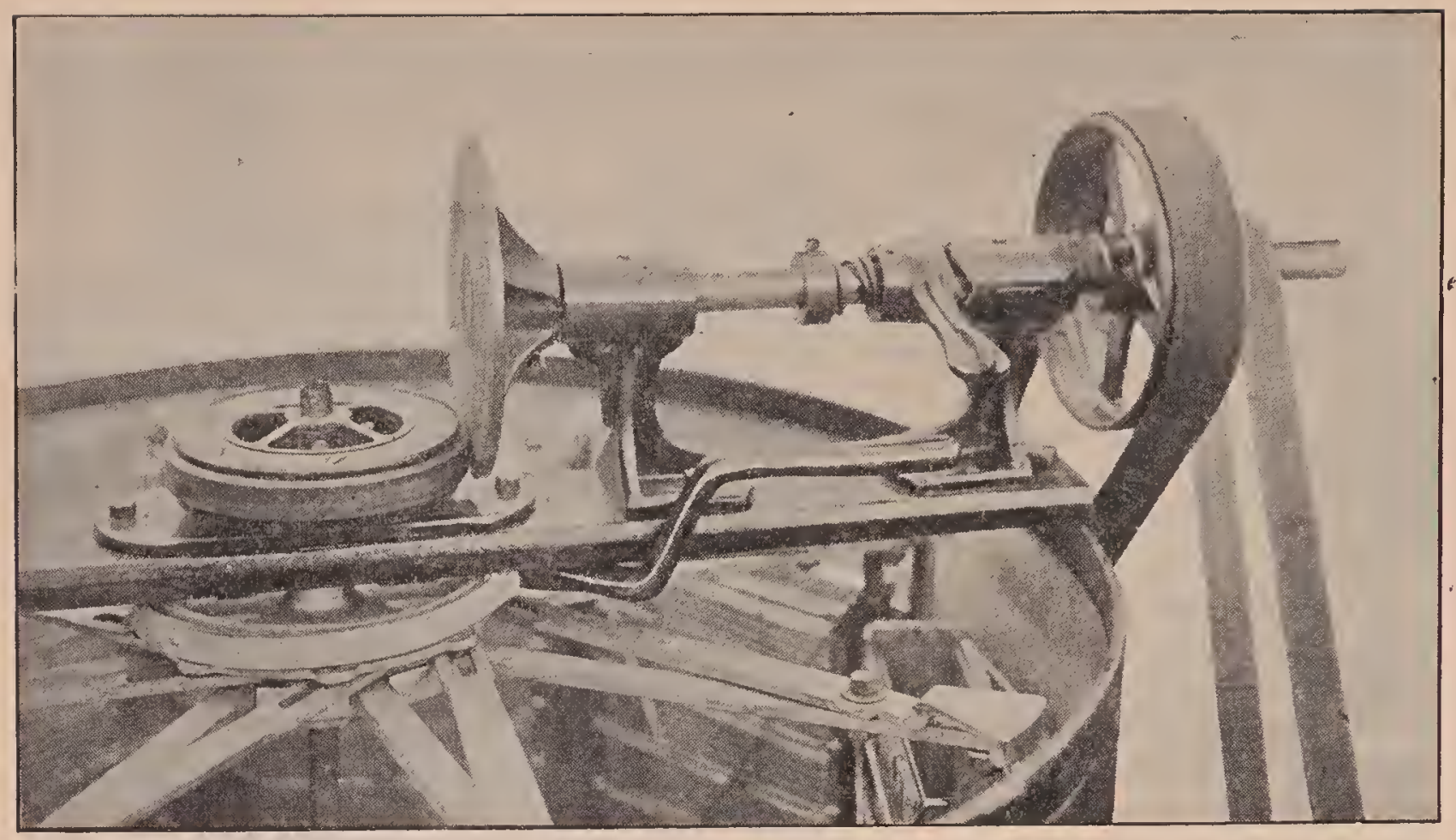

DETAIL OF FRICTION-DRIVE POWER EXTRACTING GEAR-BAR,

Control lever in horizontal position, which means that the reel is at rest. Raising this lever to vertical position engages friction dise with paper-rimmed pulley, causing the reel to revolve To reverse the baskets, release lever by moving into horizontal position, and pull the brake lever which tightens brake band causing reversing lub to move slower than reel. This difference in speed of hub and reel reverses the baskets thru the action of the reversing arms.

if the combs are new. Of comse, if the combs are old such a precaution is not necessary, eren for a speed of 350 revolutions per minute.

Record was made of the honey extracted from two yards. The total amount extracted was 15,4261/2 pounds; amount of honey separated from the wax below the capping melter, 2,852 pounds; wax from the eappings, 316 pounds.
FRICTION DRIVE.

Thle friction drive has been in use several years, and has been found the most satisfactory form of drive for a honey extractor. It is not adapted, however, for a hand extractor, as the ratio of drive is about 1 to 1 - that is, equal. The paperrimmed pulley on the vertical shaft may be raised or lowered, thus changing the ratio of the speed; and while this is of - great advantage in case the engine speed is not exactly right, or the size of the pulley is too large or too small, nevertheless it is not possible to "gear up" enough to -drive the extractor by hand with a crank. In other words, it would be impossible to turn the crank fast enough to extract the honey sufficiently. For this reason some of the smaller producers who desire a large extractor, but who do not
The cam lerer in a vertical position. The dise is thus crowded over against the paper wheel on the vertical shaft so that the reel turns. 
wish a gasoline engine, prefer the older beveled-gear drive, with the ratio of 2 to 1 - that is, one revolution of the erank shaft means two revolution of the reel carrying the comb.

Many beekeepers having less than 100 colonies use power outfits, but when there are more than 200 colonies to be extracted from, a gasoline engine and eight-frame extractor will almost pay for themselves in one season.

They do much quicker and more thoro work. It is impossible to extract all the honey by hand; and the result is, the combs go back to the hives very wet. Some of this honey will be saved by the beess, but a large part of it is consumed and thereby as good as wasted.

An important advantage of the larger extractors is their greater stability. With the two or even four frame size, it is necessary to put combs of equal weight opposite each other. Even then bracing must be done or else the can will tear itself loose from the floor. In case of the larger sizes, the difference in the weight of the combs does not throw the cans out of balance appreciably, hence no bracing or equalizing is necessary.

EYE, COMPOUND.--An examination of the large compound eyes of a bee will show that the outside is made of hexagonal areas, thousands in number. Each of these hexagons is the outside of one of the elements of which the compound eye is composed; and, since they are all constructed alike, a description of one will serve for all. Each of these elements is called an ommatidium. If, then, we take a section thru one of the compound eyes parallel with the top of the head of the bee, we shall get some of them cut lengthwise, thereby showing best the structure, altho it is also necessary to cut other sections at right angles to this plane in order to get the shape of some of the parts. The figures which accompany this show the ommatidium ent lengthwise. Another figure shows an ommatidium from the pupa state.

The outside portion, already mentioned, is the lens layer $l$, and is composed of chitin, as is all the rest of the outside covering of the bee. The section shows this cut open, so that only two sides of the hexagon are shown.

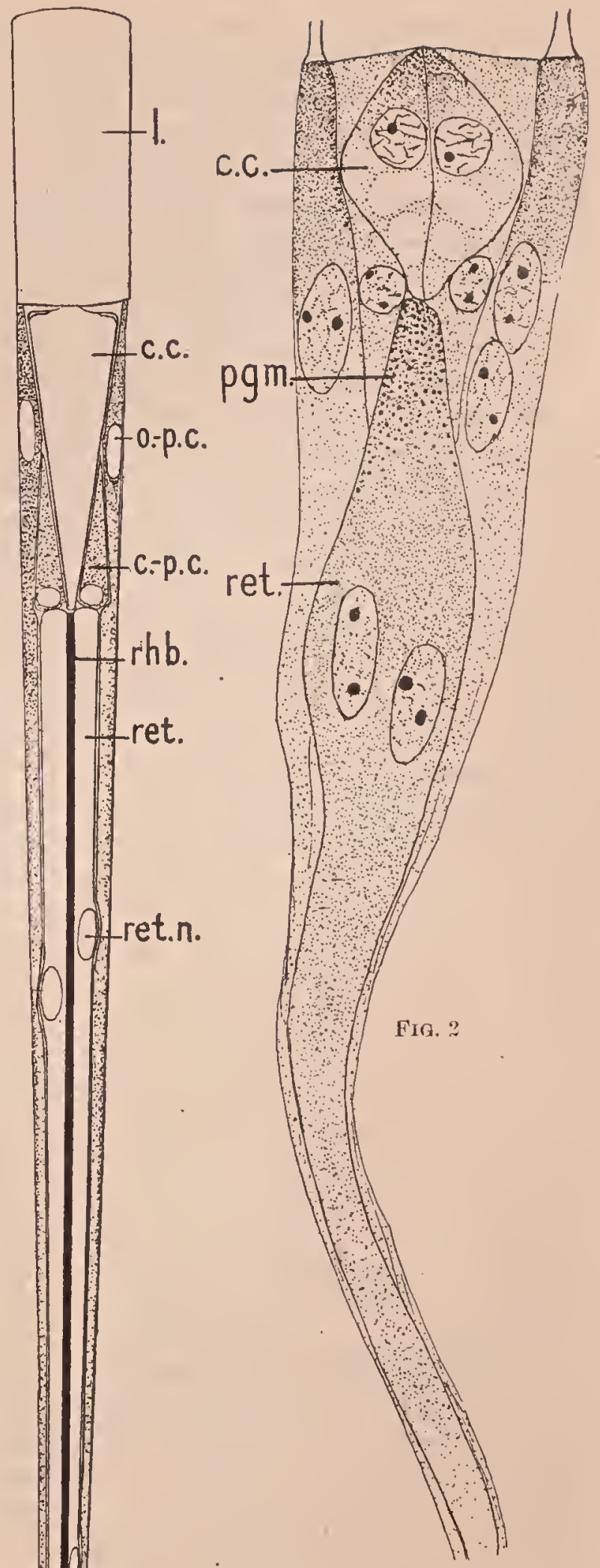

Fig. 1.-Ommatidium of adult eye of hee: l, lens; c. c. crystal line cone; o. p. c., outer pigment cells; c. p. c., corneal pigment cells, which, in the early stages, secrete the lens; r. h. b., rhabdome; ret, retinula; ret. n., nuclei of retinula cells; $b$. m., basement membrane.

FIC. 1. FIG 2.-Ommatidium of pupa; lettering as in Fig. 1 ; p. g. m. pigment forming in retinula.

bm.

In Fig. 1 the pioment is not shown in the center portion of the retinula cells, 
The next lower structure is the crystalline cone $c, c$, which is composed of four cells, of which only two show in the long section. In the pupa stage the boundaries are much clearer, and the nuclei larger than they are in the adult eye. This cone is clear, and, like the lens above it, gathers in the rays of light so that they can act on the nerves below just as the lens in the human eye gathers together rays of light so they can affect the nerves behind it.

Directly in line with the cone is a long rodlike structure which runs clear to the bottom of the ommatidium, called the "riabdome," rhb. This probably contains the ends of the nerves, which are sensitive to light.

Around the rhabdome are eight retina cells ret, which have poured out a secretion while in the pupa state to form the rhabdome.

Around the cone and retina cells there are pigment cells $o . p . c$. and $c . p$. c., that keep the light from passing from one om- matidium to the otherr, and thus making a confused image, just as the inside of a camera is painted black to avoid reflections. In the human eye we also find pigment, which is also located just behind the nerve-endings, and answers the same purpose. There are two kinds of these pigment cells. The ones at the base of the cone, o. p. c., are two in number, and do not extend below the base of the cone. The other pigment cells, c. p.c., extend from the lens to the base of the ommatidium, and are generally twelve in number. The pigment in these cells is located principally at the outer portion of the eye; and the retina cells also contain a pigment, thus making a complete sheath of pigment around the nerve and nerve-endings in the middle.

The nerve lines in the eye extend down along the eight retina cells, and at the bottom come together, and the united nerve extends toward the brain. See cut.
FAIRS, EXHIBITS AT.--See HoNEY ExHIBITS.

FARMER BEEKEEPERS.-Sometimes the professional class of honey-producers lave a feeling of antipathy, if not disgust, toward the farmer who keeps a few bees, especially if he is in the immediate neighborhood. In some cases, at least, there is some justification for that feeling. Some farmers have too many irons in the fire. They do a little of everything to make a little money, but they do nothing particularly well.

A farmer of this class usually has hard luck. His buildings are in a tumble-down condition, machinery out in the weather, his fences down, his stock ill fed, and, on top of it all, he is in debt. When he keeps bees he allows them to take care of them- selres, his swarms get away from lim, hives are robbed out, and, if weakened by disease, foul brood is scattered far and wide. He does not take any agricultural paper, much less a bee journal, and sells his honey at any old price.

He never gets any honey unless the season is extraordinary. It is no wonder that the real progressive beekeeper finds such a farmer a menace to his business.

Fortunately, the majority of our farmers are well-read, comfortably well off, and if they keep bees they secure fair returns from them. There is nothing that will yield for him larger returns for the money invested than bees. His wife and children may just as well get a little money on the side by keeping bees as by keeping chickens; and the chances are two to one that 
they will make more money, and at the same time keep the home supplied with the most delicious sweet that the world has ever known. Such a class of farmers are adding dignity and strength to their calling; and when they keep bees they get a better seeding from their clover fields; more and better fruit from their orehards (see Fruit Blossoms and Pollination); plenty of honey for the family, and a little extra clean cash.

It is not an uncommon thing for a few hives on the farm to bring in a net return of five and even ten dollars per colony. For the money invested there is nothing like it.

Of course it is only. fair to say that some years on the farm the bees will not do much; but it is a poor farmer beekeeper who cannot make the bees pay their own way during poor seasons, and even make handsome returns when the season is good. The farmer who has an orchard and raises alsike, sweet clover, or alfalfa, will be able to keep his few colonies more than busy.

Every up-to-date farmer, especially if he raises clover seed or fruit, should keep bees. See Fruit Blossoms; Backlot Beekeeping; Bees and Fruit-growing; Bees and Poultry; A B C of BeekeepING.

FEEDING AND FEEDERS.-Feeding is practiced for two purposes-to prevent starvation, and to stimulate brood-rearing at times of the year when no honey is coming in from natural sources. These will be referred to later under separate heads. Whenever possible, feeding should be avoided; for at best it is a messy job, expensive, and, in the case of the beginner, liable to cause robbing. In a good locality it may be possible to avoid feeding altogether. Especially would this be true in those places where there is plenty of buckwheat or fall flowers. To buy sugar by the barrel every fall is very expensive, and the beekeeper should lay his plans to avoid it as far as possible. In many cases fall feeding is made necessary by extracting too closely, in some cases even from the brood-nest. This is bad practice and decidedly poor economy. Natural stores go farther, pound for pound, than sugar syrup. But there are times when it is nec- essary to give the bees food either to keep up and stimulate brood-rearing or to prevent actual starvation.

When the honey already in the hives at autumn is of good quality, and nicely sealed, it would be folly to extract it, put it on the market, buy sugar, make syrup, and feed it to the bees. There would be very little gained by it, even if the honey sold at a higher price, and the sugar syrup were cheaper. Where the natural stores are dark, of poor quality, or bad honeydew, it might be advisable to extract and put in their place sugar syrup. Yet of late years it is coming more and more to be the practice to let the bees have everything of their own gathering, provided it is nicely ripened and sealed in the comb, no matter what the source; and it is very seldom that that any one will lose bees in outdoor wintering by reason of poor food.

Where one does not have combs of nice stores sealed, it will be necessary to feed sugar syrup. The cheapest and best food for this purpose is ordinary white granulated sugar. Some of the brown sugars may be used; but experience has shown that they are not so good, and not so cheap in the end, altho selling at a lower price. Moreover, they contain gums that are not a good feed for the bees.

Sugar syrup when capped over makes an excellent food for winter. It does not cause dysentery, and is cheap; but it is not the equal of good honey for breeding, as it is lacking. in some of the necessary food elements in honey. (See HoNer as a Food.) On the other hand, sugar syrup is, perhaps, a little better as a winter food during the coldest part of the winter in the North. It is less stimulating-that is, less inclined to start up premature breeding in winter or very early spring.

It is always poor practice to extract good honey out of the brood-nest. While at times the natural stores might bring twice as much as the same weight of sugar syrup, the labor of extracting and the wear and tear of the colony itself in feeding and evaporating the syrup down are so great that no economy is effected. Ordinary sugar stores should be supplied only to make up the deficiency, if any.

In midwinter, if the bees are short of food, they should be given a comb of sealed 
honey laid on top of the frames, or candy made of granulated sugar. See CANDY FOR BEES.

The difference in cost between a first quality of extracted honey in the comb and sugar syrup when sealed in the comb is so little that, if there are combs of good natural stores, rather than extract them it would be better to set them aside, and then in the fall give these combs to such colonies as have an insufficient supply. But in any case it would be wise not to use all such combs, because, in the spring, it is sometimes very handy to have them ready, in case of an unexpected shortage, so that they can be placed right down at the side of the brood-nest of a colony. If combs of sealed stores are not to be had, it is advisable to give cakes of candy, as described under CANDY fOR BEES.

\section{HOW TO MAKE THE SYRUP.}

Something will depend on whether the bees are to be fed for the purpose of inducing brood-rearing or to give a supply for winter. For stimulating, a syrup made of one part of sugar to two of water by bulk is about right. If the water is hot the sugar will dissolve more readily. For a winter food given early in the fall the proportion should be about two parts of sugar to one of water. For late feeding, just before cold weather comes on, the ratio should be about two and half to one. When made as thick as this the syrup is liable to go back to sugar to some extent, and sometimes it is necessary to put in about a teaspoonful of tartaric acid to every 20 pounds of sugar. Others find it better to use honey. The proportion of honey should be about one-third by bulk of the amount of water used. If honey is used care should be taken to see that it comes from hives where there has never been any foul brood.

A syrup made by mixing two parts of water to one of sugar, or equal parts of both, does not necessarily require heat. The water may be poured into a receptacle cold, and sugar stirred in until the requisite quantity is reached. The stirring will have to be continued until the sugar is dissolved. If there is any quantity to be mixed in that way, an ordinary honey-extractor serves as a very excellent agitator.
The machine is filled nearly half-full of water, when the sugar is poured in little by little while the reel is being turned. It will have to be revolved until the sugar is all dissolved. After a vigorous turning of the crank, even after the sugar is thoroly mixed, there will be a number of small airbubbles. These will all disappear if the syrup is allowed to stand for a while. When the proportion of the sugar is two to one or tivo and a half to one, it is advisable to use hot or boiling. water.

Syrup can be mixed in a common washboiler where heat is employed. In that case the boiler is put on the stove and filled witl the requisite quantity of water. After it has come to a boil, the sugar is slowly stirred in, a little at a time. While on the stove the mixture must be kept thoroly stirred to prevent the undissolved sugar from settling on the bottom and burning. Care should be taken, because burnt sugar or syrup is liable to be fatal to the bees.

In many cases syrup has to be prepared at the outyard. Or perhaps the good wife objects to having her stove mussed up. While an oil or gasoline stove will heat the water, either one is very slow. Some use and recommend a good-sized common galvanized washtub, such as can be obtained at any hardware store at a comparatively low price. This is placed outdoors on four or five stones of suitable size. The right proportion of water is poured into the tub. A fire is then built under, and when the water comes to a boil the granulated sugar is slowly stirred in. After it is all dissolved, the fire should be scraped out from under the tub to prevent overheating or burning. This work should be done on a cool or rainy day when the bees are not flying; otherwise robbing may be started.

\section{FEEDERS.}

There have been hundreds of feeders invented and put on the market. Some of them are very complicated, and the more so the less useful. If one desires to keep down his investment he may use common tin pans. These can be placed in the upper story of the hive and filled with syrup. On top of the syrup should be laid a strip of cheese cloth that has been dampened in water. The bees will crawl up on the cloth and get the syrup without danger of 
drowning. One objection to pans is that, after the feed is all taken, the eloth is likely to be stuck down by the dried crystals. Boiling water, however, will very soon clean them.

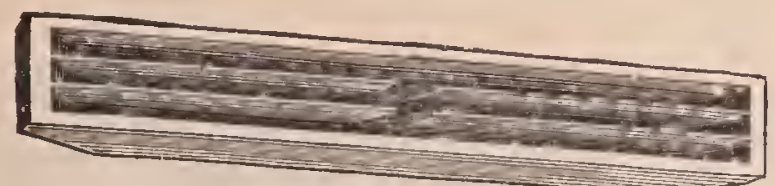

Simplicity feeder

A feeder that has been used very largely is the Simplicity trough feeder. It is an excellent feeder, cheap in price, and occupies very little room on top of the broodframes; or it may be used in front of the entrance at night when the weather is warm. It should not, of coursie, be placed there during the day on account of the danger of robbing.

Another feeder that las been used very largely consists of a common wooden butter-dish, or pie-plate, such as one gets at the grocery when he buys butter. A hundred of these can be nested together so as to take but very little room, and the price is insignificant. It is not necessary to use chrese cloth with the butter-dish. Set it on the top of the frames, and fill it with syrup.

FEEDERS ON THE ATMOSPHERIC PRINCIIPLE.

The principle of giving chickens water on the atmospheric principle has been applied to feeders for bees. A common Mason jar, for example, filled with syrup, and covered with a common saucer, when inverted will make a very good feeder for bees. But in order to provide for a proper flow, three or four toothpicks should be put between the jar and the saucer. At this time the saucer will be right side up, and the jar upside down. As fast as the bees take out the syrup air will enter the jar, and syrup will flow into a sancer.

The device is rather crude and unhandy. A better atmospheric feeder may be made out of a Mason jar and cap in this way. Break or remove the porcelain in the top of the cap, and then pinch two or three holes about the size of a conmon pin. Fill the jar full of syrup, screw on the cap, and invert. In that position it must be held by some contrivance where it will be secure from robbers and where the bees can go under and take the syrup thru the above-mentioned perforations.

Manufacturer's make a special Mason jar-cap with perforations; and with this cap they supply a block of wood bored to receive a Mason jar when inverted. This will hold the jar $3 / 8$ of an inch above the bottom of the hole in the block. Thru the bottom is a mortise or slot that communicates with the entrance of the hive when the feeder is attached to the hive. This is accomplished by inserting the projection into the entrance.

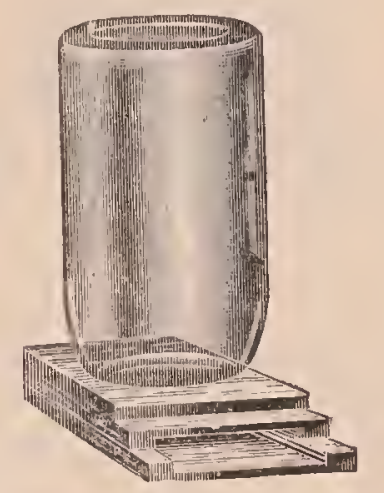

Boardman entrance feeder.

This does not require the opening of the hive, and, what is of some importance, permits the apiarist to see at a glance by looking down a row of hives what feeders are empty or nearly so. One can take a wheelbarrow load of filled cans, lift the empty ones out of the blocks, and substitute filled ones. It is the work of but a ferv minutes to supply every colony in the apiary with a filled can of syrup. This is especially convenient during a dearth of honey when it is desired to keep up brood-rearing for increase. For further particulars regarding this feeder see FeEding to Stimulate farther on.

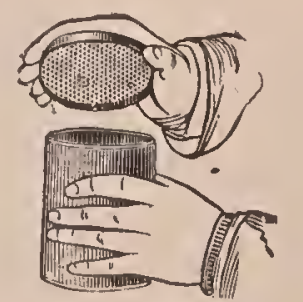

Pepper-box feeder.

The pepper-box feeder is another form of atmospheric feeder that has been advertised quile extensively. While this can be inserted into an entrance block like the Boardman, it is not so easy to determine when it is empty. Ordinarily it is used in 
an upper story or super above the broodchamber.

\section{THE ALEXANDER FEEDER.}

This is a very popular feeder, and some prefer it to anything else. It is on the principle of the Simplicity trough feeder and is a little longer than the width of the hive. The buttom-board is shoved forward the width of the feeder, and in the space left racant is placed the feeder. The projecting end is used for filling, after which it is closed by a wooden block.

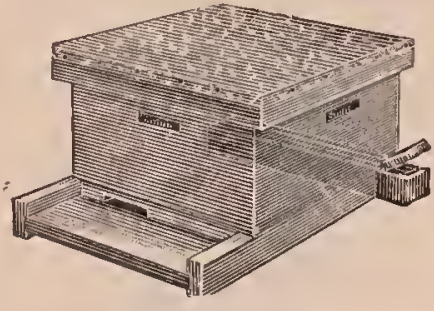

Alexander feeder.

While this feeder is very handy, it does not, like the Boardman, regulate the supply of feed. The bees will empty it in an hour or two, and then be inclined to rob, because the large amount given stirs them up to the point of excitement. One serious objection to the Alexander feeder is that it is sometimes difficult, owing to the unevenness of ground, to adjust the feeder to the back end of the hive. See FEEDING to Stimulate further on.

\section{FRICTION-TOP FEEDER}

Perhaps about as handy a feeder as any is the friction-top feeder, which has been coming into favor during recent years.

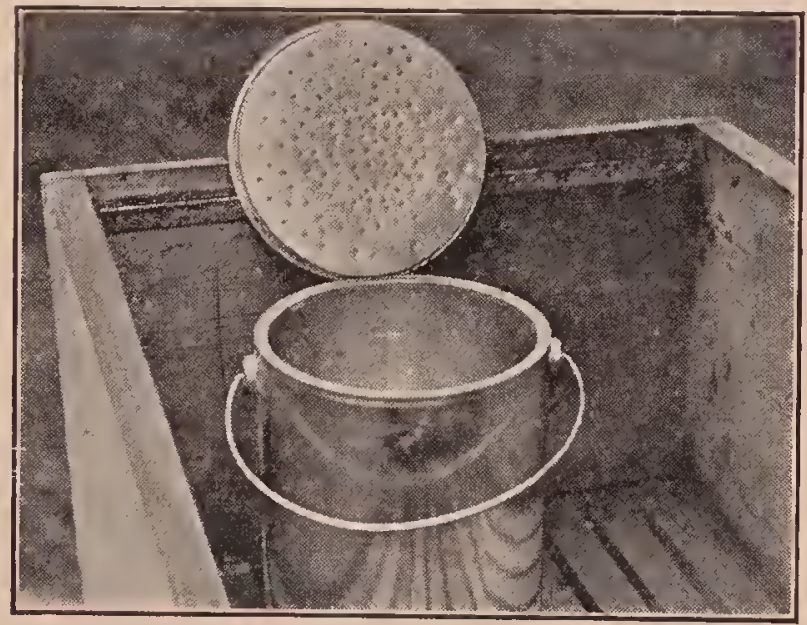

The 5 and 10 pound friction-top pails that are used so largely make the simplest and best kind of feeders for supplying winter stores. Punch the lid full of very fine holes, fill with sylup, about two parts of sugar to one of watel (warm if weatler is cool), and crowd the lid down tightly.
This feeder is a five or ten pound frictiontop pail having a lid punctured with about 130 holes made with a threepenny nail.

The feeder's are filled with a syrup, 2 or $2 \frac{1}{2}$ parts of sugar to one of water, the density depending upon the lateness of the

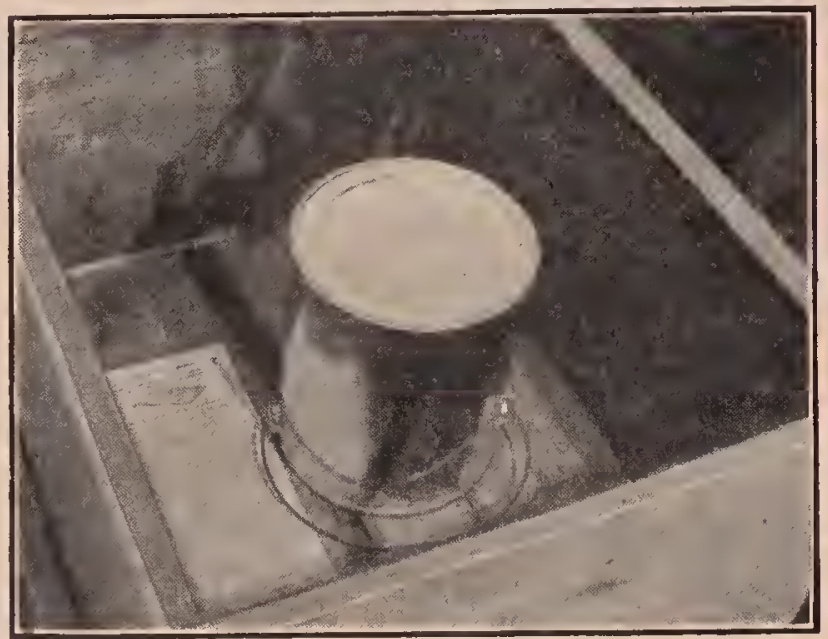

Invert the pail over the hole in the escape-board directly above the cluster in the brood-chamber. There is plenty of space to permit the bees to work over the whole surface of the lid.

season. In cold weather the syrup should be quite thick and warm. Over the colony to be fed, an empty super is placed, and one of these pails of syrup inverted immediately over the cluster and covered with an old sack to prevent the heat of the clus-

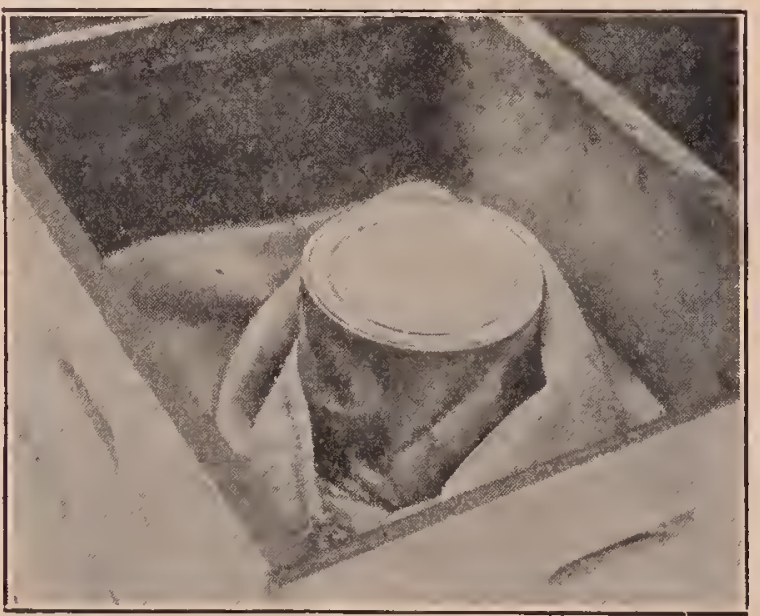

Or, dispense with the escape-board altogether and put the pail directly on the top-bar's of the broodframes. Cover all around with an old sack. The syrup cannot run out any faster than the bees take it.

ter from escaping above. Some strong colonies will take the contents of a tenpound pail in a day. If not taken as rapidly as it should be, the residue of the cold feed should be removed and replaced by warm sylilp. 
THE DOOLITTLE DIVISION-BOARD FEEDER.

For cool-weather feeding, or fall or winter feeding, the friction-top feeder and the Doolittle are superior to those previously mentioned.

The Doolittle has the same outside dimensions as an ordinary brood-frame, but is two inches wide. It will hold about 6 pounds of syrup, and usually about four feederfuls will supply a colony with

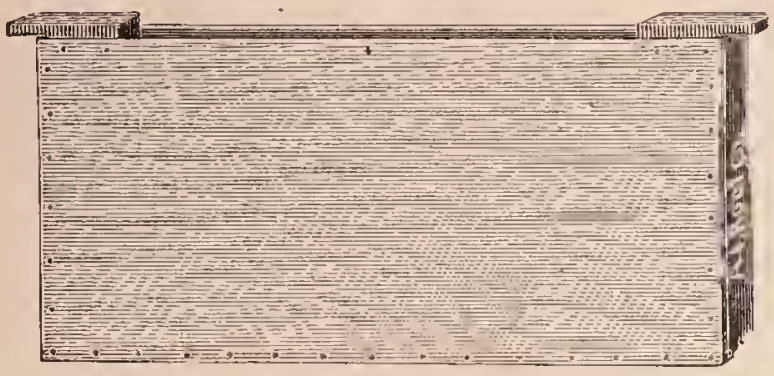

Doolittle feeder.

enough stores for winter, provided the syrup is made two and one-half to one as already described. It is the author's practice to use the Doolittle feeder during cool weather or in the fall, and fill it with warm syrup. It may be used as a dummy or a division-board.

\section{THE MILLER FEEDER.}

When one desires to feed 20 to $25 \mathrm{lbs}$. of syrup at a time, all in one feed, the Miller feeder is the best of anything. It is a little less in dimensions than the inside of an ordinary super to a hive, and is always used is connection with a super or upper brood-chamber. For late feeding, where

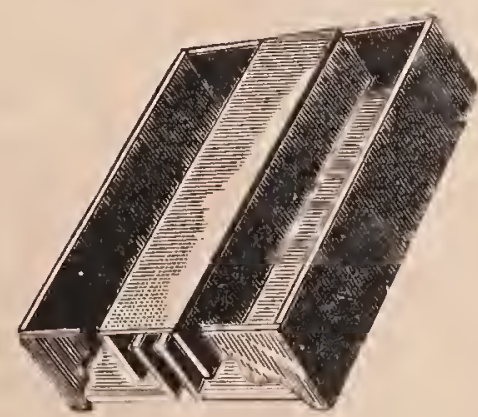

Miller feeder.

one desires to do the work all up at one time, he can feed with this feeder 25 lbs. of thick syrup. If the weather is cool and the syrup hot when poured in, the bees will take it down in a single night. The feeder can then be transferred to some other hive.

The peculiar merit of this feeder is the fact that the entrance to it is directly over the center of the brood-nest. Bees can rise up thru the space $\mathrm{E}$ shown in the sectional drawing, follow the direction of the arlows, and reach the syrup. The syrup in

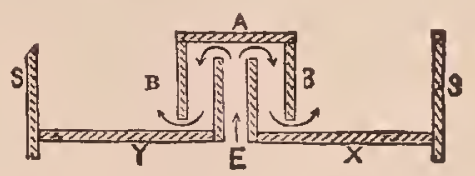

the compartments $\mathrm{B}$ B will rise to a corresponding level in the two outside passages under $\mathrm{A}$.

IEEDING WITHOUT A FEEDER TO PREVENT STARVATION.

If one has been so careless as to allow his colonies to reach the point of starvation, and has no feeders on hand, he may feed thick syrup or honey known to be free from disease by placing a brick under the front of the hive in order to give the hive a backward tilt, and then pouring the feed over the tops of the frames at the back of the hive. Care should be taken not to cause robbing by giving a colony so much feed that it will run out at the entrance or out between the hive and bottom-board in case the bottom-board is not tight.

\section{FEEDING TO STIMULATE BROOD- REARING.}

As previously intimated, feeding to stimulate brood-rearing is a very different proposition from feeding to supply the bees with the necessary winter stores. In the case of the former, it is desired to get a large force of bees (not stores) for the approaching harvest or the approaching winter, the method of procedure being the same in either case. To stimulate broodrearing, approximately half a pint of syrup daily should be fed; but if that amount be given in an ordinary open feeder, such as the Simplicity, Doolittle, or Alexander, the bees will take it all up in about as hour's time. The result, if the syrup is given in the morning or during even the middle lours of, the day, is to excite the colony unduly. Bees will rush out into the open air to ascertain where the sudden supply of food may be obtained. If a whole apiary is fed in this way, there is a general uproar of excitement, often followed by robbing of some of the weaker 
colonies and "nuclei, for the bees in the field will pry into everything. An entrance unguarded is immediately attacked; and unless there is sufficient force to repel the onslaught, robbing will get so far under way that it may cause the robbing-out of the attacked colony. But this is not all. When the supply of syrup in the feeders fails, bees are apt to be cross, sometimes attacking passers-by or stock in the fields. This is particularly so if robbing gets under way. For these reasons it is usually advisable to feed toward night.

Happily it is possible to avoid all this trouble by using a feeder that will make a quart or a pint of syrup last during the entire 24 hours of the day. In the case of a nucleus, the amount can be so regulated as to last 36 or 48 hours.

When the supply of food comes in very slowly, about as it would come in from a very moderate honey flow, enough to give the bees and queen encouragement to keep up brood-rearing, they will rear more brood than if the supply is intermittent. All excitement-that is, uproar in the air -as well as robbing is avoided. It is impossible to fix the Simplicity, Alexander, and Doolittle feeders so that they will not give out the syrup too fast; but it is possible to regulate the friction-top, pepperbox, and Boardman entrance feeders. This is accomplished by using lids having but three or four holes or perforations.

For stimulating, this slow feeding is a great convenience, because one can give his bees a supply of food to keep up the normal functions of the colony for two or three days. For very slow feeding one hole is better than more. A strong colony will require more openings than a weak one; and in all cases syrup for stimulating should be in the proportion of about 66 per cent water and 33 per cent sugar, thoroly stirred until the sugar is dissolved.

Perhaps the reader does not own any friction-top, pepper-box, or Boardman feeders, and yet would like to practice slow feeding as herein directed. All he needs to do is to procure a quantity of self-sealing tin cans that can be readily obtained at the ordinary grocery. Thru the top punch a hole just large enough to admit a common pin. If this hole does not prove large enough to let out sufficient food, two holes may be used, or even three, depending upon the size of the colony. This can should then be filled with syrup, and the top pushed firmly in place.

Experiments have shown that this scheme of slow feeding will raise more brood for the sugar used than where the same amount is given intermittently in open feeders like the Simplicity, Alexander, and the Doolittle. The author prefers the Boardman entrance-feeders because it is possible to see at a glance tluru the glass when the syrup has been used up. If the supply has been taken, it is very easy to put a filled can in the place of the empty without disturbing the hive or the bees.

\section{FEEDING FOR WINTER.}

If colonies are to be wintered on sugar syrup mainly, the general practice is to feed some time in September, in the northern tier of States. Still, in many localities in central United States, there is warm weather in October sufficient to start broodrearing, and much of the stores fed in September may be consumed so that what is left is not sufficient to last until the new honey flow. For this reason it is often unsafe to feed in September and give no further attention to the bees. There are other cases when, for one reason or another, feeding may be delayed until cold weather begins. If one is running a number of outyards it is impossible, without hiring a large force of men, to feed all these yards at once, and by the time the last yard is reached it may be rather late.

But before we begin the actual work of feeding we make a preliminary canvass of the whole apiary. This we do by "hefting" each hive; that is, we lift up either the front or back of the hive. A little practice will enable one to determine approximately the amount of stores in each hive, provided there is not too large a force of bees. In that event, we must allow for a corresponding increase. As we go over each hive we mark on the cover with a piece of chalk the number of pounds that will be required. If the colony is a strong one, we allow. for a total of 25 or $30 \mathrm{lbs}$. if it is to be wintered outdoors; or if indoors, about two-thirds that. We aim to have each colony strong enough so that it will require an average 
of about $30 \mathrm{lbs}$. each for outdoor wintering. After all the hives are marked we proceed to the actual work of feeding.

For this late fall feeding there are no better feeders than the Miller, or the tenpound friction-top pail previously described. The Miller feeder will hold at least $25 \mathrm{lbs}$. of feed at a time, and the friction-top feeder holds ten pounds, so that if one wishes to give a colony a large feed at one time, two or more feeders must be given the colony. Both of these feeders can be quickly put on or taken off without much disturbance to the brood-nest. Or the otlier hand, if the colonies are not quite as strong as they should be, so that some contraction is necessary, the Doolittle division-board feeder, holding about 6 lbs. of thick feed at a time, may serve a better purpose. During the season, any combs that are too old, or which, for some reason or other, are not perfect, whether due to drone-cells or irregularities, can be gradually pushed to the outside of the brood-frames; then in the fall, when it is time to put in the feeder, provided the division-board feeders are used, these defective combs can be very easily taken out to be melted up later, and with no loss of brood. Furthermore, if the colonies need feeding, these outside combs will not contain much honey. On a cool day an outyard can be looked over very quickly, and the old combs that are on the outside of the brood-nest removed with very little trouble. If a follower is used, the removal of one comb and the follower makes room for the feeder; but, if the combs completely fill the hives, two combs must be removed.

The best time of day for putting feed into the feeder is toward the close of the afternoon. It is not advisable to do the work in the morning or early in the day, for the reason that the bees become excited, and robbing might be started, especially if it were warm enough for the bees to fly. Right here is a point in favor of the chilly-weather feeding, for there is no such danger of robbing, of course, when the bees cannot fly on account of the cool temperature.

It is the usual practice to prepare the feed at home and carry it to the yards hot, in the regular five-gallon honey-cans, as these are about the largest-sized cans that can be handled conveniently by one person. If two were doing the feeding a larger can might be used.

While the syrup is still hot it is poured into the cans and loaded upon the auto truck and carried to the outyards. It is then fed while hot.

\section{FEEDING IN FREEZING WEATHER.}

Altho colonies have been wintered well when fed after cold or freezing weather, much the safer plan is to have it all done not later than October, for the northern States, that they may have the syrup ripened and entirely sealed. If the weather is not too cold, one can feed with the frictiontop or Miller feeder as previously intimated. If one has been so careless as to have bees that are in need of stores at the beginning of winter, frames of sealed honey should be given if they can be obtained; and if not, candy is given. See Candy.

If hot syrup is covered with cushions or something equivalent, it may be fed at any time, altho it does not seem to be as satisfactory under all circumstances as combs of sealed stores.

When feeding in cool or cold weather, one is very apt to chill the cluster, or leave openings that will permit the warmth of the cluster to pass off. When colonies first commence raising brood in the spring they need to be packed closely and snugly. Making a hole in the quilt or cushions above the cluster, and placing the feeder over this so as to close it completely, does very well, but is not, after all, as safe as giving the feed from below. For feeding in early spring, where the colony is weak, candy or combs of sealed stores should be given.

\section{FEEDING IN THE SPRING, OR FEEDING ENOUGH IN THE FALL TO LAST TILL THE NEXT HONEY FLOW.}

Some years ago it was the' general practice to feed in the spring to stimulate brood-rearing, such feeding taking place as soon as settled warm weather came on. The purpose of this was to get a large force of young bees for the coming harvest; but in later years the tendency on 
the part of our best beekeepers has been toward feeding enough in the fall to last not only all winter but during the spring and until the honey flow. Experience seems to show that spring feeding very often does more harm than good by over-stimulation. Brood is expanded beyond the capacity of the bees to cover and keep warm. Robbing is often induced. Beginnel's especially are apt to overdo it; and even a veteran will sometimes get his colonies so strong before an extra supply of nectar comes in, that swarming will be brought on prematurely.

This question of feeding leavily in the fall to last until the honey flow the following year, or feeding moderately in the fall and stimulating the following spring, depends somewhat on the locality, and very largely on the man himself. Many beekeepers of experience, especially in some localities, can doubtless practice spring feeding to advantage; but, as a rule, beginners will do better to give all their colonies enough in the fall.

FEEDING AT NIGHT OR DURING A RAIN" WHEN ROBBERS ARE BAD.

During a dearth of honey, when robbers are bad, especially in hot climates, colonies can be fed during a light rain, or at night if it is a case of emergency. When the rain is over, or as soon as daylight comes, the feed will, in all probability, be taken up, and all excitement in the hive be over. When feeding at night, a lantern can be used; but it should be placed some little distance from the hive where feed is being given. A small pocket flashlamp can be used advantageously to place the feeders and to pour the syrup, after which, to prevent attracting bees, the light should be cut off.

In warm or tropical elimates it is never advisable to feed during the day if there is a dearth of honey, as it is liable to stir up the whole apiary, resulting in serious robbing and the destruction of some of the weaker colonies.

As a matter of fact, feeding at all times should be avoided, if possible. It should be considered only as a necessary evil, as a rule. Natural stores are much superior to sugar syrup, except during cold weather when there is no brood-rearing.
FEEDING BACK.-This subject is one interesting a large number of beekeepers in the comb-honey class, the main object, perhaps, being to prevent unfinished sections.

Many who attempt to feed back, fail on account of the many difficulties encountered. J. E. Hand of Birmingham, Ohio, has made a thoro study of this subject, and he finds that, while the work can be profitably done, much attention must be given to the details, since there are many things to take into consideration.

It is more practicable, he says, to use a feeder in which the honey can be given below the brood-chamber instead of on top, as this is the more natural way for the bees, and they take it more read'ly. The Quinby feeder has a tin tray, 2 inches deep, enclosed by a wooden frame of the same depth, which is the same width as the hive, but $2 \frac{1}{2}$ inches longer. The tin tray is exactly the same length as the hive, and when in use is pushed to the back end of the frame surrounding it, leaving a space of $2 \frac{1}{2}$ inches in front for the bees to pass out and into the hive. The other end of the tin tray projects $2 \frac{1}{2}$ inches beyond the hive at the back to allow space for filling it. A framework of slats lengthwise of the feeder sits in the tray for the bees to travel over while working in the feeder so that they may not be drowned. The feeder rests squarely on the bottom-board, and the hive covers the feeder except the $2 \frac{1}{2}$ inches at the back end, which space is covered by a little board. The bees cannot get into the place where the feed is poured in, and the honey (about six quarts) flows evenly under all parts of the hive, where it can be quickly taken up by the bees.

Many fail in their attempt at feeding back because they select the wrong time of the year. It is best to begin right after the main honey flow has ceased before the work in the supers. is over, and use fresh honey the day it is extracted. At this time the bees naturally go right on as tho the flow had not stopped. It is best to give about six quarts of thinned-down honey to each colony every other day. The interval between the feeding allows the bees time to remove the honey from the brood-cells, where it is first placed, to the supers. No definite rule can be given for thinning 
down the honey, since the density varies so much. For average honey enough water must be added so that the syrup will be 75 per cent honey and 25 per cent water. Very thick honey needs more water, while thin honey needs less.

It is necessary to have the brood-chamber well occupied by brood, for bees never do well in supers over brood-chambers containing much capped honey. The first requisite, then, is a good queen, which will be able to hola her own against any amount of feeding. The brood-chamber must be contracted, furthermore, so that the queen will be able to keep every comb filled with brood. In this connection the sectional hive is very convenient for the reason that one section may be removed, thus contracting the brood section and still allowing brood in the shallow frames to be under the entire super. It is quite important, however, to have the combs in the broodchamber as new as possible, for the bees are quite apt to carry up bits of comb to be used in capping cells in the supers, and old dark comb will discolor the supercappings to quite an extent.

The thinned-down honey should be put into the feeder just before sundown, so that there may be no uproar that may cause robbing. It is not desirable to have more than two supers of sections on the fed colonies at a time. As soon as the combs in the super next the brood-chamber are nearly capped, this super should be raised up and the upper one placed under it next to the brood-chamber. As soon as the top super is finished and capped solid to the wood, it may be removed and a fresh super placed next to the brood-chamber. Of course it is not essential that combs be built out and capped solid to the wood. The combs all capped over, except cells next to the wood, would grade No. 1.

\section{CAUTION : FED-BACK COMB HONEY LIABLE TO} GRANULATE.

Under Comb Honey, to Produce, subhead, "Bait Sections," reference is made to the fact that bait sections or fed-back comb honey is more liable to granulate than ordinary comb honey. Dealers have complained that the former granulates very rapidly on their hands; and when they know it they will not accept it unless for immediate sale. It should be sold in one's own locality, and sold as early as possible. While not all of it will granulate, the history of such honey is decidedly unfavorable.

FEEDING OUTDOORS.-After what has been said elsewhere in this work regarding the danger of exposing sweets in the open air during the robbing season, it may seem the height of folly to recommend what appears to be the same thing that has been condemned; but, as will be shown, this outside feeding may be practiced without the bad results that follow from the exposure of sweets under other conditions. It is well known that, when bees are busy in the field in a natural honey flow, hives can be opened without any robbing. Now, then, if the bees can be kept busy by making them go after food, set outdoors, that is of the consistency of raw nectar, much the same result will be artificially accomplished.

But proceeding farther the question may be asked, "Why feed outdoors at all if the proper stimulation can be given by placing the food inside the hives that need it, rather than supplying all colonies alike, irrespective of whether they need stores or not?"

While it is ordinarily better to feed each individual colony according to its needs, there are times when one can feed a whole apiary by placing a weak syrup in an outdoor feeder. At any time when robbers interfere with the manipulations of the colonies, sweetened water outdoors diverts the meddlers by making a sort of artificial honey flow. When the bees can gather anything from the fields they are not disposed to rob. In the same way if the bees can be kept busy artificially, much the same results can be accomplished. This can be done with an outdoor feeder and sweetened water, as explained farther on. If one engages in queen-rearing, or desires to extract when bees will ordinarily rob, an outdoor feeder can be started so that the necessary work can be performed easily and secure from pilfering bees. Again, it will sometimes happen that the whole apiary is on the verge of starvation, and outside feeding can be used to tide the bees over until the expected honey flow starts, 
or until feeders can be installed on the hives and colonies fed in the regular way.

Outdoor feeding ean also be employed to advantage to "call the bees off" when robbing the neighbors' preserves during the canning season. The same calling-off process can be used when the bees are robbing candy-stands or stands where lemonade or cut melons are on display for sale.

Within a quarter of a mile of our home yard there is a fairground, and sometimes we find it necessary, if bees are inclined to rob, to start outdoor feeding the day before the fair opens, and keep it up during the fair. If there is a severe dearth at the time, bees are inclined to meddle with the candy-stands and soda-fountains. While the amount they actually steal is insignificant, their presence "drives away trade."

\section{DISADVANTAGES OF OUTDOOR FEEDING.}

Having said this much in favor of outdoor feeding of a whole apiary, it should be clearly and emphatically stated at the outset that it is an expensive way of feeding bees. When a colony can take the syrup from an ordinary feeder, either at the entrance or on top of the hive, and place it in the combs, the wear and tear on the bees is nothing as compared with that which takes place when the bees are compelled to leave the hives, fly to the feeder, scuffle with each other, and then rush back in pell-mell haste to their hives to unload.

One year, when robbing was very bad, and when we desired to keep on with our queen-rearing operations, we fed for several weeks in outdoor feeders. It was very noticeable that the field bees had their wings badly worn, and at the end of the queen-rearing operations the fielders were conspicuous by their absence, and only young bees were left. While outdoor feeding stimulates brood-rearing, it does so at a large cost. Besides the wear and tear on the wings themselves, there is the labor of reducing a nine-to-one sugar syrup or sweetened water (nine parts of water to one of sugar) to a well-ripened sugar syrup of two and one-half parts of sugar to one of water. When feeding in the hive, the syrup should be never weaker than one part of sugar to one of water; and it is often two parts or even $2 \frac{1}{2}$ parts of sugar to one of water. It will be readily seen that outdoor feeding of bees involves an enormous drain on the colony.

There are also other serious drawbacks to outdoor feeding. It feeds all the bees in the vicinity, the neighbors' included, and might perhaps be instrumental in the spread of foul brood. It also causes a disproportionate amount of syrup to be given to the colonies. The strong ones will have a great deal more than their share, and the weak ones considerably less. By feeding within the hive, one can regulate the supply for each colony or nucleus.

\section{HOW TO FEED OUTDOORS.}

While an expert can set out unfinished sections for bees to clean, as spoken of under the head of Comb HoNer, to ProDUCE, subhead, "Unfinished Sections," the practice on the part of the beginner should be discouraged. But he can feed outdoors without stirring up an uproar by feeding a very thin sylup, about nine parts of water to one of sugar. As already explained, this is virtually sweetened vater. At the beginning a little stronger syrup will have to be made in order to start the bees. Then it can be weakened down to nine-to-one basis.

We prefer the regular trough feeder for the purpose either the Alexander or the Simplicity. Twenty-five or fifty of them will be required, all set out in a row on a couple of $2 \times 4$ scantlings properly leveled up. When these feeders are not available, two or three common washtubs can be used, but the surface of the sweetened water should be covered over with sticks or corncobs to prevent the bees from drowning; and there should not be much more than an inch of liquid in the tubs, or at least not more than will be required to supply the bees all day or as long as it is desired to keep them busy. If the sweetened water is left out over night during warm weather, it is liable to sour, so that a supply greater than the bees can take up for the day should never be given.

To prevent the bees from crowding, it is desirable to use a large surface; hence it is recommended to use two or three tubs with an inch of sweetened water in each rather than one tub with three inches of liquid. When the surface is comparatively small, the bees crowd each other in a way that is 
injurious to their wings; and by spreading the feed no bee will be compelled to crowd against its neighbor.

\section{FENCE.-See COMB HoNEY.}

\section{FERTILE WORKERS.--See LAYING WORKERS.}

FERTILIZATION OF FLOWERS BY BEES.--See Pollination.

FIGWORT (Scrophularia marilandica). -Also called heal-all, square-stalk, and carpenter's square. A strong-smelling herb, 3 to 6 feet tall, with square stems, opposite leaves, and small greenish-purple flowers, growing in woodlands and hedges from Massachusetts to Kansas and Louisiana. The abundant nectar is secreted in two large drops by the base of the ovary. In 1879 a small field of figwort at Medina, O., made a remarkable showing. Honeybees visited the flowers from morning until night during the entire period of blooming. On the average a flower was visited once a minute. After the nectar was removed other drops would exude in about two minutes. At one time this plant excited a considerable furore among beekeepers, as it was thought that for artificial pasturage it would exceed anything then known. The honey obtained would not warrant, however, the large expense of its cultivation. The flowers are also very frequently visited by wasps. Several other species of figwort occur in this country. $S$. nodosa is a European species.

FIRE BLIGHT.-About a score of years ago bees were accused of being a serious factor in the spread of fire blight. Altho this charge was based on wholly insufficient observation and experiment, it was generally accepted, doubtless, as Merrill observes, because bees are so abundant in orchards at blooming time. By tending to check the growth of bee culture this belief has been injurious to both beekeepers and fruit-growers. But during the last halfdozen years evidence has rapidly accumulated, which shows that blight is spread by other agencies and fully exonerates the honeybee.

\section{THE NATURE OF FIRE BLIGHT.}

Fire blight is a bacterial disease, which attacks the twigs and ends of the branches of apple and pear trees and blights the leaves and flowers. If not checked it may extend to the entire branch, or may finally even kill the tree. Usually the infections die out in a few weeks; but, here and there, at the point where the dead limb joins the living wood, a few survive the winter. In the spring they resume their activity and exude a gummy substance filled with germs. They are called "hold-over cankers." From these cankers the germs are widely disseminated thru the orchard, and a new outbreak of blight follows. The question at once arises, what agencies act as carriers of the germs. It is certain that the honeybee is not one of them, for it restricts its visits entirely to the bloom of the trees. There is not a single instance on record of a bee visiting the exuding cankers. Nor is it claimed that it does. During three years' close observation at blooming time W. A. Ruth did not observe a single case of an insect visiting the exuding cankers. It has been suggested that ants, which roam everywhere, may carry the blight bacteria to plant-lice feeding on the leaves; but this supposition does not appear to be based on direct observation. It is probable that the wind, not insects, as will be shown later, is the chief agent in their distribution.

\section{WHEN OUTBREAKS OCCUR.}

There may be repeated outbreaks of fire blight in April, May, June, July, and August; but the chief months for blight are May, June, and July. Thus this disease is by no means confined to the blooming time of the apple and pear. Clearly the appearance of fire blight, when there is no bloom on the trees, can not be attributed to the honeybee, for it can prove an alibi; it is busy elsewhere. Yet these outbreaks are as severe as, or more so than, those which occur in blooming time.

\section{LEAF HOPPERS IMPORTANT CARRIERS.}

In a paper on the control of fire blight by A. C. Burrill, published in Phytopathology, December, 1915, there was described a series of experiments, which shows that aphids, or plant lice, and leaf hoppers carried the infection from blighted leaves to perfectly healthy shoots of the wild crab apple. After five years' experience Bur- 
rill belieres that in the orchards and nurseries of Wisconsin leaf hoppers (Empoasca mali) are the most important carriers of blight during July and August.

\section{PLANT LIFE CHIEF DISTRIBUTORS.}

In Kansas, according to J. H. Merrill, (Bee Inspector's Report, Iowa, 1916, page 33) plant lice, which are the most common and widespread sucking insects in Kansas orchards, have been found to be the chief distributors of blight bacteria. Aphids, which had been permitted to crawl thru pure cultures of fire blight, were then placed on terminal twigs and enclosed in cheese eloth to exclude all other insects. These twigs blighted and were the only ones that did. Furthermore, it has been observed that in seasons during which plant lice are most abundant, fire blight is also most prevalent. In 1913 in Kansas orchards they were very common and so was fire blight; but in orchards in which they were controlled there was little blight. In 1914 there were few aphids and little blight, and this reciprocal relation was again noticeable in 1915 and 1916. Merrill says that the amount of blight can be decreased by controlling the aphids. Stewart also observed that in apple nurseries fireblight epidemics follow rapidly in the wake of aphid epidemies.

\section{SUCKING INSECTS IMPORTANT DISTRIBUTORS.}

In New York orchards in July, according to Stewart, the tarnished plant bug and several other sucking insects are important distributors of blight. Finally D. H. Jones has added to the list a beetle of the genus Scolytus, and on further observation many other insect carriers will doubtless be discovered. There is no lack of puncturing and biting insects in immense numbers, which, it is certain, are active in spreading fire blight.

\section{BEES NEVER PUNCTURE LEAVES.}

It will be noticed that all the insects mentioned in the two preceding paragraphs have mouth-parts, which can puncture or bite thru the epidermis of the leaf. In this way the germs are placed in the tender tissues, multiply rapidly and produce infection. "Insects," says Merrill, "with sucking month-parts are admirably suited to this purpose." Stewart and Leonard state that except for blossom blight the bacteria can not gain an entrance in the host tissue and produce infection except thru a wound or the punctures made by insects. Honeybees never puncture the leaves; indeed, under normal conditions they never visit them; nor do they puncture the flowers of the apple or pear, for the nectar is easily accessible on a flat disc. If, however, blight is chiefly distributed by the wind, the pricking in of the germs, altho a great advantage, is not an actual necessity.

\section{AN ALIBI FOR BEES.}

It is clear that all infection of the leaves and twigs must be due to other agencies than the honeybee, since the latter confines its visit strictly to the flowers. Furthermore, since bees visit the trees only during blooming time, it is only during about two weeks out of 14 or 15 that it can be accused of being a carrier of blosson blight. Let us now inquire if honeybees are responsible for the spread of blossom blight. As they do not visit the foliage they can not be the agency, which, in the first place, brings the blight to the bloom. In Kansas orchards, Merrill states, this is done by plant lice, which in large numbers enter the apple buds and suck their juices before they open, at the same time inoculating them with blight bacteria. Thus the flowers blight in the bud before bees begin their visits. Once the bloom is blighted it is no longer attractive to honeybees; for, if we remove the petals of a healthy pear blossom, bees will at once cease to visit it, altho they will continue to visit other flowers near by. Twenty-three pear blossoms received 24 visits from honeybees in half an hour; the writer then removed all the petals and in the half hour following there was not a single visit, altho the denuded blossoms contained nectar and the bees often visited other flowers near them. Thus bees might fly indefinitely between the uncontaminated blossoms without disseminating the blight. But it must be remembered that the bloom is visited by many insects besides bees, especially by flies and beetles which do not exhibit flower fidelity. As they alight on the leaves both in search of food and by chance, and will freely visit the blighted blossoms, they can not fail to 
spread the blight among the flowers. Incidentally it may be remarked that not all blighted pear blossoms are the result of fire blight. In the Hudson Valley, according to Dr. E. Porter Felt; the injury is caused by pear thrips. These little insects, which are about 1-20 of an inch long, appear on the trees as the buds start and seek shelter in the expanding flower buds, blasting the bloom, which presents a brown seared appearance.

\section{SUMMARY OF ABOVE OBSERVATIONS.}

A brief summary of the above statements is as follows:

1. Fire blight appears both before and after pear and apple trees bloom, and in nursery plantations which have never bloomed. With such outbreaks the honeybee has no connection. 2. It has been shown experimentally that fire blight is spread by hosts of sucking and biting insects, such as plant lice, leaf hoppers, the tarnished plant bug, and probably many flies and beetles which puncture or feed on leaves and flowers. 3. Since honeybees restrict their visits to flowers they do not earry hlight from the foliage to the bloom. This is done in many instances by plant lice, which creep in and infest the buds before they expand; and also doubtless by many flies and beetles which fly freely back and forth between the leaves and the bloom. Honeybees will not visit blighted inconspicuous bloom, but flies will often do so. While honeybees may occasionally carry the germs, they are of so little importance compared with other distributors that their absence from orehards would probably not affect the prevalence of blight.

\section{PEAR BLIGHT WIND BORNE.}

At this point the defense of the loneybee against the accusation of earrying fire blight rested up to Nov. 1, 1918. On this date there appeared in Science a paper by F. L. Stevens, W. A. Ruth, and C. S. Spooner of the University of Illinois, entitled "Pear Blight Wind Borne," which advanced new and revolutionary evidence in favor of bees. A brief abstract of this paper, given largely in the words of the authors, is as follows: Twelve-mesh wirescreen cylinders, $15 \mathrm{~cm}$. in diameter and $30 \mathrm{~cm}$. long were constructed to enclose parts of single branches. Some of the cylinders were slipped into closely fitting sleeves of fine bolting eloth. The ends of both kinds of cylinders were covered witl canvas extending past the wire far enough to permit secure tying. The exposed wire of the first type of cylinder was painted with a mixture of tanglefoot and benzine. No insects were found in any of the cylinders except one which was accidentally permitted to dry, and in which two insects were found, but the shoot did not blight. The purpose of the following experiments was to discover whether infection was as common in the cylinders as in the open. Ten cylinders enclosed flowering wood. Flower's in two of the eages blighted. Forty cylinders, 20 of the bolting eloth and 20 of the tanglefoot type, enclosed terminal growtli. Thirty per cent blighted, which was practically the same proportion as prevailed among the unenclosed terminal shoots, as was shown by a count of a thousand terminal shoots on these and adjacent trees of the same variety and age. Since insects did not obtain access to the shoots the blight bacteria must have been carried by the wind; and "insects were not even of primary importance as carriers." This conclusion was further supported by two facts: (1) there was a lack of insects in the orchard in sufficient numbers to account for the large amount of twig blight -aphids and leaf hoppers were entirely absent during the period of infection; (2) insects were entirely absent from the exuding cankers, where they might receive their initial contamination. During three years of close observation during blooming time not a single insect was seen to visit the cankers.

\section{FIREWEED.-See WILLOW-HERB.}

FIXED FRAMES.--See Frames, SelfSPACING.

FLIGHT OF BEES.-The distance bees go in quest of stores varies very greatly according to conditions. Usually on level country, more or less wooded, they do not go over one and one-half miles. If, however, there is a dearth of pasturage within that distance, and plenty of it along some river bank three to five miles away, they may or may not go that far. When bees 
go out after stores they evidently try to find their nectar as near the hive as possible. They will not go over half a mile if they can get a sufficient supply within that distance; but in most cases that range does not supply enough pasturage, and it is evident they keep increasing their flight until they go as far as one and one-half miles. If they are unable to secure enough, and if there is forage on beyond, they often go farther.

Bees will sometimes fly over a body of water or a valley from an elevation three or even five miles, particularly if there are fields in sight that are somewhat showy. Whether they have a long-range vision or not has not been proven; but the fact that they will find white patches of buckwheat five miles away across a valley is somewhat significant. In a like manner they will go across a valley four or five miles to orange bloom in California. Whether they are guided by sight or smell in either case is difficult to prove; but it is quite probable that a breeze will carry the odors of a buckwheat field or of an orange grove in full bloom to bees five miles away. While we might not be able to detect odors at such a distance, the scent organs of the bee are much more acute than ours; and they might and probably would get a knowledge of its presence in a given locality.

As a general rule, as stated at the outset, bees do not fly much over one and one-half miles. Where they have to go greater distances their wings sometimes show wear, especially if they have to pass thru shrubbery.

We once had one yard located in an aster district. The supply of nectar gave out in the near-by fields; but we traced some of the bees of that yard to asters five miles away. That fall there was a very rapid decimation of bees. Colonies that were strong just before the asters came into bloom dwindled down to three and two frame nuclei. The surviving bees had their wings badly frayed. The presumption is that in dodging thru and over shrubbery in their long flights they tore their wings more or less, with the result that large numbers of them never got back home.

When bees are going to and from the field, they fly as low as possible to avoid the wind. Instead of flying over shrubbery they will dodge thru it for forage on the other side. At other times they will fly over it. We have observed, however, at one of our yards, that bees would go no farther than a piece of woods half a mile away. The probabilities are that, on rising to the height of the trees, they encountered a current of wind in the opposite direction. It is a well-known fact that bees can not fly against a strong wind.

\section{THE RANGE OF FLIGHT AND ITS RELATION TO} OUTYARDS.

In the location of outyards one should take into consideration the general lay of the land and the character of possible beeforage. In ordinary white clover regions where there are patches of woods, buildings, or much shrubbery, bees do not fly much over one and one-half miles; but when clover ceases to yield, and basswood can be found two or three miles away, those same bees will fly farther; and when conditions are right, they will fly from three to five miles, and even seven miles across a body of water. But locations that furnish such long ranges are very rare.

The flight of bees will determine somewhat the size of the beeyard. If they do not go farther than one and one-half miles, probably not more than 50 colonies can be kept in the location, and possibly 30 would be better.

In some parts of the country as inany as 500 colonies can be kept in one place. The late E. W. Alexander kept 500 colonies at Delanson, N. Y., on a hill overlooking a valley. He traced his bees five miles from home many times, and secured large crops of honey. J. F. MeIntyre, at his celebrated Sespe apiary near Ventura, Calif., kept over 500 colonies. (See ApIAry.) In both of these cases it is evident that the bees would have to fly at least five miles in order to get the proper yield per colony. When an apiary of 50 colonies secures a good yield, the presumption is that the bees do not fly very far; and it sometimes happens that 30 colonies will do better than 50. In that case they should be located about three miles apart, making a radius of flight of one and one-half miles.

FOOD VALUE OF HONEY.-See

HONEY AS A FOOD. 
FOUL BROOD.-The term foul brood covers two brood diseases-one known as American, or the old-fashioned diseased brood, caused by Bacillus larvae, and one the European, a disease of comparatively recent introduction, caused by Bacillus pluton. There is some evidence to show that European foul brood was present in this country as early as 1890 ; but it was not until 1899 that the author discovered that there are two distinet foul brood diseases here. (See Gleanings in Bee Culture, page 858, for 1899.) Shortly after, others, including the foul-brood inspectors of $\mathrm{New}$ York (where the European foul brood was first found), also recognized the difference.

\section{AMERICAN FOUL BROOD.}

The American foul brood, often called "ropy" foul brood, because the dead matter assumes a gluey, sticky, tenacious character, was well known in Europe, and has been referred to by Dzierzon and other writers. But Moses Quinby of St. Johnsville, N. Y., was the first one to recognize it in the United States and prescribe for its cure. The Quinby cure is the basis of the only successful mode of treatment known and recognized today.

As a general rule, the beekeeper will not discover it in its incipient stages. He is not expecting it, and, if it comes, does not see it. His first intimation of its presence will be occasional cells of sealed brood showing sunken, greasy cappings and cells with irregular perforations. American foul brood is confined mainly to brood that has died after the cells have been sealed; but 25 or 30 per cent of unsealed cells will show dead brood, and the dead larvæ in both sealed and unsealed will vary in color from a yellowish brown to a dark brown, and finally to a brownish black. The larva that has just died holds its shape. As the disease advances it begins to shrink, and the dead matter becomes so rotten and putrid that the skin breaks, and on the lower side of the cell is seen a melted-down mass of matter that is very ropy-that is to say, sticky and tenacious. As this dries down it forms a hard scale that sticks tightly to the cell wall. These scales are not readily seen by looking straight into the cells; but if the top of the comb is tilted toward the observer and held so the light will shine into the cells, the scales can be seen on the lower cell wall. In American foul brood the scales lie in uniform position (Figs. e, i, p, s, page 368), while in European foul brood their position is somewhat irregular. The scale of European foul brood does not adhere so tightly and may be removed. The worst specimens of American foul brood are usually found in the cells that have been sealed, altho the melted broken-down form of larvæ will be found in some unsealed cells.

The initial stages of American foul brood are usually confined to the sealed cells. After the disease has advanced so that 75 per cent of all the sealed brood in a comb is affected, there will be found quite a sprinkling of stray cells of young larvæ that have never been capped orer that are dead. But usually the grub will be almost fully grown before it dies in the unsealed cell, tending to show that American foul brood does not usually kill the larva until after it is sealed in the cell, or just before that sealing.

European foul brood in its first stages is usually confined to the unsealed cells. The dead larva will have a light-yellow color instead of a brownish-dirty one verging on to very nearly black. The American may be found at any time of the year when brood-rearing can take place; but the European usually-shows up at its worst early in the season, and before the main honey flow.

One may find occasional dead larvæ just before sealing that do not indicate disease of any sort. A few such scattered over the combs may be due to starvation-that is, improper feeding. This occur's occasionally when there is too much brood for the number of nurse bees to the hive. One will occasionally find dead brood, due to chilling or overheating. When the brood area expands too fast in the spring, an occasional cold night will cause the cluster to contract, leaving some of the brood uncovered. This chills and dies, and is carried out and deposited at the entrance. The larvæ will be white or slightly grayish, but not brown or yellow as in either of the foul broods. All sucl dead brood should be carefully distinguished from brood affected with either European or American foul brood. If, after a week or two, no 


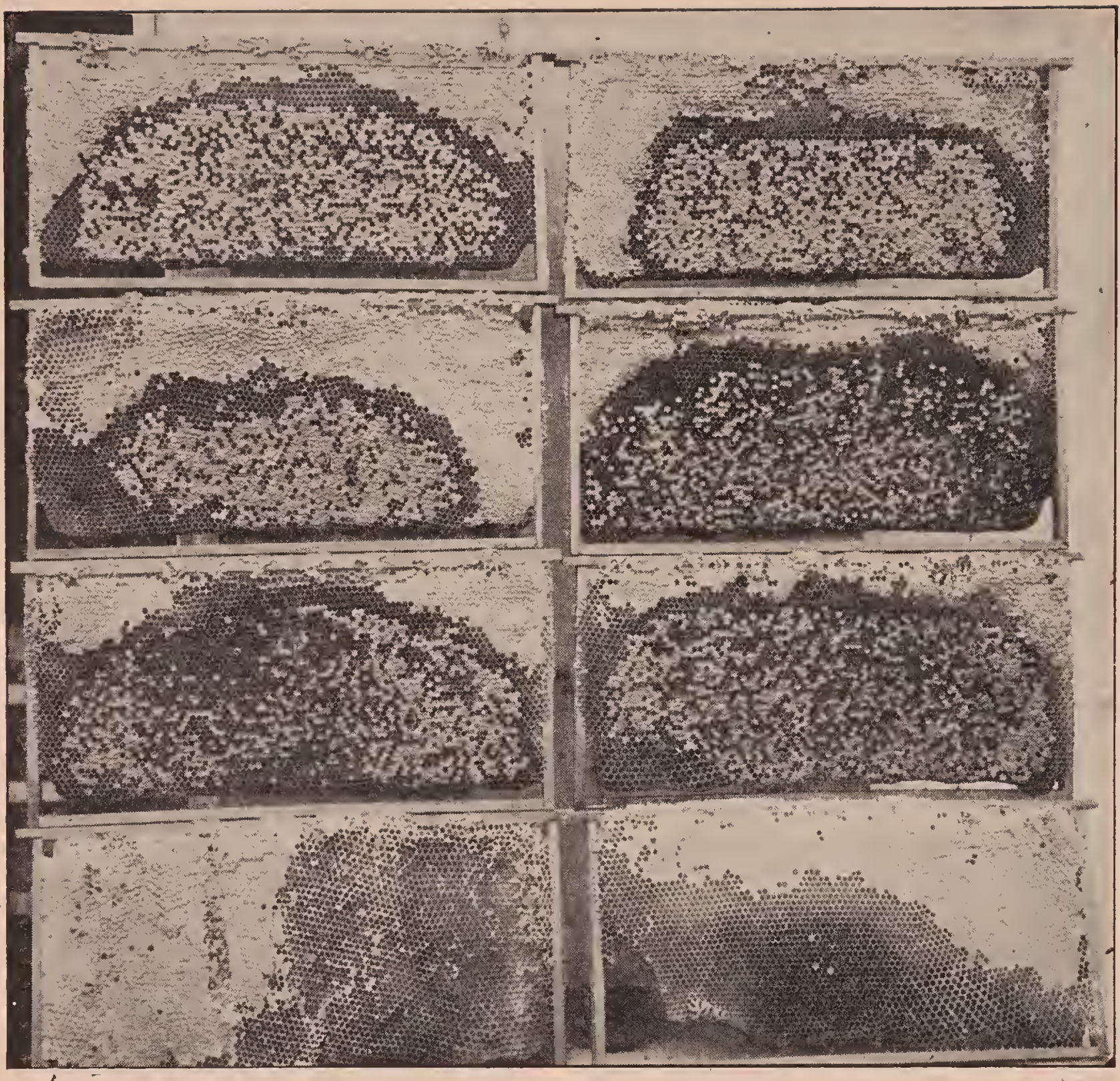

Combs showing the irregular, mottled, scattered cells with their perforated and sunken cappings of American foul brood.

more dead larvæ appear, one may assume there is no disease.

On the other hand, if one finds larvæ that are dead and an increasing number of them as the days go by, especially if they are brown or yellow, he may suspect trouble. If the dead larvæ seem to melt down, lying on the lower side of the cell, and if, further, they turn yellow or brown, and take on a tenacious, gluey consisteney, it is an indication of American foul brood. If a common toothpick, thrust in to the dead matter, and given a little twist, and drawn out, leaves a fine thread two or three inches long, it is an indication of American foul brood. If nearly all the dead larvæ, especially those in sealed cells, show this ropy or stringy appearance the indication of American is very much stronger. In this connection it should be stated that European foul brood in some stages will rope; but the thread is coarser, somewhat lumpy, and is more of a salve-like consistency. Only occasional cells will show a tendency to rope, and even then after considerable poking. The occasional ropy cells prove nothing.

The roping test, alone, must not be considered as conclusive that the disease is American. If, after a few days, some of the dead matter dries down into a hard scale so that it can not be removed without destroying the cell to which it is attached, one may conclude that he has real American foul brood. While the scale of European will dry down, it seldom or never adheres tightly to the cell wall. Once more: 
If, on careful examination, one finds here and there a few dead pupæ-that is, young bees almost fully developed-lying on their backs with their tongues projecting upward, sometimes full length and sometimes half way, he may be reasonably sure that he has the American before him. Sometimes these upwardly projecting tongues seem to be glued to the upper wall of the cell. Sometimes they project upward only half way; but wherever these projecting tongues are found it is a pretty sure indication of American foul brood. So far as the author knows, these projecting tongues are never found in the European.

The name "foul brood" suggests a foul odor. In the case of American the smell is very much like that of a cabinetmaker's gluepot. With European there is a sour or musty smell in the first stages. In the later stages of European the odor is very bad, reminding one of dead fish or old carrion that has been allowed to stand for a considerable length of time. The odor of American foul brood is not nauseating, but nevertheless it is quite characteristic. Neither is the odor of European foul brood nauseating in its early stages. Sometimes it is very hard to detect any odor. In the later stages of European the odor is "just awful." It seems to be a combination of the odor from dead animals or fish, with the suggestion of ammonia and of decay.

One who is expert can very often locate the disease by these odors; but it should be remembered that the odor alone is by no means conclusive; but in connection with the other symptoms it is very helpful in enabling one to decide what form of brood disease he has.

On one occasion the author located a colony having foul brood by an occasional whiff he could catch at the entrance; but it was nearly a week after that when he found one cell containing dead matter. Apparently, the colony had nearly cured itself. But there still remained a characteristic odor which could not be eliminated. Experience shows that a colony which seems to cure itself does not stay cured. The stock may be vigorous enough to keep the disease down, to some extent; but an occasional cell will manifest itself for several vears, and in the mean time be a constant source of infection to all the rest of the apiary. There might be some colonies that would not be able to resist, hence the danger.

\section{THE ODOR OF DEAD BEES LIKE THAT OF} AMERICAN FOUL BROOD.

Sometimes one can detect a gluepot odor at the entrance of one of the hives. He may be alarmed and conclude that, because he has perceived the unmistakable smell, the disease is surely present in his apiary. This fear will be dissipated if he understands that the same foul-brood odor, or at least one very much like it, may liave come from a lot of putrid dead bees after a severe winter. These dead bees may be found in the hive or at the entrance. Again, orerheated brood or chilled brood, if neglected until it fairly rots, will give off a similar odor.

\section{PINHOLE PERFORATIONS.}

There is a kind of pinhole perforation that does not signify anything wrongindeed, quite the contrary. As bees seal up their brood, there is a stage when there will be a small round hole in the center of the cap. Sometimes these holes are not closed up, and then there is what is called bareheaded brood. But the perforations in bareheaded brood are very different from the perforations in cells containing foul brood, either American or European. The bad cells will have sunken cappings. The perforations are ragged, triangular, and the edges appear to be somewhat greasy, while in the perforations in bareheaded brood the cappings are slightly convex, and the hole is circular.

HOW AMERICAN FOUL BROOD IS CARRIED TO NEIGHBORING HIVES.

When a colony is badly affected the disease has progressed to such a stage that the probabilities are that other colonies in the same locality are affected, especially those having entrances pointing in the same direction or similarly located. At this point the beekeeper should be warned that colonies next to the one badly affected are very apt to show the disease. This is explained on the ground that young bees, and even the adult ones become more or less confused at their entrances, and so get into 
the wrong hive. As they do not ordinarily show any of the manifestations of ordinary robbers, they are admitted. If they carry honey from an infected colony, as many of them do, they will tranșmit the disease as soon as they give pap made out of such honey to young brood; and that explains why there will be only a single cell or a group of cells, perhaps, one square inch that will have foul brood, while all the rest of the brood in the hive is perfectly normal. If one can be sure that the comb containing the diseased cell or cells is the only one affected, the removal of that comb may effect a permanent cure. As will be stated further on, all such colonies should be carefully watched to see that the disease does not develop later on.

\section{THE TREATMENT AND CURE OF}

\section{AMERICAN FOUL BROOD.}

At the outset the Quinby method was spoken of as being the basis of the most successful treatment for American foul brood. This plan involved the melting-up of the old combs (shaking bees into clean hives) and compelling the bees to start anew. As this treatment was described before foundation was known, of course no mention of it was made. Practically the only improvement over the Quinby treatment is giving the bees starters or full sheets of foundation instead of empty frames with mere wooden guides. In more recent times the late $\mathrm{D}$. A. Jones of Beeton, Ont., gave out what he called the "starvation" plan. It involved the same principles as the Quinby treatment, with this difference, that he shut the combless bees, after shaking, in a large wire-cloth box or a box with wire-cloth cover, and set it in a cool place until the bees had consumed all the honey in their honey-saes. His idea was to eliminate all possible sources of infection before the bees were put on frames of foundation and fed. The treatment worked admirably; but it was found in later years that it was not necessary to starve the bees -that they would use up any infected honey that they might have in their sacs in drawing out foundation, provided the hive had no combs. Later, William MeEvoy of Canada, who had then recently been appointed foul-brood inspector for Ontario, had been very successful in shak- ing the bees into their own hives, and giving them frames of foundation starters. They were allowed to build combs on these for four days. His idea seemed to be to let the bees use up the infected honey in building the combs and storing it in the built comb. These combs supposed to contain infection were then removed, and the colony was given full sheets of foundation. But experience has shown in thousands of cases that it is not necessary to remove the first set of combs built on foundation starters, and tliat such removing involves a large amount of waste; and that, when the second set of foundation is given, the bees are in a demoralized condition, and quite inclined to swarm out.

Years ago, when an apiary of the publishers had foul brood, they shook 80 colonies and gave then only one set of frames with full sheets of foundation in clean hives. The treatment was a success in every case. Altho the author lias prescribed this same treatment in hundreds if not thousand of cases, he has never had one report saying that the disease had returned. The bees, as a matter of fact, will either consume or use up all the infected honey in drawing out the first set of foundation; and it is very important to give the bees either a clean hive or disinfect the old one. When he shook into the old hive the disease came back in some cases. This disinfecting may be best accomplished by scorching the inside of the hive with an ordinary blow torch, such as is used by telephone men and painters to remove paint from a house; or it may be accomplished by smearing the inside of the hive with kerosene, touching a lighted match to it, and letting it burn until the inside of the hive is charred to a light brown. The fire may be easily quenched by using a little water and putting on the cover immediately. The steam, generated when the cover is clapped down, immediately puts out the fire. But there may be an objection to kerosene leaving an offensive odor in the hive. Another plan is to use a handful of common dry straw, setting it on fire, and then with a stick poke the burnin 9 straw around the hive so that every portion of it will be slightly scorched. The straw should be dumped out and a little water dashed in the hive. 
The shaking treatment, to be carried out as it should be, requires some precaution to prevent absconding. The Bureau of Entomology has recommended a mode of procedure which the author most thoroly indorses. As government experts have made foul brood a more careful study than any other men in the United States, the reader should follow faithfully the treatment recommended in Farmers' Bulletin 1084, "Control of American Foullbrood," by Dr. E. F. Phillips, in Charge of Apiculture, Bureau of Entomology. For convenience of the reader we give it here.

\section{SHAKING TREATMENT.}

The shaking treatment consists essentially in the removal of all infected material from the colony, and in compelling the colony to take a fresh start by building new combs and gathering fresh stores. This is done by shaking the bees from the old combs into a.clean hive on clean frames.

Time of Treatment.-The shaking treatment should be given during a flow of honey, so that other bees in the apiary will not be inclined to rob. If this is not possible the operation may be performed under a tent made of mosquito netting. The best time is during the iniddle of a clear day when a large number of bees are in the field. It is sometimes recommended that shaking be dome in the evening, but this is impossible if many colonies are to be treated. The colony can be handled more quickly when the field force is out of the hive.

Proparation.-All implements that will be needed, such as queen and drone trap, hive tool, and lighted smoker, should be in readiness before the operation is begun. A complete clean hive with frames is provided, as well as a tightly closed hive body in which to put the contaminated combs after shaking. An extra hive cover or some similar apparatus should be provided to serve as a runway for the bees as they enter the new hive. The new frames should contain strips of comb foundation from one-fourth to one inch wide. Full sheets are not desirable, and if combs built on full sheets of foundation are desired they may be built later.
Operation.-The old hive containing the diseased colony ( $A$, cut below) is lifted to one side out of the flight of returning field bees, and the clean hive (B) set exactly in its place. The cover $(G)$ is now taken off and a few frames (E) removed from the center of the hive. If unspaced frames are used, those remaining in the hive should be pushed tightly to either side of the hive, thus making a barrier beyond which the bees can not crawl as they move to the top of the hive after shaking. This largely prevents them from getting on the outside of the hive. If self-spacing frames are used, a couple of thin boards laid on the top-bars on either side will accomplish the same result. The runway (D) is put in place in front of the entrance. The old hive is now opened for the first time. The frames are removed one at a time, lowered part way into the new hive, and with a quick downward shake the bees are dislodged. The frames are then put into the extra hive body (C) and immediately covered to prevent robbing. After all the frames are shaken the bees remaining on the sides of the old hive (A) are shaken out.

If honey is coming in freely, so that thin honey is shaken out of the combs, cover the runway (D) with newspapers and shake the bees in front of the new hive (B), leaving all frames in place and the cover on. After the operation the soiled newspapers should be destroyed. In shaking in front of the entrance the first one or two frames should be so shaken that the bees are thrown against the entrance, where they can locate the hive quickly. They then fan their wings and the others follow them into the hive. If this is not done the bees may wander about and get under the hive or in some other undesirable place.

After the bees are mostly in the new hive a queen and drone trap (F) or a strip of perforated zinc is placed over the entrance to prevent the colony from deserting the hive. The queen can not pass thru the openings in the perforated zinc and the workers will not leave without her. By the time that new combs are built and new brood is ready to be fed, any contaminated honey carried by the bees into their new hive will have been consumed and the dis-

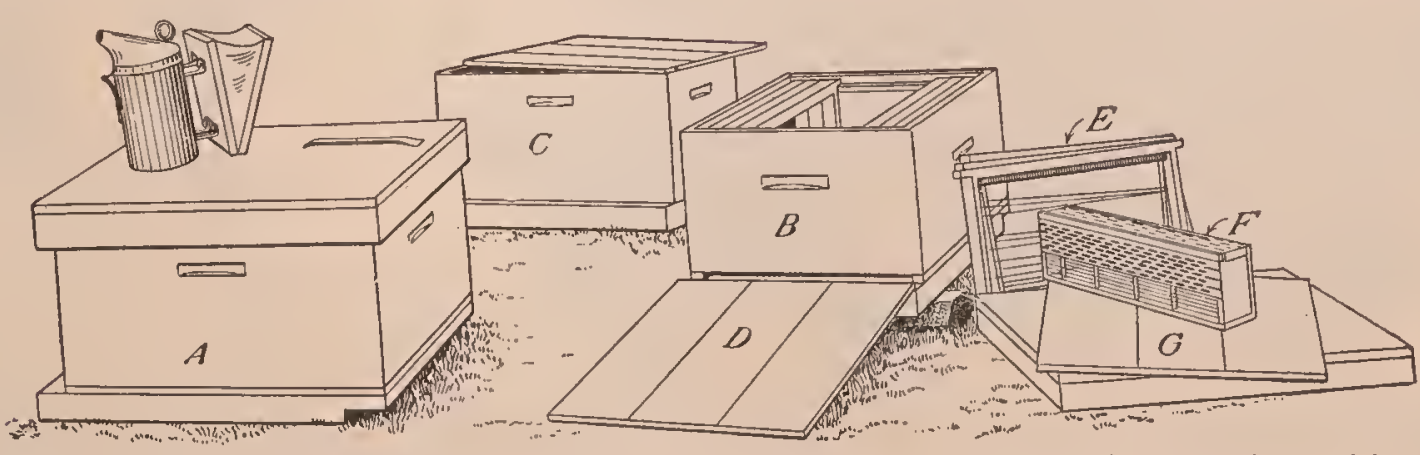

Apparatus for shaking treatment: $A$, Hive containing diseased colony (formerly in position of $B$ ) $B$, clean hive; $C$, empty hive to receive combs after shaking; $D$, hive cover used as runway; $E$, frames ro. moved from $B$ to give room for shaking; $F$, queen and drone trap; $G$, cover for clean hive, $B$. 
ease will rarely reappear. If it should, a repetition of the treatment will be necessary.

saving the Healthy Brood.-The old combs are now quickly removed. If several colonies are being treated at one time it may

old combs. After the contaminated frames are taken to the honey-house the combs should be kept carefully covered, so that no bees call reach them until the wax can be rendered. This should not be delayed very long or the combs may be ruined by waxmoths. The slumgum or refuse remaining

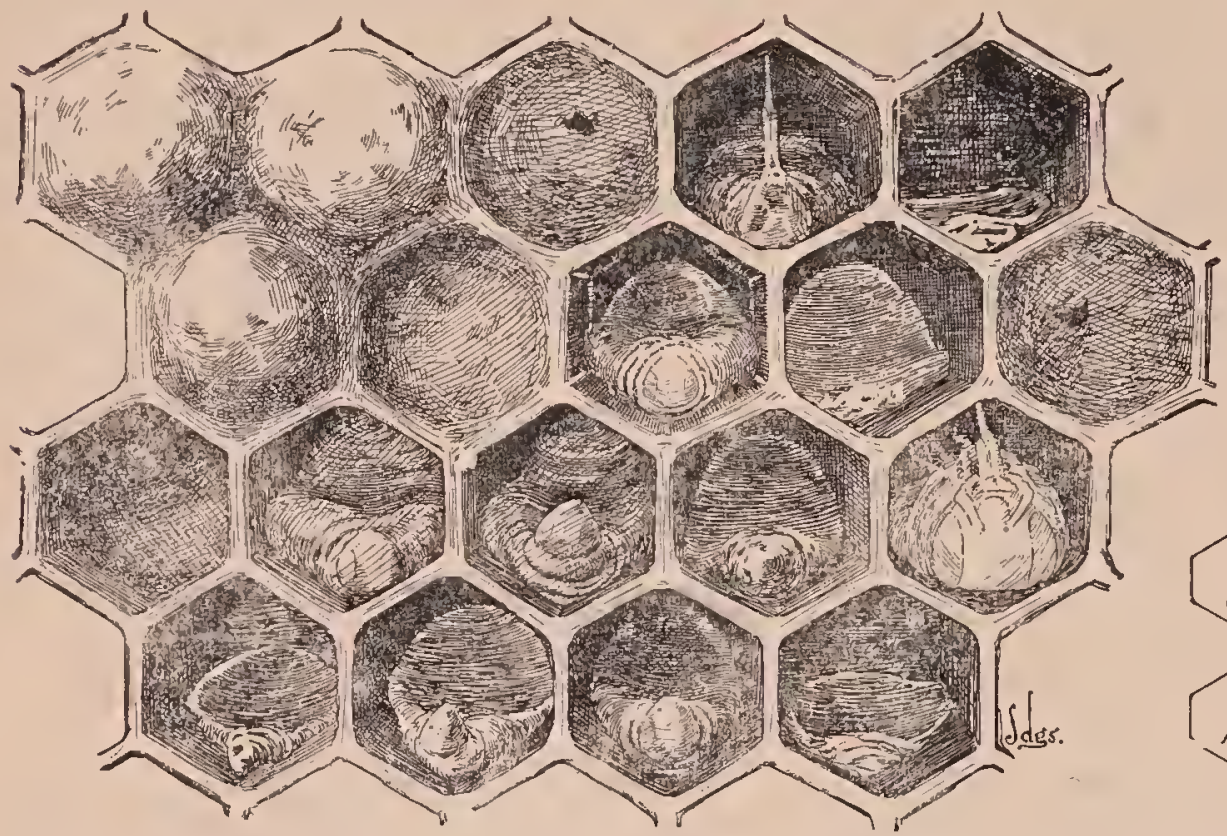
after the wax is removed should be burned. Contaminated combs should not be put into a solar wa $\mathrm{x}$-extractor for fear of spreading the disease. The wax f r o m contaminated combs may safely be used for the manufacture of co $\mathrm{mb}$ foundation.

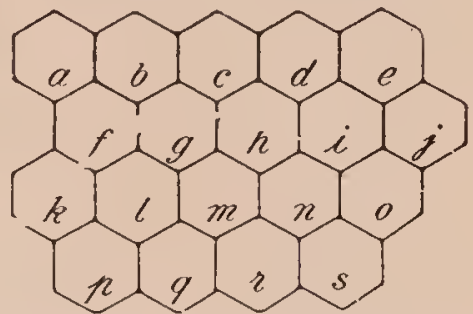

American foul brood: $a, b, f$, normal sealed cells; $c$, $j$, sunken cappings, showing perforations; $g$, sunken cappings not perforated; $h, l, m, n, q, r$, larve afferted hy disease; $e . i, p, s, s c a l e s$ formed from dried-down larre; $d$, 0 , pupre affected by disease. Three times natural size. (Original.)

pay to stack several hive bodies containing contaminated combs over a weak diseased colony to allow most of the healthy brood to emerge, thereby strengthening the weak colony. [Unless there is a heavy flow of honey at the time, the entrance to this colony should be contracted, for robbers would be apt to spread the disease.-Ed.] After 10 or 12 days this colony is treated in turn and all the combs rendered into wax. If only one or two colonies in a large apiary are bring treated it will not pay to do this.

Melting the Ertrating Combs.-Since the extracting combs have not contained any of the diseased larvae, many beekeepers ask whether it is neeessary that these be melted up, or whether it is safe to use them over other colonies. In some cases such combs may be used, as in colonies where there is only a little of the diseased material or where no honey has been coming to the hive since the disease was contracted. The saving of such combs, however, is extremely dangerous, and such a policy is not to be advised. The beekeeper who takes all the precautions which it is possible to take is the one who most quickly and cheaply eradicates American foul brood from his apiary.

Saving the Wax.-Any but a very small apiary should have included in its equipment a wax-press for removing wax from
Cleuniny the Hive.-The hive which has contained the diseased colony should be thoroly cleaned of all wax and honey, and it is desirable that it be carefully disinfected by burning out the inside with a common gasoline blue-flame torch. If this piece of apparatus is not available several hive bodies may be piled together on a hive bottom and some gasoline or kerosene poured on the sides and on some straw or excelsior at the bottom. This is then ignited; and after burning for a few seconds a closefitting hive cover is placed on top of the pile to extinguish the flames. The inside of the hive bodies should be charred to a light brown. The careful cleaning and disinfec-

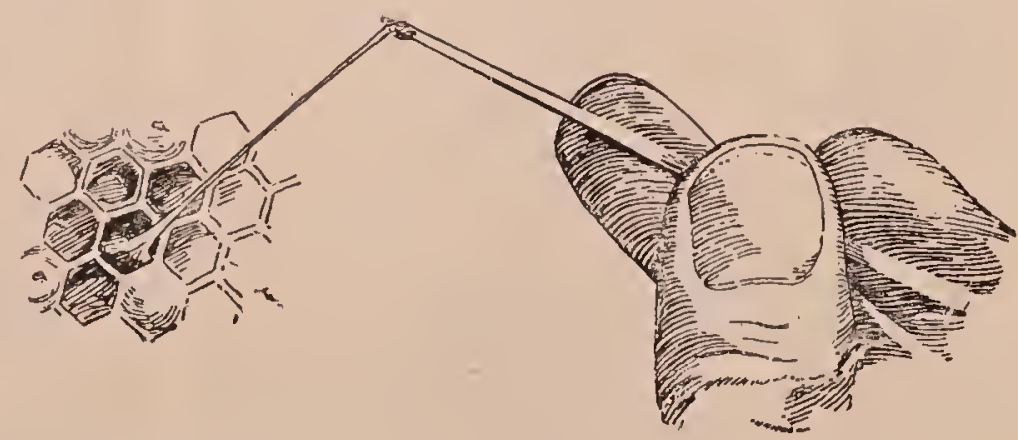

The ropiness of American foul brood. (Original.) tion of frames always cost considerably more in labor than new frames would cost. but these may also be carefully cleaned and used again. Frames may be cleaned by boiling in water for about half an hour, but 


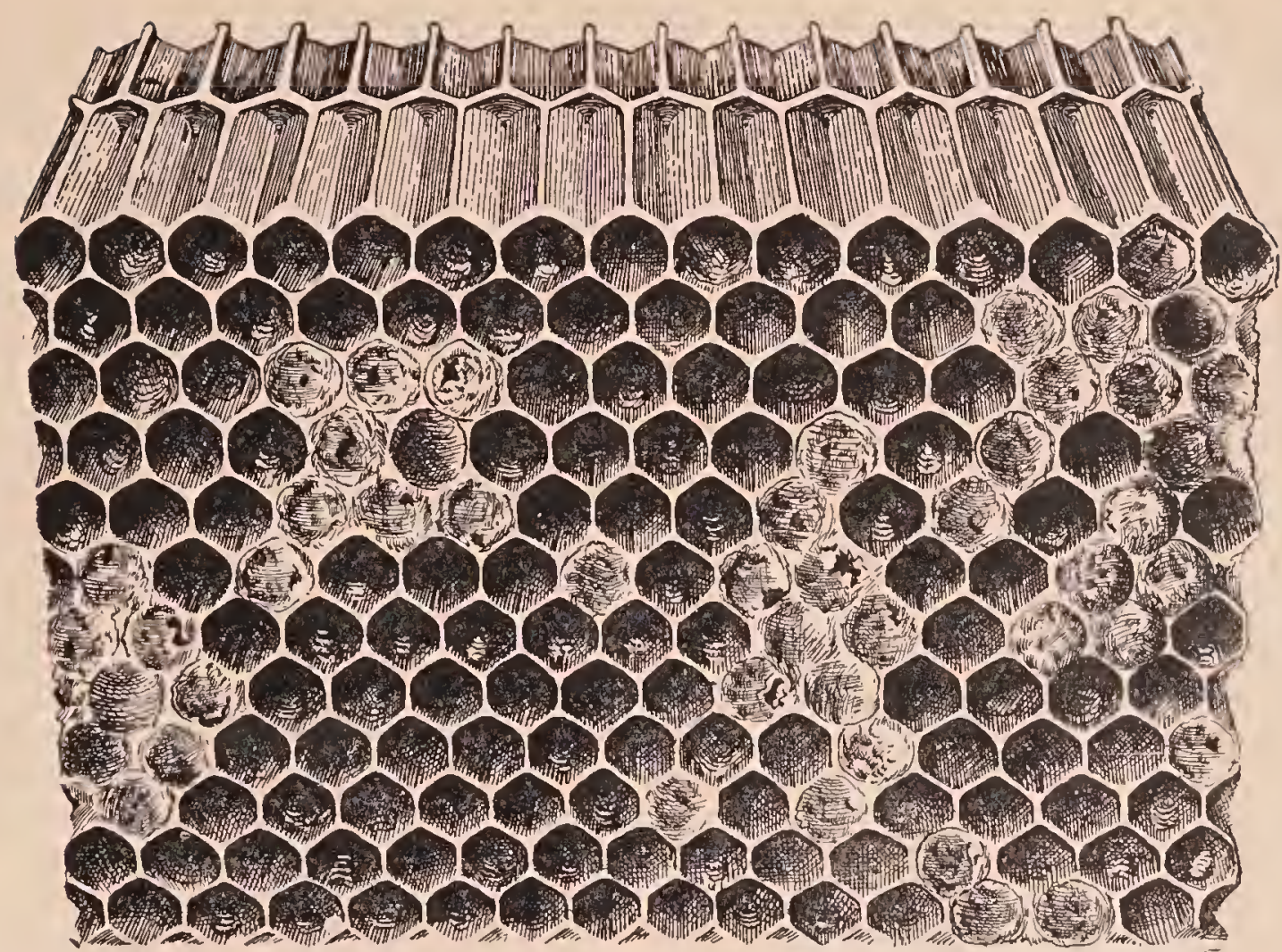

American foul-brood comb, showing irregular patches of sunken cappings and scales. The position of the comb indicates the best way to view the scales. (Original.)

this frequently causes them to warp badly. The disinfection of hives and frames with chemicals is not recommended, as the ordinary strengths used are valueless for the purpose.

Disposal of the Honey.-If there is a considerable quantity of honey in the contaminated combs, it may be extracted. This honey is not safe to feed to bees without boiling, but it is absolutely safe for buman consumption. If there is a comparatively small quantity it may be consumed in the beekeeper's family, care being taken that none of it.is placed so that the bees can ever get it.

To place such lioney on the market is contrary to law in some States. There is always danger that an emptied receptacle will be thrown out where bees can have access to it,
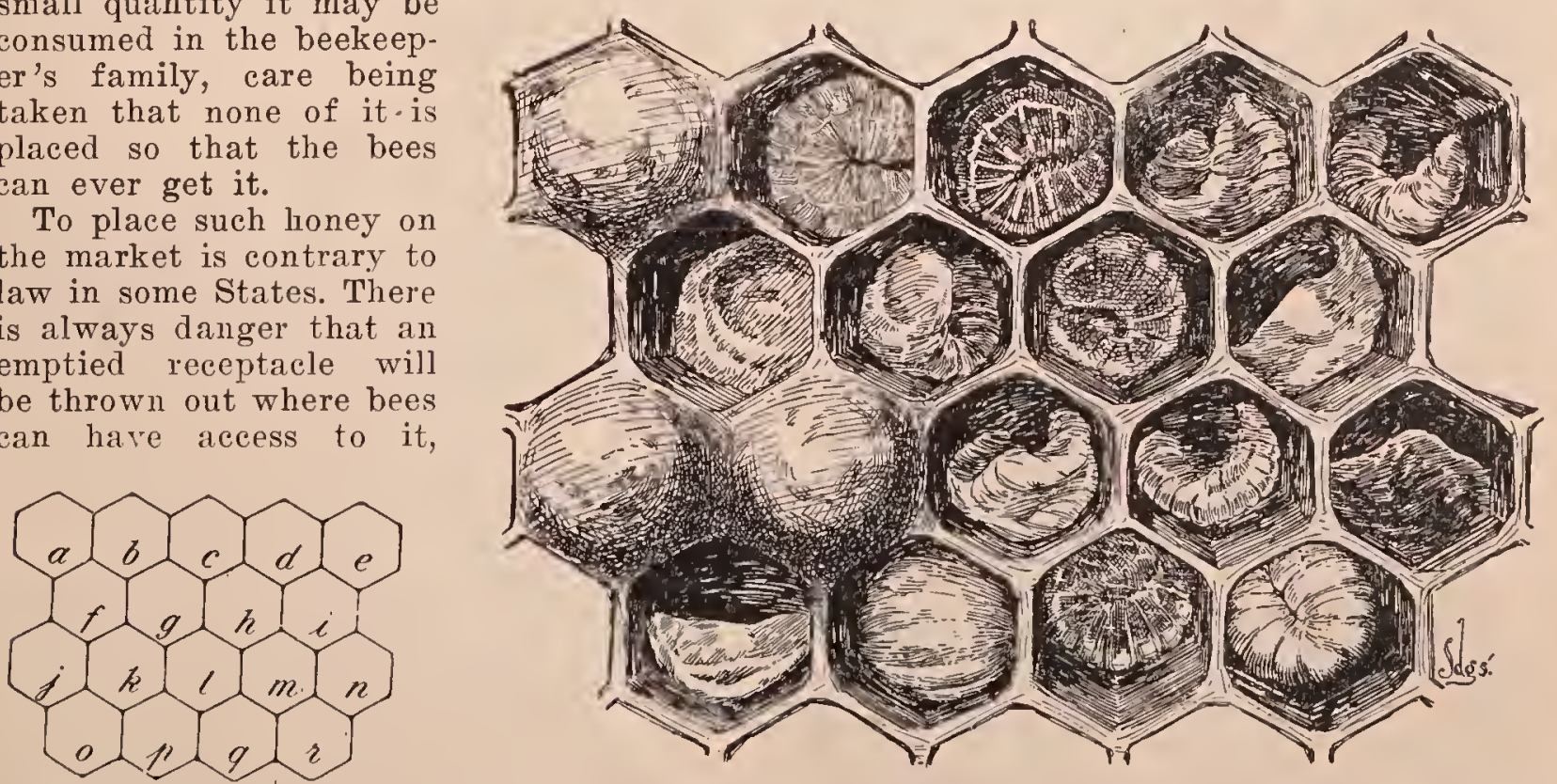

European foul brood: $a, j, h$ mormal sealed cells; $b, c, d, e, g, i, l, m, p, q$, larvæ affected by disease; normal larvæ at age attacked by disease; $f, h, n, o$, dried-down larvo or scales. Three times natural size. (Original) thus causing a new outbreak of disease. It can be safely used for feeding to bees, provided it is diluted with at least an equal volume of water to prevent burning, and boiled in a closed vessel for not less than one-lialf hour, counting from the time that the diluted honey first boils vig. orously. The honey will not be sterilized if it is heated in a vessel set inside of another containing boiling water. Boiled honey can not be sold as honey. It is good only as a 
food for bees, and even then should never be used for winter stores, as it will probably cause dysentery.

The Second Shalie.-Some beekeepers prefer to shake the bees first on to frames colltaining strips of foundation as above described, and in four days to shake the colony a second time on to full sheets of foundation, destroying all comb built after the first treatment. This insures better combs than the use of strips of foundation, but is a severe drain on the strength of the colony. Since it is desirable to have combs built on full sheets, the best policy is to replace any irregular combs with full sheets of foundation or good combs later in the season.

The Cost of Shaking.-If the treatment just described is given at the beginning of a good honey flow, it is practically equivalent to artificial swarming, and results in an actual increase in the surplus honey, especially in the case of comb-honey production. The wax rendered from the combs will sell for enough to pay for the foundation used if full sheets of foundation are employed. Since a colony so treated actually appears to work with greater vigor than a colony not so manipulated, the cost of treatment is small. If treatment must be given at some other time, so that the colony must be fed, the cost is materially increased. In feeding, it is best to use sugar syrup, or honey that is known to have come from healthy colonies.

Treatment With Full sheets of Foundation. - In order not to have any combs in the apiary built on strips of foundation, some beekeepers prefer to shake the bees into a hive containing full sheets of foundation. In the place of one of these frames there is put in the hive an old piece of comb-one that has been baken or which for some reason will not further be useful. Into this comb the bees soon place the honey which they have carried over in their honey-stomachs, and the second morning after treatment the hive is carefully opened, with as little confusion as possible, and this old comb is removed. As little smoke as possible should be used in this operation and the comb should be taken out quickly in order that the bees may not again take up the honey before it is removed. In the place of the old comb there is inserted a new frame containing a full sheet of foundation and the treatment is complete. It will be fatal to success if the old comb is not removed, for then the disease will almost certainly reappear.

Treatment With Bee-Escape-As a substitute for the shaking treatment just described, the bees may be removed from their old combs by means of a bee-escape. The old hive is moved to one side and in its place is set a clean hive with clean frames and foundation. The queen is at once transferred to the new hive and the field bees fly there on their return from the field. The infected hive is now placed on top of or close beside the elean hive and a bee-escape placed over the entrance, so that the younger bees and those which later emerge from the cells ean leave the contaminated hive but can not return and therefore will join the colony in the new hive. If desired, the infected hive may be placed above the clean hive and a tin tube about 1 inch in diameter placed from the old entrance so that the lower end is just above the open entrance of the new hive. The bees follow down this tube and on their return enter the new hive. When all of the healthy brood has emerged from the infected combs the old hive should be removed. This treatment induces less excitement in the apiary and is preferred by many experienced beekeepers. Care should be taken that the old hive is absolutely tight to prevent robbing. The old hive and its contents of honey and wax are treated as indicated under the shaking treatment.

\section{FALI TREATMENT.}

If it is necessary to treat a colony so iate in the fall that it would be impossible for the bees to prepare for winter, the treatment may be modified by shaking the bees on to combs entirely full of honey so that there is no place for any brood to be reared. This will usually be satisfactory only after brood-rearing has entirely ceased. Unless a colony is quite strong, it does not pay to treat in the fall, but it should be destroyed or united to another colony. In case a diseased colony dies outdoors in the winter there is danger that other bees may have opportunity to rob the hive before the beekeeper's can close the entrance. In case bees are wintered in the cellar it is more advisable to risk wintering before treatment, for if the colony does die the hive will not be robbed.

\section{DRUGS.}

Many European writers have in the past advocated the use of various drugs for feeding, in sugar syrup, to diseased colonies, or the fumigation of contaminated combs. In the case of American foul brood, of which the cause is known, it has been found that the drugs recommended are not of the slightest value.

\section{EUROPEAN FOUL BROOD DIFFERENTIATED.}

As has been already explained, this is a disease that has some symptoms that are similar to those of American foul brood; but it has other symptoms that are quite different. In its general appearance, especially in its advanced stages, a comb having the disease will look somewhat like 
that of American foul brood; but a more careful exanination will show a decided difference.

1. Larva affected with European foul brood in its first stages are not usually ropy, but when they do rope the thread is coarser and does not string out as far. Anerican will often rope from four to six inches in a fine thread near the end. The dead matter of European has more of a jellylike consistency; and, if it clings to a toothpick, the roping is coarse, lumpy, and salve-like, and will not extend more than an inch or wo at most and then break like a rotten rubber band.

2. European in its first stages comes on mainly in the early part of the season, and it is confined largely to the unsealed brood. The dead larvæ first turn gray, then light yellow. Sometimes a yellow spot shows in the center of the grub before it turns yellow all over. It does not finally assume a shapeless melted-down mass as is found in the American disease. It retains its shape without a break in the skin, finally shriveling up into a dry scale which the bees easily remove. The dried scales of American foul brood, on the contrary, stick to the side of the cell like so much glue; and it is very easy to detect combs previously affected with this disease, altho it may be a year or so afterward, because the lower sides of the cell look as tho they had been daubed over with some sort of dark-brown gluey substance with a remnant of larval skin.

3. The ordinary gluepot or foul-brood odor is almost entirely lacking in combs affected with European foul brood. There is, in place of it, a sour, musty, or rọtten-egg smell that is not as easily recognized as the odor of the other brood disease. In the later stages, it takes a spoiled-meat or carrion ocior with a suggestion of ammonia, in which stage the sour sinell seems to be lost or obscured by the more pronounced odor of decay. The color of European foul brood in its earlier stages is a yellow or gray or combinations of these two colors. Later the yellow and gray change to quite a dark brown.

4. European foul brood seems to spread much more rapidly than American. If an apiary is affected at all, more colonies will be involved; but in the American disease, honey seems to be the main source of infection. In the European type, while honey may be a source, it certainly does not seem to be the only means of transmission.

5. Black and hybrid bees are much more subject to the ravages of European foul brood. If the disease is not too far advanced and the colonies are strong, the mere introduction of a vigorous strain of young Italian queens may cure the whole apiary. There are some localities in New York and Virginia where Italian apiaries are surrounded by apiaries of black and hybrid bees; and yet the remarkable fact is that these Italian yards are almost entirely free from disease, while the yards of black or hybrid bees around them are affected with it in spite of treatment by shaking.

6. There also seems to be a general agreement among authorities that weak colonies are the ones that are first attacked by European. It is important, where this disease gets into a yard, that all the weak colonies be doubled up; for it is only the strong and extra strong that are able to combat it, even when they are given every assistance possible on the part of the owner.

7. Again, it has been noticed that, as soon as a good lioney flow is on, European foul brood begins to disappear; and sometimes as soon as there is a dearth of honey it breaks out again, particularly when brood-rearing is well under way in the spring, for that is the time of the year when it usually makes itself manifest.

8. In the case of American foul brood it has been proven that combs or honey from a diseased colony are sources of infection. While all the honey could be extracted out of the combs, it has been demonstrated over and over again that it is impossible for a colony of bees to remove the germs by any process, for the simple reason that the dead matter sticks like glue to the sides and bottoms of the cells. On the other hand, the combs of European foul brood, because the dried larvæ do not stick, can be readily cleaned up by a vigorous colony of Italians and used over again. Before they have been cleaned up they may trans- 
mit the disease.* Hybrids and blacks, for some reason, do not effect this clean-up; and hence it is necessary either to melt up the combs, or, better, Italianize.

To recapitulate, combs of American foul brood must be melted up or burned. Combs of European foul brood need not be destroyed, and can be used again, when given the proper environment. In the last stages of European where the combs are rotten the combs should be melted up or burned.

9. American foul brood seems to be no respecter of persons, or, more exactly, no respecter of strains or races. European foul brood, in the first stages on the other hand, yields rapidly to a resistant strain of Italians without the destruction of combs. But not all Italians are equally resistant. Some strains, especially the yellow, inbred until their vitality has been weakened, are no better than the ordinary blacks and hybrids.

It seems to be apparent that bees which are good workers, and stand wintering well, are usually found to be very resistant to European foul brood, altho the rule does not universally hold true. When Italians, therefore, are spoken of as "resistant," it should be remembered that there are Italians and Italians - some better than others.

10. While the shaking or brushing on to frames of foundation in clean hives is almost sure to cure American foul brood, it is only partially effective witl European. It often does more harm than good because it weakens the colony. In many cases, European foul brood will reappear after shaking. It is, therefore, apparent that, if shaking is employed, additional curative measures must be applied-doubling up and requeening.

\footnotetext{
* I think the disease will not be transmitted by a diseased larra even tho still undried, if it is so far decayed that the nurse bees will not eat it. By the way, this theory, original with me, has never been advanced by any one else, and, as it has never been objected to by any one, it is safe to say that it is the best theory yet advanced to explain how the disease is conveyed, and at the same time to explain how and why the dequeening or caging cures. Here's the theory in brief: When a diseased larva dies, the nurses suck its juices, feed them to the young larvæ, and thus the disease is transmitted; but after the diseased larvæ become so far decayed as to be offensive, the nurses will no longer suck their juices, but leave them to become dried, or remove them without sucking them. So a break in brood-rearing that leaves no longer any eatable diseased larvia stops the continuance of the disease.C. C. Miller.
}

CONFUSING SYMPTOMS OF AMERI-

\section{CAN AND EUROPEAN FOUL BROOD EXPLAINED.}

For some time the beekeepers of California, as well as other parts of the United States, have been greatly confused by a disease that appeared to be American foul brood, and yet yielded to European foulbrood treatment. This even led some beekeepers to believe the two diseases identical.

Being greatly interested in these new symptoms, the author, while in California in 1919, succeeded in getting Dr. Phillips to send his bacteriologist, Mr. Sturtevant, to investigate the matter. After spending some time there he came to the following tentative conclusions.

In American foul brood he almost never found mole than one organism, Bacillus larvae, the cause of the disease - a fact that accounts for the usual uniformity of symptoms of this disease. The germ is characteristic in appearance. Under conditions unfavorable to its active growth it forms a small egg-shaped resultant body or "spore," which resists drying and high temperatures. Under favorable conditions the germ kills the larva in a peculiar manner, leaving the trachea and chitinous parts intact and making a gluey substance of the soft parts. This causes the clraracteristic sliminess or ropiness, and, later on, adherence of the scale to the cell wall. The gluepot, or, as Mr. Sturtevant says, the fish-glue odor, is also quite characteristic. However, it is now found that there may be stages where the larvæ may not have been dead long enough to have developed the characteristic ropiness and adherence to the cell wall. At this stage the partly dried-down mass may not have even the characteristic odor, nor adhere to the cell wall, thus leading to the belief that the disease may be European foul brood.

The dead larva of European in the unsealed cells can usually be distinguished from the dead larva of American in unsealed cells, by the position which it takes. The former may be coiled in the bottom of the cell, or it may be extended, lying more or less irregularly, somewhat diagonally in the cell. A careful examination will show this difference. 
Again, in the case of American there may be found pupae, (almost fully developed bees) lying on their backs; with their tongues extended out and pointing upward. Sometimes the end of the tongue will be stuck to the upper side of the cell. Sometimes it will project upward only about half way. These dead pupae with projecting tongues are never found in European foul brood; and their presence in any comb slowing the general symptoms of American, is a strong indication of American. When one finds almost every cell of the dead matter will rope, here and there dead pupae with their tongues projecting upward, and especially if he finds scales that adhere tightly, he may conclude that he has American.

The germ causing European foul brood, Bacillus pluton, does not form these resistant spores. The germ also seems to be less active in the way it decomposes the dead larvæ. According to Sturtevant, in European foul brood along with the organism that kills the healthy larvæ may often be found several germs which are secondary invaders, having no relation to the cause of the disease, but simply causing the larvæ to decompose. There is one organism in particular, Bacillus alvei, originally supposed to be the cause of the disease, which is often associated with European foul brood in large numbers. It appears that, the more of these organisms there are present after Bacillus pluton kills the larvæ, the more the appearance will change. Instead of the typical moist melting stage of the disease there are found, due to the action of the Bacillus alvei, more and more larvæ that have not died until after they have become capped. In this stage it is often difficult to distinguish European from American foul brood; as the dead larvæ may, before they dry down, show a tendency to sliminess, to rope somewhat, and develop the coffee-brown color. However, the way they rope is different from the characteristic fine thread of the American. It is coarser, at times lumpy, and too moist to stretch far; also, as it becomes a little more dried it will stretch like an old rubber band; and in breaking, instead of snapping back it will remain stretched ont. At this time the mass has a very disagreeable spoiled-meat odor. If, however, the case is watched for a few days longer, allowing the dead material to dry down, it will be found that these masses which generally lie very irregularly in the cells may be easily removed entire, while in the case of American foul brood it is practically impossible to remove an entire scale. Furthermore, instead of being brittle, like the American seale, these irregular masses will bend like a piece of old rubber.

Owing to the fact that European foul brood has been so neglected in California, due to the custom of treating for American, Bacillus alvei, the secondary decomposing organism, has increased. to such numbers that it lias changed some of the symptoms of the disease, in its last stages particularly. Therefore it is not safe to jump to conclusions too hastily in the case of the brood diseases, since there are stages at which it is very difficult to differentiate without the aid of a microscope. If it is impossible to get a microscopic diagnosis, Mr. Sturtevant recommends that the best plan is to treat the case vigorously as if it were European foul brood by dequeening the colony, and in ten days requeen with good Italian stock and then watch developments. This kind of treatment with good Italian stock, and making the colonies strong, is good beekeeping, disease or no disease, and the only way to secure a crop. If it is European foul brood it will clean up. If it is American foul brood it will not clean up, and soon the definite characteristic appearances will develop.

This treatment as prescribed will eliminate the melting-up of combs in European foul brood, and is the safest course to pursue where European is known to be prevalent.

To recapitulate, it is apparent that there are only two serious brood diseases, the same as we have heretofore known. In the American foul brood no new development lias arisen. The European, however, takes a later stage much resembling American. At first all the symptoms that heretofore have been given for European appear. Later on, if nothing is done to effect a cure a secondary invader, Bacillus alvei, comes in and modifies the symptoms to such an extent that European takes on the form similar to American, but yields to the treatment of European. The Bacillus 
alvei apparently slows up the action of the Bacillus pluton, which is the real cause of European, so that the dead matter appears mainly in the sealed cells, while the unsealed larvæ look a little like the dead larvæ of American.

TIIE SEQUENCE OF BROOD DISEASES.

In those areas in which both American foul brood and European foul brood are often found in the same apiaries, some beekeepers actually believe that one of these diseases turns into the other. So strong is this belief in some places that it is often discussed in beekeepers' meetings; and the idea has even erept into some of the bee journals, this unfortunately adding to the confusion already existing in the minds of many beekeepers who have to contend with both diseases.

It should not be necessary to call attention here to the fact that the cause of each of the two most destructive brood diseases is positively known, the cause of American foul brood being a specific germ Bacillus larvae, and the cause of European foul brood being an entirely different germ, Bacillus pluton. The work of Dr. White in the investigation of the cause of these brood diseases has been verified by Sturtevant as well as other investigators; so there can be no reason for doubt as to its being correct. For Bacillus pluton to change into Baccillus larvae is just about as impossible as for wheat to change to corn, or tomatoes to change to apples.

Why should such a belief become prevalent among beekeepers? What could they have observed that could possibly lead them to such a conclusion? The explanation is found in the difference in the behavior of the two diseases.

Eliropean foul brood is usually at its worst in the spring, often disappearing later in the season, so that sometimes its presence cannot be detected in the apiary even by a careful examination of the combs; while American foul brood persists thruout the season, usually growing worse as the season advances. European foul brood usually spreads with surprising rapidity thruout the apiary during the spring; while American foul brood, if not checked by the beekeeper, spreads slowly but surely thruuout the season, especially during the robbing seasoll. European foul brood is more destructive to weaker colonies, since strong colonies, especially if Italians, are better able to resist it; while American foul brood destroys the strong as well as the weak, often being found first in the strongest colonies.

When both diseases are present the beekeeper sees chiefly European foul brood during the spring and chiefly American foul brood during the fall, altho both diseases may be present thruout the season. The variation in the symptoms of European foul brood, by which it sometimes closely resembles American foul brood in appearance at first glance, may lead the beekeeper to think that he has only European foul brood in the spring, and the disappearance of the characteristic symptoms of European foul brood later in the season leads him to believe that he has only American foul brood left. If he send a sample to the Bureau of Entomology at Washington for examination in the spring when his trouble is overwhelmingly European foul brood he is almost sure to select a sample of this disease; and, if he sends another sample in the fall when European foul brood is diffieult to find, he is almost sure to send a sample of American foul brood.

When both diseases are present a bad case of spring dwindling, following poor wintering, may be diagnosed as "disappearing disease." The colonies thus weakened become easy prey for European foul brood. Even with this handicap the colonies may build up during the honey flow and clean up the European foul brood to a large extent, so that later in the season the beekeeper sees only American foul brood. Noting this sequence of evils the beekeeper may be led to the erroneous and absurd belief that one disease turns into another.

TREATMENT AND CURE OF EUROPEAN FOUL BROOD.

Before proceeding to the actual cure of a colony after the disease has been contracted, it should be stated that good beekeeping, according to the Government officials, makes it very difficult for European foul brood to get a start. This is only another way of saying that prevention is better than cure. Good beckeeping means 
strong colonies of good bees. Not only that, but they should be strong in the spring. In order to have such colonies it means good wintering; and good wintering, in the northern States at least, implies an abundance of natural stores and protection. This protection, if the bees are wintered outdoors, may be in the form of double-walled hives, or winter cases described under the head of "Wintering Outdoors" at the close of this work. In connection with this protection there should also be a good windbreak. Protection may also mean putting the bees in a good cellar, the essentials of which are described under "Wintering in Cellars."

In the milder climates, to have strong colonies in the spring requires a larger amount of stores to the colony; because when the bees can fly two or three times a week, many old bees are lost in the fields, never returning. The others that do return with nectar and pollen start breeding, and this calls for a large reserve of stores-at least double the amount required in the colder States. The author is convinced that a moderate amount of packing could be given to advantage in addition.

In the treatments now about to be given for the cure of European foul brood, after it once finds lodgment, it will be seen that the fundamentals are strong colonies; dequeening to allow the bees to clean up the infected material, and requeening with a resistant strain. Before we proceed to the exact details of treatment, the history of how the best methods were discovered is important.

In 1899 and the early 1900's, when European foul brood was known in New York as a foul brood that was different from the old-fashioned kind, the shaking method was applied exclusively. It was soon discovered that the disease was continually coming back. Later it was learned that shaking was effective in most Italian colonies. Then it was discovered that some Italians were more resistant than others. Finally the inspectors advised that shaking and Italianizing should be applied. If colonies were not strong it was recommended to double up until they were. Then a few beekeepers began to notice that the mere introduction of a resistant strain of Italians would effect a cure.
In 1904 E. W. Alexander of Delanson, $\mathrm{N}$. Y., referred to in several places in this work, reported to the author that one of his neighbors had blundered upon a cure which he thought was effective. At that time he was not prepared to state whether it would bring about a cure or not; but after he had experimented with it on some 500 colonies he gave out what has since been called the Alexander treatment, which is now the basis of all the modern methods of control for the European foul brood. In brief the Alexander treatment is as follows:

Every diseased colony in the apiary not very strong is doubled up or united with other. weak colonies until all are made strong. In some cases building up or strengthening of the weak can be effected by taking frames of emerging brood from the stronger and giving them to the weaker. The next procedure is to remove the queen from every infected colony, and in nine days destroy every mature queen-cell, or any virgin if emerged. In the meantime a quantity of cells are to be reared from the best Italian breeder in the yard. These cells, when ripe, are given to the colonies made queenless 20 days before. Durin? this interim of queenlessness the bees clean out the combs, polish up the cells, and when the new queen starts laying, which will be on the 27 th day, approximately, the new brood will be liealthy from that time on. It is not necessary to remove any combs from the hives nor apply any kind of disinfection. The old queens that were renoved in the first place are to be destroyed.

In a series of articles which Mr. Alexander wrote defending his treatment-for he encountered all sorts of opposition from those who failed-he laid strong emphasis on the importance of making all colonies extra strong, using a vigorous resistant strain of Italians and keeping the colony queenless for at least 20 days, at the end of which time a ripe queen-cell or a virgin just emerged was to be given.

S. D. House of Camillus, N. Y., told the author that a vigorous strain of Italians would almost alone clean out European foul brood after the colony had been queenless for a period. He showed colony after colony that had been rotten with the disease, and which at the time of our visit were entirely free of it. He stated that 
European foul brood was rampant all around him in the black and hybrid colonies. In spite of the fact that it was within reach of his bees he had no fear of it. He wrote a series of articles for Gleanings in Bee Culture in 1911, and among them was one, on page 330, giving his method of treatment that is similar to Alexander's. This attracted considerable attention at the time. The editor of Gleanings was severely criticised by some of the State inspectors for giving publicity to such heresy; but old Father Time has demonstrated that Alexander and $\mathrm{Mr}$. House were nearly right.

In later years European foul brood broke out in the apiary of Dr. C. C. Miller of Marengo, Ill., an authority referred to many times in this work. The author advised him to follow the Alexander or, better, the House treatment, which he did, with marked success. By accident he discovered that it was not necessary to have the colonies queenless more than ten days; that a vigorous strain of bees would do a good clean-up job in the period named. After experimenting with the disease for two or three years he finally announced the following modified Alexander-House-Miller treatment, which is much the same as that used by S. D. House. Dr. Miller says:

'First, no matter whether the case be severe or mild, make the colony strong. In a severe case, kill the queen; and as soon as the colony recognizes its queenlessness, say within 24 hours, give a ripe queen-cell, or immediately at the time of killing the queen, give a virgin not more than a day old or a cell in a protector. That's all; the bees will do the rest. In a mild case, make the colony strong, and cage the queen in a hive for a week or ten days-only that. But don't expect the disease to be at once and forever stamped out. Last year I liad the disease in a mild form in about one colony in four; this year in about one in twenty.

It will be noticed that Dr. Miller, like $\mathrm{Mr}$. Alexander, emphasized the importance of making all colonies strong, in the treatment of either a severe case or a mild one. Later on, after considerable discussion, he added this:

A correspondent asks, "What do you do to save the combs?" Nothing. Just use them the same as if there had been no disease. Vigorous bees with a vigorous queen will clean them out. Spores may be left, and here and there the disease may break out again; but in the long run the loss will be less than if the combs were destroyed. and possibly the returns of the disease will be no more frequent than if all combs are destroyed. In my own apiary I think there were no more fresh outbreaks where the old combs were left than where the bees were thrown upon foundation.

A large number have followed Mr. House and Dr. Miller and have been very successful. This does not mean that every trace of the disease will be wiped out after treatment, but it does mean that the disease will be brought so nearly under control that a case only here and there will show up, and even then in a very mild form. It is possibly true that some queens of a resistant strain are not quite so resistant as othcrs. In that case dequeening for ten days and requeening again will complete the cure.

In this connection it should be noted that the presence or absence of an early honey flow makes considerable difference in the response of this disease to treatment. Mr. House and Dr. Miller were able to reduce the period of queenlessness because their locations furnish an early honey flow from white clover, which in itself causes the bees to clean out the dead larvæ more vigorously, while Alexander's experiments were conducted in the buckwheat region where the honey flow does not begin until August, but little if any honey being gathered from white clover in June. This longer period before the lioney flow in the buckwheat region or in any region where the honey flow comes late gives European foul brood a better chance and increases the difficulties in treatment.

\section{SACBROOD.}

For many years there has been recognized a form of dead brood under the name of pickled brood that is neither European nor American foul brood. It comes and goes at certain seasons, but is never as destructive as either one of these diseases. Sometimes it has the appearance of foul brood so far as color is concerned; but it is never ropy like the American type; and, while similar to the European, it seldom gains very much headway in a colony.

It is mildly infectious, and the infected larvæ turn yellow and then brown. Sometimes the color is gray. The dead specimens may be in unsealed cells, but are gen- 


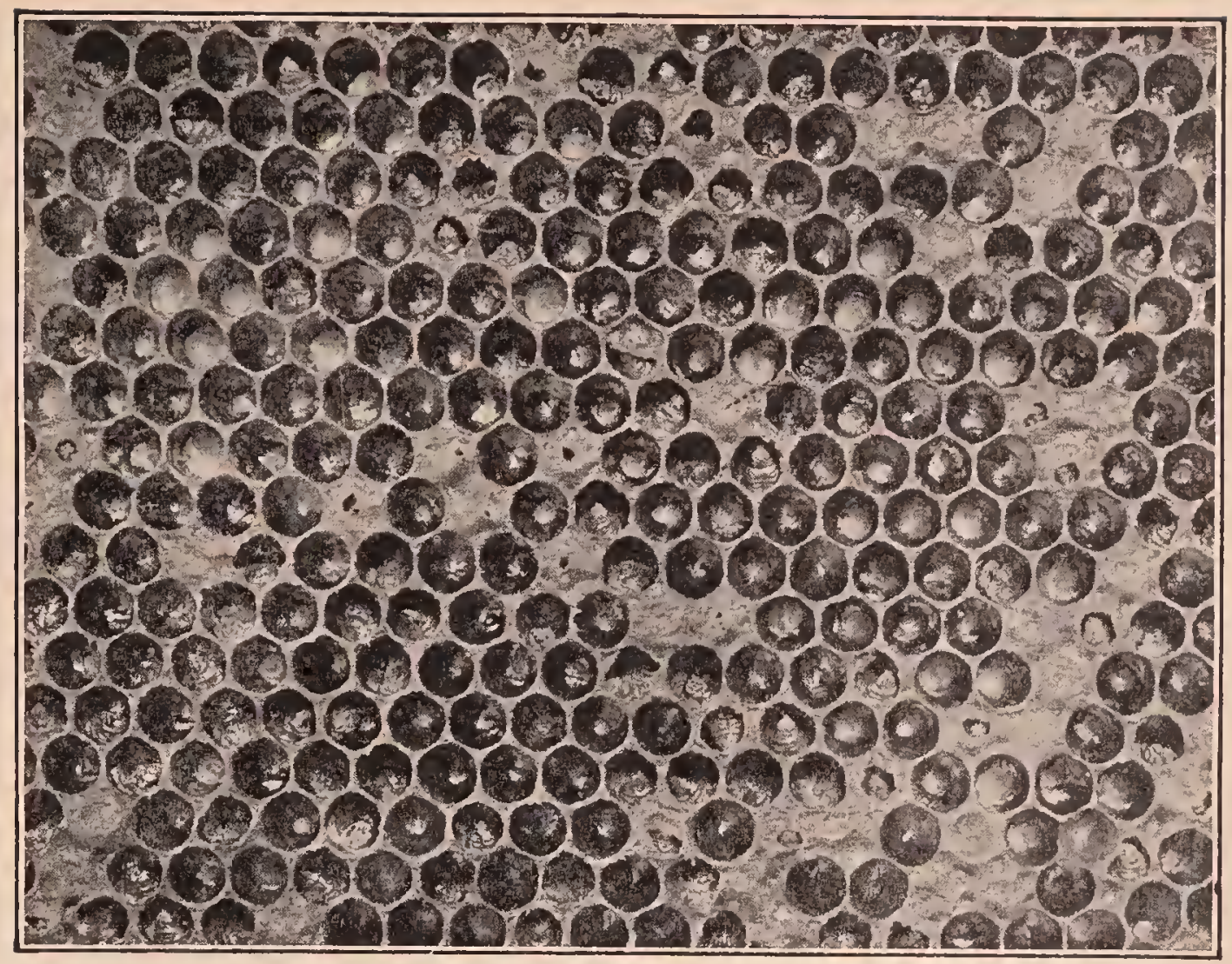

Heavy sacbrood infection, showing a numter of different stages of decay of larvæ. Eggs, young larvæ in different stages of development, and diseased larvæ in same area. Natural size.-From Bulletin 431 , Department of Agriculture, Washington, D. C.

erally in the sealed ones. The dead larvæ, says Dr. White in Circular No. 169, Bureau of Entomology, are "almost always extended lengthwise in the cells, and lying with the dorsal side against the lower wall. The form of the larvæ dead of this disease changes much less than it does in foul brood. The body wall is not easily broken, as a rule, and on this account often the entire larvæ can be removed from the cell intact." . . "When removed they have the appearance of a small closed sac. This suggests the name of sacbrood."

\section{CAUSE OF SACBROOD.}

So far no microbe or fungus has been discovered as the cause of the disease. Whatever it is, it is so very small that it will pass thru a Berkfield filter. Sick and dead larvæ of sacbrood have been macerated and diluted with sterile water. The product was then passed thru a Berkfield filter; but it was found that the filtrate would again give the disease to other colonies. It is evident that the disease is infectious. Dr. White concludes that "sacbrood is an infectious disease of the brood of bees caused by an infecting agent that is so small or of such a nature that it will pass thru the pores of a Berkfield filter."

This led us to the conclusion that the foul-brood inspectors of the country might be compelled to quarantine an apiary where sacbrood might be found; but Dr. E. F. Phillips, in charge of apiculture in the bureau, does not think that this would be necessary. The disease at its worst is not very destructive; and when it does make its appearance it affects so few larvæ in a colony that it need cause no great alarm. While he might at times advise treating or isolating colonies, he does not believe it would be necessary to quarantine an apiary where it was found.

STARVED OR NEGLECTED BROOD.

There is another form of dead brood that very greatly resembles sacbrood; and that is, starved or neglected brood. Early in the spring, when natural pollen is scarce, and brood-rearing is well under way, some of the brood will die for the lack of the nitrogenous element of their food as obtained from pollen. It is starved, not from a lack of honey, but from a lack of proper bread-and-milk diet made up of pollen and 
honey. Considerable of this dead brood will be found in the early spring. The bees readily pick it out of the cells; and as soon as natural pollen comes in, the trouble will disappear.

DEAD BROOD FROM DRONE-LAYING QUEENS OR LAYING WORKERS.

Under BROOD, reference is made to the fact that drone brood or laying-worker brood will often be found dead, and a stinking mass. The cells will be perforated, and the odor will be very much like that from American foul brood in an advanced stage. The fact that it does not rope rather suggests to the inexperienced that it may be European foul brood; and many times A B C scholars write us, describing this trouble, and asking whether it is foul brood.

The remedy is, of course, to remove the drone-laying queen or break up the layingworker colony.

One may rest easy if he finds all worker brood healthy, and nothing but drone or laying-worker brood dead.

\section{EXPERT DIAGNOSIS.}

Even tho the symptoms of the two brood diseases have been given very minutely, the reader, if he has never seen either one, may not be able to distinguish which one he may have. Possibly he has nothing worse than sacbrood or chilled or starved brood. While it was the custom of the author to examine all suspected samples sent in, and determine what they were, it is much better to send them to the Apicultural Investigator, Bureau of Entomology, Washington, D. C. The samples will then be examined by experts equipped with microscopes, after which a report will be sent back immediately, giving the exact nature of the diseases with full directions how to proceed.

There are some cases that are so confusing that even the inspectors themselves can not determine whether the case is American or European. Nothing but examination by competent bacteriologists can determine what it is. It has several times happened that the foul-brood inspectors have treated America for European, and vice versa, with the result that nothing was accomplished, and valuable time was lost.
It is highly important that the apiarist in any event send a sample to the Bureau in order to avoid expensive mistakes.

\section{FOUNDATION.-See ComB FOUNDA-} TION.

FRAMES.-These are devices for holding combs while in the hive and are sometimes called racks. They make possible modern manipulation by which every comb can be inspected, removed, transposed-in fact, the whole internal economy of the hive can be determined. The straw skep and the box hive of olden days had no frames, nor does the same hive in use today in parts of Europe and southeastern United States. See Box Hives.

As shown under Hives, Evolution of, there were many crude ways of making combs movable-some better than others. Perhaps the crudest of all was to cut them out and put them back again. Later on, combs were built from single bars. This necessitated cutting the combs from the sides of the hive to effect a removal. To these bars were later attached other bars, making up a complete frame. But such frames were almost immovable. While they could be taken out of the hive it required a great amount of patience and time, to say nothing about bee-killing.

It remained for the Rev. L. L. Langstroth, of this country, then a Presbyterian minister, to discover a principle that would make every comb or frame removable. To construct a frame that will inclose a comb required no great act of invention; but to make a frame so it could be readily removed from its fellows, without smashing or irritating bees, required the work of a genius, and that genius was Langstroth.

Under the head of A B C OF BeEkeepING, Hives, Evolution of, and BeE-SPACE, it is explained that he discovered the principle of a bee-space - a space that bees respect, and never fill with comb or bee glue. (See BeE-SPACE.) Taking advantage of this principle, Langstroth saw that, in order to make his frame movable, he must provide a bee-space all around. The next problem that he met was how to support and hold each frame so that there would be not only a bee-space all around between it and the top, bottom, and end of the hive, 
but also a bee-space between each and all of the frames. It is just as important to have every frame separable from its neighbor as separable from the hive. This he accomplished very nicely by making the top-bar of his frame long enough to have a projection at each end. These projections as a means of support were made to rest in rabbets in the upper edge of the ends of the hive. (See Hives and A B C OF BeEKEEPING) Langstroth, therefore went ahead of his predecessors in two important points-in providing a bee-space and in giving a means of support so that the frames would not be glued fast to each other nor to the hive. His predecessors, as will be seen by a perusal of Hrves, EvoLUTION OF, made their frames close-fitting, like drawers in a bureau, and each frame came in contact with its neighbor. (See the Huber hive under Hives, Evolution of.) These early devices, perhaps, would have been all right had it not been for three things-the ever present bee glue sticking everything fast with which it came in contact, the erushing of the bees whenever parts of the frames came together, and the slirinking and swelling of the parts making the frame anything but movable. A few crushed bees, many of them squealing with pain, will infuriate a whole colony; and it is no wonder that our forefathers resorted to the use of brimstone and refused to accept the so-called movable frames that were invented before Langstroth. The so-called movable combs of Dzierzon made it necessary to cut every comb loose. This process necessarily caused a great deal of dripping honey. During a dearth of nectar this would cause robbing. '(See-Robring.) When, therefore, Langstroth by his great invention of a really movable frame demonstrated that he could make every comb movable-that he could take the hive all apart without killing a bee and without receiving a sting - he revolutionized for all times the methods for handling bees. While bees always will sting, and do sting, yet it is now possible, under favorable conditions and with proper use of smoke, to open and examine a Lang'stroth hive without receiving a sting. See Manipulation of Colonies; also see Stings.

The various crude attempts to make combs movable are set forth under the head of Hives, Evolution of. The methods of adjusting modern Langstroth frames in modern Langstroth hives are deseribed under Hives and A B C of Beeneeping.

Langstroth desired to bring out a frame that would be really movable, and in doing so went to the limit. His frames had no point of contact with each other. They were simply hung or suspended in the hiverabbet. They often hung out of true, and, worse still, were often badly spaced; but in spite of all this, many beekeepers prefer the principle today. There are others who consider it an advantage to have projections on the frames, such projections being a half bee-space beyond the comb. These self-spacers will always hang true and the proper distance apart. (See SPACING Frames.) The advantages of these selfspacing frames are shown in the article on Frames, Self-Spacting.

\section{SIZE AND SHAPE OF FRAMIES.}

There has been endless discussion as to the best size of frames. Some prefer one that is square approximately a foot wide and a foot deep. Others consider 12 inches too great a depth, and prefer to have the extra comb area extend laterally. A great majority of modern beekeepers prefer today a frame longer than deep, such as we find in the Langstroth dimensions. As the dimensions of the frame determine the size and shape of the hive itself, a further consideration of the subject will be found under Hrves.

\section{THICK-TOP FRAMES.}

In the early 90 's the thick-top frame was introduced to the public; but some years prior to that time J. B. Hall, then of Woodstock, Ontario, Can., had been ising frames with top-bars 1 inch wide by $7 / 8$ inch thick. Sóon after he began using them he discovered that the tops of these frames were free from burr-combs. Likewise there were no brace-combs between the frames. He made his top-bars thick, he said, not because of the burr or brace comb nuisance, but because he desired to prevent their sagging. It was not long after that Dr. C. C. Miller called the attention of the beekeeping' world to Hall's discovery, and in a very few years the 
thick-top frame came to be almost universal. After, the top-bars were made stronger and heavier, the end-bars as well as the bottom-bars were made thicker and wider. The natural result of all this was a stronger and more serviceable frame.

Before proceeding further it will be in order to define precisely what is meant by burr-combs and brace-combs. The former refers to those pieces of comb that were built in the olden days lengthwise and crosswise of the top-bars between the hive and the super or between the two sets of frames when the queen occupies both stories. Brace-combs refer to the strips of comb built between the top-bars. Burrcombs were much more troublesome. While the thickness and width of the top-bar are both important in the elimination of these troublesome combs, the width has more to do with their eradication than the thickness. A top-bar $1 \frac{1}{8}$ wide and $3 / 8$ thick, provided the top-bar does not sag, will almost eliminate burr-combs but not quite. If the top-bar sags, as will happen in the case of any top-bar less than $3 / 8$ thick and as long as the Langstroth, it increases the bee-space to a point where bees will build burr-combs. To prevent sagging, the topbar should not be less than $1 / 2$ inch. As the $7 / 8$ or, more properly, the $13 / 16$ topbar can be made just as cheaply, it has been thought to be more practicable to use the combination of a thick and wide topbar 1 1/16 wide by 13/16 thick.

In this connection it should be stated that the thin top-bar will not eliminate brace-combs; but one 13/16 thick will do so most effectually.

Before the advent of thick and wide bars it was necessary to use a broad-bladed putty knife, or a common hoe or trowel to scrape the burr-combs from the frames every year, and sometimes two or three times a year. During the height of a honey flow, whenever a super or upper story was removed it was necessary to break these attachments between the upper and lower stories-not an easy job, by the way. Each time there would be a lot of bleeding or dripping honey all over the bees, combs, and clothing, to say nothing of stings and of the hands being smeared with honey. Practically all modern beehive factories are now furnishing almost exclusively to their trade thick and wide top-bar frames.

After the thick top was introduced it was impracticable to use vertical wiring that had been used with the old $7 / 8$ by $3 / 8$ thin top-bars. Horizontal wiring was then introduced. (See Comb Foundation; subhead WIRING FRAMES.) At the time thick top-bars were introduced in the early 90 's, comb honey was produced much more generally than within the last four or five years. It was a great advantage to get away from the burr and brace combs so troublesome between the brood-nest proper and the super containing sections. It is not at all strange that the beekeeper, when he bought new equipment, would purchase that which would relieve him from this nuisance. In later years the tendency of the beekeeping world has been toward the production of extracted honey. This was particularly accentuated during the period of the World War, 1914-1918.

Along about that time came a general call for a frame that would have more brood to the comb. (See Comb FoundaTION, subhead WIRING FRAMES.) As a good queen can more than fill an eight or ten frame Langstroth hive, it has become necessary to raise brood in the two stories. At the end of the heavy breeding period the brood-nest is reduced to one hive. It has been discovered that the queen will go into the second story more readily where thin narrow top-bars are used and brace-combs are built in between. Notwithstanding this is true, the beekeeping fraternity prefers to avoid the nuisance of burr-combs, and therefore continues to use thick-top frames. If any change at all is made it will be along the line of the reduction of the thickness, leaving the width $11 / 16$ as now. This is a matter, however, for the future to determine.

Whether a frame should be made reversible is discussed under the head of $\mathrm{RE}_{\mathrm{E}}$ vERSING. Whether a frame should have the erid-bars come in contact the entire length or only part way, or whether they should stand rather than hang, is discussed in the next subject.

FRAMES, SELF-SPACING.-By these are meant frames held at certain regular distances apart by some sort of spacing 
device, forming either a part of the frame itself or a part of the hive. Under SpaCING OF Frames, elsewhere, and under ExTRACTING, the distances that frames should be apart are discussed. Some prefer $1 \frac{1}{2}$ inches from center to center; but the majority prefer $13 / 8$ inches. Self-spacing frames are those that, when put into the hive, are spaced automatically, either $13 / 8$ or $1 \frac{1 / 2}{2}$ inches from center to center. Loose or unspaced frames differ from them, in that they have no spacing device connected with them, and are, therefore, when placed in the hive, spaced by eye-or, as some the parts of the frames that come in contact, he will not kill any bees. The fact that some of the most extensive beekeepers of the world are using self-spacing frames, and the further fact that the number of self-spacing-frame users is constantly increasing, shows that this supposed bee-killing is more fancied than real. When frames are handled but two or three times a year, as is now the practice of some of the best beekeepers, all these objections lose their force to a large extent.

There are many styles of self-spacing frames. Those most commonly used in this
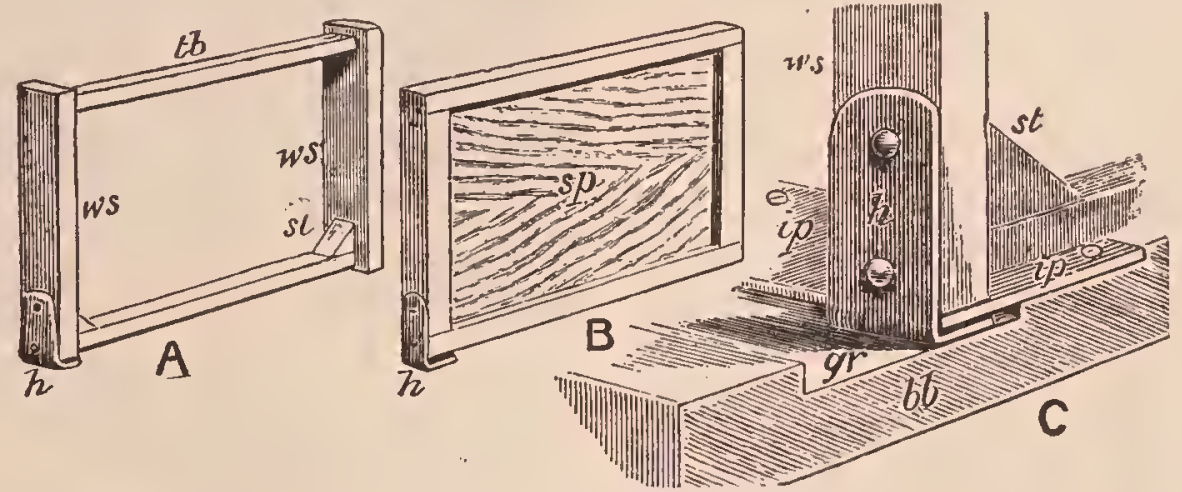

How the Quinby frame hooks on to the bottom. From Cheshire

have termed it, "by guesswork." Such spacing results in more or less uneven combs; and beginners, as a rule, make very poor work of it. The advocates of selfspacing frames claim that they get even, perfect combs, comparatively few burrcombs, and that, without any guesswork, the combs are spaced accurately and equally distant from one another. Selfspacing frames are always ready for moving, either to an outyard, to and from the cellar, or for ordinary carrying around the apiary. Unspaced frames, on the contrary, while they are never spaced exactly, often cannot be hauled to an out-apiary, over rough roads, without having sticks between them, or something to hold them in place.

It is contended by some also, that selfspacing frames can be handled more rapidly. (See Frames and Manipulation of Colonies.) On the other hand, the advocates of the unspaced frame urge, as an objection, that the self-spacers kill the bees. This depends. The careless operator may kill a good many bees. If he uses a little common sense, a little patience, applying a whiff or two of smoke between country will be described first, and then some of the others that are now used or have formerly been used in Europe. Among the first-mentioned are the closed-end Quinby, the Danzenbaker, the Heddon, the Hoffman, the thick-top staple-spaced, metalspaced Hoffman, and the nail-spaced.

The closed-end Quinby is, as its name indicates, one whose end-bars are wide their entire length. The top and bottom bars are one inch wide. These closed uprights, or ends, when they come in direct contact, cause the combs which they contain to be spaced accurately from center to center. The cut at $A$ shows one such frame. Several of the closed-end frames are made to stand, and have very often been called "standing frames." Mr. Quinby, in order to keep such frames from toppling over, invented the strap-iron hook on one corner, as shown re-engraved from Cheshire; $h$ is the hook that engages the strap iron $i p$ in the bottom-board; $g r$ is a groove to admit the hook, and at the same time render it possible to catch under the strap iron, as shown in cut.

The combined end-bars make the end of the hive, and these liooks are therefore on 
the ontside of the hive proper, and hence do not kill bees, nor are they filled with propolis as they would be if made on the inside of the hive. A and B are respectively the frame and the follower, altho they are drawn somewhat out of proportion.

The ordinary closed-end frames come together laterally. The Quinby frames may be placed laterally up against each other; but the usual practice is to insert them from the end of the live, sliding the endbars past each other. The movement being endwise, if it is properly performed, all bees that may be on the edge of either of the frames will be brushed aside.

The Quinby frame is a considerable departure from the Langstrotl principle, because the Quinby live and frame have no bee-space back of the end-bars. None is needed, for the reason that the combined end-bars make the end of the hive; but the frame does have a bee-space above the topbars and under the bottom-bars. Without the top and bottom bee-space Captain J. E. Hetherington could never have handled 3000 colonies as he did in the 60's, 70's, and 80 's on the Quinby frame for years in the

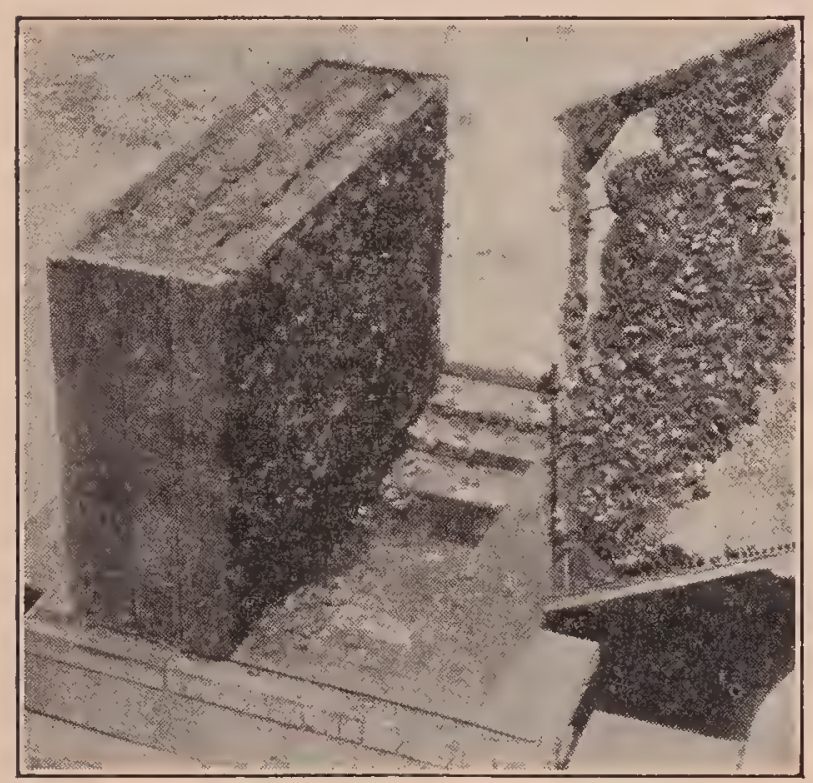

QUINBY CLOSED-END FRAME.

This shows low the brood-nest can be split up or dissected for examination.

Mohawk Valley, New York. P. H. Elwood was, at the time this was written (1917), using a large number of colonies on the same frame in Herkimel County, New York, and using them successfully.

With a panel on each side, a cover and a bottom-board, the Quinby-Hetherington hive is complete, the ends of the frames forming the ends of the hive; altho, for additional protection in the spring the users have an outside case to set down over

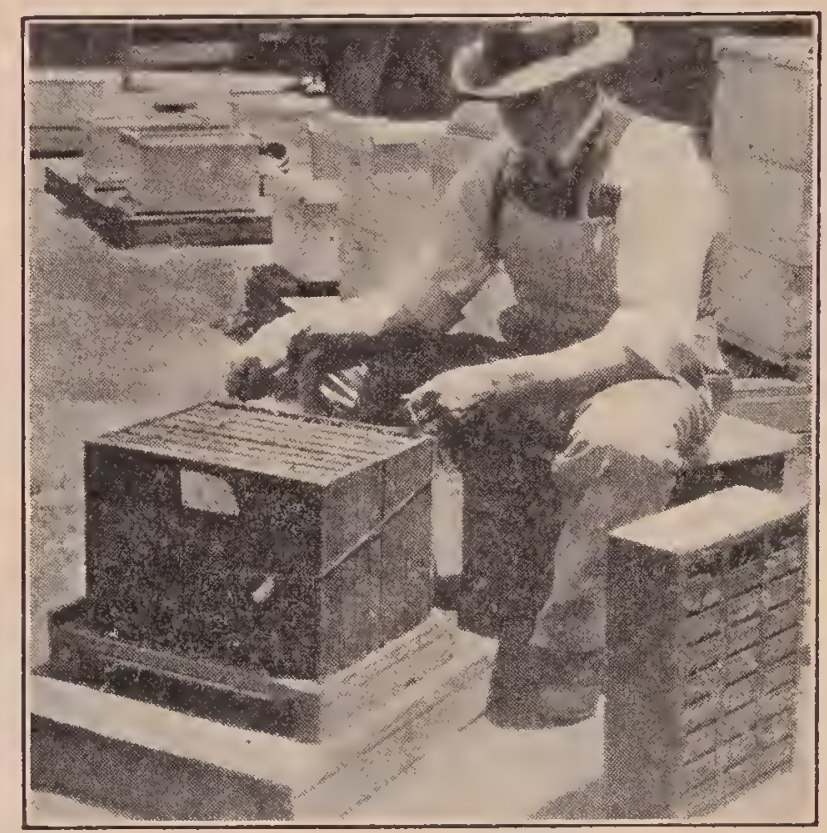

The Quinby frames when placed together and a panel on each side are held together by a string wound once around and tied.

the whole. This makes a very cheap hive that has many desirable features in it. For fuller details in regard to this frame and its manner of construction, the reader is referred to "Quinby's New Beekeeping."

\section{THE DANZENBAKER CLOSED END-FRAMES.}

Many people prefer what is known as a "hanging frame," which has decided advantages over the standing frame. The Danzenbaker is a closed-end hanging

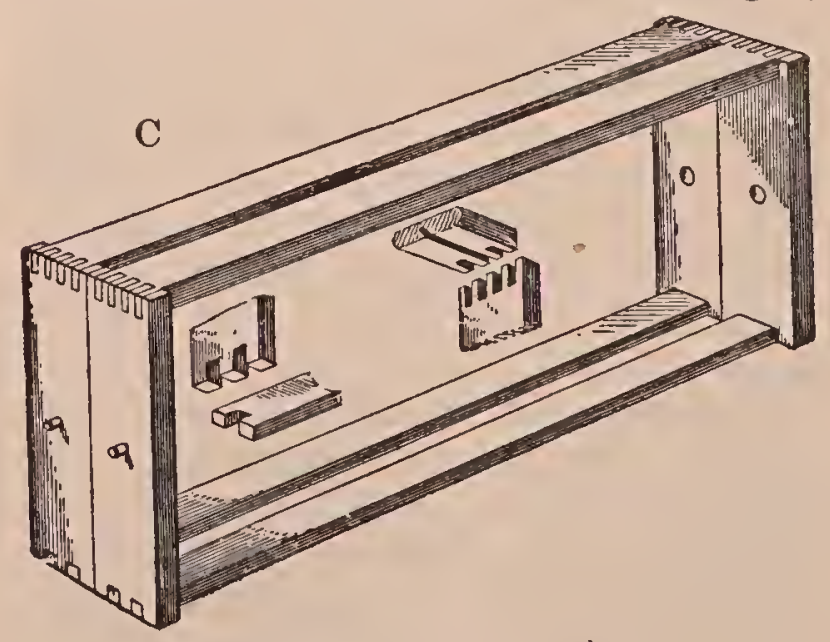

Danzenbaker closed-end frames.

frame. The end-bars are pivoted at the center, the pins resting on hanger cleats secured to the ends of the hives. These 
pins make a very small line of contact, whereas the ordinary standing closed-end frame resting on tins secured to the bottom edge at the ends of the live will crush a good many bees. The pins have the further advantage that, if there is any reduction in the depth of the hive due to shrinkage, the bee-space above and below the frames will be affected only half as much as if the fyame were standing. These frames have practically gone out of use.

\section{IMPROVED HOFFMAAN FRAMES.}

This is a modification of the original frame used by Julins Hoffman, then of Canajoharie, N. Y. The top-bar's as well as end-bars had projecting edges at the ends; but as he used a special hive without a bee-space at the top, that construc-

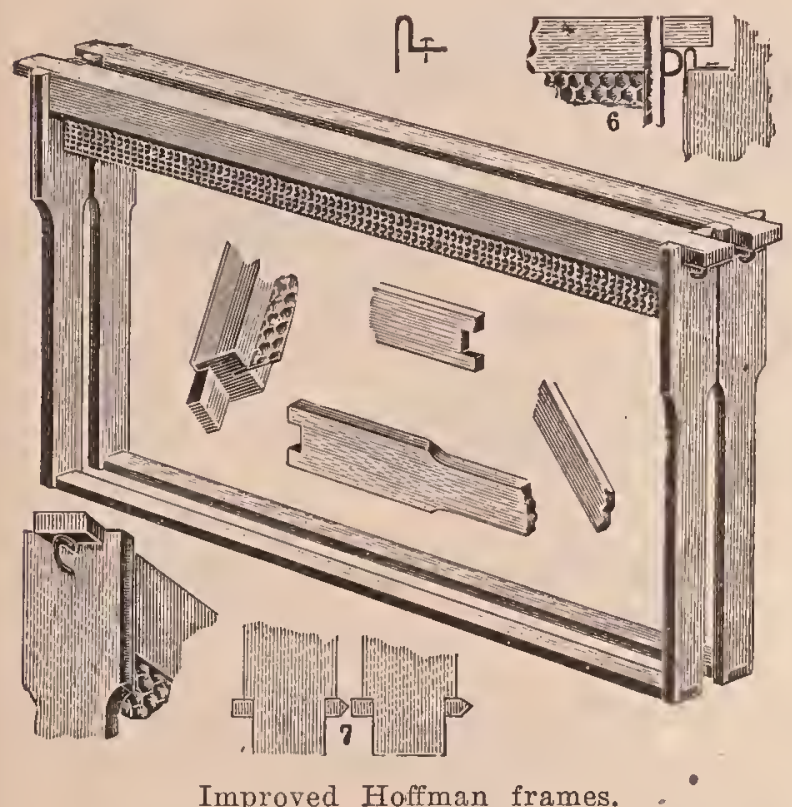

tion was perfectly practicable. When the Hoffman-frame principle was applied to the regular Langstroth hive, with a beespace on top, it was found that closed topbars at the ends were impracticable because the bees went on top of the frames and glued the tops together and to the rabbets. In the Hoffman hives the bees were shut out from the tops, and, of course, could not stick the parts together. The modern Hoffman frames are, therefore, made having only the end-bars wide at the top. This greatly facilitates rapid handling, and preserves at the same time the essential feature. of the original Hoffman by which it was possible to handle numbers of frames in lots of two, three, and four at a time, or space them all at one operation against the hive side. While the act may kill some bees, yet this can be avoided by blowing smoke down between the end-bars, and shoving the frames all together. In this respect the modified Hoffman has the great advantage over the original frame. This will be shown more clearly under Frames and Manipulation of Colonies.

Another feature of this frame is the endspacing staple that abuts against the tin rabbet shown at 6 , in the cut. The ends of the top-bars are cut off so as to leave a bee-space around them. With the old-style frames the bees would sometimes glue the ends of the top-bars to the rabbet. This objectionable feature has been orereome in the style shown.

When the top-bar is long enough to reach and almost come in contact with the ends of the rabbets, the bees would chink in bee glue between the ends of the topbars and the rabbets. After the ends of all the frames have been thus glued, it is somewhat difficult to remove any one comb, because the fastening of each frame must be loosened before the comb sought can be lifted out; but when the top-bar is shortened, as at 6 in the illustration, and the staple is used, there is none of this kind of gluing, the only fastening being that between the upright edges of the end-bars themselves; and this fastening, for the majority of localities, so far from being a disadvantage, is useful in that it holds the frames together while the lives are being moved, and yet does not hold them so as to prevent easy handling.

The Hoffman is the most extensively used self-spacing frame in all the United States, and there is even a possibility that it is used more generally than any other frame whether spaced or unspaced. Most of the hive manufacturers supply it as a part of the regular equipment of their standard hives.

For details concelning its use, see Frames and Manipulation of Colonies.

\section{METAL-SPACED HOFFMAN FRAMES.}

All that has been said in favor of the regular Hoffman will apply with equal force to the metal-spaced frame here shown. In some localities where propolis is very abundant, sticky, or hard, the 
wooden projections of the regular Hoffman sometimes split off when the frames are pried apart. For localities where this condition prevails the metal-spaced is recommended. It can be used interchangeably

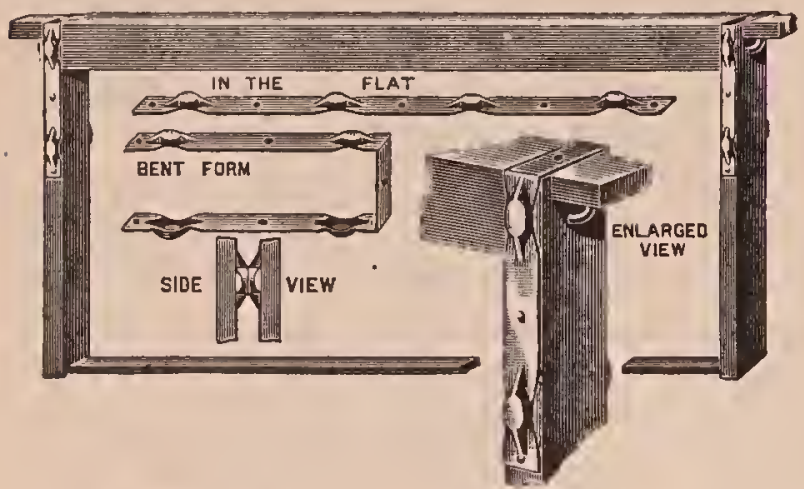

with the regular Hoffman. The spacers on this frame are stamped out of metal and must necessarily be accurate. The form of its construction in the shape of the letter $U$ bending over the top-bar projection prevents the latter from breaking thru careless handling.

STAPLE-SPACED FRAMES.

There are a few others who prefer frames with staples for side-spacer's as here shown.

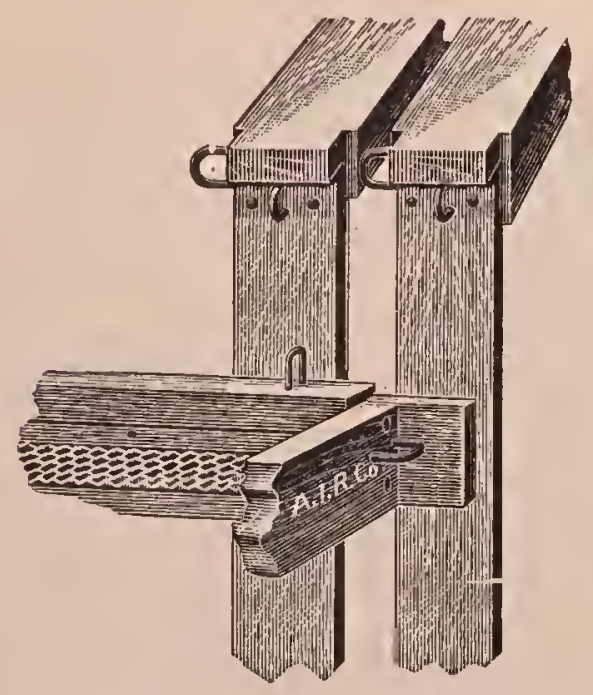

Others use nails in place of staples; but the latter with their rounding edges allow the frames to slide past each other more readily.

OTHER SELF-SPACING DEVICES.

Various spacing devices have been suggested at different times. A few of these are presented here, the reader being left to judge of their relative merits. It will not be necessary to describe them in detail, as the engravings make plain their manner of construction and use.
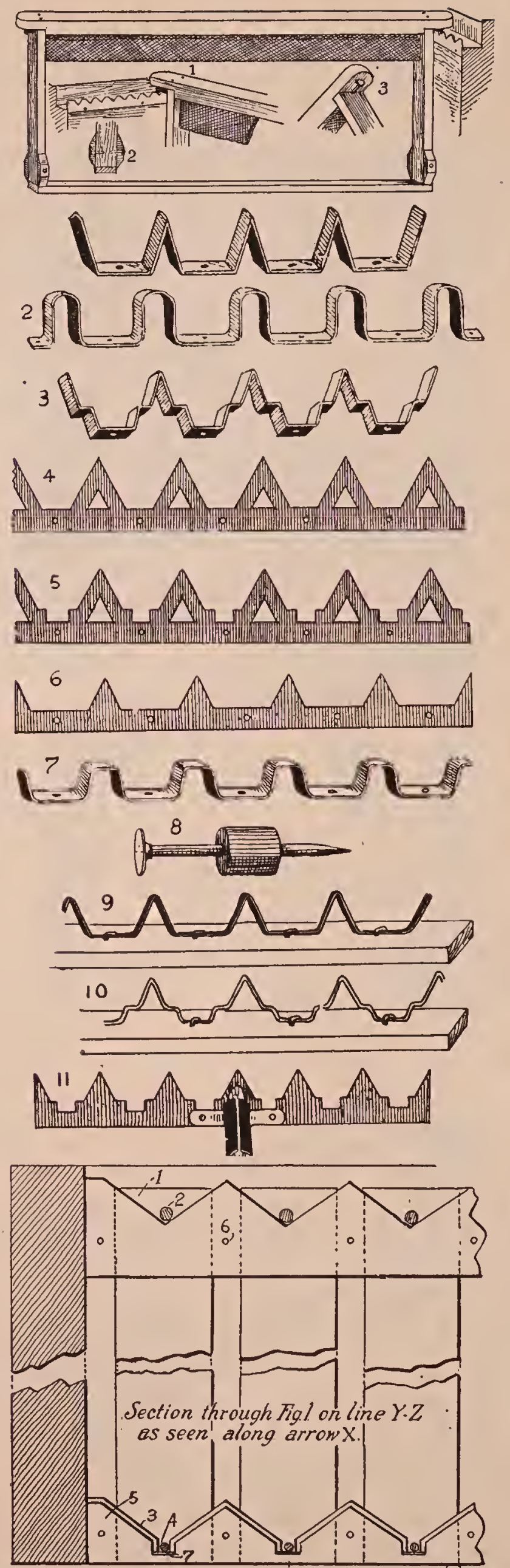

Hive-rabbet spacers. 

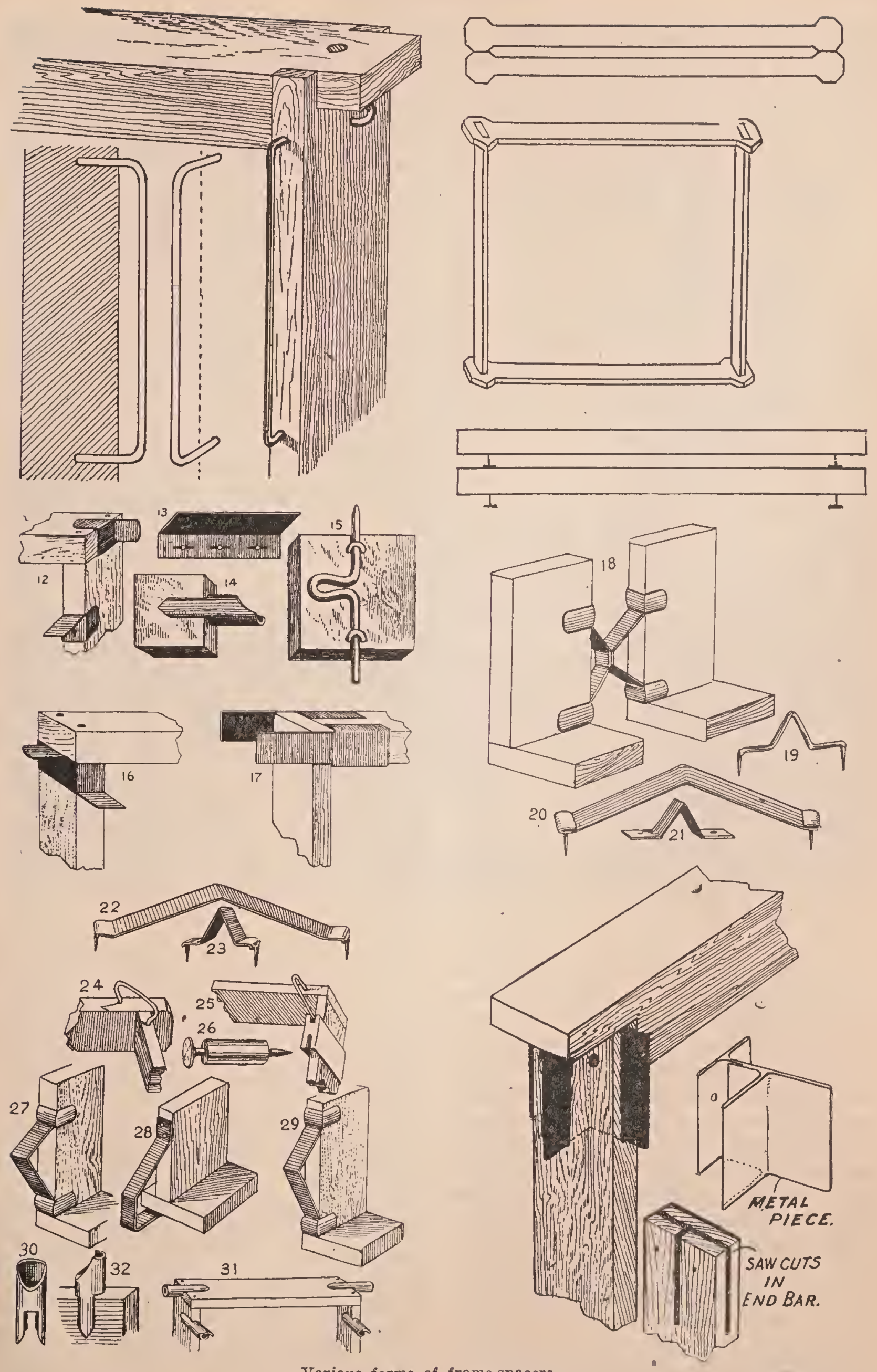
It will be noted that there are two kinds of spacing devices. One is made a part of the frame and the other a part of the rabbet. It would seem at first glance that the latter would be a very happy solution of the problem of automatic spacing, as it would leave the frames without projections in the way for uncapping; but the fact is, rabbet or hive spaces have never been very popular, and therefore are very little used. The principal objection to them is that one cannot move the frames en masse or in groups, thus saving time in handling the brood-nest. The advantage of group-handling is made more apparent under Frames and Manipulation of Colonies.

The rery fact that no extensive beekeeper is using these self-spacing devices as a part of the hive, and the further fact that all other's who try them in a small way sooner or later abandon them, should discourage would-be inventors from wasting any time on them.

\section{SELF-SPACING FRAMES-ADVANTAGES.}

Self-spacing frames make possible straight, beautiful, and regular combs; are practically free from burr-combs; can be hauled without any special preparation over the roughest roads, turned upside down, and rolled over without disturbing the combs. They permit, to a very great extent, the handling of hives instead of frames. Under Frames and ManipulaTION OF COLONIES is shown how frames can be handled in pairs and trios-in fact, half a hive at a time. They can also be inverted, thus causing the combs to be built out solidly to the bottom-bar; and, when once completed, they can be restored to their upright normal condition. They can be liandled as rapidly as the loose frame. Indeed, the inventor, Julius Hoffman of Canajoharie, N. Y., owner of some 600 colonies on Hoffman frames, said he could work nearly double the number of colonies with his frame that he could on any frame not spaced or close-fitting, and he had used both styles.

SELF-SPACING FRAMES FOR SMALL BEEKEEPERS.

Whatever may be said regarding the adaptability of Hoffman frames for the ex- pert, it is evident that, in almost every instance, they are better for the beginner, average farmer beekeeper, or any one who does not propose to make a specialty of the bee business, but desires to keep only a few colonies to supply himself and neighbors with honey. Such persons are apt to be a little careless, and, with ordinary loose unspaced frames, make bad spacing. It is seldom indeed that one can look into the hives of this class of beekeepers and find their loose frames properly spaced. In some instances the combs are so close together that opposite surfaces are gnawed down to give the bees sufficient space to pass between; and in others they are so far apart that small patches of comb are built between. This is because it is an invariable rule laid down in beehive economy, not to leave more than proper bee-spaces.

FRAMES, TO MANIPULATE. - See Frames and Manipulation of Colonies.

\section{FRUCTOSE.-SEN HONEY.}

FRUIT BLOSSOMS. - A very large amount of nectar is annually gathered by bees from fruit bloom, apples, pears, plums, cherries, and peaches; but it is seldom that more than a small surplus is obtained. Apple-bloom honey is of great value in stimulating brood-rearing and in tiding over a period of scarcity. There is a proverb in New York State that "As goes apple bloom, so goes the season." Half a century ago Moses Quinby of St. Johnsville, N. Y., wrote: "In good weather a gain of 20 pounds is sometimes added to the hive during the period of apple blossoms." In 1877, at Borodino, N. Y., a surplus of $1662 / 3$ pounds of mostly comb honey per colony, spring count, was obtained, probably the largest average of apple-bloom honey ever recorded. But the weather is seldom continuously fair at this season; often it is rainy, cloudy, windy, cool, or there is even a frost, when instead of a gain there is a decrease in the stores in the hives. If there were a larger number of bees, a much greater quantity of apple-bloom honey would be gathered. As a rule the bees do not succeed in getting more than a living one year in five. Applebloom honey is light in color, a little strong at first, but acquires a pleasant aromaric 


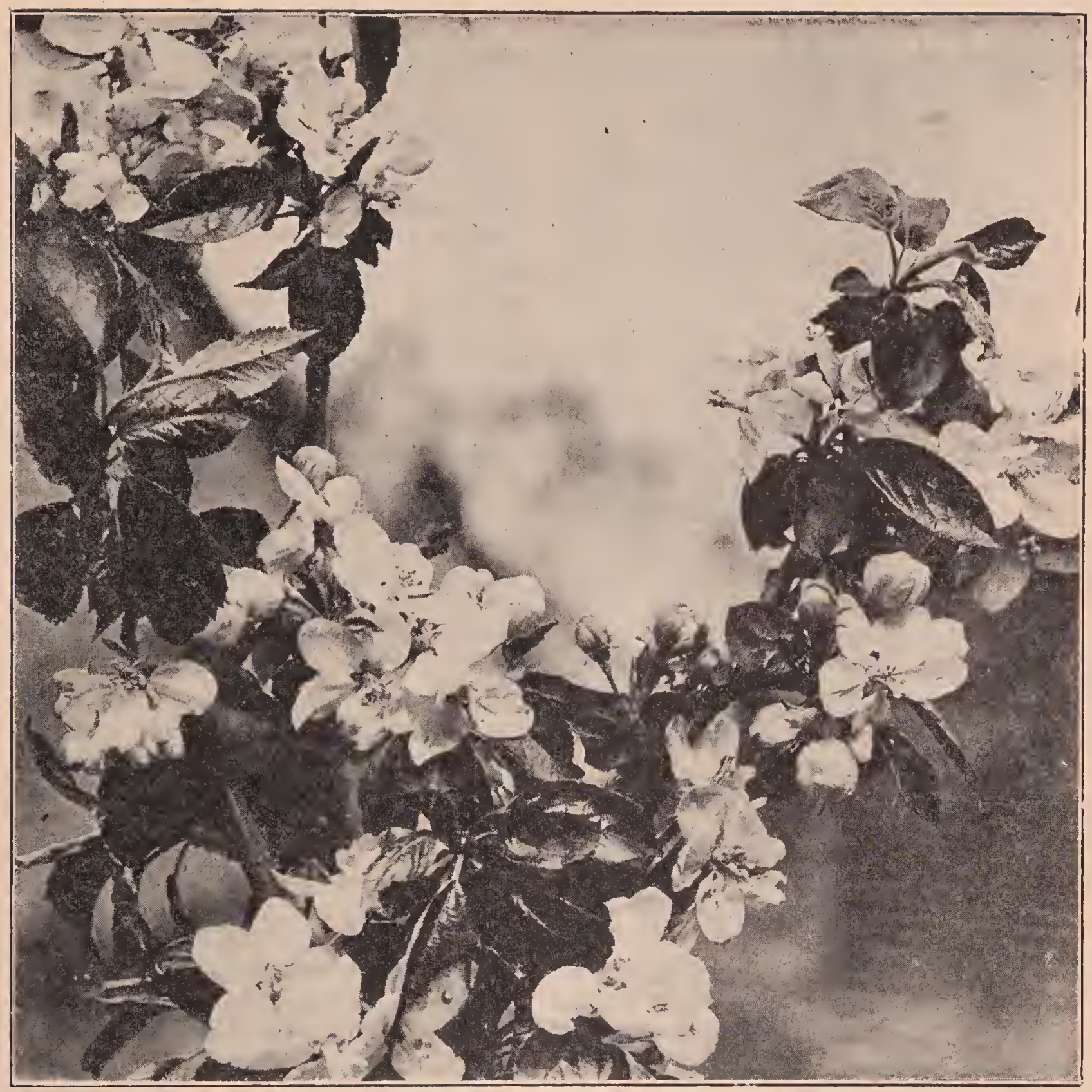

Apple blossoms.

flaror with age. It granulates about as quickly as basswood.

A surplus of pear honey is obtained in California if the weather is warm. At times the flowers of the pear secrete nectar so freely that it falls in drops to the ground. A surplus is also obtained in California from plums, peaches, and probably from cultivated cherries. In Florida wild black cherry (Prunus serotina) yields a surplus of dark-red, bitter honey with the flavor of the cherry pit.

SPRAYING DURING BLOOM DESTRUCTIVE TO BEES AND BROOD.

The spraying of fruit trees for the control of injurious insects and fungi is so profitable that the practice has become almost universal among commercial fruitgrowers and farmer's. The quantity of fruit obtained is larger and the quality is better. But unless the fruit-grower is acquainted with the habits of the injurious insects affecting his crops the results of spraying are likely to be very unsatisfactory. Spraying during bloom not only injures the flowers, but destroys in large numbers the bees, which are indispensable for their pollination. Large orehardists, with a spraying equipment too small to care for the acreage, often begin operations before their trees are out of bloom. Another class of offenders are those who make a business of spraying; and, seeking to 
extend their work over as long a time as possible, spray continuously thruout blooming time. A third class consists of those who are ignorant of the harm done by this practice.

When the trees are sprayed while in bloom, many bees are killed, much brood dies, and often valuable queens are lost. Beekeepers in all parts of the country have reported that as the result of the use of poisonous spray entire colonies have been destroyed and other's greatly weakened. In 1912 about half the bees in Pecos Valley, N. M., were killed in this way. A small apple orchard on the Ohio Experiment Station Farm was sprayed with Bordeaux mixture, to which had been added Paris green at the rate of 4 ounces to 50 gallons of the mixture. Three colonies of bees were located near by. A few days later one colony suddenly became extinct and a second greatly reduced in numbers, dead bees being abundant in both hives. Chemical analysis showed the presence of arsenic in the dead bees.

Experiments conducted at the Cornell and the Geneva Experiment Stations showed that the spraying of trees in full bloom decidedly injured the blossoms. The poison retarded or checked the development of the pollen and was harmful to the stigma. Pollen placed in a thin syrup, about the consistency of nectar, to which was added a quantity of ordinary spraying liquid, failed to grow. The fruit-grower can not afford to injure the delicate reproductive organs of the flowers. Moreover, spraying when the trees are in bloom, says the Vermont Experiment Station, is entirely useless; it is a waste of both time and spraying material.

\section{SPRAY POISONING.}

Fruits vary in their necessity for crosspollination from complete self-sterility to self-fertility. Some of the best-known commercial varieties of apples, pear's, cherries, etc., are entirely dependent on pollen from other flowers. Even in case of selffertility it has been demonstrated conclusively that more perfect fruit results from cross-pollination than from self-pollination. Bees, either the many native wild species or the hive-bee, are the most important agency for carrying pollen from flow- er to flower. From the point of view of fruit-growing, therefore, every thing possible should be done to have plenty of honeybees, as they are the only insects under the control of man.

Progressive fruit-growers appreciate the importance of bees in setting a crop of fruit, and commonly rent colonies of bees for the blossoming period, paying $\$ 5.00$ per colony and allowing one colony to each acre or two of orchard. The increasing custom of growing a honey-producing cover crop would make the combination of orcharding and beekeeping particularly desirable, were it not that some fruitgrowers overdo their spraying so as to allow spray poison to drip from the trees. This poison, falling to the blossoms of the cover crop, is taken up by the bees and has resulted in the destruction of so many bees as to cause commercial beekeepers to move away to safer zones.

In return for their good services many bees meet a pitiful death at the hands of those they help. For two or three days after the spraying of an orchard near-by bees frequently die in large numbers. The field force first is depleted, either failing to return, or sometimes bringing into the hive sufficient poison to cause destruction to brood and nurses. Many colonies of bees have been completely exterminated. Others were so harmed that they failed to build up even during the honey flow, and later succumbed to disease or were winter-killed. Instead of producing honey these colonies must be fed that the remnant may survive.

\section{SOURCE OF THE POISON.}

Bees secure poisonous fruit sprays as a result of the following improper horticultural practices:

a. From the drip upon honey-producing cover crops grown under the trees. This is a fault of excessive application.

b. From spray reaching fruit bloom. This is a fault of spraying too early, before the blossoms have dropped.

c. From spray mixing with honeydew, the excretion of plant lice. This is a fault of neglecting to keep plant lice under control.

d. Another source is from foliage before the spray has dried, especially in the semiarid regions of the West, where water 
is difficult to obtain, since the rainfall is light and the rivers and ponds dry up in summer.

\section{SYMPTOMS OF SPRAY POISONING.}

Tho arsenic is a slow-acting poison, those bees that secured a full toxic dose may fail to return to the apiary. Countless dead bees have been noticed between the orchards and the apiary. Especially about their watering places do the bees congregate, visiting moist ground, a brook or a ditch, as tho in an endeavor to quench an unnatural thirst. Many come back to their homes laden with pollen and poisoned honey, but drop fagged out, instinctively remaining outside to die.

Those that receive poison close by may deposit their load in the combs before becoming affected, and bring death to the nurses and the brood. Few of the poisoned bees die within the hive and are carried out. Such is the remarkable instinct among; bees, where the family comes before the individual, that, when the bees reach the stage of poisoning characterized by a diarrhoea, they crawl forth even thru the night to void the poison outside of their home.

On the following morning the field workers sally briskly forth, but because the poison in their system has paralyzed the wings their attempt at flight results in failure. Down they drop from the alightingboard-usually never to rise again. At first excited and nervous they scurry about, climbing up weeds and grass, clustering on the outside of the hive, which because of the diarrhoea afflicting them they spot profusely. With wings quivering they jump along, trying to fly a few inches at a time, gradually getting farther and farther away from the hive. In a few minutes a stupor overcomes them; they have less and less control over their movement; they are barely able to crawl; they fall over on their sides; some spin on their backs; they clutch convulsively with their legs; their tongues become extended full length. As the paralysis becomes complete they quiet down, accumulating in depressions of the ground 20 or 30 feet from the apiary by handfuls or even by literal quarts. Their mission in life is over, altho unfulfilled.

As the sun warms up, some of these af- flicted in less degree revive sufficiently to fly or crawl away from the vicinity of the hives. Such bees probably never completely recover. It is doubtful if they ever return, for we have noticed that other insects once stricken with arsenic become unable to digest food, and tho they may linger on for days and even weeks finally die of starvation, if not of poisoning.

The poisoned loney brought into the hives kills the nurses and young bees. Drones and queens are also affected; one observer reporting, however, that in some colonies everything was killed but the queens, so that he had a dozen lone queens surviving. The brood in all stages is destroyed. Sometimes only unhatched eggs remain after the plague has swept thru, the helpless new brood appearing but to perish unattended. In case of incomplete destruction of the colony, poisoned honey is stored away to be drawn on later, when symptoms of arsenic poisoning reappear. Such after-effects are common when bees are removed from the orchard region. Thus it is also that bees may show symptoms of poisoning early in the spring, before the spray season opens.

FINANCIAL LOSS TO BEEKEEPERS FROM SPRAY POISONING OF BEES.

Questionnaires sent in recent years to beekeepers in the fruit-growing districts of Washington reveal the widespread and serious nature of spray poisoning. By tens of thousands colonies of bees are being so depleted as to become nonproductive, and by thousands colonies of bees are being completely wiped out. The money loss for a single season has been computed to be more than $\$ 50,000$.

Aside from financial considerations there enters the question of fair play and moral and legal rights. Why should one group of people be permitted to put poison in the path of so industrious a benefactor of humanity as the honeybee? When it is further realized that bees are all-important to iruit-growing the question becomes even mole pertinent, for it becomes suicidal to best orchard interests to drive away the honeybee and to destroy year after year the native insect pollenizers.

To avoid actual extermination beekeepers are forsaking the orchard districts. It 
is their silent protest but best retaliation to their neighbors who manifest so little regard for the rights of others. Bees are gradually becoming a rarity in those districts where they are most needed.

CORRECTION OF THE TROUBLE INVOLVES NO ACTUAL HARDSHIPS.

If bees are to be won back and propagated in the fruit-producing districts the following conditions must be met:

a. The calyx spray must not be begun until fully 80 per cent of the blossoms have dropped. This is consistent with best spraying. practice. At that time the nectar flow has ceased.

b. Cover spraying should not be overdone. A tree will take up a definite amount of spray without dripping, to any great extent, provided a fine mist spray is used, and the orchardist must use this kind of a spray with plenty of pressure so as to do a good job.

c. Cover crops should be used that will not be in bloom at the time of spraying. The annual sweet clovers can be planted so as to come into bloom after the spraying season is passed. Where insect and fungus pests necessitate continued spraying thruout the entire summer it might be advisable to use the sod culture system and secure the nitrogen from some nitrogenous fertilizer instead of obtaining it from legumes. This system of orchard management has been adopted in some leading fruit sections.

d. Aphids must be kept in check on such varieties of fruit as receive summer applications of arsenicals. This would prerent the occurrence of contaminated honeydew. These can be controlled by spraying with nicotine sulphate or black-leaf forty. Aphids are killed only by a contact spray, and the orchardist must direct the spray so as to hit them.

It is possible, but not very probable. that some chemical may yet be discovered. which will render poisonous sprays, when added to them, repellent to bees; and thus enable the fruit-grower to raise cover crops and spray his trees regardless of his little friends. Lime-sulphur, nicotine, lime, and creosote have each been suggested for this purpose, but information is too meager to give out a general recommendation as yet, In some preliminary experiments, which have been made, it lias been observed that bees act in unexpected ways to substances nauseating to ourselves. Limesulphur, carbon disulphide, and naphtl alene were perceptibly avoided by bees; while ill-smelling butyric and pyroligneous acids were unnoticed. It may be that calcium arsenate will be less destructive than lead arsenate; it may be that dry dusting will be better than liquid spraying.

CORRECTIVE LEGISLATION WILL AFFORD THE QUICKEST BENEFITS TO ALL.

While it is inconceivable that any fruitgrower conversant with the facts would wilfully place poison in the path of his neighbor's honeybees, yet all appreciate how slow is the directing of reforms thru appeals for sympathy. In the meantime the beekeeper must live by the lives of his bees. His part is not to beg for humane consideration of his troubles; he cannot wait on educational propaganda; he cannot take chances on losing his all; and so he moves away until the fruit-men come to realize that they need the bees more than the beemen need the orchard flowers.

Some States in the interest of beekeeping have enacted laws prohibiting the spraying of trees in blossom. This alone would not meet the situation in the Northwest, because the custom there of growing a corer crop is responsible for most of the trouble.

For the ultimate good of fruit-growing, as well as of beekeeping, every State should enact a law forbidding the placing of poison inadverter tly or deliberately, where bees or other insect pollinators will unavoidably secure it. Such a law would apply only to the careless orchardist, who would either have to cut his alfalfa before spraying or else hereafter use care in spraying not to overdo the application.

\section{SPRAYING FOR THE CODLING MOTH.}

The insect which is most important for the orchardist to control is the apple worm or codling moth, a pest which may reduce the erop of sound fruit by one-fourth to three-fourths. The moths emerge from their cocoons during the months of May and June. The mimute whitish eggs are laid partly on the leares and partly on the fruit, and hatch about three weeks after the trees have 
blossomed. The young worm crawls to the blossom end and enters the apple, burrowing into the interior. After feeding for about four weeks the worm deserts the apple, and spins its cocoon under the rough bark or in a sleltered place. The last of July or early in August the second brood of moths appear. These moths in turn deposit eggs, which in due time hatch, and the worms enter the apples thru the side. There are thus two broods of worms. The second brood of worms do not transform to moths until the following spring after the trees have bloomed.

There are three well-defined periods when the trees should be sprayed. Spray for the first time ten days after the dropping of the white petals, while the green calyx lobes still remain open and the newly set fruit stands erect. Direct the spray so that it will fall into the calyx eup and lodge there; for, as it is at this point that the worm enters the fruit, it will eat the poison and die. The first treatment is more efficient than all subsequent treatments. Spray for the second time about three weeks after blooming time, when the eggs of the codling moth are beginning to hatch. Spray for the third time during the last of July or early in August, when the second brood is hatching and preparing to enter the fruit. If in the first and second sprayings Bordeaux mixture is used as a carrier of the poison, these treatments will prevent apple scab.

HOW BEES ARE KILLED WHEN THE SPRAY FALLS ON COVER CROPS IN ORCHARDS.

While many commercial orchardists employ clean cultivation,-i. e., the ground under the trees is frequently harrowed and no vegetation is permitted to grow-other fruit-growers sow cover crops. In many localities these crops are of great benefit in protecting the roots of the trees from sun, wind, and drouth, and in furnishing both humus and fertilizer. A variety of leguminous plants are grown for this purpose, as alfalfa, red clover, crimson elover, vetch, and yellow annual sweet clover.

In western Colorado red clover has been extensively used as a cover crop. The poisonous spray applied to the trees falls on both the leaves and flowers of the clover. In the arid elimate of this region water is difficult to obtain, and the bees eagerly gather the poisoned water found on the cover crops and are destroyed in imnense numbers. In 1914 and 1915 whole apiaries perished, particularly in the vicinity of Montrose; while other colonies were so weakened that they yielded no financial return.

The spraying of cover crops presents a new and serious problem, the only remedy for which seems to be the cutting of the cover crop before it blooms or ploughing it under, or the use of some crop that will not come into bloom when the trees are sprayed.

LAWS AGAINST SPRAYING FRUIT BLOOM.

A number of States liave passed laws against spraying fruit bloom, but they have not proved entirely effective. Where the penalty is low, from $\$ 15$ to $\$ 50$, it is often ignored, owners of commercial spraying outfits preferring to pay the fine rather than to stop work. Beekeepers, moreover, hesitate to incur the trouble of enforcing the law. In general, education will be found more effective than legislation. Selfinterest will prevent a well-informed fruitgrosver from spraying the bloom. Let him once fully understand that the production of fruit depends upon the pollination of the flowers by bees, as explained in the latter part of this article, and he will be as eager for their protection as the beekeeper himself. But there will always be a few orchardists who will persistently remain ignorant and who will resent any restraint on their operations, insisting that the bees are not injured or are not needed. A few unprineipled owners of spraying outfits and ignorant employers may become a menace to an entire community. An educational campaign will not suffice in such cases, and the beekeeper should be protected by a law imposing heavy penalties for spraying the bloom of fruit trees, while provision should be made for its enforcement by a state official.

\section{POLLINATION OF FRUIT BLOOM.**}

In former years beekeepers and fruit-

* In order to understand better the structure of the flower it is suggested that the reader turn first to the subject of POLLINATION OF FLOWERS. It will also serve to illustrate the different methods of pollination referred to in this article. 
growers came in conflict; the latter asserted that bees injured the bloom, punctured the fruit, and interfered with the packing, and consequently in some cases they asked the beekeepers to remove their bees on the plea that they were a nuisance. The fruit-growers little realized that they were driving away the agency necessary for the proper pollination of fruit bloom. Happily at the present time the two factions understand that their industries are mutually dependent. Fruit-growers, indeed, derive very much more benefit from bees than the beekeepers themselves, as they have been repeatedly taught by costly experience. Some years ago a beekeeper in Massachusetts was obliged to remove bees from a certain locality on the complaint of the fruit-growers that they were a nuisance; but after a year or two had passed they were very glad to have the bees back again, because so little fruit set on the trees in proportion to the bloom. The beekeeper was recalled; and, as was to be expected, not only more but finer fruit was produced.

The practical application of the discovery of the agency of insects in the pollination of flowers in the cultivation of fraits and vegetables has been of inestimable value to agriculturists. It can be shown easily that there are many different kinds of plants which, in the absence of insects, would remain partially or wholly unproductive. In the work of pollination the services of the bees, or Anthophila (flowerlovers), are the most important; while among the bees the honeybees, because of their highly specialized pollen-gathering apparatus, great numbers, and industry, far surpass all other species. Fruit orchards cannot be planted profitably on a very extensive scale without maintaining in connection with them numerous colonies of honeybees; and it is estimated by Dr. Phillips, of the Bureau of Entomology, that beekeeping adds indirectly more to the resources of the country annually by flower pollination than by the sale of honey and wax. Several enthusiastic horticulturists have eren declared that for all practical purposes in pollination the honeybee is alone sufficient; but this assertion must be sometwat modified; for, in the country as a whole, domestic or hive bees are aided by wild bees, wasps, flies, butterflies, and to a less extent by beetles. At the time of its discovery honeybees did not exist on the Western Continent, and for many thousands of years its varied wild flora had been dependent for pollination on the native insects, especially the wild bees. Neither were honeybees found in Australia, New Zealand, or other Pacific islands when they were first visited by Europeans. The indigenous insects had in all probability more or less successfully pollinated the natural floras of these regions in the absence of the honeybee. In extensive areas of the unsettled wilderness there are still many flowers which rely chiefly on the wild insects, and everywhere they are helpful allies of the fruit-grower.

But while in every country the indigenous insects play an important part in the pollination of the wild flora, it is nevertheless true that modęrn fruit culture requires the special agency of the honeybee. In sections where immense orchards cover many square miles of territory and fruit is grown by the ton and carload, the wild insects are wholly inadequate to pollinate the great expanse of bloom, and many apiaries must be established to obtain the best results. The only pollinating insects under the control of man are honeybees, and these must be introduced in large numbers in order to make fruit-growing commercially profitable. Fruit-growing has a marvelous future before it, and must ever be associated with bee culture.

\section{THE - NUMBER OF CULTIVATED PLANTS.}

Only about 44 species of cultivated plants were known to the ancient world. In his "Origin of Cultivated Plants," De Candolle enumerated 247 species cultivated for their roots, leaves, flowers, or fruit, of which the Old World furnished 199, America 45, and 13 were of uncertain origin. While De Candolle described the majority of plants most valuable to the human race, Sturtevant has enumerated in manuscript, according to Hedrick, 1113 domesticated species, which are cultivated today; and a total of 4447 which are partially edible. Not all cultivated plants are pollinated by insects; a part are pollinated by the wind and a part are self-fertilized. In order to avoid confusing these different groups it is 


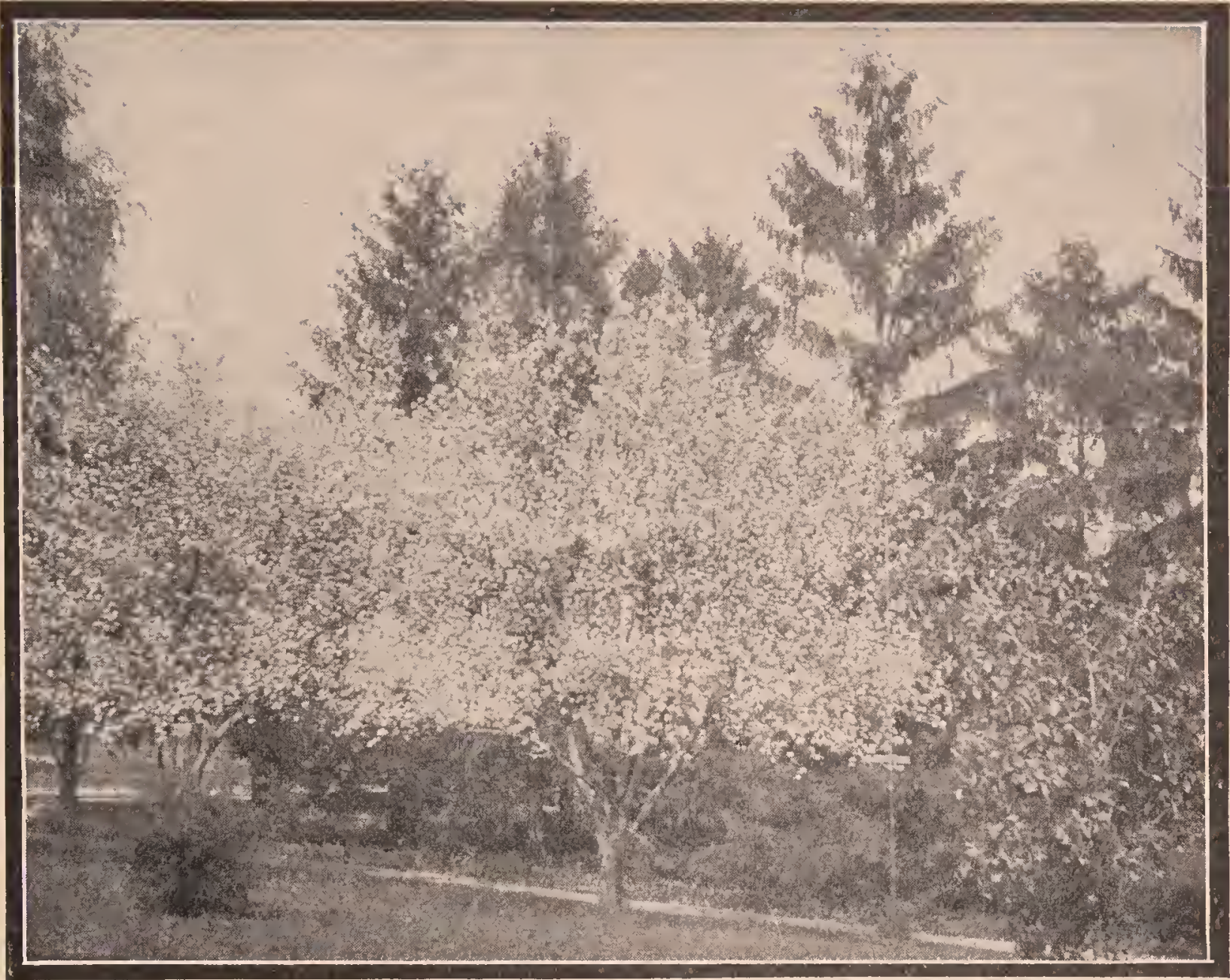

Apple trees in bloom in A. I. Root's orchard.

desirable to describe briefly the common wind-pollinated and exclusively self-pollinated species.

\section{CULTIVATED PLANTS POLLINATED BY THE} WIND.

The wind is a much older, agency in pollination than insects. (See Poluination of Flcwers.) The edible nuts of North America, as the walnut, hickory, acorn, beech, hazel, butternut, and pecan are almost invariably pollinated by the wind; but the chestnut in the temperate zone and many tropical species producing nuts are insect-pollinated. Altho the bloom of the chestnut is nectarless, it is often visited by honeybees and other insects for pollen, which is very abundant. The pollen is adhesive, not dry and loose as in wind-pollinated trees. The common nut trees pollinated by the wind not only have the stamens and pistils in different flowers but in different flower-clusters, so that the pistillate flowers are necessarily sterile unless cross-pollinated. The pecan, hickory, and chestnut are the only nuts domesticated in this country; but since nuts afford a wholesome and nutritious food nut culture is rapidly extending, and it is predicted that in the South in time the pecan groves will rival the cotton fields in extent. The flowers of the wind-pollinated nut trees are nectarless.

The grasses, or Gramineae, which are all wind-pollinated, include the common cereals, corn, wheat, barley, rye, rice, and oats; also sorghum, sugar cane, and millet. The flowers are usually perfect, but selfpollination is prevented by the anthers and stigmas maturing at different times. But sonietimes the stamens and pistils are in separate flower-clusters, as in Indian corn. Buckwheat is usually classed with the cel'eals; but it is not a grass, and the seed is, therefore, not a true grain. The flowers are pollinated by insects, not by the wind. They possess the power of self-fertilization, but when covered with netting they are early in the season almost wholly selfsterile and produce hardly any seed. But 
seed is produced in abundance if the flowers are cross-pollinated. In the fall the bloom becomes highly self-fertile. Nectar is secreted freely, and nine-tenths of the visits of insects, it is estimated, are made by honeybees, upon which the seed crop is largely dependent.

The hop vine, the white and black mulberry, the date palni, and many other palms are also anemophilous or wind-pollinated. According to Swingle about onehalf of the trees of the date palm in nature are staminate, or "male," and onehalf pistillate, or "female," so that crosspollination is a necessity. Under cultivation a single staminate tree will serve to pollinate artificially 50 or more pistillate trees. In each of the fruiting clusters a small branch of pollen flowers is tied.

\section{THE POLLINATION OF THE LEGUMES.}

In the pulse family, or Leguminosae, the seeds are produced in pods called legumes. The flowers for the most part are adapted to pollination by bees. The nectar is secreted at the bottom of a slender tube, formed by the union of the stamens, which raries greatly in length in different species. This great family includes many plants which are valuable to the beekeeper for honey, and to the farmer for forage or their edible seeds, as the clovers, alfalfa, sweet clover, vetch, sainfoin, peas, cowpeas, pole and bush beans, and the Lima bean. The honeybee is the chief agent in the pollination of a very large number of leguminous species, but there are a few which are pollinated wholly by bumblebees, or are self-pollinated. No other family of plants is of so much interest to the beekeeper as the pulse family.

When insects are excluded from the bloom of white clover by netting, it is largely sterile. Honeybees, which visit the flowers in immense numbers and gather tons of nectar, are the most important pollinators. The floral tube is only about half as long as the tongue of the honeybee. Alsike clover is equally dependent on honeybees for pollination, and as it yields nectar most abundantly is very attractive to them. It is well established that in the absence of honeybees, it is impossible to obtain a good crop of seed. The chief areas for the production of alsike-clover seed are western
New York, northwestern Ohio, Indiana, southern Michigan, Wisconsin, Idaho, Oregon, and Canada. Sinaller quantities are harvested in Iowa, Minnesota, and Illinois. In all of these sections there are thousands of colonies of bees.

Spontaneous self-pollination occurs only to a small extent in sweet clover (Melilotus $a l b a)$. When the flowers are cross-pollinated with pollen taken from another plant a higher percentage of pods is obtained than in any other way. A plant of sweet .clover was enclosed in a cage of cheese cloth and all insects excluded. Of the 904 racemes of flowers produced, 594 produced no pods, while 150 produced but one each. The average number of pods per raceme was .63, or six-tenths of a pod. An isolated plant, which insects were permitted to visit freely, produced 239 racemes with an average of 41.6 pods per raceme. The great advantage of cross-pollination is evident. The flowers of sweet clover are visited by many insects, as the nectar can be easily gathered. "But the honeybee is the most efficient pollinator, and it is believed that in many sections it is responsible for the pollination of more than half of the flowers." The smaller bees are important, but are not numerous enough to pollinate large fields of sweet clover. As the result of the heavy and reliable flow of nectar, honeybees visit the flowers constantly, and probably a large part of the honey offered for sale in the large markets comes from sweet clover. The financial value of the services of the honeybee in pollinating white clover, alsike clover, and sweet clover is evidently not easily overestimated and should be more generally known.

Alfalfa flowers are often self-pollinated especially in the western States, and a fair crop of seed may be produced in the $a b-$ sence of all insects. Cross-pollination is an advantage over self-pollination, and in a series of experiments while 30 per cent of the self-pollinated flowers set pods, 46 per cent of the cross-pollinated flowers produced pods. Cross-pollination is nearly always effected by bees. Leaf-cutting bees pollinate 90 per cent of the flowers visited, bumblebees 30 per cent, and honeybees only about 1 per cent. Out of 500 visits by honeybees to alfalfa flower's Westgate observed only one flower tripped. Sladen 
did not observe any flower's tripped by honeybees. While honeybees trip only a small percentage of the flowers visited, where large apiaries are located near alfalfa fields, the great number of bees probably pollinate thousands of flowers. Western farmers claim that, where there are an abundance of honeybees, the crop of seed is nearly doubled, and the seed is larger and better developed. Over 90 per cent of the alfalfa in the United States is west of the Missouri River, and thruout the larger part of this region the bloom yields nectar and supports colonies of bees by the hundred thousand. East of the Missouri River the bloom is, as a rule, nectarless and is only very rarely visited by bees. In sainfoin automatic self-pollination is excluded, and the flowers in the absence of insects r'emain sterile. The most frequent guests are holleybees, which are estimated to pay nine-tenths of the visits.

Red clover was formerly largely pollinated by bumblebees, but in most seasons and in most localities honeybees do the work. When there is sufficient rain to permit a heavy growth of the flowers the nectar is so decply concealed that it can not always be reached by the honeybee. Sometimes not a single honeybee can be found on a field of red clover, while bumblebees are common. But, according to Westgate of the Department of Agriculture, Washington, D. C., under normal conditions Italian bees are not only seen on red clover in large numbers, but they do good work in pollinating blossoms, altho perhaps not so well as bumblebees with their longer tongues. Italians have slightly longer tongues than black bees. As the seasons are more apt to be dry than wet, honeybees will be more apt to be found on red clover than not. In the vicinity of Medina, where red clover is grown largely, honeybees are very common visitors on red clover.

The experience of farmers in both Australia and New Zealand in growing red clover shows conclusively the dependence of this species on bumblebees for pollination. At the time of their discovery neither honeybees nor bumblebees were found in these islands. In New Zealand at Matamata large bee farms of Italian bees were established, which were near thousands of acres of red clover. They very seldom vis- ited the bloom, and rery little seed was produced; from a commercial standpoint the crop was ralueless. Bumblebees were then imported from Europe, and, as soon as they became abundant, the red clover bloom became very fertile and large crops of seed were obtained.

But in very dry seasons the tubes of red clover are shorter, and honeybees then gather the nectar by thousands, pollinating the bloom at the same time. It is also claimed that the floral tubes of the second crop of red clover are shorter than those of the first crop, and this is no doubt frequently true, as the second crop is less luxuriant than the first.

The garden and field pea (Pisum sativum) is self-pollinated. Out of 10,000 cases examined by Mendel there were only one or two flowers pollinated by insects. Neither honeybees nor bumblebees have sufficient strength to depress the keel. Repeated observations of the bloom have failed to discover a single insect visit. In the course of four summers Mueller saw only three bees upon the flowers, none of which were honeybees. The cultivated pea, altho thousands of acres are grown annually, is of no value either for pollen or nectar. This is also true of pole and bush beans, excepting the Lima bean. Only large bumblebees are strong enough to work the flower mechanism. After long and constant watching only a few bumblebees have been observed to seek the bloom. The bean is able to fertilize itself very perfectly and produces great crops of seed. While in California there are vast areas of bean fields (Phaseolus vulgaris) which are of no benefit to the beekeeper, the Lima bean ( $P$. lunatus) is an excellent honey plant yielding large crops of honey.

\section{THE HONEYBEE AND FRUIT CULTURE.}

Altho many nut trees, the cereals, the date trees, and cocoanut trees are pollinated by the wind, the fig trees by wasps, and several widely cultivated forage and leguminous plants are self-pollinated, or pollinated by bumblebees and leaf-cutting bees, it is still true that the honeybee is a most important visitor to the majority of cultivated plants. It is an essential factor in fruit culture, and in the pollination of fruit bloom its significance becomes para- 
mount to that of all other insects. When the value of the fruit crop is considered both from a hygienic and economic point of view, who can overestimate the services

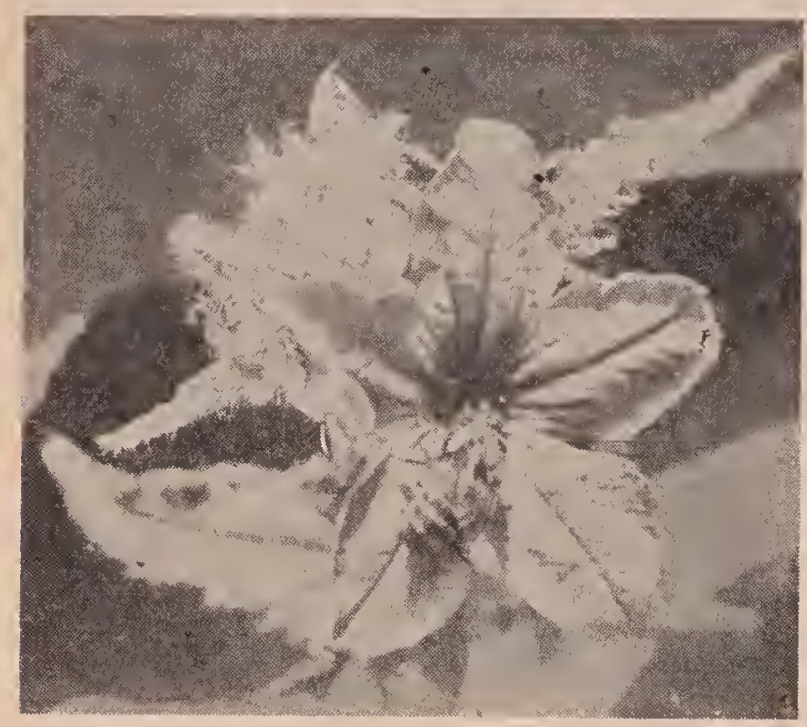

Cucumber blossom with a bee on it; caught in the act.

of the domestic bee to the human race? $\mathrm{Nu}$ merous species and countless varieties of fruits are already under culture, and within the next century many new forms will be domesticated and improved. or introduced from foreign lands.

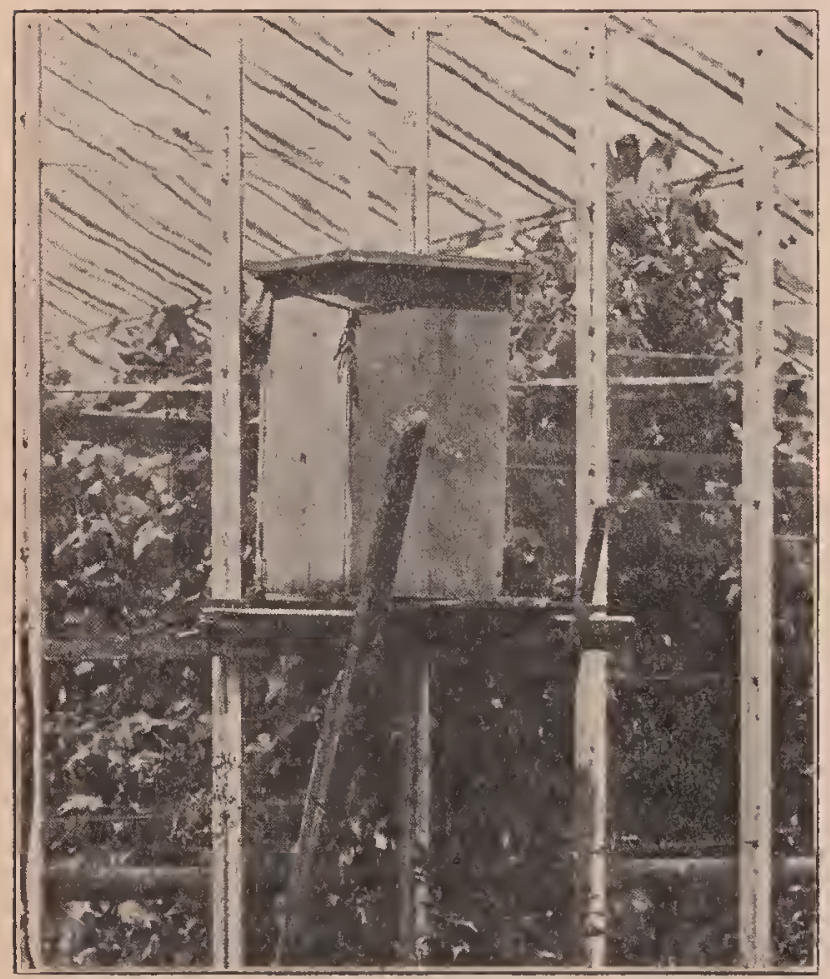

Interior of cucumber greenhouse; hive with entrance inside.

A great variety of fruits were introduced into this country after its discovery, but wild fruits have always been abund- ant in the western continent. Hedrick calls North America a natural garden. "More than 200 species of tree, bush, vine, and small fruits were commonly used by the aborigines for food, not counting nuts, those occasionally used, and numerous rarities. There are now under cultivation 11 American species of plums with 588 varieties; 15 species of grapes with 1194 rarieties; 6 species of blackberries with 86 rarieties; 5 species of dewberries with 23 rarieties; 2 species of cranberries with 60 varieties; and 2 species of gooseberries with 35 varieties, or a total of 45 species of American fruits with 2014 rarieties."

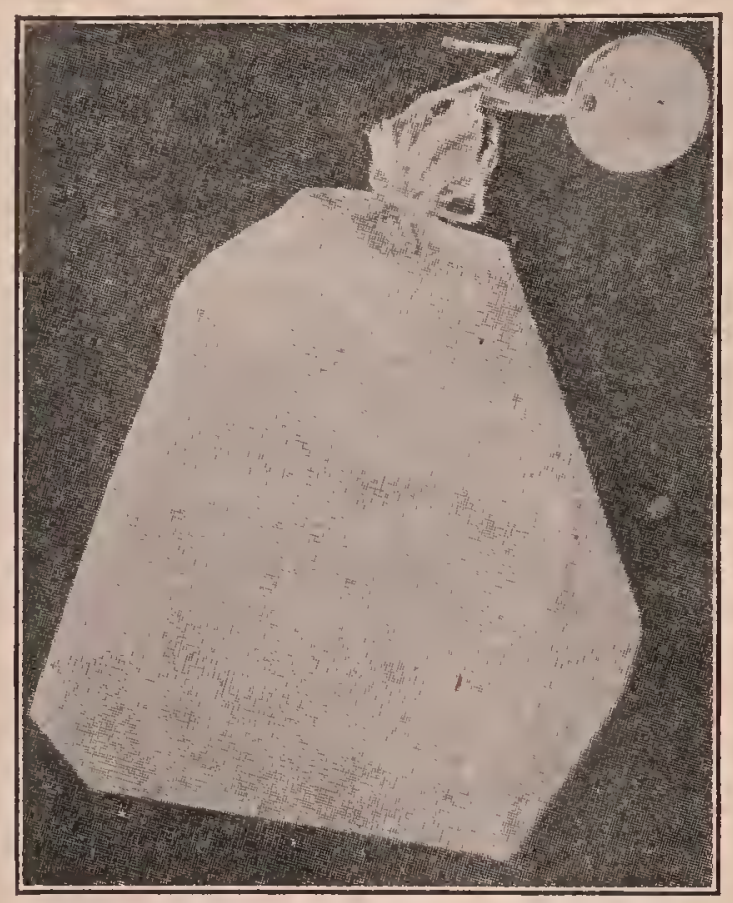

Method of bagging a cluster of flower buds to determine whether the variety is self-fertile or selfsterile.-(After Lewis and Vincent.)

This number is destined to be greatly increased in time by the domestication of other wild fruits. Coville has recently shown that blueberries can be cultivated; and it may be expected that improved varieties will be obtained of blueberries, huckleberries, juneberries, elderberries, wineberries, ground cherries, thorn apples, buffalo berries, highbush cranberries, cloud berries, native mulberries, pawpaws, and persimmons. A beginning in the culture of the fig, the avocado, and the date has been made in California; while the mango, a delicious fruit, of which there are more than 500 varieties, has been introduced into Florida. Hybridizing can multiply new forms indefinitely and yield 


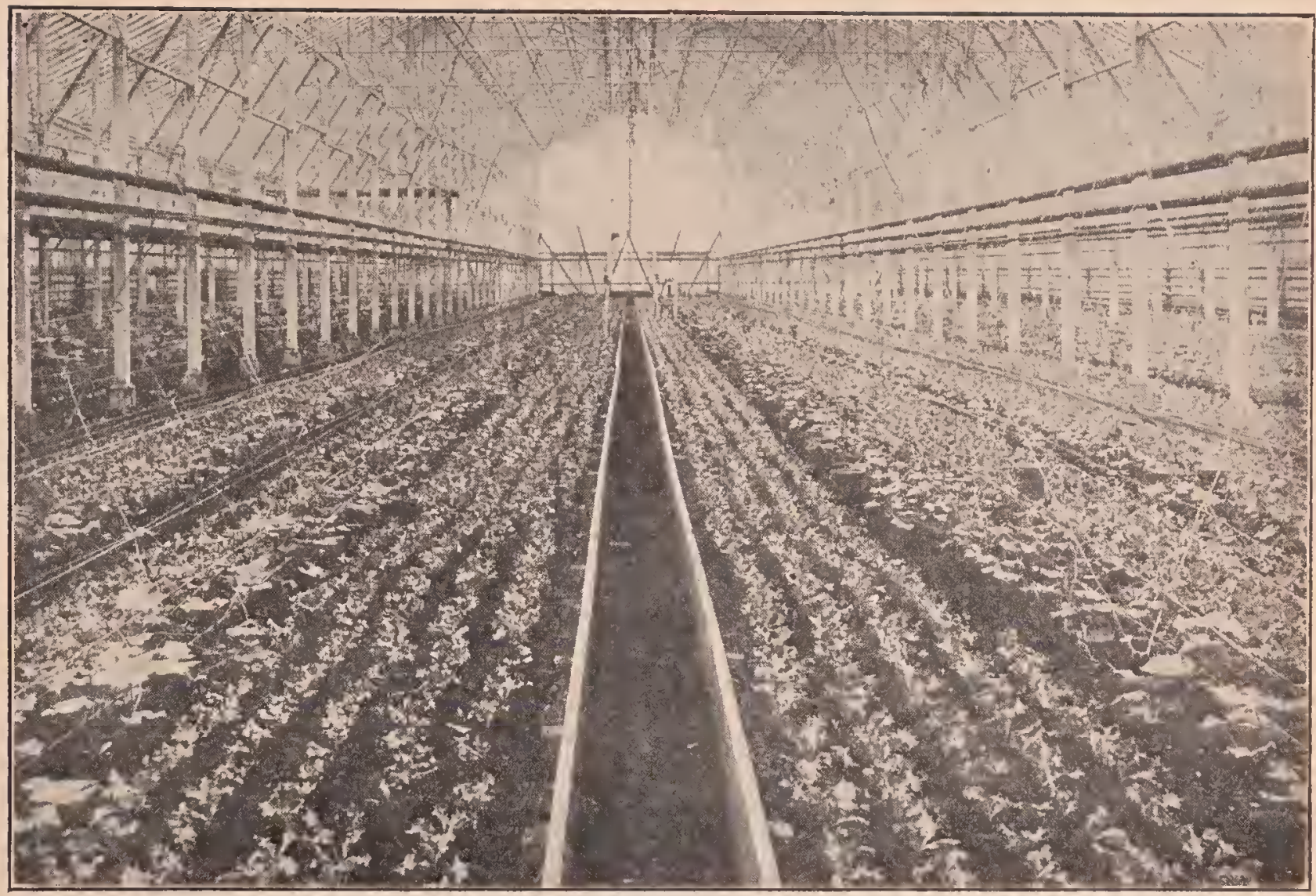

One-half of the great glass building at Ashtabula, Ohio. Cucumbers are replacing the lettuce and there are thousands of the golden yellow blossoms yielding to the bees their pollen and nectar. Many of the blossoms are visited by two or three bees in five minutes. The results show that the cucumbers are not only more perfect in shape but that the crop is much larger.

such anomalies as the loganberry and the blackberry dewberry. In the rast and splendid future of fruit culture the inportance of the honeybee will now be shown by an examination of the pollination of the more important fruits.

\section{POLLINATION OF CUCURBITACEOUS FRUITS.}

The flowers of the squash, cucumber, melon, and pumpkin are monœcious; that is, the stamens and pistils are in different flowers on the same plant. Self-fertilization is thus impossible, and in the absense of insects the vines cannot (unless they are artificially pollinated) produce fruit. The staminate flowers open a few days before the pistillate, are larger, and-are often on longer stalks. The nectar is secreted within a fleshy cup formed by the fusion of the base of the calyx with that of the corolla. In the squash (Cucurbita maxima) and pumpkin (C.Pepo) this cup is large, and, except for three narrow slits, is covered in the staminate flowers by the column of stamens. The flowers are pollinated chiefly by honeybees and bumblebees, which visit then in great numbers and can reach the nectar with their long tongues. On a clear warm day in August the writer has seen a staminate flower of the squash visited in ten minutes by eight honeybees and four worker bumblebees (Bombus terricola). Another flower in ten minutes received six visits from honeybees and six from bumblebees. One of the long-tongued wild bees (Xenoglossa pruinosa) is said to visit only the flowers of the pumplin. In the vicinity of pickle factories there are usually from five to six hundred acres of cucumbers under cultivation, yielding 75,000 or more bushels of fruit. The immense number of blossoms require many colonies of honeybees for their proper pollination.

Honeybees are also largely used for pollinating cucumbers grown in grcenhouses for early market. In Massachusetts some 2000 colonies are required annually to pollinate the cucumbers raised under glass, one large grower using 80 hives. For the crop of cucumbers, squashes, melons, pumpkins, watermelons, and kindred fruits we are thus wholly indebted to bees. 
POLLINATION OF THE TOMATO.

The flowers of the tomato are nectarless, but are visited by bees gathering pollen. Cross-pollination is favored by the stigmas maturing two or three days before the anthers. The different varieties, as Champion, Ponderosa, and Peach can be easily crossed, but are largely self-sterile. At the Ohio Experiment Station, Green set out in August 200 plants of Drarf Champion in a greenhouse, and by winter they had made a fine, thrifty growth and were fruiting nicely. A good crop of tomatoes was expected; but when January came and the fruit began to ripen, the bulk of it was about the size of hickorynuts and without any seeds. Fink also states that plants from which insects were excluded yielded few and small fruits.

In the commercial greenhouses of Oregon, according to the observation of $\mathrm{Bo}$ quet, as high as 6 or 10 per cent of the blossoms of the tomato are unfruitful. The cause of this unfruitfulness is the absence of insects and the relative position of the reproductive organs in the development of the flower. Hand pollination reduced the number of unfruitful blossoms from 66 to 20 per cent. In one commercial greenhouse a block of tomato plants regularly pollinated produced 80 per cent of fruitful blossoms. Nine pounds of fruit per plant was secured, while unpollinated plants yielded only three pounds. Handpollinated flowers produced fruit as much as 21 days earlier than self-pollinated flowers. In some cases artificial pollination thru the increased yield paid the entire cost of producing the crop. Eighty thousand tomato blossoms were under observation. Where tomatoes are grown in the field the visits of honeybees in large numbers for the purpose of gathering pollen would probably increase the crop to an extent sufficient to pay most of the cost of production.

\section{THE POLLINATION OF BERRY PLANTS.}

GraPE.-It is well established that many kinds of grapes are self-sterile; and, since in this country an immense area is devoted to the culture of this fruit, ignorance of the manner of pollination of the different species and varieties must result in great loss. Some 40 species of grapes hare been described, of which about 20 oceur in North America. They are widely distributed thruout the north temperate zone, but are especially abundant in the region of the Caucasus and in the eastern United States. There are now under cultivation some 16 species, 1194 varieties, of which 790 , or threefourths, are hybrids. Foreign grapes do not succeed well in this country when planted outdoors, but grow satisfactorily in hothouses. Grape-growing on a commercial scale in America takes its beginning in 1849, when Nicholas Longworth of Cincinnati, after 30 years of experiment with foreign grapes, turned his attention to our native species and planted extensively the Catawba, a variety of the common wild Vitis labrusca.

The flowers of the vine are small and green and oceur in dense thyrsoid elusters. The calyx is minute, and the five petals cohere to form a little hood, which falls away entire when the flower opens. The five stamens produce only a small quantity of pollen: alternating with the stamens are five nectar glands. The flowers are very sweet-scented with an odor suggestive of mignonette, which can be perceived for a long distance. A part of the plants produce perfect or hermaphrodite ${ }^{*}$ flowers and a part staminate flowers with a rudimentary ovary.

Many varieties of American grapes are self-sterile. Of 169 cultivated varieties inrestigated by Beach at Genera, N. Y., 37 were wholly self-sterile, and in the absence of cross-pollination produced no berries; 28 were so nearly self-sterile that the clusters were unmarketable, and thus from a commercial point of view of no more value than the previous group; 104 varieties produced marketable clusters when self-fertilized, but of this number 66 had the clusters loose, and only 38 yielded compact perfect clusters. Among the varieties wholly sterile were Aminia, Black Fagle, Essex, Oneida, Eaton, Salem, and Wilder: nearly sterile varieties were Brighton, Canada, Geneva, Vergennes, and Woodruff; wholly or nearly self-fertile varieties were Delanson, Moore's Early, Niagara, Worden, Agawam, Catawba, Champion, Clinton. Concord, Isabella, and Victoria. The self-

* See Poluination of Flowers for a definition of these terms. 
fertility of a eluster was tested by enclosing it in a Manilla paper bag before any of the flowers had opened, thus excluding pollen from all outside sources. (Beach, S. A., "Self-fertility of the Grape," Bull. No. 157; "Fertilizing Self-sterile Grapes," Bull. 169, et cetera, N. Y. Agr. Exp. Sta.)

Nearly all the self-sterile rarieties are hybrids; when pollinated by other self-stel- usually regularly self-pollinated, and ar'e, therefore, largely independent of insects. While occasional pollination by the wind may occur, the flowers are adapted to insect pollination. The strong fragrance compensates for their inconspicuousness. In central Europe the five fleshy nectaries secrete no nectar, but in warmer climates it is said to be abundant. The quantity of

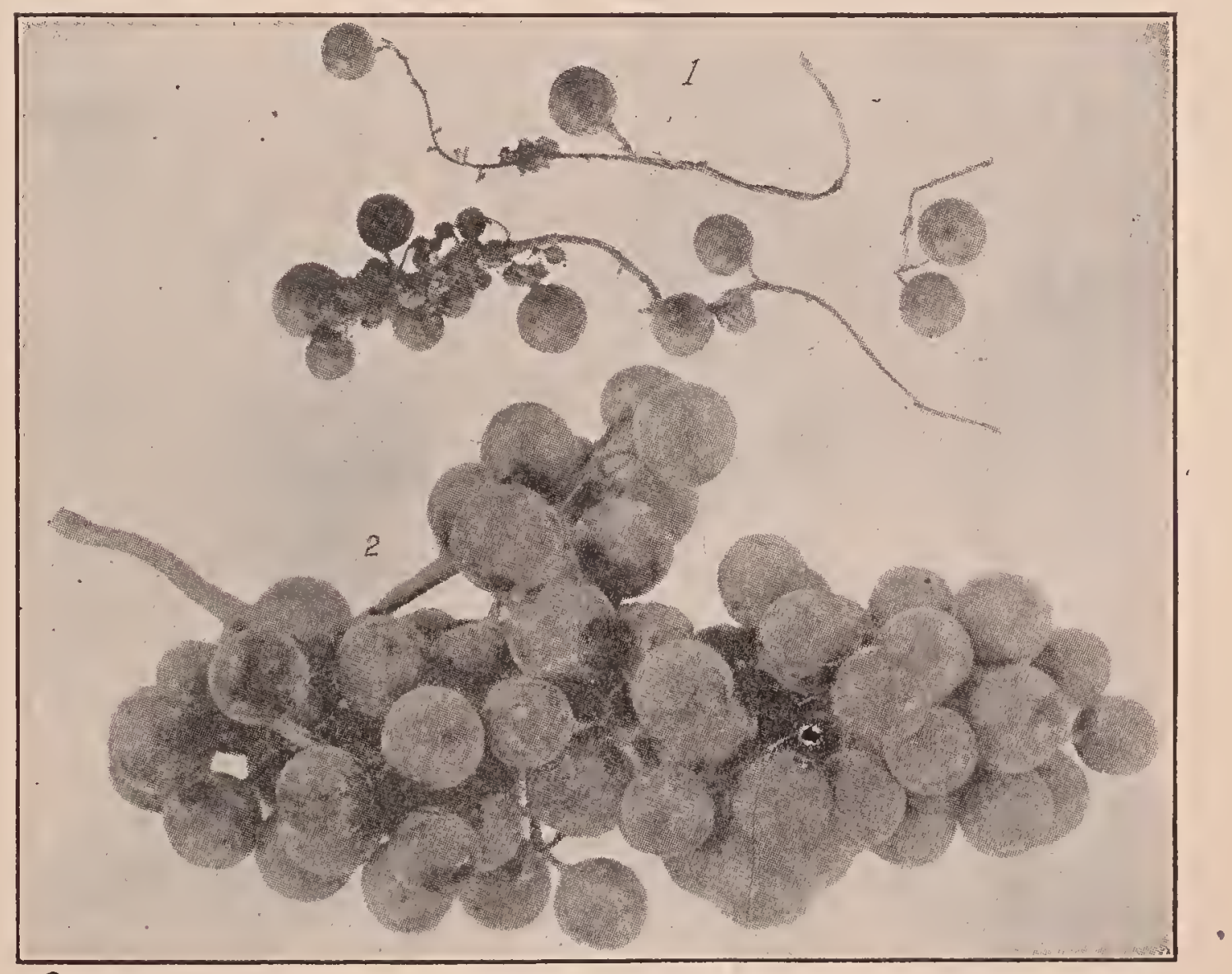

1. Brighton grape self-fertilized; 2. Brighton grape cross-fertilized.-(After Beach.)

ile rarieties they yield no fruit, but. when pollinated by self-fertile varieties they produce marketable clusters. In a vineyard of self-sterile varieties, therefore, there must be a sufficient number of strongly self-fertile vines to pollinate them properly. Care must be taken to select varieties which bloom simultaneously. Self-sterility is due to lack of potency of the pollen, the selfsterile varieties aways having shorter stamens than the self-sterile forms.

The grape remains in bloom from six to ten days according to the temperature of the air. Both anthers and stigmas matuie at the same time, and the pollen retains its ritality for at least two weeks. Speies with the stamens longer than the pistils are pollen is small, but it is gatherer by honeybees, bumblebees, and wild bees. Beetles are sometimes very destructive to the inflorescence. But where the varieties are self-sterile, as is the case with the muscatine grapes (varieties of Vitis rotundifolia) which have been extensively planted in the southern States, bees do not visit the Alowers as frequently as would seem to be desirable. Efforts shonld be made to obtain vines which secrete nectar freely, and also a bee-yard should be located in or near the vineyard.

StRATBERRY.-A strawbelry-grower of great experience says that more trouble, failures, and dissatisfaction arise among fruit-growers-particularly among small 


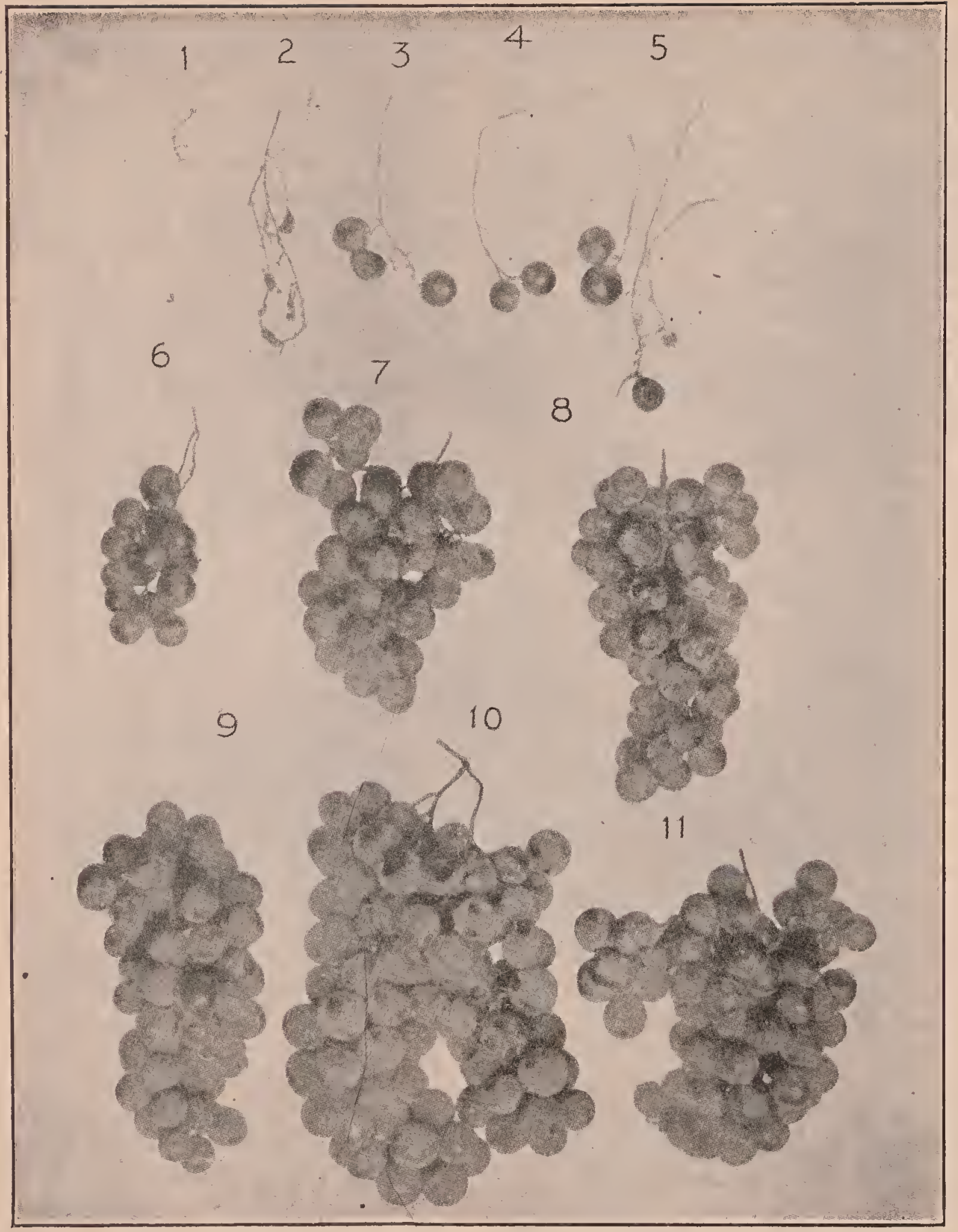

Brighton grape pollinated by 1, Salem; 2, Crereling; 3. Lindley; 4, pollen of another vine of same rariety; 5 , self-pollinated; 6 , by Nectar; 7 , Jeffer'son; 8, Niagara; 9, Worden; 10, Vergennes; 11, Rochester.-(After Beach.)

growers-from ignorance regarding, the sex of strawberries than from any other cause. In this genus there is a marked tendency for the stamens and pistils to occur in different flowers. A part of the plants produce staminate flowers, a part pistillate, and a part perfect or hermaphrodite flowers, as is especially well shown by the Eu- ropean strawberry, the hautbois, or highwood strawberry of Germany. Plants with taminate flowers are comparatively rare, thile the other two forms are common.

The strawberry grows wild thruout a large part of Europe, Asia, North America, and Chile, S. A. Little improvement was made in the fruit until after the be- 
ginning of the nineteenth century, when by crossing and selection hundreds of new varieties were obtained and the berries greatly improved in size and flavor. In eastern North America there are only two well-defined wild species, Fragaria virginiana, the common field strawberry, and the wood strawberry, $F$. vesca. On the western coast of both North and South America $F$. chiliensis is common. All the American species intercross easily.

Owing to their greater productiveness preference in field culture is often given to the pistillate varieties, which are marked "P" in the catalogs of nurserymen. Pistillate varieties which have been extensively planted in the past are Crescent, Manchester, and Bubach; while the Sharpless is perhaps the best known of the older perfect varieties. Where pistillate plants are used in order to provide for their pollination, every fourth row must be planted with perfect or hermaphrodite plants; otherwise the pistillate plants will be barren. It is not at all rare, according to Fuller, to find perfect plants which are largely sterile to their own pollen, altho the pollen is perfectly potent to fertilize other varieties. A variety may have both stamens and pistils, and yet, owing to selfsterility, 90 per cent of the plants be barren. It is of the greatest importance, therefore, to ascertain by growing individual plants under glass whether perfect flowers are self-sterile or not, or, where this is not known, to plant more than one variety. The best-flavored strawberry ever produced by Fuller was discarded becanse, altho hardy, freely blooming, and perfect, it was largely sterile both to its own pollen and that of other varieties.

The pistillate plants are entirely dependent on insects for pollination; no insects, no berries, except in instances where a few stamens may be present. The nectar is secreted by a fleshy ring at the base of the receptacle between the stamens and pistils. It is not abundant, and there is no record of a surplus of strawberry honey. The stigmas mature before the anthers. The flowers are visited by honeybees and many wild bees, which gather both pollen and nectar. It is evident that all the flowers are benefited by cross-pollination and that an abundance of bees is most desirable in strawberry-growing.

RASPBerRy ANd BlackberRy.-The raspberries and blackberries, which belong to the genus Rubus, are widely distributed thruout the north temperate zone of both hemispheres. The nectar is secreted by a narrow ring at the base of the receptacle. In the raspberry it is very abundant, and a large surplus of white honey with a delicate comb and exquisite flavor is obtained annually. (See RAspeerry.) The petals, which drop off on the second day, stand erect when the flower opens and hold the stamens closely against the convex mass of pistils, ensuring self-fertilization in the absence of insects. When insects visit the flowers, especially bees, they regularly effect cross-pollination by rubbing the pollen adhering to their bodies on the numerous stigmas. Since the flowers are visited by innumerable honeybees besides a great company of wild bees, cross-pollination largely prevails. A large amount of fineflavored light honey is gathered from wild raspberry in northern Michigan.

The flowers of the blackberry are larger than those of the raspberry, and the petals. spread out, affording a convenient landingplace for insects. The stamens bend away from the center; and, as the outer anthers dehisce first, the flowers are usually crosspollinated before the inner anthers, which may effect self-pollination, have opener. In the raspberry and blackberry the anthers and stigmas mature at about the same time. The flowers of the blackberry are visited by: many honeybees, wild bees, flies, and beetles. On a small piece of cultivater blackberries growing near the apiary of the writer, the insect-visitors were collected during a succession of days, and the wild bees were found greatly to outnumber the honeybees. The latter manifested a preference for collecting the pollen rather than the scanty supply of nectar. In the eastern States, and even in Michigan, where it covers large areas from which the forest has recently been cleared, the blackberry is a poor honey plant; but in the southeastern States a wild blackberry yields a dark, smoky-colored honey of poor flavor.

Currant and Gooseberry.-The currants and gooseberries, which belong to the 
genus Ribes, all secrete nectar and are largely dependent on insects for pollination. The Journal of the Board of Agriculture, England, says that when insects were excluded from gooseberries, red and white currants, practically no fruit was formed. When artificially pollinated with pollen from the same flower or variety they all proved self-fertile, and set fruit perfectly; but the pollen is so adhesive that it is not readily transferred from the anther's to the stigma except by the visits of insects.

In the European gooseberry (Ribes grossularia) the anthers open before the stigma is fully grown and capable of pollination. Moreover, the flowers hang downward, and, as the anthers stand at the same level as the stigma, the pollen cannot, as a rule, fall on it, and thus in the absence of insects no fruit is produced. The flowers are adapted to bees, and honeybees, bumblebees, and wild bees are very frequent visitors. A bee while sucking nectar touches the stigma with one side of its head and the anthers with the other side, so that in a succession of visits it cannot fail to effect cross-pollination. The European gooseberries do not succeed well in this country; and our native northern gooseberry (Ribes oxyacanthoides) has been extensively planted in the northern States under the name of Houghton. It is easily cultivated and enormously productive. At the Connecticut Experiment Station 72 species of insects have been listed as visitor's.

The flowers of the red currant (Ribes rubrum) are also usually cross-pollinated by insects; but, as the anthers and stigma mature simultaneously and the flowers often stand sidewise, self-pollination may occur by the pollen falling on the stigma. Honeybees, wild bees, and flies are very common visitors. In the black currant (Ribes nigrum) the pistil is a little longer than the stamens, and self-pollination may occur regularly in the absence of insects by the pollen falling on the stigma. In an Alpine species of currant (Ribes alpinum) the stamens and pistils are in different flowers so that no fruit sets in the absence of insects. .

CranberRY.--The cranberries are adapted to pollination by bees. The anthers close= ly surround the single style, and are prolonged upward into long tubes, which open by pores in the ends, from which pollen falls on the head of a bee seeking nectar. The stigma projects beyond these tubes, and thus receives pollen collected by the approaching insect from other flowers. Individual flowers remain in bloom for more than two weeks. On a large cranberry bog the flowers are as numberless as the sands of the sea, and the indefatigable industry of bees is alone equal to the work of pollinating them.

The United Cape Cod Cranberry Company, which has some 700 acres of cranberries under cultivation, has discovered that the wild bees are not sufficiently numerous to do this work satisfactorily; and that the yield per acre can be greatly increased by placing colonies of bees near the bogs. "One test," says E. R. Root, "was significant. The cranberry bog at Halifax contains 126 acres. On one side of this there were three or four colonies of honeybees last year. It is evident that this number was inadequate to cover the entire field, and it is noteworthy that the yield of cranberries per acre was in direct proportion to the proximity of such acreage to the bees. The yield was heaviest close to the hives, and became thinner and thinner as the distance from the hives increased. The showing was so remarkable in this and other bogs that it is proposed to increase materially the investment in bees another year. A small area of cranberry bog was screened to exclude the bees. The screened portion had very little fruit, while that free to the visitation of bees had a large yield. In consequence many cranberrygrowers are planning to go into the bee business for the purpose of obtaining a greater crop of cranberries. In our travels over the United States we never saw a situation that demonstrated more clearly the value of bees as pollinators than did this piece of cranberry bog."

Blueberry and HuCKLEBerRy. - The most valuable of American witd fruits are the blueberry and huckleberry from which there are annually gathered several million dollars' worth of fruit. There are in this country more than 150 species belonging to these two genera growing in a great variety of situations, as dry rocky pastures, 
swamps, and woodlands. T'le inverted urnshaped flowers, with concealed nectar, are adapted to pollination by bees, among: which the honeybee is common; but in remote and obscure localities the wild bees are often the chief visitors.

It was long supposed that blueberries could not be domesticated; but Coville has recently shown that they will grow in an acid soil, and thrive best in one composed of peat and sand. In southeastern New Jersey there are thousands of acres of peaty well-watered pine barrens now unused for agriculture, but which are well adapted to growing blueberries. When the

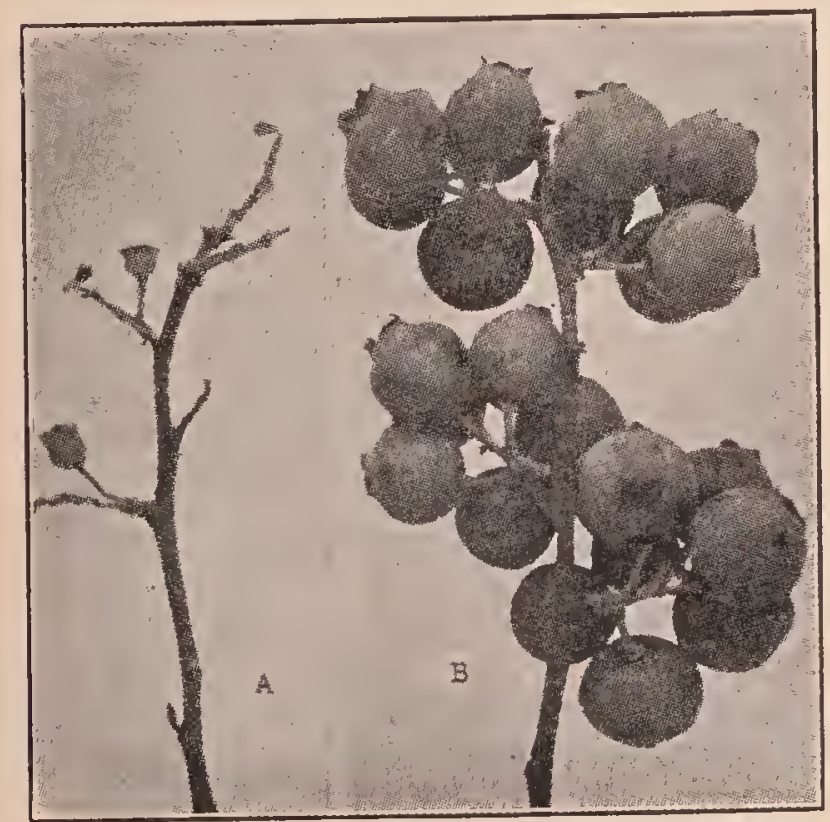

A. Self-pollinated blueberries. B. Cross-pollinated biueberries. These two twigs (reduced onehalf) bore the same number of flowers, and were pollinated at the same time by hand. But $A$ was pollinated with pollen from other flowers on the same bush, and B with pollen from another bush. The self-pollinated flowers produced no ripe fruit, all the berries that set remaining small and green and later dropping off; while the cross-pollinated flowers produced a full cluster of large berries. A plantation made wholly of cuttings from a single bush would produce little or no fruit. (From Corille.)

bushes are grown in rich garden soil they are small and dwarfed. Microscopic examination shows that there is on the roots a minute fungus, without the assistance of which the plants appear unable to nourish themselves properly. This fungus requires an acid soil.

Blueberry bushes are propagated from cuttings rooted by a special method, as they do not come true to seed. Care must be taken to select only plants which produce berries with a good flavor, as some wild blueberries are sour or cren bitter. A blueberry plantation will come into bearing in about four years, and, once well established, will last a lifetime. Blueberries have already been produced of the size and color of Concord grapes.

When blueberry flowers were self-pollinated, only a few berries and seeds were produced, altho the self-pollinations were made very carefully by hand. On some bushes not a berry matured. Berries that resulted from self-pollination were smaller and later in ripening than cross-pollinated berries from the same bush. Neither will plants raised from cuttings taken from a single bush pollinate each other successfully, but the pollen acts the same as tho taken from different flowers on one bush. Coville says: "From these experiments it became clear that if a blueberry-grower should set out a whole field with plants from cuttings of a single choice bush his plantation would be practically fruitless.

The best procedure is to make up the plantation with alternating rows of plants propagated from two choice varieties. Each will then set fruit in abundance thru pollination by the other." In such a plantation bees will not be merely beneficial but indispensable.

THE POLLINATION OF FRUIT TREES. THE PLUA.

The cultivated plums may be divided into three groups according to their origin: The European, the Japanese, and the American. Familiar varieties of European plums (Prunus domestica and $P$. insititia) are the Yellow Egg, Bradshaw, Lombard, German Prune, Damson, and Green Gage; of the Japanese plum (P. triflora), Burbank, Abundance, and Red June; and of American plums, the wild plum (P. americana), the Canada plum ( $P$. nigra), and the Wildgoose plum ( $P$. hortulana). All the species, according to Waugh, hybridize, the Japanese plums crossing easily with the American, but the European and American varieties cross with difficulty. It is believed that hybrids of great value will eventually be obtained. The plum has also been crossed with the peach, cherry, and apricot.

The pollination of plum trees is a matter of great economic importance. "When the native plum trees first began to be culti. 
vated in this country," says Waugh, "their general self-sterility was a drawback, which in many cases proved fatal to their success." Waugh's observations extended over five years and included many varieties, especially of native species. All the varieties of American plums proved self-sterile, with the exception of the Robinson, and this variety is not wholly reliable when selfpollinated. The Japanese plums were also found to be generally self-sterile. Of the European plums a part seem to be selfsterile and a part self-fertile, but no satisfactory experiments are on record. All of the hybrids are self-sterile. The experiments made, says Waugh, show beyond question that the majority of plums do not bear well, and most of them set no fruit at all unless two or three varieties are mixed in the same orchard. The reason for this is that the blossoms of most varieties do not pollinate themselves. In general the varieties in each group pollinate each other better than they do varieties belonging to another group. (Waugh, F. A., "Plums and Plum Culture;" also Bulletins 53, 67, 89, etc., Vermont Experiment Station.)

Self-sterility in plums may be due to several causes. The stigmas may mature two, three, or even five days before the anthers. A part of the pistils may be defective, but usually there are enough perfect pistils to ensure a full crop. The pollen may be impotent. The stamens are shorter or at least do not exceed the pistils in length so that pollen cannot fall on the stigmas unless the flowers stand sidewise. The plums bloom profusely, and the limbs of the Japanese varieties are often completely wreathed with flowers. In small orchards the air is filled with insects hovering about the trees. In a little over an hour the writer collected 100 specimens of wild bees, mostly species of Andrena and Halictus, and these were only a small part of the number present. Honeybees are also frequent visitors, both sucking nectar and collecting pollen. Wild bees man cannot control, but he can raise honeybees, and horticulturists recommend that he place them in large numbers in the orchards.

\section{THE POLLINATION OF THE PRUNE.}

Prunes are varieties of plums containing so little moisture that they can be dried in the sun or in evaporators. Large quantities of prunes are produced in France, Spain, Germany, and Serbia. In America prunes are raised chiefly in California, and, to a less extent, in Oregon. The Santa Clara Valley in California is largely planted with prunes, principally the French variety, with smaller interplantings here and there of the Sugar and Imperial varieties. No other dried fruit is sold in that State in such large quantities. During the height of the blooming season in the Santa Clara Valley a great scarcity of insects, especially bees, has been observed. In some localities one might work for days among the blossoms without seeing a bee.

To test the value of honeybees as pollinators of prune trees a series of experiments has been made by the Berkeley Agricultural Experiment Station in an orchard of 180 acres on the Sorosis Ranch in Santa Clara County. The orchard contains chiefly French (Agen) prunes, 18 to 25 years old; but there are four rows of Imperial prunes. In the entire orchard in 1916 there were only six colonies of bees, and only 3.6 per cent of the blossoms of the French variety set fruit; but in 1917, with 115 colonies 13.2 per cent of the flowers set fruit. The Imperial variety yielded equally well (7.2 per cent) during' both years, and showed no response to the increased number of hives. Other orchardists obtained equally favorable results. At Saratoga 50 hives of bees were placed near the edge of a 50-acre prune orchard, and the branches were literally broken down under the burden of the crop. A cherry orchard near by also yielded a large crop. In another orchard in Santa Clara there were 50 hives, and the trees were loaded to their full capacity. At Yuba City 113 hives were placed in a mixed orchard, and all varieties of trees yielded exceptionally heavy crops, which were attributed by the owner to the agency of bees. Branches of trees covered with netting produced no fruit.

At the Sorosis Ranch a tree of the French prune was enclosed alone in a tent of mosquito netting, and all insects excluded. Altho covered with blossoms, less than one-half of one per cent (0.43) of them set fruit. Under similar conditions only 0.34 per cent of the blossoms of a 
tree of the Imperial variety set fruit. The almost total failure of these trees to mature fruit shows that bees are a necessity for distributing the pollen, and that without them the orchards would be largely unproductive and unprofitable.

But when a single tree of the French prune was enclosed in a tent with a hive of bees, 19.4 per cent of the blossoms set fruit, which was some 6 per cent higher than the average of the orchard, and shows that the bees very thoroly performed the work of pollination. This variety is evidently selffertile provided there are insects present to distribute the pollen properly. When a single Imperial prune tree was enclosed in a tent of netting together with a colony of bees, 3.02 per cent of the blossoms set fruit. As this variety is largely self-sterile, it was a surprising feature of the experiment that enough flowers were stimulated by the numerous visits of the bees to produce a satisfactory commercial crop. Possibly, it is partially self-fertile occasionally. This has been observed to be true in the case of the apple. According to the Oregon Experiment Station: "Some varieties of the apple have been found to be self-sterile three years out of five, and selffertile the other two." When a French and an Imperial prune tree were inclosed in the same tent together with a colony of bees, cross-fertilization was observed to be beneficial. In the orchard the results of three years showed that French trees close to the Imperials yielded better than those farther away. It would appear from these experiments that prune trees are almost wholly dependent upon bees for pollination.--Mendrickson, A. H., "The Cominon Honeybee as an Agent in Prune Pollination', 'Univ. Cal. Pub., Nos. 274 and 279.

\section{POLLINATION OF THE ALMOND.}

The almond (Prunus Amygdalus) can be grown only in limited areas in California, as it is injured by frost. While there are orehards of 100 acres or more, the average orchard consists of about 30 acres. At Dunham eight colonies of bees were placed in a five-acre orchard. As a result, 9,500 pounds of almonds were harvested, or neariy a ton per acre, while the other orcharas in the district averaged only about 300 pounds per acre, and some even less. The orchardists of that locality were so strongly convinced of the importance of bees that 200 or more colonies could have been placed in groves at once.

\section{THE POLLINATION OF THE CHERRY.}

The cherries belong to the same genus (Prunus) as the plums, and the structure of the flower is similar. Cultivated cherries are popularly divided into two groups, the sour cherries and the sweet cherries. The sweet, heart, mazzard, bird, and Bigarreau are varieties of Prunus Avium, a species found wild in Asia; while the sour, pie, and morello cherries are varieties of $P$. Cerasus, also an Asiatic species. The two groups lybridize.

The sweet cherry (Prunus Avium) is in bloom five or six days. The stigma and the anthers mature simultaneously; but, as the flowers are usually pendulous and the stamens diverge from the pistil, self-pollination rarely occurs. Common visitors are honeybees and wild bees, and their value in pollination is well illustrated by the following experience. The crop of a sweet-cherry orchard in 1912 was 13 tons. To secure cross-pollination, the owner in 1913 cut branches from seedling cherry trees at blooming time and placed them in buckets of water thruout his orehard. In addition, several colonies of bees were placed in the orchard. With no better season and with the trees only one year older, the crop was 39 tons.

Among the orchard trees of Oregon the cherry ranks fourth in importance, being surpassed only by the apple, prune, and pear in the order named. A poor cherry crop affects the income of many persons. The rapid increase in the area planted with cherries has been followed by complaints that in spite of the heavy bloom there was not sufficient fruit to be profitable. In some instances the new orchards have never paid expenses, while old orchards have become less productive. Altho sorely perplexed by these conditions the cherry-growers, unfamiliar with the mutual relations of flowers and insects, have been slow to believe that lack of proper cross-pollination is the chief cause of the failure of their trees to set fruit. But the cherry orchards of a decade ago were of small size and mixed rarieties; while recently orchards of 
10 to 100 acres liave been planted consisting wholly of one or more of the standard varioties. It has been commonly recognized that rain fog, temperature, the condition of the soil, and the age of the trees are influential factors; but few in the absence of definite information have considered the possibility of self-sterility.

In order to determine the cause and remedy these failures Gardner in 1911-13 investigated the pollination of the sweet cherries. Thousands of flowers were pollinated with their own pollen and insects excluded by bagging. All of the 16 varieties tested

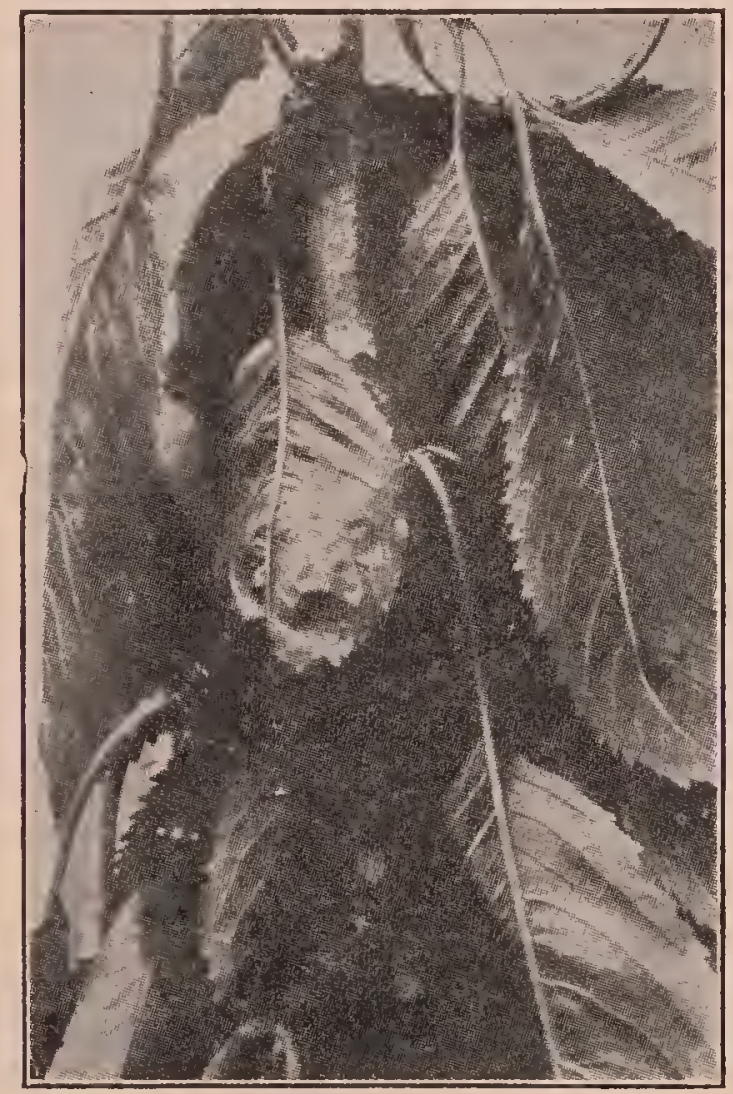

1. Bing sweet cherry crossed by Napoleon yields no fruit.- (After Gardner.)

proved self-sterile. The self-sterility was in no ease due to the inability of the pollen to germinate, for in the case of each of the varieties tested the pollen was potent in producing fruit with some other variety. Ninety per cent of the commercial plantings consist of the varieties Napoleon, Lambert, and Bing, all tluree of which are intersterile; that is, each of these varieties is sterile to the pollen of the other two varieties as well as to its own pollen. Napoleon, where planted in solid blocks, yielded little fruit altho interplanted with Lambert and Bing. But each of these three varieties is effectively pollinated by Black Republican,
'Tartarian, and Waterhouse. (Gardner, V. R., "The Pollination of the Sweet Cherry." Oregon Experiment Station, Bulletin 116, 1913.)

"The importance of honeybees as agents in cross-pollination," says Gardner, "cannot be over-emphasized." This is clearly shown also by the experience of cherrygrowers in California. For several years the cherry crop of Vaca Valley, Solano County, Cal., had not been good, altho it had formerly been quite sure. It was recollected that formerly; when the cherry crops were good, wild bees were very plenti-

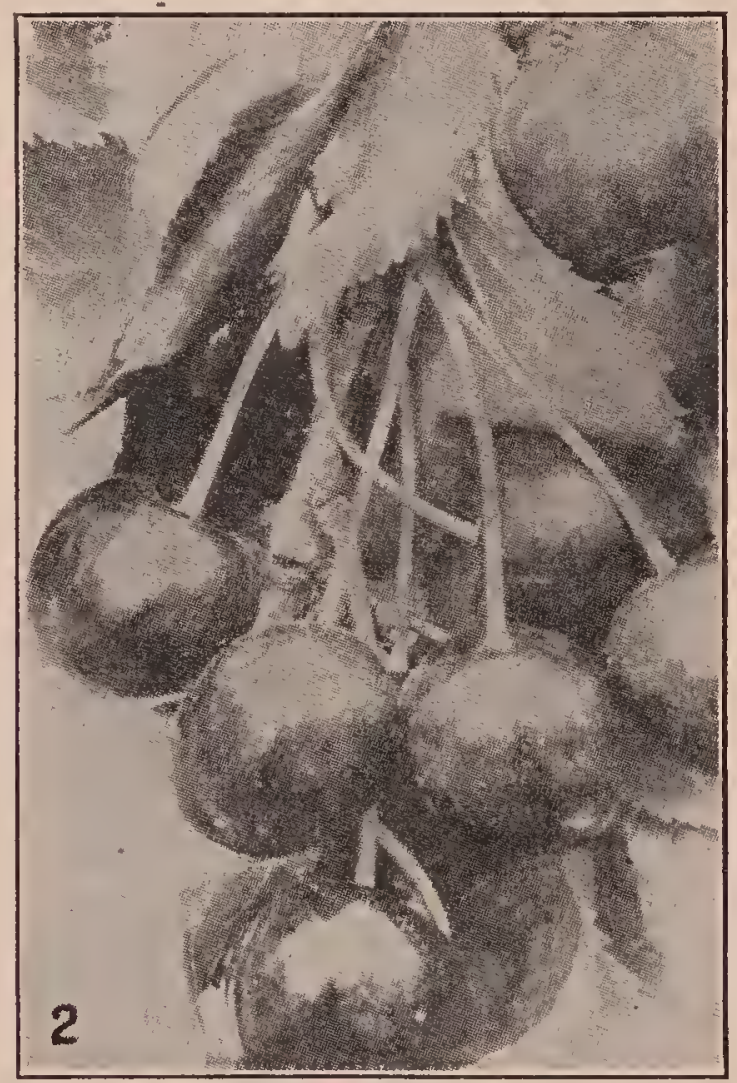

2. Average cluster of Bing crossed by Williamette. (After Gardner.)

ful in the valley, and since most of the bees had disappeared it was thought that perhaps the lack of fruit might be due to imperfect pollination. To test the matter the Messrs. Bassford, therefore, placed several hives of bees in their orchard in 1890 . The result was striking, for the Bassford orchard bore a good crop of cherries; while other growers in the valley who had no bees found their crops entire or partial failures. In 1891 there were some 65 hives in the Bassford orchard, and H. A. Bassford wrote to the Entomologist: "Our crop was good this season, and we attribute it to the bees. Since we have been keeping bees our 
cherry crop has been much larger than formerly, while those orchards nearest us, five miles from here, where no bees are kept, have produced but light crops."

The flowers of the sour cherry ( $P$. C erasus) closely resemble those of the sweet cherry, but the petals are flatter and the stigma matures before the anthers. Selfpollination is thus at first impossible. The position of the stamens and the opening of the anther's outwardly also tend to prevent automatic self-pollination. Not a single fruit set when insects were excluded from cherries, says the Journal of the Board of Agriculture, England. Neither did any fruit mature when the flowers were pollinated with their own pollen, but all the flowers pollinated from another variety set fruit. So necessary are the honeybees for cherry orchards that the grower's have imported in one case a carload of bees from the Soutl.

A very interesting case came under the observation of the author of this book. $\mathrm{He}$ was asked to put bees in a cherry orchard about ten miles from his home town. There were ten acres of trees, and, therefore, there were ten colonies put in the orchard. The season was very cold and backward at the time the trees came into bloom. There was only an hour or two that the sun shone and it was warm enough for the bees to fly. At the close of the season, only those trees near the hives of bees yielded cherries in abundance, while those remote from the bees had very few or no cherries at all. It was very noticeable that the yield of cherries on the trees was almost in direct ratio to the distance of the trees from the bees.

THE POLLINATION OF THE PEACH.

The peach also belongs to the genus Prunus (P. Persica). The rose-red flowers appear in early spring before the leaves. Nectar is secreted within a cup-shaped receptacle and attracts both honeybees and wild bees. One cold rainy spring a colony of honeybees was placed in the center of a small block of peach trees so that the bees could easily visit the flowers. The result was that this orchard set all the peaches the trees could carry thru the following dry season; while other peach orchards, which bloomed equally well, but were without bees, failed to set a crop (20tlı An. Rep.
Mass. Fruit-growers' Assoc., 1914, p. 52). According to Fletcher, however, 2939 Gold Drop peach blossoms showed no benefit to this variety when cross-pollinated with pollen from three other varieties.

THE POLLINATION OF THE PEAR.

The pollination of pear trees has been studied by Waite, who was the first in America to show that many varieties of orchard trees are self-sterile. In his earlier experiments clusters of buds were enclosed in bags of papers or cheese cloth which were not removed until the blooming period was over; but in his later experiments the bags were opened and the anthers carefully removed and the flowers hand-pollinated. There were employed in these experiments 144 trees belonging to 38 varieties. More than one-half of these varieties when selfpollinated proved to be wholly or nearly self-sterile and produced little or no fruit. Among the wholly or nearly self-sterile varieties were Anjou, Bartlett, Clapp's Favorite, Howell, Lawrence, and Winter Nelis; self-fertile varieties were Angouleme, Bose, Buffum, and Flemish Beauty.

A brief summary of Waite's conclusions is as follows:

Pollen from another tree of the same variety is no more effective than pollen from the same tree.

The pollen of a self-sterile variety may be perfectly effective when applied to another variety.

Even in those varieties which can be self-fertilized the pollen of another variety is prepotent, and when insects are not excluded most of the fruit seems to be the result of crossing.

Self-fertilized pears contain small vestigial seeds and are smaller and less perfect than those produced by crossing.

The ineffectiveness of the pollen in selfsterile varieties is due to no defect in the pollen.

In 1892 Waite visited the large pear orchard of the Old Dominion Fruit Company near Scotland on the James River. The orchard consisted originally of about 22,000 standard Bartlett pear trees. It had been planted some 18 years previously, but had never borne a full crop. The maximum crop was three-fifths of a peck per tree, while a standard Bartlett tree 12 years old 


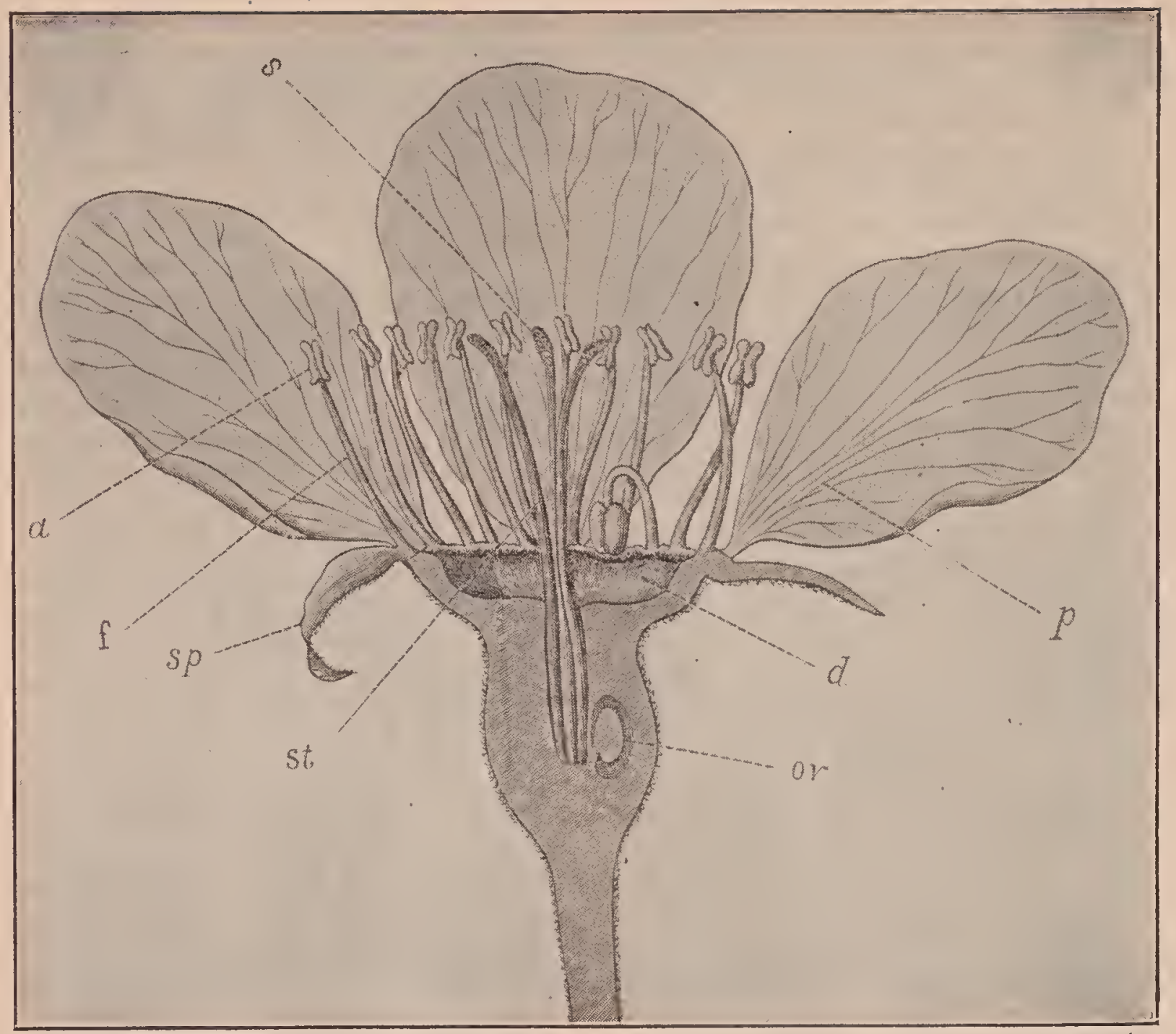

Enlarged section of the flower of a Bartlett pear; sp, sepal, the five sepals form the calyx or cup; $n$, petal, the five petals form the corolla or crown; the stamens consist of two parts, $f$, the filament or threadlike stem, and $a$, the anther, composed of two sacs which contain the pollen; the pistils consist of three parts, $o v$, the ovary ; st, the style, and $s$, the stigma; $d$, the disc in which the nectar is secreted. Pollination is the transfer of the pollen to the rough sticky surface of the stigma. The pollen grains send out slender tubes, which pass down thru the strle to the ovules. From the end of a tube a sperm cell passes into an orule and unites with an egg cell- this is fertilization.-(After Waite.)

should easily yield five times that amount. In 1892 the crop was less than 100 boxes of three pecks each. The trees in the orchard had always bloomed heavily, and were every year snowy white with blossoms. It was clearly indicated that something was wrong. In three places in the orchard, where the trees had died, two Clapp's Favorite and a Buffum tree had been planted by mistake, and in their vicinity the Bartletts fruited heavily. A small orchard containing a variety of trees had been very productive, and the Bartletts near this orchard also bore well. Waite determined the difficulty in the following way: After removing the stamens from a number of unopened buds he pollinated a part of them with pollen from Bartlett trees and a part with pollen from different varieties, and then enclosed them in paper bags. In the orchard at large, a week after the petals had fallen, the young pears all dropped off. Most of the trees were absolutely barren. Of the flower's enclosed in bags, not one pollinated with Bartlett pollen had set fruit, while a large proportion of the crosses with other varieties produced pears. As there were a sufficient number of insects to carry the pollen, it is evident that, had there been other varieties of pears scattered thru the great orchard, the crop would not have been a failure. The Bartlett pear is largely self-sterile.-Waite, M. B., "The Pollination of Pear Flowers," Div. Veg. Patl. Bull. No. 5, 1895; also Yearbook Dep. Agr., 1898.

A pear flower remains in bloom seren or eight days. There are 20 stamens in four 
cycles and five pistils. 'The stigmas mature two or three days before the anthers, at which stage self-pollination is impossible. In the bud the stamens are bent inward, but gradually bend backward after the flower opens, the anthers on the outer row opening first. Self-pollination may occur by the styles finally bending backward until the stigmas touch the anthers, or in the case of flowers standing sidewise by the pollen falling on the stigmas. The quantity of nectar secreted within the concave receptacle is greatly affected by the weather; but sometimes it collects in large drops which overflow and fall to the ground. A great variety of insects, as honeybees, wild bees, wasps, flies, and beetles visit the flowers. Waite collected 50 and Mueller 30 species. At Washington, D. C., Rochester, N. Y., and the Connecticut Experiment Station, the ground bees belonging to the genera Andrena and Halictus were found to outnumber all other insects. The writer observed a medium-sized pear tree in full bloom for an hour and a quarter, but during this time saw no insects except honeybees, which were very abundant. A cluster of seven blossoms received eight visits in a quarter of an hour; and two other clusters consisting of 16 flowers received 16 visits. This was an average of a little.more than four visits to each flower on the tree per hour.

The great service rendered by insects in the pollination of pear blossoms is well illustrated by the experiments of $\mathrm{V}$. H. Lowe at the Genera Experiment Station, New York, in 1889. A number of small pear trees were covered with a hood of sheeting which came down over the tree like a bag, and was tied at the lower end around the trunk of the tree. On all the trees so covered there was a large number of buds, and all the conditions were favorable for a good crop, except that the visits of insects were entirely prevented. As a result, on the whole lot of trees covered there was just one fruit. On another set of trees of the same sort and size, not covered, there were 145 pears. In the case of another tree a large limb was enclosed in a bag with similar results.

Extensive experiments on the pollination of Bartlett and Kieffer pears have also been made by Fletcher. Thirty thou- sand and eighty-one Bartlett blossoms, carefully deprived of their anthers and pollinated with Bartlett pollen, produced only six small fruits as compared with 763 fruits produced by 7170 Bartlett flowers pollinated with Bartlett pollen, produced only six small fruits as compared with 763 fruits, produced by 7170 Bartlett flowers pollinated with Lawrence, Anjou, Dutchess, and. Kieffer. Two large 18-year-old Bartlett pear trees were completely covered, just before the blossoms opened, with muslin sheeting in such a way that all insect visitors were excluded; but two limbs on each tree were permitted to protrude beyond the sheeting and were open to insect visits. These two limbs were loaded with fruit; while the flowers under the sheet, which were dependent on self-pollination, produced only 10 small pears. One thousand two hundred and sixty-eight Kieffer pear blossoms pollinated with pollen of the same variety produced only five pears; while 2363 Kieffer blossoms pollinated with Bartlett pollen produced 446 pears. Kieffer is, therefore, almost completely selfsterile (Fletcher, S. W., "Pollination of Bartlett and Kieffer Pears," An. Rep. Va. Poly. Inst. Agr. Exp. Sta., 1909-10). As in the case of the other fruits the importance of honeybees, which can be imported, is clearly apparent.

It was long believed that bees were active in spreading fire blight; but more recent and careful observations show that the spores of this fungus are distributed by other agencies. See Fire Blight.

\section{THE POLLINATION OF THE APPLE.}

The apple is the most important of all fruits, and the value of the crop annually in the United States is at least $\$ 100,000$,000. Every orchardist should know what varieties are self-sterile and how they can be properly pollinated. Of 87 varieties of apples tested by Lewis and Vincent in Oregon 59 were found to be self-sterile; 15 were self-fertile but gave better results when pollinated by some other variety; and 13 were partially self-sterile.* Among the self-sterile varieties were Bellflower, Gravenstein, King, Rhode Island Green-

\footnotetext{
* The question whether a variety is sterile to its own pollen varies according to locality. For exam ple, the bellflowers in the Pejario Valley, Calif., are self-fertile; elsewhere they appear to be self-sterile.
} 


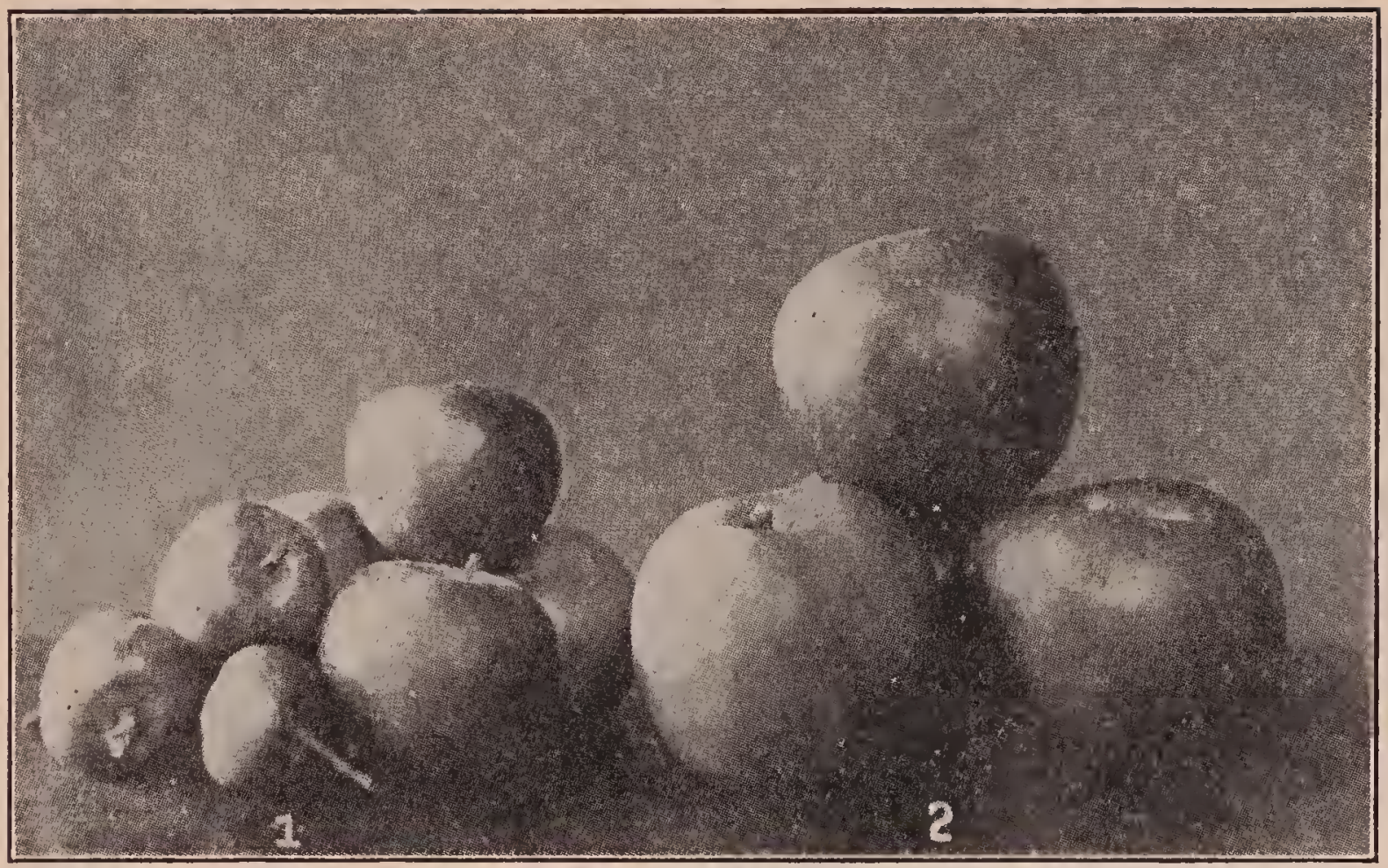

1. Self-pollinated Newtown apples, producing at least one-third of the apples undersized. 2, Newtown apples pollinated by Grimes Golden; no small apples.-(After Lewis and Vincent.)

ing, Tolman Sweet, Wealthy, and Winesap; among the self-fertile were Baldwin, Oldenburg, Shiawassee, Washington, and Yellow Newton; partially self-fertile were Ben Davis, Stark, Spitzenburg, and Yellow Transparent. The experiments showed that in the majority of cases cross-pollination is a necessity to ensure a profitable crop. Crossing always gave better results than self-pollination, and is the rule, while self-pollination is the exception. Crosspollinated trees gave larger and finer fruit with well-developed seeds; while selfpollinated trees gave smaller fruit with

the seed usually wanting or abortive, as is shown in the following table:

EFFECTS OF SELF AND CROSS POLLINATION. Oregon Exp. Station, 1908.

Newtown Apple

Pollinated

by Self

by Esopus

by Grimes

by Self

by Newtown by Baldwin
Av.wt. fruit 73 grams

147 grams

173 grams

Esopus Apple

100 grams

126 grams

157 grams
Av.wt. seeds .05 grams

$.66 \mathrm{grams}$

.60 grams

.13 grams

.65 grams

.71 grams

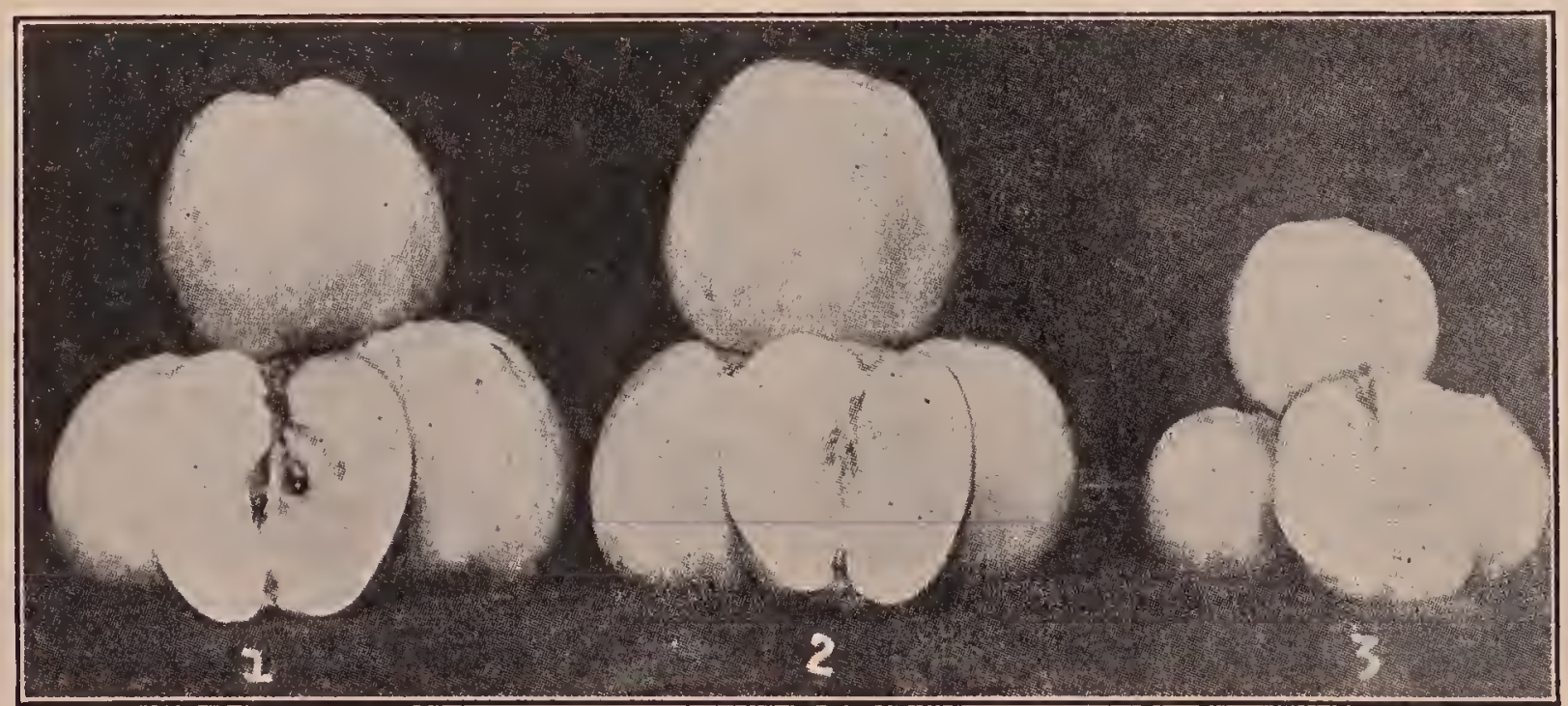

1, Keswick Codlin apple cross-pollinated; 2 and 3 , self-pollinated. Notice the absence of seeds in the self-pollinated apples. - (After Lewis and Vincent.) 


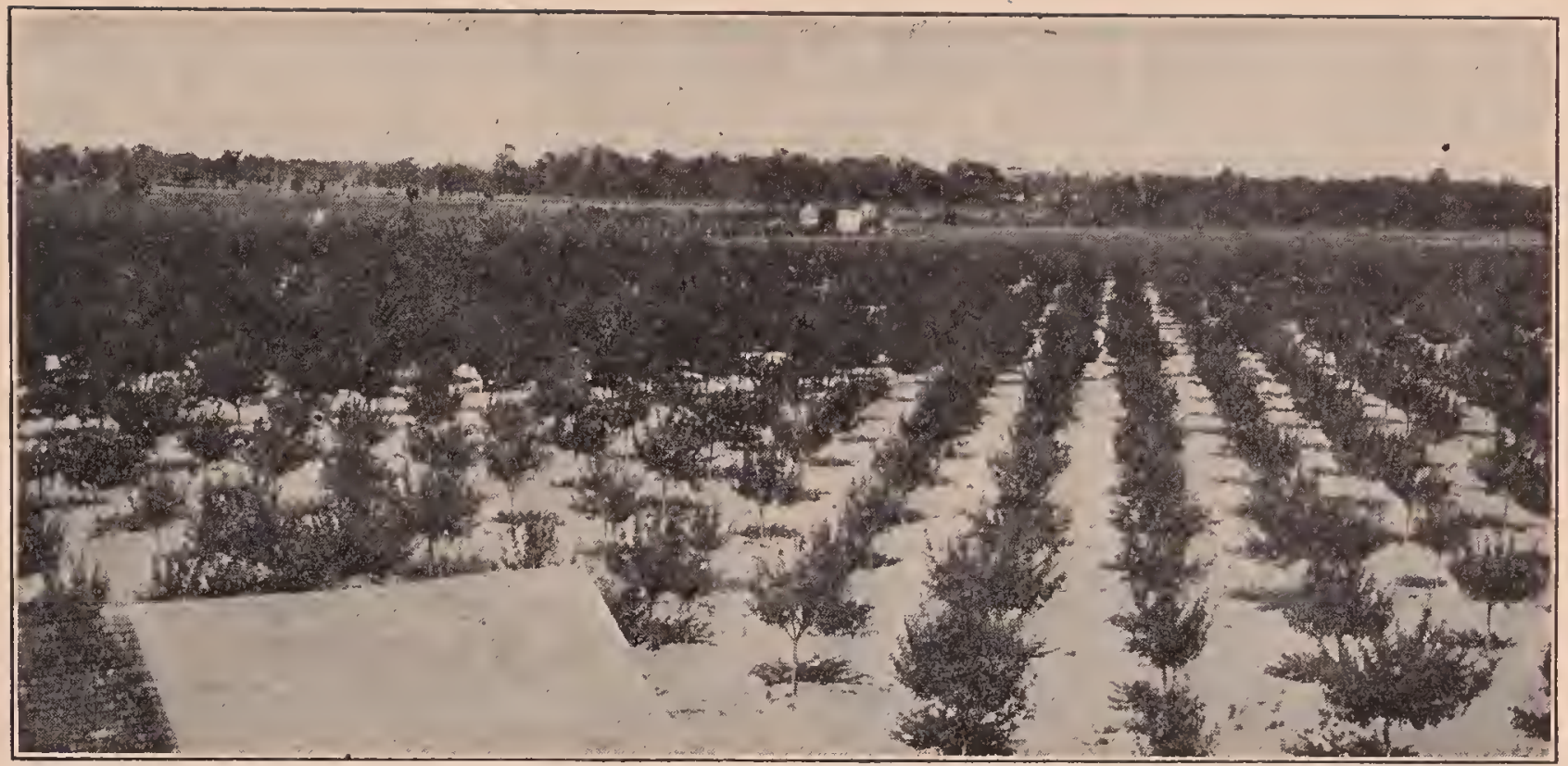

The 17-acre orrhard that in its tenth year produced 6 arloads of apples with the lielp of the bees.

Waite found that hancl-crossed Baldwins were highly colored, well-matured, and contained many seeds; while the self-fertilized fruit was seedless, only slightly colored, and only one-quarter to two-thirds of the regular size.

The Journal of the Board of Agriculture, England, says that out of 63 varieties of apples on which unopened blossoms were enclosed and left untouched the only one that matured fruit was Irish Peach. Of those enclosed and pollinated with their own pollen by brush, only a few matured fruit. Others failed to yield any fruit when pollinated with pollen of the same variety. On the other hand, of the 64 crosses made, 43 were successful. In Illinois there were formerly many large orchards of 40 to 80 acres of a single variety which seldom or never bore large crops; while mixed orchards in the vicinity often gave bumper yields (An. Rep. Mass. F. G. Assoc., 1914, p. 47). But under certain circumstances a single variety planted in large blocks has been known, according to Waite, to yield satisfactorily, as the Ben Davis at the Olden Fruit Farm in Missouri. In Oregon it has been the practice to plant two rows of one variety, then two rows of the variety used as a pollinator, followed by two rows of a third variety. Varieties must be selected, of course, that bloom at the same time.

The flower's of the apple are larger than those of the pear, partially rose-colored and pleasantly scented, especially in the evening, when they are attractive to moths. The stigmas mature two days before the anther's. The stamens stand erect, so covering the nectary that the nectar is not as easily accessible as that of the pear. Bumblebees, which seldom visit pear flowers, are common on apple bloom. At the Connecticut Experiment Station 52 insects were listed as visitors, among which were 26 species of bees.

It is a matter of common observation that where an apiary is located near an apple orchard honeybees are frequent visitors to the bloom, and often appear to be the only insects present. Waite observed that in large orehards covered with blossoms there were not sufficient bees to pollinate the trees; and this is no doubt often the case in sections where apple-growing is the principal industry. The president of the Vermont Horticultural Society found on examination that in orehards which failed to produce abundantly there were no bees or too few to be of much use. Wherever there were large apiaries there was in every instance a large apple crop (Gleanings in Bee Culture, March 15, 1912). "Plant mixed orchards," says Waite, "or at least avoid planting solid blocks of one variety. Be sure that there are sufficient bees in the neighborhood to pollinate the blossoms properly." A large fruit-grower in California declares: "Bees and fruit go together. I can't raise fruit without 
bees." (Waite, M. B., "Cross-pollination of Apples," Year Book Dept. Agr., 1898, Lewis, C. I., and Vincent, C. C., "Pollination of the Apple," Oregon Exp. Sta., Bull. No. 104, 1909.)

\section{THE POLLINATION OF THE QUINCE.}

The common quince (Pyrus Cydonia) has solitary flowers, which are larger and bloom later than those of the apple or pear. The stigmas mature before the anthers, but self-pollination occurs regular-

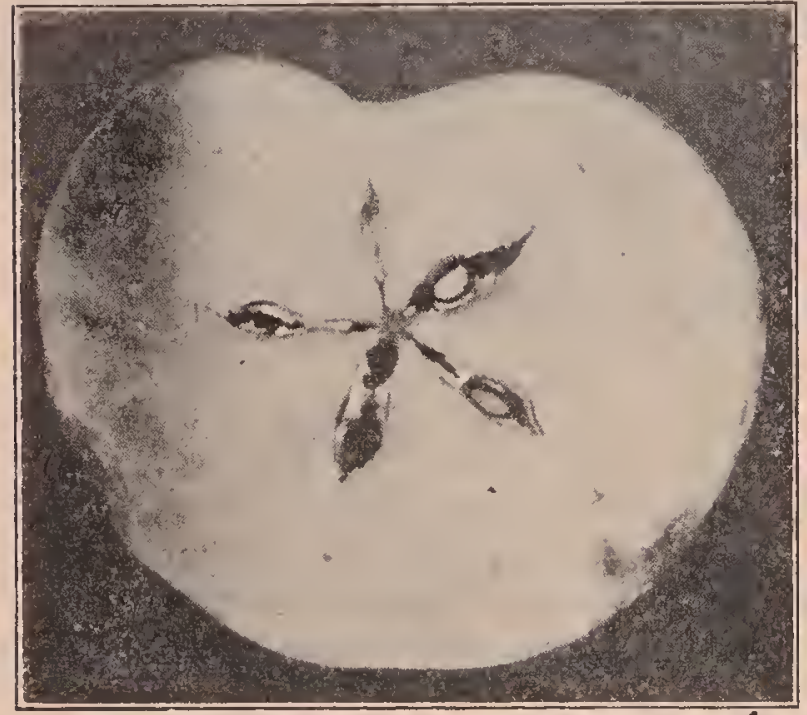

The result of imperfect pollination. Note the shriveled condition of the upper seed and the depression of the apple on that side.

ly. The flowers yield nectar, and 30 species of insects have been enumerated by the Connecticut Experiment Station as visitors.

Experiments in crossing were made by Waite at Rochester, N. Y., in 1892-93. Pollen from Orange, Rea, Champion, and Meach were used, and the flowers (from which the anthers had been removed) were enclosed in paper and cheese cloth bags. Both the crossed and self-pollinated flowers produced a fairly good percentage of fruit and practically an equal quantity. The experiments showed no striking benefits from crossing as did those with the apple and pear. (Waite, M. B., Yearbook of Dept. Agr., 1898, p. 178.)

\section{THE POLLINATION OF THE ORANGE.}

Numerous crosses have been made by the Department of Agriculture between the common orange and other species for the purpose of obtaining hardy and improved varieties with promising results.
The flowers of the orange in California secrete nectar so freely that at times it drips upon the foliage and grass beneath the trees. After a foggy or rainy day it is often so abundant that the horses employed in cultivating the groves and the clothing of their drivers are wet by the dripping nectar; while even the ground is dampened by the many falling drops. When a grove is properly irrigated, it has been estimated, that from. 500 to 800 colonies of bees can be placed in one location. Thousands of colonies are moved annually in southern California from the sage regions to the orange groves, where a surplus of 60 to 120 pounds of honey may be obtained.

No definite experiments have as yet been made showing the effects of cross-fertilization of the bloom of the orange trees in increasing the quantity of fruit and improving its size and quality; but many growers are positive that the quantity of fruit per acre is much larger, when bees are numerous in the orchards. Other growers, liowever, claim that they can see no difference.

Most lemon-growers desire to have colonies of bees placed in their orchards. But a lemon grove is not considered a desirable location, since the trees bloom in winter, when it is so cold, that many bees become chilled, while gathering nectar, and are unable to fly back to the hive. Citrus fruitgrowers both in Florida and Califormia very generally today recognize the importance of honeybees as agents in the pollination of the orange, lemon, and grapefruit.

Formerly the orange-growers of Florida opposed the placing of colonies of honeybees in the groves, believing that they injured the flowers and fruit. Beekeepers were obliged to pay for this privilege. But with a better understanding of the value of bees in pollination their presence is now recognized as desirable. Around Bradentown the citrus men are actually offering bee-yard sites free of rent, and in many in. stances even buy bees to place among the trees. The Manatee Fruit Company of Palmetto has established three bee-yards in connection with their groves and wish for more. They declare the nearer the bees to the groves, the larger the quantity of fruit and the better the quality. An orange- 
grower of Terra Ceia for six years or more has had 40 colonies of bees in his grove and every year during this time has had a fine crop of fruit, which has attracted wide attention. The marked increase in the quantity and quality of the oranges raised around DeLand is largely attributed to the greater number of bees kept near the groves. Twenty years ago there were not ten lives and now there are hundreds. There should be at least five hives to the acre. (Baldwin, E. G., The DeLand News, Dec. 23, 1914.)

\section{CONCLUSIONS.}

Many nut trees, cereals, and a few fruit trees are pollinated by the wird; but in general fruit bloom is either pollinated by insects or is self-pollinated. The few pollen grains distributed by the wind are of no importance. This is clearly shown both by the structure of the flowers and by repeated experiments. A noteworthy example is given in the bulletin of the Oregon Experiment Station for 1909. From 1500 blossoms on a seven-year-old apple tree all the petals were removed in order that they might not attract insects. The result was that only eight bees were seen to visit the flowers, while another tree about 20 feet away, which bloomed profusely, received 40 visits from bees in half an hour. The stamens were also removed to prevent selfpollination. Only five flowers set fruit. Evidently the wind did not pollinate a single blossom.

Self-sterility is very common among cultivated fruits. It is partly due to the separation of the stamens and pistils in different flowers and partly to the impoteney or ineffectiveness of the pollen in self-pollination. Hybrids, as among the grapes, are usually self-sterile. A variety may be sterile to its own pollen and also to the pollen of another variety; e. g., the Napoeon and Bing sweet cherries are selfsterile and mutually inter-sterile. A knowledge of self-sterility is, therefore, of the greatest importance in fruit-growing.

\section{(3)}

Among cultivated fruits cross-pollination by insects usually prevails, even among species possessing the power of self-fertilization. Pollen from anotler variety is generally prepotent over pollen from the same variety. Self-pollination in the early stages of most fruit blossoms is prevented by the stigmas and anthers maturing at different times (dichogamy), also by their relative position. Fruits resulting from cross-pollination are usually larger, better formed, and contain fully developed seeds.

'In the absence of cross-pollination many fruit blossoms may be self-pollinated in various ways. According to Waite self-pollinated and cross-pollinated flowers of the quince were equally productive, but this statement may be modified by further observation. Fruits from self-pollinated and selfi-fertilized flower's are usually smaller, less perfect, and contain only vestiges of seeds. Automatic self-pollination is as effective as self-pollination by hand. At the Oregon Experiment Station two sets of flower buds of different varieties of apples were enclosed in bags. One lot was left untouched. The bags of the other lot were opened, the flowers pollinated by hand, and the bags then replaced. Both lots gave practically the same results.

Beetles, flies, butterflies, moths, sawflies, wasps, and bees are all useful agents in pollination; but sometimes certain beetles and flies do more harm than good. Ants are invariably hurtful. The bees and wasps are the most beneficial, next come the flies, followed by the butterflies and moths, while the beetles stand last.

In wild or thinly settled regions and in small orchards the wild bees are very beneficial; and their visits to plums, cherries, blackberries, and in some instances other fruits greatly outnumber those of the honeybee. But many of the wild bees fly only from 30 to 90 days; a part are vernal and a part autumnal; and as they build their burrows largely in the ground they are destroyed or driven away by intensive culture. They cannot, therefore, be relied upon in extensive fruit plantations for pollination. 
( 7 )

The pollination of cultivated fruits can be controlled with certainty only by the aid of honeybees. This has been repeatedly pointed out in the preceding pages. It is confirmed by the practical experience of hundreds of fruit-growers. As these are essentially similar and all agree that honeybees are a necessity, it will be sufficient to give a few examples. In a remarkable statement of Albert Repp of Repp Brotheis, owners of an 800-acre fruit farm at Gloucester, N. J., he says:

"I could not do without bees. I never take a pound of their honey. All I want them to do is to pollinate the blossoms. I'd as soon think of managing this orchard without a single spray-pump as to be without bees. I've got 50 colonies now, and am building up the apiary each year."

About nine miles north of the plant where this work is published is a 50 -acre apple orchard operated by J. L. Van Rensselaer. This orchard for a number of years had been neglected in that it had not been sprayed nor pruned. Mr. Van Rensselaer finally leased it, sprayed and pruned the trees, and asked the publishers to put some bees on the place, which was done. The first year, 16,000 bushels of perfect apples were harvested, when, prior to that, scarcely 500 bushels were obtained. Every year since that, from 10,000 to 15,000 bushels have been secured. Mr. Van Rensselaer enthusiastically says the bees play a very important part in securing these results.

The apple-growers of the country are waking up to the fact that there must be bees in the orchards; and beekeepers are now having a considerable demand from the large fruit-growers for bees for this purpose.

The editors of the various fruit journals, among them The Fruit-grower, of Rochester, N. Y., and Better Fruit, Hood River, Ore., have a number of times published strong editorials in favor of putting bees in orchards. Among the leading agricultural journals is the Rural New-Yorker, whose editor makes the following statement: "I have seen the certain results of the good work of the honeybee in a neighbor's orchard. Those bees break the trees down just as truly as tho they climbed on the trees by the million and pulled on them. The appearance of those trees after a few years of beekeeping would have convinced any fair-minded man that our little buzzing friends are true partners of the fruit-grower."

It is the unanimous opinion of all progressive fruit-growers that honeybees and fruit culture are inseparable.

Besides pollination the fruit crop is influenced by the weather, the temperature, the condition of the soil, and the age of the trees. Insect pests, fungous growths, diseases, and spraying the trees while in bloom, are also injurious. Cold rainy weather, by preventing the flight of insects, interferes with the proper pollination of the blossoms. 


\section{G}

GALLBERRY (Ilex glabra).-Inkberry. Evergreen winterberry. An evergreen shrub, 2 to 6 feet tall, with oval or elliptic leathery leaves, smooth, shining, deep green above, and paler and dull beneath. The diffusely branched bushes form dense thickets which withstand the encroachments of all other plant growths, and can be passed thru with difficulty. The gallberry multiplies both by offshoots and by seed, and in the southeastern States is rapidly extending over land which has been recently cleared from forest.

The blooming period lasts for about a month beginning with May and closing early in June. The small flowers, in a multitude of little clusters, are produced in the greatest profusion, and 3000 have been counted on a bush witl a stem only half an inch in diameter. Innumerable sprays of white bloom, variegated with green leaves, toss and wave in the wind like a great foam-crested sea. The flowers are largely dioecious, i. e., a part of the bushes chiefly staminate and a part mostly pistillate flowers; and they are, therefore, dependent on insects for pollination. The sterile flowers are in clusters of 3 to 6 , while the fertile are solitary. The bushes begin to bloom the second year. The berries (drupes) are shining black, and are sometimes used for dyeing wool or in 'making a substitute for ink, whence the name inkberry. They are also called winterberry because they remain on the bushes in great number's during the winter and afford a never-failing food supply for birds. Ripe fruit can be found on the bushes every month in the year. In the spring when they are in full bloom there still remain on the branches a part of the fruit of the previous year. As the name indicates the fruit is very bitter; but to some extent the gallberries are eaten by birds.

The gallberry grows in sandy soil along or' near the coast from eastern Massachu- setts to Florida and Louisiana. It is the most valuable honey plant in the southeastern section of the United States, rivaling or surpassing the gum trees in the amount of honey produced. It covers thousands of acres of the sour or acid soil of the Coastal Plain where sweet clover, white clover, and tobacco will not flourish. The limestone soils so necessary to the prosperity of the elovers are unfavorable to this shrub. Without it there would be an immense area of sour soils with no honey plant well adapted to the needs of bee culture. Upon the surplus secured from this species the South is largely dependent for a good table honey. In the swampland are found the gum trees, or tupelos, while on the higher ground grow the gallberry, blackberry, and huckleberry. Much of this land can never be drained or reclaimed, and will thus always remain inviting territory to the beekeeper. So abundantly is the nectar produced that in southeastern Georgia the little drops can be plainly seen glistening in the flowers. So much better and abundant is this source of nectar, that honeybees were observed by E. R. Root to actually desert the tupelos in the height of the honey flow and devote their attention wholly to the newly opening bloom of the gallberry.

The gallberry first becomes important as a honey plant in the swamps around Norfolk in southeast Virginia where with the gum trees it seldom fails to yield a surplus. In Tidewater North Carolina, there is a vast area of low land comprising 20,000 square miles, the eastern half of which is not more than 20 feet above sea level. Gallberry covers thousands of acres along the rivers and bays, blooming from May 10 to June 1 and yielding an excellent but rather thin honey, which is liable to ferment unless well ripened.

The Coastal Plain is far superior to any other part of the State for beekeeping, and "there is practically," writes the State Spe- 
cialist in Beekeeping, "no limit to the extent beekeeping can be dereloped in this section."

Owing to the much smaller area of swampland in South Carolina the gallberry is less important than in Nortl Carolina; but in southeast Georgia it is a very common honey plant, and a great yielder of nectar. It blooms ten days later than in North Carolina. "We have never failed," says J. J. Wilder, "to get a surplus from it even during the most unfavorable weather "conditions." In over half a century there is no record of its ever once disappointing the beekeeper. The largest surplus that has been obtained from a single colony is 147 pounds. During the honey flow the bees disregard all other bloom, working for pollen until about eight o'clock in the morning, when the flow begins and continues for the remainder of the day. The honey is of a light color, very heavy, and very mild and pleasant in flavor. When free from other sources it tastes and looks very much like white clover. When it is pure and well ripened it has never been known to granulatel. Wilder declares that he has never known a gallberry section to be overstocked, and in one location 362 colonies did nearly as well as 100. Good gallberry locations in Georgia are, in his opinion, nearly numberless, and large quantities of this fine honey are annually lost for want of bees to collect it. Beekeepers often regret that fires started by the men engaged in the production of turpentine burn the gallberry thickets, but a much better growth is thus secured the following year. Wilder reports that he makes a practice of burning over one-half of the gallberry lands in his location once in two or three years. On a burned-over section the bushes make a rank growth, while on a section not burned over they are thin and scattering.

But a word of warning is given by $\mathrm{E}$. R. Root to the northern beekeeper who proposes "to go southeast." He must not suppose that there are no obstacles to overcome or no failures. A large part of this remarkable bee country is swampland and will aways remains a wilderness. There are venomous snakes and hosts of mosquitoes and red-bugs; the population is sparse; the villages are small and primi- tive; the country roads are very pool'; the winters and springs are damp and chilly while the summer's are very hot; and there are few modern conveniences. But there is reported to be very little malaria, and from most of the dangers and difficulties enumerated the adventurous apiarist call protect himself.

Pure gallberry honey has nearly the flavor of white clover; but it differs from this blend in that it has a slightly tart reaction ten to fifteen seconds after it has been tasted. Its flavor is often injured by an admixture of honey from black titi (Cliftonia monophylla), which is abundant in the swamps and blooms a little earlier.

Swamp gallberry (Ilex lucida). This species is also an evergreen shrub, resembling the common gallberry in leaf, flower, and fruit; but it is a little larger, blooms a little earlier, and grows in swamps. It extends from Virginia to Florida and Louisiana. The honey is very similar to that of I. glabra, but is reported to be a little milder. Other species of Ilex of value to the beekeeper are holly ( $I$. opaca), dahoon (I. Cassine), yaupon (I. vomitoria), possum haw (I. decidua) and black alder ( $I$. verticillata). See Holuy, also The Honey Plants of North Airerica.

\section{GLOVES FOR HANDLING BEES-} Altho a good many apiarists work with bare hands and bare wrists, there are a few who prefer to use gloves with long wrists, and quite a large number who use them with fingers and thumbs cut off. If the bees are hybrids, and extracting is carried on during the robbing season, it is a great convenience to use something that protects the back of the hands and wrists, leaving the fingers bare, so that, for all practical purposes of manipulation, one can work as well with protectors as without.

Women beekeepers and men who are at all timid, and a very small number who seem to be seriously affected by even one sting, might use gloves to great advantage.

A very good glove for working among bees is one made of kid or dogskin. While the sting of a bee will often puncture the former, one does not get much more than 
just the prick of the sting. By removing the glove, the sting is remover automatically.

Then ther'e is a kind of glove, shown in the illustration, made of heavy drilling

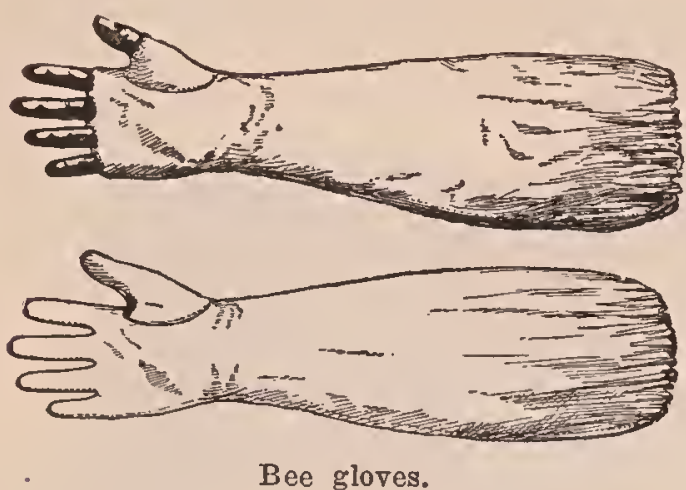

soaked in linseed oil or white-lead paint, made specially for the purpose. Some prefer to use them plain or uncoated, but where the bees are especially cross, the fabric will need to be further reinforced with paint or linseed oil. After one becomes more familiar with handling bees, he can cut off the finger tips so that the fingers themselves come actually in contact with the frames. One can work better when he can feel as well as see what he is doing.

For further particulars regarding beedress, see VeILs.

GLUCOSE.-This name is applied to the thick viscous liquid obtained by the concentration of a solution coming from the incomplete hydrolysis of starch. The word is misapplied by a great many, especially in the sugar-cane belt, for the reducing sugars present in the cane. From a purely chemical side, glucose means the sugar dextrose, so with these various applications of the word some little confusion exists. In the commercial world, however, the first is the accepted meaning of the word. In the United States the source of glucose is corn starch, but in Germany all is made from potato starch.

Its manufacture consists in the heating of the freed starch with water and a small percentage of hydrochloric acid under pressure. The process is carefully conducted and stopped at the proper point of hydrolysis. The liquid is neutralized with soda and concentrated to the desired consistency, which is a liquid of about 15 to 20 per cent 14 water. Formerly sulphuric acid was the acid used for conversion; but on account of it. "arrying arsenke its use was stopped. 'T'he solids of commercial glucose consist of about one-third dextrose and two-thirds dextrin. The dextrins present in commercial glucose are of a different character from those present in floral honey or honeydew, and by this property its presence in honey can be easily detected.

By increasing the amount of acid, and also lengthening the time of heating, products are made which contain more dextrose and less dextrin. These are known 'commercially as "70," "80," and "anhydrous starch sugar." They are, for the most part, solid. Their use in honey adulteration is very rare, and, if used, their detection is comparatively easy for a trained chemist.

Commereial glucose is sometimes known as corn syrup.

The ease with which commercial glucose can be detected when mixed with honey has led to its disuse except in mixtures so labeled. See Adulteration of Honey.

Analysis of American commercial glucose according to Bryan, published in the Journal of the Franklin Institute for October, 1911, shows the following average, maximum, and minimum figures:

\begin{tabular}{|c|c|c|c|}
\hline & rerage & ximum & Minimum \\
\hline Tat & $16.47 \%$ & $20.00 \%$ & $95 \%$ \\
\hline 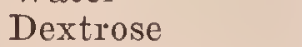 & 35.51 & 39.56 & 3 \\
\hline Matter & .52 &.. & \\
\hline Undetermined & 47.50 & 52.4 & 40.46 \\
\hline \multicolumn{4}{|c|}{ Oirect Polarizations: } \\
\hline At & & & \\
\hline At $\varepsilon$ & +1 & +1 & + \\
\hline \multicolumn{4}{|c|}{ vert Polarizations: } \\
\hline At $20^{\circ} \mathrm{C}$. & +1 & +18 & +155.6 \\
\hline At 8 & & -1 & +146 \\
\hline
\end{tabular}

The undetermined matter, so reported, is composed of dextrose and partially converted starch products.

The percentage of dextrose given is reallyt the percentage of reducing (of Fehling solution) bodies calculated as dextrose. It may contain the sugar maltose and some of the reducible dextrin.

German glucose, according to Herzfeld, published in the above article, shows the following :

\begin{tabular}{lccc} 
& \multicolumn{3}{c}{ Average Maximum } \\
Water & $19.7 \%$ & $20.4 \%$ & $18.0 \%$ \\
Dextrose & 40.7 & 47.4 & 36.5 \\
Mineral Matter & .267 & .404 & .179
\end{tabular}


Polarization:

Direct at $20^{\circ}+161.6+181.2+149.6$

Invert at $20^{\circ} \quad+154.7+161.2+138.4$

Starch sugars show the following composition according to Bryan (also given in same paper).

Crystalline sugars (often referred to as Anhydrous Sugar):

$\begin{array}{lccc} & \text { Average Maximum } & \text { Minimum } \\ \text { Water } & 7.42 \% & 9.94 \% & 5.04 \% \\ \text { Dextrose } & 86.33 & 90.70 & 81.52 \\ \text { Dextrin } & .39 & .54 & .16 \\ \text { Mineral Matter } & .73 & 1.06 & .48 \\ \text { Undetermined } & 5.13 & 7.53 & 2.77\end{array}$

Polarization:

100 grams to $100 \mathrm{ce}-$

$$
+27.89+28.65+27.50
$$

Dextrose calculated from polarization$91.59 \% \quad 94.08 \% \quad 90.31 \%$

"Climax sugar" or 80 sugar:

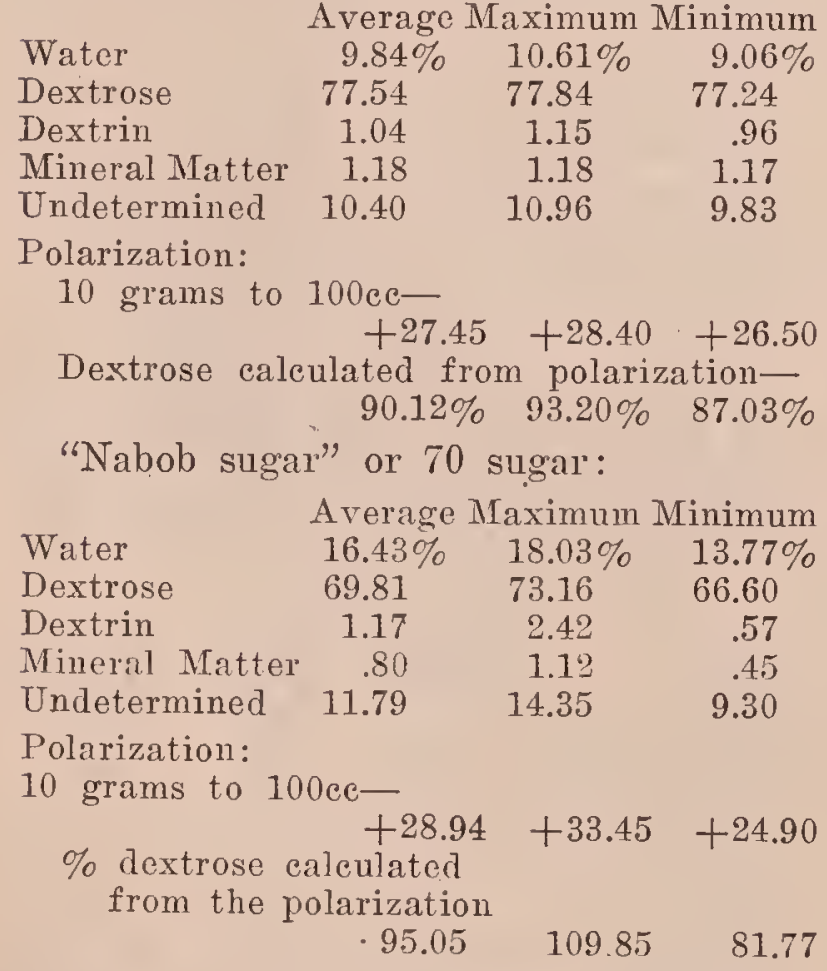

In these tables it is noted that the two percentages of dextrose given do not agree. That one calculated from the polarization is always high on account of the influence of the amount of dextrin (this having a larger polarization influence than dextrose).

GOLDENROD (Solidago.)-The goldenrods and asters are the most common and conspicuous of autumnal flowers in eastern North America. Both genera belong to the Compositae, the great family which stands at the head of the plant kingdom. The inflorescence of the Compositae represents Nature's greatest triumph in flower-building. Intercrossing by insects, economy of time and material, a large number of seeds well adapted to germinate, and their wide distribution have all been very perfectly secured. The individual flower is small and of little significance as compared with the community. Conspicuousness is gained by massing a large number of flowers in a head or capitulum, an arrangement which permits insects to visit them very rapidly. While in the common whiteweed, or daisy, the number of florets may exceed 500, in the head of the goldenrod there are only from 16 to 30 , according to the species; e. $g .$, in the cream-colored goldenrod ( $S$. bicolor) there are about 16 ray and 14 dise florets, and in the tall hairy goldenrod (S. rugosa) about 8 ray and 6 dise florets.

The stately and beautiful genus of goldenrods begins to bloom at midsummer, or earlier in the case of the early goldenrod, and in November there are still visible the flower clusters of the Canada goldenrod and the tall hairy goldenrod, while the salt marsh goldenrod may prolong the season until December. There are about 85 described species, confined chiefly to North America, with a few in South America and Europe. Fifty'species occur north of Tennessee and east of the Rocky Mountains. They are closely allied, often hybridize, and are difficult to distinguish. There is a form adapted to almost every kind of location. The woodland goldenrod ( $S$. caesia) is found in open woodlands, the field goldenrod ( $S$. nemoralis) is very common in dry fields, the rock goldenrod ( $S$. rupestris) prefers rocky situations, the swamp goldenrod ( $S$. neglecta) lives in swamps, while the seaside goldenrod ( $S$. sempervirens) thrives in salt marshes.

Altho the individual heads are so small conspicuousness is. gained by massing them in great plume-like clusters or panicles. Their bright yellow color renders them visible both by day and evening; and as the temperature at night is several degrees above the surrounding air they sometimes serve as a temporary refuge for insects. The floral tube is very short, seldom over one millimeter in length, so that there are few insects which are unable to gather the nectar. In Wisconsin Graenicher has taken on the early goldenrod (S. juncea) 182 different species of bees, wasps, flies, butterflies, and beetles either sucking or collect- 
ing or feeding on pollen; and on the Canada goldenrod ( $S$. canadensis) 141 visitols. The honeybee visits the florets so rapidly that the number of visits per minute cannot be counted. A large amount of pollen is gathered both by the domestic bee and by wild bees. So abundant, indeed, are the flowers, and so ample the stores of pol- waste lands, and are almost the sole dependence of the beekeeper for winter stores. The bees work on the flowers with great eagerness, and the activity in the apiary equals that of the midsummer honey flow. In Massachusetts a marketable surplus, according to Burton N. Gates, is often taken in September. Allen Latham

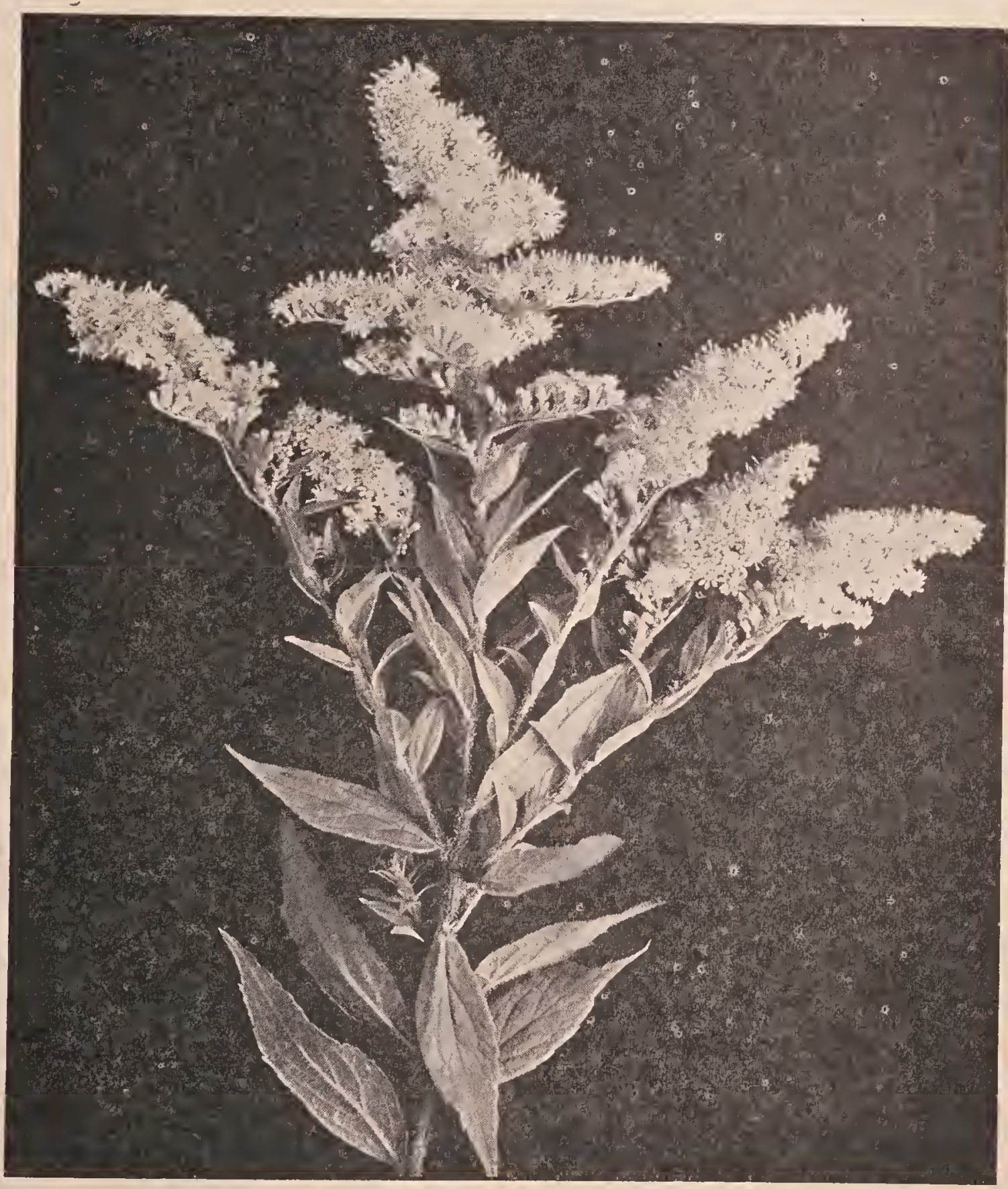

Hairy golden rod.

len and nectar that four or five of our native wild bees, which fly only in autumn, never visit any other plants. Some of the goldenrods are pleasantly scented. Others are nearly odorless.

In New England many species of goldenrod grow luxuriantly in pasture and states that once in three or four years strong colonies in his apiary on Cape Cod would store upward of a hundred pounds from fall flowers. In southern Maine the bees never fail to fill many frames with goldenrod honey, which because of its golden-yellow color and fine flavor is pre- 
ferred by many persons to white looney. In other sections, as the South and West, it is of less importance; but it comes at a time of the year when it helps to keep the bees busy, and at the same time serves to make up the loss in stores during the latter part of the summer.

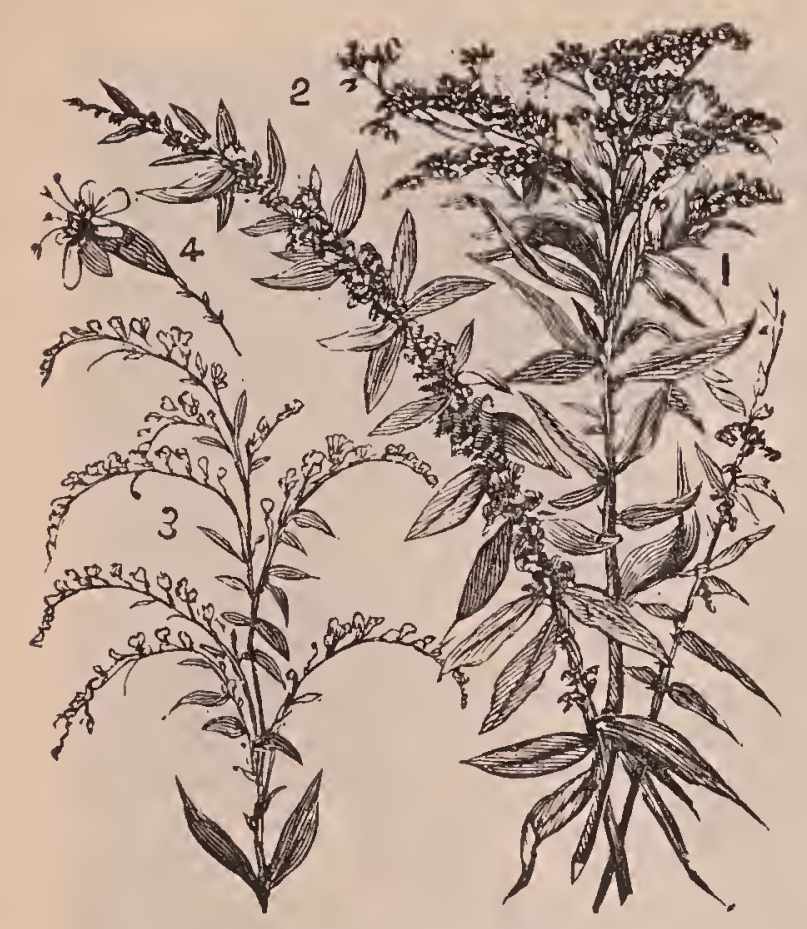

Three species of goldenrod.

The species most common and valuable to Eastern beekeepers are sweet-scented goldenrod ( $S$. odora), early goldenrod $(S$. juncea), field goldenrod (S. nemoralis), Canada goldenrod ( $S$. canadensis), late goldenrod ( $S$. serotina), tall hairy goldenrod ( $S$. rugosa), and in great abundance in salt marshes and along sea-beaches, the seaside goldenrod ( $S$. sempervirens). Unlike most of the other species the inflorescence of the common bushy goldenrod ( $S$. graminifolia) is in large flat-topped clusters or corymbs. It is one of the best nectar-yielder's, and a favorite with loneybees. Once in a woodland pasture largely overgrown with the hairy goldenrod ( $S$. rugosa) a dozen or more plants of the bushy goldenrod were found. Honeybees were the only insects present, and they showed a marked preference for the bushy goldenrod. They were repeatedly seen to leave the latter species; and after flying about, but not resting on the flowers of the hairy goldenrod, return to the plants they had left a few moments before. A plant of each of the above species was bent over so that their blossoms were intermingled, appearing as a single cluster; a honeybee alighted on the bushy goldenrod, and it seemed very probable that it would pass over to the flowers of the hairy goldenrod, but such was not the case, for presently it flew away to another plant of the former. The flowers have a sweet fragrance, and are visited by over a hundred different species of insects. All the goldenrods in New England yield nectar, altho the early goldenrod ( $S$. juncea) seems to be of less value than some of the later kinds; but, singularly enough, at Marengo, Illinois, they are of little importance to the beekeeper.

The quantity of nectar secreted by the goldenrods varies greatly in different localities. They are most valuable as honey plants in New England and Canada. In a large part of New Fngland beekeeping is chiefly dependent on this genus of plant and the clovers, and in the absence of either group would yield little profit. The goldenrods are also abundant in Nova Scotia and New Brunswick and in parts of Quebec, Ontario, and Manitoba. They yield nectar freely, and 40 or more pounds

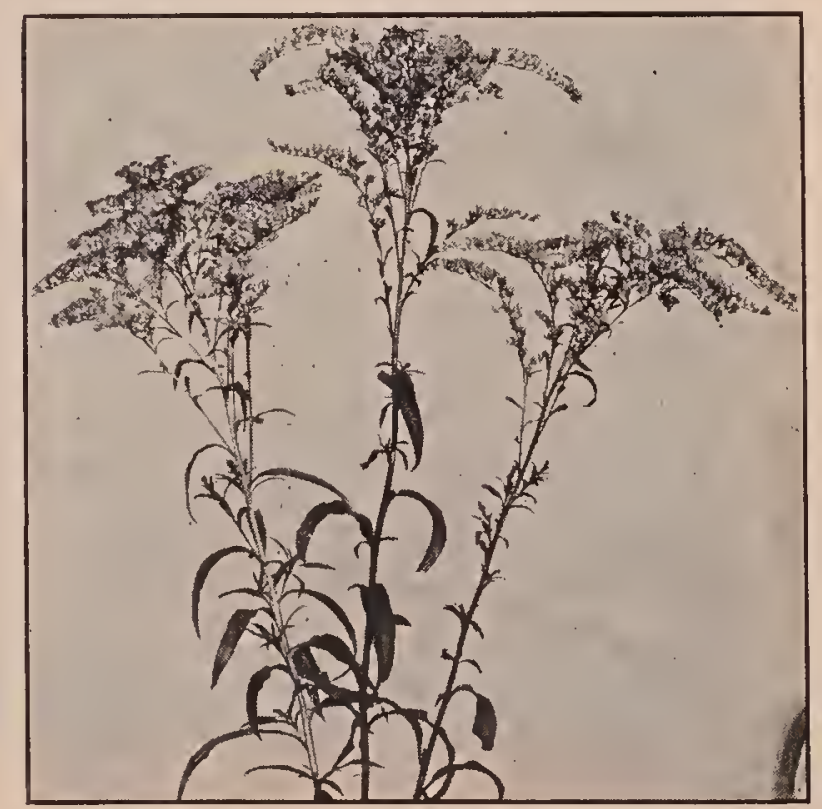

Sweet goldenrod (Solidago odora.)

of honey per colony from this source may be obtained, but usually it is mixed with aster honey. This genus is also listed among the honey plants of British Columbia, Michigan, and Tennessee, and is "widely distributed in New York, New Jersey, and 
other eastern States, altho not of great importance. It is apparently of more value in Florida, Louisiana, and Texas.

But in the white clover belt, in Iowa, Illinois, and the adjoining States, the goldenrods yield little or no nectar. Great masses of the clustered flowers are visited only occasionally by bees. The conditions which produce the secretion of a great amount of nectar in white clover do not produce the same results in the case of goldenrod. In the arid cactus region of the Southwest, and in the semiarid region of the Rocky Mountain Highlands these plants are either absent or no lielp to the beekeeper. Again, in California they are the source of a small amount of honey. In New England the bushy goldenrod ( $S$. graminifolia) and the tall hairy goldenrod ( $S$. rugosa) yield the most nectar; in Canada, $S$. squarrosa and $S$. puberula; and in California $S$. californica and $S$. occidentalis.

While the bees are bringing in the nectar, the whole apiary is filled with a disagreeable sour smell, which on a calm evening can easily be perceived at a distance of 100 feet. The odor observed during a goldenrod honey flow has sometimes been likened to that of decaying carrion, but this is a mistake. When such an odor is present in the apiary, it is caused in most cases by one or more stinkhorn fungi (Phallus impudicus). Where there is decaying organic matter, as near old stumps, these fungi frequently spring up in the fall. They, exhale a strong fetid scent like putrefying carrion, which may easily mislead the beekeeper, as we liave learned by experience. The stem is hollow, and the caplike top deliquesces into a sticky, semiliquid mass, filled with spores, which is very attractive to carrion flies. The flies feed on the thick syrup and thus become an agent in distributing the spores. As soon as the fungi are removed the carrionlike odor disappears. The sour smell of the nectar also vanishes in a few days.

Goldenrod honey is very thick and heavy with the golden-yellow. color of the blossoms. The quality is poor when first stored, but when capped and thoroly ripened the flavor is rich and pleasant. It is the general testimony of New . England beekeeper's that many persons prefer this honey to any other. They regard its color, body, and flavor as the qualities of an ideal honey. When served on a plate for table use it is hardly less attractive than whiteclover lioney. Its genuineness is never questioned. But the flavor is stronger than that of white clover, which would probably be given the preference by the majority as the great universal staple to be used with bread and butter. Extracted goldenrod honey crystallizes with a coarse grain in about two months.

Goldenrod seldom fails to yield freely even in cold and wet weather, but it does exceptionally well during a warm dry fall. The honey has always proven an excellent winter food for bees, and without it there would be little hope for bee culture in New England. So far as the beekeeper is concerned goldenrod is well named, and it would be a want of gratitude on his part not to uphold its claims as our national flower.

GRADING COMB BONEY.-The average comb-honey producer, unless he sells his product thru an association of beekeepers, either does not grade his honey at all, or else does it so poorly that it is not worthy of the name of grading. One large dealer in honey, who buys and sells hundreds of thousands of dollars' worth every year, makes the statement that practically all the comb honey that comes into his hands must be regraded before it is fit to send out; and, of course, he has to charge this up to the producer. Even beekeepers who are supposed to be up to date, he says, apparently pay very little attention to this important matter. A poorly graded honey, or one that is not graded at all, brings two to three cents less per pound on the whole shipment. If the producer has not the time, he could easily find some one who would be willing to do such work for him for about half a cent a pound. As a rule the grading should be done by some member of the family, or some one interested in the sale of the honey. A hired man is inclined to be careless, and a poor grader reacts on his employer.

Ordinary marketable comb honey can be divided into three or four classes: Fancy, No. 1, and No. 2, or choice. Nothing but fancy should be put into the fancy, and nothing but No. 1 in No, 1 . The author 


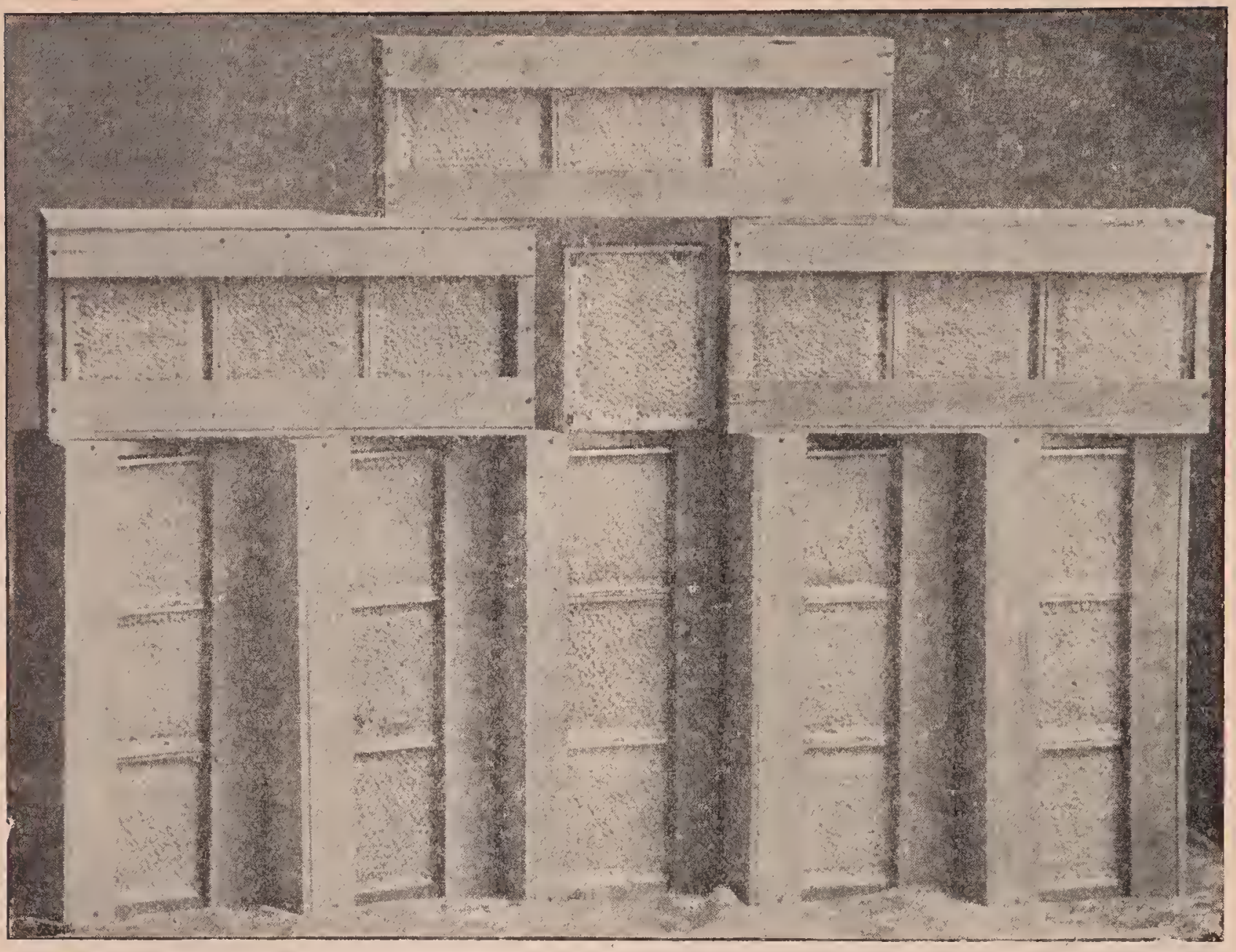

Honey sent by the Ontario Beekeepers' Association to the late King Edward. Note.-This would grade as Extra Fancy by the Root grading rules.

lias personally inspected thousands of pounds of comb honey that had gone to market, and it is certainly surprising how some of the intelligent producers will mix the fancy among the No. 1 and the No. 1 among the fancy, and even go so far as to put choice among the fancy. This disgusts the buyer or commission merchant, and, of course, he charges up the cost of regrading to the producer. Or if he does not grade the honey over, it is sent out directly to the consumer or retail merchant, who will pay at least two or three cents a pound less because the honey is of such uneven quality.

In order to get the largest price possible for comb honey, it will be necessary to grade it; and the more thoroly and honestly the work is done, the higher will be the price secured. If one is careless in grading there will be inferior sections mixed in with sections of a higher grade; and, if the commission man or buyer discovers this, he is likely to "knock down the price" of the whole caseful to the price of the inferior sections. It is very important to have every section in a case of the same grade.

Not much will be accomplished if there are a dozen different systems or rules of grading. Various rules have been adopted by the National Beekeepers' Association; but they have never been accepted by the large buyers and commission men of the country; nor have they received the general indorsement of even the beekeepers themselves. The great difficulty encountered has been the diversity of conditions and variety of notions on the part of the producer. For example, one section of the country will have only white honey; another will have largely amber and dark. One locality prefers double-tier shipping cases; another single-tier. Some beekeepers prefer plain sections, and others want beeway. The Colorado beekeepers prefer double-tier cases and $1 \% / 8$-beeway square sections. Under these diverse conditions it is a little difficult to get an agreement on one set of rules covering the whole country. However, the Colorado beekeepers 
have adopted a set of rules which, with some slight modifications from time to time, have been accepted and used by the beekeepers thruout the great West and to some extent in the East. After the new net-weight law went into effect, the rules were modified in that provision was made for weight of honey in a section exclusive of section and shipping case. The revised rules, as put out in February, 1915, by the Colorado Honey Producers' Association, are as follows:

\section{COMB HONEY.}

Fancy.-Sections to be well filled, combs firmly attached on all sides and evenly capped except the outside row next to the wood. Honey, comb, and cappings white, or slightly off color; combs not projecting beyond the wood; sections to be well eleaned. No section in this grade to weigh less than $121 / 2$ oz. net or $13 \frac{1}{2}$ gross. The top of each section in this grade must be stamped, "Net weight not less than 121/2 oz."

The front sections in each case must be of uniform color and finish, and shall be a true representation of the contents of the case.

Number One.-Sections to be well filled, combs firmly attached, not projecting beyond the wood, and entirely capped except the outside row next to the wood. Honey, comb, and cappings from white to light amber in color; sections to be well cleaned. No section in this grade to weigh less than $11 \mathrm{oz}$. net or $12 \mathrm{oz}$. gross. The top of each section in this grade must be stamped, "Net weight not less than 11 oz." 'The frout sections in each case must be of uniform color and finish, and shall be a true representation of the contents of the case.

Number Two.-This grade is composed of sections that are entirely capped except row next to the wood, weighing not less than $10 \mathrm{oz}$. net or $11 \mathrm{oz}$. gross; also of such sections as weigh $11 \mathrm{oz}$. net or $12 \mathrm{oz}$. gross, or more, and have not more than 50 uneapped cells altogether, which must be filled with honey; honey, comb; and cappings from white to amber in color; sections to be well cleaned. The top of each section in this grade must be stamped, "Net weight not less than 10 oz." The front sections in each case must be of uniform color and finish, and shall be a true representation of the contents of the case.

Comb honey that is not permitted in shipping grades:

Honey packed in second-hand cases.

Honey in badly stained or mildewed sections.

Honey showing signs of granulation.

Leaking, injured, or patched-up sections.

Sections containing honeydew.

Sections with more than 50 uncapped cells, or a less number of empty cells.
Sections weighing less than the minimum weight.

All such honey should be disposed of in the home narket.

\section{EXTRACTED HONEY.}

This must be thoroly ripened, weighing not less than $12 \mathrm{lbs}$. per gallon. It must be well strained, and packed in new cans; 60 lbs. shall be packed in each five-gallon can, and the top of each five-gallon can shall be stamped or labeled, "Net weight not less than 60 lbs."

Extracted honey is classed as white, light amber, and amber. The letters "W," "L. A.," "A" should be used in designating color; and these letters should be stamped on top of each can. Extracted honey for shipping must be packed in new substantial cases of proper size.

\section{STRAINED HONEY.}

This must be well ripened, weighing not less than 12 lbs. per gallon. It must be well strained; and, if packed in five-gallon cans, each can shall contain 60 pounds. The top of each five-gallon can shall be stamped and labeled, "Net weight not less than 60 lbs.", Bright clean cans that previously contained honey may be used for strained honey.

HONEY NOT PERMITTED IN SHIPPING GRADES.

Extracted honey packed in second-hand cans.

Unripe or fermenting honey weighing less than 12 lbs. per gallon.

Honey contaminated by excessive use of smoke.

Honey contaminated by honeydew.

Honey not properly strained.

As stated, the revised rules are modified to conform to the federal net-weight law, which specifies that only the comb and honey inside of the section and not the section and honey shall be the measure of the quantity sold by weight. Formerly the section surrounding the comb was included. Under the old rules it was permissible to sell the gross weight of the section and the honey at so much per pound. It will be noted, therefore, that the new Colorado grading rules specify the minimum weight, net, and one ounce more gross, as the sections weigh approximately one ounce.

Before a limit was placed on the weight of the sections, producers put up their honey in haphazard ways. Heavy and light sections-good, bad, and indifferent in other respects-were all put together in one case. This caused no end of complaint. Under the new set of rules, this is impossible. 
Producers of the country, after the federal net-weight law went into effect, September, 1914, were compelled to mark every section by weight. Sections that are approximately of the same weight are put in a class by themselves. But no section in that weight shall be less than a certain definite figure in ounces. For instance, under the Colorado grading rules, for "Fancy," no section inay weigh less than $121 / 2$ ounces net or $131 / 2$ ounces gross. In grade No. 1 the figures stand respectively 11 and 12 ounces; in No. 2, 10 and 11 ounces.

The operation of the federal net-weight law at first caused a general grumbling on the part of the producer and the dealer alike; but the result has been salutary, because the dealer and the consumer now know exactly for what their money is paying. While the producer at first lost a little because any weight in excess of the minimum figure was given to the consumer, the producer soon learned that it was necessary for him to charge enough, more for his product to cover one ounce per section.

The "fancy" grade provides that the comb shall be "firmly attached on all sides and evenly capped"; No. 1 grade provides that comb shall be "firmly attached, not projecting beyond the edge." The No. 2 grade makes no statement as to how the combs are to be attached, but still provides that "it shall be entirely capped except the row of cells next to the wood."

The revised rules provide, also, that honey must not be packed in second-hand cases nor in badly stained or mildewed sections. It must not show any signs of granulation or leaks; must contain no honeydew, and must not have an undue amount of cells uncapped.

While these mules are perhaps adequate for the great bulk of comb honey produced, they are not quite flexible enough to take in honey that will be above the Colorado "Fancy" and No. 1 grade. The A. I. Root Company have the following set of rules which, it will be observed, provide for "extra fancy," fancy, No.1, and No. 2.

In liarmony with the federal net-weight regulations and the statutes of many States, all comb honey we handle is figured with the weight of the section box as well as the case excluder. To get the net weight, deduct the weight of the empty case and $1 \mathrm{lb} .8 \mathrm{oz}$. for the weight of 24 sections ( $1 \mathrm{oz}$. each).
COMB HONEY.

E.xtill Funcy.-Sections to be evenly filled, combs firmly attaclicd to the four sides, the sections to be free from propolis or other pronounced stain, combs and cappings white, and not more than six unsealed cells on either side. No section in this grade to weigh'less than 14 oz net. Cases must arerage not less than 22 lbs. net.

lancy.-Sections to be evenly filled, comb firmly attached to the four sides, the sections free from propolis or other pronouneed stain; comb and cappings white, and not mole than six unsealed cells on either side exclusive of the outside row. No section in this grade to weigh less than 13 oz. net. Cases must average not less than 21 lbs. net.

No. I.-Sections to be evenly filled, comb firmly attached to the four sides, the sections free from propolis or other pronounced

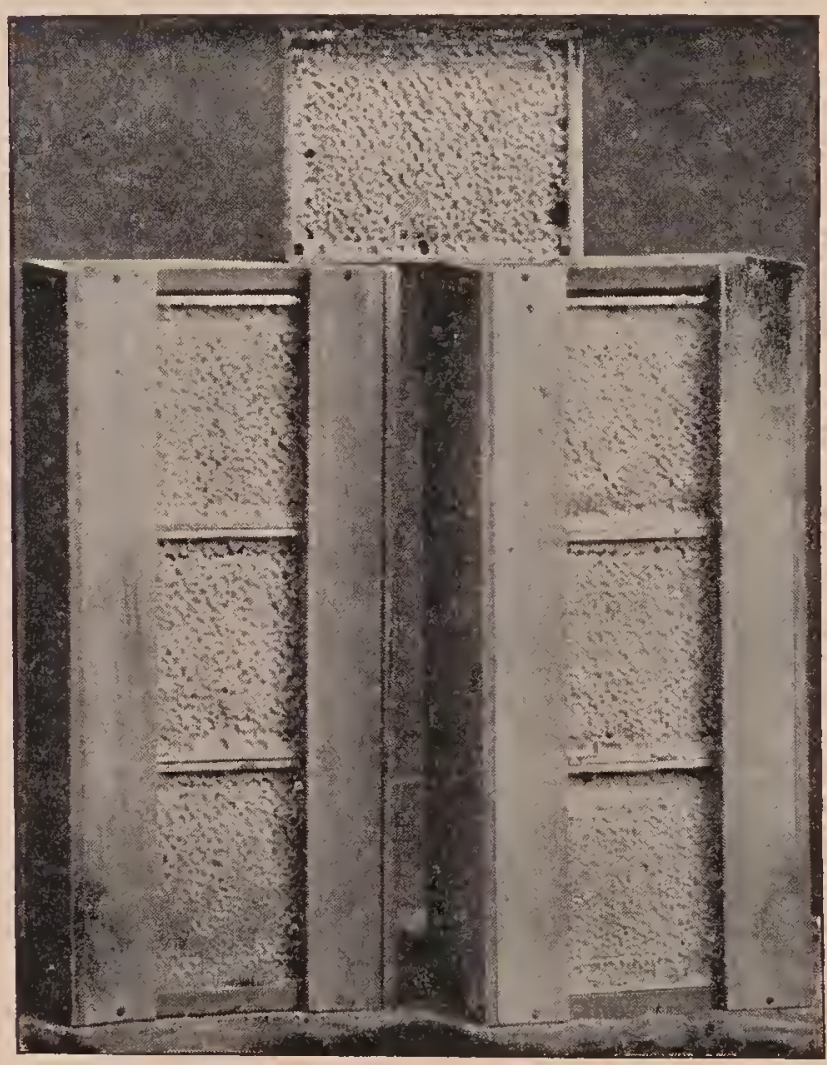

Fancy comb in $4 \times 5$ plain sections.

stain; comb and cappings white to slightly off color, and not more than 40 unsealed cells, exclusive of the outside row. No seetion in this grade to weigh less than $11 \mathrm{oz}$. Cases must average not less than 20 lbs. net.

No. 2.-Combs not projecting beyond the box, attached to the sides not less than twothirds of the way around, and not more than 60 unscaled cells exclusive of the row adjaeent to the box. No section in this grade to weigh less than $10 \mathrm{oz}$. net. Cases must average not less than 18 lbs, net. 
CUHA COML HONEY.

Cull honey shall consist of the following: Honey packed in solid second-hand cases or that in badly stainer or propolized sections; sections containing pollen, honeydew honey, honey showing signs of granulation, poorly ripened, sour, or "'weeping', honey; sections with combs projecting beyond the box or well attached to the box less than twothirds the distance around its inner surface; sections with more than 60 unsealed cells, exclusive of the row adjacent to the box; leaking, injured, or patched-up sections; sections weighing less than $10 \mathrm{oz}$. net.

\section{EXTRACTED HONEY.}

This must be well ripened, weighing not less than 12 lbs. per gallon. It must be well strained, and, if packed in five-gallon cans, each call sliall contain 60 lbs. The top of each five-gallon can shall be stamped and labeled, "Net weight not less than 60 lbs." Bright clean cans that previously contained clean light honey may be used for extracted honey.

EXTRACTED) HONEY NOT PFRMITTEDD IN SIIIPPING GRADES.

Extracted honey packed in second-hand cans, except as permitted above.

Unripe or fermenting honey, or weighing less than 12 lbs. per gallon.

Honey contaminated by excessive use of sinole.

Honey contaminater by honeydew.

Honey not properly strained.

It will be noted that while these rules are somewhat similar to the Colorado rules, they go further in providing an "extra fancy" or sections weighing not less than 14 ounces net, and a case not less than 22 lbs. net. That of course means some of the, combs will weigh more than 14 ounces in order to bring up the entire weight to 22 pounds. The "fancy" grade goes a little further than the Colorado fancy in making the net weight $1 / 2$ ounce higher, and providing that the weight of all sections in the case sliall not be less than 21 pounds net. This means that the average weight will be exactly 14 ounces. This provision of the net weight per case puts the grading where many producers will not or cannot meet it; but if they can they will get paid for it, as there is a fancy trade that is willing to pay for a high standard.

There is no doubt that the Colorado rules as written will cover 95 per cent of all comb honey produced; but they do not cover special lots that will meet certain require- ments, and for which a correspondingly ligher price will be secured.

\section{GRADING BY PICTURES.}

Some effort has been made to grade honey by means of p pictures; but nothing definite has been accomplished, as it is difficult to make photos flexible enough to take in the various comb surfaces and cappings of honey that can be included in one grade. It is possible engravings may be used in connection with the rules, to enable one to determine what section will grade Fancy, No. 1, and No. 2. It must be understood that different persons would have a different notion as to whether one section should be graded as No. 1 or Fancy, and a set of pictures showing the iclea of an expert on grading might be helpful to. a novice. A few half tones are here shown that may give an idea of what is meant. But it should be understood that in the pictures the unsealed cells show blackmuch more in contrast than in the actual combs themselves; or, to put it another way, in any thing but an extra fancy, where no empty cells slow, the pictorial lepresentations do not show up as well as the real article.

'The honey sent to the late King Edward would be what is called "extra fancy white," according to the Root grading, for it is white honey put up in plain sections, and, as the illustration shows, it is evenly and nicely filled. When cells next to the wood are all sealed, or nearly so, it should be designated as "extra fancy"; but as such comb honey is the exception rather than the rule there will be very little "extra fancy" on the market, altho such honey is generally shown at exhibitions when competing for a prize.

In the half-tone engraving above shown the honey in the top case, with its sample section opposite, would, by the Root grading, grade Fancy; that in the middle case Fancy or No. 1, according to the amount of soiled surface, and that in the bottom case would be about No. 2.

\section{TRAVEL-STAINED AND OTHER SOILED} SECTIONS.

There are really four classes of discolored sections, each due to a distinet and separate cause. First there is what is 


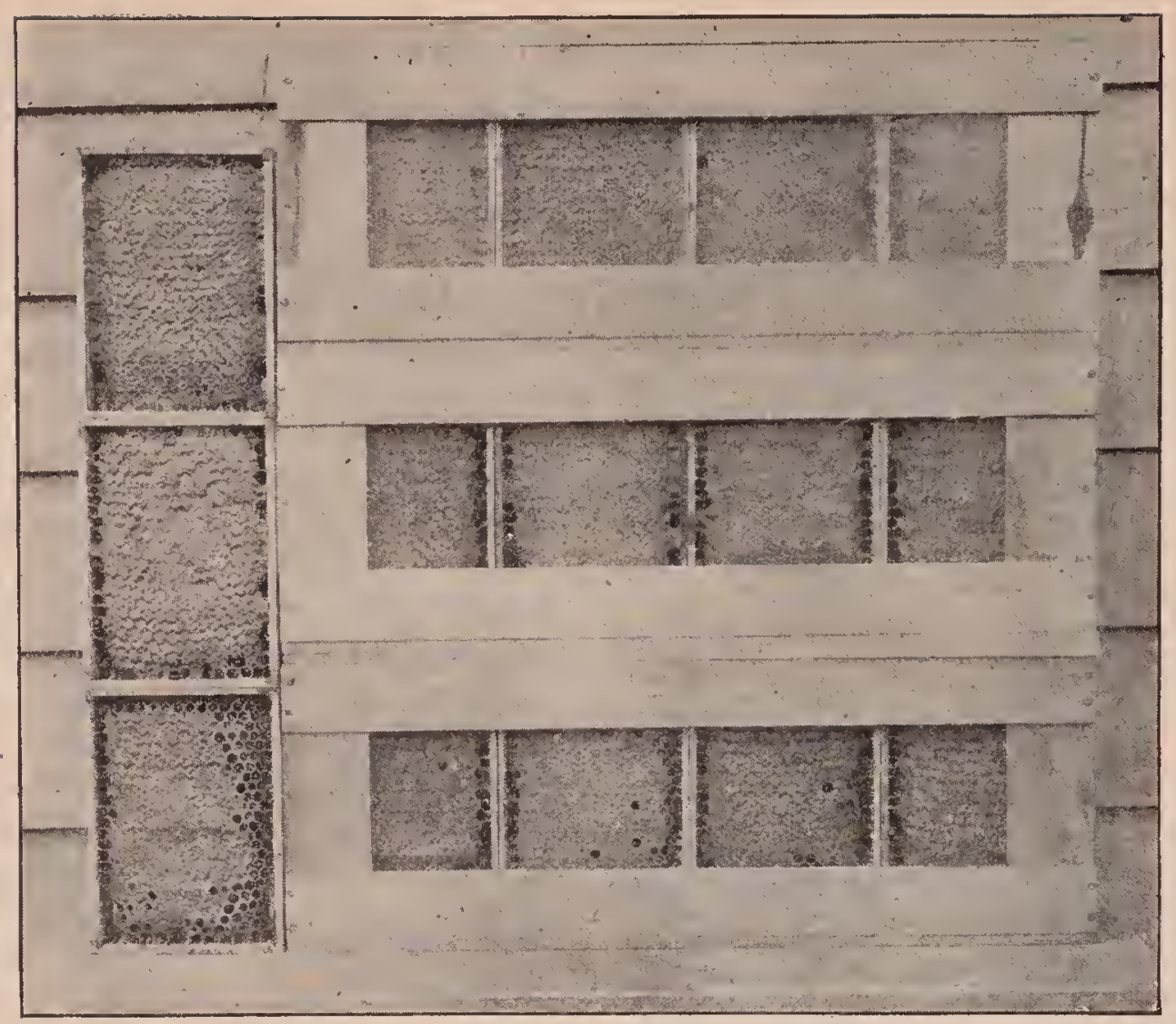

Grading rules illustrated.

called the real travel-stained section. As its name indicates, the cappings are soiled because the bees have gone over the surfaces of the cappings with their dirty feet.

Then there is another lot that are stained because the sections are capped over in the vicinity of old comb, dirt, or propolis. If the faces of such sections are examined carefully, it will be found that the stain or disooloration goes clear thru. These discolorations are due to the bees taking up pieces of old black wax, propolis, or anything that will answer as a substitute or filler for pure wax. The cappings of some sections of this sort are filled with bits of old rope, lint from newspapers, small hard chunks of propolis, fine slivers of woodanything and everything that is handy. Sections of this class often look like those of the first class, hence the frequent confusion.

In the third class are those with soiled cappings, due to the pollen dust or possibly a thin layer of propolis stain.

The fourth and last class takes in all those that are called "greasy" or "watersoaked," having cappings that lie on the honey. The covering to each cell is more or less transparent, or water-soaked-the transparent part being half-moon shaped, or in the form of a ring encircling a white nucleus center that is not greasy nor transparent.

GR.ANULATED HONEY.-Nearly all kinds of liquid honey, and most comb honey, if given time enough, are liable to cloud and partially solidify at the approach of or after cold weather; that is, it assumes a granular mealy condition something like moist fine white granulated sugar. The granules of candied honey may be about the size of grains of ordinary table salt, or they may be much finer. Comb honey granulates less readily than extracted, and only after a much longer period. While cold weather is much more conducive to solidification, yet in some localities, and with some honeys especially, the granulation takes on the semi-solid form even in warm weather. Some honeys will candy in a month after being taken from the comb, and others will remain liquid for two years. The honey most likely to candy is extracted alfalfa, the action taking place in from three to five months. Mountain sage from California and tupelo from Florida remain 
liquid for a year or longer. Ordinary comb honey in sections, if well ripened, will usually remain liquid as long as the weather is warm. After that time, especially if it has been subjected to cold, there are likely to be a few scattered granules in each cell. These gradually increase in number until the comb, honey, and wax' become almost one solid mass. In such condition it is unsuitable for the market, the table, or for feeding back, and should be treated by the plan described farther on. Seo Comb Honey, to Produce.

\section{IS GRANULATION A TEST OF PURITY?}

In the eyes of the general public, granulated honey is not pure, many thinking it has been "sugared," either" with brown or white sugar. But the very fact that it granulates solid is one of the best proofs of its purity. If honey granulates only partially, in streaks, it may be evidence that it has been adulterated with glucose. But even pure honey will assume this comdition, while honey that is nearly twothirds or three-quarters glucose granulates very little. Here, again, it must not be taken as positive evidence that, because honey refuses to granulate, or does so only slightly, therefore it is adulterated. The purity of any honey can usually be determined thru the taste by an expert beekeeper who has tested various grades of honey and knows their general flavor. But, again, even taste must not be considered as infallible. Doubts can be removed only by referring a saniple or samples to an expert chemist. See Adulteration of Honey.

\section{CAUSE OF GRANULATION.}

As already stated, the primal cause of granulation is alternation of cold and warm weather. During any very cold temperature, prolonged for days, honey probably would not candy at all, but chill into a hard waxy mass, readily softening again in a warm atmosphere. Honeys that contain a larger amount of dextrose granulate more readily than where the reverse is true. Stirring or violent agitation hastens granulation; and if some granulated honey is mixed with ordinary liquid extracted, the action is likewise hastened; for when honey once starts to cloud, the process goes on very rapidly, altho it may take from ten days to six months for the honey to pass entirely from the liquid condition into solid.

Under BoTTLING reference is made to the method of preventing from granulating by the use of heat. For full particulars regarding this, see Bottling Honey.

\section{THE SCIENGE OF GRANULATION.}

While no one knows very much as yet about the theory of honey granulating, yet it is known that, while the nectar of flowers may be, chemically, cane sugar, yet after it has been stored in the hive by the bees, and partially digested or worked over as explained under HoNEY elsewhere, it becomes an invert sugar. Ordinary honey is a combination of dextrose and levulose, in approximately equal portions, with a little water. "Honey candies upon standing," says Dr. Headen, of the Colorado Experiment Station at Fort Collins, "because of the ability of its dextrose to assume a crystalline form much more readily than the levulose." At the Colorado State beekeepers' convention some year's ago he showed samples of free dextrose and levulose. The former looked like rery nice light-colored brown sugar; the latter appeared like a cheap grade of dark-colored molasses. The doctor explained that, if granulated honey were subjected to a sufficient pressure, the greater portion of the levulose could be obtained, leaving the solid mass largely dextrose. The levulose of honey candies slighty, but is very different in appearance from its dextrose constituent.

\section{FREAKS OF HONET-GRANULATING.}

This problem of honey-granulating is very interesting. It sometimes happens that of two lots taken from the same barrel or can, and placed in two self-sealing packages, the honey in one will soon granulate while in the other it will remain liquid, notwithstanding that both packages have been subjected to the same temperature and general conditions. If this liappened in the case of sealed packages only, it might be inferred that the sealing of one package was less perfect than the other; but that the candying does not depend on the sealing altogether is shown by the fact that the two lots of honey may not be sealed at 
all, and yet one of them turns to a solid while the other remains liquid. These instances are by no means frequent; indeed, they are rare; yet they occur just often enough to excite curiosity.

The author has seen alfalfa honey after. it had been in glass jars seven years, and was told that it had candied solid within a few montlis after being taken from the extracting-cans. At the time (seven years after), it was going back to the liquid condition. Some cans were almost entirely liquid, and others had streaks of granulation reaching out like the branches.of an evergreen tree all thru the package. There was every evidence to show that so far it had undergone a slight chemical change. This change was doubtless due to the continued effect of light upon the granules.

\section{HEATING LIQUID HONEY TO PREVENT}

\section{GRANULATION.}

There is no plan that will act as an absolute preventive, but granulation can be deferred for one or two years. Even after treatment, if the honey is subjected to a freezing and thawing temperature for a series of days, it will be almost sure to start candying again. Continuous cold weather with the mercury slightly above zero is not so favorable as alternate cold and warm weather.

After the first few days the honey will appear slightly cloudy. This murky appearance grows more pronounced when the action proceeds more rapidly, until the point of solidification is reached. But there is no excuse for having loney at any time, either comb or extracted, kept in a zero or freezing temperature; for all practical purposes it is possible to prevent extracted honey from granulation for a year on the average.

\section{HEATING TO LIQUEFY GRANULATED HONEY.}

There are two methods of heating honey. One is, to put it in a double boiler or vat and gradually raise the temperature to 150 or 160 degrees Fahr., holding it at that point till all the honey is melted. It should then be put into bottles or tin cans, and sealed while hot. Another plan is to liquefy the granulated honey slowly, and keep it at a temperature of 130 degrees Fahr. for three days. It should not go above
135 degrees when the heat is prolonged. The process of melting will be very slow, and a continuous slow heat so acts on the honey that it will remain liquid much longer than when the heat is applied more rapidly and raised to a higher point.

For full particulars on bottling honey to keep it in a liquid condition, see Botruing HoNEx.

To liquefy honey in a granulated state, or to heat it to prevent its getting into that condition, the honey should be placed in a double boiler-that is to say, a tank with double walls, having the space between the walls filled with water. This may be placed on the store and filled with honey.

Where one doesn't have such a boiler, and cannot afford one, he can make a very good substitute by taking a large washboiler. Into this he puts some blocks about an inch square. On these blocks he places one or possibly two 60-lb. square cans of granulated honey, with caps removed. Or he may put in two or three tin pails, or as many as will go into the boiler. Should he have something larger than a wash-boiler it would be all the better, especially for square cans. The honey is then poured into the tin pails. If granulated solid in a barrel it may be handled with a spade after removing the head. Water is poured into the wash-boiler until it comes within two inches of the top of the pails. The whole is then placed on the stove, and subjected to a slow heat. When the water reaches a temperature of 160 , or nearly that, the fire is checked; the honey should not become any hotter because it may otherwise injure the flavor as well as the color. Honey should never be brought to a boiling temperature except to kill the germs of foul brood, when all such honey may be fed back provided it has boiled at least one-half hour with a cover on, after having been first thinned down with water so it will not burn. Some recommend again bringing to a boil just before feeding.

C. W. Dayton of Chatsworth, Cal., has another and very simple outfit to liquefy honey. As it can be made out of materials found in any beekeeper's yard, at very small cost, many will, perhaps, prefer it to the double boiler. 
As will be seen from the following cut, Mr. Dayton makes use of second-hand 60pound square cans. He cuts off the top at a convenient height, then washes out the cans thoroly. For the purpose of liquefying he uses eight on top of an ordinary cookstove. To keep the honey from burn-

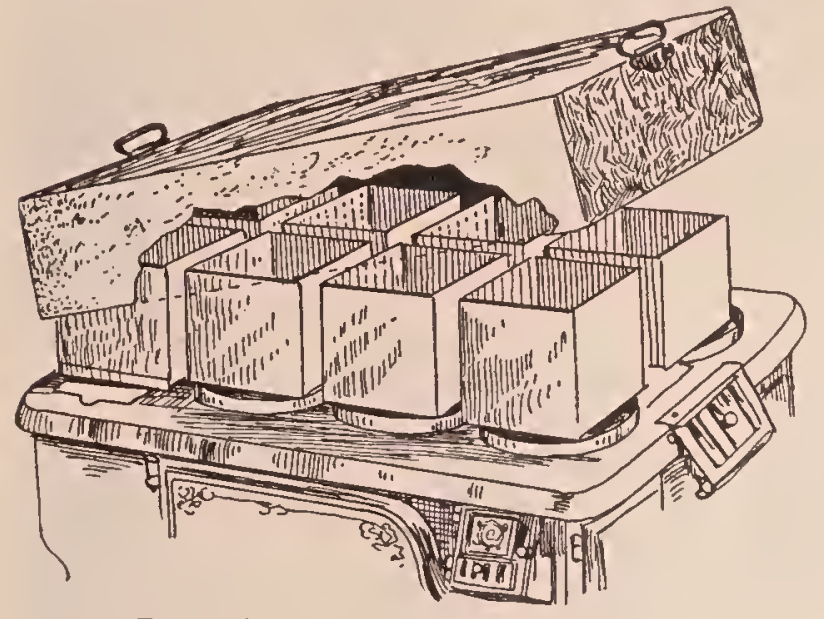

Dayton's outfit for liquefying honey.

ing he gets some band iron, $3 / 4 \times 3-16$, at some hardware store, and makes a series of hoops on which the cans are to stand while heating. Eight of them are placed together as shown; then, to conserve the heat further, a tin cover large enough to slip down over the whole is provided.

Witl the help of this outfit $\mathrm{Mr}$. Dayton says he can melt up $200 \mathrm{lbs}$. of honey in a very short time. These cans would be more convenient to handle, were he to take heavy wire, make some bails and hook them into holes punched on two opposite sides. He would then have a very serviceable pail at a small cost. When the honey is melted, he could lift it off the stove and pour it into some other receptacle from the corner of the cans. This corner makes the finest kind of pitcher mouth.

\section{POUDER'S METHOD OF LIQUEFYING.}

Undoubtedly the best arrangement for liquefying granulated honey in square cans is that formerly used by Walter S. Pquder. Here is wliat he says of it:

For years I have depended upon the hot water tank for melting five-gallon cans of granulated honey, but have found many inconveniences connected with the method, and have been obliged to adopt a safer and speedier method. To take care of the expansion I have used siphons, coal-oil pumps, funnels soldered to perforated screw caps, and other methods, but have always found a lack of tidincss; and in some instances we have ruined very superior honey by overheating. If we overlooked a nail-hole near the bottom of the can we would find a can of sweetened water instead of honey; and in lifting heated cans from the water I have had the handles pull off; and the can, in falling back, would cause the hot water to slop over and scald my toes till I have seriously wished I did not have to dabble in honey at all.

I have longed for a method in which the liquid honey would flow away from the heat as fast as it became fluid, and at last I have such a device in use, and I believe many readers of this work will be interested. It is simply a gas oven, made of heavy galvanized sheet iron, and of a capacity for six cans, three on each side of the gas burner, cans to be suspended on brackets in an inverted position with caps removed. When in use the honey-gate at the bottom of the oven is left open; and as fast as the honey becomes liquid it flows to the outside tank. Considerable experimenting was required in order to maintain proper temperature, and we have learned to regulate the temperature by using a thermometer before we place any honey in the oven. Naturally the highest temperature is nearest the top of the oven, and we are able to keep within 180 and 190 , and the temperature declines toward the bottom of the oven, hot air being circulated thruout. Some heat is slightly radiated against the lower part of the cans, and I find this in my favor, as it tends to prevent openings of cans being clogged with granulated honey.

The two round openings in the front are for ventilation, and to secure perfect combustion. There is a three-inch space between the burner and the bottom of the oven; cans are suspended with a 12-inch space between the bottoms of the cans and the bottom of the oven, and a two-inch space over the tops of the cans; and there is also a 12-inch space between the two rows of cans. We also find the device very convenient in melting jars of granulated honey without so much as injuring the label by simply inverting the open jar on a heavy wire screen.

Such an oven could be constructed for any capacity-for two, four, or six cans at one time, and could be used over a gasoline stove where gas is not obtainable. A thermostat could be added, thus making it an automatic arrangement; but in my business I have not found it necessary. The honer, as it flows into the outside tank, is just right to be strained into our bottling-tank, and there is no deterioration, because it could not be overheated.

Visiting beekeepers pronounce the entire arrangement a model of perfection, and I submit the above description by request.

Under Bottling Honey will be found a description of a similar oven using steam. 


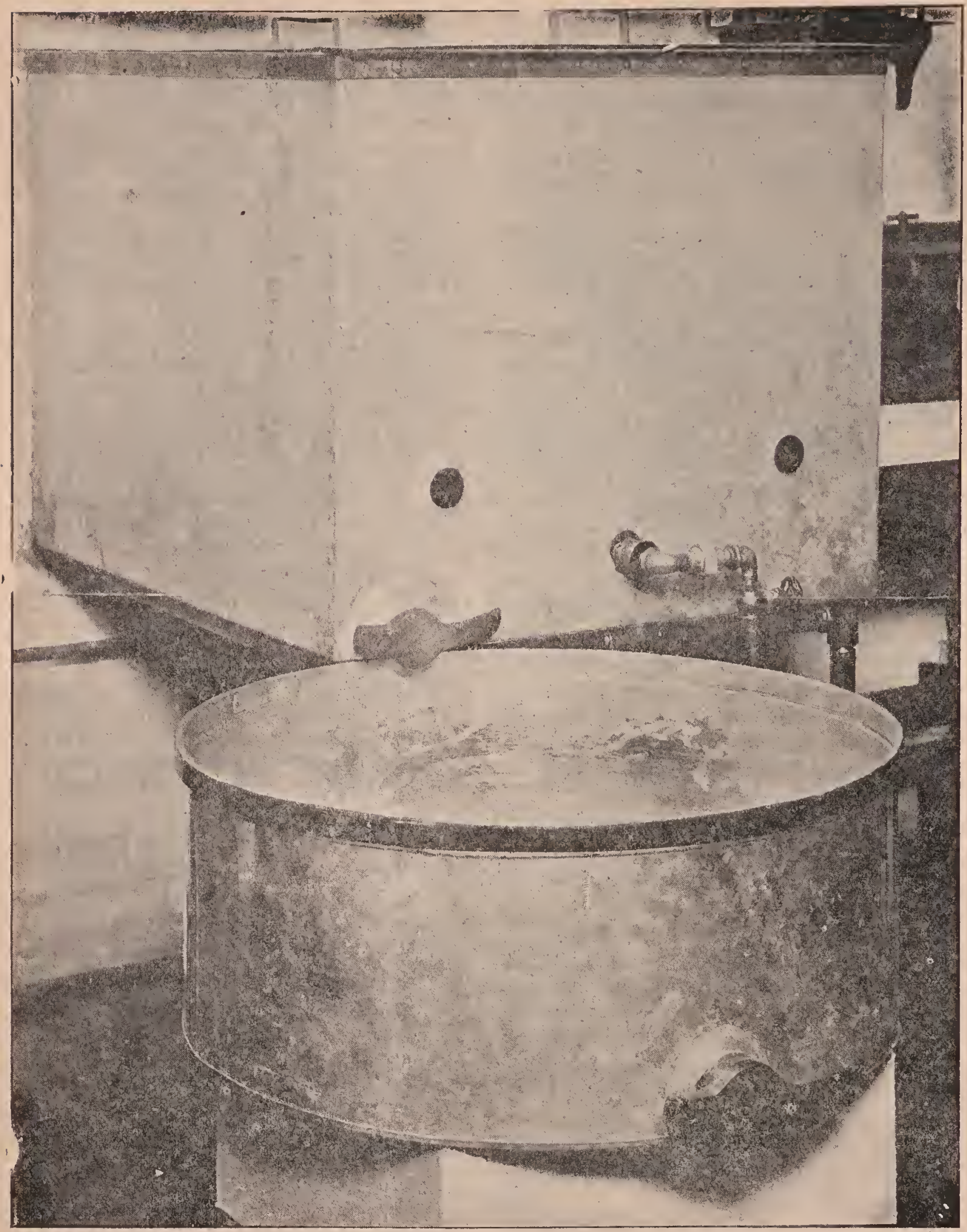

FIG. 1.-Pouder's hot-air oven for liquefying honey in sixty-pound cans. The cans are held upside clown, as shown in Fig. 2; and the honey, as fast as it becomes liquid, runs down to the bottom of the oren and from thence out the gate, away from the heat.

\section{MELTING HONEY IN A CAPPING-MELTER.}

Under the head of Fixtracting and Comb. Honfy the use of a capping-melter is described with a set of illustrations. This outfit is also well adapted for melting cranulated comb honey, Ordinarily granulated extracted will run thru it very readily without any danger at all of impairing the flaror, and, what is more, it will be strained in the process. In the case of granulated comb honey, the wax and honey will be very nicely separated by reason of the heat causing the wax to melt. 


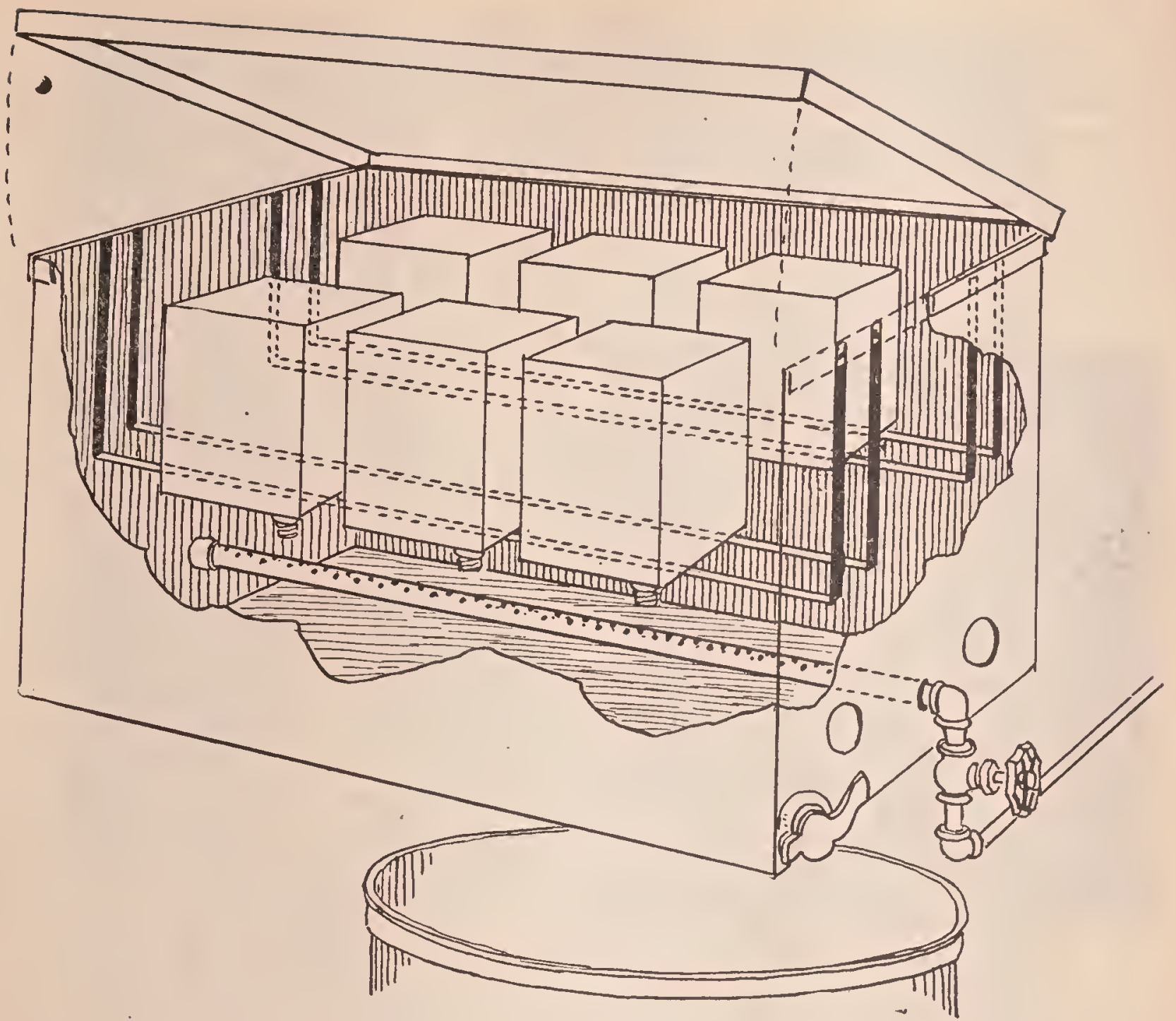

FIG. 2.- Pouder method of liquefying granulated honey, showing the position of cans and gas-burner in the oven.

HOW TO GET GRANULATED HONEI OUT OF BROOD-COMBS AND YET SAVE BOTH.

Where honey granulates at all in broodcombs, it will usually be only partially, so after uncapping, M. M. Baldridge of St. Charles, Ill., recommends placing all such combs in the extractor, and throwing out any portions of the honey remaining liquid. $\mathrm{He}$ next lays the combs in the bottom of a clean wash-boiler, and, from an elevated dipper, pours water slowly into the cells. $\mathrm{He}$ then turns the comb over and treats the other side the same way. As fast as the combs are splashed with water he places them in a hive or super. After they have all been doused he takes them out and sets them over strong colonies. He says the bees, by aid of the water, liquefy the whole mass, clean the combs, and save both the combs and honey.

Granulated comb honey in sections can scarcely be treated in this way, as it would be impracticable to uncap the cells. These should be treated in a capping-melter, as directed.

\section{HOW TO MARKET GRANULATED HONEY.}

Some years ago attempts were made to put up granulated honey in small packages for retail purposes. R. C. Aikin of Loveland, Col., put up his honey in cheap lard pails. He allowed it to granulate, and then sold it direct to consumers. As the packages were cheap he could afford to put the honey on the market at a price that would compete with ordinary sugar. A little later on he conceived the idea of using stout paraffin-paper bags instead of pails, and made a complete success of it.

Alfalfa honey, as is well known, granu. lates very rapidly. As soon as the graining begins to show he draws the honey off into the bags, and allows them to stand in 
a cool place, when it soon becomes solid. The illustration shows the solid cake of granulated honey after the bag is torn away preparatory for the table. The only expense is for bags, which can be bought in various sizes. It was thought for a time that eastern clover and basswood noneys would not granulate solid enough when put up in this shape; but experience

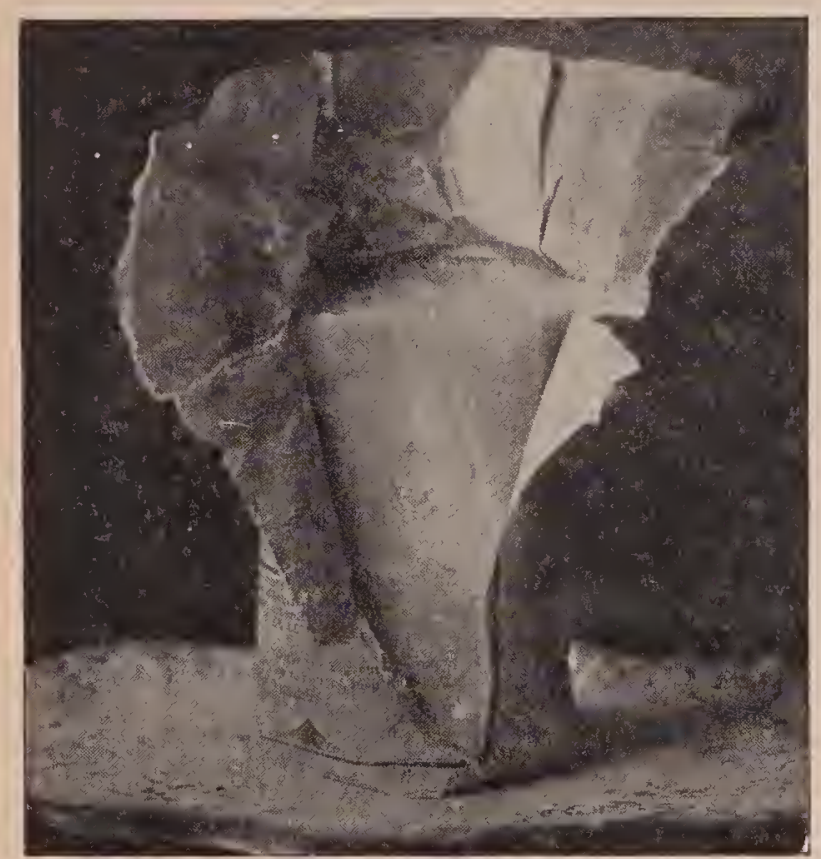

Aikin's paper-bag package dissected for the table.

shows that they as well as alfalfa can be handled in that packige, provided they are already graining when the bags are being filled, or if a little old candied honey is mixed in to expedite the process. This point is very important in putting up such honey in bags or pails.

On each paper package are printed directions for liquefying, reading like this:

The solid condition of this honey is proof of its purity. If preferred liquid, put it into a pail, and the pail into warm water, but not hotter than you can hold your hand in. Never let it boil, for boiling spoils the honey flavor. To remove the bag, cut from top to bottom, then peel it around.

Granulated honey in paper bags should, if possible, be sold before hot summer weather comes on.

GRANULATED HONEY IN OYSTER PAILS.

Another package, somewhat similar to the Aikin bag, is the ordinary oyster pail. When honey begins to granulate it can be drawn off into pails of proper sizes, the covers put on, and the boney allowed to stand. In the course of a few weéls in cool weather it should become quite solid; but it should be remembered that at an extremely cold temperature honey will not granulate so readily as during alternately warm and cool weather. Oyster pails have the advantage that beekeepers can buy them at any grocery, and they are almost as cheap as the Aikin paper bags. They have the merit, also, that honey car be sold in-them in a practically liquid condition without fear of leaking. They can also be handled quite roughly. If the honey should granulate, so much the better.

CUTTING GRANULATED HONES INTO BRICKS.

Honey in 60-lb. square cans that is granulated solid requires a considerable amount of treatment before it can be gotten out, put into bags, and candied again. The cans must be immersed in a boiler of water of about 160 degrees, and kept there for hours at a time, before the honey melts enough to be poured out. Jesse A. Warren conceived the plan of stripping the tim away from the honey within, leaving it in the form of a solid cake. With a pair of snips the top and bottom of the can are cut off; then it is slit down at one corner. A strand of steel wire, after attaching a handle to each end, is slipped under the cake of honey about two inches. The wire is then folded around the cake, the two ends crossed, and with a handle in each hand the operator draws slowly, sinking the wire gradually into the cake from all four sides, until continuous pulling causes it to pass clear thru. A thin-bladed knife is now inserted in the slit where the wire entered, and slabs off a chunk like that shown in cut next page. Other pieces are slabbed off in like manner. These are then cut up into bricks, using the same general plan-bricks all the way from $5 \mathrm{oz}$. up to 2 lbs. They are wrapped in paraffin paper, on which are general directions explaining. how to liquefy.

\section{CUTTING FRANLLATED HONEY WITH $\wedge$ MACHINE.}

The plan just described can be used in only a very limited way. It has the further disadvantage that it is almost inpossible to cut the eakes in regular sizes. A 


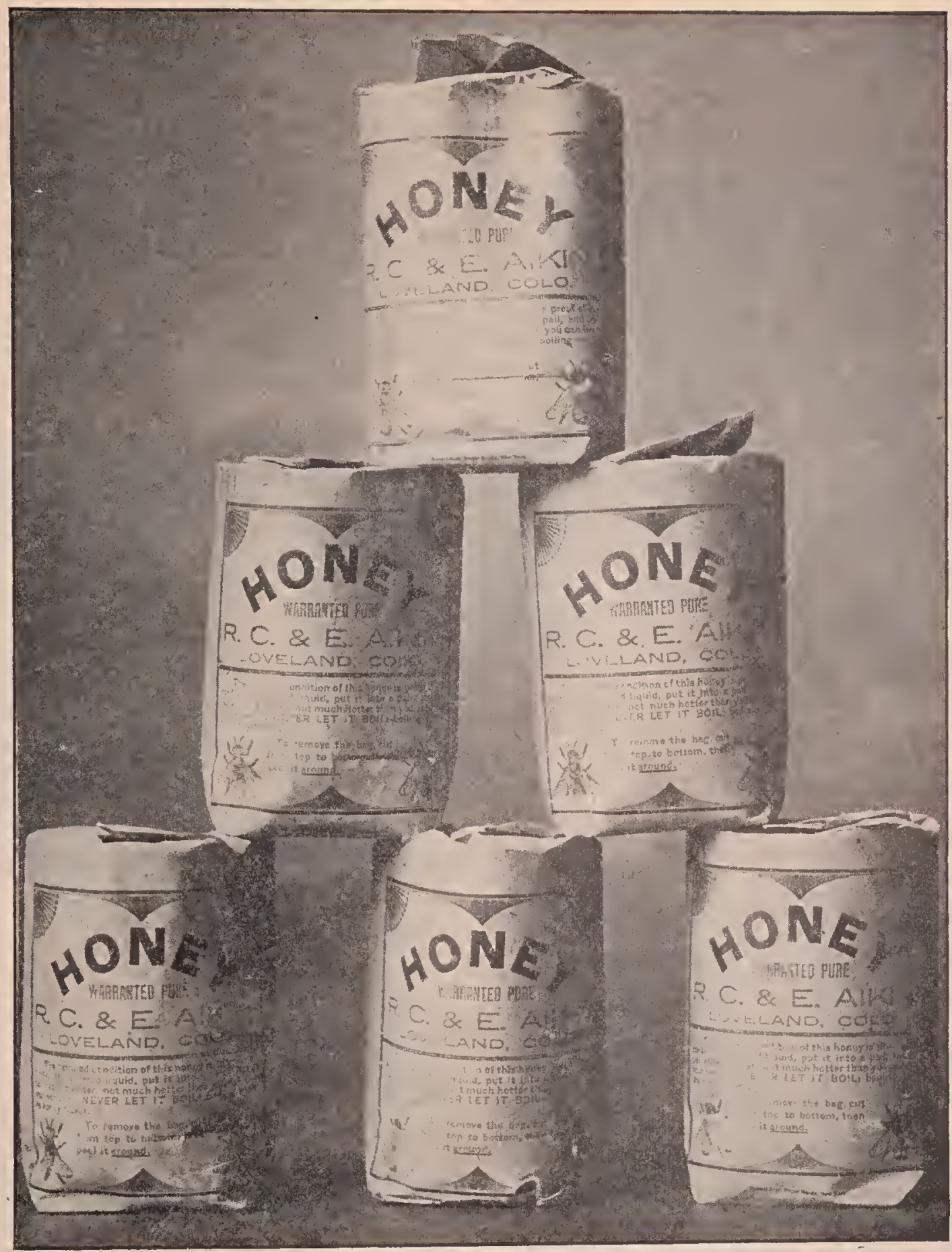

Nikin's paper-bag honey-package for granulated honey

far better apparatus is the ordinary butter-cutter shown on page 435, and sold by the Cleveland Galvanizing Works, Clereland. Ohio. The same thing, or something like it, can be obtained of any dealer in dairy supplies. This butter-cutter employs the same principle - a wire drawn taut for cutting butter. Since butter has about the same consistency as hard-granulated honey, the same machine will slice up a cake of granulated honey in uniform bricks, and do it more quickly and neatly than can possibly be done with a single strand by hand.
In using the machine, care should be taken not to crowd the frame holding the strands of wire too fast, as it is a job that cannot be ruslied without danger of breaking the wires. $\perp$ gentle continuous pressure is what is requirer.

For the perpendicular "uts two heary weights are applier in such a way that, after the eake of honey is put in place, the horizontal frame and its wires gradually work their way thru the mass. When the rake is ent the other way, on the horizontal line, the operator takes hold of the gate, as it were, pulling gently. 
All that then remains is to take a thinbladed knife, pick up each brick and lay it on a piece of paraffin paper. The brick is then neatly wrapped, when it is slipped

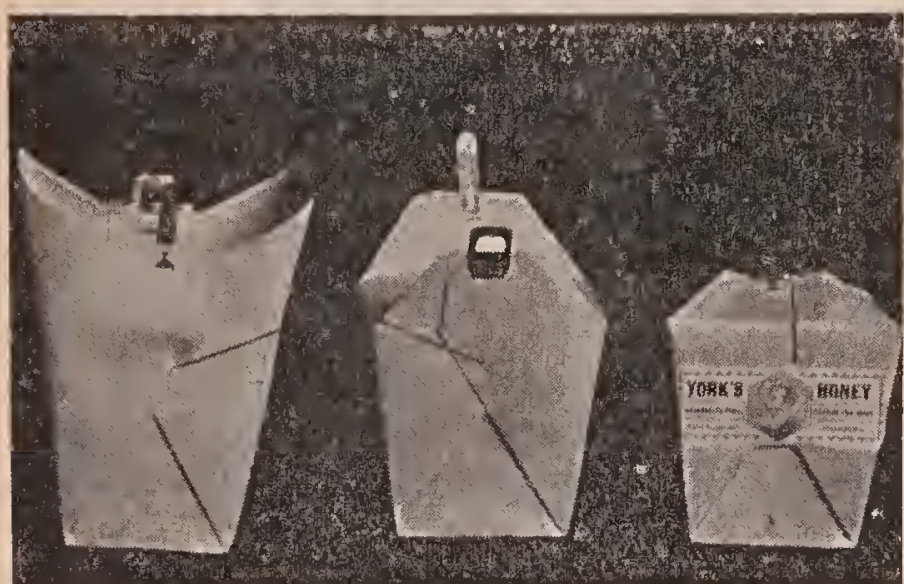

Square oyster pails for granulated honey.

inside of a special carton made just large enough to receive it. The carton is then covered with another wrapper, neatly lettered, and containing directions how to liquefy the honey when desired. As a rule, the consumer is advised to use the honey in the solid form by explaining that it can be spread on bread like so much butter.

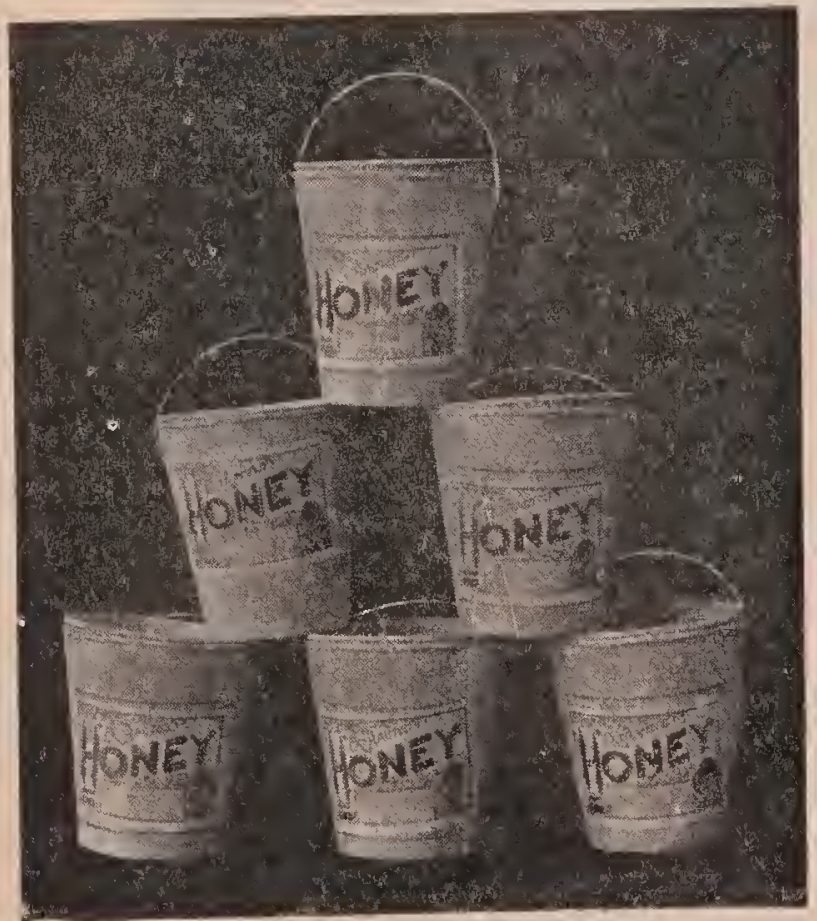

Round oyster pails filled with granulated honey.

It is advantageous to adopt the $11 / 4-1 h$. brick or 48 to the $60-1$ b. cake from the square can.

CAUTION.

The tin should not be ent off from the can of candied honey unless the honey is very solid. If it is slightly mushy there will be trouble. The mass of granulated honey will settle out of shape, and run all over everything. There is no use in trying to cut up honey like this into bricks. It should either be melted or put into oyster pails, where the process of solidifying can be completed.

It may be questioned whether it pays to cut off square cans and take the honey in a solid chunk; but it enables one to fill rush orders for granulated honey on short no-

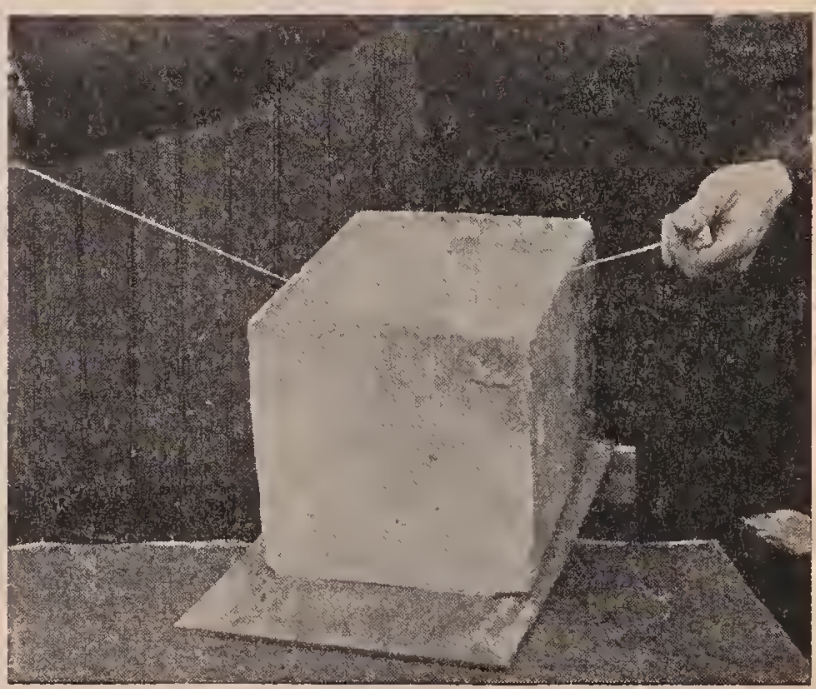

Slab of honey nearly cut thru by wire.

tice. Second-hand cans are worth only a few cents; whereas to melt the honey out and re-candy is out of the question.

GENERAL REMARKS ON HOW TO MAKE HONEY GRANULATE QUICKLY.

As already explained, continuous zero weather is not so favorable as weather somewhere near the freezing-point, now moderating up to the thawing-point, then

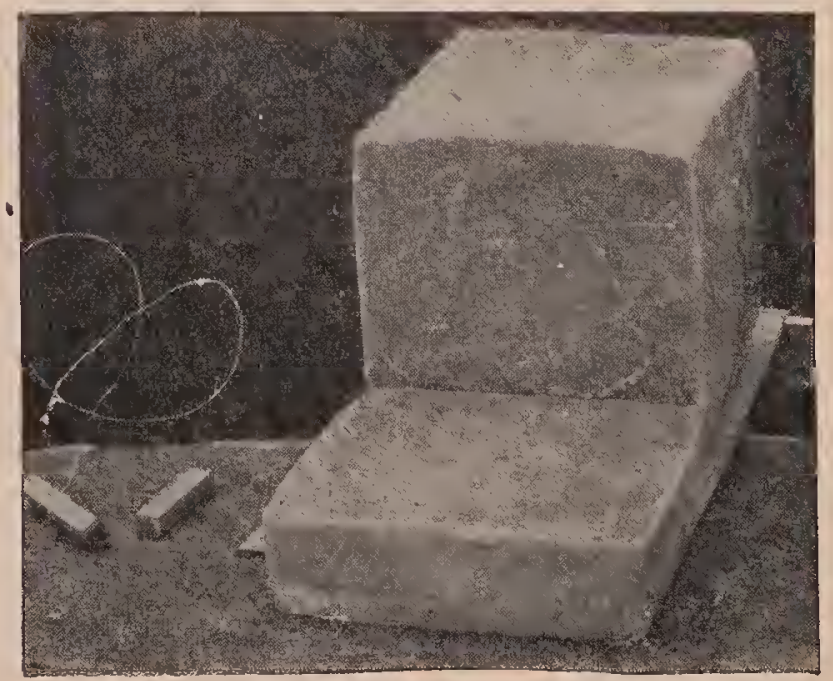

Slab of honey cut off. 
freezing, then thawing again. When the weather remains continuously cold, set the honey out in pails or bags in a room where the temperature goes a little below freezing, leaving it for a day or two, then bringing it into a warm room. After it is thoroly warmed up, put it into the cold room again, and so continue with changes of temperature. Stir the honey occasionally, and always make it a rule to have some granulated honey mixed with that which is to be brought to a solid condition.

\section{EDUCATING THE PUBLIC TO GRANULATED HONEY.}

The question may arise whether it would be everywhere practicable to sell granulated honey in any one of the forms described. It could hardly be deemed advisable to furnish buyers or commission

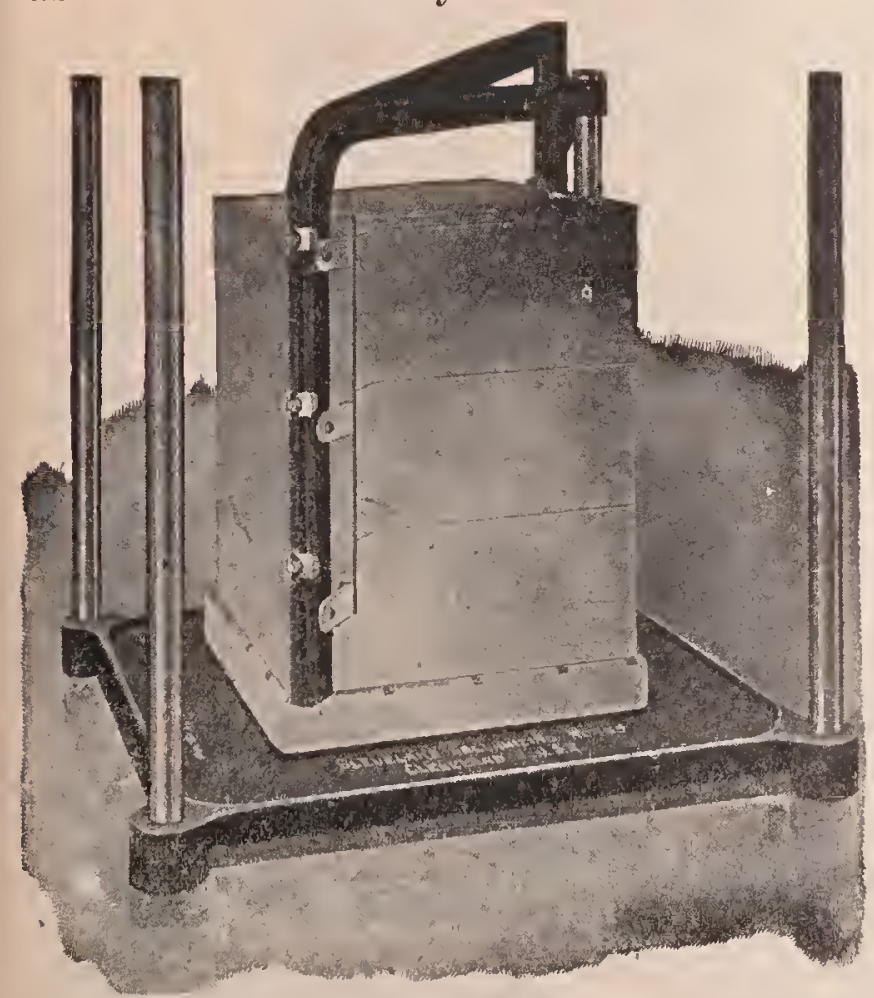

Butter-cutter for cutting granulated honey into bricks.

houses that know neither the shipper nor the real character of the honey. The packer or producer must first introduce it to his own customers-people who know him. The nature of the honey must be explained; how put up; that only the purest and best can be solidified in this manner; and that it can be liquefied. In short, the trade must be educated to it. The fact that no unripe or glucosed honey can be put up in bags or bricks will be a strong "talking- point" on the purity of the honey. When the facts once become known, old prejudices give way.

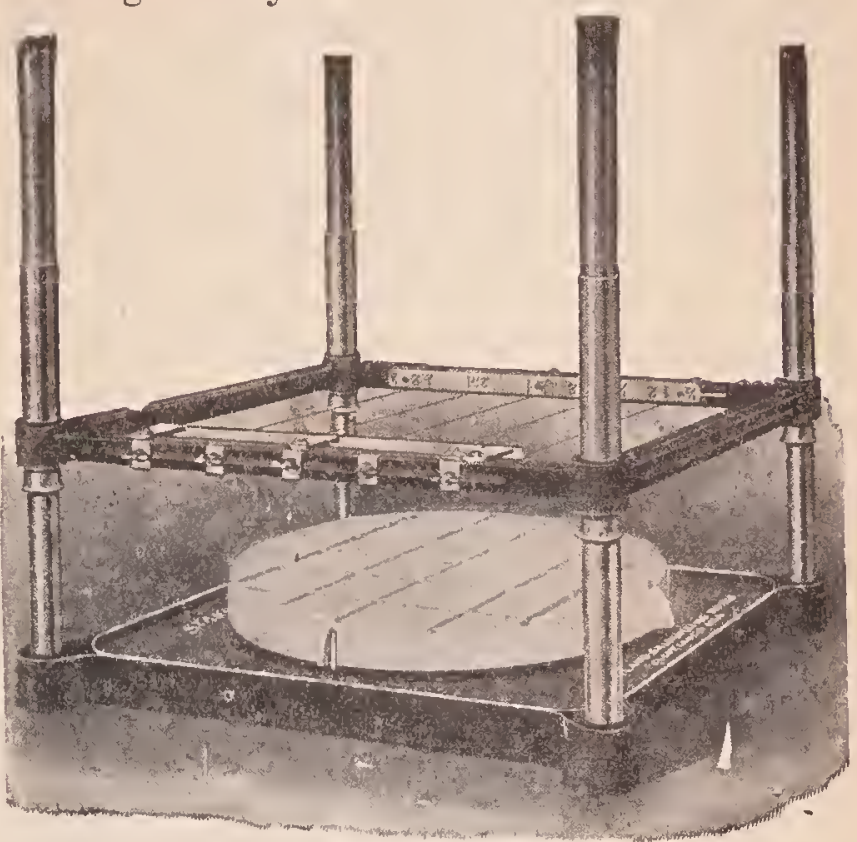

Machine for cutting granulated honey.

In the early days the author cut up some brick honey with a wire into packages weighing 5 ounces. These sold for a nickel. They went off so fast the demand could not be supplied. For the sake of experiment one 60-lb. can of granulated honey was cut into 160 cubes. The honey cost $61 / 2$ cents per pound. These cubes were retailed at 5 cents, or $13 \frac{1}{2}$ cents a pounddoubling on the money.

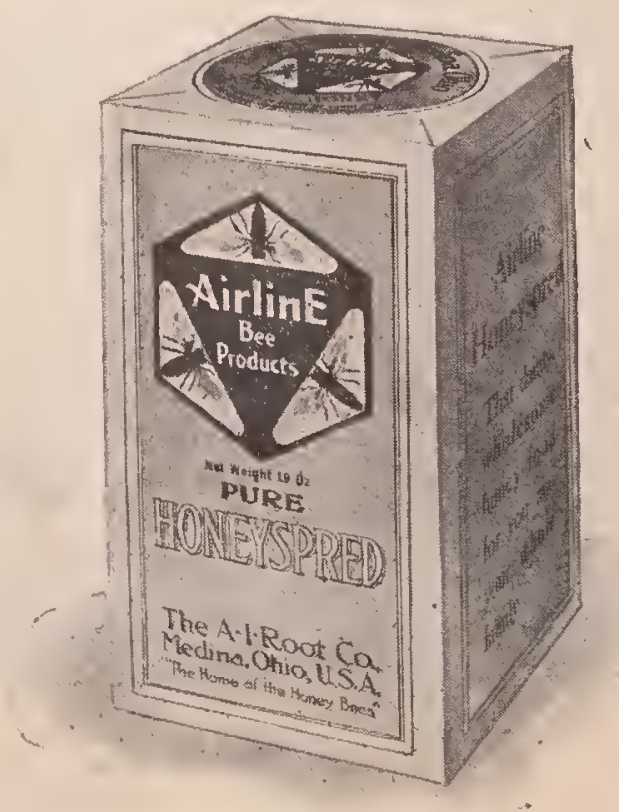

Granulated honer put up in bricks.

After the trade gets educated to buying boney in this form no effort at all is neces. 
sary to sell it. The cost of the package is practically nothing, and all trouble from the honey candying again is overcome, becanse the trade has been educated to know that such honey is the pure article.

The time may come when granulated honey will be known on the market as a common article of commerce; because when the public generally understands that such honey must be of the best quality, and absolutely pure, it will sell without any trouble.

For particulars on how to prevent comb honey from granulating and how to dispose of it when it does granulate see CoMB Honey, To Produce.

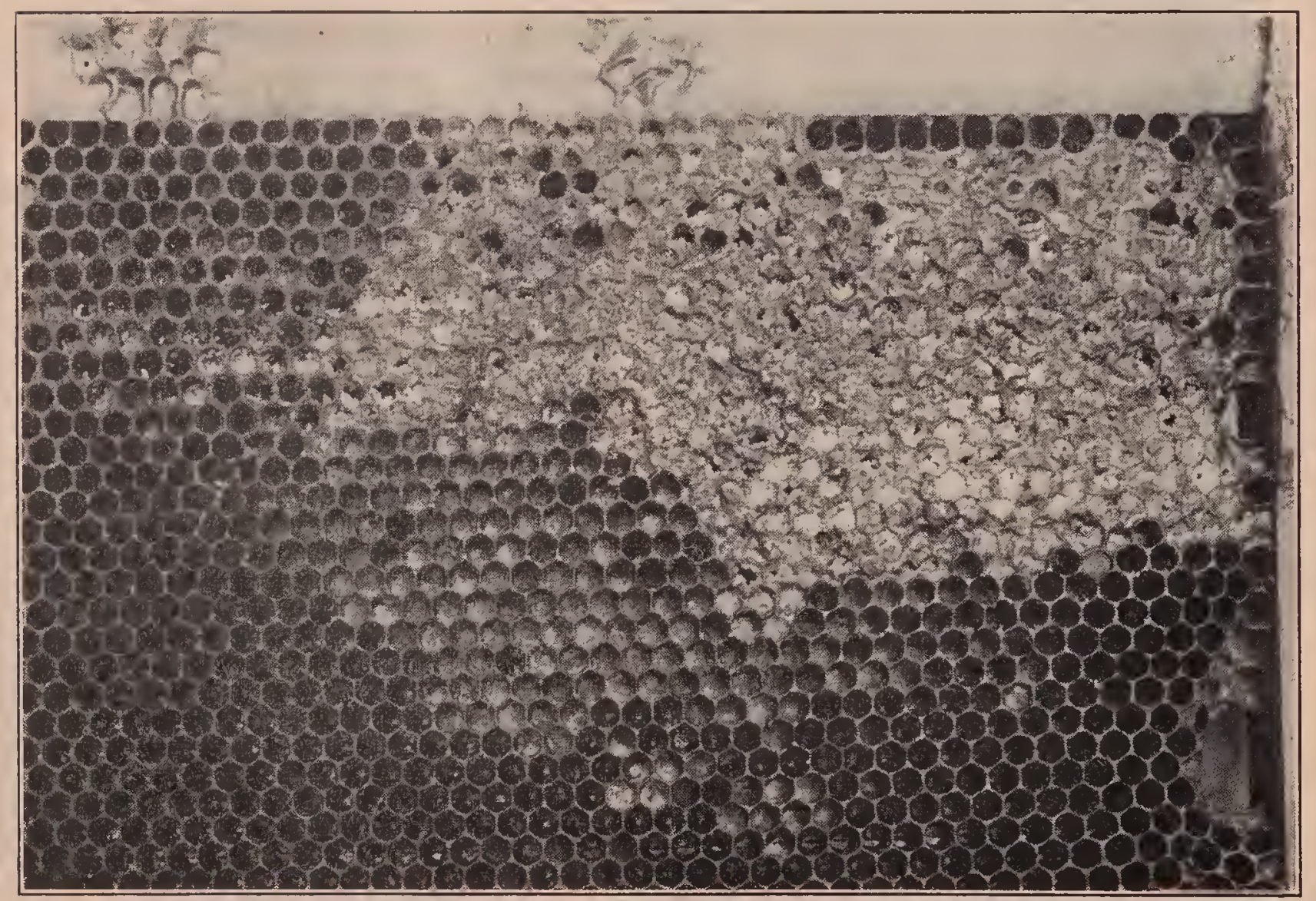

Comb containing aster honey granulated so solid that the bees could not use it. Note the granules in the open cells at the left. These were almost like flint. The bees had gnawed the cappings from the other cells but had left the honey. 


\section{$\mathrm{H}$}

HANDLING BEES.-See MANIPULAtion of Colonies; Franes, Self-Spacing; Anger of Bees; also Stings, and Hives.

HAULING BEES.-See Moving Bees. tral Nortl America, particularly in Illinois, Kansas, and Nebraska. In the lastnamed State it reaches a lieight of from three to five feet, and grows luxuriantly on all waste and stubble lands. The flowers in

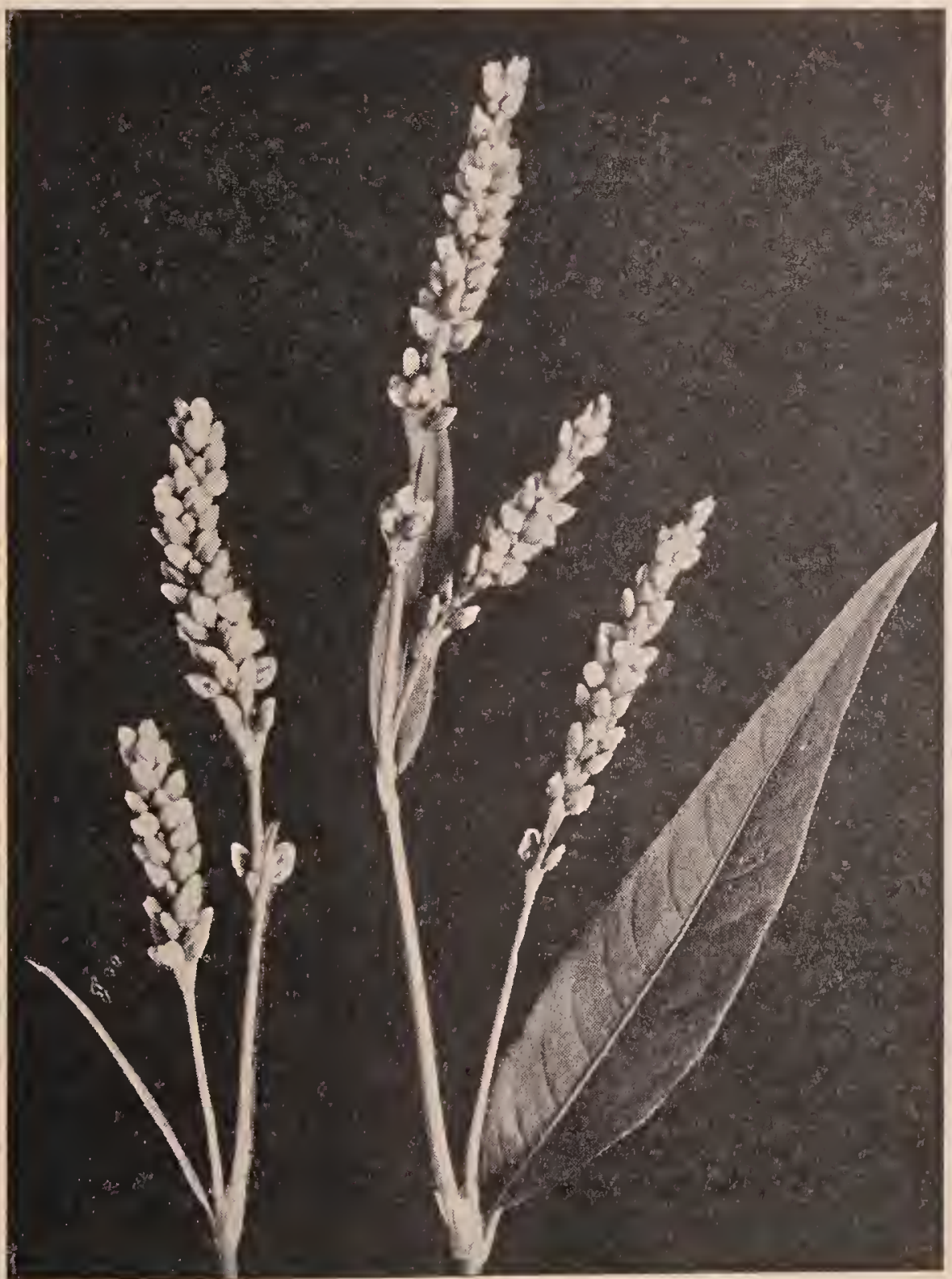

Heartsease or swartweed.

HEARTEASE (Polygonum Persicaria). -This is one of the large family of neetar-bearing plants of which the common buckwheat is one. Heartsease, sometimes known as lady's thumb, knotweed, or heartweed, is naturalized from Europe, and is widely distributed over eastern and cen- oblong cluster's are generally reddish purple, and, in rare instances, white. It yields in Nebraska, and other States in that section of the country, immense quantities of honey. One beekeeper, 1. R. Delong, at the North American convention leld in Lincoln, Neb., in October, 1896, reported 
two of his colonies yielded each $450 \mathrm{lbs}$. extracted honey, and that the average for his entire apiary was 250 lbs. per colonyall heartsease. While perhaps these yields were exceptionally large, quite a number of other beekeeper's reported at the same convention an average of $200 \mathrm{lbs}$. from the same source. There are in Nebraska acres and acres of this honey plant extending over the plains as far as the eye can reach; and, as it secretes nectar from August until frost, the enormous yields are not surprising.

The extracted honey varies in color from a light to a dark amber; and the flavor,

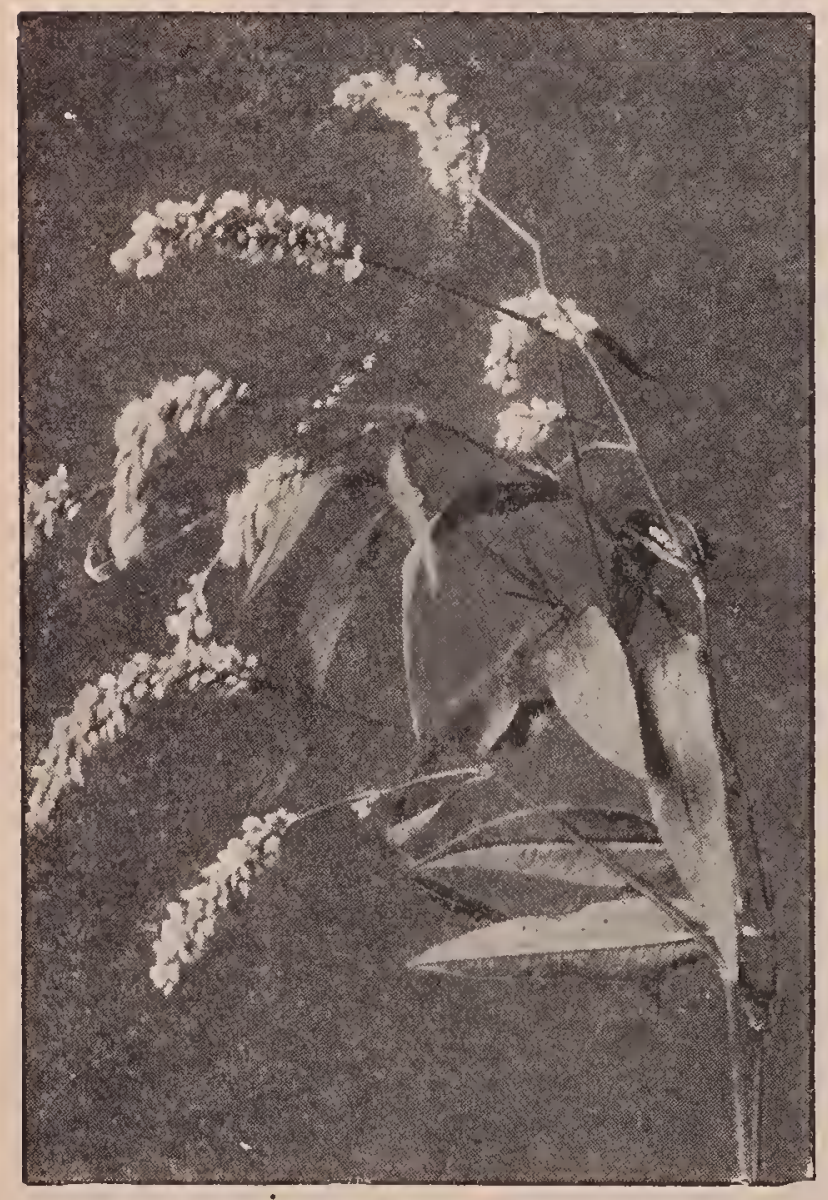

Heartsease.

while not quite up to that of white honey, is very good. Heartsease comb honey, in point of color, is almost as white as that of clover. The extracted granulates in very fine crystals, and looks very much like the candied product of any white lioney. Care should be taken in liquefying, as heartsease honey is injured more easily by overheating than any other honey.

HEAT.-See Artificial Heat.

HERMAPHRODITE BEES.-These are nothing more nor less than freaks of na- nature-that is to say, one will sometimes see worker bees having drone heads and drones with worker heads. They are not very common, it is true; but about once a year there is sent in to the author specimens of either the one or the other kind of bees that have, apparently, appropriated the wrong head. The beginner needs to be reminded that the head of a drone is rery different in appearance from that of a worker or queen. The two compound eyes of the former are large and well developed, while in the latter they are much smaller.

Under the head of Drones, to which the reader is referred, mention is made of another freak of nature-namely, drones with rariously colored heads.

HIVE-MAKING.-Unless one is so situated that freights are high, and unless, also, he is a mechanic, or a natural genius in "making things," he would better let hive-making alone. Hives can be bought usually, with freight added, for much less than the average beekeper can make them himself, if spoiled lumber, sawed fingers, and the expense of buzz saws are considered; moreover, hives made in the large factories, where they are turned out by the thousands, by special machinery run by skilled workmen, are generally much more accurately cut.

The following letter from a. practical planing-mill man, who ought to know and does know what he is talking about, sets forth the actual facts as they are:

\section{ELIAS BAMBERGER}

Manufacturer of SASH, DOORS, BLINDS

Contractors' and Builders' Supplies including all kinds of Window Glass Cor. Exchange and Adams Sts.

Estimates Furnished on Application.

Freeport, Ills., June 11, 1907.

The A. I. Root Co., Medina, Ohio.

Gentlemen:-I received five of your $\Lambda \mathrm{E}$ 525-10 hives yesterday, and find that I can not make my own hives and supplies as cheap as yours and use the same quality of lumber. You can see by the head of this letter that if any one can make hives cheaper than your prices or ally of the so-called "trust-hive" manufacturers, I ought to be able to do it; but, using the saine quality of 'lumber, I can not. John H. Bamberger.

But there is fun in making things, even 
if they are not so well made; and there are some rainy or wintry days in the year, when, if one is a farmer, for instance, he can as well as not, and at little or no expense for time, make a few hives and other equipment. Again, if one lives in a foreign country, he may not be able to get the hives here recommended.

\section{REQUISITES OF A GOOD HIVE.}

While it is very important to have good well-made hives for the bees it should be clearly understood that the hive will not insure a crop of honey. As the veteran Mr. Gallup used to say, "A good swarm of bees will store almost as much honey in a half-barrel or nail-keg as in the most elaborate and expensive hive made, other things being equal." This is based on a good colony in the height of the honey season. If the colony were small, it would do much better if put into a hive so small that the bees could nearly or quite fill it. This would economize the animal heat so that they could keep up the temperature for brood-rearing and the working of wax. Again, should the bees get their nail-keg full of honey, unless more room were given them they would have to cease work or swarm, and either way a considerable loss of honey would be the result. The thin walls of the nail-keg would hardly he the best economy for a wintering hive, nor for a summer hive either, unless it were well shaded from the direct rays of the sun.

P. H. Elwood of Starkville, N. Y., who owns over 1,000 colonies, said in Gleanings in Bee Culture some time ago, "A good hive must fill two requirements reasonably well to be worthy of that name. 1. It must be a good home for the bees. 2. It must in addition be so constructed as to be convenient to perform the various operations required by modern beekeeping. The first of these requirements is filled very well by a good box or straw hive. Bees will store as much honey in these hives as in any, and in the North they will winter and spring as well in a straw hive as in any other. They do not, however, fill the second requirement; and to meet this, the movable-frame hive was invented."

Under A B C of Beekeeping, subhead, The Modern Hive, are shown the general features of the hive, and under Hives and
Frames will be shown styles and the special features that belong to each. But there is only one live that is used largely thruout the United States, and that is the Langstroth-that is, it embodies the Langstroth dimensions. The frame is $175 / 8$ long by $91 / 8$ deep, outside measure. This establishes the length and depth of the hive. As to width, that depends upon the number of frames used. It is the rule to allow 5-16 bee-space between the ends of the frames and the inside ends of the hive. This will make the inside length of a Langistroth hive 181/4 inches, or the outside length 20 inches if made of $7 / 8$-inch planed lumber. It is the rule to make the depth of the hive $3 / 8$ inch deeper than the frame- $1 / 8$ inch under the frame and $1 / 4$ inch on top. For dry climates a greater allowance should be made on account of shrinkage. The selection of the frame, the number to the hive, and the distance they are spaced apart determine the dimensions of the hive itself.

As stated, the Langstroth is the standard thruout the United States; but there has been a tendency on the part of a very few toward a frame of the same length, but two inches deeper. There is also a tendency to go to the other extreme in adopting a frame of Langstroth length, but two or three inches shallower, using two stories of such a hive for a single brood-nest.

On account of the diverse notions of beekeepers and the peculiarities of locality, it would hardly be worth while to give general directions for the manufacture of any one hive; and, besides, no printed directions will give as good an idea of the construction of a hive as the very thing itself. For these and other reasons it would be far better for the one who intends to make hives to send to some manufacturer for a sample in the flat, all complete. With the several pieces for patterns he will then know exactly the shape and dimensions, how to make rabbets, and in general how the hive is constructed in every detail. If one does not find on the market just such a hive as suits his notion, of course he sees, or thinks he sees, "in his mind's eye" something better; but in that case the author would strongly urge him to make a sample or two before he makes very many of them; for nine times out of ten-yes, 
ninety-nine times out of one hundred-he will discard the one of his invention, and adopt some standard made by manufacturer's generally.

\section{HIVE ON SCALES.-See SCALE Hive.}

HIVES.-The word "hive," broadly speaking, covers any sort of inclosure in which bees make their home. In the primitive days these consisted of hollow logs two or three feet long with a board for the cover and another board for the bottom. Later, boxes were construeted. (See Box Hives.) In early times straw slieps were used, and are still used in parts of Europe and southeastern United States. See SkEP.

The modern hive consists, first, of a brood-body, a box without top or bottom, to hold a series of frames. (See Frames.) Each frame incloses a comb. But no hive is complete without a roof or cover, and a bottom, usually called a bottom-board. In addition to the roof and live-body, with its frames and bottom, there are upper stories, or' supers. A super, just as its name indicates, is an upper story-a box without cover or bottom to hold either a set of frames, the same as in the brood-nest or shallower, or a set of holders to support section honey-boxes in which bees store honey. For a further description of modern hives, see A B C of Beekeeping. For particulars regarding comb-honey supers, see Conb Honey, Appltances for. For directions to make see Hive-MAKING. For a description regarding the hives of early days, leading up to the present, see Hives, EVOLUTION OF.

\section{DIIIENSIONS OF HIVES.}

Hives based on Langstroth dimensions are the standard. Some 30 years ago there were in use the American, Gallup, Langstroth, Adair, and Quinby frames. All of these required, of course, hives of different dimensions. Between the Adair, the Gallup, and the American there was but very little difference, comparatively, as they were cubical, and very nearly of a size. The Langstroth was long and shallow-the shallowest frame that had then been introduced; and the Quinby, having about the same proportions, was the largest frame in general use. 'By consulting' the diagram containing the different sizes of frames it will be seen that there are practically two classes-the square and the oblong. As there would be but very little difference, theoretically and practically, between the results secured with a Gallup, American, and Adair, the arguments for the square frames will be considered.

\section{SQUARE TRAMES.}

In nature, bees have a tendency to make a brood-nest in the form of a sphere; patches of brood are more inclined to be circular than square or oblong. 'Theoretically, then, a cireular frame would be the

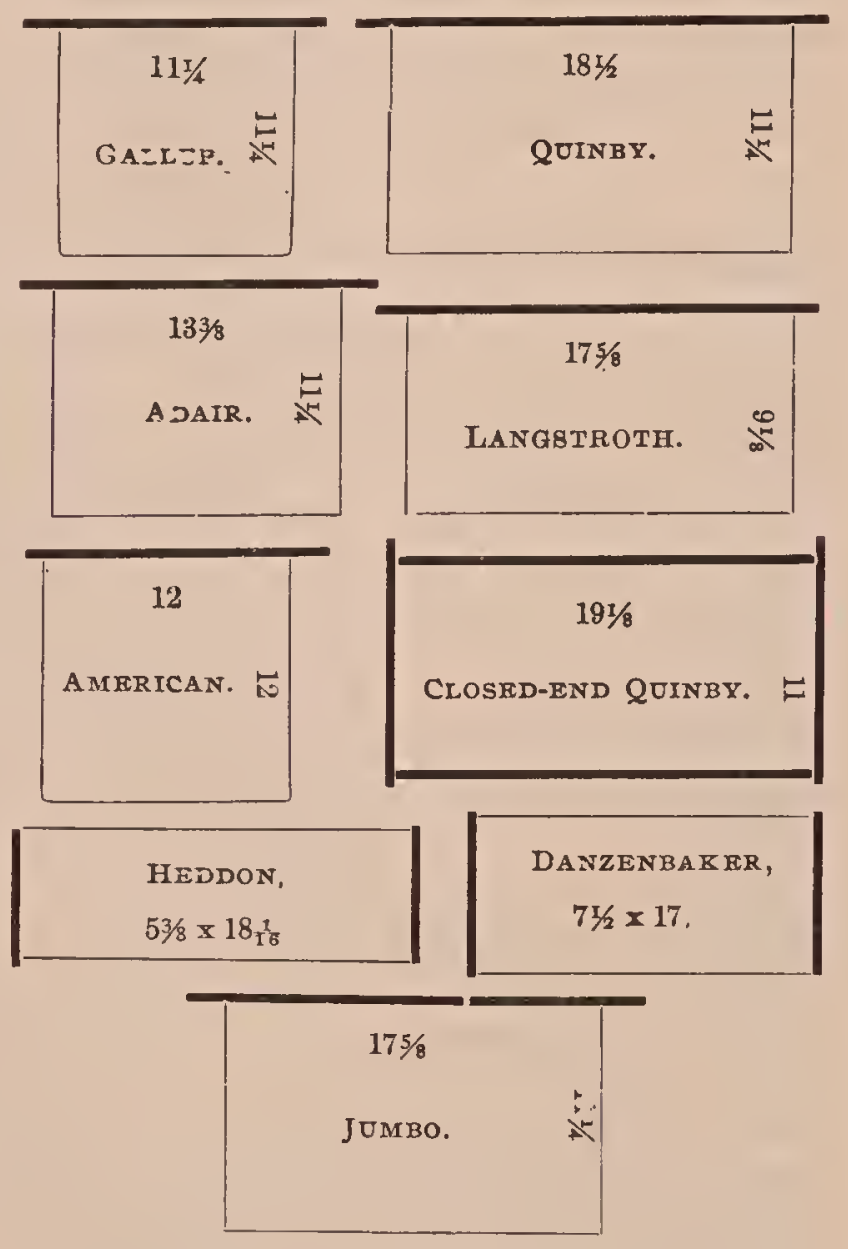

best; but as that would not be practicable, owing to the difficulty in the construction of the frame and hive, obviously the square frame would come the nearest in conforming to nature and a perfect cube for the hive. The square frame, as a r'ule, calls for a hive in the exact shape of a cube. If, for instance, the frame was 12 inches square, outside dimensions, then the hive, if the combs were spaced $13 / 8$ incles apart, and $123 / 4$ inches wide inside, should take in just nine American frames. Such a hive, it was argued, would conserve the heat of 
the bees to the best adrantage, would give the greatest cubical contents for a given amount of lumber-barring, of course, the perfect sphere. As it economized heat in winter, it would winter bees better than a hive having oblong frames.

All of this seemed to be very pretty in theory; and there are some users of square frames who insist that the theory is borne out by actual experience. But the great majority of beekeepers, after having tried the square and the oblong frames, finally decided in favor of the Langstroth.

At this point the reader should read the article on bee-spaces, found under BEESPACE, and also Franies. Both of these articles discuss principles that are vital in the construction of a modern hive.

\section{THE LANGSTROTH FRAME AND HIVE AND}

WHY IT BECAME THE STANDARD.

1. A shallow frame permits the use of a low flat hive that can easily be tiered up one, two, three, and four stories high. This is a great advantage when one is running for extracted honey, as all that is necessary when the bees require more room is to add upper stories as fast as the bees require them, and then at the end of the season extract whenever it is convenient. Square or deep hives eannot be tiered up very high without becoming top-heavy and out of convenient reach of the operator.

2. The long shallow frame is more easily uncapped because the blade of the uncapping-knife can reach clear across it.

3. The shape of the Langstroth frame favors an extractor of good proportion.

4. A deep frame is not as easily lifted out of a hive and is more liable to kill bees in the process of removing and inserting frames.

5. The shallow frame is better adapted for section honey. It is well known that bees, after forming a brood-circle, are inclined to put sealed honey just over the brood. In a frame as shallow as the Langstroth, there will be less honey in the brood-nest and more in the boxes; for bees, in order to complete their brood-circle in the Langstroth, will, with a prolific queen, often push the brood-line almost up to the top-bar, and, consequently, when honey comes in, will put it into the supers or boves just where it is wanted. (i. When bees are left to themselves they will generally form a cluster late in the season, immediately orer the entrance of the hive, and down two or three inches from the top of the frames. As the season proglesses the cluster eats into the stores above it; and on reaching the top it works backward. It therefore happens that the cluster reaches the top of the hive where it is the warmest during the coldest part of the year. In the case of the ordinary square frame the bees will be found just over the entrance, four or five inches from the top; but in the midst of the coldest weather the bees may not and probably will not be near the top of the hive, as

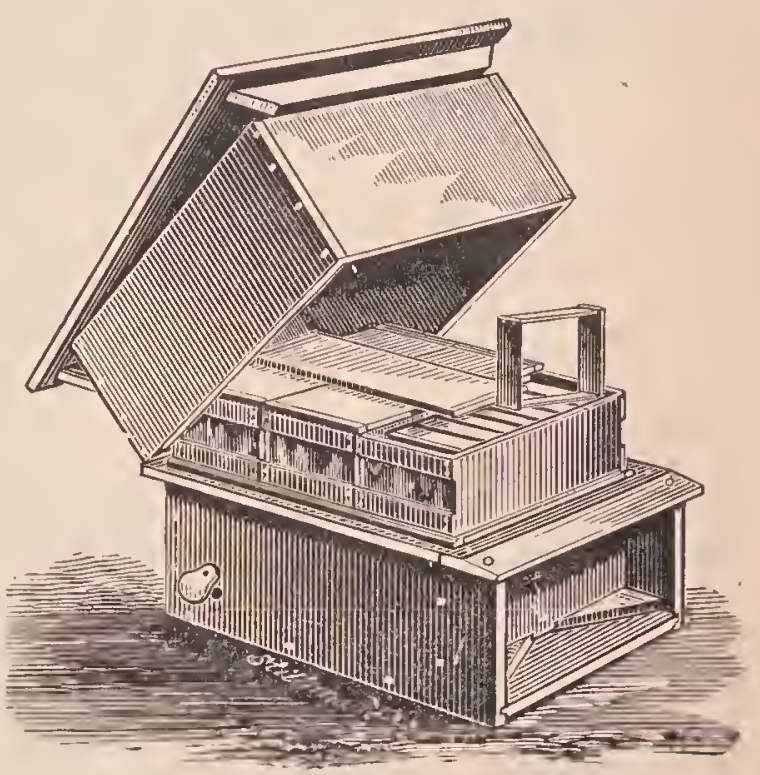

The original Langstroth hive.

on reaching the top they can progress backward only a comparatively short distance because the top-bar of a square frame is relatively short. In the case of the Langstroth hive, the bees during the entire cold part of winter stay in the top of the hive, where it is the warmest. $\Lambda$ s the stores are consumed they move backward and gradually reach the back of the hive, and by that time warmer weather will probably prevail.

In actual experience bees seem to winter just as well on a Langstroth as any other: and, as the shallow frame is better adapted to section honey, beekeepers naturally turned toward the shallower frame, with the result that now probably 99 per cent of all the frames in the United States are of Langstrotl dimensions: and whatever advantage there may be in favor of the 
square shape, the beekeeper is able to buy standard goods so much cheaper that he adopts the Langstroth frame.

FRAMES SHALLOWER AND DEEPER THAN THE LANGSTROTH.

A few years ago there was a tendency toward a frame still shallower than the Langstroth, which resulted in what is called the Heddon; but as eight or ten of these frames, or one super, make too small a brood-nest, two sets of such frames are used to accommodate a whole colony. Of the Heddon hive more will be given farther on. See Contraction.

There is another class of beekeepers who feel that the Langstroth is not quite deep enough, and who, therefore, prefer the Quinby. They argue that 10 such frames, or frames Langstroth length, and two inches deeper, are none too large for a prolific queen, and that these big colonies swarm less, get more honey, and winter better. Of these, more will be said under the subject of "Large vs. Small Hives."

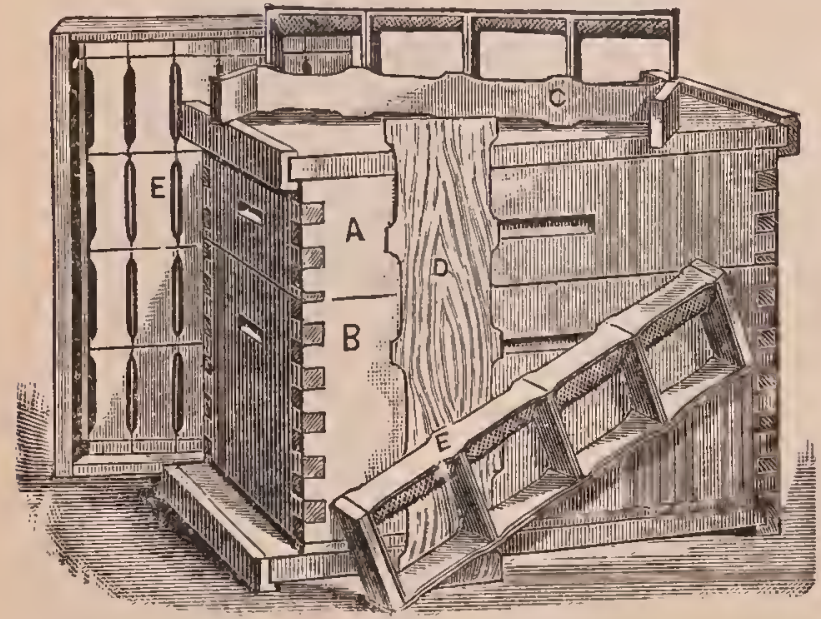

Original dovetailed hive, Langstroth dimensions.

The old original Langstroth hive that the Rev. L. L. Langstroth put out contained 10 frames $173 / 8 \times 191 / 8 . *$ Each hive had a portico, and eleats nailed around the top edge to support a telescoping cover, under which were placed the comb-honey boxes, or big cushions, for winter. There was a time when this style of hive was the only one used; but owing to the fact that it was not simple in construction, that the portico was a splendid harboring-place for cobvebs and gave the bees encouragement for clus-

* The length for nearly 50 years has been $17 \%$ instead of $17 \%$. tering out on hot days instead of attending to their work inside of their hives, a far simpler form. of hive was devised. The Simplicity, first brought out by A. I. Root, having Langstroth dimensions, was the result. Instead of having telescope covers the contiguous edges of the hive were beveled so as to shed water and give in effect a telescoping cover. The cover and bottom of this hive were exactly alike, the entrance

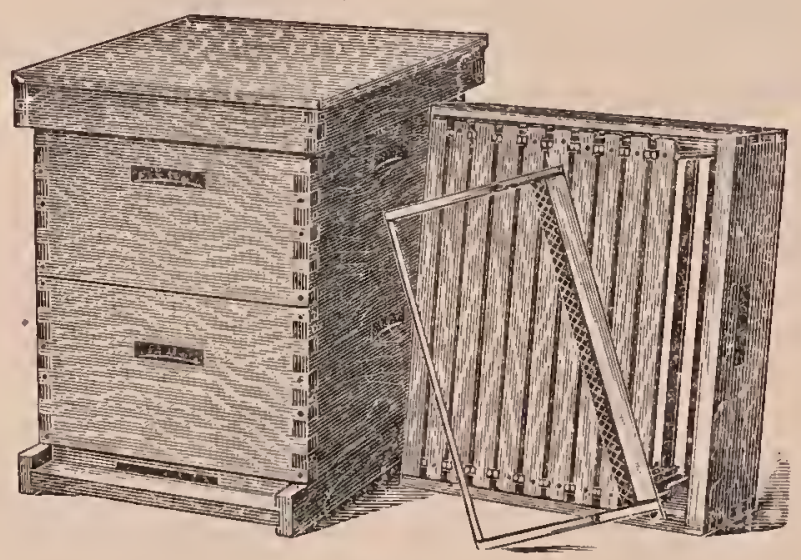

being formed by shoving the hive forward on the bottom, thus making an entrance as wide or narrow as seemed most desirable. But it had one serious defect, and that was the beveled edge. It was found to be practically impossible at times, on account of the bee glue, to separate the upper story from the lower one without breaking or splitting the bevel. Finally there was introduced a hive very much the same, having straight square edges, and along with

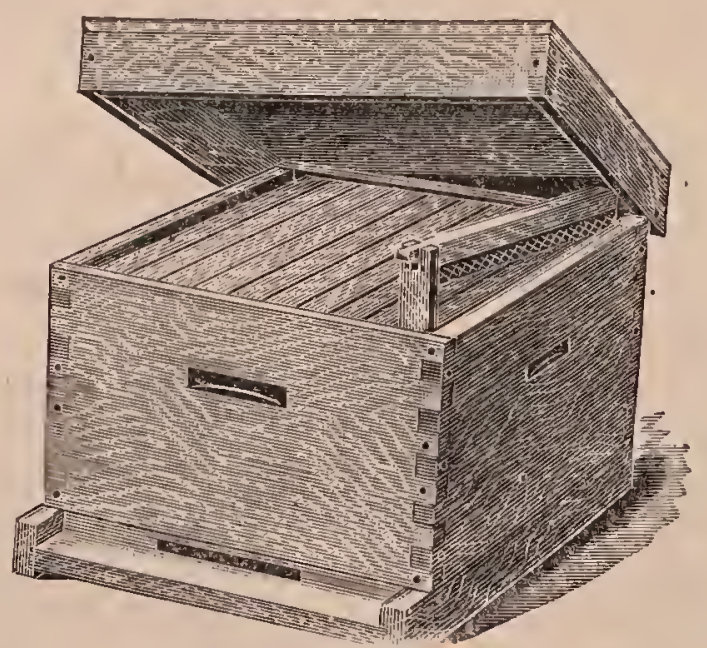

Modern hive based on Langstroth dimensions.

it came the feature of dovetailing or lockcornering, as shown.

This hive was introduced in 1889, and seemed to meet with the general approba- 
tion of beekeepers. It embodied in the main the Langstroth dimensions, but used eight instead of ten frames; for at the time it was introduced, nearly every one preferred eight frames. The original Dovetailed hive had a flat cover, and a bottomboard made the same as the cover, except that there were side-cleats to raise the hive off the bottom-board.

Since that time there have been modifications of the hive, and it is now made in eight, ten, and twelve frame sizes. While the eight was used almost exclusively, the ten-frame size has nearly supplanted it. There is also a tendency toward the twelveframe size. See the Twelve-frame Hive further on in this article.

The cover is made single or double. The body is locked at the corners, and the bottom-board is made in several styles. See ENTRANCES.

The Hoffman self-spacing frames, described under Frames, Self-SPACing, and Frames, to Manipulate, also Frames, are used in the Dovetailed hive almost exclusively. The supers for this hive are the same as those shown under CомB HoNEY.

As now constructed the hive embodies the very latest developments in hives and

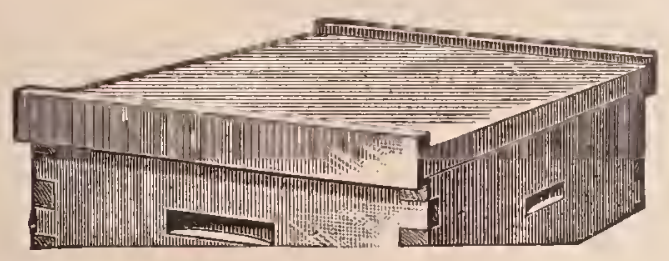

Flat cover, old style.

hive-construction. It can be handled rapidly, and is especially adapted for outapiary work, where frequent moving from one field to another is necessary. It is standard, being made by all the supplymanufacturing concerns, and is for sale everywhere. The lock corner is especially well adapted for hot climates; and for any place it is far superior to corners depending on nails alone. The ordinary miter or halved joint is inclined to pull apart in parts of California, Texas, Florida, and other portions of our country subject to extremes of heat, or hot dry winds.

Having discussed hives in a general way, it will now be in order to take up covers. A very important requisite of a good hive is a good cover. While the flat cover -one making use of one flat board and two cleats-was a good one, yet, owing to the width of the single board, and increasing scarcity of such lumber, something made of two or three narrow boards had to

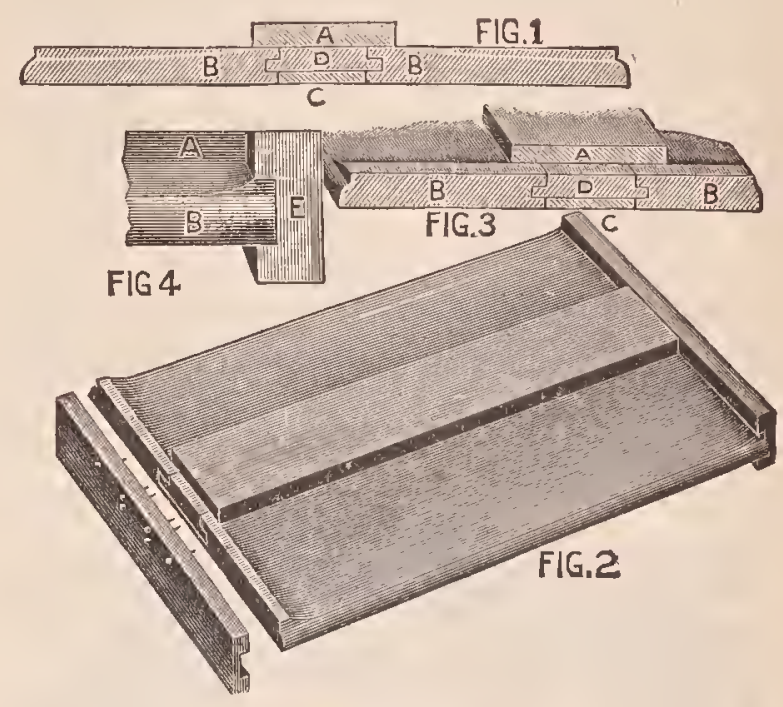

Excelsior flat cover.

be used. Accordingly, the Excelsior was devised. It consists of boards not exceeding 6 inches in width, because narrow boards can be easily secured, and because they will not shrink and check under the influence of the weather like the wide ones. The two side boards, B, B, are beveled or chamfered on one side so that the one edge is left only about three-fourths the thickness of the other edge, but the ends are left full thickness of the boards to shed water

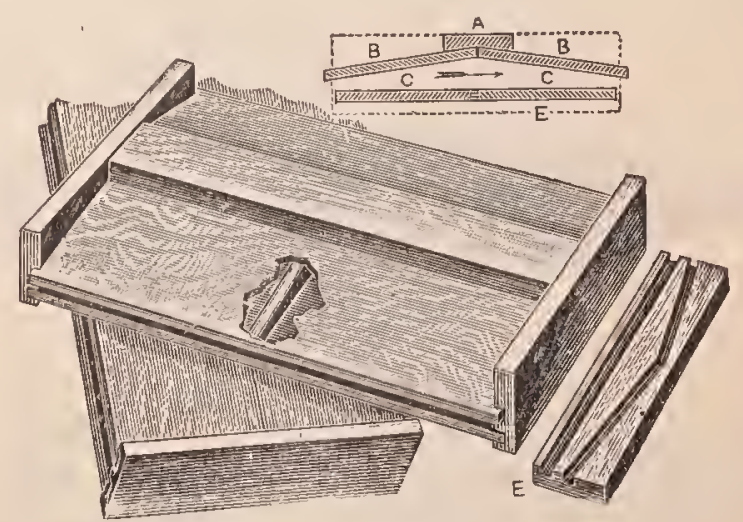

Gable cover.

away from the edge and to give more nailroom for the grooved end-cleats, E, that slip over and bind the whole together. The purpose of the chamfering is to shed water to the sides of the hive and away from the centerpiece, AD. Of this centerpiece, AD, 
the part $\mathrm{D}$ projects beyond $\mathrm{A}$. It is tongued and grooved to fit a corresponding tongue and groove edge of the two side boards that were beveled to shed water. The space under $\mathrm{D}$ is filled with a thin board $1 / 4$ inch thick, the ends of which project into the $7 / 8$-inch groove of the endcleats, E, where it is securely held in place.

In very hot climates a two-thickness or gabled cover is used. The lower part of the cover is flat, and the upper part gabled, as shown in the preceding cut.

\section{TELESCOPE COVERS.}

There is a strong and rapidly growing tendency at the present time toward a double or telescopic cover, as is shown in the illustrations.

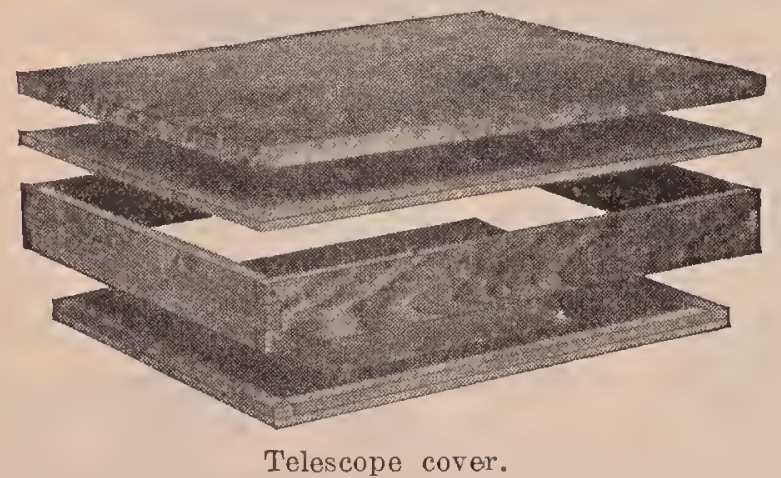

The lower cover consists of two or more tongued-and-grooved boards, $3 / 8$ inch thick, with rim of $3 / 8 \times 7 / 8$-inch wooden strip around the edge. At the center there is a hole for a Porter bee-escape, so that by inserting the escape the inner cover can be nsed as an escape-board. The inner cover takes the place of the metal-bound supercover as used formerly. It lies directly

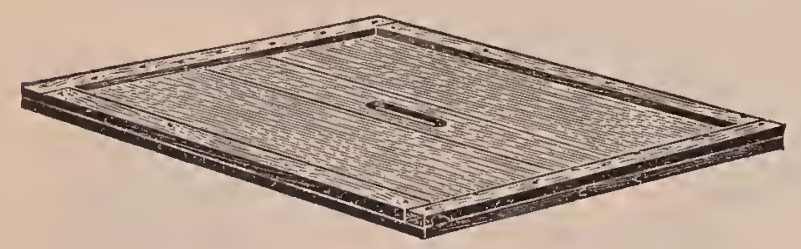

Inner cover.

over the frames, and over this is placed a shallow telescoping cover made of $3 / 8$ lumber, and covered with sheet metal or roofing paper.

A top protection of this sort is not only better than a single-board cover, but it shuts out the weather. The air-space between the two covers gives the bees better protection from the direct rays of the hot sun if the hives are out in the open, and, if kept painted, such a cover will last indefinitely. The lower cover will be sealed down by the bees. The upper one cannot blow off because the downwardly projecting sides hold it in place. Of course such an arrangement makes extra handling in opening and closing the hive; but the majority of beekeepers are beginning to see that this is more than offset by the greater durability and better protection.

This cover is so far superior to all the other cover's previously shown that it is rapidly superseding them. It is warmer in winter and cooler in summer. It is also more durable.

\section{HIVE-BODIES OR BROOD-NESTS.}

These are plain boxes without top or bottom, preferably lock-cornered. They are rabbeted at the upper inside ends to receive the projections of the frames referred to later on. Under the head of "Frames" and "A B C of Beekeeping" there will be found a diagram showing the position of the hive-body or brood-nest, and how the frames to hold the combs hang in the rabbets before mentioned. Practically all of the hives sent out by the regular beehive factories are lock-cornered for additional strength. When made in local planingmills the corners are usually "halved" by cutting out a rabbet in the sides or ends; but the lock-cornering is much preferable for the reason stated.

\section{HIVE BOTTOMS, OR FLOORS.}

The general practice is to make the bottom or floor of the hive separate from the hive-body. Bodies are made to sit down upon raised edges of the floor or bottom. This floor should preferably have a deep

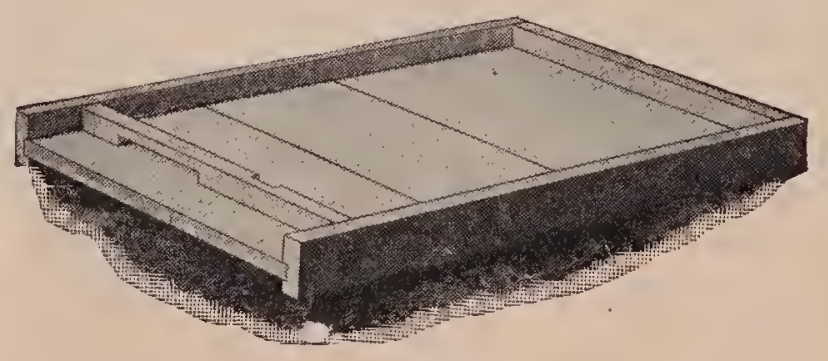

Bottom-board.

side and a shallow side. During hot weather it is customary to use the deep side to give more space under the hive, affording a larger entrance and better ventilation. This 
deeper side is usually $7 / 8$ inclu in depth; the shallower side, only $3 / 8$ inch, is used by those who prefer to have a shallower space under the hive. When the wide space is used it is customary to have a contracting entrance-cleat. When colder weather comes on, or where the colony is weak, it is good practice to contract the entrance down to the space of $1 / 4$ inch by any size from $1 / 2$ to 8 inches wide. See Extrances.

There are different styles of floor-boards or bottoms; but the kind used by those who have factory-made lives is like that shown in the illustration.

\section{BROOD-FRAMES.}

The modern hive consists not only of the parts already mentioned-cover, body, and bottom-but a series of frames, all of

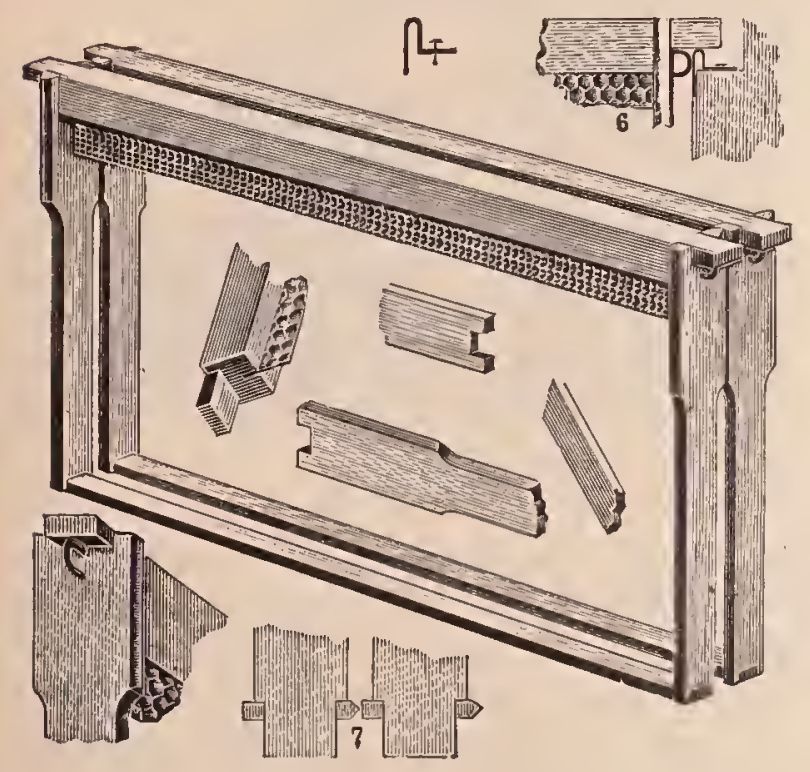

which hold a comb. In a modern hive the top of the frame has projections at each end that hang in the rabbets of the hivebody. Each of the frames is removable, and may or may not be self-spacing. Some frames liave the same width all around. Some have the end-bars made a little wider near the-top, and some have end-bars that make contact with the adjacent end-bars their entire length. The latter are called "closed-end" frames.

For particulars regarding frames the reader is referred to the $A$ B C OF BEEKEEPING at the beginning of this work, and Frames and Framies, Sfrif-spacing.

As the closed-end frames make up a part of the inner walls of the hive in which they are used, a description will be given at this point.

\section{CLOSED-END FRAMES.}

Closed-end frames may be divided into two classes - the standing and suspended. The Quinby, already spoken of under Frames, Selif-spacing, the Bingham, and the Heddon are of the first-mentioned class; the Danzenbaker belongs to the latter class. It is generally considered that frames with closed uprights, while not so convenient, perhaps, for general manipulation, are better adapted to wintering. Frames with partly closed end, like the Hoffman, or open all the way up, like the unspaced hanging frame, permit of currents of air around the ends of the frames, and (it is clained), as a consequence, bees are not so much inclined to bring their brood clear out to the end-bars as they do when closed ends are used. The difference is more theoretical than real.

\section{THE BINGHAM HIVE.}

Mr. Quinby was the first to apply $\mathrm{Hu}$ ber's principle of closed-end frames in this country (see Hives, Evolution of). This he introduced shortly after the appearnce of the Langstroth hive. Not long after,

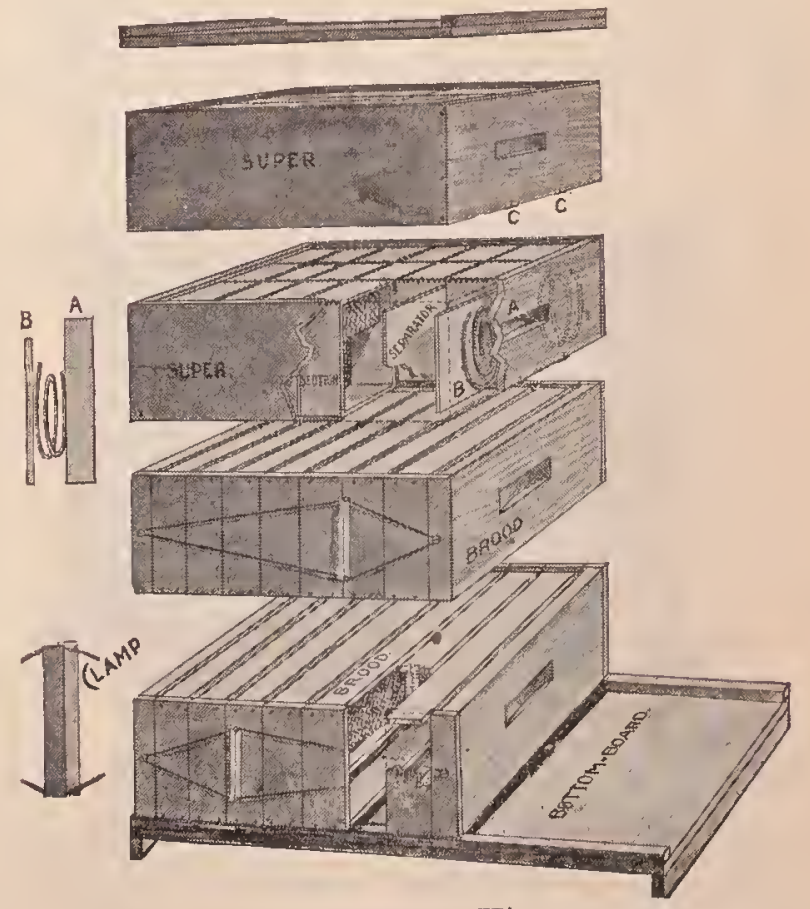

The Bingham Hive.

Mr. Bingham in 1867 brought out his hive with closed-end frames with a narrow topbar and no bottom-bar, but still embodying the chief features of Huber's hive of 
1789. But the peculiar feature of the Bingham was that it made use of shallow frames only five inches deep, a series of them being lashed together by means of a wire loop and stretcher sticks, said loop drawing on the follower-boards in such a way as to bring tight. compression on frames enclosed in the manner shown. Seven of these brood-frames in the hive made up a brood-nest, and an entire brood-nest might consist of one or two sets of frames. The top-bar was dropped down from the top of the end-bars a bee-space, while the bottom-bars were flush with the bottoms of the end-bais. With a bottom-board having a $3 / 8$-inch strip on each side, the ordinary bee-space is preserved thru the several divisions of the hive.

The super is like any ordinary one adapted to comb honey, except that it uses coiled springs to produce the necessary tension.

Altho Mr. Bingham used this hive for a great many years, and quite successfully too, no one else seems to have done much with it; but a modification of the hive is shown in the Danzenbaker and the Heddon.

\section{THE DANZENBAKER HIVE.}

The Danzenbaker consists of a broodchamber of the same length and width as the ten-frame Langstrotl Dovetailed hive, but deep enough to take in a depth of

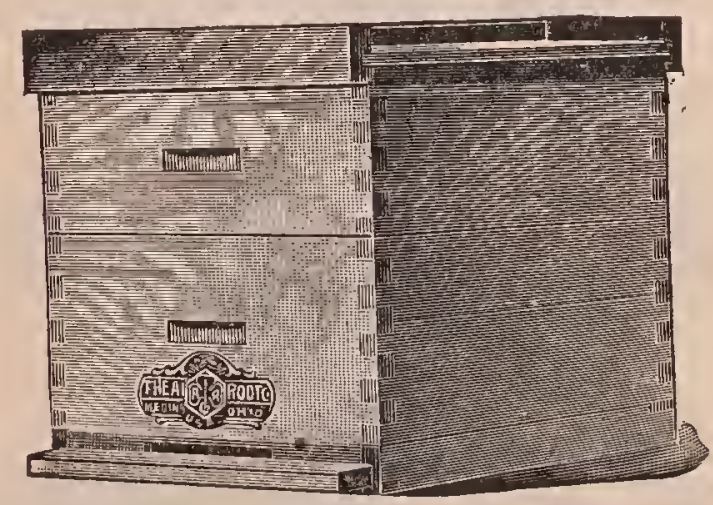

frame of only $7 \frac{1}{2}$ inches. The rabbet, instead of being near the upper edge, is dropped down about midway; or, more strictly speaking, there is a cleat or board nailed on the inside of the ends of the hive. On this support hang the closed-end broodframes, pivoted at the center of the endbars by means of a rivet driven thru from the inside, as shown in the cut below. Ten of these frames fill tlie live. As these frames are pivoted in the center, as shown below, they can be reversed; and this feature, while it costs nothing, is something to be desired, as it enables us to have all frames filled solid with comb.

The bottom of the hive is the same as that for the Dovetailed hive, already described. The super for comb honey takes

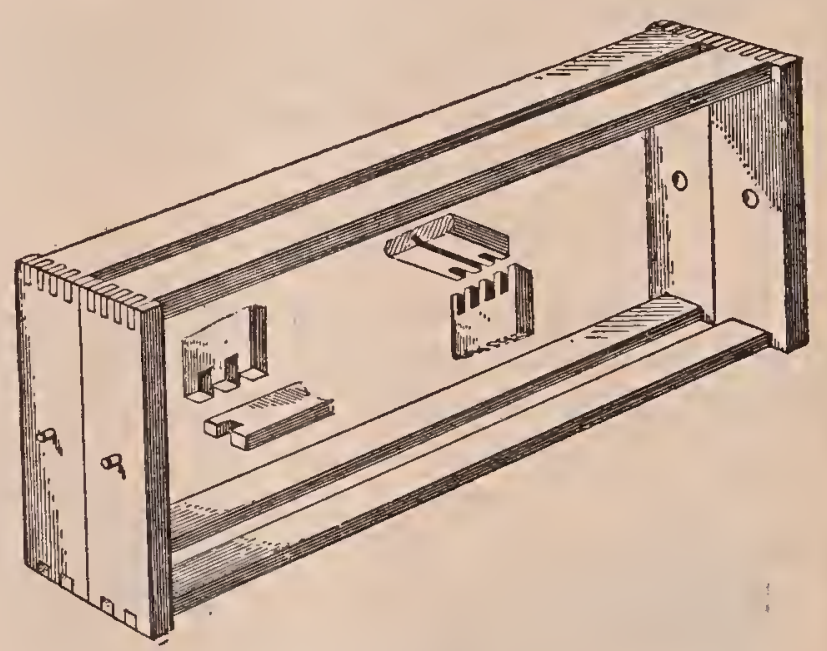

in the $4 \times 5$ plain section, and makes use of the fence-separator system. The sections are supported in section-holders; indeed, the whole arrangement is the same as the section-holder super already described in COMB Honey.

This hive was designed primarily for the production of comb honey. As a combhoney hive it is a very good one; but on account of handling the brood-frames it has become so unpopular that it has almost gone out of use. Any hive with Hoffman or with the unspaced frames, will, in a given time, permit the examination of three or four times the comb surface of the closed-end frames unless a single exception be made of the closed-end Quinby, illustrated and described under the head of Frames, Seitf-spacing.

Where bee glue (propolis) is very abundant the closed-end frames become so badly gummed up that it is almost impossible to separate them at times. For that reason the foul-brood bee inspectors generally advise against the Danzenbaker frames.

The same general criticisms above mentioned would apply with equal force against the Heddon hive next described, which likewise, and for the same reasons, has all but gone out of use. 
THE HEDDON HIVE.

This hive was patented and introduced in 1885. Its peculiar and distinguishing feature was in the use of one broodchamber divided into halves horizontally, each half containing a set of eight closedend close-fitting brood-frames, $53 / 8$ inches deep by 18 1-16. The end-bars, as already stated, were close-fitting - that is, the brood-frame slid into the hive with just enough play to allow of its easy removal and insertion. On the bottom inside edge of the ends of each case were nailed strips
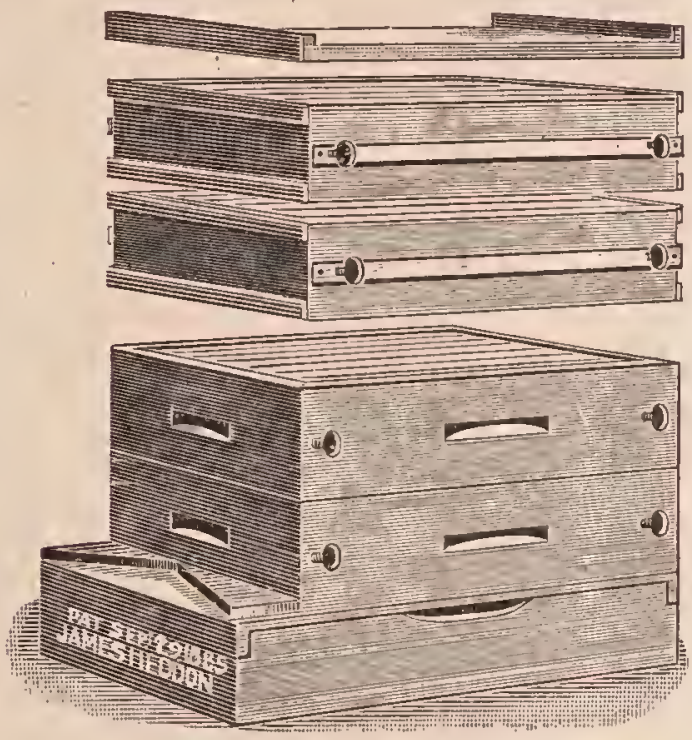

The Heddon Hive.

of tin to support the frames, and the whole set of eight were squeezed firmly together by means of wooden thumbscrews as shown. Under the head of Comb Honey mention is made of the value of compression for squeezing sections or section-holders or wide frames. The more tightly the parts are held together, the less chance there is for bees to chink propolis into the cracks.

The bottom-board of this hive was much like that used on the standard hives, in that it had a raised rim on the two sides and end to support the brood-chamber, to provide a bee-space above the bottom-board, and at the same time provide for an entrance at the front. The cover was the ordinary flat one-board, cleated by the ends.

The purpose of the inventor in having the hive divided in this way was to afford more rapid handling, and to accomplish contraction and expansion by simply taking from or adding to the brood-part of the hive one or more sections. This divisible feature of the hive, according to its inventor, enabled him to handle hives instead of frames, to find the queen by shaking the bees out of one or both of the shallow sections. The horizontal bee-space thru the center of the brood-nest he considered an advantage in wintering, in that the bees can move up and down and laterally thru the combs.

This hive, as was explained at the close of the article on CONTRACTION, was responsible in a large measure for the failure of the crops of those who used it. The principle of small hives and excessive contraction has been shown to be a monumental failure.

\section{THE DADANT HIVE.}

Almost the very opposite of the Heddon in principle and general construction is the Dadant hive. While $\mathrm{Mr}$. Heddon divided the brood-chamber into one, two, or three separate portions, the Dadants have it all in one large complete whole. The frames are $181 / 2 \times 11 \frac{1}{4}$ - that is to say, they have the Quinby dimensions. There are ten to the hive. Such a hive has about the equivalent capacity of a twelve-frame Langstroth, regular depth. The Dadants have always insisted that their ten-frame Quinbys, when compared with the ten-frame Langstroth, averaged up year after year, would give far better results, both in honey and in economy of labor. This opinion is not based on the experience of two or three years, but on a period covering a good many years. In the large hives, they claim, bees swarm less, produce more honey, and winter better. They claim they do not have to exceed two per cent of swarming, and this average has been maintained year after year. Apparently the colonies in these. large hives have very little desire to swarm; but when they do swarm the swarms are enormous.

\section{THE TEN-FRAME HIVE OF EXTRA DEPTH.}

It was suggested by A. N. Draper, formerly of Upper Alton, Ill., one of $\mathrm{Mr}$. Dadant's follower's, that, instead of making a hive after the Quinby's dimensions, and on the Dadant pattern, a hive be constructed after the pattern of the regular ten-frame Dovetailed, having Langstroth 
dimensions sare in one measurement-that of depth. He would ard to the hive and frame $2 \frac{1}{8}$ inches. As the Dadants use nine frames in their original Quinby hives,

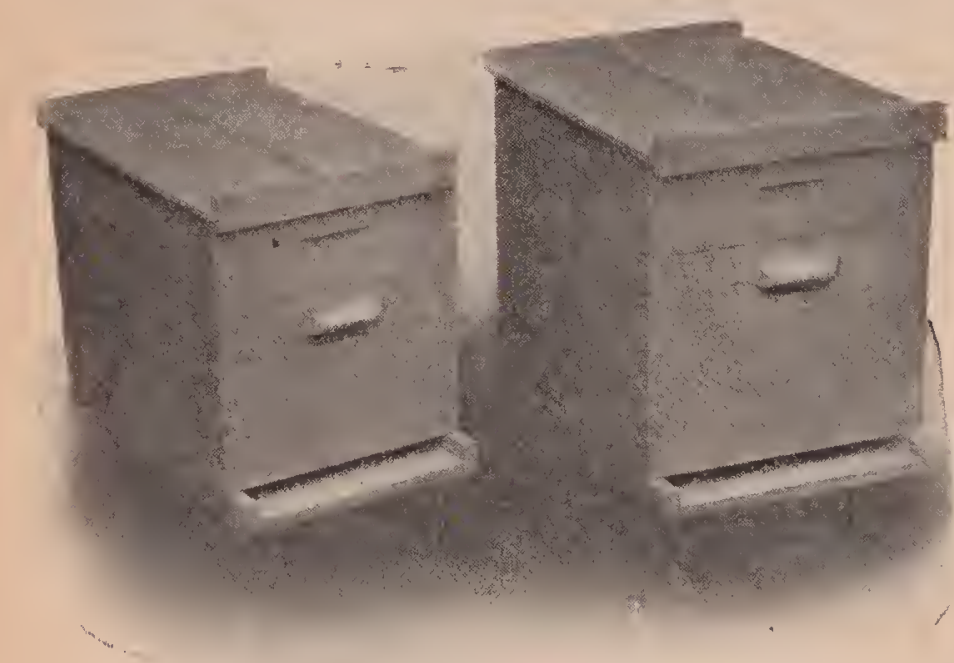

The comparative difference in size between a regular eight-frame hive and a ten-frame Jumbo.

ten frames $21 / 8$ inches deeper, with Langstroth top-bar, would give the hive equal capacity. Such a hive would take regular Langstroth ten-frame bottom-boards, covers, supers, honey-boards, winter-cases-in fact, everything, adapted to the regular tenframe Langstroth Dovetailed hive. As the ten-frame hive is one of the standards, if the large hive is really better, such a hive would be more simple and cost less than to adopt regular Quinby-frame dimensions.

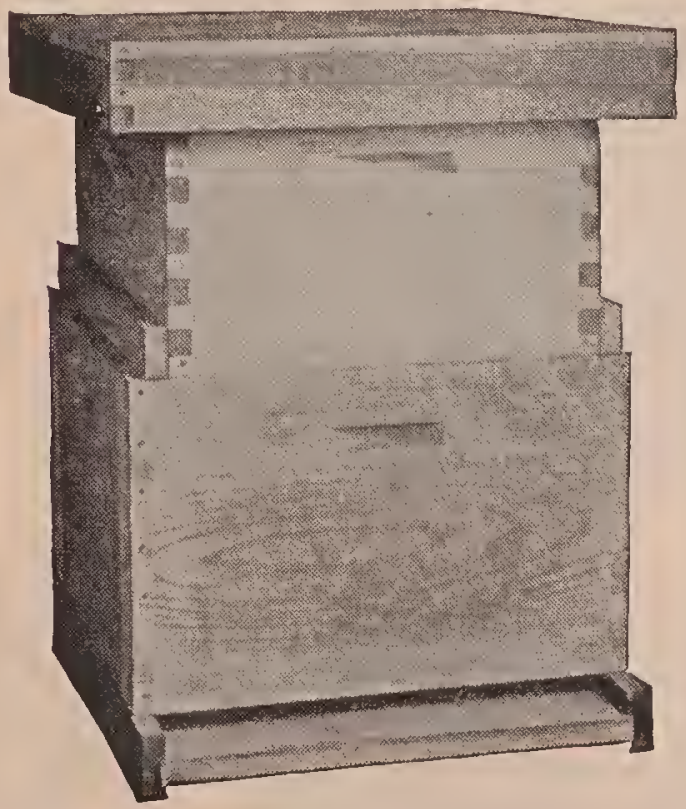

The modified Darlant hire with a regular ten-frame langstroth upper story. As the latter is narrower it is necessary to close up the space with a couple of cleats.
The supply-dealer will make the broodchamber for about 25 per cent more than the regular ten-frame Langstroth Dovetailed; the supers, covers, and bottomboards would, of rourse, cost no more.

\section{THE MODIFIED DADANT HIVE.}

In 1917 the Dadants brought out something similar to the one just deseribed, except that it was 11 frames wide, 11/2-inch spacing, Langstroth length, and Quinby depth. The extra frame makes it a little too wide to use supers and hive-bodies of standard dimensions without cleats to close up the space as shown. This hive requires a special bottom-board and a special cover.

\section{THE TWELVE-FRAIIE LANGSTROTH HIVE.}

There are some other's besides the Dadants who believe that the ordinary tenframe Langstroth hive-body makes too small a brood-chamber; that a good queen, such as ought to be in every hive of the up-to-date honey-producer, will easily fill a twelve-frame hive with brood. There is no use in denying the fact that the ordinary user of a common ten-frame hive often wishes he had a hive of two frames more capacity. To put on a upper story to take in the extra frames sometimes gives too much room.

R. F. Holtermann of Brantford, Canada, operates something like 700 colonies on twelve-frame hives. He is one of the best and most extensive honey-producers in America. He tried out the ten and twelve frame hives side by side and gives his veldiet in favor of the latter.

\section{THE THIRTEEN-FRAME LANGSTROTH HIVE.}

There are a few who use a thirteen-frame Langstroth hive, which is practically the same as the twelve-frame hive that has been in use so long. The advantage claimed is that the hive is larger and exactly square. This makes it possible to reverse the position of the frames with reference to the entrance, during summer or winter, by merely turning the hive around onequarter-turn on the bottom. During the winter it is an advantage to love the sides of the frames exposed to the entrance. During the summer it is certainly better to have the ends of the frames next to the 
entrance, because then the air can blow in clear thru the hive, cooling it in hot weather.

The advocates of the thirteen-frame hive, like those of the twèlve-framers, claim almost immunity from swarming, and a hive large enough to accommodate practically all of the best queens. It is very seldom that any queen will go beyond 14 frames of brood, so that the thirteen-frame reaches the maximum capacity of most queens.

\section{TWO-STORY TEN-FRAME OR EIGHT-FRAME LANGSTROTH HIVES.}

Where the eight or ten frame hive is used, it is customary to have the colony breed in two stories. As already explained, the average queen will go beyond ten frames. If she or the bees are not given unlimited room for breeding, cells may be started and a swarm may follow. To prevent this it is usually eustomary to put on another hive-body, or upper story containing combs. In order to start the queen above, one or more combs of brood are put upstairs, and the empty ones from the upstairs are put downstairs, preferably on either side of the brood-nest. 'The brood in the upper story induces the queen to go above when she might not otherwise do so, and thus expand the brood-nest, with the result that there may be thirteen or fourteen frames of brood, the other frames containing honey or pollen. In the production of comb honey it is customary, at the beginning of the flow, to put all the sealed brood in the lower story, removing the upper story and putting the other combs of brood in a weak colony. A super of sections is then put on the lower story, from which the upper story was removed. See "Comb Honey" and "Swarming;" particularly the subjects of prevention and control of swarming. When producing extracted honey the practice is to put a queen-excluder between the upper and lower stories after the flow starts, with the queen below.

One reason why the ten-frame live is so popular is because many beekeepers believe that the twelve and thirteen frame hives are too heavy to lift-that the ten is large enough; that by the use of two stories, and raising brood in the upper story, all the breeding room that the queen needs, will be afforded and at the same time swarming will be kept under control.

The author has tried to control swarming by using two-story brood-nests, and finds that swarming is held under control nearly if not the same as in the larger hives with the advantage that everything is standard.

Ninety-nine per cent of the honey-producers of the country are using hives of Langstroth dimensions. It is possible for the expert beekeeper or the novice if he will study directions carefully, to manipulate his brood-chambers of Langstroth dimensions so that he not only can secure the maximum amount of brood and bees of the right age for the harvest, but he will be able to keep down swarming, for the production of extracted honey or for comb honey. For particulars regarding this see Swarm Control, under Swarming.

\section{LONG-IDEA HIVES.}

Some 50 years ago the long-idea hivesthat is, 30 and 35 frame hives all in one brood-nest-were advocated by various beekeepers in the United States. Many at the time were very enthusiastic in praise of this hive; but when comb foundation and the one-pound section honey-box came to the front these hives were dropped by nearly every one because they were not adapted to the production of comb honey. In later years, especially during and following the period of the Great War, extracted honey was produced almost exclusively. During this time attention was again directed to the Dadant-Quinby hive, the ten-frame Jumbo, practically the same thing, and the twelve and thirteen frame hives. The last two mentioned, it was argued, would not have to be tiered so high, because three thirteen-frame hives, for example, would be the approximate equivalent of five eight-frame hives that would be so top-heavy and tall that they would require rails or props to keep them from being blown over. The ten-frame Jumbo requires two sizes of frames-one for the brood-nest and one for the extractingsupers.

While quite a number were favoring the larger hives of the styles mentioned, there were a few who were going back to the old long-idea hive containing all the way from 
25 to 35 frames. The dimensions of these hives would be more like those of a coffin or a trunk. The advocates of these hives, particularly O. O. Poppleton of Florida, who had always used them, claim that they are large enough so that no tiering up is required-no lifting on or off of upper stories, no manipulation of brood-combs from the lower to the upper story to hold back swarming-in short, nothing heavier to lift than a single brood-frame. They also claim almost entire immunity from swarming.

The usual practice with such a long hive is to have the entrance on the side, the long way, and place the brood-nest in the center of the live. This leaves room for ten or twelve frames capacity for more brood on either side. Mr. Poppleton argued that a queen would move sidewise from one broodframe to another more readily than from one brood-frame in a lower hive-body to a brood-frame in the hive above, and he was undoubtedly right. The argument was briefly this: That the average Langstroth frame will have a circle of brood running within about two inches of the top-bar. The general reason for this is because the comb will stretch near the top, making neither worker nor drone comb. The queen avoids this, and the bees fill it with honey. In a hive of two stories the queen is apparently slow about getting over this two inches of honey, $7 / 8$.inch of a top-bar, $3 / 8$ inch of a bee-space, $1 / 4$ inch of a bottombar and another bee-space before she reaches the comb proper in the upper hive. In the long-idea hive it is claimed that the queen can move from comb to comb on a horizontal line, because the brood surfaces are within $3 / 8$ inch apart, the space between being filled with bees. When the queen expands the brood-chamber in the natural way she moves from comb to comb. If the worker-cells are not stretched, and there are no obstructions, she will move vertically as well as horizontally; but in the modern tiered-up hive she may not move upward unless the brood is carried upstairs by the apiarist himself. It is for this reason that the old long-idea live has been reevived.

Another advantage claimed for the long single-story hive is that it is adapted to the use of old men, and women, young and old, or any one else who, for physical reasons, can not lift a weight of a filled super of 40 or 50 pounds, but who can handle individual units of one comb at a time.

Finally, it is argued that during winter or cool weather the brood-nests can be confined down to about twelve or fifteen frames, and the space on either end filled with packing material. If the cover of the long-idea hive is three or four inches deep, and telescoping, additional packing can be put on top. The hive is, therefore, adapted for wintering as well as for summering bees.

This hive is especially adapted to the use of beginners who either will not learn how to handle swarms in standard hives or have not time to do so. A colony in sucl a large brood-chamber that can expand laterally will require less attention than any other hive here slown. However, in localities where brood diseases are prevalent, neither this hive nor any other should be left to itself without frequent examination during the breeding season.

It should be understood, also, that the same objections that apply to especially large brood-chambers apply to this one. As a general rule, the ordinary beekeeper would do well to have everything standard. The Langstroth ten-frame hives described in these pages are more standard than any other hive in the United States if not in the whole world. None of these big hives are adapted to the production of comb honey in sections, and none of the advocates make any claims for them along this line. There are times when comb honey brings such good prices that it is advantageous to change over from the production of extracted honey to honey in sections, and this is entirely practicable with the standard hives.

Last, but not least, if one wishes to sell his apiary at any time he can get the best price for it, if it is in standard Langstroth hives.

The author does not advocate the general adoption of any of these special hives in a large way. If the reader is interested, let lim experiment with half a dozen or a dozen hives; and if the tests of the few are satisfactory he can use more. It is usually a safe policy for the average reader of this work, especially if he is somewhat of a be. 
ginner, to follow in the beaten paths, or, more exactly, use standard ten-frame Langstrotl hives and equipment. As a rule, bees will sell at a higher price in these hives than when they are in something that is odd-sized or irregular. Moreover, the average dealer or beehive manufacturer always has the standard equipment in stock. While the regular Langstroth may require extra manipulation and extra lifting (if they be compared with the long-idea hive), it would be wise to use these hives until the general public has proved that what packing-cases, as the single walls hardly afford sufficient protection to enable the average colony to go thru the winter safely, or without great loss both in bees and in stores. The poorer the protection, the greater the consumption of stores. A colony poorly protected outdoors will probably consume twice as much as one adequately protected and with the possible handicap of dysentery.

In the South, of course it is not necessary to carry the single-walled hives into the cellar or winter repository; but north

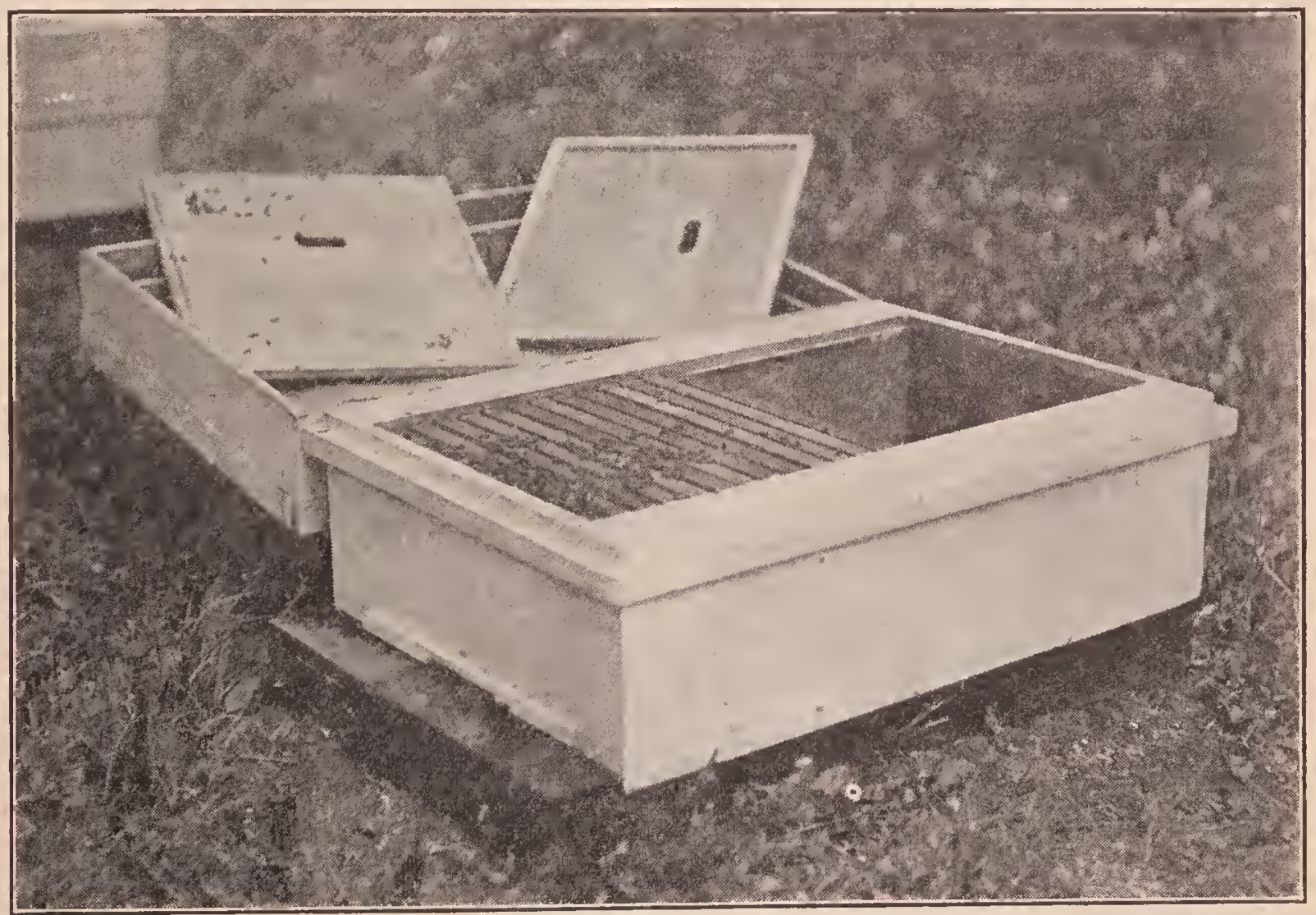

Long-idea hive holding twenty-five Langstroth frames. Two regular 10 -frame supers may be placed side by side on this hive, as it is two and a half times the size of a regular 10-frame hive.

some may call "freaks" are better than the standards.

\section{DOUBLE-WALLED OR CHAFF HIVES.}

The lives thus far described and illustrated are what may be called single-walled hives; that is, the outer shell or case consists of a single-board thickness of lumber. Such hives in the northern climates, as a rule, cannot very well be wintered outdoors on their summer stands. They must either be carried into the cellar at the approach of cold weather, or else be put in ontside of latitude 40, hives of single-board thickness ouglit to be either housed or protected with winter cases. Where one from choice or neressity has to winter outdoors, what are known as double-walled hives should be used. These have the same inside dimensions as the single-walled hive, and are generally made to take the same supers and the same inside furniture. The one shown in the illustration next following represents a ten-frame Langstrotl single-story double-walled hive; and as it represents the simplest form of wintering hive, we will describe this only, leaving the reader 
to adapt it to the dimensions of whatever frame he is using.

The space between the walls is filled with some porous material like dry leaves, planer shavings, cut straw or hay, ground cork, or any material that is light, loose, and porous. An examination of the fol. lowing illustrations will show how this warm ideal hive differs from the others.

Bees are essentially warm-blooded animals, and if they are not warmly housed in our northern climates they will die during winter.

Careful observations have shown that these double-walled packed hives will yield
But this is not all. While bees in singlewalled hives often do come thru the winter successfully, the result is attained at a considerable loss in stores. Overfeeding on the part of the bees, in order to keep up the temperature of the cluster, causes overloading of the intestines, and this sooner or later brings on the fatal disease known as dysentery. (See Dysentery.) Nothing will use up a colony's vitality in the spring more than this. On the other hand, bees in double-walled packed hives unless the winter is severe will rarely have it. They come thru stronger, cleaner, and better with a larger stock of stores in reserve to

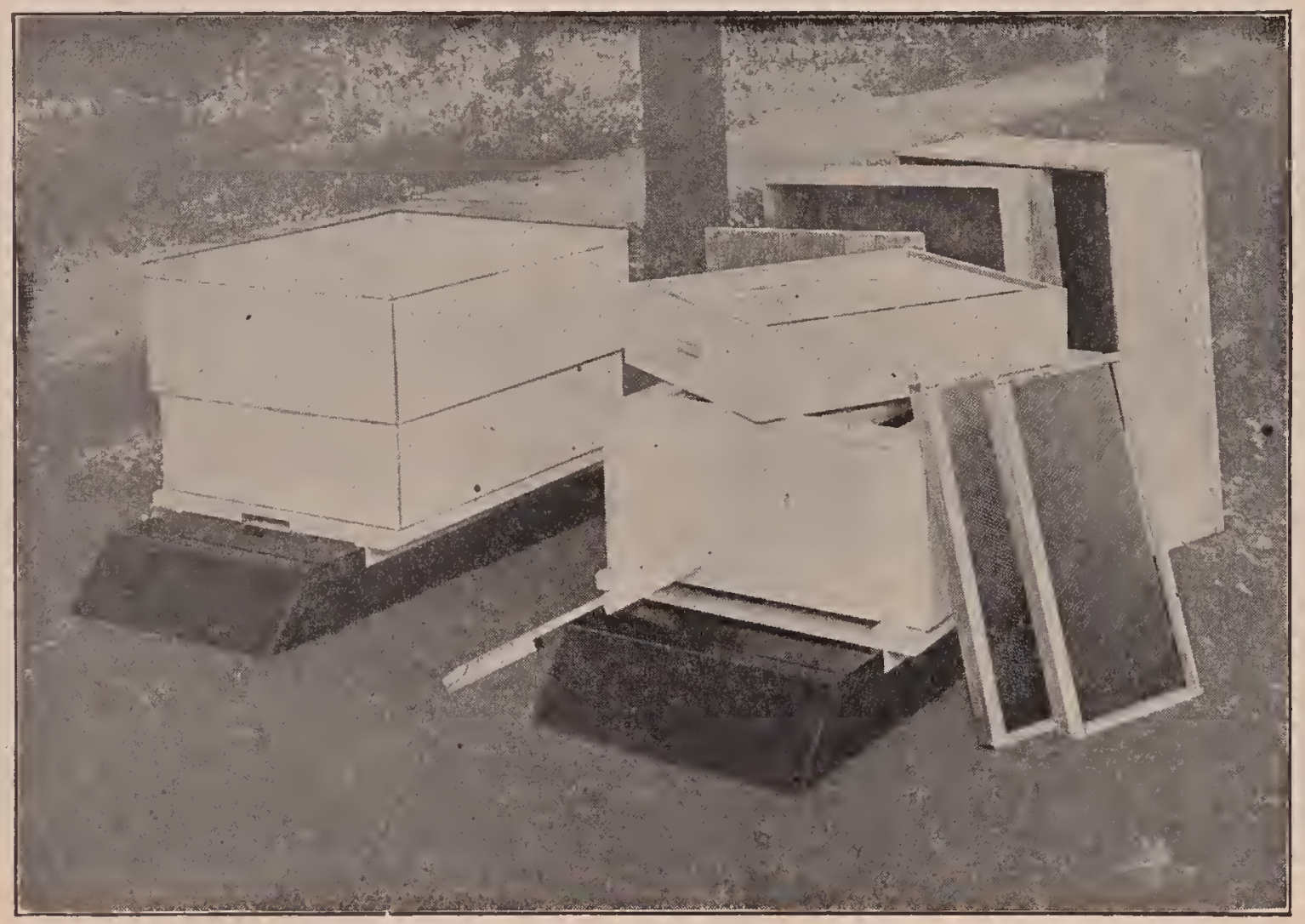

Root double-walled hive with removable bottom.

larger returns in honey. For it is a wellknown fact in the domestic economy of a hive that comb-building cannot progress unless a temperature of 98 degrees is maintained. Frequently in good honey-gathering weather the nights are cold enough so that the inside of the hive will be chilled, and comb-building will stop; for the bees are compelled to leave that work to hover around their brood to keep it warm. In the double-walled packed hive brood-rearing and comb-building can continue, during ordinary summer weather, no matter what the temperature may be outside. take care of the necessary brood-rearing that takes place as soon as warm weather opens up.

The reason for this is plain: Experiments show that the internal temperature of a single-walled hive outdoors during winter is only slightly higher than that outdoors. On the other hand, the internal temperature of a double-walled packed hive is at least 25 to 50 degrees higher than the outside temperature. (See Gleanings in Bee Culture, page 78, for 1912.) The colder the atmosphere in which the bees are kept, the more they have to eat. 
Overfeeding plus cold causes dysentery.

Taking everything in consideration, if the double-walled hives cost more than the single-walled, they will save from 25 to 50 per cent of the stores and at least 50 to 90 per cent of the winter losses, year in and year, out. During spring and summer a larger return in honey may be expected for the reason the bees are not obliged to stop their comb-building because their super is too cold nor stop brood-rearing in the spring. Neither are they foreed to eat too much of the freshly gathered stores in order to keep up bodily heat.

Under WINTERING OUTDOORS will be found a description of the quadruple winter cases. Bees in four single-walled hives packed in one of these cases will be as well if not better protected than bees in the double-walled hives. In some localities, where migratory beekeeping is prac-

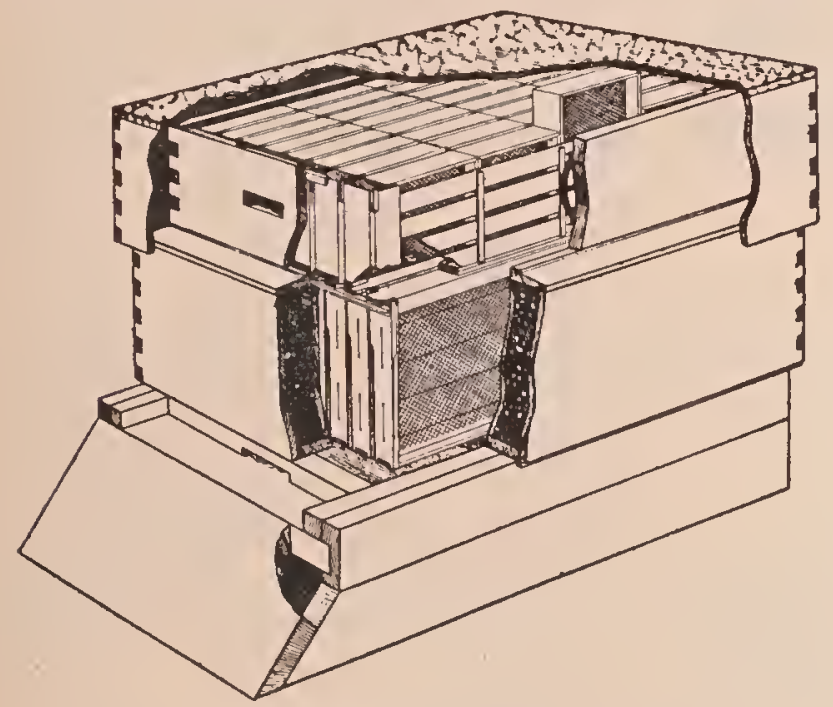

Buckeye double-walled hive with space between the walls filled with packing material.

ticed, or where a scheme of out-apiaries is used, a single-walled is preferable to a double-walled hive, because it takes less room in the wagon or truck, is lighter, and more easily handled. Where such hives are used, they should be kept in a winter pącking-case until settled warm weather comes.

The double-walled hive has the advantage in that it is more suitable for the backlot beekeeper, the farmer beekeeper, or those who desire to leave their bees on the same stand the year round, and who, on account of other duties, cannot fuss with putting bees in the cellar and taking them out again, or packing and unpacking in large winter eases. Even when bees are wintered in the cellar, a double-walled hive is a great advantage in that it protects the brood and the bees after the bees are set out of the cellar in early spring. If they could be kept in the cellar until settled warm weather, the bees would not be subjected to the rapid and severe changes of weather conditions. But this not practicable. In localities where the climate is very severe, many find it advisable to put these double-walled hives in the cellar and set them out in the spring. Bees need protection, not only during cold winter weather, but in the spring, after they are set out when changes are often frequent and severe.

\section{CONSTRUCTION OF THE BUCKEYE HIVE.}

The brood-chamber is made of an outer and inner rim of select $3 / 8$-inch lumber, lock cornered together for strength. The space between the two walls is covered over with a sort of picture-frame watertable. This is secured to the inner chamber in the manner shown; cleats II, as well as the water-table, are then nailed to the inner and outer wall. The unfinished hive is turned upside down before the bottom cleats are nailed in and the double wall filled with packing material.

Experience shows that the top needs protection more than the sides. Hence we have tray $\mathrm{E}$ made of $3 / 8$-inch lumber with a bottom of common burlap, which is left in a baggy condition so that the tray will fit tightly to the hive, thus preventing the wind from whistling in under the tray: Cover $\mathrm{D}$ is put in place after the frames and the bees are in the hive, then tray $\mathrm{E}$ is put on top of the whole. This is filled level full of packing material, such as leaves or planer shavings, and over this then is placed the large cap or cover that goes over the whole.

It will thus be observed that this double hive is made on the plan of an ordinary refrigerator, or like a safe cabinet built to protect its contents from fire. Anything that will keep ice from melting will in like manner keep water from freezing. The principle is the same as that of the wellknown thermos bottle. The thermos bottle will keep water cold or hot for hours and hourș. The double-walled hive here 
shown will keep a cake of ice, if the entrance is closed, almost as well as a refrigerator. It will also hold a pail of boiling water and keep it hot for hours on the principle of a fireless stove.

The general features that go to make up a refrigerator or a fireless cooker apply equally well to a beehive.

Some have the idea that a hive having so-called dead-air space will winter bees as well as one having space filled with packing

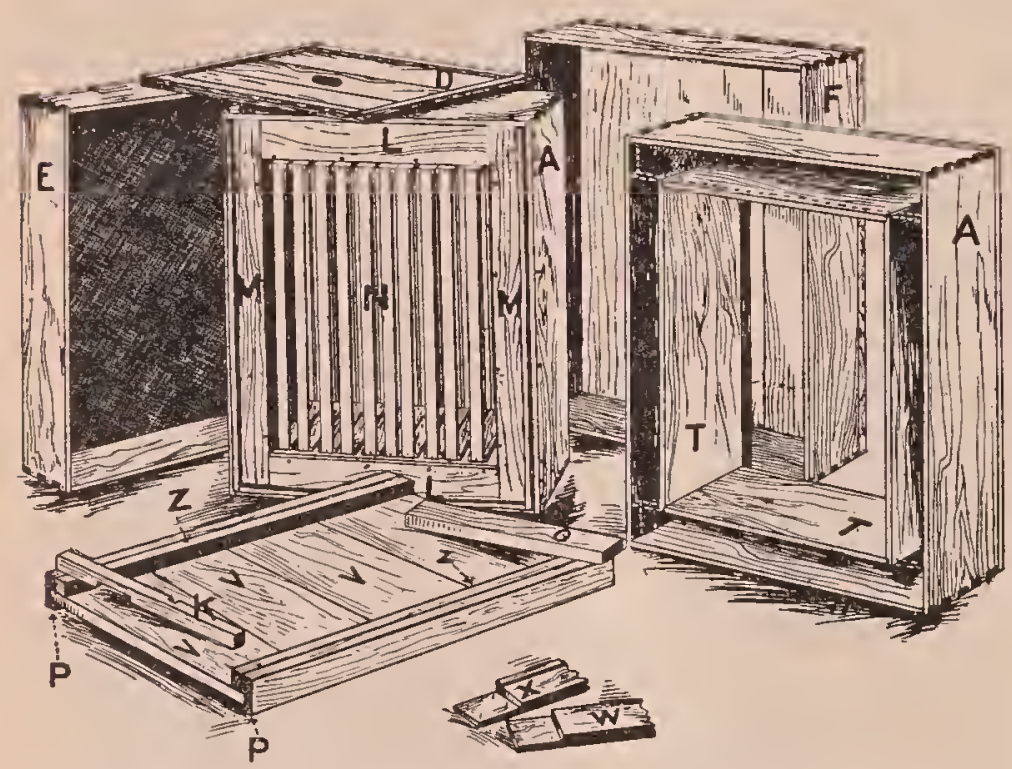

Buckeye hive dissected, showing separate parts, and how the brood-chamber packing is shut in by cleats $M$ and $L$. A, outel wall brood-chamber; $T$, inner wall brood-chamber; $\mathrm{X}$, W, packing space cover; $I$, M, packing space bottom; $F$, telescope cover ; E, chaff-tray; D, super-cover.

material. This is a mistake. Tn the first place, there is no such thing as "dead air" space in a beehive or in anything else. Air is bound to circulate. The air next to the outer wall that is cold cools and necessarily circulates over to the other side or inner side where it is warm. The cold air rushing over to the warm side cools the warm side, thus making the inner wall almost as cold as the outer. When a hive is so designed that it can hold packing material, this material holds an infinite number of pockets of air in little compartments. As the air in these compartments cannot circulate, it follows that the onter wall may be comparatively cold, while the inner one will be warm. The fact that all refrigerator's have the space between the walls packed with material, goes to show that the theory of "dead air" space between two walls is wrong. Not only that, but actual practice shows a big difference between the so-called double-walled dead-air-space hive and a real double-walled hive, the spaces between which are packed.

The hive just described is one of the standard double-walled hives that has been on the market for a number of years. There is a feeling, however, on the part of Government officials and others, that for very cold localities it does not afford enough packing. Indeed, Dr. E. F. Phillips, in charge of Bee Culture Investigations in the Bureau of Entomology at Washington, D. C., stated that, in his opinion, the original twostory A. I. Root chaff hive was much better and was the best winter hive that was ever on the market. It provides for two or three times the amount of packing on the sides and top that is given in the Buckeye hive. The author's experience with it showed that the bees wintered in it much better during severe winters than in the Buckeye. Moreover, the bottom was packed, as well as the sides, ends, and tops. In the early editions of this work it was shown that bees wintered in this hive in the Medina climate for a series

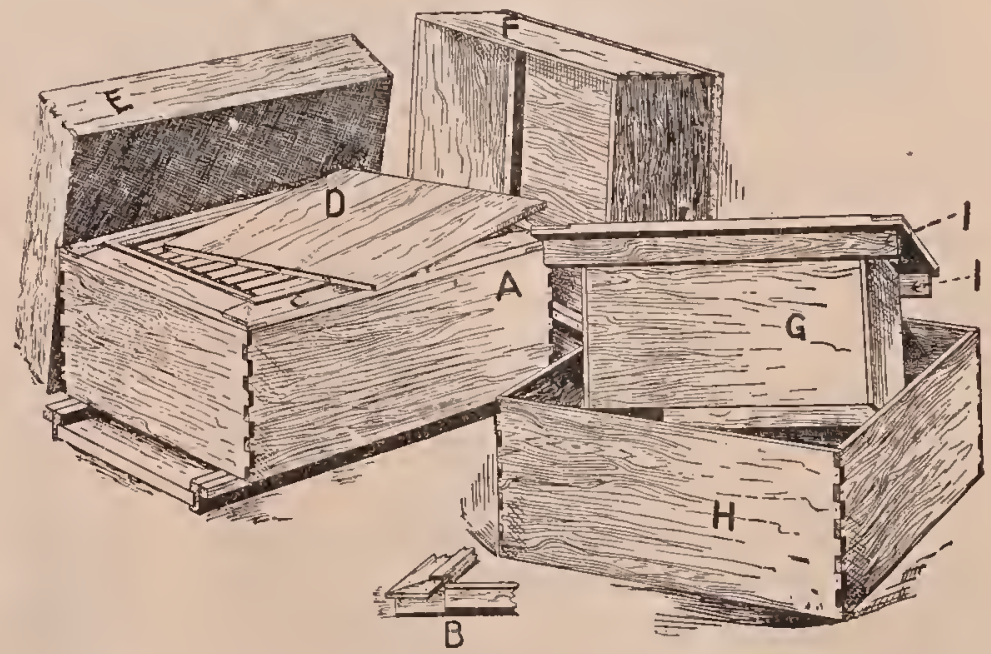

Buckeye hive dissected, showing the inner walls detached from the outer walls of the brood-chamher.

of twelve years with a loss not exceeding on an average three per cent. This is a record beyond that subsequently secured in 
the Buckeye hive. For the average locality, where it is not too cold, where there is plenty of snow, or where there are good windbreaks, the Buckeye hive affords sufficient protection. It is admirably adapted

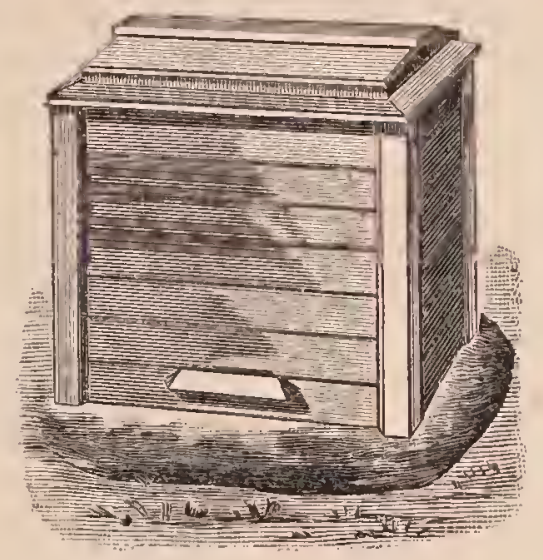

Original Root ehaff hive.

for localities like that of Tennessee, some of the other southern States, and many parts of California, where the nights are cold, down almost to freezing, and the days are warm. The double walls prevent the bees from coming out too freely on warm days, and protect the brood at night.

\section{PACKING MATERIAL.}

In former times, when chaff from wheat or oats was available, this was the material used. In later years planer shavings from a planing mill have been user very extensively with excellent results. Dry forest leaves when packed solid are perhaps better yet.

\section{HIVES, EVOLUTION OF.-}

Primitive hives were simply the trunks of hollow trees in which bees were lodged, cut down and carried wherever the beekeeper desired. This plan of beekeeping is still practiced in some parts of Europe, in southeastern United States, and is common enough in Africa. The stinglessbee apiaries of South America have hives of this description.

The next step was to construct a cylinder resembling the trunk of a tree, either of wood or earthenware. In northern climates straw came into use, but lad to be fashioned in the shape of a bell to make it easy of construction. This is the kind of hive which was so highly praised by poets. It has the merits of extreme simplicity and cheapness. Usually it had cross-sticks added inside to keep the combs from falling down. See Skeps.

Not all beekeepers were satisfied with these hives; and as early as the 17th century some few began to cast about for something better. Della Rocca, who wrote a book on bees in the 18th century, mentions bar hives as in vogue in the islands of the Grecian Archipelago, where he lived for many years. Bar hives and movable combs are referred to in a book published in Italian in $\mathbf{1 5 9 0 .}$ The author was Giovanni Rucellai. Such hives were known even to the ancient Greeks. They resembled large flowerpots with wooden bars on which the bees were to fasten their combs. The shape of the hive made it practically impossible to cause a breakdown of the combs except by heat.

The plan of a movable roof was another step in advance, as it gave the beekeeper an opportunity to put on an upper story or a super to hold the surplus honey where it should be, and remove it at the end of the honey harvest.

Mewe, in Great Britain, constructer hives of wood on somewhat the same plan as
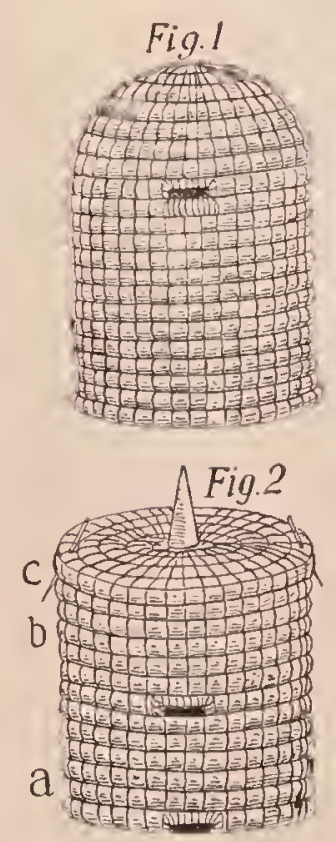

Fig.4
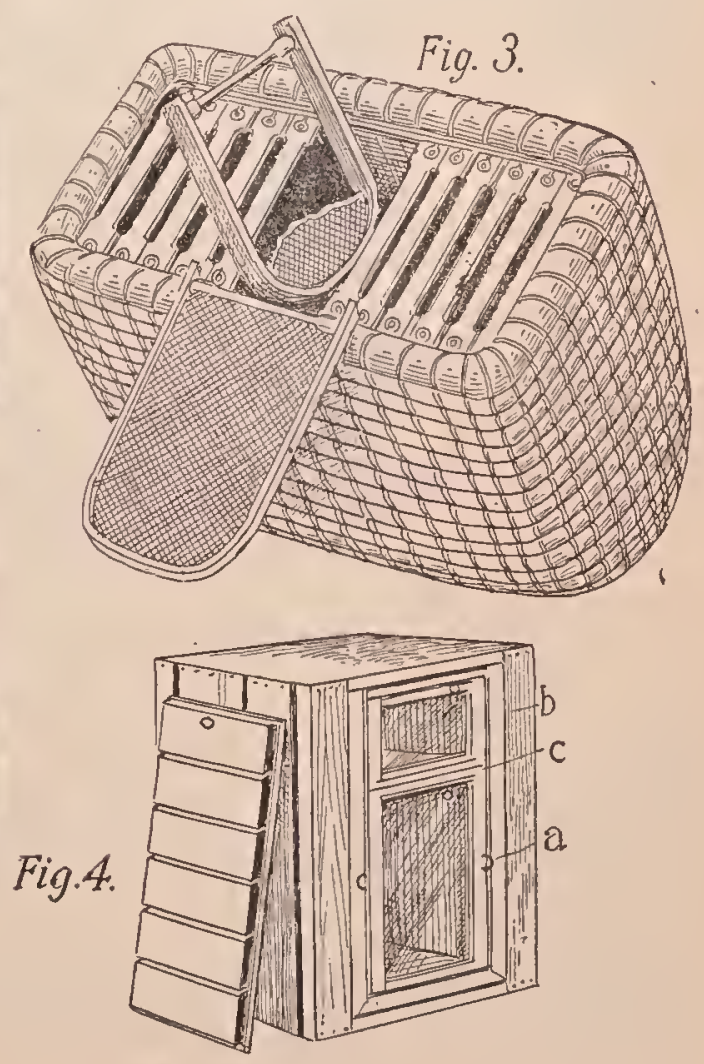

Yarieties of the skep. 
early as 1652, and these were gradually improved by various inventors.

Maraldi, about the same era as Mewe, invented a single-comb observation hive made with glass sides, which contained the germ of the movable-comb frame. He allowed too much space for one comb, and the use of these that he was able to make the discoveries in apiculture which so astonished and delighted the scientific world (see Fig. 2). Huber invented these hives about 1789, or perhaps a little earlier. It has been contended by some writers that Huber's hive was not practical; but some

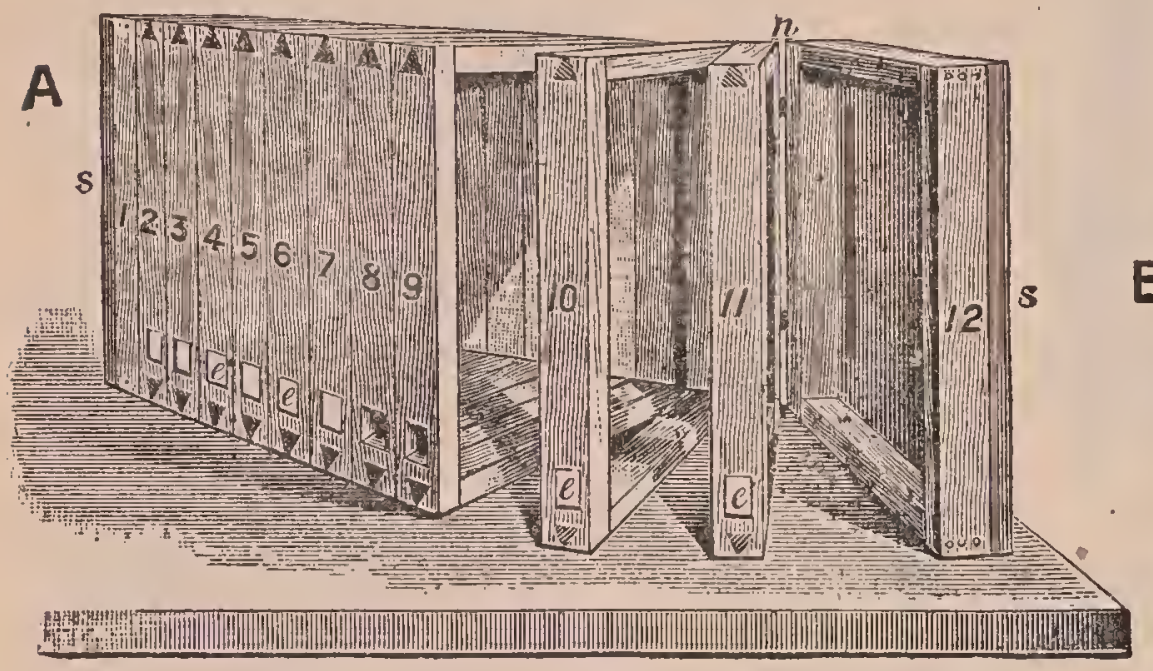

Fig. 1.-Huber's leaf hive, 1789.-From Cheshire.

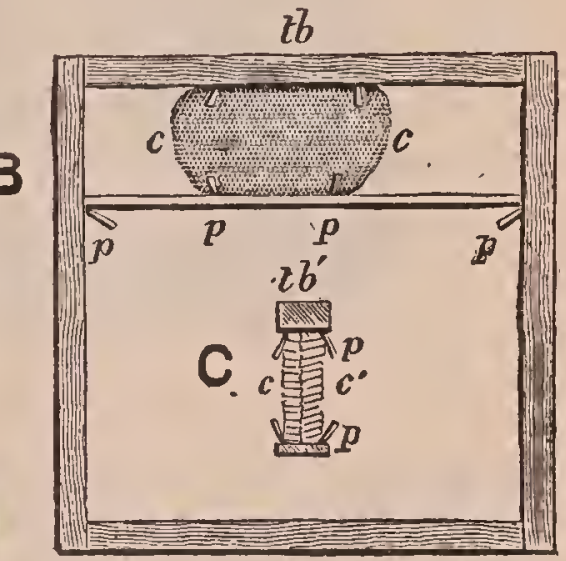

Fig. 2. frequently the bees built their combs crosswise. Still there was in the Maraldi hive the important advantage of handling one comb at a time, and by this means to get a far better conception of what was going on inside the hive. Huber extended this idea by his improvement, Fig. 1, which came very near to the hanging movable of the most practical beekeepers the world has yet produced used modified Huber hives, notably Quinby and Hetherington, beekeepers of New York State, whose names are revered by American beekeepers.

An examination of the illustrations of Inuber's hive makes it plain that he had a

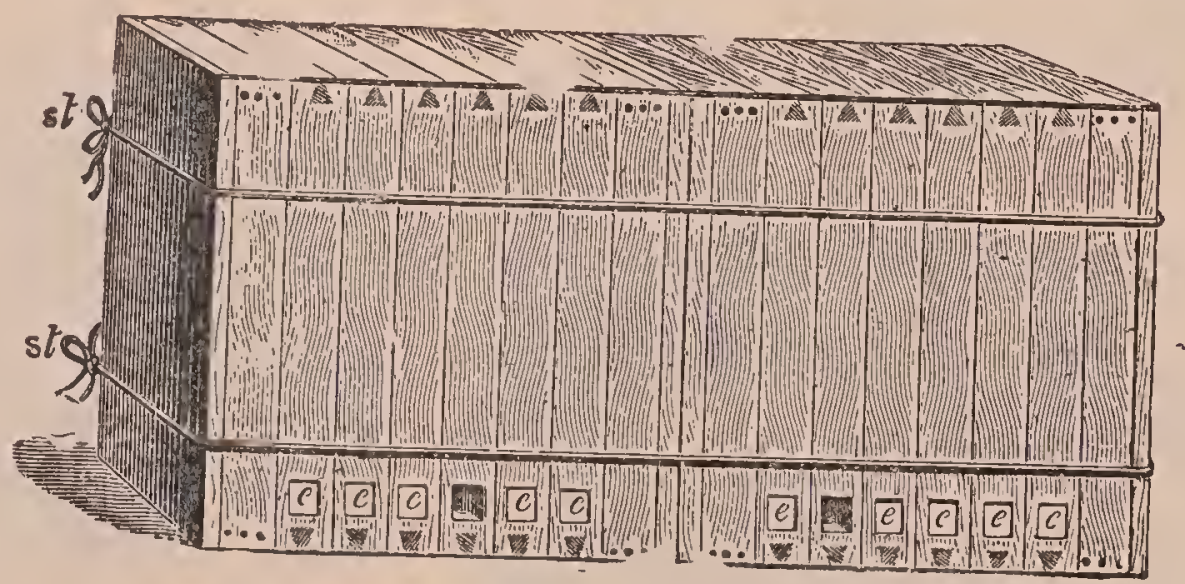

Fig. 3.-Huber hive, showing how he artificially increased the number of his colonies. E, E, E are entrance holes.-From Cheshire.

frame invented by Langstroth 60 years later.

To Huber belongs the credit of inventing hives with movable frames, ${ }^{*}$ and it was by

* This honor is usually ascribed to Langstroth, for indeed, he was the first one to invent an all-round practical hive and frame-a frame that provided a bee-space all around it; but he did not invent the first movable frame (see Frames). clear idea of what was required in a hive for practical purposes. Fig. 3 shows how he increased his apiary by artificial means. In this case he divided a strong colony by slipping a board between the frames, thereby splitting it in two. His plan of providing a part of each frame for surplus honey (Fig. 2) is excellent. Thus it is evi- 
dent that Huber invented some of the principal features of our movable-comb hives. The Heddon and Bingham hives are on the movable-comb plan. See Hives.

About 1819 Robert Kerr of Stewarton, Scotland, invented a bar hive of considerable merit, shown in Fig. 4. This hive was used very successfully, and is still in use, but with movable frames instead of mere bars. It was still further improved by Howatson, also of Scotland, about 1895. Here we have the tiering principle elearly comprehended; and had this author and inventor grasped the idea of movable-comb frames instead of bars he would have invented a hive on the Heddon principle.

Prokopovitseh, a Russian, about 1830, invented and made in large numbers a

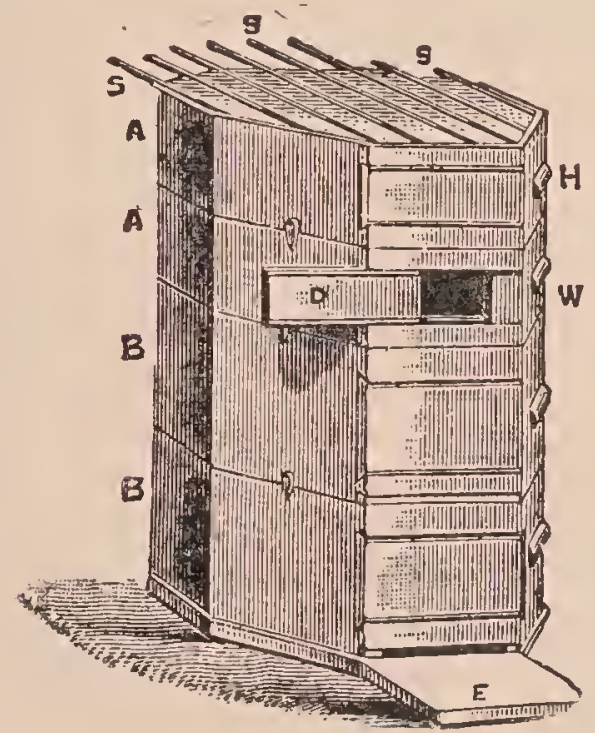

Fig. 4.-The Stewarton hive, 1819; shallowbar hive with glass strips between bars. -From Cheshire.

movable-comb hive of great merit. See Fig. 5. In his own apiaries, of which he liad many, were over 3000 of these hives in actual use. His pupils (for he established a school of beekeeping) had many more in use.

It may be noted that his surplus frames bear considerable resemblance to our beeway sections, and that his hives were dovetailed. Prokopovitsch was certainly a beekeeper of remarkable abilities. He employed means and methods far ahead of his time.

It has been claimed by some writers that Dzierzon of Germany invented movable frames in 1845; but it is evident he has no claim whatever to this distinction. As a matter of fact, according to his own statements, he used bars until 1855, when he was persuaded by Baron Berlepsch to use movable frames, which had just been introduced from America. (See Dzierzon; also Dzierzon Theory.) Dzierzon's bar combs were removed by using a long' knife to eut the attachments from the back of the hive one by one; for, to reach the comb at the front of the hive, all the other combs had first to be removed. His hive was far inferior to those already mentioned. When

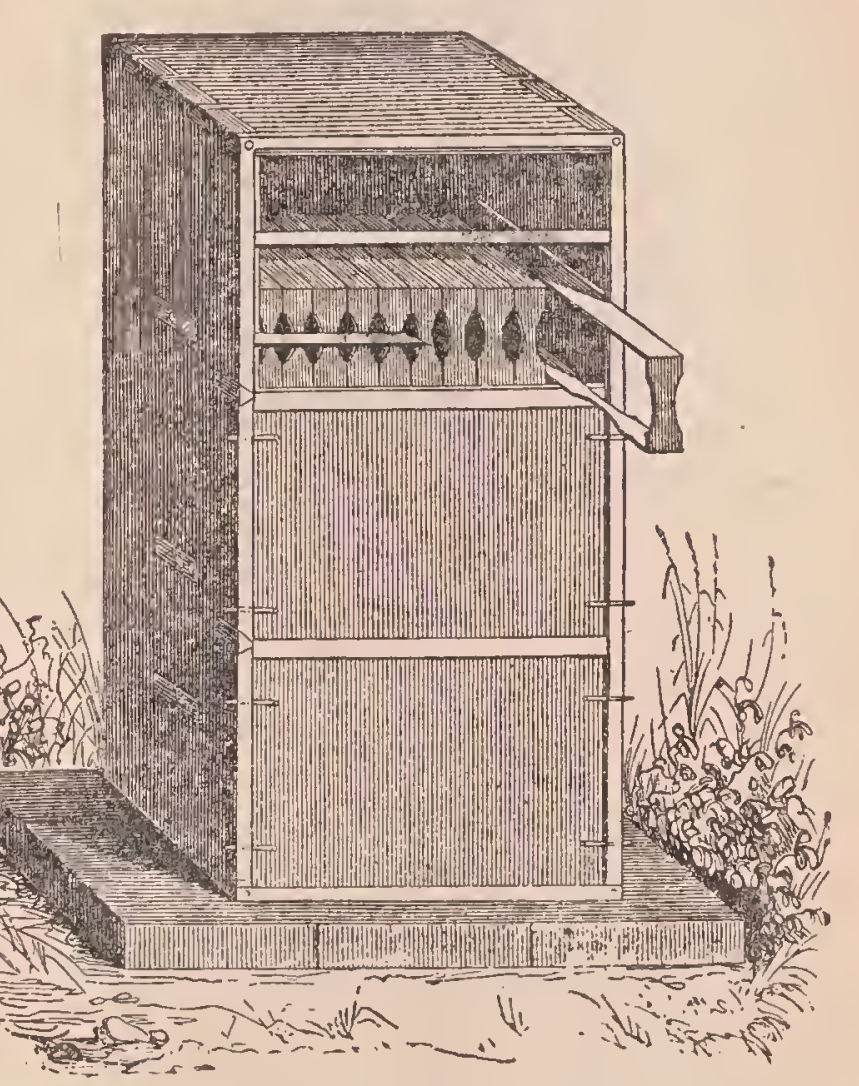

Fig. 5.-Prokopovitsch's hive, 1830.-From Framiere. he adopted frames he did not ehange the construction of his hives in the least.

Next came Langstroth with his epochmaking movable-comb hive with movable roof, which combined the essential requirements of a.hive. All the combs in the Langstroth hive are readily removable without the slightest annoyance either to the beekeeper or the bees. Langstroth did his work so well that he left very little for future inventors to do. Many have tried to improve his hive, but in most cases the so-called improvement has proven to be a backward step. The striking feature of the Langstroth hive is the provision for a beespace on all sides of the comb. This beespace cannot be less than one-sixth of an 
inch nor more than one-third. This alone was a great discovery, and placed Langstroth far above the mere inventor. See BeE-SPACE and Frames; also A B C OF Beereeping.

From his writings it is evident that Langstroth knew nothing about what others

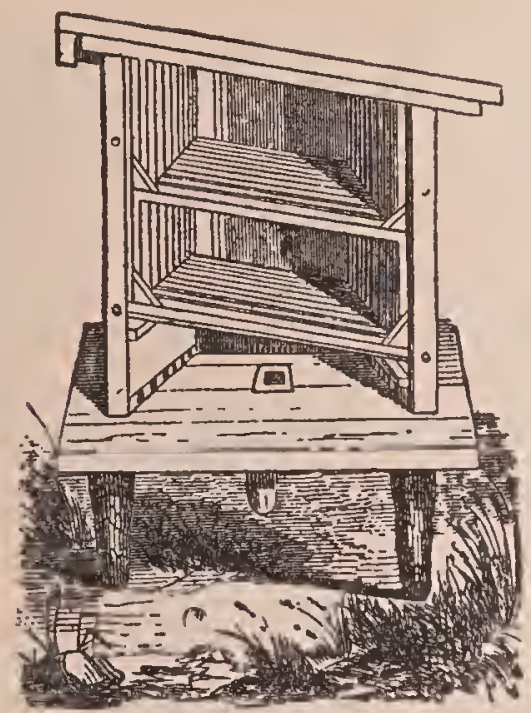

Debeauvoy's hive, 1845; invented in France before Langstroth's hive appeared.

had done before him in this line; and it is apparent that his invention was the result of a profound study of the bee and its habits. To some extent he was misled by others into thinking that the principle of the Langstroth hive had been discovered by Dr. Dzierzon independently, whereas it is now proven that the German beekeeper had no claim to the invention of the hanging movable comb, to say nothing of the beespace and the movable roof, which are essential features of the hive.

Langstroth's invention, accompanied by an excellent treatise* on the art of keeping bees, created a revolution in beekeeping in a short time, linking his name with that of Huber as the two founders of modern apiculture.

HIVES, MANIPULATING.-See MANipUlation of Colonies.

\section{HIVE-STANDS.-See ÁPIARY.}

HOLLY (Ilex opaca).-American holly. White holly. A small evergreen tree, 20 to 50 feet tall, with a trunk sometimes six feet in circumference. Bark smooth and grayish white, twigs light brown. The leaves are elliptical, leathery, spiny-toothed,

* A reprint of the original work has been pub. lished by The A. I. Root Company; price $\$ 1.50$. dark green, shining above and dull beneath, with bright red berries in the axils. As in the common gallberry the flowers are small, white, and a part are pistillate and a part staminate, the staminate being clustered and the pistillate solitary. Only one kind of flower occurs usually on an individual tree. Holly extends thruout the southern States from Florida to Texas, and in the Mississippi Valley northward to Missouri, and along the coast to Massachusetts, but is not abundant north of Virginia.

American holly is widely distributed in Georgia, but is seldom very common in any one locality. The flowers expand in April, and, altho the honey is never obtained pure, it is undoubtedly excellent. In Florida it is confined to the northern part of the State, where it blooms a little earlier than in Georgia. The honey is always mixed with that from other early spring flowers; for example, on the eastern coast it forms a fine blend with the honey of the saw palmetto. In South Carolina holly is also considered a valuable honey-producer, and the odor of the flowers is very noticeable in the apiary when the trees are in bloom. In Massachusetts the holly does not flower until June. There is in this State a variety with yellow fruit.

But locally thruout western Mississippi and southern Arkansas holly is an important honey plant, and the source of a large amount of surplus. At Graysport, Grenada County, Mississippi, it is the only honey plant yielding a surplus. The honey is almost white or a very light amber color, heavy, excellent in flavor, and when pure will not candy for years. "I would go out of business," writes a beekeeper from this town, "were it not for holly. It is always reliable except when it rains constantly during the blooming period. I have had strong colonies store 17 pounds per day from holly." A large quantity of holly honey is also secured in the Yazoo Delta.

HONEY.-Many readers of a work of this kind, no doubt, have a good idea of the physical properties of a honey, and may be able from the taste to determine to some extent from what special plant any given honey was mainly produced. It may be possible, perhaps, that they have an 
idea of chemical composition. They may also be able to supply a good definition of a honey. But for the benefit of others, a brief statement covering this extensive field may not be out of place.

As regards definition:

According to the Century Dictionary, "Honey is a sweet. viscid fluid collected from the nectaries of flowers and elaborated for food by several kinds of insects, especially by the honey bee (Apis mellifica)." An accepted German definition is, "Honey is the nectar obtained from flowers by worker bees, which, after modification in the honey-stomach of the latter, is stored in the cells of the comb for the nourishment of the young brood." In this country the food standards consider "honey as the nectar and saccharine exudations of plants." This comes about in that many plants contain sugar in their saps, and, when an exudation of sap takes place, and the water in the sap is evaporated, a saccharine residue remains, which is gathered by the bees. Also, many trees exude a sweet sap when stung by some insect, and this is also gathered by the bees. See HONEYDEw.

Physically considered, honey may be a solid block resembling a pound cake of creamery butter or it may be semi-solid or decidedly liquid. The old idea that crystals of dextrose in a honey indicated beyond doubt that the product was badly adulterated with sugar should be and has been dispelled.

In color, honey may be water-white, or it may grade thru the yellows to the brown into the seal brown and nearly to the black. It has been known to be decidedly red in color, and again at another time to have a greenish tinge-none of these indicating by any means the addition of artificial colors, but being due entirely to the source of the bees' food. Honey may be as mild $01^{\circ}$ as strong in flavor as one can imagine, and may possess all the fragrant aroma imaginable, and again have a nauseous aroma. Yet in each case it will be absolutely pure.

The consuming public are very apt to jump at conclusions as to the purity of this product on account of these various flavors and aromas. A person used to clover or alfalfa honey would immediately say buckwheat lioney is not honey at all; and, vice versu, one used to buckwheat honey would say clover honey is nothing more than a mild-flavored sugar syrup.

As regards composition:

Honey belongs to the carbohydrate foods. It is practically a solution of the two sugars, dextrose and levulose in water with sucrose in varying small quantities, naturally flavored and containing aromas imparted to it by the flower and by the bee. Early analyses of honey were very incomplete. Hassall in his "Food-Its Adulterations and the Methods for their Detection," published along in the sixties, reports moisture, cane sugar, glucose, insoluble matter, and nineral matter in four samples. In his report he states, "With the exception of these, so far as we are aware, no reliable analyses have yet been made."

Wiley in Part 6, Bulletin 13, Division of Chemistry, published in 1892, gives a rather complete analysis of a number of American honeys. But by far the most complete and exhaustive study of American honeys was made by Browne and published in 1908 as Bulletin 110, Bureau of Chemistry, United States Department of Agriculture. Following this, in 1912, Bryan published results of examinations of imported honeys from Cuba, Mexico, and Haiti as Bulletin 154 of the same bureau and department. Miss Alice R. Thompson in 1908 published results of the examination of Hawaiian honeys as Bulletin No. 17, Hawaiian Agricultural Experiment Station.

Abstracting these, we obtain some interesting facts, and at the same time a fairly complete analysis of representative American honeys, together with those likely to enter the American market.

Browne made a classification of his samples according to floral origin; that is, placing all those supposed to be obtained from clover together, etc., and then attempted drawing some conclusions as to physical and chemical constants of each variety. While the results do show some conformity to type, they are not as close as could be desired, for examination of the pollen found in the samples showed that the bees had gathered nectar from other flowers, altho the prevailing pollen was that of the species under which the analysis had been classified. 


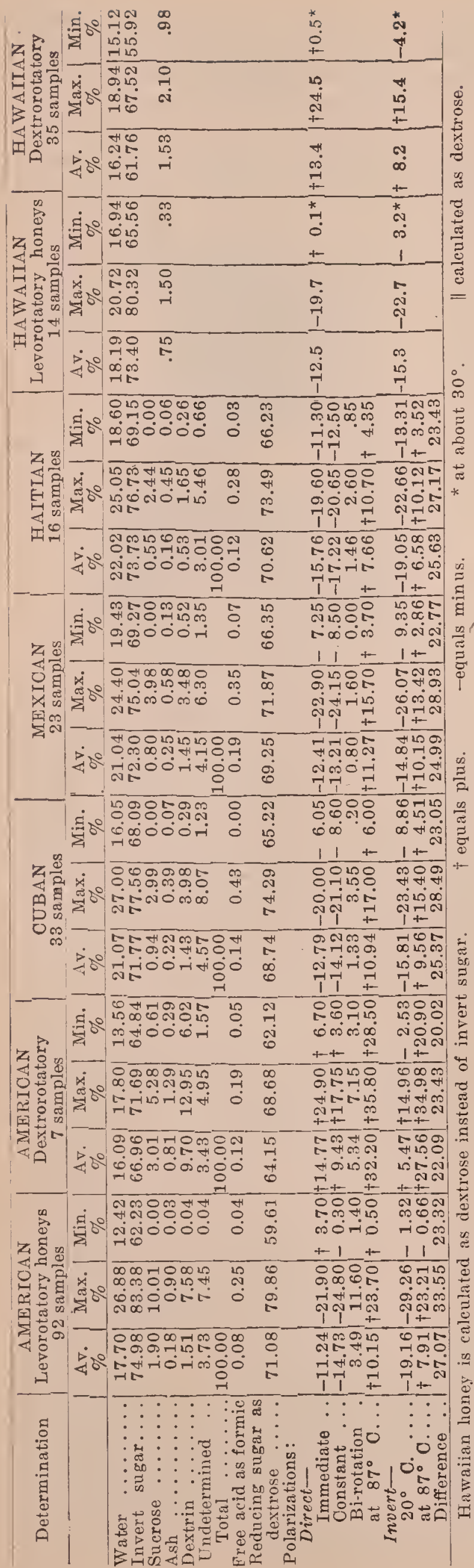

In this same bulletin is a rather exhaustive study of the several kinds of pollen found and the characteristics of the pollen of the various individual flowers. The quantity of pollen varied considerably in the samples, hence the examination for pollen cannot give any index of the percentage of adulteration. From the kinds of pollen found one can judge with some degree of accuracy the kind of flowers visited, but it is hardly safe to say that with the absence of a certain pollen, the nectar from that flower has not been gathered and stored.

In the preceding table are contained the analytic results of the examination, showing the average, maximum, and minimum figures for American, Haytian, Cuban, Mexican, and Hawaiian honeys.

It is noted that the American as well as the Hawaiian honeys are divided into two classes levorotatory and dextrorotatory. The former may be termed honeys under the National Food Law, while the latter are honeydew honeys. The standard of food products under the national law states that "Honey should be levorotatory, and should contain not more than 25 per cent water, not more than .25 per cent ash, and not more than 8 per cent of sucrose.

The quantity of ash stated is too low, as Browne's examination has shown 0.90 per cent ash.

The analytical figures given in the analyses are for percentage of moisture, invert sugar, sucrose, dextrin, ash, and undetermined matter. The acidity of the honey samples has also been given.

In American honeys there is an average of 3.73 per cent of undetermined matter. The composition of this material is the subject of much work now, and the substances found in this class by the chemist are often the deciding figure in determining the adulteration of honey with commercial invert sugar.

The composition of the sugars reported as invert sugar, viz., percentage of dextrose and levulose, are sometimes of value. Taking Browne's results for the average of the various species of honey we find:

Kind of Honey Dextrose Levulose Alfalfa ............ $36.85 \% \quad 40.24 \%$ White clover ........... 34.96 40.24

Alsike clover .......... $36.06 \quad 40.95$ Sweet clover ........ $36.78 \quad 39.59$ 
Catsclaw ............ 38.21

Mesquite ........... 38.04

Locust ............ 35.98

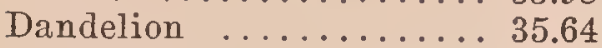

Goldenrod ............ 34.45

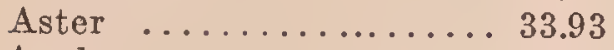

Apple .............. 31.67

Raspberry .......... 33.57

Buckwheat ................. 36.75

Wild bnckwheat........ 35.39

Cotton ............. 36.19

Basswood ............ 36.05

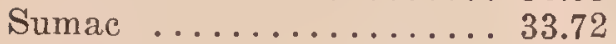

Tupelo ............. 24.73

40.81

41.03

40.35

41.50

37.85

41.31

42.00

41.34

40.29

41.36

39.42

39.27

37.61

48.61

In every case the levulose predominates. This is of value, as in commercial invert sugar the two are equal or the dextrose predominates. See Invert SugAR.

The distinction between honey and honeydew honey is only possible by means of the polariscope. If a solution of the honey turns a polarized ray of light to the left it is levorotatory, and the honey is a true honey; but if it turns the ray to the right it is a honeydew honey; provided no commercial glucose has been added.

For further consideration see Granulated Honey, Extracted Honey, HoneyDEw, Honey as a Food, Honey, ANatysis of, and NeCTAR.

\section{PHYSICAL CHARACTERISTICS OF HONEY.}

The amount of water present in honey depends upon the degree of evaporation to which the bees have brought the product in the hive. Honey which has been taken out of the hive prematurely is said to be "unripe." According to the committee on food standards and also the German standard, honey which consists of more than 25 per cent of water must be classed as immature. It is obvious some standard percentage such as this is necessary, even tho arbitrary, in order that a basis may be had for determining what honeys are unripe.

Honey which has not been capped over is sometimes ripe, but more often unripe; and the combs of unripe honey should never be placed on the market as anything but immature honey. It possesses poor keeping qualities. Honey extracted from uncapped combs should be exposed to evaporation before bottling.

The amount of moisture in honey is not conditioned by the nectar of the flower from which the honey is derived. It varies in some degree, however, with the environ- ment of the apiary. Evaporation within the hive is promoted or retarded by local conditions of humidity. For this reason honey from arid parts of the country is thicker in general than honey from regions where rainfall is plentiful. The difference in average water content of ripened honeys between those from the humid States of the upper Mississippi and those from the Southwest, is 3.5 per cent, according to the tests in the Government sugar laboratory.

The degree of granulation which a particular sample of honey may reach, as well as the length of time it takes to granulate, is another physical characteristic worth noting and forms roughly an index to its purity. Honeys high in dextrose are prone to granulation: This characteristic of alfalfa honey is well known. Conversely, honeys low in dextrose do not granulate readily. Note that tupelo, a non-granulating honey, shows only 24.73 per cent of dextrose, while alfalfa, an early granulating honey, shows by the table 36.85 per cent. See science of granulation under Granulated Honey. Impure honeys, such as honeydew honey and honey adulterated with glucose, do not granulate as readily as pure honey. Sage and tupelo by nature seldom granulate. This characteristic is utilized by packers in preparing a product which will not readily erystallize on the market when exposed to changes in temperature. See Botrtling.

Ordinarily honey is judged by its color, flavor, and density. There is an almost endless variety of flavors, making it practicable to suit the most exacting connoisseur. The flavors, like the evanscent aroma of honey, are very difficult to describe and really cannot be satisfactorily communicated thru printed description. Alfalfa, buckwheat, basswood, cotton, orange, and several other kinds of honey have a characteristic flavor and aroma which any one accustomed to them can recognize without difficulty. The presence of honeydew is usually detected by a burnt-sugar flavor. The flavors of some of the prominent honeys are described under the respective plants.

Color is a fair guide, but not always so, for the famous heather honey of Europe is quite dark, and yet no honey stands higher in popular esteem on that continent. The 
best honeys of this country are usually spoken of as white, and, tho this is not quite correct, still it is near enough for all practical purposes without coining a new word.

Clover honey may be taken as the typical white honey by which others may be conreniently judged. For the purpose of comparison some may be a little lighter, and others a little darker shade; but these nice points of distinction are visible only to an expert. See HoNeY aNd Its Colors.

It has been the custom of a number of honey producers to market their products under such names as "white clover honey," "sage honey," and "pure orange honey." Upon this practice, Bulletin No. 110 of the Bureau of Chemistry makes the following statement: "Bottled honeys are frequently labeled by some floral designation, and these honeys, even when within the standard, often show a suspicious variation from the analyses of such honeys of known floral origin, especially as regards sucrose content. The miscroscopic examination of these honeys frequently shows an almost complete absence of pollen from the flower ir question. Beekeepers and bottlers of honey are sometimies extremely careless in the labeling of their products and apply the name of almost any flower, thinking that they keep within the requirements of the law so long as their product is pure honey. This is a mistake, as the product should be labeled exactly according to its origin." See Labels for HoNey.

HONEY, ANALYSIS OF.-Outside of the determination of moisture or water content, the methods of analysis of honeys can hardly be carried on by the beekeeper or bottler; first, on account of the rather complicated procedures, and, second, on account of the expensive apparatus needed. The moisture determination described below for the beekeeper or bottler is not so accurate as that one described for the chemist, hut it will yield comparative results. It is the one in general use by makers of maple, sorghum, and also cane syrup.

The analytical procedure described for the chemist are all well-known methods and should yield accurate results. It is on the interpretation of analytical results that the chemist may fail, if he has not had some little experience with honey. This latter phase of the question would easily fill many pages, and then it would be doubtful whether the whole field had been covered in such a way as to explain all cases and conditions. So one can give here only the outline of the general and special methods used in honey examination, followed with some remarks about detecting adulteration.

For sake of conrenience and ease of presentation, the method of procedure adopted is to divide the matter into statements of the methods for the individual determinations; then follow with maximum and minimum figures obtained on pure honeys for each determination. Maximum or minimum figures not given may be obtainer from the table of analysis given under HONEY.

The first step in any analytical examination is the drawing of a representative sample. This is of greatest importance and prevents difficulties with honey on account of partial erystallization or candying of numerous honeys.

\section{SAMPLING.}

ComB.-In comb honey it is necessary to select either a representative comb or better to take portions of a number of combs. Then by means of a knife cut across the top of the comb and allow the honey to drain from the cells. Should the honey have sranulated in the comb, it will be necessary to heat the comb in a water bath at a temperature not above $160^{\circ}$ Fahrenheit until the wax liquefies, stirring, then allow the whole to cool. The wax will solidify in a layer on top. This can be removed and the sample is ready for analysis. Should the liquid so obtained be full of dirt, treat it as given below inder "Extracted Honey."

ExTRACTED HoNey.-If the sample is free from granulation, and also clear and clean and in a perfectly liquid condition. no preparation is necessary. When the sample has granulated or shows partial granulation, it should be heated on a water bath (never over a direct flame) to a temperature never over $160^{\circ}$ Fahrenheit until the crystals are in solution. If the sample is dirty, it can be passed in this state thru a fine linen eloth to filter. The heated honey is allowed to cool to collect and solid. 
ify the wax. It is then ready for analysis.

Drawing representative samples from. large containers is a difficult proposition. The best procedure in sucl cases should be to liquefy the whole, then stir before taking the sample. Under these conditions only could one obtain an average sample.

\section{MOISTURE METHOD FOR BOTTLER.}

The necessary apparatus is a Baumé hydrometer graduated from $0-50$, which can be obtained from any wholesale druggist or chemical house, and a tin cylinder as shown in cut about two inches in diameter. and twelve inches high.

\section{BY BAUME HYDROMETER.}

$\Lambda$ hydrometer or spindle is an instrument for showing the density of a liquid. Hydrometers are graduated to various

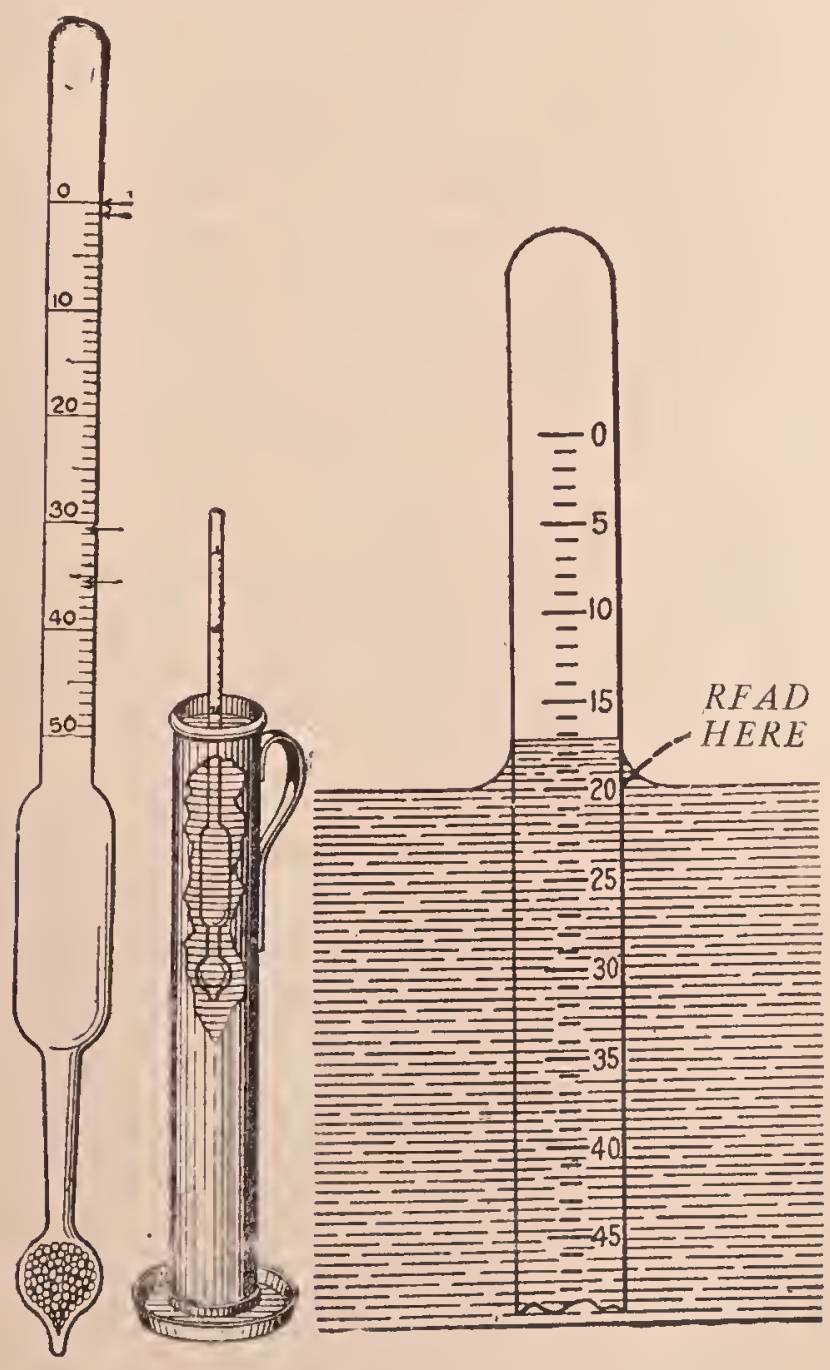

Hydrometer and its position in the liquid.

scales and for various purposes. The one generally used for rough sugar work is the Baumé. The standard of graduation is an arbitrary one and varies somewhat with different makes. The usual Baumé hydrometer is made of glass and shows a graduation from zero to 50, divided into degrees, as shown in figure below. The density is measured by floating the hydrometer freely in the liquid, which is generally held in a tall cylinder, as shown in the illustration. The point on the scale where the instrument comes to rest is considered the density. It will be noted that the surface of the liquid is curved up at the points of contact with the metal cylinder, and also with the hydrometer. The correct reading of the instrument is on a line witl the surface of the liquid as shown in the cut and not at the upper edge of the curved portion. The temperature at which Baumé hydroneters are standardized is $60^{\circ} \mathrm{F}$., unless it is otherwise marked on the stem of the hydrometer, so for correct readings the honey should be cooled to that temperature. A honey of standard density has a Bammí reading of $40.9^{\circ}$, but if measuring the density of the warm honey ly drawing some out into a cylinder the density will be somewhere about $37^{\circ}$ to $40^{\circ}$, and on cooling $40.9^{\circ}$ to $41.5^{\circ}$. This is readily understood when one considers that the zero of the hydrometer is at the upper end and the 50 at the lower end. On heating a liquid, there is an expansion and the liquir is lighter, so the hydrometer sinks further down than on cooling, when there is a contraction of the liquid. The accuracy of these glass hydrometers is very much affected by using them in hot liquids, hence it is not good practice to use the accurate instruments in the hot honey.

The following table shows the solid content and the water content for different degrees Baumé. These figures are only approximate. A gallon of the honey shonld be weighed to give accurate results.

It is not to be understood that a degree Baumé corresponds to 1.7 per cent of sugar, for the hydrometer mensures other dissolved solids also.

In order to determine relatively the number of degrees Baumé of the cooled honey when the reading is made with the hydrometer at a high temperature, it is necessary to take the temperature at the same time that the hydrometer is read. Subtract 60 from the number of degrees Fahrenheit of the heated honey (this being the normal 
DBY SEBSTANCE AND WATER CORRESPONDING TO EACH DEGREE BAUME.

\begin{tabular}{|c|c|c|c|c|c|}
\hline 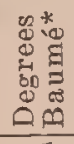 & 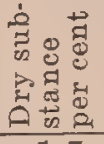 & 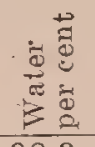 & 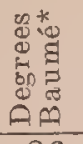 & 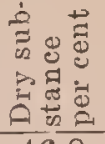 & 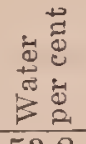 \\
\hline 1 & 1.7 & 98.3 & 26 & 46.8 & 53.2 \\
\hline 2 & 3.5 & 96.5 & 27 & 48.6 & 51.4 \\
\hline 3 & 5.3 & 94.7 & 28 & 50.5 & 49.5 \\
\hline 4 & 7.0 & 93.0 & 29 & 52.4 & 47.6 \\
\hline 5 & 8.8 & 91.2 & 30 & 54.3 & 45.7 \\
\hline 6 & 10.6 & 89.4 & 31 & 56.2 & 43.8 \\
\hline 7 & 12.3 & 87.7 & 32 & 58.1 & 41.9 \\
\hline 8 & 14.1 & 85.9 & 33 & 60.0 & 40.0 \\
\hline 9 & 16.0 & 84.0 & 34 & 61.9 & 38.1 \\
\hline 10 & 17.7 & 82.3 & 35 & 63.9 & 36.1 \\
\hline 11 & 19.5 & 80.5 & 36 & 65.8 & 34.2 \\
\hline 12 & 21.3 & 78.7 & 37 & 67.8 & 32.2 \\
\hline 13 & 23.0 & 77.0 & 38 & 69.7 & 30.3 \\
\hline 14 & 24.8 & 75.2 & 39 & 71.7 & 28.3 \\
\hline 15 & 26.6 & 73.4 & 40 & 73.7 & 26.3 \\
\hline 16 & 28.4 & 71.6 & 41 & 75.7 & 24.3 \\
\hline 17 & 30.3 & 69.7 & 42 & 77.7 & 22.3 \\
\hline 18 & 32.1 & 67.9 & 43 & 79.7 & 20.3 \\
\hline 19 & 33.9 & 66.1 & 44 & 81.8 & 18.2 \\
\hline 20 & 35.7 & 61.3 & 45 & 83.8 & 16.2 \\
\hline 21 & 37.5 & 62.5 & 46 & 85.9 & 14.1 \\
\hline 22 & 39.4 & 60.6 & 47 & 88.0 & 12.0 \\
\hline 23 & 41.2 & 58.8 & 48 & 90.1 & 9.9 \\
\hline 24 & 43.1 & 56.9 & 49 & 92.2 & 7.8 \\
\hline 25 & 44.9 & 55.1 & 50 & 94.4 & 5.6 \\
\hline
\end{tabular}

* Taken at $60^{\circ} \mathrm{F}$.

temperature) and multiply the difference by 0.0265 . This figure (which is the temperature correction expressed in degrees Baumé) is added to the Baumé reading of the hot honey; and the result is the Baumé reading of the cooled honey. For example, a heated honey shows a reading of 38 at a temperature of $160^{\circ} \mathrm{F}$. Then-

$160^{\circ}$ minus 60 equals 100

100 times .0265 equals 2.65

38 plus 2.65 equals 40.65

The cooled honey would read 40.65 , or by above table have about 25.5 per cent water.

\section{MOISTURE FOR THE CHEMIST.}

Weigh 2 grams of the sample in a flatbottom aluminum (or platinum) dish $2 \frac{1}{2}$ inches in diameter containing from 10 to 15 grams of fine quartz sand which has been thoroly washed and ignited. A small glass stirring rod is weighed out with the dish and sand, and after the addition of the honey and weighing dissolve the latter in 5 to $10 \mathrm{cc}$. of distilled water and thoroly incorporate with the sand by stirring with the rod. Then place the dish in a vacuum oven and dry to constant weight at from $68^{\circ}$ to $72^{\circ}$ ('. under a 20 to 24 inch raculum.

\section{ASH (MINERAL MATTER).}

Carefully weigh 5 grams of the honey in a tared platinum dish, add a few drops of olive oil, and heat the whole over a flame, using care not to lose any honey by spattering. Then ignite in a muffle or over direct flame at a low red heat. Cool, weigh, and calculate percentage. Should the asl run around .1 per cent it would be well to check the result by using 10 grams of the honey. The greatest care is necessary in ashing a product not to overheat.

\section{DEXTRIN.}

Transfer 8 grams of the honey to a 100 cc. flask with 4 ec. of water and add sufficient absolute alcohol to bring up to the mark. (The transfer is best made by decanting as much as possible of the liquid honey into the flask, then adding 2ec. of water to the dish (from a burette) to take up adhering honey and again decanting. By using 1ec. more of the water in two successive washings and adding a few cubic centimeters of the absolute alcohol each time before decanting, the honey can be completely transferred without the necessity of using more than 4 ce. of water. Finally rinse out the dish with absolute alcohol and then add it to the flask with continual agitation until the rolume has reached 100ce. Allow this to stand until the dextrin has settled out on the sides of the flask and the supernatant liquid is perfectly clear.

Then decant the clear solution thru a filter and wash the precipitated residue with 10ce. of cold 95 per cent alcohol to remove the adhering liquid, pouring the washings also thru the filter. Dissolve the residue adhering to the flask and the particles which may have been caught upon the filter in a little boiling water and wash into a tared platinum dish. Eraporate the contents of the latter and dry in a vacuum oven to constant weight as for the moisture determination. The alcohol precipitate is liable to carry sugars with it; so it is necessary to determine the weight of these and therefore make corrections for them.

After determining the weight of the dried alcohol precipitated, redissolve the 
latter in water and make up to a definite volume. If the alcohol precipitate weighs as much as 0.5 gram, the volume should be $50 \mathrm{cc}$. f from 0.5 to $1.0 \mathrm{gram}$, it should be $100 \mathrm{cc}$; from 1.0 to 1.5 grams $150 \mathrm{ce}$. and so on. Determine the sugars in aliquots from the filtered solution of the alcohol precipitate, both before and after inversion. The total alcohol precipitate less the weight of invert sugar and sucrose gives the weight of dextrin, from which the per cent can be obtained.

\section{REDUCING SUGARS.}

Take 10cc. of the solution used for the immediate polarization determination (see later) before inversion and make up to $250 \mathrm{ce}$. in a flask with water. Use 25ce. for reduction according to Allihns' method. Calculate the results expressed as dextrose to invert sugar by the factor 1.044. If Munson and Walker's method is used for reducing sugar determination, use 25ce. of the above sugar solution and 25ce. of water. Allihns' method and also Munson and Walker's method are given in detail in the Official Methods of the Association of Agricultural Chemists, in various handbooks for sugar chemists, such as Browne's, Spencer's, and in most works on food analysis as Leach's, etc.

\section{SUCROSE.}

Determine the total sugars after inversion by transferring 10ce. of the 55ce. solution (see.later) used for the invert polarization to a $250 \mathrm{cc}$. flask and making up to the mark with water. Take 25ec. for a reduction by either Allihns' or Munson and Walker's method. Calculate to per cent invert sugar. Subtract the per cent of invert sugar before inversion from this figure and multiply the difference by the factor 0.95 to obtain the per cent of sucrose. The percentage of sucrose cannot be determined accurately from the polarizations.

\section{POLARIZATIONS.}

Transfer 26 grams of honey to a 100ce. (true ce.) flask with water, and add 5cc. of alumina cream; make up the solution to volume at $20^{\circ} \mathrm{C}$, and filter and polarize the liquid at once for the "immediate polarization." Transfer 50ce of this filtrate to a 50-55ee. flask; add 5ee. of concentrated hydrochloric acid, and allow the whole to stand over night for inversion. Place the remainder of the filtrate in a flask, after removing the quantity necessary for the reducing sugar determination, and allow to stand over night. On the following day again polarize the two solutions at $20^{\circ}$ and also at $87^{\circ} \mathrm{C}$, making a total of five different readings.

The polarization at $87^{\circ} \mathrm{C}$ is a rather difficult one to make. It is necessary to have a water-jacketed tube and run water at about $95^{\circ}$ thru at first to bring quickly the temperature up to around $85^{\circ}$, then run the water at about $90^{\circ}$. When the solution itself has reached $87^{\circ}$, make a reading. If much time is necessary to bring the solution up to $87^{\circ}$, it might be well nearly to nentralize the invert solution before making the reading. This practice will give different results, and also the solutions will turn much darker, making a reading more diffieult.

The purpose of the $87^{\circ}$ reading is to obtain a reading after the invert sugar has become optically inactive. With substances other than honey dextro readings at $87^{\circ}$ on the inverted solution would indicate the presence of commercial glucose. In honeys the reading is due to the excess of dextrose plus the natural dextrins. Many chemists have fallen into this mistake.

\section{ACIDITY.}

Dissolve 10 grams of honey in water and titrate with tenth-normal sodium hydroxide, using phenolphthalein as indicator. Express the acidity as formic acid.

It is known that the sting of a bee is due to formic acid, so all analyses are calculated to formic acid. Experimental work on the acids of natural honey has shown that there are two groups of acids. present, volatile and non-volatile acids. Of the former, formic acid forms about one-half, the others being butyric, valeric, caproic, and capric. Of the non-volatile acids lactic acid predominates, then malic acid, succinic, and oxalic have been recognized. Where the honey has soured or fermented the acid formed is acetic.

DEXTROSE AND LEVTLOSE.

The percentage of these sugars can be 
calculated from the polarizations and reducing sugar contents. The results are only true when the reducing sugar, content has been determined by Allihns' method. The calculation is as follows:

Multiply the direct polarization at $87^{\circ}$ by 1.0315 ( $100 \mathrm{ce}$. of solution at $20^{\circ} \mathrm{ex}-$ pands to $103.15 \mathrm{ce}$ at $87^{\circ}$ ). Subtract this figure from the direct constant polarization at $20^{\circ}$, and then divide by the factor 2.3919. The figure thus obtained is the grams of levolulose in the normal weight of honey. Hence to find percentage, this must be divided by 26 .

The percentage of levulose, so found, if subtracted from the percentage of invert sugar obtained by reduction will give very closely the percentage of dextrose if these two sugars are present in nearly equal amounts. If these two sugars differ widely in percentages an error is introduced into the original calculation of invert sugar and hence in the percentage of dextrose. The most accurate procedure is to reduce the levulose to its dextrose equivalent in copper-reducing power by multiplying by the factor 0.915 . This subtracted from the total reducing sugars as dextrose will give the true percentage of dextrose. The results then of this determination, viz., pel' cent of dextrose plus per cent of levulose, will be greater than the percentage of inrert sugar found by reduction, but such results are correct.

\section{UNDETERMINED.}

The sum of the percentages of water, sucrose, levulose, dextrose, ash, dextrin, acidity, subtracted from 100 gives the percentage of undetermined matter. This consists of wax particles, pollen grains, albuminoids, proteids, tannin, essential oils, combined acids, and a number of other substances.

\section{PROTEIN.}

Weigh out 2 grams of the honey and transfer to a $500 \mathrm{cc}$. Kjeldahl flask; add 10 grams of powdered potassium sulphate and 25ec. of C. P. sulphuric acid. Place the flask in an inclined position, and heat below the boiling'point of the acid for from 10 to 15 minutes, or until frothing has ceased (a small piece of paraffin may be added to prevent extreme foaming).
This part of the operation is tedious on account of the sugars in the honey. Gradually increase the heat until boiling is obtained, then continue boiling until the mixture is colorless or nearly so, or until oxidation is complete. This may take over five hours. Cool and add 200ee. of water, then neutralize with sodium hydroxide solution (a few drops of phenolphthalein may be added to the liquid to determine easily when enough soda has been added). Connect immediately with a condenser and distill into half or tenth normal acid. Titrate this with tenth normal alkali, using cochineal as an indicator. A blank should be run with the reagents and the results subtracted from those obtained from the honey before calculating the percentage of nitrogen. The per cent of nitrogen times 6.25 gives the per cent albuminoids or protein.

American honeys run from 0.1 to 1.0 per cent, and even higher. German honeys average about 1.08 per cent with a range from 0.30 to 2.42 per cent.

DETECTION OF COMMERCIAL GLUCOSE.

The dextro rotation of a honey at 87 is due to honey dextrins. These are different in character from those dextrins obtained by the acid hydrolysis of starch, or such as occur in commercial glucose. One point of difference is the fact that honey dextrins are not colored by iodin solution, while the dextrin of glucose, except those of high-conversion products, are colored by iodin. Due to this fact Beckman has proposed the following test, which is qualitative in nature.

Prepare a one-to-one solution of honey with water and add a few drops to 2cc. of iodin solution. If commercial glucose be present the solution turns red or violet. The depth and quality of the color depend upon the quantity and nature of the glucose employed for adulteration. A blank test with a pure honey of about the same color, using the same quantity of iodin solution, should be made at the same time for the purpose of securing an accurate comparison of color.

If the original honey is dark in color or the test is not delicate enough, one can take the honey solution, add absolute alcohol until all the dextrins are precipitated, allow these to settle (never filter), decant 


\begin{tabular}{|c|c|c|c|c|c|c|c|c|}
\hline 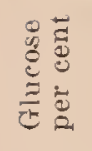 & 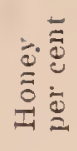 & 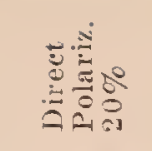 & 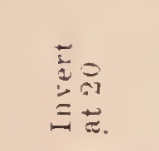 & 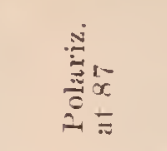 & 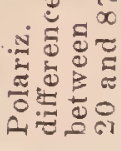 & 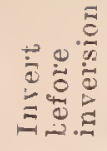 & 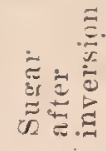 & $\begin{array}{l}50 \\
500 \\
20\end{array}$ \\
\hline 100 & & +153.8 & +153.34 & +144.32 & & 30.02 & 30.45 & \\
\hline 50 & 50 & +67.0 & $\begin{array}{r}+65.67\end{array}$ & $\begin{array}{r}+73.81 \\
\end{array}$ & 8.14 & 53.67 & 54.50 & 56.9 \\
\hline 20 & 80 & $\begin{array}{l}+15.4 \\
\end{array}$ & $\begin{array}{r}+13.42 \\
\end{array}$ & +33.00 & 19.58 & 69.00 & 70.35 & 19.2 \\
\hline 10 & 90 & $-\quad 2.4$ & $-\quad 4.84$ & +18.59 & 23.43 & 74.42 & 74.12 & 8.8 \\
\hline 5 & 95 & -11.5 & -14.30 & +11.66 & 25.96 & 75.74 & 77.80 & 3.8 \\
\hline 3 & 97 & -14.2 & -16.94 & $\begin{array}{r}+\quad 9.13 \\
+\end{array}$ & 26.07 & 76.62 & 78.01 & 3.7 \\
\hline$\underline{2}$ & 98 & -16.0 & -18.70 & +8.14 & 26.84 & 76.64 & 78.34 & 1.2 \\
\hline 1 & 99 & -18.2 & -20.90 & $+\quad 6.93$ & 27.83 & 77.20 & 78.87 & .0 \\
\hline 0 & 100 & -19.5 & -22.11 & $+\quad 5.94$ & 28.05 & 77.68 & 78.93 & .0 \\
\hline
\end{tabular}

liquid, and dissolve the dextrin in hot water, then treat with iodin. By this means as low as 2 per cent glucose can be detected.

To determine the quantity of commercial glucose the following method by Browne gives fair results. It is better than other proscribed methods.

METHOD FOR ESTIMATING GLUCOSE FROM

\section{THE POLARIZATION.}

The invert polarization at $20^{\circ}$ is subtracted from the invert polarization at $87^{\circ}$, and the result multiplied by 77 (the average per cent invert sugar after inversion in pure honeys). This product is divided by the per cent invert sugar after inversion found in the sample under examination. This figure is multiplied by 100 and the result divided by 26.7. The result so obtained is the percentage of pure honey in the sample under examination. This percentage subtracted from 100 gives the per cent glucose.

The table at the top of page gives results by this method on mixture of honey witl varying percentage of glucose.

The percentages actually found agree fairly well with those added. However, it is not safe for the percentage of glucose in mixtures with less than 10 per cent. Its presence in small quantities is easily told thru the qualitative test described above.

\section{ENZYMES.}

Enzymes are bodies of varying chemical nature (considered to be albuminous in nature) which occur in the constitution of animals and plants and effect decomposition of certain chemical compounds occurring in association with them without being used up themselves. They are all destroyed by high heat, but at lower temperatures are more or less affected. In honey, both invertase and diastase are present and are the principal ones. Invertase is capable of breaking up sucrose into dextrose and lerulose while diastase is capable of changing starch into dextrose. All honeys contain these enzymes. Boiling a honey destroys them. Heating a honey to $170^{\circ}$ or $180^{\circ} \mathrm{F}$. (a temperature above that recommended for liquefying a honey) destroys the action of invertase and weakens but does not destroy diastase. To destroy the activity of the latter it is necessary to bring the temperature up to $200^{\circ} \mathrm{F}$.

The test for enzymes is then important in assisting in the determination of adulteration with commercial invert sugar. A color reaction (See below Browne's or Bryan's modification of Fiehe's test) and a positive diastase test would signify commercial invert sugar.

The method of carrying on the test is as follows, "Moreau method."

Ten grams honey with 2 to $3 \mathrm{ce}$. of water are added drop by drop, shaking constantly to 100 ce. absolute alcohol. Allow to stand, then decant, and add cold recently boiled distilled water to the precipitate and filter. Repeat this process on a second 10 grams of the honey, boiling the filtered solution a few minutes. According to another method use the same amount of honey, but add $250 \mathrm{cc}$. of $95 \mathrm{per}$ cent alcohol, shake and centrifuge, then wash the precipitate repeatedly with 75 per, cent alcohol to remove all sugars, next dissolve in cold water and neutralize the solution to methyl-orange, using tenth normal sodium hydroxide, then add $1.5 \mathrm{ec}$. of one per cent formic acid.

The invertase is determined by adding 5cc. of ten per cent sucrose solution to a 
portion of the honey-extracted solutions, made to $100 \mathrm{ec}$. with cold recently boiled distilled water and determine the reducing portion of each of the honey-extracted solutions. To the remainder of the solution, add 5 drops of toluene to prevent growth of micro-organisms; place in an oven at 25 to $30^{\circ} \mathrm{C}$. for four days and again determine reducing sugars. For diastase, use the same procedure as described above, starting with 10 grams of honey, except that a solution of starch equivalent to 0.25 grams of potato starch is substituted for sucrose and the solution is kept at 45 to $50^{\circ} \mathrm{C}$. for 24 hours in place of 4 days at 25 to $30^{\circ} \mathrm{C}$. The results in each case are expressed in grams of reducing sugars per 100 grams of honey.

The following figures for diasțase on pure German honeys have been obtained: 0.60 to 3.68 , and for invertase 1.05 to 12.02 . There are no figures so far published for American honeys.

\section{ALBUMINOID PRECIPITATE "LUND'S TEST."}

In the undetermined matter of honey, there are varying quantities of substances precipitated by the addition of tannin and also phosphotungstic acid. The quantity of the precipitate so obtained has been used as a measure of adulteration. Commercial invert sugar contains none of these materials, hence no precipitate, so that a figure for this test below the minimum of a pure honey in conjunction with the diastase test and color test strongly indicated adulteration.

For these tests a special glass tube is necessary, similar in form to a Horvet maple tube. The tube should hold over $40 \mathrm{ce}$, and have a mark at the $40 \mathrm{ce}$. point. The lower portion of the tube should hold 4ce., and be $8 \mathrm{~mm}$. in diameter and be graduated into tenths of a cubic centimeter. The upper portion should be $16 \mathrm{~mm}$. in diameter. The lower portion of this part should be graduated into half cubic centimeters up to $20 \mathrm{cc}$; from $20 \mathrm{ce}$. to $40 \mathrm{ce}$. there need be no graduation.

\section{LUND'S TANNIN TEST.}

Take 20ce. of a filtered ten-per-cent honey solution in the tube and add 5ce, of a five-per-cent tannin solution (in distilled water), then add distilled water to the $40 \mathrm{ce}$. mark and shake thoroly. Allow the tube to stand 24 hours and then read off the volume of the precipitate. Results in Germany on this test show pure honeys never go below $0.9 \mathrm{ce}$. of the precipitate and seldom below 1.2ec. and may go as high as 4.0ce. Adulterated honeys show figures from nothing up to 0.30 and higher, but seldom above $1.0 \mathrm{cc}$.

\section{LUND'S PHOSPHOTUNGSTIC ACID TEST.}

In a tube described above, add 20ce. of a filtered ten-per-cent honey solution and then 5ec. of the following reagent: phosphotungstic acid, 2 grams; sulphuric acid (1 to 4), 20 grams; water, 80 grams; then water to the $40 \mathrm{ce}$. mark. Shake as before and allow to stand 24 hours. Pure honeys show from $0.3 \mathrm{cc}$. to $40 \mathrm{cc}$. of a precipitate, while adulterated honey much less. This latter test has been used more than the tannin test. Results from American honeys by American chemists have not been published.

COLOR TESTS.

In the commercial manufacture of invert sugar there is more or less decomposition of a small percentage of the levulose, giving rise to furfural or oxymethyl furfural. This latter body when treated with various reagents develops brilliant colors. This, then, is the basis of a color test for commercial invert sugar. As levulose and dextrose are present in pure honey, it is claimed that by overheating these same furfural bodies will be formed. Much has been written pro and con on this point, possibly mainly to cast doubt on these very delicate color tests. Heating as earried on by the beekeeper (up to $160^{\circ} \mathrm{F}$.) will never develop furfural in a pure honey. Heating to boiling and then cooling will not develop this substance. Boiling a very acid honey may give a very slight test, but taken along with the strength of color shown by commercial invert sugar when present in as low as 5 per cent no one would be confused by the test.

The number of these color tests proposed are too many to be given in one place. The following are easily worked. 
BROWN'S ANALIN ACETATE TEST.

Prepare fresh each time it is used the following reagent:

To 5ec. of anilin (this should be waterwhite) add 5cc. of water, shake, and then add glacial acetic acid to clear the emulsion (generally about 2ce. is necessary). To 5ce. of a 1-to-1 solution of the honey with water in a test tube add 1 to 2 cc. of the above reagent. Allow the latter to flow down the walls of the test tube to form a layer. In the presence of commercial invert sugar a red ring forms at the junction of the two liquids.

\section{BRYAN'S MODIFICATION OF FIEHE'S TEST.}

Prepare the following reagent fresh at each time of testing:

Five-tenths gram of resorcinol in $50 \mathrm{ce}$. of hydrochloric acid (Sp. Gr. 1.19). Place 10ce. of a 50-per-cent honey solution in a test tube and run 5ee. of redistilled ether on top. Shake contents gently (taking care not to form an emulsion), and allow to stand until ether layer is perfectly clear; transfer 2ec| of the clear ether solution to a small test tube, and add a large-sized drop of the reagent. Shake, and note the color immediately. In the presence of.commercial invert sugar the drop in the bottom assumes an orange-red color, turning to a dark red. Most pure honeys show this coloration when allowed to stand anywhere from half to one hour, but never on the immediate application of the reagent. Heated honeys do not develop an immediate coloration.

\section{FEDER'S ANILIN CHLORIDE TEST.}

Prepare freshly each time it is used the following:

To 100ec. of C. P. anilin add 30ce. of 25 per cent hydrochloric acid. For the test, 5 grams of the honey are mixed directly in a porcelain dish with 2.5ce. of the anilin reagent. A bright-red color indicates commercial invert sugar. Pure honeys may show a faint pink color at the start, but on standing this very often disappears.

\section{SUMMARX.}

To form a conclusion on a sample of honey it is necessary to make most of the determinations deseribed above. A moisture determination gives the data as to whether a sample complies with the United States standards in this particular. The determination of reducing sugars before and after inversion gives the only reliable data as to sucrose content. In this connection it should be noted that a fresh honey may show a high percentage of sucrose, but on standing show less, little, or none, depending on the activity of the enzyme invertase in the honey. The polarization figures, together with the reducing sugar content, furnishes the data along with the Beckman test for the presence or absence of commercial glucose. The presence of large quantities of sodium chloride in the ash would also help in deciding on commercial glucose. Too much dependence cannot be placed on the chlorine content of a honey unless it is known that the honey was not produced near salt water.

For commercial invert sugar the percentage of dextrose and levulose, the amount of ash and composition of the ash, the amount of tannin and phosphotungstic acid precipitate, the diastase and invertase reaction, the percentage of nitrogen, and the color tests are all helpful and needed. The presence of tartaric, phosphoric, hydrochloric, and sulphuric, also acetic acids in appreciable quantities are extra, and are valuable determinations. The quantity and kind of pollen, also appearance, are sometimes of value in deciding on a honey.

For the further consideration of this subject see Granduated Honex, ExTraCted Honey, Honeydew, Honey as FOOD, and Nectar.

HONEY AND ITS COLORS.-The various kinds of honey differ very much in color, flavor, and density. One variety may be practically colorless, while another produced in the same locality, under the same conditions, by the same bees, but from different flowers, may be a dark brown. One kind may contain less than one-sixth of water, while another may contain a fourth. The proportions of dextrose, levulose, and sucrose vary considerably; but as the extent of the variation is known to ehemists they are compelled to take this into account in forming an opinion from the analytical figures.

Ordinarily honey is judged by its color, flavor, and density. There is an almost 
endless variety of flavors, making it practicable to suit the most exacting connoisseur. Color is a fair guide, but not always so, for the famous heather honey of Europe is quite dark, and yet no honey stands higher in popular esteem on that continent.

The best honeys of this country are usually spoken of as "water-white," and, tho this is not quite correct, still it is near enough for all practical purposes without coining a new word.

Clover honey may be taken as the typical white honey by which others may be conveniently judged. For the purpose of comparison some may be a little lighter, and others a little darker shade; but these nice distinctions are visible only to experts

Taken by this standard, in the North there are all the clovers-white, alfalfa, ${ }^{*}$ crimson, mammoth, alsike, sweet-and the European. sainfoin; basswood, raspberry (wild), willow-herb (or fireweed), milkweed, Canada thistle, apple, cucumber (pickle), and Rocky Mountain bee plant. In the South white loney is obtained from the following: Gallberry (holly), sourwood, tupelo, mangrove, cotton, palmetto, bean, huajilla, catsclaw, huisache, mesquite, California sage, orange, and some others of less importance. In the American tropics the chief white honey is from logwood or campeche; on all tropical seashores, from campanilla (Cuba), and the mangrove.

Amber-colored honey comes from many sources. Among them, only the more faniliar ones can be noted in a popular book of this kind; namely, goldenrod, wild sunflower, heartsease, Spanish needles, sumae, poplar, gum, eucalyptus, magnolia, marigold, horsemint, horehound, earpet-grass, and the hog plum (hobo), rose-apple, and royal palm of the West Indies.

Of dark honeys there are two great examples-the buckwheat of the United States and Europe, and leather, which is confined to Europe alone. The latter, tho dark, is a rich, strong-flavored, thick honey, so dense that the extractor is not used to take it from the combs. That produced in Scotland commands a very ligh price, while that of England is cheaper, being. gathered from another species of heather. In North Germany the heath or heather

* This is a light amber in southern California and Arizona. honey commands a good figure. It is largely produced by migratory beekeepers, their bees existing on white clover during summer, and in the fall being moved to the heaths.

Buckwheat honey is not nearly so good as clover, either in flavor, density, or color: but it is so liberally produced in buckwheat localities that it is a paying crop to the beekeeper. It blooms late, hence the bees can be prepared in ample time to profit by its bloom. This feature alone makes it very valuable to the beekeeper who is fortunate enough to live in a buckwheatgrowing section. In those parts of this country where buckwheat is grown largely, consumers are willing to pay as nuch, or almost as much, as they will for fine white honey. Indeed, many prize it more highly.

In France there is a great demand for buckwheat honey from bakers of a kind of bread which has been made for centuries. No other sort of honey is desired by these bakers, who derive nearly all their supply from Brittany, where buckwheat is commonly sown. Attempts have been made to get the bakers to use other dark honeys, but without success.

In Europe there are some prominent honeys which are almost or quite unknown in this country. Heather has been mentioned. Sainfoin is another which is quite common, being almost the same as our alfalfa honey. Narbonne honey belongs to this class. In southern Europe romarin (rosemary) is very highly spoken of; and in Greece there is the classically famous honey of Mount Hymettus, from wild thyme. In Australia the honey of encalyptus is highly appreciated, but attempts to sell it in England have alrays ended in failure, altho it ought to be useful for persons suffering from coughs and colds. Instead of the eucalyptus flavor proving to be an attraction it proved to be a drawback. In California, encalyptus has a limited demand.

HONEY AS A FOOD.-During the centuries previous to the advent of cane and beet sugar, honey was the only concentrated sweet in the world's dietary. In those times honey was not produced in abundance as now, and people could not freely indulge their desire for sweet. Cheap 
granulated sugar has made a very great change in the situation. The use of sweets has increased almost beyond belief. In the United States, for instance, the per capita consumption is about 85 lbs. per year-an enormous amount, viewed from any standpoint. People at large have not stopped to consider the probable effect of eating so much sugar; but it is a serious question nevertheless, whether the present generation would not be benefited if honey were restored, at least partially, to its former place in the diet. A study of dietetic values discloses at least two reasons why honey should be given a preferred place among the sweets.

First, honey is more easily assimilated than any of the other sweets. Granulated sugar and allied products have a tendency, when eaten in more than small amounts, to produce irritation in the digestive tract. This sometimes results in nothing more than a hindrance to digestion; at other times it is severe enough to cause real indigestion. Especially is this true with sedentary workers. Honey is remarkably free from this fault. To begin with, it does not require digestion at all; it is ready for absorption into the blood without change. In addition, it is much less likely to have the hindering effect on digestion noticeable in the case of cane sugar. This has been recently elearly demonstrated by Philip B. Hawk, of Jefferson Medical College, Philadelphia, Pa. Professor Hawk carried out a series of experiments, upon a normal man, to determine the influence of honey on gastric digestion. He first fed the man 40 grams of wholewheat bread alone. The contents of the stomach were analyzed for acid and pepsin at 15-minute intervals, and an accurate and detailed record was kept. The experiment was then repeated, adding to the bread half its weight in honey (20 grams).

The following quotation tells the result of the work in Prof. Hawk's own words:

"An examination of the chart will show that the bread with honey was digested and left the stomach as quickly as the bread alone. Similar pepsin values were obtained; and, while there was a slight depression of acidity such as always follows the ingestion of foods containing much sugar, digestion was completed as soon as with the bread alone, altho the addition of honey had practically doubled the food value of the product from the energy standpoint.

"The use of honey with bread and in similar ways would, therefore, appear to be generally preferable in the case of children to the eating of candies. Honey serves to make the highly nutritious bread far more palatable, leading to greater consumption of body-building foods instead of depressing the appetite, as is likely to be the case with candies which are eaten between meals. At the same time, honey furnishes the body very considerable amounts of energy in the most available form. The ligh place given to it in the diet is therefore well deserved."

There is a second reason why honey deserves a pleferred place among sweets. It is a reason the importance of which is seldom appreciated, but a reason which should be of vital concern to every one interested in good health. Honey differs from most of the other concentrated sweets, notably granulated sugar, in that it is not pure sugar. Granulated sugar is so pure that it is practically a chemical entity, sucrose and nothing else. It contains no mineral matter at all. It is too pure, strange as that may sound. On the other hand, honey contains, besides its sugars, numerous "accessory components." From a dietetic standpoint, these accessory components are important because we have in them practically all the mineral elements found in the human body. It is true that they do not occur in large quantities in honey, but the amounts are comparable to the amounts found in numerous other foods of importance. It may be wondered whether the stress placed on the presence of mineral matter in our food is well founded or not. Some may be inclined to think that enough mineral matter is found in other foods to cover up the deficiency in white sugar. But it must be considered that white sugar is used in literally enormous amounts. This situation is most clearly set forth by Prof. Henry C. Sherman, one of the foremost authorities on food and dietetics in the United States. We quote:

" Dogmatic statements regarding the

*"Food Products," by Henry C. Sherman. (Macmillan.) 
proper place of sugars in the diet are apt to be seriously misleading. The problem is complicated and the evidence in many respects is still obscure.

"Until relatively recent times sugar was too expensive to be used freely by most people; but, with the development of the industry and the cheapening of the product, the consumption of sugar has increased at an exceedingly rapid rate.

"The thoughtful student of food problems must legard this development with mixed emotions. The cheapening of a staple article of food, which is almost universally popular and which, like the refined sugar of commerce, is of uniform and well-known composition and practically free from danger of adulteration or harmful deterioration, would be a source of great satisfaction but for the fact that refined sugar constitutes an extreme case of a one-sided food, its sole nutritive function being to serve as fuel so that, as the energy requirement of the body is met to a larger and larger extent by the consumption of refined sugar, there is a constantly increasing danger of unbalancing the diet and making it deficient in some of the substances which are needed for the building and repair of body tissue and for the regulation of physiological processes.

"The fuel value of sugar is about 1800 calories per pound, so if, as estimated, the consumption of sugar in the United States now amounts to 85 pounds per capita per year, the energy obtained from eating sugar must amount to about 420 calories per capita per day. If the per capita energy requirement be estimated at about 2000 calories per day it follows that about one-fifth of the energy requirement is being met by eating sugar (of course not all of this sugar appears on the table as such) and that the intake of protein, phosphorus, calcium, potassium, iron, and other essential elements and of such important tho imperfectly understood substances as the lipoids and vitamines, is on the whole about one-tenth lower than would be the case if the sugar were reduced one-half and the energy now derived from sugar were supplied by an increased consumption of the other articles of food. Are we to assume that the ordinary dietary of the people of the United States furnishes such an abun- dance of all the essential elements and each specific necessary compound that a difference of 10 per cent in the intake is of no consequence? The investigations of recent years indicate clearly that no such assumption is justified.

"The objection to the too free use of sugar, on the ground that it serves only as fuel and may replace to an undue extent other food materials which meet other nutritive requirements, applies equally to commercial glucose and to most candy. It does not hold to the same extent as regards molasses and those syrups which contain the natural ash constituents of the plant juices."

Before closing the discussion of the food value of honey, it is very important that mention is made of the vitamine content of honey. The reading public has learned a great deal about vitamines in the last two or three years, and nearly everyone has been educated to a realization of the importance of these almost intangible "food accessories." For those who do not feel sufficiently acquainted with the subject it is suggested that the article Vitamines, further on in this volume, be read. The matter may be summarized here by saying that Prof. Hawk, mentioned above, has proved the presence of what many scientists consider the most important class of vitamines, Fat Soluble A, in comb honey. This places comb honey in a class entirely apart from all the rest of the sweets, none of which have any vitamine content at all.

In concluding, it may be said briefly that honey is preferable to other sweets, from a dietetic standpoint merely (if from no other), for the following reasons: First, it is far easier to assimilate than the other sweets, especially white sugar, in that it taxes the digestion not at all; second, it is not super-refined, and utterly lacking in accessory food components, like white sugar; and third, comb honey contains the rarest and most important of the vitamines, Fat Soluble A. See also Sugar, and Vitamines.

\section{THE USE OF HONEY IN COOKING.}

The simplest way to serve honey is the most common-just spread it on bread or rolls, either in the form of comb or liquid. 
It goes as far as jam in this way. Honey is often served with rice, breakfast cereals, pancakes, and similar foods. Honey and cream is an ideal combination. Honey can be used to advantage in flavoring ice cream, gelatine creams, and delicate blanc-manges. Honey combines particularly well with oranges, apples, bananas, peaches, and dried fruits. $\Lambda$ delicious substitute for maple syrup is made by honey diluted with hot water, and the same syrup cold is superior to undissolved sugar for sweetening summer drinks. This method of flavoring goes well with carbonated water.

Fruits cooked in honey keep indefinitely. Bar-le-Duc currants, which sell ordinarily at a high price, are often made by cooking currants in honey. A brighter color is present in fruits so preserved than in those bottled in the usual way, as honey is a preservative.

Indiscriminate substitution of honey for corresponding amounts of molasses or sugar in recipes does not always give the expected results. The cook should keep in mind the difference in chemical nature between honey and syrup before making up a recipe. Better make a small amount as a test before entirely filling a new recipe.

Less soda is required when substituting honey for ordinary molasses. Experiments. in the government nutrition laboratory have shown that $1 / 4$ level teaspoonful of soda is generally the amount required with a cupful of honey. In baking with sour milk and soda it is well to add a pinch of baking-porvder to every pint of flour. Cakes will be lighter and finer grained if this is done. When baking-powder is substituted for soda use a little more.

When honey is used in a recipe less milk is required on account of the water in the honey. Compared with some of the "corm syrups" on the market, honey is sometimes considered, pound for pound, more expensive, but where two or three cups of syrup will be required in a recipe only one of honey is necessary. The cake or cooky is improved in flavor and healthfulness with no increase in cost.

Baked foods keep much better when prepared with honey instead of with sugar. It was formerly believed that cakes baked with loney absorb moisture from the air, but experiments have been made in the government nutrition laboratory which seem to show that the softness of the honey cake is due to the presence of the levulose in the honey. The fact that such cakes, tho soft, never become soggy, even tho exposed to moist air for a long time, seems to bear out this conclusion. Cakes should be allowed to "ripen" for a day or two at least, to develop the honey flavor. Honey fruit cakes, hermits, and the like are better at the end of two or three weeks.

Cakes made with honey and butter will keep until the butter grows rancid. Cookies made with honey will not dry out. Dough itself containing honey will stay fresh indefinitely. The remarkable merits of goods baked with honey have led largé wholesale bakers and cracker manufacturer's to use quantities in their product. Some big firms buy honey annually by the carload. The same power in retaining moisture and freshness is present in icings made with honey. The icing will last for months unimpaired in consistency and taste, and is especially valuable for such cakes as fruit cakes which are to be kept for a long time. Orange, bitter almonds, lemon, and fruit flavors generally blend well with honey, as do also anise, cardamon, coriander, and other spicy seeds.

Contrary to directions for cooking honey, as given in some of the old cook books, it is seldom necessary to bring honey to the boiling-point and then skim and cool it. Bringing honey to the boiling-point is sure to give a burnt flavor. It should not be kept unnecessarily hot for any length of time.

\section{THE HONEY RECIPES.}

All of the recipes here given have been thoroly tested; but any recipe, while it may be successful in the hands of the originator, often needs modification when it is tried by others. All will give good results, but the following 20 recipes (pictured on page 475 ) are especially fine. In this connection particular attention is drawn also to the one for making cereal coffee. The ingredients used are so simple and the work of preparing consumes so little time that there is no one who should miss trying this delightful drink. It has a very rich flavor, especially when cream is used, without the scorched, bitter taste that most 
cereal coffees have. The expense, of course, is so little as to be practically nothing. The honey and egg used allow the bran to brown to a rich color without burning, so that the final result is surprising. Try it.

\section{1. -OATMEAT, COOKIES.}

2 cups rolled oats

2 cups fiour

1 teaspoon soda

1 tablespoon grated chocolate or cocoa

$1 / 2$ teaspoon cinnamon

$1 / 2$ teaspoon cloves

Sift the dry ingredients together (except the rolled oats) and add all other ingredicnts, the soda dissolved in the sour cream. Stir well, and drop by teaspoonfuls into cooky pans, or bake in gem-pans. Nuts may be omitted.

\section{2.-HONEY RUSKS.}

3 cups flour

2 cups milk

$1-3$ cup honey

$1 / 2$ cup warm water

1 cake compressed yeast

$1 / 4$ teaspoon salt
$1 / 2$ teaspoon nutmeg

$1 / 2$ teaspoon salt

1 (up chopped raisius

12 cup chopped nuts

cup hones

1 cup sour cream

2 eggs
Dissolve the yeast in the warm water. Mix the flour, milk, honey, yeast, and salt and set in a warm place to rise. When very light, add the beaten egg, butter, and enough flour to make a stiff dough. Knead lightly and mold in small biscuits or twists, Raisins, currants, or cardamon seed may be added at discretion. Rub the top with beaten egg; cover, and let them rise again until they are double in bulk, and are very light and fluffy. Bake 20 to 25 minutes in a moderate oven, glazing them with sugar and water just before removing them from the oven.

\section{3.- HONEY BAKE? BEANS}

Soak wrer night one pint of small white beans. Bring to a hoil, adding baking soda the size of a bean, and allow to simmer for half a h hour. Drain, and cook till tender in salted water, but not long enough to hreak the skins. Drain and rinse the beans, and put them in an eartheln bean-pot. Pour over them a pint of milk, adding a tablespoonful of butter, 2 tablespoonfuls honer, and a pinch of cayenne pepper. Cover closely, and bake in a slow oven till the milk is absorbed.

\section{- LADY FINGERS.}

1 cup honey

2 eggs

$1 / 2$ cup buttèr

4 cups flour

$1 / 2$ teaspoon baking 1 ow-
der
$1 / 2$ teaspoon soda
1 teaspoon salt

Sugar

Blend the honey warmed with butter, add beaten eggs and flour, sifted with the dry ingredients. Cut in strips. Roll in sugar. Bake in a quick oven.

$$
\text { 5. MARSHMALLOW CREAM }
$$

$\begin{array}{cc}1 / 4 \text { cup honey } & 1 / 2 \text { cup boiling water } \\ 1 \text { teaspoon gelatine } & \text { Whites } 2 \text { eggs } \\ 1 / 2 \text { cup cold water } & 1 \text { teaspoon vanilla } \\ 1 \text { tesspoon lemon extract }\end{array}$

Dissolve gelatine in the usual way, heating it over a teakettle until thoroly dissolved. Cool, but do not chill; stir in the houey, and add to the whites of the eggs beaten very light, a few spoon. fuls at a time, beating constantly. Divide into 2 parts; to one part add a color and flavor with va. nilla, about 1 teaspoon; to the other part add 1

teaspoon lemon extract. Mold in layers, adding nuts to one part aud maraschino cherries to the other. Serve with or without whipped cream.

\section{6.-FRUIT CANNED WITH HONEY.}

Prepare fruit as usual in canning. Put on to boil. When the fruit is ready for canning add honey, about as much of it as one would use of sugar. Be sure to let the fruit come just to the boiling point; after adding the honey do not boil, as this is liable to damage the fine flavor of the honey. Have the jars ready, clean, and very hot; put in the fruit and seal. Fruit canned thus keeps better than by the old method of canning with sugar; it has in addition the delicate flavor of the honey. Only those who regularly use honey in can. ning and preserving can appreciate the rich flavor and the fresh natural color of the fruit thus prepared.

\section{7.-SOUR-MILK CAKH}

$1 / 4$ cup lard or butter

$1 / 2$ cup sugar

$1 / 2$ cup honey

$1 / 2$ cup sour milk

$1 \mathrm{egg}$

$12 \cdot 3$ cups flour

\section{$1 / 2$ teaspoonful soda \\ 1 teaspoon baking pow- der \\ $1 / 2$ teaspoon cinnamon \\ $1 / 4$ teaspoon cloves \\ Pinch salt}

Nutneg

Beat the sugar and lard to a cream and then add the egg well beaten and the other ingredients. Use little nutmeg and mix the soda with the flour. Bake in either jelly-tins ol loaf in a moderate oven, and put together with caramel frosting.

\section{8.-GRATHAM PUDDING.}

$1 / 4$ cup butter 2-3 cup honey $1 / 2$ cup milk 1 egg

Melt the butter; add the honey, milk, and egg. well beaten; dry ingredients mixed and sifted, and raisins. Turn into buttered mold; cover and steam $21 / 2$ hours. Serve with pudding sauce.

$$
\text { 9.--HONEX NOUGATINES. }
$$

$1-3$ ('up lioney

1-3 cup pure coln syrup Paraffin (size of a pea)

1 rup sugar

$1 / 4$ teaspoon salt

$1 / 4$ ('up water

Mix the honer, corn syrup, or slucose, sucrar, paraffin (piece size of pea), and water and boil until a drop makes a hard ball when dropped in cold water $\left(248^{\circ}\right.$ E.). Stir occasionally while boiling. Pour part of the syrup gradually on to the whites of the eggs, beaten dry. Add the salt. Beat constantly in pouring. Boil the remainder of the syrup until it is brittle when tested in cold water $\left(290^{\circ} \mathrm{F}.\right)$, and again pour on the eggs, this time all of the syrup, and beat constantly while pouring. Then boil the mixture and beat constantly until it is crisp when tested. Cool in a buttered tin. Cut in oblong pieces and coat with chocolate.

$$
\text { 10.-HONEY DROP CAKES. }
$$

1 cup sugar

2 tablespoons honcy

2 or 3 eggs

2-3 cup shortening

1-3 cup buttermilk or sour cream

$1 / 4$ teaspoon soda.
2 teaspoons baking powder

Pinch salt

$1 / 2$ teaspoon vanilla, orange, or lemon to taste

About $31 / 2$ cups flour
Creain the sugar, shortening, and honey, add the eggs well beaten and then the buttermilk. Sift the 


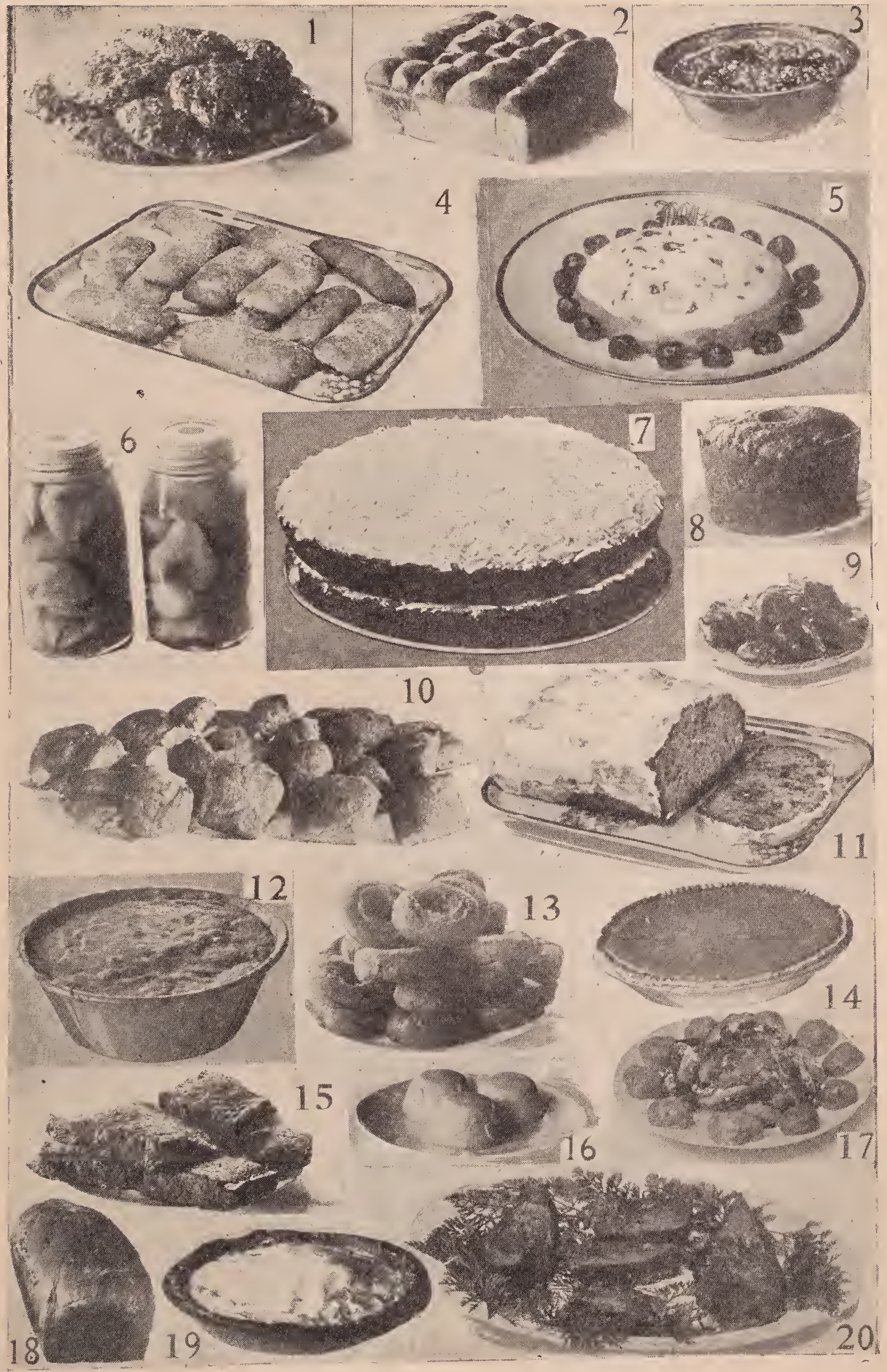

The results of twenty of the recipes selected as the best. See preceding and following pages: 
dry ingredients in fiour enough to make a stiff batter to drop from spoon. Bake in moderate oven. These cakes will run together in baking, and must be cut apart with a knife, but are much better than rolled, and much less trouble to bake.

\section{1.-FRUIT CAKE.}

$\begin{array}{lc}3 / 4 \text { cup honey } & 1 \text { cup maraschino } \\ 1 / 2 \text { cup butter } & \text { cherries, cut up } \\ 2 \text { eggs } & 3 \text { teaspoons baking pow- } \\ 1 / 4 \text { cup milk } & \text { der } \\ 1 \text { cup raisins } & 1 / 4 \text { teaspoon salt } \\ 1 / 2 \text { cup chopped citron } & 1 \text { teaspoon ginger } \\ & 5 \text { cups flour }\end{array}$

Warm the butter, honey, and milk over a slow fire; cool, and add the well-beaten eggs, the salt, and the ginger. Sift the baking powder with the flour; dredge the fruit with flour, and add these alternately. Mix well and baked in greased loaf. tin about an hour.

\section{2.-APPLE PUDDING.}

$\begin{array}{lc}\text { Apples sliced fine } & 2 \text { eggs } \\ 1 / 4 \text { cup honey } & 1 / 2 \text { cup water } \\ \text { Cinnamon } & 3 \text { or } 4 \text { slices bread } \\ \text { Butter } & \text { crumbled } \\ 1 \text { teaspoon salt } & 1 \text { cup cooked rice }\end{array}$

The rice should be cooked for several hours. Beat into this the yolks of the eggs. In the bottom of the pan place a layer of crumbs with dots of butter here and there; then a layer of apples, with honey and cinnamon on top. The third layer is a mixture of rice, egg, and salt. The fourth and fifth layers are a repetition of the first and second. Add water and bake in a moderate oven. Cover with meringue.

\section{3.-DOUGHNUTS.}

$\begin{array}{lc}1 \mathrm{egg} & 1 \text { teaspoon cleam tartar } \\ 1 \text { cup sweet milk } & 1 \text { teaspoon soda } \\ 1 \text { cup honey } & \text { Flour } \\ 2 \text { tablespoons shortening } & \text { Pinch salt }\end{array}$

Cream the honey and shortening together and add the egg, well beaten, and the other ingredients. Mix well, and add flour enough to roll out and cut easily. Roll out on baking board, and cut with doughnut-cutter. Fry in hot lard. The honey in this recipe makes the doughnuts a delicious brown, and also keeps them moist for a long time.

\section{4.-PUMPKIN PIE}

2 cups sifted pumpkin

2-3 cup sugar

1 cup honey

4 tablespoons flour

2 teaspoons ginger

1 teaspoon cinnamon

3 cups milk

Mix the flour with the sugar and add to the pumpkin. Then stir in the honey, the spices, and the milk with all its cream. Recipe makes 2 pies.

\section{5. - GINGER DROP CAKES.}

$\begin{array}{lc}1 \text { cup sugar } & 3 / 4 \text { cup sweet milk } \\ 1 \text { cup honey } & 1 \text { tablespoon ginger } \\ 1 \text { egg } & 1 / 2 \text { teaspoon salt } \\ 1 \text { cup lard } & 1 \text { teaspoon soda }\end{array}$

Cream the sugar, lard, and honey together. Dissolve the soda in a little hot water. Add the egg well beaten and the milk. Use enough flour to make the batter stiff enough to drop from spoon. Bake in greased gem pans in moderate oven, or drop on greased pan from spoon.

\section{6. - HONEY CORNSTARCH PUDDING.}

1-3 cup honcy

$1 / 4$ teaspoon salt
$4 \frac{1}{2}$ tablespoons cornstarch 4 cups scalded milk
Mix the honey, salt, and cornstarch. Stir in the liot milk gradually, stirring until smooth. Stir and cook over boiling water until the mixture thickens. Cover and cook 15 minutes. Turn into a wet mold, chill, and serve with cream and sugar.

\section{7. 一 HONEY FONDANT.}

2 cups granulated sugar $1-3$ cup honey $1 / 2$ cup water

Mix, put over fire, and stir only until the sugar is dissolved. Boil carefully until able to shape a very soft ball when tested in cold water (about $238^{\circ}$ F.). Do not stir while boiling and do not scrape off sugar which adheres to the side of the pan. When done pour into greased platter and partially cool. Beat and stir with a wooden spoon until it begins to crumble and then knead with the hands like dough. Pack in a bowl, cover. with cloth, and set aside until needed. When ready for use the bowl of fondant may be set in hot water until soft enough to handle. Any flavoring may be added when shaping into candies. The honey flavor alone is delicious when the fondant is used to stuff dates.

The use of noney in fondant obviates the necessity of using cream of tartar. The slight acidity of the honey keeps it from graining too soon. If the fondant is boiled too hard, pull until white; the result will be a fine taffy.

\section{8. - WHOLE-WHEAT BREAD.}

1 quart whole-wheat, flour (may be $1 / 2$ graham or 1.3 rye) scalded milk cold
1 pint water (may be $1 / 2$

\section{1 large cooking spoon} honey

$1 / 2$ compressed yeast cake, or the equivalent

$1 \frac{1}{2}$ teaspoons salt

Butter, size of an egg
Dissolve the yeast thoroly in the water; have the water slightly warm in cold weather. Add the honey; mix well; add the salt, and stir until dissolved. Mix the flour and water thoroly by means of a large cooking spoon, putting all together at once. The dough should be rather sticky and soft. If the dough is too stiff with a pint of water, more may be added, a teaspoonful at a time thoroly incorporated, until the right consistency is' obtained. If the bread is wanted rather dry, leave the dough stiffer.

Cover closely, keeping in a warm place in cold weather, and vice versa. In the morning turn the dough out on the board, and knead into it the butter, flouring the board and hands as lightly as possible. Make 2 loaves in narrow pans, cover, and keep warm to rise. It should about double in bulk. If the dough is not covered closely the surface will dry so as to form a skin. This will cause streaks in the bread. Bake 30 to 40 minutes in an oven not too hot. This bread does not become stale as soon as other bread. It contains all the vitalizing elements of the grain.

\section{9.-TIP.TOP LEMON PIE}

$\begin{array}{lc}3 \text { eggs } & 1 / 2 \text { lemon } \\ 1 / 2 \text { cup honey } & 1 \text { teaspoon melted butter } \\ 1 \text { tablespoon flour } & 11 / 1 \text { cups rich milk }\end{array}$

Combine thoroly the yolks of the 3 eggs beaten light, the honey, flour, the juice, flesh, and grated rind of half a lemon, and the butter. Mix thoroly in the order given and add the milk; pour into a pie-plate lined with a good crust, pricked to prevent air blisters. Bake until set. Cover with a meringue of the whites, beaten with 3 tablespoons honey and a few drops of lemon juice, and brown lightly.

Many prefer to bake the crust separately and also cook the filling in a double boiler before putting it in the shell, 


\section{0. - BAKED SQUASH}

Peel and slice the squash into pieces about $1 / 2$ inch thick. Place slices in the bottom of a large bread pan. Dot each slice with a generous piece of butter; strew honey over squash, 1 teaspoon to each slice; then pour in enough hot water to cover the bottom of the pan. After cooking on top of the range for 10 or 15 minutes, turn each slice with a knife and boil until tender. More hot water may have to be added. Place the pan in the oven and let the squash take on a delicate brown. Serve at once after removing from the pan.

\section{HONEY CAKES.}

LEMON CAKES.-Bring $1 \frac{1 / 2}{2}$ cupfuls of honey to the boiling point. Skim if necessary. Add $1 / 4$ cupful of butter and cool. Add 2 cupfuls of pastry flour, stirring it in carefully. Let this mixture stand over night. When ready to bake, stir in the grated Jellow rind of 1 lemon, 2 tablespoonfuls of lemon iuice, $1 / 2$ cupful chopped blanched almonds; add $1 / 2$ teaspoonful of soda dissolved in a little lukewarm water, and bake in small round tins. Ice when cool.

NuT CAIES.-Beat to a cream $1 / 2$ cupful of but ter and 1 cupful of powdered sugar. Beat into this $1 \mathrm{egg}$ well beaten and $1 / 2$ cupful of lioney. Stir in 2 cupfuls of pastry flour, previously sifted, with 2 teaspoonfuls of baking powder, and last stir in $1 / 2$ cupful of finely chopped filberts. Let the mixture stand where it is very cold (do not freeze) over night. When ready to bake, roll the dough very thin, cut into fancy shapes, brush them over with the white of an egg diluted witl a teaspoonful of warm water. Sprinkle the cakes with granulated sugar and chopped filberts. Bake in a hot oven until a golden brown.

SHort CAKE.-Three cups flour, 2 teaspoonfuls baking powder, 1 teaspoonful salt, $1 / 2$ cup shortening, $1 \frac{1}{2}$ cups sweet milk. Roll quickly, and bake in a hot oven. When done, split the cake and spread the lower half thinly with butter, and the upper half with $1 / 2$ pound of the best-flavored honey. (Candied honey is preferred. If too hard to spread well it should be slightly warmed or creamed with a. knife.) Let it stand a few minutes and the honey will melt gradually, and the flavor will permeate all thru the cake. To be eaten with milk.

SOFT CAKE.-One cup butter, 2 cups honey, 2 eggs, 1 cup sour milk, 2 teaspoonfuls soda, 1 teaspoonful ginger, 1 teaspoonful cinnamon, 4 cups flour.

EGgLess CAKE.-One cupful sugar, 1/2 cup honey, 1 cupful sour milk, 2 tablespoonfuls of butter, 1 cupful chopped raisins, 1 oupful chopped dates, 1 teaspoonful soda, $2 \frac{1}{2}$ cupfuls flour. Spices may be added to taste.

SPONGE CAKE.-One coffee-cup honey, 1 cup flour, 5 eggs. Beat yolks and honey together. Beat whites to a froth. Mix all together, stirring as little as possible. Flavor with lemon juice or extract.

RAILROAD CAKE.-One cup honey, 1 heaping cup flour, 1 teaspoonful eream tartar, $1 / 2$ teaspoonful soda, 3 eggs, and a little lemon juice. Stir all together ten minutes. Bake 20 minutes in quick oven.

LWMON CAKES.-One cup butter, 2 cups honey, 3 eggs well beaten, 1 tablespoonful essence of lemon, $1 / 2$ cup sour milk, 1 teaspoonful soda. Flour enough to make as stiff as can well be stirred. Bake at once in quick oven.
JELLY RoLL.-Three eggs or yolks of 6, 1 cup of white sugar (scooped), 1 cup of flour (heaped), 1 teaspoonful of butter, 2 tablespoonfuls of sweet milk, 2 teaspoonfuls of cream tartar, 1 teaspoonful soda or 2 of baking powder. Bake in an oblong pan, spread with granulated honey, and roll at once. Set where it will cool quickly.

SwISS CAKF.-Melt 4 ounces butter; add $1 \mathrm{lb}$ of honey, stirring well; take it off the fire and let it cool. Add the minced rind of a large lemon, 4 ounces sweet almonds chopped fine, a little nutmeg 2 scant teaspoonfuls of baking soda, dissolved in a little water. Mix these well and add flour until very stiff, and set in a cool place 12 hours. Roll out $1 / 2$ inch thick, cut into squares, decorate with nuts and chopped citron. Bake in hot oven. Make two dozen cakes from this amount.

Pork CAKF.-One pound fat pork chopped fine, 1 pint boiling water poured on pork; 2 cups honey, 3 teaspoonfuls soda, 2 cups raisins, 2 teaspoonfuls each of cloves, cinnamon, and nutmeg; about 7 cupfuls of flour.

COFFEE CAKE.- 1 cup of honey, $1 / 2$ cup of sugar, shortening size of an egg, 3 cups flour, 1 teaspoonful soda dissolved in 2-3 cup of cold coffee (scant), 1 teaspoonful of cinnamon, $1 / 2$ teaspoonful of cloves, $1 / 2$ teaspoonful of nutmeg, 1 .cup of raisins (floured). If too thin, add a little more flour.

FRUIT CAKE.-Two cups of honey, 2 cups of raisins, 1 cup of shortening, $1 / 2$ cup of soul milk, 1 teaspoonful soda, $1 / 2$ teaspoonful cloves, $1 / 2$ teaspoonful cinnamon, $1 / 2$ teaspoonful nutmeg, 4 cups flour. Bake 40 minutes.

Frurt CAKE.-One and one-half cups honey, 2-3 cup butter, $1 / 2$ cup sweet milk, 2 eggs well beaten, 3 cups flour, 2 teaspoonfuls baking powder, 2 cups raisins, 1 teaspoonful each of cloves and cinnamon.

Frurt Care.-One-half cup butter, $3 / 4$ cup honey, 1-3 cup apple jelly or boiled cider, 2 eggs well beaten, 1 teaspoonful soda, 1 teaspoonful each of cinnamon, cloves, and nutmeg; 1 teacupful each of raisins and dried currants. $\mathrm{K}$ arm the butter, honey, and apple jelly slightly; add the beaten eggs, then the soda dissolved in a little warm water; add spices and flour enough to make a stiff batter, then stir in the fruit; and bake in a slow oven. Keep in a coverfed jar several weeks before using.

FruIT CAKE.-Two eggs well beaten, 1 cup butter, $1 / 2$ cup sour cream, 1 cup honey, 1/2 cup sugar 1 teaspoonful soda dissolved in warm water, 1 teaspoonful cinnamon, $1 / 2$ teaspoonful cloves, 1 cup raisins, 1 cup currants, 2 cups flour.

HONEY TEA-CAKE.-One cup honey, $1 / 2$ cup sour cream, 2 eggs, $1 / 2$ cup butter, 2 cups flour, scant $1 / 2$ teaspoonful soda, 1 teaspoon cream of tartar. Bake 30 minutes in a moderate oven.

Fruit Cake.-Four eggs, 5 teacups flour, 2 teacups honey, 1 teacup butter, 1 teacup sweet milk, 6 teaspoonfuls baking powder, 1 lb. raisins, 1 lb. currants, 1 teaspoonful cloves, 1 teaspoonful cinnamon, 1 teaspoonful nutmeg. Then bake in slow oven. The above will keep moist for months.

CrTRON CAKE.-Two eggs, 1 cup dark honey, 4 tablespoonfuls butter, 1 cup milk; 3 cups flour, $1 / 4$ lb. citron chopped fine, 2 teaspoonfuls baking powder, 1 teaspoonful lemon.

RAISIN CARE.-Three eggs, 1 cup honey, 4 tablespoonfuls melted butter, 1 cup sweet milk, 1 1-3 cups raisins chopped fine, 3 cups flour, 1-2 tea- 
spoonful soda, 2 teaspoonfuls baking powder, 1 tea. spoonful ranilla extract.

DROP CAKLS. - Two eggs beaten without separat ing, 3 tablespoonfuls softened butter, 1.3 cup honey, 1 1.3 cups flour, 1 1-3 teaspoonfuls baking powder. Drop on buttered baking-sheet about $1 / 2$ teaspoonful of batter to a cake. Put then well apart spread lightly with the bowl of a tin spoon, dipped in cold water; press one pecan nutmeat on the top of each.

Drop CAKES.-One cup honey, 1/2 cup sugar, 1/2 cup butter or lard, $1 / 2$ cup sour milk, 1 egg, 1/2 teaspoonful soda, 4 cups sifted flour. Flavor to taste.

CHOICE DROP CAKES.-One gallon honey (dark honey is best), 15 eggs, 3 lbs. sugar (a little more honey in its place may be better); $1 \frac{1 / 2}{0 z}$. baking soda, 2 oz. ammonia, 2 lbs. almonds chopped up, 2 lbs. citron, 4 oz. cinnamon, 2 oz. cloves, 2 oz. mace 18 lbs. flour. Let the honey come almost to a boil; then let it cool off, and add the other ingredients. Cut out and bake. The cakes are to be frosted afterward with sugar and white of eggs.

DRoP CAKES.-Take $1 / 2$ cupful of butter, $1 / 2$ cup. ful of sugar, and blend them; after which add 1 cupful strained honey, the beaten yolks of 2 eggs, 3 tablespoonfuls of lemon juice, and the whites of 2 eggs beaten dry. Mix well, and add $3 \frac{1}{2}$ cupfuls of flour and 1 teaspoonful of soda; 1 teaspoonful baking powder, a little nutmeg. More flour may be added, if needed, and it often is, for the dough should be stiff enough so that it will drop by spoonfuls on to a buttered bakingpan. Shape round, and bake in a moderate oven.

TEA CAKES.-Blend 1.3 cup honey, 1 teaspoonful butter, 1 egg well beaten, $2-3$ cup floul, sifted with half a teaspoonful of baking powder, and a pinch of salt. Drop by teaspoonfuls on a tin, and bake in a quick oven. These proportions will make about 20 cakes.

GiNger Cake.-One cup honey, $1 / 2$ cup butter, or drippings, 1 tablespoonful boiled cider, in $1 / 2$ cup hot water (or $1 / 2$ cup sour milk will do in. stead). Warm these ingredients together, and then add 1 tablespoonful ginger and 1 teaspoonful soda sifted in with flour enough to make a soft batter. Bake in flat pan.

GINGERBREAD.-Warm together $1 / 2$ cup of brown sugar and honey, with 1-3 cup of shortening.' Remove from stove; add $3 / 4$ cup sour milk and 2 eggs pour gradually into bowl containing. 2 cups of flour sifted with a tablespoonful of ginger. Flour to make rather stiff batter.

GINGERHREAD.-One egg, 1 cup holley (dark), 1 cup milk (sour), 2 tablespoonfuls butter, $1 / 2$ teaspoonful soda, 1 teaspoonful ginger. Flour to make it rather stiff batter.

Ginger CAKE.-Put 1 cup darkest honey into a dislı with $1 / 2$ cup brown sugar; 1 teaspoonful salt, 2.3 teaspoonful vanilla, $1 / 4$ teaspoonful ground cloves, $1 / 2$ teaspoonful cinnamon, $1 / 2$ teaspoonful ginger. To this add 2 tablespoonfuls soda dissolved in 1 cup boiling water. Stir together well; $1 / 2$ cup cold watel. Nearly 1 cup shortening. Stir in flour until thick as molasses. Break in 1 large egg; beat thoroly with egg-beater. Pour into two 9 -inch jelly-tins and tuck in raisins. Bake in an even, brisk oven.

Gixger CAKE.-Three cups flour, $1 / 2$ cup butter; rub well together. Add one (ul) brown sugar; 2 large tablespoonfuls ginger; same of caraway seeds if you like; 5 eggs, 2 cups honey, 3 teaspoonfuls baking powder. Beat it well, and bake in an iron pan an hour or more.

LAYER CAKE.-Two-thirds cup butter, 1 cup honey, 3 eggs beaten, $1 / 2$ cup milk. Cream the honey and butter together, then add tws eggs and milk. Then add 2 cups flour containing $1 \frac{1 / 2}{2}$ teaspoonfuls baking powder previously stirred in. Then stir in more flour to make a stiff batter. Bake in jelly-tins. Whon the cakes are cold take finely flavored can. died honey, and, after creaming it, spread between layers.

\section{HONEY COOKIES.}

AUNTT MILLIE'S COOKIES.-One cup butter beaten light, 1 cup sugar beaten to cream with butter, 1 cup honey. Let honey warm; put 1 teaspoonful of soda in the honey. If you have fermented honey, use that with soda, as it is as good as cream tartar. If you have not the fermented honey, then use 2 teaspoonfuls of cream tartar and 1 teaspoonful of soda, or 2 teaspoonfuls of baking powder. When the honey has cooled, beat light and add to the but. ter and sugar. Then add 1 cup cold water, 1 teaspoonful vanilla, flour to make a very stiff dough. Fill a salt-shaker with powdered sugar; shake over the sheet of dough after it is rolled; press the sugar by rolling the rolling pin over it once more. Then cut out and bake brown in a moderate oven.

CREAM CoOKIES.-One teacupful extracted honey, 1 pint sour cream, scant teaspoonful soda, flavoring if desired; flour to make a soft dough.

FowLS' CookIES.-Three teaspoonfuls soda dis solved in 2 cups warm honey, 1 cup shortening con taining salt, 2 teaspoonfuls ginger, 1 cup hot water; flour sufficient to roll.

VINEgAR COOKIES.-One cup of butter and lard mixed; 1 cup of sugar, 4 eggs, 2 cups of honey, 3 teaspoonfuls of soda in $1 / 2$ cup of boiling water; spices to taste; flour to roll out; $1 / 2$ cup of vinegar.

HARD-TIME COOKIES.-One pint of honey, $1 / 2$ teacupful of granulated sugar, $1 / 4$ pint of melted lard and butter mixed; 1 even teaspoonful soda dissolved in $1 / 4$ cup warm water; $1 / 2$ teaspoonful of ginger, $1 / 2$ teaspoonful nutmeg, a little salt. Roll rather thin, and bake quickly.

SWISS CookIES.-Prepare some dough as for the gingerbread, and mix with it $1 / 3 \mathrm{lb}$. crushed almonds, orange and lemon juice, and cinnamon; and, if desired, cloves to suit the taste.

TenNessee Cookins.-Melt together 1 cup of honey and 1 cup of lard or butter. When cold, add 1.3 of a cup of sugar, a pinch of salt, a tablespoon of soda and 1 egg. Stir in flour enough to make a stiff dough; roll, and cut into small cakes, and bake on greased tins, in a moderate oven.

SUGARless Cookies.-Two cups honey; 1 cup butter, 4 eggs (mix well); 1 cup buttermilk (mix); 1 good quart flour; 1 level teaspoonful soda or saleratus. If it is too thin, stir in a little more flour. If too thin it will fall. It does not want to be as thin as sugar cake. Use very thick honey. $\mathrm{Be}$ sure to use the same cup for measure. Be sure to mix the honey, butter, and eggs well together. You can make it richer if you wish by using clabbered cream instead of buttermilk. Bake in a rather slow oven, as it burns very easily. To make the cookies, use a little mole flour, so that 
they will roll out well without sticking to the board. Any kind of flavoring will do.

GrNGer Cookres.-One cup honey, $1 / 2$ cup of sugar, $1 / 2$ cup shortening, $1 / 2$ cup warm water, 1 teaspoonful soda, 1 teaspoonful ginger, 5 cups flour, pinch of salt.

HoNEY-JUMBLES.- Two quarts flour, 3 tablespoonfuls melted lard, 1 pint honey, $1 / 4$ pint molasses, $11 / 2$ level tablespoonfuls soda, 1 level teaspoonful salt, $1 / 4$ pint water, $1 / 2$ teaspoonful $\nabla a$ nilla.

Ginger Cookres.-One cup honey, 1 cup sugar, 1 cup buttermilk, 1 cup lard, 1 teaspoonful salt, 1 teaspoonful cinnamon, 1 teaspoonful ginger, 1 teaspoonful soda, heaping; 1 teaspoonful lemon extract. Stir stiff with flour; for gingerbread, mix stiff and roll out and cut and bake in quick oven. Also very good with caraway soeds instead of spices.

GINGERSNAPS.-One pint honey, $3 / 4$ lb. butter, 2 teaspoonfuls ginger. Boil together a few minutes, and when nearly cold put in flour until it is stiff. Roll out thin and bake quickly.

DARK COOKIES.-One cup brown sugar, $1 / 2$ cup sour cream, 1-3 cup butter, 2-3 cup dark honey, 1 egg, 1 tablespoonful cinnamon, 1 scant teaspoonful soda. Flour to make thick batter. Improved with chopped nuts sprinkled over and pressed in with the bowl of spoon.

LEMON SNAPS.-Mix 1 quart honey, 1/2 lb. powdered sugar, $1 / 2 \mathrm{lb}$. fresh butter, and juice of two oranges or lemons. Warm just enough to soften the butter. Beat the mixture very hard. Add a grited nutmeg. Mix in gradually 2 lbs. or less of flour. Make a dough hard enough to roll out eas ily. Beat it well all over with rolling-pin. Roll $3 / 8$ inch tbick; cut with tumbler dipped in flour. Bake well on buttered tins.

OATMEal CoOKres.-Cream together 1 cup sugar, $1 / 2$ cup honey, $3 / 4$ cup lard or butter, 6 tablespoonfuls milk, $1 / 2$ cup raisins, 2 cups rolled oats, 2 eggs; sift together 2 or more cups flour, $1 / 2$ teaspoonful salt, 2 teaspoonfuls cream of tartar, 1 teaspoonful soda; 1 teaspoonful cinnamon. Mix together, and roll quite thick.

Doughnuts.-One egg, 1 cup sweet milk, 1 cup honey, 2 tablespoonfuls shortening, 1 . heaping teaspoonful cream tartar, $1 / 2$ teaspoonful soda. Flour to roll and cut easily. Pinch of salt.

Doughnuts.- Take two eggs, butter, the size of an egg; $1 \frac{1 / 2}{2}$ cupfuls alfalfa honey; 1 cupful of sour milk to which has been added 1 teaspoonful of soda and flour to roll, to which add 2 teaspoonfuls of cream of tartar.

SUgAR CoOIIES.-One and one-half cups sugar, $1 / 2$ cup honey, $1 / 2$ cup butter or lard, $3 / 4$ cup sour milk, 1 level teaspoonful soda, $1 / 2$ nutmeg, grated, 1 pinch of salt. Add floux to make a rather soft dough. Roll out to $3 / 4$ inch thick, and bake in quick oven.

\section{BREAD, GEMS, ETC.}

BROWN BREAD.-One heaping coffee-cup of corn meal; 2 cups graham flour; sift three times together, then beat together with 1 cup of honey, 2 cups sweet milk, 1 cup sour milk, 1 dessertspoonful soda and 1 teaspoonful salt. Place in form, and steam $3 \frac{1}{2}$ hours.
BROWN BREAD.-One cup corn meal, 1 cup ryo meal, 1 cup sour milk, $1 / 2$ cup or less of honey; a teaspoonful of salt and a teaspoonful of soda. Steam 4 hours, and then dry in the oven $15 \mathrm{~min}$ utes. It may be added that most of the molasses now sold is not fit to eat, and in any case honey is much better.

STEAMed BRown BREad.-Two cups graham flour, sometimes heaped, depending on condition of milk, 1 sup meal, 2-3 cup dark honey or sugared honey, 2 cups sour milk, 1 teaspoonful salt, 2 teaspoonfuls soda dissolved in one tablespoonful boiling water, stirred into the milk and honey; $1 / 2$ cup of raisins. Stir thoroly; fill pound baking powder cans half full; cover tight, and steam 3 hours.

Grairam Bread.-Three cups graham flour, 1 tablespoonful salt (scant), 2-3 cup honey, 2 cups soui milk, 1 teaspoonful soda dissolved in warm water; pinch baking powder; a few nuts chopped fine. Bake 1 hour and 15 minutes.

Graham Brean.-One pint sweet milk, $1 / 2$ cup extracted honey, $1 / 3$ cup sugar, 1 teaspoonful soda, a pincb of salt, $2 \frac{1}{2}$ cups graham flour. Stir all iuto a batter in a vessel in which it is to be steamed for 3 hours. Then remove from the steamer and bake $1 / 2$ hour.

GRAHAM BREAD. - One and one-half cups sour milk, $1 / 2$ cup shortening, $2-3$ cup honey, 1 egg, 1 teaspoonful soda, 3 cups graham flour.

Honey Graham Biscuits.-Use 2 cups graham flour, 2 cups white flour, $1 / 2$ cup butter, $1 / 2$ cup honey, 2 teaspoonfuls baking powder. Sift the flour and baking powder well together; rub the butter into the flour thoroly. Add the honey, and just enough sweet milk to make a soft dough. Roll out and bake in a quick oven.

Frenci Mufrins,-One and one-half pints flour, 1 cup honey, $1 / 2$ teaspoonful salt, 2 teaspoonfuls baking powder, 2 tablespoonfuls butter, 3 eggs, and a little over a half pint milk or thin cream. Sift together the flour, salt, and powder; rub in the butter cold; add beaten eggs, milk, and honey. Mix smoothly in batter as for pound cake. About half fill sponge-cake tins, cold and well greased, and bake in good steady oven for eight minutes.

CORNMEAL CAKE.-One cupful cornmeal (yellow), $3 / 4$ cupful white flour, putting both in flour sieve; add one level teaspoonful soda and a rounding teaspoonful cream of tartar, and sift all to. gether; then add 1 cupful of honey, $1 / 2$ supful of shortening; add enough sweet milk to a batter that will not run, but drop from spoon in a lump. Bake one-half hour in hot oven.

BRAN GEMS.-Take 2 cups bran, 1 scant cup wheat flour, 1 large pinch salt, $1 \frac{1}{2}$ cups buttermilk, 1 level teaspoonful soda, 3 tablespoonfuls strained honey. Mix the bran, flour, and salt thoroly, add buttermilk, in which soda has been dissolved; lastly, add honey. Bake until (crusty) thoroly done in greased gem-pans in a hot oven.

\section{MISCELLANEOUS.}

HONey Cereal COfFeE.-Use 1 egg, 1 cup honey (preferably dark), 2 quarts wheat bran. Beat the egre, add honey, and lastly the bran, and stir until well blended. Put in oven and brown to dark brown, stirring frequently, being careful the oven is not too hot. To prepare the coffee, allow one heaping tablespoonful to a cup of hot water, and boil for at least ten minutes. 
Plum Butrer.-Take 4 quarts of plums after being rubbed thru the colander. Let it come to a boil; then add 1 quart of honey, and 1 quart of sugar, or 2 quarts of honey, and boil until it crusts on top when cooled, or about fifteen minutes. Stir frequently to prevent burning.

APPLE BUTTER.-One gallon good cooking apples, 1 quart honey, 1 quart honey vinegar, 1 heaping teaspoonful ground cinnamon. Cook several hours, stirring often to prevent burning. If the vinegar is very strong, use part water.

BAR-LE-DUC PRESERVES. - These preserves are believed to be the finest of their kind, and have hitherto been imported at extravagant prices. Other fruits besides currants may be treated in this way, as honey is of itself a preservative. These preserves do not require to be kept absolutely airtight.

Take selected red or white currants of large size, one by one; carefully make an incision in the skin $1 / 4$ of an inch deep with tiny embroidery scis. sors. Thru this slit remove the seeds with the aid of a sharp needle; remove the seeds separately, preserving the shape of the fruit. Take the weight of the currants in honey, and when this has been heated add the currants. Let it simmer a minute or two, and then seal as for jelly. The currants retain their shape, are of a beautiful color, and melt in the mouth. Care should be exercised not to scorch the honey; then you will have fine preserves.

Custard.-Use 1 egg, 1 tablespoonful honey (or more to suit individual taste), 1 cup rich milk, nutmeg or other flavoring. Beat the eggs, and add the honey and other ingredients.

HONEY BEANS (NAVY). - Soak beans and bacon over night and cook till skins crack. Place 1 onion, $1 / 4$ pound bacon, and butter the size of an egg in the bottom of a bean-pot or iron spider. Pour over the beans 2 tablespoonfuls olive or cooking oil, and 2 tablespoonfuls best quality extracted honey. Lay sliced Greening apples to cover over the top of beans. Keep moist while baking. Bake until well done. Add pepper to suit taste.

BAKED BEANS. - Boil 2 pints of beans in slight ly salted water until tender; then add 1 cupful of extracted honey and $1 / 2$ cupful of butter, with salt and pepper to suit taste. Bake in a covered baker until solid, but not dry.

SUMMER DRINK.-One spoonful fruit juice and 1 spoonful honey in $1 / 2$ glass water; stir in as much soda as will lie on a dime, and then stir in half as much tartaric acid, and drink at once.

FILLING FOR LAYer CAKE.-Take 1 tablespoon. ful of lemon-juice, 2 heaping tablespoonfuls of granulated honey; stir to a smooth cream. When cake is done, lay on a plate; spread with the honey while hot.

PICKLED GRAPES IN HONEY.-Seven pounds good grapes (wine grapes if possible) on the stalks, carefully packed in a jar without bruising any of them. Make a syrup of 4 pounds of honey, a pint of good vinegar with cloves, etc., to suit the taste. Then boil the syrup for twenty minutes, carefully skimming it. While boiling hot, pour the syrup over the grapes and seal up. This will keep perfectly for years, as the honey is a preservative.

Honey Crab-Apple Jelly.-Boil fruit with as little water as possible; squeeze thu'u a jelly-bag.
Add $7 / 2$ cup of honey and $1 / 2$ cup of sugar to 1 cup of juice; then boil about twenty minutes, or until it begins to jell. Pour into glasses. Do not cover up until cool.

BAKED APPLES.- - Spit some sour apples, cut out the core, and fill pan. When they begirs to soften, fill the cavity with some honey and lemon juice. Set back in oven to finish baking.

SALAD Drhissing.-Take 1 egg, well beaten, with 2 dessertspoonfuls honey. Add a pinch of salt; pepper to taste; $1 / 4$ teaspoonful of mustard. Stir well together, and add $1 / 2$ cup of vinegar. Let come to a boil, stirring constantly. Cool, and add $1 / 2$ pint of sweet cream just before using.

SALAD DRESSING.--Take the yolks of 4 eggs, beat well, add 4 tablespoonfuls cider vinegar, 2 tablespoonfuls butter, 2 tablespoonfuls honey, 1 teaspoonful mustard. Mix thoroly together, and cook in a double boiler to a smooth paste, stirring constantly. Mix with thick sweet cream, when ready to use. It will keep two weeks in a cool place.

Steadied PUdDing.-Use 2 eggs, $2 / 3$ cup honey, 1 cup chopped raisius, $1 / 2$ teaspoonful salt, $1 / 2$ teaspoonful soda, $1 / 2$ teaspoonful cinnamon, $1 / 4$ teaspoonful cloves, $1 / 2$ teaspoonful allspice, 2 teaspoonfuls baking powder, 2 tablespoonfuls ground chocolate, 1 "up swcet milk, $1 \frac{1 / 4}{4}$ cups flour; more if needed. Steam three hours.

Mince ,Meat.-Four pounds of apples, pared, cored, and minced; $1 \frac{1 / 2}{2}$ pounds of raisins, stoned and minced; 4 pounds of beef suet shredded, or 2 pounds butter; 1 pound honey and $1 / 2$ pound sugar; $1 / 4$ pound of mixed spices, minced rind of 4 lemons and juice of two lemons. Make a month before using. If apples are very sour, use more honey.

BUCKWHLAT Pancakes.-Take scant 2 quarts of water a little below blood heat-cooler if weather is warm; dissolve salt in the water till it tastes almost briny; $2-3$ compressed yeast cake, thoroly mixed in water before flour is added. Mix in the water a large tablespoonful of liquid honey; add the buckwheat flour thru a sieve. The batter sliould then be stirred or beaten a long time. If any batter is left, set away in a cool place, not too tightly covered. When ready for the next batch add the necessary quantity of salted warm water and the honey; stir thoroly, and then add the buckwheat as before. It is better to mix a little too thick rather than too thin. Water can be safely added before baking, if necessary. If sour in the morning from being kept too warm, use a little baking soda, dissolved in warm water. The old batter is useless after the soda treatment.

Buckwheat Pancakes. - When buckwheat pancakes are raised over night and the soda is put in when ready to bake, add one or two spoonfuls of extracted honey. It makes them bake nice and brown, and gives them a fine flavor.

JUNKET.-To a pint of milk, just warm, add 2 dessertspoonfuls of honer and $1 / 2$ junket tablet, dissolved in cold water; flavor to taste. Set in a warm place until firm.

\section{HONEY CANDY.}

CARAMELS.-Take 1 pint honey, 1 teaspoonful cinnamon or vanilla, $1 / 2$ pound cocoa, $3 / 4$ pound pecau nuts, 2 pounds sweet almonds. Cut the nuts fine, and boil them with other ingredients until thick. Cool and roll out. Cut in squares and dry in the oven. 
Caramels.-One cup extracted honey of best flavor; 1 cup granulated sugar; 3 tablespoonfuls sweet cream of milk. Boil to "soft clack," or until it hardens when dropped in'o cold water, but not too brittle-just so it will form into a soft ball when taken in the fingers. Pour into a greased dish, stirring in a teaspoonful extract of vanilla just before taking off. Let it be $1 / 2$ or $3 / 4$ inch deep in the dish; and as it cools cut in squares and wrap each square in paraffin paper, such as grocers wrap butter in. To make chocolate caramels, add to the foregoing one tablespoonful melted chocolate, just before taking off the stove, stirring it in well. For chocolate caramels it is not so important that the honey be of best quality.

TAFFY.-Boil some honey until it hardens when dropped into cold water. Pull it till it becomes white. Any quantity may be used. A pound requires twenty minutes' boiling and stirring. Great care must be exercised not to burn the honey. It makes very fine taffy.

Peanut Honey Candy.-Take 1 cup butter, 2 cups honey, 2 cups sugar, 1 cup boiling water, 1/4 teaspoonful cream tartar, $1 / 2$ teaspounful glycerine, a tiny dash of soda. Boil ten minutes to a soft ball, and set in a cool place. When it has cooled slightly, stir in one or two tablespoonfuls of peanut butter, or to snit the taste; keep stirring till creamy; then pour into buttered pans; mark in squares.

Peanut Candy.-Use 1 cup honey, 1 cup granulated sugar, 4 tablespoonfuls sweet cream. Boil until it cracks when dropped in cold water. Re move from the fire and stir in a pound of peanuts that have been previously shelled and well crushed with the rolling-pin. Pour into a greased pan and set to cool.

PEANUT Rolus.-Take 1 cup butter, 2 cups honey, 1 cup boiling water, $1 / 4$ teaspoonful cream tartar, $1 / 2$ teaspoonful glycerine, a tiny dash of soda. Boil ten minutes; pour over a layer of rolled peanuts which have been scattered evenly over the bottom of the buttered pan. When nearly cold, mark off in long strips and roll up tight; then slice across with a sharp knife, before it gets quite cold.

HONEY CHOCOLATE.-Chocolate sweetened with honey rather than with sugar is excellent. It is very easily made: Melt 1 pound of gelatine in a pint of water; add 10 pounds of honey, thoroly warming the same, then add 4 pounds of cocoa. Flavor with vanilla when. taken off the fire, and then pour into greased dishes or molds.

French CANDIES.--In an enameled sance-pan melt 1 part of gelatine in 1 part of water, stirring well. When at the state of a soft paste, add 4 parts of honey previously warmed, stirring lively. parts of honey previously the. desired flavor and color, mixing carefully, and pour into a shallow lightly greased dish. Let it dry for a few days.

NougAT.-Take 3 cups granulated sugar, $1 \frac{1}{2}$ cups any kind nut-meats, $2-3$ cup honey, 2-3 cup hot water, white of one egg beaten stiff. Boil the sugar, honey, and water together until they make rather hard ball when dropped in cold water. Remove from the fire, pour in the beaten white of Remove from the briskly with a silver fork. After beating a while, pour in the nut-meats and beat until it begins to form a hard creamy mass, then pour into a buttered tin to cool.

TAFFY.-Use 3 cups sugar, 2-3 cup extracted honey, $2 / 3$ cup hot water. Boil all together till it 16 spins a thread when dropped from a spoon, or hardens when dropped into cold water. Pour into a greased ressel. Whell coul, pull until white.

POPCORN BALLS.-Use 2 gallons of corn, 2 cups granulated sugar, 3 tablespoonfuls honey, 2 tablespoonfuls apple vinegar, $1 / 2$ cup of water. Stir together and boil until it will rattle in water. Then pour over the corn, and mix well . Dampen the hands in cold water and form into balls.

PorCoRN BALLs.-Take 1 pint extracted honey; put it into an iron frying-pan, and boil until very thick; then stir in freshly popped corn, and, when cold, mold into balls. These will specially delight the children.

Good Candy.-Use $2 \frac{1}{2}$ cups sugar, $1 / 2$ cup honey, $1 / 2$ cup water. Boil until thick syrup. Pour one cupful of syrup on the beaten whites of 2 eggs, stirring meanwhile. Boil remainder of syrup till it hardens when dropped in water; then pour it into the syrup and eggs, stirring briskly. Add a cupful of peanuts. Stir until it begins to harden; then spread in a pan and cut in squares. Flavor to taste. If properly made it will be soft and pliable.

Crystallized HONEY POPCORN.-Take 1 teacupful water-white honey, 1 teacupful white sugar, $1 \frac{1}{2}$ tablespoonfuls butter, 1 tablespoonful water. Boil until brittle on being dropped in cold water. Have ready 2 quarts of nicely popped corn, and pour the candy over until evenly distributed over the corn, stirring briskly until nearly cool.

HONEY CANDY.-Take 1 cup sugar, 2 tablespoonfuls honey, 2 tablespoonfuls of water, walnut meats. Cook and test like molasses candy.

CANDY.-Granulated sugar 1 cup; strained honey 1 tablespoonful; butter, size of walnut; sweet cream enough to dissolve the mixture. It does not need much cooking. When taken from the fire, beat with a spoon until smooth.

\section{HONEY REMEDIES.}

Cough SYRuP.-One-third teaspoonful of pow. dered ipecac dissolved in 1 teaspoonful of cold water. Add a teacupful of warm water, table. spoonful of extracted or strained honey, and boil down half.

HONEY-AND-TAR COUGH-CURE.-Put a tablespoonful liquid pine tar into a shallow tin dish and place it in boiling water until the tar is hot. To this add a pint of extracted honey and stir well for half an hour, adding to it a level teaspoonful pulverized borax. Keep well corked in a bottle. Dose, teaspoonful every 1,2 , or 3 hours, according to severity of cough.

Cough SyruP.-Buy a five-cent package fof lobelia herb; put about $1 / 8$ of it in a large cup of good cider vinegar; put it in a granite dish to simmer on the stove for not less than $1 / 2$ hour, but do not let boil after the strength is well out of the herb. Strain, put back on the stove, stir in about as much honey as you have used vinegar. See that the honey is well mixed while hot. Bottle ready for use. Dose, about $1 / 4$ teaspoonful every 15 minutes if the cold is bad.

Cougr Srrup.-Make 3 pints of strong tea by boiling a good-sized bunch of old field balsam in a covered vessel; strain, add $11 / 2$ cups of sugar; boil to 2 pints; take from the fire; add a small teaspoonful of pine tar; let cool five minutes, then add $1 / 2$ cup of strained honey. Dose: 1 teaspoon- 
ful as often as needed-2 to 4 hours, according to the case.

HOR COLDS.-Boil 2 ounces of flaxseed in a quart of water; strain, and add 2 ouluces of rock candy, $1 / 2$ pint of honey, juice of 3 lemons. Mix, and let all boil well. Let cool and bottle. Dose: One cupful on going to bed; $1 / 2$ cupful before meals; the hotter the better.

HONEY FOR FRECKLES.- Half a pound of honey, 2 oz. glycerine, 2 oz. alcohol, 6 drams citric acid, 15 drops ambergris. Apply night and morning.

BALM OF GILEAD SALVE.-Four ounces mutton tallow; 1 pint balm-of-Gilead buds; 3 ounces loaf sugar; 1 ounce castile soap; 1 ounce rosin; 3 ounces beeswax; 1 ounce alum; 1 pound lard. Put the buds in a kettle with the lard, and boil slowly for half an hour, stirring often. Strain, and take the buds out. Put in the rest of the ingredients, and cook slowly, until done. This usually takes from one-half hour to an hour; excellent for chapped hands or lips, soles, or cuts, flost bites, and piles.

HONEY AS A SOFTENER OF THE HANDS. Many are unaware that the very best cosmetics are made with honey as a prime ingredient. Here is one for the hands, which is said to be very fine: Rub together 1 llu. of homey and the yolks of 8 eggs; gradually add 1 ih. oil of sweet almonds, during constant stirring; work in $1 / 2 \mathrm{lb}$. bitter almonds, and perfume with 2 drams each of attar of bergamot and attar of cloves. Of course, the quan. tities nay be reduced if necessary.

HoNEY SoAp.-Cut 2 pounds of rellow soap in thin slices and put into a saucepan with sufficient water to prevent the soap from being burned. Place on the fire, and as soon as all the soap lias dissolved add 1 pound of. honey and stir until the whole begins to boil. Then remove from the fire, add a few drops of essence of cinnamon, poul into a deep dish to cool, and then cut in squares. It improves by keeping.

HONEY-PASTE FOR CHAPPED HANDS.-In excellent paste for chapped hands is made as follows: The white of $1 \mathrm{egg}, 1$ teaspoonful of glycerine, 1 ounce of honey, and sufficient barley flour to compose a paste.

Coln Cream.-One cup of holey, $3 / 4$ of a cup of beeswax, 1 cup of cottolene. Melt all, take it off the fire, and stir till it is cool. Rose or violet perfume may be added. It should be well protected from the ail. The blending should be well done. This is fine for chapped or rough hands, if they are slightly moistened before applying.

POLISH FOR KID SHOES.-Beeswax softened with neatsfoot oil. The composition is made by mixing the oil with the melted wax so as to be, when cold, about like butter, soft enough to "spread." A small portion of lampblack is also mixed in while the mass is melted. If there is any ordinary shoe polish on shoes, it should be washed off and the surface allowed to dry. An old toothbrush can be used to apply a thin even coat, which is then polished with a soft woolen rag, see-sawed acloss the surface.

TATERPROOFING FOR LEATHER.-Take 2 pounds tallow, 1 pound resin, $1 / 2$ pound beeswax. Molt over a slow fire; and before applying to the uppers of boots or shoes, fill the leather with neatsfoot oil, as there is less danger of burning the leather, and they will keep soft and pliable louger. For the soles use the tallow and resin in equal parts. Be careful not to luurn the leather.

\section{BIBLTOGRAPHY.}

In Bureau of Chemistry Bulletin No. 13, Part VI. (out of print), page 871, will be found a bibliography of honey literature for the years 1867 to 1891, inclusive. In Bulletin No. 110, page 89, will be found a continuation of this up to the first part of 1907. In Bulletin No. 154, page 17, the bibliography takes the literature up to the close of 1911. These bibliographies were compiled by $A$. H. Bryan, chief of the sugar laboratory, and are complete.

Browne, C. A. Chemical Analysis and Composition of American Honeys. Bul. 110, U. S. Dept. Agr. Bureau of Chemistry. 1908.

Browne, C. A. Methods of Honey-testing Hawaiian Honeys. Bul. 17, Hawaii Agr. Bureau of Entomology, 1911.

McGill, A. Strained Honey. Bul. 217, Inland Revenue Dept. Ottawa, Canada, 1911.

Van Dine, D. L., and Thompson, A. R., Hawaiian Honeys. Bul. 1, Hawaii Agr. Exp. Sta. 1908.

Root, H. H. The Use of Honey in Cooking. A. I. Root Co.; Medina, 1916.

Hunt, C. L., and Atwater, H. W. Honey and its Uses in the Home. U. S. Dept. Agr., Farmers' Bul. No. 653, 1915.

Honey for Cooking, special number of Gleanings in Bee Culture, Medina, vol. 42, Oct. 1, 1915.

Michaelis, Reinhold. Deutsches Honigbuechlein, 1911.

HONEY-BOARDS. - See EXTRACTED Honey, and Hives.

HONEY - BUYING. - See Marketing HoNex.

HONEYCOMB.-A beautiful thing in nature is a piece of comb honey with its snowy whiteness and its burden of sweetness. Aside from its whiteness and sweetness, the marvelous structure of the comb compels our admiration. The walls of its cells are so thin that from 3000 to 4000 of them must be laid one upon another to make an inch in thickness, each wall so fragile as to crumble at a touch, and yet so constructed that tons of honey stored in 
them are transported in safety thousands of miles.

Formerly the word "honeycomb" meant both the comb and the honey contained in it; in other words, what we now call "comb honey" was called "honeycomb." Wherever the word "honeycomb" is found in the Bible, it means "comb honey."

It is only in comparatively recent years that the real source of the wax of which comb is constructed has been known. In 1684 Martin John discovered that with the point of a needle he could pick scales of real beeswax from the abdomen of a bee working at comb-building.

These wax scales may be found plentifully on the floor of a hive at a time when much comb-building is going on. They are somewhat pear-shaped, as shown in cut below, where is shown also the powerful jaw of the worker by which the wax is worked. These wax scales are much more brittle than the wax that has been worked into comb, and are transparent, looking somewhat like mica. Some say they are white, some say pale yellow. Likely enough both are right, the color depending upon the pollen consumed.

These wax scales are secreted by eight wax-glands on the under side of the abdomen of the worker bee, as seen in cut, next column.* Examine a swarm lately hived, and plenty of bees will be formed showing this appearance. When first secreted, wax is liquid. It is derived from the blood of

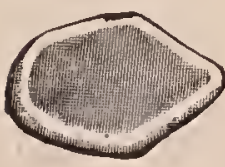

Wax scale.

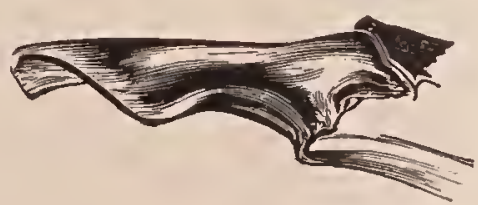

Jaw of a worker bee. the bee by cell action. So it is an expensive product, and one might well say it is derived from the "sweat and blood" of the bee, for it is sweat out from the blood by the wax-glands. Just how expensive it is seems a hard matter to learn. For many years the stereotyped expression was, "Every pound of wax requires 20 pounds of honey 'for its production." Later investigations have cut down that estimate greatly. But there is no agreement. Some

* For a description of how these are removed by the lees see W.I. estimate is low as $3 \mathrm{ol}^{\circ} 4$ pounds of honey to one of wax. Other's say $7,7.5$, or some other number's.

Some hold that the secretion of wax is involuntary, and that, if not utilized, there will be so much dead waste, and so nothing can be gained by trying to save the bees the

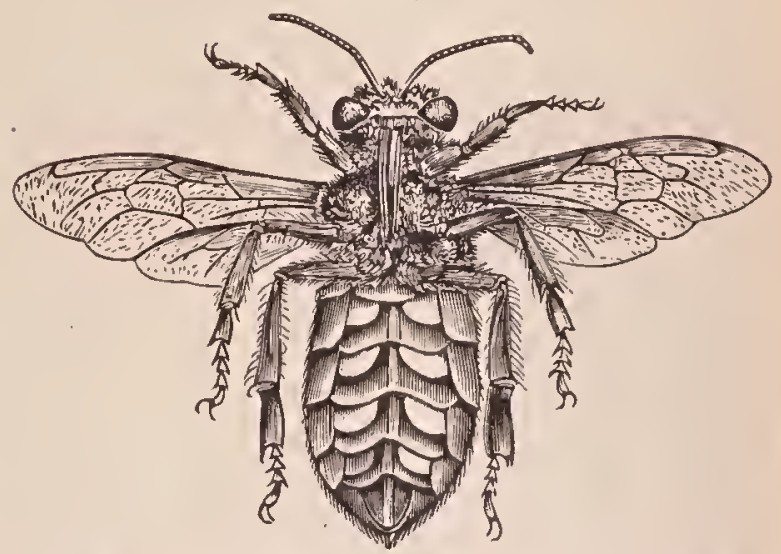

Wax seales on the under side of the abdomen of a worker.-After Cheshire.

work of wax secretion. But this is by no means the general view. Cowan says, in "The Honeybee," page 171, "Wax is not produced at all times, but its secretion is voluntary." The practically unanimous agreement among beekeepers, that a very much larger quantity of extracted than of comb honey can be obtained, is hard to explain without admitting that the furnishing of drawn combs saves the bees much labor in the way of wax-production, and that production depends on conditions that come largely under the control of the beekeeper.

A high temperature favors the secretion of wax, and when it is produced in large quantities the bees hang inactively in clusters or festoons.

"Wax is not chemically a fat or glyceride," says Cheshire, in "Bees and Beekeeping," Vol. I., page 160, "hence those who have called it 'the fat of bees' have grossly erred; yet it is nearly allied to the fats in atomic constitution, and the pliysiological conditions favoring the formation of one are curiously similar to those aiding in the production of the other. We put our poultry up to fatten in confinement, with partial light; to secure bodily inactivity we keep warm, and feed highly. Our bees, under Nature's teaching, put themselves up to yield wax under conditions so parallel that the suitability of the fatting-coop is vindicaterl. 
"The wax having been secreted, a single bee starts the first comb by attaching to the roof little masses of the plastic material, into which her scales are converted, by prolonged chewing with secretion; others follow her example, and the processes of scooping and thinning commence, the parts removed being always added to the

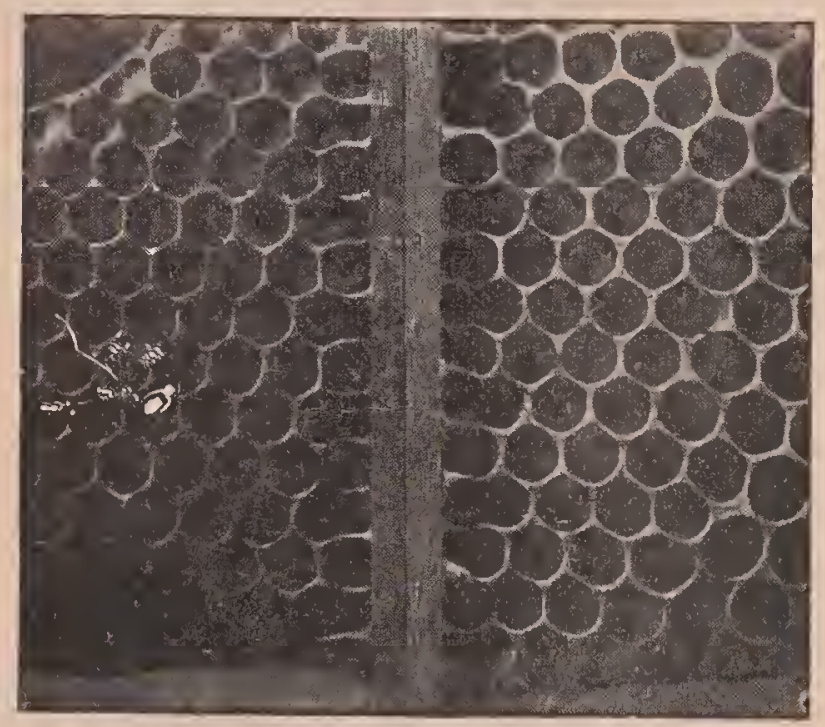

How combs are attached to a rertical support.

edge of the work, so that, in the darkness, and between the bees, grows downward that wonderful combination of lightness and strength, grace and utility, which has so long provoked the wonder and awakened the speculation of the philosopher, the naturalist, and the mathematician."

A chief use for the honeycomb being to furnish cradles for the baby bees during their brood stage, the problem is to find what arrangement will accommodate them in the least space and with the least expenditure of wax. If a number of cylinders with rounding bottoms be piled, and just back of them, back to back, and, as closely as they can be packed, another series of cylinders piled, there will be an arrangement that will leave a great waste of room between the lines of contact of those cylinders, and another waste between the points of contact of the rounding bottoms. If pressure be exerted on those cylinders so that the sides and bottoms come into contact, there will be cells that are six-sided, with bottoms that are made of three lozenge-shaped plates, or what, as a whole, is an exact counterpart of honeycomb. Some have argued that bees make the cells cylindrical in the first place, and then, by pressure from within, force the cells into the forms of hexagons; but, unfortunately for this theory, plaster casts, of which cross-sections have been made of combs in all processes of construction, show that bees start their work by making true hexagons and not circles or cylinders. This can be seen by looking thru a piece of glass on which combs have been built. However the combs are made, their general construction is such that the great economy of space and material is effected, both for holding brood or honey. There would be an equal saving of wax if the cells could be square with flat bottoms; but such cells would not fit the young bees, nor would the comb be as strong. The hexagonal is the very best form of construction.

By far the larger portion of the cells in a hive will be found to measure about five

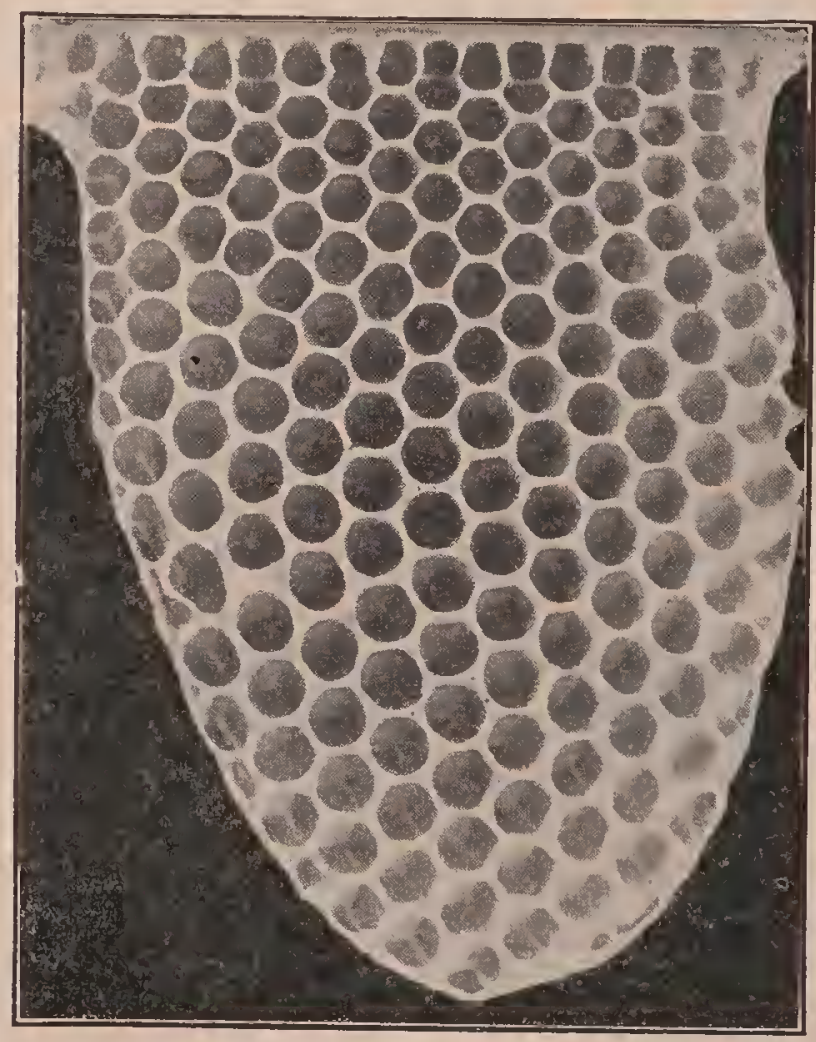

A charactcristic spur of natural comb built from a horizontal support.

to the inch. These are called worker-cells, and may be used for rearing worker-brood, or for storing honey or pollen. A smaller number of cells will be found to measure about four to the inch. These are called drone-cells, and may be used for rearing drone brood, or for storing honey-seldom for pollen. 


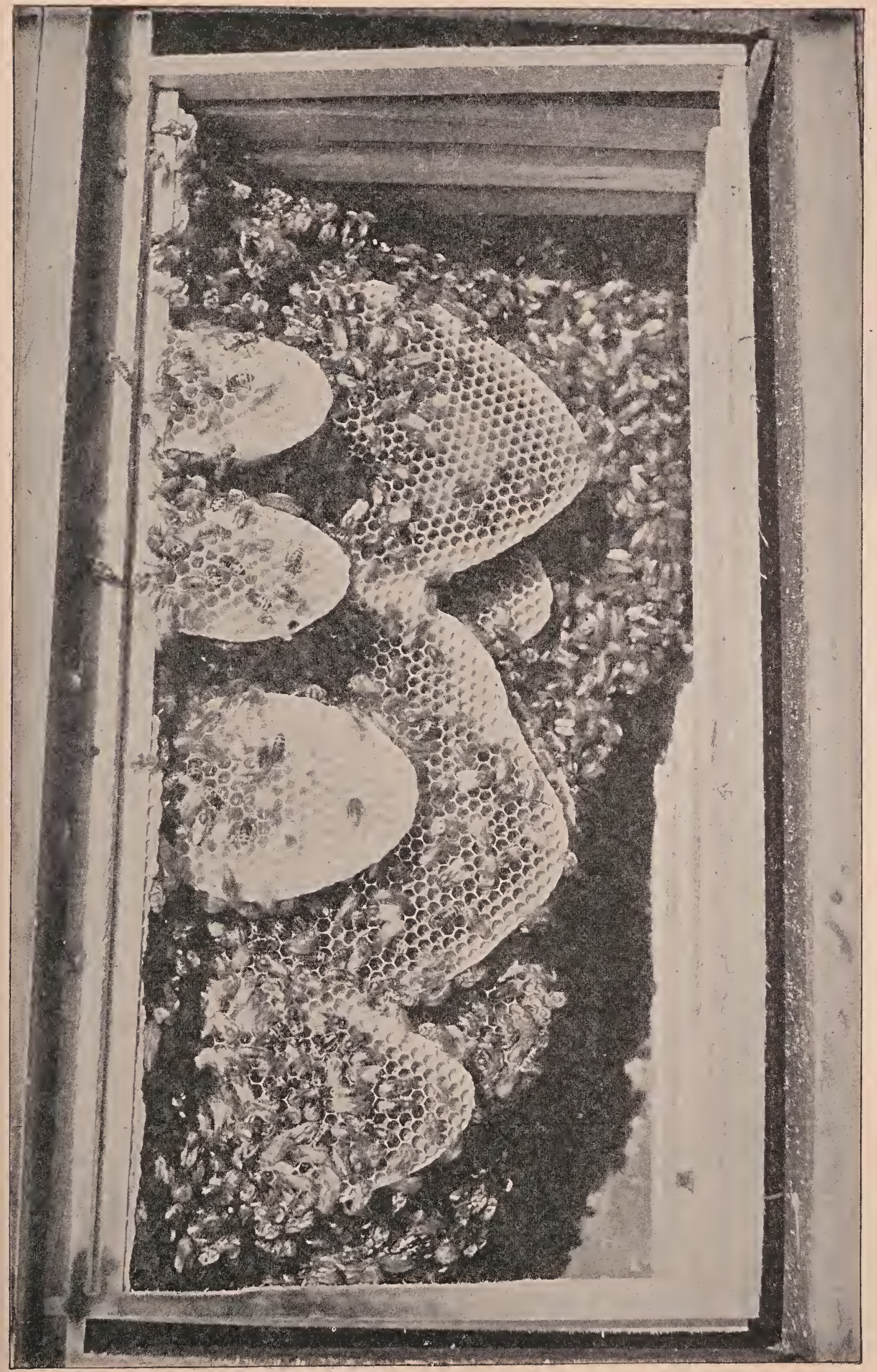

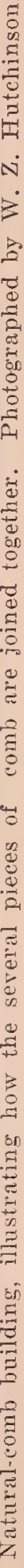


If the worker-cells were exact hexagons measuring five to the inch, there would be exactly 28 13-15 cells to the square inch on one side of a comb. But there is not this exactness, as will be shown by careful measurement, altho the eye may detect no variation. Count the number of cells in a griven length in a horizontal row of cells, and then make the same count in one of the diagonal rows, and it will be found that they are not precisely the sane. That shows that the cells are not exact hexagons.

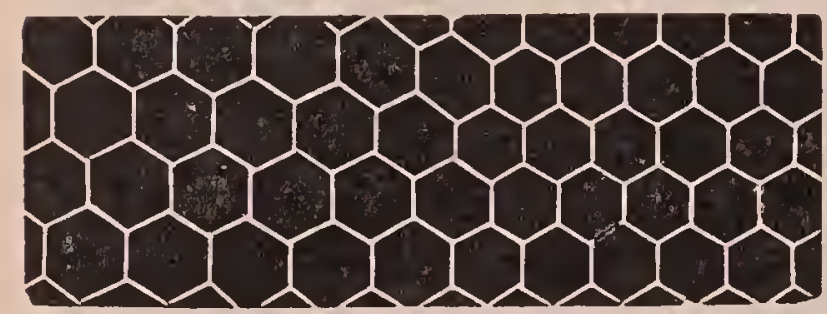

The merging of drone to worker comb.

Measure the cells in a number of combs built by different colonies, or even by the saute colony, and it will be found that they are by no means all of them five to the inch.

This, of course, refer's to natural comb built by the bees without any comb foundation being supplied to them. Comb foundation is generally made with cells of such size that worker comb built upon it contains about 27 cells to the square inch.

Instead of lessening our admiration, the slight variation from exactness in the work of comb-building, when the bees are left free to take their own course, rather increases it, just as a piece of "hand-made" work is often more admired than that which is "machine-made." The marvelous ingenuity displayed in adjusting the work to rarying circumstances is something far beyond machine-like exactness. Cut a few square inches of comb out of the middle of a frame of worker comb in the middle of a good honey flow, and the chances are rather that the bees will fill the hole with drone combs. A few cells will be built that are neither drone-cells nor' worker-cells, and these are called accommodation cells; but so, skillfully are the adjustments made in passing from worker to drone cells that a) a liasty glance one would likely say that all were either worker or drone cells. Observe the small pieces of comb starterl at different points on the same top-bar on previous page. They may be at such distances apart that, when the two combs meet, if built with rigid exactness, the center of a cell in one comb will coincide with the edge of a cell in the other comb. Yet so skillfully are measurements made, and so gradual the change as one comb approaches the other, that the unaided eye can detect no variation from an unbioken

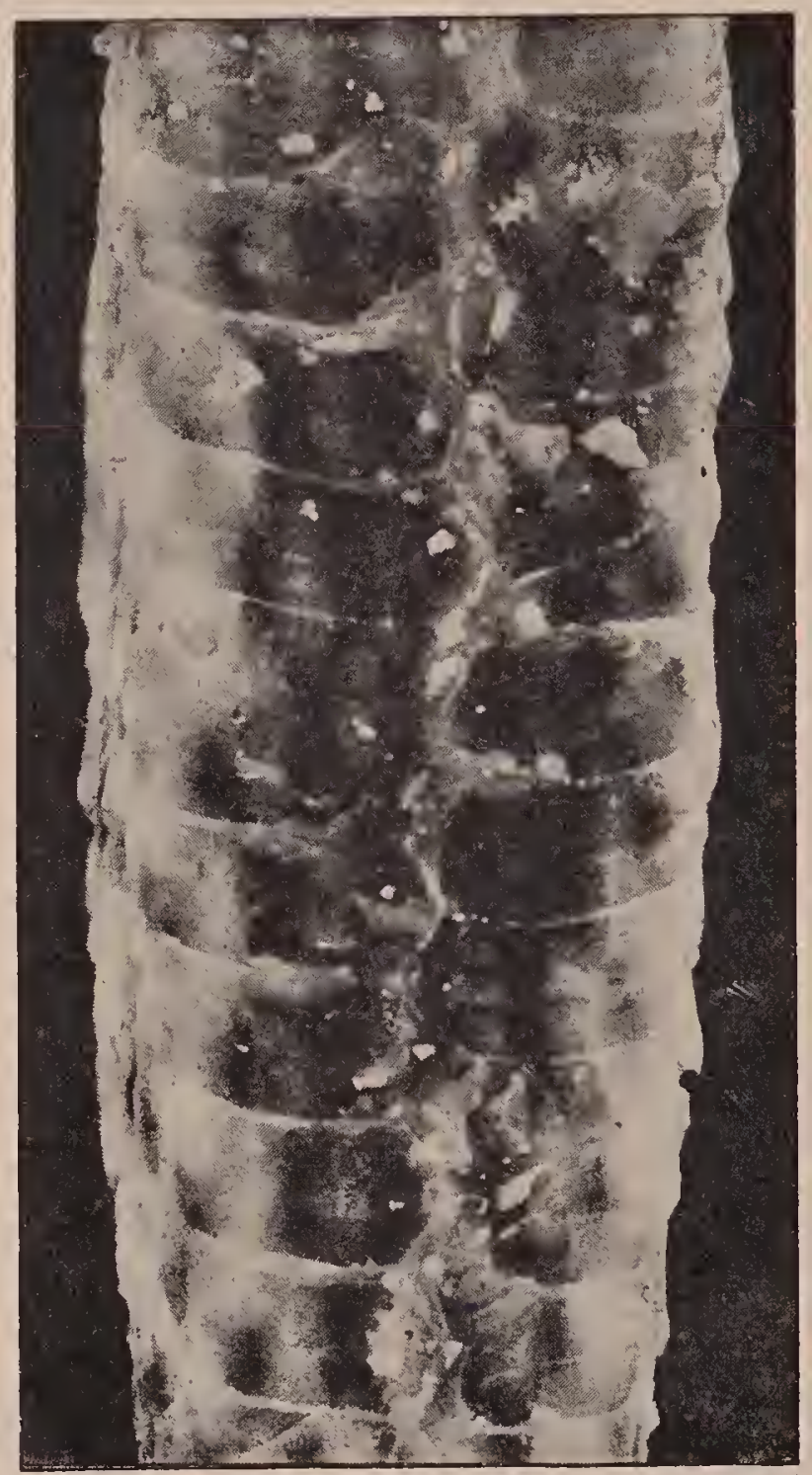

Cross-section of honeycomb, enlarged view. The cells are partly filled with honey. This illustration shows that the cells are not straight and horizontal, but curved and slanting upward.

comb of workel-cells, and the whole is such an exquisite work of skill as no human expert can equal. Besicles the worker and drone cells, queen-rells are built at times, as described.

In general, comb is built so that an angle is at the top and bottom of each cell. as in Fig. 1; and this is believerl to give greater strength than if the cells were buit like Fig. 2. 


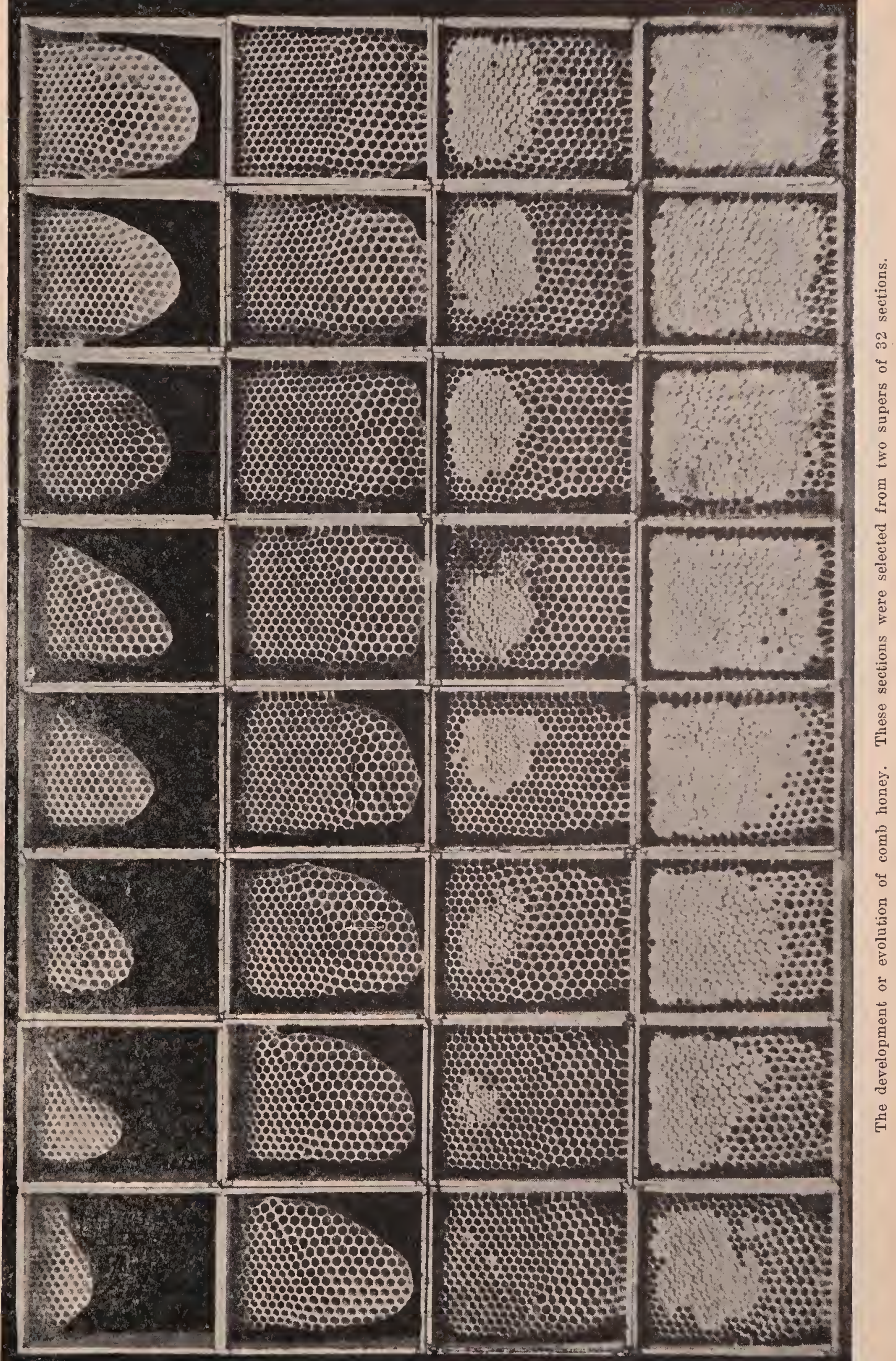


When combs are built upon foundation, the rows of cells run in a horizontal line with exactness. But when the bees build at their own sweet will, there is no little variation from the horizontal.

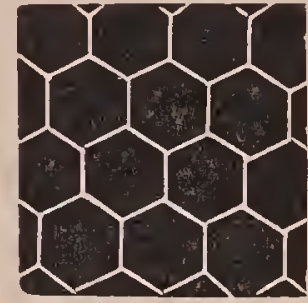

FIG. 1.

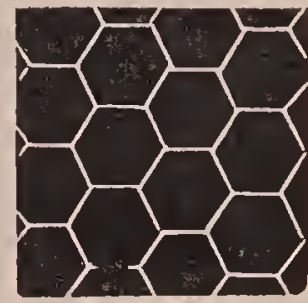

FIG. 2.
While the cell-walls vary from $1-3000$ to $1-4000$ inch in thickness, the septum is thinner, sometimes being as thin as 1-5000 of an inch when first built. But as successive generations of young bees are reared in the cells, cocoons and secretions are left at the bottom of each, and in time the septum may become $1 / 8$ inch thick. From this it happens that, altho worker comb is $7 / 8$ inch thick when first built, specimens of old comb may be found measuring an inch in thickness, since the bees draw out the cell-walls at the mouth of the cell to balance the additions made at the bottom of the cell, so as to maintain the same depth in an old cell as in a new one.

When, however, worker-cells are used for storing honey, if there be room for it, the depth of the cells may be so increased that the comb may be two or three inches thick. Drone comb is even more likely to be thus built out. The cells of both kinds slant upward from the center to the exterior of the comb, yet so slightly that to the casual observer they appear entirely horizontal. Yet when the comb is so greatly thickened for the storing. of honey, the slant may be much increased, giving the cell a curved appearance.

Formerly it was taught that the cappings placed over honey are air-tight, and this in spite of the fact that it is a common thing to see white comb honey become watery and dark when kept in a damp place, the thin honey finally oozing out thru the cappings. Cheshire, who at one time held that the sealing of honey-cells is air-tight, says (Bees and Beekeeping, Vol. I., page 174), "By experiments and a microscopic examination, I have made evi- dent that former ideas were inaccurate, and that not more than 10 per cent at most of the sealing of honey is absolutely impervious to air." The sealing of broodcells, however, is very much more porous still (see Brood), no doubt for the sake of allowing proper air for the brood. The brood-cell cappings seem to be made up of shreds of cocoons, pollen, and almost anything that comes handy, with only enough wax to weld the whole together.

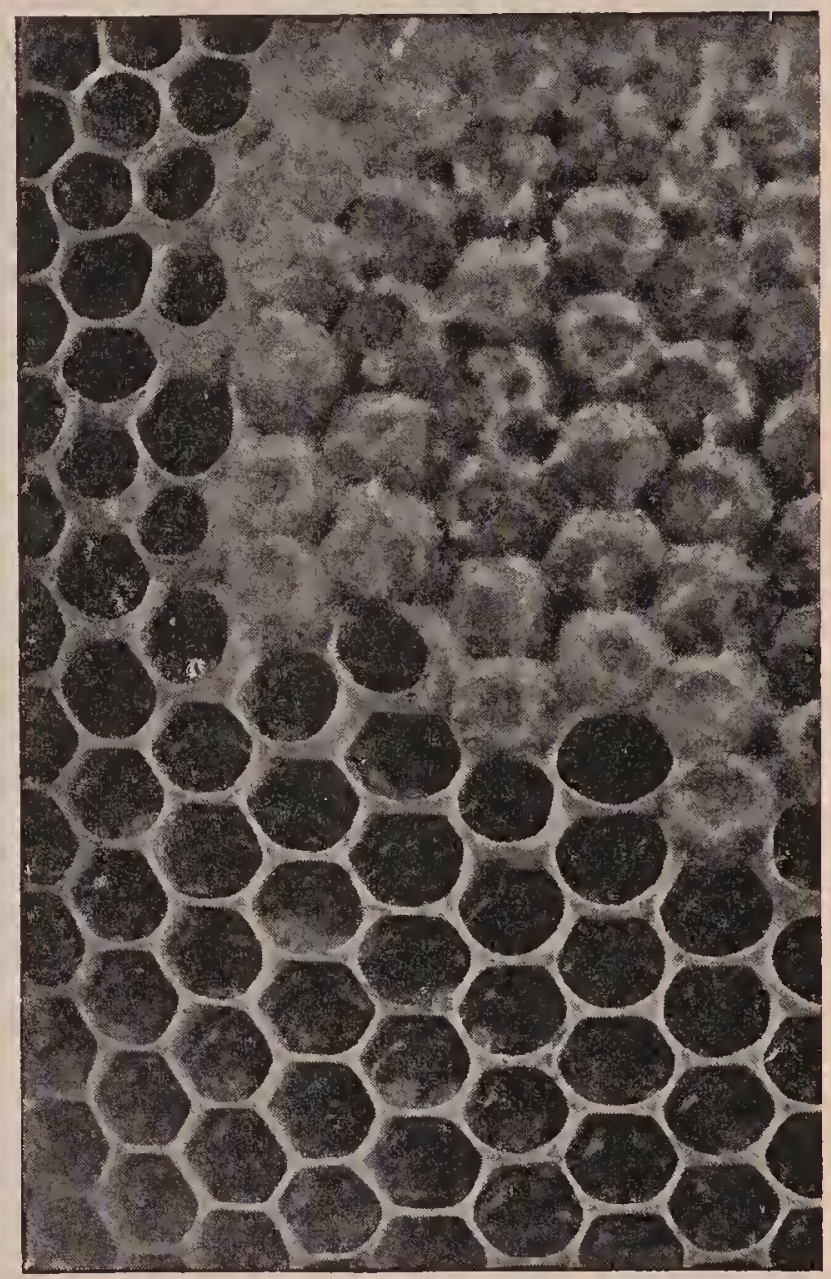

Drone-cells used for honey storage. It will be seen that the lower part of the opening is capped first. This, with the slant of the cells, keeps the new honey from running out.

The beautiful white color of honeycomb becomes dark with age, and when used for brood-rearing becomes nearly black.

Drone comb measures just about four cells to the inch, but the bees seem less particular about the size of it than with the worker. They oftentimes seem to make the cells of such size as to fill out best a given space; and, accordingly, the cells differ from worker size all the way up to considerably more than $1 / 4$ of an inch in width. Drones are raised in these extralarge cells without trouble, and honey is 


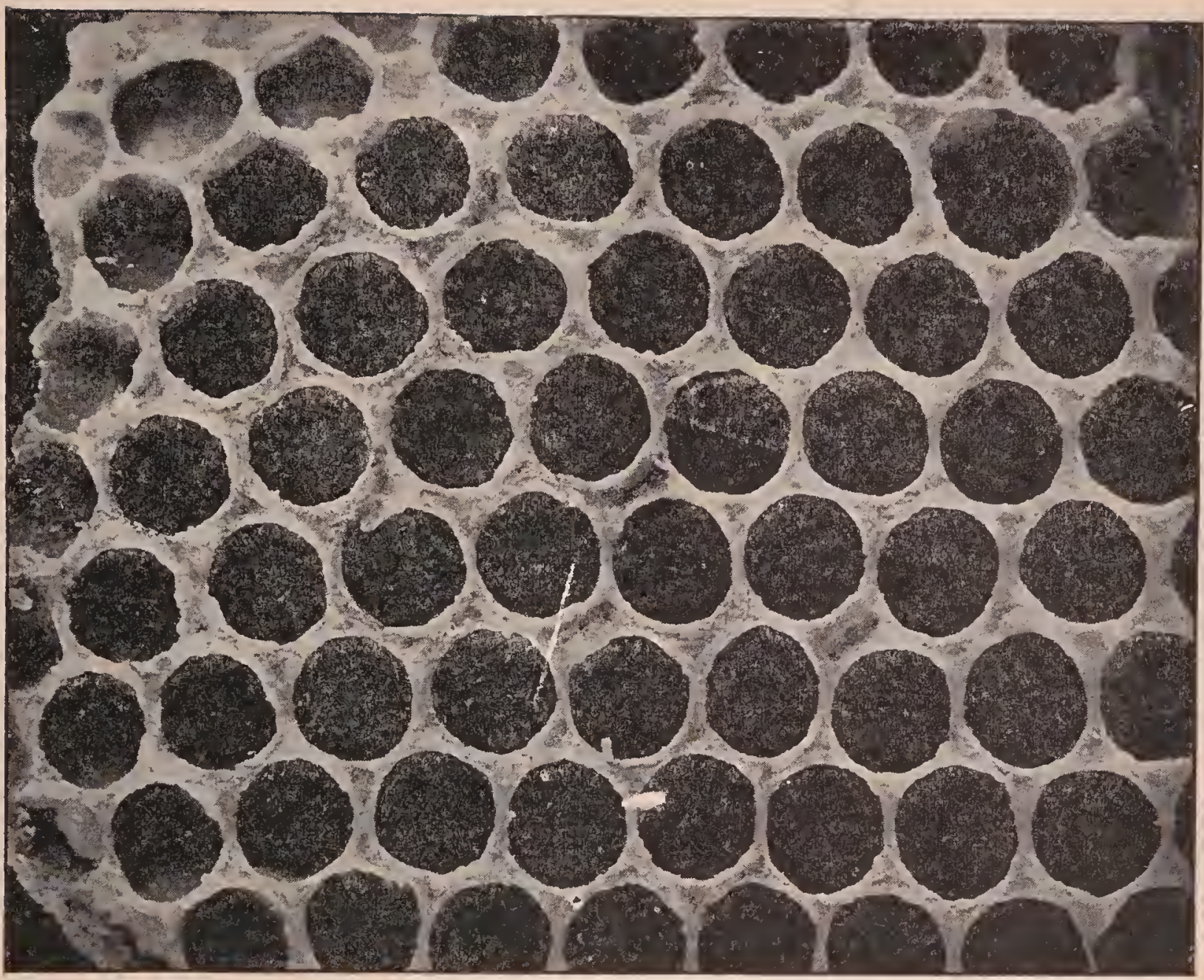

Top view of honeycomb greatly enlarged, showing the thick circular rim or coping at the top of the cell.

also stored in them; but where they are very large, the bees are compelled to turn them up, or the honey would flow ont. As honey is kept in place by capillary attraction, when cells exceed a certain size the adhesion of the liquid to the wax walls is insufficient, of itself, to loold the honey in place. Where drones are to be reared in these very large cells the bees contract the mouth by a thick rim. As an experiment, some plates were made for producing small sheets of foundation, having only $3 \frac{1}{2}$ cells to the inch. The bees worked on a few of these, with these same thick rims, but they evidently did not like them very well, for they tried to make worker-cells of some of them, and it proved so much of a complication for them that they finally abandoned the whole piece of comb, apparently in disgust. Bees sometimes rear worker brood in drone comb, where compelled to from want of room, and they always do it in the way already mentioned, by contracting the mouth of the cells and leaving the young bee a rather large berth in which to grow and develop. Drones are sometimes reared in worker-cells also, but they are so much cramped in growth that they seldom look like fully developed insects. See Laying Workers; also Brood.

Several times it has been suggested that the race of honeybees could be enlarged by giving them larger cells; and some circumstances seem to indicate that something may be done in this direction, altho there is little hope of any permanent enlargement in size without combining with it the idea of selecting the largest bees from which to propagate. By making the cells smaller than ordinarily, small bees are obtained with very little trouble; and the author has seen a whole nucleus of bees so small as to be really laughable, just because the comb they emerged from was set at an angle so that one side was concave and the other convex. The small bees came from the concave side. Their light, active movements, as they sported in front of the hive, made them a pretty and amusing sight for those fond of curiosi- 


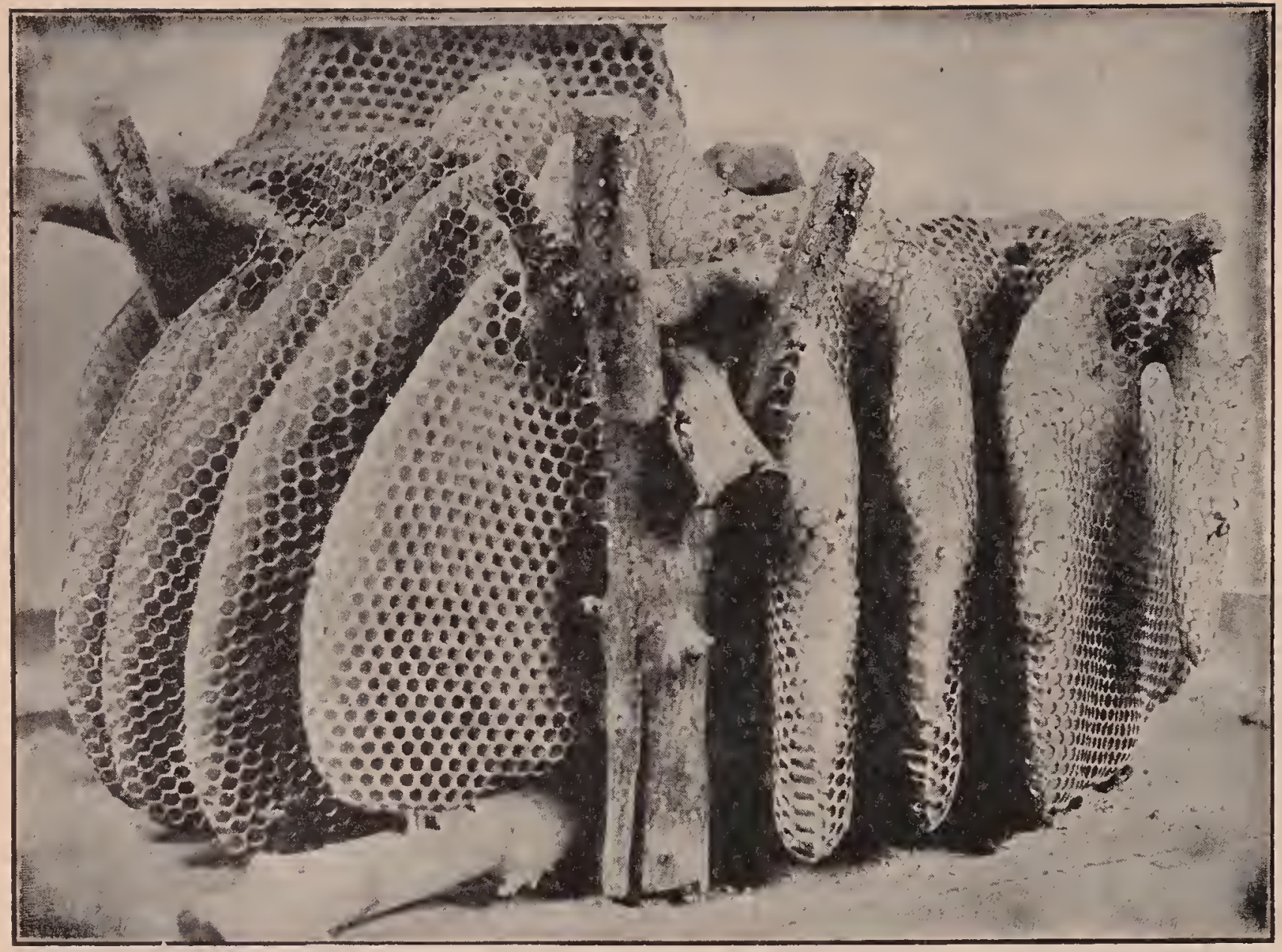

Natural-comb building in a hire made entirely of glass.

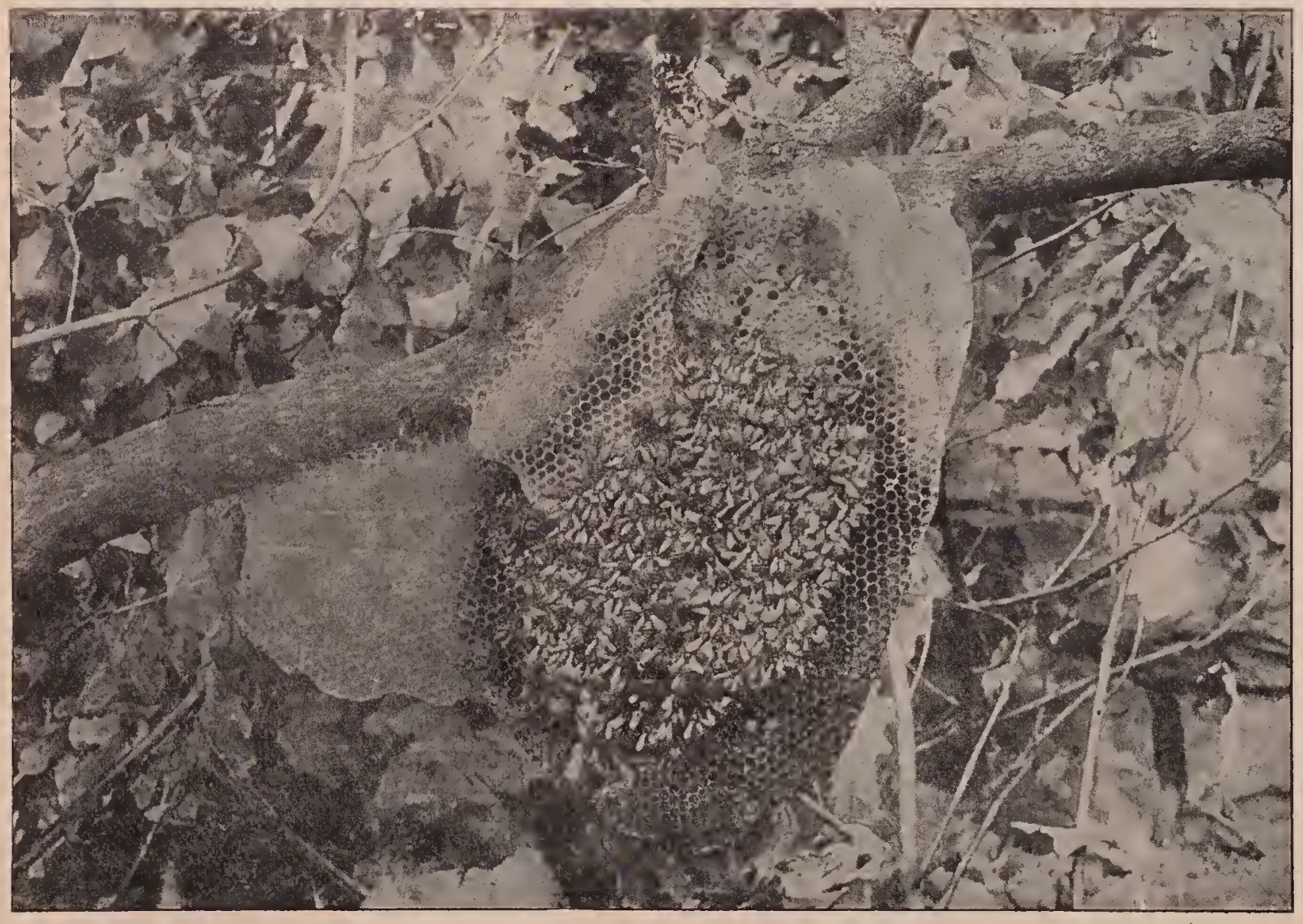

Bees living on combs built in the open air. 
ties. Worker bees reared in drone-cells are sometines extra large in size; but as to whether they can be made permanently larger by such a course is very doubtful. The difficulty, at present, seems to be the tendency to rear a great quantity of useless drones. By having a hive furnisher entirely witl worker comb, it is possible to restrict the rearing of drones down to a comparatively suall number. A few cells near the bottom or colners of a frame are sometimes reconstructed into drone comb. See large illustration unclel BROOD AND Broon-Rearing; also Coxib Foundation.

\section{HOW BEES BUILD COMB.}

In this day and age of bees and honey it would seem that one should be able to describe how hees build comb, with almost as much ease as one would tell how cows and hor'ses eat grass; but for all that, records are lacking of car'eful and close experiments, such as Darwin made many years ago. In the author's ho: se-apiary there were dozens of hives where the bees were building right up close to the glass; and all one had to do, in ordèr to see how it was done, was to take a cliair and sit down before their. But the little fellows have such a queer sleight-of-hand way of doing the work that one hardly knows how they do accomplish it.

If one will examine his bees closely during the season of comb-building and honeygathering, he will find a good many of then with wax scales protruding between the rings that form the body, and these scales are removed from their bodies as described at the beginning of this article. If a bee is obliged to carry one of these wax scales but a short distance, it takes it in its mandibles, and looks as business-like with it thus as a carpenter with a board on his shoulder. If it has to carry it from the bottom of the honey-box, it takes it in a way that it is difficult to explain any better. than to say it slips it under its chin. When thus equipped, one would nerer know it was encumbered with anything, unless it chanced to slip out, when it will rery dextrously tuck it back with one of its fore feet. The little plate of wax is so warm from being kept under its chin as to be quite soft when it gets back; and as it takes it out, and gives it a pinch against the romb where the bnilding is going on, one would think it might stop a while, and put it into place; bnt not that bee; for off it scamper's and twists around so many different ways one might think it was not one of the working kind at all. Another follows after it sooner or later, and gives the wax a pinch, or a little seraping and burnishing with its polished mandibles, then another, and so on; and the sum total of all these manewrers is, that the comb seems almost to grow out of nothing; yet no one bee ever makes a cell.

The finished comls is the result of the united efforts of the moring, restless mass; and the great mystery is, that anything so wonderful can erer result at all from such a mixed-up, skipping-about way of working as they seem to have. When the cells are built out only part way they are filled with honey or eggs, and the length is increased when they feel disposed, or "get around to it," perhaps. It may be that they find it easier working with shatlow walls about the cells, for they can take care of the brood much easier, and put in the honey easier, too, in all probability; and. as a thick rim or coping is always left around the upper edge of the cell (see page 489), no matter what its depth, they liavo the material at hand to lengthen it. 'This thick rim is also very necessary to give the bees a secure foothold, for the sides of the cells are so thin they would be very apt to break down with even the light weight of a bee. When honey is coming in rapidly, and the bees are crowded for room to store it. their eagerness is so plainly apparent, as they push the work along, that they fairly seem to quiver with excitement; bnt for all that they skip about from one cell to another in the same way, no one bee working. in the same spot to exceed a minute or two at the very outside. Quite frequently, after. one has bent a piece of wax a certain way. the next tips it in the opposite direction. and so on until completion; but after all have given it a twist and a pull, it is found in pretty nearly the right spot. As nearly. as the anthor can discover, they moisten the thin ribbons of wax with some sort of fluid or saliva. As the bee always preserves the thick rib or rim of the comb at the top of the cell it is working, the looker-on woukd suppose it was making the walls of consid- 
erable thickness (page 489); but if it be cut away, and this rim be broken, its mandibles will have come so nearly together that the wax between them, beyond the rim, is almost as thin as tissue paper. In building natural comb, of course the bottoms of the cells are thinned in the same way, as the work goes along, before any side walls are made at all.

When no foundation is furnished, little patches of comb are started at different points, as shown on page 485. Then, as these patches enlarge, their edges are united so perfectly that it is sometimes difficult, when the frame is filled solid, to determine where the pieces were united, so perfect is the work. At other times there is, perhaps, a row of irregular or drone cells along the line of the union.

The midrib of natural comb becomes thicker as it approaches the line of support and tapers toward the bottom. Why this is so is evident. It seems wonderful that there should be a gradual gradation in thickness from top to bottom in spite of the haphazard, skip-about work on the part of so many different bees.

For the consideration of the thickness of combs and how far to space them apart see Frames, Self-Spacing; also Spacing Frames and Comb Foundation.

\section{NO ARTIFICIAL COMB HONEY.}

Some persons who are foolish enough believe there is a honeycomb made from wood pulp, punk, putty, paraffin, or perhaps material other than wax. Why foolish? Because a wise man changes his mind (when it becomes necessary); but a fool, never. It would not be surprising in these days of sensational journalism and of false nature-stories if one should get the notion that artificial comb honey really exists; but the foolish part comes in when a person, totally inexperienced with bees, stoutly and smilingly maintains that there is such a thing as manufactured honey in the comb. The inimitably foolish expression of such a person is, perhaps, the origin of the colloquialism, "The smile that won't come off." No use. Do not argue. It won't come. "Why, I've seen in at the stores. Grocer told me all about it-was sereral cents cheaper. I tried it; we didn't like it as well as the genuine." And then the beekeeper goes away, not a wiser but a madder man, and wonders why the foolkiller doesn't do his duty, and why every one except the beekeeper knows all about bees and their products. See ComB HoNEx, also Honey Exhibits.

HONEYDEW.-Honeydew is a sweet glutinous liquid excreted in large quantities on the foliage of plants by Hemipterous insects, chiefly plant-lice and scale-insects. It is often so abundant on the leaves of trees and bushes that it drops upon the grass and sidewalks, covering them with a glistening coating resembling varnish. At times it falls in minute globules like fine rain. Altho readily gathered by honeybees, it has an inferior flavor and is detrimental to beekeeping. The ancient Roman naturalist Pliny supposed that honeydew fell from the stars, and this belief was generally accepted for centuries. The honeydew gathered by bees is produced chiefly by five families of insects belonging to the suborder Homoptera of the order Hemiptera or bugs; plant-lice (Aphididae), barklice or scale-insects (Coccidae), lanternflies (Fulgoridae), jumping plant-lice (Psyllidae) and white flies (Aleyrodidae). A small amount of honeydew is also excreted by a few species of tree-hopper's (Membracidae), which are attended by ants.

The white flies (Aleyrodidae), small winged insects covered with a whitish powder, were formerly classed with the scaleinsects, as in their immature-state they are scale-like in form. In warm regions they are reported to exude honeydew in large quantities, but in the temperate zone they are not sufficiently abundant to produce much of this excretion.

The jumping plant-lice (Psyllidae) are small winged insects about one-sixth of an inch in length. Many of the species form galls. The pear tree Psylla often destroys pear trees by sucking the sap from the twigs. According to Slingerland it excretes honeydew copiously. "It literally rained from the trees upon the vegetation beneath; in cultivating the orchard the backs of the horses and the harnesses often became covered with the sticky substance dropping from the trees. It attracts thou- 
sands of ants, bees, and wasps, which feed on it."

More than 400 tons of honeydew are shipped from the Hawaiian Islands annually, most of which is an excretion of the sugar-cane leaf-hopper (Perkinsiella saccharidica), a species belonging to the family Fulgoridae. In 1903 these insects became so abundant as to prove a serious check to the cultivation of sugar cane. For several years it caused a loss of about $\$ 3,000,000$ annually to the planters; but it has been brought under control and today the plantations are again producing heavy crops of sugar. The honeydew from the sugar-cane leaf-hopper is described by Phillips as very dark amber in color and slightly ropy. In flavor it strongly resembles molasses; while most honeydews granulate very rapidly, this type does not granulate at all. Samples several years old are as clear as when first extracted. A small amount of this honeyderv mixed with the light-colored algaroba honey imparts its color and flavor to the entire amount. Bees prefer floral nectar to the excretion; but, when the floral nectar is not abundant, they gather both and the honey is a mixture.

The chemical composition of Hawaiian honeydew honey differs so widely from floral honey that many buyers on the mainland have charged that it was adulterated; but after careful investigation Phillips was convinced that it was a natural sweet product collected by bees and shipped without the addition of other sugars. It is not placed on the market in competition with the honeys of the mainland derived from flower's, but is sold to bakers, who have found that it has superior baking properties and prefer it to algaroba honey. On the New York market it commands a slightly higher price per pound than algaroba honey.

Analysis (see table) of the honerdew honey of the sugar-cane leaf-hopper shows that the ash content is rery high, ranging from three to six times the amount found in normal honeys. The percentage of dextrin is also very high, and its acidity is three times that of algaroba honey. The percentage of sucrose or cane sugar is a little higher than that of the average of floral honeys. A ray of polarized light is turned to the right by the honeydew, while pure floral honey turns the ray to the left.

The Coccidae are commonly known as scale-bugs, scale-insects, bark-lice, mealybugs, and Coccids. The species are very numerous and infest the bark and foliage of a great variety of plants, and also nearly every kind of fruit. They excrete great quantities of honeydew both in temperate and tropical regions. Only the adult females exude honeydew. Not all of the species produce honeydew, as many excrete wax or resinous substances. In early autumn a great quantity of honeydew is occasionally gathered from oak trees, the limbs of which are covered with a great number of small Coceids, gall-like in form, about a quarter of an inch in length, from the ends of which there flows continuously a clear sweet liquid. So profusely is the honeydew exuded that the trees appear as tho they had been sprayed with hundreds of gallons of it. When it dries it solidifies and hangs in small stalactites. This honeydew is produced not by a gall, as is often reported, but by the adult females of a species of Kermes, which are remarkable for their gall-like form. "So striking is the resemblance," says Comstock, "that they have been mistaken for galls by many entomologists."

Species of Lecanium, a genus of Coccids found everywhere on plants, attack basswood, tulip tree, maples, and many other trees, covering the leaves with a sweet liquid similar to that yielded by plant-lice. In California a scale-insect (Lecanium oleae) coats the foliage of citrus fruit trees with great quantities of shining dew. $\Lambda$ fungus often grows luxuriantly on such leaves, forming a dense felt over their surface. At Amherst, Mass., and at Guelph, Canada, thousands of bees have been observed gatliering from spruce trees the sweet excretion of a scale-insect (Physokermes piceae). They are found at the base of the new growth and have the appearance of little buds. Pine trees are likewise at times prolific sources of honeydew gathered from scale-insects living at the base of the leaves.

Probably more honeydew is produced by plant-lice or aphids (Aphididae) than any other family of insects. They occur on a great variety of trees and shrubs, a part of the species living on the leaves, a part 
on the limbs, and other's on the roots. Among the deciduous-leaved trees on which honeydew is very frequently found are oaks, beecli, poplar, ash, elm, lickory, chestnut, maple, willow, basswoor, g’um trees, fruit trees, graperine, currant, blackberry, and hazel. The aphids are so well known that they require only a brief description. They are small, thick, usually greenish insects witl pear-shaped bodies and long legs. On the back of the sixth abdominal segment of Aphis and Lachnus there is a pair of tubes caller cornicles. A part of the forms are winged and a part are wingless. In the fall botl males and fenales appear. The females are wingless, but the males may be either winged or wingless. After mating the males soon die; the females lay one or more eg's, after which they die also. The eggs may often be found on the terminal buds of trees; e. g., on many of the terminal buds of the apple tree three or four minute black eggs are laid. Early in the spring the eggs latch, but produce only females known as stem-mother's. By budding they give birth to living young instead of laving eg's. The second generation consists like the first wholly of females, from which again come living offspring. Reproduction under these conditions without pairing may continue for eight or more generations, until with the approach of winter botll sexes are again produced. From time to time a part of the females are winged and thus provide for the spread of the species. The winged forms fly from tree to tree, and are likely to infest the tencler upper growing shoots. Later they spread to the lower branches. Tirgin reproduction (parthenogenesis), or the production of young withont fertilization, is of special interest to the beekeeper, as worker bees are able to lay egg's which produce only drones, and the unfertilized eggs of the queen also give birth to males alone.

Plant-lice multiply with extreme rapidity and it has been estimated that the offspring of each plant-lonse, if all survived, would in 100 days amount to over 3,200,000 individuals. Fortunately they are held in clieck by a vast number of parasitic insects, as syrphid flies, lady beetles, and plant-lice lions, or they would threaten the destruction of all regetation. Their de- relopment is also probably greatly influenced by the weather. Occasionally there comes a year when plant-lice and scale-insects appear in hosts, and there is consequently a great abundance of honeydew, as in 1884 and 1909 in this country and 1898 and 1907 in Great Britain. In 1909 there was in eastern North America an unprecedented amount of honeydew, while the crop of white clover and basswood was almost a complete failure. Most of the honeydew came from the leares of hickory and oak. While gathering it the bees were exceptionally cross. Since it became alternately partially liquid in the forenoon and gum-like in the afternoon, they were able to work on it only in the morning lours; the moisture in the air softened. it at night, but by noon the sun again dried it to a viscous state. Honeydew honey is often stored by the ton, and in certain localities as in the Sacramento Valley, Calif. a crop is gathered almost every year.

The dew is forcibly ejected or flipped from the end of the abdomen, and when there are many aplicis falls in a spray. of minute globules. If the dew were not thrown a. little distance from their bodies they would soon be gilued together. As they usually feed on the under side of the leaves, the sweet liquid naturally drops on the foliage beneath them. As it is gumlike it may dry and remain on the leaves for a long time, so that the absence of plant-lice is no proof that it is of vegetable origin. If it is rel'y abundant it may drip from the leaves to the ground. In 1891 Busgen observed that a single plant-louse on a maple leaf produced 48 drops in 24 liours (the drops were 1-25 of an inch in diameter), on a basswood leaf 19 drops, and on a rose leaf only 6 drops. The production of loneydew has been found to be most active in the middle of the day when the temperature is highest. The pair of tubes, or cornicles (also called siphons and nectaries) are commonly believed also to excrete loneydew; but this is denied by Forel and other entomologists, who assert that they exude only a gluey substance, which is not souglit by ants. The tubes do not connect with the digestive tract, and the liquid which issues from them is produced by glandular cells at their base. In 
a part of the aphids the tubes are wanting or are greatly reduced in size.

Hemipterous insects of the families deşcribed live wholly on plant sap. The mouth-parts form a jointed beak consisting of four slender bristles enclosed in a jointed sheath, which is a prolongation of the lower lip. With this pointed beak the insect easily pierces the bark or leaf and sucks out the sap of the plant tissues. The jointed sheath permits of a change of position without the removal of the beak. A part of the sap is digested and is used for growth and the production of young, while the residue is expelled as a waste substance known as honeydew. It is thus undoubt-
This type night perhaps be used by manufacturers of blacking or of lubricants. It is not a safe food for winter. If the bees are left on the summer stands and can obtain frequent flights, they may winter in fair condition; but, if they are placed in a cellar, they will all probably perish from dysentery. For brood-rearing in the spring it is unobjectionable, and it is, therefore, advised that it be removed from the hives in the fall and sugar syrup fed in its stearl.

The composition of honeydew honeys as compared with floral honeys is shown in the chemical analyses given in the following. table:

\begin{tabular}{|c|c|c|c|c|c|c|c|}
\hline$\cdot$ & 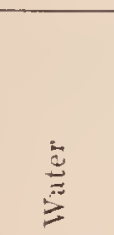 & 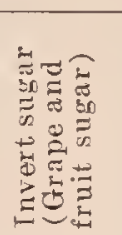 & 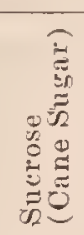 & 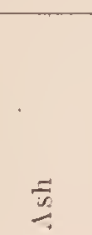 & 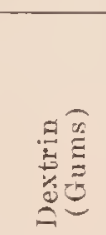 & 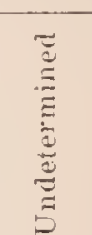 & 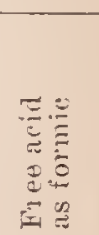 \\
\hline \multicolumn{8}{|l|}{ Floral honeys } \\
\hline Sweet clover & 17.49 & 76.20 & 2.24 & 0.12 & 0.45 & 3.50 & 0.12 \\
\hline White clover & 17.64 & 74.92 & 1.77 & 0.07 & 0.82 & 4.78 & 0.06 \\
\hline Alfalfa & 16.56 & 76.90 & 4.42 & 0.07 & 0.34 & 1.71 & 0.08 \\
\hline \multicolumn{8}{|l|}{ Honeydews } \\
\hline Hickory & 16.05 & 65.89 & 2.76 & 0.78 & 12.95 & 1.57 & 0.12 \\
\hline White oak & 13.56 & 55.87 & 4.31 & 0.79 & 10.49 & 4.98 & 0.08 \\
\hline Hawaiian sugar cane. & 15.46 & 64.84 & 5.27 & 1.29 & 10.01 & 3.13 & 0.15 \\
\hline
\end{tabular}

edly an excretion which escapes by way of the anal opening. It may not, however, consist entirely of the waste products of digestion. MacGillivray states that in plant-lice, which produce honeydew abundantly, the posterior portion of the rectum is greatly enlarged and is lined with large active cells, which may excrete the honeydew. The objection to honeydew on the ground that it is an excretion rather than a secretion is largely imaginary, as secretion is the more general term including exeretion.

The quality of boneydew varies greatly according to the plant on which it oceurs and the insects producing it. When freshly gathered it may be clear, sweet, and agreeable in flavor, or at least not unpalatable. The better grades find a ready sale to bakers, who prefer it for baking purposes to floral honey. But usually it is very inferior in quality, for when it remains for days on the foliage it gathers many impurities. A black smut sometimes covers the leaves so that the extracted honeydew is inky black resembling. coal tar.
From the above table it is apparent that honeydew honey contains less invert sugar; but more sucrose or cane sugar, dextrin or gums, and ash. It is because of the larger percentage of gums and ash that it is unsuitable for winter feeding. Honeydew honey may also be distinguished from floral honey by mrans of the polariseope. A ray of light passer thru a solution of floral honey is turned or rotated to the left, but passed thru a solution of honeydew honey it is turned to the right. If floral honey turns the ray to the right, it has been adulterated with glucose. No floral honey is obtained from the windpollinated flowers of hickory and white oak.

Besides bees honeydew is attractive to wasps, ants, flies, and other insects. liees pay no attention to plant-lice, but ants care for them and stroke them gently with their antennæ in order to induce them to yield honeydew more freely. This beliavior ler the botanist Linnæus to call $A$ phis the row of the ants (Aphis formicarum vacea). Ants defend plant-lice from their enemies, 
- move them to new pastures, care for their eggs, and build over them cover's of earth or cow-sheds to keep them warm. Ants also extend their protection to scale-insects.

The term honeydew should be rigidly restricted to the sweet excretions of insects gathered by honeybees. Nectar is the secretion of nectaries whether fioral or extra-floral. It has been asserted by many beekeepers and not a few botanists in the past, that there is a third sweet liguil, which, under favorable weather conditions, is exuded directly by the leaves. The statement of Gaston Bonnier is often quoted to the effect that he liad often seen trees on which there was not a single plantlouse, covered with a sweet liquid which exuded from the leaves. Cowan, editor of the British Bee Journal, gives the following opinion: "We are perfectly aware that opinions are divided as to the source of honeydew; but we agree with those who think it generally is an exudation from the pores of leaves under certain conditions of the atmosphere, altho it may sometimes be produced by aphides. We have on several occasions examined trees producing honeydew in abundance that were free from aphides." Many similar views might be given. But in the majority of cases it has been conclusively shown that the sweet liquid found on the foliage of trees is of insect origin, and that the assertions to the contrary were based on insufficient observation and superficial investigation.

Recent investigations by Davidson and Teit, however, show that from the tips of the leaves of the Douglas fir in British Columbia, and Washington State wrest of the Cascades, there is exuded a sweet liquid in large quantities. "Fir sugar" was known to the Indians of British Columbia long before the discovery of America, and in recent years its presence has repeatedly been reported by beekeepers, but it does not occur every year. The sugar-yielding firs (Pseudotsuga Douglasii) are confined chiefly to the dry belt of British Columbia between the parallels of latitude 50 and 51 degrees and the meridians of longitude 121 and 122 degrees. The sugar is not formed on trees in the dense forest, but only on those in comparatively open areas, on gentle slopes facing the east and west, during hot summer droughts. In leaves of the
Douglas fil exposed to continuous sunlight a laryer quantity of carbohydrates is formed during the day than can be stored or carvied away to the growing tissues. In the hot dry atmosphere transpiration ceases and the leares become gorged with water, which is forced out thru their tips. A beckeeper at Victoria states that many of the firs, particularly isolated trees, are well spattered with the exudation, and the needle-like leaves studded with pale amber diamouls. A large number of bees gather the liquid and in some years two or three supers of sections are filled with it. The honey is fair in quality, pale amber in color, with rather dark cappings. It crystallizes quickly. By the evaporation of the water the liquid is transformed into white masses $1 / 4$ inch to 2 inches in diameter. This solid may again be dissolved by rain and recrystallized in patches at the base of the tree.

A beekeeper living in the Olympic National Forest, Ore., 21 miles from Port Angeles, reports that his bees stored 150 pounds of fir sugar during a very dry season. The following winter many bees died from dysentery, which was attributed to the effects of the sugar. This seems very probable, as the composition of this excretion is very different from that of floral honey. It contains among other constituents nearly 50 per cent of the rare sugar, melezitose.

It is certainly not improbable that other species of conifers may under specjal climatic conditions exude a sweet liquid. In Switzerland about 40 per cent of the honey crop is gathered from the weisstanne (Picea excelsa), a fir tree. From an excretion found on the leaves of this fir tree the beekeepers in the Vosges Mountains, the Black Forest, and in parts of Switzerland harvest large crops of "honeydew," also called "waldhonig." J. A. Heberle believes that this honey is of plant origin, since metereological conditions seem to determine its production. Unfortunately most assertions that the leaves of coniferous and hardwood trees exude occasionally a sweet liquid are based on observations that are too superficial to be conclusive. But in the case of the Douglas fir the investigations of Davidson and Teit appear to establish beyond question 
the existence of such an exudation. This liquid differs widely in its composition both from honeydew and honey, and should be clearly distinguished from them. Such exudations of leaves should receive a special name, as leaf-dew or leaf-sugar.

The exudation of neariy pure water by the leaves of many plants is clearly very closely allied to the exudation of sweet liquids, and it may prove that there is no sharp line of demarkation. 'The Fuchsia, Indian corn, jewelweed, cabbage, primrose, grapevine, potato, elm, plane tree, the aroids, and other species of plants often exude drops of water from the tips and marginal teeth of the leaves. These drops may be observed on lawn grass, the ends of corn leaves and the margins of jewelweed leaves in the morning when they are-likely to be mistaken for dew. The exudation of drops of water may easily be shown experimentally by placing a young cabbage plant grown in a flowerpot under a belljar. In a few hours drops of water will appear on the apices or margins of the leaves, gradually increase in size, finally fall off, and new drops form. A surplus of water in the plant thus escapes when the air is too damp to permit of its passing off as water vapor thru the leaf pores. A great amount of water may thus be exuded, and in a single night a leaf may excrete half its weight in water. A vigorous leaf of Calocasia has been observed to eject water at the rate of 195 minute drops per minute, so that there seemed to be an almost continuous jet of water. The liquid is pure water except for a trace of salts (one-tenth of one per cent). Excreted water has probably been mistaken by some observers for honeydew, and, as has been stated, it is possible that the water under certain conditions, as in the Douglas fir, may contain more.or less sugar. Many hairs on leaves have been reported to excrete drops of water, but this is open to doubt, altho possible.

HONEY EXHIBITS.-Very much indeed has been accomplished by the exhibits of bees, honey, and apiarian' implements at state and county fairs. Several of the larger fair associations have had very pretty buildings erected on the fairgrounds for these displays.
Such exhibits have a decidedly educational influence on the public. They show how beautiful honey is; how it can be produced; how it can be produced by the ton and carload. On account of newspaper yarns, that were current some years ago, there existed an impression that has all but been removed, that comb honey is manufactured, and that the extracted article is adulterated with glucose. It is hardly necessary now to say that it is impossible to manufacture comb, fill it with honey, and "cap it over with appropriate machinery"-just as impossible as it is to manufacture eggs. The publishers have had for many years a standing offer of $\$ 1000$ to any one who would show where comb honey was manufactured, or even procure a single manufactured sample which could not be told from the genuine. Altho this offer has been published broadcast in the daily papers, no one took it up. The conditions of this offer were printed on a neat little card, which has been distributed by beekeepers at fairs and other honey exhibits, so that, if such a thing had been possible, the offer would have been taken up. As to extracted honey, there was a time when it was adulterated somewhat, but owing to the action of state and national laws there is very little of it now. See Adulteration of Honer, also the last paragraph on HoNEYCOMB.

Beekeepers, besides educating the general public as to the genuineness of their product, can create a larger demand for honey. As a usual thing, exhibitors are allowed to sell their honey, distribute circulars, and do a great deal of profitable advertising. This not only helps the individual, but helps the pursuit in general.

The accompanying engravings will give an idea of how model exhibits should be arranged.

There should be shelving ar'ranged in the form of pyramids, octagons, and semicircles. The honey should be put up in tin and glass, in large and small packages, and the whole should be neatly "set off" with appropriate labels. As a general thing, glass packages should have a very small label, so that as much of the liquid honey as possible will show. Tin receptacles should have labels to go clear around the can. Comb honey should be put up in 


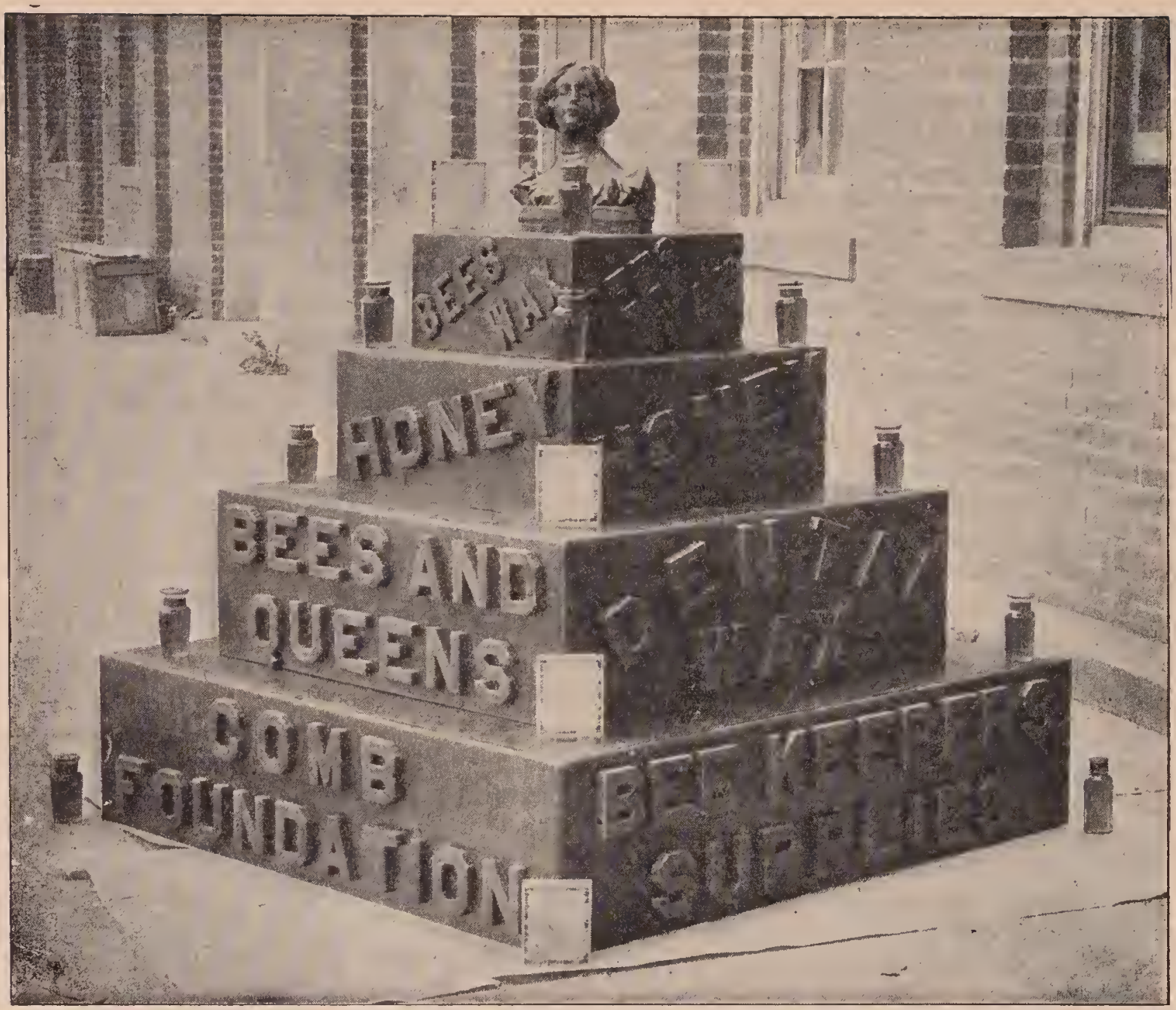

Suggestion for a beeswax exhibit at state fairs.

cartons and shipping cases: and yellow cakes of wax should be shown in a variety of shapes.

In one of the illustrations will be seen a large pyramid of beeswax, supporting on its several shelves packages of honey, the whole surmounted by the bust of a goddess. A series of square shallow boxes are made of such sizes that, when piled one on top of another, they form a perfect pyramid. These are completely covered with sheet wax having the edges that come in contact nicely cemented together with a hot iron. The letters are eut out of inch boards with a jigsaw, after which they are dipped in hot wax, and secured with nails to the pyramid. The next thing to make is the goddess of liberty, or the bust of a prominent man. These in plaster can usually be purchased at any of the stores for a small sum of money, and, after being dipped in hot wax, give a very fine wax figure.
Besides the exhibit of honey in various styles of packages, there should be a collection of bee-supplies, so that when the interested persons come along with their string of questions, they can be shown step by step the process of producing honey and its final putting-up for market. $\Lambda$ goor many questions will be asked in regard to the extractor. It will be called a churn, a washing-machine, and everything else except what it really is. This should be explained. There should. be one or more observatory hives to show how bees behave when at lome, and particularly the queen.

Very much can be done by having a glass hive and live bees, with an entrance communicating outdoors thru the sides of the building where the exhibit is made. What is equally good, or perhaps better, is a one-frame nucleus having glass sides, making, as it is called, an observatory hive. This should contain one frame of nice healthy brood, regular and perfect comb, 


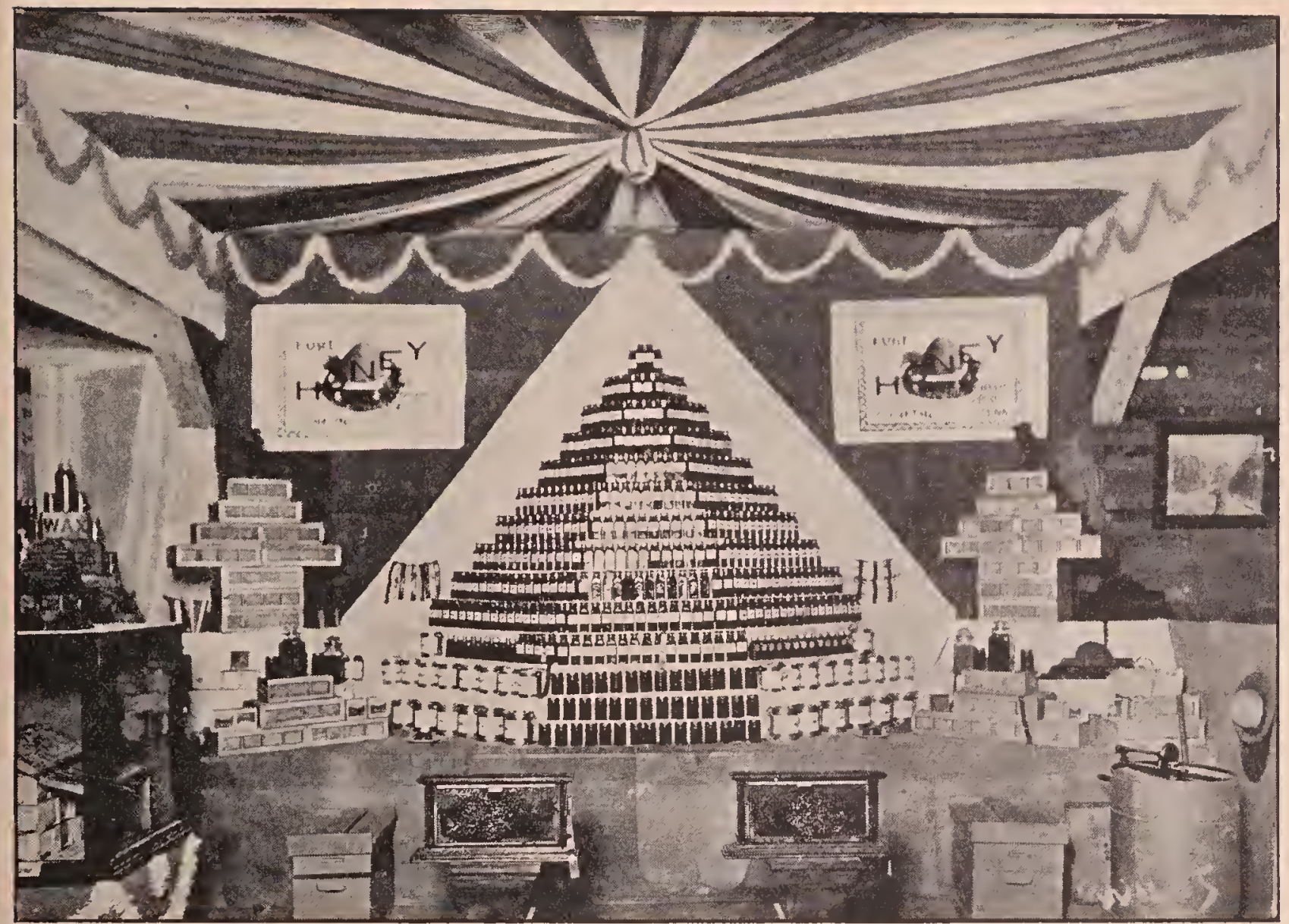

Exhibit of .T. M. Buchanan. Franklin, Tenn., at Tennessee State Fair, Nashville, October 9, 1909

finely marked bees, and a bright-yellow queen. Hundleds of people will stop and examine, and ask a valiety of questions about the bees and the gureen.
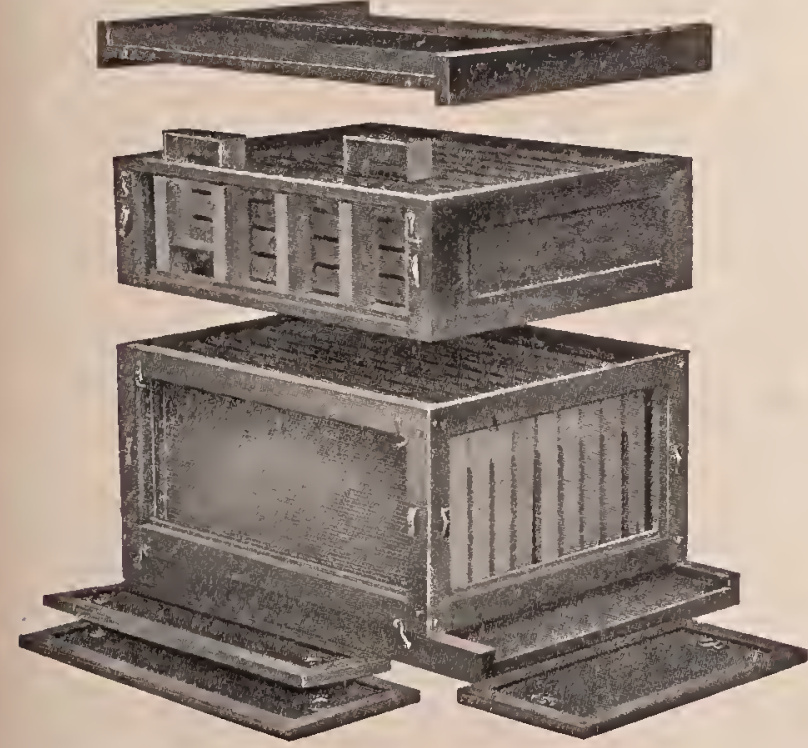

Olsservation hive and comb-honey super.

Bees in an observatory hive will stand confinement for two or three days but not longer. Ordinarily at fairs and other places, where the show lasts only two or three days, the confined hees will do rery well. But at expositions, where they are sllown week after week, it is necessary to give them a flight every two or three days. Some arrangement slould be made with the management by which these glass hives may be placed next to the wall of the building, the entrance communicating with a hole thru the building. Where this can not be rlone, one can lave two or three observatory lives, and keep one or two on exhibition all the time while the other is being freshened up by a flight outdoors. After these latter have had two or three days in which to cleanse themselves the entrance is closed at night, when the live is set back on its stand, and another observatory hive takes its place. Thus in alternation each one of the two or three lots of bees can be freshened up.

Where it is impossible to place the observatory hive next to the outside wall of the builuing, a long tube from the hive communicating with the outside wall of the building can sometimes be userl. But the distance must not be over eight or tril feet.* 'The bees, strange as it may seem,

The exit from the building should be alove the heads of pedestrians. To make this possible, the tube will have to slant upward from the hire. 


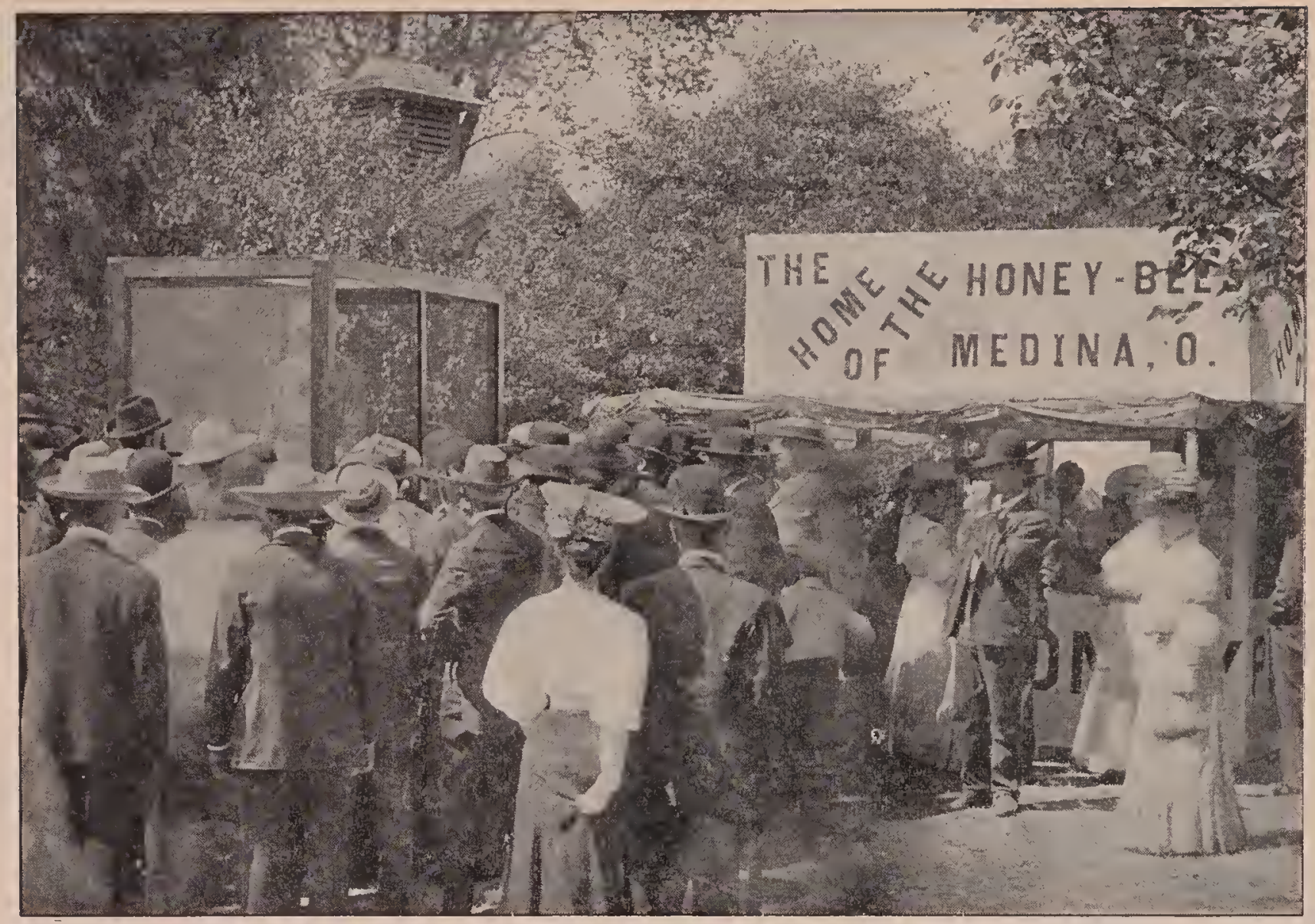

Demonstration work at the Ohio State Frir, Columbus.

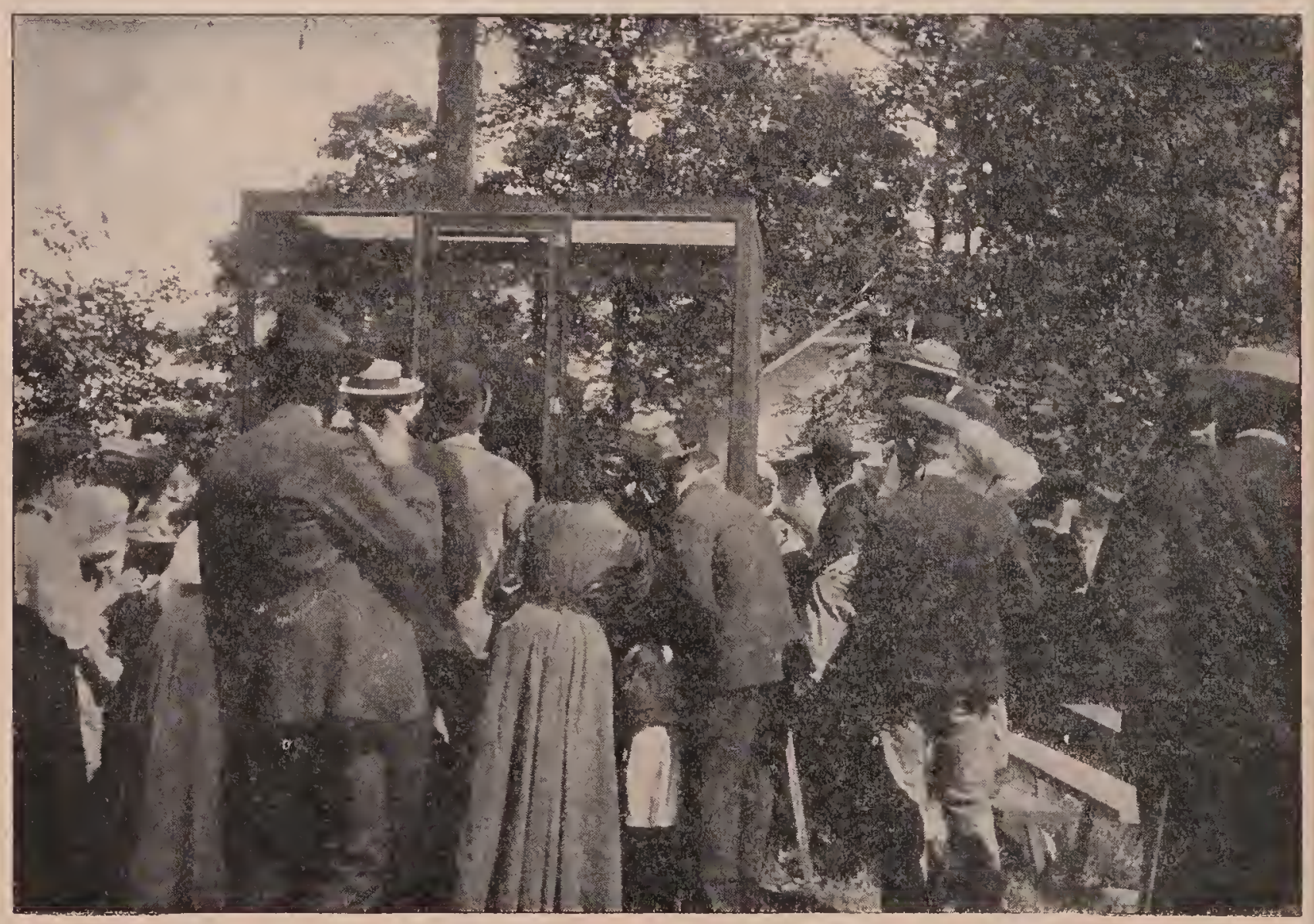

The .1. I. Root Company's demonstrating-cage at the Medina County Fair. 
will pass out thr'u the tube to the outside and return to their hive. This avoids a replacement of bees, and permits the normal work of the colony to go on uninterruptedly. Bees coming in with loads of pollen can be seen; and their rejoicings, with a quick nervous wagging of their bodies, attract the attention of the visitors.

THE ADVERTISING VALUE OF OBSERVATORY HIVES IN SHOW-WINDOWS OF GROCERIES AND DRUGSTORES.

In the fall, when the active selling season for honey naturally starts, a beekeeper can very often to advantage place a single-comb observatory hive in the show-windows of groceries and drugstores where his honey is on sale. (See OBSERVATORY HIVEs.) The presence of live bees, the honeycomb, the sections just above, in addition to their educational value to the general public, call attention to the honey on sale in the window as nothing else can. The sidewalk will very often be blocked by

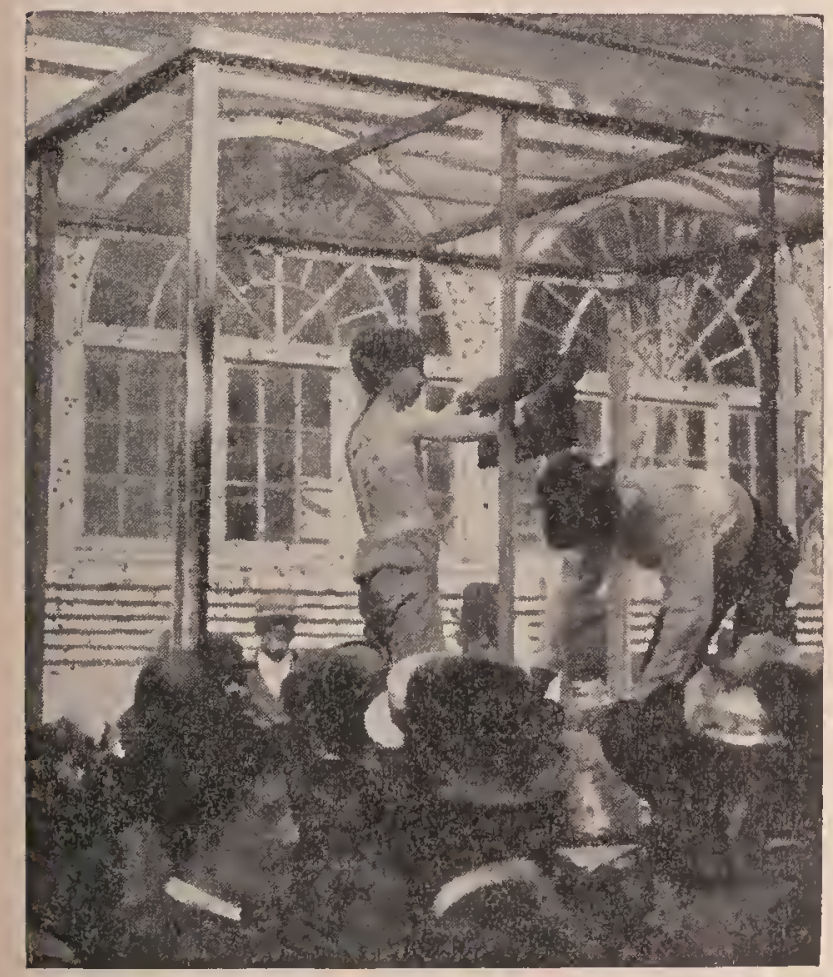

Charles Mondeng and his son Norman demonstrating bees at the Minnesota State fair. Mr. Mondeng and his son were awarded the first prize for bee demonstration; first prize on golden Italian bees; first prize on leather-colored Italian bees.

crowds to see the "king bee" as they call it, and the bees making honey. When both comb and extracted are displayed in packages of various sizes in show-windows along with the exhibit of live bees the by- stander will naturally step inside and buy a package of honey. The first package will taste so good that it will call for another and another.

The advertising value of live bees can scarcely be overestimated, especially in lo-

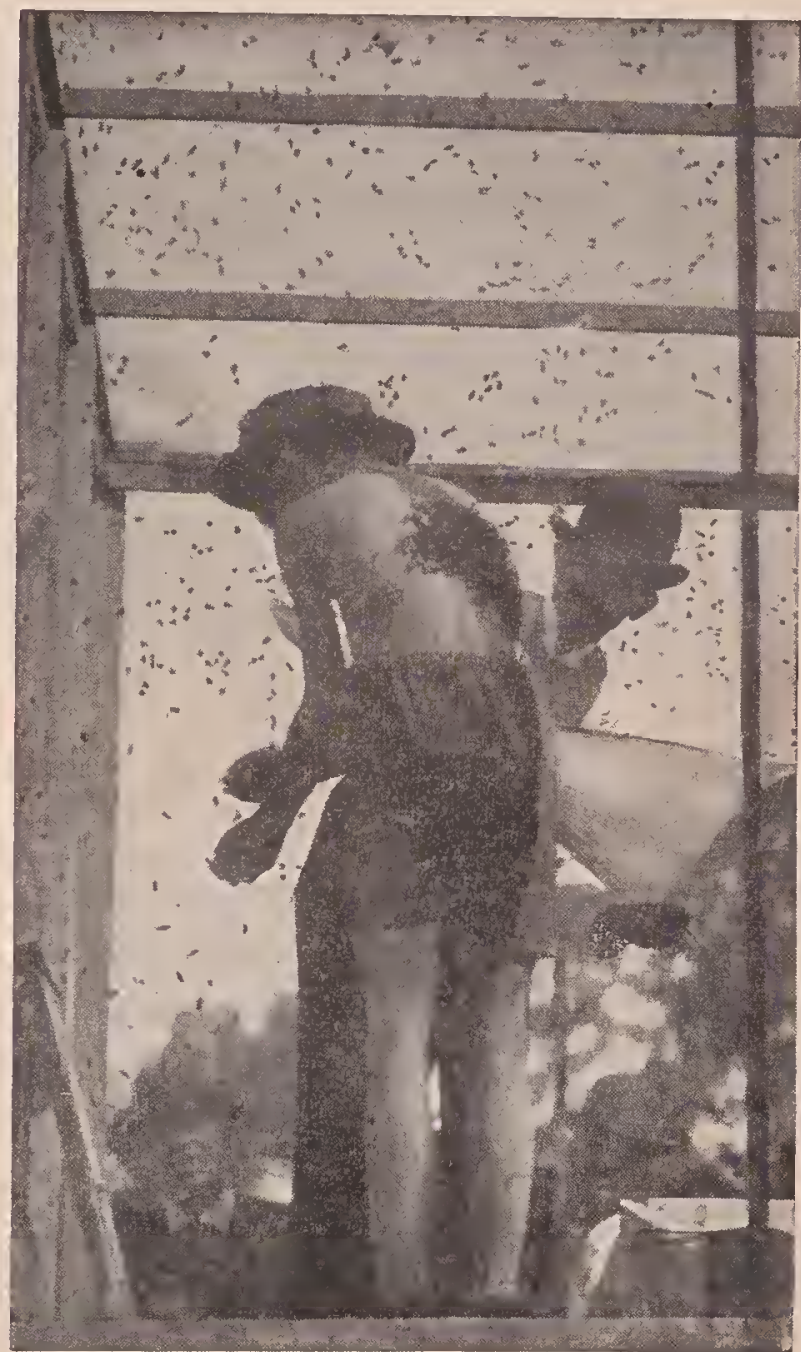

Norman Mondeng was only eleven vears old, yet he handled bees without fear. His entire clothing was a bathing suit.

calities where such exhibits have never been made before. When sales of honey are once started they will keep on and on. See Marketing Honet; also Botthing Honey.

It should be understood that bees in show-windows should be replaced every three or four days. After that time they will become logy and die. The "exhibit" from that time loses its advertising value.

LIVE-BEE DEMONSTRATION WORK TO ADVERTISE HONEY AT THE FAIRS.

In connection with an exhibit inside of a building, there should be a placard directing the visitor to a bee-show outside, 
as neir the building as possible. This should be a demonstration of the method of handling live bees inside a wire cage, the operator taking them up by handfuls and forming artificial swarms. Where the two exhibits, one of honey and bee-supplies, and the bee-show itself, can be located outdoors, it will be better. 'The former should then be in a temporary booth or tent, since it would not be advisable to have the exhibits of wax and comb honey exposed to the direct action of the sun. The demonstrating cage should be locater close by, within ten or twenty feet. It consists of a wire-cloth structure large enough to take in a man, a hive of bees, and room enough to practice ordinary bee-manipulation. This eage slould be elevated on a stand four or five feet above the groundthe higher the better, because there will be a great jam of people around to see the man inside pick up live bees by the handful.

Announcement should be made from outside of the cage that, during certain hours,

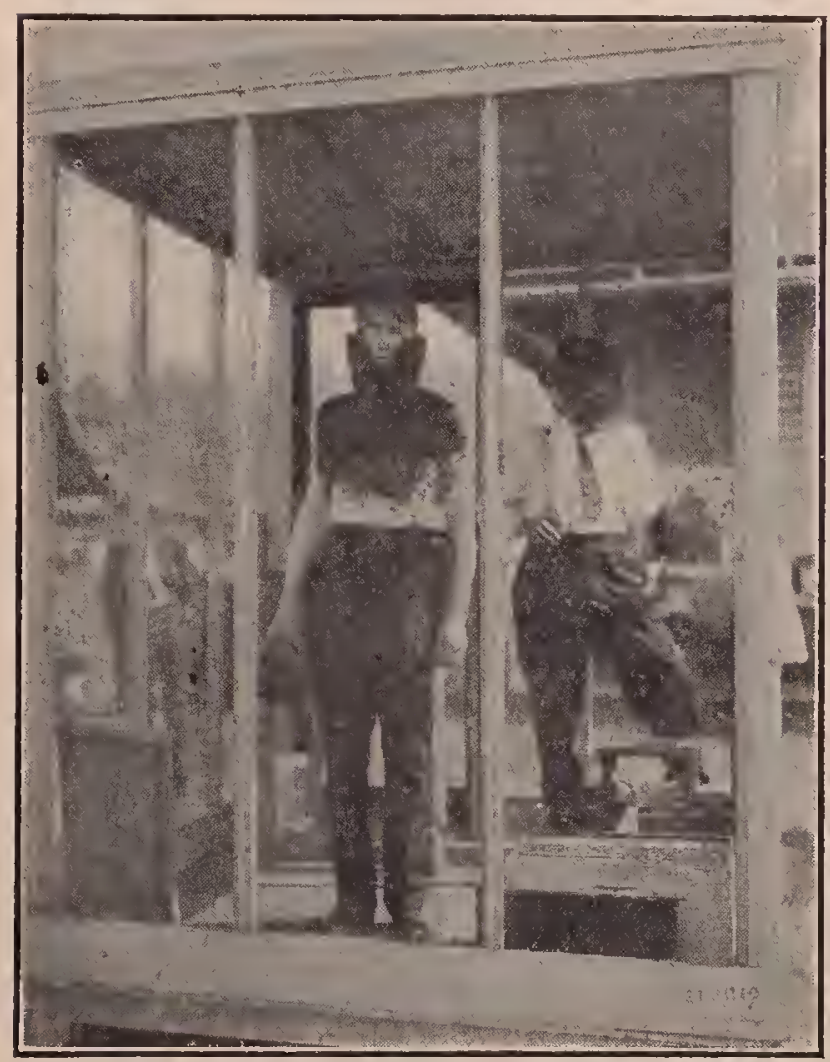

Mr. Wallace with his fine cape of bees.

an operator, barehearled and barearmed, will perform some wonderful stunts in landling bees. When the performance begins, the people will surge around the stands, and that is just what is desired in order to sell honey at the other stand a few feet allay.

'The operator begins his performance by stepping inside the cage of live bees, and closing the door. He then tells the crowd

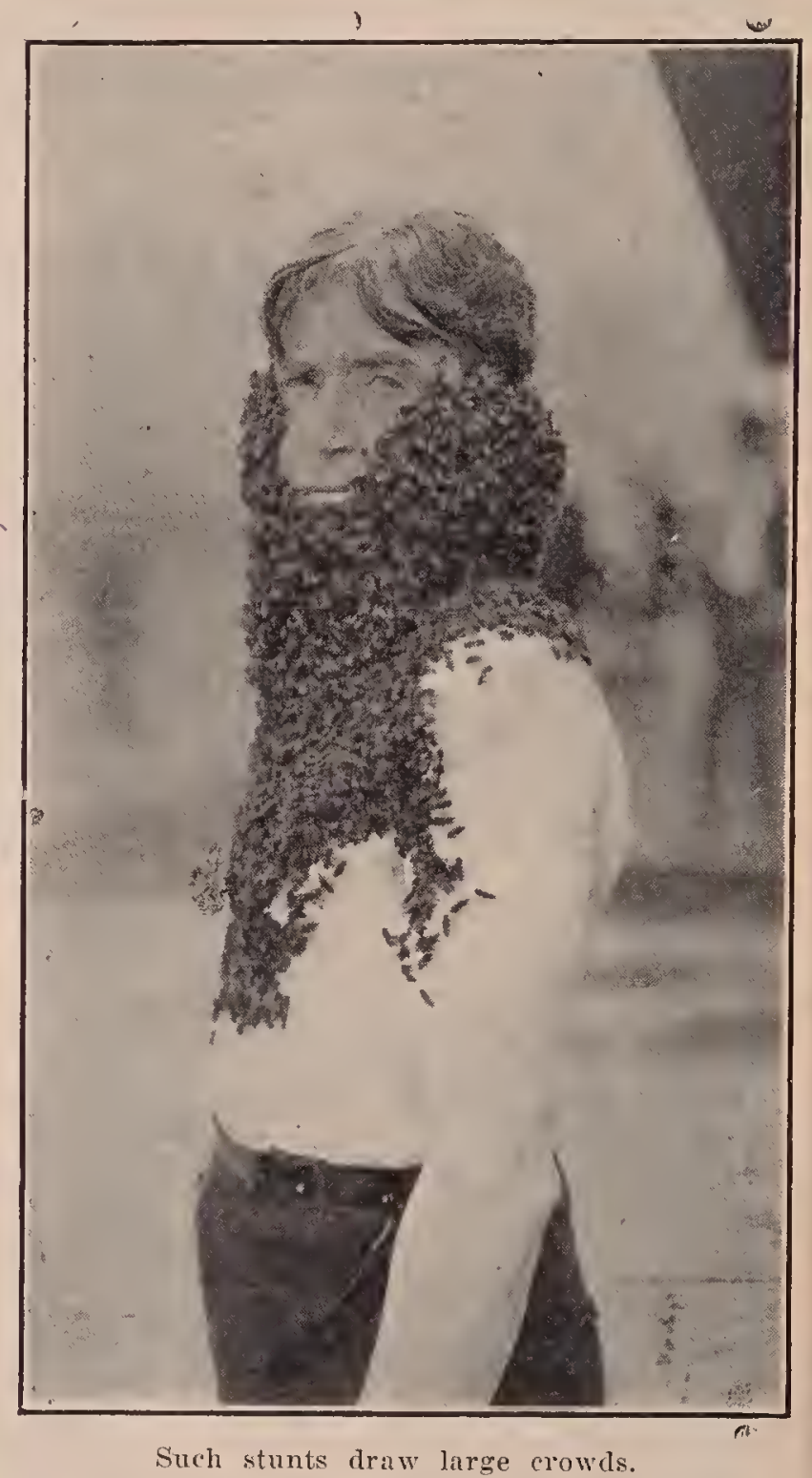

that he is going to handle live bees, every one of which is armed with a sting: and if any one doubts it to come forward and he will furnish the "proof." He proceeds to take off his coat and rest and roll up his sleeves, take off lis collar, and tuck down his shirt-band. It will then be necessary for him to put on bieycle pants-guards, or slip his trousers into his stookings. The crowd will quickly appreciate this part of the performance, because the operator tells them the bees will sting if they get inside of his elothing. With a lighted smoker he opens up the live. After pulling out the frames he shows the bees and queen on the comb; then lie calls out for everybody to 


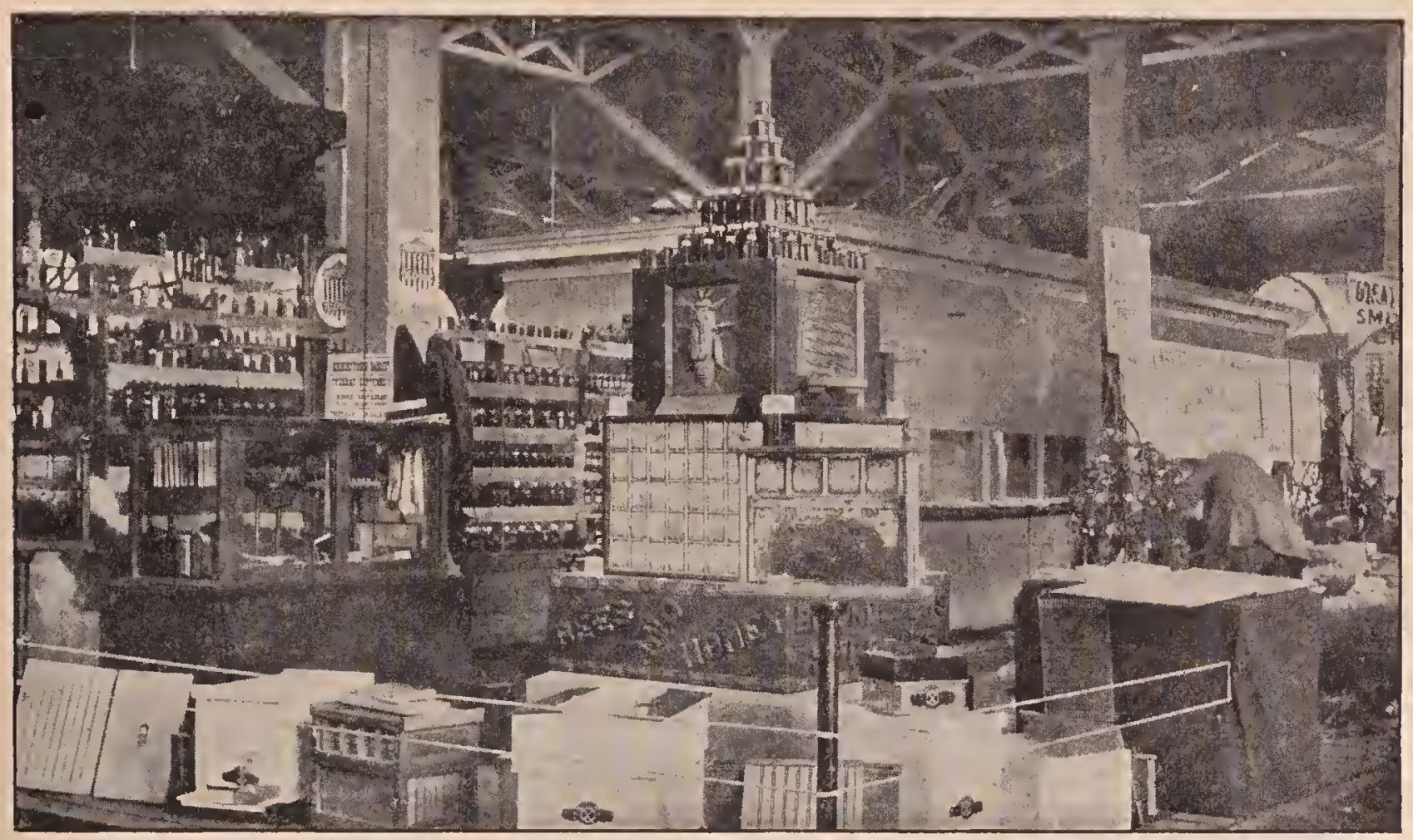

The A. I. Root Company's exhibit at the Ohio State Fair.

wait and see the next stunt, for he is going to make a swarn. With a large dishpan, which he has previously provided, he shakes the bees from two or three combs into this pan. Then he takes it up and turns to the crowd, saying, "The bees are

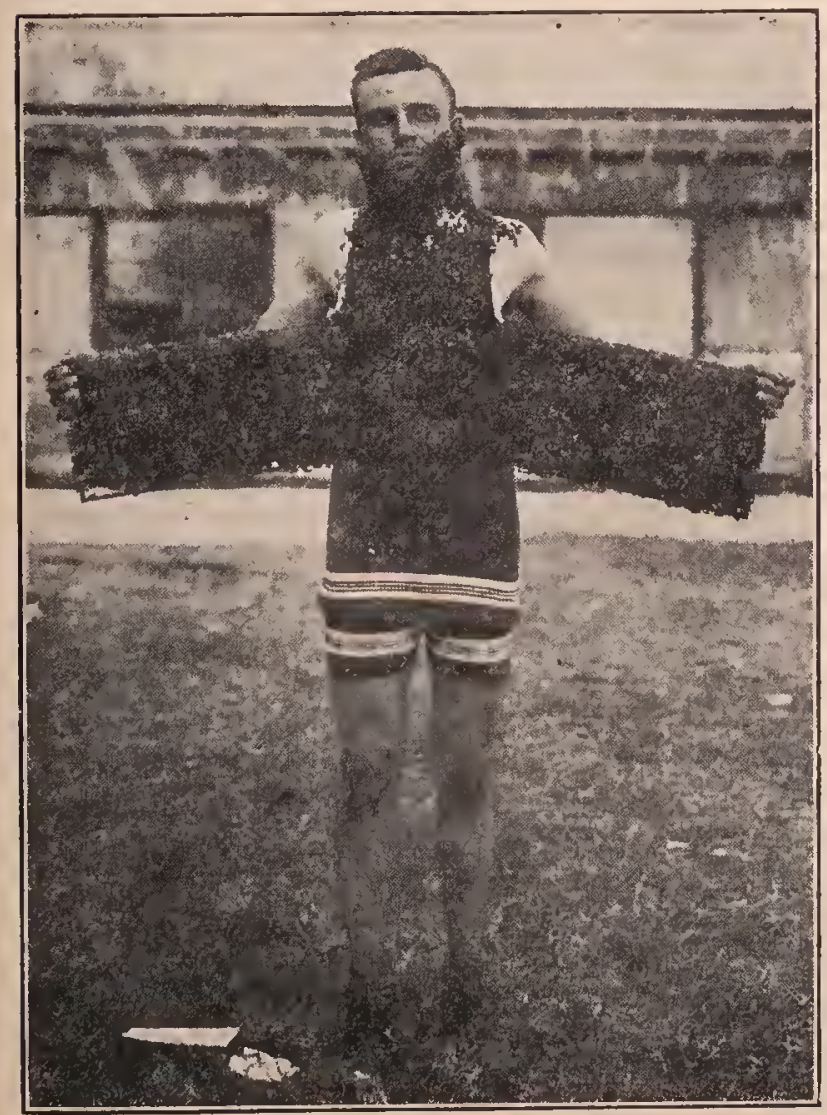

William H. Crowson demonstrating bees at the Tri-state Fair, Memphis, Tenn. not real mad ret, so I'll begin to shake them up to make them so." 'The people wonder what he is going to do, seeing him barearmed and bareheaded. He lieeps on shaking until he has the bees all in one big ball, and to the unitiated it looks as if they would sting him to dath. But, no! the continual shaking is the very thing that makes them gentle instead of cross. He now runs his hand under the ball of bees, pushing it under gently, being careful not to pinch any. The movement must be very deliberate- so slow indeed that the hand scarcely seems to move. He picks up a handful and holds them up for the crowd to examine. If he has good nerves he can put three or four bees in his mouth; shake a handful of bees on top of his head, and in the meantime pick up another handful.

$\Lambda t$ the next performance there will be big crowds around to see the work. While the man is doing his stunts with the bees he tells what honey is, saying that it is a wholesome sweet, and that there is no such thing as manufactured comb honey, and that he will pay $\$ 100$ for a single sample of it. At that psychological moment he draws attention to the fact that he has some good loney at the stand opposite or in the building yonder. The crowd will then go round to the stand and buy the honey. 
The preceding illustrations show the exlibits of bees and honey, the exhibit of the live-bee cage, and the crowd that assembled around it, both at the Ohio State Fair held at Columbus, and the Minnesota State Fair.

After the exhibitor gets his questioner interested, he can hand out one of his advertising cards, and at the same time give him a little sample of honey to taste. This can be done very readily by handing out some strips of strong manila paper, which are to be dipped in the loney and then transferred to the mouth.

HONEY-HOUSE. - See ExtraCTINGHOUSES.

HONEY, METHODS OF ANALYSIS. -See Honey, Analysis of.

HONEY ON COMMISSION.-See MARKETING HoNEY.

HONEY-PEDDLING.-Únder MARKETING HoNer farther on in this work are given specific instructions on selling honey. Under this head making a house-to-house canvass will be considered. There are two objections to this method of selling. One is, that it antagonizes the grocers who may be selling the same honey. The other objection is that peddling is in more or less disfavor among the housewives. The first objection does not apply where honey is sold in the country; and the second can be overcome where the right methods are employed. Dan White, a progressive and practical beekeeper, struck upon a novel plan that entirely eliminates the several objections. He thus describes it:

\section{PEDDLING MADE EASY.}

I packed my grip and took two 12-pound eans of lioney and started out. About all 1 had in my grip was a good supply of those leaflets published by the A. I. Root Co.; also 50 postals addressed to inyself.

I got into the town just before noon; and after eating a good meal at a boarding-house I filled my pockets with leaflets and took one lioney-can and commenced business. I started down a street and did not miss calling at every house. After ringing the bell, or rapping, a lady would open the door and look at me with more or less suspicion. I would say, "I made the call to ask you if your family were fond of honey."

They generally answered yes, but believed they would not buy any.
"Well," I would answer, "but I am not selling honey today. I am giving it away, and should be glad to give you some in a sauce-dish.",

Some would look astonished, others would smile, and say "'That's funny," but in every instance I was invited in. I would pour out the honey, then hand out a leaflet, telling them to read every word of it. "You will find it very interesting; it will tell you all about honey-how and why we extract it, etc. Then here is a postal card addressed to me; and should you decide to want a 12-pound can, put your name, street, and number, on the card; drop it in the office; and when I deliver in ahout ten days you will get a can of honey."

Well, there were enough cards put in he mail within five days to take thirty cans if honey. I promptly made the delivery en time, taking along twenty extra cari that sold about as fast as I could hand them out; and since then $I$ have received orders for 50 more cans from the same town. I tell you, it has got all over town that a honey-man had been there selling real honey. I am certain that this one place will take over 2000 pounds, all in one-gallon cans. Now, then, 18 pounds of honey given away from house to house, 50 postal cards, 200 leaflets left at houses and handed to people on the street, and one day walking over a very small portion of the town, has found a place for at least 2000 pounds of honey. Then think what I can do next season should I secure a good crop. All I shall have to do is take a big load and go up there and hand it out.

By the way, the lioney sold there was thrown out of clean white combs, over every inch of whose surface the uncapping-knife had to go. It weighed strong 12 pounds to the gallon-just as good as the best comb honey, only it was out of the combs. Of course, I can go back just as often as I choose; yes, and the people will be glad to see ine.

New London, Ohio.

It would appear that one of the prime requisites is a first-class article of wellripened extracted honey. Many persons make a mistake right here, and, of course, if the honey is poor, one is not likely to make a second sale. Mr. White's scheme is to have the honey taste so good that, when it is gone, the good people will drop that postal for more.

In a similar way Herman F. Moore of Chicago retailed large amounts of honey. His plan, like tliat of Mr. White, was to go around and solicit orders. In the cities of Cleveland and Toledo, or even those of smaller size, he would start out on foot, 
exhibiting a sample of his honey in a quart Mason fruit-jar. His reason for using this package was that almost any family would be willing to take a household article of this kind, for the simple reason that it would not have to be thrown away when it had served the purpose of holding the honey.

With this package Mr. Moore would call at private houses, one after another, and ask for a dish and spoon, saying that he had some very nice honey, and that he would like to give the women-folks a sample to taste. He then held up the beautiful transparent goods to the light, told them he was a beekeeper, and dealt only in pure honey; explained how it was produced, and finally named the price. If the lady of the house cared to take any he would take her order and deliver the next day. As a rule he took an order.

In this way he made the rounds of a certain section of the city. When he first began he took the orders one day and delivered the next; but his business grew so rapidly that he was finally obliged to take on a helper, his brother, and, a little later on, two more men and a man and his wife. The two last named washed the jars and filled them. Two of them delivered while he and his brother took orders. In this way they sold enormous quantities of honey; and as it was always the finest quality, and guaranteed to be pure, they built up a large trade.

There is another plan, provided one can trade honey for other useful articles too numerous to mention. Even if one did not sell much he would get a day of royal sport.

TRADING HONEY FOR DUCKS, PIGS, PUPS, ETC.

In all the literature on bees and honey, we are urged to develop the home market. Acting on the advice, after $I$ had traveled over my regular route this fall $\mathrm{I}$ went into an entirely new locality. After enjoying the scenery and the sunlight for about a fivemile drive $I$ called at a farmhouse and inquired of the good lady if she would like some honey.

"Well, yes, I should like some, but I have no money."

Seeing some ducks, I offered to trade honey for ducks; and for a pair I gave four pint jars of lioney.

Calling at another louse, I sold $\$ 2.00$ worth for cash; and while I was talking with the man one of the ducks gave a quack, which led to an inquiry as to what I had. I told them I had traded honey for ducks.

"Well, now, look here; can't I trade you some hens for honey?",

I traded for half a dozen, and made the children, I hope, happy (I was). In this way I passed the day, and on my drive home I was trying to figure out my profits. I had disposed of two gross of pint jars, and 120 pounds of comb honey. For the pint jars I received 25 cents; also 25 cents each for the sections of comb. I had had a royal day's sport; and as I listened to the quack of the ducks and geese, the cackle of the hens, and squeal of the pigs, and looked at the large box of eggs that I had in the wagon, I thought I would have to send for some egg-preservative. After getting home I took account of stock. I had $\$ 54.40$ cash, 108 dozen eggs, 8 ducks, 1 goose, 2 pigs, 24 hens, and 1 bullpup. (The pup is for sale.)

Charlton City, Mass.

Another experience is thus given by $\mathrm{G}$. C. Greiner of La Salle; N. Y.:

Peddling honey has, like everything else, its ups and downs. We don't always strike it rich. Some days it may seem like terribly steep uphill business, while other days the money may roll in by the handfuls. As an illustration, and a proof that the latter sentence is almost literally true, let me give you one day's experience.

Late last fall I chanced to take a trip to Niagara Falls with the intention of making a display of my goods at the city market. At first things looked a little gloomy. Purchasers did not flock in as I had hoped, until after some minutes of patient waiting. One passing lady, in looking at my honey, asked, "Is your honey pure?", The reply I made must be imagined, for it would fill more space than the editor would be willing to allow. But let me emphasize-here is where the blabbing came in. In answering her question I delivered a good half-hour lecture in less than two minutes, trying to convince her of the purity, and all the good points of my honey. In the mean time, passing people had stopped to listen; and by the time my lady friend was ready to buy one of my quart cans I had quite a crowd around me. To cut the story short, for quite a few minutes I handed out cans, mostly quarts, as fast as I could make change (many of the purchasers promising to buy more the next time I attended the market, if the honey proved to be what I had recommended it to be).

When the market closed, at 11 a. m., I had a few cans left. With those I drove to Main Street and tied my horse in front of one of the stores, where I har a little business to transact. A few minutes later, while I was conversing with the storekeper in- 


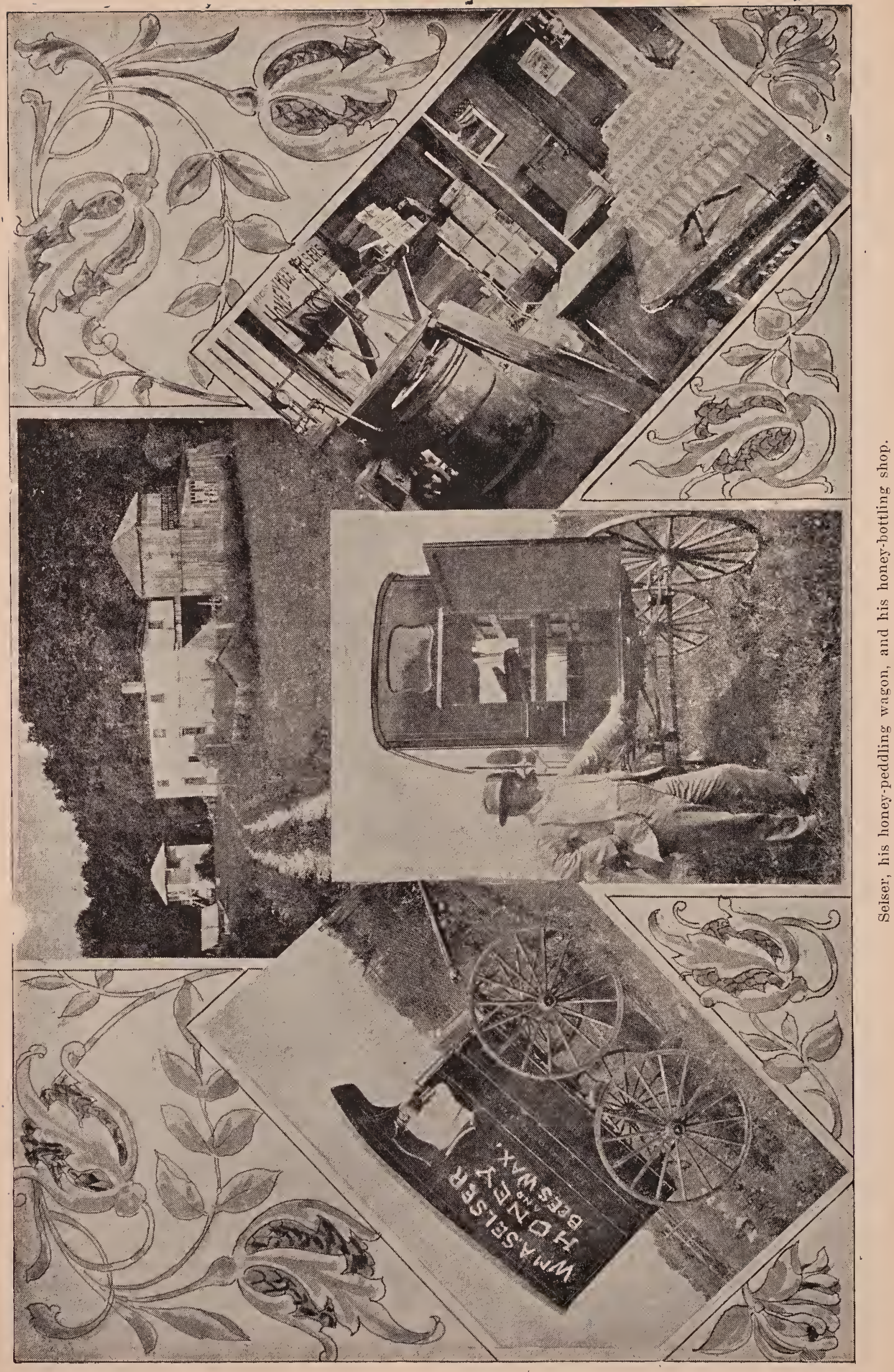


side, some one opened the door and inquirea:

"Hello! where is this honey-man?"

After introducing myself he requested me to show him what I had to sell. It did not take very long to convince him that I carried the genuine article; and what pleased me still more was the fact that he ordered two cans to be left at the corner drugstore across the street.

When I delivered the cans they were closely scrutinized by the clerks and some other parties who happened to be present, and one of the clerks asked:

"What guarantee have we that this is pure honey?",

Here another lecture-like conversation, too long to be repeated, took place, the substance of which may be concentrated in $\mathrm{my}$ reply:

"First, pure honey and my name and address are on every package; and, second, back of this is the New York State law that prohibits all honey adulteration.",

Before I left the place I sold two more cans to those other parties.

A great help in selling honey on the roar is a proper traveling-outfit, which enables us to present our products in clean, neat, and inviting appearance. I know from experience that at least one-fourth of $\mathrm{my}$ sales of honey can be traced back to this feature.

PEDDLING HONEY AT GROCHRIES AND OTHER RETAIL STORES.

W. A. Selser of 10 Vine St., Philadelplia, is not only a practical beekeeper, but he was also a large buyer of honey. In addition to the amount he produced in his own apiaries, he bought up every year the product of several large yards. All of this, mostly extracted, he peddled out from a honey-wagon to the retail trade.

The secret of his success in selling and in getting good prices was in putting up always a first-class article in a neat and attractive form. He advertised liberally, and every one knew him about Philadelpliia as "the honey-man."

After several gross were put up, Mr. Selser loaded all he could carry in a speeial wagon, shown at the left of the illustration on the preceding page. He then visited the city stores and replenished their stock. After he had supplied all the city retail places he then went into the country, visited the suburban towns, and even drove as far as the city of New York, supplying some stores.

In these days of light automobile deliv- ery cars the territory can be oreatly extended; in fart, a bottler can make several outlying towns, and follow up the trade, taking care of a large line of fancy grocery stores. Light antomobile trucks with tops of the familiar Ford type are now being used for this very purpose - to sell and distribute honey.

HONEY PLANTS.-The importance to American beekeepers of a thoro knowledge of the honey-producing flora of this count] y cannot be overestimated. A beginning in this work has already been made by several States. An excellent preliminary list of Texan honey plants by Louis H. Scholl was published in 1908, and in 1911 there appeared a carefully prepared bulletin on the honey plants of California by M. C. Richter. In both these lists much attention is given to the geographical distribution within the state limits of the species enumerated. More or less complete lists of the chief mellifluous plants of Massachusetts, North Carolina, Iowa, Oklahoma, and Arizona have also been prepared. So helpful have these publications been to beekeeper's that there can be little doubt that similar bulletins will soon be issued by other States. Such investigations promise to bring to light many interesting and valuable facts. No one should enter extensively upon the production of honey without first investigating the flora on which he must depend for a marketable surplus. Success or failure may often depend upon such information.

The geographical distribution of honey plants in the United States presents many striking peculiarities. While some occur over the entire country, others are restricted to a small area. The sumacs extend from the Atlantic to the Pacific; so do the carrot ard carpetweed, tho the latter is commercially most valuable in central California. Sweet clover is spreading everywhere; and the goldenrods and asters know no north nor south. While heartsease grows thruout nearly all North America, the wild sunflower is confined chiefly to the West, cotton to the South, white clover to the East, and willow-lierb to the North. Much narrower are the limits of many other speries. The white-tupelo region is a tract of land along the Apalachi- 
cola River and the coast of South Carolina, Georgia, and Alabama; manchineel occurs in the extreme south of Florida; the black mangrove in tide-water marshes in the southern half of the same State; our native acacias belong to Texas, the sages to southern California, and scores of other honey plants are equally restricted in their distribution. But it is not only in individual states that they are very variable in their range, but in almost every township; for example, within less than a mile of each other, yet without invading each other's territory, there may be found the salt-marsh goldenrod, the field goldenrod, and the wood goldenrod.

Honey plants are likewise very variable in the preference they exhibit for different soils. The tupelo and willows grow in wet swamps, the tickseed in marsh lands, the smooth sumac prefers a rocky soil, the mesquite and cacti are dwellers in the desert; the gallberries in Georgia avoid a limestone region, while sweet clover will grow nowhere else. The spikeweed and the alkaliweed thrive in alkaline soil; the Rocky Mountain bee plant in a dry saline soil; the salt-marsh goldenrod in a soil and atmosphere impregnated with salt, while the fireweed springs up in profusion on burnt lands, and the production of nectar in wild alfalfa is greatly stimulated by a mountain fire.

Undoubtedly the secretion of nectar is often, if not always, correlated with the character of the soil, the temperature, and water supply. Alfalfa, which, in irrigated sections of California, is a large and most reliable yielder, is of little value along the coast or in the East. A heavy thundershower followed by a sudden fall in the temperature may bring a successful honey flow from buckwheat or basswood to a premature end. Wild alfalfa may produce nectar abundantly on one side of the Coast Ranges, and very little on the other side. Heavy rains are likely to lessen greatly and light rains may either stimulate or retard the quantity of nectar secreted by a honey plant. The last honey obtained from lima beans and alfalfa is darker than the first. On a sandy soil the honey obtained from alfalfa is lighter in color than on a heavy soil, and lime in a soil is also reported to render a honey lighter. A prolonged drouth is apt to bring loss and disappointment, tho it shortens the tubes of the red clover so that part of the nectar is available. Black sage requires a elear warm season preceded by abundant rain. Blue gum and red clover are very reliable yielders, and are largely independent of the weather.

Nor must the periodicity of honey plants be overlooked. The orange tree and the cabbage palmetto in Florida can be depended upon only about one year in three; but orange is a fairly reliable source in Califormia. Sage does its best one year in five, and is a partial failure every other year. The rules which govern the blooming of white clover have not yet been formulated. Manchineel does not afford a heavy flow every year. The different species also vary greatly in the length of time they are in bloom. In many cases they are in flower for only a few weeks; but carpet grass yields from May until frost; pepper bush from July to September; pin clover in California begins in February and continues thru the summer, and alfalfa from April to October. The different kinds of honey vary also in the rapidity with which they granulate. After 10 years white tupelo is still liquid, while the honey from blue curls granulates in the cells before they are sealed. Usually a honey granulates within six months after it is extracted.

A honey containing a large percentage of grape sugar (dextrose) crystallizes much more readily than one containing a small percentage. For example, alfalfa honey, which granulates in a few months, contains 36.85 per cent of grape sugar (dextrose) and 40.24 per cent of fruit sugar (levulose); while tupelo honey, which never granulates, contains only, 24.73 per cent of grape sugar and 48.61 per cent of fruit sugar. The reason for this is that grape sugar granulates easily, while fruit sugar usually remains a liquid. Frequent changes of temperature also hasten granulation. See Grandlation of Honey.

Even where there is a good honey flora fair weather is essential, or the bees can not bring the nectar into the hive. The willows and the gallberries, which bloom in the spring when there are much rain and foggy weather, are, therefore, not so desirable as species which flower later. The suc- 
cession of honey plants should also be considered. In California, after the orange trees have ceased to bloom, the bees if moved to the șages will get honey from that source if it is a season when they yield honey. After the sages comes the Lima bean.

More information about the honey plants of foreign countries should be obtained. Who can say what happy surprises Africa, Asia, and the Pacific islands may yet afford the beekeeper? It should not be forgotten that sweet clover, alfalfa, pin clover, borage, eucalyptus, horehound, carrot, catnip, wild marjoram, thyme, and red, alsike, and crimson clovers are all introduced plants. Our agrieultural and horticultural explorers are successfully seeking new fruits, grains, and flowers; but do they ever look for new honey plants?

The possibilities of artificial pasturage are only partially recognized. In many localities the apiarist might greatly increase the number of nectariferous flowers by sowing each season a few pounds of sweet clover in waste places and along the roadside. There are many plants which produce paying crops, and are at the same time raluable to the apiarist, such as cotton, alfalfa, mustard, buckwheat, clovers, the orange, and a great variety of fodder plants and fruit trees. When it is remembered that more than one-half of the principal honey plants of Florida are arboreal, and that many shade and timber trees yield nectar freely, there would seem to be good reason to expect that in the future forestry and bee culture may be united.

By hybridization and selection many new varieties of fruits and flowers have been originated; and the laws of heredity and breeding are studied more zealously today than ever before in the history of biology. Why should not plants, especially those valuable for fruits and seeds, be developed with a creater capability for secreting nectar? Insects have shown us what is possible in this direction. It is probable that there would have been very few nectarproducing flowers but for their agency. There may yet be an apple tree that, in addition to excellent fruit, will yield nectar as freely as does the orange or basswood. The orchardist of the next century may obtain a crop of honey from fruit bloom which will rival in ralue the later harvest of fruit. No effort has yet been made in this direction, and many of the achievements of the horticultural experimenter appear to have offered greater difficulties. There may yet be plants of which it may literally be said that they flow with nectar.

\section{POLLEN PLANTS.}

Probably no factor was more important in determining the development of the families of bees than the rise of the habit of feeding their brood on pollen. The wasps feed their young on animal food, and had the ancestors of the bees, which were wasp-like insects, continued to use the same kind of food for brood-rearing, the bees would never have come into existence. Deprived of pollen at the present time the bees would speedily disappear. There is nothing in Nature which can be used as a satsfactory substitute for pollen, altho bees sometimes collect the spores of fungi and mosses to a small extent. Pollen famines occur in Australia, when the brood dies in the hive, and no artificial substitute gives satisfactory results. The same scarcity of pollen occurs in the tupelo region of Florida, in southern Alabama, and in parts of Texas. It is highly important, therefore, that the beekeeper should be familiar with the sources of pollen, on which the bees in his apiar'y are dependent for brood-rearing.

Of the true flowering plants called angiosperms, because they have their seeds enclosed in a seed case, and receive the pollen on a prepared surface known as the stigma, there have been described in North America north of Mexico about 14,600 species. Of this number, at least 3000 are nectarless, but of necessity produce pollen. Very marry of them have small green or dull-colored flowers, and are pollinated by the wind, as the alders, birches, poplars, elms, beeches, oaks, and hickories; the grasses, sedges, and rushes; many homely weeds like pigweeds, ragweeds, nettles, pondweeds, sorrels, hemp, and meadow rue. Usually the stamens and pistils are in separate flowers, which are borne on the same plant (monœcious), or on different plants (diøcious). They are commonly without nectar, since they depend on the wind for pollination; but they produce great quan- 
tities of pollen, and are consequently often valuable to the apiarist. See PoLlen.

Other pollen plants bear large handsome flowers like the roses and poppies, which are pollinated by insects, and are called pollen flowers; they contain no nectar, and insects visit them for pollen alone. Mistakes are often made in regard to these flowers, and bees are reported as bringing in nectar when such is not the case. Possibly some of these errors have arisen from the presence of honeydew on the leaves. A list of the more important pollen plants is, therefore, given separately. No attempt has been made to include all nectarless flowers, but only those of importance to beekeepers. A great number of flowers yield both nectar and pollen; but these are placed under Honey Plants. The species in the following list are nectarless unless otler'wise stated.

\section{PLANTS THAT YIELD POLLEN ONLY.}

Alder (Almus).-Wind-pollinated; the small brownish flowers appeal in early spring. The aments (staminate) of the common or hoary alder (A. incana) are visited by honeybees for pollen.

Anemone (Anemone quinquefolia). - Large white pollen flowers; pollen gathered by bees in spring.

Ash (Fraxinus). - Some species are pollinated by insects, others by the wind; small greenish flowers.

Bayberry (Myrica).-Shrubs blooming in spring; flower's small, greenish, wind-pollinated.

Beech (Fagus).- - Large trees, with small windpollinated flowers. Honeydew is found on the leaves.

Birch (Betula).--Small greenish or golden-yellow flowers, appearing with or before the leaves in spring; wind-pollinated; mostly trees.

Bloodroot (Sanguinaria canadensis).- - Large handsome white pollen flowers in April or May. Visited by honeybees in large numbers, which remove nearly all the pollen.

California Poppy (Eschscholtzia californica).Large orange-yellow pollen flower's; great numbers of bees visit them for pollen.

Castor-oil Bean (Ricinus communis).-The small flowers are wind-pollinated; stamens very numerous; an abundance of pollen; extra-floral nectaries at the base of the leaves.

Chestnut (Castanea).-The chestnut tree (C. dentata) lias small, pleasantly scented, pale-yellow pollen flowers; but chinquapin (C. pumila), a spreading-shrub, is reported to be a valuable honey plant in the South.

Clematis.-A part of the wild species and the large handsome flowers of the cultivated varieties of C. Jackmanni are nectarless, but are visited by bees for pollen. Other species yield nectar including the common wild Clematis (C. virginiana).

Cockle-burr (Xanthium canadense).-Small flowers from which bees obtain pollen in the fall. They contain a little nectar.

Corn (Zea Mays).-Wind-pollinated; hees gather pollen from the spindles; in some seasons they gather also large quantities of honeydew from the leaves.

Cone trees (Coniferae).-Fir, spruce, pine, redar, juniper, and many other cone trees. While they produce enormous quantities of pollen, it is not used bu bees-probably too resinous. From the foliage of pine trees aud spruces bees obtain much honeydew. See Honydew. Gymnosperms.

Date Palm (Phoenix dactylifera).-Large areas of California and Arizona are adapted to date culture. There are extensive plantations of great age in Lower California and Mexico. In southern $\Lambda$ sia and northern Africa this tree is of inestimable value. The staminate and pistillate flowers are produced on different trees, or the trees are partly "male" and partly "female." In nature pollination is effected by the wind, but under cultivation by binding a sprig of staminate flowers among the pistillate. Flowers small, in large clusters; in California bees visit the staminate flowers freely for pollen. Bloom in early spring.

Elder (Sambucus). - Small white pollen flowers in large clusters; bees sometimes gather the pollen.

Elin (Ulmus americana).- Small purple flowers which appear in the spring, and are wind-pollinated. They are visited by great numbers of bees for pollen.

Furze (Ulex europaeus),-Gorse. Introduced from Europe. A pollen flower, yields considerable pollen, which honeybees and wild bees gather and also search the flowers for nectar. In Australia the large area over which it has spread presents a golden landscape in spring; reported to yield. nectar in warm regions.

Grape (Vitis).-Valuable for pollen; yields some nectar. Honeydew occurs on the foliage.

Grasses (Gramineae).-Sinall greenish flowers, with a great abundance of pollen; wind-pollinated; sparingly visited by insects. About 429 species in North America.

Hazelnut (Comylus americana).-Small yellowish flowers, valuable for pollen in early spring; wind. pollinated.

Hepatica (Hepatica triloba).-Handsome blue or white pollen flowers; attractive to bees in early spring.

Hemp (Cannabis sativa).- Small flowers pollinated by the wind.

Hickory (Carya).-Pecan, mocker nut; large trees with small wind-pollinated flowers; valuable for pollen; much honeydew on the leaves.

Hop (IIumulus Lupulus).--Small greenish flowers, wind-pollinated; common.

Hornbeam (Carpinus caroliniana).-Large tree witl small wind-pollinated flowers.

Indian Wheat (Plantago ignota).-Very abundant over vast areas of sandy mesas in Arizona, where it affords valuable pasturage for attle. The flowers are nectarless, but are valuable for pollen.

Loosestrife (Lysimachia vulgaris). - Mediumsized yellow pollen flowers.

Lupine (Lupinus). -The flowers are nectarless, but are frequently visited by honeybees and other bees for pollen. Honeybees sometimes vainly at. tempt to suck nectar from the flowers. Blue lupine (L. subcarnosus) is very abundant in Texas, and is often visited by bees for pollen.

Meadow-rue (Thalictrum).-Common; white or greenish pollen flowers visited by honeybees for pollen. Rue anemone (Anemonella thalictroides) produces a great abundance of white flowers in low land; wind-pollinated.

Mullein (Verbascum).-Common; bright-yellow pollen flowers. A part of the species are nectarless. Others contain some nectar.

Mulberry (Morus rulra).-A tree with small wind-pollinated flowers.

Nettle (Trtica).-Greenish flowers in summer; wind-pollinated.

Oak (Queveru).- Small greenish or reddish 
flowers; wind-pollinated. Honeydew is found on the foliage of many species. In California enough honeydew is gathered from blue or rock oak (Quercus Douglasii) to winter bees.

Olive (Olea europaea). - The flowers are windpollinated and do not yield nectar. A beekeeper located near 5,000 olive trees in California reports that bees store no honey from the bloom.

Pigweed (Chenopodium.). - Goosefoot. White mèaly garden weeds, with small greenish sessile flowers in large clusters, wind-pollinated. Also amaranth; also called pigweed (Amaranthus retroflexus); coarse wind-pollinated weeds in cultivated ground; flowers in large clusters, of some value for pollen.

Poppy (Papaver).-The poppies are very large showy pollen flowers visited by honeybees. The scarlet color does not repel bees, as has been re. ported.

Plantain (Plantago).-Partly pollinated by wind and partly by insects. Tery common, nectaless weeds, often visited by bees for pollen.

Poplar (I'omulus).-Aspens. Small purplish flowers, wind-pollinated; pollen abundant, forcibly expelled from the anthers; valuable; nectar-glands at base of leaf-stalks. Honeydew sometimes occurs on the foliage. It should be distinguished from the tulip tree (Liriodendron Tulipifera).

Prickly Poppy (Argemone).-Large yellow or white pollen flowers. A. platyceras in Texas blooms in June, and honoybees gather large quantities of its pollen.

Ragweed (Ambrosia).-Small green flowers pollinated by the wind; valuable in the fall for their alundant supply of pollen. Two common species are Roman wormwood (A. artemisiifolia) and great ragweed (A. trifida)

Rockrose (Helianthenum canadense).-Large, solitary, sellow pollen flowers; common in the easter'n States.

Roses (Rosa).-These handsome well-known flowers are nectarless, but yield much pollen which is gathered by honeybees and many wild bees. The sweetbrier rose in Europe and the Cherokee rose in northern Geargia are reported to yield nectar.

Rushes (Juncaceae). - Snall, green, lily-like flowers; wind-pollinated.

Sagelrusl (Artemisia). - Wind-pollinated herbs and shrulss, which produce a large amount of pollen. Thousands of acres are covered with sagebrush in Utah and Nevada.

St. John's-wort (Hypericum).- Small yellow pollen flowers; common; attractive to bees after pollen.

Sedges (Cyperacene). - A large family of grasslike plants; flowers small, green, wind-pollinated. The so-called "tule honey" has been reported to be gathered from species of Scirpus growing along the Sacramento River, California; but this is undoubtedly a mistake.

Sorghum (Sorghum vulgare).-Pollen very abundant; a grass.

Tick-trefoil (Desmodium). - Flowers resemble those of the field-pea, or vetch; many species are nectarless, and do not appear to be visited by honeybees, tho the pollen is gathered by bumblebees. Sometimes listed as honey plants.

Walnut (Juglans). - Large trees with small windpollinated flowers. Valuable for stimulating early brood-rearing in the spring.

Many liandsome garden exoties, as pelargonium and hybrid petunias, are nectarless.

\section{PLANTS THAT YIELD NECTAR.}

A honey plant may be defined as a plant which serretes nectar, accessible to honey- bees, in quantities sufficiently large to be of practical importance to beekeepers. This, of course, implies that in some locality it is a common plant. If a list of all plants secreting nectar were desired, it would be easy to enumerate thousands of species; but very few of them are of practical importance in bee culture. Many are rare, others grow in the deep recesses of forests and swamps, while still others yield so little nectar that the larger bees pass them by unheeded. The bunchberry (Cormus canadensis) is very common in open woodlands; but the small flowers contain so little nectar that bumblebees ignore them entirely, and loneybees visit them only occasionally. They are left to flies, beetles, and the smaller bees. Then there are many flowers adapted to moths, butterflies, bumblebees, and humming birds, which have the nectar so deeply concealed that it cannot be reached by honeybees. Many a beginner in beekeeping has fondly imagined that his flower garden woukd supply his bees with a rich harvest, wholly unconscious that the gaudy exotics of cultivation are often nearly or quite nectarless. In the following list the more important honey plants in North America, so far as known at present, either wild or cultivated, have been briefly described.

Acacia.-There are about 300 species of Acacia in Australia and 150 in other parts of the world. Some 60 species have been introduced in California. Half a million trees have been planted in Golden Gate Park, San Francisco. The species consist of herbs, shrubs, vines, and stately trees, and are well adapted to semiarid regions. In Texas catsclaw and huajilla yield a large surplus of excellent white honey, but many, of the species are chiefly valuable for pollen which is produced in great quantities. The small yellow or white flowers are in globular heads or oblong clusters. The Acacias are often called wattles. See CAtsclaw, HuA Jilla, Huisache, and Silver Wattle.

$\Lambda$ gave.-A large genus of over 100 species found chiefly in Mexico. The plant consists of a rosette of fleshy leaves from the center of which there grows it stalk bearing many densely clustered flowers. See Century Plant.

Agarita (Berberis trifoliata).-The trifoliate barbary is valuable in sontheast Texas for both nectar and pollen. The bright yellow flowers open in February. Common in waste places and in open woodlands.

Alfalfa (Medicago sativa).- - 1 very valuable honey plant in irrigated sections west of the Missouri River. Honey white to light amber, heavy, with a pleasant slightly minty flavor; granulates in a few montlis. See ALFALFA.

Alfilerilla (Erodium cicutarium).-Maine to Texas and California, but most common in the West. Honey of good quality and flavor. Blooms early, valu. 
able also for pollen. E. moschatum is also an im portant honey plant; honey similar to that of the preceding species.

Algaroba.- See Mesquite.

Almond (Prunus Amydalus).-Extensively cultivated in the warm temperate regions of Europe and Asia. Succeeds well in California. The large pink flowers open before the leaves appear and yield both nectar and pollen. Apiaries are often placed in almond groves.

Alsike Clover (Trifolium hybridum).-One of the most important honey plants of the United States. Its cultivation is restricted largely to the northeast ern State,s but it is also widely grown in Idaho, Washington, and Oregon. The honey is excellent, similar to that of white clover. As a honey plant it is more reliable than white clover. It requires less lime in the soil than red clover. See ALSIKE CLOVER.

Andromeda.- Shrubs in worthern Florida, yielding a reddish yellow pungent honey.

Anaqua (Ehretia elliptica). - A small tree or often a shrub, with white flowers, growing along the Rio Grande River.

Apple (Pyrus Malus).-Often yields a small sur. plus; honey light in color and of good quality, rather rank-flavored when newly gathered but becoming milder and aromatic. Crab apple ( $P$. coronaria) is also of value.

Apricot (Prunus armeniaca).-Blooms very early in the spring, helpful for brood-rearing. Flowers have the odor of honey; nectar concealed in a little cup. Temperate regions.

Arizona Acacia (Acacia constricta).-A spiny shrub, 3 feet tall, on di'y hills, in Arizona. Valuable chiefly for pollen.

Arizona Mesquite (Prosopis velutina).-In the hot dry valleys of Arizona, southern California, and Sonora. The largest of the mesquites. Blooms from April to middle June. Honey white, excellent, crystallizes quickly after extracting.

Arrowweed (Pluchea sericea).-Grows along the ditches of southern California and southern Arizona and yields a fine flavored honey.

Artichoke, Globe (Oynara Scolymus).-Freely visited by bees, but honey unknown.

Artichoke, Jerusalem (Helianthus tuberosa).-A good honey plant, cultivated for its tubers.

Asparagus (Asparagus officinalis).-Widely cultivated. Yields an amber-colored honey, which loses its peculiar flavor when ripened. Wild, it is very abundant on the waste steppes of Russia, where it is eaten by cattle.

Aster (Aster).-Common fall flowers, most abund. ant in the middle States. Honey white, strong-flavored when first gathered, but later acquires a pleasant aromatic flavor; granulates with a finer grain than goldenrod. See Aster.

Bachelor's Button (Centaurea cyanus.) -Blue bottle. Corn flower. French pink. Yields in Oregon a dark amber honey with a peculiar greenish reflection. The body is moderately heavy and the flavor rather strong with a bitter aftertwang.

Banana (Musa Sapientum and Musa Ensete).The flowers produce large quantities of pollen and nectar. Cultivated in Florida.

Barberry (Berberis vulgaris, eastern States; $B$ pinnata, California; $B$. trifoliata, Texas).- Shrubs yielding both pollen and nectar. Sometimes a small surplus, honey amber-colored.

Basil (Pycnanthemum virginianum).-Mountain mint. Bees visit it freely. Minnesota to Georgia and Alabama.

Basswood (Tilia americana and T. heterophylla). -Fine trees with greenish white fragrant flowers. Yield a large surplus, but not reliable. Honey white with an aromatic flavor. The European bass wood, or linden, is equally valuable, and is widely planted as an arenue tree. See BAsswood.

Bearberry.-See MANZANITA.

Bee-balm (Melissa officinalis).- In gardens, spar. ingly wild.

Bitterweed (Helenium tenuifolium). $-A$ canary. yellow honey of heavy body and attractive appearance, but as bitter as gall. It granulates quickly after extracting. Virginia to Kansas and southward to Florida and Texas. Plant 1 to 2 feet tall, with threadlike leaves and yellow flowers. See SNEEZEWEED.

Blackberry (Rubus.) - Numerous closely allied species, Rubus allegheniensis being the most common in the northern States. In northeastern North America the blackberry, either wild or cultivated, yields very little nectar, and is more frequently visited by wild bees than honeybees. In north Genrgia wild blackberries yield in April about 25 pounds per colony of thick amber-colored honey, which does not granulate readily. In California from Rubus baileyanus and $R$. vitifolius surplus crop of light-amber honey of fine flavor are obtained.

Black Brush (Acacia amentacea). - A shrub constituting 70 per cent of the vegetation on many thousand acres in southeast Texas. Of value chiefly for pollen.

Black Gum.-See TupeLo.

Black Haw (Viburnum prunifolium).-Of value for early brood-rearing.

Blackheart-So called from a dark triangular spot on the center of each leaf. See Heartsease.

Black Mangrove (Avicennia nitida). -Tide-water marshes on the east and west coasts of southern Florida and on the Keys; extracted honey amber. colored, not very sweet, with a slight brackish or salty flavor due to the trees growing on sand flats, which are often flooded with salt water by the tide. It is very largely used in the manufacture of sweet cakes. A remarkable yielder of honey.

Blueberry ( Faccinium corymbosum). - In southern New England blueberry honey comes from species of the bush type. The flow comes in May or in early June and lasts for about 10 days. The honey is amber-colored and the quality is good.

Blue Curls (Trichostema lanceolatum).-_Yields a milk-white honey that granulates very quickly with a very fine grain, often before it is sealed. Tons of honey are stored from this plant in Fresno Coun. ty, Calif. Blooms in August and September when it gives the dry fields and hills a soft purple tinge. Vinegar Weed. Camphor Weed. Turpentine Weed.

Blueweed (Echium vulgare).-Viper's bugloss. Blue thistle. Formerly very abundant in the Sheuandoah Valley, Virginia, but it has rapidly decreased as the result of extensive cultivation of the land. The honey is light amber, and has a good flavor and body. The plant is 2 feet tall, with bright blue flowers and blooms in August and September.

Bokhara.-See SwEET CLOVER.

Boneset (Eupatorium).-Thoroughwort. Common in Tennessee and Kentucky, where it yields a surplus. Valuable also in Alabama and Texas. Honey a dark amber, thick and heavy, with an unpleasant herby flavor and odor. There are many species, $E$. perfoliatum being the most common.

Boston Ivy (Ampelopsis Veitchii).-Climbing vine introduced from Japan, covering acres of wall in northern cities. Blooms in July; honey strong and unpleasantly scented.

Borage (Borago officinalis).-Cultivated from Europe, an excellent honey plant. It has spread to some extent in southern Australia.

Box Elder (Acer Negundo).-A small tree on which the flowers appear before the leaves. Yields nectar, also honeydew in the fall. 
Brazilwood (Condalia obovata). - A small tree, or only a spiny shrub, forming dense thickets in soutlorn Texas. Blooms in spring. The loney is dark amber and does not granulate readily.

Broomweed (Gutierrezia texana).-Plains of Texas and Arkansas: Honey dark amber and strong flavored, but good for winter. September to October.

Brunnichia (Brunnichia cirrhosa).-A perennial vine of the buckwheat family. The greenish flowers are in clusters of two to five, and appear from May to June. In the Yazoo Delta in western Mississippi it produces great sheets of bloom and probably yields a surplus. It is also reported to yield a small surplus in southeast Texas.

Buckbush (Symphoricarpos occidentalis).-Common in the northwestern States. The extracted honey is white with a pleasant flavor and after three years had not granulated. A shrub with white bell-shaped flowers.

Buckeye (A esculus glabra).-Ohio to Kansas and southward. Considerable honey is obtained from the California buckeje (A esculus californica).

Buckthorn (Rhamnus cathartica).-This species is found in the middle States. Cascara sagrada ( $R$. purshiuna) is the main honey plant at Sonora, Calif. Comb honey from this plant is so dark that it sells poorly where it is known, but is highly valued for its medicinal properties; does not granulate. A profusion of flowers on which bees work for about 25 days. The coffee-berry ( $R$. californica) yields a heavy amber honey.

Buckwheat (Fagopyrum esculentum).-A darkpurplish honey, of heavy body, with a more or less sickish taste to those unaccustomed to it. Extensively cultivated thruout the temperate regions of Europe, Asia, and North America; thousands of acres are grown in New York and Pennsylvania. Yields nectar only during the forenoon. See Buor. WHEAT.

Bur Clover (Medicago hispida).-Common on the hills and plains of California. Occasionally yields a surplus, but of more value for stimulating broodrearing. Belongs to the same genus as alfalfa.

Buttonbush (Cephalanthus occidentalis).-Important on the overflowed land of the Mississippi, and in swamps in many States. A mild light-colored honey.

Buttonweed (Senecio glabellus).-Several species of Senecio, or groundsel, appear to be of value as honey plants.

Cabbage Palmetto (Sabal Palmetto).-North Carolina to Florida and in the Bahamas and Cuba. Honey nearly white, mild, and so thin that it runs almost like water. The flavor is not equal to the honey of the scrub palmetto. A great drooping flower cluster bearing hundreds of small white flowors. See PaLMETTo.

Cabbage (Brassica oleracea).-Cabbage, rape, turnip, radish, cress, horseradish, mustard, and many other species of the mustard family (Cruciferae) are of value. See Mustard.

Cachinella (Berthelntia sericea).-A shrub about 3 feet tall, with pink flowers and silky leaves. In New Mexico yields a light colored honey.

Cactus or Prickly Pear (Opuntia Engelmannii).Southwestern Texas, southward and westward. Sometimes a surplus of honey of light-amber color; body heavy and stringy, of rank flavor. Flowers vellow inside, red outside. The prickly pear introduced from Rio de Janeiro into Australia in 1789 as food for the cochineal insect now badly infests an area of $30,000,000$ acres, to which about 1,000,000 acres are being added annually by natural increase.
Christmas bells, Christmas pop. Honey pearly white, equal to alfalfa in flavor. Mexico, Cuba, and $\mathrm{Ja}$ maica. See Camíanilla.

Canada Thistle (Cirsium arvense).-A cominon weed from Europe; honey light-colored, of fine flavor and quality. Common in Canada, the central States and westward.

Carpet-grass (Lippia nodiflora).-One of the principal honey plants of central California, also valuable in the West Indies. Honey light-colored, of mild flavor. $L$. lanceolata and $L$. repens are likewise visited by bees, but less important. See CARPET-GRASS.

Carrot (Daucus Carota).-This weed is often very abundant in the fields and by the roadsides. In the East it does not often give a surplus, but in the Sacramento Valley, California, it yields a white honey with the flavor of the foliage, which granulates in a few months.

Cascara sagrada.-See Buckthorn.

Cassia.-The species of Cassia bear pollen flowers. The partridge pea ( $C$. Chamaechrista), however, lias extra-floral nectaries on the leaf stems, which yield large quantities of nectar for more than 100 days. This species is common in the sonthern States, and in northern Florida; the woods for miles are yellow with the blossoms; honey light amber, very clear and thin, but with a strong flavor. Wild senna (O. marylandica) also has extrafloral nectaries.

Catnip (Nepeta Cataria).- Secretes nectar freely under cultivation, but quality of honey unknown. See Catnip.

Cat's-ear (Hypochaeris radicata).-California dandelion. A weed naturalized from Europe, and common in California from Marin County to Humboldt County; also abundant in Oregon and Wash ington west of the Cascades. An amber-colored honey, which darkens the honey from willow-herb. Catsclaw (Acacia Greggii).-From the Rio Grande Plain to southern California. A bushy shrub or small tree, 15 to 20 feet tall, armed with curved spines. Blooms early in May. Honey white and of the finest quality. Paradise flower. Devil's Claws. See Catsclaw.

Celery (A pium graveolens).-Yields a surplus in the truck gardens along the lower Sacramento Riv. er, California. The honey at first has the odor of the plant.

Century Plant (Agave americana).-Extensively cultivated in Mexico under the name of maguey. The immense flower-clusters yield nectar copiously and are visited by hundreds of bees. It thrives on semiarid land, and blooms after 10 or more years.

Chapinan's Honey Plant.- See Globe Thistle.

Chamise (Adenostoma fascimulatum).-Greasewood. An evergreen spreading bush, 10 feet tall, forming dense thickets on the foothills of the Coast Ranges. Honey light-colored, of good body, with a rank flavor. An unreliable honey plant.

Cherry (Prunus).-The cherries, of which there are many species, are nectariferous. In Florida the black cherry (Prunus serotina) is the source of a dark-red, bitter honey with the flavor of the cherry pit; a very little of it spoils the first orange honey. In Sacramento County, Calif., one of the most valuable honey-producers among cultivated fruit trees is $P$. cerasus.

China-berry.-See Soapberry

Chinaquapin (Oastanea pumila and C. nana).Reported to yield a thick dark honey resembling molasses in color and suggestive of it in flavor. Blooms in early spring. Florida to Louisiana.

Clethra.--See PEPPERBUSH.

Clover. - The genus Trifolium contains about 250 species, of which some 65 occur in North America. 
White clover ( $T$. repens) is the most important honey plant in the eastern and central States; honey white, of the finest quality. A part of the nectar of red clover ( $T$. pratense) is available in dry seasons; the honey is similar to that of white clover, but is a little nearer water-white. The honey of alsike clover ( $T$. hybridum) and of crimson clover ( $T$. incarnatum) differ little, if at all, from that of white clover. The yellow clovers are of no importance. Sour clover (T. furcatum) is the source of considerable honey in the alkaline regions of central California. See Clover.

Clover.-See Sweet Clover, SaInfoin Clover, and BUR CLOVER.

Colima (Xanthoxylum Fagara).-A thorny shrub or small tree, growing in Florida and southern Texas. The honey has a good flavor and body.

Coma (Bumelia lycioides).-A small tree, or in Texas often a shrub, growing along streams from Florida to Texas. A good honey plant in the Rio Grande Plain, Texas. Bloom from December to April. Honey light amber, of fair flavor with a twang suggestive of buckwheat. A thorny rough shrub covering hundreds of acres.

Coralberry (Symphoricarpos orbiculatus).-In. dian currant. Grows on rocky soil from New York to Texas. Secretes nectar freely. The snowberly (S. racemosus) yields a large amount of honey in Iowa. The wolfberry ( $S$. occidentalis) is common in the Missouri River basin and in Idaho. See BUCKBUSF.

Coral Sumac (Rhus Metopium).-Poison wood. Doctor gum. A tree 40 to 50 feet tall, growing in the extreme southern part of Florida. The foliage is poisonous to the touch, and it exhales a volatile oil that is poisonous to some persons at a distance. It yields a large amount of nectar, but the honey is always blended with other honeys.

Cotton (Gossypium herbaceum).-The cotton plant possesses both floral and extra-floral nectaries; most of the nectar is gathered from the nectaries on the under side of the leaves. In Texas and some other parts of the South it yields well, but in some localities no honey is obtained from it. Nectar secretion is greatly influenced by the weather. The quality of the honey varies greatly in different localities; in the southeastern States it is likely to be thin and of poor quality, but on the Black Prairie of Texas it is nearly white, very heavy, and mild in flavor. It granulates early. The flow lasts from June until frost. See CotTon.

Cowitch (Cissus incisa).-A fleshy vine, 30 feet long, growing on sandy shores from Florida to Texas. A surplus has been reported from Gunnison, Mississippi and from Texas. The black berries are very sweet and the juice is attractive to bees in the fall.

Cowpea (Vigna sinensis).--From China, widely cultivated in the southern States for forage. In Georgia it is grown in all parts of the State, bloom ing from June to September. The nectar is secreted not by the flowers, but by extra-floral nectaries situated near the ends of the long flower-stems, which bear two or three flowers. The honey is light-colored, but inferior in quality.

Creosote Bush (Oovillea tridentata).-A spreading evergreen shrub with small bright yellow flowers. Dry plains and mesas of the southeastern deserts. Near Tucson, Arizona, blooms for three months. Yields sufficient nectar to stimulate broodrearing and to furnish a small amount of yellowish honey.

Crimson Clover (Trifolium incarnatum).--Italian clover. Carnation clover. Widely cultivated for hay. In Delaware, North Carolina, Ohio, and several other States it in some seasons yields a surplus. Honey very similar to that of white clover.

Crownbeard (Verbesina virginica).-Pennsylvania to Texas. The white flowers bloom in the fall, and yield a honey of fine quality. The yellow-flowered $\vec{V}$. occidentalis is valuable in Tennessee.

Cucumber (Cucumis sativus). - In the vicinity of pickle factories there are hundreds of acres of cucumbers, which yield a small surplus of honey after clover is over. The honey is pale yellow and at first has a strong flavor suggestive of the fruit.

Currant (Ribes).- - The many species of currants and gooseberries, both wild and cultivated, are widely distributed. They bloom early and yield both pollen and nectar. The Missouri gooseberry ( $R$. gracile) is a fair honey plant in the middle States.

Dandelion (Taraxicum officinale).-Eurasia, North America, and many other parts of the world. Valuable in spring for both pollen and nectar. Honey golden yellow, thick, strong flavored, crystallizing in a few weeks.

Dogwood (Cornus).-Cornel. Shrulus with many flat-topped clusters of small white flowers. Usually unimportant, but where very abundant bees have been seen on the bloom in large numbers.

Eryngo (Eryngium articulatum).-A dark honey of good flavor. California.

Eucalyptus.-Abundant in Australia, and more rarely found in New Guinea, Timor, and the Moluccas. There are about 150 species, of which not far from 100 have been introduced into California. The flow of nectar is surpassed in quantity by no other plant. The honey varies in color from dark brown to amber, yellow and nearly white; and in flavor from a most agreeable to a peculiar acid taste in blue gum ( $E$. globulus), which renders it unsalable at retail. The blooming time varies so greatly that there are species in flower during every month of the year. The future of Eucalyptus in California promises to be of vast im. portance to bee culture in that State. See EUCALYPTUS.

False Indigo (Amoryha fruticosa).--In Iowa and Nebraska this tall shrub is a valued lioney plant. Bees in great numbers gather nectar and pollen from the bloom in early spring.

Figwort (Scrophularia).- The figworts would be excellent honey plants if they were more common. In $S$. marilandica (Simpson honey plant) the nectar is secreted in two large drops by the base of the ovary. Honeybees are constant visitors. Massachusetts to Kansas and Louisiana. In southern California $S$. californica is a valuable honey plant.

Forget-me-not (Myosotis macrosperma).--In Oregon sields a thin light amber honey with the aroma of the blossom.

Gallberry (Ilex glabra).-A very important honey plant in eastern North Carolina and southeastern Georgia. Also valuable in Florida, Alabama, and Mississippi. A reliable yielder in early spring. Honey white, superior in quality. An objection to a part of the gallberry region is the absence of later sources of honey. See GALLbERRY and HoLLy. Gaura (Gaura filiformis).- In sandy soil in Texas, accasionally yields a surplus. Pink-purple flowers, in summer.

Germander (Teucrium canadense).-Central States. Honeybees common on the flowers sucking nectar.

Giant Hyssop (Agastache nepetoides).-Vermont to Nebraska and southward. In bloom about six weeks, many honeybees.

Gilia (Gilia floccosa).-Common everywhere in 
southern Arizona. There are many species of Gilia in the western States. The bloom is visited by honeybees in large numbers.

Globe Thistle (Echinops spherocephalus).-Thistle-like herbb from Europe, 3 to 6 feet tall, with spinose leaves. $\Lambda$ t one time it was believed to be a most promising honey plant. Three acres of it were plauted by Herman Chapman of Versailles, New York, whence it was known as Chapman's honey plant. It proved unsatisfactory and coday is almost unknown to beekeepers.

Goldenrod (Solidago).-Numerous species. Surplus in New England; honey golden or dark amber; thick, of fine flavor. See GOLDENROD.

Gooseberry.-See Currant.

Granjeno (Mormisia pallida).-A thorny shrub in southern Texas, growing on sandy soil and considered a good honey plant. (Syn. Celtis pallida.)

Gum Plant (Grindelia squarrosa).-Many acres of the dry plains of Manitoba and Minnesota are covered with its yellow flowers which are very at tractive to bees.

Hackberry (Celtis).-Sugarberry. Nettle-tree. Shrubs or small trees on which the greenish flowers unfold before the leaves. From the common hackberry (C. occidentalis) in Illinois and Mis souri in some year's the bees gather a large amount of nectar. There are more species in the South than in the North.

Hawthorn (Crataegus).-A great number of closely allied species, blooming in May; valuable for both nectar and pollen.

Heatler (Calluna vulgaris).-In northern and western Europe heather or ling covers vast areas called moors. Honey amber-colored, with an aromatic flavor, and a pungent aroma, but so viscous that it is difficult to extract. On an estate in South I uancaster, Mass., there have been planted two or three acres of heather. The plant is hardy and seeds itself.

Heartsease (Polygonum Persicaria).--Naturalized from Europe thruout a large part of North America; honey varies from light to dark amber; flavor very good. Water smartweed ( $P$. punctatum) occurs in wet lands thruout North America; honey dark and of poor quality. Many other smartweeds are of more or less value; about to species in North America. See Heartsease.

Fledge Nettle (Stachys).-Many species secrete nectar freely, and attract a large number of bees.

Holly (Ilex opaca).-American holly. White holly. A small evergreen tree which in the southern States blooms in $\Lambda$ pril. In western Mississippi and southern Arkansas it is an important honey plant yielding a large surplus. Honey nearly white, heavy, excellent, and when pure will not candy. See HoLIY.

Hollyhock (Sidalcea malvaeflora).- Checkerbloom. Grows in profusion along the roadsides and irrigating ditches of southern California and sonthern Arizona. $\Lambda$ good source of nectar in winter, sometimes yiélds a small extracting. Stimulates brood-rearing.

Honey Locust (Gleditsia triacanthos).-A large thorny tree bearing small greenish flowers. Rich woods from New York to Texas. The bloom secretes nectar freely, but the tree is too rare to yield a surplus.

Honeysuckle (Ionicera).-Honeybees are able to gather the nectar of several species of bush-honeysuckle; but the nectar of the climbing garden honeysuckle ( $L$. Periclymenum), adapted to moths, and of the trumpet honeysuckle ( $L$. sempervirens), adapted to humming birds, is beyond their reach.

Horse-chestnut (Asculus Hippocastanum).-A bumblebee flower, but honeybees obtain both nectar and pollen.

Horsemint (Monarda punctata).- New York to Florida and Texas. One of the main yielders in Texas; honey of good quality, but rather strong. flavored. $M$. clinopodioides is likewise very valuable; honey has been compared to that of bass. wood. See HoRsEMINT.

Hop-tree (Ptelea trifoliata).-A small tree with greenish white flowers, which have a disagreeable odor. In rich woodlands from Minnesota to Flor. ida and Texas. Blooms in June. Very frequently visited by honeybees. Valuable when abundant. Also called whahoo and wafer ash.

Horehound (Marrubium vulgare).-Good yields of dark honey, but it is so bitter as to be almost worthless except for medicine. See HoREHound.

Huajilla (Acacia Berlandieri).-A shrub forming dense thickets in the Rio Grande Plain. Honey white with a fine flavor and pronounced aroma. It granulates quickly with a coarse grain. See HuA. JILLLA.

Huisache (Vachellia farnesiana).-Yellow opanax. Cassie. Florida to southeru California. A shrub or small tree. Chiefly valuable for pollen. (Syn. Acacia farnesiana).

Jackass Clover.--See Stinkweed.

Knotweed.-See Hzartsease.

Isavender (Lavandula officinalis). $-A$ garden herb cultivated for the strong aromatic foliage. The honey is very thick and difficult to extract.

Lemon (Citrus Limonium).-Valuable for honey in southern California. Honey light-colored, of excellent flavor with none of the tartness of the lemon.

Lima Bean (Phaseolus lunatus).-More than one-half of the commercial crop of lima beans is grown in southern California in a narrow belt, 20 miles wide, within reach of the ocean fogs. In Ventura County 50 pounds of honey per colony is often secured from the bean fields. Lima bean honey is a heavy white honey with an excellent flavor. A bush variety is planted by the thousand acres and is yielding nectar better than the old variety.

Linden.-See BASSWOOD.

Locust, Black (Robinia Pseudo-Acacia).-Common in the mountains of the central and southern States. Widely cultivated. The cream-white flowers open in May. Honey white, mild-flavored, heavy and slow to granulate. A colony of bees has been known to store 15 pounds in one day. See LOCUST.

Logwood (Haematoxylon campechianum).-Common in the States bordering on the Bay of Campeche; introduced into Florida, Jamaica, and in the West Indies; honey nearly water-white, of good body, and unexcelled in flavor and aroma. See LOGWOOD.

Loquat (Eriobotrya japonica).- Sometimes wrongly named Japan plum; South and in California; valuable because it flowers late.

Lucerne.-See ALFALFA.

Madrona (Arbutus Menziesii).-An evergreen tree common in the Coast Ranges of Oregon and California. The honey is light amber, with a good body and flavor. A reliable honey plant, but it blooms before settled weather.

Mayweed (Anthemis Cotula.)-Honey light yellow and very bitter.

Mallow (Malva).-The flowers of several species are very frequently visited by honeybees for nectar and pollen, but not important except perhaps locally.

Manchineel (Hippomane Mancinella).-Southeast Florida and on the Keys. Nectar very abundant. Small trees with apetalous, greenish flowers. 
Manzanita (Arctostaphylos manzanita).-Valuable in California for both nectar and pollen. Honey white to amber-colored, with a fine flavor suggestive of the berry. A surplus of more than 20 pounds may be obtained. Blooms in December, and honey is used by bees for spring breeding. A branching bush, about 12 feet tall, covering large areas of the Coast Range slopes. White to pink urn-shaped flowers. Manzanita is Spanish for "lit tle apples," so called from the form of the berries, Bearberry.

Maples (Acer).-The different species are of inuch value, yielding both nectar and pollen for early brooi-rearing. The sugar maple (Acer saccharvm Marsh) produces a profusion of flowers.

Marigold (Gaillardia pulchella).-One of the main honey-producing plants of Texas. Honey rich golden, and of good quality. See MARIGold.

Marjoram. (Origanum vulgare). - Introduced from Europe; in gardens, and sparingly escaped. A favorite of honeybees, but not common enough to be of much value.

Mêlilot.-See Sweet Clover.

Melons (Cucumis Melo).--Melons of all kinds are valuable to apiarists.

Mesquite (Prosopis glandulosa).- Southwest in semiarid regions. Main source of honey in Texas. In the Hawaiian Islands the mesquite is not only the chief, but almost the only source of floral honey. The honey is water-white, about as thick as that of white clover, and has an agreeable altho peculiar flavor. Seo MESQUite.

Milkweed (Asclepias). - In northern Michigan $S$. syriaca is very common, and may yield a surplus of 50 pounds per colony. Honey nearly waterwhite, thick, fruity in flavor with a slight tang. Milkweed is also valuable in California. The pollenmasses become attached by dry membranous clips to the claws and tongues of honeybees; if they are unable to extract them, they finally perish-dead bees are sometimes found on the flowers. See MiLKWFis,

Milk-vetch (Astragalus).- The various species are visited by honeybees, and the more common are valuable in favorable sections.

Mint (Mentha spicata).- - In Sacramento County, Calif., yields in the fall a large amount of ambercolored honey. Peppermint.

Mountain Laurel (Kalmia latifolia).-Bee-flowers. Common in sandy soil from Ohio to Florida and Iuouisiana. Reported to yield a poisonous honey but this is doubtful. See PoIsonous Honey.

Mustard (Brassica).- Honey light, of mild flavor; not as heavy as alfalfa; candies quickly; a large surplus in Lompoc Valley, Calif. S'ee MusTARD.

Napa Thistle (Centaurea melitensis).- Tocalote. Common in grain fields in California. The yellow flowers open in May and yield a liglit amber honey of good quality.

Onion (Allium Cera).- - Surplus yields of loney are olvtained from fields of onions cultivated for seed; the peculiar onion odor and fiavor disappear as the honey ripens.

Orange (Citrus Aurantium).- - Yields a surplus in Florida and California. Honey nearly transpar ent, of delicious flavor, with the aroma of the blossom; candies after a few months. See Orange.

Palo Verde (Cercidium torreyanum). $-\Lambda$ small tree with green bark growing in the deserts of California, Arizona, and Sonora. The yellow flowers open in May. They yield less nectar than mesquite bloom, and the loney is inferior in quality. The leaves appear in March and April, but soon drop off. (Syn. Parkinsonia torreyana).
Parsnip (Pastinaca sativa).-A surplus is gath ered from the big parsnip fields along the Sacramento River, California.

Partridge Pea (Cassia Chamaechrista).-Nectarless flowers pollinated by bumblebees. The nectar is secreted by sessile glands on the upper side of the leaf-stalk. Nectar is secreted abundantly, but it is mostly water. In dry soil, New Engalnd to Florida and Texas. The honey is light amber, exceptionally thin, and has only a fair flavor.

Peach (Pruns persica). - Sometimes a suall surplus.

Peanut (Arachis hypogea).- Extensively culti vated in the southern States, Virginia, Tennessee, the Carolinas, Georgia, and Florida. A surplus is obtained, in Florida. The honey is very light amber colored, thick, and has a mild characteristic flavor, which differs from that of peanut butter. There are tliree months of bloom. It is not a reliable source of honey.

Pear (Pyrus communis).-In some localities yields nectar so freely that it drips upon the ground, in others of little value. Less important than the apple. In California a surplus is usually obtained if the weather is warm during the bloom.

Pennyroyal, Florida (Satureja rigida). - A shrubby, perennial plant growing on pine lands and sandy barrens in southern Florida. It is of little value to the beekeeper north of I iake Apopka. Blooms in January and yields a white honey with a minty odor and flavor. Bees build up rapidly dur. ing the honey flow, and 50 pounds per colony has been secured. Important in Lee County. (Syn. Pycnothymus rigidus.)

Pepperbush (Clethra alnifolia).-White alder. On the coastal plain of Georgia and in northern Florida it yields a surplus; honey white and of superior quality; blooms from June to October. Maine to Florida near the coast.

Pepperidge.-See TUPELO.

Pepper-tree (Schinus molle).-California and Florida; honey amber-colored, and of pronounced flavor. See PePper Tree.

Pepper vine.--See SNowvine.

Persimmon (Diospyros virginiana).-Connecticut to Florida and Texas; a large tree; blooms in spring; valuable.

Phacelia.-At Ventura, Calif., a water-white loney is obtained from Phacelia hispida; it has a fine flavor, but candies soon after extracting. In central California $P$. tanacetifolia yields a mild light-amber honey. See PHACELIA.

Pigeon cherry (Prunus pennsylvanica).-Considerable nectar is obtained from the flowers.

Pink Vine (Antigonon leptopus).-Mexican rine. Cultisated in the South for ornament. Yields nectir abundantly.

Plums and Prunes (Prunus).-All kinds of plums yield nectar.

Poison Iry (Rhus Toxicodendron).-Poison Oak. Bushy, or a vine climbing by rootlets. Poisonous to the touch. Yields a light-colored honey which is reported to be mild and good. This honey should be thoroughly ripened before using.

Prairie Clover (Petalostemum candidum).- $\mathrm{Be}$ longs to the pea or pulse family; reported as valuable.

Prickly Ash (Xanthoxylum americanum).-A small tree blooming in spring, and much visited by bees for nectar. Canada to Virginia.

Pumpkin (Cucurbita Pepo).-Cultivated; honey amber-colored; candies quickly.

Purple-flowered Mint (Mesophaerum spicatum). -Very valuable in Alachua, Polk, DeSoto, Pinellas, Hillsboro and several other counties in Florida. The honey is medium amber, mild. and does not crystallize. Blooms from March, when the plant is only 
eight inches tall, to November, when it is 8 or 10 feet high. The small flowers are purple. Belongs to the mint fainily, or Labiatae.

Rabbitbrush (Chrysothamnus nauseosus). - The small yellow flowers are in ample flat-topped clusters. In Inyo County, California, it yields a dark honey which has an odor and taste so nauseous that even the Indians will not eat it. There are many species of rabbitbrush in the western States. The honey is dark yellow, poor in quality, and granulates quickly. The flowers appear in the fall.

Raspberry (Rubus idaeus, variety aculeatissimus.)-Very cominon in northern Michigan; a white honey of the finest flavor. See RASPBERRY.

Rattan (Berchemia scandens). - In Texas, in favorable seasons, yields a surplus of dark-amber honey used for manufacturing purposes.

Red Bay (Persea Borbonia).- In swamps along streams near the coast, from Virginia to Florida westward to Texas. The yellowisl flowers open from March to May. The honey is dark and strong. Tisswood. Sweet bay. Laurel-tree. Florida malogany.

Red Bud (Cercis canadensis). - Tudas-tree. The pink purple flowers appear from March to May before the leaves and are valuable for early broodrearing. Of wide occurrence in rich soil east of the Mississippi River. The Texas red bud and the California red bud are of minor importance in Texis and California.

Red Clover (Trifolium pratense).-A bumblebee flower. In dry seasons the corolla-tubes are so short that honeybees secure a surplus from the blooin. and sometimes in wet seasons.

Red gum (Eucalyptus rostrata).-Nectar abundant; a promising species. See EUCALYPTUS.

Retama (Parkinsonia aculeata).-Horse bean. A small tree or shrub. The fragrant light yellow flowers open in spring, but may appear at any time. Does not yield a surplus, but the bloom is attractive to bees.

Rockbrush (Eysenhardtia amorphoides). - A branching shrub growing on the dry plains of southern Texas and northern Mexico. Blooms in spring and yields a good crop of fine honey.

Rhododendron.-Bumblebee flowers. The flamecolored azalea ( $R$. calendulaceum) is very abundant on the mountain slopes of North Carolina. The honey is reported to cause nausea and dizziness. It Divide, West Virginia, great quantities of nectar in large drops have been observed dropping from the flowers, but not a single bee was observed gathering it. The nectar was very sweet and pleasant to the taste. See PoIsonous HoNEY.

Rocky Mountain Bee Plant (Cleome serrulata).Grows widely over the plains east of the Rocky Mountains. It was formerly of great value in Colorado, but is at present much less abundant. The honey is light colored and has a fair flavor.

Royal Palm (Oreodoxa regia).-Honey light amber, very thin, and a strong unpleasant flavor. Florida, Cuba, and Porto Rico.

Sage (Salvia).-Black or button sage (S. mellifera) is one of the chief honey plants in California: honey, thick, white, of delicious flavor, not inclined to candy. Purple or white-leaved sage (Salvia lencophylla) yields a similar honey, but is less abundant. White sage ( $S$. apiana), tho one of the commonest, does not yield nectar as freely as the two above-named species, but the honey is equally good. Creeping sage ( $S$. sonomensis) is common in the mountains and S'ierra foothills. The honey is of ahout the same quality as black sage. Annual sage ( $S$. columbariae) yields a surplus of excellent honey in Monterey County, Calif. The lance-leaved sage $(S$, lanceolata $)$ is listed as a honey plant in
Nebraska, and the blue sage ( $S$. azurea) in Texas. Many species of sage are adapted to bumblebees, or in South America to honey-sucking hirds, and the nectar cannot be obtained by honeybees. See SAGE.

S'ainfoin (Onobrychis sativa).-Cultivated for hay or fodder. Honey similar to that of white clover. See SAINForn.

Saw Palmetto (Serenoa serrulata).-This species closely resembles serub palmetto. The two species usually bloom at the same time and the honey is generally mixed. North Carolina to Florida and Texas.

Sea Grape (Cocrolobis uvifera).-A small tree or shrub with twisted branches. Common in south ern Florida. At Sarasota it is reported to yield much nectar. Buckwheat family.

Scrub Palmetto (Sabal megacarpa).- - Honey lemon yellow, thick and heavy, with an aromatic flavor and odor. Granulates quickly. Common on sandy soil over the southern two-thirds of Florida. Flowers small, white, in a branched drooping cluster 3 feet long.

Silver Wattle (Acacia dealbata).- -Silver wattle and black wattle ( $A$. decurrens) are planted extensively for ornament in California. They furnish much pollen in January and February.

Simpson's Honey Plant.-See F'rGWorT.

Smartweed.-See HEARTSEASE.

Sneezeweed (Helenium autumnale). - Swamp sunflower; in wet land and thruout the eastern States. Honeybees gather both nectar and pollen. In Texas, bitterweed ( $H$. tenuifolium) yields a golden-yellow honey of heavy body, but very bitter, "as if 50 per cent quinine and some pepper were added."

Snowberry (Symphoricarpus racemosus). northern shrub, Nova Scotia to Alaska and south ward to Pennsylvania. $\Lambda$ large amount of fine honey is obtained from the bloom in Iowa.

Snow-vine (Cissus arborea).-Pepper-vine. In wet land from Virginia to Florida and Texas. A hushy vine with pinnate leaves. At Doctortown, Georgia, yields a dark amter honey of fair quality for 6 weeks. Bees prefer the bloom to that of cotton.

Soapberry (Sapindus Drummondii).-Wild China. China-berry. A tree common along creeks in Louisiana, Texas, and New Mexico. Yields nectar freely. Two ather species of soaplerry are found in Florida.

Soapbush (Porliera angustifolia).-In Uvalde County, Texas, bees store honey from this shrub in very dry seasons. The large purple flowers open in April. Honey white, and has a good flavor, but granulates quickly.

Sourwood (Oxydendron arboreum). $-A$ splendid honey-producer. The nectar is so abundant that it can be shaken from the blossoms: a white honey, with an aromatic flavor, that does not candy readily. See SOURWOOD.

Spanish Needles (Bidens aristosa).-Marshy lands of .Mississippi and Illinois Rivers. Honey golden-yellow, of fine flavor and good body. See SPANISH NEEDLES.

Spider-plant (Cleome spinosa, formerly called $C$. pungens).--Introduced from tropical America; cultivated; escaped in waste places from Illinois to Lonisiana. Thirteen flowers have yielded a spoonful of nectar. "Under favorable conditions one of the most remarkable honey plants in the world." The Rocky Mountain bee plant ( $C$. serrulata, formerly called $C$. integrifolia) grows in dry saline soil from Minnesota to Kansas, and westward among the mountains.

Spikeweed (Centromadia mungens).-- "On the al. kaline plains of the upper San Joaquin (Calif.) this 
species covers tens of thousands of acres; honey amber, of good quality, but granulates quickly."

Squash (Cucurbita maxima).-Nectar abundant in a little reservoir at the bottom of the flower.

Star Thistle (Centaurea solstitialis). - Very abundant in grain fields in Sonoma, Napa, and Solano Counties and northward in the Sacramento Valley. Rapidly spreading. Blooming from early summer until frost. Honey white, very mild in flavor, and heavy bodied. The plant is well adapted to arid soils. Napa thistle or tocalote ( $C$. melitensis), first introduced at Napa, yields a light amber lioney in Sacramento County.

Stinkweed (Wislizenia refracta).-A rank-scented annual, abundant in the San Joaquin Valley, Calif. A mild water-white honey, becoming pastelike after granulation. Blooms heavily every other year, from August to October. A large surplus is sometimes obtained. A most promising honey plant, called by local beekeepers "Jackass Clover."

Sumac (Rhus glabra).-New England and southwestward. A surplus in Connecticut; honey bright amber; very heavy, but at first has a bitter odor and flavor which disappear as it ripens; waxes instead of granulating. Mountain sumac ( $R$. copallina) yields a surplus in Georgia and Texas. $R$. diversiloba is common thruout California. See Sumac.

Sunflower (Helianthus annuus).-Common, wild in the West; yields a surplus of amber-colored honey with a characteristic flavor.

Sweet Clover (Melilotus alba and $M$. officinalis). -Introduced from Europe; white and yellow sweet clover are spreading thruout the entire country. Honey white, with a slight greenish cast hardly equal to white clover honey. See SweET Clover.

Sweet Fennel (Foeniculum vulgare).-Cultivated from Europe, and escaped in waste land. Honey light amber.

Tarweed (Hemizonia fasciculata).-Along the coast of southern California. Honey dark amber, with a strong tarweed odor; granulates in a few months; said to be used in the manufacture of chewing tobacco. Yellow tarweed ( $\boldsymbol{H}$. virgata) yields in central California a heavy light-yellow holley of good flavor.

Teasel (Dipsacus fullonum).-The honey is very thin and white, in fact one of the whitest honeys, but the flavor is not as good as that of clover or basswood. Of minor importance.

Teneza (Leucacna pulverulenta).-A large tree growing on the rich bottomlands of the Rio Grande River, Texas. Valuable at Brownville; yields nec tar from April to September. (Syn. Acacia pulver ulenta.)

Texan Ebony (Siderocarpos flexicaulis).-A small evergreen tree of southern Texas. Blooms in June, and yields a small surplus of good honey. If there is much rain it blossoms several times. (Syn. $A c a$ cia flexicaulis.)

Thistle.-See CANADA THISTLE.

Thyme (Thymus vulgaris).-The classical honey from Mount Hymettus was from this species. Nec. tar very abundant, with all-aromatic flavor.

Thyme (Thymus serpyllum).-There are many acres in the Berkshire Hills, Mass. Yields a surplus. Honey good, with an aromatic flavol.

Tie Vine (Ipomoea trifida).-A common honev plant in southeast Texas. Grows only on black land. Blooms in September. At Victoria yields an amber-colored honey, with a nild flavor.

Titi, Black (Cliftonia monophylla).-Spring titi. Buckwlieat-tree. An evergreen slirub or small tree growing in swamps from South Carolina to Florida and Louisiana. It blooms in March and April, and yields an amber-colored honey of medium quality, which injures the honey from gallberry and tupelo,
The small white flowers are in terminal racemes. It often forms dense thickets known as titi swamps.

Titi, White (Cyrilla racemiflora).-Red titi. Ivory bush. Leather-wood. Summer titi. Like the black titi this species belongs to the titi family or Cyrillaceae. An evergreen shrub, or small tree found in swamps from Virginia to Florida and Texas. It blooms in June, and while it yields less nectar than spring titi it is valuable for maintaining broodrearing and may yield a small surplus. The honey is dark amber and has a decided flavor which becomes milder with age.

Tobacco (Nicotiana Tabacum).-In Connecticut the plants are permitted to flower and seed. From the first of Angust to frost there are hundreds of acres to tobacco flowers covered with bees. The honey is reported to be of fair quality.

Tornillo (Strombocarpa odorata).-Screw bean. A small tree growing from western Texas to California. Common in the river valleys of New Mexico. Spikes of yellow flowers in April. Valuable for brood-rearing. (Syn. Prosopis pubescens.)

Tulip tree (Liriodendron Tulipifera).-White poplar, Whitewood. Common in the southern States, blooms in April and May; honey bright amber when new, but becomes darker with age and very thick, of fair quality. See Tulip TreE.

Tupelo $\left(N y s s^{\prime}\right)$. - There are 5 species in North America, 4 are trees and one a shrub. The flowers are small and greenish and appear with the leaves. White tupelo (Nyssa aquatica) is also called white gum and water tupelo. In river swamps from Virginia to Florida and Texas. A nearly white honey, very heavy in body, and mild in flavor, which does not granulate. Black tupelo ( $N$. biflora) is also known as black gum. In swamps from Virginia to Florida and Louisima. The honey is similar to that of white tupelo. Ogeche plum ( $N$. Ogeche) is peculiar to the swamps of South Carolina, Georgia, and Florida. Ogeche lime. Black tupelo. A white honey like that of the other tupelos. Highland tupelo or sour gum ( $N$. sylvatica) is a large forest tree growing in moist upland woods from Maine to Florida and Texas. The largest of the tupelos. Beekeepers often fail to distinguish between this species and black tupelo. Bush tupelo ( $N$. acuminata) is peculiar to the swamps near the coast of Georgia.

Turkey Mullein (Eremocarpus setigerus.) "Woolly white drought weed." Abundant in the fall in dry grain fields of the Sacramento and San Joaquin Valleys. Honey amber-colored.

Varnish Tree (Ailanthus glandulosa).-Tree of heaven, Chinese sumac. Small greenish flowers; the staminate are ill scented, and the honey has a bad flavor.

Velvet Bean (Mucuna utilis).-There are about five million acres of this legume grown in the southeastern States. A light amber honey of mild flavor.

Verbena or Vervain (Verbena).-Once or twice in 30 years at Center Point, Iowa, purple vervain (Verbena hastata) has been so abundant as to give the landscape a bluish tinge. The honey is white. mild-flavored, resembling white clover honey; it does not granulate quickly. The purple pollen gives the comb a bluish tinge. In California $V$. prostrata is of value along the coast.

Vetch (Vicia sativa). - Sand or winter vetch is a hardr forage plant. The flowers have a corolla tube $12 \mathrm{~mm}$. long and are adapted to bumblebees. Many species of Vicia have extra-floral nectaries on the under side of tlie leaf-stems, which secrete nectar in sunny weather. In Oregon these extra-floral nec taries yield a large amount of a white heavy honey difficult to extract.

Vine Maple (Acer cercinatum), - Mainly west of 
the Cascades in Oregon and Washington. The honey has a fine flavor and is amber color with a faint pinkish tinge.

Viper's Bugloss.-See Blueweed.

Water Moody (Baccharis glutinosa).-Bottomwillow. A bush from 4 to 6 feet tall. In southern Arizona blooms in spring and yields a surplus of white honey of excellent quality. Most common on land that is inundated in the river valleys.

White Clover (Trifolium repens).-White Dutch clover. The most widely known and possibly the most important honey plant. Secretes nectar most freely on limestone soils, where the mean sunmer temperature does not exceed 77 degrees F. Honey white, excellent, the standard with which all other honeys are compared.

Wild Alfalfa (Lotus glaber).-An important honey plant in the Coast Ranges of California; honey white to amber; the yield is very variable in different yęars and in different localities.

Wild Buckwheat (Eriogonum fasciculatum).-A bushy shrub common on the plains and mountain slopes of southern California. The honey is light amber, with a fine flavor and granulates early. The honey flow comes in July and August. Usually the honey is mixed with that of the sages, but in Antelope Valley, Ventura County, it has been obtained pure.

Wild Cherry.- See Cherry.

Wild China.-See Soapberry.

Wild Senna.-See Cassia.

Willow (Salix).-Valuable in early spring for both nectar and pollen. In New York the honey resembles that of apple bloom, and has a pleasant aromatic taste; but in California it is described as bitter-flayored and amber-colored. See WILLOW.

Willow-herb (Epilolium angustifolium.) - Canada, the northern States, especially Michigan; confined chiefly to regions where there have been forest fires. Flowers red-purple; honey clear, limpid, literally water-white; very sweet; aromatic.

Woodbine (Psedera quinquefolia).-A woody climbing vine with small green flowers in clusters. Yields nectar abundantly. Common in thickets and often cultivated.

HOREHOUND (Marrubium vulgare). -A woolly herb with small white flowers in whorls. Naturalized from Europe, horehound is widely distributed thruout the United States. In Texas it yields nectar freely from February to July. The honey is very sweet with a peculiar, rather nauseating flavor. It is common in the foothills of the Coast Ranges and Sierra Nevada, in the Sacramento and San Joaquin valleys, and in southern California, where it yields a dark amber honey, too strong for table use, but largely used in medicine. Horehound is a pest on a sage range, for, if only a small quantity of its nectar is gathered, the color and flavor of the sage honey are impaired. Horeliound is very common in Australia, where it was introduced by the early settler's. The hon$e y$ is valued for its medicinal qualities.

HORSEMINT (Monarda punctata).-The genus Monarda, which was named for
Nicolas Monardes, a Spanish physician and botanist who lived in the 16th century, contains about 15 species, all natives of North America. The most valuable species to the beekeeper is the common horsemint M. punctata. It is a perennial herb with lance-shaped leaves, and two-lipped yellowish flowers spotted with purple, which grows in sandy fields and prairies from New York to Wisconsin and southward to Florida and Texas. In western Wisconsin and eastern Minnesota it is common on the sandy jackpine lands and oak barrens, where it yields nectar abundantly and is very attractive to honeybees. In Iowa it occurs only in the sandy sections along the Mississippi, Wapsipinicon, Cedar, and Iowa rivers. It is likewise listed as a honey plant in western Mississippi and northwestern Louisiana. In Texas it is an important source of surplus.

Horsemint was first brought into notice a few years ago, when it was highly recommended to beekeepers and the seeds sold quite extensively. Subsequently it was almost forgotten until large crops of honey from this source obtained on the low alluvial lands bordering on the Mississippi River attracted attention. Afterwards wonderful reports came from different parts of Texas. While horsemint is found in nearly every county in eastern Texas it is most abundant on the Black and Grand Prairies. According to the reports of hundreds of Texan beekeepers it ranks second in importance among the honey plants of that State, and it is estimated that 19 per cent of the total surplus comes from this source. Beginning in June or a little earlier it blooms from four to six weeks, or, if there is much rainy weather, for a much longer time. The surplus in the cotton belt is largely dependent on the horsemints, and the average per colony in commercial apiaries ranges from 20 to 100 pounds. But it is not reliable every year, and in hot dry seasons the flow greatly decreases. The extracted honey is clear light amber in color, a little darker than the comb, and of good body. It has a pronounced flavor, and has been compared with the basswood honey of the North. Horsemint honey is preferred to white clover honey by many persons, but it is the 


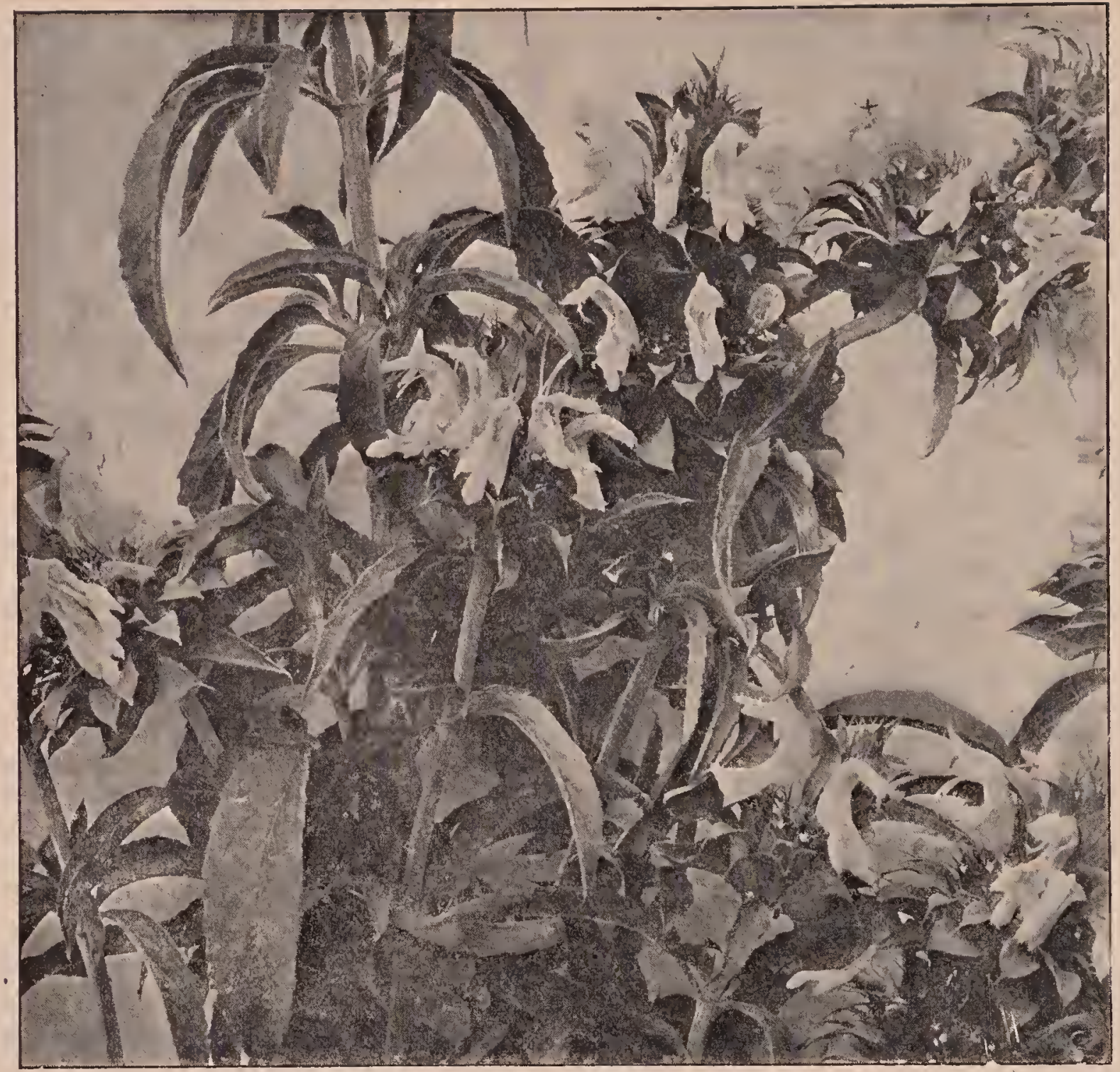

Texas horsemint.

general opinion that it has a little too strong a flavor.

Since horsemint yields an essential oil, from which thymol, a powerful antiseptic used in dressing unhealthy wounds can be obtained, it became economically important during the Great War. In Texas it has been cultivated in several localities for six or seven years, but the surplus of honey obtained did not pay expenses. The foliage was usually attacked by a purple rust which killed the plants. It is the practice to break up the soil of an old field with a dise harrow and sow the seed about the middle of August. If there are a few fall rains there will be an abundant growth of horsemint the following year. After the seed has ripened, if the soil is again harrowed, another crop will be assured.

In the Black Prairie region of Texas lemon mint (Monarda citriodora), an an- nual with pink or nearly white flowers, is abundant. In localities, where there is much line in the soil, the flowers are bright red. The corolla-tube is about the same length as that of the preceding species and the nectar is readily reached by honeybees. $M$. clinopodioides is also very common on the dry plains of Texas. The form of the flower and the time of blooming are nearly the same as in $M$. punctata. There are also several other species of borsemint growing in Texas the nectar of which can be easily gathered by honeybees.

But a part of the species of this genus have long corolla-tubes and are adapted to insects with a much longer tongue than the honeybee, so that even if common they are of little value to the apiarist. Brad. bury's Monarda (M. bradburiana) oceurs on dry hills in Illinois, Missouri, and Kan- 
sas. The pink flowers have a tube $18 \mathrm{~mm}$. long and are adapted to female bumblebees, but butterflies and luumming birds also are common visitors. The tube at times fills witl nectar for more than half of its length, and, as its mouth flares sufficiently to admit the head of the honeybee for $5 \mathrm{~mm}$., worker bees in large numbers have been seen gathering the nectar. Wild bergamot ( $M$. fistulosa) is another bumblebee flower. It is found abundantly by the roadside and on dry hills from Maine and Minnesota to Florida and Louisiana. The corolla-tube is $18 \mathrm{~mm}$. long, or a little less than three-quarters of an inch. The pink flowers attract many butterflies. Wasps bite looles in the base of the tubes in order to obtain the nectar, and loneybees very often make use of these perforations to gain a part of the sweet spoil. Bee balm or Oswego tea (M. didy$m a)$, with scarlet flowers and very long corolla-tubes, seems to be adapted to humming birds. The horsemints belong to the nint family or Labiatae.

\section{HOUSE-APIARY.-See APIARY. ....}

HUAJILLA (Acacia Berlandieri).-The Rio Grande Plain includes that portion of southeastern Texas lying between the Gulf of Mexico and the San Antonio River on the east and the Rio Grande on the south and west. Its northern boundary is the escarpment north of San Antonio. It is a semiarid country with many days of inense sunshine and an average annual rainfall, which ranges from 16 to 26 inches according to the locality. The soil is sandy, gravelly or rocky, and the surface is partly level and partly broken by ridges and hills. The dry uplands are about one-half covered with a scrubby, thorny growth, 2 to 12 feet tall, often forming impenetrable thickets. Mesquite, white brush, prickly pear, Texas ebony, catsclaw, retama, and huajilla are abundant and yield a large surplus of honey. There are nearly 80 species of small trees and shrubs in the Rio Grande Plain, not one of which appears in the Atlantic forests of east Texas. The three main honey plants are mesquite, catsclaw, and huajilla, but huajilla is the most important of the three. Huajilla occupies the rocky ridges and hills in the northern part of this section extending

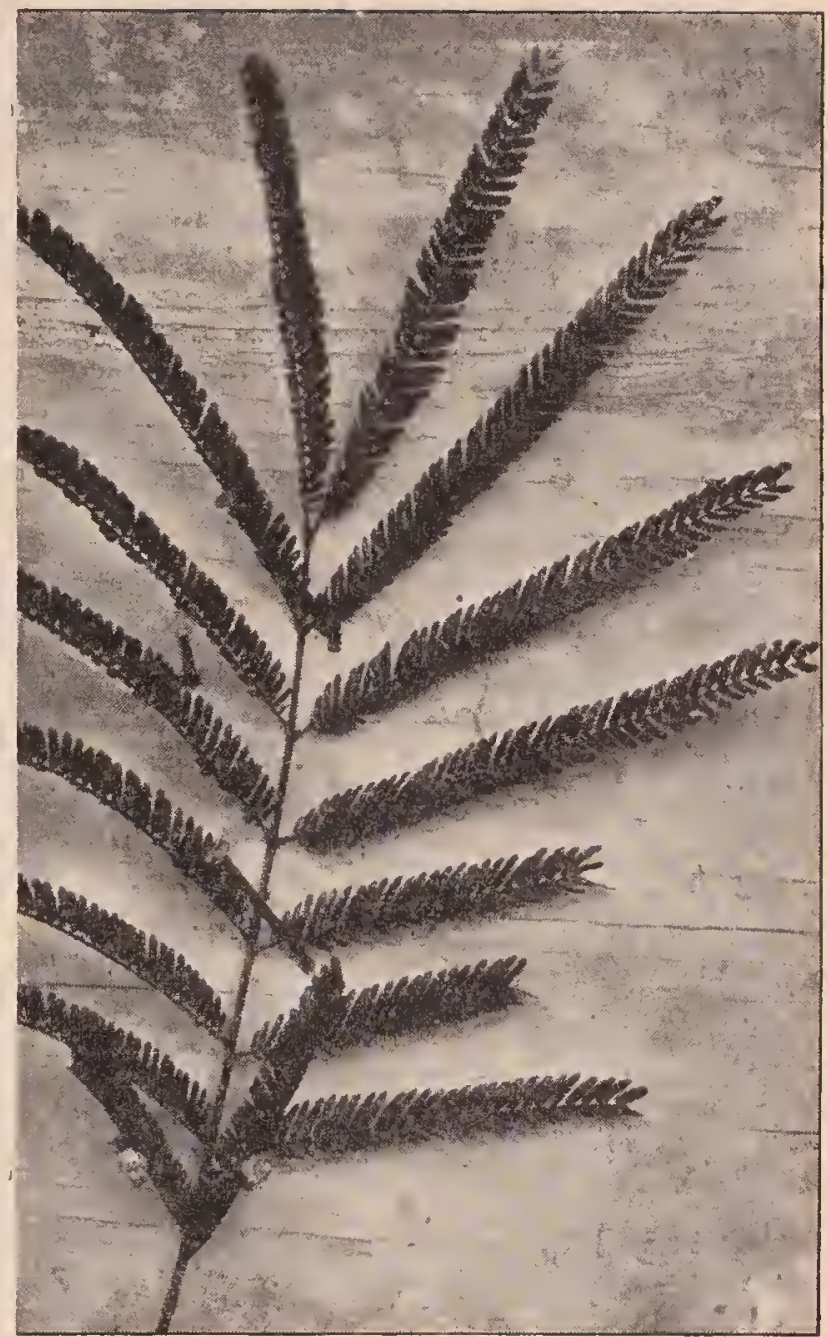

Huajilla.

from the Nueces River to the Rio Grande. It is not found in Cameron County in the extreme soutl, but is common in Uvalde and other northern counties. It is a nearly unarmed shrub with pinnate leaves, and small yellow flowers in globular clusters. It blooms in April and yields nectar for about 15 days in such abundance that it is impossible for the bees to gather it in farorable seasons. The honey is white or a very light amber, and is probably the lightest-colored honey produced in the State. It has a very mild flavor and is famous for its excellent quality and pleasing aroma. It granulates early with. a coarser grain than catsclaw honey. The flow is not reliable every year. Huajilla honey unmixed in commercial quantities is difficult to get, as this species and catsclaw usually bloom at the same time.

HUBER, FRANCOIS.-More perhaps than any other branch of agriculture, beekeeping has a generous list of great and beloved names folded down in its chronicles. 
Even after laying aside the thought of literary sideliners like Virgil of old and Maeterlinck of today and others like them (are there any others like them, tho?--will there ever be?), men who have immortalized the charm of the bee, there are still practical apiculturists, experimenters and scientific investigators whose names are dear to the entire beekeeping fraternity.

From among them all, could only one be selected for a sketch who would not choose the great Swiss naturalist-blind Francois Huber? It is good to renew, in even the small measure of such an article as this, our acquaintance with this dauntless soul.

He was born in Geneva, Switzerland, in 1750. What a city and what a time for a scientist to be born in! Horace Benedict de Saussure, the eminent Swiss physicist and geologist, who at 22 years of age accepted the chair of physies and natural philosophy at the University of Geneva, was a romping boy of 10 years when $\mathrm{Hu}$ ber, his future famous pupil, was born. Charles Bonnet, another great Swiss naturalist and philosopher, was 30, but he guessed no more than the boy De Saussure how great and dear a friend was born in his own native city that day. This was the same Charles Bonnet who had startled the scientific world 10 years before, when only 20 , with a paper on aphids, in which parthenogenetic reproduction was first described. No wonder this achievement made him, young tho he was, a corresponding member of the French Academy of Sciences. This was a full century before Johann Dzierzon, the pastor of Karlsmarkt, grew from a sideline beekeeper into a special student of apieulture and with the aid of his detachable cells discovered the parthenogenetic origin of drones.

Huber's own family was well known and wealthy. He probably never remembered his great-aunt, Marie Huber, for she died when he was only three years old; but she was a literary woman of wide interests, not only a tireless writer on religious and theological subjects, but also the translator of the Spectator. Then there was another relative with a fine chemical laboratory, who, alas, could not, even in the modern, progressive, scientific spirit of the Geneva of the mid-eighteenth century, lay aside his stubborn belief in alchemy. How long and patiently they labored, those old alchemists! And there was the boy's own father, Jean Huber, from whom he inherited his deep love of nature and keen powers of observation.

What a brilliant, gay, light-hearted, charming and likable gentleman this Jean Huber must have been. Known as a wit, he had also many and varied talents-he was a poet and a musician, a painter and a sculptor, and he served for many years as a soldier. But he took life lightly, tossing the hours about like bright-colored balls to be played with, and so made no lasting mark in any line, tho his "Observations on the Flights of Birds of Prey" won him considerable reputation. However, he was doubtless a delightfully entertaining daddy. What music he could make! How he loved the out-of-doors and what fascinating things he could discover there and what seerets lie could then tell about them! What strange and splendid specimens he had collected! And what miracles he could perform with a piece of paper and a pair of shears! Indeed, the cutting out of landscapes and silhouettes from paper became such an art in his hands, that he may fairly be called its originator. How he must have amazed and delighted grown-ups as well as children that time he tore a profile of Voltaire from a card with his hands behind his back-and that other time when he broke his own record by so skillfully guiding and turning a flat piece of cheese that his cat ate out therefrom another profile of Voltaire! Fortunately only his brilliance and talent descended to his son, and not the undue levity that undoubtedly marred his own career.

This father's library, his cabinets of specimens and his ricl observations roused in the boy an early and unceasing love of nature, which was well developed into methodical observations at an age when few children have learned to observe at all. Then there were also the usual social activities of the children of such families, and young Francois was sent to dancing school. So, too, was little Marie Lullin, whose father was one of the Magistrates of the Swiss Republic. They became childish sweethearts, these two. But oh, how little their child hearts guessed, as they followed 
the steps of their dancing master, the greatness of the tragic days to come.

From early childhood Francois attended lectures at Genevan College. Before he was 15, he had completed a course in physies under De Saussure. He had familiarized himself with chemical manipulations in the laboratory of the old alchemist. But a too intense and steady application to his studies and the habit of constantly rearling' late into the niglit by dim lamplight or dimmer moonlight seriously injured his health. At fifteen, he broke down, utterly prostrated and threatened with blindness. His terrified father-all gayety forgotrushed lim to a famous doctor in Paris who ordered him to the country. Near Paris is the quaint little village of Santi, and here the boy Huber ploughed and sowed and milked and lived the life of an ordinary peasant lad. His youthful strength rebounded swiftly and he returned to the eity witll rigor completely restored. But there another doctor, a celebrated oculist, broke to them the solemn news that his eyesight could not be saved. Slowly but surely he was to become totally blind. One eye had the same disease that had "quenched the orbs" of Milton-amaurosis; the other had cataract, which the doctors were unable to cure. Francois and his father went back to Geneva. And the boy went bravely on.

The childish love between Francois and Marie was deepening with the years, and now his only fear was that his affliction might alienate her. So he constantly minimized its seriousness, even to himself, scarcely admitting its steady desolating development. He talked always as tho he could see perfectly, and so formed the habit, later carried so noticeably into his writings, of speaking about seeing with perfect clearness what he saw only with the inner eye-altho there certainly with perfect clearness. Bnt he need not have worried about Marie. Her affection was so deeply rooted that not even her father's bitter opposition, which at times amounted to persecution, could turn lier from this greatsouled young man who was so soon to pass into complete outer darkness, but who held so bravely and steadily to the stronger light within. As soon as she reached hel majority she married him, shortly before he be- came totally blind. The tender devotion that brought her to that shadowed altar made beautiful 40 vear's of married life. She was at different times her husband's reader, his secretary, his observer; and was always closely absorbed in the work that absorbed his attention. When he was an old man he once said, "As long as she lived I was not sensible of the misfortune of being blind."

Another close personal association came to Huber thru Francois Burnens, whom he first employed as a serrant. Soon, however, the keen inner sight of the mastel had discovered in the man those rare talents that make the skillful observer. So Burnens became his invaluable and highly trained assistant in working out his one life purpose, research into the life and labits of the honeybee, displaying remarkable patience and skill thru countless experiments and under literally thousands of questions, by which Huber guided, directed, sifted, and tested his efforts. In one experiment to learn something about laying workers, Burnens caught one by one every bee in two hives which were suspected of having laying workers. This required 11 days of steady work, during which time he stopped only long enough to rest his eyes (the pathos of the master's insistence upon this!). Huber gave public testimony to his wortl, insisting upon slaring his own honors with one who "counted pain and fatigue nothing compared with the great desire he felt to know the result."

The results of Huber's observations and his long extensive investigations were written as letters to lis famous naturalist friend, Bonnet, whose own sight was failing so that he had given up his active scientifie investigations and was devoting his later years to philosophy. When these letters appeared later in book form as "New Observations on the Honeybee," some scholars at first raised mental eyebrows and smiled doubtfully at observations conducted by a blind man assisted by a peasant. But that attitude could not last. Scientists are neeessarily just and honest, and these swiftly threw aside their first prejudice and accorded to Huber's book the great place it stills holds after the passing of all these years.

He wrote in a wonderfully lucid style 
with lively picturesqueness-clearness of phrase growing out of clearness of vision, inner vision. His work is marvelous in its accuracy and fullness. Boundless patience and infinite skill unearthed lidden truths for him that had been searched for in vain for generations, from the seekers of ancient days on down to his own eminent friend Bonnet.

$\mathrm{He}$ built the first observation hivesone for a single comb and others for several combs, opening like books with hinged leaves, each leaf containing a comb. Among his important discoveries are the impregnation of the queen in mid-air and the fact of one fertilization being sufficient; the development of eggs of an unmated queen into drones; the fact that a queen apparently knows what kind of egg she is about to lay and always deposits it in the right cell (tho he acknowledged and clearly stated a mystery in this matter of eggrs and sexa mystery that later was largely cleared up by Dzierzon's great discovery of the parthenogenetic origin of drones) ; the rivalry of queens; the fact that queens can be reared from worker larvæ; that if bees are given worker-cells containing worker eggs or larvæ, and also royal jelly, they will never raise workers, but queens-and if queens are not desired, they will destroy the worker brood and devour the royal jelly; that eggs are true eggs--the embryonic development and emergence having been watched; that some workers sometimes become layer's; that drone eggs will produce drones even when reared in workercells-tho they may be small; and that worker eggs will produce workers even when reared in drone-cells-and they will not be larger.

He aided in the discovery of ovaries in workers, thus doing away with the age-old idea of neuters. He ascertained that the slaughter of the drones never takes place in a colony lacking a fertile queen, or in one still fostering swarming ambitions. By placing eggs in cells of blown-glass, and thru these walls observing the spinning of cocoons, he concluded that drones and workers spin complete cocoons, while queens spin imperfect ones, which, enveloping the head and thorax, extend only to the second segment of the abdomen, and inferred that if these cocoons were com- plete the queens could not destroy rival pupæ. He observed that the laying of drone eggs is either coincident with swarming preparations, or precedes them, and established many facts about swarming. He demonstrated by many experiments that bees, eggs, and larvæ all absorb oxygen and give off carbonic acid. In studying the air of the hive in this connection, he discovered the fact and the details of systematic ventilation, and the renewal of air in the hive by wing work. He studied thoroly the Sphinx atropos (death's head moth) and its ravages in the hive. He learned that the odor of the poison of the sting rouses other bees to stinging. $\mathrm{He}$ discovered the origin of propolis.

Huber discovered that wax comes from the under side of the abdomen of the workers. He also proved it to be produced by the digestion and conversion of honey, tho it had long been supposed to come from the conversion of pollen. He confined one swarm of bees on honey only and another on pollen only. New comb was built in the first hive, and removed, seven times; whille 'none at all was made in the second. But why, then, he promptly wondered, do bees gather pollen? Not for the sustenance of the adult bee, he concluded after further study (in which he proved honey to be essential), but for larval food. After close scrutiny he decided that workers swallow pollen and later regurgitate it as food for the larvæ. Marked bees were seen to eat pollen, go to the brood and plunge their heads into cells containing larvæ. After they left, these cells were examined and found to contain a supply of larval food. Another thing that he discovered was that flowers do not always contain nectar, as had been supposed-and that nectar secretion is influenced by variations in atmospheric conditions.

The entire process of comb construction was observed and recorded in all its detail. Bees were watched removing wax scales from the under side of the abdomen and passing them forward to the mandibles, whence, later, the plastic and cohesive wax issued and was attached to the top of the hive. One bee alone, he reported, starts the comb-building. When her supply of wax is exhausted, another follows, proceeding the same way, guided by the work of 
her predecessor. When this waxen wall is about one inch long and about two-thirds as high as one cell, they begin excavating it into cells one on one side, two on the other, the joining of the two being exactly opposite the center of the one. Only these first cells, however, are so excavated, all the others being built in their regular cell form.

Huber's work has been the foundation on which modern investigation has rested. Not only did he make countless valuable discoveries of his own, but by many patient and skillful experiments he verified and established beyond disproof many theories that had been advanced by others. And while a few minor errors have been corrected by the higher efficiency of later research, yet to an astonishing degree modern investigators (outside of Dzierzon) have merely verified the work of the great blind master.

Huber's mind was strong and active. Like his father, he loved music. He had mastered counterpoint, and could build the harmonies of a musical composition when the bass was dictated to him. After one repetition it was hị own. He invented a printing machine on which he corresponded with his friends. He loved to walk in the open air, and arranged to have knotted cords strung along the rural walks around his home, so that he could follow these paths without other assistance, and know his whereabouts by the knots.

While he had every advantage that ingenuity and wealth could bring, coupled with the tenderest devotion and quickest sympathy with his work, all of which helped to bring light into the dark days, yet the real source of his serenity lay in his own strong unshrinking soul. To old age he retained a deep affection for his friends, boyish ardor, steady delight in nature, noble enthusiasm, and that sure sympathy for youth which keeps age young. His mental faculties remained strong and alert to the end of his long active life. One day in his eighty-second year, he wrote a letter to a friend and two days later, in the arms of his daughter, dropped quietly off in the last sleep-"the immortal inrommunicable dream."

HUBAM.-See Sweet Clover, White ANNUAL.

\section{HUMBLEBEES.-See BUMBLEBEES.}

HYBRIDS.-A hybrid may be a cross between species or between varieties of a species. Bees mentioned under this head belong to the class last mentioned-a cross between varieties, and usually between Italian and common black bees. Everybody who has had Italians very long probably knows what hybrids (a cross between Italians and common black bees) are, especially if he had kept bees when the honey crop was very suddenly cut short during a long and severe drouth in the fall. They are very much crosser than pure Italians or blacks. Many of the old veterans in the business have concluded, even tho the hybrids will secure as much honey', and sometimes even more, that it pays to Italianize. A good strain of leather-colored Italians* will be almost as gentle as flies, and will gather fully as much honey as hybrids. Generally the half-bloods can be handled, when weather conditions are right, nearly as easily as Italians; but as a rule they require more time in that the operator must proceed much more cautiously in order not to stir them up.

While hybrids are by no means as hard to handle as pure Cyprian and Holy Land bees, they are bad enough. The very fact that hybrid queens, if sold at all, bring only about one-fourth the price of pure Italians, gives one some idea of their relative value in the open market.

But the most serious objections to hybrids and blacks is the fact that they are an easy prey to the ravages of European foul brood (see Foul Broop, sub-head "European Foul Brood"). While hybrids are more immune than the blacks, the arerage pure Italians seem to be able to resist the disease much better than the arerage crosses. In some parts of the country the hybrids and the blacks are dying off for the simple reason that they cannot stand the ravages of European foul brood'as do the Italians.

Not all Italians are immune; but good vigorous strains will resist the disease provided other curative measures are applied.

In many large apiaries thruout the country hybrids are tolerated simply because

* For test as to what constitutes a hybrid, see ITALIAN BEES. 
their owner's do not take the time to Italianize. Where one owns a series of outyards, comprising from 500 to 1000 colonies, it would be rather expensive to buy Italian queens; but if he will follow directions given under QUEEN-REARING in this work he can rear his own queens; and this brings up the question whether the blacks and the hybrids in a locality will not make it inmpossible to rear pure stock. If one will use drone-traps on all colonies where there are black or hybrid drones, and then insert a drone comb in the center of the brood-nest of the best Italian colonies, he will soon have a great preponderance of pure Italian drones. The result will be that the most of the young virgins will meet drones of their own race., See Drones; also QueEN-REARING.

Another plan to insure pure mating, is to wait till after the main honey flow when all colonies unless fed will kill off their drones. If two or three colonies, having select or pure drones, are fed a little every day, these drones will be kept while all others will be killed off. If a batch of pure Italian virgins of the right mating age are let loose at this time, they will meet only the select drones of the fed colonies. In this way pure matings can be secured even where hybrid and black colonies greatly predominate. It is important, however, to feed the colonies of select drones if not queenless a little every day until all the queens are mated. If even one day is skipped, the drones will be killed off.

A beginner should never open a hive of hybrids without smoke. A little should be blown in at the entrance, and each movement should be preceded by a light puff of smoke. If the beginner is a little tinid it would be well to have an attendant operate the smoker, while he, with a pair of gloves, proceeds to manipulate the colony. See
Manipulation of Colonies; Smoke and Sirokers; also Stings.

\section{IYYBRIDS OF CARNIOLANS AND CYPRIANS WITH ITALIANS.}

In this country at least, very little has been done to determine with accuracy the value of different crosses which can be made rery easily. A cross between Italians and Caucasians has been spoken of very favorably by J. J. Wilder of Wayeross, Ga., one of the most extensive beekeepers of the country. Mr. Wilder says this cross will rear brood under conditions and at seasons of the year when pure Italians will do practically nothing. In some parts of the South it is very desirable to have a strain that will rear brood in and out of season, because of certain honey flows that may follow shortly after. A pure Italian stock has a tendency to stop brood-rearing almost entirely after the main honey flow. If there be another flow two or three weeks later, without brood-rearing in the meantime, the force will be greatly reduced, and the bees that are left will be of little value:

In the same way $a_{1}$ cross between Carniolans and Italians has been found to be equally profitable.

Other hybrids may be considered by the beekeeper who has in mind to produce a superior strain of bees for some particular purpose. It is well known that crossing, as a rule, increases the size, courage, and stamina of our domestic animals; and it is probably so in bees, yet beekeepers have made but little progress along this line, because it is so difficult to distinguish between the crosses and pure breeds in many cases.

See Drones; Parthenogenesis; DzierzON THEORY, subhead "Recent Evidence in Support of Dzierzon Theory." 
INCREASE-Under the head of NuCLEUS several methods of forming nuclei are explained; but under this head the subject will be dealt with more from the standpoint of the honey-producer who actually desires to increase and at the same time to produce some honey. One can divide up a strong colony into three or four nuclei; but in so doing he would probably destroy all his chances of securing a crop of honey, and at the same time would be almost sure to cause brood to die. It should always be borne in mind that the field bees will go back to the old stand. The nucleus left will necessarily have more than its proper proportion of bees on account of old bees returning, while those moved to the other locations may have too few bees to take care of young brood. The loss of brood may be minimized to a great extent, if not entirely, by making only one division-that is, splitting the old colony into two parts. Most of the sealed brood and two-thirds of the bees are put into a hive on a new stand. The old hive is left with most of the unsealed brood, and onethird of the bees on the old stand. If the division is made in the morning on a warm day, all the old bees will go back to the old stand before night. This will leave the division of bees nearly equal. Each part should be left with a queen or a queencell. When both of the divisions have built, up to full colonies the operation can be repeated if the season is not too far advanced. Other plans are described under Nucleus.

The following is also a good plan that enables one to make a moderate increase as well as to secure a honey crop, provided there is a fall flow. It was practiced and recommended by one of the most extensive beekeepers in the United States, the late E. W. Alexander, who was recognized as an authority on general practical apiculture, for indeed his crops of honey went up into the carloads. He first made the plan public in 1905, after having tested it many years. So many favorable comments were received from beekeepers who had tried it and found it to be a success that it is given here with some slight modifications.

When a colony is nearly full enough to swarm naturally, and it is desired to make two from it, lift it from its stand and put in its place a hive containing frames of comb or foundation the same as a hive for a swarm would be prepared. Remove the center comb from this new hive, and put in its place a frame of brood from the old hive, and be sure to find the queen and put her on this frame of brood in the new hive; also look it over carefully to see that it con. tains no eggs nor larvae in any queon-cells. If it does, destroy them. Put a queen-excluding honey-board on top of this new hive that contains the queen and frame of brood with their empty combs, then set the full queenless colony over the excluder; next put in the empty comb or frame of foundation taken from the new hive and close the new hive except the entrance they have thru the excluder into the hive below. Leave them in this way about five days, then look over the combs carefully, and destroy any larvae in the queen-cells unless they are of a good strain of bees, for they frequently start the rearing of queens above the excluder very soon after their queen was placed below the excluder. If so, they had better be separated at once; but if they have not started any queencells above then leave them together 10 or 11 days, during which time the queen will get a fine lot of brood started in the lower hive, and every egg and particle of larva that was in the old hive on top will have matured, so it will be capped over and saved. Next separate them, putting the old hive on a new stand. It will then be full of voung bees mostly, and capped brood, and in about 24 hours they will accept a ripe cell, a virgin, or laying queen, as they will then realize that they are hopelessly queen. less. I would advise giving them a laying queen, as I never like to keep my full colonies without a laying queen for even a day longer than I can help.

In this way it is possible to secure two strong colonies from one, without losing a 
particle of brood or checking the laying of this queen; and with me it almost wholly prevents swarming. This is the way we have made our increase for several years, and we like it much better than any other method we ever tried. In doing so we keep all our colonies strong during the whole summer, and it is the strong colonies that count in giving us our surplus.

The mere fact of having a large number of colonies does not amount to much unless they are strong in bees and are well cared for at all times. This is a fact that many have sadly overlooked; and when the seasoll comes to a close, giving them a small surplus, they feel disappointed and lay the fault on many things that have had but little to do with their failure.

In making increase in the above way the new swarm on the old stand is in fine shape for a super of sections, as it has a large working force backed up by having its hive nearly full of brood, and but little honey, as the bees have been in the habit of storing their honey in the old hive that was on top, so they will soon go to work in the sections with no notion of swarming. Then the old hive that has been set away can usually spare 15 or 20 lbs. of honey, which can be taken with the extractor, giving its new queen plenty of room to lay, and in a short time will be one of your best colonies, and also have no desire to swarm.

If directions are followed as I have recommended in the above, keeping them-snug and warm, and feeding them a little thin warm syrup nearly every day for the first 30 days after they have commenced to fly, you can have two good strong colonies in the place of one ready to commence work on the clover harvest, which here commences about June 15 .

From an extensive experience along this line I find I can get nearly twice the amount of surplus by dividing as above stated over what I was able to acquire either by letting them go undivided or dividing in a way that caused the loss of a greater part of their brood. This losing of brood we must guard against at all times if we expect to secure a fine surplus. It costs both time and honey to produce it, and it is the principal factor in obtaining those strong colonies that give us tons of honey.

I find that nearly all who have made a failure of the methor have taken colonies that had already made some preparation for swarming by having eggs or larvae in their queen-cells.

During the summer I received a few letters from parties who had made a failure of this method in about the same way. Some had taken colonies that had capped queen. cells in their hives at the time they put the queen in the under hive, and, of course, they swarmed in a day or two. I cannot see that these failures are any proof of fault in the method. When we work with our bees we must always use some discretion in such matters. If a colony is very strong in bees it certainly requires different management from one rather weak.

Several years ago one of my sons bought nine colonies of bees in common box hives, about the first of June. He brought them home and transferred them at once to movable-frame hives, and in about three weeks divided them, making 20 colonies of the 9 he bought, using some queen-cells I had on hand for his surplus colonies. He then at tended to those 20 colonies so they were all strong at the commencement of our buckwheat harvest. I then lent him 20 hives of enipty combs to put on top of his colonies to extract from. He took $2849 \mathrm{lbs}$. of extracted honey from those 9 colonies and their increase, and left them in good condition so every one came out the next spring in fine order.

Another son, the same season, took one colony, divided into three, and received 347 lbs. of extracted honey. They also came thru the following winter in good condition. I speak of these cases simply to show that it is not necessary to keep hundreds of colonies in order to get a little honey. If you will keep only strong colonies and give them the best of care you will soon find both pleasure and profit in beekeeping.

Perhaps no one article that was ever published in Gleanings in Bee Culture called forth more discussion than this. A few did not succeed with it to their entire satisfaction; but the great majority made a success of it. Large numbers of some of the best beekeepers in the country practice the method, believing that there is no other equal to it. It is evident, however, that the article must be read with some poetic license. That is to say, it should be modified to suit peculiar conditions. Mr. Alexander had a remarkable locality. $\mathrm{He}$ had a fair clover flow in June, and this was followed in August by a heavy flow from bickwheat, goldenrod, and aster. The locality was so exceptional that for years he maintained 500 colonies in one location. Usually it is not practicable to have more than 100 in one place.

The basic principle of placing the brood into a upper story for a few days over an excluder before making the division is acknowledged by all to be good. The saving of all the brood and conserving the heat are factors that make this superior to any other method of dividing.

Dr. C. C. Miller, to whom reference is made in various portions of this book, how- 
erer, said that if he were to divide his colonies before the clover flow as recommended at the close of Alexander's sixth paragrapl it would be only at a loss of the honey crop. It can generally be set down as an axiom in beekeeping that it is not practicable, ordinarily, to secure increase and a full honey crop at the same time; and therefore Mr. Alexander's statement that he can secure by this plant "two good strong colonies in the place of one, ready to commence work on the clover harvest," seems impossible of accomplishment if it is taken with the other statement in the next sentence that he secured nearly twice as much of clover as he would have secured without dividing.

The trouble seems to hinge on the point of laving two good colonies in place of one at the opening of the clover harvest by June 15. If the reader will turn to the article, fifth paragraph, he will see that $\mathrm{Mr}$. Alexander recommends that the directions be followed exactly - that bees must be kept snug and warm, and that they must be fed a little thin syrup nearly every day. The two colonies must be given every help possible.

Note that he did not say that he secured by this method "nearly twice the amount of surplus" from clover as might be inferred from the last sentence of the preceding paragraph. To one who knows his locality it is clearly evident that he meant of all honey-buckwheat, goldenrod, and aster as well as clover. He could have meant nothing else.

It will be noticed that Mr. Alexander began his work of increase about April 15 with queens not over ten months old. He does not claim that both colonies will be equal in strength, nor that one colony will gather as much as the other.

Many beekeepers will have to substitute the world "alfalfa" for "clover," or "buckwheat" for "clover."

This method of making increase, if the testimony of some of the best beekeepers in the country is to be believed, gives the largest returns, because all the brood is saved. The expert beekeeper will be able to make his own modifications; but the beginner will do well to follow Mr. Alexander, not forgetting the importance of young queens, daily feeding, and keeping bees in a warm hive, preferably doublewalled, or single-walled hives in packingcases.

INSPECTORS. - Under the head of "Laws Relating to Foul Brood" will be found references to bee inspectors, whose duties are to discover and eradicate bee diseases. Under this head an attempt will be made to give the qualifications of a bee inspector. First of all, he should be an experienced beekeeper; second, he should have a theoretical and practical knowledge of all bee diseases, particularly those relating to brood; third, he should be intelligent, broad-minded, and tactful.

Taking up the first requirement, a bee inspector will be very seriously handicapped if he does not have both a theoretical and a practical knowledge of bees. One of the most important factors in the elimination of disease is the instruction given the beekeeper in the first place on how to keep bees, on the principle that prevention is better than cure. The inspector should explain the normal conditions in a hive so that the owner of the bees will be able to recognize at once those that are irregular and abnormal. A large number of those who keep bees have but little knowledge of the business. In many cases swarnns alighted on the premises and were hived. In other cases the bees were bought at auction because they were cheap; in still others, some of the family may have gotten the bee fever, and, after building up the apiary to four or five colonies, left home. The rest of the family have but little or no interest in the bees, but are glad to get the honey if there is any. These little yards of bees, no matter how acquired, are left to shift for themselves, and the result is they afford favorable places for the attack of bee disease. Their owners are not apt to read bee books, but will receive personally any amount of instruction on liow to take care of them. A good bee inspector, one who thoroly understands his job, can be the indirect means of putting in nice condition all these little yards that would otherwise be neglected. The owners will be getting a revenue; and if bee disease does make a start they will be able to arrest it in time.

The second requirement implies a theo- 


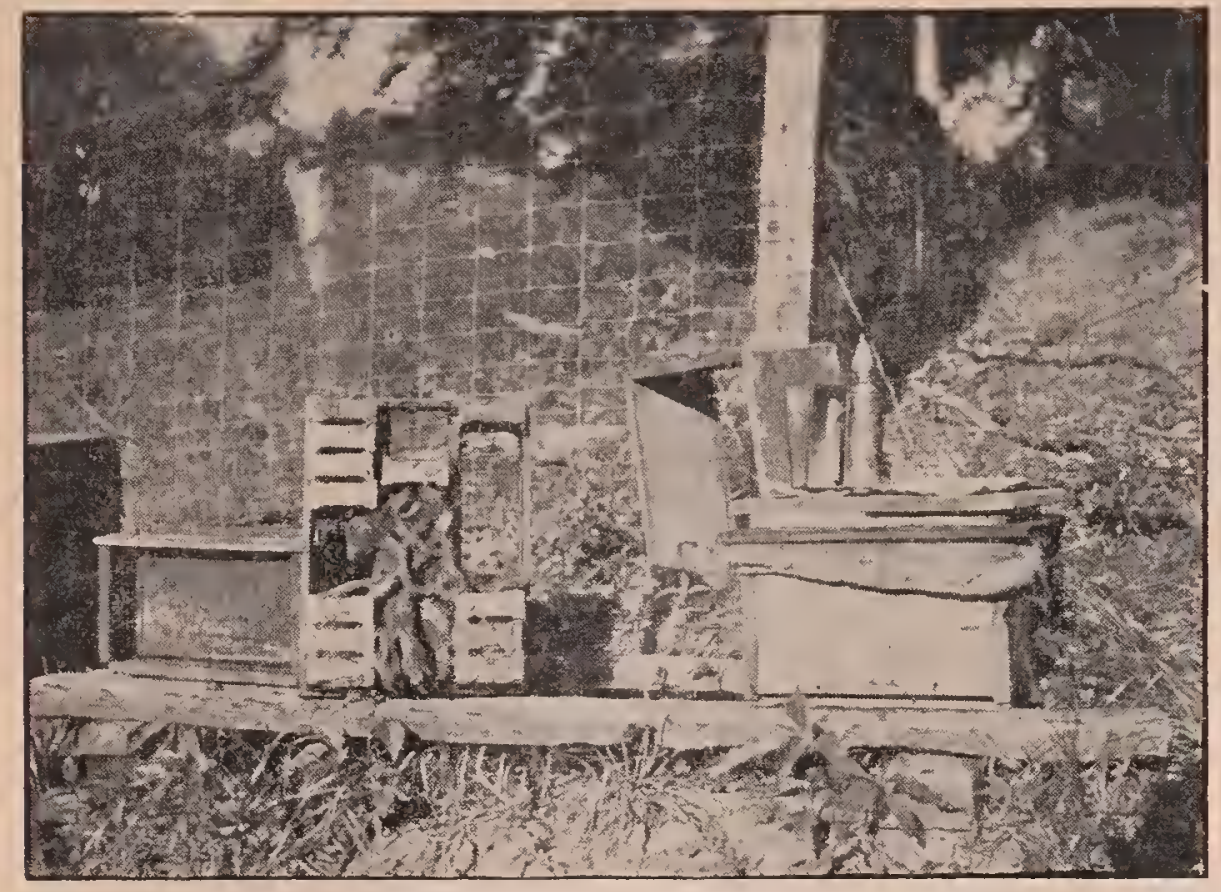

Too frequently inspectors meet conditions like this.

asks him if he has any bees, and how they are doing, he will usually meet with a pleasant response. The inspector can then say that lie is sent by the State to give instructions on how to keep bees, and that if he can be of any help he is free to command, etc. Then the beekeeper will be interested. Mr. Inspector can very gracefully volunteer the statement $\mathrm{th}$ a $\mathrm{t}$ there is considerable bee disease in the country, and if.any is

retical and practical knowledge of bee diseases. If the owner of the bees discovers that a man sent out by the State does not thoroly know disease when he sees it, the inspector is under a handicap. If the beekeeper himself is a practical man, he will probably do just as he pleases, thinking he knows more than the representative of the State. As a general rule the bee inspectors are thoroly informed in regard to bee diseases before they are sent out.

The third requirement is sometimes hard to meet. It is not difficult to get a man who understands bees and bee diseases; but it is not so easy to add to those qualifications the third one - intelligence a $\mathrm{n} d$ tactfulness. An inspector who goes out on tours of inspection meets all kinds of people. He should be able to size up his man at a glance. If he should approach the beekeeper an $\mathrm{d}$ say, "I am the State inspector, and I require to see your bees," he might meet with some opposition: but if, on the other hand, he approaches his man with smiles and a handshake, and present in the hives he will be glad to tell how to eradicate it. If he is tactful, he will not put forth any show of "authority," nor invade the premises without finding some member of the family. If the owner is not present he can ask permission from some one in the house to see the bees, explaining the matter in a tactful way. Usually the good housewife is perfectly willing to tell him where the bees are.

\section{PAY OF INSPECTORS.}

At this day and age a good inspector can hardly be secured for less than $\$ 5.00$ a day and expenses. In some cases it may some-

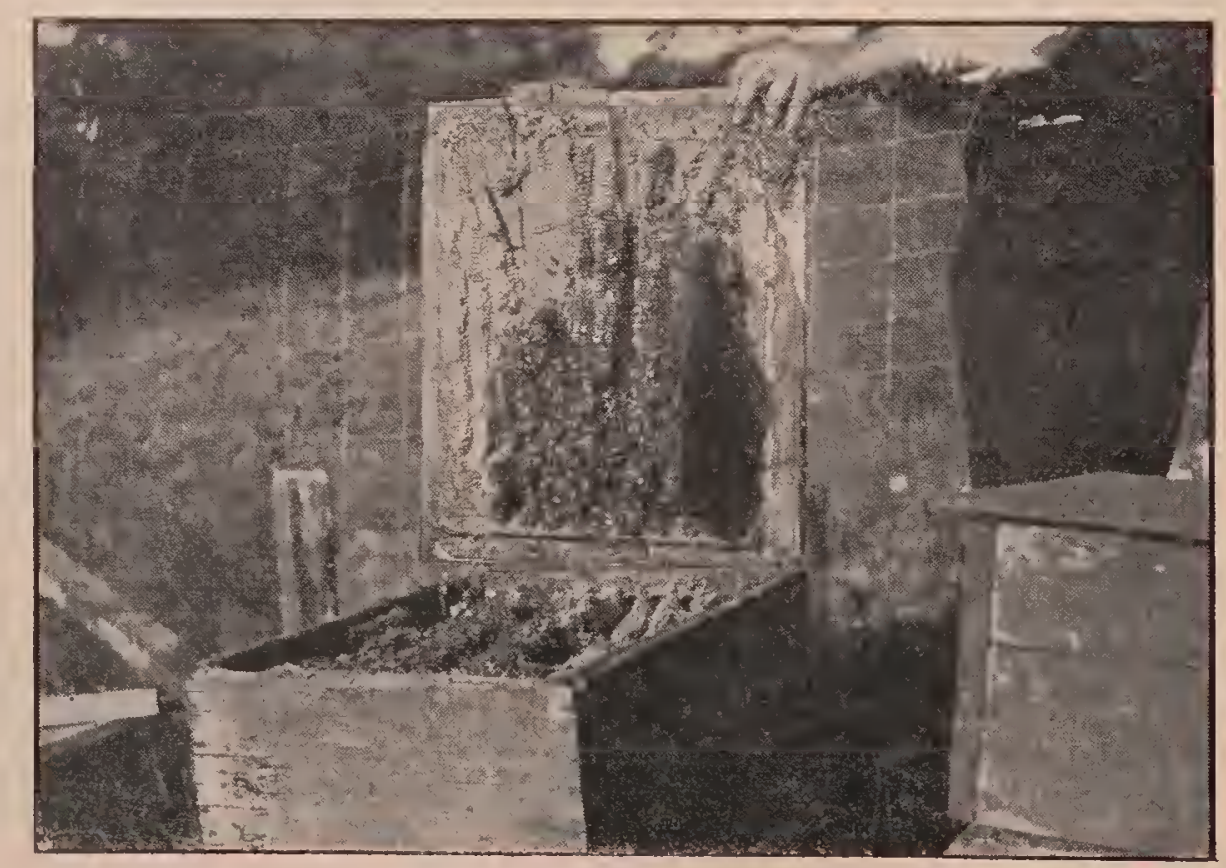

But what can the poor inspector do? 
times be necessary to pay as high as $\$ 8.00$, because a competent beeman can hardly leave his own bees and work for three months for the State at $\$ 5.00$ a day and then find lis orvm bed and board for the remaining nime montlis of the year. But a good man can usually be secured for $\$ 5.00$ a day provided the State can give employment the yea: round. If he is a good beekeeper and a good talker he can be used to give lectures and demonstrations at farmer's' institutes during' winter', and he can be used to assist in rarious ways in the general state work ontside of bee culture prorided he is a man of some edncation and of ordinary ability.

Students from apicultural schools that are scattered orer rarious parts of the country can usually be secured for a very moderate sum. These men, after having taken on an apicultural and agricultural course, have a theoretical and practical knowledge of general farm problems, such as soils, fertilizers, fruit-growing, and the like. When it is not possible to use an inspector in the line of beework, his talent can be turned to very profitable account along other agricultural lines. It is desirable to have a bee inspector who not only understands bee culture but agriculture in general.

The nursery inspectors who are sent out over the country are rendering excellent aid by telling farmers how to handle their fruit trees in order to keep down blight, San Jose scale, and, in general, how to secure a large amount of fruit. These men are rendering their respective States most raluable service, because there is nothing like a practical demonstration in the orchard of how to treat the trees and how to trim them so as to secure the maximum results. This kind of actual field demonstration work is invaluable, not only in orchard work but in actual beekeeping. If possible, a bee inspector should be one who understands both orchard and bee work; as they naturally go hand in hand.

Under head of laws relating to foul brood, it will be seen that the better plan is for the inspector to keep in the background all show of authority and law, and put emphasis on general extension work. For other particulars see LAwS Relating to Foul Brood.
INDIAN WHEAT (Plantago ignota).This species is abundant orer vast areas of sandy and grarelly mesas in Arizona. The silvery hairy leaves have a grayish appearance, so that it is difficult to determine at a glance whether the plants are alive or dead. The flowers are entirely nectarless and are visited by bees for pollen only. On the slopes another plantain ( $P$. aristata) is also very common.

The plaintains, of which there are about 200 species in the world, are most frequently pollinated by the wind. None of the species yield nectar, altho several of them have sweet-scented flowers. Honeybees often visit the bloom for the purpose of gathering pollen. Horering in the air the bee moistens the pollen with nectar gathered elservhere, and then brushes it off the anther with the tarsal brushes of the forefeet. At the same instant a little cloud of pollen rises from the shaken anther. The pollen is then packed in the pollen baskets in the usual way. In windy weather it behaves differently, according to Mueller, brushing its legs over the anthers, and thus securing a part of the loosely held pollen. A large amount of pollen is devoured by flies, which are very frequent visitors.

The stemless flowers of the plaintains are usually in long spikes and green-colored; but in some cases there is more or less red or purple coloring. Only one whorl of flowers opens at a time. Several species of plaintain are very abundant in southern Arizona, and as they are often visited by honeybees many beekeepers suppose that they contain a little nectar; but, as has been shown, they supply only pollen. $A s$ sources of pollen they are no doubt of much importance in this arid country. Indian wheat seldom grows on the Arizona deserts more than 5 to 6 inclies tall. It is one of the principal forms of regetation, and affords a valuable pasturage for cattle.

INTRODUCING.- I'nder normal conditions only one queen will be tolerated in a colony at a time. Should there by acrident be two, there is likely to be a royal battle, when they meet, until one of them is killed. Queens are, as a rule,jealous rivals; but there are exceptions. Under certain con- 
ditions, as when an old queen is about to be superseded, the young daughter may be tolerated in the hive along with her mother -both laying side by side; but in the course of a few days or weeks the mother will be missing. Whether she dies of old age or the daughter kills her is not known. There are other conditions where two and sometimes a dozen laying queens will be found in the hive, but under circumstances which seem to be abnormal.

Again, it may be stated that a normal colony of bees will not readily accept a strange queen, even tho they have no mother of their own, much less will they accept an interloper when there is already a queen in the hive. It may, therefore, be set down as a rule that has exceptions, ${ }^{*}$ that it is not safe to liberate any queen, young or old, in a colony that already has one. Likewise, bees that are queenless will not, under ordinary conditions, accept another, no matter how much they may need one, until she has been "introduced." It follows that, in the process of requeening, the apiarist is compelled to put a new queen in a wire cloth cage and confine her there (where the other bees cannot attack her) until she has acquired the same colony odor or individual scent as the bees themselves. This usually takes two or three days, at the end of which time the queen may be released when they will treat her as their own royal mother. It is not known how bees recognize each other, or how they can tell a strange queen from their own, except by the scent factor.

It is a fact well recognized that a dog ran pick out his master from hundreds of others thru the agency of scent. $\mathrm{He}$ can also track his master, if he loses sight of lim, by catching the scent where he has walked, in spite of the fact that hundreds of other people may have gone over the same ground. This scent that is so acute in a dog is undoubtedly highly developed in the bee, otherwise it would be difficult to account for some of the phenomena in the domestic economy of the hive. See ODOR OF LAYing QueEns under QueENS.

*If a virqin nuenn. on returning from a mating. - trip enters by mistake a hive where there is an old laying queen she nuv, and very often does, supplant the old queen. The virgin is young and vigorous, and more than a match for the old queen full of eggs. Even tho the colony odor be lacking, the bees in this case accept the supplanter.
From what has been stated it is natural to conclude that, by the sense of smell, bees distinguish their own queen from a new or strange one.

Again, it is learned that, if two queens have exactly the same colony odor after being caged for two or three days in a queenless hive, either one may be liberated, and the bees will accept one just as readily as the other. If both be liberated at the same time, one in one corner of the hive and the other in the opposite corner, both will be tolerated by the bees; but once the queens come together themselves there is danger of a royal battle* resulting in the death of one. From this fact it is inferred that the bees, provided a queen or queens have the requisite colony odor, will accept at any time one or more such queens under many conditions; that, further, when two queens have the same colony odor, if they can be kept apart by means of perforated zine both will continue to lay eggs in the same hive without interference. This condition will be allowed so long as the colony prospers, or until a dearth of honey comes, when the bees shows a disposition to rob. They may then destroy one of the queens.

Bees that have been thrown into a box or pan, and then shaken or bumped again and again until they are demoralized or frightened, are much more tractable than those not so disturbed. Such bees if made queenless just prior to the shaking, and confined without combs or brood in a cool place for a few hours, will usually accept a queen at once. The factor of colony odor then apparently does not operate, for the bees are put out of their normal condition.

Very often the queens of two colonies may be made to exchange places. Two hives can be opened, and before either colony can discover that it is queenless, the queens may often be exchanged; but when this excliange is made, the precaution must be taken to open the hives very quietly, using but little smoke. The idea seems to be to disturb the colony as little as possible, so that their normal condition may continue. Not suspecting any change in queens, the

* We say "danger" of a battle. Queens will not always fight when so put together. The relative ages of the queens makes a great difference. If one queen be an old one there probably will be no fight, and even if there is, the young queen will be more than a match for the old one. 
bees are not looking for any, and allow the new mother to go on where the previous queen left off. On the other hand, if either colony is queenless long enough so that it sets up a loud buzzing or a ery of distress, it will be pretty sure to ball any queen that may be given it.

Young bees just emerged will at any time accept any queen. Therefore, it comes about that, when one desires to introduce a valuable breeder on which he desires to take no chances whatsoever, he causes her to be released on a frame of very young or emerging bees; but consideration will be given to this later.

Virgin queens, if just emerged, will usually be accepted by a colony, if not too long queenless, without the process of introducing or even of caging; but when one of these queens comes to be four or five days old she is very much more difficult to introduce than a normal laying queen.

When a little honey is coming in, it is much easier to introduce and unite bees than during a dearth.

A queen in the height of her egg-laying: will be accepted far more readily than one that lias been deprived of egg-laying, as in the case of one that has been four or five days in the mails.

Some colonies are more nervous than others. To open a hive of such on an unfavorable day might arouse the inmates to a stinging fury. Indeed, such colonies will often ball and sting their own queen when the hive is opened if the day is unfavorable.

It is easier to introduce toward 'night, or' after dark, than during the day. The reason of this is that after dark the excitement of the day has subsided. There is no chance for robbing and no reason for vigil. In short, bees are not expecting trouble and are not inclined to make any.

A fasting queen, or, rather, a queen that is hungry, will usually ask for food, and hence will generally be treated more considerately than one that shows fear or fight.

A colony queenless long enough to have ripe queen-cells, or. long enough to have laying workers, will not accept a queen as readily as one that has been without a mother for only a few hours. Reference to this will be made later.

Having stated, therefore, the basic prin- ciples governing the relation of the queen to the bees the reader can now more intelligently proceed to the metlıods of introduction, most of which are based on the theory that the queen to be introduced must first have acquired the colony odor of her new subjects.

The eages that are sent thru the mails are supplied with soft bee candy (see CANDY), so tliat, in case the bees do not feed the queen, she will not starve. In some cages the bees release the queen by eating away the candy and letting her out. Other cages are so constructed that bees outside the cage must tunnel inder the cage by tearing away the comb, in order to release her. In still other cases the apiarist himself liberates her after she has been confined the requisite length of time or until sucl time as she has aequired the colony odor.

Most of the cages are sent out by queenbreeders with directions how to perform this operation; and it is usually safer for the beginner to follow these directions implicitly.

MAILING AND INTRODUCING CAGE.

The mailing and introducing cage that has been used over the country is called the Benton, and is shown in the accompanying illustration. It consists of an oblong block

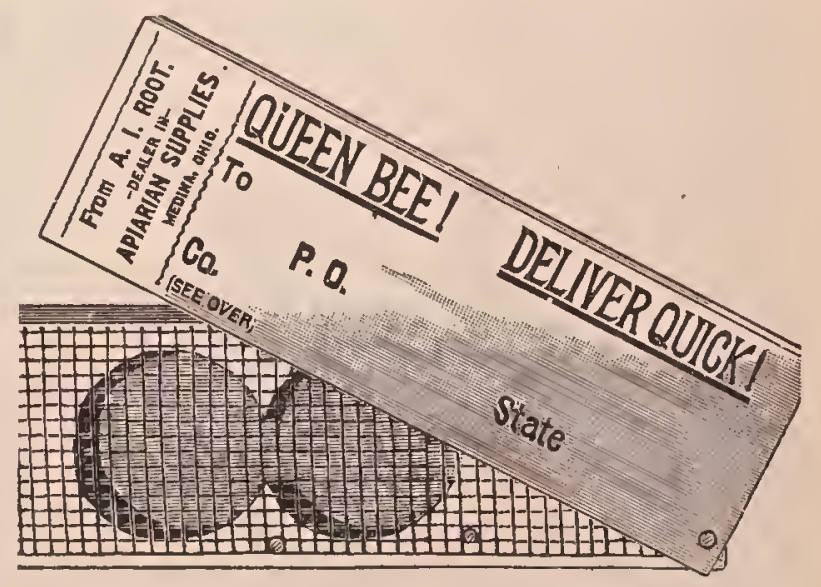

Benton mailing-cage. Postage on this cage is one cent. A larger size for longer distances, as shown next page, requires two cents.

of wood witl three holes bored nearly thiru, one of the end holes being filled with soft candy (see CANDY), and the other two left for occupancy by the bees and queen. On the back of the cover are printed full directions for introducing, and at each end of the cage is a small hole 
bored thru lengthwise the grain of the wood. One hole (next to the bees) is covered with a piece of perforated metal, secured in place with two small wire nails driven thru the perforations. The other hole (that is at the candy end) is covered over with a piece of pasteboard slightly narrower than the loole. In this way the bees have an opportunity to taste the candy at the edges, and finally pull away the pasteboard entirely.

Oftentimes, after the eage lias been thru the mails, and been on the journey for several days, the bees in the cage will have consumed two-thirds or three-fourths of the candy. If those in the hive to which the queen is to be introduced gain access to the candy direct they would eat out what little there is of it in five or six hours, liberate the queen; and probably kill her. In order to accomplish introduction safely the cage should be on the frames (where the bees can get acquainted with the queen) for at least 24 hours, and longer wherever practicable. As it takes generally from 12 to 24 hour's for the bees to gnaw away the pasteboard before they can get at the candy, and from 6 to 24 hours to eat out the candy, at least 18 lours is assured before the bees can release the queen; and generally the time is longer-all the way from 24 to 48 hours. The pasteboard has another advantage, in that it makes the introduction entirely automatic. The one who receives the queen pr'es off the cover protecting the wire clotli, and then by the directions which he reads on the reverse side of this cover he learns that all he lias to do is to lay the cage wire eloth down over the space between two brood-frames of the queenless colony, and the bees do the rest. It is not even necessary for him to open the hive to release the queen: indeed, he should let the colony entirely alone for three or four days, as opening the hive disturbs and annoys the bees to such an extent that often they will ball the queen, seeming to lay to her door what must be to them a great disturbance in liaving their home torn to pieces.

There are some who object to the use of the pasteboard on the ground that the bees may gnaw it away too soon, and, so release the queen, before the bees will treat her kindly. These objectors tack a piece of tin over the candy. At the end of two or three days the tin is removed or revolved to one side, exposing the candy. As soon as the bees eat thru, the queen is released. The use of the piece of tin niakes sure that the queen will be confined long enouglı

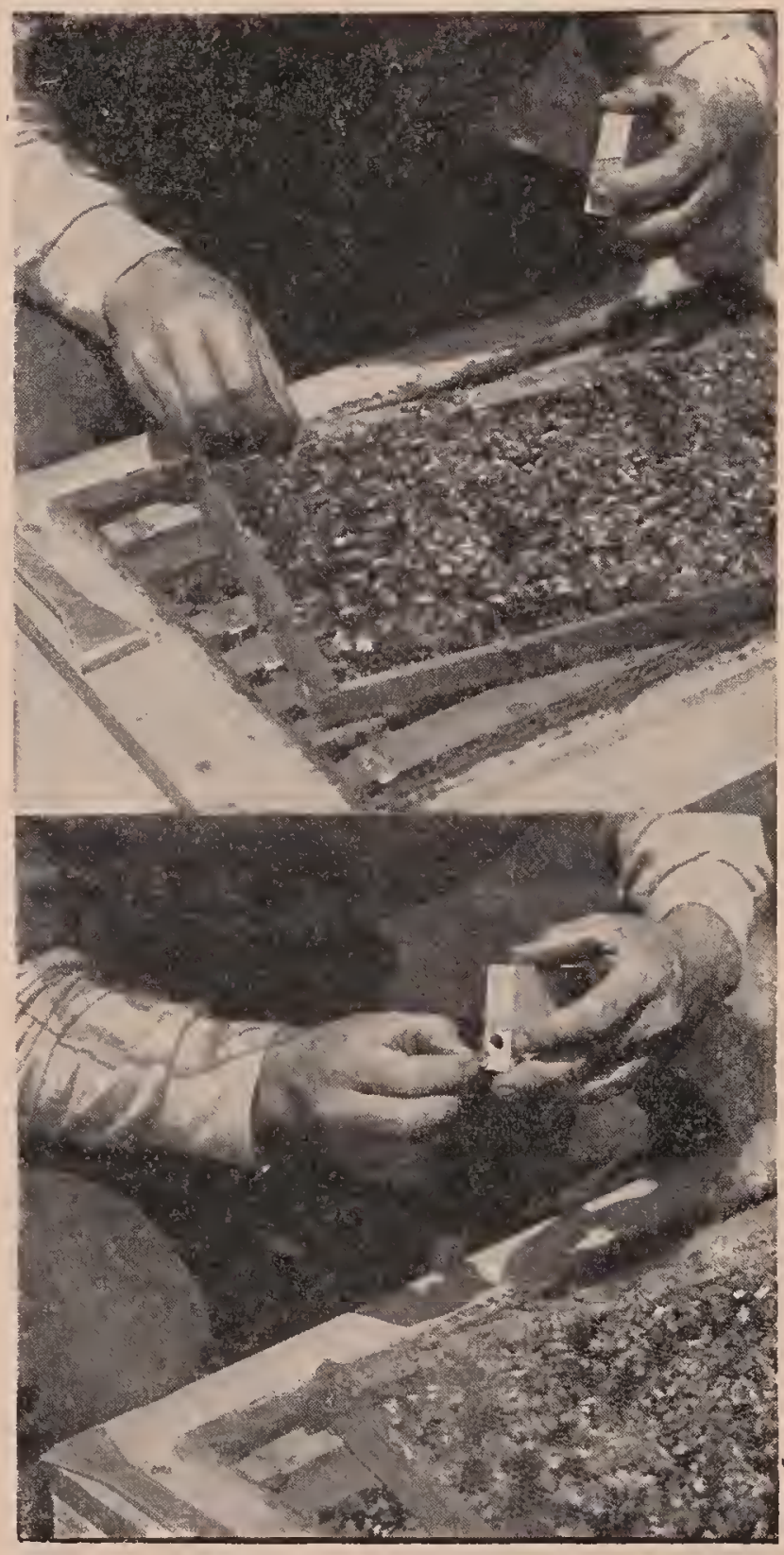

How bees and queens are put up in a mailing-cage.

for the bees to get well acquainted with her before they get to her.

The manner of filling a cage with bees and queen for mailing is to pick it up with the left hand in such a way that the thumb covers the hole over which the perforated metal has been nailed, but which, before the time of filling, should be revolved around on one side or taken off entirely. The queen is first to be picked up by the wings, and her head is puslied into the hole as far as possible. After she runs in, the thumb 
is placed over the hole. Worker bees are next picked up in a similar manner, and poked in, selecting bees that are not too young or too old, preferably those that are filling with honey from open cells. For the small cage there should be about a dozen attendants. If the cage is larger, two dozen may be used; and if it is extra large, four or five dozen. When cages are mailed during cold weather there should be more bees put in, to help keep up the animal heat.

There are several sizes of these Benton cages - the larger ones being used for longer distances. The one on p. 533 is good for 1000 niles thru the mails, altho very often used for twice that distance. This may be called a combination mailing and introducing cage. Ordinarily, if one has much introducing to do it is better to use something especially adapted to the latter purpose alone. The Miller introducingcage, mentioned next, has been used very largely.

\section{MILLER INTRODUCING CAGE.}

It is very convenient to have in the apiary small special cages for introducing and holding queens that come out with swarms until they can be introduced or disposed of. The one illustrated here is an excellent one. It is especially handy for introducing young virgins. The cage is so flat it can slide in at the entrance without even removing the cover of the hive, and the bees will release the queen by the

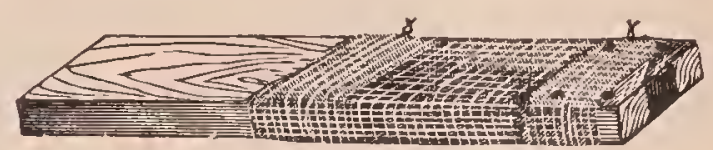

C. C. Miller's introducing-cage.

candy method. Yet for introducing fertile or valuable queens it should be inserted between two combs which are then drawn together until they hold the cage. The queen thus acquires the scent of the combs, brood, and the cluster, and hence when released will be more likely to be accepted.

This cage, like the Benton, will give very much better results if a piece of pasteboard is nailed over the end. This the bees will gnaw away, gaining access to the candy, which they eat out. As already mentioned under the Benton eage, a double thickness of pasteboard or a piece of tin will keep the queen confined longer, and the author would advise "playing safe" even in introducing.

Another feature of this cage, of great importance to beginners, is as a queencatcher. It can be put down over the queen after the wooden slide is removed,

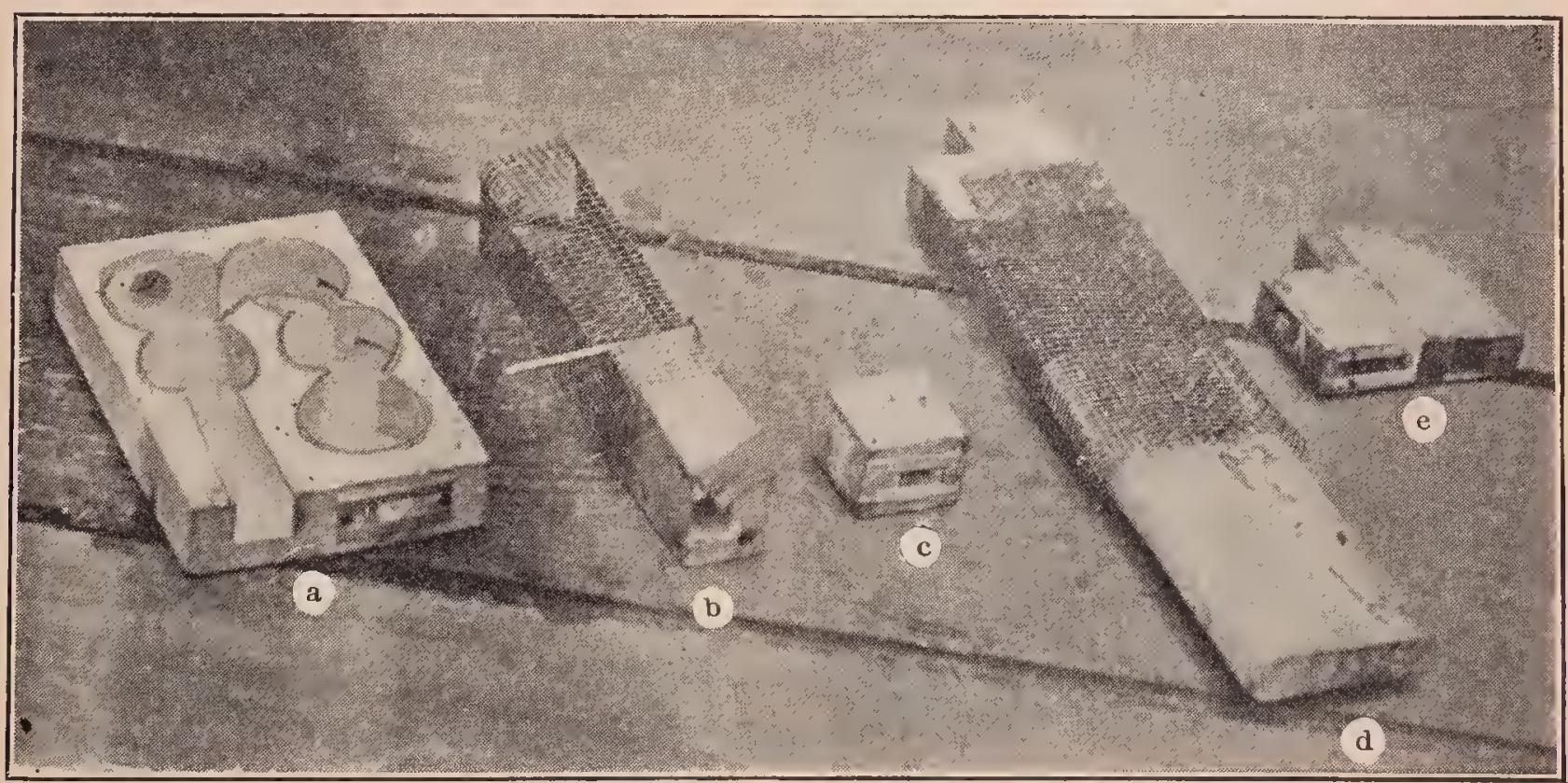

Introducing-cages with the Thomas Chantry principle applied. Letter a shows the cage with a long channel on the left side to receive candy. The other side has a piece of perforated queen-excluder nailed over the hole that communicates with the interior cage. The space back of the perforated zinc is filled with candy, as also the entire space on the left side of the cage. In operation the kees will go thru the perforated zinc and eat out the candy in about 24 hours; but it will take them two or three days to eat out the candy on the left side before the queen is released. In the mean thime the bees in the hive have been going in and out thru the perforated zinc, giving the queen the colony odor. b, $c, d$, e are different applications of the same principle. 
and when she erawls upward the plug may be replaced.

THE CHANTRY PRINCIPLE OF INTRODUCING.

Introducing cages have been constructed to permit the bees to have access to the queen, thru a single opening of perforated zinc, a day or two after inserting tle introducing cage. This permits workers to pass

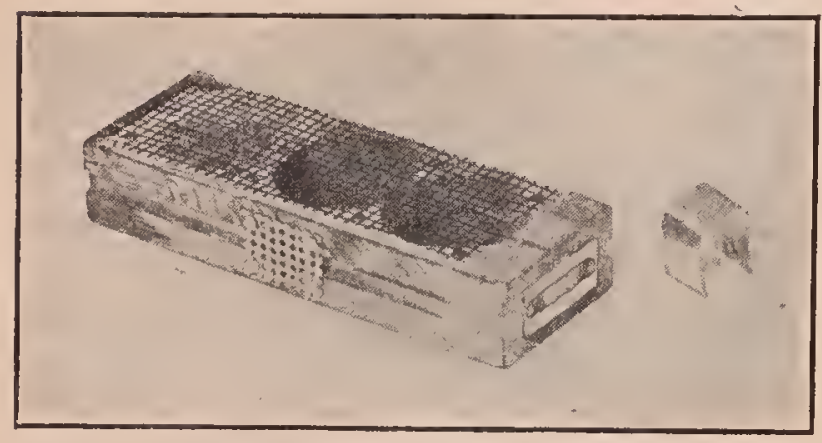

Benton Introducing-cage with the Thomas Chantry feature added. The U-shaped piece of tin slides over the perforation as shown in the next cut. The queen is caged in the hive in the regular way. At the end of 24 to 48 hours the U-shaped piece of tin is removed, when the bees enter thru the perforated zinc opening. On a day or two later the apiarist releases the queen.

in and out of the cage for about two days before she is released, carrying with them the odor of the laying queen. Since the bees do not attack a queen while she is in the cage, the perforated metal prevents any danger of the queen's being balled or killed. The bees on entering the cage begin to feed the queen, and since these bees

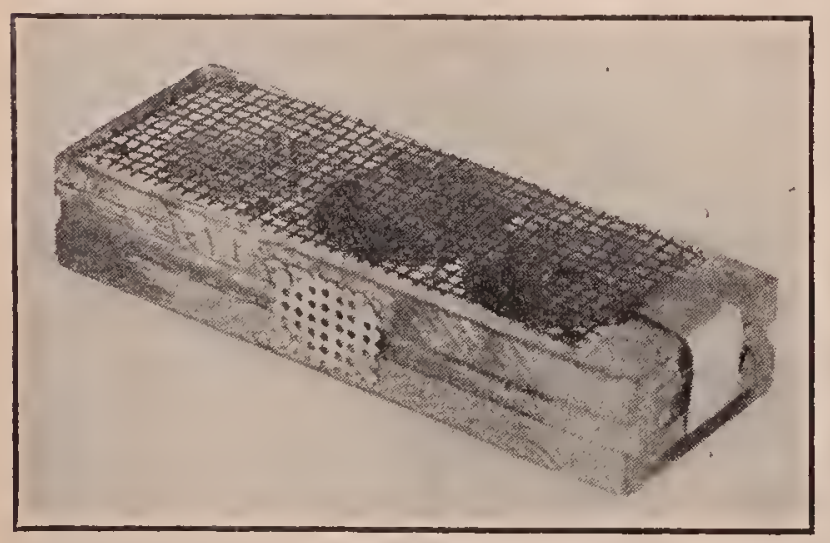

Benton cage with the opening over the zinc temporarily closed to prevent the bees from getting at the queen.

afterward go outside and mingle with the bees of the colony, the queen is really introduced before she is released from the cage. By having two plugs of candy in the cage, a short one covered with the perforated metal that the bees will eat out in about two days and a long one which requires about four days for the bees to eat thru, such a cage automatically gives the bees access to the queen thru the perforated metal after two days, then releases hel after four days. Some object to this arrangement and prefer to use a stopper of some sort over the perforation. This is removed at the end of the second day when the bees enter the perforation.

\section{PUSH-INTO-COMB-CAGE PLAN OF INTRODUCING.}

During' 1911 and '12, and again in 1919, there was considerable discussion in the bee journals concerning the method of introducing known as the push-into-combcage plan-that is to say, a plan which permits a queen being caged over a few cells of honey and brood. This is accom-

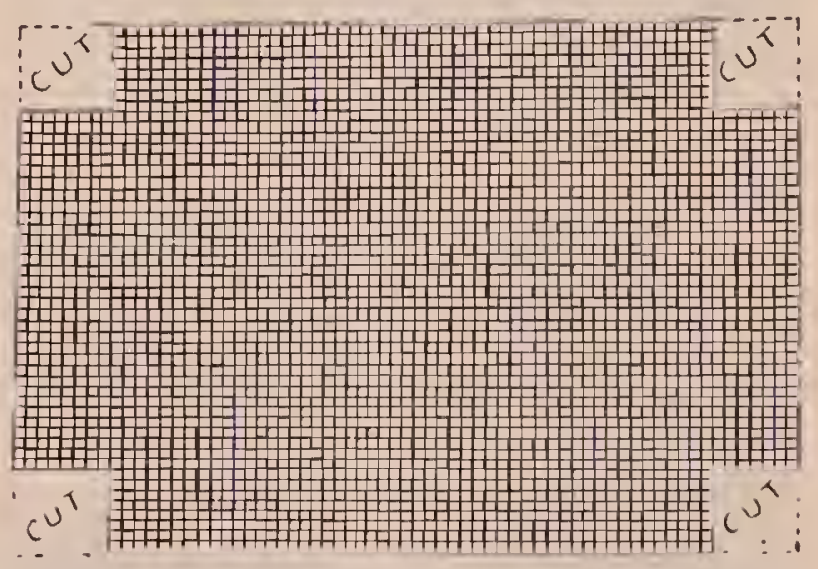

Wire-cloth corners cut ont before folding to make the introduction cage that telescopes over the wooden part.

plished by taking a square of wire eloth of suitable size and cutting a small square out of each of the four corners. The projectings ends are then folded down so as to make a wire-cloth box without bottom. This is pushed into a brood-comb with the

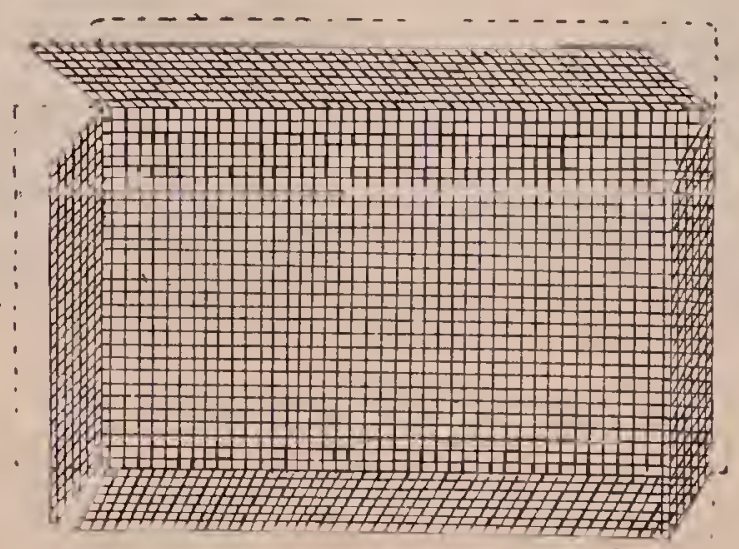

The manner of folding the cage. 
queen under it. If it is not pushed in too deep, the bees will usually release her in 36 to 48 hours by gnawing under or tunneling under the wire cloth. Reports of this method of introducing have been uniformly favorable, and one reason for this is due to the fact that the queen has immediate access to cells of honey; and if she should lay a few eggs in the comb before she is released she will have the odor of a laying queen, and this odor is one of the elements that go to make up successful introduction.

Some years ago a prominent queenbreeder offered to replace all queens that he sent thru the mails, provided this plan of introduction were followed. He reportthat it was so successful that he searcely ever had to replace a queen; and he be-

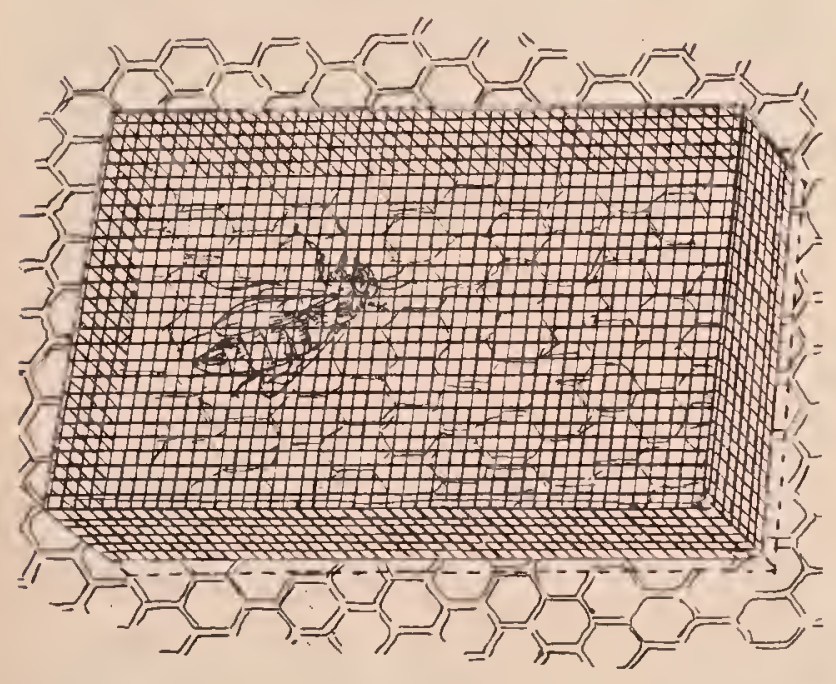

Cage pushed into the comb, showing the manner of introducing the confined queen.

lieved that these replacements were due mainly to the fact that the recipient failed to carry out his instructions.

But one difficulty with a plan like this is that not every one will have on hand the proper material nor have the necessary skill for making up a cage of this sort. Another and more serious difficulty is the problem of getting the queen transferred from the mailing-cage to the introducingcage pushed in the comb, without injuring her or allowing her to get away during the process. Another difficulty is that some push the cage into the comb so far that the bees fail to release her, altho in such cases no harm results, because the apiarist can remove the cage and release her.
THE SMITH INTRODUCING CAGE.

This cage is a great improvement over the one just described, without its objections. As devised by Jay Smith of Vincennes, Ind., it consists of a framework of wood about $3 \times 4$ inches, covered on one side with wire cloth, the other side or edge having a series of teeth. The two side

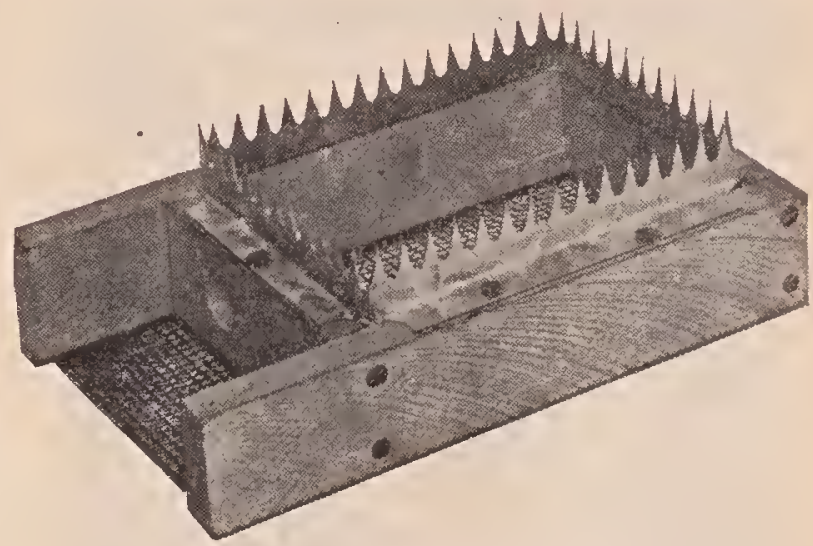

The Jay Smith Introducing Cage.

pieces project a short distance beyond the cross-piece in the end. In operation the teeth are pushed clear down into a piece of old comb containing some empty cells, cells of honey, and perhaps a little sealed brood, the two prongs or projections pointing upward. (If a new comb is used the cage will have to be held with a rubber band.) The mailing-cage containing the queen to be introduced is slipped down between the prongs in such a way that the hole of the

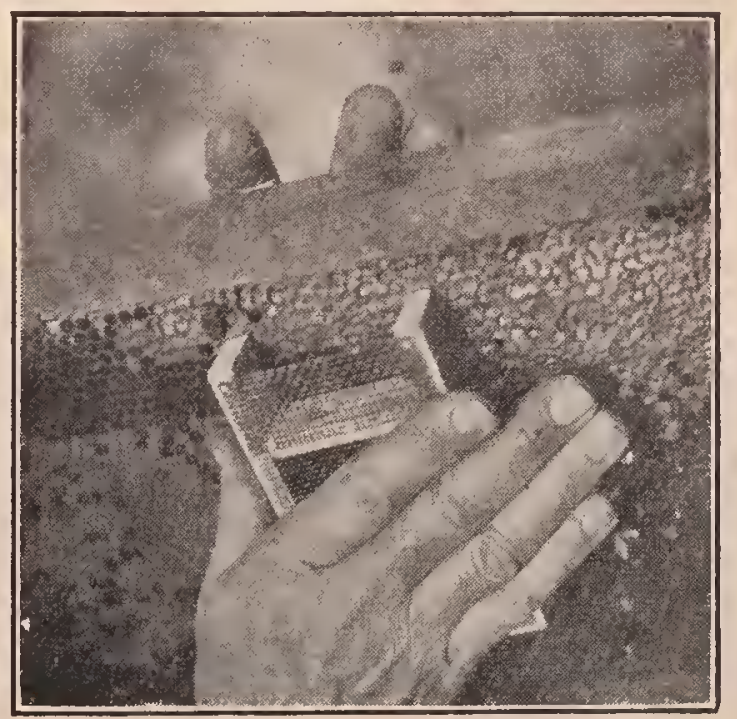

Method of crowding the Smith cage on the comb.

cage matclies the liole of the other, as shown in the illustration. This overeomes the difficulty of getting the queen caged on the comb. 
The queen can then pass into the lower cage, where slie will find cells of honey and empty cells where she can lay. In the mean time some of the brood may emerge, giving her more cells. As soon as she lays she will have the egg-laying odor, which is always an important factor in introducing.

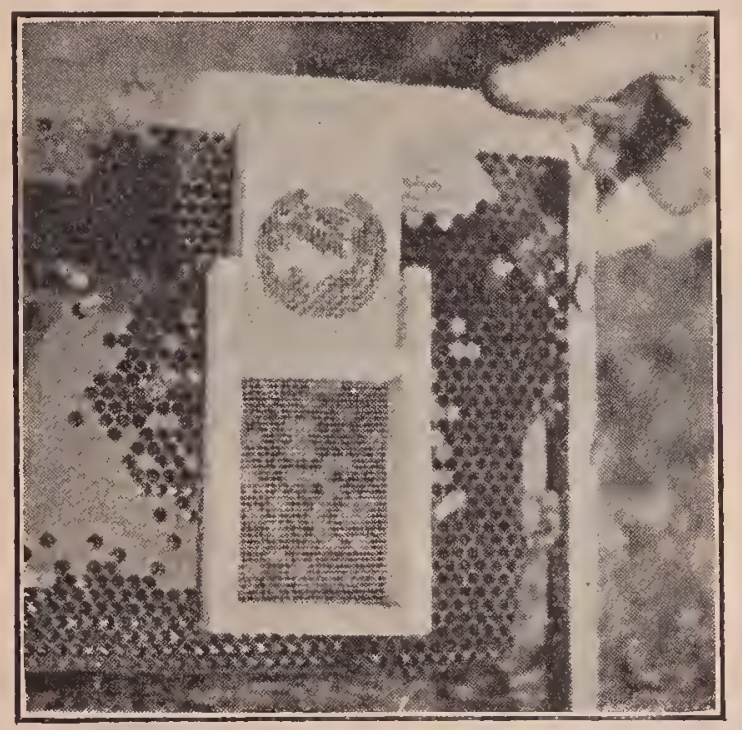

Smith eage in place with mailing cage in the top.

A laying queen, or, rather, one that has just been laying, is much more readily accepted than one just from the mail-bag, and that has not been laying for perhaps a week.

After the queen has been confined three or four days, but not until she has laid a few eggs, she is released. If she is treated kindly the live is closed up with as iittle disturbance as possible. If the bees seem a little hostile she is caught and caged again, and held confined until such time as the bees will treat her as their mother.

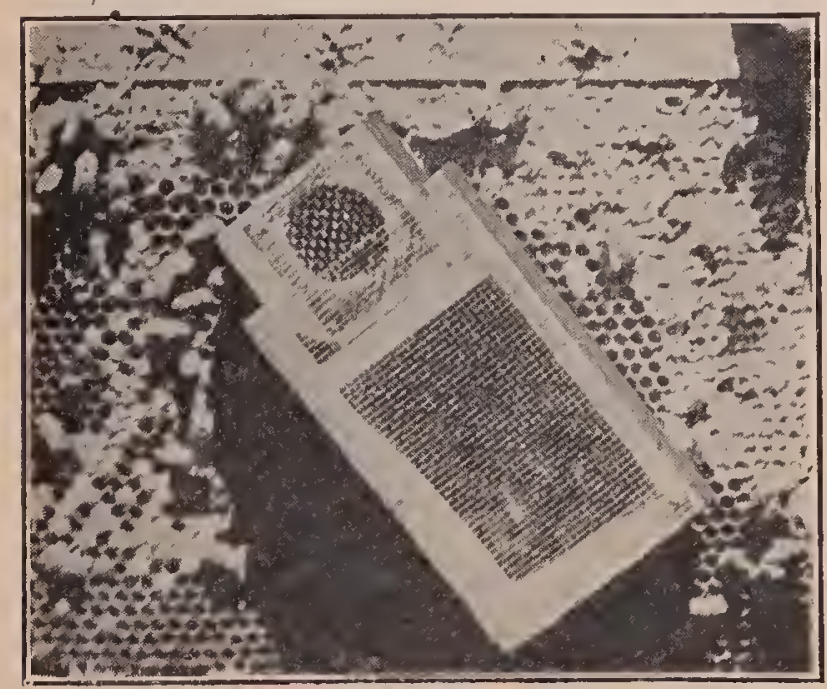

Smith cage with reception cage in the top.
The foregoing was the plan that Mr. Smith originally used; but he later found that it was advisable to apply the Chantry feature as follows: He first runs the queen into a reception cage that is inserted between the two prongs in place of the mailing-cage. From this, after a few hours, she is allowed to run into the Smith eage and on to the comb. At the end of two days the reception cage is removed and a piece of perforated zine is placed over the hole or exit. The bees of the hive go thru the metal, and at no time will there be in the cage more than a few bees. They will feed her, and at the same time give her the colony odor. Thus the queen is gradually introduced to her subjects. After she has been laying the perforated zine is slid over, when she has the full liberty of the hive. The scheme outlined is the Thomas Chantry method already described; and those who have tried it, particularly Mr. Smith, say it is good. The latter now feels that the combination of the Chantry and his principle affords a sure inethod of introduction.

A simpler application of the Chantry principle is to use the mailing cage as first described-run the queen with smoke into the lower or Smith cage; close the hole thru which she went, and keep her confined two or three days. At the end of this time slide a piece of perforated zine over the opening to hold her and allow the bees of the hive to go in where she is. They will not ball her, but feed her; and after two days the metal can be remored, allowing the queen to have the liberty of the hive, when she will be accepted.

Objection has been made to the Smith cage that it involves a lot of work, and also disfigures the comb; "but," says Mr. Smith, "if it provides a safe method of introducing a valuable queen, or any queen, in fact, it is worth it."

THE MILLER SHOKE OR DISTRESS METHOD OF IN'TRODUCING.

In 1913 Arthur C. Miller of Providence, R. I. (who wrote the article on BEE BEHavior and Nucleus in this work), introduced to the beekeeping world a new method of introducing queens. While one feature of it was old, the general procedure was original with Mr. Miller. Many years 
ago Henry Alley introduced queens by smudging the colony and queen with tobacco smoke. The plan was successful in many instances, but it was too often a failure and for that reason it seems to have been dropped. A. C. Miller's method, while similar only in the use of smoke, is enough different to make it practically new, and fairly reliable when directions are followed. There are conditions under which it is superior to any other plan of introducing queens, unless it be the Smith-Chantry method just described.

The plan has been used for requeening box hives with a considerable degree of success, and that, too, without finding or removing the old queen. But the success of this method of requeening without dequeening will depend on the superiority of the alien over the old queen; for by the smoke metliod both queens will be equally acceptable to the colony; and so far as the colony is concerned it appears to be a choice between the two, resulting in favor of the better queen.

HOW TO INTRODUCE BY THE MILLER SMOKE METHOD.

The colony to receive a queen has its entrance reduced to about one square inch. Strips of wood, entrance cleats, or even grass or weeds, may be used for the purpose. The smoker bellows is worked until a white smoke is blown out - not a hot transparent smoke, as that would be destructive. Three or four long puffs are then blown in at the entrance. The amount may vary according to the size of the colony, the condition of the fuel, and the fuel itself. At all events, enough smoke is blown in at the entrance until the colony sets up a roar, which will take place in 10 or 20 seconds. If the roar does not take place it shows not enough smoke has been used. The queen to be introduced is now run in, either from the fingers or from a queen-cage, and followed by a gentle puff of smoke, when the entrance is entirely closed, and left so for 10 or 15 minutes. At the expiration of that time it is reopened and the bees allowed to ventilate and quiet down, but the opening should not be wider than the original contraction of one inch, as the idea is to let the colony quiet down slowly from its distress. A full entrance is not given for an hour or more, and better not till the next day. Where grass or leaves are used they may be left to wilt and be pushed out by the bees. They are handy at outyards.

In order to niake the plan work successfully there is one very important requirement. The colony should not be larger than one story and the frames and bees should occupy the whole of the story. It has been found impracticable to use this plan of introduction when only a third or a half of the hive is occupied with bees and combs, for the simple reason that the bees and queen may get out of the smoke and thus be remote from the smoke that induces the necessary condition-distress.

The theory of this method is based on the principle that bees in distress know no enemy or alien. Each is looking to the other for help or food. The colony spirit is entirely broken up, and every bee that comes under the influence of the uproar is seized with the same emotion, to be relieved of her distress. It is important, also, that the queen be under the same spell or influence; hence the directions to follow her up, after she goes into the hive, with a puff of smoke.

This method can be used for introducing virgin queens five or six days old. Such queens are usually rejected by a colony, or even by a nucleus. These six-day-old queens after introduction by this plan have been known to take a flight the very next day, and to be laying shortly after.

The question might be raised here, why the smoke or distress method is not used in the directions for introducing sent out by queen-breeders in the mailing-cages containing queens. The reason of it is, there are some very nice points in introducing by the distress method, and the average beginner will succeed better by the cage plan. As a general thing, queen-breeders use the cage plan for introducing virgins, which are usually quite young, because it takes less time to go thru the procedure of introduction. An introducing cage is inserted between the frames and left there. That is all there is to it. The smoke method of introducing requires considerable time and a great exactness of procedure, or the plan will fail.

The question has been raised whether so 
much smoke inducing distress is not hard on the bees and the queen. The author believes that when queen is valuable one of the other methods should be used.

\section{A SURE WAY OF INTRODUCING.}

There is one perfectly sure way of introducing a very valuable queen, such as an imported one, if the conditions are observed carefully. Two or three frames of emerging brood are removed from several hives; every bee is shaken off, and the brood put into an empty hive contracted to a small space; and unless the weather is very warm, the whole is placed in a warm room, or over the hive of a strong colony with screen wire cloth between the two. The queen and her attendants are let loose in this hive, and the young bees, as they emerge, will soon make a colony. As several who have tried this plan have been so careless as to leave the entrance open and let the queen get out, the beginner is warned especially to have the hive closed, so that no bee can by any possibility get out.* If the frames selected contain no unsealed brood, there will be very little loss; but otherwise the larvæ, having no bees to feed them, will mostly starve. As soon as a few hundred bees emerge, the queen will be found with them, and they will soon make a cluster. When the conrbs have been taken from strong colonies, where the queen is laying hundreds of eggs in a day, the colony will become strong in a week or two. Three frames will do very well at first, and one or two more may be added in the course of a week or two. To live bee is to be given to the queen, and the hive must be kept in a warm place - the nearer 90 degrees $\mathrm{F}$. the better.

\section{THE CALIFORNIA PLAN OF INTRODUCING.}

This makes use of the principle just described of putting the queen on emerging brood, only in this case the frame, brood, queen, and all are put in a large wire cage which is then set down in the center of the upper story of a strong colony. The brood is thus kept warm, until it emerges. When the young bees are all out, the cage is removed and taken to a separate hive. The

* The entrance can be opened in four or five days. frame, bees, and queen are then removed and set in the hive. A comb of honey or a division-board is put next when the hive is closed and the entrance is contracted. In cool weather this is the only way a queen can be introduced to emerging bees.

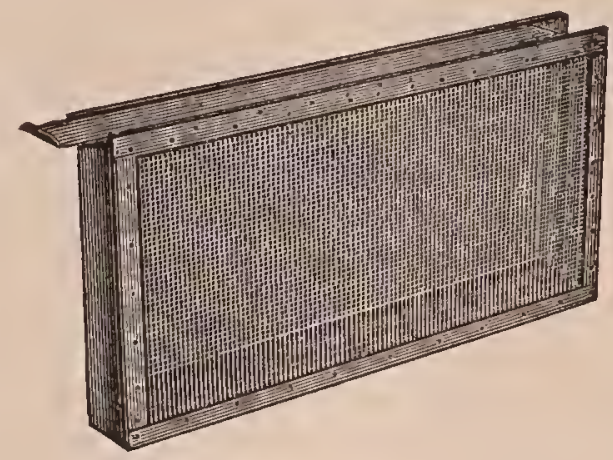

The California Introducing Cage.

This same method can be used for introducing to a strong colony. But in that case the cage is left in the hive for five days, at the end of which time it is lifted up high enough to slide off the cover when it is set back, and the queen will mingle with the bees. The eage, not at this time but later, is removed. This plan will not work, of course, if there is a possibility of a virgin or a cell in the hive.

\section{INTRODUCING TO YOUNG BEES.}

There is another way that has proved to be good. In order to describe it an extract is made from an editorial in Gleanings in Bee Culture, page 539, Vol. XXI.

We have just received a consignment of 30 imported Italian queens, direct from Italy, by express. Every queen came thru in good order, and they are now introduced into the apiary without the loss of one. Our method of introducing with this lot was something we had not tried before on so large a number of queens. We took four or five strong colonies, and divided them up into 30 one-frame nuclei. This was done in the forenoon. In the afternoon we transferred the imported queens, without any attendants, to Miller introdueing-cages, plac: ing one in every nucleus above mentioned. Most of the queens were out at the expiration of two days, in good order, and they are now all out.

You see, the point is here: These newly divided nuclei will have old and young bees, and more or less emerging brood. Before the imported queen is released, the old bees will have returned to the old stand, and it is these old bees that always make trouble in introducing. By the time the queen is released, there are none but young bees, including those that were brought to the nu. 
cleus-stand and those that have emerged in the interim. These, of course, all being young, will accept their new mother, without any trouble.*

\section{DIRECT METHOD OF INTRODUCTION.}

Where it is desired to introduce a queen from a nucleus to a queenless colony, both in the same yard, the operation can usually be performed with safety and with very little labor, as follows: The colony to receive the queen should be made broodless a few hours in advance. Go to the nucleus and lift out two frames, bees and all, with the queen in between. Put these down in the center of the queenless colony; close up the hive and don't go near it for several days. The bees that have been queenless and broodless are crying for a mother. When she is given them with a large force of her own subjects, she seems to be protected, even if she does not have the odor of the new colony which, by the way, has been modified by the bees and brood given them from the other hive.

This is a modification of the Simmins direct method of introducing. It could not be used in the case of a queen sent thru the mails.

\section{THE SIMMINS FASTING METHOD.}

While this has been discussed to a greater or less extent in the bee journals, the plan, while very simple, is not one that the author would recommend in the case of a valuable queen, or in any event to a beginner. It is as follows.: The queen to be introduced should be put in a cage at night without attendants and without food. She should thus be confined for 30 minutes when she must be released at dusk over the frames of the queenless colony. The hive is not to be opened again for 48 hours.

\section{DUAL PLAN OF INTRODUCING.}

Another plan is to introduce two virgins or laying queens at one operation to save the necessary time it takes for the bees to get acquainted with the queen. This is described in detail under the head of QUEEN-REARING, to which the reader is directed.

* Ire used the same plan with a full colony. Set the colony on a new stand, leaving on the old stand - hive with a frame of brood to catch the fielders. After introduction the hive may be returned.-C. C. MILI.ER.
HOW SOON WILL AN INTRODUCED QUEEN BEGIN TO LAY.

As a general thing, she may be expected to begin laying in two days; but sometimes, if the queen has been a long time prevented from laying, as in the case of an imported queen, she may not lay for three or four days, or even a week. If introduced in the fall, she may not commence laying until early spring, unless the colony is fed regularly every day for a week or more. This will usually start a queen that is good for anything if the weather is warm enough.

\section{HOW TO TELL WHETHER A COLONY IS QUEENLESS OR NOT.}

Having discussed mailing and introducing eages, it may be pertinent at this point to give one of the prime essentials in successful introducing. The very first thing to be determined before an attempt to introduce is made, is to determine that the colony is certainly queenless. The fact that there may be no eggs nor larvæ in the hive, and that the queen cannot be found, is not sufficient evidence that she is absent, altho such a condition points that way. But during the earlier part of the summer there should be either brood or eggs of some kind if a queen is present. Yes, there should be eggs or brood clear up until the latter part of summer. In the fall in the northern States, or after the main honey flow is over, old queens generally stop laying, and shrivel up in size so that a beginner might conclude that the colony is queenless, and therefore he must buy a queen. In attempting to introduce the new queen, of course he meets with failure, as she is stung to death, in all probability, and carried out at the hive-entrance. If eggs or larvæ cannot be found at any season of the year when other stocks are breeding, and the supposedly queenless colony builds cells on a frame of unsealed larvæ given them, it may be concluded as a general rule that the colony is probably queenless, and it will be safe to introduce a new queen. But when eggs, larvæ, and sealed worker brood are found, the presence of queencells simply indicates that the bees are either preparing to supersede their queen or making ready to swarm. See SwarmING. 
The statement was made that old queens would stop laying in the fall if no loney was coming in. It should be noted that young queens will lay, flow or no flow, if there are sufficient bees and stores.

\section{HOW LONG SHALL A COLONY BE QUEENLESS}

BEFORE ATTEMPTING TO INTRODUCE?

Colonies that have not been queenless more than two days are to be preferredjust long enough to determine whether cells are started, and just long enough so the bees begin to recognize their loss, but not long enough for them to get cells under way. Cells nicely started or capped over are quite apt to make the colony act as if it wanted something of its own; and when a laying queen is introduced to them they take a notion sometimes that they won't have anything but their own raising.

The worst colony to introduce a laying queen to is one that has been queenless long enough so that there is a possibility of one or more virgin queens being in the hive. It is hard to decide definitely in all cases when such colonies are queenless. Most virgins, after they are three or four days old, are very apt to be mistaken for worker's, especially by a beginner.

WHAT TO DO IF BEES BALL THE QUEEN.

Very often when the bees decide they will not accept the queen let loose among them they will begin to pull at her, pile on her in such numbers that they form a ball around her. Every bee in the ball will seem intent on pulling her limb from limb. Unless the owner comes to her rescue she may be stung to death or be suffocated.

When queens were introduced in the oldfashioned way-that is, before cages were constructed so as to release queens automatically-much trouble was encountered by bees balling queens. If they were not ready to accept her when she was released by the apiarist, they were pretty sure to ball her. Right here is a point that it is well to observe: When the bees let out the queen they very rarely ball her. But when it is necessary for the apiarist to perform the work of opening the hive, and making a general disturbance, there is danger of balling. Suppose she is balled. The ball should be lifted out of the hive and smoke blown on it until the bees come off one by one; but hot smoke must not be blown on the queen. When the queen is foind, set hold of her wings and pull the rest of the bees off from her by their wing's. Cage her again as at first, and give her another trial. The advice has been given to drop the queen, when she is balled, into a vessel of lukewarm water. The angry bees will immediately desert the queen, when she can be easily taken out of the water, and recaged.

Another way of saving the queen without having to recage her is to carry a small oil can with a spring bottom, such as is used on a sewing machine, filled with thin syrup. When the bees are found balling her, saturate the ball thoroly by pressing hard upon the bottom of the can, causing the syrup to penetrate thiru the ball. Close the hive and the bees will turn their attention to cleaning themselves and the queen, when she will be accepted without further trouble.

WHAT TO DO WHEN THE QUEEN FLIES AWAY.

Sometimes a beginner is very nervous, and by a few bungling motions may manage to let the queen escape from the hive where he expects to introduce her. Or this may happen: The queen may become a little alarmed because there are no bees about lier, take wing direct from the frame and fly. In either case, one should step back immediately after opening the hive, and in 15 or 20 minutes she will be likely to return to the same spot and enter the hive. If she is not discovered in the hive in about half an hour, she may be found in one of the other hives near by. If a ball of bees somewhere down among the frames is found, it may be surmised that here is the queen that flew away, and that she has made a mistake, and entered the wrong hive.

\section{INTRODUCING VIRGIN QUEENS.}

As previously explained, a young virgin just emerged, generally weak and feeble, can usually be let loose in a queenless colony without caging, and be favorably received; but one from two to six days old is, as a rule, much more difficult to introduce than a laying queen; and one ten days old, more than old enough to be fer- 
tilized, is most difficult. Such queens can be introduced to a strong colony by using the Miller smoke method or the SmitllChantry plan. Better give them a cell or a virgin just hatched, thus saving time and vexation; for even should the old virgin be accepted, she may be deprived of a leg, or be so deformed from rough treatment as to become in a large measure impaired for usefulness. Under head of QUEEN-REARING are described "baby nuclei;" and, as already stated, it is much easier to introduce any queen, either virgin or laying, to a nucleus or weak force of bees than to a strong, vigorous colony; so if one would attempt to introduce four or five day-old virgins, give them to nuclei-the smaller and weaker the better.

INVENTIONS RELATING TO BEE CULTUR.E.-It would be quite impossible in the limits of an article in this work to record all the inventions relating to bee culture; but it is perfectly feasible to include those that have been adopted, and which are in use more or less by the progressive beekeepers of the country.

There are four inventions that revolutionized the methods of work with bees, and which really form the basis of all modern methods of management today. First and foremost was the invention of movable frames by L. L. Langstroth in 1851. No one today, either in Europe or this country, questions Mr. Langstroth's right to the honor of this great invention, for practically all hives and frames in use today are Langstroth. See Frames, Hives and HiveMAKING.

Next followed the invention of - comb foundation by $J$. Mehring in 1857 . But the foundation he made had no side walls, and so it remained for Samuel Wagner, A. I. Root, and A. Washburn to develop the product that is now used witl side walls.

The next was the invention of the honeyextractor, by Major Francisco Hruschka, in 1865. The fourth was the invention of a bellows bee-smoker by Moses Quinby.

There have been a large number of improvements that have made the inventions of Langstroth, Mehring, Hruschka, and Quinby much more workable than they were originally. However, it is but fair to say that Langstroth eame very near making his hive and frame almost perfect at the very, start; and there are possibly a few of the readers of this who would consider the later improvements made in the Langstroth frame and hive of doubtful value. It is, nevertheless, a fact that the old movable frame, as first made by $\mathrm{Mr}$. Langstroth, both as regards dimensions and style, is still in use all over the world. For extracting purposes some of the large honey producers will have no other. They regard anything in the way of a selfspacing attachment, as part either of the hive or frame, as unnecessary, and a backward step. See Frames, Self-Spacing.

The original comb foundation by Mehring was a very crude product; and it may be questioned whether or not Wagner should not share equal honor in the invention. The great improvements that were made in this article liad more to do with the machinery for making the product than the thing itself. A. I. Root did more to perfect comb foundation than perhaps any other man unless it was his colaborer and mechanic, Alva Washburn. He certainly introduced it to the beekeeping public. The first foundation was turmed out on plates, and was, therefore, a very crude article; but $\mathrm{A}$. I. Root conceived the idea of having it made by means of a pair of rolls. This suggestion came to him when noticing the wet clothes as they came out from a common wringer in his own home. After consulting his friend and mechanic, Mr. Washburn, a pair of rolls were made, the product of which was nearly the equal of any comb foundation made on modern machines. To Mr. Washburn belongs the credit of making perfect foundation on rolls that were mechanically correct. The only improvement made on the Washburn mills was in the method of making them, by which they could be duplicated, and manufactured not by hand but by machinery, in such a way that every roll is perfect. Later improvements were made by E. B. Weed, H. B. Blanchard, and H. H. Root.

As regards the invention of Hruschka, several machines were made and put on the market. The one made by J. L. Peabody consisted of a can that revolved without gearing. The limitations of this were such 
that very few of them were ever sold. To A. I. Root belong's the credit of making some of the first all-metal extractors that use gearing, a stationary can, and a reel with baskets to hold the combs, the reel connected to the gearing, and mounted to revolve independently of the can. Thousands and thousands of these machines were sold, and very little in the way of improvement was made until the reversible extractor was put on the market. The Cowan principle was applied to the twoframe inachines, and later came the Root principle of a series of baskets geared together in such a way that the reversing of one pocket reversed all at the same time. A few years later came the invention of Frank G. Marbach, by means of which the pockets could be reversed automatically by simply applying a brake and slowing down the speed of the machine. This was followed by a slip gear and better mechanism, by which the extractor of today has from two to ten times the capacity of the earlier machines.

In later years another type of machine has been developed, that employs the principle of reversing the individual pockets for holding the combs on a central pivot, as is shown under the head of ExTRACToRs. This plan of reversing is much easier on the combs, providing for a higher speed and thus doing cleaner work. The centralpivot principle also makes it possible to reverse the combs when the extractor is going at full speed. The detail of this last machine 'was worked out by $H$. H. Root and G. L. Howk.

Mention should be made of the honeypump that is now being used successfully on the large-sized extractors to deliver the honey from the extractors to a tank at one side or in an adjoining room.

The fourth important invention is the bee-smoker. Quinby. was the inventor of the bellows bee-smoker, which he brought out in 1875. This was further improved by T. F. Bingham, L. C. Root and H. H. Root, younger son of A. I. Root. The modern bee-smoker is almost as indispensable as an extractor and movable frames; for without smoke, applied by means of a convenient instrument, the work of handling bees would be disagreeable if not impossible at times. The invention of Mr.
Quinby forms the basis of all the modern smokers. But to T. F. Bingliam belongs the eredit of devising a smoker that blows air into the fire-cup without sucking any smoke into the bellows. Mr. Bingham's invention consisted in leaving out the tube connecting the two parts of the instrument. While that at first thought might seem to be no invention, yet it made all the difference in the world between a workable tool and an unworkable one. The latter would go out and elog up with creosote, while the former would continue burning, burn any kind of fuel, and not elog up.

E. B. Weed, formerly of Medina, was the inventor of what is known as the "Weed New Process" for making comb foundation of a very superior kind in large quantities. His automatic machinery, with Washburn's and Howk's improvements for turning out the product, is now used in nearly all civilized countries of the world.

A little later on H. H. Root and H. B. Blanchard made some great improvements in comb foundation machines. Rolls of these machines instead of having cut or engraved die faces use a harder metal cast at a type foundry. This makes it possible to use individual type that are fastened to rings surrounding the rolls. The shape of the type faces is more nearly accurate than those that are engraved on soft metal and for that reason will wear longer. The shape of the type heads conforms more nearly to the bottoms of the cells of the natural combs. See Comb Foundation.

At the same time that this invention was brought out Prof. Holmes of Oberlin, Ohio, developed a process for a refining wax, a product that is much superior to anything that has hitherto been put on the ' market.

An invention which is now in almost universal use, in this country at least, is that of Julius Hoffman, in what is known as the Hoffman self-spacing frame. While the old-style Langstroth non-spacing frame was once the leader, yet during late years the Hoffman-Langstroth is one that is listed by large and small manufacturers and dealers all over the country. The present Hoffman frame is not the same as the original; or, to, put it in another way, the modern Hoffman retains only the self-spacing 
end-bars of the original, and not the Hoffman top-bar.

Another improvement was suggested by Francis Danzenbaker-namely, the lock cornering on hives. This feature has now come to be adopted by all modern hivemakers thruout the United States, and, to a great extent, thruout the world.

The invention of the sectional honey-box is not attributable to any one person; however, A. I. Root was the first to make one holding one pound. His first pound sections were dovetailed all around. Later on came the invention of the one-piece section, on which J. H. Forncrook secured a patent; but after long litigation from one court to another, the Supreme Court finally declared it "null and void for want of novelty." It. was shown that one J. Fiddes and a number of others had made and used sections of this kind; so in the matter of one-piece sections the honor will have to be divided among four or five different people. The late James G. Gray of Medina made the first practical machine for making onepiece sections in quantity. Later, machines for turning out section honey-boxes in lots of one hundred thousand a day were the invention of George L. Howk.

The Porter bee-escape is one of the best little inventions that have been brought out. It is one of the few patented inventions that survived and is now used very largely.

Queen-excluders in the form of perforated zine and spaced wires are inventions of merit. In connection with these will be found entrance-guards and Alley traps that are useful. The Alley trap is another patented invention that survived.

T. F. Bingham and Mr. Hetherington were really the inventors of the modern uncapping-knife popularly known as the Bingham. The Bingham-Hetherington shape is now used in all uncapping-knives, whether steam-heated or plain.

The steam uncapping-knife (see ExTRACTING) is an invention that is coming more and more into use. The cappingmelter for melting cappings as fast as they come from the knife gives promise of being one of the inventions that will last. It enables a competent man who follows directions to melt his cappings and separate the honey from the cappings immediately, so 18 that when the day's work is done he will have his honey free from cappings, and the cappings converted into wax ready for use.

Arthur C. Miller was the discoverer or inventor of the principle that is now used in all modern foundation-fasteners using a hot plate; yet, strangely enough, not one of these fasteners bears his name. Mr. Miller was also the inventor of two or three different uncapping-machines, and of the steam-heated uncapping-knife. If he had applied for letters-patent on this kind of knife it would have been granted him, and he would be today considered the inventor, as he really is, of the steam-heated uncapping-knife.

No one seems to have invented the double-walled packed hive for outdoor wintering; but A. I. Root was, perhaps, in connection with J. H. Townley, the first to apply the principle of chaff packing in double walls. As chaff is not now obtainable, other packing material is used. Langstroth in the early ' 50 's used double hives but not packed.

In the early ' 80 's there was a score of inventions relating to feeders, foundationfasteners, and reversing attachments for movable frames, nearly all of which died a natural death because they were impracticable and only increased the cost of management.

Among the later hive inventions that have merit is the Aspinwall hive, based on the principle designed to prevent swarming. (See Swarming.) But its cost of construction and the large number of extra parts that must be manipulated at intervals have prevented this hive from displacing the present standard hives to any great extent. The swarming problem is not a serious one in the production of extracted honey; and while probably threefourths if not four-fifths of all the honey produced in the world is extracted, it will be seen that there will be a very limited demand at best for non-swarming hives.

In the way of minor inventions or improvements mention should be made of the omission of porticos on hives, and of bevel edges between the parts of the hives. A hive plain and simple, with a detachable bottom-board and a plain simple cover, is much more workable than some of the com- 
plicated domiciles of the early days with moth-traps, porticos, and the like.

It is another improvement to have the hive-body and supers of the same dimensions and the same depth, except in the case of half-depth supers. In a word, the modern hive is made up of multiples of parts that will fit each other in any combination, permitting of any degree of expansion and contraction to accommodate a large or small colony. This feature of interehangeability is prized almost as much as any one single invention, barring only the four great inventions first mentioned.

It might be interesting and perhaps enlightening to some would-be inventors to record here a list of the inventions that have died a natural death. Some of these at the time were heralded as revolutionary; yet they never "revolutionized," but, on the contrary, sickened and died, as thousands of other's had done. It is well that they did.

As an example of this may be cited the case of the Heddon divisible broodchamber hive that was exploited by Jas. Heddon from 1884 to 1890 . He believed that it was possible to handle hives in smaller sections in place of frames. The idea was so alluring and the principle so successfully pushed that large numbers of beekeeper's adopted it; but in practically every case those same beekeepers later complained of poor seasons and of small crops. Mr. Heddon apparently lost sight of the importance of large hives, and for a period of from 1885 to 1890 his followers were almost compelled to go out of business, because of what they believed was a failure 'due to the peculiar seasons, but for what is now known to have been due to the brood-nest being too small, resulting in too small a force of bees. As will be seen under the general discussion of HIVEs a good queen will occupy about double the capacity of what Mr. Heddon thought would be the correct size of his double brood-chamber.

It is but fair to say to inventors that a patent or patents on any invention or improvement relating to bee-feeders, methods of wiring frames, or foundation-fasteners, are generally a waste of time, and can only lead to disappointment. There is a large list of patents in the Patent Office covering all forms of bee-feeders, not one of which is equal to any of the unpatented feeders described under the head of FEEDERS. In the same way it is a waste of time to try to invent a beehive, something new and better than those that are generally accepted by the fraternity at large. Every conceivable form of hive has been made the subject of a patent. With perhaps a dozen important exceptions there is hardly a patent on bee-fixtures that is worth the paper on which it is printed: and the beginner, at least, will be very wise if he accepts the standard hive and appliances which are described in this or any standard work on bees. It is true, patents will be granted on almost anything; but any one who is familiar with patent claims knows that they can be and usually are so loosely drawn that they are worthless. The poor inventor supposes that because he has been granted a government parchment a fortune awaits him. But he is doomed to disappointment as sure as fate. See Patents, elsewhere.

\section{INVERTING.-See REVERSING.}

INVERT SUGAR.-Chemically considered, this is a mixture of equal parts of the two sugars, dextrose and levilose, coming from the inversion or breaking down of sucrose. In common terms, sucrose is the ordinary white sugar of commerce, such as beet sugar or cane sugar. This breaking down of sucrose occurs when it is dissolved in water and boiled. The action then is very slow; but by the addition of a very small percentage of any acid the action is made more rapid. Hence, in the commercial preparation of this product white sugar is dissolved in water, then tartaric, acetic, phosphoric, or hydrochloric (muriatic) acid is added and the whole boiled. Of the two sugars of invert sugar, dextrose is easily crystallizable, while levulose remains a liquid under most conditions, but on long standing and under concentration the dextrose will crystallize out. As regards sweetness, dextrose is not so sweet as sucrose, while levulose is much sweeter; hence invert sugar is generally said to be siweeter than sucrose.

The preparation of invert sugar from sucrose by using water and tartaric acid was patented a number of years ago by Herzfeld in Germany. The proportion he 
uses is approximately as follows: cane sugar, 25 lbs.; tartaric acid, 1/2 oz. (avoirdupois); water, 1 gallon. Bring to a boil and keep at that temperature for $1 / 2$ to $3 / 4$ hour.

When prepared as above the product is liable to be yellow or brown in color, but it is perfectly possible by concentrating in racuum or under reduced pressure to produce an invert sugar water-white. It can be made to appear like a high-grade clover honey. Its analysis is very similar to that of a clover honey.

During the preparation of this sugar, a small amount of the levulose is broken down into furfurol or methylfurfurol. This product even in very small quantities gives strong color reactions with some reagents as resorcin-aniline acetete which forms a partial test for invert sugar.

Attempts have been made to make invert sugar which would not give these color reactions, but on a commercial scale they have not been altogether successful. The enzyme, invertase (from yeast), will break down sucrose into dextrose and levulose without the formation of these furfurol bodies, but on concentration these bodies are formed. Other ways have been tried. It is true, tho, that invert sugar can be made commercially that gives only slight color reactions, and improvements in manufacture of late year's have yielded a product which has very much less of these furfurol bodies present, but the chemist does not need these color reactions altogether to prove the presence of commercial invert sugar in honey.

Commercial invert sugar is generally put on the market as a water-white liquid at the same price aș granulated sugar. It has anywhere from 50 per cent to 75 per cent invert sugar, from 1.5 per cent to 30 per cent of sucrose, and from 18 per cent to 30 per cent of water. If a mineral acid as phosphoric, muriatic, or sulphuric is used for the inversion, this is generally partially neutralized with soda, and hence the product will have from 0.5 to 3.08 per cent of ash. Where acetic acid or phosphoric acid unneutralized is used, or where tartaric acid is used, there is practically no ash unless the sucrose carried some. For the detection of commercial invert sugar see HoNey ANALysis and Adulteration.
ISLE OF WIGHT DISEASE.-See Drseases of BeEs.

ITALIAN BEES.-At present the Italians, and even hybrids, have slown themselves so far ahead of the blacks that all discussion of the matter is at an end. Many times colonies of hybrids will be-found that go ahead of pure stock; but, as a general thing (taking one season with another), pure Italians, where they have not been enfeebled by choosing light-colored bees to breed from, are ahead of any mixture. There has been a great tendency in the case of bees, as well as other stock, to pay more attention to looks than to real intrinsic worth, such as honey-gathering, prolificness of the queens, and hardiness.

Even if it were true that hybrids produce more honey than pure Italians, each beekeeper would want at least one queen of absolute and known purity. Altho a first cross might do very well, unless he had this one pure queen to furnisli queen-cells he would soon liave bees of every possible grade, from the faintest trace of Italian blood, all the way up. The objection to this course is that these blacks, with about one band (with the exception of the Easteln blood), are much crosser than Italians; they also have a very disagreeable way of tumbling off the combs in a perfectly demoralized state whenever the hive is opened. Neither will they repel bee disease like pure Italians. See FouL Brood, subliead, "European Foul Brood;" also "HrBRIDS." If for no other reason, one can well afford to Italianize because in no other way can European foul brood be controlled. This disease, in some sections of the country, is cleaning out the blacks and hybrids, while the good Italians are nearly immune to it if kept strong.

The pure Italian stocks can be opened at any time and their queens removed, scar"cely disturbing the cluster, and, as is sometimes the case, without the use of any smoke, by one who is fully conversant with the liabits of bees. Hybrids are generally cross and will not repel the moth as do the pure Italians.

The queens, and drones from queens obtained direct from Italy, vary greatly in their markings, but the normal worker bee shows three yellow bands. 
While the presence of three yellow bands has for many years been supposed to be an absolute test of purity, a recent work by Prof. Wilmon Newell, then of College Station, Texas, shows that this may not be entirely correct. But reference to this is made under head of Dzierzon Theory, subhead "Recent Evidence in Proof of Dzierzon Theory."

Every worker bee, whether black or Italian, has a body composed of six tubes, or segments, one sliding into the other, telescope fashion. When the bee is full of honey these segments slide out, and the abdomen is elongated considerably beyond colored down, J, K, L, M, one on each of the four middle rings of the body but none on the first and none on the last. These bands of down are very bright on young bees, but may be so worn off as to be almost or entirely wanting on an old bee, especially on those that have been in the habit of robbing very much. This is the explanation of the glossy blackness of robbers often seen dodging about the lives. Perhaps squeezing thru small crevices has thus worn off the down, or it may be that pushing thru dense masses of bees has something to do with it. Such shiny black bees are often seen in great numbers, in
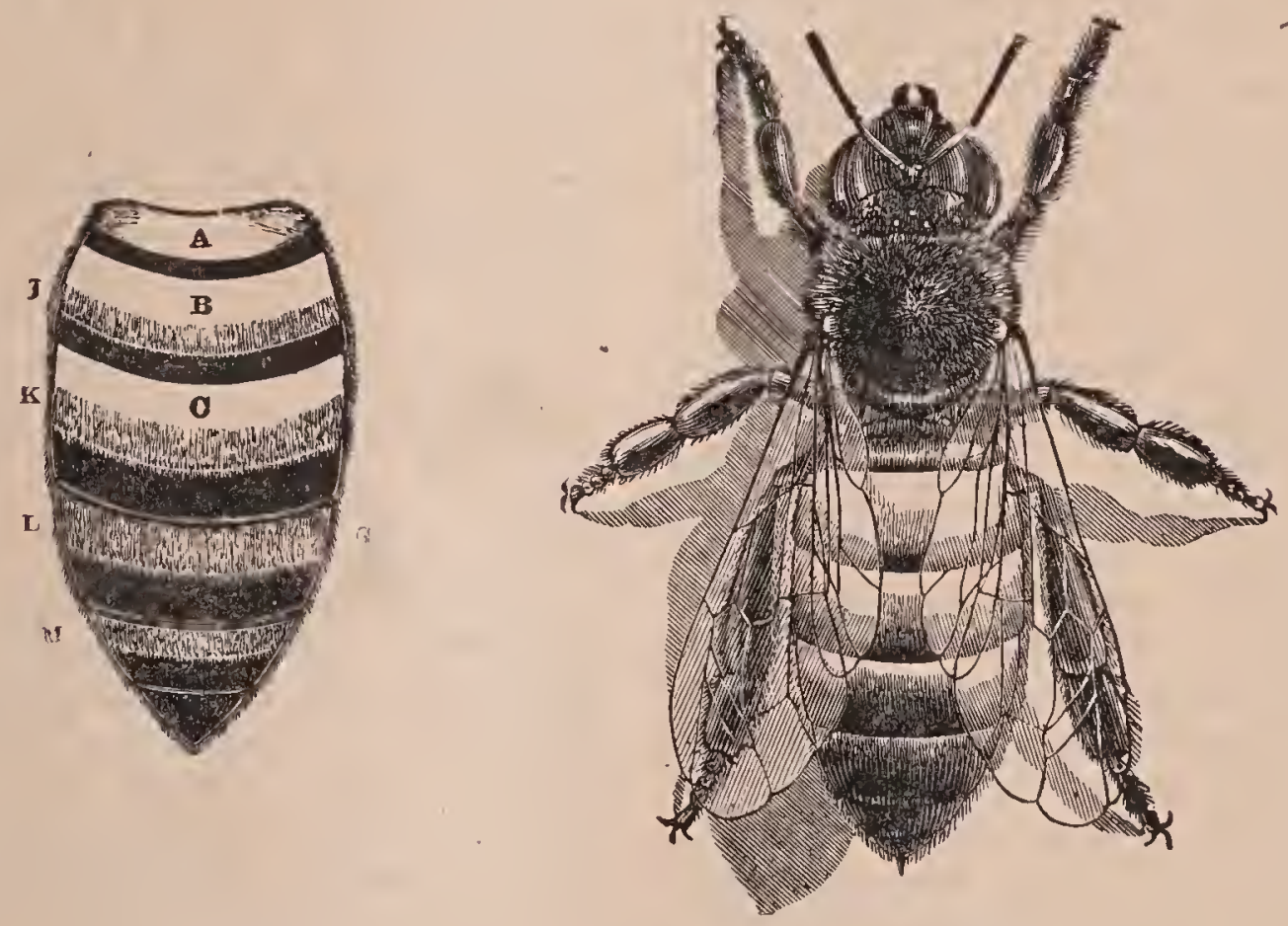

the tips of the wings, which are ordinarily about the length of the body. Sometimes one sees bees swollen with dysentery spreading the rings to their fullest extent, and in that condition they sometimes would be called queens by an inexperienced person.

On the contrary, in the fall when the bee is preparing for its winter nap, its abdomen is so much drawn up that it scarcely seems like the same insect.

The engraving shows the abdomen of the bee detached from the body, that one may get a full view of the bands or markings that distinguish the Italians from our black bees. It is important to observe particularly that all honeybees, black as well as Italian, have four bands of bright-

stocks that have been nearly suffocated by being confined to their hives in shipping, or at other times.

These bands of down differ in shades of color from nearly pure white to a rich orange or to a brown, many times, and this is the case with the black bees as well as with the Italian. Under a common lens the bands are simply fine soft hair, or fur, and it is this principally which gives the light-colored Italians their handsome appearance. One may have noticed the progeny of some particular queen when they first came out to play, and pronounced them the handsomest bees he ever saw; but a few weeks after they would be no better looking than the rest of the beies. This is simply because they had worn off their 
landsome plumage in the "stern realities" of hard work in the fields. Occasionally will be found a queen whose bees have bands nearly white instead of yellow, and that is what has led to the so-called albino bees. When the plumage is gone, they are just like other Italians. These bands of down have nothing to do with the yellow bands that are characteristic of the Italians; for, after this has worn off, the yellow bands are much plainer than before. $A, B, C$ are the normal yellow bands of which so much has been said, and they are neither down, plumage, nor any thing of that sort, as will be seen by taking a careful look at an Ttalian on the window. The scale, or horny substance of which the body is composed, is yellow, and almost transparent, not black and opaque, as are the rings of the common bee or the lower rings of the same insect.

The first yellow band, A, is down next the waist. It is very plain, when one knows what to look for, and no child need ever be mistaken about it.

At the lower edge of this first yellow band is the first black band; this is often only a thin sharp streak of black.

The second, $B$, is the plainest of all the yellow bands, and can usually be seen in even the very poorest hybrids. The first band of down is seen where the black and yellow join, but it is so faint one will hardly notice it at first in some specimens.

$A^{*} t$ the lower edge of the scale there is a narrow line of black; when the down wears off, this shows nearly as broad as the yellow band.

In hybrids are found a greater diversity; for while the bees from one queen are all pretty uniformly marked with two bands, another's will be of all sorts, some beautifully marked Italians, some pure black, others one or two-banded. Some will sting with great venom, while others with only one or two bands will be as peaceable as the best Italians. Without a doubt, many queens have been sent out as pure that produced only hybrids; but since the author's recent studies in the matter he is quite well satisfied that several queens have been sold as hybrids that were really pure.

In the matter of rearing queen-cells, either the Cyprians or Holy Lands will rear more queens than any Italians, Car- niolans, blacks, or lybrids. As many as 100 natural cells have' been frequently found on one frame. One instance is recorded where 25 virgins from a Holy Land queen emerged within a few minutes of each other; and so vigorous were they that some of them actually flew the moinent they popped out of their inclosures.

The recent craze for five-banded bees, golden bees, and yellow-all-over bees, has complicated the marking problem somewhat. For instance, a colony that produces four or five banded bees, when crossed with a black or Carniolan drone, may produce the same kind of bees; but the second cross, at least, will show three-banded bees that are in reality hybrids but still showing the typical three yellow bands.

Under the Dzierzon Theory, subhead "Recent Evidence in Support of the Theory," it will be found that the first cross between an Italian queen and a Carniolan drone may have generally the markings of the yellow bees. The second cross will make one, two, or three banded Italians, and the bees will be distinctly hybrid, showing characteristics of the two races.

While the presence of three yellow bands does not necessarily prove the purity of Italian stocks, the test is fairly reliable in an Italian apiary that has not been run to color to get four and five bands, or in a yard where there have not been raised Carniolan, Caucasian, or black drones for several years previously.

\section{FOUR AND FIVE BANDED ITALIANS.}

Reference has already been made to the extra-yellow bees. For a good many years back there has been a demand for beautiful bees, and in all probability there always will be such a demand. A few queenbreeders in the country have been endeavoring to meet it. The time was when breeders guaranteed to furnish queens that would furnish "yellow-all-over bees" and "five-banded bees." While an occasional queen may produce a majority of such bees, it should be said that the most of the extra yellow stock does not show more than four bands; and the yellow-all-over bee is a "rare bird" indeed. It may be said that there is no such thing as a five-banded Italian or yellow-all-over Italian. The nearest approach to it is the very yellow three- 
bander bees and four-banded-perhaps the fourth band showing a predominance. As to the real practical value of these bees there is considerable discussion. While it is true that some of these very yellow bees are also good workers and good bees to winter, the facts are that many of them, at least, are worth very little in the field, and die early in the winter. Many breeders, in their efforts to get color, have lost sight of other desirable qualities; and it is, therefore, coming to pass that many extra-yellow bees are poor workers, cross, and iacking in hardiness. On the other hand, it is only fair to say that there are some very yellow bees that combine to a remarkable degree other desirable qualities.

A good many readers of this will prefer good bees and those that are gentle. Usually the typical Italians that have been bred for business will be found to have not more than three yellow bands, often not more than two showing distinctly. These are usually called "leather-colored" Italians because they are typical of the native bees in Italy. These two-banded Italians, however, will show a third band if full of honey and placed on the window. These may often be confused with the ordinary two-banded hybrids. There is, however, a very marked difference in their general deportment and general behavior.

\section{HOLY LAAND AND CYPRIAN BEES.}

In 1882 considerable excitement arose over two new races of bees brought over from the old World by D. A. Jones of Beeton, Ontario, Canada, who was then the leading beekeeper of his country. They were called Cyprian and Holy Land bees, from the places where he found them. The former, from the Isle of Cyprus, seem to have been for many years isolated, and are a distinct and uniform race.

While they look like bright I talians, and night be classed as such by beekeepers not familiar with their peculiarities, they have a few distinguishing characteristics. Holy Land bees show whiter fuzz-rings, and the bodies are slimmer than those of the ordinary Italians. They are more like the ordinary albinos. In fact, most of the albinos formerly sold were of Holy Land extraction. The ('vprians look very mush like the four and five banded Italians. The yellow bands are of a deeper orange than those of the Italians, slightly wider, and sometimes more than three in number. Just at the base of the thorax, and between the wings, there is a little yellow spot that is quite distinct and prominent, called the "shield." This is seen on some Italians, but less distinctly.

When Italians are crossed with Cyprians or Hioly Lands it is a little difficult to see the difference except by their nervousness.

\section{TEMPERAMENT OF EASTERN BEES.}

Eastern bees are more nervous, especially the Cyprians. Sometimes smoke seems to have no power over them. They will fly up 20 or 30 at a time without warning, and sting the moment they touch the apiarist. The more they are smoked, the more enraged they become. Cyprians especially are the crossest bees ever brought into this country-so cross, indeed, there is not a breeder in the United States who has them for sale. The same objection, tho to a less extent, applies to the Holy Lands.

The author once sold an imported Cyprian queen; and the customer, after he had kept her for a while, returned her, saying that her bees were so vicious that on one occasion they stung everything in sight. and drove the family down cellar. After she had been back a few weeks and her bees had begun to emerge, it was found that it would be hardly safe to keep them in the yard. They would become so enraged at times that the whole colony would rush out in battle array. While the progeny of this queen was exceptionally cross, the general run, both of Cyprians and Holy Lands, is so disagreeable to handle that they are now well nigh discarded in the United States.

The only possible redeeming feature is that they are good brood-rearers; but they breed to excess after the honey flow, using up all their available stores in raising bees, when Italians would conserve their energies and leave enough honey for winter.

ITALIANIZING.-- "How shall I Jtalianize?" and "When shall I do it?" There is cenerally a loss in removine a q'reen and substitutine another, even where one has laying queens on liand; and where he is to use the same colony for rearing the 
queen, there is still greater loss. Under the heads of NuCLEUs and QUEEN-REARING these points will be found fully discussed.

The average beginner at least can better afford to buy untested Italian queens rather than to rear his own on account of the inferior or black drones in his locality. Unless he uses drone-traps or unless he waits till the blacks and hybrids begin to kill off their drones before he attempts to mate his queens to select Italian drones of a colony that is queenless or one he is feeding, he will have inpure matings. (See Hybrids.) Young Italian queens can be bought during late summer and early fall at low prices, 'so low indeed that it would hardly pay those who have only a few colonies to rear their own.

Probably a large majority of the extensive honey-producers likewise buy their queens because they argue that they can make more money producing honey than raising queens. As a general thing they will buy them in lots of a hundred at a time, when they are the cheapest and at prices usually from 40 to 50 per cent lower than retail prices.

Not every honey-producer has a locality that is free from inferior drones, and by buying these queens from some reputable breeder he will improve his stock rather than have it revert backward.

Where one has plenty of time and would like the fun of raising his own queens the article on QUEEN-REARING should be read. He can purchase three or four choice tested queens, and rear his own queens from them after the honey flow. He should then put drone-traps on all his black and hybrid colonies, leaving only the Italian drones the freedom of the air. (See Drones.) Or, better yet, he should wait till the blacks and lyybrids begin to kill off their drones, at which time he can secure pure matings if he feeds the colonies of Italians. (See HyBRIDS.) If the breeders are bought in the spring or summer montlis, the old queens should not be removed until near the close of the summer flow of honey. Instead of allowing natural swarming, two or three frames from each old stock may be taken about swarming time, making nuiclei, and giving cells from the breeding stock. See Nucleus.

When these queens begin to lay the nuclei can be built up, with frames of brood given one at a time until they are full stocks. By such a course one will have the full benefit of old queens during the honey season, until the new ones are ready to take their places. After the honey yield the old queens can be removed, new ones introduced, and the now small colonies given queen-cells. This does the swarming for the season, and the Italianizing, at one and the same time. See Increase; also NuCleus.

After the stocks have all been provided with Italian queens, by either of the plans given above, if one wishes the bees to become pure Italians he is to commence replacing all queens that prove to be hybrids, as soon as the young bees have emerged in sufficient numbers to enable him to decide. (See Italian BeEs.) If honey only is the object these hybrids should not be replaced until after the honey flow; for they will average nearly if not quite as good honeygatherers, and will raise just as pure drones as pure Italians. If the bees of any particular queen are too cross to be endurable she can be replaced. These hybrid colonies should not be allowed to swarm naturally; for if they raise a queen she will produce hybrid drones; ${ }^{*}$ and this is something we wish most scrupulously to guard against.

\footnotetext{
* To get rid of black drones, see Drones.
} 
LABELS FOR HONEY.-The Federal Food and Drug Act has been amended by the "Gould Amendment," which changes the wording of the original act regarding the labeling of net weight and makes it compulsory for food in package form to bear a statement of its net weight, etc. The section as amended reads:

That, for the purpose of this Act, an article shall be deemed to be misbranded:

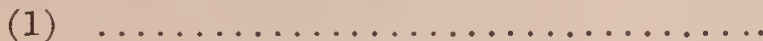

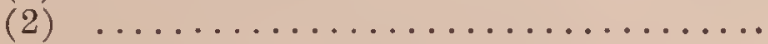

(3) If in package form, the quantity of the contents be not plainly and conspicuously marked on the outside of the package in terms of weight, measure, or numerical count. Provided, however, that reasonable variation shall be permitted, and tolerances and also exemptions as to small packages shall be established by rules and regulations made in accordance with the provisions of section three of this act.

In the case of extracted honey, packages holding two ounces or less weight, or one fluid ounce or less by measure, do not have to have the contents stated on the label, but for larger ones the statement must be on the label in a conspicuous place. The net weight so placed must be the actual net weight, and the variations in individual packages must be as often above as below to relieve one of prosecution under this act.

In the case of comb honey, "The net weight of the comb honey is considered to be the weight of the honey and comb, exclusive of the wooden section. As it is not practicable to mark the exact net werght on eacl, the sections are sorted into groups and on each section in the group should be marked its minimum net weight. (See Comb Honex, to Produce.) This may be marked in accordance with paragraph (h) of Food Inspection Decision No. 154. (A copy of this can be obtained by addressing the Bureau of Chemistry, United States Department of Agriculture, Washington, D. C.)

"The individual units must be nuarked, and the shipping case may be if desired.
The marking should be done before their introduction into interstate commerce.

"While the regulations do not prescribe the manner of marking, as to whether a rubber stamp may be used, the law requires that the statement shall be plain and conspicuous. Stamping by means of aniline ink is frequently illegible, owing to failure to print or to the running of the ink. If such a stamp is used, eare should be taken to make the statement plain and conspicuous, as required by the act."

The above is a letter signed by the Secretary of the Committee on Regulations, Net Weight, and Volume Law, and represents the committee's views as to which weight be considered final.

LARVAE.-Brood while in the worm state. See Brood and Brood-rearing; Behavior of Bees; and Development of BEES.

LANGSTROTH. - Lorenzo Lorraine Langstroth was born in Philadelphia, Pa., Dec. 25, 1810. He graduated at Yale College in 1831, in which college he was tutor of mathematics from 1834 to 1836. After his graduation he pursued a theological course of study, and in May, 1836, became pastor of the second Congregational Church in Andover, Mass., which position ill health compelled him to resign in 1838 . He was principal of the Abbott Female Academy in Andover in 1838-'39, and in 1839 removed to Greenfield, Mass., where he was principal of the High School for Young Ladies, from 1839 to 1844. In 1844 he became the pastor of the Second Congregational Church in Greenfield, and after four years of labor here, ill health compelled his resignation. In 1848 he removed to Philadelphia, where he was principal of a school for young ladies from 1848 to 1852. In 1852 he returned to Greenfield; removed to Oxford, O., in 1858, and to Dayton, O., in 1887.

At at early age the boy Lorenzo showed 


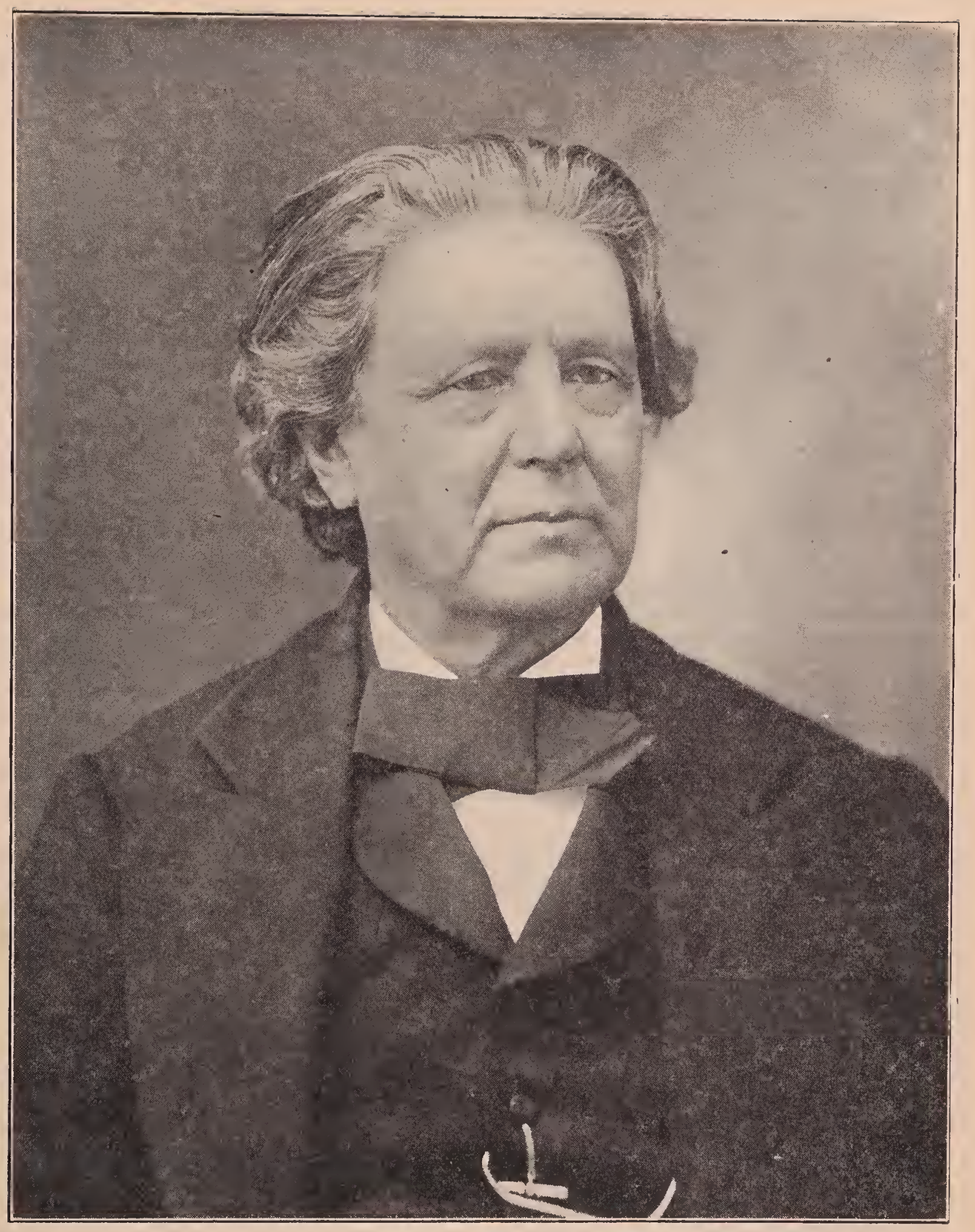

youn affectionetaly,

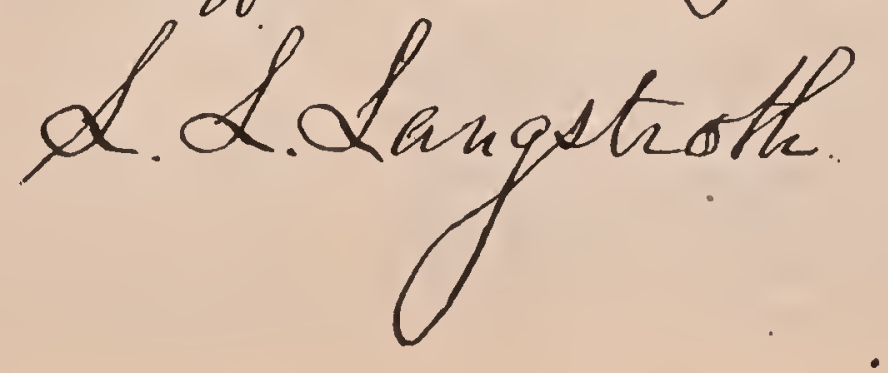


a fondness for the study of insect life; but "idle habits" in that direction were not encouraged by his matter-of-fact parents. In 1838 began his real interest in the honeybee, when he purchased two stocks. No such helps existed then as now, the first bee journal in America being issued more than 20 years later, and Mr. Langstroth at that time had never seen nor heard of a book on bee culture; but before the second year of his beekeeping he did meet with one, the author of which doubted the existence of a queen! But the study of the bees fascinated him, and gave him the needed outdoor recreation while engaged in literary pursuits, and in the course of time he became possessed with the idea that it might be possible to construct a hive so that its contents in every part might be easily examined. He tried what had been invented in this direction, bars, slats, and the "leaf-hive" of Huber. None of these, however, was satisfactory, and at length he conceived the idea of surrounding each comb with a frame of wood entirely detached from the walls of the hive, leaving at all parts, except the points of support, space enough between the frame and the hive for the passage of the bees. In 1852 the invention of the movable-comb hive was complete, and patented October 5 of that year. See Frames, Hives, and BeESPACE.

It is well known that, among the very many hives in use, no other make is more popular than the Langstroth; but it may not be so well known that, in a very important sense, every hive in use among intelligent beekeepers is a Langstroth; that is, it contains the most important feature of the Langstroth-the movable comb. Those who have entered the field of apiculture within a few years may faintly imagine, but can hardly realize what beekeeping would be today, if, thruout the world, in every beehive, the combs should suddenly become immovably fixed, never again to be taken out of the hive, only as they were broken or cut out. Yet practically that condition of affairs existed thru all the centuries of beekeeping up to that time when to take out every comb and return them to the hive without injury to the colony, was made possible by the inventive genius of Mr. Langstroth. It is no small compliment to the far-seeing inventive powers of Mr. Langstroth, that, altho frames of different sizes have been devised and tried, and improvements, so-called, upon his hive have been made by the hundreds, yet today his hive and frame still stand, and their use is almost universal thruout this country and over a large part of Europe.

As a writer Langstroth takes a high place. "Langstroth on the Hive and Honeybee," published in May, 1853, is considered a classic; and any contribution from the pen of its author to the columns of the bee journals was read with eagerness. Instead of amassing the fortune one would think he so richly deserved, Mr. Langstroth at the time of his death was not worth a dollar. He sowed, others reaped. At the date of his invention be had about 20 colonies of bees, and never exceeded 125 .

In August, 1836, Mr. Langstroth was married to Miss Anna M. Tucker, who died in January, 1873. He had three children. The oldest, a son, died of consumption contracted in the army. Two daughters survive.

After his twentieth year, Mr. Langstroth suffered from attacks of "head trouble" of a strange and distressing character. During these attaclis, which lasted from six months to more than a year (in one case two years) he was unable to write or even converse, and he viewed with aversion any reference to those subjects which particularly delighted him at other times. Mr. Langstroth was a man of fine presence, simple and unostentatious in manner, cheerful, courteous, and a charming conrersationalist.

In reply to a question, he wrote, under date of March 26, 1888: "I am now a minister in the Presbyterian Church. Altho not a settled pastor I preach occasionally, and delight in nothing so much as the Christian work. My parents were members of Mr. Barnes' chureh, in Philadelphia, the mother Presbyterian church in the United States."

Mr. Langstroth died Oct. 6, 1895, at the Wayne Avenue Presbyterian Church, Dayton, Ohio, where he was preaching that day. Before he began, the pastor of the church, Rev. Amos O. Raber, moved the pulpit to one side and placed a chair in front where 
Mr. Langstrotl could sit while speaking, for his enfeebled condition would not permit him to stand. After a few preliminary sentences, and requests for prayer on the part of the congregation, he said: "I an a firm believer in prayer. It is of the love of God that I wish to speak to you this morning-what it has been, what it is, what it means to us, and what we ought -"

His daughter, Anna L. Cowan, who was present, thus describes the last scene:

"As he finished the last word lie hesitated; his form straightened out convulsively; his head fell backward, and in about three minutes he was absent from the body, at home with the Lord.

"There was no scene of confusion in the church. Tears were runining down every cheek, but there were no screams, no loud sobbing. As one person remarked, 'Heaven never seemed so near before. It seemed but a step." "

Then, witls no fiery throbbing pain, No slow gradations of decay,

Death broke at once the vital chain

And freed his soul the nearest way.

Thus was finished the remarkable career of one of the great men of the country. He would have been great had he never known anything about bees; but his contributions to bee literature, and his basic invention that revolutionized beekeeping thruout the world, place him in the very front if not the greatest beekeeper who ever lived-not in the money he made, but what he did in making money for others who followed the directions given in his delightful book, "The Hive and the Honeybee." (The publishers of this work have published a reprint just as he wrote itprice $\$ 1.50$.)

For further particulars regarding his invention, see Frames, also Hives.

The statement was made that Mr. Langstroth was a great man. Some interesting sidelights showing the greatness of his character are set forth in an article by his old friend A. I. Root in Gleanings in Bee Culture for Oct. 15, 1895, just after Mr. Langstroth's death.

\section{A. I. ROOT'S PERSONAL RECOLLECTIONS OF THE REV. L. L. LANGSTROTH.}

Tn the introduction to our A B C book you will find sone mention of the incidents of my first acquaintance with the honeybee, and how I came into possession of Lang. stroth's book.

I made the acquaintance, by letter, of Samuel Wagner; got hold of Vol. I. of the American Bee Journal. I wonder whether there is anybody living now who will enjoy reading the first edition of Langstroth and the first volume of the American Bee Journal as I enjoyed it then. Why, the very thought of those old days of enthusiasm makes the blood even now tingle to my fingers' ends.

As soon as I found that Mr. Langstrotli was living at Oxford, Butler Co., O., I commenced correspondence. Then I wanted the best queen bee to start with that the world afforded. It was pretty well along in the fall, but I could not wait till spring, as some of $\mathrm{my}$ friends advised me to do. I soon learned to look up to friend Langstroth with such confidence and respect that I greedily read again and again every word I could find from his pen-even his advertisements and circular in regard to Italian bees. When the book was read thru once I read it again. Then I read certain chapters over and over; and when summer time came again, and I had little miniature hives or nuclei under almost every fruit tree in our spacious dooryard, each little hive containing a daughter of that $\$ 20$ queen, then I read Langstroth's book with still more avidity and eagerness, finding new truths and suggestions in it. eacli time.

I think I met hin first and heard him talk at a couvention in Cincinnati. He was a wonderful talker as well as writer-one of the most genial, good-natured, benevolent men the world has ever produced. He was a poet, a sage, a philosopher, and a humanitarian, all in one, and, best of all, a most devoted and humble follower of the Lord Jesus Christ. His fund of anecdotes and pleasant memories and incidents was beyond that of any other man I ever met; and his rare education and scholarly accomplishments but added to it all. No one I ever saw could tell a story as he would tell it. A vein of humor and good-natured pleasantry seemed to run thru it all. I think he enjoyed telling stories-especially stories with good morals; and they all had to have a good moral or they could not come from L. L. Langstroth. Not only the play of his benevolent face and the twinkle of his eye, but the motion of his hands as he gave emphasis to the different points in his narration, showed how thoroly he entered into his topic.

It was my good fortune to listen to him one or more times from the pulpit. He preached to us once here in Medina. The church was full, but I hardly believe any one else in that large audience enjoyed his talk as I did. They did not know him as I did.

You must not think from what I have said 
that our good friend always agreed with every one else. He had opinions of his own, and he could be stubborn and almost contrary when he got "hot" in a discussion. But the gentle spirit was back of it all. I remember once being out in his apiary, explaining to him some wonderful improvement I had just been working out. He, however, did not see it as I did, and stoutly maintained that the old way-his way, in fact-was better. All at once I stopped and concluded we had better give up the subjeet. Pretty soon he laid his hand on my arm, and said:

"Friend Root, will you not forgive me? I was rude and uncourteous. You have practiced this thing, and are succeeding. Very likely you are right and I am wrong.';

Mr. Langstroth paid us a visit. He told us a long story about his patent. This poor nian had dwelt on it so long that even he, a minister of the gospel, and a successful one, had lost his peace of mind; and if he had not lost his faith in God it shook his faith in humanity. I called his attention to the hopeful text, "But I say unto you, Love ye your enemies; do good to them that hate you; bless them that curse you, and pray for them that lespitefully use you." But even he did not eateh on. I urged until he seemed anmoyed, and I was afraid of a return of his malady. With a sad heart I gave it up. As it was getting to be late and toward bedtime I went with him to his room. He said very little, altho he was naturally exceedingly talkative, and I felt I had offended him by my importunity. In the morning, when breakfast was ready, as he had not put in an appearance Mrs. Root thought I had better go to his room. It was warm weather, and the door was wide open. The old gentleman was awake and partly sitting up, leaning on his elbow. As soon as he saw me he beckoned me to come up near him, with his finger. I was really afraid he was going into one of his "spells." He took his wateh ont from under his pillow and asked me to listen. As I was a watch repairer I supposed there was something wrong with the beat; but when I told him that it seemed to be in perfect order, and that it beat clearly and regularly, what do you think he said? He asked me what the watch said to me. I replied that it did not "say", anything, and now felt sure that he was losing his mind. This is what he said:

"Mr. Root, that wateh has been saying 'Quinby; Quinby! Quinby!' all night long, and I can't stand it any longer. I am going to start today. I an going to see Mr. Quinby. I am llot going to say a word about the patent or the hive. I am going to him as tho we har always been friends."

Friend Langstroth went to see Mr. Quinby, as he deelared he would do, and they had "the best time in the world,",

His last mublic ta'k to beekeepers, if I am correct, was the one given at Toronto; and
I felt anxious at the time that some shorthand reporter might be at liand who could give all his works and even his little stories just as he gave them to us. Perhaps others fid not enjoy this talk as I rid, because they lid not know lim as I did. Why, that history of long ago, telling of the troubles, blunders and mistakes in introdueing the Italian bees from Italy to America, should be handed down to coming generations. It should be embodied in some of the standard works on bees, in order to secure its preservation.

Langstroth and Quinby-those two old pioneers-have now both passed away, but "their works do live after them," and shall live for a thousand years or more. I feel anxious that the first edition of both Langstroth and Quinby should be preserved. There is something to me more interesting in their first efforts-Quinby's book, for in. stance, telling how to keep bees with a box hive, and Langstroth telling his first experiments with the movable-frame hive. Those early editions should be preserved.

When quite a child I was greatly interested in reading the life of Benjamin Franklin. When I first became acquainted with Langstroth I could not resist the suggestion that he was much like Franklin. The maxims of Poor Richard suggest the thought. Mr. Langstroth was remarkably well read in ancient literature. He was familiar with the writings of great men in all the ages. It rejoices my heart now to know that he has been remembered for many years at our national conventions, and to know that he was even present with his daughter at the one that oceurred so short a time before his death. He never seemed to have a faculty for accumulating property, but what is millions of money compared to the grateful remembrance with which Langstroth's name will be spoken in every eivilized land on the face of the earth?

\section{LAUREL.--See POISONOUS HoneY.}

LAWS RELATING TO BEES. - The subject of bees takes up but little space in law. The old law writer's, the men who really laid down the basic principles of our law during its formative period, classified bees and defined the rights of the keeper's of bees in a few brief paragraphs, yet they seem to have covered the subject as fully as was necessary at the time at which they wrote.

As to legal opinions handed down in cases that have been adjudicated by a court of last resort, and which opinions form the bulk of our law of today, those pertaining to bees are very meager in volume. There have been, no doubt, many cases in the minor courts, but the decisions 
in such cases are binding only on the courts that decided them, and then only where there is a lack of higher authority. It matters not how much was involved in a case, nor horv ably it was presented and argued, nor how learned and scholarly was the opinion handed down by the trial judge, nor what the verdict of the jury was, provided it was a jury case; unless the case was appealed to a court of last resort the decision is not available law. Usually it is only the decisions that have been handed down in cases that have been appealed to a court of last resort that are published, and available to the lawyers and the courts in general and can be considered as law by them.

GENERAL PRINCIPLES OF LAW PERTAINING TO BEES.

But the fact that but little litigation concerning bees has reached the courts of last resort does not mean that the law gorerning bees and their keeping was in an undetermined state. Law deals primarily with principles; the subject matter is secondary. To ascertain what the law is in a given instance, all that is really necessary to do is to apply an established principle of law to the facts in the case. For example, to steal the property of another per'son is larceny, and it matters not whether the subject matter stolen be an automobile, a eaged lion, an aeroplane, or a hive of bees, as it is the act that constitutes the offense.

The law as laid down by Blackstone and other law writers of his time and of times prior is briefly as follows:

That bees are wild by nature; therefore, tho they swarm upon your tree they are not yours until you have hived them, any more than the birds that have their nests in your trees or the rabbits that run wild thru your fields. But when they have been hived by you they are your property the same as any other wild animal that you may lave reduced to possession. Animals that are wild by nature and have been captured by you, should they escape, you still liave a right in them if you follow then with the idea of recovery. A swarm of bees that has left your hive continues to be yours so long as you can keep them in sight and under any probability of recovery; 2 Blackstone Com. 392; Coopers Justinian Inst. Lib. 2, tit. 1, No. 14; Wood's Civil Law, bk. 2, chap. 3, p. 103; Domat's Civil Law, rol. 1, bk. 3, pt. 1, Subd. 7, No. 2133; Puffenrorf's Law of Nature, 4, chap. 6, No. 5; Code Napoleon No. 524; Bracton's Law, 2 , chap. 1 , No. 3 ; and see notes in 40 L. R. A. 687 ; 62 L. R. A. 133.

During the early development of our eastern States the general principle of law relative to ownership of bees was adjuclicated in a number of cases. The questions raised and the decisions rendered are briefly as follows: Where bees have escaped and so properly may be considered as wild bees and without any owner at the time of their discovery it has been lield that such bees in a tree belong to the owner of the soil where the tree stands. Merrills vs. Goodwin, 1 Root 209; Ferguson rs. Miller, 1 Cow. 243; 13 Am. Dec. 519; Goff vs. Kilts, 15 Wend. 550.

That bees are ferce naturae, that is, wild by nature, but when hived and reclaimed may be subject of ownership. State vs. Murphy, 8 Blackf. 498; Gillet vs. Mason, 7 Johns. 16; Rexroth vs. Coon, 15 R. I. $35 ; 23$ Atl. 37.

But the finding of a swarm of bees in a tree on the land of another, marking the tree and notifying the owner of the land does not give the finder such property in the honey as will entitle him to maintain trover for the honey. Fisher vs. Steward, Smith 60.

Where one discovers wild bees in a tree, and obtains license from the owner of the land to take possession of them, and marks the tree with his initials, he gains no property in them until he takes them into his possession. Gillett rs. Mason, and Ferguson vs. Miller, supra.

Where bees take up their abode in a tree, they belong to the owner of the soil even tho they are reclaimed; but if they have been reclaimed and their owner is able to identify them as in a case where he followed the bees and saw them enter the tree, they do not belong to the owner of the soil, but to him who had former possession, altho he cannot enter upon the land of the owner of the tree and retake them without subjecting himself to an action for trespass. Goff vs. Kilts, 15 Wend. 550.

In a case decided in 1898 and entitled State of Iowa vs. Victor Repp, 104 Iowa, 
305, 40 L. R. A. 687, it was held that the mere finding of bees in a tree on the land of another did not give the finder any title to the bees or to the tree. The facts were, one Stevens who found the bees trespassed on the land and hived the bees in a gum belonging to another. The defendant Repp removed the bees from where they had been hived and was for that act arrested and tried for larceny, Stevens, the man who hived the bees, being the complaining witness. The trial court convicted Repp, and the case was appealed to the Iowa Supreme Court. The court reversed the trial court, and in rendering the decision, Justice Ladd said: "The title to a thing ferce naturae cannot be created by the act of one who was at the moment a trespasser, and Stevens obtained no interest in the bees by the - niere wrongful transfer of the bees from the tree to the gum. Having neither title nor possession he had no interest then in the subject of the larceny. As the information alleged ownership in Stevens, and the case was tried on that theory, we need make no inquiry as to any taking from Cody (the owner of the land)."

\section{WHERE BEES SHOULD BE LOCATED.}

Bees should be located by their owner so that in the natural course of events they will not molest others. If a keeper of bees locates his bees so that they will be prone to attack other people or their horses he is guilty of negligence. A case in point is Parsons vs. Manser, 119 Iowa 92, 62 L. R. A. 132 , decided in 1903 , the facts of the case being that the beekeeper had a hitehing post in front of his house. This post was located in the public highway; about 2.5 feet from the post, but in the beekeeper's yard, there were two bee-gums. The plaintiff, Parsons, was a medicine peddler. He called at Manser's house and tied lis horse to the hitcliing post. The bees attacked the horses and stung them to deatli. "The beekeeper was held liable for the death of the horses, as the evidence showed that he was aware of the fact that the bees would attack horses when hitched to the post. A beekeeper is not liable, however, unless he has been negligent. In other words, the beekeeper must have been at fault, and if thru no fault of the beekeeper some other person is injured, the beekeeper is not liable. It was so held in a New Tork case, Earl rs. Van Alstine, 8 Barb. 630, which was an action for damag'es caused by plaintiff's horses being stung, resulting in the death of one of the horses.

EARL VS. VAN, ALSTINE.

The facts in this case were: That Van Alstine was the owner of 15 hives of bees. The bees were kept in his yard, adjoining the public highway. Earl, the plaintiff in the case, was traveling along the highway with a team of horses, and when he passed Van Alstine's place the bees attacked his hor'ses and stung them so severely one died.

Action was brought in the Justice's Court and Earl secured judgment for the sum of $\$ 7.25$ and costs. The case was appealed. to the County Court of Wayne County where the judgment was reversed. From the County Court the case was appealed to the Supreme Court, Seventli J11dicial District, which court affirmed the decision of the County Court, the decision being of date June 4, 1850.

The opinion was written by Justice Selden, and he discussed rery thoroly the questions involved, the opinion being in part as follows:

This case presents two questions:

1. Is any one who keeps bees liable, at all events, for any injury they may do?

2. Did the defendant keep those bees in an improper manner or place, so as to render him liable on that account?

It is insisted by the plaintiff that, while the proprietor of animals of a tame or domestic nature (domitae naturae) is liable for injuries done by them (aside from trespasses upon the soil) only after notice of some vicious habit or propensity of such animal; that one who keeps animals ferae naturae is responsible at all events for any injury they may do, and that as bees belong to the latter class, it follows, of course, that the defendant is liable.

In order to deternine this question, upon which no direct or controlling authority exists that I have been able to find, it becomes necessary to look into the principles upon which one who owns or keeps animals is liable for their vicious acts. It will be found upon examination of the authorities upon this subject that this classification of animals by the common law into animals ferae naturae and domitae naturae has reference mainly, if not exclusively, to right of property which may be acquired in them; those of the latter class being the subject of ab- 
solute and permanent ownership, while in regards to the former only a qualified property can exist, and the distinction is based upon the extent to which they ean be domesticated or brought under the control and dominion of man, and not at all upon the ferocity of their disposition or their proneness to do mischief. For instance, the dog, some species of which are extremely savage and ferocious, is uniformly classed among animals domitae naturae, while the hare, rabbit, and dove are termed ferae naturae altho completely harmless. It would not be natural to suppose that a classification adopted with exclusive reference to one quality of animals could be safely used to define and regulate the responsibilities growing out of other and different qualities; nor would it accord with that just analysis and logical accuracy which distinguishes the common law, that it should be resorted to for that purpose.

Chitty, under the head of actions on the case for negligence, gives the following rule: "The owner of domestic or other animals, not naturally inclined to do mischief, as dogs, horses, and oxen, is not liable for any injury committed by them to the person or personal property unless it can be shown that he previously had notice of the animal's mischievous propensity;', Chitty Plead. 82. This accurate elementary writer did not fall into the error of applying the rule to the whole of the class of animals. domitae, but adds the qualifications, "not naturally inclined to do mischief." By his arrangement of the subject, too, he confirms the view of Peake that the liability is based upon negligence.

These authorities seem to me to point to the following conclusions:

1. That one who owns or keeps an animal of any kind becomes liable for any injury the animal may do, only on the ground of some actual or presumed negligence on his part.

2. That it is essential to the proof of negligence and sufficient evidence thereof that the owner be shown to have notice of the propensity of the animal to do mischief.

3. That proof that the animal is of a savage and ferocious nature is equivalent to proof of express notice. In such cases notice is presumed.

Having slown then, I think clearly, that the liability does not depend upon the classification of the animal doing the injury, but upon its propensity to do mischief, it remains to be considered whether bees are animals of so ferocious a disposition that any one who keeps them, under any circumstances, does so at his peril. If it is necessary for the plaintiff to aver and prove the mischievous nature of the animal, nothing of the kind lias been done in this case; but if the courts are to take judicial notice of the nature of things so familiar to man as bees, which I suppose they would be justified in doing, then I would observe that however it may have been anciently, in modern days the bee has become as completely domesticated as the ox or row. Its habits and instinets have been studied, and thru the knowledge thus acquired it can be controlled and managed with nearly as mucl certainty as any of the domesticated animals; and altho it may be proper still to classify it among those ferae naturae, it must nevertheless be regarded as coming very near the dividing line, and in regards to its propensities to do mischief, I apprehend that such a thing as a serious injury to person or property from its attacks is very rare, not occurring in ratio more frequent certainly than injurjes aris ing from the kick of a loorse or a bite of a dog.

There is one rule to be extracted from the authorities to which I have referred, not ret noticed, and that is that the law looks with more favor upon the keeping of animals useful to man than such as are noxious and useless. And the keeping of the one, altho in some rare instances they may do injury, will be tolcrated and encouraged, while there is nothing to excuse the keeping of the other. In the case of Vrooman vs. Lawyer, 13 John. Rep. 339, the court. says: "If damage be done by any animal kept for use or convenience, the owner is not liable to an action without notice." The utility of bees no one will question, and hence there is nothing to call for the application of a very stringent rule to the case. Upon the whole, therefore, I am clearly of the opinion that the owner of bees is not liable at all events for any accidental injury they may do. The question is still left whether the keeping of bees so near the highway subjects the defendant to a responsibility which would not otherwise rest upon him. I consider this question substantially disposed of by the evidence in the case. It appears that the bees had been kept in the same situation for eight or nine years, and no proof was offered of the slightest injury having ever been done by them. On the contrary, some of the witnesses testified that they had lived in the neighborhood and had been in the habit of passing and $\mathrm{r}^{\circ} \mathrm{C}$ passing frequently with teams and otherwise without ever having been molested. This rebuts the idea of notice to the defendant, either from the nature of the bees or otherwise, that it would be dangerous to keep them in that situation, and of course, upon the principles already scttled, he could not be held liable.

The iudgment of the county court must be affirmed.

The two cases last mentioned (Parsons rs. Manser and Earl rs. Van Alstine) are in perfect harmony. In the first case the evidence showed the beekeeper was at fault; in the second, no.negligence of the 
beekeeper was proven. From these cases it can be seen that the law governing the location of bees is very simple. For a beekeeper not be liable for any injury that his bees may inflict on some other person who is acting within his rights the bees should be located in such a way that the beekeeper knows or should ordinary know that they will not be troublesome, for if he has knowledge that in the course of ordinary events the bees in the position where they are located are liable to molest others, he can be held to answer for whatever damages they may commit, and that means not only actual but punitive damages should the facts warrant.

\section{BEES NOT A NUISANCE.}

The liability of a beekeeper for any injury done by the bees to another person or the property of another rests on the doctrine of negligence, and not on the doctrine or theory that bees are a nuisance per se; that is, in themselves a nuisance. In the case of Petey Manufacturing Co. vs. Dryden (Del.) 5 Pen. 166; 62 Atl. 1056, the court used the following language: "The keeping of bees is recognized as proper and beneficial, and it seems to us that the liability of the owner as keeper thereof for any injury done by them to the person or property of another rests on the doctrine of negligence." Also see Cooley on Torts, 349 .

\section{CITY ORDINANCES DECLARING BEES A NUISANCE.}

The right to follow any of the ordinary callings of life, to pursue any lawful business vocation, is one of the privileges of citizens of this country; but it must be done in such a manner as is not inconsistent with the equal rights of others. Butchers Union vs. Crescent City, etc. 111 U. S. 746 ; 28 L. Ed. 591.

A city has a right under what is termed in law "Police Power" to pass ordinances for the public welfare, even tho the thing prohibited limits and restricts some person in the exercise of a constitutional right, if the act is for the public health and welfare. For example, laws prohibiting the maintaining of slaughter-houses in certain districts and the prohibiting of livery stables on certain streets have been held to be valid police legislation. But the act specified in the ordinance must, in the particular instance mentioned therein, be a nuisance. The mere fact that the city has passed an ordinance does not of itself make it so unless the bees are in fact a nuisance.

\section{ARKADELPHIA VS. CLARK.}

Arkadelphia vs. Clark, 52 Ark. 23; 11 S. W. 957 , is a case in point. 'This particular case was decided in 1889, and a report and history of it was published by Thomas G. Newman, then General Manager of the National Beekeepers' Union, for free distribution to the members. From the history of the case as given by Newman it seems that Z. A. Clark, the defendant in the case, was not in political harmony with those in power. He was a beekeeper, and it was sought to punish him and get rid of his presence by prohibiting the keeping of bees within the corporate limits of the city of Arkadelphia. So in May, 1887, the Arkadelphia city council adopted an ordinance which read:

Be it ordained by the Council of the City of Arkadelphia, That it shall be unlawful for any person or persons to own, keep, or raise bees in the City of Arkadelphia, the same having been declared a nuisance.

That any person or persons keeping or owning bees in the City of Arkadelphia are hereby notified to remove the same from the corporate limits of Arkadelphia within thirty days from the date thereof.

The ordinance also provided a penalty of not less than $\$ 5.00$ nor more than $\$ 25.00$ for violation of the ordinance.

In June, 1887, Clark was given notice to remove his bees. This he did not do, and he was arrested on January 2, 1888, and fined day after day for ten successive days. He did not pay his fines, so was committed to jail by the order of the mayor of Arkadelphia. Being a member of the National Beekeeper's' Union, he appealed to it for protection; and as it was considered that Clark was in the right the National Beekeeper's' Union engaged attorneys to defend the suit.

The decision as handed down by the Supreme Court was that "Neither the keeping, owning, or raising of bees is, in itself, a nuisance. Bees may become a nuisance in a city, but whether they are so or not is a question to be judicially deter- 
mined in each case. The ordinance under consideration undertakes to make each of the acts named a nuisance without regard to the fact whether it is or not, or whether the bees in general have become a nuisance in the city. It is therefore too broad and is invalid."

Another instance where a city tried to prohibit beekeeping within the city occurred in 1901, when the city of Rochester, N. Y., enacted an ordinance similar to the one enacted by the city of Arkadelphia. It was repealed on the ground that it was unconstitutional.

W. R. Taunton, a member of the $\mathrm{Na}$ tional Beekeeper's' Association, was living in Rochester. The National Association had an investigation made, by which it was ascertained that Taunton was handling his bees in such a manner as not to annoy his neighbors, and that he ought to be protected, so advised him not to remove his bees, and assured him that in case of trouble the association would defend him.

Taunton was arrested for refusing to comply with the ordinance and was tried in police court. The defense was that the ordinance was unconstitutional and void, and it was so held by the court, and the defendant was discharged.

A case where the bees were, from the evidence given at the trial, declared to be a nuisance, is that of Olmsted vs. Rich, $25 \mathrm{~N}$. Y. S. R. $271 ; 6$ N. Y. Supp. 826, which was an action for an injunction prohibiting the keeping of bees in a certain place and for $\$ 1500$ damages. At the trial the evidence showed that the beekeeper had a large number of hives of bees on a village lot adjoining the man who desired the injunction, and that during the spring and summer the bees interfered with the enjoyment of his premises. The bees drove him and his servants and guests from his garden and grounds, stinging them, and otherwise making his dwelling and premises unfit and unsafe for habitation, constituting a nuisance. The verdict was against the beekeeper for six cents damages and a permanent injunction was granted, which was affirmed on appeal.

\section{SHIPPING BEES BY RAIL.}

The general rule is, that it is the duty of a common carrier to carry all freight that is tendered to be carried. As to the right to refuse shipment, in Porcher vs. Northeastern R. R. Co. 14 Rich. L. 181, the court quoted with approval from Story, Bailments: "If he (the carrier) refuses to take charge of the goods because his coach is full or because they are of a nature which will at times expose them to extraordinary danger or to popular rage because he has no convenient means of carrying such goods with security, etc., these will furnish reasonable grounds for his refusal, and will, if true, be a sufficient legal defense to a suit for the non-carriage of goods." In Boyd vs. Moses, 74 U. S. 7 Wall 316; 19 L. Ed. 192, it was held that "A carrier" may refuse to take lard which is packed in such a condition that it cannot be carried without injury to the rest of the cargo." Also see note in 36 L. R. A. 649 .

The law, therefore, appears to be that if bees are properly packed for shipment it is the duty of a common carrier of freight to take them, but should they be not properly packed for shipment so that the carrier could refuse the shipment on any of the previously stated grounds he could legally refuse to accept them.

\section{LIABILITY OF RAILROADS FOR LOSS IN SHIPMENT OF BEES.}

It is the duty of a railroad to furnish a proper car when they undertake the transportation of bees; and the railroad company with which the contract for shipment is made is liable for injury caused by a defective car, even tho the car has left the initial road and was in possession of a connecting railroad. This was held to be the law in the case of International and G. N. R. R. Co. vs. Aten, a. Texas case reported in 81 S. W. 346, in which case the station agent was informed that the car was desired for a shipment of bees. The car furnished was not suitable, and by reason of the car not being suitable the bees were injured on a connecting road.

\section{BEES INJURIOUS TO FRUIT.}

That bees are an essential agent in the pollination of fruit blossoms, and that they are never injurious to sound fruit, or in any way injure fruit trees are matters that are firmly established. 
That bees do not injure fruit or fruit trees has also been established in a court of justice to the satisfaction of a jury. It was in the case of Utter vs. Utter, tried at Gosher1, N. Y., in 1901. As the case was not appealed from the trial court, the decision is not to be found in the reported cases. Iu the Utter case, like the Arkadelphia case, the bees were merely incidental. The facts were, that there had been years of previous trouble between the parties, and the suit over the supposed or alleged injury caused by the bees was but the culmination of the long-continued quarrels.

It was claimed by the plaintiff that the bees of defendant ate and destroyed plaintiff's peaches, and the trial was to ascertain if such were the case.

At the trial there appeared as witneșses for the defense A. I. Root and E. R. Root of Medina, Ohio; Frank Benton of Washington, D. C., and several others prominent in the world of apiculture. Frank Benton, at that time Assistant Entomologist of the Department of Agriculture, Washington, D. C., by reason of lis standing as a scientist and his general knowledge of matters pertaining to apiculture, was a very important witness.

The testimony of Mr. Benton established the following facts:

That the honeybee has a soft, pliable tongue, and could not puncture sound fruit; that the inner tongue of the bee is spoon-shaped and covered with hairs; that the tongue of the bee cannot become rigid; that the bee laps up the nectar; and that the feelers of the bee are soft and cannot pierce anything, being only organs of touch and smell. Mr. Benton's further testimony was to the effect that birds and other insects do the puncturing, and that then the bees may suck the wasting juices.

The jury found the bees not guilty of injuring the fruit and returned a verdict for the defendant, J. W. Utter.

\section{FRUIT DRYING.}

Where fruit is being dried is another matter, and there is no doubt but tlat damage is done by bees to drying fruit if they are allowed to work upon it. The sugar that bees carry away from the drying fruit is deducting just that amount of weight from the fruit, besides injuring its appearance. Bees can also make themselves a nuisance to those at work where fruit is being dried. In one instance known to the writer a beekeeper in California by reason of there having been a poor season in the mountains brought his bees to the small town where he lived. The principal crop in and about this town was fruit, and when the apricot drying season came on the bees became so thick on the newly cut fruit that a large force of girls who were cutting the fruit had to be laid off and operations stopped for the day. That night the beekeeper removed his bees some three miles away, and the next day made a satisfactory settlement with the fruitdryer, and so the trouble ended.

\section{LAWS RELATING TO FOUL BROOD.}

-In controlling bee diseases in a community, past experience has shown that it is necessary that every beekeeper do his part; otherwise the work done by individuals is largely nullified by the carelessness or neglect of a few. Where all the beekeepers are progressive, a simple plan of co-operation would be enough; but, unfortunately, there are in almost all communities some beekeepers who are either ignorant, careless, or willfully negligent. If any of these will not voluntarily care for their bees there must be some legal means of compelling them to abate a public nuisance when disease appears among their colonies.

Laws providing for inspection of apiaries with the object of controlling diseases are, therefore, drafted primarily for the beekeeper who does not voluntarily treat diseased colonies. The progressive beekeeper needs so such law to compel him to do his duty. The inspector of apiaries, however, in actual practice, is much more than a police officer; in fact, his police duties are but a small part of his work. However the law may be worded, the good which an inspector does is due in the greater part to his work as an educator. It is the duty of the inspector, specified in the law in most cases, to instruct the beekeepers how to know disease and how and when to treat.

Hawaii and the following States now have laws of some kind providing for inspection: Arizona, California, Colorado, 
Connecticut, Delaware, Florida, Georgia, Idaho, Illinois, Indiana, Iowa, Kansas, Kentucky, Maine, Maryland, Massachusetts, Michigan, Minnesota, Mississippi, Missouri, Montana, Nebraska, Nevada, New Jersey, New Mexico, New York, Oliio, Oklahoma, Oregon, Pennsylvania, Rhode Island, South Dakota, Tennessee, Texas, Utal, Vermont, Washington, West Virginia. Somewhat similar laws exist in New Zealand, some States in Australia, Ontario, Ireland, and parts of Enrope. The beekeepers in several other States are now agitating the passage of bee-disease laws.

These laws may be divided into two groups-those in which the work is done by men employed by the State, and those in which the county authorities appoint inspectors for the county only. Of these the work by the State officers has proven much more effective. In States where the counties are small, as in the East, county inspection is practically of no value.

In California the county plan for inspection has given fairly good results. The counties are very large, some of them as large as or larger than some States in the East. However, it has been felt that the State ought to have one general State Bee Inspector or State Bee Adviser, so that the work of the various counties would correlate a little better than it does now.

The chief weakness in county inspection is the lack of co-operation among the inspectors in neighboring counties. The differences in the ordinances or laws necessarily make inspection in one county more rigid than in another. In some cases, there is not only a lack of co-operation, but too often a jealousy between the various bee inspectors. In California this could be remedied by having a State Apiarist who night have more or less of a supervision of the rarious inspectors or bee advisers of the various counties. Where the States are smaller and likewise the counties, the scheme of county inspection has proven to be a failure.

Practically all laws in force, whether State or county, provide for inspection of apiaries; penalties for resisting the entrance of the inspector on the premises; penalties for failing to comply with instructions for treatment if the hives are found to be diseased, and penalties for. selling or bartering bees, hires, or appliances before the apiary has been pronounced free of disease. Usually additional provision is made for more than one inspection of queen-rearing yards. This is very wise as they might spread infection far and wide.

The Minnesota foul-brood law, based on the one in Wisconsin, is one of the best, and is here given as one of the best in force.

\section{APIARY INSPECTION LAW OF MINNESOTA.}

47323. State Inspector-Deputies.-There shall be appointed by the govermor a practical apiarist to be the State inspector of apiaries, who shall hold office two years or until his successor. qualifies, and who shall have power within the limitations set qut in section 12 [4734] of this act to appoint deputy inspectors as they may be required in the interest of time, economy or in emergency for inspection and treatment of apiaries in different parts of the State. The term inspector when used in this act includes deputy inspector unless otherwise specified. Vacancies in the office of State inspector of apiaries shall be filled for the unexpired term in the manner above prescribed for original appointment.

4724. Duty of Inspector.-It shall be the duty of the State inspector to aid the development of the bee and honey industry. and to adopt proper measures for the prevention and suppression of contagious diseases and infectious diseases among bees.

4725. Powers and Duties.-The State inspector shall have authority at his discretion to visit and examine personally or by deputy any apiary for the purpose of ascertaining the existence, or the treatment or destruction of any disease among bees or brood; and for this or any other purpose within the scope of this act he may enter upon private property. When notified of the probable existence of contagious or infectious disease of bees or brood in any apiary he shall visit and examine said apiary personally or by deputy as he shall deem most expedient within thirty (30) days from receipt of said notice. Wherever any contagious or infectious disease of bees or brood shall be found the inspector shall in. spect all apiaries within a radius of three miles of said apiary of which he is able to learn by diligence. After inspecting any apiaries or appurtenances thereof of bees or brood in which contagious or infectious dis. ease has been found he shall thoroughly disinfect every portion of his person and clothing and every tool and appliance used by him that may have been in contact with in. fected material, and shall cause every assistant with him to do likewise. No person shall refuse to assist in the inspection and in the 
necessary treatment or destruction of his infected brood, bees, honey or appurtenances, nor shall any person impede, hinder or obstruet an inspector in any of his duties. (As amended 1921, Chap. 517, Sec. 1.)

4726. Diseased bees declared nuisanceAbatement.-All bees, brood, and apiary appurtenances, infected with any contagious or infectious diseases which, after inspection by an inspector, who is hereby made sole judge of the character thereof, shall have been declared by him to be incurable according to his best judgment, and which appurtenances cannot be successfully disinfected, and are liable to spread disease, are hereby declared and adjudged to be public nuisances, and subject to abatement as such according to law. The inspector or deputy shall also cause said bees or brood or apiary appurtenances to be immediately destroyed by fre under his personal supervision, and the owner thereof or the person in charge of the same is hereby required to assist him in said work and to carry out such destruction according to his directions.

4727. Treatment of disease.-Wherever in the judgment of the inspector or his deputy it shall be practicable to cure the diseases or any of them which shall be found in any apiary, by treatment, he may order the bees and apiary appurtenances affected therewith to be treated for twenty-one days or until cured. Whenever treatment shall be so ordered the owner and the person in charge of said bees or appurtenances shall carry out proper treatment as prescribed. The inspector shall also inspect such diseased apiaries a second time after twentyone days when he shall cause all bees, brood, and appurtenances and honey in which the disease shall be found not to have been cured to be destroyed as in section 4 [4726] hereof so far as may be necessary to prevent the spread of the disease; and wherever said property shall be so destroyed the owner thereof shall receive no compensation therefor.

4728. Transfer of bees.-The State inspector or his deputies at his discretion may order the owner or the person in charge of bees dwelling in log gums, boxes or other receptacles in which the combs are stationary, to transfer said bees to hives wherein the combs shall be movable. In default of such transfer said bees and all the articles in which they are contained are declared to be a public nuisance, and shall be disposed of according to section 4726, General Statutes of Minnesota, 1913. (As amended 1921, Chap. 517, Sec. 2.)

4729. Offenses-Penalties.--(a). No person shall sell, barter, offer for sale or barter, move, transport, deliver, ship or offer for shipment, any apiary, bees, comb, or used beekeeping appliances without a permit from the inspector of apiaries; or in lieu thereof, if shipped or transported from with- out the State, a certificate duly issued by the official State inspector showing that said apiary, bees, comb or appliances have been inspected and found not infected with any contagious or infectious disease of bees. Such permit or copy of such certificate shall be affixed to the outside of every package, box, crate, or bundle containing bees, comb, or used beekeeping appliances. The inspector may refuse such permit whenever such refusal is necessary, in his judgment, to prevent the dissemination of any contagious or infectious disease of bees, or until after he finds by inspection that the said apiary, bees, comb, or appliances are not infected with any such disease.

(b) No person shall accept for shipment, ship or transport, any such bees, comb or used beekeeping appliances unless such permit or certificate is affixed on the outside of the package, box, crate or bundle containing the same; and the inspector or any of his deputies may forthwith seize and destroy any such shipment found at any time or place without such permit or certificate affixed as aforesaid.

(c) The use of any invalid or altered permit or certificate and the misuse of any valid permit or certificate are hereby prohibited.

(d) No person shall expose in any place to which bees have access, any bee product, hive, or other apiary appliance in such manner that contagious or infectious diseases of bees could be disseminated therefrom.

(e) Any person who knows that any bees owned, possessed or controlled by him are infected with any contagious or infectious disease shall at once report to the inspector of apiaries, stating all other facts known to him with reference to said contagion or infection.

(f) The words "person" and "owner", as used in this act include natural persons, firms, associations, and corporations; and any person who, himself, or by his agent or employe or as agent or employe for another violates any provision of this act, or any regulation or order made in pursuance thereof shall be punished by a fine of not less than five dollars nor more than one hundred dollars. (As amended 1921, Chap. 517, Sec. 3.)

4730. Queen bees, etc.-Any person engaged in the rearing of queen bees shall have his queen-rearing apiary inspected at least three times each summer season; on the discovery of the existence of any contagious or infectious disease in the bees, brood, or appurtenances of said apiary he shall cease to sell or give away any queen bees from said apiary until it shall have been declared free from disease by an inspector after inspection thereof. Candy used in mailing cages of queen bees shall be made from honey which has been boiled thirty minutes or more. Any person violat. 
ing this section shall be guilty and liable as prescribed in section 7 [4729] of this act.

4731. (Repealed 1921, Chap. 517, Sec. 4.)

4732. Affidavits.-Whenéver destruction or treatment of any bees or apiary appurtenances shall have been ordered the State inspector may require the owner or person in charge of said property to file an affidavit with him that the destruction or treatment has been carried out effectually.

4733. Meaning of "apiaries." -Apiaries within the meaning of this act shall mean any places where one or more hives or colonies of bees are kept.

4734. Salaries.-The State inspector shall receive a salary of fifteen hundred dollars $\$ 1,500.00)$ per annum in equal monthly payments, and shall be allowed the expenses necessarily incurred by him in the discharge of his duties. Deputy inspectors shall each receive six dollars $(\$ 6.00)$ per day for each day actually spent in the performance of his duties. The total expenses of the office, including salaries and compensation of all employes, shall not exceed the appropriation therefor. (As amended 1919, Chap. 100, Sec. 1.)

4735. Biennial report.-Record. - The State inspector shall make a biennial report to the governor stating the number of apiaries inspected, and the number where disease shall be found, the number of colonies treated, cured and destroyed, an itemized expense account of his deputies, and such in. formation as he nlay deem important to the State and of value to the art of apiculture. This report shall be printed by the State printer and copies thereof sent by the State inspector of apiaries to the members of the Minnesota beekeepers' association and to all in the State who may apply for it. He shall also keep a record of all apiaries and the location thereof in which contagious or infectious diseases shall be found within the last year of his office and turn the same over to his successor. (As amended 1921, Chap. 511.)

4736. Oath and bond.-The State inspector of apiaries shall take the usual oath of office and give bonds in the sum of two thousand dollars for the faithful discharge of his duties.

LAYING WORKERS.-These queer inmates, or, rather, occasional inmates, of the hive are worker bees that lay eggs. The eggs they lay do hatch, too; but they hatch only drones, and never worker bees. The drones are rather smaller than the drones produced by a queen, but they are nevertheless drones, in every respect, so far as is known. It may be well to explain that ordinary worker bees are not neuters, as they are sometimes called, but undeveloped females. Microscopic examination shows an undeveloped form of the special organs found in the queen, and these organs may become, at any time, sufficiently developed to allow the bee to lay eggs, but never to allow for fertilization by meeting the drone as the queen does. See ParTHENOGENESIS, DzIERzoN THEORY, and QUEENS.

\section{CAUSE OF LAYING WORKERS.}

It has been suggested that bees capable of this eg'-laying duty are those reared in the vicinity of queen-cells, and that by some means they have received a small portion of the royal jelly necessary to their development as bee-mothers. This theory has been entirely disproved by many experiments; and it is now pretty generally conceded that laying workers may make their appearance in any colony or nucleus that has been many days queenless, and without the means of rearing a queen. In the case of Cyprians, Syrians, and their crosses the laying workers are common, eren tho the colony has a good queen; and a case is known of a yearling queen in full vigor, a queen a few weeks old and reared in the same colony, and scores of laying workers, all busily laying on the same combs. The stock was Cyprian.

Not only may one bee take these duties, but there may be many of them; and wherever the beekeeper has been so careless as to leave his bees destitute of either brood or. queen for two or three weeks, he is liable to find evidences of their presence, in the shape of egg's scattered about promiscuously; sometimes one, but oftener half a dozen in a single cell.

Sometimes the eggs will be found stuck on the sides of the cell. In that case it is evident the laying worker cannot reach the bottom of the cell. Very often there will be found several eggs in a queen-cell.

If the matter has been going on for some time, one will see now and then a drone larva, and sometimes two or three crowding each other in their single cell; sometimes bees start queen-cells over this drone larva; the poor motherless orphans, seeming to feel that something is wrong, are disposed, like a drowning man, to catch any straw.

HOW TO GET RID OF LAYING WORKERS.

Prevention is better than cure. If a col- 
ony, from any cause, become queenless, be sure it has unsealed brood of the proper age to raise a queen; and when one is raised, see that she becomes fertile. It can ner er do any harm to give a queenless colony eggs and brood, and it may be the saving of it. But suppose one has been so careless as to allow a colony to become queenless and get weak, what is he to do? If he attempts to give them a queen, and laying workers are present, she will be pretty sure to be killed; it is sometimes difficult to get them to accept even a queencell. The poor bees get into a habit of accepting the egg-laying worker's as a queen, and they will have none other until they are removed; yet they can not be found, for they are just like any other bee; one may get hold of them, possibly, by carefully noticing the way in which the other bees deport themselves toward them, or one may catch them in the act of egglaying; but even this often fails, for there may be several such in the hive at once. A strip of comb containing egg's and brood may be given them, but they will seldom start a good queen-cell, if they start any at all; for, in the majority of cases, a colony having laying workers seems perfectly demoralized, so far as getting into regular work is concerned.

It is difficult to introduce a laying queen to such colonies; for as soon as she is released from the cage she may be stung to death. No better results would follow from introducing an ordinary virgin; but the giving of a queen-cell, or a justemerged virgin, if the colony has unt been too long harboring laying workers, will very often bring about a change for the better. In such cases the cell will be accepted, and in due course of time there will be a laying queen in place of the laying worker or workers; but often cells will be destroyed as fast as they are given. Some have recommended to scatter brood and bees among several other colonies, perhaps one or two frames in each. From each of these same colonies take a frame or two of brood with adhering bees, and put them into the laying-worker hive. The bees of this hive, which have been scattered into several hives, will for the most part return; but the laying worker or workers will remain and in all probability be destroyed in the other hives. Of course, the colonies that have been robbed of good brood will suffer somewhat; but if it is after the honey season, no great harm will have been done. They will proceed to clean up the combs; and if they do not need the diones they will destroy them.

While it is difficult, as lias just been stated, to introduce a queen to a colony that has laying workers it can be done, but no valuable queen should be used for the purpose. To introduce to laying workers use either the Miller smoke method or the Smith introducing cage as explained under INTRODUCING.

See that every hive contains at all times, during the spring and summer months at least, brood suitable for rearing a queen, and laving workers will not appear.

HOW TO DETECT THE PRESENCE OF IAYING WORKERS.

If no queen is found and eggs are scattered around promisenously, some in drone and some in worker cells, some attached to the side of the cell, instead of the center of the bottom, where' the queen lays them, several in one cell and none in the next, it may be assumed that laying workers are present. Still later, if the worker-brood is capped with the high convex cappings, it indicates clearly drone brood. Finding two or more eggs in a cell is never conclusive, for the queen often so deposits them in a weak colony where there are not bees enough to cover the brood. The eggrs deposited by a fertile queen ar'e usually in regular order, as one would plant a field of corn; but those from laying workers, and usually from drone-laying queens, are irregularly scattered about.

\section{LEVULOSE.-See HoNer.}

\section{LIME.-See Alfalfa and Clover.}

LIMA BEAN (Phaseolus lunatus.)Seventy-five per cent of all the beans harvested in the United States are grown in California, and more than 50 per cent of the entire crop comes from the southwestern counties of Ventura, Orange, Santa Barbara, and San Diego. In 1920 Ventura County reported 66,000 tons, Orange County 25,000 tons, Santa Barbara County 13,000 tons and San Diego County 11,000 
tons. Of the various varieties of beans raised in California only the Lima bean is of value to the beekeeper, altho the blackeyed bean has been erroneously stated to yield an amber-colored honey.

The crop of Lima beans in southern Califormia in 1918 was $1,505,000$ bags; in 1919 , it was 810,000 bags; and in 1920900,000 bags. It is estimated that in 1920 there was under cultivation 149,837 acres. California produces 85 per cent of all the Lima beans grown in the world. The only other place where they are planted on a commercial scale is on the island of Madagascar. The Lima bean is adapted to a coastal strip 20 miles in width, extending from Santa Barbara County southward to San Diego County, which is subject to heavy ocean fogs. Cool sea fogs and the absence of protracted hot spells are required for the maturing of the plant, otherwise it is apt to blight; but the dense fogs often retard the flight of bees.

This species is a twining vine with racemes of small white flowers, and compound leaves of three-pointed, ovate, entire leaflets. The pod is scimitar-shaped with a few large flat seeds. A bush variety of the Lima bean has been very extensively planted during the past few years. It is grown a little farther away from the ocean and is irrigated. In 1920 thousands of acres of this bean were planted in the San Fernando Valley which was the haven of many a migratory beekeeper. Nectar was yielded in abundance by irrigated bushLima bean fields, while bees dependent on the older variety of pole Limas were starying. The vines bloom in July and August and yield a heavy, white, mild honey which has an agreeable flavor. Most of the honey is secured during the first two weeks of bloom. It granulates quickly. The lioney crop from this source is rather uncertain as it is influenced by weather conditions. If there are many days of hot sunshine little nectar is secreted, and too much fog prevents the flight of the bees.

Ventura County leads the world in the production of beans, the larger portion of the acreage being devoted to Lima beans. There are rows of Lima beans a mile in length. In this county the crop of bean honey is usually fairly reliable, and an average of 50 pounds per colony is secured in a good season. But as much as 150 pounds per colony lias been obtained. Twice the crop has been a failure. Some years ago a hot wind literally withered the bloom, and again in 1920 the bloom was reported as nectarless. After the honey flow from the sages is over many beekeepers move their colonies to the bean fields. There have been as many as 2,000 colonies in a radius of three miles, and it has been estimated that nearly 500 beekeepers migrate to the bean fields.

As a rule the beans never receive a drop of rain from the time of planting to harvesting. The ground water and the ocean fogs furnish all the moisture they receive. The beans are planted in drills about 3 feet apart, and 10 inches apart in the row, by a machine planting three or four rows at a time. All weeds are destroyed by cultivation and hand-weeding. As there is no rain the vines do not require poles, but can lie on the ground without rotting. The beans are harvested by a machine with two knives, each knife cutting one row. After threshing the beans are sacked and transported to great warehouses 300 feet long by 100 feet wide. The crop ranges from 1,000 to 2,000 pounds per acre. After the bean crop is removed the fields are so bare that a sheep would starve on a hundred acres, and there is no pasturage for bees.

Bean farming in California is conducted on a very extensive scale. On the Irving ranch in Orange County, which is one of the largest single tracts of land in the West, 25,000 acres of beans are planted each year. Between Los Angeles and the Palmis there are several ranches which contain 2,000 to 3,500 acres. Probably not less than a dozen bean ranches in soutliern California contain 10,000 acres of land. The land is plowed and liarrowed by tractors working day and niglit. Modern bean farmers are beginning to practice irrigation and intensive cultivation on tracts of 40 to 300 acres in extent, as the result of the high rentals paid for the use of the land.

\section{LINDEN.- See BASSWOOD.}

LIVE-BEE DEMONSTRATION. - See HoNeY EXHibits.

LOCALITY.-No one should enter extensively on the production of honey until 
he lias found a suitable location, for the foundation of success in beekceping is the location. Many of the manipulations recommended for one locality will not answer for another. The same hive under different conditions may give very different results. The length of the flow and the time it begins must receive careful consideration. If the honey flow is short and rapid, as in the basswood regions where the honey is mainly white, it is, as a rule, more profitable to produce comb honey than extracted honey. But a slow honey flow extending over three or four months may render the production of comb honey impracticable since the combs will be travel-stained and will not command the highest market price.

Locality also exerts a great influence on the treatment the bees should receive. If no honey is stored after the middle of July, and the beekeeper lives in a State where snow falls in winter and cold weather prevails for five or six months, he will not encourage brood-rearing till September when he will feed to stimulate and to provide sufficient winter stores. If, however, he has a fall flow he is fortunate to get the colonies in the best possible condition for winter. If the beekeeper is located in the South the bees will require a much larger amount of stores than in the North, for in a warm elimate the bees are more active and consume more honey in broodrearing. The bees in the northern States are likely to perish from cold; in the southern States from starvation.

Some localities are so cold that only cellar wintering is practicable. (See WINTERING IN Celuars.) South of these extremely cold places outdoor wintering in doublewalled hives or packing cases is preferable.

Some regions of the country are favorable for the propagation of European foul brood mainly for the want of early flows to build up the colonies in the spring.

Many inqurries have been received as to the best locations for beekeeping. So many factor's enter into this question that a sat. isfactory reply is difficult to give, and often the beekeeper can remain at home to advantage. The value of a locality depends on the personality and methods of the beekeeper, as well as on the honey flora. "The poor quality reported for many regions," says Phillips, "is probably due to poor beekeeping. In many sections adequate trials of commercial beekeeping have not been made. The prevalence of foul brood is not a serious drawback to a genuine beekeeper and there are advantages in choosing a location where it has cleaned out competition."

Beekeeping is only moderately successful in New England, but the bee pasturage of this section might be greatly improved by more commonly planting alsike clover instead of red clover. Excellent results have been obtained in the Champlain Valley, Termont, where there are limestone soils and the surplus comes from white and alsike clover. Other good locations are Aroostook County, Maine, the Berkshire Valley, Massachusetts, and portions of central Connecticut.

In the production of honey New York leads the eastern States. On the glacial till soils of St. Lawrence and Jefferson Counties the clover's yield an immense amount of white honey. A second white clover belt extends from Buffalo to the Hudson River, which includes a large number of apiaries located among the Finger Lakes, Cayuga County, and around Syracuse, Onondaga County. The southern portion of the State, especially the southwest corner, is the great buckwheat country, where this plant is usually a reliable source of honey. Another important center for bee culture is found in the eastern part of the State in Schenectady Connty where the clovers, buckwheat, and basswood are abundant.

Southeastern Pennsylvania is in a very high state of cultivation and few follow beekeeping as a vocation. Along the northrentral border and in the northwest corner thousands of acres of buckwheat are grown. Within the mountains there are many fertile valleys with limestone floors, where the clovers flourish and yield well. Southwestern Pennsylvania in the region of the great steel mills and oil fields affords little pasturage for bees. New Jersey, Delaware, and Maryland are not considered beekeeping States from a commercial point of view and the average surplus per colony is low.

Thruout the southern States many of the colonies are still in "gums," but beekeepers 
are transferring into modern hives very rapidly. The number of colonies per square mile is greater here than elsewhere in the country, which indicates good beekeeping conditions." The solution of the problem in the South," says Phillips, "lies in the development of a few extensive beekeepers relatively who will practice migratory beekeeping. If the difficulties of transportation can be overcome the South can produce enormous crops of loney." In the southeastern States the honey crop comes chiefly.from the swamps or from the mountains, and in both locations the honey plants are mostly shrubs and trees. Much of the soil is acid and white clover is found only to a limited extent.

The pine barrens of eastern Virginia offer little opportunity for bee culture. A good locality is the section of the Piedmont Plateau east of the Blue Ridge. In the Great Limestone Valley west of this range of mountains and in the smaller limestone valleys in the southwest portion of the State the area of sweet clover and white clover is yearly increasing. There is, however, little commercial honey production in Virginia. Beekeeping is most prosperous in Kentucky in the famous blue grass region or the Lexington Plain. It is a limestone area, and in Pendleton and Bracken Counties there is a great acreage of sweet clover. The Coastal Plain of North Carolina, with its vast area of swampland covered witl gallberry, gum trees, huckleberry, and blackberry, offers, in the opinion of E. R. Root, great opportunities to the specialist. The cotton belt is the poorest part of the State for beekeeping. Sourwood and tulip tree yield a large surplus in the western highlands and mountains. Beekeeping is in a very undeveloped condition in Sonth Carolina. More than $10,000,000$ acres of pine barrens are largely destitute of honey plants. Good opportunities may be found in Horry County on the coast, and in Pickens and Oconee Counties in the northwestern part of the State.

In southeastern Georgia where the gallberry and tupelos are abundant the honey crop is usually reliable, and a surplus of 100 pounds per colony is often obtained. There is little commercial beekeeping in northes'n Georgia. About one-thind of the honey crop of Florida comes from the black and white tupelos growing in the swamps of the Apalachicola River.

A light crop of honey is often obtained in central and southern Florida from orange and palmetto, and black mangrove in some seasons yields well in the southwestern part of the State. Migratory beekeeping is found to be fairly profitable on the Keys. (See Migratory Beereeping.) In general, beekeeping in Florida is not as profitable as in many northern States. The great advantage of the peninsula State is from the standpoint of health, and for this reason much of the available bee-territory is overstocked.

In Alabama and Mississippi the best section for beekeeping is the Black Belt, or sweet clover belt, a tract of land which extends from Union Springs, Alabama, to Noxubee County, Mississippi, where it follows the State line northward to Tennessee. Thousands of acres of sweet clover flourish in this section, and the apiaries, which range from 50 to 200 colonies, are much larger than in other parts of the State. In the Yazoo Delta are the most fertile soils in Mississippi and a more dense acreage of cotton can not be found elsewhere in the South; but none of the honey plants are of great value except holly, without which, declares a beekeeper, it would not pay to keep bees. Fair opportunities for beekeeping may be found near the swamps and in most of the river valleys of both Alabama and Mississippi.

In Louisiana the alluvial tracts along the Red and Mississippi Rivers and the Atchafalaya River Basin are as well adapted for honey production as any portion of the southern States. It is in these sections that white clover has taken such a strong hold. It grows here more luxuriantly than in the North and yields a large amount of honey. Unfortunately only a few beekeepers are located in the territory as yet. The southeast half of Arkansas belongs to the Coastal Plain, and, as the honey flora of the lowlands is dependable, it offers excellent opportunities for engaging in beekeeping on a commercial scale. A thorny chaparral of Mexican origin cover's the Rio Grande Plain in southeastern Texas. Huajilla, ratsclaw, mesquite, coma, and a score of 
other shrubs yield nectar so copiously that in a favorable season it is almost impossible to overstock this region with bees. On the Black Prairie, which extends from San Antonio to the north border line, cotton is a reliable honey plant, and seldom fails to yield a large surplus. West of the Pecos River agriculture is dependent upon irrigation, and alfalfa is the main dependence of several large honey producers.

In most of the southern States the honey yields are lighter than in the North. As in California the queens from continual breeding wear out, leaving colonies weak when they should be strong.

In no part of the United States are the soils and weather conditions better adapted for the growth of white clover than in northwestern Ohio, eastern Indiana, southern Michigan, southern Wisconsin, southern Minnesota, and in Louisiana along the rivers. In the Upper Peninsula of Michigan alsike clover is very abundant and thousands of acres of unoccupied territory invite the beekeeper. In southwestern Indiana large crops of honey are stored from climbing milkweed, and in the northwestern corner Spanish needles and boneset in the Kankakee swamps are valuable in the fall. White clover, sweet clover, and heartsease are so common in Stephenson County that no other portion of northwestem Illinois produces so large a surplus of honey. On the Mississippi River, where there is a wide valley, Spanish needles, heartsease, and boneset assure a dependable fall flow. Northern Wisconsin is at present only partially developed, but the pioneer beekeeper will find it one of the most promising sections in the United States. Also in the cut-over region of northern Minnesota there is little competition and a profitable crop of honey may be expected annually.

In Iowa there are two sweet clover regions, one in the eastern part of the State, especially in Jackson County; and the other in the western part of the State along the Missouri River extending southward from Sioux City. Good results may be expected in almost every county in this State. The majority of successful beekeepers in Missouri are located near the Missouri and Mississippi Rivers and their tributaries, but there are not many commercial beekeepers in this State. When white clover fails on the uplands, a crop may be obtained from the fall flowers along the rivers.

Thruout the western States semiarid conditions prevail, except in the rain belt west of the Cascade Range, and commercial beekeeping is dependent almost entirely on irrigated alfalfa and sweet clover. The bee pasturage of North Dakota is promising; but in South Dakota there is a large area of sweet clover in the southeastern counties, and in the Black Hills there are thousands of acres of irrigated alfalfa. The Belle Fourche Valley is an ideal farming region. Where alfalfa is grown without irrigation in Nebraska the yield varies greatly in different sections and in different years. It is most reliable in the valley of the Platte River, which crosses the State from west to east. In Kansas likewise alfalfa in many portions of the State is an uncertain honey plant, but it is most dependable on all streams west of Topeka. Good locations in Oklahoma are found along the larger streams, as the Canadian and Washita Rivers. In Nebraska, Kansas, and Oklahoma the future of beekeeping will depend largely on the increase of the sweet clover acreage, which is now coming on very rapidly.

The largest surplus of honey in Montana comes from the irrigated lands along the Yellowstone River and from Ravalli County in the Rocky Mountains. Probably in no State in the Union are larger crops of honey produced than in northern and southeastern Wyoming. In the Great Plains of Colorado bee culture is profitable only in the valleys of the South Platte and Arkansas Rivers. There are few bees in the Rocky Mountains, but on the Western Slope irrigated alfalfa and sweet clover along the irrigating ditches seldom fail to yield a bountiful harvest. Bee culture in New Mexico is restricted mainly to the valleys of the Rio Grande, Pecos, and San Juan Rivers.

At Sandpoint in northern Idaho white clover, buckbush, and fireweed are excellent sources of honey. In southern Idaho the best locations are the irrigated alfalfa fields in the Boise Valley and in the vicinity of Twin Falls. Most of the beekeepers of Utah are found in the Uinta Basin and the mountainous tract extending thru the 
central portion of the State. Nexada is largely a desert, but the western counties produce the finest and whitest alfalfa honey. The Salt River Valley of Arizona was for many years a famous country for beekeeping, but during the World War, the great fields of alfalfa were ploughed, and seeded with long staple Egyptian cotton, which is largely used in the manufacture of automobile tires. The decline in the price of cotton has rendered its cultivation unprofitable, at least temporarily, and neither cotton nor alfalfa is likely to be extensively grown for a few years.

Commercial beekeeping in Washington and Oregon is confined wholly to the irrigated areas west of the Cascade Range. In the Yakima Valley, Washington, and in Umatilla County, Oregon, irrigated alfalfa is the chief honey plant. In the lumbered regions of the Coast Range, where there is a heavy rainfall, fireweed offers wonderful possibilities, but the colonies require special management and the nectar flow is not always reliable. Undoubtedly California leads all the States of the Union in the total amount of honey produced. The most important honey plants are orange, the white, black, and purple sages, Lima bean, and alfalfa. The secretion of nectar is largely dependent on irrigation, rainfall, and fog. Alfalfa is the chief source of surplus in the Central Valley, but star thistle is very important northward. In the southwestern counties of Santa Barbara, Ventura, Los Angeles, Riverside, San Bernardino, Orange, and San Diego most of the commercial beekeepers are located. Migratory beekeeping is extensively practiced. The home apiary is usually located in the foothills near the orange. groves. After the flow from orange bloom is over, it is mored to the sage ranges, then to the bean fields, and perhaps later to wild buckwheat. Within 150 miles of Los Angeles, says E. R. Root, there are more bees and beekeepers than in any other part of the United States, and full 50 per cent of them are located in the sage ranges. One difficulty in southern California is bee diseases, both the American and European foul brood. The bees breed almost every month in the year and of course the brood diseases can continue for ten or eleven months. It takes good beekeeping to orercome this and the tendency for the queens to wear out, leaving the colonies with insufficient brood at a time of the year when it is most needed to insure a force of bees for the orange. In the Imperial Valley the surplus flow comes almost wholly from irrigated alfalfa and cotton. A fair average is 75 pounds per colony and it is seldom that a crop is a failure. Few bee ranges are unoccupied and no one should migrate to this section without first investigating. The valley was formerly known as the Colorado Desert.

In a general way it may be said that the yields per colony in the North are larger than in the South. Moreover the higher the altitude and the further north one goes, the better the quality of honey and the larger the average yields.

LOCUST (Robinia Pseudo-Acacia).Variously called common locust, black locust, white locust, yellow locust, false Acacia, pea flower, locust, post locust, and locust tree. This is one of the finest honey trees of the eastern and southern States. It belong's to the great family of the Leguminosae, which includes many of the best honey plants, as the clovers, sainfoin, red bud, honey locust, sweet clover, and huajilla. It is a native of the inountains from Pennsylvania to Georgia, and westward to Missouri and Arkansas; but has become extensively naturalized in Canada, New England, and the eastern States. Large plantations of it have been made for timber. The wood is hard and very durable, and is much used for posts. There is a saying that stone will crumble before locust will rot. The tree grows to medium size, and is long-lived except when attacked by borers. It spreads rapidly by, sprouts rising from the roots, which run under grounid for long distances near the surface. When the trees are cut or killed by borers the roots send up a great many sprouts, which grow very rapidly and flower within two or three years.

The white, very fragrant flowers are similar in form to the blossoms of the garden pea, but are in pendent clusters like those of wistaria. They appear in May or June, and the blooming period lasts for abont 10 days. Under farorable conditions a large amount of milk-white honey of heary body and mild flavor is secured, but it is not a 
reliable honey plant and does not bloom every season. In Rhode Island locust seeds freely and new growths are appearing at points quite distant from the old plantations. In some parts of the State it towers 50 to 60 feet tall with a diameter of 2 feet. Its planting is urged by the Agricultur- the nectar. Black locust is common in the villages everywhere in Kentucky, but it is less abundant in the forests. It is one of the honey plants which help to carry the bees thru the first half of the season. In the eastern Tennessee Valley and in the Central Valley around Nashville locust is

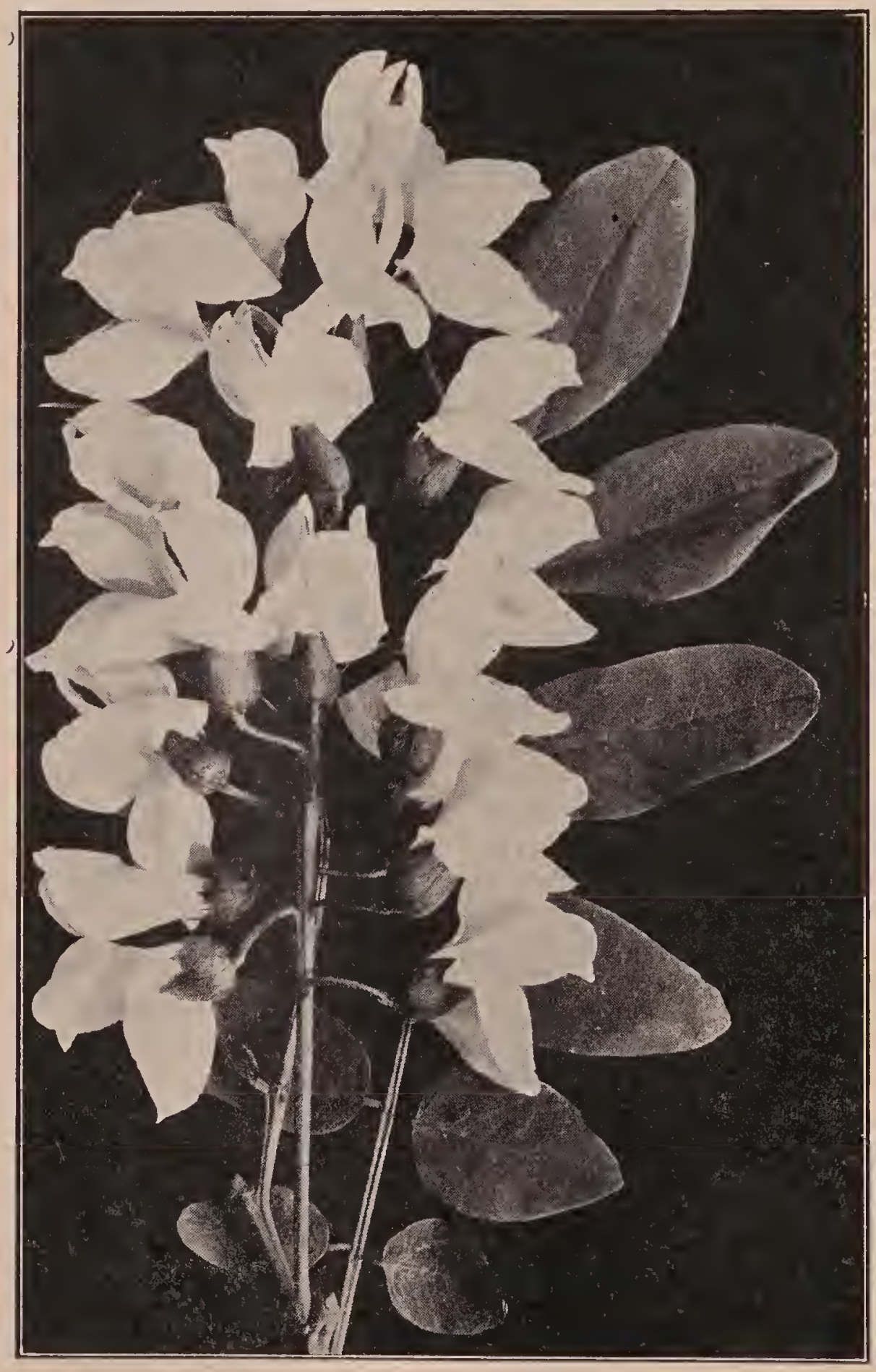

Common Locust.

al Department of the State. In southeastern Indiana it is rery common, and strong colonies of bees secure a surplus from the bloom. But the flowers appear so early and last for so short a time that weak colonies are able to gather only a part of listed as important. At Laurelsprings, N. C., a full super of honey is gathered from the locust bloom. There are thousands of trees in the pastures, for the farmers never cut them except for fence posts. The honey is excellent, thick, and white 
and does not granulate quickly. Unfortunately frost kills a part of the bloom in late seasons, but trees on the hills do not suffer as much as those in the valleys.

'Two other species of locust occur in eastern North America. The clammy locust, or $R$. viscosa, is similar to the above; but its flower's are tinged with pink and are inodorous. It is a native of the mountains from Virginia to Georgia, but has been introduced in the North where it seems perfectly hardy. The other species, bristly locust or rose acacia (R. hispida), is a shrub growing from three to ten feet high. The stems are covered with bristles, hence the name. The flowers are large, rose-colored, not fragrant, and few in a cluster. It is a native of the mountains from Virginia to Georgia, but has also been introduced and become established in the North. While of no particular value as a honey. plant, it is very beautiful as a cultivated shrub.

LOGWOOD (IIaematoxylon campeachianum).-A tree found in the West Indies and Central America, the heartwood of which furnishes one of the important vegetable dyes. In its early stages the heart is only a small colored core, but at maturity there is little sapwood between the heart and the bark. The dyewood is prepared for shipment by digging up the trees by the roots, and chipping away the outer sapwood; the colored core is then ready to be rendered into dye.

There are large areas in the tropics, where this tree is the predominating growth. When in full bloom, many square miles of country are suffused with the mellow beauty of its golden blossoms, and the air is everywhere filled with the pleasing and delicate perfume. The honey is almost white, very dense, and possesses a peculiarly pleasant flavor suggestive of the fragrance of the bloom. But in American markets it does not sell as readily or command as high a price as white clover honey.

In Jamaica logwood is the principal source of honey. There are usually two main periods of bloom-one occurring in November and the other about Christmas time. The first bloom is not wholly dependable, as it is usually light. At the same time there are other plants in bloom, as bitterbush, which yield an inferior honey, so that the finished combs held up to the light reveal a patchwork of various colors. But this mixed flow is valuable since it enables the bees to fill the brood-chambers, and thus later causes them to carry the main logwood flow into the supers.

The second or main flow occurs about Christmas time, and may last thru January. Here lies the hope of the apiarist. 'Two factors then contribute to his crop. The first is the condition of his colonies. They must be ready, or the finest honey of the year goes to brood and brood-combs. Even if barrels of sugar must be fed, a super should be on every hive, and bees in the supers by the middle of December. The second factor is rain. "We have watched," says a Jamaican beekeeper, "the great strings of buds drooping heavily downward, and the forests beaded with folded blossoms all ready to burst-one factor was missing-rain. We have seen, while full apiaries waited, the untempered torrid sun burn the blossoms into crumbled dust. But let the rains fall at the proper juncture, and thousands of acres burst into fairyland. We have seen evenings when everything looked hopeless. That night a shower fell. At daybreak the apiary was a-roar, and the clear atmosphere was black with bees." Of course, the duration of the principal bloom is also dependent upon light intermittent showers. There have been seasons when the main bloom lasted for six weeks, and individual colonies made as high as 500 pounds of honey. In four days 250 colonies are reported to have gathered 6000 pounds of honey. A rain at night abruptly ended the flow and the blossoms the next inorning had turned brown.

Is there no danger of the logwood forests being destroyed? Hardly, unless the land is desired for agriculture. Logwood grows spontaneously in the forests and the growth is so extensive that there is no necessity of planting young trees-the only attention required is the thinning out of the yearly natural propagation. Otherwise the logwood estate needs little attention. The main expense is to prepare the mature stock for market, and this consists in paying laborer's so much per ton for "chipping." Owing, howerer, to the rapid introduction of aniline dyes, the logwood in- 
dustry is being supplanted by others that are more profitable-such as cultivation of sugar rane, bananas, etc. But where a gen-. uine logwood estate can be found, the beekeeper can afford to establish an apiary of some 500 colonies.
MANGROVE, BLACK (Avicennia niti$d a)$.-There are in southern Florida three different trees called mangrove, the red mangrove, the white mangrove, and the black mangrove. The red mangrove (Rhizophora Mangle), an evergreen shrub or tree, belongs to the mangrove family. Along the coașt of southern Florida and the Keys it forms dense tidal swamps, advancing into the water where the shores are flat and mucky. The seeds germinate, while still on the tree, and falling into the mud in an upright position immediately strike root. The trunk and branches send out aerial roots, which descending in an arched fashion give the tree the appearance of stepping forward. The flowers are small and yellowish.

The white mangrove (Laguncularia racemosa) also called white buttonwood, is a member of the white mangrove family. It is common on the seashore of peninsular Florida and in the West Indies and tropieal America. In Florida it is usually a shrub with leathery oval leaves and small greenish flowers. Neither the red mangrove nor the white mangrove is of value to the beekeeper.

The black mangrove (Avicennia nitida), also called blackwood and black tree, belongs to the verbena family, most of the species of which in the North are herbaceous plants. It grows on the seashore of southern Florida, the Keys, and eastern Texas, also in tropical America. In Florida it is not found to much extent north of Ormond on the east coast. It usually grows back of the red mangrove, and in localities where both grow together the red mangrove fringes the shore and makes new land, while the black mangrove is a soil-former.
Both are valuable in catching drift and lodging humus and grachally transforming the shallows into reefs and islands and finally into solid land. But the black mangrove does not actually grow in the water.

The black mangrove, when it grows to the size of a tree, resembles a scragly old oak with a rongh brown bark. It may be 25 to 50 feet tall, with a trunk diameter of four feet, or on the Keys it may attain even greater size. Northward it is seldom more than a shrub. The leaves are leathery, oblong, with very short stems, and when they unfold are somewhat hairy, but later become bright green and shining. above, paler or nearly white beneath. The flowers are small, inconspicnons, in terminal clusters, appearing at all seasons of the year. The wood is dark brown and very durable in contact with the soil. When used as fuel it burns with intense heat.

As a source of honey the black mangrove has attracted more attention than any other tree in Florida. Up to the year of the "big freeze," in 1894, phenomenal yields were reported. As much as 400 pounds of honey from one hive in a single season have been recorded. In these earlier days migratory beekeeping was in practice, and many colonies of bees were moved to the vicinity of Hawks Park from points up and down the coast and from inland localities 50 miles distant. It was hardly possible then to overstock a mangrove section in a favorable season. But the severe winter of 1894 froze and killed the mangrove to the ground. It did not recover from this check for 18 years, and not until 1909 did it again yield nectar, and then only in small quantities. Since that year the bushes have gradually grown 
in size and the yields have increased also, but as yet they can not even be compared with those preceding 1894.

On the numerous small islands of Indian River and along the east shore of Florida southward from Ormond, there are thousands of acres of black mangrove from six to fifteen feet tall. There are a few beekeepers located in the mangrove swamps of southwestern Florida, but not so many as on the east coast, as at Ariel and near New Smyrna. At Cocoanut Grove, Dade County, a mixture of mangrove and cocoa-

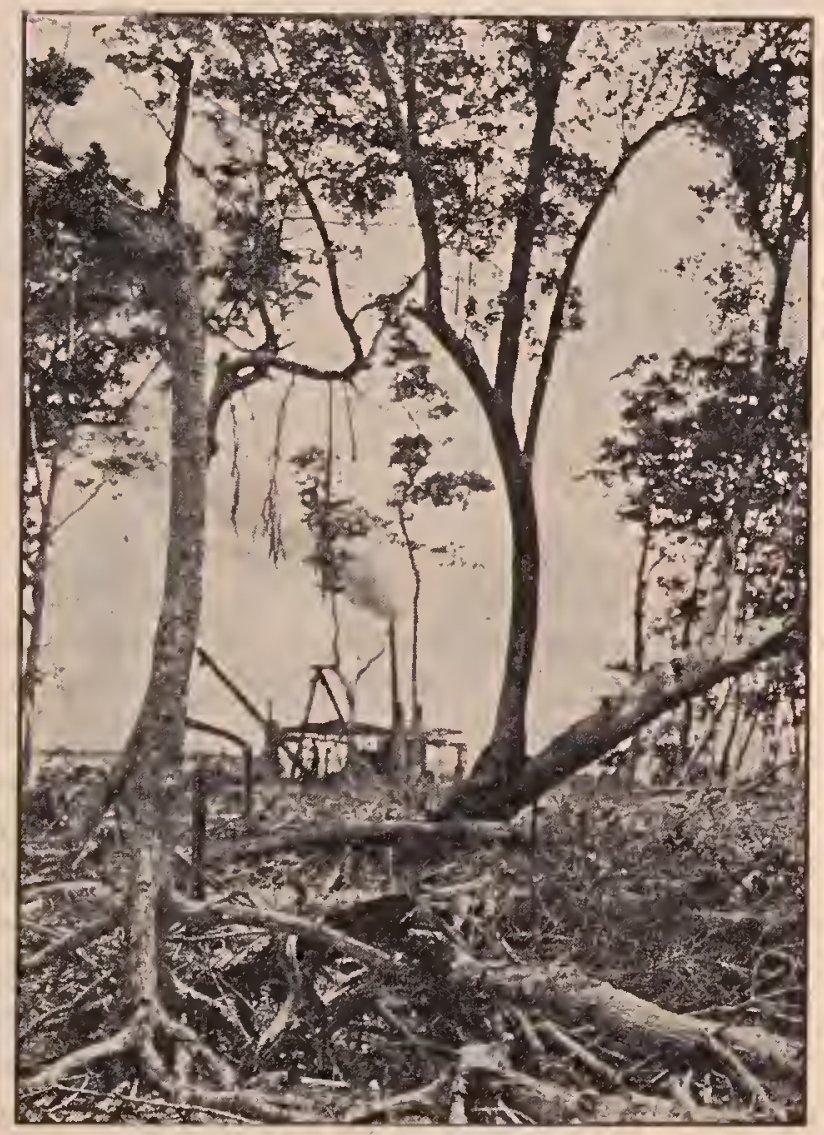

Black mangrove on the right; red mangrove on the left.

nut honey is secured, which is much lighter than the mangrove honey alone, owing to the cocoanut honey. There are also a few colonies of bees in the vicinity of Everglade, which is about 70 miles south of Fort Myers. This is a promising section, but it is wholly undeveloped, and the country is as wild as it was 40 years ago. It is the home of the Seminole Indians and few white people live there.

At Punta Gorda on the west coast black mangrove begins to bloom from May 1 to 15 according to the season, and remains in bloom until July 15 or a little later. When atmospleric conditions are favorable the nectar can be seen in large drops shining in the little cups, and-a bee can obtain a load from a single blossom. According to Frank Stirling of the State Plant Board of Florida, the honey is dark colored and is used very largely in the manufacture of sweet cakes. On the east coast it is usually blended with the honey from cabbage palmetto, which blooms at the same time, and is in consequence lighter colored. At Punta Gorda, says Ward Lamkin, when there is a heavy flow, the honey is light colored but thin and not very sweet, with a salty or brackish taste, as the trees grow on the sand flats which are often flooded witl salt water by the tide.

The secretion of nectar is greatly influenced by the weather. In 1911 near New Smyrna it yielded well early in the season, and the bees left their hives for the mangrove swamps almost before dawn hurrying across the coves of salt water the entire day; but after two weeks the weather suddenly changed and hardly a bee was seen again on the blossoms, altho they still continued to open. At Punta Gorda in 1919 the crop of mangrove was very small, but in 1918 it probably exceeded 100 pounds per colony. In this same year a beekeeper below Ft. Myer's reported the crop a failure.

\section{MANIPULATION OF COLONIES.-}

Success or failure in the bee business depends very largely on manipulation. Colonies can be so handled as to make the business an entire failure. Sometimes improper handling so disgusts the would-be beekeeper that he never becomes one. Temperamentally he may not be fitted for the business, or else mentally he may be incapable of acquiring the art of handling them. A great majority of persons, however, who love honey and who enjoy outdoor work, have no difficulty in learning to handle what perhaps a few erroneously regard as a "mighty dangerous proposition." Over and over the statement has been made, "Bees would sting me, even if I were half a mile away from them. The further I am away from them, the better I like it." There is a sort of silly fear, on the part of a few at least, that bees are "mighty dangerous animals," and that their disposition is to rule or ruin, and to 
take possession of the field because they are possessed of that small but mighty weapon, the sting. Nothing could be further from the truth.

There is probably not one person in a hundred who is not perfectly capable of handling bees. Whether he can make money or honey out of them is not a question so easy to answer, but that he can learn to handle them-that he can overcome all natural fear and prejudice - has been demonstrated by thousands who have commenced beekeeping, and know no fear of them.

Under the head of ANGER OF BEES and under STINGS it is shown that bees are not the irascible little creatures that many

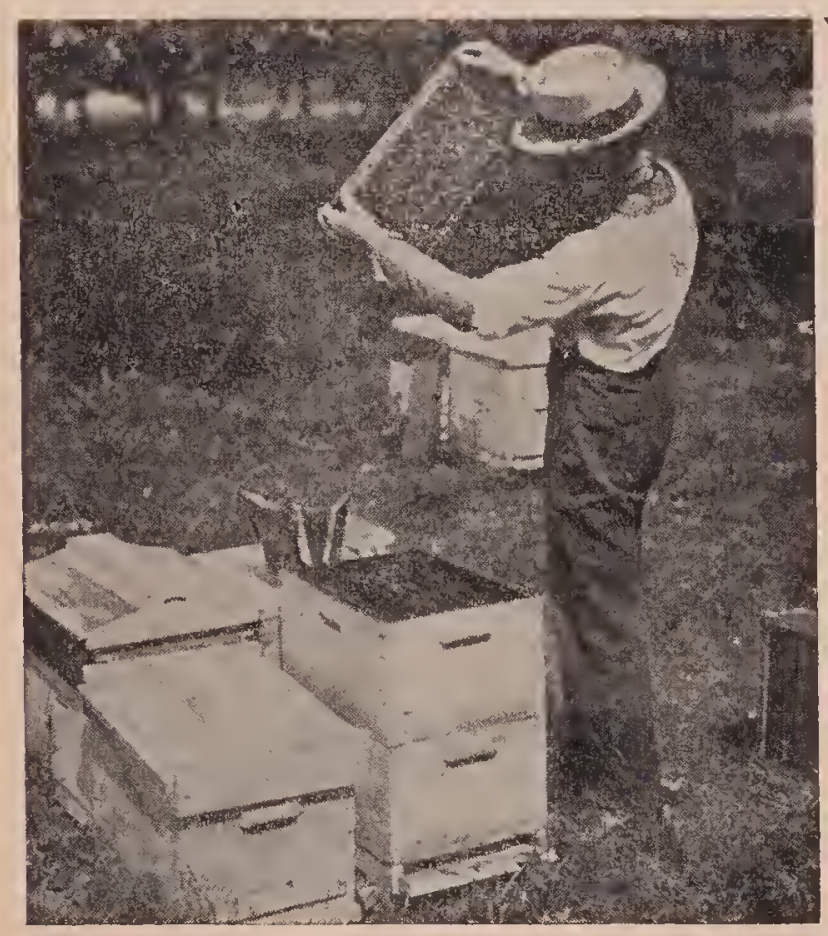

people suppose; that they are, on the contrary, when their nature is carefully studied, as gentle as kittens; and when one goes about it in the right way, they can be handled almost as safely. (See A B C of BEEKEEPING at the beginning of this work.) But one cannot thoroly know this until he has actually opened a hive or seen it opened, and actually handled the combs for himself. This is not saying bees will not sting when handled improperly or at the wrong time.

The beginner should understand that bees can be worked very much better when weather conditions are right. The day should be warm, the sun shining, and the time selected for the manipulation between ten in the morning and three in the afternoon. Experienced beekeeper's can liandle them at any time under practically all conditions; but even the veterans endeavor to do it when they can work to the best advantage. In early spring or late in the fall, or when the atmosphere is chilly, or at any time immediately following a rain, or after a sudden stoppage of the honey flow, bees are inclined to be cross. When it is cold, the bee glue in the hives is brittle. In order to open a hive at such times it is necessary to break this bee glue with a snap or jar. This always has a tendency to irritate the bees, even when weather conditions are favorable. The beginner at least should select his time, and of course will endeavor to make his movements very deliberate, avoiding quick jerky movements, all snaps or jars. There are times when one will be compelled to open hives when the bee glue snaps and when the bees sting; but he will then have the experience and proper appliances for doing the work.

\section{TOOLS FOR BEE WORK.}

Before details of manipulations are considered, it will be necessary to take up tools and conveniences, without which the handling of colonies would be difficult or even impossible at times. There are several essentials which may be mentioned in the order of their importance: A beesmoker (see SMOKERs) for quieting the bees; a bee-veil (see VEILS), and suitable clotling for protection against stings, and some form of knife, screwdriver, or hivetool to separate the frames and parts of the hive from each other that are usually stuck together with bee glue. Without the smoker and its intelligent use one would feel almost inclined to go back to the days of our forefathers when they brimstoned their bees (see Box Hrves). But with smoke properly applied, one can render bees tractable that would be otherwise nervous and hard to handle. Even when conditions are bad, weather chilly and propolis hard, they can generally be brought under control. The intelligent use of the smoker will often render the use of the veil unnecessary; and not a few experienced beekeepers do not use a veil constantly, but have it conveniently hanging from 
the hat, whence it can be pulled down, whenever necessary. A bee-veil, horvever, is generally worn by veterans and beginners alike all the time while at work among bees. It is annoying and disconcerting to have cross bees buzzing around the face with the possibility of a sting in the eye, nose, or mouth. The beginner will always have a greater sense of security when his face is protected, and the old hand works with less interruption.

Gloves (see Gloves) are recommended to the novice when he opens a hive for the first time. After he has learned the habits of bees he may dispense with them, because he will at most receive only an occasional sting on the hand. Very often experienced beekeepers wear a long gauntlet that reaches from the elbow to the wrist. This should be made so. that no bees can get up the sleere. It should fit tightly around the wrist, or, better yet, reach far enough to cover the hand, leaving the ends of the fingers exposed.
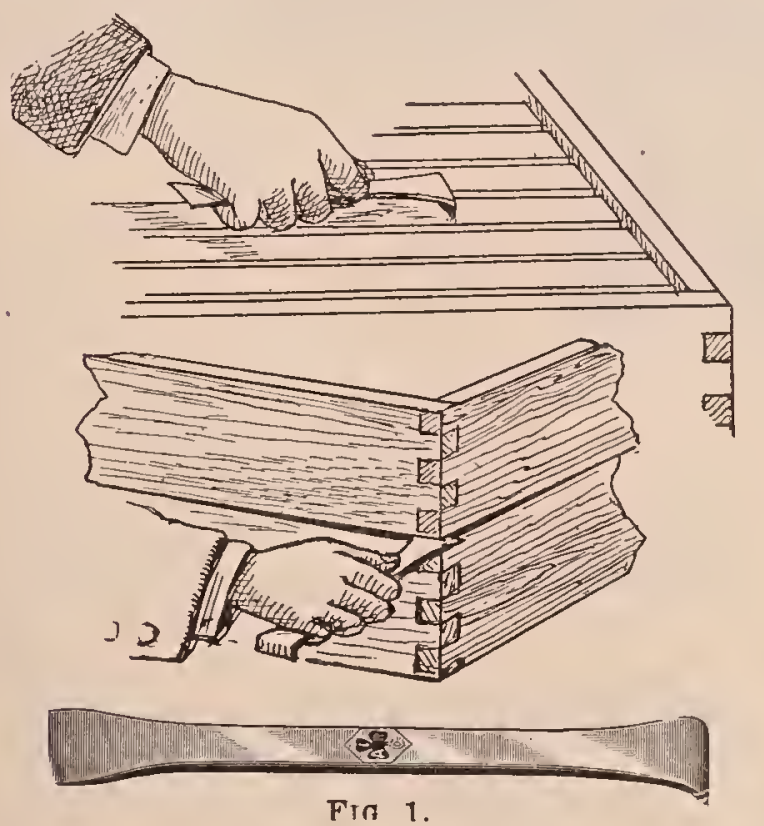

If one is ver'y timid, or is unusually susceptible to stings, he can wear gloves that protect the fingers as well as the whole hand, wrists, and forearm. See Gloves.

In the line of tools a common jackknife or a common screwdriver may often be used in lieu of something better. But a hive-tool made for the purpose is far superior.

The subjoined illustrations show a form of tool that has given general satisfaction among beekeepers.
It is something that any blàcksmith can make out of an old buggy-spring or any good piece of spring steel. It must not be tempered too hard or it will break. Each end should be flattened out while hot, and brought to an edge. One end is bent to a right angle, and the other is left straight. The tool is then finished on an emery wheel or grindstone, eare being taken to have the edges straight and square.

The hooked end is ordinarily used for scraping propolis or wax from the frames or bottom-boards, while the other end (also useful for scraping) is pushed between the two parts of the hive. The drawing (Fig. 1) shows the tool held improperly. The bent or curved end should be placed directly against the palm in order that sufficient pressure may be exerted to shove the other or straight end between the two hive parts.

Either end of the tool may be used for separating Hoffman frames, or, in fact, any style of frame tluat one happens to use; but the author prefers the hook end. This is inserted between the frames to be separated, as shown in Fig. 2, when a side twist of the wrist will exert considerable leverage, forcing apart the frames very gently. However, there are some who prefer to use the straight end of the tool in the manner shown in Fig. 3; but the method given in Fig. 2 exerts more of a leverage, and, at the same time, is less liable to erush bees.

Fig. 4 shows how the tool may be used for crowding all the frames over to one side in one block; or one can, if he prefers, use the plan shown in Fig. 2; but it will generally be found that the one shown in Fig. 4 is more convenient. In Fig. 5 the curved end is used to good advantage in lifting the division-board out of the hive. See also, in this connection, Fig. 9.

Some prefer a hive-tool having a narrowed end like a screwdriver; but the continuous use of a tool like this abrases the edges of the hives so that, after a time, it leaves bruise marks and cracks, inviting winds and storms, and robbers when they are prowling about. For separating two hives heavy with honey there is nothing better than a wide thin blade made of good spring steel, tempered just enough to have the resilient qualities of a buggy-spring. 

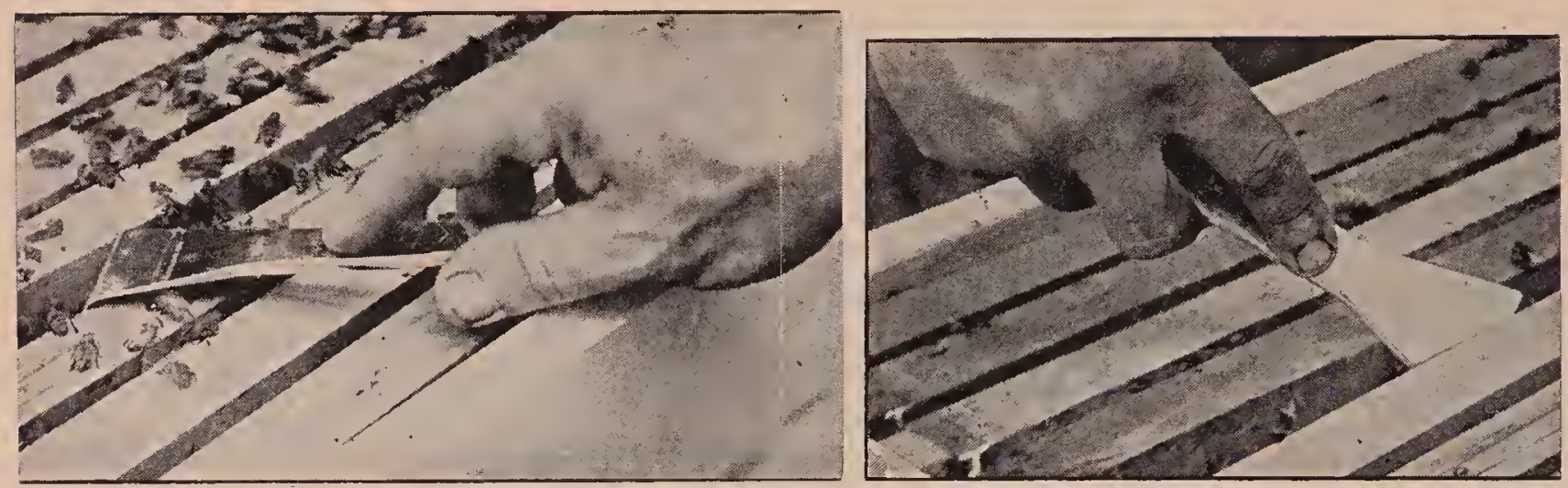

Fig. 2.-A side twist of the tool affords a strong Fig. 3.-Another method of using a hive-tool when leverage by which the frames are separated easily and without jar.

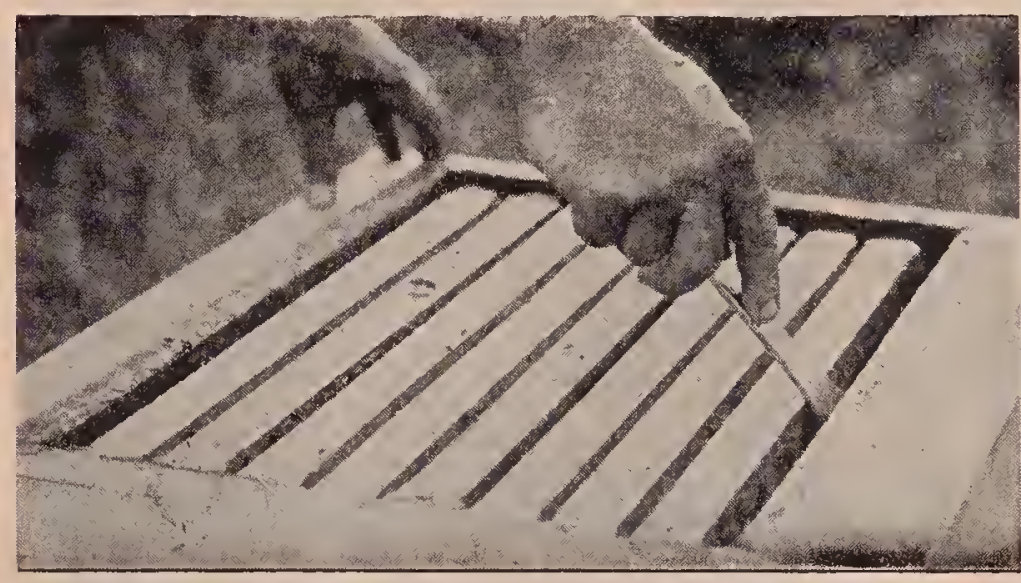
prying the frames apart.

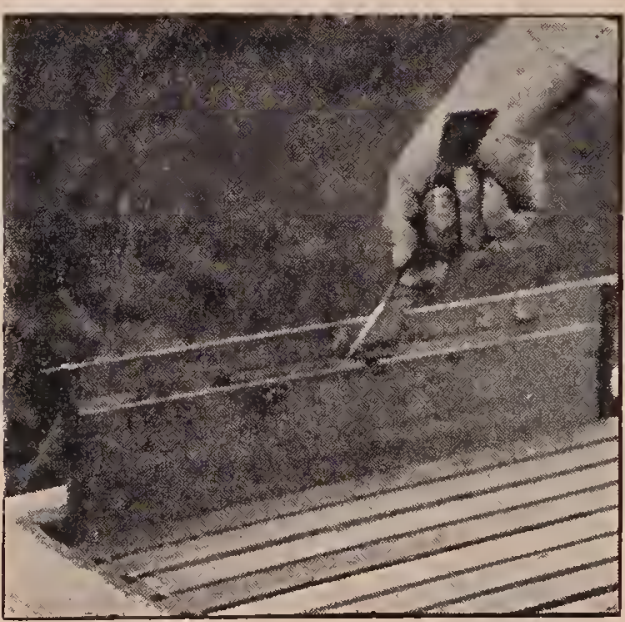

FIG. 4.-The proper way to pry all the frames over at one operation.

HOW TO WORK OVER HIVES.

Many yard men prefer to work with a sort of stool and hive box combined; yet others wish to have nothing to lug around except the bee-smoker and the hive-tool. As most lives are placed on or near the ground, one must either sit down on some object or kneel in front of the hive, to bring himself to the proper working distance. Many use a hive-cover as shown in Figs. 6, 7, 8, 9. It is always handy and has the further advantage of a milk-stool in that one can shift his body back and forth on the hive-cover in order to reach frames toward the near or far side of the hive, as the case may be. A seat that does not allow one to shift his body back and forth, necessarily requires more stooping or bending of the back.

Occasionally it will be found desirable to turn the cover up lengthwise, and the author always uses it in that manner when he desires to place the weight of the body against the frame that is crowding over against its fellows. (See Fig. 8.) In pulling out a division-board, one lias a little more leverage if he sits high rather than low.
FIG. 5.- How the hook end is useful in fishing out frames and division-boards.

(See Fig. 9.) But if he merely wishes to separate the frames, then spend several minutes hunting for the queen or looking over the brood, as shown in Fig. 7, he should sit on the narrow side rather than on the end. In this the operator assumes a very natural, easy, and comfortable position. The left arm rests upon the knee, supporting the weight of the frame, while the right arm holds it in a position for examination.

A change of position is often restful. After one has been working over a number of hives, sitting down on the hive-cover, he finds it convenient to vary the position by resting on the linees close to the live; and still again he may. find it comfortable to vary the monotony by standing upright, bending over only when it is necessary to remove a frame.

Perhaps it may seem that the operator in Fig. 9 is taking things easy. There are times when only one hand can do good work. If one can assume a comfortable attitude, even tho it be only momentary, he ought to do so.

Some of our apiarists will say they have no time to sit down, much less "loaf on the 


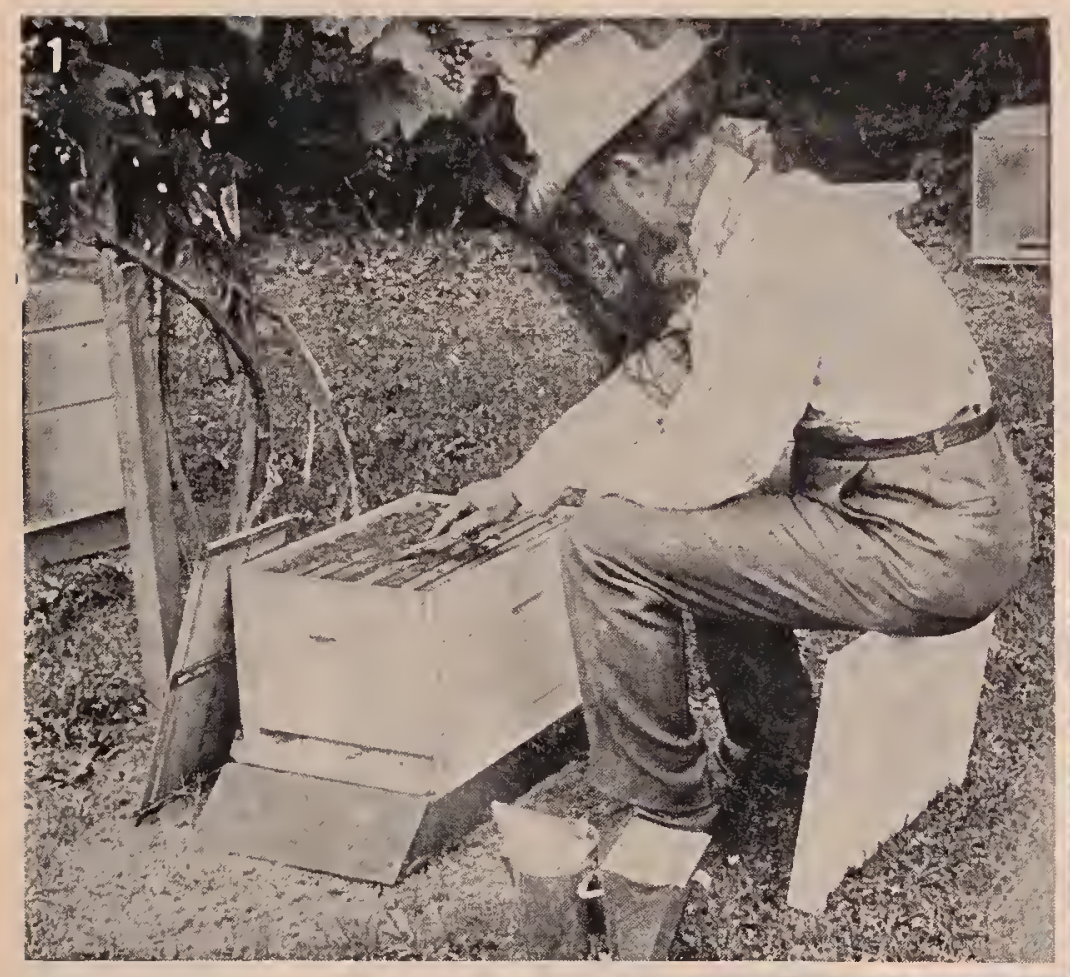

The smoker has a hook on the bellows so that it can be carried in the manner shown. With this whole outfit one has practically all the tools he needs, including smoker fuel, for a day's work.

The exact dimensions of the seat are not important. The one here shown is 13

FIG. 6.--Making a gap between the frames so that one can be easily l'emoved.

job," as unight appear in Fig. 6 . The more one can save his legs and arms the more he can actually accomplish in a day. In hunting for a queen one cannot afford to stand up on the job, but should get right down where the eyes can do their best work, as seen in Fig. 7, always holding the

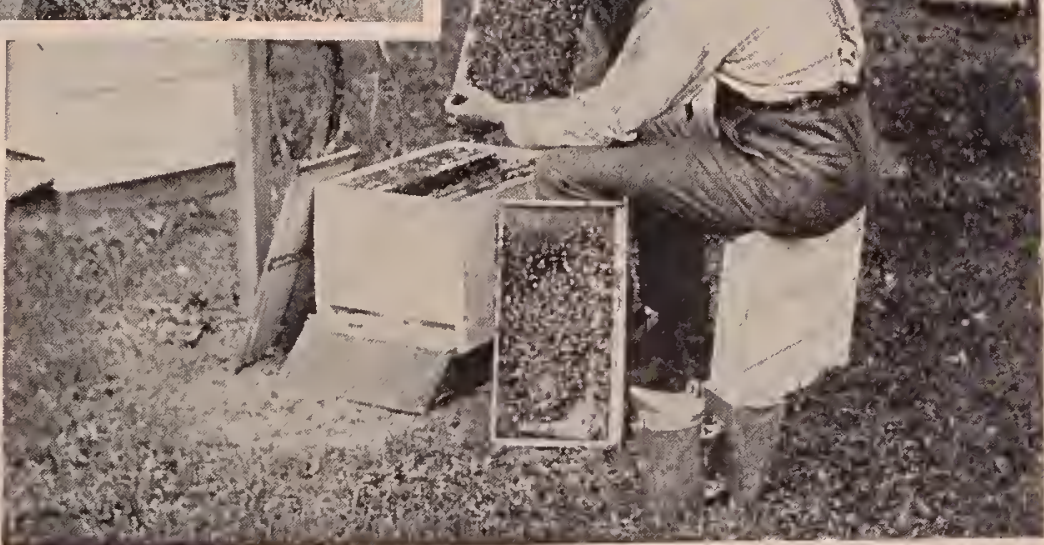
frame in such a way that the sunlight will strike it squarely. In looking for eggs this is very important, especially if the operator is getting old when eyesight is not at its best.

Where one is working over bees day after day, a special hive-seat is a great convenience. The adjoining illustration shows one used quite extensively.

The top is made of $7 / 8$ lumber, having two oblong holes in the center to provide a handle by which to carry the box. The legs are also of $7 / 8$, while the sides, ends, and bottom are of $3 / 8$. The compartment in the side, reached by the oval hole, is very handy for holding broken section pieces for record work, and other small articles, while the two compartments on the ends usually hold the smoker fuel, hive-tools, hanmer, bee-brush, queencages, and other articles of like nature.

inches high by 22 long, ontside measurement.

\section{HOW TO OPEN A HIVE.}

The prospective beekeeper should approach the hive and blow smoke into the entrance. This is not always necessary, but it will be found to be a wise precaution for the beginner and for an experienced

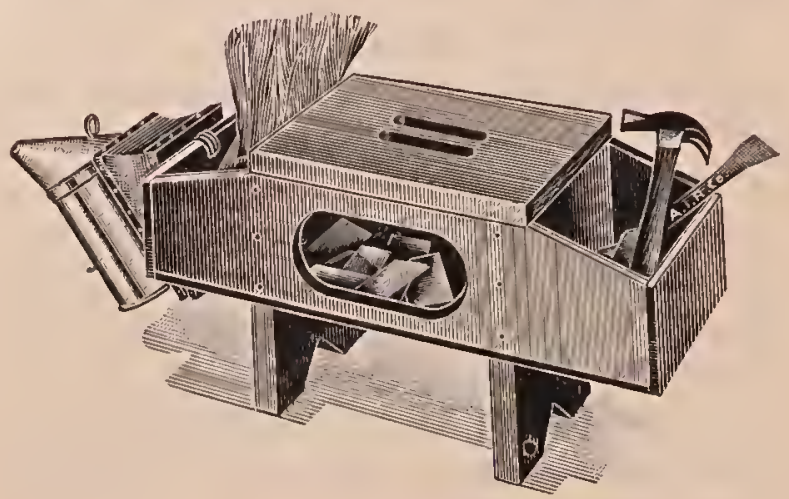

Handy seat and tool-box for yard work. 
man on a bad day. After the beginner learns the individual temperament of his different colonies, and also discovers that on certain days, and certain times of days, the bees can be handled much better than on other's, he will of course use his judgment in the matter. If he has reason
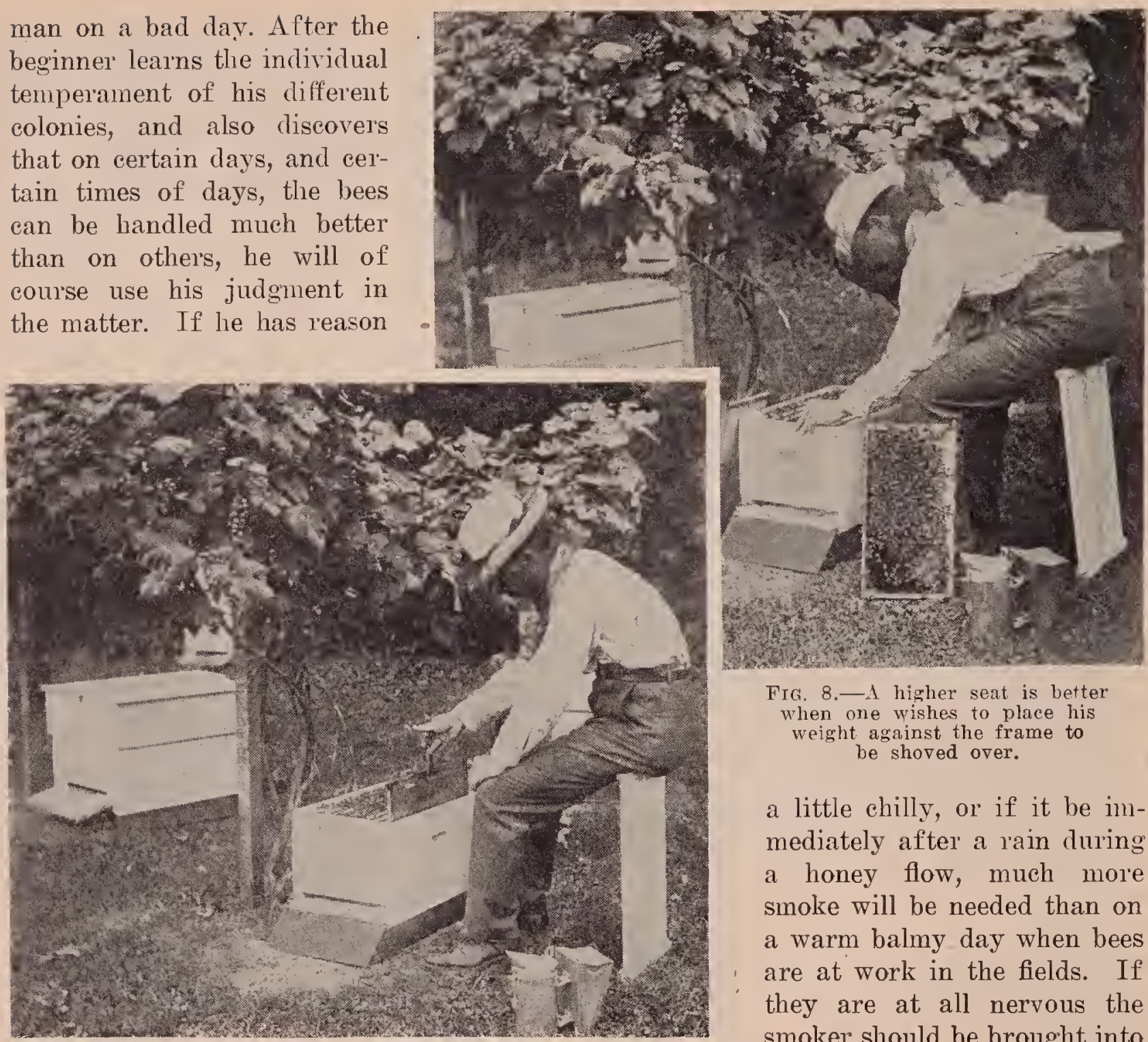

FIG. 8.-A higher seat is better when one wishes to place his weight against the frame to be shoved over.

a little chilly, or if it be immediately after a rain during a honey flow, much more smoke will be needed than on a warm balmy day when bees are at work in the fields. If they are at all nervous the smoker should be brought into FIG. 9.-Pulling out a refractory division-board that resists removal. play again; indeed, at such times it should be put be-

to believe that a colony would be irritable lie should send two or three puffs of smoke into the entrance. He will now push the screwdriver; or special hive-tool already shown, under the cover. He should do this gently, working the thin edge of the blade between the two hive parts until the cover is raised about the thickness of the blade, but not wide enough to allow any bees to escape. Thru the gap thus made he should blow three or four puffs of smoke. He then shoves the tool a little further, increasing the gap, following it up with some more smoke. He now lifts or lowers the hand holding the tool so that the cover is raised an inch above the hive. The smoker is next set down upon the ground, when the cover is gently lifted off -gently, because this is important.

Some times much more smoke will be required than at other's. If the atmosphere is tween the knees. See SMoke AND SmorERS.

This nervousness on the part of the bees may not immediately be recognized by a novice; but for his special benefit it should be said that, when bees are subdued and require no more smoke, they will be down between the frames almost out of sight; but if they are inclined to "resent the intrusion," dozens and dozens of them may have their heads sticking up; and as the apiarist proceeds to lift out a frame he may meet with a "warm reception." A few bees may hop up two or three inches and then drop down again. This apparently is a warning or a bluff that something worse will happen if the apiarist is not careful. But before this takes place he will usually see on the part of the bees a nervous, quick movement, their bodies twitching either to the right or to the left, 
apparently ready to take wing. When they do so, it may be a hop of two or three inches or a quick sharp dart, without warning, for any exposed part of the beekeeper's anatomy. But even if the bees do make a general onslaught, and grab as if about to strike, stings may be averted if. the operator is quick enough to brush the bee or bees off. There is an interval of a fraction of a second, not very long, it is true, in which, after the bee shoves its claws into the flesh, it can be brushed off, just before the sting gets into action, for a bee, when it stings, must have a good strong hold, and it is while it is taking this hold that. the apiarist can often save himself many a wicked jab.

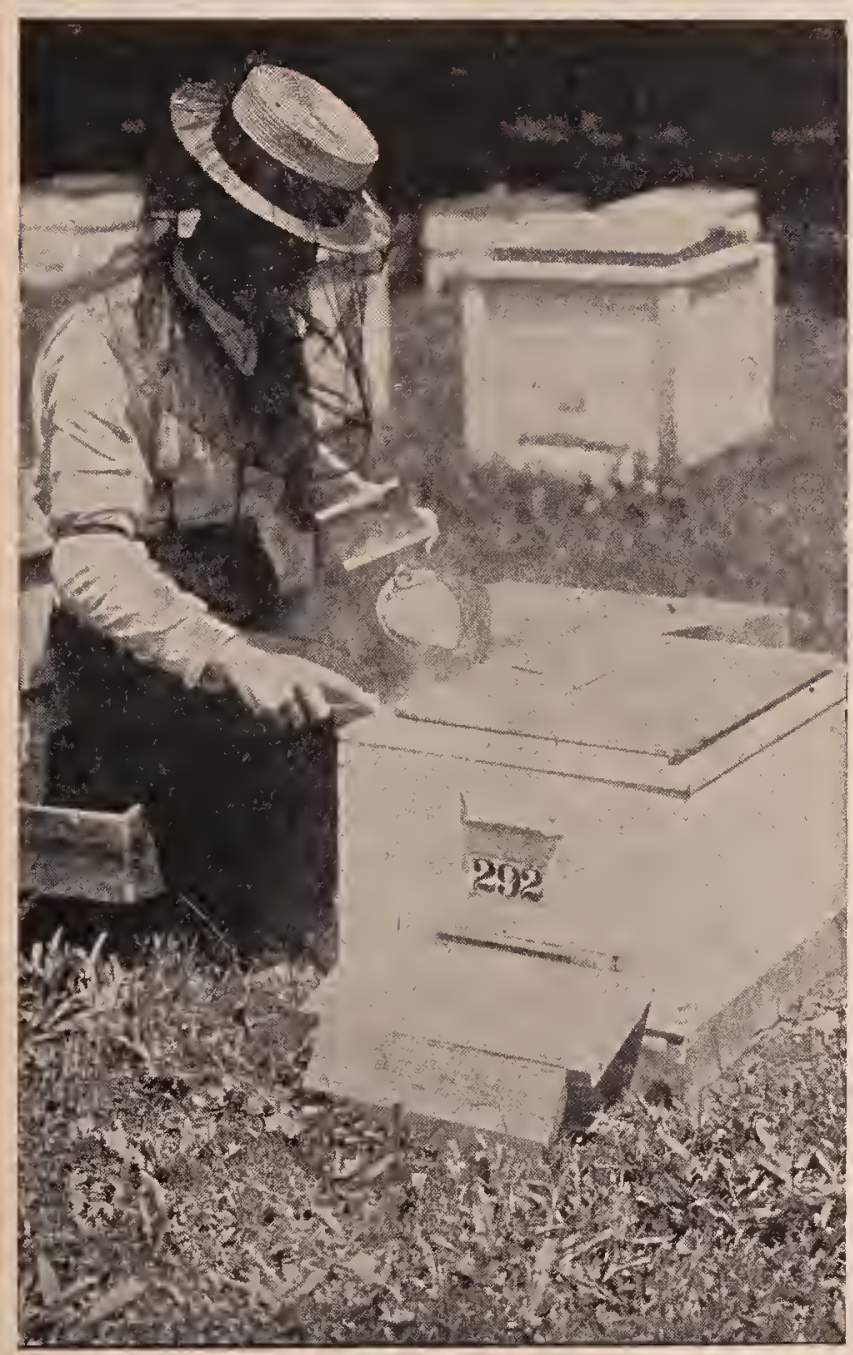

Fia. 10.-Method of inserting the hive-tool under the cover; blowing smoke into the gaj thus made.

If, then, the bees seem inclined to fly 11 , they should be smoked just enough to keep them down. If an attendant is present, let lim use the smoker. See Strings, subhead "How to Avoid Being Stung."
HOW TO TIANDLE UNSPACED FRAMES.

To get at the center frame, crowd the frames adjacent to it, one at a time, toward the sides of the hive. This will give room to lift out the desired frame. Beginners are very apt to pull the frames out without spacing the frames apart. This rolls the bees over and over, enrages and maims them, and moreover runs a pretty good chance of killing the queen. Lift the frame out carefully, and be careful not to knock the end-bars against the sides of the hive. If it is one's first experience he may be nervous, and do things a little hurriedly. As a reward, the bees will quite likely sting lim and make him still more nervous. To avoid this, proceed very cautiously and make the movements deliberate. Having removed the frame, hold it up as shown in Fig. 1, called the first position.

$$
\text { HOW TO FIND THE QUEEN. }
$$

Perhaps the queen is not to be seen on this side, so it may be necessary to turn it over and see the other side. If the comb is not heavy with honey, it can be turned right over with the bottom-bar resting horizontally. But a better way, and a good habit to fall into, and one that beekeepers usually adopt, is to raise the right hand until the top-bar is perpendicular, as in Fig. 2.

Now revolve the frame like a swinging door, or the leaf of a book, so that the opposite side is exposed to view (see Fig. 2 ). Lower the right hand as in Fig. 3 until it reaches the position as shown in Fig. 4. To examine the other side follow the exact reverse order.

Having examined this frame, lean it up against the side of the hive, and remove another frame next to the one already taken. Examine this in like manner. Lean this also against one corner of the hive, or return it to its place; lift out another, and so on until all have been examined. Should the queen not yet have been found, look the frames all over again, being careful to examine the bottom edge of the combs. See How to Manipulate Hofman Frames.

If the queen is not found on the second examination it may be advisable to go over the frames once more; but very often it is better to close the live and wait an hour or 
two, after which one can go back and search the frames as before. By this time the colony will have recovered itself, and the queen, in all probability, have shifted her position from the bottom or sides of the hive to one of the combs. Nine times out of ten she will be found at the second going-over of the frames, without any

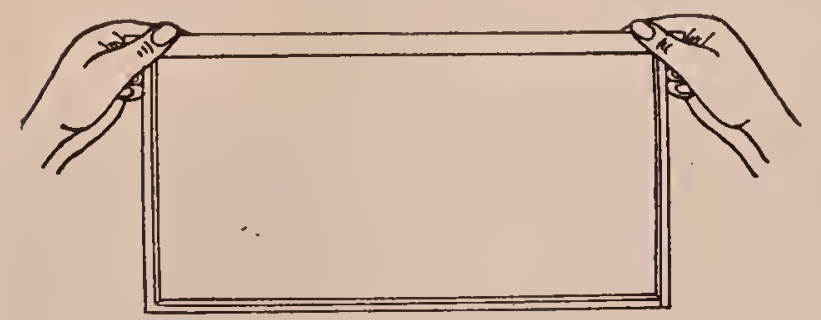

FIG. 1.-First position of frame.

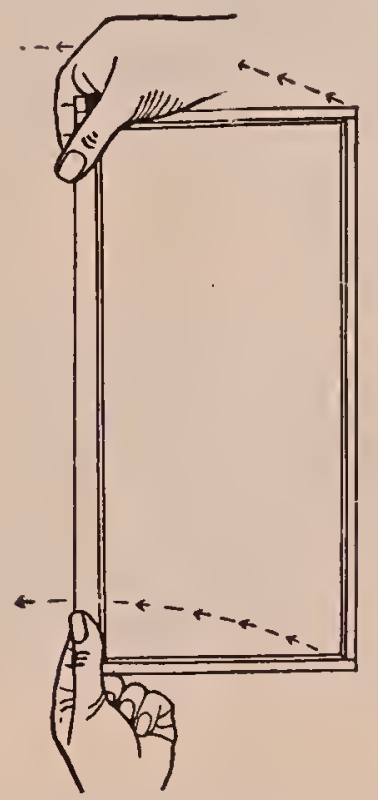

F-G. 2.-Second position. Arrows show direction in which the frame is now to be turned.

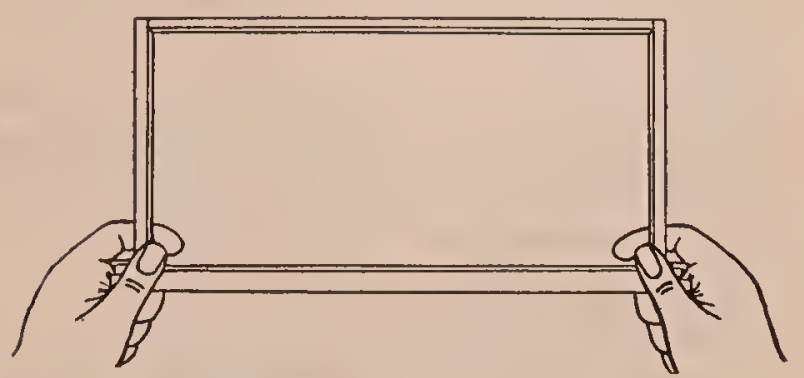

FIG. 4.-Fourth position of frame.

trouble. When the queen cannot be found the second time going over, as a rule hunting longer is not advisable because one is liable to waste a good deal of valuable time; and it is, therefore, better to wait till the queen cones out of her hidingplace back to the brood-frames themselves.
If the bees are inclined to rob, use an empty body to hang half of the frames in, placing them in pairs, and pair-off the rest in the hive being worked.

In the case of black colonies, especially where very popnlous, it is sometimes necessary to lift the hive off the stand and put it down to one side. On the old stand place an empty hive, affixing an entrance-guard. (See Drones.) Take the frames one by one out of the old hive, and shake them in front at the entrance of the empty hive on the old stand. Black bees fall off very readily; and as they crawl toward the hive the queen can be easily seen; but if she eludes serutiny she will be barred by the perforated zine where she may be readily discovered trying to make her way thru. After all the frames are shaken, if she cannot be found, take the old hive, now empty, and dump it, causing the bees to be thrown before the zine. She will soon be seen trying to pass the guard.

So far, details have been given on how to find the queen; but the reader must not imagine that it is going to be as difficult as this every time. She is usually to be found on the center frames; and, especially with Italians, is likely to be found on the first or second frame handled.

When loose frames or frames witlout spacing' shoulders are put back in the hives they must be spaced carefully $13 / 8$ inches from center to center as near as it is possible. It is not practicable by the rule of thumb or finger to get them all exactly this distance so that there will be some combs a little thicker than others, even when the greatest of care is used. If one is a little careless (as most people are) there will be considerable variation in the thickness of the combs, and the thicker ones will have to be shaved down with an umcapping-knife at the first extracting. If the combs are left thick and thin there will be danger of killing a good many bees in inserting and removing the frames, especially when the position of the frame is changed. All of this nuisance of irregularity in thickness of combs ean be avoided by the use of selfspacing or Hoffman frames.

There is no eut-and-try spacing as with unspaced frames, no big and little fingers to get the distances wide and narrow, and the beginner hạ no difficulty in determin- 
ing just low far to place the combs; for if he places the shoulders in contact they will always be the right distance apart.

There is not much danger of killing bees provided one proceeds carefully, using a little smoke in blowing the bees away from the contact edges of the frames. When the hive is ready to close up, all that is necessary is to shove together the frames that are separated two and three incles apart, and crowd the whole together, finally putting on the cover. On the other hand, when unspaced frames are handled, each frame must be put back into position separately. This takes a large amount of time whatever may be said of the time consumed in separating spaced frames apart. See Frames, Self-spacing; also. Frames.

Mr. Hoffman, the inventor of the frames, stated that the judicious use of a smoker would save time, avoid bee-killing, and, taking it all in all, he could handle twice as many colonies on his spaced frames as he could on the ordinary old-style frames without spacing attachments.

Much has been said by those who are not familiar with the Hoffman frames of how bees are killed by them. Those who have used them largely know that this need not be true.

There are some localities where propolis, or bee glue, is much worse than others. In such places the Hoffman metal-spaced frame has the advantage. The illustrations will show their special features. They are somewhat more expensive, but they are stronger; and as they have only points of contact there is less danger of killing bees.

HOW TO MANTPULATE HOFFMAN FRAMES.

The manner of opening hives containing Hoffman or any other self-spacing franes, is just the same as that for hives containing loose or unspaced frames already described, but the manner of handling the coinbs is somewhat different.

If there is a division-board in the hive this is first removed in order to give room for the handling of the frames themselves. If there is none the outside frame is pried over to the side of the hive and lifter out rery carefully. This will then make room for the removal of any two, three, four, or five frames all in blocks. $\Delta \mathrm{s}$ an ordinary Hoffman or self-spacing frame will be somewhat gher together by propolis, it will be necessary to use the hive-tool to separate the frames.

In removing self-spacing or Hoffman frames from a brood-nest, it is not necessary to scatter them all around the outside

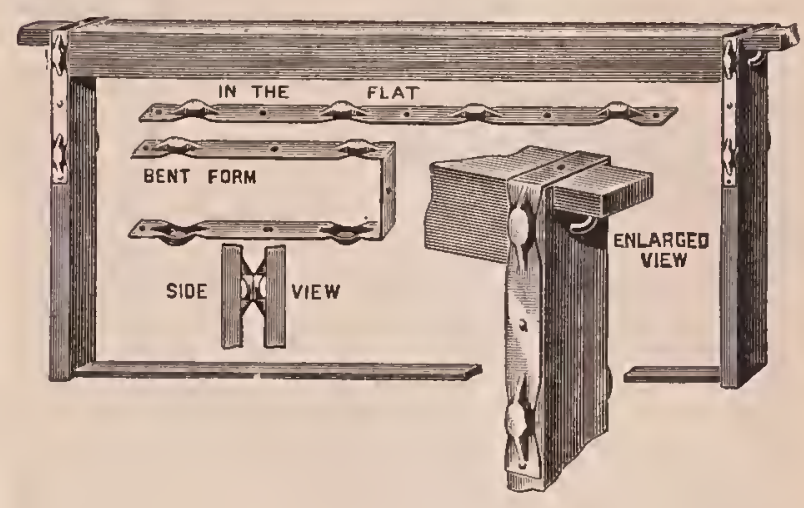

Metal-space Hoffman frame.

of the hive, leaning them up against each other in such a way that it kills bees, but each group of frames, two, three, or four, as the case may be, can be left sticking together stationed on the outside of the hive. There is no danger then of killing the bees between the frames, and the necessary information can be secured from the one or two surfaces of combs examined. When the ordinary unspaced frames are used, it is necessary to handle each frame individually, because they cannot be picked up very well in groups of three or four like the Hoffman or any other good self-spacing frame. See Frames, Self-spacing.

In ordinary practice it is not necessary to liunt up the queen. The examination of the surface of one or two combs will show whether eggs are being laid. If eggs and brood in various stages are found in regular order it may be assumed that the queen was in the live within three days at least.

The location of the queen can be determined somewhat by the manner in which the eggs are laid. If the examination of one comb slows no eggs and an examination of another shows that there is young brood, the position of the queen can be traced by the age of the brood until eggs are found; the queen may at the time of the examination be at one side of the broorl-nest rather than the other. After she goes elear across she is quite liable to jump from one side clear to the other. 

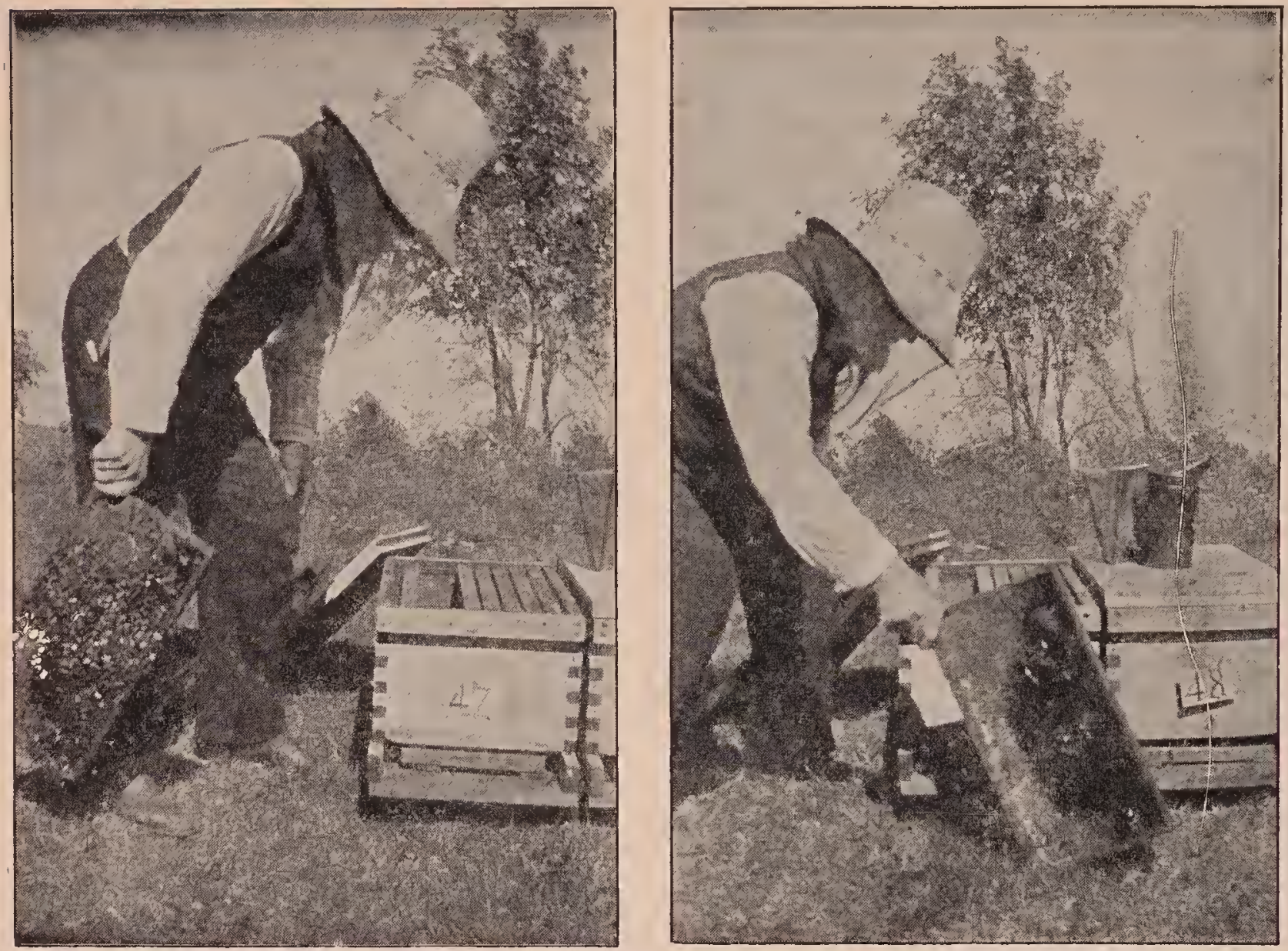

Dr. Miller's method of jarring bees off the combs.

Sometimes the behavior of the bees is such as to indicate where the queen is. Her location can generally be determined immediately after releasing the queen when in-

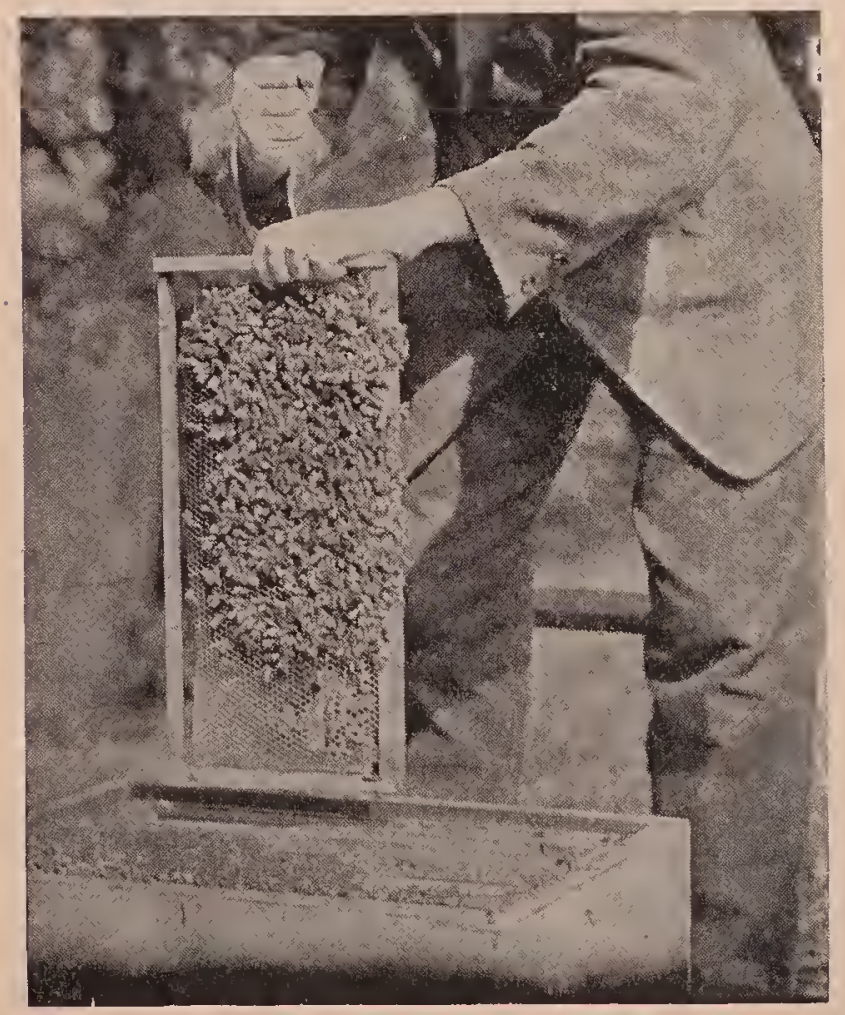

How to bump the bees off a comb. troducing, because the bees will liave their heads pointing in one direction; and sometimes by a hum of rejoicing the queen can be traced, especially if she has been well received.

\section{DISLODGING BEES FROM COMBS.}

For many manipulations like giving brood to another hive, or for the purpose of extracting, it becomes necessary to dislodge the bees from the frames. This can be done by brushing them off as shown under Extracting, or they can be pounded off with a blow of the fist on the back of the hand, grasping the end-bar. Or one may grasp the end-bars solidly, and with a quick downward jerk remove all or nearly all of the bees. When more convenient one can swing the frame, pendulum fashion, with one arm, letting the corner drop violently against the ground while the other end is held in the hand, as shown above.

HOW TO ASCERTAIN THE CONDITION OF TIIE HIVE WITHOUT HANDLING FRAMES.

A good many, in working for extracted honey, operate on the tier-up principle, 

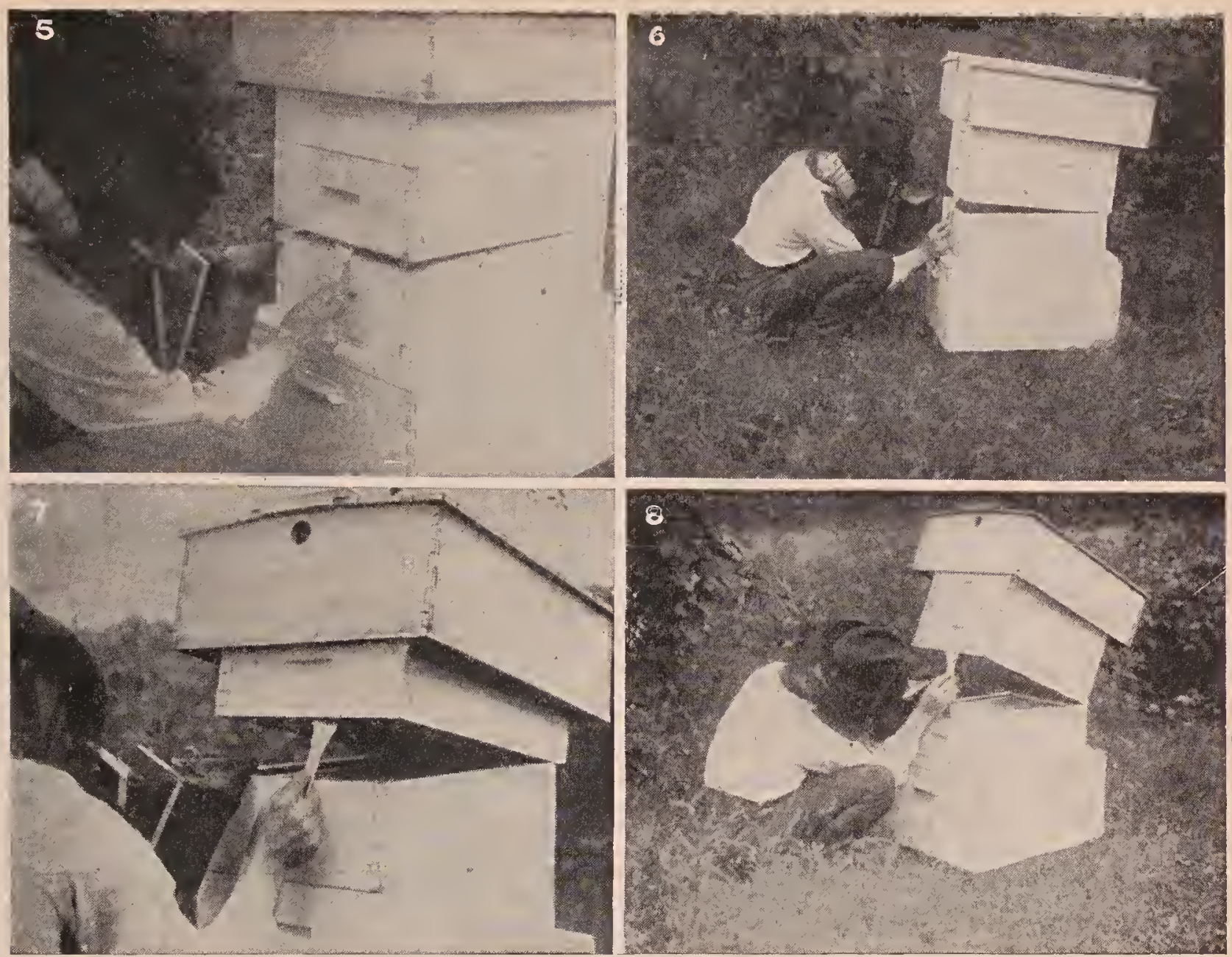

Learning condition of hive without removing cover or pulling to pieces.
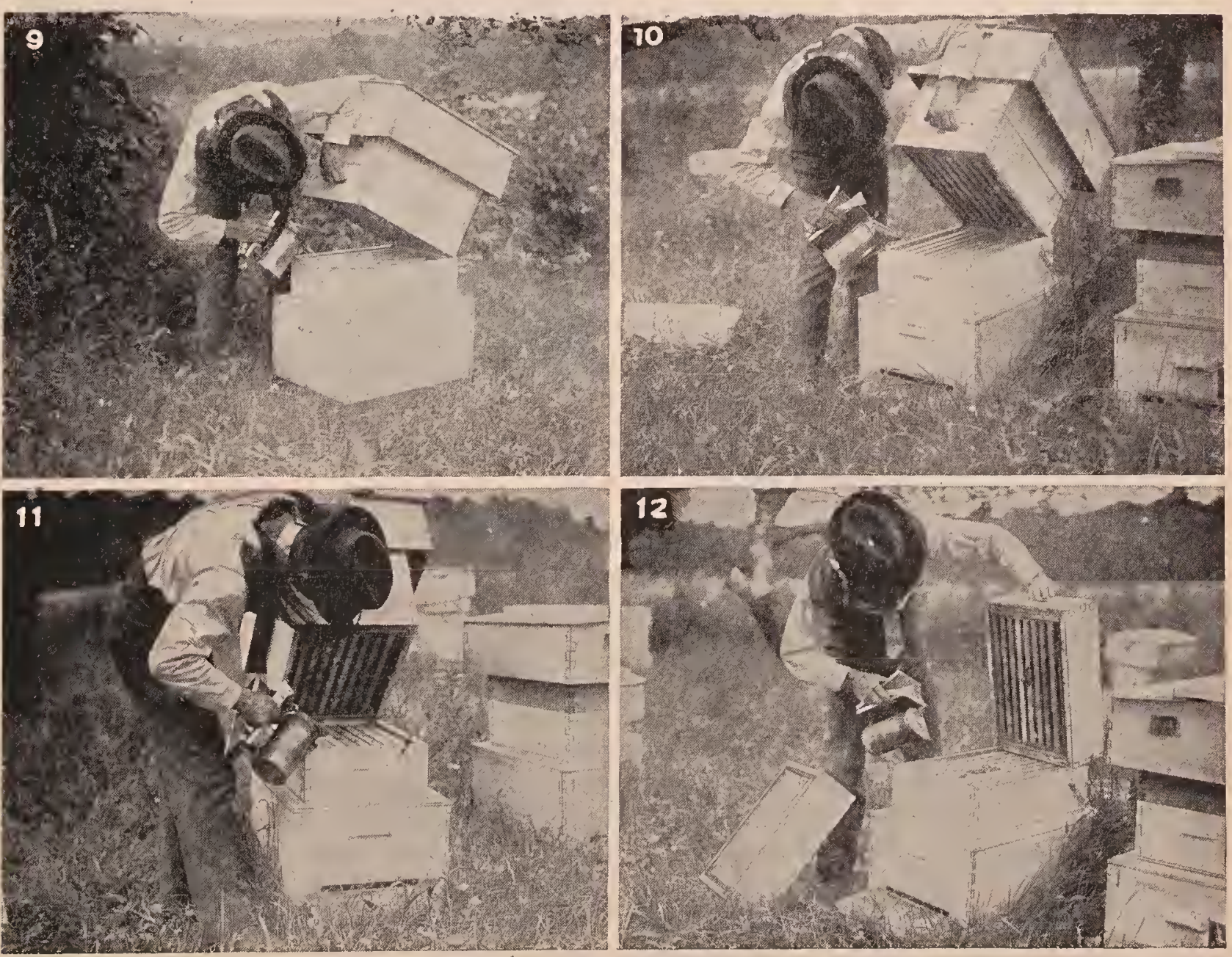

Determining the filling of the supers nnd whether ready to come off. 
leaving all the supers on the hives until the season is over. By that time it is important that robbers be given no opportunity to help themselves to sweets, when the loney is taken off; but before doing so the condition of the supers should be determined in advance. In order to keep ahead of the bees it is necessary to make an examination from time to time. Toward the early part of the season it is customary to place the empty supers under those partly filled. As the season begins to draw toward its close, the process is reversed--that is to say, the empties are put on top of those partly filled.

In order to determine the amount of honey in any super, it is not necessary to take off the cover and pull the hive apart. If it is tiered up four and five stories high, it involves a large amount of labor and considerable lifting to pull the supers off one by one, inviting the attention of robbers in the operation. If one is supplied with a good strong steel hive-tool and a smoker, he can get a fair idea of the filling of any super, without even remoring the cover from the hive. In the series of snapshots on previous page, the reader will be able to gather, almost at a glance, the exact unethod to be used in determining what the bees are doing.

Take an example. Let the operator start with the hive shown in Fig. 5, previous page. It has three supers. The middle one is the one on which the bees began work first, and at the time of this examination it should be completely filled. The bottom super was placed under after the middle one was about half filled. The colony was again crowded for room, but since there was only a week or so more of honey flow, the third super was put on top, so that the first two will be certain to be completely filled before the bees begin work on the third.

$\Lambda$ this time it is desired to know what the bees have actually done; so, without remoring the telescope cover on top nor the super cover directly beneath, the thin blade of the hive-tool, broad end, is entered between the two lower supers, at the back end of the hive; for one should always endeavor to keep out of the flight of the bees. This is gradually shoved in until the blade has been pushed in anywhere from $1 / 2$ to a full inch. A gap is now formed, of approximately 1-16 inch, just wide enough so that a little smoke will drive back the bees. A slight pressure downward separates the two-upper supers about an inch at the back end, when more smoke is blown in. The tool is pushed down a little further, making the gap a little wider. (See Fig. 6.) But the operator is not quite satisfied as to the condition of the supers, so he pushes the tool and supers upward, as shown in Fig. 7, until he has the hive-tool in position as shown in Fig. 8. Here it acts as a prop, when, with the intelligent use of the smoker, he can drive back the bees enough so that he can see the condition of the two supers, or

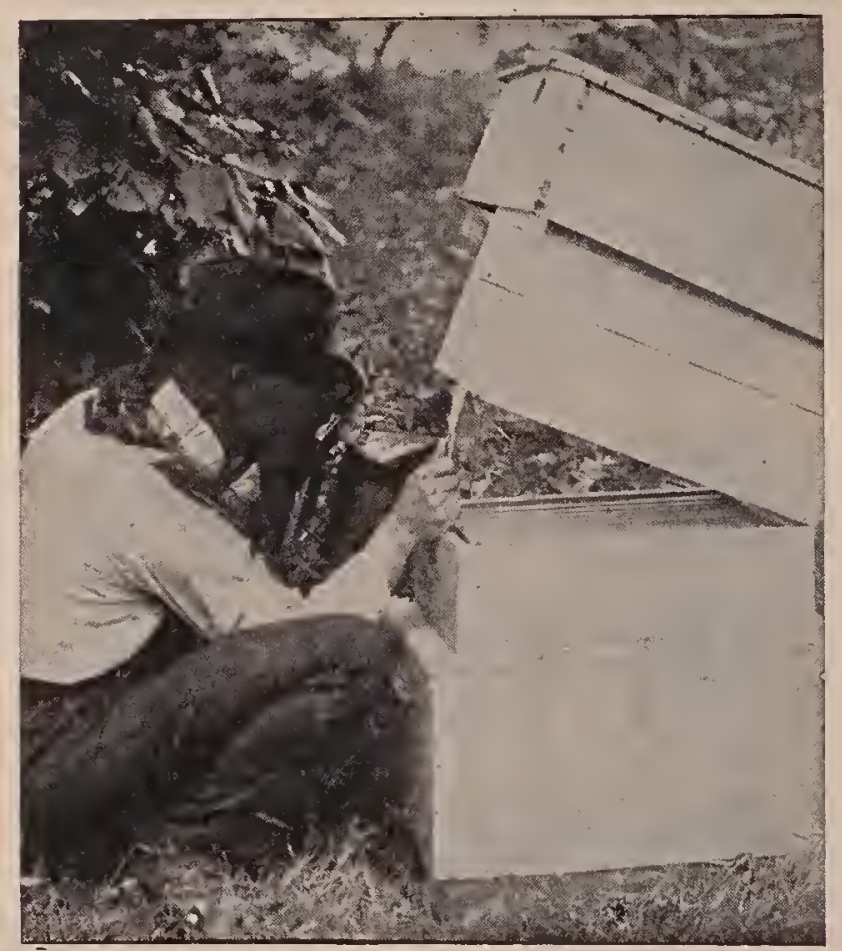

Fic. 13.- How a smoker and a hive-tool will enable one to learri the condition of the super's at one glance.

enough to determine whether the bees need more room.

But suppose he is not quite satisfied yet. As shown in Fig. 9, he lifts the supers higher, disr'egarding the hive-tool falling on the ground. When doing this lie slides the two supers about an inch backward so that the other end will fulcrum on a safe bearing. If the super is slipped forward, as shown in Fig. 7, it can be readily seen that it cannot be tilted up very high without sliding off in front. See Figs. 9, 10, 11.

Usually an examination of this sort is quite sufficient. If the super's are not filled 


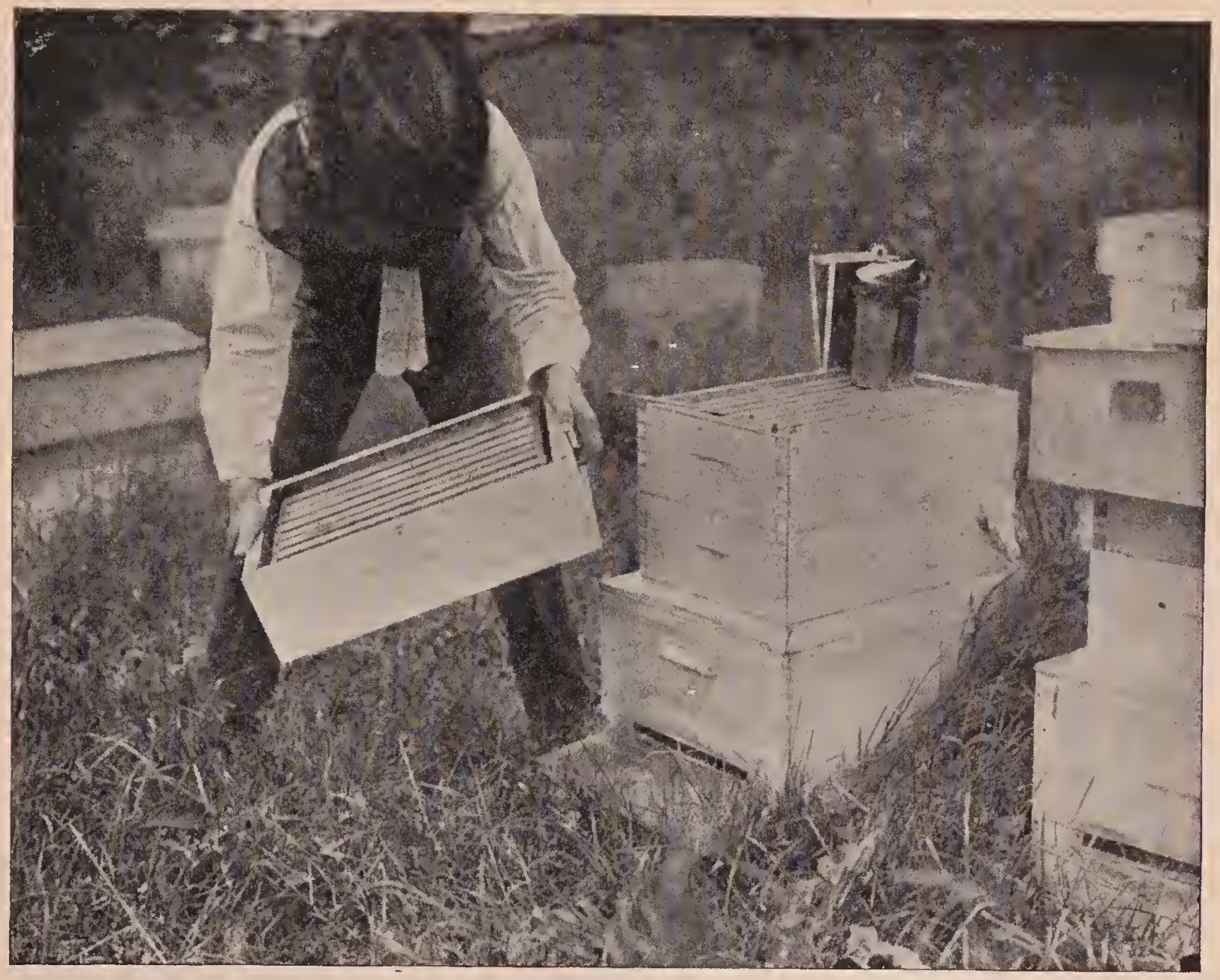

FIG. 11.--Shaking bees out of a super.

they are quietly let back into place, using sufficient smoke to drive the bees away so they will not be crushed as the hive parts come together again. The operation shown in Figs. 5, 6, 7, 8, 9, 10, 11, is then repeated with other hives, taking from 30 to 60 seconds per hive. At no time has the operator lifted but a part of the dead weight. When the supers are held at an angle the load is on the fulcrum point of contact, while the hand sustains only a small part of the weight.

Fig. 12 shows the method employed when supers are apparently well filled and ready to come off. The top super is removed and leaned up against the leg of the operator. The middle super that has been filler can now be taken off; but before doing so a second examination is made as shown. It is set off, when the bottom super may also be removed if ready. If so, the top super is put back, the idea being to confine the bees to as small a super capacity as possible as the season draws to a close, in order to make the bees finish their work.
Fig. 13 shows a slightly different pose from that indicated in Fig: 8. While the position of the operator is somewhat cramper, it is true, yet it is much easier than tearing down the hive, super by super, and replacing.

In Fig. 14 is a case where the season is closing abruptly. The bees have only partially begun work in the top super. To leare it on would mean that all the supers would have honey in, and none of them quite completed. Accordingly the bees are shaken out of the top super when it is. moved. If there should be some good rains and warm weather, the season may take another start. In that case a super cover temporarily placed between the top super and the two below is removed, when work will be resumed in the third super. If it could be known that the season was drawing to a close, the top super should be removed in the first place.

\section{HOW TO PUT ON ESCAPE-BOARDS.}

Some beekeepers have an awkward way of putting on escapes. They will pull the 
hive apart, super by super, place the escape on the brood-nest or on a super partly filled, then one by one put back the supers. If no loney is coming in, this will probably mean that robbers will get started.

There is no need of removing any super, nor a cover, for that matter. All that is necessary is to apply the principles illustrated in Figs. 5, 6, 7, 8, 9, 10, 11. See also illustration under Coms Honey, To Produce, showing how to put on an escapeboard.

MANCHINEEL (Hippomane Mancinella).-An evergreen tree with smooth leares resembling a pear tree, growing on sandy beaches in southeast Florida, on the Keys, in the West Indies, and tropical America. It has an acid milky juice, which is very poisonous and was used by the Caribs to poison their arrows. "Probably the most poisonous member of our arborescent flora. The juice and the smoke from the burning wood are very injurious to the eyes." The yellow green flowers are very small and open from February to April; in certain years they are reported to yield nectar heavily.

MANZANITA (Arctostaphylos manzanita).-Manzanita is an evergreen slurub, 10 to 15 feet tall, with wide-spreading crooked branches. Associated with scrub oak, chamise, and other spiny bushes it forms dense thickets, called chaparral, a characteristic feature of Californian scenery on the Coast Ranges and the Sierra Nevada. The flowers appear from November to March, often opening about Christmas time. Ordinary freezing nights do not affect the bloom. It secretes nectar so freely that the hives are often filled with manzanita honey. This early flow starts broodrearing, but as there are no other nectaryielding flowers at this season and the weather is often cold, the honey is speedily consumed by the bees. The honey is ambercolored with a fine flavor and the fragrance of the bloom.

MAPLE (Acer).-The maples bloom so early in the season that their value as honey plants is usually greatly underestimated. In early spring the colonies are so weak that a surplus from this souree is seldom obtained, and the maples are regarded as important only for brood-rearing. There are about 100 species in the gellus Acer, which are confined eliefly to the northern hemisphere. Many of the trees are very common and the rock maple forms extensive forests. In the States east of the Rocky Mountains a small surplus of maple honey has been reported in Iowa and Alabama.

The red maple (Acer rubrum) is a wellknown tree in the eastern United States extending from Canada to Georgia and westward to Missouri. The scarlet flower's appear in early spring before the leaves, and yield large quantities of pollen and considerable nectar; but the weather is often so cold and stormy that it prevents the bees from flying freely. In New England and in the region of the Great Lakes the forest in many sections is almost $e^{x}$ clusively made up of the rock or sugar maple ( $A$. saccharum). The trees are completely covered with yellowish green, pendulous flowers, which are attractive to great numbers of honeybees. Their contented hum is audible at a long distance. Strong colonies in many localities should store a surplus from this source. The flowers of the silver maple ( $A$. saccharinum) appear in earliest spring in advance of the leaves. As in red maple the stamens and pistils are in different flowers and usually on different trees. It is widely distributed thruout the eastern States. The box elder or ash-leaved maple ( $A$. Negundo) grows from Manitoba to Texas, but is not found near the coast. The small green flowers appear before the leaves and are a valuable source of nectar.

In Washington and Oregon broadleaf or Oregon maple (A. macrophyllum) is an important spring honey and pollen plant blooming in April and May. It is found mainly west of the Cascades, below an elevation of 3,500 feet. Vine maple ( 1 . circinatum) is a much more important honey plant than broadleaf maple. It grows below an altitude of 5,000 feet mainly west of the Cascades, and blooms a little later than the preceding species. The honey has a fine flavor and is amber-colored with a faint pinkisl tinge. In both the Oregon trees the flowers appear a little after the leaves. 


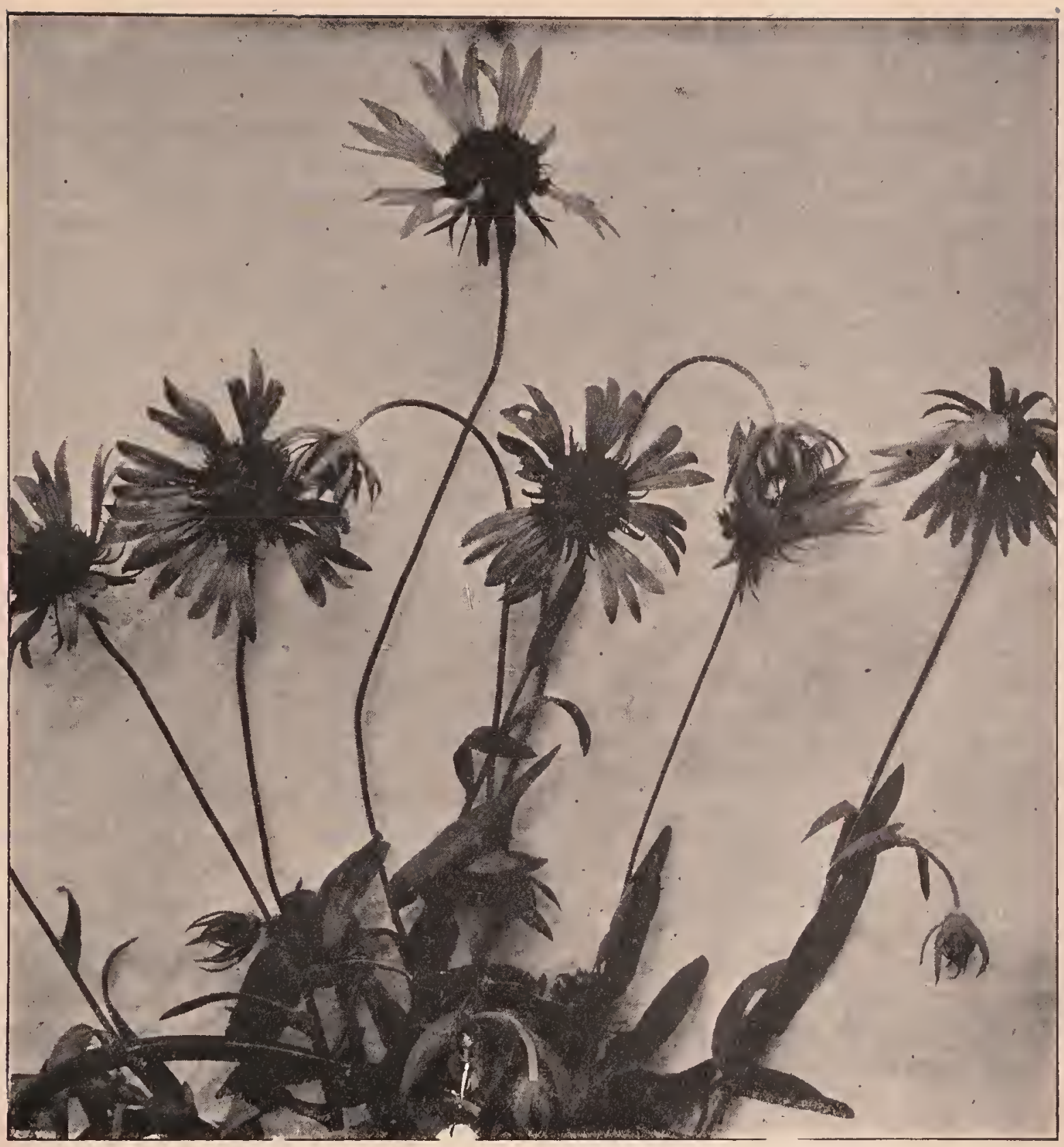

Marigold, great honey plant of Texas, but found all over the United States.

MARIGOLD (Gaillardia pul hella).An annual, diffusely branched herbaceous plant, very common on the prairies and by the roadsides from Nebraska sonthward to Louisiana and Texas. It is a species of Compositae, and the showy heads are 1 to 3 inches broad with numerous yellow rays. The leaves are 2 or 3 inches long, toother, and without stems. $\Delta$ s a honey plant it is valuable chiefly on the Black Prairie of Texas and the neighboring limestone hills. It is not abundant on sandy or clay soils. It begins blooming in May, and at San Gabriel an average of 30 pounds of honey per colony was obtained in 1920. Large crops from this source are occasionally reported. The honey is amber-colored and inferior in quality, but finds a market. The comb honey is golden yellow, not white.

MARKETING HONEY.-It is one thing to produce a crop of honey and quite another thing to sell it. During the period of the Great War when sugar could be obtained only in very linited quantities there was no difficulty about selling honey either in small lots or ear lots at high prices. Shortly following the armistice there was at period where there was a buyers' strike. when practically all commodities, including honey, were a drug on the market. The result was that producers all over the country were trying to sell in a retail, wholesale, or jobbing way. It was then 
that many a producer discovered he was not a salesman.

The question of selling at retail or in a small way will be discussed in detail further on. The problem of the beekeeper who has from 100 to 1,000 or more colonies will now be considered. These larger producers are usually not salesmen, and it therefore becomes necessary for them to dispose of their entire product to some large wholesaler, jobber, broker, or commission house. $\Lambda$ beekeeper witl a hundred colonies during normal times has no difficulty in selling his entire product to the wholesale grocery and in some cases to the retail g'rocer. He may find it possible to sell to a dealer who handles dairy produets, for honey, butter, and milk, including ice cream, are often sold from the same counter.

He may find it advisable to sell it in a retail way from his own door, provided he is located on some automobile highway, but this likewise will be discussed farther on.

There are now large buyers of honey in nearly all the large cities of the United States. They will usually, during the selling season at least, take honey at its market price in lots of a thousand pounds to a whole car load. Indeed they will sometimes on a rising market buy ten cars. 'They' will have their buyers located in various cities, and of course they will seek to get the honey at the lowest figure possible. They are sometimes inclined to talk a "slug'gish market" and "over-production;" in short, their" policy is to "bear" the market.

To offset this in some instances lal'ge producer's are organized into exchanges thru which the products of its members are sold, because the individual beekeeper is sometines at the mercy of the large buyer, and unless he is well informed with a knowledge of market conditions thruout the United States he is liable to sell his honey at a sacrifice. He can protect himself by taking one or more bee jomrnals when he will be able to follow on theix market pages general conditions relating to production and sale of honey and the price at which it is being sold in carlots in the various cities. The United States Bureau of Markets is sending out direct to beekeeper's reports of sales for the various markets of the country. Information gleaned thru this source, thru the bee journals and the local beekeeper societies and honey-producers' exchanges whele organized will usually give one a fairly accurate idea of prevailing conditions and whether lie can afford to sell.

On a rising market one can sometines afford to hold his crop, but he should also remember it is wise not to wait too long. Marketing in a car-load way usually begins to start in September. The price may rise during the months of October and November. From the middle of November to about the first of December prices usually reach their maximum. Sometimes the market will hold strong after the holidays, but usually the demand is slow and irregular from that time on until the new crop is ready.

During later years, however, it is encouraging to note that the honey market in carlots slows more and more an inclination to hold a general level thruout the season.

Producer's should clearly understand that the amber or dark grades of honey usually bring in carlots from two to five cențs less per pound than the light-colored or table lioneys. It should generally be understood also that honeys of the North are usually superior in color and flavor to those of the South. As a general rule, the further one goes toward the equator, the darker will be the honey. There are some marked exceptions to this, however, as one will see by consulting the article, "Honey and Its Colors," found elsewhere in this work.

Where possible one sliould always sell for cash. But before doing so it is necessary to know the financial standing of the jobber or dealer making the offer. Many a beekeeper has sold his honey to a concern without a rating, only to find lie has lost his lioney and that the account is not collectable. Some of the representatives of these concerns are smooth, plausible talkers but are dishonest. They know enough about law to keep themselves safe from prosecution. No one should sell his honey to a stranger without inquiring first at the local bank of his standing. If he is not rated let him alone. If one cannot get satisfactory information from that source, 
he should write the publisher's of one or more of the bee journals. It will take only a few days to get a report, and it may save for the producer his entire crop of honey.

A great deal of loney is now shipped in carlots, a draft being attached to the bill of lading. The producer may feel that it is perfectly safe to ship in this way, and usually it is, as the money must be paid to the bank before the honey is delivered. If the concern is not reliable or dishonest it may seek a consignment in this way with the deliberate intention to reject the car, thus placing the producer at a great disarlvantage and making him feel he will have to accept the terms offered in order to dispose of the honey. If he does not accept such terms it may be necessary for him to make a trip clear across the continent, in the meantime paying demurrage to the railroad company while he is seeking a new customer.

Taking everything into consideration the producer should deal only with wellknown responsible concerns that can furnish good references as well as satisfactory rating in either Dun's or Bradstreet's commercial ageney. In the case of a new company, it will be well to learn what the bee journals think of them.

It is sometimes not practicable to sell for casl. Perhaps no offering can be secured. In that erent honey may sometimes be disposed of to good adrantage to reliable commission houses.

\section{SENDING HONEY TO COMMISSION HOUSES.}

While commission houses thruout big rities are aids to beekeepers in disposing of their honey, yet a word of caution should be entered against being in too great haste to limp off one's honey to these places. One may argue that he would not have time to dispose of his product in small amounts; but many a beekeeper has found to his sorrow the mistake he made in contributing to the flood of lioney at a rertain commission house. T'he consequence is, that at that place lioney is a "glut on the market."

But it very often happens that one can get a higher price by sending to these commission men. The general trade looks to them for supply, and they make it their. business to find a market.
The temptations in the commission business are very great; and if the broker is not lonest he may take advantage of the producer. Commission men charge all the way from 5 to 10 per cent commission; and in addition to this the shipper is required to stand freight, drayage, and all breakage.

Most commission houses will make adrances in cash on receiving the honey; and a few of them will make payments as fast as it is sold; but a majority make no remittance until all the honey is sold, and sometimes not even then until the beekeeper writes complaining, and inquiring regarding lis honey or his money.

At the time of making shipment, send bill of lading to the commission liouse, and name price below which the honey must not be sold. A commission house has no right to sell at a lower figure until it is given instructions. Before the honey is packed it should be carefully weighed so that one will know exactly how much honey he has sent. Large shipments should not be sent at first. If in any case honey is sent, and the commission house fails to make returns, or refuses to do so, it is a criminal act. Such a house has no right to appropriate one's honey without rendering some sort of returns. Never take a note in payment from an irresponsible firm or individual, for legally a note is a settlement.

\section{SELLING HONEY IN A RETAIL WAY.}

The beekeeper with four or five colonies of bees will have no difficulty in selling his honey to his neighbors. It soon becomes known that he has a few hives of bees, and the people in the vicinity, feeling that they ean buy "real honey," will go to the neighbor and pay good prices, furnishing their own utensils. If the honey is of first quality there is no trouble about selling from the doorway the entire crop.

When one has from fifty to a hundred colonies his problem is not so easy. If he is not a salesman, he should dispose of his loney in a wholesale way to his local grocer. If lie is located in the country on a main highway where automobiles are passing to and fro, he may be able to sell his entire ('rop) from the roarlside the same as ordinary farm products are sold. He should be careful to consult the market to 
learn what the retail prices are and sell it at retail. It is always a mistake to cut prices under the grocer, because if the beekeeper ever antagonizes that individual he may shut off an important outlet for his honey some seasons when he can not sell his entire product from his home. In any event it is always wise to work with, and cooperate with, the local dealer as far as possible.

Whether selling from the roadside or from the shelves of the grocer the beekeeper should have his goods put up in neat, attractive form. Cheap labels or poor glassware have a tendency to give the honey a cheap look. The more attractive the package, the more readily will it sell. It is usually customary to put up the honey in tumblers, one-pound and twopound glass jars, 21/2, 5, and 10 pound self-sealing tin cans or pails. It is advisable to use a package that the housewife can use over again. Tumblers, Mason jars, and tin pails are always useful around the home. Glass packages should be of clear glass and not a pale green.

Labels should not only be attractive but show in pounds and ounces the exact amount of honey in the packages. They should be printed by some concern who makes a specialty of printing labels, and not by some local printer who puts neither art nor style on the label.

In roadside selling the sign should be neatly lettered. Signs poorly lettered, especially with the words misspelled, often do more harm than good in disposing of the honey. It is advisable to have about a dozen signs a foot or eighteen inches long containing the simple word "honey." One of these signs should be placed about every hundred feet down the road each way toward the place where the honey is to be sold. There should then be one large sign calling particular attention to the goods and prices. Honey should be on display in a neat little booth, showing both tin and glass packages. If a customer wishes to sample, give him a liberal taste.

If one is a natural salesman he may be able to dispose of his entire crop by peddling; for particulars on how to do this see Peddling Honey.

It should be emphasized that the honey sold should be of uniform quality and good flavor. 'The poorer or dark honeys should be disposed of to some jobber for manufacturing purposes. In large quantities such honey is msed in the baking trade. This trade demands honey of pronounced flavor rather than the mild honey, the flavor of which would be obscured by the cake itself with its other ingredients.

\section{HOW TO BOOST LOCAL SALES OF HONEY.}

There will be times when honey, at the local groceries and perhaps along the roadside, will be moving slowly. When this occurs the beekeeper can do much to stimulate the demand for his product. By turning to Orservatory Hives, he will find an illustration of a single comb hive with glass sides, the upper part showing a series of four sections of honey. The purpose of this is to illustrate the exact relationship of the combs below to the sections above.

When one of these glass hives is filled with bees and the comb shows brood in all stages, the queen, and the bees, it makes an exhibit that commands attention from the public. Obtain permission from the groceryman to put one of these glass hives containing live bees in his show window, place around this glass hive both comb and extracted honey in attractive packages; and a display card should explain something about the bees, how they work, calling particular attention to the queen. On important days and Saturday afternoons the beekeeper himself should get into the show window and explain how honey is produced, at the same time telling something about the queen, bees, and drones.

At such a time it is advisable to have an open can of honey. If the demonstrator is provided with short strips of wood, he can dip one of these into the honey and ask the prospective purchaser to taste it: If children are present, give them all a taste, and everyone else who would like to know how delicious good honey really is. As fast as these sticks have been used for tasting, they should be thrown into a box and afterwards burned. It is important to give every person who tastes a fresh clean stick.

If the local beekeeper is not a good talker, let him employ someone who is, and he will be surprised how his honey will sell. 
Grocerymen are usually very willing to grant window space and otherwise get back of the whole proposition. They sometimes have a member of their selling force who can do the "demonstrating" better than the beekeeper himself, especially so if that beekeeper is not a natural talker or salesman.

This kind of demonstration work with live bees on display can be undertaken most profitably at county fairs, street fairs, or at food shows. Sometimes space can be secured in one of the buildings. At other times it may be advisable to have a special tent at some good location on the grounds, where honey can not only be sold but where a good demonstrator can help push the sales.

It is sometimes a very great advantage to have a beekeeper open up a hive inside a wire cage. This cage is usually' about six feet high, four or five feet wide, six feet long. Inside of this cage, an operator without bee-veil or gloves can show just how he handles bees. If it is advertised that bees are manipulated in this cage at certain hours during each day of the fair, large crowds will come to see the man barehanded, bare-faced, handle the bees. With a good salesman or saleswoman at the tent, large quantities of honey can be sold.

A large and important advantage secured from this demonstration before the public is its permanent advertising value. If these demonstrations are then followed up with appropriate window displays at the local groceries, there will be no trouble about the selling of the honey.

No one will dispute the fact that "Tt pays to advertise," especially so when it is done judiciously. It is advisable for the beekeeper to do a little advertising in the local papers. If these announcements refer to certain groceries where beekeepers' honey is sold the groceryman will very often be glad to pay half the expense. He should be more than willing to do this, because when a customer comes in to buy honey he is more than likely to buy something else.

MATING OF QUEEN AND DRONE.See Drones.

MESQUTTE (Prosopis glandulosa).This genus includes about 15 species of trees or shrubs growing in the warm arid legions of both the Old and New Worlds, but most abundant in America. In the United States there are two species $P$. glanäulosa and $P$. velutina. Texas mesquite (P. glandulosa) is also called algaroba and honey-pod. In the lower Rio Grande Plain it is a large tree attaining a height of 40 feet and a diameter of 2 feet; but on the dryer soil south and southwest of San Antonio there is a vast mesquite forest consisiting of trees 10 to 15 feet tall. On arid land the mesquite becomes a straggling shrub with crooked branches. It is found from Kansas to 'Texas and soutlivard into Mexico, and westward to New Mexico and "southern Nevada.

It is probable that the mesquite first invaded Texas from Mexico near Matamoras about 150 years ago. Until comparatively recently the Rio Grande Plain was a grassland, but the mesquite and various shrubs have spread over it very rapidly. There are many who remember when hundreds of acres now brushland were in grassland. At present a scattered growth of mesquite is found over the larger part of Texas except in the northwest corner of the Panhandle or Staked Plains, and that portion of eastern Texas east of the lower Brazos River, the Navasota River, and a line extending northward to Hunt County, and then running westward to Montague County. The heaviest growth of mesquite is in the twelve counties of Atacosa, Bexar, Dimmit, Frio, La Salle, Live Oak, McMullen, Medina, Nueces, San Patricio, Uvalde, and Zavala, embracing an area of 14,915 square miles southwest of San Antonio. The annual rainfall averages between 20 and 30 inches. The greater portion of this area is covered with a shrub-like growth of mesquite which stools out at the ground into a number of slender crooked stems. On the higher and dryer land huisache and catsclaw are associated with it. The mesquite trees in 'Texas are about 10 feet tall, and average less than 4 inches in diameter. Along the streams it is erowded out by elm, ash, hickory, and live oak. Only about 9,000 acres, located in San Patricio, Uvalde, and Live Oak Counties, are commercially valuable for logging. The logs average only 3 feet straight length and 3 to 4 inches in diameter.

Thruout the central denuded region from 
Hardemen and Tillbarger Counties on the Red River to Valverde County on the Rio Grande mesquite is grenerally distributed, but thruout' its northern range the trees become more dwarfed and the stands more scattering. Short, crooked trunks with long irregularly curved branches produce scragly trees, suggestive of long-neglected orchards. The trees have a large taproot which extends to a great depth, and it is not uncommon to find the -larger part of the tree under rather than above the ground.

The rapid sprear of mesquite is largely due to the abundance of seed and to its wide dissemination by live stock, but its distribution is determined chiefly by the character of the soil. It can not compete with the native trees, and is forced to occupy low or level areas where the soil is fine and compact. It does not occur on very moist soils along the streams because it is crowded out by the native hardwood trees. It occupies the level areas with fine silty soils, which are less porous, known as "mesquite flats." Large areas of the mesquite prairies have been reclaimed for agricultural purposes, but fortunately the greater part of the land is planted witl cotton, which is as valuable as mesquite as a source of honey. In parts of the TransPecos region mesquite is one of the surplus honey plants, altho the main dependence of the beekeeper is irrigated alfalfa.

The leaves are bipinnate, composed of two branches or pinnae, each of which bears from 6 to 25 pairs of narrow leaflets. At the point of union of the two branches of the leaf there is a gland. The small fragrant flowers are in yellowish cylindric spikes, 3 to 5 inches long. There are 5 sepals, 5 petals, and 10 stamens. The fruit is a round pod 6 to 8 inches in length, which is greedily eaten by cattle. Even human beings find that the beans have a good flaror, and children particularly relish them each season as they ripen. They vary, however, considerably in taste, some being so bitter that they cannot be eaten, while other's are very sweet and agreeable in flavor. Their chief value is as food for cattle.

The mesquite has usually two separate and distinct blooming periods during the year, altho in some seasons there is no in- terval. The first comes during $\Lambda$ pril and the second during the last of June or in July. These periods are sometimes a week or more earlier or later according to the season, the occurrence of cold weather, and the rainfall of the preceding fall and winter. If rain has been abundant during the winter no matter how dry the following spring and summer, there will be a profusion of bloom and a heavy flow of nectar. The long taproot penetrates the soil to a great depth and is thus able to obtain water, which is beyond the reach of many other shrubs and trees.

Mesquite is one of the main honey plants of Texas and the source of a rery large surplus. From 25 to 100 pounds of honey per colony are stored from the bloom according to the locality and weather conditions. The honey is light amber in color and of good quality. It is a better table honey than any other of the Texan honeys, since one never tires of it, as is apt to be the case with a honey having a more pronounced flavor. The honey, altho ranked very high in Texas, would in the North probably be classed with the amber honeys. Nectar secretion is more reliable on light sandy soils than on heavy land.

In New Mexico in the valley of the Rio Grande River beekeepers formerly depended on mesquite and other desert plants, but now pay attention only to alfalfa and sweet clover. At La Mesa in some seasons the mesquite flow is fine, but is often a failure. Mesquite is also valuable in Otero County. Texas mesquite is also found in southern Nevada. In Lincoln Connty there is a large acreage of mesquite, which with the mild winters and early springs should be very valuable for an early honey flow.

Arizona Mesquite (Prosopis velutina). This tree is the largest of the mesquites often attaining a height of 45 feet or more. It grows in the loot dry deserts of southern Arizona, southern California, and Sonora. The leaves, flowers, and pods are very similar to those of l'exas mesquite. Arizona mesquite blooms for the first time in May and again in July. On the arid deserts it is often not over 15 feet tall. It yields bountifully in the Buckeye Valley west of Phoenix and at Sentinel, Maricopa County. In the latter locality there are no cultivated crops and the honey plants are villow, 
mesquite, catsclaw, and ar'owbead. At Casa Grande mesquite and catsclaw are the chief dependence of the beekeeper. At Wellton also it is the most reliable honey plant for surplus. At Polonias in the eastel'n part of Yuma County there is an apiary of 65 colonies, which stores about a can of honey per colony from mesquite. In midsummer it becomes very hot and dry on the deserts; and, as there are no other honey plants and no honey flow of any kind, the bees must depend on the stores gathered earlier in the season or die of starvation. Along the Colorado River in the eastern portion of Imperial and Riverside Counties, California, there is an extensive growth of mesquite which yields a large early honey flow. The Liguanea Plain on the south side of the Island of Jamaica is largely covered with a third species of inesquite (Prosopis juliflora).

\section{MESQUITE IN THE HAWAIIAN ISLANDS.}

In the Hawaiian Islands mesquite is not only the chief but almost the only source of floral honey. Here it is called algaroba, or in the native tongue, keawe. The history of honey plants offers no more interesting chapter than that describing the introduction of this tree and its rapid increase, until today it yields annually more than 200 tons of algaroba honey, and has rendered beekeeping profitable in sections of the islands where previously little honey was stored. In earlier times the apiaries seldom exceeded 50 colonies, and they were located near forest trees growing in the mountains, which yielded comparatively little nectar.

About 1828 the seed was brought from the Royal Gardens of Paris by Father Bachelot, founder of the Roman Catholic missions. Once introduced the mesquite increased witl remarkable rapidity. It thrives from the level of the seacoast, where the spray of the waves falls on its foliage, up to an altitude of 2,000 feet, but succeeds best at a slight elevation in a semiarid climate. As the Hawaiian Islands are of recent volcanic origin the kinds of soil here are limited. The algaroba forests are confined chiefly to the lee or western side of the islands. The reason for this is that the windward or eastern side is exposed to the trade winds, which blow, witl few excep- tions, during the entire year. As the result of these winds the climate on one side of the islands is entirely different from that on the other side, even in the case of an island that is only a few miles across. On the windward side there is a heavy rainfall, in some places in excess of 200 inches for the year, and it may exceed 400 inches. On the lee side there is much less rain, or the climate may be so arid that the land in places may be little better than a desert. Where there is much rain the mesquite is entirely absent or does not grow well.

On the western side of the islands there are vast forests of algaroba trees covering thousands of acres. On the island of Oahu alone there are not far from 17,000 acres. Cattle are continually disseminating the seed, and the number of trees is also largely increased by systematic planting. Prior to October, 1916, there were planted orer 100,000 trees in Oahu. It has been estimated that a tree with a 30 -foot spread of branches will produce $2 \frac{1}{2}$ pounds of honey in a normal year. One strip of algaroba forest in Molokai supports nearly 2,000 colonies. It will not average more than half a mile in width, and about 30 miles of it are used for bees. Of the 600, or more, tons of honey produced in the Hawaiian Islands more than 200 tons come from the flowers of algaroba. The trees begin to bloom when they are from four to six years old. There are two periods of blooming. The first begins in March or later, according to the locality of the island, and lasts until August. In Hawaii the second period ends about the first of October. The long period of blooming adds greatly to the value of the tree to beekeeper's.

The honey is water-white, about as thick as that of white clover, and possesses an agreeable altho peculiar flavor. It is suitable for table lioney. Honey which has granulated in the combs is placed in liuge solar extractor's which will hold several hundred combs at a time. The sun's heat liquefies the honey without darkening it, and also melts most of the wax, which is extracted from the "slumgum" by .the usual methods.

The trees grow rapidly, and attain a height of 45 to 50 feet, with a diameter of 2 feet or more-much larger than they grow in Texas except in the Rio Grande 
Valley. If necessary the roots will go down to a great depth for water. Owing to its irregular liabit of branching, the tree does not present an attractive appearance. The spikes of sweet-scented, densely crowded small flowers are five or more inches long and produce an abundance of pollen. The yellow pods are six to nine inches long, and are eagerly eaten by cattle. The annual crop of pods in the island of Oahu is estimated at 25,000 tons.

METAMORPHOSIS OF BEES. - See Developaient of Bees.

MIGRATORY BEEKEEPING.-Experience has shown that the secretion of nectar in a given locality varies sometimes, even within a distance of only a few miles. It will occur sometimes that the homeyard bees will be gathering no honey when an outyard eight or ten miles away will be securing a good erop. This is due to the fact that the character of and moisture in the soil make possible the growth of some plants that will not take root in other locations only a few miles away. For example, a beeyard may be situated in a ralley close to a stream; along which there will be a heavy growth of honey-yielding plants. Within a few miles from there, perhaps on higher ground, and soil less productive, there will be nothing.

Sometimes one finds conditions like this -in one locality a large amount of buckwheat will be grown; ten miles away from there, there will be none whatever. The same is true of red elover, alsike, and a number of other artificial-pasturage crops.

Again, it 'will happen that in one year when there is an-excess of rainfall the location in the valley will be too wet for the proper growth of plants yielding nectar, while on the higher ground, a few miles away, conditions will be just right for a fine flow of honey.

The knowledge of these varying conditions in localities only a fer miles apart has led some beekeepers to practice what is known as migratory beekeeping. For example, in one yard it is evident that bees are not getting any honey, and there is no flora of any sort that gives any promise of any. On the otlier hand, there is another yard that is doing well; and there are still other locations without bees where there are immense quantities of alsilie or red clover, or of buckwheat. Evidently it is a part of wisdom and business sense to move the yard that is yielding no returns to the location in which the honey can be secured.

In California, for example, it is quite customary for the beekeeper to move from the orange district into one with an abundance of sage, then from the sage into the bean fields, or into localities where alfalfa is being grown. Similarly, bees in the East are mored fron the clover. into the buckwheat fields. For particulars on moving bees, see Moving Bees.

Migratory Beekeeping iș being practiced on a large scale in the extreme western part of the United States. Bees are being moved in carlots from Texas, Idaho, Montana, and Nevada into California and back again. In many cases the large producers find that they can move the bees from Idaho, Montana, or Wyoming in one and two carlots in the fall to the citrus groves of California, build them up on eucalyptus during the winter, eatch a crop of orange honey in the spring, then mountain sage, after which the bees are loaded on the ears and moved to the State whence they came where they catch a crop of alfalfa. In one case in particular one large producer says he cleaned up in this way $\$ 50,000$ in one season; but this was during war-time prices when honey was up to $22 \mathrm{c}$ a pound in carlots. Some good beekeepers even during normal prices are making migratory beekeeping pay handsome returns.

Bees are also moved in package form without combs in lots of a thousand pounds at a time by express. (See Moving Bees.) One large producer in Nevada had 1,200 two-pound packages of bees sent him by express from California after the orange and sage bloom.

\section{MILKWEED (Asclepias syriaca).-} There belong to the milkweed fanily, or Asclepiadaceae, some 1900 species, widely distributed in the temperate and tropical regions of both hemispheres. About 22 species occur in eastern North America, and 25 more in the southern and western States. The common milkweed, or silkweed (A. syriaca) is the most common species in the northern States. It is a stout plant, four or five feet tall, with oblong leaves 
and purple flowers, growing in fields and waste land. In California L. mexicana and A. speciosa are of great value to beekeepel's.

Milkweed has been listed as a loney plant in many States, as Massachusetts, North Carolina, Tennessee, Texas, Nebraska, California, and Michigan; but it is comparatively rare in the prairie region. In Michigan, milkweed is very abundant in the northern part of the Lower Peninsula in Cheboygan, Emmet, Charlevoix, Antrim, and Grand Traverse Counties, where an average of 50 pounds surplus per colony is sometimes obtained. When the weatlier is favorable the nectar is secreted very rapidly, and a large colony may gather 13 to 17 pounds in a single day. A colony has been lnown to bring in an average of 11 pounds

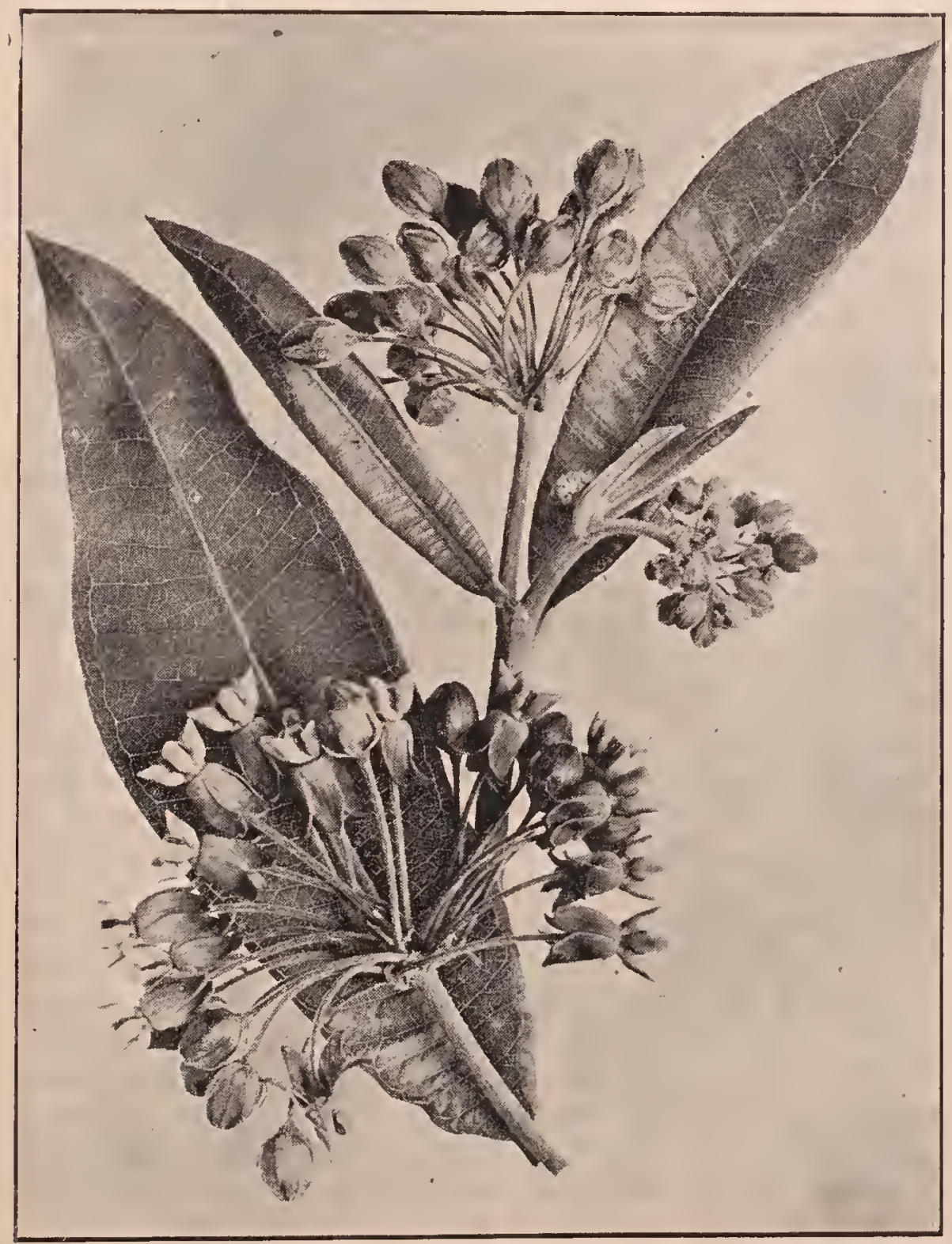

Common milkweed. per day for 10 snecessive days, and in one apisury a yield of 95 pounds per colony was obtained. The plants grow on every lind of soil, from a shore sand to heavy clay land, but it is chiefly from plants growing on heavy soil that the nectar is obtained. In special localities milkweed is so abundant as to exclude largely all other vegetation. It is classed as a noxious weed, and farmers are required by law to mow it down and often try to eradicate it; but except on a small seale this is impossible. It appears to be spreading: and às the raspberry disappears it is yearly becoming inore valuable as a honey plant.

The common milkweed (A. syriaca) blooms from about July 15 to August 15. The honey is excellent and compares well with that obtained from raspberry. It is white, or tinged witl yellow, and has a pleasant fruity flavor somewhat suggestive of quince, and with a slight tang. It is so, thick and heavy that it may be necessary to warm the combs before extracting. The cap ping s of the comb honey is nearly always pearly white. It sells readily by reason of its fine flavor, and is in every way suitable for table use.

The small flowers a re in flat-topped cluster's or unbels, and are green, white, yellow, red, or purple, but never in our species blue. They are called pinch-trap flowers since they possess a remarkable clip - m e c h a n is m found in no otler family of plants in the world.

Many species of milkweed are probably li a r m less to 
honeybees - only A. syriaca and A. mexicana, indeed, have been reported as causing much loss. In the case of these species the bees probably seldom perish except when several legs or other parts become entangled at the same time. More often the activity of the bee is crippled by the many clips and pollinia attached to its tongue, legs, or antennæ. Butterfly-weed (A. tuberosa) and purple milkweed ( $A$. purpurascens) are butterfly flowers.

In South America Araugia albens, another member of the milkweed family, attracts hosts of moths to its sweet-scented flowers. The tongues of the moths are caught in the slit-like notehes, and as they are unable to free themselves they die a lingering death. Some years ago it was seriously proposed by an economic entomologist to employ this plant in the extermination of the codling moth, so injurious to apples. But this well-laid scheme went agley, as the moth would not visit the flowers.

The way in which the pollen masses are clamped to the feet or legs of insects is of much interest to beekeepers, and every season there are many inquiries in regard to this queer phenomenon. The five anthers stand close together, forming a sheath around the stigma. Each anther is provided with two lateral wings; and where the wings of two adjacent anthers touch, there is a narrow slit, larger at the base than at the top. The anther, it will be recalled, usually consists of two sacs containing the pollen. But in the milkweed the grains of pollen are not separate, but are bound together in waxy flattened masses ealled pollinia. Two of these pollinia, or club-shaped masses of pollen, belonging to two different anthers, are attached by flexible bands to a small dry membrane, or dise, midway between them. In this flat triangular disc there is a wedge-shaped slit at one end. The dise stands directly back and above the slit between the two anther wings. This is the pinch-trap ready for action.

Let us now observe what happens when a bee alights on the flower. in search of nectar. In its efforts to obtain a foothold on these small smootl flowers it thrusts a claw or leg into one of the slits between the anther wings. Presently its leg is drawn upward into the wedge-shaped slit in the little membranous dise, which soon becomes firmly clamped to its leg, or in some cases to one of its antennæ. The harder the bee pulls, the tighter does the little pinch-trap lıold. When it flies away to another flower the pollen masses which, as described above, are joined to the little dise by straps, are foreibly torn from their pouches. Exposed to the air the strap-like stalks dry and draw the pollinia close together. Then as the bee alights on another flower they are easily thrmst thru the slit between two of the anther wings; but once inserted, and the insect's leg drawn upward, they can not again be withdrawn. The bee ean obtain its liberty only by breaking the connecting bands. If this happens, the pollen masses are left in a chamber near the stigma, and the bee bears away the membran-

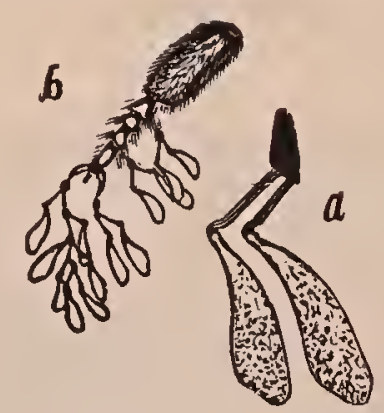

Pollen of the milkweed attached to a bee's foot.

ous dise with its empty stalks. Dise after dise may thus become attached to an insect until it is crippled or helpless.

It is stated on the authority of Gibson that one season an English beekeeper lost thousands of bees from the effects of strings of these clips. It was at first supposed that they were being destroyed by a fungus. Many different explanations have been given of these curious structures by persons not familiar with the flowers of the milkweed. Some think them a parasite, others a protuberance growing on the bee's foot, and other's a winged insect enemy of the bee. We give here an engraving of this curiosity, magnified at $a$, and also a mass of them attached to the foot of a bee. If the insect is not strong enough to pull out the pollinia, or later to break the connecting bands, then it perishes slowly of starvation, probably with little pain. These dry membranous dises are often described, even in botanical works, as glands, or as being glutinous or sticky, but this is not the case.

Climbing Milkweed (Cronolobus lnevis). 
Also called sandvine, angle-pod from the angled firuit, blue rine from the bluish color of the flowers, dry weather vine since it secretes nectar most freely in dry weather, and shoesting vine. A twining herbaceous vine with a tough stem which may attain a length of 40 feet. The oval heartshaped leaves resemble those of the morning glory or sweet potato. The small bluish white'flower's are in numerous axillary cluster's, and resemble the flower's of the milkweed. The pollen grains are in waxy masses. The pods are very large, thick, tapering to a point; the seeds bear a tuft of long silky hairs, and are carried for miles by the wind.

Climbing milkweed, or blue vine, is widely distributed over the central and Gulf States from Iowa to eastern Texas, eastward to the Appalachian Ranges. As a honey plant it is important chiefly in southwestern Indiana and in central Missouri. It grows luxuriantly on the rich alluvial soils of the river bottomlands, but does not thrive equally well on upland or thin clay soils. Commercially it is most valuable to the beekeeper in extreme southwest Indiana, along the lower portions of the Ohio, Wabash, and White Rivers. In this region it is the main source of surplus. At Bloomfield on the West Fork of the White River blue vine is reported to be spreading each year. As it is a perennial it dies down in the fall, but comes up again in the spring. In the wet season of 1915 the bees neglected the bloom entirely and no honey was secured. It yields well only in dry seasons. In Daviess County, also on the White River, there are thousands of acres of riverbottom corn fields which give an unlimited pasturage of blue vine. Early in the season it is held in check by the cultivator. But as soon as cultivation stops blue vine climbs the cornstalks, twining around the spindles, and reaching across from one row to another. It begins to bloom during the latter part of July and by August 15 the honey flow is at its best. The plant is killed by the first frost. Sixty to eighty pounds of honey per colony are not unfrequently obtained. A hive on seales recorded a daily gain of 4 pounds for 15 consecutive days. The honey is nearly white, or has a slight pinkish tinge, and an aromatic flavor. The flowers have a pleasing fragrance, which is very noticeable in the erening; and, when the sections of honey are removed, this delightful fragrance is at once apparent. It does not granulate readily even in cold weather.

Climbing milkweed should prove a good honey plant along the Ohio River in southern Illinois. At Brunswiek, Missouri, at the junction of the Grand River with the Missouri River, climbing milkweed is very abundant, and in a cornfield of 1,200 acres there was not a stalk on which there was not a vine. It blooms from July to about September 10 and in dry seasons yields well. The honey is described as having the color of Colorado alfalfa and a fine flavor.

MOTH MILLER. - In the old box-hive days and the early days of the movable frame, the bee moth or wax worn was regarded as the most serious enemy witl which, the bees had to deal. Many of the beekeepers of those times were driven out of the business because their bees were cleaned ont by the pest. So serious was it regarded that numerous moth-traps and moth-proof hives were invented. These were worse than useless, as they had all kinds of "retreats," cracks, and crevices for the very purpose of trapping moths. Instead of catching them they made the finest kind of breeding places for the pest.

In this day and age the modern beekeeper regards the bee moth as more of a joke than a pest. In fact, it is almost a disgrace for one to allow it to get a start among lis colonies or among the combs. It has been practically eliminated from all modern apiculture, and it is only occasionally that it gets in its work among good combs; and when it does, the owner is or should be ashamed of his own carelessness.

The bee moth does not exist as a real beeenemy anywhere in the United States except in some of the southern States where black bees are kept in box hives exactly as they were in the days of our forefathers (see Enemies of Bees). They are just as ignorant of modern principles; and so today the bee moths, or, rather, the larvæ of the wax worm, eliminate all except the rery strong colonies. See Box Hives.

There are two species of wax moth-the 
larger one, Galleria mellonella, and the lesser wax moth, Achroia grisella. The former is much the more general, and, because of that, more destructive. Fither species thrives among the ignorant and superstitious beekeepers, and particularly in box lives of black bees. In some of the southern States the bee moth is a serious enemy in that it destroys all second, third, and fourth swarms, leaving only the first swar'm. Even the parent colony goes down with the rest. If it were not for the bee moth these old-time beekeepers would probably be keeping three times as many bees, and, of course, getting a proportionately larger amount of honey. Unfortunately, some of this class will not be the ones who read a work of this lind; and it is to be hoped that the extension workers sent out
HOW TO DETERMINE TIE PRESENCE OF WITE WAX IVORMS.

The egg's hatch, and soon the larvæ begin their chank, chank, chanking: If one will listen he will be able to hear these loathsome worms eating their way thru the combs. Their presence can be easily determined also by a sort of webwork spotted with their excreta just beneath the surface of the coinb, where, evidently, they try to keep out of sight, and away from the bees. As they become more numerous they fill the space between the combs with web. In the earlier stages a few young Italians will keep out the worms and carry them out of the entrance; but black bees, unless the colony is a strong one, will let them go on until all the spaces between the combs are

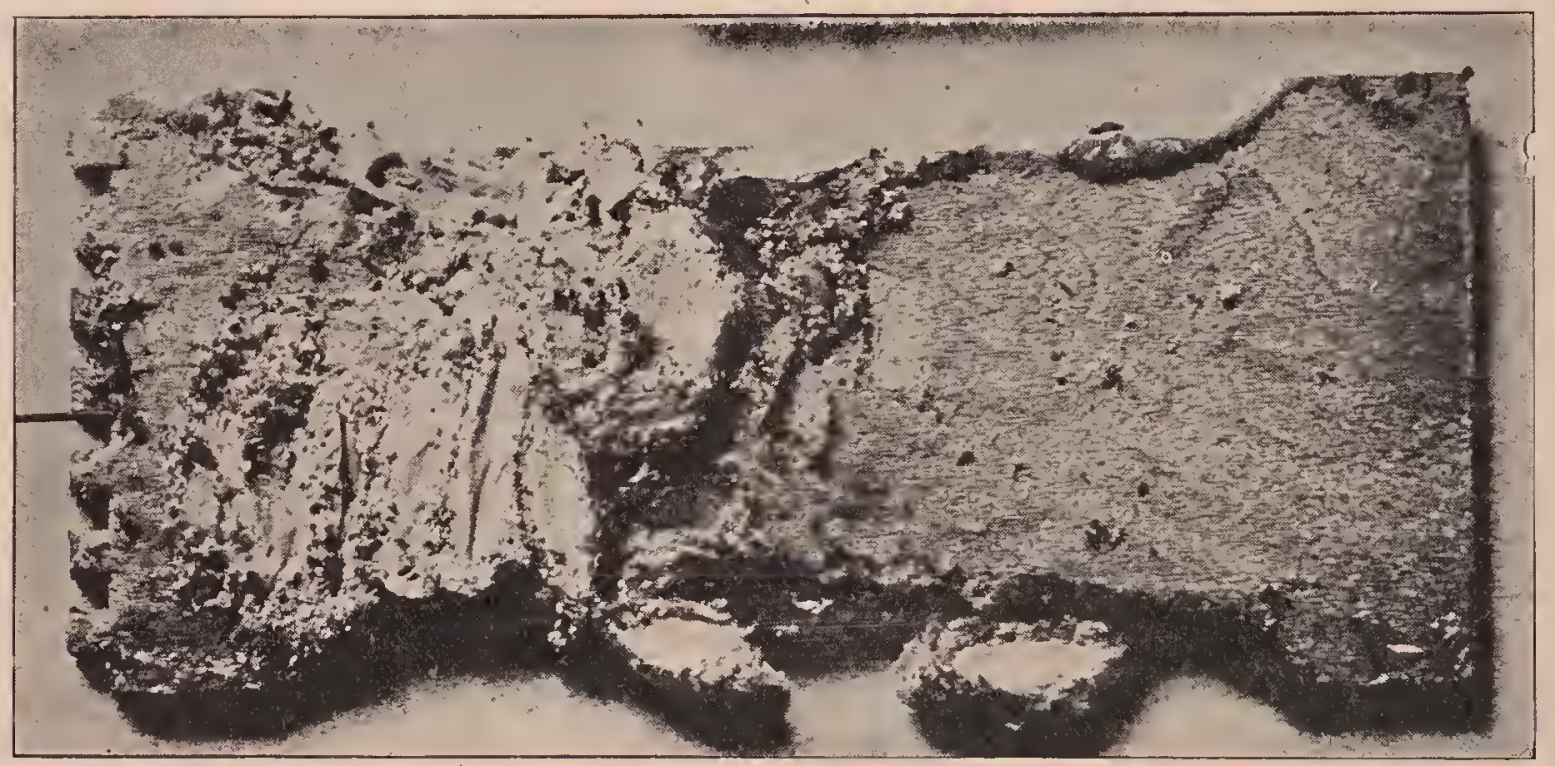

A sample of how the eggs and cocoons of the bee moth are deposited on wood. Sometimes the wood is grooved or eaten out. The illustration fails to convey the real filthiness of the mass.

by the United States Govermment will soon be able to teach them modern methodsmethods that will eliminate the bee moth and render possible a very fair living (see Box Hrves). The statement was made at the outset that the bee moth is regarded as a joke by the modern beekeeper, and so it is. Since the introduction of the Italian bee and the movable frame there is no excuse for having the pest among colonies or combs. In the first place, the Italian bees themselves will eliminate it, whether it be in a nucleus or a strong colony. Even an admixture of Italian blood will keep it under control. A weak colony of black bees is easily destroyed by the bee moth. filled with the web and these ugly wriggling worms. Brood-rearing will be brought to a standstill, and the elimination of the colony will take place about the time the old bees begin to die off. A strong colony of black bees will prevent the wax worm from making any progress in the hive, but a weak one of blacks is an easy prey. Here comes in the advantage of movable combs, which the owner can inspect. When he finds unmistakable traces of the wax worm he can help out the bees by cutting out the webs and worm witl a knife or a stick; but it will be very difficult for him to eliminate all the egos of the moth which may be scattered all thru the hive in cracks and crevices be- 
yond the reach of the bees. The old patent moth-proof (?) hives of early days were full of these cracks and crevices, and of course much worse for their propagation than the regular simple hives without moth "contraptions."

In modern apiculture the moth, or, more properly speaking, wax worm, can do no damage except among combs which are laid aside for the time being. Combs from colonies of Italian bees will usually be safe when they are put away in bee-tight extracting-supers for the season.

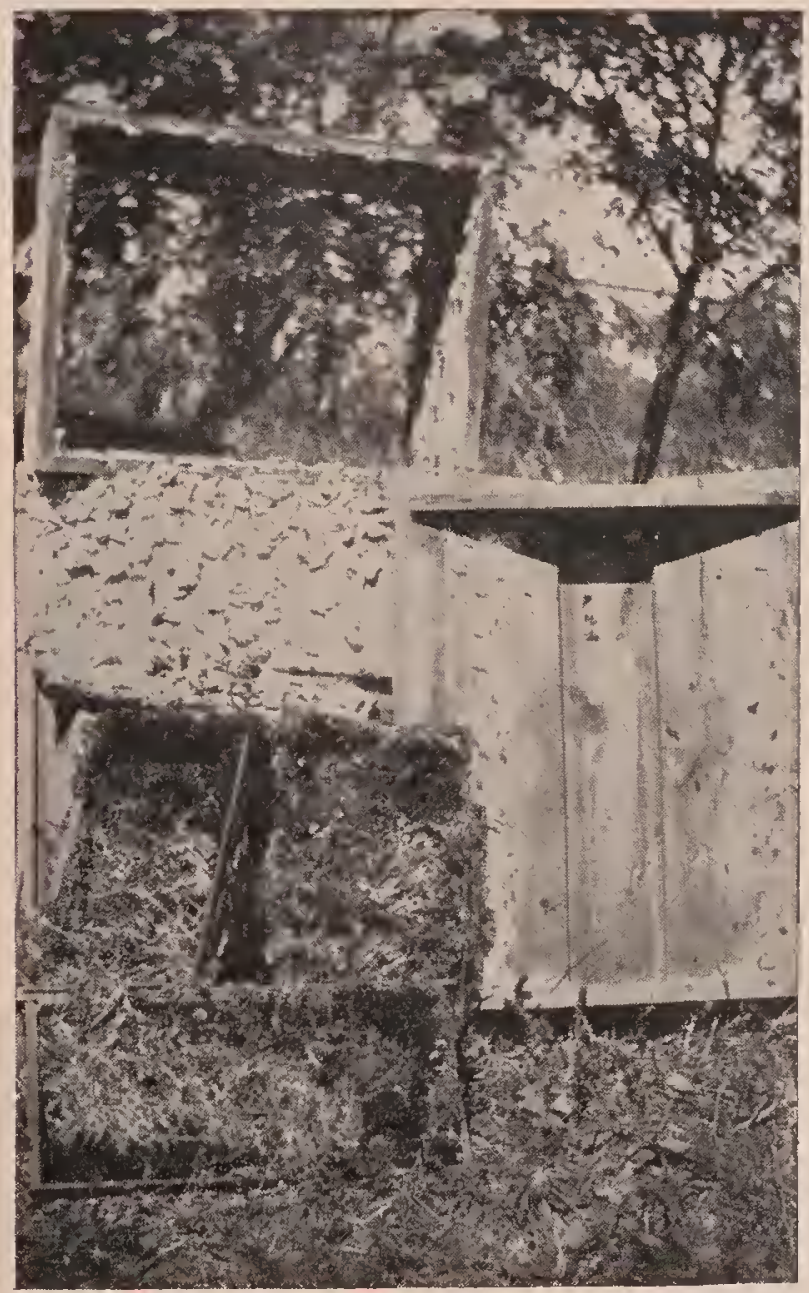

How moths ruin combs that are not taken care of.

In this connection combs in unspaced frames-that is, frames without shoulders -are much more subject to damage from the wax worm than those in spaced or Hoffman frames. The former when put away for the season are generally put into the super and laced together in close contact. Combs that are spaced like the Hoffman, the ordinary distance apart-13/8 inches from center to center-are much safer, because they cannot be placed in close contact. If they are set 2 inches apart, the damage, if any, will usually be confined to one comib.

It is generally regarded as perfectly safe to take the combs out of the hive right after the season is over, and confine them in hive supers stacked up. If these stacked supers are covered so as to make them beetight there will be practically no danger from a bee moth. All combs should be put into supers so that neither the moth miller nor robber bees can gain access to them. As a general thing, some combs will contain a little honey; and the first warm day during a dearth of honey these combs, unless put into bee-tight compartments', will invite the worst kind of robbing. Not only this, there will always be danger of the bee moth. Combs confined in bee-tight hives or supers, if they have eggs of the moth in the first place, may develop the wax worm later; but in an Italian apiary this will rarely occur; and even when the moth-eggs are in the comb they will be killed by the first winter freezing. Right here is one explanation of why the bee moth is much more destructive in the South than in the North. All stray eggs or larvæ are killed by ordinary freezing weather. Combs stored away in the fall in bee-tight supers will usually be safe if freezing weather follows shortly after. They can also be rendered safe from the depredations of the moth worm by the use of carbon bisulphide, mentioned further on.

TWO OTHER SPECIES.

The work of the lesser wax moth is somewhat similar to that of the larger species; but the galleries are smaller, and the webs are finer and more on the surface of the comb. The photo, by G. W. Tebbs, shows the cliaracteristic nest of the lesser wax moth.

There is still a smaller species that infests combs, known as the Mediterranean flour moth. This is not really a wax worm, and its presence is due to the fact that it eats the pollen in the comb; but it leaves in its wake a lot of webs as shown in the illustration on next page.

\section{BEE MOTH IN HIGH ALTITUDES.}

In Colorado, at least in the region of Denver, where the elevation is fully a mile above the level of the sea, the ordinary wax 


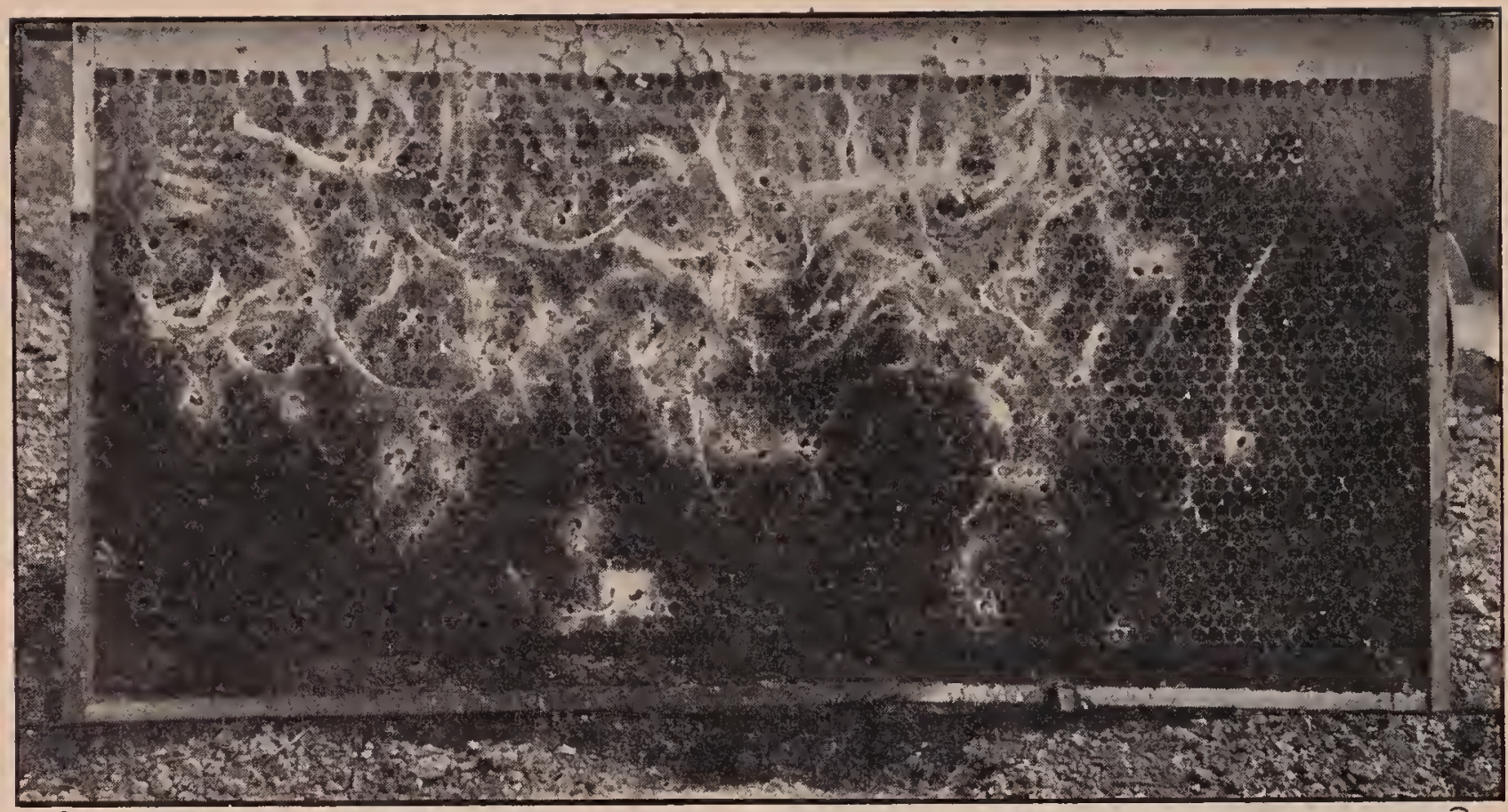

Combs infested by the lesser wax moth. This photograph was sent us by George W. Tebbs, Hespeler, Ontario, Canada, who wrote that the frame was taken from a hive which had originally contained an Italian colony, but which had been empty during the winter.

moths are unknown. The great elevation seems to be more than they can stand. There is, however, a very small wax worm, but it is not the same that ordinarily troubles beekeepers.

\section{'H'HE MOTH MILLER SOMETIMIES A BLESSING} IN DISGUISE.

The moth miller is not altogether an unmitigated nuisance. This pest, as already explained, seldoin troubles the professional or up-to-date beekeeper. It is only the slipshod, careless, don't-read-the-paper'sclass that it visits. Their bees become weaker and weaker, and finally die in the winter, leaving combs more or less filled with honey, and smeared over with the dead matter from foul brood. Unfortunately, these "old gums" containing diseased honey are a constant source of infeetion to all the bees in their vicinity. The healthy bees within range rob them out. In the mean time the moth millers, if present, get in their work. Their larvæ de-

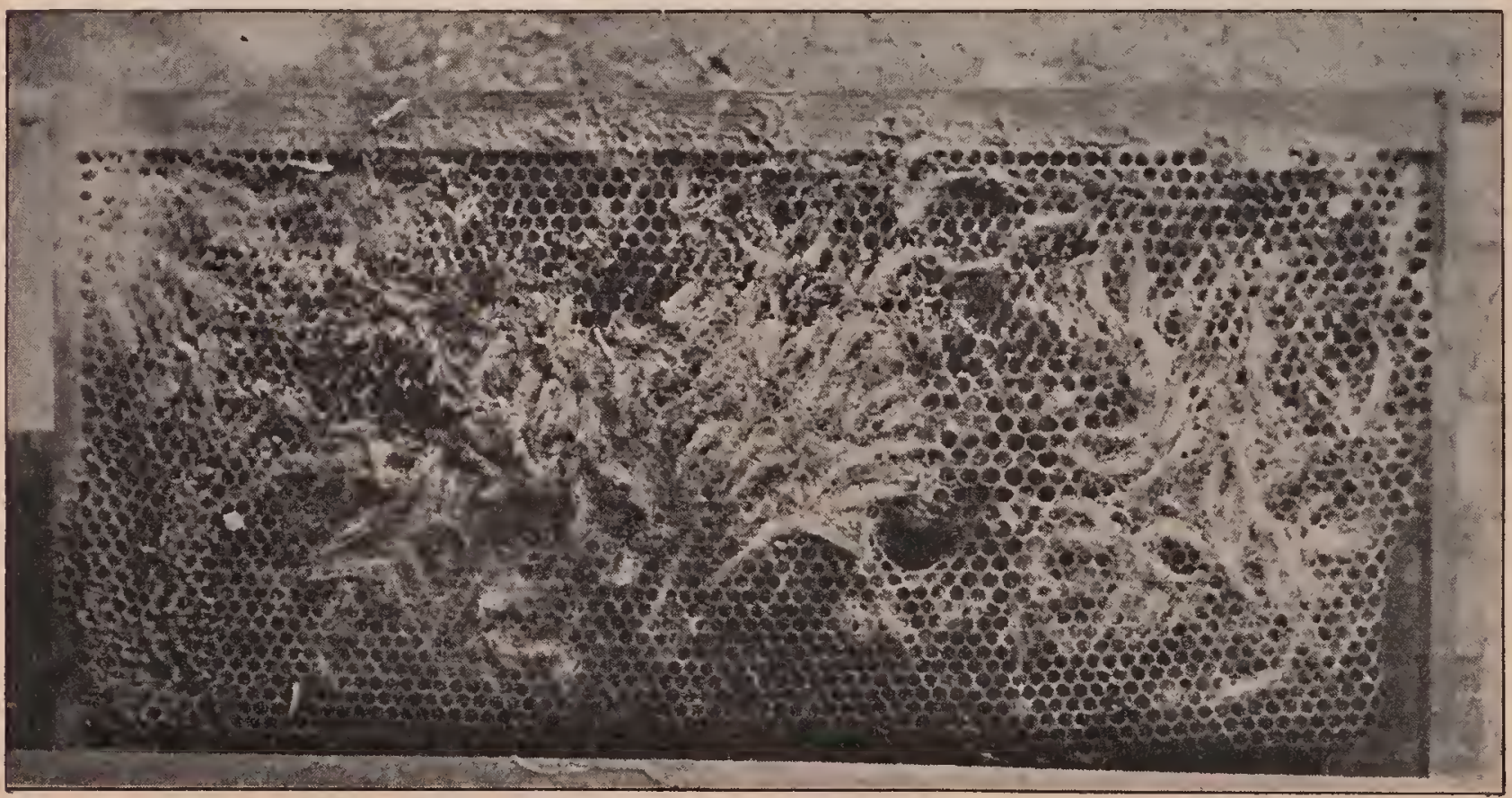

Work of the Mediterranean flour moth. 
stroy the combs so that no future swarm will find these old hives a suitable abidingplace. It is right here that the moth miller proves to be a blessing in disguise. These old combs smeared with foul-brood scales would, unless destroyed by some agency, attract swarms; for experience

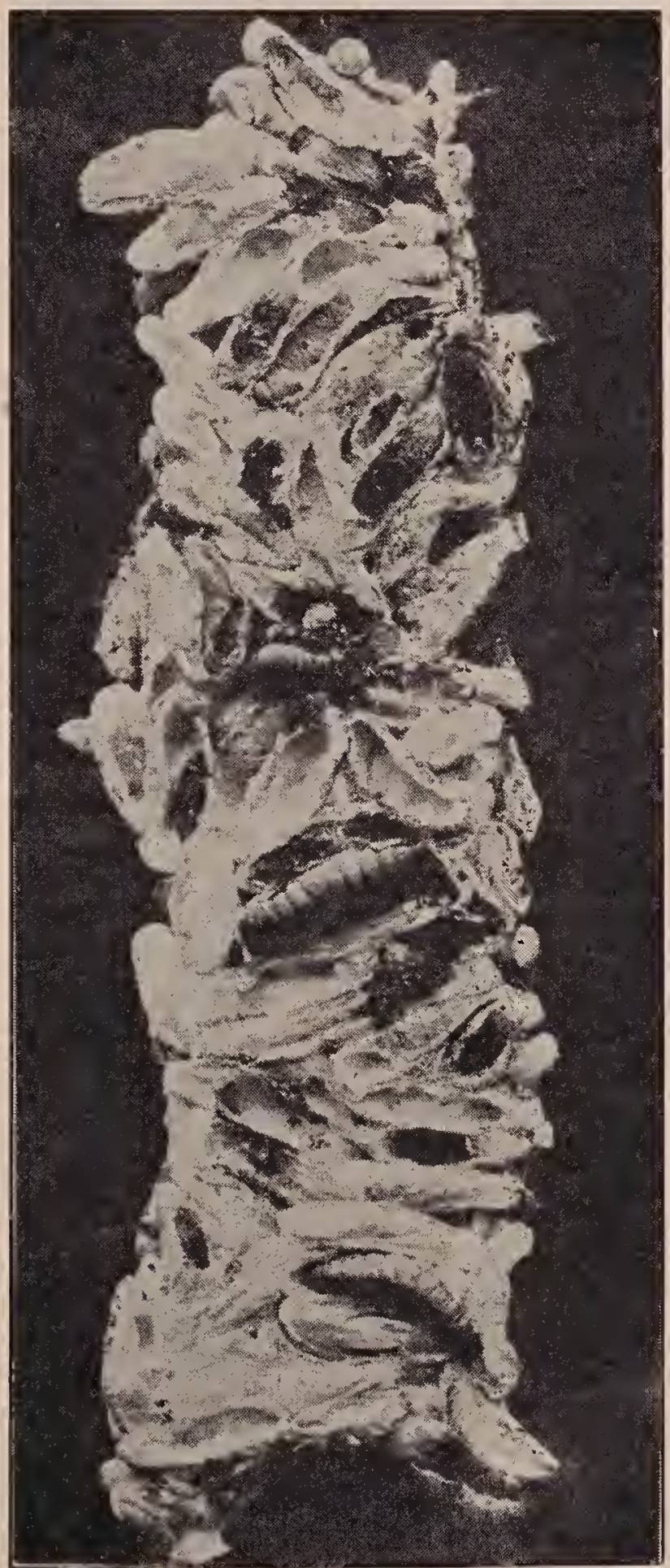

Cluster of bee-moth linva photographed exact size. -Texas Agricultural Bulletin No. 158.

has shown that they are frequently occupied by stray swarms. The bees get nicely started in lousekeeping, begin to fill the combs witl honey and brood, when lo! bee

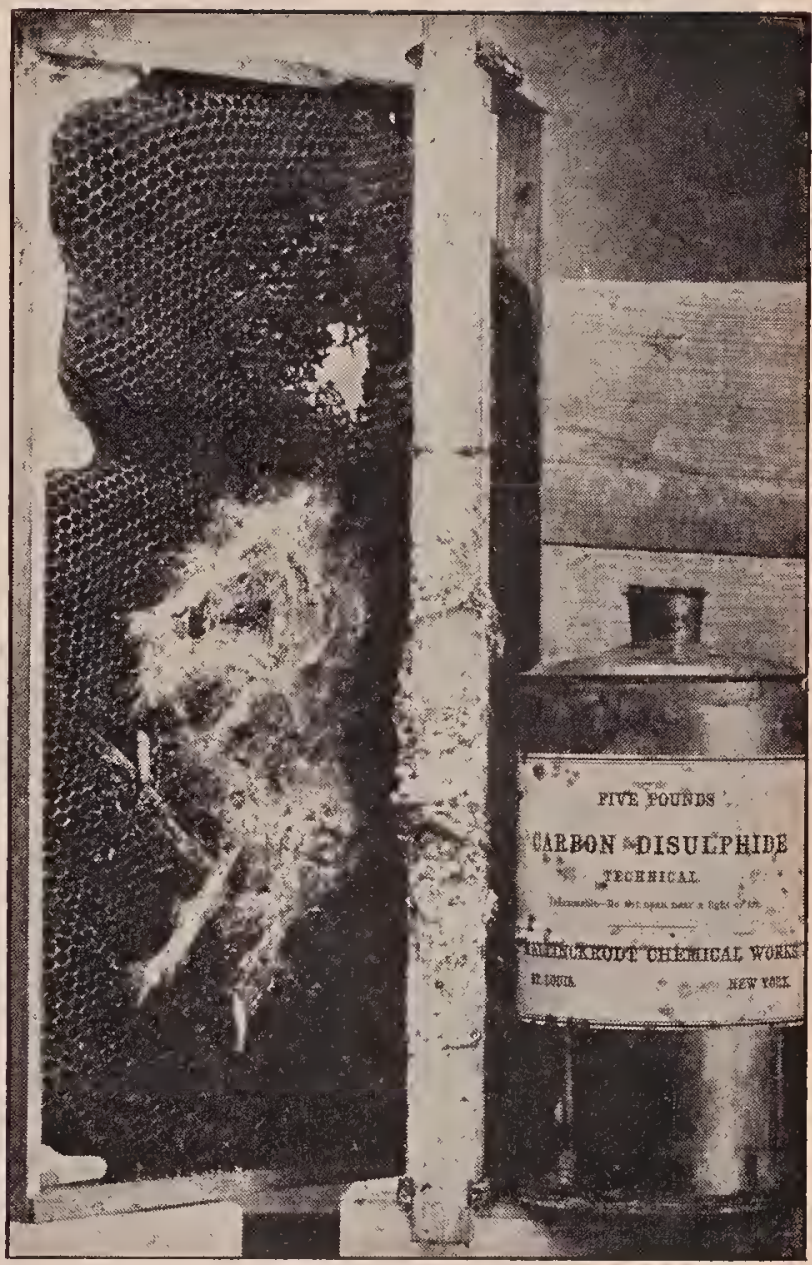

Web and cocoons in the center of a brood-frame. -Texas Agricultural Bulletin No. 158.

disease begins to make its appearance. The colony dwindles, of course, dies in the winter, and is again the source of infection to the neighboring bees. They rob it out once more; but if there are moth millers in the locality they soon destroy these old combs and leave in their place a mass of webs that is so repellent that no swarm of bees will make a home there. Said one of our Ohio bee inspectors, "The moth miller, after all, may be a friend to the progressive beekeeper in that it destroys one great source of infection-old diseased combs and 'gums' in his neighborhood that might otherwise remain in bee-trees and old hives for years and years, and for year's and years spread the disease."

One of the most thoro treatises on the wax moth or wax worm is a bulletin issued by the Texas Agricultural Experiment Station, No. 158, June, 1913. Among other things it discusses the life-history of the bee moth or wax worm. The author, F. B. Paddock, made a very exhaustive study of the larger species, Gallevia mellonella. As 


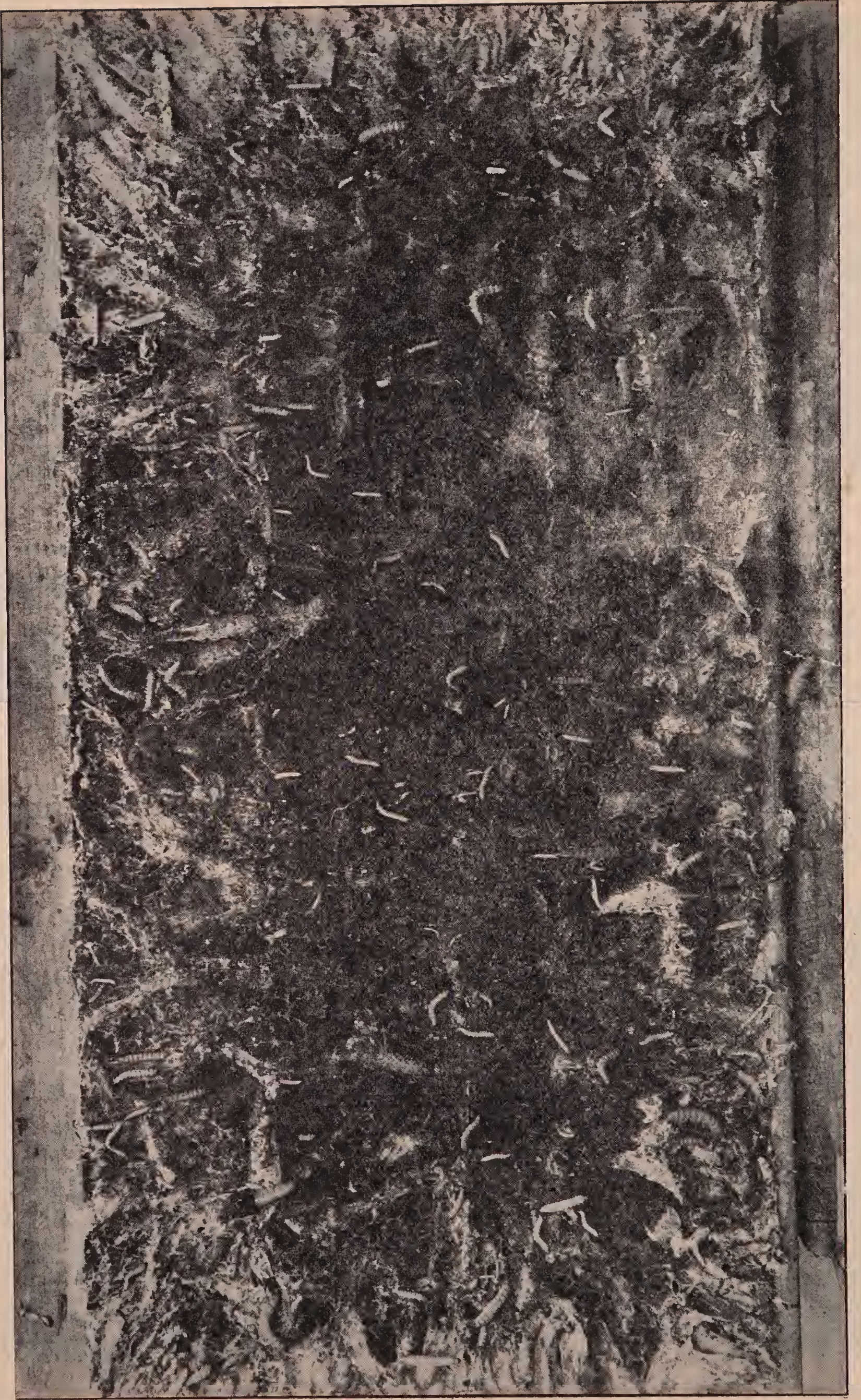


this bulletin covers the development, lifehistory, and the control of this pest, it is reproduced here in part, including the engravings.

ORIGIN AND DISTRIBUTION OF THE BEE MOTH. THE ADULT MOTH.

There is some dispute and no little uncertainty about the origin of the bee moth. Dr. A. J. Cook has this to say in regard to its origin: "These moths were known to writers of antiquity, as even Aristotle tells of their injury. They are wholly of Oriental origin, and are often referred to by European writers as a terrible pest." "*

The bee moth was introduced into America about 1805, tho bees having been introduced some time prior to this. The time of the introduction of the bee moth into Texas is not known. The insect is now found in Italy, Germany, France, England, Ireland, India, Australia, and in most of the beekeeping sections of the United States. This insect is distributed practically all over Texas.

The larva ("web-worm"), upon reaching maturity, constructs a cocoon by means of silken threads which it is able to spin. After the cocoon is completed the larva changes to the pupal stage. This is the stage in which the form of the larva is reconstructed to make the moth which will emerge later from the cocoon. The moths mate and the females deposit the eggs which hatch into the larvine. This is called the "life cycle."

\section{THE ADÚLT MOTH.}

The adult bee moth (Plate II, a) is abont five-eights of an inch (15 millimeters) in length, with a wing expanse of about one and one-quarter inches ( 30 to $32 \mathrm{~mm}$ ). The moth with its wings folded appears ashygray in color, but the back third of each front wing is bronze-colored, and this wing is thickly covered with fine scales which rub off easily when the moth is touched. On the outer and rear margins of the fore wing is a scanty row of short hairs. The hind wings are uniform in color, usually gray, with traces of a few black lines extending from the outer margin inward toward the base; on the outer and rear margins is a thick fringe of hairs on which is a dark line running parallel with the border of the wing. The body is brown, the shade varying, with a covering of scales. These scales rub off easily and are not always present on the older moths. The male is slightly smaller than the female. A difference between the sexes is noticed in the fore wing, which, in the case of the male, is deeply scalloped on its outer margin. This scallop carries a heavy fringe of hairs, almost black in

* "Manual of the Apiary," $\Lambda$. J. Cook, page 485. color. Another difference is in the mouth parts, the palpi of the male being rudimentary.

\section{IHABITS.}

The moths emerge entirely at night; and in the cases observed, no moths emerged after 9 p. m. They at once seek some protected place in which to expand their wings and dry, and by the next morning they are able to fly. During the day the moths seek a sheltered place away from light and enemies, where they apparently settle down and draw their wings around them, remaining very still and quiet. Usually they are well protected by their color, which resembles weather-beaten wood. If disturbed during the day, the moths will make a dart or short flight, acting as tho blinded by the light. When an object is met, the moth quickly settles down, and seems very anxious to avoid flight. That they are hard to disturb in the daytime is shown by the fact that in several of the cages used in the experiments small ants attacked the moths and killed them without any apparent struggle on the part of the moths. Only by close examination could it be detected that the moths were dead and not resting in the usual manner. It is only during the latter part of the oviposition period that the females are act ive during the daytime.

The male moths emerge a few days earlier than the females and are much longer lived. In several cages, closely observed, the males lived an average of 26 days, which was 14 days longer than the average life of the females. The male moths are very active thruout their existence. Just how long the males are functional has not yet been determined. In some matings under artificial conditions one male fertilized two females at an interval of ten days. During the first part of the emergence period the males are in excess of the females, since the males emerge first as a general thing. Later on, the number of males and females reaching maturity at the same time is about equal. During the latter part of the emergence period the females predominate. However, for the brood as a whole, taking sometimes as long as a month for all of the individuals to reach maturity, the males and females are about equal in number.

The first and the last emerging individuals of the brood are smaller in size than the average, regardless of the sex. The quality of the food has a great deal to do with the size of the adults. The last larvæ of the brood are undersized, but are almost always able to pupate and reach maturity. Several matings have been made with oddsized individuals, such as large males and small females, and vice versa. The results of these matings indicate that those larvæ which were forced into pupation prematurely may transform to functional adults. 


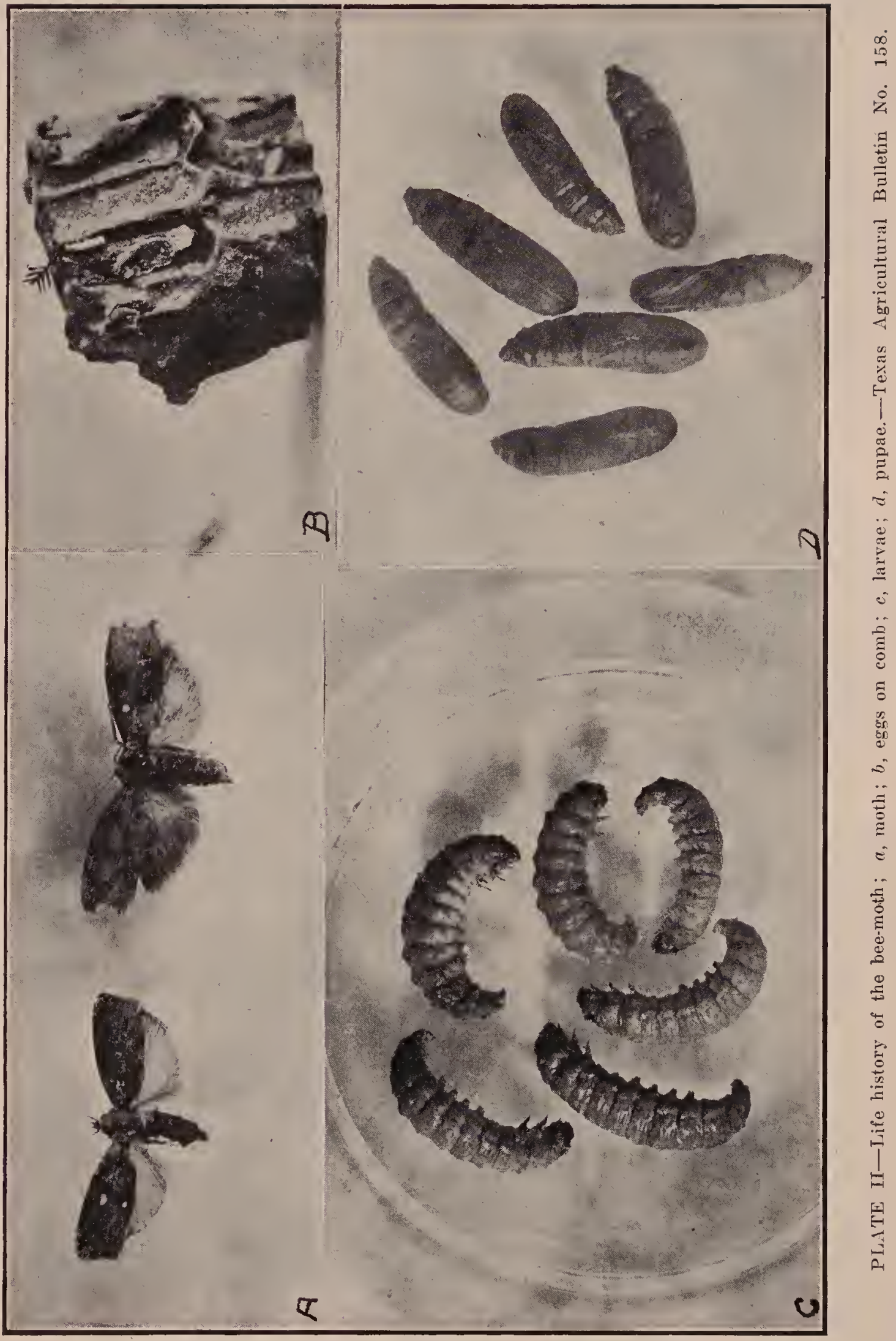


MATING AND OVIPOSITION.

During the mating period the males are more active than the females; and at this time can be noticed "drumming" with their wings, the vibrations of which are, at times, sufficient to produce a low hum.

- The moths probably mate very soon after emergence, tho no direct observations have been made upon this point. However, females only one and one-half hours old were killed and their ovaries examined. It was found that, at this time, fully two-thirds of the eggs were of full size and well down in the oviducts. tho not packed closely. as was found to be the case in the older moths. The eggs had the appearance of being ready for deposition.

Mating takes place at night, as would naturally be expected from the nocturnal habits of the species. In one cage a pair of moths were observed in coitu early in the morning. but this was no doubt an abnormal condition, as the female died in a short time. Another case was observed where the moths were in coitu from $7 \mathrm{p}$. m. till $10: 30 \mathrm{p} . \mathrm{m}$. The next morning no eggs had been deposited, but the following night the female began ovipositing. This was an exceptional case, as the female had been confined for a week after emergence before having the opportunity to mate.

It would seem that the female commences to oviposit in a comparatively short time after emergence. However, in the cages, an average of six days elapsed between the time of emergence and the first egg-laying. This period varies with the different broods of the year. Oviposition usually takes place at night and the moths generally start laying the eggs soon after dark. In the cages they have been observed busily engaged in ovipositing as early as 7 p. $\mathrm{m}$. While depositing eggs the female seems mindful only of the task she is performing, and is not easily disturbed, tho she is active, seemingly nervous, darting in and around the comb. While thus engaged the antennæ vibrate continuously and perhaps are used to locate suitable crevices in which to place the eggs. The ovipositor is long, equal in length to the last two abdominal segments and is very slender. It is constantly moving over the comb to detect a roughened spot wherein to deposit the egg. It thus has the appearance of being dragged after the female in her travels over the comb.

Having found a suitable place for the egg, the ovipositor is spread at the tip, the female braces herself as tho pushing backward to force the ovipositor into the comb, and then. after a quick jerk of the abdomen, an egg is forced down the ovipositor to its destination. In many instances females have been observed depositing their eggs at the rate of one every minute for a period of 30 minutes, and then, after a short rest, have continued again at the same rate. The eggs are always securely fastened to whatever ohject they are laid upon. The eggs are always laid in cavities. In the cage experiments this was on the side of the comb, often where the walls of a cell had been turned in. An example of this is shown at Plate II, b. Only one egg is deposited at a time, altho in working over the comb a female often places the eggs close together. On the smaller pieces of comb, furmished to moths confined in cages, as many as seven eggs were found in a single cavity. The number of eggs actually deposited by one female has not been determined, but females which had not deposited eggs were killed and the eggs in their ovaries were counted. The largest number of eggs found in ovaries of a single female was 1,128, and the average number was 1,014 .

In the cages, under artificial conditions, if comb was not supplied for the female, she would deposit her eggs in any rough place detected by her ovipositor. In many instances the females would refuse to oviposit on cappings which were furnished in some of the cages, but would go around the base of the lamp globe in which they were confined and fill every crevice with eggs. Sometimes these eggs would be fastened on the outside of the glass, and in such cases the globe would be fastened to its resting place.

The average time consumed in depositing the full quota of eggs varies with the hrond In the first brood it is nine days, but in the second only seven days. During the last part of the egg-laying period the female appears to be in a great hurry, and during the last few days she oviposits during the day as well as during the night, at times stopping to rest. If disturbed during the resting periods, she vigorously resumes her egg-laying. The females usually die while ovipositing, and the last three or four eggs are barely extruded from the ovipositor. If a female is being killed or injured, she will attempt to oviposit even after she is unable to walk.

The females will deposit their eggs even when they have not had the opportunity to mate. In all cases where the sexes were not properly paired, the females would finally oviposit, the period of oviposition being, however, much shorter than the natural one. Altho many females which did not mate were confined in cages, and altho they deposited eggs, none of these unfertilized eggs ever hatched. It seems a fairly safe conclusion that parthenogenesis does not occur with this species.

THE EGG.

The egg (Plate II, b), is elliptical, measuring about one-fiftieth of an inch $(.48 \mathrm{~mm}$.) in length and .43 in width. The shell is pearly white in color and. slightly roughened by wavy lines running across it diagonally at regular intervals. If the egg is 


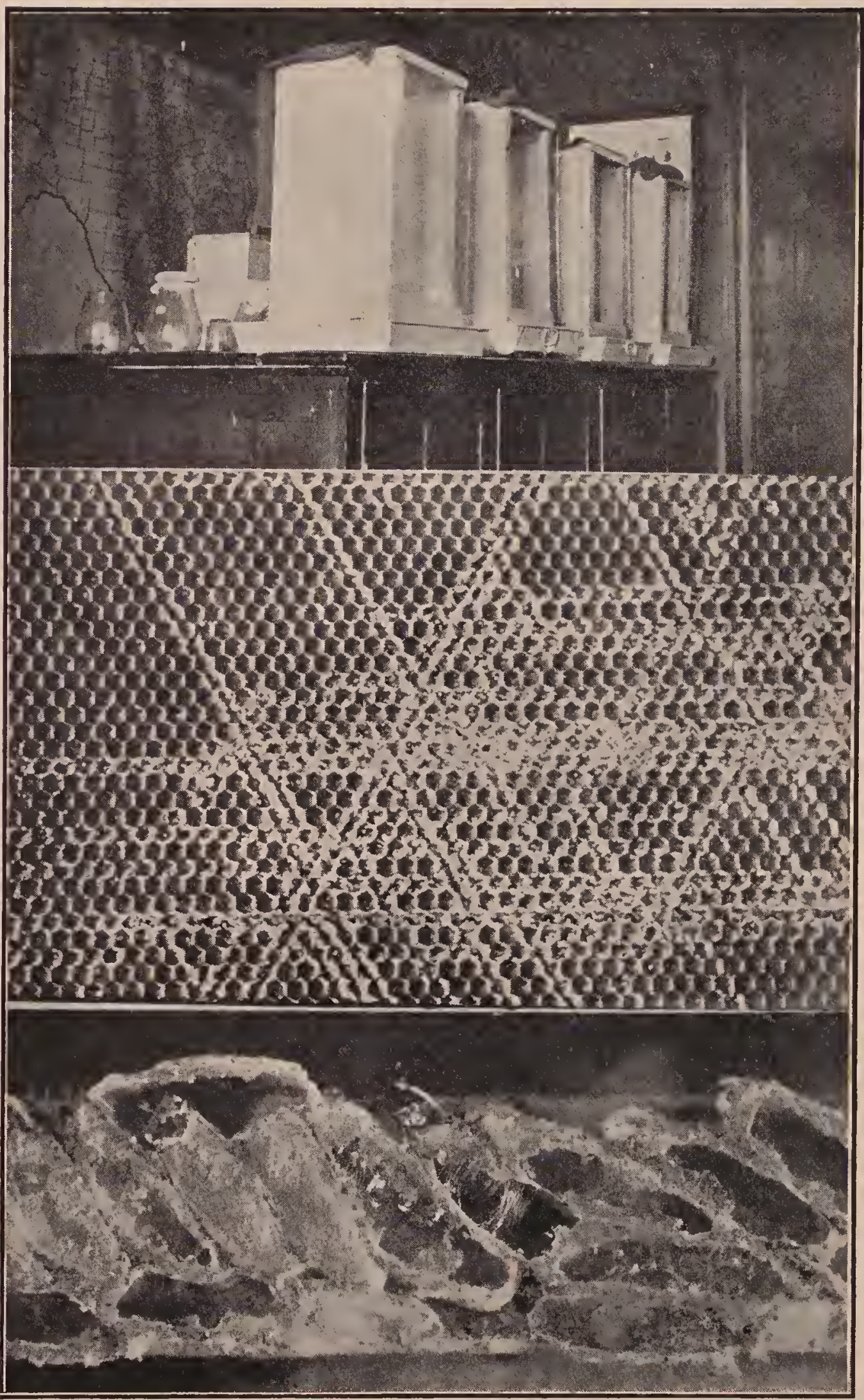

PLATE III.-Above, cages used in studying the development of the bee moth; at center, work of wax worm, or larva, on comb foundation; below, mass of cocoons, one of which shows larva repairing damaged cocoon.- Texas Agricultural Bulletin No, 158. 


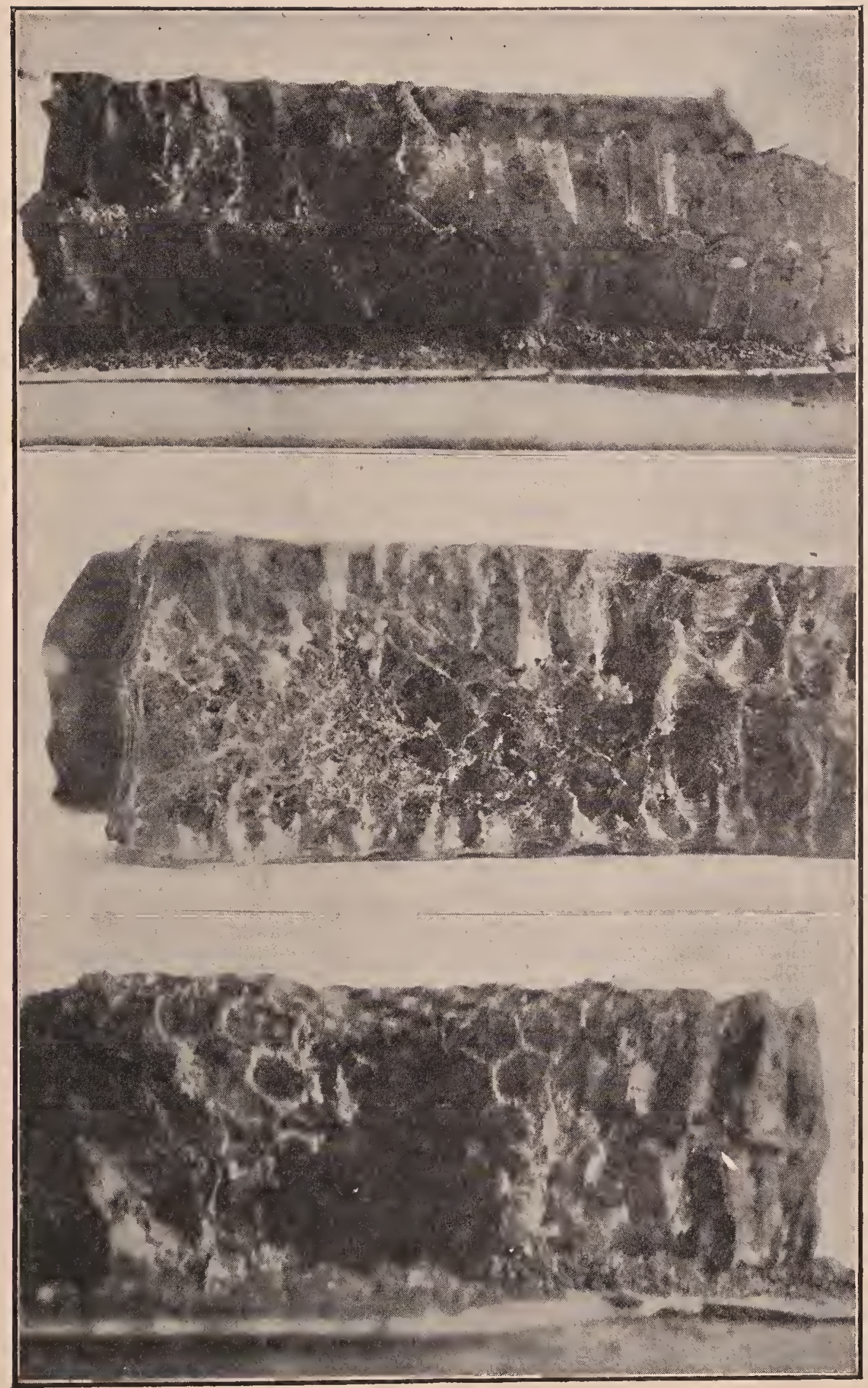

PLATE IV-Characteristic work of the wax worm on empty comb.-Texas Agricultural Bulletin No. 158. 
not deposited on dark comb it is very diffcult to see, and even then experience is necessary to detect all the eggs present.

The embryonic development of the egg has not been studied, but a few observations have been made upon the incubation period. During this period the egg gradually changes from a white to a yellow color. About four days before hatching, the developing larva becomes visible as a dark ring inside of the shell. The perfectly formed larva can be distinctly seen for at least 12 hours before the shell bursts. During this time the larva is engaged in cutting an opening in the shell and its final emergence from the egg is made thru a ragged hole in the top. After the larva is out of the shell it appears white and clear.

The egg stage of the first brood averages twelve days and of the second only ten days.

\section{THE LARV 尼.}

The larvæ ("worms") when first hatched are white in color and very small, only oneeighth of an inch $(3 \mathrm{~mm}$.) in length. After emerging from the shell they are quiet for a short time while they are apparently drying and stretching in preparation for their work of destruction. Soon they become very active, but only upon close examination can they be seen hurying over the comb in their attempt to gain an entrance before being detected by the bees. During this short period of one or two hours they are at the merey of their enemies. Within a short time after hatching, the first meal is taken, and this consists of scales of wax which they loosen from the comb in their attempts to gain an entrance. The entrance is made at the top of the cell-wall between the cells.

The entrance is extended by the larvæ into tunnels directed toward the bottom of the cells. Their presence is now noticeable, for in their work the bits of chewed wax not used for food are pushed back of them and out of the tunnel, making the surface of the comb appear rough and poorly kept. This tunnel affords protection and food for the larvæ and also leads to their desired feeding place, the center of the comb. Usually four days are consumed in reaching this point.

When the center of the comb is reached, the larvæ leave their tunnels aud wander over the bottom of the cells or, in the case of a comb containing honey, tunnel along the midrib from cell to cell. If disturbed, they seek their tunnels for protection. At first only small holes are eaten thru the bottoms of the cells, thus affording a passageway from cell to cell thru the center of the comb, so that, if disturbed, they can pass into passages of silk spun by the larvæ in their attempt to escape. In two or three days these openings are enlarged and outlined by threads of silk spun by the larvæ in their travels from cell to cell. These threads soon become numerous enough to form a silken gallery, which gives almost complete protectiou from the bees or other enemies. From this central gallery the feeding is extended out along the bottoms of the cells or the middle of the comb. The silk is spun wherever the larvæ go, so that very soon the bottoms of the cells are replaced by a layer of silk thread covered with excrement of the larvæ and particles of chewed wax. This condition is showen in Plate IV.

After the midrib has been eaten, the larvæ start on the walls of the cells, the ones furthest away from the light being the first that are destroyed. As this feeding continues out along the cell-walls, the threads of silk are extended to cover the new feeding-ground, and not only serve to protect the larvæ, but also act as a scaffold to support the damaged cells. Soon the center of the comb appears as a mass of tangled refuse and discarded wax. This condition is also shown at Plate IV. The feeding continues until the walls are entirely eaten, but the top of the cells is never eaten, perhaps because this would expose them to outside influence and enemies. An example of this is shown at Plate IV, lower photo. The area of feeding is gradually extended from the point of infestation to include finally the entire comb. If the comb does not furnish sufficient food for the larvæ that are present, they will begin to feed in the refuse under the comb in which there is considerable wax in small pieces. In this they construct such a large amount of web that they are absolutely protected from enemies.

The length of the larval period for the first brood is 45 days, or about six and onehalf weeks. In the second brood this period is shortened to 35 days, or five weeks.

The full-grown larva, shown at Plate II, c, is about three-fourths of an inch (18 mm.) in length. The body is large and the head is small and pointed. The general color of the body is a dirty gray, with the first segment brown on top and a broad line across it. The head is brown in color, with a light $V$-shaped line on top, this " $V$ ', opening toward the front of the head.

Having completed its growth, the larva secks a place in which to pupate, tho sometimes the end of the feeding gallery may be enlarged and closed to serve as a cocoon. The cocoon may also be spun in the refuse nnder the comb and this mass of webs affords an excellent protection to the pupa. The most common place is in some crack or corner about the hive, as shown in Plate $V$, below, or between the frames and the hive or in the "bee space" at the end of the topbars, as is shown in Plate VI, right. The larva prefers to get into a place which it can chew in order that a cavity may be constructed and the cocoon thus be better protected.

Having prepared for the location of the cocoon, the larva begins to spin the silk 


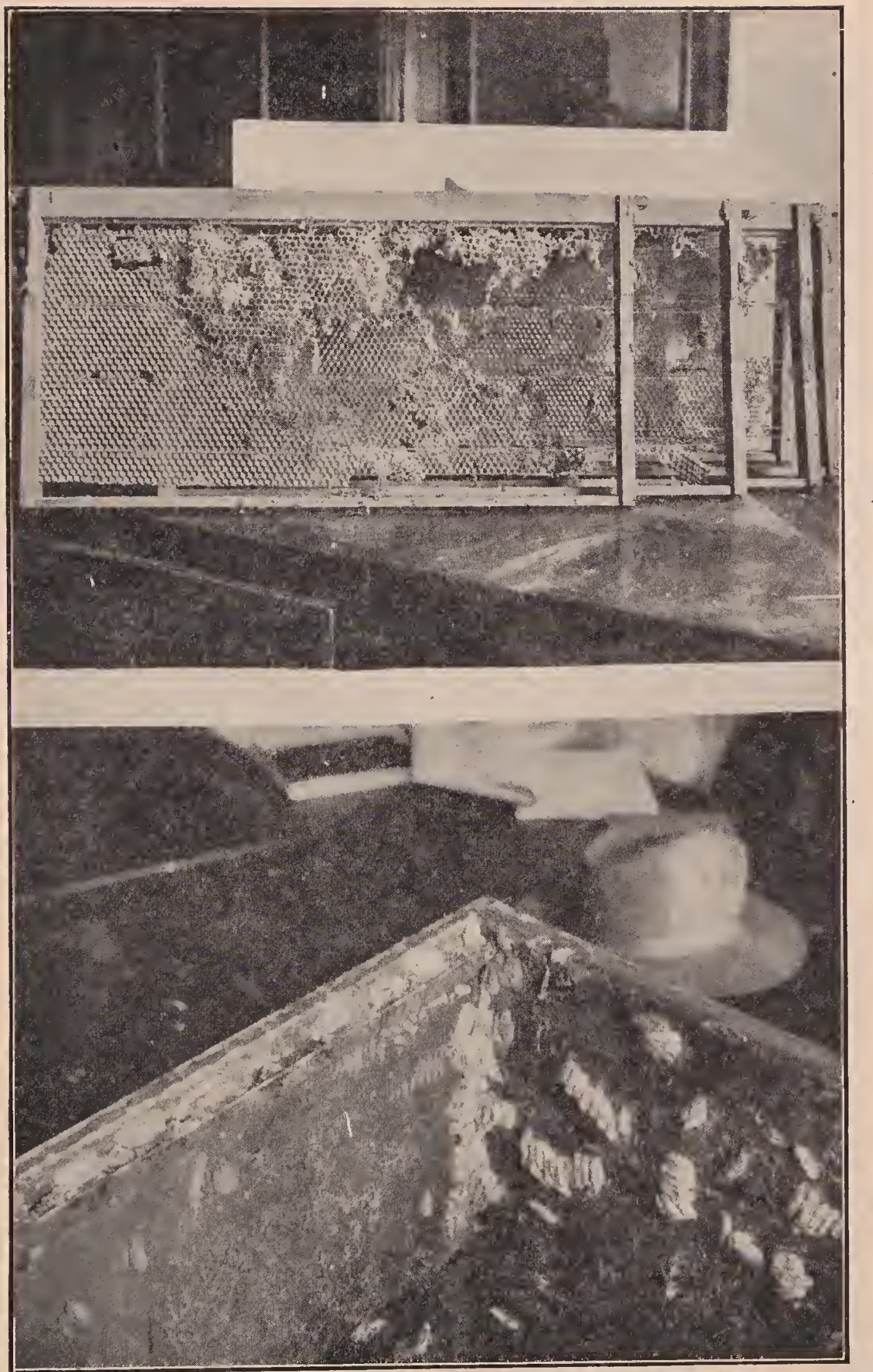

PLATE V -Above, comb and foundation destroyed by wax worm; below, characteristic appearance of cocoons inside of beehive.-Texas Agricultural Bulletin No. 158. 
thread about itself, starting just above the head and working backwards more than the length of the body. A thin layer of silk is spun in the general shape of the cocoon; and this framework is covered with fine silk from the inside. The larva is able to reverse itself within the cocoon, which it does many times during its construction. The outer layer, upon hardening, becomes very tough and even like parchment, while the inner layer remains soft and fluffy. Cocoons, both whole and broken open, are shown at Plate III, below, and in Plate VI, left. The average time consumed in the construction of the cocoon was two and one-fourth days in the case of the larvæ observed in our cages.

\section{THE PUPA.}

As the cocoon nears completion, the larva becomes very sluggish and the body shortens. The last act of the larva is to make an incision in the cocoon near the head eud which provides for an easy emergence of the moth at maturity. The average time elapsing from the completion of the cocoon to the formation of the pupa was thrce and three-fourths days in the cages of the experiments.

The change to the pupa takes place during the night. The newly formed pupa is white. At the end of the first 24 hours it turns to a straw color, very. light at first, deepening slowly. By the end of the fourth day the pupa is light brown and this color gradually deepens, so that by the end of the pupal period the insect is a dark brown. (Plate II, d.) The male pupæ average 14 millimeters (about two-thirds of an inch) in length and the female pupæ are fully 16 millimeters in length. A row of spines arises just back of the head and extends to the fifth abdominal segment; the body line is somewhat curved downward. The time from the formation of the pupa to the cmergence of the moth was seven and threc-fourths days in the cage experiments.

The total time from the starting of the cocoon to the emergence of the moth averages two weeks.

\section{LIFE HISTORY.}

From the work which we have done in trying to identify the different broods, or generations, of this insect, it appears that there are three broods in the extreme southcrn part of the United States. The third brood is not nearly as large as the first two, due to the fact that some of the second brood of larva do not pupate until late fall. There is a decided overlapping of the generations, which makes it difficult to determine the exact number of broods a year. At almost any time, from early spring until December, examination of a colony of bees is likely to reveal this inscet in all stages. It is often assumed that the life history is short and that there are several generations each year.
In well-protected hives the development may continue thruout the year without interruption. Usually the winter is passed with about one-third of the insects in the pupal stage and the remainder in the larval stage. Warm spells during the winter cause some of the moths to emerge from their cocoons; in the laboratory many moths emerged when the temperature was maintained constantly at 60 degrees $\mathbf{F}$. It is not unusual to see moth's on the windows of the honey-house, trying to escape, during the warm spells in December and January. Their presence may be accounted for on the supposition that they have just emerged from their cocoons or they may have been in hibernation as adults and become active with the rise in temperature. Such moths do not reproduce in localities where freezing temperatures are frequent. Even the most vigorous moths cannot withstand a freezing temperature for more than three days. Moths in well-protected places can survive an outside temperature as low as 26 degrees.F. for as long as five days. The moths are never active during the day when the temperature is below 50 degrees F., so at such times reproduction does not take place.

\section{NATURAL ENEMIES.}

Of the natural enemies of the bee moth, the most important is the loneybee itself. It is a well-established fact that if the colony be kept strong, healthy, and with a vigorous queen, it will defend itself against the bee moth. This is particularly true in the case of "Italian", bees. "In the Ohio Cultivator for 1849, page 185, Micajah $\mathrm{T}$. Johnson says: 'One thing is certain: if the bees, from any cause, should lose their queen, and not have means in their power of raising another, the miller and the worms soon take possession. I believe no hive is destroyed by worms while an efficient queen remains in it.' This seems to be the earliest published notice of this important fact by an American observer."**

This fact is of vital importance in the fight against the bee moth, for if the pest can be kept from its favorite food, control measures are made much easier. The fact, that the bees under natural conditions are able to defend themselves should leave the problem of control to such means as will destroy the pest in places other than the hives. Recently it has been found advantageous to introduce Italian blood into the colony. as the workers of this race seem to be more efficient fighters of the bee moth. In most cases this is sufficicnt for the control of the pest in the colonies, but it must be remembered that the colony cannot be kept under close observation and maintained at full strength unless domiciled in a frame hive.

* "Langstroth on the Hive and Honeybee," by Chas. Dadant, page 469 . 


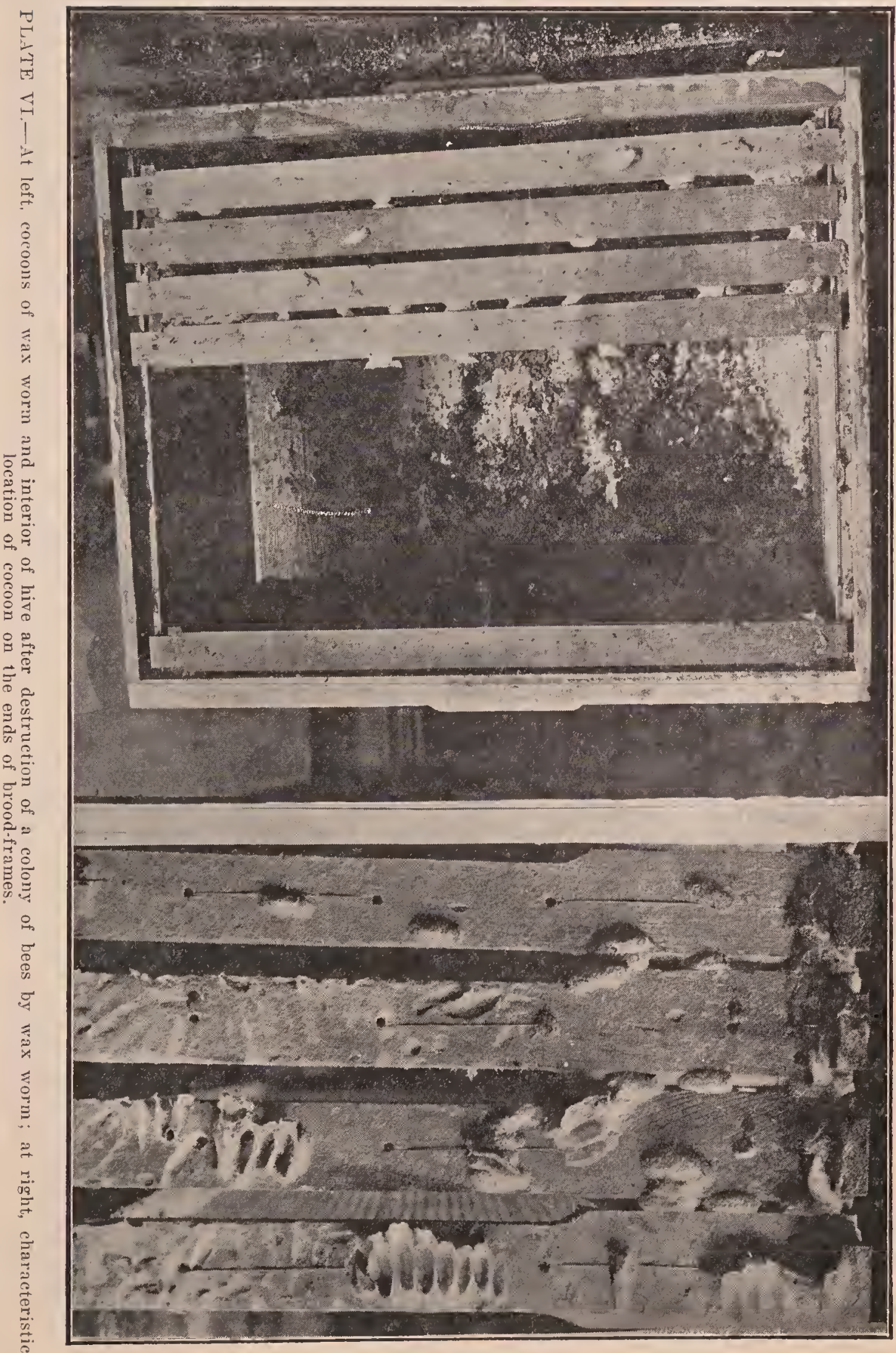


A small red ant, Solenopsis, sp., $\nmid$ has been found to be an enemy of the bee moth, as many of our cage experiments were destroyed by this ant killing the moths and larvæ. The attack is made on the moths during the day or when they are at rest. Usually the ants crawl under the wings of the moth and begin the attack upon the abdomen. There is no apparent struggle on the part of the moth, for close examination is necessary to determine that the moth is dead and not resting. The abdomen seems to be all that is desired and this is carried away in small pieces to the nest of the ants. This same species of ant also destroyed moths which had recently been prepared for exhibits. At such times only the abdomen was taken by the ants. In their attacks on the larvæ the ants entered the cages and crawled over the comb and wax in search of their prey; and if any larvæ were exposed they were attacked. The larger larvæ are more frequently attacked, as they are less active and usually feed in more exposed places than do the smaller ones. Unless the larva were well protected by webs in the refuse, they were destroyed by the ants. Apparently there are days and even parts of days when the ants are most active in their destruction. Never were the ants present in sufficient numbers to attempt tracing them to their nests. No observations have been made upon this ant in or about the apiary, and, while it proved very destructive under artificial conditions, the moths and larvæ might be better able to protect themselves under natural conditions.

Three hymenopterous parasites have been recorded from the bee moth. One is a chalcid, Eupelmus cereanus, found by Roudani in Italy; another is Bracon brevicornis, which was found by Marshall in France, and a third species, Apenteles lateralis, was recently found by A. Conté in France.* This last species was found near Lyons, where it spread very rapidly. It is apparently of considerable importance since it has also been reported to attack the larvæ of several other moths in England and Germany. The adult parasite is about one-sixth of an inch (4 mm.) in length, very lively, and avoids light; the body is black and the wings are transparent, with black specks. The larvæ of the bee moth are attacked while quite young and never attain a large size. A single parasite develops in each larva. The bees are said to pay no attention to the presence of the parasite, so that it can easily enter the hive in search of the bee moth larvæ. It was artificially introluced into hives by Conté with very satisfactory results.

ARTIFICIAL, CONTROL。

Unfortmately, the only natural enemy of

+ Determined by Wilmon Newell

* "A Hymenopterous Parasite of the Bee-moth." a Conte (Compt. Rend. Acrd. Sci, Paris, 154 pp. $41,42)$ the bee moth that is present to any great extent is the honey bee itself. In the absence of any other natural enemies of importance, the measures of artificial control must be made all the more effective if the beekeeper is to free his apiary of the pest. If the moths are driven from the hives by strong colonies of Italianized bees, they will surely seek scraps of comb and wax about the ground and stored comb and honey in the honey-house. It seems quite likely that in such cases the eggs are deposited as near to the comb as possible, as along the cracks between the supers, and the larvæ, after hatching, find their way to the comb thru crevices much smaller than the moth could enter.

One of the best methods of artificial control, and one upon which many beekeepers depend, is fumigation of combs and honey. Gas is able to penetrate material that it is not possible to treat in any other manner. The fumigation process is not difficult, for, when once started, no further attention is necessary until the treatment is complete. It is not necessary to watch the entire process. Stored material, such as comb honey and empty combs, should be examined from time to time, and at the first evidence of the wax worm they should be fumigated. Stored material of this kind should be examined at least once every week during the summer. and once every month during the winter season, so as to detect the infestation at the start.

\section{FUMIGATION.}

In the present investigation two materials have been used in the fumigating experiments. These were selected because almost every beekeeper is acquainted with them and they can be obtained in practically every locality at a reasonable price. They are sulphur and carbon bisulphide, or "'high life."

\section{SULPHUR.}

Dry powdered sulphur, or "flowers of sulphur," is a light-yellowish powder, with which every one is familiar. When sulphur is burned it mites with the oxygen of the air and forms a poisonous gas known as "sulphur dioxide." This gas is quite effective in killing some kinds of insects, including the wax worm. A common method of burning the sulphur is to place it on a pan of red-hot coals and immediately tier up the infested supers over the burning sulphur. The bottom super should not contain any infested material, and the pile should be covered as quickly as possible. A number of experiments were made with sulphur for fumigating combs containing the wax worms. The results of these experiments are given in the following table:

Table I.- Results of Fumigating Infested Combs with Sulphur Dioxide. 


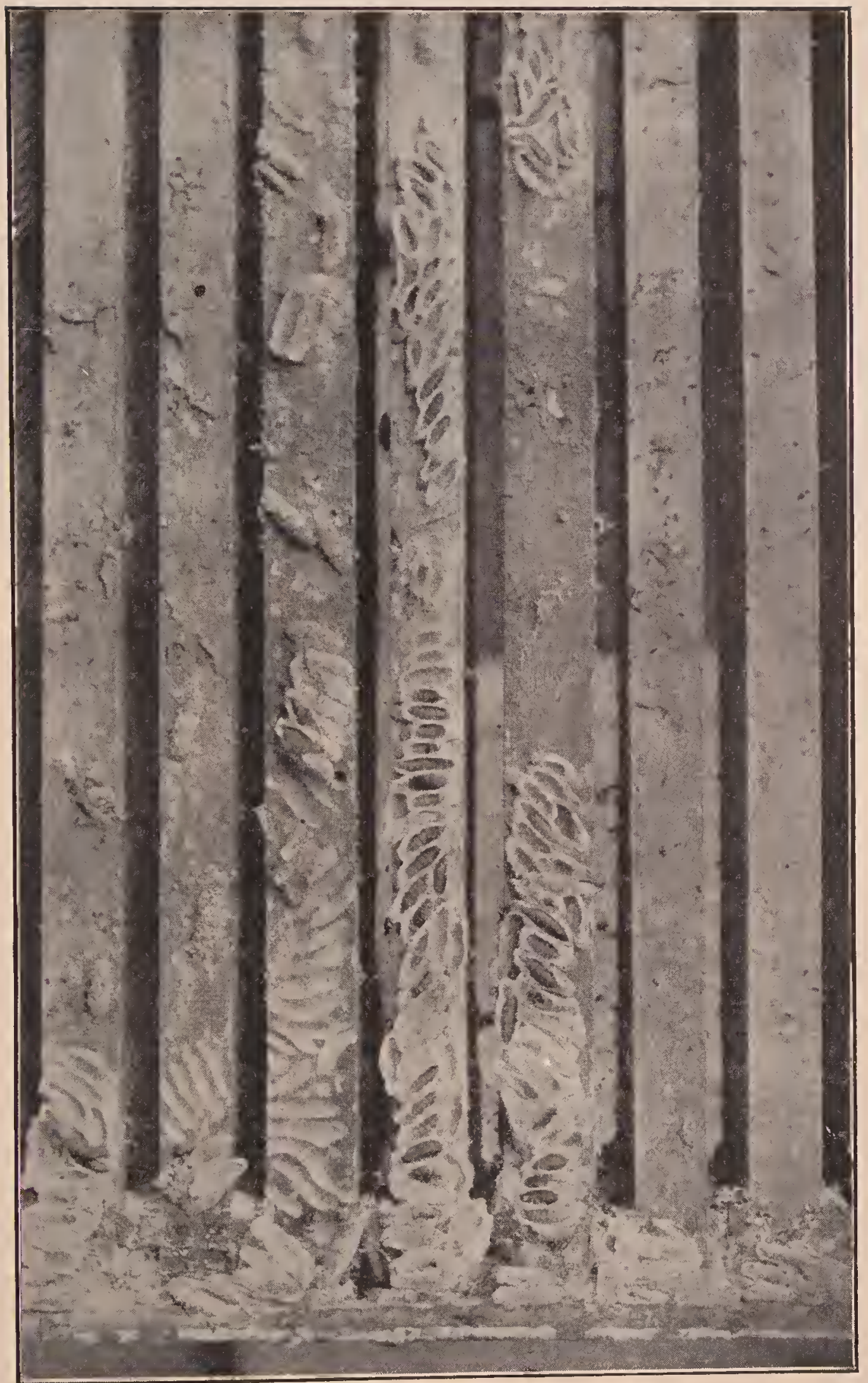

PLATE VII - Appearance of infested hive with cover removed, showing cocoons broken open and the larva inside of them.-Texas Agricultural Bulletin No. 158. 
Larvæ.... 1/4 oz...... One hour..... Killed Larvæ.....1/2 oz...... One hour..... Killed* Larvæ.... \% oz...... One hour......Killed*

The larvæ which were used for these experiments were ten to twenty days old, and in every case they were well protected by the webs and refuse.

From the experiments with sulphur dioxide it is evident that only extremely large doses will affect the eggs of the bee mothso large, in fact, that such fumigation would not be practical.

The larvæ which were used in the experiments were of different ages and some were better protected than others. When the larva are not very well protected they are quite susceptible to the gas, but the larger larvæ, which are often enclosed in a mass of webs, are not killed except when extremely large doses of sulphur are used.

These results seem to indicate that the sulphur fumes are not ordinarily penetrating enough to affect the eggs, and only when the larva are young and not well protected will the gas affect them. While the method is simple, there are minor details upon which the success of the operation depends. The sulphur must be burned at a high temperature in order to generate the most effective gas. While the method is generally effective under proper conditions, it cannot be recommended in preference to fumigation with carbon bisulphide.

\section{CARBON BISULPHIDE ("HIGH LIFE")}

The commercial bisulphide is an oily liquid, very volatile and exceedingly foulsmelling. It is cold to the touch; and because of its rapid evaporation it produces a freezing sensation when dropped on the skin. When exposed to the air at ordinary temperatures the bisulphide changes to a gas quite rapidly, and this gas, or vapor, is a little more than two and one-half times as heavy as air. This is a point to be remembered in its use, since it goes first to the bottom of whatever it is confined in. When mixed with air it becomes highly inflammable and sometimes explosive. Such a mixture of air and bisulphide gas may be exploded by even a spark, such as might be made by hitting a nail with a hammer. The liquid, on evaporation, leaves a residue of impurities. Its rate of evaporation is in proportion to the temperature and the area of the exposed surface. Its efficiency is greatest with rapid evaporation, and this is secured in relatively warm weather, but artificial heat must never be used to hasten its change into gas. Carbon bisulphide is obtainable from practically every druggist.

When carbon bisulphide is to be used for fumigation of infested material, the great-

* Eggs which were present on these combs were not killed by the sulphur dioxide, as larve were found emerging a few days after the fumigation, est precaution should be used to kecp all fire, such as lights, cigarets, etc., away from the liquid and where it is being used. For this reason it is well to take the material that is to be fumigated to some place out of doors and at least a hundred feet away from any building. The infested material should be placed in supers or hive-bodies if possible. These are piled as high as is convenient and all eracks between the supers made as nearly gas-proof as possible. Especially slould the bottom be tight. A good plan is to place an inverted hive cover on the ground, lay a piece of canvas over it, and then tier up the supers on this. After the pile has been completed, an empty super should be put on top. In this should be placed a large shallow pan into which the bisulphide is to be poured. When all is in readiness, pour the bisulphide into the pan and immediately put a hive cover on the top of the tier to confine the gas. This operation is best performed in the evening, and the pile of supers slould be left intact until the following morning. When the supers are taken down the confined gas will escape from them immediately, even before they can be carried separately into a building.

MOVING BEES. - Young bees, when they first start out, or old ones on the first flight of the season after a winter's confinement, hover in the air about the hive entrance, take a careful survey of surroundings, making wider and wider circles, each time taking in new objects by which they may familiarize themselves with the home. When the location is once carefully marked they will go back and forth without taking any note of distinguishing objects. But when the hive is moved only a few feet there is apparent consternation and confusion.

One cannot therefore, move his bees a few feet or a quarter of a mile witlout liaving the great majority of them go back to the old spot unless treated by the plans liere described. Some strains of black bees when moved will find their hives. See "Black Bees," under head of RACES of BEES. The bees that do not get back perish or possibly get into some other hive near their old location, with the result that there is a fight, and many becs are killed.

If one desires to move. his bees, and wishes to take them at least a mile and a half or two miles away, the problem is quite easy, for then they will stay wherever they are placed. As soon as they are liberated in their new position they will mark 


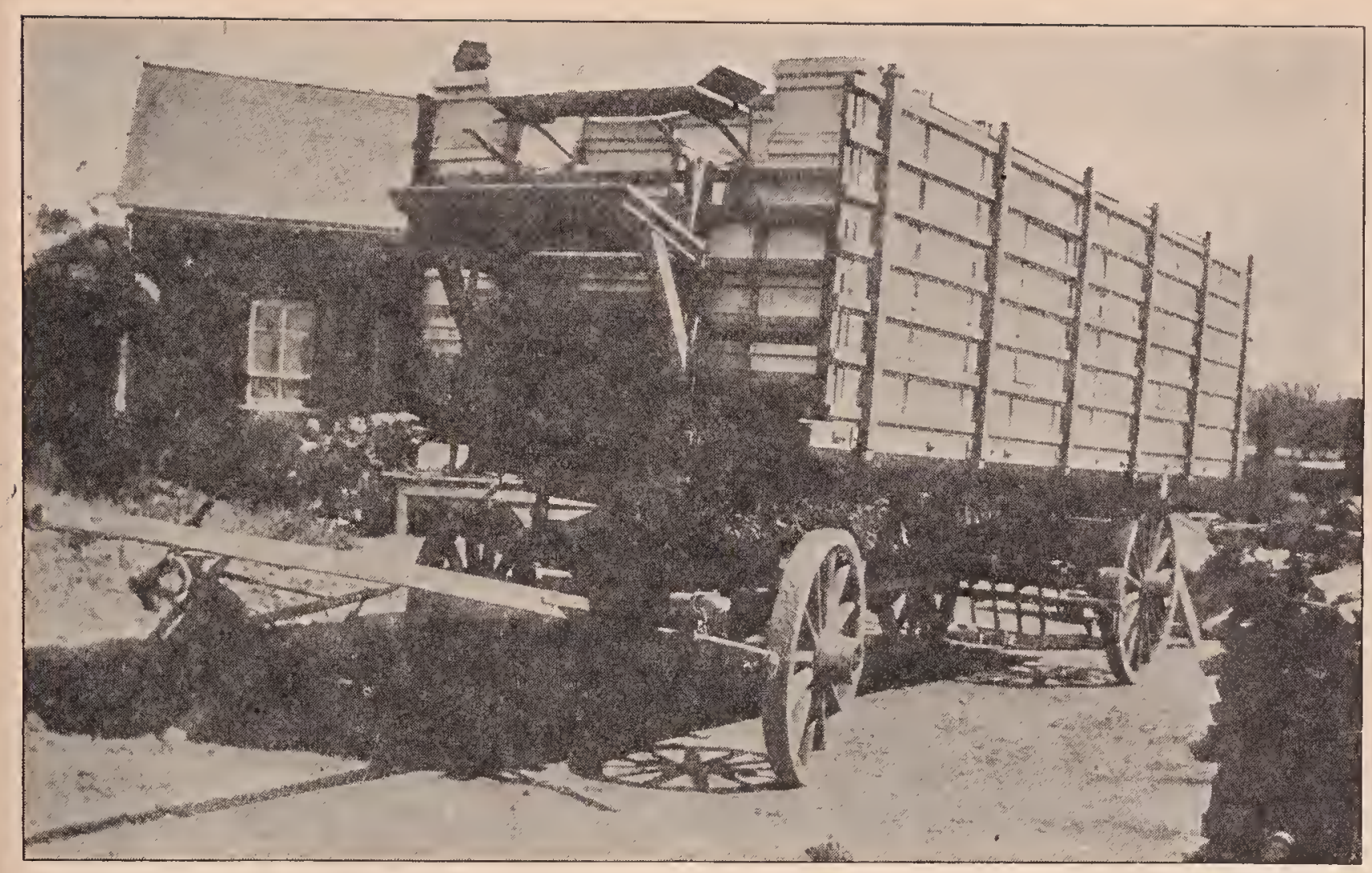

Rack made in California, especially for hauling bees.

the location as thoroly and carefully as when taking their first flight. After that they will go to and from the same spot as if it had always been their home.

But to move bees from the front to the back yard, or from a fourth to half a mile, is not so easy. They are familiar with the whole range of flight within a mile of the old stand; and when they go over their old hunting-ground, so to speak, instead of returning to the hive from which they have just come they will return to the old location. How then, shall we make them stay where placed? One way, and the very best one, is to wait till fall or winter. After they have quit flying for the season, move them to the spot desired. If they are confined a week or two weeks by cold weather, or longer, they will mark their new location and go back to it as their regular and permanent home. It will be better still if they can be confined for several montlis in the cellar; then when put out in the spring, they should be placed in the new location; for it is well known that cellared bees can be placed anywhere the following spring without reference to their old stands. Wherever they are' placed they will mark their location, and that must be their fixed position for the season.
But suppose it is the midst of summer, and for some reason the bees must be moved a few rods from their old location. Perhaps complaint is made that the bees in the front yard are interfering with passersby, and to avoid trouble it seems desirable to move them to the back yard. In an emergeney of this kind the following plan may be used:

Tack wire cloth over the entrances, carry the hives down cellar, and keep them there for at least five days, and longer if they appear to be quiet. While the bees are in the cellar, change the surroundings in the front yard or in the old location as much as possible. 'After the bees have served out their allotted time of confinement, put them in the back yard in the same order as before it if can be done conveniently. While. some of the bees may, perhaps, go back, the great majority will stay in their new location. Those that do return should be given a frame of brood in a hive; and when they have clustered on it they should be taken to the new location and dumped in front of the entrance to the hive. If the bees are confined during cool or rainy weather when they cannot fly, there will be no loss of honey that might be gathered from the field. While the bees are confined 


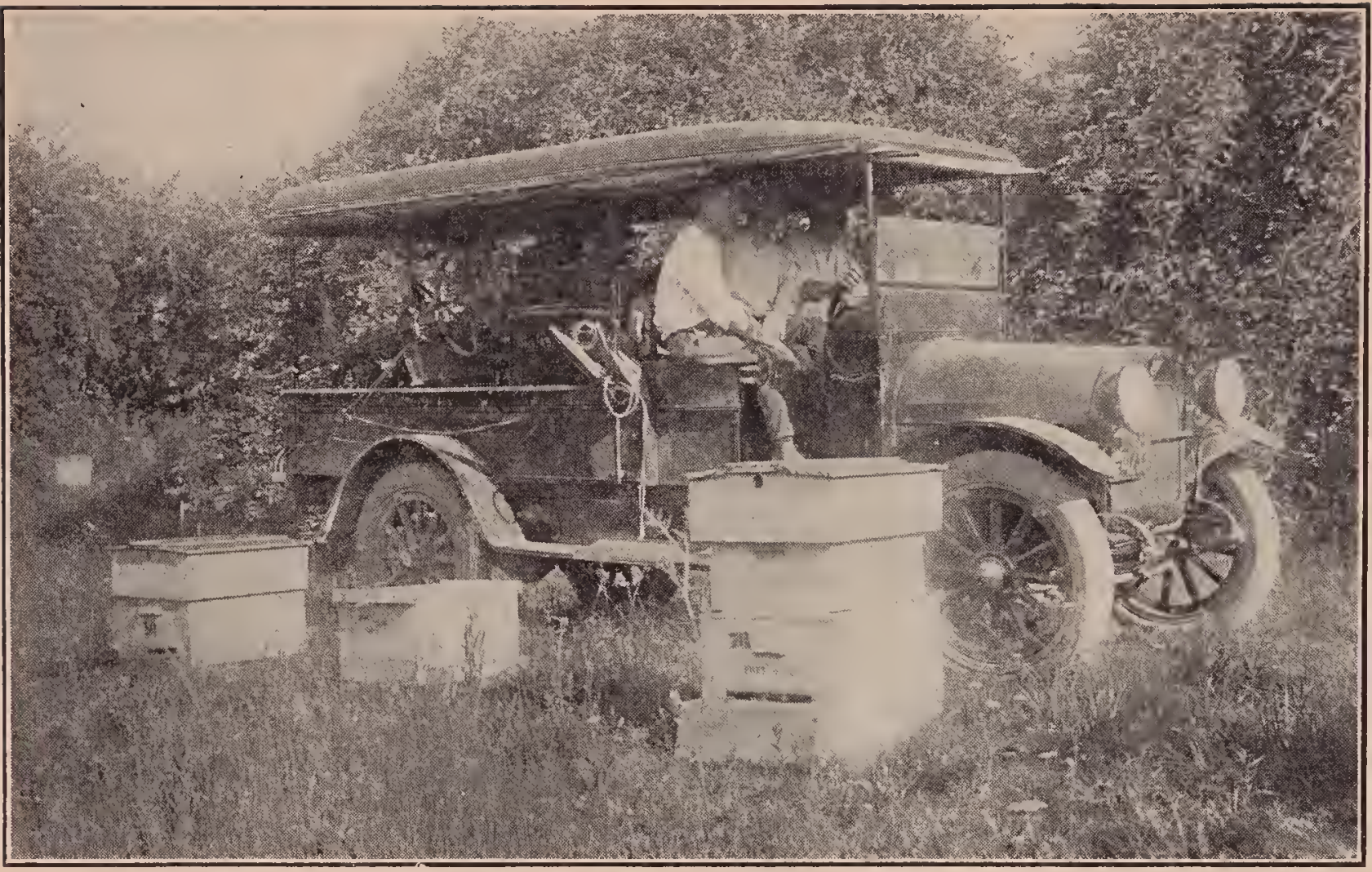

The auto truck with bees or supplies runs right into the apiary. No danger of stings causing runaways.

in the cellar a sharp watch should be kept on them to see that they do not suffocate; and, if practicable, the whole top of the hive should be covered with wire screen.

There is still another method; and wherever it is practicable to carry it out it is better than carrying them into the cellar; that is, move the bees to a point a mile and a half or two miles from the old location. Let them stay there two or three weeks, then move them back. But this involves considerable labor, so that the average person would not think it practicable.

Another plan that has been spoken of very favorably, and possibly may be better than any of the others mentioned heretofore except the plan of moving to an outyard and then moving back again, is this: In the cool of the morning, at a time of year when no honey is or has been coming in, colonies may be moved a few feet or a few rods with very little trouble. The hives are put on a wheelbarrow early in the morning, and after smoking at the entrance are trundled as roughly as possible clear over to the new location, for it is important that the bees get a general shaking-up in moving. If the frames are selfspacing there will be no damage done to the combs nor to the bees. The live is set down on its new stand, when it is given a little more smoke. Any number of colonies can be moved in this way; but the moving should be done at once, and the old location should be changed in appearance as much as possible. Very few bees will go back when so treated. The author has tried it in a limited way, and found that it works admirably. The bees should not be mored a short distance when a loney flow is on or has been on for two or three days. When they have been going regularly to the fields for a number of days they get their location well fixed, and it is almost impossible to move them short distances at such times without a general returning of field bees to the old stands. A correspondent reported that he attempted to move bees to a neighboring lot when the honey flow was on, and he says he never saw bees crosser in his life. When, therefore, a neighbor complains that the bees are interfering with public traffic along the highway, and they must be moved at once, one must take into consideration whether there is a loney flow on. If so an explanation should be made that moving bees at such times will only make the trouble complained of much worse. See Bees as a Nuisance; also APIARY. 


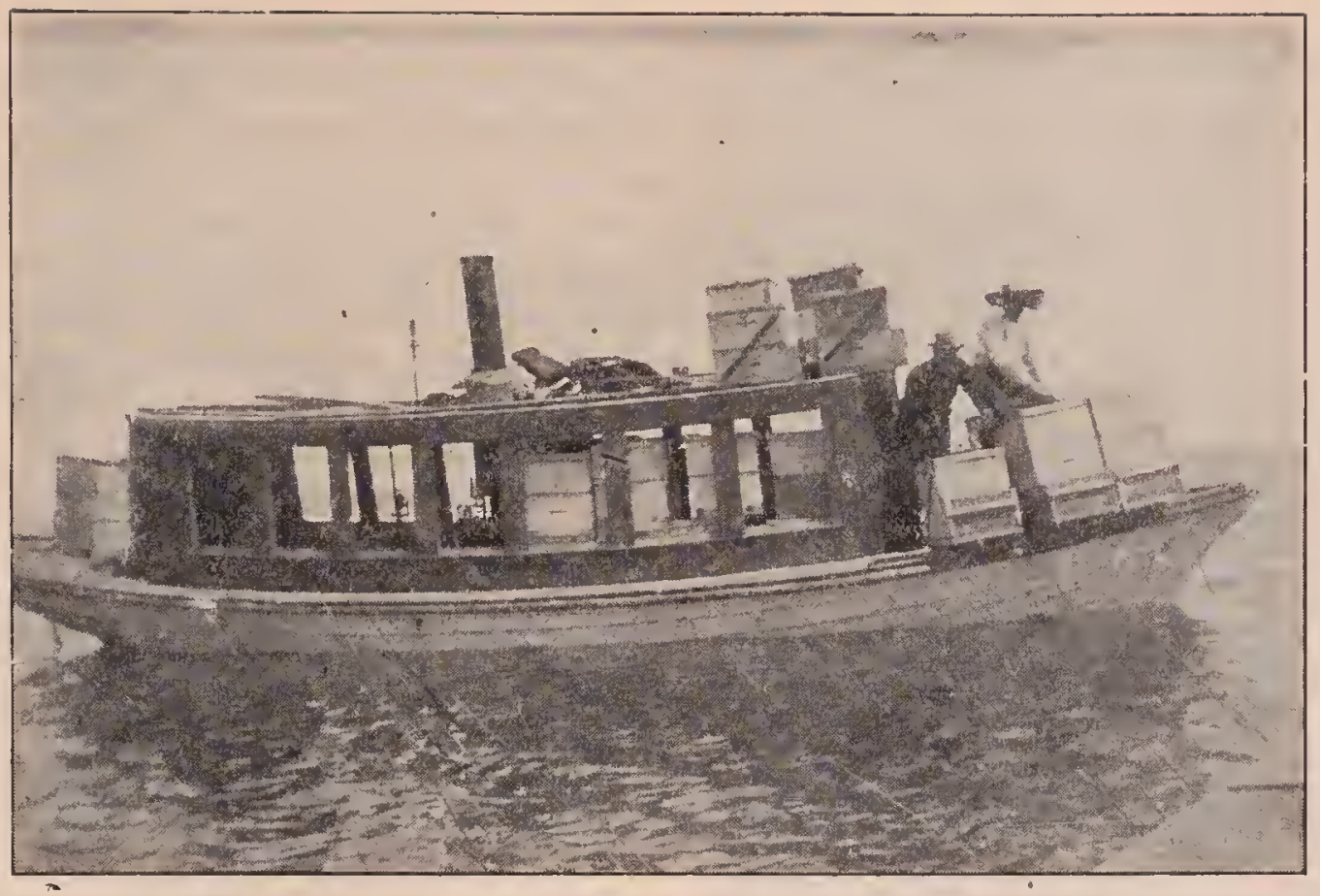

Moving bees by boat.

The author tried another plan that has given good results; but this, like the other, must not be attempted when a honey flow is on. Move the hive a few inches a day, and each time make a bigger jump than the one preceding. After the bees have been moved in this way from two to five times they learn to expect a change in location, and therefore will hunt out their hive wherever it may be. Sometimes in such moving it is advisable to put up a board against the entrance just after moving, in order to arrest the attention of the bees when they come out. This forces them to mark their location anew.

Ordinarily, as a matter of convenience, the bees should be moved in the cool of the morning, when no honey flow is on, giving the bees as much of a shake-up as possible, but of course not violent enough to break the combs.

\section{HOW TO MOVE BEES A DISTANCE} OF SEVERAL MILES.

The remarks that have been made heretofore apply to moving bees only a short distance; but when they are to be carried a considerable distance, and jolted over rough roads, they require more ventilation than can usually be afforded by an ordinary entrance. If they are shut up during the middle of the day, those in the field are liable to be lost. Ordinarily they should be confined at night or in the early morning - better at night unless the weather is hot.

If the bees must be mored during the middle of the day, a live with a comb of brood should be left on the old stand, when the owner can start a nucleus very conveniently with the returning bees.

Many beekeeper's fasten the bottoms to their hives permanently, so all that is necessary in such cases is to secure the cover and put a wire-cloth screen over the entrance. If very warm a screen should also be used over the top. A very good plan during cool weather is slown in the next engraving, consisting of two cords or ropes.

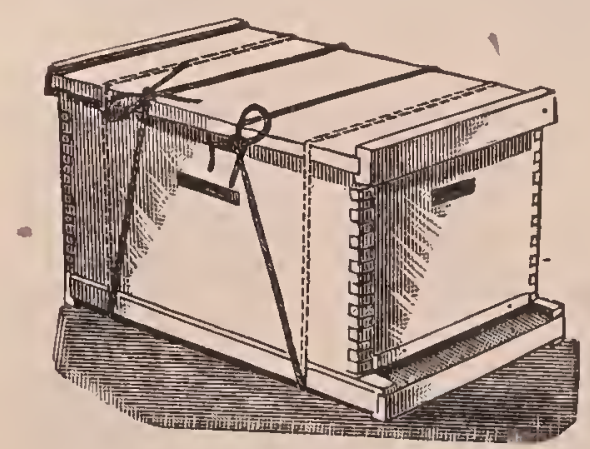

Fastening bottom-board and cover.

One rope is drawn around as tight as possible at one end, and the other is put on the other end. The cords are then drawn together at the top in such a way as to produce a strong tension.

Another plan, somewhat similar, is to use one cord or rope. It is drawn around the hive, and tied loosely. A stick is then 


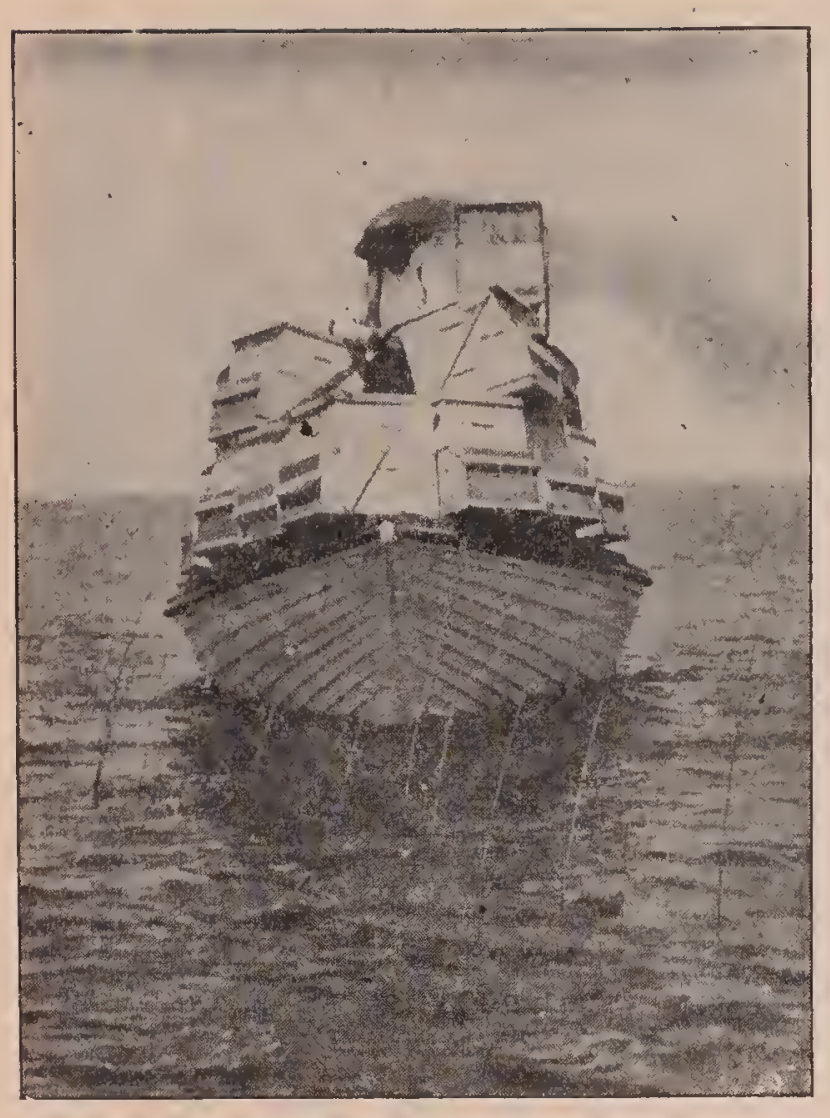

Under way.

slipped into the cord and given a halftwist in such a way as to draw the loop up very tight.

But by far the most satisfactory plan, certainly the safest, and one the authors adopt in their moving, is that of nising a special staple (obtained at the live factories) shown in the accompanying illustrations. One leg of the staple is driven into the bottom-board, and the other into the hive-body. Two staples on each side will be sufficient to hold the bottom-board. The cover is fastened in the same way. The staples are very easily removed with a screwdriver at least a foot long, if they are not driven down too tight. The tool is shoved under one side, close to a leg of the staple, and given a quarter twist; then it is moved over to the other side, and twisted again. When the staple is raised high enough so the screwdriver can get under and give it a good pry it can be easily removed.

\section{PREVENTING BEES FROM SMOTHERING.}

In the early part of the season, in the spring or fall, or any time when the weather is cool, it is not necessary to have any more rentilation than will be secured witls an ordinary entrance covered with wire eloth. As the weather warms up, additional air will liave to be provided. Sometimes this can be secured by taking pieces of section stuff $1 / 3$ incls tlick, and placing one at each of the four corners between the hive and cover. The latter should be secured by ropes or staples, as previously shown. This makes a crack all around $1 / 8$ inch wide, but not quite wide enough to let bees thrin.

A far safer and better arrangement is to use wire screen in place of the cover. A wooden frame $11 / 2$ or 2 inches deep should be made of $7 / 8$ lumber, the same length and width as the hive. $\Lambda$ piece of wire eloth large enongh to cover it is tacked on, and over the marginal edges are nailed strips of wood $7 / 8$ inch wide and $1 / 2$ of an inch thick. The purpose of the $1 / 2$-inch strip is twofold--to help hold the wire cloth in place and raise the next live that may be piled on top crosswise at least one-half inch above the wire cloth.

The screen frame is held on by the use of crate staples as shown below on this

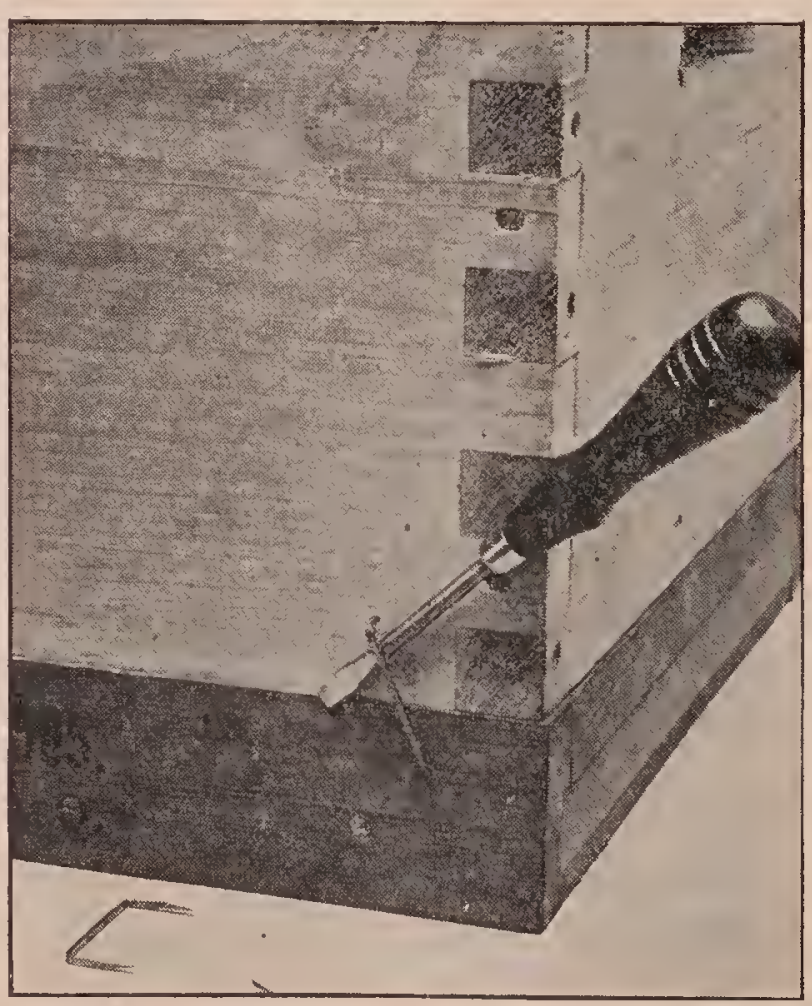

Removing the staples.

page. They are quickly applied, and easily remored with a serewdriver. It is always advisable to use wire sereens in moving bees during hot weather. It is hardly safe to depend on the rentilation at the en- 
trance or thru narrow $1 / 8$-inch slots between the covers and hives.

When hives of bees are loaded on to a wagon or truck they should be placed in such a way that ventilation thru the top screen will not be shut off. In the case of an ordinary hayrack the hives may be spread out over a large surface in the bottom of the wagon and over the rack. In this way it will not be necessary to pile one hive on top of another.

\section{SACKING BEES.}

Where hives are old and full of cracks, putting screens on top and at the entrance would do little good. In such cases, one can use second-hand burlap sacks of a size large enough to take in a whole hive. One of these can be slipped over a hive and tied, in much less time than it takes to put on screens. The mode of procedure is shown step by step in the accompaning engraving.

Where one can secure a quantity of large burlap sacks without holes in the sides this method of shutting in bees can be used on good hives as well as old ones. The same sacks, of course, can be used over and over again. The author has helped move bees in sacks over rough roads without a single bee escaping. There is no danger of the bees suffocating, because they can crawl into the sack.

\section{LOADING AN AUTO TRUCK.}

When using an automobile truck, where hives have to be piled on top of each other, an open framework of $2 \times 4$ 's should be placed between the several tiers of hives. Without some scheme of keeping the hives apart, the bees in all except the top tier of hives would smother.

The most satisfactory entrance-closer is a piece of wire cloth, the length of which is the inside width of the hive, and bent in the form shown in eut on next page.

This is easily placed in the entrance of the hive by tacking the upper right-angled piece against the upper part of the entrance.

The main feature of this is that it holds its place without any tacks, altho one or two are needed to prevent its jolting loose when on the automobile truck or wagon. Moreover, the angle that projects into the

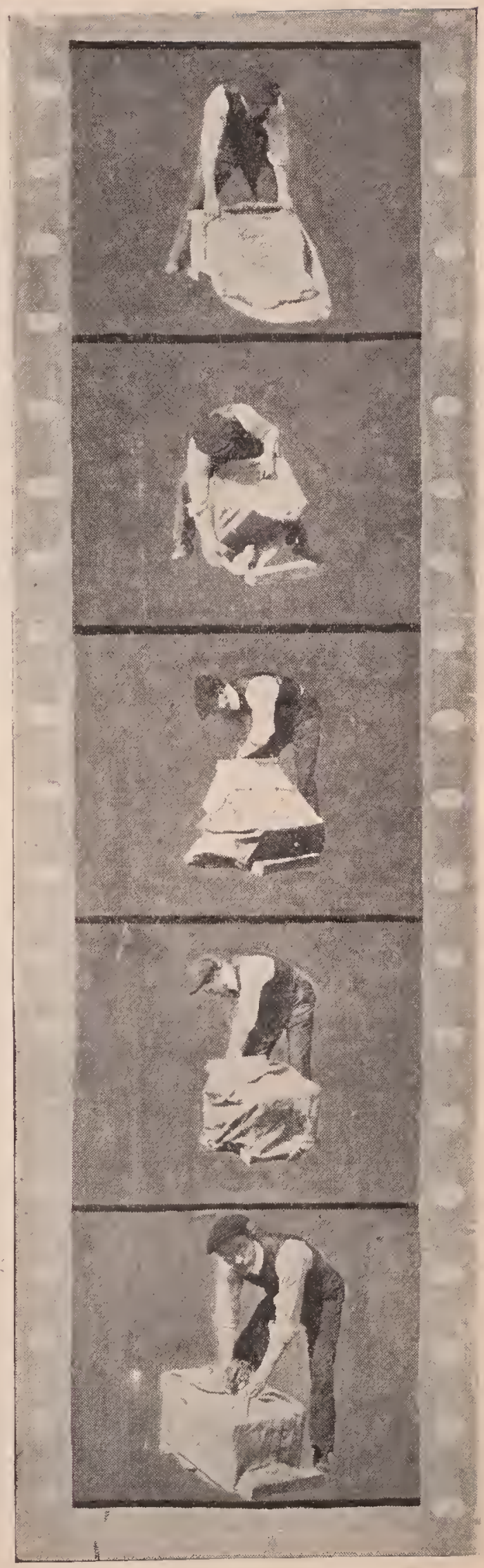

Above is shown stage by stage a method of sacking bees for moving. The exact mode of procedure is shown in the order of the pictures, reading from above down. Where the hives are old, especially if they are full of cracks, or the cover does not fit tightly, this plan of moving bees is ideal. Even if the hives are good, it is probably cheaper than the entrance-clnser and a hive screen nver the top. To sack a colony is a matter of seconds only. 
entrance increases the amount of rentilation just in proportion as more wire cloth is used.

\section{MOVING BEES BY TRUCK OR WAGON WITHOUT SHUTTING THEM IN THE HIVE.}

This can be done very often without the necessity of using wire screens at the top, nor even entrance screens. Before the hives are loaded, smoke is blown into the

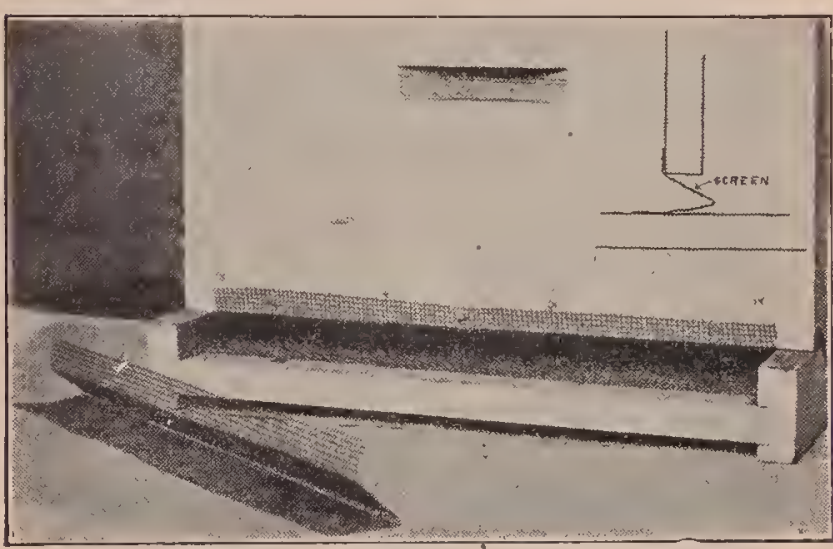

Screens bent in this shape can be wedged into the entrance. No tacks are needed except for long hauls.

entrances to prevent rushing out and stinging when the hive is disturbed. Just before the start is made, the entrances are smoked again. The subsequent jolting over the roads, so far from making the bees ugly, quiets them. If the weather is exceedingly warm the bees will crowd out and cluster round the front of the hive rather than smother to death.

The objection to this plan is that some bees get out all over the hives. For this reason it should not be used with an ordinary horse-drawn wagon. It has the further disadvantage that there will be a lot of flying bees around the hives, some of which will be lost as the truck moves forward. But when one is not provided with screens of any sort he can very often pick the bees up, put them on the auto truck, and land them at the outyard without any further trouble.

\section{WHEN TO LOAD BEES.}

No bees should be loaded on a wagon or truck during the middle hours of the day, since many field bees would be lost. They should be loaded very late in the day or early in the morning while all the field bees are in. The hives may be made ready at night, and the bees may be moved any time the following day, altho on account of rising temperature they should be started as soon as possible. In warm weather it is better to move at night after all the bees are in.

\section{AUTOMOBILE TRUCKS OR HORSE-DRAWN WAGONS.}

In this day and age, on account of the danger from stings the self-propelled wagons are to be preferred. They will make a trip to the outyard and back in about a fifth of the time; and when bees are removed to an outyard on a warm day quick moving is far better than slow moving with a team. Moreover, speed develops air currents that are highly important in moving. Ordinarily it takes a team of holses nearly half a day to get to a yard four or five miles and back, and that spoils the whole forenoon or afternoon. A motor truck, on the other hand, in the same time can make three or four such trips.

For the author's apiaries a light Ford is used with a small wagon-box on the rear to make trips to the yards. This will easily carry two men and 12 hive-bodies with empty combs, or half that number when the combs are filled with honey. This wagon-box is just right to carry tools and appliances, including hives, so that for ordinary outyard work one can make quick trips and carry back and forth all he practically needs. A light Ford truck will do general out-apiary work at about onethird the cost of a larger machine capable of carrying a ton and moving correspondingly slower. Experience shows that the small machine will make a run to outyards for from five to seven cents a mile, while the larger ones cannot do it for less than fifteen cents. This includes wear, tear, depreciation, and interest. Where one is engaged extensively in the business he can afford a light motor truck and a large one besides. But as a general thing a small machine will do 95 per cent of the moving, and the other 5 per cent can be moved on hired machines of large capacity.

The illustration shows a light two-passenger Ford with a light wagon-box, which can be secured at one-third or one-half the price of a larger truck costing two or three times as much to operate per mile. Moreover, the Ford can be operated by 


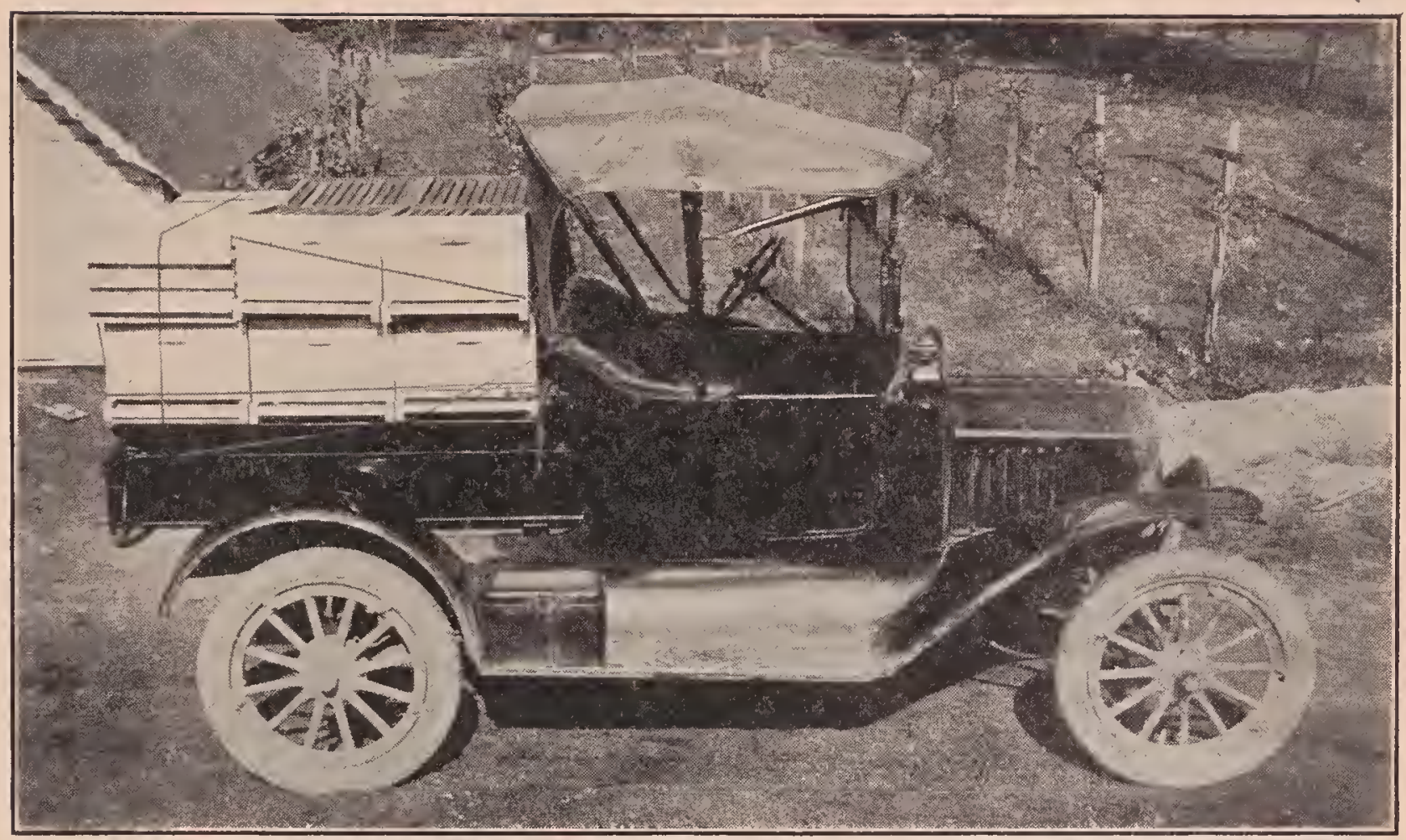

Ford runabout converted into a light truck.

any one on account of its simple gear shift, while the large two-ton trucks requiring the use of sliding gears are complicated.

\section{SHIPPING BEES LONG DISTANCES BY EXPRESS.}

During warm weather it is advisable to have the shipping boxes or hives with wire screen at bottom as well as top. The express agents are usually careless, and, in spite of instructions to the contrary, will leave bees out in the hot sun or in a small express room with all kinds of packages piled on top. For that reason additional ventilation should be provided. Provision

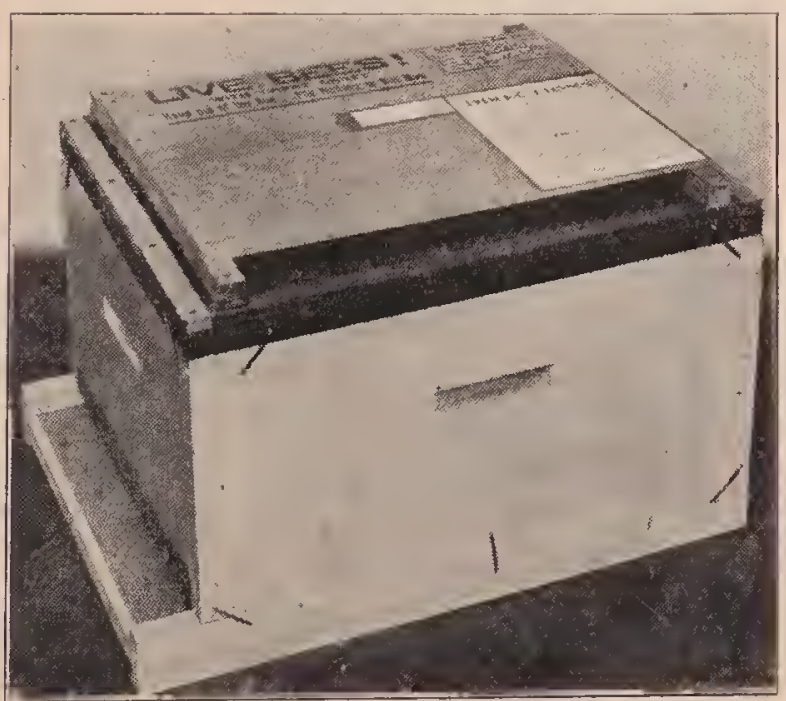

The Dovetailed hive prepared for shipping bees. should be made to protect the bottom screen and insure ventilation at all times.

The illustrations herewith show packages of bees in colonies and nuclei put up as they should be for shipment. If unspaced

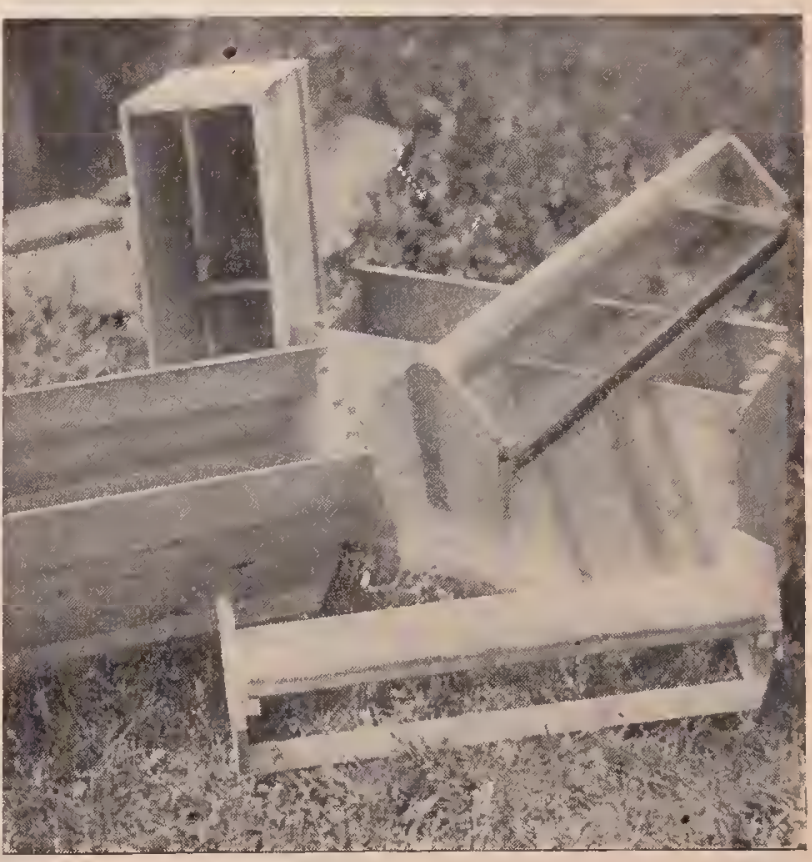

Empty three-frame nuclens shipping boxes. Note that the boxes are made of light thin stuff, and screened top and bottom.

frames are used they should be secured by notched cleats as shown.

On top of every shipment of bees there should be a label cautioning agents against learing the bees out in the hot sun or piling 
anything on top of them, thus shutting off the ventilation; that bees are perishable property, and should be moved without delay, and that on arrival at destination the

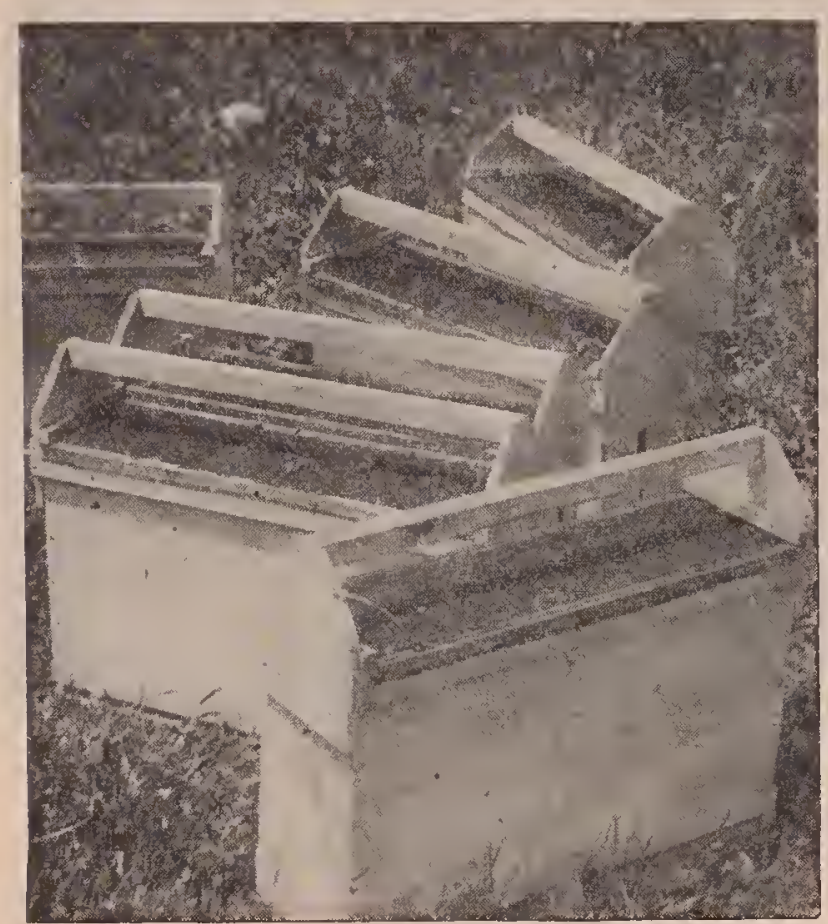

Three-frame nucleus shipping boxes filled with hees. The screen tops (with the convenient crossrail for a handle) are secured to the nucleus box proper with two screws at each end. Such boxes are very handy for moving bees, either for ship. ping or carrying from one part of the yard to the other. They are also very handy for carrying combs.

owner should be informed by telephone or messenger. For moving or shipping bees without combs, see Shipping BeEs, also Beginning with Bees.

MUSTARD (Brassica arvensis).-Wild mustard, or charlock, belongs to the same family (Cruciferae) as the turnip, cabbage, radish, and rape, all of which secrete nectar while in bloom. Introduced from Europe it has become naturalized over all the United. States, and is often very abundant in grain fields, where it sometimes presents an almost unbroken expanse of yellow. Almost equally common is the black mustard ( $B$. nigra), which flourishes everywhere in waste places.

Many species of the mustard family are extensively cultivated for seet, and in the vicinity of large acreages of any of these plants, it would doubtless be profitable to establish apiaries. But unless the crop of seed will pay the expense of cultivation, it would not be advisable for beekeepers to plant any of the mustards for honey alone.

The seed should be sown very early in the spring, either in shallow drills so far apart that the cultivator can be used between them, or broadcast. The former plan is, of course, the better one for nearly all honey plants, but it is more trouble. From 6 to 10 lbs. per acre will be needed, sown in drills, and from 15 to 20 when sown broadcast. If the seed is to be saved it should be sown not later than July 1.

Two kinds of mustard-the English yellow and the Trieste or red-are extensively cultivated in the Lompoe Valley, California. The latter comes from Austria, and gets its name from a town in that country where it is grown on a large scale. From this crop alone in a single year the farmers of this valley have realized a quarter of a million dollars. The average yield per acre is from 800 to 1,000 pounds. The average price of seed is 3 cents per pound, tho as much as 8 cents has been obtained.

The cultivation of mustard in the Lompoc Valley, says E. A. Oates, is easy and inexpensive; but it must be grown in rotation with other crops, as it will not produce bountifully two years in succession on the same land. When a majority of the pods are ripe it is ready for the reaper, and should be cut early in the morning or late in the afternoon, when there is moisture in the air to prevent the seed from shelling out of the pods.

The bees work alike on both the yellow and red varieties, indicating there is no difference in the amount of nectar secreted. The period of flowering lasts about a month; and where the sowings are made at different intervals it can be prolonged for a period of tell weeks. The honey is mild in flavor and light in color, and commands the same price as sage. Tho not as heavy-bodied as alfalfa, it has the same tendency to candy quickly. It may candy in the tank in four or five days, but this may be prevented by using a tank with a glass top, protected by a wooden shutter, which is removable at will, exposing the honey to the sunlight.

When sage is in bloom, bees appear to prefer its nectar to that of mustard. When it is not necessary, it has been observed by 
M. H. Mendleson that they will not gather from an inferior source. In 1884, he says, one colony out of 200 gathered exclusively from an abundance of mustard bloom; the 199 gathered from the sages. This was an exceptional case.

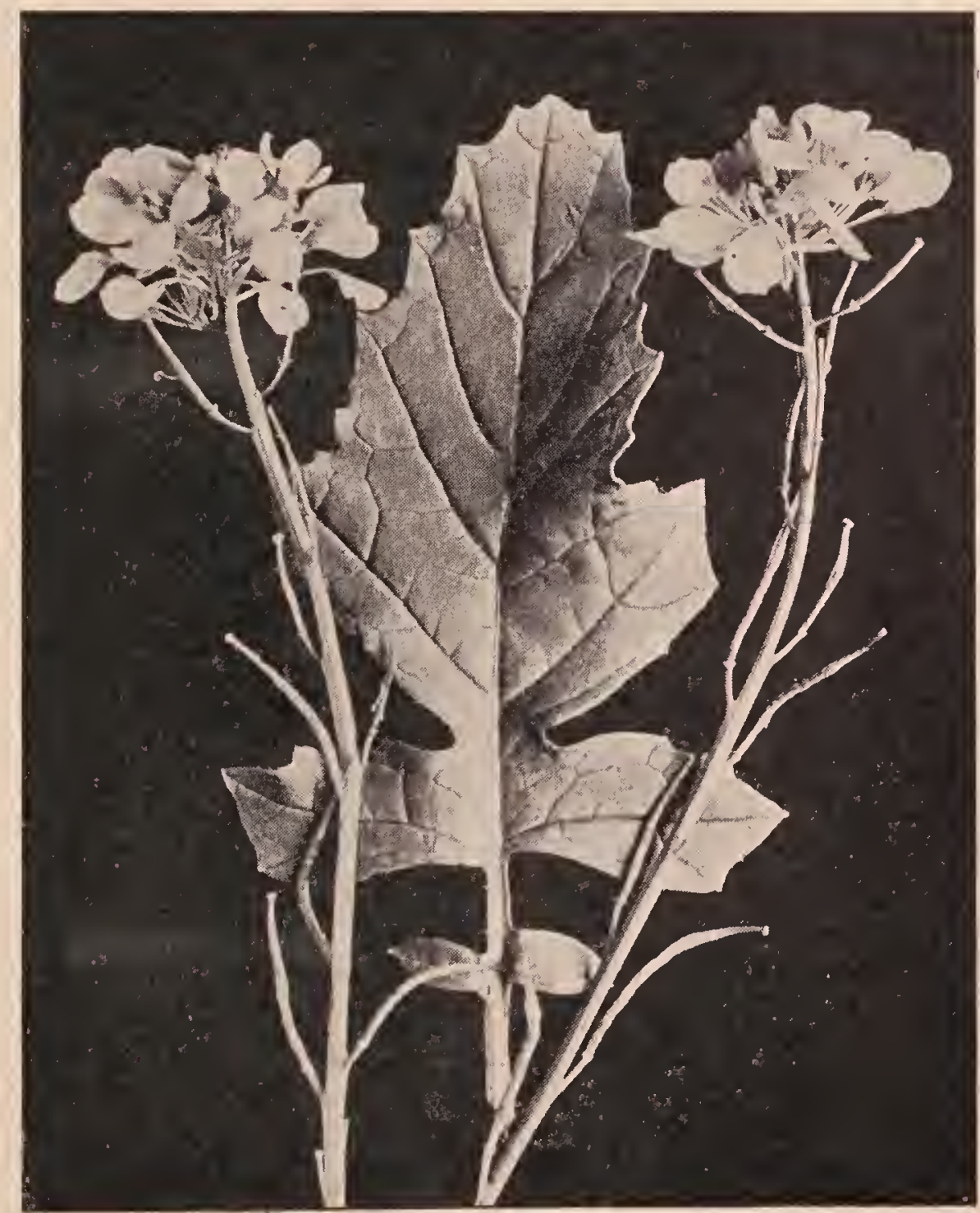

Black mustard. 


\section{$\mathrm{N}$}

NECTAR.-Strictly speaking nectar is a cane sugar (sucrose) gathered from flowers by bees. It is thickened and transformed by them into honey. (See Honer.) Many times has honey been analyzed by competent chemists, but very seldom has there been an attempt to analyze nectar, owing to the difficulty of securing a sufficient quantity for experimental purposes.

The only satisfactory experiments of the kind which have yet appeared are those of Prof. Planta, of the University of Zurich, Switzerland, who was not only one of the best chemists in Europe, but also a competent beekeeper besides.

It will be noted he experimented with the nectar of two American plants, Agave americana (century plant) and Bignonia radicans (trumpet creeper). The former is a prodigious yielder of honey, far excelling any plant we know of in the North, and excelled only by some tropical trees such as Protea millifera, Hakeas, and Leucodedendron, and perhaps, others not yet known. It grows in the southwest part of the United States, and is common in Mexico.

Several translations of Dr. Planta's article on nectar analysis have appeared, and we give one which we deem best for our purpose.

In the Zeitschrift fuer Physiologische Chemie, Band X., Heft 3, Dr. A. de Planta describes his researches on the chemical composition of some of the neetars in plants. He says it was a great pleasure for him during his.researches on the life of bees to have established the relation which exists betwen nectar and honey, nectar serving for the preparation of honey. There was a great difficulty in getting a sufficient quantity of nectar, as plants yield it usually in small quantities, but there are some exceptions. Among these are Protea mellifera, Hoya carnosa and Taco a radicans, o! trumpet creeper, which contains such large quantities of nectar that it is easily collected. Thunberg says in his "Flora Carpensis" of Protea mellifera (Zuykerbosches Zuykerboom, Tulpboom) that it flowers in

autumn; that is to say, in March and the following months. The flowers are often half filled with watery honey which furnishes an excellent syrup after it has been filtered to rid it of insects and impurities, and slightly evaporated by gentle heat.

This syrup is an article of commerce at Cape Town. Two bottles of it were produced, the specific gravities being 1.375 and 1.372. It has a slight acid reaction, but contained no albuminoids or nitrogenous matter. It contained 73.17 per cent solids, 10.08 being glucose and 1.31 per cent cane sugar. By glucose is meant a mixture of crystallizable grape sugar (dextrose) and uncrystallizable grape sugar (levulose), both having a similar chemical composition. This glucose may already be formed in the nectar by the action of the ferments it contains upon the cane sugar, transforming it into glucose; and this inversion can be continued in new honeys, owing to the action (which he had already demonstrated in 1879) of the saliva of bees which also transforms cane sugar into glucose.

Grape sugar from the syrup was also obtained in a crystallized form. No trace of formic acid could be detected in the syrup, tho quantities of pollen were found in sus. pension, determined by Professor C. Cramer to be that of Protea mellifera, testifying to its genuineness.

Wishing to compare this with fresh nectar, he succeeded, after great difficulty, in getting three bottles. The specific gravity was $1.078,1.079$, and 1.077 . These contained 17.66 per cent of solids, of which 17.06 was grape sugar. They contained no cane sugar. There was not the least trace of formic acid. A comparison of the two shows that the difference was due only to the extra quantity of water contained in the fresh nectar.

Besides these he also examined the nectars of Hoya carnosa and Bignonia radicans, both in the fresh and evaporated states. The following table gives the results:

\section{Nectar of}

Protea mellifera, fresh

Protea mellifera, dry

Hoya carnosa, fresh

Hoya carnosa, dry

Bignonia radica

Bignonia radicans, dry 99.85

Dr. de Planta has also made aqueous extracts of various flowers, among others those of Rhododendron hirsutum and Onobrychis 
sativa. In order to obtain 1 gram of sugar (equal to $1.3 \mathrm{grams}$ of honey) the bees must visit at least 2,120 flowers of Rhododendron hirsutum and 5,530 of sainfoin (Onobrychis sativa).

As honey is almost entirely formed from nectar, he gives the following table, comparing the quantity of water he has found in nectars and also in old and new honeys:

\section{Nectar}

Protea mellifera,

Hoya carnosa,

Bignonia radicans

Fritillaria imperalis

Honey from

Department of Landes

Water in-
Nectar Old New
honey honey

84.70

93.40

Senegal

Melipona

Grisons (alt. 600m.)

Sainfoin 19.44

Canton Grisons (alt. 1,395 m.) 17.52

Canton Grisons (high Alps)

Buckwheat

Acacia from Ingoldstadt

Whereas the nectars vary between 59 and 93 per cent, the quantity of water contained in old honey varies only between 17 and 21 per cent, and that in new honeys 20 to 21 per cent, with the sole exception of buckwheat honey, in which he found 33 per cent.

From these observations he thinks that the bees throw off a considerable quantity of the water while it is in their stomachs. He does not admit that it is evaporated entirely in the cells, for the analyses he has made of honey newly deposited in the cells show that it already reaches them considerably concentrated. The following table shows the relative proportions of sugar contained in different honeys:

\section{A-Old honeys from}

Department of Landes Senegal

Canton Grisons

(alt. $600 \mathrm{~m}$. )

Sainfoin

Canton Grisons

(alt. 1,395 m.)

$\mathrm{B}$-New honeys from

(Alpine region)

(alt. $600 \mathrm{~m}$.)

(Alpine region)

Altho most of the nectars contain a considerable quantity of cane sugar it is found in very few of the honeys of the Alps. Some honeys contain a little, while in others it is entirely absent. It is clear that, during the formation of honey, the cane sugar in the nectar is converted into grape sugar by the saliva of the bees, which contains a ferment endowed with this property (see his researches on this subject in Deutsche Bienenzeitung, 1879, No. 12).

Another difference between honey and nectar consists in the former containing nitrogenous substances and formic acid. Mullenhof has shown how this last is deposited in the honey, and E. Erlenmayer has proved its antiseptic properties.-British Bee Journal.

Probably all nectars do not analyze alike; but Dr. Planta's analysis will be found, until we get something better, suffciently near an average to satisfy all practical requirements.

It will be observed Dr. Planta attributes the inversion of nectar to the saliva of the bees. It seems on the face of this to be only a "guess," and yet it has been repeated ever since by many writers on the honeybee. Inversion is known to take place even while the nectar is still in the corolla of the flower, and it occur's long after the honey has been made and deposited, for new honey contains quite a large percentage of sucrose (sugar) whereas old honey contains little or none. This change is caused by enzymes. For this and other reasons the composition of honey is quite variable. Old honey is actually superior to new, for the process of inversion is usually complete. If kept in a dry place it also contains less water. If exposed to the air it tends to lose the ethereal essential oils or essences of the flowers from which it was gathered; therefore nectar collected even from poisonous plants may become quite innocuous if allowed sufficient time to ripen. See HoNEY.

NUCLEUS.-This word, when applied to bee culture, means just what the name signifies-a small colony of bees. It may mean a hundred bees with a queen, and as such it is called a small baby nucleus; but, as shown in QUEEN-REARING, so small a number will not long survive without help. Reference will be made to this later. 'The term "baby nucleus" more properly means a larger force-anywhere from five hundred to a thousand bees with a queen-a force large enough to set up housekeeping in real earnest. Usually these babies are put on minature frames in miniature hires. 
See Baby Nuclei under the head of QUEEAT-REARING.

Generally speaking, the word "nucleus" signifies one or two full-sized frames of bees, either in a full-sized hive or one just large enough to hold two frames and no more. When it has five or six frames of bees and brood it is usually called a light or a weak colony.

These small aggregations of bees must be built up to full-sized colonies in order to make them useful for honey production; for it requires a fair colony of not less than eight or ten frames in size to produce honey, and a two-story colony of bees and brood at the beginning of the flow is far better. While a two or three frame nucleus will furnish a little extracted honey, the amount that it will produce in comparison with a large colony is relatively small. Or, to put it another way, ten twoframe nuclei will produce only a fourth as much honey as one two-story ten-frame colony. How to build up these nuclei into colonies so they will be of some use is fully described under the head of BUILDING UP Colonies, and Tncrease.

Nuclei are used for one of two purposes - for making increase and for the mating of queens. It is a waste of time and bee force to have virgins mate from a full colony. While cells should be raised in such colonies, the queens should be mated in miniature hives having anywhere from five hundred up to one thousand bees. For particulars regarding this phase of the subject, see QueEn-REAring.

Nuclei may also be useful for the purpose of instruction. A beginner can handle a light force of bees much more freely than a big colony. 'The small babies or the twoframe nuclei can be manipulated by the average A B C scholar very rapidly. Queens can be introduced mucl more easily than to the large stocks. As the nucleus grows in size, the beginner, who is constantly watching them, grows in experience; and by the time the colony reaches the full size he is perfectly capable of handling it, provided, of course, he has read articles on $\mathrm{A} \mathrm{B} C$ of Beekeeping, Manipulation of Colonies, Stings, and ROBBING.
BABY NUCLEI REQUIRE WATCHFUL CARE.

At the very outset mention was made of the fact that baby nuclei of only a hundred bees are not practicable. Some years ago the late E. L. Pratt of Swarthmore, Pa., found he could mate queens from very small nuclei. Sometimes he used a single section of honey, placed in a little box, and gave it about a hundred bees and a cell or a virgin. He had a large number of these in use, and found it possible to mate his queens, using only a very small number of bees. While he succeeded, it has been found that these little babies of 100 bees are too fickle; that many times, when the virgin goes out to mate, all of her bees follow her. They are constantly swarming outso much so that it has been found to be much more practicable to use at least five hundred bees, and, better, a thousand. A hundred does not make up a strong household, and the bees know it. They know that something is wrong, and so they swarm out on the least provocation.

Moreover, it lias been discovered that these little babies of a hundred bees are robbed out. The powerful colonies in the vicinity make their lives miserable. Even contracting the entrance to a passage large enough for only one bee has not been found sufficient; and the poor little chaps have to give way to the superior numbers of their enemies, with the result that their homes are despoiled, and the nucleus broken up.

A pound of bees consisting of approximately five thousand makes a very nice nucleus. As mentioned under BeginNing with Bees and Moving Bees, the selling of bees in pound packages without combs is getting to be quite an industry. When bees die in the spring, a pound of bees will give a new lease of life to a nucleus that is all but gone, but having a good queen. A little later in the season, the beginner can take a pound of bees, and by feeding have a good colony at very small expense by fall. See Feeding and Feeders, ThCrease, Bullding up Colonies, and BeGINNING WITH BeEs.

FORMING NUCLEI FOR INCREASE.

As already explained, dividing colonies into nuclei for the sake of increasing the 
number of hives containing bees is a mistake if honey is the object. But after the main honey flow, increase can be made by splitting up the colonies into units of two and three frames, supplying each with a cell, virgin, or laying queen. The process appears to be much simpler than it really is. The question often comes up in the mind of a beginner, "What can be easier than to take a ten-frame colony and divide it into five two-frame nuclei on as many hive-stands?" If the bees moved from the parent stand would stay where placed, the problem would be very much easier. Unfortunately the old field bees, especially right after a honey flow, will go back to the parent stand, leaving nothing but the young bees to take care of the brood, which, in a great many cases, is neglected and dies. This is not all. Robbers, during a dearth, will be ready to invade the entrances of these deserted nuclei with just a few young bees; and before Mr. Beginner knows it he has a perfect uproar, and the loss of some thousands of bees, and perhaps trouble with the neighbors on account of robbers smelling around the entire neighborhood after they have wrought havoe with the nuelei. See RobBing, subhead "Robbing of Nuclei."

If the beginner buys a colony of bees from some farmer or beekeeper two or three miles away he can bring it home ard make the divisions before the bees mark their location, and the bees of each nucleus will stay where they are placed. This will effect an equal division, and everything will be easy, provided, of course, that the entrances are contracted and the beginner uses ordinary caution. At the time the nuclei are formed, each should be supplied with a cell, virgin, or a laying queen. If it is desired to make increase rapidly, the nuclei will make greater progress when supplied with laying queens. If it is desired to let each nucleus raise its own queen, precaution should be taken to see that eggs or very young larvæ are in each nucleus; but it should be understood that the progress will be very much slower, and that queens reared in nuclei are never the equal of those reared in strong colonies.

In many cases the colony.or colonies to be divided have grown so strong the beelieeper desires to make increase and to keep down swarming at the same time. How shall he do it and avoid having many bees going back? This can be accomplished after forming the nuclei by putting wire cloth over the entrances, and keeping them closed for three or four days. In the mean time, if the nuclei are not already shaded and the weather is hot it would be well to put a shade-board over the hives to prevent any danger of suffocation. At the end of the third or fourth day the wire eloth can be removed. This shutting-in practice for strong nuclei is not advised.

Usually it is better not to make too great a division after the first of July or August. If the beginner splits his colonies up into halves, the problem will be very much simpler. In the morning he should remove about two-thirds of the bees, all sealed brood, or as much as possible, and the old queen, to the new location, leaving the unsealed brood and about a third of the bees on the old stand. The latter should be given a cell or virgin. Most of the flying bees will return to the old home, making the division somewhere near equal, with the chances that the old hive will have the larger force of bees in 24 hours. But the split-off, or nucleus, on the other stand, will have all the sealed brood and emerging brood, and will soon be more than able to mateh forces with the other colony. The old queen, which will act as an attraction to hold the bees in the parent colony, will soon supply it with eggs and young larvæ as fast as the bees can take care of it or as fast as the brood emerges.

In a similar way three colonies can be made out of one; but most of the sealed brood and most of the bees should be given to the nuclei on new stands, always keeping in mind that most of the flying bees will return to the old stand. If, however, the entrances are kept closed for three or four days there will not be so much returning. Of course, the nucleus on the old stand will not need to have its entrance closed. If it is discovered that one of the nuclei, or both of them, are short of bees, a frame or two of bees from some other colony can be shaken at night in front of the entrances of the nuclei on new stands. When doing this, it may be advisable to cage the queen for a day or two.

If the nuclei are formed immediately 
after the honey flow, all the old bees will go back to the old stand; but if two or three weeks or a month elapses, during which little or no honey has been gathered, there will be very much less returning.

The beginner should take this fact into account when he forms his nuclei, and in a day or two afterward he should see that there are bees enough in each division so that the young brood at least is not neglected. This is the reason why the advice is given to put the sealed brood on the new stand and the unsealed brood on the old stand. For a few days, or until the brood emerges in the new stands some of the young brood may be neglected; and this is a point that should be carefully taken into account.

The Alexander plan of increase, as given under INCREASE, explains how nuclei can be formed on another plan for the purpose of securing honey as well as increase.

Under the head of FEEDING AND FEED. ERS, subhead Feeding to Stimulate, will be found full particulars on how to feed up these nuclei if there is no nectar in the fields. The Boardman one-hole feeder should be used for the purpose, and the entrances should be kept contracted down to the space in which only, two or three bees can pass at a time. If the division is made on the basis of five nuclei out of one full colony, the respective entrances should be closed down to an opening that will permit only one bee to pass at a time.

As soon as the nuclei begin to prosper, an extra comb may be added on the outside.

In 1892, on the principles already outlined, the writer, without any special effort, increased an apiary from ten colonies, some of which were almost nuclei, to 85 good colonies, and obtained about 2,000 lbs. of honey. These were not fed, but depended entirely on nectar gathered from the fields, for the season was a good one. Colonies were divided in the latter part of May, and given frames of foundation and laying queens. They were given every possible advantage, and by fall there were 85 nice colonies with plenty of winter stores gathered from fall bloom.

SOMERFORD METHOD OF FORMING NUCLEI.

W. W. Somerford described a method of forming nuclei that lias worked very satis- factorily, especially when the work is done at ontyards. While it involves some of the principles already described, it is enough different to warrant giving it a place here.

To begin with, in all your fancy stock remove the queens or cage them, after getting the brood-nest well filled with brood (the more brood the better-8 or 10 frames in a hive if possible). Wait ten days after removing the queen, when the bees will generally have cells on every comb, and be in a broody or listless condition, waiting for cells to hatch. Divide and remove the frames quietly, giving each new hive two frames of brood and all adhering bees, and one good frame of honey, using it for a division-board (and, by the way, such division-boards are to my notion the best in the world); put the two frames of brood and bees next to the wall of the hive, and let the honey-frame be the third from the side of hive. Be sure to see that you have at least one good ripe-looking cell in each new hive, or division, and don't forget the frame of honey. As soon as each division is made, stop the entrance of the hive by stuffing it full of green moss. If you haven't any green moss, use green grass or leaves, and be sure to stuff them in tight-as tight as tho you never intended the bees should gnaw out, and be sure there are no cracks or holes that a single bee could get out at: for if there are, your division will be ruined by all, or mearly all, the bees that can fly leaving it. Each parent colony should make four or five good divisions that will make booming colonies in 40 or 50 days, and I have had them the best in the apiary in less time. Leave or loose the old queen (if not too old) on the old stand, and the bees from it will work straight ahead, as they don't have to be confined to make them stay at home.

Don't be uneasy about the divisions that are stopped up, unless you failed to stuff the entrances well, for they will not smother, but busy themselves gnawing at the moss or grass for two or three days, possibly four or five, if you have done an extra good job at stuffing the entrance. At the cnd of that time you will find they have all gnawed out so as to secure egress and ingress. Then you can move enough of the grass or moss to give them a clean entrance, $1 \frac{112}{2}$ to 2 inches wide; and by looking into them you will be astonished at the quantity of bees you have in each hive (and they, too, well satisfied), having consumed so much time in gnawing out that the queen had time to hateh and kill off her rivals and be ready for the wedding trip by the time the entrance is cleared. So, instead of, in a week's time, having a worthless weak division with a chilled inferior queen, as is the case in the old-style way of dividing, where ninetenths of the bees return to the old live, you 
have a strong rigorous queen and a nice little satisfied swatm of bees, rearly for business in the way of pulling foundation before they are three weeks old.

I have succeeded with 19 out of 20 divisions made in the above way, when I did not even see them until the third week, after dividing as above; and for the average beekeeper who has out-apiaries I think there is no better way in the world to make increase.

In the above method of increasing, you have no queens to buy, no robbers to bother with, and but little time lost, as an expert can make 20 divisions an hour.

Navasota, Tex.

In the first paragraph, Mr. Soinerford mentions removing or caging the queen. It should be explained that usually any queen ran be caged in her own hive fol weeks at a time, and lıer bees will talie cale of lıer thru the wire cloth. If a queen is removed entirely it is implied that she is to be caged in another hive, or introduced. She may, however, be. put in a cage supplied with queen-cage candy, and kept for a week or ten days in a warm room. But there would be danger of losing her, as she might die, because, under artificial conditions, she cannot get the "balanced rations" that she needs to keep up lier bodily functions.

Another plan of making two colonies out of one is given undel the head of INCREASE. For full consideration of the subject of Babr Nuclei, see QUEEN-REARING.

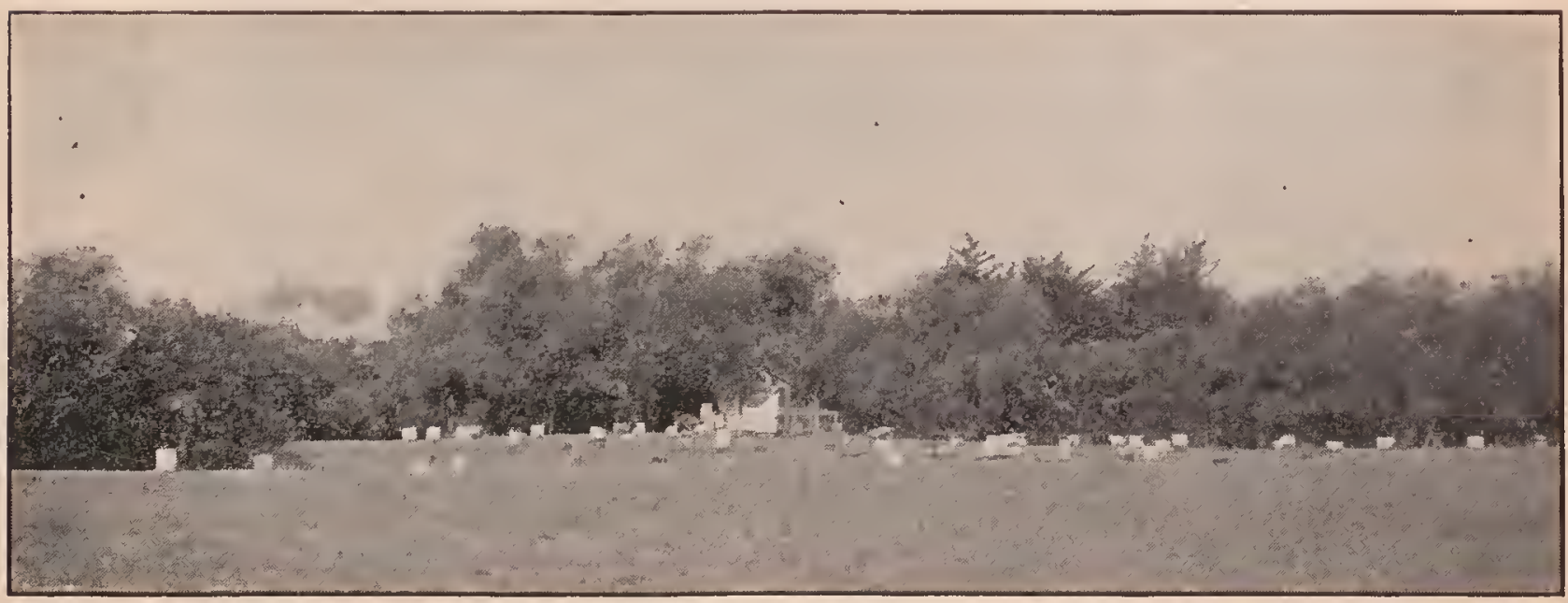

A portion of Mr. Stewart's apiary, Contra Costa County, Calif. 


\section{O}

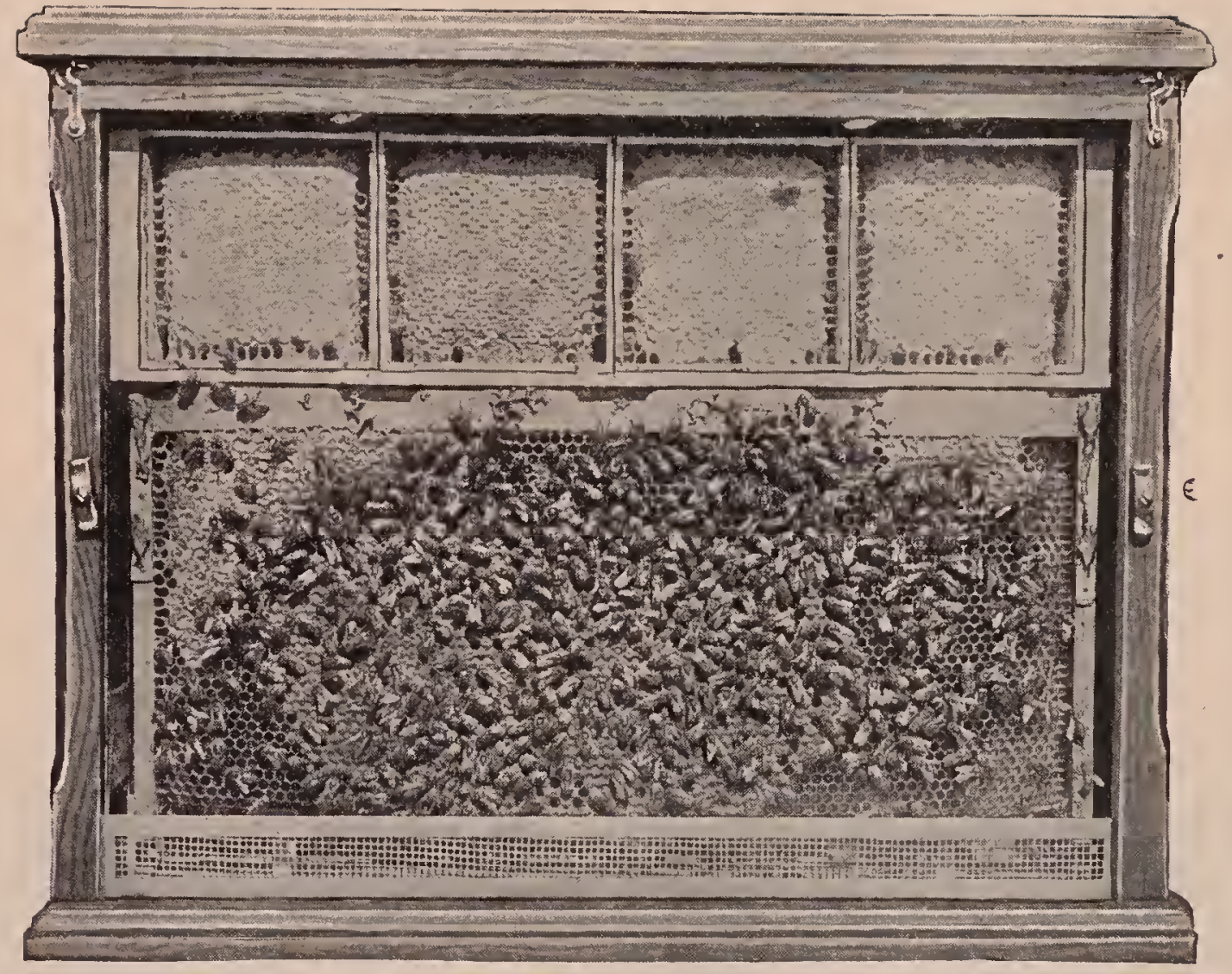

Ordinary observatory hive for showing a single comb and a set of sections as they appear in a regular hive. This form of glass hive is often on display in grocery win dows where honey is for sale, or at fairs and expositions to illustrate the relation of combs to sections.

OBSERVATORY HIVES.-The origin of hives with windows or transparent sides is lost in the mists of antiquity. In very ancient times pieces of transparent substances such as horn, isinglass, mica, etc., were let into the sides of the hives that the work of the bees might be observed. Such windows, however, afforded but meager opportunity for studying the behavior of the bees in the hive. The first approach to the modern type of observatory hive was invented by W. Mew of Easlington, Gloucestershire, England, about 1650. This appear's to have been but little more than a hive with glass windows. At about the some time, John Thorley of Oxon, England, put bees in a bell glass and used bell wlasses as surplus chambers on his hives.
No practical advance was made from this until about 1730 , when Reaumur the eminent French naturalist established a swarm between two panes of glass. These panes were so far apart that the bees could build two combs between them, hence much of the work of the bees and queen was hidden. Bonnet the Swiss naturalist recommended a hive with "doors" only so far apart as to permit the bees to build one comb between them; and Huber, about 1790, adopted this suggestion, and the result was the wonderful advance which he and his faithful assistants, his wife and his servant Burnens, made in the knowledge of bee life. From that time until the present, little change has been made in observatory hives. except in so far as the use of mov- 
able-comb hives changed the methods of stocking them.

The usual type of observatory hive consists of a single-comb hive with glass panels. Sometimes there is a row of sections on top to show the relative position of the sections to the brood-nest while they are being filled by bees in the regular way. Of course it would not be possible to produce section honey in a single-frame nucleus; but when an observatory hive with sections is displayed in a window where honey is on sale, it not only attracts prospective buyers but it educates them, in that it shows a part of the brood-nest with the bees and the brood, and the sections of honey just as they are on the hive. It advertises honey as nothing else does. Great crowds congregate on the street watching the bees on the comb "making honey."

The bees are usually left in the window for two or three days. By that time they will need to be renewed or they will soon die; and by that time, also, the most of the people in the vicinity will have seen them.

Experience shows that this display hive of bees will immediately increase the sales. of honey, both comb and extracted, and grocers who have had it are loud in their requests to have bees put in their windows -especially if their neighbor across the street has them in his window.

The single-comb hives can be studied to good advantage in the home or in the school. In either case they are placed on a shelf on a level with the window sill so that the entrance will pass under the window sash. The space on each side is closed with a stick. The bees will set up housekeeping, go to the fields, and enter upon their ordinary work as tho there were no one on hand to see why and how they do it.

Sometimes an observatory hive can be placed some ten or twelve feet from the window or side of the building. In that case, a tube connects the hive to a hole thru the side of the building. Strange as it may seem, the bees will learn to go thru this long tube to the outside. At the San Francisco Exposition in 1915, an observatory hive was arranged in this way, and the bees used this long tube entrance the entire season. This, of course, made it unnecessarv to replace the bees every so often.

When nature study is being taught in schools these observatory hives are used to a considerable extent; and very often beekeepers themselves who desire to become more intimately acquainted with the habits of the bee find pleasure and profit in keeping one of these hives up next to the window of the living-room.

When the bees come in with fresh loads of pollen or new honey, they show the usual signs of rejoicing by shaking their bodies, apparently to attract attention, and thus induce other bees to find the treasures that they have brought home. A great many other interesting things can be discovered with one of these hives where the comb is parallel with the glass panel. But what transpires in the cells and behind the cappings cannot be determined with this kind of glass hive.

Arthur C. Miller of Providence, R. I., an ardent student of bee culture, and one who has watched the bees for many hours at a time, discovered a plan by which he can see the bees at work and the larvæ spinning their cocoons as well as if he had X-ray eyes.

It was his desire to see what the bees were doing in the cells; and one day when a small burr of comb was found built against the glass, and a bee seen at work in it the idea was conceived of fixing in an observatory hive a small comb or several of them, so that a whole row of cells was parallel to the glass. It is not necessary to describe the many and crude attempts before success was achieved, but at last a stage was reached where a row of combs was fixed between two panes of glass about four inches apart, and a small colony established therein.

The hive was placed indoors before a window, the bees passing in and out beneath the partly raised sash. The little colony started at work nicely, and soon honey and pollen were being stored in the cell against the glass. By accident the wooden shutters were left off the hive for two or three days, and when it was observed at the end of that time the bees were found at work in a perfectly normal manner and no running over the glass was noticeable. Obviously, the shutters were not necessary, and their abandonment seemed to mark a distinct advance. A cold storm which occurred shortly after nearly 
destroyed the colony, and the shutters were again used. Matters improved, and the colony gained until anotler storm put them back again despite the shutters. Investigation showed a sharp draft thru the hive from the entrance to the sundry ventilators. These were closed, but the entrance did not furnish sufficient air, and other troubles

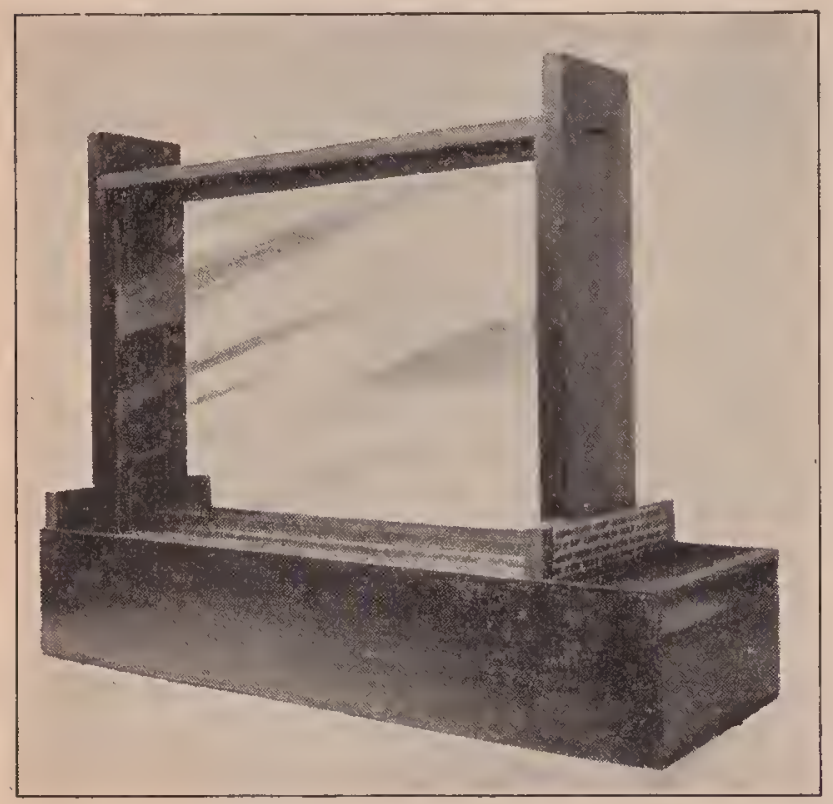

Miller's observatory hive.

appeared. Then followed long experimenting with ventilation until at last a relatively large area at the bottom of the sides of the hive was opened for ventilation, and screened to confine the bees. This was all below the combs, and the bees could have as much or as little air up among them as their instincts dictated. That was a success, but it developed another trouble, for every time the door of the room was opened or closed, or if the wind was strong toward the window, the bees were blown out of or into the entrance in a most troublesome way. A short passage or tunnel considerably larger than the hive entrance and having a wire-cloth top was put between the entrance and window opening, and that trouble stopped.

This was not all done in one hive, or in one season, but extended over several years. The colony would seem thrifty for a time, then it would meet with some reverse, and it would often take a season or two to find the cause of the trouble.

There came a day when eggs were seen in cells next to the glass, and in due time they hatched and the larvæ were fed and grew until they tonched the glass, then the bees pulled them out. The shutters were tried but with not much advance. Then "storm sash" in the form of an extra pane of glass on each side were applied and the hive was a success. A quarter of an inch confined air space was left between the panes.

From then on, the bees used the cells next to the glass as readily as the others. Almost every action was observable; the bees could be seen every way except face to face. Another hive was made and stocked and a piece of comb was put in which was less than half a comb, for it was only the cell walls from one surface of the comb. The glass wall of the hive was to-and did - form its new base. The bees used it as readily as the other combs, and the queen laid in it and bees were raised in it. The book of nature had been opened at a new page. Thereafter the development of the hive was a matter of detail. As now made it has a base about six inches wide and deep enough for a groored feeder block to be slid into it under the floor of the hive. Access to this feeder is obtained thru several holes bored in the floor and guarded with excluder metal to keep the queen from

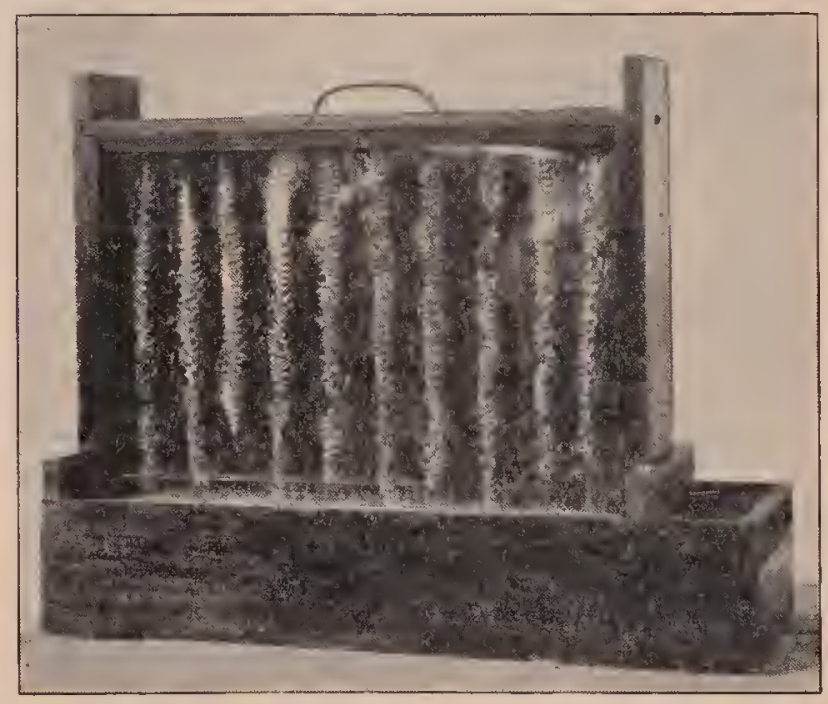

Miller's observatory hive.

wandering in. A similar guard is adjustable at the live entrance to prevent the loss of a swarm if the colony has to be left to itself for an extended period, for if thrifty it soon becomes overcrowded. The uprights are approximately three inches wide and grooved for four panes of glass. the inner panes being about one inch apart and the outer ones a quarter of an inch 


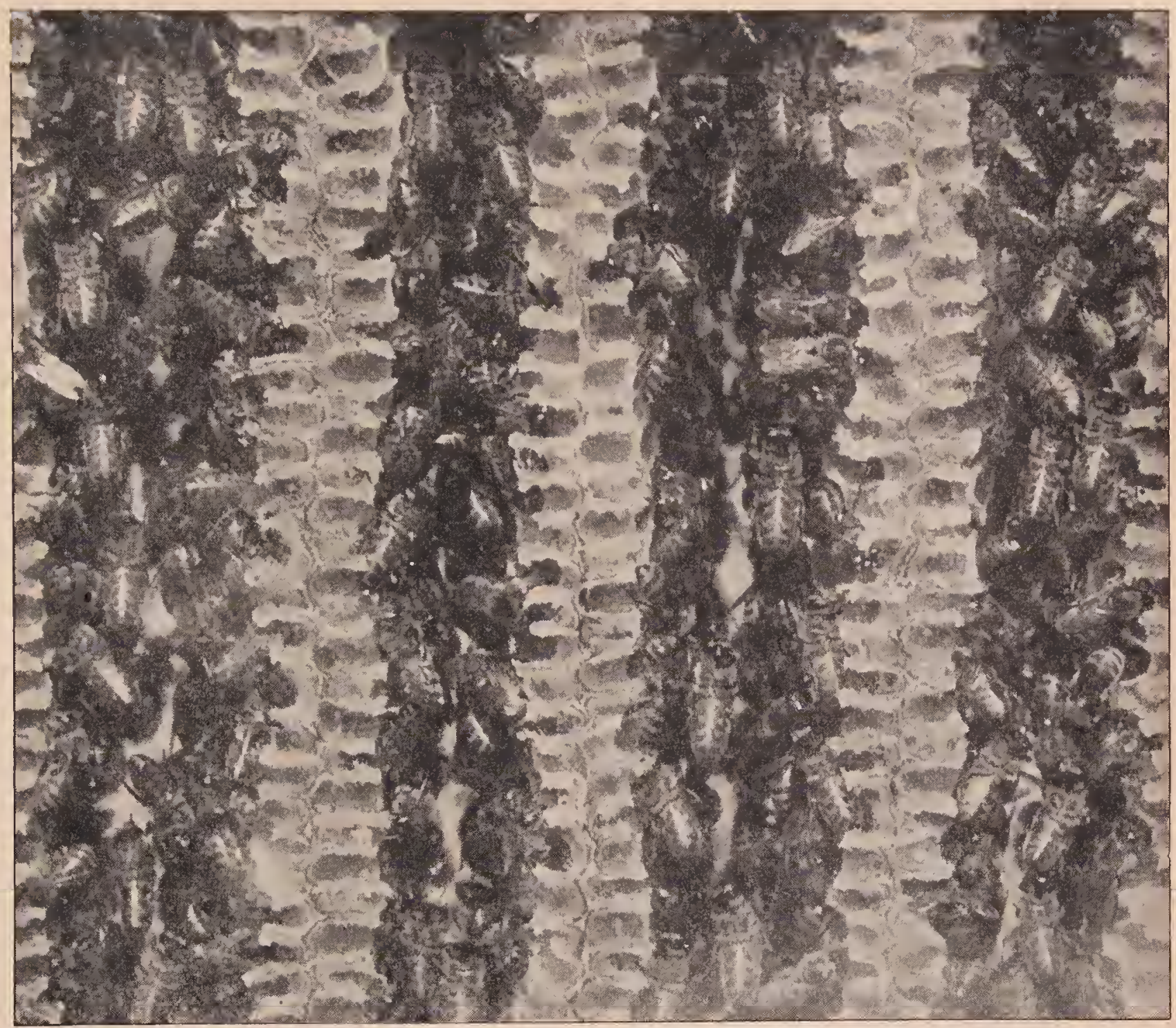

A close view of comb built against the glass of the Miller observatory hive. This form of hive en ables the observer to see the bees at work in the cells, the hatching of the egg, and the development of the larvae.

from the others. Panes fifteen inches long by ten inches wide have been found to be a very satisfactory size. The uprights are fastened to two horizontal pieces extending across the base. These latter pieces each have a groove one-half inch above the floor. Into these grooves are slid two strips of glass to close the space at the bottom between each pair of panes. Between these strips and the raised sides of the base, strips of wire cloth are put and furnish the ventilating area. Galvanized wire cloth of fine mesh has proved preferable to ordinary painted wire cloth. The woodwork of the hive and the wire cloth is painted a dead black, both inside and out. This gives a sharp contrast with the combs, and is advantageous when taking photographs. The outside of the hive may be finished in natural wool, but the inside of uprights and under side of top should be dull black.
The distance between the inner panes has been varied from half an inch to three inches. The former is too close and the latter unnecessarily wide. An inch to an inch and a quarter is best, and then no bee can completely escape observation.

To stock this type of observatory hive is a little troublesome. The two panes of one side of the hive are removed and the hive is laid on its side in a box prepared for the purpose, the "tunnel" of the hive connecting with an entrance in the side of the box. If this box arrangement is not used, trouble will be experienced by bees clustering on the outside of the ventilators. A sheet of new comb has previously been given to a colony; and as soon as it has larvæ one to three days old it is ready for use. It is cut vertically into strips just a little narrower than the space hetween the inner panes. These strips are then laid 
in the hive, spacing them about an inch and a lialf from center to center. It is de-. sirable that comb containing some honey be used also, and if there is not any honey in the upper part of the brood-comb, a strip or two of comb containing honey should be cut from some other sheet. If cells with the ends against the glass are also desired, a little more delicate work is neeessary.

From a new dry comb a strip somewhat wider than needed is cut, then with a hot knife, the cells are cut from the base. These baseless cells are very delicate and must be cut to the required dimensions with the hot knife. They are then lifted on a cool knife $01^{\circ}$ piece of cardboard and slid into position in the hive. No gluing or waxing is needed, for the bees will do that perfectly.

The other pair of panes are next carefully slid into place. If any of the strips were cut too wide the glass will hit and move them and cause a lot of trouble, but otherwise the operation is easy. The entrance guard is lifted, a queen put in and the guard replaced, and the cover put on the box. On a wide board in front of the entrance are now shaken the bees from two combs taken from any hive. The older bees will go home, the others will crawl into the hive. They go in better if the hive is dark; hence the putting of tlie cover on the box; but it may be opened from time to time to watch matters. If they are a little slow to enter they may be hurried by a gentle puff of smoke now and then, but on the whole it is better to let them take their time.

This operation is preferably done near the close of the day, and at a time when nectar is being secured, then robbing is not troublesome.

The hive is left in its horizontal position for a couple of days, the box being sliaded from the direct rays of the sun. If it is found that not enough bees are in the hive to fill the spaces fairly between the strips of comb, more may be sliaken in front at any time. In about two days all of the combs will be seen to be attached to the upper one of the inner panes. By the time this is noted, it may be certain that the combs are likewise attached to the lower one of the inner panes. The hive may now be taken from the box, set in an upright position, and taken away.

\section{MAINTENANCE AND OPERATION.}

As soon as the hive is in its place syrup should be given in the feeder and feeding continued for several days, for the little colony has virtually no field force, and will soon exhaust the honey in the combs. Also the feeding will stimulate wax production and enable the bees to complete the combs. During a heavy honey flow these little colonies will gain stores, but in a light flow their field force is too small and help may be needed in the shape of syrup or honey in the feeder.

By coloring syrup (using a candy color) it is easy to see just where it is put first and more or less of it moved afterward. An ounce of deeply colored syrup is enough to use at a time for this experimen'.

If feeding is necessary in cold weather, use a hot syrup, nearly filling the feeder (a half-pint). It will warm the hive and arouse the bees, and as soon as the syrup cools suffieiently they will take it. Use for this purpose a syrup made of two parts sugar and one of water. If the weather is very cold, close the hive and remove it to a warm room, keeping it there until the bees have taken up all or most of the syrup. If, however, the combs were packed with stores before settled cold weather, and the room temperature keeps between 35 degrees, and 60 degrees F. as the extremes, the bees will not need feeding until spring.

If the hive becomes over-populous, it should be removed at night to some other window and in its place should be put any convenient box containing a piece of comb with unsealed brood, or a caged queen. The next morning the field force will start out as usual, but will return to the old location where the brood or queen will hold them. As soon as the population of the observatory hive seems to be reduced enough, its entrance should be elosed to prevent the escape of more bees. Within two or tliree hours the box on the old location inay be closed and taken away and the hive put back and the entrance opened. The removed bees maý be destroyed or kept confined for a few days, and then at nightfall be dumped into some hive in the yard.

If the colony in the observatory hive becomes weak, it is most easily strengthened by tuming in a lot of young bees. An 
easy way to do this is to shake into a box the bees from a comb from some thrifty colony in the apiary, and cover the box with a piece of wire cloth. Carry it to the observatory hive and fix it so the edge of the box is close to the opening to the tunnel: Remove the wire cloth over the box and the bees will soon enter the hive.

The same manner of weakening and strengthening may be followed with the prevailing types of observatory hives, but it is often easier with them to remove the comb and bees and restock the lives completely.

The new type of observatory hive is good for about two years without renewing the comb, but by that time the comb becomes dark and opaque and the glass more or less coated with wax lumps, propolis, cocoons, etc. Therefore it has proved more satisfactory to restock the hive every year.

Bees winter nicely in these little lives provided the temperature of the room does not go to freezing nor stay below 40 degrees F. very long at a time. A room temperature up to 65 degrees or even 70 degrees does not cause trouble in the winter, provided the hive entrance is wide open. A few bees may venture to go out; but by the time they reach the outer end of the tunnel they meet the cold air and turn back. A window facing south is the best for winter; but any exposure will do for summer, tho one not facing the prevailing winds is to be preferred.

All types of observatory hives should have the ventilating space solely at the bottom of sides or ends, and with double glasses with a confined air space between them. Extra space into which the bees may spread and yet not build comb is greatly to be desired, particularly in singlecomb hives. This and ideal ventilating conditions are secured by having the floor wider than the hive and having such extension covered by wire cloth spaced half an inch above it.

ORANGE (Citrus Aurantium).-The orange is a native of southeastern Astia, whence its cultivation has extended since the tenth century thruout the warmer regions of both worlds. It is believed that the Arabs carried it into Africa and Spain, and that the early Spanish settlers intro- duced it into Florida. Later colonists found large groves of wild orange trees. There also belong to the genus Citrus the grapefruit ( $C$. Decumana), the lemon ( $C$. Limonium), and the lime (C. Limetta) and the mandarin or tangerine ( $C$. nobilis). All the species are evergreen trees or shrubs. Most of them have fragrant white flowers, tho those of the lemon are purplisl.

The cultivation of the orange and other citrus fruits is confined in Florida chiefly to the southern half of the peninsula, altho when given special care and protection during cold winters, they will flourish as far north as Jacksonville. In northwestern Florida, west of the Suwanee River, and northeastern Florida north of St. Augustine only a very small area of citrus fruits is under cultivation. In the central lake region comprising the eight counties of Alachua, Marion, Putnam, St. John, Volusia, Orange, Lake and Sumter there are over a million and a half of trees. Along the west coast in Citrus, Hernando, Pasco, Hillsboro, and Manatee Counties there are also numerous orange groves, Hillsboro reporting a larger acreage than any other county in the State. Farther south, Polk, Brevard, and De Soto Counties each contain over 200,000 trees. Lee County, the seat of the Big Cypress Swamp, commonly regarded as a wilderness, has also many orange groves. Lemons are produced principally in southern California ; but there is a small acreage in southwest Florida, chiefly in Monroe County. The grapefruit orchards are found largely in western Florida, in Lee, Manatee, and Hillsboro Counties. Limes are grown eommercially only in the southern tip of Florida (Monroe County) and the adjoining islands. It has been estimated that there are in this State 10,000 square miles adapted to orange culture.

The date of the beginning and the length of the period of blooming vary greatly according to the variety of the fruit, the extent of cool weather in winter and early spring, and differences in rainfall and soil. For instance, in the middle of the State flowers have been seen on the round orange as early as Feb. 6; but in 1912 the first bloom did not appear until March 15 . On an average Feb. 20 is the date on which 
blossoms begin to appear in this section. The spring of 1915 was unusually cold and rainy, and the flowers did not open until about the first of March, and did not yield nectar well until the end of the month, when the bloom became very abundant. Usually nectar is not gathered later than April 10; but this year a hive on seales showed a gain of three pounds on April 20 , and the flow did not cease entirely until a few days later.

The trees remain in blossom for about four weeks, if the weather is not too hot and dry. As a rule the later the bloom appears, the sliorter the time it lasts. Cool

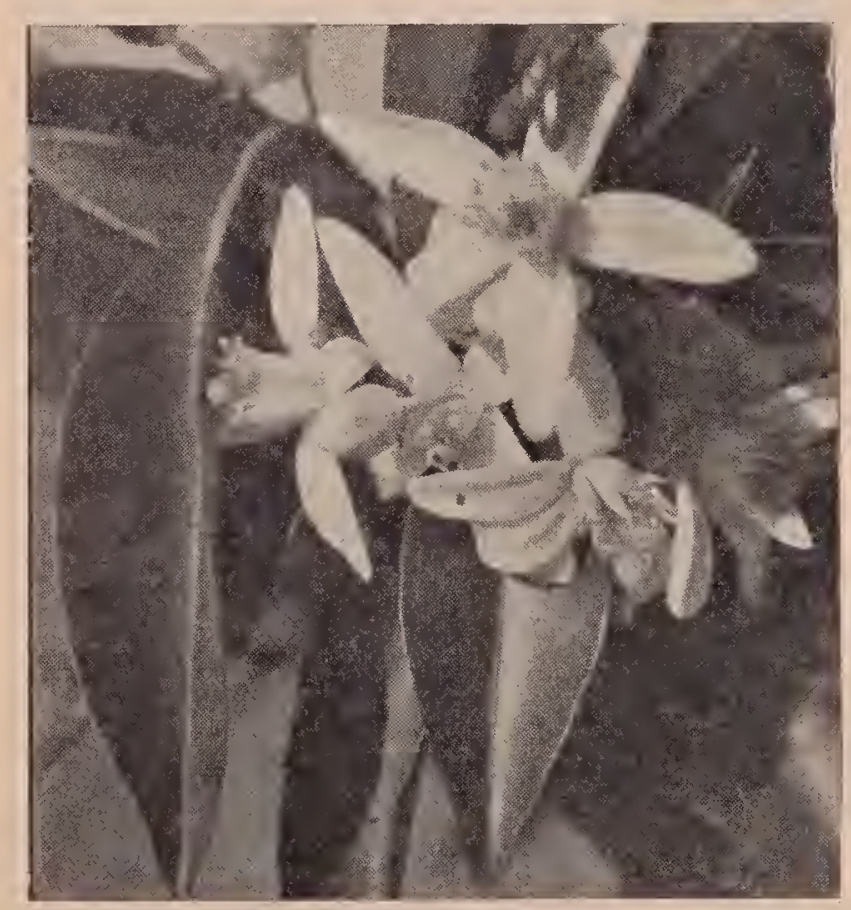

Orange blossom.

and frosty weather will prolong it unless the frost is so severe, as in 1911, that it injures the blossoms, when it brings the flow speedily to a close. The average surplus in a good year is about 40 pounds. The best hive in an apiary at DeLand in 1914, stored 200 pounds and, in 1915, 150 pounds. At Plant City, about 100 miles south of DeLand, in 1915, there was an average of not more than 10 pounds per colony-the poorest record since 1904 .

An orange grove in full bloom, displaying innumerable white blossoms among the dark-green leaves and exhaling a sweet fragrance that can be perceived for a quarter of a mile in all directions, is beautiful beyond description. The bloom is as sensi- tive to weather conditions as is that of the mangrove. Fither very hot and dry weather, or sudden changes to cold and wet weather, will lessen the flow. In 1915 at DeLand the flow varied more, according to E. G. Baldwin, than he had ever noticed in any previous season. One day the scales would show a gain of 11 pounds, the next day it would drop to four or five, then rise to seven or eleven, then drop to four again. A warm dainp day, with sun and cloud alternating, seems to be most favorable for the secretion of nectar. Then it can be seen in the early morning shining in the white blossoms, and the bees are heavily laden thruout the entire day. Because of the uncertainty of the secretion of nectar, orange trees can not be counted on for honey oftener, on an average, than one year, in three.

The honey is light amber, clear, and crystalline, without the thick opaque appearance sometimes observed in even elear amber palmetto honey. It has a body heavier than cabbage palmetto, but not as heavy as serub palmetto honey. The flavor and aroma, which preserve the fragrance of the blossom, are delightful, and can not be duplicated in any other honey. E. R. Root once said of this honey "We are inclined to think the flavor is a little finer than anything of the kind we have ever tasted."

Pure orange honey in Florida is searce and always will be. Altho shipped from California by the carload it is not easy to get in Florida for the reason that there is only a limited area where the trees are sufficiently abundant to yield a surplus unmixed with nectar from any other source. There must be thousands of trees within an area six miles in diameter, and little else in bloom at the same time. A little admixture of wild cherry or andromeda will spoil the pure article and give it a dark tint and a pungent taste. While there are many orange groves in Florida they are so widely scattered that there are not many good orange-honey localities. Probably Volusia County has more sections where pure orange honey can be obtained than any other single county in Florida, unless possibly it be Manatee County on the west coast. There are also extensive groves which are attractive and promising 
at Wauchula, De Soto County, and Orlando, Orange County.

A large acreage of oranges, mostly of the Satsuma variety, lias been planted along the coast of the Gulf of Mexico from Florida to Texas. The bloom does not yield much nectar. About 40 miles below New Orleans, La., in the Delta of the Mississippi River in Plaquemines and Jefferson Counties there are many miles of almost continuous orange groves. The first orange trees were planted in this section more than one hundred years ago. In Texas the orange orchards are largely restricted to Galveston and Brazoria Counties on the Gulf coast, but citrus-growing is in course of development in the Rio Grande Valley.

In Arizona orange culture is an important industry in the Salt River Valley in Maricopa County where there are 2,500 acres. The orchards are confined to the slopes, which are free from orange-killing frosts. The oranges in this section ripen early, and the first shipinents often reach the eastern markets in time for the Thanksgiving trade. The culture of orange and grapefruit will expand considerably in those parts of the Salt River Valley where winter temperatures permit, and there is an average water supply.

The orange was introduced into California by the early Catholic misssionaries, but its cultivation on a commercial scale began about 45 years ago. Today the State has two-thirds of the trees and produces threefourths of the crop, devoting 234,600 acres of its fertile soil to growing oranges and lemons. In 1920, 15,000 families received $\$ 81,000,000$ for citrus fruits, or an average of $\$ 475$ for every acre of bearing trees. The area of orange groves bearing fruit was 133,500 acres and of non-bearing or young groves 50,400 acres. Of bearing lemon trees there are 33,000 acres and 17,000 acres of young trees. This is probably the largest area of citrus-bearing fruits in the world.

While oranges are grown to some extent in many counties in California there are two well-defined dense areas of production. The smaller area is in the foothills of the Sierra Nevada in the San Joaquin Valley. In Tulare County there are over 800,000 trees, and the crop of citrus fruits in 1910 was valued at $\$ 4,000,000$. In Fresno and Kern Counties the number of trees is much smaller, the total being about 200,000 . The larger area of citrus fruits is located on the southern and western foothills of Los Angeles, Orange, San Bernardino, and Riverside Counties. In Los Ängeles County there are 34,000 acres of orange groves and 10,000 acres of lemon trees, in San Bernardino County 43,000 acres of oranges and 7,000 acres of lemons, while Riverside County has an acreage almost as large. There is also considerable commercial production in Santa Barbara, Ventura, and San Diego Counties. Northward in the Central Valley in Butte County many acres of orange trees are successful. Citrus fruits can indeed be grown in favorable localities from San Diego County to Shasta County.

As with many other honey plants, the secretion of nectar varies in different localities and is greatly influenced by weather conditions. In the cool regions near the coast there is little nectar. Fog also often interferes with the flight of the bees so that there may be very few days which are ideal for field work. In the foothills it is occasionally very cold; and an apiary at an elevation of a few hundred feet has been snowed under for a few hours, while in the valley below the orange trees were also white-but with flowers, not snow. At Redlands the weather is very warm and there is little fog with the result that, four years out of five, orange bloom yields a fair crop, in proof of which may be cited the experience of a beekeeper who states that he has shipped one or more carloads of pure orange honey every year except 1904. Yet even here the weather is sometimes so cool that tons of nectar are lost because the bees are forced to remain in the hives. Even in fair weather the flowers have been known to yield only a scanty supply of nectar. But when the conditions are suitable there is probably no other plant in the United States which secretes nectar more copiously. At times the clothing of pickers and pruners is wet by the dripping nectar, and the horses and harness require washing at the close of a day's cultivation among the trees; while even the ground is dampened by the many falling drops.

The very heavy water-white honey is un- 
surpassed in flavor; but as it usually crystallizes in a few months many dealer's prefer to buy sage honey. It is very easy to obtain orange honey pure, for sage does not blossom until the weather is warmer. At Pomona the land for miles is entirely occupied by groves, and it is difficult to obtain room for an apiary. Here after the honey flow is over the bees bring in nothing for the rest of the season except a dribble of dark honey from pepper and hoarhound. Taking it all in all, the orange is the most dependable source in southern California.

A large acreage in California is devoted to the cultivation of the lemon and grape fruit, but these trees do not yield nectar as freely as does the orange. The other eitrus trees are not common.

In the hope of maintaining a more even temperature in both summer and winter a six-acre lemon grove at Corona, Calif., was . covered with tobacco cloth, a strong kind of mosquito netting. This netting was stretched over wire, and was supported by posts about 16 feet tall. Two colonies of bees were placed in the grove and given sections of drawn comb; but they died out entirely in a few months from close confinement and lack of pollen. The stronger in a short time filled 12 or 15 sections with lemon honey. The color of this honey was very light and the flavor excellent, with none of the tartness of the fruit. Under these conditions the manager estimated that the crop of lemons was increased fourfold. Unfortunately, a heavy wind wrecked the structure, and when removed the trees dropped to their previous rate of production.

In southern California the trees are in bloom during the last of Mareh and thruout April, or about six weeks. The period of blooming varies greatly-sometimes being much later than usual. It would be for the advantage of apiarists if the honey flow was later, for while it aids in building up the colonies, the latter are often not sufficiently strong to bring in all the nectar, or the cold compels them to remain inactive. With large colonies and clear warm weather the nectar comes in very rapidly. At Redlands a hive on seales showed a gain of 119 pounds in 17 days from April 7 to 23. The honey was secured in about five hours of each day from 11 to 4 o'clock. During the morning the bees brought in pollen from various flowers, but before noon they were all at work on the orange bloom. A surplus of from 60 to 120 pounds per colony is obtained. The neetar is frequently very thin when first gathered, and naturally after irrigation is thinner for a few days; but toward the end of the flow, if the weather is warm, it becomes much thicker.

OUT-APIARIES. - Within late years this term has been used to apply to a beeyard remote or distant from the home yard by about two or three miles. It is a wellknown fact, that only a limited number of colonies, comparatively, can be supported in any one locality, different places being able to support widely different numbers of colonies.

\section{NUMBER OF COLONIES IN AN APIARY.}

The number of colonies of bees that can be profitably kept in one locality is limited by the amount of pasturage. Of late years quite a number of beekeepers have established one or more out-apiaries, for the sake of keeping more bees than the home pasturage would support. Just how many bees can be supported in a single locality has probably never been ascertained, and it is just as probable that it never will be. One field may support five times as many as another, and the same field may support five times as many this year as last. Most beekeepers, however, think it inadvisable to keep more than 75 to 100 colonies in one apiary, while a few think their locations so good that 200 or more can be profitably kept together. As many as 500, and in one case even 700 , have been kept in one yard. These cases are very rare, however, as it is seldom that the bee pasturage is strong enough to support so many.

As a general thing, most localities will not support to the best advantage over fifty colonies to the yard. In a series of outyards owned by the authors it was found an advantage to have not more than 50 , altho there are some seasons when a larger number could be operated to advantage.

The number of hives per apiary will depend very much on the amount of available forage for the bees. A locality that has a large acreage of alsike, some red clover, as 
well as white clover, will support twice as many colonies as one where there is only white clover. The presence of considerable sweet clover will help materially.

In western territory where alfalfa and white clover are grown, the number of stocks will depend on the number of acres grown as well as on the time when the alfalfa is cut. Some ranchmen cut their alfalfa earlier than others. Some grow alfalfa for seed. Where seed is raised, a muchl larger number of colonies can be landled to advantage.

It is ahmost impossible to give a definite number per apiary. One may have to experiment to determine how many he can keep. In an eastern locality if there have been early spring rains and there is a considerable amount of alsike, sweet, and white clover, and especially if there is some basswood, 75 colonies to the yard could be operated to advantage. If there is only white clover available, probably not over 30 could be placed. In that case the farmers should be urged to put in alsike. If they can be induced to give it a trial on the basis of the beekeeper's furnishing the seed at lialf price, they will probably continue to use it year in and year out, with the result that the locality will be measurably improved. (See "Alsike" under Clover.) As a rule it is better to have too few colonies than too many to the yard; and it should always be borne in mind that strong, powerful colonies will gather relatively more than the weak or medium. See BuildING UP COLONIES.

In tlíese days of automobiles, by which one can cover three or four yards in the afternooll, it is not so necessary as it was in the olden days of the slower horse and wagon to have so large a number of colonies per yard. For that reason, if for no other, it is safer to err on the smaller number.

Sone yards will show up much better than others year after year. In that case a larger nmmber can be placed in such yards.

DISTANCF BETWEEN APIARIES, AND LOCATION TIIEREOF.

$\Lambda$ location for an ont-apiary must, of course, be far enough distant from the lome apiary not to interfere much; but 21 just how far is best, it is not easy to decide. Perhaps, all things considered, a good distance is from three to five miles apart. As the area of flight is a circle, the ideal plan of locating out-apiaries so as to occupy fully all adjoining territory is to put them in hexagonal form, in which case a circle of six will surround the lome apiary.

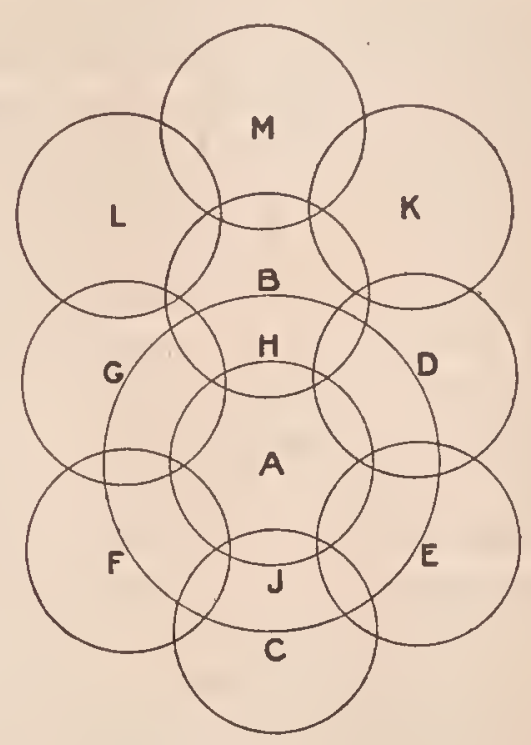

In the diagram, $\mathrm{A}$ represents the lome apiary, and B, C, D, E, F, G, the outapiaries, at equal distances from $\mathrm{A}$ and from each other. If more than seven are needed then a second series may be started, as at $\mathrm{K}, \mathrm{M}, \mathrm{L}$, indicated by the letters. The circles representing the area of flight from each apiary are seen to overlap each other; but this is at the outer parts, where the ground is more sparsely occupied, and the doubling on the same ground is compensated by the convenience of the shorter distance to go from one apiary to another. But this ideal plan, altho a good thing to work from as a basis, is not likely ever to be fully carried out. Many reasons will make it desirable to vary. The roads may run in such directions as to make a difference; no good place may be found for any apiary at some of the points. It may be remarked that the area of flight is not always a circle. An apiary placed in a valley between two ranges of hills might have an oblong area, the bees perhaps flying twice as far along the line of the valley as in the other direction. When an apiary is on a hill overlooking a valley bees will fly further than when on a level. (See Futght of Briss.) If only a single out-apiary is 
to be planted, it is probably best to go in the direction of the best pasturage- a thing not always easy to determine. Sometimes one location proves to be better than another, year after year, altho no apparent reason for it can be seen. It may even be worth while to vary a location a mile or more for the sake of having it where pleasant people live. But one can do much toward making the people pleasant by being pleasant limself. As little trouble as possible should be made, and one should be still more careful than at home to aroid everything that may invite robbing, for robbing begets cross bees on the place.

Since the days of the automobile and the antomobile truck it is feasible to locate heeyards mucl further apart than was practicable under the old plan of horse and buggy or team. While it is true that bees often do not fly more than a mile, and sometimes not over half a mile, it is equally true that some seasons they will go five miles in the same location. As already stated, the general lay of the land, the condition of the roads, etc., will determine to a great extent the location of the outyard. As far as possible, apiaries should be located l'emote from macadam, stone, or brick roads. They should also be placed in sight of some dwelling house. While this is not absolutely essential, yet the fact remains that thieves are less inclined to meddle with the bees when the apiary is in sight of some dwelling house.

It is desirable to have the apiary located where there are suitable windbreaks. (See Apiary and Wintering.) This is especially important if the bees are wintered on their summer stands; for good wintering cannot ordinarily be secured outdoors when the hives, no matter how well packed, are exposed to piercing winds.

HAULING BEES AND BEE SUPPLIES TO OUTYARDS.

Out-apiary management demands some sort of conveyance, not only to carry the beeman and his helpers to and from the outyards, but to haul the bees and the supplies. Formerly a horse and buggy or a team and wagon were used exclusively for the purpose; but the rate of travel was so very slow that the time lost on the road was considerable of an item. With a horsedriven vehicle it is not practicable to handle more than one or two outyards in one forenoon or afternoon, and generally about half the time is spent on the road. If a beeman's time is worth in the height of the season one dollar an hour, and his helper half that, and if the time of the team is worth $\$ 5.00$ a day, it makes the net cost $\$ 2.00$ an hour.

On the other hand, an automobile will make the trip to the yards in one-fifth or one-seventh of the time. A safe average running speed is about 15 miles an hour, altho on good roads one can run as high as 20 or even 25 iniles. It costs anywhere from 5 to 20 cents* a mile to operate an automobile if depreciation of the machine itself, wear and tear, tires, gasoline, and oil are included. But even on this basis the automobile is considerably cheaper, provided, of course, there is a series of not less than three or four outyards, or, better, five or six. The self-propelled vehicle makes it possible to have yards further apart; and this makes it feasible to have a less nım-ber of colonies to the yard, and a larger average yield. If a yard is overstocked it will not, of cour'se, give as large an average per colony.

It is not necessary to buy an expensive truck. An ordinary light machine selling for less than $\$ 490$ with a wagon-box on the back will handle practicaily 95 per cent of the out-apiary work provided there are not more than four or five yards. For very heavy hauling, a big truck can usually be hired at an expense of about 20 cents a mile, including driver; and this will be far cheaper than for the beekeeper to own the masline. Or a trailer can be hitched on the light machine and carry $750 \mathrm{lbs}$. in addition to 500 or $750 \mathrm{lbs}$. on the truck itself. The automobile without a trailer can carry $750 \mathrm{lbs}$. to the trip, and thus do practically all the work, even to hauling the bees home in the fall, altho there is an increasing tendency on the part of outapiary beekeepers to winter their bees at outyards in large quadruple winter cases. (See Wintering Outdoors.) In thiat case the small machine can do all the haulin provided the owner manages to take a

\footnotetext{
* 1 Ford will run for from 3 to 5 cents as against a ton automobile truck at 15 to 20 cents per mile.
} 
light load at each trip, both going and coming.

If there is a series of eight or ten yards one can well afford to have a light machine to carry the men to and from the yards, and a trailer capable of carrying $750 \mathrm{lbs}$. more, ${ }^{*}$ altho it is surprising to see how much work can be accomplished with a Ford alone.

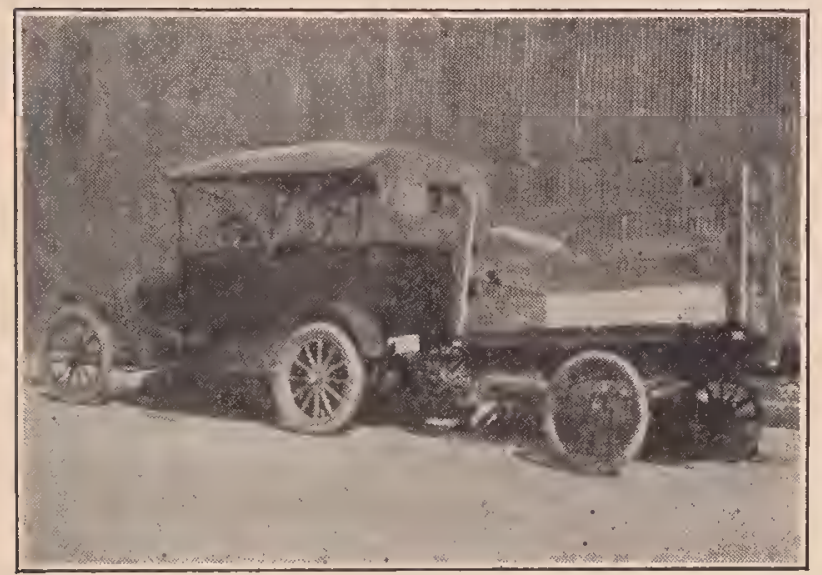

Ford and trailer.

A two-wheel trailer, if rightly designed, will carry from 70 to 1,000 pounds. In some places one can be rented for $\$ 1.50$ a day. Its cost will run all the way from $\$ 50$ to $\$ 150$. It is a very common practice in California for beekeepers to move their bees with a two-wheel trailer.

The upkeep of an automobile costing less than $\$ 400$ is about a third of the cost of operating the larger machines costing $\$ 1,200$ or more. The former use small tires, and, what is of great importance, the first cost is much lower. Beekeepers should understand that the main expense of operating an automobile is depreciation, which cannot be figured at less than 33 per cent the first year; 25 for the next, and 10 per cent for each succeeding year. The depreciation is the largest item; and as the cost of the low-priced machine is less than half the ordinary machines, the depreciation is accordingly less.

But there is another item to be considered. The little high-speed engine in the small machine will give about twice the mileage per gallon of gasoline of the heavier machines, and this is no inconsiderable item.

By lengthening the wagon-box a much larger bulk of hives can be carried at a

*E. L. Hoffman, Zanesville, Minn., handles 1,000 colonies with one assistant, a Ford, and a trailer. He secures big crops of honey, and with his Ford he sells and delivers his crop in his locality. The Ford with trailer is used rery commonly in California ind other States. load; and, generally speaking, the author would advise having the wagon-box stick out at the rear at least two feet or more, because a great deal of the stuff carried to the outyard is bulky but not heavy. But when the wagon-box is enlarged, precaution should be taken not to put on a load of more than $750 \mathrm{lbs}$. While the chassis of a light machine will carry 1,000 lbs., such a load is rather hard on the tires, and it is advisable to make an extra trip rather than trying to do the whole job in one load.

Whatever the kind of hive used, some plan must be adopted for fastening in the bees, so that they may have abundance of ventilation while being hauled. As, however, the hauling is done in spring and fall, less rentilation is needed than during hot weather. The ordinary entrance, say 14 inches by $7 / 8$ covered by wire cloth, will answer, as that gives a ventilating surface of about 12 inches, altho more would be much better. (See Moving Bees.) Of course, the bees should all be shut in when not flying, and in spring it is a good plan to shut up in the evening all that are to be hauled the next day. In the fall the weather may be such that bees will not fly at any time in the day, otherwise one must get to the out-apiary early enough in the

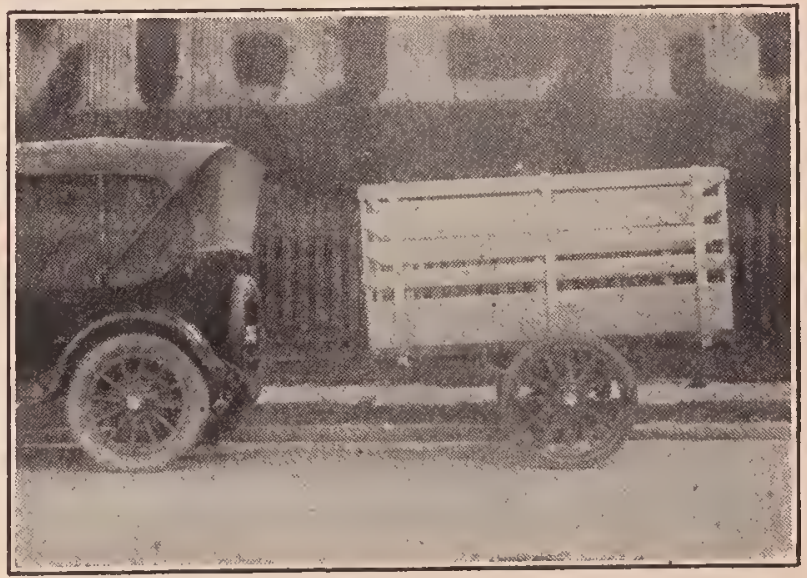

This is a better trailer and costs about $\$ 150$. It will handle easily at one load 50 colonies, or one ton of weight. For moving bees it is always best to have a strongly built inachine.

morning to shut in all the bees he will haul that day. If one is to take bees to an outapiary in the spring, the sooner it is done the better, as pasturage is then apt to be rather scarce at best. Where bees are to be brought home in the fall to be cellared, they may as well be brought just as soon as heavy frost occurs, or as soon as they 
stop gathering; at least they should be brought early enough to have a good fly before going into winter quarters. After being unloaded from the wagon the bees may be liberated by blowing a little smoke or dashing in some cold water at the entrance; or, if loaded too late in the evening to fly, they may be quietly set down; and if carefully opened, no smoke need be used. For particular's on the difficulties in hauling bees see Moving Bees.

\section{RENT FOR,OUT-APIARIES.}

The agreement between the beekeeper and his landlord, for rent, is as varied as the cases that occur. Some pay a fixed sum, five to twenty-five dollar's per year; some pay ten cents per colony; others agree to pay a per cent of the crop; some make a bargain to pay so much for every swarm lived by some one of the landlord's family, and so on, while some cannot get the landlord to agree to take any rent whatever. In this latter case it is only right to make sure that the landlord has a good supply of honey for his family to use during the coming year. In any case, be sure to do a little better than expected.

\section{GENERAI ${ }^{\prime}$ MANAGEMENT OF OUT-APIARIES.}

The management of outyards will depend very largely on the man, the locality, and the general conditions. Sometimes up in the mountain country where the roads are very poor, and a very large number of colonies can be supported per apiary, it is more practicable to have a man at each yard who camps on the job night and day until the main honey flow is over. Of course, it is not necessary to have a man at the yard during the dormant season; but when warm weather sets in some one should be on hand to build up the colonies and put them in proper condition to eatch the honey flow.

As a rule, however, a man at each yard is too expensive, and it is, therefore, better to have one force operate all the yards, using an automobile, even if an occasional swarm does get away. This plan has the advantage that the owner of the bees can always be present with the men, directing the work, thereby securing efficiency and at the same time better service. The helpers usually work better when the boss is around; and the boss who does not superrise his own job will soon run himself out of business. One who is capable of operating a series of outyards is capable of directing his men, and usually he is a man who has gradually grown into the business, increasing it from year to year as knowledge and experience permit. It follows, therefore, that when the owner can keep his eye on every colony at every outyard, and direct the individual treatment, he gets far better results than if he has a hired man out of his sight at each outyard.

The owner of the bees, when he takes his helper or helpers, should make his plans well in advance before he starts for the yard. He should not only know what he is going to do, but whether he has the proper equipment with him to work out the plans for the day or trip. He slould go further and have his plans matured a week in advance so that he can take care of each yard at a definite period. He slould see to it that he has on hand sufficient supplies of every description; and if he does not have enough equipment at each yard he should so arrange his work that he can carry what is necessary at each trip; otherwise he will be working at a great disadvantage.

It is not essential that a helper should have experience. The beeman who uses his brains can take a comparatively raw man or.boy and almost double his own capacity for work in a day. The autlior's yardman takes along with him one or two helpers. The helper with smoker opens up the hives in advance, so that all is ready when the boss makes his inspection. His practiced eye will see almost at a glance what treatment is required, and he will, therefore, direct his helper or helpers to bring him the necessary equipment to put the colony in proper condition. An experienced man who has his plans well worked out will be able to keep one man bringing him stuff. As the men acquire more experience the boss simply tells them what to do with a colony. In the meantime he studies the needs of the next colony.

A good beeman who is capable of getting along with help will be able to take care of seven or eight liundred or perliaps a thousand colonies with one helper during the active season. Then conditions are right, 
and with the proper system, he sometimes may be able to handle twice the number with the same help.

Of course it goes without saying that the owner or boss should know how to operate his automobile. As already pointed out, he cannot afford to waste time with a horse and buggy, as he will thus kill valuable time.

But perhaps it may be urged that the roads are bad and almost impassable for any automobile, and that a horse and buggy must therefore be used. But usually a Ford with a good driver will go where any horse can.

No beekeeper should go to an outyard without a spare inner tube and an outer casing, with a boot to provide against blowouts, and patching stuff to make repairs to inner tubes. In the rush of the season it is the height of folly to get caught on the road with a blowout or a puncture without means for making repairs. To run on an uninflated tire is the ruination of the inner tube and a damage to the casing. As a general thing the author would recommend having a Ford equipped with detachable rims. With this extra rim carrying a tire already inflated, one can get started in a very few minutes.

An extra box should be provided on the running-board of the machine to hold smoker, smoker-fuel, hive-tools, bee-brush, grass-hook, or anything else that may be required at the outyard. These tools will be needed on every trip, besides the combs, supers, and other equipment that will ordinarily be loaded in the wagon-box for that special trip.

Sometimes it is necessary to take along a, scythe, and while the boss is making an inspection of colonies his helpers can be employed in cutting down grass and weeds and leveling up the hives. This last item may not seem to be essential; but if a hive is on a tilt it will have its combs in the section-supers built out of plumb. If the season liappens to be a good one, and there are four or five supers on the hive, a stiff wind just before a thunderstorm may blow the whole thing over. 'It is important, therefore, to have a good foundation for each hive at the yard.

At every outyard there should be a small collapsible building. (See Buıldings.) Thiș is to hold extra combs, supers, and equipment; and if the extracting is performed with a small hand machine it can be done in a building of this sort.

As given under ExTrACTING, the author advises one large extracting-outfit at the home yard, where the work can be done inside of a bee-proof building. It is not advisable ordinarily to extract at outyards, on account of the danger of robbers, and because conditions usually are not favorable for putting up an extracting-outfit.

In the case of bee disease it is sometimes necessary to extract at the outyard, in order to avoid mixing the combs, and danger of carrying disease to the home yard. But even in that case, if one plans rightly he can arrange to take his combs off, load them on the machine, carry them home, extract, and return. There should be a drippan in the wagon-box to catch any drip from the supers after extracting. And it may be advisable to throw a large canvas over the load to keep any bees in the home yard from getting a taste of the honey. In any case the extractor should be thoroly washed out with boiling water after extracting from diseased or suspected combs. Such work cannot be done too carefully.

\section{WINTERING OUT-APIARY BEES.}

It is the practice of some to haul the bees home from the outyard and put them in a large cellar; others winter in large quadruple winter cases at the outyard. (See Wintering Outdoors, subhead "Quadruple Winter Cases.") If there is any danger that the bees may be tampered with during winter by thieves or boys, it is advisable to haul the bees home and winter them under the eye of the owner. Usually an outyard can be located in sight of some house. If the land is rented from the owner of the house he will be'willing to keep a watch on the bees; but as a usual thing bees may be left out of doors year in and year out without disturbance.

If the bees at the outyards are well supplied with stores in the fall, and put into double-walled hives or large winter eases, they will not require much attention except to see that the entrances do not become clogged with dead bees, which may happen along late in the winter. Usually some one near the outyards can be hired to rake 
the dead bees out of the entrances, as it may not be practicable for the owner to make a visit when roads are bad.

For building up outyard bees the reader

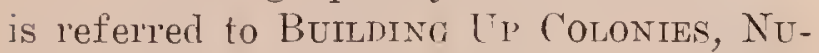
CLFUS, and INCREASE.

\section{FAILING LOCATIONS}

Experience has shown, in many instances, that a yard which in years gone by has furnished tons of honey is now practically worthless, or so nearly so that the moving of the bees to some more favorable location is a necessity. For example, four or five vears ago an apiary furnished an abundance of basswood honey; but the basswoods have all been cut off; there is no clover and the field is worthless. Again, a locality had once furnished immense quantities of white clover; but intensive agriculture has set in, and clover pasturage has given way to immense wheat fields. The inroads of civilization sometimies cut off the honey resources of a locality; at other times they augment them very considerably. There are a few locations in New York State that formerly gave very little honey until the farmers in recent years introduced buckwheat to such an extent that these are now exrellent honey locations; and the yield of this dark rich honey plays a considerable part in the net profits of the season. In California some sage locations that were formerly good were ruined by fire. In other places in the State the planting of orange groves has made these places good for bees.

\section{A SCALE HIVE AT AN OUT-APIARY.}

It is a well-known and established fact, that one yard may yield quite a crop of honey while another, only a few miles distant, requires to be fed. It is highly important to be able to tell just what the bees are doing at stated periods during the season. One beekeeper kept a hive on scales at each yard; and every time he visited one he consulted the scales. If they indicated an increase of several pounds, he knew the bees in this apiary needed more room, and were also liable to swarm; but, if they indicated a loss of several pounds, he inferred that the whole yard was losing likewise, and that some colonies needed to be fed. Of cour'se, the hive on the scale should contain a fair average colony. In many cases it is not always possible to visit yards at regular periods, and in that case some resident near the apiary can be employed to watch the seales, and report by postal card or telephone. See ScALE Hive.

\section{A CAUTION ABOUT ENTERING INTO THE} OUT-APIART BUSINESS.

While there are many beekeepers who have brains and capacity enough to manage a series of out-apiaries, there are also more who should never think of going into the business. To be a keeper of several out-apiaries means great perseverance and a good deal of system, besides ability to manage not only the bees, but the help who are to take care of them. If one cannot make 50 or 60 colonies pay in one location, he should not delude himself by establishing a series of out-apiaries. The man who can not make a small business pay probably will not make a large one do so. When one can manage successfully his home apiary, it may be profitable, as soon as the increase is sufficient, to take a part of it to an outyard.

OVERSTOCKING.--This means putting more colonies in a locality than can be supported profitably. Sometimes a local beekeeper makes the mistake of putting too many bees in a place; but it more often happens that another, observing that the locality is good, brings in one or more yards, thus crowding the territory that was already overstocked in the first place. See under Apiarx, Backiot Beekeeping, Farmer Beekeeping, and OUt-apiaries.

A given locality with only ten colonies to gather the nectar in it may show a large average per colony-perhaps 200 or 300 pounds. When the number is tripled or quadrupled, the average will be cut down a half. The locality should be carefully studied, and only that number of colonies used which on an average, one year with another, will give the largest results in honey, with a minimum of labor and capital. If 75 hives during an average season would furnish an average of 150 pounds to the hive, then, perhaps, the number might be increased to 100 or even 150. If, 
on the other hand, the average is only 50 lbs. of extracted honey, and there are only 50 colonies in the apiary, then, clearly, 50 wonld be all there could be kept with profit in that spot; and it could be questioned whether or not 35 might not be just as profitable, and at the same time save a little in the investment and some labor in gathering and harvesting the crop.

In some locations, notably Wyoming, Montana, Irlaho, Utah, California, Colorado, Cuba, and in some portions of New York, one can have as many as 300 or 400 colonies, and in some rare instances 500 colonies in one apiary. The late E. W. Alexander of Delanson, N. Y., had some 700 colonies in one beeyard; but he had immense acreages of buckwheat and goldenrod. The celebrated Sespe apiary in southern California, owned by Mrs. J. F. MeIntyre, has, in one yard, 600 colonies of bees. The great mountains on either side, the fertile valley and the great abundance of honey flora make such a number possible. See Apiary; also OUt-apiaries.

\section{OVERSTOCKING AND PRIORITY RIGHTS.}

A new phase of orerstocking has been developed within recent years, bringing up a rather difficult and serious problem. In good localities such as, for example, the irrigated regions of Colorado, the keeping of bees is much more profitable, or at least once was, than in some of the less favored localities in the central and northern States of the Union. It has come to pass that, in recent years, certain beekeepers, learning of the wonderful yields in California, Nevada, Colorado, Idaho, Wyoming, Montana, and Arizona, in the irrigated alfalfa regions, have started apiaries within less than a mile of some other beekeeper haring 100 or 200 colonies in that locality. When the new comer establishes another apiary of 100 colonies, the place becomes overstocked, with the result that beekeeper No. 1 has his average per colony eut down very materially. There is only a certain amount of nectar in the field to be gathered; and if all the colonies get a proportionate share, then beekeeper No. 2 practically r'obs beekeeper No. 1 of a large percentage of honey that he would have obtained had not other bees been brought into the locality to divide the spoils. There is no law against such a procedure. The only protection that the original squatter has is the unwritten moral law that is observed among the better class of beekeepers, to the effect that no beekeeper should locate an apiary so close to another as to rob him of a certain amount of nectar in the field which is his by priority of location. In a good many localities, unfortunately this unwritten moral law is only loosely observed. Locations that once afforded an average of 100 or 150 pounds per colony now afford only about 50 or 75 pounds.

For the other side, on this question of priority of rights it may be said that the first-comer beekeeper has in no sense leased, bought, or borrowed the land growing the plants from which the nectar is secreted; that any and every one has a right to the product from the flowers. Legally the second comer has just as much right to the field as his neighbor.

No attempt will be made to define moral distinctions which may be involved in this question any more than to state that, if a beekeeper has, by luck, careful observation, or at great expense, discorered a locality that yields large amounts of honey, he ought to be left in the peaceful enjoyment and free possession of his discovery, to the extent that no one else should locate an apiary nearer than a mile and a half from any of his apiaries; and right here it would appear that the principle of the golden rule ought to be used to settle all such problems; for it is practically certain that beekeeper No. 2, who comes into an already occupied field to divide the profits, would not regard with very much favor such action on the part of another if he were in the position of the one having prior rights.

In many localities there is a very strong sentiment on the part of local beekeeper's established in good territory against new comers putting more bees into a place already overstocked. This sentiment is so pronounced and strong that the new man is often glad to sell out or move away of his own accord. Sometimes he is stubborn, and attempts to fight it out; but usually he is the loser in the end, because he does not know the locality as do the old-estab- 
lished beekeeper's, and his yields per colony will be considerably less. While the policy is not here advocated, local beekeepers sometimes agree on the plan of freezing out, or, more exactly, starving out, the new comer. The latter enters the territory with a yard of bees. Immediately the old-established beekeeper or beekeepers will place around that yard, within a quarter of a mile of it or less, a lot more bees-enongh to overstock the place very greatly. The old residents, knowing the locality, build up their colonies, and are ready for the nectar when it does come in. As there is not enough to go around by considerable, the bees will not secure an average of ten pounds per colony. But the old resident beekeepers will secure more than the new comer because they know the locality and how to meet the conditions. After Mr. Newcomer has tried it out one season, and finds he cannot make anything, he will move out. This freezing-out or starving-out game has been worked to a finish in a good many places in the West. As a rule the resident beekeepers in the locality will agree among themselves to divide up the territory and put no more bees to the yard than the locality will sup- port. This policy prevails in many of the orange and sage districts of California and the alfalfa districts of the West. A good feeling exists, and in some places they cooperate among themselves to sell their honey, perhaps picking out one of their number to visit the big markets. Such a policy is much more sane than for every one to grab territory and compete against his neighbor, with the result that no one can make a fair living.

In one or two localities Mr. Newcomer has been met by a shotgun. He is told to get out or "take the consequences." As such a policy is, of course, indefensible, a milder and gentler means should be employed.

As a rule the new comer can find territory if he will make some inquiry before he attempts to squat his yard or yards. By making a personal visit and becoming acquainted with the beekeeper's in any given locality, he can usually make satisfactory arrangements, and open territory may be assigned if there is any. Sometimes none is available. In that case, Mr. Newcomer should not attempt to crowd in, for he may find some one beekeeper who will resort to the shotgun argument.
PALMETTO.-The palm family (Palmaceae) is represented in Florida by 15 native species, not including the cultivated date palm. There are in the world 130 genera and over 1,000 species of palms, which are nearly equally divided between the tropies of both hemispheres. Palm trees with their slender, unbranched columnar trunks, surmounted with a crown of immense fern-like leaves, are among the most stately and graceful of trees, and occupy an important place in both story and listory. The individnal flowers are small, stemless, and white or greenish-colored, resembling the flowers of a rush; but they are borne in enormous branched spikes or flower-clusters. The largest flower-cluster in the world, which is 40 feet in length, is produced by the Talipot palm of Ceylon. The natives of the tropies utilize every portion of the palms for food, wine, clothing, medicine, and dwellings. 
In Florida the cabbage, scrub and saw palnettoes, and the royal palm are valuable as sources of nectar. The cocoanut paln is reported to yield a surplus, but further observation is desirable. The date palm is wind-pollinated and the flowers are nectarless; but bees often in large numbers gather the pollen. The cabbage palmetto

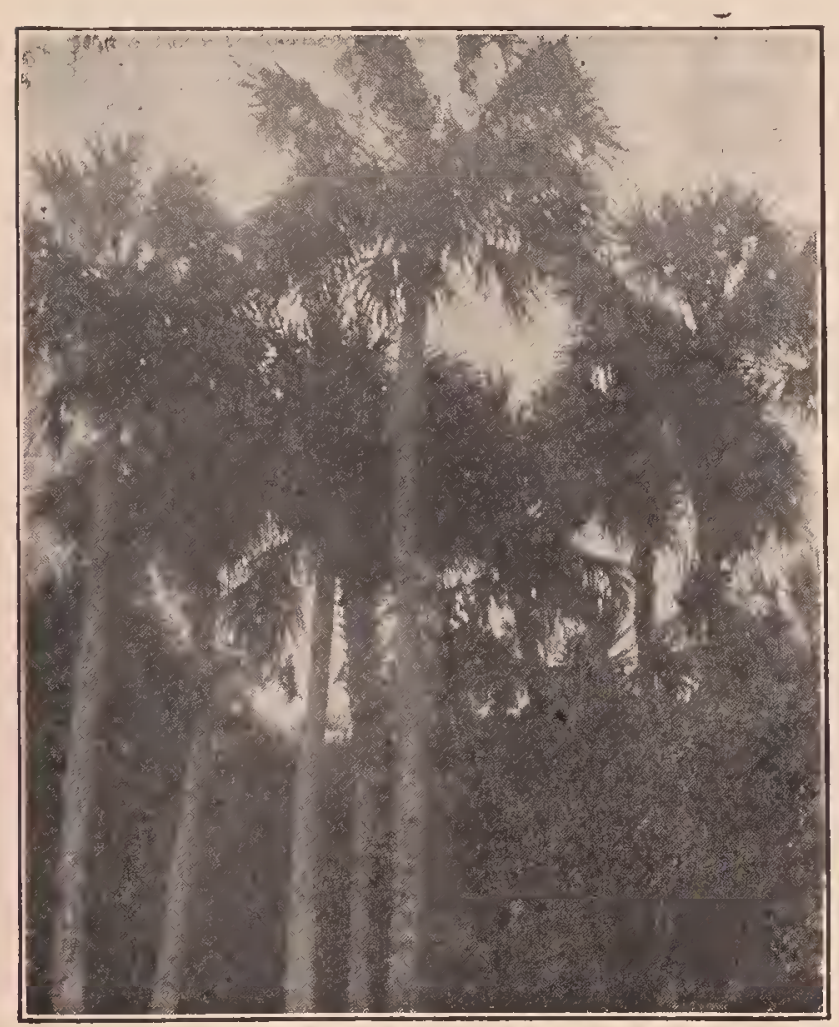

Cabbage palmetto.

(Sabal Palmetto), so called from the cabbage-like terminal bud, which is boiled and eaten like a cabbage, is found in the sandy coast regions from North Carolina to Florida, and also oceurs in Cuba and the Bahamas. It grows from 20 to 50 feet tall, and is abundant along the east and west coasts, on the banks of rivers, and in hammocks thruout southern Florida. The erect trunk is gray-colored and bears a crown of fan-shaped leaves, about 5 feet in length and almost equally broad, having long footstalks. The flower's have $3 \mathrm{sep}-$ als, 3 petals, 6 stamens, and a 3-celled ovary. It is a pictnresque tree and is widely planted for ornament. The drooping flower-cluster, which is 3 or more feet in length, consists of a central, much branched axis, bearing over the ultimate smaller branches hundreds of small white, stallkless flowers. They exhale a strong fragxance, as pronounced as that of apple bloow.
In the extreme southern part of Florida the cabbage palmetto begins to bloom about the first of July, but in the northern portion of the State not until August. The flowers are very sensitive to the weather; too much dampness blights, and a hot dry atmosphere blasts the bloom. According to Baldwin it is on an average a good yielder only one year in three, e. g., 1907, 1909, and 1912. In a good year it secretes nectar very freely, and on the St. Lucie River 65 colonies gathered 3,500 pounds of extracted honey in two weeks.

The honey is nearly white, or light amber-colored, and has a characteristic aroma, which does not resemble at all that of scrub palmetto. It is very thin, and in warm weather runs almost like water, and even in cold weather it never thickens. The flavor is extremely mild, but it is inferior to that of serub palmetto. Gas bubbles may frequently be seen under the capping's of the sealed cells, and during extracting

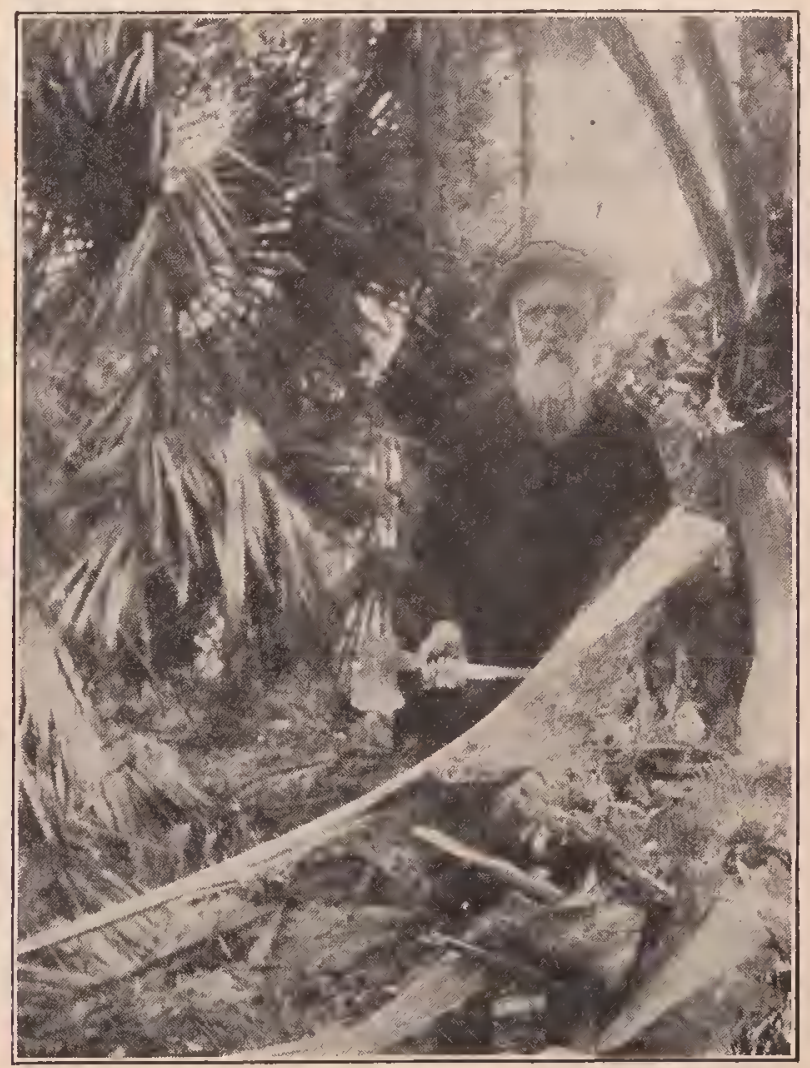

Saw palmetto.

the honey foams considerably, as tho it was fermenting, but after it has stood for a few days the bubbles wholly disappear. But honey from unsealed cells will ferment enough to deprive it of its flavor. In the list of Florida honeys it has been ranked fifth or sixtl. $\Lambda \mathrm{s}$ it is a mild loney it 
blends well with other honeys. In the vicinity of Hawks Park, Fla., it blooms almost simultaneously with mangrove so that the two honeys are always secured together. Farther south they are obtained separately. Of this blend of honeys, Langstroth, the father of American bee culture, wrote, "In color it is unexceptionable and its flavor is very pleasant."

\section{THE SCRUB PALMETTOES.}

Two low shrubs with ereeping or horizontal stems, called scrub palmetto (Sabal megacarpa) and saw palmetto (Serenoa serrulata) are also valuable honey plants in Florida. Beekeeper's frequently fail to distinguish between them, and regard them as a single species. The leafstalks of the scrub palmetto are sharp-edged, but not toothed, while the leafstalks of the saw palmetto are armed with numerous sharp spink teeth. The true palmettoes (Sabal) may readily be distinguished by the threadlike fibres on the margins of the leaves. In the serub palmetto the three cells of the ovary are wholly united, but in the saw palmetto they are free at the base. The two species also differ in distribution. The scrub palmetto is confined to peninsular Florida, while the saw palmetto grows in dry soil from North Carolina to Florida and Texas, extending northward to Arkansas.

The scrub palmetto (Sabal megacarpa) is a low shrub with long, crooked, creeping stems, which are partly subterranean. At intervals the stems root and send up clusters of light-green fan-shaped leaves four to seven feet tall. The plant is not injured by frosts, and when burned to the ground a new growth requires only a year. The scrub palmetto grows well over the southern two-thirds of the peninsula of Florida, becoming rarer and smaller toward the northern boundary of the State. It reaches the largest size south of a line extending from Tampa to the east coast. On the west coast for miles north and south of Tampa it forms an unbroken sea of green. The traveler on the Seaboard Airline Railroad may ride for miles without losing sight of the scrub palmetto, which offers an impressive appearance in such large masses. It grows over all of the "flatwoods," or low pine lands, which overflow more or less during the rainy season, also along all the water courses, and on the edgres of the heavy hammocks. The latter places are most suitable, for there the shrubs grow 8 feet tall or more, and yield the most honey. The stunted plants in the flatwoods do not yield as well. There are still large areas of scrub palmetto hammocks and flatwoods as yet unoccupied by beemen, which offer an attractive field for bee culture. An objection to these localities is that the palmetto is usually the only nectar-secreting plant in the region, and colonies must be watched closely or they will run out of stores in seasons when it does not bloom. But year in and year out there is no more reliable honey plant in Florida than the scrub palmetto.

It begins to bloom at Fort Myers and Miami in April, and farther north in May. The small, white, stalkless, fragrant flowers are borne in a great many-branched flowercluster, which is 2 to 4 feet in length. Too much rain during the blooming period produces mildew; too much heat and dry weather parch the bloom and cause it to wither early. Both conditions are detrimental to nectar secretion. When soil and weather conditions are favorable there is a profuse secretion of nectar. From 6 to 8 pounds daily per hive have been reported from this source, and 8 or 9 pounds are not unknown; an average of 100 pounds per colony has been secured. The honey is lemon yellow, thick and heavy, with an aromatic flavor and fragrance. It is considered one of the finest honeys in Florida, but possibly is surpassed by white tupelo honey. It granulates early but not as quickly as orange honey.

Saw palmetto (Serenoa serrulata) closely resembles scrub palmetto in flower and fruit, and also gives a large honey flow. The honey is similar to that of scrub palmetto, with which it is usually mixed, as both species bloom at the same time. As has been pointed out the saw palmetto has a much wider distribution, extending far beyond the boundaries of Florida. In the extreme southern portion of the State it becomes a tree 20 feet tall.

The cocoanut palm (Cocos nucifera) grows in southern Florida, and thruout the West Indies and the tropical regions 
of both worlds. It has been reported to yield an amber-colored honey witl a flavor resembling horehound honey. On Key Biscayne on the east coast of Florida the cocoanut is said to be practically the only source of lioner, but in Porto Rico it is not considered a good honey plant. As the bloom is wind-pollinated, and the stamens and pistils are in different flowers on the same tree, further observation is desirable. When, howerer, the stallss of the great flower-chuster, 3 to 6 feet long, are wounded, a sweet sap flows freely, which in the East Indies is collected and evaporated into a crude sugar. Possibly honeybees gather sweet sap rather than nectar from the cocoanut palm.

The royal palm (Oreodoxa regia) which is also found in southern Florida, Cuba, and Porto Rico, is pollinated by insects and is nectariferous. The tree has no regular time of blooming, but the flowers appear at intervals thruout the year, and there may be fruit of four different ages on the tree at one time. The tough buds open with a sharp eracking sound exposing the clusters of flower's, which are 3 or 4 feet long, and consist of hundreds of blossoms. It is not usual to get a surplins from this palnu, altho once in a while a strong colony will store a pound a day; but it is a raluable honey. In localities where the royal palm covers large areas a small amount of honey may be placed on the market. The honey is light amber, very thin, and has a strong flavor.

PARTHENOGENESIS. - In the great majority of cases the sex cells disintegrate unless they unite with the products of the opposite sex of the same species; but in some cases of the animal kingdom cells are given off from the ovary, which, without fertilization, are able to undergo development. That these cells are true eggs is evident from their origin, appearance, behavior, and fate, while the only difference between these egg's and eggs requiring fertilization is that the former are able to divide and grow withont receiving the stimulus given by the male sex cell. To this phenomenon the name "parthenogenesis" is applied.

The word parthenogenesis (virgin development) was first used in this sense by
Professor r. Siebold in his classic paper, "Parthenogenesis in Lepidoptera and Bees," in 1856.

However, earlier writers described the phenomenon under various other names.

In 1745 Charles Bonnet described the parthenogenetic development of plant lice; and Prof. Oscar Hertwig, the great German embryologist, designated this work as marking one of the milestones in the history of the science of development.

Just one hundred years later the Rev. Johannes Dzierzon of Carlsmarkt, Germany, put forth the theory that the drone or male bee is produced from an egg which is not fertilized. This work, published in the Eichstadt Bienenzeitung, may well be looked on as the starting point of the theory of parthenogenesis, since it began a very important discussion, and marked the origin of a host of works along similar lines. Dzierzon based his views on the following facts observed by him and since confirmed by many others:

1. An unmated queen occasionally lays egres, but these produce only drones.

2. Workers under certain peculiar circumstances lay eggs, but these develop only into drones. Worker bees have never been known to mate.

3. Old queens may exhaust their supply of spermatozoa received in mating, and thereafter produce only drones. As the supply diminishes they lay an ever increasing percentage of drone- eggs. See Dzierzon Theory.

While this theory is based on the work of Drierzon, it must not be forgotten that its establishment is due in no small part to the researches of Professor Leuckart and ron Siebold of Germany.

The facts brought out in the examination of this work liave an important bearing on the practical work of the apiary, and it is necessary for the queen-breeder, at least, to know the application. If, for example, a Cyprian queen is mated to an Italian drone, the resulting workers are a cross between the two races, or Cyprio-Italians. Any queens reared from this colony are also Cyprio-Italians; but the drones of this cross-mated queen are pure Cyprians, the Italian drone in the cross having no influence on the male offspring of the Cyp- 
rian mother. If, therefore, but one purely mated queen is obtained, her daughters produce pure drones, regardless of mismating, and the race may be established in an apiary.

The conclusion frequently drawn from this theory is that the queen can voluntarily control the sex of an egg by withholding or allowing its fertilization. It is sometimes further held that all eggs in the ovary are male, and the sex changed by fertilization. These conclusions are not based on obserration, and proof is entirely lacking. In a statement of the theory, therefore, it is necessary to stick to facts.

The Dzierzon theory has been combated by many different scientists, more recently by Dickel, a German beekeeper with scientific aspirations. While the theory has been somewhat modified by recent work, it remains the prevalent riew today, and Dickel generally receives the condemnation so richly deserved. See Dzierzon.

Parthenogenesis occurs in many other order's of both plants and animals, and a comparison of the various results is most interesting. Merely to cite some cases for comparison: In the bee, only males are produced parthenogenetically; in certain lepidoptera, only females are.so produced; while in plant lice and certain small crustacea, both males and femaes are produced from unfertilized eggs. Ants were formerly supposed to have a parthenogenetic development identical with that seen in the honeybee; but more recent work makes this doubtful as a general statement. The silinworm is occasionally parthenogenetic.

PARTRIDGE PEA (Cassia Chamaechrista).-Also called sensitive pea. The genus Cassia contains more than 275 species, which are very abundant in tropical America. It is of interest to note that the flowers of this great genus are both nectarless and odorless. They are pollen flowers. While all the species may be cross-pollinated by insects, risiting them for pollen, they all retain the power of self-fertilization. The species consist of lerbs, shrubs, and, in tropical regions, of trees, witl evenly pinnate leares and yellow or white flowers. There are five species in the nortlieastern States, and 25 species in the south- eastern States, a part of the species being common to both areas.

Partridge pea is an herbaceous muchbranched, spreading annual with pinnate leaves, and showy yellow flowers which often have the petals purple-spotted at base. It extends from Maine to Florida and westward to Indiana and Texas, but it is valuable as a honey plant chiefly in Florida and Georgia. In the north-centra] part of Florida there are thousands of acres in bloom during July and August, and for miles the ground is covered with a yellow carpet of flower's. It is also common in Georgia; in many dry sandy sections of the South, indeed, it is the main dependence of the beekeeper, making beekeeping possible in very unfavorable localities.

The blooming period is long, beginning the last of June and closing late in September. The flowers are wholly nectarless, and are pollinated by bumblebees, which visit them for pollen. But nectar is secreted profusely by extra-floral glands located on the upper side, near the base, of the leafstalks (petioles). This gland is saucershaped, and there is usually only one to a leaf. Unless the summer rains are too heary and continuous, nectar is yielded every season for more than 100 days. Much rain washes the nectar from the glands before the bees can gather it. In early morning and late in the afternoon there is a large drop of nectar on each gland, but during the middle of the day it is greatly reduced in size by evaporation unless it is cloudy. During the night the nectar is secreted in such large quantities that it runs down the stems, and wets the ground for an inch or more around the base of the stalks. The nectar in the daytime is very thin and probably at night contains a very large percentage of water. Surprise has been expressed that the bees do not gather more honey from this source, but the thinness of the nectar is probably the reason in part. From one to three supers of honey are stored from partridge pea, and 100 pounds per colony have been obtained.

The honey is medium-light amber, exceptionally thin, with a poor flavor. At Fort White, Fla., the surplus comes from partridge pea and chinquapin which yields a bitter honey. Inferior as is the flaror of this honey, its fine appearance has caused 
it to sell at a high price. The extracted honey is bought by bakers, and the large quantity obtained partly atones for the quality.

\section{PAsturage. - See Artificial Pas-} TURAGE.

PATENTS RELATING TO BEE CULTURE.-Under the head of INvENTIONS Relating to Bee Culture is given a list of all the useful ideas and inventions, patented or othervise, that have been accepted by beekeepers. It is but fair to state that there is in use today hardly a hive of value that is covered by an unexpired patent. The field of apicultural invention has been so thoroly covered by some 3,000 patents on file in the Patent Office that it is very difficult to secure a patent on any hive or bee-appliance today that will have claims of any value. Even if the patent is granter, the claims are generally so loosely drawn, and so complicated to aroid conflicting with other patents, that it is usually worthless. As already pointed out at the close of the article on inventions, no patent granted today on beehives or bee-feeder's will be worth anything to the inventor. The unpatented hive has so far reached the point of utility and perfection that it would be practically impossible to make any improvements; and the improvements, if any, would not be fundamental.

When the field was wide open, as in the days of Langstroth, it was possible to secure fundamental patents; but even with a fundamental patent Langstroth was robbed of the fruits of his brain, and died almost penniless, notwithstanding the fact that his invention was so useful that it was accepted, at the time of his death, practically thruout the whole known world, but long years after his patent of 1852 lad expired.

In the early days of bee culture the country was full of patent-right venders who sold county or state rights. Some of these sharks reaped a harvest in selling moth-proof hives. Practically all of these patent-right venders sold useless contraptions, and most of them wer'e men, without principle-so much so that the business of selling out county and state rights has become of sucli ill repute that it has been discontinued.
PEDDLING HONEY. - See HONEYPEDDLING; also ExTRACTED HoNEY.

PENNYROYAL (Satureja rigida).Perennial shrubby plants, 2 to 3 feet tall, growing on sandy barrens and pine lands thruout southern Florida; but it is of little value to the beekeeper north of Lake Apopka. The stems branch diffusely and bear head-like clusters of light purple, 2-lipped flowers. It is abundant in the southwestein part of the State below Tampa on the west coast, and near Stewart on the east side.' The loney flow comes in January, at a time unfortunately when the colonies in this section are usually weak, but the plant does not cease entirely to bloom until Marcl. During the flow colonies build up very rapidly and fill the hives, with stores. While good crops have been obtained three years in succession, rainy weather is very likely to interfere with the flow.

The honey is light colored and has a minty flavor and odor. The aromatic taste might not be agreeable to everyone, but only a small quantity of the honey is placed on the market. A beekeeper at Hansford writes under date of Jan. 17: "I examined 15 colonies yesterday and found them full of bees, with from 4 to 6 frames of brood in each hive and an average of 50 pounds of surplus in the supers. Pennyroyal is now just at its best and has yet 60 days to vield. Don't call it erratic; this is the third season I have secured a surplus." See Purple-Flowered Mint.

PEPPERBUSH (Clethra alnifolia).Sweet pepperbush. White alder. A shrub 5 to 10 feet tall, with wedge-shaped, sharply toothed leaves and numerous racemes, or oblong clusters, of very fragrant white flowers. It is common in swamps and wet woodlands from Maine to Florida near the coast. A surplus of honey from this shrub has been reported in sontheastern Massachusetts, Rhode Island, and southeaster'n Georgia. In New England the comb honey is white; the extracted loney is tinged with yellow, and has a fine slightly peculiar flavor suggestive of the spicy fragrance of the flowers. T'he honey often fills with bubbles; which may force off the cappings if it is taken from the supers too early; but it finally ripens if left in the hive. It is 
slow to granulate, and extracted honey two years old still remained liquid. It forms an excellent blend with the honey of white clover.

The sweet pepperbush region of Massachusetts extends from Middleboro to Sandwich on Cape Cod and to New Bedford on Buzzard's Bay. At Westport, Mass., where it blooms during the last of July or early August, 900 pounds of pepperbush honey have been gathered by three colonies in a single season. Often there are 7 or 8 supers on one hive. It is an uncertain yielder, and there is usually one poor year in every three, owing to late frosts, damp or cloudy weather, or other causes. In 1916 there was a large surplus, but in 1917 the foliage turned a dark brown and very little nectar was gathered. In 1918 there was a fair yield. In 1919 at Lakeville, Mass., seven 4-frame nuclei in 10-frame hives filled the brood-chamber, and produced 12 supers of comb and extracted honey. In Rhode Island sweet pepperbush often yields no surplus, but sometimes there is a "flood" of nectar. A prominent beekeeper reports the honey as aromatic flavored and very white. It should not be removed until late in the season.

In southern Georgia in the great swamps pepperbush gives a good surplus and maintains brood-rearing, when there are few other honey plants in bloom. The flowers appear early in July, and the blooming period is of long duration. It is more or less abundant thruout the Coastal Plain from Virginia to Mississippi, but it never grows very near the coast.

PEPPER TREE (Schims molle).From Peru. This is really not a pepper tree at all; its flowers and the honey have a peppery flavor, and the seeds resemble pepper. It is a magnificent shade tree, and in California has been very largely planted. The honey is thick and dark, but it serves a very useful purpose in helping the bees to tide over bad times without feeding. It is under a ban now, as it is supposed to harbor injurious insects; but it seems probable these pests would still exist even if all the pepper trees were destroyed.

PERFORATED ZINC.-See DRONES.

PHACELIA (Phacelia tanacetifolia).--
Fiddle-neck. A hairy herbaceous annual, 6 inches to 2 feet tall, with bluish flowers in scorpioid racemes, 3 to 4 inches long, common from Sacramento Valley to southern California. It blooms in about six weeks from seed and furnishes an excellent bee pasturage for about the same length of time. The honey is amber-colored with a mild aromatic flavor. The color of the pollen is blue. It was formerly very abundant in California, but owing to the over-pasturing of the cattle ranges it has almost disappeared from thousands of acres of wild land. It is now found chiefly in the underbrush where it can not be reached by cattle. It has been introduced into Europe where it has been highly praised as a honey plant. In Sweden on a trial plot of 500 square meters one kilogram of phacelia seed was broadcasted and harrowed into the soil. The plants came up in 8 or 10 days, and by the middle of August had reached maturity. averaging a half meter in height. Eight weeks after planting they began to bloom, and the blooming period lasted for about 4 weeks. Thruout the entire time the field was constantly visited by bees from 3 o'clock in the morning to $9: 30$ at night. The field is estimated to have yielded 50 to 60 kilos of honey, and if the summer har not been dry the crop would undoubtedly have been larger. The honey was clear and thin, and excellent in quality.

The racemes of the caterpillar phacelia (Phacelia hispida) are coiled and covered with slender white hair's, whence the common name. Its range is from Santa Barbara County to San Diego County. It was formerly very abundant in Ventura County, but it has been largely destroyed by mountain fires. It grows luxuriantly if there have been abundant winter and spring rains, and attains a height of 2 to 4 feet. One season M. H. Mendleson of Tentura secured frou this honey plant a large surplus. The honey was extracted into a seven-ton tank; and, before the tank was full, it granulated at the bottom. A few feet of liquid honey were drawn off, and about 3 feet of solid candied honey were then shoveled out. "The honey," writes Mendleson, "is water white and has a fine mild flavor; in the candied condition it is like a fine flour paste. I have nerer 
had a surplus before nor since that season from this source."

PICKLED BROOD.-See FOUL BROOD; subhead "Sacbrood."

\section{PLAYFLIGHTS OF YOUNG BEES.-}

Under the liead of Robbing mention is made of the playflights of young bees as being rery similar to the performances of robbers as they fly about in front of the entrance of the colony they are trying to rob. As soon as settled warm weather comes on in the spring, especially after a few days when the bees have been shut in, there will be a very pronounced demonstration of hundreds of bees flying around in front of the entrances of a number of hives.

The so-called "playflights" of young bees are flights of orientation. For one or two days after the young bees leave the cells they are so weak and helpless that they move about very little, and take no active part in the work of the hive. Then for ten days or more they act as nurse bees, clean the cells, build new combs and serve as guards. Before they leave the hive for the field they perform the flight of orientation. On a warm clear morning, or sometimes later in the day, hundreds of them may be seen flying up and down, and back and forth in front of the live. Their heads are always turned toward the hive, as they hover about in the air and they even at times fly backward slightly. In this way they form a memory picture of the appearance of the hive and its exact position, and occasionally they describe larger orientation circles, and thereby impress upon their memory the near surroundings. According to Dzierzon, the distinguished discoverer of parthenogenesis in the honeybee, "There is not the slightest doubt that bees find their way back to the hive guided by memory pictures of their dwelling and the near surroundings. Instinct is the explanation, in so far as they are led to observe accurately the position of their hive and the nearest surroundings in the first flight out. In the first flight (Torspiel or first play) they gain an exact impression of the neighborhood and the hive." If young bees or brood-nurses, which have not yet had their flight of orientation, are carried a short distance away, and released, none find their way back to the hive. But if this experiment is performed with old bees, they quickly return to the hive even from a long distance. Again if the queen be removed from the first swarm, which is composed of old bees, they quickly return to the hive; but if the queen is removed from an after-swarm, which is composed for the most part of young bees, they buzz about for a long time and finally enter strange hives. Without the flight of orientation the young bees would not be able to locate their hive on returning from their first trip to the fields.

When the beehives are moved from one location to another, unless the older bees also orient themselves before they leave for the fields, they are likely to be lost and fail to find the hive again. In Germany, according to Buttel-Reepen, colonies which are sent to buckwheat fields are always brought out to these fields before the buckwheat blooms, so that the bees can learn thoroly the new locality. If the bees are not moved until the fields are in full bloom they rush out without orientation and many are lost. If the weather is mild and clear unoriented bees are not always lost, but they soon return, often after 5 or 10 minutes, because not finding the customary landmarks they seek orientation. If a colony of bees is moved several miles, and the old bees are carried 100 feet from the hive before they have been able to make their flight of orientation and released, none of them will find their way back to the hive even from this short distance, if a house or a tree intervene between it and the place where they were set free.

Buttel-Reepen found that if the height of the hive is changed so that the entrance is suddenly made, let us say, one or two inches higher or lower, then the bees continue to fly exactly to the spot where the entrance was before. Hours and often days may pass before the bees fly directly to the entrance in its new position. Bees are accustomed to fly in and out the hive at the same point of the entrance. If a bee is powdered on entering at the outermost right corner of the entrance, it will be seen that, in unmolested flight, it uses the same corner constantly in a straight line, even if the entrance is very narrow. If the entrance is stopped up, except for 
the breadth of an inch, they will try to press in at the point they have been accuistomed to use, and will find the open part only after more or less searching.

Occasionally the "playflight" is mistaken tor a case of robbing. There are, however, two important differences. When bees are making a flight of orientation there are no fighting bees, as in a case of robbing. But in a genuine case of robbing when a colony has been overpowered, the robbers will fly around in front of the entrance in a manner very similar to orienting bees. Secondly, a "playflight" is of short duration. With robbing there is no let-up. If the flight before the front of the hive continues for more than fifteen minutes, robbing is indicated; and the entrance should be trèated as recommended under RobBing. If the supposed robbing after treatment stops suddenly, it may be assumed that the bees were only at play.

POISONED BROOD.-See FRUIT BLOSsoms and FOUL Brood.

POISONOUS HONEY.-The earliest account on record of honey causing sickness is given by Xenophon in the fourth book of the Anabasis. Tt oceurred 400 B. C., during the memorable retreat of the Ten Thousand, in the mountainous country of the Colchians, in the province now called Trebizond bordering on the Black Sea. A literal translation of Xenophon's description is as follows: "The number of beehives was extraordinary, and all of the soldiers who ate of the combs lost their senses, vomited, and wer'e affected with purging, and none of them were able to stand upright. Those who had eaten little were like men intoxicated; those who had eaten much were like madmen, and some like persons at the point of deatli. They lay upon the ground in consequence, in great numbers, as if there had been a defeat; and there was general dejection. The next day no one of them was found dead; and they recorered their senses about the same hour that they lost tlem on the preceding day; and on the third and fourth day they got up as if after laving taken physic." The passage is given entire, as it has probably done more to establish a general belief that certain kinds of loney are poisonous than any otlier account ever written. The ancients believed that this honey was gathered from a species of Rhododendron, probably $R$. pontica.

It is noteworthy that the honey was obtained from beehives, not from trees or lollows in the rocks. It may be doubted if the symptoms described by Xenoplion are strictly accurate, altho there can be no doubt that the lioney caused nausea and purging. Apparently it did not affect the natives in a similar manner. The Greek soldiers plundered the Colchian villages, and the probability is that they ate excessively of unripe honey as the number of lives was very large. It does not necessarily follow that the lioney was actually poisonous.

Poisonous honey in the United States was reported first by Barton, an early American botanist, in 1794. Since then poisonous honey has been repeatedly reported in the mountains of New Jersey, Virginia, and Nortlı Carolina. The honey, it is believed, is gathered from the mountain laurel (Kalmia latifolia) and the Rhododendrons. Mountain laurel is often called poison ivy in Tennessee and Alabama; poison laurel in Alabama, and ivy in Virginia, North Carolina, Soutl Carolina, Mississippi, and Maryland.

In 1921 a beekeeper living at Morganton, North Carolina, deseribed conditions in that locality as follows: "There are districts in western North Carolina in which the so-called "poison honey" is produced. About one-tliird of this county (Burke) can not be used for this reason. I have known beekeepers deliberately to throw hundreds of pounds of lioney into the streams. As to the effects, I liave seen and have also personally experienced the acute sickness which this honey produces. Within a few minutes after it is eaten a staggering, deathly nauseous sensation is experienced which lasts several hours. While I have seen whole families rolling in their dooryards I have nerer known of any fatal results. But the poisonous honey is eaten by bees year after year without injury. It is beieved that the poisonous honey has become more abundant in recent years due to the spreading of ivy over areas wlich have been cleared of forest. 
Most officials seem to doubt the existence of this loney."

A jar of poisonous honey was obtained from Blowing Rock, Watauga County, in the Blue Ridge Mountains, which when gathered two years ago was very poisonous. The extracted honey in the jar was dark brown, and lad a pronounced disagreeable or nauseous odor, and a nauseous flavor. A small teaspoonful produced sliglit nausea, leadache, and burning in the throat. In large quantity the effect would doubtless be serious. It is difficult to understanil how sucli a poor lioney could find a market, or even he eaten by the beekeeper producing it. The comb was lightcolored and did not differ in any way from the arerage comb. The honey was stated to have been gathered not from nountain laurel, but from Leucothoe, probably from mountain Leucothoe (L. recurva). A honeybee is said never to have been seen on mountain laurel in this locality. In the absence of careful observations the source of this honey remains in doubt, but it should receive thoro investigation.

Numerous letters of inquiry were sent to beekeepers living in western North Carolina. Tith two exceptions they all replied that they liad never personally obtained any poisonous honey, but the majority had heard that in the mountains it was oceasionally gatliered from the flowers of the mountain laurel. According to one report bees never risit the flowers of mountain laurel except in years, when there. is an extreme dearth of honey. Two other beekeeper's state that they liave never' seen a loneybee on the blossoms of this bush, and one of them adds that the poisonous honev comes from the genus Leucothoe, a shrub 2 to 4 feet tall. In New England the closely allied species of Kalmia, sheep laurel, or lambkill, (Kalmia angustifolia) vields very little nectar and is only occasionally visited by bees, mostly solitary hees.

Kalm, the Swedish traveler, after whom the genus Kalmia is named, says that if domestic aninals eat the leaves of the laurels they fall sick, and in some cases die, but that they are harmless to wild animals. But Dr. Tacob Bigelow, Professor of Materia Medica at Harvard University, states in American. Medical Botany that he repeatedly chewerl and swallowed a green leaf of the largest size without perceiving the least effect in consequence. A powder made from the leaves recently dried in doses from ten to twenty grams produced no perceptible effect. The taste of the leaves is perfectly mild and nucilaginous. Dr. Bigelow believer that the noxious effect of the leaves on young domestic animals is due to their indigestible quality.

The reports are so indefinite, and there is so much uncertainty as to whether bees evel store much lioney from the mountain latrel that it is impossible to reach any satisfactory conclusion. Evidently the mountain lamel as a honey plant should be scientifically investigated by a flower ecologist.

In Georgia and Florida the yellow jessamine (Celsemium sempervirens) is very abundant and bees risit the yellow blossoms from February to Mareh. But it is doubtful if a surplits of jessamine honey is ever obtained. It is useful chiefly for

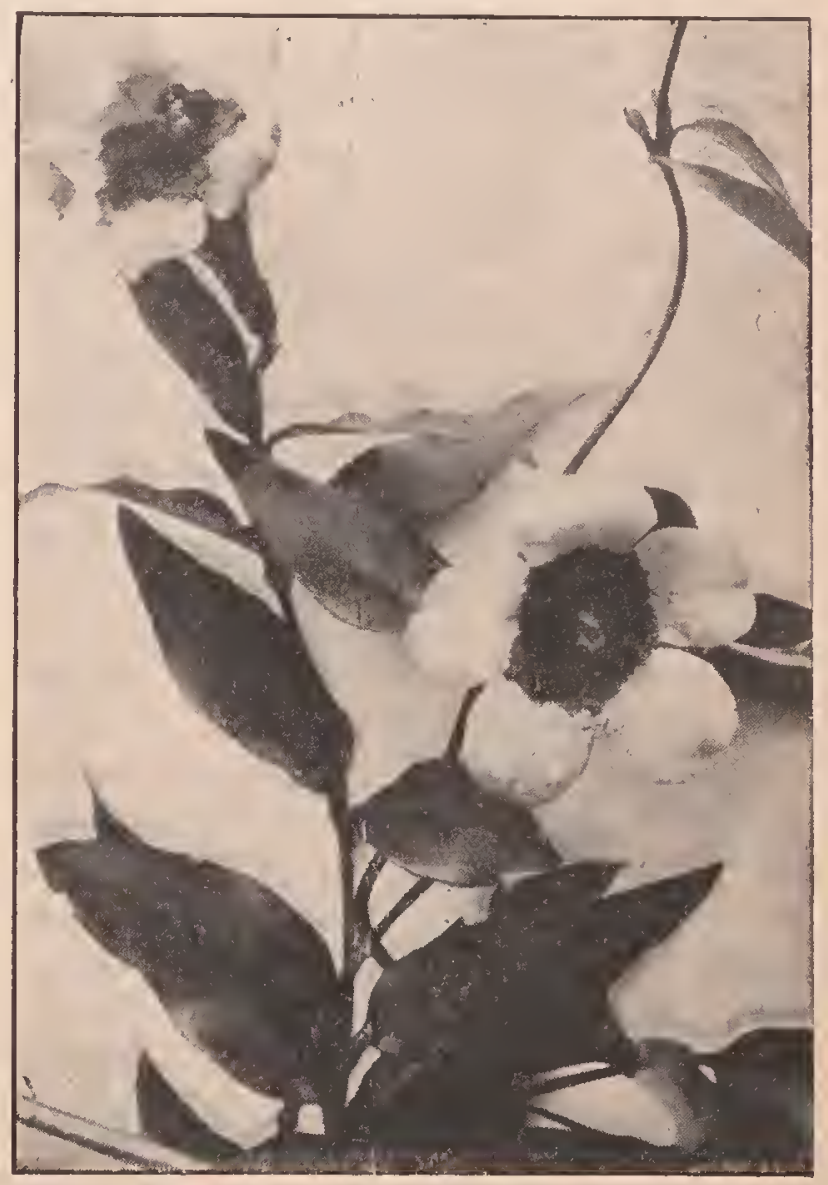

Yellow jessamine.

spring stimulation. According to one published statement the uncapper honey is poisonous and has even produced death, but the capped honey is perfectly wholesome. According to E. G. Baldwin no in- 
jurious effect has ever been observed either from the nectar, or the honey in the hives.

In addition to the laurels, Rhododendrons, and yellow jessamine, poisonous honey is supposed to be yielded by species of Andromeda, Leucothoe, and Pieris. It will be noticed that all these plants belong to the heath family, or Ericaeae. One writer, indeed, refer's to this entire family as a source of poisonous honeys; but this is clearly false, since the honeys gathered from sourwood and the heathers are excellent. The flowers and flower-clusters of Pieris, Andromeda, and Leucothoe are rery similar to those of sourwood, and they may well yield an equally harmless nectar.

Thousands of bees are said to be killed by the nectar of the soapberry tree (Sapindus marginatus), a small tree found in the South. It belongs to the same genus as the maples, and the nectar is undoubtedly equally harmless. It is in the highest degree improbable that any plant prodices nectar which is poisonous to the insect pollinators. Nectar is an allurement, the role of which is to induce the visits of insects and to secure cross-pollination, and the production of poisonous nectar would tend toward self-destruction. It is impossible to imagine how such a condition could arise. But flowers often have poisonous petals, the purpose of which, in the opinion of Darwin, is to prevent leaf-eating insects from feeding upon them.

There have been a few cases in which severe sickness and even death have been reported from eating poisonous houev. While such statements may be accepted with reserve, yet until more proof to the contrary is produced, it would be well to err on the safe side by eating such honey in very small quantities if at all. Inferior grades of honeydew, or fruit juices, which had undergone partial decomposition, might occasionally cause sickness. It is also possible that in rare instances bees may get access to unwholesome or harmful liquids. It is extremely probable that the nectar of many species of plants when first gathered would produce sickness. The poisonous species of Rhus, as poison oak, and poisonwood of Florida, yield a' large amount of honey. Very likely ill effects would follow the eating of this honey, before it is capped. But thoroly ripened it is said to be harmuless. It is well to remember in this connection that thoroughwort and cascara sagrada yield medicinal, honeys and rabbitbrush a nauseous honey. Further investigation is desirable, and meanwhile the so-called poisonous honeys should be used with great caution.

POLLEN.--The anthers of flowers are composed of four sacs, which contain nutmerous small dust-like grains called pollen or microspores. Pollen is a highly nutritious food which is eagerly eaten by many insects, and is gathered in large quantities by bees as food for their brood. A pollen grain is protected by an inner and an outer coat (in a few species there is but one coat), and is filled with a semiliquid in which float many minute granules. Its contents form a complete food, consisting

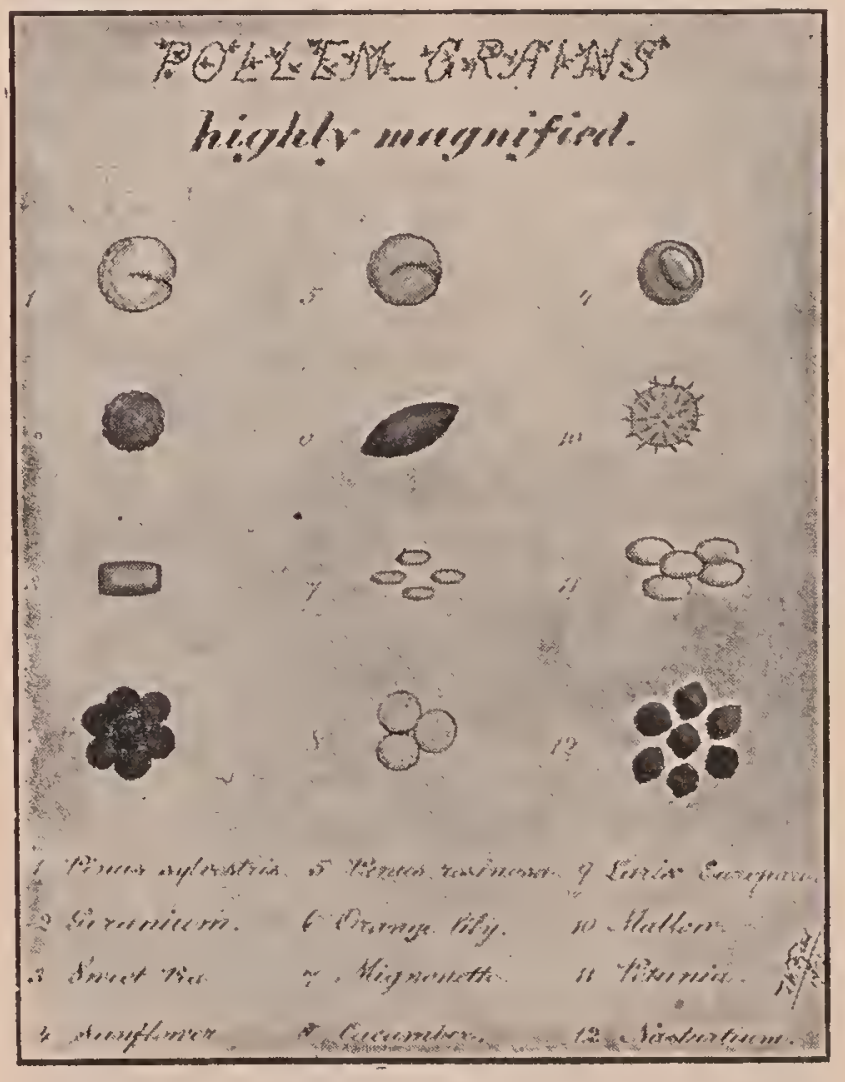

-After Fletcher.

of proteids, substances rich in nitrogen, sulphur, and phosphorus; and carbohydrates, or starch, oil, and sugar. Pollen thus offers a rich supply of easily obtained nourishment to all insects, especially to those which are not predaceous.

Pollen grains vary in size from $1 / 100$ of an inch in iris to. $1 / 3000$ of an inch in some saxifrages. The number of pollen 
grains is also very variable but is usually large. Each anther of the peony has been estimated to prodnce 21,000 grains; and if there are 174 stamens to a flower there would be $3,654,000$ grains. In wistaria there are said to be 7000 grains to each ovule. The excess of pollen is thus so large as to permit of much waste. In shape the grains may be globular, ellipsoidal, polyhedral, or of the form of a dumbbell in the borage family; or in some Polygalaceae they have the shape of "a wickerwork basket." "The outer coat may be banded, ribbed, or checkered, and beset with sharp teeth, points, spines, prickles, or knobs; variation in the sculpturing is, indeed, almost endless. The air in the numerous little pits and hollows on the surface of the grains protects them from contact witl water. The projections enable them to adhere to insects. Thile yellow is the prevalent color, red, blue, brown, and green hues also occur.

\section{THE BEHAVIOR OF BEES IN COLLECTING POLLEN.}

The beharior of bees in collecting pollen is of great interest to both beekeepers and fruit-growers. Bees are the only insects which feed their brood on pollen, to obtain which in sufficient quantities they are compelled to visit a great variety of flower's, and incidentally are thus most valuable agents in pollination. The small primitive bees of the genus Prosopis have nearly smooth bodies, and the pollen-brushes on the hind legs are so feebly developed that they are little better adapted for carrying pollen than the wasps: The common ground bees of the genera Halictus and Andrena show a much greater advance. The body is hairy, and the hind leg's are entirely covered with collecting hairs, which become filler with loose, dry pollen grains. A further step in the development of the pollencollecting apparatus of the hind legs was the acquisition of the habit of moistening the pollen with honey. Among the solitary hees. Marropis and the Panurgidae carry in this way large balls of damp pollen moistened with freshly gathered nectar. Finally among the bumblebees and honeybees there occur on the hind legs structures called corbiculæ or pollen-baskets in which the damp pollen is packed, while the tarsal brushes are highly specialized. In honeybees the tibial spurs on the hind legs, used by the wasps and solitary bees in digging holes in the ground, have been lost because no longer useful.

In another series of bees the Megachilidae, or leaf-cutting bees, the pollen-collecting hairs form a stiff brush on the under side of the abdomen. These hairs slant backward and vary in length and color in the different species. As the bees crawl over level-topped flowers, like the sunflower and other species of Compositae, which have a large amount of free pollen on the surface, the abdominal brush becomes filled with dry pollen. The leafcutting bees are also rery common visitors to leguminous flowers, as the vetches and clovers, which have an apparatus for placing pollen on the underside of the bodies of insects. This large family of bees has become adapted to collect pollen chiefly from these two groups of flowers. None of the species moistens the pollen with honey.

The hehavior of the honeybee in collecting pollen has been carefully investigated

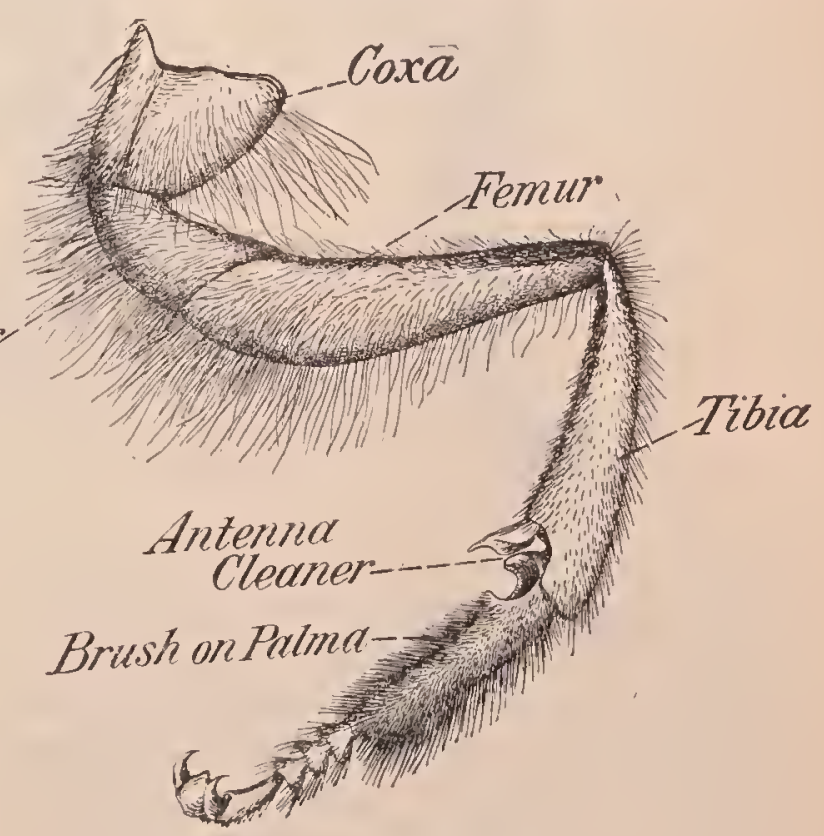

FIG. 1.-Left fore leg of a worker bee.-Bulletin No. 121, Bureau of Entomology.

and described by Casteel. ("Behavior of the Honeybee in Collecting Pollen," D. B. Casteel, Bur. Ent., Bull. 121.) Honeybees collect pollen from flowers by the aid of the mouth parts, the three pairs of legs, and the dense coat of long plumose hairs. 


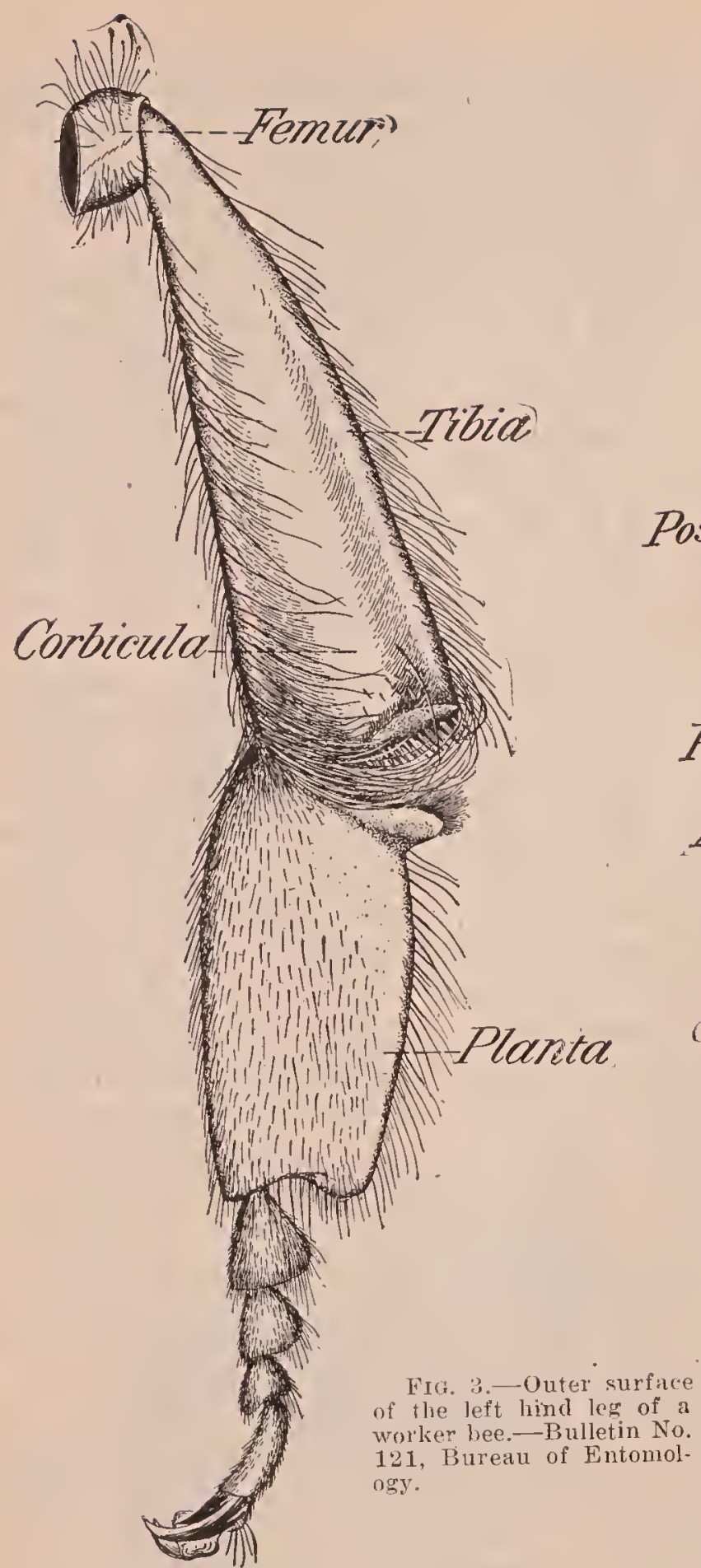

The featler-like structure of the hairs enables them better to retain the nollen which falls upon them. The nouth parts are especially serviceable in the case of small flowers, or of those which produce little pollen. The mandibles are actively used in biting and seraping the anthers and freeing the pollen, which is brushed up by the marillae and slender tongne. All the pollen gathered by the mouth parts is very thoroly moistened with nectar or honey which comes from the mouth. It is, inreed, so wet that in its transfer to the pollen-baskets the hair on the breast and

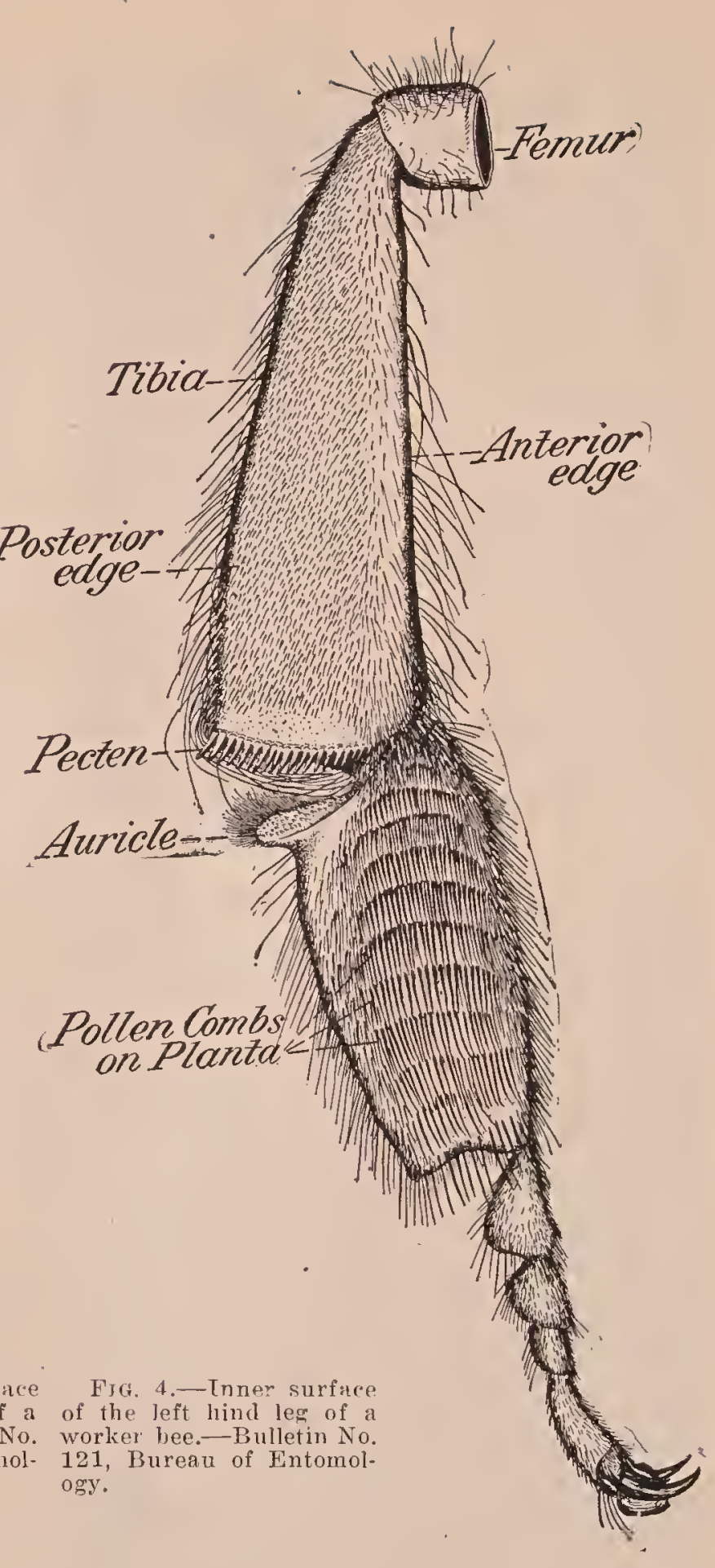

the brushes of the legs becomes so damp that it easily moistens the dry follen swept from the bee's body.

The leg of a bee is composed of nine segments: The coxa, by which it is attacher to the body; the trochanter, fenmur or thigh, tibia, or shin, and the five tarsi. The first tarsal segment, or metatarsus, is as long as the four tarsal segments together. This segment of the fore-leg's is caller the palma (palm), and of the middle and hind legs the planta (sole). 'The inner side of the metatarsal segments of all three pairs of legs bears a dense brush of iun- 
branched hairs, which on the plantae of the hind legs has become modified into a regular series of transverse combs. The fraluar brushes of the fore-legs take away the mass of wet pollen. from the mouth parts, and collect the dry pollen from the pubescence on the head.

The metatarsal brushes of the middle less receive the pollen from the first pair of leg's and transfer it to the plantar brusles of the hind legs. This transfer is effected by drawing each of the middle lears between the plantae of the liind legs. In this way the pollen on each middle leg is seraped off on the pollen combs of each groove on the onter side of the tibia. It is broadest at the lower end and is nearly surrounded by a salient rim. On the front edge of the tibia there is a frimge of hairs orerarehing the pollen-basket, and on the hind edge a. row of lrairs slanting backward. The floor of the basket is nearly smooth except for a few small spines near the entrance. The moistened pollen is held in position largely by its adhesiveness. The lower end of the tibia, except the articulation, is truncated, slightly concave, and fringed along its inner margin, with 15 to 21 stiff spines, inclined backward, called the pecten. Inmediately below the flat-

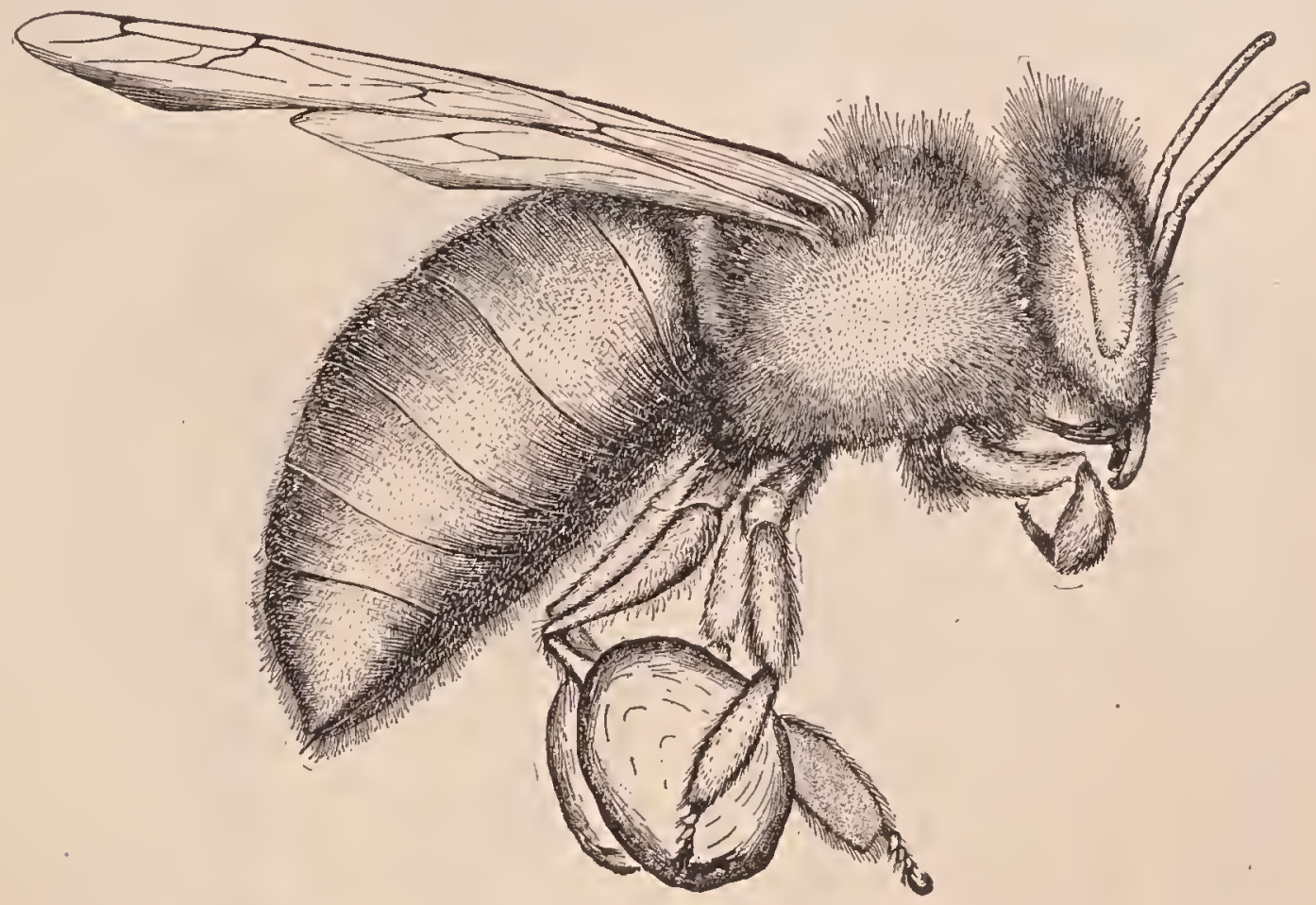

Fid -1 bee upon the wing, showing the position of the middle legs when they touch and pat down the pollen masses. A very slight amount of pollen reaches the corbiculae thru this movement.-Bulletin No. 121, Bureau of Entomology.

opposite hind leg'. 'T'he middle legs also brush off the pollen entangled in the hair on the thorax, which is moistened by coming in contact with the wet pollen from the mouth parts. The middle leg's are further used to pat down and compact the growing pollen mass in the pollenbaskets.

The lind legs are very highly specialized for carrying the pollen masses. 'The tibia is dilated at its lower extremity and the metatar'sal segments (plantae) are much thinner and wider than the corresponding' segments of the fore and middle legs. The pollen-basket or corbicula is a longitudinal tened end of the tibia on the rpper edge of the planta is the auriele. The ear-shaped structure is coneave and corered with short spines. Its inner edge, when the leg is straightened, slips along the spines of the pecten, while its outer edge, which is fringer with hairs, projects into the entrance of the pollen-hasket. 'The ends of the tibia and the auricle have the appearance of a pair of jaws or pincers; and in the older works on bee culture are erroneously described as being used fol taking seales of wax from the wax-pockets. The inner side of the planta, or metatarsus, is covered with about eleven transverse rows of stiff spines which 
serve as pollen combs. The spines of the lowest comb are the largest and are used for picking up wax seales. This highly specialized apparatus receives the pollen and loads it into the pollen-baskets. See illustrations.

Most of the pollen on the plantar combs of the hind legs is received from the middle legs as has been described, but a portion of it is swept from the abromen. During the left leg. A small portion of the pollen will be left on the spines and the end of the tibia. The left leg is then flexed, pushing the amricle against the flat end of the tibia, squeezing out a thin layer of pollen. The spines of the pecten prerent this layer of pollen from escaping on the inner side, but on the outer side there is a way open to the. pollen-basket. In a similar way pollen is transferred from the plantar combs
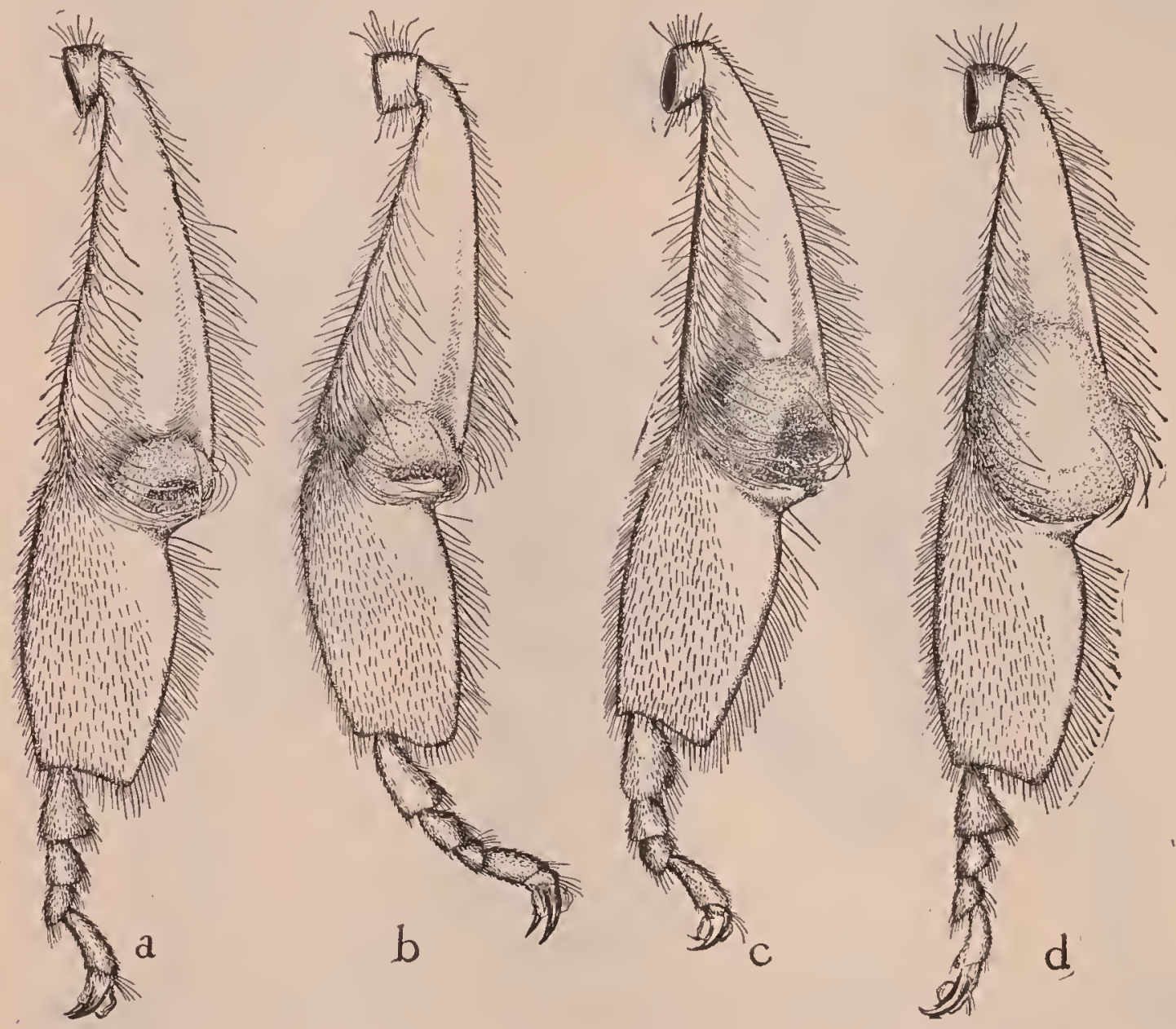

Fis. 8. Camera drawings of the left hind legs of worker bees to show the manner in which pollen enters the basket. $a$, shows a leg taken from a bee which is just beginning to collect. It had crawled over a few Howers and had flown in the air ahout five seconds at the time of capture. The pollen mass lies at the entrance of the basket, covering over the fine hairs which lie along this margin and the seven or eight short stiff spines which spring from the floor of the corbicula immediately above its lower edge. Is yet the polen has not come in contact with the one long hair which rises from the floor and arches above the en. trance. Tlie planta is extended, thus lowering the auricle; $b$, repiesents a slightly later stage, showing the increase of pollen. The planta is flexed, raising the auricle. The hairs which extend outward and mpward from the lateral edge of the auricle press upon the lower and outer surface of the small pollen mass, retaining it and guiding it upward into the basket; $c, d$. represent slightly later stages in the successive processes by which additional pollen enters the basket.-Bulletin No. 121, Bureau of Entomology.

act of loading the pollen into the corbiculæ, which has been described in much detail by Casteel, tlle hind legs hang downward beneath the abdomen, and the plantar combs are in contact for most of their length. If pollen is to be loaded into the left pollen-basket the right planta is drawn upward, scraping against the pecten of the of the left leg to the right pollen-basket. The movements alternate very rapidly, the legs rising and falling with a pump-like motion. As the amount of pollen loaded at each stroke is very small a great many strokes are required.

The pollen at first lies at the extreme lower end of the pollen-basket, but as suc- 


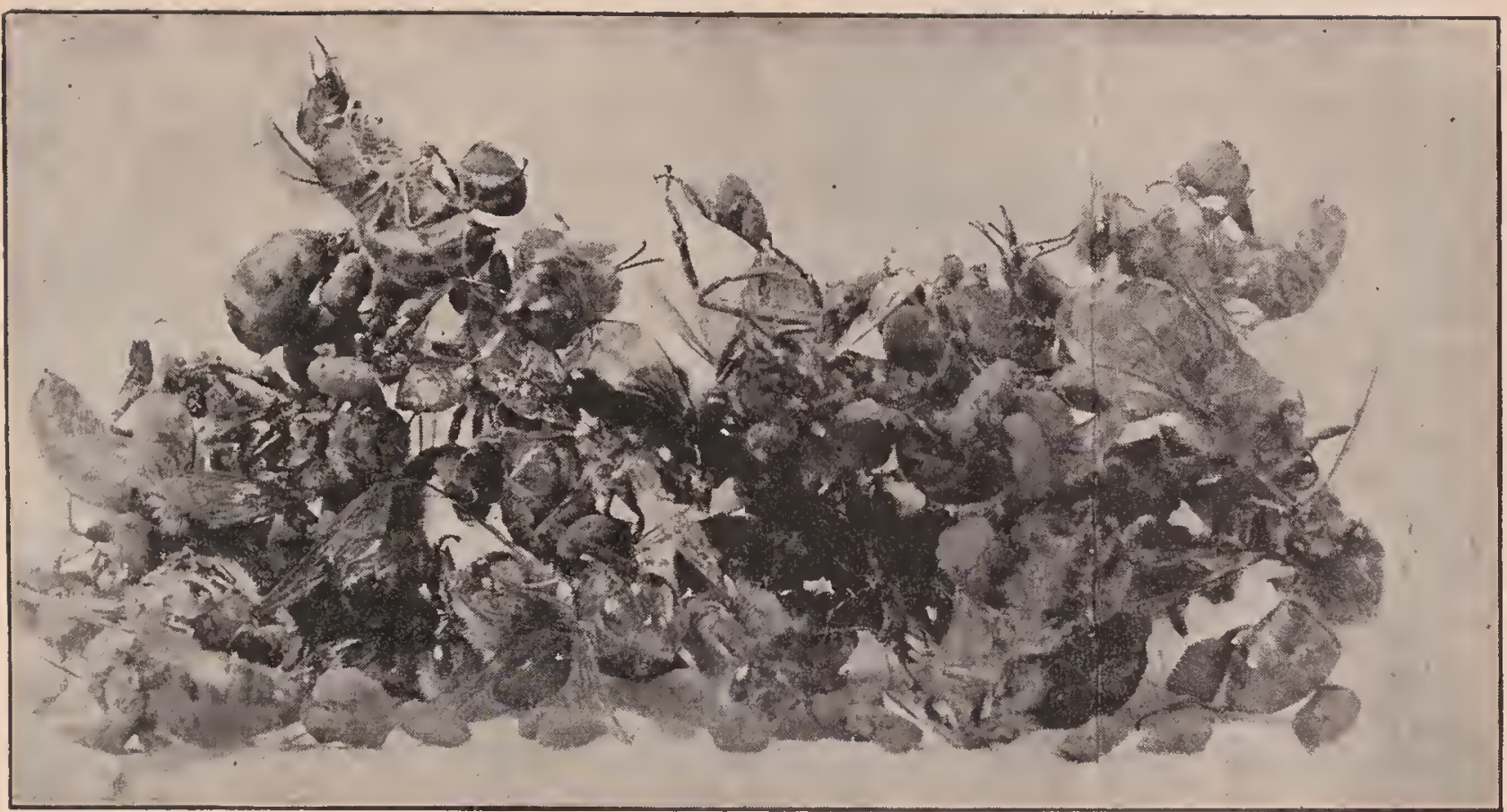

Bees with masses of pollen on their legk.

cessive layers are added it is gradually pushed upward. If pollen from different species of flowers and of different colors, which occasionally happens, is ' collected, the mass will have a stratified appearance. The shape of the pollen mass is largely determined by the hairs which fringe the sides of the basket. The liairs on the front edge, which curve inward, prevent it from projecting far forward; while the hairs on the posterior edge, inclined outward, permit it to extend backward far outside of the tibia. Casteel found it possible to manipulate the legs of a recently killed bee with a pair of forceps, and artificially load the pollen-baskets with thin layer's of pollen as has been described. It was formerly believed that in loading the pollen-baskets the hind legs were crossed, and the plantar rombs scraped over the edges of the baskets and the fringes of hair. On trial it is found that this metlıod yields wholly different results.

Chenical analysis shows that the liquid with which the pollen is moistened is chiefly honey or nectar recently gathered. In pollen taken directly from the anthers of corn the sucar content was 11 per cent, while in rollen from the pollen-baskets the sugar content was 28 per cent, showing that a large amount of sugar had been added. Since the pollen from the corbiculæ contains three times as much reducing sugar as sucrose it is indicated that the liquid arkled is honey (largely a reducing sugar) rather than nectar which contains more sucrose.

Honeybees make their collecting trips more frequently in the morning than in the latter part of the day. Young bees returning with their first loads are said to show great excitement, while the older bees move about leisurely. After a suitable cell has heen selected, which may take some time. the bee grasps, according to Casteel, one edge with its fore-legs, while the apical end of the abdomen rests 'on the onter side of the cell. The hind legs hang free within the cell, the pollen masses about eren with its maroin. The pollen masses are then forcibly thrust out of the baskets by the plantie of the middle legs. The bee then usually departs, leaving to another workel' the packing of the pollen in the cell. The pellets are broken up and pressed downward, and sugar, with perhaps some liruid, is adderl to preserve them.

NECESSITY OF POLLEN FOR BROOD-REARINT.

Both the solitary and the social bees l'equire pollen for brood-rearing. and would speedily perish if deprived of it. Alone among insects the existence of this group repends on an ample supply of pollen. While a colony of honeybees cannot produce lrood without pollen, the adult bees theniselves do not appear to use it as food, since they will live only as long as the hive 
contains honey, and, when that is consumed, they will die of starvation, altho there may be an abundance of pollen in the combs. The less specialized solitary bees, however, belonging to the genera Prosopis, Halictus and Andrena, have been observed to feed on both pollen and nectar. There are also highly specialized genera of beetles and flies, which, like the honeybee, live wholly on nectar, while the more primitive species consume both kinds of floral food. If honeybees are confined and fed only on sugar syrup they will live for a long time, build comb, and, since they roid no excrement, will not require a flight in the open air, but they will rear no brood. Pollen is a necessity for the life of often nay be seen in large numbers resorting to sawdust heaps, and collecting fine particles of wood, which contain a certain amount of nitrogenous natter. They also gather at times the spores of fungi, which are very similar in composition to pollen grains. In Michigan they have been reported as gathering loads of fine black earth from the swamps, and they have been known to collect even coal dust. The owner of a cheese factory states that one day bees were observed hovering over the shelves in the cheese-room, and, as their number's increased, they were found to be packing on their leg's the fine dust that had accumnlated from handling the cheese. Microscopic examination showed this duist was

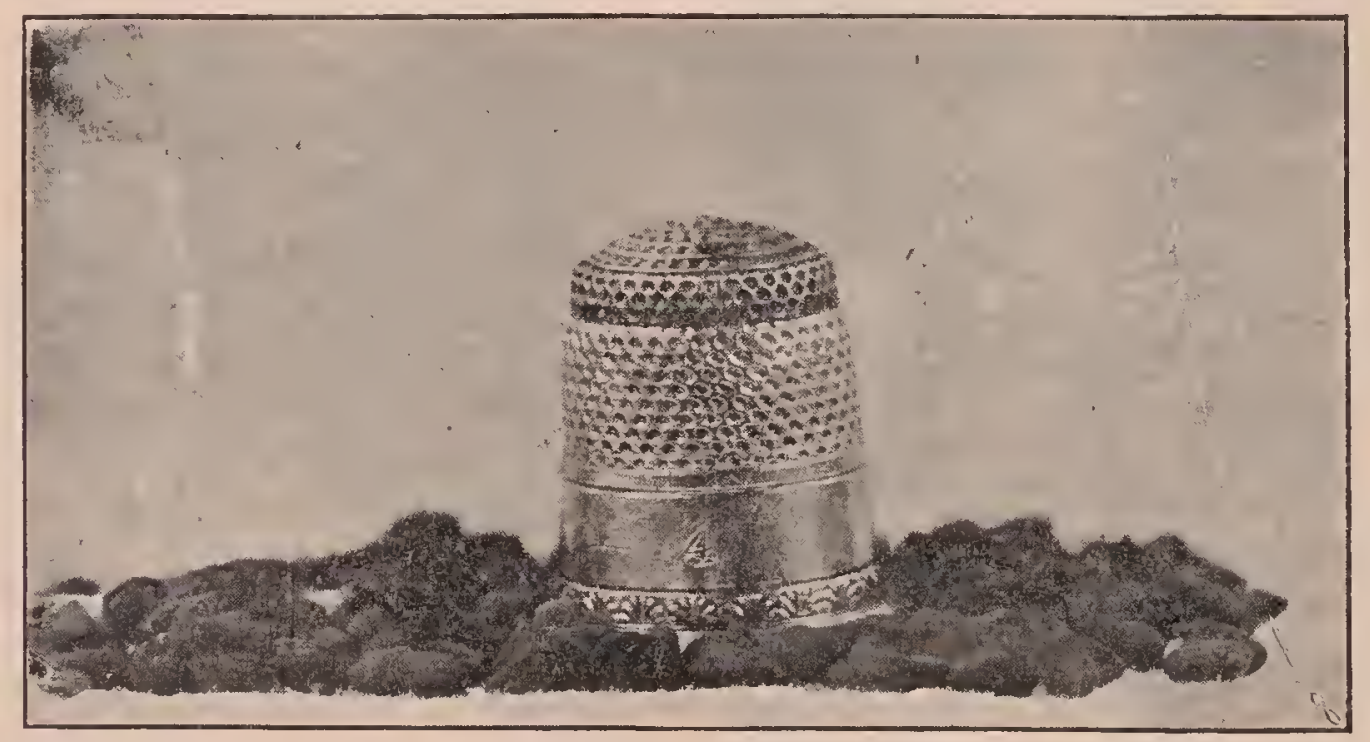

Masses of pollen taken from legs of bees. These were photographed with a thimble to
show the rehative size.

the colony, and it is for this reason that honeybees are equipped with the elaborate apparatus described above, and gather it so diligently from spring till fall. In storing pollen preference is given to the cells immediately surrounding the brood. In rery late fall it is rommon to find large quantities of pollen packed firmly in cells but not protected in any way; in other cases it is covered with honey and the cell capperl over. To provide sufficient pollen is a vital problem to both bees and beekeepers.

\section{SUBSTITUTES TOR POLLEN.}

In the absence of flower's honeybees will gather many other substances as substitutes for pollen. In early spring they embryo cheese-mites, so that the bees load actually been using animal food as pollen, and living animals at that.

At times also when there is a scarcity of pollen bees will raid barns, stables, and chicken-lionses to obtain bran or meal. There have been numerous reports of their invading the premises of farmer's, stinging the cattle and driving them out of the stables and causing general anmoyance. This difficulty may be remedied easily by supplying them with a quantity of rye meal. $A s$ it has been known for many years that in springtime bees will use the flom or neal of different kinds of grain, many beekeepers believe that they can feed, substitules for pollen to advantage. I'sually they resort to rye meal, cottonseed meal, 


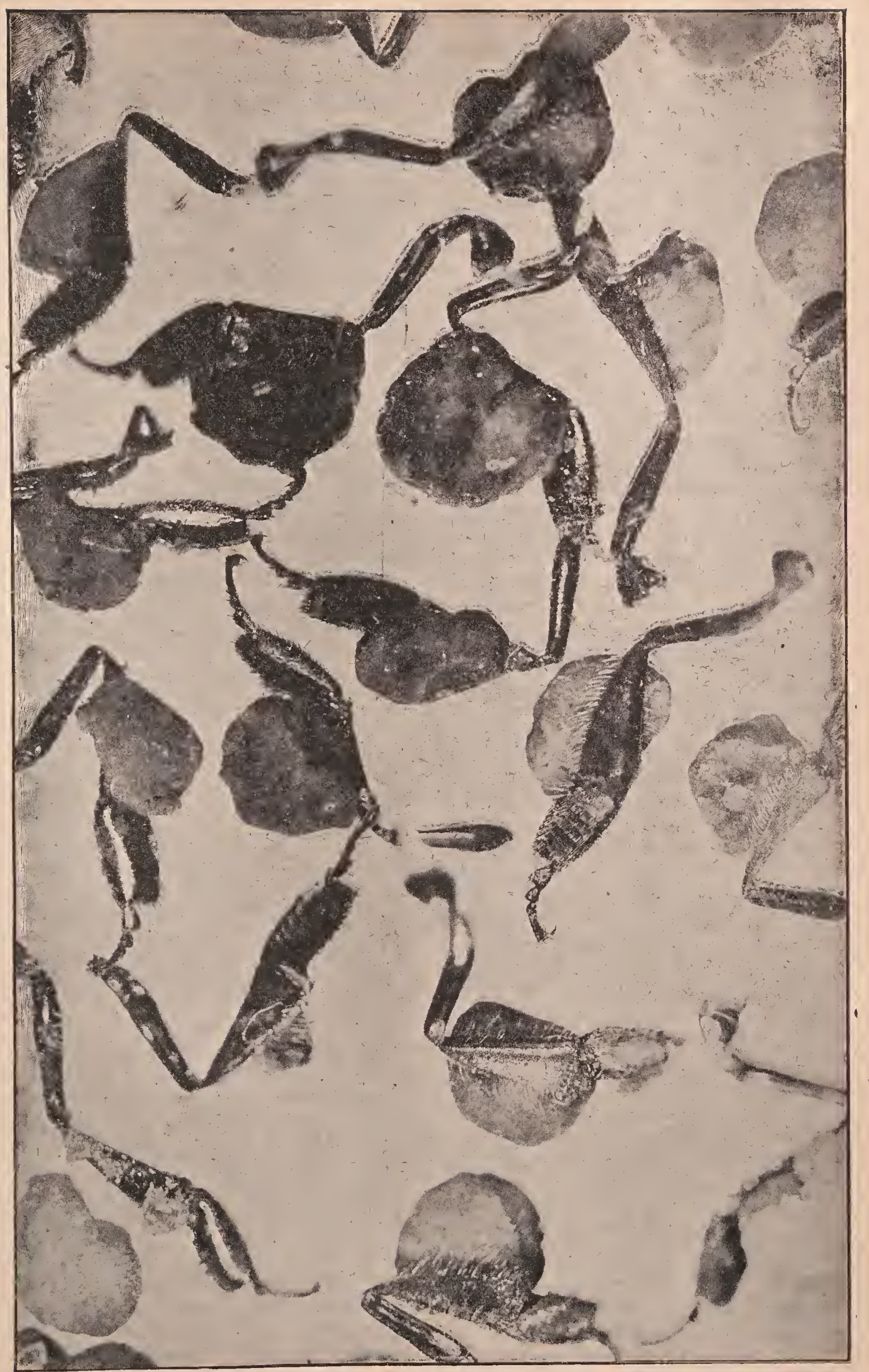

Pollen masses on legs of bees,-Photo by E. F. Bigelow. Several show side hairs (like stakes on a haywagon) to hold the load. 
wheat flour, oatmeal, or pea meal, and sometimes to strange mixtures of eggs, milk, and sugar. Rye meal is a favorite spring feed, and cottonseed meal has been strongly advocated. If it is desired to feed the meal inside the hive, flour candy is used. This is made by mixing one part of rye meal with three parts sugar and a little water, and cooking it until it will sugar. It is then rigorously stirred and poured intó greased pans. It is difficult to make, may cause brood-rearing at the wrong time, and is probably of no benefit. The dry meal is placed in shallow pans, protected from the rain and wind, and if a little dry pollen, saved from the tassels of corn the preceding season, is scattered over it, the bees will soon begin carrying it into the hives very eagerly. Care should be taken to prevent the packing of the combs with it to the exclusion of pollen later in the season.

There is no doubt but that these substitutes will stimulate brood-rearing, for in colonies in which there were healthy queens, but no pollen, egg's, or brood, three days after rye meal had been fed, there was a large number of egg's in the cells. The fact that brood-rearing can thus be stimulated has led many beekeepers to jump to the conclusion that the use of pollen substitutes must be desirable. But careful observation of the effects of feeding pollen substitutes, especially in regions where there are pollen famines, seems to show that they are not only not beneficial, but are positively injurious. In the tupelo section of Florida, along the Apalachicola River there is plenty of pollen until about June 15, but after this date there is little or none for nearly 90 days, or until September, for the tupelo furnishes rery little. The colonies become very weak and the queens cease laying, but two prominent beekeepers in this section report that they never feed meal. It is the practice of one beekeeper after the flow from tupelo is over to move his apiary southward to a locality where pollen is more abundant, and where it remains for the balance of the rear. In Australia pollen famines are as regular as the seasons themselves. There is a "critical period" in midsummer, when the pollen fails, the queen ceases to lay eggs, and the brood dies of starvation. This shortage is due to the failure of the gum-trees, or Eucalypti, to produce much pollen. So small is the supply that colonies working on yellow gum dwindle down to mere handfuls, altho there is a fine crop of honey. Beuhne says that he has used all kinds of substitutes in large quantities; but, altho hives were well filled with brood, the bees thus raised were lacking in vitality and were short-lived. He has never been able to obtain a strong force of field bees. In Connecticut Latham states that as the result of years of observation he believes that the ground grains do more harm than good. One season strong colonies were fed freely with cottonseed meal; but when examined a month later they showed clearly the futility of feeding substitutes, for they not only showed no advance but were actually weaker in bee strength. Out-apiaries which never received any meal invariably contained stronger colonies than the home apiary which was fed. Feeding meal in early spring apparently causes the bees to fly out and waste away in cold weather, when they had better remain quiet, and retards building up later on; injures their digestive powers; while the weak bees and brood thus obtained lessen in the end rather than add to the strength of the colony. In the course of centuries bees have become adapted to the use of pollen, and it is not surprising that neither the nurse bees nor the larvæ can digest meal equally well.

Discarding the feeding of pollen substitutes as of no benefit, or injurious, the only practical method in most instances of meeting a dearth of pollen would seem to be the giving of combs of pollen. It is often as important for beekeepers to reserve surplus combs of pollen as it is combs of honey. Not infrequently, especially in localities where pollen is very abundant, combs largely filled with pollen can be remored from the hive without apparent disadvantage. Bees without queens are said also to store large quantities of pollen. Such combs stored in a dry room would keep for a long time, and, introduced into the hive as required, would often make a great difference in the season's results: 
POLLEN IN THE COMBS AND SECTION BOXES.

Then pollen or meal is brought into the hive, it is usually packed in cells as near the brood as possible. If the hives are opened in spring, pollen is found scattered more or less thru all the brood-combs; but the two outside combs on each side of the hive are often a solid.mass of pollen. Should there be a fer stormy days the supply will disappear with almost unaccountable rapidity, so large is the demand for brood-rearing. As soon as it is wholly consumed brood-rearing must stop, altho the queen may continue to lay eggs. It is most important, then, that there should be an ample stock of pollen during unfarorable weather, in order that strong colonies may be obtained.

Complaint has been made by those who use shallow hives that pollen is sometimes stored in the sections. It has been claimed that this can be prerented by placing a comb of pollen in the brood-chamber, tho this mas questioned by C. C. Miller. But this practice will usually induce the storage of more pollen below the sections, eren if it does not keep them wholly free fro:n it. In hives with the brood-nest as deep as the Langstrotli, it is rery seldom that pollen will be found in the sections. It is in hires haring less depth that there is danger.

Strips of perforated zine in the slatted honer-board will largely prerent the storage of pollen in the sections, if there is a large brood-chamber. But if the broodchamber is much contracted the bees will put pollen where they please, zine or no zine.

POLLINATION OF F L O W ER S.Plants may be divided into two great series. the seedless, or lower plants: and the seedplants, or higher plants. The seedless plants include the seameeds, fingi, mosses, and ferns; the seed-plants comprise the conifers and the cycads (Grmnosperms) and the plants with flowers (Angiosperms). The possibility of diriding the plant world into two sub-kingdoms was recognized orer 150 years ago by the Sredish botanist Linnaeus who called the lower plants Crrptogams, or flowerless plants: and the higher plants Phanerogams, or flowering plants. The number of described species in each of these great groups is approximately as follows:

SEEDLESS PLANTS.

Searreeds or Algae.......... 15,460

Fungi (higher forms) ....... 63,700

Liverworts and mosses or

Bryophytes .............. 16,600

Fernworts or Pteridophytes:

Ferns ................ 5,940

Horsetails .............. 20

Club-mosses .............. 900

SEED-PLANTS.

Conifers and cyeads or Grmno-

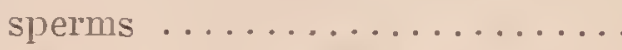

Florering plants or Angiosperms. .132,000

\section{THE ORIGIY OF SEX.}

Plant life had its origin in the osean many millions of rears ago. The first plants were miscroscopic, one-celled forms. without sex, multiplying by self-division or fission. The simplest plants are todar sexless, and still multiply wholly br repeated dirision into tro equal parts, as in the blue algae, the desmids, diatoms, and bacteria. So rapidly does fission take place that, if conditions permitted, they rould quickly pack the o:ean itself. Gradually thru the long ages of primeral time the seaweeds were dereloped. In the different groups of seameeds sex mas erolred independently again and again. Evidently for the derelopment of plants multiplication without sex mas not sufficient. Stripped of all the accessories, which attend it in the flowering plants, sex consists only of the union of two cells of umequal size, the smaller being known as the male cell or sperm, and the larger as the female cell or egg. The sperms and egos leare the organs in which they are formed, and swim about freely in the water by means of cilia, or whip-like hairs, until they meet and unite. From the cell or spore arising from this union, called a zrgote, there grows after a period of rest a new plant. The derelopment of ser was the first step in the erolution of flowers.

But regetatice reproduction was not replaced by sexual reproduction: it still continues to exist and probably more indiriduals are produced by sexless methods than by sex. Reproduction by spores, or single cells capable of groming into new indiriduals, which is a simple form of bud- 
ding, also was developed. Many plants produce spores in countless numbers: the conlmon puffball has been estimated to contain three trillions, the spores issuing under pressure like puffs of smoke. They are also very abundant in mosses and ferns.

\section{THE AGE OF SEAWEEDS.}

The first period in the history of plant life was the age of seaweeds, and during this long interval of time there were no land plants. In the warm paleozoic seas more than one hundred million years ago seaweeds were more abundant than they are today. The lower or seedless plants are of great interest because they show tlie rarious stages by which stems, leaves, roots, and sexual reproduction have been gradually developed from microscopic, onecelled plants. Step by step in the Algae and ferns the way was prepared for the evolution of the seed-plants. Without these lower groups the early history of plants would be far more obseure than it is at present. Animal life with its power of motion found the conditions in the ocean suitable for a varied and advanced development; and, responding to all the complex action of the sea, it branched and perfected itself before the evolution of land animals. All the great divisions of the animal kingdom, including the lower vertebrates or fishes, are represented. But plants could make little progress in the ocean arıd did not advance beyond the seaweeds. The development of the plant world has taken place'almost wholly upon the land. The advance of plants from the ocean to the land is justly regarded as the most important event in the history of vegetation.

\section{THE FIRST LAND PLANTS.}

The first land plants were liverworts, mosses, and ferns. The simplest liverworts which are little more than green mats, with lobed margins, growing on damp ground, probably resemble very closely the first land plants. From such seaweed-like plants, which had become only partially adapted to living on the land, are descended by different lines the mosses and ferns. The life eycle, or history of each moss and fern, consists of two different phases or generations, the earlier portion being a sex plant, the later, a spore plant. Both kinds of reproduction are apparently almost of equal advantage to the plant.

The sex plant in the ferns is a small flat brown mat or thallus, growing on the ground. It has neither stems nor leaves and closely resembles a seaweed, which is a strong reason for believing that all of the mosses and ferns have come from seaweed-like ancestors. The sex plant produces both eggs and sperms in separate organs which, so long as it is dry, lemain closed; but, as soon as they are covered with water by rain or overflow, they open and the spern swims by whip-like hairs to the ovary and fertilizes the egg. Thus fertilization in the mosses and ferns is the same as in the seaweeds, and in all three groups water is the means by which it is effected. The sex plant is indeed an aquatic plant, while the spore plant is a land plant -mosses and ferns are thus amphibians. They have never become wholly independent of their aquatic origin. After fertilization the egg grows into an entirely different plant, the leafy fern or spore plant. It is the spore plant that is commonly known and admired for its beautiful fronds. On the back of the fern leaves there grow round spore cases or sporangia, in which are produced in great numbers yellow spores of the same size, which are widely distributed by the wind. Each of these spores under favorable conditions grows into a sex-plant. Since sex-plant and spore plant thus continuously suceed each other, this life cycle is called alternation of generations.

\section{HETEROSPORY.}

The spores produced by most fernworts are of eqnal size, and grow into sex-plants which produce both sperms and eggs. But a few of the higher ferns and club-mosses have produced spores of two different kinds, small spores and large spores-heterospory. Both kinds are widely distributed by the wind. The small spores grow into male plants which prodnce only sperms; the largè spores grow into female plants which produce only eggs. Crossfertilization is a frequent result of this arrangement; but a vast number of spores are wasted since the two kinds of spores are often so widely dispersed and are so 
far apart that fertilization cannot occur. To prevent this loss in part the seed was evolver. In the cases of the seed plants the large spores were retained in the seedcases, or ovules, and became the center around which the seed was built up. The small spores are similar to pollen grains, altho not so called outside of the seedplants. Thus the production of spores of two kinds made possible the development of the seed-plants which otherwise would not have taken plice. It is the second most important event in the history of plants.

THE SEED-PLANTS, OR PLANTS ADAPTED TO POLLINATION.

Pollination oceurs only in the seedplants or Spermatophytes. To this group belong the conifers or evergreen trees and the cycads (Gymnosperms), and the flowering plants (Angiosperms). The Gymnosperms are so-called because the seeds are naked or unprotected by a seed vessel, while in the Angiosperms the seeds are enclosed in a case or capsule. The cycads and the conifer's are derived from the ferns and are very much older than the flowering plants. In the Mesozoic Age a remarkably even climate prevailed over the larger part of the land surface of the earth and gymnospermous trees were the dominant type of vegetation. The rast forests of this age composed of conifers, maiden-liair trees, cycads and cycad-like plants, and tree ferns must have displayed a foliage which in beauty of form has never been equaled before nor since in a terrestrial landscape. There are only 450 living species of Gymnosper'ms, the larger part of which produce cones.

To the Angiosperms belong the hardwood trees, as the birches, beeches, oaks, maples, and elms; all common slurubs; and a great company of herbaceous plants, as the grasses, sedges, lilies, pinks, buttercups, clover's, heaths, gentians, mints, asters, and goldenrods. The seeds are enclosed in a case or ovary; and, as the pollen can not come directly in contact with the ovules. it is received on a glutinous surface caller the stigma.

TIE ORTGTN OF THE SEFD AND OF POLLINATION.

$\Lambda$ s has already been pointer out the higher fernworts produced two sorts of spores, small spores and large spores. (This is well shown today in the water ferns, Marsilia.) The small spores were similar to pollen grains, and produced male cells or sperms alone. The large spores produced only eggs, and were often 100,000 times larger than the small spores. The small spor'es were exceedingly numerous and were very widely and easily distributed by the wind. The large spores were fewer in number and contained a reserve supply of food, which, after the fertilization of the egg, nourished the young plant. The advantage of heterospory, or the production of two different kinds of spores, was that it very frequently ensured cross-fertilization. But where both kinds of spores were set free, and widely scattered, they were many times so far apart when they fell to - the ground that fertilization could not take place. Thus the waste of spores was enormous.

To prevent this waste the seed was evolved. The first step in its development was the retention of the large spore in the spore case, called in the higher plants the ovule (the seed before fertilization). The egg was thus protected by the coats both of the spore and the spore-case. The female plant practically disappeared, or rather was reduced to a few cells, one of which was the egg. After fertilization the egg today grows into an embryo or infant plant, consisting of one or two minute leaves and a stem. Thus time is saved when later the seed germinates. The seed is called by Scott the nursery of the infant plant. But in the first seeds which were formed many million years ago there were no embryos.or young plants. They were evolved at a later period; but a quantity of food was stored in the seed then as now, and its contents were protected by the hardening of the walls of the spore and the spore case. Finally the seeds were dispersed in various ways.

The smaller spores wera identical with pollen grains, and were brought to the ovules by the wind. In the cone trees the pollen actheres to a drop of glutinous licuid or mucilage in the opening at the end of the ovule; and in the flowering plants to a sticky surface called the stigma. The reception and retention of the pollen near 
the eggrs and the dispersal of only one kind of spore greatly reduced the waste of spores. The seed also proved a great advantage in providing for the distribution of the species.

Pollination and the habit of forming seeds arose at the same time; and, as there were cone trees as far back as the Devonian Age, the origin of both is very ancient. Pollination consists in carrying pollen to the ovules of the cone trees (Gymnosperms), and to the stigmas of the flowering plants (Angiosperms). It is thus restricted to the seed plants, but its beginning goes back to the ferns.

THE FOLLINATION OF THE CONE TREES OR GYMNOSPERMS.

The Gymnosperms include the Cycads (Cycadaceae), the conifers (Coniferae), and a small peculiar group called the joint firs (Gnetaceae). There are about 100 species of cycads, 300 species of conifers and 46 species of joint firs. The cycads occur in the tropies of both the Old and New Worlds; but the conifers are found chiefly in the north and south temperate zones, where they form extensive forests. The cycads resemble tree-ferns and palms, the tallest species attaining a height of 40 to 60 feet. The conifers have needle-like leaves and include the giant firs, spruces, redwoods, and Sequoias of the Pacific Coast, among the largest trees in the world.

In the cycads and conifers the stamens and ovules are in separate cones, formed of numerous scales spirally arranged around a central axis. As the seeds are unprotected by a seed-case, the purpose of the cone of scales is to protect them from the weather; and so great is its advantage that the conifers may owe their existence to it. In the cycads the ovules and stamens are in separate cones on different trees. In the conifers (Coniferae) the stamens and seed cones are in many species on the same tree, as in the fir, spruce, and pine, or on different trees as in the juniper and yew. The seed cones are at the top of the tree or at the end of the branches, while the staminate cones are lower down on the lateral branches, an arrangement favoring cross-pollination. Thie seed cones may be of great size; in the cycal Dioon spinulo- sum of Mexico its length is 20 inches and its weight 33 pounds.

When the evergreen forests of the temperate zone bloom in May the neutral-colored cones are seldom noticed, as they do not usually contrast strongly with the green needle-like leaves. But a red pine covered with red-purple staminate cones, half an inch in length, and associated in clusters of 30 or more; and a black spruce and balsam fir bearing innumerable staminate cones, about the size and color of a field strawberry, certainly present a strikingly handsome appearance. The fertile cones are much less noticeable, but they are purple in the spruce and pale green in the fir. The seed cones of the cycads are often brilliantly colored, as orange-colored scales and scarlet seeds. None of the cones yield nectar, and the bright colors are an incidental result of no advantage in pollination.

All of the cycads and conifers are windpollinated. The quantity of pollen produced is almost incredible. Clouds of pollen rising from pine trees are sometimes mistaken for columns of smoke. The falling of pollen grains in such immense numbers that they tinge the ground yellow has given rise to reports of sulphur showers. The pollen is very light and in the pine is provided with two bladder-like wings, which greatly increase its buoyancy, and cause it to be carried upward by a slight breeze to the seed cones at the apex of the tree. On the upper side of each of the scales of the fertile cones there are two naked ovules in the end of which there is a small opening, the micropyle or little gate. The micropyle is wide open, and filled with a drop of mucilage well shown in the yew and running juriper. When the air is filled with pollen slowly settling downward, powdering the foliage, the grass and the ground, it can not fail to come in contact with the drop of mucilage. As this gradually dries up the pollen grains are drawn into the ovule until they come in contact with the spore containing the egg. The grain of pollen then puts out a tube, which enters the spore and from which there issues a sperm which unites with the egg. Tn the pine this tube grows so slowly that fertilization does not take place for over a year after pollination. Cross-pollination 
is of necessity of wide occurrence among the cone trees, and is always effected by the wind never by insects. It might be supposed that the great abundance of pollen would be attractive to bees, but there is no record of bees ever gathering it, or of flies feeding on it. Several species of beetles have been observed eating the pollen of pine trees.

IOLLINATION OF THE FLOWERING PLANTS OR ANGIOSPERMS.

Th Angiosperms are today the dominant type of plant life, and cover the larger part of the land surface of the globe. About 132,000 species have been described. They show a marvelous power of adapting themselves to all conditions, growing in swamps, salt-water, marshes, rivers, ponds, and even in the ocean; in arid deserts and alkaline sinks; under tropic heat and arctic cold and at sea-level and on mountain summits. They have been well called the Anthophytes or flowering plants. Many eminent botanists would restrict the word flower to this group, which has the seed enclosed in an ovary or seed ressel, and the pollen received on a glutinous surface called the stigma. The term as thus limited has a very definite meaning, which can not easily be misunderstood, even when the flower is reduced to a single stamen or pistil as among the aroids. This definition has also the advantage that it agrees with the popular conception of the word, and when possible for obvious reasons it is desirable that the definitions of the scientific and non-scientific public should agree.

THE ORGANS OF THE FLOWER.

If some common flower, as a buttercup. rose, or basswood blossom, is selected for examination it will be seen to consist of many small central thread-like organs surrounded by two whorls of leaves. The outer circle of leaves is usually colored green, and forms the calyx or cup, each leaf of which is a sepal. The function of the calyx is to protect the inner and more delicate organs, especially in the bud, when the calyx is visible. The second or inner circle of leaves is the corolla, or little crown, and the several leaves of which it is composed are petals. The corolla is often large and hright colored, but in many flowers it is small and greenish. When conspicuous the role of the corolla is to attract the attention of insects or birds. The two sets of leaves taken collectively are termed the perianth. The central thread-like members of the flower are the stamens and pistils. The stamens stand next to the corolla and consist of slender stems or filaments, bearing the two-celled anthers filled with pollen. In the center of the flower are the pistils. A pistil consists of three partsthe orary, style and stigma; but the style, or stalk, is sometimes wanting. The base of the pistil is the ovary, or seed-case, which contains the unfertilized ovules or young seeds; the style is a porous stalk rising from the ovary, at the upper end of which there is a glutinous receptive surface called the stigma. Pollination is the transference of pollen from the anther's to the stigma. If the pollen is from the same flower it is self-pollination; but if from a different flower it is cross-pollination. Cross-pollination between flowers on the same plant or between the flowers of plants descended from the same stock is little better than self-pollination. Cross-pollination between different strains or varieties of the same species or between different speries is hybridization.

\section{FERTILIZATION}

Soon after a grain of pollen has lodged on the stigma, if the proper conditions exist, it sends out a slender tube which grows down thru the porous style, by which it is nourished, until it comes to one of the ovules in the ovary. It enters the ovule by a little orifice (micropyle, meaning little gate), and there passes from the end of the tube a male cell, which unites with an egg cell in the ovule-this is fertilization. Fertilization does not always occur immediately after pollination; for instance. the flowers of witch-hazel are pollinated in the fall, but fertilization does not occur until the following spring.

\section{THE FORMS OF FLOWERS.}

But there are comparatively few flower's. which, like the buttercup and rose, have all the members present, separate and regular in form. In many species a part of the organs are wanting. The cat-tails, pondweeds, grasses, and sedges have neith- 
er calyx nor corolla, or they are represented only by scales and bristles. In the willows the flowers on a part of the bushes consist only of stamens, while on others they are composed only of pistils. In Jackin-the-Pulpit the flowers are reduced to a single pistil or stamen.

Flowers may be modified also in another way by the fusion or consolidation of the organs. Tubular calyces and corollas, as in the morning glory and plilox, are stronger and better adapted to protect the nectar than those which consist of separate sepals and petals. In the pulse family the stamens are commonly fused into "brotherhoods." But fusion is nowhere so common as among the pistils. So long as they are separate, pollen must be placed on the stigma of each; but when they are consolidated, one application may serve to fertilize all the ovules. Clearly a flower like the buttercup, where all the parts are separate units, is more primitive than an orchid, where they have coalesced to sucl an extent that it is difficult to determine their number. In primitive families again, like the buttercups, mallows, roses, and saxifrages, the flowers have regular forms and the sepals or petals are all alike; but in many families, which have developed more recently, the flowers liave assumed strange bizarre forms as in the sweet pea, snapdragon, and sage. The purpose of these singular forms is to compel an insect to pursue a fixed path in its visits and thus effect pollination. Such flowers are the voungest and latest to appear in the plant world; the larkspur is of later origin than the buttercup, and the elover blossom than the rose.

A flower is hermaphrodite or bisexual when it contains both stamens and pistils. Unisexual when either the stamens or pistils are wanting. Monoecious when the stamens and pistils are in different flowers on the same plant. Dioecious when the stamens and pistils are in different flowers on different plants. Polygamous when both hermaphrodite and unisexual flowers occur on the same plant.

\section{THE ADVANTAGE OF CROSS-FERTILIZATION.}

Thuruout the plant world cross-fertilization is of frequent occurrence. In the lower plants the male and female cells of different plants are of ten brought together thru the medium of water, and in the seed plants erossing is secured by cross-pollination. It is, therefore, of the greatest importance and interest to inquire what benefits result from crossing. Otherwise the investigation of the pollination of flowers becomes a blind pursuit. Plants reproduce in two ways, vegetatively or without sex, and sexually; and contrary to the common belief the chief purpose of sexual reproduction is not the multiplication of plants. As it originated independently many times among the seaweeds it was evidently necessary for the evolution of the plant kingdom. What advantage then is there in sexual reproduction, which is not found in vegetative multiplication.

\section{VEGETATIVE: REPRODUCTION.}

Plants multiply vegetatively, or without sex, by fission or self-division; by spores or single cells which are able to grow into new plants; and by bulbs, stolons, tubers, layering, or by the breaking up of the plant into fragments which become new individuals. The rapidity with which onecelled plants and animals multiply by selfdivision is almost incredible. Large areas of snow are reddened in a single night by a red alga. Some species of Euglena and Astasia are so prolific that they color the waters in which they live green or red. Other forms of Flagellata are known as "sea-lights," because in darkness they emit light, and they often exist in such enormous quantities that the surface of the sea is illuminated for miles. According to Cohn the descendants of a single liay bacillus in 24 hours equal seven septillions. Even more impressive of the enormous productiveness of one-celled organisms are their fossil remains. The most vivid imagination would hardly suppose that they had been instrumental in building up the rock strata of the earth. Yet the lofty white chalk cliffs of southern England are composed of the empty shells of Forminifera mixed with the silicious shells of diatoms. In the Indian Ocean the mountainous Nicobar Islands are built up of flinty shells of Radiolaria. As island and continent builders these little micells surjass all other forms of life, and today in the abyssmal deptlis 
of the ocean their little shells are silently falling and building up new deposits.

Fungi, mosses, and ferns produce single cells or spores in countless millions, which are capable of growing into new plants. If conditions admitted, almost any species of these groups would speedily occupy the entire land surface. The poplar tree, tulip tree, osage orange, raspberry, blackberry, and many other shrubs and trees send up numerous shoots from the roots. Many plants are readily propagated by buds, or bulbs, or by the rooting of the leaves or stems. Other plants send out numerous l'unners or stolons as white clover and the strawberry. So far as numbers are concerned the absence of sex is clearly no disadvantage to many plants.

\section{SEXUAT REPRODUCTION.}

If plants can multiply vegetatively why has sex been developed. The first plants did not possess sex; it has not taken the place of vegetative reprodnction. The latter has always been and is still very effective. Both methods still exist side by side. The offspring of plants which are produced without sex are similar to the parent form, They vary relatively very little, altho there are exceptions. Florists and horticulturists take advantage of this fact to increase their stock of new flowers and fruits by grafts or divisions of the original plant, since such varieties grown from seed are not likely to be true to name. Species which have little power of variation are clearly at a great disadvantage. If conditions change, they can not change with them and are likely to perish quickly. They can not migrate to new localities since they can not adapt themselves readily to new conditions. It is diffieult to see how the evolution of plants could have ever taken place without rariation, and sex secures greater variation.

The offspring of plants by sexual reproduction will inherit the characters of both parents, and will therefore be more variable than either. Among the variations there are likely to be some which will be beneficial, and which will enable the plants to adapt themselves to new conditions, and to take advantage of new opportunities. Variation is necessary for evolution, and the greater the variations the more rapid 22 the advance. One advantage of sex is, then, that it secures greater variation thru crossfertilization.

Greater vigor in the hybrids also usually follows cross-fertilization, as was first pointed out elearly by Charles Darwin. He was experimenting with two beds of toadflax, or butter-and-eggs (Linaria vulgaris), one set being the offspring of self-fertilization and the other of cross-fertilization. The plants had been raised for the purpose of studying heredity, and not the results of cross-breeding. To his astonishment he observed that the plants which were the result of cross-breeding were far more vigorous than the others. He temporarily abandoned all his other investigations and devoted limself to making numerous experiments in breeding, and to acquiring information as to the practical experience of horticulturists and breeders of animals. As the result of his inquiries he was convincerl that no species of animal or plant can feltilize itself thru numberless, generations, and that an occasional cross is indispensable.

Hybrids lave a greater power of assimilation, a larger root system, and the seedlings grow more rapidly and mature earlier. The leaves are larger, the stems are stronger, and there are more flowers and fruits. Why does the crossing of two strains or races prodnce greater vigor in the progeny? The following explanation has been snggested by Coulter: In the struggle for existence among plants undesirable characters tend to disappear, since the species possessing them are eliminated. The characters which survive are the most desirable ones. In order to survive a desirable character must have vigor, and each must add somewhat to the vigor of the plant containing it, and in consequence its size and productiveness will also increase. The plants having the greatest number of desirable characters are hybrids, since they contain the characters of both parents, hence hybrids will show at once a great increase in vigor and productiveness. The first generation shows the greatest vigor, after which, if there is inbreeding, the productiveness rapidly falls off. As the result of inbreeding a race tends to disappear. Crossing between flowers on the same plant or between plants derived from the same 
stock shows little improvement over selffertilization. The cross must be between two different races or strains, or between two species.

When two weak, run-out, self-fertilized strains of corn, which yielded at the rate of only 29 bushels to the acre, were crossed the hybrids yielded at the rate of 68 bushels to the acre. Thus, in cultivation of many crops, the crossing of two weak varieties may be very profitable. Hybrids between two different species of oaks and two species of elms were in eight year's one-third larger than the parent species.

The evil effects of inbreeding lave long been known in a general way, and are even instinctivelý recognized by barbarous races; but they are not so easily recognized as the good effects, for the deterioration is gradual. When corn is self-fertilized for a number of generations the plants become inferior in size, vigor, and productiveness, as compared with normally crossed plants from the same source. Many plants have become self-sterile to their own pollen, which would seem to be evidence in favor of cross-pollination.

A summary of the more important ways in which self-pollination, and consequently self-fertilization, is prevented in plants is given in the following table:

\section{A. SEPARATION OF STAMENS AND PISTILS BY} SPACE.

1. Stamens and pistils in different flowers, but on the same plant.

2. Stamens and pistils in different flowers and on different plants.

3. Stamens longer than the pistils, or pistils longer than the stamens.

4. Stamens bent away from the pistils, or pistils bent away from the stamens.

B. SEPARATION OF STAMENS AND PISTILS BY TIME.

1. Anthers mature before the stigmas.

2. Stigmas mature before the anthers.

C. MEGHANICAL SEPARATION OF THE STAMENS AND PISTILS.

1. Absolute separation. Anthers or pollen masses held in a fixed position, and never set free unless the flower is visited by insects.

2. Partial separation. Self-pollination may occur during the latter part of the blooming period.

D. PHYSIOLOGICAL SEPARATION OF 'IHE STAMENS AND PISTILS.

1. Stamens aborted in some flowers, pistils in others.

2. Pollen from a different flower prepotent over pollen from the same flower.

3. Pollen from the same flower sterile or impotent on its own stigma.

"Crossing is by no means confined to the races and varieties of the same species, but is very common between different species and may occur between different genera. It is rapidly coming to be regarded as an important factor in evolution, and Lotsy regards it as the most important agency in the development of the plant world. In Kerner's time more than 1,000 hybrids were known in the flora of Europe, and he fully believed that many new species originated in this way. Darwin had previously realized the possibility that hybridism might have played an important part in the history of evolution; but orving to the general belief that hybrids were almost invariably sterile he underestimated its significance, altho he observed that every intermediate stage existed between complete sterility and complete fertility."

"While hybrids do in general show decreased fertility, there are thousands of cases in which they multiply readily by seed. Jeffrey has recently shown that hybrids among the Angiosperms, or flowering plants, are characterized by having a part of the pollen imperfect or aborted; and, judged by this test, they are very common both among wind-pollinated and insectpollinated plants. A great many forms which have long been regarded by systematists as perfectly good species are now recognized by their aborted pollen as hidden hybrids. They are especially abundant among the roses, apples, pears, brambles, hawthorns, mulleins, gentians, nightshades, evening-primroses, thistles, hawkweeds, and asters. Among wind-pollinated flowers hybrids are very common in the sedges. rushes, pondweeds, oaks, and birches." (Lovell. J. H. The Flower and the Pee; Plant Life and Pollination, p. 277.) 
Close or Self-pollination.-But while there is wide provision for cross-pollination among flowers, they very generally have the power of self-pollination, so that, in the event of the failure of cross-pollination, before the period of blooming closes self-pollination may occur. The more common ways are as follows:

a. The stamens lengthen, contract, or bend so that the anthers touch, or drop pollen on the stigmas.

b. The pistils lengthen, contract, or bend so that the stigmas receive pollen from the anthers.

c. If lobed, the lobes of the stigma roll back so that they touch the anthers.

d. The filaments and styles become twisted together.

e. The corolla in wilting closes, causing the stigmas to be pollinated.

f. Self-pollination caused by the growth or movement of the petals.

g. Change in the position of the flower caused by the curving of the flower-stalk.

In addition to the many plants in which self-pollination occurs in the event of crosspollination failing to occur there are many plants which are regularly self-pollinated and self-fertilized. When the flowers expand, the anthers rest directly against the stigmas, which thus necessarily receive the pollen. Many plants produce, besides conspicuous flowers, small green flowers, which never open; and which, altho invariably self-fertilized, are very fertile (cleistogainy). Many of these self-fertilized plants are very common, very vigorous and fertile, and extend over a large portion of the earth, as the chickweed, shepherd's purse, and doorweed. They prove conclusively that, altho nature may abhor perpetual self-fertilization, she does not abhor selffertilization. On the contrary, it is a most valuable principle which is carefully preserved, and upon which the plant world is largely dependent. The contrivances, says Kerner, to bring about self-fertilization, are no less numerous than those which favor cross-pollination. "That flowers should be adapted at different times to two such diverse purposes as cross and self pollination is one of the marvels of floral construction."

These facts have led certain botanists to question Darwin's conclusions as to the evil results of continual self-fertilization, and to assert that the good effects of intercrossing are only'a temporary stimulant and are not permanent. In the opinion of Henslow, self-fertilized plants are best fitted to survive in the struggle for life. To sum up, he says they are very numerous, increase very rapidly, are very vigorous, flourish in the most neglected ground, and, being independent of insects, are best able to establish themselves in foreign countries, and are, therefore, of world-wide distribution.

It should, however, be noted that the forms which are continually self-fertilized are admittedly degraded or retrogressive species, or at least not advancing in development. Like certain groups of animals they are adapted to certain places or conditions in nature where they appear able to maintain themselves indefinitely. But for races of plants which are rapidly evolving, cross-fertilization appears to be essential. Darwin showed that, when the offspring of cross-fertilization were brought into competition with the offspring of selffertilization, the former always gained the mastery and survived. It would, therefore, appear that intercrossing in an advancing race of plants would be indispensable in enabling it to overcome its competitors.

\section{FLOWER-GROUPS.}

Flowers according to the ways in which they are pollinated are divided into three groups.

Flowers pollinated by the wind (Anemophilae, wind-lovers).

Flowers pollinated by water (Hyrlophilae, water-lovers).

Flowers pollinated by animals (Zoidiophilae, animal-lovers).

Flowers pollinated by animals may again be subdivided into:

Snail-pollinated flowers (Malacophilae). lae).

Bat-pollinated flowers (Chiropterophi-

Bird-pollinated flowers (Ornithophilae).

Insect-pollinated flowers (Entomophilae). Flower's pollinated by insects are divided into :

Bee-flowers.

Bumblebee-flowers. 
Butterfly-flowers.

Moth-flowers.

Fly-flowers.

Flower's visited by miscellaneous insects.

Insect-pollinated flowers may be divided into pollen flowers and nectar-flowers according as they contain nectar or only pollen. Nectar-flowers may be divided into flower's with the nectar fully exposed, partly concealed, or deeply concealed.

Flowers Pollinated by the Wind.-Windpollination is the oldest method of pollen dispersion and for many years the only methor of pollination in existence. There were wind-pollinated cone trees as far back as the Devonian Age, long before the derelopment of the higher seed plants. The wind offer's an excellent medium for intercrossing. It levies no toll for its services, and it is seldom that there is not sufficient air stirring to carry pollen. A gentle breeze is much better than a strong wind which sweeps the pollen away too quickly and too foreibly. When the weather is stormy, as is often the case when the wind is high, the anther's do not open; and, if they have alrearly dehisced, they close again to protect the pollen. An objection to windpollination is the great waste of pollen. There are no allurements to attract insects, such as nectar, bright color's, odor's, or resting places.

As has already been described, in the conifers and cycads the stamens and seeds are produced in different cones, in part of the species on the same tree, and in part on different trees. In the fir, the spruce, the hemlock, and the pine both kinds of cones are on the same tree, but the fruiting cones are above the cones producing the pollen, an arrangement favoring cross-pollination. In the juniper, yew, and all the cycads the staminate and seed cones are on different trees.

The grasses, sedges, and rushes are also all pollinated by the wind with the exception of a few cases of self-pollination. To the grasses belong the edible cereals, corn, wheat, rye, barley, oats, rice, and millet. "Next to the importance," says Ingalls, "of the divine profusion of water, light, and air, those great physical facts which render existence possible, may be recorded the universal beneficence of grass. Should its harvest fail for a single year, fanine would depopulate the earth." Many species bloom at dawn, just as the sun is rising above the lorizon, when, their anther's loaded with pollen, they exhibit an attiactiveness very different from their appearance at noonday. The stamens and pistils often oceur in the same flower; but self-pollination may be prevented by the stigmas ripening before the anthers. Common corn is an illustration of a grass which has the stamens and pistils in separate flower's. The blossoms that bear the seed are midway on the stalks, and are commonly termed the ear; the pistils are the silk. The flowers that bear the pollen are at the rery summit of the stalk, and are known as the spindle. When ripe the pollen is shaken off and falls on the silk below, or, what is still better, it is wafted by the wind to the silk of neighboring stalks, thus preventing inbreeding.

Very many deciduous-leaved trees and bushes are wind-pollinated, as the alders, birches, oaks, hornbeams, elms, walnuts, hickories, and beeches. Usually the stamens and pistils are in different flower's either on the same plant or on different plants. 'Trees the world over more often have the stamens and pistils separated, and consequently the sexes, than herbaceous plants. Anemopliilous or wind-pollinated trees bloom in early spring before the foliage has appeared, in order that the leaves may not intercept and waste the pollen.

Many coarse, homely weeds are pollinated by the wind, as pigweer, ragweed, nettle, hop, pondweed, sorrel, dock, hemp, and lue anemone. They agree in having small, green or dull-colored flowers, which are commonly orlorless, but which are produced in immense numbers. The pollen grains are round and smooth, while the stigmas are lobed or feathery to present a large receptive surface. They flourish in a great variety of situations and are well worthy of eareful observation. The Roman wormwood (Ambrosia artemisiifolia) blooms in the fall and is cornmon everywhere in old fields and waste land. The air in the fall is filled with its yellow pollen, which is believed to be productive of hay fever. The stamens of the stinging nettles are elastic; and, when the flowers open, they suddenly 
spring upward, and little puffs of pollen are projected into the air.

Flowers Pollinated by Water.-Flowers pollinated by the agency of water are conparatively rare. 'There are, however, four common species, two growing in salt water and two in fresh water, which deserve mention. The two maritime species are ditch grass (Ruppia maritima) and eel grass (Zostera marina), both of which are very abundant in shallow streams and bays along the eastern coast. The two freshwater forms are waterweed (Flodea canadensis) and tape grass (Vallisneria spiralis), which grow in ponds and canals thruout much of eastern North America. Tape glass is also called "wild celery" because it is the favolite food of the canvasback duck. The pollination of tape grass and waterveed is so very remakable that it must be briefly described. The flowers are dioecious, that is, the staminate and pistillate flowers grow on different plants. Botli kinds of flower's are formed nnder water near the base of the plants. The pistillate rise to the surface, upon which they float, anchored by a long thread-like stem. Tlie staninate flowers while still in bud break away from their stems, and rise to the surface, where they float about like little boats. Presently they expand; and when they drift against a pistillate flower the anther's come in contact with the broad leaf-like stigmas and pollinate them. Then the fertile flower is again drawn down into the watel by the spiral coiling of its stem, where its fruit is matured.

Flowers T'ollinated by Birds.-Bird-flowel's are flowel's pollinated chiefly or wholly by birds, as the cardinal flower, trumpet honeysuckle, and torcli lily. A typical bird-flower is the trumpet flower (Tecoma radicans), a woody vine, which creeps over trees and bushes in the woodlands of the South and bears scarlet, trumpetshaped flowers, two and a lialf inches long, which are often visited by humming birrls. There are three families of birds which are adapted to flower-pollination, the lumming birds, or 'Trochilidae; the sunbirds or Nectariniidae; and the honeysuckers or Meliphagidae. The liumming birds are confined to Nortl and South
America; the sum-birds to Africa and India; and the loneysuckers to Australia.

In the eastern Inited States the ruby throated liumming bird is the only species of humming bird. The number of humming bird flowers in this area is small, the most familiar examples being the trumpet honeysuckle, the rardinal flower, the trumpet flower, the painted cup, Carolina pinkroot, and the wild columbine. In the western United States some 15 species of humming birds are known. But they are most abundant in tropical America where more than 400 kinds have been described. In Brazil they are on the wing thruout the year, and Firitz Mueller thought that they visited most flowers. The bill is very long, in one species exceeding the length of the head and body taken together. The extensile tongue consists of two hollow cylinders or tubes, which can be thrust far out of the beak and draw the nectar out of long tubular flowers. Humming birds have the habits of insects and are often mistaken for hawkmoths, as they dart swiftly from flower to flower. They were first attracted to flowers, not by nectar, but by insects which feed on nectar; and altho they have become fond of sweets their. diet still consists largely of insects. The pollen is carried on the short feathers at the base of the bill. As the birds poise on the wing in sucking nectar, bird-flowers do not liave alighting or resting platforms.

Bird-flowers are usually bright red or scarlet-colored. It would be easy to enumerate more than fifty species of common bird-flowers, which display bright red lues. It seems, therefore, probable that these color's attract the attention of nectar-sucking birds. In Europe, where there are no humming birds and consequently no native bird-flowers, scarlet color's are noticeably absent.

Flowers Pollinated by Insects.-It is estimated that there liave been described in. the world up to the present time 132,584 different kinds of flowers. Kerner plares the number of species pollinated by the wind at about 10,000; but this, nndoubtedly, is an underestimate. Even if it is twice that number, there must be over 100 ,ono flower's which are regularly or occasionally risited by insects, or are self-pollinated. 
The insect-pollinated flowers are usually bright-colored, often sweet-scented, and commonly yield nectar as well as pollen. The pollen, unlike the dry dusty pollen of wind flowers, is thickly beset with teeth, spines, knobs, pits, and grooves, which cause the grains to adhere together, and to the bodies of insects. Water is always hurtful to it, and there is an astonishing number of devices provided for its protection, the mere description of which would fill many pages. It is probable that insects first visited flowers for the sake of the pollen, and that the function of secreting nectar was developed later.

Any part of the flower may secrete nectar, as the bracts, sepals, petals, stamens, and pistils; but most frequently it is secreted near the base of the styles. Its quantity varies from an almost imperceptible layer to several drops or even a spoonful. In a tropical orchid Coryanthes there collects in the hollow lip over an ounce avoirdupois.

Insects which are of importance as flower-visitors belong to four orders: the beetles (Coleoptera); the flies (Diptera): the moths and butterflies (Lepidoptera), and the bees, wasps, and their allies ( $\mathrm{Hy}$ menoptera). A few insects belonging to other orders occasionally are valuable as pollinators. Several species of bugs (Hemiptera) suck the nectar and are found on the flowers of the carrot, mustard, and aster families. A number of species of Neuroptera visit the flowers of the carrot family. The minute and active little insect known as Thrips is present in many flowers and sometimes effects pollination. It is very abundant on the flowers of the beet.

Beetles and Flowers. - It would be much better for flowers if they were never visited by beetles, for they cause more harm than benefit. As agents in pollination they are of little significance. The enormous devastation of foliage and bloom, the consumption and waste of pollen and nectar, the absence of hairs for holding pollen, and their indefinite manner of flight are factors which greatly reduce their value as pollencarriers. In New England 232 species of beetles belonging to 127 genera and 29 families have been collected by Lovell and frost on flowers. This is probably less than one-sixteenth of the total number of described species in this region. Why is it that so few feed on pollen and nectar? Their habits and forms in many instances answer this question; many are predaceous like the tiger beetles and ground beetles, or are scavengers; others are nocturnal or aquatic, or occur chiefly on the ground lurking beneath stones and boards, or living in the nests of other insects.

Beetles are usually found on open flowers with the nectar visible or nearly visible, as the cherries, cornels, New Jersey tea, and goldenrods. On the flowers of the New Jersey tea (Ceanothus americana) 58 different kinds have been collected. Most beetles feed upon both pollen and nectar and have been little modified in form as the result of their visits; but two remarkable genera, Gnathium and Nemognatha, liave acquired a slender suctorial tongue, like that of a butterfly, except that it cannot be coiled up. In one species it is nearly half an inch in length. Both genera live wholly on nectar, and thrust their tongues in and out tubular flowers with the precision and rapidity of bees.

Many beetles pass their entire life on a single kind of plant. The blue flag beetles in the larval state feed on the seeds of the blue flag, and, in the adult form, live in the flowers. Many beetles are exceedingly destructive to vegetation, as the rose chafer, the June bug, and the potato beetle.

Fly-Flowers.-The flies are of far greater importance as flower visitors than the beetles. Very many of the 8,000 North American species live largely or wholly on animal substances, but a large number also feed on pollen and nectar. The hover-flies (Syrphidae) and the bee-flies visit flowers which are similar to those attractive to bees; but for the more stupid flies there are pitfall-flowers, prison flowers, pinch-trap flowers, and flowers with deceptive nectaries, colors, and odors.

Flowers with nauseous or indoloid odors, due to the decomposition of some nitrogenous compound, are attractive to flesh or carrion flies. The petals are often fleshcolored, blood-red, or dull dark purple marked with lurid stripes or spots. To some observers they suggest putrefying flesh or reraying careasses: but in most instances 
the resemblance is not very apparent. Ther'e are also malodorous flowers which are yellowish or green. It is chiefly the nauseous odor's which draw to flower's carrion or dung-flies belonging to the genera Musca, Lucilia, Calliphora and Sarcophaga. Many strong-scented odors are also attractive to flies. Common carrion flowers are the carrion-flower (Smilax herbacea), the purple trillium, and the water ar'un (Calla palustris).

The spotted arum (Arum maculatum) is a prison flower, and, like all the Aroids, has an offensire odor. Small flies can easily pass downward into the bulbous cavity at the base of the sheathing leaf, or spathe, but for a time are prevented from returning by the ring of bristles inclined downward. After they are covered with pollen the bristles wither and the midges escape. As many as 1,000 midges may be imprisoned in a single spathe. The common Jackin-the-Pulpit, or Indian turnip, is a pitfall flower. The inner side of the spathe or "pulpit" is smooth, shining, and very slippery. When little moth-like flies (Psychoda) rest on this polished surface they cannot get a foothold, and fall into the chamber below. The staminate and fertile flowers are on separate plants. The staminate flowers are visited first since they bloom first. As the spathe withers, the inner surface relaxes and becomes rougher, enabling the little visitors, now loaded with pollen, to escape and fly to the pistillate flowers. The spathes of the latter wither less promptly, and inany of the little flies perish in the chamber. Another prison flower is the Dutchman's pipe.

The bee-flies (Bombyliidae), which are often mistaken for bees, live wholly on nectar, but the Syrphid or horer-flies (Syrphidae), feed on both pollen and nectar. They are very common risitors to flowers and are nsually dotted or striper with yellow. In New Zealand where there were, at the time of their discovery, 110 bumblebees nor honeybees and only a few solitary bees, flies were the most important visitors among the native insects.

Butterfly-Flowers.-Butterflies were called by Jean Paul "the flowers of the air." Is they do not collect pollen but feed on nectar alone they are of far less importanee as pollinators than bees, and much less constant in their visits. The tubular proboscis or tongue, which is carried coiled beneath the hearl, is formed by the extension of the blades of the maxillae, or second paix of jaws, which are held together by minute hooks.

Common butterfly-flowel's are the pinks, various primroses, lilies, and orchids, and some species of phlox. The floral tubes are so long that the nectar is far beyond the reach of bees. It is also noteworthy that the color of butterfly-flower's is usually red, the color of many butterflies; but in the genus Phyteuma there oceur blue butterfly-flowers which are visited by blue butterflies.

Butterflies do not confine their visits to butterfly-flowers, but visit a great variety of blossoms. They experience more or less difficulty in sucking nectar from flat surfaces, and consequently prefer tubular flowers. But no flowers are so frequently visited by butterflies, as social flower's of the type of the Compositae, to which 40 to 60 per cent of their visits are made. Clouds of butterflies often hover ovèr a clump of purple thistle-heads, or the yellow flowers of elecampane (Inula Helenium), or the iull white clusters of the thoroughwort. Butterflies often rob flowers of their nectar thru crevices or openings in the corolla without rendering any service in return.

Nocturnal or Hoth-Flowers.-Nocturnal flowers are adapted to pollination by moths, chiefly hawk-moths. In their relation to flowers moths may be divided into two groups, the highly specialized hawk-moths (Sphingidae) and the other moth families. Amoug the smaller moths frequently obsenved on flowers are the measuring moths, leaf-rollers, owlet moths or noctuids, and the teneids. Few of them are common floral risitors or of much significance in pollination.

The yuccas or Spanisl bayouets, liliaceous plants, which are widely ristributed in this country and Mexico, are entirely dependent for pollination on little teneid moths of the genus Pronuba. The large creamy-white flowers are borne in magnificent clusters, which never fail to excite arlmiration. Is the large bell-shaped flowers hang downward and the stamens are longer 
than the pistils self-pollination is impossible. The very existence, therefore, of the yuceas depends on the little moths of Pronuba. Soon after twilight falls the motl flies from flower to flower, and alone of all the thousands of moths in the world gathers a ball of pollen. Then she lays her eggs in the seed-vessel, after which she climbs the pistil, and stuffs the ball of pollen into the hollow formed by the stigmas. Apparently she deliberately pollinates the flowers in order that they may produce seed. If she failed to perform this service to the plant her offspring would perish for want of food. While this almost incredible act of pollination is probably the result of instinct not intelligence, its origin is very difficult of explanation.

There are about 100 species of lawkmoths in this country. They are distinguished by their swift impetuous flight, their size and sombre but liandsome garb of tan, brown, and gray colors. As flower pollinators they easily surpass all other motlis and the butterflies. The rapidity of their flight is astonishing, and a species of Macroglossa has been seen to visit several hundred flowers in a few minutes. Common hawk-moth flowers are the climbing honeysuckle, the evening species of tobaceo, thorn apple, the white lilies, several species of gentians and orchids, and the sweet-scented Gardenia. Nocturnal flowers are usually white or yellow, as bhe and red would be nearly invisible in the evening shadows.

Bee-Flowers. - As pollinators of flowers the bees far surpass all other insects. Unlike all otlier insects they feed their brood with pollen, and they are thus wholly dependent on flower's for food both for themselves and their young. As the result of their great industry and mental acuteness there have been developed thousands of flowers which are adapted to their visits and are in consequence called "bee-flowers." They have the nectar deeply placed where it cannot readily be pillaged by ants, beetles, and flies, and are often irregular in form. (The purpose of these odd and and sometimes bizarre forms is to compel the bee to pursule a fixed patl to the nectar; so tlat pollination may be effected witli greater certainty.) Finally they are very often blue or red in color.

The legume family, or Leguminosae, includes a great number of common beeflowers, as the pear, bean, locust, alfalfa, clover, vetch, red-bud, partridge pea, sainfoin, lupine, and sweet clover. The flowers bear a crude resemblance to a butterfly, as in the sweet pea. For the most part nine of the ten stamens unite to form a tube at the bottom of which lies the nectar. Four of the petals interlock around this tube, while the fifth, called the standard, is broad and erect and brightly colored to attract the attention of insects. The two lower petals enclosing the stamens form the keel or carina, and the two lateral petals are termed the wings. In order to obtain the nectar a bee rests on the two wing-petals, braces its head against the standard, thus pushing downward the keel, and exposing the opening in the staminal tube. When the keel is pressed downward, the pollen is placed on the under side of the bee's body in four different ways.

1. Elastic apparatus: 'I'he stamens and the pistil project from the keel as long as the bee remains on the flower, and then return within the keel, as in sweet clover, white clover, alsike clover, and sainfoin.

2. Explosive apparatus: The stamens and pistil suddenly spring out of the keel but never return within it, as in alfalfa and tick-trefoil. Only one effective visit is possible.

3. Pumping apparatus. A small amount of pollen is pumped out of the end of the keel, each time a bee pushes it down, by the thickened ends of the stamens, as in the lupine.

4. Brushing apparatus: A brush of hairs on the pistil sweeps out a small amount of pollen from the tip of the keel, as in the pea, bean, locust, and vetch.

In the mint family (Labiatae) and the figwort family (Scroplunlariaceae) there are many two-lipped bee-flowers. The larger flowers often mimic the heads of reptiles, animals or inanimate objects, as in the turtlehead, monkey-flower, snapdragon, toadflax, foxglove, shoe-flower, sculleap, painted cup, and dragonliead. In these flowel's the stamens and pistil lie under the upper lip, and the pollen is placed on the back 
of the bee, or the opposite of the arrangement in the pulse family. In nearly all species the stignia is toucher fir'st so that cross-pollination is ensured. Other peculiarshaped bee-flowers are the larkspur, monkshood, Dutrhman's breeches, (Dicentra), bleeding heart, climbing fumitory, the jewelweed, fringed polvgala, blue riolet, and rarious orchinds.

In the heath and blueberry fanilies there is another g'reat group of bee-flower's, bnt unlike the members of the pulse and mint families, the species are all shrubs and trees. The Rhododendrous and Azaleas are showy bumblebee flowers, but the wheelshaped flowers of the mountain lanrel are readily pollinated by smaller bees. The heaths, fetterbush, Andromeda, leather-leaf, sourwood, the blueberries, and luckleberries have small white or pink bell-shaped or urnshaped pendulous flowers, which are adapted to bees, over which pollen is sprinkled from pores in the ends of the anthers.

As the bumblebees have much longer tongues than the honeybees, in some species more than twice as long, there are a number of bumblebee flowers, or flowers with the nectar so deeply concealed that bumblebees alone of bees can reach it. Among the more common bumblebee-flowers are the led clover", larkspur, columbine, monkshood, snapdragon, the wood ebony, the Rhododendrons and many lioneysuckles, gentians, and orehids. See Bumblebees and ReD Clover.

It is a remarkable fact that bee-flowers are more often red and blue than yellow or white. In the northeastern States of 34 species of violets 17 are blue, 4 blue purple, 6 yellow, and 7 white. Of 197 species belonging to the pea family (Papilionaceae) 24 are blue, 88 blue purple, 13 red, 33 yellow, and 39 white; of 120 species of the mint family 33 are blue, 12 red, 4 yellow and $2 t$ white. In the German and Swiss floras there are 482 bee-flower's, of which 330 are red, violet, or blue, and 152 white or yellow. Honeybees ancl bumblebees have been observed to make 20 per rent more visits to red and blue flower's than to yellow and white flowers. So keen an observer as the honeybee can easily

* In later vears it has been discovered that honeybees are doing most of the pollinating of red clover. learn to associate hlue coloring with the flower's most likely to supply it with nectar.

Honeybees by no means restrict themselves to bee-flowers, but visit all flower's with nectar accessible to them, as well as many flower's which yield only pollen. Under Fruit Blossoms the great value of the honeybee in pollination has been shown in detail. It is an indisputable fact that a large number of trees and shrubs will not produce fruit unless cross-pollinated. The importance of the honeybee in this work cannot be overemplasized. The fruit culture of the future must be largely dependent on the domestic bee, the only agency in crosspollination that can be controlled by man.

The wild bees are wholly inadequate in numbers to pollinate the vast areas devoted to many crops, which are more or less sterile in the absence of cross-pollination. The production of seed by buckwheat, alsike clover, sweet clover, red clover, and sainfoin is largely dependent upon the honeybee.

North America has been called a natural garden, so abunclant are its native fruits. But in the absence of cross-pollination our native plums, cherries, blueberries, luckleberries, currants, gooseberries, and seores of other wild fruits are largely or wholly barren. Many ornamental flowers both wild and cultivated are also largely dependent on eross-pollination as Wistaria, laburnum, calceolaria, foxglove, pansy, geranium, nasturtium, passion flower, abutilon, mountain laurel, primrose, snapdragon, and many orehids. There are likewise a great number of plants with ineonspicnous flowers which produce no seed in the absence of erossing.

Finally, if erossing between different species has played as important a role in the development of the flowering plants, as Lotsy and Jeffrey believe, then a great number of forms which have been regarded as distinct species are hybrids. Cross-fertilization is every year taking place on an extensive seale, and under farorable.conditions new species arise. Thus not only in the development of the great group of flowering plants( Angiosperms) has the honeybee been a most important factor, but its services in maintaining the productiveness of many species are inestimable. 
Bibliography. -The reader who desires to pursue the subject further is refer'ed to The Flower and the Bee; Plant Life and Pollination by John H. Lovell, Chas. Scribner's Sons, N. Y. The bibliography of pollination is very extensive. In 1906 Knuth's Handbook of Flower Pollination listed 3748 titles. Among the more important investigators are Sprengel, Darwin, Mueller, Delpino, Kerner, Loew, Knuth, and Asa Gray. Their books are now out of print, but may be consulted in the larger libraries.

\section{POLLINATION OF FRUIT BLOOM.}

\section{See Frumt Broom.}

PRICKLY PEAR (Opuntia).-There are between fifty and sixty species in the southwestern States. Succulent plants. with jointed branched stems, often spinebearing; leares small and awl-shaped: flowers wheel-shaped, without floral tube. usually yellow, or vellow inside and red outside. Thruout southern and western Texas Opuntia Engelmanii is common, and under favorable climatic conditions which occur about once in four years, yields a large surplus. Extremely hot and humir weather is required during the blooming period. The honey is rery heavy and almost viscous in consisteney, laving a ropy appearance when it is extracted. The color is light amber and the flavor very good. 'The prickly pear is an important source of pollen, and one of the most dependable of Texan honey plants for this purpose.

\section{PRIORITY FIGHTS.-See OVEIRTOCK-} ING.

PROFITS IN BEES.--This question is a hard one to answer, as so much depends on the locality, the man, and the number of bees to the area.

Considering the average production of the poor and the good beekeepers, in the northern States, in what is known as the rainbelt, one might perhaps expect to get anywhere from 25 to $50 \mathrm{lbs}$. of comb honey, and perhaps from 25 to 30 per cent more of extracted. There will be some seasons when he might secure as mnch as 200 lbs. or more on an arerage, and occasional seasons when there would be no surplus of comb nor extrarted, and the bees would require to be fed. Taking one year with another, the ordinary beekeeper ought to ar- erage about io lbs. of comb honey, on a "onservative estimate, provided he has reasonable skill and love for the business. The fonb honey might net him, deducting the expense of selling, from 10 to 25 cents: the extracted, from 7 to 12 . These figures do not include the labor of producing the honey nor the cost of the fixtures. The cost of the equipment, exclusive of sertions and foundations, ought to be sufficient to cover. 10 to 20 years if no increase is made. Suppose the comb honey be put at 50 lbs. as the average, and the price secured 15 cents net. The actual money one would get from the rommission merchant or grocer might be about $\$ 7.50$ per colony; but out of this he must deduct a certain amount for labor, and 10 per cent on the cost of equipment, to be on the safe side.

With only a few bees the labor need not be considered, as the work could be performed by some member of the family or by the man of the house, who could, during his spare hours, do a little with bees. and work in his garden. In case of one. two, or three hundred, the labor item must be figured. The larger the number crowding the available territory, the smaller the profit per colony. A rough estimate for an apiary in a locality not overstocked, not including the labor on the $\$ 7.50$ actually received for honey sold, ought to leave a net profit of somewhere about $\$ 5.00$. This would be on the basis that the locality did not require much feeding in the fall. If feeding was found to be necessary, 50 cents more might have to be derlueted, making a net profit of $\$ 4.50$. On this basis it will be seen that the profit in one season ought to pay for the hives and supers in two vear's, or come very close to it, leaving the investment good for ten or more rear's. If it is figured that way the ten per cent neer not be added. For a professional man, or one who has other business, even these returns are not bar: for if lie secures only enough for family use, the diversion or change to relieve the tired brain is worth something.

The ruestion as to whether one should keep few or many bees will depend upon many conditions: but the principal one is the ability of the man. Nany a person can handle a few chickens, and get good results: but when he runs the number up into 
the hundreds he meets with failure. Some have done remarkably well with a few colonies; but when they have attempted to double or treble the number they entered into a business proposition that proved to be too much for them.

Many years ago a neighbor cleared i thousand dollars from one acre of onions. It made him wild. He bought ten more acres of the same kind of onion land, going into debt for it, and expected to clear the following year $\$ 10,000$. When he managed the one acre he did all the work himself; but when he worked the ten acres he had to hire help. The help was incompetent, or did not understand. Onions fell in price; and at the final round-up that year he had a great stock of poor onions without a buyer. They rotted. He became discouraged, and lost all he had. .

A few persons, on account of a lack of experience or perhaps business ability, not understanding their own limitations and those of their localities, will plunge into beekeeping too deeply and meet with disaster.

Many a beekeeper has done well with four or five hundred colonies when he fails with twice that number. When he or members of his family ean do all the work everything goes well; but when he has to hire help, much of it incompetent, his troubles begin, and his profits are eut in two. Said one large producer, "When I had 3,000 colonies, and my boys and I did all the work, we made money; but when I increased my number to 7,000 , and hired help, I actually did not make as much money as when I had 3,000."

There are some men who are unable to get along with their help. There are others who, when they have good help, have no ability to plan the work for others.

If it were not for bee disease and robbing, the question of hired help would not be so serious. A poor man in a beeyard may make his employer a world of trouble and expense unless his boss can be with him constantly, and that is not always possible.

One may donble or treble the number of his colonies if he can plan his work ahead and then go along with the help, taking one vard after another. After a time one of the men may be competent enough to go to the yards and manage the other help; but usually a good man can make more money by running and owning the bees himself than by working for some one else. It is difficult, therefore, to hold such a man.

If one expects to expand his bee business, tho he does not have members of his family to help him, he will probably have to work on a profit-sharing basis-a moderate salary and a percentage of the crop. This creates in the man a sense of responsibility and ownership that makes him a better man than if he merely had to put in so many hours, and at the same time holds him. If the owner can go with the help to all the yards, it is not necessary for him to hire on the profit-sharing basis.

Assuming that the help question can be solved let us look at the side of expansion of the business. Let us assume a case. Here is a beekeeper who has 300 colonies. During the busy season he is comfortably busy. But during six months in the year his time is not very profitably employeda distinct loss; for it will take him only a short time, comparatively, to get his supers ready for the next season, nail his hives, repaint them, or do other preliminary work that can easily be done indoors and yet his interest or his rent and his living expenses are going right on. Suppose, for example, that this beekeeper has 600 colonies, or 1,000 ; that he has good business ability; that he has plenty of bee-range. Suppose lie scatters this number in 15 different yards, none further than 15 miles from his home, and a good part of them not over four or five miles away. In the busy season he will, of course, have to employ help. If he has the right kind of executive ability he will see that that help is profitably employed. When the rush of work is over he will look after the marketing of the crop, put the bees into winter quarters, perhaps doing the work himself with the occasional help of one man, and a machine. In cold weather he can devote all of his time profitably in preparing for the next season. While he is operating $1,000^{\circ}$ colonies it costs him no more to live; the same automobile that will earry him to two or three hundred will carry him to the other seven or eight hundrer. If he is running for 
extracted honey, the same extractor, un(atpping-knives, and smokers can be used at a central extracting-station. He is thus enabled to put his invested capital where it will be earning money for liim all the time in the busy season instead of eating. up interest part of the time. Let it be assumed that some of his swarms get away from him; let it be assumed also that some of the work is not done as well as when he had only 300 colonies; but he has increased his honey crop by three times, possibly, and has increased his actual operating expenses only to the extent of the help that he has to pay for, extra hives, and sugar to feed. An extra man and a boy three montlis in a vear-the men at $\$ 4.00$ each and a boy at $\$ 2.00$ per day-would make his expense $\$ 450$, counting 25 working days to the month. To this should be added $\$ 70$ for extra team or antomobile truck hine. The cost of the extr'a 700 colonies with hives and supers divided by ten (assuming that they would last ten years) would be $\$ 840$ more, or $\$ 1360$. But there must be added $\$ 350$ more for sugar for feeding and $\$ 700$ for sections, foundation, and shipping cases making $\$ 2,410$ as the total added expenses for the 700 extra colonies. Say he is producing comb honey, and that he can average 35 lbs. per colony. If this nets him 15e he would get from 300 colonies $\$ 1,575$. If he has 1,000 colonies his gross income will be $\$ 5,250$ by adding only $\$ 2,410$ to his general expenses.

This is a supposable and a possible case. But it shors that the operating expenses will not be proportionately increased if the number of colonies be doubled or trebledall on the assumption, of course, that the beekeeper has the necessary skill and business ability.

PROPOLIS (From the Greek; pro, before, and polis, eity, referring to its use in partially closing the entrance or gateway to the bee commune or eity).Propolis is a gum gathered by bees from a variety of plants, but especially from the buds having some sort of gum or sticky substance. As it occur's in the beehive, it is dark reddish brown in color, and resemibles the pitch of commerce. It has an aromatic odor similar to that of the buds of the balm-of-Gilead, is extremely brit- the, melts at about 150 degrees $\mathrm{F}$., is partly soluble in alcohol, only slightly soluble in turpentine, but readily dissolves in ether and chloroform. When wax and propolis are melter in the same receptable the liquid wax, being of less specific gravity, rises to the top and the liquid propolis sinks to the bottom. Propolis quickly sinks in water.

Bees do not pack propolis in the cells, but it is applied at once to some portion of the hive. When newly gathered it is rery soft, and in an almost liquid state is forced by the bee's tongue into cracks and crevices, or spread as a varnish orel the surface of combs. It is found in every part of the hive, but is especially abundant around the edges of the cover and at the ends of the frames, often completely filling the space between the ends of the top-bar's and the front and back walls of the hive. It occurs in many parts of the hive, where it is entirely useless, as on its walls. bottom-board, middle of the cover, and on the frames and sections. In some cases it is found in pellets or small masses, in other's in narrow bands. It is stated that empty combs, which are not immediately used for brood-rearing or honey, are given a thin coating of propolis to preserve them. The spaces between the wires of queen-exchuders are often partially filled with propolis, but wax is also used for this purpose and is often covered with propolis. English beekeepers check propolizing' by rubbing chalk orer the edges of frames and covers, and whitewashing the interior of the hive is sometimes practiced for the same purpose. It is seldom, however, that any measures to prevent propolizing are necessary.

Small animals which enter the hive are stung to death, and are then sealed up in a wall of propolis. Snails, lizards, mice, and even small snakes, have been embahned in an impervious coating of glue.

If the sections are left on the hive too long, the bees will not only cover the woodwork but will also rarnish over the whole surface of the white cappings, rendering the honey almost unsalable. The best course is to take off the supers as soon as the sections are capped over, for during a strong flow of honey little propolis is 
gathered. But it is almost impossible to keep the sections entirely free from it. The sections slould be so packed in the super's as to leave few erevices and no more surface than necessary accessible to the bees. The outside of the sections may be covered entirely by -using holders having the top and bottom of the same width as the section frames. Propolis may be rearlily remover from the boxes, and partially from the surface of the combs, with sandpaper.

The quantity of propolis brought into the hive depends partly upon the race of bees, and partly upon the location. Caucasian bees use propolis much more freely than Italian races, and may nearly close the entrance to the hive with pillars or buttresses, between which are left spaces so narrow that only one bee can pass at a time. In Colorado the narrow-leared cottonwood (Populus angustifolia) furnishes so large an amount of propolis that a grove of these trees near an apiary is an objection. The gum is a bright reddish color, and exudes on the buds in such large quantities that a bee can obtain several loads from a single bud. The bees continue to gather this gummy substance long' after the leaves have fallen.

In the East the burls of the balsam poplar (Populus balsamifera) are believed to be one of the chief sources of propolis. The larger buds usually have on the ends small drops of yellow gum. Bees gather the gum with their mandibles, and it is packerl and calried in the pollen baskets in the same way as pollen. In its removal within the hive the bee is said to be aider by other workers. Huber placer some branches of a wild poplar tree before the lives of his apiary, and the bees alighter on them and remover the gum with their mandibles in threads, which were loaded first on one liind leg and then on the other.

At Banning, California, and Tacoma, Washington, propolis has been reported to produce an eruption similar to that causert by poison ivy. Poison ivy (Rhus Toxicodendron) and poison oak (Rhus diversiloba) are found in both States and are freguently visiter by bees for nectar. Probably also propolis was brought into the hives from these shrubs. 'The burning and intense irritation caused in such cases may be entirely relieved by two or three applications of sweet spirits of niter.

While propolis may be gatherer at any time during the summer, it is gatherer most largely in the fall, when the bee's instinct impels it to prepare for cold weather. During the honey flow very little if any propolis is brought in. In the absence of a natural supply of propolis bees may gather a supply from the parts of old hives, where it has been softener by the heat of midsummer. Darlant relates that in the vicinity of Matamoras, Mexico, where propolis seemer to be scarce, he saw bees collecting green paint from window blinds and pitch from the rigging of a vessel in the harbor. Bees are attracted by the smell of rarnish and will alight on a newly rarnisher object in large numbers. The superstition, formerly prevalent, that bees, in sorrow for the death of the beekeeper, would follow his body to the grave, probably gained eredence, from instances where bees were seen working on the rarnish of the coffin.

A small quantity of propolis may be remover from glass with alcohol. Frames and separators may be wholly or partly cleaned by dipping, in a wash-boiler filled with boiling water and lye: While the separators will come out entirely clean, it is usually necessary to scrape the woorlen frames. With a large boiler many frames and separators may be cleaned at one time; supers and lives may also be cleaned in the same way. Propolis may be prevented from sticking to the finger's by the use of raseline, or. oil, or a pair of light cotton gloves. It can easily be remover from the hands with alcohol, gasoline, and lye.

Propolis was known to the ancient Romans and is deseriberl by Vilgil in the foirth book of the Georgies. Surprisingly little progress has been made in oul knowlerge of the origin of this resin since those early times. Many modern books on bee culture refer to it very briefly, and compared with the collection of pollen relatively few observations have been marle. As recently as 1911 an article was published in which it was asserted that the be- 
lief that propolis is derived from the buds of shrubs and trees is entirely erroneous: and that it is a by-product arising when brood food is prepared by the nurse bees. Small drops of balsam were said to be forced out thru the mouth of the bee and deposited in corners or crevices of the hive. This theory is clearly imaginary and not supported by facts, since propolis is present in queenless colonies and in hives in which no pollen is fed to brood; but it is not without interest since it calls attention to the imperfection of our knowlerge of its origin and the few reliable observations available. Further investigation is greatly to be desired.

Under the conditions of modern bee culture the collection of propolis is apparentIy useless to the bees and a disadvantage to the beekeeper. The various parts of the hive are glued tightly together so that they are removed with difficulty; the combs are frequently stained a dark color; and the sealing of all crevices may prevent proper ven- tilation causing the interior of the hive to become damp, and ice to form in cold weather. But in the early history of the honeybee, long before the beginning of beekeeping, when honeybees built their nests in hollow trees or in cavities in the rocks, the use of propolis was undoubtedly of great benefit both in excluding rain and cold, and also ants. Altho no longer beneficial under proper methods of beekeeping, the habit still survives; and, when bees are not engaged in gathering nectar, they still continue to seek for gums and resins.

Propolis is the base of an important antiseptic preparation used by surgeons. In a hospital where 58 surgical cases were treated with propolisinvasogen (Pearson \& Co., Hamburg) there was not a single failure. The results were much less favorable in cases where this preparation was not used. It is highly commended as a domestic remedy for wounds and burns. It is also claimed that it makes an excellent polish for wood and leather.

\section{Q}

QUEEN-REARING.-Before this subject is read the subject of QueENs further on should be gone over carefully. This will unake queen-rearing more easily undelstood.

As a general rule, extensive honey-producers believe that it is better and cheaper to buy their queens than to attempt to raise them, for the following reasons: (1) When they buy queens they introduce new blood in their yards; (2) in order to raise queens it takes a large amount of skill, time, and equipment, which, if devoted to the production of honey, would yield larger results in dollars and cents; (3) there is often a predominance of black drones in their locality, so much so that their matings would produce hybrids. There are other large producers who do raise some queens of their own, such stock coming from colo- nies showing the best, average in honey production year in and year out. When sivarming is controlled by caging the queen, requeening can be effected without very much loss of time. Moreover, the best of cells can be reared during the swarming season.

There are certain of the smaller producers who raise their own queens, if for no other reason than for the fun of it. The whole process, from start to finish, is interesting and fascinating. For the benefit of these and others, some of the fundamental principles as well as the methorls that are used by our best queen-breeders will be shown. But before the breeder launches into this general subject, he should be reminded again to turn to QuEENs. After having read that he may then consider queen-rearing. 


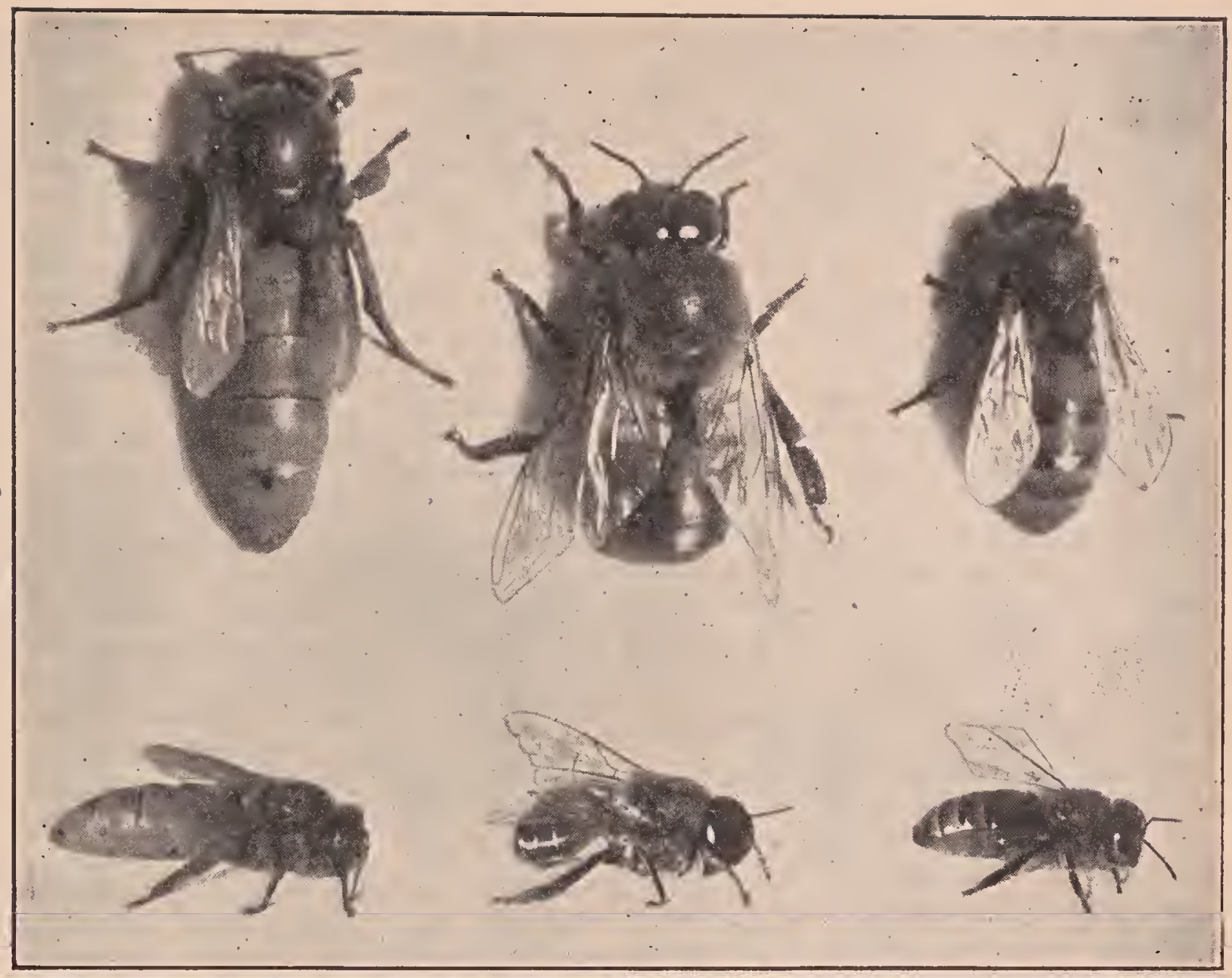

Queen drone, and worker

(ONDITIONS FALORABLE ANI) UNFATORABLE FOR REARING QUEENS.

Bees will build queen-cells, and rear young queens, when preparing to swarm (see SWARMING), when supersering an old. failing queen, or when their queen is lost thru accident or remover by the beekeeper.

Some hold that the best queens are those that are reared either during the swarming time or when the bees are about to supersede an old queen soon to fail. At such times one may see large beautiful queencells, looking like big peanuts, projecting from the side of the comb. The larve in such cells are lavishly fed with royal jelly: and when the queens finally emerge they arc usually large and rigorous.

As already stater there is one class of cells that bees rear when thev are about to supersede an old queen. When she is two or three years old she begins to show signs of failing. The bees recognize the fact that their own mother will soon die, or at least need help from a daughter, and very leisurely proceed to construct a num- bei of cells, all of which are supplied with larvæ, and fed in the same lavish way as those reared under the swarming impulse.

Unfortunately one can never determine in advance when the bees will rear supersedure cells, and it may be true that the queen about to be superserled is not desirable stock from which to rear. In like manner it may be that cells reared under the swarming impulse, if from poor stock, should be rejected; because it is certainly unwise to rear queens from any thing but the very best select stock. All of the finest swarming-cells from good queens can be reserver and kept in a warm place. Queens two or three years old can he destroyed and their colonies supplied with one of these rells. One may have good queens even three or more years old, but it is hardly probable. The majority of honey-producers think it profitable to replace all queens two years old, while a crood many make it a practice to requeen all colonies having queens one year and over.

While these swarming-cells produce the 
rery best queens, it may not always be conrenient to requeen during the swarming season, which in some localities may be a very bad thing to do, owing to the interruption that it makes in the regular production of honey; for some believe that a good many colonies will not do as well in honey-gathering when they are queenless. If good swarming-cells are available, howerer, they may be given to nuclej in order to save them.

Among the several systems of rearing queens, the one put out by Mr. Doolittle a few years ago forms the basis of some of the best now in vogue. It is very simple, requiring no special tools more than one can improvise for himself. Thoroly understanding this, the reader will be in position to carry out the more adranced ideas put forth by others.

\section{THE DOOLITTLE METHOD OF REARING QUEENS,}

While Mr. Doolittle's system seems to be artificial he endeavored to make his methods conform as nearly as possible to $\mathrm{Na}$ ture's ways. It is of prime importance in the rearing of queens to bring about conditions that will approach, as nearly as possible, those that are generally present during the swarming season or supersedure at a time when the bees supply the cellcups lavishly with royal food. One of the first requisites for cell-building is rery strong colonies; second, a light honey flow, or a condition almost analogous. viz., stimulative feeding if the honey is, not then coming in. Queens reared during a dearth of honey, or queens from cells reared in nuclei, are apt to be small. The mother's that do their best work are those that are large, and capable of laying at least from 3,000 to 4,000 eg's per day.* A queen that is incapable of this should not be retained. A colony with a good queen might earn for its owner in a good season $\$ 5.00$

\footnotetext{
* It is not necessarily the large queens which do the hest work. Also 3,000 to 4,000 is hardy the maximum of "best", queens. A Langstroth comb has approximately 6,000 cells, and good queens will not infrequently fill all of one and nart of another in 24 hours. This summor I saw 14 colo. nies, each with two 12 -frame chambers for the queen; and in several which I inspected. the rueens had the whole 24 frames filled with brood in various stages. This figures out like this: 24 times 6.000 oruals 144000 cells of brood. Divide this by 21, the time from egg to mature bee. and the result is 6837 for a day. Allowing for some pollen (and there was not much in those 24 combs) the figure 6000 rould not have bean far from what those queens were doing.-A. C. Miller.
}

to $\$ 25.00$ in clean cash. In the same season the same colony (or, perhaps, to speak more exactly the same hive of bees), with a poorer queen, would bring in less than half that amount. A queen that can average 2,000 or 3,000 eggs a day at the right time of the year, so that there will be a large force of bees ready to begin on the honey when it does come, is the kind of queen that should be reared.

The old way of raising queens was to make a colony or a nucleus queenless; wait for the bees to build their own cells; then distribute them to colonies made queenless beforehand. This plan is very slow and wasteful, and, worst of all, results in the rearing of inferior queens. Mr. Doolittle took advantage of Nature's way to such an extent that he was enabled to rear a large number of queens from some selected breeder, by increasing the number of cells ordinarily built; for the prime requisite in queen-rearing is cells-plenty of themthat will furnish good, strong, healthy queens.

The first step in queen-rearing is to provide cell cups. Many times, when an apiarist is going thru his yard he can cut out embryo cell cups. These can be utilized at some future time for the purpose of grafting. But such cells are not generally found in large numbers, and after they are gathered, are exceedingly frail, irregular in shape, and will not bear much handling.

HOW TO MAKE DOOLITTLE CELL CUPS.

Mr. Doolittle was among the first who conceived the idea of making artificial cell cups that shonld not only be regular in form but of such construction as to stand any reasonable amount of handling. Contrary to what one might expect, such cells are just as readily accepted by the bees as those they make in the good old-fashioned way; and, what is of considerable importance, they can be made in any quantity by one of ordinary intelligence.

Mr. Doolittle took a wooden rake-tooth, and whittled and sandpapered the point so that it was similar in size and shape to the bottom of the ordinary queen-cell. Preparatory to forming the cells he had a little pan of beeswax, liept hot by means of a lamp; also a cup of water. Taking one of these cell-forming sticks he dipped it 
into water, after which he plunged it about 9-16 of an inch into the melted wax. He then lifter it up and twirled it at an angle (waxed end lower) in his fingers. When cool he dipped it again, but not quite so deep, and twirled it as before. He proceeded thus until the eup was dipped seven or eight times, but each time dipping it less deep, within 1-32 inch of the previous dipping. The main thing is to secure a cup haring a thick heary bottom, but which will have a thin and delicate knife edge at the open top, or at that point where the bees are supposed to begin where man left off work. After the last dipping is cooled, a slight pressure of the thumb loosens the cell cup slightly. It is then dipped once more, and before cooling it is attached to a comb or stick designed to receive it.

GRAFTING CELLS.

A small particle of royal jelly is inserted in every queen-cell. The amount in each should be about equiralent in bulk to a double-B shot, said Mr. Doolittle. But it lias been found that a much less quantity will answer. Out of an ordinary queen-cell well supplied with royal jelly one can get enough to supply 20 cups. This royal jelly slould come from some queen-cell nearly rearly to seal, as that will contain the most. It should be stirred to bring all to about

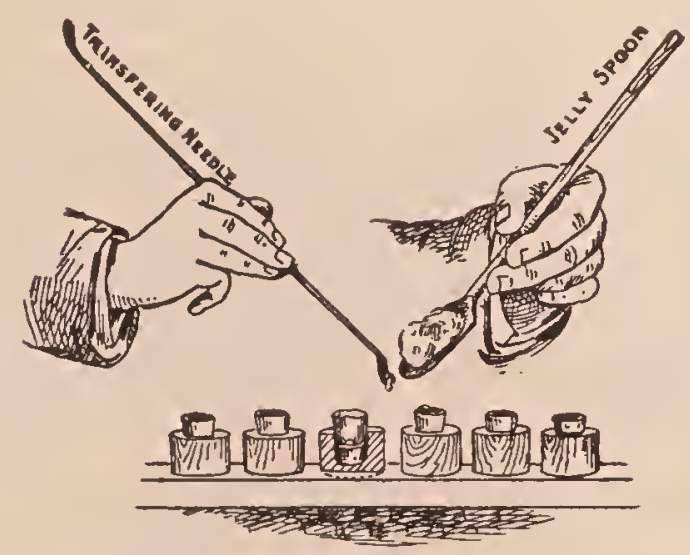

Supplying cells with royal jelly.

the same consistency, after which it may be dipped out of the cells by means of a stick whittled like an ordinary ear-spoon, or a toothpick.

The next operation is to take a frame of young larve just hatched from the eggs of the best breeding queen. Fach little grub should be lifted up with the aforesaid ear'-spoon, and gently laid on the royal food previously prepared in one of the cell cups. A larva should be given to every one of the cell cups in this manner, and when all are supplied they are to be put into the cell-building colony, to be explained later.*

\section{RELLING QUEENS IN LARGE NUMBERS.}

Thus far the original Doolittle system of rear'ing cells has been considered; and where one desires only a few for his own use he may find this method more conrenient than the one now to be described. But if he has any number to rear he should carry out the following plan. The method of preparing the colonies for cell-building will be the same.

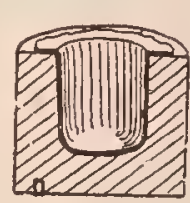

A

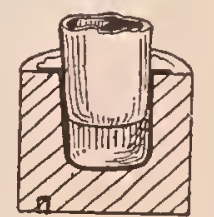

B
Cross-section of wooden cell-holder; cell cup partially pushed into place.

Instead of dipping the cells one by one with a stick, or dipping several sticks at once, compressed cell cups are marle on a plan originally devised by E. L. Pratt. With a suitable die, cells more nearly perfect than can possibly be dipped by the slow process already described are punched out at the rate of 2,000 an hour. These are furnished by dealers, and, generally speaking, it would be better to buy cell cups than to attempt to make them by the dipping process.

To facilitate general handling, the modified Doolittle system calls for woorlen cellloolder's; which may, inder certain circumstances, be used as direct cell cups.

These are eylindrical pieces of wood, $3 / 4$ inch in tiameter, $5 / 8$ inch.long. A suitable drill of the same diameter as the compressed cell cup bores a hole into the end of the plug and nearly thru. One of the wax cups is then pressed down in the hole. A series of about a dozen of these plugs, each containing a cup is then stuck on a strip of wood by lot wax. The end of the plug

*This work should be done in an atmosphere of $80^{\circ}$. 
is dipped into hot wax and before it cools, it is applied to the wooden bar as shown. These wooden cell-holders can likewise be purchased by the thousand.

The compressed cups are forced into the hole in the cell-holders by means of a little plunger-stick. When enough of them have been prepared, and secured to a cell-bar by being pressed against the under side of the cell-bar, they are ready to be grafted. This process is much the same as that aiready described in the Doolittle method, except that a much smaller quantity of royal jelly is used, and special tools are provider

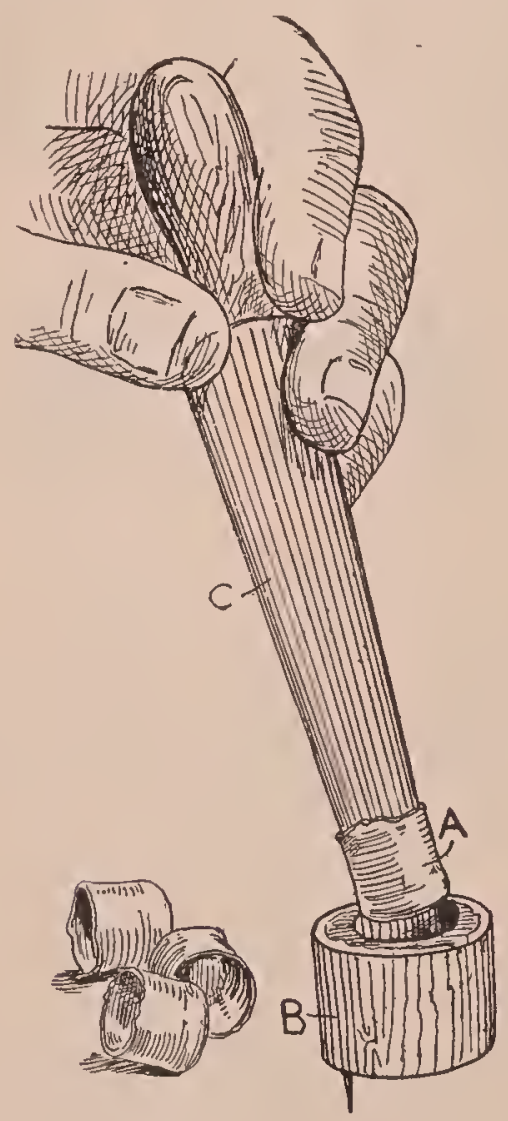

Manner of inserting cell cups in cell-holders.

for the purpose, these being obtained of the dealers. Sufficient royal jelly is gathered up from a series of cells, and the same is stirred with a special jelly-spoon. A spoonful is then held in the left hand, while the right hand uses the grafting-tool to take a speck of the royal jelly, about the size of the head of a pin. This is then placed in the bottom of one of the compressed cups. Other cups are treated in the same way until the whole series of cells is provisioned.

The next operation is to take a comb of very young larræ, just hatched, from a breeding queen. In an atmosphere not cooler than 75 or 80 degrees (the warmer the better) a young larva is scooped $\mathrm{Ol}^{\circ}$ lifted up out of a worker-cell with the flattened end of the grafting-tool, and deposited in the royal jelly of one of the compressed cups. This is repeated until all the

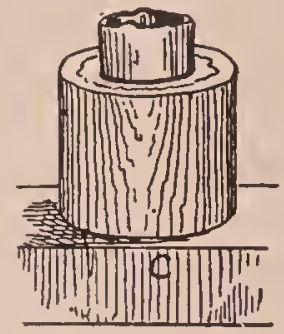

Cell-holder with cell in place.

cups are grafted. This royal jelly serves a double purpose. It affords a downy bed, so to speak, in which to lay the larva, and at the same time provides food until the bees can give it a fresh supply. Despite the claim that royal jelly is not necessary one will get more cells accepted by using it.

GETTING CELLS ACCEPTED AND BUILT OUT.

The average beginner will probably succeed best by giving grafted cells to a queenless strong colony. In about two days after making it queenless a bar of 15 cells (not more) inserted in a frame may be given. If no honey is coming in from natural sources, the colony should be fed in a manner to be explained. When conditions are right, nearly every cell, if not every one of them, will be accepted. By "accepted" is
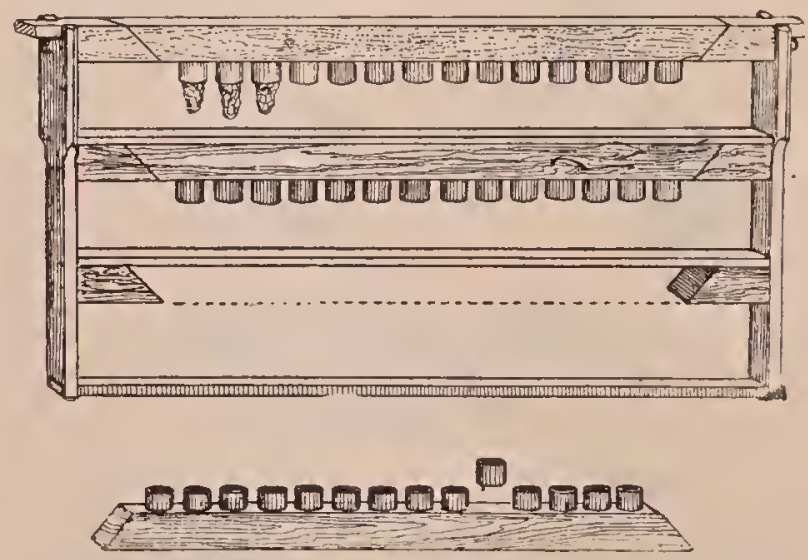

Hoffman frame with removable bars for cell. holders.

meant that the bees have begun work on them, and have added their own royal jelly. After being accepted they are given to the upper story of a strong colony, with an excluder between the two stories, to be completed. 
The question might be raised right liere, "Why not make these upper stories start as well as complete the cells?" For the simple reason that they will not start work of this sort except under the most favorable conditions; and the average queen-breeder has decided it does not pay to try to make the attempt. There should be one colony
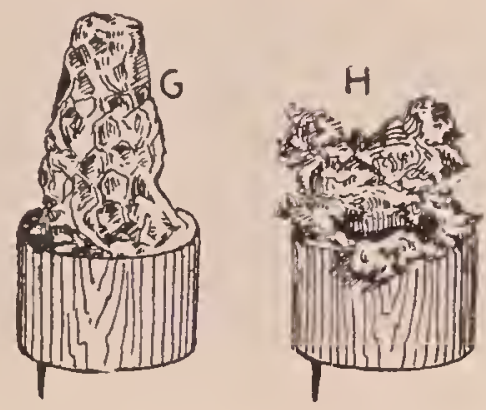

G, fully completed cell from holder; $H$, partially built cell torn away to get at the royal jelly.

to start the cells and another to complete them after they are accepted in another. colony.

After the first batch of 15 grafted cups have been accepted and removed, another. batch of 15 may be given, and so on the process can be repeated. But such cellstarting colonies should not be kept for such purpose more than three weeks, on account of the danger of laying workers. See Laying Workers.

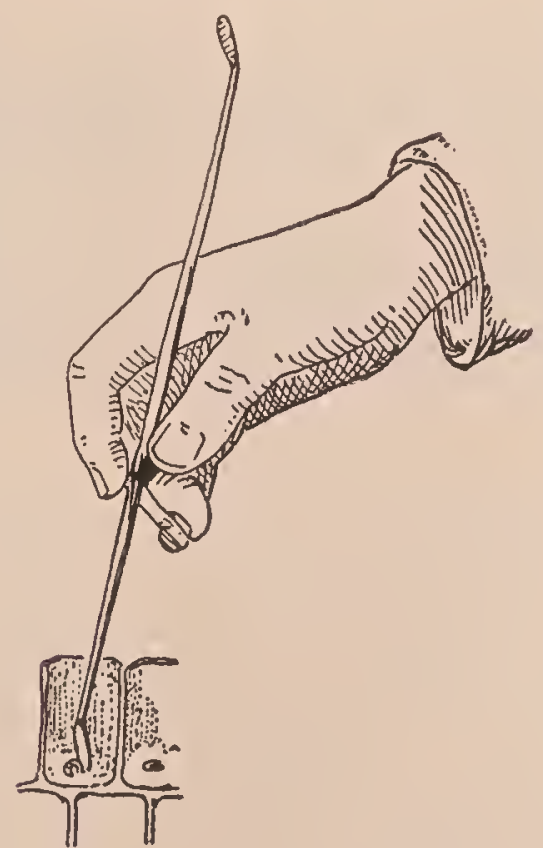

Lifting a larva out of a worker-cell.

In eight days after giving the first batch of grafted cells, it will be necessary to go over the combs very carefully and destroy any natural cells of their own; for if these are left in the hive the bees will do no work on the second batch of cells. In the meantime a virgin would emerge and trouble happen. Even after the first bateh of natural cells are cut out, it is advisable to go over the combs again in eight days, because a colony like this may steal an egg or two from some other colony.

Another excellent cell-building colony outside of the swarming season is one having a queen which it is trying to supersede. One or more such colonies will be found in a large apiary, but as a general rule the queen is hardly good enough to use as a breeder. Having found such a colony, begin giving it daily feeds at once, this being a requisite for the best results in cell-building with any colony, either with a queen or without one. This supersedure cell-building colony will not only draw out and complete one set of cups but several sets in succession; but it is best not to give any one such colony more than a dozen or a dozen and a half prepared cups at a time. Allow it to finish up one batch, and then, if necessary, give it another.

Just how far supersedure bees will continue to build out batches of cells, one after another, is not known; but if they are fed half a pint of syrup daily they appear to be willing to keep up the work indefinitely, in the hope that they will some dar be able to rear a virgin that will supplant the old queen that appears to be failing.

\section{THE FORCED-CELL-STARTING COLONY.}

There is still another plan used by queenbreeders to get cells accepted or started in a more wholesale way; and that is, make up a forced-cell-starting colony. This is done by making a strong colony queenless and broodless. The combs are taken out one by one, and shaken in front of the entrance. When combs are cleaned of bees it will be very easy to see any eggs. Combs having honey only are set back in the live. and with them two division-board feeder's. One is placed on each side and half fillerl with syrup; and an hour or two after the bees have been made queenless and broodless they will set up a roar; for witho it any brood or any possibility of producing it, they are in dire distress, and in just the right condition, psychologically, to rush upon grafted cups that may be given them. 


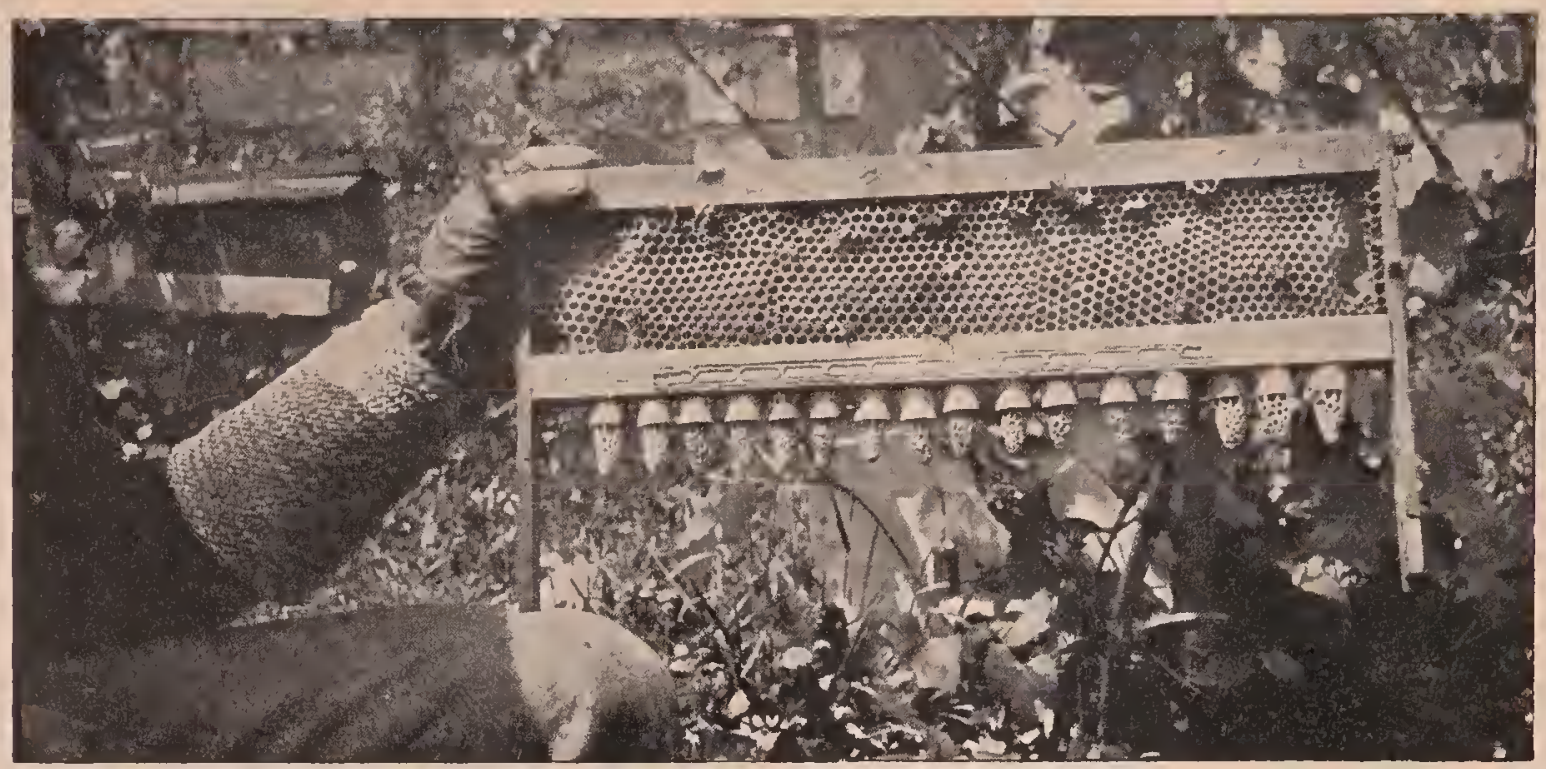

Fully completed queen-cells built on wooden cell cups here described.

The nurse bees are already supplied with pap; and with no young brood of any kind to feed they have royal jelly in any quantity to give the emps. A colony in this condition may be given 100 cells on two frames, which are placed in the center of the colony in places previously left vacant. If everything lias been done right, nearly every one of the cells will be accepted; but the attempt shonld not be made to make such a colony start a second batch. When the cells are accepted they are taken out and placed in an upper story of a cellbuilding (or, rather, cell-completing) colony next to be described.

While queenless bees will complete any cells given them, such cells will generally not be as good as those built under the swarming or supersedure impulse. For a cell-completing colony a two-story colony with an excluder between the stories is prepared. The lower hive contains the queen, but the brood is lifted into the upper story. The queen and bees below will begin rearing more brook. If no lioney flow is on, it is important to feed, because otherwise these cell-builders will tear down the work so nicely started in the other hive.

Under Feeding is described the Boardman feeder for slow feeding. After one feed is given another must be given the next day. If a rlay is skipper in feeding, the colony begins to feel that the honey flow has stopped, and apparently comes to the conclusion that there will be no neressity for continuing the work of cell-build- ing. When feeding stops, it will often destroy work nicely under way.

If feeding continues such cell-builders will take care of and build out about 15 cells at a time. When the first batch is sealed, another batch of accepted cells may be given, and so on the process may be continued thruout the season-provided, however, the colony is kept up to the maxinum strength by continuous feeding.

In about 15 days brood is again lifted from the lower to the upper hive and the combs from which brood has hatched above are put below. Brood must be kept above to keep cell-building going on.

\section{NURSERY CAGES.}

The illustration shows a batch of cells taken from one of these cell-builder's. In large queen-breeding establishments there will be 40 to 50 cell-building colonies kept constantly at work; but the ordinary beekeeper who desires a few queens of his own will not need to keep more than one such colony more than a few days.

The cells are now rearly to be placed in nursery cages. This, it will be seen, is practically a modified Alley cage. A surplus of cells often occurs in queen-rearing: - that is to say, a lack of queenless nuclei or colonies to take them. One should arrange to have more cells than he will probably be able to use, to provide for bad weather, when cells will be destroyed or young virgins will be missing. $\Lambda \mathrm{t}$ such a time, if one has extra cells or virgins that 
he can take out of a nursery, he can quickly make good the loss.

The nursery cage here shown has a large opening at the top to receive the wooden cell cup; the small hole in the lower righthand corner is filled with queen-cage candy

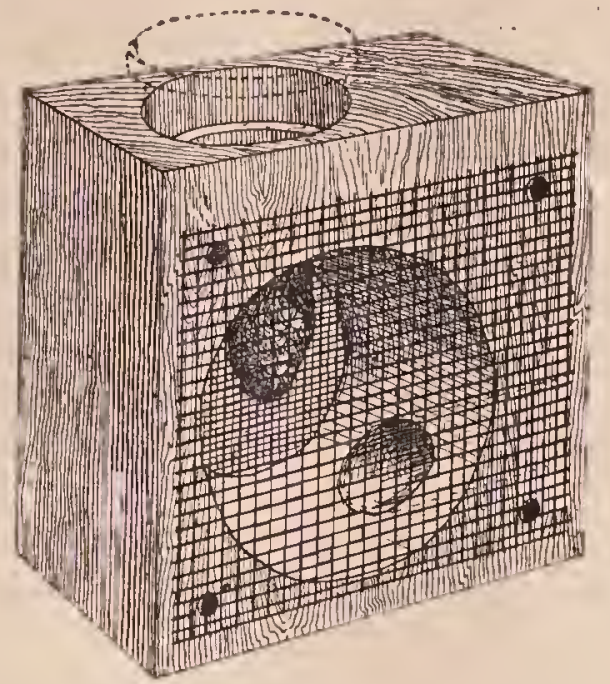

Nursery cage for cells and virgins.

to supply the young miss after she emerges. Twenty-four of these cages, supplied with cells that are capped over, can be put in a nursery-frame laving holder's which may be tilted on an angle so that any one cage can be easily remored from a holder with-

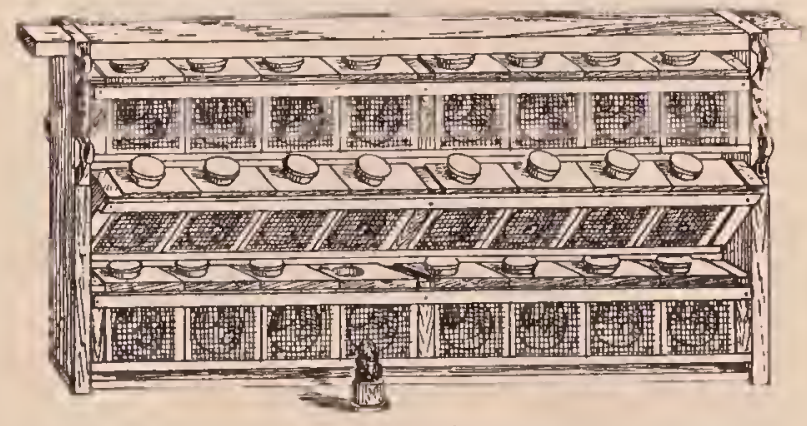

A nursery frame.

out disturbing the rest. There are three of these holders in each frame, pivoted at both ends as shown. When the nursery-frame has been filled with cages, each containing a capped cell, it should be put down in the center of a strong colony.

While various artificial-heat incubators using kerosene lamps or electric lieater's have been derised, experience has shown a majority of breeder's that nothing is quite so good as a strong cluster of bees. What is still more, when the young virgins emerge, some of the bees will be inclined to feed them thru the wire eloth, providing a stimulus that they cannot receive from the queen candy in the cage. After the virgins have enrerwed they should be transferred to introducing cages, and introduced as soon after emerying as possible. The younger the virgin, the more successful will be her introduction. After she becomes four or five days old, even if she be accepted by the bees they are likely to mistreat her so that her usefulness thereafter will be greatly impaired. While it is possible to introduce these virgins to frllsized colonies it is not practicable except by the use of the Smith cage or smoke or distress methor deseribed under INTRODUCING. It is much easier to introduce to baby nuclei.

DUAL PLAN OF INTRODUCLNG VIRGIN QUEFNS FOR EXTENSIVE BREEDERS

It sometimes happens that a breeder will have a great surplus of cells, or more virgins than he has queenless nuclei or colonies. In such cases it has been found practicable to introduce two queens at a time. First a virgin, the younger the better, is introduced in a Miller cage to a baby nucleus. After two or three days she should be released; in about four days more, being' seven days from the time of caging the first queen, another virgin may be caged among the same bees; but the candy of the second cage thru which the bees liberate the queen must be covered with a little strip of tin or the bees will liberate her prematurely. In two rlays more the first virgin will be mated, and within two or three days will begin to lay if the weather is favorable, when she is removed and sent out to fill an order. The strip of tin covering the candy of the second cage is opened to let the bees release virgin No. 2, and, having already acquired the colony odor, she will usually be accepted in less than a day's time. In about seven days from the time she was caged, a third queen, if there is still a surplus of virgins, may be put into the nucleus while No. 2 is taking her mating-flight, and so the progress may continue so long as there is a surplus of virgins.

This is really high-pressure queen-rearing, and should be practiced only when there is a surplus of virgins, or when there are rush orders for cheap queens - cheap queens, because the queens intioduced on the dual plan may or may not be the equal 
of those introduced in the regular way where a single queen is introduced at a time and is confined in a cage not more than a couple of days. If the virgin is very young, just emerged, and the nucleus has been queenless a couple of days, she can be let loose quietly over the top of the frames without any caging; but care should be taken not to allow her to touch the hands, for the scent of the human body sometimes causes tlie bees to attack and kill her.

\section{INTRODUCING QUEEN-CELLS INSTEAD OF VIRGINS.}

Some queen-breeders prefer to give ripe queen-cells to their nuclei direct, claiming that too many of the virgins that they in-

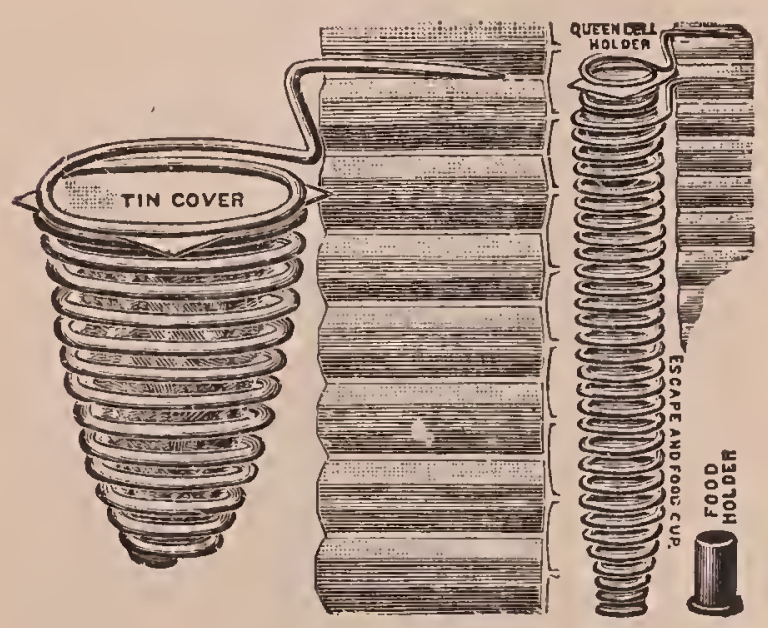

West queen-cell protector.

troduce are lost. It is true, the average beginner will succeed better with cells than with virgins; but if cells be given, the nuclei should be made strong in bees. In somle cases it will be necessary to use 11 cat queen-cell protectors to keep the bees from gnawing holes in them.

The long spiral cage is designed to slip under the queen-cell protector, and when the young queen emerges she will pass into the long cage, where she can be held secure from bees or other virgins in the colony that might kill her.

\section{MATING-HIVES.}

Before securing a lot of nice cells there should be in readiness a number of matinghives, or nucleus boxes. The usual plan is to use one or two Langstroth combs covered with bees and brood, and containing some honey, in little hives just large enough to hold two frames. Mating-hives of this kind have been used to a great extent in the past; but, as it generally happens before the season is over, the bees will need more room than the box will accommodate. For this and other reasons to be explained it has come to be more and more the practice to make use of a common Langstroth hive, either eight or ten frame. In the center, running lengthwise, is inserted a close-fitting division-board dividing the hive into two equal compartments. The bottom-board is adjusted in such a way that there will be an entrance at each end communicating with each compartment. It is customary to have a separate inner cover to each compartment; then an additional cover that telescopes over the whole. There should be enough of these double matinghives on liand ready for queen-rearing operations in the spring to take care of all

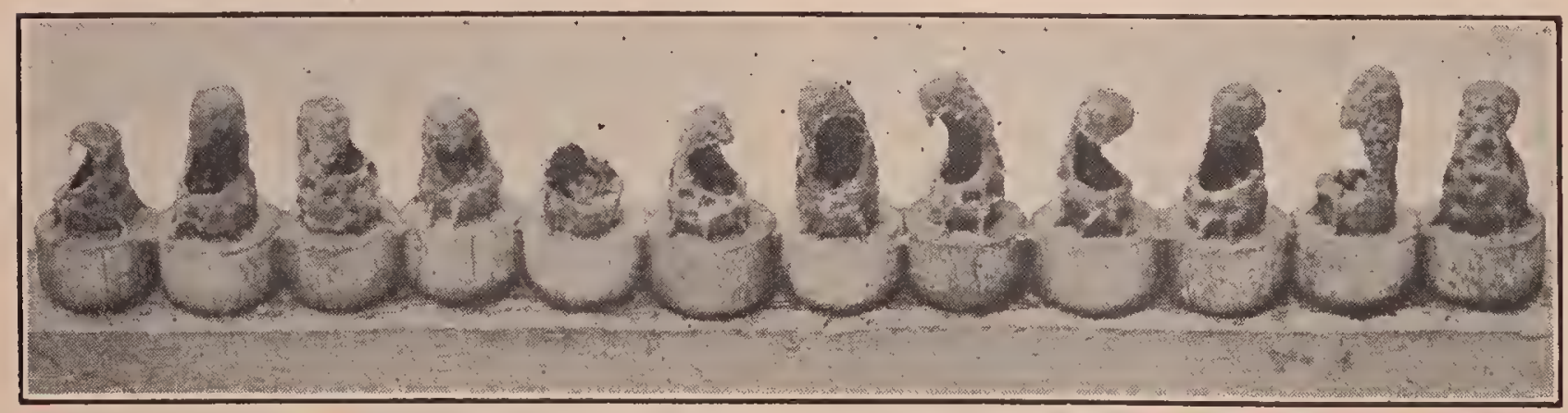

After the battle. By accident a batch of cells were left for a day or so too long in a cell-building colony. The first virgin that hatched, true to her nature, waged an unfair war upon her helpless sisters, still in their cradles. Every cell was ruthlessly torn open, and the little white queen inside killed. A virgin queen will not stand for competition. This inborn instinct of hatred against a rival does not end with youth. Two laying queens-old enough to know better--will usually fight if placed together even in strange and unnatural surroundings. Place two queens under a drinking glass in the hot sun. If they could reason, we might expect them to forget their hatred of each other in view of their common predicament of being confined away from the care of nurse bees. But the powerful instinct of hatred is so strong that they will usually fight-fight until one or the otler is stabbed by that poisoned weapon that is never used except against a rival. 
rells or virgins as fast as they are produced.

The arvantages of a tull-sized hive with ¿ double compartment are:

1. A larger capacity providing for an increase in size of the little colony thruout the season.

2. A conservation of the heat of the two rluster's of bees. In chilly or cool weather' the bees of each compartuent will be over next to the division-board, thus making one hig cluster with a thin sheet of wood betweell.

3. Economy and convenience in using standard equipment which may at any time be used for the production of honey when queen-rearing operations are over or suspended.

When it is desired to get the early mating of queens, and before settled warn weather comes on, one can divide a ten-

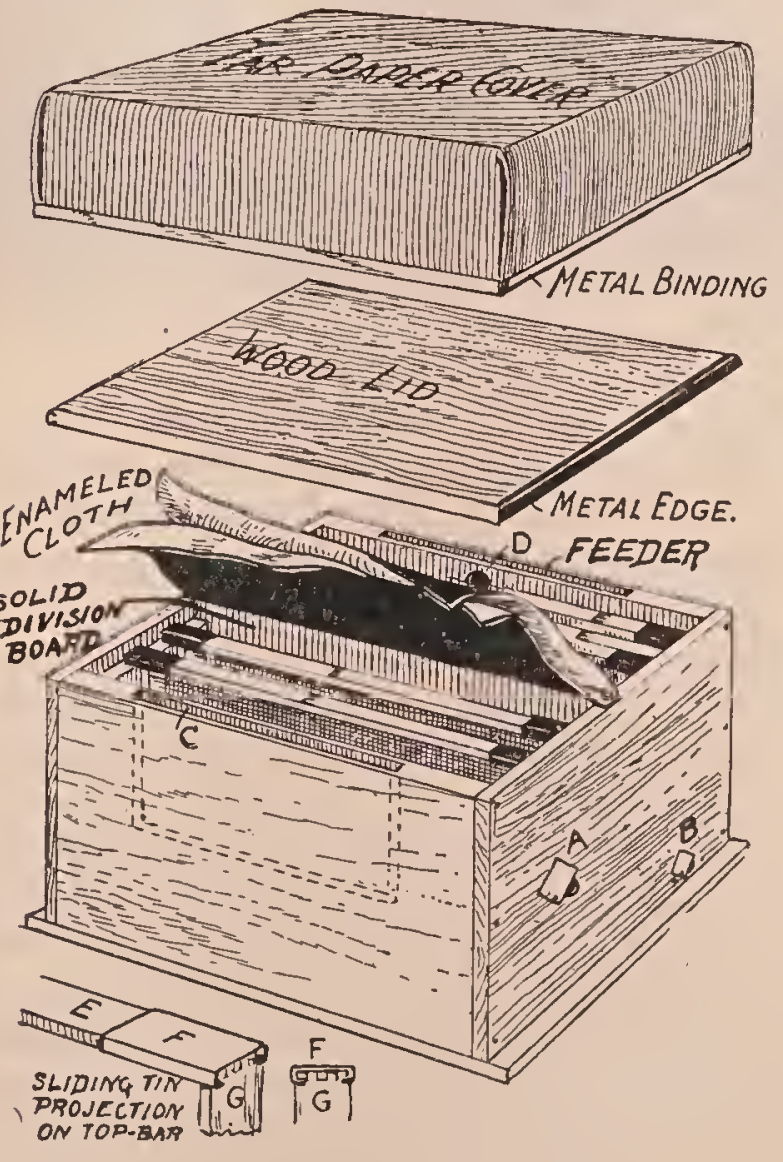

Fig. 1.-Twin mating-box

flatue Langstrotl hive into three compartments with close-fitting division-boards. Thele should then be an entrance on each side and olle in the center. The underside of this mating-box or hive-body has a wire sereen tacked on, when it is set over a strong colony in such a way as to leave an en- trance at the side and one entrance in thro rear or opposite to the entrance of the eolony beneatl. One or two frames of bees and brood containing honey are placed in each of the compartments, when they are leady for virgins or cells. The adrantagre

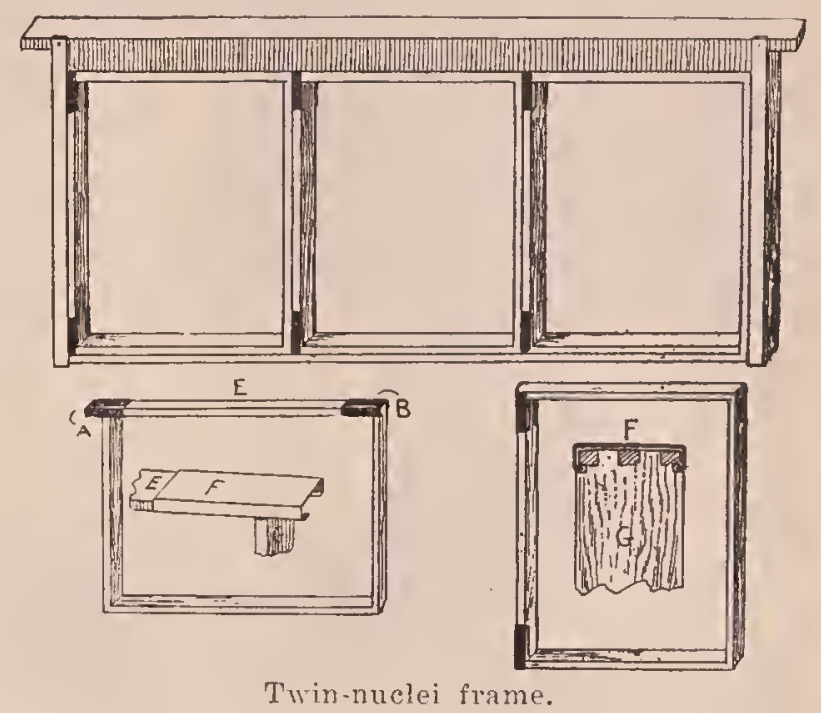

of this arrangement is that the heat from the big colony beneath will keep each of the compartments warm, thus providing for early mating. This arlangement is used quite extensively by sopne queen-breeders, but only early in the season or late in the fall.

\section{BABY NUCLEI USING BABY FRANES.}

'The mating-equipunent just described is adapted for the northern States. Of course it can be used in the South as well; but as a rule the queen-breeders of the South use what are called "baby nuclei." These use a small force of bees, which, on account of the warmer climate, will take care of cells or virgins as well as a larger force of bees in the larger nuclei. The baby hives are much more quickly handled; they require fewer bees, and cost less than the full-sized standard nuclei using Langstroth frames. But they are much more difficult to handle; and beginners, especially those who desire to rear only a few queens, should not waste any tinie or money on them.

\section{FORMING BABY NUCLEI.}

A regular hive-body that has a wire-cloth screen bottom and a removable wire-cloth screen top is prepared. Into this box some ten or twelve pounds of bees are shaken from some other yald. T!rese may come 


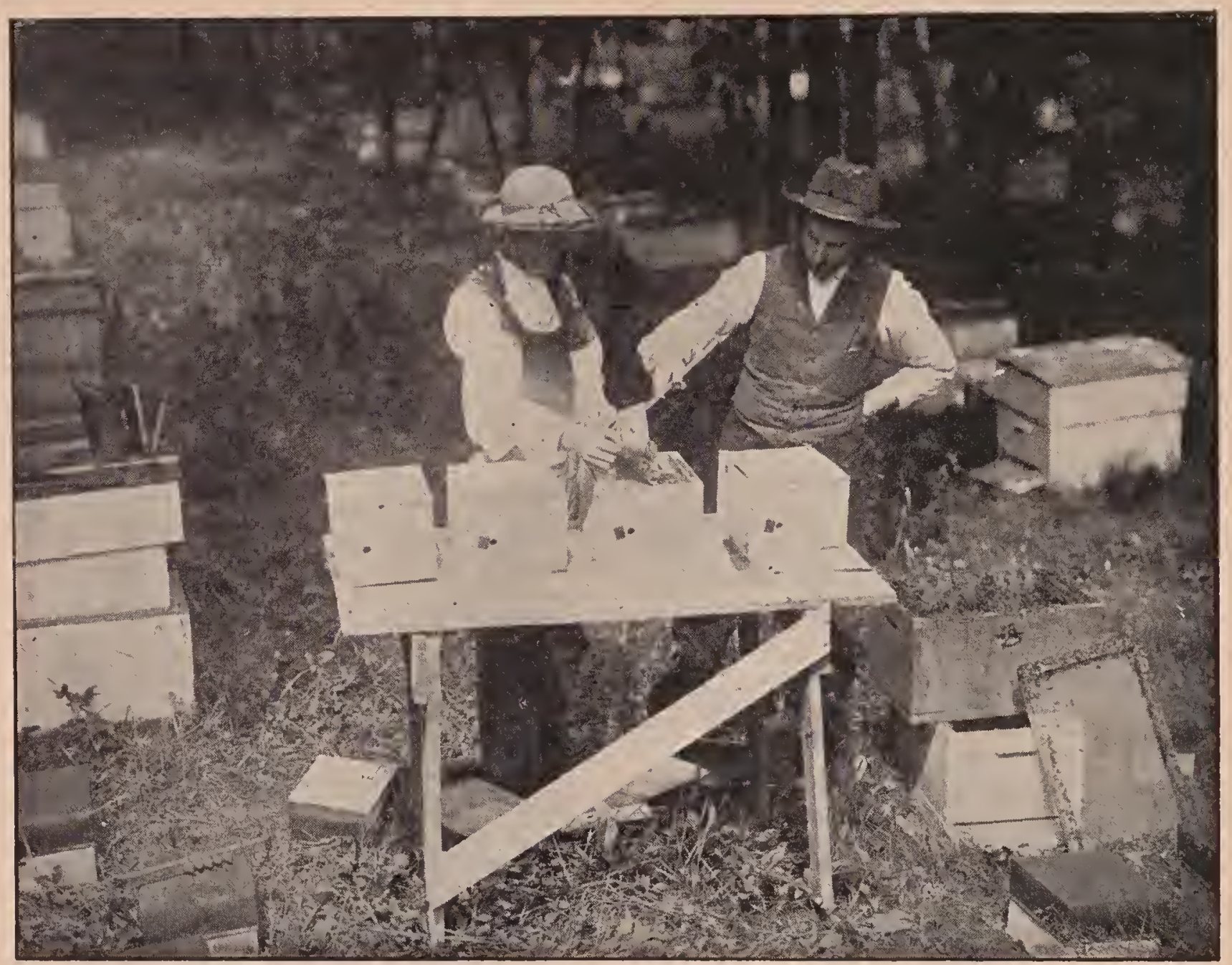

Fig. 2.- Scooping the bees with a small dipper into baby nuclei.

from four or five colonies, but generally from a dozen or more lives. This box of bees is then taken to the queen-rearing yard, where the nuclei are to be formed. Four of the twin baby hives are first placed upon a little light stand, each filled with empty combs ready to receive the bees, entrances closed, and rentilator's opened. The hive-body containing the shaken 'bees is then placed conveniently near. They are wet down with a spray, then given a jar so as to get the bees down in a mass in the bottom. With a little tin dipper are scooped up approxinnately four ounces of bees, which comprise from 1,000 to 1,200 individuals. As the bees have been previously wet down they can not fly very readily, and can therefore be scooped up a la Pratt and dumped in one of the compartments as shown in Fig. 2. An attendant stands ready with a number of virgin queens. He removes one of the frames of one compartment, and, while the apiarist is scooping up a dipperful or two of bees and dumping them in the space made racant by the re- moval of the frame, lie drops in a virgin queen just dipped in water. He now puts in the removed frame and folds back the enamel clotl. The operation is repeated in the other compartment of the box, and so on the process is continued until all of the twin mating-boxes are filled with bees and virgin queens. The baby hires are then set to one side for about 48 hour's, when they are placed on their permanent stands for the summer. Their entrances are opened at night. The next morning, as the bees come out they will mark their location and begin housekeeping with their baby queen.

After the baby nuclei are in full operation ripe queen-cells in place of virgins are given. The two frames are sprear a little apart when the cell is placed in position.

At the time of forming these baby nuclei, a thick syrup of abont $21 / 2$ parts of sugar to one of water is poured into the feerler compartment at one side. At other times, if it is a little cool it is given at night, hot, when it will all be taken up before morning. 'This feeding may be required off and 
on during the season. In some years the baby nuclei will gather enough to supply their own neerls. At other times they will require a little help.

These little twin nuclei serve only the purpose of mating. No cells are reared in them, and the comparatively small number of bees in each compartment makes it easy to find a laying queen or virgin if present. If in doubt as to whether the nucleus has a virgin, another cell should be given; and even should the virgin come back from her flight she will take care of that cell by gnawing a hole in its side and killing its occupant. Should she be lost in one of those flights the cell will provide another virgin, which will come on in due course of time. It is better to have a surplus of cells than to lose time.

These baby nuclei liave been carefully tested in one of the author's yards, and have given good results; but one needs to remember a few things in handling them or he may become digusted with the whole plan.

1. If the force becomes a little weak, a frame of emerging brood should be given, but not eggs nor larvae; or if this cannot be had, after the last queen is taken out a few more bees may be dumped in from a strong colony of the main yard. While some of these will go back, many will remain.

2. After the young queens begin to lay they should be taken out almost immediately, otherwise they will fill the two small combs with eggs and lead off a little swarm if there is a honey flow on. If not convenient to take the queen out at once, the perforated zine side should be sloved around to shut her in.

3. It is preferable to make up these little nuclei with bees from some outyard.

4. Neither side of the nucleus box should be allowed to become empty of bees. The combined heat of the two clusters brings about a better state of contentment.

QUEENS.-The most inportant personage in the hive is the queen, or mother bee. She is called the mother bee because she is, in reality, the mother of all the bees in the live.

Structurally she is much like the worker bee. The same ego that will produce a worker will also produce a queen. While a worker will lay eggs only under stress of abnormal conditions, and these only drone egg's (see LaYing Workers), the queen bee, after she has met a drone (or male bee), will lay two kinds of eggs-worker and drone. While the worker bees have all the organs of the queen, those organs are undeveloped. The workers instead of being neuters are all females but incapable of reproducing more females. The queen is the only true female. So far from being a ruler or sovereign she is little more than an egg-laying machine subject to the caprices of the worker bees.

When a colony is deprived of its queen, the bees set to work and raise another so long as they have any worker larva or eggs in the hive from which to do it. This is the rule; but there are some exceptions - so few, however, that it is safe to assume that a queen of some kind is present in the hive whenever they refuse to start queencells from eggs or larvæ of a proper age.

\section{UNDERSIZED OR IMPERFECTLY DEVELOPED} QUEENS.

Some laying queens are small* and unusually dark in color, and yet become fertilized. They lay eggs for a little while (from a week to several months), but seldom prove profitable. Sometimes they will not lay at all, but remain in a colony all

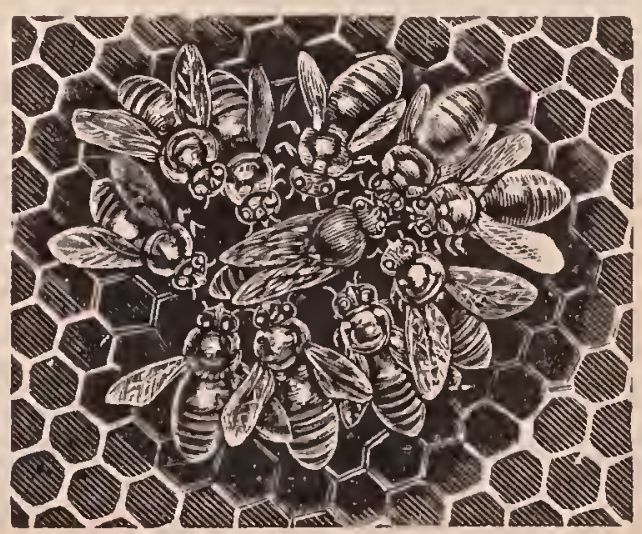

The queen and her retinue.

thru the season, neither doing any good nor permitting any other queen to be either introduced or reared. A wingless queen, or one with bad wings, will prevent another

\footnotetext{
* Small queens are not necessarily inferior. One of the most marvelous egg-producers I ever saw was a "bantam' from Golden stock. She could run thru perforated zine and hack again, hefore a worker could get started thru.-A. C. Miller.
} 


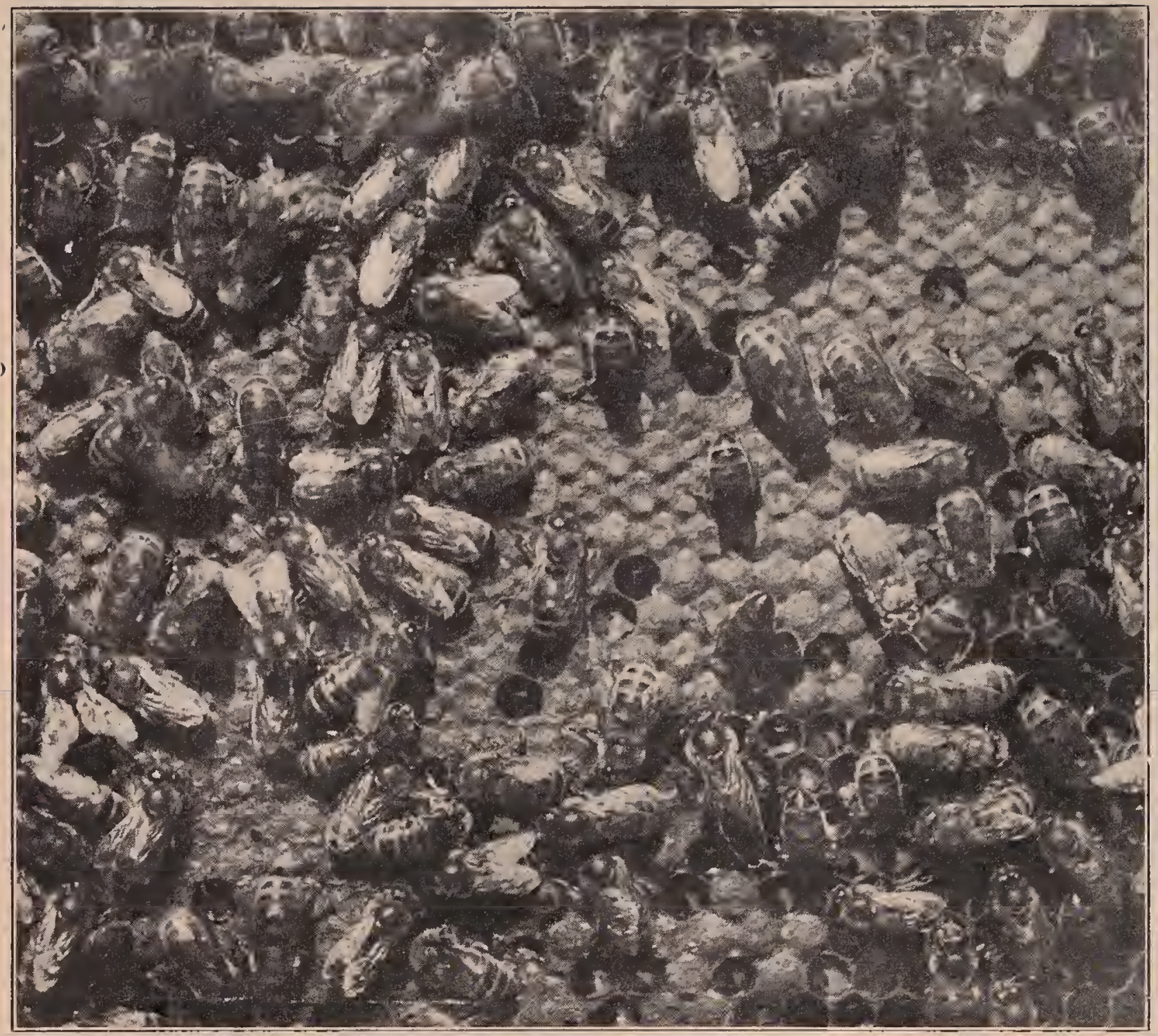

Find the queen

from beine introducel. The remedy is to hunt her out and remove her. When queens are so nearly like a worker bee as to make it hard to distinguish them, they can often be detected by the peculiar behavior of the bees toward then. See woodeut on page 697 . In the fall, after the queen lias ceased laying, she will usually look small and insignificant even tho she be an extra good one. But if it is during the laying season, when all f'ertile queens are laying, and the queen looks small, she should be removed. ITs!lally after the main or heavy honey flow is over, all queens let up on or stop laying for a short time. At such times any queen will look small.

\section{DETELOPMENT OF BABY QUEENS.}

HOW A WORFER EGG IS MLADE TO PRODUCF, A QUEEN.

This is a question that puzzles novices about as much as any question they can ask. To answer it let the following experiment be tried when the bees tell their own story: Get a frame of eggs, and put it into a colony having no queen. The tiny eggs will hatch into larvæ; but about as soon as they begin to hatch, there will be found a few of the cells supplied with a greater profusion of milky food than others. Later these cells will begin to be enlarged, and soon at the expense of the adjoining ones. These are queen-cells, and they are something like the cup of an acorn in shape, and usually occupy about the space of three ordinary cells. In the cuts will be seen cells in full stages of growtl. See QUEEN-REARING.

There are some queer things about queencells, as will be noticer. After the cell is sealed, the bees put a great excess of wax on it, make a long tapering point, and 
corrugate the sides something like a thimble. This corrugation, or roughness, when closely examined, will be seen to be honeycomb, or, rather, an imperfect representation of honeycomb on a very small scale.

It is very handy to be able to tell when any young queen will be likely to emerge; and the bees are very accommodating in this respect also; for, about the day before the queen emerges, or maybe two days, they proceed to tear down this peak of wax on the tip of the cell, leaving only a thin covering. No one knows why unless they are anxious to get a peep at their new mother. It has been said they do it that she may be better able to pierce the capping; but sometimes they omit the proceeding entirely, and apparently she has no diffieulty in eutting the cap off. If the cell is built on new comb, or on a sheet of foundation, and be held up before a strong light at about the fifteenth day, or a little later, the queen can be seen moving about in the cell. Afterward, by listening carefully, she can be lieard gnawing her way out. Pretty soon the points of her sharp and powerful mandibles will be seen protruding, as she bites out a narrow line. Since she turns her body in a circle while doing this, she cuts out a circle so true that it often looks as if marked by a pair of compasses. The substance of which the cell is mare is tough and leathery, and, therefore, before she gets clear around her circle, the piece springs out in response to her pushing, and opens just about as the lid of a coffeepot would if a kitten should happen to be inside crowding against the lid. Queens may often be seen pushing the door open and looking out, with as much apparent curiosity as a child exhibits when it first creeps to the door of a summer morning; often, after taking this look, they will back down into their cradles, and stay some time. This is especially the case when other queens are emerging, and there is a strife as to who shall be sovereign.

\section{- royal jelli.}

It will now be in order to consider the strange substance, royal jelly, on which the baby queens are fed while in the cell.

The milky food before described, which is griven to the young larva, and which is supposed to be a mixture of pollen and honey partially digested, is very similar, if not identical, in composition with the royal jelly. Bees are not the only examples in the animal kingdom where the food is taken into the stomach by the parent, and, after partial digestion, regurgitated for the use of the offspring. Pigeons feed their young precisely in this way until they are able to digest their food for themselves. It has been stated that bees use a coarser food for the worker larvæ, after they are a few days old, and also for the drone larvæ during the whole of their larval state. By "coarser food" is meant a food not so perfectly digested; in fact, drones are said to be fed on a mixture of pollen and honey,

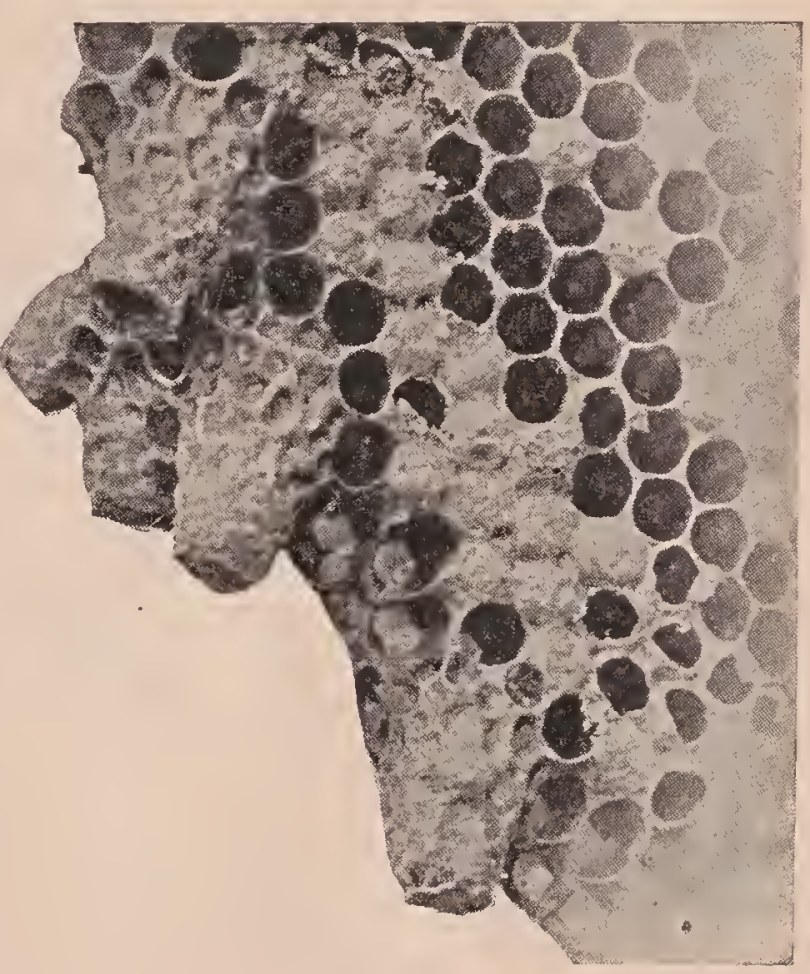

Natural built queen-cells. life size-Photographed by W. Z. Hutchinson.

in a state nearly natural. It has also been said, that queens receive the very finest, inost perfectly digested, and concentrated food that bees ean prepare. This we can readily believe, for the royal jelly has a very rich taste - something between cream, quince jelly, and honey-with a slightly tart and a rank, strong, milky flavor that is quite sickening if much be taken.

WHAT DOES THE QUEEN DO THILE SEALEI) UP?

The authol has opened cells at every stage after they were sealed until the queens 
were ready to emerge. One day after being sealed they are simply ordinary larvæ altho rather larger than worker larvæ of the same age; after two or three days, a hẹad begins gradually to be "mapped ont," and, later, some legs are seen folded up; last of all, a pair of delicate wings come from somewhere. (See Development of BEEs.) Two days before emerging the author has taken them out of the cell, and had them mature into perfect queens, by keeping them in a warm place. He has also taken them out of the cell before they were mature, held the white, still, corpse-like form in the hand, then put it back, waxed up the cell by waming a bit of wax in the fingers, and had it emerge three days after, as nice a queen as any. Mr. Langstroth mentions having seen the whole operation by placing a thin glass tube, open at both ends, in the cell, so as to lave it inclose the queen, the bees being allowed to cap it as usual. This experiment was first made by Huber. With several such glass queencells the whole operation could be watched from beginning to end. See Onservatory Hives.

WHAT BECOMES OF THE QUEEN AFTER SHE LEAVES THE CELL?

$\Lambda$ fter she pushes open that hinged door, she generally begins by poking her head into the cells until she finds one containing unsealed honey, from which she takes a sip that, at least, indicates she likes that kind of provision.

After she has had her repast she begins to crawl about, partly to enjoy using the long strong legs God has given her, and partly because she knows that it is her allotter task to tear down the remaining queen-cells, if such there are. If other queens have emerged before her, it is one of lier first and foremost duties to look them up, and either reign supreme or die in the attempt. When all other cells lave been removed, as they usually are where queens are wanted for other purposes, she has notling to do but to promenade over the premises, monareh of all she surveys. If she ever sits down to take a rest, or takes a rest in any other position, during the first week of her life, the author has nerer been able to discorer it.

But suppose she does find another cell- what then? She sometimes runs around awhile; sometimes the bees tear it down, and sometimes she tears it down herself, with the same strong mandibles that she used to eut lier way out of the cell at first. She usually makes the opening in the side of the cell.

It is said that the queen immediately stings her helpless immature sister to make a sure thing of her destruction, but there is some doubt abont this. Spots have been seen in the side of the queen that looked as if she had been stung. Such cells have been torn open, and nice queens matured from them. As these immature queens are very soft, the workers will soon pick them out of the cell, piece by piece. The author has sometimes placed them in the nursery and had them mature, minus a wing, a leg, or whatever portion the mischievous worker had pulled away. From many observations the queen generally tear's a hole in the cell, or bites into it in such a way that the workers tear it all down, much in the way they do any mutilated or broken pieces of comb. See page 694.

When queen-cells have been cut out, all the larve that are in any way injured are at once thrown out, and none but the perfeet cells preserved. Bees never fuss with cripples, nor try to nurse 11] a bee that is wounded ol maimed. They liave just the same feeling for their fellows that a locomotive might be expected to have for a man whom it had run over. They battle against anything that threatens the extinetion of the colony, it is true. There are no signs of their caring for one of their number, or even having compassion on their helpless brood when it is wounded and suffering.

When a queen emerges, the remaining cells are very soon torn down, as a general thing, but there are many exceptions. Where two queens emerge at about the same time they also generally attempt to kill each other; but both are not killed. 'This probably results from the fact that they can sting their livals only in one certain way; and the one that, by. strength or accident, sets the lucky position in the combat is sure to come off victorious. This explains how a very inferior virgin queen, that has entered the live by accident, may some- 
times supplant an old laying queen. Two queens, when thus thrown together, genererally figlit very soon, but this does not always happen. Several cases are on record where they have lived in peace and harmony for months, even when they emerge at about the same time, and it is quite common to find a young queen lielping her mother in the egg-laying duties of the hive, especially when the mother is two or three years old. If the season is good, and the hive populous, they may divide up their forces, and after-swarming occurs. See A FTER-SWARMING.

Sometimes the queen will pay no attention to the remaining cells, but will let the young queens emerge, and then their

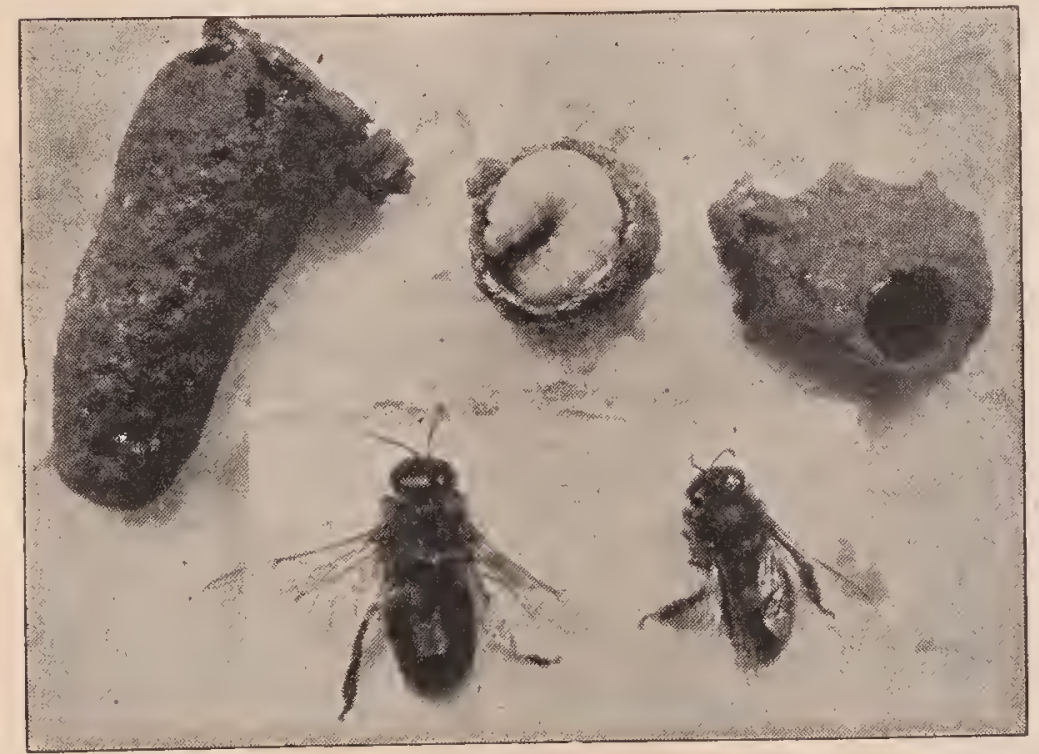

Natural queen.cells at different staces-The capped cell on the left has been detached from the comb, and is ready to give to a colony; cell in the center, five or six days old, has been shaved down to show the queen larva just before it is ready to stretch out lengthwise of the cell: cell on the right shows the mouth of a cell just before capping.

"little differences" are adjusted afterward, either" by swarming or by the usual "handto-hand" conflict "until'death." Many losses in introducing queens have resulted from two queens being in the hive, the owner being sure his hive was queenless-because he had removed one. See Introducing.

\section{QUEEN'S VOICES.}

Queens have two kinds of voices, or calls, either one of which they may emit on certain oceasions. It is almost impossible, on the printed page, to describe these sounds. One of them is a sort of $z-e-e-p, z-e-e-p$, zeep, zeep. Some call it piping, others teeting. Whatever it is, it consists of a prolonged tone, or a long zeep followed by several much shorter, each tone shorter than the preceding one. This piping is made when the queen is out of the cell, either virgin or laying, but nsually by a young one. The older ones are generally too dignified, or too something, to give forth any such loud squealing; but they will squeal, and lustily, too, sometimes, when the bees ball them and grab them by the legs and wings.

The other note that queen bees are known to give forth is what is called quahling, for that more nearly describes the actual sound than any other combination of letters that can be put together. It is emitted only by a young queen in the cell, before she emerges, and is nuade in answer to the piping or zeep, zeep, of one of the virgins that has already emerged, and is trying perhaps to proclaim aloud her sovereignty. The quahk will be heard, then, only when there are queen-cells in the hive.

While a young queen is being introduced she frequently utter's a note of alarm, a zeep, zeep, ete. The bees are almost alway stirred by these notes and they will often r'un after' her and cling around her like a ball, when they would have paid no attention to her had she not nttered this well-known note.

Queens, when placed near together in cages, will often call and answer each other, in tones that are probably challenges to mortal combat.

Some queens received one summer from the South called so loudly when placed on the table that they could be heard the entire length of a long room. One voice would be on a high, shrill key and another a deep bass, while others were intermediate. On watehing closely a tremulous movement of the wings was noticed while the queen was uttering the note, and one might infer from this that the sound is produced by the wings, but this is probably not the ease. Some one reported having heard a gineen 
squeal, both of whose wings harl been entirely elipped off.

\section{VIRGIN QUEENS}

The newly emerged queen is termed a virgin because she has not met a drone and to distinguish her from queens that have been fertilized and are laying. Virgin queens, when first emerged, are sometimes nearly as large as a fertile queen, but they gradually decrease in size, until when three or four days old they often look so small and insignificant that a novice is disgusted with their appearance, and, if hasty, pronounces them useless. For the first week of their lives they erawl about much as an ordinary young worker does, and it is often very difficult, if not almost impossible to find them unless an amount of time is taken that is more than a busy apiarist ean well afford to spare. It is a waste of time to look for them. It is better to insert a frame having some unsealed larvæ just hatched from the egg; then if no cells are started one can decide the queen is there without looking further. This plan answers a threefold purpose: It enables one to tell at a glance whether the queen is in the live all right or not; for as soon as she is lost they will start more queen-cells on it; it also enables the bees to raise another queen in case the former queen is lost by any accident on her wedding-flight, which is frequently the case; and, lastly, it serves as a sort of nucleus to hold the bees together and to keep them from going out with the queen on her wedding-trip, which they are much disposed to do, if in a small nucleus containing no brood. (See Baby Nuclei under QUEEN-REARING.) Unsealed brood in a hive is a great safeguard against accidents of all sorts, and some say a young queen has been started to laying by simply giving the bees some eggs and unsealed brood. Whether it caused her to rouse up and take her wedding-flight, or whether she had taken it, but was for some reason idle, can not be determined.

AGE AT WHICH VIRGIN QUEENS TAKE THEIR WEDDING-FLIGHT.

Some fix the wedding-flight from two to ten days after birth. It is probably seldom before the fiftl day. Some difference, doubtless, arises from the fact that queens often stay in the cell a day or two after they are strong enough to leave it. Sometimes a queen will be found walking about the combs when she is so young as to be almost white. Beginners will sometimes rejoice at their beautiful yellow queens, saying that they are yellow all over, without a bit of black on them; but when looked at again, they will be found to be as dark as the generality of queens. At other times when they come out of the cell they will look, both in color and size, as if they might be three or four days old. The queens generally begin to crawl about the entrance of the hive, possibly looking out now and then, when 5 or 6 days old. The next day, supposing, of course, it is fine weather, they will generally go out and try their wing's a little. These flights are usually taken in the warmest part of the afternoon. There is no prettier or more interesting sight to the apiarist than the first flight of a queen. She runs this way and that, somervat as does a young bee, only apparently much more excited at the prospect of soaring aloft in the soft summer air. Finally she tremblingly spreads those silky wings, and with a graceful movement that can not be equaled anywhere in the whole scope of animated nature, she swings from her feet, while her long body sways pendulously as she hovers about the entrance of the hive. A worker bee hovers also about the entrance and carefully observes its location when trying its wings for the first time; but she, seeming to feel instinctively that she is of more value to the colony than many, many workers, with the most scrupulous exactness notes every minute point and feature of the exterior of her abode, often alighting and taking wing again and again, to make sure she knows all about it.

Soon she ventures to circle a little way from home, always verging back soon, but being gone longer and longer each time. She sometimes goes back into the hive satisfied, without going out of sight at all; but in this case she will be sure to take a longer flight next day or a half-hour later in the same day. During these seasons she seems to be so intent on the idea she has in her head that she forgets all about sur- 
rounding things, and, instead of being. frightened as usual at opening the hive, she will pay no attention; but if the comb she is on is lifted up she will take her flight from that as well as from anywhere else. They have been caught in the hand at such times, without their being frightened; and as soon as they were allowed to go, they were off as if nothing lyad happened.

After the queen is satisfied that she will know the place, she ventures out ?ollly; and from the fact of ne: circling right np in the air, it was once supposed that fertilization truk place above the ken of hum:tn eyesight. This has been shown to be a nisstake. See Drones.

After' a successful flight she returns with the organs of the drone remaining attacher to her body. (See Drones.) This is a white substance, and is frequently so large as to be plainly seen while she is on the wing. A queen is usually gone lialf an hour, but she will sometimes return fertilized after an absence of not more than 10 or 15 minutes, and there have been reported instances where she has been gone not nore than three minutes. This accomplished, sle goes quietly into the hive. The bees are much inclined to chase after her, and they sometimes pull at the protruding substance as if they would drag it away. That they do so, is pretty well proved.

Until recently it was generally believed that the queen met the drone only once, notwithstanding the fact that Francis Huber, in his book, "New Observations," published in 1814, made the statement that queens might or might not take more thian one wedding-flight before beginning to lay. But this seems to have been overlooked until 1904, when considerable proof was adduced to show that the same queen before laying (not after) may not only take several wedding-flights, but come back on different occasions with sure evidence of having met a drone.

While it seems to be pretty well proved that the queen may take more than one marriage-flight prior to her laying, it is very much doubted whether she ever takes a second flight to meet the drone after laying. It is true that some facts seem to point that way; but when the great number of spermatozoa that she receives on her wedding-flight is considered, it hardly seems likely that a flight is taken later. According to Cheshire, the spermatozoa are extruded from the spermatheca in detachments, only a part of them being effective in the fertilization of eggs. He estimates that about $4,000,000$ spermatozoa are received at the fertilization of the queen. A good queen might, perhaps, lay two hundred thousand eggs in a season. If only one-fourth (or $1,000,000$ ) of the spermatozoa were effective, the queen could still remain fertile for five years if she laid an average of 200,000 eggs per year. 'Therefore, unless a much greater number of spermatozoa are lost, there could be no necessity for a later fertilization.

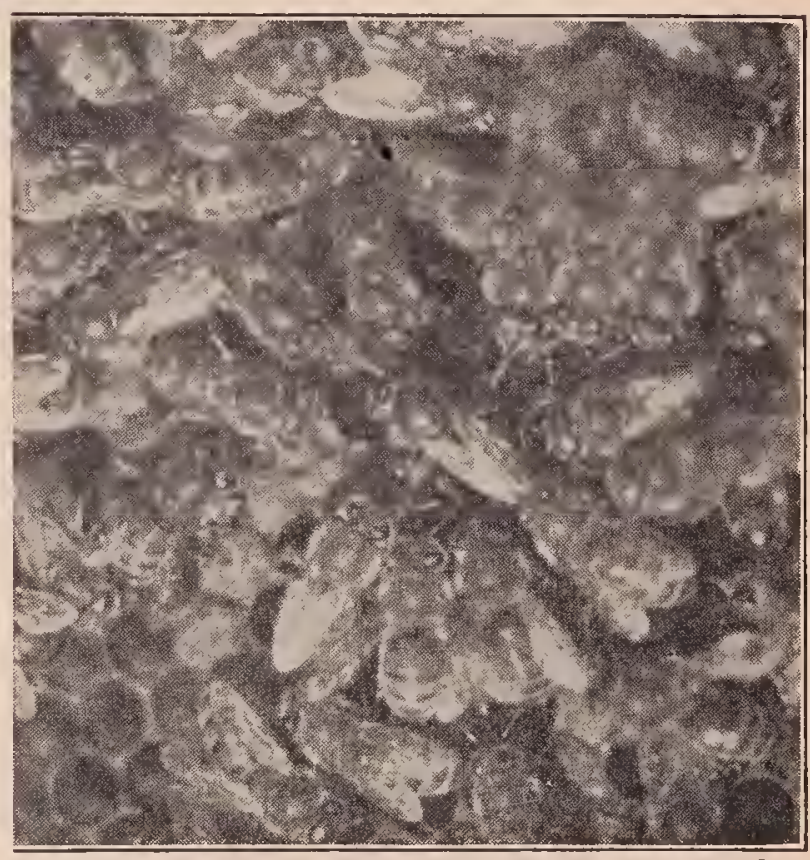

Queen Iaying, surrounding bees turned toward her.

For further particulars on this subject of mating, see Drones.

WHEN THE QUEEN BEGINS TO LAY AFTER MATING.

The $3 d$ or the 4 th day after a successful mating one will, as a general rule, find the queen depositing egg's. The arerage age at which queens begin laying is about nine days. Between impregnation and the time the first egg is laid a remarkable change takes place.

After the queen has been out and fertilized, her appearance is nuch the same as before. She runs and hides when the hive is opened, and looks so small and insignificant that one would not think of ealling 
her a fertile queen. A few hours sefore the first egg is laid, however, her body increases remarkably in size, and, if an Italian, becomes lighter in color, and, instead of 'tunning about as before, she walks slowly and sedately. She seems to have given up all her youthful freaks, and comes down to the sober business of life in supplying the cells with eggs.

\section{HOW OLD A QUEEN MAY BE AND STILL BHCOME FERTILIZED.}

As before stated, queens usually begin to lay when 8 or 10 days old, on the average; but during a spell of bad weather, or when drones are scarce, they may fail to lay until three weeks old. The longest period we have ever known to elapse between the birth of a queen and her laying workereggs is about 25 days. All queens that do not lay at the age of 20 days should be destroyed, when the season, flow of honey, and flight of drones are right. There is one important exception to this. Many imes queens will not lay in the fall at all, unless a flow of honey is produced either by natural or artificial means. Queens introiluced in the fall often will not lay until the ensuing spring, unless the colony is fed regularly every day for a week or ten days. Lilkewise young queens that are fertilized late in the season will often show no indications of being fertilized until the following spring.

\section{DRONE-LAYING QUEENS.}

If a queen is not fertilized in two weeks from the time she emerges, she will sometimes commence laying without being fertilized at all. She is then what is called a drone-laying queen. Usually her eg's are not deposited in the regular order of a fertile queen, neither are there as many of them; by these marks one is able to guess that she may not be all right, and so watch her until some of the brood is capped, when the extra height of the cappings, as is explained under Drones and Brood, shows. At times, however, the eggs are deposited so regularly that one is deceived, and the queen may be sold for a fertile queen, when she is only a worthless dronelayer; but this can be determined after the brood is capped. Such a case occurs, per- haps, once in a thousand. Whether these drones reared from drone-layer's are just as good to furnisl drones as those reared from a fertile queen, is a point not fully decided; but if the queen lays the eggs in drone comb, and the drones are large, fine, and healthy, they are probably all right. Drones reared from fertile workers, and drones reared in worker-cells, as those from drone-laying queens sometimes are, should not be used.

How to find queens, see Manipulation of Colonies, subhead "How to Manipulate Hoffinan Frames," also "How to Handle Unspaced Frames."

\section{SHALL QUEENS' WINGS BE CLIPPED?}

Many of the honey-producers practice what is known as elipping; that is, both wings on one side are cropped off, leaving merely the stumps of what were

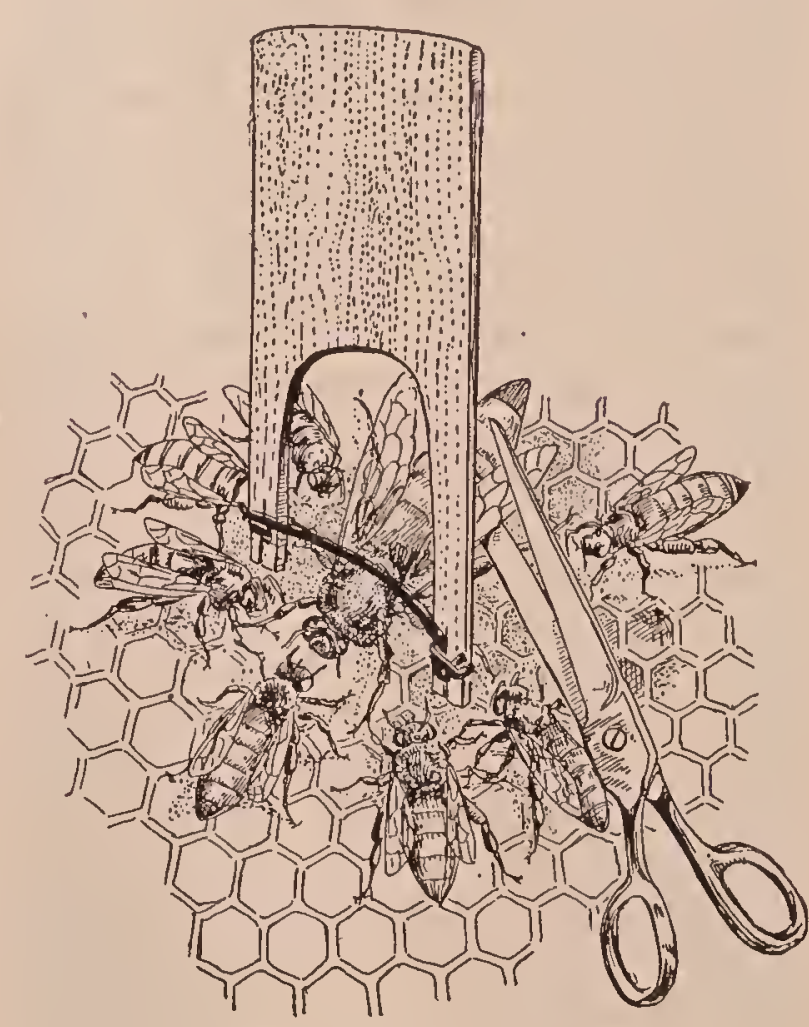

Willis queen-clipping device, and how used.

once wings. The object, of course, is to prevent swarms from going off by making it impossible for the queen to follow. See Bee Behavior, also Swarming.

There are very few who believe or profess to believe that clipping is injurious to the queen. The fact that queens after being clipped seem to do good service for two or three years, and sometimes four, and the 
further filct that such queens do as well as those not dipped, would seem to show that no detrimental results follow.

\section{HOW TO CLIP A QUEEN'S WINGS.}

There are several ways of accomplishing this. One plan is to grasp the queen by the wings with the right hand, in the usual manner. With the thumb and forefinger of left hand, take hold of her waist, or thorax. In this way she can be held very

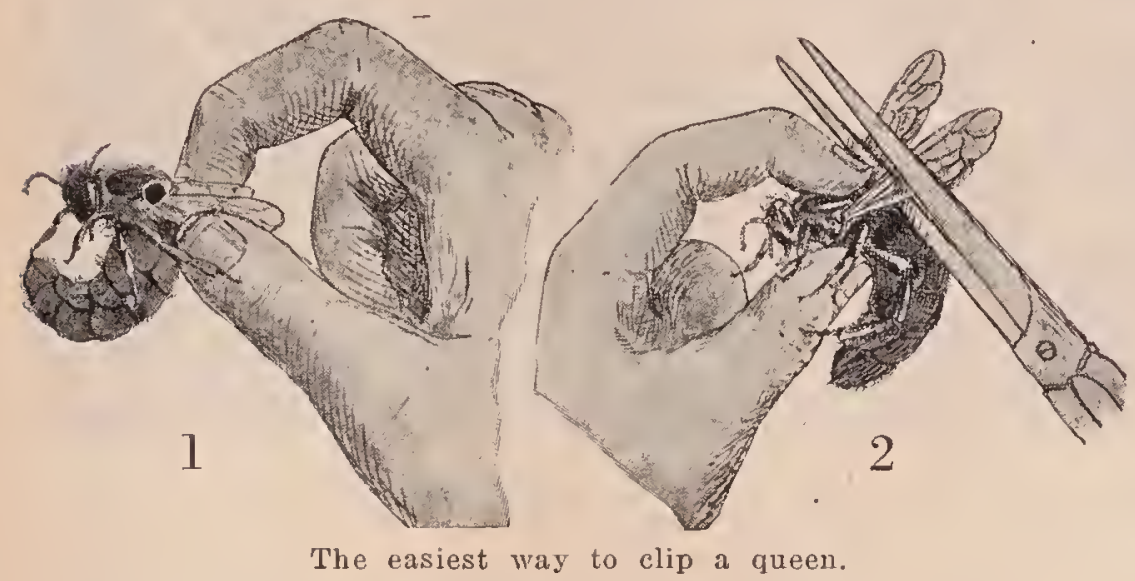

as it is a nice piere of work to do it well.

sometimes in an outyard, when a yar of scissors is not to be had, a sharp blade of a pocketknife can be used. This is passec under the wing in such a way as to cause it to bear directly upon the edge of the blade. The thumb is now pressed drown upon the wing over the blade, and then drawn back and forth seesaw fashion, perhaps two or three times. If the knife is sharp, the wing will be severed with t.wo or three strokes. If it is dull, the queen should be laid on her back, still holding her between the thumb and finger of the left hand so that her wing will bear directly upon at hive-cover or any other piece of board or wood. The edge of the knife should be brought to bear upon the wing, when a slight pressure will cause the blade to pass thru it.

During these operations securely and safely, leaving her legs as well as her wings entirely free. With a pair of slender-pointed embroidery scissors - (or any liind of scissors if these are not obtainable) clip off both wings on one side only, being careful not to cut too close. This accomplished, drop her gently between two frames of brood; but in no case let her fall more than an inch; for a queen during the height of the egg-laying season is liable to be injured if handled roughly. Some prefer, after picking up the queen, to grasp her by the legs; but this is liable to pull one or more legs off unless done just right, and therefore the first-mentioned plan is recommended.

Before any one of these plans is attempted, if one has had no experience he should first practice on drones. If these are not to be found, worker bees should be picked up by the wings until one becomes reasonably expert; but a worker should not be put between the thumb and finger of the other hand, as one will run a good chance of being stung. For this part of the work drones should be procured. Then, when one can do both operations well, he can try a queen. Even then the attempt should be made on one not much value, 23 care should be taken to handle a queen only by the wings or the thorax. This way avoids all danger of hurting her. One should be careful not to press the abdomen of any queen.

\section{HOW QUEENS LAY TWO KINDS OF EGGS.}

That queens lay two kinds of eggs no one now is inclined to dispute, since the experiments with the microscope have decided the matter so clearly, as given under Drones. Suppose a young queen goes out to meet the drones so late in the fall or so what is the consequence? Sometinies she will never lay at all; but frequently she commences to lay when three or four weeks old, and her eggs produce only drones. In fact, she can produce no other eggs, having never been fertilized. How shall such queens be distinguished from fertile ones?

No one can decide positively concerning them, until their brood is ready to seal up; then one can know by the round, raised cappings of the brood, like bullets laid on a board, as explained under Drones. (See BROOD, particularly large illustration of worker and drone brood.) One can give a pretty good guess by noticing the way in early in the spring that there are none; 


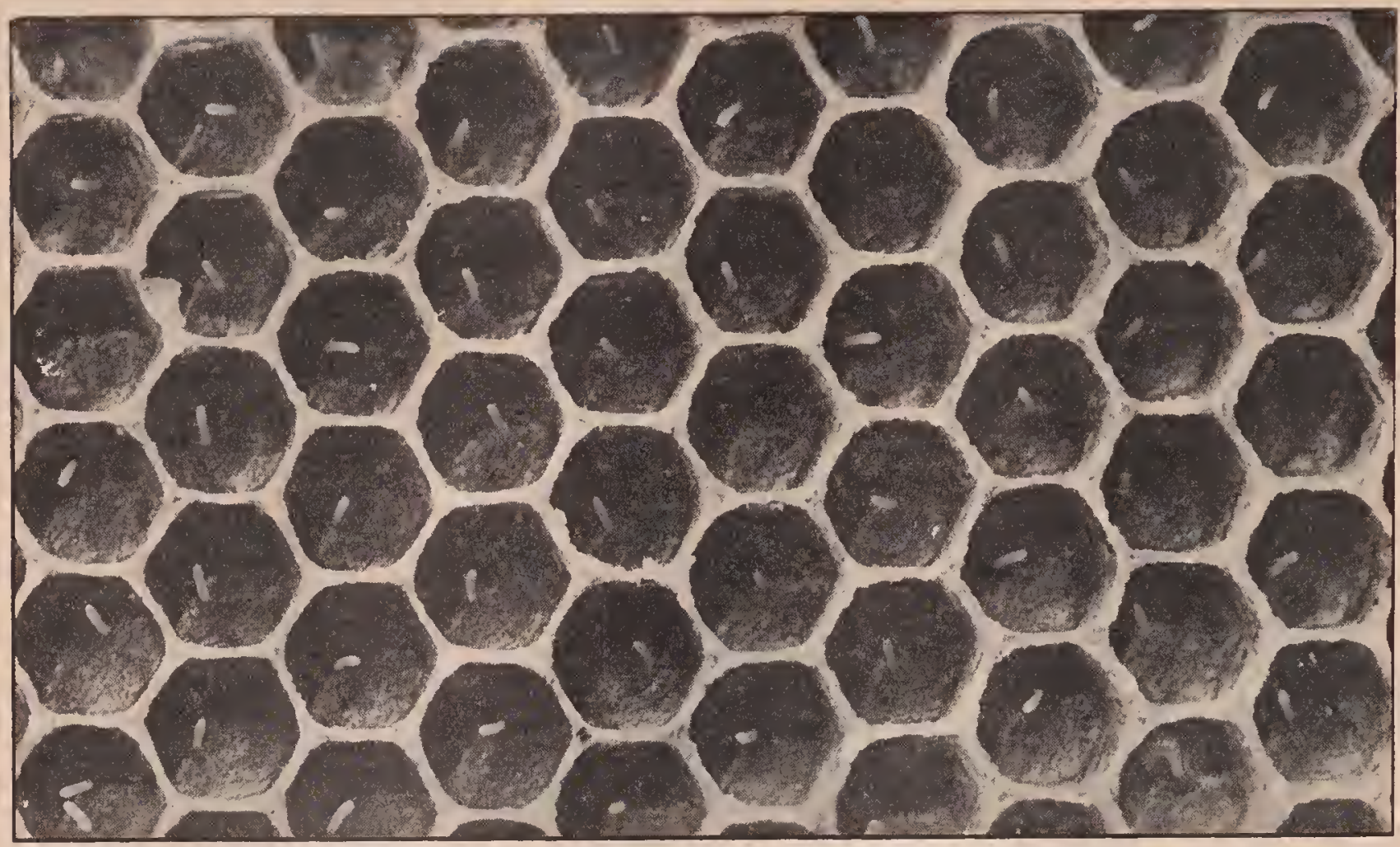

Close view of eggs. Notice the cell in the lower lefthand corner contains two eggs, while that at the right-hand corner has a larva.

which the queen lays the eggrs; if they are few and scattering, and sometimes, or often, in drone-cells, coupled witl the fact that she did not commence laying until two weeks or more old, she should be replaced. A young queen, if properly fertilized, never, or very rarely, lays an egg in a drone-cell; and when she commences to lay, she fills cell after cell in regular order, as men plant hills of corn; her work also has a neat and finished appearance that says at once to the expert, "She is all right."

In rare cases a young queen begins with all, or nearly all, drone eggs, but, after a while, lays entirely worker eggs as regularly as one could wish.* It is not known why this is; perhaps she has not yet got used to the "machinery." Again, any queen is liable any day of her life to begin laying drone eggs altogether, or in part. A nice young laying queen, taken from a hive, and shipped to a distance, may prove to be it drone-layer shortly after or immediately

\footnotetext{
* It has been suggested that this phenomenon may be accounted for by the fact that laying workers were in the hive before the young queen began to lay; that the drone eggs are not from the queen but the laying workers, and that, when the queen begins, slie lays worker eggs at the very start, while the linying workers are destroyed, and hence the drone eggs disappear. This is possible.
}

after she is receiver. Such things are not very common, but they do ocenr. Out of three or four hundred colonies one may find one drone-layer, on an average, each spring. During the summer, perlaps one more will be found. It may be that the queen was not fertilized sufficiently, and that the supply of spermatozoa gave out while she was in full vigor, thus reducing her to the condition of a virgin queen. Microscopic examination has shown an entire absence of spermatozoa in at least one or two instances where queens of this kind were killed and dissected. Similar experiments given by Dzierzon show that the spermatozoa may be injured beyond recovery by cliilling the queen, and yet the queen herself be resuscitated. Hardship and being slipped long distances may produce the same result.

Queens not only turn suddenly to dronelayers, but they sometimes produce about an equal number of each kind of egg's. In all these cases, where the queen lays drone eggs when she evidently intended to lay worker eggs, they are in worker-cells; at the same time the number of eggs laid usually rapidly decreases. The bees, as well as queen, evidently begin to think that something is wrong; queen-cells are sonn started, and after the young queen emerges 
she becomes lertile, and begins to help hol mother.

Very early in the spring, late in the fall, or at any time when forage is not abundant, a queen will pass right by drone-cells, taking no notice of them. The author has tried to get. eggs in drone-cells by feeding, but concludes that the queen knows what an egg will produce, and just how to have every egg laid in a drone-cell produce a drone. Possibly the workers have something to do with this matter, but no one knows by what means they signify to the queen that some eggs in drone-cells, or even queen-cells, would be desirable. There seems to be a constant understanding in the hive as to what is gooing to be clone next, and consequently there is no clashing. In the author's apiary there seems to be, in strong. stocks, a kind of understanding that eggs shall be laid in drone-cells about the last of Mareh and drones are found, therefore, some time in April, ready for the first queens that may, by any accident, make their appearance. Those who insist that there is only one kind of eggs can satisfy themselves very easily by taking a larva hatched from a worker-egg and placing it in the bottom of a queen-cell. In due time this will develop into a queen. "On the other hand, if a larva from a drone-egg is placed in a queen-cell no queen results.

Occasionally a queen is found that will never lay at all; again, queens that laid eggs which never hatched into larvæ have been several times reported.

After having related some of the faults and imperfections of queens, it should be stated for their credit that, when once properly installed in a good strong colony, they are about as safe property as anything, because, in the great majority of cases, they live and thrive for years. While a worker lives only a few months, queens often live three or four years. One that was imported from Italy furnished the author brood and eggs for queen-rearing. for four summiers. She was sold for $\$ 2.00$, and she died in being sent less than 50 miles. She was very large and heavy, and, probably, being so old could not cling to, the sides of the eage like a younger one.

\section{LOSS OF QUEEN.}

It is a very important matter to be able to know at once when a queen is lost. During the months of May and June in the States east of the Mississippi and north of the Ohio the loss of a queen from the hive a single day will make quite a marked difference in the honey crop. If it be assumed that the number of-eggs a queen can lay in a day is 3,000 , by taking her away a single day there might be just that number of bees short during a yield of honey. To put it very moderately, a quart of bees might be taken out of the hive by simply eaging the queen for a single day. Beginners should remember this, for their untimely, or, rather, inconsiderate tinkering, just before the flow of honey comes, often cuts short their income to a very considerable degree. Whatever is done, it is very important not to drop the queens off the combs when they are handled at this time of the year, nor should one needlessly interrupt the queen in her work by changing the combs about so as to expose the brood or upset the little loousehold matters of the bees.

Witl a little practice one will be able io detect a queenless hive simply by the way the bees behave themselves in the hive and on the outside. When they stand around on the alighting-board in a listless sort of way, with no bees going in with pollerr, when other colonies are thus engaged, it is well to open the hive and take a look at them. (See Diagnosing Colonies.) If egg's and worker-brood are found one may be sure a queen is there; but if not, proceed at once to see if there is not a queen of some kind in the hive, that does not lay. If one is not found they should be given a frame of eggs to see if they build queencells. Incipient ones should be found in about twenty-four hours if the bees have been some little time queenless. If these are found a queen should be given. If no queen is to be had, they may be allowed to raise one, if the colony has bees enough. If it has not, they should be united with some other stock.

THE CRY OF DISTRESS FROM A QUEENLESS COLONY.

A queenless colony will reveal its condition, if not of long standing, by the behavior of the bees in the hive. They will 
set up a peculiar ery-that is to say, all thru the hive they will be buzzing as if in distress, and they surely are, because they have no queen. As soon as a hive of this kind is opened they will begin this ery of distress. Sometimes only a part of the bees will be involved, and at other times apparently every bee in the colony. This buzzing of the wings is so marked that the practiced beekeepeer recognizes it as an indication that a colony may be queenless; and if he finds no eggs nor young brood at a time of the year when both should be present, he is quite sure that the hive has no queen. If he finds queen-cells, all doubt will be removed. Sometimes a colony that is not queenless will set up a buzzing as if they were without a mother. It is then evident that the show of distress is not because they have no queen but because of the disturbance. Too much smoke, for example, with most colonies and a little smoke with some colonies will cause them to make this sign of distress. It must, therefore, be regarded as not an infallible sign of queenlessness. Colonies that have been queenless for a long time will no longer indicate their condition in this manner.

ODOR OF A LAYING QUEEN.

After bees have been some time queenless they usually become, if no laying workers make their appearance (see LAYING WORKERS), very eager for the presence of a queen; and in no way can this eager behavior be described, so well as to describe another way of testing a colony that is thought to be queenless. Take a cage or box containing a laying queen and hold either the cage or simply the cover of it over the bees, or hold it in such a way as to let one corner touch the frames. If queenless, the first bees that catch the scent of the piece of wood on which the queen has been, will begin to move their wings in token of rejoicing, and soon nearly the whole colony will be hanging to the cage or cover. When they behave in this manner there will seldom be any trouble in letting the queen out at once. Such cases are generally where a colony is found without brood in the spring.

There is something very peculiar about the scent of a laying queen. After having had a queen on the fingers, bees will often follow and gather about the hand. They will often hover for hours about the spot where the queen has alighted for even an instant, and, sometimes, for a day or two afterward. Where clipped queens get down into the grass or weeds or crawl.sometimes a considerable distance from the hive, they may often be found by watching the bees that were crawling about along the path she had taken. When cages containing queens are being carried away bees will often come and alight on the cage, making that peculiar shaking of the wings which indicates their joy on finding the queen.

\section{QUEENS' STINGS.}

There is something rather strange in the fact that a queen very rarely uses her sting, even under the greatest provocation possible, unless it is toward a rival queen. In fact, she may be pinched or pulled limb from limb, without even showing any symptoms of protruding the sting at all; yet as soon as she is put in a cage or under a tumbler with another queen, the fatal sting is almost sure to be used at once. There seems to be a most wise provision in this; for if the queen used her sting on every provocation as does the worker, the prosperity of the colony would be almost constantly endangered.

It was just stated that a queen very rarely uses her sting; but it is the exception that proves the rule. The following will explain:

One very young virgin queen that stung me was well developed and later proved to be a good queen for business. The other virgin, also very young, that stung me was from a good-looking cell, and I suppose was all right. As it was so much easier to crush her than to endure her continued stinging till I could get her out of my clothing, she was killed without knowing positively what kind of a queen she would have proven herself to be.

Ceres, Calif.

\section{CAUTION IN REGARD TO DECIDING A STOCK} TO BE QUEENLESS.

As a rule it may be said that absence of brood or eggs is a pretty sure indication of queenlessness; but it should be borne in mind that all colonies, as a rule, in the eastern and northern States, are without 
eggs and brood in the fall and early winter months, or, in fact, at any time when there is a considerable dearth of pasturage. At such seasons, beginners are more apt to think their colonies are queenless, because the queens are much smaller than when they are laying profusely, and therefore are not as easily found. In the North queens often cease laying during the whole of the winter months. They will not lay much when their colonies are in the cellar except sometimes the last month in the cellar. In California and the semi-tropical States of the South queens may lay every month of the year.

For further particulars regarding queens, see Drones, Queen-Rearing, and` Bee BeHAVIOR.

QUEENS, HOW TO FIND.-See MANIPUlaATION OF COLONIES, subhead, "How to Manipulate Hoffman Frames," and "How to Handle Unspaced Frames;" also Diagnosing Colonies.

QUINBY.*-Moses Quinby was born on April 16, 1810. During his boyhood his family removed to Coxsackie, Greene Co., New York.

In 1828 at the age of 18 , he earned his first money, working in a sawmill, and with it purchased his first swarm of bees and began the 25 years of study and experiment which prepared him for the writing of his book, published in 1853. In 1832 he married Miss Martha Powell Norbury, also of English extraction, and, like Mr. Quinby, a Quaker. They were married at the Norbury homestead. From this time till his removal to the Mohawk Valley he lived at the home. There was a mill on the place, and he earned the support of his family in these early years running the turning-lathe and doing cabinet work, many specimens of household furniture made by him being now the valued possessions of his granddaughters. Here also he made his lives and the first honey-boxes.

I have reason to believe that at this period there were more bees kept in this section than in any other part of the United States. For years after Mr. Quinby's death I have been to this location to buy bees to replenish my home apiaries.

\footnotetext{
* Written by his son-in-law, L. C. Root.
}

On a recent visit I saw small apiaries, many of them using the form of hive Mr. Quinby had recommended.

He says he "commenced without any knowledge of the business to assist him, save a few directions about hiving, smoking them with sulphur, etc." Beekeeping was considered a matter of Iuck. His friends and neighbors on all sides discouraged him. One wise old man predicted failure for him because he pottered with them too much, boring holes in the top of the hives and disturbing them. All of this advice only stimulated him to greater action. He prefixed to the word "Iuck" a big $P$, and underlined it.

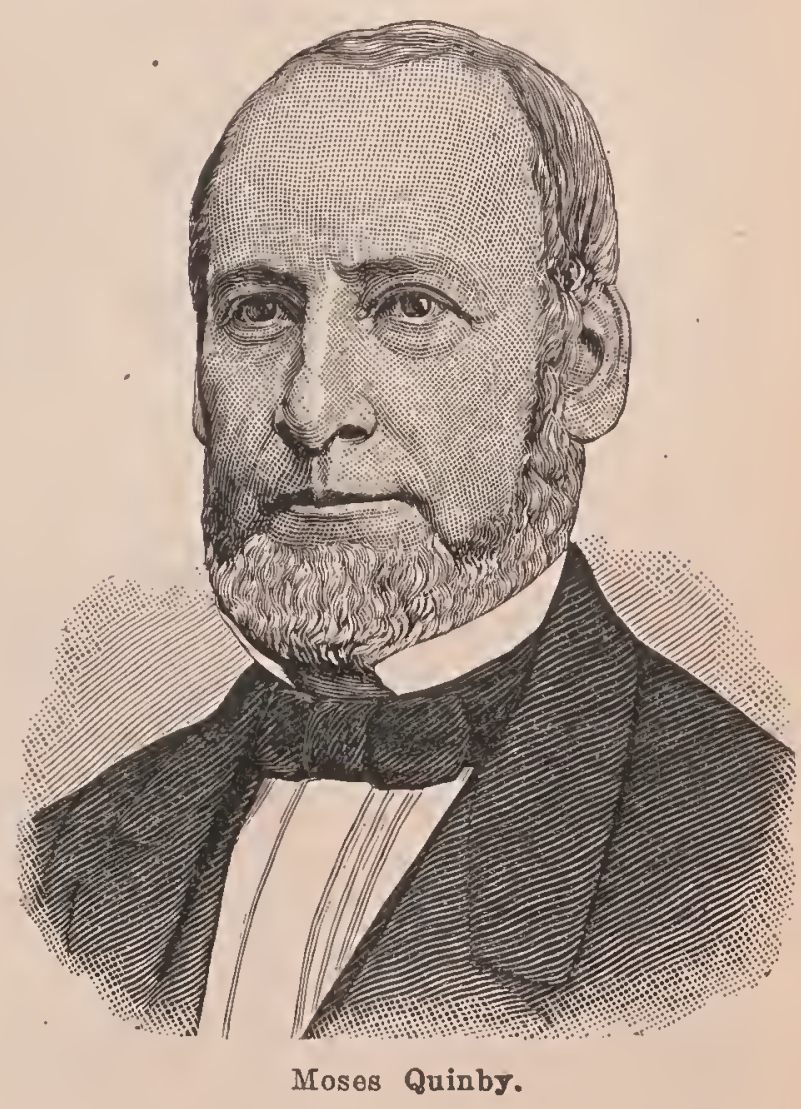

Here he spent 25 years experimenting and writing, with a determination to place beekeeping on the same successful financial basis with other branches of agriculture. All his experiments during this period were made with bees in box hives, there being no better ones at that time.

His first move to avoid destruction of the bees in securing the honey was by boring holes in the top of the hives, for he found that the bees would fill large boxes put over the hive. These were the forerunner of the super and section.

Another menace to success in beekeeping 
was foul brood. Rereading the chapter in his first book, in the light of morlen science of contagious diseases and bacteriology, shows it to be a marvel of careful observation and accurate reasoning that would do credit to the present day. The principles of his treatment of the scourge can never be changed. These and many other facts Mi. Quinby found had never been published; so, being by nature philanthropic, and having an unselfish desire to help others in a practical way by sharing his knowledge, he wrote this accumulated experience of 25 year's into his "Mysteries of Beekeeping Explained, being a complete analysis of the whole subject," as the title-page quaintly states. As I reread the book I realize how fully up to date it was for 1853, and how fundamentally correct were his statements and deductions on many points. It bears evidence of being entirely the author's own work. He started with no knowledge of the subject, but with an inquiring and open inin'd had no help from others, and only theoretical information from the limited literature on the subject of bees.

The keynotes of its snceess appear to me to be the scientific attitude of its author, unusual at that period-the clearness and plainness of its style, and the effort to help and instruct the reader rather than impress him with the accomplishments of the writer.

We do not know just when he was able to make beekeeping his sole business and the support of his family; but he certainly did so after his removal to St. Johnsville, Montgomery County, New York, in 1853, the year his first book was published. During the next ten years he owned the largest number of colonies at any time during his business career. He began to send large amounts of honey to the New York market, eren while still using the box hive. There being only a moderate lemand at that time, he nearly glutted the market. This was, indeed, the beginning of the reconstruction period in beekeeping. In $1856 \mathrm{Mr}$. Quinby's attention was called to Mr. Langstroth's invention of a movable-comb hive. He saw its advantages, and at once adopted it in a modified form. Then followed the introduction of Italian bees, honey-extractor, comb foundation, single sections for comb honey, and his own invention of the bee-smoker. These were indeed gratifying days to Mr. Quinby. Who was there in all of the beekeeping world so well prepared as lie from the standpoint of practical experience to meet the needs of this wonderful forward movement?

Mr. Quinby's non-swarming' standingframe hive enabled him to accomplish large

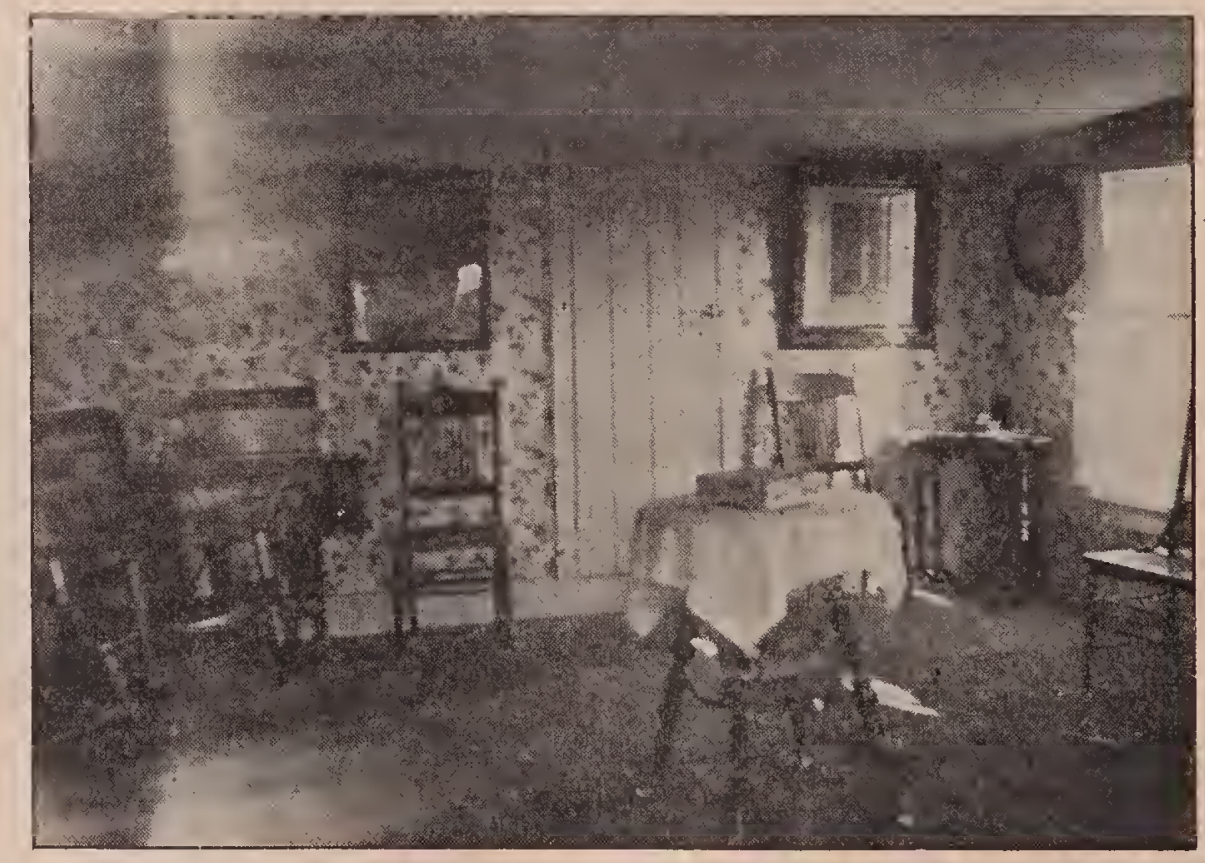

The ronm where Mr. Quinby wrote the 1853 edition of his book.

results under his management. Much might. be said in regard to Mr. Quinby's preferring the lareer frame. Marked success can be secured only by extremely populous swarms. I have proved the larger frames very advantageous to that end.*

I shall never forget the enthusiasm which was caused at our home when the words "centrifugal force for removing honey from the combs" were received in the report of the invention of Major de Hruschka of Vienna. An old fanning mill, which had been used for cleaning grain, was at once

* See "Frames, Self-sparing, for a description of his self-spacing frame; aud "Hives," subhead "The Dadant Hive," for a descrintion of the merits of the litge hive and frame. 
taken apart, the fans removed, and wire cloth stretched around its four sides. A larger box was made, inside of which this frame was arranged to revolve, and with the gearing of the fanning mill it was set in motion. The gratification with which Mr. Quinby saw the honey thrown from the first combs cannot well be described. $\mathrm{He}$ soon made an extractor in more workable form, which was afterward perfected by A. I. Root, and known as the Novice extractor.

Mr. Quinby realized that, tho fearless himself, people were deterred from keeping bees by fear of being stung. Smoke had been used in various erude ways; but he knew that, if it could be easily and conveniently adapted, it would be a great boon, especially to the amateur. His invention of the bee-smoker did this, being so arranged with upright bellows and firetube as to burn standing upright, but to go out when placed on the side, and to be easily manipulated with one hand. The principle of it las never been improved upon.

New York State, where Mr. Quinby's influence was most in evidence, became the largest honey-producing center in the world. One of the first articles on bees he ever wrote for publication was for a Philadelphia paper, expressing doubts as to the possibility of a writer having secured a gain of 20 pounds of honey from a swarm in two weeks. In these later days he had seen that amount gathered in two days, and 500 pounds of extracted honey taken from one colony in a season. Mr. Quinby sent in these days generally from 5,000 to 30,000 pounds of honey to the New York market annually.

While essentially a scientist and teacher, his first object was to enable others as well as himself to make beekeeping a commercial success by knowing how to gather in quantity this useful, natural foodstuff and delicacy. As Mr. Quinby became well known from his books and articles in agricultural papers, his home was quite a center for those seeking the information he so gladly imparted. Mr. Quinby was never so happy as when passing on his knowledge and experience to others. Few people who were not personally acquainted with him can realize how devoted he was to his ques- tioners, whether in person or by mail or thru the press. From the start to the last evening of his earthly life he never proved a principle in bee culture the benefit of which he did not give to the public. Two hours before he passed away he was at his desk, where he left an unfinished article.

The late Captain J. E. Hetherington was one of his most energetic pupils. It is still a joy to me to recall his enthusiasm during his frequent visits to Mr. Quinby's home, and the eager way in which he asked questions and received answers. $\mathrm{He}$ soon became one of the large bee-owners, first of box hives, but, as improvements followed, always up to date. Of these early visitor's, almost the last one living was P. H. Elwood of Starkville, New York, an intelligent, thoughtful worker and genial friend.

In $1865 \mathrm{Mr}$. Quinby published a revised edition of his book, and from the tone of the preface it is gratifying to see his pleasure in the success and popularity of this first edition.

In March, 1870, the Northeastern Beekeepers' Association was organized at $\mathrm{Al}$ bany, with Mr. Quinby as its first president, an office he held for five years, declining re-election at the meeting preceding his death. He was elected president of the North American Beekeepers' Association, at Cleveland, in 1871, and served one year.

Thus witl modest honors and much satisfaction in his work and in the fruitgrowing on his place, a happy home life and wide outside interests in the anti-slavery cause, temperance work, and all good and progressive endeavors, the years went by. Death came suddenly on the night of May 27, 1875, and a life of usefulness was over.

I am writing this article with the extreme - desire to show Mr. Quinby's devotion to his chosen calling. It would be impossible for any one who did not come in daily contact with him in his manipulation of bees, in the beekeepers' conventions, and, most of all, in his home, to have a full appreciation of how completely his work filled his thoughts. How well I remember the emphasis he gave the words when he once said to me, "I want it distinctly understood that I cannot afford to spend any time making money!" 
He gave 47 year's of constant application in honest effort to place beekeeping on a firm business basis. I am somewhat acquainted with the history of the beekeeping of the past, and I feel justified in pointing with pride to these 47 years of levotion which should warrant the name of "Father of practical commercial beekeeping in America."

\section{RABBITBRUSH (Chrysothamnus).-} Rayless goldenrod. Chico. Shrubby plants swith narrow entire leaves, and rayless yellow flowers, which bloom in the fall. Rabbitbrush yields a surplus of deep yellow honey which is thin and poor in quality. It granulates quickly, even in the comb; and when it is present in a section of alfalfa or sweet clover honey, it granulates before either of these honeys. The intense yellow color of the pollen often stains the surface of the combs. At Independence, Inyo County, Cal., C. nauseosus, a perennial plant, is abundant in waste land. The small yellow flowers in terminal clusters, on ash-colored or white stems, open in September and October. The honey is dark and las so disagreeable an odor and so nauseous a taste that even the Indians will not eat it. Beekeepers remove their sections when rabbitbrush begins to bloom. There are 18 species of rabbitbrush in the Rocky Mountain Highlands, several of which are very common on the dry hills and plains of Colorado and Wyoming, as $C$. lanceolatus, C. pumilus, and C. frigidus.

RACES OF BEES.-This volume deals particularly with Italians, the common black bees of this country, and the crosses between the two, because they are used almost exclusively. The crosses are often given the name "lhybrids;" and as the name has been generally adopted, it is retained. For particulars regarding these bees the reader is referred to Hrbrids. The Italians are spoken of specifically under the heading of Italians, elsewhere in this work.
BLACK OR GERMAN BEES.

As the name indicates, they are black. One variety in the South is of a brownish black; another distinctly black, and if anything, a trifle smaller.

The black bees are more inclined to rob than the pure Italians, are not as good workers, but are equal when nectar is abundant, or when there is dark honey like that from buckwheat to be gathered. They are much more nervous; and when a hive of them is opened they run like a flock of slieep from one corner of the hive to another, boiling over in confusion, hanging in clusters from one corner of the frame as it is held up, and finally falling off in bunches to the ground, where they continue a wild scramble in every direction, probably crawling up one's trousers-leg, if the opportunity offers. Black queens are much harder to find, their bees are not so gentle, and, worse than all, they have a disagreeable fashion during robbing time of following the apiarist about from hive to hive in a most tantalizing manner. This habit of poising on the wing before one's eye is extremely annoying, and some bees will keep it up for a day at a time. When angry bees trouble in this way, one should work in another part of the apiary or stop work entirely for a time. If the trouble continues, he should requeen with queens of a more gentle strain.

Comb honey from the blacks is a little whiter, if anything, than that made by pure Italians, because the capping is raised up, leaving a slight air-gap between it and the surface of the honey in the cell. But 
this difference in the whiteness of capping is so very slight as compared with that on comb honey made by selected Italians that it really cuts no figure in the market. The blacks are also much easier to shake off the combs than pure Italians, which can hardly be shaken off, and some prefer blacks or hybrids, when extracting, for that reason alone.

Blacks, when their hives are moved a short distance, will find their entrances much more readily than Italians. The returning bees will nose around every hive until they find their own, when they will enter as tho they had always lived there. On the other liand, Italians cannot be moved in this way. Many of them will be were introduced into this country in 1884 . They are very gentle, but no more so than Italians. As stated, they resemble blacks, and might easily be mistaken for them; but there is a difference. They are larger, and their abdomens are of a more bluish cast, the fuzzy rings being very distinct. They are gentler, and do not, like the blacks, boil over in confusion when the hive is opened. They have not the fixity of character of the Italians-colonies of the same race differing quite widely. The general verdict is, that they are excessive swarmers, and this trait alone makes them very undesirable for comb-honey production, altho some like them for the production of extracted honey. Their rlose resemblance to black bees

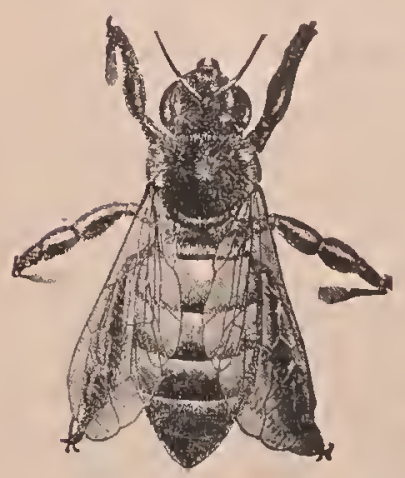

Worker.
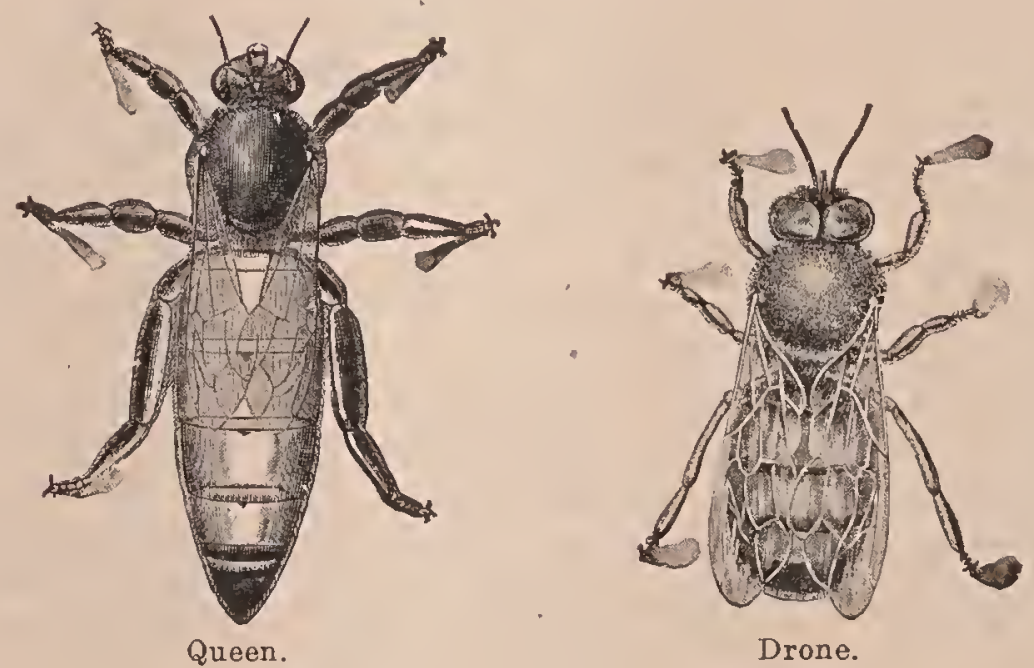

found on the ground on the old location, and die, only a few of them, comparative$1 y$, finding homes in other near-by hives. See MOVING BeEs.

Many believe that blacks are more persistent than the Italians in that they will stand unfavorable weather conditions better than Italians; but it has been proven over and over again that they will not resist brood diseases as do the yellow bees. Indeed, they rapidly succumb under the ravages of European foul brood where some strains of Italians will seem to be almost immune from it. Practically all Italians will resist brood disease of botll European and American foul brood better than the average strain of black or hybrid bees. See Foul Brood.

\section{CARNIOLANS.}

The Carmiolans, evidently a rariety of black bees, which they rery much resemble, makes it difficult to detect the crosses of the two races. This fact, coupled with their great swarming propensity, has prevented their meeting with general favor.

But the Carniolans have one good trait in their favor, and that is, they deposit as little propolis as any bees ever known. In the production of comb honey this is quite an important item. See Hrbrids of Carniolans and Cyprians.

\section{CAUCASIANS}

This is a race that. looks very much like Carniolans and the common black bee of this country, but it resembles the latter more than the former. So close is the general resemblance that even experts in some cases have been unable to distinguish them. But there is a vast difference in their general habits and temperament.

The claim has been made that Caucasians are the gentlest bees known; and this claim, 
in. part at least, has been established, altho they are no more so than some good strains of pure Italians. Beemen are not agreed, however, as to their honey-gathering qualities. Some consider them very. interior, while others believe they are equal to any race in this respect. All admit that they are bad propolizers, sticking large chunks of gum in all parts of the hive - a trait that becomes more manifest as cold weather comes on. In this one respect they differ radically from Carniolans.

The most serious objection to them is their propensity to swarm. It is even more pronounced than with the Carniolans.

\section{BANAT BEES.}

These are named from a district of Hunyary from which they were imported. They much resemble the Carniolans in appearance and habit but with less inclination to swarm. They are gentle, and impart this trait to their offspring when crossed with Italians. Even after several generations this character is in evidence. The queens are of a dark tan color, and no more prolific than good Italians, but they build up the colonies more rapidly in the spring. They are worthy a more extended trial both in their purity aud in their crosses.

\section{TUNISIANS.}

This black race, natives of North Africa, are sometimes called "Punics." They have been tested to some extent in this country, but so far have not been able to establish any claim in their favol that would entitle them to consideration on the part of American beekeepers. They are cross, and so inclined to smear everything with a red bee glue that they are entirely unsuited for the production of comb honey. They are no better honey-gatherers than gentler races.

\section{EGYPTIANS.}

The Egyptian bee is reputed the most beautiful species of Apis. It has been named Apis fasiata by entomologists; has been cultivated for thousands of years by the Egyptians, and was probably the first species used by mankind for domestic purposes.

In the time of the ancient historian Herodotis, apiaries were transported up and down the Nile so as to keep pace with the seasons in Upper and Lower Egypt. This practice is continued at the present day to a limited extent. Inscriptions on tombs show the practice in use 4,000 years ago, at least, and that the honeybee was highly reverenced by the people of that age.

The Egyptian bee is so much smaller than the Italian that the two do not hybridize very well; on the contrary, the queen, if compelled to mate with a European drone, frequently dies soon after fertilization. It is probably, however, the mother-species of the Cyprian, Holy Land, and Grecian bees. It is a fast, excellent worker. but reputed to possess an irritable temper tho kept domesticated for thousands of years. Possibly in a climate similar to that of Egypt it would exhibit a better temper than in Northern Europe. It could hardly be otherwise.

In color Egyptians are almost identical with Italians, but in addition liave a coat of white hairs, which adds to their appearance. There are varieties, or races, of the same species in countries next to Lower Egypt. One feature of these bees would please Americans, namely, their ability to keep themselves pure and uncontaminated with other races. There is a similar species in Senegal known as Apis Adansonii, of which we know but little.

\section{ALBINOS.}

Albinos are either "sports" from Italians, or, what is more generally the case, a cross between Holy Lands and Italians. After testing them the author finds them little different from conmon Italians. The fringe, or down, that appears on the rings of the abdomen of young bees is a trifle whiter than usual, yet no one would observe it unless attention is called to it. The queens are very yellow, while the workers, as honey-gatherers, are decidedly inferior. even in the second generation; and when light-colored bees or queens are selected for several successive generations, unless care is used, a weaker progeny lacking ability as honey-gatherers and endurance will be developed.

EASTERN RACES OF BEES.

Cyprians, Holy Lands, or Syrians, are 
mentioned elsewhere under head of TTALIANS. Of other Eastern races Frank Benton, formerly Apicultural Expert of the United States Department of Agriculture, wrote a special bulletin, from which the following extracts are made:

\section{THE COMMON EAST-INDIAN HONETBEE.}

\section{(Apis indica, Fab.)}

The common bee of Southern Asia is kept in very limited numbers and with a small degree of profit in earthern jars and sections of hollow trees in portions of the British and

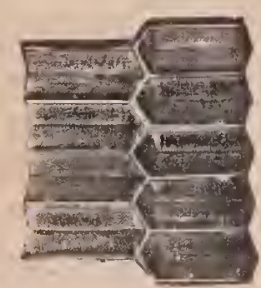

Fig. 1-Worker-cells

Hom

Dutch East Indies. They are also found wild, and build when in this state in hollow trees and in rock clefts. Their combs are composed of hexagonal wax cells, and are arranged parallel to each other like those of A. mellifica, but the worker brood-cells are smaller than those of our ordinary bees,

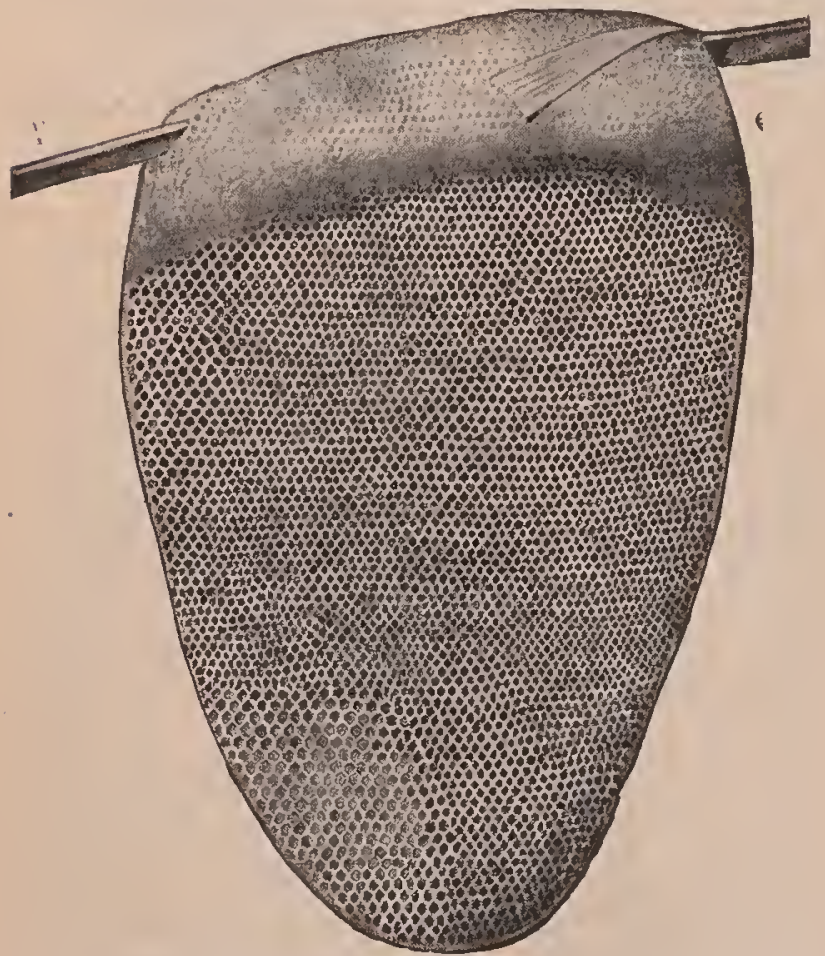

Fig. 2.-Wurker-cells of Common Fast Indian Houeybe (A vis inflica), one-third natural size.

showing 36 to the square inch of surface instead of 29 ; while the comb where workerbrood is reared, instead of having, like that of A. mellifica, a thickness of seven-eighths inch, is but five-eighths inch thick. (Fig. 1.)
The workers.-The bodies of these, threeeighths inch long when empty, measure about one-half inch when dilated with honey. The thorax is covered with brownish hair, and the shield or crescent between the wings is large and yellow. The abdomen is yellow underneath. Above it presents a ringed appearance, the anterior part of each segment being orange yellow, while the posterior part shows bands of brown of greater or less width, and is covered with whitishbrown hairs; the tip is black. They are nimble on foot and on the wing, and active gatherers.

The queens.-The queens are large in proportion to their workers, and are quite prolific; color, leather or dark copper.

The drones.-These are only slightly lar. ger than the workers; color, a jet-like blueblack, without yellow, their strong wings showing changing hues like those of wasps.

Manipulations with colonies of these bees are easy to perform if smoke be used; and, tho they are more excitable than our common hive bees this peculiarity does not in-
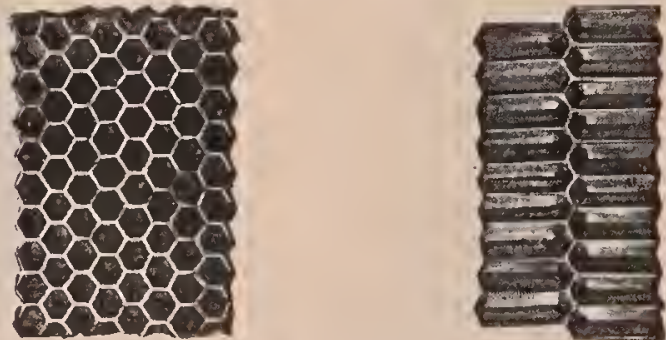

Fig. 3.-Worker-cells of the tiny East Indian Hon ey bee (Apis florea), natural size.

duce excessive stinging, but seems rather to proceed from fear. The sting is also less sev̄ere.

Under the rude methods thus far employed in the management of this bee no great yields of honey are obtained, some 10 or 12 pounds having been the most reported from a single hive. It is quite probable these little bees would yield more if imported into this country, since they could no doubt visit many small flowers not frequented by the hive bees we now have, and whose nectar is, therefore, wasted; but very likely they might not withstand the severe winters of the North unless furnished with such extra protection as would be afforded by quite warm cellars or special repositories.

Of the smallest honeybees in the world the same writer says:

\section{THE TINY EAST-INDIAN HONEYBEE.}

$$
\text { (Apis florea, Fab.) }
$$

This bee, also a native of East India, is the smallest known species of the genus. It builds in the open air, attaching a single comb to a twig of a shrub or small tree. This comb is only about the size of a man's 
hand, and is exceedingly delicate, there be ing on each side 100 worker-cells to the square inch of surface (Figs. 2 and 3 ). The workers, more slender than house flies, tho longer-bodied, are blue-black in color, with the anterior third of the abdomen bright orange. Colonies of these bees accumulate so little surplus honey as to give no hope that their cultivation will be profitable.

\section{GIANT BEES OF INDIA.}

\section{(Apis dorsata, Fab.)}

A few years ago much was said regarding the East Indian "giant" honeybees, Apis dorsata, and the possibilities of having them imported and domesticated in this country. Mr. Benton, having been in their native land, describes them.

This large bee, which might not inappro priately be styled the Giant East-Indian bee, has its home in the far East-both on the continent of Asia and the adjacent islands. There are probably several varieties of this species, more or less marked, and very likely Apis zonata, Guer., of the Philippine Islands, reported to be even larger than Apis dorsata, will prove on further investigation to be only a variety of the latter. All the varieties of these bees build huge combs of very pure wax-often .5 to 6 feet in length and 3 to 4 feet in width, which they attach to overhanging ledges of rocks or to large limbs of lofty trees in the primitive forest jungles. When attached to the limbs of trees they are built singly, and present much the same appearance as those of the tiny East-Indian bee, shown in the accompanying figure (Fig. 3). The Giant bee, however, quite in contradistinction to the other species of apis mentioned here, does not construct larger cells in which to rear drones, these and the workers being produced in cells of the same size. Of these bees - long regarded as a myth by beekeepers of America and Europe-strange stories have been told. It has been stated that they build their combs horizontally after the manner of paper-making wasps; that they are so given to wandering as to make it impossible to keep them in hives, and that their ferocity renders them objects greatly to be dreaded. The first real information regarding these points was given by the author. He visited India in 1880-81 for the purpose of obtaining colonies of Apis dorsata. These were procured in the jungles by cutting the combs from their original attachments, and it was thus ascertained (as might have been expected in the case of any species of apis), that their combs are always built perpendicularly; also that colonies placed in frame hives and permitted to fly freely did not desert these habitations, and that, far from being ferocious, these colonies were easily handled by .proper precautions, without even the use of smoke. It was also proved by the quantity of honey and wax present that they are good gatherers. The execution at that time of the plan to bring these bees to the United States was prevented only by severe illness contracted in India.

These large bees would doubtless be able to get honey from flowers whose nectaries are located out of reach of ordinary bees, notably those of the red clover, now visited chiefly by bumblebees, and which it is thought the East Indian bee might pollinate and cause to produce seed more abundantly. Even if not further utilizable, they might prove an important factor in the production; thruout the southern States, of large quantities of excellent beeswax, now such an expensive article.

At one time a few in this country were advocating the importation of Apis dorsata into this country for the reason that these bees would be able to get honey from red clover and other flowers with deep tubes. It is doubtful, however, whether' they would be able to adapt themselves to this climate. In California there is too great a change of temperature from night to day, and in Florida and in the southern States the climate is not hot enough. The inpression prevails that they are too much like bumblebees to be of any commercial value. For the last 20 years there has been very little said about them.

RASPBERRY (Rubus idaeus variety aculeatissimus).-The wild red raspberry is a valuable honey plant in the northern part of the southern peninsula of Michigan, in the Adirondack region of New York, in north-central Pennsylvania, and to a smaller extent in northern New England. Probably no raspbemy location is so well known as that of the lower Michigan Peninsula. The northern portion of this section of the State was once covered by an extensive forest of white and Norway pine, in which there were belts of magnificent hardwood timber consisting largely of beech, maple, and elm. Nearly all of the pine has in recent years been cut for lumber. During the first dry season following the cutting, fire burns over the stump-land leaving a blackened, desolate, almost weird, pine barren. Two or three years later willow-herb may spring up, but raspberries are either entirely absent from the pine barrens, or are so short and stunt- 
ed as to be of little value as honey producers.

It is upon tracts from which the hardwood lumber has been cut that the wild red raspberry offers as reliable a bee pasturage as is to be found anywhere. So luxuriant is the growth that it is possible, in riding along a woodroad, to pick the luscious ripe berries from the tall bushes bending with the fruit. If the land is not burned over, the rich loam, mulched with brush, produces large thrifty bushes which yield great crops of honey for several years. A hive on scales showed in fair

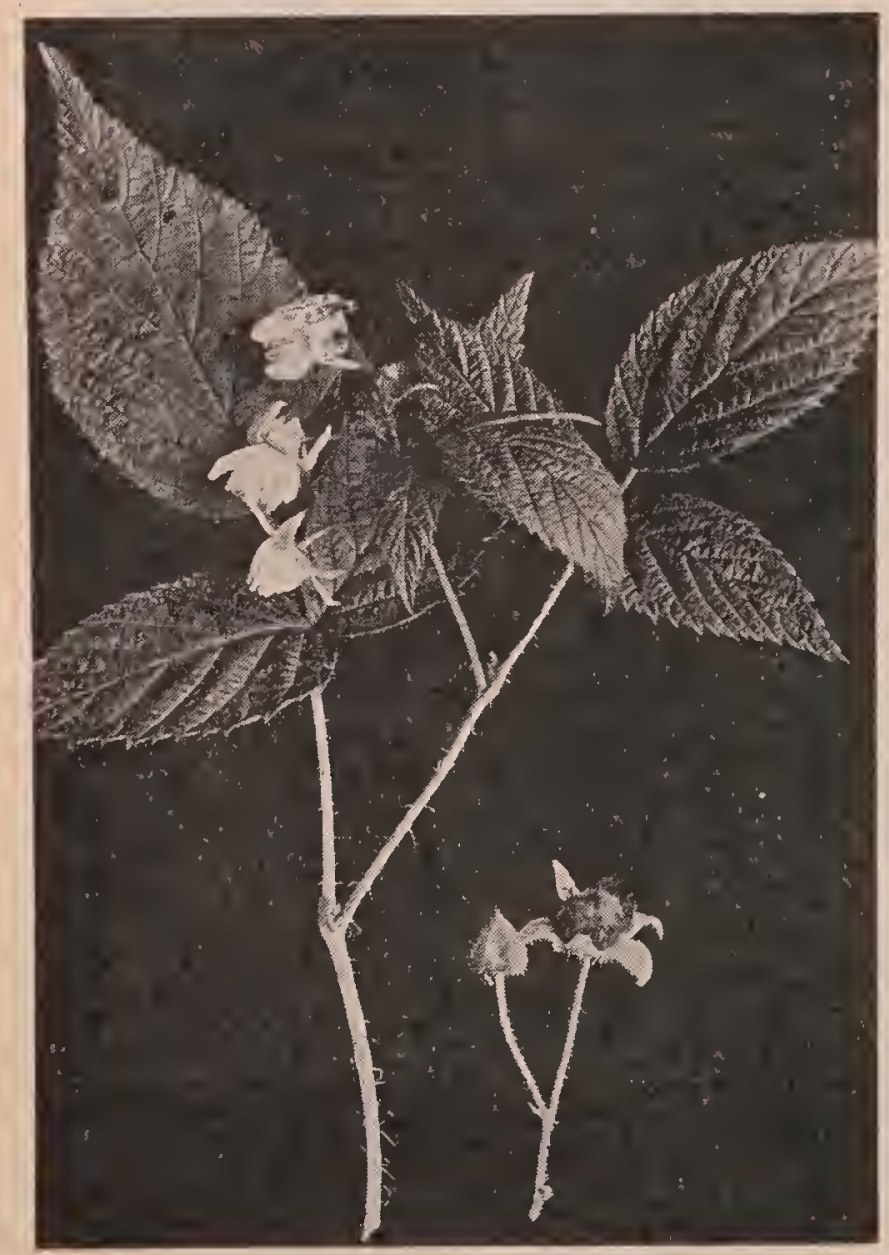

Raspberry

weather a daily gain of 6 to 13 pounds. But the rapidly growing young trees soon smother the bushes, and the beekeeper is forced to seek a new location. If, however, the land is occasionally burned over, the average annual surplus is less, but the bee pasturage lasts much longer. Thus the raspberry district is constantly changing, and this shrub is not a permanent source of nectar in one locality like white clover. As new areas are lumbered off "new pastures are offered to new comers." There is only one way, according to Hutchinson, to find a desirable location and that is to hunt for it."

Wild raspberry honey is described by Hutchinson, who produced it in large quantities, as having a delicious raspberry flavor, and, while not as white as white clover honey, it is still classed as a white honey. In a warm season it begins to bloom about the first of June, but if the spring is cold and backward the flow does not start until the middle of June. "I think that I can safely say," wrote Hutchinson, "that the wild raspberry never fails to produce nectar. It does not winter-kill as does clover, and nectar secretion is less affected by the weather. I have seen bees doing well working' upon it, when the weather was so cool that clover would not yield a drop of nectar." A luxuriant growth of bushes yields more nectar than a stunted one. The bloom lasts fully as long as that of white clover, and bees liave been seen gathering nectar from it during the latter part of July. If there is a drought in August, followed by rains and warm weather in September, it sometimes blossoms again and furnishes a second crop of honey. The blossoms are inverted. a provision for protecting the nectar from rain.

A long-settled comntry is of no ralue for wild raspberries, since the land is so highly cultivated that there will be no berrybushes except along the fences and the edges of the clearings. Support for several luundred colonies can be found only where the hard timber has recently been lumbered and the land has not been sold for farms. The lumbered regions on which the wild raspberry is abundant are isolated and remote from the settlements. The only buildings available are $\log$ shanties and deserted lumber camps. The beeman who goes to northern Michigan must expect. to "rough it," and live in a shanty. The severity of the winters and the danger from forest fires are also objections. The time will eventually come when this country will be cleared and cultivated, as is the case in the southern portion of the State, but this will be many years hence. But probably no location is so inaccessible at present that the beekeeper can not get his crop to miarket. The wild- 
erness has, moreover, to the lover of nature a fascination of its own. The streams are stocked with speckled trout, the forest with game, and the cut-over land furnishes an inexhaustible supply of huckleberries, blackberries, and raspberries.

Across the Straits of Mackinac in upper Michigan raspberry is abundant on the cultivated hardwood land, and is second in importance only to alsike clover. In the acid sandy soils north of the Adirondack region in New York the clovers do not thrive, but raspberry is abundant and yields well. Raspberry honey is produced in commercial quantities year after year near Massena Springs. It is the only source of surplus and about 50 pounds of extracted honey per colony is obtained. Considerable of Franklin County is to be included in the raspberry area, as from Malone southward.

Where the raspberry is cultivated on a large scale for market it is also an important honey plant. The largest acreages of bush fruits are located on the eastern shore of Lake Michigan, on the southern shore of Lake Ontario, in southern New Jersey; and around Cincinnati, Ohio; St. Louis, Missouri: and Los Angeles and San Francisco, Cal.; and Salem and Portland, Oregon. The red varieties, especially the Cuthbert, are believed to furnish the most honey. Bees work on the flowers closely, and the honey is excellent in quality. The raspberry blooms between fruit trees and white clover, so that large fields of it are a great acquisition.

Finally it is both of historical and practical interest to quote Langstroth's opinion of raspberry honey: "Tn flavor it is superior to that from white elover, while its delicate comb almost melts in the mouth. When it is in blossom, bees hold even white clover in light esteem. Its drooping blossoms protect the honey from moisture, and bees work upon it when the weather is so wet they can obtain nothing from the upright blossoms of the white clover."

RATS-Rats may do a great deal of damage in a honey-house. There are some old fellows clever enough to avoid traps and poison. The only thing to do with such is to shoot them by watching when they congregate about five o'clock in the afternoon in and about the out-buildings. A 32-caliber Flobert rifle with shot cartridges, or, better, a taxidermist's 44-caliber shotgun, will do good execution.

One of the best traps that was ever made is the old-fashioned rabbit-trap with grain spread on the botton of the box. The trigger to. close the trap should extend down to the grain. The rats in eating will bump against the trigger and set it off, when they are imprisoned alive, after which they can be drowned.

Poison can be given in the form of dough made of one-fifth part of barium carbonate, or barytes, and four-fifths meal. This poison has no odor nor taste; and it is better than strychnine because its action is slower, giving the rats a chance to get off the premises before they die.

RECORD-KEEPING OF HIVES:-Almost every apiarist has a plan of his own, whereby he can record the condition of the hive at the time of its examination, so that, without depending on memory, he may tell at a glance what its condition was when last examined.

Many of the large honey-producers have what they call a record book. This has a page for each colony, the number of the page corresponding with the number of the colony. The book should be small and compact, just about right to carry in the hip pocket, and securely bound. It should always be carried when at work among the bees. On each page is supposed to be a record of each colony's doings within a year-when it became queenless, when it had cells or brood, when it swarmed, and, toward winter, the strength and quantity of stores it had when last examined.

There is an advantage in this method, as the book can be consulted in the house, and the work mapped out beforehand for the day. If the record book be for an outapiary, the work can be planned while riding to the yard; and, upon arrival. the plans formulated can be executed. It is thus possible to know in adrance just where to get the cells to give to queenless colonies; just which colonies will be likely to have laying queens; which ones may cast swarms, and which ones will need more room in the $w^{-\cdots}$ of sections or surplus combs. 
There is one objection to the record book, however. It is liable to get lost, or to be left out in the rain; and if the book is lost, the whole knowledge of the apiary, except so far as the apiarist can remember, is gone. Another thing, only one can use the book at a time.

Others prefer card indexes. Each live in the apiary will have a number, and corresponding to that number will be a card. Boxes of these card indexes can usually be obtained at the stationer's or at the bookstores at a moderate price. The advantage of such index is that, when some particular card for some hive is full, it can be replaced by another card bearing the same number for additional data. The most important advantage is that one can look thru his index at home; and when he comes across a card, the corresponding hive of which requires some particular attention, he can remove that card entirely from the index. In like manner he can remove the cards of all other colonies of the yard requiring special attention. These cards can then be slipped into the hip porkets and carried to an outyaid or handed to an assistant with proper instructions; and after the hives have received the requisite attention, the necessary record can be attached. On returning home the cards can be put back.

Where there is a series of outyards, one should have one index for each yard. As there will seldom be more than 200 colonies to the yard, one can liave an index of 200 cards. For example, yard No. 1 will have cards up to 199; yard No. 2 from 200 to 399; yard No. 3 from 400 to 599, and so on. If any of the cards should get mislaid or get mixed with another index, the first figure of the number will indicate to what yard or index it belongs.

For the purpose of queen-rearing, the card index is invaluable because it enables one to keep a complete record of a queen, even her pedigree for several generations back. When she is sold, the record can be made, showing to whom she was sold, so that, if the purchaser complains that her bees are not pure, or that the colony is diseased, the breeder can easily go to the identical colony from which she came, and prove or disprove eitlier assertion.
The value of the card index can be materially increased by the use of colored cards to slip into the index here and there to indicate immediate or early attention to some particular number. As the apiarist goes over his records the colored cards will indicate just where the cards are, referring to a specific colony. Let us suppose a case. No. 241 at the time of examination looked suspicious. The presence of foul brood is feared. A red card is put right in front of card 241, for red indicates danger. Blue, green, and yellow cards may be used to indicate other conditions such as queenlessness, short of stores, failing queen, about to swarm, etc. If one is making preparations to feed he will hunt over the blue cards. Either pull the cards back of them out of the index or note down on a slip of paper the numbers of the hives that require feeding.

In this connection it should, perhaps, be stated that one can purchase at very small expense loose-leaf note-books with an alphabetical or numerical index. These books are so constructed that any particular page can be removed and another page substituted or added, on the principle of looseleaf ledgers. Such books can be used in place of a card index. In other words, it will be a pocket card index that can be carried to and from the yard; and as such books are usually bound in leather they will stand rough usage.

Of course, with any books or card index it goes without saying that every hive in the yard should be numbered. These numbers may be put on the hive with a brush, using black paint. But it is preferable to use a detachable number. Such a number may be stenciled on a sheet of tin and the tin tacked on the hive. The objection to these is the expense. Fortunately there can now be secured of supply dealers, numbers printed on heavy manila tag's that are afterward soaked in boiling paraffin so they will stand the weather. These numbers can then be tacked on the cover, or on one side or end of the hive. As a rule it is better to use the front end just over the entrance. In the course of two or three years it may be necessary to replace the old number with a new and 
fresh one. As these card numbers are very cheap the expense of renewal is small.

\section{RECORD-KEEPING IN OR ON THE HIVE.}

There are many beekeepers who think they cannot afford to fuss with books, card indexes, nor anything of that sort. Some of them simply write the record inside of the cover; but in most cases the form or make of cover renders this impracticable.

One of the best schemes to accommodate this class of beekeepers is what may be called, for want of a better name, wooden writing tablets. These are made out of broken sections, $1 \frac{1}{2}$ or 2 inches wide, by 4 or 5 inches long. But these, unless dipped in white lead, will soon weatherstain so that the lead-pencil record will be blurred if not entirely obliterated. To coat a thousand of these, dip in thin white lead, and lean against something until dry. In every case after they are painted they will hold lead-pencil records the entire season. At the author's yards both the card index and the wooden tablets coated with white lead have been used. The tablets are for a temporary record, which record is later transferred to the eard index. In connection with the white tablets some painted different color's to indicate different conditions are used. With these one can stand in one position in the yard, and at a glance can easily locate a colony having a blue, red, yellow, or green tablet, each color carrying its own special meaning.

But these wooden tablets will blow off the hives, and become lost. This difficulty is easily overcome by the use of little spring clips made of brass; and in lieu of anything better, the ordinary steel super springs coated with paint make a very good substitute. Each spring clip should be fastened down with a staple. The advantage of these clips is that they not only hold the tablets fast to the hive, but they enable one to place the tablet in front or on top. Where a colony needs attention at the next visit, a red tablet is placed on top of the white one bearing the record. If a colony needs feeding, a blue tablet will be used; if it is queenless, a green one; and thus one can use a great variety of colors tu indicate as many conditions of the colony. In most cases a red tablet may be used to show anything that requires inme- diate attention. For example, a colony may be starting to build queen-cells. They should be eut out, of course. At the next trip they will need to be cut out again to forestall swarming.

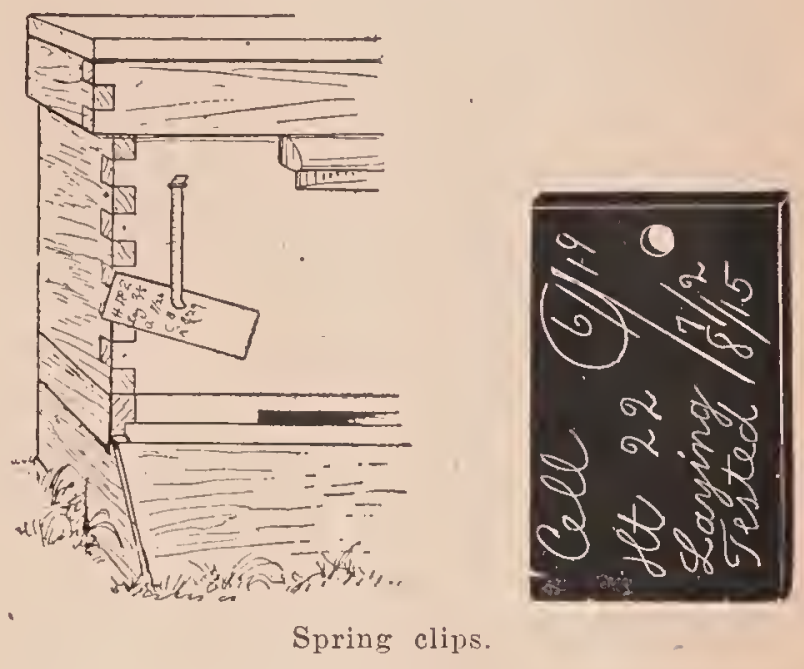

Again, a red card may indicate a failing queen, or a poor queen which needs replacing soon; a colony that is on the verge of starvation, a colony that has suspiciouslooking brood, that will need another examination a week hence before its nature can be fully determined. In like manner a red card may be used to indicate any conditions that need rectifying at the time of the next visit.

The spring clips should usually be made out of brass, and those used in the author's apiaries are made of that material, 24 gauge, $1 / 4$ inch wide, and about 4 inches long, bent as shown in the illustration.

\section{QUEEN-REGISTER CARDS.}

Another system of record-keeping that is popular with a few is what are called register cards. The accompanying plan shows how they are used. To indicate the

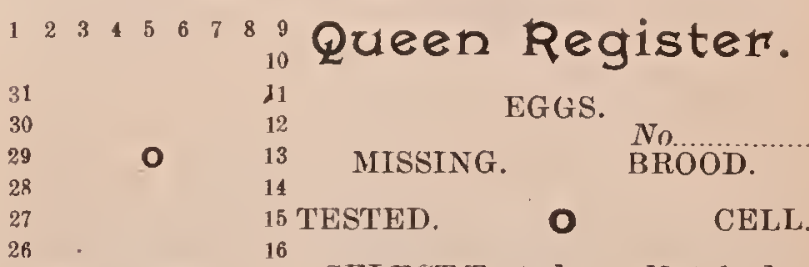

252423222120191817 SELECT'Tested. Hatched

MARCH.

LAYING.

OCT. APRIL. SEPT, O MAY, conspicuous part of the hive or nucleus: then, with a pair of pliers, force a common pin into the center of each circle, art pit whe it is bent in such a circle, at the why it is bent in such se- 
date, the pin heads are revolved so as to point to the proper place. There is no writing, and nothing to do except to turn the pointers to the right place.

\section{RED CLOVER.-See ClOver.}

REVERSING.-This, as the term signifies, is a scheme or plan for inverting, or turning over, the comb. It may be accomplished by inverting the frames individually or the whole hive at one operation.

Reversing began to be discussed in 1884; and for three or four years following there was much said on the subject. Reversible frames and reversible hives were invented by the dozen. Some of them were quite ingenious, while others were clumsy and impractical.

Taking into consideration the fact that the bees store their honey immediately over the brood, and that, as a consequence, their combs at this point are much better filled out, certain beekeepers conceived the idea of turning the combs upside down at frequent intervals. "Why," said they, "when the combs are reversed, bringing the bottom-bars uppermost, the combs will be built clear out to the bottom-bars, and the honey next the top-bar, which is now at the bottom of the hive, will be carried up into the supers, just where it is wanterl." This seemed very nice in theory, and even in practice it seemed to be partially carried out. Many beekeepers reported that, when the combs were reversed, the bees. rather than have the honey in the bottom of the combs, near the entrance, and accessible to robbers. would uncap it and take it up into the sections. Infortunately. honey rarried above was often poor and dark in color. Many times also the bees did not carry the honey above but allowed it to stay at the bottom of the hive, so that the only real advantage secured was getting the combs filled actually to the bottom-bars, now at the top.

A very few claimed that reversing, when done at the proper time, would destroy queen-cells, and so control swarming. Rut this worked better in theory than in practice.

The only real and direct advantage of reversing is in getting combs filled out solid in brood-frames. (See MANIPUlation OF. Cotontes.) When hunting queens it is much easier to find one where there is no horizontal space between the edge of the comb, and the bottom-bar, and no boles to furnish her hiding-places. Moreover, having combs filled out solid gives better fastening to the frame and increases the capacity of the hive just in proportion to the new comb built after reversing. Nearly every frame that is not reversed is liable to have a space of $1 / 2$ inch or $3 / 8$ between the top of the bottom-bar and the comb; and this is a waste that ought to be utilized if possible. To a certain extent this space can be filled in non-leversing frames by having sheets of foundation reach from framebottom to top-bar, wired in with perpendicular wires; but even such combs are never as well filled as those reversed. Having the combs built in the upper story causes the bees to build them down to the bottom-bar much better than when built in the lower story.

Several good reversible frames liave been proposed; but no one should think of adopting any of them unless it has some points of merit outside the one exclusive feature of reversing. A reversible frame that is not good for all-around use-easy to handle-would be very unprofitable.

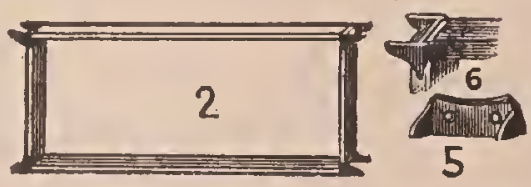

The Van Deusen reversible frame.

One of the first practical reversing frames was the Tan Deusen, having metal corner's or ears. This was essentially a standing frame, and could be used just as well one side up as the other. The frames. were spaced apart by "spacing-ears," and these very ears offered some distinctive adrantages in the way of handling the frame. This frame was used rery largely by the one-time most extensive beekeeper in the world, Captain J. E. Hetherington of New Tork, also by his brother in Michigan. Out side of its reversing feature it offered one very decided advantage; namely, the facility with which it could be handled like the leaves of a book. By taking out one or two frames the rest could be thumbed over without lifting them out of the hive. Notwithstanding, it is not now used. 
Two other reversible frames are the Danzenbaker and the Heddon (see Hrves; also Frames, Selaf-SPacing, and ManipuLATION OF COLONIES), either one of which can be used as well one side up as the

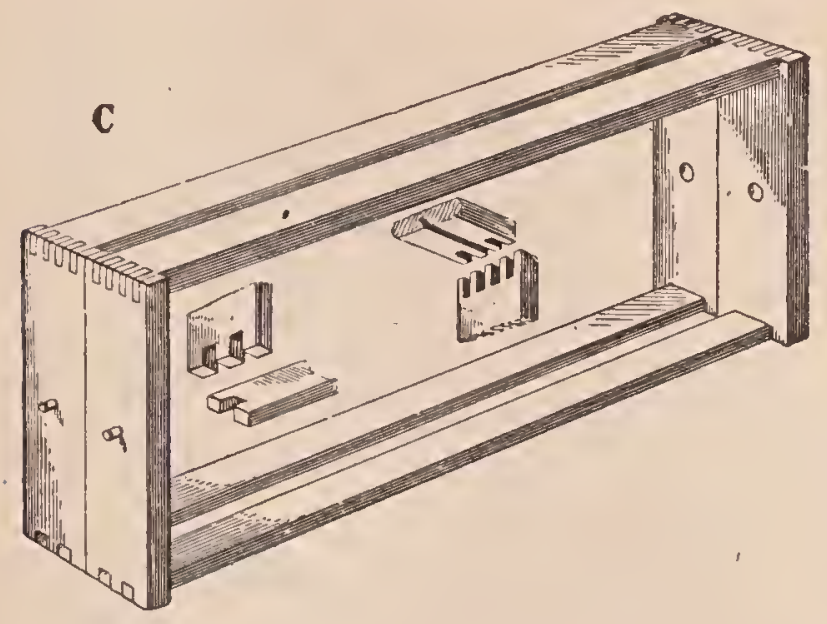

Danzenbaker reversible frame.

other; in fact, any closed-end standing frame, except the Quinby, can be used as a reversible frame.

The fact that none of these frames nor any other reversible frames are in use to any extent would seem to argue that the advantages of reversing are more theoretieal than actual.

HOW TO REVERSE ORDINARY FRAMHS SO THAT COMBS WILL BE BUILT DOWN TO THE BOTTOM-BARS.

The ordinary frame in general use, as before stated, will have a space of from $1 / 4$ to $1 / 2$ inch between the bottom edge of the comb and the bottom-bar. There is only one way to make the bees fill this out, and that is to turn the combs upside down for a short time. With the Hoffman frames, the hive-body and all containing the frames can be inverted. To prevent the frames from siding down on to the bottom-board when the whole thing is reversed, a couple of cleats should be placed on each end, equal in thickness to the bee-space on top of the frames and the bee-space in the bottomboard. An ordinary bottom, after the cleats are in place, should be put on top of the hive in place of the cover, after which the bottom-board, hive, frames, and all may be turned the other side up for a week's time. The time selected for doing this should be just at the beginning of the honey flow. After the frames have been upside down for ahout a week they can be set back to their normal position w'th the top-bars on top as usual.

A few beekeepers do not like to have these empty bee-spaces under the bottombars, for two reasons: They think this space is an actual waste; and, second, it provides an excellent hiding place for the queen when it is desired to find her to elip her, or otherwise see how she looks.

ROBBING.-As the term signifies, "robbing" is an act or series of acts by which bees pilfer or steal from each other, or from any source where sweets in the form of jam, jellies, syrup, or honey, are left exposed. Like some human beings, when the opportunities are given, bees find it easier to steal than to work. The passion for stealing or robbing, if neglected, becomes a habit-a habit that is exceedingly hard to break up.

When bees discover that a large amount of sweets can be secured without working for it, they are quick to profit by the chance; and in the space of a few minutes they may start an uproar. This not only means pillage, but death to the bees and stings to their owners.

Paul says that the love of money is the root of all evil; and similarly the love of honey on the part of the bees is a root of a great leal of the evil that takes place in bee culture. When they find it easier to help themselves to the results of the honest toil of others they will enter into the business of plundering without scruple.

One of the A B C class has said that he found a single bee making visits to over 100 clover-heads before it obtained a loar sufficient to carry to its hive. It is probably true that during a great part of the season a bee will be absent a full hour, or, it nuay be, during unfavorable spells, as mueh as two hours, in obtaining a single load. The time during which a bee may be absent is very variable. If the nectar secretion is heavy it will return much quickel than if it is light. Ts it at all strange that a bee, after having labored thus hard during the fore part of the day, should, in the afternoon, take a notion to see if it could not make a living in some easier way? Would it be very much worse than many types of humanity? As the bee noses around to other hives it catches the per- 
fume of the honey other bees have gathered, and, by some sort of an operation in its little head, it figures out that, if it could abstract some of this, unperceived, and get it safely into its own hive, it would be so much the richer. It has no sort of care whether these other bees die of starvation or not. That is none of its concern.

With all their wonderful instincts, no one has ever been able to perceive that the bees of one hive have any spark of solicitude as to the welfare of their neighbors. If, by the loss of a queen, the population of any hive becomes weak, and the bees are too old to defend their stores, the very moment the fact is discovered by the other colonies they rush in and overpower the sentinels, with the most perfect indifference, plunder the ruined home of its last bit of provision, and then rejoice in their own home, it may be but a yard away, while their defrauded neighbors are so weak from starvation as to have fallen to the bottom of the hive, being only just able to attempt to crawl feebly out at the entrance. Had it been some of their own flock, the case would have been very different indeed; for the first bee of a starving colony will carry food around to its comrades, as soon as it has imbibed enough of the food furnished to have the strength to stagger to them.

Suppose a robber bee, in prowling around in the afternoon or some other time, should find a colony so weak or so careless that it could slip in unobserved, and get a load from some of the unsealed cells, and get out again. After it has passed the sentinels outside it usually runs little danger from the inmates that seem to take it for granted that every bee inside is one of their number. There is danger, tho ; for should the robber betray too great haste in repairing to the combs of honey they often -suspect something; so it assumes an indifference it is far from feeling, and loiters about very much as if it were at home, and finally with a very wellassumed air of one who thinks he will take a lunch, it goes to the cells and commences to fill up. Very often, when it gets pretty well "podded out" with its load, some bee approaches, apparently to see if all is right. When the robber once gets its head into a cell, however, it seems to have lost all sense or reason; and if it is discovered at this stage to be a stranger and a thief, it is often pounced upon and stung with very little ceremony.

How do bees know a stranger from one of their own number, where there are so many? It is said they tell by the sense of smell; this may be the principal means, perhaps, but apparently they depend greatly on the action and behavior of a bee, much as men do when judging of the responsibility of a man who asks to be trusted. One can give a very good guess, simply by his air or manner, or even by the sort of letter he writes.

If a robber bee is suspected, and a bee approaches for the purpose of satisfying itself, it is a very critical moment, and one becomes intensely interested in watching the performance. The robber will stand its ground, if it is an old hand, and permit itself to be looked over with wonderful indifference; but one who has watched such scenes closely will detect a certain uneasiness, and a disposition to move slowly toward the entrance, that it may be the better able to get out quickly, when it discover's things to be too hot for it inside. If the bee that first suspects it concludes it is an interloper, it begins to bite it, and grab hold of its wings to hold on until others can come to help. The thief has now two chances to escape, and sometimes it seems meditating which to adopt; one is, to brave it out until they shall perhaps let it alone, and then slip out unobserved. The other is to break away and trust to its heels and wings. The latter plan is the one generally adopted. One that has been many times in such scrapes will usually get away by an adroit series of twists, turns, and tumhles, even tho three or four bees have hold of it. at once. Some of these fellows, by a sudden and unexpected dash, will liberate themselves in a manner that is even wonderful, and then, as if to show their audacity, will wheel about and come back close to the noses of their captors of a minute before.

In case the bee secures its load and makes its way out unobserved, it gets home very quickly, and, under the influence of this new passion for easily replenishing 
its hive with the coveted sweets, it rushes out with a vehemence never known under any other circumstances. Back it goes and repeats the operation, with several of its comrades at its heels. Does it tell them where to go?

When a bee comes into the hive in such unusual haste, podded out with its load in a way also rather unusual when obtained from the flowers, its comrades at once notice it, and, either from memory or instinct they are suddenly seized with the same kind of passion and excitement. Those who have had experience at the gambling-table, or in wild speculations of other kinds, can understand the fierce and reckless spirit that stirs these little fellows. The bees, when they see a comrade return in the way mentioned, seem to know, without any verbal explanation, that the plunder is stolen. Anxious to have "a finger" in the pie," they tumble out of the hive, and look about, and perhaps listen, too, to find where the spoil is to be had. If they have, at any former time, been robbing any particular hive, they will repair at once to that; but, if it is found well guarded, those used to the business will proceed to examine every hive.

\section{INTELLIGENCE OF THE HONEYBEE.}

The following incidents, described in Gleanings in Bee Culture, are worth reprodueing here:

"One afternoon, the door of the honeyhouse being left open, the bees were soon doing a 'land-office' business before the mischief was stopped by closing the door until they had clustered on the windows in the room, which were then opened, and the process repeated until all were out. All the rest of the afternoon they were hovering about the door. Toward night they gradually disappeared; and when the author went down about sundown, to try a new feeder, not a bee was near the door. The feeder was placed in front of a hive where bees were clustered out; and as soon as a few bees had got a taste, and filled themselves, they of course went into the live to unload. We expected a lot to come out; as soon as these entered with their precious loads, but were much astonished to see an eager crowd come tumbling out as if they were going to swarm, still more when they rusher right past the feeder and took wing for-where do you suppose? the honey-house door, of course. How should they reason otherwise, than that it had again been left open, and that was where these incomers had found their rich loads? On finding it closed, back to the hive they came to repeat the maneuvers over.

"As another evidence of the wonderful intelligence and almost reasoning power of the honeybee, another instance will illustrate further.

"Some years ago in September a carload shipment of honey came in 60-pound cans so badly damaged that the contents had leaked out and run thru the floor of the box car. The railroad company had agreed to take the car away at half-past ten; and as the weather was cool the bees had not discovered it at that time. Unfortunately the company failed to move the car as agreed, and we knew nothing of it till we were apprised something was wrong by the unusual number of bees swarming around the windows and doors. We carried a hose over to the leaky car and washed away the honey, cleaning it from the gearing, ironwork, and underside of the car until the bees were pretty well satisfied there was nothing more to get, altho they were hanging around in great numbers. To prevent the bees from getting the honey inside the car, our boys covered the floor pretty well with sawdust. About three o'clock the engine came around and pulled the car away. A little after four, some men who were loading wheat informed us our bees were making them a great deal of trouble. We at once jumped to the conclusion that the company, instead of taking the car entirely away, as agreed, had only removed it to another location in the yard, and that the sticky car was still enticing our bees. We saw the sawdust on the floor on which they were dumping bags of wheat, and concluded it was the honey-car; but, while we were puzzling to account for the fact that the ironwork under this ear showed no trace of honey or water either, a man called and pointed to another car in still another location, just swarming with bees around its door', inside and out. Then we 'caught on.' There was not a particle of honey in or around either of the two cars we were looking at. $\Lambda$ fter the honey-car had 
been pulled clear out of town, the bees, not willing to give up, proceeded to 'leave no stone unturmed,' and were investigating every car having an open door that, in their judgment, might be the one that had been pulled away. When they found one with sawdust spread over the floor they naturally concluded that was the car; and got down on their hands and knees searching in the sawdust for honey. The other bees, seeing them thus employed, naturally concluded this was the place. Others, having learned that one box car contained so rich a find, concluded that a search thru all the cars in the yard might possibly reward them for their investigation; and it was only in the cool of the evening that they were willing to stop digging in that sawdust, and be convinced there were no more honey-cars.

"It , may not be true that bees recognize color's, but they certainly do take in the general make-up of objects. They are not only able to recognize a hive, but they know a box car at sight; and even if it is moved to a different location they take in its general appearance so that they know pretty well how to find it in case of removal. We are not prepared to prove that they read the letters 'Big Four' on the side of that car, nor that they remembered there was an enormous figure 4 printed in white on the red door of the car they wanted; but they came pretty close to it."

\section{HOW BEES COMMUNICATE.}

Of course, bees have particular notes, as for joy, sorrow, anger, despair, etc., which are produced by the wings, usually when flying; but probably they are unable to communicate to each other more than a single idea. In other words, they have no faculty of telling their fellows that a lot of honey is to be had in a feeder at the entrance, and that it would better be brought in quickly or other bees may find it. A bee goes out in the spring, and, by smelling around the buds, discovers honey and pollen; when it comes into the hive the others see it and start out to hunt up the source of supply in a similar way.

WHEN BEES WILL NOT ROB.

By turning back and reading ANGER OF
BEEs, one will get a very good idea of the causes that start bees to robbing. Read, also, Bee-hunting, Feeding, and Bee BeHAVIOR. As a general thing, bees will never rob so long as plenty of honey is to be had in the fields. During a bountiful flow the author has tried in vain to get bees to take any notice of honey left around the apiary. At such times one can use the extractor right in the open air, close to the sides of the hives, if need be. On one occasion at Medina a comb of unsealed honey was left on the top of a hive from morning until noon, and not a bee touched it. It seems they preferred to go to the clover fields in the regular way rather than to take several pounds from the top of a neighboring hive. It ran readily be sup. posed that they did not have to visit anything like a hundred blossoms at this time, and perhaps they secured a load in going to not more than a dozen.

After the season begins to fail, one must expect that every colony in the apiary will be tried. As a rule, any fair colony will have sentinels posted to guard the entrance as soon as there is any need of such precaution. The bee that presumes to think it may enter for plunder, will be led off by "the ear," and this will be repeated until it learns that there is no chance for robbing at that house. At the close of the honey harvest precaution should be taken that there are no weak colonies, especially if they are queenless, that may be overpowered, for one such may start the fashion of robbing, and make it much harder to control. An apiary, like a community, may get so demoralized that thieving becomes a universal mania. "A stitch in time will save" a great many more than nine in this case. The space occupied by the bees also should be in proportion to their numbers. Likewise the entrance should be in proportion to the size of the colony. They should have only as many combs as they can cover if they are to defend themselves properly from either moths or robber's. Colonies without either queen or brood are not apt to fight for their stores very vigorously. It is hardly necessary to repeat what has been said about I talians being better able to defend themselves than black bees. A few Italians will often pro- 
tect the hive better than a whole swam ot black bees.

\section{HOW TO KNOW ROBBER BEES.}

It sometimes puzzles beginners exceedingly to know whether the bees that come out are robbers, or ordinary inmates of the hive out for a general playspell. There are times when a playflight looks very much like robbing. See Playfligmts of Toung Bees and Drifting.

Wlien the robber bee approaches a hive, it has a sly nervous manner, and flies with its leg's spread in a rather unusual way, as if it wanted to be ready to use its heels as well as wings if required. It will move cautionsly up to the entrance, and quickly dodge back as soon as it sees a bee coming toward it. If it is promptly grabbed on attempting to go in, never fear. When a bee goes in and it cannot be determined whether it is a robber or not, a close watch should be kept on all the bees coming out. This is sure way of telling when robbers have yot a start, even at its very commencement. A bee, in going to the fields, comes out leisurely, and takes wing with but little trouble, because it has no load. Its body is also slim, for it has no honey with it. A bee that has stolen a load is generally plump and full; and, as it comes out it has a hurried and "guilty look." "Most of all, it finds it a little difficult to take wing, as bees ordinarily do, because of the weight. In BeE-Hunting is related how a bee, laden with thick undiluted honey, would stagger under its load before it conld take wing for the final trip home. The bee, when coming out of the hive with honey it has very likely just uncapped, feels instinctively that it will be quite apt to tumble unless able to take wing from some elevated position, and therefore cravls up the side of the hive before launching out. When first taking wing it falls a little by the weight of its load, before its wings are fully under control, and therefore, instead of starting out as a bee ordinarily does, it takes a downward curve, coming quite near the ground before rising safely and surely. With a little practice one can tell a robber at first glance by its way of coming out of the hive and taking wing.
HOW 'TU 'TELL WHEKE 'THE ROBBERS BELONG.

If one is a bee-hunter he will probably line them to their hive without any trouble; but if he is not, he can easily find from which hive they come by sprinkling them with flour as they come out of the hive being robbed. Watch should be kept'on the other hives, to see where the floured bees are going in. If the robbing is confined to one or two colonies, as is often the case, they should be put down cellar and kept there for sereral days where they can not incite other colonies. Reference will be made to this further on.

ONCE A ROBBER, ALTAYS A ROBBER.

After bees once get into the fixed habit of robbing it is a mistake to let them ont again; for no sooner are they out than they are at their old tricks again. It is better to confine them, and then after they have been imprisoned for 24 lours they may be brushed down into a box from the sereen or from whatever portion of the building in which they have clusterec. They should then be carried to an outyard. It is not advisable to let them loose again in the same yard where they have learned their bad tricks of stealing. If allowed their liberty they will be continually prowling around for days to see where they can effect an entrance to the honey-house or an unguarded hive. It may be cheaper in the end to kill them outright, especially if there are not more than half a pound of bees. If there are many more, it may be desirable to save them; but they should not be let loose again in the same yard. If taken to another yard they will cause no trouble.

\section{ROBBING OF NUCLEI OR WEAK COLONIES.}

There is another kind of robbing that is much more common, and which is apt to perplex the beginner more than anything else, and that is the onslaughts that are often made on weak colonies or those that are disinclined to make a defense, especially if queenless. Nuclei with large entrances are especially subject to the attacks of bees from strong stocks, and may be cleaned out entirely before the apiarist discovers the mismief. By that time the whole apiary will be in a perfect uproar. As soon as the 
supply of honey has been exhausted in the one nucleus the robbers will hover around all other entrances, and on finding one poorly defended will get in more bad work. During a dearth of honey there are always some bees that make a business of smelling around, and it is a wise precaution always to have the entrances of nuclei contracted to a width where only one or two bees can pass at a time.

One of the most prolific causes of robbing is a warped cover on an old hive, the corner of which has split open. All such makeshifts should be replaced. In an emergency a handful of múd plastered into the opening or crack, or some cotton stuffed in, will go a long way toward preventing serious trouble later on. During a good honey flow small cracks large enough for bees to get thru do no particular harm, but during a honey-dearth extra precautions must be taken. Weak colonies especially cannot defend several entrances, and that is why poorly fitting covers or leaky lives must not be tolerated. The robbers seem to realize that the regular entrance is more likely to be well guarded, and that is why they are often seen trying to crawl thru some unguarded crack.

\section{HOW TO STOP ROBBING.}

As to the best mode of procedure, a good deal will depend on circumstances. When bees in the whole apiary are robbing in a wholesale way from the honey-house, or from any place where a supply of honey or syrup is liept, the obvious remedy is to cut olf the supply.

Bees soon stop robbing when all sweets within their reach are removed or so protected that they cannot get at them; but even then the apiary will be out of balance for the rest of the day, and more or less for two or three weeks following, because the bees will be trying to find where they can get more sweets.

Sometimes robbing is started by some one in the neighborhood making sweet pickles, canning fruit, or doing anything that causes a strong odor of sweet or sour during its preparation. The only thing the beekeeper can do is to have the house screened; or if the case is very bad, and the bees keep on "sticking their noses into other people's business," the entrances of all the hives shonld be smoked with tobaceo smoke. Half a dozen puffs of smoke should be blown into each entrance, one after the other. In half an hour the dose should be repeated. This will cause the bees to quiet down until such time as the canning or the pickle-making is over at the house where bees are "making themselves too familiar."

The best treatment for a general robbing thruout the apiary is prevention. The screen door and other openings into the honey-house should be self-closing. Unless they are, some one will be almost sure to forget and leave one of them open. If the doors are not self-closing, all the honey or syrup stored in the building should be put into hives, shipping cases, cans, barrels, or any receptacle where bees can be kept from lielping themselves; then, if perchance the door is left open, no harm will be done.

Let it be supposed that a colony has been overpowered, and that its own bees are making no defense, realizing, probably, that resistance is useless. If anything is to be done to save the colony, it must be done quickly. One way is to grasp a handful of long grass, strew it closely around the entrance, and then spray or sprinkle a dipperful of water on it, and scatter more wet grass over the entrance. A very little carbolic acid added to the water nnakes the spray more offensive to robbers. The invaders will not, as a rule, crawl thru the wet grass to get into the hive, while on the other hand those that have already entered the hive will get out and return to their homes. In the mean time the regular inmates of the hive, as soon as they are given a little assistance, will begin to set up a defense. The grass slould be kept wet for at least an hour or two, and possibly till sundown; but before strewing the grass the entrance should be contracted so that only one or two bees can pass at a time. The entrance should never be closed entire$l y$, no matter how bad the bees are robbing. On a hot day the large number of robbers in the hive, together with the regular inmates, would be almost sure to smother to death.

Another and a better way to treat colonies or nuclei that are not making a good defense is to carry them down cellar or put 
them in any cool place where they will have an opportunity to recover themselves, and where, too, robbers cannot continually keep up the policy of pestering the life out of them. In 24 hours the robbers in the yard will have quieted, when the nucleus or robbed colony can be taken out and set back on its stand. But at this time the entrance should be contracted to a space just wide enough so that only two or three bees can pass at a time.

A still better plan for the treatment of a colony that is being overpowered by robbers is to set a wire-cloth eage or tent over it. This cage need not be larger than will cover the hive. The illustration. shows the style used by the authors. Three or four of such cages are kept in the yard ready for an emergency of this kind.

There is no robbing except when the regular apiarist is temporarily a w a y and a new man has been left in charge. Such a man or boy will sometimes let robbing get well under way, not knowing that trouble is brewing. In very short order it will be. apparent that the colony or the nucleus is not making a de$\mathrm{f}$ ense. Sometimes even a strong colony will be taken by surprise, and before it is aware of what is happening the robbers will be piling into the hive at a

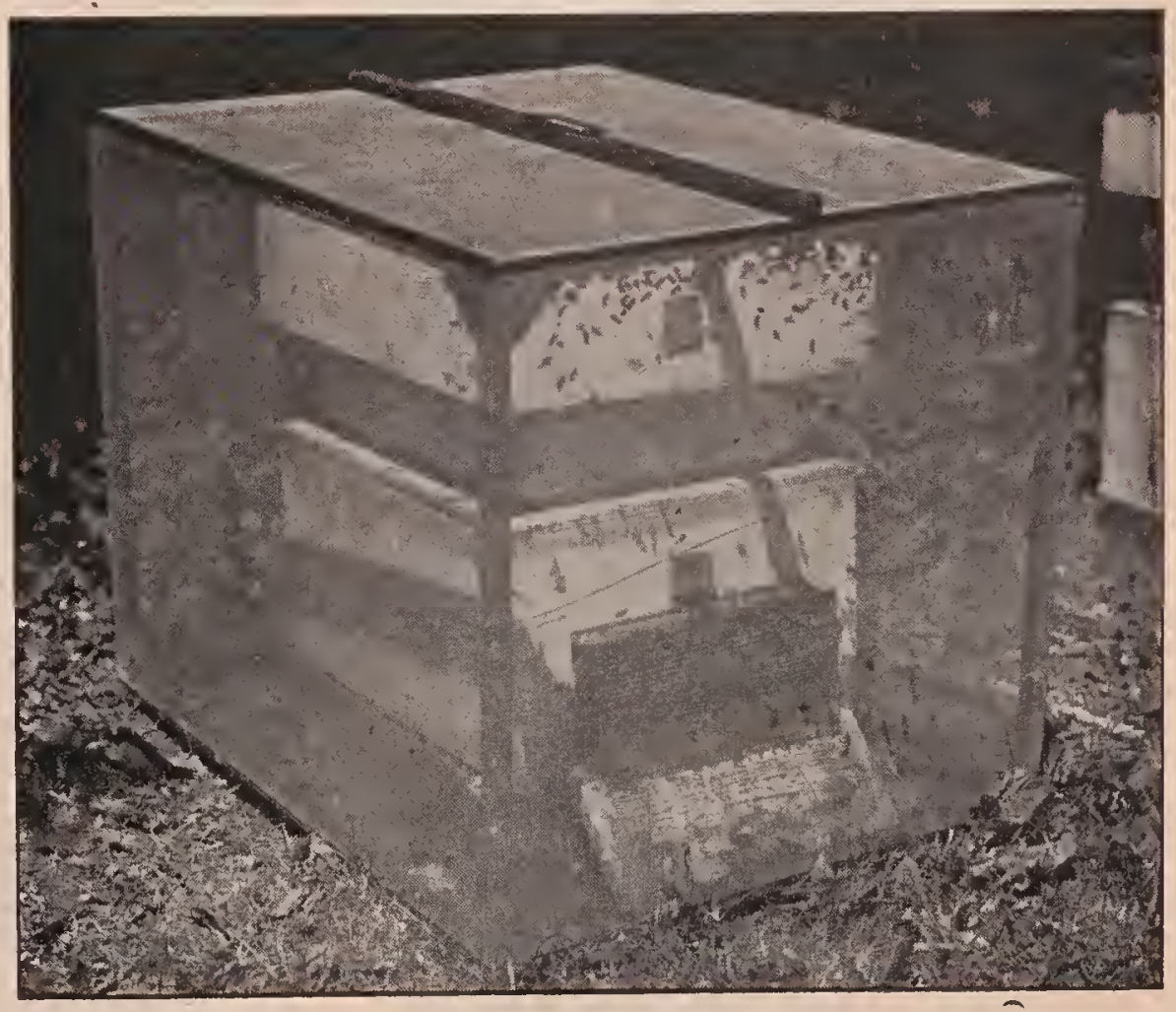

Convenient cage to set over hive that is being robbed.

furious rate. At other times there are not enough bees in a nucleus to make a respectable defense. Such colonies or nuclei need help, and that right speedily. If one has a wire cage, he can set it over the hive, and that immediately stops any more robbers from getting in. As soon as the marauders in the live fill up, they will rush out of the entrance pell-mell; but instead of going back to their own hive they are imprisoned in the eage. In the mean time there will be a big horde of robbers ontside of the cage. Raise the cage up for three or four seconds, when all the outside robbers will pounce on the entrance. Right here the reader may think this a mistake. The scheme is to catch every robber that has been carrying on the business of stealing for the last few minntes or half-hour, so as they return from their hive the cage is lifted up at intervals when the robbers rush in. The bees that have been imprisoned will cling to the top of the cage, even tho it be lifted for the moment. In the mean time their number will be reinforced by more robbers coming out of the hive. In the space of about thirty minutes, if the robbing has not been going on too long, every robber will be in the top of the cage, and there they will stay. It is a serious mistake to let such bees loose 
a few mole bees, the precaution being taken, howerer, to cage the queen, as the new bees might kill her.

Some good beekeepers doubt whether it is best to let these robber's loose after they have once been trapped. Where there are very many of them it would be bad to destroy them. If only a few they should be killed.

\section{A CONVENIENT ROBBER CAGE.}

This consists of a light framework of $7 / 8$-square stuff held together at the intersections by means of three-cornered blocks. The whole is then rovered with wire rloth, and across the top a strip is nailed to provide a handle so the cage may be lifted up with one hand. It is advisable to have in addition one or two larger cages-big enough to take in a man while he is operating over the hive. These cages may be of various sizes, but they should be light enough so that one can carry then around easily and squat over a hive to be manipu-

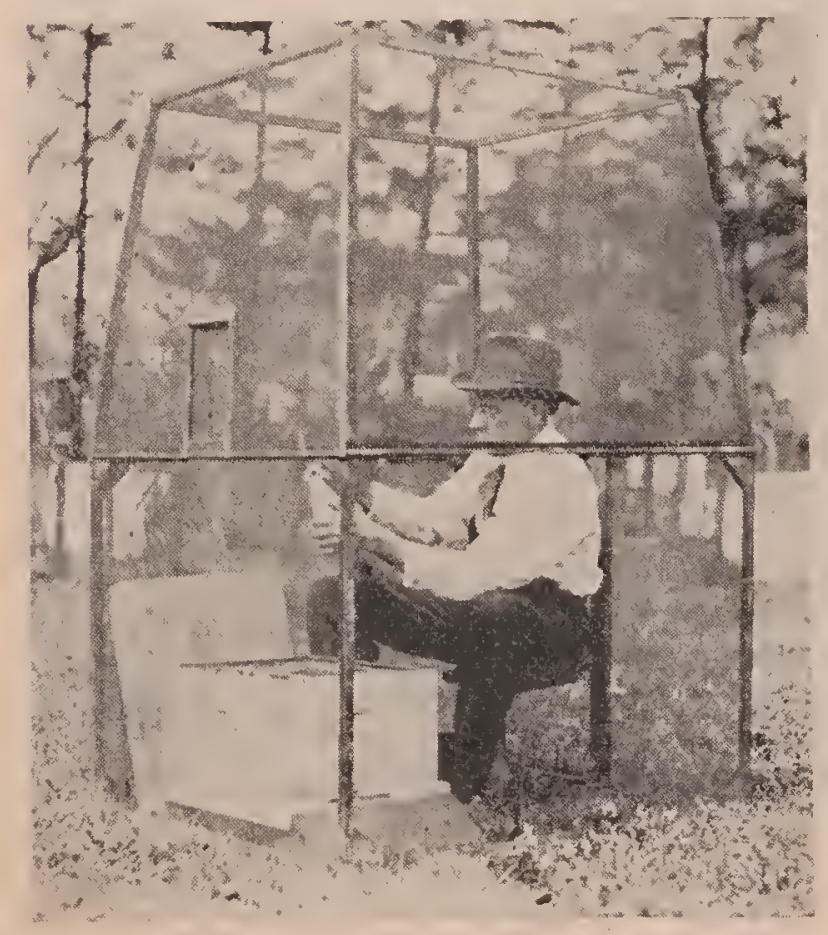

Open top robber cage.

lated. The larger cag'es should be made in the same way as the small cages, of $7 / 8$-square stuff braced at the intersections by three-cornered blocks, except that the top need not be cuvered. Cross-rails on each side two feet from the bottom serve as convenient handles, so that the man on the inside can pick up the rage and walk from one hive to another. 'Tlur use of cheese cloth is quite as effective as wire cloth for these large cages, and much cheaper. With the large cages it is not necessary to have the top covered. The average robber that is supposed to make trouble will hover along on a level about the top of the hive that is being operated. It does not have sense enough to rise up and dive down over the top. At the same time bees that belong to the hive that is being manipulated will easily escape. On the other hand, the cages that have tops will cage the bees so they will be bumping around the head of the operator. Unless they are actual robhers, it is better to let them loose; and as soon as the operator has left the hive they will go into their own entrance.

For raising queens these topless cages are very convenient when the robbing season is on. The queen-breeder, while he is on the inside of one of these cages, can work over a hive as long as he pleases, secure from robbers. If he uses the cage continually, robbers will seldom get a taste of honey; and therefore there will be little or no trouble.

\section{EXCHANGING PLACES WITH THE ROBPING AND ROBBED COLONIES.}

Trying to people the house-apiary in the fall, when it was first built, the author had trouble with one certain colony. In fact, when robbing was going on anywhere it was sure to be these hybrids that were at the bottom of the mischief. After trying erery plan recommended, and still finding these fellows would persist in pushing into every new colony started, the idea occurred that, on the principle that it takes a rogne to catch a rogue, it would be well to try to see how these would repel other robbers. The greater yart of the combs were taken from the robbers, bees and all, carried into the house-apiary, and put into the hive which had been robbed. The effect was instantaneous. Every laden robber-bee that went home with its load, on, finding the queen and brood gone from the old stand at once showed the utmost constemation, while the passion for robbing was instantly changed to grief and moaning for the lost home. The weak colony which they liad been robbing, and which had only a queencell, was carried to them, and ther soon took up with it and went to work. The rob- 
bers newly domiciled in the house-apiary repelled all invaders with such energy and determination that the rest seemed to abandon the idea which they, doubtless, had previously formed; viz., that the house-apiary was a monster hive but ill garrisoned, so we had very little trouble afterward. Before they were transposed, as mentioned, we had serious thoughts of destroying their queen, simply because they were such pests; but the year afterward, this colony gave in the house-apiary over $100 \mathrm{lbs}$. of comb honey.

HOW TO KNOW WHEN A HIVE IS PUTTING UP A GOOD DEFENSE.

The half-tone shown below is a good illustration of how a powerful colony will deploy its sentinels or guards during the time when other colonies near by are being robber. This colony is prepared for any kind of an onslaught; for the minute that

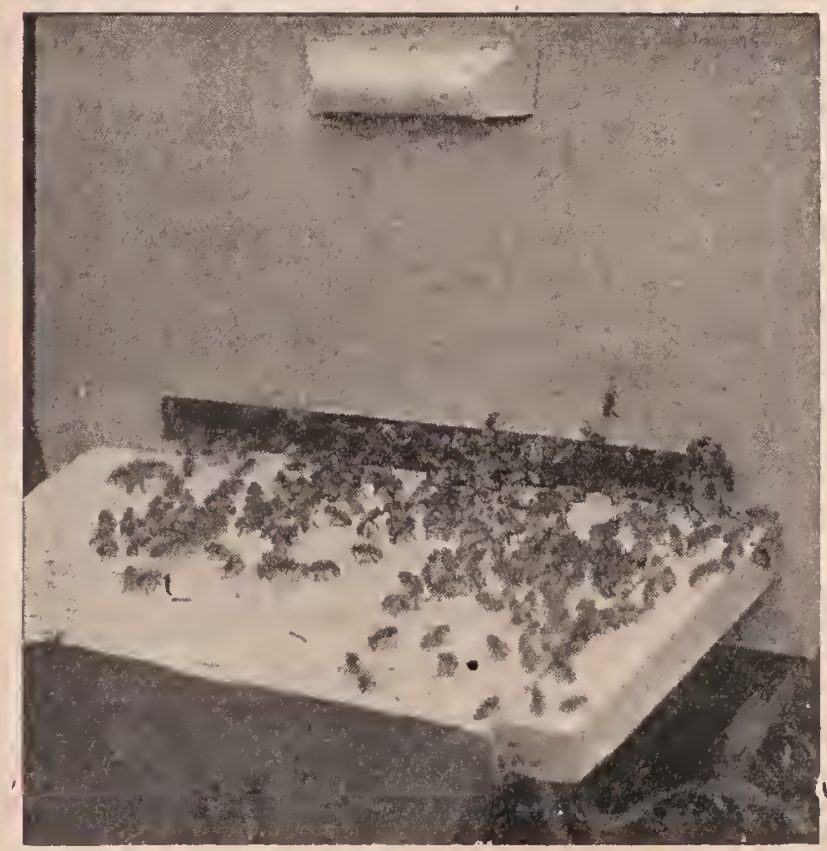

A colony that is ready to meet any kind of on slaught from robbers. Robbers had hovered around the entrance. The result was, the guards were out in good force to repel the attack.

a robber hovers over the entrance it is promptly met in mid air by one of the sentinels. They immediately elutch in a rough-and-tumble fight, drop to the ground, roll over and over, and lucky is the robber if it gets away without having its hair or legs pretty vigorously pulled. Such "a warm reception" will discourage any would-be robber from tackling that colony again. The entrance is rather wide open and the colony is strong enough to put up a defense and a rigorous one at that. If the colony were not so strong it would be proper to contract the entrance as shown elsewhere under Entrances to Hives and WINTERING.

WORKING WITH BEES BY LANTERN LIGHT WHEN ROBBERS ARE TROUBLESOME DURING THE DAY.

Some years ago, when the conditions happened to be such that most of the colonies were not much more than two or three frame nuclei, it was necessary to build them up by means of stimulative feeding. No honey had been coming in, and the bees were very troublesome about robbing. The moment the hive was opened, robbers would pounce down on the combs. Feeding by day was quite out of the question. It was finally decided to try going thru the colonies by lantern light. It was found possible to examine hive after live, and get a pretty accurate idea of their condition. Of course, no robbers would bother at such a time. The bees were given some weak syrup at the time of the examination, and by morning it would be all taken up. By working a few nights in this way by lantern light the whole apiary was built up without any trouble from robbers, and by late fall there was a lot of fine colonies well supplied with stores and young bees.

The only difficulty one will experience will be the disposition on the part of a few bees to fly out toward the light. Some of them will buzz around against the lanternglobe. But the trouble from this souree is not very great. Other bees. will have a tendeney to crawl up one's sleeve or his clothing. To prevent this the ordinary fingerless gloves as described under GLOvES should be worn.

HOW TO REMOVE THE ROBBING TENDENCY BY OUTDOOR FEEDING.

When honey is coming in there is no robbing; but as the nectar supply stops, bees begin to pry around to find what they can steal. At such times, when hives are opened for examination robbers will be about, and if the combs are exposed very much by such handling they will pounce rpon the hive and combs in ereat numbers, and then altark the entranre after the hive 
is closed up. If one is trying to rear queens the results will be discouraging. Bees get cross, refuse to start cells (or, if built out, tear them down), kill off drones, and destroy drone brood.

The fact that there is no robbing when honey is coming in suggests the remedy; viz., feed outdoors a thin syrup of the consistency of raw nectar. See Feeding OUTDOORS.

\section{HOW TO FEED OUT UNFINISHED SECTIONS OR WET EXTRACTING COMBS.}

While these can be scattered out in the open, it is quite sure to result in fearful robbing and stinging after the supply is exhausted. To forestall this, the combs and sections should be put in hives or supers, one tiered above another on a regular bottom-board, and the entrance contracted so that not more than one or two bees can pass at a time. To make it wider results in a scramble and robbing of weak colonies in the yard. The top of the tier of hives or supers should, of course, be covered.

These tiered-up hives with smạll entrances are much used to clean up scraps of honey, extracting-combs, and to empty out partly finished sections. (See ComB Honey.) This slow robbing also has a tendency to draw off robbers from the nuclei and weak colonies and therefore serves a double purpose.

WHAT HAPPENS IF ROBDING IS NOT STOPPED.

When robbing is under genuine headway, the honey of a strong colony will disappear in from two to twelve hours; the bees will then starve in the hive, or scatter about and die. This is not all; when the passion is fully aroused robbers will not hesitate to attack the strongest stocks, and bees will be stung to death in heaps before the entrances. This may finally put a stop to it, but they may push ahead until every hive of the apiary is in an uproar. At such times the robbers will attack passersby in the streets, and even venture an attack on cats, dogs, hens, and turkeys. Like the American Indians when infuriated at the sight of blood, every bee seems to have a demoniacal delight in selling its life while inflicting all the torments it possibly can, feeling sad only because it can not do any more mischief.
The worst robbing time seems to be after the heaviest or main honey flow is over, when bees become especially crazy if they get even a smell of honey left carelessly anywhere near the hives. One who has never seen such a state of affairs can have but little idea of the furious way they sting every thing and everybody. The remedy is to get a good smoker and put in enough fuel to insure dense smoke; then, using one hand to work the smoker bellows, with the other, contract the entrance of every hive that shows any symptoms of being robbed. Shut up every bit of honey where not a bee can get at it, and do the work well; for at such times they will wedge into and get thru cracks that would make one think inch boards were hardly protection enough. Be up betimes next morning to see that all entrances are close and small, and that all the hives are bee-tight. An experienced hand will restore peace and quietness in a very short time to such a demoralized apiary. Black bees are much worse than Italians, for the latter will usually hold their stores against any number of assailants; good, strong, well-made hives, filled with Italians, with plenty of brood in each, will be in little danger of any such "raids," altho the author has seen the wounded and slain piled up in heaps before robbers would desist and give up trying to force an entrance. See ANger of BeES.

\section{BORROWING.}

Before closing this subject of robbing there are a few more points. to be mentioned. There is a kind of pillaging called borrowing, where the bees from one hive will go quietly into another, and carry away its stores as fast as gathered; but this usually happens where the robbed stock is queenless, or has an infertile queen. As soon as they have eggs and brood, they begin to realize what the end of such work will be. This state of affairs seldom goes on long; for it either results in downright robbing, or the bees themselves put a stop to it.

Caution to Beginners.-The first year the author kept bees there was constant fear that they would get to robbing. One afternoon in May a large number of bees were 
seen passing rapidly out and in a partienlar hive, and the more they were examined, the more it appeared they were being robbed. The entrance was contracted, but it seemed to make little difference. It was finally closed almost entirely, compelling the bees to squeeze out and in, in a way that must have been quite uncomfortable, at least. After awhile they calmed down, when there was only the ordinary number of bees going out and in. Behold, the robbers were at another colony, and they had to be put thru the same program; then another and another; until it appeared a host of robbers had come from somewhere, and made a raid on the apiary, and that, had some one not been on hand, the whole of them would have been ruined. When the whole performance was repeated the next day, it began to appear that bee culture was a very trying pursuit. In due course of time it developed that there was no robbing at all, but that it was just the young bees taking their afternoon playflights, for as already stated, a playflight of young bees often looks like a case of robbing. See Playflights of YOUNG BeEs.

\section{ROCKY MOUNTAIN BEE PLANT} (Cleome serrulata).-A smooth annual, 2 to 3 feet tall, with 3-foliolate leaves, and showy rose-colored flowers in racemes. It extends from Minnesota soutliwest to New Mexico and Arizona. The value of the Rocky Mountain bee plant in Colorado has been greatly overestimated, altho it formerly yielded a much larger amount of honey than today. In exceptionally favorable seasons it is still the source of considerable surplus on the plains east of the mountains. The honey is reported to be light colored and to have a fair flavor. The flowers appear in July. About 1890 the Michigan Agricultural College experimented with several acres of this plant for the purpose of testing its value. A good stand of plants was not secured, and the honey obtained was far from paying expenses.

Two other species of this genus also deserve description. Spider-flower (C. spin$o s a$ ) is cultivated for its handsome white or rose-colored flowers. It grows in waste places from Illinois southward to Florida and Louisiana, and often yields nectar very copiously. With a medicine dropper a teaspoonful of nectar has been drawn from 13 flowers. It has, indesd, been gathered with a spoon in sufficient quantities to taste its flavor, and often a single bee cannot gather all there is in one blossom. A single plant may produce several hundred blossoms, and the flow of nectar may continue until late in the fall.

Yellow Cleome (C. lutea). The yellow Cleome has yellow flowers and blooms in June. It is found in the western highlands from Nebraska to Washington and Arizona. Unlike the purple Cleome, which

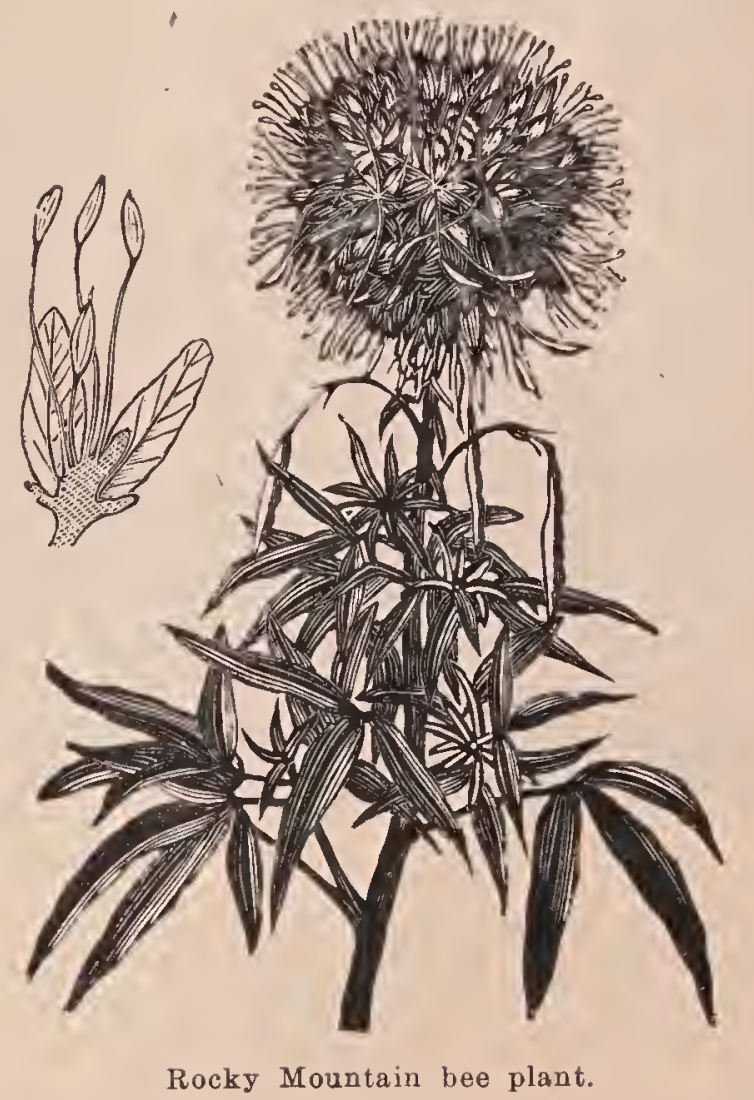

seems to prefer cool well-watered locations in the creek bottoms and upper mountain valleys, the yellow species is seldom found anywhere except in the desert and in the cultivated land of the warmer valleys. If the winters are dry the seed does not germinate, but lies dormant in the soil until there is sufficient moisture, so that there may be few or no plants for several years. But, after a winter with a sufficient precipitation of rain or snow, it springs up so thickly that the desert for miles looks as tho it were covered with a carpet of -gold. In moist or irrigated land it grows to the height of two feet or more, and blooms nearly all summer. Usually it grows only 
12 of 18 inches tall, and dies in $t$ wo or three weeks after it begins to bloon. Under favorable conditions it yields a moderately large amount of honey. Nearly a super per colony has been obtained. The lioney is rather dark colored but the llavol is good. Cleome fills in the gap between fruit bloom and alfalfa.

ROYAL JELLY. - See QUEENS; also QUEEN-REARING.
SAGE (Salvia).- Sage honey, which is widely known for its delicious flavor in Europe as well as in America, is a product peculiar to California. The erops of honey secured from black sage during the past 25 years have been so immense that fine sage honey is now offered for sale in many of the principal cities of the world. During the past 40 years there have been two or three exceptionally heavy flows when 200 pounds per colony were secured. At Ventura Mendleson has obtained an average of 300 pounds per colony in a single season from the black and purple sages. While the black sage occurs to a limited extent on Mt. Diablo near San Francisco and in localities in San Mateo County, practically the entire sage region of this State is restricted to the Coast Ranges, extending from the foothills in the northern part of San Benito and Monterey Counties to San Diego County in the soutliwest corner. The largest amount of sage honey comes from Ventura and San Diego Counties, while a somewhat less surplus relatively is secured in Riverside and San Bernardino Counties. The sages belong to the genus Salvia (from the Latin salveo, to save, from the supposed medicinal value of some of the species), and to the mint family or Labiatae. This is a large genus comprising nearly 500 species widely distributed in both temperate and tropical regions.

The three species most valuable as honey plants in California are black sage, white sage, and purple sage. Black sage is so called because the foliage is a very dark green, and also because the flowers after blooming turn black and adhere to the bush until the next season. Purple sage has pur- ple blossoms and the foliage has a grayishpurple appearance on the hilisides. When the two shrubs are seen side by side in the distance on the foothills, the contrast is very marked, the one looking dark or black

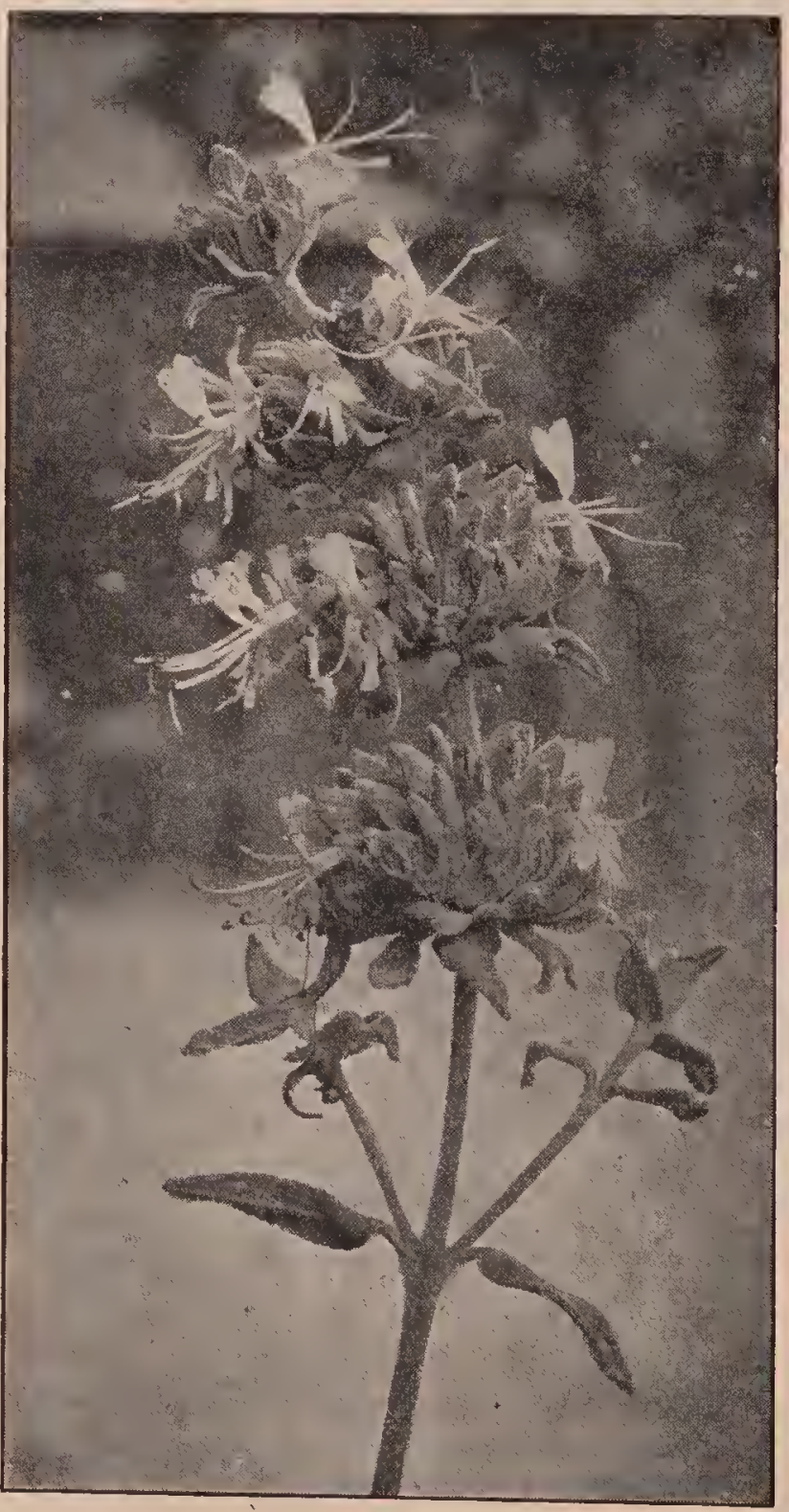

A stem of California black sage with blossoms. 


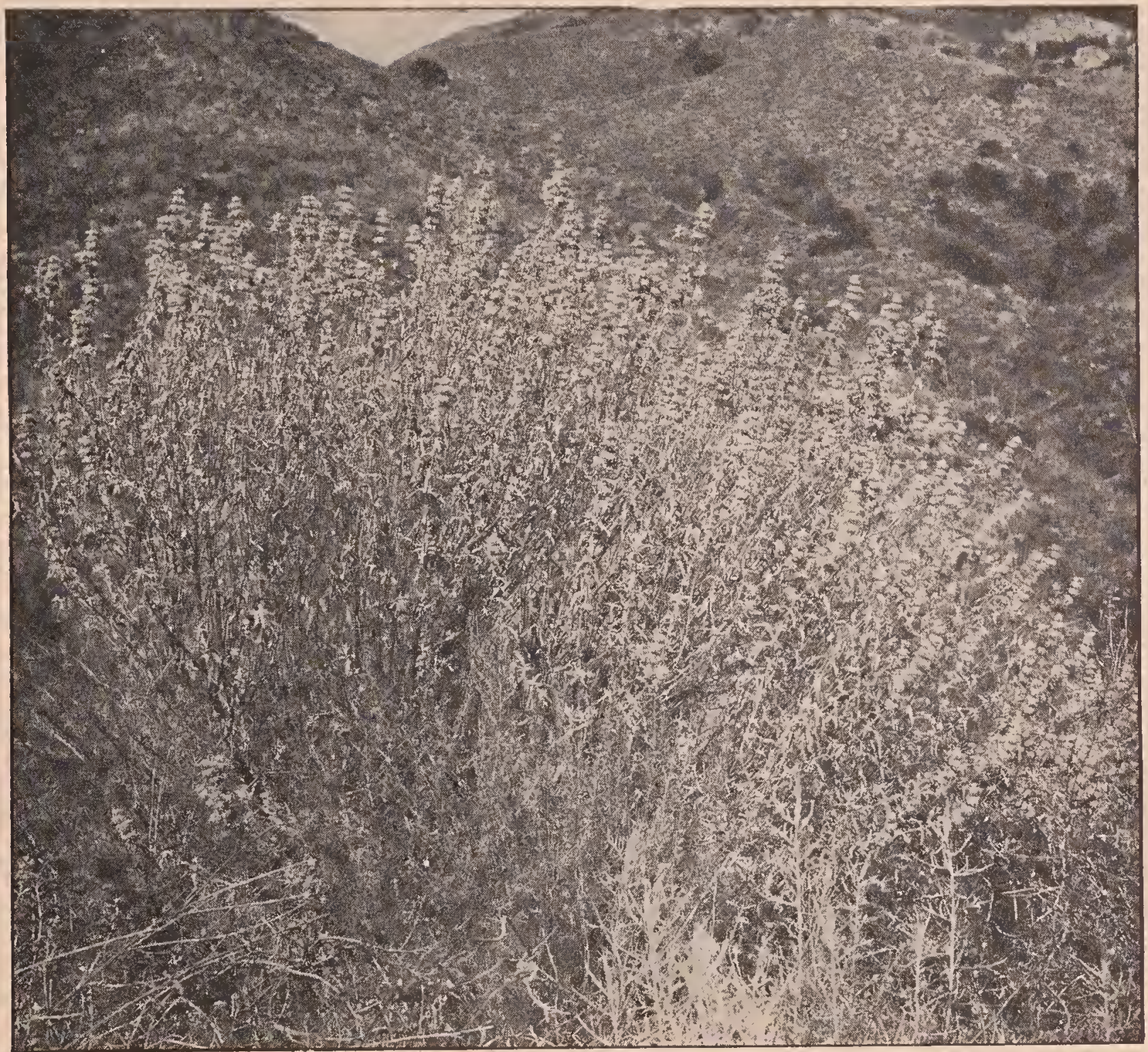

A bush of California purple sage."

and the other purple. The foliage of the white sage is grayish white and the flowers are also white. The black and purple sages are bushy shrubs very leafy at base, but the white sage has longer stems and is less bushy. The purple sage is much larger than the black sage and is sometimes six feet tall. The white sage grows on the flat mesa lands, while the black and purple sages are abundant on the foothills and the sunny slopes of the canyons.

Black Sage (Salvia mellifera).--Also called button sage and blue sage. The black sage is a shrubby plant 3 to 6 feet tall, with oblong leaves, dark green above and woolly beneath, and numerous flowering branches, which bear about five dense whorls or "buttons" of flowers. The corolla is 2-lipped, white or pale purple, and rather small. The whorls, the larger of which are about an inch across, diminish, in size toward the tip of the stalk, and in fading the flowers turn dark, but do not fall from the bushes.

The honey flow lasts from the middle of March, or the first of April, until about the first of July. The crop is unreliable every other year, and there is a total failure once in three or four years. Every fifth year a large crop may be expected, and if the rainfall has been ample a fair surplus is sometimes obtained three years in succession. The black sage does not yield nectar freely unless there has been at least ten inches of rain during the winter, followed by a clear warm spring. The rainfall varies greatly in different years, presenting great extremes, but frequently it is less than 12 inches; in 1882 there was only, 2.94 inches, while in 1905 it amounted to 22.12 inches. 


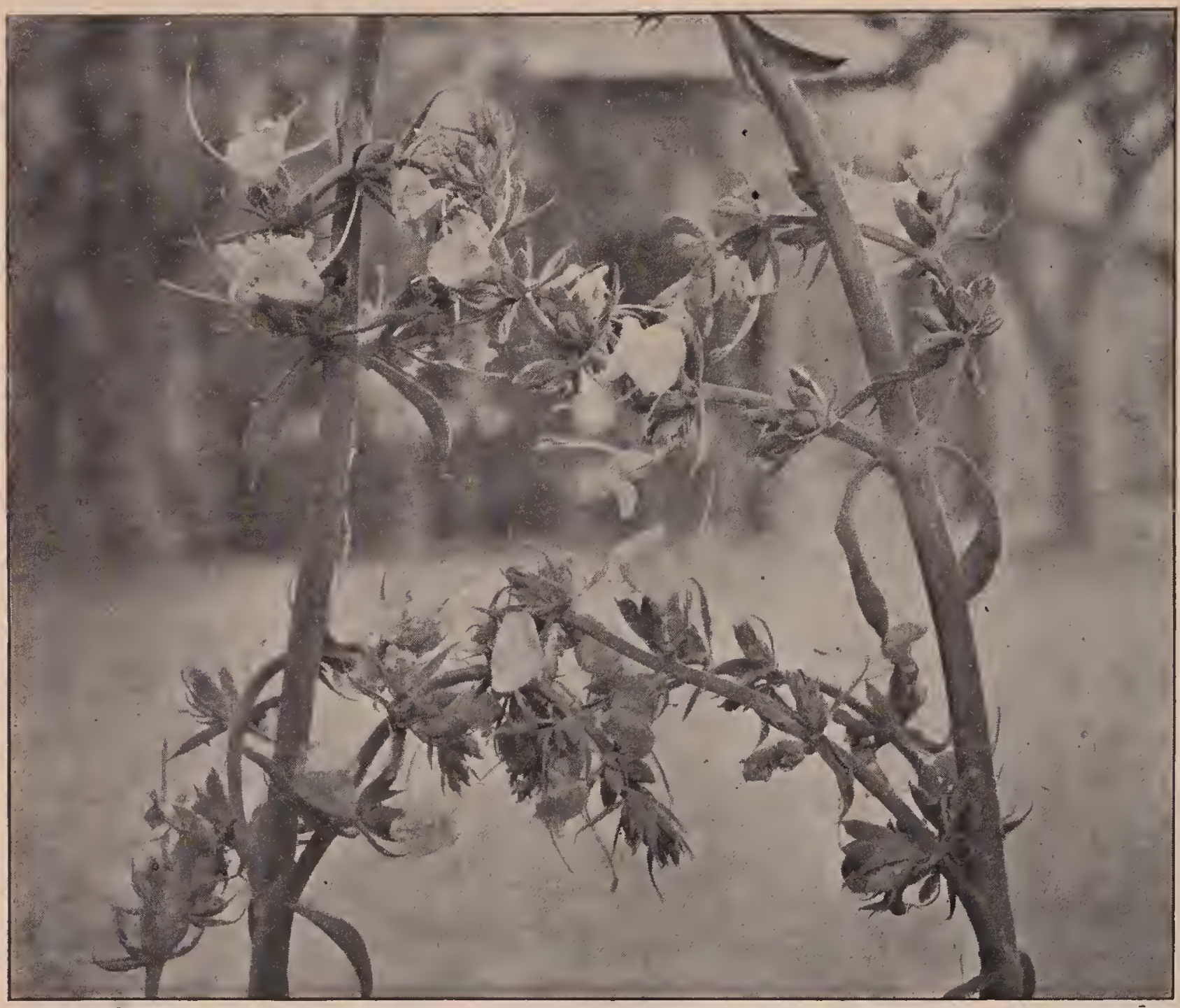

Stems and blossoms of California white sage.

Altho the plants are well adapted to live in semiarid regions, if there is a drought, they dry up and become valueless to the beekeeper. The flowers are often injured by the sage worm, and the foliage by rust. The honey is water-white, thick and heavy, and does not granulate.

Purple Sage (Salvia leucophylla).-This species is a much larger shrub than the black sage and the whorls of light-purple flowers are nearly twice the size of those of the latter species. The honey is waterwhite, does not granulate, and its flavor is considered a little superior to that of the other sage honeys. It begins to bloom usually a little later than the black sage, but the honey flows from both species nearly coincide. Purple sage is most abundant in Ventura County where it is a characteristic feature of the vegetation of the foothills.

White Sage (Salvia apiana).-A shrub
3 to 8 feet tall, which is less bushy than the black sage, the branches being long, straight, and slender. The 2-lipped white flowers are produced in great profusion in lateral racemes and the leaves are grayish white on both sides. The lower flowers open first. It begins to bloom the latter half of May and the blooming period lasts from six to eight weeks. On the dry plains or mesa lands and foothills of southern California there are thousands of acres of this beautiful shrub and one may ride thru avenues of it for miles. One range is described as a mile wide and two miles long, consisting practically of unbroken white sage.

The white sage secretes much less nectar than does either the black or purple sage. In districts where both the black and white sages are abundant beekeepers have estimated that the black yielded ten pounds of honey to one from the white species. To 
produce a vigorous growth and a profusion of flowers there must be a sulficient rainfall. The honey is white and heavy, and does not candy; while the quality is nearly as fine as that of the black sage. Much of the white sage honey so-called comes from the black sage. At Caldwell, Idaho, white sage is reported to yield a surplus of honey. A colony of bees carried eight or nine miles away from the alfalfa fields to a sage range gathered fully as large a crop as colonies near alfalfa. The honey was water-white and its flavor was excellent (Gleanings in Bee Culture, Sept. 15, 1908).

The larger portion of the surplus comes from the three species described above. The black and purple sages yield almost equally well, but the white sage is not a heavy yielder altho the surplus varies in different years. Black sage is practically the only species of Salvia found in Monterey County. It grows plentifully along the coast and on southeast and southwest slopes, decreasing inland as ridge after ridge is passed, and disappearing in eastern San Benito County. In the Salinas Valley, it blooms from April $15^{\circ}$ to June 5; in the northern part of the county it remains in bloom until July 1, and along the coast until July 15. In the Gavilan Mountains northeast of Gonzales seed of the white sage was sown in 1885, and this species still perpetuates itself in this locality. Purple sage has been reported near Monterey. In San Luis Obispo and Santa Barbara Counties all three species occur, but white sage is not common in San Luis Obispo County.

The distribution of the sages in Ventura County is described by M. H. Mendleson as follows: "Purple sage is. most abundant in this county, altho there is a large amount of black sage scattered thru the interior; but there is only a small amount along the coast. The white sage is the rarest in this county. Following a wet winter the black and purple sages are about equally valuable for the production of honey. The black sage blooms first, then the purple, and last of all the white sage, the blooming periods usually overlapping. The white sage can seldom be depended upon for a crop, and the honey is inferior to the flavor of that stored from the other two species. The white sage honey invariably granulates while the black and purple, when well rip- ened and wathered in the interior, remain liquid; but on the coast they invariably candy. The time of blooming varies from March 1 to June 1, depending on climatic conditions, as rain and a cold or warm winter and spring; but usually it begins from April 15 to 30 , and closes between June 20 and July 10."

"According to my experience of 41 years most of the sage honey comes from the black and purple species and only a small percentage from the wlite. All of the sage honeys darken with age, and become the color of inolasses, altho still remaining translucent. A bottle of sage honey, 36 vear's old, lias lost its sage flavor but has the flavor of a delicious syrup."

"Many thousands of acres of the sages are destroyed annually by stockmen, and in the near future good sage ranges will be at a premiun. The great destruction of brush by fire is lessening our rainfall. The government should take steps to reforest the State promptly, as the good soil washes away during leavy rains leaving a soil so poor that it will not maintain a new growth." (Ventura, August, 1921.)

In Los Angeles County the white sage is most abundant, and the black sage the rarest. White sage is found on the mesas adjacent to the footbills, and as high as 2,000 feet above sea level. The black and purple sages occur in the canyons and high hills up to an elevation of 4,000 feet. The sages bloom in May, June, and July, and the duration of the honey flow depends upon rainfall and temperature. The black and purple sages bloom at nearly the same time, but the white sage blooms several weeks later, and remains in bloom for a month or six weeks.

In San Diego County in the soutliwest corner white sage is estimated to be three times more abundant than black sage. Purple sage is less common than northward. The black and white sages occur in San Bernardino County on the foothills in the southwest portion. The black sage is the better honey plant, blooming several weeks before the white.

In Riverside County, according to T. O. Andrews, the black sage, which is found on the foothills and mountain slopes up to 3,500 feet, is most abundant and the best yielder of nectar. It often begins to bloom 
in February and in some seasons continues to bloom until July 20. The white sage grows on more level land and on better soil at the foot of the hills. It begins to bloom in May and may last thru June. There is little purple sage. This species is central in Ventura County near the mountains and is less widely distributed then either the black or white sage. In 1920 there was in Riverside County the best flow from black sage in 25 years. Strong colonies averaged over four pounds per day for 15 days. The honey was water-white and very heavy. The purple and white sages also yielded well.

There are several other species of sage, which deserve mention. The creeping sage (S. sonomensis), or ramona, covers the ground with a mat-like growth, from which arise flowering stems four or five inches tall bearing light-violet flowers. This species is rare, but it is widely distributed in the Sierra Nevada and Coast Ranges and in localities is important. The honey is like that of the other sages. Annual sage ( $S$. columbariae), or ehia, is common in the foothills and mountains of the Coast Ranges, and in some districts yields a surplus. The seeds were formerly used for food, and were also considered of medicinal value in cases of fever. It blooms in April and May. Thistle sage ( $S$. cardua$c e a)$ likewise yields a white honey of fine flavor. Two or three stems rise from a rosette of root-leaves, and bear from 1 to 4 whorls or "buttons," of light-blue flowers. The leaves are more or less spinytoothed, whence the English name common in southern Califormia and the San Joaquin valley. It blooms in June.

The common garden sage ( $S$. officinalis) is reported to yield a white honey, where it is extensively eultivated as a culinary herb. Lance-leaved sage ( $S$. lanceolata) grows in bare fields and on dry plains from Nebiaska and Kansas to Texas and Arizona. It is about a foot tall, with lance-shaped leaves and blue flowers, and yields nectar from early in June until frost. It is helpful in maintaining the strength of the colonies. The blue sage (S. azurea) is listed as a honey plant in Texas. In Australia the verbena sage ( $S$. verbenacea), introduced from Europe, yields a little honev during the dry months of the year. But
IIIany species of Salvia have a corolla tube so long that they are adapted to bumblebees. Other species, as the crimson sage of California, the cardinal sage of Mexico, and various Brazilian species witl scarlet or bright corollas, are humming-bird flowers; and the nectar is secreted at the bottom of a tube 2 inches long, far beyond the reach of bees.

The opinions of the early leaders in bee culture in this country on the different kinds of honey are always of interest. Langstroth's description of the flavor of sage honey is recorded by A. I. Root as follows: "We well renember the first taste we had of the mountain-sage boney. Mr. Langstroth was visiting us at the time, and his exclamations were much like our own, only that he declared that it was almost identical with the famed honey of Hymettus, of which he had received a sample some years before. This honey of Hymettus, which has been celebrated both in poetry and prose for ages past, is gathered from mountain thyme; and thyme and sage not only belong to the saine family but are closely related. Therefore, it would not be strange if Mr. Langstrotl was right in declaring our California honey to be almost identical in flaror with the honey of Hymettus."

SAINFOIN (Onobrychis sativa).--Also called crocetta, asperset, esparsette, French grass, and hen's-bill. Sainfoin is the French word for wholesome hay. It has been extensively grown for a long time in England, France, and Belgium; and it is successfully cultivated in. Ontario, Canada, and various parts of the United States. It succeeds best on a light, dry, calcareous soil, but it will thrive in places where clover fails. It makes an excellent hay and is suitable for grazing, especially for sheep; but it is not suitable for a semiarid country. The stems of sainfoin are shorter and smaller than those of alfalfa, and it does not yield as many tons of fodder per acre. Like the clover's, alfalfa, and sweet clover it belongs to the pulse family.

The spikes of light-pink flowers appear. in summer, and bees gather nectar from them very eagerly. The honey is pale yellow, very elear, and does not granulate readily. Its quality is excellent and cont 
pares well with that of white elover honey. Some retailers prefer it to alfalfa honey.

"The chief honey plant on the chalky uplands of southeast England," says Sladen, "is giant sainfoin, a variety of Onobrychis sativa. It is eut twice sometimes in a single season. It blooms first about June 10 , and yields a crop of honey if the weather is not too wet and it is fairly warm. It blooms again in July when the main crop is gathered. It often blooms for a third time in middle August, but it yields no nectar, altho the fields are pink with bloom and the conditions appear to be as favorable as in july."

SCALE HIVE. - Many of the most prominent beekeepers have in their yards during the season when honey is coming a sort of barometer of the daily honey flow or, more exactly, a scale hive. This consists of 'a hive mounted on ordinary platform spring scales with a dial to indicate any increase or decrease in the weight of the colony. As the honey flow begins, it will be apparent that the hive will gain slightly in weight. This weight will increase during the day that there is a fair honey flow and decrease somewhat during the night owing to evaporation of the nectar. As the season continues it is very easy to determine the strength of the honey flow, what days are best, what conditions are best for a honey flow, and when the season nears its close the dial will show a smaller and smaller increase until no gain is shown at all.

For a scale hive it is advisable to select a strong colony-one of the very best in the yard, because a medium or indifferent one might not show any increase in wejght, while the stronger colony would be alle, to record whether any honey at all were coming in. While of course it is understood that this strong colony is not a fair average of all the others in the apiary, it indicates, to some extent, what the nectar secretion is in the field. If, for example, the best colony should record a pound or two pounds in a day, it might be assumed that the poorer or weaker colonies would show proportionately anywhere from a half to a full pound of nectar inerease in weight. Still again, the best colony on the scale might not show more than a quarter of a pound increase. Correspondingly the other colonies of the apiary might not show any gain if they were on the seale, Therefore, it is important to have the best colony in the yard.

One might naturally ask why it is important to have a scale hive. It might be argued that an expert beekeeper would be able to determine by the flight of the bees going into the hives whether a honey flow was on, whether there was a good flow, whether it was inereasing, or whether it was letting up. Very true, but the actual record of the best colony in the apiary, together with the observation of the flight of the bees at all entrances, gives an experienced beekeeper a much more accurate idea of what is going on. In a practical way, the scale hive enables the apiarist to determine whether he should put his extra super on top of those partly filled, or whether he should place it under. See Comb Honey, to Produce.

Suppose that it is at the beginning of the honey flow and that the bees have partly filled the first super given. If the scale hive shows a good record day by day, it would be advisable to place the next empty super under the one partly filled. If, on the other hand, the season is getting toward its close and the scale shows a gradual daily decrease, then it would be advisable to put the extra super on top of the one partly filled, or perhaps, better still, not put it on at all.

The scale hive is very useful also in determining how far it is advisable to continue extracting in the yard. If the season is drawing toward a close and one desires to leave enough stores in the hive for winter, or to take care of brood-rearing, in anticipation of another honey flow to follow in another month or six weeks, then obviously it is not advisable to extract if such extracting would leave the hives without any stores, making it necessary later on to feed sugar syrup.

The scale hive is of value to the honeyproducer by enabling him to determine what policy to pursue during the season, so that in producing comb honey he will not have too many unfinished sections on his hands; or, if he is running for extracted, he will not leave his brood-nests bare of honey, it he extracts at all from the brood-nest as 
some beekeeper's do. $\Lambda$ gain, there are some producer's who, tho they do not extract from below, desire to have left over for winter a large number of extracting combs well filled with sealed honey so that at the close of the season they can give the bees the necessary stores by simply giving these combs. In cool or cold weather they are invaluable. They save all feeding, and considerable extra time, besides the cost of sugar.

The yield per day for a strong colony of bees may vary all the way from half a pound to twenty or even mole pounds. T'en or mole pounds would be considered a good daily gain from clover, but more than double the amount is often gathered in a day by strong colonies from sage, orange blossoms, or other rapid yielders of nectar.

SCOUTS PRECEDING SWARM.-See AbSCONDING Swarms, also Swarming.

SECTIONS.-See Comb Honey, APPLIANCES FOR and HIVES.

SELLING HONEY. - See BotTLING Honey, Extracted Honey, Comb Honey, Marketing Honey, Shipping Cases, and SPECIALT'Y IN BeEs.

SELF-SPACING F R A M E. - See Frames; also Frames, Self-Spacting, and Hives.

SEPARATORS. - See COMB HoneY, APPLIANCES FOR.

\section{SHADE FOR HIVES.-See APIARY.}

SHIPPING BEES.-Under MigRatonY BEEKEEPING mention is made of the advantage of moving bees from one locality to another to catch the honey flow. The practice has been extended so that bees are sometimes moved from one state to another in carlots. This enables the owner to gather two or three crops of honey; whereas if he were to remain in one locality he would secure only one.

Shipping bees in carlots from one place to another has been practiced more in the West and North than in the East; but some beekeepers in the northern states, just before winter sets in, move their bees to the extreme South, build them up during the early winter or spring, eatch a crop of honey, then move them back north to eatch the clover honey flow.
'The publishers of this work have moved several carloads of bees in this way. In their first two shipments they were successful; but later ones were not as successful, for the reason that the seasons both south and north were unfavorable. Unless there is a fairly good crop of honey to be secured at both ends of the route the practice of moving bees in carlots is not a paying one; and as the seasons are somewhat uncertain, the movement of bees from north to south and from south to north is attended with considerable risk.

Usually the freight alone on a carload of bees from Florida to Oliio will run over $\$ 1.00$ per colony, provided there are 350 colonies to the car. The larger the number of colonies, the lower is the freight relatively. Unfortunately" the railroad companies require that the attendant who goes with the bees pay regular railroad fare. This ruling is decidedly unjust, because the attendant in a carload of horses can gro free. The freight rate on the bees themselves, the loss of some bees and brood during shipment, railroad fare of attendant. lis time on a basis of twenty hours a day,* make the expense of moving from the extreme South to the North about $\$ 2.00$ per colony. If the bees are moved back to the North there must be entered a charge of about $\$ 4.00$ against each colony. In order to cover this expense the season will have to be good at both ends of the route to yield a profit.

In some cases the weather is extremely liot when the bees are moved. If the temperature ranges around 80 or 90 in the shade, the loss of bees and brood will be considerable in spite of the precautionary measures on the part of the attendant in spraying the bees with water, as'will be explained further on. This loss may amount to nearly 50 per cent of the bees and brood. If colonies are worth, with the queens, $\$ 10.00$ each, it will be seen that in addition to the charge of $\$ 2.00$ there will have to be entered another of $\$ 5.00$.

It sometimes happens that the car is unnecessarily delayed en route; and every day of delay means the loss of bees as well as brood. Ordinarily a car of bees will not

* He won't get much sleep, as he will have to be on the alert almost day and night. 
stand more than four or five days of hot weather.

While the moving of bees from Florida to some northern State is attended with considerable risk, so much so that such long-distance shipments to and from these points have been practically discontinued, it is comparatively easy to move bees from Idaho, Montana, and Wyoming into California in the fall or early winter. (See Migratory Beekeeping.) The distance is much shorter and one is much more sure of catching a crop at either end of the route than he is when he moves a car to Florida and back to his own State, in the North. No one should attempt to move bees in carlots anywhere without reading this article very carefully. If possible he should consult those who have already moved bees successfully.

Where one desires to move only 100 or 150 miles and the roads are suitable, using a large traction motor truck, with a trailer, will be cheaper than sending by rail. Even tho one has to pay at the rate of ten or fifteen cents a mile, the cost of moving will be less than moving by rail. Usually a motor truck with a trailer can be secured that will move one or two hundred colonies at a trip. The cost of loading will be very much less, because when bees are shipped by rail they must be securely fastened to take care of the severe end jolts of a freight train that are heavy enough to jar every hive loose from its moorings and let loose the bees. The motor truck, on the other hand, will be under the direct control of the owner of the bees. It can start gradually, and be run slow enough to avoid jolts over the "thank-you-ma'ams" and chuck-holes.

HOW TO PREPARE A CARLOAD OF BEES EOR SHIPMENT.

It is important to get the local agent to make arrangements all along the line to see that the bees are moved with all possible speed. At transfer points it is especially important to get an order from the operating lines to have the bees transferred without delay. Arrangements should be made at least a week or two in advance, as it takes time for the correspondence to get orer the lines. It is also important that the rate of freight be determined in advance.

If there are not more than 250 colonies to be moved, a small car should be secured, in order to reduce the minimum weight on which freight must be paid. Usually the average gross weight of the hives of bees will be below minimum freight; therefore the more bees there are loaded on to a car the less the relative cost per colony. The average 36 -foot car will take about 350 hires, piled four tiers high, two rows on a side, leaving a small alleyway between the tiers of hives and an entrance-way opposite the car doors, for there must be room for the attendant to place a cot-bed where he can sleep, when conditions will permit, either night or day. The minimum weight on a 36 -foot car is 14,000 lbs. The average shipping weight of a colony is about 50 lbs., including the erate. This will make the gross weight 17,500 lbs., or $3,500 \mathrm{lbs}$. in excess of the minimum. If one were to ship only 200 colonies he would have to pay freight on the minimum of 14,000 lbs., and on this basis he would be paying for 4,000 lbs. of freight, with nothing to show for it. Hence it is important to load up to the minimum.

Formerly it was thought necessary to build a series of shelving made of $4 \times 4$ 's and $2 \times 4$ 's to hold the hives one tier above another, as it was supposed that some colonies might need individual treatment en route. But experience shows that this is impracticable. Moreover, the arrangement of shelving wastes space, and makes the loading and unloading very difficult and expensive.

$A$ better plan is to provide a series of cratings made of $2 \times 4$ 's and long $7 / 8$-inch strips 4 inches wide. The cratings should be put together in such a way that the $2 \mathrm{x} 4$ 's stand on edge. For cool or cold weather they might be laid flatways and thus save a little room. The long strips are to be nailed on each side, making in all a framework 4 inches thick plus two $7 / 8$-inch strips, or a total of $5 \frac{3}{4}$ inches.

Figs. 1 and 2 show how the crating is put together. Each crate should be long enough to run from the ear door to the end of the car, and wide enough to take two tiers of hives side by side the narrow way. The $7 / 8$-inch strips are nailed on each 
side at intervals, center to center, equal to width of hive. The two by fours are spaced a distance equal to the length of the hive. A crate is set down on the car floor to provide bottom ventilation. Two rows of hives are piled on the crate side by side, lengthwise of the car or so the combs are parallel with the rails of the track.

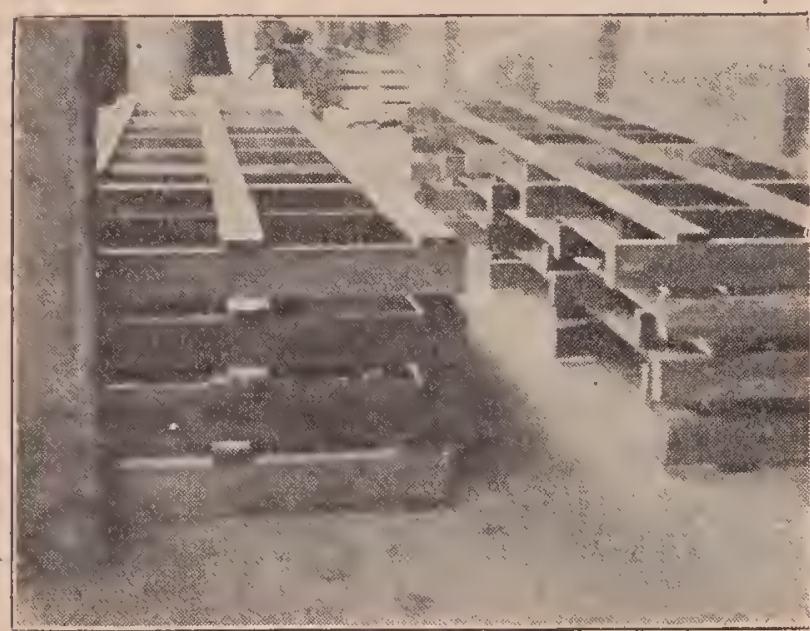

Fig. 1.-Crating on platform ready to load.

If everything has been done right the edges of each live will rest npon the long 4 -inch strips. Every other $2 \times 4$ in the crate is made a little longer so that it can be bolted to an upright $2 \times 4$ that binds the four tiers of hives together. The operation of loading is as follows:

One crate is placed on the ear floor. Two rows of hives with sereens at top and bottom are loaded on the erate. In hot weather it is not advisable to try to wet along with only a top sereen. Over the first tier is then placed a $\mathrm{n}$ o t $\mathrm{h}$ e $\mathrm{r}$. crate; on top another tier of hives until there are four tiers.

The other sides of the car are loaded in precisely the same way. When all are in place, the upright $2 \times 4$ 's as long as the height of four tiers are bolted to the projecting end of the horizontal $2 \times 4$ 's in each rrate. Polts are used because they are more easily remored than nails and are stronger. Thus there is a set of two tiers of hives on each side of the car with an alleyway between these sets. The two sets are then braced from each other by means of ties across the top and bottom. To stand the end shocks the two sets of tiers in each end of the car are securely braced apart by $4 \times 4$ 's. These ties or braces must be at the top and bottom so that the operator can reacl every colony with a watering pot.

There will be a space in the alleyway of about 14 to 15 inches between the two sets of tiers lengthwise and a space of the width of the car between the car doors and between the ends of the tiers. This latter space is occupied with tools, cot-bed, bedclothing, lanterns. hammer, saw, nails, a few extra bolts, a brace and bit, and a little extra lumber. Usually it is an advantage to carry along a little oil stove to heat water for coffee or do a little light cooking, as one gets a little tired of all "cold grub" on so tedious a journey. It is important that each of the hives should be sereened top and bottom as explained under Moving Bees Short Distances. That makes it necessary to remove covers and bottoms.

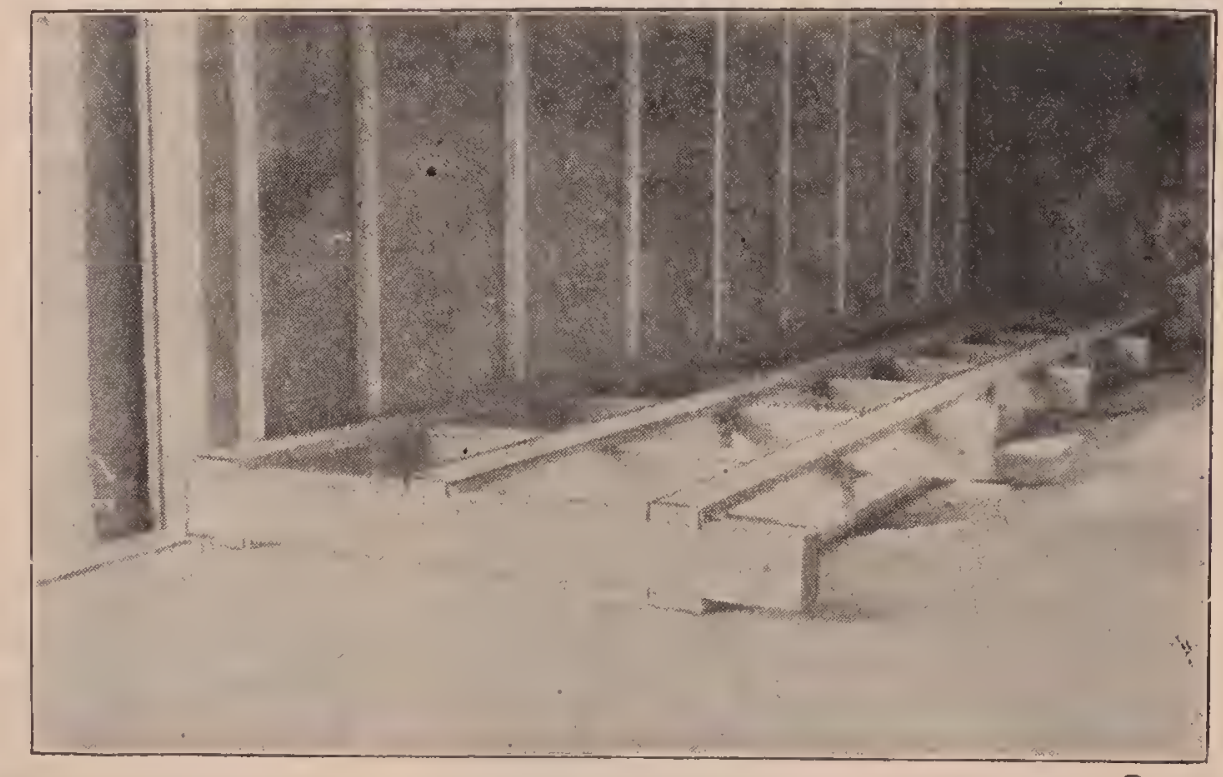

Fig. 2.-One rection in the car ready for the hives.
These should be piled on top of the tiers of hives just nnder the car roof. They should be secured by means of a rope or wire.

Where a cattle-car is used the crates can be wired to the frame of the sides of the car. This helps. to hold each tier to itself. 


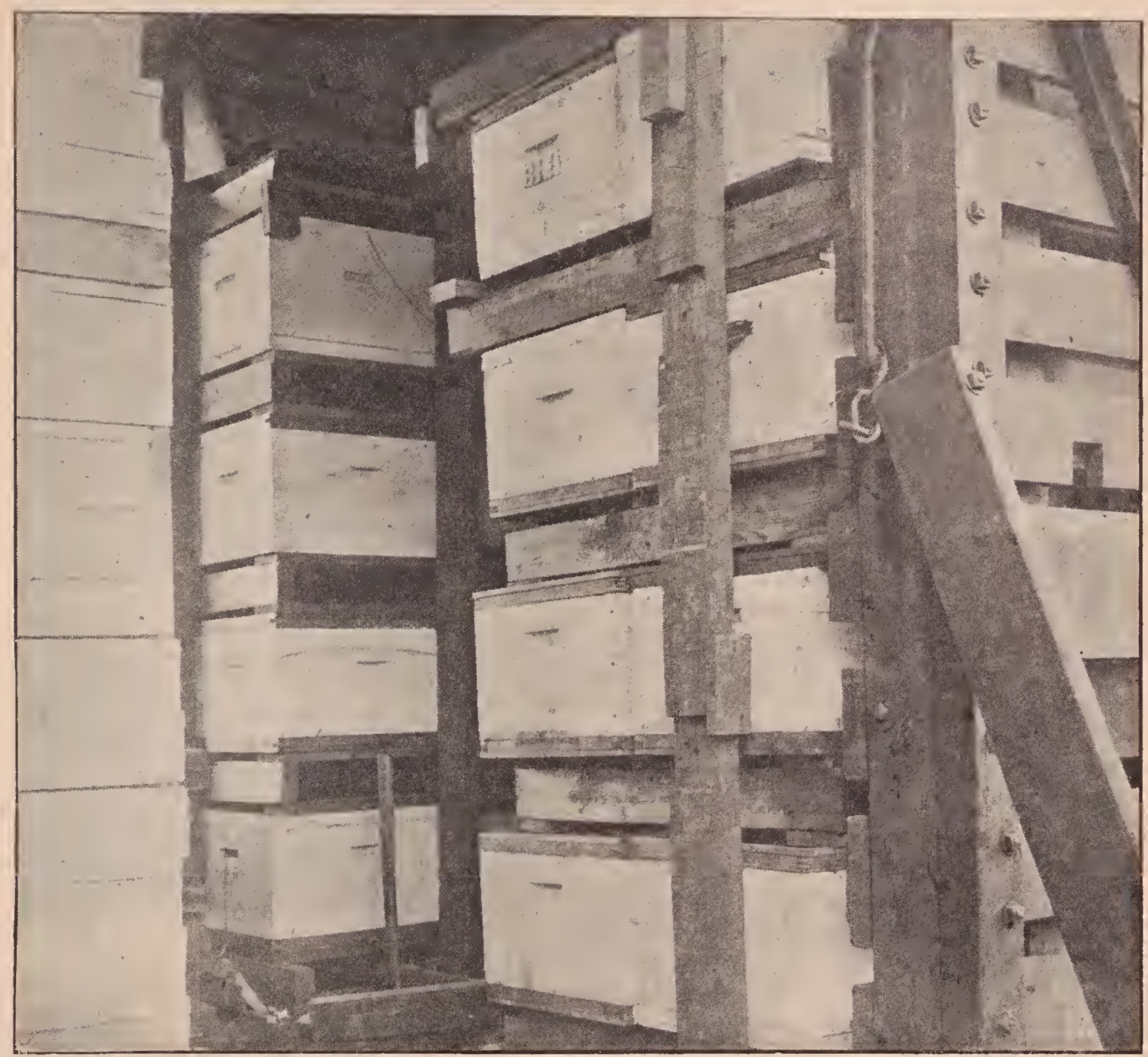

Fig. 3.- Interior of first car of bees from Virginia, May 21, 1915, just hefore the work of unloading.

SPRAYTY THE BEFS TO KEEP THEM COOL.

Mention was made of the fact that the operator should have room enough so he ran go back and forth between the hives to sprinkle them with a watering-pot or forcepump. It is important to liave in each car at least one or two barrels of water along with the bed and tools. During hot weather on a trip of six days bees will use up several barrels of water en route. When the car stops and the weather is hot, bees will be thickly clustered over the wire cloth. To prevent their becoming overheated the wire cloth should be sprayed. Care should be taken not to overdo it, as the young brood will be chilled. As a general thing, unsealed brood, either on account of too much heat or chilling in bad weather, will be lilled, altho shipments have been brought thru from the Soutl with all the brood in good condition; but the weather was cool, and the hives were sprayed only when the car was not moving.

The attendant must make up his mind that a trip with a carload of bees is not a Pullman ride. He will have to watch the framework very carefully, especially after each end shock. Whenever the car stops he will have to look after the spraying. When the car has to stand on a side track for a few hours he may be compelled to tack some sheeting on the exposed side of the car to shut out the hot rays of the sun.

While one can get 350 single-story colonies of bees in a 36-foot car, he can load 200 two-story colonies in the same space. This saves some crating and time in handling individual units. Colonies that are very 
strong will not go thru as well as those that are lighter. Ordinarily $3 \mathrm{lbs}$. of bees and six or seven frames of brood are enough for a single-story hive. Colonies, however, may be proportionally stronger in cool or cold weather.

\section{HOW TO SHIP BEES IN REFRIGERATOR CARS.}

Shipping bees in the ordinary way in cattle cars during hot weather where they are on the road several days, is usually attended with some loss. First, a refrigerator car must be selected that has ventilating coops on top of each end. Some ventilation, even in iced cars, is important. The bees are put into the cars in much the same way that they are packed in open cattleears, with this difference-that less of ventilation to the individual colony is required. Every hive should have a wire-cloth screen on top; and between each two tiers of hives there should be placed $2 \times 4$ 's; and these should be braced in the usual way so that the end shocks as the result of stopping and starting may' not break loose the fasteners.

During hot weather much stronger colonies can be shipped in refrigerator cars than in open cattle-cars; but one must be careful not to overdo it. Some men think it is necessary to have a half-depth super on top to provide extra elustering room. Some say the hives can be packed solid like so much cordwood. This may be satisfactory for short distances, and where the car is moving along on schedule time. On longer distances it is advisable to have an alleyway thru the middle of the car, so that an attendant can note the condition of the bees. He should see that the car is iced every day if necessary, or where it can be done. In any case, should the car get out of ice the result will be disastrous. In the event of an accident or delay, so that ice can not be procured, the bees must be immediately unloaded, for they can not be confined in a refrigerator car without ice. They should then, after a flight, be reloaded into an ordinary cattle-car, provided a refrigerator car fully iced can not be obtained.

It is important that the attendant get on top of the car himself when it is being iced, and, if necessary, help fill the ice-conıpartments. Railway employees sometimes do not see the importance of fully icing the car, with the result that the owner of the bees may suffer lieavy losses.

Arrangements should be made in advance to have the car iced often-the oftener the better, because the bees will generate a large amount of heat. If they can be kept cool as they are when in a cellar, and the car be kept moving, except for icing, they will go thru with the loss of hardly a bee.

Where colonies are very strong, or of honey-gathering strength, it is advisable to use two stories. If they are fairly boiling over with bees it may be necessary to use top and bottom screens in addition. The shipper will have to use his own judgment, always erring on the side of giving too much ventilation or too much room.

It is important to ice the car at least 12 hours before the bees are put into it in order that the temperature may drop down and get the inside of the car cool. Of course the car will warm up somewhat while the bees are being loaded in. After the bees are in, the car should be re-iced, as some of the ice will melt while the loading is taking place. It is advisable, also, to keep some ice in the center of the car between the tiers of bees.

It goes without saying, that the attendant does not ride in the car with the bees where ice is used. He can have the "comforts" of the ordinary caboose, and to see how things are moving, lie should open the car only when the train stops. On entering he should close the door immediately to shut out the warm air and the light.

The important factor in moving bees in iced cars is the exclusion of heat and light. If bees can be brought down to a cellar temperature, and kept in total darkness, they will soon become accustomed to the rumble and jolts of the train.

The reader should understand that shipping bees in refrigerator cars is something comparatively new and should not be undertaken without knowing how. It is vitally necessary to have a refrigerator car with coops on top at each end. These, when opened, will let in a certain amount of ventilation; for even when the bees are packed in ice they need some air.

For short distances the author would generally recommend cattle-cars. It is only 


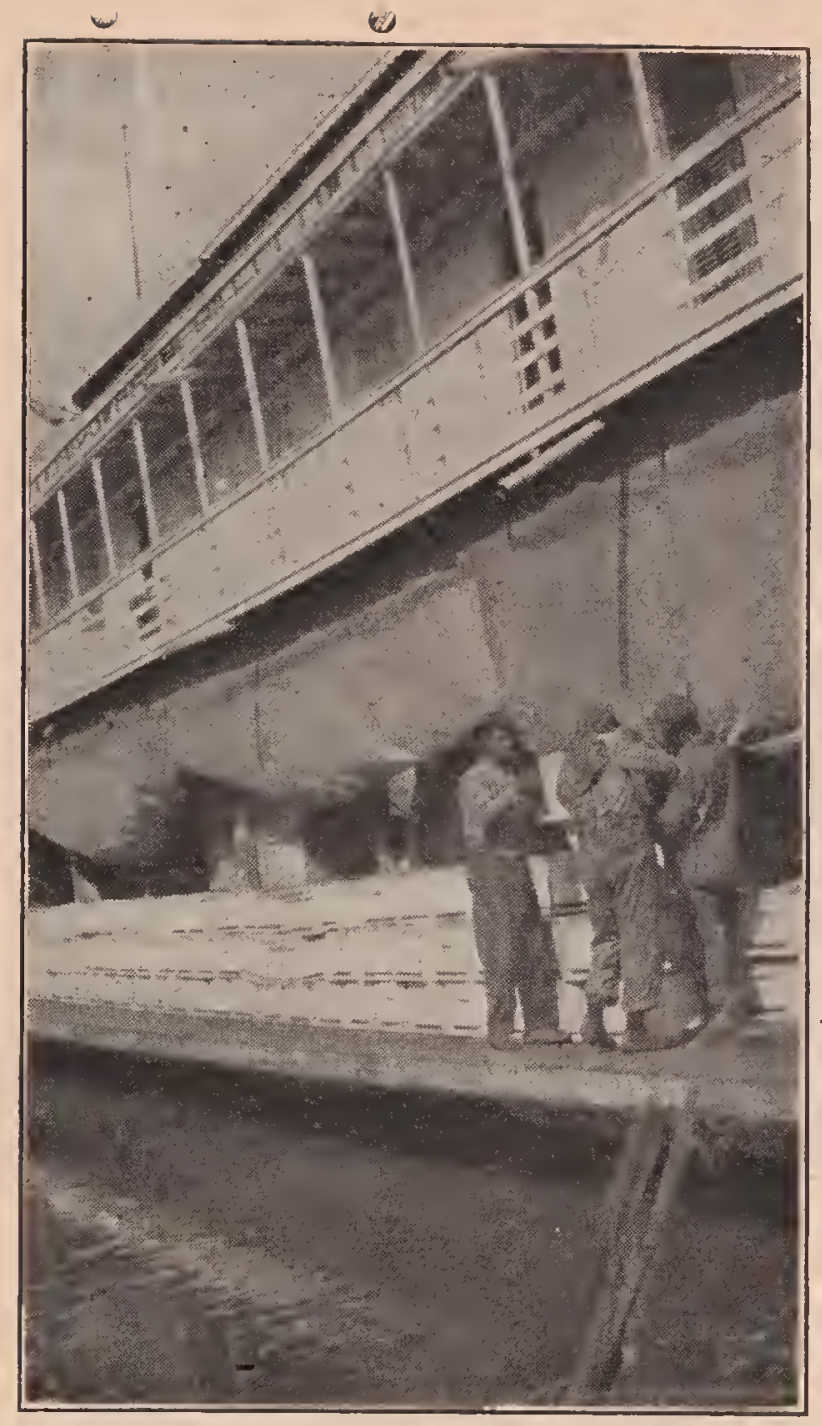

Loading the bees on the steamer.

for long distances in hot weather that the refrigerator car should be used.

When bees are moved in rool weather, say along in the fall, a eattle-car of the kind already deseribed is as good as anything that can be used; but if it is desired to move them in hot weather, the cattle-car can still be nsed, provided the hives are placed far enough apart to insure ventilation and the screens are wet down with water.

SHIPPING BEHS BY BOAT.

Where water privileges are arailable, bees can often be shipped best by boat, either up or down river or down bays. In 1914 the publisher's shipped bees up the Apalachicola River. The ordinary flat-bottom boats used on those shallow river's answer a very excellent purpose. 'The hives are loaded on the outside platforms; and as there is no jolt, the individual hives do not need to be braced together. Bees on boats like this can be carried one or two hundred miles very easily. As the air on water is usually cooler, there is but very little danger from suffocation, but they will need to be sprayed at intervals.

For migratory beekeeping small boats can be used, carrying forty or fifty colonies at a time for ten or fifteen miles. The illustration on next page shows bees that were loaded and moved on the Apalachicola River in 1914.

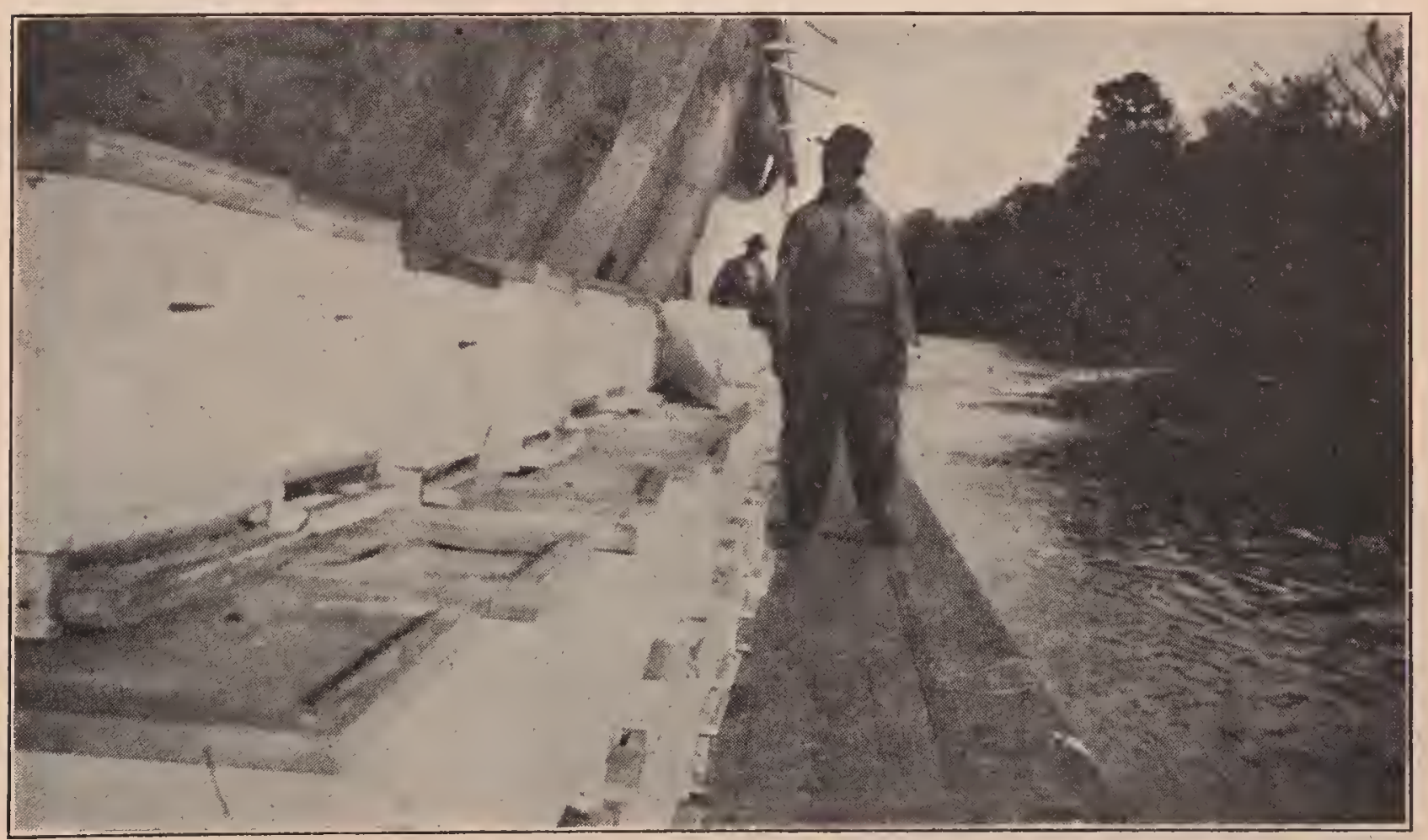

On the boat down the Apalachicola River, hetween Bainbridge and Randlett's Landing. 


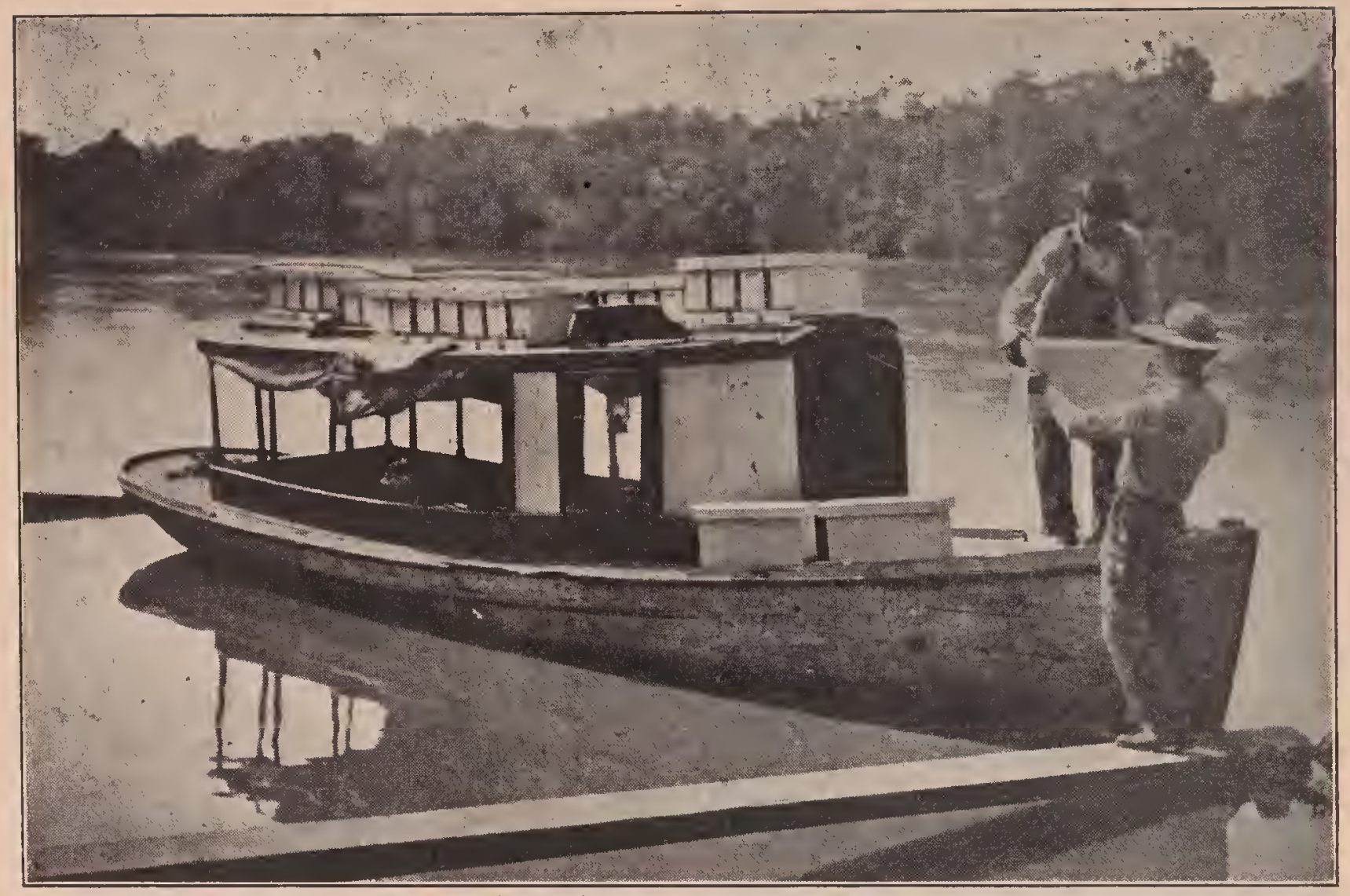

Loading three-frame nuclei on launch preparatory to trip five miles up the river to the nucleus yard.

SHIPPING BEES WITHOUT COMBS.

On account of the danger of transmitting foul brood from one locality to another when bees are sent in hives or on combs, the practice of shipping bees without combs, or in pound packages, is becoming more and more common. Not only is there no danger of scattering disease, but it is actually cheaper. A colony of bees on combs, besides being liable to convey the germs of foul brood, is relatively heavier -much heavier than the light wire-cloth (age or shipping box containing an equivalent capacity in bees without combs. Scores of instances have shown that the threeround package of bees without combs is practically equiralent to an average colony wintered over in the North. So fai as their ability to secure a crop of honey is concerned, package bees, when hived on combs, will make a good colony, if rightly handled, by the time the ordinary honey harvest conles on. The time has arrived when beekeepers are considering whether it would not be cheaper to buy bees in three-pound packages from the South rather than go to the expense of wintering over bees of the previous fall that will eat up honey or good stores and possibly die before spring.

Many of the largest beekeepers in the North are having shipped to them in early spring three-pound packages of bees in lots of one and two dozen packages to a

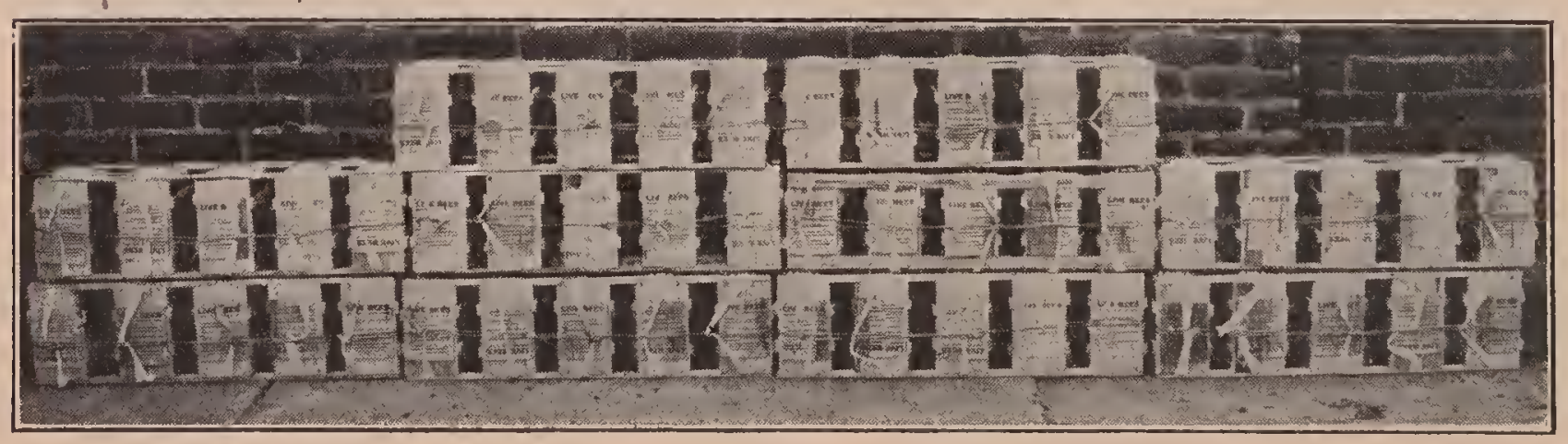

Bees in package form ready for shipment. 


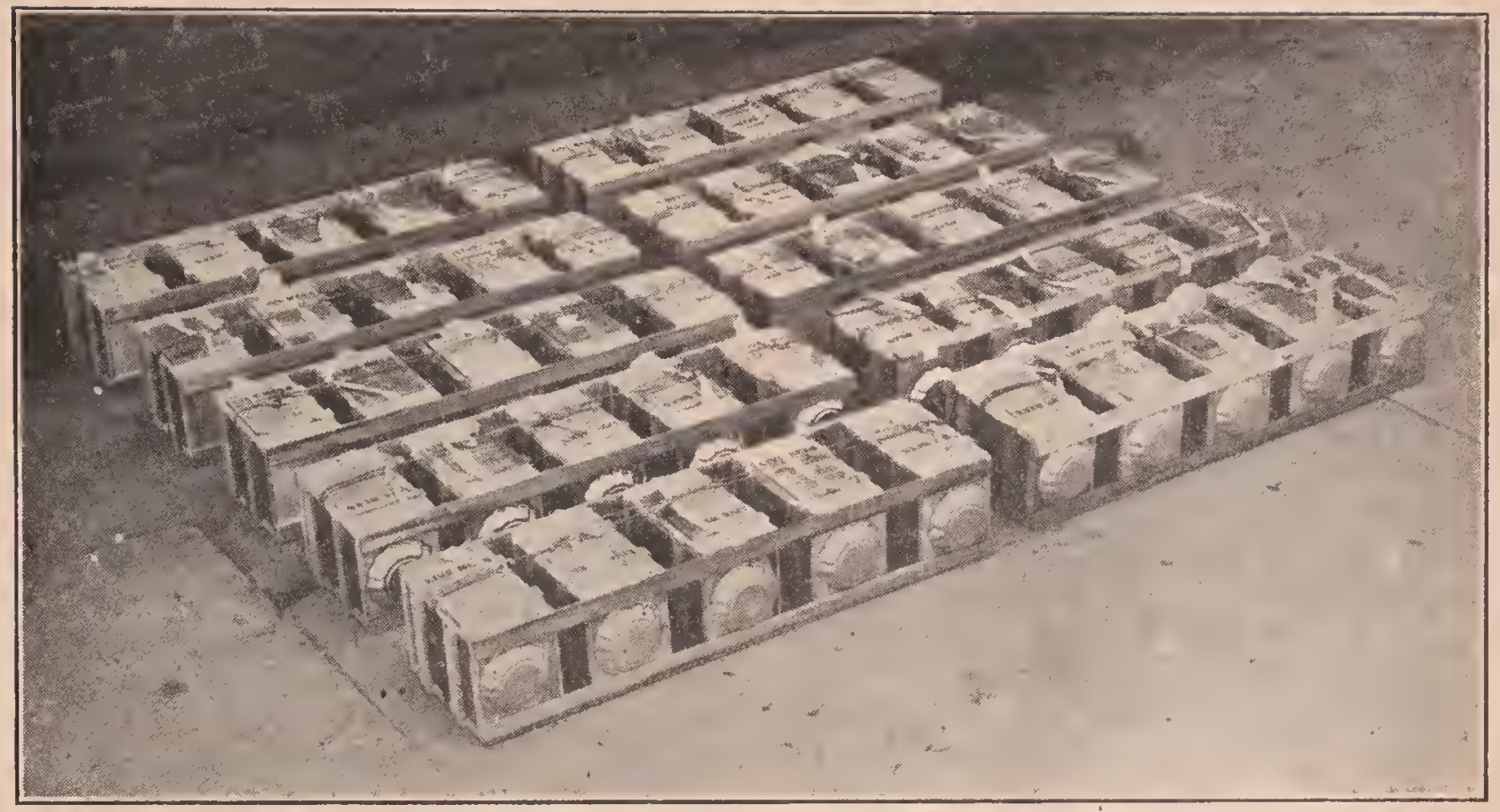

Fifty lound packages of bees ready for shipment.

"rate. These packages keep coming in about three days apart until the whole shipment has been received. Three pounds of young bees, with a queen, will soon have a lot of brood, and in many cases will be very much ahead of a colony wintered in the North having more bees, but superannuated, and ready to die in a short time.

The inference should not be drawn that the author believes that the beekeepers of the North shonld, allow their colonies in summer to run dowll in strength, and starve out, because such a procedure would only mean a needless destruction of good property that might have been saver by the use of sugar syrup.

The demand for bees in package form has been so great that large numbers of northern beekeepers have been disappointed in getting deliveries early enough to be of any value in securing a crop that season. Sometimes the packages are received

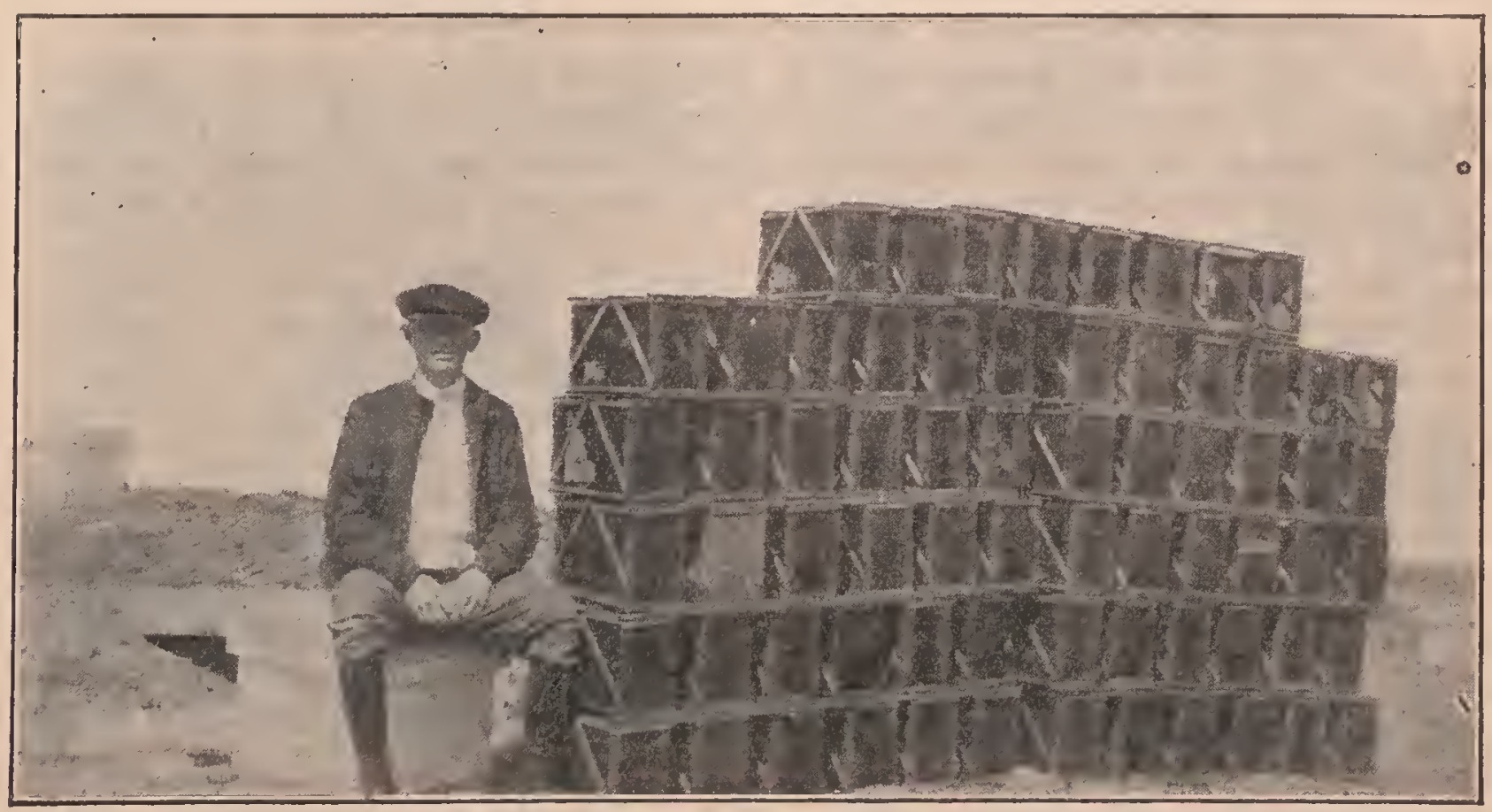

One shipmont of bees made up into crates of six each, with one crate of two. Fach cage has 3 pounds of bees, a can of syrup, half water and half sugar, and a queen caged among the bees. Experience shows this is better than to have her loose. 
in bad order. $\Lambda$ delay of three or four weeks means a severe loss to the consignee, because the bees will not be able to build up in time for the harvest. For the present, at least, it would be better for the average beekeeper in the North to rely on packages of bees to recoup the losses that may accrue from wintering and to make such increase as he may deem possible. After a very severe winter, when many colonies die outright, and they are too weak to build up, the apiary can be put in condition to do business from package bees from the South more cheaply than by buying up colonies in the North, provided they can be lad. A single pround of young bees let loose in a colony of half strength will put that colony in fine condition as nothing else will. When bees are wintered in quadruple cases, with plenty of stores, the chances are that they will make stronger colonies, and be better prepared for the harrest, than the three-pound packages of bees received from the South with a queen, even when received early.

It is perfectly obvious that the average person should buy bees of the old established breeders-those who have been in business so long that they know not only how to ship bees without combs, but who will have enough bees in early spring to make deliveries in time to enable the bees to build up ready for the harvest. Nothing is more exasperating than to order a lot of package bees and then have them come two or three months late.

Those who get bees from the Soutl in package form should read the article "Beginning with Bees," particularly the part that tells how to hive these combless bees; for in all essential particulars they are swarms and should be handled as such. Unless precaution is taken they will be liable to swarm ont and leave for parts unknown.

\section{C.AGES FOR SHIPPING COMBLESS BEES.}

A number of different styles of cages for shipping bees without combs have been devised. Most of them have solid wooden ends with wire cloth for sides, top, and bottom. Others make use of a wooden framework around which the wire eloth is secured. Still other's use what is essentially the old-fashioned nucleus shipping box that has sides and ends of solid wood, but wire clotl at top and bottom. Over the wire eloth are mounted protecting sereens

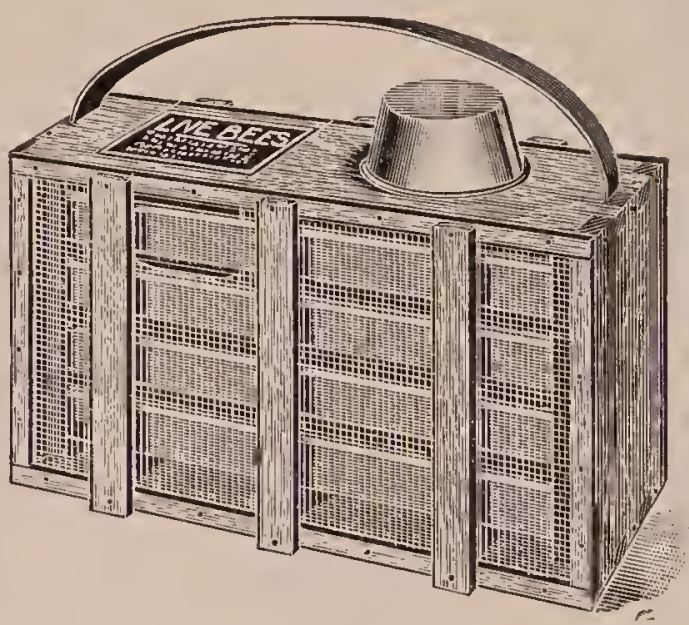

of wood. Such a shipping cage ran acconmodate one or more frames of foundation. When the combless bees are hived on

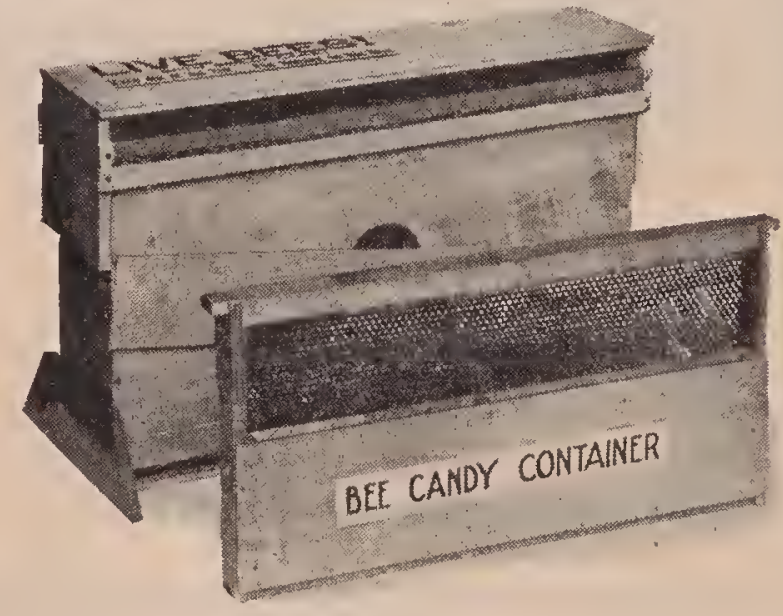

foundation they will draw it out, and the queen will very often lay some eggs in the partly drawn comb. In such a box bees are screened from the hot rays of the sun,

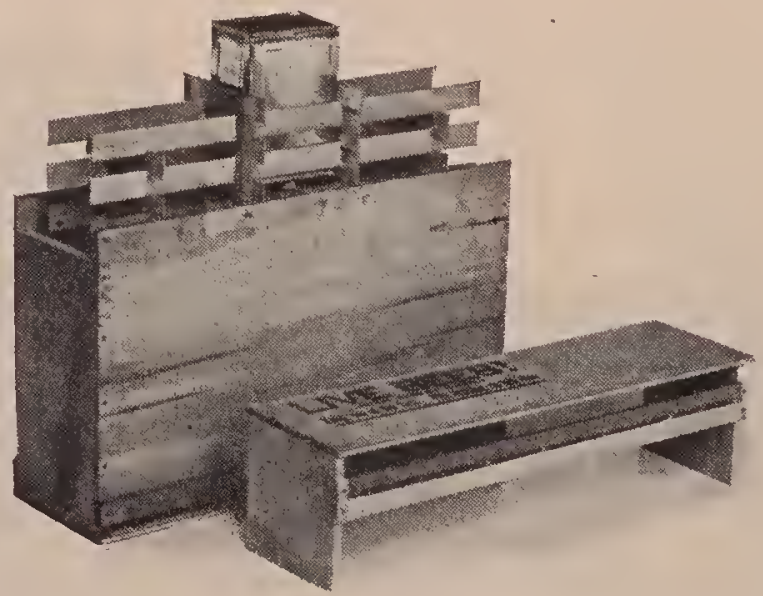

and at the same time are ready to begin housekeeping; so to speak, thus insuring a degree of contentment that conld not be 
secured where the bees are exposed in the regular wire-cloth cages.

There is another style that is the same as the nucleus shipping box. In lieu of frames of foundation it has a series of slats on which the bees may cluster. In the center of this slatwork is placed a tin can containing syrup-about 50 per cent water and 50 per cent sugar. Sometimes the syrup is fed thru a small hole in the bottom of the can. At other times a larger perforation is made, thru which is pushed a piece of candle-wicking that allows the syrup to percolate thrn slowly without dripping. E. B. Ault of Calallen, Texas, uses a screw cap thru which is punched a hole about half an inch in diameter. Over this hole, on the inside, is placed a piece of felting or thick cloth, when the cap is screwed down in place. After the can is filled with syrup it is turned upside down, when the syrup will percolate thru the cloth or felting.

The use of thin syrup for sending bees in package form is getting to be more and more common. While queen-cage candy was formerly used (see CANDY) tests made at this writing would seem to indicate that the syrup is very much more satisfactory. It is not always easy to make a candy that is soft enough to enable the bees to utilize it during the entire trip; but the syrup will always be uniform, and any one can make it.

\section{SHIPPING CASES FOR COMB} HONEY.- It is one thing to produce a fine crop of comb honey with sections nicely filled out, well scraped and graded, and another thing to deliver that honey to market without leakage or breakage. It should be borne in mind that a section of honey is exceedingly fragile, much more so than a bottle containing pickles, syrups, or any other commodity. For many years back comb-honey producers have been putting their nicely built sections in poorly designed cases, resulting in a large amount of breakage and leakage. This loss is usually assessed against the producer, and sometimes the item alone is enough to wipe out the entire profit of the season. When he gets his returns he is so disgusted that he either quits the business entirely or produces cxtracted honey only thereafter.
The old-style shipping cases were made of light thin stuff having a glass front with a paper tray in the bottom and cross-cleats to support the sections of honey. They were altogether too light to protect their fragile contents; and the bottoms of the cases, or, ratlier, the cleats supporting the sections, were rigid, so that whenever they received a bum o $\mathrm{p}$ jar from any cause, some sections were broken. The patent-medicine men and bottlers of canned goods put up their product in such a way that each separate bottle will be cushioned or protected from the ordinary rough usage that the whole box receives in the hands of the truck men and the express handlers, to say nothing of the damage received when shipped by freight.

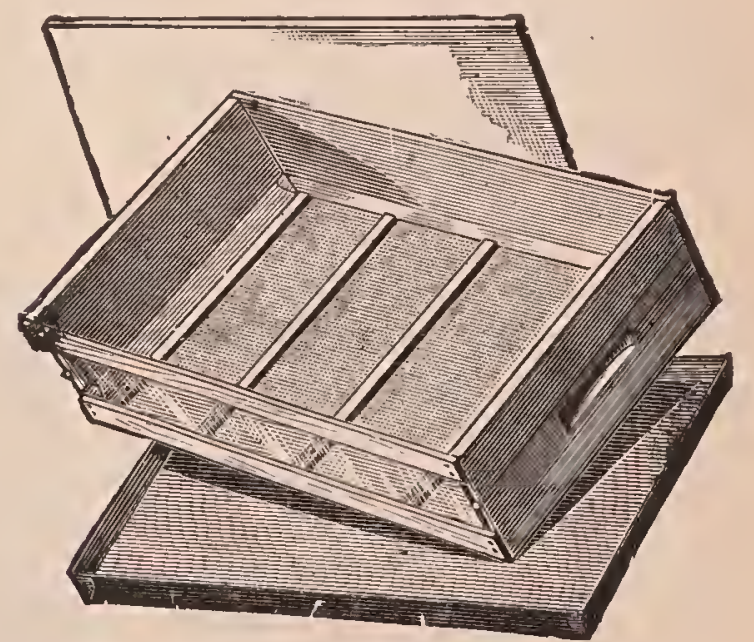

Old-style shipping case with paper drip pan and no drip cleats.

The cut shows one of the old-style cases that provided a rigid or unyielding support for the sections to rest on; namely, the wooden cross-cleats. The next tivo illustrations show a much more strongly built case. It will be noticed in the next cut that the bottom is padded with ordinary corrugated paper, the same material that is used by the patent-medicine men in packing their bottles of medicine. The shippers of all bottled goods are now using corrugated paper around the bottle and under the botton also. This material likewise makes an excellent cushion for the more fragile comb honey, so that when the case is dropped or receives a sudden jar the cushion of the corrugated paper absorbs a large part, if not all of the shock. Comparative tests show that sections in a case having corrugated paper will stand much 
rougher usage without breakage than similar sections placed in a case having rigid cleats across the bottom that, of course, cannot absorb any of the concussion. Experience has also demonstrated that it is wiser to use narrower glass. It shows enougly of

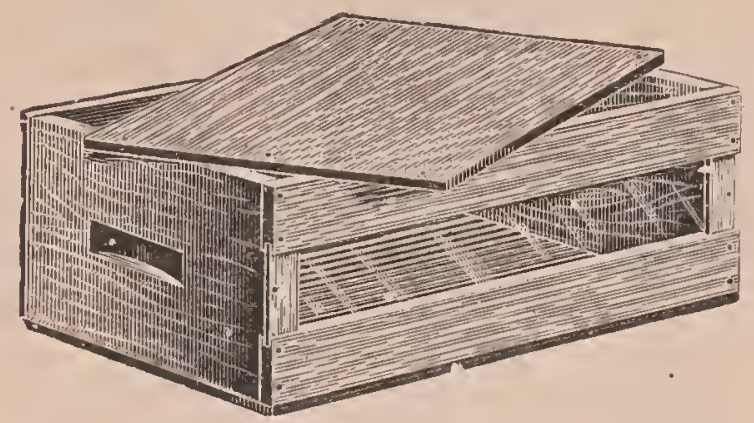

Regular 12-1b. shipping cass

the lioney, and at the same time permits of the use of wider cleats and more nails in the front. When these are properly nailed, the case is much stronger. '

Sometimes cross-partitions of colrugated paper are used, and at other times cartons of cheap strawboard, such cartons slipping around each indivilual section. If these are a litthe larger than the sections, and especially if a little deeper, they will sustain all the weight that may be placed on top of the case, learing the sections which they contain without any strain upon them. The cartons have, the further advantage that ther can be sold with the individual sections. In this way the delicate romb is protected, not only durin re shipment, but while in the manket basket on the way from the norery to the home.

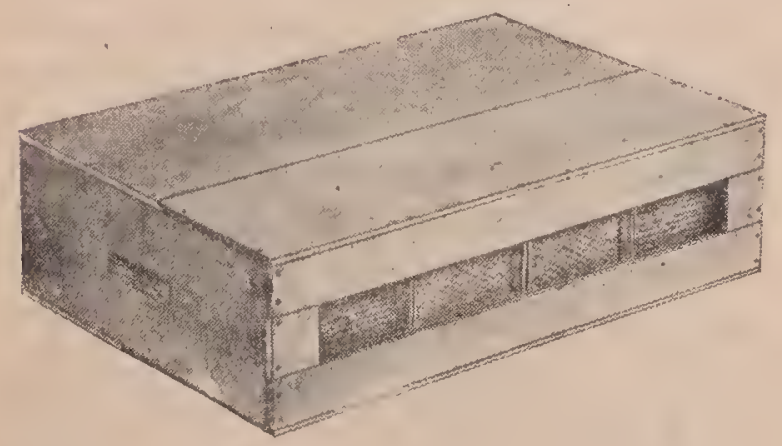

Regular single-tier 24-1b. shipping case.

If there is anything that disgusts the housekeeper, it is a leaky section of honey that besmears all her other groceries, mak- ing a broken, sticky mess of everything. If the comb-honey producer would have the consumer pleased as well as the large dealer and buyer, he must make sure that his goods are protected clear to the consumer.

The illustration below shows how the corer-boards are halved together, and how the glass is let into the strips. The strips should be thoroly nailed, two nails in each end: in fact, the case slould be well nailed all over. So far as possible it should be made very rigid, so that it will not spring nor twist. If the case is at all frail the sections are almost sure to receive damage, particularly so if corrugated paper and cartons are not used.

- While shipping cases containing cartons and corrugated paper and built on scientific lines cost more, as a matter of course, than the old-style cases, yet the producer can well afford to use then, because he will save a considerable breakage, leakage, and no end of complaint, and, besides, avoid
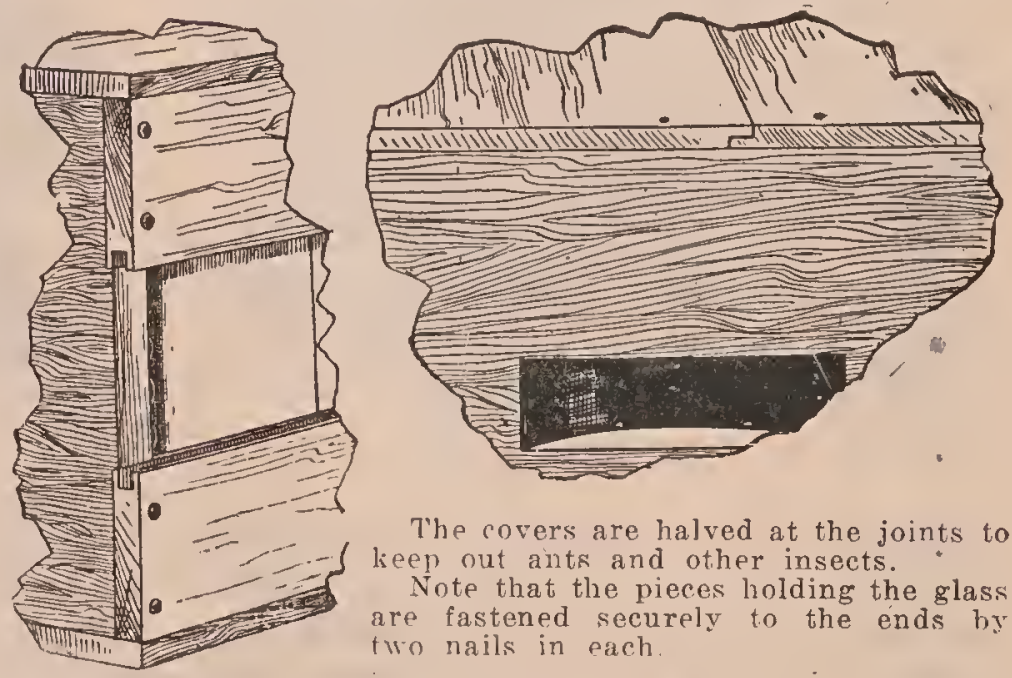

The covers are halved at the joints to lieep out ants and other insects.

Note that the pieces holding the glass are fastened securely to the ends by two rails in each

practically all trouble with the commission merchants or the dealers who buy the goods. When the comb honer goes thru in bad order there is considerable correspondence as to what would be a proper adjustment Should the serrices of an attorney be needed, and suit brought, still greater expense is incurred.

\section{WHY IT PAYS TO USH BHTTER SHIPPING CASES.}

One large buyer of comb honey who buys honey in car lots made the statement that his brakage carefully figured up in one season showed a loss to the producer of not less than 11 3-10 per cent. If the ship- 
ments that are made from all parts of the country, in all kinds of shipping cases, should be taken into consideration, this loss would reach nearer 25 per cent.

But there are a large number of beekeepers who feel that they cannot afford to purchase even the cheap factory-made cases. If the loss should be from 10 to 20 per cent witl the cheap cases, it may be figured that the loss would be at least from 25 to 50 per cent with the ordinary homemade cases or cases made at planing mills. The objections to the home product are the poor sawing, inaccuracy, and their miserable appearance. Even if the honey goes thru safely, the cases look so cheap and poor that the average buyer will deduct at least one or two cents per pound on the honey. The honey may be ever so nice; but if it is put up in a roughly made container it will bring a lower price.

The most serious objection to homemade cases is their variation in size. Some of them will be so shallow that when the cover is nailed down it will break nearly every section in the case. Another case will be too deep and too long, with the result that the sections will rattle about in the case and break down nearly as badly. The average planing-mill man does not understand the importance of making the rase absolutely accurate. His saws have very coarse teeth making rough edges, and his gauges are not accurate. His product will be anything but satisfactory for shipping so expensive and fragile a product as romb honey. When a good factory-made rase with rartons or corrugated paper ran be bought for a little more money, it is folly to pay a planing-mill.man a few cents less for a case that will bring a loss in breakage and leakage amounting to 50 per eent on the honey.

SHIPPING CASES MADE OF CORRUGATED PAPER.

A few rears ago some effort was made to use shipping cases constructed out of col'rucated paper or strawboard-the same material that is used in the safety cases, to cushion the sections. I. E. Crane of Middlebury, Vt., used this kind of case for sereral years, and was well pleased with them: but some of the large commission houses and buyers of honey protested against their use. They claimed that they are not strong enough to stand the rough handling of the railroad men; that as it is not practicable to put glass in them the fragile contents of the package are not understood, and, as a result, they receive a much rougher handling. Again, it has been claimed that the paper cases will not stand rain or wet like the wooden ones. If a single section is broken down, it is liable to cause the bottom of the case to soak up with honey, and this weakens the case so that it is of but little use to protect the rest of the sections.

While such cases seem to answer very well for honey in bottles, it should be remembered that a bottle of honey or a bottle of syrup or pickles will stand very much rougher handling than the ordinary section of honey.

In later years the paper eases for comb loney have practically disappeared, and nothing more is neard of them. See BoTthing Honey; also Marketing Honey.

\section{HOW TO SHIP COMB HONEY.}

One may have his shipping cases factorymade, or ever so perfect, and yet have his fine comb honey shipped in them broken down. As a rule it is not advisable to send? such a product by express, altho it can be done. The experience of the authors has shown that comb honey sent by freight not only goes thru at a less cost, but in much better condition.

Much will depend on whether comb honey is sent in carlots or in less than carlot shipments. As a rule a single case of comb honey or half a dozen or a dozen of then can not be sent without being put into a special carrier or crate. No matter how modern the cases may be, with plenty of corrugated paper for top, bottom, sides. and ends, if they are sent uncrated, either hy freight or express, there is almost sure to be a breakage and leakage of the comb honey. Where a customer wants a single case. or a couple of them, they should be put in a box large enough so that they can be well packed all around in straw. Comb honey is seldom shipped in less than four to eight cases at a time, making an aggregate weight of not less than 100 pounds. The carrier or crates that are ordinarily used will take eight cases, or the equivalent weight of 200 pounds. 


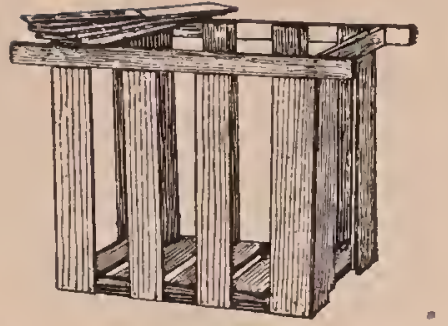

The carrier here shown is lined on the inside with paper to conform to the rulings of the railroad companies. On the bottom is then placed six or eight inches of loose straw evenly distributed, when the cases are piled in, one on top of the other, until the carrier is level full, four single-tier cases deep, of 24 pounds each,and two cases long. The paper is then neatly folded oveí, after which the cover boards are nailed in place as shown in the next cut.

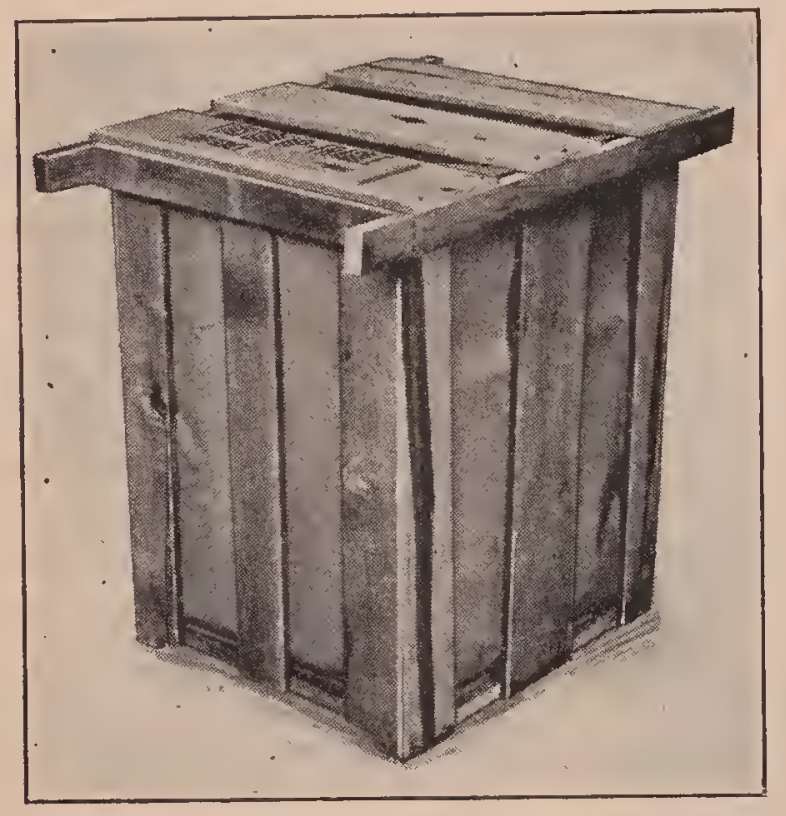

The carrier shown is so big and heary that it can not be picked up by the freighthandlers and dumped or thrown. The handles sticking out suggest the method for moving it, and that means two men, to pick it up and carry it wheelbarrow fashion. Two can easily pick it up and move it from truck to car and from car to truck, and from truck to destination with perfect ease. Such a carrier will go either by freight or express-preferably by freight without breakage or leakage. If 500 or several thousand pounds of comb honey are to be shipped, carriers like those here shown should be used. While they entail some additional expense they insure safe delivery of the honey, save loss from breakage and leakage, and leave a pleasud customer at the other end of the route.

In very many instances the beekeeper can and should carry his own comb honey with his own truck to his near-by towns and cities. On bad roads, in a common wagon with no springs, plenty of straw should be put in before loading the honey; but usnally an automobile truck is provided with springs, which, in connection with pneumatic tires and careful driving, will insure safe delivery without any carriers or crates or straw in the bottom.

It sometimes happens that all the local markets in the towns near by, as well as the cities, are more than supplied with comb honey. In that case, less than carload shipments should be sent in carriers.

HOIV TO SHIP COMB HONEY IN CARLOTS.

When sending honey in carlots the carriers are not needed. The railroad companies should furnish a strong serviceable car that will stand rough usage - one that has not been used for carrying phosphate, wool, or live stock. A wagonload of straw should be provided in advance. The floor should be swept out when the car is ready. The cases of comb honey should be neatly piled in the car one on top of the other, and of even height, like cord wood, leaving a clear space of at least a foot from each end of the car. It is important that the cases be piled snugly against each other, in such a way that the combs will be parallel with the track beneath. Any intervening space left on the sides nest to the car should be filled in with crating, boards, or straw tightly wedsed in. 'There is not a great deal of side morement in a car; but it is important to provide for a slight amount of it. The whole car should then be filled out with comb honey of an even depth until within a foot or 18 inches of each end. It is not advisable to pile the honey up higher than about eight cases single tier, or four cases double tier. The intervening space of 18 incles at eacl end of the car should be filled in with closely packed straw. Tlis can not be packed in too snugly. The purpose of the straw is to provide against serious end shocks due to stopping or starting of the train. Tt sometimes happens that a car of comb hon- 
ey is shot ahead on a switch; and mless a man is on top of the car at the brake the car may be jammed into another car. It is, therefore, important to see that the end spaces at the end of the cases in the car are cushioned with tightly packed straw. To keep the straw from working up at each end, thus allowing end shock between the cases, boards should be put over the top of the straw and held down by cleats on each side of the car.

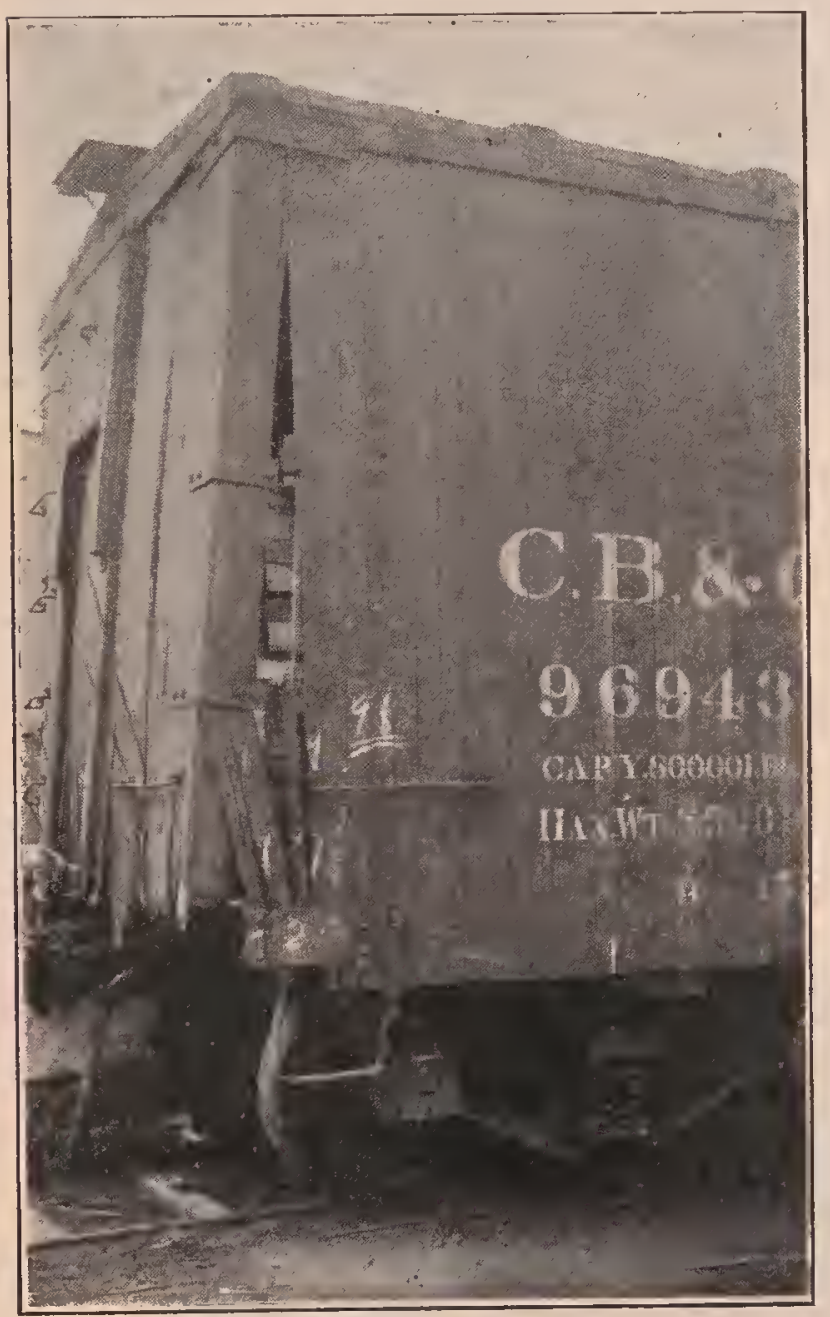

Why honey needs solid bracing in a car. In this instance the car was bumped so violently that the honey went right on thru the end.

Should there not be quite enóugh comb honey to fill the car it would be well to leave the space next to the doors, and fill in with very rigid bracing made up of 2 ly 4's fastened in sucl a way that they can not possibly work loose. Many and many a car of comb honey sent long distances has had a heavy breakage, caused by carelessness on the part of the shipper or by his inexensable ignorance in not seeing to it that the comb honey was packed solid and properly cushioned at the ends and sides of the car. The shipper slould make up his mind that his comb honey is more fragile than eggs in egg-carriers; that it is relatively heavy; that the railroad companies en route will give his lioney the heaviest end-banging it has ever had. He must play safe. While he may recover damages from the railroad company, the process for doing this is exceedingly long and difficult, with the possible and probable result that the railroad company will get out of paying for the damage, or it may pay a merely nominal sum.

Perhaps in all beedom there is nothing more aggravating than a car of brokendown comb honey. If it is sent against a draft attached to the bill of lading, the consignee is liable to refuse payment. It lies on the tracks while telegrams are flying' back and forth; and; even tho a compromise be effected, no one is satisfied. In the mean time robber bees get busy, sting the railroad men who are trying to "clean up." This is not all. Foul brood may be scattered far and wide. So, be careful, Mr. Beekeeper.

The subjoined illustration shows what happens in a good many cases when proper provision is not made for the end shocks that must inevitably' occur' when the train stops or starts. When comb honey, heary as it is, is jostled about in the car, say the space of a foot or more between the cases, and the cases slide this way and that, the inevitable result is a breakdown. Possibly the whole end of the car may be shoved out as shown in the cut.

\section{SIZE OF FRAMES.-See Hives.}

SKEP.-The term "skep" is often used by old-fashioned beekeepers to refer to a colony of bees in any kind of hive; but more properly it applies to box hives and straw skeps-the last named meaning basket in old English. In England and even many of the countries on the continent of Europe, the old straw skep is still used quite largely, because humber is expensive and straw cheap. The bees are allowed to build the combs just the same as mentioned under the head of Box Hives; and under Hives, Evolution of. On'top of the flattop type of skeps, modern supers containing 


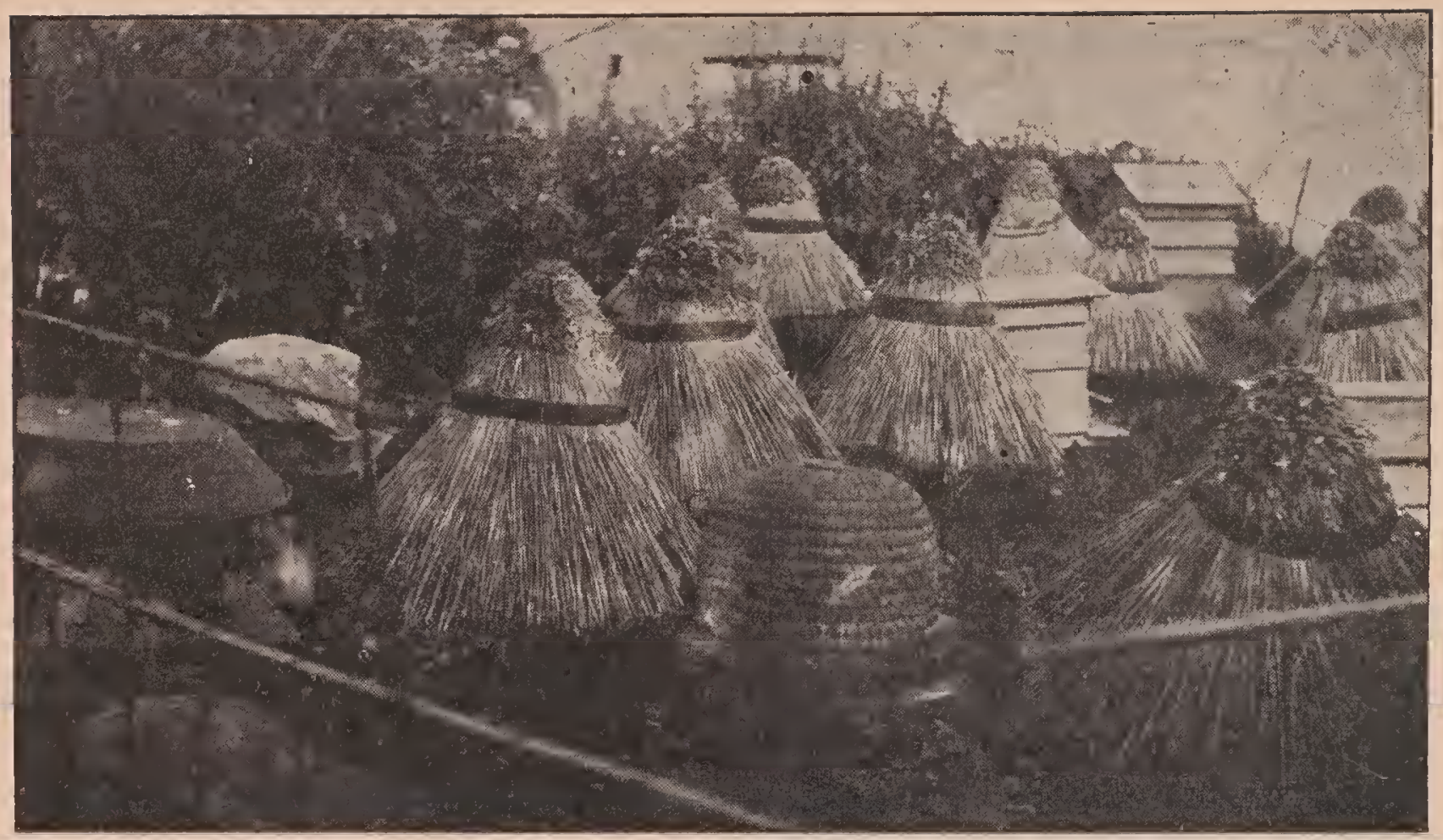

Straw keeps the hises cool in summer and warm in winter.

sections are sometimes used. The making of straw skeps for cottagers is quite a little business of itself-requiring a certain degree of skill and industry.

Straw skeps are not used in this country: and if it were not for the familiar pictures of "ye olden times" Americans would know but little about them. See Bor HIVES.
SMARTWEED.-See HEARTSEASF.

SMOKE AND SMOKERS.-One can drive cattle and horses, and, to some extent, even pig's, with a whip; but one who tries to control cross bees withont smoke will find to his solrow that all the rest of the animal kingdom are mild in comprarison, especially so far as stubbornness and

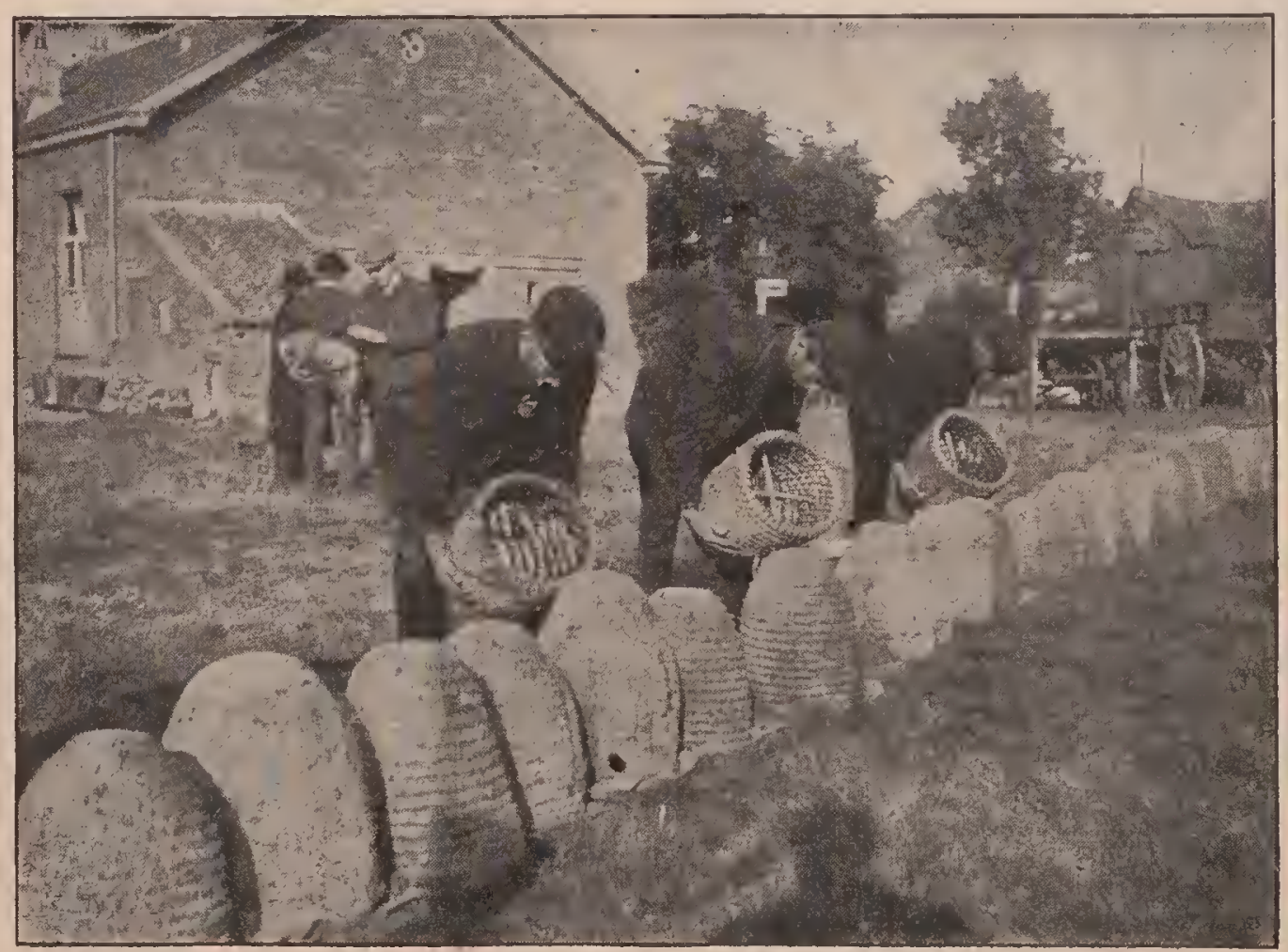

Dutch swarm specialists inspecting bargains at the bee market in Holland. 
fearlessness of consequences are concerned. One may kill them by thousands or may even burn them up with fire; but the death agonies of their comrades seem only to provoke them to new fury, and they push on to the combat with a relentlessness which can be compared to nothing better

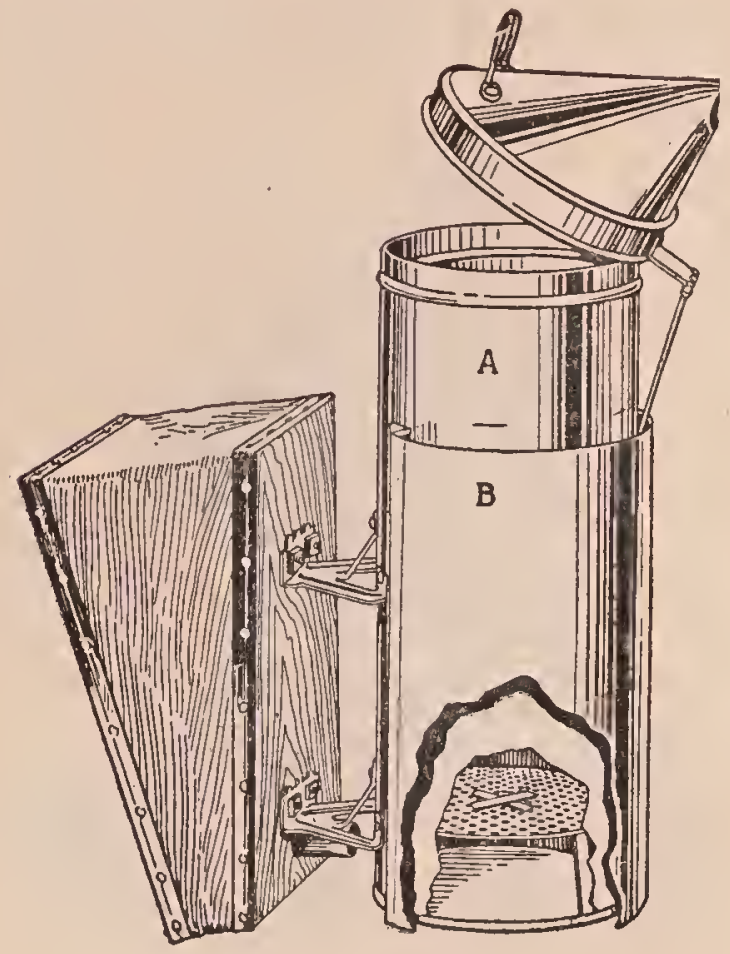

Bingham smoker.

than a nest of vellow-jackets that liave made up their minds to die, and to make all the mischief they possibly can before dying. It is here that the power of smoke recting smoke on the bees, such as a tin tube containing slow-burning fuel, with mouth-piece at one end, and a removable cap and a vent at the other end for the issuance of smoke. By blowing on the mouth-piece, smoke could be forced out. Others, again, have used a tin pan in which was some burning rotten wood. This was put on the windward side of the hive so that smoke would be blown over the frames. All of these, however, were crude makeshifts in comparison with the improved smokers which are on the market today.

Moses Quinby (see Quinby) has the credit for first giving us a bellows beesmoker. This was a decided step in advance over the old methods of introducing smoke among the bees. It combined the tin-tube idea with a bellows. In principle his original smoker did not differ essentially from the Bingham and the L. C. Root, which were introduced later. It had, however, one serious defect; and that was, it would go out, the fire-pot not being properly ventilated to insure a good draft. Some years after, T. F. Bingham, L. C. Root, sonin-law of Mr. Quinby, and A. I. Root introduced bee-smokers on the principle of the original Quinby hellows smoker, but with several decided improvements. The fire-cups, at the same time, were made rather larger, with a blast vent near the bottom. Thru this vent a continuous draft
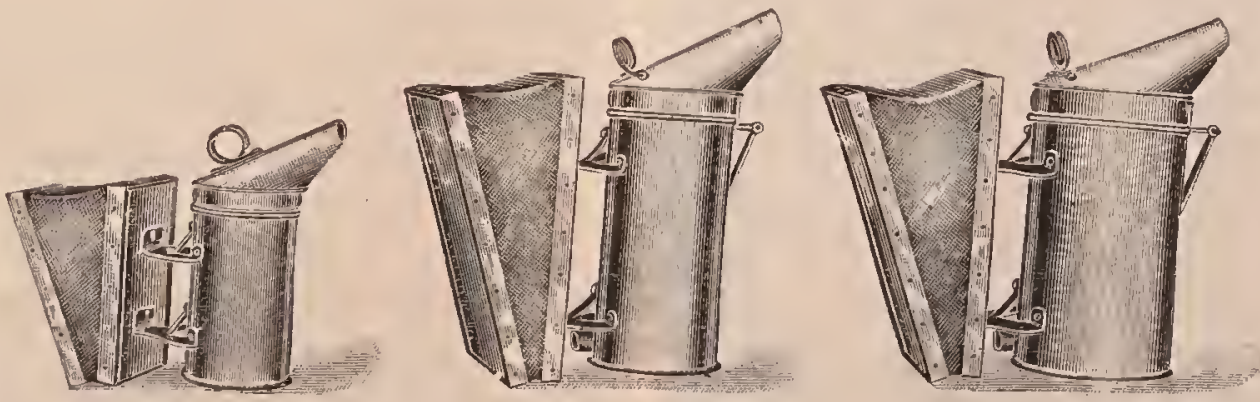

Three sizes of Root smokers.

colnes in; and to one who is not conversant with its use, it seems simply astonishing to see them turn about and retreat in the most perfect dismay and fright, from the effects of a puff or two of smoke from a mere fragment of rotten wood. What could beekeepers do with bees at times, were no such potent power as smoke known? See Bee Behavior; also Anger of Bees.

There have been rarious devices for di- could be maintained, even when the smoker was not in use, thus prerenting them from going out like the original Quinby.

Of the two smokers, the $\mathrm{I}_{\text {. }} \mathrm{C}^{\prime}$. Root was taken off the market some rears ago. The Bingham is still sold, and is now furnished in various sizes by dealers.

All the smokers of today employ what is known as the hot-blast principle-that is, the blast of air from the bellows is blown 
thru the fire. This makes a heavy volume of smoke-volume enough with the proper fuel to subdue the crossest bees.

The improved Root smoker on the same principle witl its new snout is very neat and substantial. The old-style nozzles were somewhat topheavy, having a tendency to tip orer or flop open at a most inconvenient time. The ones here shown are not only compact in appearance, but will hold their position on top of the stove withont danger of toppling over, no matter how roughly used.

The object of the deflected nozzle on all three of the leading hot-blast smoker's is to prevent fire dropping. In the old-style

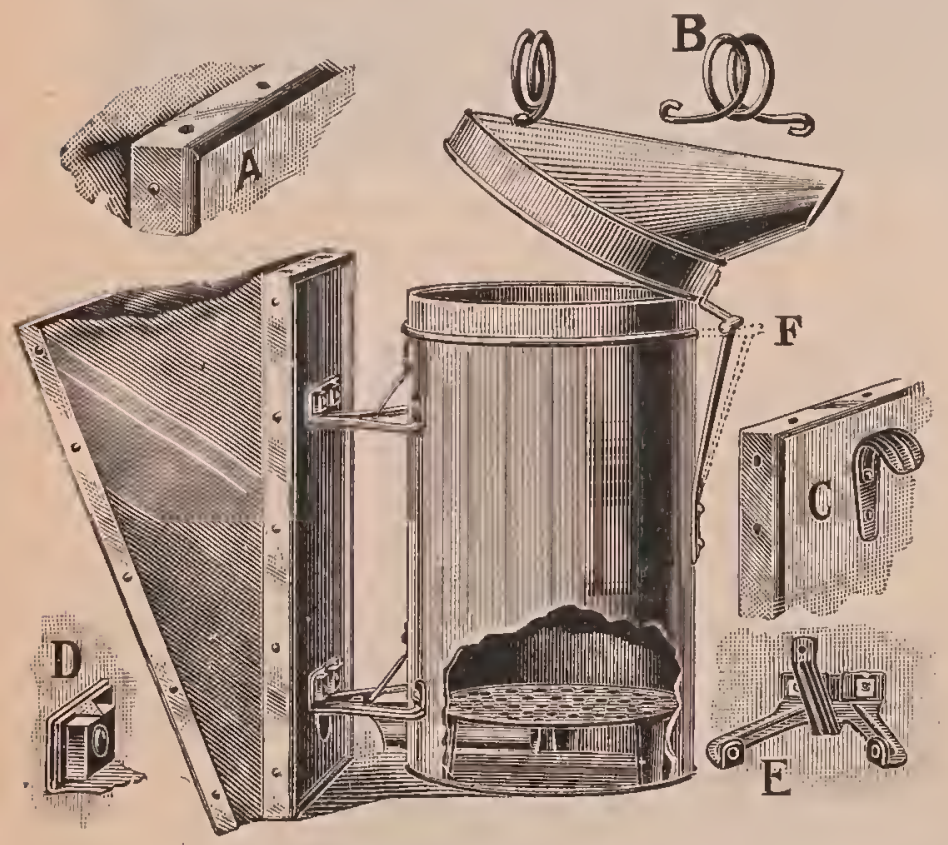

Fig. 1.-Details of the Root smoker-A.-Metal projection to aid the fingers in holding bellows: P.-Coiled wire handle; G.-Hook; D.-Lock nuts for legs; E.-Stamped metal legs; F.-Flexible hinge.

smokers it was necessary in blowing smoke to tip the barrel almost upside down, or at such an angle that the fire-embers would sometimes fall on the brood-frames and the bees. The bent nozzle permits one to use the smoker almost right side np, and yet a stream of smoke can be poured on the combs.

\section{FUEL FOR SMOKERS.}

It will be unnecessary to give directions for using these smokers, as printed directions accompany all smokers sent ont by each manufacturer; yet it may be well to allude to the different kinds of fuel that have been nser. Rotten wood is good, and aceessible to all, but it burns out too rapidly. Some recommend sound hard wood for the smoker. Others prefer turninglathe hardwood shavings, or, if these are not available, planer shavings. In certain localities peat can be obtained very cheaply, and it makes an excellent fuel. Some use old rags; others old discarded hivequilts that are covered with propolis. These last make a very pungent subduing smoke. In some parts of the South, dry pine needles are used.

W. L. Coggshall, one of the most extensive beekeeper's in the world, uses a special fuel made out of old phosphate sacks rolled around a half-inch stick, tied at regular intervals, and then chopped into convenient lengths with a sharp ax. The rolls should, of course, be of the right diameter and length to fit inside the smoker used. The sacking must not be rolled too tightly nor made too snug a fit, or else it will choke the draft and put out the smoker. The reader is, therefore, recommended to make a few experimental rolls before he makes up a lot for a season's use.

To facilitate lighting with a match, one end of the roll is dipped half an inch into a solution of saltpeter, and allowed to dry. If a little red lead be sprinkled in the solution it will be very easy to tell which end of the roll is for lighting.

A quantity of old sacking, says $\mathrm{Mr}$. Coggrshall, will be sufficient for one season's use, and the fuel gives a lasting smoke without sparks. He further says that he can take a cold smoker, and in ten seconds have all the smoke he requires, as the saltpeter ignites instantly.

When old sacking cannot be obtained, old carpets or old burlap can be used. Even new burlap would not be expensive, altho Mrr. Coggshall says the fabric should be partly rotted to give the best results. $\mathrm{He}$ lays his old phosphate sacks out in the weather for about three months and then rolls them up.

\section{GREAST WASTE AS A SMIOKER FUEL.}

The anthors have been using greasy waste in a smoker with great success. It requires no treatment with any chemical to to make it light easily, and it is almost impossible to extinguish it after it is once lighted, even tho it be stamped in the mud. This is perhaps the very best smoker fuel, altho in some places it may be somewhat 
difficult to obtain. It furnishes a strong subduing smoke, and is almost free from creosote. It can usually be had for the asking at any machine shop or printing shop, and it may be picked up along railroads, altho as a rule it would take too much time to hunt up greasy waste in this way. A piece could be found here and there, but generally not enough to pay for

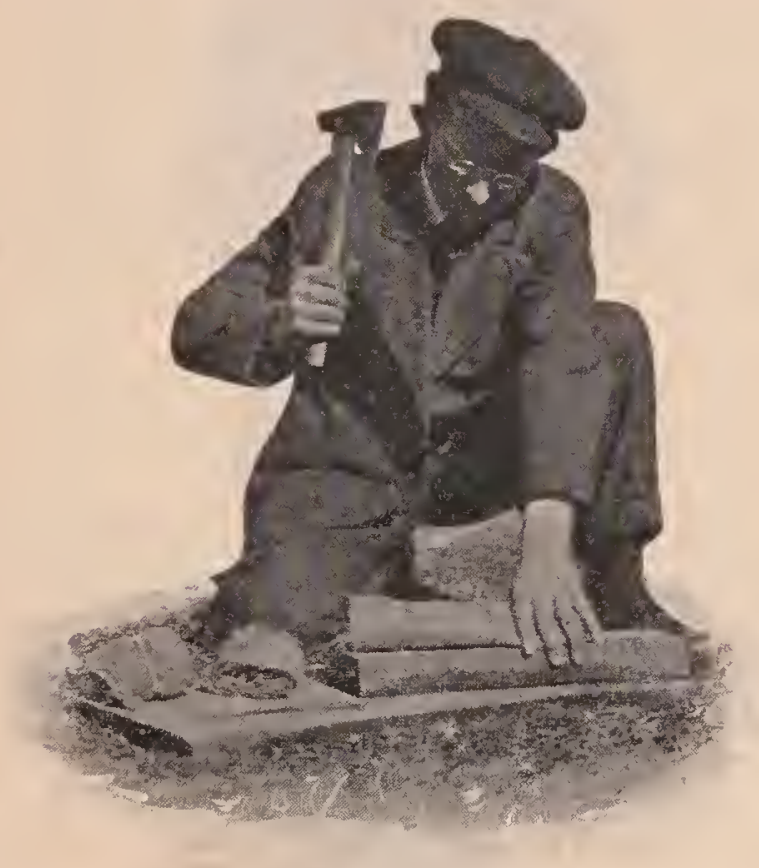

Fig. 2-Chopping un rolls of burlap for smoker. fuel. An old sack is rolled up, tied at intervals, and then eut in pieces between the strings.

the trouble. A supply can be obtained at any factory to last a whole season. It gives a strong, pungent smoke; does not make a hot fire; is easily lighted; will not go out as long as any fuel is left.

\section{ABUSES OF A SMOKER.}

A good smoker should last a number of seasons, but it will very quickly cease to be a good implement if it is not well taken care of.

One of the most common abuses of a smoker is to leave it out in the rain. Many smokers are left out in all kinds of weath$\mathrm{el}^{*}$; and it is needless to say that the bellows leather soon becomes hard, and cracks, and the fire-box becomes rusty. Many beekeeper's keep their smokers in an empty hive and thus avoid the danger of a costly fire. If the whole hive should bu'n, the loss would not be so very great.

A better plan than this is to build a small tool house. This need not be over five or six feet high and two or three feet square. There should be a shelf, on which smokers, hive-tools, veils, ete., may be kept. It is a good plan to provide a piece of heavy sheet iron about half an inch above the shelf for the smoker's to stand on, so that there will be no danger of setting fire to anything. The fuel is kept below this shelf. There is room enough usually to hold a supply for a whole seitson; and when it is kept in this way it is always dry and ready for use. The authors have such small buildings at all their. outyards, and consider them almost indispensable.

A nother common abuse of the smoker is to allow creosote to collect at the top. until the cap will not fit down over the fire-box. In a new smoker with the flexible hinge

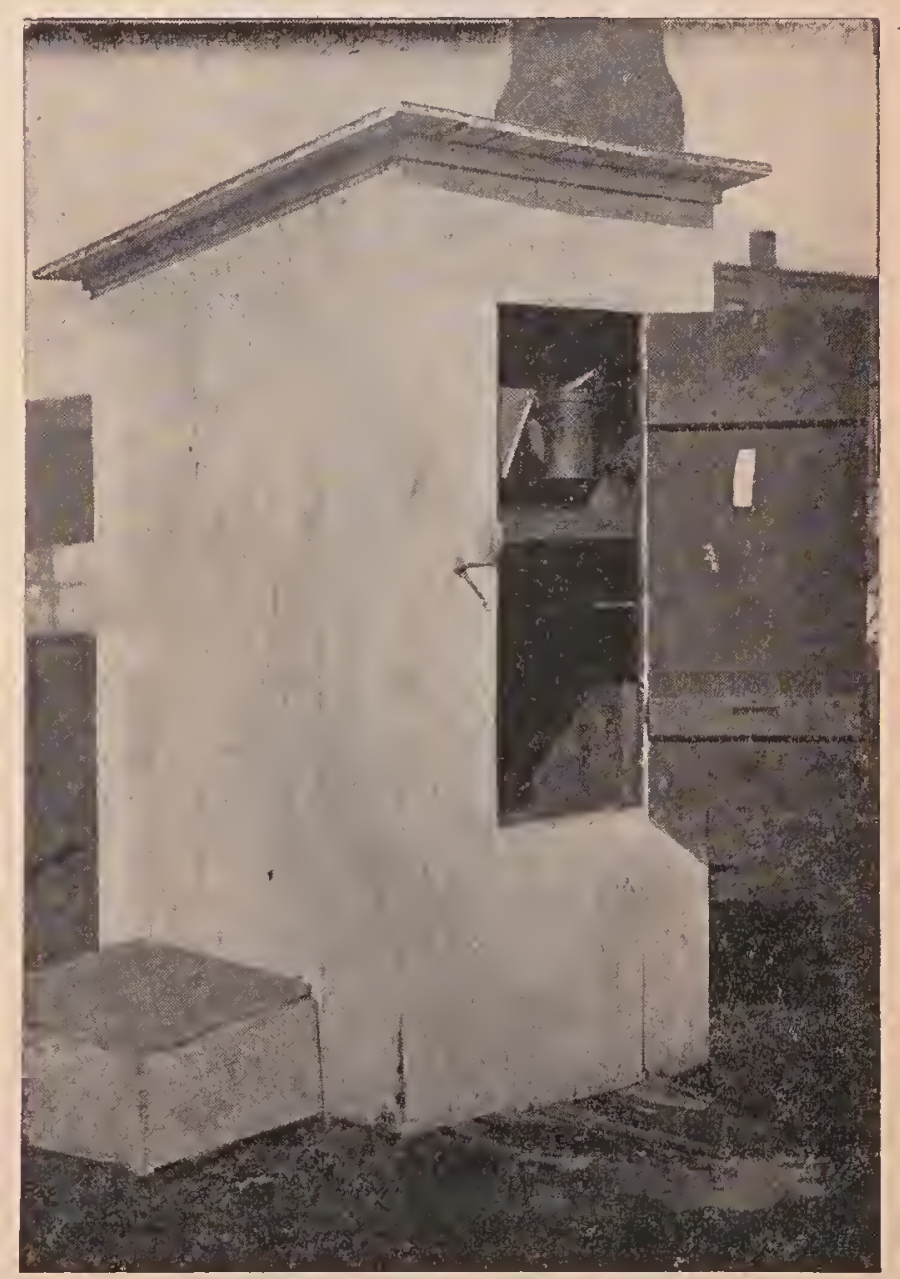

Fig. 3-A tool house for smokers, tools, veils, and fuel. The fuel is kept in the lower part under the shelf.

there is not apt to be so much trouble in this way, but at the same time it is well to spend about ten seconds once a week or so with a screw-driver in cleaning off this accimulation. 
Sometimes beginners in their eagerness to test new smokers work the bellows so vigorously as to blow fire from the nozzle, and before they know it the fire-box is redhot. This means, of course, that the tin is all burned off, leaving the bare iron to rust thru in a short time. There is usually no need of having a hot flame in the firebox, for this implies perfect combustion. The secret of getting plenty of smoke is to have imperfect combustion. For this reason it is best to use fuels that burn. slowly.

While it is impossible to avoid dropping a smoker once in a while, as a rule bee-

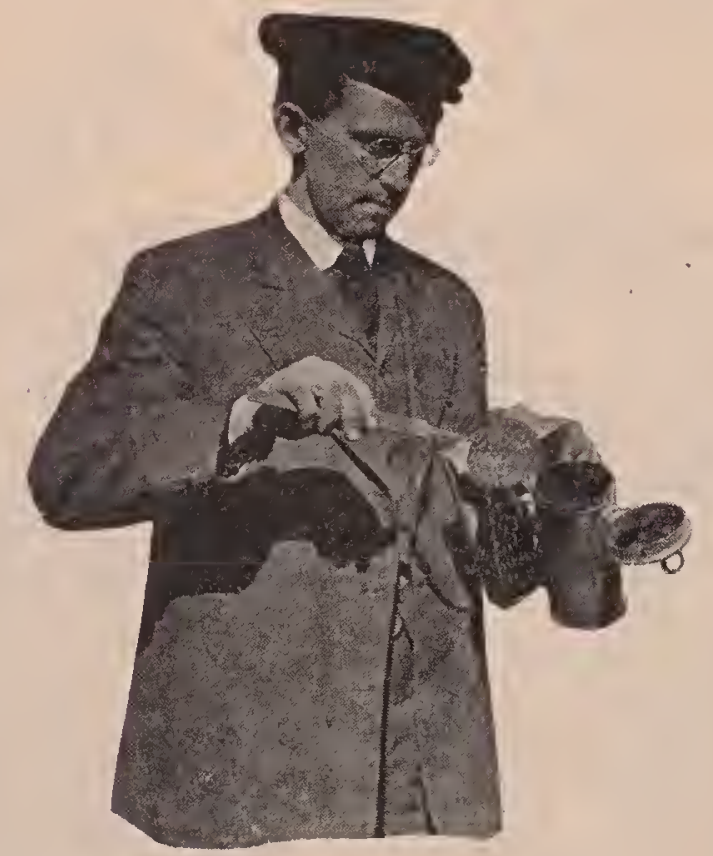

Fig. 4 -It is very seldom the grate becomes so filled up that it has to be cleaned; but when this does happen it is the work of only a moment to insert the point of a file in one of the holes and lift out the grate, as here shown. It pays to keep the grates clean. There are a larger number of holes near the outside of the grate than in the center, consequently the fuel burns evenly and does not throw sparks until it is all consumed.

smokers are handled pretty roughly. It does not take long to learn to use reasonable care in handling a snioker, whereby it will last enough longer to pay.

When a fuel is issed in which there is a good deal of pitch it is sometimes difficult to raise the cap or nozzle after the fire is out and the metal has become cold. There are numerous instances in which the cap has been battered almost ont of shape after being stuck down solid. It is always best where such fuel is used to raise the cap when putting the smolier away. If it is left open there will be no sticking. t'he grate will usually kecp rlan: but in some cases when it gets stopped up, insert the point of a file into one of the holes and

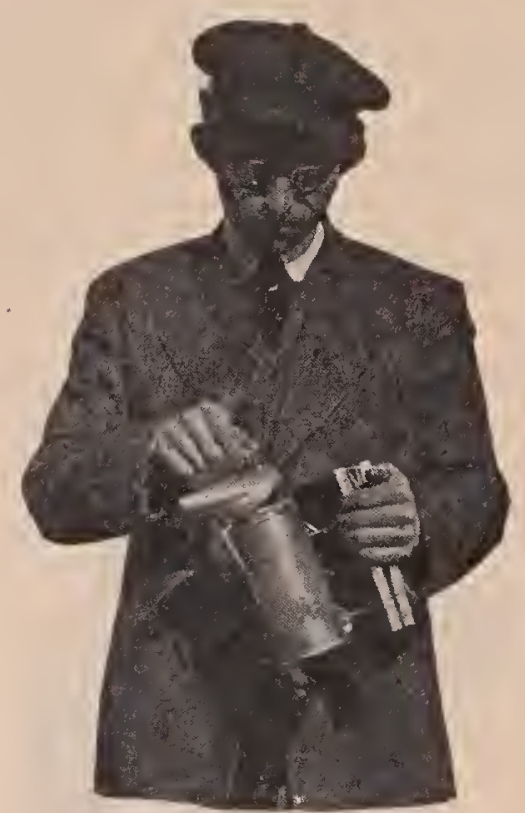

F'ig. 5-How to hold the smoker when raising the cap. Compress the bellows in order to give the fingers a firmer hold.

lift it out. It can then be easily cleaned and replaced.

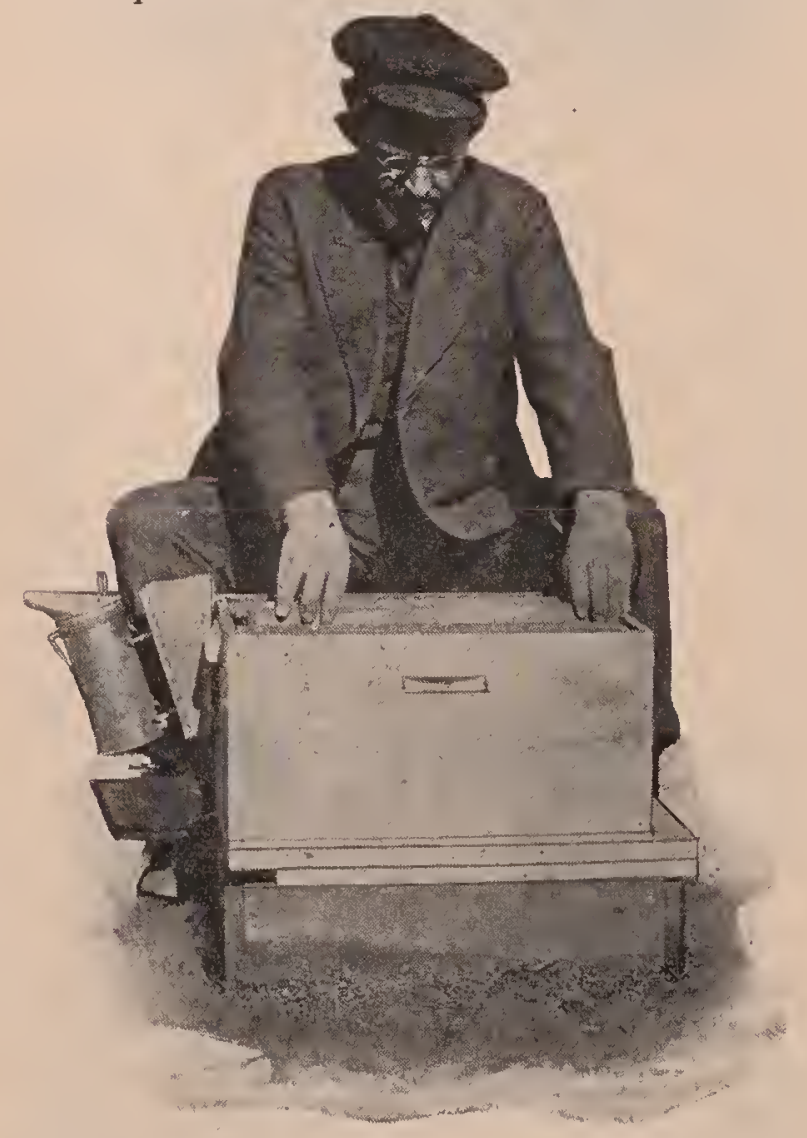

Fig. 6-The convenience of a hook in the back of the bellows. The smoker is always at hand at a second's notice.

\section{HOW TO USE A SMOKER.}

Perhaps the majority of beekeepers understand using a smoker without any spe- 
rial instructious, but, as a rule, too much smoke is 'used. It is best to use just as much as is necessary and not any more. A beginner so often stupefies the bees that they appear completely overcome. It is needless to say that this is a very bad plan. Very often colony after colony ean be opened without the use of smoke, especially when the bees are working; but at the same time it is well to have a smoker. near at hand.

It is not considered good practice to smoke bees out of comb-honey supers, as they are frightened at the smell of smoke,

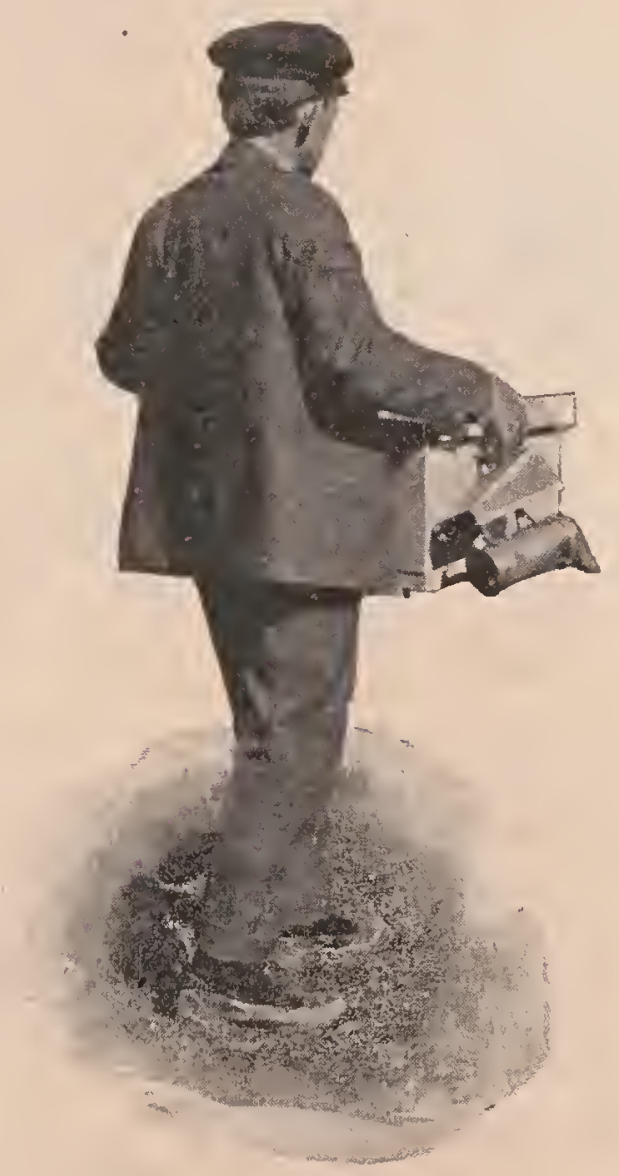

Fig. 7.-Carrying a smoker with the little finger when the hands are full.

and, in their desire to save honey, uncap some of the cells and thus spoil the appearance of what might otherwise be fancy honey.

In looking for a queen use as little smoke as possible, as it is very easy to set the bees running over the combs, making it next to impossible to locate the queen. At such times the frames should be handled slowly and carefully, the beekeeper doing nothing to disturb or excite the bees. See last part of $\mathrm{A} B \mathrm{C}$ of Beekeeping and ManipulaTTON OF C'OLONIES.
Fig. J shows the inost natural way of holding the smoker when the eap is opened. $A$ hetter hold is secured with the left hand

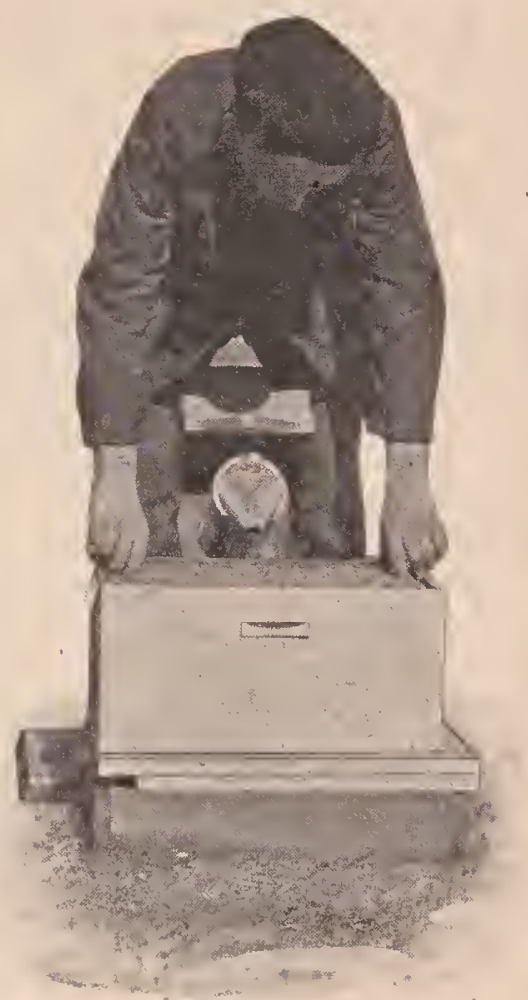

Fig. 8.- Holding a smoker between the knees while manipulating frames.

if the bellows is compressed as shown. Take hold of the coiled-wire handle with the right hand and it will be seen that the cap can be raised very easily without the

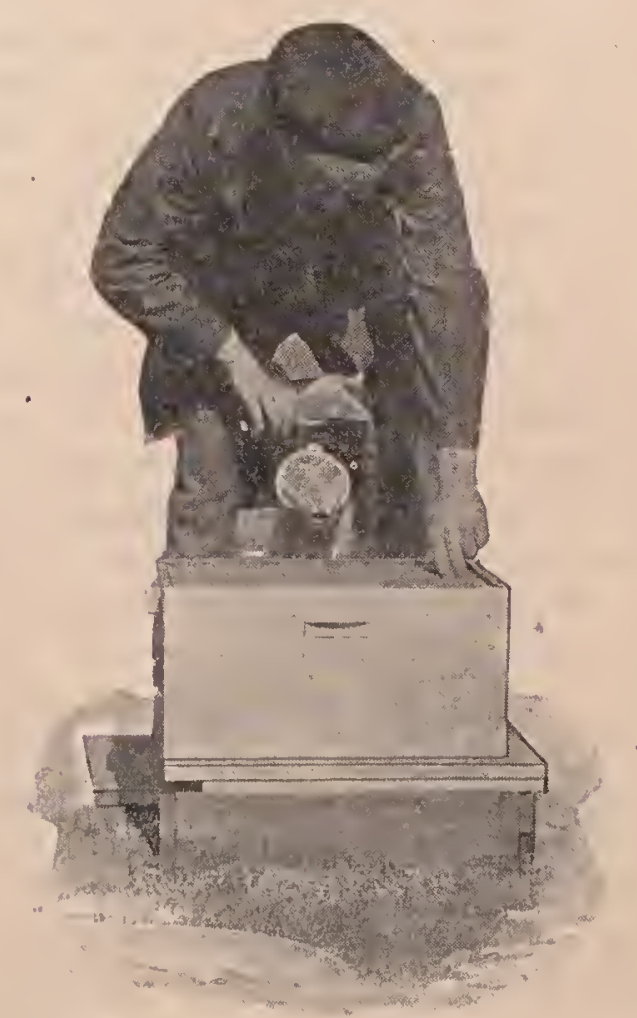

Hig. 9-Manipulating frames while holdiug the smoker between the knees and working the bel. lows. 
least danger of burning the fingers. 'T'he coiled-wire handle remains cool, no matter how hot the fire is.

S OLAR WAX-EXTRACTOR. - See Wax, also BotTling HoNey.

SOLITARY BEES.--The bees, or $A n$ thophila, according to their economy, may be divided into two groups, the social bees which live in communities, as the honeybees, bumblebees, and stingless bees; and the solitary bees, among which each female builds her own nest and provides alone for her brood. The social bees are described elsewhere in this work.

$\mathrm{Up}$ to the present time there have been lecorded in North America over 2,000 species of native bees. This is about one-quarter of the described species in the world, which are estimated at 8,000. In Europe there also occur about 2,000 species; 200 are known in England, 440 in Germany, 510 in Hungary, and 413 in Algiers. The majority are solitary forms, since the social families do not include over 500 species. But the indigenous bees of North America are as yet only partly known. Immense tracts still remain unknown, so far as their bee fauna is concerned. Manitoba, British Columbia, the whole tier of southern States along the Gulf of Mexico, as well as many western States, are as yet practically unexplored, and will doubtless afford a rich harvest to the diligent collector. The number of species found in any one locality is usually not large, and is greatly influenced by the climate and soil. In Maine there are about 200 species, in Illinois 300, and in New Mexico 500. The Anthophila may be classified in fourteen or more families according to the conception of family adopted by the mellitologist. In this division the more important characteristies employed are the structure of the mouth-parts, and the pollen-brushes, and the veining of the wings.

\section{SOLITARY BEES AND FLOWER POLLINATION.}

In their relation to flowers bees may be divided into two series, the short-tongued forms and the long-tongued forms. The long-tongued bees are able to reach the nectar in nearly all flowers except those adapted to butterflies, moths, and birds, but they confine their attention chiefly to bec flowers.which lave the nectar more or less concealed, such as the columbines, larkspurs, elovers, vetches, many mints and figtvorts, thistles, and many other Compositae with long corolla tubes. The shorttongued bees are compelled to visit open,

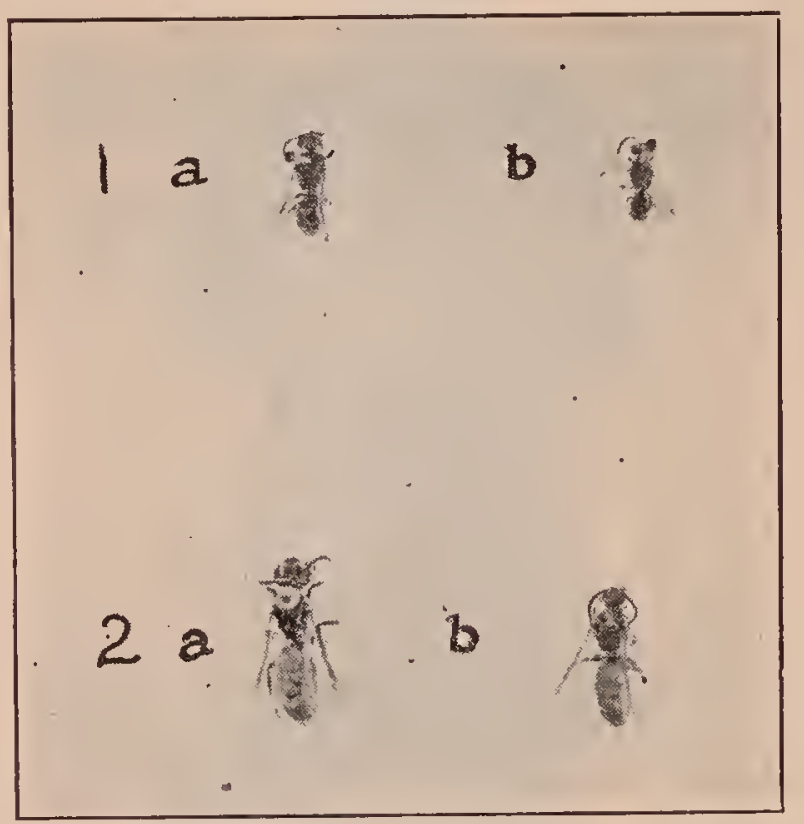

Fig. 1.-Primitive bees: 1 , Prosopis modesta; $a$, female; $b$, male. 2. Sphecodes ravunculi; $a$, female; $b$, male. Tongues short, bodies smooth and nearly hairless, without pollen-brushes. The pollen and nectar are masticated as collected, and the regurgitated liquid is stored in the cells as food for the larvae.

rotate flowers with the nectar exposed or only slightly concealed, as the plum, strawberry, blackberry, raspberry, pear, apple, and basswood, or flowers with very short corolla tubes like the goldenrods. In North America the more common genera of shorttongued bees are Prosopis, Colletes, Sphecodes, Halictus, Andrena, and Macropis.

THE SHORT-TONGUED BEES AS FLOWER VISITORS.

The most primitive bees belong to the genus Prosopis, and are elosely allied to the sand wasps from which probably they are derived. Among these small coal-black bees there are no adaptations for visiting flowers. Their nearly hairless bodies are destitute of pollen-brushes, and they have short, broad, emarginate tongues like the wasps. Were it not that they feed their offspring on a paste of pollen and nectar and consequently visit flowers more frequently, they would be of no more value than the wasps as pollinators. The semiliquid paste stored in their cells consists of 


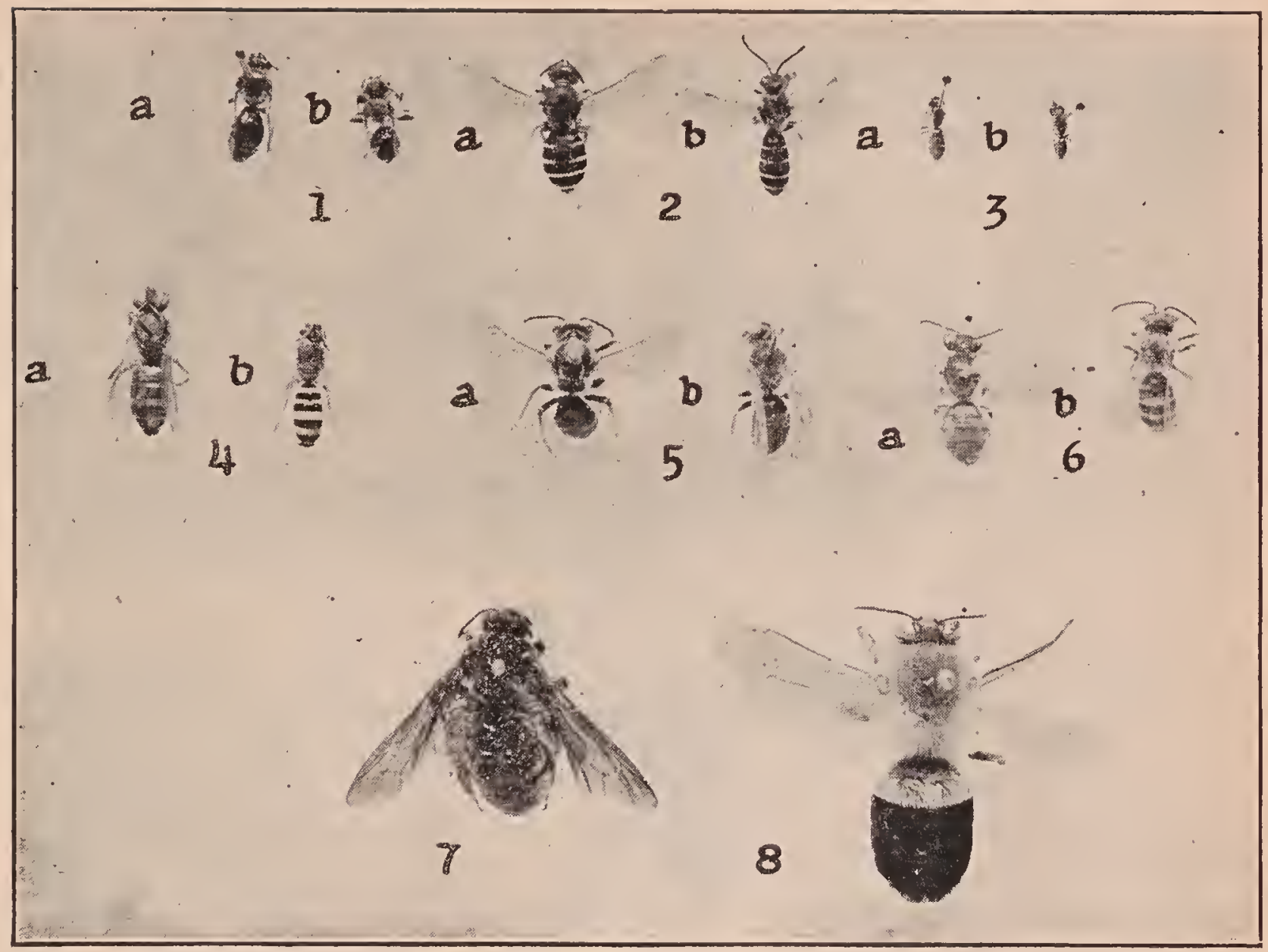

Fig. 2.-Short-tongued bees. 1. Macropis ciliata; $a$, female; $b$, male. 2. Halictus lerouxii; a, female; $b$, male. 3. Halictus hortensis; $a$, female; b, male. 4. Agapostemon radiatus $a$, female; $b$, male. 5 . Andrena crataegi; $a$, female; $b$, male. 6 . Andrena erythrogaster; $a$, female; $b$, male. 7 . Nomia heteroptera, female. 8. Mregacilissa electa, male.

partially digested pollen and nectar, which have been regurgitated. The bees of this genus tunnel in the pithy stems of brambles, and naturally are common on the flowers of blackberries, but they are also often found on the blossoms of the stonecrop (Sedum acre), prickly sarsaparilla (Aralia hispida), goldenrod, mignonette, and collecting pollen on wild roses. Almost equally primitive is the genus Sphecodes, except that they have acquired a short pointed tongue. They are nearly hairless and are without pollen-brushes, and the food supply furnished their brood is similar to that of Prosopis. Great interest attaches to these two genera since they show the early stages of bees before they were much modified as the result of flower visits, and doubtless closely resemble the ancestral forms of the honeybee (Fig. 1).

No other genera of the solitary bees are represented by so many species and individuals as Halictus and Andrena. They show a marked advance over the preceding genera in their adaptations to flowers. The tongue is longer, the thorax is thickly pubescent, and the hind legs for nearly their entire length are covered with a dense scopa of hairs. They carry the pollen dry and chiefly on the thighs, while the honeybees moisten it with honey and,pack it on the tibia. The ground bees are very important in wild regions where there are no honeybees, and before the discovery of America probably played the chief role in the pollination of fruit bloom. On warm days in spring clouds of these bees fill the air around the bloom of the willows, plum trees, cherries, blackberries, and at times nearly all fruit trees and shrubs. Observations made at the experiment station of Connecticut showed that in that locality they were by far the most common visitors to the apple, pear, quince, gooseberry, currant, blackberry, and raspberry. For instance, out of 359 Hymenoptera taken on the sweet cherry 349 belonged to Andrena and Halictus. But in very large orchards 
and in general, honeybees are the most valuable. The ground bees are also common on blueberries, cornels, Viburnum, roses, sumaes, goldenrods, and hundreds of others (Fig. 2).

All of the genera of short-tongued bees, thus far described, carry the pollen dry; but Macropis is the first genus to moisten it with honey. The brush on the hind tibiæ is long and dense and is often heavily loaded with damp pollen. A common species of this genus is $M$. ciliata, or the loosestrife bee, so called because it is usually found on the flowers of the common loosestrife (Lysimachia vulgaris), a pollen flower (Fig. 2). hind legs, and the other on the under side of the abdomen.

The leaf-cutting bees (Megachile), the mason bees (Osmia), and the cotton bees (Anthidium) have on the under side of the abdomen a stiff brush of unbranched hairs inclined backward. When they move over level-topped flower-clusters, like the sunflower and many other Compositae, this abdominal brusl sweeps up the pollen while the bees are at liberty to suck nectar. They are also well adapted to pollinate leguminous flowers, as the pea, bean, veteh, and their allies, where the anthers lie on the under side of the irregular flowers and come directly in contact with the abdomi-

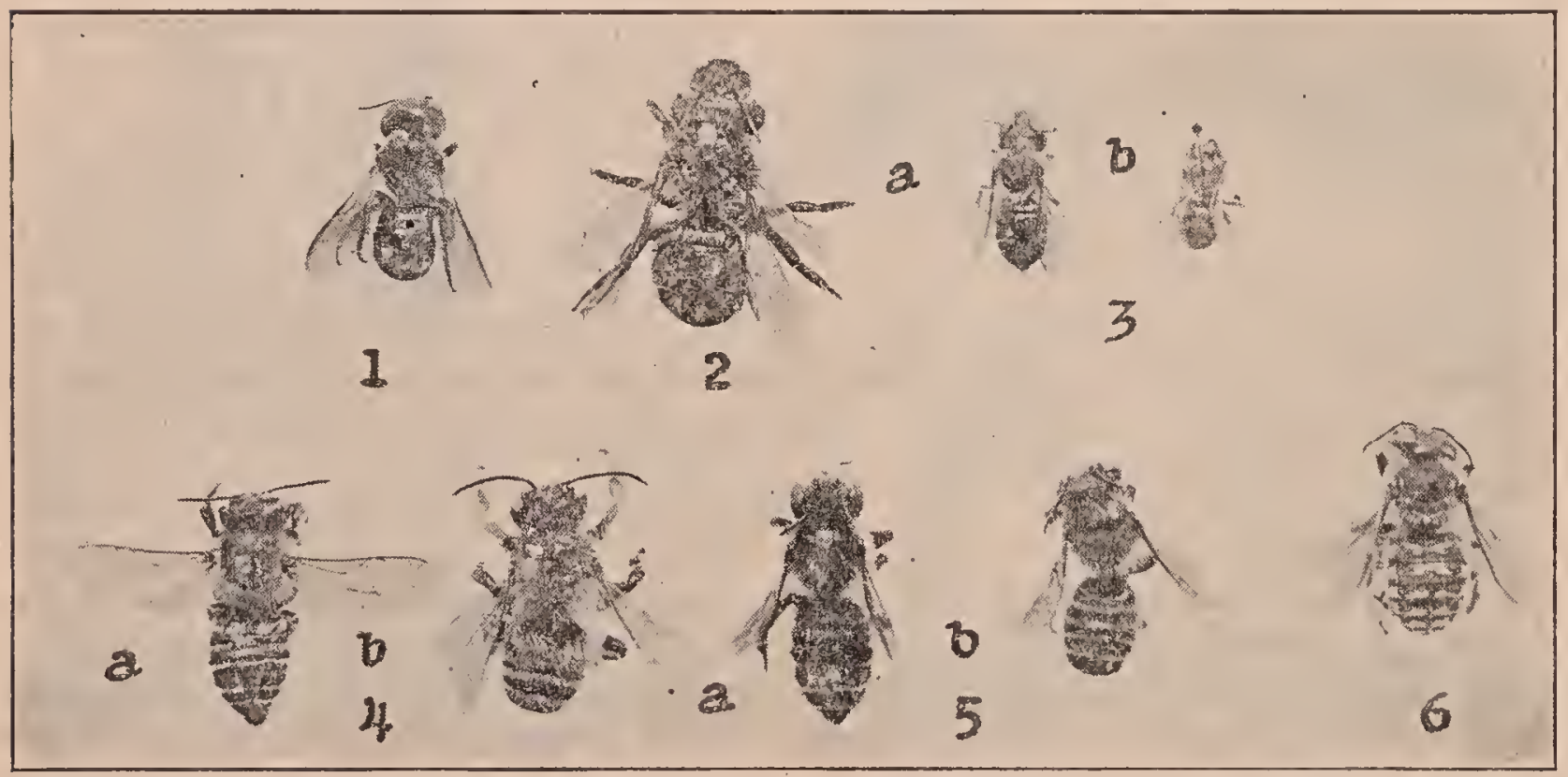

Fig. 3.-Long-tongued bees with abdominal pollen-brushes. Mason bees: 1, Jsmia mandibulans. female; 2, Osmia megacephala, female. 3. Osmia utriventris; $a$, female; $b$, male. Leaf-cutting lees: 4. Megachile latimanus; $a$, tenale; $b$, male; 5 . Mestrohile vidua: $a$, female; $b$, male; $b$, Anthidirm cognatum. female.

THE LONG-TONGUED SOLITARI BEES AS FLOWER VISITORS.

The long-tongued bees include all the social bees as well as many generia of solitary bees. The length of the tongue varies greatly, the medium length being $6 \mathrm{~mm}$., as found in the honeybee, and the extreme length 21 to $22 \mathrm{~mm}$. in some female bumblebees. They restrict their visits chiefly to bee flowers and thus avoid the competition of many short-tongued insects and are likely to find a more ample supply of neetar. The long-tongued solitary bees may be divided into two series in accordance with the way they collect and carry pollen. One series has the pollen-brushes on the nal scopa. The tongue in this group is usually less than $6 \mathrm{~mm}$. long, and the pollen is, of course, always carried in the dry state. (Fig. 3.)

A part of the long-tongued bees with polleniferous scopa on the hind legs carry the pollen on the femora, or thighs, as Panurginus, and the carpenter bees (Xylocopa); while a part carry it on the hind tibiæ. The Anthophoridae, or eliff bees, have a world-wide distribution, and in their senses and general appearance resemble bumblebees, but are smaller in size, and there are no flowers especially adapted to them. The collecting hairs in some genera are extremely long; as in Dasyporda, and 
great balls of pollen, half the size of the abdomen, are carried on them. The common genera Anthophora and Melissodes visit the same flowers as bumblebees (Fig. 4).

Many bees with a short term of flight visit only one or a few allied species of flowers, which are abundant and in bloom during the time the bees are on the wing. Certain vernal species of Andrena visit only the flowers of the willows, while other
HOST BEES AND GUEST BEES.

According to the way in which they provide for their young, bees may be divided. into nest-builders and brood parasites. The nest-builders are industrious insects, constructing their nests with great care and skill, and provisioning them with food for the use of the brood. The brood parasites, on the contrary, neither build nests nor gather stores for their offspring; but in the ease of the solitary bees they lay their eggs

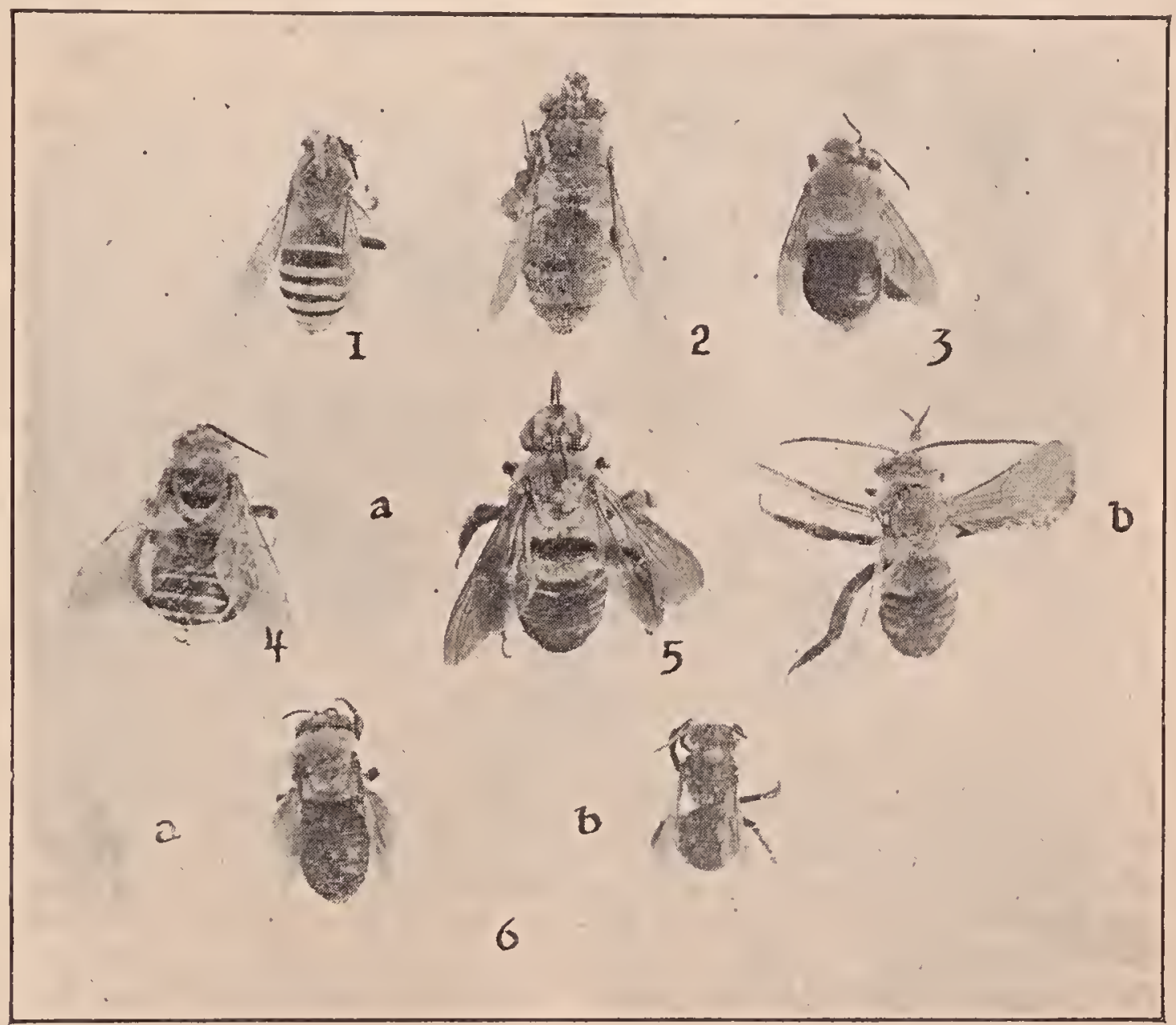

Fig. 4--Long-tongued bees with pollen-brushes on hind legs. Anthrphoridae: 1. AnthoFhora smithii, male. 2. Anthophora occidentalis, female. 3. Centris aprealis, female. 1. Melissodes atripes; $a$, female; $b$, male. 6 , Melissodes dessnonsa; $a$, female; $b$, male.

autumnal flying species confine their visits to the goldenrods and still others to the asters. There are indeed a number of bees which obtain their supply of nectar and pollen exclusively from the Compositae. These flowers, as in the case of the goldenrod and thistles, are very common, yield ample food supplies and are easy to visit. This habit has arisen because of the adrantage thus vained by the bees and is alled oligotropism. at a favorable opportunity in the cells of the nest-builders. The latter are often called host bees and the former guest bees.

\section{HABITS OF THE NEST-BUILDING BEES.}

The genus Prosopis, says Knutlı, stands at the lowest level among bees and belongs to them only because it feeds its young on pollen and nectar. The female builds a row of cells in the hollow stems of hlackberry bushes from which she has excavated the 
pith. The cells are lined with a thin coating of saliva, which hardens into a smooth cement, and are provisioned with a semiliquid paste of partially digested nectar and pollen. An egg is laid in each cell. After the tunnel has been closed the mother bees still linger in the vicinity (Fig. 1).

The two commonest genera of the shorttongued bees are Halictus and Andrena. The species of Halictus; often called "sweat bees," vary in size from some of the smallest bees known to forms as large as the loneybee. The sexes mate in the fall, and the females (like the queen bum-
Beginning with the cell in which she was born, each female digs a new group of. cells connected with the main tunnel. Altho there are then no males in existence, she provisions her cells with balls of beebread and lays eggs, which by parthenogenesis give birth to both males and females. There are thus two generations among the Halicti. The autumnal generation, consisting of both sexes, produces the following spring only females, which, altho unable to mate, yet produce by parthenogenesis both sexes, and in like manner the cycle is repeated from year to year. (Fig. 2).

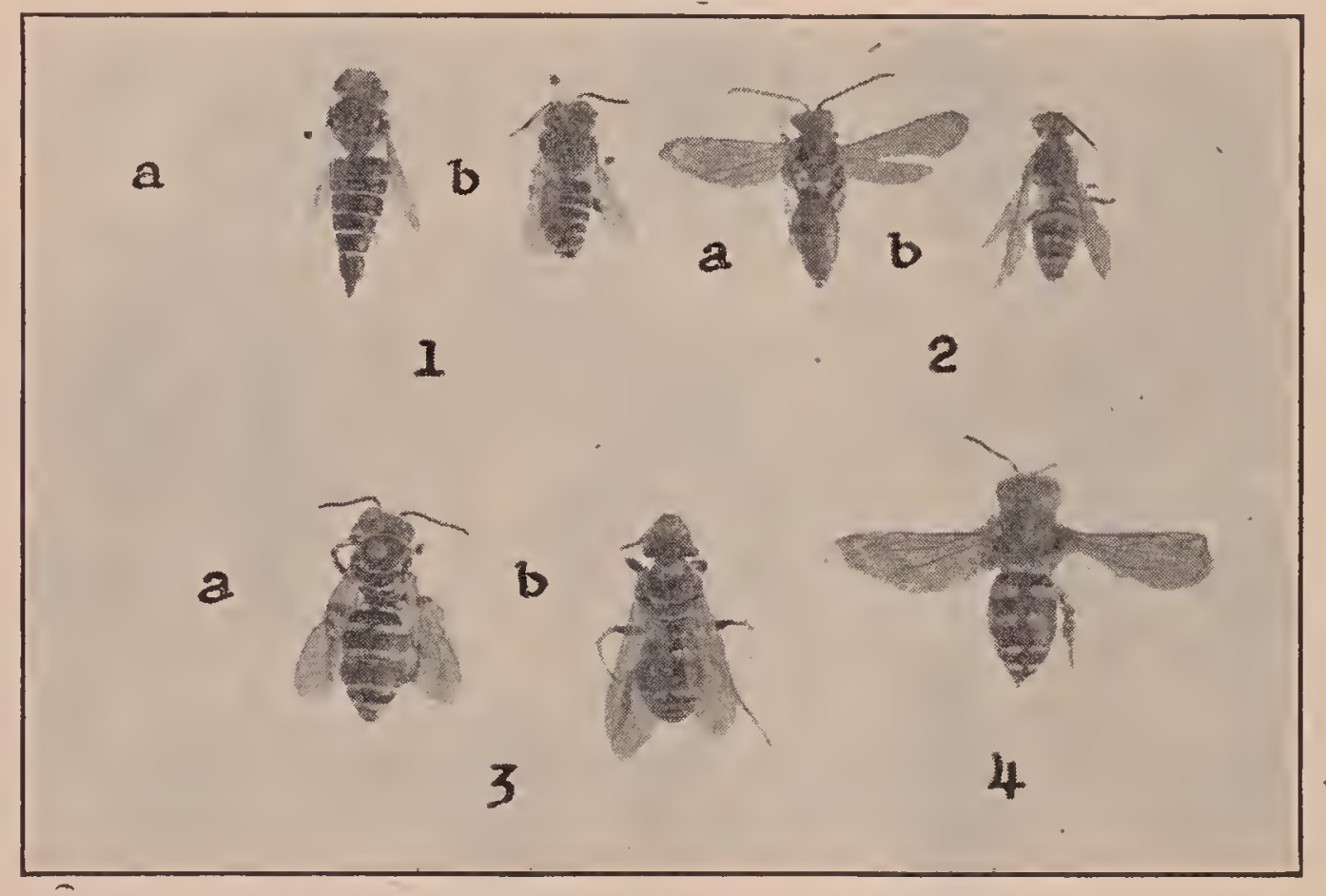

Fig. 5.-Parasitic bees: 1. Coelioxys rufitarsus; $a$, female; $b$, male; 2 , Nomada liella a, female; $b$, male; 3 . Triepeolus donatus; $a$, female; $b$, male; 4 . Melecta miranda,
female.

blebees) hibernate during the winter. 'They reappear in the spring and dig burrows in the ground which are five or six inches in depth and have several short branches, in each of which and at the lower end of the tumnel a cell is built. In each cell a little ball of beebread, composed of pollen and honey, about the size of a small pea is stored for the use of the larvæ. Halictus does not close the entrances to the cells. Fabre has apparently shown that the first generation of several species consists wholly of females. He is probably right. The eight or ten sisters, the offspring of one mother, continne to return to their cells at night and to share together their old home.
Andrena is our largest bee genus, and more than 250 species lave been described in America. Thousands often tunnel in the same sandy bank of earth until the ground appears as tho filled with shotholes. It is, says Smith, a village or city of homes. A part of the species are vernal and fly only in the early part of the season, and a part are autumnal and fly only in autumn. Each burrow has a number of short lateral branches. In these passages and in the enlarged lower end of the burrow the female stores a small mass of pollen and honey and lays an egg. The speries are closely allied and are called ground bees, (Fig. 2.) 
The mason bees of the genus Osmia vary greatly in the manner of building their nests. Some make use of the stmuns of hollow reeds, tubes, or empty snail shells, while other's build their cells in small cavities in stone walls or posts. Several American species build earthen cells about half an inch in diameter which, tho rudely fashioned of mud on the ontside, are beautifully polished and glazed within: In France, according to Fabre, the Sicilian Chalicodom projecting tiles, which in the course of years cover five or six square yards, and with their great weight threaten the destruction of the roof. (Fig. 3.)

The observations of Fabre show that the mother Osmia determines the sex of her offspring and can lay at will either a male or female egg. The males of Osmia are much smaller than the females, and theil. cells are consequently smaller and contain a less amount of stores than those of the latter. When an old nest is used a second time female eggs are invariably laid in the large cells and male eggs in the small cells. Fabre induced a large number of females to build their cells in glass tubes of various sizes. When the tubes were sufficiently large the bees always laid first a series of female ergs and then male eggs. By varying the size of the tubes he succeeded in obtaining series in which the order of laying was reversed and began with males; or in which the entire laying contained only males. "Tlie egg, as it issues from the ovary, has not yet a fixed sex. The final impress that produces the sex is given at the moment of laying, or a little before."

The leaf-cutting bees of the genus Megachile build their cells of round and oval pieces of leaves or flower petals. They do not dig burrows for themselves, but make use of the burrows of other bees or of the straight tunnels of large eaith-worms. If the shaft is longer than is needed the approach from below is blocked by fragments of leaves piled in irregular order. After this barrier come five or six pockets or cells composed of elliptical and round sections of leaves which the female $\dot{M}$ egachile cuts out with her mandibles. The sides of the cell are formed of six or eight oval pieces in one or two overlapping rows, with the lower ends bent inward to form the bottom. Any little crevices are covered with small ovals to render the leaf-pot watertight. The top of the cell is closed by two, three, or six, or even ten circular pieces which, by some marvel of geometry, are the exact size to fit the cell. The sections of leaves are taken from a great variety of plants, and no special preference is manifested for any particular species. The cells are provisioned with pollen and honey. (Fig. 3.)

The thimble-shaped cells of the cotton bees of the genus Anthidium are nuade of white cottony hair's gathered from various kinds of thistles, mulleins, and the cotton rose. Only dried hairs from dead plants are used since hairs containing sap would be likely to mildew. The little nackets of cotton, the results of many journeys, are felted or matted into a layer which forms the entire cell. So firmly are these little bags woven together that they may all be removed without separating. The cotton bees make use of the tunnels of $A n t h o-$ phora, or the holes of earth-worms, or the stumps of hollow reeds. Other species of Anthidium employ empty snail shells, and are called resin bees since they divide the hollow spiral into cells by partitions of gum gathered largely, from conifers, especially the juniper. (Fig. 3.) The economy of the carpenter bees is described under XYLOCOPA.

The Anthophoridae, or cliff bees, are distributed over the entile globe and are one of the largest bee families. The females of Anthophora drive tunnels six inches or more in length in the sides of precipitous cliffs, extensive colonies selecting the same location. In the chalk pits at Northfleet, England, there was a colony so large that in the month of April the countless numbers assembled cast a dark flickering shadow on the ground. The inner walls of their cells are glazed with a thin cement of saliva applied with the tongue, which on hardening becomes impervious to moisture. An egg is laid on the surface of the stores, which are in a semi-liquid condition. The larvæ pass the winter in the cells and change to pupæ the following spring. Common genera are Anthophora, Melissodes, and Xenoglossa. (Fig. 4.) 
THE PARASITIC SOLITARY BEES.

Notwithstanding that the bees are proverbial for industry beyond any other group of insects except, perhaps, the ants, there are many parasitic genera which no longer gather stores of pollen and nectar, but rear their brood at the expense of the nest-building genera. They are variously called guest bees, brood parasites, inquilines, or cuckoo bees, while their unconscious victims are known as host bees. The guest bees are usually allied in structure with their hosts, and both are probably derived from the same primitive stock. Thus the bumblebees (Bombus) and the false bumblebees (Psithyrus) doubtless have a common ancestry. Common genera of parasitic bees are Nomada (parasitic on $A n$ drena), Coelioxys (parasitic on Megachile), Stelis (parasitic on Anthophora). (Fig. 5.)

The manner in which a cuckoo bee enters the nest of her host varies greatly with different genera. Melecta boldly enters the burrows of Anthophora, even when the female is present, and the latter seems wholly unconscious of the danger. Triepeolus more prudently waits until her host Colletes has departed for the field before entering the tunnel. In France, according to Fabre, Stelis nasuta opens with great difficulty the hardened cells of Chalicodoma, sealed with clay cement, lays several eggrs and again closes the opening with a pellet of clay. The American parasite Stelis sexmaculata lays her eggs in the nests of Alcidamea producta, which are found in the stems of the blackberry or sumac. The lawful owner Alcidamea lays her egg on the top of a conical mass of beebread, but the parasite Stelis places her egg near its base where it is likely to escape notice. There may be as many as four cells, each closed with a felt-like mass of chewed strawberry leaves.

Graenicher has observed and described the tragic end of the host larva. The larva of the parasite is armed with long sharp mandibles, but those of the host larva are blunt and bifid and not well adapted either for defense or attack-so the latter is doomed from the beginning. When the two larvæ, while feeding on the beebread, meet, the parasite seizes the body of the liost larva between its sharp mandibles. The host larva may struggle a little but soon succumbs, and after sucking out its liquid contents the parasite again turns to the beebread. If there are two larvæ of the parasite Stelis sexmaculata a combat between them is sure to occur, and the victor is the larva obtaining the first hold on the body of the other; but two larvæ of Alcidamea can not injure each other.

The handsomest parasitic bees belong to the genus Nomada, and Smith ealls them the most beautiful of all the bees found in Great Britain. They are often called waspbees, because of their gay coloring. They are dark red in color, often suffused with black, and maculated with bright or pale yellow. Their larvæ are often found in the nests of.Andrena.

In the pollination of flowers the parasitic bees are of much less importance than the nest-builders. Since they have no occasion to gather pollen, they have largely lost their pollen brushes and visit flowers only to procure nectar for themselves. A part of the species restrict their visits largely to the Compositae which yield neetar freely.

SOURWOOD (Oxydendrum arboreum). Also called sour gum, sorrel tree, lily-ofthe-valley tree, and elk tree. A fine tree, belonging to the heath family, or Ericaceae, growing 40 to 60 feet tall and a foot in diameter. The smooth bark is brownish red, and the young twigs are light green. The leaves are oblong, pointed at the apex, smooth on both sides, and have a sour taste. The numerous white urn-shaped flowers are in slender one-sided racemes, 5 to 6 inches long, which hang in clusters at the ends of the branches. From the resemblance of the blossoms to those of the little perennial herb of the garden, sourwood is often called lily-of-the-valley tree. The popular names sourwood and sorrel tree are derived from the sour odor and flavor of the leaves and twigs.

Sourwood grows in rich woods from southern Pennsylvania to western Florida and southern Alabama, westrvard to southern Indiana, the Arkansas Mountains and western Louisiana. It is most abundant in the mountainous tract of country occupied by the Alleghenies and the Blue Ridge, but 
castward it extends in places as fin as tidewater and westward to central Tennessee. It is planted for ornament as far north as Massachusetts, but as a source of nectar it is chiefly valuable in the mountainous regions of North Carolina, South Carolina, and Tennessee. It flourishes on high dry soil, and is common on poor woodland lidges, but in the forest along the rivers, where the soil is rich and deep, it makes a much larger growth, and the forests are of-

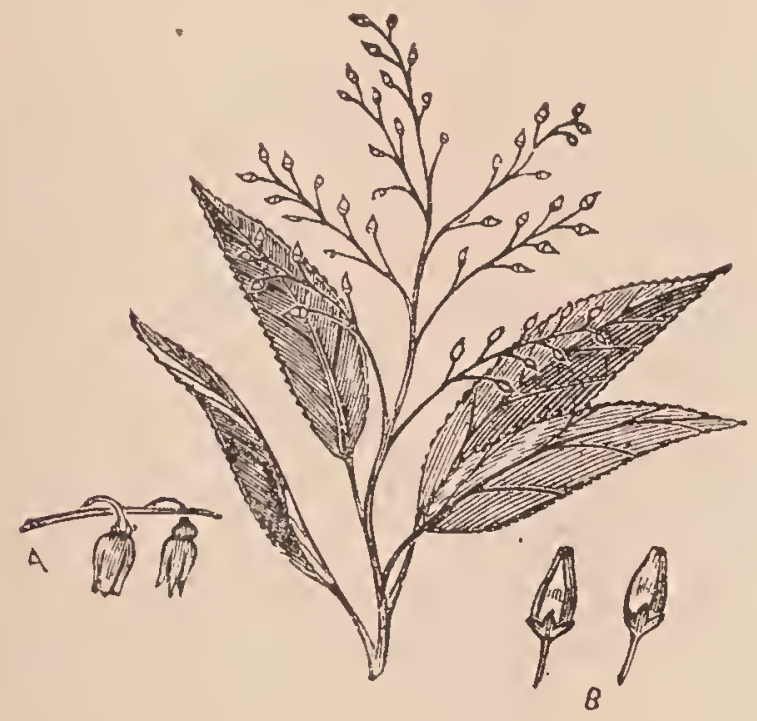

Sourwoul leaf, flowers, and seed-pods.

ten beautifully checkerer in July by the white blossoms. On the Piedmont Plateau in North Carolina it is frequently a scraggy tree not exceeding 30 feet in height. In the dense forests the trunk is tall and unbranched, and furnishes fine straightgrained lumber used by cabinet makers. The name of the genus, Oxydendrum, is Greek, signifying sour wood.

Sourwood begins blooming about June 20 , and the harvest from this source usually lasts until the latter part of July. The urn-shaped corolla is pendulous and contracted at the mouth, so that the bountiful supply of nectar is protected both from rain and useless insects. Sourwood is considered one of the most important honeyproducing trees of the South. The nectar is secreted in such abundance that it may be shaken in small drops froin the bloom. The honey flow is usually dependable; and in localities, where it is abundant, the beekeeper seldom misses a harvest. Altho compared with some other honey plants the season is short, there is no difficulty in securing a jrotitable crop. In northwest North Carolina the surplus comes largely from this source, and the flow is reliable three years in five. At Brookneal, Virginia, there is a total failure about one year in four. As the honey flow comes so late the beekeeper. has ample opportunity to build up strong colonies which can gather nectar very rapidly during the short honey flow.

Under favorable conditions, sourwood honey is produced in enormious quantities, but it is seldom found in the markets outside of the region in which it is gathered. It is nearly all consumed in the localities where it is produced, as it is regarded ar one of the finest-flavored honeys in the United States, and often commands in local markets a prenium of a few cents per pound. The honey is white or light colored, with a delicious, slightly aromatic flavor, and is very slow to granulate. It is, however, often mixed with basswood honey, or with persimmon honey gathered earlier in the season.

Few are acquainted with the merits of sourwood outside of the region where it is an important source of honey, and it is sometimes confused with black yum and sour gum, much to its disparagement: $\lambda$. heelieeper, familiar with the honeys of basswood, tulip tree, clover, buckwheat, coldenrod, and aster, declares that it has no superior among the honey-producing trees of the United States either in its beautiful appearance or in the amount of nectar secreted.

SPACING FRAMES.-In nature combs will be found spaced from 13/8, 11/2, 15/s, and sometimes up to two inches from center to center. Dzierzon, one of the very first to conceive the idea of a movable comb, gave $1 \frac{1}{2}$ as the right distance until Wyprecht made accurate measurements in straw hives having straight combs built in them. Out of 49 measurements, the average distance was scant $13 / 8$ inches. Baron ron Berlepsch, by 40 other measurements, rerified this result. In the United States, prominent apiarists have found the distance of natural-built combs averaged 11/2 inches from center to center. It lias been observed that, in the center of the broodnest, the combs are spaced more closely than those on the outside, the latter lang- 
ing anvwhere from $15 / 8$ to 2 inches to center's.

The author has measured the combs in hundreds of box hives in the Southland, and he finds that the average spacing for worker brood comb seems to be slightly under $13 / 8$ inches. The store combs run all the way from $1 \frac{1 / 2}{2}$ to $13 / 4$ and even 2 inches. In a large number of cases it was noticed that the combs were spaced wider apart at the top of the box or comb, and closer together toward the center and the bottom. The illustration shows a tendency that way, but it is not so pronounced as a number of others that were seen.

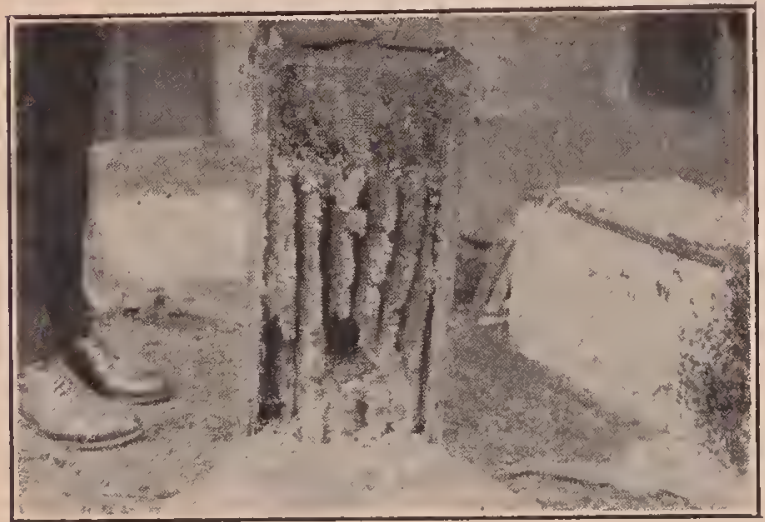

The "innards" of a box hive after the bees have been drummed out. Notice now irregularly the bees have spaced the combs and wider at the top.

For worker brood it was apparent that nature indicates $13 / 8$ inches; for drone comb, $1 \frac{1}{2}$, altho there are wide variations.

Hundreds of these measurements were taken on colonies that were being transferred; and if nature were to be followed it would seem that $13 / 8$ is the correct average for worker comb, and $1 \frac{1}{2}$ for drone. Store combs may have a spacing of 2 iruches or more from center to center.

The beekeeper should adopt that spacing which will give him the best results-the most brood and surplus honey. A large number of beekeepers are using 11/2 spacing for their frames. The reason for this is, principally, because they happened to start with this spacing. But not a few who have given special attention to the matter, trying both spacings, agree that the right distance is $13 / 8$, or, if anything, a trifle scant, and some use quite successfully 11/4-inch spacing. Many, indeed, who had self-spacing frames adapted for $11 / 2$ inches, have gone to the enormous expense of changing over to the $13 / 8$. Similarly, some of those who have used $13 / 8$ spacing have adopted $11 / 2$. Brood comb is found to be, on an average, $7 / 8$ inch thick; capped brood, one inch thick. On $13 / 8$ spacing, this will allow $1 / 2$ inch between uncapped combs and $3 / 8$ between combs of capped brood.

The following paragraph is taken from an article published in Gleanings in Bee Culture, page 673, Vol. XVIII., written by Julius Hoffman, inventor of the Hoffman frame, and it applies here exactly:

If, for instance, we space the combs from center to center so as to measure $1 \frac{1}{2}$ instead of $13 \%$ inches, then we have an empty space of $5 / \mathrm{s}$ inch between two combs of brood instead of $1 / 2$, as it ought to be; and it will certainly require more bees to fill and keep. warm a $5 / 8$ than a $1 / 2$ space. In a $1 / 2$ space, the breeding bees from two combs facing each other will join with their backs, and so close up the space between the two broodcombs; if this space is widened, however, to $5 / 8$, the bees cannot do this, and more bees will be required to keep up the needed brooding temperature. What a drawback this would be in cool spring weather, when our colonies are still.weak in numbers yet breeding most desirable, can readily be understood.

Where wider spacing is adopted, there is apt to be more honey stored in the combs, and less of worker (but more drone brood). Close spacing, on the contrary $(13 / 8)$, tends to encourage the rearing of more worker brood, the exclusion of drone brood, and the storage of less honey below. This is important.

Under the head of SwARMING, subhead "The Dadant System of Swarm Control," it will be seen that C. P. Dadant believes that 11/2:inch spacing tends to reduce swarming, and that the regular $13 / 8$ spacing is too close. On the other hand, it may be said that the self-spacing Hoffman frame adapted to $13 / 8$ spacing will gradually, on account of propolis accumulations, increase to $11 / 2$.

For further information on the spacing of frames see Frames, Self-SPacing; HiveMAKING; Hives; Honeycomb.

SPANISH NEEDLES (Bidens aristosa).- The honey has a golden color, excellent flavor, and good body, weighing 
fully 12 pounds to the gallon. It is so thick that there is little water to evaporate, and the cells can be sealed soon after they are filled. This plant has showy largerayed heads, and yields immense quantities of honey along the low bottom lands of the Mississippi and Illinois rivers. It is found in swamps from Illinois to Louisiana, blooming from August to October, and yielding a honey, which is superior to, or is unsurpassed by, that from any other fall flower.

A typical Spanish needles swamp is located at the foot of the bluffs of the Illinois River where there is a broad expanse of low marshy land from 3 to 5 miles wide. This land is subject to an overflow from the river once a year, which usually occurs in early spring. A large portion of the soil is unfit for tilling purposes, and in consequence Spanish needles has secured a permanent foothold to the exclusion of nearly all other plants. Early in September the bright yellow rays begin to appear and in a short time the whole district is aglow with the bloom, and its dazzling brilliancy reminds one of a burnished sheet of gold. The bees revel in this great field of flowers; so rich in nectar, and rapidly secure a surplus. A single colony has stored 63 pounds of honey in six days, and 43 colonies produced $20^{2} 1$ pounds in 10 days, an average of 47 pounds per colony.

Another important Spanish needles region is in the Kankakee Valley, where there are extensive swamps along the Kankakee River in northwest Indiana and eastern Illinois. Commercial apiaries usually range from 50 to 100 colonies, but at Hebron there are 300 colonies in one yard.

There are many other species of Bidens widely distributed thruout America, all of which are probably of more or less value to bees. The common beggar-ticks (Bidens frondosa) is one of the most abundant. They are all fall flowers, and usually grow in wet places-one species being aquatic.

SPECIALTY IN BEES.-The question of making beekeeping a side line or hobby has already been pretty thoroly discussed under the head of Beainning WITH BeEs, Backlot Beekeeping, Beekeeping for Women, Bees and Fruit-Growing, Bees aNd Poultry, and Farmer Beekeepers. 25
Under this head, "Specialty in Bees," will be discussed the feasibility of making bees the sole means of livelihood.

There are farmers who produce potatoes only. Others grow small fruits; still others, onions and celery. In the line of professions there are physicians who make a specialty of the eyes, some of the ears, and others both of the eyes and ears. Others give their whole time to the treatment of the lungs or the throat, and others to diseases of the skin. Some beekeepers specialize on queen-rearing and others on extracted honey. The number who confine their attention solely to the keeping of bees, while not large, is growing at a rapid rat?.

Whether one shall keep more bees and drop all other pursuits will depend on a good many conditions. First is the question of locality; second, the man; third, the state of his finances.

\section{LOCALITY.}

No one should attempt to make a living entirely from bees unless he has a locality that is capable of supporting a large number of colonies. (See Locality and OverSTOCKING.) In some places, probably not more than twenty-five or fifty colonies could be maintained to a yard. Two hundred parceled out in five or ten apiaries two miles apart would increase the expense of operation. To put a man at each yard would be out of the question. A horse and wagon would be too slow, because the apiarist would thus be one-third of the time on the road. An automobile truck is expensive. If one has a locality that will support five hundred to a thousand colonies in from ten to twenty yards, the gross earnings would warrant the purchase of an automobile truck and a runabout, perhaps, for making quick trips. (See Moving BeEs and OUt-APiaries.) As a rule, a few bees as a side line can be kept profitably almost anywhere; and therefore if one has a notion of making beekeeping an exclusive business he should seek some locality where there is an abundance of flora capable of furnishing a good table honey that will bring a good price, and a locality which, at the same time, is not already occupied by other beekeepers, thus overstocking. See Overstocking. 
THE QUESTION OF THE MAN.

Some men who do well with a small business would make a failure with a large one. Going into beekeeping extensively requires not only capital and brains but a large amount of business ability. With the element of business ability comes the question of experience. Certainly no one should engage in the bee business in an extensive way unless he has had a large amount of practical knowledge of a lind that starts from the bottom and works upward. (See Beginning with Bees; also Backlot BEEKEEPING.) A large business gradually built up from a small beginning is much more sure of success, especially if the man who made the start is still the presiding genius of the large business. While one can sometimes hire a man of wide experience, it is better for the boss to have the know how himself; otherwise, if his man leaves him for any cause he would be sadly crippled. Moreover, if he knows the business himself, his help can not impose on him by pretending to "know it all."

\section{CAPITAL}

Capital is another important requisite. This need not, however, be a serious obstacle if one would be willing to start with a small beginning and make the bees pay their own way, as is taught all thri this work. One will be much more likely to meet with success if he gradually enlarges his business, bearing in mind the danger of trying to expand too fast.

SPECIALIST BEEKEEPERS; WHERE LOCATED.

The number of persons who make beekeeping a specialty is constantly increasing; but most of the specialist beekeepers are located west of the Mississippi and north of the Ohio. Where alfalfa and sweet clover are grown extensively there will be found beekeepers who number their colonies by the thousand. The mountain-sage and orange districts of California make specialized beekeeping a possibility. As a general proposition, however, it may be stated that where there is one specialist beekeeper there are a thousand who combine the business of honey production with some other profession or business.

SPECIFIC GRAVITY OF HONEY.Ordinary well-ripened honey when ready for the market should run about 12 pounds to the gallon, normal temperatures, which would mean a specific gravity of from 1.40 to 1.45 , or on the Baumé scale from 41 to 43. (See Baumé Hydrometer under HoNEY ANALissis.) It should, however, be noted that a gallon can that will hold 12 pounds of ripe honey at normal temperatures will hold only 11 pounds 12 ounces when that honey is heated to 160 degrees to prevent granulation. When, however, this honey cools, 4 ounces more of cold honey can be added, but as a rule most gallon cans of honey contain that amount less than the 12 pounds, and should be so labeled to conform to state and federal laws.

There are some honeys that run about $11 \frac{1}{2}$ lbs. to the gallon, but they should never be put in sealed cans nor marketed when as thin as that, as they are almost sure to sour. They should rather be stored in open vats or cans in a dry room for a few weeks, so that the excess of moisture can escape. Honey exposed in a damp atmosphere will take on more moisture. It is, therefore, important that the artificial ripening process take place in a warm dry room, heated artificially if necessary. As a rule, it is not wise to extract honey in the eastern States unless three-fourths of all the cells are capped over; and sometimes then the honey should be left on the hive until all the cells are sealed. In the western States where there is a drier atmosphere, or during extremely hot dry weather in the East, a larger percentage of unsealed cells may be permissible at the time the combs are extracted; but it is best to store in open cans for a short time before shipping. See Honer, Analysis of.

When honey is not thoroly ripenedwhere it runs a little short of $12 \mathrm{lbs}$. to the gallon, the thinner portion is apt to rise to the top while the heavier part will settle to the bottom (see Extracted Honer). The top will have a tendency to sour, and it will not be long before the whole mass will be involved. If the souring or fermenting process has not gone too far, the honey may be saved by heating, thus destroying the yeast plant. But if it has gone too far, nothing can be done but convert it into vinegar. See VINEGAR.

SPIKEWEED (Centromadia pungens). -A branching annual with spinescent sweet-scented leaves. The yellow flowers 
yield an amber-colored honey of good quality, which granulates quickly. Carloads of spikeweed honey have been shipped from Fresno County, California. Jepson describes spikeweed as "abundant on the plains of the lower San Joaquin, soutliward to southern California and westward to Walnut Creek and Alameda. On the alkaline plains of the upper San Joaquin this species covers tens of thousands of acres, and often forms thickets 4 or 5 feet high. It is also abundant in more or less alkaline land on the plains of Solano County, and forms extensive colonies in summer fields. It is a valued bee plant.

\section{SPRAYING FRUIT TREES. - See Fruit Blossomis.}

SPRAYING DESTRUCTIVE TO THE BROOD.-See Fruit Blassoms.

SPREADING BROOD.-As is very well known, queens are inclined to lay their eggs in circles in the comb, the circle being larger in the center combs and smaller in the outside ones. The whole bulk of eggs and brood in several combs thus forms practically a sphere which the bees are able to cover and keep warm. When the queen has formed this sphere of brood and egg's she curtails her egg-laying for the time being until enough brood emerges to increase the size of the cluster, when she will gradually enlarge the circles of brood to keep pace with the enlarged ball of bees.

Yet the queen very often is overcareful - that is, she errs on the safe side, so that when warm weather has fully set in. she sometimes lays fewer eggs than she should in the judgment of the apiarist, and accordingly he inserts a frame of empty comb in the center of the brood-nest. In this comb the queen may commence laying at once to unite, as it were, the two halves of brood. More often she does not. In that case more harm than good has been done. If the queen does fill the first one given she will be likely, if the weather is not cold, to go into the second comb and fill it with eggs on both sides; for nice, clean empty cells are very tempting to her. In a word, this operation of inserting empty combs in the center of the brood-nest is called "spreading brood," its object being to increase the amount of brood, and thus insure a larger force of workers for the prospective harvest.

While this spreading of the brood may be performed by experienced beekeepers because its stimulates the queens to greater egg-laying activity, yet when practiced by beginners and the inexperienced it genelally results in much more harm than good as already stated. A beginner without previous experience might, on a warm day in early spring, think it high time to put empty comb in the center of the broodnest. The queen immediately occupies it, filling it with eggs. Tliis, of course, requires a largẻ force of nurse-bees to take care of the young bees and hatching larvæ. A cool spell of weather is almost sure to come on, witl the result that the cluster of bees is contracted, leaving the brood that was forced outside, out in the cold, where it chills and dies. The outside edge of the cluster, in its effort to take care of this brood, is likewise chilled, and the colony suffers a check and setback far worse than had it been left to its own devices.

Ordinarily the spreading of brood can be practiced safely only after settled warm weather has arrived. The beginner who desires to give extra combs for egg-laying, especially in the early spring, would do well to put those extra combs at the outside; but after settled warm weather has come, when the temperature does not go below 60 degrees Fahrenheit at night at any time, he may insert a frame of empty comb at the center of the brood-nest.

It should be borne in mind that the practice of spreading brood has been largely abandoned, even by experienced beekeepers. When the queen has plenty of room somewhere in the brood-nest (and that "somewhere" should be outside the broodcluster), both bees and queen will ordinarily rear as much brood as they can safely and profitably care for.

SPRING DWINDLING.-This is a malady confined to bees outdoors or those just set out of the cellar, and appears only in spring-hence the name. It was once supposed to be a disease; but it has now been definitely determined to be only the natural result of a severe winter on a colony too weak or a normal one not protected to stand the cold. Gradually the individual 
members die off until the original bunch of bees is reduced to a few dozens. 'This deciimation may be due to a low vitality on the part of the old bees that are inclined to die off anyway before spring, or it may be due to dysentery. (See Dysentery.) If it is caused by the first mentioned, it shows that the colony went into winter quarters with almost no young bees; that is to say, the great force representing the colony was made up of old bees whose length of days would naturally expire at the beginning of the spring, even under good or the best conditions; when, therefore, the conditions are not favorable, naturally these old bees die off much the sooner.

On the other hand, if spring dwindling is due to dysentery, the condition of the colony in the fall previous, if it could be known, would probably show an insufficient protection, or a cluster too weak in the first place to stand even an ordinary winter, to say nothing of one that is exceptionally cold. Under DYSENTERY it is shown that this disease or malady, rather, is the result of overfeeding. Overfeeding is caused by an attempt on the part of the bees to keep themselves warm. A cluster too small, or a normal cluster in a single-walled hive, in a cold climate, will overeat; and as the bees have no opportunity for flight, their intestines become overcharged, resulting finally in purging, and this purging fouls up the whole hive. An examination down in the brood-nest at about this stage in the spring shows a small weakened cluster, bees uneasy and somewhat scattered, and combs emitting an ill-smelling odor of excrement. The bees have greatly distended abdomens, showing that they are overloaded with fecal matter, as explained under Dysentery. A normal colony should show a compact quiet eluster of bees. See Temperature.

A good flight in warm weather will enable diseased bees to cleanse themselves and make a new start. In fact, continuous warm weather is a relief for spring dwindling. But, unfortunately, in many localities there will come a week or two of warm weather at which time bees will start brood-rearing. When a cold spell comes on, the already greatly attenuated force attempts to hover its brood, with the result that both brood and bees die. A changeable condition of weather, therefore, is hard on nuclei that are suffering from spring dwindling.

In this connection, spring dwindling caused by dysentery may be due to bad food; but in most cases it is caused by insufficient lousing-that is, a lack of proper packing. See Spring ManageMENT.

There is a form of spring dwindling, or perhaps more properly speaking winter dwindling, that occurs in semi-tropical climates, particularly in California. It is similar to the kind of spring dwindling that one encounters in the nortlern States of the East. In California, Virginia and many of the southern States the bees can fly nearly every day in the year. The sources that furnish nectar and pollen entice the old bees out of the hive, some of which never get back on account of a sudden chilling of the atmosphere. These pollen sources also start breeding. It very often occurs that the emerging of the young bees does not keep pace with the old bees dying in the fields, with the result that the colonies become weaker and weaker, until a tenframe colony will get down to about three frames of bees and little brood about the time that the first real honey flow comes on. In some localities in California the eucalyptus, furnishing both neetar and pollen, is thought by some to do more harm than good, in that it starts brood-rearing during midwinter and forces the old bees into the fields, many never returning as explained. In most parts of California there is a severe change of temperature during midwinter from the middle hours of the day to two or three o'clock in the morning before daylight. These sudden drops in temperature cause a great deal of the brood to chill and at the same time hold back the queen.

Much of the winter in the semi-tropical States is similar to spring weather in the northern and eastern States. In general characteristics the winter dwindling in these States is almost precisely the same as spring dwindling, with this difference, that there is never any dysentery.

There is another kind of winter dwindling that is due to an entire lack of pollen both in the hives and in the fields. When that condition occurs, in semi-tropical cli- 
mates, the colony will dwindle very rapidly even tho there is plenty of honey in the hive. The remedy, of course, is to lay aside a set of combs containing pollen, when pollen is coming in freely, and put them in the hives during February or March or earlier if necessary.

\section{REMEDY FOR SPRING DWINDLING.}

Sometimes several of the nuclei that have been reduced by spring dwindling may be united; but in most cases this does little or no good. While the combined force of bees all in one hive look well at the time of uniting, yet in a few days this large force seems to have diminished very rappidly, and, unfortunately, it is no better so far as strength or appearance is concerned than any one of the several nuclei that went to compose it in the first place.

Probably the best way to unite is on the Alexander plan, as given nnder the head of UNITING. If practiced early it will prevent spring dwindling.

As a further preventive colonies should be made to rear brood as late in the fall as possible. If there is any fall flow, bees will rear brood naturally, and the hives will be filled with a large force of young bees. If there is no fall flow, stimulation should be practiced. (See FEEDrNG.) This stimulative feeding may not start up broodrearing if the queens are two or three years old. As a rule, it does not pay to keep queens longer than two years; and many think that they should not be older than one year. Young queens will lay readily in the fall if given stimulative feeding, while old ones may require considerable coaxing. It follows that one of the best preventives for spring dwindling is a young queen in the fall. Such queens will lay until a large amount of stores is used up in August and September, in the northern States, and the beekeeper should, therefore, see to it that they have sufficient after they cease brood-rearing.

For particulars on how to protect the colonies to avoid spring dwindling, see Spring Management and Wintering. For the causes that induce dysentery in colonies that spring dwindle, see DysenTERY. For particulars on how to feed in the fall, see Feeding and Feeders, subhead, "Feeding to Stimulate." For the consideration of the question of uniting, see the Alexander method under the head of UNITING.

SPRING MANAGEMENT. - All colonies should be gone over very carefully as soon as bees can $\mathrm{fly}$, to determine their stores. Unless they have two or three combs of honey, stores should be taken from some other colonies that can spare them. If no hive has a surplus, the needy should be fed a thick syrup consisting of two parts of sugar to one of water. See Feeding, especially those instructions urging fall rather than spring feeding.

Feeders should be placed on top of the frames, and covered with packing. It may turn cold shortly after; and even if the syrup is left in the feeder, starvation will be averted, for the bees will cluster around it and help themselves as they have need. When the weather is cool or cold the syrup should be given hot.

If colonies have been well housed and fed in the fall as they should be, there will be no occasion for feeding or equalizing of stores. Of course, there is liable to be occasionally a colony which, by reason of bad stores, may have dysentery. In that case the front of the hive will be soiled with dark-brown spots, and there will be a quantity of dead bees in front of the entrance and on the bottom of the hive. Such a colony, even with the best of nursing, may die before settled warm weather comes on. If considerable honeydew has been gathered during the previous summer, one is likely to find some spring dwindling and dysentery in some of the hives. Some honeydews will make a very fair winter food; but the majority of them, especially those gathered from hickory and oak, are bad. If this is the case as much of it as possible should be used in brood-rearing in the summer, and then sugar syrup should be fed.

Some springs the weather will turn warm very suddenly with no natural pollen available. The warm weather may last several days. During this time brood-rearing will start up rapidly; and if there is no pollen in the hives the bees will be hunting around in the barns and stables and chicken-coops for bran or chopped feed. It is necessary at such times to give artifi- 
cial pollen. Trays should be set out in sunny places, under cover if possible, containing a few quarts of rye or pea flour.

Unless bees can have natural or artificial pollen when brood-rearing starts, considerable brood will be found dead. On seeing this the beginner is apt to conclude his bees have some form of bee disease-pussibly foul brood. If the brood dies shortly after a sudden warming-up spell, during which there is very little natural pollen in or out of the hives, the owner of the bees should await further developments. See PoLLEN, subhead, "Substitutes for Pollen."

When bees are taken out of the cellar it may be advisable to put them in doublewalled packed hives. Generally one would consider that such hives are too expensive to maintain; but if they enable the beekeeper to get a erop of honey they would be a good investment, because the first cost should be divided orer a period of years. If one feels that he cannot afford double-walled hives he can very often use to advantage tar-paper wrappings, as shown under WINTERING.

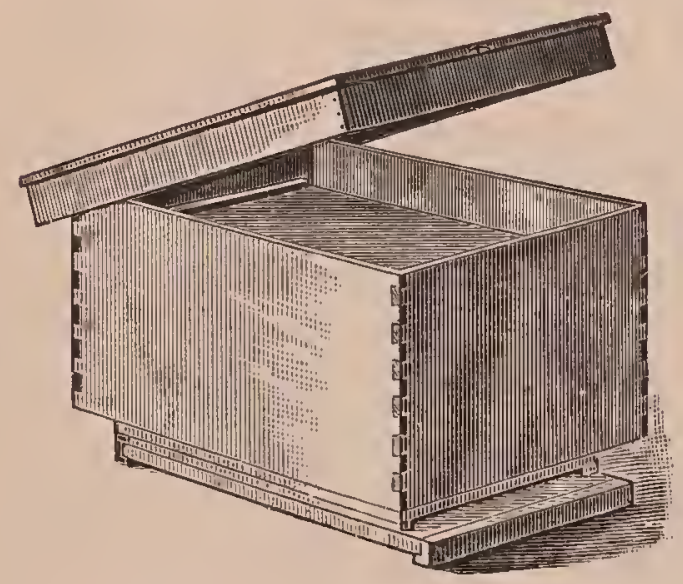

Outer case used for spring protection.

If the cluster of bees can not fill the whole hive it should be confined to the number of combs that it can occupy, after which layers of newspapers should be folded over the frames, covering top and sides down to the bottom-board, when waste paper or leaves may be put in on the two sides and the spaces filled up.

Another plan is to wrap a newspaper vertically around a frame of ordinary comb, and then tie with a string. The newspaper should be long enough to project beyond the end-bars on each end, so as to close up spaces between end-bars and the ends of the hive. When the wrapped comb is inserted the bulging fold at top and bottom of the comb should close up the space between the cover and the bottomboard. This makes a close-fitting serviceable division-board at little expense. Additional layers of papers can now be put over the top of the frames. It would be advisable, in addition, to set on top a halfdepth or full-depth super and fill this with planer shavings or leaves. When the frames wrapped in paper are inserted on each side of the cluster, combs of honey can be put on the outside. As soon as the bees need more room or stores they will eat away the paper and occupy the whole hive.

The newspaper packing above described costs nothing except the time employed, and that certainly would pay a big dividend, not only in the colder climates where bees dwindle in the spring, but in semitropical climates where bees suffer from chilly weather.

If colonies wintered in the cellar are very weak it may be advisable to unite before they are set out. See Uniting.

One difficulty in uniting outdoor bees is that those moved to a new stand are quite inclined to go back to the old hive. This can be overcome to a great extent. ( See UNITING.) Uniting in the spring is often unsatisfactory. Never unite two weak ones, but add a weak one to a medium, and thus make it strong. Unless the colony is very weak take out the surplus of combs that it does not occupy or use, and crowd the little cluster on as few frames as it can occupy. In that case, division-boards should be moved over, and the frames set over on the other side. The hive should be warmly packed, and the entrance contracted down to one inch wide to prevent robbing and to conserve heat.

In going over the yard in early spring one is likely to find, if the bees are wintered outdoors, one or more dead colonies. Their entrances should be shut up bee-tight, for otherwise on the first warm flight day they will be robbed out by the other bees, resulting in a general disturbance of the whole yard. (See Robirng.) Combs on which bees have died may be used later on by putting fresh bees on them. Unless they are very badly soiled with dysentery so they are fairly smeared over with a 
brown excrement, or the stores are very bad, they can be used again. But badly soiled comb, or otherwise undesirable ones, should be put thru the wax-extractor. See WAX; also Drsentery.

In early spring it may be necessary to rake out the dead bees in the entrances of some colonies. If a colony is strong it will usually do its own house-cleaning; but sometimes the dead accumulate in such numbers as actually to block the entrance. In all such cases there is danger that the few survivors may die outright.

Perhaps very weak colonies may be found with a queen; while there will be another colony fairly strong without any. In that case it is best to unite these two, moving the weak colony over to the strong one. See Uniting; also Introducing.

Some experienced beekeepers can "spread brood" in early spring; but the beginner will do well not to practice it. See SpreadING BROOD.

It sometimes happens that there will be wèak and strong colonies in the same yard. The latter will be too strong and the weak too weak. Some have practiced exchanging places with the two colonies. If they are next adjoining, this can be done very nicely; but the exchange should never be made except during warm weather. The flying bees of the strong colony will then enter the hive on their old stand where the weak colony has been placed. This will build it up while the old colony on the stand of the weak one will be depleted of bees. No harm to the brood will be done if the weather is warm and the entrance contracted.

This plan is practiced to a considerable extent by some of our large beekeepers and particularly by Ira D. Bartlett of Michigan.

\section{STATISTICS CONCERNING THE} BFE AND HONEY BUSINESS.-Except for some few States and some particular localities in some other States, there are no accurate figures concerning the number of beekeepers, the number of colonies of bees, and the amount of honey produced. It is true that the United States census for 1900 , 1910, and 1920, includes bees and honey among other rural industries and products; but, unfortunately, these reports, so far as they relate to bees and honey, are limited to bees on farms of three acres or over, or farms of less acreage but which produce over $\$ 250$ worth of agricultural products. As will be shown, such a classification excludes a very large number of beekeepers and practically all of the commercial honey-producers that produce the great bulk of the honey consumed out of the State where it is produced. While it is true that a large number of farmers keep bees, and while it is true that for a few States the great mass of beekeepers are likewise farmer's, the fact remains that in other States, such as New Jersey, Rhode Island, Connecticut, southeastern Nerv York, and eastern Pennsylvania, the population is largely suburban. The great mass of the people of those States are not farmers but suburbanites; and not one suburbanite in ten under the ruling of the census can be classified as a farmer. For example, the United States census for 1900, 1910, and 1920, credits New Jersey with having $14,000,10,000$, and 12,000 colonies of bees respectively, or an average, covering 20 years, of about 12,000 colonies of bees. According to E. G. Carr, the State Apiarist and Bee Inspector, an actual count shows that in New Jersey there are over 36,000 colonies of bees, with not all the territory counted. This shows that, on a conservative estimate, counting only the colonies on the farms New Jersey has actually three times as many colonies as the census report shows. Almost the same ratio should apply to the number of beekeepers in that State, because so many suburbanites not listed as farmers keep bees.

While no accurate count has been made of the number of beekeepers or the colonies of bees in other States having a large suburban population, like, for example, Massachusetts, Connecticut, and Rhode Island, if the same ratio should hold true in these States as in New Jersey, we should have to multiply their census figures, so far as they relate to bees or beekeepers, by 2 or 3-more likely the latter figure. In the same way the suburban population around any large city, as we know from various private sources, contains a large number of beekeepers, not one of whom could be classified as a farmer under the census ruling. 


\section{THE UNITED STATES CENSUS REPORTS SHOWING BEEKEEPING ON FARMS.}

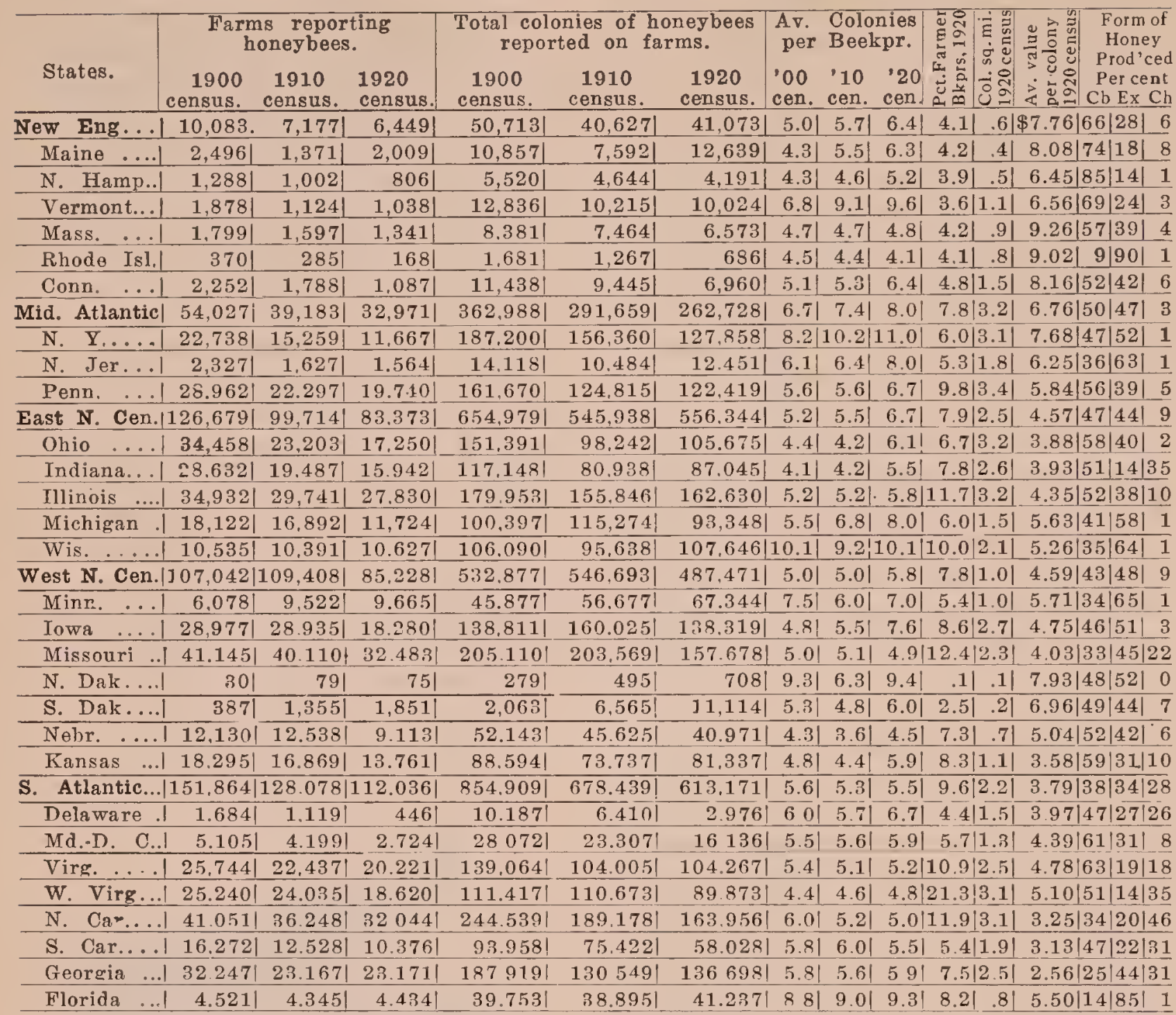

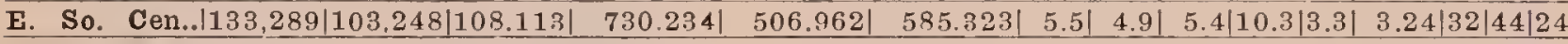

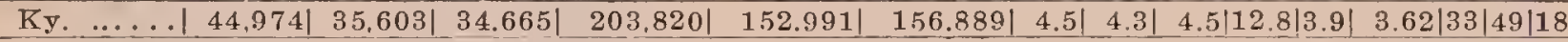

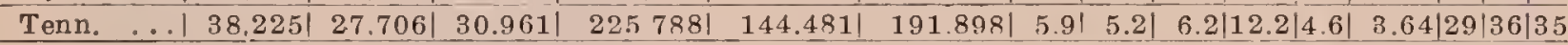

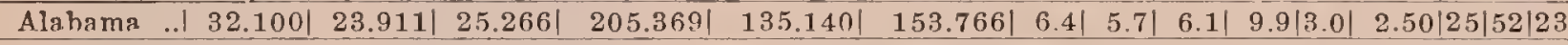

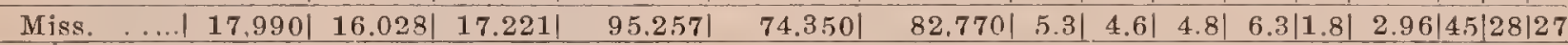

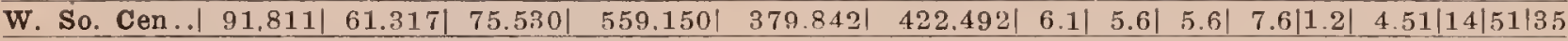

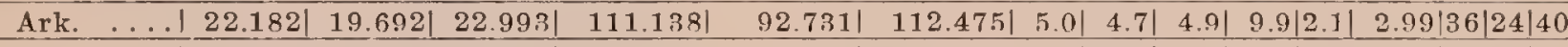

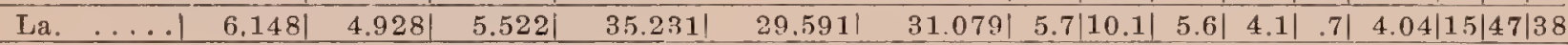

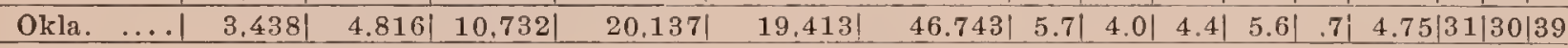

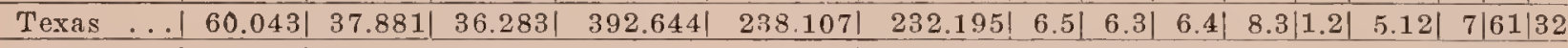

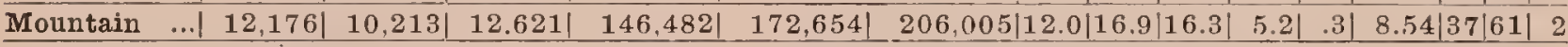

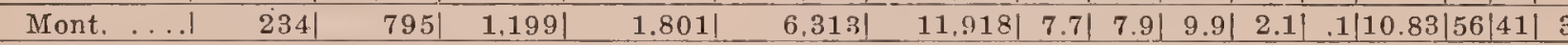

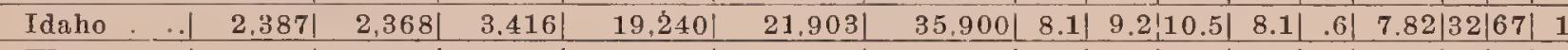

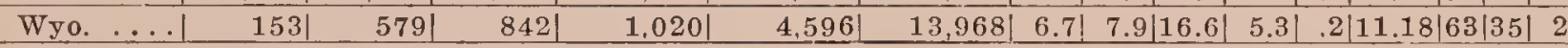

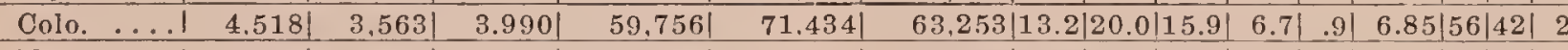
N. Mex... $\quad 410|\quad 418| \quad 750|\quad 6.164| \quad 10.052|\quad 15.733| 15.0|24.0| 21.0|2.5| .2|7.48| 44|46| 10$

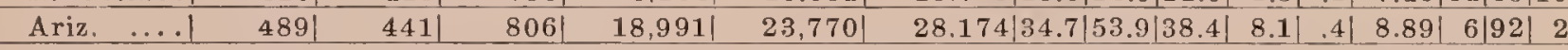

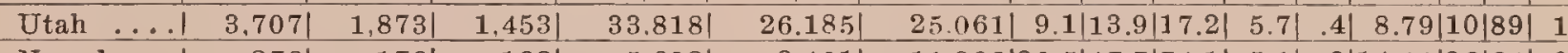
\begin{tabular}{llllll|l|l|l|l|l|l|l|l|l|} 
Nevada & .1 & 278 & 176 & $162 \mid$ & $5.692 \mid$ & $8,401 \mid$ & $11.998|20.5| 47.7|74.1|$ & 5.1 & $.2|14.11| 36|64|$ & 0
\end{tabular}

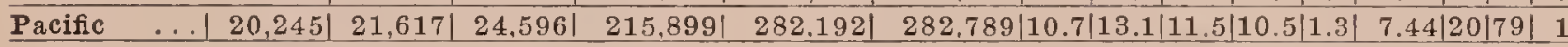

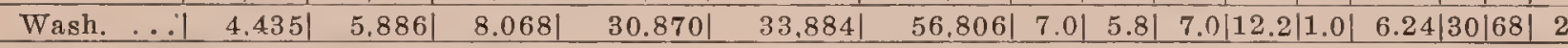

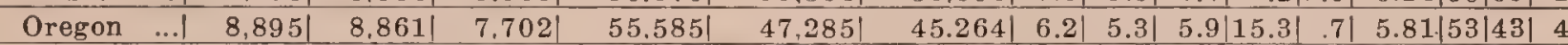

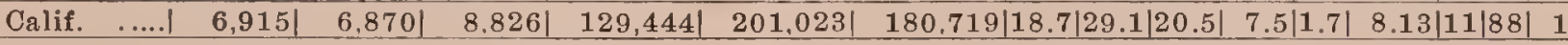

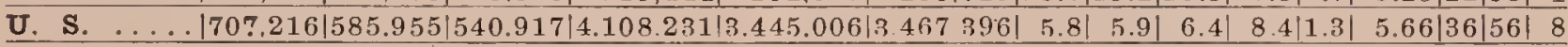

The United States Census, so far as it relates to bees and honey, is very inadequate and misleading, because it does not include the great army of back-lot beekeepers located in towns and cities nor those in suburban districts not on farms. Nor does it include (except in a few instances) professional bee. keepers who produce honey in ten-thousand pound lots and by the carload. The census is only valuable in showing beekeeping on farms. See text. For some good estimates see "Introduction" to this work. 
Again, California, the State that undoubtedly leads off in the number of its beekeepers and the amount of honey produced, in spite of the fact that the census puts Texas ahead, has more commercial honey-producers than any other State in the Union. In California it may be said that at least three-fourths if not four-fifths of the honey-producers (the men who send honey out by the carload) live in the cities and towns and not in the outlying districts where their apiaries are located. They would not be included in the census reports. For example, some of the largest honey-producers in California, and, in fact, of the whole United States, live in San Diego, Los Angeles, San Bernardino, Riverside, Pasadena, Fresno; and San Francisco. A vote has been taken at varions conventions in California, and, in fact, all over the United States, showing that the largest honey-producers in the country are almost never listed in the census report-not because the enumerators have refused to call upon them, but because, under the ruling, no beekeepers can be listed unless they are farmers or produce over $\$ 250.00$ worth of farm products.

There are several other States, such as Maine, New Hampshire, Vermont, Virginia, North Carolina, South Carolina, Georgia, North Dakota, South Dakota, Washington, and Oregon, having a population very largely rural, where the census figur'es would be more accurate. If 25 per cent were added to their totals the figures would be reasonably correct.

It will be admitted that the census reports, so far as they relate to populations of cities and towns, and the country at large, and to general products, will be reasonably accurate; but so far as they relate to the production of commercial honey and the aggregate mass of honey produced, they are grossly inaccurate-so misleading, in fact, that they are a joke. After the 1900 and 1910 census reports on bees were prepared, the deficiency in those reports, relating to the bee industry, was laid before the Bureat, and a promise secured that, when the 1920 census was being prepared, the names of all beekeepers, whether in eities, in towns, or on the farm would be secured; but for some reason the matter was overlooked or not deemed pos- sible. At all events, when the 1920 figures were available, the same old inadequate scheme of taking account of only bees and their products on farms was put thru.

Taking it all in all, the only value that the United States census has, is in giving something more than a guess at the number of bees and the amount of honey produced in States having no large cities and a relatively large rural population. Again, the census figures for 1900, 1910, and 1920 are very valuable in showing that beekeeping on farms, instead of going forward is going backward. This is easily explained on the ground that foul brood, both European and American, is cleaning out the farmer beekeepers, and the business is now going more and more into the hands of the intelligent backlotter, intelligent farmer, and the commercial honey-producer.

For the United States as a whole, the totals for all the States as to the amount of honey and wax produced could be multiplied with entire safety by the minimum figure 2. It would probably be more accurate to use 3 . When it comes to the number of beekeeper's in the United States, either of these multipliers would be altogether too high. A minimum of 25 per cent could be safely added, with the probability that 50 per cent increase would represent more accurately the number of beekeepers in the United States. This ratio of difference should be explained on the ground that, while the number of beekeepers in the United States has not made a very great increase during the last twenty years, the actual amount of honey and wax produced has increased by a ratio of from 300 to 500 per cent.

If any beekeeper wishes to know what his own individual State is doing he will have to apply a multiplying figure according to the conditions. If his State is largely suburban, like New Jersey, he can safely use the multiplier 3 as applying to both bees and honey. The same rule would apply to Massachusetts, Rhode Island, and Connecticut. For New Hampshire, Vermont, Virginia, North Carolina, South Carolina, Georgia, Kentucky, Tennessee, Nortl Dakota and South Dakota, Missouri, and Arkansas 25 per cent should be added to the nnmber of beekeepers and the amount of honey produced. For the States of 
Iowa, Minnesota, IVisconsin, Michigan, New York, and Pennsylvania the number of beekeepers should be twice those of the census figures, and the amount of honey produced should be nearly three times as large.

For the State of California it would be safe to add 100 per cent to the number of beekeepers, and 500 per cent to the amount of honey shown in the census. For the States of Montana and Wyoming, those having no city population, the figures of the census will be more accurate; but in those States beekeeping on a large scale is carried on as it is in California. The same ratio that would apply to the number of beekeepers would not apply to the amount of honey produced. Perhaps 25 per cent should be added to the number of beekeepel's, and 500 per cent to the amount of honey produced. The same thing could be said of Arizona, Nevada, and Colorado.

Texas, Florida, and Louisiana stand almost alone by themselves. They have no large cities, and their population is largely rural. Most of their honey is consumed within their own borders; but because they have so large a number of commercial bee"keepers, and because they have so large a rural population, they should hardly be put in any other class. It would, perhaps, be accurate to add 25 per cent to the census figures for the number of beekeepers, and 100 per cent for the amount of honey and wax produced.

Ohio, Illinois, and Indiana are in a class by themselves. There is some very poor territory in those States, and some other territory that is most excellent for beekeeping. All three of the States have a large percentage of suburban populationparticularly Ohio and Illinois. It is safe to say that the census number for beekeepers should be doubled, and likewise the amount of honey produced could be doubled.

Alabama is the greatest bee and queen rearing State in the Union. A very large number of its beekeepers are living in Montgomery and the big towns. Scarcely one of these men would be listed in the census. We would have to add at least 25 per cent to its figures.

It will have to be admitted that the ratios suggested above are not based on accurate figures; but they are based on an intimate knowledge of bee supplies going into and the amount of honey shipped out of those States where beekeeping is carried on in a commercial way. It is reasonable to suppose that the States having a rural population are fairly shown by the census, provided an increase of 25 and 35 per cent be made, both for the number of beekeepers and the amount of honey produced.

\section{STINGLFSS BEES.-See BeEs, Sting-} LESS.

STINGS. - Many persons, doubtless, would keep bees were it not for the natural fear of stings; but when their habits are thoroly understood this fear disappears. The average beekeeper pays no more attention to a sting or two received on his fingers than the mechanic who bruises his knuckles when a wrench slips. When bees are properly handled the number of stings can be reduced to a very low percentage. Very often one can work all day among his bees and not receive a single jab; and at other times, if he is a little careless, or if he takes chances, he may get a regular onslaught of a dozen at a time. When, however, one exercises ordinary precaution he will receive only an occasional sting; and even the effects of that, if he is quick enough, can be minimized to such an extent that it will be difficult for him to find it an hour afterward. The writer once worked a whole month without a sting.

As will be pointed out later, the moment a sting is received it should be removed instantly-the sooner the better. If it is left in the wound it will gradually work itself into the flesh by muscular contraction, discharging the contents of the poison-sac, and the result will be far more severe than if it had been removed immediately, care being taken, of course, not to squeeze the poison-sac during the operation.

It is always advisable for the beginner to wear a bee-veil and a pair of gloves at the start. A good bee-smoker, with the fuel burning well, should be at hand. The time selected for handling the bees should be between 10 o'elock in the morning and 3 in the afternoon of a warm day. The operator should never stand in front of the entrance-always to one side. A little smoke 
should be blown in the entrance. The cover should next be lifted gently and more smoke blown between the cover and the hive before the hive is opened. More particulars in regard to opening the hive are given further on under this head; also under Manipulation of Colonies, subhead "How to Open a Hive;" and in the last part of the "A B C of Beekeeping."

Even after one does receive a sting he should go about his work as tho nothing had happened. If he does not allow his mind to dwell upon the pain he will not find it so severe. If a sting is received thru the elothing or a glove, it will be a mere prick, and can be instantly removed without getting very much of the effects of the poison.

If one expects to be a beekeeper he should make up lis mind that he can overcome his natural fear. He should understand that when properly handled and the directions are carefully followed as to time and conditions, bees will be as gentle as kittens; that even when their hive is torn to pieces, and their combs scattered here and there, they will not make a protest. If, however, Mr. Beginner thinks he knows it all, and proceeds to open up a hive without suitable protection, he may be severely stung, with the result that he will conclude beekeeping is an exceedingly hazardous business. On the contrary, it is one of the safest. The average young horse or a Jersey cow is more dangerous than a colony of bees; for either one of them, unless their habits are thoroly understood, can cause loss of life. If one attempts to step into a stall on a dark night, surprising the horse without saying "whoa!" or giving notice of his presence, he may be kicked clear across the barn. In the same way, a stranger who does not know the pranks of a Jersey cow will be dealt with so severely that he may conclude that the animal ought to be slaughtered rather than to be allowed to live. In the same way street cars, automobiles, rowboats, are all sources of danger; and it would be just as reasonable to avoid horses, cows, street cars, and automobiles as it would be to avoid bees because some people have been stung or even have lost their lives. Any one of them is safe when properly handled.

Perhaps it may be urged that the pain of the sting could be endured provided there were no further swelling or disfigurement of the features. If one will wear a beeveil carefully fitted to his clothing, there will not be very much excuse for having a swollen eye or a distorted lip. As a matter of fact, after one has been stung a certain number of times his system will become hardened or immune so there will be but little or no swelling. The average beekeeper can be stung on his face or hands a great many times; and beyond the mere pain for two or three minutes there will be no after-effects except a slight soreness for a few hours at the point where the sting was received. The number of stings that one must get before he becomes immune depends somewhat on the individual himself. A very few never have any swelling, and others will become immune after a comparatively small number of stings. Usually in a season's operations one will become proof against swelling after a sting.

Too much emphasis cannot be placed on the absolute importance of removing the sting the moment it is given. This can be done by quick rubbing or mashing motion, and very often one can parry or prevent a sting altogether by smashing the bee or brushing it off before it can get in its work. The bee, in order to sting, must take time enough to sink in its claws before it can force its weapon thru the epidermis of its foe. At the precise instant that one feels the claws of a bee sinking into the skin he should dislodge it if he is in position to do so. Sometimes when he is holding a frame with a valuable queen on it he must "stand and take;" but even then the frame can be set down gently and the sting removed. Usually, if there is just a mere prick of the skin there will be little or no swelling, and the pain will be hardly noticeable.

THE PROPER WAY TO REMIOVE A STING.

With the blade of a knife, scrape the sting loose, being careful not to break it off nor to press on the poison-sac. A pressure on the latter will force the poison into the wound, making it much worse.

When a knife is not handy, push the sting out with the thumb or finger nail in much the same way. It is quite desirable that the sting be taken out as quickly as possible, for if the barbs (to be deseribed 
further along) once get hold of the flesh, muscular contraction will rapidly work the sting deeper and deeper. Sometimes the sting separates, leaving a part (one of the splinters, so to speak) in the wound. It has been suggested that care should be taken to remove every one of these tiny points; but after trying many times to see what the effect would be, the author concludes that they do but little harm, and that the main thing is to remove the part containing the poison-bag before it has emptied itself into the wound. When very busy, or having something in the other hand to make it inconvenient to remove the sting with a knife or finger-nail, rub the sting out against the clothing, in such a way as to push the poison-bag off sidewise; and altho this plan often breaks off the sting so as to leave splinters in the wound, there will be found little if any more trouble from them than usual.

\section{REMEDIES FOR BEE-STINGS.}

Medicines of all kinds are of so little avail, if of any use at all, that the best way is to pay no attention to any of them. This has awakened a great deal of arguing, and the remedies that have been sent, which the writers knew were good, because they had tried them, have been enough to fill this whole chapter. The author has tried a great many of them, and, for a time, imagined they were of value; but after giving them a more extended trial, he has been forced to conclude that they were entirely futile. They not only did no good, but if the directions with the remedy were to rub it in the wound, they did positive harm. The friction would diffuse the poison more rapidly into the circulation, and make a painful swelling of what would have been very trifling, if let alone. It should be borne in mind that the poison is introduced into the flesh thru a puncture so minute that the finest cambric needle could not, except by enlarging the puncture, enter where the sting did, and that the flesh closes over so completely as to make it practically impossible for the remedy to penetrate this opening. Even if there is a remedy that will neutralize the poison in something the same way that an alkali neutralizes any regular acid, how is it possible to get it directly in contact with the poison? There is no way of doing it unless resort is had to a surgical operation. There is no remedy except to remove the sting immediately, and then let the wound alone, and going on with the work without even thinking about it. But, suppose one gets under the eye a sting that closes up that very important organ; shall he go on with his work? That depends. If it brings on headache or causes great discomfort, rest for the day. If one is not immune, he should keep very quiet after a hard sting, especially if the heart action is too high or there is shortness of breath. And in the meantime apply a cold wet cloth until the local fever is allayed. Sometimes applying a hot and cold wet cloth alternately brings relief.

Kerosene was suggested as a remedy, and two beekeepers regarded it of such importance that they almost got into a controversy about who was entitled to the honor of the discovery. After having received a very bad sting on the liand, the author went for the oil can and dropped oil on the spot for some time. As kerosene will remove a rusty bolt or screw when nothing else will avail, and as it seems to have a wonderful power of penetrating all cracks and crevices, we began to have faith that it might follow the sting of the bee, and in some way neutralize the poison. But the only result was one of the most painful and lasting wounds we ever had.

WHAT TO DO WHEN HORSES ARE STUNG A GREAT NUMBER OF TIMES AT ONCE.

Severe cases of stinging are usually the result of carelessness, either from allowing combs to be scattered, causing robbing, or because a hive has been bumped over by careless driving, or by some animal allowed the range of the apiary. There are a number of cases on record where horses have been stung to death; and it is hardly safe to hitch such animals within a few feet of a hive, nor yet to let them run loose in a bee-yard, altho a few sheep may be let in to keep the grass down to advantage.

Chalon Fowls of Oberlin, O., left a horse hitched near some hives of what he thought were gentle Italians; but by some means or other the animal bumped one of the hives, irritating the bees, causing them to rush out and sting. The horse, of course, began 
to plunge and kick, with the result that he demolished completely all the hives within reach. Mr. Fowls said the horse, when he could get to him, was almost literally covered with stings. He unhitched and led him away, and immediately called for a boiler of hot water. This was brought out as soon as it could be heated. Cloths and blankets were immersed in it, almost boiling hot, wrung nearly dry, and laid over the animal, now writhing in the severest agony. The moment Mr. Fowls applied the hot blankets he says the horse quieted down. During the escapade he himself was terribly stung in the face and on the hands; and he says that, as soon as the hot cloths were applied to his face he felt almost instant relief. The cloths were applied to the horse on every portion that was stung, and Mr. Fowls had the satisfaction of knowing that he could save his horse, which was soon as well as ever.

In the summer of 1902 at one of the author's outyards we had an experience which we thought at the time would be fatal to both man and beast. It came about somewhat in this way: A neighbor, who had a field of timothy near the yard, had allowed his horse to eat grass within a few feet of the hives while he went to the further end of the field to look after some work. In the mean time the horse had managed to get over among the bees." The result was, she knocked over five hives, and was literally covered with stings when our neighbor came up. Being a practical beeman as well as a horseman himself, he rushed into the fray, freed the horse, and started her for the barn. The animal was beginning to swell badly, and it was evident to him that she would die before relief could be given by a veterinary, even if called. He accordingly rolled up about a pound of common table salt in a paper, opened the animal's mouth, and with the left hand grasped her tongue, pulling it out as far as he could. He then with his right hand shoved the salt clear down her throat, reaching to his elbow. This done, he quickly closed her mouth and elevated her head until he saw the wad of salt go down the gullet. In a short time the horse showed relief, for the salt probably neutralized, to some extent, the effect of the acid poison. It also acted as a physic; for when a horse is sick in the stomach he can not vomit, and it is necessary to give him something at once to keep the bowels open. In three or four hours the horse was greatly relieved.

Our neighbor did not apply wet blankets wrung out of hot water; but the veterinary who was consulted afterward, said that the giving of the salt was one of the best things that could have been done, and added that he would have wrapped the animal up in a blanket wrung out of hot water. If to this water is added a small quantity of ammonia, all the better.

The moral of this is to keep bee-yards fenced off so that no stock or horses can get in. It is also advisable to locate the apiary a few rods from any line fence or hitching-post. See APIARY.

WHAT TO DO WHEN A PATIENT SUFFERS

SEVERELY FROM ONE OR MORE STINGS.

It is rare indeed that one sting causes any more than a local pain. Red blotches may break out all over the body. In other cases there may be a shortness of breath, a faintness, some nausea, and a weak heart action. When the heart is affected it is very important to keep the patient quiet and cool, and to get the services of a physician at once to administer some heart stimulant. If the patient has been stung a great many times, cloths should be wrung out of hot water and applied to the body. Feet and hands should be kept warm, and the patient, if he has a weak pulse and difficulty in breathing; should be placed near an open wndow, or, better still, out on the porch where the cool breezes can strike him. If there is no air stirring, it would be well for some one to keep up a vigorous fanning of the face. The body should be warmly covered and protected until the doctor arrives. Where electricity is available an electric fan may be made to play across the face of the patient.

When one suffers a shock and shows a weak pulse (and these cases are rare) he should, after he recovers, carefully refrain from attempting to do any hard manual labor for two or three weeks as he will probably suffer from the shock. He should avoid becoming overheated, and for a day or two after being stung he should be very quiet, keeping as cool as possible. Any exertion may bring back the old trouble of 
weak pulse, and this of course introduces an element of danger, if not the danger of leaving a permanent legacy of a bad heart.

Where there is no weak action of the heart, that is, the pulse seems to be good, but one suffers from a general fever over the body with red blotches all over, applications of cold cloths wrung out of water sometimes are sufficient to bring relief. Sometimes hot applications are better still, and very often it happens that hot and cold in alternation prove beneficial.

HOW ONE WHO IS SERIOUSLY AFFECTED BY

A SINGLE STING MAY BECOME COM-

PARATIVELT IMMUNE TO THE POISON.

There are some who are so seriously affected by the bee-sting poison that even a single sting will cause the body to break out in red blotehes. Only one person in ten thousand is thus affected. So rare are the reported cases that the editors of Gleanings in Bee Culture, a journal with a circulation of over 25,000, do not hear of them once in ten years. But there are quite a number of others who are less affected, but who aver that a single sting produces great discomfort. While there is no danger of loss of life, the results of a sting are such that they have been obliged to give up the delightful pastime of keeping bees, very much to their regret. All such persons were formerly advised when going among bees, to be veiled and to wear gloves. But ir Iate year's a better remedy has been found. It was suggested by the fact that the average person becomes less and less affected by the bee-sting poison. Inasmuch as the human system has the power to withstand increasing doses of many poisons, after the first one, why should it not be able to make itself immune to a certain extent against the virus of a bee-sting? It is a wellknown fact that opium and morphine fiends are able to take doses of those drugs in amounts that would kill ten people who are not in the habit of taking them. The same thing is true of alcohol. It is evident if one who is very seriously affected by bee-sting poison would just merely prick himself with a sting and then brush it off before it has had time to throw much of its virus into the wound, the after-effects would not be very serious; and that if the dose were repeated some four or five days afterward, or about the time the effect of the previous sting had passed away, he could, by continuing this. process, ultimately apply the dose at more frequent intervals until in time his system would be no more affected than that of an ordinary person.

An interesting case came under observation. A boy, when stung, became so affected that his body would break out in great red blotches; his breathing grew difficult, and his heart began to pound. It was really a question whether there was not danger of losing his life. Nevertheless he was very desirous of engaging in beekeeping, and determined to work with bees. A live bee was pressed on the back of his hand until it merely pierced his skin with the sting. It was removed immediately; and since no serious effect followed another sting prick was administered inside of four or five days. This was continued for some three or four weeks, when the patient began to have a sort of itching sensation all over his body. The hypodermic injections of bee-sting poison were then discontinued. At the end of a month they were repeated at intervals of four or five days. Again after two or three weeks the itching sensation came on, but it was less pronounced. The patient was given a rest of about a month, when the doses were repeated as before. He then went to school and was not back for eight or nine months. On his return the applications were given again, when it was plainly noticeable that the after-effects were becoming markedly less. He then went out into the bee-yard and was stung occasionally, but, beyond a small local swelling, there was no unpleasant effect.

Some months afterward he was assisting at one of the yards, when, without warning, a colony of bees that was being handled made a most furious attack on both the men. The young man who had been taking the immunizing doses of bee-virus received, he estimates, ten or a dozen stings all over his body. He had no veil nor gloves, for the other man was doing the work with the bees. He expected serious consequences; but, greatly to his surprise and gratification, no unpleasant effects followed. What was more, there was no swelling. It should be remembered that this 
person used to be so seriously affected that a single sting would cause his parents to worry, for they feared he would not be able to survive the attack. He now handles bees with the same freedom that any experienced beekeeper does.

\section{HOW TO AVOID BEING STUNG.}

If the reader will turn to the $\mathrm{A} B \mathrm{C}$ of Beekeeping, also Manipulation of ColoNIES, subhead "How to Open a Hive," and if he will read carefully the beginning of this article, he will have a general knowledge of how to avoid stings. It will be proper at this point to summarize and to amplify some things already said. The subject is so important that it cannot be gone over too fully, even at the risk of repetition. Whether one will be able to make a success of beekeeping or not, will depend very largely on how carefully he follows the directions given below.

1. He should have a good bee-smoker with the fuel well ignited. The author prefer's greasy waste, which is procurable at almost any machine shop or garage, and can usually be had for the asking. See SMOKERS.

2. He should have a bee-veil that is securely attached to the hat and to the waist or shirt. See VeILs.

3. His clothing should be loose, not fitting closely to the body; a blouse or shirt with sleeves buttoned or tied securely around the wrists should be worn. If he is shaking bees from the combs, he should have his trousers stuck in his socks or folded around the ankles, holding them in place by means of strings. The shoes should be high enough to project under the trousers; and in the case of a woman the skirt should be long enough to reach the tops of the shoes. Or, better yet, let her wear a farmerette suit. Some of these suits are very neat and becoming. When bees are shaken on the ground care should be taken not to allow them to crawl up on the feet. If perchance they do get on the foot, it should be stamped on the ground, jarring them off. When the weather will permit, the man should have both his coat and vest off. A very good suit is that worn by garage men and railroad engineers in the form of a union overalls suit.
Those who are very timid should wear gloves or gauntlets. See GLoves.

4. One should never stand in front of a hive-always at one side or in the rear. When bees are flying to the fields back and forth they are more liable to sting, apparently working on the assumption that the obstruction has no business to be in the way.

5. A good hive-tool is important. In the absence of a special tool, a screwdriver or a knife with a strong blade may be used.

6 . The middle hours of the day, if one is a beginner, should be selected for the manipulation of bees. The novice should never attempt to open a hive on a cool or chilly morning, or late in the afternoon, and never after a chilly rain.

7. One should avoid opening a hive or going out into the apiary at a time immediately after a heavy rain or after any other cause that suddenly checks or stops the honey flow. Either a rain or a cold spell may stop the secretion of nectar. The more sudden the stoppage, the crosser will be the bees; and when they work on buckwheat or honeydew, they are apt to be cross when the flow stops along during the middle hours of the day, until it begins again during the afternoon.

8. Having selected a favorable time for the manipulation, the beginner should blow one or two puffs of smoke into the entrance of the hive. With a hive-tool, screwdriver, or knife, he should separate the cover from the hive by merely entering the blade, leaving a gap wide enough for the entrance of smoke, but narrow enough to prevent the exit of bees. A couple of puffs of smoke should be forced into the crack made by the hive-tool, after which the cover may be lifted and more smoke blown over the frames. The cover may be set down by the side of the hive. However, it is usually advisable to jar the bees from the cover by giving a sharp blow on the ground just in front of the entrance, when they will quickly run in. This is important, because the crawling bees on the ground are quite liable to get under the clothing; and a crawling bee always moves upward.

9. Before proceeding further, the operator should carefully note the behavior of the bees. If they crowd up closely between 
the frames, making quick movements, and one or two start flying up as if about to attack, more smoke should be blown over the combs. If, however, a few of them crawl leisurely over the combs, apparently paying no attention to anything, the frames may be separated with a hive-tool or a serewdriver; but the smoker should be kept conveniently in the other hand; and if at any moment the bees show a disposition to rush out or sting, more smoke should be used.

10. If there is a division-board in the hive it should be removed. The frames should be separated on either side of the one that is to be taken out. If the operator or beginner is timid he should blow smoke over the tops of the frames, and then very quietly lift the frame selected, being careful to avoid jerks or quick movements, and especially careful not to roll the bees over when pulling it out. This cannot be emphasized too strongly. Crushed or maimed bees may stir up the colony to a fighting pitch. This should be avoided by all means. After the first comb is remored, the others may be taken out very easily.

11. The operator should not only avoid mashing or killing bees, but he should never jerk the hands back, even if two or three bees do rush out and make a bluff as if they were about to sting, which they will seldom do. If the hand is held stationary when they make these onslaughts they will seldom sting; but if the hand is jerked backward it may be stung by two or three bees. Just the moment that a bee inserts its claws the hand should be withdrawn, and, when away from the hive, quickly rubbed against the clothing in such a way as to brush the bee off before it can sting.

12. One should learn to distinguish between bees that are angry and those that are flying about aimlessly. Cross bees will be detected by their high keynote and their quick darting movements in flight. $A$ bee that nervously flits back and forth before the face, giving out a high kevnote, is cross, and will sting unless the operator has his face protected by a veil. The best thing to do with such bees is to pay no attention to them, if protected.

13. When replacing the frames, they should be put back in the same order they were in originally, being careful not to pinch any bees.

14. Bees are much more inclined to sting during a time when there is a dearth of honey, and when robbing has been allowed to get started. (See Robinng.) One should not leave a hive open very long when stray bees from other hives are hovering over the tops of the combs, now and then darting into the hives or on to the combs, attempting to steal.

15. After the hive has been opened up and has stood for a while without any manipulation, the frames left in the hive should receive two or three puffs of smoke before handling. This is to drive down the guards.

16. Hot breath from a human being or an animal when combs are handled very often starts bees to rush off the combs by the dozen and alight on the veil. If one has no face protection he may receive a dozen stings in the fraction of a second.

17. Bees are niore apt to sting a man or an animal when he is sweaty and gives off a strong odor. However, the practical beekeeper pays but little attention to what his condition may be. His experiences will determine what to do if the bees show a disposition to be cross. At such times the smoker should always be ready. It is the indispensable implement in the yard, and should be in condition to give off a volume of smoke at any instant-not that one's life depends on it, but rather to save time and to avoid stings.

18. Children should not be allowed to race thru a bee-yard when bees are busy in going to the field, or at any other time when they might be a little cross. They should be cautioned to go around the apiary. While the children of beekeepers sometimes become careless, they should avoid, as far as possible, doing anything that will cause unnecessary irritation to the bees, thereby provoking them to sting.

19. Never hitch a team or a horse near a hive of bees. A single sting will sometimes cause a horse to break loose, rush thru the yard, knocking over hive after hive. If for any reason he becomes entangled in his harness he will be stung to death, and at the same time the life of the owner may be in danger in trying to save the animal. When hives are knocked over 
as the result of a runaway horse or team, there is liable to be a general stinging fracas. The owner should not be tempted to go into a yard at such times without veil and gloves, and a smoker well ignited. To do so without protection is only inviting disaster.

\section{WHAT KINDS OF BEES STING WORST.}

The general decision now is, that pure Italians, Caucasians, and Carniolans are the most easily handled. (See RACES of BeEs.) Not only do they sting less, but as they keep their places on the combs without getting excited when the hives are opened properly, they are far less likely to get under one's elothing than black bees. Queenless bees are not as quiet as those that have a queen. It may be because they seldom work with energy, and have therefore no fresh accumulation of stores that would tend to put them on their good behavior. All bees are much worse after a sudden stoppage of nectar secretion, especially after a basswood or buckwheat flow. A great many stings are received from bees that are in no way badly disposed at all, simply from getting pinched accidentally while on the person of the beekeeper.

The pure races may be handled all day, with no mishap; but after working among the old-fashioned blacks or hybrids one often finds a dozen or more under the coat, in the sleeves, if they can get up, and, worst of all, up the trousers, unless the precaution has been taken to tuck them into the boots-or stockings when wearing low shbes. (See VeILs.) This one thing alone should decide one in favor of the Italians, if they were no better than the blacks in other respects. Hybrids, as before stated, are worse to sting than either of the races when pure; while Cyprian and Holy Land bees are so much worse still, that sometimes smoke has no effect on them. See Crprians, under Italians; also RACES OF BEES.

\section{BEE-STING POISON.}

When bees are very angry and elevate that portion of their bodies containing the sting, a tiny drop of some transparent liquid can often be seen on its point. This liquid is the poison of the bee's sting. It has a sharp, pungent taste; and when thrown in the eyes, as sometimes happens, it has a stinging, acrid feeling, as if it might be a compound of cayenne pepper, onion-juice, and horseradish combined; and one who tastes or gets it in his eyes, concludes it is not so strange that such a substance, introduced into the circulation, should produce severe pain and local fever for a few hours.

\section{HOW IT IS DONE.}

It is quite an interesting experiment to let a bee sting one on the hand, and then observe the whole performance without disturbing it. After the bee has worked the sting so deeply as to be satisfied, it begins to find itself a prisoner, and to consider means of escape. It usually gets smashed at about this stage of proceedings unless successful in tearing the stingpoison-bag and all-from the body; however, if allowed to work quietly it seldom does this. After pulling at the sting to see that it will not come out, it seems to consider the matter a little, and then commences to walk around the sting, in a circle, just as if trying to twist a screw out of a board. If one can be patient and let the bee alone, it may work it out, but in most cases the sting either tears out from the body of the bee or breaks off. In either case it should be removed from the flesh at once.

\section{ODOR OF BEE-STING POISON.}

After one sting has been inflicted, there seems a much greater chance of getting more stings. Mr. Quinby has suggested that this is owing to the smell of the poison, and that the use of smoke will neutralize this scent. It is advisable to blow smoke on the wound. The heat relieves the pain somewhat, and the smoke does, no doubt, obscure the bee-sting odor.

POISON OF THE BEE-STING AS A REMEDIAL AGENT.

For some years past there have been running in the daily press many reports in regard to the agency of bee-stings in the cure of certain forms of diseases, especially rheumatism. From the facts put forth, any candid reasoner will have to admit that being stung frequently does have the effects of relieving certain forms 
of rheumatism, lumbago, paralysis, and perhaps dropsy.

Numerous accounts have also appeared of various persons affected with rheumatism being greatly relieved by stings, especially on the affected parts. Some others have reported that they could discover no appreciable effect one way or the other.

It has happened at various field-day gatherings of beekeepers that certain parties who read these reports, having suffered severely because of rheumatic pains, have presented themselves and asked to have experts cause the bees to sting them on the affected parts. The operator picks a bee from a comb by the wings and presses it against the flesh until the sting is driven into the skin. This has been done on several occasions, and in each case the patients have said they experienced relief.

At the Jenkintown field-day meeting, June 26, 1906, an old gentleman got up on the platform, and, before about one thousand people, stings were applied to his arm until nearly a hundred were imbedded deeply in the flesh. Did it hurt? Oh, yes! But the induced fever of the stings, he said, seemed to bring a warmth and toning of the muscles that were after all a relief: for, strangely enough, this large number of stings does not seem to affect a rheumatic leg or arm as it does a healthy member.

It is a well-known fact that the homeopathic school has for many years used beesting poison in a remedy called "apis mellifica." There are large wholesale drughouses that buy stings taken from live bees. The stings are then dropped into small vials containing sugar of milk. Orders for bee-stings to the extent of 10,000 in one lot have been filled repeatedly. From a frame of live bees placed in a convenient position a bee is picked up with a pair of broad-nosed tweezers and immediately crushed. This act forces out the sting, which is immediately grasped by another pair of fine-pointed tweezers, when they are given a sharp rap over a wide-mouthed bottle. In this way the stings are extracted one by one until the whole number has been pulled. But the operator, after having extracted four or five thousand stings, experiences a sort of tingling and itching sensation in the face, and finds he has to take a rest of some days before he can re- new his work. At other times he can extract only a few hundred a day when that itching sensation will reappear. This is probably due to the fact that he inhales some of the fumes of the poison, which, entering the lungs, is absorbed by the blood and carried thru the system.

At other times a pound or so of bees is put into a large wide-mouthed bottle or jar of alcohol. But the poison of the stings extracted in this way must necessarily be mixed with the other juices of the bees.

Homeopathic physicians have "apis mellifica," thus made from bee-stings, supplied to them in the form of a liquid. It smells not unlike bee-sting poison, and is often given internally to relieve the pain of rheumatism or swellings in general. But it is evident that a hypodermic injection of the bees, given directly on the affected part, would be a hundred times more productive of good results, assuming, of course, the poison does have a remedial effect.

\section{SMOKE NOT ALWAYS A PREVENTIVE OF BEE-STINGS.}

There are some colonies that, under some conditions, can not be conquered, even with smoke. If the atmosphere is a little chilly, or immediately after a rain, or if the supply of nectar has suddenly stopped short off, a few colonies may be very hard to handle. While most bees under these conditions will yield to smoke, it seems to infuriate others. The only thing to do is to let them alone for the time being; then the next day or two, when the weather is favorable, blow a little smoke in at the entrance, raise the cover very gently, blow in a few whiffs more, when, presto! the fiends of the day before are as gentle as one could wish.

\section{MECHANICAL CONSTRUCTION AND OPERATION} OF THE STING.

After a bee has delivered its sting, and torn itself from that member, a bundle of muscles partly enveloping the poisonbag will be noticed. The curious part of it is that for some considerable time after the sting has been detached from the body of the bee, these muscles will work with a kind of pump-like motion forcing the sting 
further into the wound, as if they had a conscious existence and burned with desire to wreak vengeance on the party attacked. Even after the sting has been pulled from the flesh, and thrown away, if it should stick in the clothing so the flesh will come in contact with it, it will commence working again, pull itself into the flesh, and empty the poison into the wound, precisely as if the living bee were itself working it.

The author has suffered many times from a sting unconnected with any bee. It would hold life enough to give a very painful wound, for some minutes afterward.

Muscular contraction of the sting has taken place under the field of the microscope 20 minutes after being detached from the bee. This phenomenon is wonderful, and, while watching the sting sink into the rim of a felt hat, one can ponder on that wonderful thing, animal life. Why should that isolated sting behave in this manner, when the bee to which it belonged was perhaps far away, buzzing thru the air? Why should this bundle of fibers and muscles behave as if it had a life to throw away?

Under the microscope the sting is found to be a beautifully fashioned and polished instrument, whose delicate taper and finish make a most surprising contrast with any instrument man has been able to produce. In slape it appears to be round; but it is, in reality, egg-shaped, of a dark-red color, but transparent enough to show the hollow.

The sting proper is composed of three parts - the outer shell, or husk, D, and two barbed spears that slide partly inside of it. Fig. 2 shows the spears. The barbs are much like those on a common fishhook; and when the point of one spear, A, penetrates far enough to get one barb under the skin, the bee has made a hold, and has no difficulty in sinking the sting its whole length into the wound; for the pumping motion at once commences, and the other spear B, slides down a little beyond A, then $A$ beyond $B$, and so on. With a motion like that of a pair of pump-handles, these spears are operated by small but powerful muscles attached thereto. These muscles will work, at intervals, for some time after the sting has been torn from the bee, as has been explained. They work with sufficient power to send the sting thru a felt hat or into a tough buckskin glove. It is interesting to watch the bee while attempting to get its sting started into the laard cuticle on the inside of the hand. The spears often run along the surface diagonally, so that it can be seen how they work down by successive pumps.

It was formerly supposed that the ducts OO were for the purposes of conducting the poison from the poison-bag up the barbs; but Snodgrass, of the Bureau of Entomology, has shown that this is a mistake.

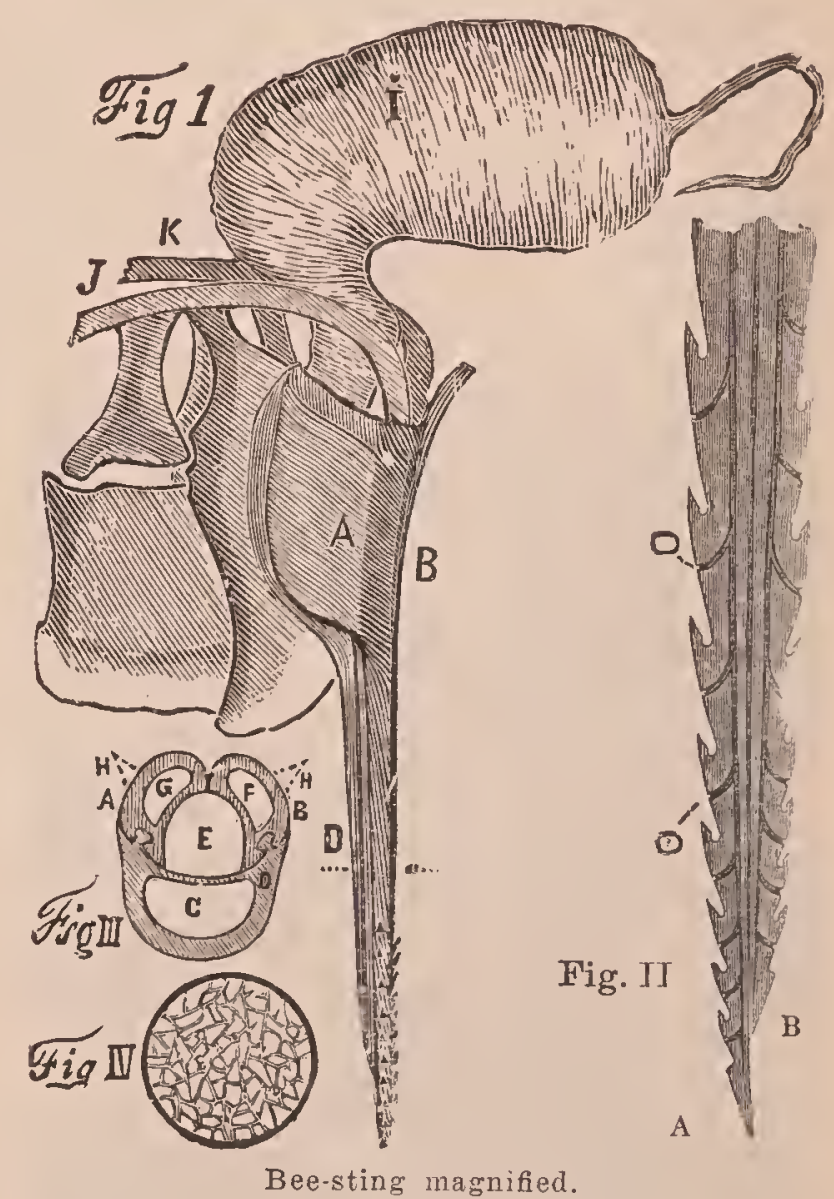

Fig. 3. is a transverse section, sliced across the three parts, at about the dotted line D. A and B (Fig. 2) are the barbed spears; F and $G$ (Fig. 3) the hollows to give them lightness and strength; $\mathrm{H}, \mathrm{H}$, the barbs. It will be observed that the husk, $\mathrm{D}$, incloses but little more than onethird of the spears. The purpose of the main shaft $\mathrm{C}$ is to hold the spears in place, and to allow them to slide easily up and down, also to direct them while doing this work. To hold all together, there is a groove like a sliding dovetailed joint in both spears, with a corresponding projection in the husk, which fit each other as 
shown. (See Fig. 3.) This allows the barbs to project to do their work, and yet holds all together tolerably firm-tolerably firm, for these spears are very easily torn out of the husk; and after a sting is extracted they are often left in the wound, like the tiny splinters before mentioned. When torn out and laid on a slip of glass they are scarcely visible to the naked eye; but under the microscope they appear as in Fig. 2.

Stings do not all have the same number of barbs. There are as few as seven and as many as nine. The two spears are held against each other as shown in Fig. 3, and it will be observed that the shape and the arrangemeni of the three parts leave the hollow, E, in their center. The working of the spears also pumps down poison, and quite a good-sized drop will be collected on their points, as can be readily seen under the microscope. J. R. Bledsoe found a valve that lets it out of the poison-bag into this wonderful little pump, but prevents its returning. The drop of poison, after lying on the glass a few minutes, dries down and seems to leave a gummy substance that crystallizes into strange and beautiful forms, a diagram of which is shown in Fig. 4.

\section{SUCROSE.-See CANE'SUgar.}

SUGAR.-The term sugar is applied by common consent to the white sugar commercially prepared from the sugar cane and the sugar beet, or sucrose. To the layman, and possibly to the chemist, the word "sugar" means white granulated sugar; if it is powdered, the adjective "powdered" is added to sugar as "powdered sugar;" if it is moist and soft, and either white or only slightly yellow in color, it is termed "soft sugar;" while if it is brown in color, moist and soft, it is termed "brown sugar." In distinction the word "sugars" refers to the whole class of sugar, of which there are some 150 or more, many of which are rare and some of more common occurrence. Grape sugar is the sugar dextrose, while fruit sugar is the sugar levulose. See INverT Sugar.

Common sugar is composed of the elements in the following proportions: Carbon, 12 parts; hydrogen, 22 parts; oxygen, 11 parts. It is found free in nature in many roots, as beets and turnips; in the stems of plants, as sorghum, sugar cane, cornstalks, and in the sap of trees like maple, birch, etc., and in many fruits. It has never been commercially prepared from the elements.

A white sugar or granulated sugar is practically pure sucrose, while the varying off-colored sugars ranging from lightyellow to brown are mostly mixtures of crystals of sucrose surrounded with molasses. These yellow or brown sugars are all produced by the refineries from the liquors after the production of the white grades. Formerly one had brown sugars direct from the cane, but now these are not produced to any extent in this country. Louisiana sugars in hogshead used to be these old brown sugars.

There has always been a discussion as to whether white sugar made from beets is the same in every particular as that made from sugar cane. Both contain practically the same amount of sucrose, also water and mineral matter, but the organic impurities which may amount to from .05 to $.1 \mathrm{per}$ cent are often different in beet white sugar from those in cane white sugar. These impurities may play a part in some manufacturing processes, and prevent the use of beet sugar in all places where cane sugar has been used. However, as a sweetener and for table use or for jelly or preserving work it is doubtful whether there is any notable difference between beet and cane sugar. See Cane Sugar.

SUMAC (Rhus).-This genus is represented in the United States by about 15 species. Most of them are shrubs, but a few are small trees and one is a shrubby vine. The large handsome leaves are trifoliate, or odd-pinnate presenting a fernlike appearance. The pinnate-leaved species are highly ornamental as foliage plants, and in autumn display the most brilliant red and scarlet colors. The small flowers are borne in dense clusters, or panicles, at the ends of the branches or in the axils of the leaves. The stamens and pistils are usually in different flowers, one tree or shrub bearing only staminate flowers and another only pistillate. In the common staghorn sumac the staminate flowers are in large white clusters while the pistillate are in dense green clusters, which 
stand well above the foliage. The white flowers yield both nectar and pollen and attract many more insects than do the green, which offer only nectar; but honeybees visit both kinds. The sumaes may be

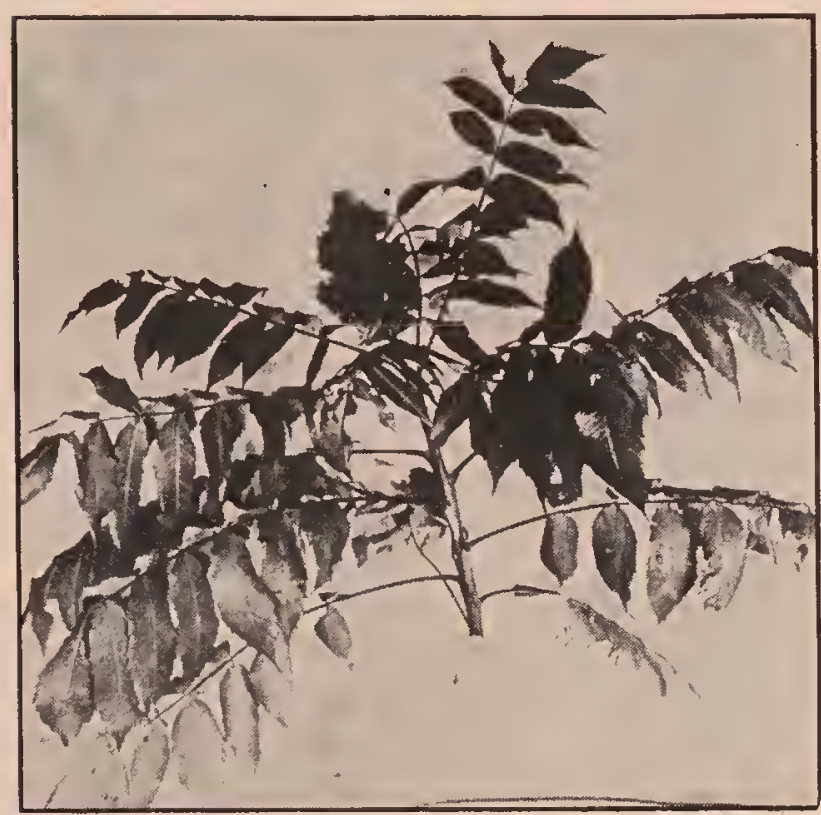

Sumac, smooth (Rhus glabra).

divided into two groups; the non-poisonous sumaes and the poisonous sumaes.

Staghorn Sumac (Rhus typhina). This species reaches a height of 10 to 25 feet, and has orange-colored wood and crooked branches, covered witl soft, velvety hairs, resembling the horns of a stag. The clusters of fruit are clothed with acid crimson hair. The staghorn sumac grows in dry soil from Nova Scotia westward to Missouri. The flowers are visited by honeybees in large numbers; and, as the nectar is unprotected, by a great company of other insects. The flowers appear in June and July.

Smooth Sumac (Rhus glabra). Upland sumac. Scarlet sumac. This species is an irregularly branched shrub, seldom more than 10 feet tall. It has a very wide distribution, extending from Nova Scotia to Florida and westward to Mississippi and Minnesota. In Connecticut, where much of the surface is covered with glacial moraines, it is very common in hillside pastures, and along stone walls. The blooming period lasts for about three weeks, from July 8 to the beginning of August. The flowers secrete nectar very freely on hot clear days, but in cloudy, foggy, or cool weather the flow ceases almost entirely.
If there are "hot waves" in July strong colonies will bring in 20 pounds of honey during an ideal day, and will store from 40 to 100 pounds each. But if there is much cool or rainy weather there may not be an average of 20 pounds to the colony. At its height the flow is very rapid and heavy. While the bees are busy on the bloom there is a very strong odor in the apiary, and the new honey is more or less bitter to the taste. Fortunately, the bitterness is only transient, and by winter the honey is edible.

One must eat sumac honey to appreciate it, says Latham. There is a riclness, but at the same time a mildness about it, that will suit the most sensitive taste. Once a customer, always a customer, if one buys sumac honey. When pure the honey has a golden color. If properly ripened, it has no noticeable odor, but is very heavy, and,

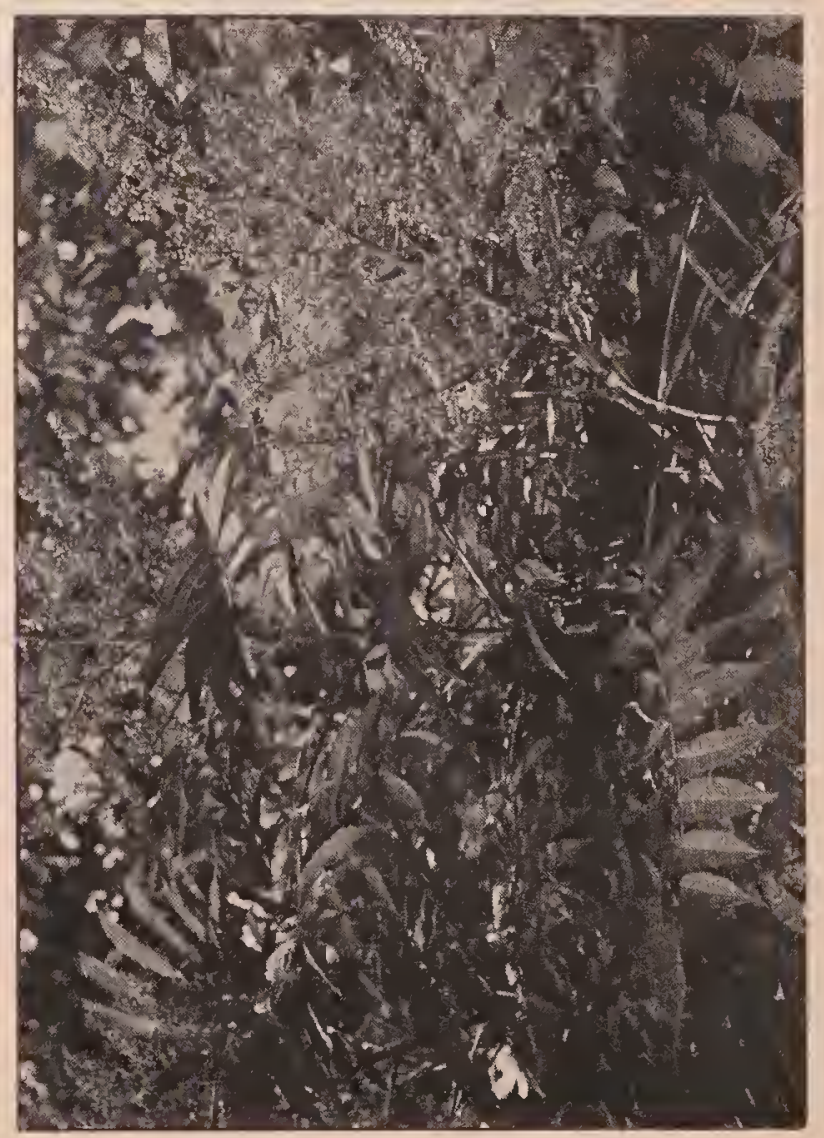

Sumac flowers and leaves (Rhus glabra)

like apple-blossom honey, waxes instead of candying. It is safe to say that much of Connecticut would be worthless to beekeepers but for this plant.

The bloom also yields a large amount of pollen, great loads of which the bees bring in during a slow flow. Even during the 
height of the honey flow the bees gather pollen during the morning hours, before the sun has stimulated the nectaries. Later in the day little pollen is brought in.

In Georgia there are several species of sumac, which are valuable, but the most important is Rhus copallina, common names of which are dwarf sumac, and mountain sumac. This species extends from Maine to Florida and Texas and westward to Minnesota. In a few localities in north Georgia it is the main source of marketable honey. In this State it blooms in August. In Texas in favorable seasons, depending upon rain, it also yields a surplus. In southern California Rhus laurina may yield one or more extractings of an amber-colored honey with a strong flavor.

SUNFLOWER (Helianthus annurs).An extensive American genus embracing 60 or more species. The common sunflower grows wild thruout the West, especially from Minnesota to Texas on the prairies and waste lands lying between the Rocky Mountains and the Mississippi River. In Nebraska it becomes a "veritable herbaceous tree," and completely takes possession of large waste areas 10 to 25 or more acres in extent. The tall plants also grow along the roadsides and about cities and towns. This species is likewise common in California, and one year M. H. Mendleson of Ventura extracted a carload of wild sunflower honey, but the yield had never before been so large. According to Richter, the honey is amber-colored, with a characteristic flavor not disliked by many. Scholl says that in Texas bees gather much propolis both from the flowers and leaves. The stems yield a textile fiber, the seeds oil, and the flowers a yellow dye. Many other species of sunflower are exceedingly common both in the West and South. The Jerusalem ar-. tichoke ( $H$. tuberosa) is a good honey plant, and bees visit the flowers in myriads. In Contra Costa County, California, there are acres of this plant growing wild. The tubers are used as a vegetable.

\section{"WILD SUNFLOWER OF FLORIDA."}

This name is rather loosely applied by beemen of Florida to various species of Compositae that grow over the southern half of the peninsula, including Gaillardia lanceolata, Helianthella, Coreopsis, and burr-marigold. South of a line drawn thru Stewart and Osprey, the one on the east coast and the other on the west, there are thousands of acres of these beautiful plants, which resemble the Spanish needles and Chrysopsis of the Nortll. They extend as far north as Osceola, but beemen of the southern third of the State are most enthusiastic over them. The "savannas" about the edges of the Everglades seem to be their best habitat, while they are not common on high pine land. The blooming period is in September and October. The yield is rather unreliable, and nectar is secreted only during very dry falls. A fair crop can be counted on about every two or three years; a "bumper" about once in five years. The honey is amber, fairly good body and rather mild; but it is, after all, a fall-flower crop, and by no means ranks with the best honeys. It is fine for putting the colonies in good condition for the close of the year.

SUPERSEDURE OF QUEENS. - Supersedure is the replacing of an old or failing queen with a young one and is one of the natural impulses under which queencells are built. A colony in a large hive or hollow tree may not cast a swarm or be deprived of their queen by accident for several seasons. But every queen grows old and must be superseded. Cells built under the supersedure or swarming impulse are more uniform in size and better fed than any others. One can usually tell under which impulse the cells are built. If under the supersedure impulse, the queen will not lay fast enough to keep up with the hatching brood.

SUPERS.--See Comb Honex, APpliANCES FOR; also HIVES.

SWARMING.-The ter'm "swarming" is applied to the act of a family of bees leaving their lome to establish a new lome elsewhere. In the broadest sense the term includes not only reproduction of colonies by normal swarming when the colony divides itself by part of the bees leaving, but also swarming out from various causes when the entire colony migrates. The term is sometimes applied to the division of 
colonies, as in artificial swarming. Usually the term swarming means the issuing of normal swarms when the colony is prosperous, only a part of the bees leaving the hives. Normal swarming is, therefore, a division of the colony for the purpose of reproduction. The term "swarming out" is usually applied to the migration of the entire colony as in the case of lack of food (hunger swarms), recently hived swarms that are dissatisfied, swarms that leave because of American foul brood, and small nuclei that swarm out with the young queen when she takes her mating flight or because the little colony is dissatisfied. The migrating family of bees is called a swarm, tho this term is sometimes applied to the colony after it has established itself in its new home, to distinguish the new colony from the parent colony. In a strict sense the term swarm applies only during migration. As soon as a swarm establishes itself in its new home it is called a colony.

CHAIN OF EVENTS LEADING UP TO SWARMING.

A colony of bees that is normal and prosperous increases its brood in the spring as its adult population increases, either until all the available brood-comb is occupied or until the queen reaches the limit of her capacity in egg-laying. Early in the spring only worker brood is reared, but when the colony becomes stronger the rearing of drone brood is begun, thus providing for male bees in anticipation of swarming. Finally, when the brood-chamber becomes crowded with emerging and recently emerged young bees and the combs are well filled with brood, several queen-cells may be started. When eggs are placed in these partially built queen-cells the colony has then taken definite steps in preparation for swarming, the swarm usually issuing eight or nine days later at about the time the more advanced queen-cells are sealed. The exact time of the issuing of the swarm depends to some extent upon the weather. Sometimes it must be postponed a few days on account of rain, and sometimes during hot weather the swarm will issue before any of the queen-cells are sealed, especially if the bees are Italians. Normal swarms usually issue between $10 \mathrm{a} . \mathrm{m}$. and 2 p. m. In hot weather most of the swarming is over by noon.
SYMPTOMS OF SWARMING.

In their natural state and when neglected or poorly managed the bees usually slow down in their work after queen-cells have been started in preparation for swarming, especially during a few days just previous to the time the swarn issues. The field workers in increasing numbers stay in the hive instead of working in the fields, bringing about a crowded condition sometimes resulting in a great cluster of bees hanging on the outside of the hive. This clustering on the outside of the hive was formerly considered a symptom of swarming provided it occurred during a honey flow, but it is by no means a reliable symptom. Clustering out during warm weather when there is a dearth of nectar is quite another thing and has nothing to do with swarming.

A more reliable symptom that the colony is jueparing to swarm is a lack of the usual flight at the entrance, due to many of the field bees staying at home. When this is noticeable, by looking into the supers it will be noted that they are crowded with bees, sometimes wedged into every nook and corner, this being quite unlike the normal condition in the supers. These idle bees are usually filled with honey, which makes tliem appear unusually large because of their distended abdomens. These conditions when present during a honey flow are practically a sure indication that the colony is preparing to sivarm. In wellmanaged colonies this slowing down of field work does not always occur, but little if any difference in the work being noticeable even on the day the swarn issues.

The only certain indication of swarming is the presence of queen-cells containing egg's or larvae during the swarming season. By noting the advancement of the queencells it is often possible to predict on what day the swarm will issue. Queen-cells built under the swarming impulse are sometimes called "swarming cells" to distinguish them from queen-cells built at other times to supersede the old queen. See How to Distinguisit Between Sirarming Cellas and Strpersedure Cells, page 815.

THE PRIME SWARM.

When the first swarm issues a varying proportion of the adult bees, together with the old queen, fly from the hive, leaving be- 
hind them some adult worker bees, a large number of unemerged young bees, and several unemerged young queens. This is called the prime swarm to distinguish it from after-swarms which may issue from the parent hive about a week later. The number of bees that accompany the swarm depends somewhat upon the weather. Swarins are usually smaller when the weather is cool and larger when the weather is hot.

Just why some go and others stay is not known. While the division may be somewhat according to age, there is apparently no fixed rule for this. Many of the older field bees remain in the parent colony, and often during hot weather many bees too young to fly attempt to accompany the swarm. Some of the drones accompany the swarm, but many of them remain in the hive. Sometimes three-fourths or more of the bees go with the swarm. Swarms from strong colonies sometimes weigh from 10 to 15 pounds, but usually they weigh less.

Sometimes the queen leaves the hive among the first, but oftener she leaves after half or more of the swarming bees have left, and sometimes she is among the last to leave. Occasionally she does not find her way out of the hive at all, in which case the swarm will return unless it unites with another swarm having a queen.

As the swarming bees rush from the hive they circle about in the air, covering a wide area at first but gradually drawing together and finally clustering on some conrenient support such as the limb of a tree. After an interval usually varying from about 15 minutes to several hours, or even in exceptional cases a day or more, they break cluster and fly away to find a new home. Occasionally a swarm will leave the hive and go directly to a hollow tree or empty hive, apparently having previously selected their new home; but, as a rule, they cluster near the apiary before going away.

There is considerable evidence indicating that scouts are sent out to find a new home either previous to swarming or while the swarm is clustered. Many have noticed a few bees working around a hollow tree or an empty hive shortly before a swarm came and entered, and the remarkable directness of the flight of the swarm from the hive or clustering place to a hollow tree or other suitable abode would be difficult to explain in any other way. For this reason the advice is usually given to hive the swarm as soun as it has clustered and move it away so returning scouts cannot lead the swarm away. Sometimes swarms travel several miles before finding a new home, clustering and breaking cluster several times while on the way.

Swarming bees are usually good-natured and pay little if any attention to the beekeeper, even when he walks about in the midst of the circling bees. Sometimes, however, after they have been clustered for some time they will sting viciously when disturbed, especially if they have remained clustered for several hours or overnight. There is also considerable difference in the way the bees behave depending upon the weather, so it is not safe to assume that swarming bees are always good-natured.

Before leaving their hive, the swarming bees fill themselves with honey, so that they take their lunch with them when seeking a new home. They are, therefore, prepared to begin building comb in their new home almost immediately. Within a few days the newly formed colony becomes well established. The queen begins to lay in the newly built combs before the cells are fully drawn out, and, if nectar is abundant, comb-building and the storing of honey are carried on rapidly. During the first few days the bees build only worker comb; but usually, after building the equivalent of four to six standard frames of comb, they begin to build drone-sized cells. If the queen is old they usually begin to build drone-cells earlier than if the queen is young and vigorous. Apparently when the bees build worker comb faster than the queen can fill it with eggs, they begin building the larger cells, these being for the storage of honey. If a swarm is hived on one or two empty combs, the remainder of the live being vacant; the bees begin at once building drone-sized cells.

\section{AFTER-SWARMS.}

About a week after the prime swarm issued the first of the young queens emerges from her cell if the swarm issued at the time the first queen-cells were sealed. Instead of destroying the other young queens and permitting this first-emerged young queen to become the new mother of the colony, the bees, if left alone, usually swarm 
again, this after-swarm being accompanied by the young queen. If the beekeeper does not interfere other after-swarms usually issue with an interval of one or two days between, each being smaller than the preceding until there are no longer enough bees left to divide among the remaining young queens. fuses the workers so they cease guarding the unemerged queens, and several may emerge at once while the hive is open. When subsequent after-swarms issue there may be several young queens at large in the hive, and sometimes several of them accompany the swarm.

When the first young queen emerges she

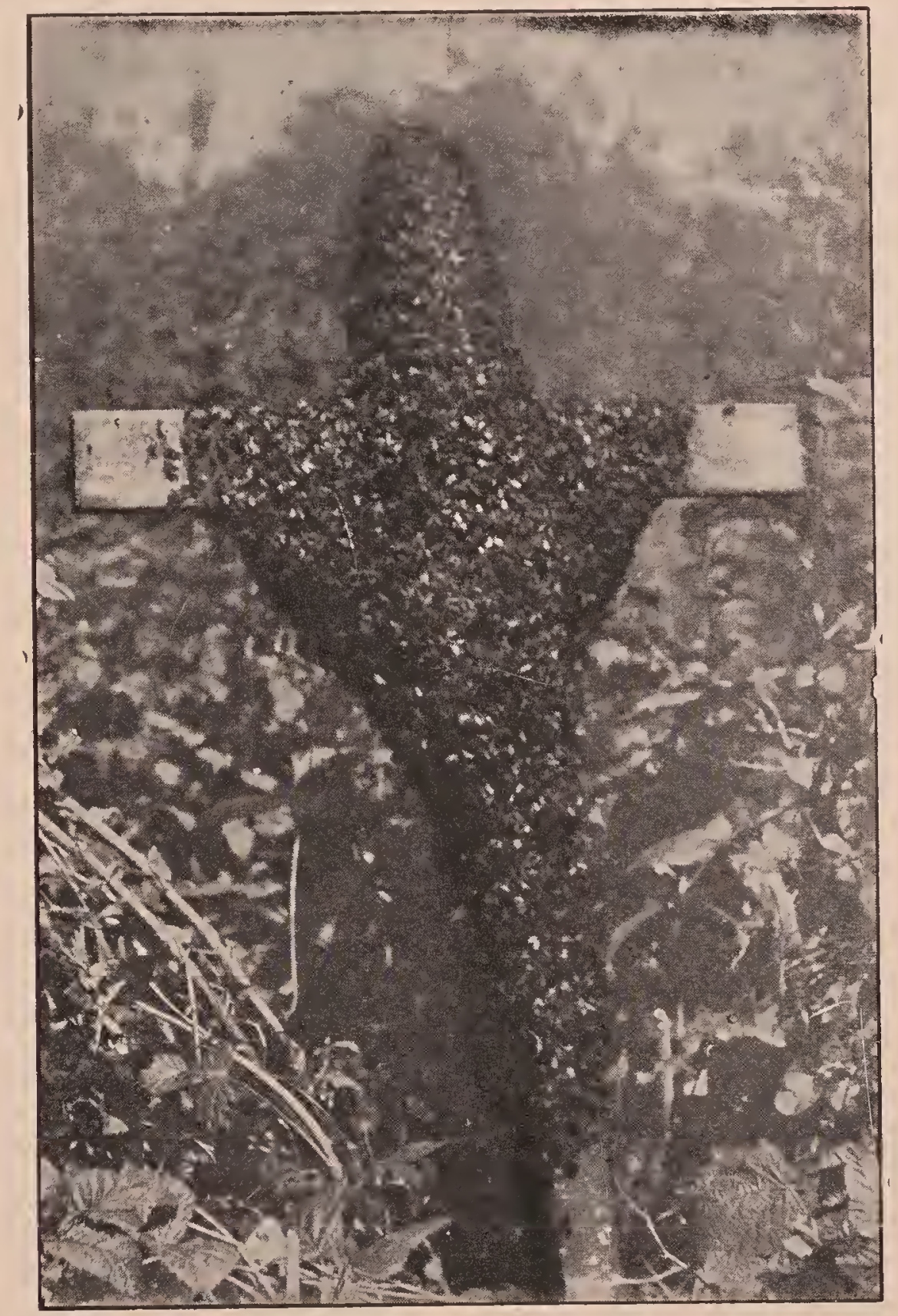

A cross of bees that are not cross.

Apparently after the first young queen emerges the bees hold the other young queens prisoners within their cells until the first after-swarm issues. If the hive is opened just before the issuing of the first after-swarm, usually but one of the queencells will be found vacant; but the disturbance of opening the hive apparently con- begins "piping" (see QUEEN-REARING, subhead QUEEN's VOICES), and her rivals confined in their cells answer her call. This "piping" can best be heard in the evening and usually may be expected about a week after the issuing of the prime swarm. When "piping" is heard in the evening an afterswarm may be expected the next day un- 
less the weather is prolibitive. If other after-swarms are to follow, the piping may again be heard after one or more afterswarms have issued. Each after-swarm seeks a new home where it establishes itself as a new colony. If sufficient food is available these little colonies may build up to normal strength for winter; but too often they are not able to do so, for sometimes the last of the after-swarms to issue contains less tlian a pint of bees.

When further swarming is given $n p$, sometimes after the casting of from two to five after-swarms, all but one of the remaining young queens are killed. About 10 days after emergence the surviving young queen usually begins to lay, and the parent colony again takes up brood-rearing. This makes an interval of about 16 days when no eggs were laid in the parent colony.

PRIME SWARM WITH A YOUNG QUEEN.

Conditions somewhat similar to those in after-swarming are sometimes brought about without the issuing of a normal prime swarm accompanied by the old queen. If. the old queen is failing or is removed from the hive by the beekeeper or is lost thru accident, the bees proceed to rear another. Instead of rearing but one queen they build several queen-cells, and if the colony is prosperous at the time the first one of these young queens emerges, and especially if nectar is abundant in the fields, the bees usually swarm instead of permitting the young queen to destroy the others. In this case the first swarm is accompanied by a young queen, and after-swarming follows in one or two days instead of after an interval of a week or more as when the prime swarm is accompanied by the old queen in the normal way. In such cases the first swarm, tho accompanied by a young queen, may be as large as the nornual prime swarm.

It will be noted that after-swarming is a result of a plurality of young queens and that in nature the division is often carried too far for safety, since many of these little swarms are doomed to perish the following winter, and sometimes the parent colony is so depleted by excessive afterswarming that it fails to store enough honey for winter. Obviously the beekeeper cannot afford to permit the bees to carry out their program of swarming in their own way as described above. He therefore manages to prevent after-swarming (see AFTER-SWARMING) and also, as far as practicable, to eliminate all swarming.

\section{THE SWARMING SEASON.}

Normal swarming takes place during a more or less well-defined period called the "swarming season." In some localities there are two or more swarming seasons during the year, but usually most of the swarming takes place witlin from two to six weeks. The swarming season for any locality comes at about the time the colony has the greatest amount of brood and emerging young bees in the spring. The swarming season may begin as early as March in the extreme south, while in the far north it may not begin until the first of June or even later. If the colonies are not strong enough and prosperous enough to build up to great strength early in the spring, the swarming season may come later after the colonies have built up to swarming strength. In localities where there is an early honey flow in the spring, followed later by a fall honey flow, there may be a secondary swarming season during the fall honey flow. For example, in some parts of the buckwheat region the bees will swarm in May or June when sufficient nectar is available from fruit bloom and clover, then again in August or even in September during the fall honey flow. Where the early and late honey flows overlap each other, forming a long continuous honey flow, the swarming season may be greatly prolonged, especially if the bees were not uniform in strength in the spring, so that some become strong enough to swarm early while others reach swarming strength later. Swarming does not often occur after the elose of the honey flow. If preparations for swarming have been delayed until near the close of the honey flow, the bees often tear down. the queen-cells and give up swarming as soon as nectar becomes scarce. On the other hand, early in the spring colonies often swarm even when not enough nectar is available to keep them from starving unless fed by the beekeeper. The instinct to swarm is much stronger when the colony first reaches swarming strengtl than afterwards. 
LOSS FROM SWARMING.

In the days of the box hive when honey was obtained by killing some of the colonies in the fall, swarming was considered desirable because in this way the number of colonies for slaughter was increased. Modern beekeeping has entirely reversed this view, stvarming now being considered extremely undesirable. Up-to-date beekéepers are careful to reduce swarming to the great: est possible degree and where it can be done profitably prevent it entirely. Increase can be made to better advantage artificially (see INCREASE), for this can be done at the convenience of the beekeeper instead of watching the apiary every day during the swarming season in order to take care of issuing swarms.

Where swarming is not controlled by the beekeeper, the loss from absconding swarms and from the interruption in the work of the bees often causes the loss of good crops of honey which might otherwise have been obtained. In those localities where swarm ing occurs during the honey flow, as in most northern locations, swarming if untrolled causes great loss, often preventing the bees from storing any surplus at all; for if colonies are permitted to divide their working force into two, three or more parts during the honey flow, this division usually marks the end of storing honey in the supers for the season unless the honey flow is unusually long-long enough to permit each division again to build up strong enough to work in the supers.

In some regions as in parts of the South, the swarming season comes six or eight weeks before the main honey flow. In such cases if after-swarming is prevented and botll the swarm and the parent colony have sufficient stores to build up to full strength again before the honey flow, the division is advantageous; but, even in such cases, it is nsually less trouble for the beekeepers to make the division instead of permitting the bees to do so.

\section{BEEKEEPERS' PREPARATION FOR SWARMING.}

The beekeeper should have on hand some extra hives containing empty combs or frames with full sheets of foundation for hiving swarms that issue, unless he expects to practice the requeening method mentioned later for swarm control. These should be prepared in advance of the swarming season, so that it will not be necessary to nail up the hives and put the sheets of foundation in the frames after the swarm has issued. It is not necessary to have as many empty hives as there are colonies in the apiary, for under good management only a part of the colonies will swarm even during a season when the bees are much given to swarming. Some make it a rule to have half as many empty hives as there are colonies of bees if considerable increase is desired, but the beekeeper who has several hundred colonies and does not care for further increase may provide only one extra hive for every four or five colonies, and in some cases much less than this.

As a preventive measure for swarming as well as for the purpose of securing as much honey as possible, an abundance of supers should be provided so that the bees can be given all of the super room they will need during the season. In the production of extracted honey it is important to have plenty of empty combs for the extractingsupers. If these are not to be had, the extracting-supers should be supplied with frames containing full sheet: of foundation. Empty combs are not only better for the purpose of producing the largest pus. sible crop of extracted honey, but at the same time they are better so far as the prevention of swarming is concerned. For comb-honey production the comb-honey supers should be supplied with sections containing full sheets of foundation which nearly fill the sections. This not only results in more surplus honey as well as honey of a finer appearance, but also helps to reduce swarming, inasmuch as combs are built more rapidly when full sheets of foundation are used than when narrow strips only are used.

Some time before the swarming season. preferably during the fruit bloom period of early spring, the queen of each colony should be found and her wings clipped, as explained under QUeEns. Most honey producers today consider this important, because it is much easier to handle any swarms that may issue and because it prevents the escape of the swarms if the beekeeper is absent. While some of the queens mav be lost if swarms issue while the beekeeper is away, it is better to lose the queen than to lose the whole swarm. Of course, 
if a swarm issues during the beekeeper's absence and loses its queen because she is clipped, the swarm having returned to the hive, it is necessary for the beekeeper to examine the bees carefully within a week to destroy all but one of the queen-cells before any of the young queens can emerge, since otherwise a swarm would issue accompanied by a young queen. If the queen's wings are clipped early in the spring, during fruit bloom if possible, it is not difficult to find the queen because there are not so many bees in the hives at this time.

During recent years beekeepers have made such great progress in the matter of the prevention of swarming that some claim it does not pay to clip the wings of the queen because only a few swarms ever issue. . In some localities where swarming is easily prevented it does seem useless to find and clip the queens every spring when practically none of them ever attempt to swarm; but in locations where swarming is troublesome the beekeeper will feel much safer, especially in out-apiary work, if all of the queens are clipped.

Some object to clipping the queens on the ground of the difficulty in finding them; while others are timid about picking up the queen to clip her wings, fearing they might injure her. Again, there are cases where the combs cannot be taken out of the hives to find the queen on account of being built crosswise. In all such cases the Alley trap. as described under Drones, can be used. This does practically the same thing as clipping the queen's wings, but goes a step further since it catches the queen and holds her a prisoner until the beekeeper can take care of the swarm.

\section{HOW TO HIVE A SWARM.}

When the queen's wings are clipped or when the Alley trap is used, hiving swarms is a simple matter. The parent hive is moved away while the swarm is out and a new one put in its place, so that the bees upon missing their queen will return and enter the new hive. See AFTER-SWARMING.

While the author does not recommend that swarms be permitted to issue without either the queens' wings being clipped or the use of the Alley trap. many swarms are permitted to issue in this way, therefore directions are here given for hiving such swarms.

When a swarm issues it is not necessary to ring bells or beat tin pans as was formerly done in order to induce the bees to settle. So far as can be determined, such a procedure has no effect whatever upon the swarming bees. In most cases after circling about for a short time, the bees will form a cluster without any help on the part of the beekeeper. It is sometimes a help to use a spray pump or a hose to throw water among the flying bees to prevent two swarms from uniting while in the air or to drive the swarming bees away from tall trees to induce them to cluster in a more convenient location. Throwing water among the flying bees is sometimes also useful to stop a swarm that is leaving for the woods. A good drenching may cause them to cluster instead of absconding. Ordinarily, however, nothing need be done until the bees have clustered.

If they cluster on a limb of a tree or bush where they can be conveniently reached, one of the simplest ways of hiving them is to cut off the limb above the clustered bees and carry it to the hive. Care must be taken in cutting off the limb not to jar it or the bees may drop off from the limb, take wing and cluster elsewhere. When the swarm is carried to the hive the limb can be laid down gently in front of the hive so that the bees will be as near as possible to the entrance. Some of the bees are then gently pushed into the entrance by means of a feather or twig so that they will start running in. As soon as they begin to run into the hive they set up a call for their comrades to follow, this probably being done by odor. When the bees are running into the hive rapidly the limb can be shaken to dislodge the remainder of the bees if it is desirable to hasten matters. but if there is no hurrv about hiving the swarm on account of the possibility of other swarms issuing and uniting with it, the bees can be left to take their time in crawling into the hive.

If the bees cluster on a limb that cannot well be spared or that is too large to cut off, they can be shaken from the limb into a basket, then carried to the hive and poured out in front of it when they should immediately begin to run into the hive. When bees are poured out from a basket in this way some of them may start to run in the wrong direction, but they can be guided toward the entrance by means of a feather 
or brush. It is well to place a wide board in front of the hive on which to pour the swarm when hived in this way.

Sometimes it is more convenient to carry the hive to the cluster than to carry the cluster to the hive. In such cases the hive should be carried to its permanent location as soon as the bees have entered. Where there are many colonies in the apiary swarms should be hived as quickly as possible or other swarms may issue, and several of them unite if not cared for promptly.

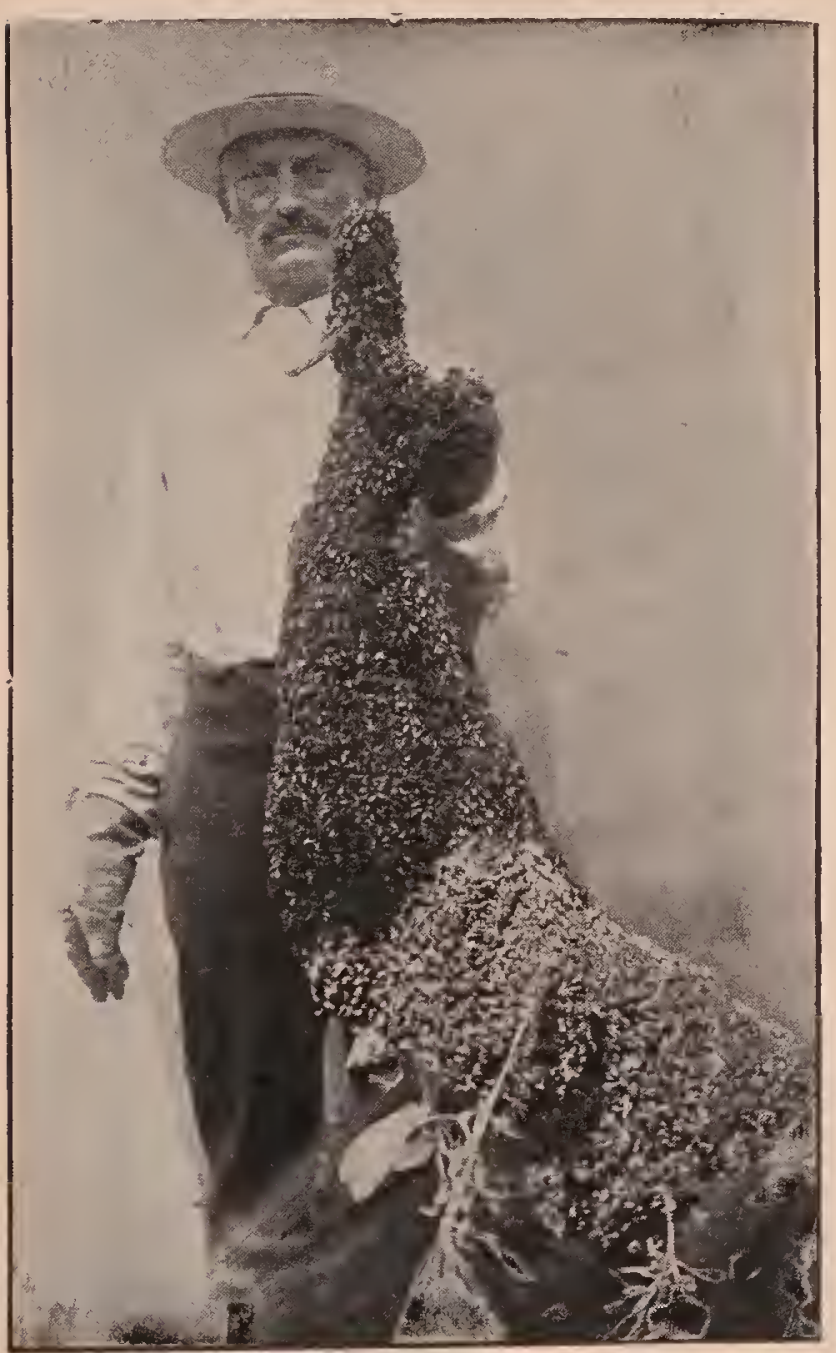

This swarm of bees issued June 7 from a colony of bees that produced 180 pounds of comb honey the same season.

If a swarm clusters on a limb too high to be reached from the ground, it is sometimes necessary to use a ladder to reach them. If the bees cluster on a limb too large to be cut or shaken, part of them can sometimes be scooped up in a dipper and poured out at the entrance of the hive. In such cases it is well to put the hive on a stepladder or a box so its entrance will be against the cluster. By scooping up some of the bees or by brushing them so they will fall upon the alighting-board of the hive, they can be induced to enter and set up a call for their comrades to follow.

\section{HOW TO GET A SWARM FROM AN INACCESSIBLE LIMB.}

Sometimes a swarm will alight upon a limb beyond the reacl of any ladder. Possibly, also, the limb upon which the bees are clustered is so far out from the body of the tree that it would not sustain the weight of any one climbing after them. Such a swarm can usually be reached in the following manner: A stone about as large as the single fist is tied at the end of a good line. If one is not a good thrower himself he can get some boy who is a good ballplayer to perform the throwing act. He should uncoil a considerable quantity of the line, and then throw the stone into a crotch if one is near the swarm. If he is lucky enough to land the stone in the crotch, he should draw gently on the line until the stone catches in the fork. One quick jerk will dislodge the bees, and after that the limb should be kept in a tremble until the bees cluster on some other spot, which they will do presently if the limb is kept agitated for five or ten minutes. They may cluster higher up, but the probabilities are they will seek some other spot more accessible.

If there is no convenient crotch at the right point, the stone should be thrown so it will pass over the limb, taking about one foot of line. The string should be given a good jerk, causing the stone with the line to whirl around the limb a couple of times. If one does not succeed in doing this the first time or two, a third or fourth attempt may be successful. It is not a very difficult trick; but the main thing is to get the line attached to the limb at some point near the swarm.

Some throw a line over a limb above the swarm and then use the line to draw a light rope over the limb to which a hive can be attached. If the hive can be brought up close to the cluster and the limb shaken to dislodge the bees, so that many of them will fall into the uncovered hive, the entire swarm may then enter the hive when it can easily be lowered to the ground. 
HOW TO BRING A SWARM HOME FROM A DISTANCE.

A swarm will sometimes escape and be traced a mile or so from the beeyard. At other times a farmer will report that a

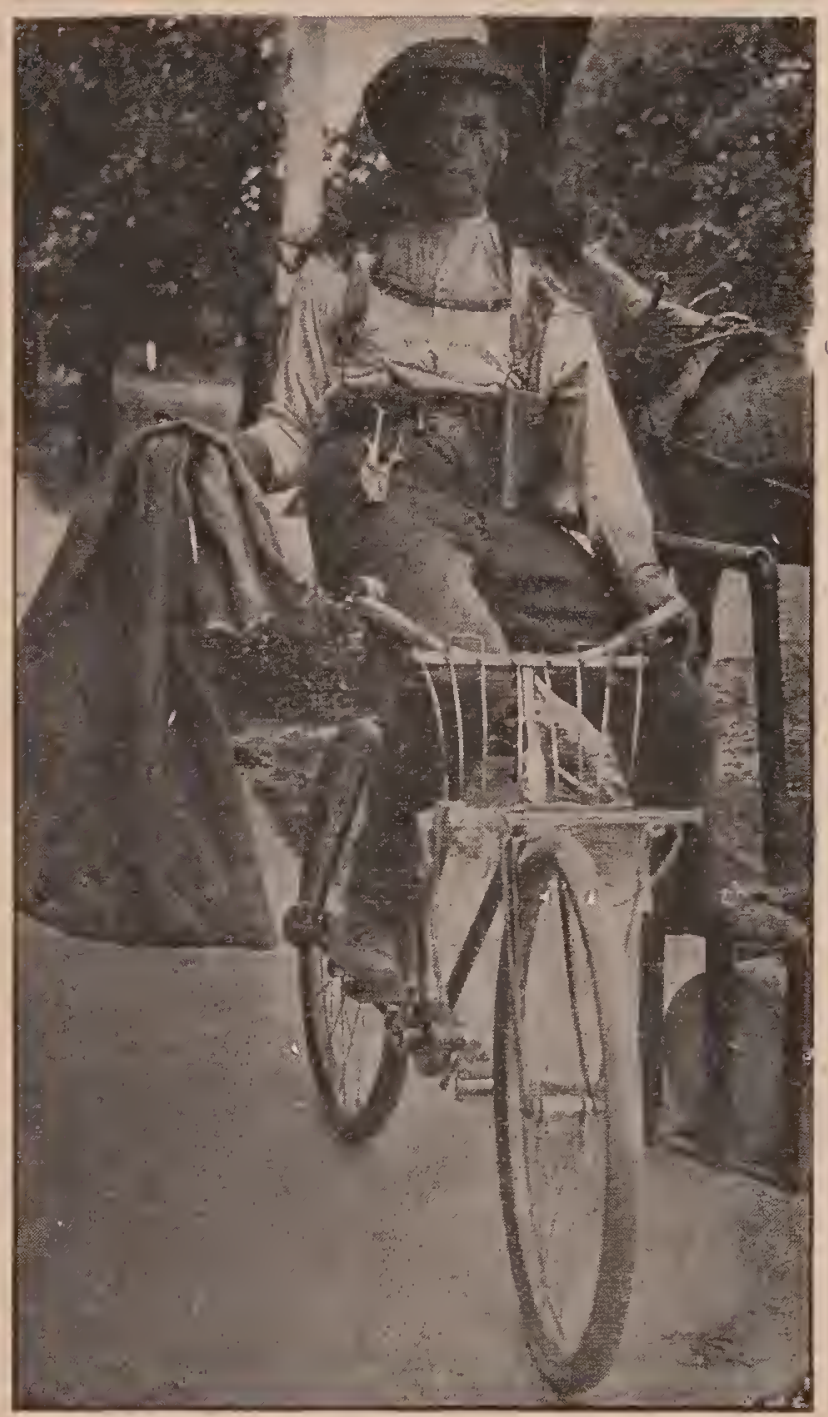

Carrying a captured swarm on a bicycle.

swarm of bees is hanging to one of his trees, and that, if the beeman will come and hive them, he can have them. A good swarm is sometimes worth going after; but how shall it be brought back with the least expenditure of time when bees are swarming at home? A boy can be sent on a bicycle, equipped with a burlap sack, a pair of pruning-shears and a smoker, these latter fastened to the rider. The bicycle enables him to make a quick trip, and on arrival the bag is quietly slipped around the swarm of bees, clustered on a limb of a tree, and the bag tied. The pruning-shears cut the limb, when the bag and all are stung over the handle-bars, or carried in one hand while the other guides the machine home.
PLURAL SWARMS UNITING.

Sometimes when the swarming-note is heard in the apiary other colonies seem to catch the excitement and issue one after another while the first is still in the air. Of course if the wings of the queens are not clipped they will unite in one, and as many as a dozen have been known to come out in this way and go to the woods before anything could be done to stop them. If for no other reason the wings of all queens should be clipped. Even then if a stray virgin queen is present all the bees may unite as one swarm, taking her along.

When the queens are clipped, they can be caught and caged as the swarms issue; then the large cluster of bees can be divided up into as many parts as there are queens and bived in the ordinary way, each division being given one of the queens.

\section{SOME HANDY SWARMING-DEVICES}

Almost every apiarist has his own peculiar notion as to how a swarming-device should be constructed. Some of these implements are very ingenious, and of valuable assistance during the swarming season. Their particular use is to remove a swarm after it has clustered, and place it in the hive where it is desired that it take up a new abode. The first one to which attention is called, not because it is the best but because it is the simplest, is a sort of butterfly-catcher.

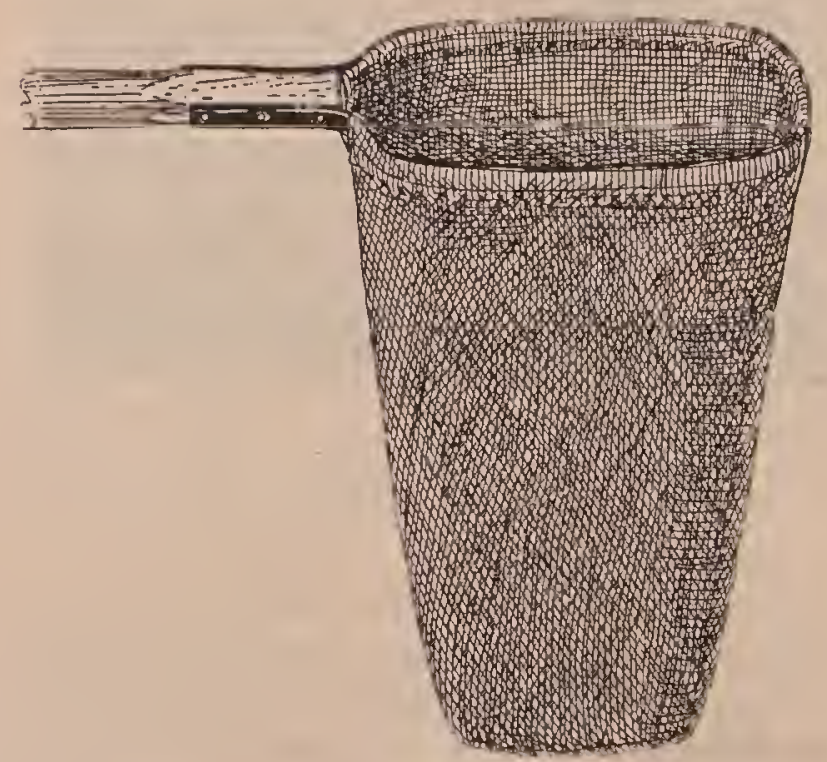

A simple and inexpensive swarm-catcher.

The hoop is made of band iron, about 20 inches in dianteter. The ends are secured, as shown, to a suitable pole. When the bag is attached to the hoop, it is de- 
signed to be put up under the swarm, and the hoop is then made to cut off the cluster so that the bees will fall into the bag. It is then turned edgewise, so as to confine them while being taken down and carried to the hive. It may be necessary to hold the bag in the air to catch the flying bees. These will shortly cluster on the outside. As the bag is made of cheese-cloth, the bees inside have plenty of air. To empty the bees turn it inside out.

\section{A. E. MIANUM'S SWARMINGG-DEVICE.}

This consists of a wire-cloth basket made in the shape of an inverted pyramid, and pivoted at the opposite corners so as to

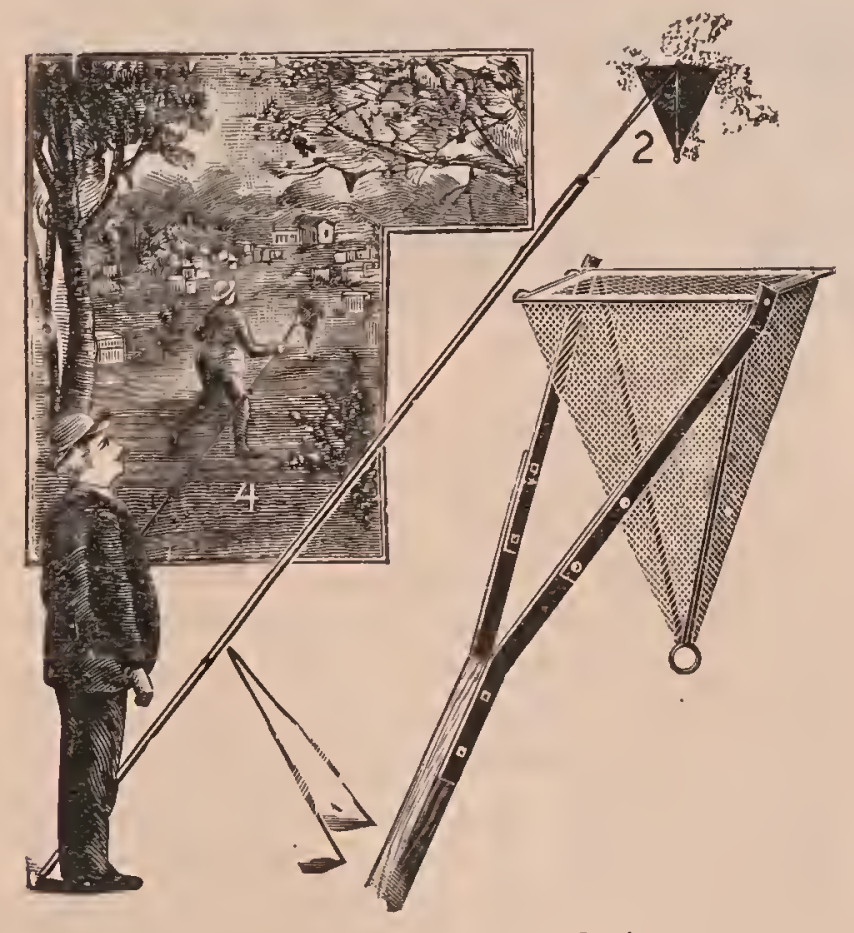

Manum's swarm-catcher device.

hang always in an upright position. When a swarm is captured the basket may be grasped by the ring at the small end, and inverted, dumping the bees into the hive prepared for them.

As soon as the cluster beginning to form on a tree or bush is half or nearly completed, the basket is shoved up to and around the cone of bees. An assistant, if present, gives the limb a jar so as to disengage the bees into the basket. In case no one is ready to assist, a sliding movement of the basket will precipitate the cluster into the wire-cloth cage, when it is quickly lowered. This operation, in passing down thru the limbs, will usually catch the wirecloth lid, and close it witli a slam. In case it is not closed, the apiarist does it himself.
Half or two-thirds of the bees are generally confined. In all probability the queen is there also. As the bees can not get out, those still flying in the air will very readily cluster on the wire cloth, surrounding the majority of their companions inside. To make this more expeditious the tripod is adjusted and the cage suspended in the air right where the bees are flying thickest. In five or ten minutes the remainder of the bees will be clustered on the outside. At this stage of the proceeding the apiarist comes forward, folds the two short legs against the pole, grasps it at its center of gravity and walks off to the hive, which he has previously prepared.

One of the special features of the Manum arrangement is that the basket can be adjusted to almost any position, all the way from two to ten feet from the ground. All that is necessary is to adjust the tripod so that the basket will be held where the bees are flying. In the meantime, unless the hive is already prepared, the apiarist has ample time to get it ready. After this he can return to the swarm just now clustered. Most of the devices require to be held nntil the cluster has settled. It is a tedious job to hold a pole at arm's length, with face upturned.

In the absence of any special tools or appliances one can extemporize in a very few minutes a swarm-catching device out of the ordinary material on a farm. A small sapling, long and slender, is cut. All the branches are trimmed off, care being taken to leave a fork or crotch in the end. This extemporized swarming-pole should be generally from 12 to 15 feet long. A common bushel basket is hooked into the fork at the end of the pole. The combination is almost as good as the one just described, with the further advantage that the basket can be detached from the further end of the pole as soon as the swarm is caught.

After being hooked on to the end of the pole, the basket is elevated to a point just below where the swarm is hanging on the tree. It is gradually pushed up until the swarm is nicely placed therein. The pole is given a sharp push upward, care being taken not to unhook the basket. This sudden jar will dislodge the swarm; and before the bees have an opportunity to take wing, the basket is lowered and un- 


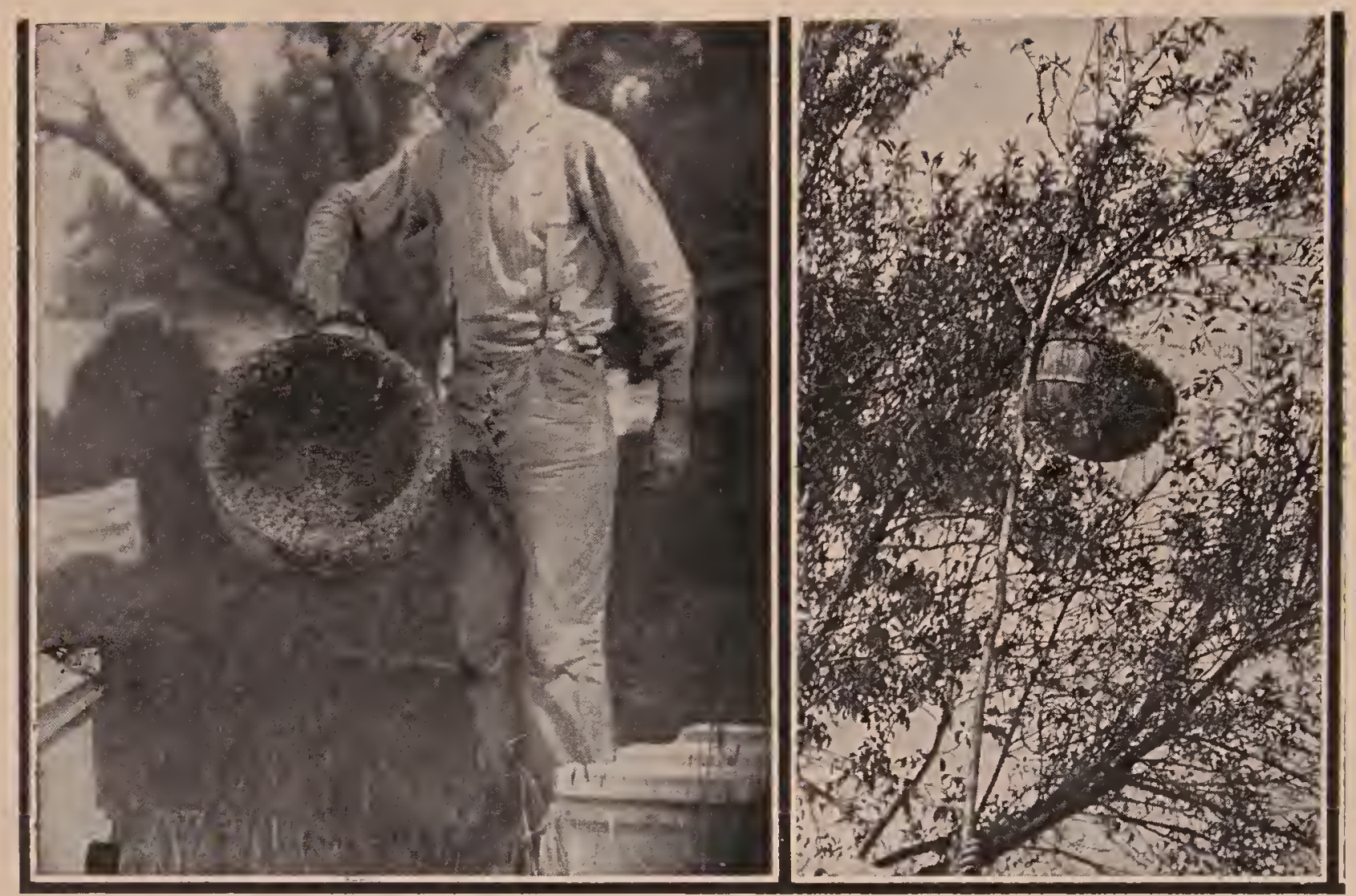

S. D. Chapman of near Mancelona, Mich., and his method of hiving swarms with a forked fole and a bushel basket.

hooked from the end of the pole. It may now be dumped in front of the hive where it is to be placed. In all probability a few more bees may cluster back on the old spot. If so, the operation is repeated, after which the second bunch of bees is placed where the first was dumped.

\section{THE SWARM-HIVING HOOK.}

With most of the hiving-devices a hivinghook can be used to considerable advantage at times. It is simply an iron hook mounted on the end of a long pole, and resembling, somewliat, a shepherd's crook. One of the hiving-devices is passed beneath the swarm. This hook can be used to reach over, grasp the limb on which the swarm is clustered, and by one or two smart jerks jar the bees into the basket, bag, or box.

\section{SPRAY-PUMP FOR CONTROLLING SWARMS WHILE IN THE AIR.}

One of the most useful implements in the apiary when queens are not clipped is a good hand force-pump. A swarm of bees in the air with a queen that might otherwise circle about for fifteen or twenty minutes can usually be made to cluster in from two to five minutes by its use. Whether the fine particles of water dampen the wings, and so impede their flight, or cause the bees to think it is raining, or both, and that therefore they had better cluster at once, can not be proved; but certainly the spray has a very decided effect. One who becomes moderately expert will be able not only to make the bees settle but to compel them to cluster on some point easily accessible to any of the ordinary hiving-devices just described. Occasionally a swarm will make for the top of a tall tree. With a pump they can be headed off, causing them to settle on a lower branch. Even when a swarm is clustered twenty or thirty feet from the ground, by adjusting the stream nozzle and letting it play directly on the swarm itself, it can, many times, be dislodged, thus causing the bees to take wing and finally settle again upon a lower limb or bush. Again, several swarms may come out simultaneously, and two or more attempt to cluster together. By the timely use of the spray, each swarm can be kept separate by dampening the wings of the stragglers of the two swarms about to come together. A good many times a swarm that is about to abscond can be headed off and made to cluster.

\section{THE SWARM-CATCHER.}

This is simply a large wire-cloth cage, in the shape of an oblong box, about three or 
four feet high, by 12 or 15 inches square, one end being open, and made to fit against an ordinary hive-front.

It very often happens that the apiarist is on hand just at the time the swarm begins to pour out from the entrance. With one of these wire swarm-catchers han-

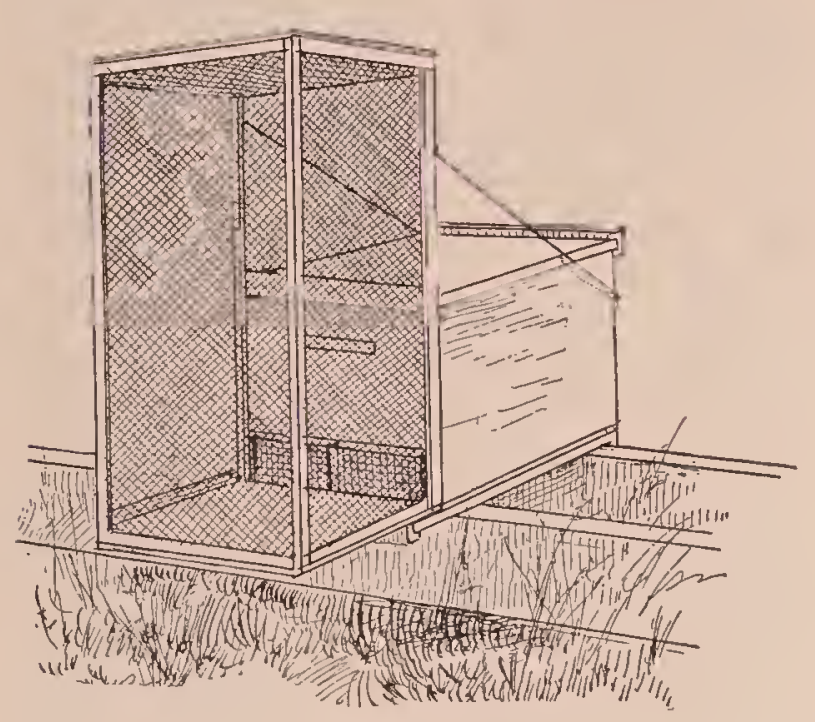

Swarm-catcher.

dy he simply attaches the mouth to the entrance, and the outpouring bees fly pell-mell in to the top of the cage, and are there confined. When the apiarist succeeds in catching two-thirds of the bees, the rest will cluster on the outside. The cage is set mouth end down very near where the bees come forth. Meanwhile the apiarist prepares his hive, if he has not already done so, and then brings the cage of bees and dumps them into the hive, replaces the cover, and the swarm is hived without having had any swarm in the air-not even giving them a ghost of a chance to fly all over the neighborhood, and possibly finally alight upon the limb of a tree 40 feet from the ground. But it should be borne in mind that the swarm-catcher is serviceable only when the apiarist happens to be on the ground just as the bees are beginning to pour forth.

A large cage that comes down over the whole hive is much better than something adjusted to the entrance, because it can be set down over the hive and proceedings stopped. As soon as the bees are all out, the cage is lifted gently, and carried to the hive where it is proposed to dump the swarm. The cage is held squarely over the prepared hive with its cover off, and given one quick jolt. This will dislodge the bees so that most of them will land in and 26 around the hive. As soon as they have settled, the cage is remored and the cover put on the hive.

THE AUTOMATIC HIVING OF SWARMS.

For many years back there has been an effort on the part of beekeepers of an inventive turn of mind to get up an arrangement that would automatically hive swarms in the absence of an apiarist or attendant; and since out-apiaries have begun to assume such importance where the production of honey is carried on extensively, some sort of device that will hive the swarms automatically-yes, do the work just as well as if the apiarist were present himself, is greatly to be desired. Several devices have been introduced; but most of them have been proved to be more or less a failure.

The general plan contemplates some scheme having an empty hive placed near the colony expected to swarm. This empty hive may be alongside, in front of, or below the other one. In the case of the first-mentioned plan, an entrance-guard is placed in front of each hive; and connecting the two is a tube of wire cloth or perforated zinc. When the swarm comes forth, the queen, finding herself barred by the perforated metal, runs along until she finds the tube communicating with the entrance-guard of the other hive. In this tube she runs up against a bee-escape or wire-cloth cone. She passes this; but, being unable to return, is compelled to enter the entrance-guard of the new hive. Upon discovering that the queen is not with them, the bees rush back to the old stand; a part of them find the queen in front of the new hive, enter with the queen and "set up housekeeping." But the plan often fails because the majority fail to find her, and re-enter the parent colony.

WHERE TO LOCATE NEWLY HIVED SWARMS.

Wherever the swarming season comes on during the main honey flow, as in the clover region of the northern States and the orange region of southern California, the early-hived swarms should be located on the old stand, the old hive being placed close to one side if comb honey is being produced, or placed on top of the supers if extracted loney is being produced, in order to keep 
the working force of the colony together in the same hive while the honey flow lasts. (See After-SWARMing, also ARTIFICIAL SWARMING.) In comb-honey production the parent hive should be moved away a week after hiving the swarm in order to draw away the young bees that have learned to fly in the mean time, adding them to the colony on the old stand, thus strengthening the colony that is working in the supers and at the same time preventing after-swarming.

In locations where the swarming season occurs several weeks previous to the main honey flow, so that both the parent colony and the swarm can be built up to fullgathering strength before the honey flow, it is not necessary to carry out this procedure, but all after-swarming should be prevented either by moving away the parent colony just before the young queens emerge or by killing all but one of the queen-cells. If after-swarms were permitted to issue the parent colony would be depleted too much to build up before the honey flow, and the after-swarms would be too small to be productive.

\section{WHAT TO USE IN THE NEW HIVE WHEN HIVING SWARMS.}

For extracted-honey production either empty combs or full sheets of foundation may be used in the new brood-chamber when hiving swarms. When there are not enough empty combs for a full set in each hive, usually a few empty combs are used and the remaining spaces filled out with frames containing full sheets of foundation. Sometimes only one empty comb is used, the rest of the frames containing full sheets of foundation. This is better than to use a full set of frames of foundation.

For comb-honey production it is not advisable to use a full set of empty combs in the new brood-chamber when hiving swarms, for when this is done the bees are inclined to store their honey in these combs, neglecting the work in the supers. This is especially true for colonies that are of only medium strength. For this reason it is better to use full sheets of foundation in the brood-chamber when hiving swarms in comb-honey production. When this is done at least one empty comb should be used to reduce the tendency to swarm out, as sometimes occurs when frames of foundation exclusively are used in the new brood-chamber. If no empty combs are available for this purpose, it is well to place an empty hive-body under the new brood-chamber for two or three days if the bees are inclined to swarm out.

At one time it was thought best to use only narrow strips of foundation in the frames in the new brood-chamber, on the theory that the bees will then be compelled to store their honey in the supers on account of the greater length of time necessary to build comb in the brood-chamber when the narrow strips of foundation only are used. Under some conditions this plan gives excellent results in comb-honey production; but it is open to the serious objection that entirely too much drone comb is built in the brood-frames, and also there is a tendency to store pollen in the sections during the first few days after being hived since there is no comb in the brood-chamber in which to store pollen. This latter objection can be overcome by using one empty comb in the new brood-chamber to catch the incoming pollen; but this would, to a certain extent, defeat the purpose of the use of narrow strips of foundation only, for it would afford a place for immediate storage of nectar in the brood-chamber instead of in the sections. Another objection to the use of empty combs in the new broodchamber in connection with frames containing only narrow strips of foundation is that the bees would begin the building of drone combs just that much sooner. Usually the bees will build the equivalent of four or five standard frames of worker comb before they begin building drone comb. For this reason some beekeepers have advocated contracting the new brood-chamber to five standard frames when hiving swarms, but this plan has been largely abandoned because it leaves the colony destitute of honey and greatly weakened at the end of the season.

It is sometimes convenient to hive swarms on combs containing honey. When combs of honey which are.mostly unsealed are used the bees will begin to transfer the honey into the supers almost inmediately after being hived; but if combs of sealed honey are used the bees will often sulk or work with less vigor in the supers, apparently objecting to uncapping and transferring the sealed honey to the supers. It 
is sometimes a good plan in comb-honey production to have frames of foundation drawn out in the second story of the strongest colonies at the very beginning of the honey flow to hold down swarming, and then use these newly built combs containing unsealed honey on which to hive swarms.

If the beekeeper runs out of hives and frames during the swarming season he can utilize the hive of a parent colony, choosing one that swarmed ten days or more previously. In this case the bees in the parent colony can be shaken from their combs in front of the recently hived swarm standing by its side (see Where to LOCATE NewLY Hrved Swarms, page 801); then this hive, together with the comb containing now only sealed brood, can be used for hiving another swarm. When such combs are used there are so few vacant cells that the bees will not neglect super work on account of the empty combs below, but the few cells that are vacant will soon be occupied by eggs which the queen will lay soon after the swarm is hived. As the remaining brood emerges the vacated cells are usually prepared for eggs until toward the close of the season when the bees will put in more honey.

When either narrow strips of foundation or full sheets of foundation are used in the new brood-chamber a queen-excluder should be placed between the brood-chamber and the supers at the time of hiving the swarm, since otherwise the queen would probably establish a brood-nest in the supers.

\section{SWARMING OUT.}

Sometimes newly hived swarms "swarm out," deserting their new hive and absconding if the queen is not clipped. They may do this within an hour or two after being hived or the next day and sometimes even on the third day after being hived. Swarming out may occur either with natural swarms or artificial swarms. The tendency for newly hived swarms to swarm out is greater some seasons than others. This trouble is apparently a result of a lack of room in the new hive or of discomfort from some other cause, tho sometimes newly hived swarms will leave the hive when there is no apparent cause for their dissatisfaction.

Swarming out can be prevented, or at least greatly reduced, by placing an empty hive-body below the new brood-chamber for two or three days; by providing ample ventilation and shade for the new hive at the time of hiving the swarm, and by using one or more empty combs which had been previously used for brood-rearing in the new brood-chamber instead of frames of foundation exclusively.

If the queen is elipped, colonies that swarm out can not abseond unless by chance they unite with another swar'm that has a queen able to fly that happens to be out at the same time. When bees swarm out they can be handled in the same manner as a swarm with a clipped queen (see directions under AFTER-SWARMING), by simply caging the queen, thrusting the cage into the entrance and waiting for the swarm to return. Sometimes it is not necessary to make any change of conditions to induce the bees to stay after they have swarined out once or twice. Sometimes, when bees swarm out they become demolalized and do not all return to their own hive, some going into adjacent hives. When bees swarm out in the absence of the beekeeper the queen is liable to be lost by entering another hive. If the queen is not clipped it is well to place an entrance guard or an Alley trap over the entrance for a few days if the bees are inclined to swarm out. This will prevent the escape of the queen, and the bees will return to their hive.

\section{THE CAUSE OF SWARMING.}

Since swarming is the natural method of reproduction of colonies, upon which the existence of the species depends in nature, beekeepers are willing to accept the deeply seated reproductive instinct as the fundamental cause of swarming, but they want to know just what calls forth this instinct at certain times and why it is apparently dormant at other times. It is well known that some colonies go thru the season piling up a large surplus of honey, apparently without a thought of swarming, while other colonies in the same apiary stubbornly persist in carrying out their program of swarming; that some seasons practically all colonies go thru the season without attempting to swarm, while in other seasons a majority of the colonies attempt to swarm; and that in some localities, as in some parts of the tropics, well-managed colonies seldom swarm, while in other 
localities, especially in the far north, swarming is troublesome nearly erery season. No wonder that beekeepers have been searching for the thing that throws the switch which leads some colonies headlong into swarming, while others continue on the main track of gatlering and storing honey.

\section{INFLUENCE OF HEREDITY.}

In the search for the thing that throws the switch, some have looked upon the tendency to swarm as an inherited trait that might be bred out; and at one time American beekeepers made a serious effort to eliminate swarming by careful selection of breeding stock. Some even elaimed actually to have accomplished this, but today it is generally agreed that a non-swarming strain of bees can not be developed by breeding. The swarming tendency has been greatly reduced, of course, by the elimination of stock too much given to swarming without sufficient excuse.

\section{INFLUENCE OF SIZE OF HIVES.}

Lack of sufficient room is generally reeognized as contributing to the tendency to swarm. As a rule, colonies in large hives swarm less than colonies in small hives. Formerly much was said about colonies of bees established in attics never swarming, because such colonies had the whole attic for a hive. But swarms do issue from colonies housed in atties and other large cavities, and have been known to issue from colonies established under the eaves of buildings, having the whole out-of-doors for a hive. Swarms sometimes issue from the largest of hives, even when tiered up five or six stories high. Swarms have been known to issue from two-story hives having 20 combs of which only four or five contained brood, the rest of the combs being practically empty and not occupied by the little colony.

While large hives and an abundance of room in the form of good empty comb greatly reduce swarming, they do not prevent it in all localities every season.

\section{INFLUENCE OF THE HONEY FLOW.}

It has been said that bees swarm because of the honey flow, which makes them feel sufficiently prosperous to divide the colony and build a new home. In the North swarming does usually come during the early honey flow; but in some localities, especially in the South, swarming oceurs before the main honey flow, swarms sometimes issuing when the colonies are gathering scarcely enough for a living. In some places swarming ceases entirely on the arrival of the honey flow, while in other places swarming usually begins at the beginning of the main lioney flow.

While the honey flow often influences swarming, it can not be considered the cause.

\section{INFLUENCE OF DRONES.}

The presence of drones and drone brood has been considered as the cause of swarming. Working on this theory Aspinwall constructed wooden combs by drilling holes into the ends of blocks of wood to form the cells in order to have all cells of worker size to prevent the rearing of drones. After year's of research along this line he abandoned this theory of the cause of swarming and took up another theory to be mentioned later, which finally resulted in the invention of a non-swarming hive. In this hive instead of eliminating the drones he provided wide spaces between the combs, inserting in these spaces slatted dividers to prevent comb-building in these spaces.

INFLUENCE OF AGE OF QUEEN.

Old queens have been put forth as the cause of swarming. Some said that the old queen becomes broody in her second year. Others said that a queen, after laying so many eggs in the spurt of spring broodrearing, becomes tired and seeks a rest by swarming.

At one time it was believed by many that a queen does not swarm during the first season of her life, and several beekeepers in the North tried to prevent swarming by requeening their colonies in the spring with young queens from the Soutl- - only to find that many colonies so treated swarmed, tho, of course, they no doubt had less swarming because of the young queens.

Much of the trouble from swarming in colonies having old queens, is no doubt from supersedure during the swarming season (see Supersedure of Queens) when colonies often apparently depart from the original plan of supersedure and swarm because queen-cells are present. In many re- 
spects such swarming is quite different from normal swarming.

Gravenhorst, a German writer, laid down the rule that a colony having a laying queen reared this season will not swarm this season, provided the queen was reared in this colony. If she was reared elsewhere, the colony may swarm this season. But we know that if the old queen is removed at swarming time and all queen-cells (if any) are destroyed, then all queen-cells again destroyed ten days later, a young laying queen from another colony may be given a few days later with the same safety from further swarming as tho the young queen had been reared in this colony.

The important thing to note here is that when a young queen is reared in this colony this year, there is (except in some cases of supersedure) an interval of at least 16 days during which no eggs are laid. When a similar break in brood-rearing is brought about by removing the queen, it does not make any difference whether the young queen is reared in this colony or elsewhere, so far as swarming is concerned. Even when the old queen is given back to the colony after 16 days, there is usually no further swarming.

Apparently the condition of the colony brought about by the period of queenlessness has more to do with the prevention of swarming than the age of the queen.

\section{HOW YOUNG BEES CONTRIBUTE TO}

\section{SWARMING.}

Gerstung, a German investigator, put forth the theory that swarming is brought on by a preponderance of young bees. This fits in well with the well-known fact that the swarming tendency is strongest early in the season when young bees are emerging in greatest numbers, as well as explaining why swarming is worse in those localities where the bees build up most rapidly in the spring and during those seasons when because of favorable conditions building up is most rapid, thus resulting in an unusual number of emerging and recently emerged young bees. This theory would also explain why colonies are willing to give up swarming when their brood is taken away as in artificial swarming, as well as why the swarming impulse disappears completely about 20 days after removing the queen when the dequeening plan is used to prevent swarming.
Using this theory as a basis, comb-honey producers about 20 years ago worked out plans by which the brood and youngest bees were taken from the colony at swarming time, kept in a separate hive until old enough to do field work and then returned to the main colony. Producers of extracted honey, instead of putting the brood and young bees into a separate hive, placed the chamber containing the brood above the queen-excluder, the queen being confined below, thus separating the young and emerging bees from the colony below. In 1908 E. E. Coveyou advised placing the chamber of emerging bees above the supers to separate them still further from the colony. (See Gleanings in Bee Culture, 1908, pages 640-641.) This was further emphasized by A. C. Allen in 1910 (American Bee Journal, page 94) and by Chalon Fowls in 1915 (Gleanings in Bee Culture, 1915, page 574). Mr. Fowls especially emplasized the importance of having all the young bees in the old brood-cliamber above the supers, having only bees old enough to work in the fields in the new brood-chamber below.

The Aspinwall non-swarming hive was based upon the young-bee theory as the cause of swarming. It provided extra room for these young bees between the combs.

Gerstung, however, carried his theory so far as to attempt to explain swarming as caused by an excess of nurse bees in proportion to the number of larvae to be fed, the unused larval food causing a physiological condition in the nurse bees bringing on the swarming impulse. He evidently quite forgot that when an artificial swarm is made by shaking there are no larvae to feed during the first three days; yet the bees are willing to give up swarming if properly handled, even tho these same nurse bees are shaken with the older bees and there should be a much greater excess of larval food than before shaking. Under conditions mentioned below colonies made up largely of older bees have been known to swarm, tho this is quite unusual.

While a large proportion of young bees, no doubt, contribute to bringing on swarming, they alone evidently are not always the cause.

HOW FIELD BEES CONTRIBUTE TO SWARMING.

During the honey flow from elover in 1916 the plants apparently did not begin 


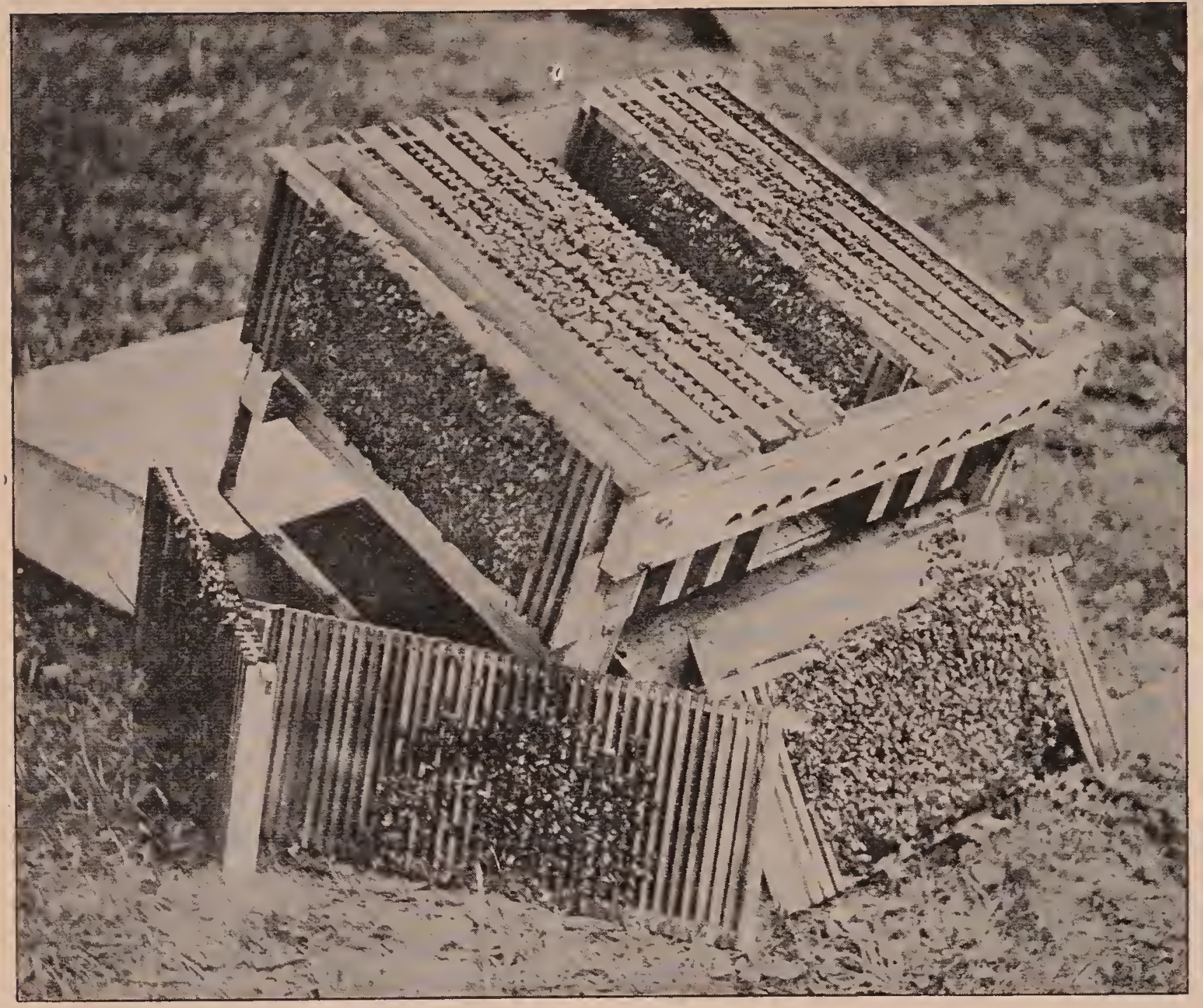

Aspinwall hive dissected, showing brood-frames and slatted dividers.

to yield nectar until late in the forenoon, since the bees did not go to the fields until about 11 o'clock. During these hot forenoons the great army of field bees remained in the hives, crowded into the space below the frames and pushing upward among the combs, apparently waiting for the signal to rush to the fields. But few, if any, field bees could be found in the supers during the forenoons, but the brood-chambers, especially the lower portion, were literally jammed with these old workers. Just previous to the honey flow the field bees had been confined to their hives by several weeks of almost continuous rain, and when the honey flow finally came they staid at home during the sultry forenoons waiting for the nectar to come. Excessive swarming was reported that season wherever this condition existed.

The author has carefully gone over the back rolumes of the bee journals for reports of seasons of excessive swarming; and in every case, excessive swarming was attended by some factor which caused the field bees to stay in the hives during the heat of the day,-such as rain or the flowers yielding only a part of the day.

While a large proportion of bees too young for field work is apparently conducive to swarming, if to these is added the great horde of field bees all trying to stay within the already crowded brood-chamber, the congestion and discomfort are too much for even the best-bred bees, which at such times often forget their manners and swarm most unreasonably.

ONE FACTOR ALWATS PRESENT IN SWARMING.

Fifty years of accumulated experience of beekeepers waging a bitter fight against swarming indicates that one thing is always present in normal swarming, so far as the prime swarm is concerned, whether the hive is large or small, whetlier the colony is weak or strong, whether the queen is two years 
old or two weeks old. This one thing that is always present is a congestion of bees within the brood-nest, bringing to the colony a feeling of strength or a need for expansion.

This, then, must be the cause of swarming. The many other things, often mentioned as the cause but which are not always present, are contributory to swarming only inasmuch as they may help to bring about the crowded condition within the brood-nest (not in the entire hive), which suggests to the colony its strength or need for expansion.

If this congestion is brought about in weak and medium colonies by the colony's confining its work to the brood-chamber, leaving the supers and remote brood-combs vacant and crowding the queen by surrounding the brood-nest with honey, the congestion within this little brood-nest is as real and as potent in bringing on the swarming impulse as tho the colony were 20 times as strong. The remedy is stronger colonies or a strain of bees less inclined to crowd the queen in this manner. If the congestion and discomfort are brought about by a lack of ventilation or shade, the remedy is obvious. If the congestion is caused by a preponderance of young bees which are inclined to stay in the brood-nest too long, the remedy is to invite these youngsters upstairs by giving a set of attractive empty combs immediately above the brood-combs, or if comb honey is being produced, a skilful management of the supers to attract the younger bees into the supers to the greatest possible degree. If the congestion is brought about by field bees staying at home as they often do, even when nectar is plentiful, because the hive is already crowded and uncomfortable, the remedy is to invite more bees upstairs and give more ventilation if needed. How foolish for field bees to stay at home because the hive is not comfortable, when by doing so they orly add to the discomfort!

Congestion of the brood-nest is a matter of distribution of the bees rather than numbers, for the hive can be expanded to accommodate all; but the bees must be induced to expand their work also as the hive is expanded. If most of the bees can be induced to leave the brood-nest, going either into the supers or to the fields, all is well. If the congestion in the brood-nest is caused by field bees staying at home during the heat of the day waiting for the flowers to begin to yield, the problem becomes more difficult; but here again anything that adds to the comfort of the colony should help. Anyway, it is some comfort to know the cause of swarming even tho we have not yet learned how to remove it in every case.

\section{PREVENTION OF SWARMING.}

Under this head will be considered the methods which reduce the tendency to swarm. Swarm-preventive measures, as here considered, are those which result in fewer colonies building queen-cells preparatory to swarming. After a colony has started to build queen-cells in preparation for swarming, especially after the queen-cells are well developed, the beekeeper may apply some measure to prevent the issuing of a swarm, such as removing the queen or making an artificial swarm. These are really remedial measures instead of preventive measures and are accordingly discussed under a separate head. See Remedial Measures.

The reader will understand from the discussion on preceding pages that swarm-preventive measures which work well in one locality may fail entirely in another; and that measures which prevent swarming one season may fail to do so the next; and that measures which will prevent swarming in one colony may fail to do so in another colony in the same apiary. However, swarming can be greatly reduced for any locality during any season, and in some localities entirely prevented by careful attention to well-known preventive measures.

Following is a summary of some of the most important swarm-preventive measures. It will be noted that, with the exception of the first and the last items in the list, each of these is directly concerned with the prevention of congestion and discomfort within the brood-nest itself; or, in other words, the removal of the cause of swarming as given on the preceding pages. No doubt if all of the facts were known, even the firstmentioned item, that of the selection of stock less inclined to swarm, would also be included in the list of measures tending to reduce congestion and discomfort within the brood-nest, since some strains of bees are much more inclined to erowd the broodnest than other strains. 
(1) BREEDING TO REDUCE SWARMING TENDENCIES.

When things are allowed to take their own course in the apiary most of the increase is made during the swarming season, and the queens are reared from swarming-cells. The question has been raised whether such queens will not inherit more of the swarming tendency than those reared under the supersedure impulse. There can be no doubt that the indiscriminate use of queen-cells taken from swarming colonies will result in much poorer stock, but the fact that the queen-cells were built in preparation for swarming instead of for supersedure probably does not change the tendency of the resulting queen toward swarming.

So far as is known, there is no objection to the use of swarming-cells from colonies that are otherwise desirable, but that have been forced to swarm thru neglect or bad management. Neither is there any objection to having queen-cells built in swarming colonies, the larvae for which have been transferred from the colonies having the breeding queens. Since swarming-cells are built at the time the colony is quite prosperous such cells usually result in fine, vigorous young queens.

The strain of bees can be greatly improved by killing the queens of any colony which prepares to swarm when there is no excuse for swarming, and replacing them with queens reared from colonies which show less tendency to swarm under the same conditions.

\section{(2). LARGE BROOD-CHAMBERS TO CONTROL SWARMING.}

In the colder climates, brood-rearing is usually carried on with a rush during the spring, and for a short time at least the colonies will have a larger amount of brood than in warmer climates. During this short (and intensive) brood-rearing period it is important that the queen shall have all of the room she can occupy for brood. If the brood-chamber is too small for the capacity of the queen, the colony will become crowded and probably swarm. For this reason some beekeeepers prefer to use brood-chambers larger than the standard ten-frame hive of Langstroth dimensions. Some use the Jumbo hive, especially for extracted- honey production; while others prefer a hive even larger than the ten-frame Jumbo, some advocating using these frames in hives holding eleven, twelve or thirteen frames.

Those who use the regular standard hive usually add a second story in the spring as soon as the queen needs more room. Since it is for a short time only that more room is needed, one of the regular extractingsupers is loaned temporarily to the use of the queen and becomes a part of a larger brood-chamber. After the peak of the spring brood-rearing period has passed, the queen can be put into the lower hive-body and the other one again becomes an extracting-super, if extracted honey is being produced. Many comb-honey producers use the same plan, leaving on the second story until the beginning of the honey flow when the hives are reduced to a single story and the comb-honey supers put in place. The extra hive-bodies that are removed are then either tiered up on certain colonies set aside for this purpose, or are used in making increase. If no increase is desired, the extra hive-body, together with the extra combs of brood and honey and enough bees to take care of them, can be used to make a good-sized nucleus, which should be supplied with a ripe queen-cell and the hive placed close beside the original hive. At the close of the season the two colonies can be united by the nerwspaper plan (see Uniting Bees). In the majority of cases the young queen will be retained when no attention is paid to the queens, but to insure this the old queen should be killed.

An excellent plan for supplying an abundance of room for early brood-rearing to prevent swarming and at the same time greatly stimulate brood-rearing with the standard 10-frame hive when producing extracted honey, was described in Gleanings in Bee Culture in 1908 by E. D. Townsend as follows:

E. E. Coveyou of Petoskey, Mich., has a very good plan for handling his bees during the fore part of the honey flow. He uses tenfrime hives, and before the honey flow he gives the colonies another story of combs without putting an excluder between. The cells of these combs should be of the worker size, for the queen is allowed full sway thru this story until the colony needs a third one. At the time this third story is given, the queen is placed below in the 
first story, a queen-excluder is put on, and then the third story of empty combs put over it. Finally, on top of all, the second story partly full of honey and brood is added. This plan has the advantage of giving the colony an abundance of comb room and also an unlimited amount of breeding space for the queen during the critical swarming period previous to the honey flow.

When the bees are wintered in a single story, the second story should be given a little before the combs in the lower story are completely filled with brood, honey, and pollen, and at least several of the combs in the second story should be old dark brood-

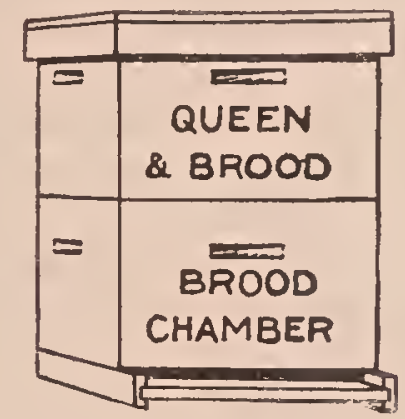

Previous to the honey

flow the queen occupies both stories.

combs to attract the queen above promptly. Since in the North this second story should be given about the first of May (sometimes even the latter part of April in well-wintered colonies) the hives, if packed, should be left in the packing-cases and the packing material replaced around the upper story. If enough early honey is stored in the up-

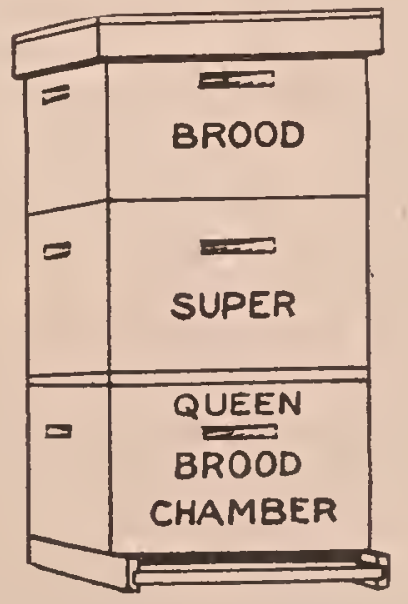

Queen is put below excluder and brood plac. ed above the super.

per story to crowd the queen there (which often happens with strong, well-wintered colonies in the spring even when weak ones in the same apiary are starving), a third story of empty combs should be given even tho the main honey flow is still several weeks in the future. To save trouble when putting the queen down later, it is well to put the queen-excluder over the second story to keep the queen out of the third story. When strong colonies are managed in this way the queen usually abandons the lower stoly soon after the second story is given, but carries on her work of filling the second story with apparently increased vigor.

After the queen has been above so long that most of the brood left in the lower story has emerged, she should be put.down. This will usually be about three weeks after the second story was given if the queen went up promptly when the second story was given. To put the queen below, some prefer setting off the second story and hunting ont the queen, when she is simply picked up and transferred to the lower story; while others prefer to shake the bees from the combs of the second story, to be sure that the queen is put below, instead of finding her.

Strange as it may seem, putting the queen back into the lower story and confining her there by means of the queenexcluder is a swarm-control measure of great importance, just as inviting her into the second story was a few weeks previously. At first thought one might expect that limiting the queen to a single story should increase the tendency to swarm. To have confined the queen to the lower story earlier in the season without having permitted her to go into the second story would result in swarming in many cases, but conditions now are quite different.

The bees are now compelled to establish their brood-nest anew in the lower story, which at this time contains but a little brood. This brood is rapidly emerging, and the colony behaves much like a newly hived swarm. There is usually considerable pollen stored in the lower set of combs, which probably retards the work of the queen to some extent; but, where the honey flow is short, this is often an advantage. The conditions are as tho an artificial swarm had been made, the swarm being in the lower story, below the supers and the parent colony above the super's, but all the bees are in the same hive.

Nine or ten days after the brood was put up and the queen put down, all queen-cells 
built in the top story not needed in nuclei may be destroyed and this former broodchamber left on the hive as a super. It is not always necessary to destroy these queencells if this brood-chamber now on top is separated from the lower brood-chamber by at least two standard-depth supers. The emergence of young queens in the top story then usually causes no trouble. By pushing one of the upper stories forward far enough to form an opening at the back the drones can escape from the hive, and a young queen may be permitted to go forth to mate thru this opening.

While this plan can not be depended upon everywhere to prevent all swarming, if properly put into effect it should be as effective as or more so than a larger broodchamber on account of the added stimulus to brood-rearing resulting from the establishment of a new brood-nest above, then later below the excluder in a set of combs being rapidly vacated by emerging young bees. It should be noted that the standard 10 -frame brood-chamber is ample for the queen except possibly during a few weeks in the spring when she is permitted to go into one of the extracting-supers temporarily.

\section{(3). IMPORTANCE OF PERFECT WORKER.} СОМв.

Not only does a large amount of drone comb in the brood-chamber result in the rearing of a great number of drones, which can only be in the way, and help bring about a crowded condition within the broodchamber, but also every cell of drone comb or every distorted cell that cannot be used for rearing workers really reduces the size of the brood-chamber so far as brood-rearing is concerned.

\section{(4). Barriers in the WAY OF THE QUeEN.}

There should be no barriers in the way of the free expansion of the brood-nest in the spring. If combs which are unsuitable for brood-rearing are between good combs, the poor combs stand in the way as a barrier. Sometimes rather than to cross such a barrier the queen will confine herself to one side of the hive and the colony will become crowded even with an abundance of empty comb beyond. This is more liable to happen witl weak colonies than with strong ones; but, even with strong colonies, there should be nothing in the way of the free expansion of the brood-nest in the spring. If two stories are used for broodrearing it is important that the combs in the lower story at least have worker-cells to the top-bar so that the queen will pass readily up into the second story. When there is an abundance of room in the second story the queen, after beginning work there, often abandons the lower story entirely unless she becomes crowded in the upper story. Before this happens, the queen should be put below again so that the colony need not be crowded for room for brood-rearing.

\section{(5). PROViding abUNdant ventilation.}

If the entrance is very much contracted it render's it extremely difficult for the bees to ventilate the hive properly. This is a very important factor, especially in a hot season. Therefore at the beginning of the honey harvest all colonies should have their entrances very much enlarged; and if any of the colonies still seem inclined to cluster and loaf, more ventilation should be given by placing four $7 / 8$-inch blocks between the hive and the bottom-board. This will provide an opening on all four sides. While the bees will use the front entrance mainly, they will also fly from the others. With so much rentilation the bees, unless the colonies are extraordinarily strong, will go back into the hive and go to work. Some beekeepers go so far as to claim that the procedure will almost entirely eliminate swarming.

During the swarming season the weather may be very hot or even sultry; but, no matter what the outside temperature, it is very important that the internal temperature be kept down to about 96 . If it goes much higher, a large portion of the bees will be forced outside.

By giving plenty of bottom ventilation it will take fewer bees to keep the hive cool than when a restricted entrance is used. In this connection it may be well to explain that one set of bees will place themselves in such a position that they force a current of air into the hive, and another set forces the warm moist air out of it. After the bees have been lieavily at work in the field, if one will light a match and hold it in front of the entrance, he will find there is a strong current of air going in on one side and another strong current going out at the other side. Sometimes the air seems to 
go in at both sides and come out in the center. See VENTILATION.

During extremely hot weather many extracted-lıoney producers use Dr. Miller's plan of "staggering" the stories--that is, the second story is shoved forward enough to leave a ventilating space of lialf an inch at the back between the two stories. The third is shoved back to leave a similar space at the front between the second and third. The fourth is shoved forward, etc.; and, last of all, the cover is shoved forward to leave another half-inch space. When raising comb loney it is necessary to keep the supers warm enough so that comb-building may continue at night. Therefore stories should not be "staggered" in comb-honey production.

When the hives are not blocked up to allow additional ventilation a large space between the bottom-bars of the frames and the floor of the hive is advantageous in lot weather. In hives as ordinarily made in this country this space is $7 / 8$ of an inch, which is about as much as can be given without bees' building combs below the bottom-bars of the frames, especially in combhoney production. A space two inches deep or more would be better still, so far as swarming is concerned, if the bees would not build comb in this space. Sucl a space can be used, however, by putting a slatted rack under the frames to prevent the bees from building comb in this space. This affords a large amount of room for the field bees during the night as well as during the day if the flowers yield only a part of the day, and also provides an abundance of ventilation.

In order to add to the space between the combs in the brood-chamber C. P. Dadant, who uses the large Quinby frame, prefers to have these spaced $11 / 2$ inches from center to center. Mr. Dadant regards this wider spacing as quite important in reducing the tendency to swarm.

\section{(6). GIVING SHADE.}

Practically the same reasons that apply for giving an abundance of rentilation also apply here. A colony in a hive that is exposed to the direct rays of the siun has a nuch more difficult problem in keeping the interior of the hive cool than when the hive is in the shade. Under the head of APIARIES, various means for shading the hive are illustrated and described. If a hive is exposed to the hot sun it requires a good many bees to keep up the ventilation, and these bees might otherwise be in the field at work.

Painting the hive white adds to the comfort of the bees, because the light color reflects the rays of the sun and prevents the hive from being heated as much as would be the case if it were a darker color.

\section{(7). BARRIERS OF SEALED HONEY AROUND THE BROOD-NEST.}

Colonies that are weak or only of medium strength at the beginning of the honey flow are inclined to store the honey in the broodchamber adjacent to the brood, thus surrounding tlie brood-nest with honey. When the brood-nest is crowded in this way, the bees are not inclined to pass over the finished sealed honey readily to go into the supers when given. Sucl colonies, therefore, block off and occupy only a portion of their hive, and crowd this limited portion even tho empty combs are given in the supers above. On the other hand, the strong colonies readily expand beyond such barriers. For this reason it is often more difficult to prevent swarming in colonies of medium strength than in strong ones. Barriers of this kind between the brood-nest and the supers are especially objectionable in colonies of medium strength. This part of swarm prevention, therefore, reaches back to the spring, the winter, and the preceding fall and late summer management.

\section{(8) IMPORTANCE OF STRONG COLONIES.}

Strange as it may seem, it is usually easier to prevent swarming in strong colonies than in weak or medium colonies. Strong colonies expand readily in the supers when they are needed and push their work beyond bariers that would ordinarily stand in the way of expansion of weak colonies. In this way the bees of a strong colony distribute themselves thruout the hive and supers, thus relieving the brood-nest from congestion. Not only for swarm prevention is it desirable to have the colonies uniformly strong in the spring; but, as is well known, this is one of the first requirements in producing a large crop of honey. Fortunately, therefore, this phase of swarm prevention is simply good beekeeping. 
(9) EARLY WORK IN SUPERS.

Since the tendency to swarm is stronger during the early part of the honey flow if the colonies are strong in young bees at that time it is important that each colony expand into and occupy promptly the first super that is given. To accomplish this it is necessary that the first super be attractive to the young hive-workers. If supers, either for comb honey or for extracted loney, having only foundation be given to a strong colony just before the honey flow, the bees will not take possession of them and begin work on the foundation to any extent until the honey flow has actually begun. In the meantime the colony may become crowded for room. The addition of this super, therefore, does not affect the distribution of the bees until they take possession of and occupy the super, while in the meantime conditions for swarming may develop rapidly. On the other hand, if a super of empty combs is given to a strong colony some time previous to the honey flow, the younger bees in great numbers immediately take possession of the super and begin to repair the comb and to prepare it for use.

The first super for extracted-honey production should be supplied with empty combs if these are available. If not enough empty combs are at hand for this, at least half of the frames in each super should contain empty combs. If no empty combs are available, some of the combs of brood should be taken from the brood-chamber and put into the super to induce the bees to move up promptly.

The first comb-honey supers are usually put on later than supers for extracted honey. They should contain some sections in which the combs are already built, which were saved from the previous year. These combs will induce the bees to occupy the super earlier than would be the case if only foundation is used in the section.

It should be remembered that, in the case of comb honey, the room that can be occupied by the bees in the super actually decreases from the time the bees begin to build combs until the combs are completely drawn out. This makes it necessary for some of these bees to go back into the broodchamber, which is exactly what they should not do, so far as swarm prevention is con- cerned. The super workers forced out of the super back into the brood-chamber, added to those emerging rapidly in the broodchamber, give a large number of bees there which must remain unemployed until they are old enough for field work unless additional super room is given.

During the early part of the honey flow when stvarming is imminent, additional supers should be added as the bees need them before any of the workers are crowded back into the brood-chamber. If the honey flow is good, the additional supers should be given as fast as the bees can be induced to occupy them, in order that the expansion of the work and the room in the supers shall keep pace with the oncoming of the young workers. Each newly added super should be so accessible, comfortable, and attractive that young bees will come up and occupy it at once, which they may fail to do if the newly added supers are too hot, too cold, too remote, difficult to ventilate, or otherwise unattractive. During the latter part of the honey flow as the swarming season begins to wane, bees may be crowded as to super room to induce them to finish the work well and concentrate the honey in fewer supers, but by this time there is less danger of swarming. See Comb Honey, то Produce, subhead Tiering up.

\section{(10) ROOM IN COMBS FOR RIPENING NECTAR.}

It should also be remembered that the thin incoming nectar requires more room in the combs than it does after it has been ripened. Besides this the bees do not fill the cells full of thin nectar but place only a small amount in each cell in order that it may be more promptly ripened. For this reason it is necessary to provide more super room than would be needed otherwise. When adding supers it is well to keep in mind this extra need for room for ripening nectar as well as for the storage of ripened honey.

\section{(11) REMOVING ONE OR TWO COMBS OF} BROOD.

It is somtimes advisable to take out one or two combs of brood from the broodchamber and place them in the super, putting in their place empty combs in order to give the queen more room if she becomes erowded. In addition to giving the queen more room, there is no doubt some advan- 
tage in having these young bees emerge in a supel, possibly at the top of the hive, remote from the brood-chamber in order to bring about a better distribution of the young bees thruout the hive. This plan is not so well adapted to comb-honey production altho some who produce comb honey remove one or two frames of brood from colonies that are crowded, giving these removed combs to nuclei or weak colonies.

\section{(12) DESTROYING QUEEN-CELLS.}

In some cases destroying queen-cells is really a remedial measure; but, if destroyed when first started and more super room or more ventilation is given at the same time, it may be proper to consider destroying queen-cells as a preventive measure. There are same very nice points in cell-killing. As Dr. Miller had the largest experience of any man in the United States, if not in the world, the author asked him to give his views; and the reader will do well to go over very carefully what he said:

I have yours asking some questions about cutting out cells to combat swarming, and proceed to reply. We don't call it cutting cells here, but "killing cells," the term "cutting cells" being applied to cutting out ripe queen-cells that are to be used for rearing queens. When we find queen-cells constructed as a preparation for swarming, we never cut them out. If a cell contains a larva several days old, it is simply mashed with the end of the hive-tool. If an egg or a small larva is in the cell, it may be mashed or the egg or larva may be dug out. In either case the work is very quickly done, and a very slight defacement will cause the bees to reject the cell.

We begin looking for swarming cells just as soon as we think there is any danger of their being started, or a little before. The first time we look in a few of the strongest colonies-perhaps the first of June, before the bees begin to store from white cloverand if we find no cells started in these we go no further, for if the strongest have not thought of swarming the weaker ones may be trusted for a time longer. After that we try again in eight or ten days. Ten davs may be as well as a shorter time. Indeed, as the young queen will be started from the egg there is no danger that she will go off with a swarm under fifteen days. But if we go beyond ten days, complications may arise bv means of swarming with the old queen, and. as there is some danger of delays from rainy weather or other cause, it is not a bad nlan to make eight days the period. Then if it is delaved a dav or two for any cause, we are still all right.

The second time we look augain in the strongest colonies, and if no cells are found in these we go no further. But whenever we find one or more cells started in any one of these strongest colonies, then every colony must be exanined. At least that will be the way early in the scason; later on there will be exceptions.

Some one may ask at what stage of the growth of queen-cells they are destroyed. At any or all stages. In fact, no thought is given to whether advanced cells or only eggs are to be found. Every eight or ten days we go thru each colony and kill all cells found.

At the first overhauling and at any subsequent one so long as no cells have been found at a previous overhauling, the bees are shaken from each comb. One sharp shake will usually leave the comb clean enough. This allows the cells to be more easily seen, whereas if all the bees are left on, some cells may escape detection. If no cell is found, then the page of the colony is found in the record book, and the entry "no c." is made after the date. Some years we have omitted such entry so long as no cells have been found in the colony that season, leaving it to be understood that so long as no entry as to cells appears, no cell has been foudd. But it is a little safer to make the entry, for then we can be sure that we have not killed cells and forgotten to make the entry.

When at any time cells are found, they are of course killed, and the entry of that killing is made with some degree of particularity. The entry " k 1 eg", means killed one egg; "k 2 eg" means killed two eggs; "k 1 e", means killed one unsealed cell; "Ir $1 \mathrm{~s}$ c" means killed one sealed cell. Often there will be killed one or more eggs and one or more grubs, when the short but comprehensive cntry will be made, "ke," meaning killed cells. Indeed, that is the most common entry made.

After the first time around, before opening a hive, the book is always consulted as to previous history, and if cells have been previously killed it is a matter of some judgment as to what is to be done. If the previous entry was "ke" there is a good chance that the bees are bent on swarming. and it will not do to shake the bees off the comb, for we may want to find the queen, and stirring up the colony by shaking the bees would make the finding difficult. So the combs are carefully examined without shaking the bees off. If no cells are found after thus looking over the combs, or at least a good part of them, then the bees are shaken off the combs and a thoro examination made. Instead of this, we are more likely to find a number of cells well advanced, in which case some sort of treatment that involves finding the queen will usually be decided upon, and the queen will be found before any combs are shaken. This shows the importance of examining the record before opening the hive, for without that we would not know whether to shake the combs or not.

The beginner is very likely to think that 
all that is necessary to prevent swarming is to continue regularly killing cells, believing that there will be no swarming so long as no cells are allowed to approach the sealing stage. But it doesn't work out that way. After a colony once fully gets into the notion of swarming, it seems only to make it more stubborn to have its cells lrilled, and finally it may swarm with nothing further than eggs in queen-cells, if indeed there is that much preparation.

So it is a matter of some nicety to decide when it is wise to continue to depend upon killing cells and when to resort to some other measures. Suppose a colony had cells killed June 10, and it is again visited Jume 18,19 , or 20 , and at this time nothing further than eggs are found in queen-cells. No trouble to decide in this case. Kill the eggs, and continue killing them each time no further advance is made. It sometimes happens that eggs are found upon one or two visits, and then the bees go thru the rest of the season without any further thought of swarming.

Suppose, however, that in the same hive, upon visiting it June 18 or 20 , we find queen-cells in number, some of them well advanced or even sealed. In this case it will be useless to think of depending upon any further cell-killing.

Between these two extremes, only eggs and many advanced cells, come all degrees of advancement, and it is not easy to know where to draw the line. If only small larvae are found, they may be considered the same as eggs, and killing cells continued. Something depends on the number of cells found. If not more than three or four, even tho quite well advanced, it may be counted safe merely to kill them. Something, too, depends upon the time. Early in the season the bees are more persistent about swarming, whereas later the killing of cells may be more relied on, even tho well advanced. Also cells late in the season may mean superseding the queen, especially if the cells be few in number.

It is no little trouble to keep killing cells every eight or ten days, and the question as to how efficient the plan is is a fair one. Also, it is a matter of some consequence to know what bearing this sort of management has upon the crop. These questions may be fairly well answered by quoting from Gleanings in Bee Culture for 1905, page 1174, where I reported:

"Of 160 colonies run for comb honey that were fair subjects for comparison, $13 \frac{3}{4}$ per cent went thru the season without ever offering to start queen-cells; $12 \frac{1}{2}$ per cent started cells one or more times, but gave it up when their cells were destroyed; and $733 / 4$ per cent seemed so bent on swarming that they were treated by being kept queenless ten or fifteen days. The colonies that were left with their queens all the time averaged $36 \frac{1}{2}$ per cent more sections than those that were treated. But that's better than they would have done if left queenless for twenty-one days, which would have been the case practically if swarms were shaken." Altho it is mentioned that treatment was given that left colonies queenless ten or fifteen days, it should be said not often did the time extend beyond ten days.

Of course seasons differ: but likely enough 1905 was about the average. It should be remembered that this was with 8 -frame hives run for section honey. With larger hives, or with extracted honey, the result would have been better.

One trouble with so much shaking of bees off the combs is that it sometimes happens that on a certain visit we find a colony with no cells and then at the next visit queenless, the queenlessuess in some way no doubt caused by the operator.

I said that early in the season every colony must be examined and cells killed, but later in the season there were exceptions. Those exceptions become more numerous as the season advances, and oceur whenever a young queen of the current season's rearing is introduced. We then write in the record book the word "Pass," and for the rest of the season that hive will not again be opened. It is possible that a colony with such a young queen may swarm, but it so rarely happens that it is not worth while to keep watch for it. When a colony is treated for swarming, if its queen is not a little better than the average, it is always desirable that she shall be replaced by a voung queen, and thus the ranks of the "Passers" are constantly recruited, and the work of killing cells is lightened.

When it is best to stop the business of killing cells it is not easy to say; but hardly much before the waning of the fall flow. If continued too late it may interfere with those colonies that want to supersede their queens. But killing cells in the later months is by no means so important as earlier, for a swarm in August will interfere very little with the crop as compared with one in June.

\section{REMEDIAL MEASURES.}

After everything has been done that is possible to prevent swarming, conditions beyond the control of the beekeeper may bring about preparations for swarming in some of the colonies. When any colony persists in building queen-cells preparatory to swarming and refuses to yield to preventive measures it is necessary either to apply a remedy to prevent the issuing of the swarm or permit the swarm to issue and hive it as previously described. When the beekeeper can be among his colonies every day during the swarming season it is usually just as well to permit the bees to complete their program as to swarming and to 
hive the swarms that issue in such a manner that the crop of surplus honey shall not be reduced. (See AFTER-SwARming.) A beekeeper who operates out-apiaries or one who is away from the bees during the day finds it necessary to treat the colonies to prevent the issuing of swarms at a time when he can not be in the apiary.

Generally speaking, there are two remedial measures which will satisfy the bees as to swarming without the swarm's issuing. One of these is the making of an artificial swarm (see ARTIFICIAL SwARMS); and the other is the removal of the queen, destroying all queen-cells at the time the queen is removed and again nine or ten days later, then introducing a young laying queen, or, in some cases, giving the colony a queencell. In the one case the beekeeper brings about a condition similar to that of the recently-hived natural swarm, and in the other case a condition similar to that of the parent colony.

When the beekeeper expects to be absent from the apiary during the day during the swarming season he should use every precaution to prevent swarming. Then as the swarming season approaches he should examine the strongest colonies to determine if queen-cells are being built in any of them. If any are found it now becomes necessary either to begin a systematic examination of each colony every week or ten days during the swarming season to find which colonies are preparing to swarm and to treat those which need treatment; or, to treat all the colonies whether preparing to swarm or not. Usually the first method is the one used. The uncertainty of weather conditions in many parts of the country during the swarming season makes it difficult to work out a system that gives good results year after year by which all the colonies are treated at the same time when producing comb honey. In extracted-honey production, however, such a system can well be worked out to suit the conditions of the locality and the season.

If the plan of treating only those colonies which prepared to swarm is carried out, it often pays to destroy queen-cells in those colonies which are just starting queencells. Some colonies will give up swarming if other conditions are favorable when queen-cells are destroyed, provided the cells contain only eggs or very small larvae.
HOW TO DISTINGUISH SUPERSEDURE CELLS FROM SWARMING CELLS.

When bees are preparing to supersede their queens they usually build only a few queen-cells instead of building many as they do when preparing to swarm. Sometimes only one or two queen-cells are started, then later the bees may start other cells, so that there may be queen-cells in all stages of development from one containing only an egg to one or more from which the young queen is almost ready to emerge. On the other hand, when preparing to swarm the bees usually start a number of queen-cells, sometimes as many as a dozen or more at about the same time, so that they are all in about the same stage of development.

It is also possible to tell supersedure cells from swarming cells by the condition of the colony. In the case of supersedure cells there are usually indications of the queen's beginning to fail, such as a somewhat scattered condition of the brood, while in the case of swarming there is usually an unusual amount of brood in the hive. It must be remembered, however, that colonies may start queen-cells under the supersedure impulse, and, if during the swarming season, the presence of these cells apparently causes them to switch over to the swarming impulse.

\section{REMOVING THE BROOD A REMEDY FOR SWARMING.}

When a colony is found having well-advanced queen-cells during the swarming season, thus indicating that it will send out a swarm within a few days, it is not necessary to wait until the bees get ready to swarm, but a swarm can be made artificially at once. See Artificial Swarming.

THE DEMAREE PLAN.

The usual procedure when producing extracted honey is simply to find the queen and put her, together with a comb containing a small patch of brood, into an empty hive-body, filling out the remainder of the hive with either empty combs or frames of foundation. This new hive-body is now put in place of the old one, a queen-excluder is placed on top of it and the supers put in place above the excluder. The queen-cells are then destroyed in the old brood-sham- 
ber, after which it is placed on top of the supers as tho it were another super, which it becomes in fact after the brood has emerged unless it be taken away a week later to make increase. Instead of finding the queen some prefer to shake all the bees from their combs, shaking them back into the old brood-chamber and putting the combs of brood without bees into the new

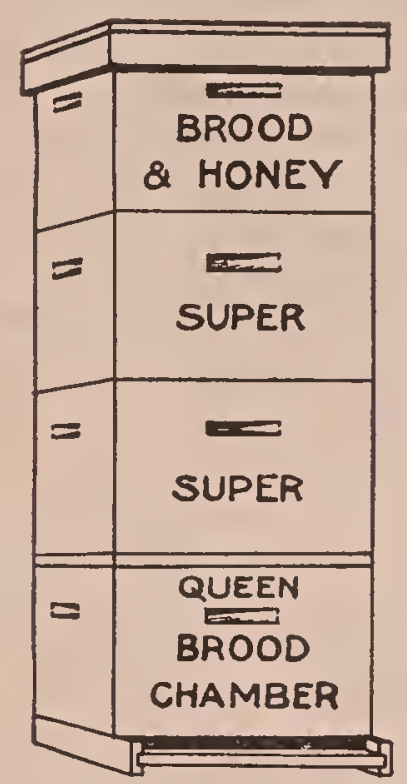

The Demaree plan. The queen, together with one comb of brood, is placed in a new brood-chamber and the old brood-chamber is placed on top of the supers.

brood-chamber. The parent colony is now on top of the supers and the artificially made swarm is below the supers, but all the bees are in the same hive. When treated in this way the bees usually behave as tho they had swarmed, and go to work with great energy.

Some seasons the swarming instinct is so strong that it is necessary to take away the comb containing brood which was put in the new brood-chamber after a couple of days or the bees may build queen-cells on this comb and swarm. Where there is trouble of this kind, it is well to put one or two empty brood-combs in the new broodchamber at the time of making the artificial swarm instead of giving a comb containing a small patch of brood.

The bees usually build queen-cells in the old brood-chamber now on top of the supers. These should all be destroyed nine days after making the artificial swarm unless there are at least two full-depth supers between the new brood-chamber below and the old brood-chamber above, when it apparently causes no trouble if young queens emerge above. One of the supers should be pushed forward on the hive far enough to permit drones to get out of the hive, since otherwise they would worry themselves to death in trying to get out, and obstruct the passage thru the excluder.

\section{REMOVING THE BROOD WHEN PRODUCING COMB HONEY.}

For comb-honey production the procedure is similar except that the parent colony is not placed above the supers, for this would result in the surface of the newly built combs in the sections being soiled from the old comb above. The removed brood is, therefore, put into a separate hive which is placed close beside the original colony, and enough bees are left on the combs of brood to take care of them. Usually the bees should be shaken from all but two of the combs of brood, those left on the two combs being enough to take care of the brood. The combs containing the best queen-cells should not be shaken, since to do so would injure the young queens in the cells. This parent colony in artificial swarming is to be left by the side of the artificially made swarm for a week or until about the time for the young queens to emerge, when it should be moved to a new location to prevent afterswarming in exactly the same manner that the parent colony in natural swarming is handled. See AFrer-SWARMING.

\section{REMOVING THE QUEEN A REMEDY FOR STIARMING.}

If only those colonies which attempt to swarm are to be treated, it is necessary to examine the colonies every nine or ten days to determine which are preparing to swarm. When colonies are found that are building queen-cells preparatory for swarming, the queen should be taken out at once. If it is desirable to keep her, she may be placed in another hive together with the comb of brood in which she was found, thus forming a nucleus. If the queen is not of special value she can be killed at once.

This plan for swarm control requires as a preparation that queen-cells be started in time to have young laying queens about ten days after the old queen is taken out of the hive. It is, therefore, necessary to start queen-rearing a little before the colonies begin to build cells preparatory to swarming. and for best results there should be enough 
nuclei so that young laying queens will be on hand in sufficient numbers to replace all queens whose colonies prepare to swarm. While the old queen could be saved in a nucleus and given back to the colony after an interval of ten days or more of queenlessness, it is much better to rear young queens for this purpose and kill the old one.

If queen-cells have already been started, these should all be destroyed at the time the queen is removed. Ten days later all queen-cells should again be destroyed, care being taken that none are overlooked. Either at this time or a few days later a young laying queen should be introduced by means of an ordinary introducing cage. (See INTRODUCING.) To do this the cage may simply be thrust into the entrance of the hive with the candy end of the cage inward. When the cage is placed in the entrance in this way it is not necessary to open the hive to see if the queen has been released.

Some beekeepers, instead of introducing a young laying queen, destroy all but one of the queen-cells and permit the colony to raise its own queen from this remaining queen-cell. A serious objection to this plan is that the swarming instinct is still present at the time this young queen emerges, which sometimes results in a swarm issuing led by this young queen, thus leaving the colony hopelessly queenless, and, if in an outapiary, the swarm absconds if no one is present to hive it.

Those who have not provided for young laying queens at the swarming season can still use this plan by taking out the old queen, keeping her in a nucleus for ten days or more, then reintroducing her into the colony, being sure, of course, that no queencells are permitted to develop in the meantime. It is not necessary to return the same queen, but a queen may be taken from any colony for this purpose. If the original queen is to be returned to the colony she may simply be eaged within the hive during the interval of ten days instead of being taken from the hive, and then a few days after the queen-cells have been destroyed she may be released among the bees. When the old queen is returned to the colony in this way, however, the tendency to prepare to swarm again is considerably greater than when a young queen that has just begun to lay is given. A colony to which a young queen is given after an interval of queenlessness of at least ten days is more nearly like the parent colony in nature and usually does not prepare to swarm again the same season.

It sometimes happens that a colony swarms during the absence of the beekeeper, and if the queen is elipped she may be lost. In such cases the colony has really dequeened itself, and the subsequent treatment is the same as tho the beekeeper had taken the queen away at the time the swarm issued. It must be remembered, however, that the swarm usually does not issue until about the time the queen-cells are sealed, and it is therefore not safe to wait ten days before destroying the queen-cells. The only safe plan is such cases is to destroy all queen-cells five days after the swarm issued, then again five days later when a young laying queen may be introduced.

Where a system for dequeening all the colonies and later requeening them is worked out suitable to the conditions of the locality, there are various plans by which the removal of the queen can be greatly simplified. For instance, the queen can be permitted to occupy two stories during the building-up period of spring; then, four or five days before the queens are to be taken away, a queen-excluder can be inserted between the two hive-bodies, thus confining the queen to one of them. On the fourth day afterward or later, one can quickly determine which hive-body the queen is in by looking for eggs, for by this time all of the eggs in the hive-body from which the queen was excluded will have hatched. The hivebody, which contains eggs and therefore the queen, can then be taken away, supplied with a bottom and cover, and set beside the original hive. If this is done at the beginning of the honey flow the supers can then be put on the original hive, which can now be left alone for ten days when all the queen-cells must be killed and a young laying queen introduced. Great care is necessary in destroying the queencells to see that none are overlooked. In order to be sure of this it is usually necessary to shake the bees off from the broodcombs, for sometimes queen-cells are hidden away in the space between the lower edge of the comb and the bottom-bar of the frame. The old queen in the brood-chamber which was removed can be easily found 
after most of the bees have gone back to the original hive much more easily than she could have been found in the full colony.

SWEET CLOVER (Melitotus. Greek word from meli, honey, and lotus, a leguminous plant).-There are about 20 species of sweet elover, natives of Asia, Africa, and Europe. Nine species are found in France. Four have been introduced into North America. The sweet clovers were known to the ancient Greeks more than 2,000 years ago, and in the Mediterranean region were valued as honey plants, as well as for forage and green manure. They are now distributed over the entire civilized world, usually growing on waste land; but in Australia, South Africa, and the United States they have been cultivated with remarkable success. Many species of sweet clover have been more or less utilized in the old world, but those most commonly cultivated in the United States are: The white biennial sweet clover (Melilotus alba), white annual sweet clover (Melilotus alha var. annua), the large yellow biennial ( $M$. officinalis), and the small yellow annual ( $M$. indica). The white annual sweet variety, commonly known as Hubam, will be described farther on under a separate head.

The large yellow biennial sweet clover ( $M$. officinalis) is also called yellow melilot, balsam-flowers, heart's clover, and king's clover. It was introduced into this country from Europe, and grows well in waste places both in the northern and southern States. Yellow sweet clover is a biennial plant, storing in its roots the first season a reserve food supply, which is utilized in producing seed the second season. It closely resembles white sweet clover; but it has finer stems and does not grow as tall, seldom attaining a height of more than 3 to 5 feet. The flowers are yellow, in long racemes; and bloom about two weeks earlier than those of the white species. It is thus valuable to the beekeeper, since it affords bee pasturage earlier in the season. Nectar is secreted freely and the honey does not differ essentially from that of white sweet clover. It is less easily exterminated, as the mower frequently passes over the decumbent stems, which thus remain to re- seed the land. It is much less generally cultivated than the white species.

The small yellow annual sweet clover (M. indica), or bitter clover, grows wild in southern California and Arizona. It may easily be distinguished from the preceding. species by its inuch smaller yellow flowers. The annual does not succeed well in other sections, and the biennial yellow sweet clover should be given the preference. In Ohio the annual was planted in a field which had been limed and inoculated with the proper bacteria. The seed germinated fairly well, but the plants grew so poorly that the erop was a complete failure. Melilotus indica is the only one of the sweet elovers which will make a satisfactory winter growth in California. It is suitable for a green manuring erop and has been used in the citrus groves of both California and Arizona. The annual white sweet clover (Hubam) probably would do well there; but at this writing it has not been tried.

The seed of the annual yellow is largely obtained from the screenings of wheat, and unless thoroly recleaned is likely to contain much weed seed. Many samples of this seed also show from 5 to 20 per cent of hard seeds, which do not germinate the first season. It is advisable, therefore, to sow from 20 to 35 pounds of seed per acre, when all the land in the orehard is planted. The seed is very small and should be broadcasted in dry soil and lightly harrowed into the surface. The land should then be irrigated as completely as possible in order to obtain a uniform stand. In the citrus sections bitter or annual yellow clover should be sown by the middle of October or a satisfactory growth can not be obtained by ploughing time. When used as a green manure, it has increased the yield of the following erops more than any other legume listed in this section. It is practically immune to the attacks of plant-lice.

White sweet clover $(M$. alba) is also known as Bokhara clover, white melilot, bee clover, honey clover, tree clover and honey lotus. White sweet clover was introduced into the United States by European colonists as early as 1738, but its value was not recognized to an appreciable extent until within the last 30 years. More than half of the States passed laws classing sweet clover as a noxious weed. Supervisors of 
roads were required in Ohio to mow it as well as Canada thistle, burdock, teasel, and other pernicious plants. Many farmers devoted a large amount of their time to endeavors to eradicate it, and there yet remain a few uninformed persons who regard it as a dangerous weed. But gradually its value became recognized, and today there is not an agricultural experiment station in this country that does not recognize its worth and approve of its cultivation.

White biennial sweet clover is an herb with smooth branching stems, and compound leaves composed of three oblong leaflets. The first season it grows 18 to 20 inclies tall and stores up in a very large taproot reserve foods for a rapid and vigorous growth the following season. The second year it makes a growth of 8 to 12 feet, blooms profusely, and dies after maturing its seed. The small white flowers resemble those of white clover, but are in long slender racemes instead of heads. The pod is egg-shaped, wrinkled, and contains a solitary seed. Young plants resemble alfalfa, both species belonging to the legume family; but it may readily be distinguished by the color of its bloom.

The plant has a strong odor, and the leaves a bitter taste due to cumarin. $\mathrm{Cu}$ marin is a vegetable substance usually obtained from the Tonka bean, but also occurring in sweet clover and some other plants. It is well known to physicians and has long been used as a corrective, tonic, and antiseptic in intestinal disorders. It imparts a characteristic flavor to certain kinds of Swiss cheese. Cumarin is believed to lessen the danger of bloating in cattle, which sweet clover causes much less frequently than the true clovers and alfalfa. It is much less bitter in early spring than later in the season. Cattle may at first refuse to eat the hay, but by sprinkling it with brine, this difficulty may be readily overcome. Possibly cumarin contains a narcotic principle, for stock soon become fond of sweet clover hay, and often give it the preference to other forage plants. Much effort has been made to obtain a variety of sweet clover free from cumarin, both by selection and by hybridizing the white species with smaller less valuable species of this genus which are not bitter. An attempt has also been made to introduce less bitter races from foreign countries. It may, however, be doubted if this is desirable, as the presence of cumarin may be a medicinal benefit, and the dislike of stock to the bitter flavor can readily be overcome.

White sweet clover in many parts of the country is utilized for pasturage and hay and, to a less extent, for ensilage, as, with the possible exception of alfalfa, no other legume will furnish from spring until fall more nutritious forage. It is also a great soil-improving crop. By means of its large roots it breaks up the deeper layers of the soil, and when ploughed under adds a large amount of humus to its constituents. In common with other legumes it increases the amount of nitrogen in the soil by the aid of the nitrogen-fixing bacteria which live in the tubercles on the roots. It is also a valuable honey plant, secreting nectar freely in all sections of the country. In the following pages of this article its uses will be described at greater length.

\section{WIDE DISTRIBUTION AND ADAPTABILITY.}

White sweet clover is adaptable to great extremes of climate and soil, and will produce a valuable crop of forage in sections where alfalfa and red clover will not, succeed. It is as vigorous in the severe climate of Quebec, Canada, as in middle Alabama. It thrives in the semiarid regions of Utah and Colorado as well as in western Washington, where there is a rainfall of over 100 inches. White sweet clover will grow on rocky limestone knolls and hills, almost bare of vegetation, and in a few years furnish excellent pasturage. If planted on poor, sterile land it will deepen and enrich the impozerished soil and again render it productive; but it requires a compact seed bed, and should not be planted on loose sand. It is more tolerant of poor drainage, overflow, and seepage than either alfalfa or the clovers. It will grow well on wet lands near large reservoirs, which are useless for ordinary crops; but it can not be planted in the rice lands of the South. Provided they contain lime and the required bacteria, both clay and sandy loams will yield a good crop of this legume. It will endure more acid than clover and more alkali than alfalfa. While it grows most luxuriantly in fertile ground it can be 
seeded for pasture on the poorest fields. Eroded and gullied lands with thin and much depleted soils can be reclaimed and built up by its use. It is often abundant by the roadsides, on canal banks, and in waste places. It is destined to be the most valuable and most extensively cultivated leguminous crop in North America.

\section{SWEET CLOVER HONEY.}

White sweet clover honey is usually water-white, but in parts of the East and in California it is reported to have sometimes a greenish tinge; and, like alfalfa honey, under certain conditions the color may be light amber. The flavor is suggestive of vanilla; by many it is regarded as a little too strong, while others describe it as mild. When the nectar is secreted very freely the characteristic flavor is less pronounced; thus the flavor, like the color, is somewhat variable. Sweet clover honey in the West. is generally mixed with that from alfalfa, and in the central States with white clover honey, forming a blend that is superior to either honey alone. Honey-distributors prize it highly for mixing with other honeys. The body is medium. The honey from yellow sweet clover is essentially the same as that from the white species, but it blooms about two weeks earlier and in a few instances has been reported superior for bee pasturage. Sweet clover honey is now marketed by the carload, and the quality is generally admitted to be excellent whether in the comb or extracted. It always commands good prices. The present distribution and the future outlook of this honey plant deserve the careful consideration of every beekeeper. Its cultivation is receiving today more attention than that of any other fodder plant in North America.

\section{SWEET CLOVER AS A HONEY PLANT.}

Altho many experiments have been made, beekeepers have as yet failed to discover any honey plant which it is profitable to cultivate for honey alone. Sweet clover is almost an exception, and thousands of pounds of the seed have been sown to advantage along the roadsides, on railroad banks, in waste places, and in pastures. In no other way can the area of honey plants be so easily increased at so small a cost, and yet witl advantage to all interests. Sweet clover has already been a great benefit to bee culture in this country, and is: likely to exert a greater influence on its; future than any other honey plant. There are millions of acres of land, which will grow sweet clover, but are of little value for any other crop. Its present distribution, therefore, deserves the most careful attention. In considering the regions in which it is of special benefit to beekeeping, it must be remembered that while it will grow to some extent on widely different soils this plant will not thrive except under proper conditions. It is not true that it will yield a profitable crop everywhere.

To understand why there are sweetclover regions and belts in various parts of the country and why in other sections it is of little value, the conditions to which it is well adapted must be briefly considered. Sweet clover will not grow well unless there is lime in the soil, hence it is abundant in limestone regions. On clay soils, which apparently contain little lime, it does not spread rapidly or produce a luxuriant growth; such soils, however, doubtless contain more or less lime due to the decomposition of the silicates. In Alabama and Mississippi the sweet clover belt is on a limestone soil, and where the clay soil begins the sweet clover ends so abruptly as to excite comment. It will not grow in the rice lands of the South or in land saturated with moisture, or in the desert regions of the Southwest. It requires a hard, compact seed bed. In a loose cultivated soil the seed does not sprout readily, and the plants die out during a drouth, or northward freeze out in winter. But the area over which sweet clover succeeds is very large and its cultivation is yearly extending. The regions in which it is of the greatest value to bee culture today are the north-central States (Ohio, Indiana, Illinois, Iowa, Wisconsin), Kentucky, the sweet clover belt of Alabama and Mississippi, the Great Plains region (Kansas, Nebraska, and the Dakotas), and the western highlands (Colorado, Utah, and Wyoming). It is also valuable in many other sections, but it is in these areas that it reaches its highest development and has largely increased the production of honey. 
The claim has been made that sweet clover in the Rocky Mountain regions produces as much honey as alfalfa. While it is not cultivated as much as alfalfa, it grows well along the irrigating ditches where it is never cut.

\section{CANADA AND THE EASTERN STATES.}

Sweet elover is abundant in parts of the provinces of Ontario and Quebec, and in the vicinity of Toronto it covers hundreds of acres. It continues to bloom after white and alsike clovers have ceased to be of value, but tho the bees visit it freely it secretes nectar sparingly. In New England it is not important as a honey plant except in localities. At Middlebury, Vt., it is highly prized for fodder, green manuring, and as a weed eradicator.. At Crawford, Mass., it grows well on the thinnest soil, even where the white limestone is exposed. An apiary of over 40 colonies obtained almost its entire surplus from this source. In the limestone soils of New York it also gives most promising results to both the farmer and the beekeeper; but it is still widely regarded as a weed in this State. In the sand belt in Schenectady and Albany counties the soil is so poor that alfalfa can not be raised; but sweet elover grows luxuriantly and is converting this impoverished soil into a rich loam. At Jonesville, N. Y., the land along the railroad track was formerly covered with sweet clover, and the bees in that vicinity stored from 75 to 150 pounds of honey per colony. A law was passed compelling the railroad company to cut all bushes and weeds along: the track, and the honey yield fell to 25 and 50 pounds per colony. In Pennsylvania sweet clover prolongs the honey flow fully two weeks after white and alsike clovers are out of bloom. It also gives good results in New Jersey, but its importance thrmout this entire section is much less than in the following regions.

\section{IN THE NORTH-CENTRAL STATES.}

In Ohio, Indiana, Illinois, Iowa, Wisconsin, and Michigan, altho sweet clover must compete with alsike and red clover and alfalfa, its cultivation is steadily increasing. In Ohio sweet elover grows spontaneously along tramped roadsides and on abandoned roads and compact land everywhere. At one time an Olio statute compelled its cutting as a noxious weed like burdock and thistle, but today it is grown in fields under proper tillage by hundreds of farmers. At Rochelle, Ill., there are over 1,200 acres of sweet clover practically all in one field. Here it pastures three head of cattle to the acre, is raised for seed, cut for silage, and employed to renovate the soil. A few years ago the average farmer in this section ridiculed the claims of both alfalfa and sweet clover. On the banks of the Chicago Drainage Canal there are hundreds of acres of sweet clover. At Milledgeville it begins blooming early in July, and is in full flower when white clover and alfalfa have ceased to blossom. Where very abundant it has been known to yield nectar for two months. When pastured or mowed, it will bloom a second time and continue in bloom until after hard frosts. Bees have been seen on it in October, when few other flowers were to be found. While it stands a drought well, it yields better when there are frequent rains. It is not unusual for the bees to store from 50 to 100 pounds per colony. With sufficient rain the secretion of nectar is reliable in Illinois, but in very dry weather it has been known to fail entirely; for instance, one year at Kenney, Ill., during a severe drought, when vegetation generally withered, the bees were starving with 160 acres of blooming sweet clover within easy reach.

In the western part of Iowa, where the land is rolling and hilly, some of the hills are so steep that it is impossible to plow or harrow them. When the seed of sweet clover is scattered over the tops of these hills it grows readily without further attention. In the eastern part of the State, in 1916, 320 colonies of bees produced 40,000 pounds of honey and increased to 500 . Near Delmar, Frank Coverdale, one of the earliest advocates of the planting of sweet clover, has 170 acres under cultivation. His apiary of 300 colonies store most of their honey from this plant. After very careful study he estimates that an acre is worth from $\$ 3$ to $\$ 5$ for bees alone. Altho the yield varies at different times, he obtains a surplus every year. At Onawa 60 hives stored 2,500 pounds of honey chiefly from 
sweet clover. Doubtless, in the near future the acreage in this State will be greatly increased.

\section{THE LIMESTONE HILLS OF KENTUCKY.}

Sweet clover has had a wonderful development on the limestone hills of northern Kentucky, and almost the entire territory of the three counties, Pendleton, Bracken, and Robertson, are devoted to its culture. Fifty years ago tobacco was grown on much of the land; in Pendleton County this was the chief agricultural industry. In this hilly country the fertile, tho shallow, surface soil was gradually washed away by heavy rains, and the eroded and often gullied fields became bare and unproductive. Farm after farm was abandoned, and in many instances sold for taxes. More than one-third of the population of Pendleton County moved away. Then sweet clover was introduced, apparently at first by beekeepers, and on the many limestone knobs and hills it found a most congenial home and multiplied apace, spreading in every direction. At first it was destroyed as a noxious weed likely to render the land even less valuable, but it outran the farmers and overran the fields. Gradually the soil was renovated and again became productive. The farmers began to return, while a part of the abandoned farms were bought by new settlers. Dairy farming and the sale of sweet clover seed brought great prosperity and comfort.

THE SWEET CLOVER BELT IN ALABAMA AND MISSISSIPPI.

In this section sweet clover is found chiefly on the limestone hills and knolls of central and western Alabama and northeastern Mississippi, where the soil is thin and poor in humus. No other crop succeeds so well on this limestone soil, which in three years it deepens and improves so much that the land may be profitably used for general farming purposes. In addition to renovating the fields, it prevents the washing of hilly land and is excellent for fodder. In the black soil of the prairie section of these States alfalfa is also grown. While sweet clover grows spontaneously in the limestone section, it has not extended to any great extent to the clay soil immediately adjoining; and so sharp is the line of demarkation that the abundance of sweet clover on the limestone soil and its absence from the clay soil a few feet away have often been remarked. Thousands of acres are in bloom in June, July, and the larger part of August. The larger part of this area has been occupied by beekeepers, but along the line between the two States for 100 miles north of Meriden there are many good locations. The apiaries range from 140 to 170 colonies, and frequently 200 and rarely 500 colonies are found in a single yard. At Fitzpatrick there are 900 colonies in 11 apiaries, which are devoted chiefly to the production of bees and queens. Eighty pounds per colony seems to be a fair average, and there is a well-authenticated record of 100 pounds per colony being stored for 10 years in succession. No reports of sweet clover failing entirely have been published. The farms are highly improved and there are many evidences of general prosperity. While sweet clover is the main reliance of the beekeeper, other honey plants are tulip tree, black gum, locust, and white clover.

\section{IN THE WEST.}

Sweet clover has not received as much attention in the West as in the East, and in the arid sections will not grow without irrigation. In many States it is still regarded largely as a weed, especially where irrigation is practiced, and the water carries the seed upon the alfalfa fields. In the Great Plains region it is extensively cultivated in the States of Oklahoma, Kansas, Nebraska, and the Dakotas. In Nebraska there are many scattered fields, but it is not planted as continuously as in Kentucky or Alabama. In the eastern part of the sandhill district it has greatly improved the quality of the soil and increased the yield of hay. Since its introduction there has been an increase both in the quantity and quality of the honey. In Kansas at Garden City there are about 3,000 acres of white sweet clover, the owner preferring it to alfalfa. At Augusta one farmer prefers the yellow variety since it blooms earlier by about two weeks, and the bloom lasts until the second.crop of alfalfa is in full flower.

In South and North Dakota the future 
of sweet clover is most promising. It is already cultivated over a section extending more than 200 miles north of Sioux City, Iowa, and is rapidly spreading northward and westward. It is expected that soon it will cover a million farms in the Dakotas, Wyoming, and Montana, and that this region will support thousands of colonies of bees and produce millions of pounds of honey. 'The opportunities for' beekeeping in South and Nortli Dakota deserve careful consideration.

Already some townships of North Dakota are reported to have 40,000 acres of sweet clover, and some farms or ranches have as many as 10,000 acres of the same plant.

Of course, such immense acreages make some wonderful bee-pasturage and some enormous yields are reported.

In Colorado and Utah sweet clover is grown to a considerable extent. In the irrigated section surrounding Ferron, Utall, there are many farmers who are enthusiastic in its praise. There are extensive areas of sweet clover in Colorado, but usually on land which call not be used for other agricultur'al purposes; from 70 to 100 pounds of lioney per colony may be obtained. There seems little probability that in the Rocky Mountain region sweet clover will displace alfalfa. It is rapidly spreading in central California and is common in moist valleys northward.

\section{AS A SOIL IMPROVER.}

Its power of renewing the fertility of eroded ground has been mentioned. By its vigorous growth and the decay of the large roots it will replace humus where it has been weathered away, and by its power of taking nitrogen from the air will bring up in fertility poor, run-down soils.

The plant takes nitrogen from the air by means of the nitrogen-gathering bacteria which inlrabit nodules on the roots. This adds more nitrogen to the soil and makes possible the growth of other plants. The bacteria which inhabit the root tubercles of sweet clover and alfalfa are identical, or at least capable of living on either plant, and for this reason sweet clover is valuable as a pioneer crop for alfalfa, insuring proper inoculation of the soil.

Besides, the large flesliy roots of the biennial sweet clovers store up a great deal of plant food the first year of growth, in order to get an early and running start in the spring of the second year. This supply of food, not altogether used up, goes back to the soil on the death of the plant, adding to and enriching the humus.

The roots being fleshy instead of fibrous decay more rapidly and so hasten the increase of fertility. Their rapid decay moreover releases the stored-up nitrogen about the ends of the rootlets sooner than in the case of roots of the true clovers.

The exceeding rapidity of the decay makes plowing an easy operation-much easier than plowing an old alfalfa field.

In contrast to the other legumes which gather nitrogen in the same way but which need considerable humus, sweet clover thrives where humus is quite absent. This emphasizes its value as a pioneer crop.

The long taproots, piercing the lower layers, make way for roots of other crops which are not able to penetrate where the ground has not been broken up. The continual growth and decay of the heavy roots slowly convert sand into fertile soil.

Where it is planted as a fertilizer, the application of manure or straw will help it to get a start and will hasten the work of soil restoration.

"It is best to delay the sowing" of other" grass two or mole years after the sweet clover has been seeded. Areas should not be pastured, but the sweet clover allowed to fall down and form a surface mulch. On badly eroded areas, sweet clover and the yellow locust form an excellent combination." *

Sweet clover's valuable power of soil renewal the Ohio Experiment Station sums up as follows: "It belongs with the clovers, and it may be used to improve the land on which it grows. This appears to be its mission. It occupies lands which have become unfit for good growth of other forage plants. Its rank then is as a useful forage plant, capable of increasing the fertility of land."

\section{RUN-DOWN LAND RESTORED.}

One of the most characteristic examples of this service to the land is its work in

\footnotetext{
* Ohio Experiment Station, Circular 129.
} 
alkali regions of Colorado. In some places irrigation and the growth of alfalfa for a number of years had forced the alkali out of the earth and on to the surface. The alfalfa roots, piercing the layers of the subsoil, brought up saline and other deposits which in turn destroyed the life of the plants.

Nothing but a kind of salt grass could be made to grow. Whole farms and towns were deserted. Finally farmers accidentally discovered that sweet clover would grow where nothing else would, that cattle could be pastured on it successfully, and that it could be used for hay or harvested for the seed.

Finally-and this is most importantthe alkali deposits on the surface and in the subsoil somewhat began to disappear. Now alfalfa again is grown. The crops are rotated with sweet clover and the soil maintained in its fertility.

Lands of this nature, formerly unfit for alfalfa, corn, or wheat, now yield immense crops of all three. In some cases the value of farms in Kansas, Oklahoma, Missouri, Nebraska, Colorado, Wyoming, and Montana, where sweet clover has been grown, has risen nearly 50 per cent.

Sweet clover has transformed King Island, off the coast of New South Wales, from an island of useless sand dunes into one of the best grazing regions in the commonwealth. Sown on white beach sand, sweet clover changed the character of the soil until at the end of five years much of it had become dark brown in color, and in some places almost black. Each year it is improving the value of the land. At present the export trade of King Island consists of fat cattle, dairy produce, and horses, and by far the most extensively used fodder is sweet clover.

\section{AN EXCELLENT PASTURE.}

As a pasture, sweet clover is very satisfactory. According to an analysis by the Wyoming Experiment Station, it does not differ greatly from alfalfa in food content.

Altho cattle will sometimes refuse grass in order to feed on sweet clover, it is sometimes a little difficult to get them to acquire an appetite for its rather bitter leaves. For this reason it is sometimes a little difficult to get them started. To create this appetite, they should be turned into the field early.

"A man prominently identified with livestock interests in the Middle West once told me that no self-respecting animal would eat sweet clover. I wish he could see my steers today," wrote C. E. Gapen in the Country Gentleman, interviewing W. P. Graham, an Illinois sweet clover grower and authority.

Mr. Graham pastures three head of cattle to the acre with success, instead of the traditional "one head to the acre." $\mathrm{He}$ maintains, by the way, that sweet clover is a better soil renovator than alfalfa.

For pasture for cattle, seeding it with timothy or any of the native grasses gives best results. The sweet clover acts as a nurse crop for the timotlyy. The former is richer in protein and the latter in carbohydrates, two. constituents as necessary in a stock ration as in human. Then, too, if one fails, the other is likely to take its place.

In pasturing hogs, an acre of sweet clover will do for about twenty shoats. A superior pasture is secured by seeding with oats on good ground. These fields will provide an immense feed for two seasons, and, if enough is left to reseed itself, the pasture will be perpetual.

In regard to this, Mr. Coverdale, the authority already mentioned, says:

\section{SWEET CLOVER FOR HOG PASTURE.}

Nine years ago I sowed a sixty-acre field to white sweet clover, and also a forty-acre field. Altho the plants started, not a single one lived until winter, and the whole undertaking was a failure because of the poor and impoverished condition of the soil. Many others around here lost their seed in the same way. The tables have turned, however, for we are now securing perfect stands of this bume. The hogs keep it down to about six inches high by continual browsing. My neighbor has a field of alfalfa adjoining this; and he has been changing the hogs from one to the other, but he is much better pleased with the results from the sweet clover, as it is so much more hardy. He has now bought seed to change his alfal$f a$ field into sweet clover, as the alfalfa won't stand being pastured. A few more farmers in this neighborhood have secured seed, and will have hog pastures just like this one.

The field sown is identical with our own, especially our hog pasture. I have come to 
the conclusion that every farmer can and should have a hog pasture like it. Every one around here who has come to my knowledge is very enthusiastic over the success, and is securing new supplies of seed to be sown next spring. This fact speaks louder than any other. My seed is all sold.

One authority advises mowing the second season, if the white clover threatens to get too tall and grow woody. The guards on the mower should be turned very high in order to prevent killing any of the plants.

No injurious effects on the stock can be noticed. On the contrary, it prevents bloat in cattle. After feeding it a number have reported that their cattle were troubled with very little digestive disorders.

"At one time when we fed our three Jerseys for several weeks on sweet clover and bran, we decided that it made a little nicer butter than anything else." This is from J. A. Green, Boulder, Col.

Care should be taken in pasturing stock on sweet clover that they do not crop it so closely that it has no chance to bloom. They should be given a field so large that the plants will be able to reseed themselves. Fortunately the plant, particularly the yellow biennial, is not easily discouraged.

\section{VALUABLE FOR HAY.}

Hay made from the sweet clover when the plant is in the right stage of growth, and properly cured, some farmers think equal to the best quality of hay from the cowpea vine or any of the clover family. It does not bring as much on the market per ton as clover or clean timothy, but it is often used instead of these.

The quantity of hay to the acre is remarkable. The Utah Experiment Station found in 1892 that sweet clover produced more than double the yield of the clover and grasses compared with it. Other stations have reported phenomenal yields.

Very complete directions for handling sweet clover for hay have been given by Frank Coverdale of Delmar, Iowa, who is perhaps the best authority on sweet clover in this country.

\section{SWEET CLOVER AS A HAT CROP.}

When I first began to grow sweet clover I had little thought of ever using it for a hay crop; but as time passed I began to see that it would answer very well as a dry feed. We experimented with one patch, and, contrary to what I had expected, a fine hay crop of superior quality was secured. The first field that we tried had been sown about the first week in May, and had been pastured to hogs until August, when all hogs were taken off. By October 10 the sweet clover stood 22 inches ligh, and then the mower was started. Just as soon as the hay was well wilted (but not dry enough to put in barns) it was raked into windrows and shaped into well-formed small cocks. These cocks, by the way, were just large enough so that they could be thrown on the rack in one good fork-load all at one time. This avoided scattering the leaves, which are as valuable as so much wheat bran. From this the reader will see the importance of putting up the hay so that it is not too dry when handled. All the handling, in fact, should be done while it is green and tough, when it can be gotten into cocks before any leaves will be scattered around. It should stand in cocks until it is sufficiently cured to keep in the mow. We have always found that this clover has kept well when managed in this way.

White sweet clover is the worst of any of the clovers that I know of to scatter its leaves when overdry; and the leaves being thick and meaty are surpassed by those of no other legume. A dairyman is lucky who has a good winter supply of first-year sweet clover hay for his cows.

The cocks referred to will stand many rains and still be very good feed. The Roots have had sweet clover exposed to rainy weather for several weeks after it had been cut. After it stopped raining it was gathered up and put into the barn. Strange to relate, the cows and horse, after all this wetting down, preferred it to good timothy hay. Sweet clover sheds water better than common clover, and it has a smooth stem. The common red clover, because of its hairy stem, holds moisture, and quickly turns black and becomes unfit for feed. I have been happily surprised to find that this first-year hav cures the nicest of any that I have made.

I know of no other elover that can be depended upon to make a good hay crop the same year as sown.* It has often been tall enough to mow in July; but at this time it would be very dangerous to mow it unless care were taken; for as yet there are no crown sprouts started; and if one mows the clover close to the ground in July, much of it will be killed outright. On this account, if one wishes to mow the first clover in July, or before the crown sprouts start, the machine must be set so as to cut high enough to leave stubbles that have a few leaves to make a start for the next crop. When the crown sprouts are started, the mower may be run close to the ground with perfect safety. These crown sprouts on the firstyear crop will be seen close to the roots after

* This was written before the new annual white sweet clover was discovered. 
removing about an inch of dirt. This is the reason, by the way, why this clover will not winterkill. The crown sprouts are about an inch below the surface of the ground, so that a covering during the winter is a certainty -a point of vast importance to one who is depending upon it the coming season.

\section{MAKING HAY FROM SECOND-YEAR GROWTH.}

Handling the second-year growth is, perhaps, a more difficult problem, as the clover gets very rank early in the season before good curing weather arrives. In this respect it is just like alfalfa. We have never dared to try to cure the hay until along in June; but at the same time every effort that we have made has been successful; we have never yet made a forkful of poor sweet clover hay. With the improved variety of white sweet clover that we now grow, I am not sure but that we might cure the hay even as early as the first of June. If we could do this, the problem of making hay from second-year white clover would be solved, and two good cuttings could be easily made during the second year, and a seed crop secured late in the fall.

There are many ways in which this elover can be handled for hay. One plar, which is very successful and easily carried out, is to wait until the clover is in bloom, and just beginning to form seed. This is just before the leaves begin to show yellow. While the foliage is still on, go over the field with a self-binder and set in shock rows, two and two. These bundles will cure nice and green, and will dry very quickly. They should be hauled and stacked like oats until winter, when the bands may be cut and the bundles thrown into the mangers for any kind of stock. It will keep perfectly dry if well stacked, and will make very satisfactory feed. The binder should be run high enough to leave behind a stubble which contains a few leaves, otherwise it will die out. If the leaves are left on, a nice crop of seed of excellent quality can be cut later in the fall.

Another plan is to pasture the second-year clover with some kind of live stock until late in May or the first of June. The hay will then be just about right in good hay weather, and can be made just as tho it were a first-year crop.

The reader may be interested to know that clover of any kind in this part of Iowa was very rare last year, as severe drouth had killed all other clovers except a little alsike here and there. Sweet clover grew as tho there had been no drouth.

An Alabama farmer who owns 640 acres grows 160 acres a year of oats and sweet clover, and cuts the combination erop expressly for hay. He says the hay when baled and marketed in Birmingham, Ala., sells readily at $\$ 15$ a ton.
Sweet clover should be cut as soon as the first blossoms appear. If left longer, the stems become woody and a great many leaves fall off when it is cured. The mower should be started in the morning as soon as the dew is off. Great care should be taken to prevent sun-burning as this destroys its palatableness and nutritive properties.

Sometimes the plants are high enough in May for mowing; but since hay cannot be cured at that time, the field may well be used as pasture until haying weather comes.

Care should be taken against feeding too much of the hay. Stock may become cloyed and go "off feed."

Sometimes, just as in pasturing on sweet clover, it is a little difficult to get stock started to eating it. The taste for sweet clover is an acquired one. By moistening the hay with brine they can usually be made to eat it. This should no more be urged as an objection to the use of sweetclover hay than the fact that western cattle will sometimes refuse corn is an argument against the use of corn as a feed.

Cut while young and tender the fall of the first year, sweet clover may be put into silos just as corn. During the winter it may be fed to stock just as other silage. In 1914 W. P. Graham of Ogle County, Ill., fed steers with 70 tons of sweet clover which he hąd put up in a tile silo.

\section{SEEDING SWEET CLOVER.}

At almost any time of the year the plant may be sown and will mature, on account of the hard seed coat which makes germination slow.

In December, January, February, and March the seed may be sown broadcast on the snow or on ground honeycombed by frost. Spring rains soften the seed coat and bring about germination in the spring. Spring sowing is the plan most popular in northern Kentucky where sweet clover makes its greatest suceess.

Sowing in March allows the seeds to be covered by the rains and alternate freezing and thawing.

Spring sowings take place in April or May. At that time it is covered lightly and the soil firmed with a roller or drag. Some authorities believe this spring sowing the best, all things considered.

In a country where the winters are mild, 
seed may be planted in the fall. Part of the clover comes up before winter, but the growth is not so heavy the second season since the roots do not have time for development. What seed fails to germinate during the fall usually does so in the spring.

Alfalfa must be sown between Aug. 15 and Sept. 1 for proper development before winter, while sweet clover may be delayed as late as Oct. 1 with fair results. This makes it possible for sweet clover to be planted in fields in which crops are too late in maturing to admit of alfalfa.

One of the peculiar characteristics of sweet clover, and one which, more than any otleer, has caused difficulty in its cultivation is its demand for a hard seed bed. Farmers have often been amazed to see the apparent ease with which the plant will appropriate railroad banks and flourish without any care whatever; yet in their own fields where it is planted as a forage crop it would do only indifferently.

SOWING SWEET CLOVER WITH OATS.

With regard to this, Mr. Coverdale, already referred to, says:

Secure from a druggist a few sheets of litmus paper. Stick a spade three inches into moist surface soil; withdraw the blade and put in a sheet of blue litmus paper and press the soil tightly against the paper for ten minutes. After removal, if the litmus paper has turned pink, lime is needed for best results. However, if there is only a slight pink color on the paper, it is possible to get along without the lime.

In either case, Early Champion oats is the best variety to seed with. Sow a third less than the usual seeding of oats. It is a pretty good plan to inoculate the seed. I prefer the glue and dust method when it is done right. Select some soil three inches under the surface, where sweet clover has grown for years. Dry it in a cellar-not quite dry, but so it will pulverize nicely. Moisten the seed well with glue water that is just a little sticky when put between your fingers and thumb. Mix thoroly, allowing all the dirt possible to hang to the seed. I have had the best results by sowing this inoculated seed by hand, because in this way the dirt sticks to the seed, whereas a seeder rubs and grinds it loose. None of the extras need be put oll where sweet clover has been growing in late years. Do not allow the sunlight to strike the seed before covering.

It will pay to make a seed bed on the surface, cultivating it quite well, as the white sweet clover always makes a stronger growth oul such prepared land. It is always the poorly cultivated as well as the corners that are missed that do the poorest.

If the soil cuts in well, one good harrowing will be sufficient. If not, double and harrow. It probably would not pay to plow unless the land is a tough sod. I always plow such fields with good results, and seeure a good deal of seed or hay the first seasoll.

If one does not want to disk or plow the ground, I would advise sowing the seed in March just as the snow is going off.

\section{NEEDS A GOOD SEED BED.}

A good seed bed is necessary. Otherwise plants will be heaved out by the frost in the winter intervening between the first and second seasons of growth. Just enough loose earth should be placed on top to cover it.

Frank Coverdale gives some valuable notes on seeding:

"Sow sweet clover on ground well prepared, on a good mellow seed bed. A sod field that has been plowed the previous fali is best of all. Spring-plowed sod is all right, and will answer nearly as well, and will work into a good seed bed. Where the rainfall is sufficient, harrow the seed in shallow. But in arid sections a drill is best, putting the seed sufficiently deep to insure moisture enough to make sure of a good crop.

"Sweet clover sown on such ground will grow a heavy crop of nodules on its roots; and by the end of the second season this ground will be thoroly inoculated, and can be depended upon for all time to come for routine methods, as these bacteria will live in the soil for several years.

"A stand of sweet clover is usually stre when sown on land that would grow 60 bushels of corn per acre, and a nurse crop sown with it of barley, wheat, or early oats, seeded somewhat thinner than usual. After the ground is inoculated from growing previous fields, a fair cutting of excellent hay can be mown in October after the grain has been harvested, making a crop of small - grain and a cutting of hay the same season."

SWEET CLOVER-SOWING THE SEED AMONG GROWING CORN.

Considerable has been written in various farm papers in regard to sowing sweet clover seed in cornfields just after the last 
cultivation. Ordinary broadeast seedsowers cannot be used, because the cornstalks and leaves are so much in the way. It has been several times suggested that sowing the seed while going thru the corn on horseback would answer better; and no doubt this plan is giving fair results.

About three years ago a machine was advertised for the express purpose of sowing clover and other seeds between the rows of corn. One was purchased and given a trial with excellent results. This machine has some cultivator teeth to work the seed into the soil. The publishers had a splendid stand of sweet clover, sown in 1916. They also had a splendid eatch in a field of corn where the corn was about ready to cut.

The only trouble with the machine for sowing is that it sows more seed than is needed; and there is no way of controlling the amount of seed very accurately. The cultivator teeth work well; and with the rains that came after the seed was sown, it seemed that almost every seed had germinated. As a result, there were about four times as many plants as were needed between the rows of corn.

The machine for sowing is a revolving cylinder made of galvanized iron, and the whole thing is pulled by a horse.

SWEET CLOVER STRAW AFTER THRASHING OUT THE SEED.

Horses and cattle after they get a taste of sweet clover hay will eat the dry stalks from which the seed has been thrashed; and even after these dry stalks have been out in repeated rains, so that any other kind of clover or hay would be ruined, the sweet clover seems to be hurt but very little.

\section{INOCULATION.}

Sweet clover is unable to make a satisfactory growth without the help of nitrogengathering bacteria in nodules on the roots. These bacteria, if they do not already exist in the soil, must be placed there with the seed. The process of starting the growth of the proper bacteria is what is known as inoculation. The bacteria are usually present on lands where sweet clover has been grown before.

Inoculation may be accomplished easily by gathering soil from about the roots of roadside sweet elover, moistening the seed with a thin solution of commercial glue, and mixing a few handfuls of the soil with a peck of seed. Unless the seed is thoroly dried it may spoil.

Another form of the soil-transfer method is to scatter between two and three hundred pounds of soil to the acre, the soil being taken from a field in which the plants show an abundance of tubercles on the roots. The government bulletin suggests that the seed be mixed with a small proportion of the soil and the remainder of the soil scattered broadcast and immediately harrowed in.

The work should be done on a cloudy day or during the evening, or else the soil in which the bacteria are growing should be turned under before the sun's rays have time to penetrate the particles. Sunlight destroys bacteria of all kinds.

The soil may also be inoculated by the pure-cultured method. A bottle of the pure culture of the proper kind of bacteria is opened and mixed with water. This solution is then mixed with the soil and the soil distributed over the field immediately after it has dried. The drying should be done in a shaded room away from the sunlight. This gives the sun no chance to kill the bacteria in the seed.

\section{MAKING MORE SEED GERMINATE.}

One of the great obstacles which have been found hitherto to the successful growing of sweet clover has been the uneven germination of the seed. At the price of sweet clover seed this has been indeed a fault. Some farmers have reported decided success in getting a stand while others have hardly been able to get a fair amount.

Sweet clover often grows apparently of its own free will in the most unexpected places, but efforts at starting it have been hindered by the lack of germinable seed. This has been due not to the infertility of the seed itself, but to the hardness of the cellulose case which surrounds the germ.

Sweet clover shares this fault with alfalfa and the true clovers. A large proportion usually fails to come up the first year and much of it never sprouts at all. In the wild state it has its advantages where seed falls in September and October and does not sprout until spring. By that time the rains and freezes have softened 
the seed coat so that moisture can get thru.

Several schemes for reducing the loss due to difficult germination have been tried with varying success.

In the national bulletin on sweet clover directions are given for soaking the seed in commercial concentrated sulphuric acid for half an hour, a plan which has been successful, altho somewhat dangerous. The acid eats away the impermeable seed coat sufficiently to enable the seed to absorb enough moisture to germinate. Tests made in the Department of Agriculture gave an increase in germination of 40 to 45 per cent.

After the acid is poured off, the seed should be quickly washed, using running water if possible, as sulphuric acid becomes very hot when mixed with a small proportion of water. The seed should then be dried out quickly by spreading it on a board or canvas and stirring at intervals of two or three minutes.

Since sulphuric acid burns flesh and wooden objects, great care should be taken in working with it. Vessels used for treating the seed should be of earthen or enameled ware.

After testing, seed should preferably be planted at once, as it has a tendency to dry out. Where the air is not too dry, however, it may be held two weeks or a month if necessary.

\section{SCARIFYING MACHINE.}

A new but highly promising method consists of scratching sweet clover seeds in what is called the Ames hulling and scarifying machine, brought out in April, 1915, by the Iowa Experiment Station. By its use the germination of legume seeds is reported, after extensive tests, to be inincreased to over 90 per cent.

The first machine of this efficiency was constructed in December, 1913. No announcement was made at that time, however, in order to allow time for field tests, comparing treated and untreated seed, in addition to extensive germination tests. A large number of plots were seeded on the station field in 1914, comparing treated and untreated sweet clover seed from various sources. In a large number of cases, stands which were, if anything, too thick, were secured from the treated seed, when the same seed planted at the same time, but not treated, failed to produce any stand at all.

The machine as constructed has a capacity of approximately 25 bushels per hour, and requires about four-horse power to operate it. It is estimated that it can be put on the market at a price not to exceed $\$ 90$ to $\$ 100$.

The construction of the machine represents eight years' work on the part of H. D. Hughes, Chief of Farm Crops at the Iowa Experiment Station.

During the spring of 1914 and 1915 several thousand pounds of sweet clover seed were treated for individual farmers. A farmer for whom the station treated some 3,000 pounds of seed in the spring of 1914 states that the seed germinated approximately 50 per cent when sent to Ames, but germinated 98 per cent when returned.

Another reports using 5 pounds per acre of treated seed, from which he secured a perfect stand, while the usual rate of seeding ranges from 15 to 20 pounds per acre with many failures and uncertain stands resulting from poor germination.

\section{HOW MUCH TO SOW.}

The amount of seed to sow to the acre depends upon what purpose the sweet clover is grown for. Moreover, the promising invention described above is likely to make necessary a revision of the estimates usually given.

Not less than 20 pounds of unhulled seed and not less than 12 to 15 pounds of the hulled should be sown to the acre. Ordinarily 20 to 30 pounds of the hulled and 5 pounds more of the unhulled are advised.

For sowing on waste lands, about one bushel to six acres is enough. Altho the plant spreads rapidly, it is well to sow enough to insure a good stand. 'To secure continuous growth, sow the second year also.

Can sweet clover be gotten rid of after a crop has been grown, and small grains sown the next year? This is a question which has worried farmers wherever the plant is being introduced. One reported that he had planted wheat the spring following a crop of sweet clover in the same field, and that the clover has choked out the 
wheat. The experience is unusual, to say the least.

The best crop to put in immediately following sweet clover is corn. The effect of the sweet clover will be noticed only in increased growth of the corn, sometimes as much as 20 bushels heavier than on land not previously planted in sweet clover. Sometimes corn is grown two years in succession, and then followed by wheat. No trouble with smothering is reported.

The farmer need fear no difficulty in getting rid of sweet clover after he has once sown it. The fact that the plant grows abundantly along the roadsides and seldom appears in cultivated fields, is evidence that it can be easily destroyed if necessary.

Another point on which there is question is the amount of sweet elover seed to be mixed with oats in seeding them together. Some sow 10 pounds to the acre, others as much as 20. A good average is $\mathbf{1 5}$.

Care must be taken in mixing the seed in the drill, and in not having so much in at once that the clover will work down under the oats in the drill-box. This would mean uneven proportions in the field. With care the seeding can be made even. Hulled sweet clover is more satisfactory in such a mixture, since some of the unhulled is not likely to come up the first year.

Rye and spring barley are other crops often sown with sweet elover. The grain is harvested while the clover is coming on, and the field used for pasture or for hay after the grain has been taken off.

Here is where sweet elover again is superior to alfalfa. Grow oats, wheat, or barley as a nurse crop and you get the grain besides, but best results with alfalfa are obtained by planting alone.

There is no better way to fit a piece of ground for alfalfa than to seed in sweet clover, cut off a crop of hay the first season, and plow under the second season when the clover is about a foot tall. Cultivate with a drag and harrow until the first of September. Then seed in alfalfa. This inoculates the soil for alfalfa besides fertilizing the ground by the addition of humus.

\section{GROWING FOR SEED.}

Before harvesting sweet clover for seed, it ' is always best to take a cutting of hay first. Much better seed and shorter, finer straw will result. The crop should be harvested like oats with a self-binder about the time most of the seed is showing black.

In moving, care must be taken to prevent shattering of the hulls. A canvas covering for the hayrack will save what drops off.

For thrashing small amounts of the seed, an old-fashioned flail or similar primitive instrument will do. But for larger amounts the thrashing machine is necessary. The process results in a lot of broken stalks and leaves being mixed with the seed. These can be removed with a fanning mill.

\section{MORE VIRTUES OF SWEET CLOVER.}

Among minor merits of this all-around plant is the tendency of wild sweet clover to drive out weeds. Growing luxuriantly in waste places and reseeding itself, it will even choke out the dreaded Canada thistle.

On the other hand the plant is not hard to get rid of, as suggested above. When the land is broken up, the plant is gone. Pasturing the land so no seed matures has the same effect if kept up one or two summers.

Add to these advantages its freedom from pests, both insect and fungous. A species of aphis has been reported but no appreciable damage noticed. The absence of enemies is one of its most peculiar characteristics, partly explained by the presence of cumarin, the bitter element in the leaves.

\section{SWEET CLOVER AS A COVER CROP.}

In many parts of the West, in some of the large orchards sweet clover is used as a cover crop-that is to say, the ground under the trees is harrowed when sweet clover is sown in the regular way. As soon as it reaches two-thirds of its growth it is plowed under. In a similar way red clover, alsike, and other clovers are sown and plowed under. When alsike and red are used, the clover is often allowed to come into bloom. If the trees are sprayed at this time, the nectar in the elover will be poisoned and bees that gather it will be killed by the thousands. (See Fruit Buoom, subhead "How the Spraying of Cover Crops Kills the Bees.") On the other hand, sweet clover will come into bloom, especially Melilotus indica, when the trees 


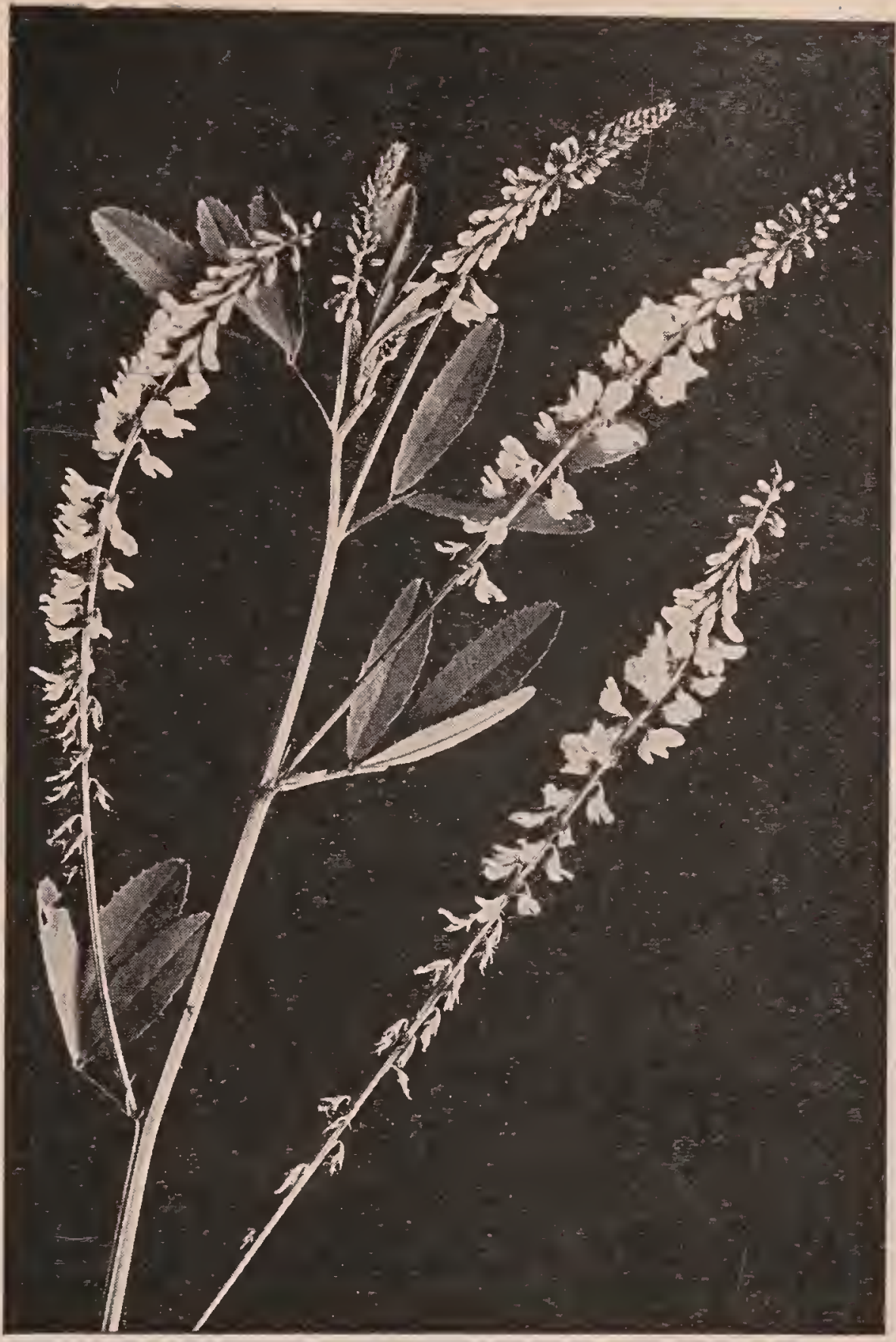

White sweet clover.

are not sprayed. It grows rapidly, and, when plowed under, makes excellent fertilizer.

\section{IN SUMMARY.}

While much information has had to be onitted from this article enough evidence is in to show that sweet clover is one of our most valuable forage plants. Long despised as a weed, sweet clover is rapidly breaking down prejudice and ignorance and taking the place it has long deserved. "The new sensational grass" it has been called. Sweet clover is new in the sense that only lately has its full value been getting recognition.
As a soil renewer, it is unexcelled. As pasture and for hay, it is nearly equal to alfalfa in feeding value. As a honey plant, furnishing nectar over a long season, it is unsurpassed. These are not the sole merits, only a few of them. Within this sketch it has been possible to suggest only some of its characteristics and its value.

In the preparation of this subject the following authorities have been consulted:

Lloyd, W. A., Sweet Clover. Circular No. 129, Ohio Agricultural Exp. Station.

Root, A. T. The Truth About Sweet Clover. A. I. Root Co., Medina, 1913.

Westgate, J. M., and Vinall, H. N. 
Sweet Clover. Farmers' Bulletin U. S. Dept. Agric., March 12, 1912.

SWEET CLOVER, WHITE ANNUAL (Melilotus alba, variety).-Hubam clover. A few years ago the Iowa Agricultural College secured some 500 different lots of the seed of the common white sweet clover for trial, which were planted in greenhouses in Jannary, 1916. All of the seed were supposed to belong to the common biennial or two-year white species. But about the first of March a number of very large plants were observed by Prof. H. D. Hughes, in charge of the Farms Crops Section, which came from one special lot of seed. They were far superior in appearance to the other plants, and were nearly ready to bloom in less than three months from the time of seeding. By the middle of April they inches tall. They now grew rapidly; and, like the 22 plants in the greenhouse, the seedlings differed greatly in height and time of blooming, tho the plants from each parent were remarkably uniform. A part bloomed $2 \frac{1}{2}$ months after seeding, while others required $3 \frac{1}{2}$ months. At $3 \frac{1}{2}$ months the best strains had reached a height of $41 / 2$ feet. During the same time the biennial, or common sweet clover, had grown only 12 to 14 inches, and the yellow sweet clover only 8 to 10 inches. Medium red clover, planted at the same time as the Hubam clover, made a growtl of only 3 to 5 inches, while the Hubam clover grew 3 to $41 / 2$ feet.

As soon as the plants had matured they were pulled and carefully examined. The root growth was found to be large and vigorous, but entirely different from that of the biennial sweet clover. The biennial at the close of the first season has a strong, large, succulent taproot, much like that of the parsnip. At the top of this root about an inch below the surface of the ground there is a crown with 5 to 50 buds, which are ready to burst

These Medina fields of biennial clover above, and of Hubam clover at the right, were both planted June 17, and photographed October 18 . Note the difference in growth.

were 3 to $41 / 2$ feet tall and most of of them were in full bloom; while the common biennial sweet clover was less than one foot high. There were 22 plants in this original lot, and they yielded enough seed in the greenhouse to grow a short row from each plant. They were not exactly alike, but varied in height and time of maturity. This seed was planted in the fields, the same year (1916), about the middle of June; and a thin seeding of oats was made with it. Other clovers were also planted at the same time for comparison. The oats were cut when the "heads were in the milk" without injuring the clover. The annual sweet clover plants were then about six

forth in carly spring. But the root of the new clover was entirely different - there was no succulent taproot or crown of buds formed for the renewal of growth the second season. The plant had made its full growth, bloomed, ripened its seed, and died -both stems and roots-clearly establishing the fact that this clover is an annual.

The new annual Hubam clover is believed to have originated on wild land in Alabama, and to be a sport or mutant of the biennial species. Hughes considered it quite certain that it did not first occur in 
a cultivated field as in such a situation it would have been lost. It evidently grew on wild land for several years without anyone noticing that it was an annual. Recently it has been definitely established that it is still found on waste land in Alabama. Considerable sweet clover seed is harvested in certain sections of the State by negroes, who either strip the seed from the plants or eut them down and thresh the seed out by hand. Thus the seed of the two clovers might easily become mixed. Its subsequent discovery in an Iowa greenhouse was a fortunate event, which bids fair to be of untold benefit to both farmers and beekeepers.

In the spring of 1918,100 seeds were sent by Prof. Hughes to each of the State experiment stations, and 50 to each seed company in the United States. Small samples were also sent to farmers and seed-growers in $\mathrm{d}$ iff e r e $\mathrm{nt}$ parts of the world for trial. Probably no other new plant ever was so widely distributed in so short a time. Altho large sums were offered for samples of the seed none was sold. The newly discovered plant was fully and freely given to the world. In the spring of 1920, 47,000 samples of seed were distributed by the Iowa station.

Reports from nearly all parts of the United States show that annual sweet clover can be successfully grown over a very wide area, and under varied climatic conditions. In Iowa, at Ames, the plants have often averaged a growth of over $1 \frac{1}{2}$ inches per day with a maximum, under greenhouse conditions, of $21 / 2$ inches in 15 hours. Spikes of seed, which measured 20 inches in length, have been produced. Planted in rows 3 feet apart the yield of seed was from 5 to 8 bushels per acre. When seeded broadcast on a weedy and poorly prepared seed bed the last of May, it overcame the weeds, made a growth of $51 / 2$ to 7 feet, and matured a seed crop. In27 dividual plants in this State have attained a height of 9 to 10 feet. In Mississippi seed was sown in the fall and the young plants survived the winter, and by May 15 were large enough to plough under as a soil-fertilizer. Seed grown in the spring matured a crop by July 10. Seed planted in April in another locality in this State was 7 feet tall in $4 \frac{1}{2}$ months. Equally favorable reports have been received from Ohio, Maryland, Kentucky, California, Oregon, and many other States. In the island of

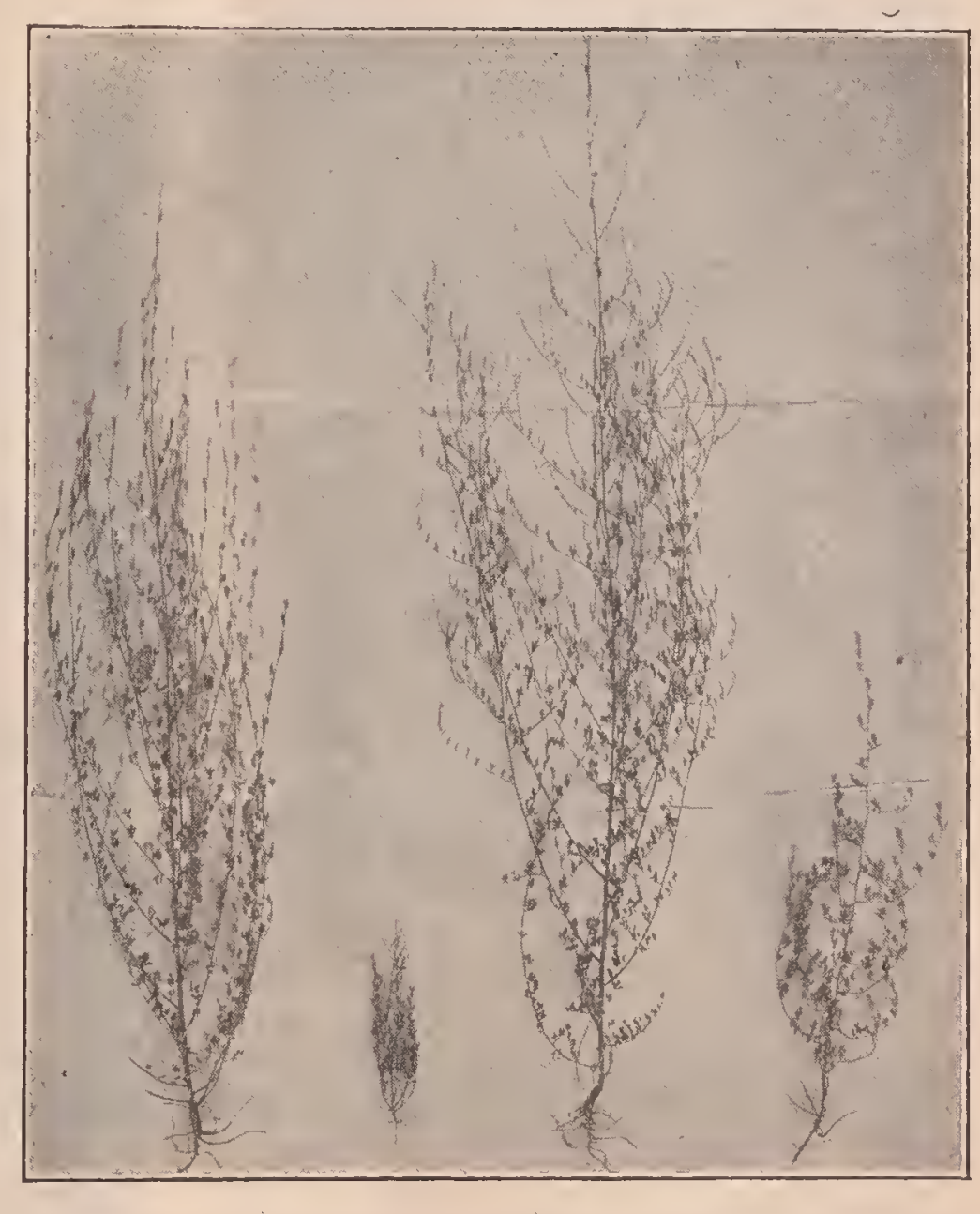

1

2

3

Nos. 1 and 2-Hubam and the annual yellow sweet clover planted the same day, cultivated and raised in the same row and under identical conditions. Nos. 3 and $4-\mathrm{Hubam}$ and the old biennial sweet clover planted the same day, cultivated and raised in the same row and under identical conditions. (Courtesy Alabama Hubam Clover Association.)

Hawaii two crops have been grown in a single season-the second crop coming from seed produced by the first crop. The first averaged 5 feet in height, and the second $4 \frac{1}{2}$ feet and remained in bloom for nearly 7 weeks.

The new Hubam variety of clover fills a place which no other legume occupies. No other leguminous plant will so quickly furnish the farmer with hay and pasturage 


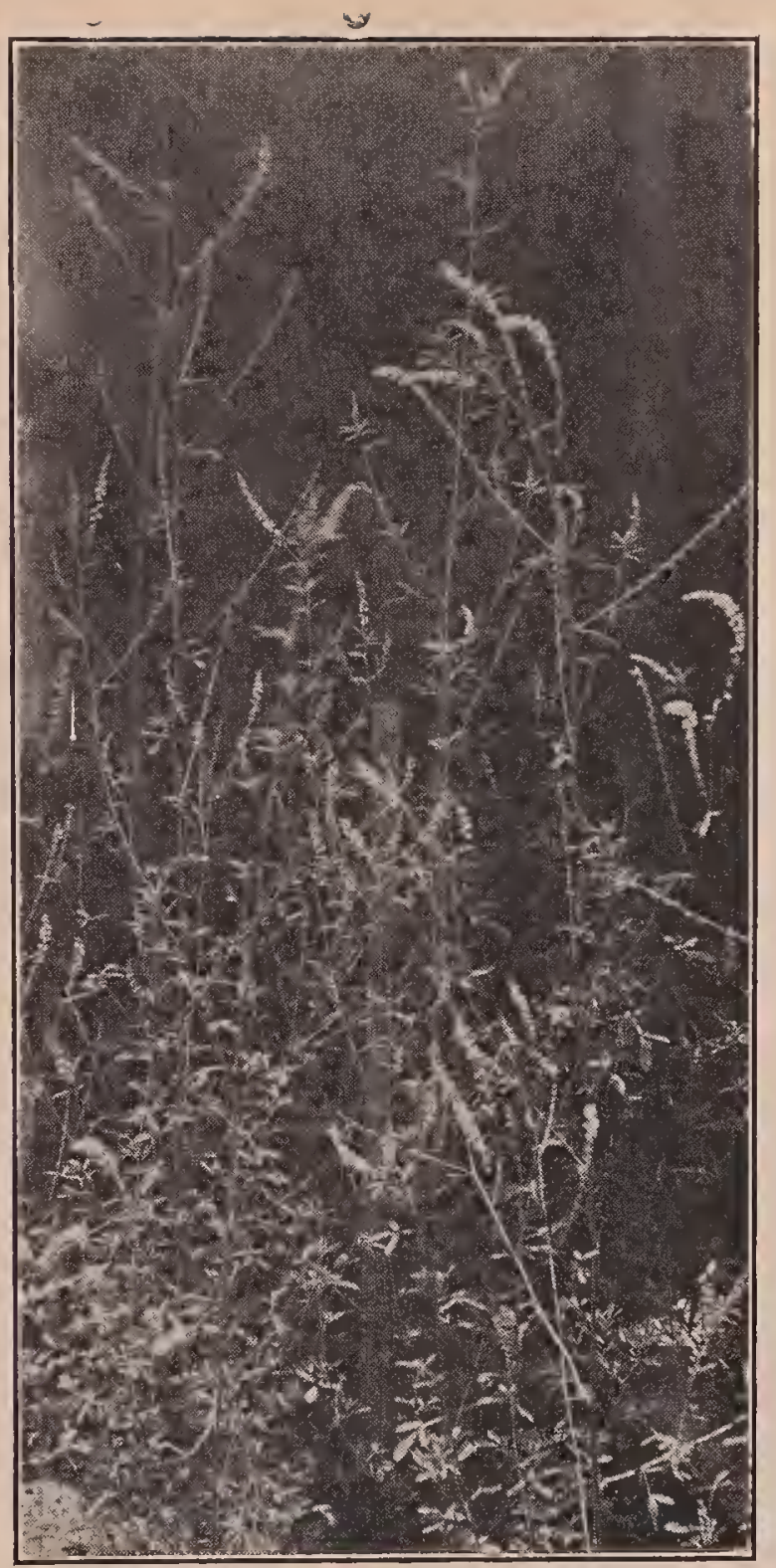

The new annual sweet clover plant that made a growth of 36 inches in 24 days, or $1 \frac{1 / 2}{2}$ inches a day.

and the beekeeper with honey. A crop of hay, which the biennial sweet clover would require 15 months to produce, the annual variety will supply in 4 or 5 months. In much less time it will offer a rapid, rankgrowing pasture to cattle and other stock. In localities where the natural grasses do not thrive well, and the farmer or stockman has been dependent on the biennial form, a crop of forage can be harvested now in a single season.

Undoubtedly the greatest use of this elover will be as a green manure erop for seeding with small grain in the spring, to be plowed under in the late fall of the same year. When used in this way in Iowa, it has made an average height of $3 \frac{1}{2}$ feet and come to full bloom after oats, with a production of over two tons of water-free material high in nitrogen. An early strain made an average height of 3 feet and fully matured a seed crop following the harvest of a crop of oats. There is no other clover, so far as known, from which such results can be secured. In the latitude of New Jersey an early farm crop can be followed by one of this clover, which by October would produce a growth of plants which would equal in value 8 or 10 loads of manure per acre. Such a crop could be followed by rye, which could be ploughed under the following spring, or left on the ground as

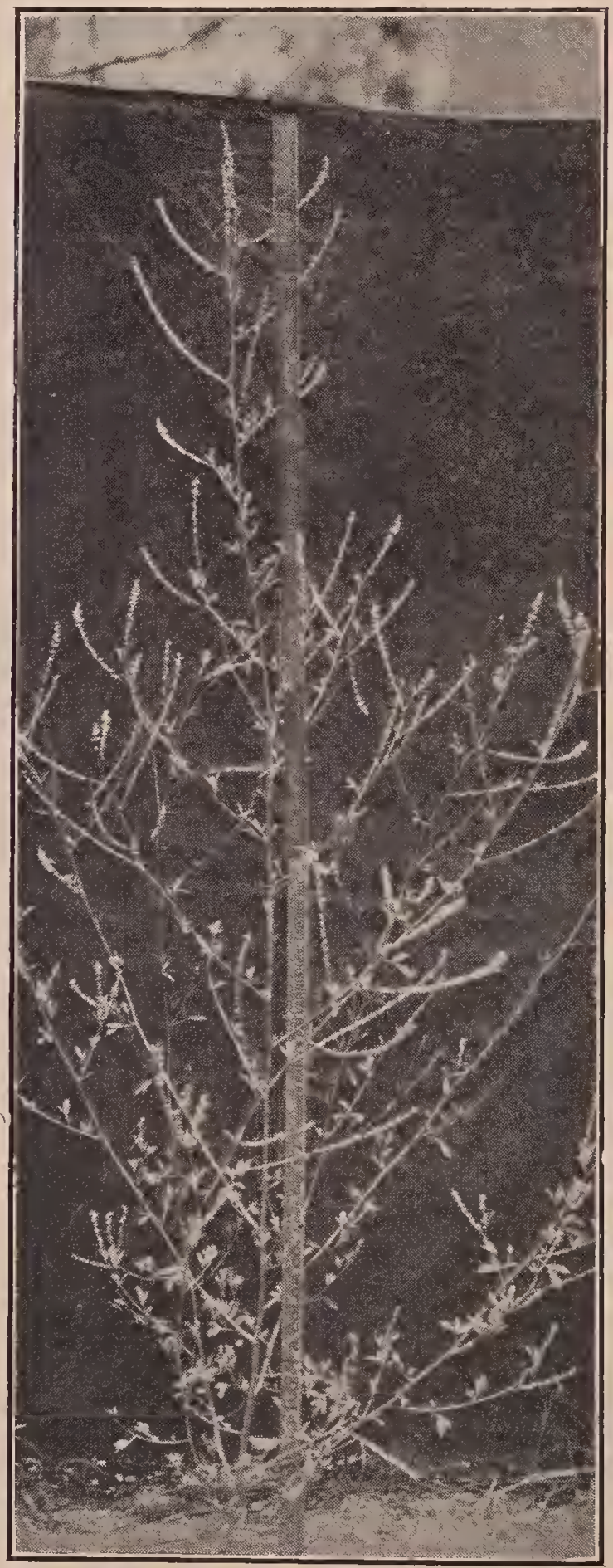

Six feet high in only 100 days from the seed. 
a cover crop. The possibilities of such a quick growth in the South are almost beyond calculation. In southern soils humus is most difficult to obtain and is one of the most necessary constituents. There are many summer-growing legumes which supply nitrogen, and crimson clover makes an excellent leguminous cover crop. Annual sweet clover will make a heavy winter growth and can be turned under by the middle of April for humus; it should give an immense impetus to southern agriculture. The rapid growth made. in short seasons may also greatly change the northern system of farming. As a cover crop in the citrus groves of California and in many other or'ehards it will be likely to replace the biennial form.

Finally Hubam clover secretes nectar as fully and freely as does the biennial white and yellow sweet clover's. It blooms three months after seeding, and the blooming period lasts for five or more weeks. Honeybees visit the flowers eagerly and in great numbers. The honey is apparently much the same as that of the biennial species. If this variety justifies present promises and is planted as extensively as is expected, it will greatly increase honey production in this country, and doubtless in many other parts of the world.

Before planting, the seed should be scarified. In an experimental test before scari-. fying, only about '34 per cent of the seed germinated, but after scarifying 91 per cent. Nearly every seed company in the United States and many individual seed- growers and farmers are now using the Ames hulling and scarifying machine perfected and given to the world by the Iowa Agricultural Experiment Station. The soil should also contain an abundance of lime and the proper sweet clover bacteria. If the soil is acid and the bacteria are absent, the plants will probably not grow more than a foot tall. It is of the greatest importance, therefore, in fields where such conditions prevail that lime should be worked into the surface, and the soil inoculated with soil gathered from an alfalfa or sweet clover field.

The biennial white sweet clover grows in many localities, which differ from each other widely in soil and climate. As a result there are many varieties of this species, but most of them are of little value and do not differ greatly from the typical form. The discovery by a happy chance of the annual variety, however, has led to a more careful search for other varieties which may be worth testing. In Grundy County, Illinois, a variety is under cultivattion, which blooms nearly three weeks earlier than the large coarse, late-bloom biennial form. It is a heavy seed-producer and ripens its seed more uniformly. With an annual variety, which blooms the same season the seed is planted, and with early and late blooming varieties of the biennial species, the beekeeper may hope for a much greater honey flow in the sweet clover sections. Other leguminous plants, as alfalfa, should receive careful observation as they also may produce valuable mutants.
TEMPERATURE.-In bee culture, temperature is one of the most important factors with which the beekeeper has to deal. The more nearly he can hold it to the exact point, the better he will be able to bring about certain desired results in the business.

Under the heads of Ventilation and
SWARMing it is shown how the bees keep down the internal temperature of the hive during hot weather by an elaborate scheme of forced ventilation. One set of bees, by means of a vigorous fanning of the wings, force air into the hive; and another set, working in collaboration, drive foul and heated air out. Under Moving BeEs, the 
importance of giving plenty of ventilation, by means of wire screens to keep down the internal temperature of the hive, is shown.

Under the head of Botruing Honey it will be seen that temperature plays an important part in preventing the granulation of liquid honey. If it is too high, the delicate flavor of the honey will be injured. If it is too low, granulation will take place soon.

Under Wintering in Celilars, referring to the temperature of the cellar it is explained that, in order to get the best results, the temperature should show not below 40 nor above 60 degrees $\mathrm{F}$. In some cellars 45 degrees gives the best results; in others, 50 ; and still others, 55.

\section{THE TEMPERATURE OF THE CLUSTER IN} WINTER.

Up to the year 1911 various erroneous notions were current. Some authorities stated that the internal temperature of a. colony in winter was blood heat; that when the cluster was broken into, no matter how cold the day, the individual members would rush out, apparently just as active as at any time during the summer. Others held that bees went into a winter sleep, somewhat analogous to a condition of semi-hibernation or even perfect hibemation.

Still others maintained that bees during winter could and do go into a state approximating death; that they had broken into their clusters and found them lifeless; had carried them into the house and put them near a stove, and found that they soon revived and flew about the room as lively as ever. From this they argued that bees were like ants in that they went into a state of perfect hibernation. This, of course, is a mistake.

Others, again, held that the winter temperature of the cluster dropped down to about 60 degrees $F$. and remained at that point until the weather warmed up, when the bees would arouse.

The fact is, there is truth in all of these assertions. The different observers had taken the temperature of the clusters at different times during the winter and under different conditions. The temperature of the honeybee cluster varies all the way, according to conditions, from $32 \mathrm{~F}$., which would shortly result in death, to 97 , which would be summer temperature. Whenever the cluster is chilled thrú, so that each individual member of it is stiff and cold, and apparently lifeless, it will die soon, unless the weather becomes warmer. If one were to dig into such a brood-nest and find such a condition, he would naturally argue that bees hibernate like ants and flies.

There was quite a school of beekeepers who, in the early days, argued in favor of reducing the surrounding temperature until the bees were chilled thru, because they said that in such a state they would consume almost no stores. Unfortunately for this argument experience shows that in a chilled condition bees cannot live more than a week or ten days. Any time within that period they may or may not be revived by placing them in a warm room. If a cluster is chilled clear thru in an outdoor colony, and it warms up outside enough so that the internal temperature of the hive reaches between 60 and 70 , the bees may revive, move to the portion of the brood-nest where their stores are, and may, if the winter is not too severe from that time on, live thru.

When the conditions are such that a cluster will chill thru during the middle or early part of the winter, the owner may rest assured that the bees will die. When he comes to open up the hive in the spring he will find a perfectly formed cluster with every bee dead.

On the other hand, when a colony is properly housed, and strong enough, there will be no danger of the cluster's chilling thru. It behooves the apiarist, therefore, to have strong colonies and then place them in a good cellar or in warm double-walled hives or packing-cases. See WINTERING Outdoors and Wintering in Cellars.

When one desirous of getting the temperature of a colony of bees during midwinter thrusts a common thermometer down into the cluster, he is misled. In an hour or two after inserting the instrument he will probably find the mercury standing at about 97, for breaking into the hive and thrusting something down into the cluster of bees arouses them so that the temperature rises rapidly till it reaches $97 . \mathrm{He}$ concludes that the temperature of the winter cluster is 97 , for has he not seen it with his own eyes? 
If, again, he were to put a dairy thermometer into the center of the cluster, allowing the upper part of the instrument to project thru the packing material, and allow it to stand, he would get a more correct reading, but not until the bees have gone back into their quiescent state previous to their disturbance. They might never go back; but in most cases a temporary disturbance does no harm, and a cluster of bees will resume its normal course. If in a day or two after the insertion of the thermometer the cover is lifted gently so as not to disturb the bees, and if the thermometer sticks up thru the packing, so that it is not necessary to uncover the cluster, a fairly correct reading may be secured, provided the cluster in the meantime has not moved. The temperature may then show as low as 57. If it is lower, the bees will proceed to raise the temperature of the cluster in a manner that will be explained further on.

In this connection it should be stated that the common mercurial thermometers are not always correct; and, what is more, it is not always possible to place them so that they will be in the exact center of the cluster; and even when they are so placed, the bees may move from one portion of the brood-nest to' another. As fast as stores are consumed in one portion the cluster will move to a fresh supply, provided it is not too cold.

It is not difficult, with these general facts before us, to understand how various observers have been deceived in forming conclusions in regard to the temperature of the honeybee cluster during winter. It is also very evident how one might jump to the conclusion that bees hibernate like ants.

It was not until the Bureau of Entomology, Washington, D. C., attacked this problem in 1912, 1913, and 1914 that the matter was definitely eleared up. Dr. Burton N. Gates, then Apicultural Assistant in the Bureau of Entomology, Washington, D. C., made a series of experiments in determining the temperature of a colony in winter. His investigations are described in Bulletin 96, U. S. Department of Agriculture. These experiments were carried on further bv Dr. E. F. Phillips, Apicultural Investigator in the Bureau, and by Geo. S. Demuth, and recorded in Bulletin No. 93,
Department of Agriculture. Dr. Gates worked with mercurial thermometers, but because of the limitations of these instruments he was unable to carry his work to a finish.

Phillips and Demuth conducted a series of experiments in wintering bees in a constant-temperature room at the University of Pennsylvania, Philadelphia, during the winters of 1912 and 1913, and 1913 and 1914. Several colonies variously prepared were placed in a constant-temperature room, where.the temperature was held by means of coils of pipes containing a brine solution-much the same apparatus that is used in cold-storage plants. On the roof of the building containing this room there were placed several colonies of bees where the conditions of outdoor-wintered colonies could be observed. A series of electric thermometers, or "thermo couples," were placed in one of these colonies on the roof and likewise in the colonies in the constanttempèrature room before mentioned. By an elaborate system of wiring, these electric thermometers were connected to an observation room in the building, entirely separate and distinct from the constanttemperature room. Here Dr. Phillips, with his assistant, could follow with the greatest precision the temperatures of every part of the hive and clusters of the several colonies, inside and outdoors.

By these temperature readings it was possible to determine the exact state and size of the cluster, when it moved, and the various reactions that took place as the result of feeding, disturbance, and the rising and lowering of the temperature outside the hives. The purpose of using electric thermometers was to avoid the disturbance incident to the use of mercurial thermometers that require the entering of the bee-room and the opening of the hive to get the readings. Moreover, it would be practically impossible for an observer to stay in a bee-room with a temperature of $42 \mathrm{~F}$. day and night, taking readings every fifteen minutes; and even if he could do so, the constant disturbance would naturally cause a rise of temperature that would be above the actual normal of a colony not so molested.

The outside-wintered colony had 19 electric thermometers, with connections to the 
observation room below. Bees were placed on the roof early in November. From then until along in March the inside and outside temperatures were taken. It was learned that the temperature within the cluster is far from being uniform, as is generally supposed by beekeepers. "At the temperature at which other insects become less active (begin hibernation) the honeybee becomes more active, and generates heatin some cases until the temperature within the cluster is as high as that of the broodnest in summer." During the fore part of the readings in November and December the internal temperature of the cluster of this outside colony had a tendeney to drop, as the outside temperature went down, until it reached $57 \mathrm{~F}$. At that point a reaction took place; that is, the generation of heat began, and from this point it began to rise in spite of the fact that the outside temperature continned to drop. The cluster heat continued to rise until the center of it registered nearly 90 degrees. After the coldest outside temperature was reached, the outer air began to get warmer, and simultaneously the temperature of the cluster began to sag.

Dr. Gates tried these experiments at an earlier period, as reported in Bulletin No. 96 , and discovered a similar inverse ratio; but he did not find the exact point at which the colony temperature ceased to drop with that of the outside. Dr. Phillips and Mr. Demuth learned that this point is $57 \mathrm{~F}$. When the colony is without brood, and the bees are not flying, the bees generate practically no heat until the coolest point among the bees reaches a temperature of $57 \mathrm{~F}$. "At this point the bees begin to form a compact cluster; and if the temperature of the air surrounding them continues to drop, they begin to generate heat." Between 57 and $69 \mathrm{~F}$. the bees do not do much in the way of heat generation.

Apparently, it is desirable to have the surrounding temperature at such a point that the internal temperature of the cluster shall not go below 57 nor above 69 ; but, as will be shown, the questions of food and syrup are additional factors to be considered.

Attention will now be directed to the colonies, or one of them at least, in the constant-temperature room, where the mereury was kept at about 42 or 43 degrees F. "This temperature was chosen as being nearly the one generally considered best by beekeeper's." There were two colonies-one fed on honey stores and another on an inferior grade of honeydew honey, that are particularly mentioned in the bulletin. Colony No. 1 , fed on honey stores, was in a constant-temperature room for 163 days, during which readings were taken hourly. At first the internal temperature of the cluster according to the chart hovered around 64 and 68. The colony fed on honeydew stores showed a higher temperature at the beginning; when up to about $76 \mathrm{~F}$. it began to take a sharp rise, going up to 91 above, and on Nov. 23 the temperature began to show a sharp drop, the line running down as low as 48 on Dec. 10, when the colony died. Clearly the poor food caused uneasiness by reason of the accumulation of fecal matter that the bees could not digest, and the uneasiness caused activity; and activity called for a greater consumption of stores. The one condition operated against the other, finally ending in the destruction of the colony. The other colony fed on good honey pursued its normal course thru the season.

It is interesting to observe that the normal temperature of the cluster of the colony fed on good stores only gradually increased, and this increase was doubtless due to the slight accumulation of feces. This accumulation was markedly less than that in the case of the colony with honeydew stores, not because the bees became uneasy, but because in proportion as the feces increased, the activity and temperature of the colony increased. This increase was not enough to cause the death of the colony, but did cause a slight reduction in the force in the spring. These observations explain the importance of good food-a food that will not clog the intestines. It also explains a common cause of dysentery.

Phillips and Demuth also discovered that the length of the life of bees either during summer or winter depends on the activity of the bees. The greater the activity, the shorter the term of life.

They also found that when brood-rearing commences or is in progress, the temperature of the cluster will rise to about that 
of summer or spring. This was to be expected, of course.

During these experiments a remarkable thing was learned--namely, that there can be, and actually is, activity inside of a cluster of bees during winter. When the temperature of a cluster goes down to 57, and the outside temperature surrounding the hive is dropping; the bees by actual muscular exercise can raise the temperature of the cluster. This activity may consist of a few bees tugging at each other, moving their bodies back and forth, or actually fanning with their wings. One bee may set up an active fanning inside the cluster during the dead of winter. Bees actually fan to cool themselves in summer and to warm themselves in winter, paradoxical as this may seem.

It is difficult to comprehend that bees can warm themselves up by exercise, like their owners; and the idea that their little electric fans, so to speak, can raise the cluster temperature as well as cool it seems at first absurd; but that it is true the anthor proved to his entire satisfaction by the experiments he conducted during the winter of 1914 and 1915. He used a hive that had double glass sides. The bees were compelled to form their winter clusters against these sides. It was thus possible to watch the internal movements that actually took place inside, and what was seen was indeed a revelation.

Various observers have opened up clusters of bees in midwinter, and found the bees inside in many cases as active as they ever are. Likewise thermometric readings have sometimes shown the temperature the same as during the summer. In the light of the observations taken by the Government, it is very easy to explain this, notwithstanding that there are times when the temperature of the cluster is below 60 to 70 . One has only to remember that, when the inside temperature of the cluster goes as low as 57, the bees raise the temperature of the cluster even tho the outside temperature is becoming colder and colder. The presumption is that, when the cluster is large enough, they keep up these "daily exercises" in order to keep the cluster warm. A prolonged cold spell, especially that down to zero, is nearly always disastrous to good wintering. This cold weather puts the bees in the cluster in a state of activity; and activity causes an abnormal consumption of stores, with no means of voiding their feces, and then dysentery follows; hence after a prolonged spell of cold weather that has lasted for weeks, we commonly find evidence of dysentery.

At the close of this bulletin the authors make the statement that "bees in winter", either in cellars or outdoors, should be disturbed as little as possible."

\section{THISTLE.--See Canada Thistle.}

TITI.-The titi family, or Cyrillaceae, contains but 6 species, which are found only in America. They are shrubs or small trees growing in wet land, or swamps, and along river's. There are 3 species in the southern States, which are valuable as honey plants. The honey is apparently seldom obtained pure, or in large quantities. It has been frequently described as dark colored, and poor flavored compared with. the northern white honey.

Black titi (Cliftonia monophylla) is also called buckwheat tree and ironwood. A smooth evergreen shrub or small tree common in swamps in Georgia and Florida and westward to Louisiana. The white fragrant flowers are in long racemes, which are drooping when young but finally become erect. They expand in March and April. In southern Georgia black titi is very abundant along streams, where it yields an amber-colored honey of fair quantity.

Sinall-leaved or red titi (Cyrilla parvifolia) is an evergreen shrub, 6 to 10 feet tall, growing in swamps and along streams from Florida to Louisiana. The leaves are oblong, leathery, shining green above but paler below. The numerous small white flowers are in racemes and appear in February and March. It yields an amber-colored honey, which is strong-flavored, but suitable for baking purposes.

White titi or ivory bush (Cyrilla racemifolia) is also a swamp. shrub, or small tree, but it is more widely distributed than the preceding species, extending from Virginia to Florida and westward to Texas. The large much-branched bushes, from 5 to 10 feet tall, are during the last half of May covered with innumerable small white blossoms. The flowers are in narrow, dense racemes, which are clustered at the ends of 
the twigs. It is the last of the spring honey plants to bloom and the bees work on the bloom very diligently, but it yields nectar only sparingly. Altho the bloom lasts for thirty days, it is seldom that more than two supers, or 50 pounds of honey, is secured. A sample of the honey from Mt. Pleasant, Alabama, is a dark-reddish-amber color, with a pleasant characteristic fragrance. It has a good body and a mild flavor, which is more pronounced, when it was first gathered. It is considered fair table honey.

TRANSFERRING. - This term might mean moving bees from one yard to another, or bees from one hive to another. In the strict technical sense, however, it means moving bees from box hives, log gums, or straw skeps into modern movableframe hives. The usual process involves the act of cutting the combs out of an old hive and fitting them into movable frames,

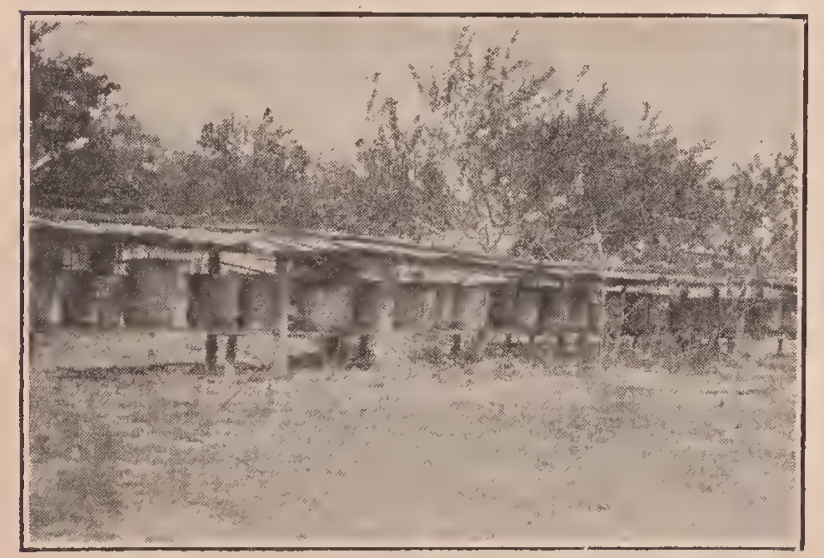

A characteristic log-gum apiary. There are several rows of, these gums that were transferred by C. L. Sams. This is not at all a rare sight in the Southland.

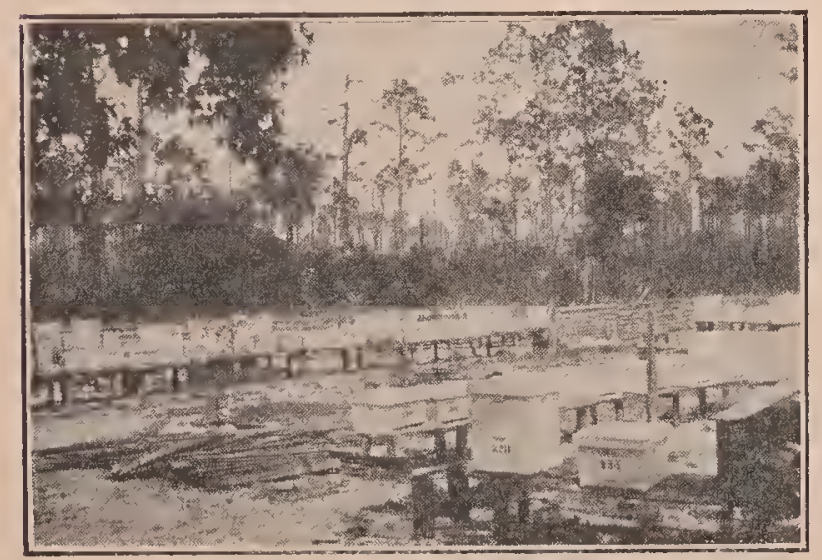

The same bees after being transferred into modern hives. This apiary of 100 colonies belonging to W. J. Martin, with the help of Mr. Sams, was easily transferred from the log gums in one week's time. after which they are placed in an up-todate hive. When one by purchase or otherwise acquires a lot of old gums, he must transfer them into modern hives before he

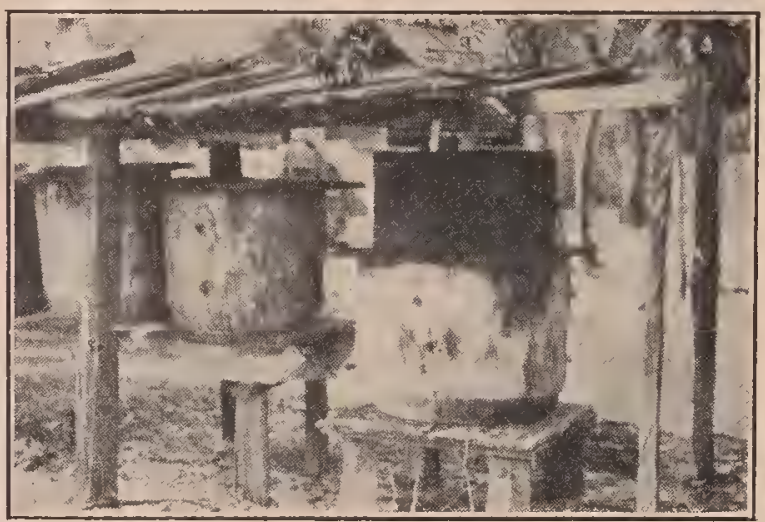

Log gums used for producing comb honey, with the "supers" in position.

can do anything. To do this he must provide himself with as many hives, with a full equipment of frames, as he has gums or old box hives to transfer.

WHEN TO TRANSFER.

A day should be selected, preferably during fruit bloom in the northern States, when some honey is coming in, or when a honey flow is on in early spring in the South. The early part of the season is recommended, because at that time of the

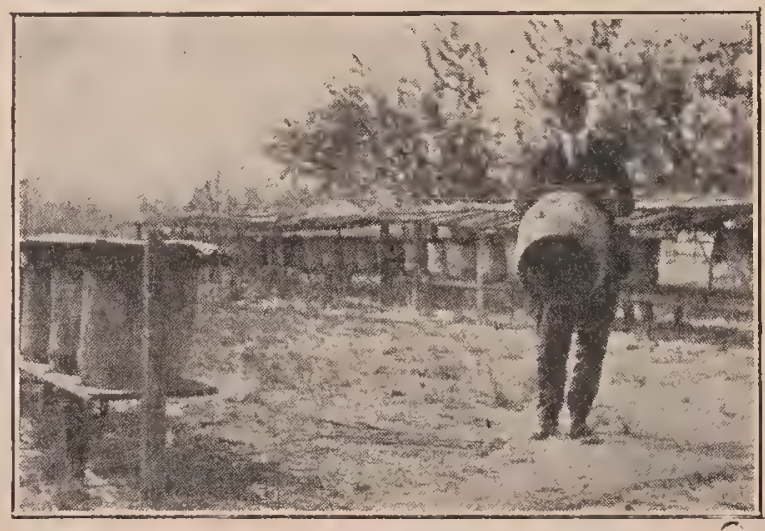

Log-gum apiary of J. S. Kelly near Wilmington, N. C. Mr. Sams holding an empty gum, and altho the bees were stinging him unmercifully, he stood his ground while the author was "snapping" him.

year there will be relatively fewer bees and a comparatively small amount of honey. If, on the other hand, the work of transferring is performed during the hottest part of the year, the gum will be full of bees and honey, and, of course, the operator will be working at a great disadvantage -particularly so if the time of work be 
selected during a dearth of honey, when the bees are inclined to rob.

A day should be selected when the weather is warm-preferably between the hours of 9 in the morning and 4 in the afternoon. Sometimes it is desirable to transfer during a dearth of honey in midsummer. A day should then be selected when there is a slight mist or rain, as there will be no flying bees. While the bees will be inclined to sting more at such times, and the operator will have to use more smoke and proceed as cautiously as possible, there will be no trouble from robbing.

At the end of the transferring, all drippings of honey should be disposed of; and if honey gets on the grass or on the ground, a pail of water should be dashed over it to wash it away. Should foul brood be present in the locality, the precaution of cleaning up everything in the way of sweets is doubly important.

Sometimes the box hives or log gums have to be carried quite a distance. In that case the gums should be put inside of burlap sacks and tied. They can be moved at any time, but preferably in the morning or in the evening. On arrival at their permanent home the sacks should be removed and the hives placed on the spots where the bees will be after transferring.

The methods that are now to be described are used by C. L. Sams, Bee Extension Agent for North Carolina. He has had more experience in transferring, probably, than any other man in the United States.

The tools necessary for transferring are a wide board, butcher-knife, and a handsaw -- preferably one having a narrow blade. In the case of a round gum a sort of keyhole saw with a long blade is better than a common handsaw. There should be, of course, modern hives with empty frames, frames containing full sheets of foundation, a pail of water, tin pans and last, but by no means least important, a bee-smoker, with plenty of fuel well ignited.

\section{HOW TO TRANSFER.}

The first operation is to blow smoke into the entrance of the box hive. This is then removed a few feet from its stand and turned upside down, and more smoke is blown over the combs to drive down any bees that may be left which would resent intrusion. A modern hive with its movable frames is now placed where the box hive stood, with the entrance pointing in the same direction. This hive should contain,

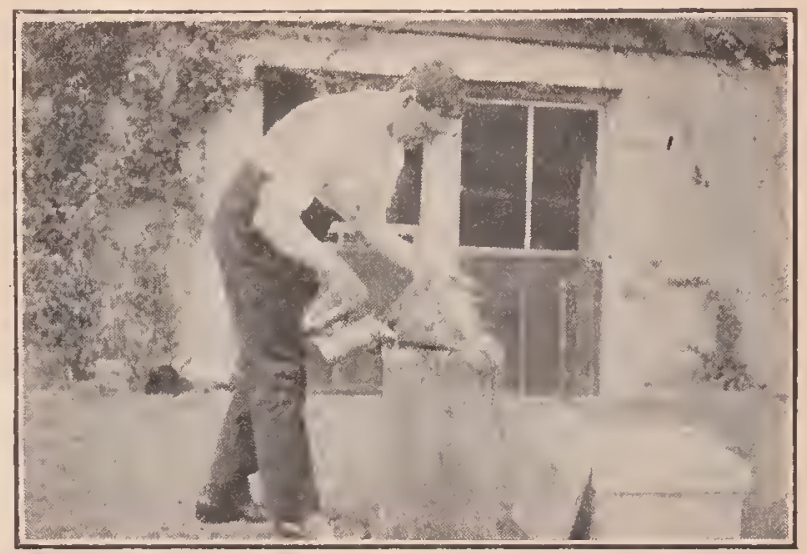

Smoking the bees in the box hive preparatory to transferring. The box hive is first turned upside down, and then the smoking is begun.

preferably, four or five frames having full sheets of foundation. Part of the frames should be on one side of the hive and the rest on the other, leaving a space in the center. Wherever possible a frame of brood and a little honey should be added from some other hive.

The next operation is to blow more smoke over the combs in the box hive, now upside down. As soon as the bees are driven down, some five or six inches of the combs is broken off or eut off. A super cover or any flat board or even the top of the hive

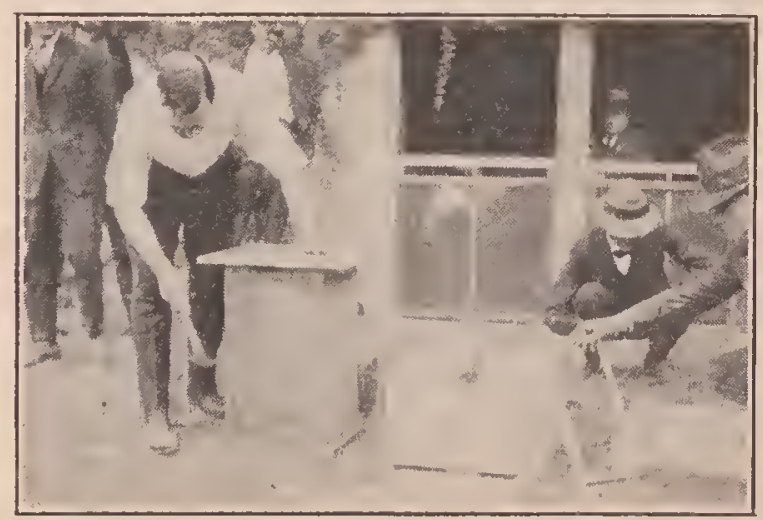

Mr. Sams drumming on the hive to drive the bees up against the top board so he can remove them and then cut out the combs. Courthouse officials of Wilmington, with an inborn sense of safety and a snap, look out from within.

is set over the box hive. A vigorous drumming, with blows not too hard, with a hammer, is now applied to the sides of the box hive. This drumming is kept up continuously for eight or ten minutes, at the end 
of which time the majority of the bees will have crawled from the combs beneath, and clustered on the super cover (now on top). During the process of drumming it is advisable to lift the cover slightly to see how the bees are coming up. When a large

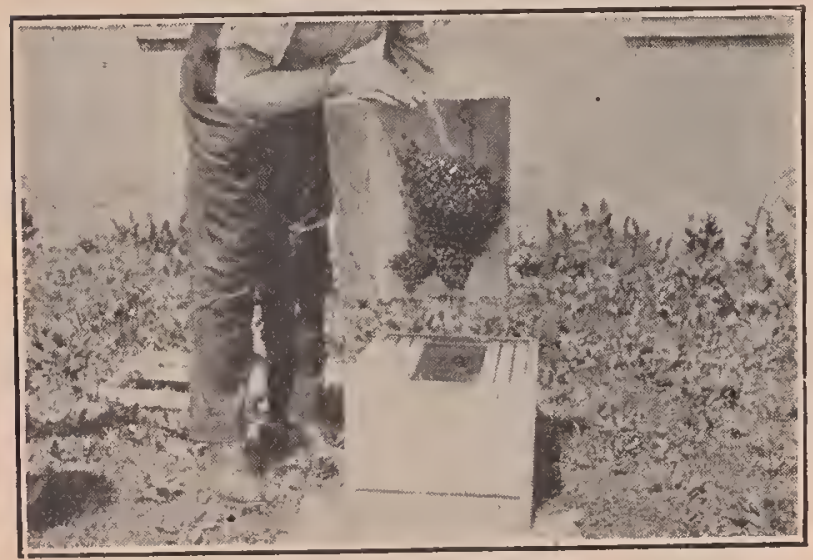

After drumming, the bees crawl upward and cluster on the super cover. This is gently placed on the new hive, after which the operation of transferring the combs begins.

cluster has formed, the super cover or flat board with its cluster of bees is lifted off the hive and set down on the prepared new hive in such a way that the cluster will extend down in the space between the frames as shown in cut above. If not all the bees are out of the original box hive, a second drumming may be applied with another super cover, but usually this is not necessary. If the first drumming be continued long enough there will be, of course, a few straggling bees left down among the combs. No attention need be paid to these, as they will not sting, having become completely demoralized by the drumming.

The plan that Mr. Sams somewhat prefers is to nail a couple of cleats even with the bottom edge of the gum, then turn it upside down. On top of this, place the new hive minus the bottom-board with a full sets of frames containing foundation, the hive resting crosswise on the cleats. The old gum.is then drummed on the side as before explained until all the bees, or most of them, go up into the new hive. This they will do very readily, but lift it up once or twice to see when the bees have gone up. The hive is then lifted off with with its bees, and set down upon the bottom-board.

It is not necessary that the two ends of the new hive sticking over on each side of the gum be closed up, for the bees will go up just the same.

This plan has the merit that the bees are driven directly from the old gum into the new hive without the use of a super-cover or box.

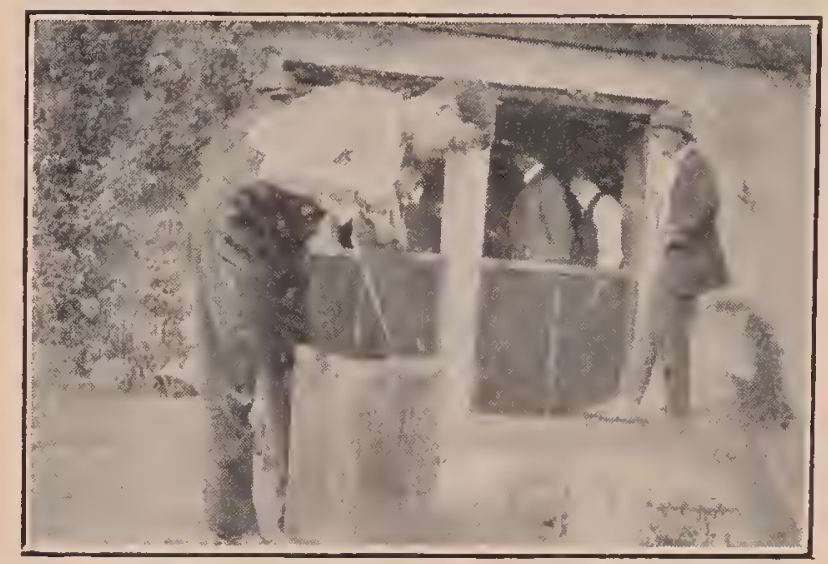

After the bees are drummed out, a common handsaw is altogether the best tool for cutting the combs away from the sides of the box.

The handsaw is now passed down between the combs and the sides of the box if it is a square gum. A good handsaw is better than a long knife for sep-

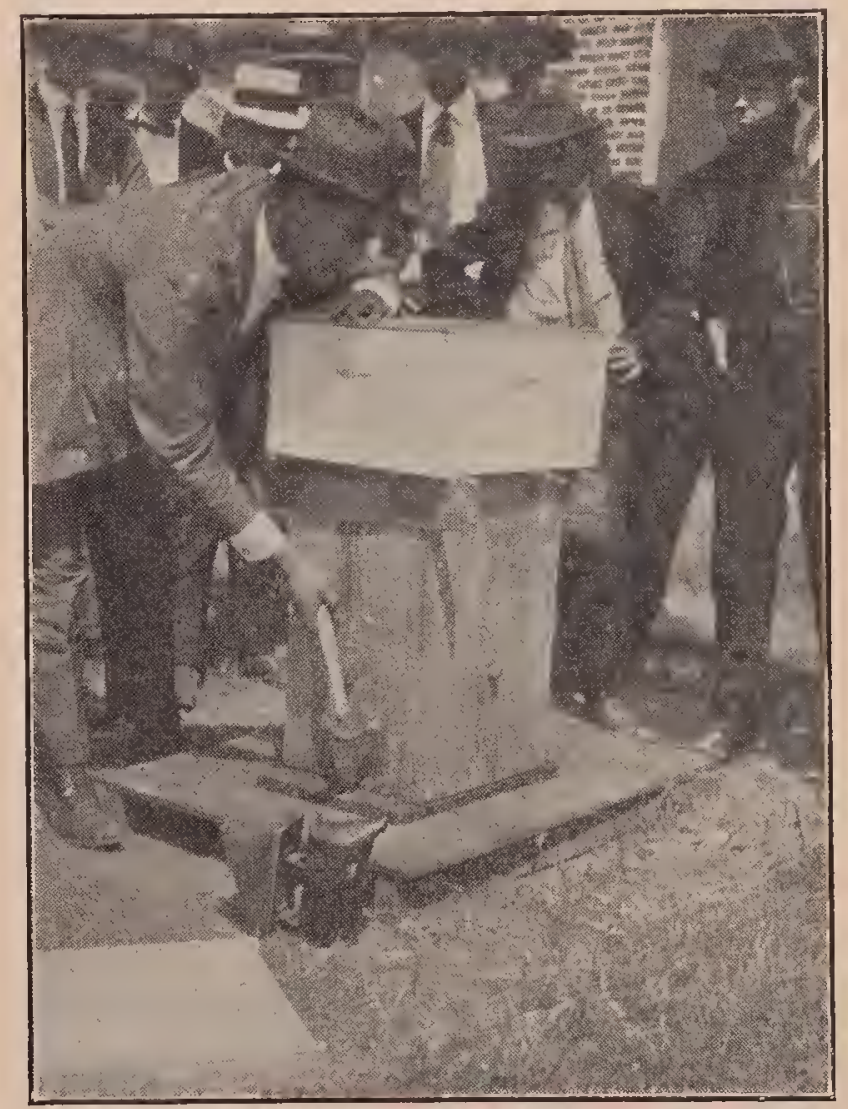

In place of a super-cover or board Mr. Sams recommends drumming the bees directly into the new hive, which is held in place by means of a couple of cross-cleats as shown. 
arating the combs; and, moreover, when it ellcounters the cross-sticks these can be sawn off where a knife would be worthless. If the cover, now at the bottom of the box hive, has not been previously loosened it can be knocked off with a hammer, when the box can be lifted off, leaving a mass of combs standing upright. The cross-sticks may be now easily removed by pulling them out and the combs separated. Only those portions of the comb that contain worker brood should be sared, because experience shows that it does not pay to transfer empty combs or combs containing honey into brood-frames. Those containing honey should be put into a tin pan and used on the table, while all other pieces not containing worker brood should be melted up into wax.

Proceed to insert the combs in the frames as follows: Lay a good comb of brood from the gum flat on the board or super cover. Over this lay one of the empty brood-frames. With a knife mark out the exact size of the comb. Lift the frame, then cut the comb to the desired shape and size. It is always desirable to cut comb a little large so it will make a snug fit, after which the brood-frame is crowded over. If the fit is good this frame of brood can be set down in the hive without any fastenings.

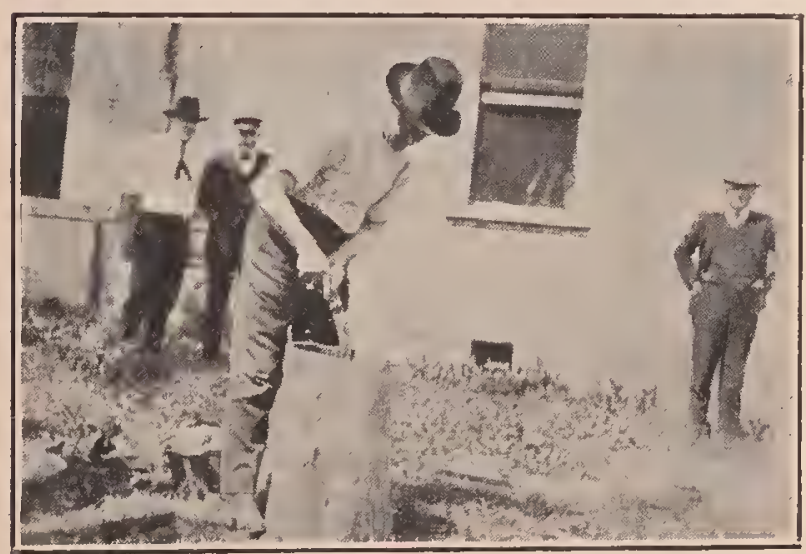

In the case of the round gums or logs, it is neces sary to use a keyhole or narrow saw, which is run clear around the inside of the $\log$, cutting the cross-sticks.

After several of the larger pieces containing brood have been fitted into frames as described, there will be a number of smaller ones, the brood in which it is desirable to save. Several of these pieces can be laid down on the board and their edges matched. In order to make a close fit it may be necessary to trim the edges a little. After the crazy-quilt combs are fitted together a brood-frame is then laid over the whole. With a butcher-knife mark out the exact shape as before described, then slip the frame snugly over the combs after

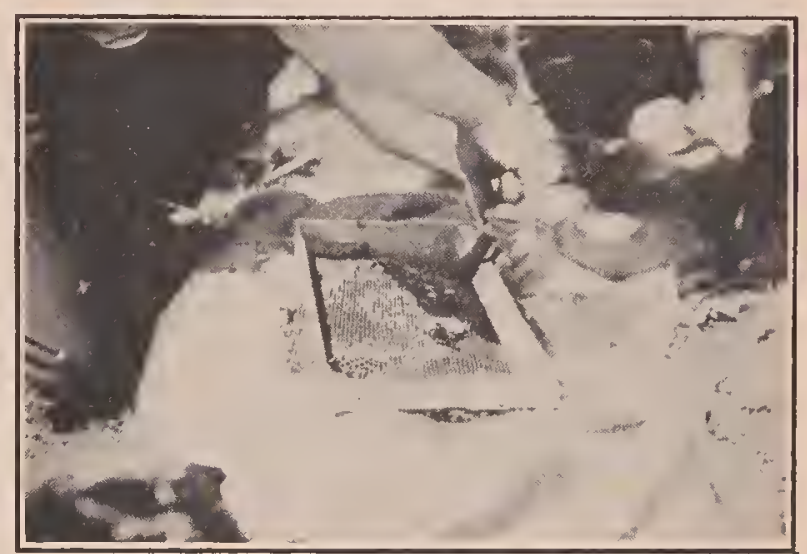

Only the combs containing the brood are fitted into brood-frames. A butcher-knife marks the size of the piece or pieces to be cut, and then the whole slice is cut large so as to fit snugly into the frame.

they have been trimmed. The whole board containing the frame and pieces of comb should then be lifted to a vertical position, as otherwise the pieces will fall out when the frame is lifted. A string is now wound around the whole several times, as shown herewith, when the frame is ready to be inserted with the other frames of brood. It

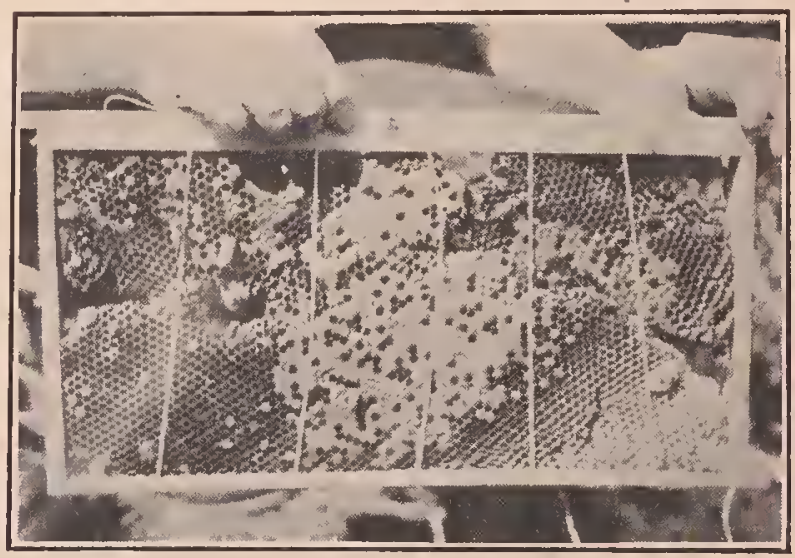

Where there are several pieces of comb it is necessary to use strings to hold them in place. These are wound around the frames several times and tied. The bees will remove the string.

will not pay to save very small pieces of brood. These should be dumped into the wax-extractor with other pieces of comb not containing honey.

In the average box hive there will be enough worker brood to fill four or five empty frames, Langstroth size. Drone 
brood should be excluded. The remaining space on either side is then filled with foundation-preferably full sheets.

Elton Warner of North and South Carolina, instead of placing the log gum up-

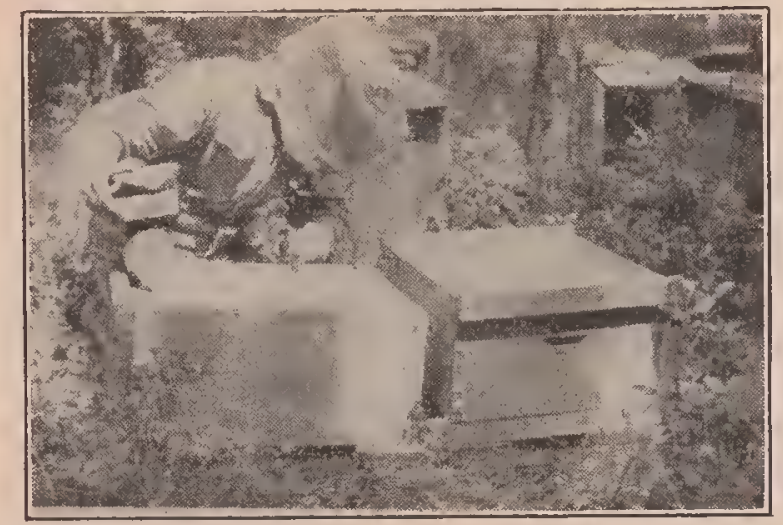

Mr. Warner smoking and drumming bees from a box hive into a modern hive.

side down, lays it on its side with the bottom facing the entrance of the modern hive. He now blows smoke into and drums on the old gum until the bees run out of it into the new hive, as shown. C. L. Sams, who has probably had a larger experience than any other person, says that, while this plan will work, it is much slower, and that the bees, instead of going into the hive, will cluster all around the space between the old gum and the new hive. Moreover, he says that bees during the drumming process will crawl upward more readily than on a horizontal plane.

TRANSFERRING WITHOUT USING THE OLD COMBS.

Another plan that is somewhat slower, but which avoids the cutting of combs of brood or honey, is as follows:

A modern live is prepared containing nine frames of foundation and a frame of brood from some other colony. This is placed on the stand now occupied by the old hive or gum. On top of the new hive is then placed a bee-escape board with the escape feeding downward. The gum, after the smoke is blown in at the entrance, is turned upside down, after which five or six inches of the comb is removed. A separate cover or flat board is then placed on top. Drumming is then applied to the sides of the gum until about half the bees and the queen cluster on the super cover in the manner before explained. The bees and queen are then dumped in front of the entrance of the new hive. If the queen is not seen running in, it will be necessary to drum until she is found. The old gum with its remaining bees is then placed on the new hive with all openings between the new hive and the gum closed except thru the escape, as shown. The young bees, as they emerge with the other bees, will gradually work down thru the bee-escape into the new hive. At the end of three weeks there will be no bees upstairs, and nothing but old comb. The old gum is then removed, and its contents cut out and melted up into wax.

The merit of this plan is that it avoids cutting out the combs and fitting them into frames, avoids daubing honey on tools and appliances and avoids robbing. The average brood-combs in the box hive are usually very poor, containing too many drone-cells. They are likewise more or less irregular. For these reasons it is better not to use them.

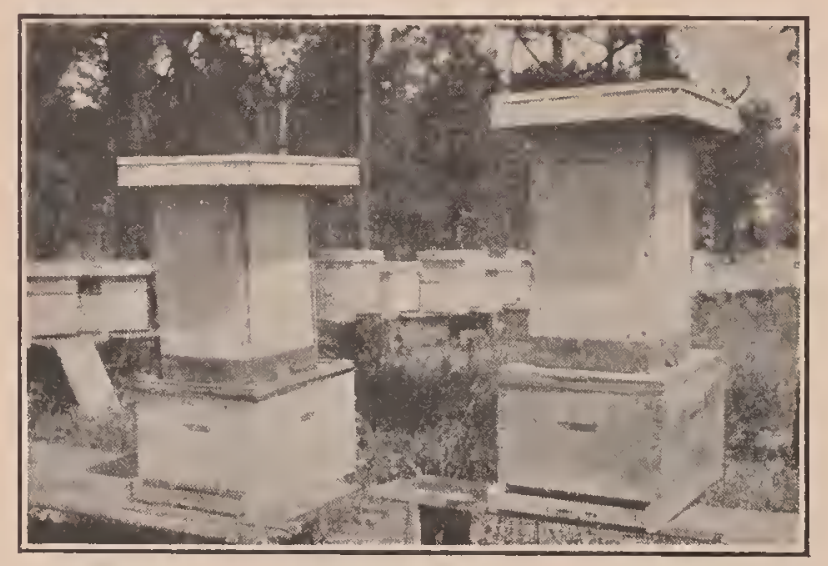

This picture shows a longer way of transferring, but it avoids the necessity of cutting and fitting combs of brood into frames. The objections to the plan are the difficulty of getting the queen into the new hive and the length of time required to complete the transfer.

The objection to the plan is that the average beginner will not be able to drum out the bees and get the queen; but an expert beekeeper can do so very readily.

THE HEDDON SHORT WAY OF TRANSFERRING.

The old box hive is moved back four or five feet, when a modern hive, with a full set of combs or foundation, is put in its place. The old hive is turned upside down, after which about two-thirds of the bees are drummed on to a board or a supercorer above, in the manner already explained. In doing this drumming it is im- 


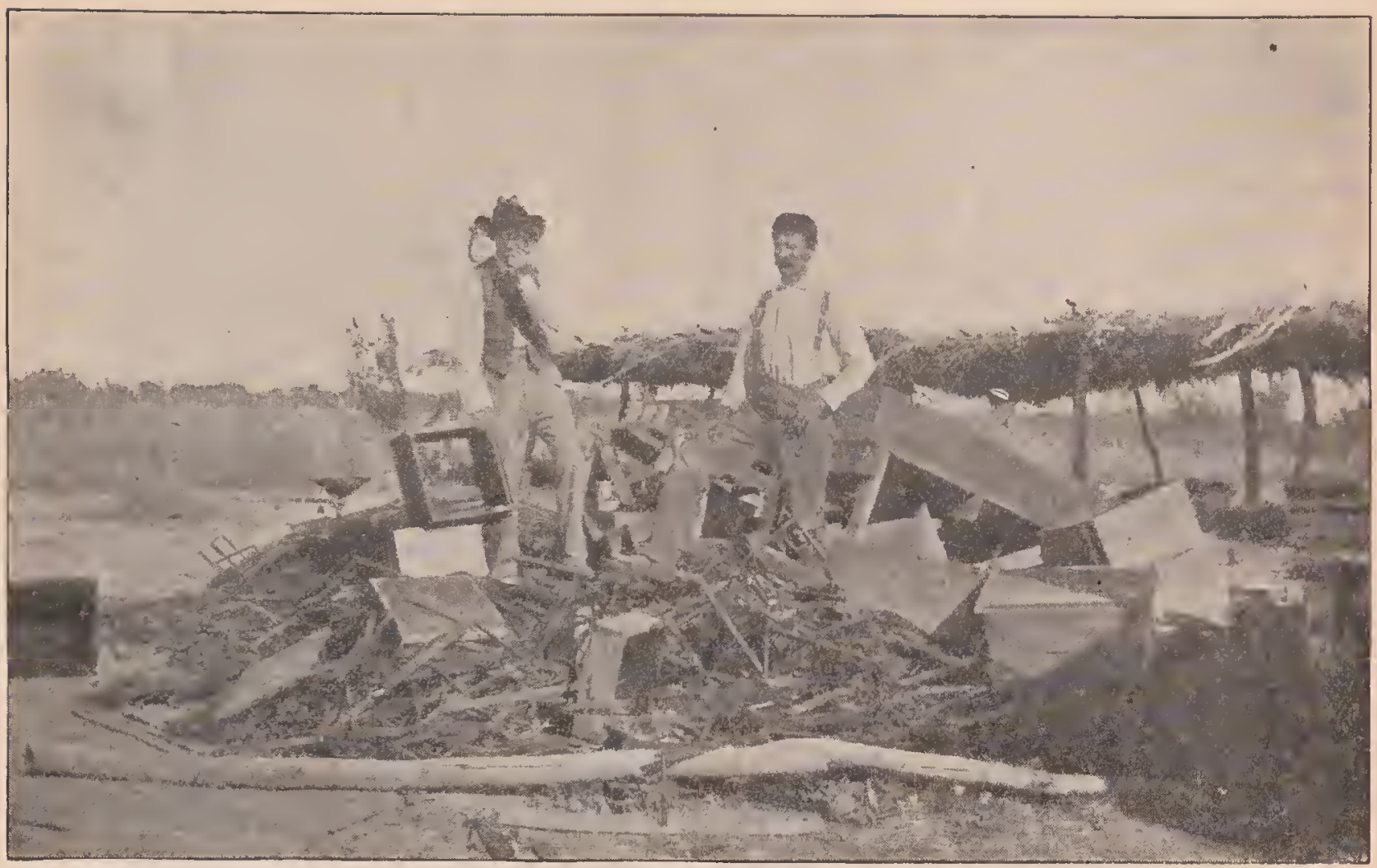

Mike Wall, Tempe, Ariz., and pile of odd-sized frames from which he had cut the comb and fitted them into Langstroth frames.

portant that the queen enter the cluster. This can be determined by dumping the bees from the board in front of the entrance of the new hive. By watching carefully, it can be seen whether the queen goes in. If she is not discovered, more bees are drummed out of the box hive, and the second lot is dumped in front of the entrance. If the queen is found this time the old box hive should be given enough bees to take care of the brood. It is then turned right side up, and put two feet back of the new hive with its entrance turned in the opposite direction. It is allowed to stand for 21 days, at the end of which time all worker brood will have emerged, and nothing will be left but a little drone brood. All bees in the old box hive are drummed out in front of the new hive having an entrance-guard. The combs in the old hive are melted up, and the hive itself burned.

At the time of making the second drive after all the brood has emerged it would be advisable to smoke both lots of bees before uniting them, otherwise there may be considerable fighting. See UNITING.

If there is no choice between the young queen which will be in the old box hive, and the old queen in the new hive, the entranceguards will not be needed. One queen will kill the other. Generally the younger and better one will survive.

\section{TRAVEL-STAIN.-See COMB Honex.}

TULIP TREE (Liriodendron Tulipifera).-Other vernacular names are whitewood and yellow poplar from the varying colors of the wood, canoe wood from the use made of it by the Indians, and saddle tree from the arrangement of the leaves in the bud. This magnificent tree belongs to the same family as the Magnolia, and among American deciduous-leaved trees is surpassed in size only by the plane or buttonwood, to which it is superior in symmetry and in the attractiveness of its foliage and flowers. Its height is usually from 60 to 90 feet, but in favorable localities it may grow 140 to 180 feet tall, with a diameter of 4 to 12 feet. Michanx measured a tree near Louisville, Ky., which at five feet from the ground was $221 / 2$ feet in circumference and exceeded 120 feet in height. The tulip tree is one of the handsomest of American ornamental trees, growing in a conical form, offering an extensive shade, and putting forth in May or June an immense number of large greenish-yellow flowers. The peculiar-shaped leaves easily distinguish it from all other 


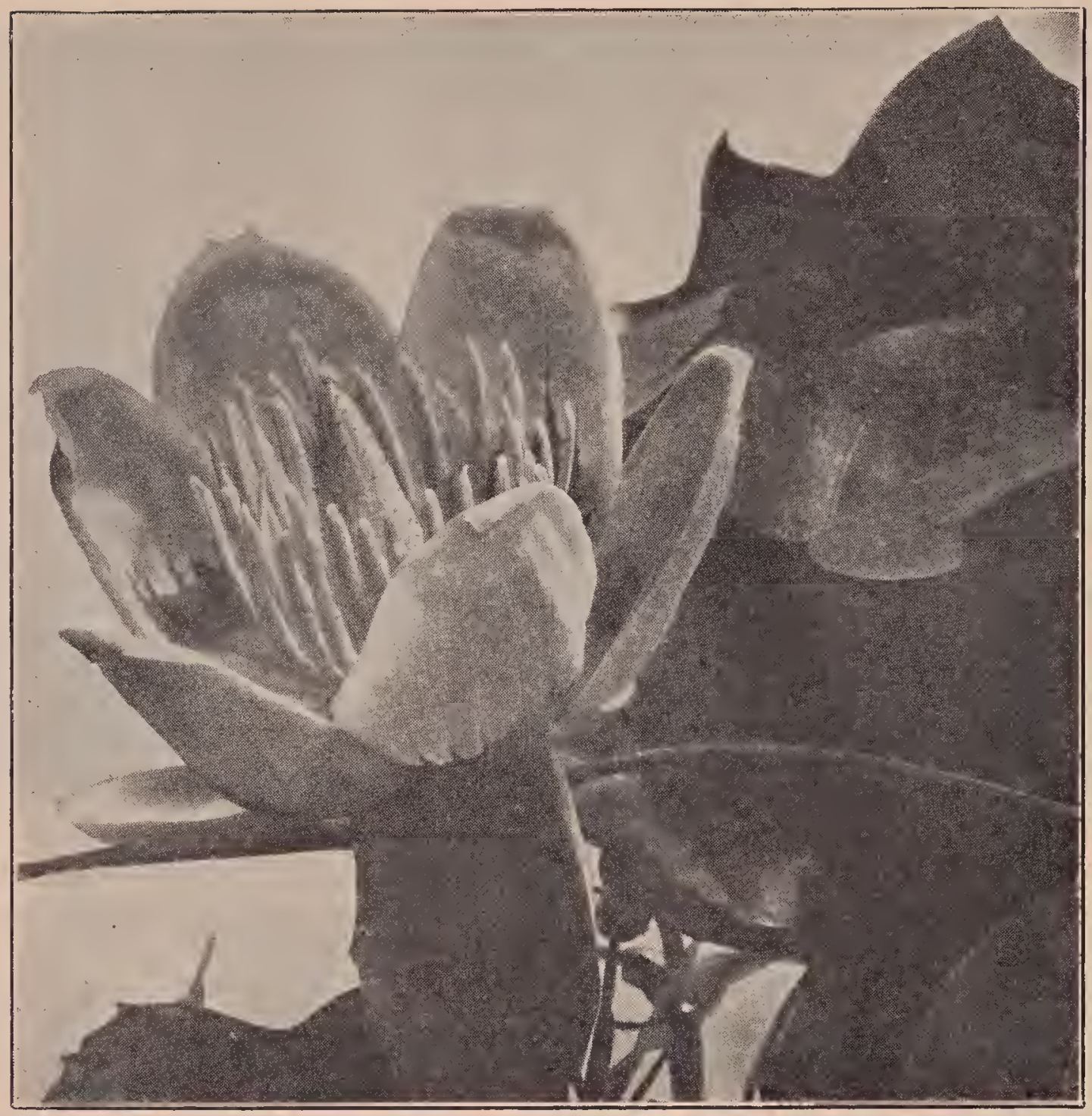

Flower of tulip tree.

forest trees. They are four to six inches long, 4-lobed, with the end abruptly truncated or broadly notehed and have a smooth bright-green surface. The bark, which is broken into large flat ridges, has a very bitter taste and was used by the Indians as a. remedy for intermittent fevers.

The slightly fragrant bell-shaped flower's are two inches long, solitary and terminal. The ealyx is composed of three oval concave sepals of a pale-greenish color, which finally become reflexed. There are six large yellowish-green petals, each of which is marked at the base with an irregular creseent-shaped bright orange-yellow spot. The stamens are numerous with short filaments. In the center there is a cone-like mass of pistils (carpels). The seeds are winged and form a dry cone 3 inches long, which falls apart in autumn. The flowers are very frequently visited by bees and also by humming birds.
The tulip tree is found in rich woods from Massachusetts and Michigan southward to Florida and Mississippi and westward to Arkanșas and Louisiana. It succeeds best in a fertile loamy soil, such as occurs in river bottoms and on the borders of swamps. As a source of honey it is im-. portant in southern Virginia, West Virginia, Kentucky, Tennessee, Maryland, North Carolina, South Carolina and northern Georgia. In southern Virginia on the Piedmont Plateau the tulip tree and sourwood are the only plants which yiéld a large surplus. In the rugged wooded region of southwest Virginia the tulip tree, sourwood, black locust, and basswood furnish a large amount of honey. Along the Ohio River in West Virginia the tulip tree is likewise abundant. On a tract of land, 625 acres in extent, near the Ohio River between the Great Kanawha and Big Sandy rivers there were counted 16,987 trees, of 
which 858 were tulip trees. This cliaracteristic tree was at one time very common in Kentucky; and, altho many merchantable trees have been largely cut for lumber, it still furnishes a part of the surplus in the less thickly settled sections of the State. Young trees are rapidly springing up and beginning to bloom. On the ridges and tablelands of the eastern and central regions of Tennessee the tulip tree and solu'wood are the most important sourees of honey. The former begins blooming about the first of May, and yields heavily for about two weeks.

In Maryland above the fall line on the Piedmont Plateau the tulip tree is sufficiently abundant to yield a honey crop regularly. On the Coastal Plain it never furnishes a surplus. Formerly in central Maryland it was one of the main surplus honey plants, and it is still important in Montgomery County, where it is associated with chestnut, walnut, and maple. But it lıas been so largely cut for pulp wood that there has been a great decrease in the quantity of honey obtained. No other honey plant in North Carolina has so wide a distribution as the tulip tree. It is found, in all parts of the State except in the eastern lowlands. The tulip tree is likewise widely distributed in South Carolina, but is most common in the Piedmont region. It extends over northern Georgia where it is usually a reliable source of honey, and it is also found in the mountainous sections of northeastern Alabama.

The nectar may be seen in both large and small drops on the orange-yellow portions of the petals, on the inner side, which thus scrve as both nectaries and nectarguides. The time of blooming varies with the conditions of the weather from the last of April to the beginning of June. When the blossoms are late in opening and the weather is warm and dry, the honey flow is very much lieavier than when the bloom is early. Under such conditions there are few if any better honey plants than the tulip tree, and each flower will yield not far from a spoonful of nectar. When the flowers appear early in the season the flow is often interrupted by cold rains. A large quantity of honey is stored even when the trees are scarce, and one or two supers are often filled from this source alone. Where the trees are abundant there is little danger of overstocking, and it has been estimated that 200 colonies could not take care of the nectar within their range. Unfortunately, there are today few sucl locations, and they are in regions difficult of access.

"The tulip tree blooms so early," writes Phillips, "that the poor beekeeper, or even the average beekeeper, does not liave colonies strong enough to get the crop. At Washington the average date at which this tree begins to bloom is not far from May 5 . It obviously requires skillful beekeeping to build up the colonies to full gathering strength at this early date. In order that the colonies may contain 75,000 to 100,000 population at the time of the arerage date of the last killing frost, brood-rearing must be heavily under way by March 1 . If this can be done, and we know that it is possible by proper winter and spring care, then the tulip tree may be expected to give a crop almost every year. At this season the the weather is uncertain and the short blooming period (rarely over 10 days) may be broken by rains, but it is indeed rare not to have a few days of good gathering. The tulip tree is perhaps exceeded by no other plant in reliability of yield, and few other trees furnish as much nectar as a tree of this species."

The honey obtained from the tulip tree is bright amber when new, but it becomes darker with age and very thick, so that it closely resembles molasses. In quality it is fair, somewhat strong, but with a rather pleasant flavor. It is in good demand locally thruout the South, but it does not sell well in the general market. As it is gathered early and does not command the highest prices, it can be used to advantage in brood-rearing and increasing the strength of the colonies for gathering the lightercolored honeys which come later. The tulip tree is a host for an abundance of plant lice in late suminer, which furnish considerable honeydew.

The seed slould be sown as soon as ripe in moderately dry fertile soil, and should be protected during the first winter. The wood is soft and fine-grained and is easily worked; it is usually nearly white but in some localities is yellowish. It shrinks badly in drying and consequently is not adapt- 
ed to exposure to the weather. When dry it resists decay and is rarely attacked by insects. It may be used for sections and brood-frames, but is very unsatisfactory for hives. It is suitable for door panels and wainscoting and in the manufacture of carriages, furniture, and various small articles. As the wood is light and strong, the Indians used it in building great canoes, capable of carrying 20 persons or more.

TUPELO (Nyssa).-Nyssa is a small genus containing only 7 species, of which 5 occur in North America and 2 in southern Asia. Four of the American species are trees, and one is a shrub. The leaves are alternate, thick and leathery, almost entire, oblong or obovate, and are brilliantly colored in autumn. The flowers are small, greenish and appear with the leaves. The stamens and pistils are usually in different flowers on different trees, the staminate are clustered, and the pistillate solitary or two to three together. The name of the water-nymph Nyssa was given to this genus on account of the aquatic habit of the species.

White Tupelo (Nyssa aquatica.) White gum. Cotton gum. Water tupelo. Tupelo gum. Swamp tupelo. In river swamps in the coast region from southern Virginia to northern Florida, westward to the Nueces River, Texas; northward thru Arkansas, west Tennessee and west Kentucky and southern Missouri to the lower Wabash River, Illinois. A large water-loving tree, attaining a height of 100 feet and a diameter of 4 feet. The bark is dark brown in color, ridged and broken into small scales. The leaves are thick, oval, pointed at the apex, dark green and shining above, paler and pubescent below. The small greenish flowers open in April and May; the staminate are in dense round heads; the pistillate or fertile are solitary on slender stalks. The blue-purple fruit ripens in September. The wood is soft but can be used for crates and packing boxes. In the older floras the Latin name of this species is given as Nyssa uniflora.

The honey of white tupelo has a very mild exquisite flavor, a thick body, and is very light in color with a pale lemon hue which renders it very attractive in glass

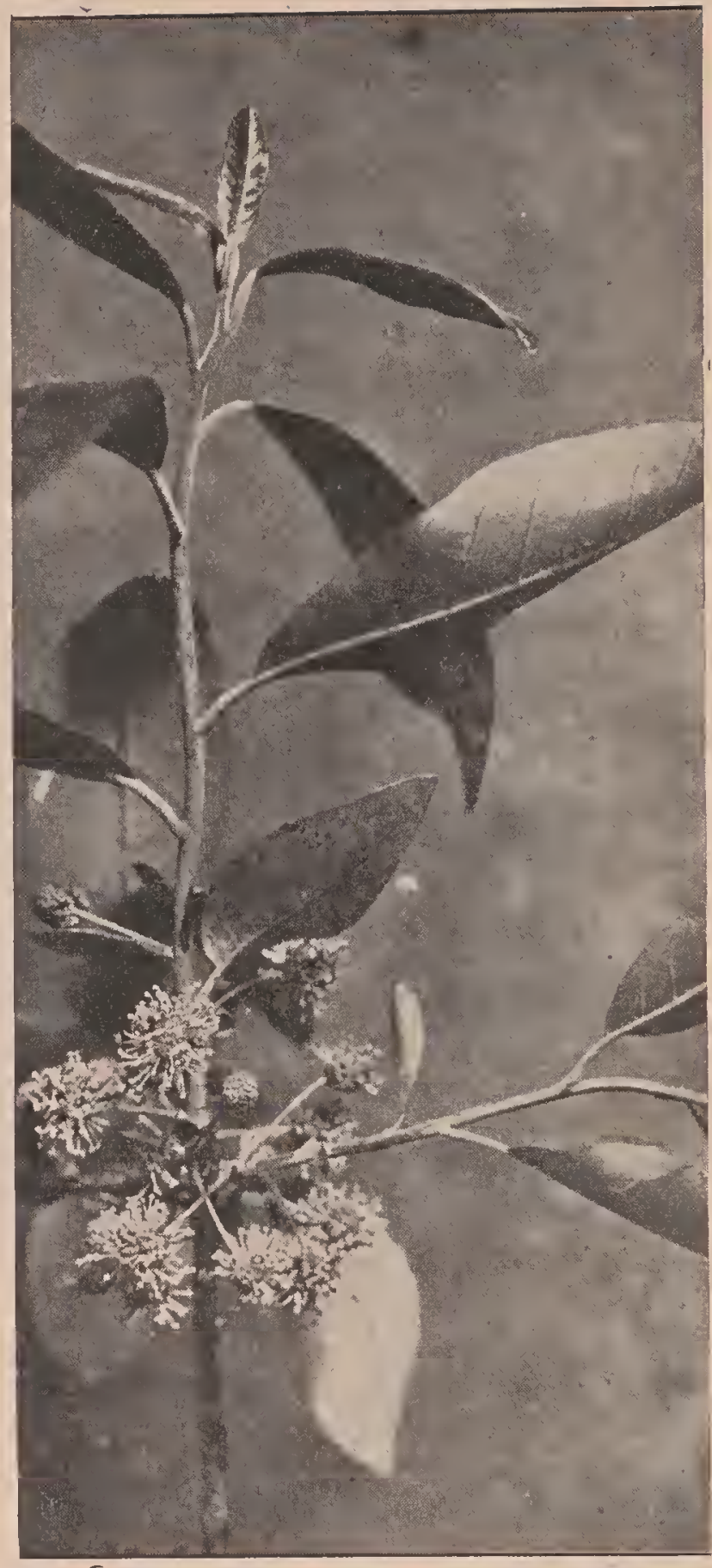

Sprig of scrub tupelo, showing the shape of the leaves and blossoms.

containers. The bulk of this honey is produced in the extracted form and shipped northward in 30-gallon barrels. It is in great demand among northern dealers in honey, who prefer it because it does not granulate. The nectar is secreted very copiously and a great amount is collected by the bees in a few weeks, but they are not numerous enough to harvest more than a small part of it. In pine-barren ponds the white tupelo is often a small tree, which may be readily mistaken for a distinct species.

Black Tupelo (Nyssa biflora). Black 
gum. Water gum. Water tupelo. This species has a much more restricted range than white tupelo, extending only from Montgomery County, Maryland to Florida and central Alabama. A large tree, attaining a maximum height of over 100 feet, with a rough, ridged, dark-brown bark. The oval leaves are smaller than those of the white tupelo, smooth on both sides, bluntpointed, with entire margins. The blossoms appear in April and May and the dark blue plum-shaped fruit in early fall; the staminate flowers are clustered, the pistillate are two together, instead of solitary as in the white tupelo. Black tupelo thruout its range is usually associated with white tupelo, but it often extends to higher land. It is abundant along lake margins and on the bottomland of small streams. The fruit, which falls into the water, sometimes accumulates in large heaps in sheltered coves.

The beginning of the honey flow is determined by the length of time the lowlands are covered by water. If there has been no overflow in early spring the trees in northern Florida will bloom in March, and the honey flow will last for three weeks. But if there has been much rain and the rivers have flooded the bottomlands, the blooming time will be much delayed. The honey when first gathered is thick, light in color, and very mild in flavor: but with age it grows darker. colored and stronger flavored.

Sour Gum (Nyssa sylvatica). Pepperidge. Black gum. This large forest tree, 100 to 150 feet tall, is the giant of the tupelos, and has a much wider distribution than any other species. It extends from the Kennebec River, Maine; Ontario and southern Michigan; to the Kissimmee River, Florida; southeastern Missouri and the Brazos River, Texas. The seventh edition of Gray's Manual ranks the black tupelo ( $N$. biflora) as a variety of this species, and undoubtedly beekeepers very often confuse the two trees. While pepperidge grows on high land it requires moist soil. In North Carolina the black tupelo ( $N . b i$ flora) is common in the southeastern swamps, while pepperidge ( $N$. sylvatica) extends westward to the center of the State. Both species are called black gum in this
State, and the beekeepers do not distinguish carefully between them.

The bark and leaves of the sour g'um or pepperidge are very similar to those of the black tupelo. The flowers open from April to June according to the locality; the staminate are in dense clusters, the pistillate 3 together. While the bloom yields nectar, it is apparently of much less value to the beekeeper than either the white or black tupelo.

Ogeche Plum ( $N$. Ogeche). Ogeche lime. Wild lime tree. Gopher plum. A small tree, reaching a maximum height of 60 feet, but seldom more than 30 to 40 feet tall. Com-

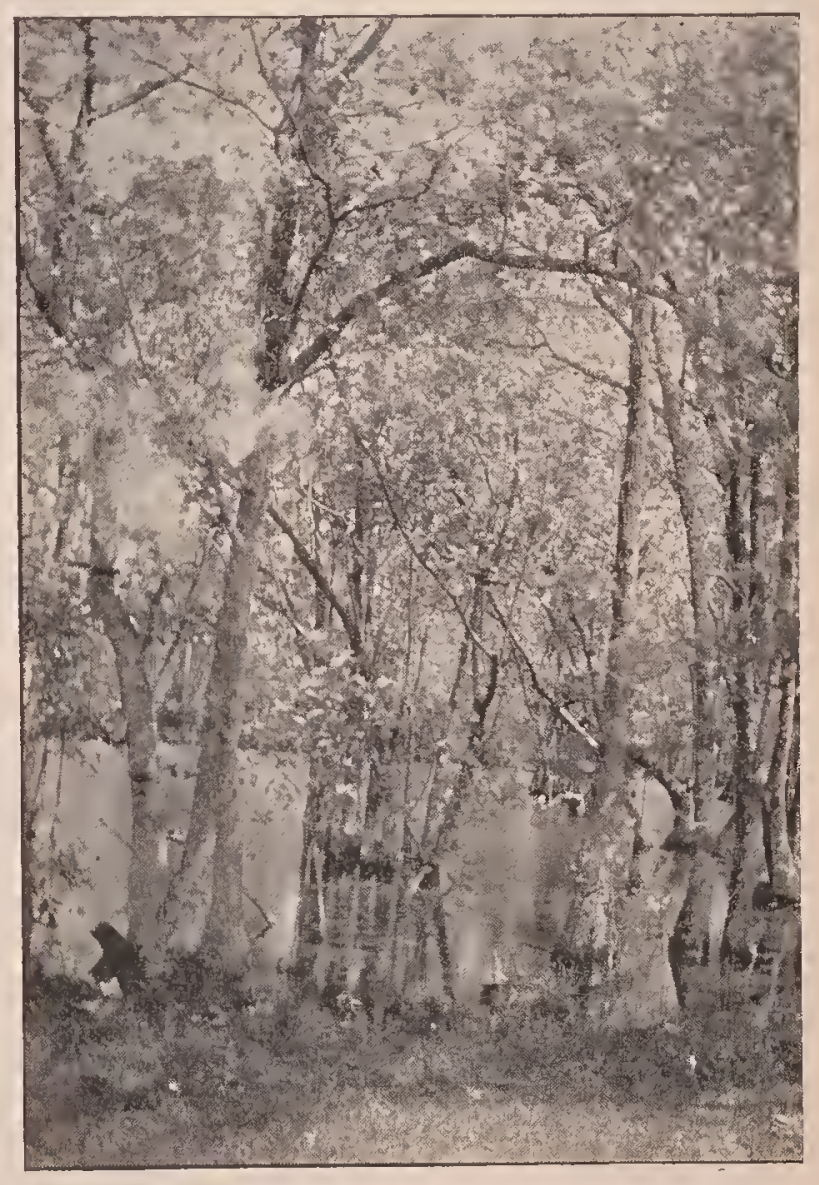

Scrub tupelo of Georgia.

mon in the river swamps of South Carolina, Georgia and Florida. The greenish-yellow flowers appear from January to May, the staminate in round heads, the pistillate solitary. The fruit is red and very acid. In Florida it has been reported to bloom just before the white tupelo and to yield a white, thin honey.

Bush Tupelo ( $N$. acuminata). This species is a mere shrub, growing 6 to 10 feet tall, and peculiar to the pineland swamps near the coast of Georgia. The bark is smooth and the branches and twigs red. 


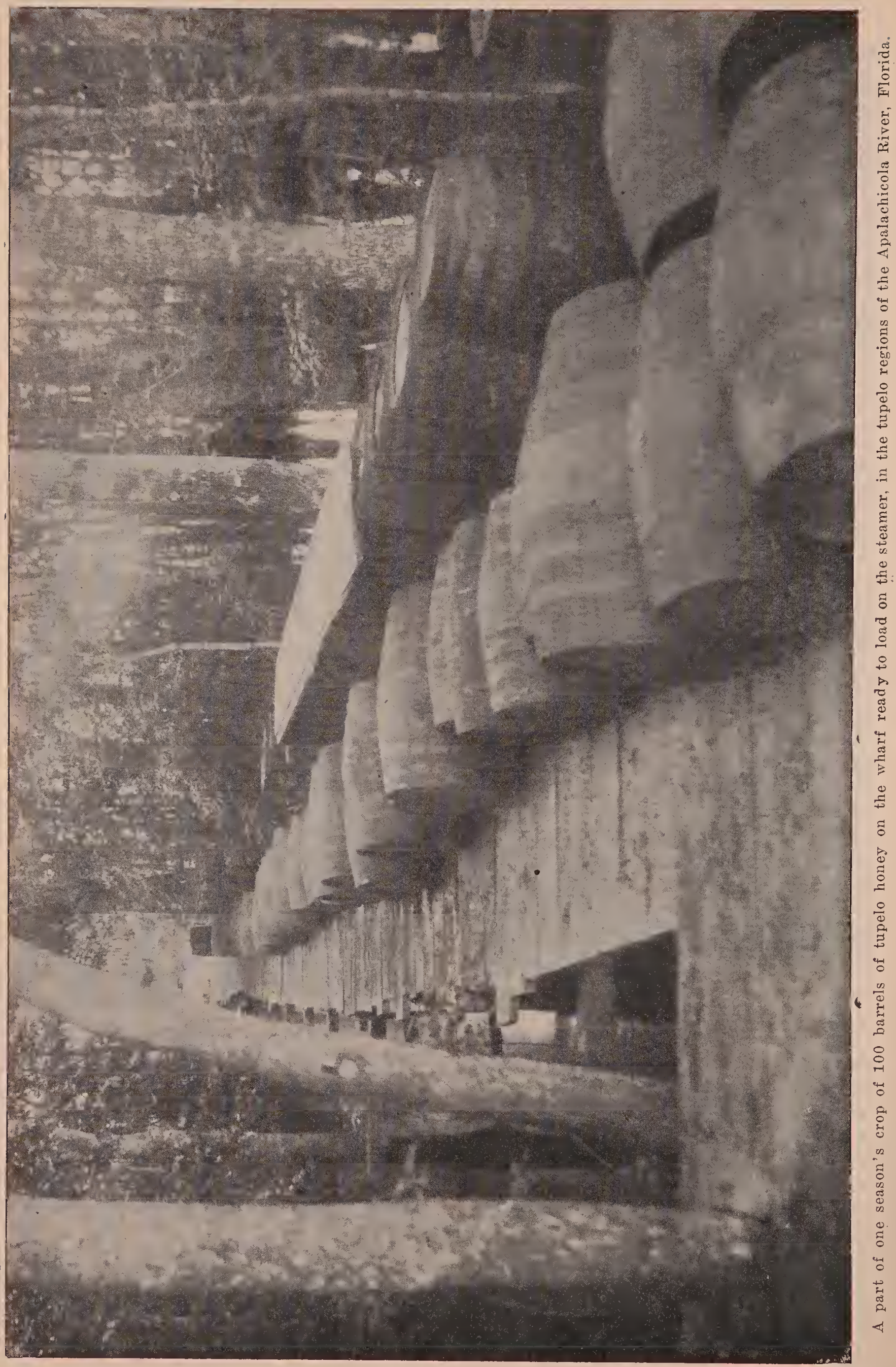


The honey is thick and white, elosely resembling that of white tupelo, but has a greenish tinge.

The white and black tupelos ( $N$. aquatica and $N$. biflora) are commonly found in the same swamplands from Virginia to Florida. In the swamps near Norfolk, Virginia, they are important sources of nectar, and only rarely does the beekeeper fail to obtain a surplus. In the southeastern swamps of the Coastal Plain of North Carolina the tupelos are very abundant, while gallberry covers much of the higher land. A large number of colonies of bees are successfully operated in this section, but much of the region is still unoccupied by beekeepers. In the river swamps of South Carolina both white and black tupelos are. again common and yield a large portion of the crop of honey. In southeastern Georgia all five species of tupelo, native to the United States, occur; but none yield so large an amount of honey as the black and white tupelos. It is in this section of the State that the largest and most advanced beekeepers are located who operate thousands of colonies of bees.

The most famous section of Florida for beekeeping is the northwestern part of the State along the Apalachicola and Ocklocknee rivers, where white tupelo, black tupelo, and spring titi are abundant. From this section comes about one-third of the honey crop of the entire State. About 50 miles from the point where the Apalachicola and Ocklocknee rivers enter the Gulf of Mexico the rivers have low banks, the main channels breaking up into small streams which wind thru the marshland. This strip of bottomland is about 10 miles wide and is covered by a luxuriant growth of tupelo trees. As it is overflowed in the rainy season, it is necessary to place the hives on platforms, 6 to 10 feet high. The season opens with the blooming in March of blapk titi, and a little later in April and May the flowers of the tupelos open. So copious is the flow that an average of 70 pounds per colony is extracted each year, and in some seasons 100 or 150 pounds; 250 barrels of extracted honey have been secured in 26 days. Vast quantities of nectar go to waste, and it is doubtful if this region will ever be fully stocked with bees. A full crop is obtained three years in five, and there is never less than a quarter of a crop. But many do not care to live in a desolate, unwholesome swamp, where malaria and mosquitoes are prevalent, roads are absent, and the only signs of civilization are sawmills. Other objections are the shortage of pollen and the absence of late-blooming plants to maintain the strength of the colonies in the fall.

In the southeastern corner of Alabama the surplus honey plants in spring are titi, the tupelos, and gallberry. The yards, which are usually small in size, in a favorable season average 60 pounds of surplus

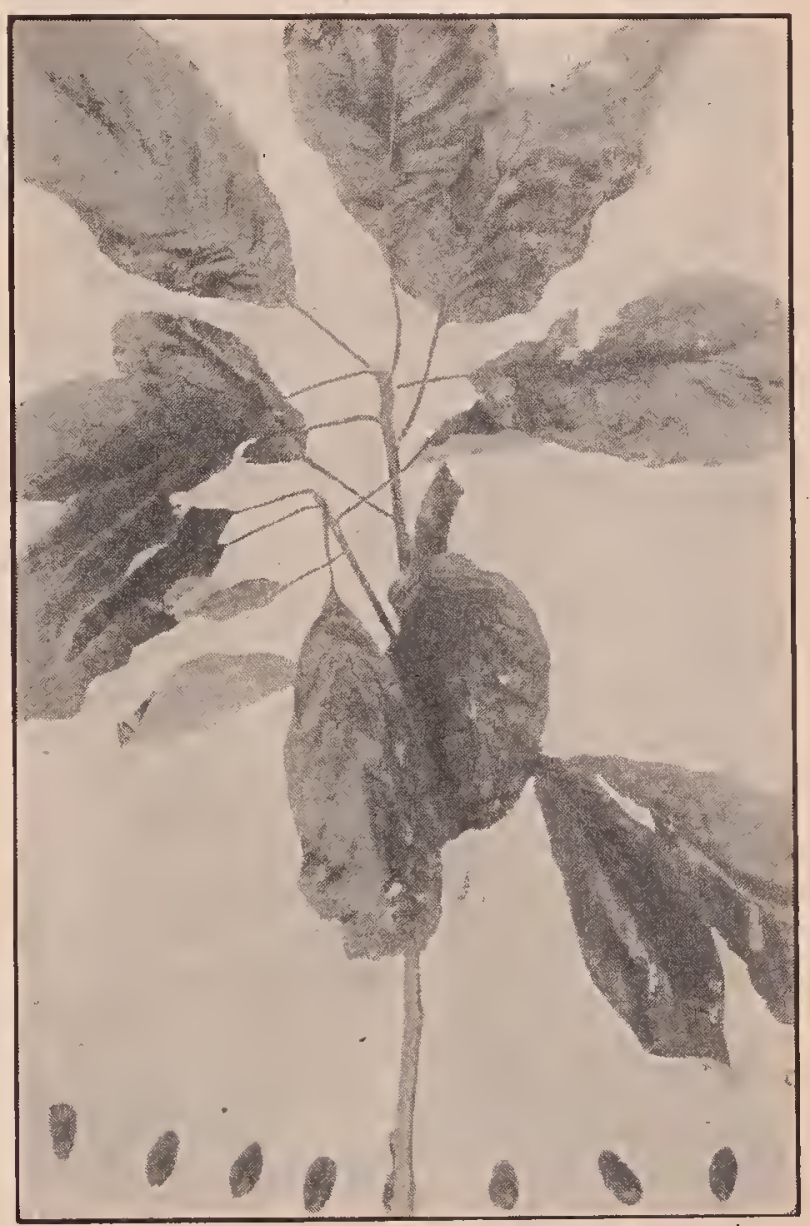

Black tupelo or gum with berries.

per colony. Altho there are a large number of colonies in this region, it is considered better adapted to queen-rearing than honey production. At Mount Pleasant on the Alabama River the main crop comes from the tupelos, holly, blackberry, and velvet bean. This is one of the best locations in the pine barrens. Beyond Alabama the black tupelo ( $N$. biflora) ceases to be an important source of honey, altho it has been reported as far west as Louisi- 
ana; but the white tupelo ( $N$. aquatica) and the sour gum or pepperidge (N. sylvatica) have a much wider distribution. In the Yazoo Delta, Mississippi, the white tupelo does not appear to be one of the surplus-making plants, since none of the beekeepers secure a surplus before June, and the white tupelo blooms much earlier. In the flood plains of Louisiana white tupelo yields a veritable flood of nectar, and the bees are busy on the bloom from early dawn until sunset; but the flow is of short duration. The river swamps of eastern Texas, mark the western limit of the white tupelo. The banks of the Nueces River are lined with white tupelo and sour gum ( $N$. sylvat$i c a)$, the belt of timber being from one to two miles wide. In southern Arkansas white tupelo is valuable, and sour gum has also a wide distribution. White tupelo is also listed as a honey plant in western Tennessee and western Kentucky.
UNITING BEES.-This term is used to refer to the putting together of two or three nuclei or weak colonies, either from the same yard or from other yards. The operation is just the reverse of dividing, in which process a colony is split up into several smaller units. See pividing, INCREASE, and NuCLEUS.

When several families of bees are put together they may or may not quarrel, depending on circumstances. If the weather is warm, and the bees are hybrids or blacks, they may, at the moment of uniting, enter into a free-for-all fight. The result, unless stopped by the timely use of smoke, may be almost the annihilation of one or both lots of bees. As a rule, even without smoke there will be no quarreling where gentle strains of bees like Italians are used; and even when they have these "family disturbances". they can be "adjusted" very nicely by the use of plenty of smoke. Sometimes more smoke will be needed than at others, especially if the two lots of bees are of fairly good strength, and persist in stinging each other to death.

In any case after uniting without smoke it is advisable to watch the bees for a few minutes to see if there is any trouble later. Many a lot of fine bees have been ruined because, after uniting, the apiarist did not go back a few minutes later to see if all was well.
There is another difficulty in uniting; and that is, that the old bees, if taken from the same yard, are quite apt to go back to the old stand. This is especially true if the uniting is performed during or immediately following a honey flow. Young bees that have never been out of the hive will stay where they are placed, and perhaps a majority of the old ones.

If the several families to be united all have queens, no attention need be paid to them if there is no choice between them. If one is better than the rest, cage her after uniting and kill the others. This is a precaution.

The old-fashioned black bees can be moved about from one part of the apiary to another with less trouble than the Italians because the blacks will find their location better. But when uniting by the newspaper plan (to be described further on) this point need not be considered.

In these days, when out-apiary beekeeping is practiced on so large a scale, the weak colonies or nuclei of two separate yards can be united very easily without any returning. Where one finds a number of undersized or weak colonies in two or more of his yards, he can put the weaklings of one yard with the undersized or medium-strength colonies of another, thus bringing them all up to normal strength either for honey-gathering in early summer 
or for wintering at the close of the season.

When there is only, one yard of bees, as in most cases, one can unite even then if he will follow the directions here given.

HOW TO PREVENT THE BEES FROM THE SAME YARD GOING BACK AFTER UNITING.

After inclement or cool weather, during which the bees have been confined for several days, they may be united with little or no returning, when, if they have been going to the fields for nectar for several days, the old bees will be almost sure to go back. It is, therefore, advisable to wait for a spell of rainy or cool weather when the bees cannot fly much, during which time they will have been confined for at least four or five days. Then in the cool of the morming the nuclei can be moved to their permanent winter stands. At the moment of uniting it is advisable to use plenty of smoke, not only to avoid any possible fighting that may occur, but to disorganize them so that, when they seek flight from their new home, they will mark their entrance anew. It is also important to remove the old hives after taking the bees from them to unite with other bees.

It very often occurs late in the fall that one will have a lot of nuclei without any brood. If these should be queenless, the bees of several of them can be shaken into a swarming-box and confined over night in a cellar or in a cool place. The intermingling of several families of bees, and confinement in a box without combs, breaks up the old family spirit that formerly existed, and almost entirely eliminates all tendency towards the old home. This lot of bees can now be apportioned out to colonies that are not quite up to standard of strength as follows:

In the cool of the morning, before any bees are flying, the hives of bees should be marked in such a, way that the apiarist can at a glance determine how many bees he shall give to each individual stand. He next approaches a hive. The marking on the cover shows that it can take two dipperfuls of bees. He gives the box a jounce on the ground so as to pile the bees up en masse on the bottom. If they are disposed to fly up, he wets them down with a little spray - just enough to dampen their wings, and thus impede their flight., Before they can crawl up on the sides of the box he now scoops up a bunch of the bees with a little tin dipper and dumps them in at the front of the entrance. If the hive in question requires two dipperfuls, then two dipperfuls of bees it gets; and so on he distributes bees to every hive that needs them.

As a matter of precaution, every hive receiving bees like this should have its queen caged for 24 hours at least, in such a way that the bees can release her by eating out the candy or gnawing away the comb. (See Introducing.) As a further precaution, after the bees have been distributed in front of the various hives, an examination should be made in about $25 \mathrm{~min}$ utes to see that there is no fighting between the new family and the old.

By uniting in this way there have been accomplished two thing's - strengthening the colonies that are not quite up to the standard, and disposing of all the weaklings in the apiary. If the first box will not hold all weaklings at the first time, it can be filled the second or third time until all nuclei that are too weak to winter are cleaned up.

\section{NEWSPAPER PLAN OF UNITING.}

There is still one more way of uniting to prevent bees returning, and this may be practiced even when bees are flying to the fields if the weather is not too hot. The moved hive with its bees is put on top of another with a single thickness of newspaper between. By the time the bees above gnaw a hole thru, some time elapses. The confinement and the gradual uniting of the bees thru the hole in the paper avert all fighting and all returning of bees to the old stands, says Dr. Miller. During hot weather there is danger that the bees in the upper story may suffocate, in which case it is advised to punch a hole thru the paper with a lead pencil.

\section{UNITING NEW SWARMS.}

This is so easily done that directions are hardly needed; in fact, if two swarms come out at the same time, they are almost sure to unite, and two such swarms are not likely to quarrel. One of the queens will very soon be killed, but the extra one may be easily found by looking for the ball of bees that will be seen elinging about her, 
very soon after the bees have been joined together. A swarm can, as a rule, be given, without any trouble, to any swarm that has come out the day previous; and if one will take the trouble to watch them a little, he may unite any swarm with any other swarm, even if it came out a week or more before. If inclined to fight, they should be smoked as before explained.

While swarms can be united it is not advisable to unite a swarm with an old colony without smoking them at first or at least waiting after uniting.

Perhaps a safer and a better way is to use a newspaper between the two stories as before explained; but when the newspaper is used on a hot or sultry day, it is advisable to poke a hole in it with a lead pencil to prevent suffocation.

\section{UNITING BEES IN THE SPRING.}

As has been pointed out elsewhere, uniting two weak colonies in the spring is usually unprofitable. Uniting a weak to a medium colony is quite a different thing, as will be presently explained. When there are two little weak colonies, or nuclei, one having a queen, it would seem the most natural thing to put the two together for additional warmth and to provide a queen for all the bees; but, unfortunately, theory is not here borne out by facts. One can unite nuclei in the spring; and while at the very time of uniting they will seem to make up a fairly good colony, yet in two or three days there will seem to be just about as few bees as there were before the uniting took place. This is because the moved bees go back to the old stand, and because the old bees die off. They would die anyway, whether in the old hive before uniting, and they would die after they were moved just the same.

All of the foregoing has reference to periods early in the spring in the northern States. Later in the spring, along about the last of May or first of June, uniting can often be practiced to advantage, especially if the newspaper plan is nsed.

THE ALEXANDER PLAN OF UNITING.

During the year 1905, and again in 1906 and ' 07 , considerable interest was manifested thru Gleanings in Bee Culture in the Alexander plan of uniting a weak colony to a strong one in the spring. Many of those who followed the method were very successful. A few, however, failed. To these latter reference will be made later. The Alexander plan of uniting as carefully revised by $\mathrm{Mr}$. Alexander himself is given:

\section{ALEXANDER METHOD OF BUILDING UP WEAK} COLONIES IN EARLY SPRING.

About six or seven days after taking the bees from their winter quarters, pick out and mark all weak colonies, also the strongest ones, selecting an equal number of each; then all weal colonies that have a patch of brood in one comb about as large as the hand. Set all such on top of a strong colony with a queen-excluder between, closing up all entrance to the weak colony except thru the excluder.

Where there are any that are weak, only a queen, and perhaps not moxe than a handful of bees with no brood, fix these in this way: Go to the strong colony you wish to set them over, and get a frame of brood with its adhering bees, being sure not to take their queen; then put the queen of the weak colony on this comb with the strange bees, and put it into the weak hive; leave them in this way about half a day; then set them on top of the strong colony where you got the brood with a queen-excluder between. Do all this with very little smoke, and avoid exciting the strong colony in any way. If a cool day, and the bees are not flying, I usually leave the strong colony uncovered, except with the excluder, for a few hours before setting on the weak colony. The whole thing should be done as quietly as possible, so that neither colony hardly realizes that it has keen touched. When the weak colony has been given some brood, and put on top in this careful and still manner, hardly one queen in a hundred will be lost, and in about 30 days each hive will be crowded with bees and maturing brood. Then when you wish to separate them, set the strongest colony on a new stand and give it also some of the bees from the hive that is left on the old stand, as a few of the working force will return to the old location, especially if they are black bees or degenerate Italians.

In every case that has come to my notice where this method has been reported a failure it has been from one of two causeseither lack of brood in a weak colony to hold the queen and her bees in the upper hive, or smoking the strong colony so that, as soon as the weak one was set on top, the bees from below would rush up and sting every one above. Therefore avoid using smoke or doing anything to excite the strong colony.

If done in a careful manner the bees in the lower hive never seem to realize that 
any strangers have been put above them, and they all work in lianony together.

At the outset mention was made of those who met with failure in following the method. As Mr. Alexander says, the difficulty doubtless arose from the fact that they failed to put brood along with the weak nucleus to hold the queen and her few bees, or else they did the work so clumsily that it stirred up both lots of bees, with the result that they came togetlier before they had the same scent. $\mathrm{Mr}$. Alexander's injunction is to put the bees together so carefully that the clusters do not really unite for some two days, at which time there is a peaceful union. The two queens go on laying, making one rousing colony, which can be divided. This makes two strong colonies where before there would have been only one, since the nucleus left to itself would have died.

Where one desires to proceed with extreme caution he is advised to put a wire-cloth screen between the two lots of bees at the time of uniting, keeping it there for two or three days, after which its place is taken by a perforated zinc honeyboard. In this connection it should be said that the wire-cloth screen should be mounted in a wooden frame about $3 / 8$ inch thick.

While this plan of uniting contemplates performing the act in early spring, something can be done at it in the fall. $\mathrm{Mr}$. Josiah Johnson, in a communication sent to Gleanings in Bee Culture, tells how he unites on the Alexander plan in the fall.

Some have had trouble in following the Alexander plan of building up weak colonies. I think the trouble in many cases is due to rousing up the bees and getting them uneasy before the weak colony is put over the strong one. Then the two colonies have war for a while. I always use wire cloth between the two hives and never have any trouble from the lower colony going up and killing the bees in the upper hive. For some time I have wintered my weak colonies this way, on the summer stands. Last winter I had several weak colonies, and I put them all over strong colonies, making an entrance in the back with my knife thru the handhole of the upper hive. This should be just large enough to allow two or three -bees to pass out at a time. This is done on some cloudy day after very cold weather comes.

Last year I had a weak colony of bees. There was just one frame of bees and a young queen. I put this frame of bees in with nine frames of honey, and put the frames in a hive and set it on top of one of the strongest colonies I had, and in February they got pretty strong, and I left them on till April; and when I set them off I had two strong colonies. Josiah Johnson.

Milan, Ill.

See Bullding up Colonies, Spring Dwindling, and Spring Management.
VEILS.-When dealing with hybrids, Cyprians, or Holy Lands, a veil is a necessity. With Italians, Carniolans, or Caucasians it is not so important; still it is advisable to have one on the hat ready to pull down. Its use in any case gives the apiarist a sense of security that will enable him to work to much better advantage than he could if continually in fear of every cross bee that chanced to buzz near his eyes.

The two objections that have been made against the use of veils are that they ob- struct the vision more or less, and interfere with the free circulation of air in hot weather'; but these objections with a good veil are not very serious. Our best beemen, as a rule, wear a veil constantly when among the bees, and it is best to do so.

The lightest veil is one made entirely of silk tulle, altho somewhat expensive. The material is so fine that a whole veil of it can be folded to go in a small vestpocket. The author carries one of these constantly during the working season of 


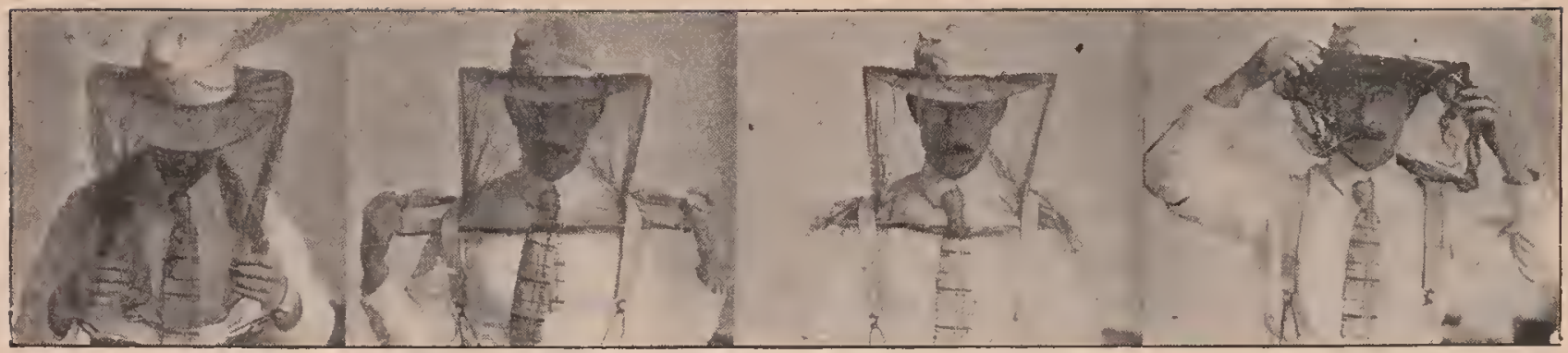

Manner of adjusting a bee-veil under the suspenders when there is no elastic cord in the bottom.

the bees, and it is always ready for an emergency. It neither obstructs the vision nor prevents the free circulation of air on hot days. A cheaper one, tho not so light nor cool, is made of grenadine with a facing of silk tulle net sewed in. The grenadine is strong, and the brussels-net facing obstructs the vision but little if any. The top of the veil is gathered with a rubber cord, that it may be made to fit closely around the crown of the hat.
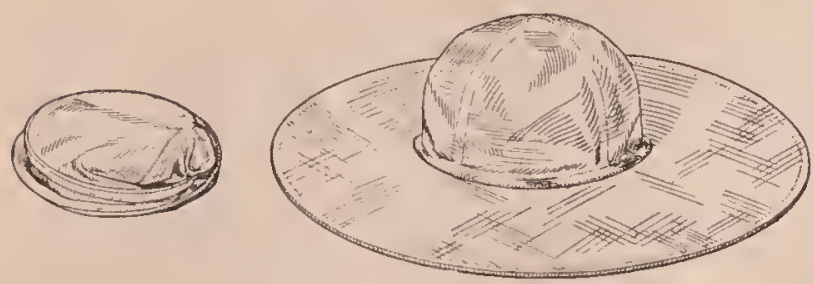

Collapsible bee-hat, folded and open.

There is a special broad-brimmed cloth hat, costing about one dollar each, that is sold by dealers. These hats are very light, will fit any head, and can be folded and put in a coat-pocket. 'This broad brim' is supported and held out by means of a steel hoop, and when the veil is placed over the hat and properly drawn down it cannot touch the face or neck, and hence leaves no possible chance for stings. During hot days when bees require the most attention in the apiary, a coat or vest is simply intolerable. In the absence of either one of these garments the corners of the veil may be drawn under the suspenders. The four views (top of page) show successively this manner of drawing the veil under the suspenders, and its position when in use. The last view of the series shows how easily it can be drawn out from under the suspenders and raised above the hat while not in use. A few apiarists work a large part of the time with the veil raised. When the suspender method of holding is used one can raise or lower and fasten the veil in a moment's time.

There are others who prefer a veil with a rubber cord inserted in the bottom, fastening the same by means of a large safety-pin to the clothing. Unlike the other veils shown with no elastic in the bottom of the fringe, this veil can be used by a man or woman, because the safety-pin can be secured to the clothing of either. In putting this on, care should be taken to draw the elastic clear down near the bottom of the waist, securing it with a pin as shown in the first illustration. No. 2 looks very nice, but the movement of the arms will soon push the cord above the shoulders, leaving it so loose that bees can readily crawl up. No. 3 is better; and if the elas-

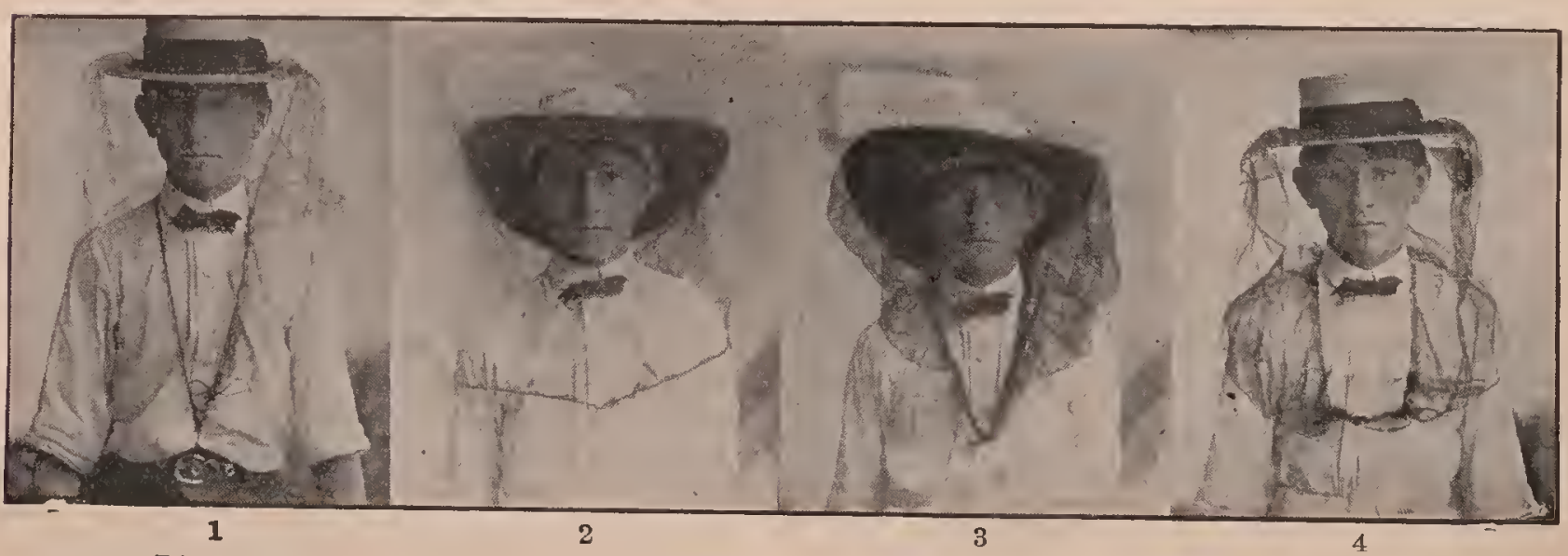

Right and wrong way to fasten a bee-veil having a rubber cord inserted in bottom. 
tic is stiff enough very good results will be secured. But if not, the veil must be drawn down as shown in the view at the extreme left, or No. 1.

No. 4 and next cut show method of fastening the veil. A piece of cotton tape is inserted in the bottom edge of the veil extending clear around the veil except in front. Across the front, a four-inch length of $3 / 4$-inch tape elastic is inserted, and the ends sewed securely to the veil, leaving the veil fulled on the elastic so that the latter may be stretched without tearing the veil. On each end of this elastic is sewed a short loop of cotton tape thru which are passed the ends of the long tape. This tape is

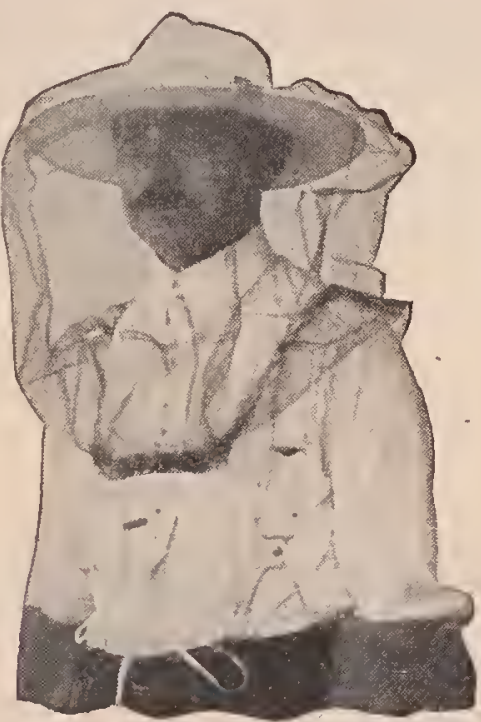

Root bee-veil.

then drawn up and crossed at the back, the ends being passed thru a two or three inch loop of tape attached to the cotton tape at the middle lower edge of the back of the veil, then brought to the front and tied. This holds the veil securely.

There are many practical beemen who prefer wire-cloth head-protectors to anything else. When first used they seem a little awkward; but the extreme comfort that one enjoys, more than compensates for their apparent outlandishness.

The next veil is what its name implies. Being made of black wire cloth it will not catch or tear on any obstruction. The skirt is made of muslin and should be drawn up snugly around the collar by means of a draw-string. The screen is shaped so that the shoulders will not push the veil off the head, and has a deep face which allows one to look down at the hive and still look through netting instead of the view being obstructed by the cloth.

The Alexander (shown at the bottom) is used by some of the most extensive beekeep-

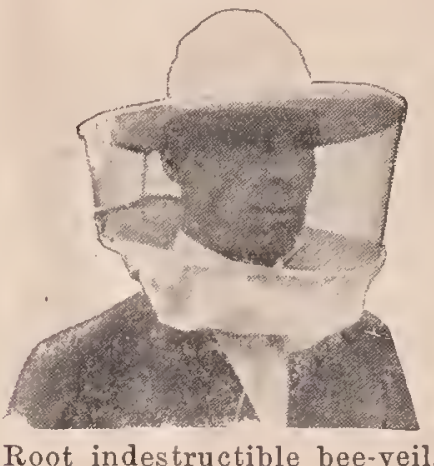

ers in the country. It is a plain wire-cloth cylinder having a circular gathering of muslin at the top, and a sort of skirt of the same material sewn to the bottom edge. With this outfit one will be required to go bareheaded or wear a small cap. Much of the work of the apiary is done during the hottest weather, and this veil is very cool. Like the one just described it does not get "hooked" in passing among trees or shmubbery, nor does it get torn like some of the veils of fabric. It has the further advantage that it can be removed in an instant without breaking any fastening, and is quickly put on again. The muslin skirt fits loosely yet snugly around the shoulders and neck.

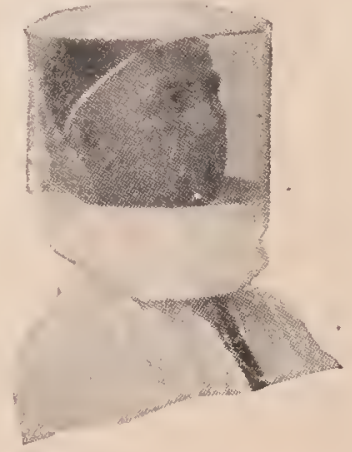

The Alexander bee-veil

The one shown in the cut uses a strip of wire eloth approximately ten inches wide and a yard long. A yard of muslin completes the material required. Where one uses a coat, the skirt of this head protection can readily be tucked inside; but even without coat or vest, the loose folds of the cloth fit with a fair degree of snugness around the shoulders and neek.

Some use with much satisfaction a sort of chopping-bowl or basket inverted for a hat. It is worn in India and other hot 
countries, and is slowly working its way into this country, particularly in the South. It is made of palm-leaf, and it is supported above the head in the manner shown below.

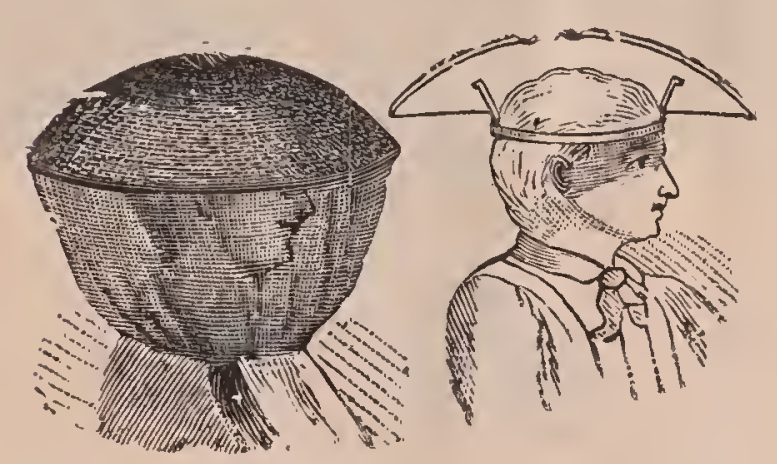

Hopatkong veil and hat.

As light breezes can circulate above and around the head, it is perhaps the coolest sunshade of any herein illustrated and described. If one cannot secure one of these, and would like to get the ventilating feature, he can take an ordinary palm-leaf hat several sizes too large. On the inside of the hat-band sew.four or five $3 / 8$-inch corks that have been cut in halves lengthwise. These, if spaced at regular distances, will keep the hat from the head, and permit ventilation.

As has already been said, one objection to bee-veils is the obstruction to the eyesight. To overcome this, John C. Capehart of St. Albans, West Virginia, glued a piece of glass in front of the veil. The difficulty with this was, that the glass would hardly ever be in range with the eyes, on account of its weight, and then it would be covered with moisture from the breath; and, worse than all, it would get broken. The brussels net or wire cloth is open to none of these objections, and is almost as transparent as glass.

Walter S. Pouder made an improvement on the glass by substituting cellul o d film such as is used for photographic film negatives. While this overcomes the objection of weight it does not prevent the moisture of the breath from accumulating on it. Moreover, it is very inflammable so much so that if a hot spark from a smoker should alight upon it, the face might be seriously burned. So far nothing has been found better than nor as good as silk tulle, or fine black wire cloth.

The Holmes veil is simply a straw hat with a broad rim, the veil being made of mosquito-bar, and the facing of brussels net. A strip of eloth lines the lower edge of the veil, and is made just large enough

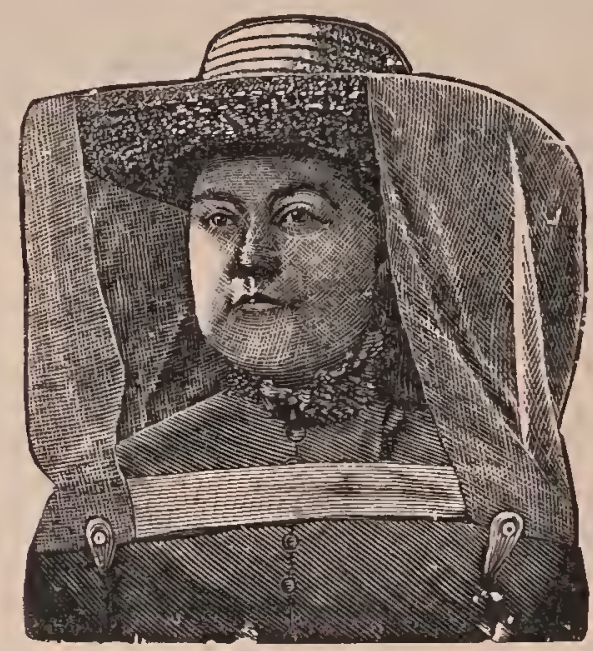

Mrs. R. H. Holmes' bee-hat.

to fit snugly around the shoulders. A

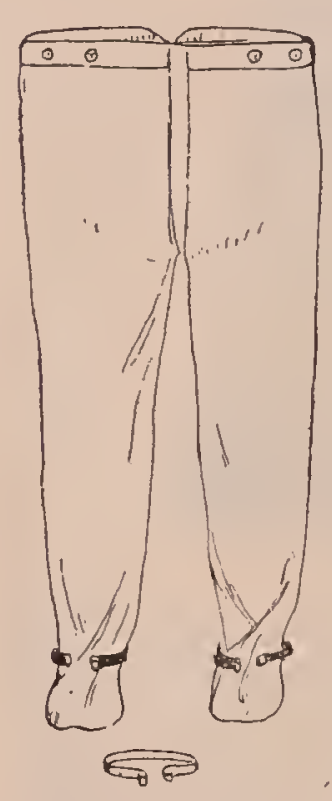
couple of cloth straps hitched to buttons pass under the arm-pits, and button on in front.

HOW TO GET ALONG

WITHOUT A VEIL.

Oceasionally one meets a person who says he does not need any bee-veil and never uses any in his bee work. Such a person is to be pitied for his sortsightedness rather than admired for his temerity. $\mathrm{He}$ will at

times spend enough time smashing bees that sting him in the face to make up many times over for the slight inconvenience of the veil. It is foolhardy and totally unnecessary to run the risk of a bad sting around the eyes, nose, mouth, or ears, and a good beekeeper is wise enough to wear a veil of some sort or have one on his hat ready to pull down.

Occasionally there will be times when one will have to do some work with the bees without a veil. Perhaps it has been forgotten, or perhaps a visitor more susceptible to stings has to have it. In such cases as these, one should make sure that his smoker is in excellent working order, with plenty of fuel. The smoker should be held 


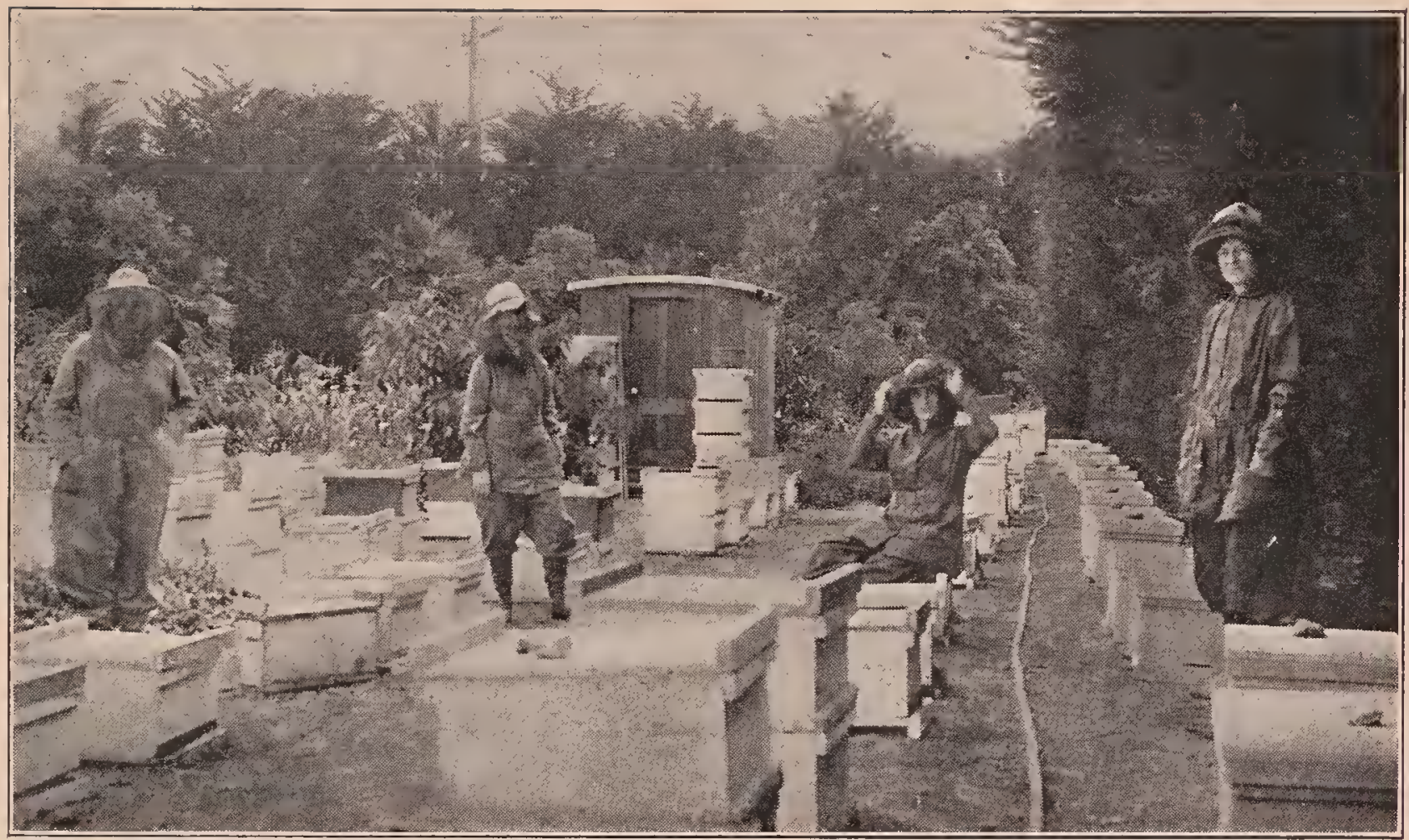

Farmerette beekeepers who, in 1918, reared queens and extracted for M. H. Mendleson of Ventura, Calif. He says they were the best help he ever had.

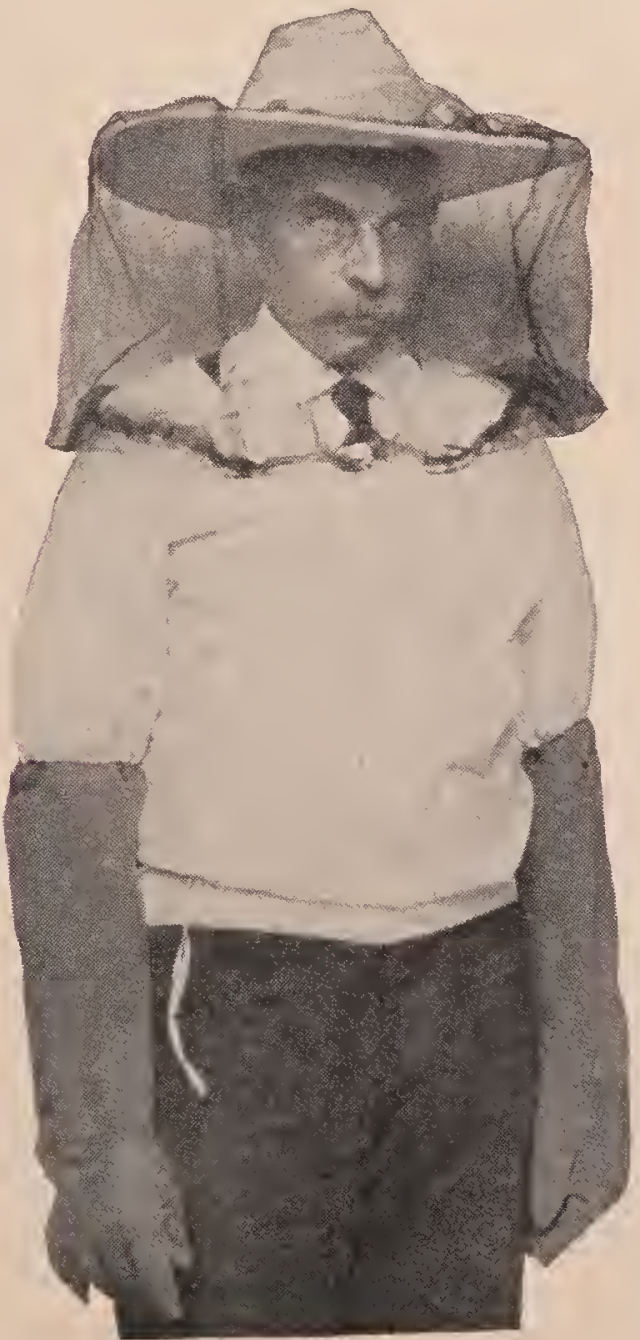

Bee-veil, warmus and 'gloves combined. between the knees when not in use so as to be ready for instant service over the frames. If the day is at all chilly smoke should be blown down over the frames quite frequently. By proceeding very cautiously, using smoke every now and then, one can get along without"a veil, but he wastes more time and uses an unnecessary amount of smoke.

With gentle Italians on warm days one can have his veil thrown back over his hat; but he should always have it ready so he can draw it down instantly in case of emergency. This is especially necessary where one has to wear glasses. An angry bee will sometimes get between the lenses and the eyes, and the owner in order to save himself from a sting will sometimes break his glasses.

BEE DRESS OR CLOTHING FOR BEEKEEPERS.

Under the head of GLoves, are described some long-sleeved gloves or gauntlets that reach away up above the elbows. Many beekeepers use these to keep bees from getting up the sleeves, and at the same time to protect the wrists, especially the inside fleshy portions of them where they are very sensitive. Others carry this same principle further, combining the gloves 
and headgear all in one, as shown. While this affords ample protection, it is a little warm on hot days; and, moreover, it is not easy to put on. After one has become mort accustomed to bees he can cut off the ends or the finger tips of the gloves so that he can work to better advantage.

As for trousers, one can get a pair of overalls at any clothing-store, and it is suggested that he get outfits such as are used by machinists and engineers. These have numerous handy pockets, large and small, in which various tools may be placed.

One-piece overalls covering arms, waist and legs are excellent. They can be slipped over the regular clothing or in hot weather can be worn without other garments than suitable underwear.

Bicycle pants-guards can be used to very good advantage during extracting and all other times, when one is shaking or brushing bees off combs. The bottoms of the trousers should be neatly folded around the ankles, and the guards slipped on to hold the folds in place.

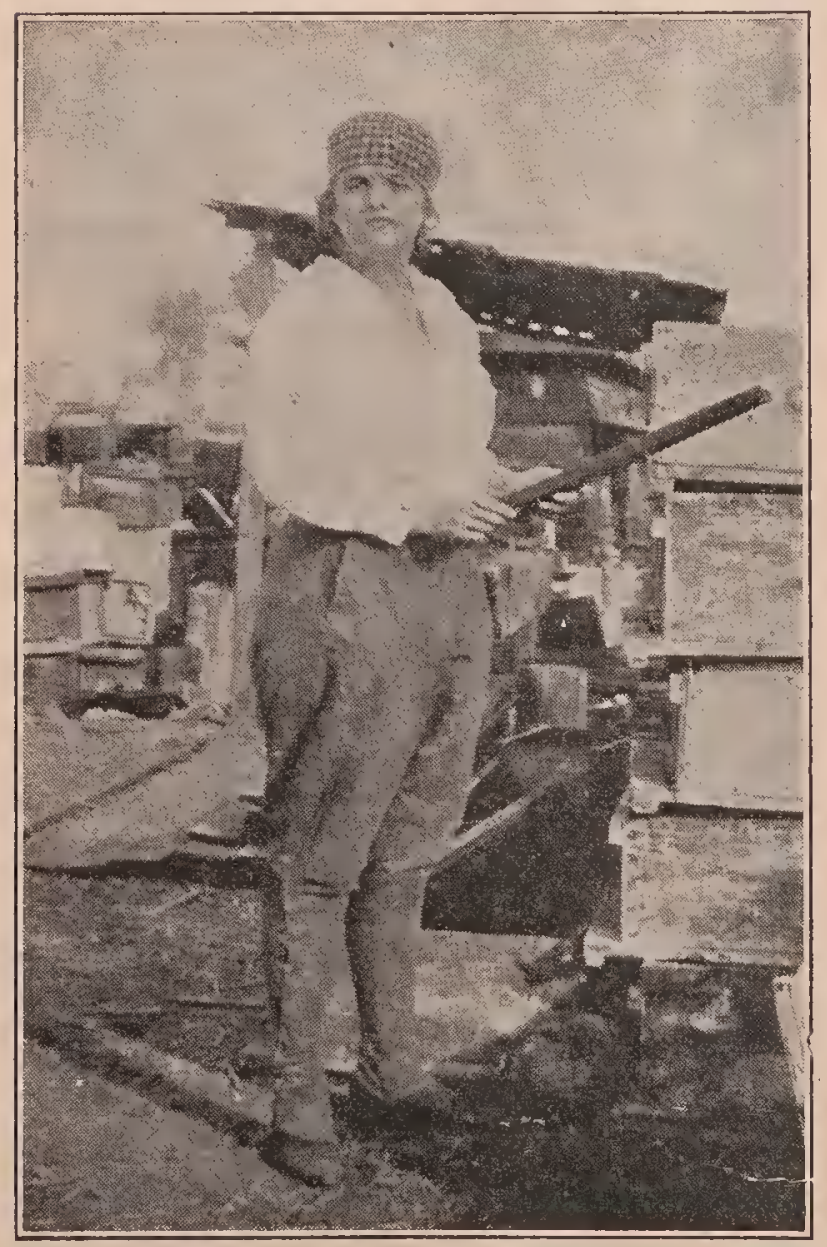

Miss Mary Culver of Calexico, Calif., in her farmerette bee-suit. Her father is an extensive beekeeper.
FARMERETTE BEE-SUITS.

In many parts of the West, as well as in some parts of the East, bee-women are wearing regular farmerette suits, either "Peggy. Janes," or one-piece overalls gathered at the shoe-tops, such as were introduced during the period of the Great War. Several of these styles are worn, and most of them are neat, safe, and sane. They are now getting to be quite common.

Many women wear overalls or bloomers when working in the apiary. If desired, a full but short apron may be worn over the overalls, or a short skirt over the bloomers. High-top shoes will also add to one's feeling of security.

VENTILATION.-Bees that are outdoors in their regular hives generally receive at the entrance all the ventilation they require. There should be, except in very hot weather, no other openings. Occasionally hives are so poorly made that they will have gaping cracks; but these, unless too large, will be closed up with bee glue-usually along toward fall; and some strains of bees, notably the Caucasians, will close them up early in the season. Indeed, they will sometimes obstruct the entrance by means of little chunks of propolis.

In olden times it was customary for the patent-right men to furnish their patrons with hives having all kinds of ventilating holes and little trapdoors; but the modern hive, as a rule, has no openings of any sort except at the entrance, which is contracted or enlarged according to the season. In hot weather it will be opened to its maximum, and in cool weather it will be reduced to one-fourth, or even less, of its largest capacity. See Entrances to Hrves and Wintẹring.

During extremely hot weather, especially during swarming time, it is sometimes necessary to provide upward ventilation in addition to that provided at the entrance. The cover may be lifted up in such a way as to leave a crack at the back end. This will allow a current of air to circulate from the top clear down thru the hive. But sometimes loosening the cover is insufficient. It is then necessary to provide ventilation for one or more supers that may be on the hive at the time. In that case, 
the second super is shoved forward on the lower one-just enough to leave a crack, front and rear. If that is not enough, the third super is staggered back so as to be in a vertical line over the bottom super; and in rare cases it may be necessary to go even further by tipping the cover up in addition. It is much better to provide ventilation in this way for extremely hot weather than to bore holes in the sides or ends of the hives or supers. The amount of ventilation that may be required thru the top of the hive by staggering the supers back and forth will depend on how hot the weather may be at the time, and whether the hive in question is shielded from the sun. So long as the bees cluster out in front, it is an indication that there is lack of ventilation. Sometimes a great cluster of bees will be clear over a large entrance, practically closing it up except what little air can filter thru the mass of bees. In cases like this, it is advisable to lift the hive up on four blocks as shown under the subject of Swarming, subhead, "Providing Abundant Ventilation." If this does not draw the bees into the hive, additional ventilation should be given at the top of the super or supers, in the manner already explained. But one should be careful not to overdo this, because comb-building cannot progress very satisfactorily in supers when chilling blasts go back down over the bees, and this is liable to occur at night, even after a hot day.

Under Swarming it has been shown that ventilation and swarming often stand in the ratio to each other of cause and effect; that is to say, not enough ventilation overheats the brood, causes the bees to cluster in front, induces loafing, cell-building, and finally swarming. Time and time again this loafing on the part of a big bunch of bees in front has been stopped by providing ventilation. When a colony in the height of the season can earn at least from five to ten dollars, it is folly to compel the poor bees to loaf and cut down their earning capacity simply because of a lack of means to keep their hive cool enough so that they can go inside and go to work.

VENTILATION DURING THE WINTER.

Under WINTERING, also under EN-
TRANCES, it is explained that bees outdoors on their summer stands do not require nearly the amount of ventilation that is needed during the summer. Yet even in cold weather a strong colony should have a larger entrance than a weak one. See EnTRANCES TO HIVES.

When bees are wintered in a cellar it is highly important that the atmosphere be dry, and that there be means provided for supplying fresh air in the room where the bees are kept. Insufficient ventilation causes uneasiness; uneasiness induces overeating, and overeating brings on dysentery. (See Drsenterx.) It is important that the cellar has plenty of ventilation during the entire period of confinement, and more air toward spring than late in the fall.

Authorities disagree somewhat as to the size of entrance that bees require while in the cellar; but the author's experience indicates that the same size that is used during moderate summer weather is better than a large one. It will depend somewhat on the size of the colony. See Wintering in Celulars.

In severely cold weather it is highly important to see that the entrances of the hives outdoors are not closed up with wet snow nor ice. A dry snow does no harm. A closed entrance closed tightly is almost sure to be fatal to the colony sooner or later if there is no upward ventilation. It sometimes happens that dead bees clog up the entrance, and the colony dies simply because a few of its dead shut off its means of ventilation.

\section{SMOTHERING BEES BY CLOSING THE ENTRANCE.}

Altho bees manage to get along with even a very small entrance, one should be on the guard against closing it entirely, in warm weather, even for only a few minutes. Many are the reports the anthor has received almost every season, of bees destroyed by simply closing their entrance while undertaking to stop swarming for a few minutes, until some other colony can receive attention. See Swarming and EnTRANCES.

W'hen bees have the swarming fever they are gorged with honey and in a feverish state. They are like a man who has been taking violent exercise after a hearty meal, 


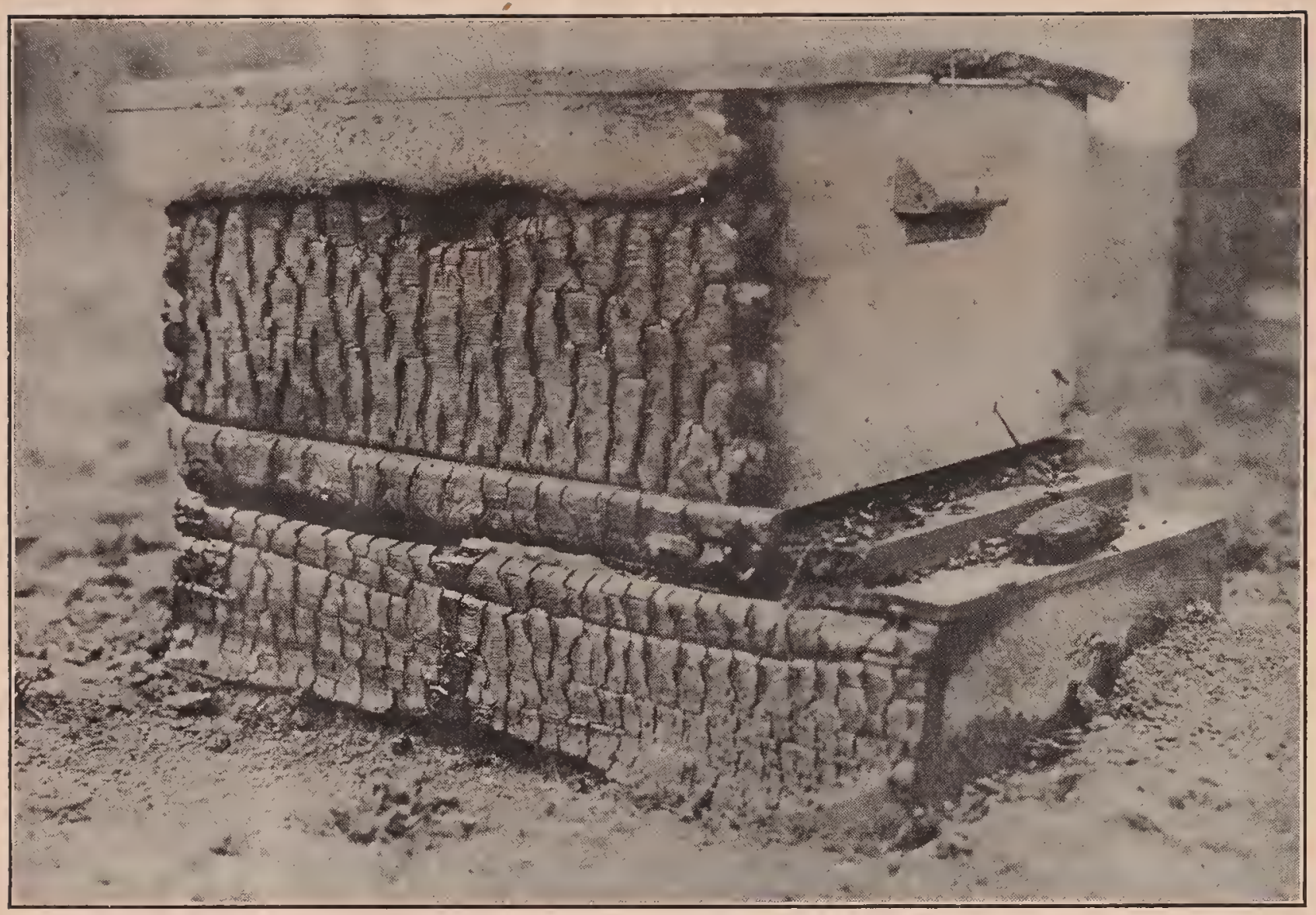

A hive of bees nearly burned up by the heat from an immense lumber yard fire close by author's plant. Somebody threw a pail of water over the hive and put the fire out. During all this heat, the bees, by vigorously fanning with their wings. kept the hive ventilated so that the combs did not melt. Combs made from paraffin or any substitute for heeswax would melt even with the heat of the sun.

and require more than an ordinary amount of air. Their breatling-tubes are in different parts of the body, under the wings and on each side of the abdomen (see Anatomy OF THE BEE) ; lience, as soon as the entrance is closed, and they crowd about it, the heat of so many becomes suffocating in a very few minutes; the honey is involuntarily discharged, wetting themselves and their companions, thus most effectually closing their breathing-tubes in a way that causes death to ensue very quickly. Heavy swarms have been known to be killed in the short space of fifteen minutes, when the hive was thus closed. The heat generated by the smothering mass often becomes great enough to melt down the combs, enveloping bees, brood, honey, and all, in a mass almost scalding hot. Bees are sometimes smothered in this way, in extremely hot weather, even when the hives have very large openjngs covered with wire cloth. In fact, bees shipped by railroad, in July and August, have been known to be smothered, when the whole top of the hive was covered with wire cloth.
HOW BEES DO THEIR OWN VENTILATING.

If one will watch a colony of bees during a warm day, he will see rows of bees standing around the entrance, and far inside of the hive, with their heads pointing one way, all making their wings go in a peculiar manner, much as they do in flying; but instead of propelling their bodies along, they propel the air behind them, and a pretty strong "blow" they get up too, as may be felt by holding the hand near them. If the air is very hot and close inside the hive, so that there is danger of the combs melting down, they manage to send cooling currents clear to the furthest parts of the hive.

At the end of a hot day when the bees have been working heavily in the fields, it is very interesting to try the following experiment: Hold the smoker, with a little smoke issuing from the nozzle, near one side of the entrance and then at the other side. It will be noticed that there is a strong draft of air on one side of the entrance into the hive, and an equally strong 
blast of air on the other side of the entrance ont of the hire. The direction of the air can be easily determined by obserring whether the smoke is sucked in or blown out.

Sometimes the air will be sucked in on both sides of the entrance, and blown out from the center. At other times the reverse will be the case.

If one does not happen to have a smoker lie can light a common match, when he will notice that the flame will be sucked in on one side and blown away on the other. The draft, whether out or in, is so strong that it will blow the match out.

The most prosperous colony the author ever owned was one that was so completely enveloped in chaff that during frosty nights in March they sent a stream of warm air out of their live strong enough to melt the frost about one side of the entrance. Of course a stream of fresh air went in at the opposite side as fast as the warm air went out.

In the fall of 1916 there were a few hives located near some big lumber piles that were burned down. So intense was the heat that one of the hives took fire, with the result that it burned thru on one side, and charred the boards under the metal cover; and yet, remarkable to relate, the bees were all right after the fire. It is presumed that some fireman, seeing the plight of the bees, threw on a pail of water; but how did the bees keep the combs from melting down in the mean time? There was no other way that they could do it than by their scheme of ventilation. Fortunately the entrance was large and wide open, so that they were able to ventilate the hive fully. The weather outside was cold. Now, combs sometimes melt down when the weather is very sultry and hot during the summer when the bees are out in the hot.sun; but there is no cold air, as there was that night in front of the hive and away from the direct radiation of heat from the burning lumber. The photograph reproduced on the previous page shows that one side of the hive was burned elear thru; yet, except for the outside comb, no damage was done either to the bees or to the other combs.

For further particulars on the subject of rentilation, see ENTrances, Coms Honey, SWarming, and Wintering.

VINEGAR.-This is one of the legitimate products of honey; and when properly made it is of excellent quality, fully as good as any other vinegar that can be made, if not better, from.whatever source. The color and flavor of honey vinegar are largely dependent on the color and the flavor of the honey used. Obviously, a mixture of honey, or a number of odds and ends, as well as the washings, may be userl to advantage. Thus honey vinegar makes a very profitable by-product for a beekeeper.

\section{HOW TO MAKE HONEY VINEGAR.}

In the first place it should not be forgotten that vinegar may be made from any liquid containing sugar, provided there is enough sugar to be of any consequience. This includes a number of the fruit juices, of which the apple and grape are the best known examples, and syrups like honey or molasses.

Vinegar is the product of two absolutely distinet fermentations: first, the vinous, or alcoholic, and second, the acetic, or acid fermentation. The first should be completed before the second is begun; otherwise the first never will be completed and weak vinegar will result. This means, for instance, that the "mother of vinegar," the thing which starts the acetic fermentation, must not be introduced until practically all the sugar in the liquid has been converted to alcohol by the common wine or alcoholic fermentation.

The alcoholic fermentation will usually start spontaneously, but it is far better to insure its starting by the addition of a small quantity of yeast. A closed vessel, such as a tight barrel or keg, or a glass jug, should be used. Of course, a small vent should be left for the escape of the "gas." The mixture should be left in a warm room, and al. lowed to stand some weeks before the first fermentation is completed.

The acetic or acid fermentation will usually start spontaneously; but, here too, it is far better to insure its starting, this time by the addition of the "mother of vinegar," referred to above. During this latter stage of the process, air is required where 
in the first stage it was to be avoided. This means that the liquid should be poured into a barrel or keg from which the head has been removed. The more adequate the air supply, the shorter will be the time necessary to finish. the process.

$A$ word as to the manner of mixing the honey and water at the beginning of the process. Five parts of water to one part of honey, by weight, will máke a liquid of about the right strength. Or, if one wishes to use washings, which are of course of uncertain strength, he should in some way determine the specific gravity or density of his material. One way is to add either honey or water, as may be necessary, with constant stirring, until an egg will float in the liquid with only a small spot above the surface. A more accurate way is to use a hydrometer, which can be purchased for a small sum, thru a druggist. If a Baumé hydrometer is used, it should read between 7 and 8 degrees; if one is to be had with the specific gravity scale, then the reading should be about 1.050 .

As a final word, it may be said that dark, strong-flavored honeys ferment much faster than light, mild ones. Also it might be remarked that the addition of almost any fruit juice will aid in the primary or alcoholic fermentation.

\section{VIRGIN QUEENS.-See QUEENS.}

VITAMINES IN HONEY.-In recent years students of nutrition have discovered the fact that food of sufficient energy value, containing ample amounts of each of the chemical elements known to be essential to the human body, is not necessarily adequate to meet all nutritional needs. It appears that certain substances, occurring in natural foods but not yet chemically identified, are thus vital factors in nutrition. These unidentified substances are known by the general term "vitamines." More exactly, they are classifiable under three heads: fat-soluble $\mathrm{A}$, water soluble $\mathrm{B}$, and water soluble $\mathrm{C}$.

There is now proof that there is a moderate amount of fat-soluble vitamine $A$ in comb honey; and it is probable that there are small amounts of the vitamine, water-soluble $B$, in all honeys, but no antiscorbutic vitamine.
The fat-soluble vitamine is the one which is often alluded to as "the growth principle," and which is contained in abundance in the fat of milk, the yolk of eggs, and in green, leafy vegetables. Incidentally, McCollum of Johns Hopkins University, who has conducted so much research along this line, considers fat-soluble $\mathrm{A}$ of the utmost importance in the diet. Being much less widely distributed in foods than watersoluble $\mathrm{B}$, there is much more danger of a deficiency of it in the diet.

The presence of these tiny dietary essentials, generally termed vitamines, is not determined by chemical analysis. For that reason they are frequently alluded to as unidentified dietary essentials, and their presence or absence in foods is determined by a long and expensive series of feeding experiments upon animals, the animals often being white rats or guinea pigs. The diet of these little animals is somewhat similar to that of human beings, and their natural span of life is short enough to permit of conclusive experiments being conducted in a comparatively short time.

The one who conducted the feeding experiments to determine the presence of vitamines in honey is no less an autlority that Philip B. Hawk, Ph.D., of Jefferson Medical College, Philadelphia. For years he has been experimenting upon the digestibility of various foods by a new process of watching the digestion at different stages in human beings, and he has also been doing research work on vitamines. $\mathrm{He}$ is a contributor to scientific journals and is very well known to the general public for his contributions to the "Ladies' Home Journal."

He wrote a series of articles several years ago on the digestibility of certain foods, and more recently an article on vitamines.

White rats were the animals chosen by Prof. Hawk for the experiments to determine whether there were present in honey the vitamines water-soluble $B$ and fat-soluble A. The first work was done in testing honey for the former. Rats were selected and divided into three groups, the rats from each litter being distributed to make the groups as uniform as possible. These were kept in sanitary cages with an abundance of water. One group was fed a diet known from previous experience to contain all the 
essential nutrients except the water-soluble $B$ vitamine, in which it was deficient. Another group was fed the same diet except that a blended extracted honey was added to it. Still another group was fed the same diet with the exception of extracted clover honey added.

These two latter diets were known to contain no water-soluble vitamines except such as might be contained in the honey. The individual rats in these groups were carefully weighed each week and records kept of their weights.

At the end of four weeks the diets were changed so that the rats of group 1 , which had received no honey, were subdivided into two groups, half of which received blended honey and the other half white clover hon$\epsilon y$. The rats of the other two groups, which had been receiving honey, now had this replaced by a starch.

After another two weeks another change in diet was made, which consisted in replacing all these previous food mixtures by milk, which was known to be adequate for growth and to contain water-soluble B. This was to show that failure to grow had been due to a dietary deficiency and not to disease or other accidental causes.

Now as to results: None of the rats on these three diets first mentioned was able to thrive and grow in a normal manner, and therefore all three diets were defieient in the water-soluble vitamine. Apparently, therefore, neither the blended honey nor the white clover honey contained sufficient water-soluble $B$ to permit normal growth when they were present in the diet, nor to permit the resumption of normal growth when they were added to a diet containing none of this vitamine.

However, while the addition of extracted honey to the diet did not permit normal growth it did slightly increase the growth, so that at the end of five weeks, in the case of one group there was a difference of 9 grams between the "starch rats" and the "honey rats"; in the other group the difference between the "starch rats" and the "honey rats" was 17 grams in favor of the honey.

To quote Professor Hawk's own words, "The differences were not great enough to be entirely conclusive, but may most reasonably be considered to indicate the slightly greater efficiency of honey for growth, due to the presence of small amounts of the water-soluble vitamine."

The experiments to determine the presence of the fat-soluble A vitamine were conducted in much the same manner, except that in this case comb honey was also used in the feeding experiments. Professor Hawk further says: "Of the eight rats fed comb honey, all but one showed a cessation of decline and distinct gains in weight. The one rat was apparently beyond recovery by dietary change. In fact, all the rats given comb honey were already showing indications of the dietary deficiency. Comb honey showed a resumption of growth in these animals, indicating the presence of distinct amounts of fat-soluble A.

"For comparison the comb honey diet was followed by one containing butter in amounts of 5 to 10 per cent. Butter is known to be rich in the fat-soluble vitamine. Hence, the fact that the rats grew about as well on comb honey as where 5 per cent of butter was added indicates that comb honey contains a moderate amount of fat-soluble vitamine, and that the comb is relatively rich."

These rats, like the first groups, were later fed milk to show that any failure to grow had been solely due to a dietary deficiency.

Extracted honey, added to a diet known to be deficient in fat-soluble $\mathrm{A}$, showed a slight gain in weight in some of the rats, but hardly enough to be conclusive. However, Professor Hawk says, "That a minimal amount of fat-soluble A may be present in extracted honey would be indicated further by the fact that our data show it to be present in comb honey."

The reader should turn to the accompanying diagram, study it carefully and see if it isn't enough to make a colony of bees buzz with pride.

Reference has been made to his finding the vitamine water-soluble $B$ in extracted honey and the vitamine fat-soluble $A$ in comb honey, and it will now be in order to tell of his experiments as to the digestibility of honey and then say something more about vitamines.

The experiments were carried out upon a normal man to determine the influence of 
honey upon gastric digestion. He was first given 40 grams of whole wheat bread alone. The contents of the stomach were analyzed for acid and pepsin at 15-minute intervals and an accurate and detailed record was kept. The experiment was then repeated, adding to the bread half its weight in honey (20 grams).

The following quotation tells the results in Prof. Hawli's own words: "An examination of the chart will show that the bread with honey was digested and left the stomach as quickly as the bread alone. Similar pepsin values were obtained, and while there was a slight depression of acidity with candies which are eaten between meals. At the same time honey furnishes the body very considerable amounts of energy in the most available form. The high place given to it in the diet is therefore well deserved."

In quoting the above from Prof. Hawk the reader should always couple it with his statement that comb honey contains distinct amounts of the fat-soluble vitamine, and where he said that honey added to the diet of white rats, which were being starved of the fat-soluble vitamine, produced the same effects as 5 per cent of butter fat, the latter being the richest known source of fatsoluble A. Remember also that his experi-

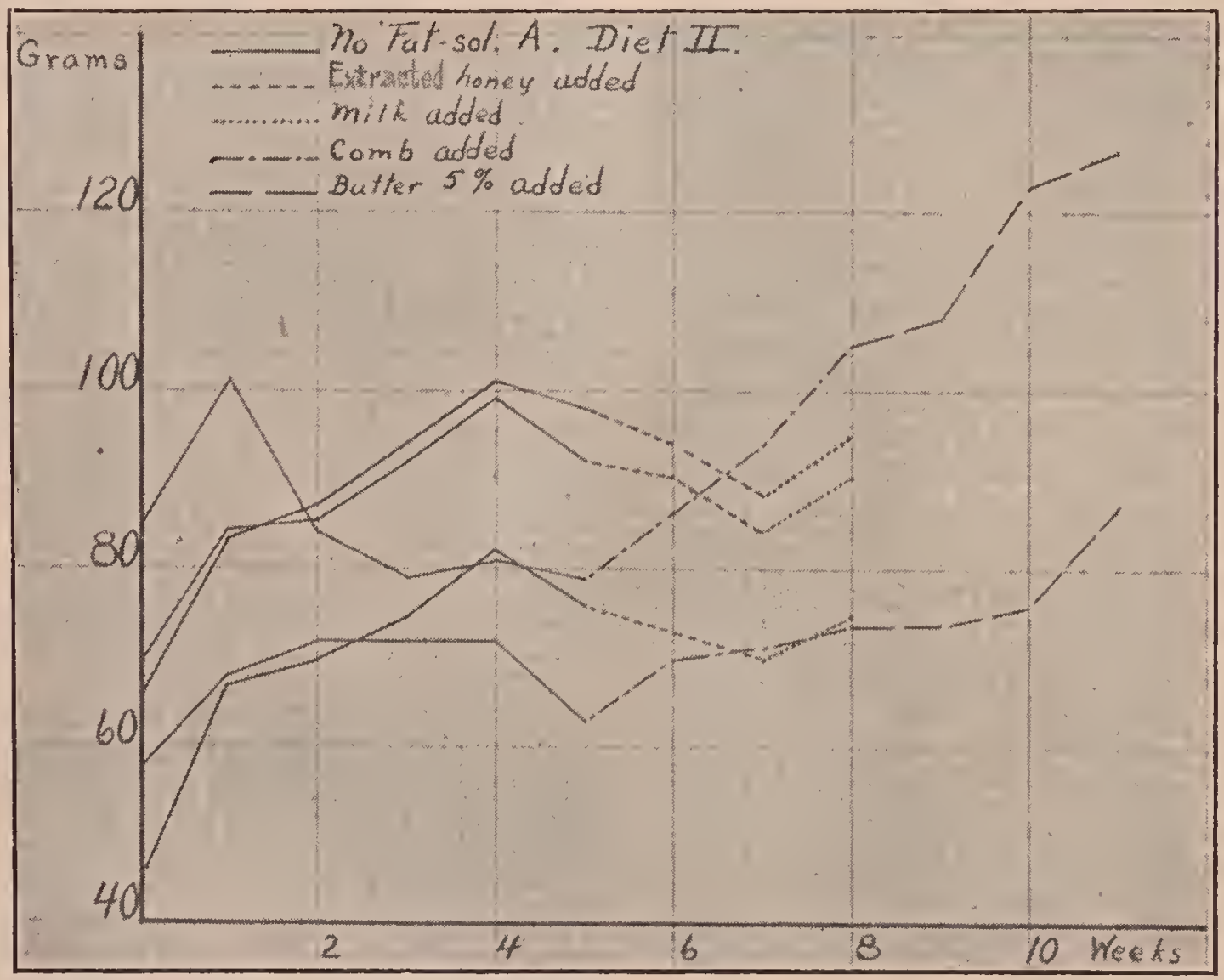

such as always follows the ingestion of foods containing much sugar, digestion was completed as soon as with the bread alone, altho the addition of the honey had practically doubled the food value of the product from the energy standpoint.

"The use of honey witl bread and in similar ways would, therefore, appear to be generally preferable in the case of children to the eating of candies. Honey serves to make the highly nutritious bread far more palatable, leading to a greater consumption of body-building foods instead of depressing the appetite, as is likely to be the case ments indicated that there are small amounts of the water-soluble $B$ vitamine in extracted honey. Therefore when we give a child bread spread with comb honey we are not only increasing the energy value by a large percentage, but are providing appreciable amounts of the fat-soluble vitamine so essential to growth, especially in the diet of the young. And, in addition, honey contains in minute quantities practically all the soluble minerals found in the liuman body.

At the beginning of this article allusion was made to the fact that Prof. Hawk's 
feeding experiments indicated that there are no anti-scorbutic vitamines, called water-soluble $\mathrm{C}$, in honey. His experiments to determine this were conducted with guinea pigs as the victims; for they were victims, developing symptoms of scurvy as soon on the diet containing honey as they did on a diet known to be deficient in watersoluble C, altho otherwise balanced.

An interesting corroboration of this report occurs in an account of three men who were separated from Stefansson's party during his polar exploration. These men depended largely upon some cached foods which they had found-flour, salt pork, butter, honey, sugar, pilot bread, preserved fruit, pemmican, meat extract, dried fruit, rice, beans, and peas. They all three developed scurvy, but were promptly cured when fed large amounts of meat, mostly raw.

Note that the honey was in this case in very good company, for the other foods mentioned were valuable even if they did lack the anti-scorbutic vitamine. The best authorities agree that even milk is of only moderate value as an anti-scorbutic, and loses most of the value when pasteurized or boiled. That is the reason that orange juice is added to the infant's diet when it is fed pasteurized, sterilized, or condensed milk. It has also been proved that milk is by no means rich in water-soluble $B$ altho it contains it in small amounts.

In spite of Stefansson's experience, feeding experiments with animals have never indicated that neat is very rich in watersoluble C. But the men of the Stefansson expedition ate it in extremely large quantities, including the fat and certain internal organs not generally eaten, and a large part of it was consumed raw. Water-soluble $\mathrm{C}$ is found in living vegetable and animal tissues, in largest amounts in fresh fruits and green vegetables.

Now that it is proven that there are vitamines in honey the beekeeper ought to be well enough informed to be able to talk intelligently about the three kinds, always remembering that history is in the making as regards vitamines, and that something new is constantly being discovered. As "repetition is the mother of education," it may not be amiss to say a little more about the vitamines, water-soluble $B$ and fat-soluble $\mathrm{A}$.

Water-soluble B occurs more widely in plant than in animal foods. It is found in practically all fresh vegetables, in cereals from which the germ has not been removed by so-called refining processes, in rice polishings, in the heart, lidney, brain and liver of animals, and in yeast, the last named being the richest known source of this vitamine. Water-soluble $B$ is essential for normal growth and reproduction, and its absence produces the diseases polyneuritis and beriberi. While there is little danger of well-defined cases of these two diseases in the mixed diet of civilization, the best authorities agree that there is a danger of a deficiency of this vitamine in the modern diet with its over-refined foods and its enormous amount of canned goods; for the long heating necessary to sterilize canned foods is known to weaken and destroy the vitamine content. This deficiency is believed to be responsible for much ill health along the lines of polyneuritis and beriberi, but less well defined.

Fat-soluble A is found in abundance in the fat of milk, the yolk of egg, and in the green, leafy vegetables, such as spinach. It 'is also fairly abundant in fish oils, such as cod liver oil and even whale oil.

Oleo oil contains a fair amount of fatsoluble $\mathrm{A}$ and therefore the oleomargarines contain it also, but not the nut margarines made wholly from vegetable oils. However, we are warned by the nutrition experts that oleomargarines are not to be considered in the same class as good butter in providing the organism with the fatsoluble vitamine.

The fat-soluble vitamine is necessary to growth and development, especially in the young, and it is necessary to the maintenance of health in the adult. Its absence causes an eye disease, xerophthalmia, sometimes so severe as to cause blindness. Of late it appears that rickets in infants may be connected with the absence of the fatsoluble vitamine.

In the past few years much has been added to the knowledge of vitamines, not only from laboratory experiments but by observation of human experience in inadequate war diets in Europe. Also a form of partial blindness has been observed to 
be prevalent in certain lumber camps where the only fat available was that from cured bacon, which would be entirely lacking in the fat-soluble vitamine.

To be consistent, here is a point which needs emphasis. Beekeepers have always plumed themselves that honey is nature's own and only concentrated sweet, uninjured by any so-called refining processes. But now Prof. Hawk's report of the fatsoluble vitamines in comb honey reveals the fact that even honey may be refined to the extent of removing some of its most valuable constituents. There is no doubt that extracted honey, will always be used. Its convenience and long-keeping qualities in that form make it almost a necessity; and even extracted honey, it should be remembered, contains small quantities of watersoluble $B$ vitamine. But comb honey, because of its fat-soluble vitamine content, is worthy of being placed in the class with milk, cream, and other dairy products, eggs and the green leafy vegetables. It is to be hoped that it may be profitable for beekeepers to turn more largely to the production of comb honey.
The question might be asked, "Why get up so much excitement over the presence of the fat-soluble vitamine in comb honey? The amount of honey eaten is so small in comparison with other foods that the presence or absence of vitamines makes little difference. Warming has been given repeatedly of late that the modern civilized diet with its devitalized, demineralized, and over-refined foods has a very small margin of safety as regards valuable soluble mineral salts and the various unidentified dietary essentials. Therefore the world's oldest and most beautiful sweet, comb honey, is a perfect sweet and a food as well.

While beekeepers and honey lovers have no doubts as to the value of honey as a food, yet it is a fine thing for the industry to have a nutrition expert of the highest authority, Professor Hawk, corroborate their belief.

There are any number of nutrition experts who are just as able as Prof. Hawk, but it is doubtful if any of them are so well known to the lay public of this country, a fact that makes his statements especially valuable for reference.
WATER FOR BEES.-Like all other live stock, bees need water. The amount required depends largely on how much brood-rearing is going on, and whether nectar is coming in to a considerable extent from the fields. Brood requires a large amount of water as well as pollen and honey. On the other hand, when new honey is coming in but little water is needed.

About the time the bees are breeding heavily they will be found around watering places, ponds, creeks, and rivers, especially during a dearth of nectar. They seem to prefer to get water where they can take a big drink without any danger of being submerged. Sometimes when creeks, ponds, and rivers are at some distance from the apiary bees may be somewhat of a nuisance around near-by watering troughs and outside pumps. Hence it is sometimes desirable for the beekeeper to have a watering font in the beeyard itself. A tub of water with chips or corncobs floating on the surface, a Mason jar filled with water inverted over a small plate, or, better, a crock placed over a dinner plate, will furnish bees water on the atmospheric principle all day or several days, in fact. A better arrangement is a wooden block or board with transverse saw-cuts as shown in the illustration on next page.

A large glass jar filled with water and in- 
verted over one of these boards will keep the saw-cuts filled with water, where the bees can get all they require without even wetting their feet. If one of these is furnished in the apiary the bees will not be likely to bother the neighbors. A closed vessel containing water is much better than a tub or pan of water, as the water cannot become stale and bad. Sometimes when one of these special fonts is first set out the bees will pay no attention to it, especially after they have been in the habit of visiting the neighbors' pumps and watering-troughs. They can, as a rule, be started by sweetening the water or by adding a little salt, for bees are fond of salt also. When bees are compelled to go a distance for water they, wear themselves out unnecessarily, and, during chilly weather in the spring, many never get back.

The statement was made above that when bees are in the fields, bringing in new honey, they require less water than at times when no honey is coming in. It is probable that the excess of water removed during the ripening process, as explained under Ventilation, supplies the bees with the proper amount of moisture.

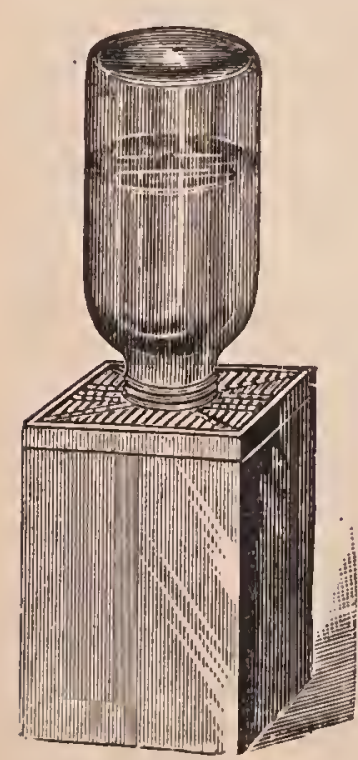

Bees also need some water during midwinter; but usually the moisture produced by condensation from the breathing of the bees will be sufficient. It was once argued that they should be supplied with water while in the cellar. If a wet sponge is placed on a cluster they will take up the water quite rapidly. This would seem to prove that they should have an artificial supply; but general practice has shown that no special provision need be made. It would be impracticable to give bees water when wintered outdoors; and it would hardly be necessary, because if one will examine down into a brood-nest during winter he will see considerable moisture around the inside of the hive and on the under side of the cover.
In taking carloads of bees from south to north and from north to south, it will be found impracticable to make these long trips in open cars without a barrel of water. If the weather is hot and sultry, bees, on account of their excitement, often require a large amount of water. This water must be supplied at intervals of every few hours or many bees will die. In some shipments of bees from south to north during hot or warm weather, a carload of bees has been known to take up seven or eight barrels of water. The water allays thirst and cools the cluster by evapoiation.

When bees are shipped in refrigerator cars as explained under SHIPPING BeEs, no water would be neeled.

While bees seem to gather water at times, they also appear to have a delicate apparatus of some sort for extracting water from nectar, and for discharging it or a part of it in flight. When they are fed outdoors with sweetened water, as described under OUTDOOR FEEDING, they will immediately, on taking flight, discharge a fine spray of water. If one will station himself between the feeders and the sunlight he will be able to perceive these bees, on rising from the feeder, discharging this thin fine spray.

That it is pure water and not sugar can be proven by tasting it. That bees also discharge water when gathering thin nectar from the fields was proved by A. I. Root many years ago. When bees are gathering a large quantity of nectar from a single blossom they'will, on rising from the plant, discharge the excess in the form of a thin spray. Enough of this spray fell on some dinner plates to be distinctly perceptible, but the taste showed nothing but water.

WAX.-This is a term that is applied to a large class of substances very much resembling one another in external characteristics, but quite unlike chemically. The wax of commerce may be divided into four general groups: Beeswax, familiar to all; mineral wax, or by-products from petroleum; wax from plants, and wax from insects other than bees. The first two are by far the most important commercially in this country. Of the mineral waxes the most common are paraffin and ceresin. 
Beeswax, the most valuable, has a specific gravity of between .960 and .972 , and melting-point of between 143 and 145 degrees $F$. The mineral waxes vary so much in hardness, melting-point, and specific gravity, that it would be useless to name exact figures. As a rule, however, the fusing-point of paraffin is much below that of beeswax, while that of ceresin may be either above or below, or practically the same. In general the specific gravity of both commercial paraffin and eresin is below that of beeswax; which fact render's it an easy inatter to detect adulteration of beeswax with either paraffin or ceresin, by a method that will be explained further on, under the subhead, "How to Detec: Adulterated Wax."

There are also known to commerce Japanese wax and China wax, both of which may or may not be the product of insects or plants.

COMB FOUNDATION.

Combs made from foundation containing 25 to 50 per cent of adulteration of paraffin or ceresin are very liable to melt down in the hive in hot weather. Paraffin is ductile enough to make beautiful foundation, but does not stand the heat of the hive. Ceresin, on the other hand, while more closely resembling genuine beeswax in point of specific gravity and fusibility, is too tough and brittle, under some conditions, for bees to work. Work it? Yes, they will, and construct combs; and in Germany considerable ceresin foundation has been and perhaps is being sold; but experience shows that it is. poor economy, and that it will lead the beekeeper or the poor bees to grief sooner or later.

Some recent work seems to show that there are certain wax compounds, that can be used to strengthen ordinary beeswax from the hive. In 1922 there was introduced a three-ply comb foundation, the center ply of which is of a much harder wax. The tests of this foundation at this writing seem to show that it is much stronger and better than ordinary foundation for the brood-nest.

BEESWAX IN THE ARTS.

Since the United States pure-food law went in effect June 30, 1906, beeswax has had a much larger use. The law will have no effect one way or the other on the use of paraffin, ceresin, and the like in any compound or mixture that does not belong either to the food or drug classes. Electrotypers can use a substitute for taking impressions, altho the great majority prefer pure beeswax, even at a higher price. Natural-wood finishers can still use paraffin and ceresin; but most of them assert that there is nothing to compare for that purpose with pure beeswax. The first mentioned gives a greasy, smeary finish, while the prorluct from the hive yields a $b^{\text {: ghly }}$ polished surface - one that stands wear as nothing else will; a finish cheaper than hard oil-not in the price by the gallon, but cheaper per square foot of surface covered.

A very satisfactory floor finish can be made by melting a pound of beeswax, and while it is cooling, stirring into it some turpentine. An exact proportion of the two ingredients is not necessary-in fact some workmen prefer the paste thick, others want it thin. When cool, if the mixture is too thick it is a simple matter to thin it by working in more turpentine.

The Roman Catholic Church uses large quantities of beeswax in the form of candles. The Church does not tolerate paraffin, ceresin, nor any of the mineral waxes, all of which give off an offensive greasy odor while burning, whereas candles made of beeswax leave a delightful perfume. Moreover, the burning of mineral wax canses a deposit that injures pictures, while beeswax mellows and preserves them.

Certain grades of blacking, harness oils, and lubricants require pure beeswax in their manufacture. A blacking containing beeswax will withstand more dampness than that made of any other substance.

The electrical-supply business is a consumer of beeswax. The windings of the wire are soaked in paraffin or beeswaxpreferably the latter, because it seems less affected by extremes of heat and by moisture. Pattern-makers also use beeswax. The profession of dentistry consumes large quantities of pure wax every year to take impressions in the mouth. Last, but not least, the beekeeper is a large consumer as well as a producer of wax.

In all the arts, paraffin, ceresin, and certain other mineral waxes can be used; 
but none of them have all the desirable qualities furnished by the product from the hive.

\section{-HOW THE BEES "MAKE" WAX.}

If the bees are watehed closely during the height of the honey harvest, or if at other times a colony of bees is fed heavily on sugar syrup for three days during warm weather, there will be found toward the end of the second or the third day little pearly dises of wax, somewhat resembling fish scales, protruding from between the rings of the under side of the body of the bee. These when examined with a magnifier reveal little wax scales of rare beauty. Sometimes these scales come so fast that they fall on the bottom-board and may be scraped up in considerable quantities, seeming for some reason not to have been wanted. During the season for the natural secretion of wax where a colony has plenty of room, wax scales are seldom wasted in this way. At swarming time there seem to be an unusual number of bees provided with wax scales, for when the bees remain clustered on a limb for only a few minutes bits of wax are attached as if they were going to start combs.

The way the bees remove these wax scales from their bodies and construct them into comb is not so easily seen. There were many wild guesses as to how this was done. The so-called "wax-pinchers" the hind legs were supposed to play an important part. The matter was definitely cleared up by Sladen and Casteel. In circular No. 161 Dr. D. B. Casteel of the Bureau of Entomology, Washington, D. C., made the whole process plain.

Briefly stated, it is this: The wax scales are scraped off by one of the large joints, or plantæ of one hind leg, the spines of the planta piercing or catching into the scale; then the leg, by a peculiar maneuvering, is moved up to where the fore leg's may grasp the scale. At this point of proceedings the scale is manipulated or masticated in the mandibles, when it is applied to the comb. During the process, the bee stands on three legs (the two middle legs on either side, and one

* The real purpose of these is explained under PoLLEN, subhead "Behavior of Bees in Collecting Pollen.' hind leg not in action), while the other hind leg and the two fore legs, in connection with the mandibles, perform the manipulation. Casteel says that the socalled "wax-pinchers" in the hind legs have nothing to do with the manipulation of wax, but are designed for another purpose, and that each individual bee removes its own wax scales.

It haș been supposed that the bees remove the scales from each other; but Casteel shows that this is not the case. The scales are sometimes found scattered thruout the hive and on the bottom-board as already stated. In some instances they show the marks of the spines of the planta of the hind leg's. In others they were probably dropped accidentally by the bees in that wonderful sleight-of-hand performance by which they transfer the scale from one portion of the body to the other. In still other cases the scales show no markings whatever, and the presumption is that they simply fell off the bees when they reached a certain stage of development.

Dr. Casteel also confirms the observation of Dreyling, that there are certain ages and certain seasons when the bees will develop these wax scales more than at others. From this it would appear that there are times when the bees cannot construct combs to any great extent, even tho they are liberally fed. In a practical way it has been found that sometimes even when the bees are fed they will not build combs; and the probabilities are that they simply can not, because the colony is made up of bees too young, too old, or both. Usually the condition of a honey flow can be supplied artificially by feeding.

\section{WAX-RENDERING.}

There are two methods of rendering wax, one by the use of artificial heat and the other by the use of the sun's rays thru a glass sash on the principle of a hotbed. When these rays pass into a glass-covered box a considerable amount of heat is generated-enough to melt wax. As the application of the solar method is quite simple, it will be described first.

\section{SOLAR WAX-EXTRACTOR.}

The general design of this machine is after a pattern made and used by the 
well-known beekeeper, G. M. Doolittle. The only objection to it is that it is rather small, but just the right size to take pieces of burr-comb and other bits of wax that accumulate in the everyday working of

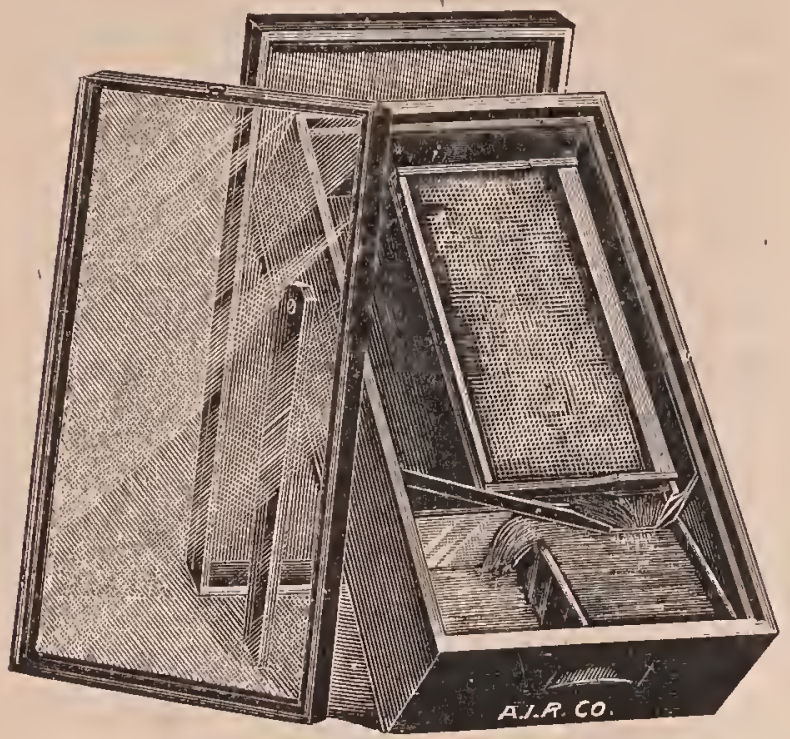

Doólittle solar wax-extractor

the apiary. These accumulations can be thrown into the machine whenever one happens to pass by it; and instead of having a lot of little scraps scattered here and there thru the apiary, to be melted up at some future time, they may be converted at once into a marketable product.

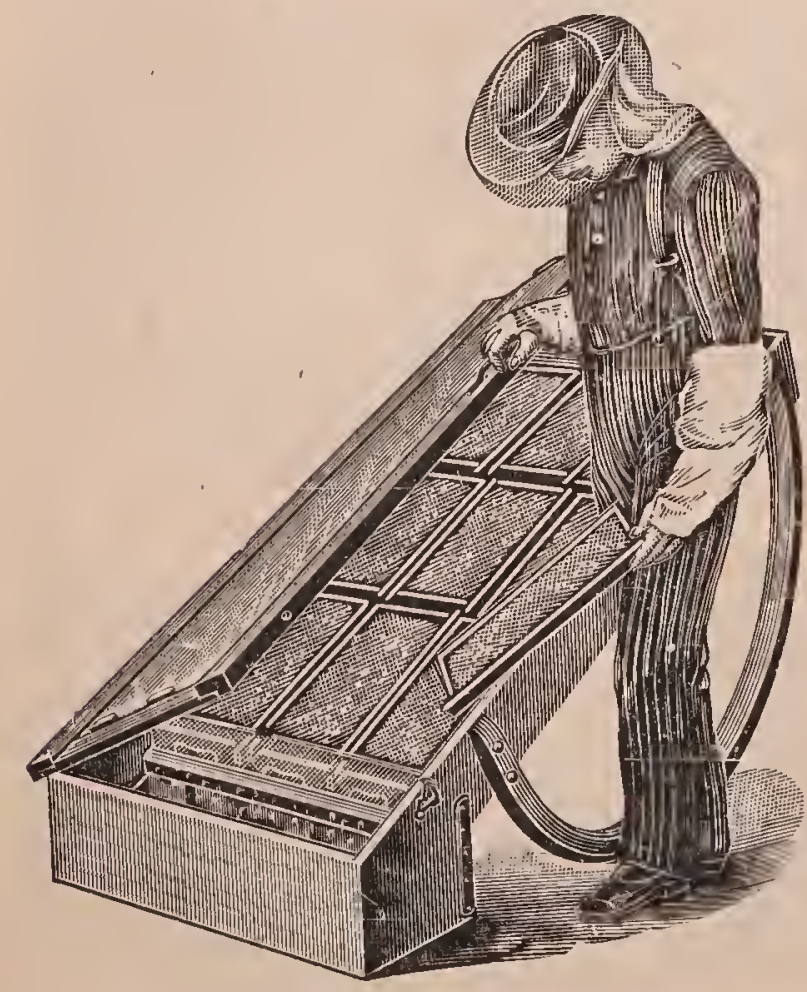

Fig, 1.-Boardman solar wax-extractor.

These small machines are not suitable for melting up combs. For that, something as large as the Boardman should be used.
THE BOARDMAN SOLAR WAX-EXTRACTOR.

This is built very much on the same general plan as the one just described, but is larger. The rockers, or runners, afford facility for transportation, and also for tilting the machine at the proper angle to the sun. A common greenhouse sash may be used; but a large glass, say $30 \times 60$, is better for the reason that the sash cuts off much of the sun's rays, making shade-lines along which the wax fails to melt. The size of glass that one is able to buy will, of course, regulate the size of the extractor;* the depth of the box or tray may be from 6 to 8 inches, the bottom being made of cheap lumber. It should be lined with common black sheet iron. Tin should not be used, because it reflects back too much of the sun's light. The whole machine should be painted black; and the glass, while the machine is in use, kept scrupulously clean.

SOLAR WAX-EXTRACTORS NOT SUITABLE FOR OLD COMBS.

Solar wax-extractors have their use to handle new combs, particles of fresh wax, pieces of burr-combs, and the like, and can be used to clarify and bleach to a certain extent wax already caked, but they are not adapted to the handling of old black combs that have several generations of cocoons in them. Large sun extractors like the Boardman will get the bulk of the wax out of such combs, but they do not get all of it. If sun heat is used at all for melting, the refuse should be further treated.

\section{RENDERING WAX FROM OLD COMBS.}

For new combs the problem of rendering wax is a comparatively simple one, since the operation consists simply in melting them in hot water and dipping the wax off the top. This is true also of cappings where the total amount of refuse or impurities is so small that there is practically no difficulty in getting all the wax. For the purpose a solar wax-extractor is satisfactory, altho not to be depended upon for speed nor great capacity unless very large, which would be expensive.

When old comb is to be rendered, the problem becomes much more difficult, as the

*Three pieces $20 \times 30$ will answer in an emergency. 
many layers of cocoons found in the cells used for brood-rearing confine the wax and make it hard to remove. It can be readily seen that, if old comb is simply melted in hot water or steam, these cocoons will become saturated with wax, making the loss very great. The following discussion, therefore, will have to do especially with the difficulties encountered in rendering wax from old combs.

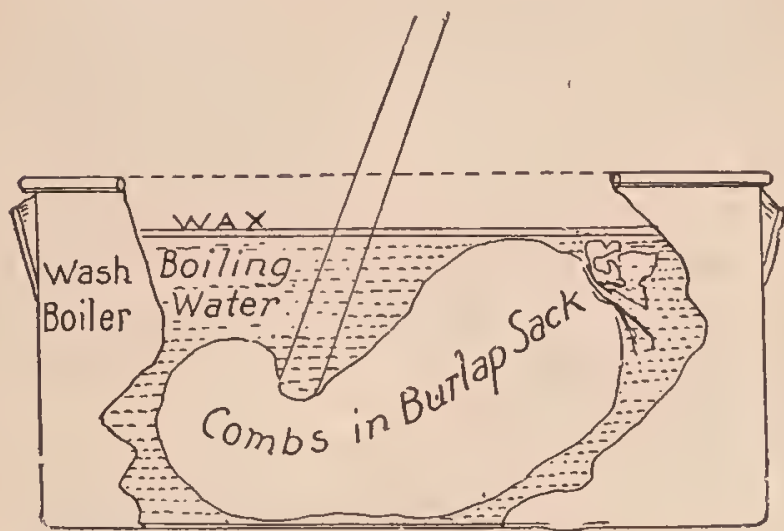

Fig. 2.-A very crude and wasteful method of rendering.

There are many different methods practiced by beekeepers to obtain the wax from old brood-combs; and it is needless to say that, in many of them, the loss is considerable. One of the crudest methods is to throw the combs into a large iron kettle of water and then build a fire and boil the contents for several hours, skimming the wax off the top of the water meanwhile. More comb is added from time to time, and the process is continued perhaps all day. Finally a piece of wire sereen is weighted down on the refuse to keep it out of the way and

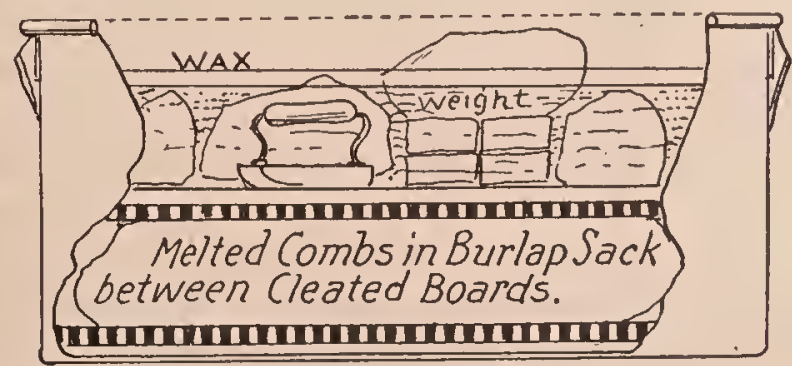

Fig. 3.-A popular but wasteful and slow method of obtaining wax.

facilitate dipping the wax. Careful experiments have shown that this method wastes from 25 to 40 per cent of the total amount of wax, while much time is required to clean and refine what little wax is secured.

Another plan which has been advocated to some extent is that shown in Fig. 2. A sack of comb is held under the surface of the water, and agitated or punched with a stick for a long time until much of the wax is released and floats to the surface, where it may be dipped off. This method results in somewhat cleaner wax; but there is apt to be waste nearly equal to that in the plan before mentioned.

There is another method that is used more, perhaps, than the two which have just been described. It is a somewhat better plan, for the amount of waste is not so great. It is shown in Fig. 3. In order to get the best results the weights should be so arranged that they can be lifted up a few inches in order to give the refuse in the sack a chance to become saturated again with hot water. The weights should then be lowered, and this process kept up for several hours, the water meanwhile boiling vigorously. The wax should be dipped off almost as fast as it rises to the surface.

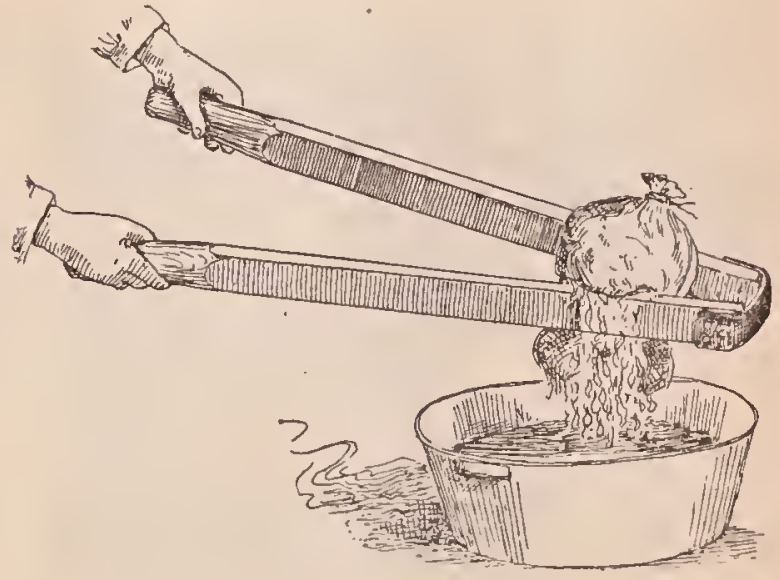

Fig. 4.-An unhandy and unsatisfactory plan

In 1904 T. J. Pennick of Williston, Tenn., suggested the use of centrifugal force applied to hot slumgum just taken out of boiling water. It was his opinion that the free wax, when hot, would by this means readily separate from the solid matter in a very short time. Extensive experiments have developed the fact that there would be a great deal of wax which would not escape from the refuse, no matter how fast it might be whirled in an extractor, showing that even great centrifugal force could not separate the wax from the refuse. Wax nearest the outside might be thrown out; but that nearest the center would be held back and not escape.

A. C. Miller of Providence, R. I., some time ago devised an agitator and applied 
it to the rendering of wax. He claimed it released all the wax and lots of dirt and coloring matter. The old combs in such an agitator are thoroly stirred and rubbed under hot water so that the wax is liberated, and rises to the surface, where it is drawn off thru a spout. As will be seen, this is somewhat similar to the plan shown in Fig. 2, before mentioned, altho it would be of course a great improvement on that very crude metlrod.

From experiments and from reports received from hundreds of beekeepers, it would seem as tho the wax-press is by all means the most satisfactory wax-extractor yet devised. It is doubtful whether anything but pressure combined with hot water can remove all of the wax. There will
Thoroly heat in boiling water the refuse to be tested, then allow it to cool slightly; seize a large handful, and squeeze it as hard as possible in the fingers. If fine lines of wax appear in the creases between the fingers considerable wax is left-perhaps from five to ten per cent or more, depending upon the amount of wax shown. The hand will not be burned in the very sliort time necessary to make this test. But, as before stated, the most conclusive method of determining the waste is to run the refuse thru a well-constructed press.

HOT-WATER WAX PRESSES.

In hot-water presses the pressure mav be continued without the least danger of chilling the combs. The hot water has the de-

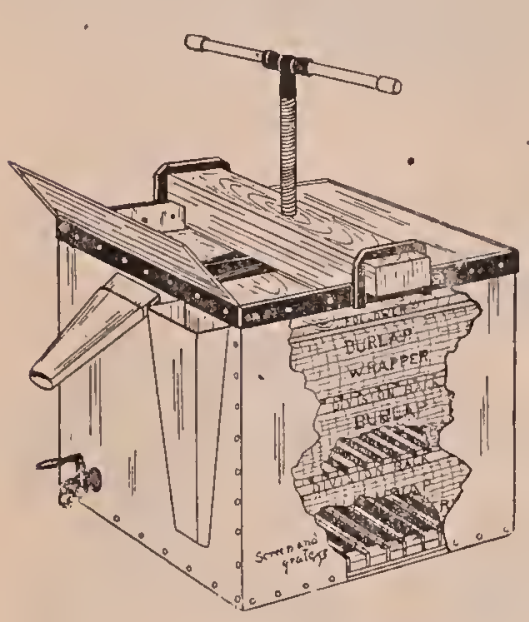

Fig. 5.-Hershiser hot-water wax-press.

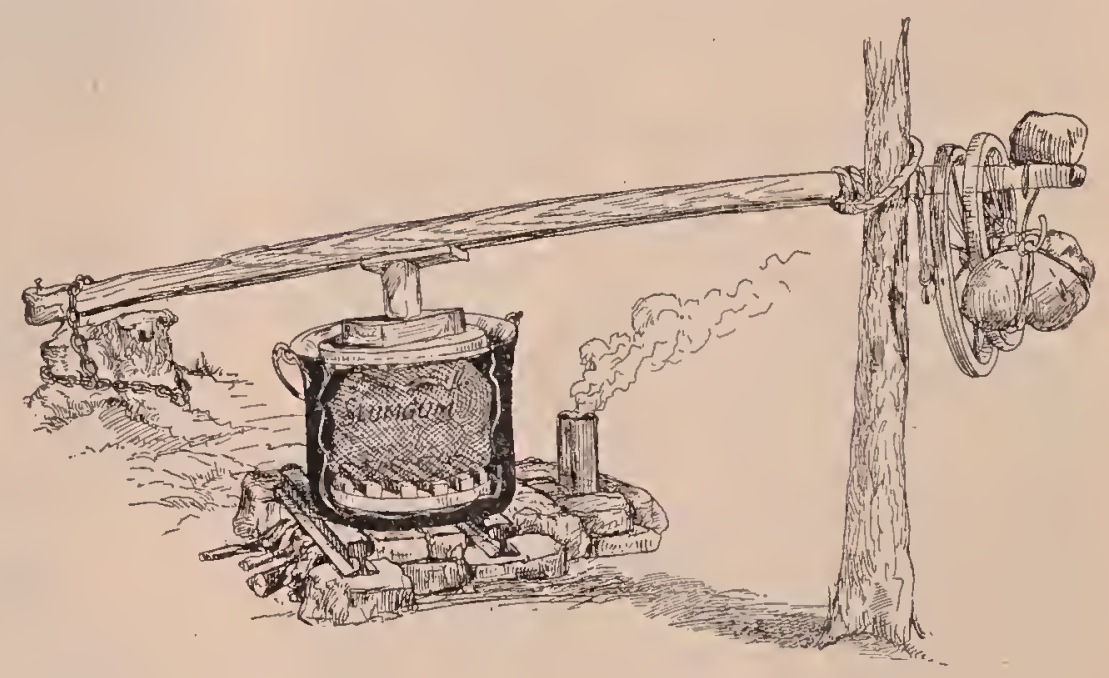

Fig. 6.-Use of the lever in pressing wax. probably never be a wax-extractor of any kind that will economically remove the last particle of wax; but if the amount of waste can be reduced to less than one per cent, the loss is negligible.

Before entering the discussion of waxpresses it may be well to add a word of caution to beekeepers who are sure that the particular method they are using enables them to obtain all the wax or practically all. If the refuse, when the wax is finished, has not been put thru a wellconstructed press there will be no way of determining the amount of waste, for it might contain as much as 20 per cent of wax and still look perfectly clean and show no traces of it when examined. On a small scale it is possible to get some idea of the amount of wax left in refuse by the following very simple plan: cided advantage in that the screw can be raised after having been turned down, when the "cheese" can become saturated again with boiling' water. The screw may then be lowered, and the hot water forced out of the refuse, carrying with it more of the wax. This operation must be repeated as often as found necessary by experience. It is thus seen that there is no disagreeable handling of the refuse until all the wax is out. Furthermore, the work, if necessary, may be confined to the one tank.

Orel L. Hershiser of Buffalo, N. Y., devised the hot-water press shown in Fig. 5. The capacity of this is large, so that it is possible to obtain as mueh as 75 pounds of wax in one day over a common stove. One great objection to hot-water presses heretofore has been their relatively small capacity of wax per day. Mr. Hershiser, by 
making the press very large, overcomes this difficulty.

The quality of wax from hot-water presses is usually not very good, because of the long-continued high temperature. In the Hershiser press more hot water is introduced at short intervals into the lower part, causing the melted wax to overflow thru the outlet at the top. In this way the wax is not left for any great length of time on the boiling water, so that the color is not darkened.

Perhaps one objection to hot-water presses is the cost of the outfit; but for extensive beekeepers they are the most practical, as much cleaner work can be done, owing to the continued intermittent pressure on the refuse surrounded by hot water. In other words, old combs rendered in a hot-water press may be pressed as many as fifteen or twenty times, so that it is possible to reduce the final loss to only a fraction of one per cent.

If one wishes to try the hot-water method by using an outfit constructer at home he can follow the plan shown in Fig. 6. An ordinary kettle may be used, altho it would be advisable to have one with a flat bottom. As it would be rather difficult to construct a crossbeam over the kettle rigid enough to stand the pressure exerted by a screw, a lever may be used as shown, tho some means will have to be employed to keep it from falling over sidewise, such as a loop around a tree or post. In using a lever it is important to have it so adjusted that the pressure will be uniform and directly downward. Any pressure exerted from a point not directly over the kettle will result in pressing the refuse to one side, so that the "cheese" will be very thin on one edge and very thick on the other. If this were the case there would, of course, be too much wax left in the thick portion. To get the best results the "cheese" should not be over an inch or an inch and a half thick after pressing.

Cleaner work can be done by an intermittent than by continuous steady pressure; and so, whether using a lever or screw, it is well to relieve the pressure about every ten minutes, allowing the "cheese" two or three minutes in which to become thoroly saturated again with boiling water. Pressure should be applied slowly at first in order to avoid bursting the burlap:

With the outdoor kettle plan, the wax will be discolored on account of the longcontinued heat unless it is dipped off the surface of the water almost as fast as it rises. About three hours of intermittent pressure for one batch of combs in a kettle will render out the wax.

\section{STEAM-PRESSES.}

Methods of rendering wax, embodying the principle of applying great pressure to combs surrounded by steam, are quite old, both in this country and in Germany, where they originated. In some ways steam-presses have advantages over other methods; but the quality of wax is usually

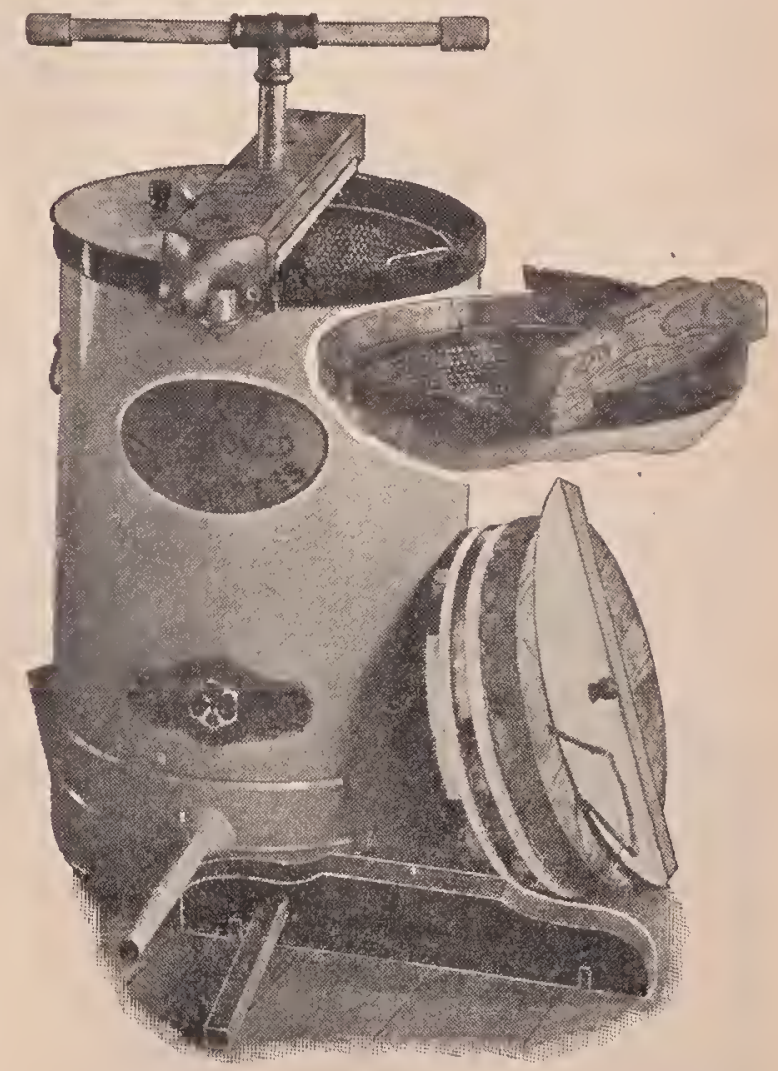

Fig. 7.-German steam wax-press.

not so good, because of the high temperature to which the comparatively thin surfaces of melted wax are subjected; altho the wax, as it leaves the refuse, falls down out of the way so that the work can be much more conveniently carried on, since there is no great depth of water in the way.

A steam-press of popular design is shown in Figm. 7. Steam is generated under a false bottom in the lower part, and, 
passing upward around the false bottom, surrounds the combs beneath the plunger in the perforated metal basket. As the wax falling from the refuse cannot get into the water on account of the false bottom, it passes out of the tube shown.

Steam-presses are very convenient as uncapping-cans; for when the perforated metal basket is full of cappings the crossarm can be placed in position, the screw run down, and practically all honey forced out. Stean then may be generated, and the wax melted into marketable shape without any second handling and with little extra trouble; or the "cheese" of cappings, pressed nearly dry of honey, may be stored away to be rendered into wax at a more convenient time later.

These presses are also very useful in pressing honey from broken combs, unfinished sections, etc., and rendering the pressed comb into wax. For the real business of rendering old combs, the presses using hot water as the heating agent are much superior.

\section{PLAIN PRESSES.}

C. A. Hatch of Wisconsin was probably the first one to make extensive use of a plain press for wax-rendering. He had used for a short time a press designed by W. W. Cary of Massachusetts in which the combs were pressed while submerged

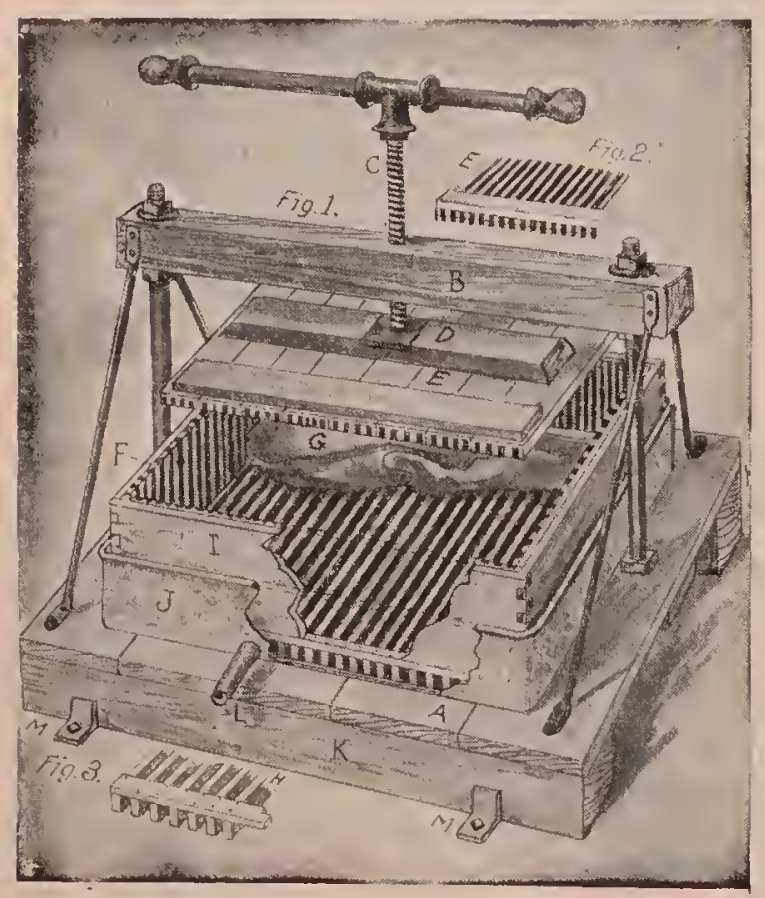

Fig. 8.-The original Hatch-Gemmell wax-press. in hot water; but he believed that he could improve on this plan by applying pressure in a different receptacle without the use of so much hot water. Later, F. A. Gemmell of Ontario, Canada, also used such a press, which finally came to be known at the Hatch-Gemmell wax-press.

The particular form of press that is sold largely is shown in Fig. 9. It will be noticed that a round can, constructed of tin, is used instead of the square wooden box and tray. The principal reason for this change is that it is easier to keep the "cheese" from bursting out sidewise when a round box or can is used, for the square box tends to bulge out in the middle, thus allowing the burlap to burst. If a round can is used, the pressure sidewise is always in a direction away from the center, and the horizontal pressure is thus equalized.

\section{THE BEST METHOD.}

In using this press a tube was thought necessary at the bottom of the can, left open during the pressing so that the hot water and wax could run away immediately. It is better, however, to have no opening at the bottom of the can, but to confine the hot water and wax, thus preventing chilling as much as possible.

If no heat is applied to the combs during the pressing it is necessary to do the work in warm weather or in some room that ean be kept hot by the heat of the stove used for melting, for when the air is cold the wax chills and the work is hindered. The efficiency of the press is greatly increased if a very small jet of steam is introduced from a steam-knife boiler or teakettle, carried by means of a rubber tube to a one-quarter-inch copper pipe about fourteen inches long, with a right-angle bend five or six inches from the bottom and with a long curve at the upper end. This is applied to the wax-press can as shown in Fig. 9. As will be noted the pipe goes down between two of the vertical cleats on the side of the can and is then extended over toward the center between two of the horizontal cleats at the bottom, under the screen. While the presssure is being applied the water and wax keep up a gentle boiling -an ideal condition. No matter how long the pressure is kept on the slumgum, nor 
how many times the screw is raised to allow the hot water to saturate the refuse again, the water keeps up this gentle boiling, so to speak, and the $\cdot$ wax on top shows no tendency to cool. It was formerly recommended to run the refuse thru the press a second time; but if steam is introduced as explained, the second melting and rendering is unnecessary unless the work has been very carelessly done. If there is any doubt as to the thoroness of the work, it is a good plan to run the refuse thru a second time to make sure that it is clean. The second rendering takes about half the time that the first did. melting the combs but are not quite so convenient owing to the difficulty in turning down the oil burners in case the combs get to boiling too hard. Wash-boilers cannot be cleaned very easily after being used for melting combs, hence should be kept for this purpose only. Many prefer to use a large square tank of galvanized iron, possibly over a brick furnace out of doors. Or a stock-feed cooker may be used, costing from $\$ 15$ to $\$ 35.00$.

The press should stand on a solid box that is firmly secured to the floor, and it should be hinged in front so that it may be tipped over to run the hot water and

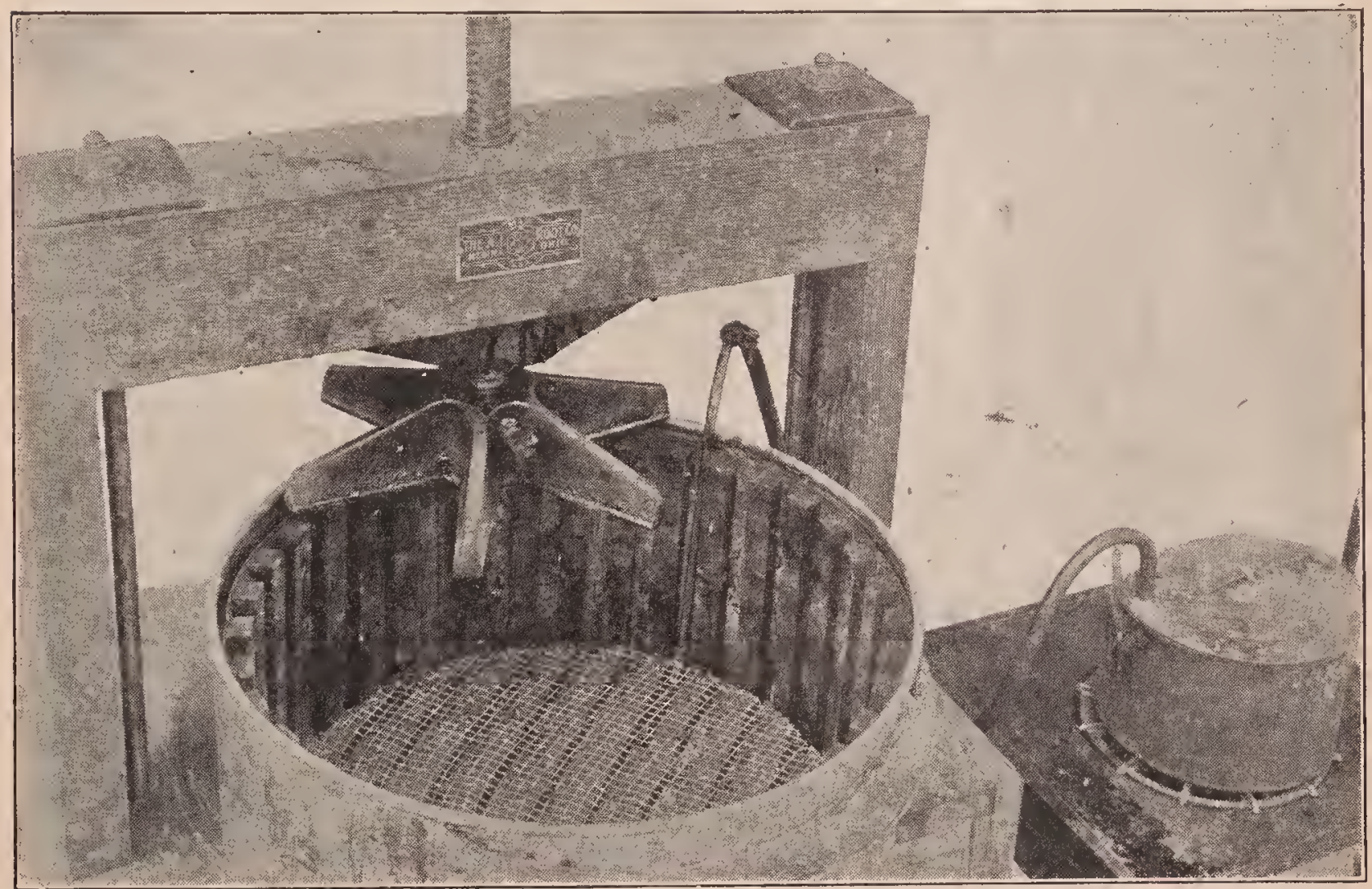

Fig. 9.-Steam from a small boiler introduced between the slats in a wax-press can. The water and wax keep up a continual slow boiling, insuring constant circulation.

AN IDEAL EQUIPMENT.

Fig. 10 shows the small outfit which the author recommends, including stoves, press, cans for melting the combs, boiler for steam, etc. A cook stove with a top large (nough to hold two good-sized wash-boilers is ideal, but frequently it is inconvenient to provide such a stove in a basement or outbuilding where the wax-rendering is done. Two double-burner gasoline stoves, one for each wash-boiler, will do as well. Oil stoves would answer the purpose for wax into the can beneatli. A large box or basket must be provided to hold the refuse after it is pressed. An openheaded barrel with a plug at the bottom is the handiest receptacle for holding the hot water and wax.

\section{DIRECTIONS FOR RENDERING.}

When ready to begin work light one of the stoves and put on a boiler a little over half full of water. If the water is very hard add a little borax. When the water boils throw in the old combs. Thirty-five. 


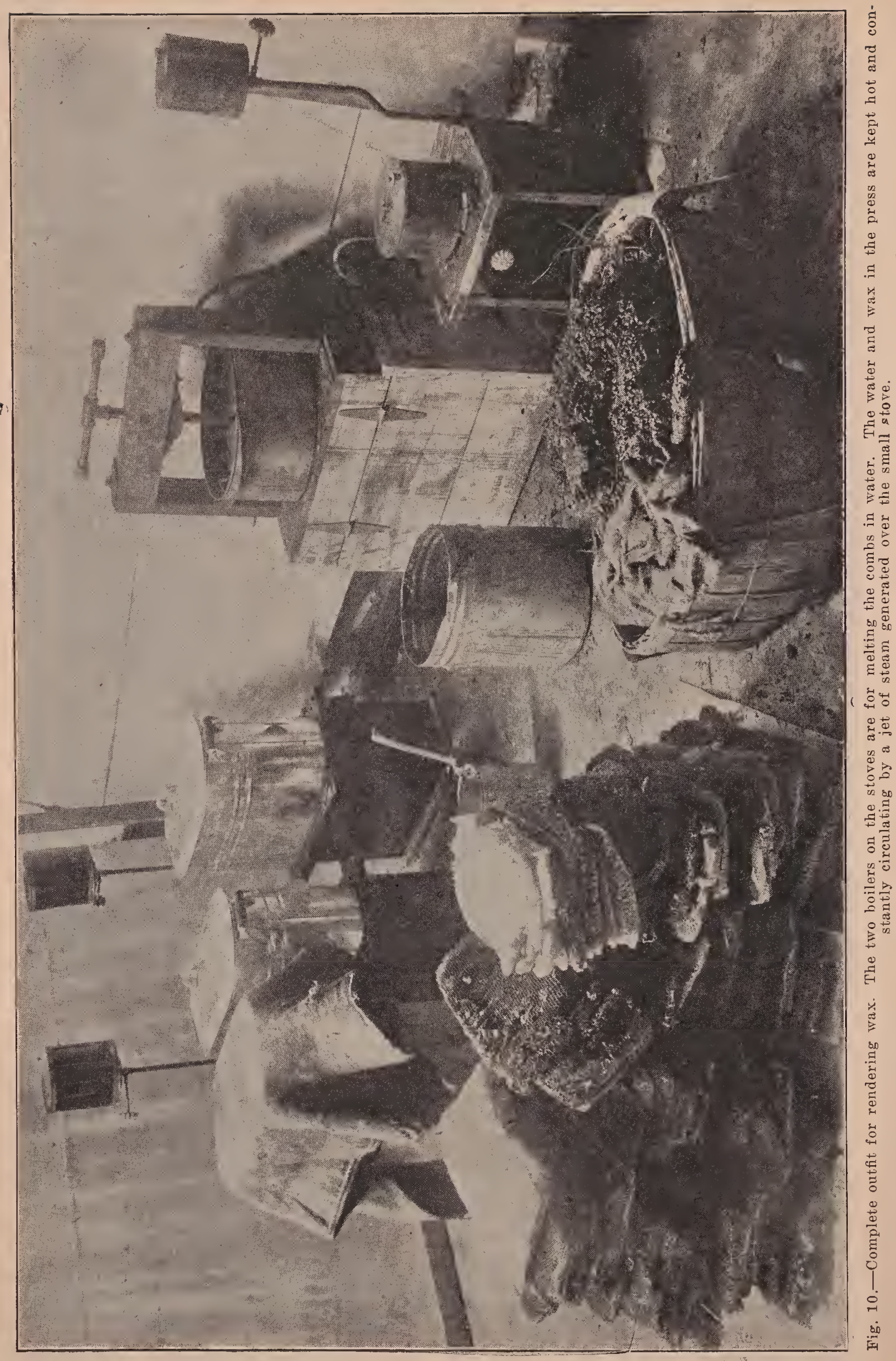


to forty combs (about half a barrel) may be put in gradually, provided they are carefully pushed down with a paddle and stirred as they melt. When all the comb that the boiler will hold conveniently has been put in, place the cover on and allow

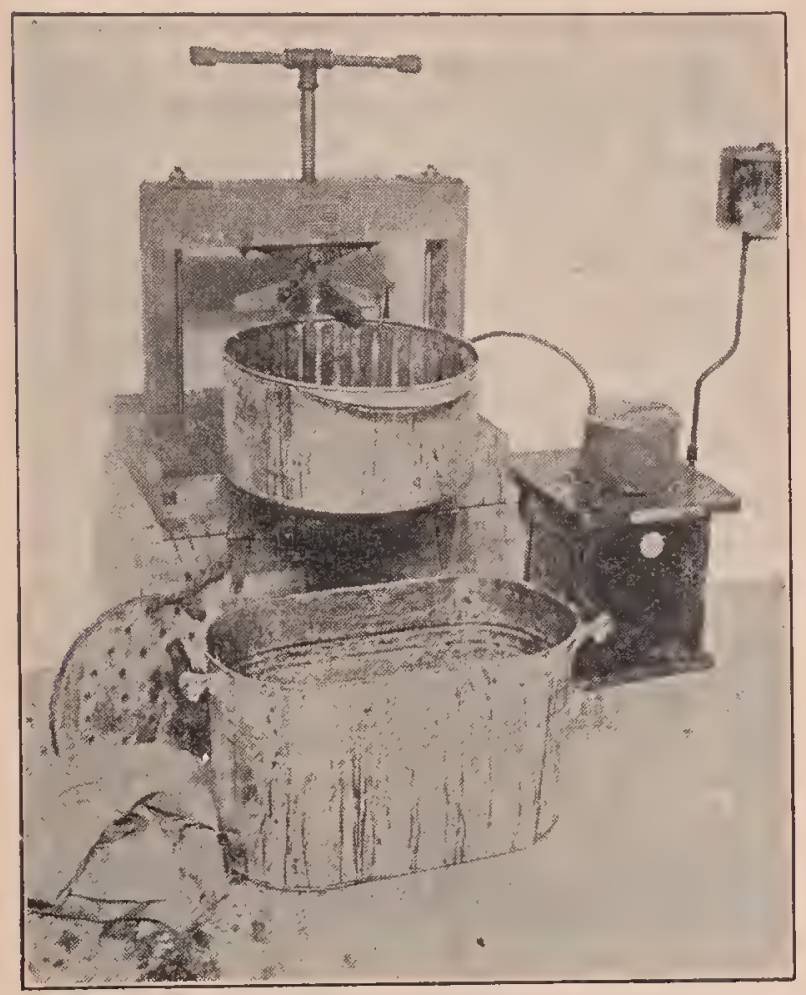

Fig. 11. - The press can be pulled forward ready for filling.

the mass to cook thoroly. About this time light the other stove and put on another boiler of water; also set going the burner under the steam-bóiler on a third stove to supply stean to the press-can.

It facilitates the work if a quantity of straw, preferably rye straw, is cut up in two-inch lengths and stirred into the melted combs. It makes the "cheeses" more porous so that less wax is left in the slumgum.

It is a mistake to begin pressing as soon as the comb is melted. Continue the cooking process with frequent stirrings until the combs are reduced to a steaming mushy mass. There must be no hard chunks.

When the contents of the first boiler are ready for pressing and the steam begins to issue from the pipe in the bottom of the press-ran, pull the can forward on the platform, holding it in position by means of the spider on the lower end of the screw resting on the top of the can, as in Fig.
11. There should be in readiness a fer pieces of good strong burlap, at least 40 inches square. Place one of these in the press-can; put the follower on top of it and throw a few dipperfuls of hot water from the other boiler into the can to heat thoroly all the parts. Pour this off and spread the burlap down into the can as in Fig. 12. Dip about two gallons of the melted comb and water into the press and fold the burlap neatly over it, as carefully as tho tying up a package. This is very important; for if there are thick rolls of the cloth in any one part of the "cheese," other parts of the refuse will not receive as much pressure as needed. To fold the burlap over, fold the back enge over toward the front, being careful to get the sides straight, then push the front edge over on top of it; lastly, fold in the sides neatly. Place the cleated circular follower in position (cleats down, of course); push the can back exactly in the center of the platform and run the screw down very slowlyFig. 13.

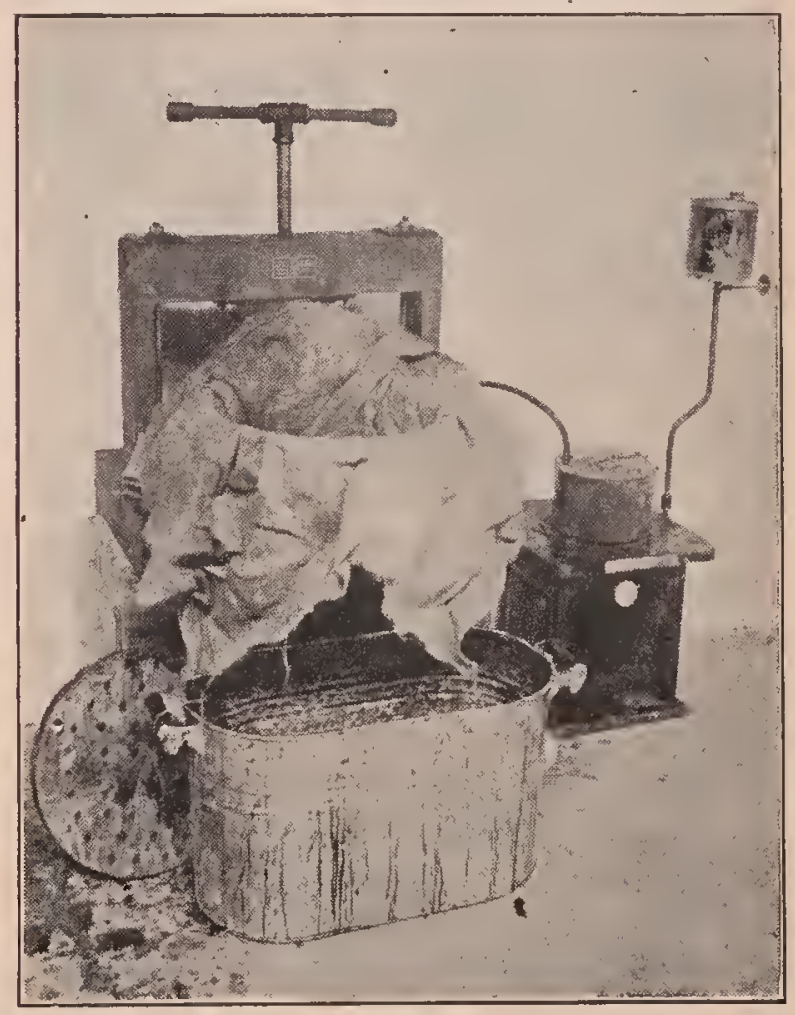

Fig. 12.-A large piece of stout burlap is the best material to use for holding the melted comb.

At this time it may be necessary to turn down the gasoline burners under the first boiler in order that the contents may not get too hot; or, if it is on a stove, pull it over to the edge. Use the utmost care to 
prevent the wax from slopping over. If it does, there is danger of having a serious fire. As soon as the water in the second boiler boils, begin filling that with combs.

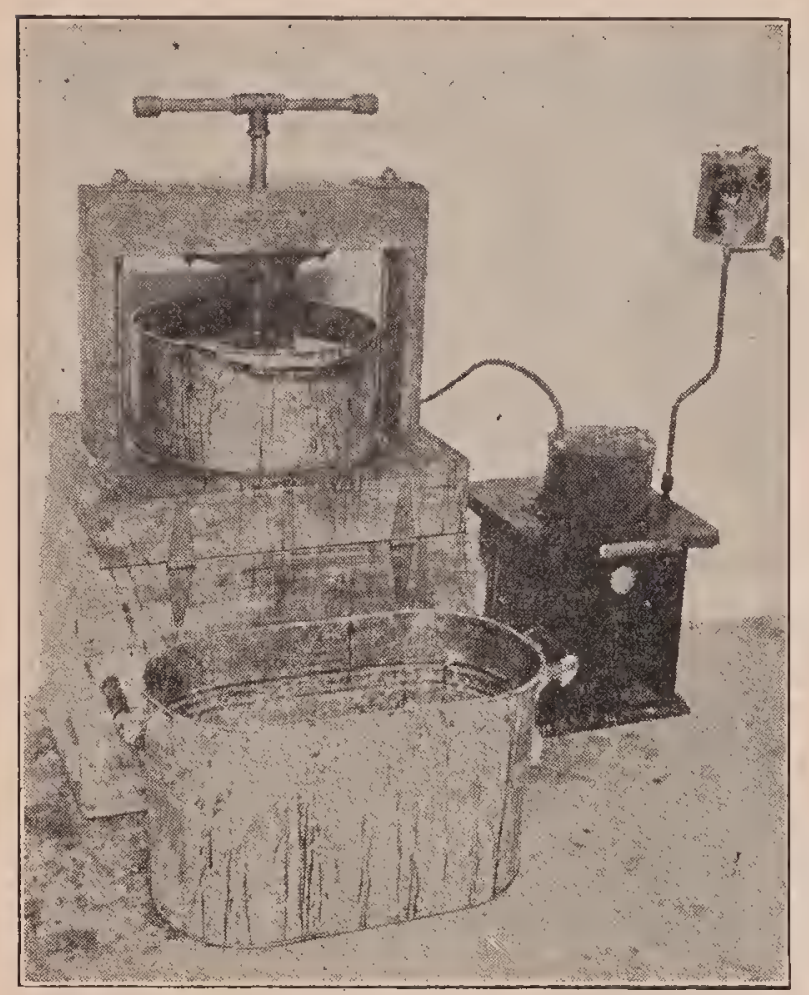

Fig. 13.-Apply the pressure. The wax rises to the top of the water. As much time may be given to the pressing as desired-no danger of chilling, because of the jet of steam.

Always turn the screw down slowly. If it is run down rapidly before the liquid in the mass inside the burlap lias time to squeeze out, the burlap and the contents inside are likely to push up around the follower, interfering seriously with the escape of the water and wax. Turn the serew only when it turns easily. Of course, when it is clear down it may be turned tight; but there is really more danger in applying too much pressure than in not applying enough.

Sufficient water should have been dipped in with the comb so that the water and wax, when the screw is clear down, will just about submerge the iron spider on the end of the screw. It ought to take two or three minutes to get the screw clear down. When it is down about as far as it will go, release the pressure until the cast-iron follower is nearly out of the liquid; pull up on the rope handle of the wooden follower until it is free from the burlap, thus allowing the hot water to saturate the refuse again. After a minute or so apply the pressure slowly once more. This process should be repeated two or three times.

Instead of using a jet of steam as described, an extra can may be used, one to be on the stove being reheated while the other is under the press.

When the screw is finally down as far as it will go, place a washtub or a large can on the floor in front of the press and tip the latter over, pouring all the water and wax out. Leave the press tipped over a few moments until the wax drains outFig. 14.

When no more wax will drain out, tip the press back into its regular position and pour the hot water and wax into an empty can or barrel having a faucet at the battom. If a barrel is used which is smaller at the top, the hot water must first be drawn off after the work is over, and the wax run into previously soaped molds' to harden. It is more convenient to use an oval-shaped can or round can that is larger at the top, so that the wax may be left

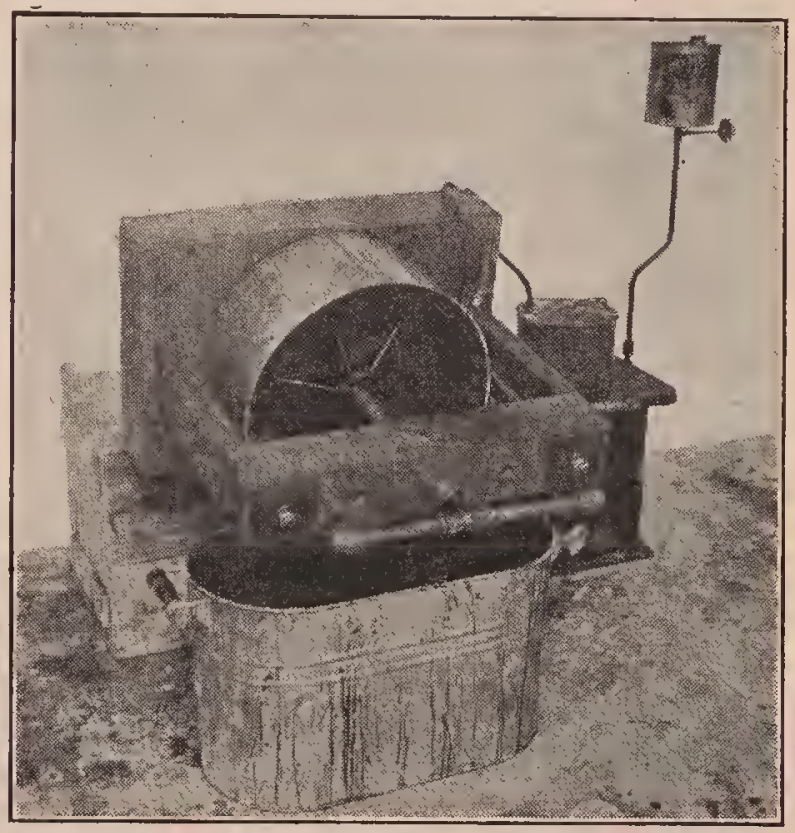

Fig. 14.-When the pressing process is completed the whole outfit is tipped up on its hinges to pour off the hot water and wax.

right in it to harden in one large cake. There is no difficulty in lifting the cake out even tho it be 8 or 10 inches thick.

The idea of the faucet at the bottom is to permit drawing off the hot water, so that it may be used over and over again. There is no object in using fresh water each time; therefore when the first boiler is empty, enough hot water may be drawn 
off from the supply-can to fill it half full again for a fresh lot of combs. When first starting out, it is a good plan to fill the boilers a little more than half full so that there will always be enough water for subsequent meltings.

If the work has been carefully done, when the screw is raised after the water and wax have been drained off, and the follower taken out, the "cheese" will be dry, comparatively speaking; and when it is dumped out into the box or basket, if a handful is taken up and pressed momentarily between the fingers, no great amount of wax will show. If only a very fine line of wax appears in the ridges between the fingers the work has been done thoroly. It is convenient, if not absolutely necessary, to wear a pair of canvas gloves during the whole process; for when the burlap is shaken out the refuse is exceedingly hot. When shaking out the burlap, if the refuse does not shake out clean, lay the cloth over the box, inside down, and quickly rub it between the hands. This will dislodge the refuse still elinging. Now place the burlap over the press again and repeat the process. The same burlap should last for a dozen pressings. Each time, however, look it over quickly to see if there is any sign of a weak spot or the beginning of a tear. If there is, discard it and use a new cloth.

A heavy' cloth or old sack should be thrown over the unheated can containing the supply of hot water and wax poured in from the can under the press; for the more this heat can be conserved, the shorter time it will take to start a new boilerful of combs.

The final waste of wax by this process need not be over 3 per cent. There is no practical process known to the author that secures all the wax.

\section{RENDERING WAX FROM OLD COMBS IN LARGE QUANTITIES.}

The foregoing plan is entirely adequate and satisfactory for a moderate amount of rendering; but when, for example, American foul brood has obtained a strong foothold thruout the apiary or several apiaries, a larger outfit is required. There are likewise those who make a business of melting up old combs for a given locality, and for such a more elaborate outfit is required.
It is not practicable to build a waxpress of a large size on the precise model just described, for the reason that the larger "cheeses" are not as easily handled, nor will they receive the same amount of pressure. Practice shows that it is much more satisfactory to use two serews over an oblong "cheese" in an oblong tank or boiler. The subjoined illustrations will show a type of double-serew press with which the author turned out 142 pounds of wax from old combs on the first day's trial, getting practically all the wax. With more practice he could turn out a larger output.

It is not practicable to heat the larger press with a small jet of steam from. a small boiler, such as one could rig up for himself. However, where one can have

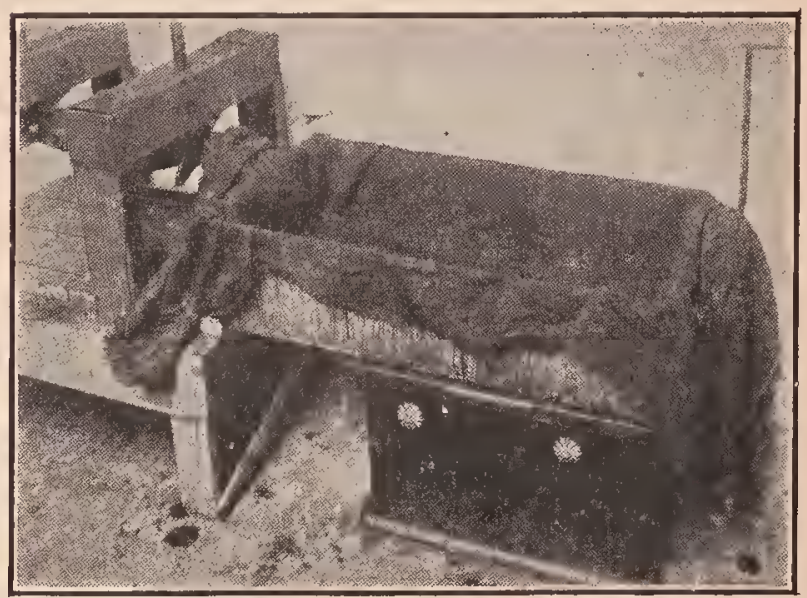

Fig. 15. - When the press is drawn out over the stove, the screws are entirely out of the way and it is therefore an easy matter to refill. A burlap $40 \times 70$ inches is used in order that the edges may be long enough to fold over and pin.

a*cess to a larger boiler, steam heating is all right; but as the great majority of the readers of this work will not be so situated they will have to employ other means. It has been found entirely practicable to put the press upon four short legs so its platform will be on the same height as a small two-burner gasoline or kerosene stove. When this stove is placed in line with the press, to heat or reheat its contents it is an easy matter to slide the boiler from under the press to the top of the stove and back again. There is no need of having heat when pressure is being applied. After several successive squeezings the boiler or tank can be slid over, emptied, and a fresh batch reheated while on the stove. This obviates entirely the nuisance of applying 
the pressure with the press on the stove, and at the same time provides a stable foundation for the press while the screws are being turned down.

\section{THE EQUIPMENT NEEDED.}

There should be three tin wash-boilers, a water-tight barrel with a one-inch augerhole close to the bottom containing a wellfitting plug, and two two-burner gasolinestoves or their equivalent. A cook stove would answer the purpose just as well, altho, being higher, it would not be quite so convenient. A large dipper is also needed, and this can easily be made by nailing a wooden handle to the side of a 10-lb. pail. The burlap used for holding the melted combs should be strong, and without holes or weak places. The size best suited for the purpose is $40 \times 70$ inches. Half a dozen pieces should be sufficient.for 500 or 600 pounds of wax. Half a barrel of water is needed. This can be used over and over again for several days if desired. If the barrel is kept covered up at night the water will still be quite warm in the morning, so it does not take so long to heat up as at first. If the water is hard, it pays to soften it with powdered borax, altho rainwater is best.

\section{HOW TO PROCEED.}

Fill two wash-boilers two-thirds full of water and put them over the stove to heat. When the water in botl boilers is boiling, start putting combs into one, which will be called No. 1, two or three at a time, poking them down in with a stick. Pour the boiling water in No. 2 into the barrel and cover with an old piece of carpet to prerent loss of heat; then fill No. 2 again twothirds full of cold water and put on the stove as before. Continue putting the combs into No. 1, poking each two or three down carefully. If the combs happen to be fairly new, as many as 50 or even 60 can be put in at a time on account of the fact that there are fewer cocoons. When all the combs are in, cover the boiler by putting over it a few thin boards cleated together. Do not attempt to start pressing before the contents have come to a boil. The mere fact that the comb seems to be melted and mushy is no indication that it is hot enough. Stir pccasionally; and when the boiling commences, take the corer off to prevent the wax and water from boiling over. If it starts to boil over, stir it a little with a stick; or, in an emergency, lift it off the fire altogether. Usually, however, this is not necessary.

Put the cleated follower into the presscan; push the can under the press and turn the screws down. Draw off a couple of pails of hot water from the barrel and pour into the can so as to heat thoroly every part. Take boiler No. 2 (containing water only) off the stove and put the stove in a position in line with the press and eight or nine inches from it. Draw off the water in the press-can; pour it back into the barrel, close the gate on the end of the can, and, after raising the screws, draw the can out aver the stove. There will be

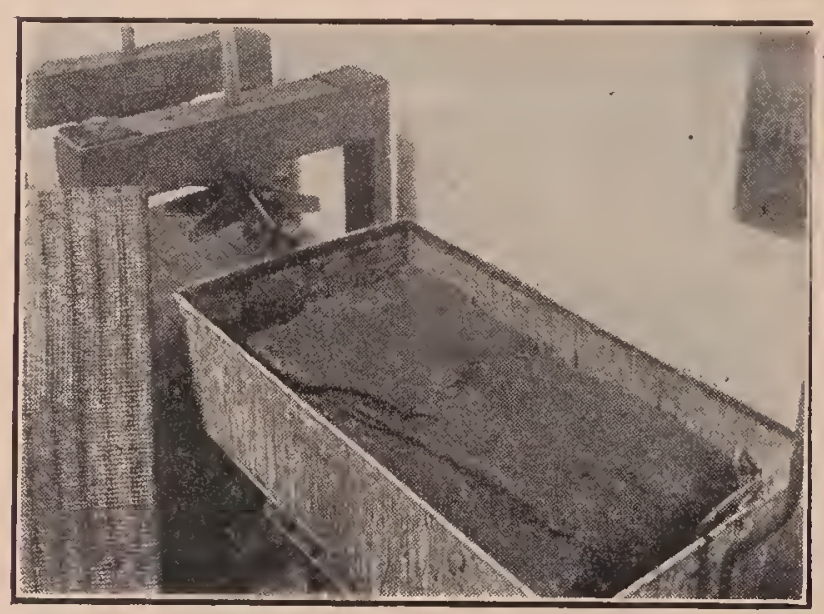

Fig. 16.-After folding over and pinning the sides with five large nails, fold over the ends of the burlap and pin with two nails. As soon as the follower is laid on, the press-can and its contents are slid under the screws. Being hot, the can slides as easily as tho it were on rolls.

enough water in the bottom to prevent burning. Take out the upper follower: spread a piece of burlap evenly over the can, tucking it down into the corners, and dip about half the melted combs in boiler No. 1 into the burlap. Then pick up the whole boiler and pour in the rest. If there is a great wad of wires, as there will be if the frames were wired originally, pull these apart with a stick enough so that they will not all be in one place. Fold over the sides of the burlap, pulling over enough so that the mass is perhaps two inches away from the edge of the can, and pin with five large nails; then fold over the ends and pin with a couple of nails. It is better to double the edges so the nails will not 
tear the threads. Be sure that there is no wad of burlap in any one place, and that the edges lie smooth. Put the follower over the burlap, screen side down, and quickly slide the can under the press. The can being hot, it slides almost as if it were on rollers, especially after a few drops of wax liave dripped on to the platform, thoroly lubricating every surface. The longer the can is used, the easier it slides back and forth.

With the ean in position, turn the screws down slowly. Especially at the start, do not make the fatal mistake of turning the screws down to the limit without stopping, for it is almost sure to burst the burlap. (If you burst the burlap just once you will always afterward be careful.) Turn the screws down only as fast as they turn easily, therefore. As soon as they turn a little hard, wait until some of the wax and hot water has had a chance to ooze out. It is all right to apply considerable pressure when the screws have been turned down nearly to the limit, for then the "cheese" contains so little liquid that there is practically no danger of bursting the burlap.

As soon as the can has been slid under the press, fill the empty boiler (No. 1) twothirds full of hot water again from the bottom of the barrel and put it on the stove by the press. Put boiler No. 2 (which should now be full of partly melted comb) on the other stove to finish heating for the next pressing.

In order to make the process continuous, start putting comb in boiler No. 1 again, now on the stove by the press. Two lots of comb are thus in the process of heating at the same time, the one to be pressed next being the nearest finished, while the other is just starting.

As soon as the screws are down practically as far as they will go, release the pressure, turning the screws up out. of the way; lift boiler No. 1 temporarily off the stove and pull the press-can out on to it. Cover it with short boards cleated together and leave it in this position until it comes to a boil, then quickly slide back under the press and press again. Repeat this process

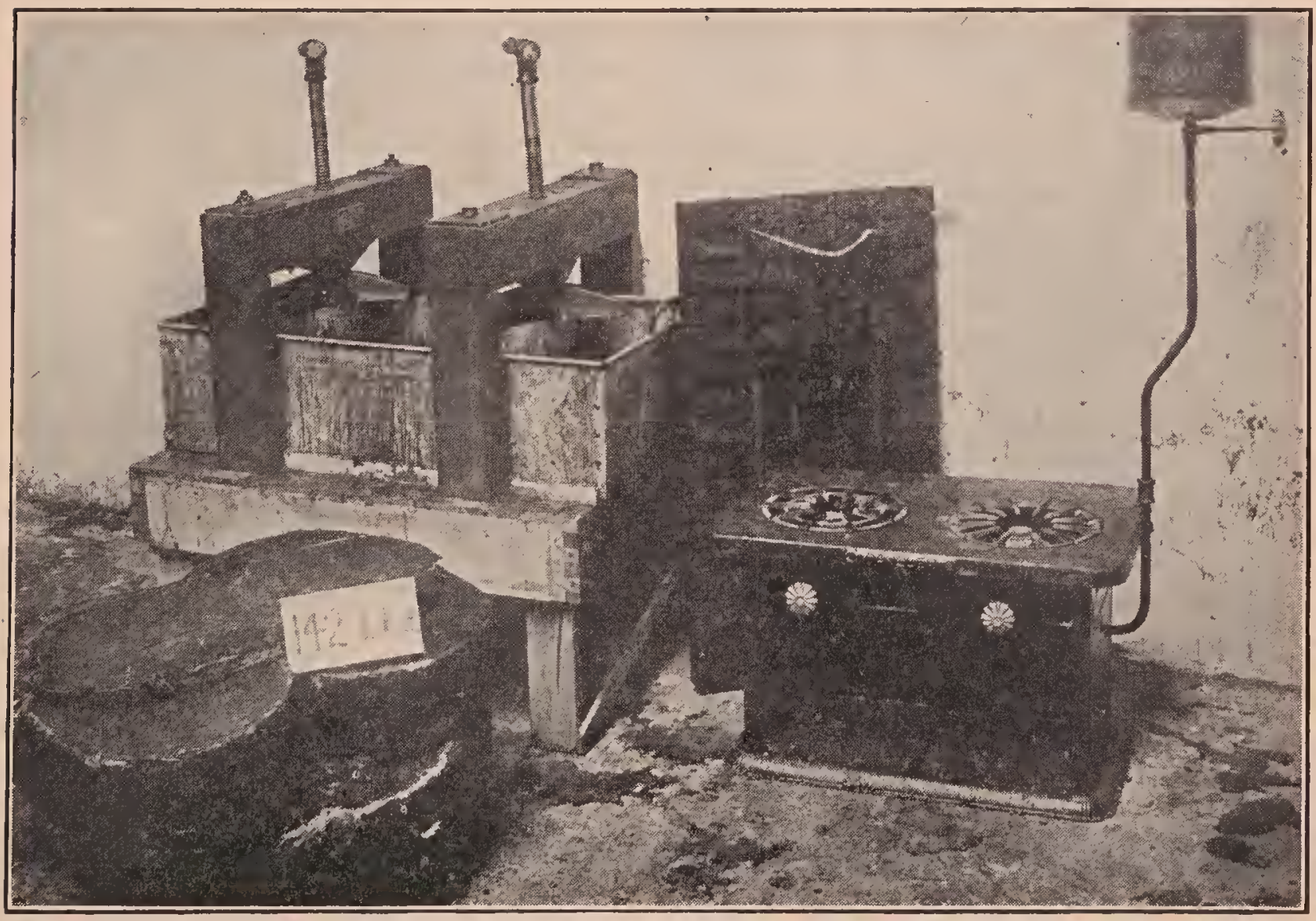

Fig. 17.-While it sounds like a tedious process yet as a matter of fact it is possible to press a batch of 40 combs every 45 minutes. Thirteen batches were pressed in a singie day yielding in all 142 pounds of clean yellow wax. The small cake on top about $3 / 4$ inch thick represents the amount of wax in a boiler after one batch is pressed-about 10 pounds. 
until the batch has been pressed three times. Between pressings always draw the can out over the fire to come to a boil. The object of this is to permit the refuse to become saturated again with boiling water. Heating to the boiling-point between each pressing makes possible a saving of about two per cent of wax. Whenever the presscan is not occupying the stove the boiler should be put back over it, so that the heat will not be wasted. The contents of this boiler, therefore, has intermittent heating while one batch is pressing, then during the pressing of the next batch it is transferred to the other stove where it has constant heating so that it will be ready by the time the press is empty again.

As soon as the screws have been turned down for the third time, practically as far as they will go, place a third boiler under the gate while the screws are still down and open the gate. Catch a dipperful of the water as it first comes out of the press and set it on the floor. When all the wax and water have run out, splash the hot water in the dipper orer the follower while the screws are still turned down, thus rinsing off the coating of the hot wax. Then tip up one end of the press so as to drain out the last of the water and wax into the boiler. Pour this hot water and wax immediately into the barrel and corer with the o!d carpet. The wax will rise to the top; and, when more hot water is wanted a little later, another boilerful may be drawn from the hole at the bottom.

As soon as empty, draw the press-can out over the stove. Take out the follower and the "cheese" and put the latter to one side for the present. If there is not enough water in the can to prevent burning, throw in a couple of quarts with the dipper. Spread a fresh burlap over the press-can and proceed as before. Later" on, when there is time, the first "cheese" set aside may be unpinned and the refuse shaken out. The burlap slould be rubbed between the hands s̀o as to lemove the cocoons that have been imbedded in the cloth. Much depends on having the burlap clean when it is used orer again.

A little experience will determine how much water to put in the boilers. There should be enough so that the surface of the liquid will be about an inch from the top of the press-can, when the follower is submerged by the screw. If the press-can is too full it makes it difficult to slide back and forth without slopping, and if there is not enough, it detracts from the efficiency of the method. During the pressing, it is a good plan to cover the can with four boards, notched at one edge, to surround the screw. This confines the heat and make it possible to do faster work.

The process as described in detail sounds complicated, but is really very simple. It is easy to finish a batch every 45 minutes. The average amount of wax secured each time is 10 pounds. As mentioned in the early part of this article, the author pressed 13 batches in a day and secured 142 pounds of wax in all. The refuse, moreover, when the work was done, contained less than two per cent of the original amount of wax.

Before starting work the second morning the cake of wax on top of the water in the barrel should be broken up and taken out. The pieces require only a little scraping on the bottom to be ready for market. The water, still warm, is quickly heated so that the work can'be resumed very shortly.

When diseased combs are rendered, especially those containing some honey, every precaution should be taken to prevent the bees from robbing. If the buildings cannot be made bee-tight, the work unust be done at night, and every tool and utensil used thoroly scalded. The refuse from the diseased combs should be burned, and the water which was used poured where the bees cannot possibly get access to it.

\section{-THE AMOCNT OF WAX IN COMBS.}

The question is often asked how much wax can be renảered from comb holding a given amount of honey; but it is quite difficult to answer such questions, as it makes considerable difference whether full shents of foundation were used, and also whether such foundation was thick or thin. In general, however, it requires about 4 lbs. of wax in comb to hold $100 \mathrm{lbs}$. of honey, or, in other words, a pound of new comb will hold about 25 lbs. of honey.

A sixteen-ounce section of honey consists approximately of. $141 / 2$ ounces of honey-a little over one-lialf ounce of wax and about one ounce of wood. Next is 
shown the result after separating the honey, wax, and wood, in a sixteen-ounce section. Of course, these results, as before mentioned, are not always the same,

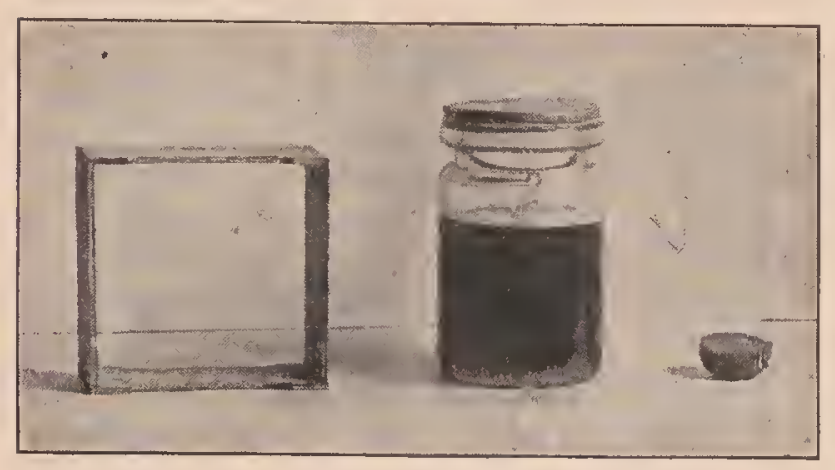

Honey pressed from a section; result-over 14 ounces honey, $1 / 2$ ounce of wax, and 1 ounce of wood.

and the different amounts vary considerably.

On one occasion the author melted over $600 \mathrm{lbs}$. of candied comb honey. Keeping careful account of the weights, it was found that the percentages of honey, wax, and wood were approximately 88,5 , and 7 , respectively.

\section{REFINING BEESWAX.}

Wax cakes, as they are brought up, are usually of all grades and colors. The difference in color is due largely to the amount of impurities the wax contains. With all of the plans for bleaching or clarifying there seems to be no practical or satisfactory way of bringing a small amount of wax to a yellow color.

Acid for refining wax on a small scale is not to be recommended, for, without proper receptacles and facilities for heating, the wax is more often injured than benefited.

\section{BLEACHING BEESWAX.}

There are methods by which beeswax can be bleached by the use of chemicals: but for practical purposes it is unwise to attempt them. Moreover, it has finally been discovered that, for the economic uses of the beekeeper, foundation made of bleache'd wax is no better than, if as good as, that having the natural yellow color. Yellow wax is more ductile, and therefore more easily worked by the bees; and even when used for section honey-boxes, the combs from yellow wax are about as white as those from the bleached; so that when capped orer no one can tell the difference. But very often dealers have a call for bleached beeswax; and the only practical way of getting it is to convert the product into thin sheets or small particles and then subject them to the sun's rays for a suitable length of time. When sufficiently bleached they may be melted up and caked.

HOW TO DETECT ADULTERATED WAX.

Mention has already been made that beeswax is liable to adulteration with paraffin or ceresin, and sometimes with ordinary grease or fat. Some unscrupulous box-live beekeepers, after brimstoning their old "skeps," and melting up the wax," add just enough tallow to increase the weight, because grease is cheap compared with the ordinary product of the hive. But such adulterations are very easily detected, both by smell and sight. 'The cakes have a greasy smell and feeling'; and when subjected to the float test, presently described, will immediately rise to the top of the liquid. Paraffin and ceresin adulterations are not so easily recognized; but nearly all pure beeswax, when chewed for a few minutes, will crumble in fine particles, while wax containing a small percentage of paraffin or ceresin will chew like sealing wax and chewing-gum.

The simplest test is the float or specificgravity test. The specific gravity of ordinary commercial paraffins and ceresins is below that of beeswax. As an ordinary article of pure beeswax is lighter than water (wax standing 965 and water at 1000), of course it will float in water.

Into a jar partly filled with water pour alcohol until a small piece of beeswax of known purity settles to the bottom, taking care not to pour in too much alcohol, for the wax should barely sink to the bottom; that is, the alcoholic liquid and the wax slould be of almost the same specific gravity. If a piece of adulterated beeswax containing 50 per cent of paraffin or ceresin is now put into the liquid it will float on the surface of the liquid. If another piece of wax that contains only 10 per cent of adulteration is now tested it will still float. but has a tendency to sink almost under the sirface. If another piece containing

\footnotetext{
* See "Box Hives."
} 
only 5 per cent is tested it may float or gradually settle to the bottom of the jar, perhaps standing upon a single point. The degree of adulteration in a suspected sample is determined by its ability to float, whether it "floats high" or barely floats.

For all practical purposes this float test is reliable; that is, it has so far shown every adulterated sample. A large shipment of beeswax was sent in. It was very beautiful, and the cakes were all of a uniform size; but the price was very low. It was suspicious, and accordingly it was subjected to the float test. Sure enough, a small piece of wax stayed on top of the test liquid. It was then put into a liquid that would let a 25 per cent ceresin adulteration sink. After hovering near the surface it gradually sank, and acted like the piece of wax that was known to contain 25 per cent of ceresin.

The shipper was advised that he would have to take the stuff back. He did it very promptly, without even trying to defend himself, any more than to say that he thought we were not very particular. $\mathrm{He}$ knew better, but thought he could unload the stuff.

\section{CLEANING WAX FROM UTENSILS.}

Perhaps the readiest means is to immerse the utensils in boiling water until all the wax is thoroly melted off, then drain, while hot. They can then be wiped off with soft newspaper. Where the article cannot be easily immersed, high-test gasoline or a solution of salsoda will readily dissolve the wax so it can be cleaned off with a cloth. Gasoline dissolves wax almost as readily as water dissolves sugar.

\section{WAX WORMS.-See MotH Militer.}

WEIGHT OF BEES.-Some very interesting experiments were conducted by Prof. B. F. Koons, of the Agricultural College, Storrs, Ct, to determine the weight of bees and the amount of honey they can carry., The results of these experiments were printed in Gleanings in Bee Culture; and the article is given here:

Some two years ago, in a leisure hour I went to my apiary and eaptured one outgoing bee from every hive and subjected them to fumes of cyanide of potassium for a few moments to render them inactive, and then weighed each bee upon our chemical bal- ances-a pair of scales so delicately adjusted that it is an easy matter to weigh the one-millionth part of a pound or the one-thousandth part of a bee. From the weight of each separate bee it was a very simple problem in arithmetic to compute the number of bees in a pound. The results showed that mine, which perhaps are a fair average in size and weight, ran from 4,141 to 5,669 in a pound. These results you published in Gleanings, and there expressed a wish that I would also determine the amount of honey carried by a homing bee. In my research for the weight of bees I took those just leaving the hive, which naturally would represent the normal weight, without extra honey or pollen.

During the present summer (when the bees were very active) I have undertaken to carry out your request as to the amount of honey carried by a bee. My method was this: From the chemical laboratory I secured a couple of delicate glass flasks with corks, marking them $A$ and B. Each was very carefully weighed, and the weight recorded. I then went to a hive, and, with the aid of a pair of delicate pliers, or pincers, I captured a number of incoming bees and dropped them in flask A. I then secured about an equal number of outgoing bees in flask $\mathrm{B}$. These were then taken to the laboratory immediately, and each flask again weighed, after which the bees were carefully counted and released. This operation was repeated quite a number of times, not on the same day, but as opportunity offered, and when the bees were bringing in an abundance of honey. I captured from 20 to 45 bees for each flask at each trip, aiming to have, as nearly as might be, the same number in each flask on any particular trip. I always weighed the flasks before starting out, lest some little bit of soil or stain, or even moisture on the glass, would render the results less accurate; I also always allowed any moisture condensed upon the inside of the flasks, while the bees were confined, to evaporate before weighing for another trip. I then treated my results as follows: From the weight of flask and bees I deducted the weight of the flask; the remainder I divided by the number of bees confined on that trip. This gave me the average weight of the bees captured at that time. The average weight of the bees in flask A, or loaded bees, was always greater, as it should be, than the average weight of the bees in flask B, or unloaded bees. The difference between these two weights gave me the average amount of honey carried by that lot of bees.

Mine are Italian and hybrid bees, but I made no attempt to determine the difference in the amount carried by the different swarms or breeds. I kept no record of the swarms except that I guarr,ed against going to the same hive for a second lot of 
bees. A considerable difference does appear, but probably that arises in part from the abundance or scarcity of honey on any particular day when the colony was viaited. My aim was to secure reliable results, as nearly as possible representing the average amount of honey carried by bees.

The following is the result of weighing several hundred each, of returning and outgoing bees. The smallest number of bees necessary to carry one pound of honey, as shown by my results, is 10,154 ; or, in other words, one bee can carry the 1-10,154 (one ten thousand one hundred and fifty-fourth) part of a pound of honey; and the largest number, as shown by the results, required to carry a pound is 45,642 ; and the average of all the sets weighed is 20,167. Perhaps, then, it is approximately correct to say that the arerage load of a bee is $1-20,000$ (onetwenty-thousandth) of a pound; or, in other words, if a colony has 20,000 bees in it. and each one makes one trip a day, they will add the pound to their stores. Of course, not all the bees in a colony leave the hive, the nurses remaining at home, hence necessitating more trips of those which do "go a-field.',

I also repeated my observations of two years ago on the weight of bees, and found that my numbers ran from 3,680 to 5,495 in a pound, and the average about 4,800 , the same as in my former test. I likewise secured the following on the weight of drones: of a dozen or more weighed, the largest would require 1,808 to make a pound and the smallest 2,122 or an average of about 2,000 drones in a pound, over against nearly 5,000 workers.

B. F. Koons. 1895

Agricultural College, Storrs, Ct., Sept. 3,

Both Professors Gillette and Lazenby, the former of the Colorado Experiment Station and the latter of the Ohio State University, conducted a series of experiments which closely approximated the figures of Professor Koons, and it may be assumed they are correct.

In round numbers there are 5000 bees to a pound. Single swarms have issued that liave contained as high as 10 pounds of bees. The swarm itself would, therefore. contain approximately 50,000 bees, most of them old or fielders. The number of bees left in the hive probably would not exceed 4 to 5 pounds of young bees, making a total population of about 75,000. Some of our best beekeeper's, however, are now takins. the view that colonies can be built up to 100,000 individuals and that such colon es will be very profitable; but generally speaking a good colony would not go much above
75,000 to 80,000 bees. Of this number there would be between 4 and 5 pounds of bees that would be too young to go to the field. If so, about a third of the entire force would be young bees, and the other twothirds would be fielders. This proportion would prevail only just before the main honey flow. In the middle of spring, when breeding is at its height, half or possibly tro-thirds of the bees would be young or nurse bees. During winter in the northern States, there would be no young, and all of them would be able to fly to the fields if the weather conditions would permit.

Again, in a colony population of 75,000 individuals there might be, in the height of the honey flow, 40,000 to 50,000 bees in the air or in the field at one time. Sometimes, during the middle hours of the day, when there is a great rush of incoming nectar, a colony will seem to be almost deserted; and then toward night it will soon be orercrowded.

Professor Fioons says that while 10.000 bees may carry a pound of nectar, 20,000 would be more nearly the average. Much will depend on the strength of the honey flow, and on how much time the bees take on each trip.

While the average colony in the height of the honey flow will not bring in more than 4 to 5 pounds of nectar in a day, it may bring in as much as 20 pounds. Some cases are recorded where as high as 66 pounds have been gathered; but these cases are comparatively rare. Assuming that a bee can carry half its own weight in nectar. and did that all day, a colony of 40,000 field bees might make a gain of 20 pounds to the hive, each bee making five trips. If, however, they brought in only one-half that amount per trip, then they would have to make at least ten trips per day. If nectar was very abundant those same bees might make twice that number of trips, or a tota] of 40 pounds of nectar. It can hardly be assumed that all bees would be equally industrious. When bees are robbing, filling up on fully ripened honey, they might make thirty or forty trips a day. A bee can fill up on honey in the space of a minute or two. It could then hike back to its hive, unload and return. It might thus pile up possibly one liundred trips. No one knows because no count has been made. 
If it takes 10,000 bees to carry a pound of nectar, one bee could carry only half its own weight. Some work has been done to show that a single bee can carry an amount of honey equal to its own weight. Honey, it will be understood, of course, would make a great deal less bulk. If the honeybee had a larger sac it might carry a much larger amount of nectar. When Professor Koons speaks of 10,000 bees carrying a pound of honey, he of course means nectar.

These figures will not mean much to the practical beekeeper unless he realizes that the force of fielders should be, in the height of the flow, three or four times as large as the number of young bees acting in the capacity of nurses, comb-builders, and keeping up the ventilation in the hive by which the incoming nectar can be evaporated. It is right here that the very populous colony-from 75,000 to 100,000 individuals-shows its great superiority over a colony of 30,000 to 40,000 individuals. If it takes 20,000 or 25,000 bees to keep house on a total population of 40,000 it is clear that that colony will not gather a large amount of honey. But if the beekeeper has made his calculations so as to have a large force of fully matured bees at the beginning of the honey flow, not less than 75,000, the chances are he will get a crop if the honey is to be had.

In the way of a summary, it may be said that there are approximately 5000 bees to a pound. While this number could carry a whole pound of honey they carry from onefourth to one-half pound of raw nectar. The number of trips a bee will make in a day will vary from perhaps two or three to a dozen or more, averaging, perhaps, from five to ten trips during the boney flow.

\section{WEAK COLONIES TO STRENGTHEN.} -See Untting, su b-head "Alexander Plan," also Nucleus and Building up ColONIES.

\section{WHITE CLOVER.-See Clover.}

WHITE HOLLY.-See GallberRY.

WILD CHERRY (Prun"s serntinr).Known locally as black cherry. Few trees of Florida are more stately and more simmetrical in their growth than the wild cherry. It is native all over Florida, on high pine lands and in low hummocks. The wood is a beautiful red, with a fine grain, and is very valuable for cabinet purposes. The wood is, however, somewhat softer than that of the wild cherry of the North (Prunus pennsylvanica). In appearance it closely resembles the wild cherry of more northern latitudes. It seldom fails to yield honey, and bountifully, too. Coming as it does just before the orange trees bloom, it gives a final spurt to brood-rearing that is valuable indeed. As a surplus honey it is more of a pest than a benefit, as the honey is dark red, and as bitter as wormwood. The flavor of a cherry pit is about that of this honey. It does not take a great deal of it to spoil the flaror and color of the first orange honey of the season, and many beemen in orange sections must extract their supers of all traces of wild-cherry honey or have their fancy orange honey touched and tinged. In the vicinity of DeLand, Fla., it is a real nuisance after the orange honey commences to come in. Up to that time it is a bonanza and a blessing to the apiarist. The writer has in many cases placed a. half-depth super on the strong colonies when they were storing from wild cherry, which was removed when the wild cherry flow was over and the orange flow began. Then he would extract the supers and put them back on the hives for the flow of orange honey.

\section{WILD SUNFLOWER.-See SUNFLOWER.}

WILLOW. (Salix).-This is a very natural or clearly defined genus of shrubs and trees found chiefly in the north temperate and arctic zones. Of the 161 described species, about 78 occur in North America, more than 30 of which are in eastern America. So variable are the species, and so freely do they hybridize, that any entirely satisfactory treatment from a systematic standpoint is impossible. The Swedish botanist Ande. son, whose monograph, published in the Prodromus of De Candolle, was the work of nearly 25 years, declared that of Salix nigricans, which has 120 svnonvms, he never saw two specimens that were exartly alike. In Great Britain the number of species of willow has been placed all the way from 12 to 80 .

The very small flowers are naked, or devoid of both sepals and petals, and are crowded together on an elongated stem or 
axis forming a cluster called an ament or catkin. The stamens and pistils in all species are in separate flowers, and are borne on different individual plants, some producing only staminate flowers, others only pistillate ones. In a staminate ament of the pussy willow ( $S$. discolor) the writer has actually counted 270 flower's, and in a pistillate ament 142 flowers. The multitude of bright-yellow anthers renders the

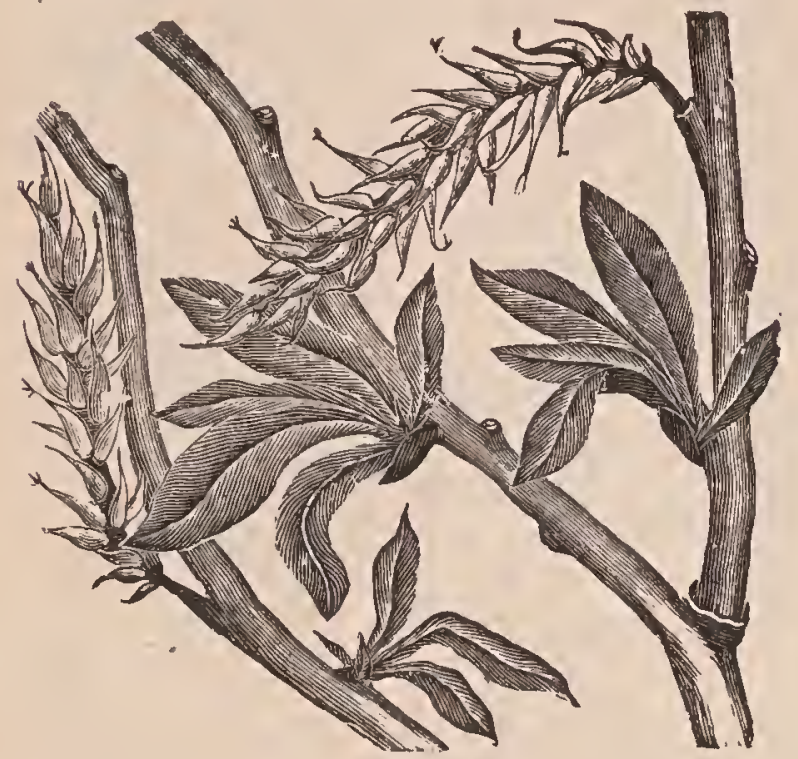

Pussy willow in seed.

staminate blossoms very conspicuous. As an evidence of their attractiveness, it may be mentioned that they are used in England for decorating the churches on Palm Sunday, and are offered for sale in New England cities by street flower-venders. The flowers are formed the preceding season, and appear in early spring before or with the leaves.

All of our species furnish both pollen and nectar, but it wonld, of course, be useless to look for pollen on pistillate shrubs or trees. The nectar is freely secreted in both kinds of flowers on the tips of minute flat glands, which in the pistillate flowers may be found at the base of the ovary. As our early willows attract great numbers of insects, the supply of nectar may be temporarily exhausted; but it should not be concluded, therefore, that it is wholly absent. If a branch of flowers be broken off and carried into the house and placed in water, and the nectaries examined after 24 hours under a miscroscope, nectar will probably be found in abundance.

The earliest willow to blossom in New
England is the glaucous or pussy willow (Salix discolor). On a calm warm day the sweet odor may be detected several rods away, and a swarm of insects may be seen hovering about the bright-yellow sprays of bloom. Besides the honeybees there are female bumblebees, the only form of bumblebee then on the wing, and great numbers of wild bees belonging to the genus Andrena gathering pollen for broodrearing. Several species of these bees are never found on any other flowers than the willows. Then there are many flies and a few butterflies and beetles. Ants often climb the stems and rob the flowers of the nectar, which is quite plentiful. In England some willows are said to be visited by moths in the evening.

The early-blooming willows are visited by large numbers of honeybees, both for pollen and nectar, and are of great value to the beekeeper. One of the commonest willows in the eastern States is the pussy willow, which is a large shrub growing on river banks. In Massachusetts it blooms along the last of March and early in April. In Georgia the black willow ( $S$. nigra) grows along the streams thruout the State. It blooms in March, and in a few localities yields a surplus of honey of medium quality. The black willow is also common in

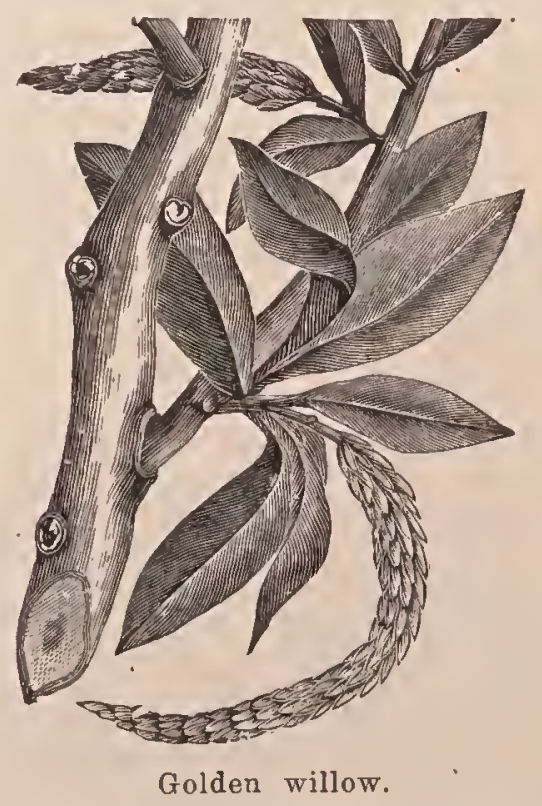

Texas, where it is valued both for pollen and honey. Other willows which are common in the eastern States are $S$. sericea (silky willow); $S$. rostrata, and $S$. cordata. In California, Richter says, the willows 
yield a surplus in several counties. It is a dark-amber, bitter honey.

Among the willows introduced from Europe, and cultivated, are the osier willow (S. viminalis); the Kilmarnock willow (S. caprea); the white willow ( $S$. alba), of which there is a variety with yellow twigs called viellina, and the weeping willow ( $S$. babylonica).

A honey flow from the willows at Borodino, N. Y., was described by G. M. Doolittle as follows:

We have three kinds of willows-the golden, the white, and the weeping willow, which are of much value as honey-producers in the order named. When these willows are in bloom, and the weather warm, the bees rush out of their hives at early dawn, and work on the flowers all day long as eagerly as they do on elover or basswood. The blossoms often secrete nectar so profusely that it can be seen glistening in the morning by holding the blossoms between you and the sun, while the trees resound with that dull busy hum from morning till night, so often heard when bees are getting honey. As this is the very first honey of the season, I consider it of the greatest value to the bees, for brood is now erowded forward with great "vim," giving us the bees which work on white clover, while the honey often very greatly helps the depleted stores of the hive.

From the few trees along a small creek near here, my bees frequently make a gain of from six to ten pounds of honey while the willows are in bloom, and one season they made a gain of fifteen pounds. This spring some of my best colonies gained eight pounds from willow, while on apple bloom they did not get more than a living from apple orchards white with bloom all about. The honey from the willow is quite similar to that from the apple bloom, and has a nice aromatic flavor. As the willows give the first pollen, and also the first honey each season, it will be seen what a great help they are to all who have them in profusion near their bees. The only draw. back is the weather often being unfavorable, for I do not think that more than one year in three gives good weather all thru the time willows are in blossom. As it is often too cold, rainy, cloudy, or windy for the bees to get to the trees at this season of the year, honey and pollen from this source are not at all certain.

WILLOW-HERB (Epilobium angustifolium).-Fireweed. Indian pink. Rose bay. A perennial herb, 2 to 8 feet tall, with long lance-shaped leaves, and handsome redpurple flower's in long spike-like racemes.
After forest and brush fires it springs up in great abundance, and flourishes for about three years, when other plants crowd it out. Wild raspberry, another good honey plant is one of the first plants to replace it, and goldenrod, asters, Canada thistle, and various slirubs also soon spring up and occupy the land. But the length of time fireweed offers a good location for beekeeping varies greatly in different parts of the continent. Near Maniwaki in the Gatineau Valley, about 100 miles north of Ottawa, the location had become practically worthless for honey production six years after a fire had swept over the land; but 200 miles north of Ottawa, halfway between the city of Quebec and Lake St. John, there was still a large amount of fireweed in bloom 15 years after a forest fire. While in the upper part of the Lower Peninsula and also in the Upper Peninsula, Michigan, fireweed is a reliable honey plant, yet in Tuscola County, according to Hutchinson, farther southward, altho very common it never yielded a pound of honey. On the Canadian Pacific Railway in British Columbia there are localities in the Rocky Mountains where fireweed blooms year after yeár and shows no signs of diminishing.

Fireweed is adapted to a greater variety of soils than either alsike clover or white clover. Moist ground and a cool temperature are favorable to its growth; but drainage is necessary; and, if the soil is swampy, both growth and secretion are poor. While fireweed thrives best in elay soils and particularly in soils rich in humus, as in the decaying remains of fallen trees, it will grow well northward for a time in rather sandy soils or on rockiy ground after a fire.

DISTRIBUTION OF WILLOW-HERB.

Willow-herb is widely distributed in the northern part of Europe, Asia, and North America. In eastern North America it extends from Labrador southward along the Appalachian Chain to North Carolina. It is abundant in New England, and in northern Michigan, Wisconsin, and Minnesota. A few years ago there were thousands of acres of this plant in northern Michigan without bees to gather its sweetness. A large part of northern Michigan (the 


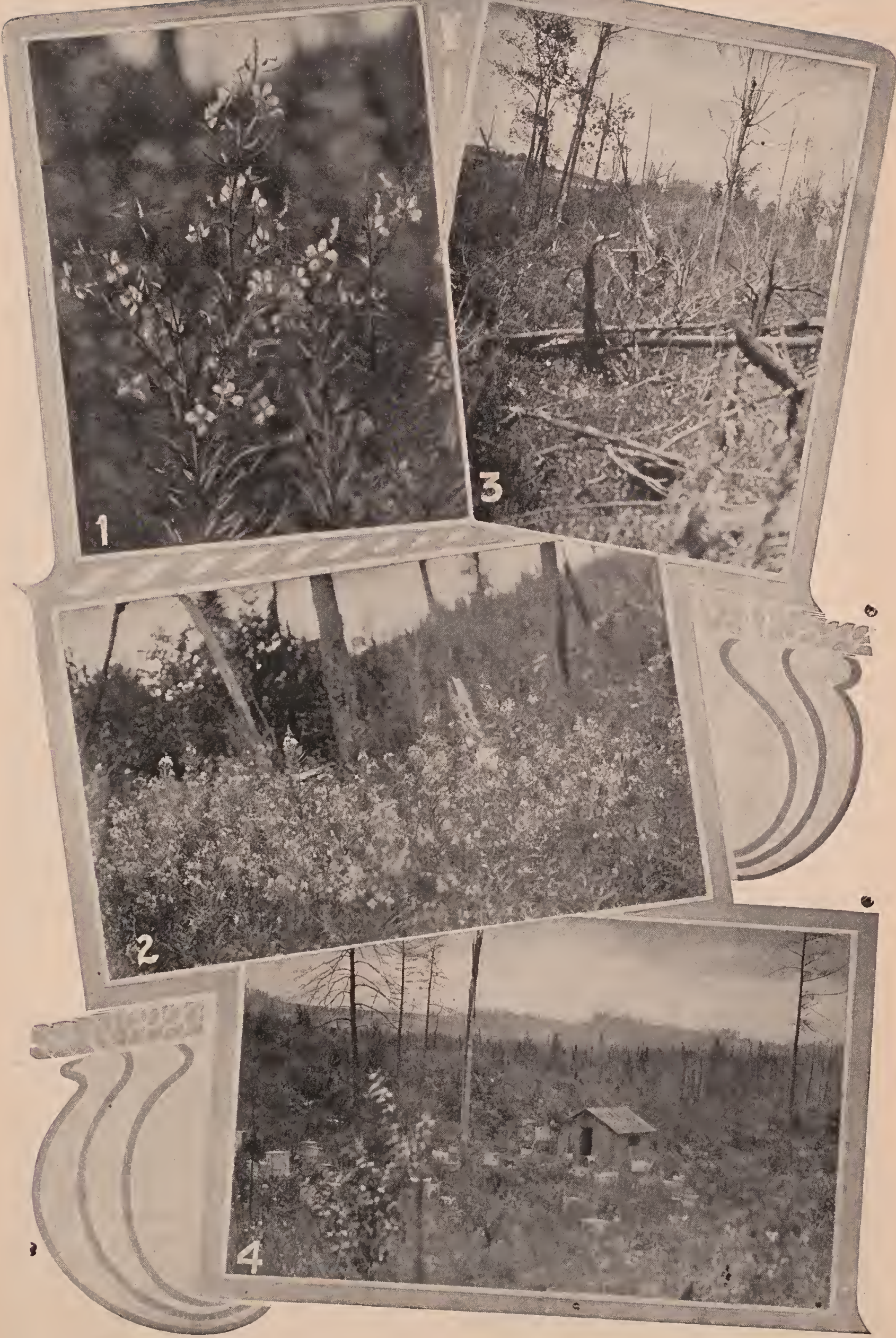

The willow-herb of northern Michigan. No. 1, the blossom; No. 2, the plant; Nos. 3 and 4, its habitat. 
Lower Peninsula) was formerly covered with white and red pine, which has now been largely cut for timber. During the first dry season after the eutting, fire burms over this stump-land, and two or three years later the growth of willow-herb comes to maturity. A few years ago it produced large quantities of honey, but as the pine has been largely lumbered the prospect is that willow-herb in the Southern Peninsula of Michigan has had its day. In the Upper Peninsula it is at present a most valuable source of surplus. Blooming at midsummer it prolongs the honey flow until the middle of August. It is easily eradicated by cultivation, but it will be many years before the beekeeper will not be able to profit from the bloom dotting the cutover lands.

It is common in the maritime provinces of Canada; in Quebec; in northern Ontario, particularly in the Rainy River district and on the clay lands; also around Lake Temiskaming; in Manitoba, especially around Lake Winnipeg and in the low moist lands of eastern Manitoba; in north-. ern Saskatchewan; and in central and northern Alberta. But it is most abundant in British Columbia both in the mountains and on the coast. It reaches its highest development both in height of the plant and in the size of the flower cluster in the lower Fraser Valley. At Hector, B. C., at an altitude of 5,200 feet and at Glacier at an elevation of 4,000 feet in the Rocky Mountains and Sellirk Range on the Canadian Pacific Railway there are large patches of fireweed in bloom year after year. Between Lacombe and Fdmonton in Central Alberta fireweed springs up and blooms in wheat fields in places, where the grain has failed to grow. It is also fairly common on serubland.

In the warmer valleys of the southern part of British Columbia the plants begin to grow so early that the blooming period may close before the end of the summer; but in the north they continue to flower until killed by about five degrees of frost. In northern Ontario a killing frost may come as early as the last of August. Travellers to the Yukon and other parts of the far north of. Canada have observed that fireweed is prevalent as far as the forest extends, even to the delta of the Mackensie River.
In the rain belt of eastern Washington and Oregon in the lumbered regions there are immense areas of fireweed, which offer as promising a bee pasturage as is perhaps to be found in the United States. In Washington its acreage is probably equal to that of any other two honey plants. At present it does not support as many colonies of bees as alfalfa, partly because of the absence of good roads, and partly because beekeepers do not realize its possibilities as a honey plant. As in other States it is confined largely to the bumed-over areas in the sections of coniferous forests, but there is probably not a county in Washington in which it does not occur. It ranges in altitude from sea level to the upper timber line. In the northeastern timbered section it is very common, and in some localities it is the leading honey plant; but it is also becoming more abundant along the irrigating ditches in the Yakima Valley and in other imigated valleys, altho here it is only a minor honey plant. It is also very important in northern Idaho. In eastern Oregon it is equally abundant, and areas of 100 acres, or more, thickly covered with fireweed occur. It remains at its best for four or five years, depending upon rainfall and soil conditions. Gradually other vegetation crowds it out. A second fire will temporarily increase its abundance, but the second period of growth is usually short, since the roots of many other perennial plants survive in the ground. After forest fires it appears in abundance in the Sierra Nevada of California. Willow-herb has a more northern range than any other honey plant of the first rank.

\section{HONEY FLOW.}

Willow-herb blooms in .July and August, but the period of blooming is influenced by altitude, latitude, and rainfall. The flowers are usually red-purple in color, but at Monteith, Ontario, Sladen observed solitary stalks of a white-flowered variety. The nectar is secreted by the green fleshy top of the ovary, where it is protected from rain, and is yet easily accessible to insects. On the outer side the nectar is enclosed by the dilated bases of the stamens and above by a ring of hairs around the style. The flowers are visited not only by honeybees and bumblebees, but likewise by many solitary 
bees, flies, and butterflies. Bumblebees are common and one was observed to make 37 visits in a minute. The pollen is pale greenish purple and is bound together by fine viscin threads. The anthers mature before the stigma, and cross-pollination regularly takes place. The flowers are odorless.

Cool nights and warm days, as in the case of many other honey plants, cause the secretion of the largest amount of nectar. The honey flow lasts longer than that of clover. In the Gatineau Valley north of Ottawa it begins one or two weeks later than clover, or about July 10, and lasts until about Sept. 5. It thus covers the larger part of the summer, or the months when the colonies are strongest. A colony on scales in a large apiary at Montcerf, Quebec, 100 miles north of Ottawa, gained 20 pounds per day for several days during August; and the average yield for six years was 144 pounds per colony of which probably 100 pounds was from fireweed.

In northern Michigan over 250 pounds of honey per colony have been stored from fireweed; and 100 and 125 pounds of surplus year after year have been reported from this source. In this region no plant furnishes more honey than willow-herb, and if the pasturage were permanent a beekeeper would find in. such a location a bonanza. It yields nectar, says Hutchinson, during weather that would stop all storing from basswood or clover, and bees have been seen bringing in honey at a fair rate with a cold wind blowing from the north. "To my knowledge it has failed only once in a dozen years." Sometimes a drop of nectar can be seen at the base of each petal. At times several pounds of honey may be brought into the hives in a few hours.

For four consecutive years a good crop of honey has been obtained at Melford in northern Saskatchewan. A beekeeper near New Westminster, British Columbia, writes: "Last year my two best colonies gave 550 pounds each. I am satisfied that most of it, if not all, came from fireweed, which grows here in great profusion." Fighteen miles southeast of Tacoma, Wash., an average of 120 pounds per colony has been secured entirely from fireweed. It has been reported that willow-herb is oc- casionally unreliable in western Washington and that hundreds of acres in full bloom may not yield a pound of honey. But the fault is probably not with the bloom, but with the methods of beekeeping. Because of excessive rains in spring and severe droughts in late summer special management is necessary in order to secure a sur-. plus. In the vicinity of St. Maries, Kenewak County, Idaho, a large area of land, which has recently been cleared of forest, is covered with a luxuriant growth of fireweed, which yields nectar until killed by severe frosts. The total number of colonies of bees in this locality probably does not exceed 100 , but it is estimated that there is ample room for at least 2,000 colonies. Unfortunately the best areas for fireweed honey-production are difficult to reach and are, consequently, seldom utilized by beekeepers. The loss of the apiary from forest fires must also be guarded against in many locations.

\section{WILLOW-HERB HONEY.}

Hutchinson, whose knowledge of willowherb honey was based on an experience covering many years, described it as follows: "Willow-herb furnishes the whitest and sweetest honey I have ever tasted. The flavor is not very pronounced, but there is a suggestion of spiciness." According to Sladen: "Fireweed honey is almost water white, has a good density, and a very mild flavor. It granulates soon after extraction." In some instances the honey has been described as being as clear as water. The comb is also very white and tender.

\section{THE PROPAGATION OF WIILLOW-HERB.}

The seed-pods of fireweed are two or three inches long and contain a great number of seeds, which bear tufts of long hairs. When the pods open the hairs, or plumes, act as parachutes, and the seeds are wafted by the wind for long distances. At times they are so abundant as to injure the eyes of moose-hunters. Fireweed also multiplies by underground rootstocks which may grow twenty feet in length. When fireweed springs up in dense shade the flowers develop imperfectly, or wither and fall from their stems, and the plants put out long rootstocks which seek to run out of the circle of shade. The more intense the 
sunlight, the brighter the colors of the flowers. After a forest fire a rank growth of fireweed may develop, not from seed but from the rootstocks of scattered plants, which languished in the dense bush without blooming. Immediately after the fire the rootstocks send up strong plants, which send forth new rootstocks forming buds at short intervals. Thus in a few years an extensive network of rootstocks may be formed. Seedlings under the same condi- pleasure I experience in working in an apiary located in a fireweed location."

WINTERING.-Under the head of ABSCONDING SWARMS, in the opening of the book, and under the subject of UNITING, the reader has been cautioned against dividing, and trying to winter weak colonies. See "Absconding in the Spring," under the head mentioned. In regard to keeping bees warm thru the winter witl ARTIFICIAL

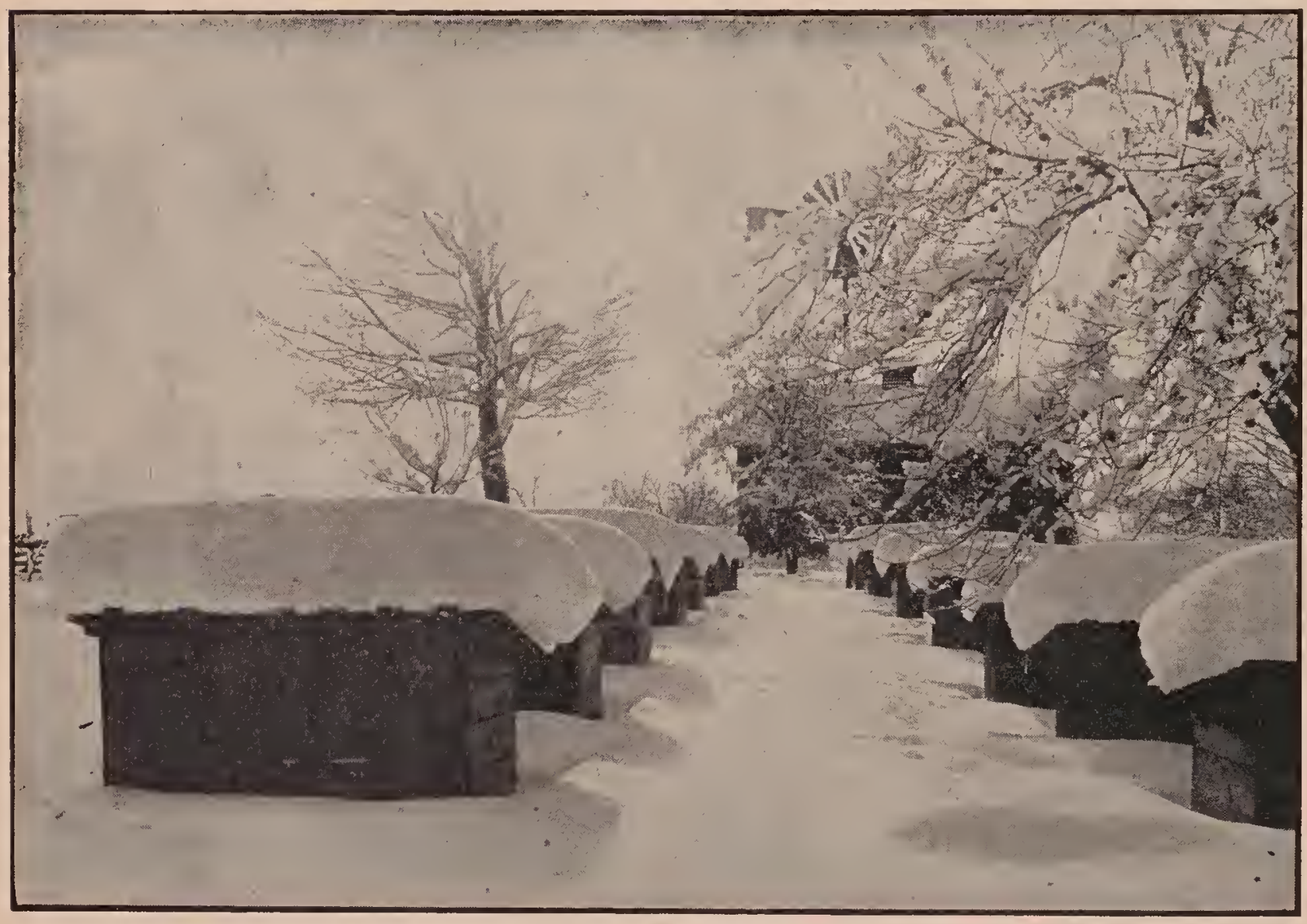

Outdoor wintering at the apiary of F. J. Miller of London, Ontario, Canada.

tions would perish for want of moisture. If the land is very dry and sandy little or no fireweed may appear, and the annual fleebane (Erigeron canadensis) may spring up instead, a plant which is fireweed's principal rival in the occupation of land newly burned-over. Unfortunately the latter spe-. cies yields practically no nectar.

The quality of the honey, the unfailing supply year after year following the flow from clover, and a period of bloom continuing until frost make willow-herb one of the most valuable of known honey plants. "No one but a beekeeper," says Hutchinson, "can realize how much real
Heat, see that head; also Temperature. Concerning the effects of different kinds of food or stores on the welfare of bees during winter, see Aster, Dysentery, HoneyDew, Spring Management, Feeding and Feeders, Candy for Bees, and Spring DWINDLING. On the subject of fixing the size of the entrances, see ENTRANCES To Hives, Ventilation, and Swarming. Some very important information is given under ENTRANCES; and it would be advisable to re-read that article before one takes up the matter further here. For management in the spring see SPRING MANAGEMENT, Dysentery, and Spring Dwindling. For a 
consideration of the different sizes and shapes of frames for wintering, se HIVES, also Frames. For the discussion of double-walled or chaff hives, see Hives. For stimulation in the spring, see FEEDING, subhead, "Feeding to Stimulate." For the consideration of windbreaks, see "Windbreaks," under APIARX. For the effect of honeydew on wintering, see HoNEYDEw.

\section{TWO METHODS FOR WINTERING BEES.}

One is called the indoor plan and the other the outdoor. Which one the reader shall use depends entirely on the locality, the climate, and kind of winter stores. time in May. Mention of these will be made further on.

In the milder climates, such as may be found south of the Great Lakes and north of the Ohio River, outdoor wintering is almost universal. In these the ordinary double-walled hives give excellent results, altho there is a tendency toward the large winter cases already mentioned. In a general way it may be said the indoor plan should never be used where the stores are of inferior quality or where the winters turn from mild to severely cold, the variations taking place every week or two weeks, unless the cellars or repositories are wholly

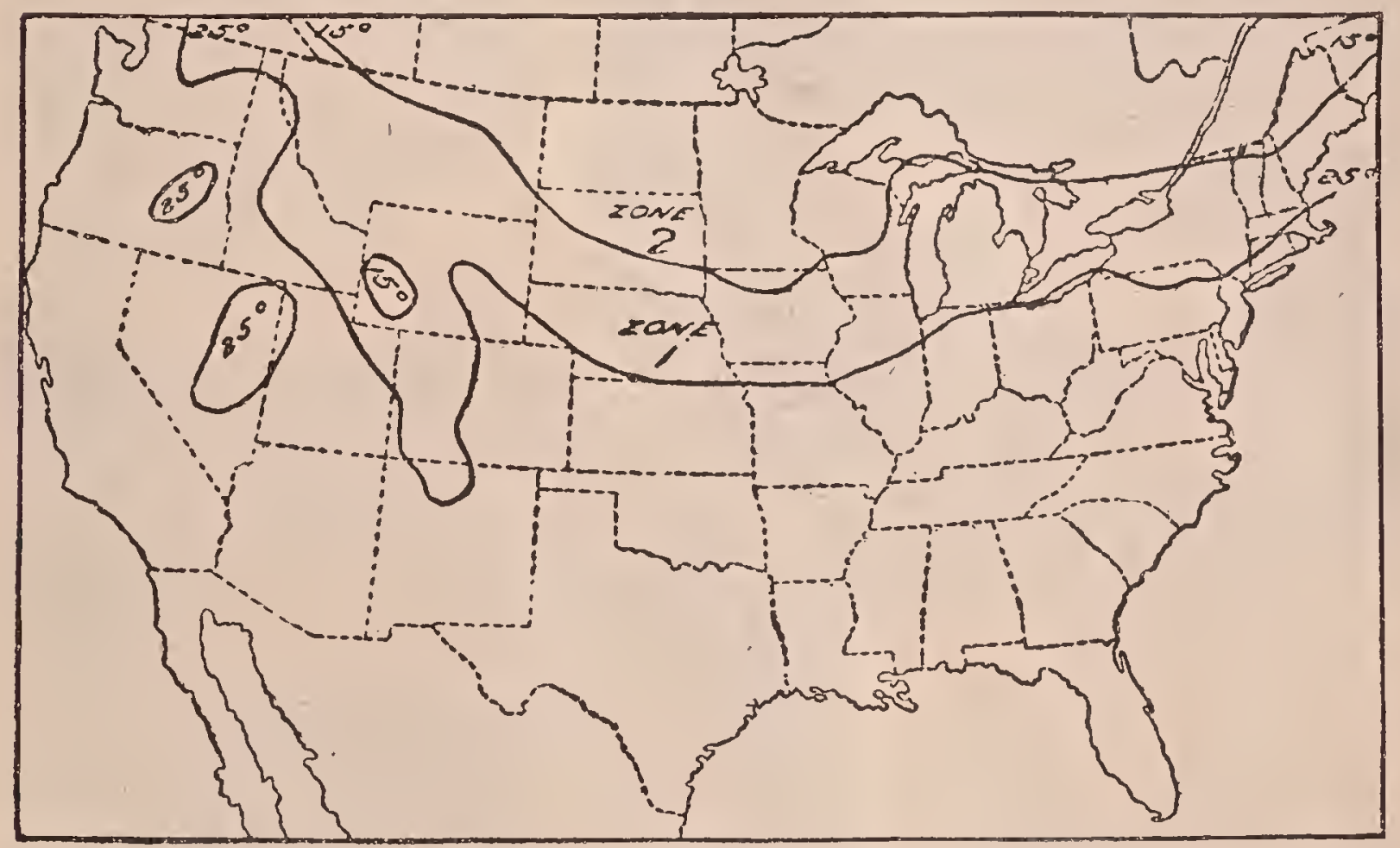

Map of the United States showing zone 1 where cellar wintering is profitable, and zone 2 where cellar wintering is preferable. This map is based on temperature as well as the quality of winter stores. Map used from Bureau of Entomology, Farmers' Bulletin 1014.

Where the winters are extremely cold, with continuous freezing weather, without a break thru the months of December, January, February, and March, the indoor plan prevails. The ordinary double-walled hives are hardly warm enough in these very cold localities unless such hives are covered with deep snow that does not thaw/and freeze during winter. Thruout Canada there is a tendency to use large winter cases capable of holding four or more hives with at least six inches of packing all around; and the bees are kept in these cases till some underground, with three or four feet of earth on top.

The Bureau of Entomology, in Bulletin 1014 on Wintering B.ees in Cellars, gives the accompanying map showing regions where cellar wintering may be practiced with profit. Where the average temperature is $25^{\circ} \mathrm{F}$., the bees may be wintered indoors or outdoors, but preferably the latter, provided the stores are good; where the average winter temperature is as low as $15^{\circ} \mathrm{F}$., cellar wintering is preferable.

Thruout the southern States it has been 
the practice to winter bees in single-walled hives on their summer stands. It has generally been considered that extra packing or double-walled hives are a useless expense; but experiments conducted by the Bureau of Entomology, Washington, D. C., in 1913 and 1914 go to show that some packing, even in the southern States, may, in some cases, be used to advantage. Reference to this will be made further on.

While the outdoor method demands double-walled hives, winter cases, or something to protect the hives on their summer stands, and a shielded location protected from the

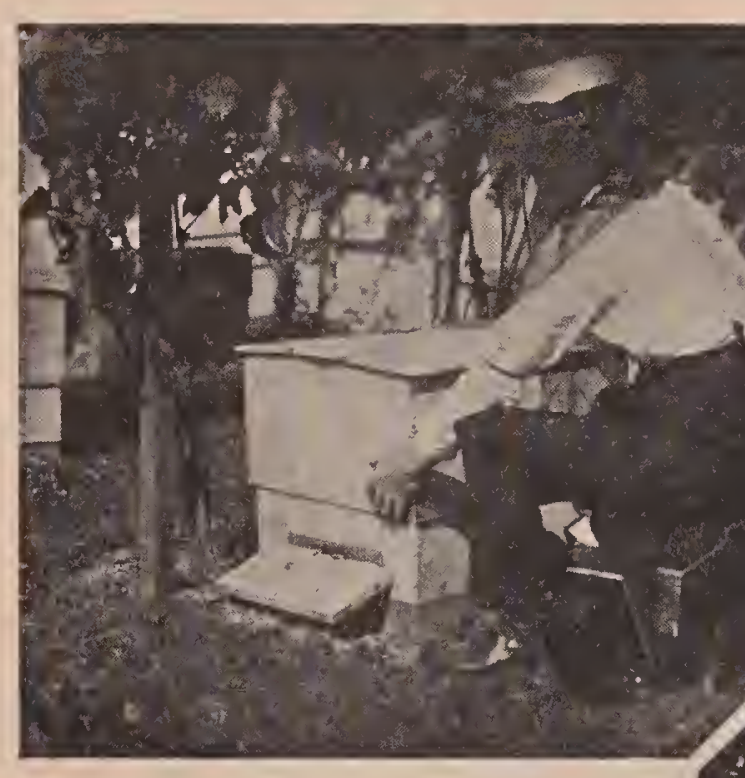

Fig. 2.-A deep telescoping cover to set over the packing tray for outdoor. wintered colonies is preferable.

prevailing winds, it does not require that degree of skill made necessary when the bees are confined in the cellar. For these reasons the majority of beginners, especially where the climate is not severe, are advised to winter outdoors. It is important to observe, however, that the spot where the bees are kept must be sheltered from prevailing winds.

When the outdoor plan is used it is fair to state that, after a very severe winter in which the mercury stays below the zeropoint for weeks at a time, and when spring is very late, with a warm spell followed by a very severe cold one, losses may be heavy, even among the most experienced beekeepers. But these losses can, to a very great extent, be minimized, even during very cold winters, provided one makes a study of his locality, regarding the average weather conditions that prevail. It will be the object of the articles that follow to set forth as nearly as possible some of the difficulties to be encountered, so that the reader may intelligently undertake the problem. Fortunately the very severe winters referred to do not occur more than once in 10 or 20 years, when for some reason the whole year seems to be thrown entirely out of balance. At all other times, if one follows carefully the directions here given, his losses will not exceed ten per cent, and he may keep them down as low as two per cent. Some have wintered their bees winter after winter with a loss not exceeding five per cent, if the one year in ten which proves abnormally severe is left out of the calculation. 
such a weakened condition as to become practically worthless for the following season. As a rule, in the northern States brood-rearing, unless there is a young laying queen, slows down after the honey flow. This is perfectly normal where there is no late summer or fall pasturage as in the case of buckwheat, asters, or goldenrods; but during the latter part of August and the early part of September, broodrearing should begin again; and unless there are natural sources of nectar the bees will require feeding with thin syrup given in small quantities daily to stimulate. This

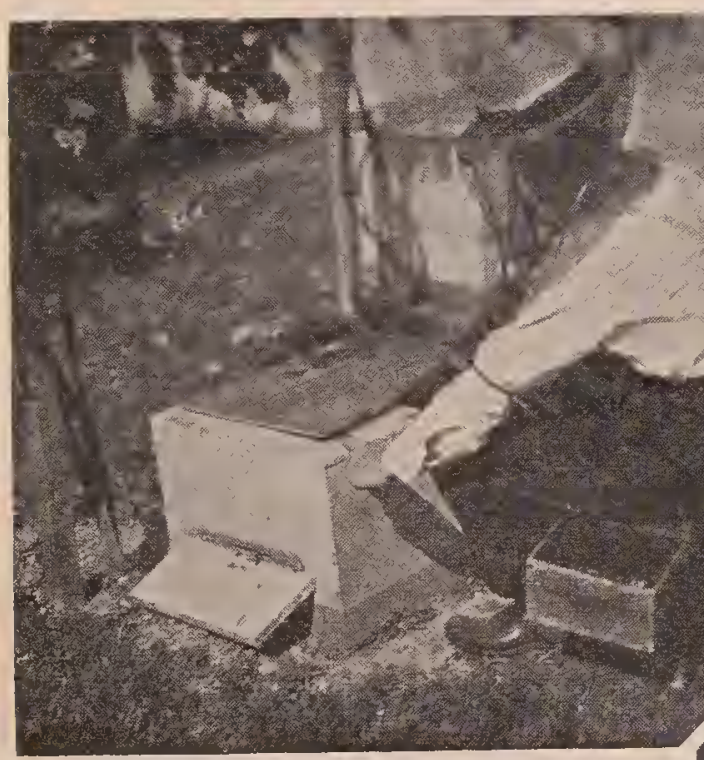

Fig. 4-The super-cover is made of $3 / 8$ lumber. This is put on the hive, and covered with the tray shown in Fig. 3.

stimulative feeding should be continued long enough to get brood in the hive so there will be a strong force of young bees to go into winter quarters. In many localities colonies will be able to gather enough nectar daily to supply themselves with young bees without any special feed-

ing. So far the scheme of raising a large force of young bees is an important requisite for either method of wintering, and especially important where bees are wintered outdoors subjected to extremes of temperature.

It is unwise to attempt to winter bees outdoors in single-walled hives north of 40 degrees north latitude. While the colonies may come thru in a weakened condition, 29 winter. the shock of the exposure will be so great that they probably will not be good for much to gather honey. It is also highly important that the hives be protected from high winds, and that the walls surrounding the hive be double and warm. Colonies in double-walled hives out in the open, and where there is a strong windsweep, may not survive, while those in single-walled hives screened by building's, woods, or dense shrubbery, may winter well. It would appear that protection from the prevailing winds is just as important as having the walls of the hives double. Special doublewalled hives are manufactured, having the space between filled with chaff, planer-shavings, leares, or other suitable material. The live is so arranger that a tray of packing under the cover helps to retain the heat of the cluster, thus causing a smaller consumption of stores in order to pot into a Doolittle division-board feeder. After sufficient syrup has been fed, the feeder is removed, the combs are shoved over, a division-board inserted,and hive closed for

keep up the necessary animal heat. It should be remembered that, the warmer and better protected the cluster, the less honey bees require to eat. It is desirable to have them, so far as possible, enter a state of quiet. An extremely cold spell will make it necessary for this cluster to raise the temperature as explained under. Temperature of the Cluster in Winter. When a colony is so poorly protected that it las to 


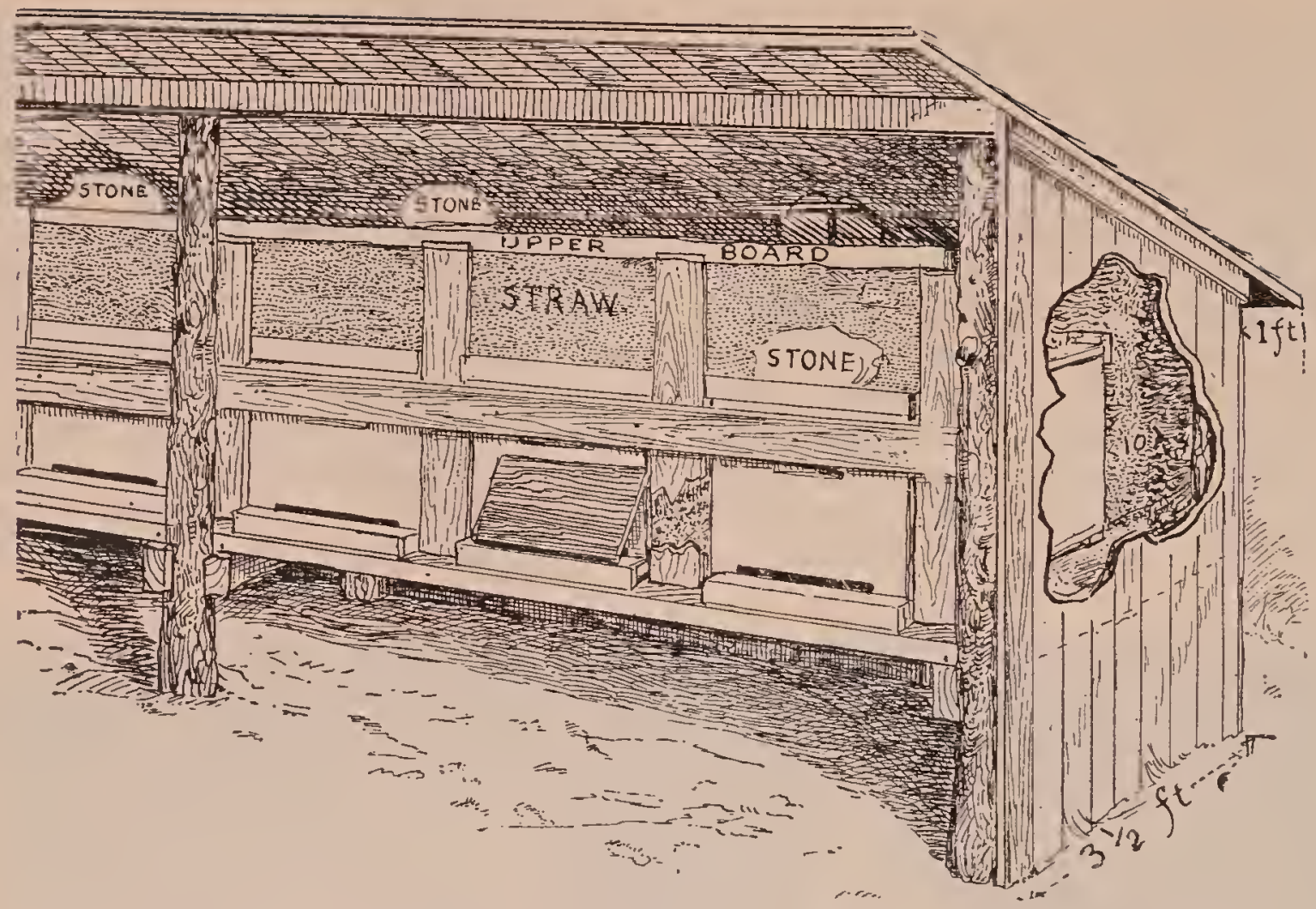

Fig. 6.-W. T. Davison's method of packing bees in straw for outdoor wintering.

go into a state of activity and overeat, the bees will become distended, and dysentery or purging is almost sure to follow. This condition occurring in midwinter or early spring means the death of the colony, as there is no cure for it but warm weather.

\section{WINTERING WITH LITTLE PACKING.}

The question of how to pack, and how much packing to give bees, will depend very largely upon the climate. South of the Ohio River, in the eastern States, thruout California, southern Nevada, Arizona, New Mexico, and Texas it is not eustomary to give the bees any more protection than is afforded by a single-walled hive; but the apicultural experts in the Bureau of Entomology at Washington, D. C., believe that some protection could be given to advantage. After having traveled over a large portion of these States the author feels inclined to agree with them. Just how much packing to give and in what form, it is rather difficult to say. In localities where bees can fly out almost every day in the year, breeding goes on more or less, and very often the accession of young bees does not quite make up for the loss of old bees that go to the fields, become chilled, and never retur'n. The author believes, fur- ther, that the use of protecting cases or a moderate amount of packing would save chilled brood, save stores, and prevent the bees from flying out during the middle hours of the day, only to be chilled and never return. Colonies without protection in the semi-tropical States suffer because the temperature goes up high during the middle hours of the day, and drops down to freezing or below during the night. Such a rapid change in 24 hours is very hard on bees. If the temperature inside the hive could be equalized by packing so that the sunshine during the middle of the day and the cold of the night would not penetrate the walls of the hive, a more even temperature within the hive would be maintained.

It is important, in addition, that the entrance be contracted to a space for the passage of only two or three bees at a time. The purpose of this is primarily to keep the cold from entering the hive, and secondarily, to prevent robbing.

\section{WINTERING IN DOUBLE-WALLED HIVES.}

For the northern climates that are subject to zero weather at times, that have more or less snow and a large amount of frost extending perhaps two feet into the ground, nothing short of double-walled 

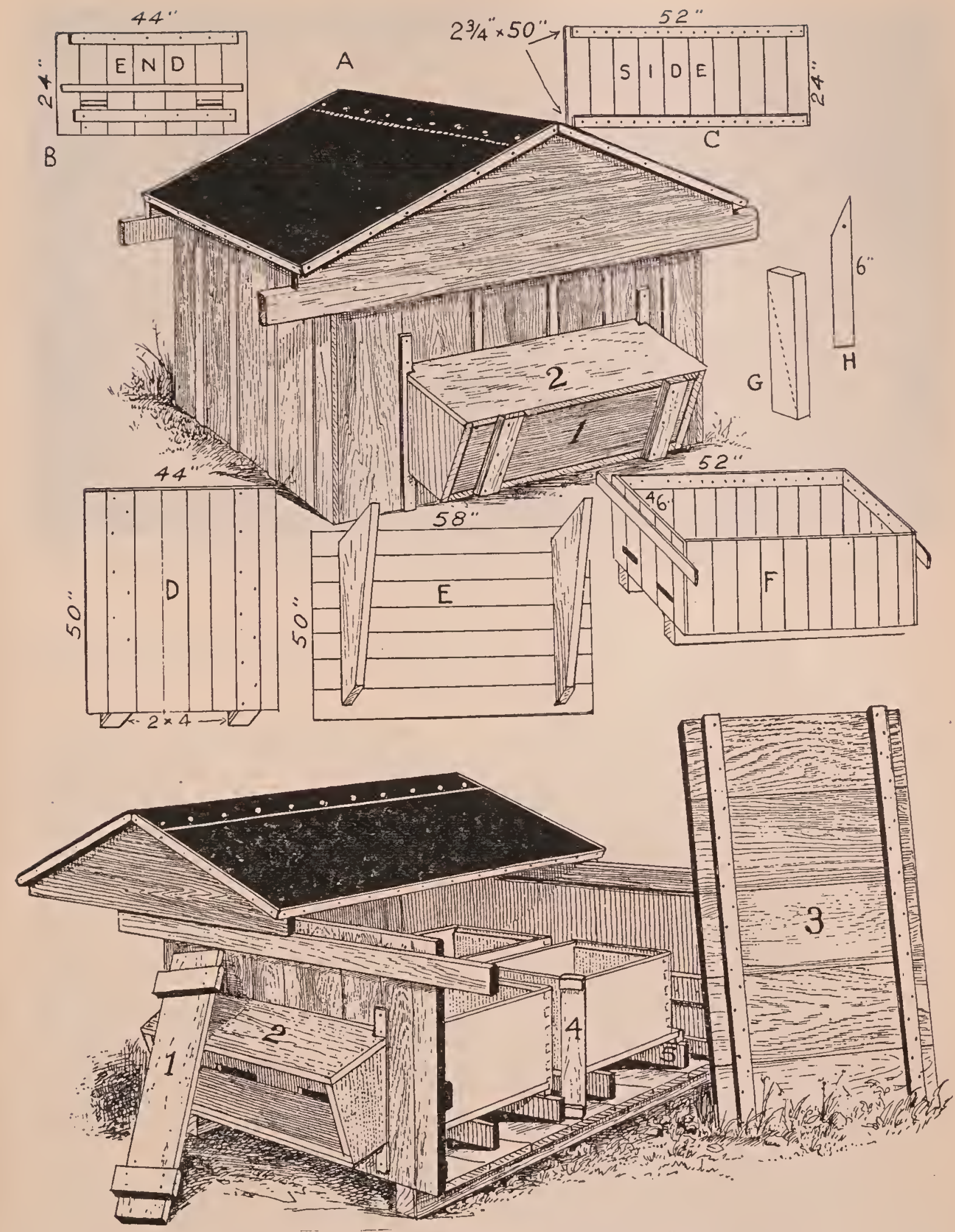

Fig. 7.-The original four-colony winter case as used by Ira Bartlett of Michigan 30 years ago. He was probably the original user of the principle.

hives, such as are described under the head of Hive-MAKING, or packing-cases, should be used. There are two forms of these double-walled hives, one having bottom packing and the other a removable bottomboard which is made of single-thickness $7 / 8$-inch lumber.
There has been some discussion as to whether these winter hives should have bottom packing or not. From some experiments with electric bulbs apicultural experts in the Bureau of Entomology came to the conclusion that there is a great advantage in having the bottom packed, as 


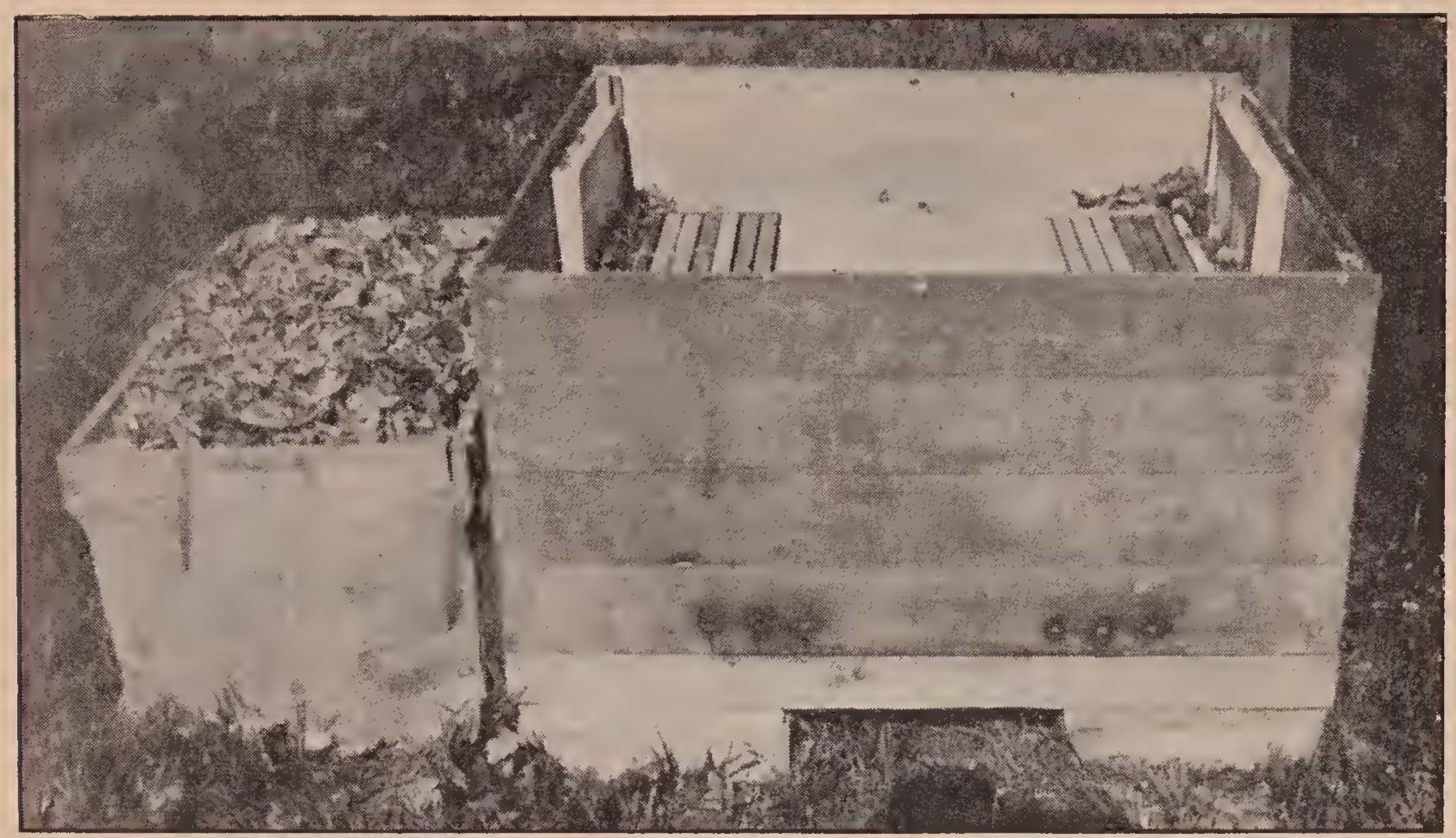

Fig. 8.-The Holtermann four-hive packing-case. Notice the three $3 / 4$-inch entrance holes. Notice also that there is no projecting ledge or doorstep to catch snow and ice, thus closing the holes, causing the death of the bees.

well as the ends, sides, and tops. In a climate not generally subject to continued zero weather these double-walled hives with two inches of packing on the sides, ends, and bottom, and four inches on top, with a restricted entrance, give very good results; but in such hives a ten-frame colony should be squeezed down to eight frames, and an eight down to seven. The space should be filled on either side witl division-boards or packing. A very good way is to wrap a comb, preferably one containing honey, in a newspaper in such a way that when it is inserted in the hive it will close up the space between the end-bars and the ends of the hive, the bottom-bar, and the bottom, and the top-bar and the cover. One of these frames should be put on each side. The purpose of these wrapped frames is to reduce the size of the brood-nest. 'Toward spring the bees will gnaw away the paper, and that releases the stores. Moreover, the wrapped frames will increase the thickness of the side protection. The top of the hive should have a tray containing four or five inches of planer shavings or leaves as shown on page 896, Fig. 3. During the coldest part of the winter the entrance should be contracted (provided there is bottom packing) to a space one inch wide by three-eighths inch high. If bottom packing is used, the experts of the Bureau of Entomology recommend a single $5 / 8$ or $3 / 4$ inch hole.

WINTERING BEES UNDER A SHED.

Some beekeepers practice putting their colonies under a shed or a series of sheds, packing straw between the hives, on top of them and behind them. It is customary to have the fiont of the shed face south or east, leaving the back toward the north or west, or toward any direction from which the prevailing winds come.

The objection to the plan is the expense and the trouble of moving the bees out of the shed for summer handling. There is a further objection, that it is not practicable to pack the front of the hives that are left exposed. 'T'aling' it all in all, the arrangement is not recommended.

\section{WINTERING BEES IN TENEMENT OR QUADRUPLE CASES.}

In climates where the winters are very severe, where the temperature goes down to zero and stays around that point for weeks at a time, much more protection is refquirer than for those methods already describer. There should be at least six inches of packing around the sides and enids of the lives - at least four inches under the hives and 


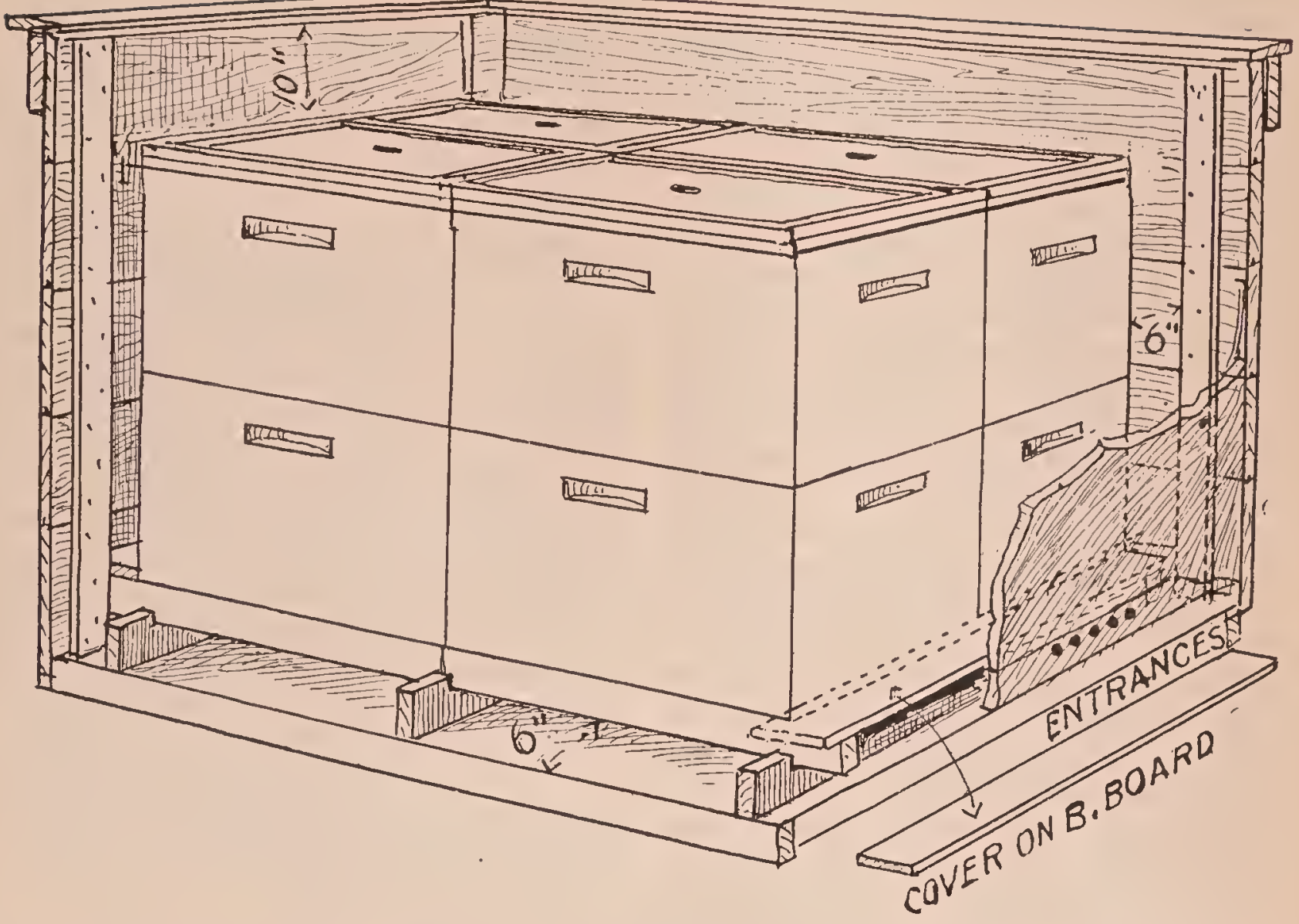

Fig. 9.-This is the plan recommended by Dr. F. F. Phillips and by a good many other beekeepers for wintering bees outdoors in single-walled hives. It contemplates a winter case made up of panels which are held together by means of screws or nails at the corners. This case should provide six inches of packing around the sides and ends, at least four inches under the bottoms of the hives, and at least ten inches on top. Plillips particularly recommends wintering in two-story hives. First, a double broodnest makes a relatively deep wintering space. Second, it provides ample room for breeding in the spling. Third, it provide ample stores. Fourth, no attention is needed during spring. Spring management is practically elininated. Attention is drawn to the five-hole entrance. All the holes except one in the center, according to Phillips, should be closed during cold weather. As spring approaches, one or more holes are opened up. The only objection to the plan here shown is the expense.

ten inches on top. While one hive can be packea in a winter case, it is more economical to make the case hold four or more hives. Some use the plan of packing ten hives in a case-cases long and large enough to take ten colonies in a row, placed side by side and in close contact. This tenlive tenement does not conserve the heat quite so well as where the lives are packed four in a group, side by side and back to back. The four-colony tenement, or what is generally called the quadruple case, has come into quite general use among the beekeepers of Canada and where the climate is very severe, and where, too, cellar wintering is practiced.

So far as can be ascertained, Tra Bartlett of Michigan was the first to suggest and use in a large way this method of wintering, for he began using the plan 30 year's ago. The illustrations, page 899 , show the original Bartlett winter case made up of panels. The only change that has been made during the later years is to leave off all porticos and doorsteps. These extra attachments, it has been found, are worse than useless. Instead of having a sort of storm door, it has been found better to have the entrances restricted without any roof or doorstep. There should be nothing to eatch snow and ice, which, when there is a ledge or projection, lodge and thus close the entrance.

R. F. Holtermann, who has been one of the strongest advocates of this system of outdoor wintering, and who by writing a series of articles practically introduced the plan into the United States and Canada, recommends three $3 / 4$-inch holes for entrances instead of a slot. George S. Demuth, formerly of the Bureau of Entomology, likewise recommends a series of five 
or six $5 / 8$-inch holes, all of which, except one, are closed during the coldest part of the winter. Both the Government experts in apiculture and Mr. Holtermann say that a hole is far better than a slot for a winter entrance. Thru the latter the cold air can go in on one side and the hot air out of the other. A slot is the thing during late spring and summer, but all wrong, say these men, during winter.

The author has met quite a number of others, notably B. F. Kindig, State bee inspector of Michigan, who have been using these one-hole entrances during winter, and always, they say, with the most gratifying results.

These restricted entrances should be used only where there is an ample amount of packing-not less than six inches-and where the bottom is packed with not less than four inches. The line drawing on the previous page shows the plan recommended by the Government experts. Two changes, however, are recommended. The first is, that provision should be made for more packing under the hives. To that end the cross-cleats secured to the bottom-board of the packing-case should be four inches wide instead of two inches. The hives are then placed upon the bottom-cleats as shown in Fig. 9, after which the side and end panels are put in place and held together with common wood screws. Some feel that one hole is not enough during the coldest part of the winter. This is a question that will have to be decided by each individual beekeeper, altho the author has seen some most excellent results where the one hole was used. Holtermann states that he does not think he would dare to close down to less than three, and he leaves his bees for six months at a time. As something will depend upon the locality and the man, the individual beekeeper will have to settle this for his own locality.

The plan shown on previous page contemplates double-story hives, four inches of packing under the hives, hives packed in close contact, back to back and side by side. A bridge connects the inner entrances to the outer entrances, after which planer shavings or dry forest leaves are poured in around the sides and on top.

It is important that the covers to the cases be securely fastened down. Winter winds will sometimes lift them off and blow the packing out, with the result that the colonies will be killed by the exposure. Covers should be either wired down or held down by hooks and eyes. There should not be less than four stout hooks-one at each corner.

\section{WINTERING TWO-STORY IJANGSTROTH HIVES IN QUADRUPLE CASES.}

The Government experts recommend wintering in two-story hives instead of single stories. There are some reasons for this. One reason, and the principal one, is to provide for stores and breeding room in the spring when the queen needs more room than the one story will supply. When two stories are used it is recommended to put the hive containing the brood-nest or bees beneath and the hive containing the stores on top. There should be not less than 45 pounds of honey or syrup distributed in both stories. When the bees move upstairs, the main cluster or breeding room is at least ten inches distant from the entrance, and away from the cold.

In the way of packing material, some will find planer shavings available, and others will use forest leaves. These latter should be raked up as they fall, and should be thoroly dried. Usually one can get all he needs by going to his neighbors, and asking them to save their leaves instead of burning them on the pavement. The one trouble with planer shavings is the sawdust that litters everything up. In the spring, when one desires to look into his packed colonies, it is almost impossible to get at the brood-nests for examination to see what the bees are doing, without letting a quantity of sawdust or shavings get down between the frames. For that reason the author favors the use of forest leaves; but when leaves are used they must be well packed down, as they are not quite so dense as planer shavings.

When the bees are unpacked in the spring, the hives are lifted out and the cases are carried to the outside of the apiary. The hives are then placed where the case was, and in the same relative position, but ten or twelve inches apart for convenience in summer working. This position should not be changed; and when it is time to pack, the hives are moved to one 
side, case set in place, and the hives set in and packed as before.

\section{OBJECTIONS TO QUADRUPLÉ PACKING-CASES.}

The chief objection, tho not a serious one, is the expense of these big cases. Their life ought to be 10 years, and with reasonable care 25 years. On the basis of 10 years they would cost only $\$ 1.00$ apiece or 25 cents per colony.

Objection has been raised that it takes 40 or 50 pounds of stores; but Phillips argues that this amount insures a strong colony that may get twice that next year. But suppose the season is a failure, and the bees have eaten 45 pounds of good honey. This is one of the hazards of beekeeping; and the only remedy is to winter in the cellar, provided one is willing to assume the first cost. Bees indoors will consume only a little more than half as many stores as those outside require. See WINTERING IN Ceiluars, further on.

Another objection has been the tendency of bees to drift when the two entrances are side by side. On the first warm day when the bees can fly, one entrance may have two or three times as many bees flying as the one right next to it. Unfortunately the bees of the latter are inclined to join the bees of the former. The result is that the weak become weaker and the strong stronger. This has happened more than once in the author's apiaries.

The difficulty can be overcome to a great extent by packing the bees very early so that they will become accustomed to their respective entrances in the fall previous, and by fastening a board 8 inches wide and 18 inches long vertically between the two entrances, or by painting the two sides different colors.

\section{AN INEXPENSIVE WIN'TER CASE MADE OF PAPER.}

The first cost of winter cases need not stand in the way of good wintering, however, for bees can be well protected for only a few cents per colony for material, by using a cheap grade of tarred paper to hold the packing in place and keep it dry.

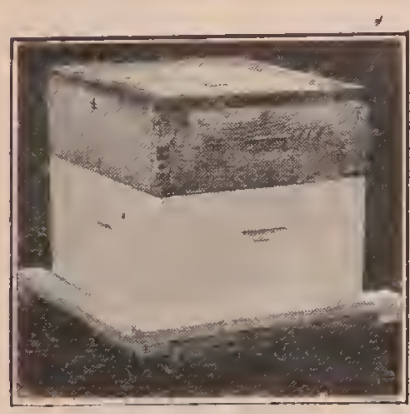

Fig. 1. - Two-inch rim in place about bottom of hive.

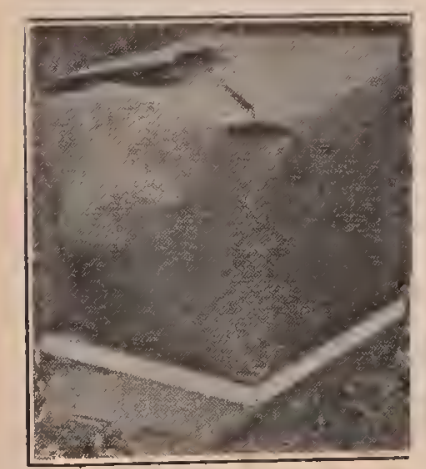

Fig. 4.-Upper edges of paper folded down.

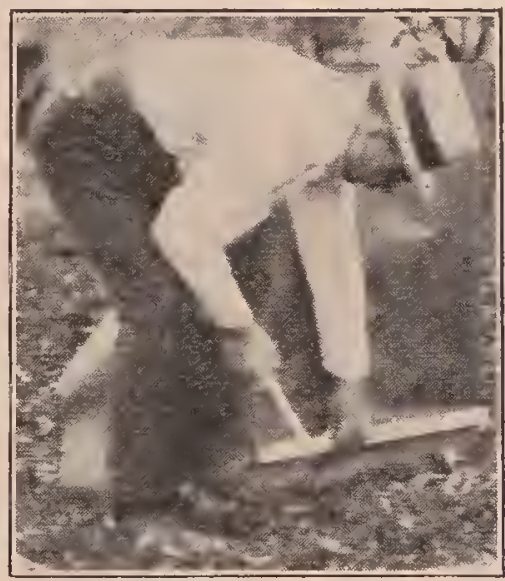

Fig. 2.- Paper is fastened to rim by means of lath.

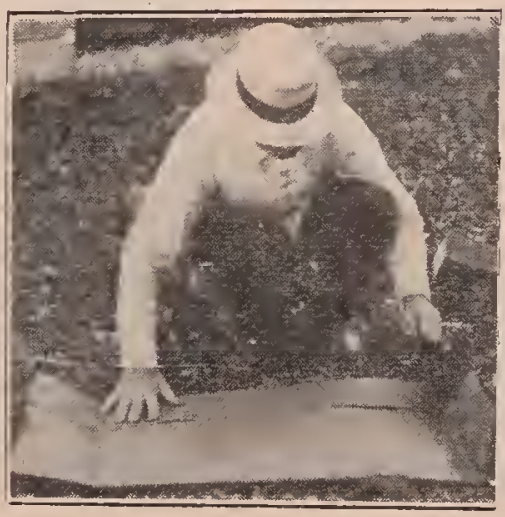

Fig. 5.-Creasing edges of cover before putting in place.

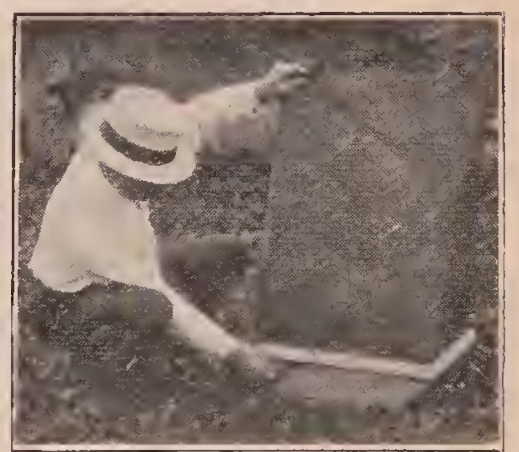

Fig. 3.-Cutting opening for entrance thru paper.

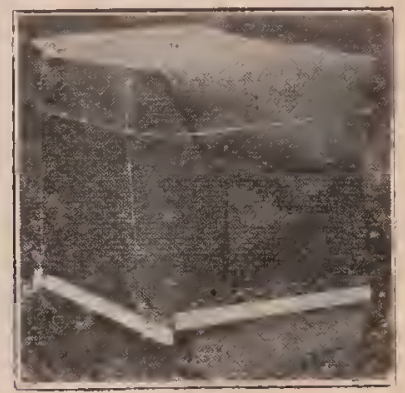

Fig. 6.-Cords are used to hold cover in place. 


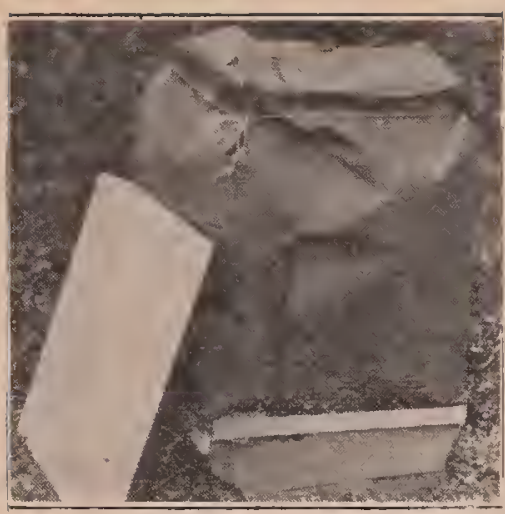

Fig. 7.-Arrangement for using regular hive cover.

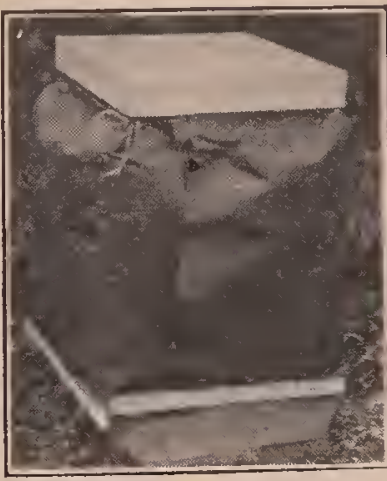

Fig. 8. - Regular hive cover in place.

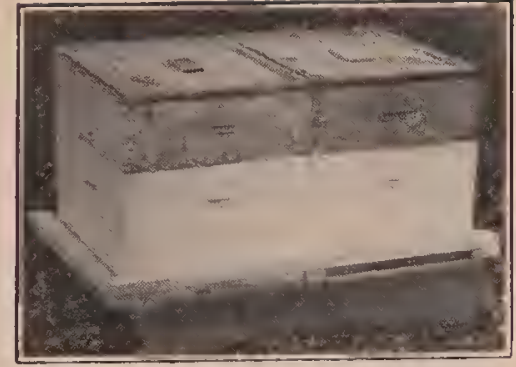

Fig. 9.-Rim in place for pack ing hives in pairs.
To pack a single colony in a regular 10 frame hive, cut two pieces, $7 / 8 \times 2 \times 201 / 4$ inches, two pieces $7 / 8 \times 2 \times 24$ inches, two pieces lath 20 inches long and two pieces 24 inches long. From a roll of 36 -inch single ply slaters' felt, cut one piece 8 feet long and another 4 feet long.

Make a rim of the 2-incl pieces which fits around the lower part of the hive (Fig. 1), by lapping orer the corners and fastening with a single nail. The piece in front should rest on the side rails of the bottomboard, leaving the entrance open. The two side pieces shonld come below the end piece in front and above the end piece at the

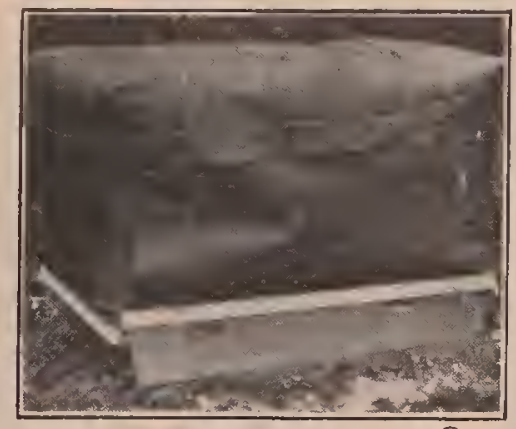

Fig. 10.-Pair of hives packed complete.

back, thus dropping the rim $7 / 8$ inch lower on the sides than in front, and $7 / 8$ inch lower at the back than on the sides. A small nail driven part way into the back end of the bottom-board supports the rim at the back.

Stand the 8-foot strip of paper on edge around the hive and tack on the lath to fasten the paper to the rim, using two nails in each lath driven only part way lome (Fig. 2). The paper should touch the ground all around the hive, the entrance now being covered with the paper. Cut a hole $3 / 8 \times 2$ inches thru the paper for an entrance (Fig. 3). This hole can easily be en- larged next spring' when a larger entrance will be needed. Where the ends orerlap, pin the paper together with two or three wire nails.

The packing material should be packerl down in the corners to make them stand out square, after which the packing is simply poured in at the sides and ends without pressing down. This is to prevent the sides from bulging. From three to six inches of packing can be put in at the sides and ends by permitting a slight bulging of the paper beyond the rim at the bottom, or a greater amount can be put in if some slack is left in the paper at the lower corners when the lath are nailed on. Fill in with 8 to 10 inches on top, then fold down the upper edges of the paper as in wrapping a package (Fig. 4).

Crease the 4-foot piece of paper, which is to be used for the cover, by folding orer the edges (Fig. 5) before putting it in place. After it is in place fold the corners neatly, as in wrapping a package; then tie a cord around the folded-down edges to hold them snug against the sides (Fig. 6). Tie a cord to one of the projecting mails in one of the side lath, pass it across the top? of the hive under both nails on the opposite side, then back to the other nail on the first side, where it is fastened.

\section{USING REGULAR HIVE COVER INSTEAD OF PAPER COVER.}

The ordinary hive cover may be used instead of the paper cover, by putting an empty hive-body on top of the live, then folding the paper against its upper edge above the packing (Fig. 7). Tie a cord around the upper edge of the paper to hold it in place, pack the upper story, and put on the cover (Fig. 8). 
PACKING HIVES IN PAIRS.

Hives can be packed in pairs with but little more material and labor for the two than for a single hive. For two colonies the 2-inch pieces for the front and back of the rim should be $36 \frac{1}{2}$ inches long (Fig. 9 ), and the lath for the front and back should be 36 inches long. The paper to form the sides should be cut about $10 \frac{1}{2}$ feet long (Fig. 10), and for the cover about $41 / 2$ feet long.

This plan has been used quite extensively by a number of prominent beekeeper's with excellent results. The labor of packing is no more than with the big cases, and the expense is much less.

\section{THE DEMUTH PLAN OH WINTERING WITH} HIVE-BODIES OR SUPERS.

The paper cases can be used only one year, and because of this some may prefer Mr. Demuth's otlier alternate plan of a small inner case to hold seven frames. If one is equipped with extra hive-bodies or supers, a very small additional ontlay will

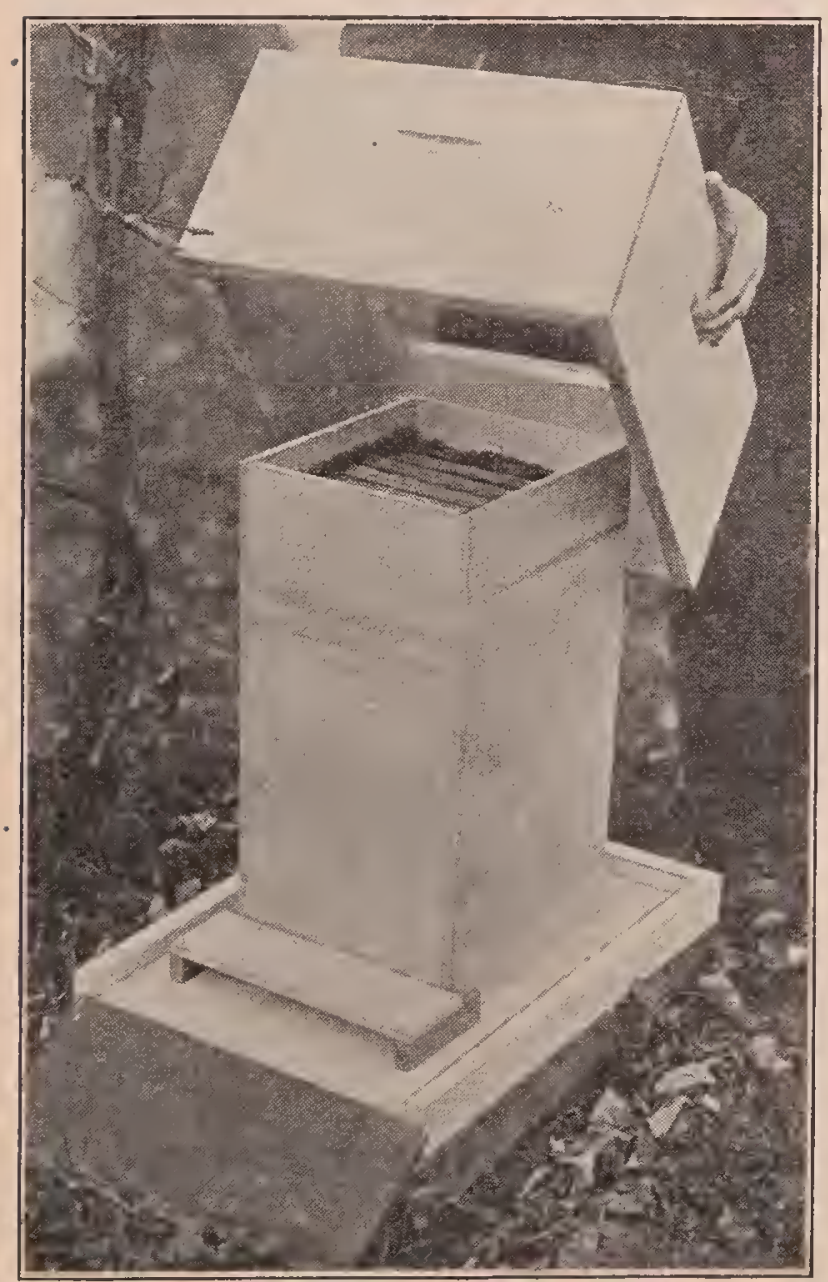

corer the inner case to hold the bees and combs stood on end. The whole is slipped inside of the three hive-bodies and packed.

The inner case is made up of $3 / 8$-inch stuff large enough to receive eight Langstroth frames on end and leave a space of about two inches at each end. There should be a clearance of at least one-half or three-eighths of an inch so that the eight frames on which the bees are to winter can be slid into the case endwise, as shown in Fig. 16, and wedged fast. A cleat at the bottom thru the center supports the frames up abont two inches from the end. The case is then set down on a regular live bottom, as shown in Fig. 11. The entrance from the inner case is formed by means of a bridge that communicates with the outer entrance. Regular hive-bodies, ten-frame size, are then slipped over the outside, as shown in Figs. 12 and 13. Two hive-bodies and one shallow extracting-case or three hive-bodies, full depth, can be made to form the onter wall to receive the packing. When in place, packing material is

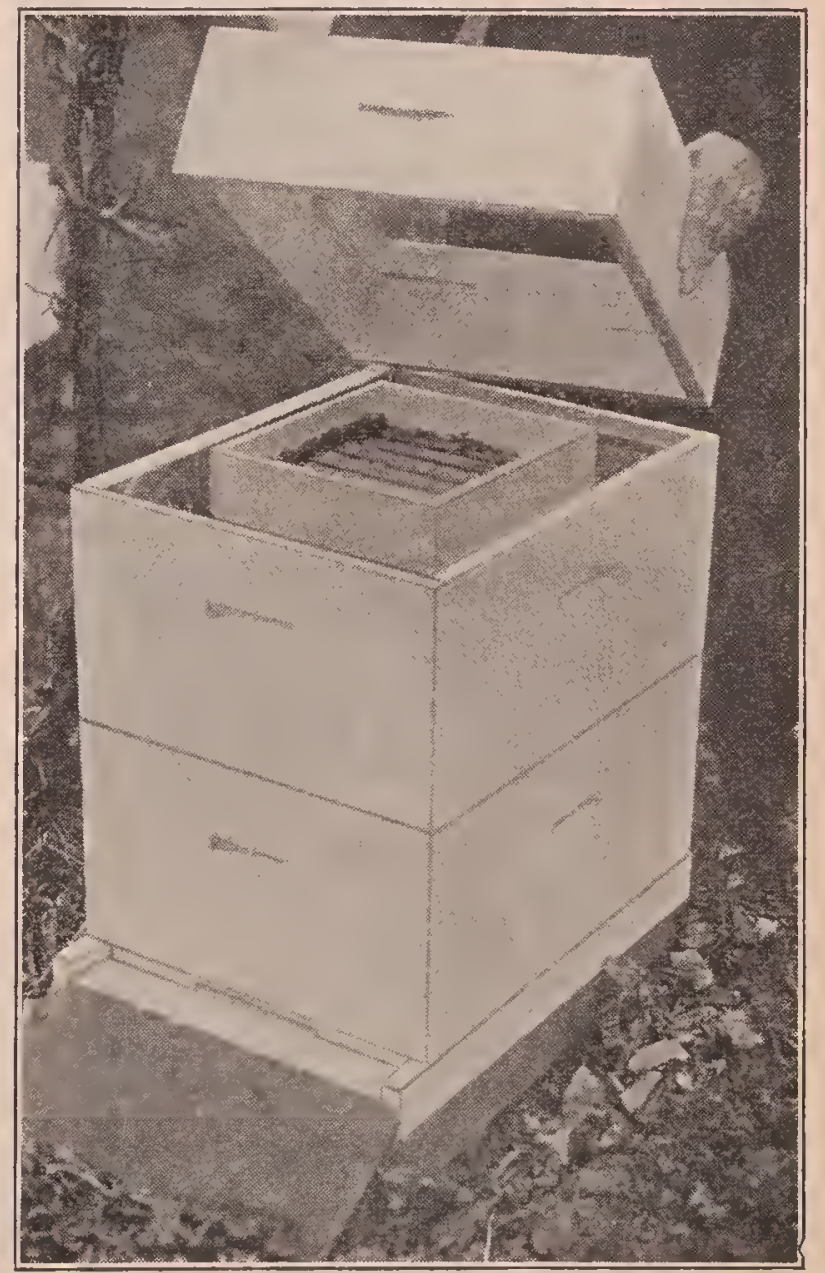

Figs. 11 and 12. - The Demuth plan of wintering bees outdoors in common hives or supers. An inner case is made so as to hold eight Langstroth frames stood on end. This makes a winter brood-nest relatively deep. During the coldest of the winter the bees will cluster in the top where it is warm. 
poured in around the inner case, as shown in Fig. 13. The sectional drawings; Figs. 15 and 16, will perhaps show more clearly the relation of the outer walls made up of three hive-bodies and the inner walls. The diagram, Fig. 16, shows the relative amount

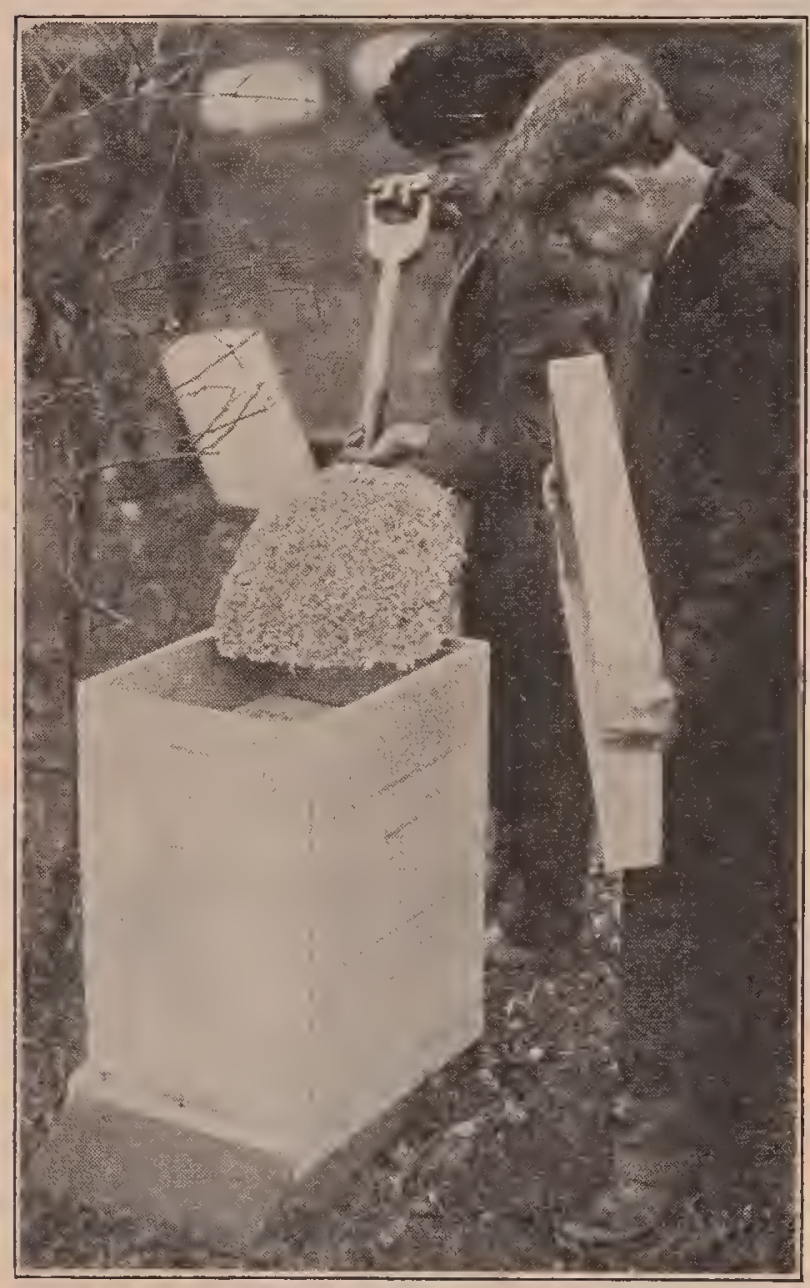

Fig. 13.-Method of pouring packing material around the inner case.

of packing between the inner and outer walls.

As in the other outdoor-wintered colonies the author recommends the use of five $5 / 8$-inch holes, all of which, except one or two, may be closed during the eoldest part of the winter. But when single holes are used it is necessary to have bottom packing.

Mr. Demuth, who devised this system of wintering, recommends arranging that the regular entrance can be entirely closed during the coldest part of the winter; then for an entrance he runs one $5 / 8$-inch tube thru the side of the hive and thru the side of the inner case, this tube being located about two inches from the bottom of the inner case. He used this scheme of a single entrance at the Government apiary with the most gratifying results.

The author has used the Demuth form of packing bees, and so far it has given as good results as the quadruple case. In some respects it is better, particularly in the matter of drifting, as the colony is by itself.

It is generally conceded that, for wintering only, a tall or deep chamber is better than one that is oblong and shallow, like the Langstroth hive. Heat naturally rises, and during the very coldest of the weather the bees will be found in the top. If a cake of hard candy (see CANDY) is put on top, as shown in Fig. 16, there will be no danger of starvation.

Mr. Demuth, while admitting that his plan has less of packing space, says less is needed, because the bees will nearly fill

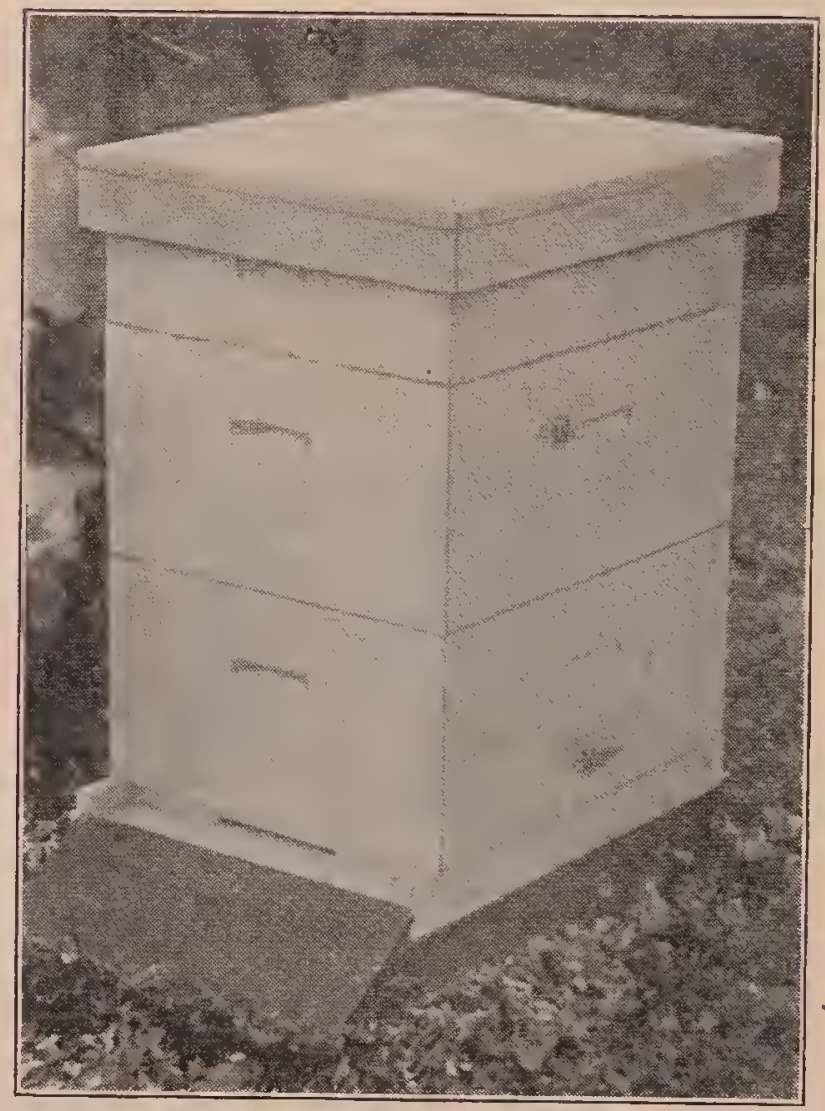

Fig. 14.-Demuth method of wintering, using two hive-bodies and one super.

the whole top of the inner case instead of being off at one end of a shallow chamber near the entrance, as in the case of the Langstroth hive. From the tests that we have made we are inclined to think that he is right.

The objection to this Demuth plan is 
that it involves a considerable amount of work, but no more than the quadruple case. Another and more valid objection is that, after the bees begin to build up in the spring, there is no room for further expansion. The eight frames will soon be filled with brood and bees; and when that time arrives it has been argued that it is a little too early to unpack. If the colony crowds the space of the eight combs, no harm will be done to unpack and restore the frames to normal position with two more combs.

\section{RECAPITULATION OF OUTDOOR WINTERING.}

The system of outdoor wintering one should use will depend largely upon the climate. In the southern States wrappings of paper without packing may be sufficient, or perhaps one can practice the manner of packing described and illustrated in SPRING MANAGEMENT.

In the colder climates, where the temperature seldom goes down to zero, doublewalled hives with two inches of packing space between the walls give excellent results; but the colonies should be contracted down to six or seven frames, and the space on either side filled with packing or dummies.

Where the elimate is so cold that the mereury goes down to zero and stays there for weeks at a time the quadruple winter case or paper case with packing or Demuth case here shown should be used for outdoor wintering. However, if there is a large amount of snow every winter, a doublewalled hive can be used.
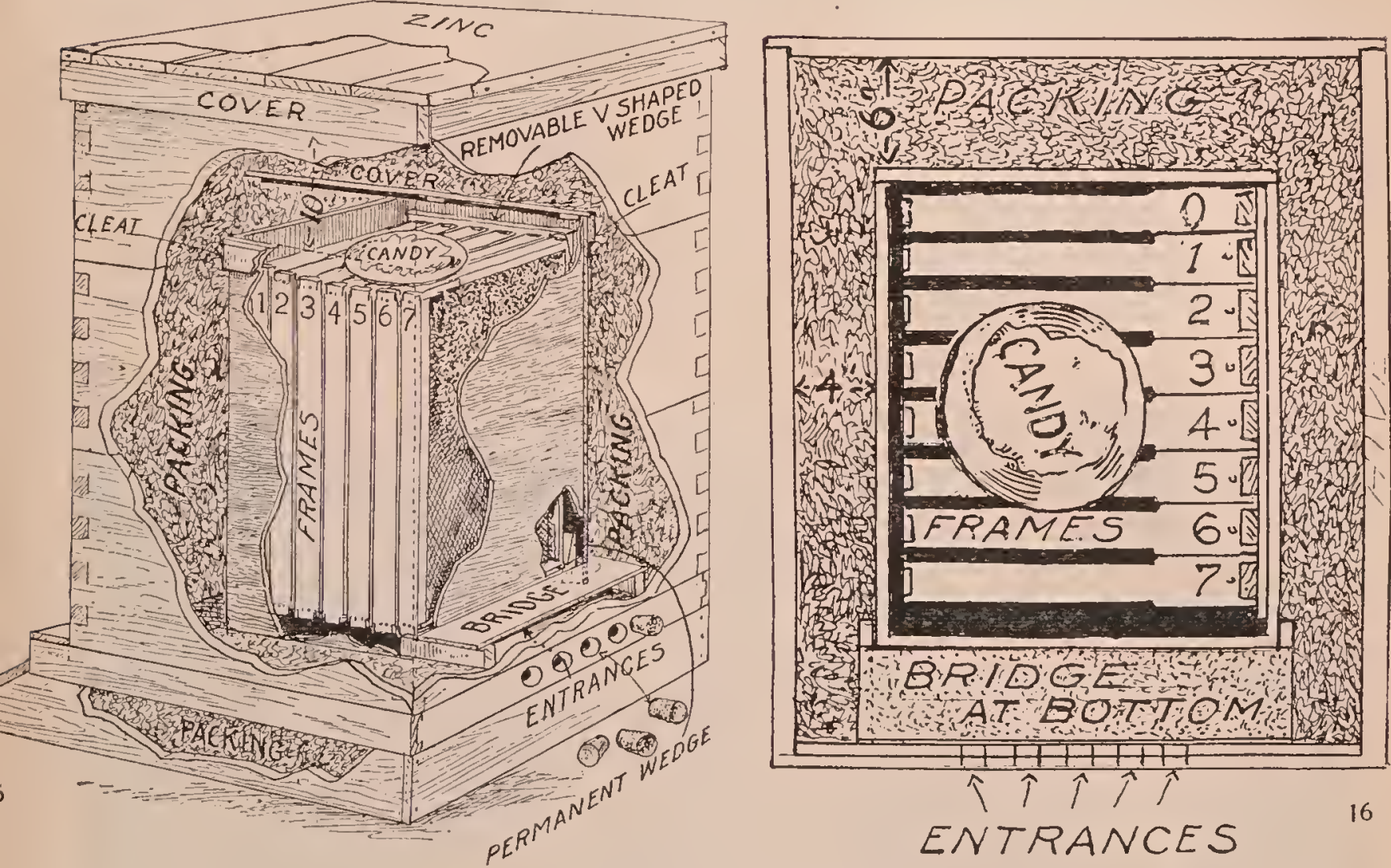

Figs. 15 and 16. These two figures represent the Demuth method of wintering a single-story colony of bees on Langstroth frames. It consists of an inner case large enough to take seven and eight framespreferably eight-placed on end instead of the way they hang in summer. The onter case consists of ivo Langstroth hive-bodies and a super, or three hive-bodies. The hive-stand may be packed full of dry leaves and set on a platform a few inches from the ground. The inner case, containing preferably eight f'rames, is then set down in the center of the two hive-bodies. Dry leaves packed solid, or planer shavframes, is then set down in the center of the two hive-bodies. Dry leaves packed solid, or planer shavcolldects the inner case to the outer for the entrance. The entrance consists of five $5 / 8$-inch holes, all but one of which may or may not be closed during the coldest part of the winter. It is important that there be no ledge to catch snow and ice under the entrance; so the bottom-boards and hive-stand are turned around to leave an entrance at the rear as shown. A cake of cands, if there is a shortage of stores, is put on top. The cost of this arrangement is only about one-fourth of that shown on page 901 , and the mount of stores will be only a little over half as much. The amount of packing to the case in this way hetween the walls will be $2 \frac{3}{4}$ inches on the sides, and 3 inches on the ends. While this is less than recommended in the Government case, the form of the winter chamber is such than less packing is required. The objection to this general plan is that it must be unpacked earlier than the hives shown on page 901. 


\section{NON-POROUS COVERS OR ABSORBING CUSHIONS.}

There has been considerable discussion in the bee journals over the question of whether there should be loose porous absorbing cushions or other material placed above the cluster of bees so that the moisture from a cluster can pass up into the packing; or whether, on the other hand, the top of the hive should have a thin board or super cover on top. If there is danger of the entrance becoming closed by deep snows or ice for weeks at a time, upward ventilation thru porous packing would probably be safer, for bees must have air.

It is a recognized principle in science that warm air can hold a large amount of moisture. This moisture is immediately condensed when it comes in contact with a cold surface, such as the side of a pitcher of ice water on a hot day. The same principle applies in a beehive. If the inner walls for any reason become cold, and the air in the hive, heavily laden with moisture, is warm, this moisture is condensed, forming drops of water on the insides and underside of the cover of the hive. On a cold day there is nothing to prevent moisture from forning on the inside walls of the hive if they are not properly packed or protected. In very cold weather, if the packing material is not thick enough the cold will penetrate into the inner walls, resulting in condensation just the same. It is, therefore, plain that, in order to stop rondensation, there must be enough packing material to keep the inside of the hive warm. In the colder climates, as in Canada, it has been the practice to use absorbing cushions right over the cluster of bees in order to let the moisture from beneath escape upward. It would be better to use enough packing material so that the cold call not penetrate, when no condensation would form either with or without a sealed cover. If the packing material is not enough to prevent condensation inside of the hive, the moisture will pass up thru the material and freeze, thus making a mass of semi-ice. It would seem, therefore, taking everything into consideration, that the question whether one should use the sealed cover or not is unimportant. But it is important to have enough packing material so that the cold may not penetrate into the inner part of the live, forming condensation or frost. It is equally important to have the entrance contracted enough to prevent the cold air from blowing in, thus defeating all the good that might accrue from plenty of packing.

To determine when the packing is thick enough, select a good colony and over the top of it imbedded in putty put a sheet of glass. If on the coldest days in the winter no moisture nor frost is shown on the underside, when the packing is lifterl, it may be assumed that there is enough.

\section{IMPORTANCE OF WINDBREAKS.}

In various places leading up to this has been mentioned the importance of windbreaks to screen the hives from a strong windsweep. A bad location for wintering bees outdoors is on top of a hill with a clear stretch of country for a mile or two in the direction of the prevailing winds. Altho the bees may be nicely housed in double-walled hives, the high winds during cold or chilly weather may and probably will have a disastrous effect on the bees. Many of them, lured out by a bright sunshine on certain days, will be caught by a chilling blast. They will drop to the ground; and, unless there is a change in the temperature or the wind they will never come back. On the other hand colonies screened in by farm buildings, by a growth of woods or dense shrubbery, will be able to withstand the cold much better.

Likewise there may be certain spots in an apiary where some hives are exposed to a long windsweep, while other's are in a more protected position. Observation covering a period of years has shown that the latter winter mucl better than the former.

Nature will very often furnish natural windbreaks that are much superior to anything man can put up where there is nothing. A sidehill gradually slanting down from the north to the south, with shrubbery, fence, or trees on top, makes an ideal windbreak. Sometimes a location can be found where the liill on the windward exposure is in form of a semicircle. Cases in point are the apiaries shown in Figs. 3 and 4, these being well protected by a hill. The sminall trees in the background and down among 


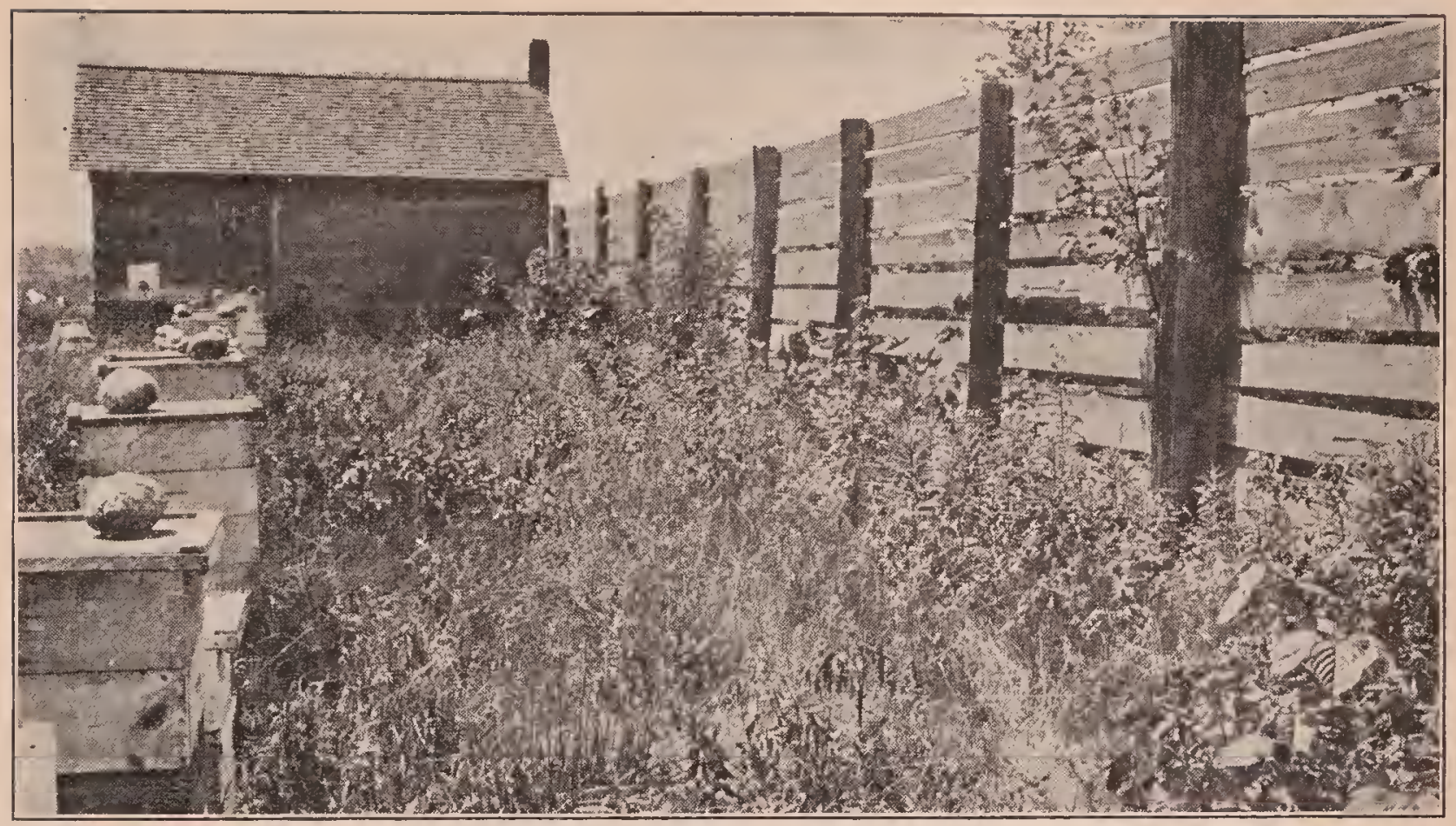

Fíg. 1. - Peter Sowínski's windhreak made of fence boards spaced ahout two inches apart and nailed horizontally on to fence posts eight feet above the ground. Open spacing breaks the force of the wind better than a solid fence.

the hives help to break the violence of the wind. Sucl a location is ideal.

A good winter location is a cleared spot near the south edge of a young timber over which the bees can fly in going to the fields. When the woods are made up of old forest trees it is too much of a good thing because the bees have to fly too high to get out.

Sometimes a spot can be found on level ground where there is a dense growth of young trees on the northwest, and an exposure on the south and east. (See Fig. 5.)

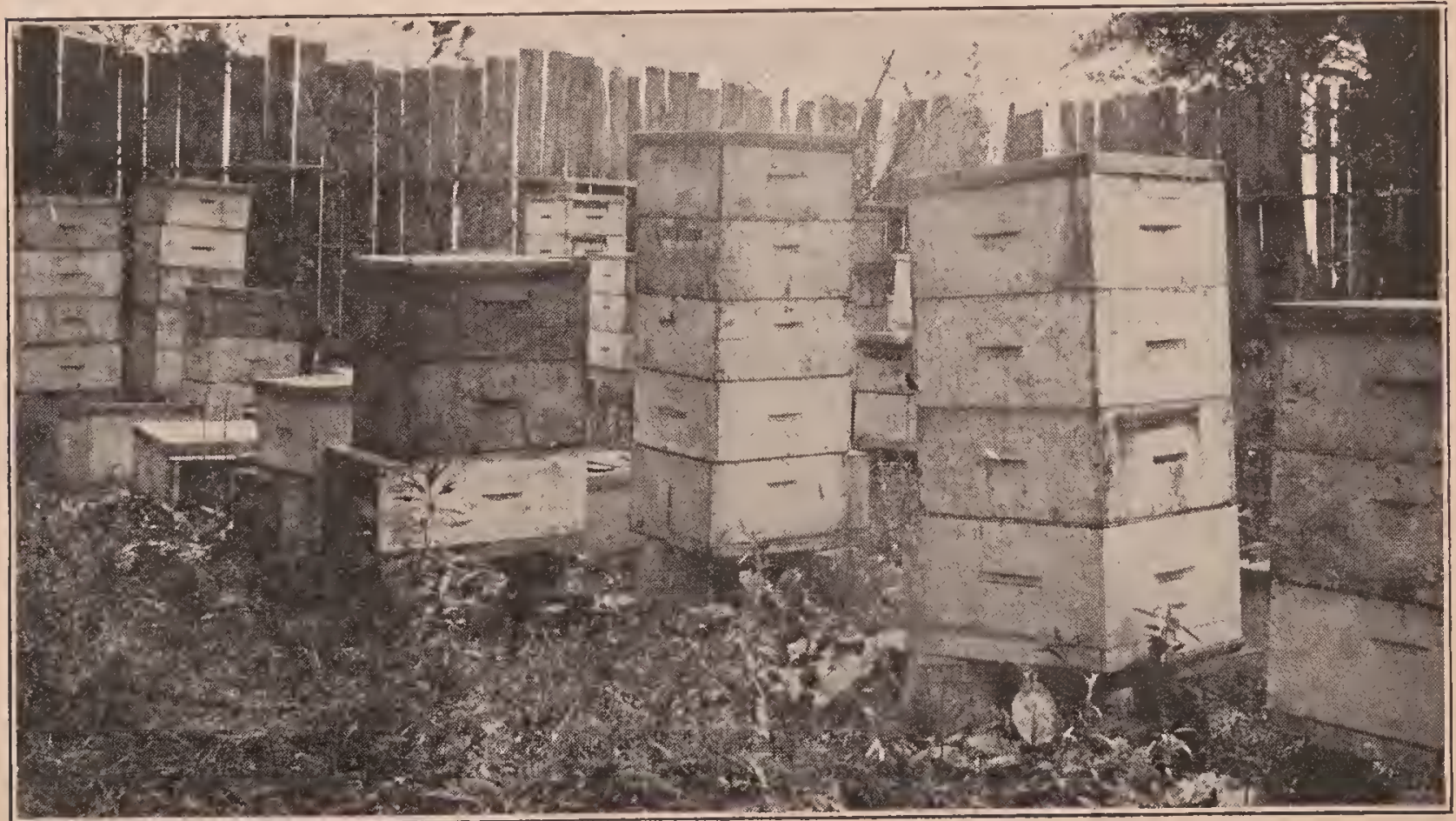

Fig. 2.-Twelve-foot fence windbreak used by R. F. Foltermann, The boards are nailed vortically on to horizontal cross pieces nailed or bolted on to the posts. This construction can be made up in panels so that the fence can be moved in sections if necessary. 


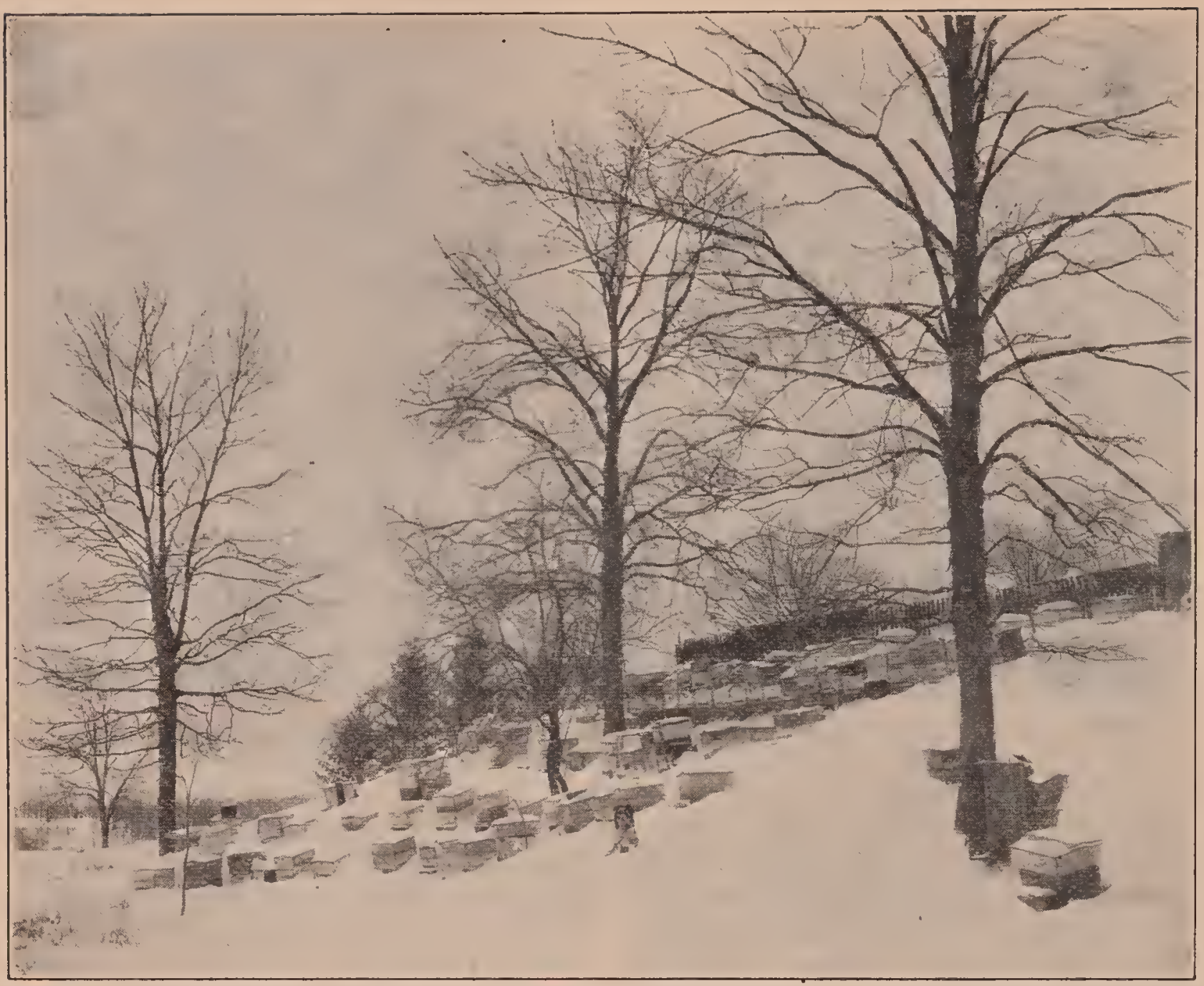

Fig. 3.-This is a natural windbreak on the lee side of a hill. Additional protection is afforded by a picket fence, some farm buildings, and a small orchard on top of the hill. It should be clearly understood that a hillside facing the south is not necessarily a good place for wintering unless some kind of obstruction is on the top of the hill to prevent a north wind from sweeping over the hill and down oll the bees. The hillside where the bees are in this case has a southeast exposure. Over on the east side, about 300 feet away, is another hill on the top of which there are some buildings and a row of evergreens. Bees have wintered well in this spot for years in what is known as the Leister yard, owned by Adam Leister, who furnishes bees every year to the authors.

'This is all right provided there is no windsweep from the south.

It often happens that no location can be found that provides any natural windbreaks. The only thing that can be made available at once is a high board fence. Experience in the author's case shows that it may be desirable to move the apiary on account of a failure of honey sources. For example, several farmers in the locality may suddenly take a notion to stop growing alsike and put in some other crop to give the soil a rest. On account of such contingencies fences are made up of panels, each panel being held in place by means of braces reaching to the ground on both sides, the bottom end of the braces being nailed to a stake. (See Fig. 8.) This construction not only enables one to "pull up stakes" literally but to move the whole apiary, windbreaks and all, at comparatively little expense. The panels of fence after being taken down can be laid on a big truck and carried to the other location. But even if there were no intention of moving, this construction is cheaper than fence posts that must be long enough to reach to the top of the fence and into the ground at least $21 / 2$ feet. They must be strong enough to withstand the heavy pressure of wind. Fence posts meeting these requirements are rather expensive; and a simple brace made up of two $7 / 8$-inch boards nailed together is vely much cheaper, with, of course, the great advantage that the whole outfit can be moved to another yard if necessary. Fig. 6 shows one of the authors' apiaries as it looks from the outside, and Fig. 7 an inside view of the same apiary.

It will be noted in the artificial wind- 
break that the boards are placed a slight distance apart. As a little of the blast of air filters between the boards it stops it from rushing upward so fast, and then diving downward as it will do with a solid construction.

\section{IMPORTANCE OF LETTING BEES FORM A WINTER NEST.}

What is meant by "winter nests"? A space of empty brood-cells in one or more combs, such space approximating the form of a flattened sphere in an ordinary Langstroth brood-nest. These empty cells surrounded by sealed stores constitute the winter nest where bees cluster when condi- has he done? He has compelled the bees to eluster upon sealed honey. The cluster is broken up into slabs approximately $3 / 8$ inch thick, each slab of bees separated by approximately an inch of solid honey. Instead of having one solid cluster separated by only the midrib of the combs, he has made a series of clusters, each within itself trying to maintain its own body heat but at very great disadvantage.

To illustrate: Two people on a cold winter's night require less bed clothing than one person would in the same bed. Suppose that, instead of having those two bed-fellows separated from each other by only their night clothing, a slab of metal or

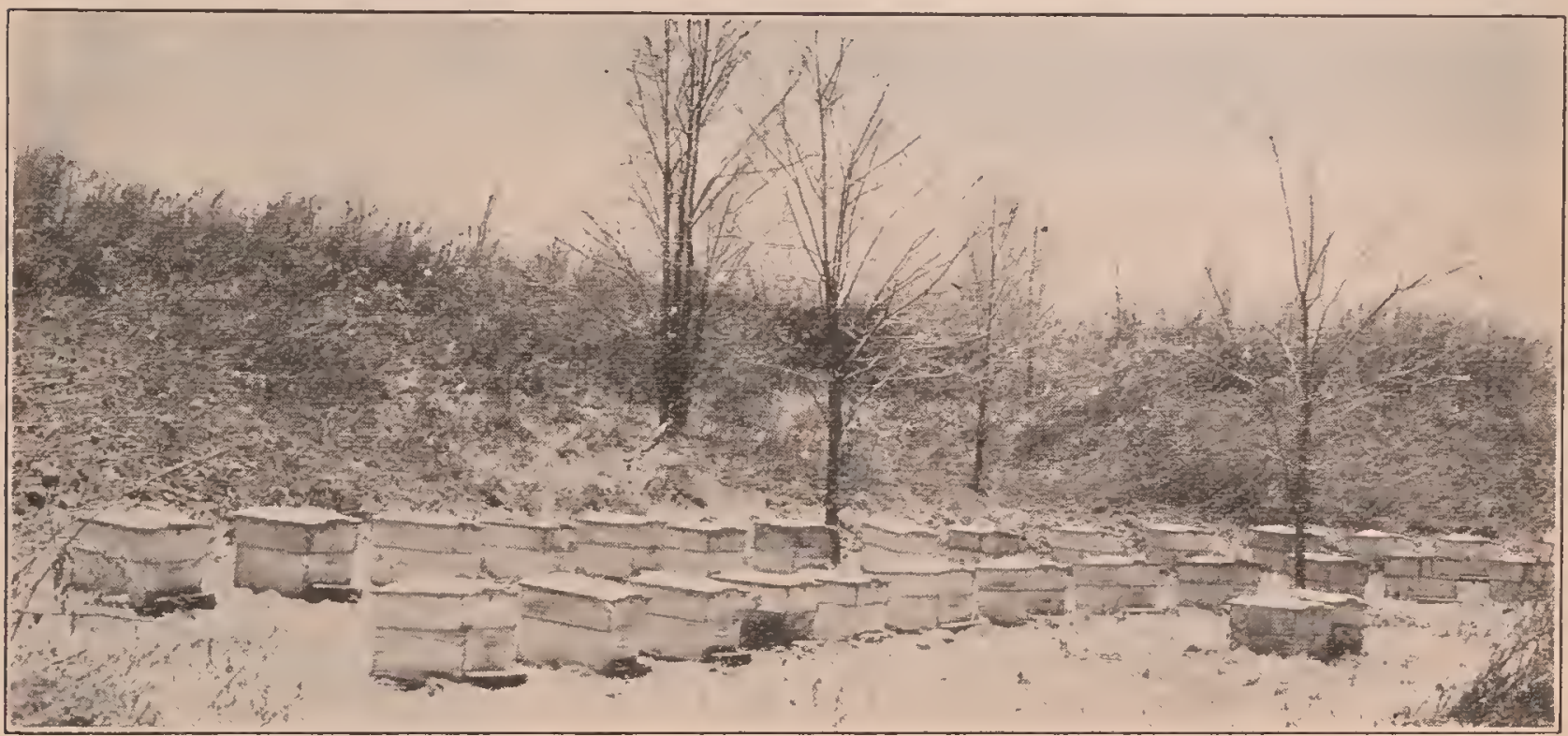

Fig. 4.- This apiary, belonging to Mr. Pritchard, is located at the bottom of a hill which forms a semicircle protecting the bees against the west, north, and east, leaving only a southeastern exposure. The thick growth of young trees on the top of the hill, together with the larger trees in the apiary inclosure, would make it impossible for any eddying currents to sweep down the hill and on the hives. The ar rangement as a natural windbreak is ideal.

tions are ideal. As the stores are consumed, the number of empty cells increases either backward or forward, but always upward. As a general thing, the ball of bees will be located near the front of the hive and regularly over the entrance. As the stores are consumed they move upward and backward: but the cluster in no case extends over the sealed honey when the bees can lave their own will.

Very often a well-meaning A B C scholar finds three or four combs in the center of the hive, having a space of empty cells as large as the hand spread out. He thinks this is all wrong and will remove the combs containing such spares, and put in their place solid combs of honey. What even wood is between them. If they are compelled to place their warm bodies in contact with that cold surface, they lose a great deal of their body heat because the cold surfaces carry away (that is, dissipate) the warmth.

There is precisely that condition when combs of sealed honey are set down into a bunch of bees. They are compelled to divide up into four or five clusters. The result is, that colonies tampered with in this manner perish or come out in the spring very weak because of their inability to maintain the requisite temperature. Where outside bees become stiff with cold they can not long endure that condition.

If a colony is fed gradually during 


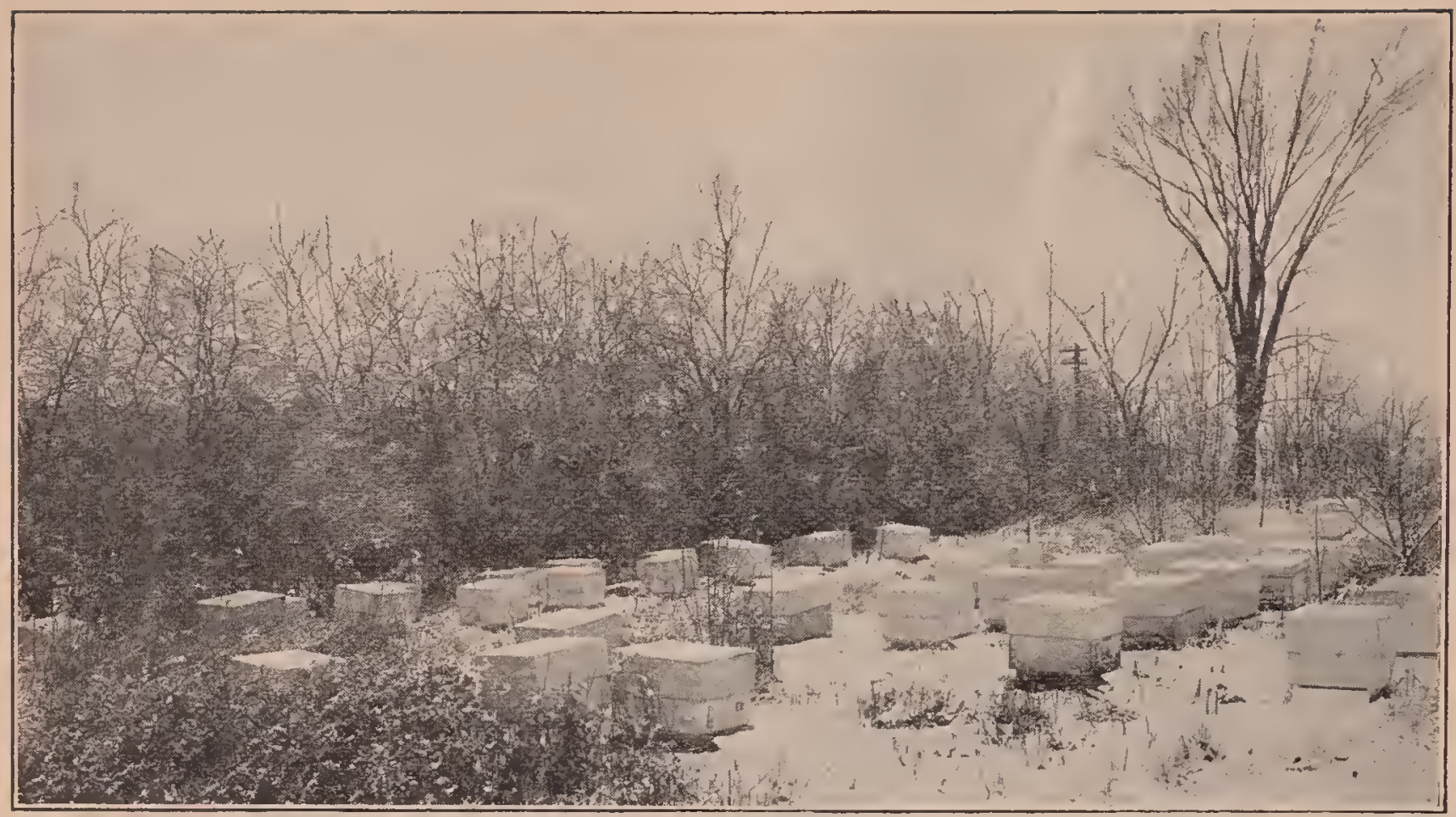

Fig. 5.-This is located like Fig. 4 in that it is scroened by trees from the north winds. The low shrubbery helps also.

October and November, they will form this winter nest. If, however, they are on the verge of starvation and they are fed 30 lbs. in a single night toward the last end of the fall, or when it is quite cold, they do not have the opportunity of forming this nest. They will carry the syrup down while it is hot; then for a few days after that, if it is so they can fly, or', rather, so the cluster can move freely about the brood-nest, they may or may not rearrange the stores. The eluster, when it actually forms up for winter, will be practically one homogeneous mass of bees separated only by thin cell walls and the midribs of the combs.

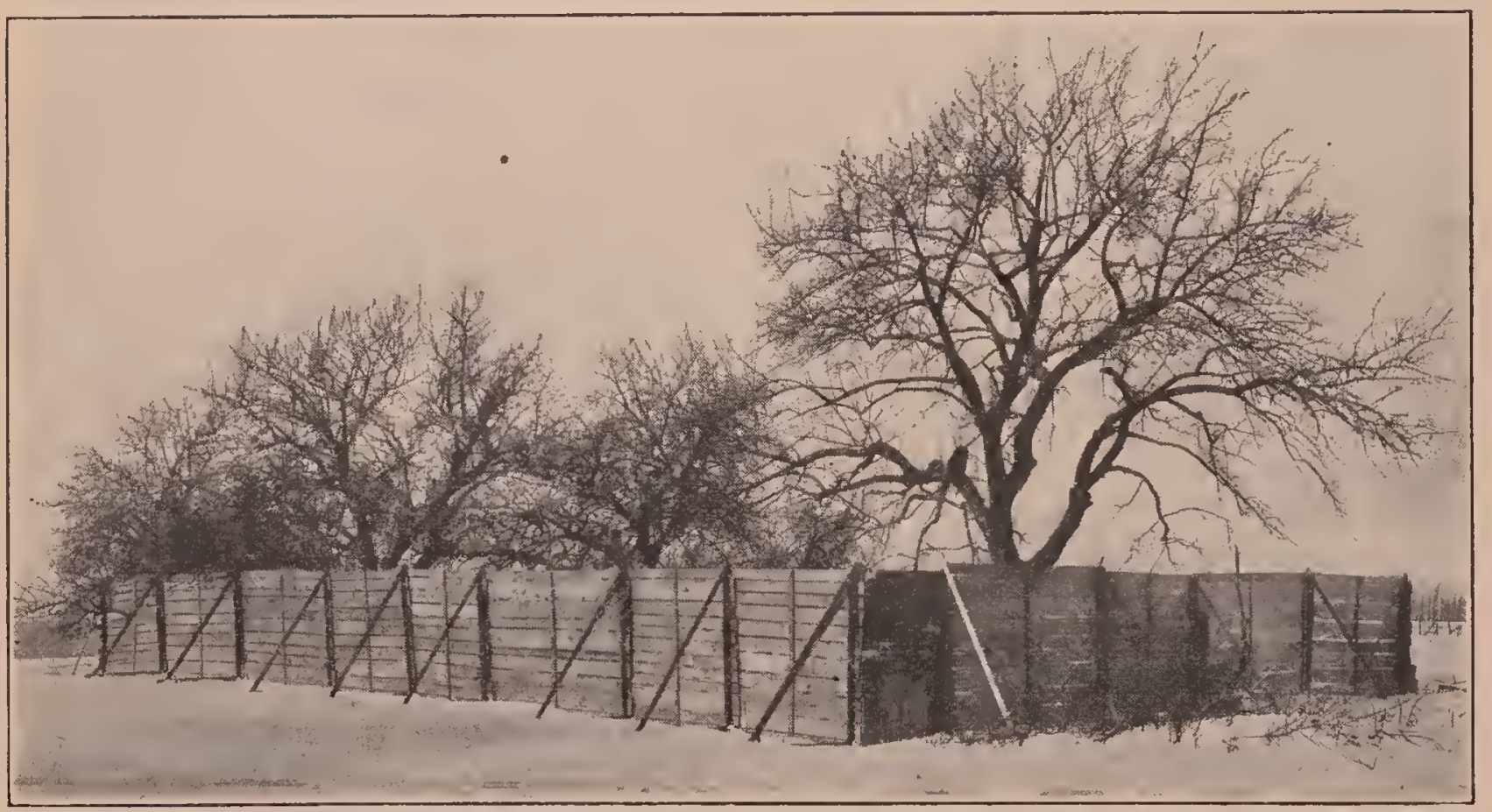

Fig. 6.-This is an artificial windbreak surrounding a Root apiary in a small orchard. But as there is a clear wiudsweep on level ground for over a mile in all directions this fence was put up. The location is desirable because it is in the center of an alsike-clover district. 


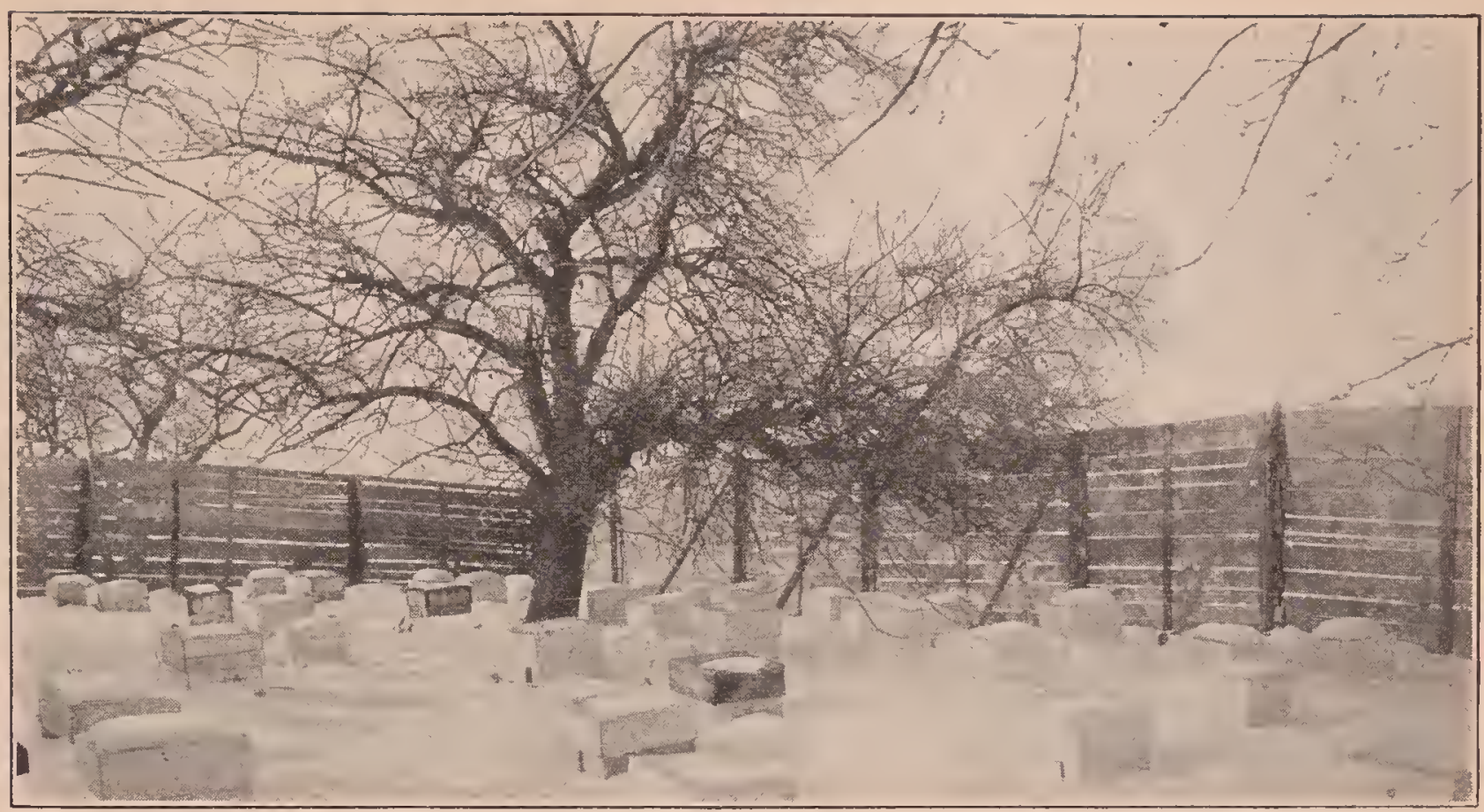

Fig. 7.-The interior of apiary shown in Fig. 6. It is always desirable to have trees inside of an inclosure like this. In the first place, they furnish shade in the summer; and in the second place they lessen the force of the air currents that strike the side of the fence. The boards are separated slightly to allow the wind to filter thru very slowly, thus preventing a blast from glancing upward and then downward.

If one doubts that bees try to have a winter nest, let lim break into several clus-

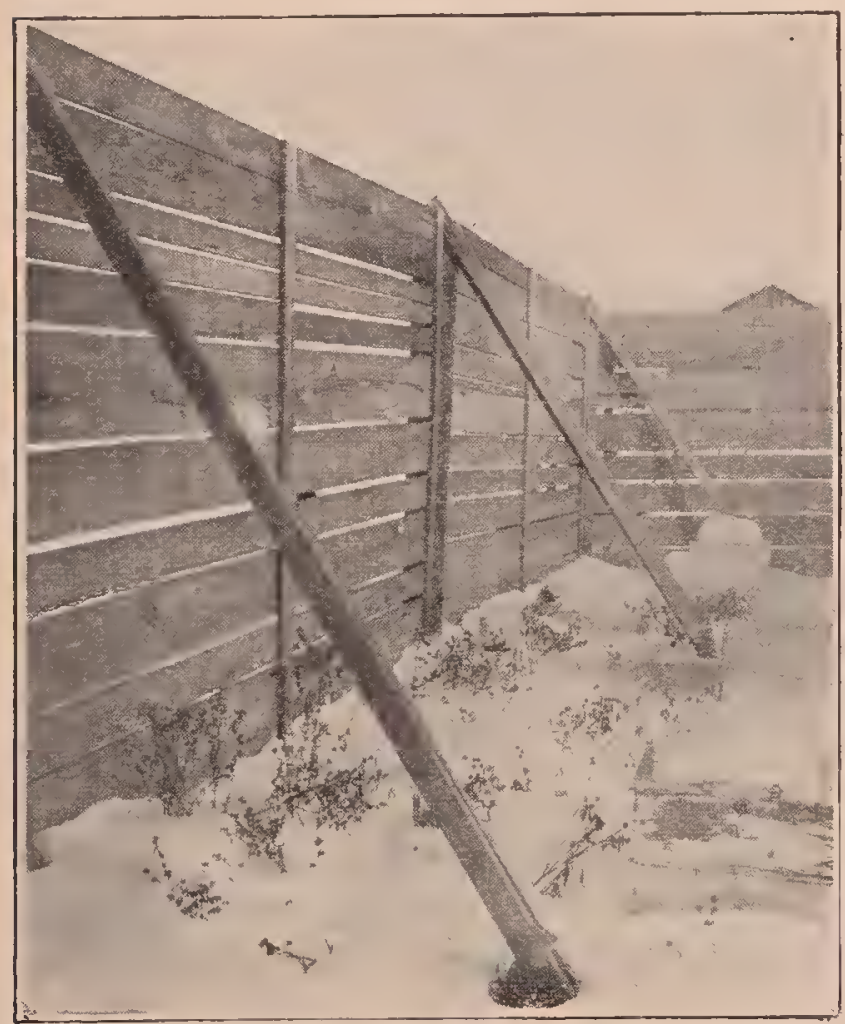

Fir 8 - Showing details of construction of an ar tificial windbreak. It will he seen that the windbreak is made up of panels, the boards of which are placed about an inch apart, each panel being held in place hy means of hraces on the nutside and inside. The arrangement makes it possible to move the windbreak as well as the apiary itself The panel is separated, the hraces loosened, when the whole is laid on a truck. ters of bees (if he wishes to take a chance) when the temperature is 5 degrees above zero. The author has done this repeatedly. If the arrangement of combs has not been disturbed in the fall, one will probably find the bees tightly jammed into the cells. And, again, he will often discover, as he goos orer his colonies in the late winter or early spring, that some of them have actually starved to death. In all such cases he will see dead bees tightly packed in the cells of the wintel nest, and a solid mass of bees filling the several spaces between the combs. Starvation is often due to the fact that cold weather has continued so long without a let-up that the bees are left high and dry, so to speak, in the center of the winter nest. They actually starve, notwithstanding sealed honey is within two inches of the eluster. The long-continued cold has given them no opportunity to warm up and shift the cluster over in contact with the sealed honey. The author has seen this condition almost every winter in his yard.

Still again, the author has often found dead colonies where some of the newer men in the beeyard had disturbed the combs, putting a solid comb of honey down thru the center of the winter nest. This made 
two bunches of bees; and both, being too small, died.

In the case of indoor wintering, where the cellar temperature does not go below $40 \mathrm{~F}$., a winter nest is not so vitally necessary. But if the temperature goes down below 40 , then the absence of a winter nest may mean the death of a colony.

Nature has worked out this problem of wintering bees; and when the beeman tampers with her plans he tampers with his pocketbook. While he can do certain things contrary to Nature, he can not interfere with her plan in the arrangement of the stores.

\section{WINTER STORES-QUALITY AND $Q U A N T I T Y$.}

Having considered the inclosure, and the hives themselves, something should be said about the quality and quantity of the stores. It is fair to say that bees outdoors consume more than twice as much as those indoors; but it is argued, on the other hand, that while the former consume this larger proportion of food they keep stronger numerically and will be in better condition at harvest time than those wintered indoors on half the amount. The opinion of the beekeeping world is somewhat divided on this whole question; but certain it is that he who winters outdoors should provide twice the amount of stores, or at least see that his colonies, after the main brood-rearing has ceased, have from 30 to 40 pounds of sealed stores and in very cold climates from 40 to 50 pounds may be needed. The beginner will need to weigh his combs for the first colony or two, to be able to estimate approximately the stores of other colonies.

As a general thing an eight-frame colony should be crowded on six combs, and a ten on an eight. The division-board must be shoved up close to the frames, and the empty space, if any, filled with leaves, or other packing material. It is desirable that bees have stores given to them at least a month before they go into their winter rest, so they may have a winter nesi around which will be sealed stores within easy reach. As to quality, there is nothing hetter than good honey. If there is a shortage, thick granulated sugar syrup) should be given. It is believed by most good beekeepers that honey will go further pound for pound than syrup. Honey is a natural food, and, besides, contains other food elements such as protein for the bees.

Altho a colony may have sufficient stores by the middle or latter part of August it may run considerably short by the first of November, especially if a fall flow induces brood-rearing. In any case it is well to go over the colonies just prior to the final preparation for winter, and make sure they do not run short. This is very important, as many a colony has been lost thru starvation when their owner supposed they had enough to last till spring. Colonies short should be fed a thick syrup. See Femedng and Feeders; also page 926.

BEES FLYING OUT ON CHILLY OR

COLD DAYS AND APPARENTLY

DYING ON THE GROUND.

In a late fall or early spring, in climates subject to snows and alternate freezing and thawing, bees will very often fly out on a bright day, whether it is very warm or not. They alight on the ground or some object, become chilled, and apparently die. Cases are on record where bees have flown out, alighted on the ground, become stiff and cold, and were apparently dead. 'Thele was one instance in particular of this kind in the author's apiary late one fall, where thousands of bees had flown out and lay on the ground apparently never to return. A cold rain set in and then it began to freeze, followed by some snow. This freezing weather lasted for a couple of days. This was followed by warm sunshine, when, wonderful to relate, those dead (?) bees came to life, took wing and flew back to their hives. Other authentic reports, showing something similar to this, have been sent in. It seems almost unbelievable, but the facts are, that bees can fly out, alight in the snow, chill thru, and seem to be dead. Tf the snow is not too deep it melts away so that the bodies of the bees can become warmed up, when they will often revive; they always revive, if it is warm enough, and they have not been chilled too long.

Beekeepers have written in at many different times, fearing that their bees having flown out in late fall, and, becoming chilled on the ground, were utterly lost. 
Fortunately when a warm day comes on a day later, these bees, if it has not been too cold, will return to their hives.

Old Dame Nature seems to have made some wonderful provisions to preserve beelife. The author is constrained to believe that bees can stand, if the temperature is not too low, chilling cold for two or thres days without being killed.

WINTERING IN CELLARS. - In discussing methods for wintering bees outdoors, some principles have been given that apply to cellar wintering. However, bees while confined do not require more than 10 or $15 \mathrm{lbs}$. of stores per colony, altho it is an advantage to have more, because it is difficult to feed when set out. With a larly directed to one man, said to understand with special thoroness the subject of indoor wintering. This man, Mr. David Running, Filion, Mich., has wintered bees for the last 12 or 15 years in a cellar of his own design, with a loss of less than one per cent. $\mathrm{He}$ is ex-president of the Michigan State Beekeepers' Association, and ex-president of the National Beekeepers' Association. As to wintering he agrees in almost every detail with that veteran authority, the late G. M. Doolittle. The fact that these two men came to precisely the same conclusions 30 years apart, the one without the knowledge of the other, makes the information now about to be given very important.

Mr. Running specifies that the whole

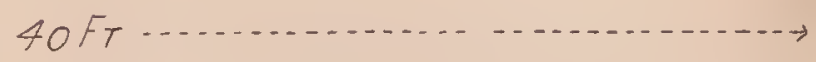

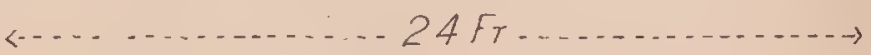

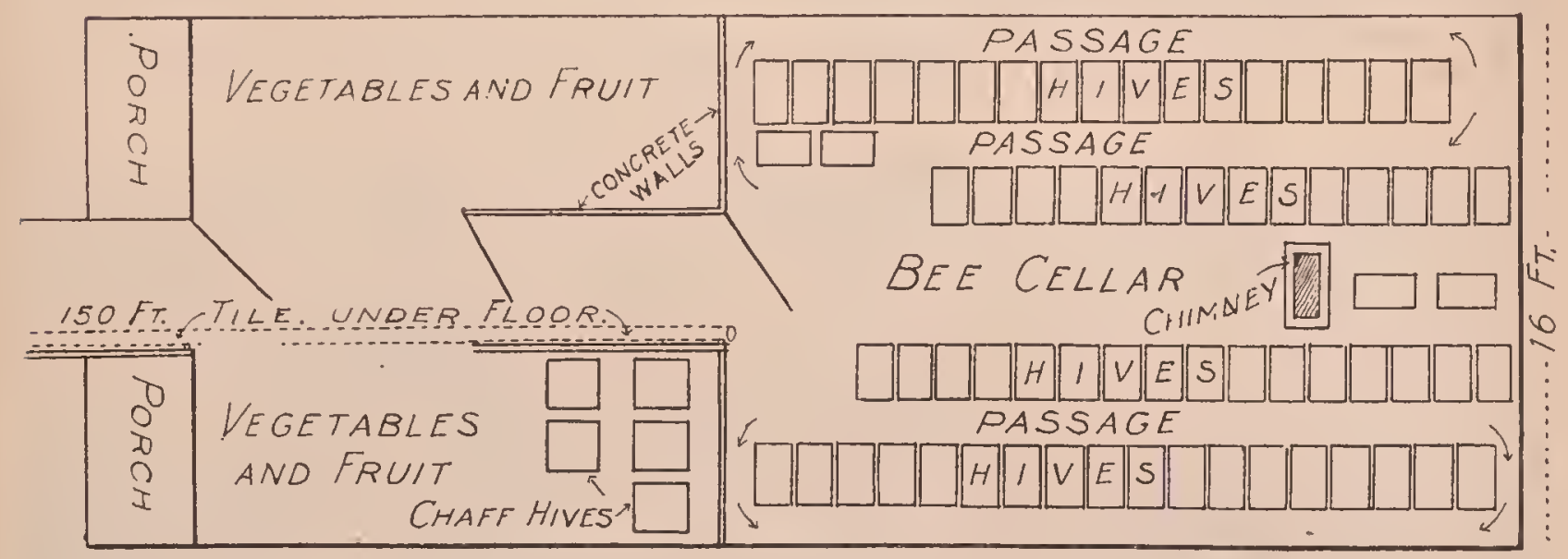

Fig. 1.-This is a diagram of the ground plan of the David Running bce-cellar which has wintered bees for the last 12 years. with a loss of loss than one per cent. The cellar proper is built in a sidehill. The bottom of the cellar is on a level with the ground in front. The walls are 6 inches thick, of concrete, with a concrete ceiling on top. Directly above the cellar is a concrete workshop and extractinghouse. Between the ceiling of the cellar and the floor of this building above there is packing material of one foot of dry sawdust and one foot of air space; and then another set of joists covered with matched flooring. Between the ceiling and cellar roof is 6 feet, and the cellar is capable of holding between 300 and 400 colonies. It will be noticed that there are three doors to shut out the outside cold. The hives are piled as shown in the diagran. The ventilator, or chimney, has a $9 \times 13$ flue which extends clear up thru the building above. The outer cellar is sometines used for wintering bees in double-walled hives.

strong force of young bees and good stores, one is well equipped to winter bees in the cellar, provided he has reasonable control of temperature and means for ventilation.

The author has been giving the matter of cellar wintering special consideration. He has traveled thousands of miles visiting some of the best beekeepers of the United States-especially those who wintered in cellars with little or no loss. After consulting some of the best beemen, and especially Government experts, he was particu- bee-cellar must be well protected from both cold and dampness. It is not enough, he says, that the whole of the cellar be underground and the ceiling on a level with the ground, unless between the ceiling and roof there is three or four feet of sawdust. Many and many a good bee-cellar gives poor results because the temperature of the inside ceiling varies with the outside temperature. A cellar where frost during severely cold weather can be scraped off the ceiling is badly designed 


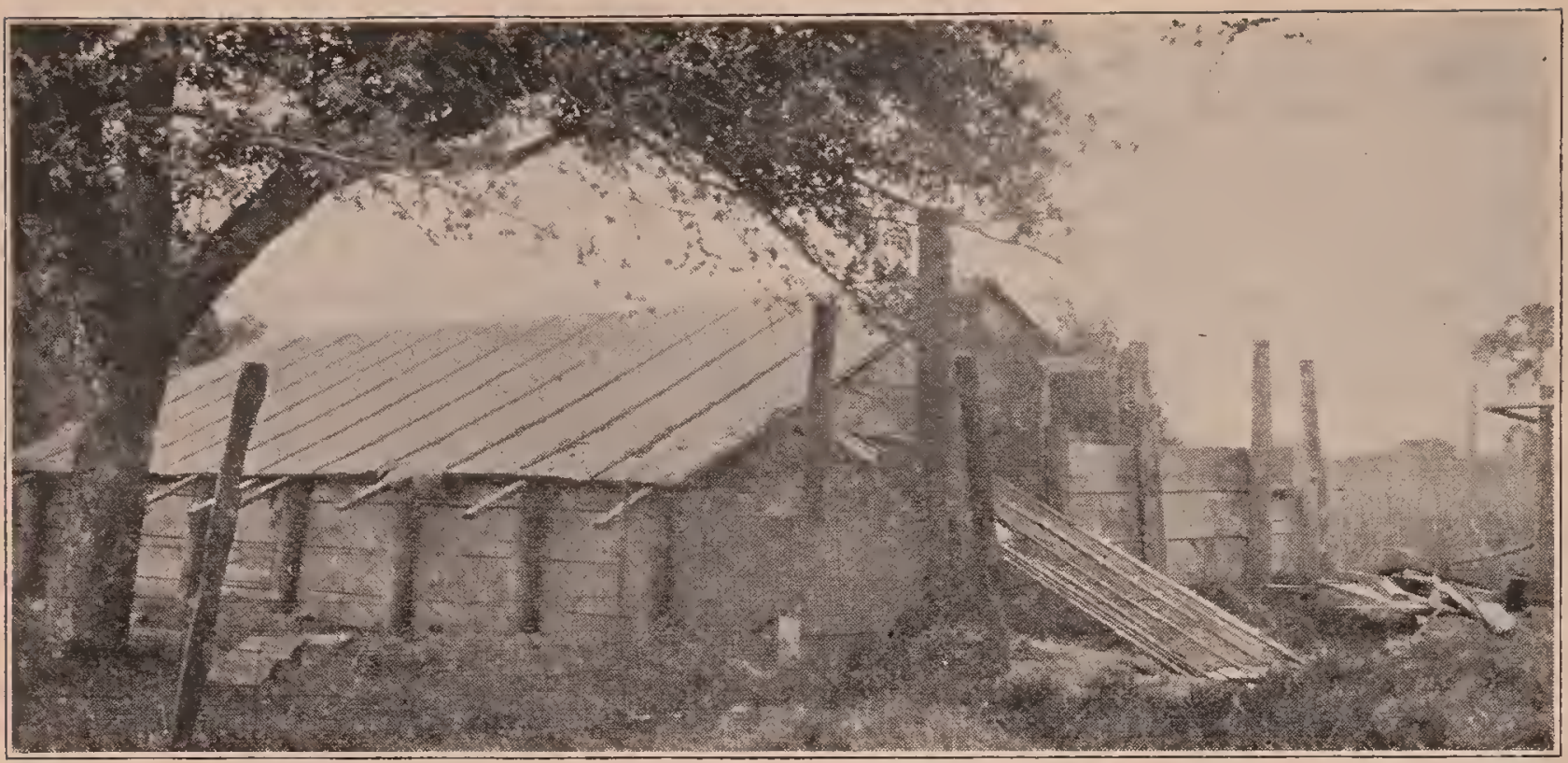

Fig. 2.-This is a bee-cellar belonging to Leonard Griggs. Flint, Mich. It is a type of an abovesround cellar embodying the ideas of David Running. The cellar proper extends into the ground about 3 feet. Then there is a three-foot embankment about 3 feet wide around the upper part of the cellar. The ceiling is covered with about 3 feet of sawdust. To keep the side embankments dry and frost-proof the roof extends entirely over the cellar, and the embankment, except in front; and Mr. Griggs thought it would be a good idea to corer this also. He has been uniformly successful in wintering bees in this cellar.

and can not be expected to give good results.

On. account of the difficulty in obtaining proper drainage it is not essential, the same authority says, that the whole cellar be submerged $2 \frac{1}{2}$ to 3 feet below the general surface of the ground to get below the frost-line. In the great majority of cases the cellar will have to be partly above ground and partly below. But the important thing to remember is that the part above the general level must be protected by three or four feet of embankment of dry earth. The ceiling of the cellar proper' must be covered with at least three or four feet of dry eartl or sawdust. Mr. Running has a workshop directly above his beecellar, making only a foot of sawdust above the cellar ceiling necessary. In order to keep the side embankments dry as well as the space orer the cellar proper, it is $\mathrm{im}$ portant that the roof itself cover not only the width of the actual inclosure, but the embankment at the sides and ends. A wet or frozen embankment means a low temperature in the cellar and that is often fatal.

Mr. Running told the author that he believed he could winter bees in a properly constructed winter bee-cellar even in Tennessee or in any of the southern States with a great saving of stores. "For," he said, "it is acknowledged that where bees can fly one or more times during erery week of the winter they will consume from two to three times the amount that bees in the North will eat." He would put them where the inside temperature of the cluster would be at the point of the least activity, or 57 degrees F. See Temperature.

Regarding the amount of ventilation, our Michigan friend has been successful in the use of one rentilator, about ? by 13 inches, in the back end of the bee-cellar, extending thru the roof, and surmounted at the top by a chimney. This shaft should extend down to the level of the cellar floor. This is for the outlet of foul air. The inlet consists of a sewer pipe running under ground, opening into the front end of the cellar. Altho he has not used it, he believes it would be an adrantage to have the inlet of this sub-earth ventilator continue in a rertical pipe to within a few inches of the ceiling. This would bring about a thoro circulation of air from top to bottom.

An electric fan can very often be used to good advantage, where electric current is available, to force fresh air into a cellar: or, better, foul air ont of the cellar.

The entrance to the Running cellar is effecter by double (or better, triple) doors thru a narrow passageway leading from the 
level of the ground to the bottom of the cellar. If the cellar is halfway below ground and halfway above, the entrance and exit are made easy by means of steps. If it is located under a sidehill, so that the bottom of the cellar is on a level with the ground in front, the eonditions are ideal.

To recapitulate: "The important thing" to remember," said Mr. Running, "is to make the cellar room so that it will not be subjeci to any outside variations of temperature; and to prevent these variations the sides, ends, and ceiling must have enough protection of dry earth or sawdust to keep the bec-cellar at the riglit temperature." In localities where there are deep snows less insulation would be needed; but, as there are some winters with little snow, it is well to have a large dry dirt embankment.

The temperature of Mother Earth, according to Mr. Running, is about right for
43 or even 40 . Taking the two extremes; 45 seems to be the average. It is evident in some cases that a high temperature is better, and in others a low temperature. If the entrances are large, $7 / 8$ inch deep by the full width of the hive, a higher temperature may be maintained than where the entrances are contracted to, say, $3 / 8$ inch deep, by 6 inches wide. In the latter case the internal temperature of the live itself, the colony being of the same strength, would be higher than where the entrance is $7 / 8$ inch deep by the full width of the hive. The real consideration after all is the temperature of the cluster of bees. That temperature should be approximately 57 degrees. Large, powerful colonies would probably require a lower cellar temperature, other things being equal, than weak ones. Again, a cellar that has powerful colonies with contracted entrances should doubtless have a lower temperature; and the same colonies witl a large entrance or

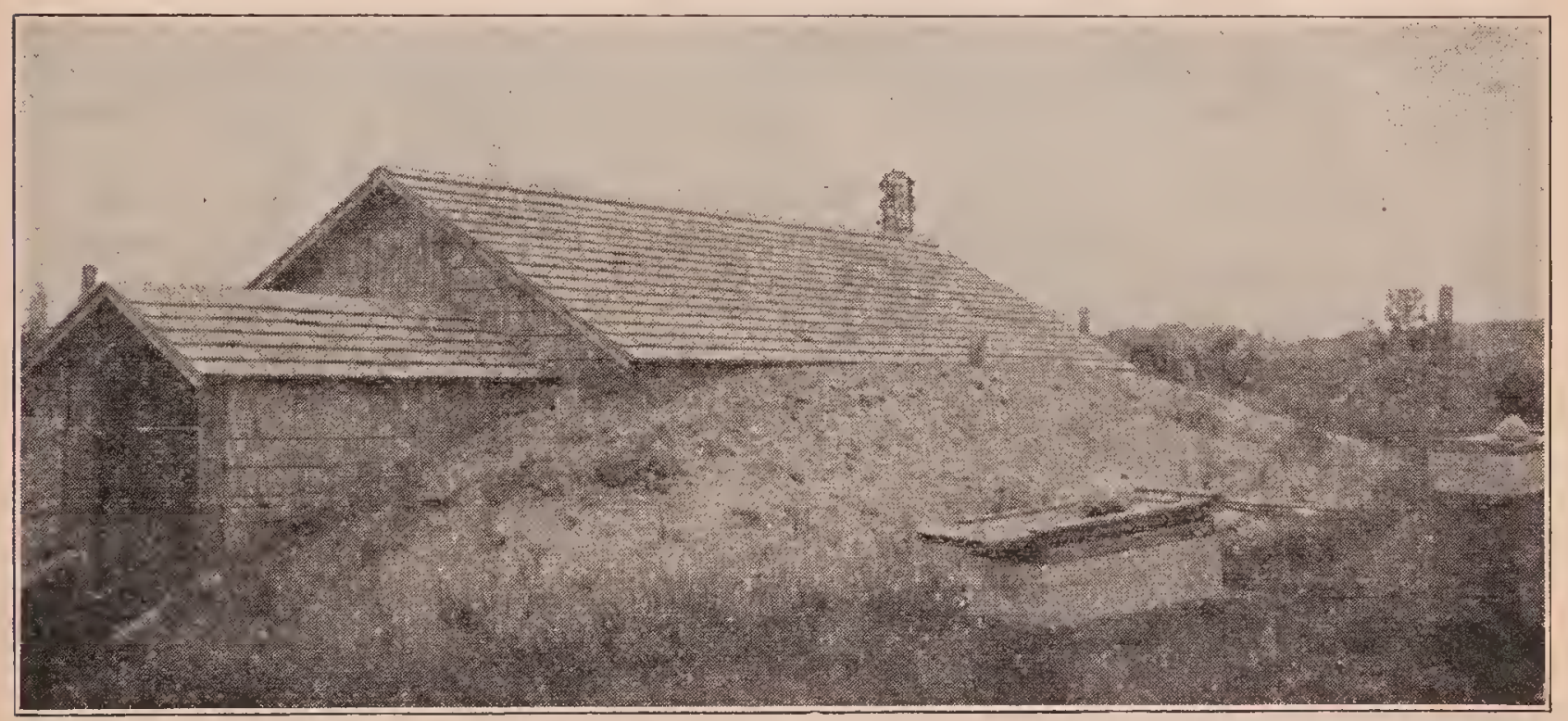

Fig. 3.-This cellar belongs to L. C. Gordon, of Bellaire, Mich. According to David Running's idea the roof should have extended over the side embankment. But these embankments are made up of sand that dries out very quickly; and in spite of the fact that it is not covered, it makes a good insulator. Mr. Gordon onc told the author that in this $12 \times 20$-foot hee-cellar the preceding winter he wintered 151 colonies without the loss of a colony. This cellar has the ventilation recommended by Mr. Running.

cellar wintering. Mother Earth varies all the way from 41 to 50 degrees. He said the best results in a cellar would be where the variation of the temperature is between 43 and 47 degrees.

While 45 degrees $F$. seems to be the nearest right point according to most authorities, there are some who hold that it may be as high as 50, and others as low as bottoms removed entirely might have a temperature of 50 or even higher.

Taking all of these factors into consideration, it is easy to see how some, without knowing why, would favor a comparatively ligh temperature, and others a low one, and yet botli would be right for their respective conditions. Coming back to the fundamental principle, that the tempera- 
ture of the cluster should be, as nearly as possible, 57 degrees thruout the period of confinement, it will be easy to regulate the size of the entrance or the temperature of the cellar, or both, so that the temperature of the cluster shall be, as nearly as possible, 57 degrees.

Unfortunately, not all the colonies of the cellar will be of the same strength. If the

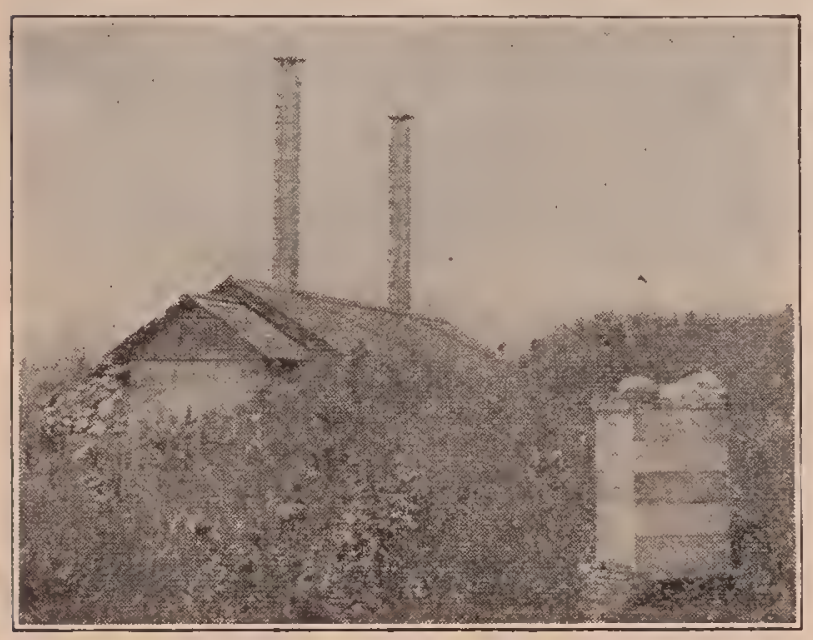

Fig. 4.-One of Peter Sowinski's bee-cellars

temperature is nearly right, say around 45 , the internal temperature of individual clusters can be regulated by the size of the entrances.

To determine the temperature, it will be inpracticable and entirely unnecessary to stick a thermometer into a cluster. For all practical purposes, if a thermometer placed on the bottom-board, inside of the entrance, shows a temperature of about 52, it may be surmised that the temperature of the cluster will be about 57. Let it be supposed, for example, that there are two small colonies in a certain cellar. The average temperature of the cellar is somewhere around 45. If there be shoved into the entrances of colonies of different strengths an ordinary dairy thermometer tested for accuracy, or even a common house thermometer (if it can be shored into the entrance), it will be possible to determine in these colonies the temperature of the bottom-board. If the variation is not very great, and the temperature stands around 52 a few inches back from the entrance, it may be assumed that the cellar temperature is about right. But if it is found that one colony has a bottom temperature of 47 or 48 , and another one a temperature of about 55 to 56 , it is obvious that the entrance of the first named should be contracter to a point where the temperature will be about 52. The other entrances should be enlarged until the mercury in the thermometer drops down to the required point. In a word, the temperature of the cellar should be at a point that will give as nearly as possible the proper temperature of the cluster, and that is 57. See Temperature.

If when one puts the bees in the cellar

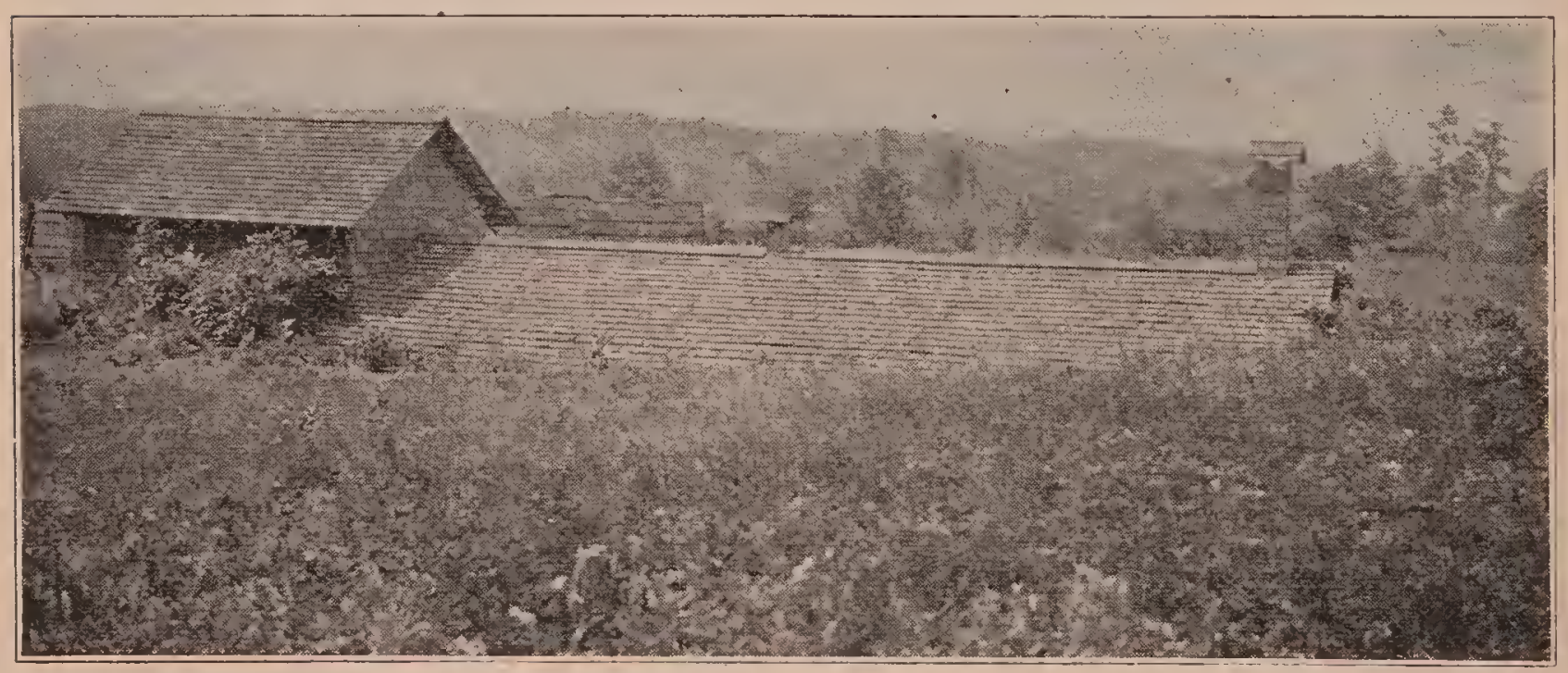

Fig. 5. This cellar $\left(7 \frac{1}{2} \times 25\right)$ belongs to Peter Sowinski of Bellaire, Mich.; so also does the cellar $(7 \times 30)$ slown in Fig. 4. Mr. Sowinski wintered 285 colonies in these two cellars witlout loss. The embankment in Fig. 4 appears to be covered. The home cellar, Fig. 5, embodies all the ideas of David Running. The author went into this cellar at the time of his visit, and, notwithstanding the temperature was 80 degrees in the shade outside, it was down to 45 in the cellar. Mr. Sowinski keeps his vegetables. butter, eggs, and other foodstuffs in this cellar. The drinking water, kept in jugs here, seems to be as cold as ice. The sclieme of ventilation was the same as Mr. Running's. 
he marks on each hive its relative strength, he will be able to determine the degree of contraction for each entrance; but, before he determines the right contraction, he should use thermometers in a few test colonies.

So far neither the question of food nor that of the age of the bees has been touched on. Mr. Running said that, of course, he would much prefer good stores; for, when they are used, there is no bad spotting of the hives when the bees are taken from the cellar in the spring, even if they have been confined from four to five months. But tho the bees will not winter as well on poor stores as on good, still if they are wintered in a properly constructed cellar, the amount of food consumed by the bees is so small that no serious consequences occur. either on account of the presence of a furnace in the adjoining room to heat the house, or because of the exposure of the walls above ground to outside temperature, which is always very variable. The author's experience has shown that where the temperature inside is variable-from 40 to 60 - there must be a large amount of ventilation, especially at the higher points. Good results were secured with the temperature ranging between 55 and 60 ; but when it is as high as this there will be a loud roar from restless bees, unless there is a constant interehange of air. It is a little difficult to bring this about in an ordinary house cellar, unless one can use an electric fan so placed as to bring about a change of air. Where there are a few colonies-10 to 15 - in a room $10 \times 12$, the matter of ventilation is not hard to overcome, especially

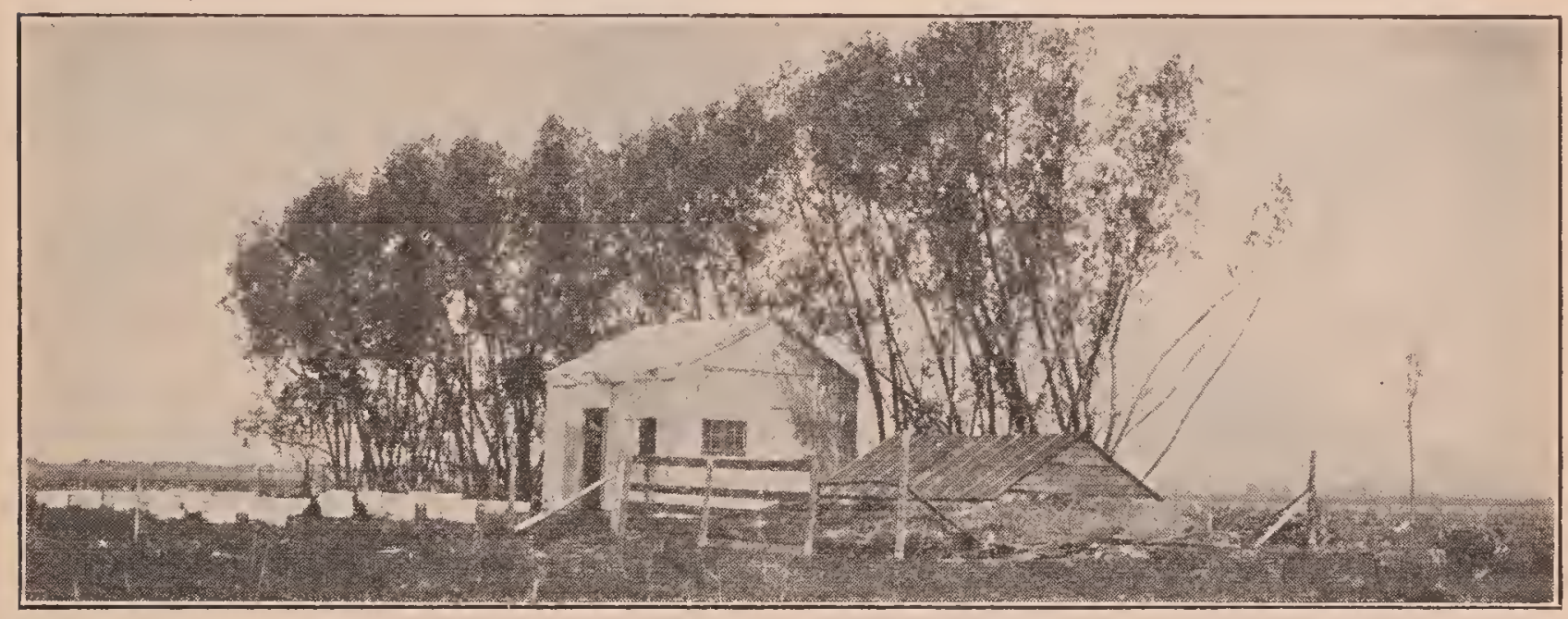

Fig. 6.-E. G. Brown's upground cellar constructed by setting four fence posts about four feet into ground at the four corners of the proposed cellar. The portion of the posts above ground are boarded up on the outside. The dirt on the inside is sboveled out, forming an embankment around the hoard fence. The whole is covered with a roof as shown.

The same authority says that many times the beekeeper can not have young bees, and many times he will have to put up with inferior stores. But he is strongly of the opinion that if bee-cellars are built lightand that, of course, means proper drainage and protection-one could winter any kind of bees. When the cellars are not properly protected, good stores and young bees are almost a necessity.

WINTERING IN AN ORDINARY HOUSE CELLAR.

Wintering in an ordinary house cellar is possible and practicable; but it should be understood that a house cellar is much more subject to variations of temperature, if the door leading from the bee-cellar into the furnace-room is left slightly ajar. It is put down as an axion that 10 colonies in a house cellar will winter better than 50 or 75 colonies, provided the temperature does not go below 40. If the cellar is not frostproof-that is, will not prevent vegetables from freezing-it will be a very poor place for bees. A cellar reeking with dampness is also bad, altho bees have wintered well in louse cellars where there was a large amount of dampness; but it was because there was a temperature not lower than 45 .

The question of whether the hives should be carried into the cellar without the 
bottom-hoards will depend on conditions. In cellars of the David Running type the bees should be put in with hive-bottoms and cover's sealed down. Mr. Running uses an entrance $1 \frac{1}{4}$ inches deep running the width of the hive for his good colonies.

\section{STORES.}

Usually a single brood-nest will have enough stores to carry the colony thru winter in the cellar; but some beekeepersnotably Leonard Griggs, who is one of the most successful producers in Michigan and who follows Mr. Running in the construction of his bee-cellar-give to every colony they put into the cellar a half-depth super of natural stores. This is in addition to what the lower story happens to have. See Fig. 2. Also see Feeding and Feeders, subhead, "Feeding for Winter." See also page 926 .

\section{HOW TO BUILD A BEE-CELLAR.}

So far no specific directions have been given on how to build a David Running cellar. (See Fig. 1 and legend beneath.) Where the clay is firm and will not cave in, sustaining walls are not necessary. But in most localities a wall or board siding is very essential. Concrete walls are probably cheapest in the end. Where the cellar is temporary or on rented land very good bee-cellars have been built by using cheap boarding nailed against wooden posts. Mr. Brown (see Fig. 6), Sioux City, Iowa, makes four holes in the ground with a post-auger. These holes are deep enough so that an ordinary fence-post will stick above the ground three or four feet. The boarding is then nailed outside of the posts above ground. He then gets inside of the inclosure and digs an oblong pit deep enough so that he will have about $61 / 2$ feet between what is the top of the ceiling of the cellar-to-be and the bottom. The inside dirt is thrown outside of the wooden barricade. This leaves an embankment of four or five feet of earth. He uses no sustaining walls in the lower half of the cellar. A ceiling is then put on, and then a gable roof is made to cover the embankment as well as the cellar proper. On top of the ceiling and under the gable roof is put from three to four feet of sawdust.

From the general investigations that the

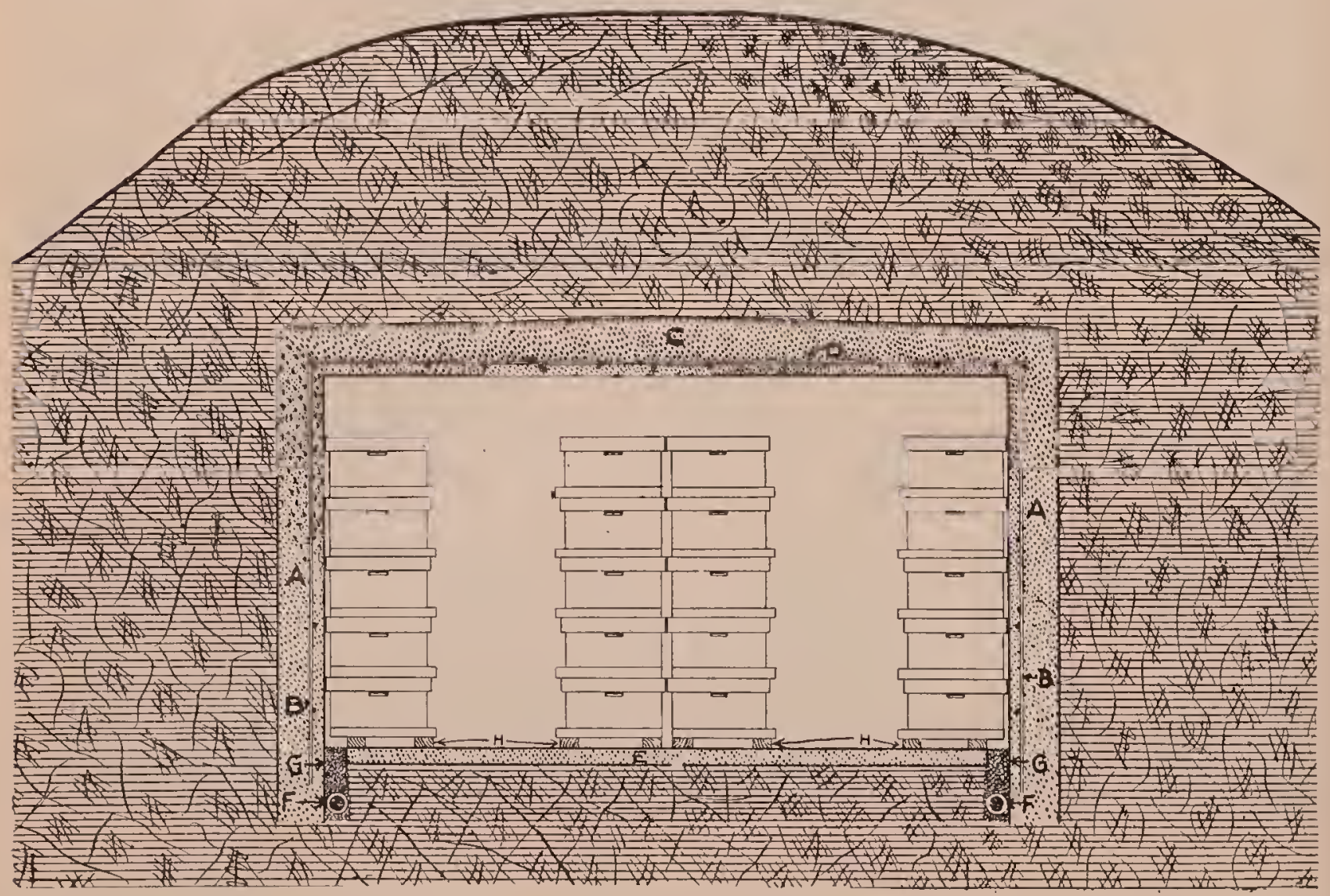

Cross-section of Root's bee-cellar showing two aisles and four long rows of hives. Two-by-fours (H) are piaced on the cellar botton as supports for the hives. The floor, walls, and ceiling of the cellar are of solid concrete, the ceiling and walls being reinforced with stcel bars (B) and (D). The drainage-tile (F) is shown covered with cinders (G). 
author has been able to make and from the results of his orvn experience, he comes to the conclusion that the ordinary bee-cellar should be relatively long with the entrance in one end. The temperature of Mother Earth in most localities where cellars are used is between 40 and 50 Fahr.-just about the right range to have inside a cellar. The walls next to Mother Earth become radiator's of heat and cold because they draw from an enormous reservoir, so to speak. The larger the amount of wall surface exposed below ground, the more even the temperature in the cellar. A relatively long, narrow cellar, submerged five or six feet below ground thru which cold can not penetrate, gives the I a r g' e st possible amount of wall and a temperature of approxi$m$ ately 45 degrees-just where it should be for good wintering in a cellar. The author's cellar is 12 feet wide by 60 feet long, by $61 / 2$ feet high inside, wholly submerged beneath the surface with concrete walls, sides, ends, and ceiling. This cellar is covered with some four feet of clay closely $\mathrm{p}$ a $\mathrm{e} \mathrm{ked.}$ The cellar opens

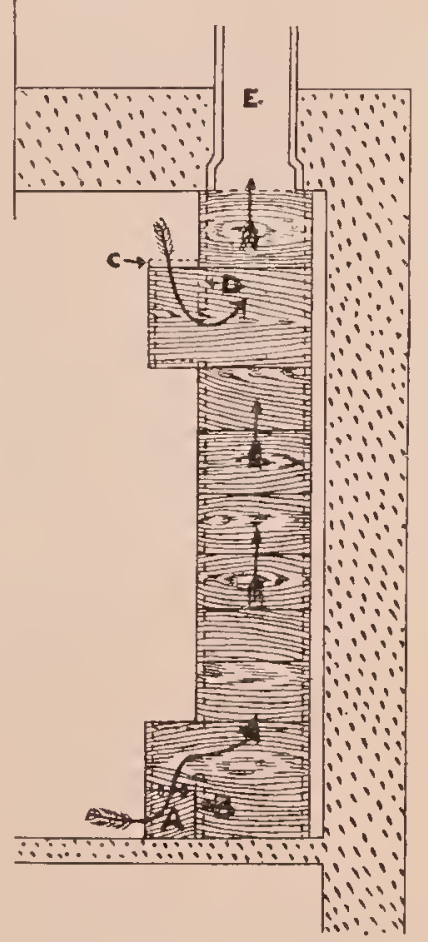

Ventilating chimney at rear of cellar. Air leaves the cellar thin the door (A), passing over the top of board (B), thru the wooden shaft and tile (E). When desired, door (A) is closed, board (C) removed, and air from the top of the cellar allowed to pass thru the upper opening under the lower edge of board (D), and up thru the chimney. up into the basement of a main warehouse building, from which ventilation is secured by means of an electric fan. Up thru the ceiling and earth, at the back end, is an 8-inch sewer-pipe chimney thru which the air is forced by the fan where there is not a natural draft. During a very warm winter, the first year this cellar was tried it gave excellent results in spite of the fact that the temperature outside was around 60 and 65 degrees for many days.
It was also found that sudden changes of temperature have very little effect on the cellar. About Jan. 9 the mercury outside dropped over 40 degrees in 24 hours; yet this did not change the temperature of the cellar one degree. Not until spring did the temperature go above 50 degrees and then only a few times; 44 is the lowest mark registered, and this only three times. The average daily variation in the bee-cellar was less than 2 degrees and the greatest change in one day was 3 degrees.

Where the soil is not impervious to water there should be a roof over the three or four feet of clay top. In our Ohio soil the clay is impervious to water and no roof is used.

\section{SUB-EARTH VENTILATORS.}

Sub-earth ventilators should be from four to six inches in diameter, made of glazed tile, about 100 feet long, and from four to six feet below the surface of the ground. The outer end is brought to the surface of the ground, and the inner opens near the bottom of the cellar. Cold air entering the ventilator is warmed in passing under ground to the cellar, and not only supplies the latter with pure air, but at the same time raises its temperature several degrees.

Sub-earth ventilators are not used to any great extent at this writing. The plan of using a furnace under the house, placing it in a room by itself adjoining the cellar, is preferable, provided, however, that outdoor air is allowed to go into the furnace room from a door or window.

\section{ARRANGEMENT OF HIVES IN A BEE-CELLAR.}

The hives may be piled up one on top of another in such a way that any one can be removed without disturbing more than the one or two above it. The reason for this will be apparent later. Strong colonies should be put in first and placed on a $2 \times 4$ scantling. On top of these may then be placed the weaker ones. This has the special advantage of having the heavy ones at the bottom and the light ones on top. The former, requiring a lower temperature, will be where it is cooler; and the latter, being weaker, will require a higher temperature, and will be where it is warmer. 
Some consider it essential to remove the bottom of the hives entirely. Others consider it good practice to have a deep space under the frames by raising the hive off the bottom in front and supporting it there by a couple of blocks. But some disastrons results in wintering seem to show that too much bottom ventilation is bad unless the cellar is kept at a temperature of about 60 degrees and thoroly ventilated. The author uniformly secured the best results with a reasonably small entrance, or one about the size used during the fall or late spring. The larger the colony, of course the larger the entrance that will be required. In the case of a strong, populous colony the entrance should be $3 / 8$ inch deep by the full width of the hive. The colonies of medium strength should have the entrance reduced accordingly.

INSPECTING THE BEES DURING MIDWINTER;

AND DEAD BEES ON. THE CELLAR BOTTOM.

Experience has proved that, when the temperature is maintained at 45 degrees, very little attention need be paid to the bees, especially in the fore part of the winter. But during the last month or two of confinement the bees require watching more carefully; for if they get to roaring many of them will be lost. It then becomes necessary to make frequent examination to determine the temperature and the quality of the air. It will also happen, perhaps, that a good many dead bees will be found on the cellar bottom. While this is not necessarily a cause for alarm, it is not as it should be. If the cellar and temperature are right there will be very few dead bees; but if they accumulate, their dead bodies should not be allowed to taint the cellar, but should be swept up perhaps every two or three weeks and removed.

A disposition to roar should be met by more ventilation, and at the same time the temperature should be reduced. If all the colonies in the cellar should become uneasy during midwinter it is evident that something inust be done at once or the whole lot of bees will be lost. They ought not to become uneasy until late in the spring. If they can not be quieted by infusion of fresh air, it may be best to give the uneasy rolonies 'a flight on the first warm day by setting them outdoors and letting them stay there for 24 hours or until they can clean themselves. Dysentery or diarrhea in the bee-cellar is generally the result of too much cold air or too high a temperature, either of which will induce too large a consumption of stores; and where bees are not able to void their feces, the intestines become distended, resulting in purging. A colony so affected should be removed as soon as a warm day comes and given a flight, when it may be put back.

WHEN TO PUT BEES IN THE CELLAR, AND WHEN TO TAKE THEM OUT.

This is a question that depends entirely on locality. Most bees go into the cellar in the northern States from the middle of November until the middle of December; but usually it is advisable to have all bees in before Christmas. As to when the bees should be taken out of the cellar, authorities differ. Some set them out in March, and then put on winter cases. Others believe it is better policy to keep bees in late or until the last cold weather is past, and then set them out. The author advises taking the golden mean, waiting until the time natural pollen comes. But when bees are uneasy in the cellar it is advised to set them out earlier than would be done otherwise.

TIME OF DAY TO TAKE BEES OUT.

The old plan for taking bees from a cellar in the spring was to wait until fairly settled warm weather had come, and then on some warm bright day all the colonies were removed at once. The difficulty with this method is that the bees are likely to become badly mixed, owing to their eager flight without carefully marking the location. This results in a bad state of affairs, and should be avoided. Another method. followed to some extent, is to put some of the colonies ont during an evening when all appearances indicate that it will be warm and bright the next day. A third of them, perhaps, are taken out, and these fly quite well the next day. The next evening another third is removed, and the last third the night following. The objection to this plan is that the bees removed first get to flying well and then start to rob colonies taken out later, thins making a fearful uproar.

E. W. Alexander, in Gleanings in Bee 
Culture, page 286, Vol. XXXIV., gave a plan open to none of these objections.

"First, get everything ready for a big job, and watch the weather closely, especially after a few nice days, for it is quite changeable at this time of the year. Then when the wind gets around in the east, and it commences to become overcast with heavy clouds, and has every appearance of bad weather for the morrow, we commence about sundown and carry out all our bees -yes, even if it takes not only all night but into the next day; and if it commences to rain before we are done, all the better, for we don't want any to try to fly until they lave been out two or three days if we can help it. By this time they will have become nice and quiet; and when a fair day arrives they will commence to fly, only a few at a time, and get their location marked, so there will be no mixing up or robbing, because they all have their first fly together. Then when the day is over we find by examining our hives that nearly every one has apparently retained all its bees."

The plan here given avoids "drifting" on the part of the bees. (See Drifting.) When bees drift from one hive to another it means that the strong become stronger and the weak weaker. Moreover, there is danger of robbing. When bees are set out at two or three different times, those first set out, having marked their losations and having quieted down, are quite liable to rob those set out afterward, because the last lot of bees are more or less demoralized until they can mark their locations and recover from their excitement.

\section{SHALL THE COLONIES BE PUT BACK ON THE} OLD STANDS IN THE SPRING?

After bees have been shut up in the cellar over winter they can be placed back on the old stand they formerly occupied or they ean be put anywhere in the yard, or, in fact, anywhere on the premises. Bees after long confinement apparently lose all knowledge of their former location, and will stay anywhere they may be placed. If one finds it necessary or desirable to move his bees a short distance, it is a good plan to wait until they are taken out of the cellar the following spring, when they may be placed anywhere.

\section{CARRIERS FOR HIVES.}

$\Lambda$ wheeled vehicle is not as good for moving bees in and out of a cellar as some sort of carrier.

$\Lambda$ wheelbarrow, if the paths are smooth, does very well. If the cellar steps are not too steep, a plank runway can be provided so that the load of bees can be delivered into the cellar itself.

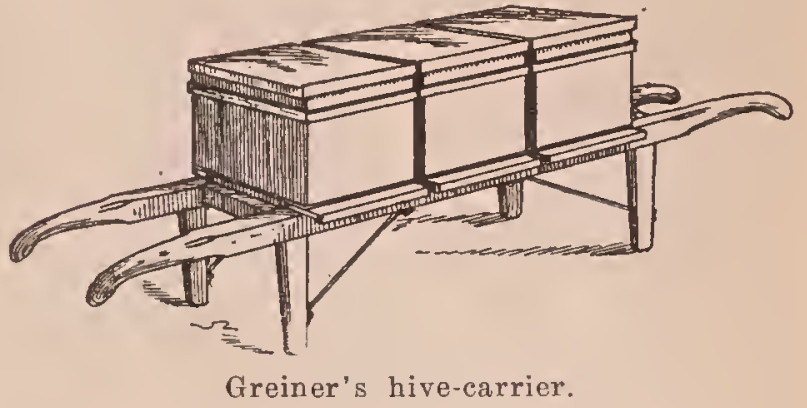

Two men can easily carry as many as five hives in this way. Where the cellar is located some little distance from the apiary this is the most convenient method yet devised.

Instead of constructing a regular hivecarrier as shown, it is possible to get along quite well by the use of two poles, but they are by no means as good. These should be about two inches square and six or eight feet long. They are placed on the ground in a parallel position, and as many hives placed on them as can be carried; perhaps three hives would be all that could be managed easily with the poles. It is much more satisfactory, however, to have the poles nailed together with a framework, making a regular hive-carrier.

\section{SOME THINGS TO REMEMBER IN CELLAR WINTERING.}

1. The temperature of the bee-cellar should be approximately 45 degrees. Whether it should be higher or lower will depend on the size of the colonies and the entrances of those colonies.

2. An excess of dampness in the cellar does no harm provided the temperature of the cellar is such as to make the temperature of the cluster approximately $57 \mathrm{de}$ grees $\mathrm{F}$.

3. A low temperature in the cellar, say 35 to 40 degrees, or any temperature at which the heat of the cluster is much above or below 57, with an excess of dampness, is a very bad condition. 
4. Bees can be wintered in a cellar without much ventilation, provided the temperature of the individual clusters is approximately around 57 degrees. With averagesized colonies and arerage-sized entrances, a constant temperature of about 45 degrees in the cellar will not require much ventilation, provided the size of the entrances is in proportion to the size of the colonies.

5. Ideal conditions for cellar wintering are the right cluster temperature, a slight amount of moisture, a moderate amount of ventilation, and absolute darkness.

6. A very bad combination is a constantly varying temperature that goes down nearly to the freezing point, and then rises to 55 or 60 degrees. Such frequent changes are very hard on the bees.

7. A high cellar temperature will require very much larger entrances, or possibly the removal of the bottom-boards entirely, leaving the whole bottom of the hive open. There are some cellars where the temperature can not be held down, and in such cases more ventilation is required as well as larger entrances.

8. Occasional disturbances by the beekeeper himself in the cellar do no harm; but these disturbances should be as few as possible, and witl no jar and as little noise as possible. No brighter light than a hand pocket electric lamp should be used. With this, one can easily make his way thr'u the cellar, taking a glance at the entrances and also a glance at the thermometer's in the entrances of some of the hives. $\Lambda$ more durable and lasting light is an electric lamp attached to a full-sized dry battery. Small pocket batteries are usually short-lived.

9. When good colonies winter well the dead bees do not collect on the hive floors nor are they seattered over the cellar floor. The live bees remove the dead ones, leaving them on the cellar floor just below the entrances. If scattered all about, it is plain that they have flown from their hives and have not wintered well. Moreover, if there are several inches of dead bees on the cellar bottom in the spring, the owner of that rellar ought to investigate and ascertain the trouble. No matter if he does bring his colonies thru alive, it could luardly be said that he is wintering his bees success- fully. An ideal cellar is one that will bring the colonies thru the winter in practically the same strength as when they went into winter quarters. No colony should lose more than one-sixth of its bees, and wellwintered colonies will have much less loss than this -in some cases as low as 100 bees.

10. Honeydew, unsealed aster honey, molasses, or syrup from brown sugar, makes a poor feed for indoor wintering. It is much better to have a good honey, well ripened, or syrup made of white granulated sugar.

11. Pollen in the combs does little or no har'm. Indeed, it is an advantage to have some of it ready for next spring after the bees are set out. The old theory that an excess of pollen in the combs is the cause of dysentery is now an exploded myth.

12. Shutting bees in the hive with wire cloth, or closing the entrance in any way, is usually attended with disaster.

13. Bees can be wintered in a common house cellar provided there is not too much variation of temperature. The trouble with most house or vegetable cellars is that they become too warm or too cold. This makes it necessary for the beekeeper to enter the cellar, often opening and closing the cellar windows at night. The disturbance is a bad thing, and the variation of temperature is still worse.

14. A cellar wholly under ground and frost-proof is much safer than the average house cellar.

15. When one has from 100 to 300 or more colonies and the winter's are so cold that there are many days of zero temperature, especially if the locality is subject to high winds, it would be well to build a special bee-repository under ground, large enough to accommodate as many colonies as one would be likely to own. The mistake should not be made of building it too small. It should be constructed on the lines indicated by David Running, as specified in previous pages. Its shape should be long and narrow and wholly under ground. That means that the roof should either be below the frost line by three or four feet, or that the portion of the repository above ground should be covered by an embankment of three or four feet for the sides above ground and three or four 


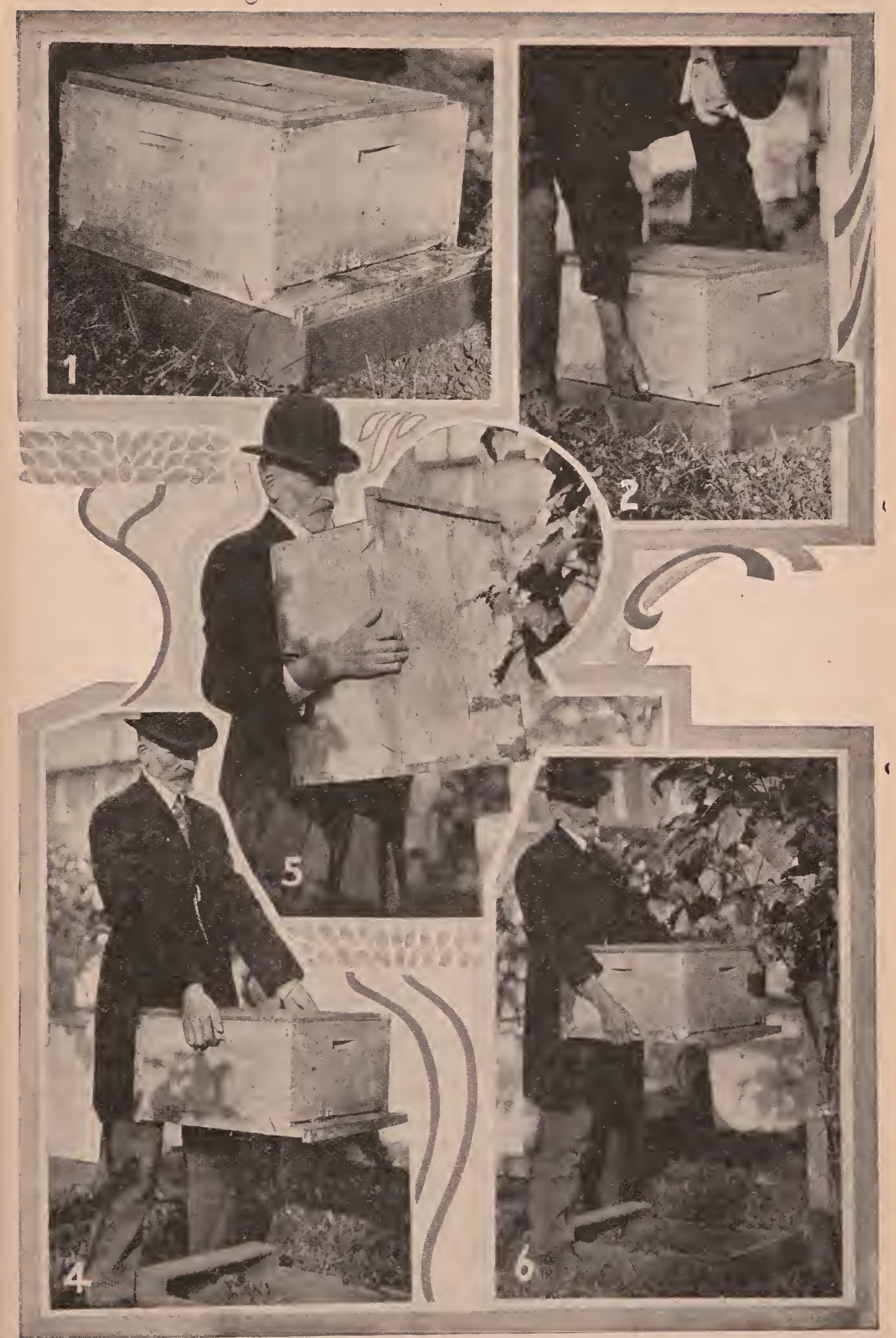

How R. F. Holtermann carries his twelve-frame hives into the cellar. He lifts the hive as slown in Fig. 2, and then brings it up against his body as in Fig. 5. Positions in 4 and 6 put an unnecessary strain on the back, and interfere with walking. 
feet on top. Err on the side of having the repository covered too deep rather than not deep enough. If the earth covering it is not a pure yellow clay that is impervious to water, it is better to make a special roof over it. Sand or gravel should always be covered to keep it from freezing.

16. An electric fan can very often be used to good advantage in ventilating a bee-cellar. Where a cellar under a dwelling house becomes too warm, an electric fan can be stationed in such a way as to force air from outdoors into the room. Bees will stand a comparatively high temperature provided the air is fresh and sweet.

\section{HOW AND WHAT TO FEED BEES DURING MIDWINTER.}

It is generally advisable to avoid feeding syrup during midwinter, either in the cellar or outdoors. If a colony will run out of stores before spring, then thick syrup, two and a half parts of sugar to one of water, may be given all at one feeding. A better winter food next to combs of sealed stores is hard candy as mentioned under the head of CANDY elsewhere, provided it is made right. Plates or blocks of this candy can be laid on top of the frames. If the candy has not been scorched in making, the bees will eluster up under it and winter on it, even tho there is not an ounce of stores in the combs themselves. But as it is a nice art to make hard candy that is just right, and as it is advisable, when possible, to avoid feeding sugar syrup, beekeepers should always have in reserve a sufficient number of combs of good honey saved out from the summer crop. When it is discovered that the colony is short, one or more of these combs can be inserted in place of the empty.

A much better plan yet is to reserve out from the season's crop of honey as many shallow extracting-supers of good honey as there are colonies in the apiary. (See page 236.) It may be argued that the honey in these supers can be sold for considerably more than it would cost to replace the deficiency in the colony with sugar syrup. While this may be true from the standpoint of dollars and cents, the better class of beekeepers are beginning to discover that the honey will go much further, and, moleorer', is much better in the spring when brood-rearing commences.

To take time and make up several batches of syrup that is just right to feed to the bees and stir them up to unnecessary activity, costs not only in time and sugar but in bees; and it may be seriously questioned whether the sugar syrup is cheaper in the long run than the honey that is already in the combs and ready for the bees. Shallow extracting-supers of combs of good honey can be given to a colony in much less time than it takes to feed a like amount of syrup. While it may give that colony more stores than it may actually need before the next crop, it is a life insurance to the colony that will probably yield more money the following summer than one fed just enough syrup to carry it thru until spring, and the honey, if any is left, can be extracter later.

In the language of Mr. G. S. Demuth, a half-depth super of honey is an "auto matic feeder," and the cost of giving it to a colony, so far as time is concerned, is much less than giving it an equal amount of sugar syrup in a feeder. While the syrup may be slightly better for the coldest part of the winter, yet, taking the winter and the spring together, it is not as good.

For a further discussion of these food chambers, see Comb Honex, to Produce, page 236.

\section{DO BEES HIBERNATE?}

The quiescent state or sleep into which bees enter when the wintering conditions are ideal, has been several times mentioned. In this period the bees seem merely to exist. With no activity the consumption of stores is very light.

As shown under Temperature, particularly the temperature of the winter cluster during winter, bees are the quietest when the thermometer is about $57^{\circ} \mathrm{F}$. If it goes below $57^{\circ}$, the bees, instead of clustering, become active, and in the manner explained under TEMPERATURE they raise the heat of the cluster sometimes almost to the brood-rearing point. When, therefore, the temperature of the eluster is either below or above $57^{\circ} \mathrm{F}$., the bees are in anything but a state of sleep or what some have called semi-hibernation. Strictly speaking, bees do not hibernate, and perhaps do not even enter into the condition called semi-hibernation when they are 
the quietest. It all depends on what is meant by that term. But there are some interesting facts showing that bees can for a short time stand low temperatures, and revive like ants and flies that are true hibernators. In the discussion which follows, however, one must not be misled. Yet it is evident that nature has provided means by which bees can stand the temperature of freezing, or below, for a short time. In order that the reader may understand what hibernation really is, a few facts should be presented.

Hibernation of bees was exploited nearly 50 years ago, when it was generally decided, and rightly too, that bees do not hibernate in the ordinary sense of the term (see American Bee Journal for 1885). But they do enter a quiescent state when the temperature has been lowered; and this state is somewhat analogous to the torpor experienced by some animals in a state of true hibernation, during which no food is taken, and respiration is considerably reduced. Dr. Marshall Hall has stated that "respiration is inversely as the degree of irritability of the muscular fiber." If the respiration is reduced without this irritability being increased, death results from asphyxia. Hibernation is usually induced by cold, and the animal under its influence attains nearly the temperature of the surrounding atmosphere, yet can not resist any amount of cold, altho its capacity for doing so varies according to the animal. Some animals bury themselves in holes, like snakes and frogs; others, like the bear. crawl under a pile of leaves and brush where they are still further covered with snow. Thus buried they will go all winter without food or water; but there is a waste of tissue. Fish may be incased in ice and still live. A lively frog may be dropped into a pail of water, four or five inches deep, and exposed to a freezing temperature. Indeed, there may be a thin coating of ice formed over the animal. The next morning, that frog, tho stiff and cold, can be warmed up into activity, but to freeze solid will kill the creature.

Flies, as is well known, will secrete themselves in window-frames and other hidingplaces, subject to cold atmosphere, for weeks at a time, and yet revive on exposure to warmth. As is well known, also, ants have been repeatedly dug out of logs, frozen solid-in fact, fairly enveloped in frost; yet on exposure to warmth they will revive. Some hibernators can endure a freezing temperature, while others, like the bear, woodchuck, and the like, can not. Other very interesting incidents may be taken from natural history; but the purpose of this article is to consider whether bees go into a quiescent state that $a p$ proaches libernation, in which there is low respiration and a small consumption of stores.

Two or three years ago the author put a number of cages of bees with some queens (laying the cages down on cakes of ice) in a refrig'erator. The bees were chilled to absolute stiffness. Every day a cage was taken out and each time the bees would l'evive, including the queen. This plan was continued for several days, and yet the bees would "come to" each time.

The strange part of it was, that the queens went on laying normally when put back in the hives, instead of laying drone egg's as expected. Just what was the temperature to which these bees were subjected can not be told, but probably below $40^{\circ}$ and above $35^{\circ}$, for the doors of the refrigerators were frequently opened, and the ice was constantly melting.

During one winter, when a very cold snap came on-the temperature going down to zero-the author put out some cages of bees, exposing them to the cold wind, which was then blowing a good gale, when the temperature was 5 above zero. It was expected that the bees possibly might be able to survive the shock for a number of lours, and yet revive; but 20 minutes of zero freezing was sufficient to kill them outright. If the bees had been gradually acclimatized to the cold, first being subjected to $40^{\circ}$, then to $35^{\circ}$, and gradually down to the zero point, they would possibly have withstood the shock for a longer time.

When the weather warmed up a little several cages of bees were taken and buried in the suow, with a thermometer so that the absolute temperature might be known. A cage of bees was taken about every two or three hours, and it was found that they could be revived without difficulty; but at the end of 24 lour's the bees, when they "came to," seemed somewhat the worse for 
the experience. 'The temperature in the snow played around the $32^{\circ}$ mark. Bnt the experiments conducted during the summer would seem to slior that bees might stand a temperature of $38^{\circ}$ for a number of days.

Bees on the outside of the ball or cluster, in an outdoor-wintered colony, will often be chilled stiff while those inside have almost a blood temperature. During very sever'e weather, the outside bees may be gradually replaced by those within the cluster; for bees are in constant movement. Experiments show that a starved bee will not stand as much cold as one that is well filled. Beekeepers who have had any experience in wintering outdoors know how repeatedly they liave taken clusters of bees that seemed to be frozen stiff, yet when warmed up before a good fire would revive and appear as lively as ever.

In view of the experiments thus far l'ecorded it would appear that bees might be able to stand a temperature of $40^{\circ}$, or slightly below that, for a number of days; but if a warm spell does not come within a week, or less, those bees in their chilled condition may starve to death. But if it warms up, the cluster will unfold and the bees take food, and so be ready for another "freeze." The author has repeatedly seen eluster's of bees, after a zero spell lasting a couple of weeks, that were dead; but the honey had been eaten from all around them within a radius of an incli $\mathrm{Or}^{\circ}$ more. If a zero spell of weather continues more than a week or ten days, some of the weaker colonies will be found in the spring frozen to death.

If the bee were a true hibernator it would save the beekeepers of the world millions of dollars, because then all that would be necessary would be to establish a sort of cold-storage plant, where the climate was open or mild, and put the bees away for winter. In cold climates it would not be necessary to have cold-storage plants. The bees could be placed outdoor's without protection, and left all winter; yes, they could easily be put on dry combs. Like the ants and flies they would remain in a dormant state; and when warm weather came on they would revive and resume their former activity. But, unfortu- nately, bees are not that kind of insect. That they will go into a quiescent state, or a kind of suspended animation, at a temperature of 57 degrees Fahr., has been clearly proven. During that period they consume the minimum of stores. If the time ever comes when we shall know enough to provide conditions so that a cluster will remain thruout the greater part of the winter at a temperature of about 57 degrees F., it will certainly sare a large amount of stores. But whether those conditions would indicate a state of semilibernation, or even an approach to it, the author is not prepared to say.

\section{WINTERING IN THE SOUTHERN} STATES. - Where bees can fly almost every day in the year, and for tell months are able to gather a little honey or pollen, no special protection other than single walls has hitherto been considered necessary. The fact that the wintering problem in the Soutl is not serious would seem to indicate that no special precaution is needed; but some experience that the author has liad in wintering bees in California, Virginia, Alabama, and Florida indicates that, even where the bees can fly almost every day in the year, a moderate amount of protection can be given to advantage. This should be in the form of light packing cases and of windbreaks to shut off the prevailing winds. While this may seem to be an unnecessary expense, the saving in brood and stores will pay for it in time. As will be seen under TemperaTURE, bees, in order to keep up the proper amount of lieat, must exereise, and this means a consumption of stores. Such activity causes the bees to fly out on a chilly day, and many never return. Again, where clusters are not large there is considerable brood in the Southland which clitls and dies. This is a heavy drain on the colonies. While a colony can survive it, the beekeeper could well afford to furnish a little protection to save this brood. See WinTERING OUtdoors and Spring ManageMENT.

As las been pointed out elsewliere under Wintering Outdoors and Spring ManAGEMENT the rapid changes of temperature from morning until night-warm sunsline during the middle hours of the day, low 
temperature or freezing at night-are very hard on bees in many of the soutlern States. The lot sun beating on the walls of the hives forces the bees out, and in an hour or so there may be a cold, chilly wind that will prevent them from getting back. They get some pollen or nectar, wlich starts breeding. As the cool nights come on the survivors attempt to hover this brood and failing to do so on account of so many bees being lost in the fields, some of the brood is clitled.
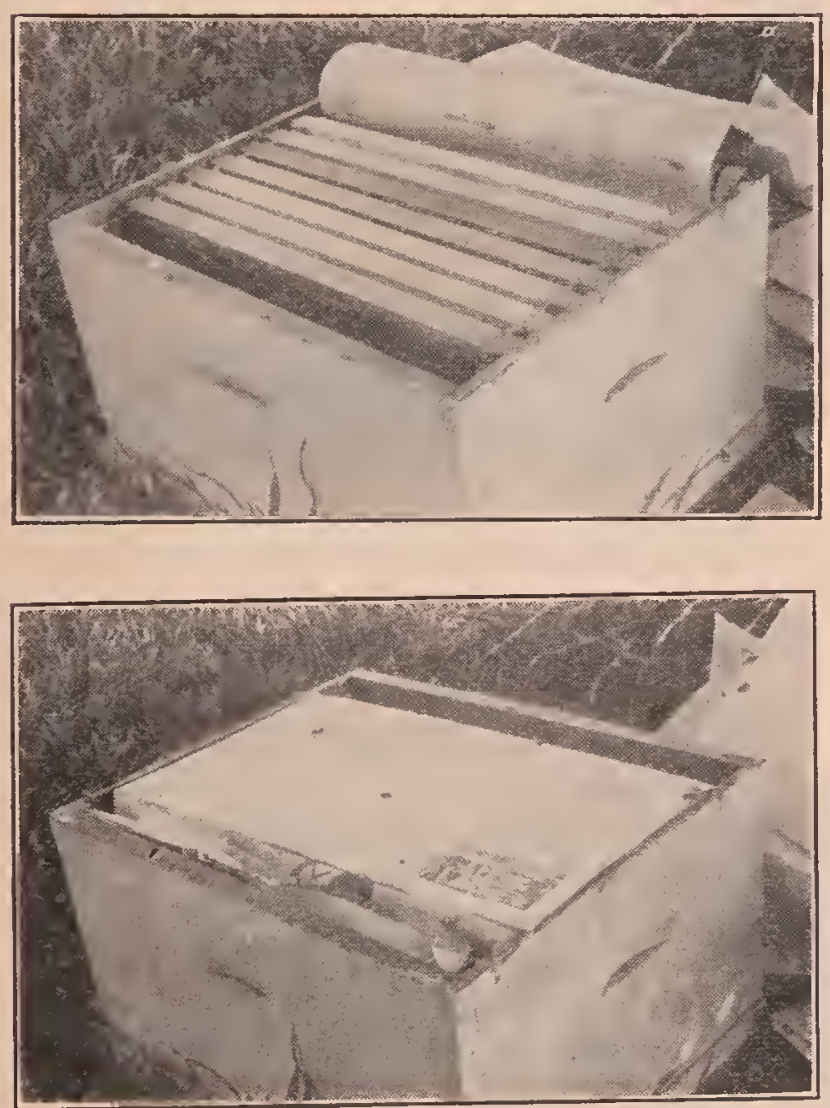

Figs. 1 and 2.-Method of packing bees with newspaper for semi-tropical states. The brood-nest is reduced down in a ten-frame hive to six or seven frames, using those that contain the most stores. These are placed centrally in the hive and covered with newspaper. The space on either side is then filled with folds of newspaper, after which the cover is put on. The smaller brood-nest with packing on the sides is better protected and will consume less stores.

A little protection in the form of paper wrappings or an outside protecting case would save heavy losses of bees. In the southern States, and particularly in California, winter losses-not of colonies but of bees-are as great as in some of the northern States. The autlior feels very certain that a moderate amount of protection would mean thousands upon thousands of dollars of saving to the beekeep30 er's in the warm States, where it is thought that there is no wintering problem.

Dr. E. F. Plillips, in charge of apiculture in the Bureau of Entomology, Washington, D. C., also believes that sone winter protection in the South will prevent some loss of bees, if not of colonies.

Altho the advantages would seem to favor some packing in the Southland, it will probably be some time before its beekeepers below the Ohio River will realize its importance enough to provide the necessary winter protection.

A very serious difficulty in wintering in the South is starvation. So serious is this, it may be doubted whether the winter problem in the South is not more serious than in the North. Bees require more stores per colony than in the North. When they can fly almost every day in the winter, breeding will be kept up more or less, with the result that the colony will use two or three times as much honey during the winter as a similar colony in the North, packed. Almost constant breeding for ten months uses up the stores at a very rapid rate. It is important for one to examine his colonies occasionally to see if they are running short; and, if so, he should supply them with sugar syrup, or combs of honey.

The fact that so many colonies become weak in the Southland makes it possible for European foul brood to make rapid headway. This disease is being scattered rapidly all over California and the southern States. It thrives on weak colonies, and the reason colonies are weak is because the bees have insufficient stores or because they are improperly packed or both. It is apparent that in the southern climate there is a winter problem as well as in the Nortli.

WIRING FOUNDATION--Under the head of Coms Foundation in this work, pages 210-213, are shown various methods of wiring frames. The purpose of the wires is twofold: (1) to keep the foundation from stretching wlile being drawn out, or afterward, when filled with honey; and (2) to liold the built-out combs solidly in the brood-frame.

Combs are often roughly liandled during shipment or in hauling. They are likewise put to a severe test in the extractor, especially if run at high speed. It is for this 
reason that the wires passing thru the endbars, or top or bottom bars, are used extensively by beekeepers everywhere, and not because they are trying to prevent sagging or stretching of the comb itself while being drawn out.

For several years back several experiments have been conducted to make a foundation before it is put into a frame so it will not stretch. Some 35 years ago, J. Van Deusen \& Sons, in New York, made a foundation that had vertical wires incorporated in it during the process of manufacture. This foundation had a flat base or flat bottom, and for that reason it was never extensively used, because the base was unnatural, and had to be reconstructed by the bees.

In later years, at various times, efforts have been made to incorporate vertical wires, or semi-vertical wires, in the ordinary or natural-base foundation, the purpose of the wires being to prevent the sheet from stretching; but as there was no method of fastening these wires already in the foundation to the frames themselves the scheme never became very popular. During 1922, however, Dadant \& Sons introduced to the beekeeping world a vertically wired foundation. This differed from the foundation tom-bar it is advised that a top and bottom horizontal wire be used to hold these sheets in place; and it may be questioned whether four horizontal wires would not be better.

Experience has shown, however, that when vertical or diagonal wires cross horizontal wires there is some tendency on the part of the bees to gnaw holes in the wax at the point of intersection. This is more apparent some seasons than others, and especially during a dearth of honey. These holes, however, will be closed up after a good flow the following season, but sometimes with drone-cells in place of worker.

THE THREE-PLY COMB FOUNDATION.

During 1922 the A. I. Root Company perfected a three-ply comb foundation

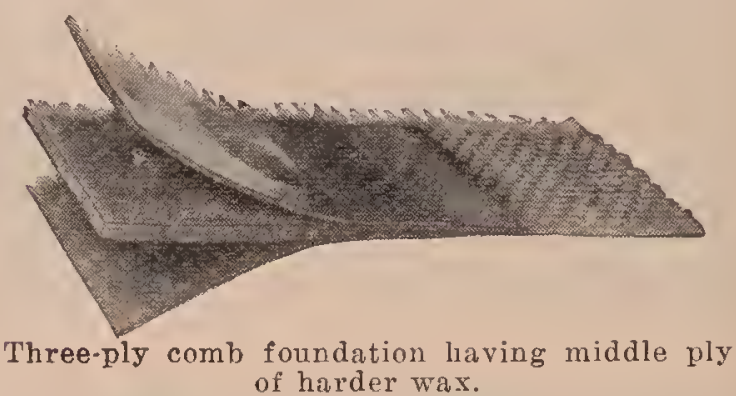

which they had tested out extensively during the season under conditions when bees would be liable to make holes at the points

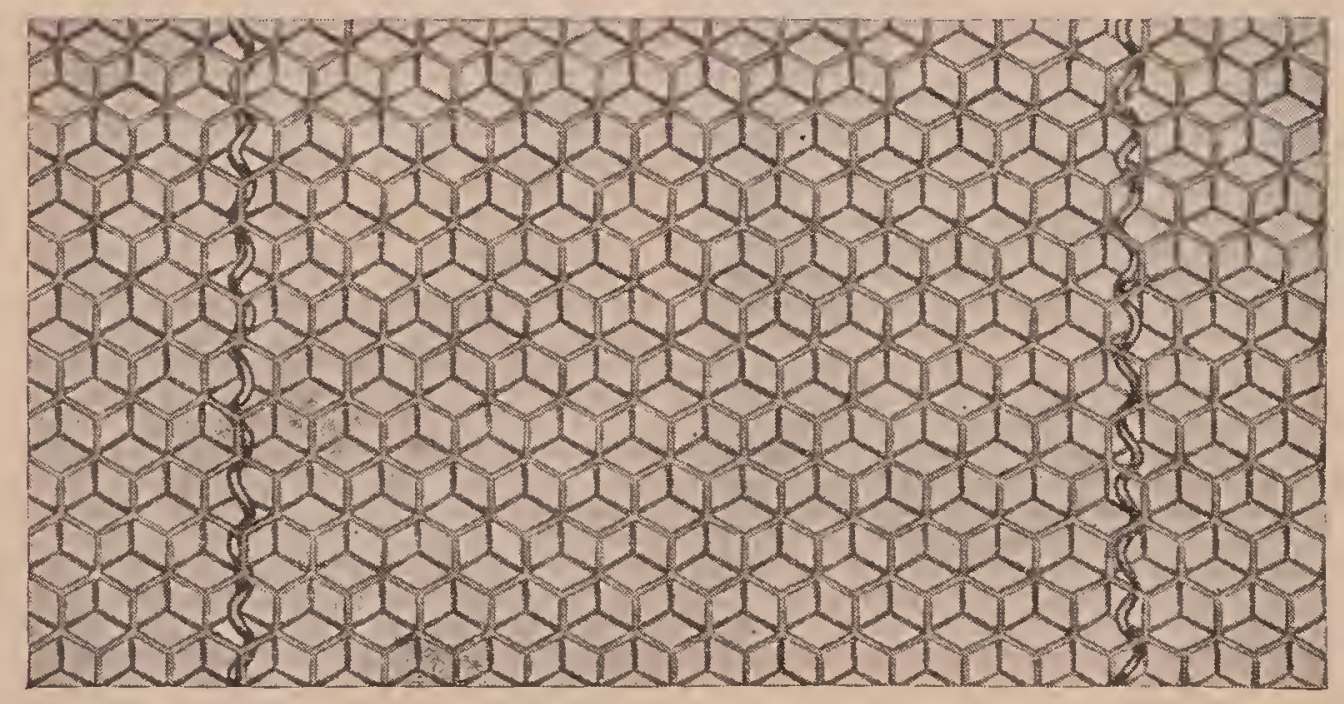

Dadant wired foundation, showing how the colrugated wires are imbedded in the foundation at the factory.

put out by the Van Deusens in two respects. First, the base of the cell walls was pointed; and, second, the wires were larger and corrugated to make them stiffer. By the use of a grooved wedge top-bar and and a split bottom-bar it is claimed that these sheets of wax with vertical wires will be held in place. Without the split bot- of intersection where diagonal wires cross horizontal wires in ordinary wiring. The center ply consists of a pure beeswax toughened by the addition of a small percentage of vegetable wax. The two outside plies are made of extra soft pure beeswax. It is constructed on what is known in the arts as laminated steel, such 
as is used on burglar-proof safe-doors, and laminated three or four ply wood such as used in chair-bottoms and other places where there is a great strain applied. In the same way this combination of a three-ply foun. dation with a hardened center sheet and a soft sheet of pure beeswax on either side is over twice as strong as any other foundation on the market. The photo of a boy hanging on a sheet of it illustrates its great strength. When it is understood that the ordinary foundation of the same thickness or weight will sustain less than half this weight, it will be seen that this new product gives promise of being a great acquisition. From the numerous tests that were made of it in the live during the summer of 1922 , this lam-

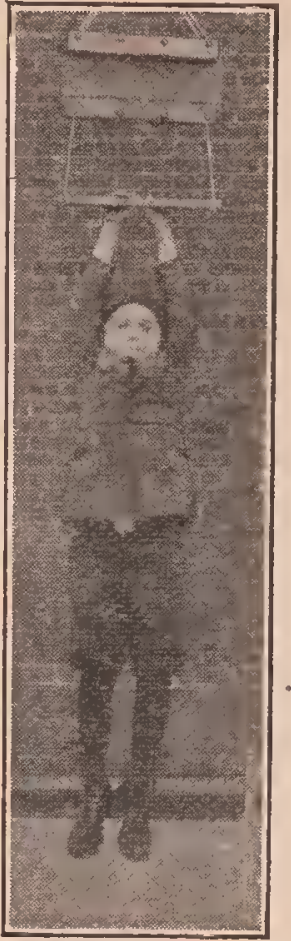

68-p o u n d b o y supported by a single sheet of three-ply co m b foundation. nated foundation resisted all stretching while being drawn out. It may be put into ordinary brood-frames without any changes. While it can be used without wires it is recommended that it be put on to four horizontal wires, said wires passing through the end-bars in the regular way. This makes a non-sagging comb that will be securely fastened to the frame of the regular pattern.

Sheets of this three-ply foundation put into the live during a dearth of honey will be drawn out into beautiful comb. The outer surface, being of softer wax, will be drawn out readily, while the tough center means that there will be little or no stretching, and at the same time makes a comb that will stand rough usage, even when being hauled over the roads or when whirled in an extractor at a high speed.

A feature that will be appreciated is that there will be no gnawing on the part of the bees around the wires, as no vertical or diagonal wires are needed; and since there are no intersecting wires there will be no holes.

One swallow does not make a summer. One year's test of any article or device may not be sufficient to show up a defect, if any, that may appear two or three years hence. While the author believes that both of the devices here shown to prevent the stretching of the sheet of foundation as it leaves the factory have merit, it will take more time yet before definite conclusions can be drawn.

WORKER COMBS.-See COMBS.

WOMEN AS BEEKEEPERS. - See BeEKeEping FOR WOMEN.

\section{$X Y Z$}

XENOPHON. - A Greek historian and general who refers to poisonous honey. See Poisonous Honey.

XYLOCOPA.-To this genus belong the carpenter bees, among which are the largest bees in the world. They are so called because they excavate with their powerful jaws tunnels a foot in length in solid wood. The cells are about an inch long, and are separated by partitions made of small chips remented together in a spiral.
The eggs are laid on masses of pollen, moistened with honey, the pollen masses being about the size of a bean. A common species in the eastern United States is $X$. virginica.

YELLOW POPLAR.-See TULIP TREE. YELLOW SWEET CLOVER. - See Sweet Clover.

ZINC, Perforated. - See Drones, Extracted Money, and Swarmina. 


\section{Beekeepers' Dictionary}

Abdomen. - The posterior of the three parts into which a bee is divided, containing the larger part of the digestive organs. In the female it consists of six visible segments or rings, and seven in the male. See "Anatomy" in the body of this work.

Absconding swarm.-A swarm which leaves for new quarters. See "Absconding Swarms", in the body of this work.

Absorbents. - Materials more or less porous placed over the brood-chamber in winter, which permit moisture to escape without much loss of heat.

Acarapis woodi.-The Latin name of the parasitic mite causing the Isle of Wight disease. It was formerly called Tarsonemus woodi, but Hirst, an English specialist in mites, has proposed to place this mite in a new genus Aearapis (acarus, mite and apis, bee).

Adair frame. - $13 \frac{3}{8}$ inches long, $11 \frac{1 / 4}{4}$ inches deep.

After-swarms.- Swarms which leave a given colony after a swarm of the same season has already left it.

Albino.-A bee which is lighter colored than normal or pure white. $\Lambda$ sport or freak of nature.

Alighting-board.-The projection before the entrance to a hive.

American foul brood.-See 'Foul Brood.'

American frame.-12 inches long, 12 inches deep.

Antenna (plural antennae).-A pair of slender, jointed appendages inserted on the head, which bear sense organs. See "Anatomy" in the body of this work.

Anther.-The upper 2-lobed portion of the stamen consisting usually of two or four cells, in which the pollen is produced. A 4-celled anther at maturity may become 2-celled by the breaking down of the partition between the pair of cells in each anther-lobe.

Aphis.-A plant louse which secretes honeydew.

Apiarian.-Pertaining to bees or an apiary. A term not much used now.

Apiarist. - A beekeeper.

Apiary.-A collection of colonies of bees; also the yard or place where bees are kept. See "Apiary" in the body of this work.

Apiculture.-Beekeeping.

Apidae.-The family to which the honeybee belongs.

Apis.-The genus to which honeybees belong.

Apis dorsata.-See "Giant Bees."

Artificial cell cup.-See "Cell Cup.'"

Artificial fecundation.-The impregnation of virgin queens in confinement

Artificial fertilization.-See "Axtificial Fecundation."

Artificial pasturage.-Plants purposely cultivated for their nectar.

Artificial pollen.-Rye meal, pea flour, or other substances fed as substitutes for the pollen of flowers.

Artificial swarm.-A swarm made by dividing a colony of bees by brushing or shaking. See "Brushed Swarms.'

Ash.-The residue remaining after incineration. The mineral constituents of honey ash are iron, calcium, sodium, magnesium, sulphur, potas. sium, whosphorus, manganese, etc. The total weight of honey ash is about 15-100 of 1 per cent of the weight of the honey.

Automatic hiver.-See "Self-hiver."

Baby uncleus. - A miniature hive of bees consist. ing of not more than 200 or 300 individuals; for the mating of queens only. It is distinguished from a regular nucleus having regular Langstroth frames in that it lias miniature frames.

Bacillus larvae.-The bacteriun or germ which causes American foul brood.

Bacillus pluton.-The hacterium or germ which causes European foul brood.

Balling a Queen.-Honeybees may cluster densely around a queen, especially a strange queen, foming a ball an inch or more in diameter. In some cases the queen is released unharmed, in others she is killed.

Banat bees.-A race of bees, resembling the Carniolan, from the Banat region, Hungary.

Bar-frame. - A name sometimes applied to a mov. able frame in Great Britain.

Beebread. The pollen of flowers gathered by the bees, mixed with a little honey, and deposited in the comb. See "Pollen'" in the body of this vork.

Bee-brush.-A brush used in removing bees off their combs.

Bee culture. - The care of bees.

Bee-dress.-A dress designed for the use of bee. keepers while working with bees.

Bee-escape. - A device to get bees out of supers or buildings, so constructed as to allow bees to pass through in one direction, but prevent their return. See "Comb Honey" in the body of this work.

Bee-gloves.-Gloves worn to protect the hands from stings and from propolis.

Bee glue.-See "Propolis."

Bee-gum.-A term much used in the South for a hive of any kind. It usually means a box hive. See "Box Hive."

Beehive.-A box or other contrivance for holding a colony of bees. See Hive.

Bee-house.-A house constructed to contain colonies of bees. See "House Apiary" under "Apiary," in the body of this work.

Bee line.-The shortest distance between two points. See "Bee-hunting"' in the body of this work.

Bee louse.-A parasite, probably a commensal, found chiefly on queens, young bees, and drones. It is comparatively harmless. The bee louse (Braula caeca) belongs to the order of flies (Diptera) and to the family Braulidae. Only a single species is known.

Bee metamorphoses.-The bee passes through three stages before becoming a perfect insectfirst the erg, then the larva, and next the nymph. The following will serve to show how this is accomplished: Queen, Worker, Drone, days. days. days.

Incubation of the egg...... 3 3

Time of feeding the lari... Larva spinning cocoons.... 1

Resting period ..............

Passing from larva to nymph.. 1

Time in the nymph state...3

Total period of growth... $\overline{15}$

Hatching takes place on....4 4

Bee leaves its cell..............

Bee flies ........................ See "Development of Bees" in the body of this work.

Bee moth.-A moth whose larvae destroy honey. combs, eating the wax; a wax moth.

Bee paralysis.-A disease of adult bees in which the wings have a trembling motion, and the bees have a shiny appearance; of little account in the 
North, but sometimes severe in the South. See "Dikeases of Bees" in the body of this work.

Bee pasturage.-Flowering plants from which bees gather nectar.

Bee-pest. - A name sometimes used for foul brood. Bee plants.- Honey plants. Common plants which vield nectar available to honeybees in quantity sufficient to render them valuable in bee culture

Bee-space.-An open space in which bees build no comb or deposit a minimum of propolis. It is a passage between combs or part of a hive of from $1 / 4$ to $3 / 8$ inch. Five-sixteenths is usually taken as the average. See "Frames" in the body of this work.

Beeswax.-The wax socreted by honeybees on the ventral abdominal segments, and used in build ing their cells. It is composed in variable quantities of myrocin, cerolein and cerotic acid.

Bee-tent.-Tent of wire cloth or netting large cnougl to contain a hive and the operator, in which becs may be manipulated without being troulled by robbers. See "Robbing" in the body of this work.

Bee-tree.-A hollow tree occupied by a colony of wild bees. See "Bee-hunting" in the body of this work.

Bee-veil.-A net veil for protecting the head from the attack of bees.

Beeway sections.--Sections having insets at the edges so as to make passages for the bees when the sections are crowded close together.

Black bees.-Brown bees. German bees. They are less gentle, less prolific, and do not resist brood diseases as well as Italian bees. The German bee was introduced into New England in 1638.

Bottom-board.-The floor of a beehive.

Box hive.-A plain box used for housing a colony of bees. Much used in the South.

Box honey.-Honey stored in small boxes or sec tions.

Black brood.--Old name for European foul brood.

Brace-comb. -The terms "brace-comb" and "burr. comb" are often used indiscriminately as mean. ing the same thing. More exactly, a brace-comb is a bit of comb built between two combs to fas. ten them together, or between a comb and adjacent wood, or between two wooden parts, as between two top-bars; while a burr-comb is a bit of wax built upon a comb or upon a wooden part in a hive, seeming to have no object but to use up wax.

Braula coeca.-See "Bee Louse."

Breathing pores.-See "'Spiracles."

Brimstoning.-The operation of killing a colony of bees with sulphur fumes. See "Box Hives" in the body of this work.

British standard frame.-A frame 14 inches long by 81,2 deep.

Brood.-Young bees in the larval and pupa state not vet emerged from their cells.

Brood-chamber. - That part of the hive in which the brood is reared. May be used as a super in extracting.

Brood-comb.- One of the combs in the brood-chamber. See "Brood" and "Combs" in the body of this work.

Brood-nest.-That part of the brood-chamber occupied by eggs and brood. The term is also used to apply to that part where the bees are clustered when they have no eggs or brood.

Brood-rearing.-Raising bees from the egg.

Brushed swarm.-An artificial swarm made by brushing or shaking part or all of the bees of a colony into an empty hive, thus anticipating and preventing a natural swarm. It is also called "shaken swarm" and "shook swarm," although some object to "shook swarm" as being un. grammatical. See "Artificial Swarming" in the body of this work.

Bumblebee.-A iarce hairy social bee of the genus Bombus; liumblebee.
Burr-comb.-See "Brace-comb."

Button or bouton.-The enlarged part at the tip of a bee's tongue.

Candied honey.-Honey that has granulated and become solid. See 'Granulated Honey.'

Cap.-1. A hive cover. 2. The covering of cells containing brood or honey; the capping; the sealing. 3. To cover a cell with a capping; to seal.

Capped brood.-Brood sealed over by the bees 8 or 9 days after the egg is laid; sealed brood. See "Sealed Brood."

Carniolan bees.-A grayish-black race of very gentle bces from Carniola, Austria. They gather a very small quantity of propolis, but swarm ex. cessively.

Carton.-A pasteboard box for holding a section of honey.

Cast.-A second swarm; also applied to any swarm after the first.

Caucasian bees.-A gentle race of black or darkcolored bees introduced into America from the Caucasus. They are much inclined to swarm and to propolize.

Cell.-One of the hexagonal compartments of a honeycomb.

Cell cup.-A queen-cell when it is only about as deep as it is wide. Artificial cell cups are made as well as natural. See "Queen-rearing" in the body of this work.

Cell-protector.-A receptacle made of wire cloth or of spirally wound wire, which protects the sides of a queen-cell from the attacks of bees, but leaves the apex of the cell uncovered.

Ceresine.-A white wax-like substance, resembling paraffin, which is derived from the mineral ozocerite. It is used in adulterating beeswax.

Chaff hive.-A hive having double walls filled be. tiveen with chaff. The term has gone into disuse and in its place has come double-walled hive that may use any packing. See "Double-walled Hive.",

Chorion.-The membrane or shell enclosing the egg. and in the honeybee covered by a network with oblong hexagonal interstices or meshes.

Chrysalis.-See pupa, the more usual name.

Chyle.-In human physiology chyme is the food which after gastric digestion passes out of the stomach, and becomes after intestinal digestion a milky fluid known as chyle. Probably neither of these terms should be used in insect phy. siology. It is almost if not quite certain that brood food or royal jelly is not regurgitated "chrle," or the contents of the ventriculus (the so-called "chyle stomach"). See "Royal jelly."

Chyme.-See "Chyle."

Clamp.-A winter repository for bees, made in sandy soil by digging a trench in which the hives are placed, and then covered with straw and earth.

Cleansing flight.- The flight of the bees from the hive after long confinement, as in the spring, when they void their feces in the air.

Closed-end frames.-Frames with end-bars wide enough ( $1 \frac{3 / 8}{8}$ or $1 \frac{1}{2}$ inches) so that their edges come in contact thcir entire length.

Colony.-A community of bees having a queen some thousands of workers, and during part of the year a number of drones: the bees that live together as one family in a hive.

Comb.-See "Honeycomb."

Comb-basket.-That part of a honey-extractor in which the combs are held. See "Honey-ex. tractor."

Comb-carrier.-A receptacle in which one or more combs may be placed and covered, so as to be easily carricd, and protected from robbers.

Comb foundation. - Thin sheets of beeswax stamp. ed to imitate a base on which the bees will construct a complete comb. 
Comb-foundation machine.-A machine for stamp. ing the foregoing.

Comb-guide.-Strips of wood in lieu of founda tion used as a guide in the construction of combs.

Comb honey.-Hones in comb together with the comb.

Corn syrup.-Mixture of dextrin, maltose. dex trose and water in nearly equal narts, formen by liydrolysis of corustarch.

Cross.- When races of bees are bred together the resulting progeny is called a cross.

Cyprian bees.-A race of bees native to the Island of Cyprus. They resemble Italian bees. but are smaller. They sting so viciously that they have been generally discarded in the Uuited States.

Decoy hive.-A hive placed with the object of at tracting passing swarms.

Dequeen.-To take the queen from a colony of bees; to unqueen.

Dextrin.-British gum, a mucilaginous material formed by heating starch. The halfway stage in the conversion of starch to the sngar dex trose. Harmful to bees: a good food for humal beings. Honeydew is unsuitable for bee-feed be cause it contains dextrin.

Dextrose.-One of the five important sugars. (See sugar.) Known also as grape sugar and as glucose. $D$. is found in fruits, honey, invert sugar and commercial glucose or corn syrup.

Dividing.-Separating a colony in a manner to produce two or nore colonies. See "Artificial Swarming.'

Division-board. - A thin board of the same size as the inside length and width of the hive, used to contract the size of the brood-chamber or to divide it into separate compartments; often called "dummy"; see "Dummy."

Double-walled hive.-A hive having an inner and outer wall, the space betweell whicl is filled with packing material such as planer shavings, leaves or chaff. See "Chaff Hives."

Dovetailed hive.-A hive with Langstroth frames. the hive having interlocked corners after the manner of lock cornering. It is in reality a lock-cornered hive.

Drifting of bees.-Bees wintered outdoors, after several weeks of confinement, on the first warm flight day may sometimes drift into wrong entrances. Similarly, bees put out of the cellar on the first warm day in the spring may drift in a like manner. This results in some colonies hecoming very strong and populous, while others will become weak. See "Drifting", in the body. of this work.

Drone.-Male bee.

Drone brood.-Brood which matures into drones, bred in larger cells than worker bees.

Drone comb.-Comb having cells which measure 4 to the inch. Drones are reared in drone comb; a.Iso honey is stored in it, but not often pollen. Drone comb is about one inch thick when used for brood; when used for honey it may be very much thicker. Drone comb has about $18 \frac{1}{2}$ cells to the square inch on each side.

Drone egg.-The egg from which a drone hatches -an unimpregnated egg.

Drone-trap-See "Queen-trap."

Drumming.- Pounding on the sides of an inverted hive to malke the bees ascend into another hive placed over. In Englaud it is called 'driving.' See "Transferring" in the body of this work.

Dummy.-A thin board of the same size as a frame, or a little sinaller, having a top-bar nailed on top. See "Division-board."

Dysentery.-Diarrhea or an affection in which an accumulation in the intestines causes the bees to discharge watery feces in the hive or on the outside front of the hive.

Dzierzon theory.-A set of 13 propositions put forth by Rev. John Dzierzon (pronounced Tseer tsone) in the middle of the 19 th century, pro- pounding the then novel idea of parthenogenesis. See "Dzierzon Theory" in the body of this work.

East Indian bees. - The eommon honeybee of southern Asia (Apis indica) is smaller than the Italian bee and builds smaller worker broodcells. Under the crude methods employed a surplus of only 10 or 12 pounds of honey is obtained. The smallest species of the genus Apis (A. florea) is also a native of the East Indies. The combs are attached to a shrub or sniall tree in the open air. See "Giant Bees."

Egyptian bees. $-\Lambda$ race of bees which has been knowu for many thousand years in Egypt. They are smaller than Italian bees. more irritable. rear a great uumber of drones, and are much less valuable.

Embryo.-The germ of the bee in the egg.

Emerging brood.- Young bees in the act of cutting off the cappings. of their cells and then emerging.

Entrance.-The opening at the front of a hive to allow the bees to pass out and in. In America the entrance is almost universally at the bottom of the hive. In Europe it is often higher up.

Entrance bloeks.-Pieces of wood for regulating the size of the entrance.

Enzymes.-Ferments, as maltase, lactase, diastase and pectase, which by contact act as accelerating agents in chemical changes without actually taking part in the reaction. In germin. ating seeds diastase hastens the transforma. tion of starel into sugar. Lipase aids in the breaking up of fats. The effect of an enzyme resembles that of a lubricating oil on the motion of an engine. An enzJme is nlso called a catalyst (power to decompose) and its effect on the reaction catalysis. Little is known of their origin. During a chemical change the quantity of the enzyme does not decrease.

European foul brood.-See "Foul Brood.'

Excluder.-A device consisting of oblong perforations or wire bars so spaced that they will exclude queens or drones but admit workers.

Extracted honey.-Honey obtained from combs by means of centrifugal force.

Extracting.-The act of taking honey from the combs by means of an extractor.

Extractor. $-\Lambda$ machine consisting of a round can in which is mounted a revolving reel carrying a series of $c o m b$ pockets. The rotation of the reel, carrying a set of combs from which the cappings have been removed, throws the honey out by centrifugal force without destroying the combs.

Extra-thin-super foundation.- Comb foundation running about $13 \frac{1}{2}$ square feet to the pound. See "Comb Foundation."

Fdn.-An abbrevation for the words "coml foun dation."

Feces.-Excreta of hees.

Fecundate.-To fertilize; to impregnate. The queen is fecundated upon meeting the drone, and is theu capable of laying eggs that will produce workers or qucens.

Feeders.-Appliances for feeding bees artificially. Femur.-Thigh of the honeybee.

Fence.-A slatted separator resembling an ordinary wooden fence. It is used as a guide to compel the bees to build combs that are straight.

Fertile.-A fertile queen is one that has mated with a drone.

Fertilize.-A queen's eggs that are to produce workers or queens are fertilized on their out ward passage by receiving one or more of the spermatozoa contained in the spermatheca of the queen. Drone eggs are unfertilized.

Field bees. - When worker bees become about 16 days old, they begin the work of flying abroad to collect nectar, pollen, water and propolis and are then called field bees.

Fielders.-Field bees.

Fixed frames.-Frames that do not liang loose in 
the hive, but touch at one or more parts of the end-bars; self-spacing frames. See "Frames, Self-spacing," in the body of this work.

Fondant. - A soft bee-candy used for feeding bees in winter or for queen or shipping cages; some tines made of glucose and granulated sugar, but more often of honey and powdered sugar. See "Crood Candy.'

Formic acid.-A colorless corrosive liquid com pound (HCO.OH), forming a very small but important part of honey.

Foul brood.-A malignant contagious disease of bees affecting the brood. There are two distinct types-one American foul brood (Bacillus lar. vae), and the other European foul brood (Bacillus pluton).

Foundation.-See "Comb Foundation."

Foundation-fastener.-A device for fastening foundation in brood frames or sections. There are several different patterns of them.

Foundation splints.-Wooden splints aloout 1-16 inch square, embedded vertically in the foundation of a brood-frame to prevent sagging. See "Comb Foundation" in the body of this work.

Frame.-A device consisting of a frame of wood of a suitable size to hold a comb and so con structed that a series of them may be held a bee-space apart in a vertical position in a box called a hive. The only practically movable frame hive was invented by L. L. Langstroth in 1852 .

Fructose.-See "Levulose.'

Fumigate-To submit to the fuines of sulphur. carbon bisulpbide or other disinfectant. Combs are fumigated to kill the eggs or larvae of the bee moth, and bees are sometimes killed by iumigation. See "Moth Miller" in the body of this work.

Galleria mellonella. - The Latin name of the larger wax moth. See "Moth Miller" in the body of this work.

Ganglion (plural, ganglia).-A nodular enlargement consisting of an aggregation of nelve-cells that receives and sends forth nervous impulses and serves to stimulate organic and psychical action: a nerve center.

Giant bees, Apis dorsata.-Natives of India, and the largest honeybees in the world. There are prohably several varieties of this species. All of them build huge combs in the open air, often from five to six feet in length and from three to four feet in width. which they attach to overhanging ledges of rock or to large limbs of trees. When attached to the latter they are built singly; not capable of domestication.

Glucose.-1. A synonym for dextrose, q. v. 2. A synonym for corn syrup, $q$. v.

Go-backs.- Unfinished sections which are returned to the hive to be finished.

Golden bees, or Goldens.-Colonies in which many of the workers show four or five yellow bands.

Good candy.-See "Queen candy."

Grafting.-Applied by beekeepers to the process of removing a worker larva from its cell into a queen-cup, with the view of having it reared into a queen. See "Queen-rearing"' in the body of this work.

Grape sugar.-See "Dextrose."

Granulated honey.-See 'Candied Honey.'

Green honey.-Uuripe honey.

Half-depth supers. - Tne same as any ordinary extracting-super, but half the deptli of the stand. ard Langstroth

Hatching brood.-Young bees just gnawing their way out of the cells. Incorrectly used for emerging brood.

Heddon frame. $-5 \frac{3}{8}$ inches deep by 18 1.16 in length.

Hermaphrodite bees.-Bees having characters com. mon to both sexes, as a worker head, and drone thorax and abdomen. or the reverse; or onehalf of the head is that of a worker, and the other half that of a drone. As there may be a combination of sexual characters Siebold called them hermaphrodites. Tlie cause is unknown.

Hive.-1. Home for bees furnished by man. The modeln hive consists of a series of movable frames held in a vertical position a bee-spacc apart in a box of suitable size. See "Frame" sec also "Hives"' in the body of this work. 2. To put a swarm in a hive or to induce it to enter a hive.

Hive-tool.- A tool used to pry up supers, pry frames apart, etc. See "Manipulation of Colonies" in the body of this vork.

Hoffman frames. - Self-spacing frames having endbars enough wider at the top to provide the proper spacing when the frames are placed in contact.

Honey.-The nectar of flowers gathered by the bees, and so changed by them that it becomes honey. According to the national pure-food law, "Honey is laevorotatory, contains not more than 25 per cent of water, not more than $25 / 100$ of 1 per cent of ash, and not more than 8 per cent sucrose (cane sugar).' Honey is composed largely of a nixture of the two sugars, dextrose and levulose, dissolved in about 17 per cent water. It also contains small amounts of sucrose, mineral mattel, protein, enzymes, etc.

Honeybee.-The honeybee belongs to the class Insecta, order Hymenoptera, superfamily Apoidea or Anthophila aud family Apidae. In 1758 Linnaeus named the honeybee Apis mellifera (honey-bearer), and three years later (1761) chang ed the name to Apis mellifica (honey-maker). Dalla Torre recognizes in the genus Apis over 180 species. Races or varieties of the domestic bee are also distinguished by the names of the geographical localities in which they occur and from which they have been exported, as Italian, Carniolan, Syrian, Cyprian, Banat, Caucasian and Tunisian.

Honey-board.-A slatted board placed between the brood-chamber and the honey-chamber to break the continuity of the two; formerly a board with holes in it to support the receptacles of comb honey. A queen-excluder is sometimes called a honey-board.

Honey-box.-A box for comb honey, closed on all sides, and provided with holes to allow the bees access. Almost obsolete.

Honeycomb. - Two series of waxen cells with a septum between them, which septum serves as the bottom for the cells of both series. In the Bible honeycomb means comb honey. See "Drone Comb"' and "Worker Brood" in the body of this worls.

Honeydew.-A sweet liquid excreted by insects, chiefly plant-lice and bark-lice, on the foliage of shrubs and trees. It was formerly believed to fall from the atmosphere. A large amount is gathered by honeybees.

Honey-evaporator.-A machine for removing water from honey deemed too thin.

Honey-extractor. - A machine consisting of two or more comb pockets or baskets arranged to revolve around a central shaft for throwing the honey from combs by centrifugal force. See "Extractor."

Honey-gate.-An iron faucet used for drawing honey from barrels, cans or extractors.

Honey-harvest.-The time when bees are gathering a surplus, or more than enough for their daily needs.

Honey-house.- $-A$ building for the purpose of honey extraction, storage, ete.

Honey-knife.-A knife used to shave the cappings from combs of sealed honey preparatory to extracting.

Honey-pump.- A device operating on the rotary principlc for elevating honey from a honey-extractor or tank into another tank.

Honey-stomach.-Honey-sac. An enlargement of the posterior end of the oesopliagus lying in the front part of the abdomen, the function of 
which is to hold the nectar gathered by hecs from flowers. The walls are very distensible.

House-apiary.-1. An apiary kept in a specially constructed building; 2 . The building itself which contains the hives, the walls of the build. ing containing holes through which the bees pass out and in.

Hybrids.-A cross between different species, or between varieties of the same species, as be tween black and Italian bees.

Hymettus.-A mountain district of Greece famous for its wild-thyme honey, and celebrated in classic poetry and history.

Imago.-The fully developed bee or other insect.

Imbedding tool.-A device for crowaing the wire of the frame into the sheet of comb foundation.

Introduce.-To give a colony a strange qucen. taking precautions so that she will not be killed by the bees.

Introducing.-Giving a strange queen to a colony of bees. Unless certain precautions are taken. a colony is apt to kill a queen to which they are not accustomed. Introducing is generally performed by hanging the queen in a cage in the midst of the strange bees several days until she acquires the odor of the hive.

Introducing-cage.-A small box of wire and wood.

Inversion.-The process of turning a hive upside down to compel the bees to attach their combs to the bottom-bar. also to remove honey from brood-frames into the supers.

Invert sugar. - $\Lambda$ mixture of equal parts of the two sugars, dextrose and levulose. with or with out water. Invert sugar is made from sucrose (cane or heet sugar) by heating with a trace of acid. It superficially resembles honey. q. v

Italian bees.-The most valuable race of bees for honey production. They were first successfully introduced into this country about 1860 . The first three dorsal segments of the ahdomen are handed with yellow. There are also four and five handed strains.

Italianize.-To change a colony of any other race to Italians hy introducing an Italian queen

Jumbo frame. $-175 / 8$ inches long. $11 \frac{1 / 2}{1 n c h e s}$ in depth. See "Hives" in the hody of this work.

Jumbo hive.-A regular standard Langstroth hive having Quinby depth hut otherwise regular Langstroth dimensions. It is $2 \frac{1 / 8}{8}$ inclies deeper than the regular standard Langstroth. It uses the same covers, bottoms and supers as the standard hive.

Langstroth frame.-175/8 inclies long by $91 / 8$ inches deep. See "Hives"; also "Frames" in the hody of this work.

Langstroth hive.-A hive having frames $175 / 8$ by $91 / 8$. In one sense, any movable-frame hive is a Langstroth hive, since Langstroth invented the movable-frame hive. See "Frame."

L. frame.-Langstroth frame.

L. hive.-Langstroth hive.

Larva (plural larvae).-A bee in the worm state; unsealed brood.

Laying worker.-A worker which lays eggs, such eggs producing only drones. Laying workers do not appear except in colonies long queen. less.

Legume. $-\Lambda$ specics of the Leguminosae, or pulse family, is often called a legume. The name of the fruit of this family, which is a $2 \cdot$ valved pod with the seeds horne on the ventral suture only.

Levulose-One of the five important sugars. It occurs in honey and in nearly all fruits except the grape. It is known also as fruit sugar or fructose.

Light brood foundation.--Comb foundation running about 9 square feet to the pound.

Ligurian bee.-Italian bee, named for the district in which the best Italian bees are found.

Lining bees.-Watching the direction of the flight. of bees so as to trace them to their home (usu. ally in some hollow tree). See "Bee-hunting", in the body of this work.

Lock-cornered hives.-A scheme of fastening the hives togethel at the cormers by means of lockcomering straight fingers of wood. Dovetailed hives incorrectly named; are really lock-cornered. in that the fingers are straight and not dovetailed. See "Dovetailed Hives" in the body of this work.

Loose frames or loose-hanging frames.-As opposed to fixed frames, those which have no provision for self-spacing, but must be spaced by the eye. See "Self-spacing Frames," also "Frames."

Mal de mai.-May sickness; a peculiar disease of bees occurring mostly in May, and giving much. trouble in Europe.

Maltose.-One of the five important sugars. It on. curs in malt products. beer and corn syrup or commercial glicose.

Mandibles.-The first or upper pair of jaws of insects. The second or lower pair of jaws are called the maxillae.

May pest.-Same as mal de mai.

Medium brood foundation.-Comh foundation run. ning about 7 square feet to the pound.

Mel-extractor.-Honey-extractor.

Melipona.-A genus of stingless bees native to South and Central America. They bite viciously but do not sting.

Metal-spaced frames.- Self-spacing frames having metal spacers on the sides of the frames.

Migratory beekeeping.-In some portions of the country, particularly in California and in the Rocky Mountain districts, it is the practice to move whole apiaries from one locality to an other to catch the successive honey flows. The bees are sent overland on trucks or by train.

Mite.-See 'Acarapis woodi.'

Moth miller.-See "Bee Moth.'

Movable frame.-A Inose comb frame which can be removed completely from the hive for the purpose of examination or use. A Langstroth frame. See "Frames."

Natural Swarm.-A swarm of bees issuing through a natural impulse from the mother colony.

Nectar.-A sweet liquid secreted by nectaries iocated chiefly in flowers and on leaves.

Nectaries.-Glands composed of specialized tissue which secrete nectar.

Neuter.-A name sometines but incorrectly applied to worker bees.

Non-swarming hive.-A hive so constructed as to control the desire to swarm.

Nucleus (plural nuclei).-A very small colony of bees. The difference between a nucletus and a colony is much like the difference hetween a boy and a man. It is not easy to say just when a nucleus becomes large enough to be called a colony. Perhaps nothing larger than three comhs with adhering bees should he called a nucleus, although in the spring many so-called colonies have much less than tliree frames of brood.

Nurse bees.-Young worker bees that feed the larvae and do other work inside the hive. They are generally less than 16 days old.

Observatory hive.-A hive largely of glass to permit observing the bees at work.

Ocelli.-The three simple eyes of the bee.

Out-apiary.-An apiary kept at some distance (generally more than a mile) from the llomo of the beekeeper.

Overstocking.-A sondition reached when there are too many bees for a given locality.

Packing-cases.- Targe cases of wood surrounding one or more hives during winter. The space between the hives and the case is filled in with packing of some sort. such as planer shavings or leaves; never used during the summer or warm months. See "Wintering Outdoors" il the borly of this work. 
Paraffin.-A white translucent substance somewhat resembling beeswax, derived from mineral oil, and sold very largely in the form of candles. It is used by beekeepers to render honey-barrels tight.

Parent stock, - The original colony that has cast a swarm.

Parthenogenesis.-Production of a new individual from a virgin female without intervention of. a male; reproduction by means of unfertilized eggs. In bees the unfertilized eggs produce only males. An unfecundated queen, and sometimes a worker, may lay eggs that will hatch. producing only drones. See "Parthenogenesis" in the body of this work.

Perforated zinc.-Zinc sheet metal having oblong holes $1-6$ of an inch in width to allow worker bees alone to pass, and exchuding queens and drones. See "Excluders."

Pickled brood.-See "Sacbrood."

Piping.-A series of sounds made by a queen, louder than any sound made by a worker, consisting of a loud, shrill tone, succeeded by several others, each sound shorter than the one that precedes it. A laying queen is seldom heard to pipe; a virgin perhaps always nipes at intervals after emerging from her cell, and in response to ker piping may be heard the quahking of one or several virgins in their cells. if such are in the hive, the quahking being uttered in a lower key and in a more hnrried manner than the piping. Piping is also called 'teeting.'

Pistil.-The pistil is divided into the ovary, style and stigma. The ovary contains the ovules which, after fertilization, become the seeds. See "Pollen" in the body of this work.

Plain sections.-Comb-honey sections with no insets or scalloped edges. See "Comb Honey, Appliances For," in the body of this work.

Playflights, or playspells.-On warm clear days young bees, which have never before left tlie hive, perform the flight of orientation. The head is turned constantly toward the hive and the bee hovers up and down, and later describes smaller and then larger orientation circles. It thus forms a memory picture of the hive and its surroundings, which later guides it when returning from the field. The older bees fly forth from the entrance without a moment's delay.

Polariscope.-An optical instrument much used in sugar and honey laboratories for measuring the quantity of or differentiating between the various sugars. Its use depends on the fact that each sugar has its own "specific rotation."

Polarization.-The specific rotation of a substance like the sugars as measured by the optical instrument called the polariscope, q. v.

Pollen.-Dust-like grains formed in the anthers, within which are produced the male elements or sperms.

Pollen-basket. - A cavity on the hind legs of the bee wherein is deposited the pollen gathered from flowers.

Power extractor.-An extractor driven by some kind of power, usually a small gasoline engine of about two horsepower. A power extractor is a machine of large capacity, containing not less than six or eight combs at a time.

Prime swarm.-The first swarm-the swarm with the old queeu.

Propolis.-A kind of glue or resin coliected by the bees and chiefly used to close up cracks and small spaces.

Pupa.-The third stage of the bee, during which it is inactive and sealed up in its cell; sometimes called "chrysalis."

Quahking.-The noise made by a young queen in her cell in response to the piping of the queen at large. See "Piping."

Queen.-A fully developed female bee; the mother bee.

Queen-cage.-A small box of wire and wood ill which queens are held prisoners.
Queen candy.-Candy made by kneading powdered sugar into extracted honey or invert sugar syrup until it forms a stiff dough; used in queencages; called Scholtz candy, because Rev. M. Scholtz introduced it in Europe. Afterward $I . F$. Good gave it prominence in America, and so it is often called Good candy.

Queen-cell.-A cell in which a queen is reared. having an inside diameter of about $1 / 3$ of an inch, hanging downward an inch or more in length.

Queen-excluder.-See "Exchuder."

Queening.-Tbe act of introducing a queen into a queenless colony of bees.

Queenless.-Having no queen.

Queen-nursery.-A cage or set of cages in which to confine queen-cells or queens.

Queen-rearing.-Raising queens.

Queen-register.-A card to be attached to a hive with pointers that may be moved so as to indi. cate dates, and conditions relating to the queen, such as "cell," "hatched," "laying," etc. See "Record-keeping" in the body of this work.

Queenright.-Having a good laying queen.

Queen's voice.-A sound made by a queen. See "Piping."

Queen-trap.-A device provided with perforated zinc, or wire bars, to be attached to the entrance of a hive, allowing workers to pass, but trapping any queeu or drone that attempts to issue. Called also "drone-trap.'

Quilt.-A cover for brood-frames made in the form of a thin cushion.

Quinby frame.-The luanging Quinby frame is

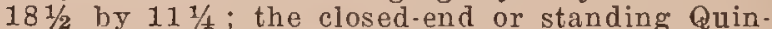
by is $191 / 8$ by 11 , is without lugs, and supported at the bottom. See "Hives" in the body of this work.

Quinby hive.-A hive invented by Mrr. Quinby based on Huber's leaf hive of the latter part of the 18th century. See "Hives" in the body of this work.

Rabbet.-1. An offset in the upper inside edge of a hive. 2. A narrow piece of tin folded in a peculiar manner to form a rest for the shoulders of the hanging frames. See "Hives" in tlie body of this work.

Race.-Groups smaller than species are variously called subspecies, race, variety, strain and form. The first three terms are nearly synonymous. A race of Apis mellifica is a geographical variety, which propagates itself sexually and interbreeds freely with other races of the same species.

Rendering wax.-The process of melting combs and refining wax from its impurities, usually done by means of hot water or steam accom. panied by pressure on the mass of material.

Repository.-A room, usually upon a hillside, partly or wholly below ground, iu which bees are wintered; a bee-cave; a bee-cellar. In a general sense the word may be used for any place in which bees are wintered indoors.

Reversing.-Turning over or inverting a hive with bees to accomplish certain results. See "In. version."

Reversible extractor.-A machine that reverses the combs inside of the can either automatically or by hand.

Ripe honey.- Honey left in the care of the bees until it contains less than 25 per cent of water.

Robbing.-As applied to bees, the taking of honey by stealth or force from the hives of other colo. nies.

Royal cell.-Queen-cell.

Royal jelly.-Brood food. A milky white, finely granular jelly with a strong acid reaction. The larvae of the queen receive no other food, but it is fed to the larvae of the workers and drones for only three days. It is not known how it is formed. The contents of the bee's stomach are brown-colored, strongly alkaline, and can not be forced back thru the stomach-mouth. Brood 
food is probably formed in part, at least, by glands in the anterior part of the head, which open by a duct in the pharynx. They are well developed in nurse bees, absent in drones, and developed in female bumblebees, but are rudimentary in the solitary bees, which do not "nurse" their brood.

Sacbrood.-A disease of brood. Slightly contagious but not serious.

Saccharose.-See "Sucrose."

Scholtz candy.-See "Queen Candy.'

Sealed brood.-Brood that has been capped or sealed over by the bees with a somewhat por ous capping; mostly in the pupa stage. See "Capped Brood."

Section.-A small frame or box open on two op posite sides, that is placed on a hive to receive surplus conib honey of slightly less than a pound; a section box. Also, the honey contained in a section box.

Section holder.-A device for holding sections while in process of being filled on the hive.

Self-hiver.-Any device by which the bees of $n$ swarm are induced to enter of their own accord a hive prepared for them.

Self-spacing frames.-Frames so made that, push en together. they will be spaced the proner dis tance apart from center to center (usually $13 \%$ inches); see "Fixed Frames."

Separator.-A very thin board or sheet of tin placed between sections to make the bees build the combs accurately.

Septum.-The middle of a honeycomb.

Shaken swarm or shook swarm.-An artificial swarm made by shaking bees from a very popu. lous colony. into a fresh hive. By this means "Batural swarming, is closely imitated. See

Shipping case.-A light box, often with glass on one side. of varying size, in which section bon ey may be shipped. The sizes nost commonly in use are those containing 12 and 24 sections each.

Skep.-A beehive without movable frames, especially one made of straw.

Skeppist.-An old-fashioned beekecper.

Slumgum.-The refuse from a wax-extractor.

Shook swarm.- See 'Shaken swarm.'

Smoker.-An implement having a fire-box with bellows attached, by means of which smoke may be blown upon bees; a bee-smoker.

Solar wax-extractor.-A glass-covered box melting bceswax by the heat of the sun.

Solitary bees.-Bees that do not live in colonies or families like the common honeybee. Of solitary bees there are over 2000 species in North America alone, or about one-fourth of all the species in the world. They are of no value in the production of honey, but do assist in the work of pollination of flowers.

Specific gravity. - The ratio of the weight of a sulsstance compared with an equal volume of water. The specific gravity of honey is 1.4 (Baume scale 42 degrees). In plain English, honey weighs $\$ 2$ pounds per gallon. Beeswax has a specifie gravity of .97 . Water, 1.00 .

Spermatheca.-A small sac attached to the oviduct of the queen, in which are stored the spermatozoa received from the drone in the act of copu lation.

Spermatozoon.-One of the germs contained in the semen of drones. (Plural, spermatozoa.)

Spiracles. - Bees breathe by a system of internal tubes, known as tracheae, which branch minutely to all parts of the organism. The external openings of the tracheae, located on the sides of the thorax and abdomen, are called spiracles.

Spreading brood.-Putting a comb without brood between two combs of brood to induce the queen to lay in the former.
Stamens.-The organs of flowers producing pol. len.

Starter.-A small piece of comb or foundation fastened in a frame or section to start the bees to building at the right place. See "Comb Foundation.'

Steam honey-knife.-An uncapping-knife kept continuously hot with steam from a light hose to facilitate the slicing off of the cappings for the purpose of extracting. See "Uncapping. knife.'

Stigma.- That part of the pistil of a flower which receives the pollen for the fecundation of the ovules; the end of tlie pistil.

Strain.-Although scientists may not all agree as to using this word. John Phin, in his excellent Dictionary of Practical Apiculture, says it " is one of the most useful, expressive and legitimate words that we have, and this is shown by the extraordinary difficulty of finding a synonym for it." Suppose one has a ccrtain race of bees. Among them lie finds some that are specially noted for some particular quality, good or bad, as gentleness or viciousness, and this quality descends with more or less certainty to their posterity. This quality does not differentiate them from others of the same race sufficiently to constitute them a different race or breed. but it is of sufficient inportance to warrant their being called a strain. Moreover. the character istics of a strain are not so fixed as the characteristics of a race, and without great care the particular characteristics will disappear, or as we say "the strain runs out." See "Races of Bees" in the body of this work.

Sucrose.-One of the five important sugars. Refined white sugar, either cane or beet, is pure sucrose.

Sugar.-The term sugar generally refers to sucrose. which is the sole constituent of refined white sugar, cane or beet. However, there are four other important food sugars, classified as follows:

Name.

Synonyms.

1. Sucrose.... Saccharose "Sugar"

2. Lactose.....Milk sugar

3. Maltose.... Malt sugar

4. Dextrose... Glucose

Grape sugar

Where found. Cane or beet sug ar or maple sugar. All milk.

Malt products and corn s y r u p o r com'l '"glucose.'

Honey, invert sug. ar. com'l "glu. cose" or c or n syrup, fruits.

5. Levulose....Fruetose Honey, invert sug Fruit sugar ar, fruits.

Super.-A recetacle in which bees store surplus honey; so called because placed "over" the hive.

Supersedure.-The rearing of a new queen to succeed or supersede the old queen, when her fertility or egg-laying power begins to fail. The old cueen either departs with a swarm or is put to death.

Surplus or surplus honey.-Honey over and above what the bees need for their own use, and which the beekeener takes from them; honey stored elservhere than in the brood-combs.

Surplus apartment.-The apartment in which surplus honey is stored.

Swarm.-A large number of bees with a queen leaving the mother colony to find new lodgings and found a new colony.

Swarm-catcher.-A net placed at the entrance of a hive, a basket at the end of a pole, or any other device intended to secure a swarm as it leaves the hive or afterward.

Swarming season.-The period of the year when swarms usually issue.

Syrian bees.-They were first brought to the United States from Palestine in 1880. In size and color they resemble Italian bees but they swarm excessively, and are relatively of little value. 
Tarsonemus woodi.-A destructive parasite (Isle of Wight disease) that finds its way into the breathing pores or spiracles of honeybees. At present confined to Furope.

Tarsus.-The five terminal segments of a bee's leg are called the tarsi; one of these segments is a tarsus.

Tested queen.-A queen whose progeny show she has mated with a drone of her own race.

Thin-super foundation.-Comb foundation running about 12 square feet to the pound.

Thorax. - The middle part of a bee between the head and abdomen, to which the wings and legs are attuched

Tibia.-The fourth joint of an insect's leg, between the femur and tarsi.

Tiering up.-Adding supers on the top of a hive to receive the incoming lloney.

Transferring.-Ordinarily applied to the process of changing bees and combs from common boxes to movable-frame hives.

Transformations.-See "Bee Metamorphoses"'; also "Development of Bees" in the body of this work.

Trausposition process.-Taking a young larva from a worker-cell and placing it in a queen-cell cup.

Travel-stain.-The darkened appearance upon the surface of comb honey wheu left long upon the hive.

Trigona.-A genus of stingless bees in South America and Asia. Some species bite furiously.

Tunisian bee.-A black race, natives of northern Africa; very cross, and much given to swarming; sometimes called Punic. The bees are bad propolizers, nervous and, from a commercial point of view, undesirable.

Uncapping-knife.-See "Honey-knife."

Unripe honey.-Honey which has not been left in the care of bees long enough to be thickened until it contains less than 25 per cent of water.

Unsealed brood.-Brood not yet sealed over by the bees. In a general way eggs are often included witl larvae under the term "'unsealed brood." See "Brood" and also "Bee Meta. morphoses."

Vinegar,-A sour liquid made by the alcoholic and subsequent acetous fermentation of any product containing a sugar in practical quantities. Obviously, vinegar can be made from honey, by properly diluting it.

Virgin comb.-Comb which has been used for honey only once, and never for brood.

Virgin queen.-An unfecundated queen.

Vitamine.-An accessory food substance very nec. essary to health and growth in all animal life. Vitamines are divided into three groups. Fat- solnble $\Lambda$. Water-soluble $B$ and Water-soluble C. 'The first occurs in comb loney, but no vitamines of any class liave been found so fal in any amount in extracted honey.

Wax-extractor.-An appliance for rendering wax by heat, or by heat and pressure.

Wax moth.-See "Bee Moth."

Wax-pocket.-The receptacles on the under side of the abdomen wherein the bees secrete their wax.

Wax-press. - A press in which the wax is squeezed out of the heated combs.

Wax-tube fastener.-A tube for applying a fine stream of melted wax along the edge of a sheet of foundation to cement it to the top-bar of a brood frame or the top of a section.

Wean.-To cease giving the highly concentrated food that is first fed to larvae, and to give coar. ser food. A worker larva is weaned when three days old.

Wedding excursion or wedding flight.-The flight of the queen when five days old or older, to mate with the drone in the air.

Wild bees.-Bees living in hollow trees or other abodes not prepared for them by man. Strict. ly speaking, they are no wilder than bees in hives.

Windbreaks.-Either specially constructed fences or barriers composed of growing trees to reduce the force of the wind.

Wintering.-The care of bees duriug winter.

Wired frames.-These are brood frames haviug wires stretched across them, either vertically or horizontally, for the purpose of holding the comb foundation and later the comb solidly iu position. See "Comb Foundation" in the body of this work.

Wiring frames.-The act of stringing wires througli holes in brood frames to hold founda. tion in place.

Wood-base foundation.-A thin veneer of wood covered on each side with shallow cell walls of beeswax having the same general appearance of the surface of comb foundation.

Worker.-A female bee whose organs of reproduction are undeveloped; well named "worker," because workers do all the work of the colony except laying the eggs.

Worker comb.-Comb having cells which measure five to the inch, in which workers may be reared, and honey or pollen stored. See "Hon. eycomb.'

Worker egg.- A fertilized egg laid by a queen bee, which may produce either a worker or a queen.

Xylocopa.-Often called carpenter bees because they excavate with their powerful jaws a chan. llel a foot in length in solid wood. They much resemble bumblebees. 


\section{INDEX}

\section{A}

A B C of Bee Cullure, How to be Real.

Absconding by Colonies, Small............... 16

Checked by Clipping.............. 14

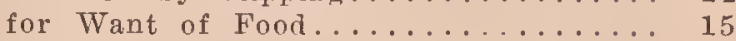

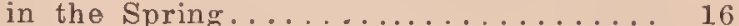

Prevented by Clipping............. 14

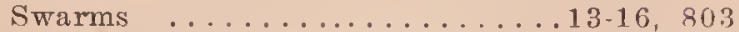

Swarms, Freaks of.............. 14

Acreage of Plants Necessary to Take Care of Colony of Bees................ 78

Adams \& Myers' Extracting Onifit............. 340

Aduiteration, Kinds of ..........16, 17 of Honey ............... 16. 19

of Honey, Not Now Common......... 17

of Honey with Invert Sugar Syrup..... 18

Adult Bee Diseases. See Diseases of Bees.

Advertising Honey ................. 592

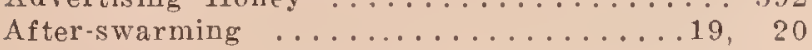

Methods to Prevent.............. 20

Prevented by Cell-cutting........... 19

After-swarms ................ . 792- 794

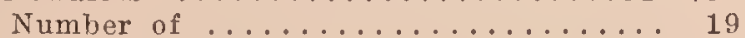

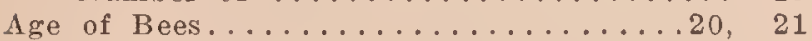

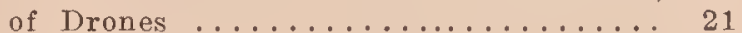

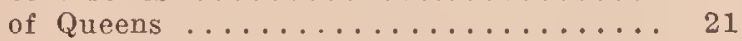

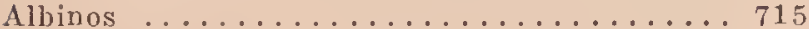

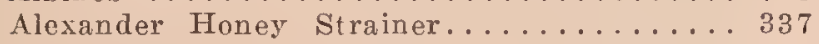

Method of Increase............. 854

Plan of Uniting............854,855

Treatment of Furopean Foul Brood... 375

Alfalfa, as Pasture and Soiling......... 33

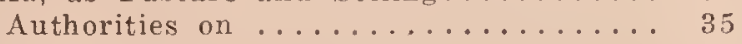

Blossom, Color of ............. 23

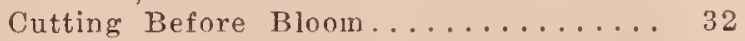

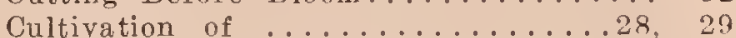

Distribution in United States......23, 26

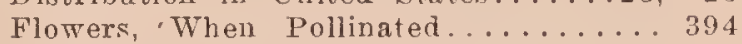

General Discussion of ..........21- 35

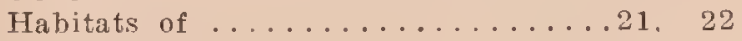

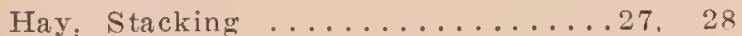

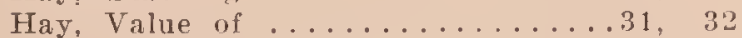

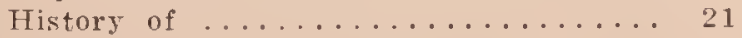

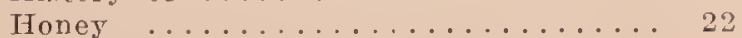

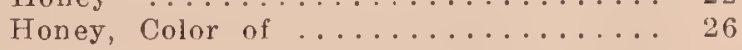

Honey Darker in Southern California... 26

Honey, First and Second Crop....... 27

in the Rockies................. 25

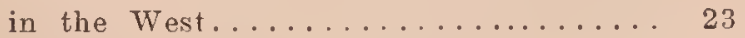

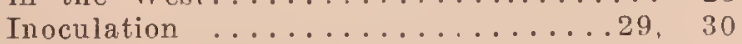

Nectarless in the Hast............ 25

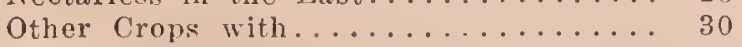

Pollination ................... 33

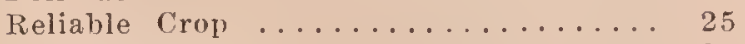

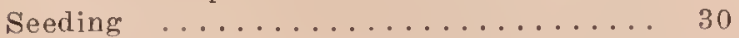

Soil, Good or Bad............... 29

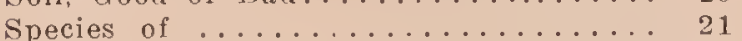

Suitable Condition for............ 28

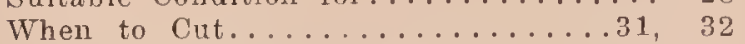

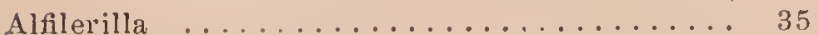

Alighting-board, Part of Entrance........ 300

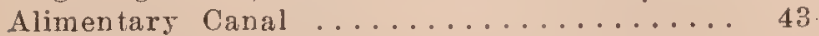

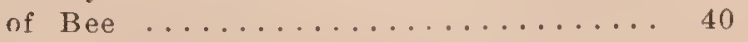

of Bee Illustrated ............. 43

Alley Drone Traps.............289, 290

Alsike Clover. See Clover.

Clover as a Honey Plant............ 194

Pollination of ..............193, 194
Aluminum Combs ..............215, 216

American Foul Brood. Sea Foul Brood, Amer. ican, under Head of Foul Brood.

Anatomy of the Bee.............35. 45

Anger of Bees................45. 49

of Bees Affected by Shrubbory.....49- 53

of Bees Depends on Source of Honey... 49

Angry Bees, How to Know............. 48

Antenna Cleaner ................. 659

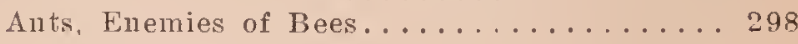

in Florida .............51, 52

in the North and in the South....... 49

More Troublesome in South......... 51

More Troublesome in Warm Climate... 50

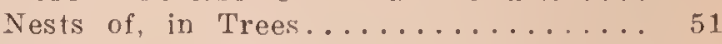

Nests of, to Destroy ................. 50

to Keep Under Control........51. 53

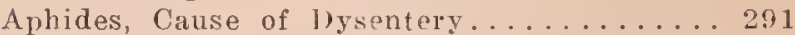

Aphis, a Source of Honeydew........493, 494

Apiary ..................................... 75

Arrangement of Hives in........70, 71

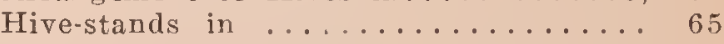

Important, Shrubbery in ......49, 56. 58

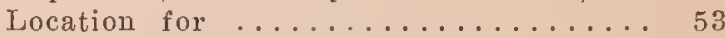

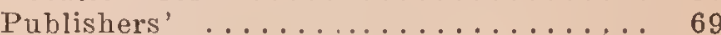

Shade for ................59. 61

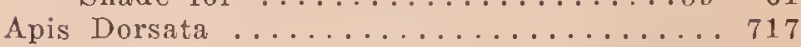

Apple Pollination ............... 409

Arrangement of Brood, Pollen and Honey.... 95

Artichokes .................. 790

Artificial Coinb Honey Does Not Fxist..... 492

Comb Honey, So-called ........... 226

Fertilization .............75, 76

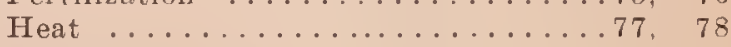

Heat for Wintering........... 77

Pasturage .................... 78

Pasturage Only Partially Recognized.... 509

Swarming ................. 79, 81

Swarning, Distinguished from Increase. 81

Sivarming, How Performed........79-81

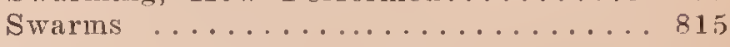

Aster ........................... 81

Honey, Chiefly from Five Species..... 82

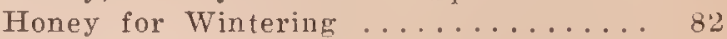

Honey, Quality of ............ 82

Automatic Hiving of Swarms...................... 802

Automatic Reversible Fxtractol.......343-346

Automobile for Out-apiary Work.....642, 643

\section{B}

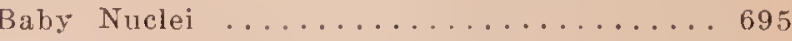

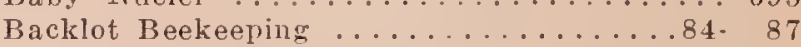

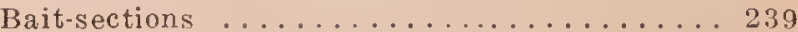

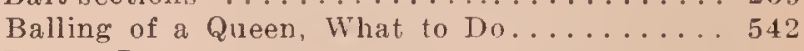

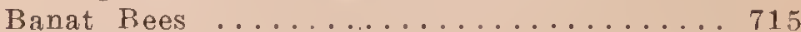

Barrel Hoops to Prevent Slippillg....... 88

Barrels ...................... 87- 89

for Holding Honey, Size of ....... 87

for Shipping Honey Not Satisfactory... 89

How to Paraffin or Wax........... 88

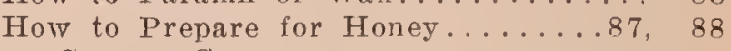

or Square Cans............... 89

Removing Granulated Honey from..... 89

to Test for Leaks................ 88

Bartlett's Original Four.Colony Winter Case.. 899

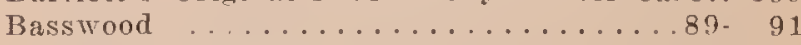
Cultivation of $\ldots \ldots \ldots \ldots \ldots \ldots \ldots . \ldots . \ldots 9$

for the Making of Sections........... 91

Honey, Quality of................ 90

Honey, Yields of.............. 90 
Rapid Grower ................ 92

Species of .............. 89

Variable Source of Honey........... 90 Baumé Hydrometer ................ 463 Bee, All Parts of .................. 39

Anatoiny of .............. 45

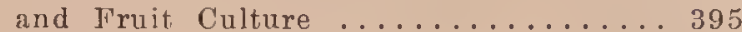

Behavior ................. 92- 97

Cellar, Dysentery in............. 292

Cellars. See Wintering in Cellars.

Cuckoo .................. 766

Dress or Clothing for Beekeepers. . 859, 860

Escape, Use of, in Bee-hunting.....100- 102

Escape Board, How to Put on.......244, 587

Escapes in Extracting ............ 323

Escapes, Porter .............. 545

Lscapes, Taking Off Comb Honey...243, 244

Flowers, More Red and Blue Than Yel.

low or White .............668

Gloves ................... 416

Gluc .................... 5

How It Sucks Up Honey.......... 37

Funting .................97- 103

Hunting Box, to Use............. 98

Hunting, Climbers for...........99, 100

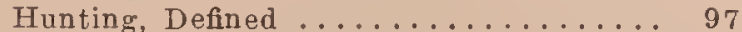

Hunting, Does It Pay?... . . . . . . . . . 102

Hunting, Equipment for.........97, 98

Hunting. Making Cross-lines......... 99

Hunting, Special Box for.......... 98

Hunting. When It Can Be Practiced.... 97

Moth. See Moth Miller.

Moth, Destroyed by Burning Sulphur... 614

Moth, Destroyed by Carbon Bisulphide.. 616

Moth, Not a Serious Pest to Modern Bee-

keepers .................. 599

Moth, Pupa ................... 612

Moth, Troublesome in Some of the South.

ern States among the Box-hive Men... 599

Moths, Two Species of ........599, 600

Paralysis, Bees Immune to......... 277

Paralysis in Australia............ 277

Paralysis Symptoms .........275, 276

Paralysis, Treatment of ........... 276

Sectional Vicw of............. 36

Shipping Without Combs.......746-748

Smoker ................... 11

Smoker and Bee Veil a Protection...... 3

Smokers as a Means of Control....... 2

Space ....................... 105

Space Above or Below Brood-frame.... 106

Space and Its Relation to Modern

Hive ..................... 379

Snace, Discovery of, by Langstroth...

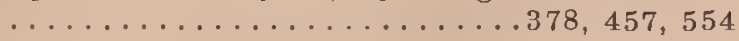

Space, Size of.............105, 106

Space Under Brood-frame......... 106

Sting Poison .................... 785

Stings and Rheumatism.......... 786

Temperament, How to Know........ 580

Territory, Moral Rights of......647, 648

Tree, How to Locate.............97- 99

Trees ..................... 13

Trees, Menace to Queen-breeders...... 103

Veil ..................... 11

Young, Behavior of ...........92, 93

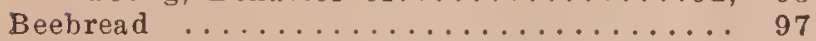

Bees Accused of Scattering Blight....... 359

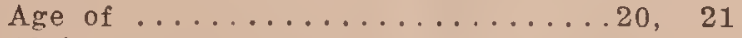

Albinos ........................... 715

Alibi for ................... 360

Alimentary Canal of ........... 40

Amount of Cold They Can Stand...... 927

Amount of Honey They Can Carry . 886, 887 and Farming. See Farmer Beekeeper.

and Fruit-Growing ..........106, 107

and Honey in Cities and Towns....777, 778

and Poultry ..............107, 108 and Queens, Early Hours of........ 93

and School-teaching ............. 1000

and Truck-gardening ............. 108

Anger of $\ldots \ldots \ldots \ldots \ldots \ldots \ldots \ldots \ldots . \ldots 45$

Attacking Fruit ............. 111

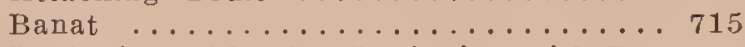

Beginning with. See Begiuning with Bees.

Behavior of, in Collceting Pollen...... 659

Black or German.............. 713

Capable of Standing a Light Freeze for

Short Time ............... 914

Carniolans .................... 714

Cliff .................... 765

Compound Eye of .........347, 348

Congestion of, Cause of Swarming. . 805, 806

Congestion of, in Brood-nest.......8 807

Cross, To Know............. 48

Cyprians .................. 715

Dead, Having Odor of American Foul

Brood .................................

Devclopment of. Sce Development of Bees.

Distance They Fly...........361, 362

Drifting ..............282, 283

Drumming While Transferring..... 842,843

Easily Handled When Understood..... 575

Fastern, Cross ................ 550

Fast Indian ............... 716

Egyptian ................... 715

Exonerated by Jury.............. 114

Favorable Time for Handling.......783, 784

Few or Many............682, 683

Field, How Influence Swarming....805, 806

First Pollen for .............. 93

Flying Out on Chilly Days Toward Winter 914

Gentleness of ................ 47

Giant Bees of India.................. 717

Good-natured in Swarm.......... 792

Holy Land .................. 715

How and where to Buy........... 121

How Made Cross.............. 47

How They Can Warm Themselves by

Exercise ................... 839

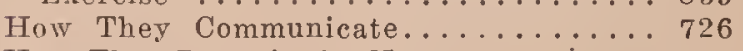

How They Deposit the Nectar........ 94

How They Do Their Own Ventilating... 862

How They Find Their Way Back to Hive 655

How They Ripen Honey ........... 94

How They Seem to Work According to a

Plan ...................... 707

How to Get Them off the Combs........ 584

How to Get Them Out of Bee-trees With-

out Mutilating the Tree........100-102

How to Get Them Out of Building..100-102

How to Handle, Rules for.......783, 784

in Cities and Towns..........84- 87

in Pound Packages............122-125

Intelligence of $\ldots \ldots \ldots \ldots \ldots \ldots \ldots .725$

Kept from Time Immemorial......... 1

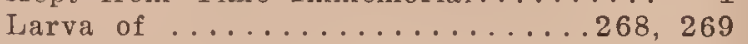

Legs Illustrated ............. 41

Legs of .................. 38

Like Mankind ..............48, 723

Male. See Drones.

Manipulating ............... 12, 13

Many Species of .............. 5

Misrepresented $\ldots \ldots \ldots \ldots \ldots \ldots \ldots . \ldots \ldots$

Mouth Parts of............... 6

Nervous System of................ 45

Not Always in a Towering Rage....... 46

Not a Nuisance in Themselves..108.111, 560

Not Cause of Fire Blight nor Pear

Blight ................. 360,361

Not Injurious to Sound Fruit..... .561, 562

Not True Hibernators........... 926. 928

Number of Trips Made in a Day......887 887

Number to a Colony.........5, 165, 887

Number to the Pound..........886, 887 


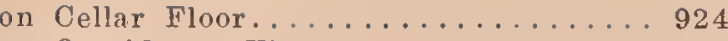

oll Outside of Winter Cluster........9928

on Shares ..............115, 116

Resting Periods of............. 94

See Italian Bees.

Shutting in a Hive During Winter in

Cellar ................... 924

Smothered by Closed Entrance.......861

Solitary ................. 5

Solitary, Collecting Pollen.......... 659

Sometimes a Nuisance in Fruit Drying.. 562

Stingless ...............116- 118

Strain of, Relation to Swarming....... 808

Strains of, Immune to Disease....... 277

Surpass All Other Insects as Pollinators. 680

Syrians .................... 715

That Sting Worst............. 785

Their Love of Home............ 13

Three Kinds of in a Hive.......... 5

Tiny East Indian ............ 716

to Enter Supers, Comb Honey......239, 241

Tongue Illustrated .............. 39

Too Many in a Locality. See Overstocking.

Tunisians

Two Kinds

Unwarranted Fear of Them.......... 575

versus Birds ..............113- 115

versus Fruit-grower ............... 114

When Become Angry............ 47

When Cross ................47, 48

When Preparing to Swarm......... 272

When Sting Remarlably.......... 48

When to Put in and Take Out of Cellars 922

Wild by Nature, in Law.......... 557

Wild, Where Isocated ............ 97

Wintering in a Warm Room........ 77

Worker

Worker in Two Divisions........... 6

Worker, Their Duties ........... 5

Young, after Emerging .......... 147

Young, Their Work ...........14i, i48

Beekeeper Farmer. See Farmer Beekeeper.

Beekeepers. Number of, in United States... . 1

Room for More in United States......

Specialist ................. 1

Beekeeping, a Recreation for Women...... 104 as an Exclusive Business........769, 770 as a Sole Means of Livelihood..... . 769, 770 as a Vocation and as an Avocation. .104, 105 Bird's-eye View of............. 5 for Pleasure ...........84-86, 104 for Professional Men ............ 84 for Women ..................103. 105

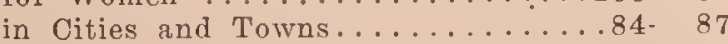
in Cities and Towns Profitable....... 87 in Olden Days.................. 1 in Suburban Towns and Cities... 777, 778 Industry Pushed Forward by the Great War

Industry, Scope and Character of.....

Migratory. See Migratory Beekeeping.

Not Hazardous nor Dangerous....... 575

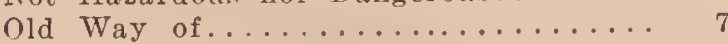

on Farms ................ 348

on Shares. See Bees on Shares.

Pleasurable Pastime............. 87

Restful Hobby ........................ 86

Territory in the U. S.............. 568. 571

Beeswax Furniture Polishes from........ 870 in Shoe Polishes.............. 870 in the Arts.......................... 870

Beginning with Bees.............118. 126

Beginning Small with Bees............ 119

Behavior of Bees..............92- 97 of Bees in Collecting Pollen......... 659 of Bees in Swarming............ 96 of the Larval Bee.............. 92

Bellflower. See Campanilla,
Bell, Ringing to Stop Swarming......... 15

Bell, Ringing When Can is Full........ 341

Bicycle for Bringing Back Swarms........ 798

Bicycle Pants-guards, Holding Trousers when Among the Bees............... 860

Bingham Smoker .................... 755

Bird's-eye View of Beekeeping......... 5

Birds, Not Bees, Attacking Fruit.......113, 114

Biting of Stingless Bees............ 118

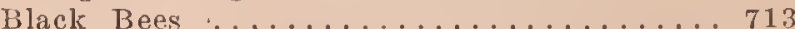

Black Brood. See Foul Brood.

Black Gum .................. 126

Black Sage .................. 735

Bokhara. See Sweet Clover.

Boonhower Knife-scraping Table....... 246

Borage .....................126, 127

Borrowing .................. 732

Bottling Honey ............... 127- 136 Honey by the Carload.........132. 135

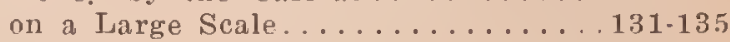

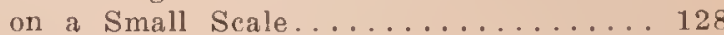

Bottonl-board, Bee-space ............. 106

Box Hives ...............6, 7, 136- 139 How to Move in Sacks....... 841

Brace-combs. See Thick-top Frames under Frames.

Brace-combs and Burr-combs Avoided by Thick-top Frames ............... 380

Breeding, Cost of in Honey............ 145 Heavy on Stores............. 143 in a Story and a Half............. 236 in Two Stories............... 449 Queens, Requirements for.......... 139 Queens, Where to Get............. 140 Stimulated by Giving a Super of Honey. 169 Stock ...................139, 140 Stock to Reduce Swarming......... 808

Brood and Brood-rearing............140, 149 and its Relation to Swarming.....794, 805 Capped Over, What Happens........ 270 Chambers Double, for Swarm Control.808. 809 Cost of in Honey.............. 145 Daily Growth of ............. 146

Dead, Determined at Entrauce....... 273

Dead, from Drone-laying Queens...... 378

Development of ............145- 147 Disease. See Foul Brood.

Diseases, Sequence of ........... 374

Drone ...................... 144

Emerging, for Weak Colonies........ 170

Frames .................. 8 , 9 How it Should be Placed During Extract-

ing ..................... 320

How to Distinguish from Capped Honey. 140 Indication of Colon $7 . . . \ldots \ldots 140,141,143$ Manipulation to Control Swarming..808, 809 Nest, Crowded, Cause of Swarming..... 807 Nest Well Filled with Brood for Comb Honey .................. 235

Placing Above in Extracting........ 319

Rearing, Decreasing in the Fall....... 141

Rearing During Midwinter........... 144

Rearing, Importance of Plenty of Stores. 169 Rearing in the South............. 144

Rearing in the Spring........... 166

Rearing in Two Stories........... 449

Rearing in Two Stories for Comb Hon.

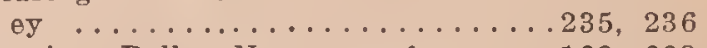

Rearing, Pollen Necessary for.....169, 663

Rearing Slowing Down after the Honey Flow ...................... 897

Rearing Stimulated by Shallow Extract. ing-supers $\ldots \ldots \ldots \ldots \ldots \ldots \ldots \ldots 236$

Rearing Temperature ........... 78

Rearing, to Insure a Crop........166, 167

Rearing Too Early ............. 143

Rearing, Water Necessary for....... 868

Removal for Swarm Control......... 812 
Spreading ..................... 771

Starved or Neglected ............ 377

Worker and Drone-To Distinguisli.... 142

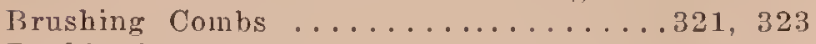

Buckbush ................... 148

Buckeye Hive. Construction of .......453, 454

Buckeye Reversible Extractors........344- 346

Buckwheat ................148-156

Amount of Seed per Acre.......... 155

as a Honey Plant.............150- 153

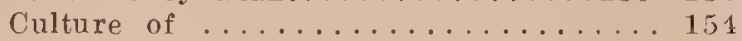

Fertilizer for ................. 155

Flow Stopping Suddenly.......... 151

Harvesting ........... . . . 155

History of ............... 149

Honey ...................... 154

Pollination of .............. 149

Seed Bed ......................... 154

Species of ............... 148

Uses of ................ 156

Varieties of .............. 155

Field of $\ldots \ldots \ldots \ldots \ldots \ldots \ldots \ldots \ldots \ldots$

Yield per Acre ................. 155

Building Up Colonies............ . 165. 170

for Early Flow................. 167

Colonies for Early Summer......... 167

Plans for ................. 161

Portable, on Wheels............. 160

Buildings ...................156- 165

Permanent for Extracting Plant...... 165

Permanent or Portable ............ 156

Portable .................162-164

Ventilation and Windows of ......... 159

Bulk Comb Honey.................. 224

Bulk Comb Honey, Objections to......... 225

Bumblehee Brood .................. 173

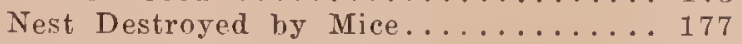

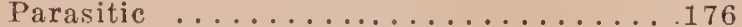

Queen ........................ 175

Queen, Egg-laying of ............ 175

Bumblebees ..................... 177

and Flower Pollination ........... 171

and Red Clover .................. 171

Having Longer Tongues Than Honeybees 681

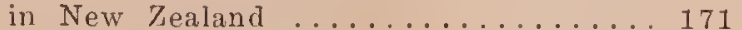

Life History of ............ 172

Sladen on .................. 177

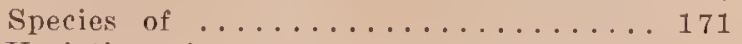

Varieties of .......................... 174

Bureau of Entomology, What it is Doing for Beekeeping

Burr and Brace Combs Avoided by Thick-ton

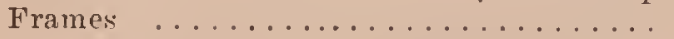

Burr Coniss. See Thick-top Frames under Head of Frames.

Buttel-Reepen on Playflights........... 655

Buying Bees ................121- 123

\section{C}

Cage to Set Over Colony That is Being Robbed ..................... 729,730

Cages for Mailing and Introducing Queen 533. 535

Cages for Queens. See Introducing.

California Sunflower .............. 790

Calorics in Honer................ 472

Campanilla ................. 177

Honey ................... 178

Pink ..................... 177

Canada Thistle ................... 178

Candied Honey. See Grannlated Honey.

Candy for Becs...............178, 179

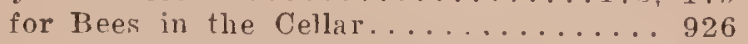

Hard, for Winter Use............. 180

Soft. Itow to Make............178, 179

Candying of Honey, to Prevent..........128. 130

Cane Sugar .................. 180

Cans for Honey. See Extracted Honey.

Improperly Boxed ..........312, 313
Second-hand. How to Clean......... 313

Cape May Warbler....................... 113

Capped Brood and Capped Honey, To Distin-

guish ..................... 140

Capping-melters ...............335, 336

Cappings, Difference in ............ 95

Cappings of Honeycomb, Not Air-tiglyt.....448

Card Indexes for Keeping Records of Hives.. 720

Carload, Bottling. See Bottling Honey.

Carload Shipments of Bees.........741-743

Carniolans ...................... 714

Carniolans. See Races of Beas.

Carpenter Bees. Sec Solitary Bees.

Carpet Grass ..................180, 181

Other species of ............. 181

Where Grown ................ 181

Carriers for Hives in Cellars .......... 923

Cartons for Coinb Honey...........228, 229

Casteel on How Pollen is Unlouded....... 93

on Pollen-Gathering . . . . . . .662, 663

on "Wax Pinchers" ............ 871

Catnip ..................... 182

Catsclaw ..................... 182, 183

Catsclaw, Where it Grows........... 183

Caucasians ....................... 714

Caucasians. See Races of Bees.

Caution, Regarding Feeding Back....... 357

Caution, Tiering Up Supers........... 241

Cell in Embryology.............266, 267

Cell, Cutting for Prevention of Swarming.... 19

Cellar, Arrangement of Hives in......... 921

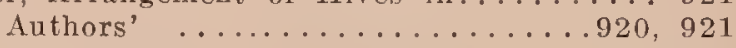

Bees, Preferably Yoling ............ 919

Dead Bees on Floor.................... 924

Disturbance, Occasional Not Harmful... 924

How to Build................ 920

Temperatures, Variable, Bad ............ 919

Under a House ................. 924

Ventilation.........861,916,921, 924

When to Put Bees in.............. 922

When to Take Bees Out of ......... 922

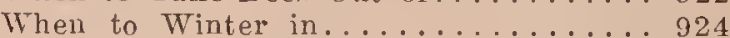

Wintering. See Wintering in Cellars.

Wintering, Some Things to Remember.923- 926

Cellars, Dampness in. Bad............. 919

Importance of Being Frost-proof for Wintering

Inspection of Bees in .............. 921,922

See Wintering in Cellars.

Cells, an Indication of Swarming........ 815

Destroying for Swarm Control.......... 817

Destroying for Swarm Control, Viller

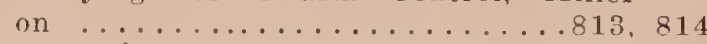

Grafting $\ldots \ldots \ldots \ldots \ldots \ldots \ldots, 6 \ldots \ldots$

How Young Queens Will Destroy ...7700.701 Pecularity of ..............698, 699 Preceding Swarming ............ 791

Queen. See Queens and Queen-rearing.

Supersedure and Swarming Distinguished 815 Symptom of Swarming............ 791

Census Figures on Bees and Honey Too Low

Report Showing Beekeeping on Farms.. 776

United States Not Accurate Relating to

Bees ..................... 775

Chickens and Bees.............107, 108

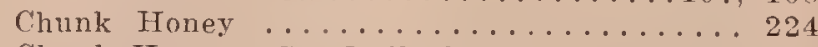

Chunk Honey. See Bulk Comb Honey under

the Head of Comb IInney.

City Beekeeping ..............85, 87

Climbers for Bce-hunting ...........99- 100

Clipping. See Queens.

Queens' Wings ............704. 705

to Prevent Absconding .......... 14, 19

Clover ...................... 183-203

. Ilsike, as a Honey Plant............ 194

Alsike, Culture of ............. 196

Alsike, Curing .............. 196 
Alsike, Future of ............ 197

Alsike, Poisonous to Horses......... 197

Alsike, Replacing Red........... 195

Alsike Seeding ................ 196

Alsike, Where Grown............. 189

Crimson .................. 200

Crimson, as a Honey Plant......... 200

Crimson, Culture of .......... 202

Crimson, Honey ................ 203

Crimson, Plowing Under.......... 203

Crimson, Seeding ............. 202

Crimson, with Buckwheat......... 202

Crimson, with Corn............. 203

How Affected by Pollination........ 187

Hubain ................ 832-835

Importance of Lime for..........183-185

Number of Species of ........... 183

on New Soils................... 4

Putting Nitrogen in the Soil......... 184

Red ................... 198, 199

Red, Affected by Moisture.......... 200

Red, Giving Way to Alsike......... 197

Red, Varied by Soil Conditions.......2 200

Sweet ............... 818- 832

Sweet, White Annual.........8.832-835

Variable Yielder of Honey.......... 190

When it Yields Honey..........188, 189

White .................... 185

White, Nectar Secretion in . . . . . . 188

White. Where Best.............190, 191

Cluster of Bees, Activity in........... 839

Cluster of Bees During Winter, How Affected

by Disturbance .............. 837

Cocoons, spinning of ................. 92

Cold, Amount Bees Can Stand.........9927

Colonies Building up. See Building up Colonies.

Equalizing Strength in Spring.....170, 775

How to Handle................. 578

Strong for Comb Honey............ 233

Strong, Less Likely to Swarm........ 811

Strong. Necessary for a Crop......... 254

Weak, Caused by Poor Season........ 254

When to Buy...............124, 125

Colony Condition, How It May Be Learned

Without Opening the Hive......584- 586

Determining Condition of, Without Look-

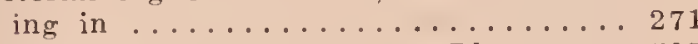

How It Seems to Work on a Plan..... 707

IIow to Open............12, 13, 579

Number of Bees in........... 887

of Bees, Manipulating.....12, 13, 575- 588

Profits .................. 682

Queenless or Not, IIow to Determine... 541

Strength in Spring............ 166

When Putting up a Good Defense Against

Robbers ................ 731

Color, Alfalfa Honey ................ 23

Color of Honey. See Honey and its Color.

Colors of Honey............469,470

Comb and Extracted Honey at the Same Time

................... 238, 239

and Extracted Honey Compared....225, 307

Building and Honey-ripening........ 95

Building Pitch for Comb Honey....... 234

Building, Variation in........... 95

Foundation ...........9, 10, 203. 224

Foundation Adulterated .......... 870

Foundation, Correct Bases.......... 204

Foundation Eliminating Drones........207 207

Foundation Fastened to Top-bar...... 219

Foundation Fastener ............ 545

Foundation, Fastening in Sections..219, 223

Foundation Filling the Section....... 224

Foundation Flat-plate Machine....... 206

Foundation, Inproved ........... 544

Foundation in Economic Uses........... 208

Foundation in Relation to Sections.... 207
Foundation, Invention of . . . .203, 543, 544

Foundation Made in Large Factories... 207

Foundation, Miter-Box for ......... 224

Foundation Not to be Spaced Too Far

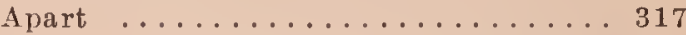

Foundation Rolls .............203, 204

Foundation Rolls Using Type......... 204

Foundation Starters versus Full Sheets.. 223

Foundation, Stretching Without Support. 209

Foundation Supported by Wires...209. 213

Foundation, Three-ply .....870, 930, 931

Foundation Touching all Four Sides of a

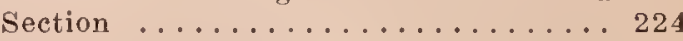

Foundation, Van Deusen ........... 204

Foundation, Vandevort .............204

Foundation, Weed Sheeted......... 206

Foundation, What It Has Accomplished. . 207

Foundation, What Weight to Use..... 208

Foundation with Exact Angles....204, 205

Foundation with Paper Midrih......... 215

Foundation with Wood Base........2 215

Honey, Appliances for .........226. 233

Honey, Artificial So-called ........... 497

Honey, Bait Sections............ 239

Honey, Barber Method of Producing... 237

IIoney, Bulk ................. 224

Honey, Comb-huilding, Pitch for...... 234

Honey, Definition of ..........224

Honey, Divided in Four Classes....... 421

Honey, Fed Back, Liable to Granulate. 357

Honey, Feeding Back for........356, 357

Honey, Flavor of ............. 225

Honey Grading, Importance of....... 422

Honey Grading Rules...........423- 425

Honey Granulated, What to Do With it.

Honey Granulating, to Stop......... 248

Honey, How to Keep.............. 248

Honey, How to Ship in Carlots....... 752

Honey. How to Ship in Small Lots. .751, 752

Honey, How to Take Off............ 243

Honey, Importance of Shallow Supers of

Honey Over the Brood-nest........ 236

Honey, Importance of Stores for Breeding 233

Honey, Importance of Strong Colonies for 233

Honey, Inportance of Well-filled Brood-

nest .................... 235

Honey in Carlots Broken Down....... 753

Honey, Keeping for a Better Market... 248

Honey, Most of It Shipped Not Graded.. 421

Honey Not Manufactured, Why?.226, 492, 497

Honey Production, Importance of Breed.

ing in Tro Stories............ 235

Honey, Sections for................... 226

Honey Sections, Scraping.......245, 246

Honey, Shipping Cases for.......749, 751

Honey Supers, Bees Refusing to Enter.

.......................239, 240

Honey Supers, Close of Seasoll....241, 242

Honey Supers, Tiering Up........240, 241

Honey. To Produce...........233. 248

Honey versus Extracted Honey....... 225

How Bees Build............4491, 492

Number of Inches in Langstroth Frame.. 252

Worker for Swarm Control.......... 810

Worker or Drone During Swarming... 792

Combless Bees. See Beginning with Bees.

Combs ...................248-255

Before the Invention of Foundation....249

Built Irregularly in the Hive........ 7

Built to Bottom-har by Reversing...... 723

Burr. See Thick-top Frames under Head of Frames.

Carrying to the Extractor.......... 324

Empty for Swarming............. 795

Empty. Importance of ........... 249

Fitting into Frames in Transferring.... 843

Good, Good Investment............ 249 
How Bees Build Without Aid........ 248

How to Fasten in Frames in Transferring 843

How to Free of Bees............ 584

How to Make the Bees Build Worker... 252

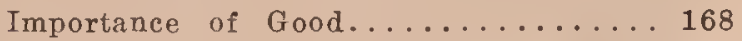

Importance of Good Fastening........ 251

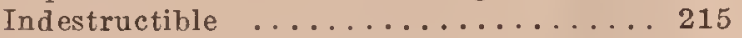

of Aluminum ......................... 216

or Foundation for Swarms........ 802

Poor, Costly Investment............ 249

Poor, Economic Waste of.........249-251

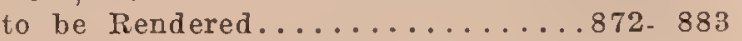

to Free from Bees in Extracting. . . 321. 323

Cougestion of Bees in Brood-nest Cause of

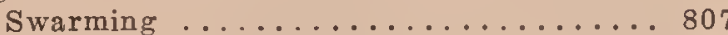

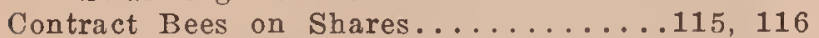

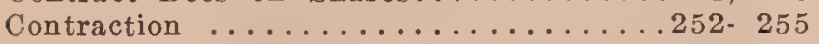

Caused by Poor Season.........253, 254

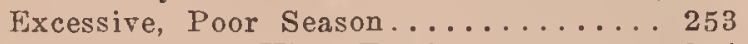

of the 8-frame Hive, Further........ 254

Theory of ................... 252,253

Coping or Thickening of the Walls or Top.. 489

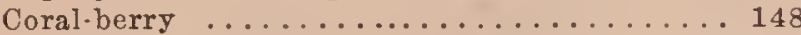

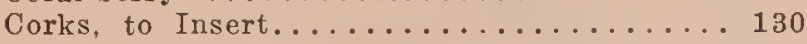

Corn Syrup in Honey................ 17

Corolla Tubes of Red Clover Affected by Mois-

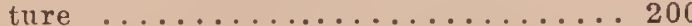

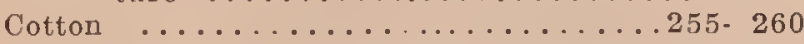

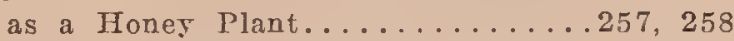

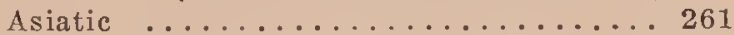

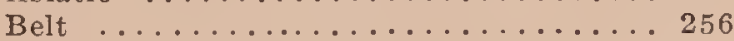

Honey, Flavor of ............ 259

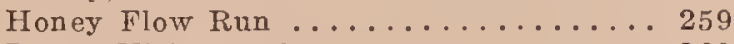

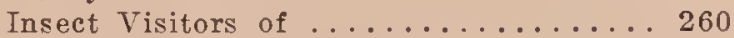

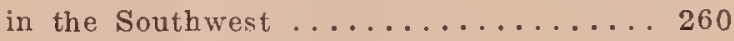

Long Staple and Short Staple............ 256

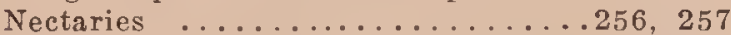

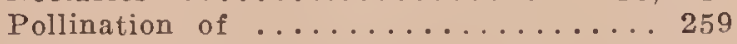

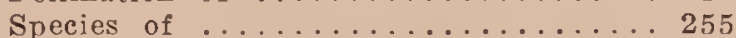

Covers of Hives...............442-444

Coveyou on Cause of Swarming........ 805

Coveyou's Plan of Swarm Control........ 808

Crimson Clover. See Clover.

Crops Dependent on Good Wintering....167-170

Crops Dependent on Strong Colonies....254, 255

Cross Bees and Effect of Shrubbery.....49- 53

Bees, Condition for ...................... 47

Bees, How to Know .............. 48

Fertilization ............... 672

Crossing Between Different Species.......681

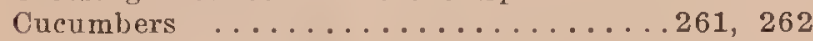

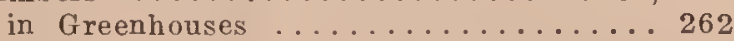

See Fruit Blossoms, subliead, "Pollina-

tion of Cucumbers."

Cyprian and Holy Land Bees........... 550

\section{D}

Dadant on Frame Spacing............768

Daisy. See Asters.

Dandelion ....................263-266

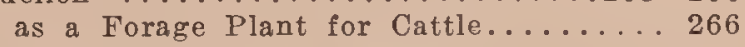

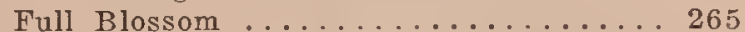

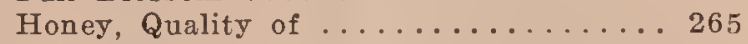

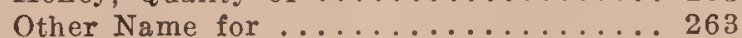

Pollen in the Honey Plant.......263, 264

Danger in Buying Bees.............121, 122

Dark and Strong-flavored Honey Excellent for

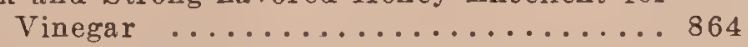

Dead Brood from Drone-laying Queens or Lay.

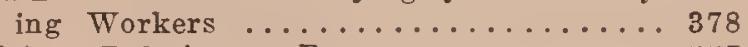

Decisions Relating to Bees............. 557

Demaree Plan of Swarm Control.319. 320, 815-817

Demaree Plan of Swarm Control. See Swarm. ing.

Demuth's Automatic Feeder............9926

Demuth's Plan of Wintering with Hive Bodies or Supers ................. 905
Deserts for the Mating of Queens........ 76

Development of Bees............266.271

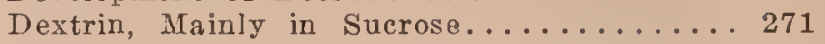

Dextrin. See Honey, also page 271.

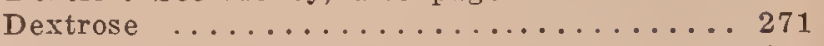

Dextrose in Glucose................ 417

Diagnosing at the Entrance, How to Save Time 275

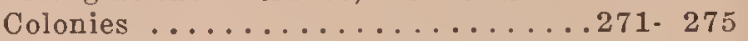

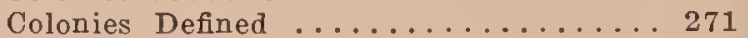

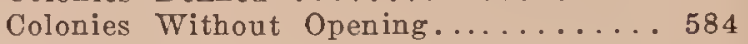

Diseases of Bees ............... 274

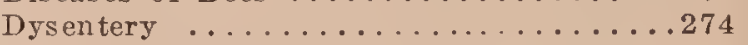

Inclination to Swarm............. 272

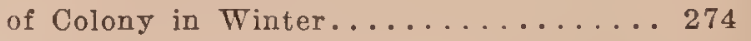

of Foul Brood by Experts....................... 378

Queenless Colony by Appearances..... 707

Diarrhea among Bees. See Dysentery.

Disappearing Disease of Bees........281, 282 Disease Probably Caused by Nosema Apis 282 Disease, Similar to Isle of Wight Disease 281

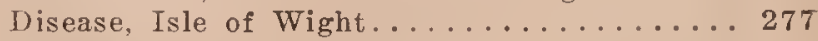

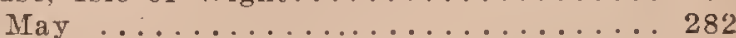

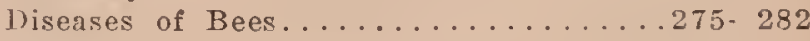

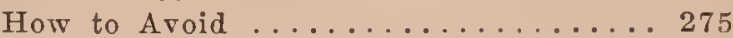
of Bees, Two Classes .............. 275 of Brood. See Foul Brood.

Distance Bees Can Fly............361, 362

Distance Bees Fly. See Flight of Bees.

Distribution of Goldenrod.........420,421

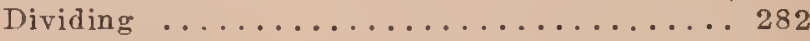

Dividing Distinguished from Artificial Swarming and Increase ............... 282

Divisible Brood-chamber Hive a Failure... . 546 Division-boards, Making Out of a Comb....900 Domestic Economy of the Hive. See Bee Behavior, Brood and Brood-rearing; also Derelopment of Bees.

Doolittle Method of Rearing Queens....688, 689

Doolittle Wide Frames for Sections....... 227

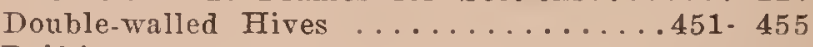

Drifting ................... 282, 283

After Bees Are Put Out of Cellars..... 923

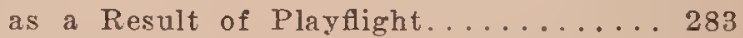

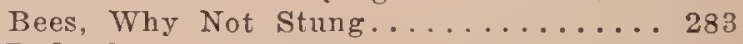

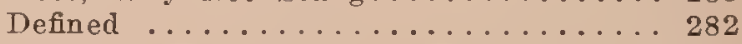

What Takes Bees Out of the Cellar... 283

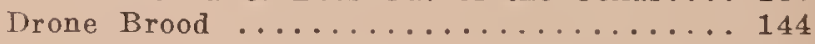
Combs, Size of ...................... 488,489

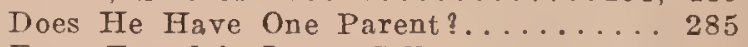

Eggs, Found in Large Cells.......... 283

Excluders ................288- 290

Laying Queens .............. 287, 704

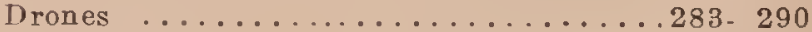

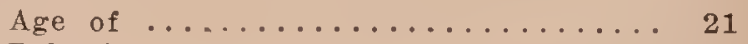

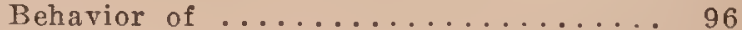

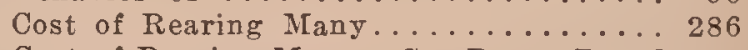

Cost of Rearing Many. See Drone Brood and Brood-rearing, also Combs with Drone-cells.

Destruction of, in Fall........... 287

Eliminated by Foundation....................... 207

Excluding Undesirable for Mating...... 76

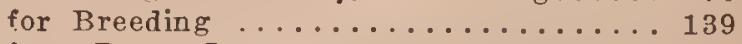

from Drone Layers ..................... 287

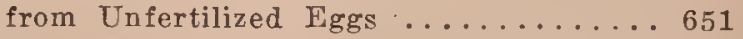

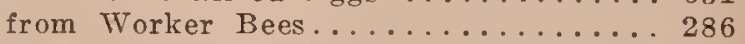

Going Out with Swarm............. 792

Influence of, on Swarming...................... 804

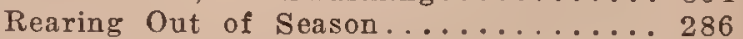

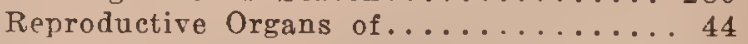

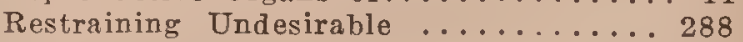

Sexual Maturity of ............ 284

with Heads of Different Colors.......... 288

Dysentery .................290. 292

a Cause of Spring Dwindling......... 772

Cause of ................290, 291

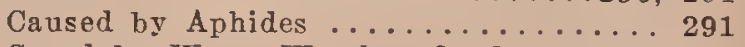

Cured by Warm Weather Outdoors..291, 292 
Determined by Entrance Diagnosis.... 274 in Bee Cellars ................ 292

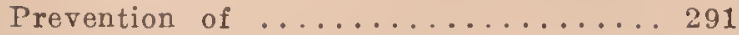

See Spring Management; also Wintering in Cellars.

Syniptoms of

Warm Weather a Cure for.....

Dzierzon and Parthenogenesis ..........661 Author of "Rational Beekeeping" and of the "Dzierzon Theory" .....293, 294 1)r. John . . . . . . . . . . . . 292- 294 Inventor of Movable Combs but Not Inventor of Practical Movable Frames.. 293 on Orientation of Bees............665 Theory .............295, 296, 651 Theory Attacked by Dickel........ 294 Theory, Recent Proof of ........... 296

\section{$\mathbf{E}$}

East Indian Honeybee................ 716

Egg, How It Can Produce Queen or Worker.. 698 Laying, Decreasing ............. 141 Laying in Combs Influenced by Several Factors ....................... 96 Laying, Maximum ............ 165 Laying, Queens Vary in........... 6 of the Honeybee.............267, 268

Eggs, Drone and Worker, How Determined.. 96 How Formed ................ 45 How the Two Kinds are Laid at Will.706, 707 How to Find................ 140 in Several Cells ............... 96 Number Queen Can Lay............ 6 of Drones, Found in Large Cells.......2 283 Producing Both Queens and Workers. See Brood and Brood-rearing. Showing Presence of Queen. Unimpregnated of Queen and Hatched.

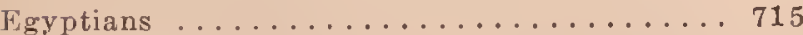

Eight vs. Ten Frame Hives........... 253

Flectric Bell During Extracting......... 341 Flectric Thermometer to Determine Tempera. to Determine Tempera- 837

Electrical Current for Wire-imbedding...217, 218 Electrical Wire Imbedding..........217, 218 Elementary Beekeeping. See A B C of Beekeeping and Beginning with Bees.

Elwood on Hives................ 439 Embryology of Bees...............266 Embryology of Bees. See Development of Bees.

Enemies of Bees. of Bees Among the Birds......... 297 The Worst for the Beekeepers . . . . . . . 299

Entrance Alighting-board ............ 300 Blocks ..................301, 302 Diagnosing ..............272, 273 Diagnosis, How to Save Time.......2 275 Diagnosis. See Diagnosing Colonies. Guard ...................289, 290 Guards. See Drones.

Guards to Prevent Swarming......... 19 Means Determining Condition of Colony. 272 of Modern Dovetailed Hive......... 303 Showing Disease................ 274 Size of in Winter.............. 301 Swarm Catcher ............... 801 Temperature in the Cellars......... 918 Usually at the Bottom............. 299 Entrances Cleaning, from Dead Bees in the Spring .................... 775 for Supers in Honey Production. . . . . . 304 Indoor Wintering ....................... 304 Keeping Grass from..............72, 300 Made up of One or More Holes for Win. tering ..............901, 902 of the Dead Colonies, Importance of Clos. ing in the Spring....................... 774

Plurality of .............. 303

Proof Against Mice............. 303 Size of, for Wintering in Cellar and Out-

doors .................... 861

Size of, in Summer ............. 301 to Hives ...................299-304

Upper, in the Production of Honey.... 304

Very Small in Winter............. 302

Enzymes in Honey.............. 467 Enzymes in Invert Sugar............ 547 Fiqualizing Strength of Colonies in Spring... 170 Escape-boards, Ventilated.............. 323 Escape-boards, How to Put On.......... 587 Eucalyptus ........................ 305 Honey, Quality of .......... 306 in Australia ................. 306

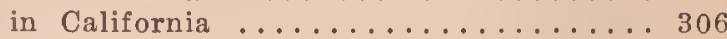

Species of ............... 305

Excluders, Drone and Queen..........288-290 Fxcluders for Extracting ............. 318

for Swarm Control ............ 809 Exhibits of Live Bees. See Honey Exhibits.

Extension Men Preaching Lime......... 185

Extracted Honey ................... 307-315

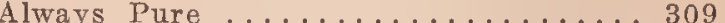
Better When Capped Over ........... 308 Cheaper Than Comb.............. 9 Clarifying by Gravity Method......337, 338 Distinguished from Strained Honey.... 307 Glass Bottles for ............... 314 Heating Before Canning.......... 338. 340 How to Keep.................. 309

Improperly Boxed ..........312, 313

Method of Clarifying............ 326

Packages for ................ 312

Pails for .................. 314

Produced, Big Force Necessary....... 315

Stored in Galvanized Cans......... 309

Taken Before It Is Capped Over...... 308

versus Comb Honey ............ 307

When to Remove from the Hives...... 320

Extracting ............................... 341

and the Control of Swarming........ 319

Building. See Buildings.

Capping-melters for .......... 335, 336

Carrying Combs During............. 324

Confinement of Queen Below.......319, 320

Equipment, Plans for ........... 338

for a Small Apiary............325. 327

Hives to Use for............... 316

Hoffman Frames Adapted for........ 318

Honey .................... 9, 10

Honey-pumps for ................. 330,331

House .................... 325

House. See Buildings.

House, Small . . . . . . . . . . . 158, 159

How Far to Space the Frames......... 316

Large Power Outfits for..........328-347

Large Scale, Locating Equipment......331

Outfit for Large Producers........328-341

Outfit for Small Producers.......... 325

Putting on Supers for........... 317

Small Outfit for............... 327

Straining Honey for ............. 337

to Get the Bees off the Combs......321- 323

Uncapping the Combs in a Large Way..

.............................. 332. 334

Choosing for a Large Producer........ 330

Cowan Reversible ............... 342

Friction Drive for............... 346

Honey, Invention of ........... 543

How It Should be Set Up........325,.326

Novice, Non-reversing . . . . . . . . . 342

Root Multiple Reversing ... . . . . . . . 342

Extractors, Automatic Reversing........343- 346

Buckeye ..................344. 346 
by Peabody ...................... 341

First ................. 341

Importance of Large Over Small..... 347

Principles of .................... 341

Eye, Compound ............. 347, 348

\section{$\mathbf{F}$}

Fabre's Observations on Parthenogenesis.... 296

Failure of Crops Due to Excessive Contrac-

tion .................253, 254

Fairs, Exhibits at. See Honey Exhibits.

Farmer Beekeepers ............. 348

Farmerette Bee-suits . . . . . . . . 859,860

Fasteners for Comb Foundation.......220-223

Fastening Foundation in Brood-frames and Sections .............219-223

Feeder, Advantage of Boardman......... 354

Alexander ................... 352

Automatic ............. 169, 926

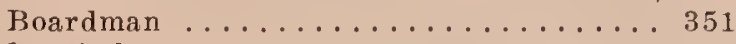

Doolittle ..................... 353

Friction-top Pail .............. 352

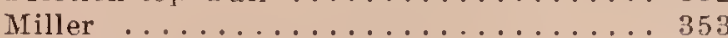

Pepper Box .................. 351

Various Forms of Construction....350-35i

Feeding and Feeders............... 349

at Night to Avoid Robbers......... 356

Back ..................356, 357

Bees During Winter ............ 926

Effective for Two Purposes........... 349

Granulated Sugar Best for......... 349

for Winter ....................... 354,355

for Winter, When ............ 354

How to Make a Syrup for......... 350

in Freezing Weather............ 355

in Spring ................ 355

in Spring to be Avoided........... 356

in the Spring versus Feeding in Fall..355, 356

Out Unfinished Sections or Wet Ex-

tracting-combs ............. 732

Outdoors ........................ 357

Outdoors, Disadvantages of ...... 358

Outdoors, How to Do It......... 358

Outdoors to Circumvent Robbers......7731

Outdoors versus Feeding in the Hives.

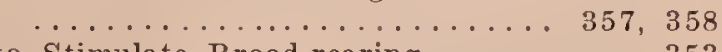

to Stimulate Brood-rearing......... 353

Female, True

Females Undeveloped $\ldots \ldots \ldots \ldots \ldots \ldots \ldots$

Fence. See Comb Honey.

Fences for Sections.............231: 233

Fences for Windbreaks...........912- 914

Fertile Workers. See Laying Workers.

Fertilization of Flowers by Bees. See Pollination, Fruit Bloom, Buckwheat, Alfalfa.

Fertilization of Queens, Artificial........ 75

Figwort .................. 359

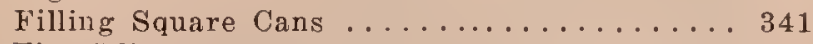

Fire Blight ....................... 3591

Caused by Bugs and Sucking Insects... 360 Caused by Leaf Hoppers... . . . . . . . . 359

Caused by Plant Life............. 360

Nature of .................. 359

Not Caused by Bees................. 360,361

When It Occurs .............. 359

Fireweed. See Willow-herb.

Fixed Frames. See Frames, Self-spacing, Par. ticularly Hoffman Frames.

Flavor of Extracted Honey Not Quite Equal

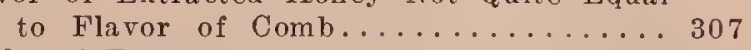

Flight of Bees................. 361,362

of Bees, Range of ............. 362

of Bees Varies According to Conditions. 362

of Orientation. See Playflights of Young Bees.

Flowers, Forms and Organs of........671

Food Chambers. See Comb Honey to Produce; also Wintering in Gellar.
Foul Brood ....................363-378

American ................. 363

American and European Confusing Symp-

toms ..................... 372,373

American. Carried to Other Hives..... 365

American, Confined Mainly to Sealed Cells 363

American, Distinguished by $\mathrm{T}$ o $\mathrm{ng}$ u es

Pointing Upward .................. 365

American, Drugs for it........... 370

American, Fall Treatment.......... 370

American, McEvoy Modification of Treat-

ment ................. 366

American, odor of .............. 365

American, Pinhole Perforations....... 365

American, Quinby Treatment........ 366

American, Roping Test .......... 364

American, Shaking Treatment as Modi-

fied by Phillips ..........367-369

American, Symptoms ........363- 365

American, Treatment and Cure....366-369

Detected at Entrance.............274

European, Alexander Treatment....... 375

Furopean, and the Relation of an Early

Honey Flow

European, Differentiated from American

European, House's Modification of Treat-

ment ................... 375

European, Miller's Treatment....... 376

European, Symptoms of .......371-373

European, Treatment of .......374, 375

Expert Diagnosis of ............ 378

Laws, Fundamental Features of...... 563

Laws in Minnesota............. 563

Laws, States Having..........562, 563

Sequence of Brood Diseases......... 374

Two Diseases .................. 363

Worst Enemy of Bees.............. 299

Foundation Having Wires Incorporated in it

Iinproved by Weed, Root and Blanchard. 544

Indispensable ................. 10

Invention of ............. 543

Laminated ...................

Narrow Strips for Swarms......... 803

See Comb Foundation.

Three-ply

Fowls on Cause of Swarming...........

Franes ...................... 378. 380

Bee-space All Around................ 105

Brood ................... 8

Closed-end ..............445-447

Closed-end, Danzenbaker .......... 382

Closed-end, Quinby ............ 381,382

Distance Spaced Apart 317, 381, 582, 767, 768

for Hives .................. 445

How to Handle .............. 13

Improved Hoffman ............... 383

Langstroth, in Dimensions Why Better

Than Other Frames.........441, 442

Langstroth, More Practical Than Any

Other ................... 378,379

Langstroth's Invention of . . . 378, 379, 543

Movable, What They Have Accomplished 2

Number of Ways to Manipulate...581, 582

Reversible ...............722, 723

Self-spacing $\ldots \ldots \ldots \ldots \ldots \ldots \ldots \ldots 381-385$

Self-spacing, for Small Beekeepers..... 386

Shallower and Deeper Than Langstroth. 442

Size and Shape of............. 379

Square versus Shallow or Oblong...440.441

Thick-top ..............379, 380

to Manipulate. See Frames and Manipu-

lation of Colonies.

Wiring. See Wiring Frames.

Friction Drive for Extractors........... 346

Top Pail for Feeding............ 352 
Top Pails

Fructose. See Honey.

Fruit Bloom, Pollination of........... 391

Blossom Honey Relatively Small in Quan.

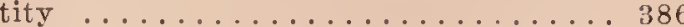

Blossoms ............... 386-414

Blossoms, Spraying with Poison.... 387. 389

Blossoms, When Poisonous Sprays Are to be Applied.

Growing and Beekeeping. 106, 107, 111. 114

How Damaged by Bees...........111. 114

Important, Dependent Upon Pollination. . 681 Furniture Polishes of Beeswax........ 870

\section{G}

Gallberry

Honey, Quality of

Where Growll

Gardening and Bees.

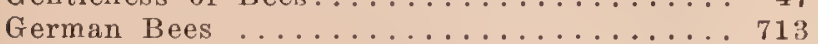

Gerstung on the Cause of Swarming...... 805

Giant Bees of India.............. 717

Glass Packages for Extracted Honey....... 314

Glass Packages of Honey. See Bottling Honey.

Gloves, Bee ....................

Recommended to Beginner When First Handling Bees ............. 577

When Can be Discarded........... 13

Glucose ...............417, 418

Detection of ............. 466

Determined by Polarization.............. 467

in Honey .................. 17

Goldenrod .................418.420

A Favorite of the Honeybees......... 420

Species of ................ 418

Honey, Quality of ...........4421

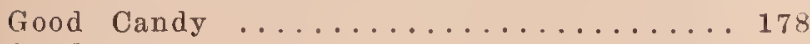

Good Seasons Returning ............. 255

Government Examination of Foul Brood.....378

Experts in Fruit Case............ 115

on Adulteration .............. 18

Grading by Pictures............. 425

Comb Honey .............421- 426

of Comb Honey, Importance of....... 422

Rules for Comb Honey.........423. 425

Rules Illustrated .............. 426

Grafting Cells for Queen-rearing.......689-691

Grannlated Comb Honey, What to Do With It

246,247

$427 \cdot 436$

Honey, Cntting Up Into Bricks....432. 435
Dayton's Outfit for Liquefying....... 429

Dayton's Outfit for Liquefying....... 429
Educating the Public to........... 435

Heating to Liquefy............... 428

How to Market............431. 435

in Oyster Pails ...............4434

Liquefying in a Wash-boiler......... 428

Pouder's Method of Iiquefying....429-431

Removing from Barrels............ 89

Root Airline Spread.............. 435

Selling in Paper Bags............4432

to Get Out of Combs...........4 431

Two Ways of Melting........... 131

Granulation, Cause of $\ldots \ldots \ldots \ldots \ldots \ldots \ldots 427$

Freaks of .............. 427

of Fed-back Honey ............ 357

Prevented by Fleating. . . . . . . . . 428

Science of .............. 427

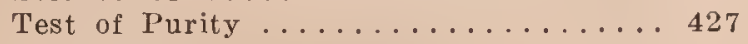

Grape Sugar ................. 271

Grass in Front of Entrances........... 300

Grass, Keeping Away from Entrances..... 72

Gravity Method of Clarifying Honey........ 337

Groceries, How to Boost Sales of Honey in.. 593

Guards, Ready to Repel Robbers......... 731

Gum, Black ..................... 126

\section{H}

Habits of Plants.......6673

Handling Bees.................5 575. 588

Handling Bees. See Manipulation of Colonies;

Frames, Self-spacing; Anger of Bees; also Stings, and Hives.

Hats, Collapsible for Use of Veils........ 856

Hauling Bees. See Moving Bees; also Ship. ping Bees.

Hawk's Experiments on Determining Vitamines in Honey ........................ 866

Hawk on Honey as a Food...........471

Heartsease $\ldots \ldots \ldots \ldots \ldots \ldots \ldots \ldots \ldots \ldots \ldots, 438$

Heat. See Artificial Heat.

Heat, How the Bees Generate It. . . . . 838, 839

Heating Honey During Extracting......338. 340

Heddon's Divisible Brood-chamber Hive a Failure ................. 546

Heddon's Method of Preventing After-swarming $\ldots \ldots \ldots \ldots \ldots \ldots \ldots \ldots \ldots \ldots \ldots$

Help in the Apiary............... 684

Hermaphrodite Bees .............. 438

Hibernate? Do Bees..............926. 928

Hibernation of Bees Exploited in the American Bee Journal ......................... 927

Hired Help in the Apiary............664

Hive, Baby, Unsatisfactory.........15, 16 Bodies ................ 8 Bodies for Comb and Extracted Honey.. 8 Buckeye, Construction of .......453,454 Carriers .................. 923 Heddon's Divisible Brood-chamber a Fail-

ure ................... 546

How to Open.............. 12, 13

Making ................ 438-440

Modified Dadant ..............448

Observatory, Advertising Value of..499-501

on Scale ................... 739

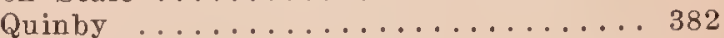

Requisites of a Good............. 439

Stands ...............65- 67

Thirteen-frame Langstroth ........448

Twelve-franie Langstroth ........ 448

Tool ...................... 11

Tool, Great Convenience of ........ 577

Tool, How to Use...........577, 578

Hives .................440-454

Arrangement of, in Apiary.......70, 71

Aspinwall, for Non-swarming........ 545

Based on Langstroth's Dimensions. .442, 443

Box. See Box Hives.

Covers for .............. 442-444

Dadant .................... 447

Danzenbaker ............... 446

Debeauvoy ................... 458

Defined .................. 440

Della Rocca ................. 455

Dimensions of .............. 440

Double-walled ............... 545

Double-walled or Chaff..........451-455

Double-walled, Wintering in . . . . . . 898

Fight or Ten Frame Langstroth....... 449

Eight versus Ten Frame........... 253

Evolution of .............455-458

Heddon ............... 447

How Bees Can Keep Them Cool Under

Extreme Circumstances ......862,863

How to Open............... 579

Huber's Leaf ................ 456

Jumbo ................... 448

Large or Small.............. 316

Lock Cornering of.............. 545

Log Gums. See Box Hives.

Long-idea ................449-451

of Langstroth Dimensions ......... 439

Prokopovitsch ..............4 457

Shallower and Deeper Than Langstroth. 442

Size of. Influence on Swarms........ 804 
Small, Encouraging Swarming.....15, 16

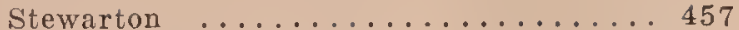

I'en-frame of Extra Depth.................. 447

to Use for Extracting............. 316

Tivo Stories for Breeding Purposes.... 449

with Square Edges ............ 442 Swarms. See Swarms Hiving.

Hodgson Ventilated Escape.boards........ 323

Hoffman Frames ..............383, 384

Frames Adapted to Extracting............. 318

Frames, How to Manipulate........ 583

Julius, on Frame-spacing.......... 768

Holly ....................... 458

Holly, American .............. 458

Holtermann's Method of Carrying Colonies in

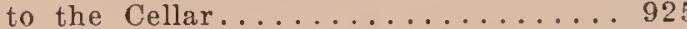

Holy Isand and Cyprian Bees.......... 550

Holy Lands and Syrians............. 715

Holy Lands and Syrians. See Italian Bees.

Honey ...................4458-462

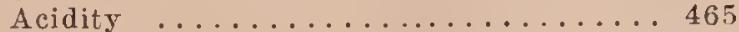

Adapted to Persons of Sedentary Habits 471 Adulteration of .............16- 19 Alfalfa ........................... 23 American and Hawaiian .......... 460 Anzong the Carbohydrate Foods....... 459 Amount the Bees Can Carry......886, 887 Analysis, Discovery of........... 469 Analysis, Moisture ............. 464 Analysis of ..............4462. 469 and Bread Easily Digested.......... 866 and Its Colors............469, 470 Annual Production in U. S......... 2

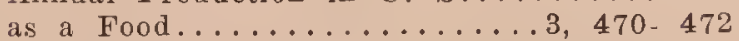
as a Food with Bread.............44 47

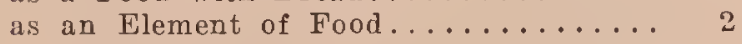

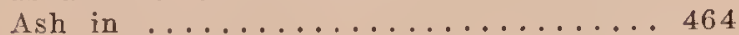

Baked Beans ................ 480 Better Than Ordinary Granulated Sugar 471 Bottling. See Bottling Honey.

Bread .................... 479

Browne's Anilin Acetate Test........4460

Business of Beekeeping, What It Could

be Made to Do................ 4

Buyers, Two Classes............... 128

Cakes Keep Longer Than Cakes Made

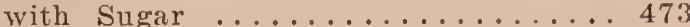

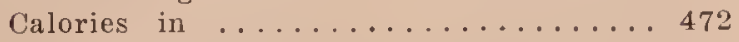

Caramels ................... 481

Cell Walls. Thickness of........... 482

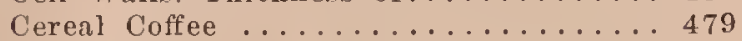

Clarifying ..................... $337-339$

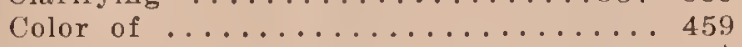

Color Tests ................ 468

Composition of ............460, 461

Concentrated Sweet ................. 3

Containing Mineral Matter......... 471

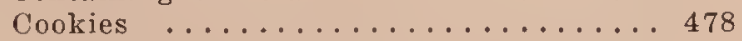

Darker, Going into Baking.......... 3

Detection of Commercial Glucose in ... 466

Dextrin in .................. 464

Dextrose and Levulose in.......... 465

Easily Assimilated Food........... 471

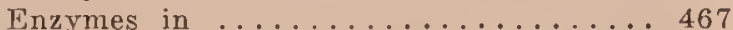

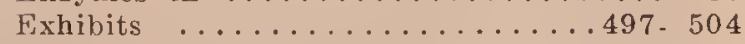

Exhibits, How They Refute Comb Honey

Canards ................... 497

Wxhibits, Live Bee Demonstrations at $501-503$

Fixhibits, Live Bees Necessary Part of. 499

Exhibits of Educational Value....... 497

Exlibits, Varied Designs........498, 499

Extracted, Cheaper .............. 9

for Cooking Purposes ............. 473

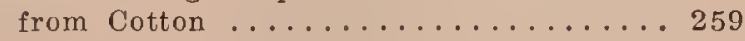

Graham Biscuits .................. 479

Granulated, Affected by Cold........ 426

Granulated. See Granulated Honey.

Grautation, to Prevent.........128. 130
Ilawk, Philip B., on ............ 471

Heating in Glass Tanks........... 132

House. See Extracting Houses and Buildings.

How the Bees Ripen............. 94

How to Analyze ............4462. 469

in Brood While on the Hive......... 309

in Supers, to Determine Without Pulling

Hive Apart ............................. 586

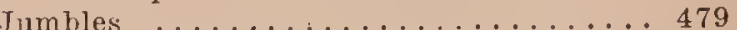

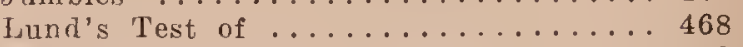

Makes Better Baked Foods Than Sugar 473

Methods of Analysis of. See Honey, Ana. lysis of.

Not Adulterated Now............... on Commission. See Marketing Honey.

Peddling ............................... 504

Peddling at Groceries.......................... 507

Peddling Made Easy............... 504

Pliysical Characteristics of.....4461, 462

Physical Properties of ........458, 459

Plants ...................... 507-519

Plants, Acreage Necessary for Colony of

Bees ........................ 78

Plants Dependent Upon Weather...... 508

Plants, Geographical Distribution of... 507

Plants, Importance of Thoro Knowledge

of .................... 507

Plants, Eist of the Most Important. .510-519

Plants, Suitable for Artificial Pasturage 78

Plants Variable in Different Seasons... 508

Plants Variable in Different Soils..... 508

Polarizations ................. 465

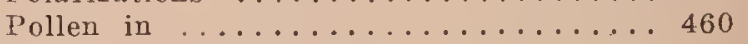

Pounds to the Gallon............. 770

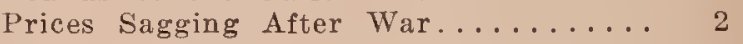

Protein in ................. 466

Pump, Invention of . . . . . . . . . . . 544

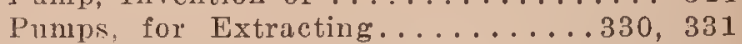

Puinps in Bottling .............. 135

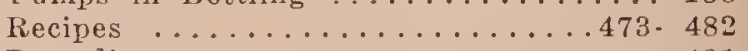

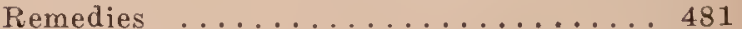

Requiring Less Soda in Cooking...... 473

Ripening of ............94, 95

Selling in Connection with Live Bee Dem-

onstrations ..............501-503

Several Blends for Bottling.......133, 134

Should Not he Extracted from the Brood.

nest to Feed................. 349

Specific Gravity of.......................... 770

Stores for Breeding ............... 169

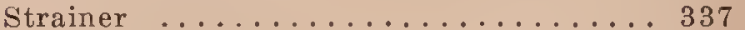

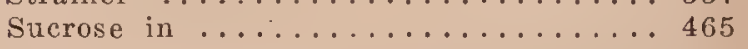

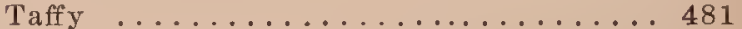

Taken by Centrifugal Force......................

Trading, for Other Commodities...... 505

Two Ways of Melting........................ 131

Undetermined Matter in ............... 466

Value of, Produced in United States.... 2

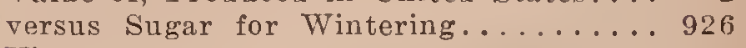

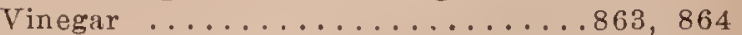

Vitamines in ................ 472

Vitamines in. See Vitamines in Honey.

Honeybee and Fruit Culture.......... 395

Honeyhees. See Bees.

Honeybee's Legs Highly Specialized...... 661

Honeycomb ................483. 492

Cappings Not Air-tight............ 488

Cells, Thicker at the Top......... 489

Construction of ......................... 486

How Bees Build ...........491, 492

Made from Wax Scales Under Bodies of

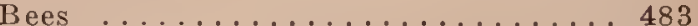

Natural-built Not Uniform......... . . . . . . . 488

Number of Cells to the Inch......... 486

IIoneydew ...................4492. 496

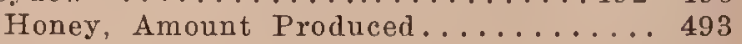

Composition of ...........493. 495 
How the Quality Varies............ 495

Mainly from Plant Lice............ 493

Not a Suitable Food for Wintering...... 924

Sometimes from Other Sources Than Indered ...............496, 497

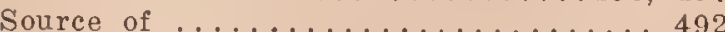

Honeys, Classifications of.........459,460

Honeys, Flavors of .............. 307

Horehound ................... 519

Horsemint ................519, 520

Horsemint, Where Growl............. 520

Horses When Badly Stung, What to Do..780, 781 House-apiary ..................72- 75

Arrangement of Hives in ........73, 74

Cross Colonies in............. 74

for Wintering ............. 74

How to Construct.............. 73

See Apiary.

Very Necessary

House's Modification of Alexander's Treat. ment

How Italians Introduce Among Blacks....... .... 526

Huajilla ...................... 521

Hubam, Advantages Over Regular White Sweet Clover ................832.835

Clover, Rapidity of Growth.......832. 834

Clover. See Sweet Clover, White Annual.

Its Greatest Value as a Turn-under Crop $83-$

Original Home in Alabama.......... 832

Huber, Francois .

Huber's Discovery of the Source of Wax... 524

Great Discoveries in Regard to the Queen 524

Letters ................... 523

Observation Hive ............ 524

Study of the Honeycomb........... 524

Hughes, H. D., on Sweet Clover....... 829

Humblebees. See Bumblebees.

Hunting-box, How to Use............ 98

Hybrids ................... 525, 526

Not Immune to European Foul Brood

Like Italians . . . . . . . . . 525

Objection to ...................... 525

of Carniolans and Cyprians with Italians 526

of Italians and Blacks.......... 525

Hydrometer Necessary in Vinegar-making... 864

\section{I}

Imbedding Wires in Comb Foundation. . 216, 217 Increase . . . . . . . . . . . . . . .527- 529

Basic Principle of the Alexander Method. 528

by Alexander Method............ 527

by Dividing a Colony up Into Nuclei... 629

Defined from the Standpoint of the Howey

Producer .................. 527

Indian Wheat, an Important Pollen Plant of the Desert

Inoculation of Alfalfa Soil............ 30

Inspectors .................5529. 531

Pay of $\ldots \ldots \ldots \ldots \ldots \ldots \ldots \ldots \ldots$

Qualifications of ................ 529

Inspector's Duty of Giving Instructions as

Well as Cleaning up Disease.....529, 530

Introducing .................551- 543

and the Relation of Colony Odors and

Queen Odors ................ 532

Basic Principles of ........... 533

California way of ............ 540

Conditions Favorable for .......532, 533

Cage, Smith's .............537, 538

Cages Variously Constructed ......533-538

Direct Method of ............ 541

Miller Smoke Method for.........538, 539

Queen-cells Instead of Virgins........664 694

Simmins Fasting Method of......... 541

Sure Way of............... 540

to Laying Workers Difficult........ 566

Virgin Queens .............542,698

When Bees Ball Queen........... 542
Inventions Relating to Bee Culture....543-546

Inventions, More Important Ones........ 543 Invert Sugar ..............546, 547 How Prepared ...........546, 547 Syrup for Adulterating .......... 18 Syrup Similar to Honey........... 547

Isle of Wight Disease................... 287 Disease, Caused by Parasites.....278, 279 Disease. See Diseases of Bees.

Disease, Symptoms ............. 277

Disease, Why Started........... 277

Italian Bees............................ 550 Bees, Location of Yellow Bands...... 549 Hybrids ................ . 547 Hybrids, Variable .............. 549 Superior to Any Other Race....... 547 Test of Purity of.............. 548 Italianizing ................550, 551 Italianizing, How Best to Accomplish It... 551 Italians, Four and Five Banded......549, 550 Italians, Three Yellow Bands Considered a

Test of Purity .............. 548

Tars and Bottles for Extracting,........ 314 Jelly, Royal ................... 69y Jumbo Hives

\section{K}

Kegs for Shipping Honey........... 87 King Birds, Destructive of Queens and Bes. 297 Knives for Uncapping. See Uncapping Knives and Extracting.

\section{I}

Labels for Honey. 552

Labels, Law as to ................135, 136

Labor Saved by Entrance Diagnosis.......275 Langstroth, A. I. Root's Personal Recollections of ............... 555, 556 a Minister of the Gospel......... 554 as a Writer Took a High Place....... 554 Death of ..............554, 555 Frame, Number of Tnches in . . . . . . 252 Lorenzo Lorraine .............552- 556 Langstroth's Dimensions, Argument in Fa. vor of ................ 441

Distressing Head Trouble......... 554 Early Fondness for Insect Life....... 554

Early Training............... 552

Great Invention of the Bee-space..... 105 Hive Most Popular................ 554 Invention of Movable Frames.........

.........378,379,543, 554

Opinion of Sage Honey.......... 738 Original Hive ............... 441

Larva, Behavior of ............... 92

Development of .............. 146 of the Honeybee ...........268, 269

Larvac. See Brood and Brood-rearing; Behavior of Bees, and Development of Bees.

Law as to Labels.............. 135 Common, Favorable to Bees......... 559 Common, Relating to Swarms........ 557 Pure Food ................. 17 Relating to Bees............556-566 Relating to Bees Based on Common Law 557 Relating to Shipment of Bees........5561 Relating to Bees in Trees.......5557, 558 Relating to Foul Brood.......... 562 Relating to Labels............. 552 Relating to Location of Bees........ 558 Relating to Ownership in Bees....... 557 Laying Workers ............565, 566 Cause of ............... 565

Difficult to Introduce to a Colony Having

Such ................. 566

How to Detect ............ 566 
How to Get Rid of............ 565 See Drones.

Legal Decision on Bees Injuring Fruit...114, 115 Legal Responsibility of Beekeepers......109- 114 Legislation Against Spraying at the Wrong

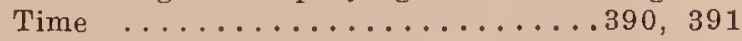
Legs of the Bee............41,659. 662 Legs of Bees, What They Perform in Wax.. 871 Legumes, Pollination of............. 394 Levulose. See Honey and Honey Analysis.

Lima Bean ................566, 567

Lima Bean, Important Honey Source in South-

ern California ................ 567

Lime for Clovers ................183- 185

Lime. See Alfalfa and Clover.

Linden. See Basswood.

List of Important Honey Plants.......511- 519

Live-bee Demonstration, How to Make..502, 503

Live-bee Demonstration. See Honey Exhibits.

Live Bees, Helping to Sell Honey.......... 633

Localities, How They Differ so Far as Bee.

keeping Practices Are Concerned..... 568

Locality ..................5567-571

Factors That Influence .......... 568

How It Modifies Bee Manipulation..... 568

Its Effect on Swarming.......... 807

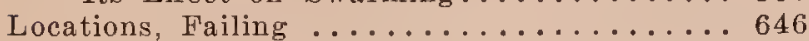

in United States Variously Compared.568 571

Locust ...................571, 572

Log Gums, Passing of ............ 137

Log Hives .................. 136. 139

Logwood ..................... 573

Logwood, One of Important Honey Trees of the Tropics

Long-idea Hives . . . . . . . . . . . . . 449. 451

\section{M}

Manchineel .................. 588 Mangrove Affected by the Big Freeze of 1894574

Black .................574, 575

Important Source of Honey in Southern

Florida ................. 575

Various Species of ........... 574

Manipulating Colony of Bees..........12, 13

Manipulation Facilities by Proper Tools.... 577 of Bees Dependent Somewhat on Weather Conditions .............. 576

of Colonies .................... 5875

of Colonies, How to Avoid Being Stung

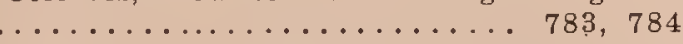

Manum's Device ................... 799

Manure for Winter Covering......... 77

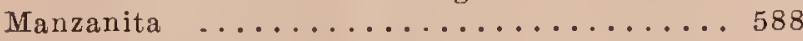

Maple ..................... 588

Marigold ........................ 589

Marketing Honey ..............589. 593

Honey Along the Roadside.......... 592

Honey at a Less Price............. 590

Honey in a Large Way........... 590

Honey Thru Commission Houses....... 591

'Thru Honey Exchanges Where in Exist-

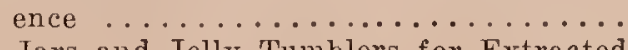

Mason Jars and Jelly Tumblers for Extracted

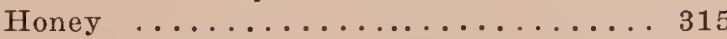

Mating Hives in Queen-rearing.......694,695 of Queen and Drone.........284,285 of Queen and Drone. See Drones.

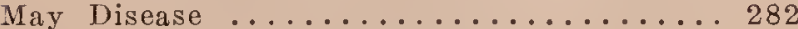

Mesquite ......................... 595 Honey, Quality of ............ 595 in the Hawaiian Islands.......... 595 One of the Main Honey Plants of Texas 594 Rapid Spread of .............. 594 Species of ..................... 593 Two Blooming Periods of .......... 594

Metamorphosis of Bees. See Development of Bees.

Methods Preventing After-swarming....... 20
Mice Destructive of Bees........... 297

Mice. See Entrances.

Migratory Beekeeping ............. 596

by Small Boats ............... 745

in Bean Fields ............. 567

in California ................. 596

Milkweed $\ldots \ldots \ldots 596.599$

Climbing or Blue Vine.......... 599

Common ..................... 597

Pollen Masses on Bees' Legs........ 598

Where Distributed ............. 597

Miller on Cell-killing for Swarm Control.813, 814

Miller's Smoker Method of Introducing..538, 539

Miter-box for Cutting Comb Foundation.....2224

Modern Beekeeping versus Old.......137, 138 Equipment, What It Has Done for Bee-

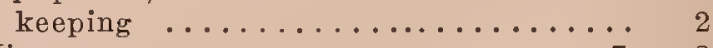

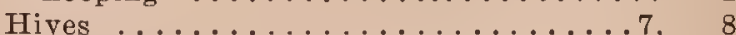

Moisture, Why Forms on the Inside of Hive.. 908 Mosquito Hawks Very Destructive at Some Seasons of Year in Florida..........299

Moth Miller .................599. 616 Miller Eggs................6607

Miller, Fumigation of . ........ 614

Miller, Habits of ............. 605

Miller, How to Control..........66 614

Miller in Combs When Stored Away from

Bees .................601 601

Miller in High Altitudes............. 601

Miller Larrae ................ 610

Miller, Life History of.......... 612

Miller Mating and Oviposition......... 607

Miller. Natural Enemies of .......... 612

Miller Origin and Distribution........6 605

Niller Sometimes a Blessing in Disguise

.................. 602, 603

Worm Galleries ...........608, 609

Worms, How They Burrow into Broodframes .................613-615

Worms, How They Destroy Comb Foundation ..................611

Mother Earth, Temperature of.......... 917

Mouth Parts of Bees............6, 39 Moving Bees ...............6616. 625

Bees after Being Put into a Sack.....6 621 Bees by Automobile Truck or Horsedrawn Wagon ...........168,621, 622

Bees by Boat .................6 619

Bees Long Distance by Express....623, 624

Bees, Preparing for . . . . . . . 619-621

Bees Several Miles..............6 619

Bees Short Distances Not Practicable.616, 617

Bees to Outyards and Back Again..... 618

Bees, When .............. 622

Bees Without Shutting Them in Hive... 622 Mustard

\section{$\mathbf{N}$}

Nectar

Abundant from Oranges ............ 639

Chemical Characteristics of ........66 627

Correlated with Character of Soil.....5 508

How Bees Extract Water from........ 869

How Deposited in Cells............ 94

How Gathered by Bee........................... 37

Secretion in Clovers ........... 188

Nectaries of Cotton............256, 257 Neighbors, Getting on the Right Side of..109, 126

Nervous System of Honeybee.......... 45

Nervspaper Plan of Uniting............ 853

Nosema Apis, Not Cause of Isle of Wight Dis-

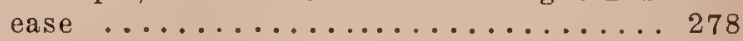

Nosema Apis, Probable Cause of Disappearing Disease .................. 282

Nuclei ..................6627-631 Absconding ................. 16 for Purpose of Instruction.........66 628 Forming .............695-697 
Forming for Increase...........6628

Forming, Problem for Beginners......6 629

Full Size or Baby, for Mating Queens.694, 695

How to Feed................. 630

Large for Queen-rearing Superior to

Small Nuclei ...............6695

Somerford's Method of Forming......6630

Used for One of Two Purposes.......6.628

Very Small, Require Watchful Care.... 628 Nucleus Defined ............627, 628 Nuisance, Bees a. See Bees Not a Nuisance.

Nursery Cage for Cells and Virgins....... 693

\section{0}

Observatory Hives ............632- 637

for Increasing the Sale of Honey...... 633

Huber's ......................... 524

Importance of Having Means of Ventila-

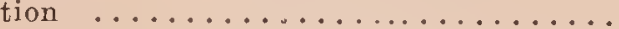

in Public Schools for Purpose of Instruction ..................6. 633

Maintenance and Operation..........6. 636

of Arthur C. Miller Type.........633-635

of Great Educational Value...........6 632

of Usual Type..............6633

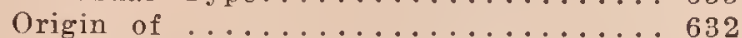

Odor in Queen Introducing............... 532

Orange ..............................637. 640

Development of, in California.....639,640

Honey in California, Quality of....639, 640

in Florida .............637, 638

Nectar Abundant in California......66 639

When in Bloom in Southern California.. 640

Order of Reading.

Ordinances Declaring Bees a Nuisance Uncon-

constitutional ..............560,561

Orientation Flights. See Playflights of Young Bees.

Out-apiaries .............6640-646

Care of Automobiles for...........6 645

Distance Between ................6.6. 641

Failing Locations of ........... 646

General Management of .........6644

Hauling Bees and Bee Supplies to and

from ...............642, 643

Helpers for ...............6.644

Number of Colonies in .......640,641

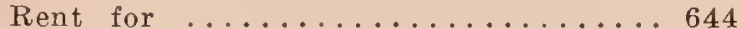

Wintering Bees at ..........6.6.6. 645

Out.apiary Business Caution.........6 646

Extension .........6.683

Location Dependent upon Conditions... 642

Scaling a Hive at.............646

Outdoor Feeding. See Feeding Outdoors.

Overstocking ..............646-648

Overstocking and Priority Rights........6 647

\section{$\mathbf{P}$}

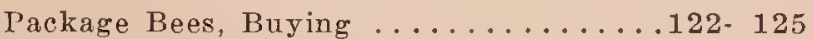

How Released .............. 124

See Shipping Bees.

Sending by Express ..........746- 748

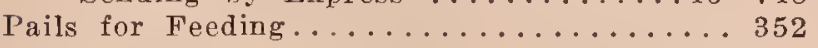

Palmetto ..................648-650

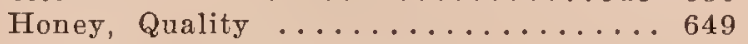

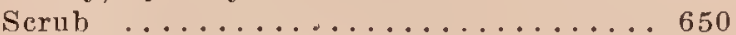

Two Kinds .................. 649

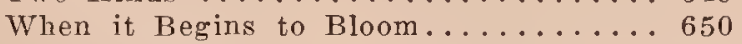

Paper for Midrib in Foundation......... 215

Paper Winter Cases.............903, 904

Paralysis of Bees..............275, 276

Parasite, Cause of Isle of Wight Disease 278, 279

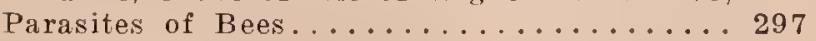

Parasites of Bees. See Isle of Wight Disease, under Disease of Bees.

Parasitic Bees .................. 766

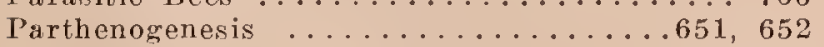
as Shown in Dzierzon Theory ....295, 296
Occurring in Many Other Orders of Both

Plants and Animals ........... 652

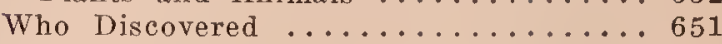

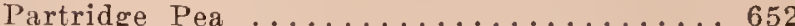

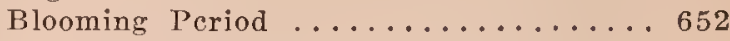

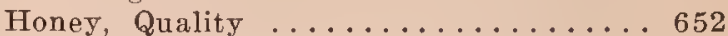

Pasturage. See Artificial Pasturage.

Patent-right Vendors ..............653

Patents, Impossibility of Securing Fundamen-

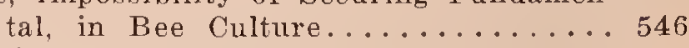

in Bee Culture ................. 546

in Bee Culture Generally of Little Value 653

Relating to Bee Culture. See Inventions

Relating to Bee Culture.

Peddling Honey. See Honey-peddling; also Ex-

tracted Honey and Marketing Honey.

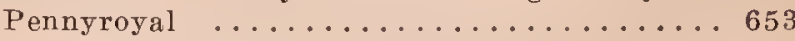

Penny royal Honey, Quality of..........653

Pepperbush ................653,654

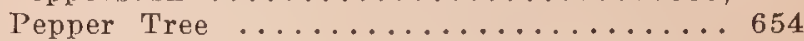

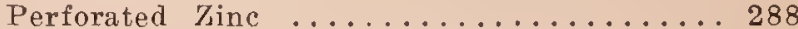

Perforated Zinc. See Drones; also Extracting.

Peterson Capping-Melter for Granulated Comb

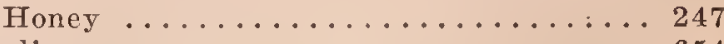

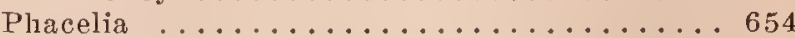

Phillips on American Foul Brood........ 367

Pickled Brood. See Foul Brood, subhead Sac-

brood.

Plant Lice, Important Source of Honeydew.. 493

Plant Life Divided in Two Classes........ 667

Plants, Flowering ................ 667

Pollination, Fertilization Occurring after 671

Producing Pollen ...........509-511

Yielding Nectar .............511- 519

Playflights, Cause of Drifting .........283

Mistaken for Robbing......655, 656, 733

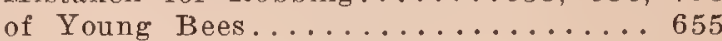

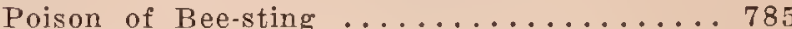

of Sting as a Remedial Agent....... 785

Sac of Honeybee............... 40

Poisonous Honey, Death and Sickness from.. 658 from Mountain Laurel ........656, 657

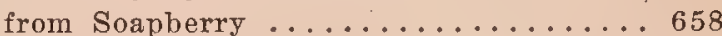
from Yellow Jessamine.......... . . . . . . . . 657 , 658 in North Carolina ...........656, 657

in United States ........................ 656

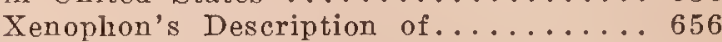

Pollen, Artificial, Sometimes Needed in Spring

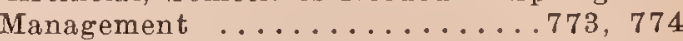

Baskets ................660.6.6. 662

Baskets, How They Are Loaded........ 663

Behavior of Bees in Collecting. . . . .659-663

Brushes ..................... 659

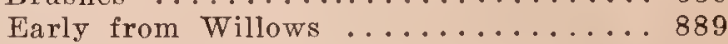

First of the Season............. 93

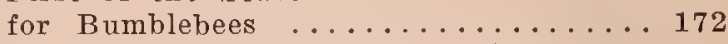

Forced into Supers by Shallow Hives.... 667

Gathered by Bees........................ 6

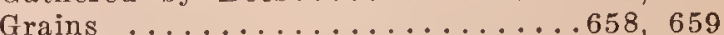

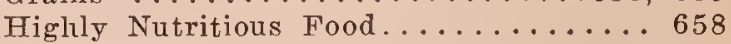

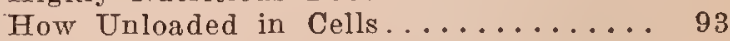

in Combs During Winter........... 924

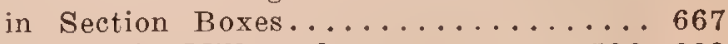

Masses in Milkweed...........598, 663

Necessary for Brood-rearing......... 169

Sometimes Called Beebread.......... 97

Substitutes for ..............6644. 66

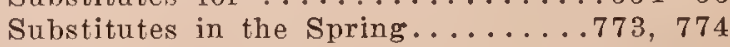

Pollination by Bees................. 4

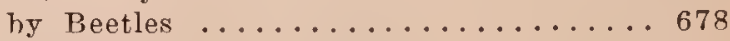

by Birds ................... 677

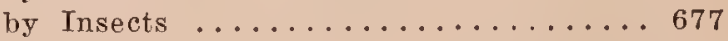

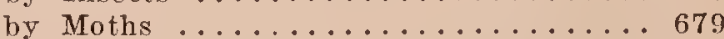

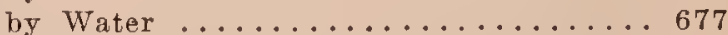

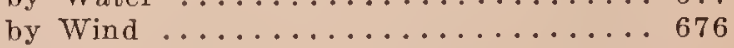

Cross ................672, 681

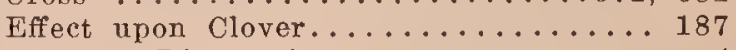

Farmers Discovering ............ 4 
Important for Certain Fruit.........681 of Alfalfa ................. 33, 34 of Almonds .................. 405 of Alsike $\ldots \ldots \ldots \ldots \ldots \ldots \ldots 193,194$ of Apples ................ 409 of Berry Plants............... 398 of Blueberries and Huckleberries...... 402 of Buckwheat ............... 149 of Cherries ..................... 405

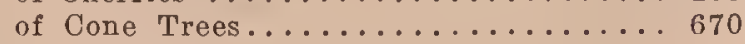
of Cotton ................... 259 of Cranberries .............. 402 of Cucumbers ..........77, 262, 397 of Flowering Plants............671 of Flowers .............667-681 of Flowers, Plant Life Divided in Two

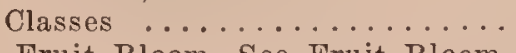

of Fruit Bloom. See Fruit Bloom.
of Fruit Blossoms, General Conclusion...

of Fruit Trees..................... 107

of Gooseberries ............... 401

of Legumes ................. 394

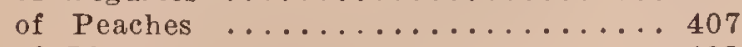

of Plums ................ 403

of Prunes ................ 404

of Quinces ................ 412

of Raspberries and Blackberries....... 401

of Strawberries ............... 399

of Tomatoes ................ 398

Organs of the Flower............ 671

Origin of Seed..............669

Plants Adapted to............. 669

Separation of Stamens and Pistils.... 674

Pollinators, Bees Surpass All Other Insects as 680

Poor Seasons, Result of Contraction....253, 254

Poppleton on Bee Paralysis..........2 276

Portable Extracting-house ........... 160

Poultry and Bees...............107, 108

Pound of Bees, Number in .........886, 887

Pound of Bees. See Beginning with Bees.

Power Extracting Outfit............329- 346

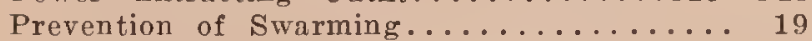

Prevention of Swarming. See Swarming, Prevention of.

Prickly Pear.

Priority Rights

Priority Rights. See Overstocking.

Producers, Large, Buy Their Queens.

Profit Dependent upon Number of Colonies..

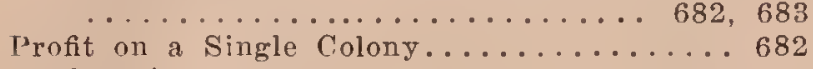

Profits, Average .................. 682

in Bees .................. 682. 684

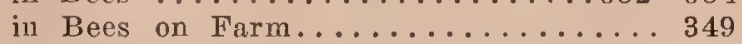

Propolis ................5, 684- 686 Base of Antiseptic Preparation....... 686 Defined .................. 684

How Gathered and Ư in Hive Dependent on Race of Bees.... 685 Known to the Ancients............665 Sometimes a Nuisance.........684- 686 Unnecessary in Modern Bee Culture.... 686 Use for ...............6684, 685

When Gathered ............... 685

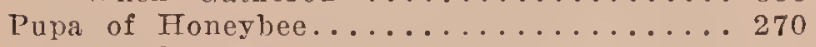

Pure Food Law ................. 17

Purple Sage ....................... 735

Pussy Willow ....................... 889

\section{Q}

Quadruple Wintering Cases..........900-902 Queen ...................697-709 After Leaving Cell............. 700

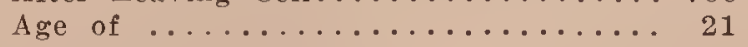
Amount of Spermatozoa That She Receives at Mating ............ 703 and Drone Mating ................ 284,285 and Retinue ................697 Barriers in the Way of .......810,811

Bee, Only One................. 6

Cage Candy ..............178; 179

Cages. See Introducing.

Cells and Their Relation to Swarming.. 79

Cells an Indication of Swarming..... 815

Cells, Symptom of Swarming........ 791

Clipping for Swarm Control......795, 796

Development of Baby............. 698

Eggs She Cail Lay................ 6

Excluders ............288, 290, 545

Excluders in Extracting.......... 318

from Same Egg that Produces a Worker 7

How Old Can be Fertilized.......... 704

How Soon Lays after Mating........ 703

How to Find................. 581

Indicated by Eggs.............. 141

Influence of, on Swarming.......... 810

Like a Worker............... 5

Meeting Drone More Than Once...... 703

Most Important Member of the Hive... 95

Not Always Necessary to Find...... 583

Odor of ................... 708

on Wedding Trip............ 7

Only Perfect Female............. 295

Overcareful in Spreading Brood...... 771

Preceding or Following Swarm...... 792

Rearing .................686- 697

Rearing, Cell Cups for, Doolittle...... 688

Rearing, Cells or Virgins........... 694

Rearing, Colonies for Cell-building..691- 692

Rearing, Conditions Favorable for...... 687

Rearing, Doolittle Method..........6 688

Rearing, Forming Nuclei, Baby Size.695. 697

Rearing, Grafting Cells for......6689-691

Rearing in a Large Way.......... 689

Rearing in a small Way............ 688

Rearing in Swarm Control........ 816

Rearing, Large or Small Nuclei for...694, 695

Rearing, Mating Hives for........... 694

Rearing, Nursery Cages for. . . . . 692, 693

Rearing, Use of Drone Trap.......... 551

Rearing, When One Can Afford to Buy

Queens .................... 686

Rearing, Wooden Cell Cups for...668-691

Register Card for Record Work...... 721

Removing, for Swarm Control.....815, 816

Shifting, to Reduce Swarming...... 809

Temperament of .............. 95

True Female ................ 6

Virgin ..................... 702

Virgin, More Nervous............. 96

When Balled, What to Do........ 542

When It Flies Away.............. 542

with Drone Organs Attached........ 703

Young. About to Emerge............ 699

Queenless Colony, How to Detect from Appear-

ances ...................... 707

Queenless Colony's Cry of Distress........ 707

Queen's Ability to Lay Drone and Worker

Eggs at Will, Berlepsch on "The Dzier-

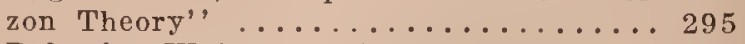

Behavior While Sealed............... 699,700

Presence, Detecting, in Diagnosing.... 273

Presence Determined at Entrance..... 273

Remroductive Organs............ 46

Stings .................... 708

Voices Variable .................... 701

Voluntary Control of Sex of Eggs..... 652

Wings, Shall They be Clipped?....704, 705

Queens .................697. 709

Age of $\ldots \ldots \ldots \ldots \ldots \ldots \ldots \ldots \ldots$

Behavior of ................. 96

Buy or Rear................ 686 Capable of Laying Two Kinds of Eggs.. 697

Drone Lavers..............287, 704 Emerging and Affect on Swarm......... 793 
Fertilization of $\ldots \ldots \ldots \ldots \ldots 75,76$ for Breeding ................ 139, 140

for Breeding, Value of........... 140

for Breeding Purposes, How to Select.. 139

for Breeding, Where to Get......... 140

Good, Importance of ..................... 139

How They Lay Two Kinds of Eggs.... 705

How They Receive Their Food....... 96

How to Secure Pure Mating......... 526

in After-swarming ............. 19

Mating Artificially ...............

Mating in a Greenhouse......... 76

Mating on Deserts................. 76

Most Important Personages..........6697

on Cake of Ice.............. 927

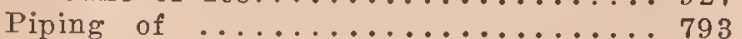

Plurality in After-swarming......... 794

Plurality of, in Swarming........... 19

Plurality of, Not Tolerated in Colony... 531

Rivalry of ............... 700

Royal Jelly for Baby................ 699

Shifting, in Swarm Control......... 809

Undersized or Imperfectly Developed... 697

Vagaries of ............... 96

Value of and How to Determine....... 688

When Take Wedding Flight......... 702

When They Will be Accepted in a Colony 533

Young, How They Destroy Cells...... 700

Young or Old, Cause of Swarming.....8 804

Quinby and Box Hives.............. 139

Believer in Populous Colonies....... 710

Inventor of the Bee-smoker.........7 710

Life of .................709-713

Successful in Management of Box Hives in Early Days................. 710

Quinby's Benevolent Spirit Toward Others... 712 Books ..................... 712

Early Shipment of Honey to New York.. 1

Invention of the Quinby Hive and Closed-

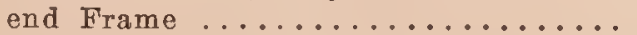

\section{$\mathbf{R}$}

Rabbitbrush

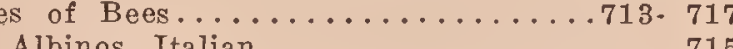

Albinos, Italian ................. 715

Banat .................... 715

Black or German Bees............7713

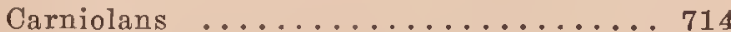

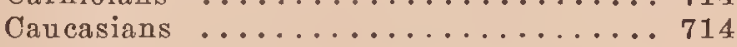

Eastern ........................ 715

East Indian .............. 716

Egyptians .................. 715

Giant Bees of India............. 717

Holy Lands and Syrians............ 715

Tiny East Indian Honeybee........ 716

Tunisians .................... 715

Rain During Fruit Bloom Destructive to Bees

and Bloom .................... 4874

Raspberry, Distribution of ........717, 718

Raspberry, Preferring Northern Woodlands.. 718

Rats Feeding on Honey.............. 865

Rats, How to Destroy............... 719

Recipes for Honey Cooking................. 482

Record-keeping of Hives............719- 722

on Hive $\ldots \ldots \ldots \ldots \ldots \ldots \ldots \ldots \ldots 721$

on Wood Tablets ................. 721

with Book ................ 719

with Card Indexes ............... 720

with Loose-leaf Book............. 720

with slate ....................... 721

Red Clover Affected by Moisture.........200

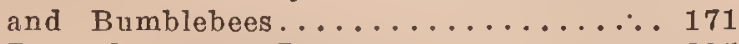

Dependent upon Bees............................... 395

Refrigerator Cars for Shipping Bees....... 744

Remedial Measures for Swarm Control. See Swarming, Prevention of.

Reproductive Organs of Drone.......... 44

Reproductive System of Queen.......45, 46
Reproduction, Sexual .............6673

Reproduction, Vegetative ............ 672

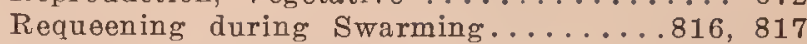

Resting Periods of Bees............... 94

Reversible Frames..............722, 723

Reversing Automatically .............. 544

Defined .................... 722

Theory of .................. 722

Rheumatism and Bee-stings ......... 786

Ripening of Honey................ 95

Roadside Selling of Honey............ 592

Robbed and Robbing Colonies Exchanging Places .................. 730

Robber Cages ...............729, 730

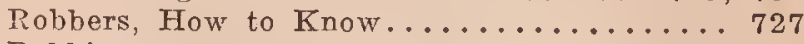

Robbing ...................723. 733

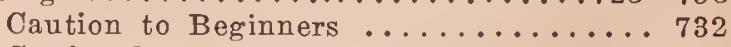

Confused with Playflights.......... 656

Defined ..................... 723

Habit When Once Formed.......... 727

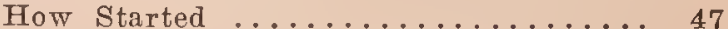

How to Stop ............... 728 - 730

if Not Stopped............... 732

of Nuclei or Weak Colonies............ 727

Passion for ................ 723

Tendency Overcome by Outdoor Feeding. 731

Use of Small Wire Cage to Set Over Col-

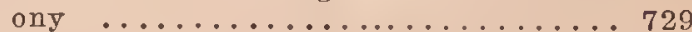

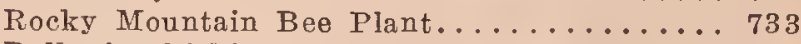

Rolls for Making Comb Foundation....203, 204

Root Granulated Honey............. 435

Smoker ................. 755, 756

Uncapping-can .............. 326

Root's Personal Recollections of Langstroth.

.................... 555,556

Roping of Foul Brood, American.......... 368

Royal Jelly for Baby Queens...........669

Royal Palm ...................651

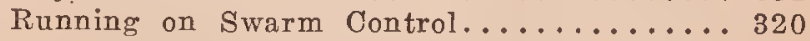

\section{$\mathbf{S}$}

Sacbrood ............................ 377

Cause of ................... 377

See Foul Brood.

Sacking Bees for Moving............... 621

Sage ...................... $734-738$

Different Varieties of ...........734. 736

Honey, Quality of ............ 737

Important Honey Plant in California.... 734

Langstroth's Description of the Honey.. 738

Three Species Most Valuable........734

Destroyed by Stockmen..............737

Distribution of, in California...... 737

Other Species of .................. 738

Sainfoin ...................... 738

Sales of Honey, How May be Boosted...... 592

Sams, C. L. ........................ 138

Scale Hive ................. 739

at Out-apiary ................ 646

Importance of ............ 739

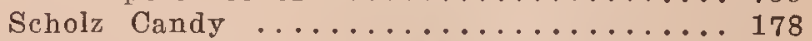

Sealed Brood. See Brood and Brood-rearing.

Scouts Preceding Swarms. See Absconding Swarms; also Swarming.

Second Swarm. See After-swarming.

Section Holders for Sections............ 230

Honey. See Comb Honey.

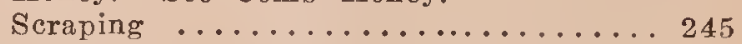

Sections and Separators............ 9

Bait ......................... 239

Bees Refusing to Enter.........239, 240

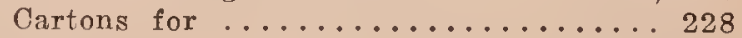

Devices for Holding............229. 232

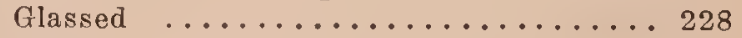

Made of Basswood ............... 91

Plain and Beeway ..........231, 332

See Comb Honey. Appliances for; and Hives. 
Tall versus Square............227, 228

Unfinished, What to Do with........243

When to Put on............... 234 Sectional Honey Box, Development of...... 545 Seeding Alfalfa ................30, 31 Self-spacing Devices, Various Styles of ..384, 385 Self-spacing Frames, Advantages of ...... 386 Frames. See Frames, Self-spacing, and Hives.

Hoffman

383,384

Selling Honey in a Retail Way.......591, 592

Honey in Connection with Live-bee Dem. onstrations ........501-503,592, 633

Honey. See Bottling Honey, Extracted Honey, Comb Honey, Marketing Hon. ey, Shipping Cases and Specialty in Bees.

Honey Thru the Groceries.

Honey to Reliable Concerns with a Rat ing Important .............. 591

Separators for Comb Honey............ 9

for Sections .............230, 231

See Comb Honey, Appliances for.

Sex, Origin of, in Plants..........6667

Sexual Maturity of Drones............ 284

Shade and its Influence on Swarming...... 811

for Apiaries ................59. 61

for Hives. See Apiary.

for Swarm Control.............. 811

Shaken Swarms .............. 80

Shaking Treatment for American Foul Brood 367

Shallow Extracting-supers for Stimulative Brood-rearing

Shallow Supers of Honey for Wintering...

Shipments of Bees in Carlots, How to Prepare ................741- 743

Shipping Bees ..............740- 749 Bees by Boat................. 745

Bees in Carlots from North to South... 740 Bees in Carlots, Importance of Spraying Bees ................... 743

Bees in Refrigerator Cars.......... 744

Bees Long Distance by Express. . . . .623, 624

Bees without Combs..........746- 748

Cases for Comb Honey.........749-753

Cases, Home-made, Objections to...... 751

Cases Made of Corrugated Paper..... 751

Cases, Poorly Designed...........749

Cases with Corrugated Paper in Bottom. 750

Comb Honey in Carlots ............ 752

Comb Honey in Carlots, Importance of

Bracing Well ................ 753

Shook Swarms Swarming........... 80

Shook Swarming. See Artificial Swarming.

Shrubbery in Apiaries..........49, 56, 58

Simmins' Fasting Method of Introducing... 541

Simplicity Feeder ................................. 351

Skep ....................753,754

Skep. See Hives, Evolution of.

Skunks, Enemies of Bees............297

Sladen on Bumblebees............. 177

Smith's Introducing Cage..........537, 538

Smoke and Smokers.............754-760 Using Too Much ................. 759 the Value of, in Handling Bees...... 755 Abuses of .................. 757

Smoker, Bee ................... 11

First Invented by Quinby.......... 755 Fuel for .......................... 7567 How to Use ............12, 757-759 Improved by Bingham and Root....... 755 Invention of .............. 543

Soils for Clover.................. 189

Soils Made Adapted to Clover........... 4

Solar Wax Extractor..........871, 872

Solitary Bees ................760-766 and Flower Pollination........... 760 for Collecting Pollen ............ 659
Habits of Nest-building Bees........763

Host Bees and Guest Bees.......... 763

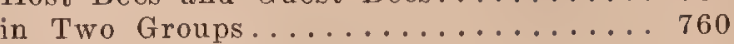

Long-tongued ............... 762

Parasitic .................. 766

Short-tongued Variety ...........7760 Somerford's Method of Forming Nuclei.... 630 Sourwood .................766, 767

Enormous Yielder under Certain Condi-

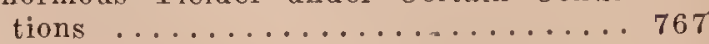

in the South .................. 767

Sometimes Confused with Black Gum... 767

Where Found ...........766, 767 Spacing Frames ...........381, 767, 768

Space, Bee. See Bee-space.

Spacing of Combs, Dadant on..........8 811

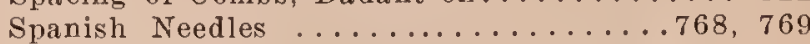

in Indiana .................. 769

Swamp ...................... 769

Specialist Beekeepers ............... 1

Beekeepers, Where Located......... 770

Beekeeping, Requirements for........ 770

Specialty in Bees.............769, 770

Species of Alfalfa............... 21

of Bees .................... 5

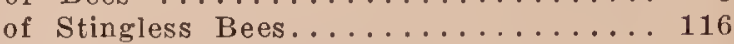

Specific Gravity of Honey............770

Spermatozoa of Drones.............. 45

Spermatozoa Received at Mating........ 703

Spiders, Enemies of Bees............. 298

Spikeweed ................... 770

Spray Pump for Controlling Swarms....... 800

Spraying Bees in Carload Shipments to Keep Them Cool

Destructive to the Brood. See Fruit Blos. soms.

for the Codling Moth..........390,391

Fruit Trees. See Fruit Blossoms.

Spray Poisoning, Financial Loss to Beekeep-

ers Due to................. 389

Spray Poisoning, Symptoms of ........ 389

Spreading Brood ................... 771

Danger in ........................ 771

Largely Abandoned ..............771

When it Can Be Practiced.......... 771

Spring Dwindling .............771- 773

Cause of .................. 772

Caused Sometimes by Bad Food...... 772

in the North Same as Winter Dwindling in California .................... 772

Not a Disease................. 771

Reduced by Packing............. 773

Remedy for ................ 773

Sometimes Due to Drsentery....... 772

Spring Management .............773- 775

Closing the Entrances of Dead Colonies. . 774

Equalizing Colonies .............. 775

Importance of Examining Colonies.... 773

Not Necessary if Colony is Well-fed and Well-housed ................ 773

Use of Paper-wrapped Combs......... 774

Warmly Housing When Taken from the Cellar

Starters versus Full Sheets............. 223 Starved or Neglected Brood.......... 376 States of the Whole Country Variously Com.

pared for the Keeping of Bees.....558-571

States Having Foul Brood Laws......... 562 Statistics Concerning the Bee and Honey

Business ..............775- 778

Steam for Bottling Honey................. 132

Sting. Barbs of .................. 787

How It Works into the Flesh......... . 785

Illustrated .................. 42

Mechanical Construction of .....786, 787

of the Bee................ 49

Poison ..................... 785

Poison, odor of ................ 785 
Stinging, Cause of $\ldots \ldots \ldots \ldots \ldots \ldots 47-49$

Stinging of Horses and Cattle........109- 111

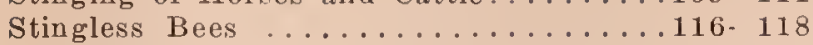

How They Bite................ 118

Where Found ..............................

Stings $\ldots \ldots \ldots \ldots \ldots \ldots \ldots \ldots \ldots \ldots \ldots 77{ }^{2} 788$

and Rheumatism ............ 786

as a Remedial Agent............ 785

Elimination of, by Modern Appliances.. 2

Fear of, Keeping Persons Out of Beekeeping

Fow, Received by the Practical Beekeeper 3

Hollow Construction of .......... 787

How Avoided . . .12, 13, 580, 779, 783, 784 How One May Become Comparatively

Immune to

Not Always Prevented by Smoke...... 786

of Queen .................. 708

Operating after Separated from the Bees 787

Proper Way to Remove........779, 780

Remedies for ................ 780

Severe, What to Do in Emergencies.780, 781

Veils as a Protection Against.....778, 779

Stores for Brood-rearing ............. 145

Good or Bad in the Cellars.........9919

Natural, versus Sugar for Wintering... 926

Should be Abundant for Production of Fxtracted Honey

Strain of Bees Immune to Disease....... 277

Straining Honey during Extracting....... 337

Straw Skeps ...............753,754

Stung, Rules for Avoiding Being......783, 784 Success or Failure Dependent upon Proper Manipulation of Colonies......... 575

Sucrose .................... 180

Sucrose Converted into Invert Sugar...... 546

Sugar, Beet and Cane Compared........788 Cane ....................... 180

from a Chemical Standpoint......... 788

Granulated ................. 788

Sucrose ...................... 180

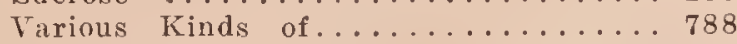

Sumac Honey, Quality of ........... 789

Sumac, Species of ................ 788

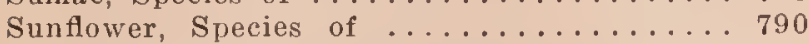

Sunflower, Wild, of Florida........... 790

Super Springs ................ 230

Super $\mathrm{T}$ for Sections............... 229

Supers Comb Honey, Tiering Up......240, 241

Early Work in, for Swarm Control..... 812

for Plain Sections...........232, 233

in Extracting, Freeing of Bees......323, 324

Shifting from One Colony to Another.241, 242

When and How to Put on.........2236

Supersedure Cells Distinguished from Swarm-

ing Cells ................ 815

Supersedure of Queens Defined.......... 790

Swarm Accompanied by Some Drones....... 792 Acompanied by Young Queen.......... 793 Catcher ...............800,801

Catcher, Automatic ............. 801 Cluster on a Limb..........796, 797

Control by Removal of Queen........8 816

Control, Coveyou's Plan.......... 808

Control in Extracting..........319, 320

Control of Importance, Worker Comb... 810

Control, Queen-excluders for........ 809

Control, Ventilation for........... 810

from Supersedure Cells........... 791

Hook ...................... 800

How to Hive....................... 8961

Prime ...............791, 792

Prime, with Young Queen............ 794

Swarming .................790. 818

After. See After-swarming.

and Queen.cells ............... 79

Artificial $\ldots \ldots \ldots \ldots \ldots \ldots \ldots \ldots . \ldots . \ldots$
Artificial, When Practicable........ 79

Bag .................... 798

Bees Good-natured .............. 792

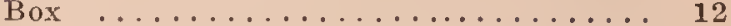

Cause of $\ldots \ldots \ldots \ldots \ldots \ldots . \ldots . \ldots 807$

Cells Distinguished from Supersedure

Cells .................. 815

Controlled by clipping............795, 796

Controlled by Early Work in Supers... 812

Controlled by Large or Small Hives.... 808

Controlled by Manipulation of Brood-

chambers .............808,809

Controlled by Removal of Brood......8 815

Controlled by Shade.............8 811

Controlled by Strong Colonies......... 811

Demaree Plan of Controlling......815-817

Device, Manum's ............... 799

Devices ................798. 801

Events Leading up to............. 791

Factors That Influence.......... 794

from Lack of Stores..............794

How Affected by Honey Flow........ 794

How Started .................. 96

Inclination, Detecting ......... 272

Indicated by Piping ............. 793

Influence of Age of Queens........ 804

Influence of Drones............. 804

Influence of, Hereditary............ 804

Influence of Size of Hives.......... 804

Influenced by Field Bees.........805, 806

Influenced by Locality ........... 807

Influenced by Queen.............. 810

Influenced by Removal of Brood...... 812

Influenced by Room for Ripening Nectar 812

Influenced by Sealed Honey in Brood-nest 811

Influenced by Young Bees......... 805

Loss from ................. 795

Natural Method of Reproduction....... 803

Necessary Evil .............19, 795

One Factor Always Present......806, 807

Ont ..................... 803

Out, How to Check................ 803

Plurality of Queens in...........794

Preparation for ................. 795

Prevented by Westroying Queen-cells 813,814

Prevention of $\ldots \ldots \ldots \ldots 795,796,807-814$

Reduced by Shifting Queen.......... 809

Remedial Measures ..........814- 817

Season ................... 794

Symptoms of ............... 791

Tendency Reduced by Breeding Stock.. 808

Various Kinds Defined.........790, 791

When Occurs ............... 795

Swarms, Absconding. See Absconding Swarms.

After ................ 792- 794

Brought Down by Bells............ 15

Bushel Basket for .............. 800

Buying of Farmers................. 121

Checked with Clipping Queen......... 803

Clustering on Unusual Places.....14, 15

Controlled by Removal of Queen..... 815

Controlled by Spray Pump.........8 800

from Hunger ................ 791

Going to the Woods.............. 13

Inacessible to Get............ 797

on Combs or Foundation..........802, 803

Proportion of Old and Young Bees..... 792

Second. See After-swarming.

Shaken Artificially ............. 80

to Bring from a Distance............ 798

What to Hive on .........802,803

When They Break Cluster......... 792

Sweet Clover .................818- 832

Abundant in Canada and the New Eng. land States ....................... 821

Also Known as Bokhara Clover........ 818

as Cover Crop................. 830

as Excellent Pasture ........... 824 
as Honey Plant ................ 820

as Soil Inırover................ 823

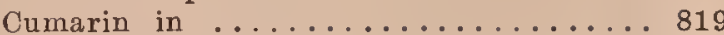

for Hog Pasture ............... 824

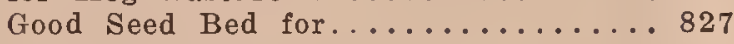

Growing for Seed............... 830

Has Strong Odor and Bitter Taste Due

to Cumarin ................ 819

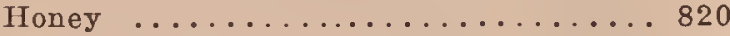

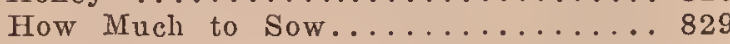

Improving Run-down Land.......... 823

in Alabama and Mississippi........... 822

in Limestone Hills of Kentucky... . . . . 822

in North-Central States............ 821

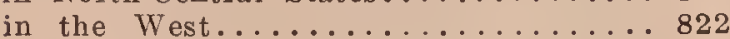

Innculation $\ldots \ldots \ldots \ldots \ldots \ldots \ldots . \ldots \ldots$

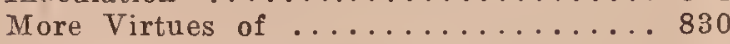

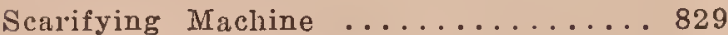

Second Year Growth ..................... 826

Seed, Making Germinate......... 828

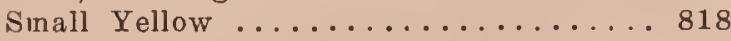

Soils Suitable for ............. 819

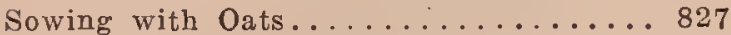

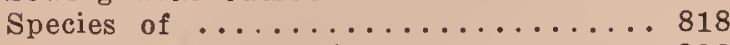

Straw after Thrashing........... 828

Summary ................... 831

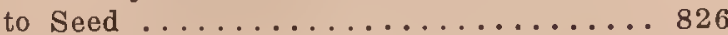

Valuable for Hay. . . . . . . . . 825, 826

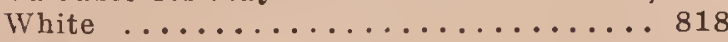

Wide Distribution of .......... 819

White Annual ..............832- 835

White Annual, Discovered by Professor

Hughes of the Iowa Experiment Sta-

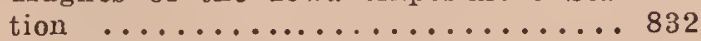

White Annual, Rapidity of Growth..832. 834 Sylup for Feeding. See Feeding and Feeders.

Syrup, How to Make............... 350

\section{T}

T'arsonemus Woodi, Cause of Isle of Wight

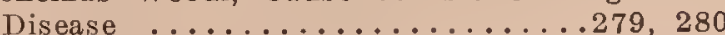

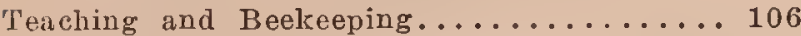

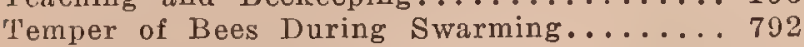

T'emper of Bees. See Anger of Bees.

T'emperature .................835-8 839 at Entrance in Cellars............. 918

at Right Point in a Bee-Cellar Important 836 During Winter, How Affected by Disturb-

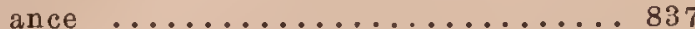

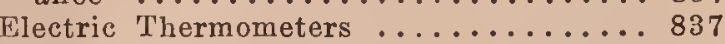

Experiment Conducted by Phillips and

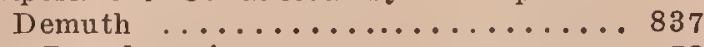

for Brood-rearing ............. 78

How Affected by Good and Bad Stores.. 838

How Bees Keep it Down in Hot Weather 835

How Bees Raise or Lower It. . . . . 838, 839

Important Part in the Bottling of Honey 836

in Cellars, Variable, Bad............ 919

in Cluster during Winter Variable..836- 839

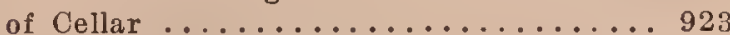

of Cluster ..........810,836-839, 918

of Colony, Various Observers Have Been

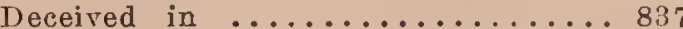

of Winter Cluster When It is Quietest.. 838

One of the Most Important Factors in $\mathrm{Bee}$

Culture .................... 835

Point When Bees Raise It During Winter 839

to Arrest Granulation............ 248 Territory for Bees, Moral Rights of . . .647, 648 Theory, Gerstung's, on Swarming........ 805 'Tiering Up ..................240, 241 Tiering Up, Caution Concerning.......... 241

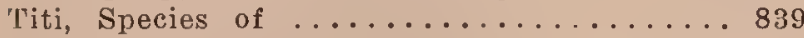
Titi Honey, Quality of ............. 840 Thick-top Frames ................. 379,380

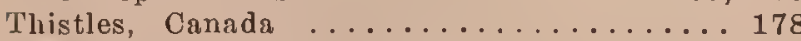
Tin Cans Tmproperly Boxed.........312, 313 Tiuy East Indian Honeybee........... 716

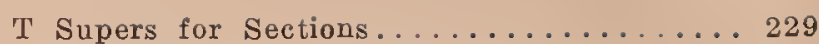

Tongue of Bee, How It Works......... 37

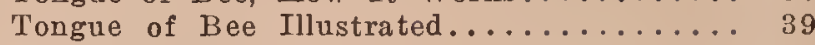

Tools for Bee Work...........11, 576-579

Tracheal System of Bee............. 36

Traclieal System of Bee Infected by Parasites

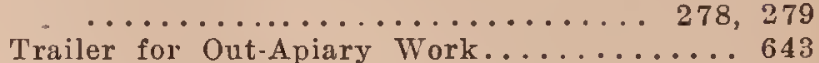

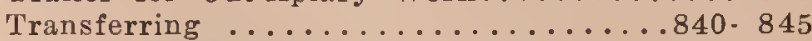

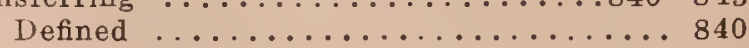

Drumming for ............... 842

Elton Warner Method............ 844

Heddon Short Way of............ 844

How Done ................... 841

How to Fasten Combs in Frames......8 843

Sams, C. L. on...............841, 842

Tools Necessary for ................... 841

Putting Combs into Frames......... 843

When ..................... 840

Without Using Old Combs......... 844

Travel-stain. See Comb Honey.

Trees, Hollow, Bees Found There........ 13

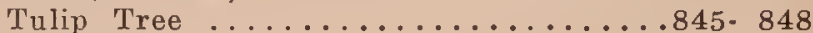

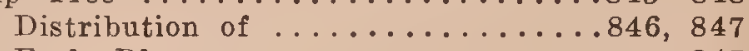

Early Bloomer ................. 847

Flower of .................. 846

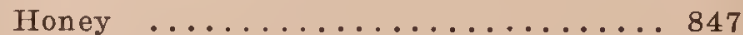

Other Names for ............... 845

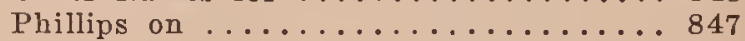

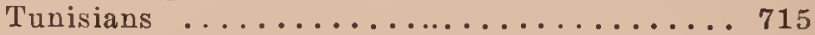

Tupelo .................

Black ................. 848, 849

Honey of ................... 848

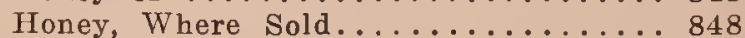

Other Names for .............. 848

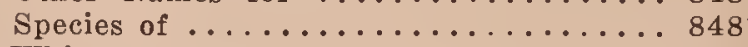

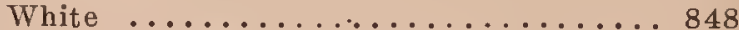

Tupelos, Black and White Found in Swamp

Lands of Virginia and Florida....... 851

Tupelos in Apalachicola Regions of Florida.. 851

\section{U}

Uncapping-box, Townsend's .......... 334

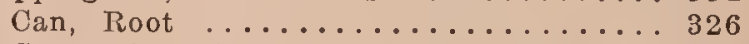

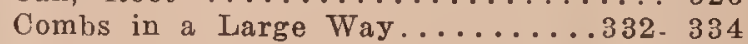

Knife ..................... 545

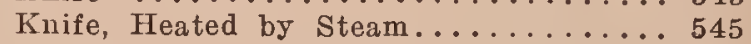

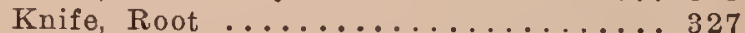

Knives and Uncapping Equipment for Extracting ..................... 333

United States Census on Bees Better Than a

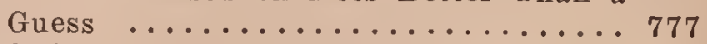

Relating to Bees Misleading........ 775

Report Showing Beekeeping on Farms... 776

Uniting, Alexander Plan........773, 854, 855

Alexander Plans Modified........... 855

Bees ........................ 852- 855

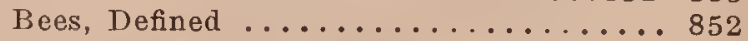

Before Bees Are Set Out of the Cellar. 774

Difficulty in ................. 852

How It May Cause Fighting Among the

Bees .................... 852

How to Prevent Bees in Same Yard from

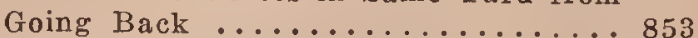

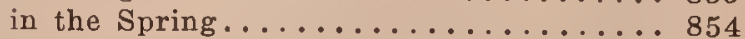

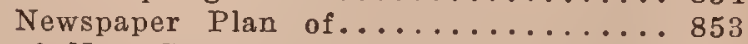

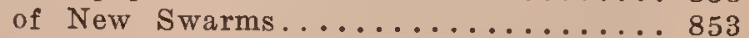

Out-apiary Bees ....................... 852

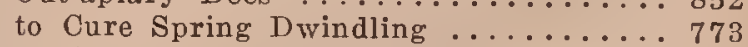

Unspaced Frames, How to Handie............ 581

\section{V}

Van Deusen's Reversible Frames........ 722

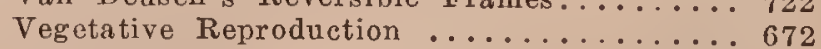

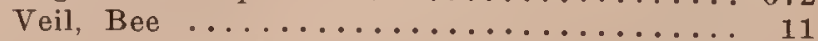

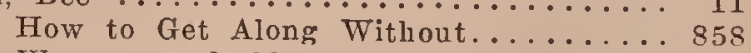

Warmus and Gloves Combined...... 85! 
and Clothing Suitable for Women...858- 860 Convenient if Not a Necessity........ 855 Indestructible .............. 857 Made of Wire Cloth........... 857

Objections to ............... 855

of Brussels-netting and Silk Tulle..856, 857 Various Methods of Fastening to Waist

...................... 856, 858 Variously Constructed ........856-859 Ventilating, How Bees Do Their Own..... 862 Ventilation ................860-863 and Swarming ............. 861 at Entrances Usually Sufficient........ 860 How Bees Obtain it Under Extreme Oircumstances .............862,863 in Swarm Control .............. 810

of Bee Cellars ..........861,921, 924 of Supers During Hot Weather....860, 861

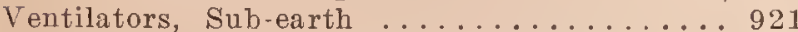
Vinegar Making, Hydrometer for......... 864 Dark, Strong-flavored Honey, Excellent. 864 Honey ..............863, 864 Honey, Color and Flavor of ....... 863

How to Make ............... 863 How to Mix Honey and Water to Make. 864 Virgin Queens, Introducing .......... 693 Virgin Queens, Why It is Difficult to Introduce 542 Vitamines, Anti-scorbutic ........... 867 Experiments on Rats .......... 865 Fat-soluble A................ 864 in Comb Honey ........... $3,867,868$ in Honey ...........472, 864- 868 in Honey, Hawk's Experiments.......884 Necessary to Some Foods.......... 864 Water-soluble B ............. 864

Water-soluble C .............. 864

\section{W}

Wasps, Destructive to Bees........... 299

Water for Bees ............868, 869 for Bees, Necessary in Brood-rearing....8 868 How Bees Extract from Nectar....... 869 How to Give to Bees............ 869

Wax ..................... 869. 886 Beeswax and Other Waxes........ 870 Bees Bleaching ............. 885 Cleaning from Utensils.......... 886 Comb Foundation from .......... 870 Compound for Comb Foundation....... 870 Extractor, Solar ............871, 872 Glands of Bee.................. 38

How Bees Make.............. 871

How to Detect Adulteration......... 885

Pinchers on Bees.............8871

Polishes .................. 870

Press, Double ..............881- 883

Press, Double, with Two Screws in Place

of Large Press .............. 881

Press, Hatch ................ 876

Press, Hot Water...... 874-877, 880- 883 Presses, How to Use........... 876- 880

Presses, Steam .............. 875 Rendering ................... 871

Rendering from old Combs......872- 884 Rendering in Large Quantities... . 881. 884 Rendering, Old-fashioned Way of...872, 873 Scales from Honeybee.........483, 871 Scales, How Bees Remove.......... 871 Scales Secreted During Swarming Time.. 871 Substances Classed as Such.....869, 870 Worms, How to Detect Presence of.600, 601 Worms. See Moth Miller.

Weather Affecting Clover............. 189 Weather Conditions and How They Affect Temper of Bees ............ 580 Wedding Flight of Queen and Drone....... $\ldots \ldots \ldots \ldots \ldots \ldots, 7,284,285,702$ Weight of Bees .............. 886- 888
White Clover. See Clover.

Holly. See Gallberry.

Wage . P. Peo Tulip Tree.

White, Dr., on Sacbrood............. 377

Why Women Should Keep Bees............ 104

Why Womeu Should Not Keep Bees......... 103

Wild Cherry ................... 888

Wild Sunflower. See Sunflower.

Willow ..................... 888. 890 Doolittle on ............... 890 Early Blooming ............... 889 Pussy ....................... 889

Willow-herb .................... $890-894$ Distribution of ..................... 890

Effect of Cool Nights on.......... 893

Honey .................. 893

Honey Flow from................... 892

in Michigan Forests ............. 891

Propagation of .................. 893

Quality of Honey of ............. 894

Windbreak ...................... 897

Windbreaks for Apiaries ..........61- 64

for Wintering, Importance of ....908-913

Made up of Panels............... 910

Natural .................... 910

Wing, Clipping to Prevent Absconding...... 14 Winter Case for Four Colonies, Bartlett's Original $\ldots \ldots \ldots \ldots \ldots \ldots \ldots \ldots . \ldots 99$ Case, Four-colony ....................... 901 Case, Four-colony, Bartlett's .......... 901 Case, Four-colony, Holtermann's ...... 901 Cases, Importance of Fastening Down

Covers ................. 902 Cases of Paper, Inexpensive........903, 904 Cases, Packing Material for............ 902 Cases, Quadruple, Objections to........ 903 Cellar, Running's ............... 915 Cellar, How to Build................. 920 Cellars, Running's Specification...915, 916 Diagnosis .................. 274 Dwindling, Due to Lack of Pollen ....... 772 Dwindling in California........... 772 Entrances ................... 301 Entrances with One or More Holes in

Place of Slots ...........901, 902 F'eeding ......................... 354,355 in Semi-tropical Countries ............ 772 Nests .................912, 913

Nests, Letting Bees Form.............. 911

Sleep of Bees..............926-928

Stores, Natural versus Sugar Stores... 914

Stores, Quality and Quantity of...... 914 Temperature for Cluster of Bees...836-839 Windbreaks for ............908-914 Wintering ....................... 894 and its Relation to Crop........167, 170 at Out-apiary ................. 645 Bees in a Warm Room............. 77

Bees Under a Shed............... 900 Entrance Contraction in.............. 900 Importance of Bottom Packing....... 898

Importance of Cellars Being Frost-proof

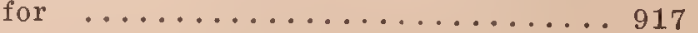

in California .............. 929

in Cellars ...................... 926

in Cellars in the South........... 916

in Cellars, Some Things to Remember.923- 926

in Cellars, Where Preferable........ 895

in Double-walled Hives........... 898

in Greenhouses .................. 898

in Semi-tropical Climates.......928, 929

in Single-walled Hives, Demuth's Plan of $\ldots \ldots \ldots \ldots \ldots \ldots \ldots$. $905-907$ in Single-walled Hives Outdoors, Unsafe 897 in Southern States............... 928

in Tenement or Quadruple Cases....... 900

Moisture, Why Forms on Inside of the 
Hive ...................... 908

on Aster Honey .............. 82

Ontdoors, Porous Cushions or Sealed

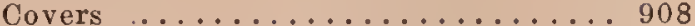

Outdoors, Recapitulation of ........ 907

Outdoors, Where Preferable......895, 896

Shallow Supers of Honey for........ 926

Two Methods Discussed.......895, 896

Two-story Langstroth Hives in Quadruple

Cases .............................. 902

Using Artificial Heat........... 77

with Little Packing. . . . . . . . . . . 898

Wire Excluders ................288- 290

Wires Imbedded by Electricity.......217, 218

Wiring Foundation .............929-931

Wiring, Different Methods .........209. 213

Frames ............209.213, 929, 930

Horizontally, How Introduced........ 380

Value of .................. 209

Why it Should be Attached to Brood.

frames .................. 930

Women as Beekeepers. See Beekeeping for

Women.

Women Beekeepers ................. 103 How They Can Keep Bees........103, 104
Wood Base for Comb Foundation......... 215

Wood Splint for Support in Foundation..... 214

Worker and Drone Brood, to Distinguish.... 142

Bees, Age of .............. 21

Bees, Their Duties ............. 5

Bees, Two Divisions of .......... 6

Combs, How to Make Bees Build..... 252

Combs. See Combs.

Workers, How They Feed Queens........ 96

Workers, Laying. See Laying Workers.

\section{$\mathrm{X}$}

Xenophon on Poisonous Honey. See Poisonous Honey.

Xylocopa

\section{$\mathbf{Y}$}

Yellow Poplar. See Tulip Tree.

Yellow Sweet Clover. See Sweet Clover.

Yolk of the Queen's Egg.............. 269

\section{$\mathbf{Z}$}

Zinc, Perforated. See Drones, Extracted Honey, and Swarming.

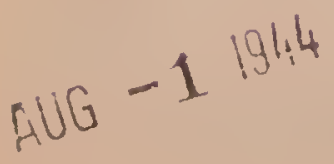







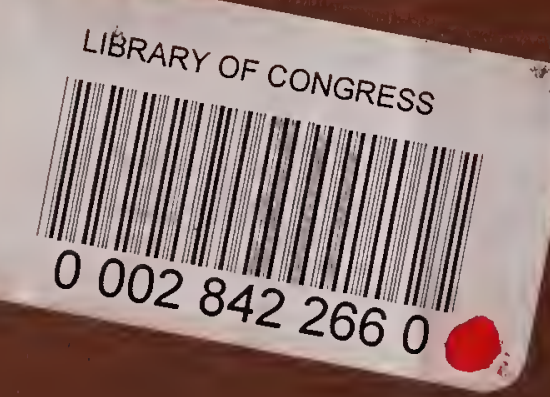

